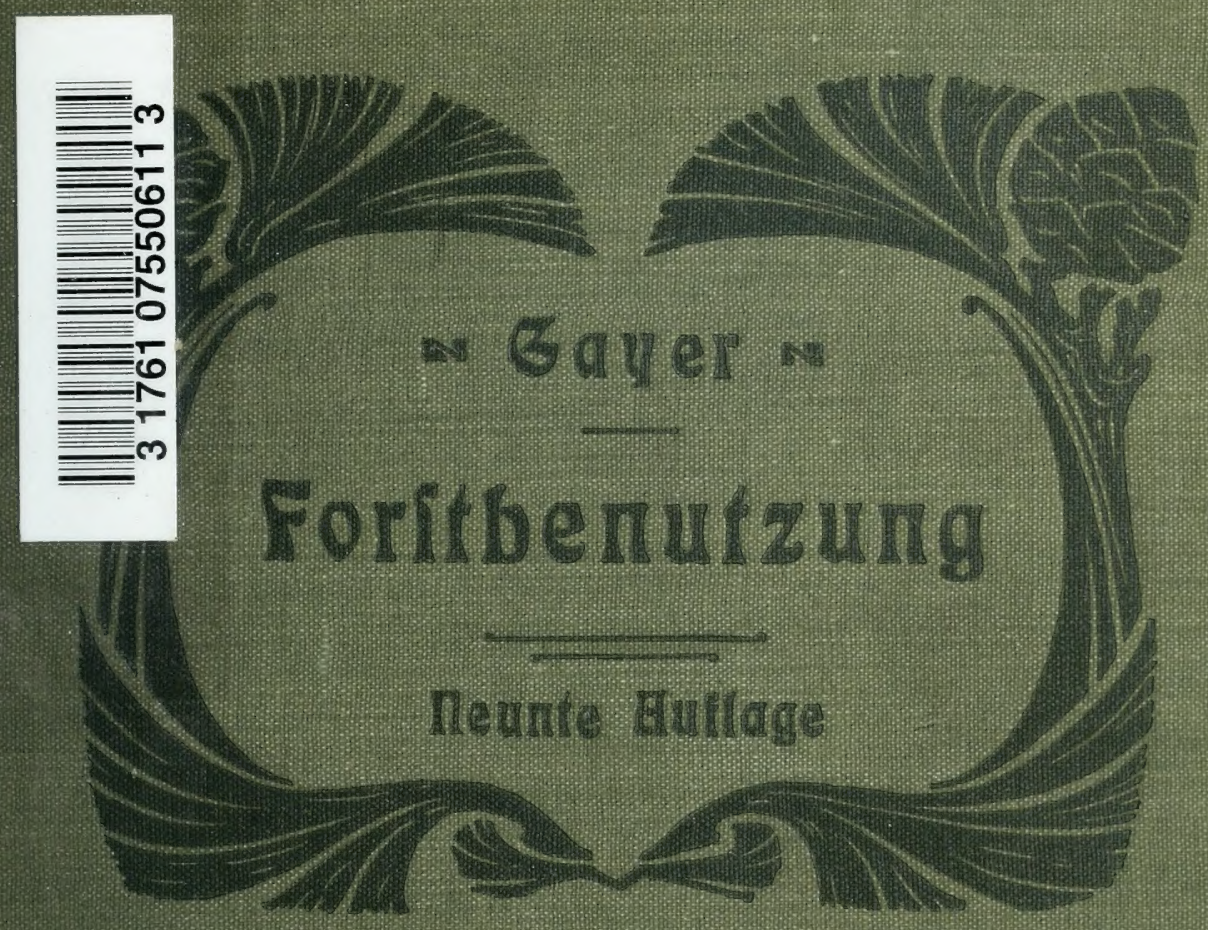

ARIVERSITY

of

TORONTO MBRRY 





\section{Die}

\section{כoxitbenutbuthg.}

Bon

\section{Dr. 筷arl Gaver,}

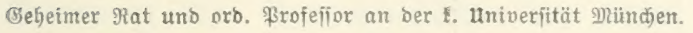

\section{Alentute, uermethrte Aluflante,}

bearbeitet unter Mitmirfung oon

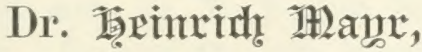

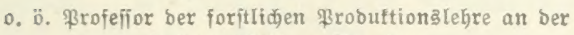

t. Univerjität zu Mündjer.

\section{LIBRARY}

\section{UNIVERSITY OF TORONTO}

Mit 341 Tertabbiloungert.

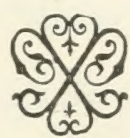

$1+5$

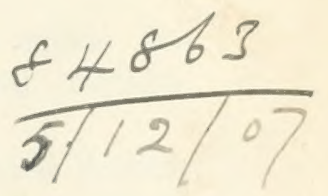

Berlitr.

Derlaggbudhandlung Paul Pareq.

Berlag fitx Randroixtiकaft, Bartenbau uno forftrofen.

SW., Ęedemannftrafize 10.

1903. 


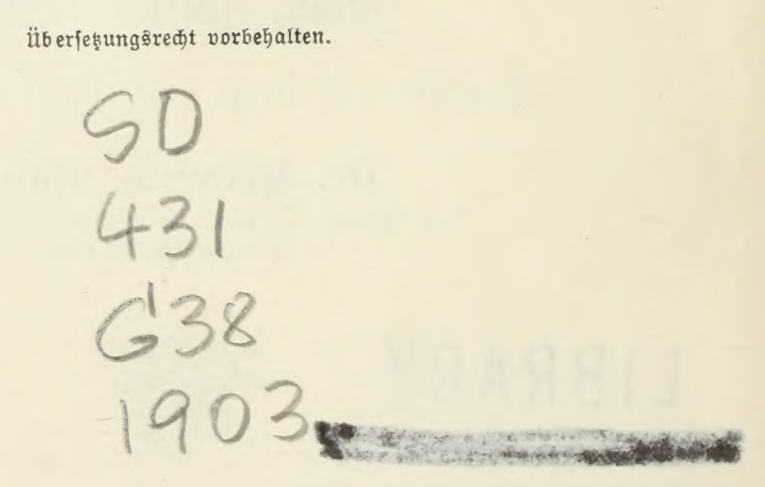




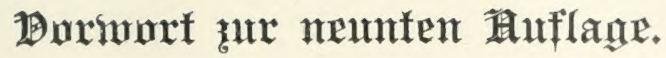

Das Beftreben, meinem Buthe über Foritbenutbung jeine biahbrige Stellung in Der Fachliteratur zu mabren, uno meine vorgerüdten Rebengjabre

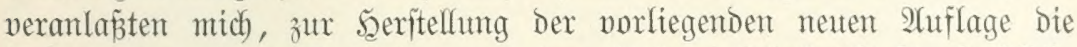
Irbeit mit meinem Machfolger auf Dem biefigen Sebrituble für forftliche Froduftionslehre, Serm Dr. Szeinrid) Mayr, zut teilen.

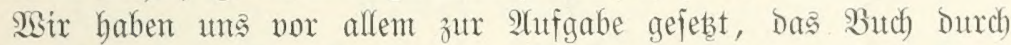
gemiffenthafte Bentbung aller Errumgenichaften des Kebten Sahrzebntes auf Den gegenwärtigen Stand umjeres SBifiens fortzufüthren, fobann

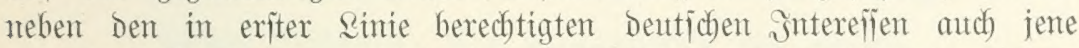
anderex Sutturländer mebr in Den Sireis Der Betradytung hereinzuziehen, fo Dá̉ bie vorliegende $\mathfrak{A}$ ufflage fich auf breiterer Grumblage aufbaut.

WSas bie Berlegung und inftematifose Gliederung des gejamten Stoffes betrifit, io iit fichon aus dem Intaltsverzeidynifie zu entrebmen,

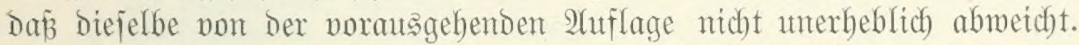
Dasjelbe gilt zum Teil aud für die ipezielle Bebanolung bes Stoffes in jadjlicher Beziehung. Umarbeitung umb Reutorittellung einiger $\mathfrak{A}(6=$ ichnitte uno Rapitel, teilmeife Ermeiterung Derjelben Durch zahlreiche,

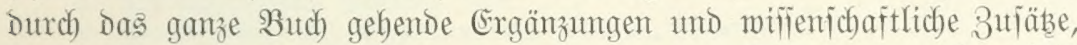
jomie Die an einigen Drten vorgenommenen Rürzıtngen geben Das̆

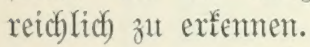

Die nete 2 fuflage mutroe um 50 neute Driginaliflutitrationen ver= mebrt und exicheint mut mit 332 atboiloungen.

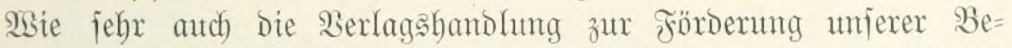
ftrebungen beigetragen, gebt aus ber in alfen Bezitehungen trefflichen

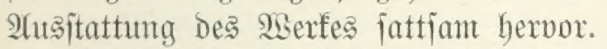

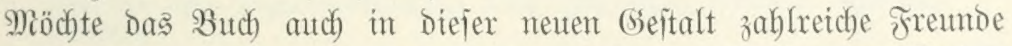
finden und Dem ftudierenden wie Dem auşübenden Foritmame Nutben bringen.

Miünden, im ฐamuar 1903.

\section{Gayex.}





\section{In $\mathfrak{h} \mathfrak{a} \mathfrak{l} \mathfrak{t}$.}

Seite

(5xitex Teil.

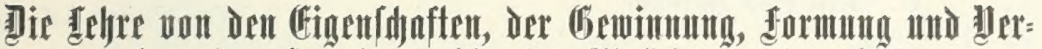 mertum oes}

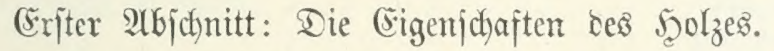

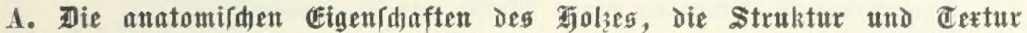

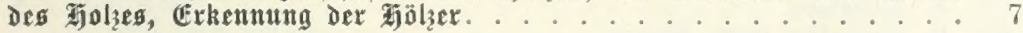

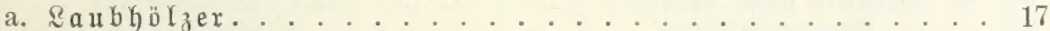

1. Die (Eichenaxten, Gattung Quercus ........... . 17

2. Die SBuchenarten, Battung Fagus . . . . . . . . . . . . 19

3. Die Eidjenarten, Grattung Fraxinus. . . . . . . . . . . . 20

4. Die Mlmenarten, Gattung Ulmus . . . . . . . . . . . 21

5. Die EDelfaftante, Battung Castanea . . . . . . . . . 21

6. Die Robinte, auch 2 ffazie gentant, Brattung Robinia . . . . . . . 22

7. Die Malnuß̧arten, Gattung Juglans . . . . . . . . . . 23

8. Die Ahornarten, Ǵattung Acer. . . . . . . . . . . . . . . . . 24

9. Die firid)en= uno Pflaumenarten, Gattung Prunus . . . . . . . 24

10. Die Sain= oder Weib̧buchenarten, (Sattung Carpinus . . . . . . 24

11. Die Exten, Battung Alnus. . . . . . . . . . . . . 25

12. Die Birfenarten, (Sattung Betula ........... 26

13. Die Sindenarten, Gattung Tilia . . . . . . . . . . . 26

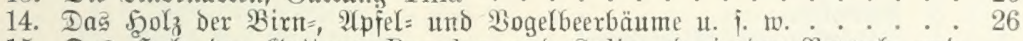

15. Das $\mathfrak{S}_{0} \mathcal{L}_{3}$ Dex Gattung Populus und Salix, D. i. Dex Pappel= und Weidenarten . . . . . . . . 27

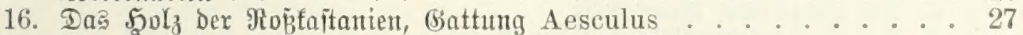

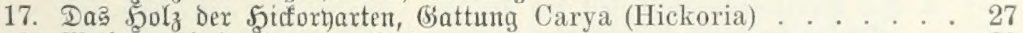

18. Mahagonifol $\mathfrak{l}_{3}$ Gattung Swietenia . . . . . . . . 28

19. Sedrela $=$ oder Bigarrentiptentyolz, aud) Bederntholz genant, (Sattung Cedrela . . . . . . 28

20. Ieaffolz (iprich) Iif) von Tectona grandis . . . . . . . . . 29

21. B̈ut)รbaumbolz, Gattung Buxus . . . . . . . . . . . . . . 29

22. Slivenholz, G̈attung Olea . . . . . . . . . . . 29

23. Focfhol $\mathfrak{z}_{3}$ Regelfugelhol $\mathfrak{z}_{3}$ Lignum sanctum, Battutg Guajacum . . 30

24. Ebenfïlzer, Sattung Diospyros. . . . . . . . . 30

25. Palijanderholz (Jacaranda) . . . . . . . . . 30

26. Яolentgolz . . . . . . . . . . . . . 30

27. Padauftolz (Padouk), Pterocarpus indica. . . . . . . . . 30

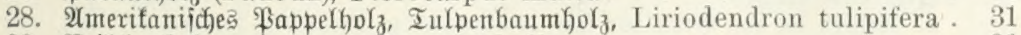

29. Beildfentfolz von A cacia homalophylla . . . . . . . . . 31 


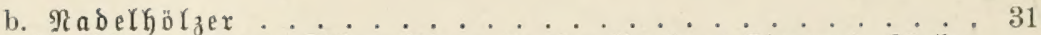

30. Fidten (Picea), Föbren (Pinus, Section Taeda et Pinaster), Särod)en (Larix), Douglapitannen (Pseudotsuga) . . . . . . . 32

31. Die 5̧ölzer Dex Birben, Gattung Pinus, Settion Cembra, und Dex Webmouthäfören, Battung Pinus, Eeftion Strobus . . . . . .

32. Die Söbzer Der Iannen, (Sattung Abies, Der Tiugen, Sattung Tsuga, Der Iarodineen, Ǵattung Sequoia, Cryptomeria und Taxodium, der

33. Dedern, Sölzer Der Familie ber Cupressineen, Gattungen Chamaecyparis, Cupressus, Thuja, Thujopsis, Libecedrus, Juniperus u. ^. . . . 35

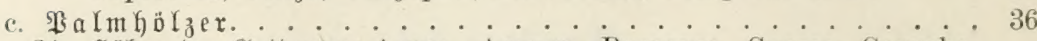

34. Fölzer Der Gattungen A reca, Arenga, Borassus, Coccos, Corypha, Livistona, Sabal u. ¡. tw. . . . . . . . . . . 36

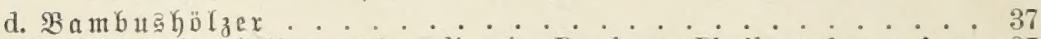

35. Şölzex Dex Gattungen Arundinaria, Bambusa, Phyllostachys u. ๆ. iv. 37

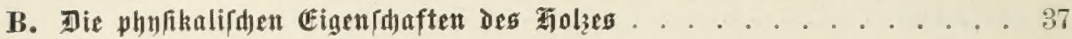

1. Tarbe. . . . . . . . . . . . . 37

I. Rern mit Jarbitofï Durd)tränft. . . . . . . . . 38

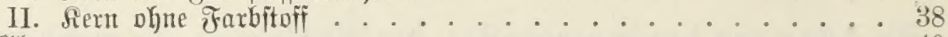

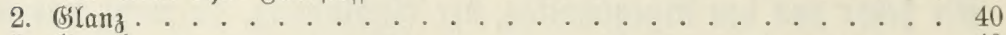

3. (Berutd. . . . . . . . . . . . . . . . . . . . 40

4. Särte . . . . . . . . . . . . . 41

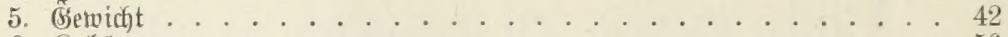

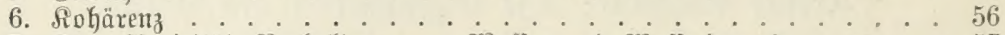

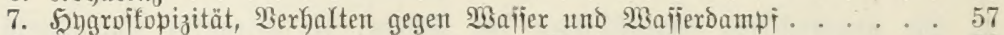

8. §llemmen. . . . . . . . . . . . . . . 63

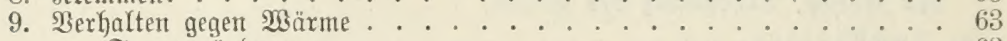

a. Tormveränderutng . . . . . . . . . . . . . 63

b. Majierbetwegung .................... 64

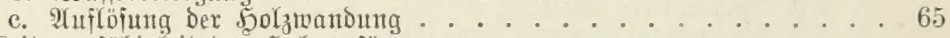

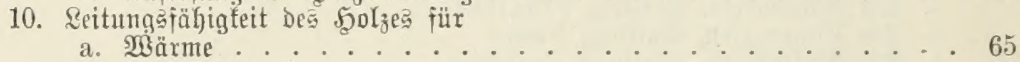

a. FEärme

c. Sdjall. . . . . . . . . . . . . . 66

d. \&icht . . . . . . . . . . . . . . 66

C. 刃ie demi

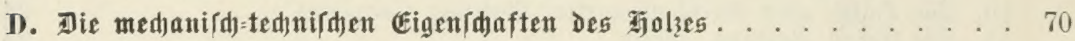

1. Jeinfajerigfeit .................... 70

2. Spaltbarfeit . . . . . . . . . . . . 73

3. Teítigfeit. . . . . . . . . . . . 75

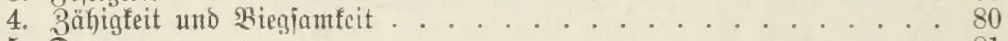

5. Datter. . . . . . . . . . . . . 81

6. Die Seiz= Doer Brennfraft . . . . . . . . . . 87

7. Die Bearbeitunggfähigfeit Deg $\mathfrak{S}_{0} \mathrm{~L}_{3} \mathrm{e}$. . . . . . . . . . 90

Berfalten gegen Edfleifen. . . . . . . . . . . . . 91

Berbaltent gegen $\mathfrak{B}_{0}$ lieren. . . . . . . . . . . . . 92

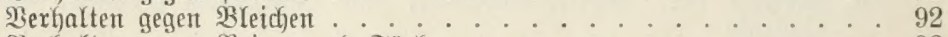

Serfalten gegen $\mathfrak{B}$ eizen und Färben . . . . . . . . . . 92

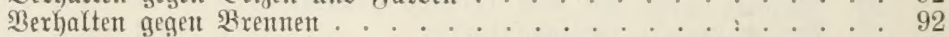

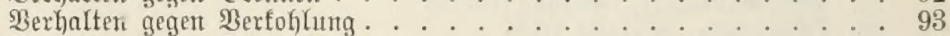

Berbalten gegen эmprägnieruntg . . . . . . . . . . . 93

8. Dimenfiout . . . . . . . . . . . . . . . 93

9. Die Ærormuerhältniffe bex Solzarten . . . . . . . . . . . . . . 94

10. Şaubarfeitzerträge Der wid)tigítent Şolzarten . . . . . . . 99

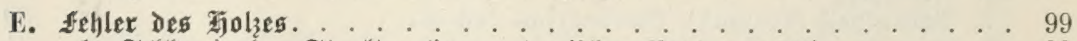

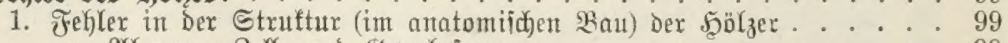

a. शrbnorme 3ell = und Gétwebeformen . . . . . . . . . . 99 
b. 2 Gnormer Fajervertnuf . . . . . . . . . 102

c. Berreib̆ung der gejunbent Bellfajer .......... 109

d. Erfranfung Der Şolziajer. . . . . . . . . . 112

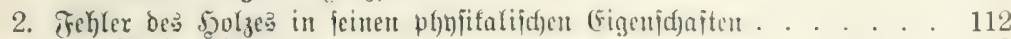
a. Farberfehler.
112

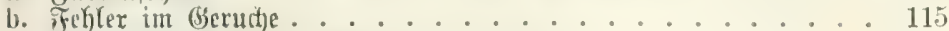

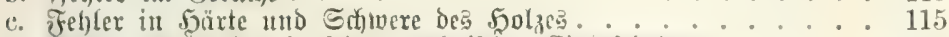

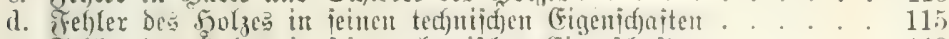

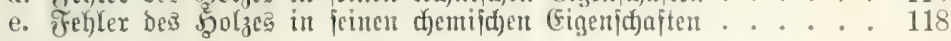

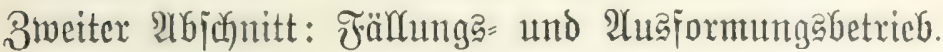

1. 2trbcitaträfte. . . . . . . . . . . 120

I. 21Igemeine Beptimmungent . . . . . . . . . . . 123

II. Beiondere Beftimunungen. . . . . . . . . . 124

III. Etrafbeftimmunget .............. . . 124

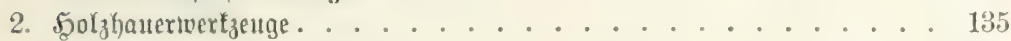

3. Beit dex f̧oldfüllung . . . . . . . . . . . 163

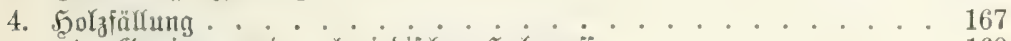

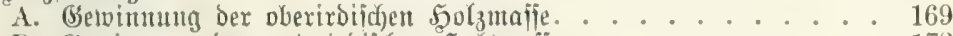

B. Bewinnung Der unterirbif(t)en 50 lamaffe . . . . . . 178

5. 2tu

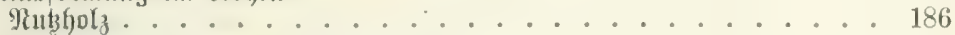

Sbremthol . . . . . . . . . . . . 186

6. Eortierung . . . . . . . . . . . 203

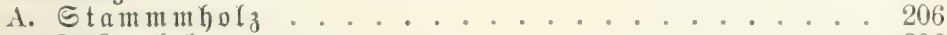

I. Eanghol . . . . . . . . . . 206

1. (Eithentolz .............. 206

2. Tadelfholz ............... 206

3. Grige 5olzarten $\ldots \ldots 207$

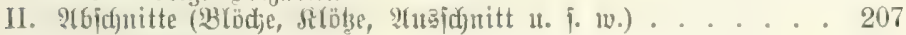

1. Eidjentjolz............. 207

2. Sindelhol . . . . . . . . 208

3. Hibrige Sgotgartent . . . . . . . . . 208

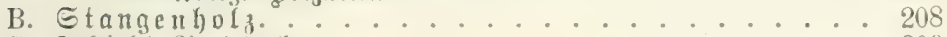

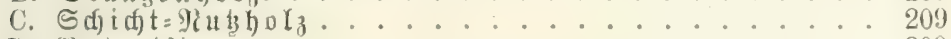

D. siutreifig. . . . . . . . . . . . 209

E. Brentrol . . . . . . . . . . . . 210

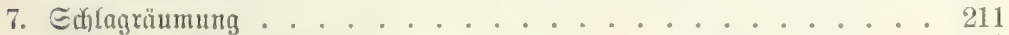

I. Broct des Rüdent . . . . . . . . . . 211

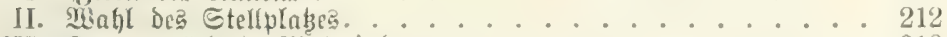

III. In zu rüntende Miaterial . . . . . . . . . . . 212

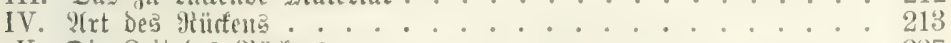

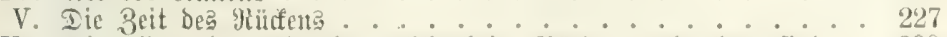

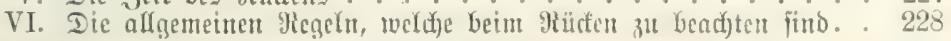

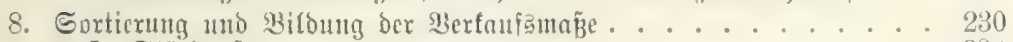

I. Stuidmaß̈. . . . . . . . . . . . . 2810

II. Băflmaß̧е . . . . . . . . . . . 230

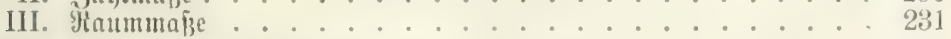

9. Ed)lagauifunhme unt Sitaififizieren . . . . . . . . 237

I. (Erhebung der Duantität. . . . . . . . . . . 239

II. Ertegung der Duatität . . . . . . . . . . 242

III. Silaffifizieren. . . . . . . . . . . . 242

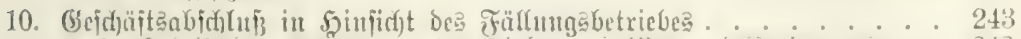

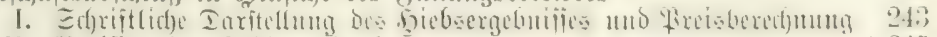

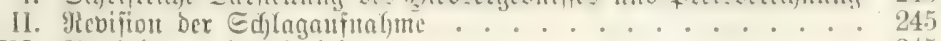

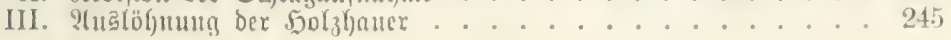




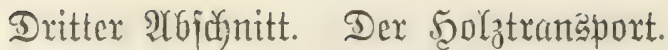

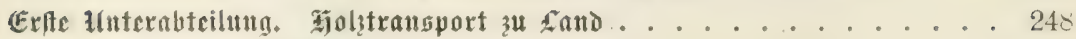

I. Straben un d 9 ege ................. 248

A. Bau und Einridjtung Der Etrapien .......... 248

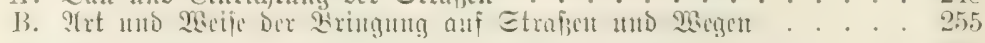

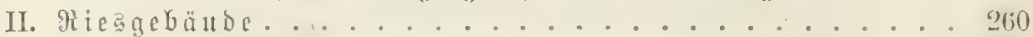

А. Bau und Einridftung der Mtiejen............ 260

1. Jjolzrieicn ........................... 261

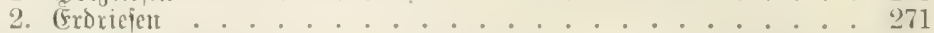

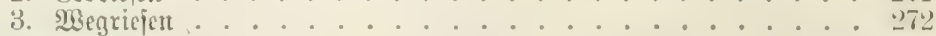

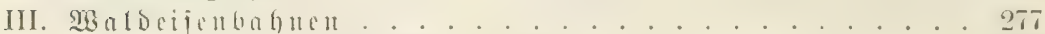

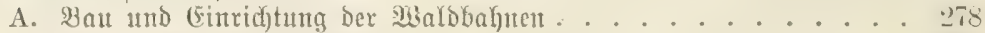

B. Betrieb auf Den Walsbahnen . . . . . . . . . . . 285

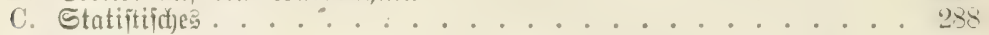

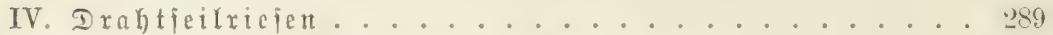

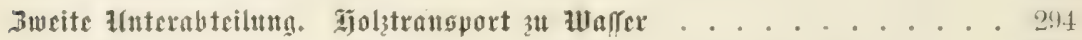

I. Ixift. . . . . . . . . . . 294

A. Die zur Irift criorberfichen (Eigenidjaften Der Iriftitrabe . . . . 29y5

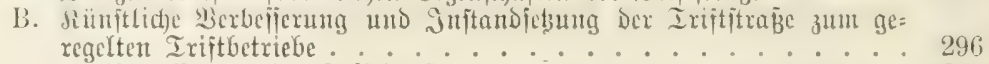

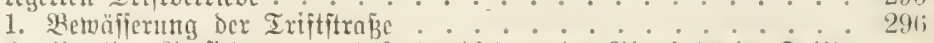

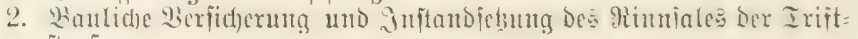
itraß̧e

3. Fanggébäude

C. Iriftbetrieb

II. Flöberei.

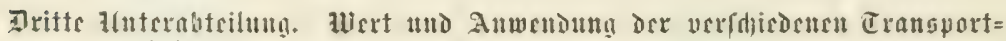
metljoden

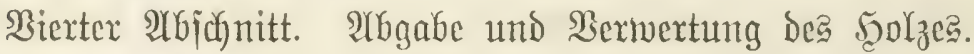

A. Augabe Des Tolzes

B. Wexwertung Deg 䇰olizes

a. Iie, Berwertungsarten .

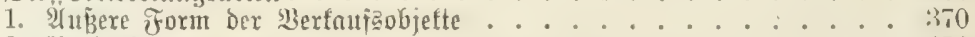

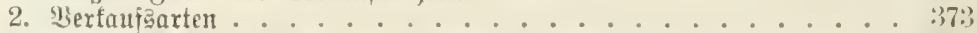

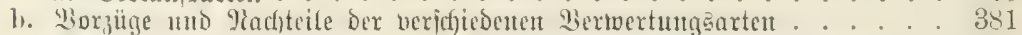

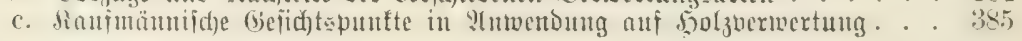

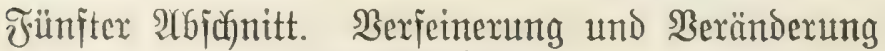

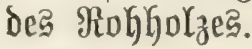

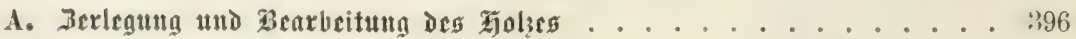

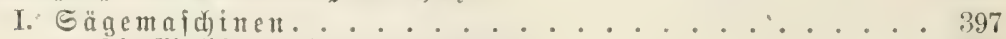

a. Die Maldjägemühlent (Ǵntteriägen) . . . . . . . . 397

b. Die Dampiiăgen (Gatteriägen) . . . . . . . . . . 402

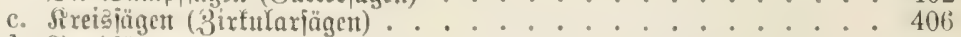

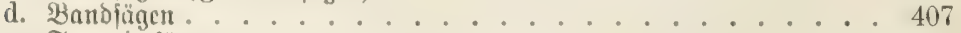

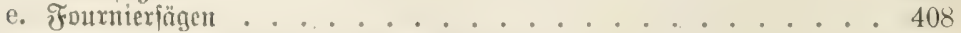

II. Ïbrige Solzbearbeitungmafdinen ......... 410

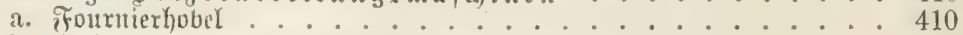

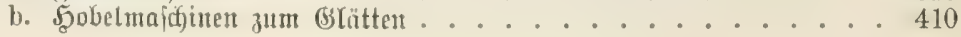




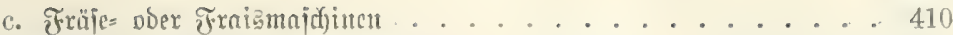

(1. 5ol3mollmaichinert ............. 411

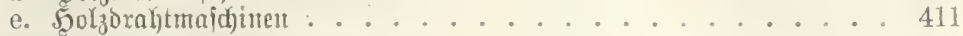

f. Solzbiegnaf(tinet . . . . . . . . . . . 411

g. 5olzpré̆majd)itten. . . . . . . . . . . . . . 411

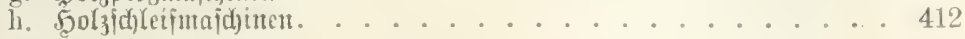

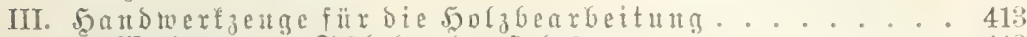

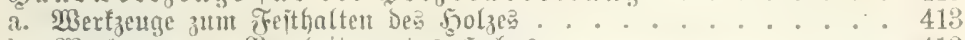

b. Werfzeuge zux Bearbcitung Des̆ Jolze ......... . . 413

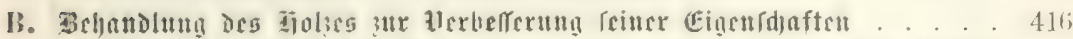

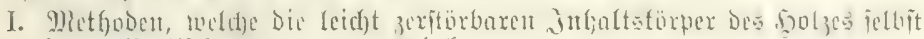
it antifeptiffye diörper vermandeln . . . . . . . . .

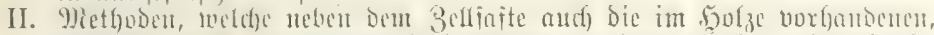

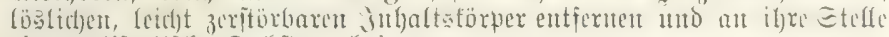
cinte antijeptifdye Subjtanz bringen.

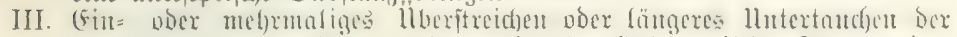

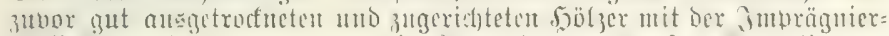
flieifigfeit: als lebtere fommt in ?tmmendung: direnfot, fincbolinem,

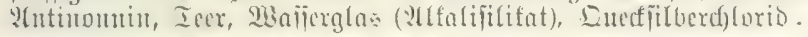

422

422

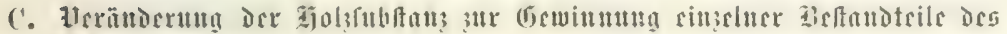
笈olics

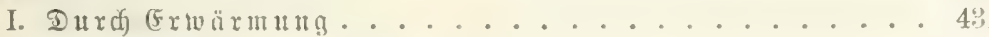

1. Die Ieftiflation Dew Solzes ............ 432

A. Serfohlung in itehenden Meilern .......... 438

a. Destidie Bertohlunghtmethode. . . . . . . . 431

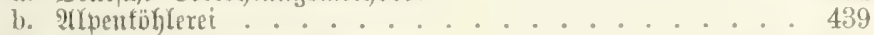

B. Berfohfung it liegenton Werfen. . . . . . . . . 441

C. Die Grubenvertohlung ............ . . 443

D. Roflenausbente ................... 443

E. Sortimente . . . . . . . . . . 445

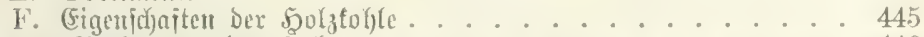

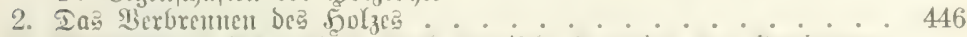

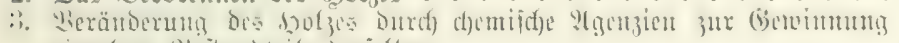

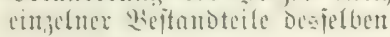

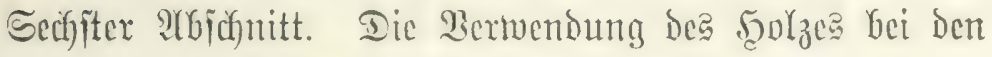 Golazerbraudenden betwerben.}

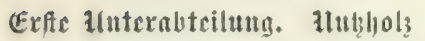

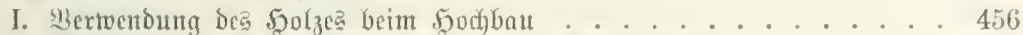

II. Mermendung De .

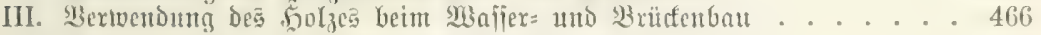

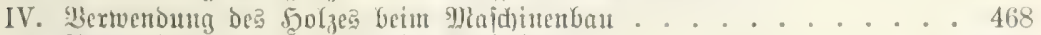

V. Mermendung Dę Jolzę beim Ed)iffball . . . . . . . . . . 469

VI. Sुolzberwendun bei ber Iijhleret. . . . . . . . . . 475

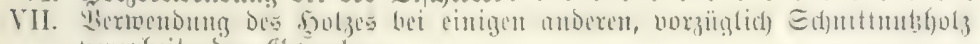

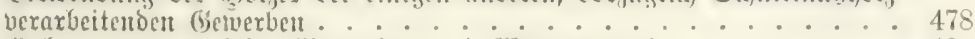

VIII. Solzoertvendung beim Magenbau mo Magengetverbe . . . . . . 481

IX. Solztermendung beim Nöttdjergetwerbe............4455

X. Fobzuermendung bei ben übrigen Epaltwarengetwerbin. . . . . . . 491

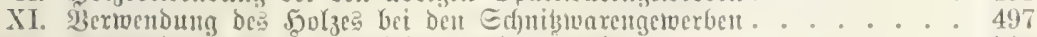

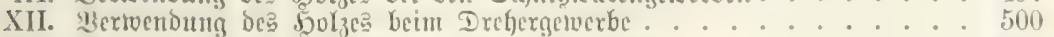

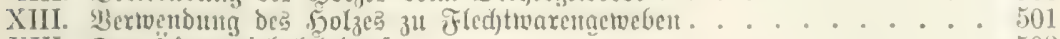

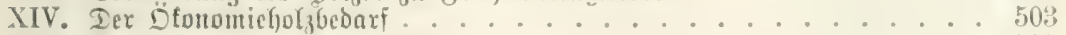

XV. Serivendung der Jolzabrälle . . . . . . . . . . 505 
3weite Interabtcilumg. Brenuljol?

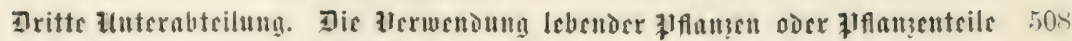

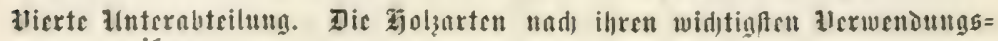
wcirru. . . . . . . . . . . . 509

1. Raubhz̈ger . . . . . . . . . . . . . 509

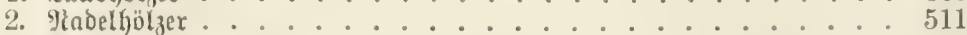

3. Erotijue 5olgarten .............. 512

\section{3 weiter Ietr.}

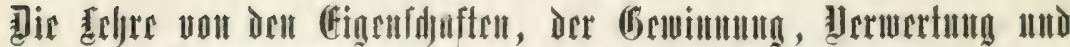

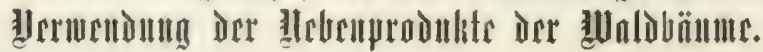

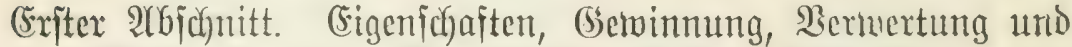
Serwendung der Baumrinde und ifrer Beftandeile.

1. Anatoutifde Eigen fidaften Der Minde

B. Die d)emifden, plunfikalifden und ted)uifden Eigendjaften Der Binde und ihrer Beftandrile.

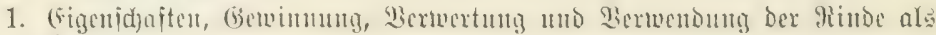
(Bananze?

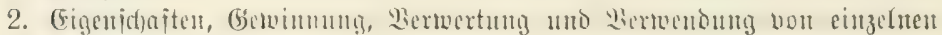
Ieilent Der Hinde ............... . . 520 Die Gerbitoffe ................ . . 520

Der Gerbftoff ber Jungeidenrinde ........... . . 523

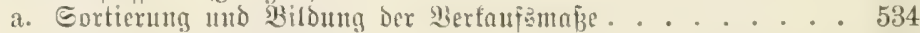

b. Siertwertung der Rohrindent ............ 535

c. Dutantitätšbeftimmungen ........... . 537

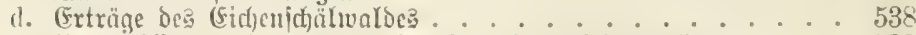

e. Mentabilität mo gegentwärtige Rage Des (Fid)entoldoes. . . . 589

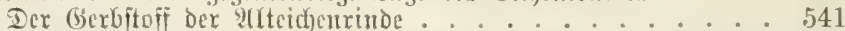

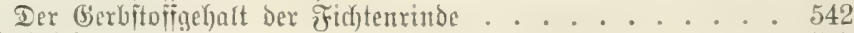

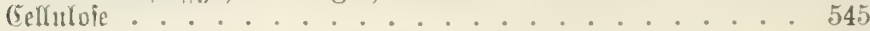

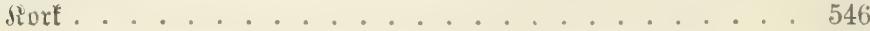

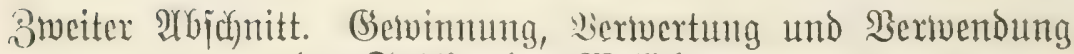
Der Frürdste Dex Malsbäume.

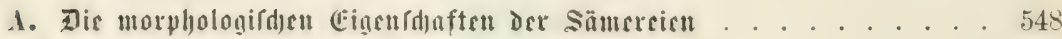

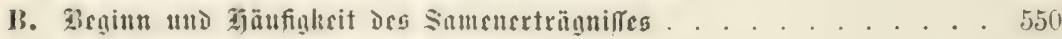

C. Dic Snmenrsife und der samrmabfall. . . . . . . . . . 552

1). Die Snurnertite . . . . . . . . . . . . 552

E. 刃ic Buridtung der sämerrien . . . . . . . . . . . 554

F. Einridtung Der Hilengantalten. . . . . . . . . 554

1. Eonuchionrem ................. 554

2. Fenerdorren ..................... 555

3. Inmpidarren. ................. . . 560

4. 2futente . . . . . . . . . . . . 564 
G. Die Aufbewalırung der sämereicn . . . . . . . . . . 565

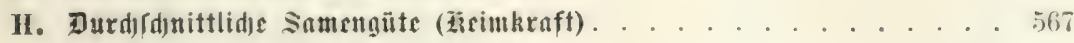

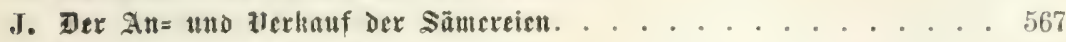

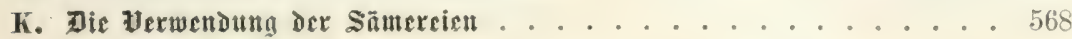

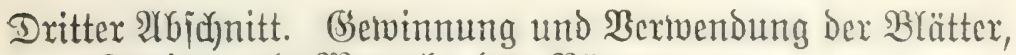

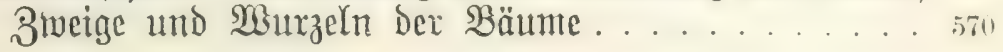

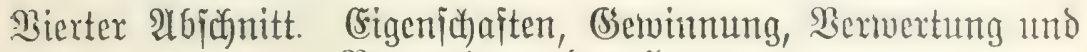
Serwentung De马 Şarze?.

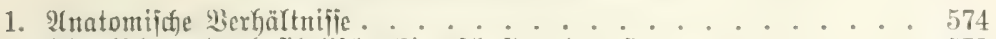

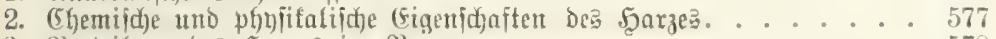

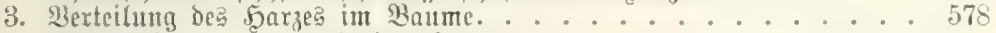

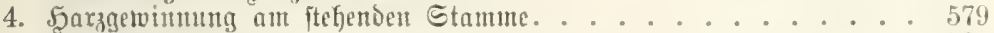

5. 2tusbente. ...................... 585

6. Die Merwertung Der 9luţung. . . . . . . . . . 585

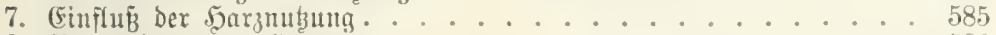

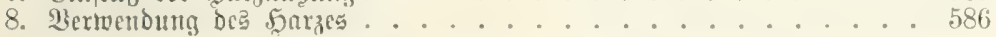

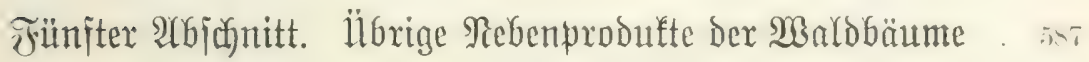

\section{Drittex Ieir.}

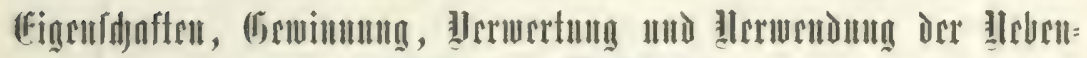

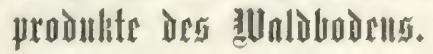

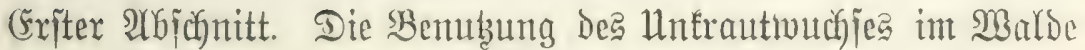
zux Füitterung.

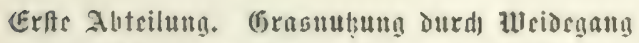
$59: 3$

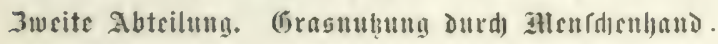

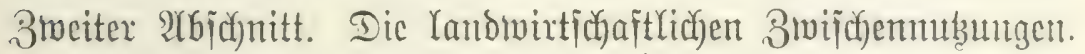

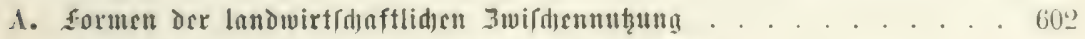

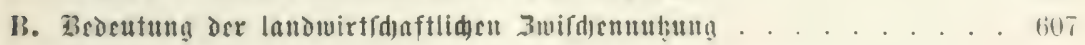

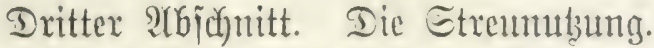

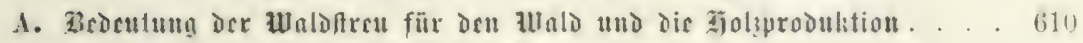

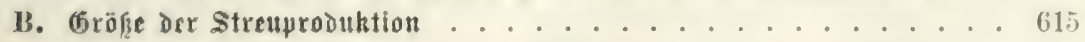

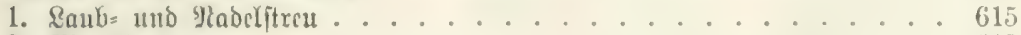

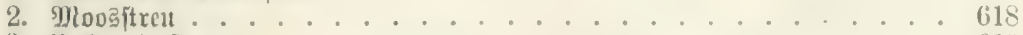

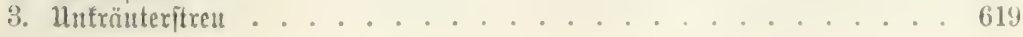




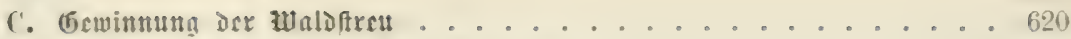

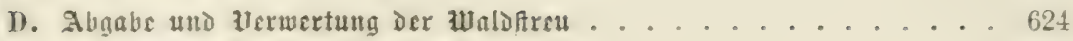

F. 3ulärigkerit Der Streuntłung. . . . . . . . . . 626

F. Wert der Waldfret für die fandwirtfjaft .......... 629

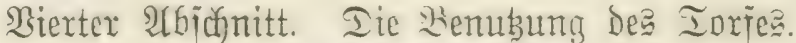

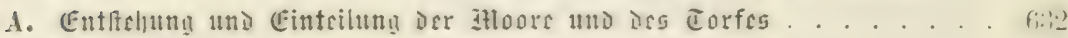

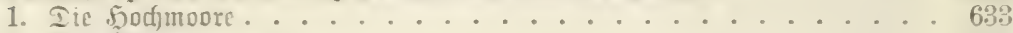

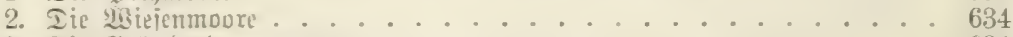

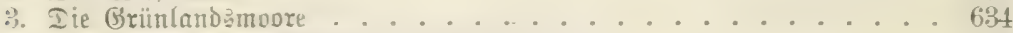

1. Ier amtorphe Iori (1'erf)= ober Epectori).......... 635

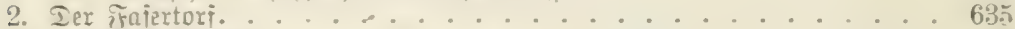

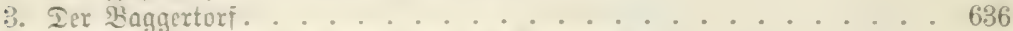

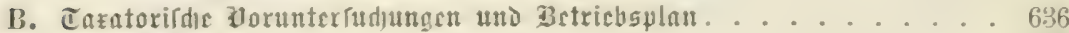

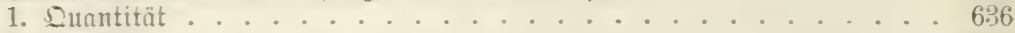

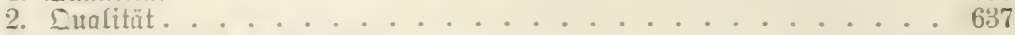

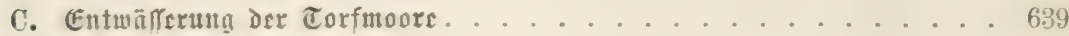

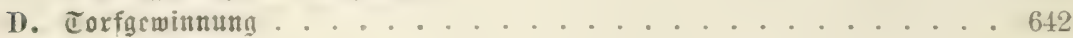

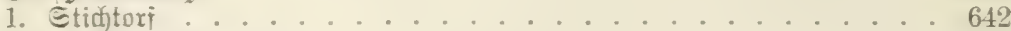

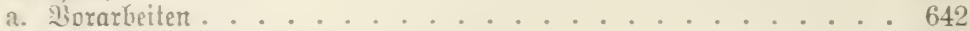

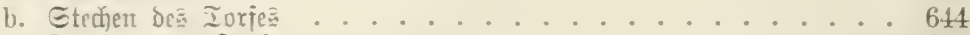

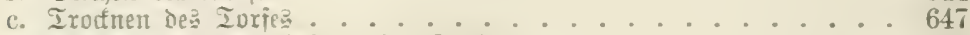

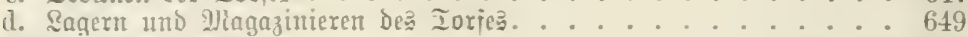

2. Mlobel= ober Etreidgtori .................. 650

a. Bubereiturg ber Iorimnije ............. 651

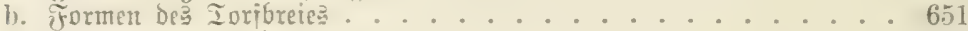

c. Iroctuct de Diodeltorip . . . . . . . . . . 652

d. Olialität . . . . . . . . . . . . 653

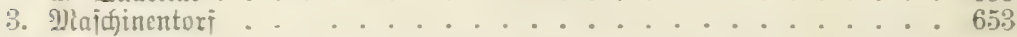

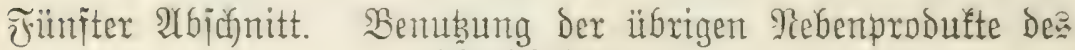
Maldboden?.

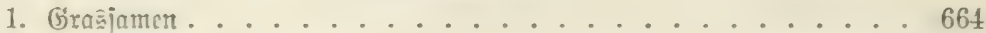

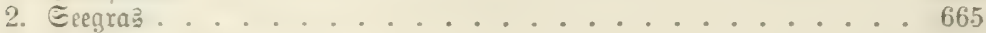

3. Binjen und Edjadterfalm . . . . . . . . . . 666

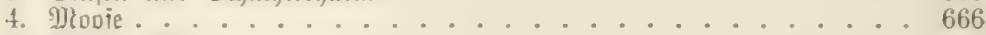

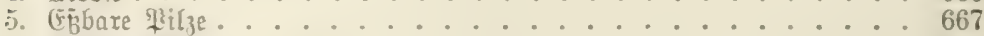

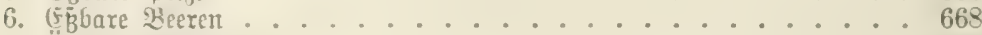

7. Übrige !lututuget . . . . . . . . . . . . 669

Biertex Teil.

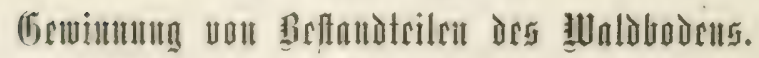

Die Pubung der Eteine und Fron 


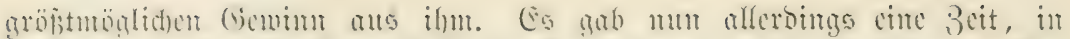

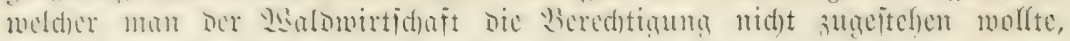

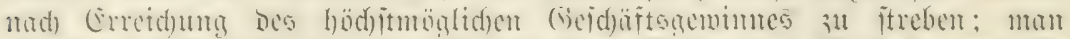

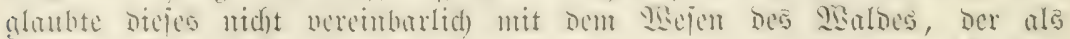

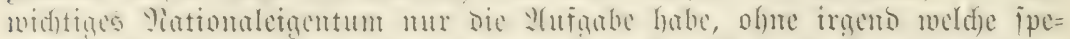

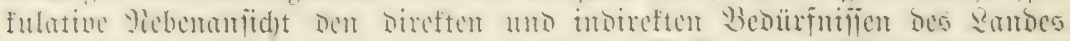

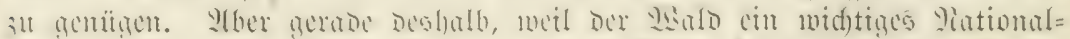

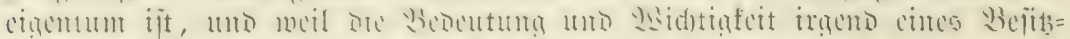

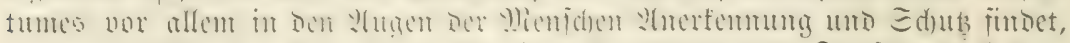

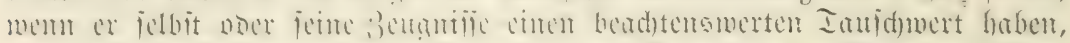

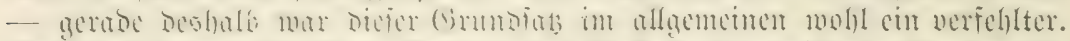

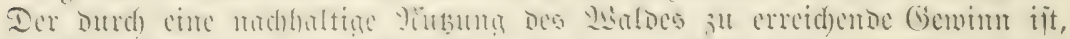

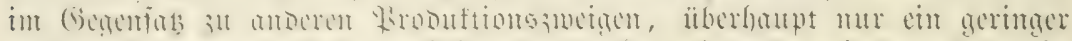

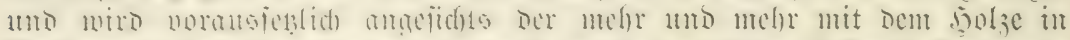

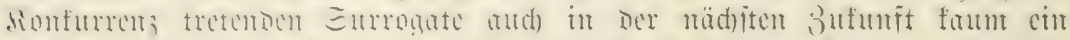

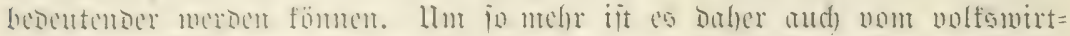

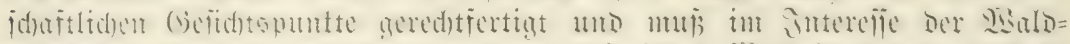

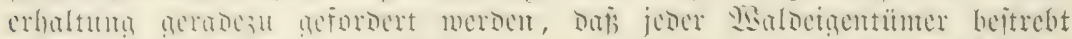

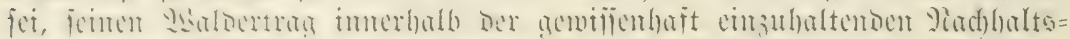

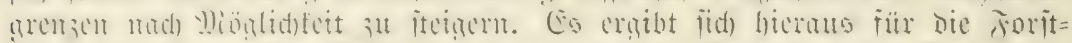

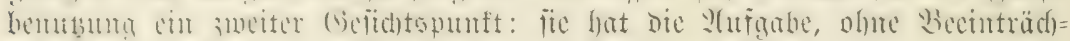

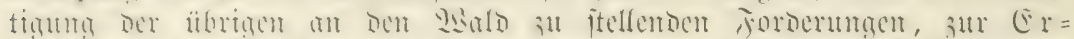
1) 9) iaje befüligt.

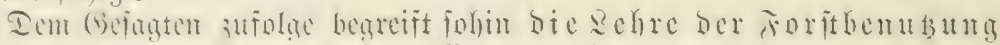

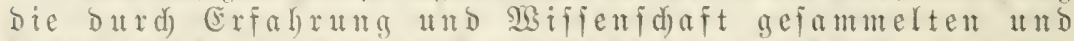

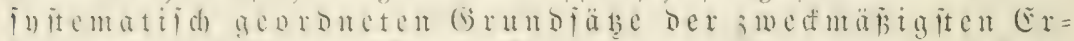
f

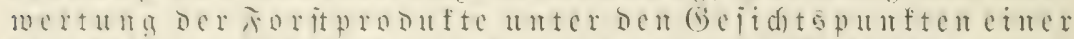
for af a d tiacu möglidjer Steigerung des Gewerbagewiunea.

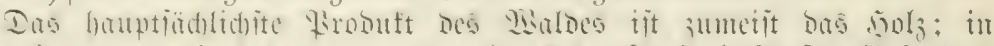

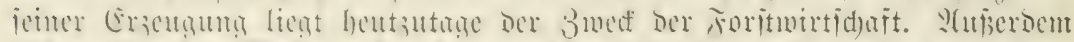
licfert aber ber

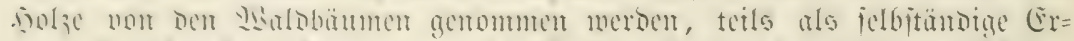

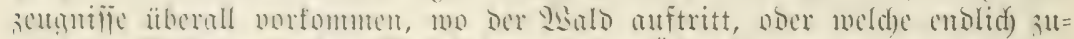

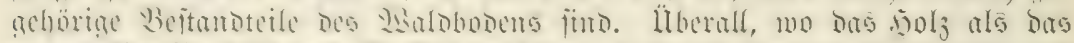

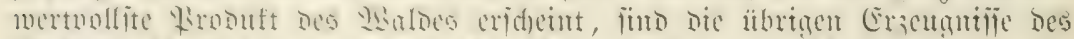

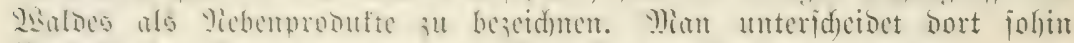

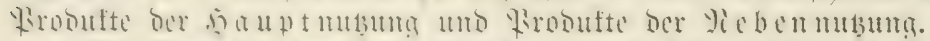

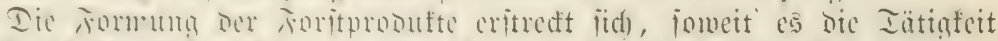

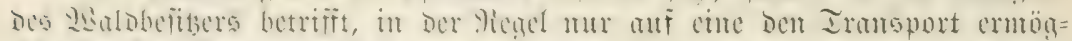

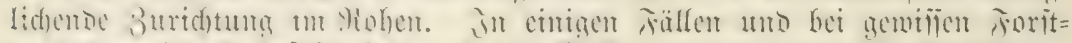

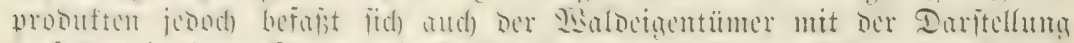

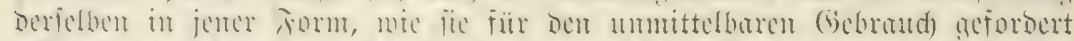

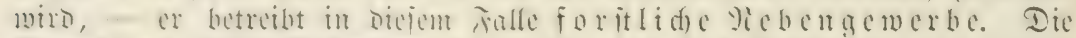

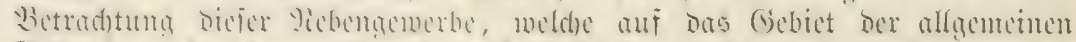

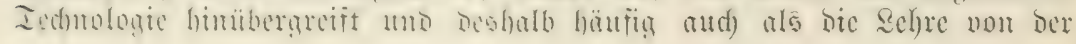




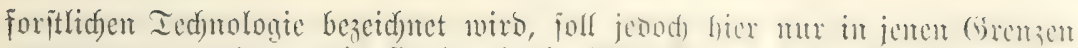

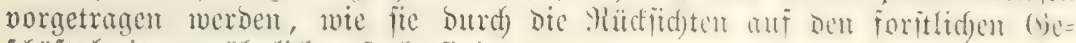

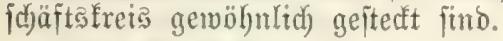

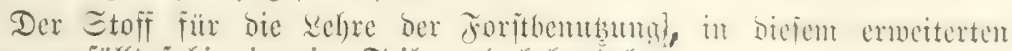
Sime, zerfällt pohin in vier Teile und behandelt

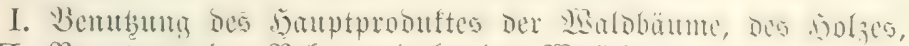

II. Bemuthung ber Reberprodufte Der Maldbä̈une,

III. Benubung ber Rebenprodufte bes Sigaldbobens,

IV. Benutzung Der Bejtandeile bes Malobodent jelbit. 



\section{Eriter exeil.}

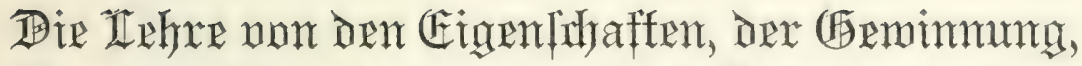

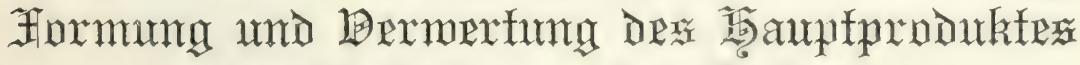

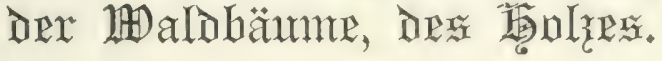





\section{Eriter 2lbichnitt.

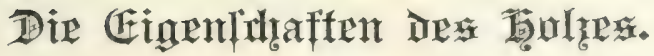

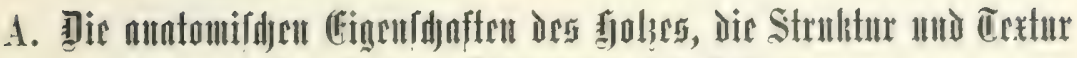

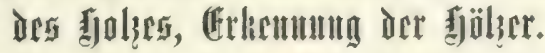

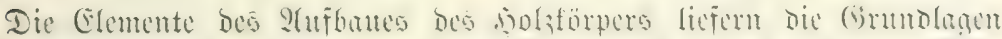

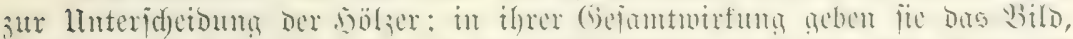

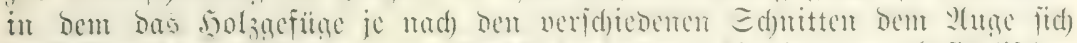

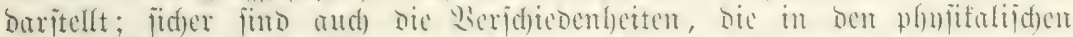

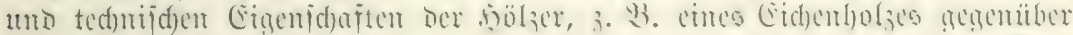

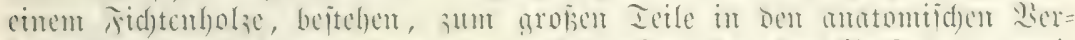

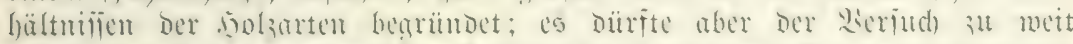

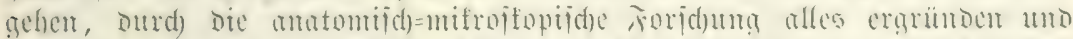

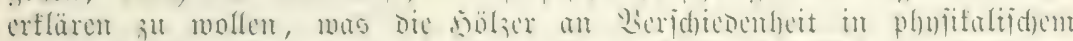

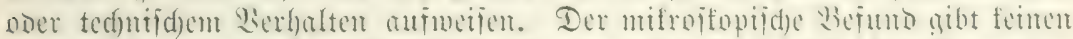

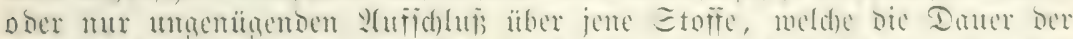
bölser bedingen, aibt teinem

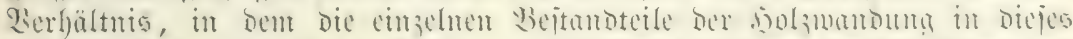

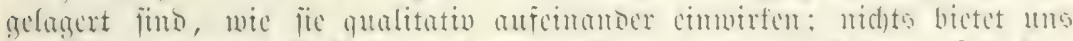

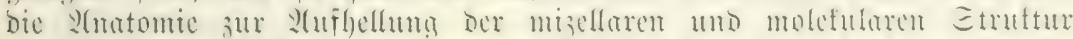

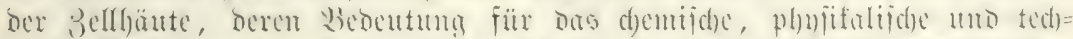

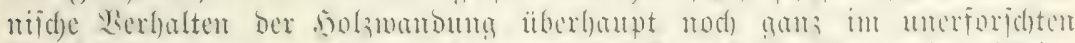

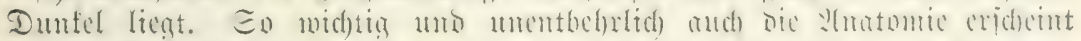

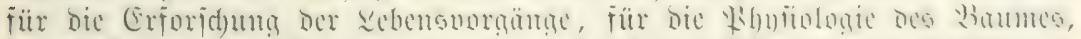

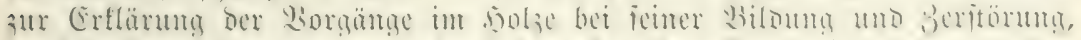

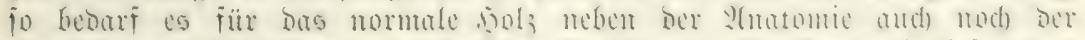

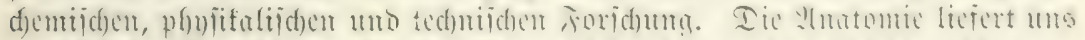

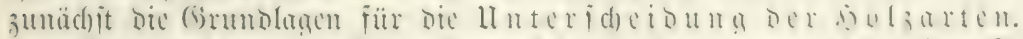

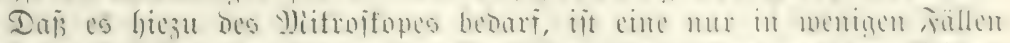

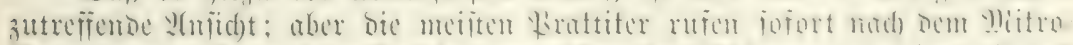

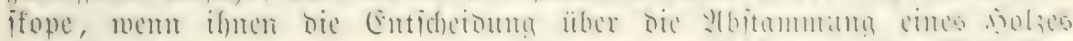

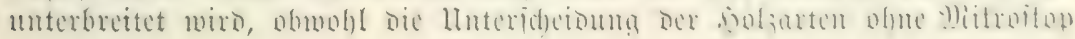




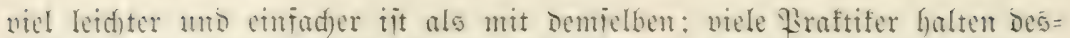

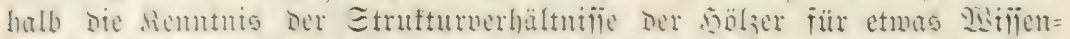

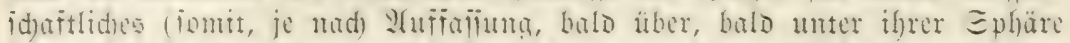

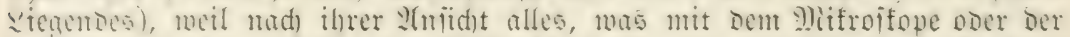

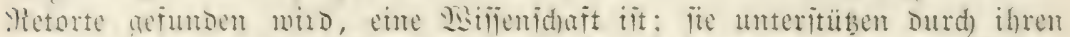

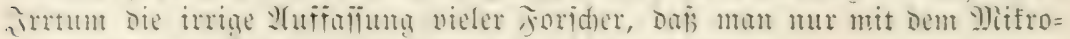

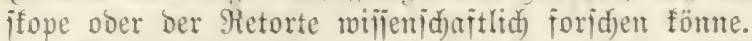

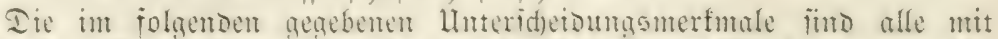

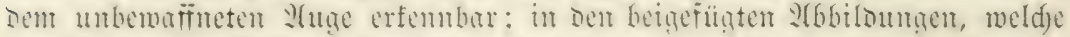

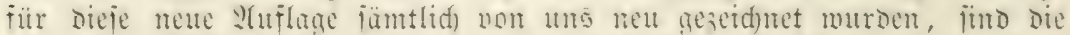

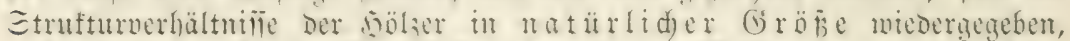

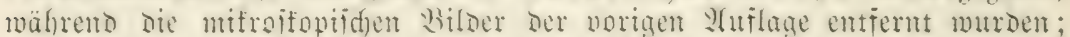

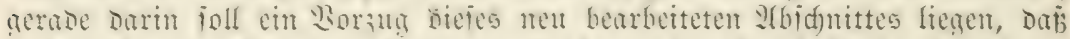
or Dom heutigen Etunopunfte ber praftichen uno wijlenidyaftliden joridyun

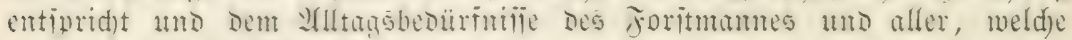

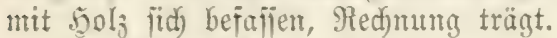

Tie Tatur hat bas Etunium ber an Den eriten Blid üherwältigenden

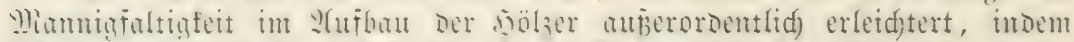

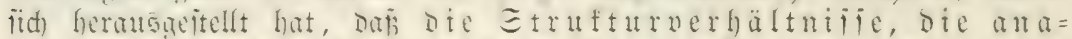

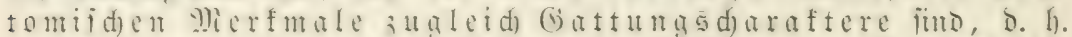

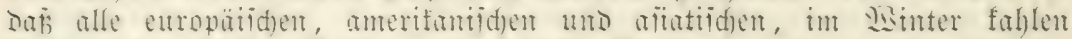

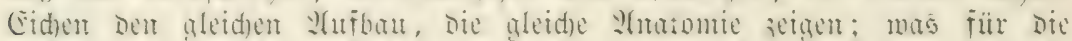

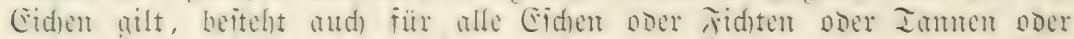
smetnadigen Tofren Der Eeftion Pinaster. Für alle Bürben ober ㄴiven=

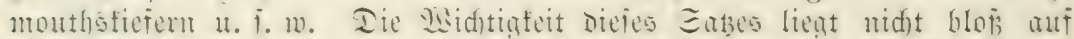

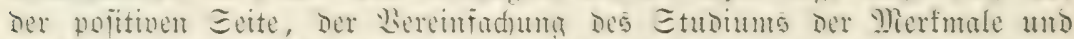
Etruftumerhaltnifie Der nolanten, fondern and) mü negativer Eette, indent

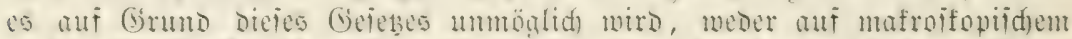

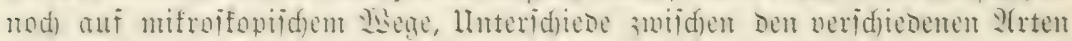

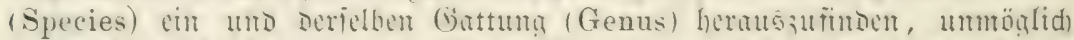

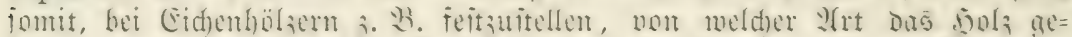

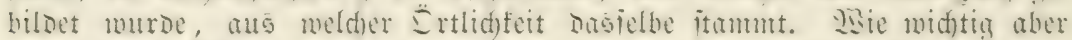

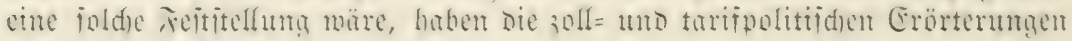
Der letsten Jahre beutlid) geseight.

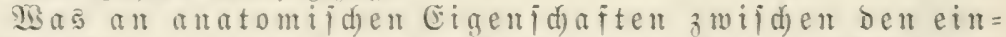
zelnen Arten (Species) einer (jattung, 3. B. innerbalb der

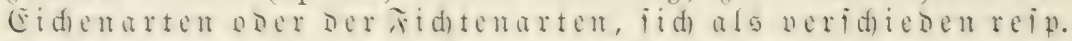
variabel erweipt, i it ad variabel nad) Jubivibuen inner=

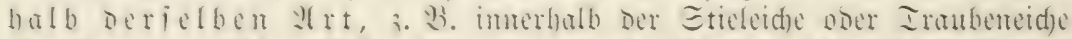

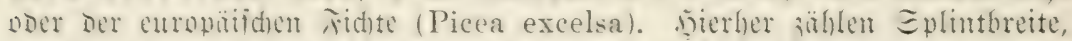

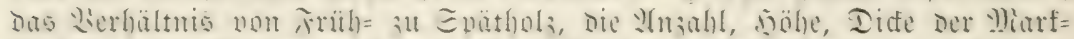

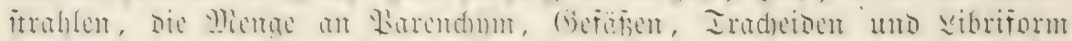

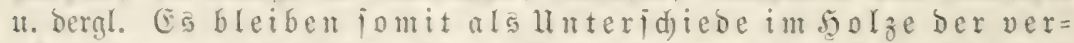

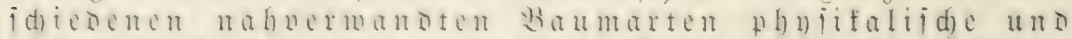
te d) n i

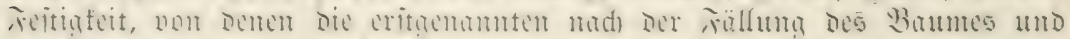

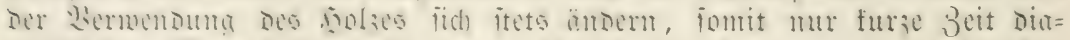

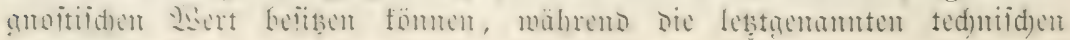




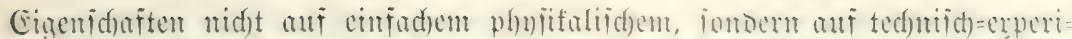

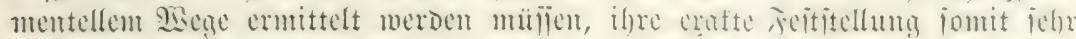

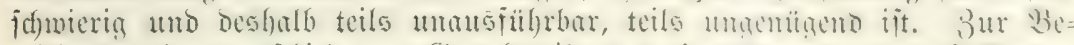

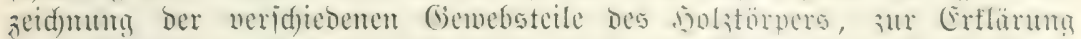
feiner Entitehung it es mentbelorlid), mit furaen

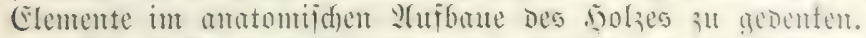

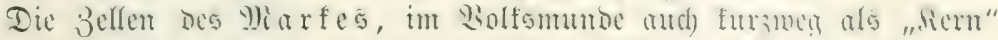

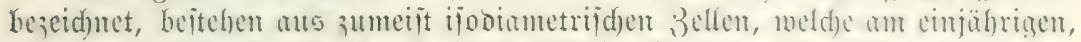

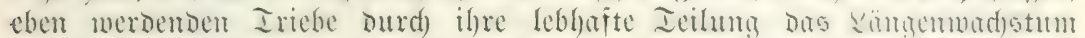

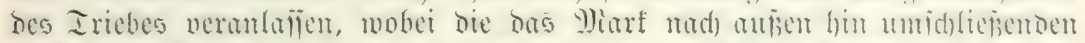

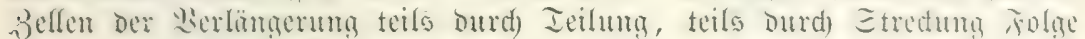
leijten. Dic Marfiellen nerlicren oit frübseitig ibren jubalt mo fïloren

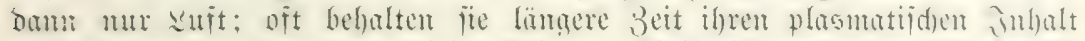

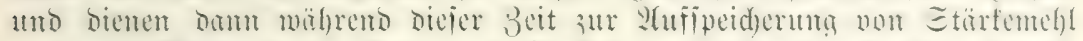

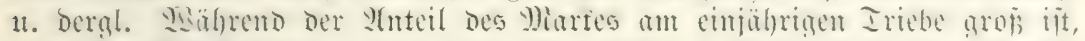

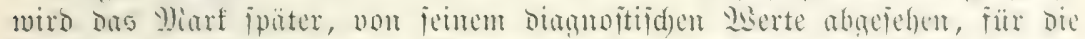

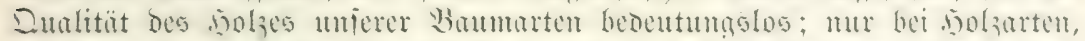

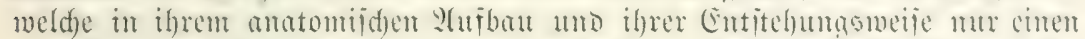

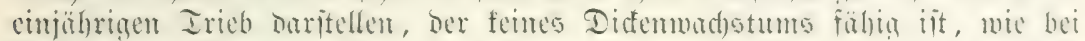
Lialmen un Des 5olzes entideibende Gtelle bei.

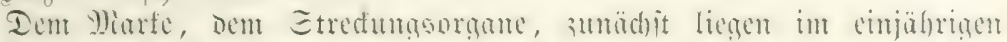

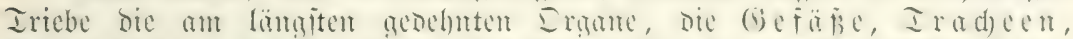

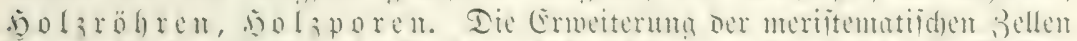

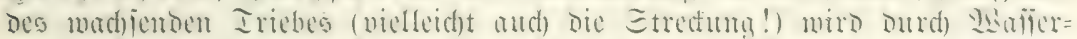

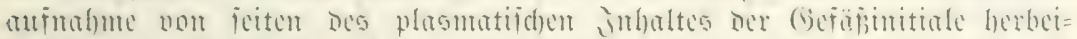

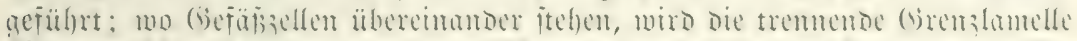

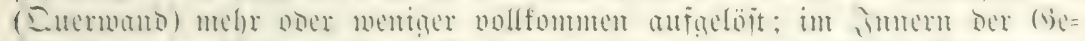

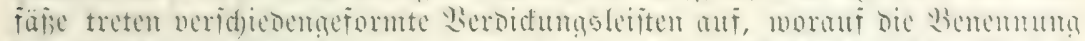

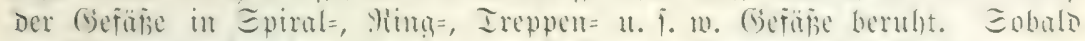

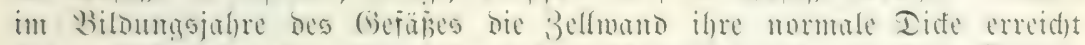

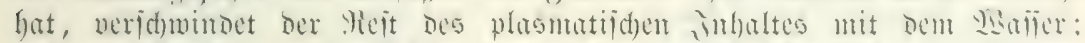

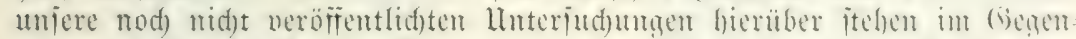

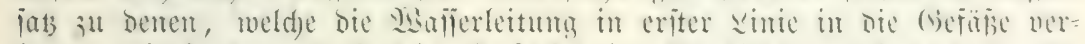

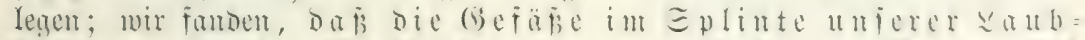
bolsarten a nidft beteiligen fönnen, weil fie normal zu feiner 3eit

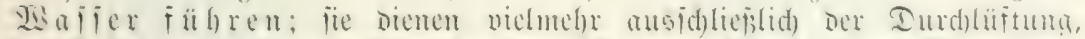

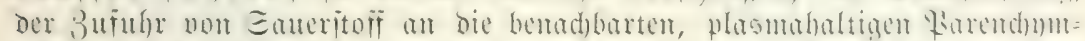

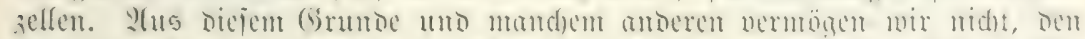

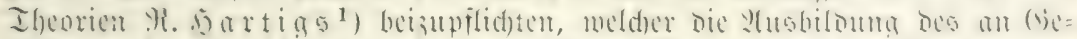

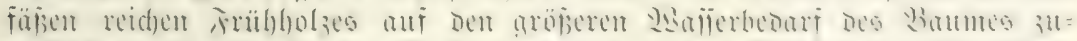

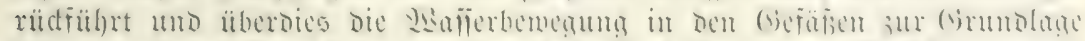

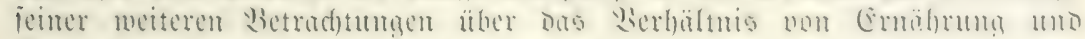
Bexdututumg zux Jejtigfeit bes Solzes mad)t.

Die $\begin{aligned} & \text { L } \\ & \text { a }\end{aligned}$

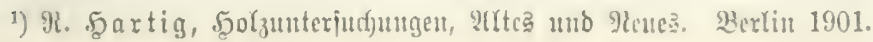




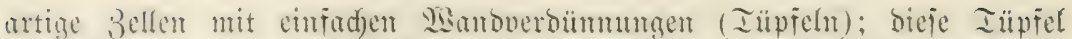

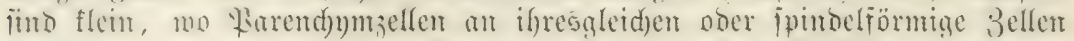

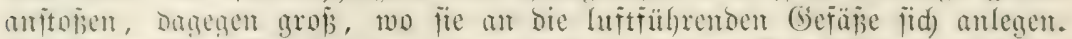
Die Wirendumzellen bebalten igren Jnbalt bei den Viabelfölgern, bis der

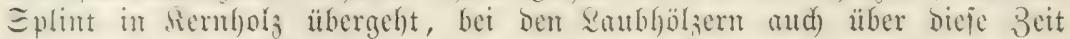

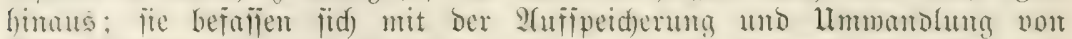

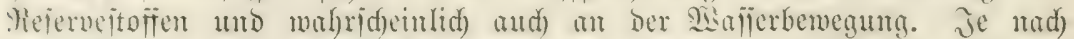

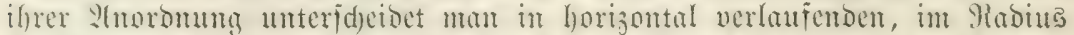

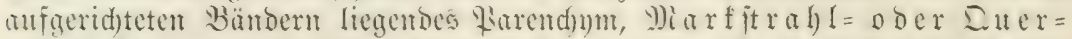

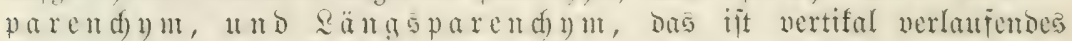
Larend)un, bas ben (Geräben anlicat, naragänge bilbet ober in jolse ser=

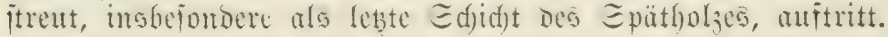

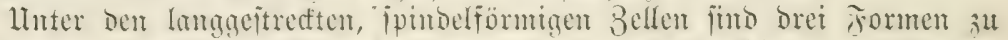

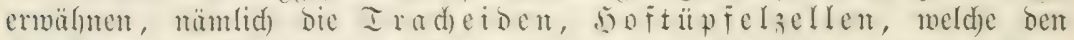

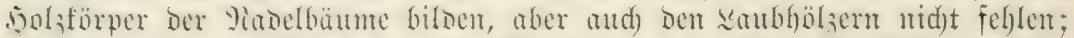

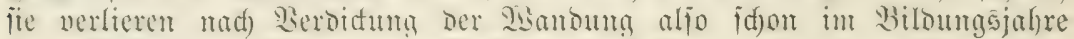

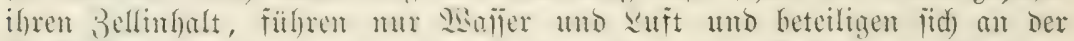

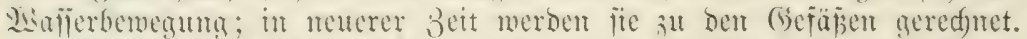

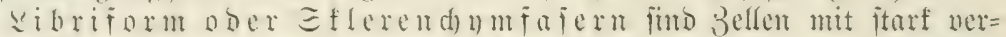
bidten

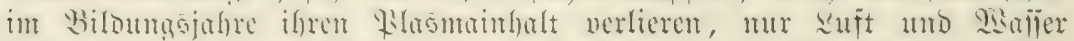

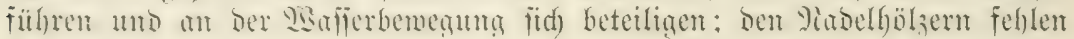
jie gan?.

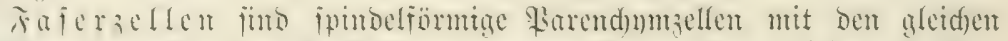

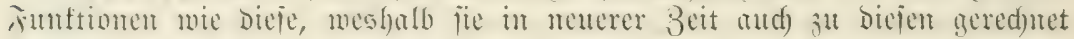
merben.

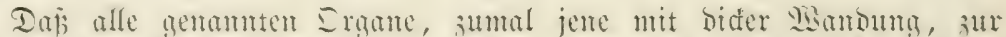

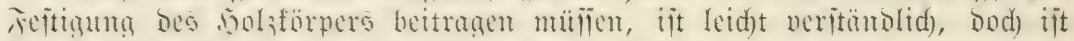

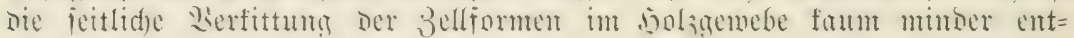

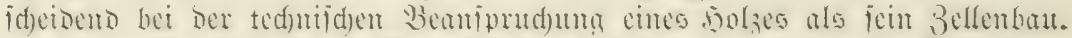

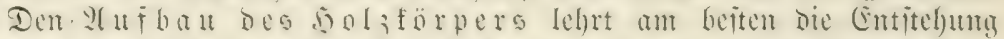

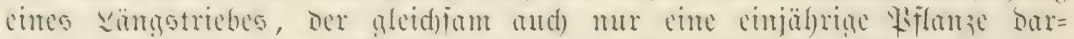

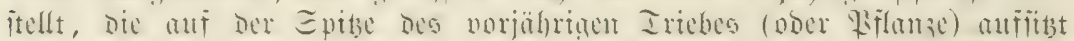

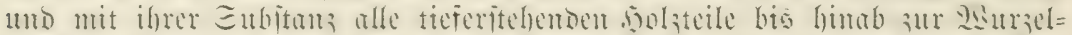

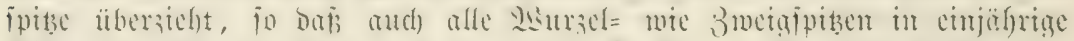

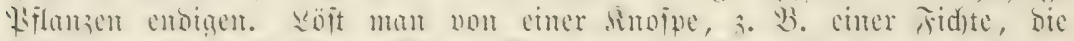

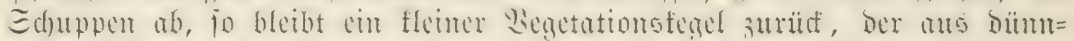

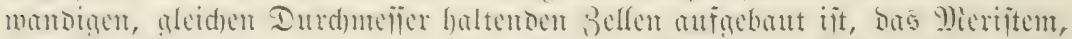

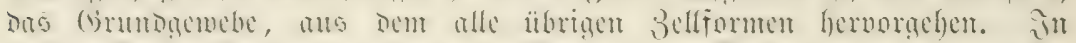

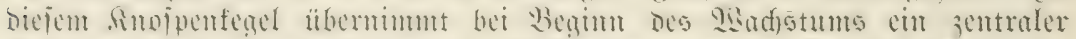

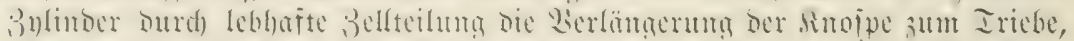

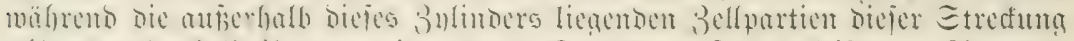

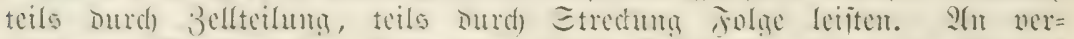

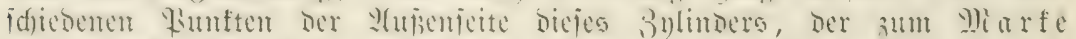

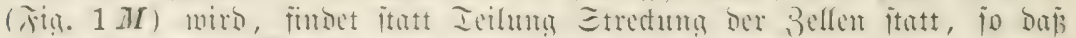

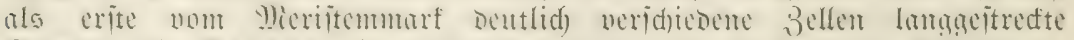

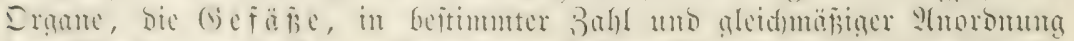

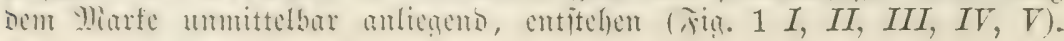




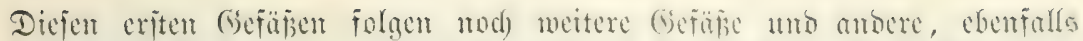

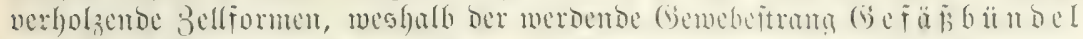

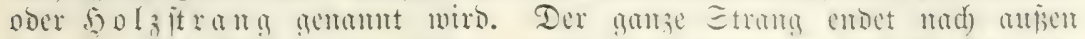

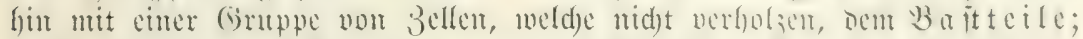

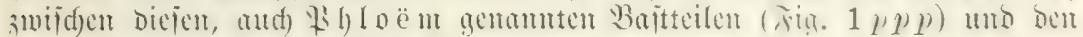
Dem Diarfe anliegenden Solzteilen ober X̃ylem (Jig. $1 x x x$ ) bleibr eime meriftematifde Bellidjidft, bas $\mathfrak{C}$ a m bium (Frig. 1 Icc', II cc'), weldees nod) in bem= jelben Jahre die Durdmefiervergrǫ̈̈e=

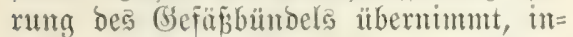
bem es nad) aujen lin, aljo zentrifugal, Bajtzelfen, nad) imen Gin, aljo zentripetal, Solzzelfen abteilt. 3wifden ben einzel= nen $\mathfrak{S}_{0} l_{3}$ iträngen $(I, I I, I I I$ ber Fig. 1) bleibt ein bas Marf $(M)$ mit ber Mimbe $(R)$ verbindendes idmales Bamb von

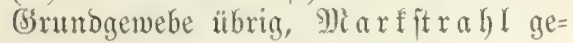

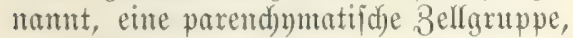
bie gleidjfan vom Miarfe atsjtrahlt und in ber Yimbe $(R)$ endet; aud imerfalb Des Wianfitralles entitelyt und in bem= jelben Jahre, vom Eambium ber (ibs= fäpbündel ausgeheno, die Eambia ber

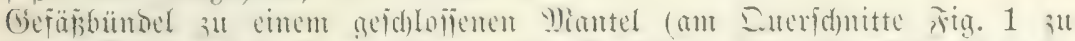

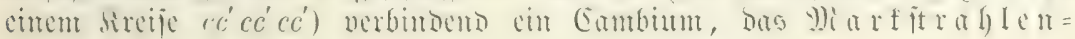

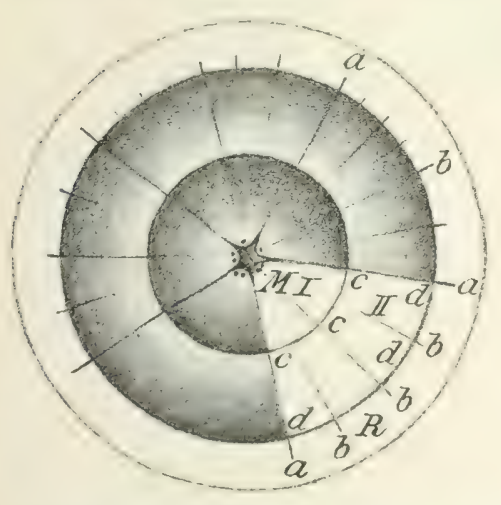

jig. 2.

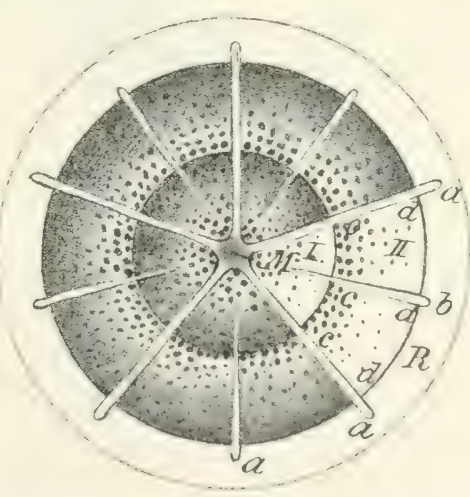

Jig. 3.

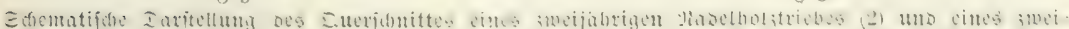
jäbrigen Saubholztriebes (3). I Jilbung bes eriten, II Silbung bes zweiten iahres; YIa primäte,

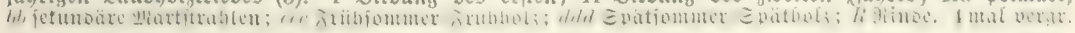

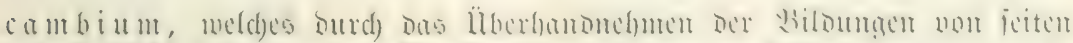

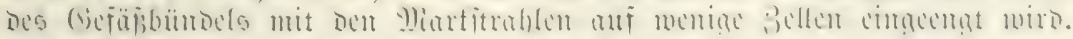

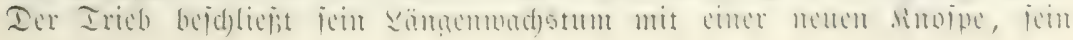


Didenmadtotum infolge ber fambialen Iätigfeit mit cinem vormiegend ants

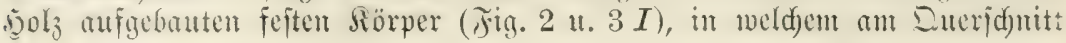

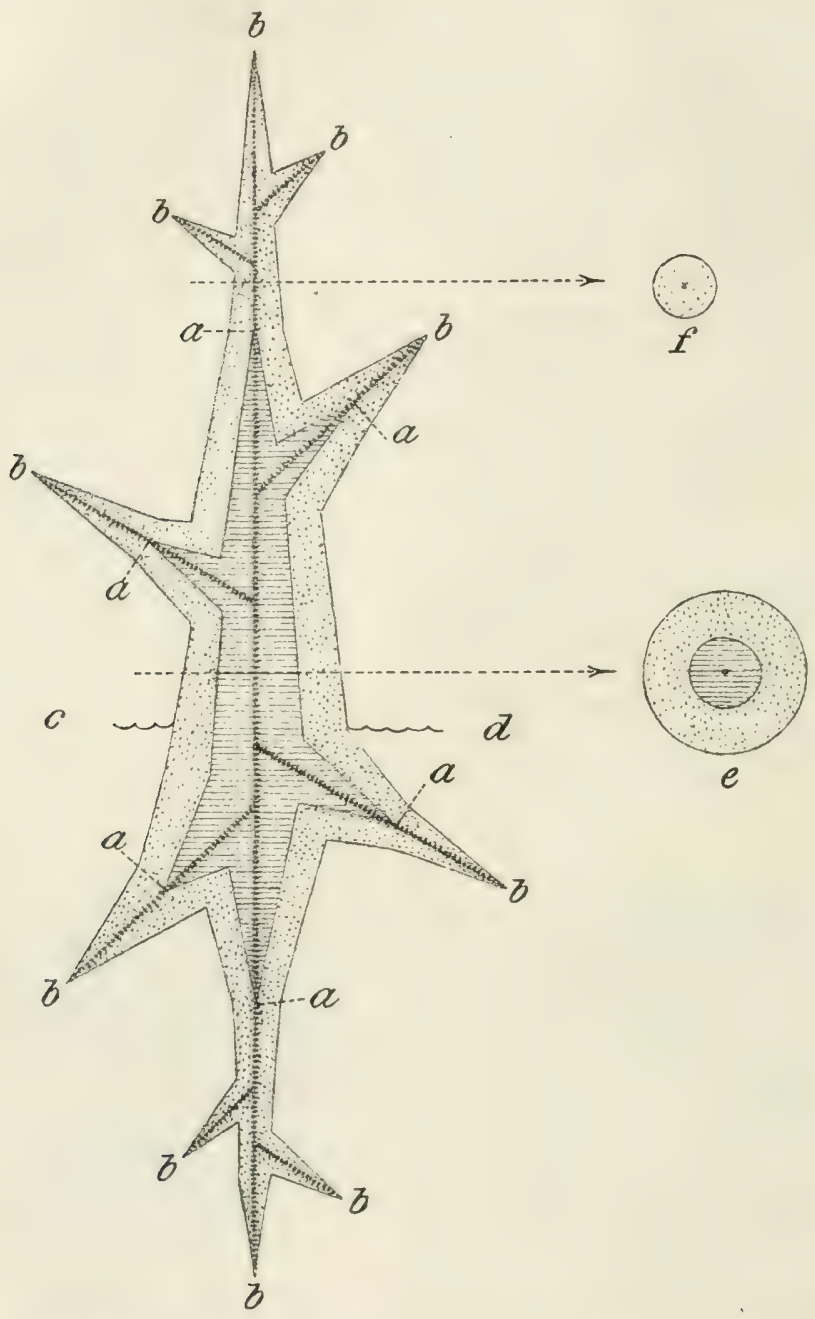

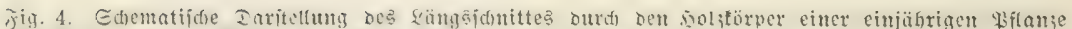

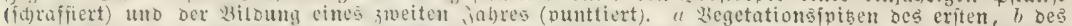

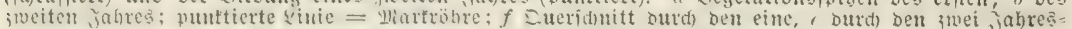

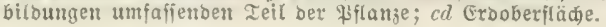

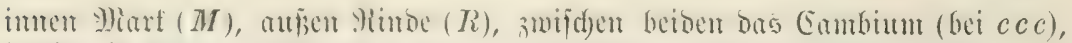

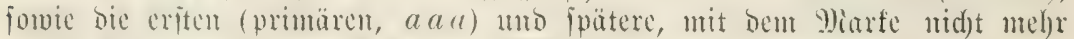

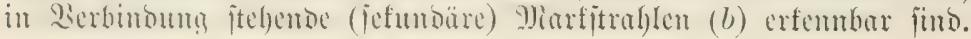




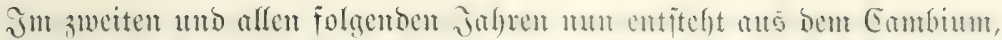

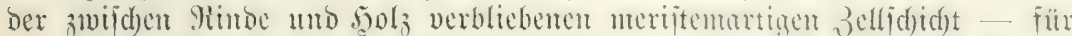

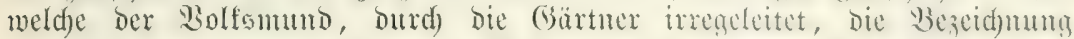

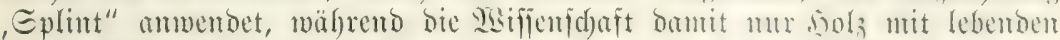

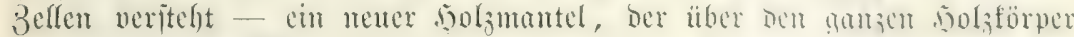

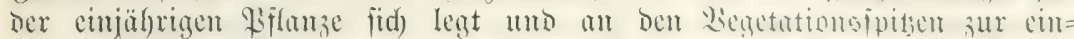

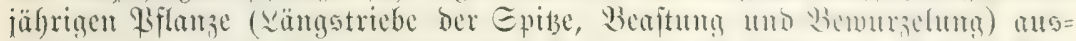

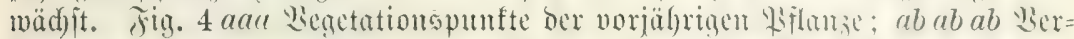

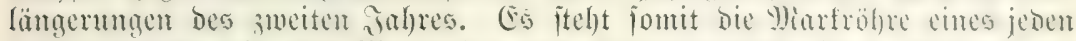

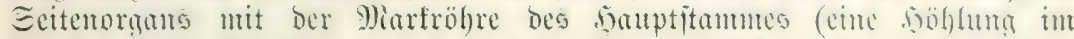

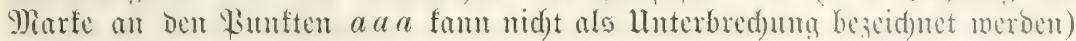
in Berbintoura.

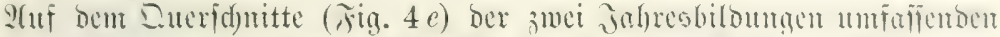

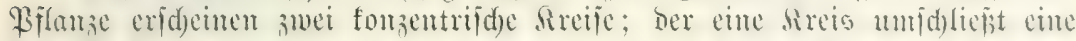

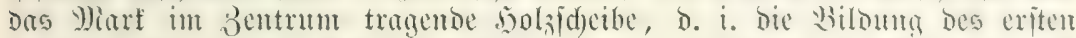

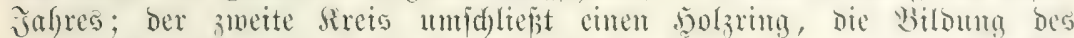

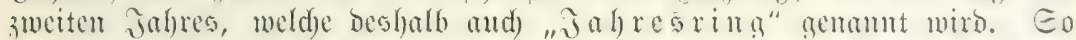

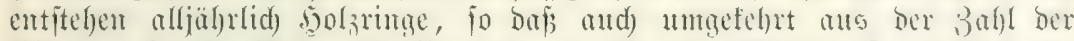
Rimge anf bas ?llter bes Bantes an bem betweffenten Eutridntitt ge= idchlofien werden fant

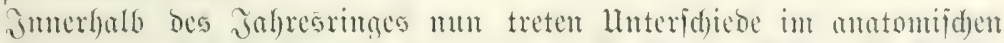

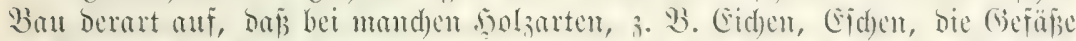

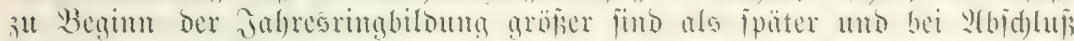

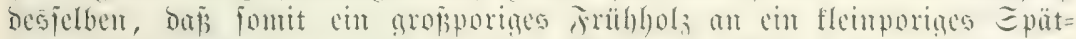

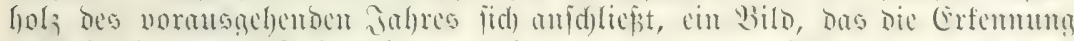

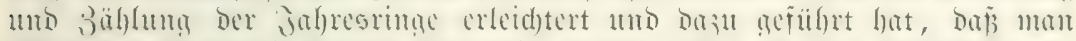

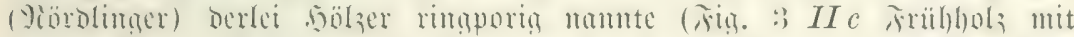

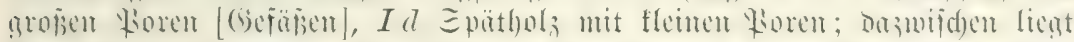

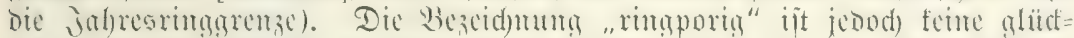

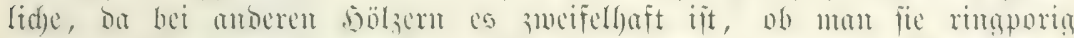

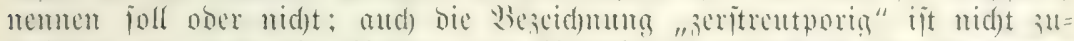

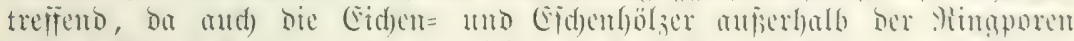

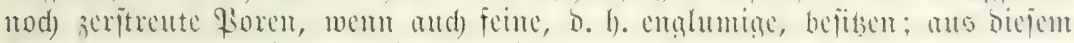

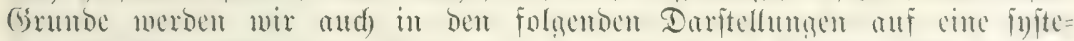

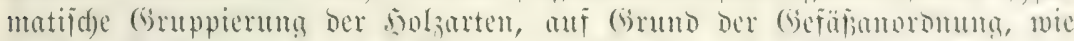

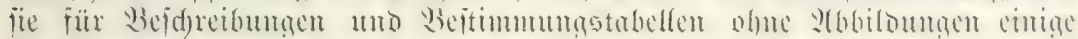
Dienite leipten mögen, ganz abiehen.

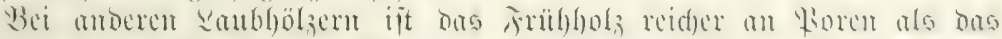

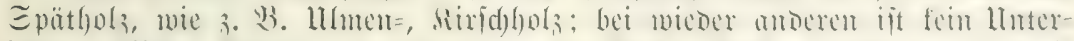

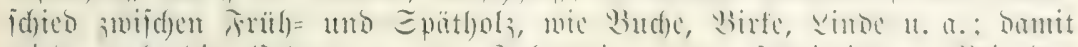

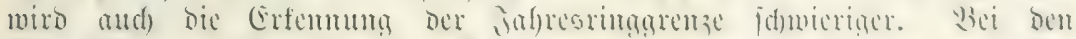

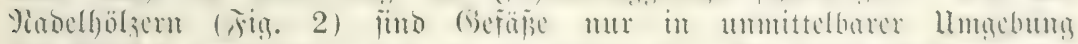

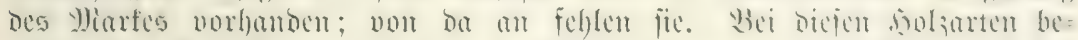

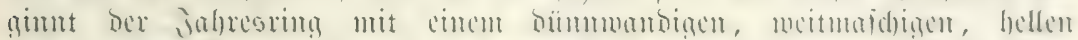

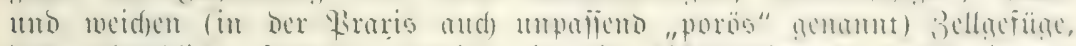

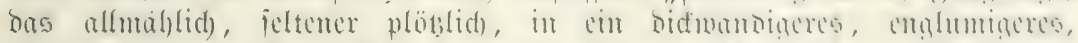

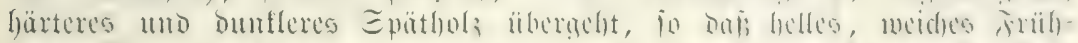

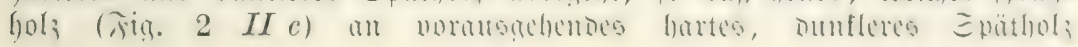




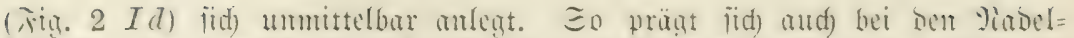

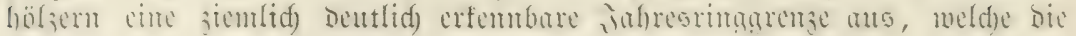
Qlltersermittlung ermöglidyt.

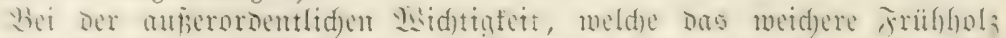

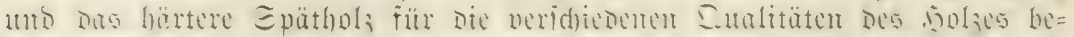

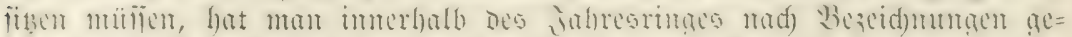

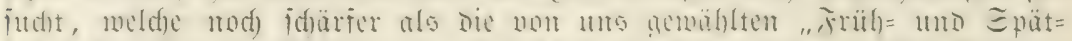

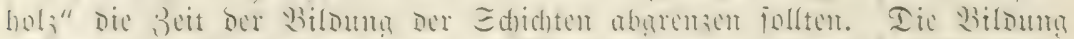

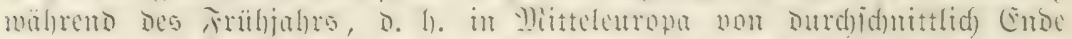

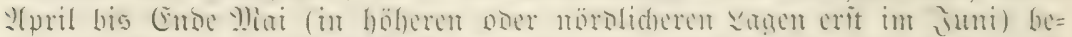

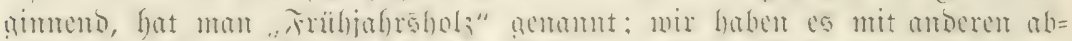

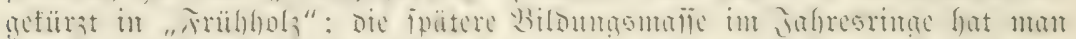

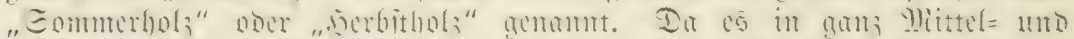

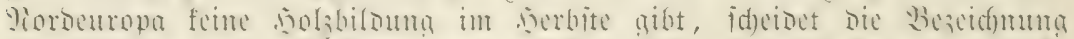

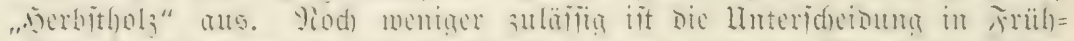

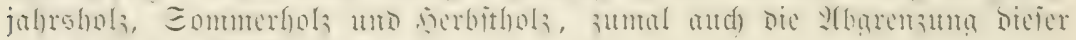
Edjidjten Der SBillfür freien Epielrantm läpt.

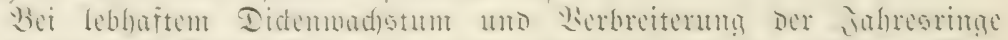

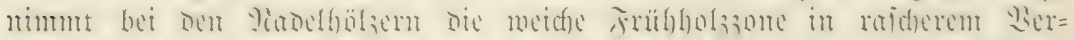

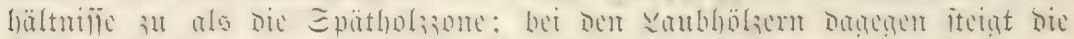

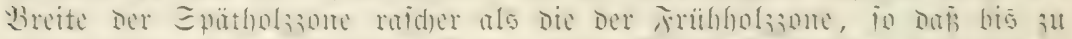

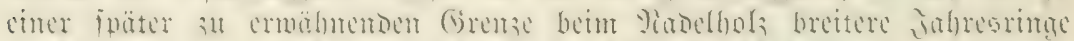

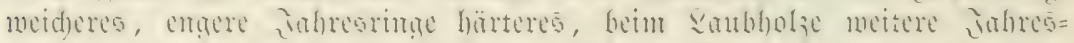

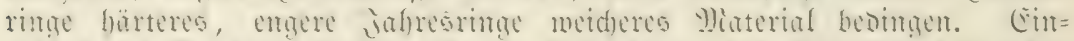

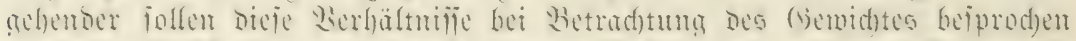

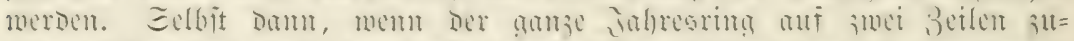

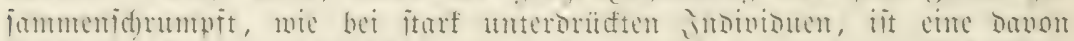

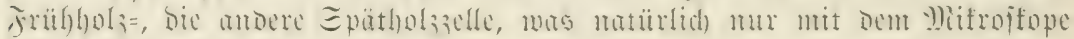
feitgeitellt merben fant.

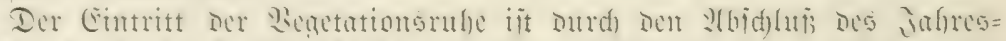

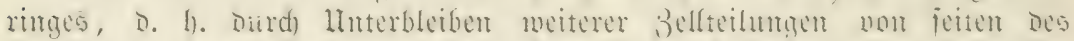

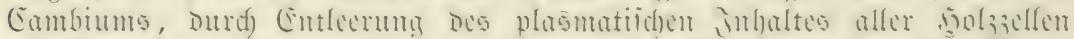

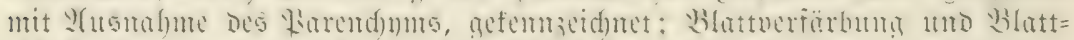

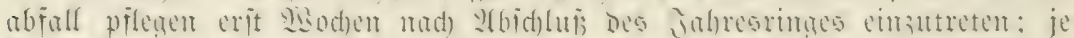

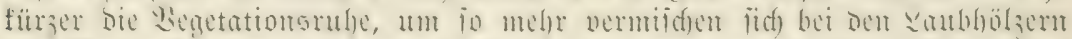

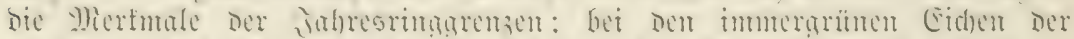

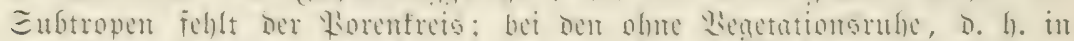

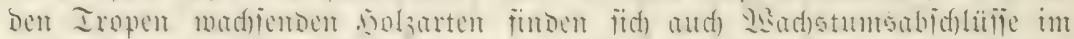

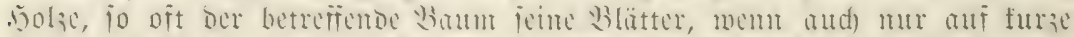

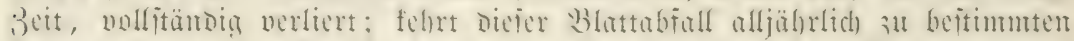

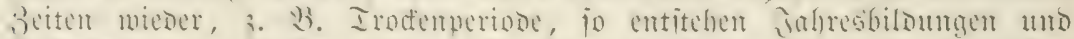

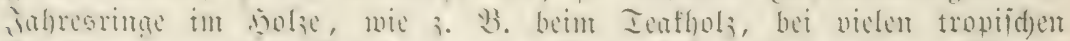

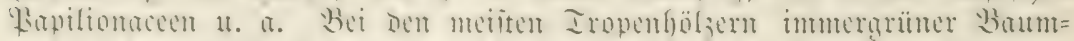

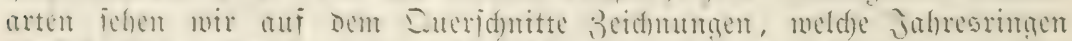

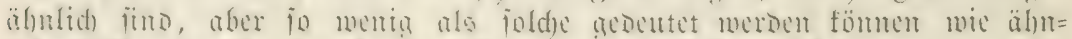

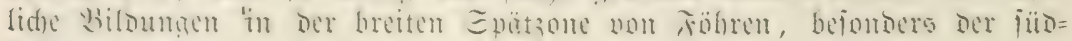
lid) Iten S(rtert.

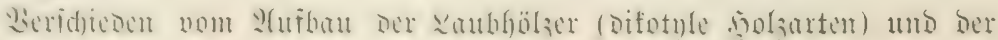




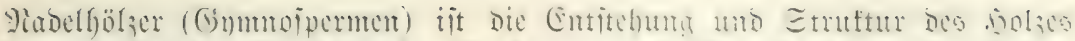

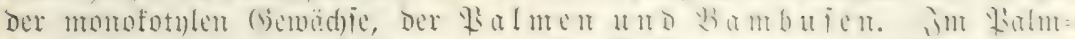

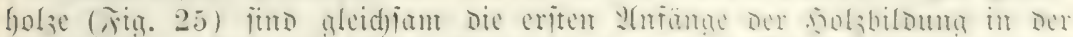

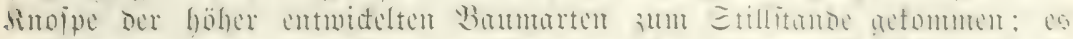

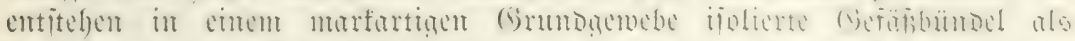

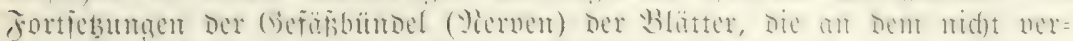

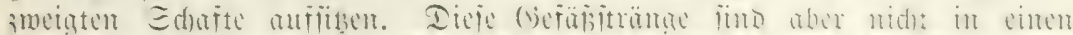

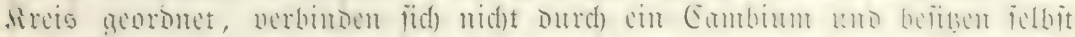

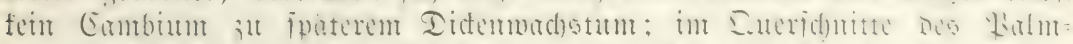

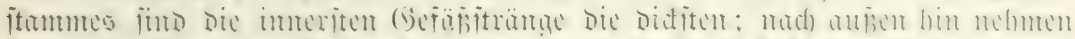

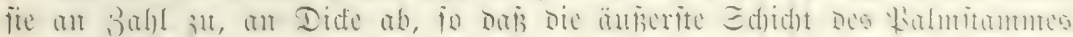

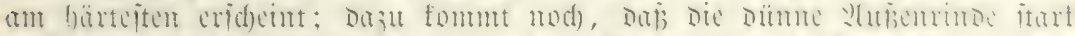

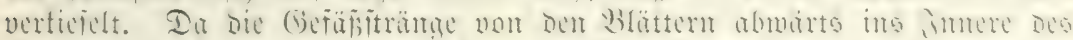

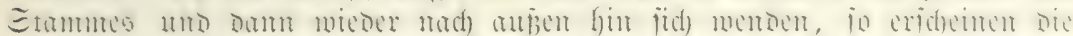

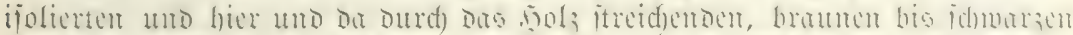

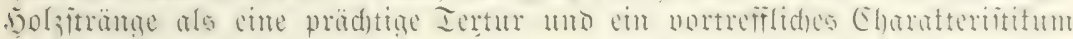
Der Balmthölzer ( ̃otg. 25).

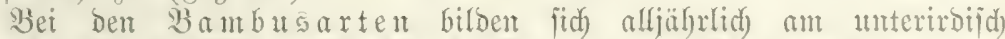

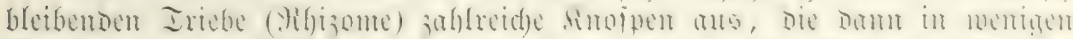

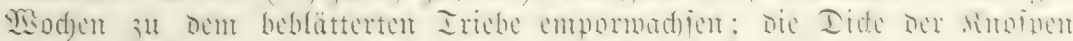

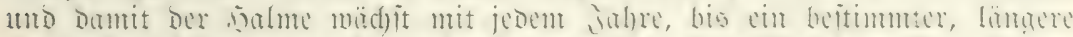

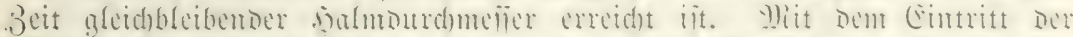

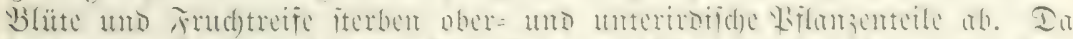
bei ben

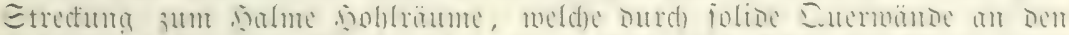

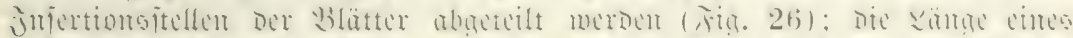

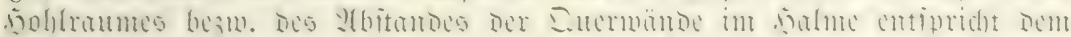

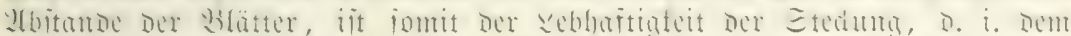

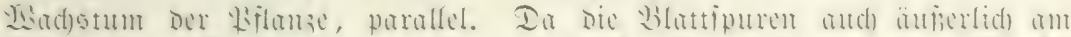

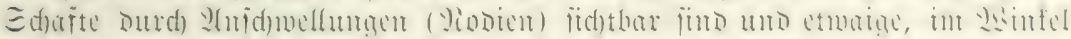

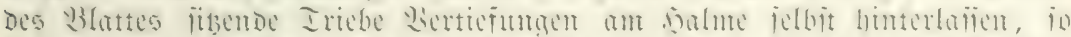

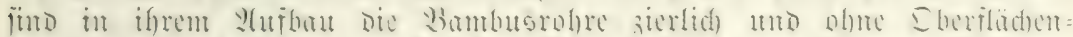

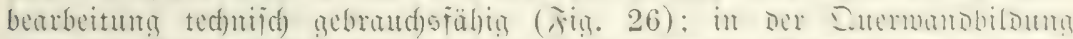

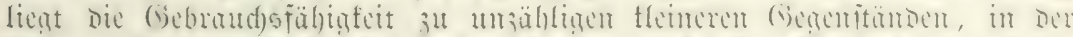

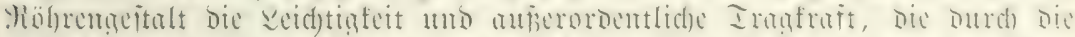

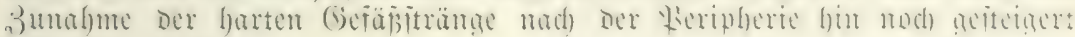
wiro, begründet.

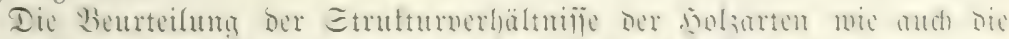

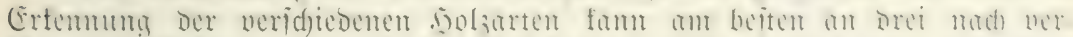

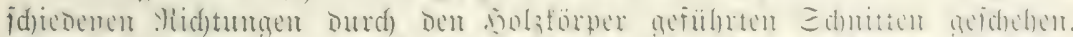

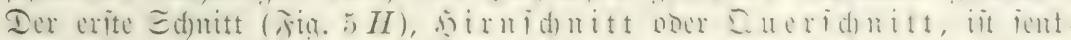

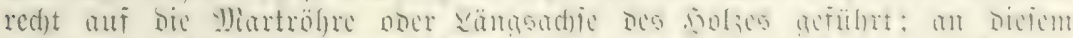

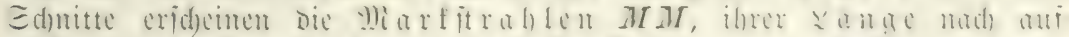

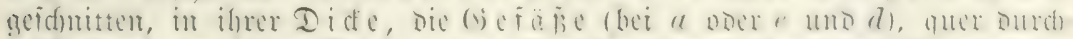

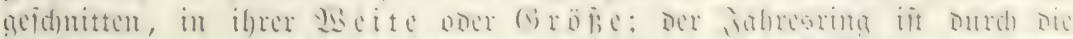

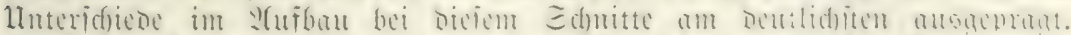

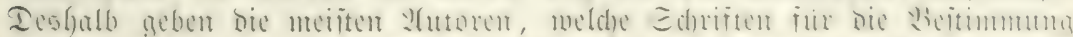

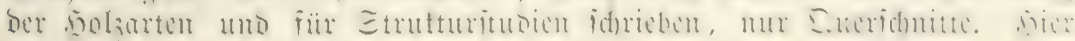




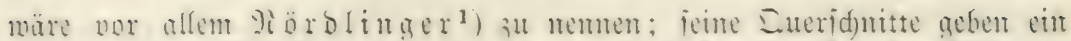

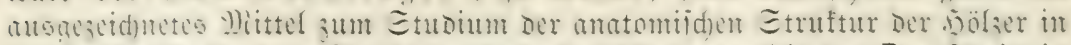

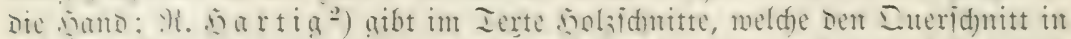

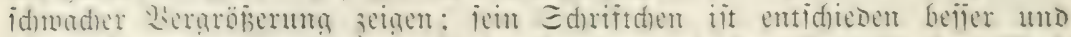

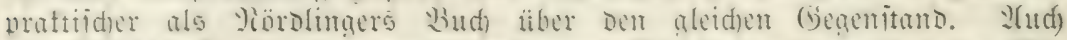
Dr.

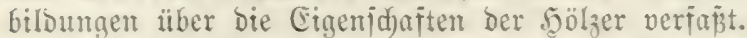

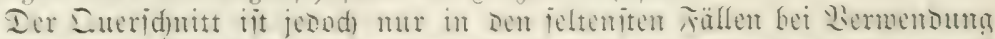

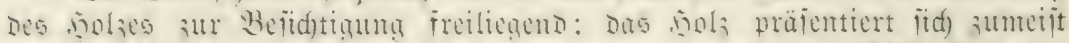

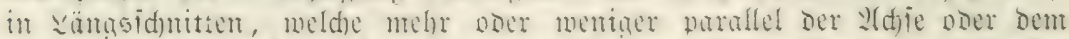

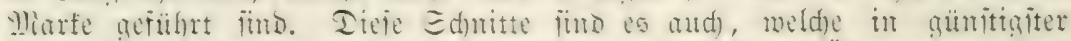

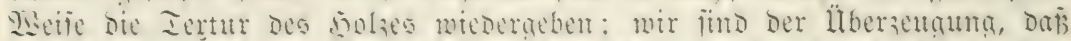

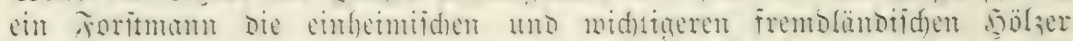

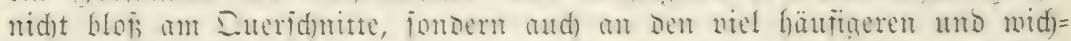

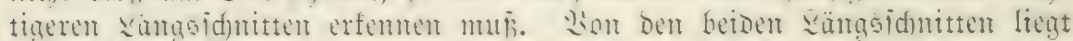

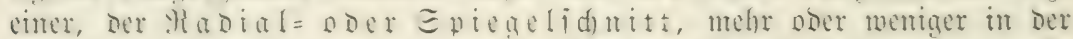

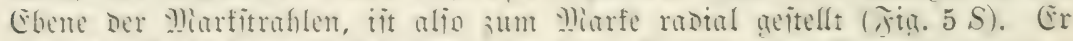

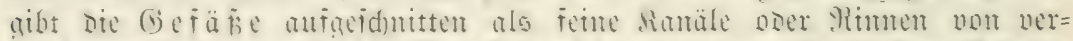

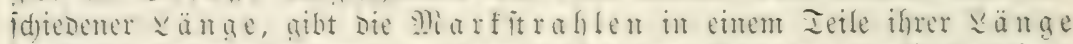

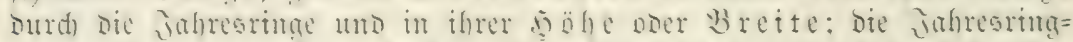

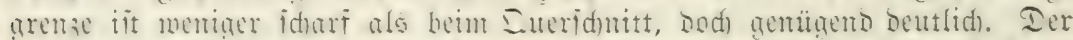

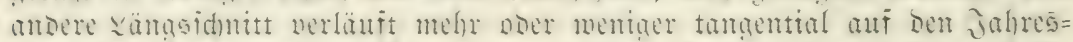

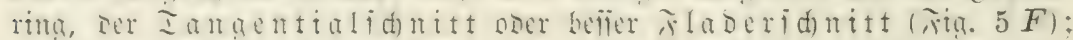

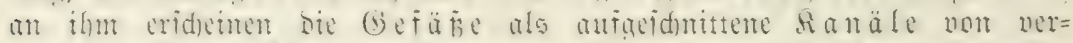

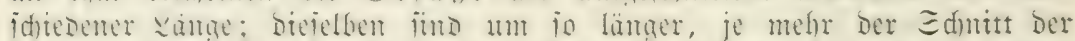

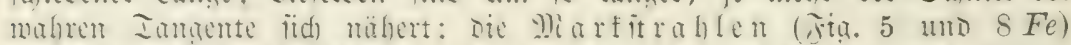

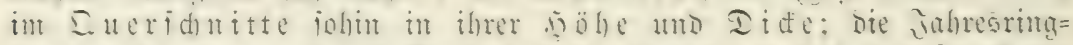

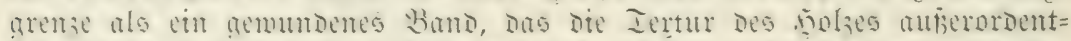

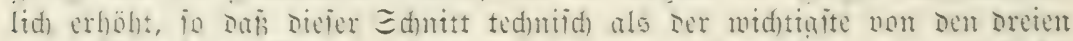

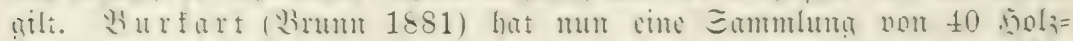

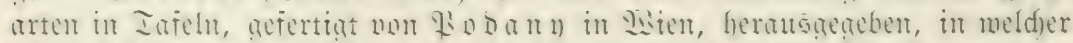

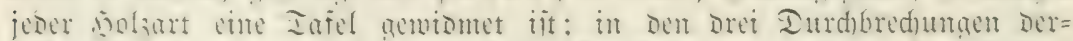

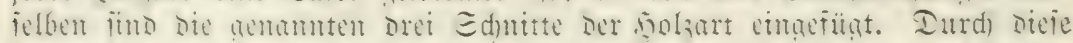

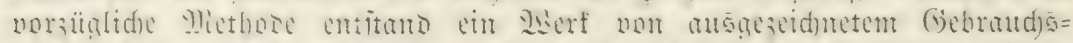

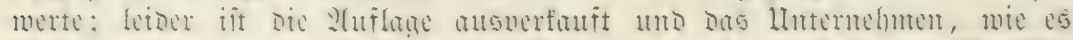

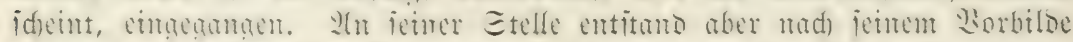

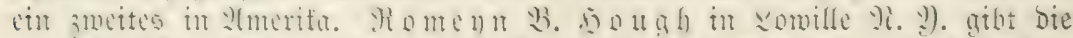

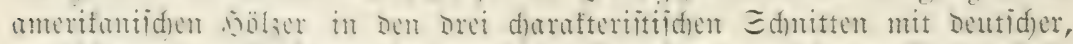

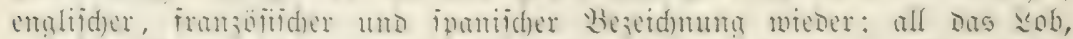

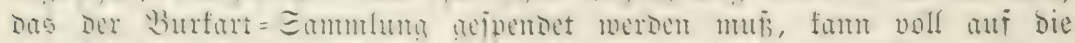

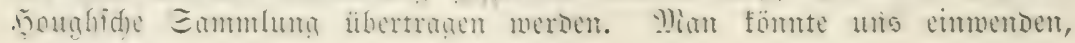

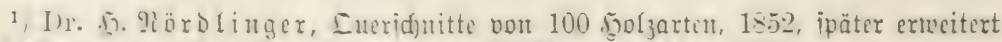

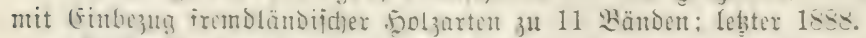

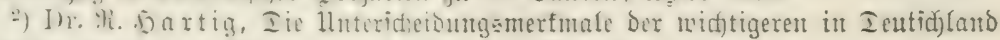

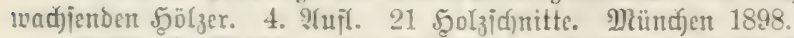

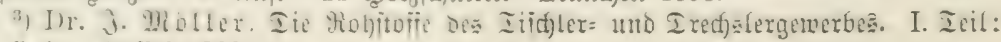
Ia Şolz. Staijel 1883. 


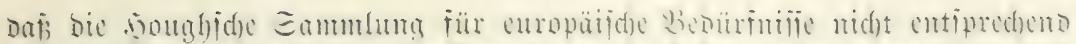

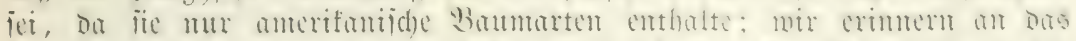

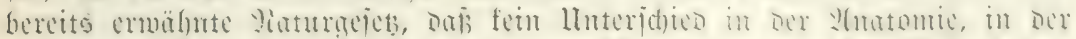

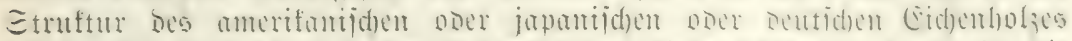

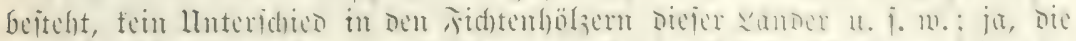

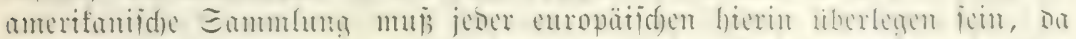

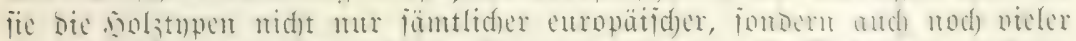

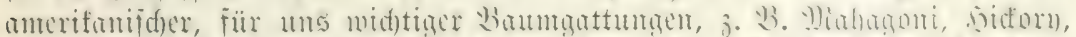

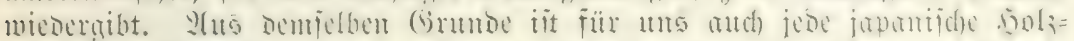

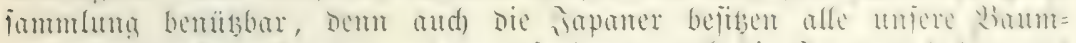

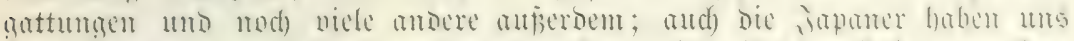

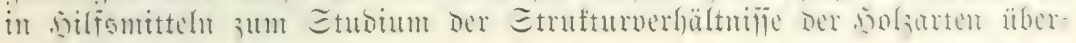
troffett.

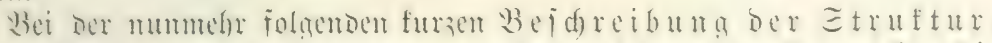

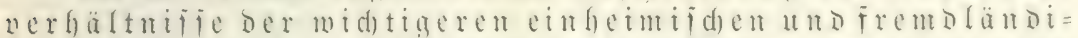

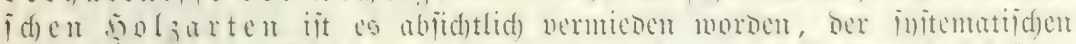

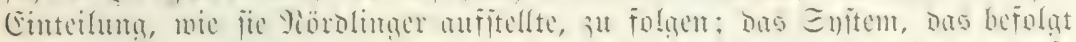

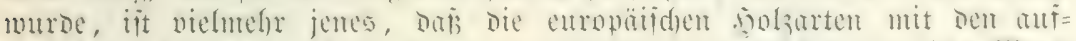

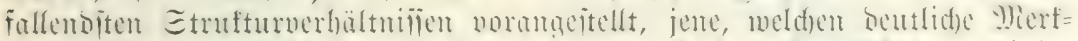

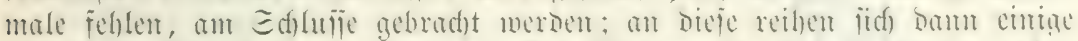

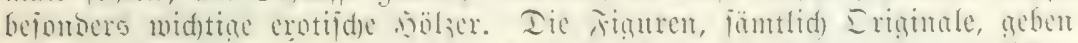

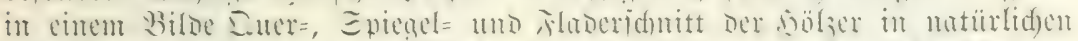

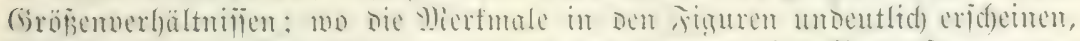

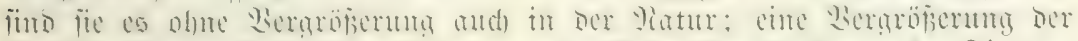

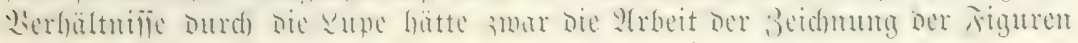
erleidjtert, aber jidjer ifjen (Sebrandjswert vermindert.

\section{a. Saxbhölzex.}

\section{1. Đic Eidjenarten, Gattung Quercus,}

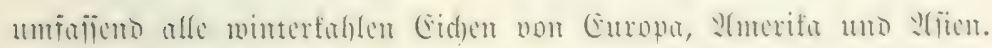

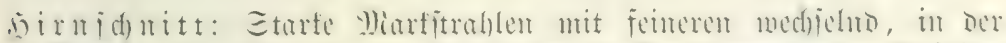

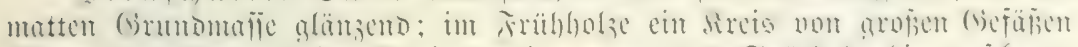

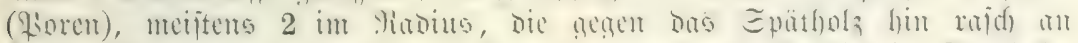

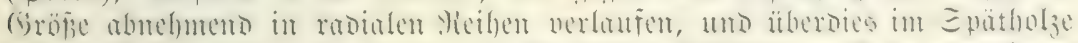

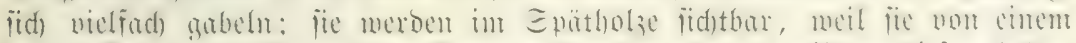

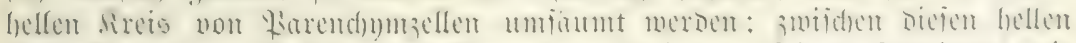

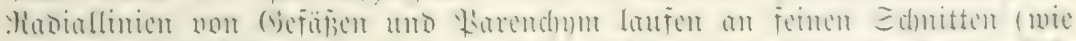

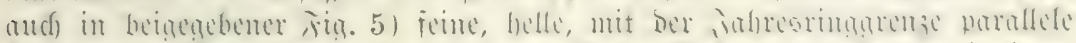

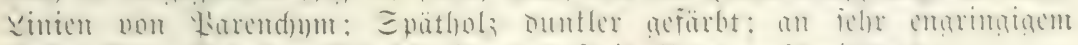

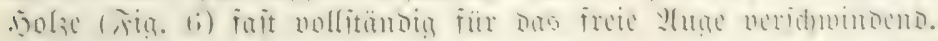

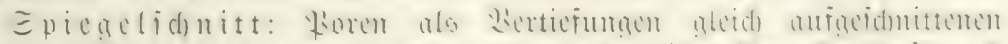

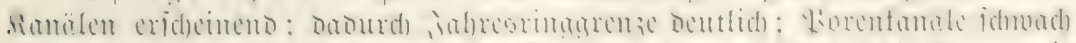

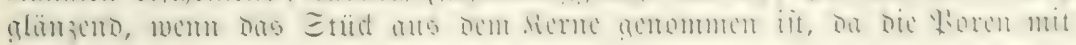

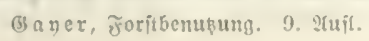




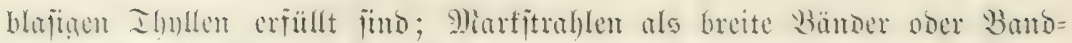

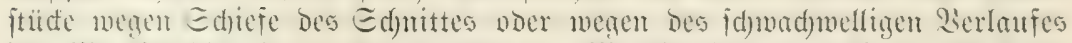

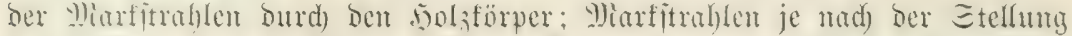
bes Ed)uttes sum vid)te bald sunfler und matter als bie lintgebung

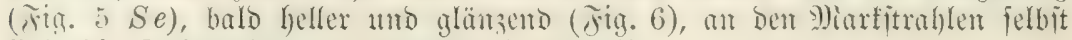
find bie Sabresbildungen burd) feine dunfle ¿inten erfembar; bas im Sirnjonitt ermälnte tangentiale Parendym aud am Rabialid)nitt als feme, Den Marfitrablen parallele sinten fidjtbar.

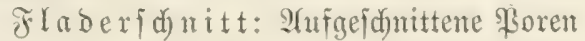
als melhr ober minder lange Jurdjen ober

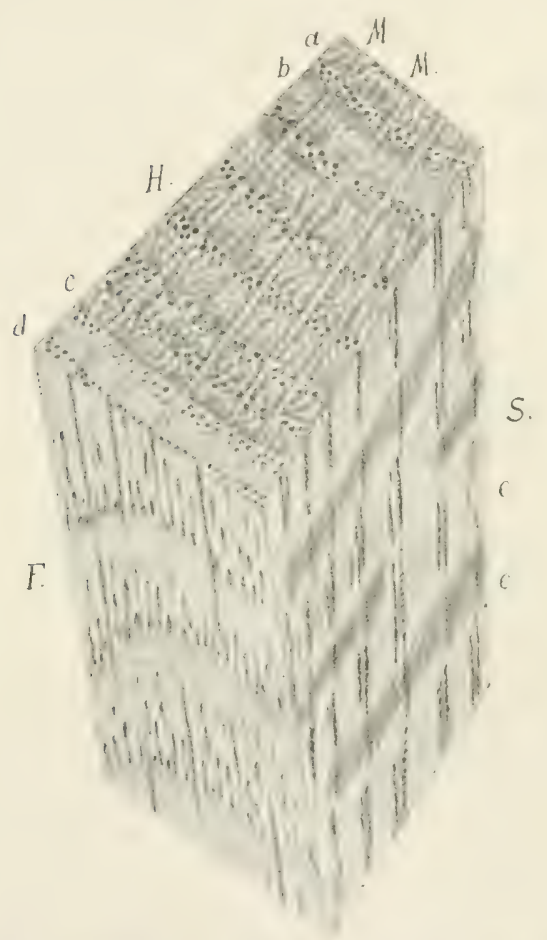

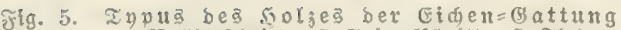
unereus. $H$ sirnj(f)nitt, $S$ Epiegeljdnit, $F$ flaber= fünitt; II II Sharfitrablen; $d-e$ Eplintbols; $e-a$ Rernbolz.

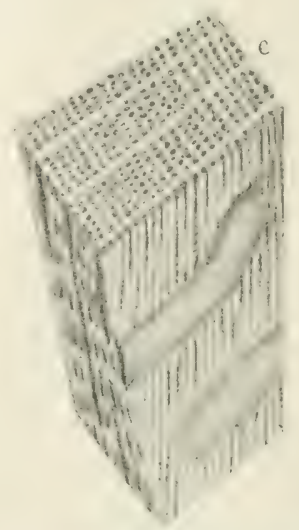

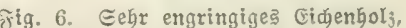
Jabresting burdi einen fireis toeiter Foren bezeidynet.

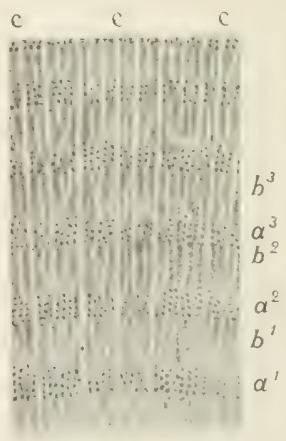

Fig. 7. 5013 ber rotetge. $a^{1} a^{2} a^{3}$ Torenzonen Des Triibholzes; $b^{1} b^{2} b^{3}$ Bonen bes Spüthol $3 e$; $c e \varepsilon$ sllart: ftrablen.

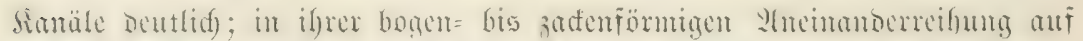

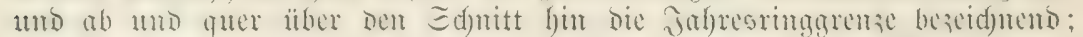

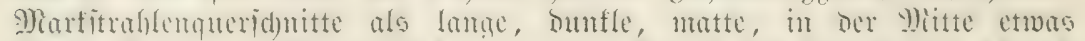

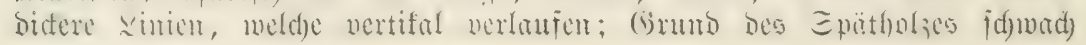
quergebändert glänzend. 
Splint 1-3 cm breit, hell, Seru von medjeluber Farbe; in

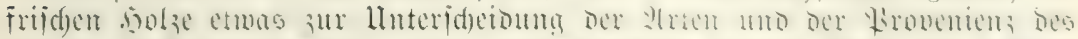

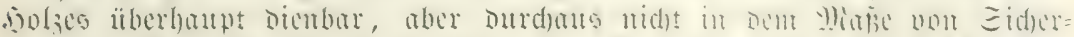

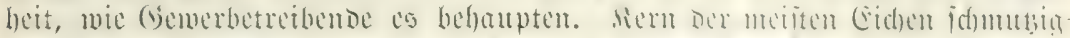

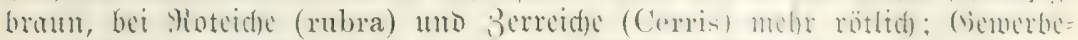

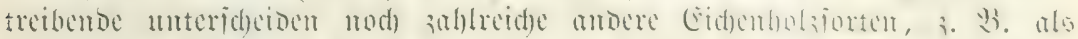

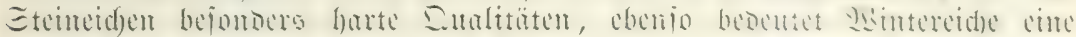

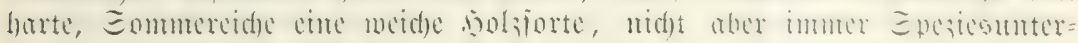

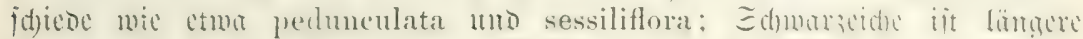

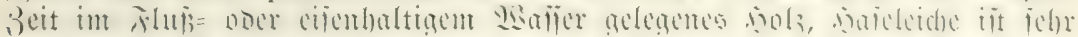

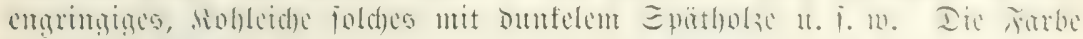

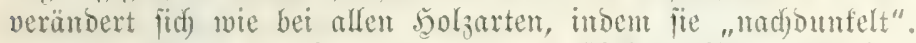

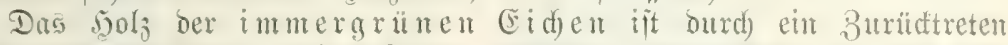

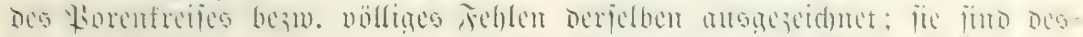

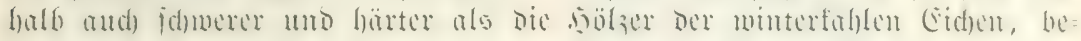
jitzen aber zumeift mur Bremtholzwert.

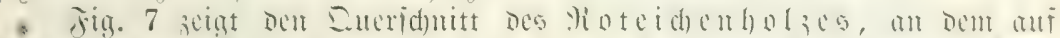

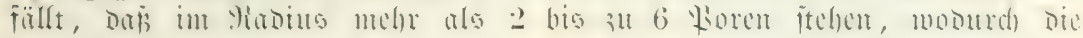
etwas weidjere Bejdaffenteit bes Syolzes fid erflären witroe; mit bem Salter bes baumes funft aber mit ber Jabresringbreite bie \$orenzahl, io Dẩ das Mierfmal als cin jtets zu= treffendes nidgt bezeidunet werben foum.

\section{Dic \$udienarten, Gattung Fagus.}

ımfañend die Buduen, it Čıropa, Itmerifa und $\mathfrak{Z}$ (iien.

Sirmidnuitt: Gefäbe uid)t jidftbar, an bümen Durdfiudftigen Ed)uitten jefor fem, jelsr zalglreid) uno ganz gleidymäßjig verteilt; 9)iart= itrablen teils itarfe, teils icine, itets glänzende sinien, bald heller, bald bunfler ala bic Grumbmaije, je mat) Sidyteinfall; Spätholz buntler alos

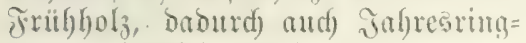
grenze jientid) beutlidf.

Spiegelidntit: Jathresting= grenze als duntle verichiconen breite Rinie nod) ocutlid); 9) artitrublen je nod Ridjteinfall bald belle und glümzente, forto dunfle uno matte Bumber

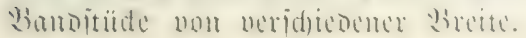

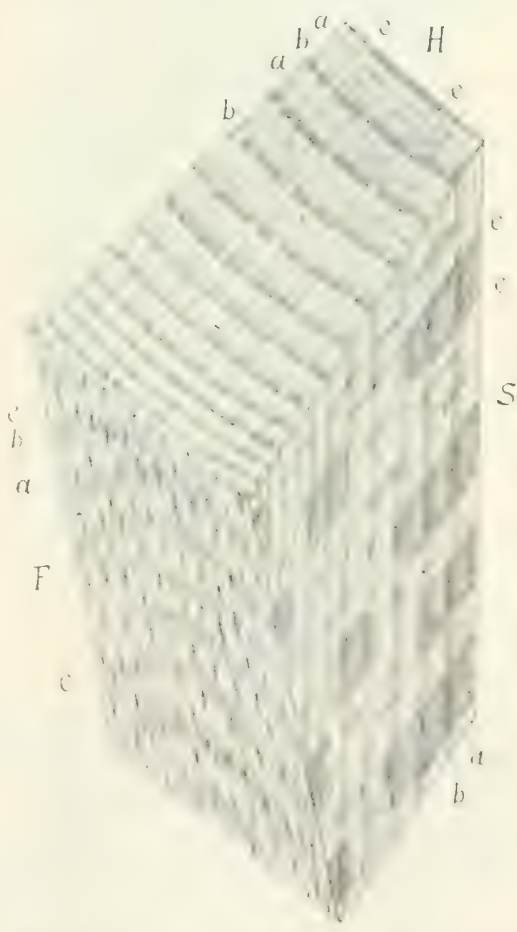

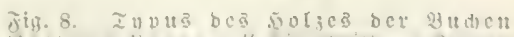

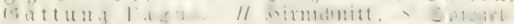

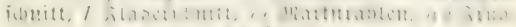

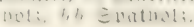




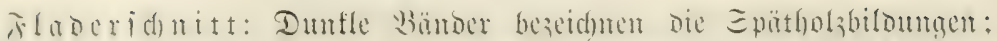

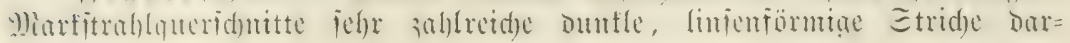
itellento.

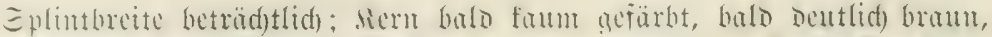

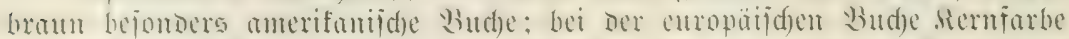

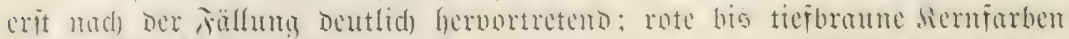

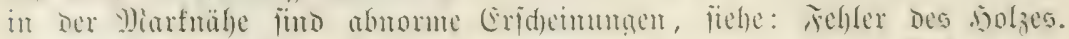

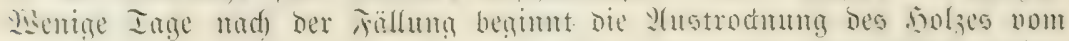
9) (arf an nad) aupen burd) Seller=

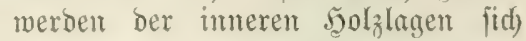
zull zeigen; bieje weiß̄lidfe Färbung idyreitet fort bis zur Rinde; dann erit jebst aflmäblid die lidgtbraume fär $=$ bung Des Budjentolzes ein.

\section{3. Đie E E (d)enarten, Gattung Fraxinns.}

Ĵn Eruropa, Amerifa und $\mathfrak{A}$ (jien ver= treten.

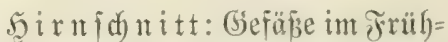
holze zalfreidf) mo gropis; im Epät= golze ipürlider, flem, von gellem
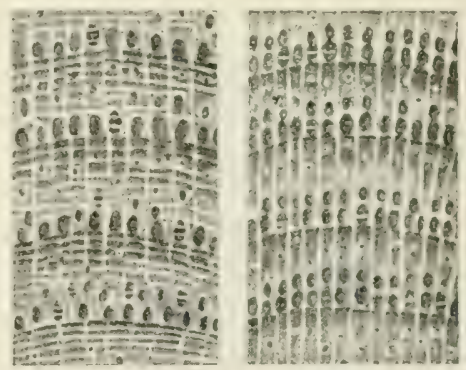

Jig. 9. Typus bes golses ber Efden, (5) attung Fraxinus.

ซrig. 10. Sints sidfornhol3, redjts cidjentols (idg)ad) vergröjert).

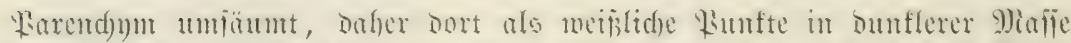

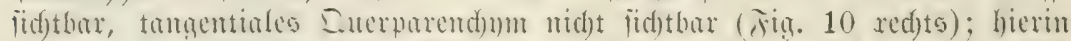

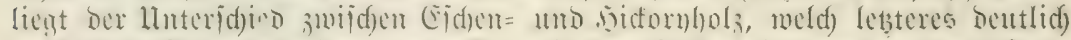

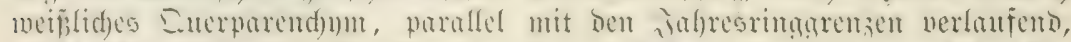

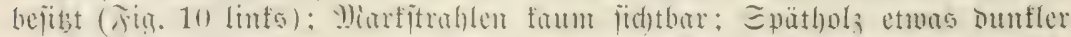

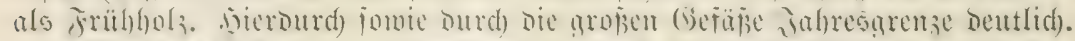

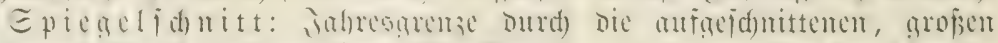

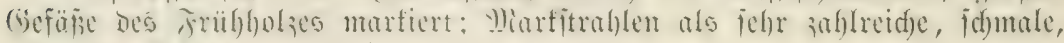
glänzende Bünber ober Flectdjen fanm jüd)tbar. 


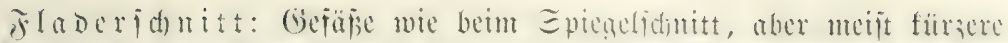

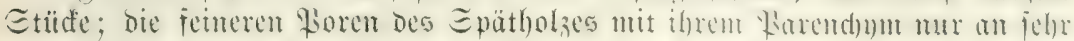

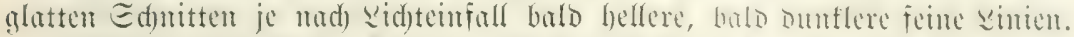

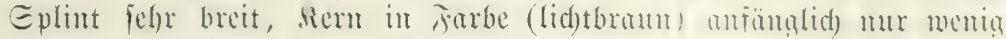
vom Eplinte veridjieden, jpäter madjounfelno.

\section{Die Ilmenarten, Gattuna Ulmus.}

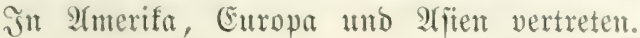

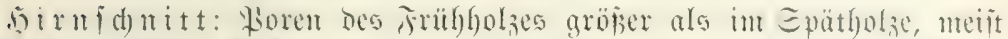

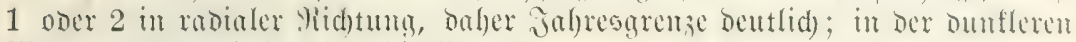
\$) Jaffe des Epätholzes find die \$oren au Sinftreifen georonet, bie Durd) die llmjäumung ber \$oren mit Gellem \$arendyum zu belfen, peripherifd ver= laufenden Mellentinien werben; Miart= ftrablen faum jidtbar.

Ma bialid) nitt: Miarfitrablen als glämzende hellbraune, furze Şän= Der ober fleme Fledden zwifdjen Der belferen, id)wad) glänzenden Grumb= mafie; Jahresgrenze burd) bie auf= geidnitteme \$oren, etwas glützento ge= fentzeidnet; SBellentinien Des Duer= id)nitts in feinen parallelen Rimien crtembar.

Flaberiduitt: Poren anf= gejd)nitten, um fo länger, je mehr ber Sdynitt der Iangente genähert ift, jonit wie beim Mabialid)nitt; Miarfitrahlaueridunitte foum ala fefr feine, furze, ounfle Etridje fid)tbar; $b a=$

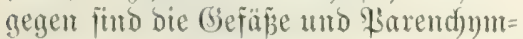
linien des Epätbolzes bentlid) als feine paralfele Bidjadfinien, meît etwas dunfler als die Inmgebung ( $j$. Jig. 11), exfembar.

Die Ulmen bejisen breiten Splint, Gellbraunen, rafd) nadjounfelnden Sierr.

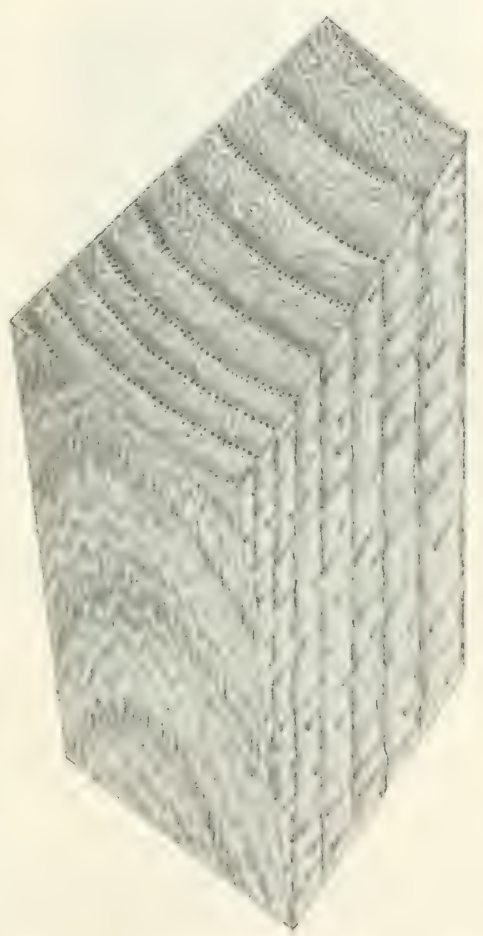

fig. 11. Iทpus bes 5olzes ber ltmen, (3) attung Ulmus.

\section{Dic Ėcllanfanie, Gattunn Castanea.}

In Imerifa, Sifien uno Curopa nertuten.

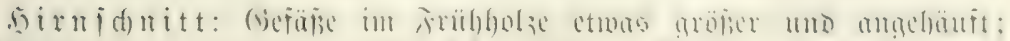

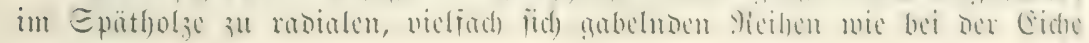




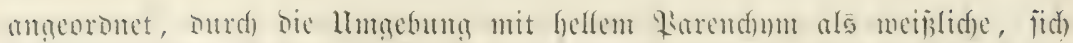

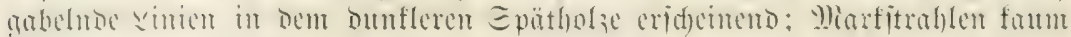
jidjtbar.

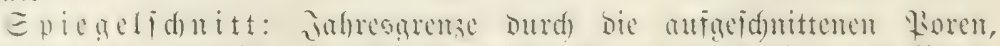

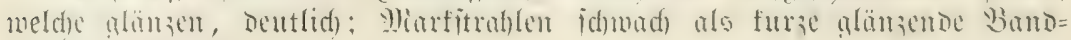
itiadiden erfembar.

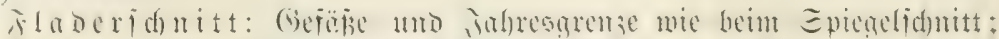

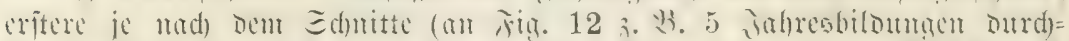

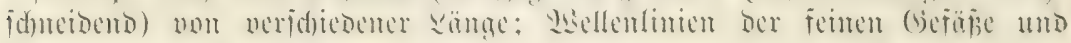
Parend)meinfofing faum erfentuar.

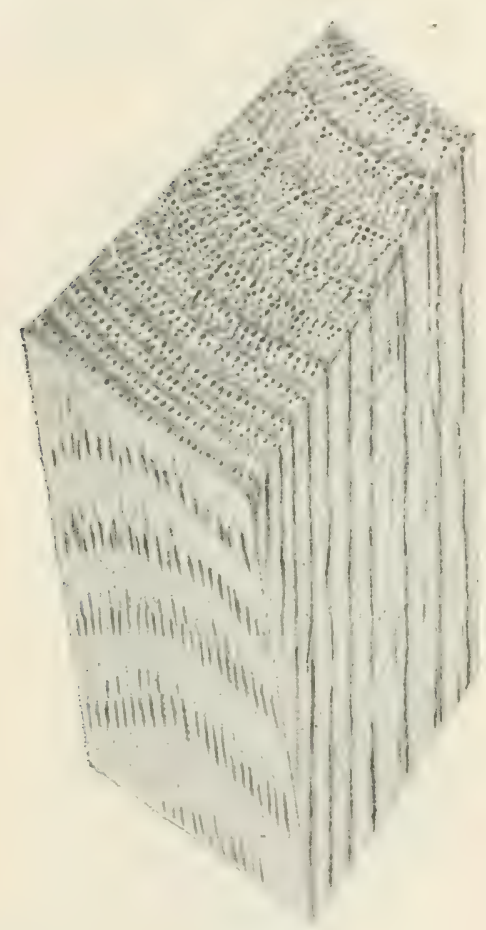

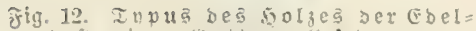
tajtauten, (s)attung Ca!stanea.

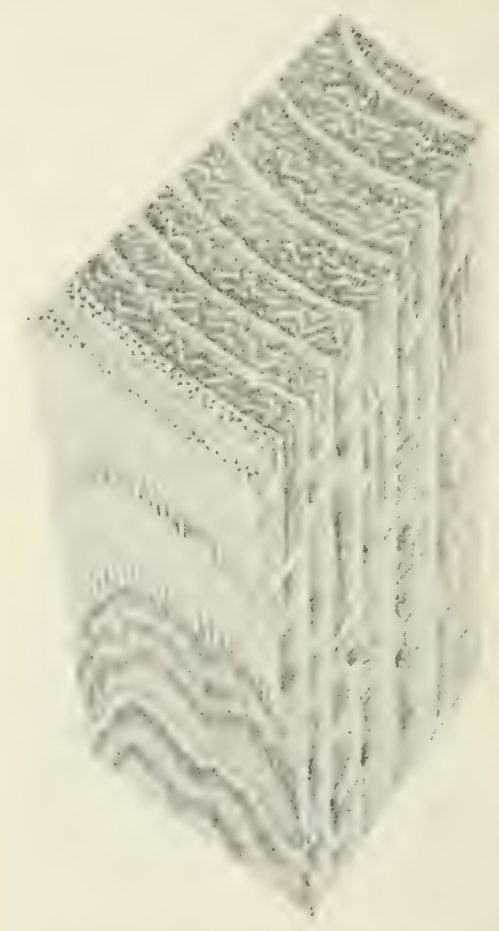

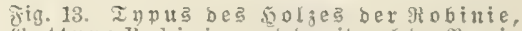
(अattung Robinia, mo bamit aud) ber $\$$ ap $i=$

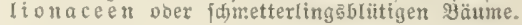

\section{Die Robiuic, nud) Alazic genannt, (6attung Robinia.}

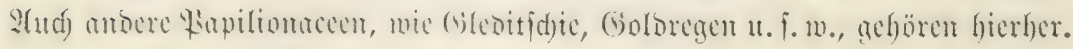

5irmidn int Eplinte (

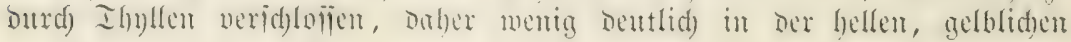




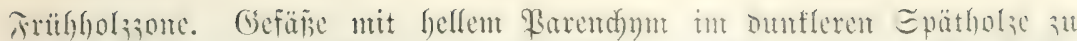

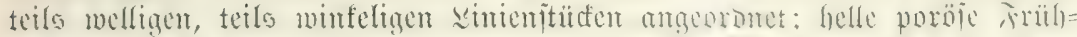

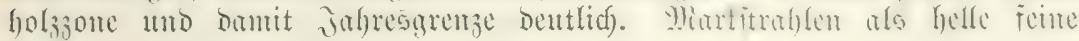
Sinien.

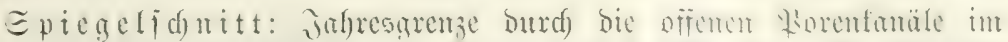

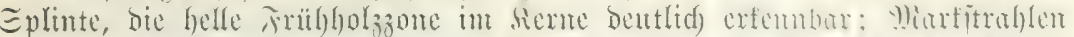

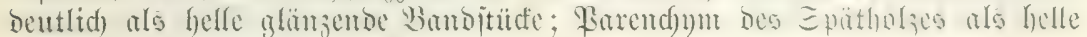

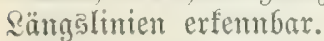

Flaberfdutt: (sefäßze des Splintes und des Rernes wie int Epiegel=

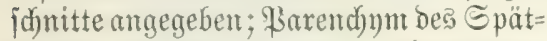
bolzes als mellige, ber Jahresgrenze parallele Bänder, je nady bem \&idytemfalle beller ober bunfler als bie Ginutomaffe.

Robinie: Splint ziemlid fodmal, Sern bell gelbgrïn, fpäter braungrïn werdento.

(S) lebitidie: Splint breit, Sern rofafarbig.

(S) old regen:: Eplint jebr fdumal, Reru rotbraun.

Cladrastis: Eplint jehr fdumal, Sern rotbraun.

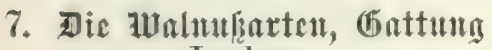 Juglans.}

Durd) 6 Irten in 2Imerifa, 2 fien und Europa vertreten.

Şirufdenitt: Poren żemlidf gleidjmäpig in Jagresring verteilt, zu= weilen etwas im Frübholze angehäuft, gröper als in Spätholze; diefes etwas

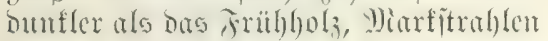

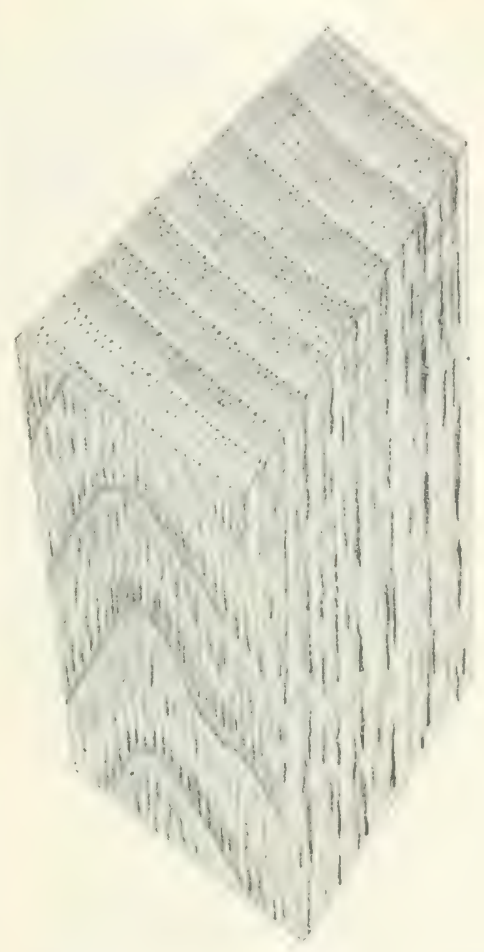

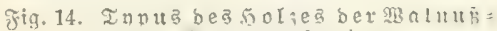

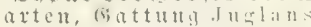
fautm jiddtbar.

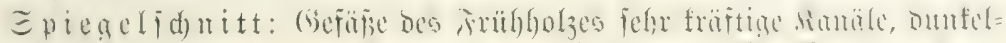

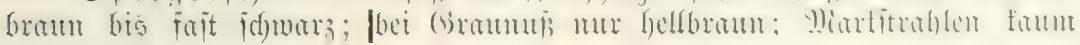
fiid)tbar.

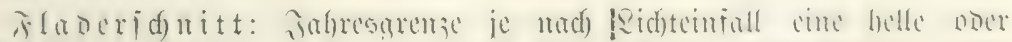

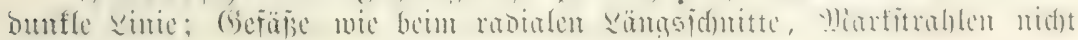
jichtbar.

Juglans nigra: Eplint breit, Sien rotbraut.

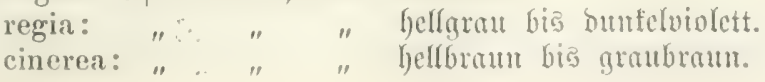




\section{8. 刃ic Aljornarten, Gattun Acer.}

In Îmerifa, Ijien und Curopa vertreten.

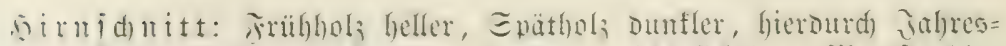

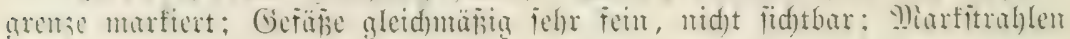

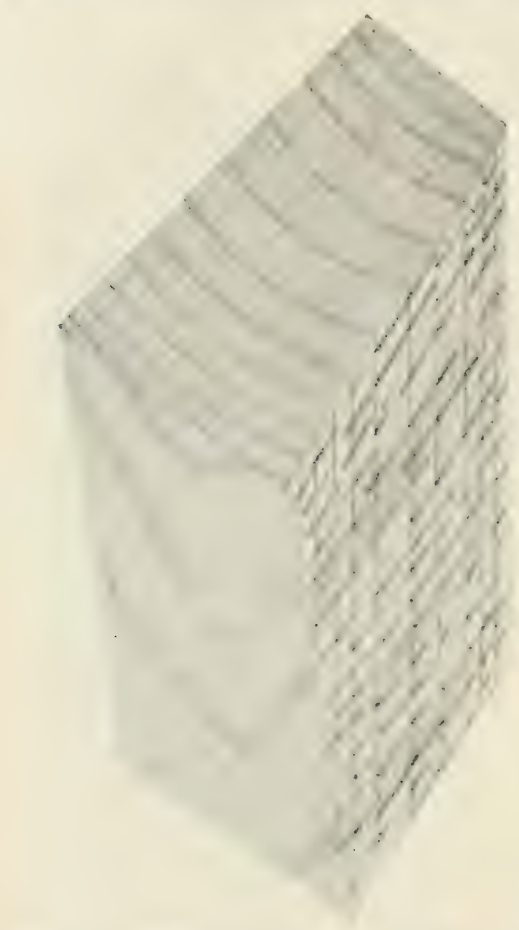

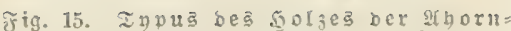
arter, (Gatiung Acer, und ber jirjoen= unb Hilaumenarten, (5) at,tung Prunus.

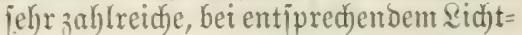
einfalle, helle und glänzenbe sinien.

Epiegelid)nitt: Jahresgrenze mir eine feine bunfle Sinte; Miart= itrahlen je mady Sidjteinfall balo helle, bald dunfle, feidenglänzenoe, jumnale, jehr zablreidje Bänber ober Fledtden.

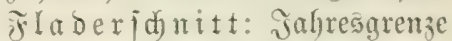
ala mur menta dunfleres Bant von verid)iebener Breite (je nad) der Sdjuttridtung); Miarfitrahlen als jefr zablretche furze Etridje, Dunfler als bie (Grmomalje jid)tbar.

Splint breit, fern ganz hell= braut, jäter etwas bunfler merbend.

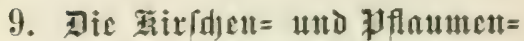 arten, Gattuna Prunus.}

In IImerifa, äten und Curopa ver= tretert.

In ben Etrufturverbältmijien

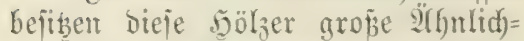
feit mit Den S(hornarten; Das Früh)=

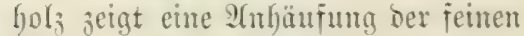
Gef̧äpe, woburdy die Jahreșgrenze beutlider wiro. Serjajieden fino aber insbejondere bie färbutgen Der $\mathfrak{y} 0$ b̆ger,

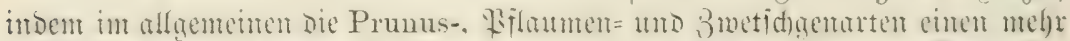
gelblidbranten, Prunus-hiridentarten mehr rötliden Ion im siente bei breitem Eplinte jeigen.

\section{Die Eain= oder Wrisbudenarten, (5attun Carpinns.}

Jn $\mathfrak{A}$ merifa, $\mathfrak{Y}$ jien uno Europa vertreten.

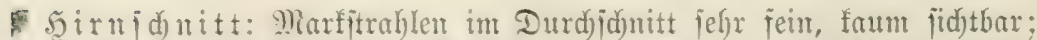
ment mehrere it chem siden

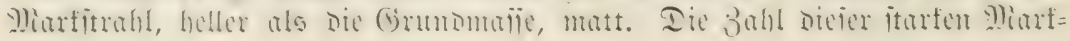




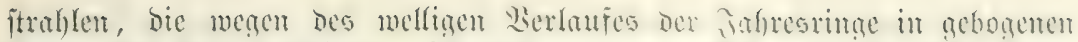

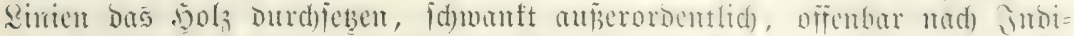

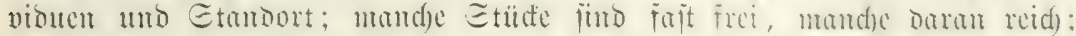

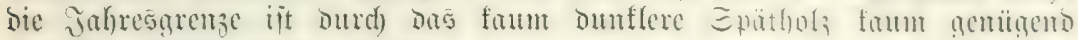

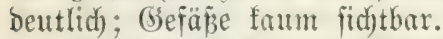

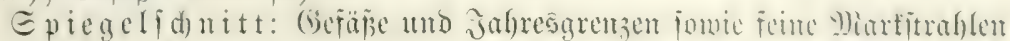

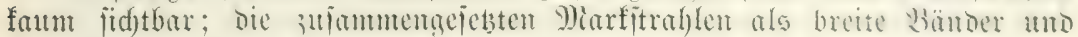
Stüde berjelben, matt, aber bentlid) erfentrar.

F) (aberid)nitt: Dic Elütholzzonen als Bidzadbänocr non je mad)

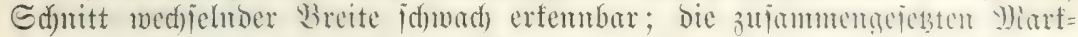
ftrablen erjobeinen als bide, buntle, matte Sinien von veridjebener Sänge. Splint und fiern in ber Farbe gleid).

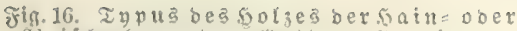
weiß, bud)enarten, (s) attung Carpinus.

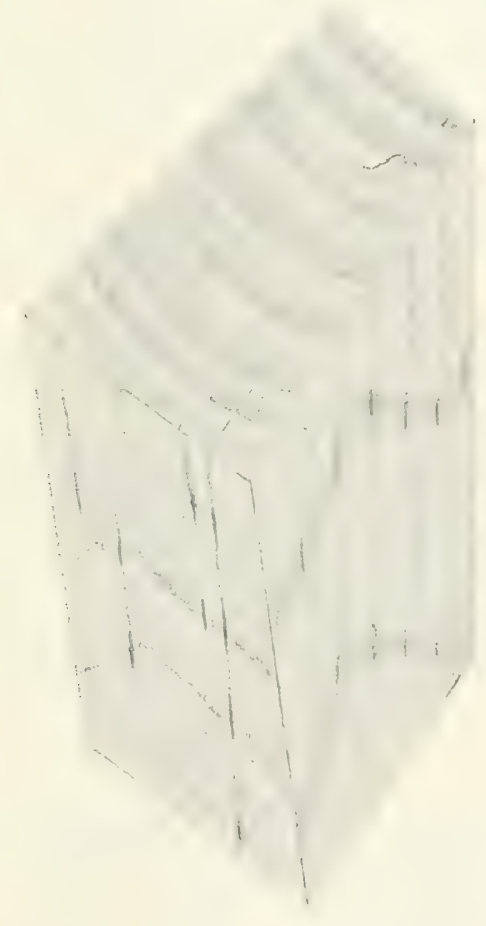

厅ig. 17. Typus bes 5olses bex Ertenarten, (i) a t tullg $A 1 \mathrm{lus}$

\section{Dic Erlen, Gattung Aluus.}

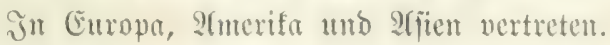

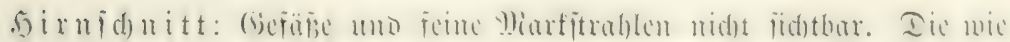

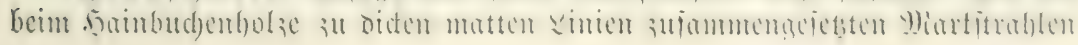




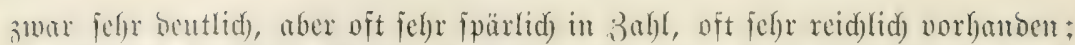

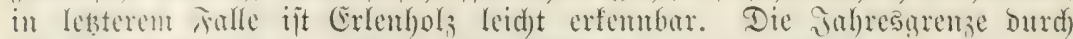

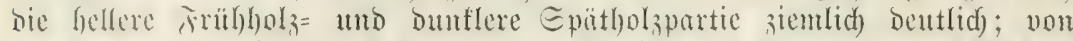

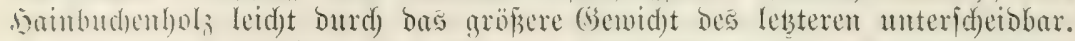

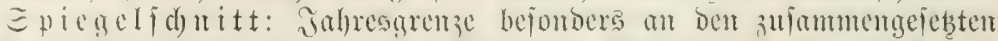
Wiarfitrablen bentlid); lebtere als breite matte 33 änocr ober Bambitüfe bas

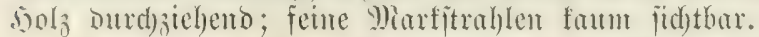

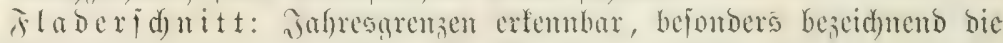

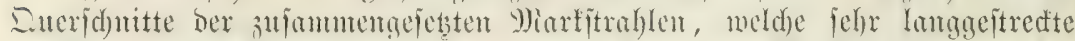
ounflere, matte sinien baritellen; font find bicje Wianfitrablen wie bei

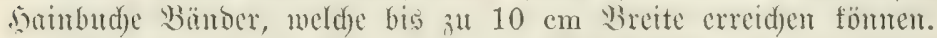

Eplint breit, hexu bald alcid)er Tarbe mit Dem Eplinte (2Beib= exlen), bald rötlid) bis belfgelbrot gefärbt (अoterlen).

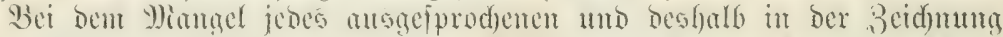

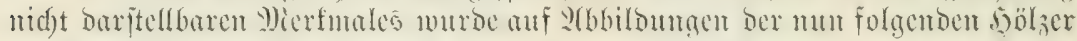

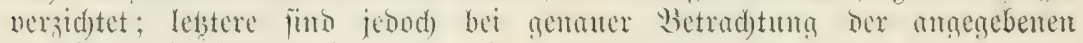
Sunfte and nidgt fofmierig zu erfemten.

\section{Dic Bixkenarten, (6attung Betula.}

In Eropa, 2(fien und 2(merifa vertreten.

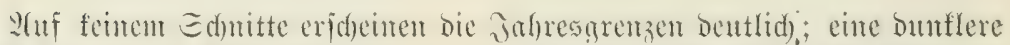

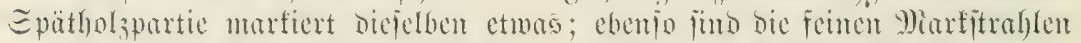
mur bei jebr alatten Epicgelfonitten erfentbar; als beites Mierfmal aber

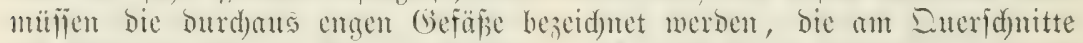

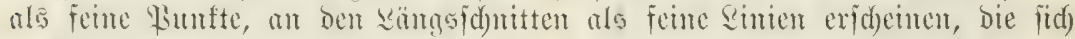
meip fürben, fobalo man bas Etüd breht mo mendet, mobet bas sidyt vont

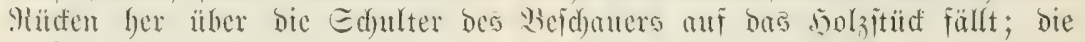

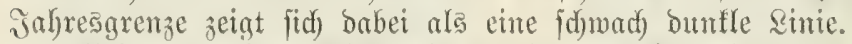

Wiei ben meiften Birfen ït Eplint und sien in ber Farbe gleid); nur

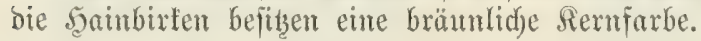

\section{Die finoenaxten, Gattung Tilia.}

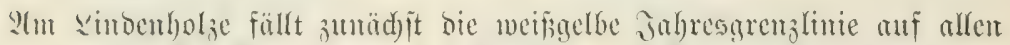

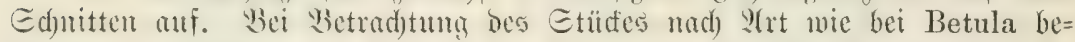

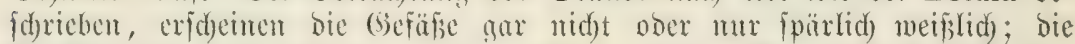

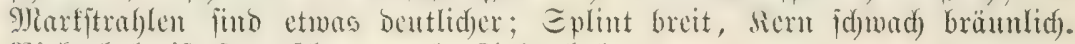
Birfenlyolz ijt itetos idjwerer als Simbentyolz.

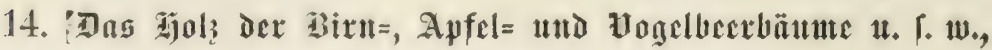

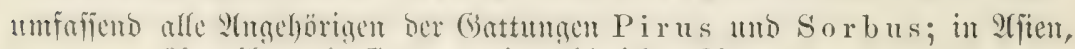
2)merifa uno Europa mit zahlreidjen 9 rten vertreten.

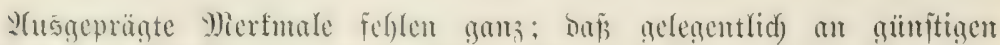

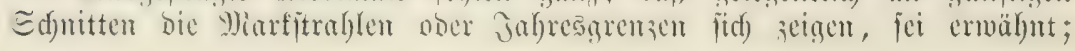




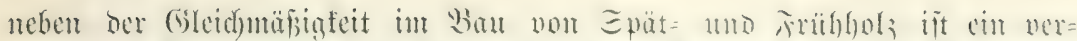

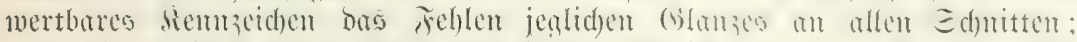

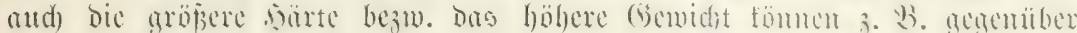
bem Rinbenbolze alo whbaltopunte benübt merden.

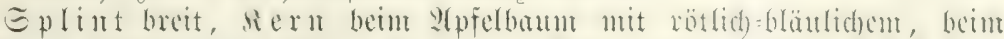

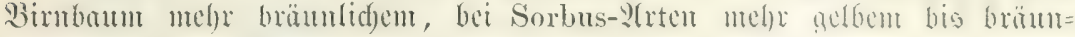
lidbem, bellerem Ion.

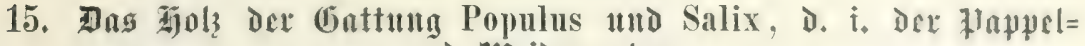 Itid Hlleidenarten.}

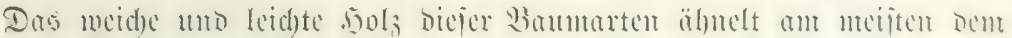

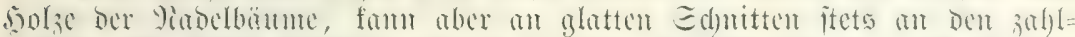

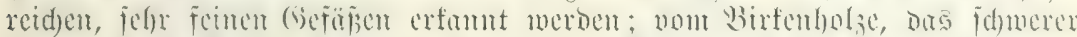

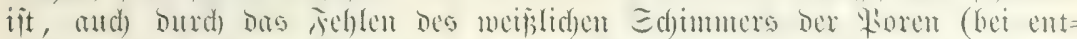

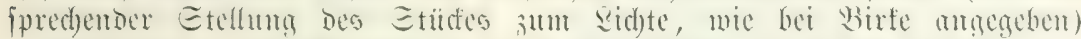

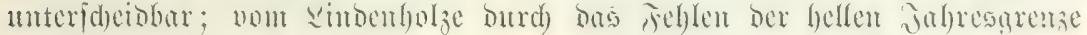
unteridfieden.

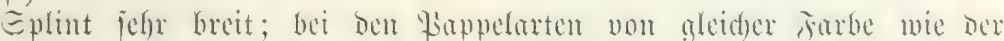

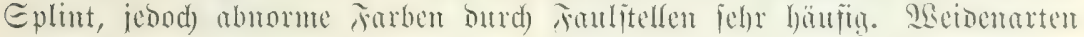

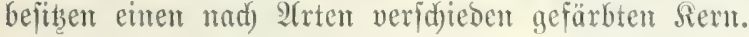

\section{6. 刃as Zolz Dex Roßzliafnuicu, Gattung Aesculus.}

Curopa, Qrifen uno 2 (merifa.

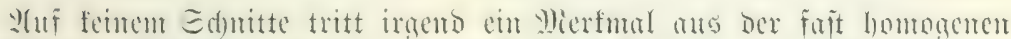

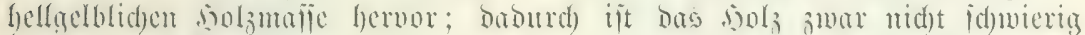

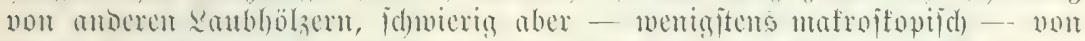

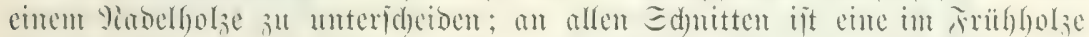

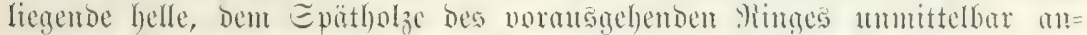

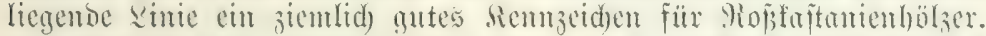

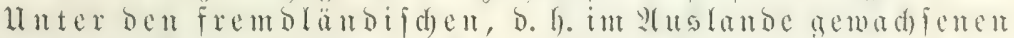
5olzarten follen mur foldhe bier fur gefdildert werben, welde anf bem

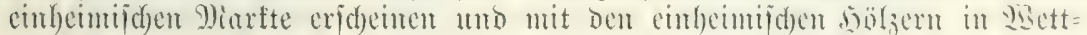

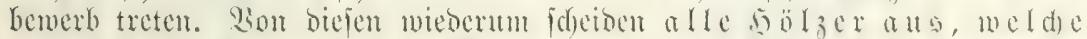

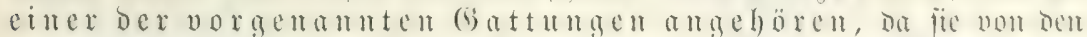

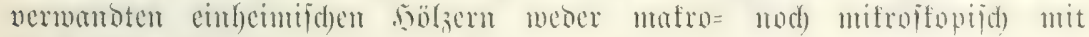
Sidjerbeit unterfodeden werden fömen.

\section{7. 刃as jolz dex Jidioryarten, Gattuna Carya (Hickoria).}

Finr in Porbanterifa vertreten.

Şierzu Fignur 10 linț.

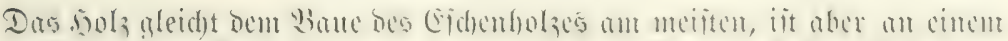

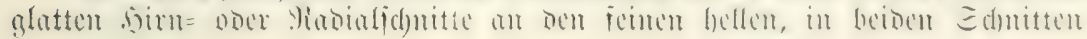




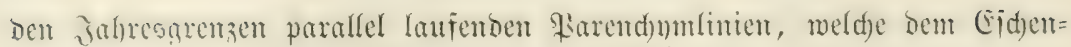
holge feglen, von diejem unichwer zu untericheiden.

ङplijnt breit, $\Re$ ern bellbräunlid).

\section{Itlahagoniljol?, Gattung Swietenia.}

গlur im tropifden 2(merifa vertreten.

Sinnjd) ntt: Marfitrablen als feine, zablreide helle simien beutlid); Gefǟ̇e gleichntäpig verteilt, teils mit jüllgemebe verieben, dann als belle, bei Feblen Derjelben als Dunfles

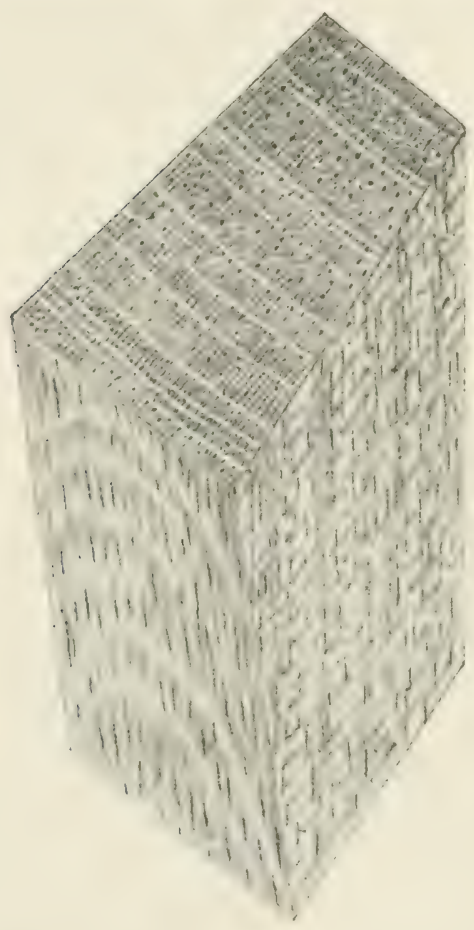

Fig. 18. Typus bes mahagoniholzes̄, (Battung $\mathrm{S}$ wietenia. Bunfte erfennbar; $\mathscr{B a d}$ ) unterbredungen burd jebr auf= fällige, helle Rinien, Jahresgrenzen ähnlid), angebeutet; jđdmad) glän= zente Gejamtmajle.

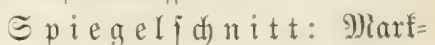
itrablem als idumale, zablreidye Banditüde glänzend in glänzender Grunomalie. Anfgeidnuttene (35e= fäße bunfel, ebenfalls mit (Slanz.

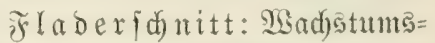
grenzen als helle SBänder, Gefäß̈e als Sanalitüfe mie beim Epiegel= id)uitt; aud auf biejem $\Subset$ d)uttte bie Solzmalie glänzend.

Splint ldymal, Rexu hell= rotbraun; im (Semid)te Den Siun= baumbolze gleidy.

\section{Cédrala $=$ oder 3igarxen= kiftenljols, aud Jeocrnljols ae= maunt, Gattung Cedrela.}

Im tropifdyen uno jubtropifdjen

Amerifa und 2 fien vertreten.

Dab Solz, bas meider uno leidter als bas Mahagonifolz ift,

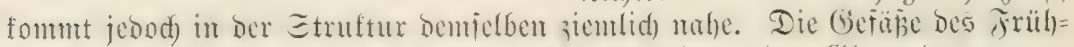

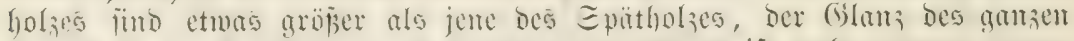

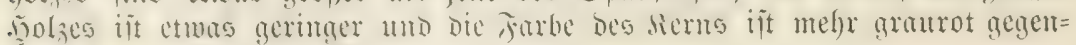
über Dem Sellrot bes Mlakagonifiglzes. 


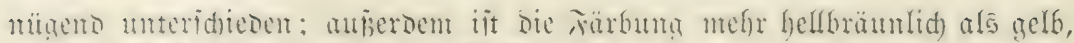

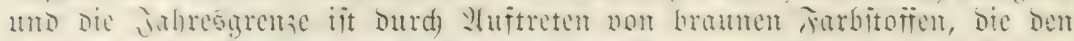

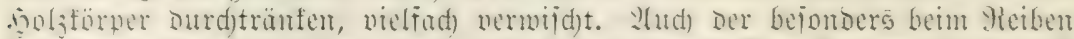

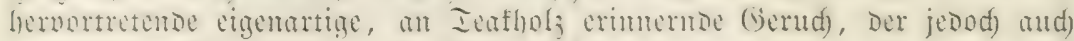

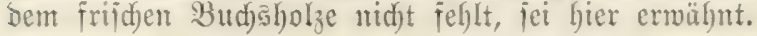

\section{3. łodilgol, Fegclkugclyoli, Lignnm sanctum, Gattıng Guajacum. Tropijdes 2 merif́a.}

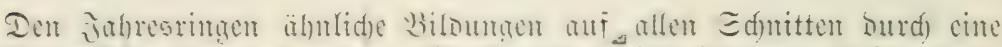

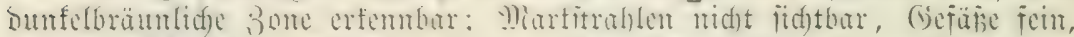

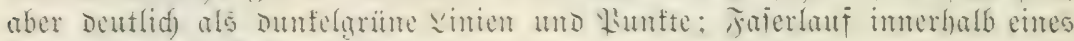
Jakfres in ber Ridjtung medjelno.

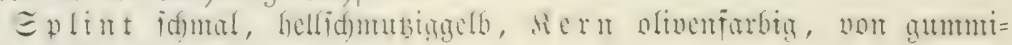
artigem Gerudje.

\section{4. ÉE Gethölz̨cx, Gattung Diospyros.}

Int ber wärmeren bis tropijd)en Banmregion jatylreid).

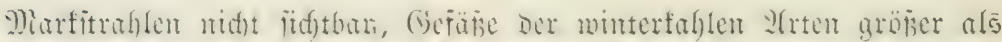

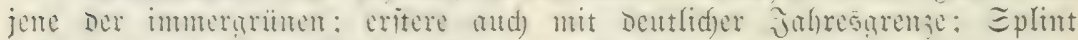

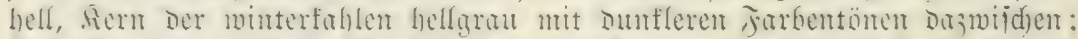

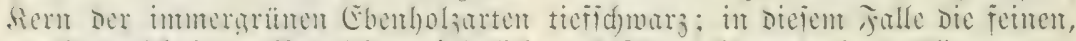

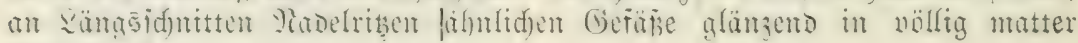
Grumbmalie.

\section{Jualifandocholz (Jacaranda).}

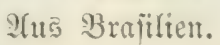

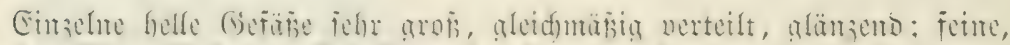

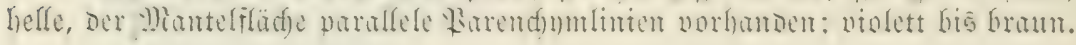

\section{6. ¥orenlols.}

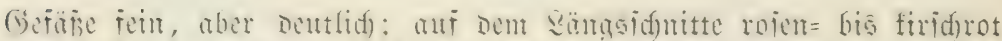

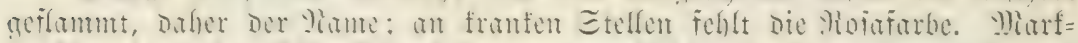

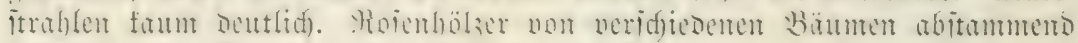
fommen แล allent tropijdjen 93 aloregionen.?

\section{Judaulihol? (Padouk), Pterocarpas indica. 2uts Dittinbien.}

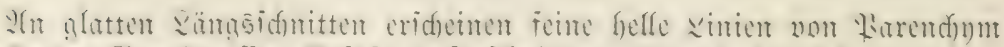

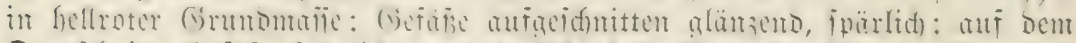

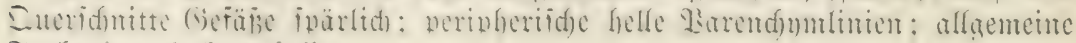
Jarbe Des Soljes helfrot. 


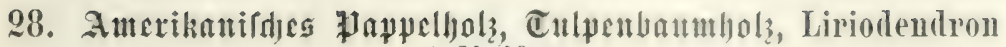 talipifera.
}

\author{
24s Ditamerifa.
}

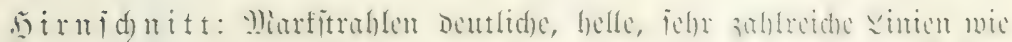

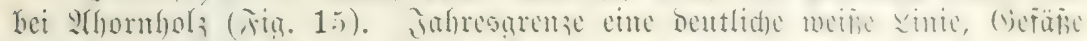
nicjt fidjtbar.

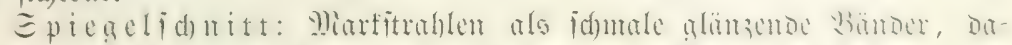

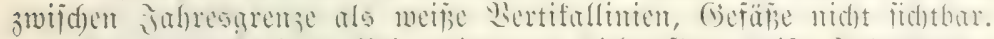

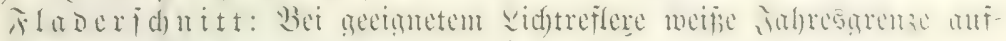
fallento, andere Merfmale fund nidjt vorljamben.

Splint breit, Rexu bellgelbgrü, hell olivenfarbig.

\section{Icildjenjolz von Acacia homalophylla.}

Sübauptralien.

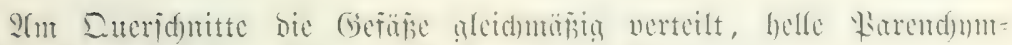

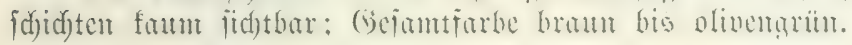

\section{b. Z̃adelhölzex.}

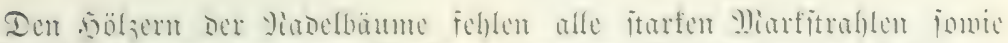

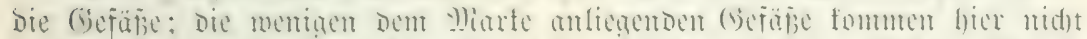

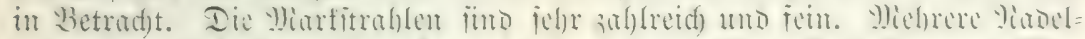

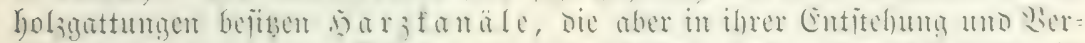

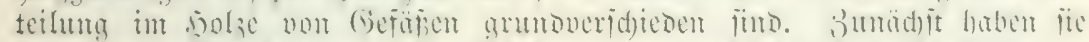

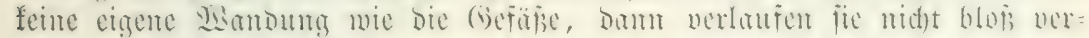

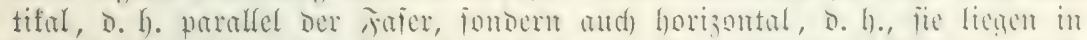

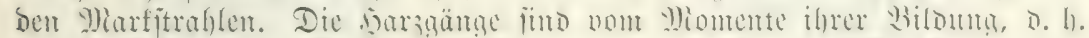

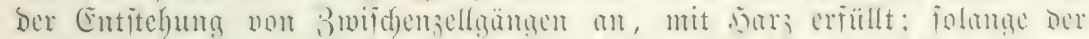

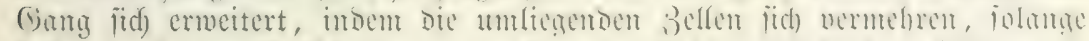

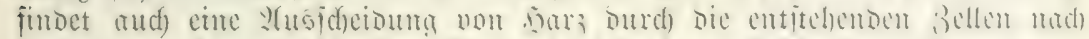

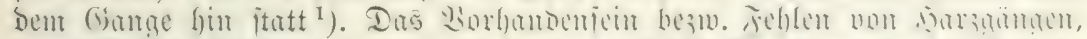

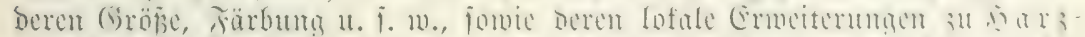

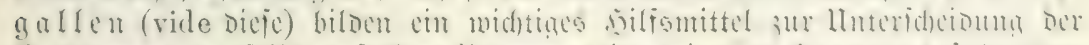

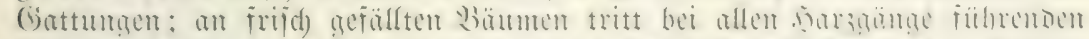
Solzarten nora a แ

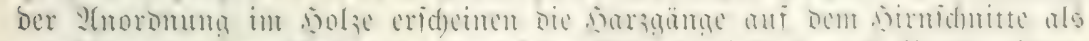

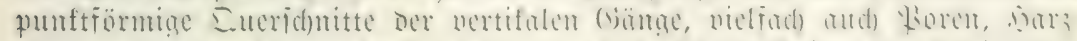

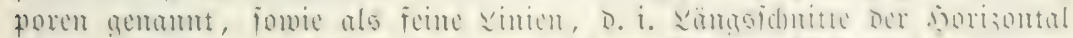

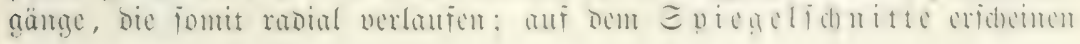

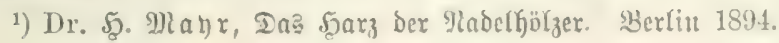




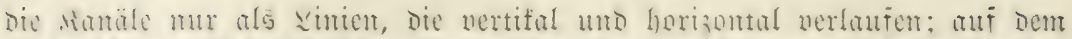

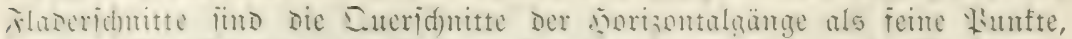

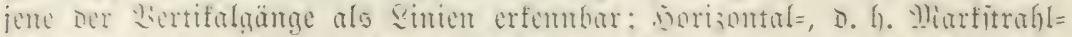

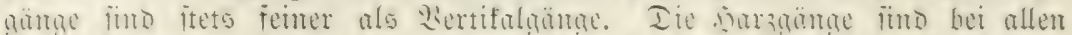

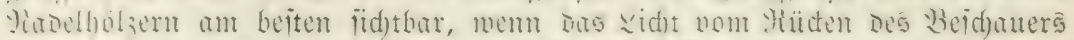

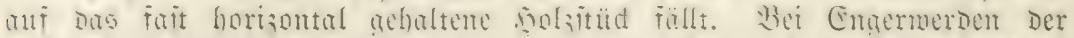

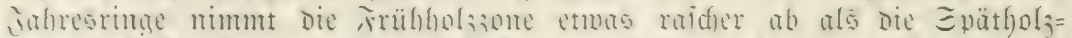

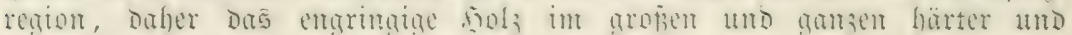

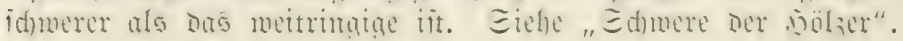

\section{0. fidjtın (Picea). föhr̊n (Pinns. Section Taeda et Pinaster), färden (Larix). Đouglastaunen (Psendotsuga).}

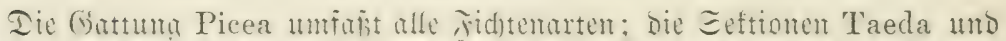

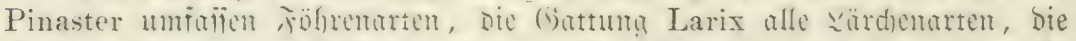

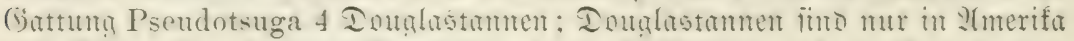
und :liten, Die treten.

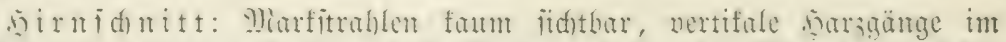

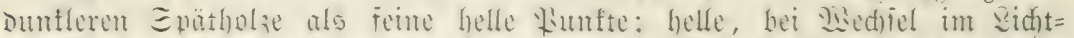

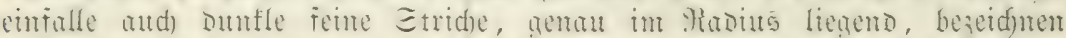

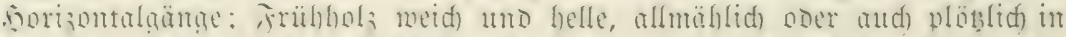

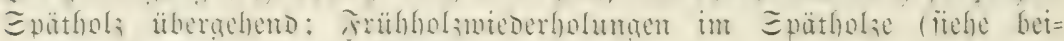
gegebene Jigux 20) nidjt jelten.

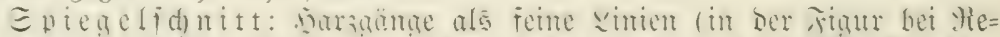

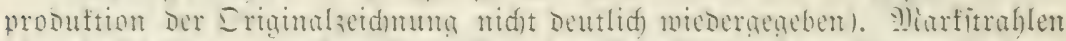

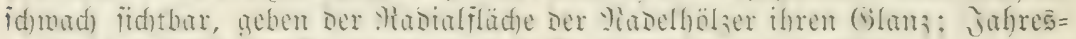

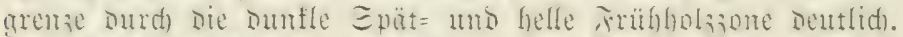

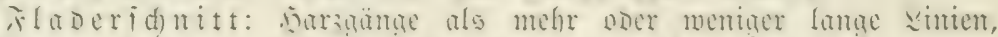

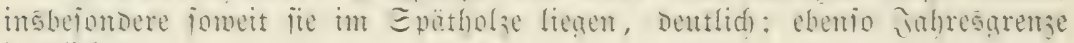
Deutlidf.

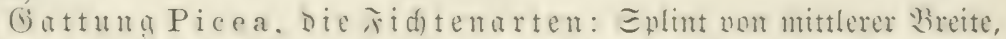

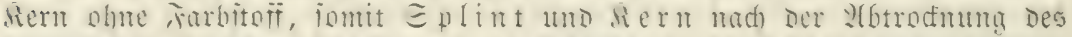

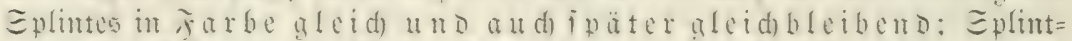

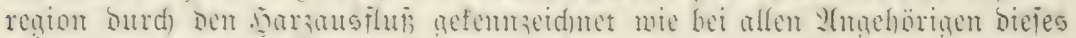
mafroifopijaen 5olatnpus.

(5) attug Pinus reip. Pinaster, Die Binapierföbren,

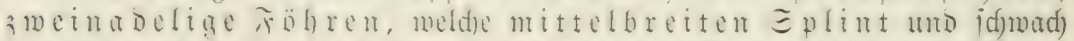

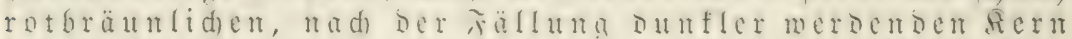

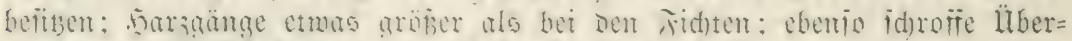

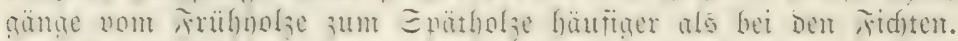

(5) attung Pinus rejp. 'Taeda, Iäbaf̈hren, oreinabelige

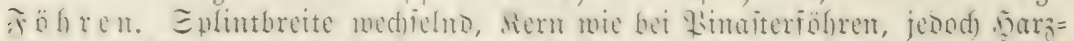

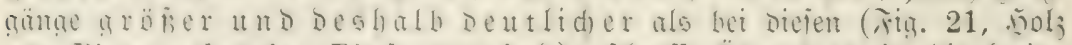

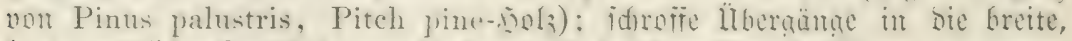

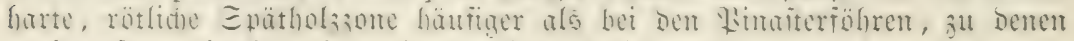

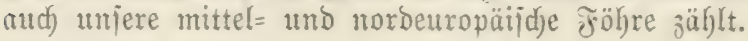




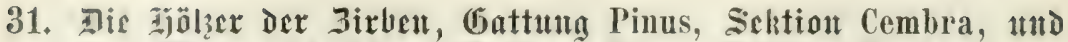

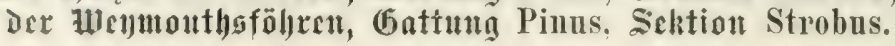

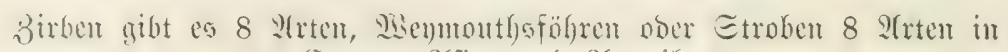

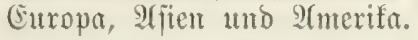

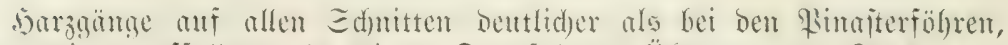

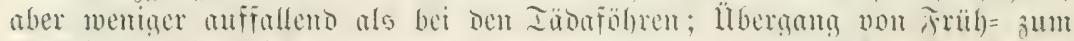

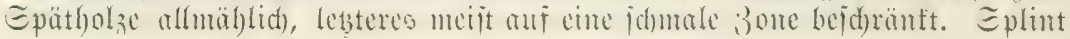
breit, Siern bellrotbran, fpäter nad)= butfelud ; engringiges, fomit aus ben

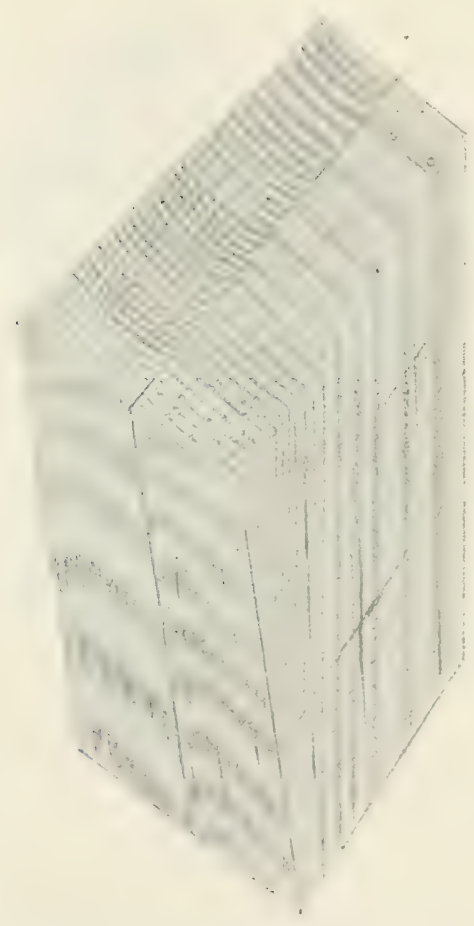

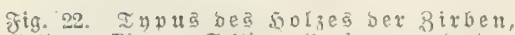
(jattung Pinus, Eeftion Cembra, und bex Gtrober, Battung Pinus, Gettion Strobus. Eng= ben Solse der Birbe völfig gleith; linte Birbe, rechts Weymultbsföhre. äuberen $\mathfrak{Y}$ olàlagent älterer Bäıme ent=

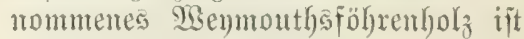
nom Birbengolze nidgt melgr unter= id)eiobar; and mifroifopifde IInter= idjiede fehlent. ringiges Étroben= ober Bermouthajobrenhol 3 ift

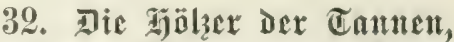 (Gattuna Abies, Dex Tlugen, (Gattung Tsuga, der Tazodinen, (6attung Sequoia, Cryptomeria und Taxodium, Der 3ederu, Gattung Cedrus.}

Die (Gattung Abiesumfajist bie Ianten= arten in 2 (nterifa, 2ffien unb ভuropa; Die Gattuntg Tsuga iit mit 7 29rten mux in 2 merifa und $\mathfrak{A}$ fien vertreten; Sequoia mo Taxodium mur in Amerifa, Cryptomeria in 2 jïen, Cedrus mit 3 Mrten in $\mathfrak{A}$ frifa uno $\mathfrak{A j i e n .}$

Da fearzäuge fehlen, fo jind feinerlei weitere Mierfmale als Farben $=$ und (serud) Solze wahrmelgmbar. Alud bie miffro= fopifde Unteridyeioung ftöbt wegen (Sleidbeit im Baue auf Edjwierig= feiten.

Die Iannenarten (Abies) find baburd) ausgezeid)met, baß

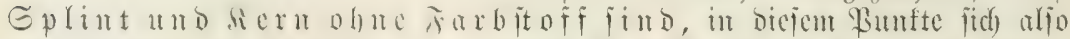

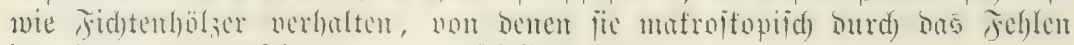

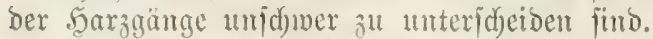

Dic Ifugenarten ('Tsuga) befiben breiten Ëplint, granten bis gran= brautur Sern.

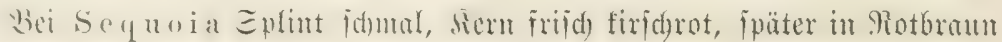




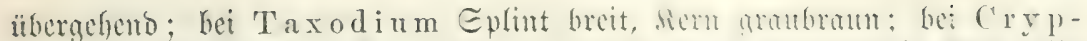

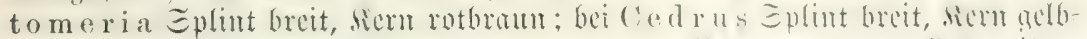

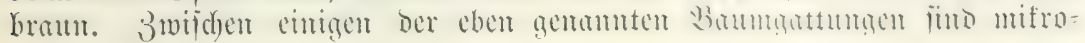
ffopifde Interjudede vorbanden.

Tig. 23. Topus ber 5öber ber ₹arnen, Uattung $\Lambda$ bies, ber $\tau$ fugen, (Sattung Tsuga, ber Sattunger Sequoia, Cryptomeria, Taxodium, Cedrus.

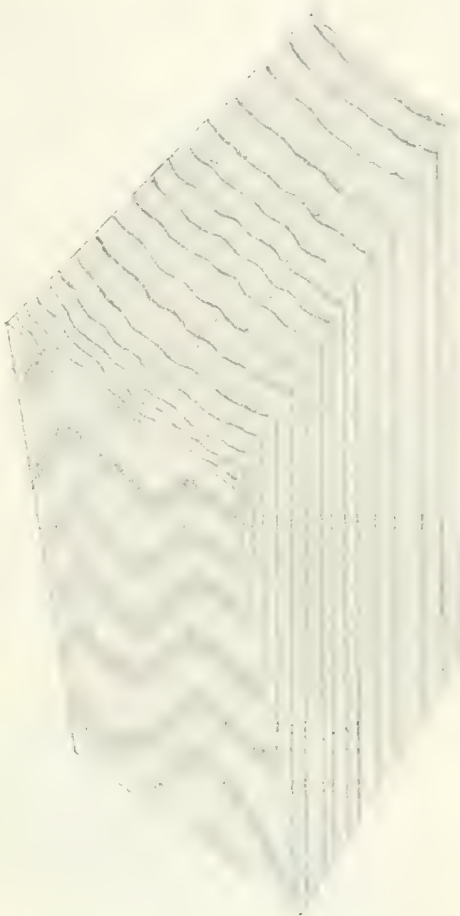

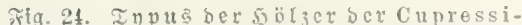
neөn, (3)attungen Cupressus, Chamaecyparis, Thuja, Thujopsis, Libocedrus, Juniperus u. a.

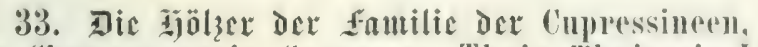
(5attungen Chamaecyparis, Cupressus, Thuja. Thujopsis, Libocedrus, Juniperus $\mathfrak{t}, \mathfrak{a}$.

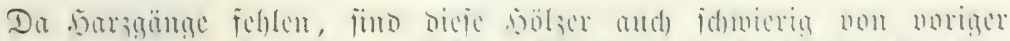

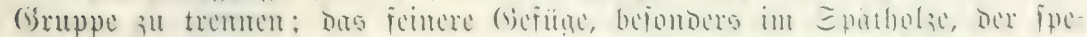

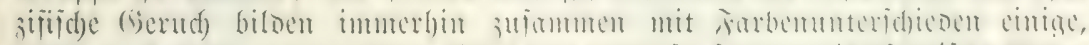

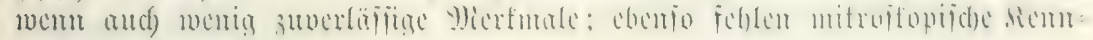
zeidjen.

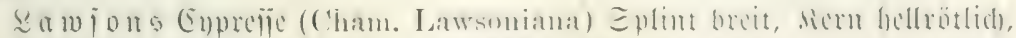

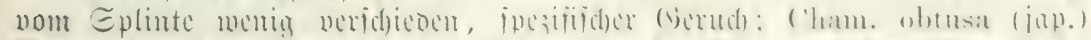

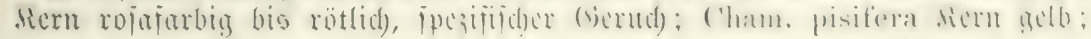


Thuja gigantea nem brömnlidonum: Thuja oecidentalis nerm bem Enlinte

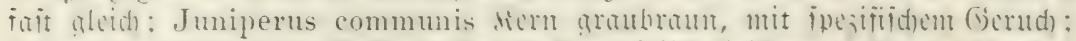

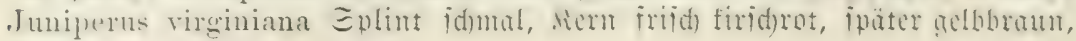
bejonders auffülliger (Gerud).

\section{c. æåmhölzex.}

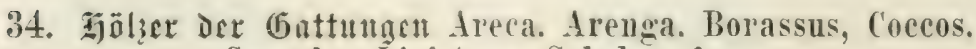 Corypha, Livistona, Sabal i. f. w.}

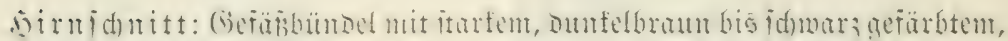

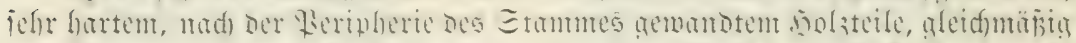

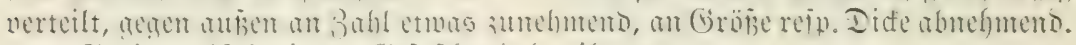

Spiegelidunitt: Gejü̈bündel teils ver= tifal, teils jdief nad) immen ober, wie an bei= gegebener Figur, nad) aแร̄en verlaufend.

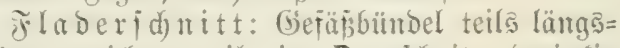
abmärta gerid)tet, teils im Eueridnntte breiedig

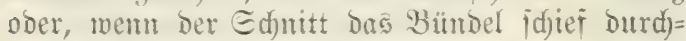
idnetibet, in sinfenform erjdeintend jiehe Jig. 25.

Die Palmbölzer zeigent je nad) Gattungen verjojieben gefärbte Solşündel, von Moja bī jum Braun uno tiefen Edjuarz.

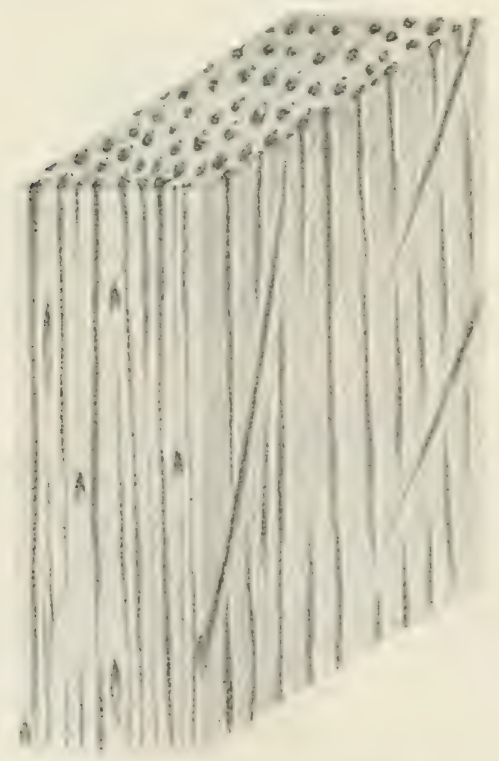

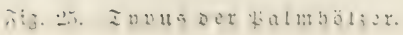

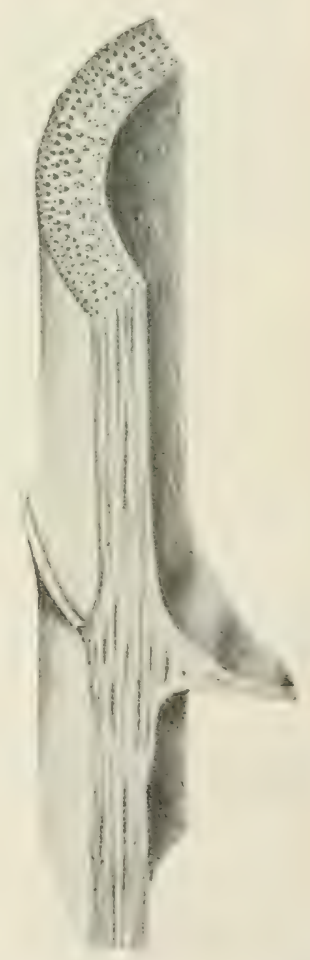

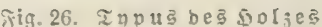
Der 8 anbusarten, lints Serindete "Iukenjeite, recits 5rohlraum mit einem Teile ber Euerwand, weldie Der 3n= fertionşitelle bes ßlattes gegen= überliegt. 


\section{d. Z̊ambutshölzex.}

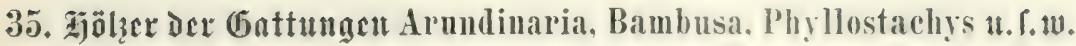

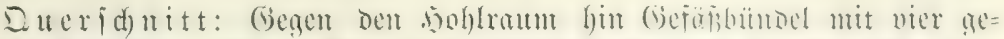

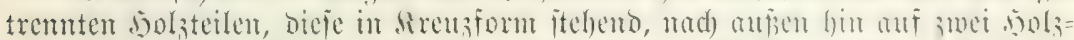

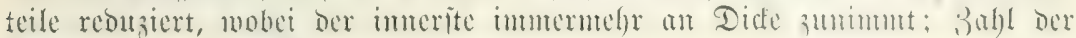
Bündel geaen die Sinbe zu iteigend.

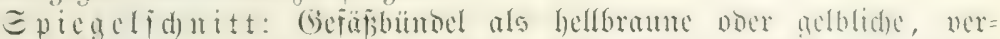

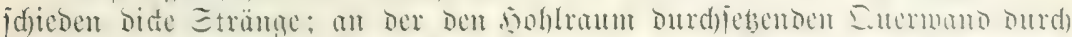

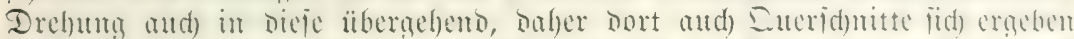

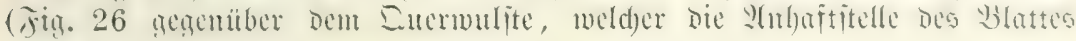
andeutet).

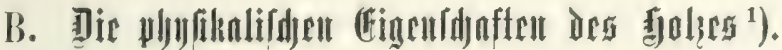

\section{1. farbe.}

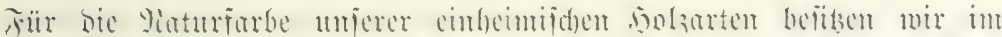

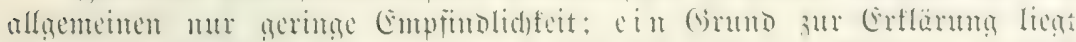

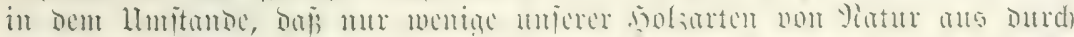

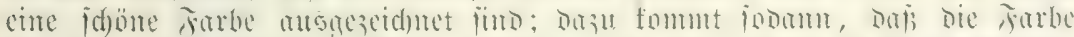

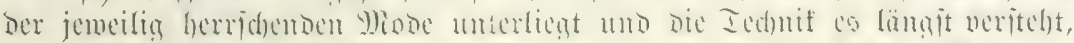

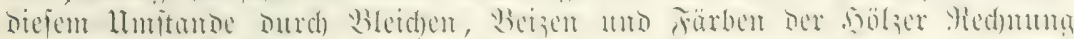

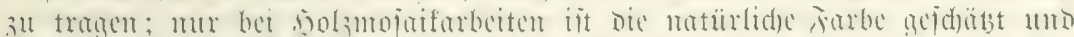

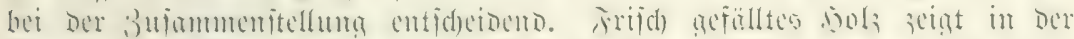

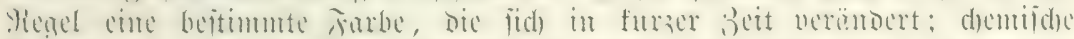

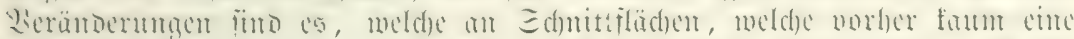

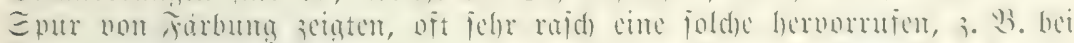

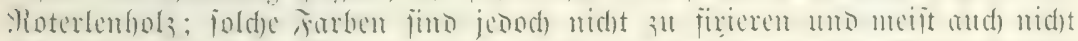

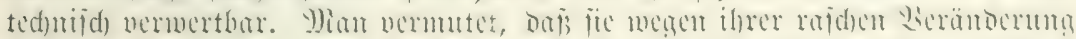

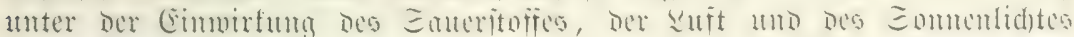

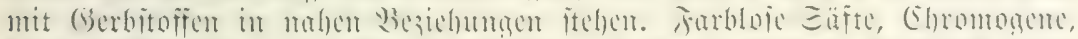

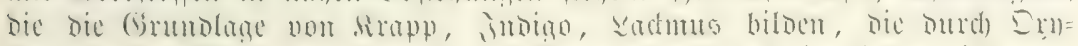

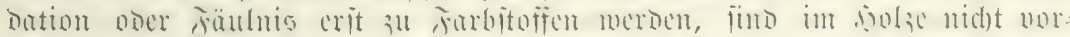

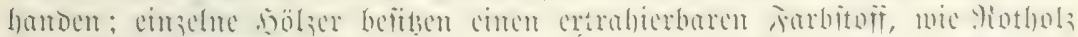

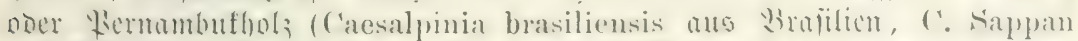

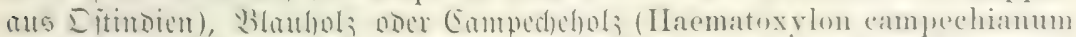

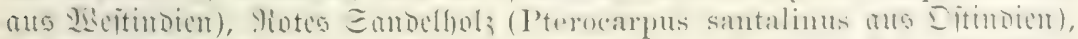

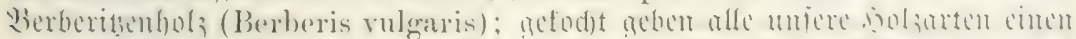

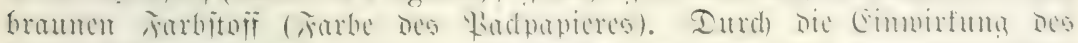

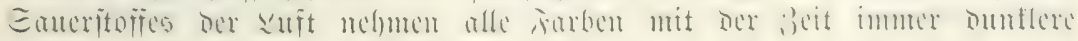

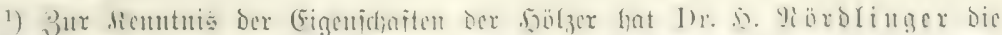

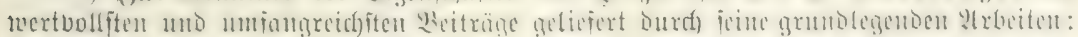

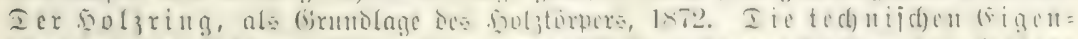

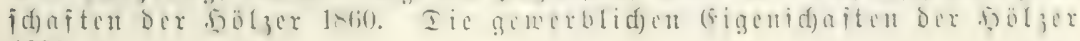
1890. 
Iöne an (Yadbounfeln); felbit bex als farblos zu bezeidnende Eplint wird Dumfler.

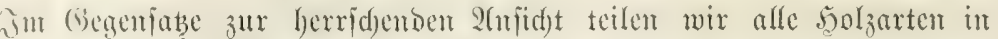

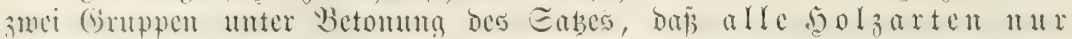
reifes Solz un alle bolzarten eimen Sern befizen, mag ber=

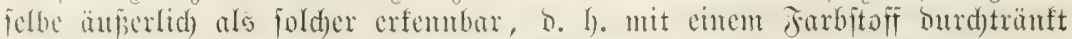

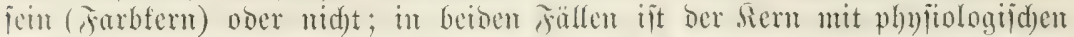
jumftionen betrant, melde jene bes Eplintes bauterno nidgt ju erfetsen ver=

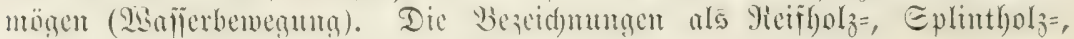
Sernbolzbäume fomment befier in 2 egfall.

Mian fan fomit alle siolzaten in folgende (isuppen bringen:

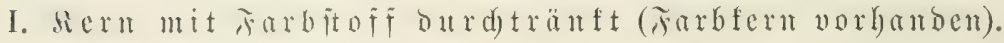

a) Sern im lebenden গ3anme waffexarm; SGaffer feblt im

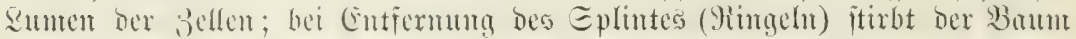

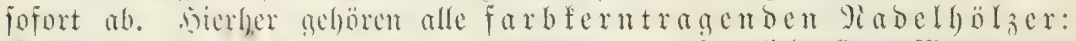
Gattungen Pinus, Larix, 'Tsuga, Pseudotsuga, fämtlidfe Cuprefïmeen uno Iarobineen $4 . \%$.

b) Sern im lebenden Banme wafiexreid); Wafjer im Bell=

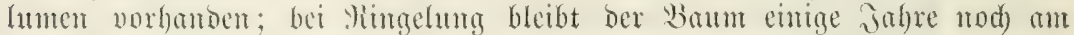

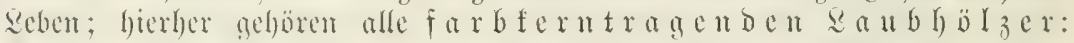
Gattumgen Quereus, Ulmus, Fraxinus, Tilia, Prunus, Morus, Castanea, Zelkowa und füntlidje \$apilionaceen t. f. w.

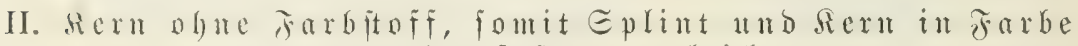
ga $a$ z ober faft ganz gleid).

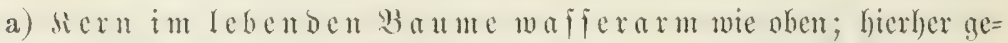

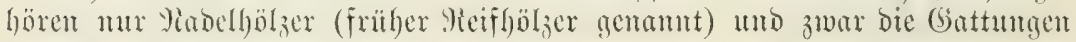
Picea, Abies, Sciadopitys, Cephalotoxus.

b) Sern im lebenden $B$ a ume wafferreid wie oben; hierber

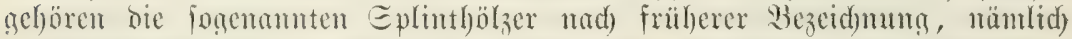
bie Gattungen Fagus, Carpinus, Betula (mit 9(usnabme der şambirfen), Acer, Aesculus $\mathfrak{1}$. $\mathfrak{a}$.

Der normale Fabfern it nom bellen Eplint meijt fdarf abgejebt; bie

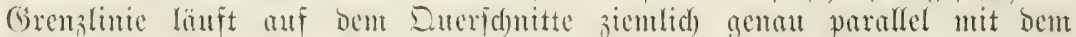

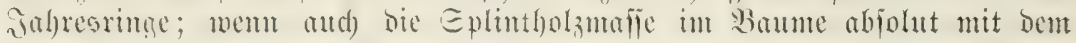

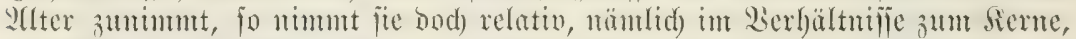
bejtänbiz ab, lezsterer fomit in ftürferer Froportion alo ber, Eplint ju, jo

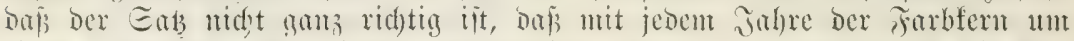

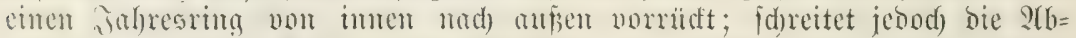

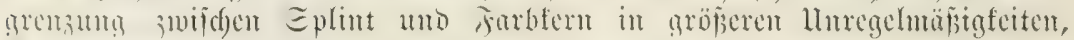

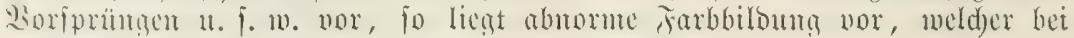
den Feflern bes fyolzes Errwälmung gejdehen foll.

Die midhtigeren einbeimifden uno fremoen bolzarten zeigen cintige 3eit nad) Der Fällung folgende Farbenverbältniffe: 


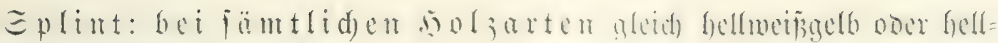
rötlidugelb gefärbt.

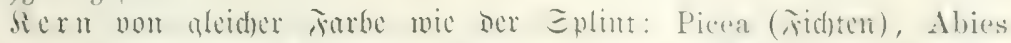
(Iomen), Evonymus, Aesculus, Populus, Betulia (然ibibtem), Sciadopitys, Fagus;

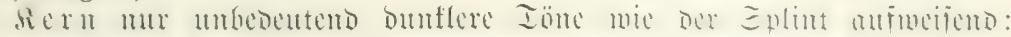
Acer, 'Tilia, Sorbus, Cham. Law'soniana, 'Thuja occidentalis;

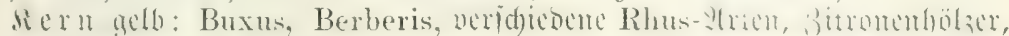
Punica Granatum, Machura, Santalum album, Chanaecyparis pisifera. Sambucus nigra, Satintholz (Ferolia);

Aeru hellbun: (Eid)e (Quercus alba, sessiliflora uno perlunculata u. a.), Ailanthus. Celtis, Sorbus, Carya, Castanea, Prunus (Wiflumen= (arton), Ulmus, Fraxinus, Pirus (Wimartent), Olea (Elmenboli), ölterés Juniperus virginiana;

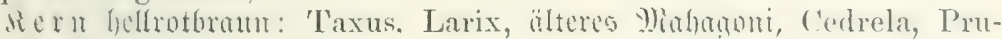
nus (sirid)en), Grenadille-sol; (Anthyllis), Bruyere (Erica arborea), Pinus silvestris, Cembra;

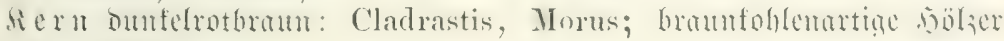
(Taxodium-2(rten).

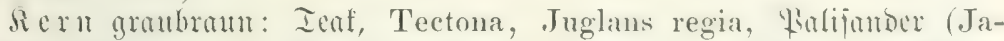
caranda brasiliensis), 'Thuja gigantea, Junip. communis, Taxodium distichum, Catalpa;

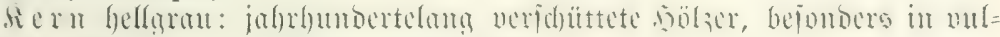
fanifden Gegenden; japantifde Simbaifgözer;

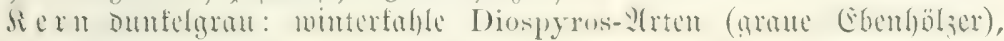
Ëifentyölzer (Siderodendron, Cupania);

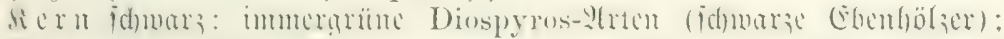

Aeru roja: frifdes Juniperus virginiana, Vojonbälect Rhodorhiza), Chamaecyparis obtusa; Picea Sitkaensis uno Hondoënsis;

Aeru gelbrot: Gleditsehia, Gymuoclodus, Cytisus, Quercus C'erris, frifdes Mialagoni; Pinus Strobus;

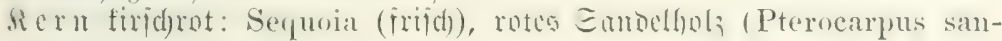
talinus);

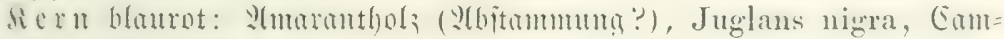
pectyeholż, Catalpa speciosa;

Sern blutrot: Pterocarpus indica;

Sern grün: Laurus chloroxylon, Cocus;

Rern gelbgrün: Robinia pseudacacia;

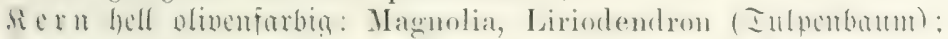

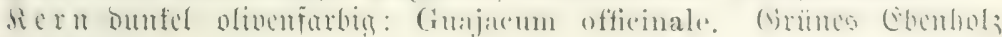
(Aspalathus).

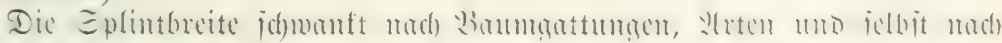

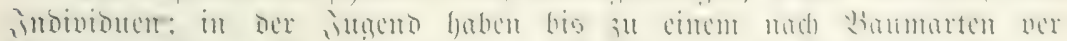

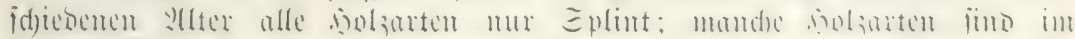

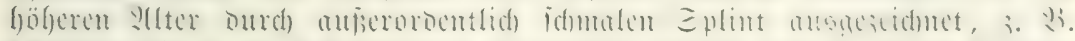

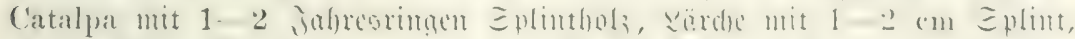

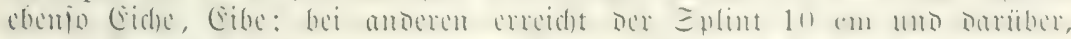

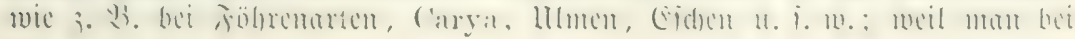


cimigen Eanbholigattumgen cinen farbfern nidjt unteridjeion fam, hat

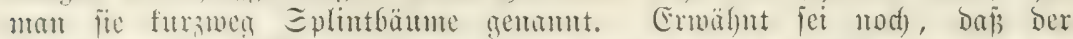

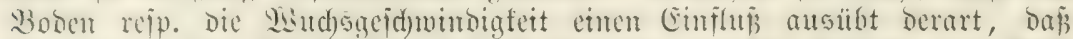

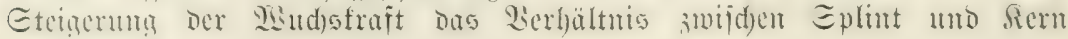
3u Intuguften bes lebteren veridoblebt.

\section{Glam.}

Da burd) bie Politur ciner jeben solzart Gilam gegeben werben fam,

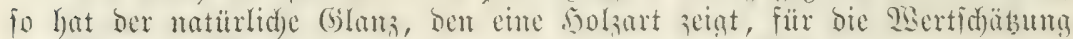

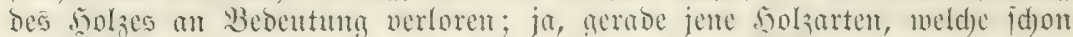

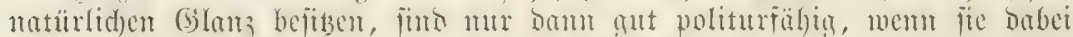

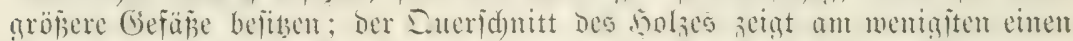

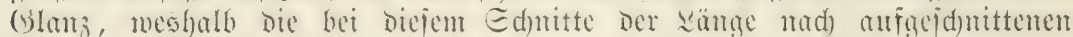

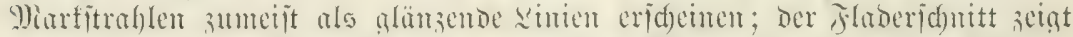

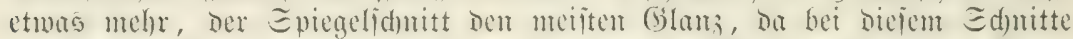

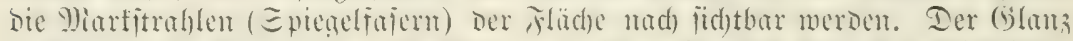

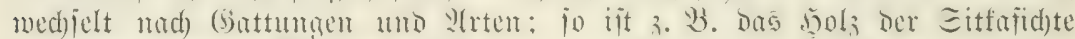

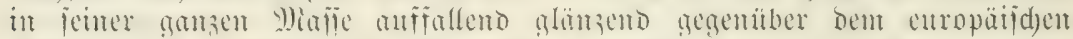

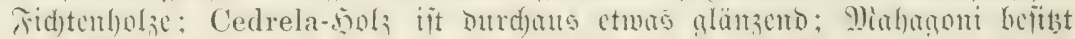

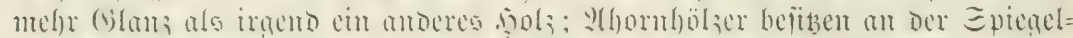

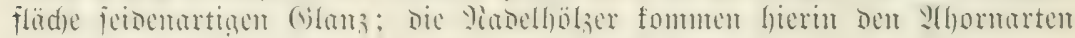
nabe; jeder Gffantz fehlt wor allem den Pirus-21rten.

\section{3. (5erud).}

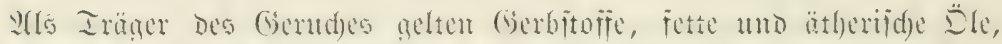

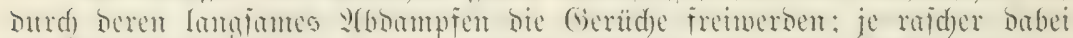

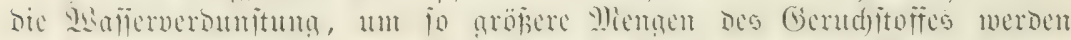

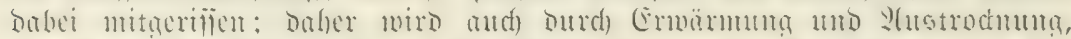

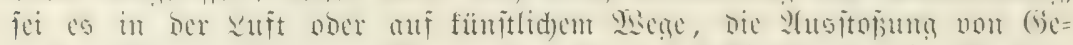

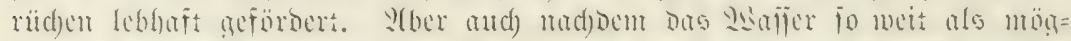

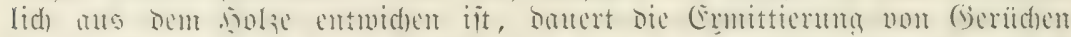

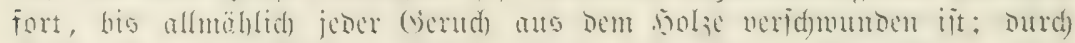

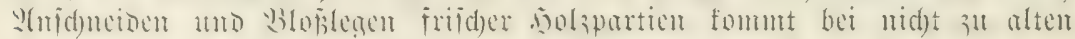

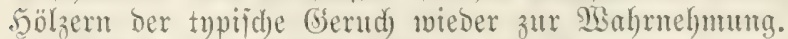

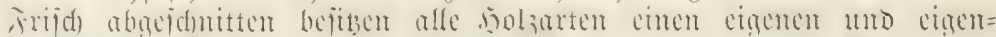

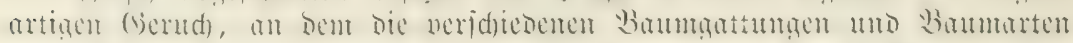

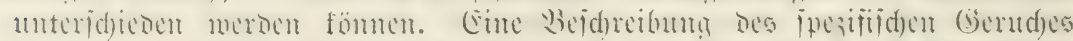

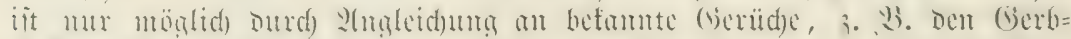

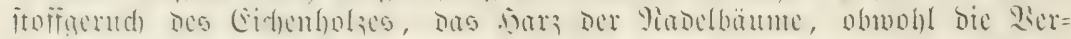

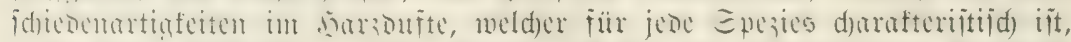

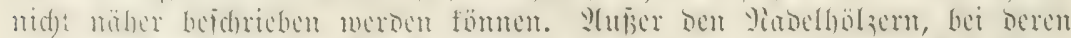

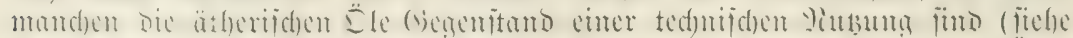

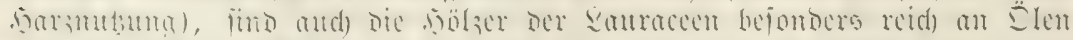

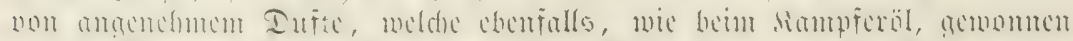

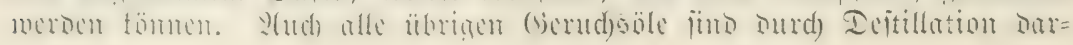




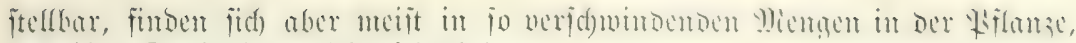
Daip ifre Darjtellutig jid) nid)t lohnt.

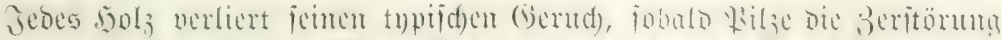

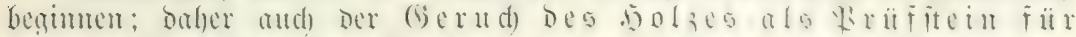

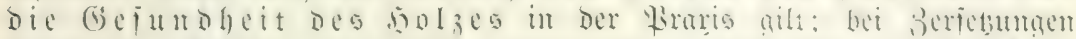

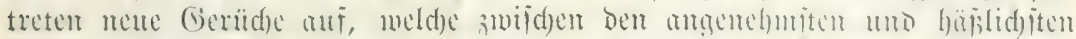

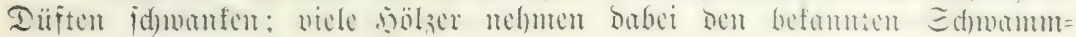
(łill $z=$ )(Serud) an.

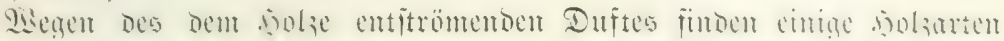

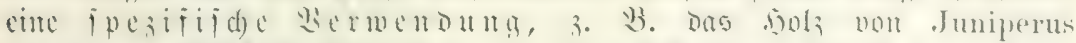

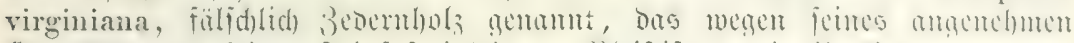

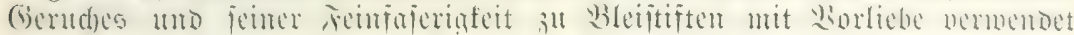

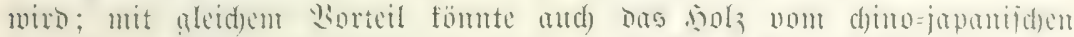

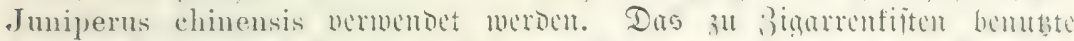

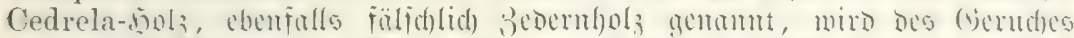

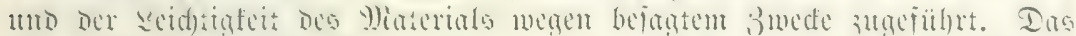

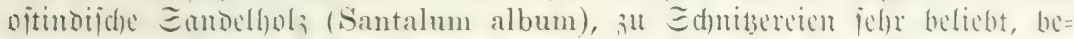

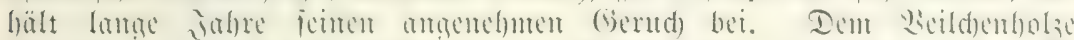

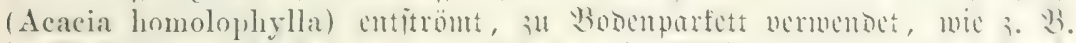

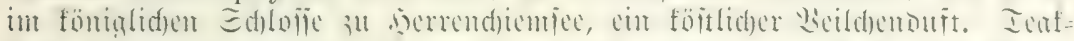

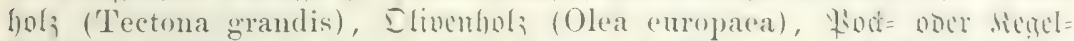

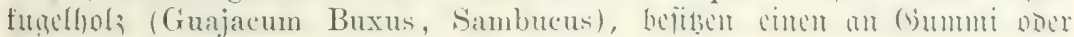
Sautjunf eximmermben, lebhafien (serud).

\section{4. สjütêt.}

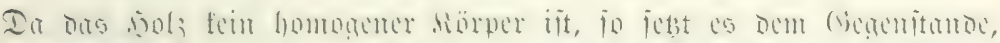

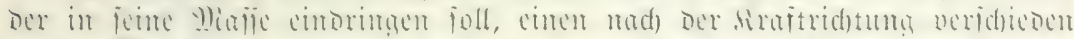

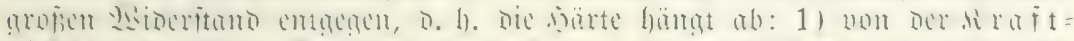

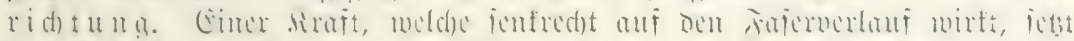

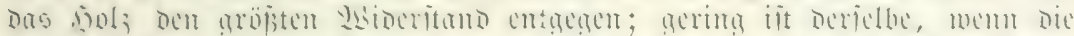

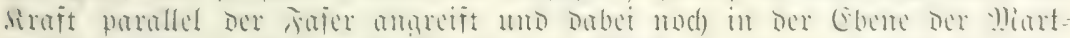

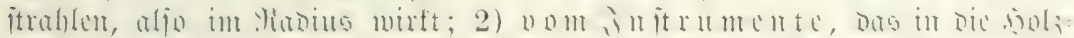

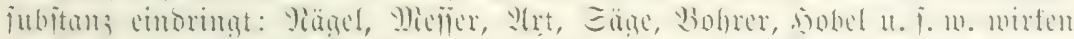

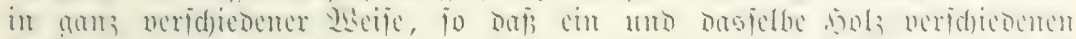

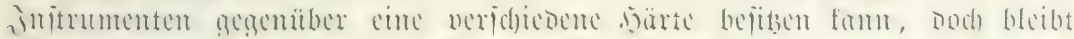

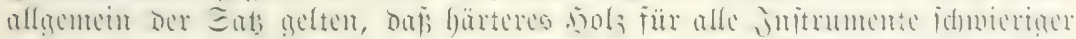
su bearbeiten it als meides; 3) vom Feudtigleitsgebalte bes b) DL äberment Dick

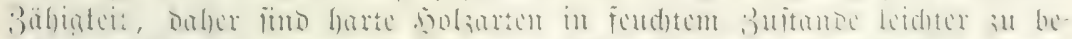

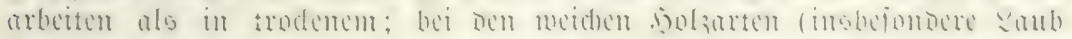

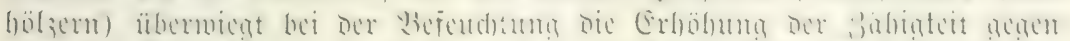

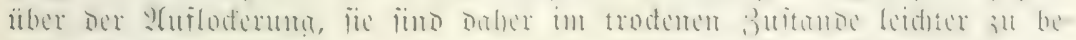

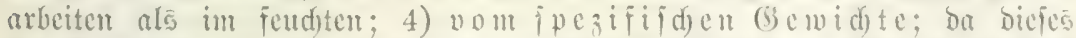

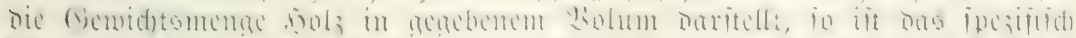

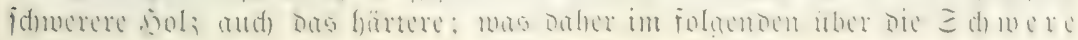




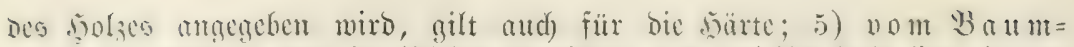

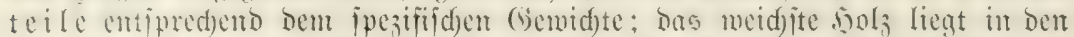

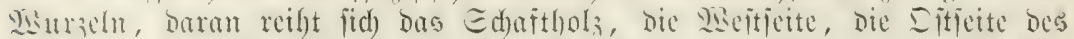

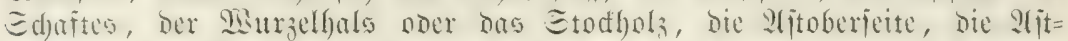

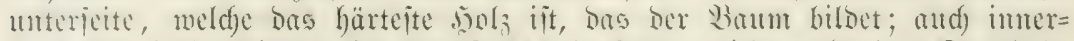

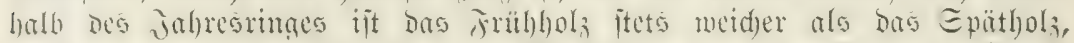

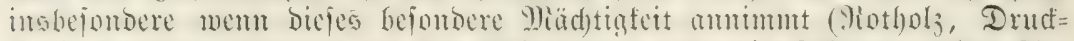

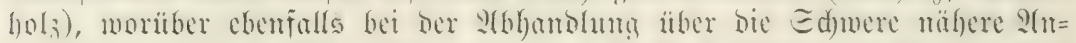

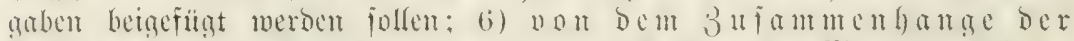

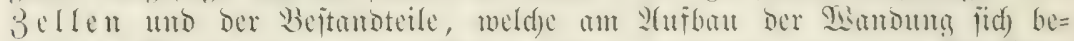

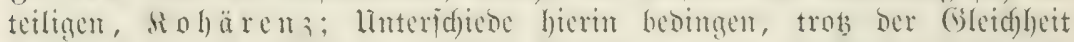

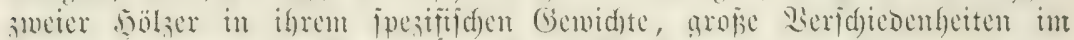

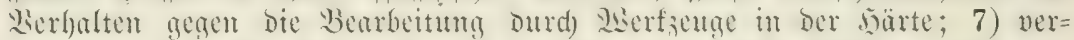

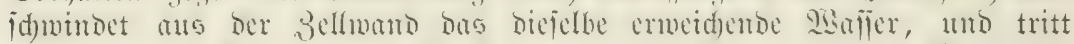

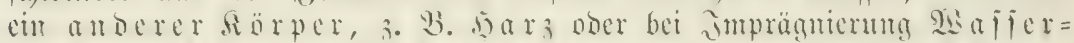

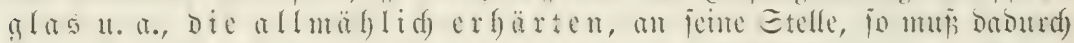

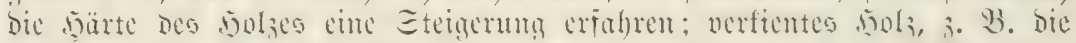

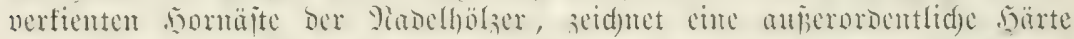
aus; 8) von ber Iemperatur, insom acfororencs nols vich bärter ijt

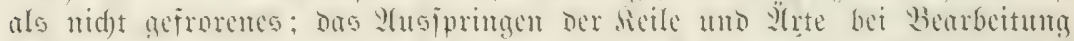

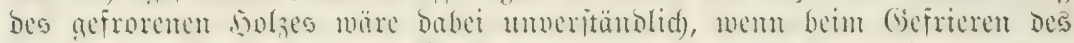

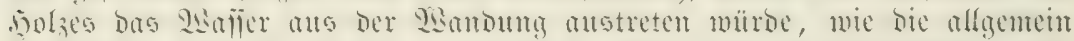

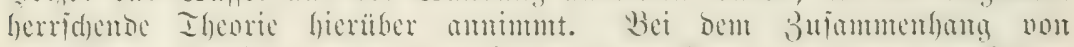

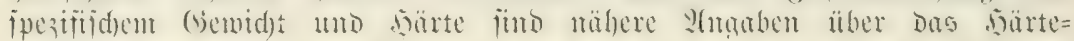

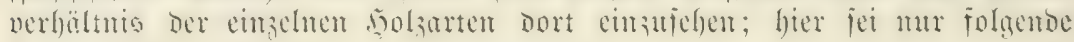
beärteftala ermälutt:

jehr hart, beinhart: Podfolz, Ëbentholz Eijenhölzer;

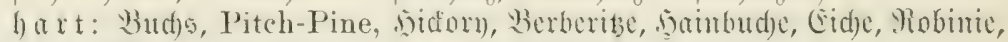

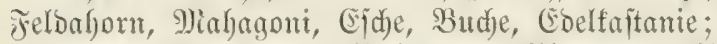

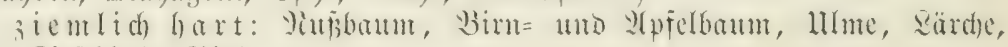
Eibe, Riridgyolz, Birte;

siemtidi) weid): Erle, Ropifajtanie;

weid): Föhre, Fitcte, Tame, Cedrela, Eupreffineen, Limbe;

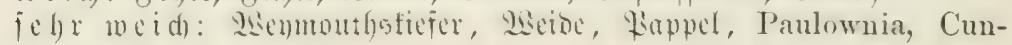
ninghamia;

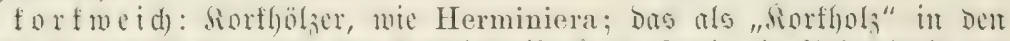

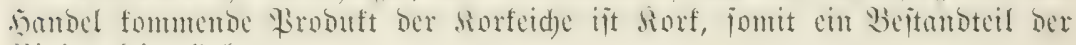
Minte, feit $\mathfrak{S C D}_{\mathfrak{3}}$.

\section{5. (Gewidst.}

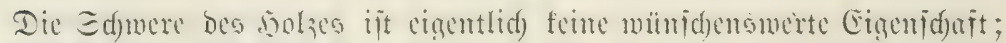

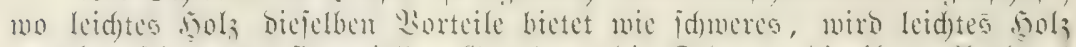

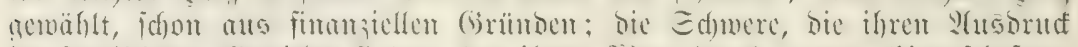

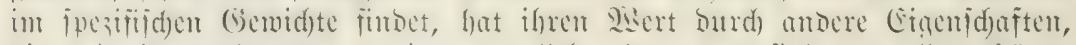
die mit ihr mefor ober mentiger parallel aefen, das fimo vor allem särte,

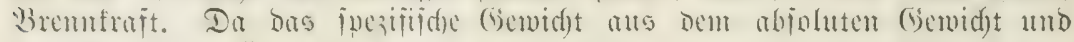

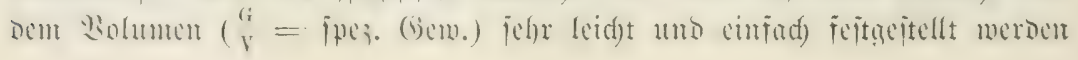




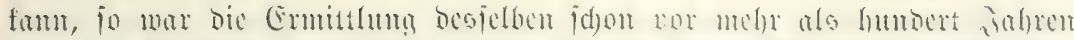

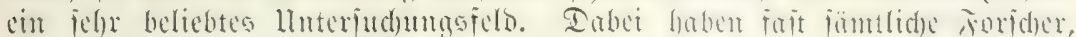

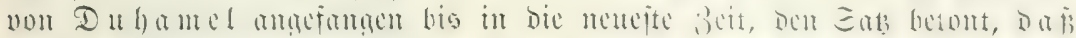

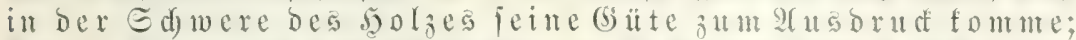

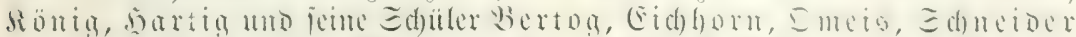

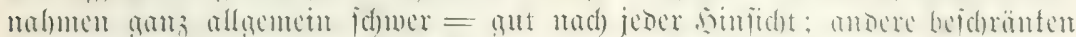

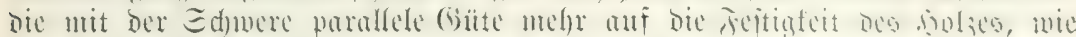

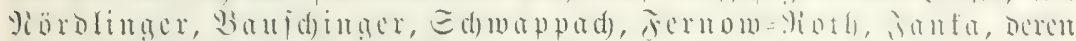

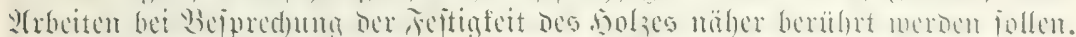

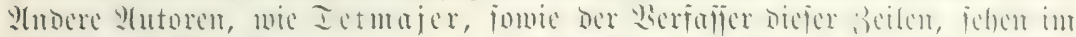

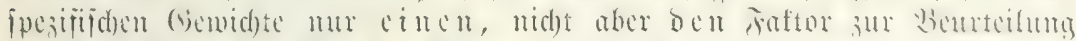

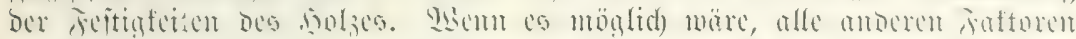

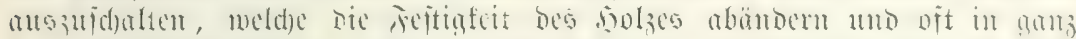

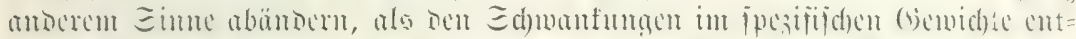

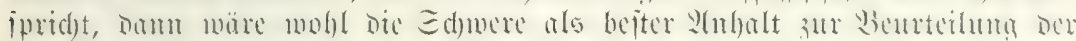

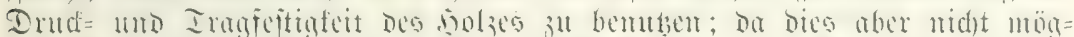

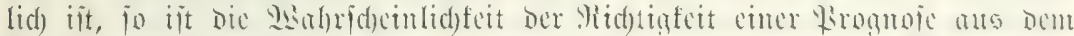

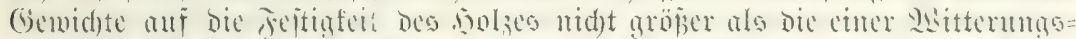

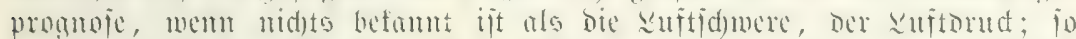

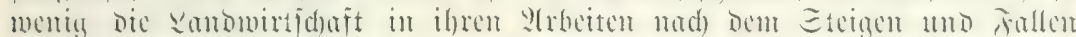

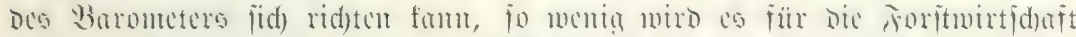

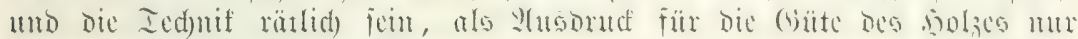
bas ipezifiche (semvidyt ju benutsen.

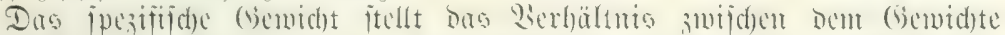

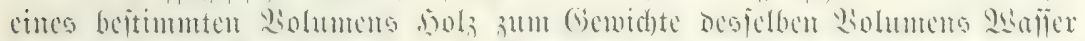

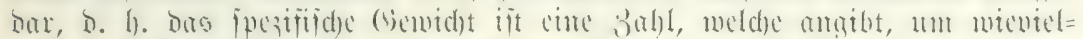

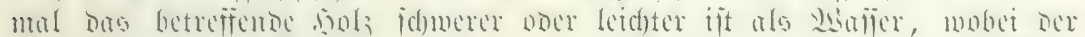

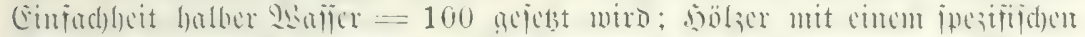
(bomidete

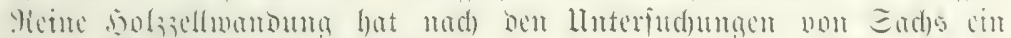

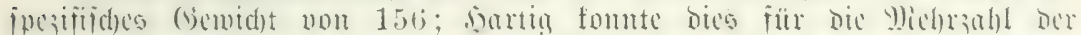

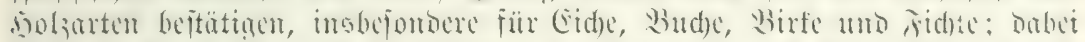

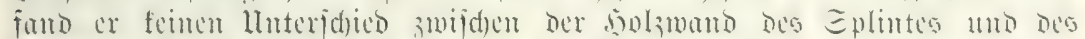

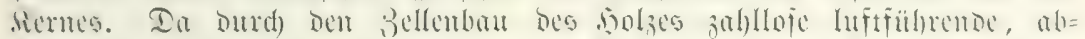

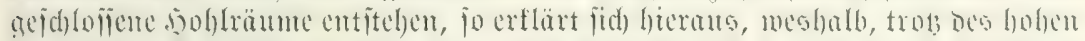

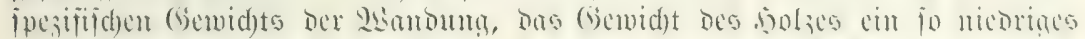

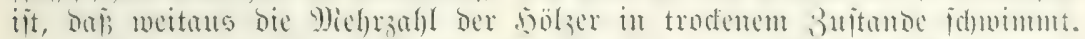

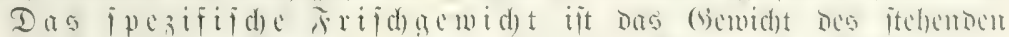

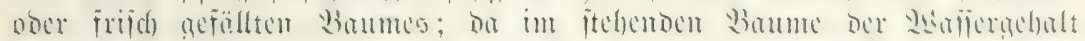

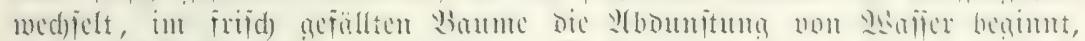

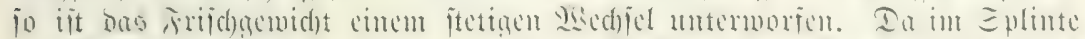

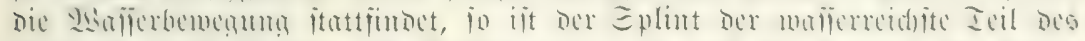

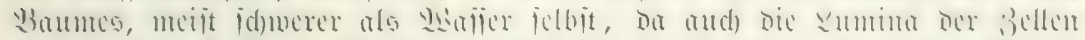

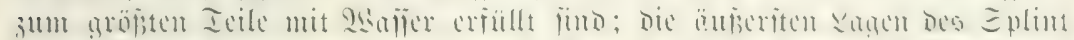

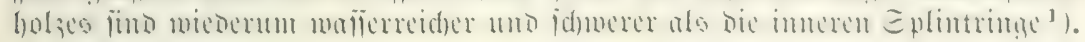

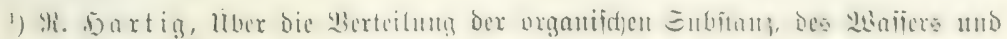
Euftraumes in Den Bäumen. Berliu 1882. 


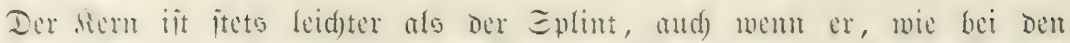

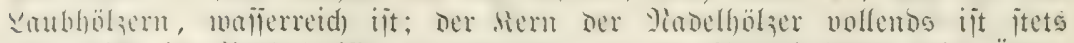

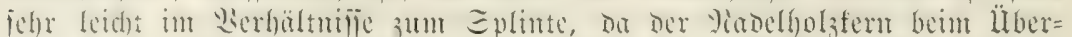

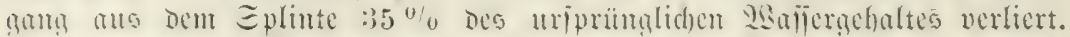

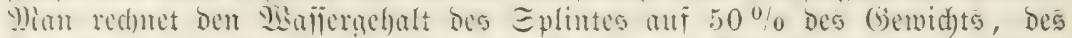

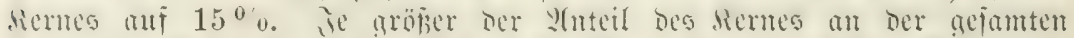

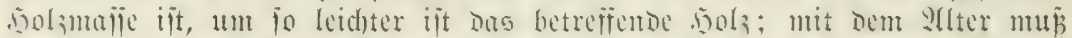

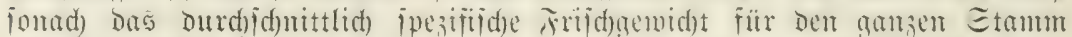

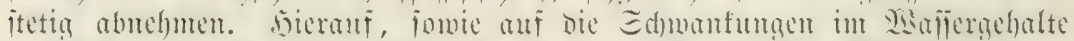

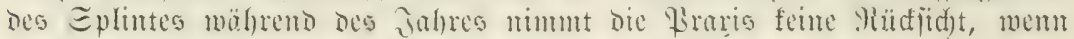

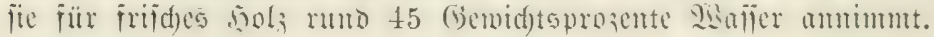

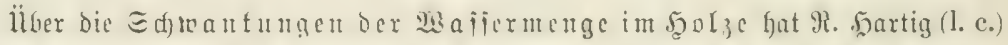

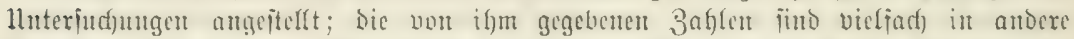

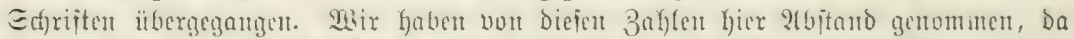

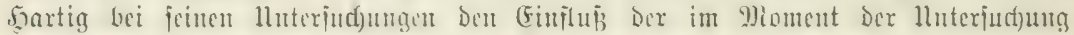

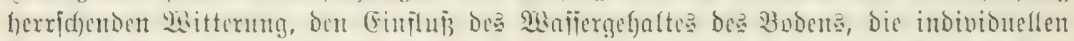

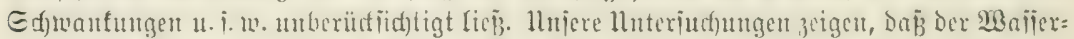

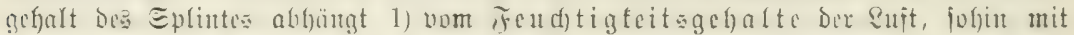

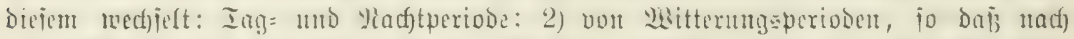
cuncr Megenperiode bie Etämme mit Wajiet angejïllt, nad) ciner Irofemperiode

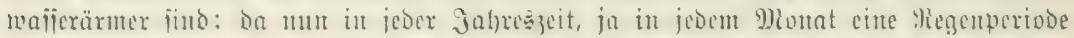

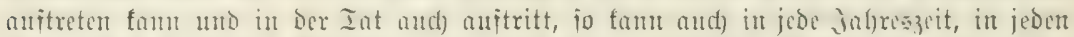

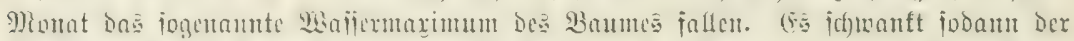

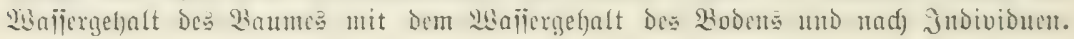

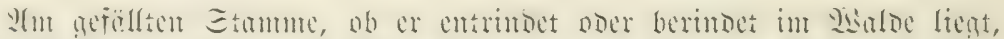

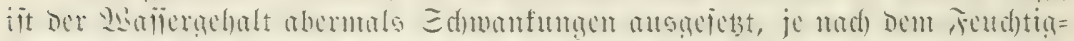

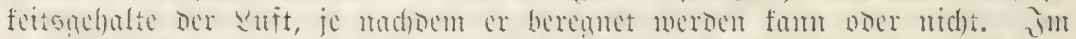

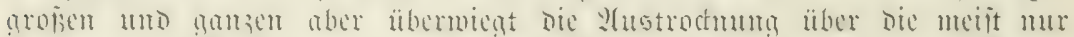

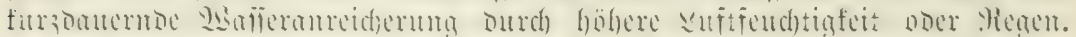

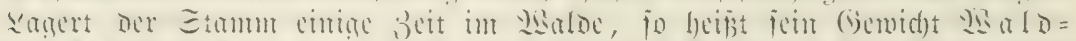

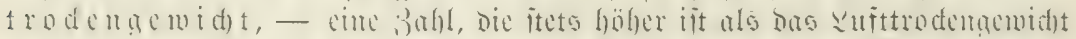

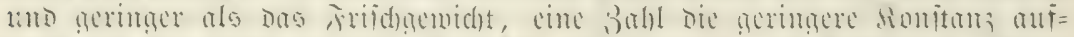

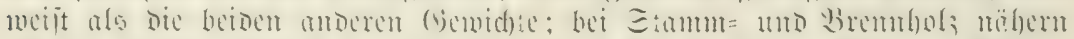

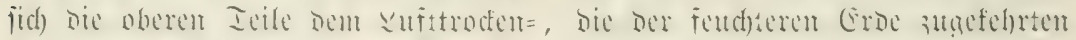

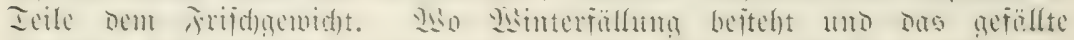

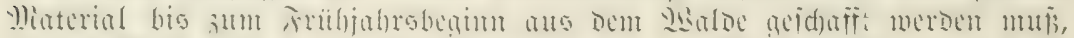

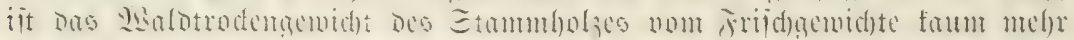

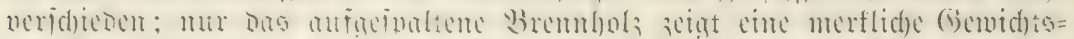

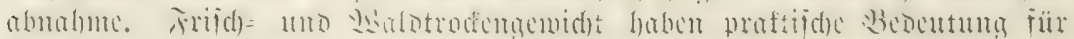
ben Solstratspori.

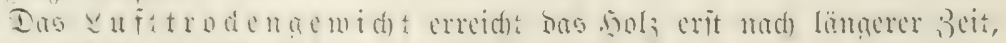

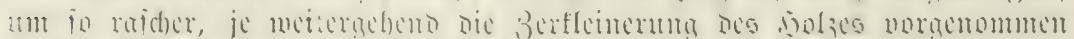

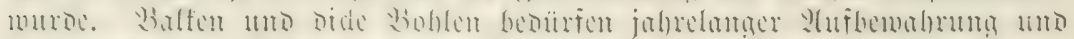

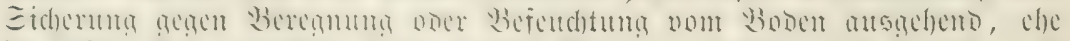

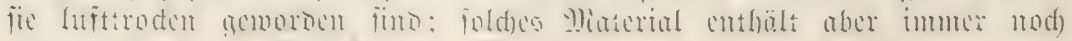

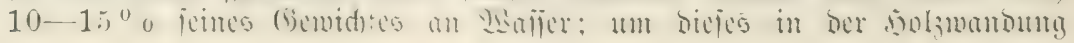




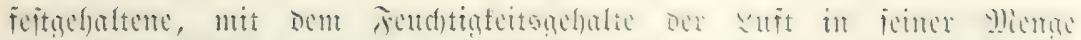

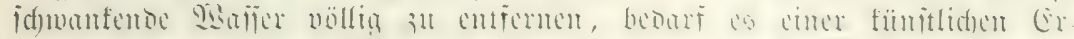

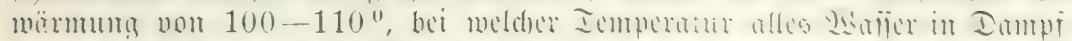

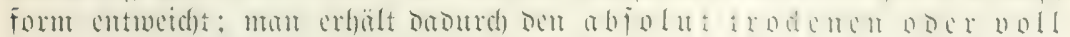
foumen trodenen 3 ut and Des Do

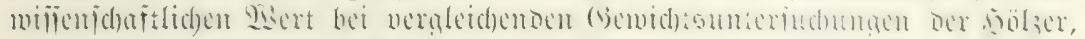
nobei der an meifen förende Fattor Mibajer eliminicrt miro.

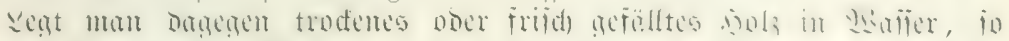

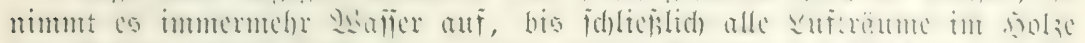

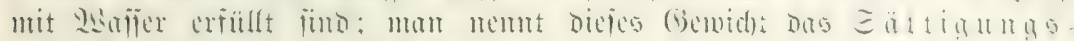

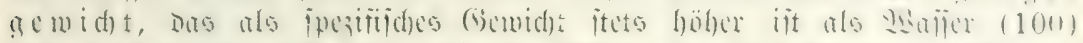

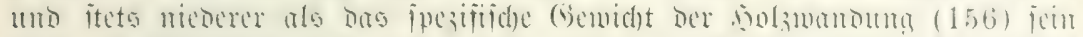

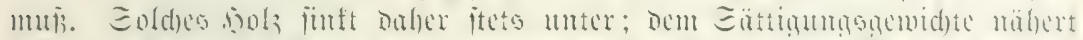

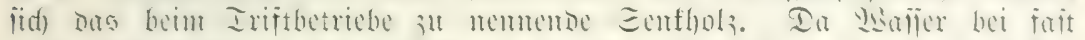

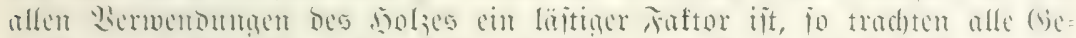

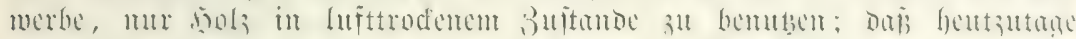

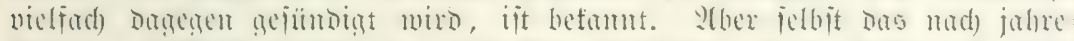

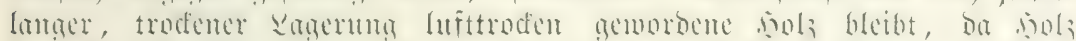

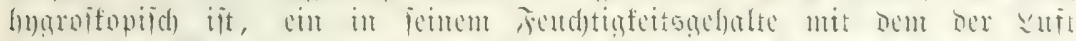

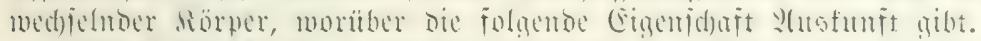

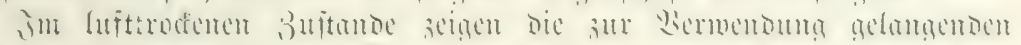

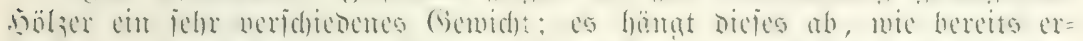

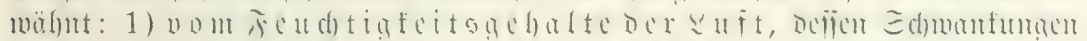

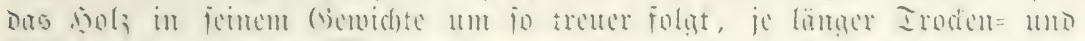

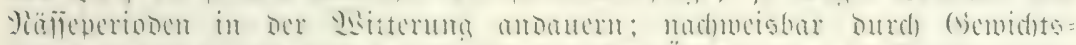

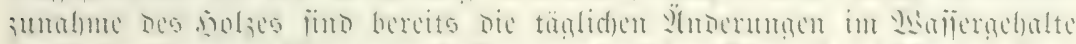

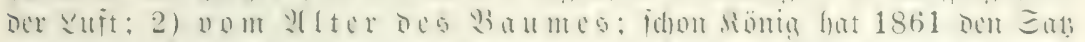

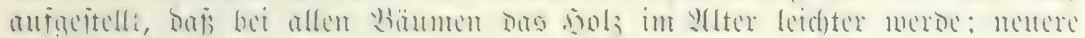

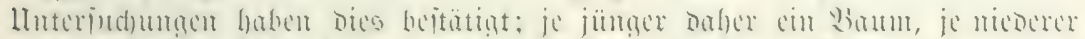

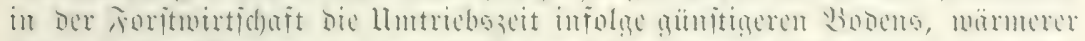

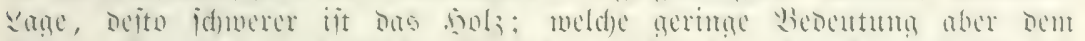

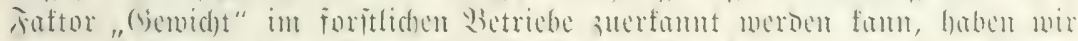

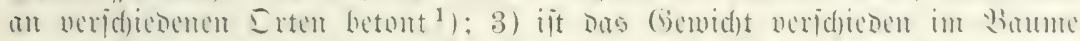

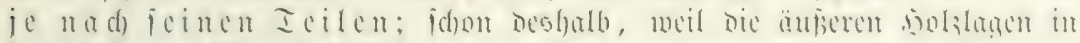
ocm ipäteren ?flter bes

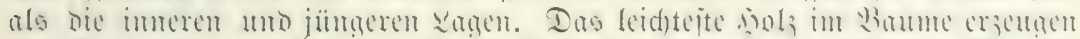

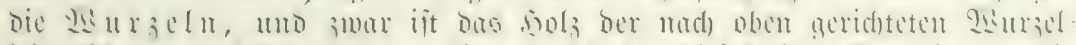

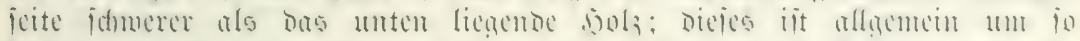

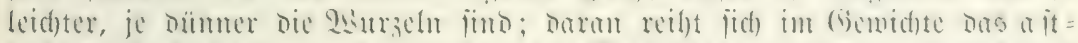

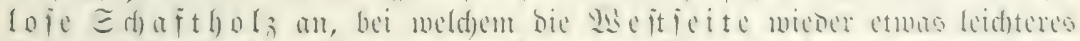

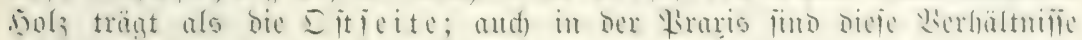

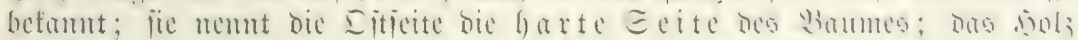

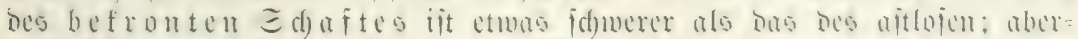

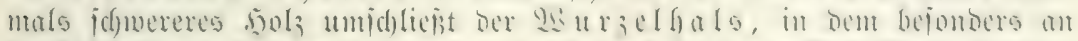

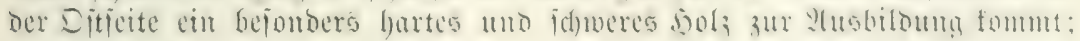

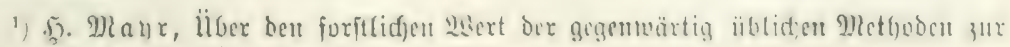
Beitimmung Der Qualität der f̧ölzer. 1899. 


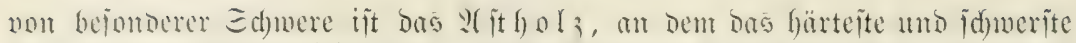

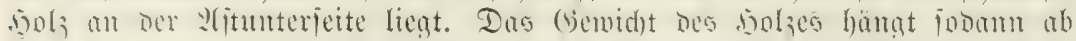
4) vou ber Jabrearingbreite und ben Berbältuife vou

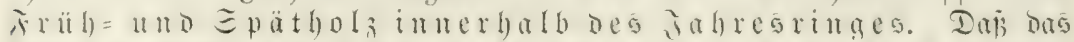

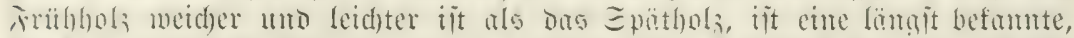

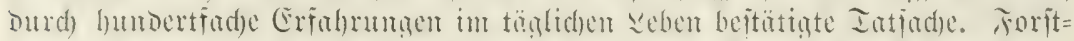

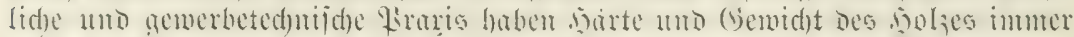

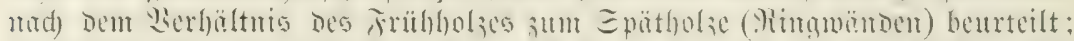

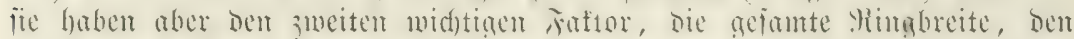

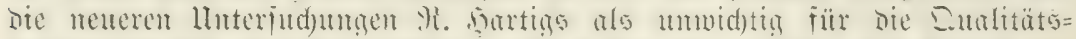

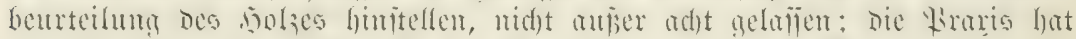

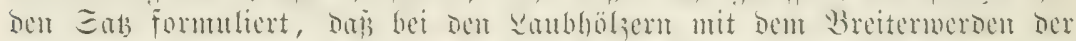

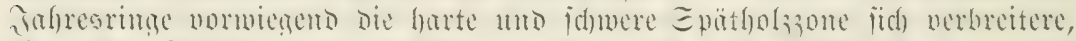

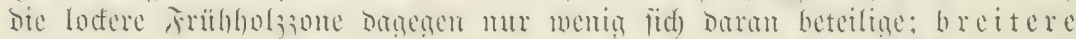
Jahrebringe bedeuten fomit beim \&aublolze eit $f$ d wereres

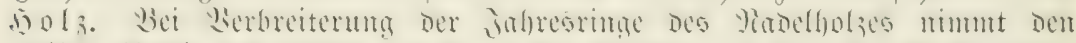

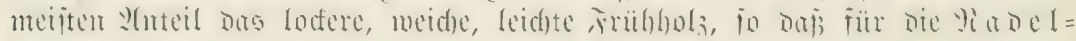
hölzer ber Eabgilt: je enger die Jafrearinge, ut fo fdwerer at d b ärter bas $\mathfrak{H}^{\circ} \mathfrak{l}_{3}$.

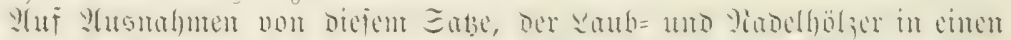

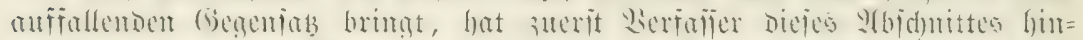

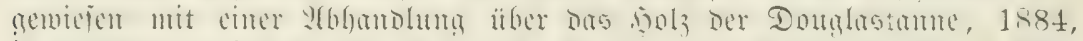

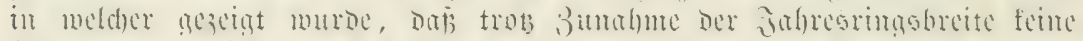

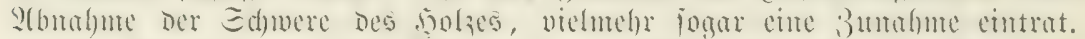

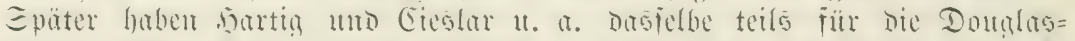

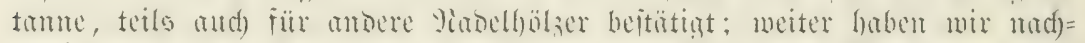

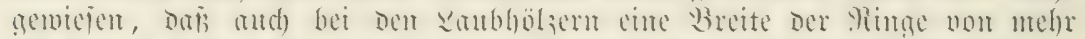

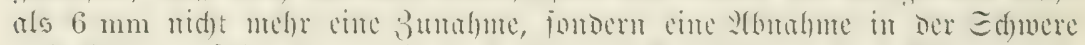

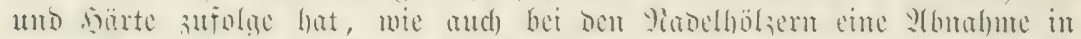

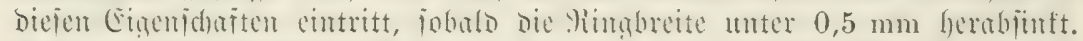

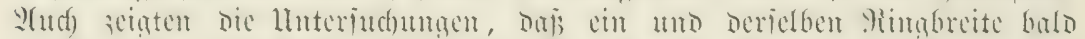

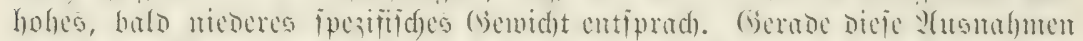

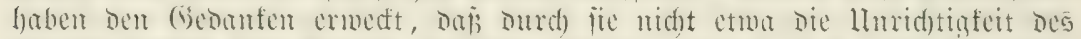

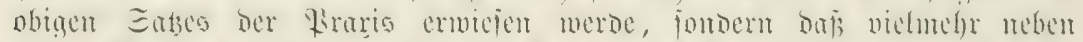

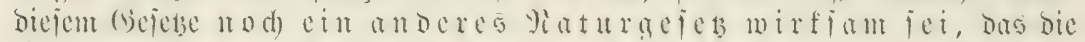

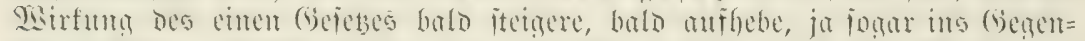

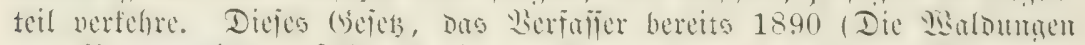

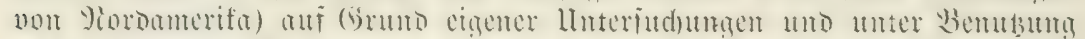

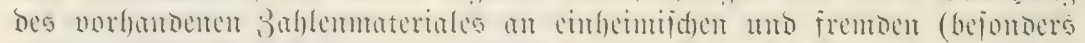

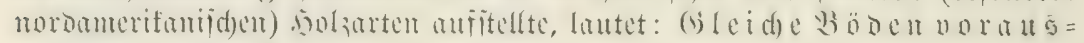
gejest, nimmt vom flimatijed Dptimum einer Solzart himbeg bas ipezififde (bemidst (jomie bie bärte) jowohl nad) Dem fübleren mie nad) dem wärmerensitima lin ab, gleidgultig, ob babei bie Jalyesringe an Breite zu= ober abmebmen, gleidgältig, ob es jid um $2 a u b=$ ober $\Re a b e l=$

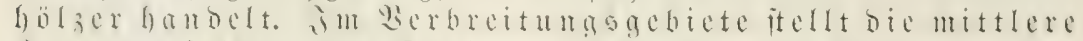

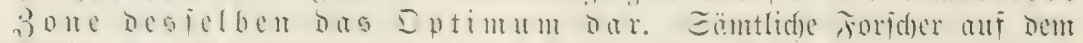

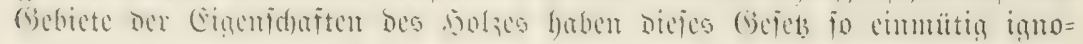




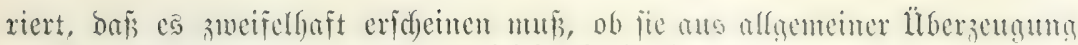
von jeiner Unridgtigfeit ober Inmoidgtigfeit fo Ganbelten.

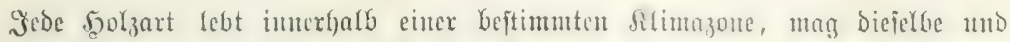

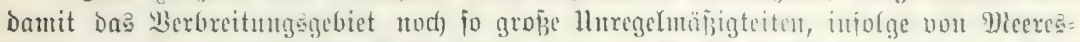

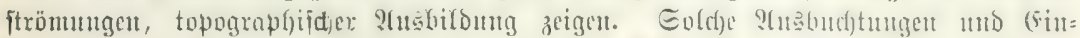

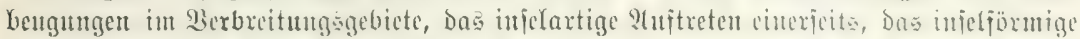

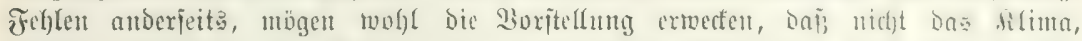

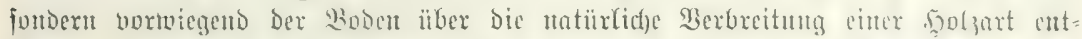

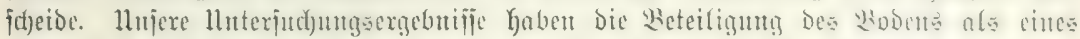

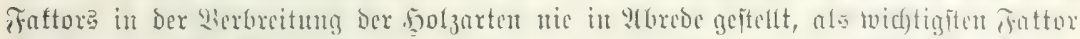

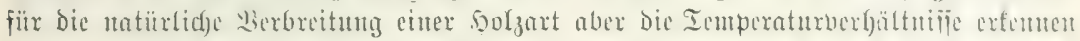

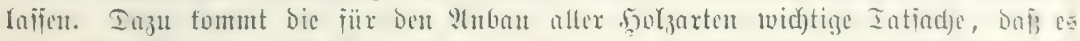

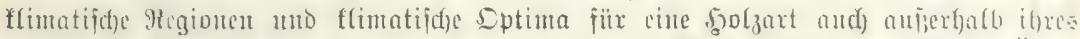

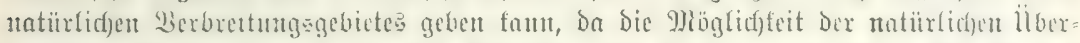

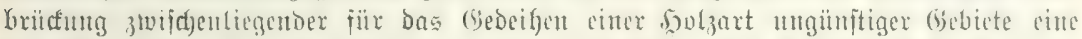

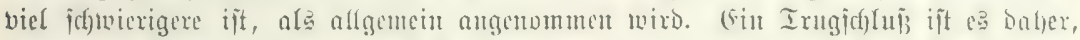

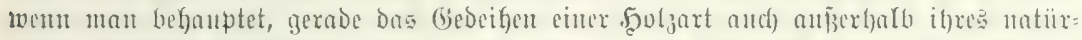

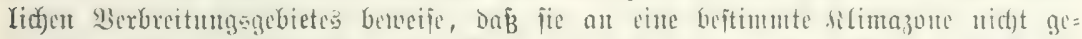

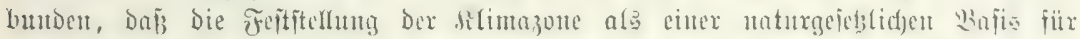

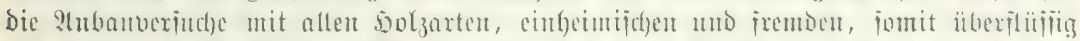

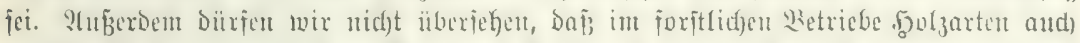

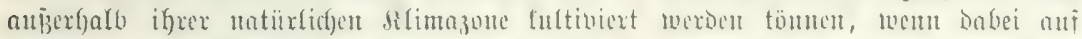

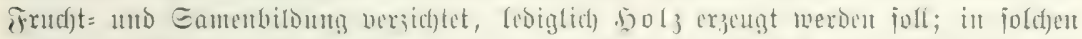

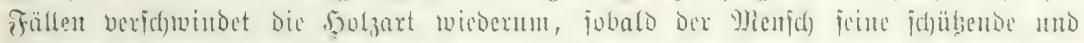
fultivierende Şand zurürf jieft.

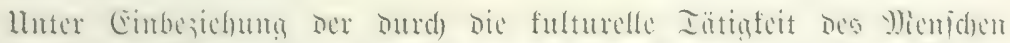

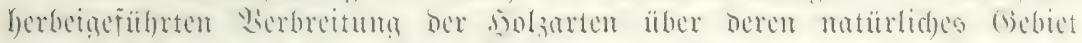

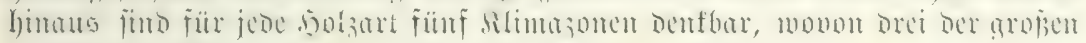
natürlid)en Silimazone, żwei der fümftlid)en angebören.

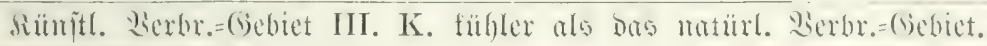

Ratuirt.
Berbr.=Gebiet $\left\{\begin{array}{l}\frac{\text { II. K. fübler als das Dptimum. }}{\text { I. Dptimum. }} \\ \text { II. W. märmer als das Dptimum. }\end{array}\right.$

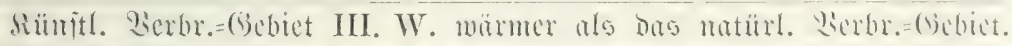

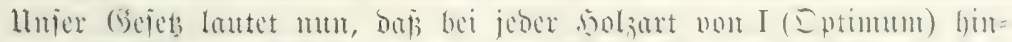

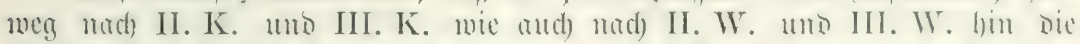

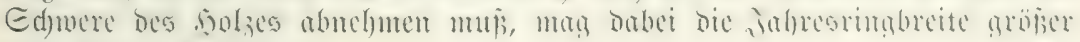
oder fleiner werben.

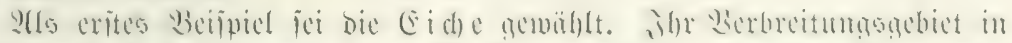

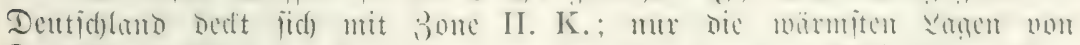

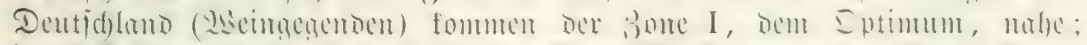

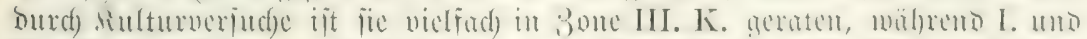

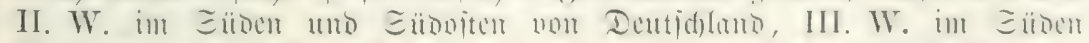

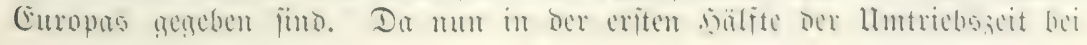




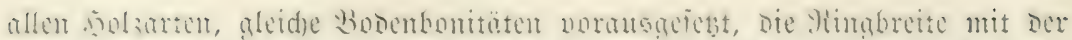

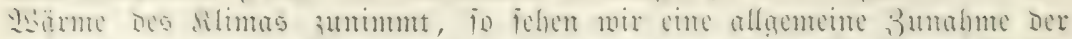

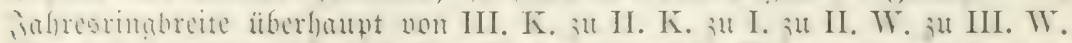

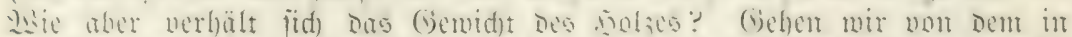

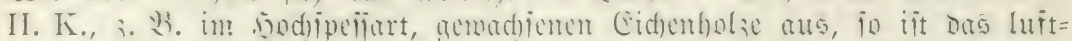

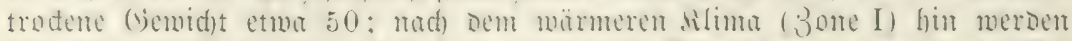

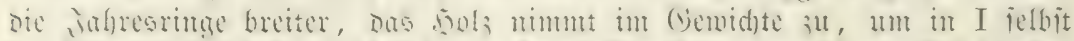

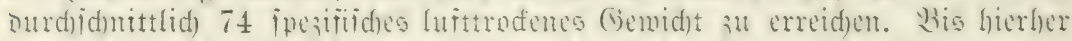

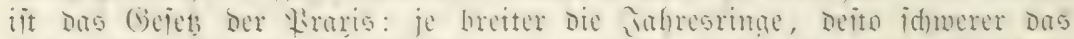

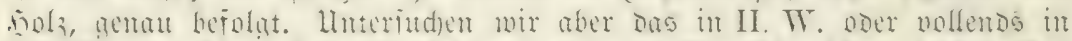

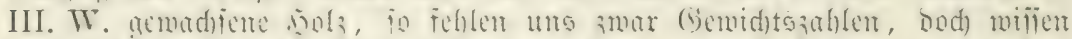

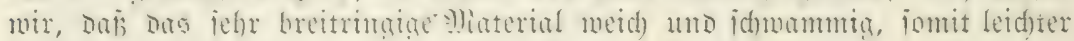
ifit als bas Jyols int I.

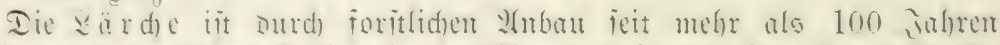

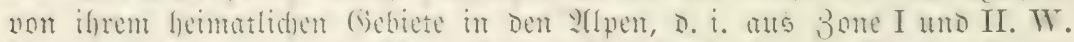

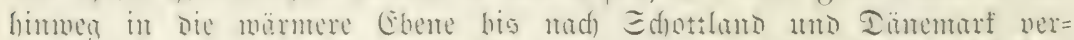

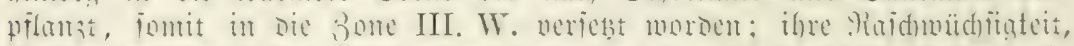

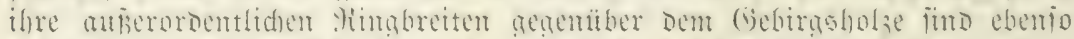

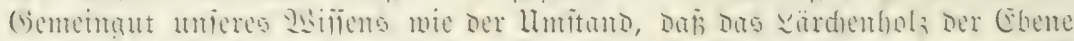

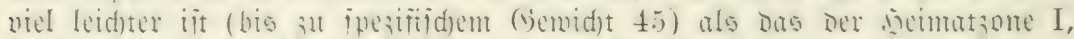

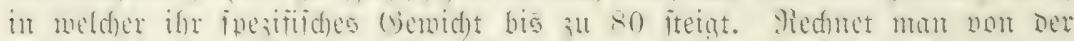

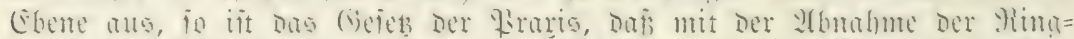

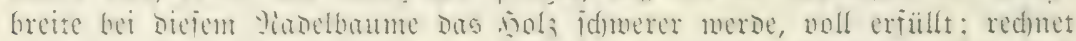

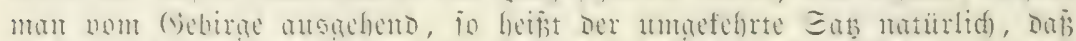

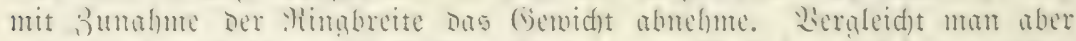

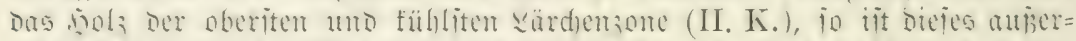

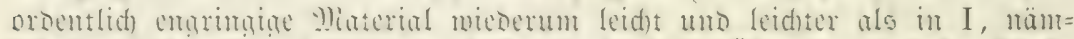

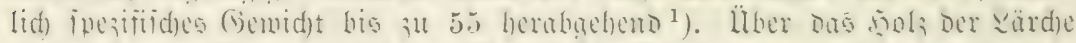

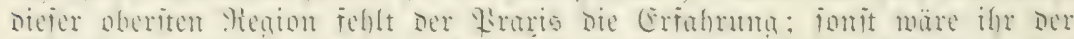

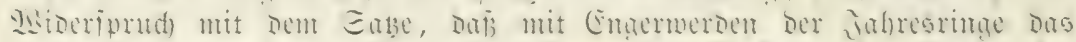

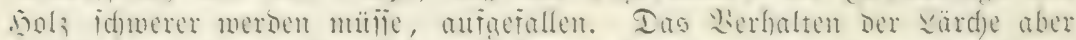

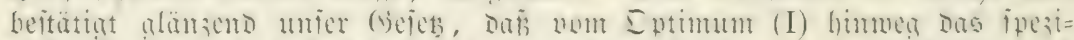

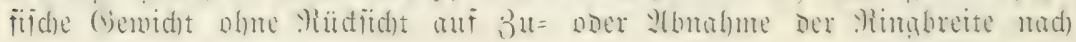
allen Eeiten hin abnimmt.

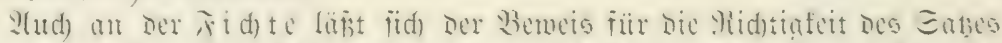

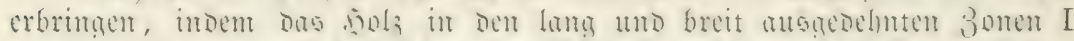

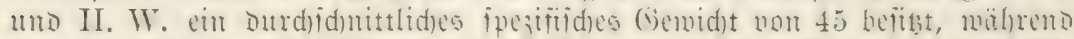

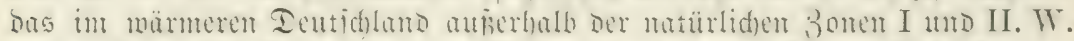

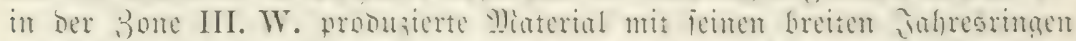

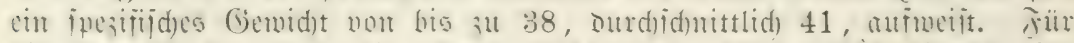

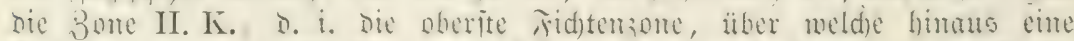

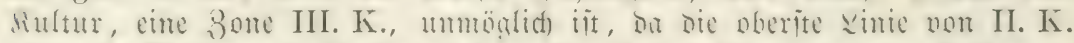

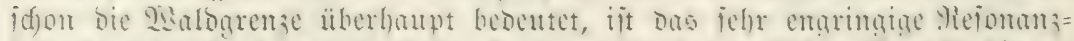

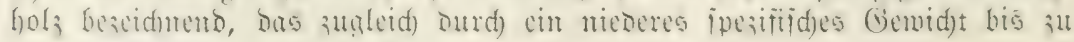
40, Durdj) junittlid) 42 , aแffällt.

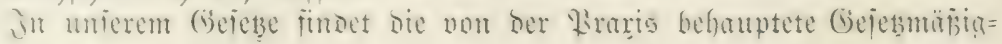

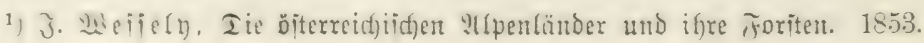




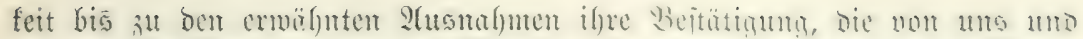

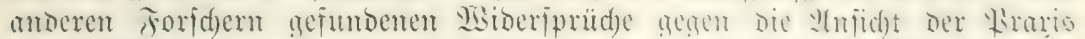

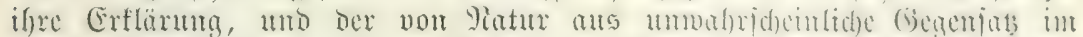

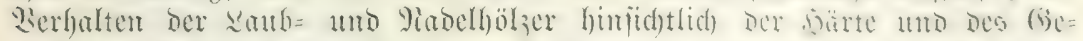

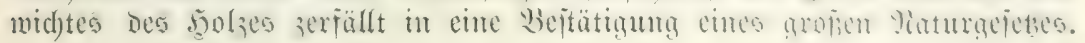

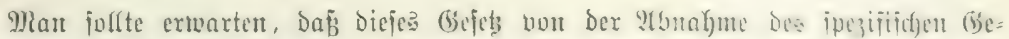

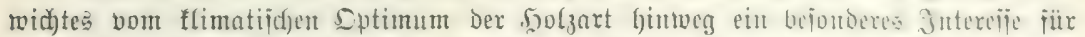

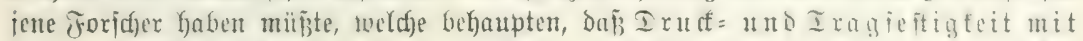

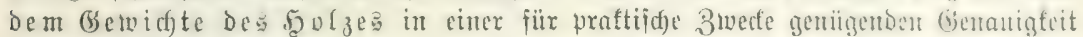

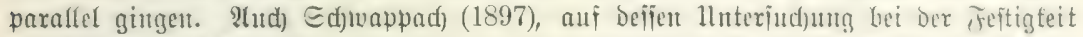

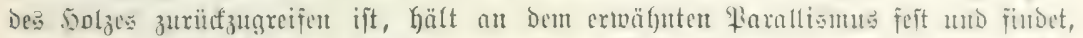

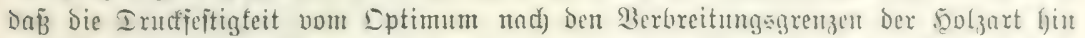

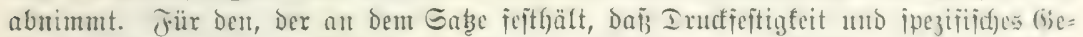

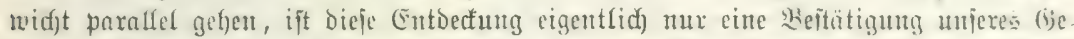
ietze?. Eo wenig roie E(f)

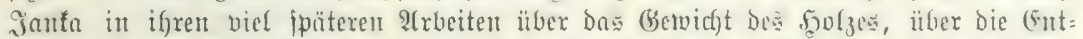
Ftehung Der Friif)= unD Epatfolzzone und if)ren Einfluß auf Das (bituidgt, über bie

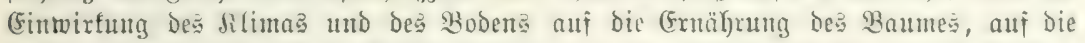

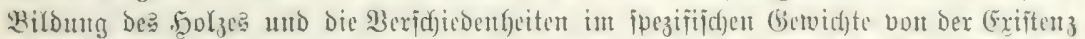

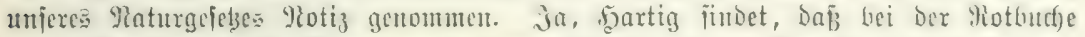

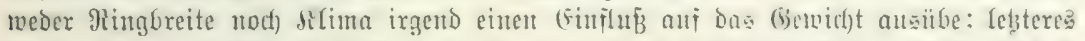

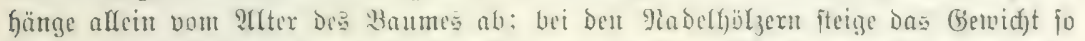

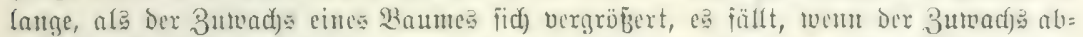

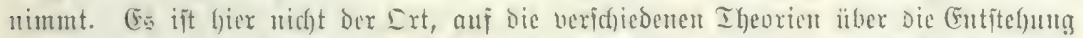

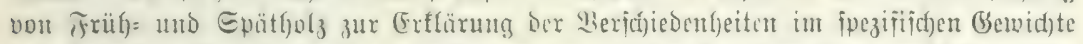

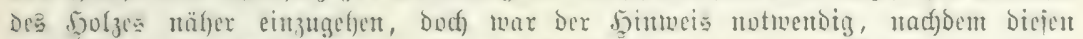

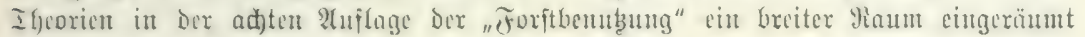
torbett toar.

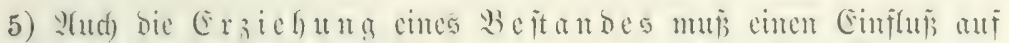

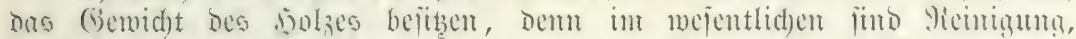

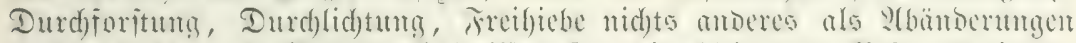

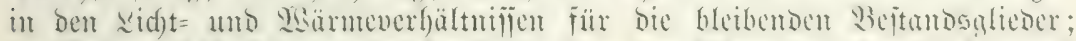

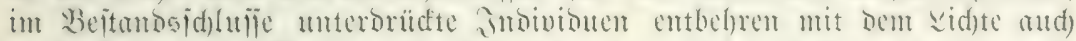

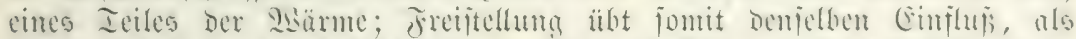

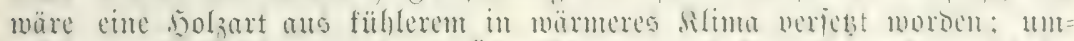

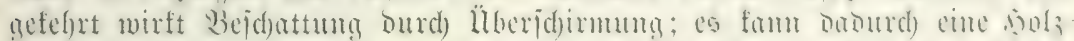

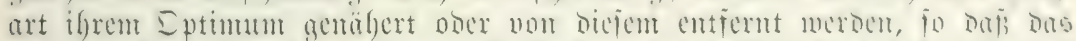

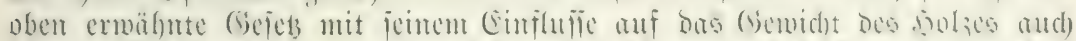

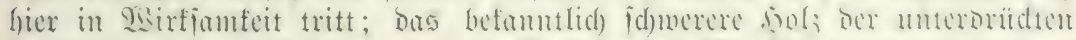

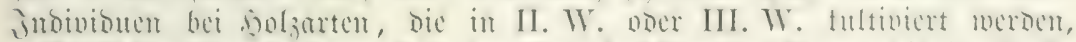

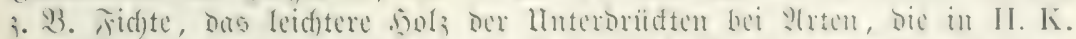

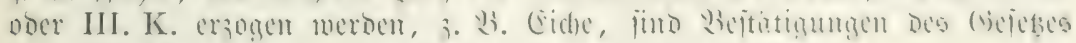

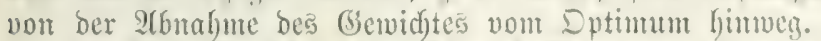

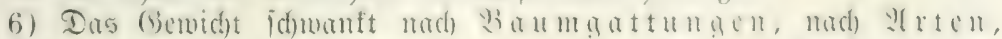

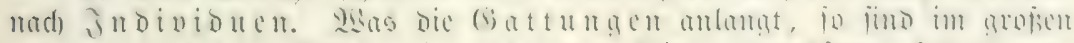

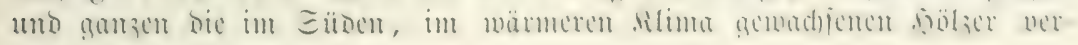

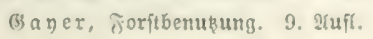




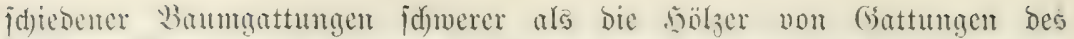

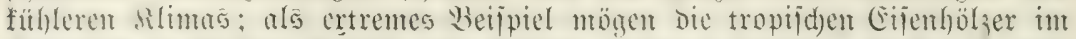

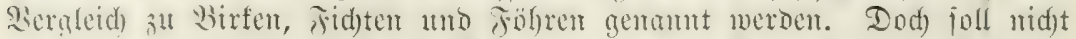

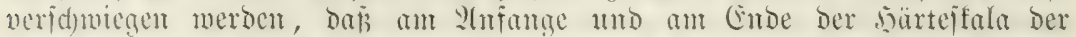

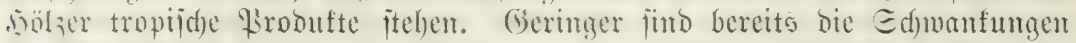

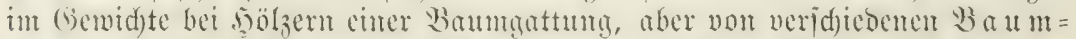

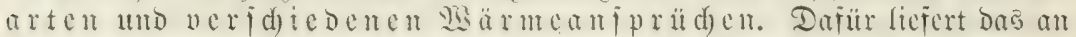

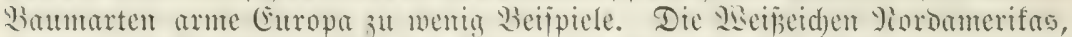
bie nur im jübliden Ieile ber Diereinigten Ettraten ${ }^{1}$ ) vorfommen, befitien

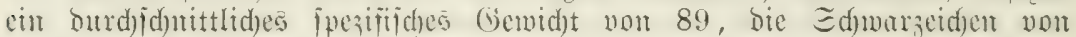

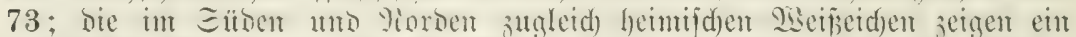

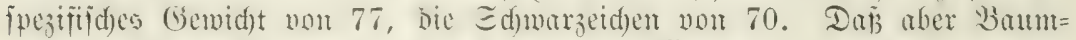

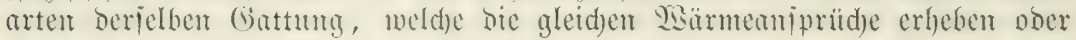

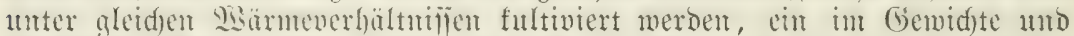

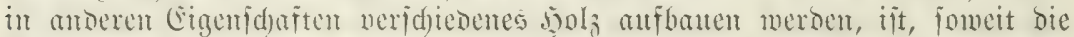

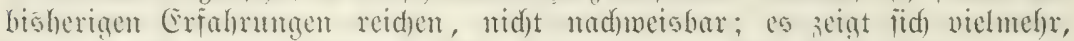

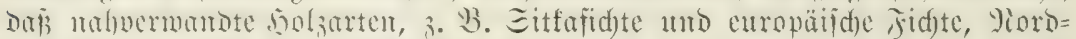
mantstante und cinflimilde Inme, Quereus alba und Quereus sessili-

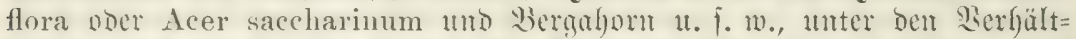

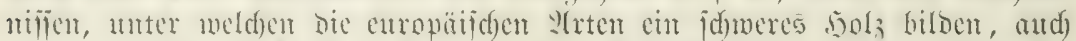

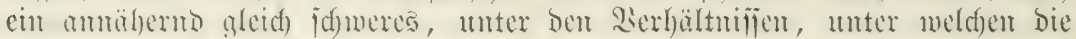

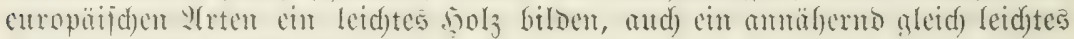
$\mathfrak{S}_{\mathrm{O}} \mathfrak{l}_{3}$ probuzieren merben.

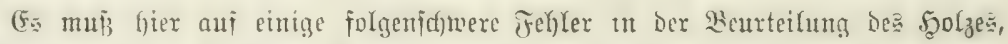

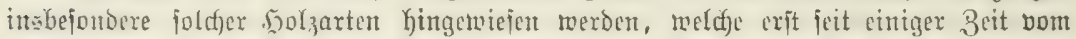

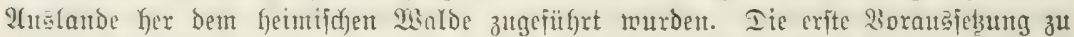

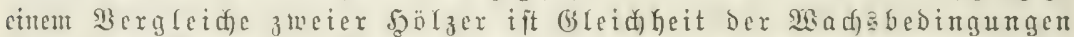

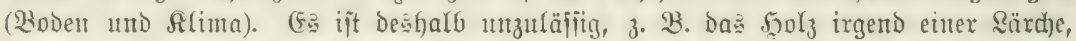

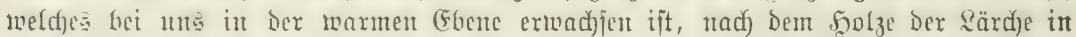

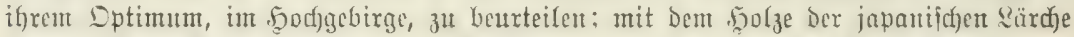

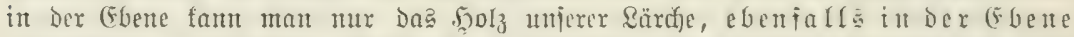

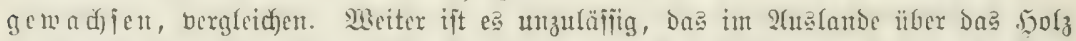

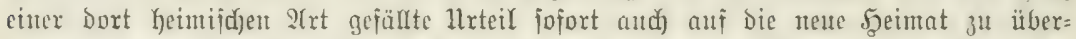

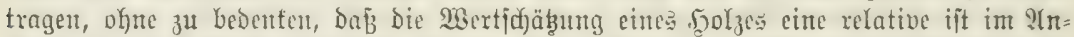

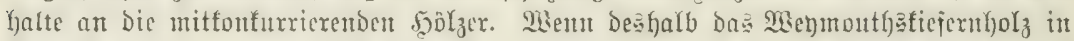

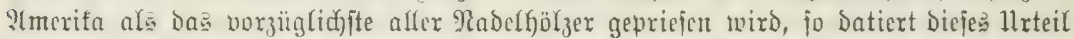

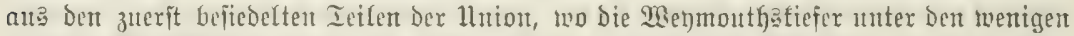

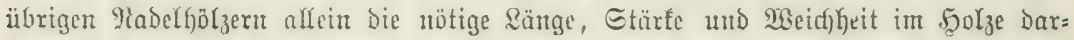

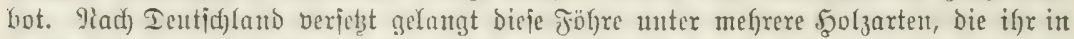

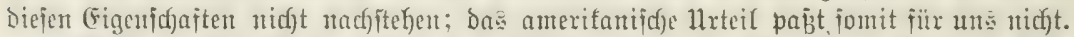

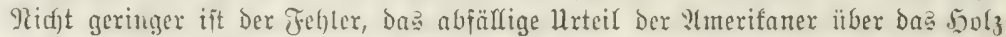
nnverer Riefert, wie P. resinosa, Banksiana, rigida, ponderosa, burent feölzer fie

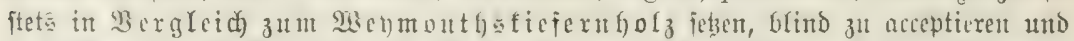

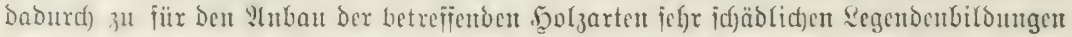

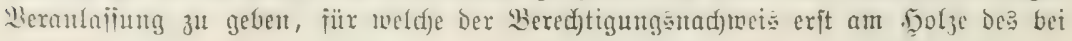

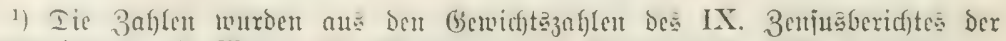

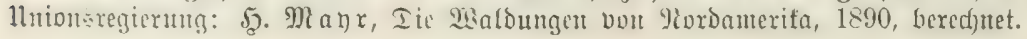




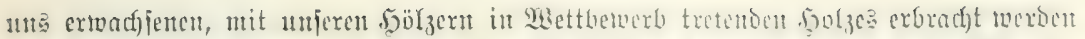

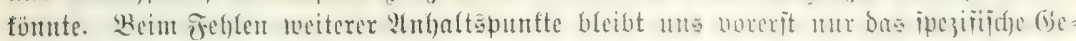

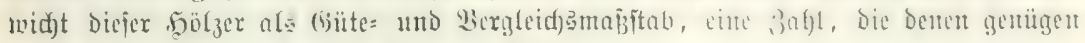
nเuß̆, weld)e auf das (Geroid)t fo hohen Mert Yegent.

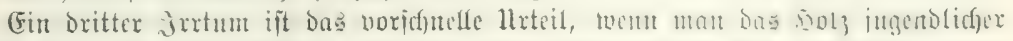

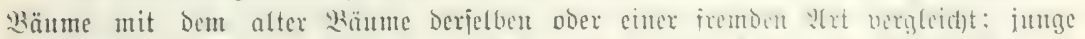

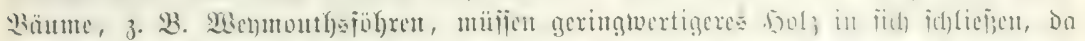

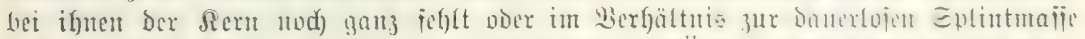

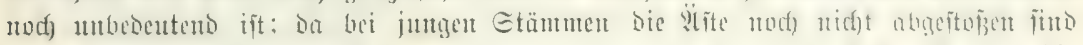

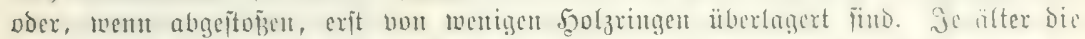

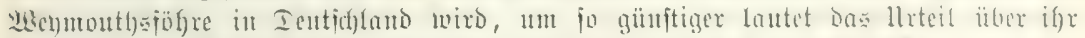

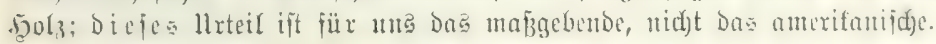

Daf; 7) aud ber SBoben, gleide filimalage vorausgejetst,

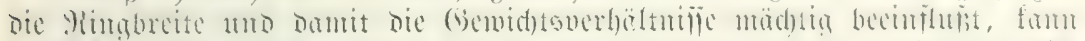

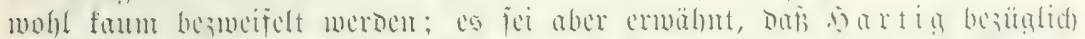

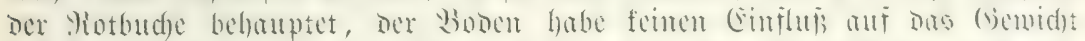

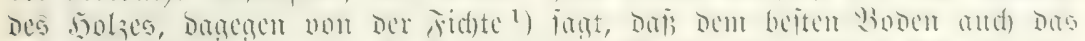

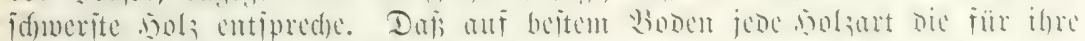

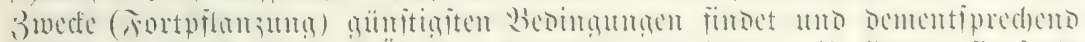

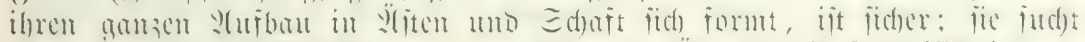

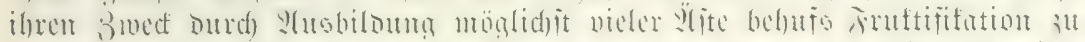

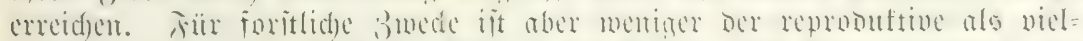

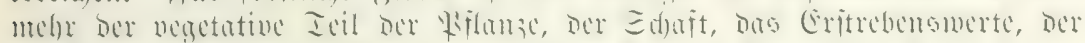

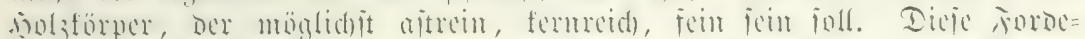

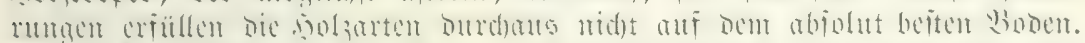

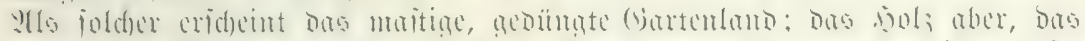
mai indesen

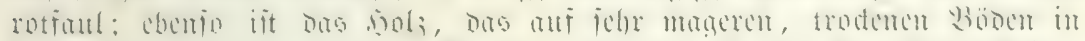

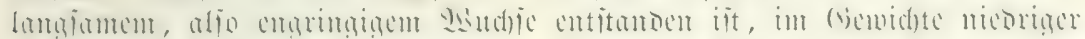

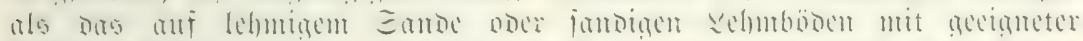

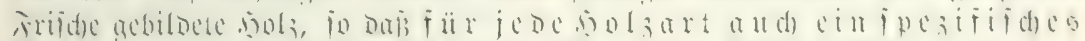

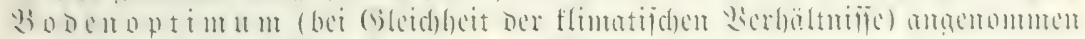
merdest mai, bo

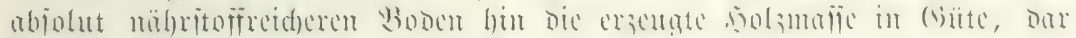
muter aud) $i m$ (b́) ewids te abnimmt.

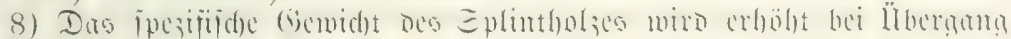
besplben in Sermbols, wenn babei ein Farb foff biuzutritt:

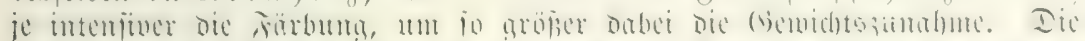

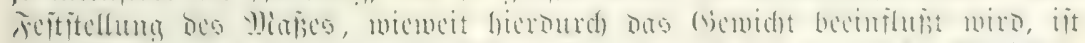

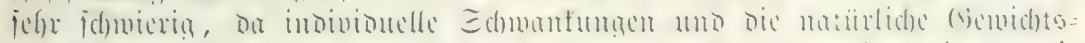

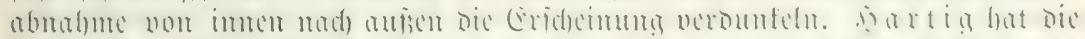

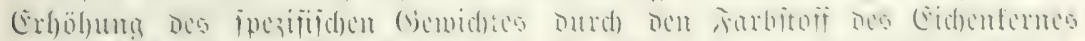

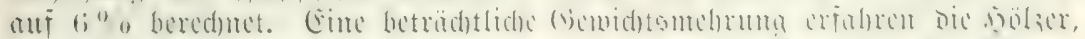

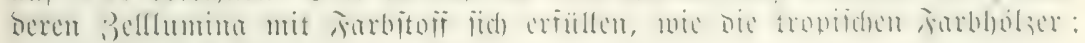
ebenjo tüuptlid) imprägnicrte bölger.

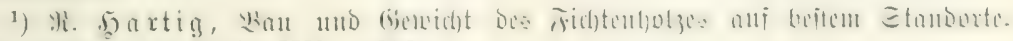
Foritน. naturw. 3citjdyrift VII: 1898. 


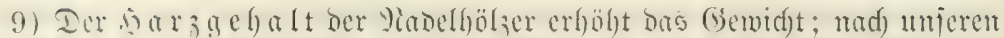
Unteriud)ungen ${ }^{1}$ ) furbet erit mad) Dem lubergange von Eplint in fiembol?

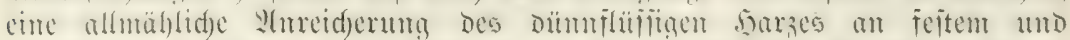

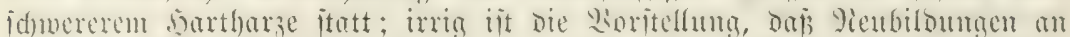

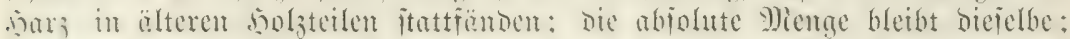
jie andert mur bie jorm, inben jie jid) anf ein höheres (bemid)t fonzentriert

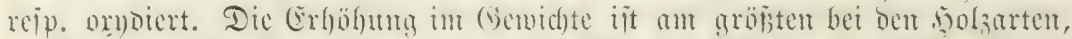

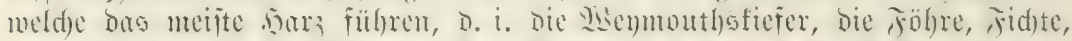

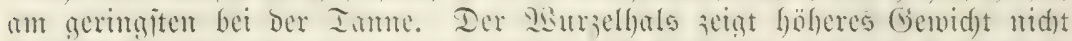

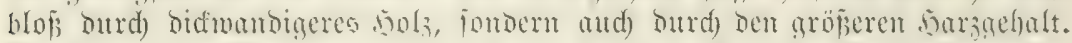

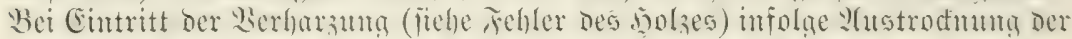

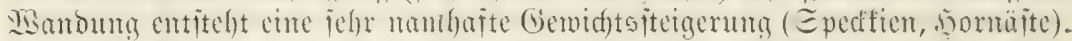

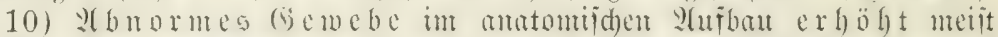

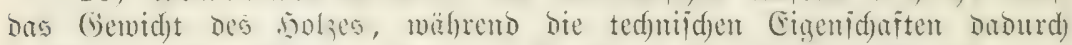

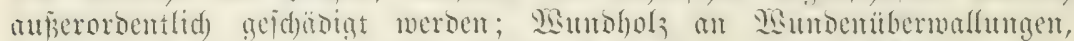

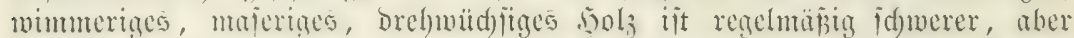

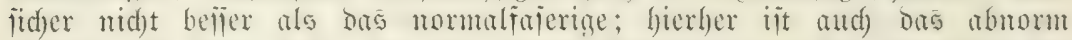

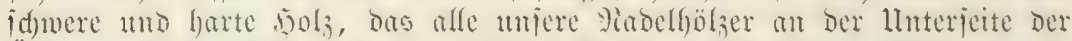

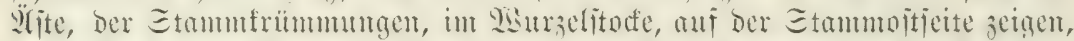

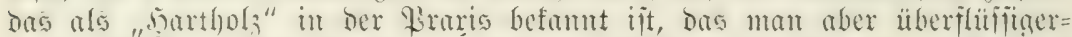
meije "Yothol:" benannt hat, zu red)nen; Viaberes bierüber bei best Teblern bes $\mathfrak{H a l z e s . ~}^{2}$

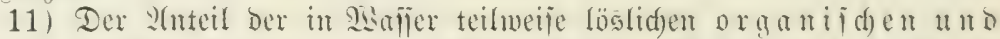

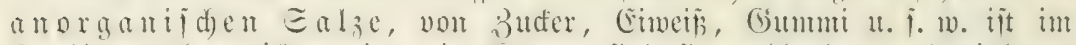

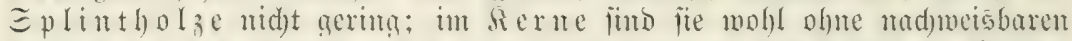

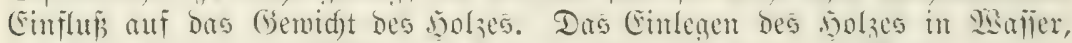

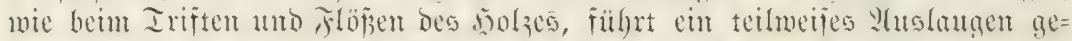
namter Etoffe ans Dem Eplinte mit jid), modurd) eine (Gemidstsminderung cintreten muip; Dic Siraris nimme an, bais bicielbe nid)t bedeutend jei;

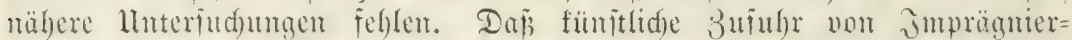

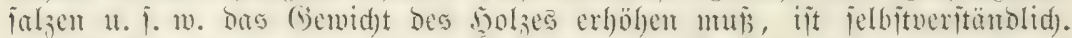

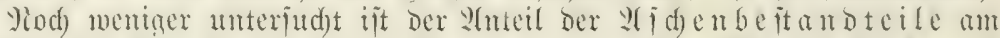

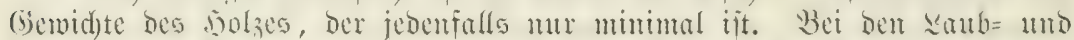

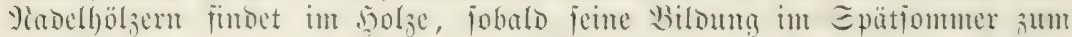

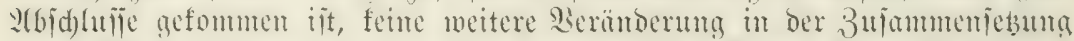

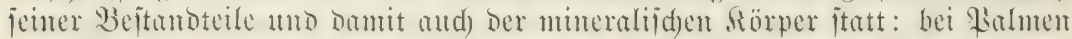

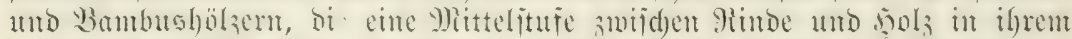

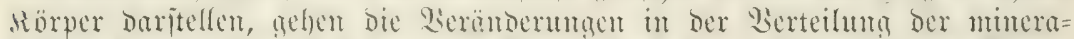

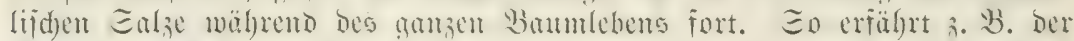

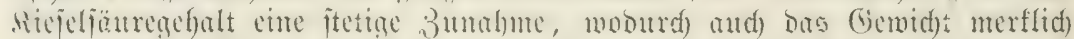

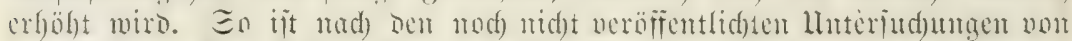

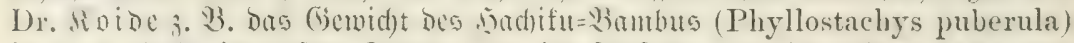
in 3 minge im criten Jabre 109, im fümften 113, im adsten 118; non

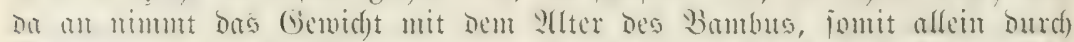

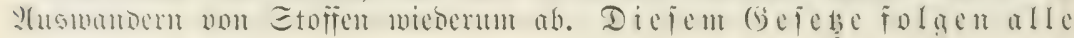
bambuらlyölzer.

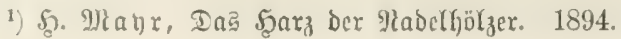




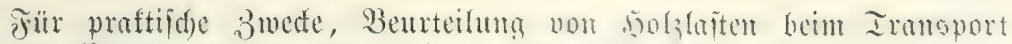

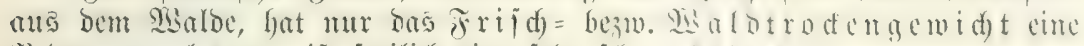

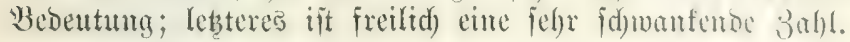

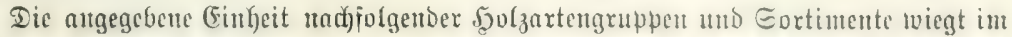

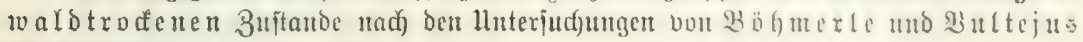
silogramm.

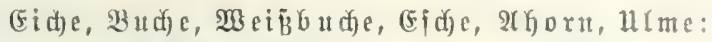

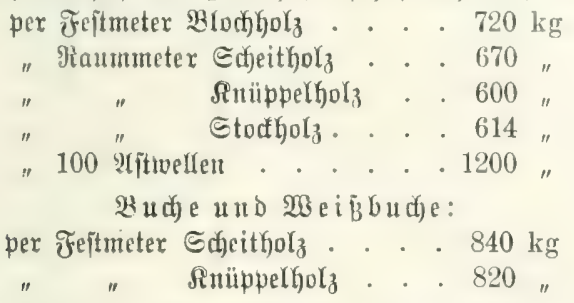

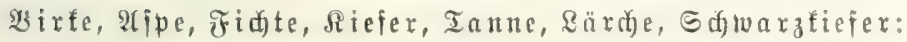

per Feftmeter $\mathfrak{B l o d}$ ) $\mathfrak{l o l}_{z}$. . . $570 \mathrm{~kg}$

" Raummeter Erfyeitfolz . . 470 "

" " Rnüppelhol . . 470 "

" " Stouffiol . . $350 "$

Ianue und $\mathcal{S}_{\text {d) }}$ urztiefer:

per Fejtmeter Echeitfgol . . . $660 \mathrm{~kg}$

" " Sinüpelfol . . 780 "

Tach von $\mathfrak{B a} \mathfrak{x}^{1}$ ) เviegt $1 \mathrm{Rm}$ :

\section{Stheitfyolz Frügetfoly}

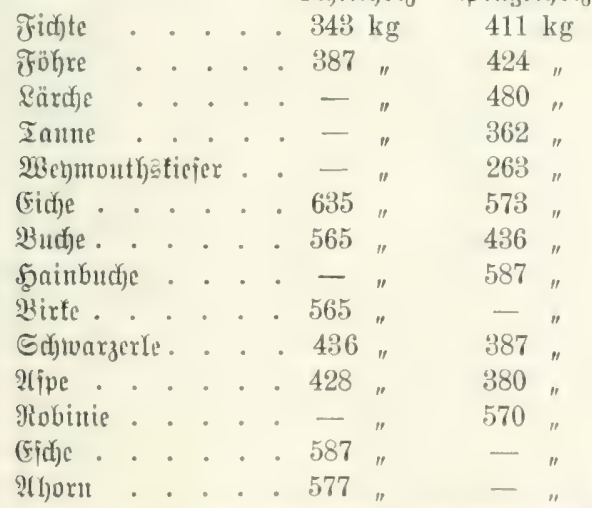

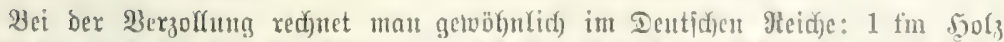

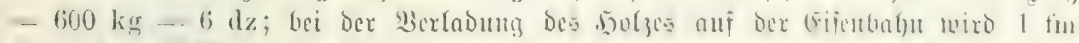

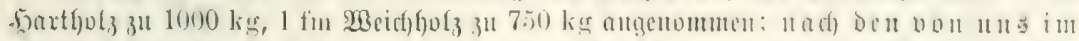

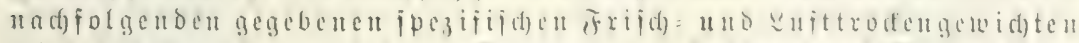

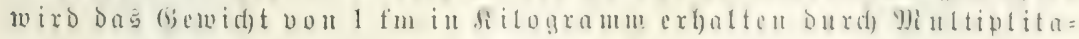
tion ber $3 a \mathfrak{h l e n}$ mat 10 , vou $1 \mathrm{Rm}$ burch ) Multiplifation mit 7,7 .

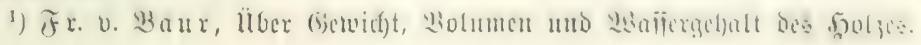




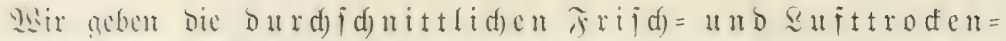

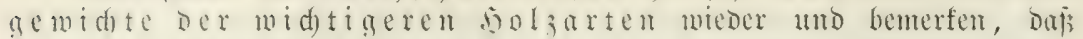
3ur Serftellung ber Gfala die von siörolinger, Ebevandier,

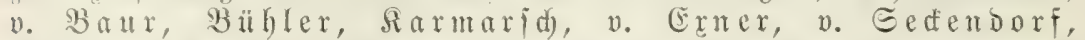

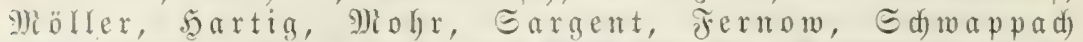

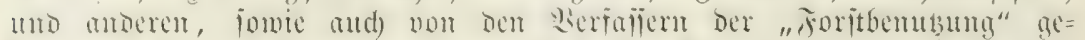

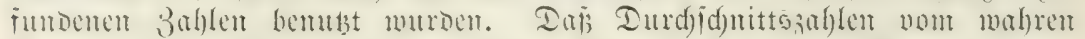

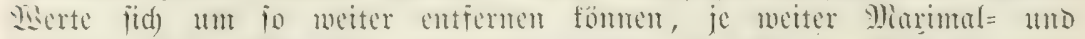

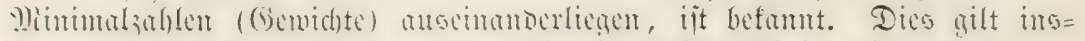

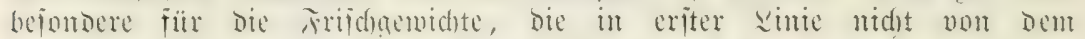

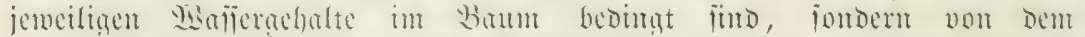

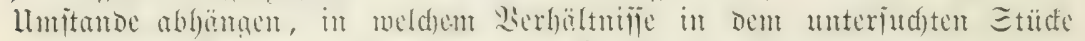

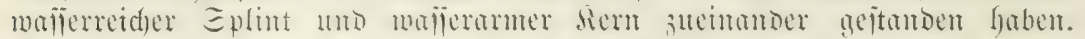

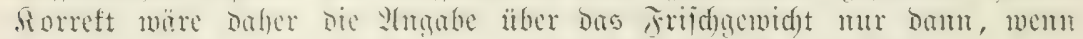
irifdes Splintgewid)t un frifdes Rerugewidst getrenut

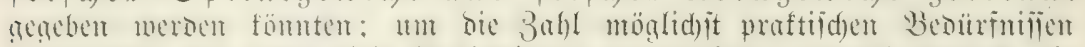
(t)

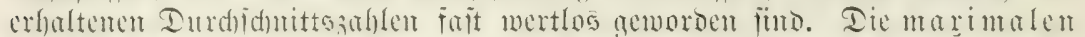

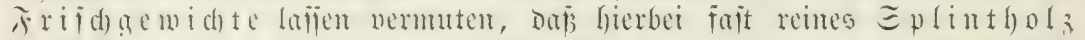

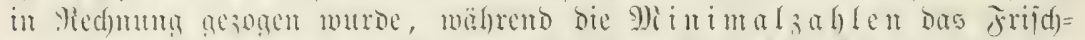

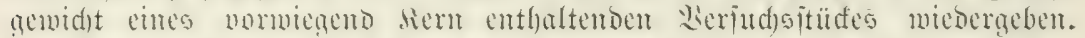

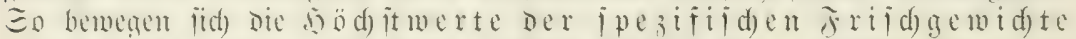

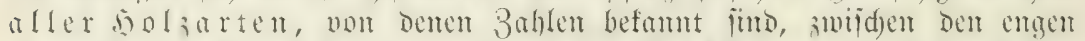

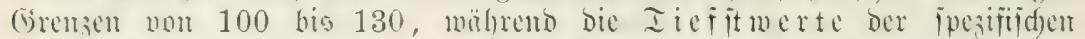

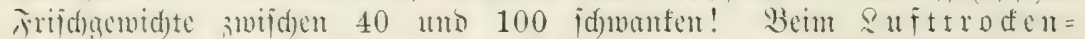

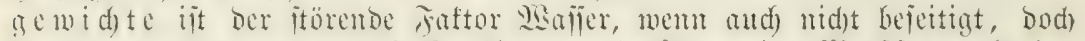

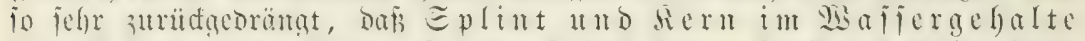

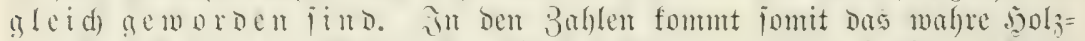

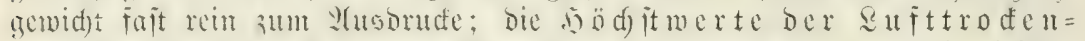

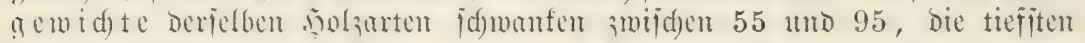
Merte şwijent 35 und 80.

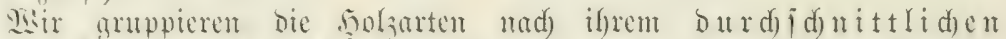

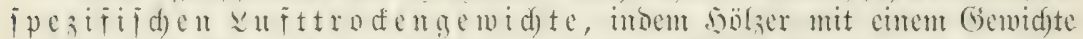

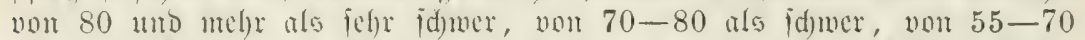

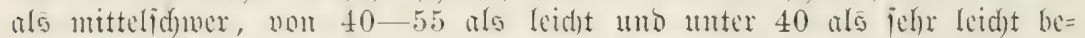

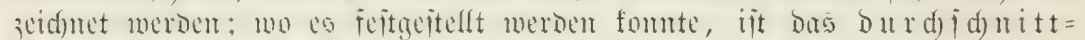
lid) ipezififde frifogewid)t beigefügt.

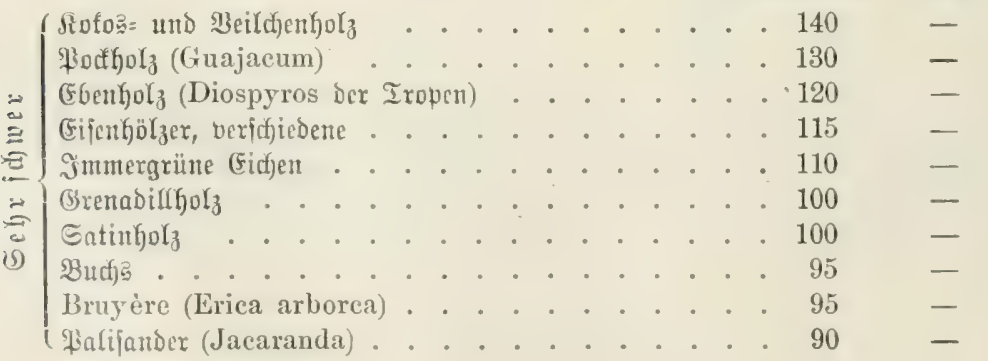




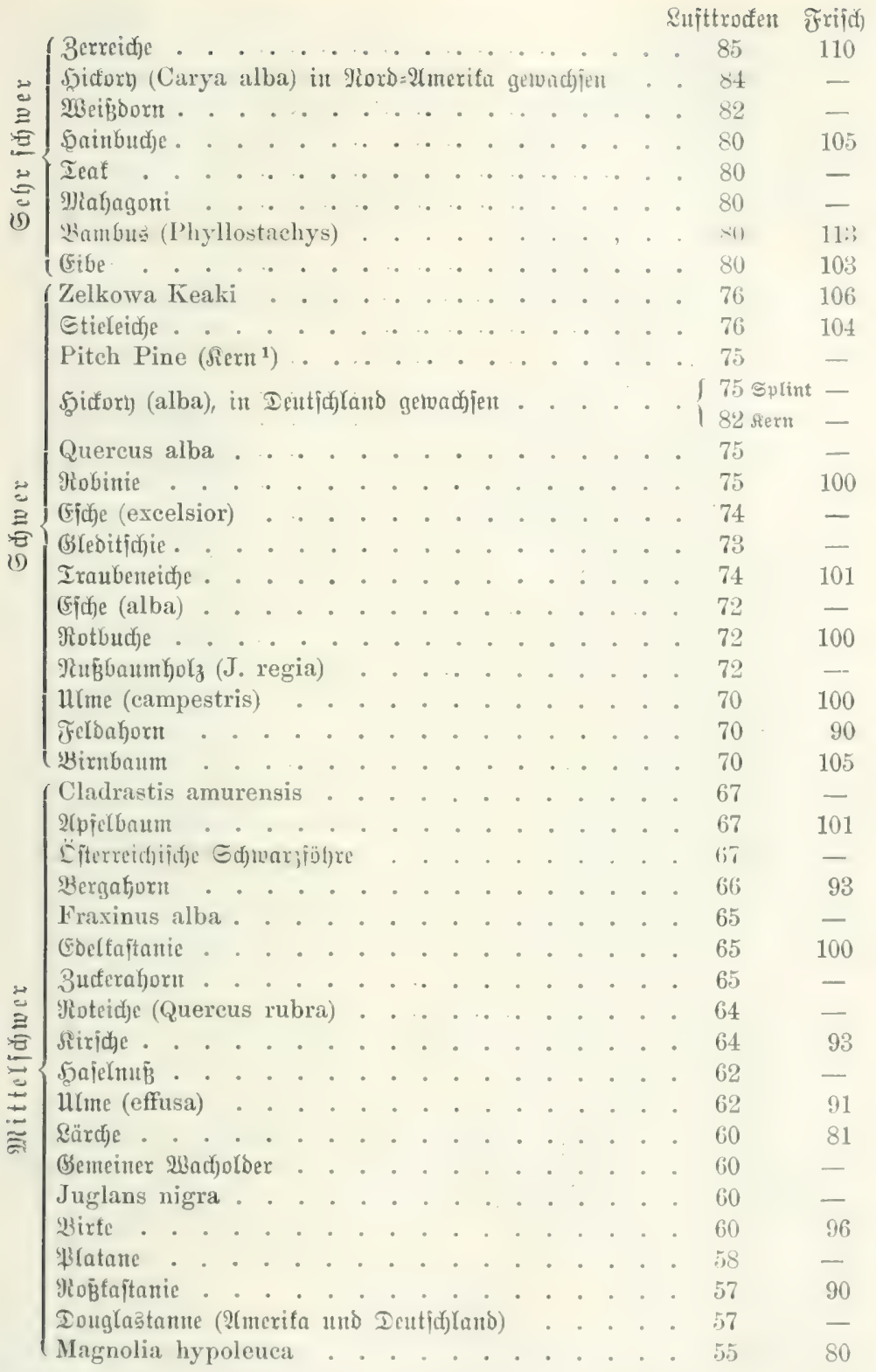

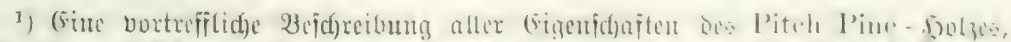

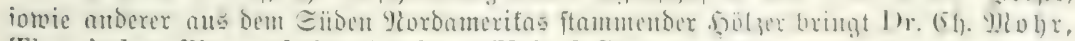
The timber Pines of the Southern United States. 1898. 


\begin{tabular}{|c|c|c|c|c|c|c|c|c|c|c|}
\hline & Ealmeide. & • & • & . & . & & . & . & $\begin{array}{l}\text { Ruftrodfen } \\
. \quad 53\end{array}$ & $\begin{array}{c}\text { Frijd } \\
85\end{array}$ \\
\hline & Pinus Banksiana & . & . & . & . & . & . & . & . 53 & - \\
\hline & (Furopätjđ)e Föbre. & . & . & - & . & - & . & - & 52 & 82 \\
\hline & Acer dasycarpum & . & . & . & . & & . & - & 52 & - \\
\hline & Rinde. . . . . & . & . & . & . & . & - & - & 52 & 80 \\
\hline & Errle . . . . & - & - & . & . & & - & - & 52 & 83 \\
\hline & Pinus rigida . . & . & . & . & . & & . & - & 51 & - \\
\hline & Juniperus virginian & & - & . & . & . & . & . & 50 & 一 \\
\hline$=$ & গadu Gargent . & . & . & . & . & & . & . & $33(?)$ & - \\
\hline & Fichte . . . & - & . & . & . & & . & . & 47 & 80 \\
\hline & Sitfajicute . . . & . & - & - & . & & . & . & 47 & 一 \\
\hline & Ianne (pectinata) & . & . & . & . & & . & . & 46 & 97 \\
\hline & Cham. Lawsoniana & . & . & - & . & & - & . & 46 & - \\
\hline & Weibe (alba) . . & . & . & . & . & & . & . & 46 & 78 \\
\hline & Truga canadensis & . & - & . & - & & - & . & 46 & - \\
\hline & Taxodium distichun & & - & - & . & & - & . & 45 & - \\
\hline & Pappel (Alpe) . . & . & . & . & . & & - & . & 45 & - \\
\hline & Gilberpapper . . & - & . & - & . & • & - & . & 44 & - \\
\hline & 3irbe . . . & . & . & - & . & & . & . & 44 & - \\
\hline & Pryamidenpappel . & . & . & . & . & & . & . & 42 & - \\
\hline & Picea pungens . & - & • & . & ${ }^{\circ}$ & & - & - & 42 & - \\
\hline & Sequoia sempervire & & . & - & . & & . & . & 44 & 88 \\
\hline & Cryptomeria japoni & & & . & . & & . & - & 42 & - \\
\hline & Catalpa speciosa & . & & . & 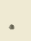 & & . & . & 42 & - \\
\hline 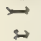 & Juglans cinerea . & - & - & - & . & & . & - & 41 & - \\
\hline$\Xi$ & Abies concolor . & - & & - & ${ }^{\circ}$ & & . & . & 41 & - \\
\hline 30 & Chamaecyparis obt & usa & & . & . & & . & . & 41 & 83 \\
\hline & Menmouthäöhre : & . & ${ }^{\circ}$ & - & 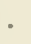 & & • & • & 40 & 75 \\
\hline & Picea Engelmanni & . & - & . & • & & . & . & 38 & - \\
\hline & Sequoia gigantea & - & 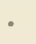 & • & ${ }^{\circ}$ & & $\bullet$ & • & 34 & - \\
\hline & Paulownia . . & • & & . & 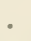 & & - & & 25 & 一 \\
\hline & Cuninghamia . . & & & & & & & & 20 & - \\
\hline & Itofielkolz (ift fein Sco & $\mathcal{L}_{3}$ & & noe & & & & & & \\
\hline & oon Quercus suber & & & & ${ }^{\circ}$ & & ${ }^{\circ}$ & . & 15 & 一 \\
\hline & effict)e Jiortfolz (Her & $\min$ & & & & & . & • & 15 & - \\
\hline
\end{tabular}

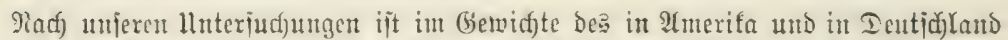

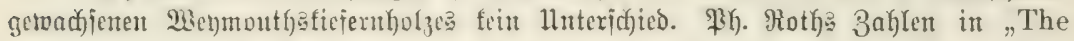
white Pine" by V. M. Spalding 1899 ftimmen Damit überein.

\section{T⿱乛龰ohärent?}

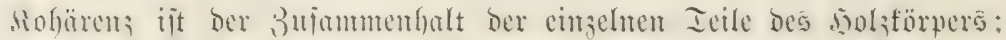

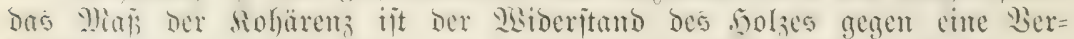

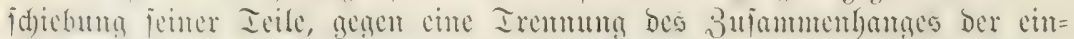

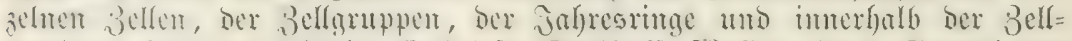

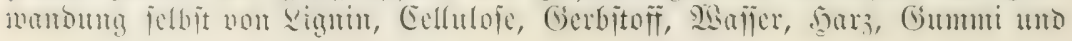




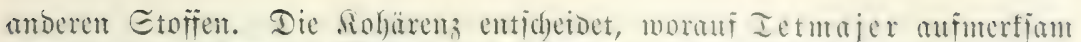

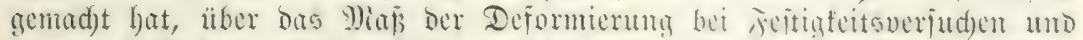

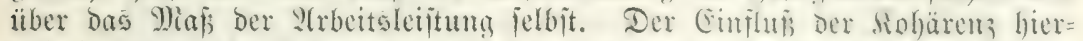

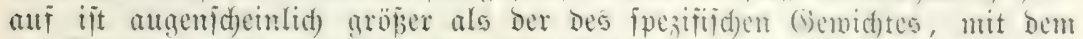

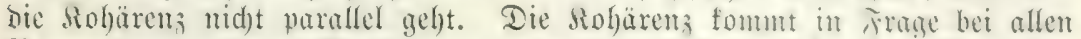

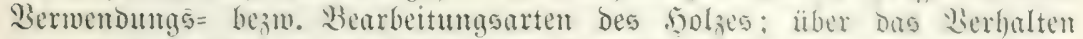

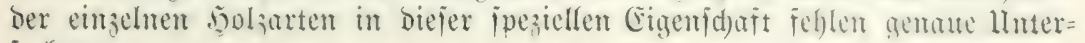
jud)ungen.

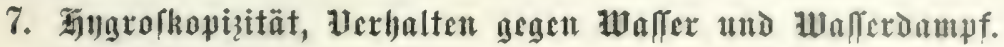

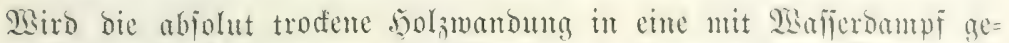

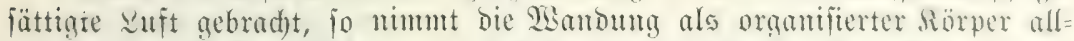

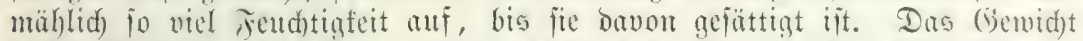

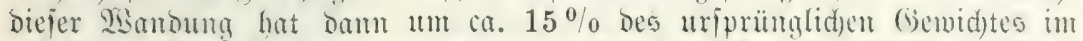
abjolut trodenen 3uftande zugenommen; befindet fid bas sol; in eimer mit $50 \%$ feud)tigfeit verfehenen suft, io nimme es allmählid) mur $50 \%$ Der

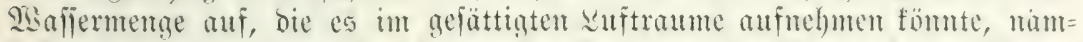

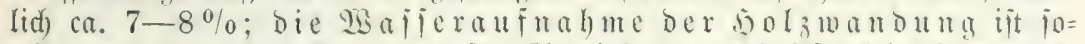

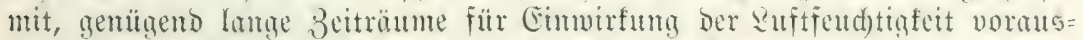

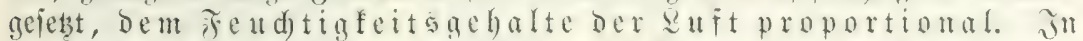

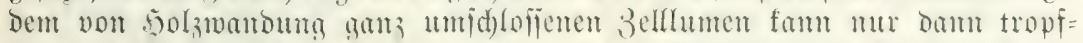

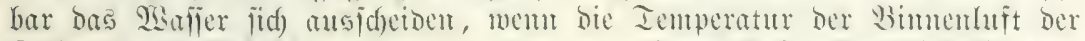

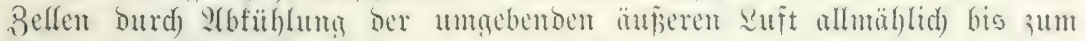

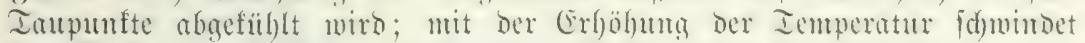

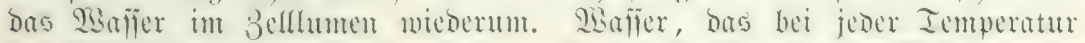

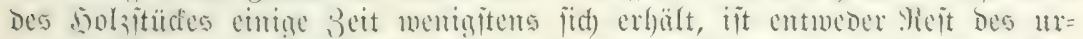

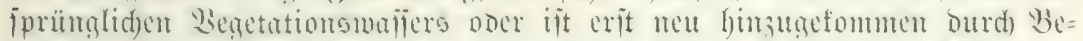

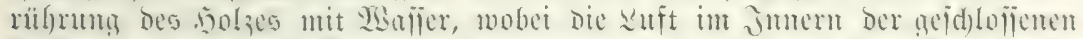

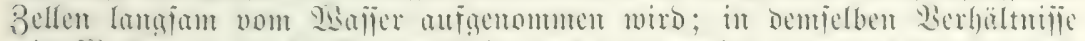

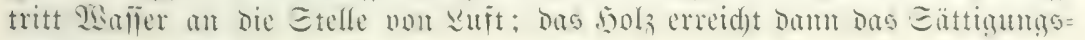
gemidjt.

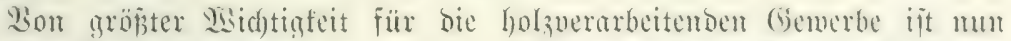

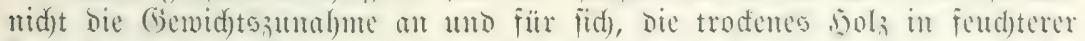

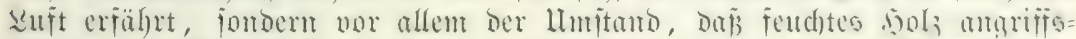

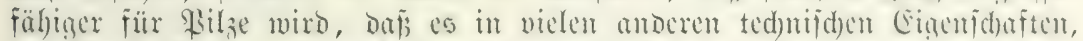

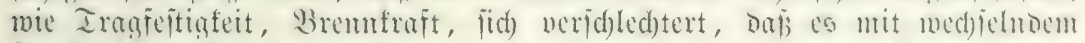

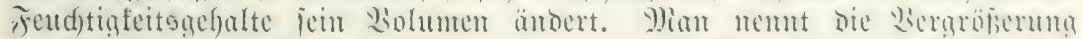

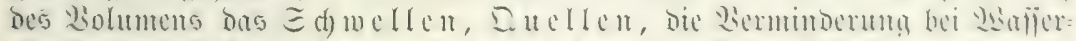
abgabe bas $\Xi$ d) winden, $\Xi$ d) rump

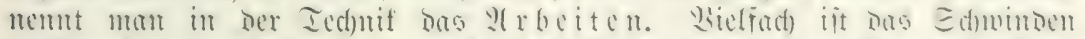

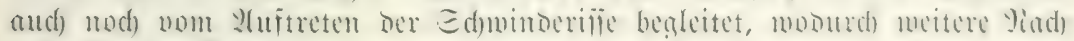
teile für die Berarbeitung bes Solzes fid) ergeben.

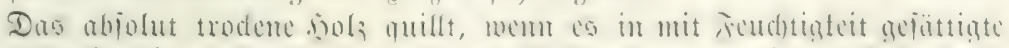

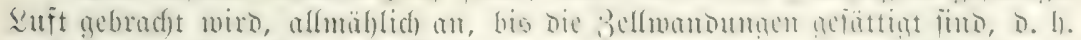

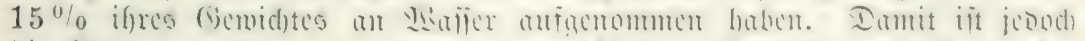

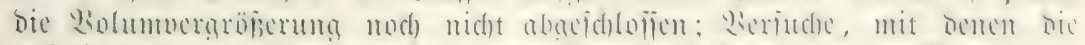

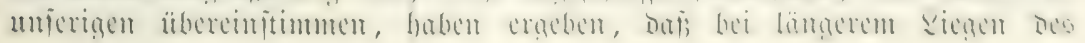




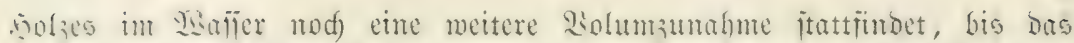

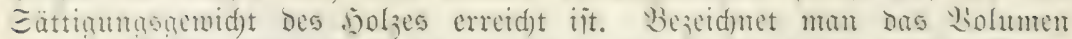

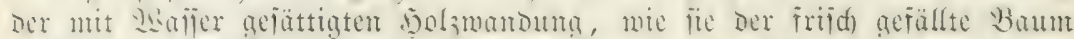

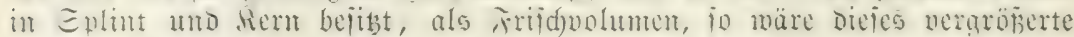
Bolumen als Sättigungàvolumen zu bezeidunen.

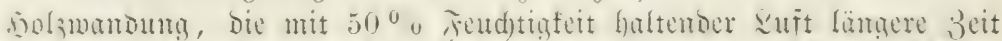

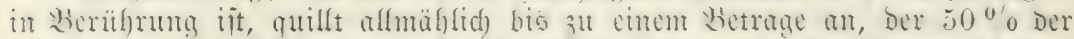

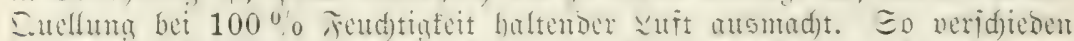

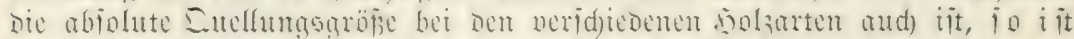

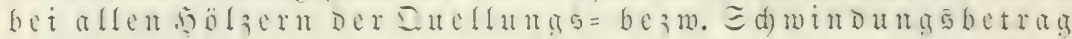

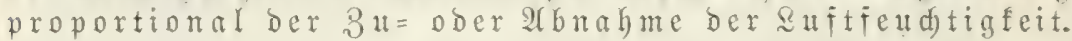

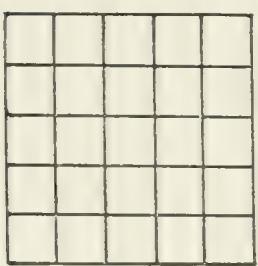

l

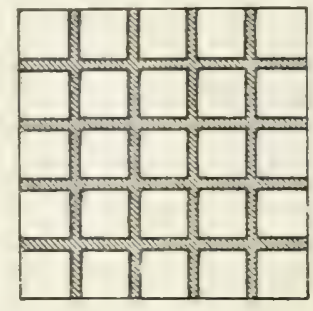

$b$

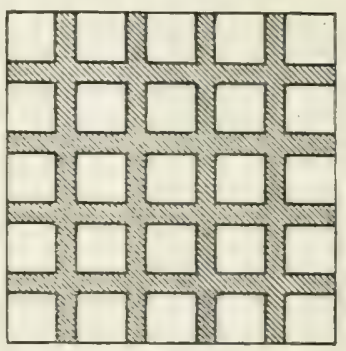

c

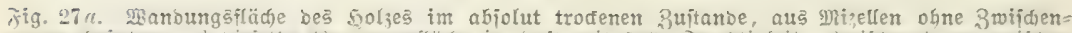

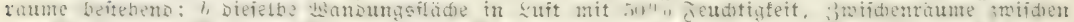

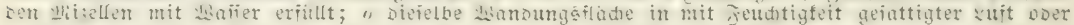

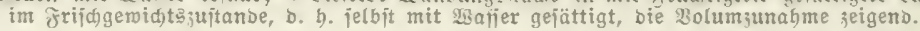

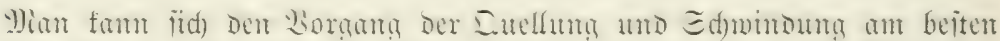

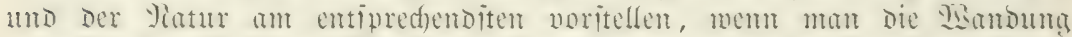

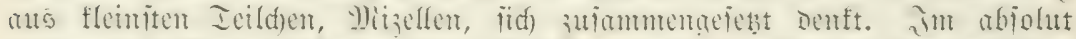

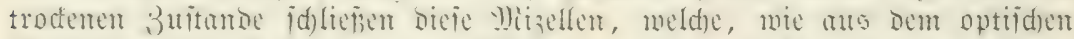

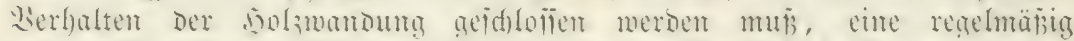

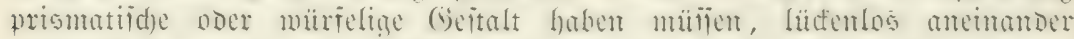
(Jig. $27 u$ ).

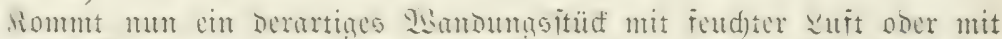

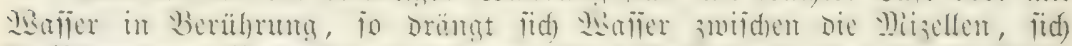

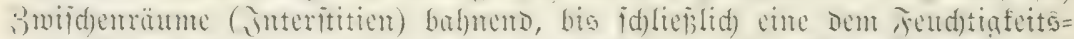

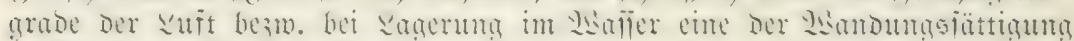

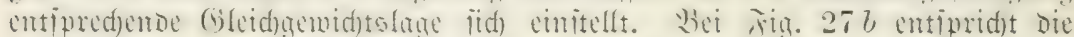

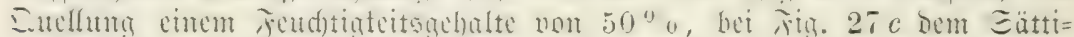

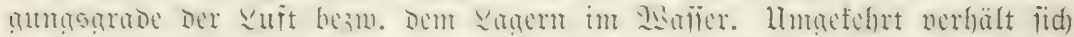

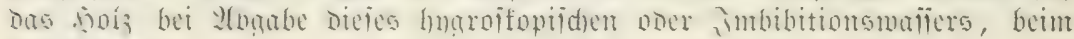
Ediminden.

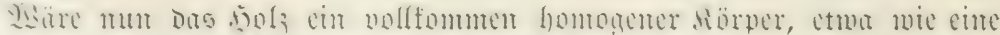

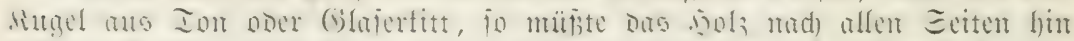

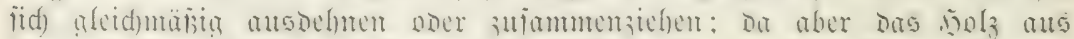

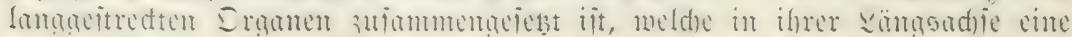

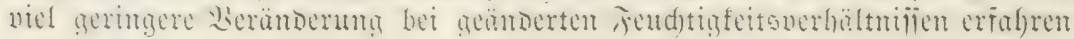




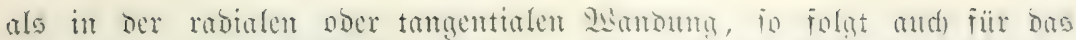

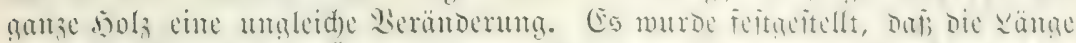

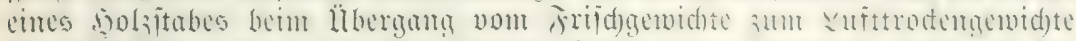

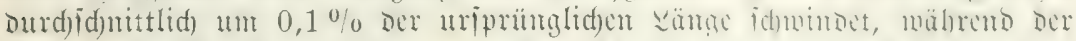

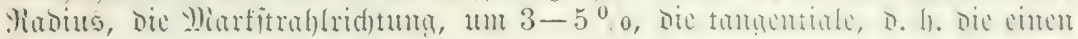

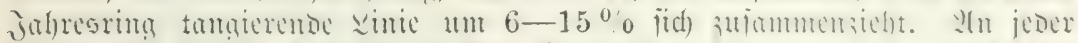

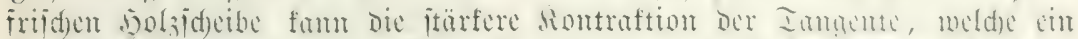

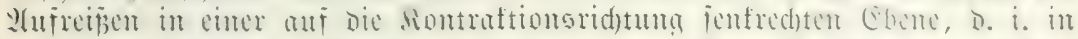

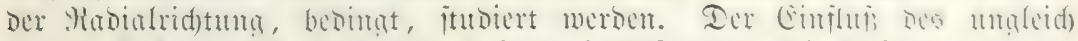

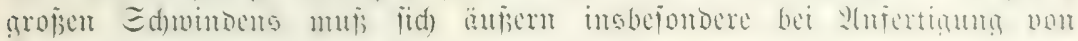
Brettern; je mebr bieje burd) ta nge $n=$ tiale Rängsjonthitte gemomten werben, um fo ftärfer die Rontraftion in ber Brettbreite; je mehr aber bie Ed)nitt= fläd)en den Rabialwänden jid̆ näbern, um io befier "ftehen" joldje Wretter (テั่ง. 28).

Die Eridjeinung, Daj trob Der Sättigutg ber Santoung mit פinafer beim $\Xi_{\text {d) wanfen bes }} 93$ a fiex $=$ gehaltes im 3 elllumen aud bie (5röpe ber Mandung entipredjenten Ŝ̉nerungen unterliegt, ijt aud) am itehenden Baume nad)weisbar. Si a i jex und Friebrid) baben burd) Slejüngen gezerat, Dap unter Ings iur jeit der

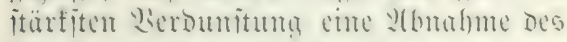
Iurd)mellers, bet litd)t bei vermunderted Berbuntung und 9 bafieranfüllung in

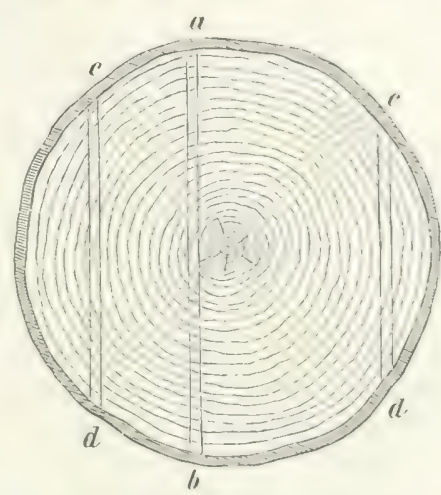

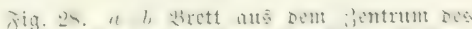

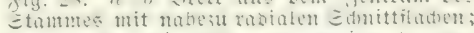

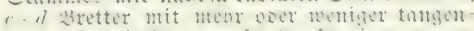

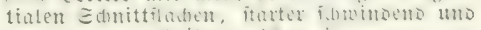
abiteno $0.5 \%$ - $h$.

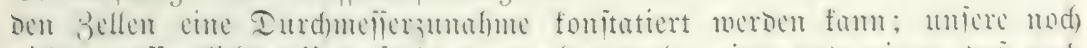

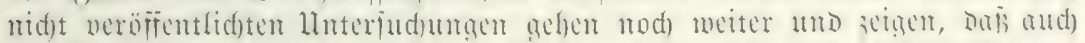

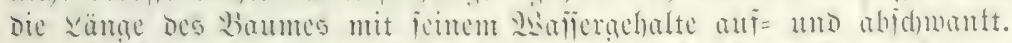

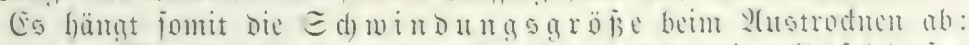

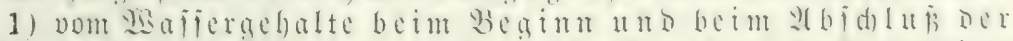

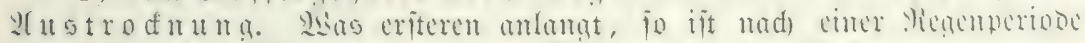

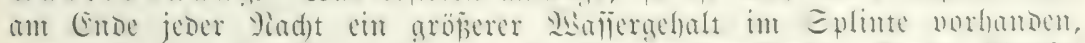

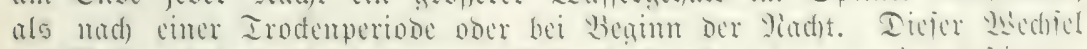

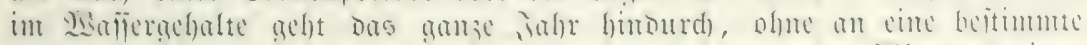

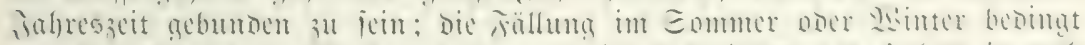

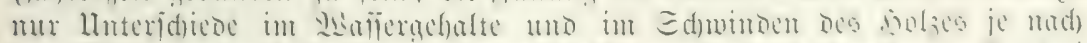

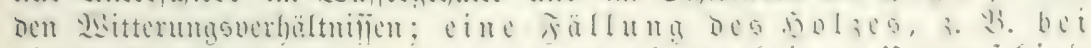
einer Irodeuperiobe im Eommer, fann feiuculluterjdicb gegenüber ber Fälung bei ciner Irodenperiobe im Minter

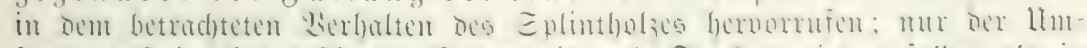

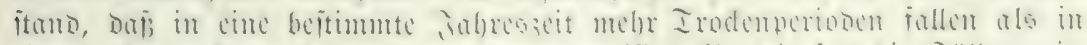

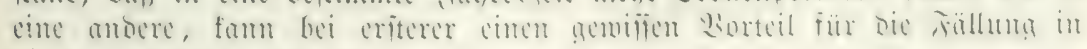
bieper Jaluresseit bebingen.

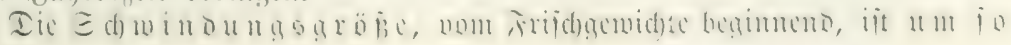




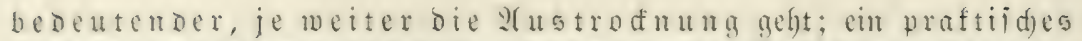

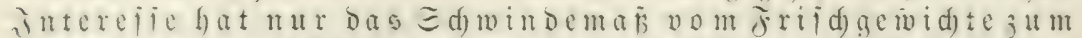

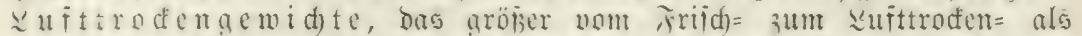

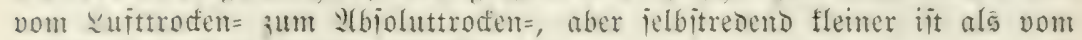

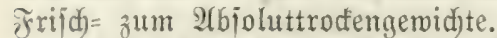

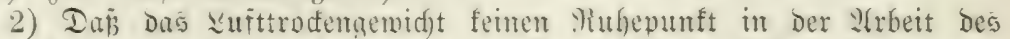

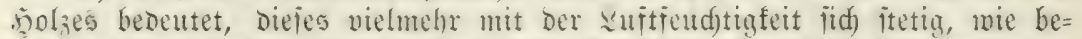

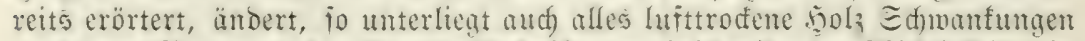
in jeinem Bolumen, Die für bie Iednif non cimidneidender 2sid)tigfeit jein müījen.

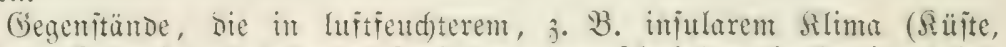

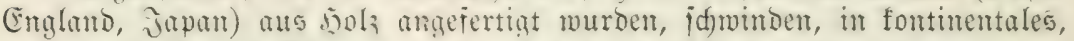

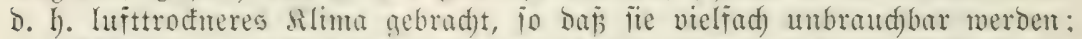

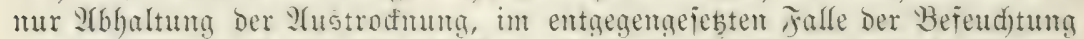

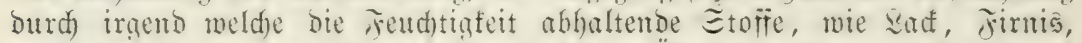

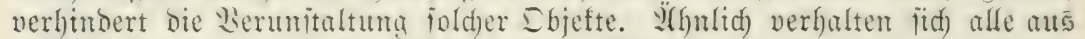

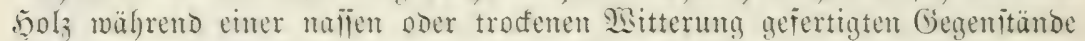

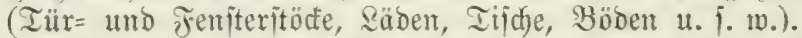

3) Ia Der diern itets mafierärmer ijt als Der Eplint, jo id)mindet Diejer bis zum Inftrodenen 3uitande jtets mentger alo ber Eplint: oer an

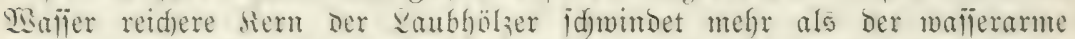

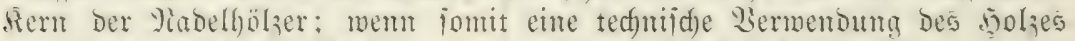
unmittelbar nad) Der Fällum notmendig ijt, jo fub die Yad)teile am ge= ringiten beim Rernholze Der Niabelbölzer.

4) Je jubitanzreider bas jolz, D. h. alio je id werer dastelbe, Deito

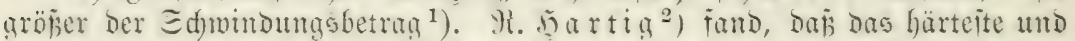

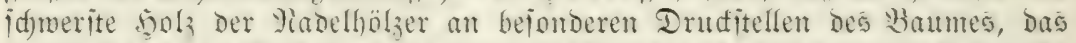

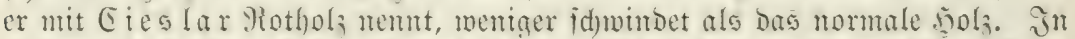

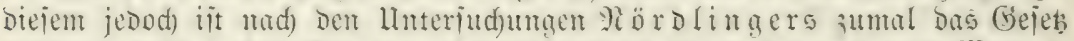

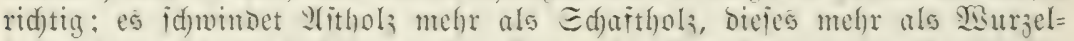

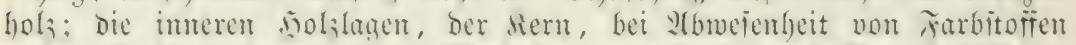
mehr als die äuferen: Diejes Derbalten non Eplint mo fiern bei Fitd)te,

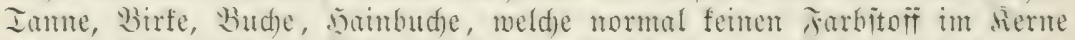

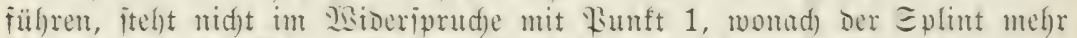

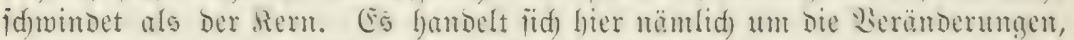

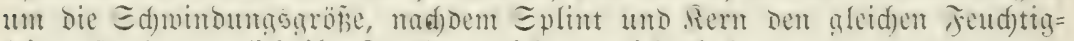

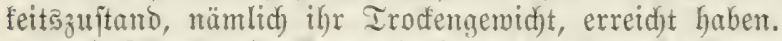

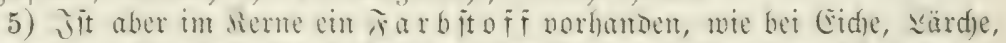

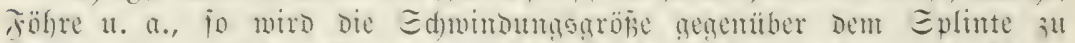

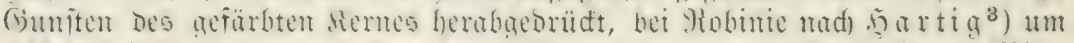

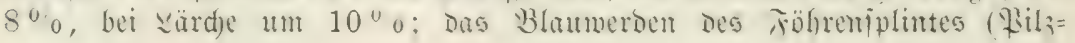

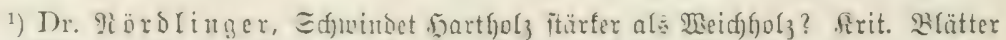

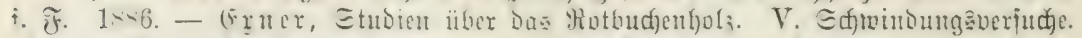

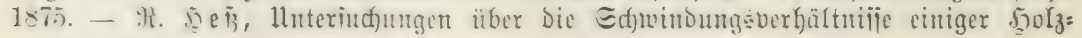
artert. 1887.

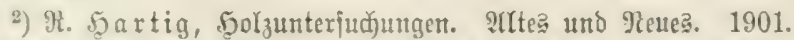

3) Itrielbe, Mad) 


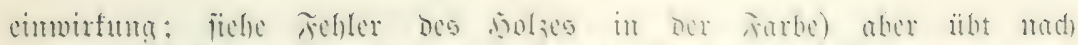
三d) jelben aus.

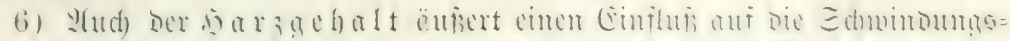

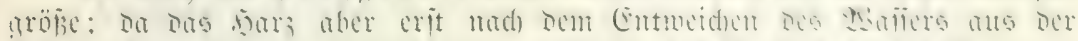

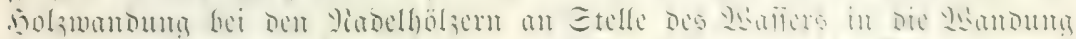

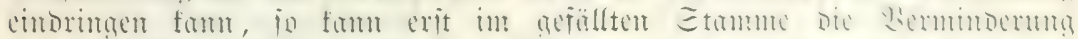

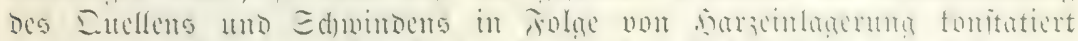

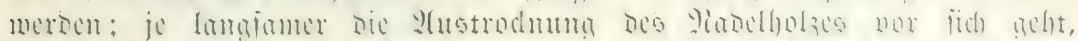

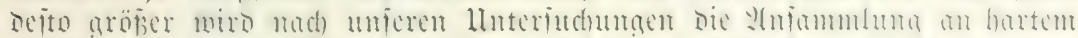

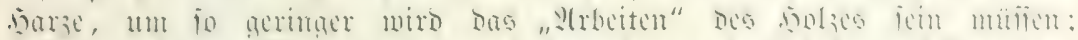

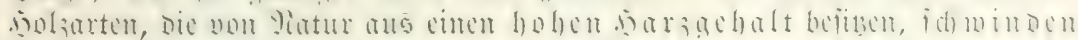

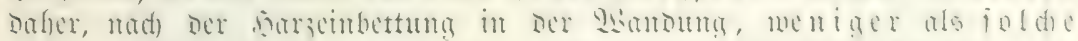
mit geringen 5arzmengen; aus biefem Grunbe formindet urb

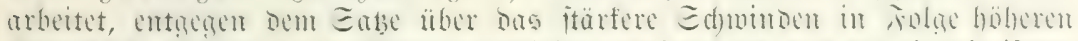

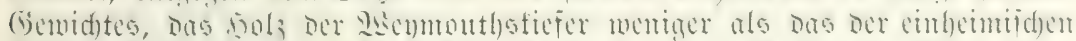

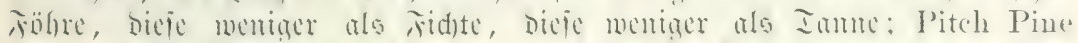

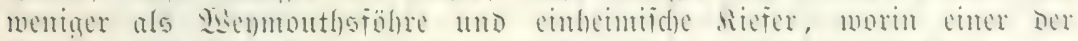

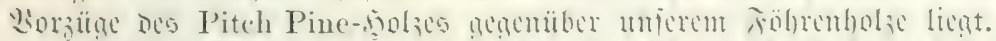

7) Das 光

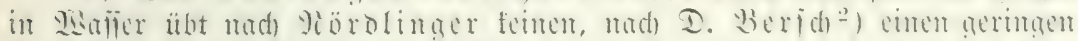

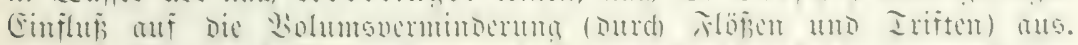

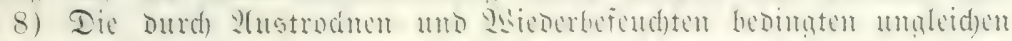

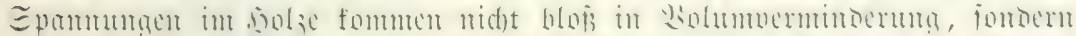

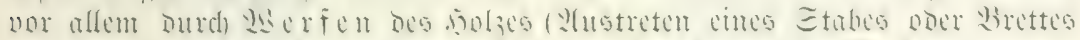

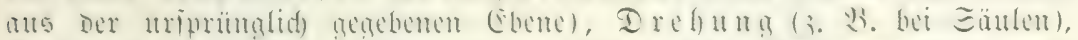
站

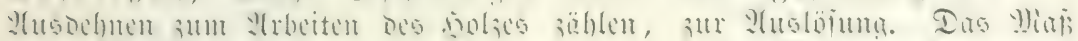

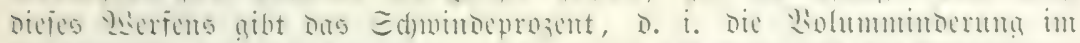

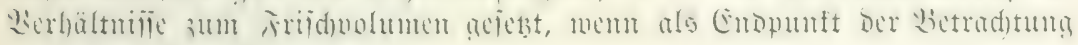
Dex luf́trodene Buftand gilt.

9)

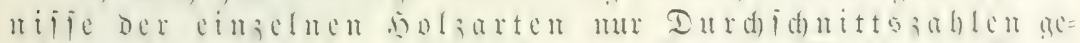

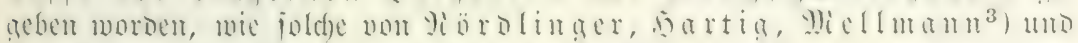

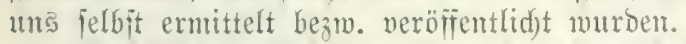

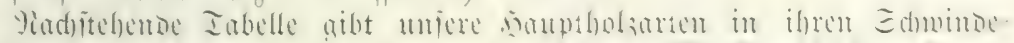

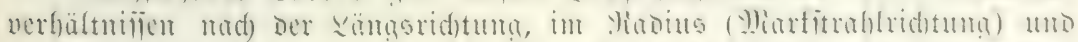

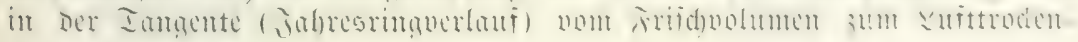
volumen:

(Iabdle $;$. nädjite Seite.)

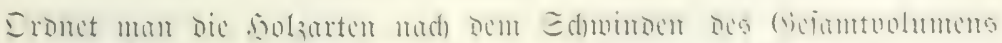

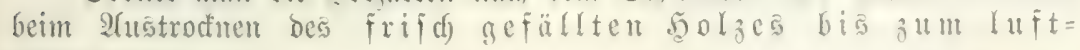

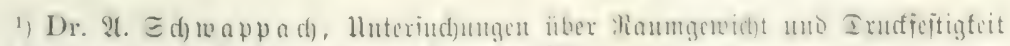

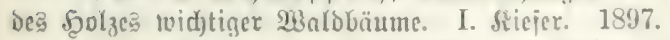

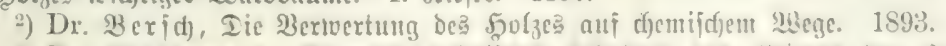

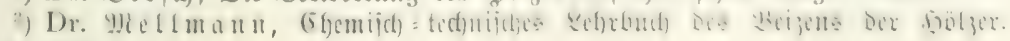
Berlint 1899. 


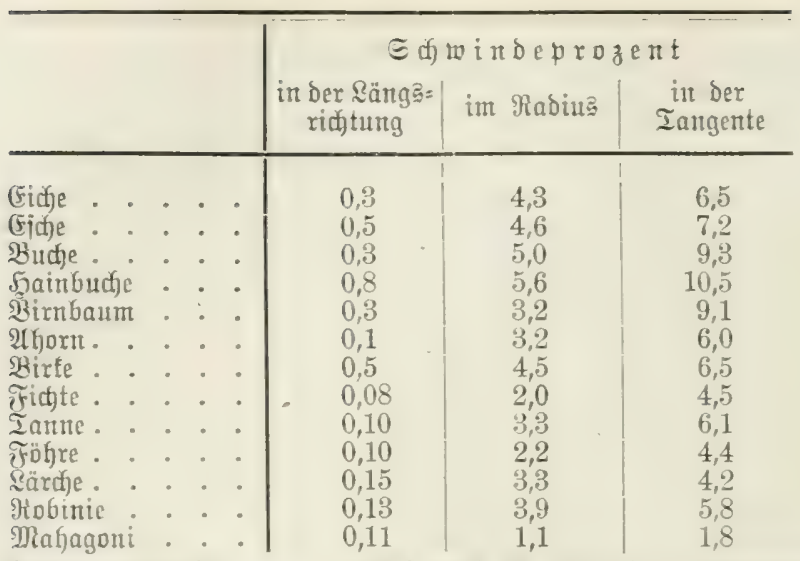

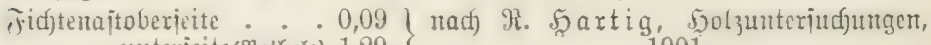
" " unterieite(Rotholz) 1,29$\}$

trodenen 3 utande in Prozenten des Frifiduolumens, jo

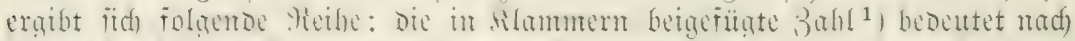

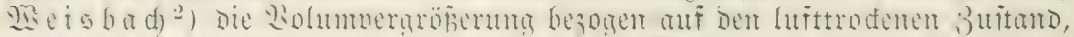

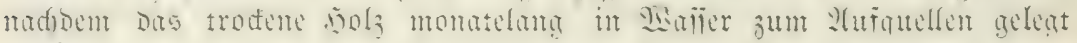
morben mar.

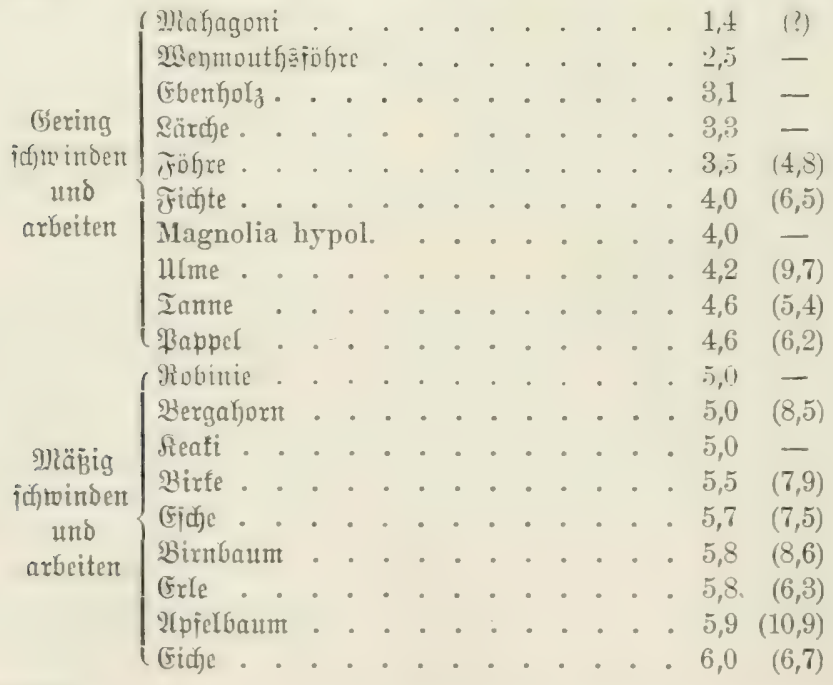

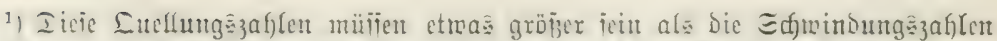

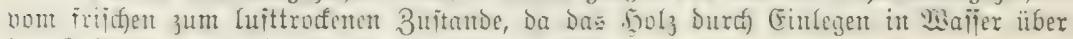

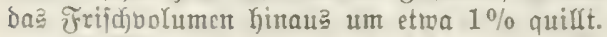

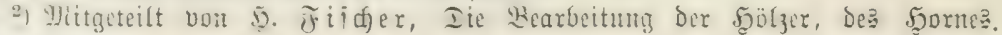
Seipzig 1891. 


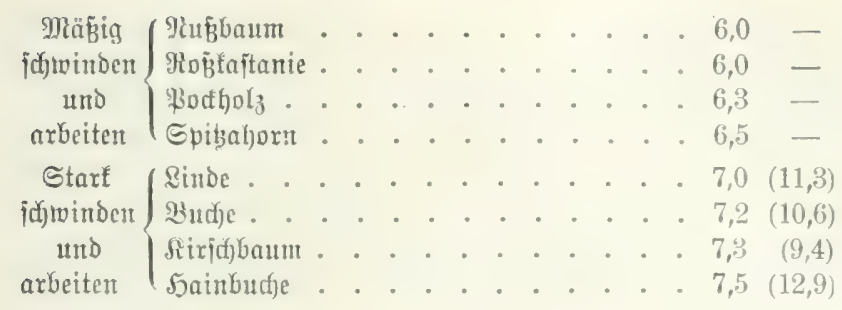

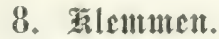

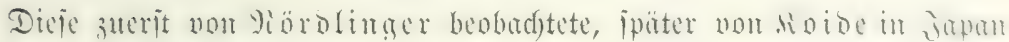

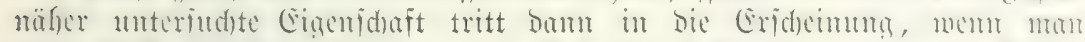

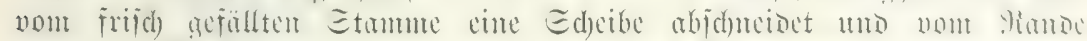

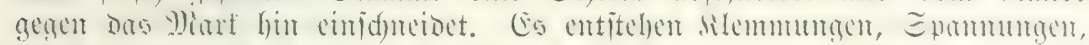

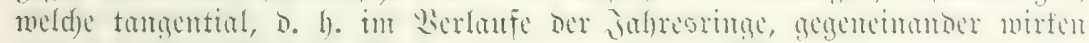

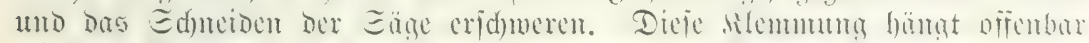

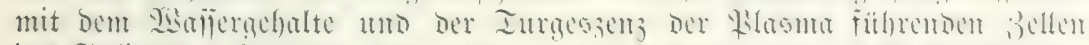

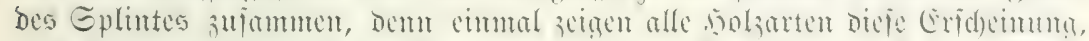

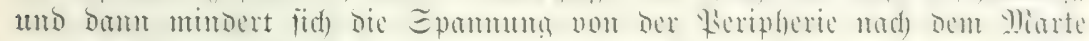

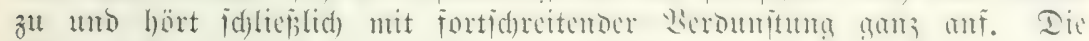
Rinde foll bas gla jis ber Slemmung mindern.

\section{9. ป⿺⿻一𠃋十}

a. Formueränderug.

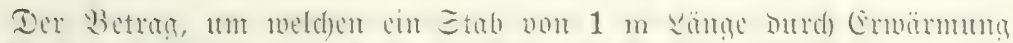

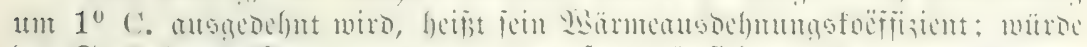

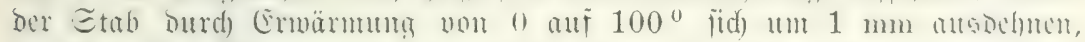

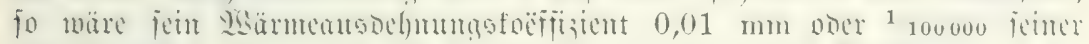

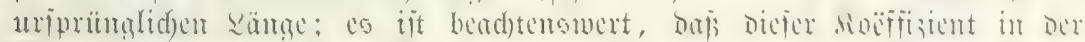

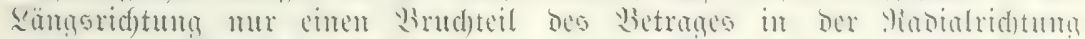

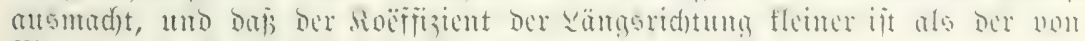
Metalfen, 3. 3. Eijen, jelbit fleiner als ber des Gílaję.

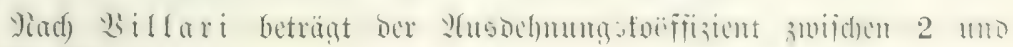
$34^{\circ}$ C. bet:

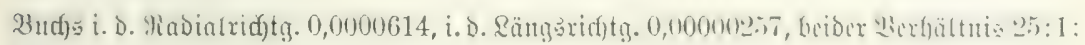

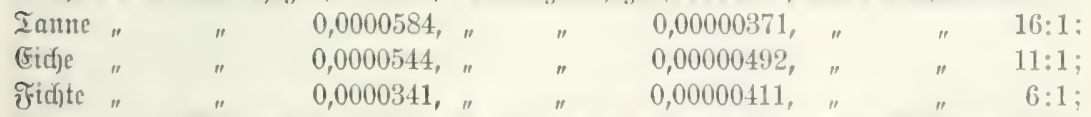

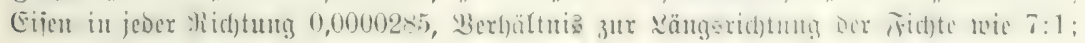

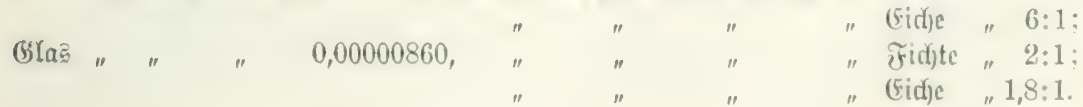




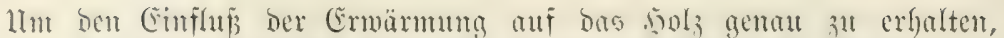

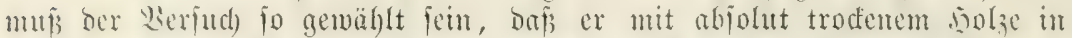
abjoht troctener suft vorgenommen miro. Jit bies nidgt ber jall, wie

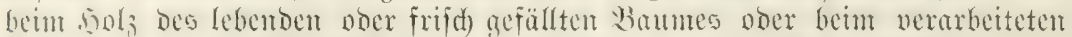

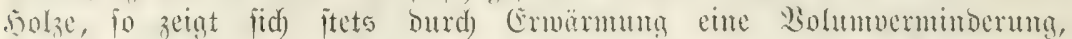

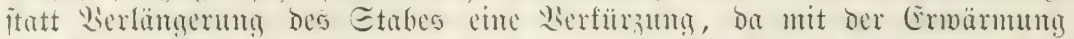

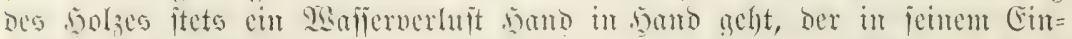

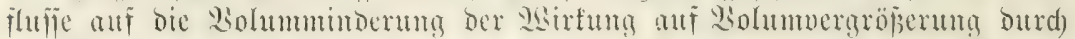
bic Ermärmuma nid)t bloj; entegegennirft, fonbern fogar cine Liolum= minderung hervorruft.

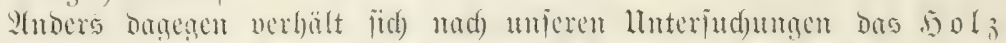

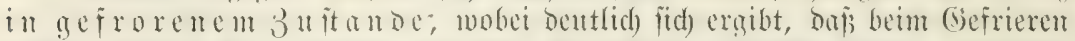

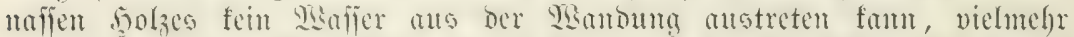

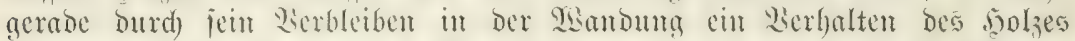

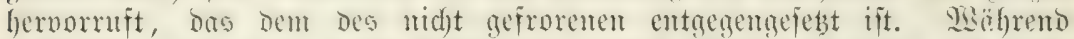

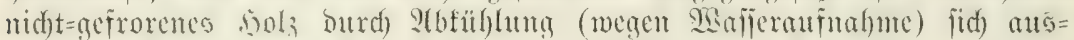

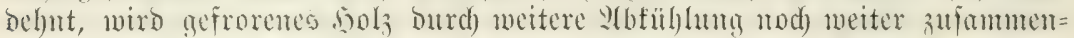
gezogen; idslieplich treten im acfromenen solje Eprünge, Epalten mi wie be einer tief abgefüblten (Eismafie. Eo entitehen Eprünge im solapilafter, an lebenden bäumen (Froitjpalten); alle Ibeorien, Durd) ungleidye Siont= traftion bes soljtörpers, Durd) abnorme, in ber Yiatur nidgt vorfommende Erfdecimmoen, wie hobe Bimnembärnte und tiefe Ylubentemperatur bes

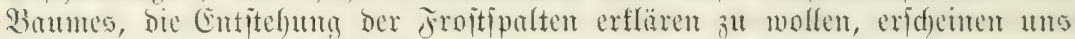
binfällig. Şolz, von $0^{0}$ a t fröäts erwärmt, folgt in feinen

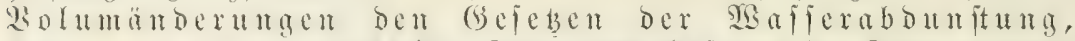

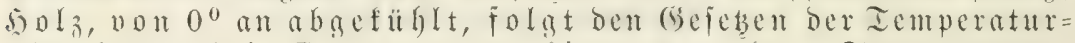
abuahme, bei Ermärmung bis zu 0 ber Temperatur= zat a hme.

\section{b. $\mathfrak{B a f f e r b e m e g u n g . ~}$}

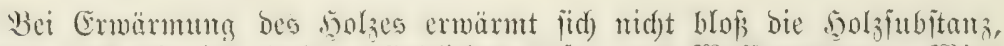
fontoern aud) bie int bolac befindliden šft= und Maffermengen. TSird

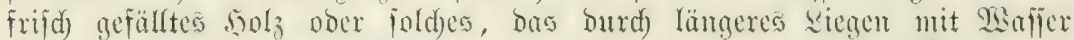

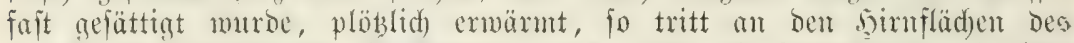

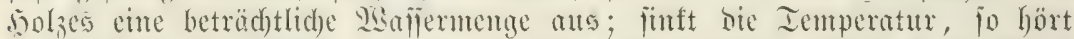

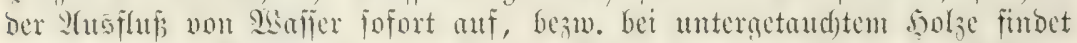

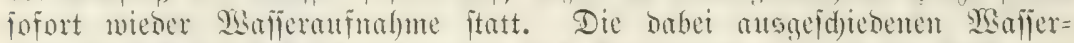

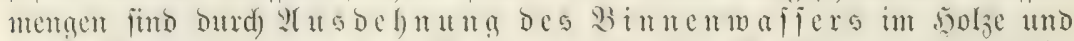
Durd) VIu fubitan felbit fommt faum in Betradet) freigemorben. Diejer Frozen

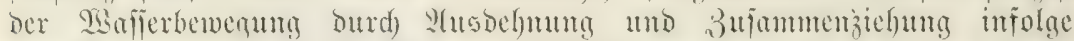

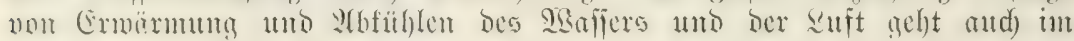
lebenden $B a$ atme vor fid), wo er eitren widjtigen Faftor für

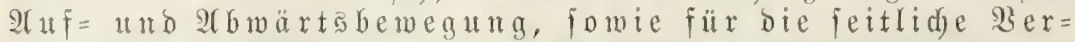

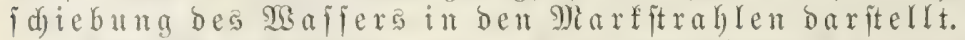

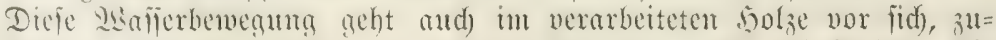

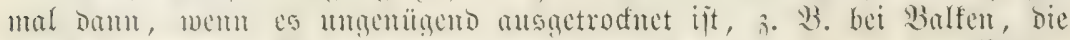

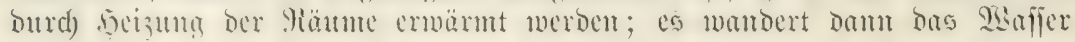




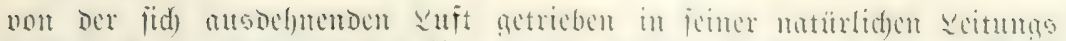

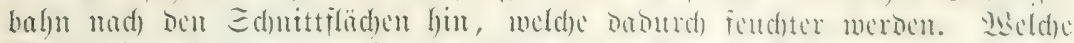

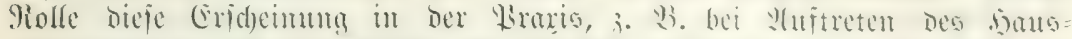

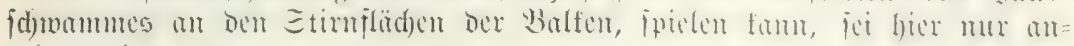
gebeutet.j

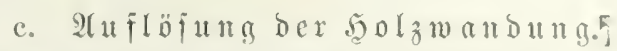

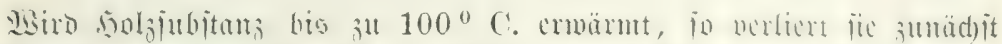

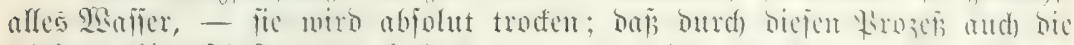

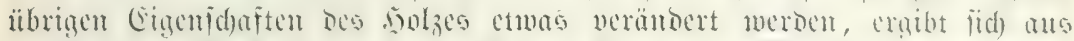

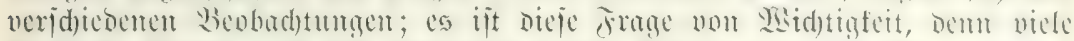

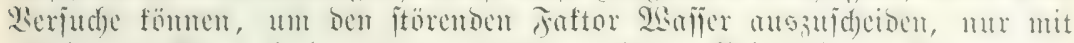

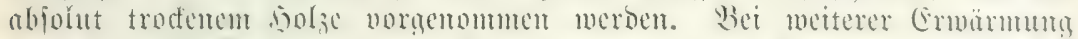

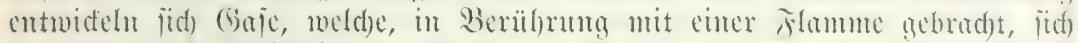

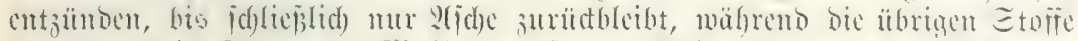

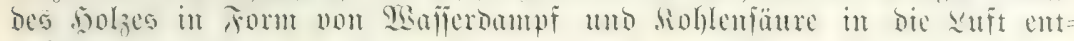
meidjen.

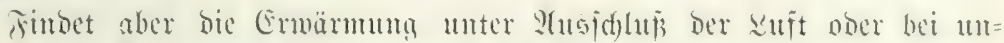

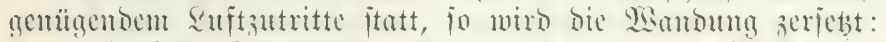

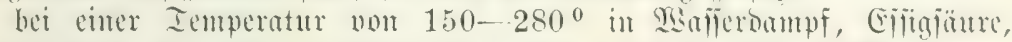

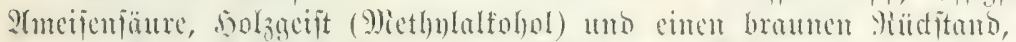

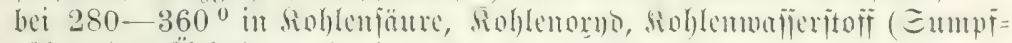

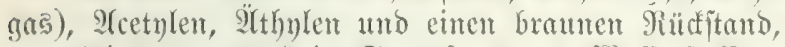

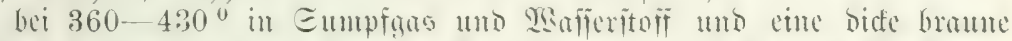

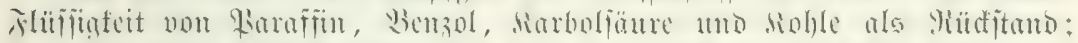

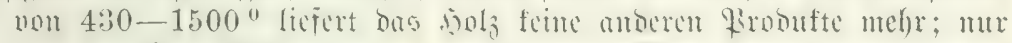
cinte ctmas aröjicre Siüditano bleibt Siohle.

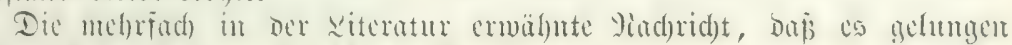

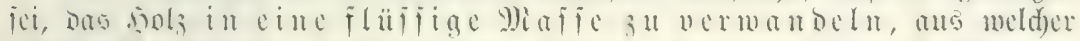

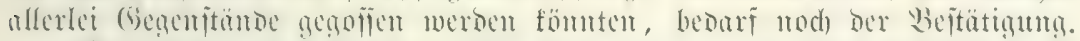

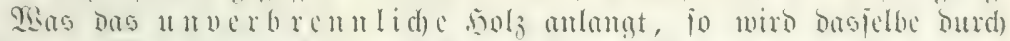

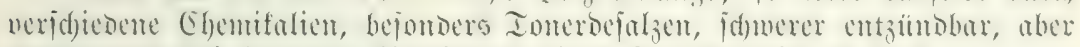

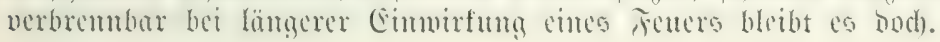

\section{Icitunggfülighcit ofs Jolzes für}

\section{a. $2 B a ̈ r m e$.}

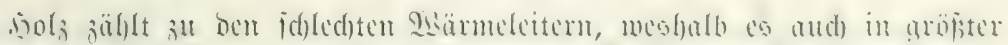

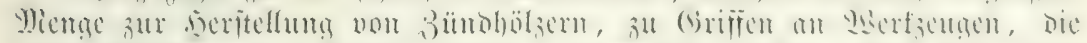

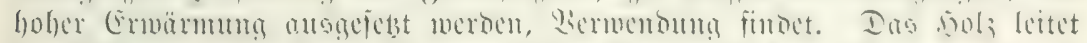

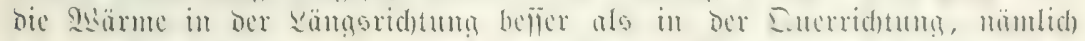

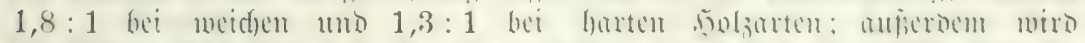

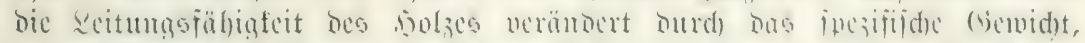

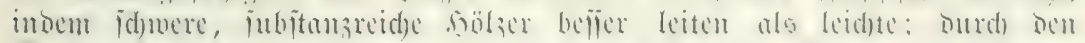

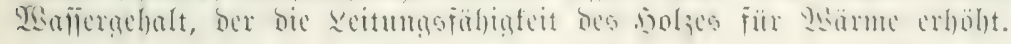

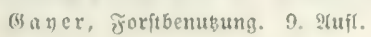




\section{b. E⿺leftrizität.}

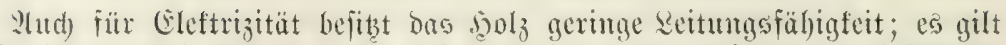
als sfolator; and hier wird ber scitungswiberitand gemindert burd) höheres

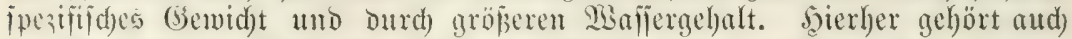

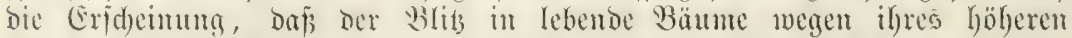

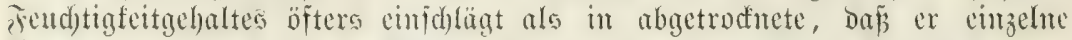

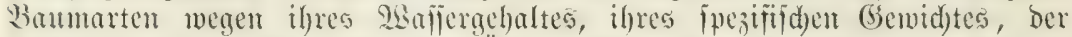

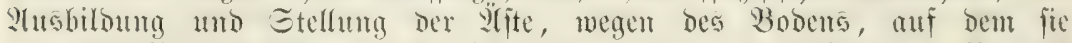

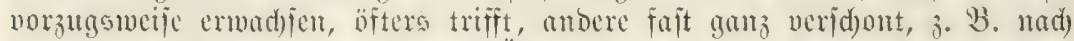

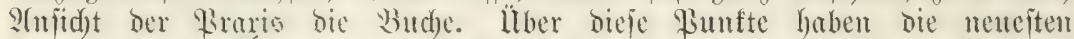

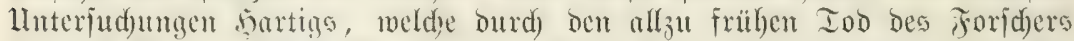

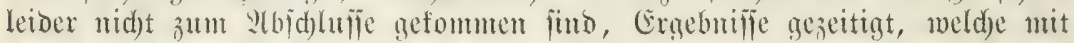

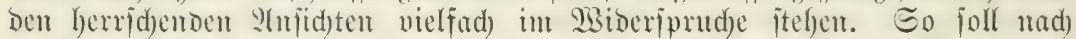

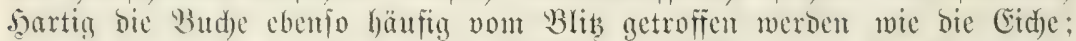

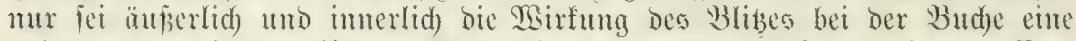

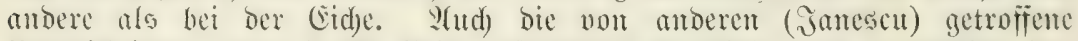

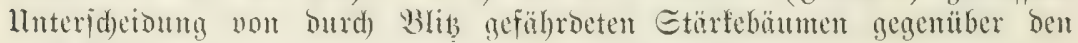
nom Blib veridgonten Fettbäumen jei fier furz ermähnt.

$$
\text { c. } S_{d} \text { all. }
$$

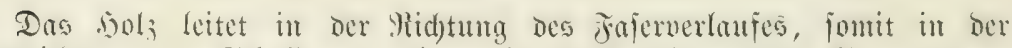

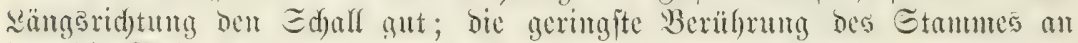

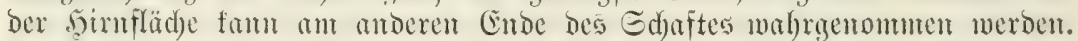
Trodentes nolz leitet beffer als naijes. Die Reitumg wirs unterbrodjen oder ber Sdyall wird acoümpft burd) franfe Stellen im Jumen bes Banmes,

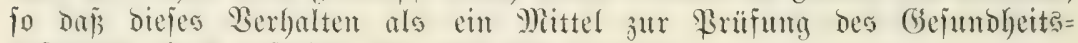

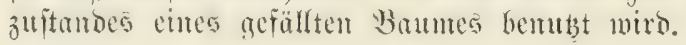

\section{d. $\& i d$ t t.}

$.50 l_{3}$ ift fïr sid)t mu bis zu geringen Iiefen Durd)oringbar; es ver=

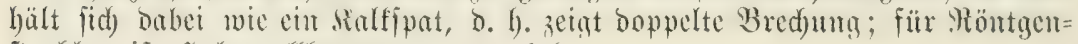
itrablen ift $\mathfrak{S g l}_{z}$ volffomment permeabel.

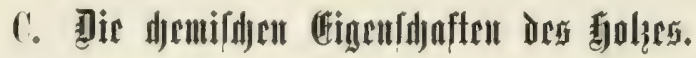

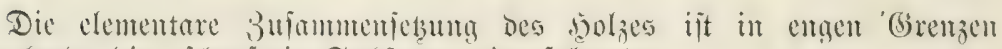

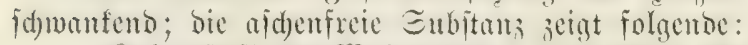

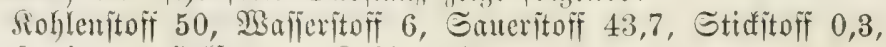
beitelyt fomit jut baälfte auts Rohlenitoff.

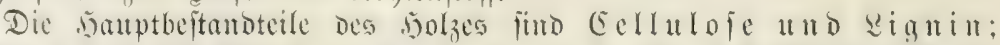

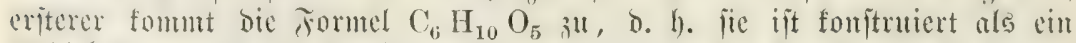

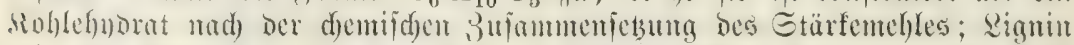

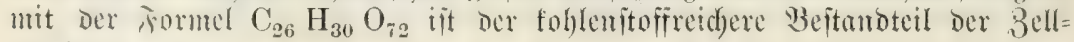
wantoung. 


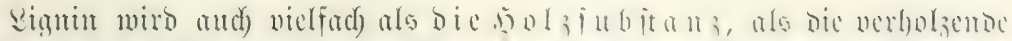

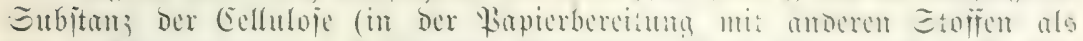

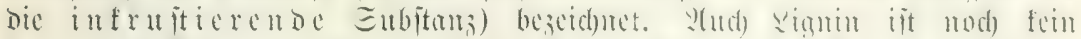

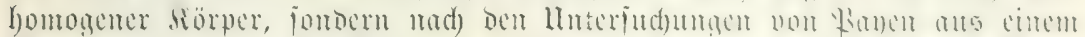

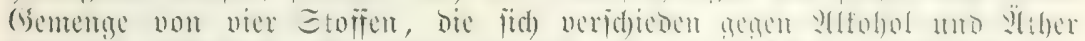

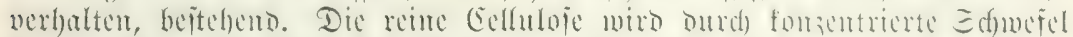

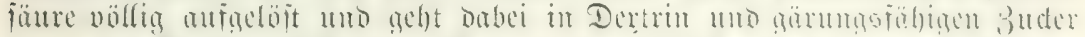

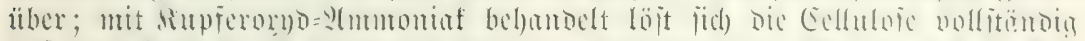
आแர แ

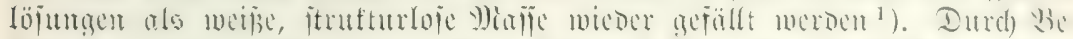

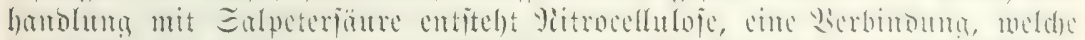

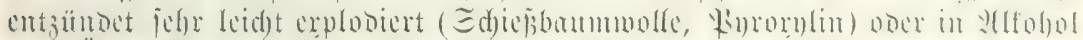
mo itruftur= แnd farbloje Mlajie (Siollobium) surüdbleibt.

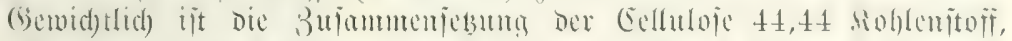

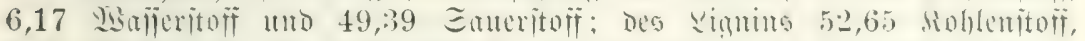

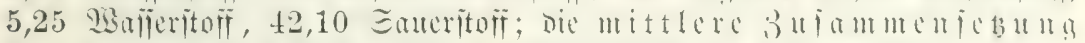
Des hol

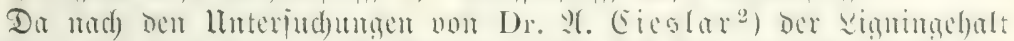
im Solse mit Dent sidht=

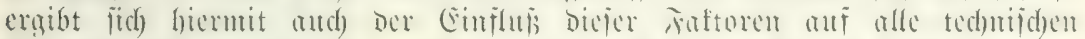

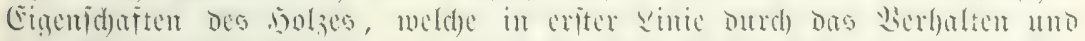

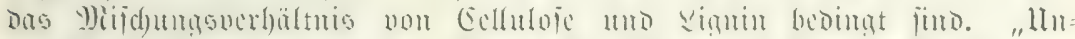

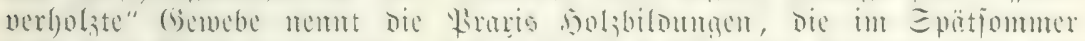

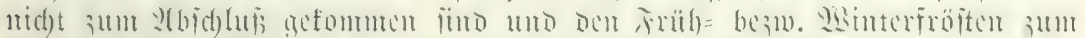

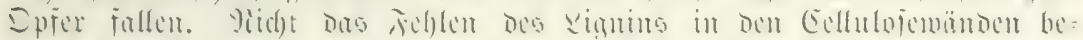

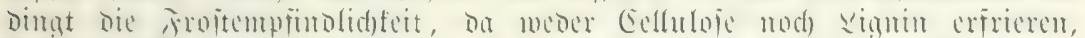

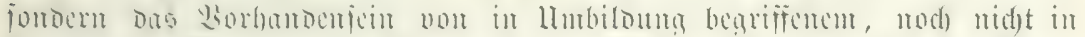

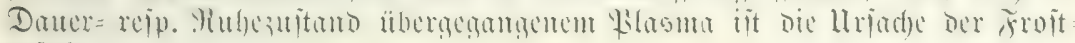
gefalyr.

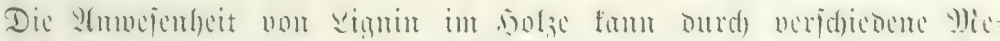

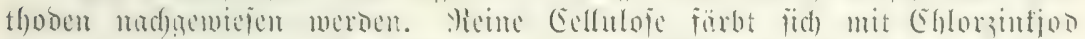

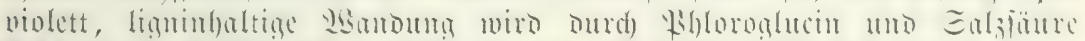

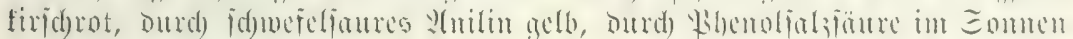
lid)te gimmelblau. u. a.

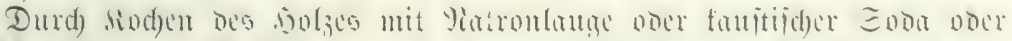

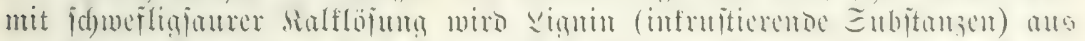

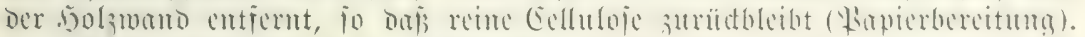

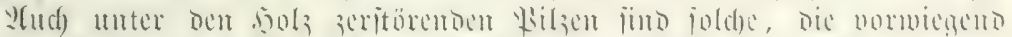

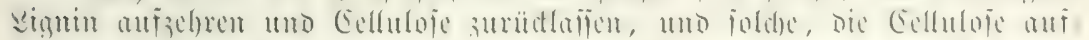

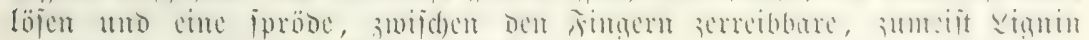
entbaltende, bräunlidye 9)iafie surüdlafien.

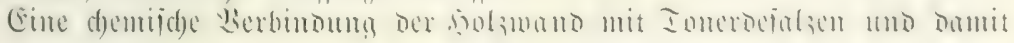

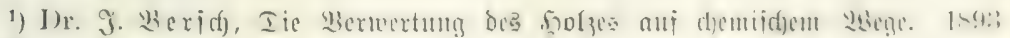
2. 2)îf.

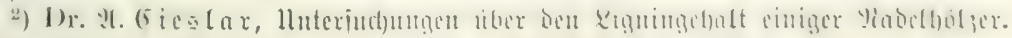
XXIII. Seft Dex lluteriddungen Dox pitere. Berjudganftalt 1897. 


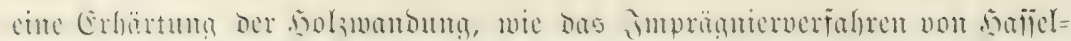

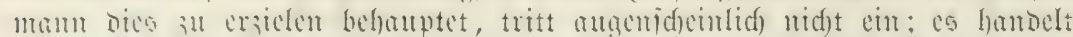

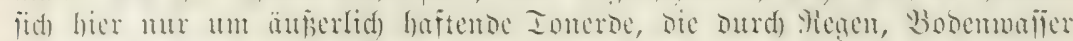
1. . w. entfernt werden fantu.

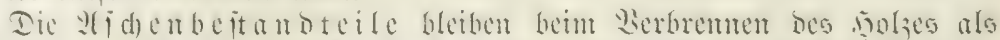

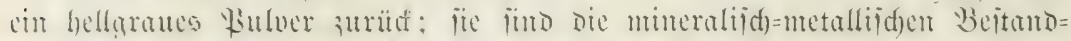

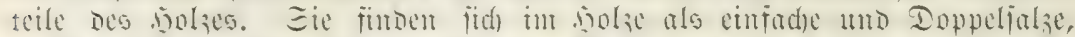

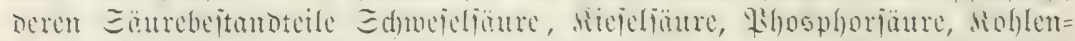

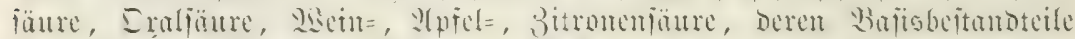

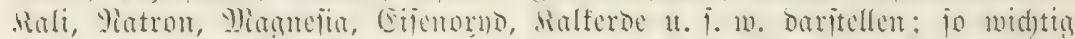

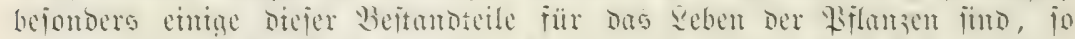

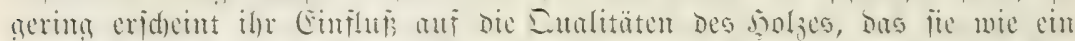

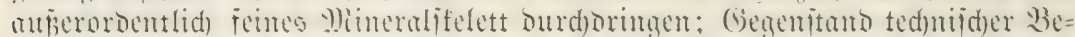

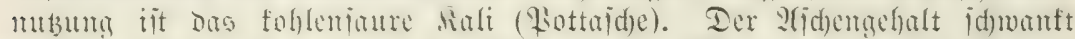

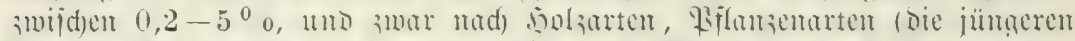

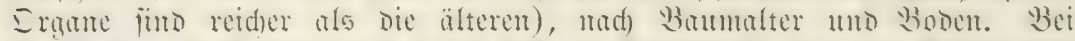

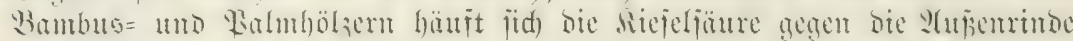

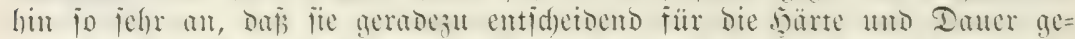

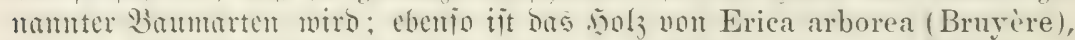

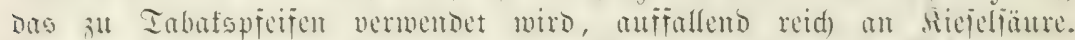

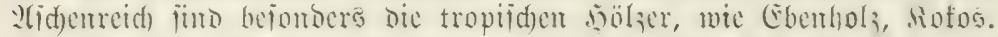

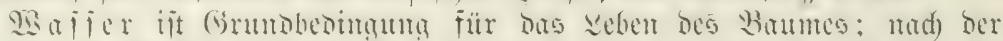

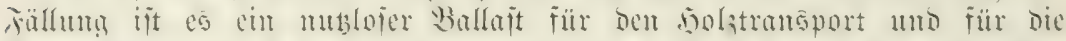

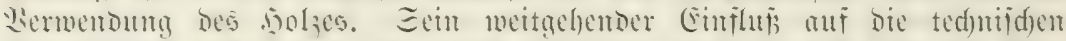

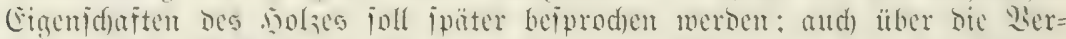

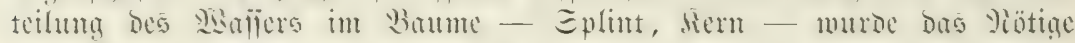
beim (Semidjte bes Syolzes bereits berïfrt.

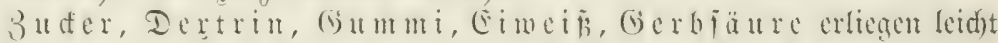

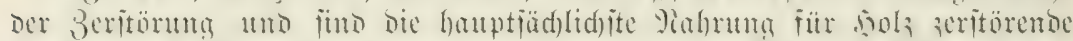

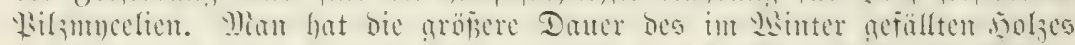

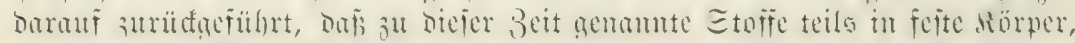

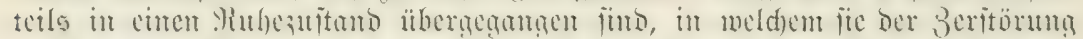

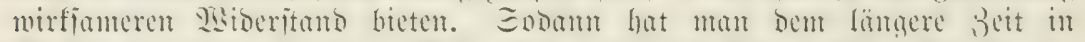

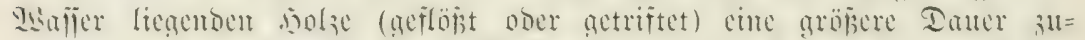

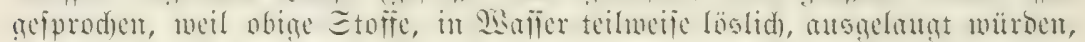

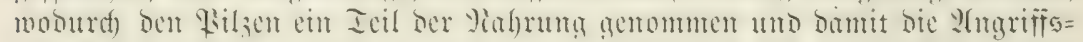

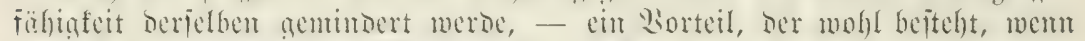

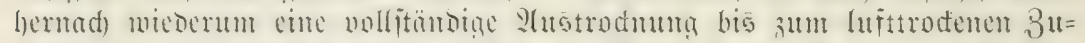

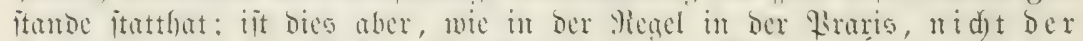

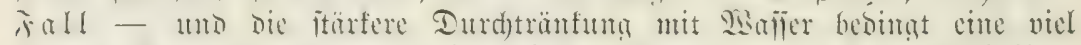

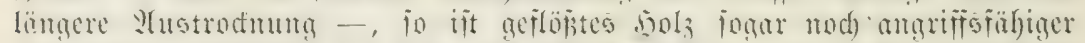

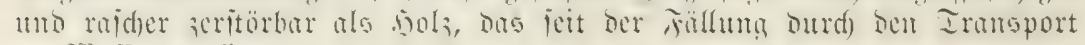
an 23 anjer verliert.

Der 3 ufer im Eafte ijt bet ben Ágornarten, Birfen, eintgen

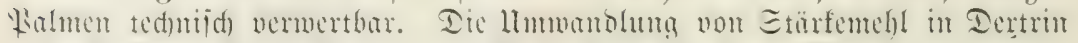
und Buder geht nad) unjeren Beobad)tungen beim ?(horn mut unter

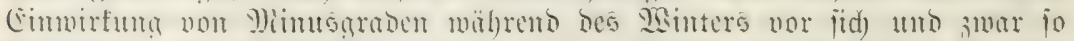

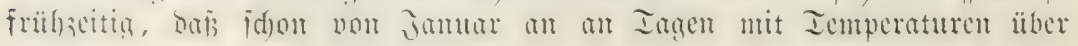




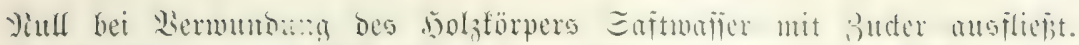

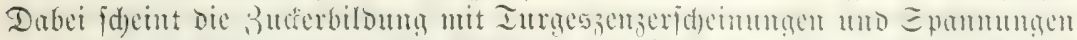

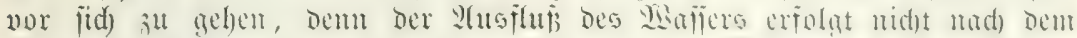

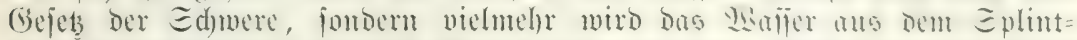

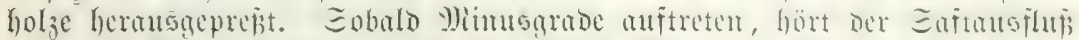

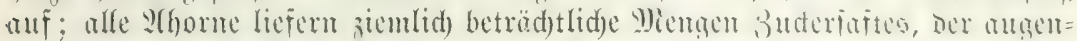

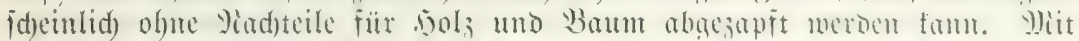

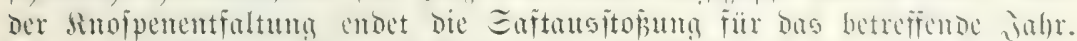

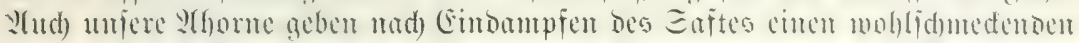

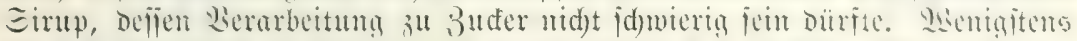

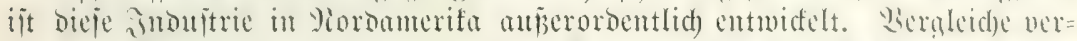

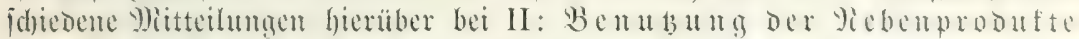

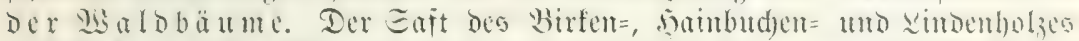

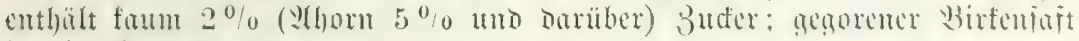
ît ein Getränffe.

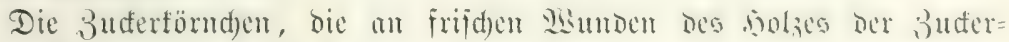
fiefer fid finden, fub als Seilmittel vermendet.

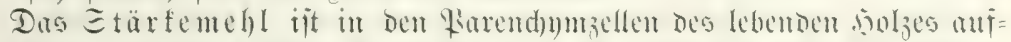

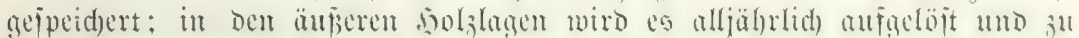

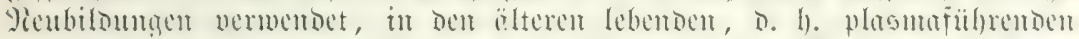

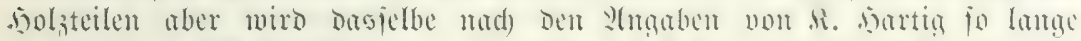

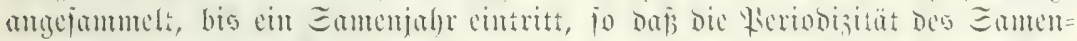

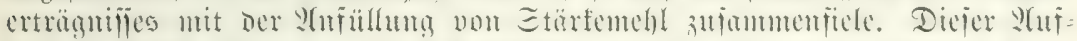

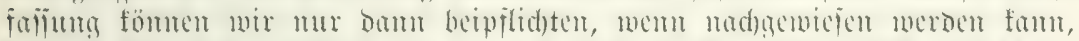

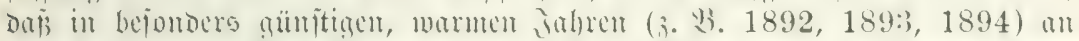

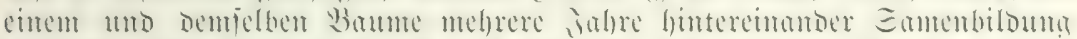

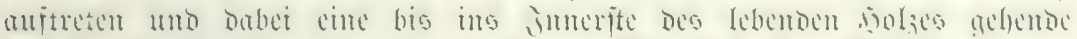

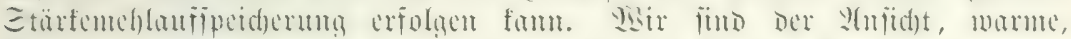

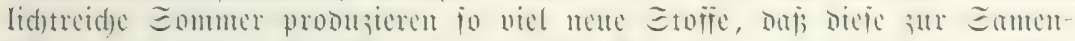

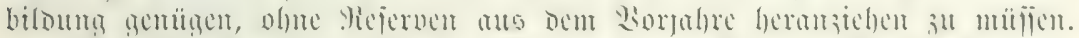

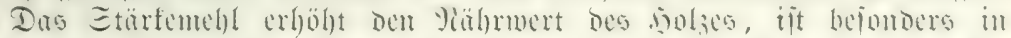

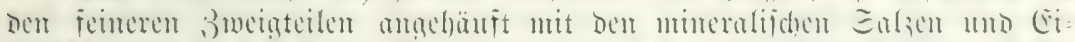

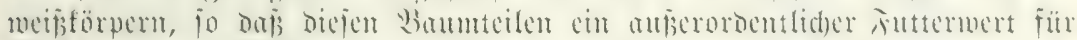

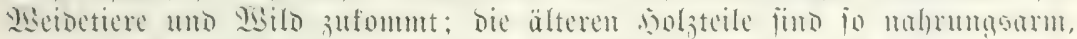

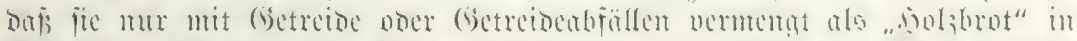

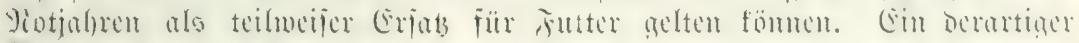

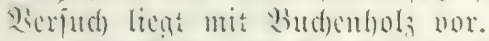

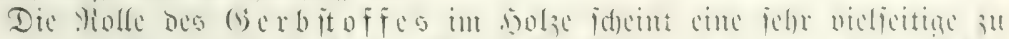

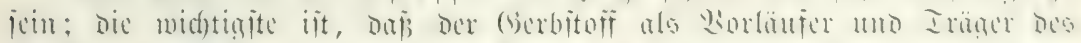

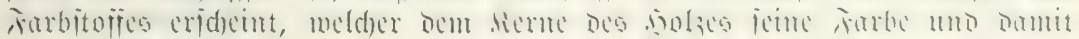
jeine Damer verleifit.

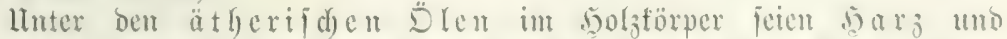

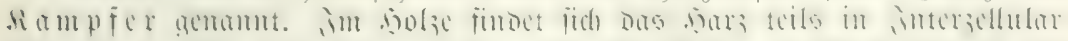

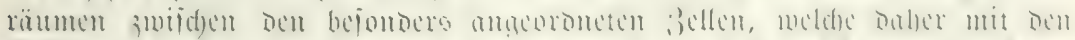

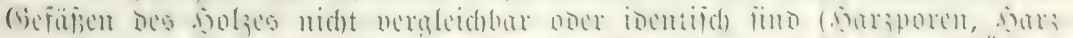

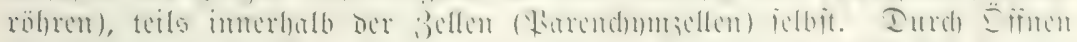
Der s)

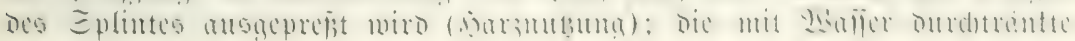




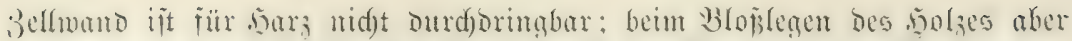

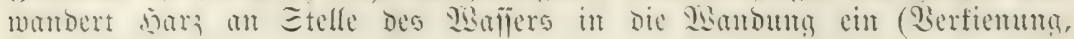
Refinoitis).

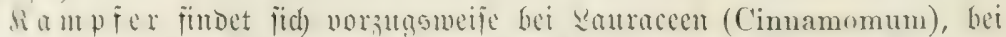

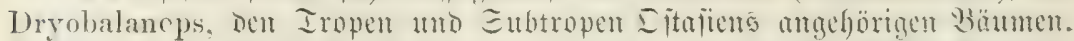

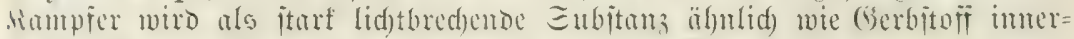
halb jactartiger Ërmeitermagen non Farend)mmellen aebilbet.

Betulin ijt cin im nolse und bex Minte der Birfen fid fimbender

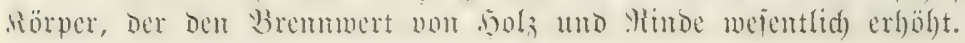

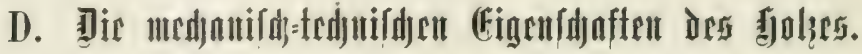

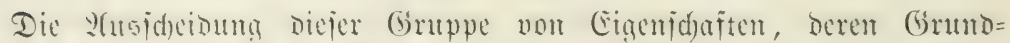

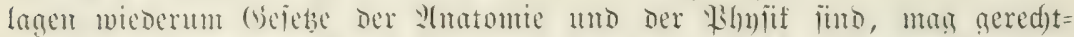

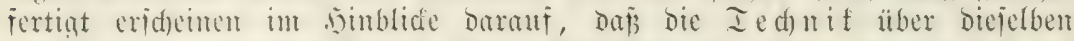

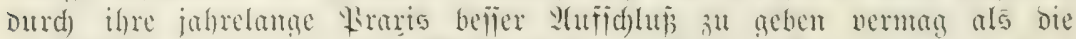

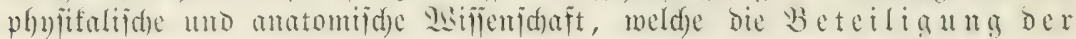
einzelnen phyfifalifden und anatomijen faftoren zu einer befamtwirfung, wie fie in einer "tednifden Eigen=

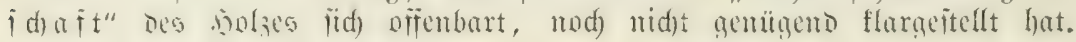

\section{1. feinfarerigkit.}

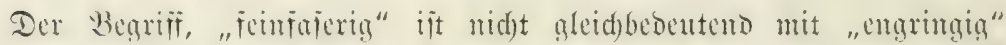

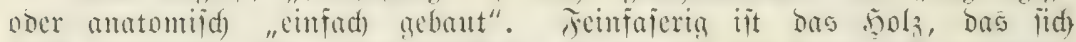

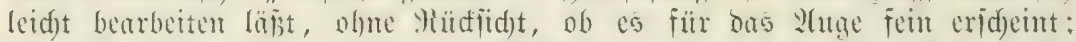

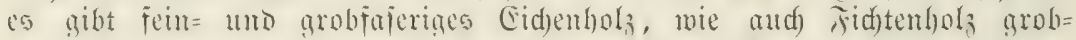

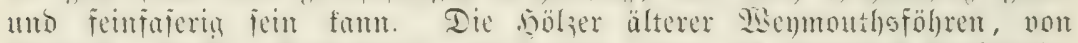

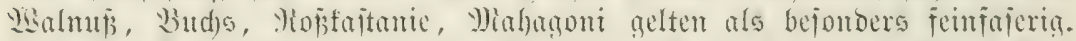

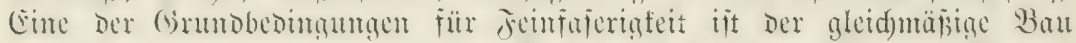

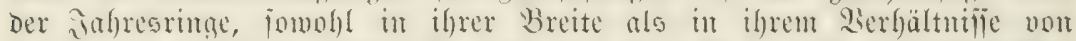

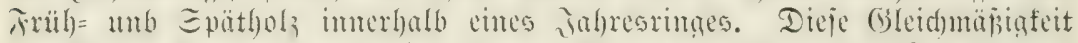

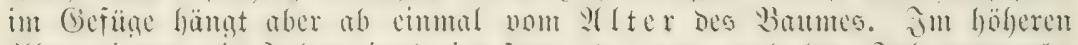

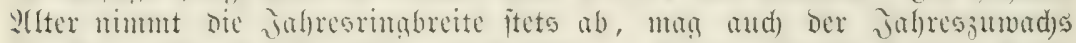

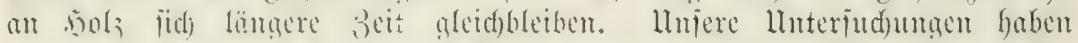

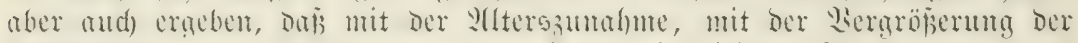

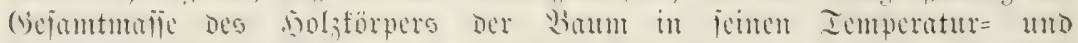

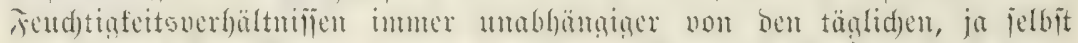

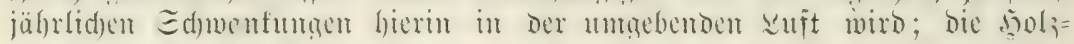

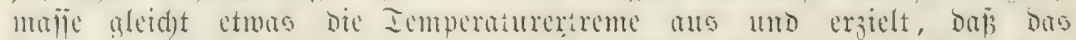

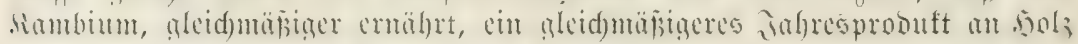
uno bamit ein feineres Gefüge bervorbringt.

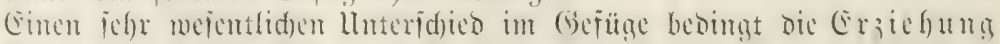
Dés

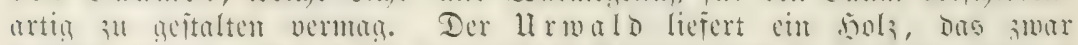

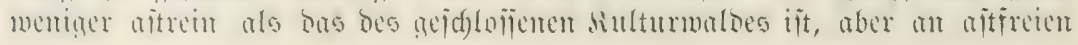




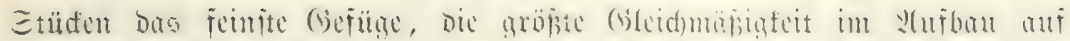

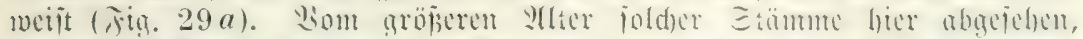

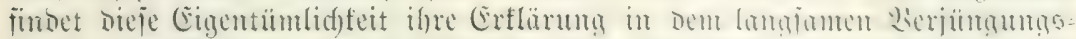

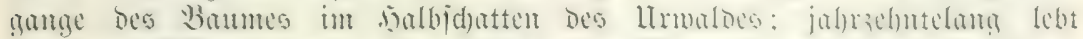

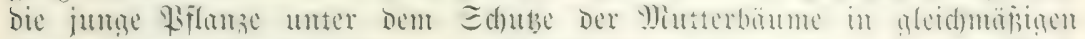

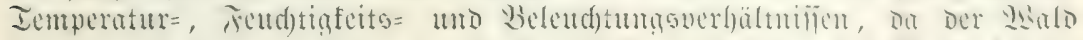

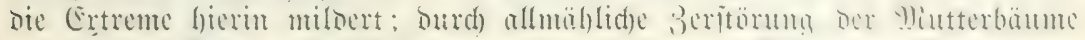

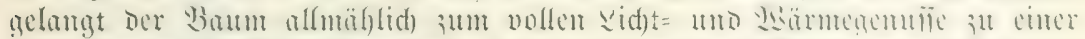

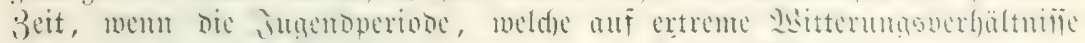

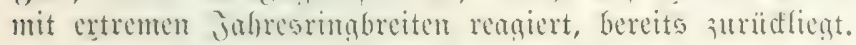

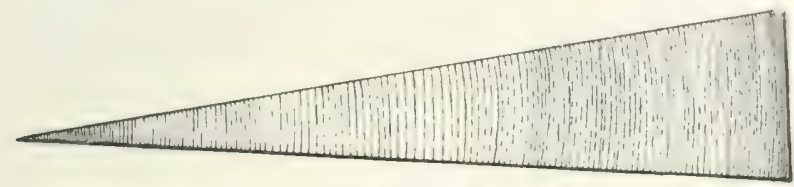

a. 150.

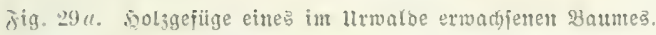

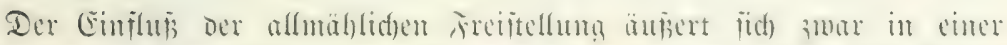

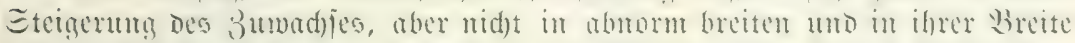

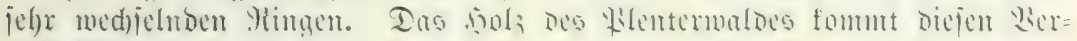
bältnifien am nädjiter.

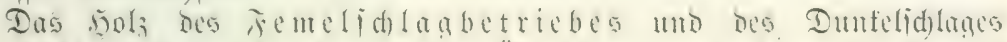

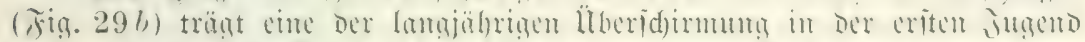

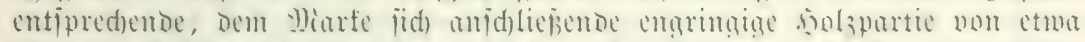

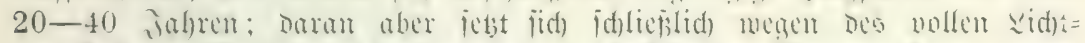

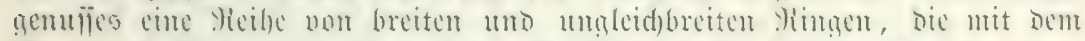

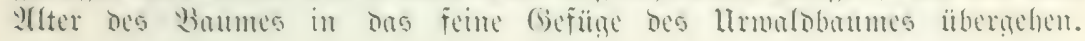

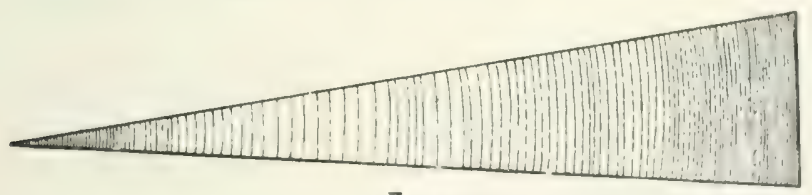

6. 120 .

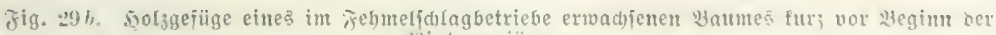
winterverjiingung.

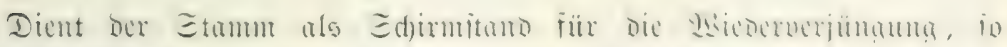
legen fid) wiederum breitere Minge ant wie in Fig. $29 \mathrm{~d}$.

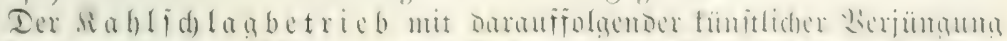

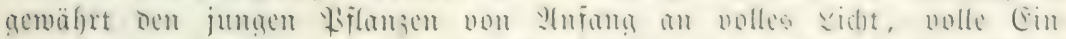

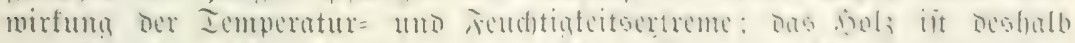

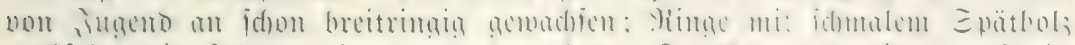

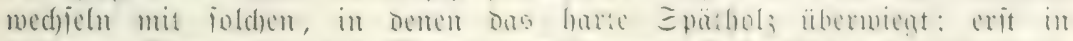

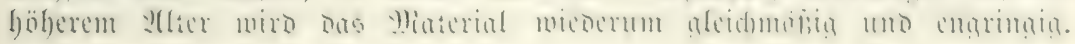


Ier diaflidala liefert iomit bas grobfaierigite Diaterial. (Jig. 29 c.)

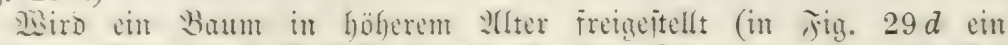
So jühriger Baum Des Bahlid)laqbetriebes), io erjolgt unter bem (Ëmpluh

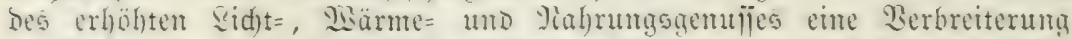

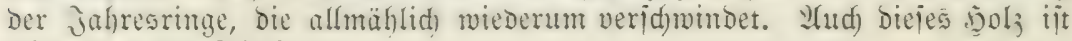
miederum grobfajerig.

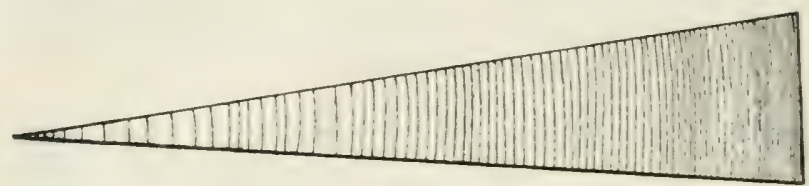

c. 100 .

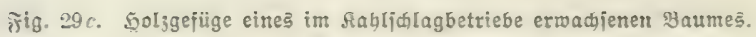

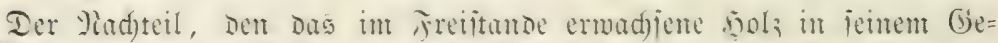

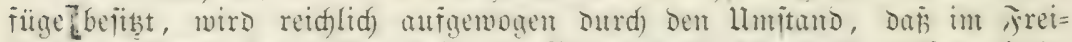

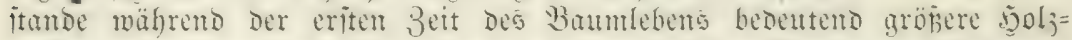
majien erzengt merden als an Den unter natürlicher 2 Serjüngung itehenden эntibiouen.

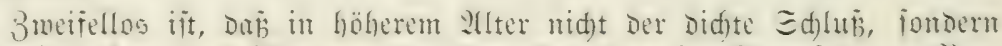

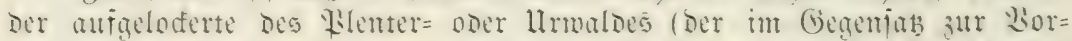

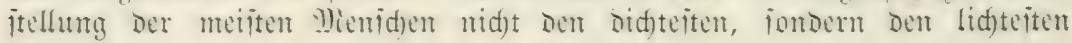

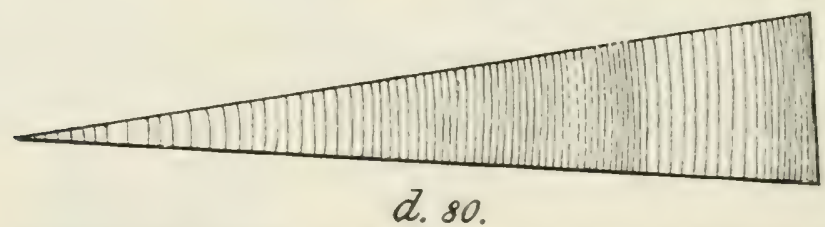

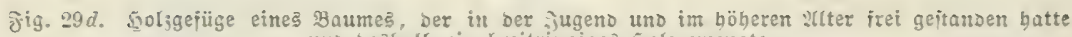
und Deshalb ein breitringiges 5013 erjeugte.

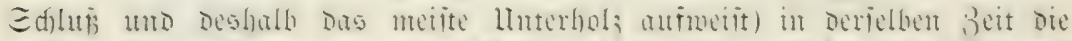

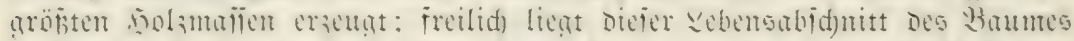

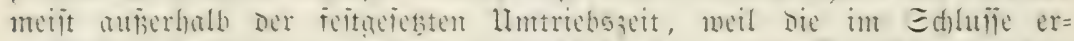

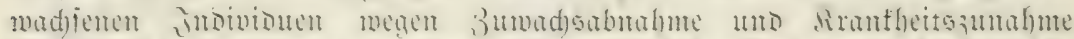

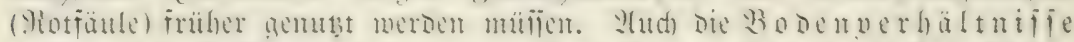

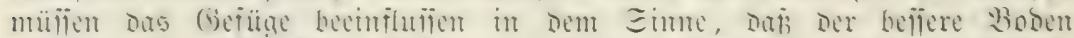

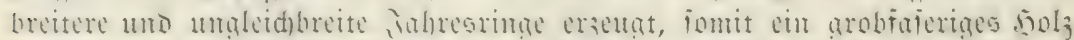
besinat. Die geringitem

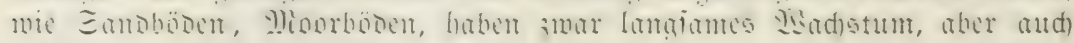
Feintajeriges

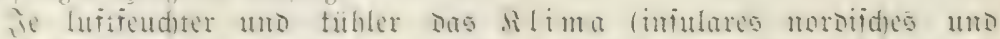

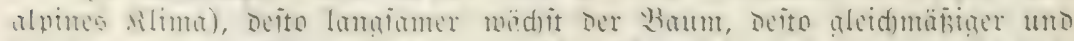

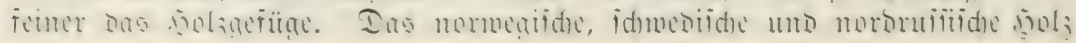




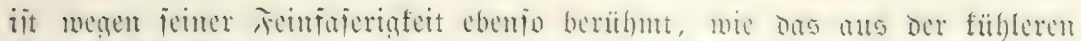

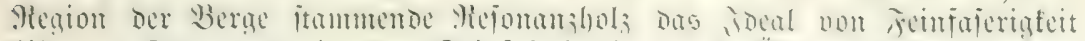

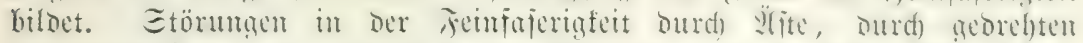

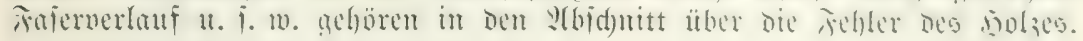

\section{Spaltuarkeit.}

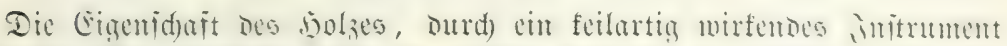

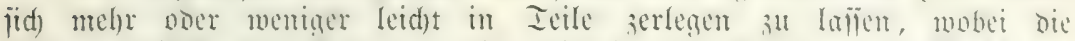

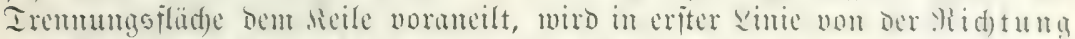

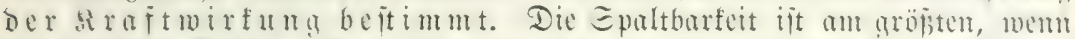

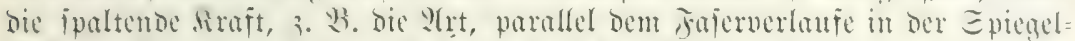

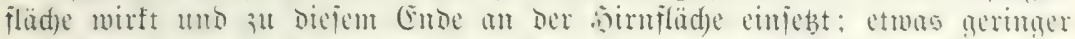

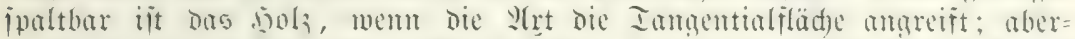

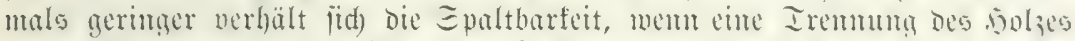

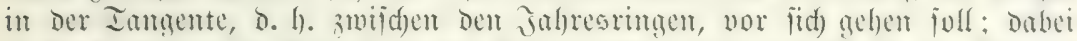

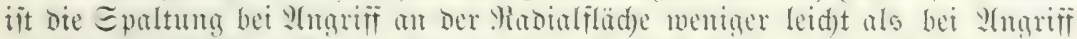

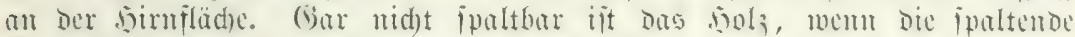

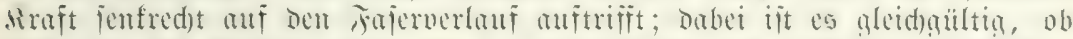

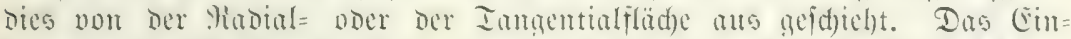

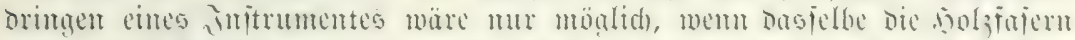

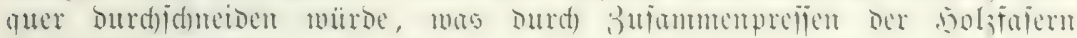
nod) eridumert mirb.

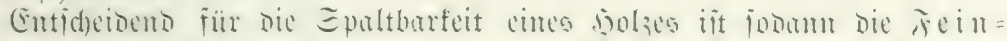
fajeriafeit, ber gerabe, uneitörte sajervertanf: alle llomente,

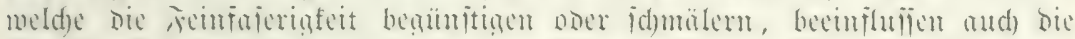

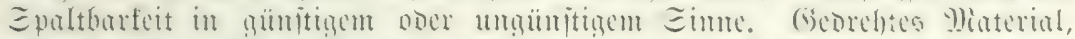

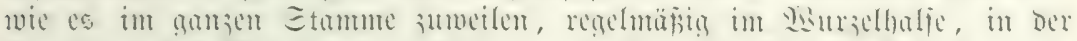

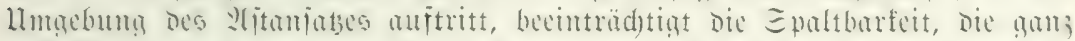

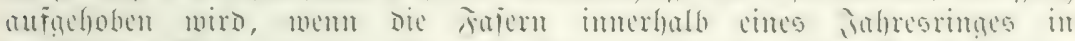

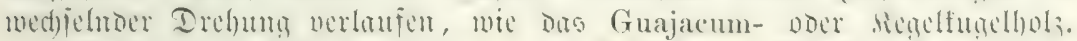

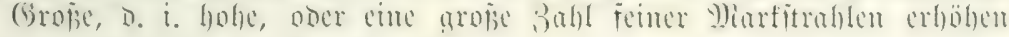
Die Epaltbarteit in ber Mabialebene.

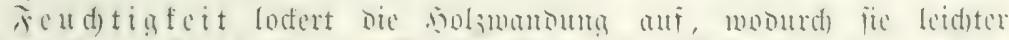

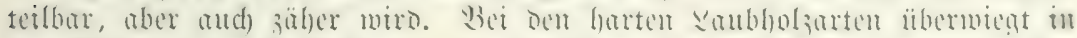

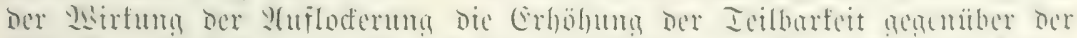

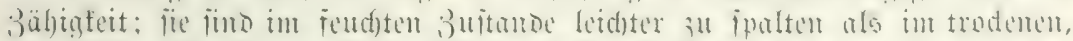

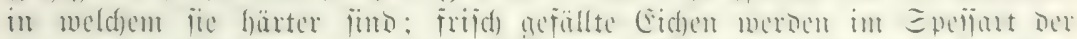

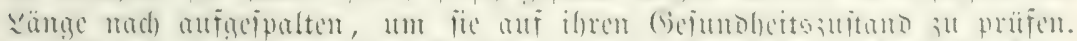
llmugefert nerhalten fich bie

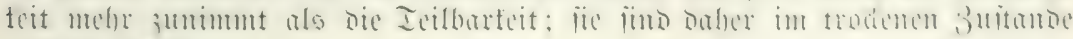
leidjter ipaltbar.

Bei gleider Feudatigfeit erböbt Die höbere Icmperatur den

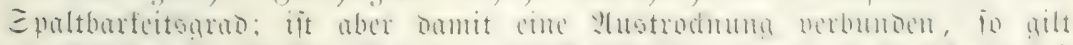

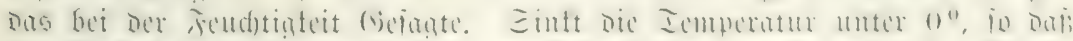

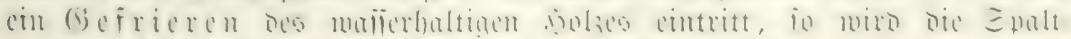

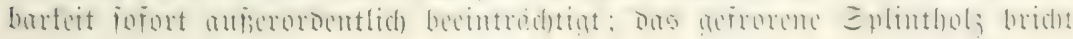


mit mujdeligen Fläd)en aủ wie ein Ėişblod, ben bas

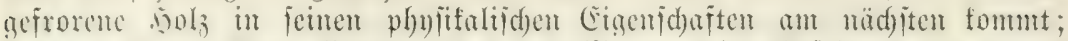

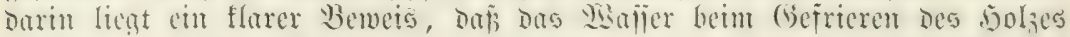
uid) a

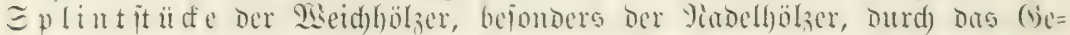

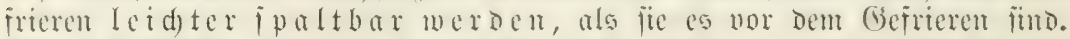
WEic Das

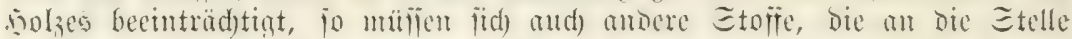

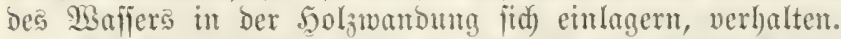

Die Epaltbarfett mindem deshalb alle jarb joffe, dic im dieme

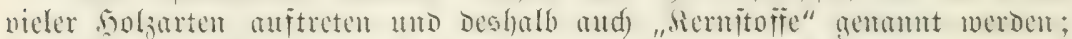

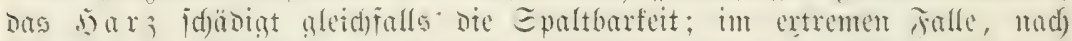

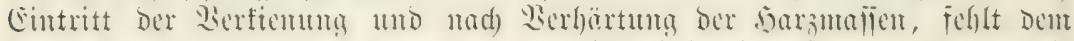

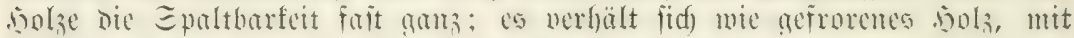
bem es in ber Iat am bejten vergliden werben fam.

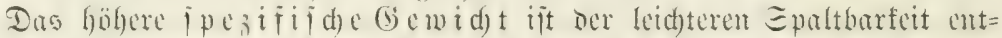

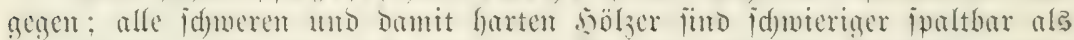

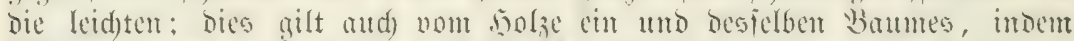

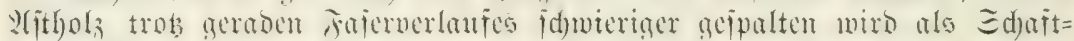

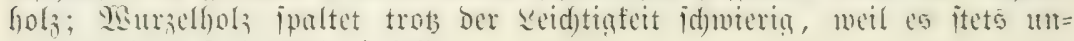

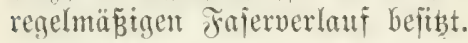

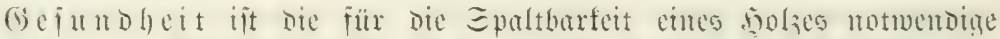

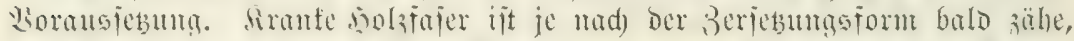

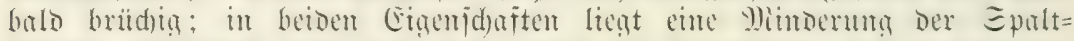

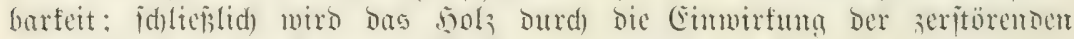

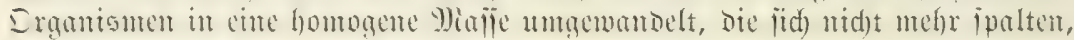
jonbern mur nod) zeridumeiden läßst.

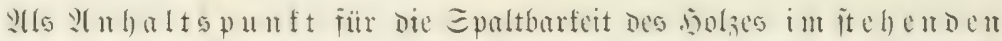

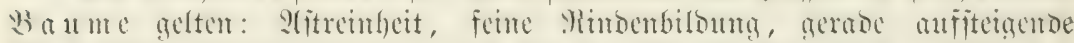
Borfenrifie; Frenclhaftermeife wiro bic Epaltbarteit feitgejtellt, indem ans bem nolac ein Epan hermegehanem und direft unteriud)t wirs.

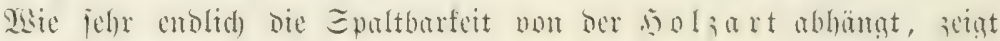
folgende Efala:

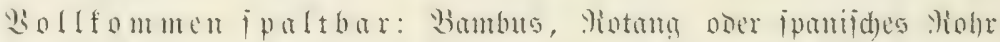

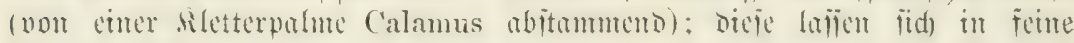
zäben zerteilen;

iebr leidit ipaltbar: Fidjte, Iame, MBeidenrute;

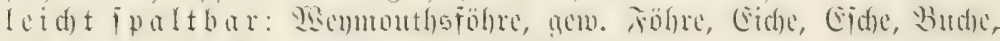

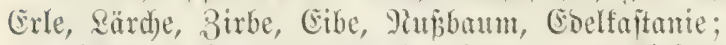

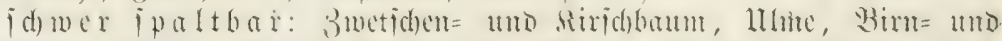

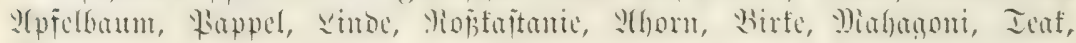
Blatane;

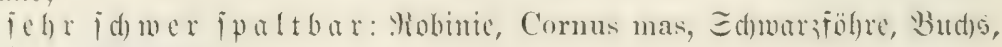
Ebentolz, Salifander;

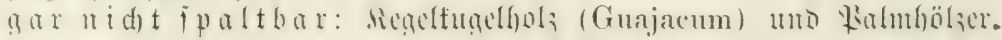




\section{3. feftiglicit.}

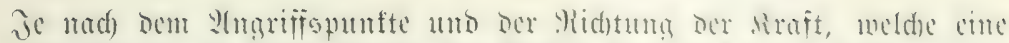

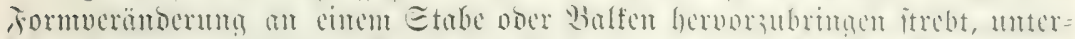

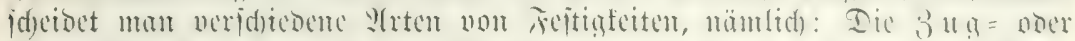

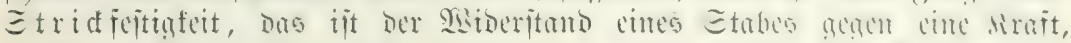

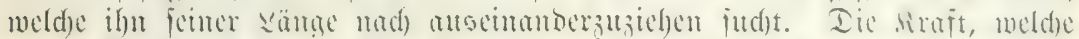

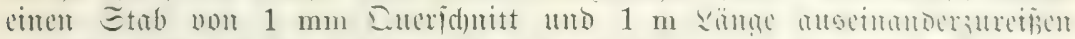

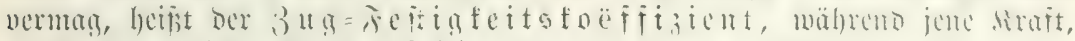

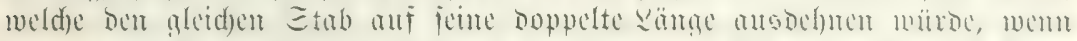

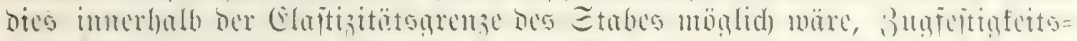

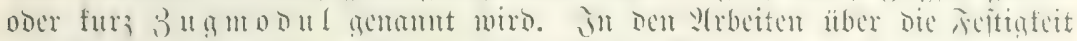

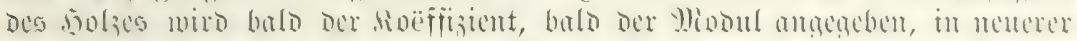
Beit in Silogramm pro Dutabratzentimeter (9ttmofphären).

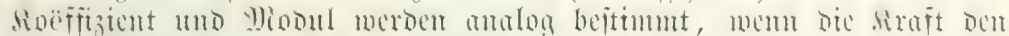

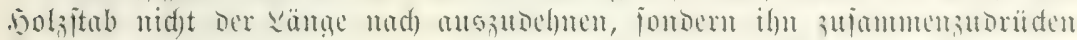

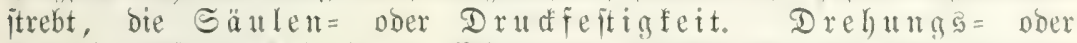

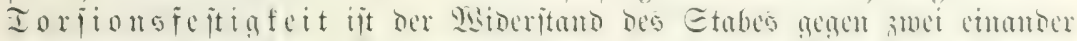

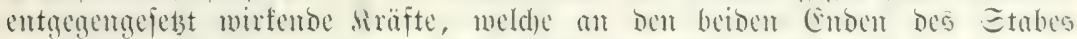

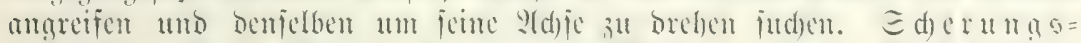

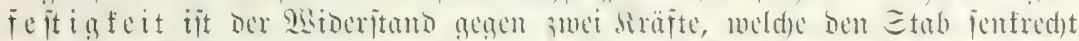

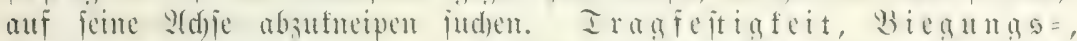

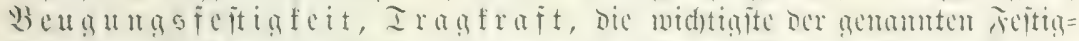

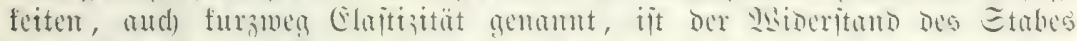

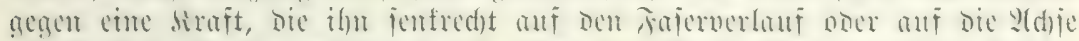

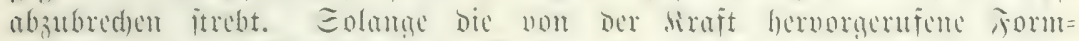

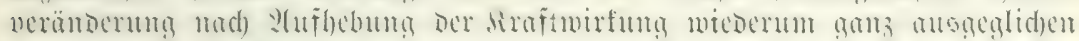

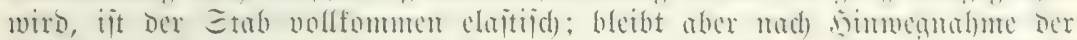

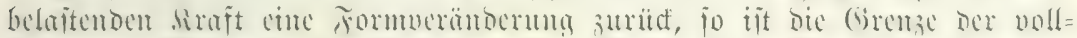

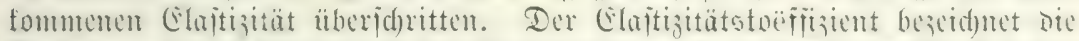

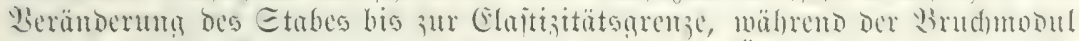

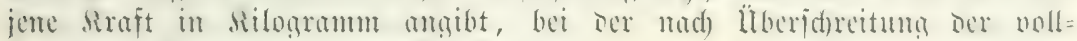

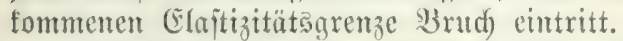

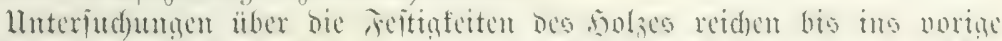

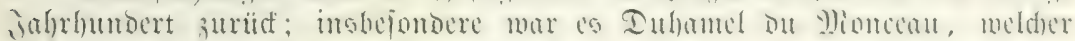

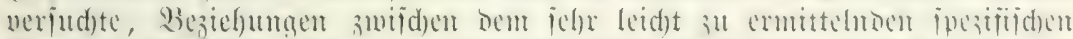

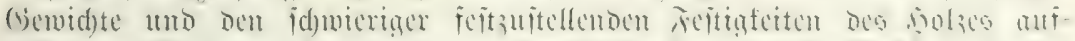

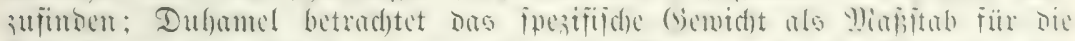

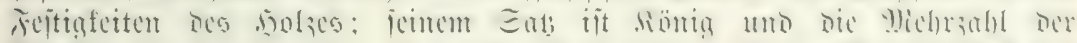

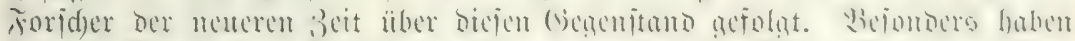

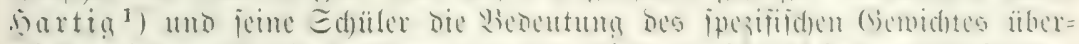

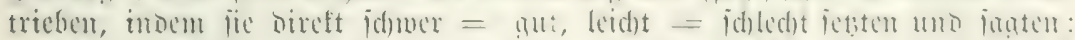

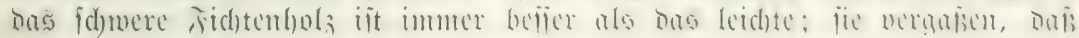

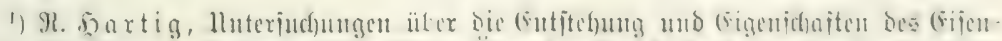

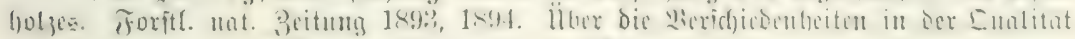

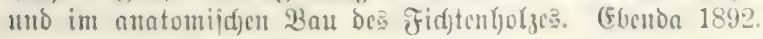




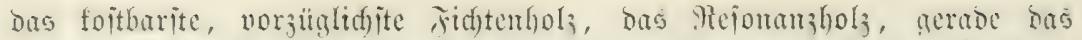

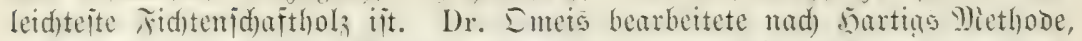

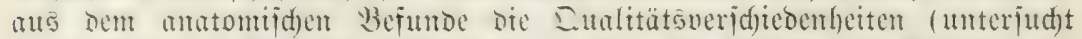

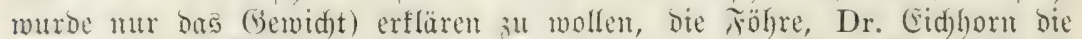

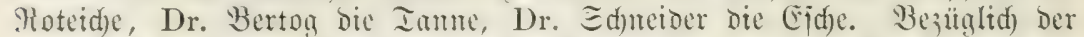

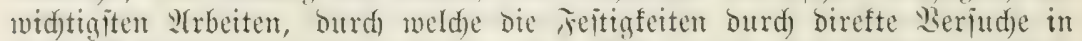
biejer Midsung ermittelt murben, jet anf bic unten angeführten 3itate ${ }^{1}$ ) verwieien.

Wad) Den Interjudumen Ietmajers, bie vorbilolid) für bie nad)=

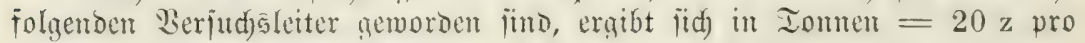
Eundratzentimeter Eueriduntt von $0,5 \mathrm{~m}$ langen Etäben:

\begin{tabular}{|c|c|c|c|c|}
\hline Iruffeftigteitsmodul: & Tamte 100,2 , & ipez. & Wittr. & (b) $\cos \mathrm{i}$ (d) $\mathrm{t}$ : \\
\hline & (Fid)e 102,7, & $"$ & $"$ & " \\
\hline & Fidute 110,9, & $"$ & $"$ & $"$ \\
\hline & Bärctge 114,4 , & $"$ & $"$ & $"$ \\
\hline & Föhre 118,8 , & $"$ & $n$ & " \\
\hline & Budfe 168,5 , & $"$ & $"$ & " \\
\hline 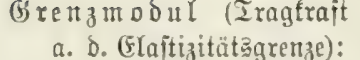 & & 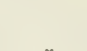 & 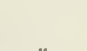 & \\
\hline & Särche 0,206 , & " & $"$ & $"$ \\
\hline & Fidite 0,210 , & $"$ & $"$ & $"$ \\
\hline & (Eid)e 0,217 , & $"$ & $"$ & $"$ \\
\hline & Tanne 0,224 , & $"$ & $"$ & $"$ \\
\hline & Budbe 0,240 , & " & $"$ & $"$ \\
\hline
\end{tabular}

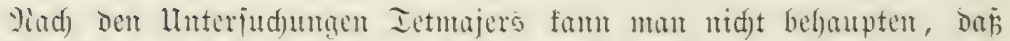
Drudfeitinfeit und Iranfraft parallel aeben. Die meiten Der unten sitierten Beobad)ter haben bie Iraghaft Direft nid)t ermittelt, jonbern fid

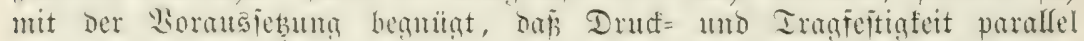
gingen.

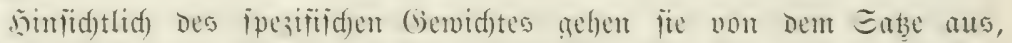

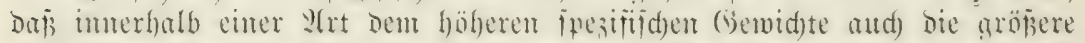

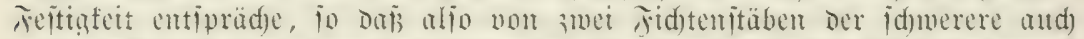

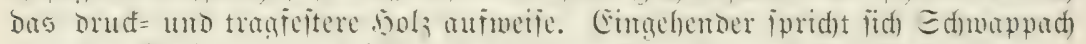

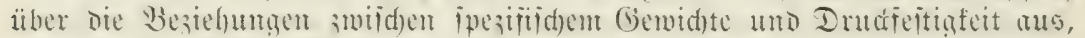
inbem er jagt: Die Drucfejtigfeit hänģt $a b$ :

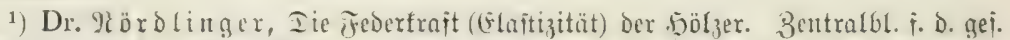
Foritweien 1 1881, 1887 -1 $8>9$. - Dr. Bauf(finger, Hnteriud)ungen ïber Die

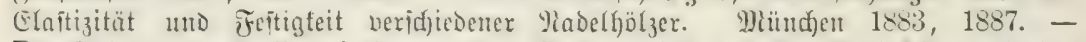

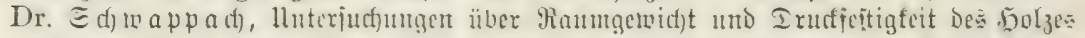

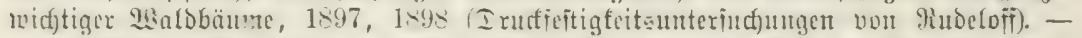

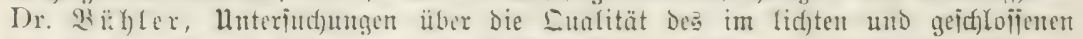

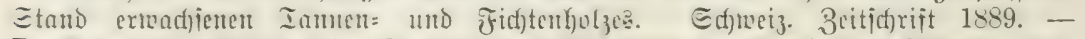

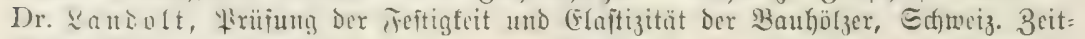

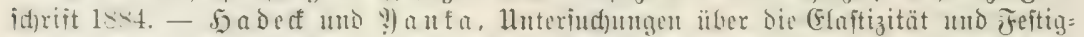

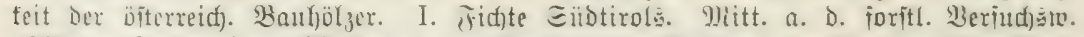

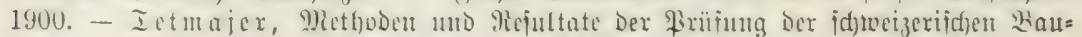

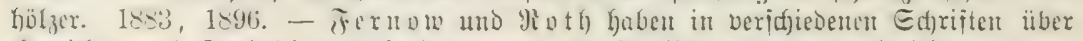
(iemid)t: 


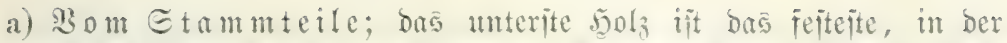

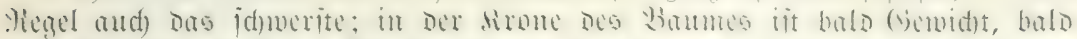

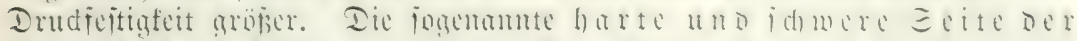

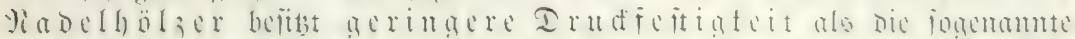

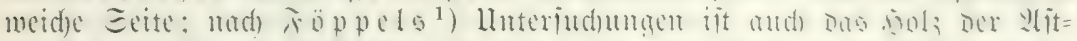

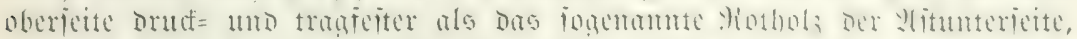
alio Das leidjtere Dolz elaitifd)=fejter als Das idjwere!

b) ㄴom

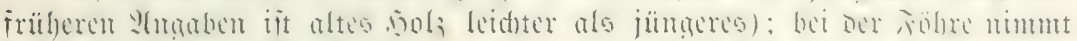

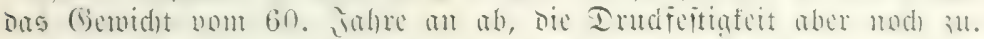

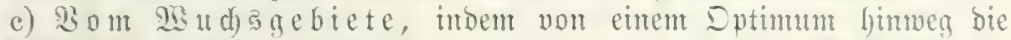

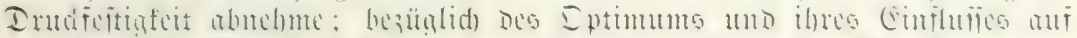

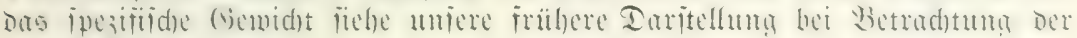
Sd)were bes solzes.

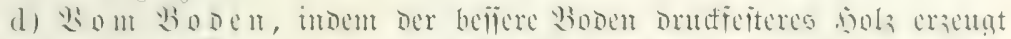

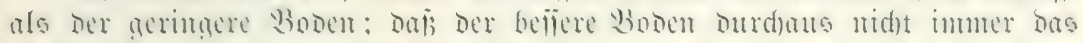
jdwwerere Solz erzengt, ijt bereits bei ber Edymere erörtert.

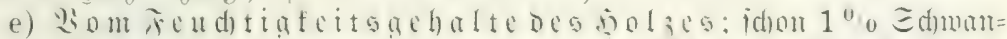

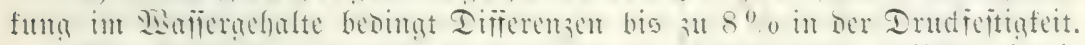

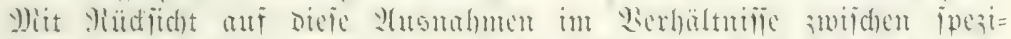

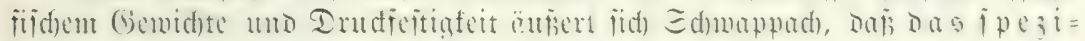

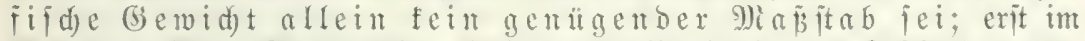

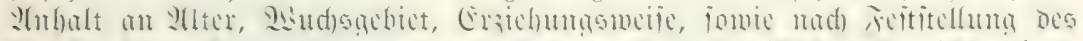

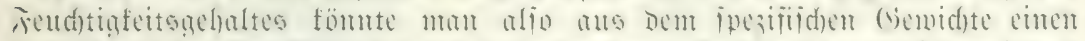

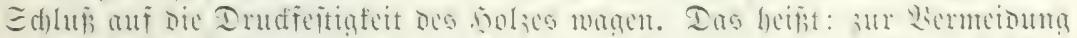

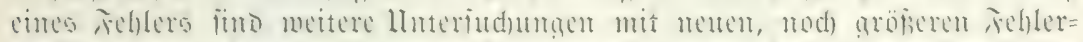

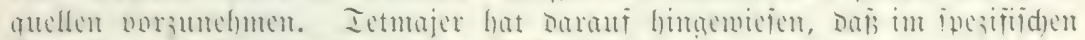

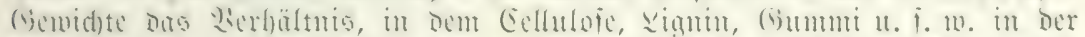

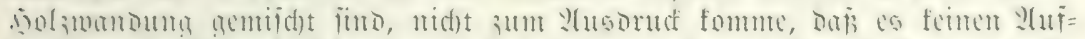

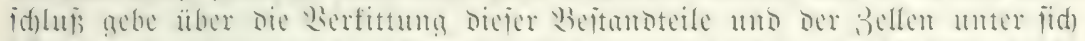

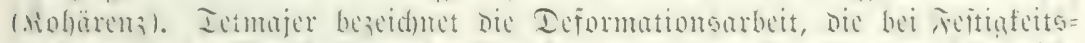

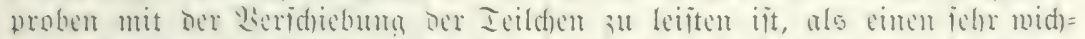

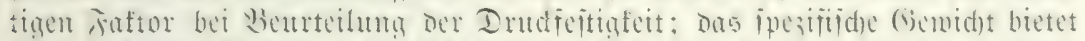

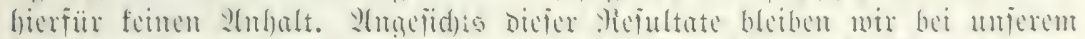

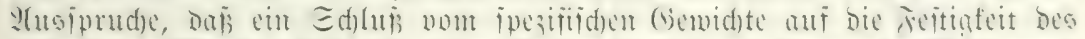

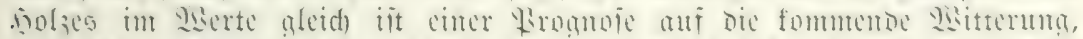

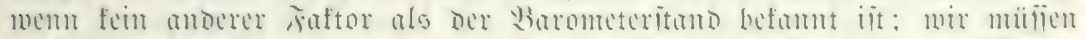

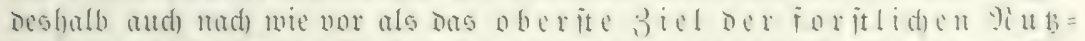

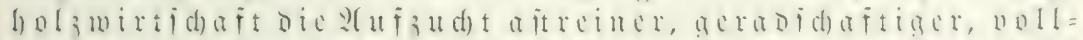

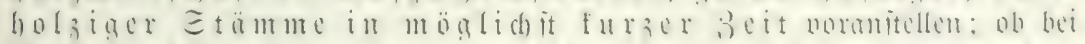

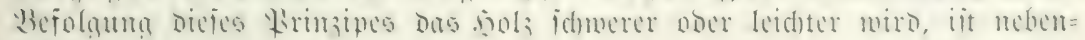
jäd)lid).

Die Iragiejtigfeit cincs Walfens bängt ab von der Il nter=

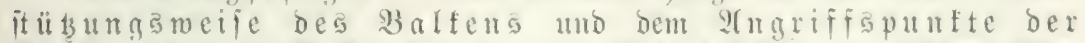

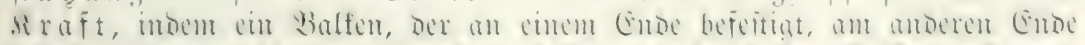

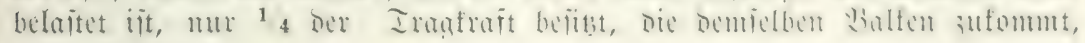

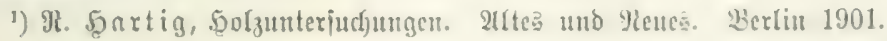


menn er anf beiden (Enden unteritüt und in jeiner Mritte belajtet wirb. Bleibt mad) Der Belajtung cine formänbernng zurïd, io ijt bie Elajtizitäts=

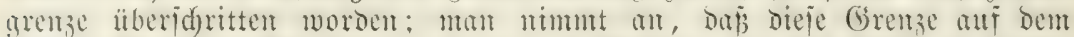
halben 13 ege zur Brudgarense liegt: ein Balfen, Der bei $8000 \mathrm{~kg}$ bridgt,

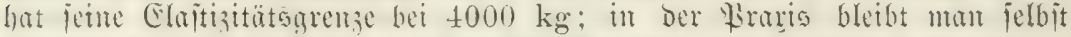

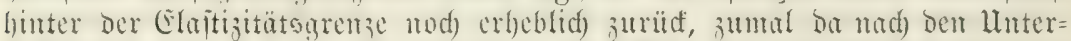

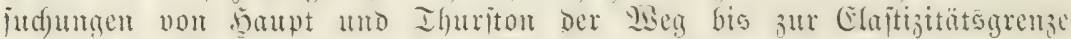

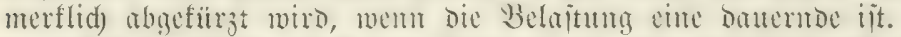

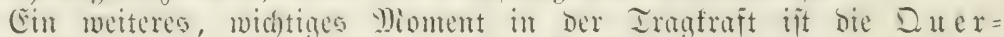

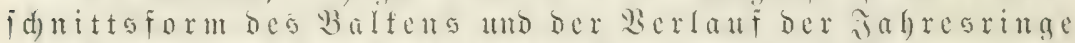

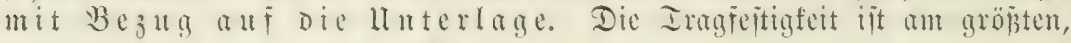

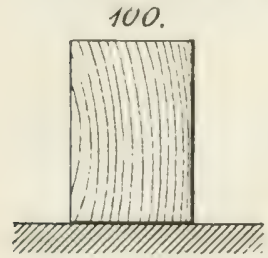

$a$.

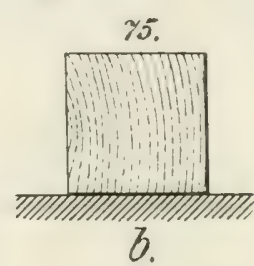

b.

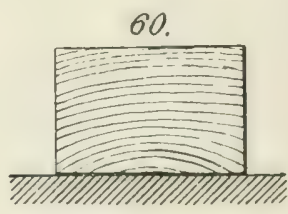

c.
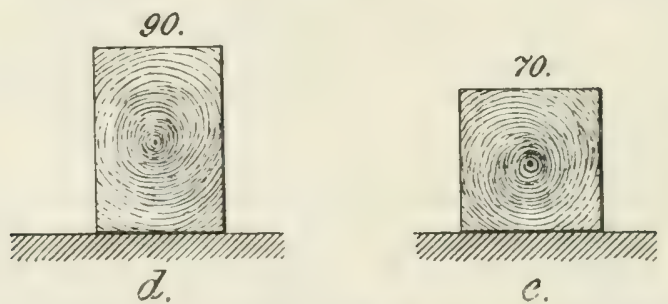

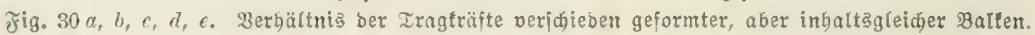

wem Der Euerid)nitt ein Med)ted im Berbältnis Der Eciten won $1: 0,7$ bar=

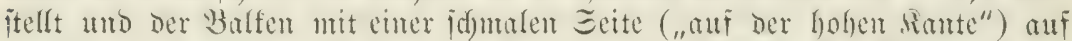

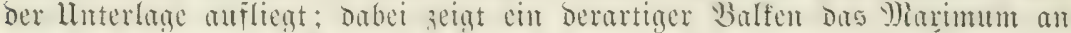

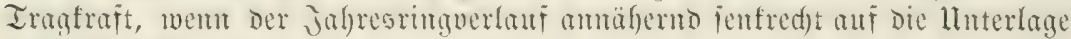
auftrifft (テ゚ig. $30 a$ ).

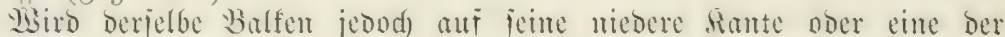
Breiticiten gelegt, jo jenft jeine Iragfrait, wem ber vorigen Zange bie

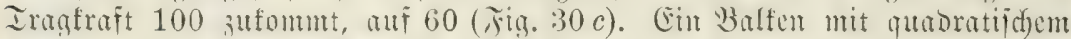

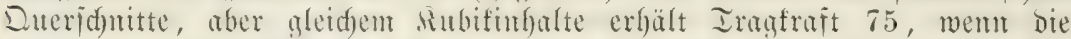

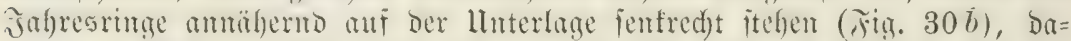
gegen ca. 65, want die jufrestinge mit der Llnterlage parallel lanfen; ein red)tediger Balfen mit Der Wiarfröhre bes Stommes in jeiner Mritte, auf

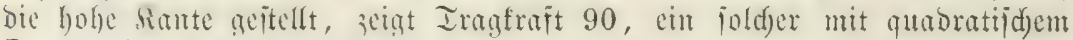
Duerfonnitte bie Iragfraft $70^{1}$ ).

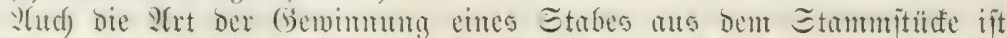

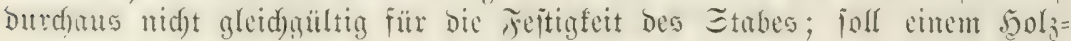

1) Madj einer anderent Nitteilung wäre $b=84, c=70$. 


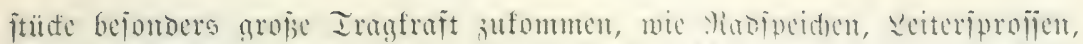

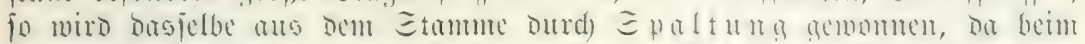

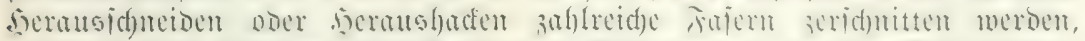

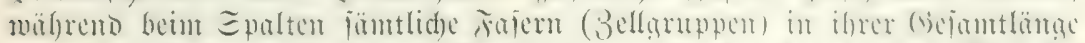

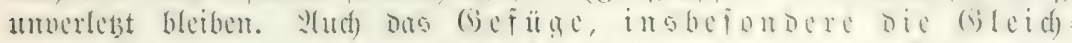
ma

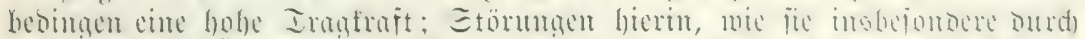
eingemad)

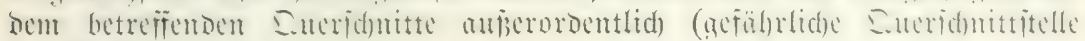
bes Balferis).

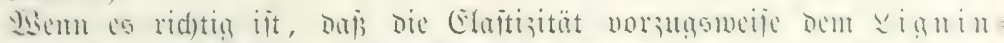

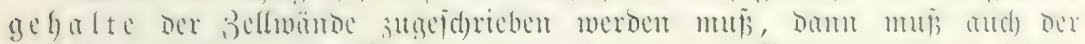
gr b

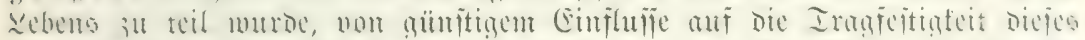

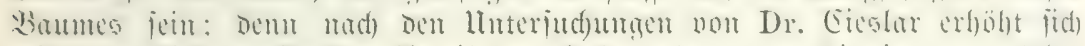

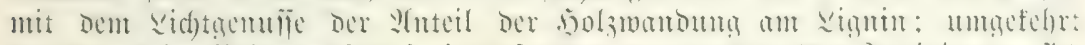

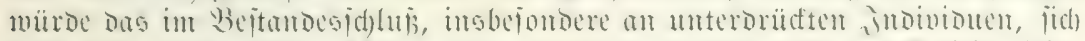

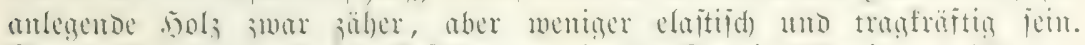

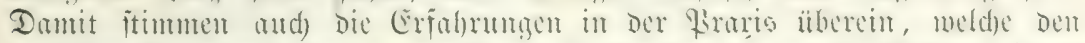

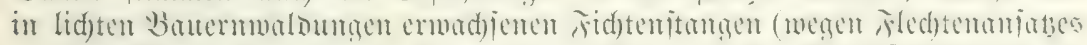

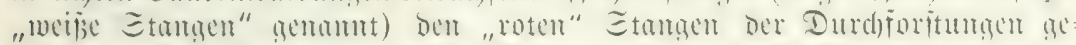

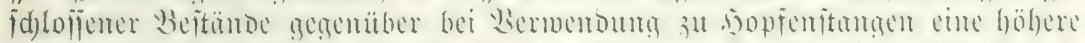

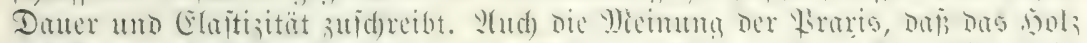

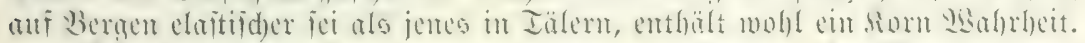

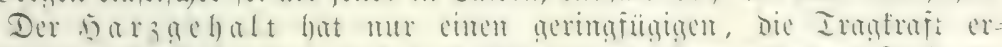

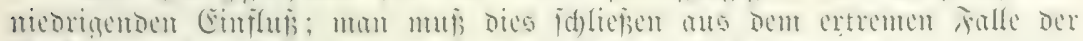

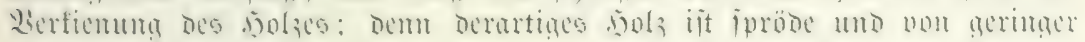
Iragfraft.

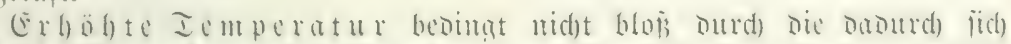

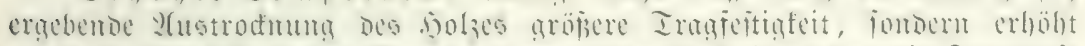

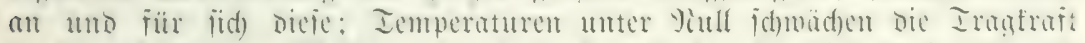

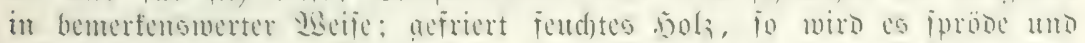

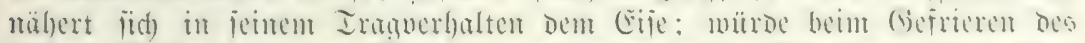

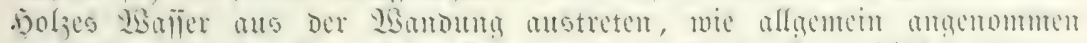

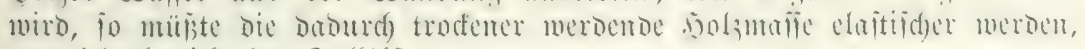
was jebod) nidat ber Falf ift.

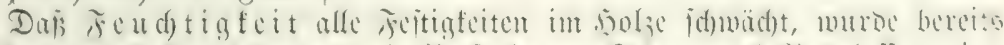

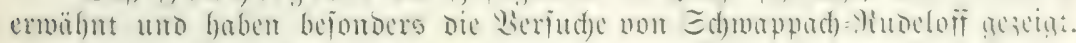

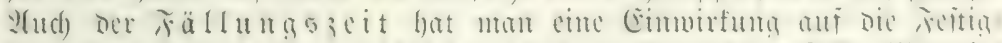

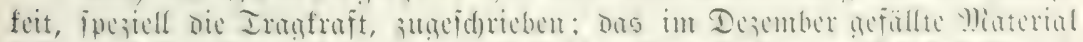

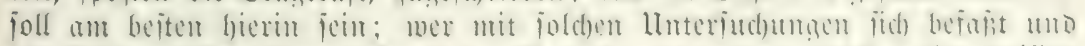

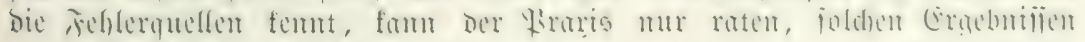
gegeniiber ablégneno jid) zu verbalten.

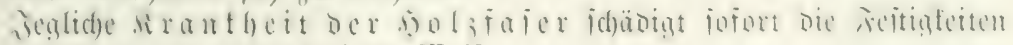

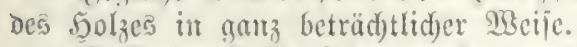

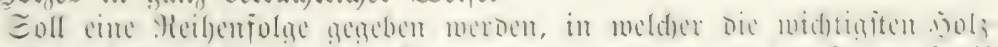

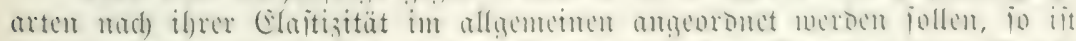

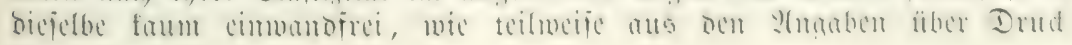




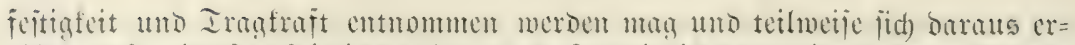

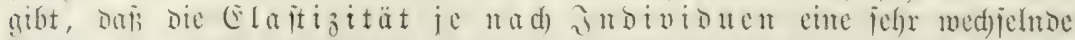

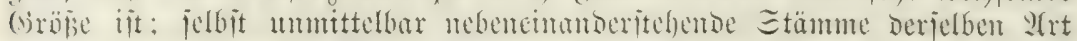

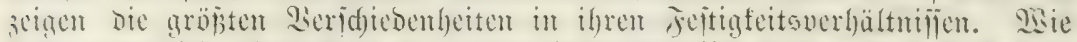

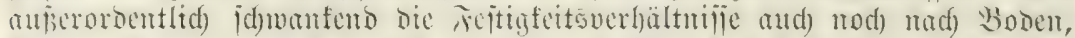

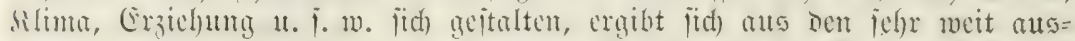

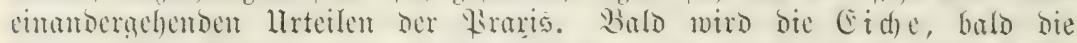

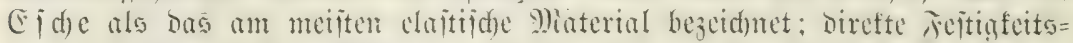

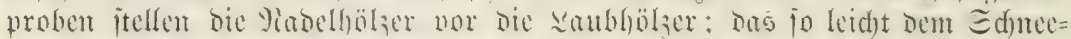

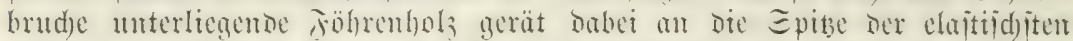

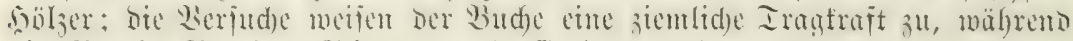

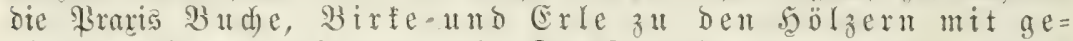

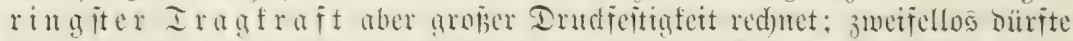

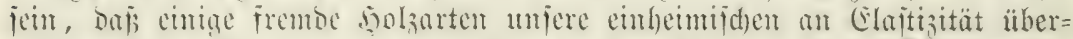

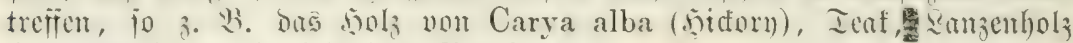

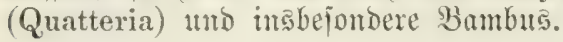

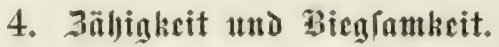

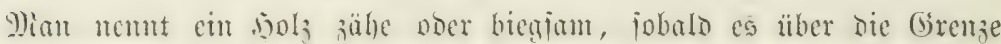
ber vollfommenen Ela fitizität hinam nod) meiter gebogen weroen fom, alio

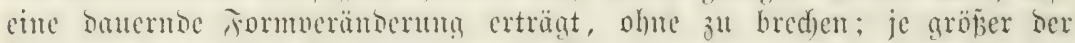

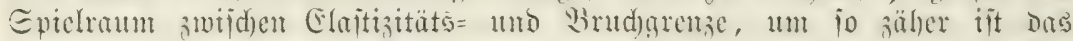

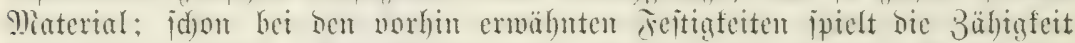
cine midtige Molle. Die Prario nemt cin bols mit geringer biegamfeit

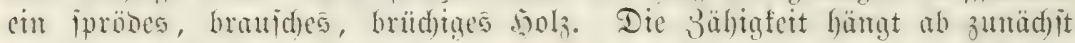

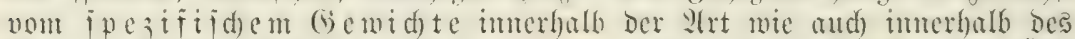

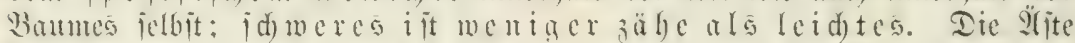

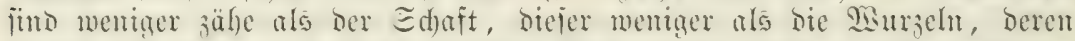
Dümnte Etränge als Bimbematerial Bermensung finten; säber als bie

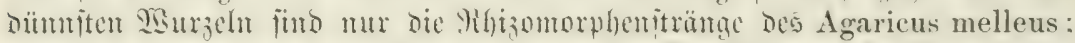

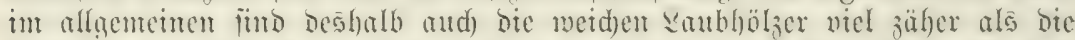

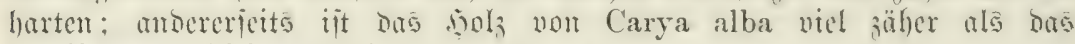
brüd)ige und leidjtere Şolz vou Carya amara.

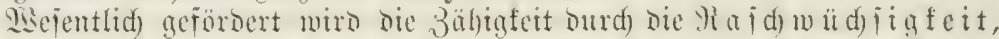
imben $\bigodot_{t}$ od a

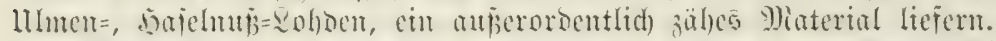

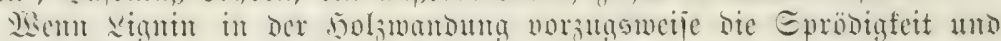

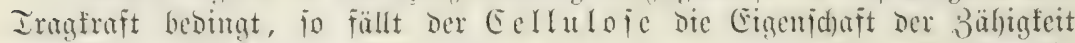

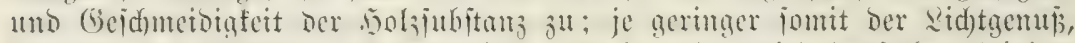

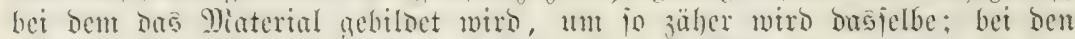

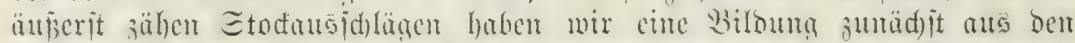

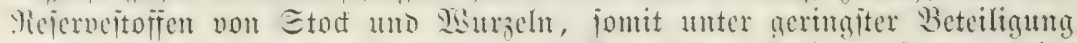

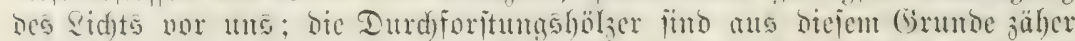

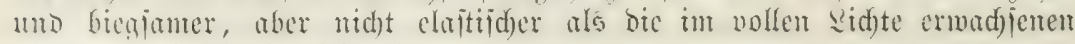
Stangen, bie ligninreidyer find.

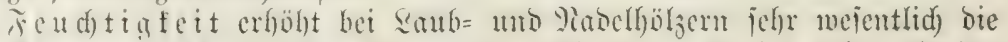

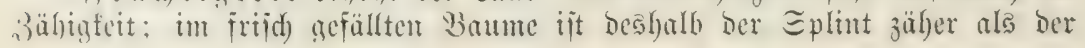




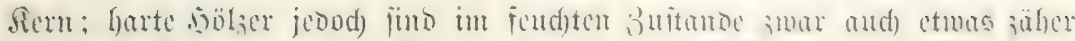

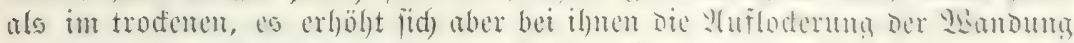

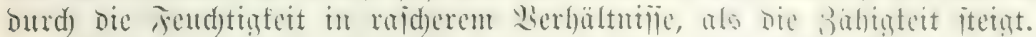

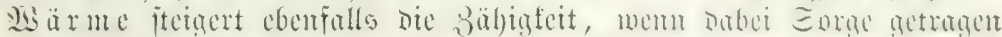

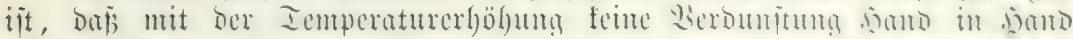

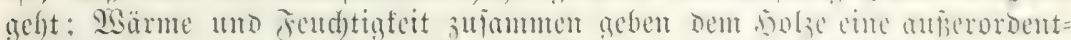

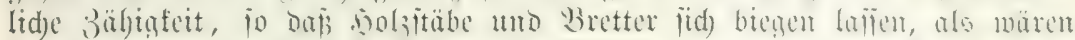

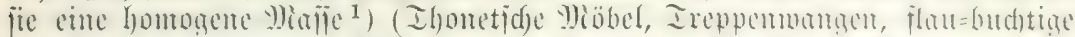

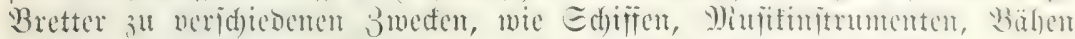

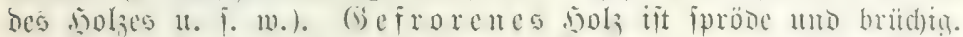

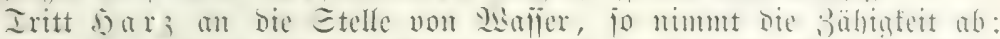

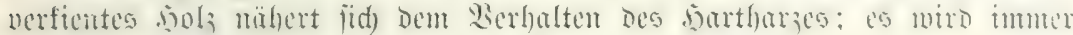
ipröber, je länger bā $\mathfrak{H a r z}_{\text {in }}$ ber Mandung verbleibt.

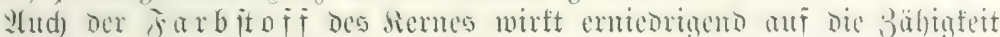

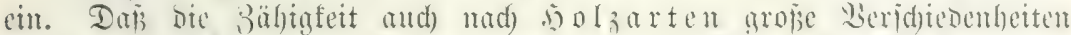

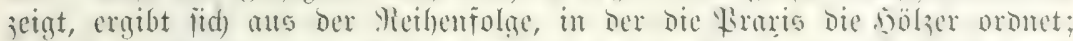

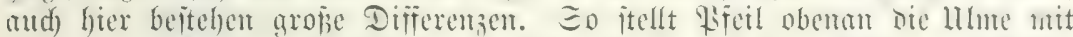

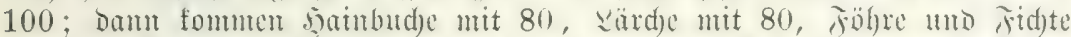

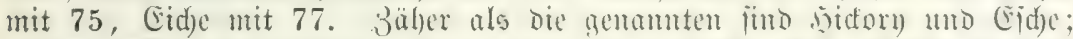

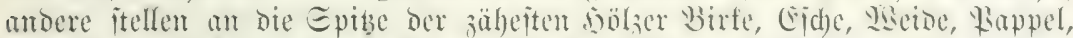

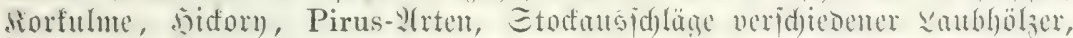

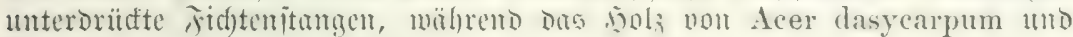
Robinie als jehr ipröbe gilt.

\section{כ. 刃nucr.}

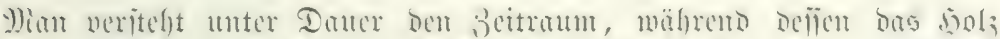

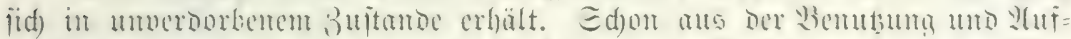

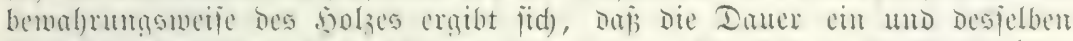

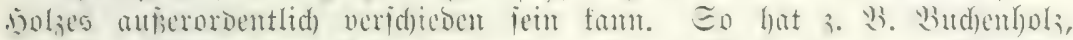

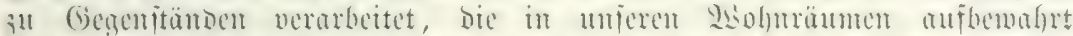

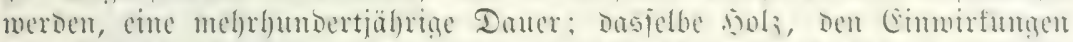

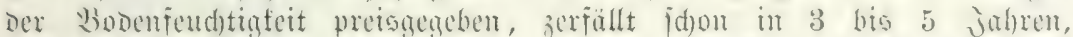

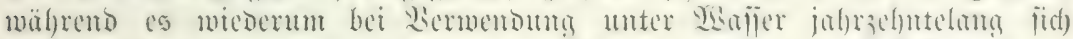

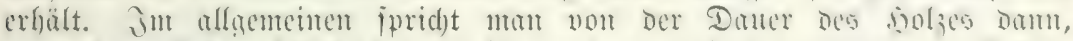

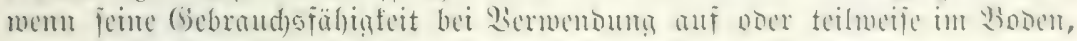
wie bei \$foiten, (Ẽifenbahnjd)wellen, in Frage fonmt.

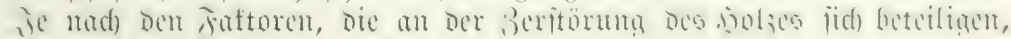
unterjd)eidet man veridjebene $\mathscr{A}$ rten ber Beritörung.

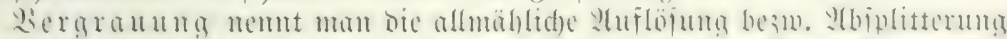

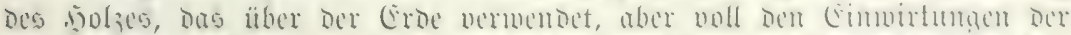

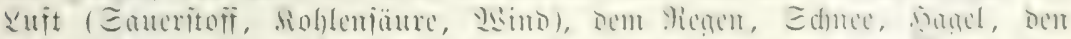

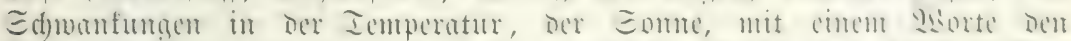

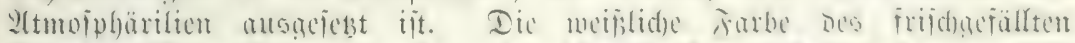

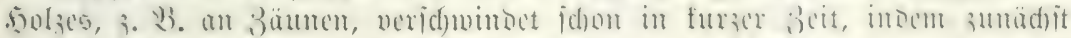

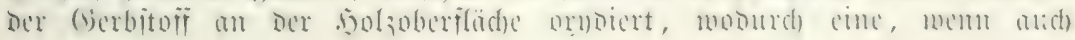

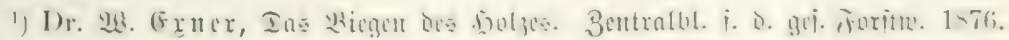

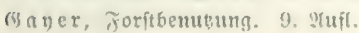




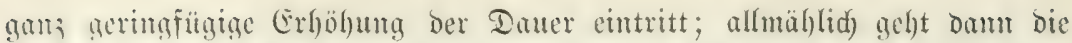

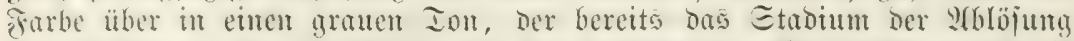
yon Bellen an Der Eberfläd) Des jolsers beocutet. Ës merben juerjt bie

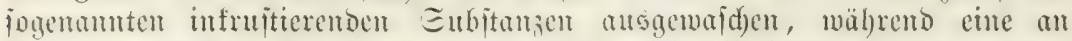
Eilluloje reidere Eubjtan surüdbleibt. Die ifolierten Bellen merben

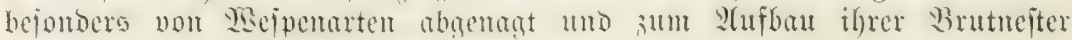
vermendet.

Die Eergramma ieritöt bic meiden inolzer früher als dic harten:

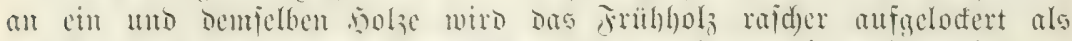

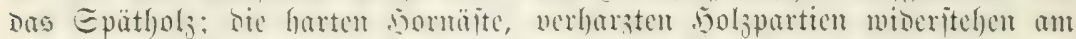

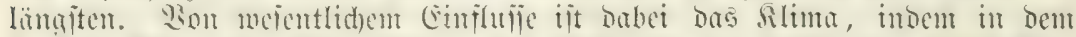

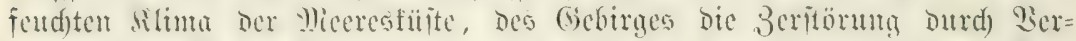

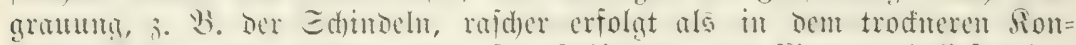

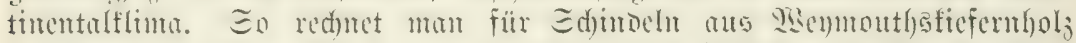
an Dex atlontifden hiajte cine Daner von 5 jafhen, in bent trodenen Fräricitarten aber non 10 mor mehr jabren. (Segalättete släd)en (gehobelte

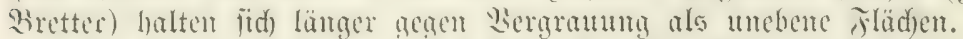

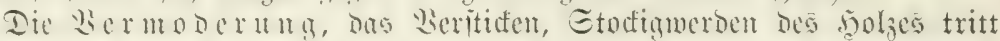

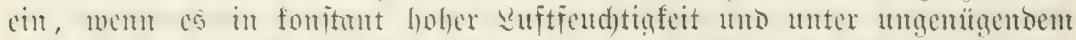

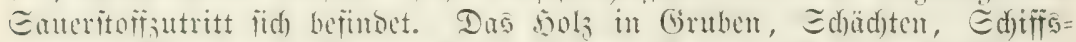

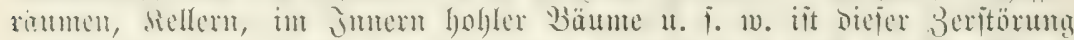

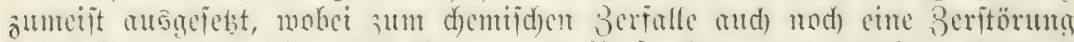

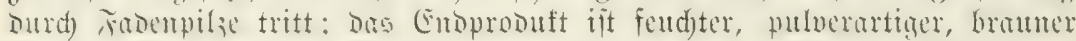

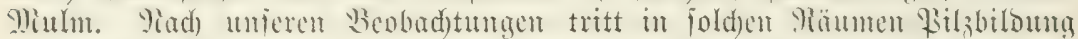
erit burn auf, wem bie relative jeudytigfeit ber suft Den Betrag non

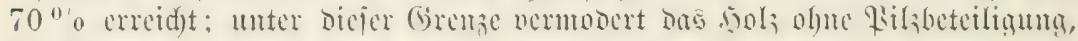
ein \$rozej, ber viel langfamer fid entwiffelt.

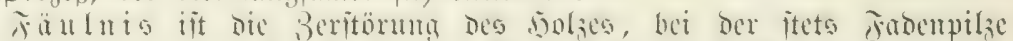

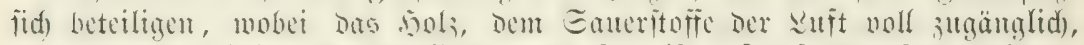

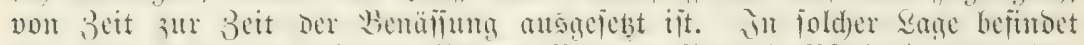

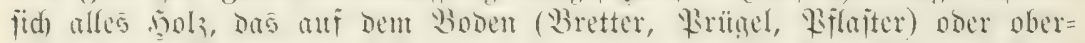

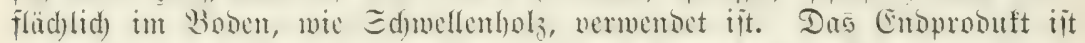

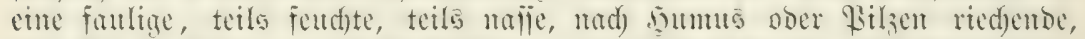
bell bis ounfelbram gefürbte Subitam; won teils fojerigem, teils frümeligem

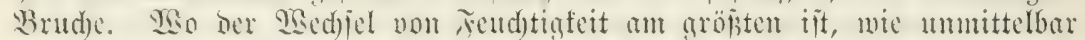
an uns in Der Bobenoberfläd)e, ift and) Die șüulnis am rajdejten auf=

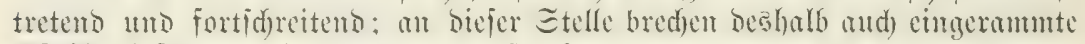
Bfäble, Bfojten umo Stangen juerit ab.

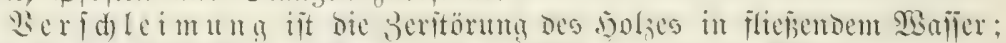

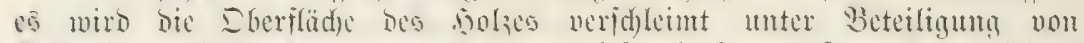

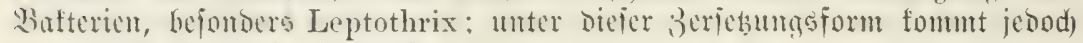

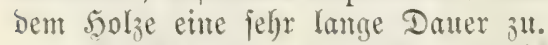

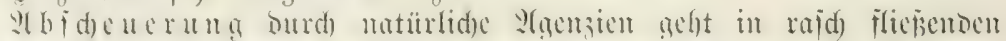

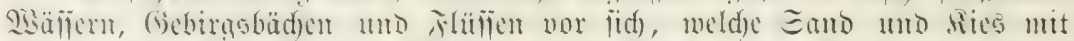

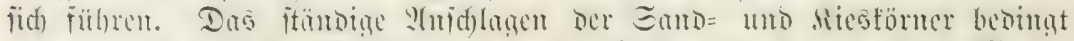

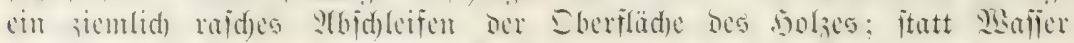

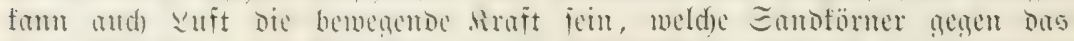

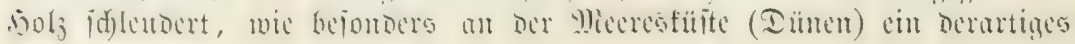




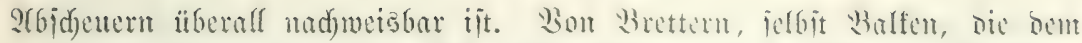

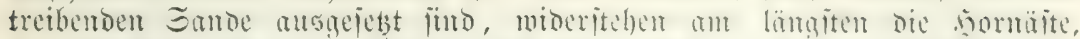

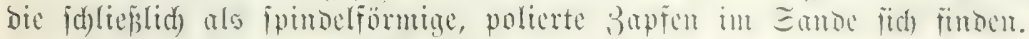

Bertorfug und gerfolglug ipt die Beritörum bes Solzes

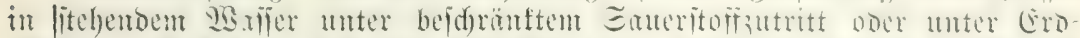

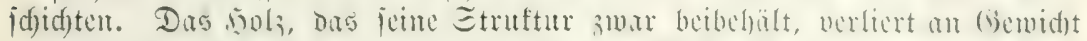

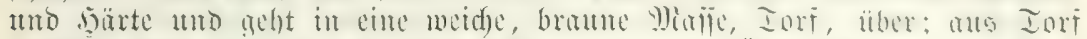

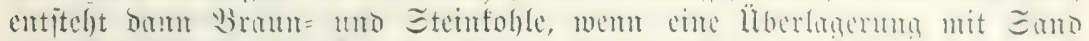

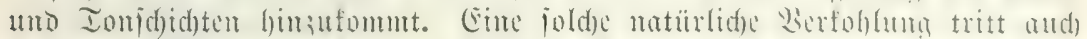

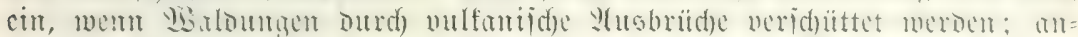

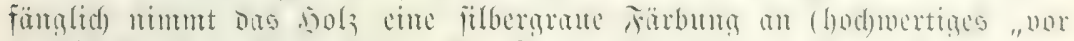

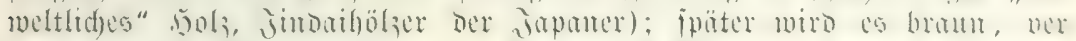

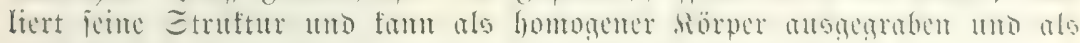

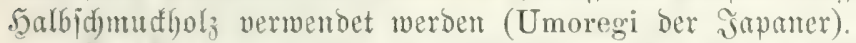

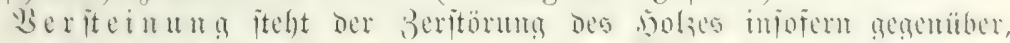

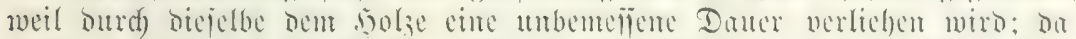

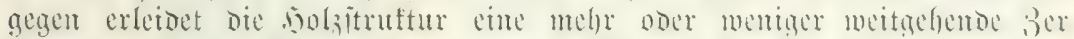

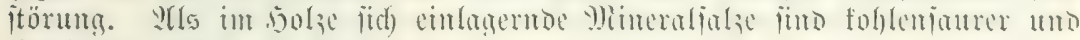
fiejeljaurer Ralf zu erwähnen.

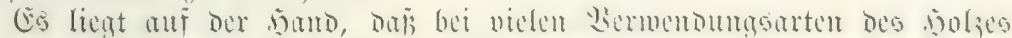

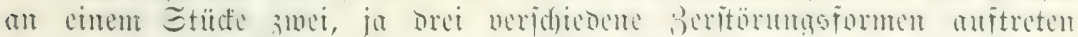

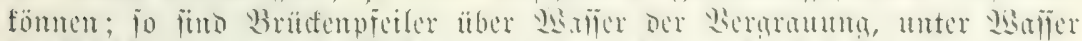

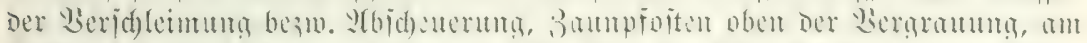

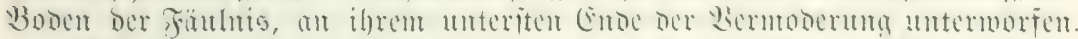

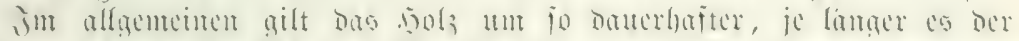

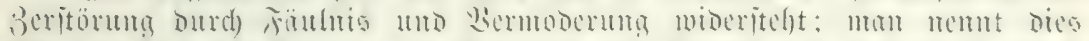

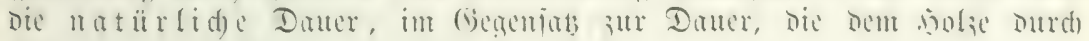
Jimprägnierung fünitlid) gegeben merben fann.

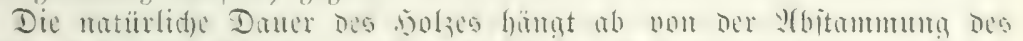

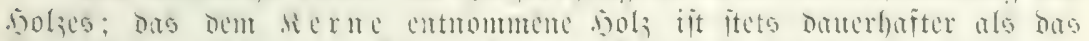

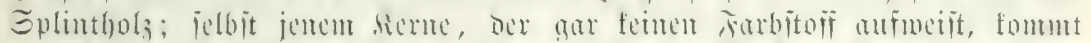

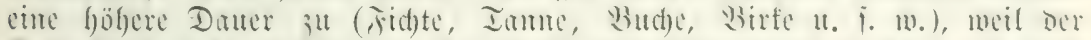

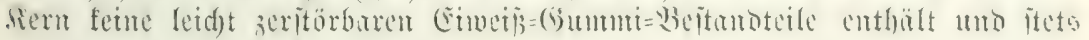
waj̈erärmer i, ale ber Splint.

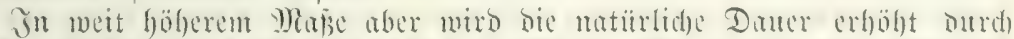

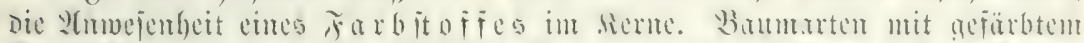

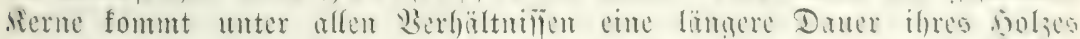

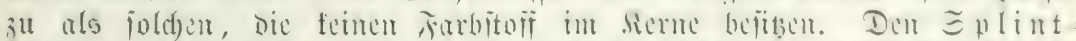

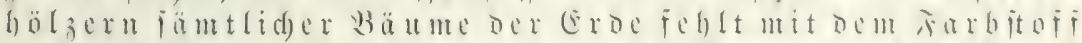

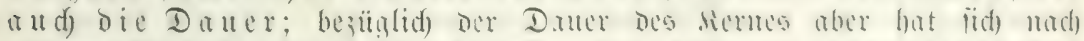

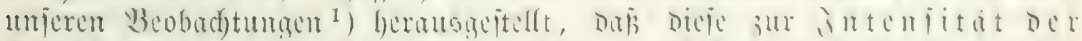

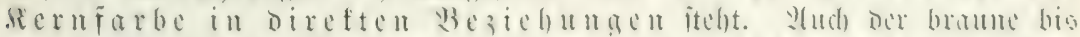

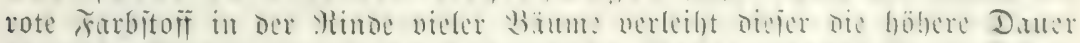

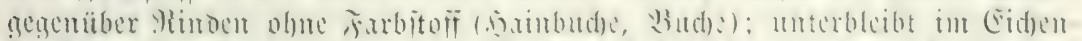

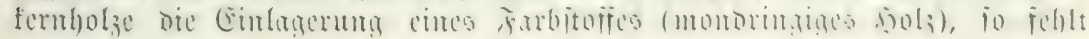
Dem betrefienden Stücte cbenfalls dic Daner.

1) Dr. 5. Mtal r, Die Maloungen in Sioroamerifa. 1891. 
im madfolgenden fei cinte Iabelle gegeben, in ber solzarten nad

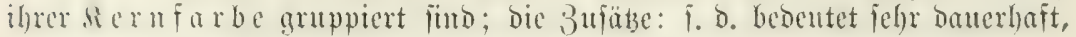
b. = bauerhait, п. D. = nidjt dauerhaft.

Aernfarben.

\begin{tabular}{|c|c|c|}
\hline Edfrarz, Graun, rot & $\begin{array}{l}\text { (brout, fellbraut, helfrot, } \\
\text { gelb, gelogrün }\end{array}$ & 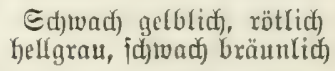 \\
\hline 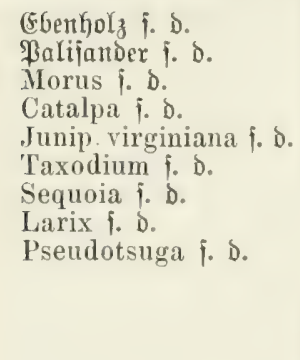 & $\begin{array}{l}\text { Magnolia D. } \\
\text { Liriodendron D. } \\
\text { Robinia D. } \\
\text { Quercus } \delta \text {. } \\
\text { Pinus-2frten infl. Wet)= } \\
\text { moutfgfiefer D. } \\
\text { Cham. obtusa o. } \\
\text { Cham. pisifera D. } \\
\text { Thuja gig. D. } \\
\text { Tsuga D. } \\
\text { Torreya D. } \\
\text { Ulmus D. }\end{array}$ & 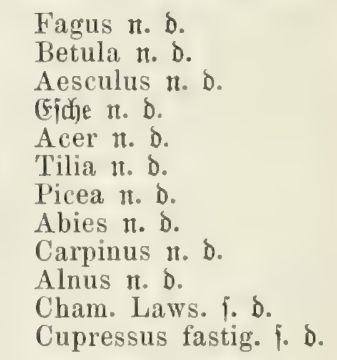 \\
\hline
\end{tabular}

QHffullend find in diejen Meiben nur Chamaecyparis Lawsoniana und Alnus; eriteres, dab es trob des yiangels emes auffallenten Farb= itoffes als jebr duterbaft gilt; Dicjer and aflen Cupressineen fommt eben

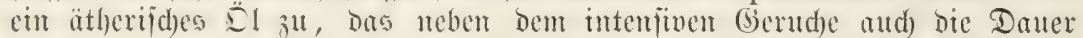

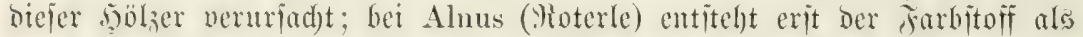
cun Exydationsprobutt eines farblojen (Ehromogenes ähnlid) wie hrapp, dom feme Dauer zufommt. Dar jarbitofi des liernes tit wohl ein Dermat bes

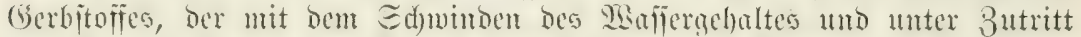
nou Eaneritofi an der Grense non Eplint und siem Durd) Ennotion

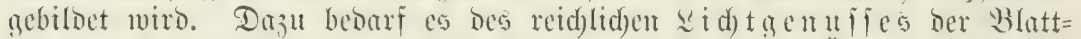

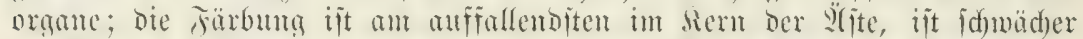

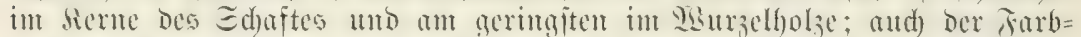

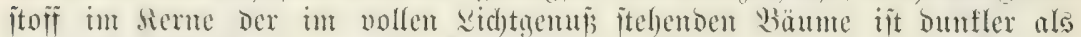

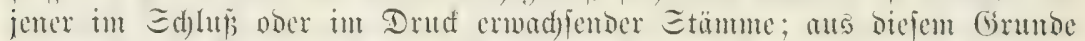

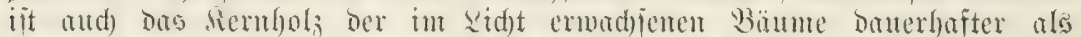

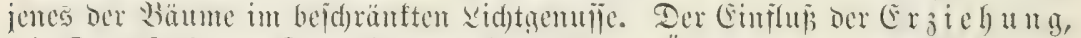

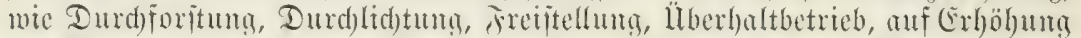

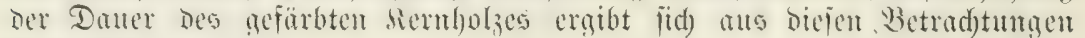
non jelbit.

Die jattejten Sienfarben und bante bie böd)ite Daner zeinen die herme Dex meiften Iropenfölser; nad) Den fübleren hlimajtridsen fin nimmt

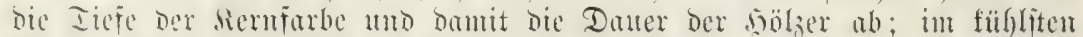

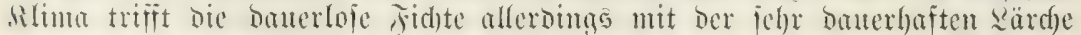

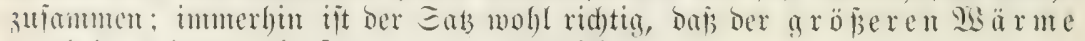
(a u d) ba

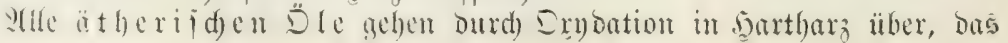




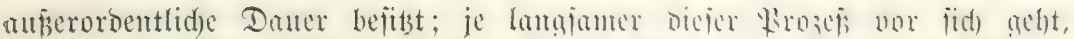

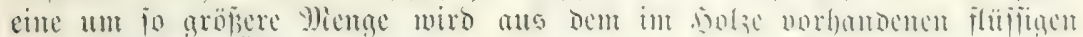

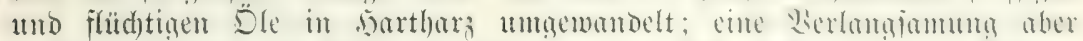

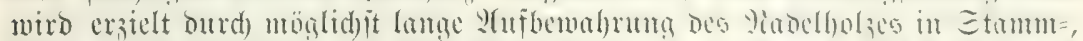

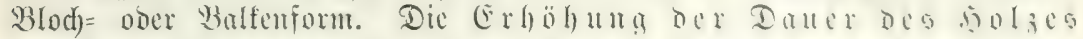

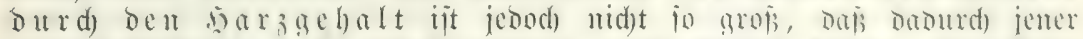

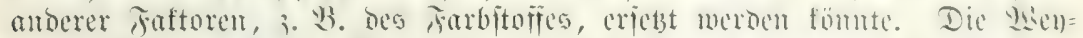

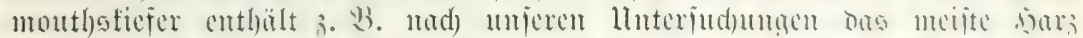

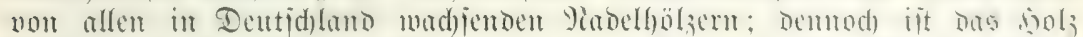

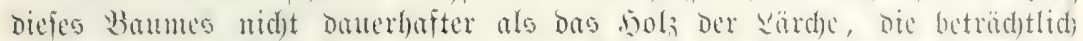

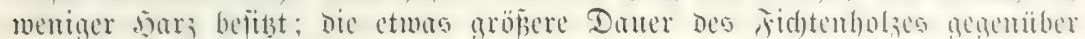

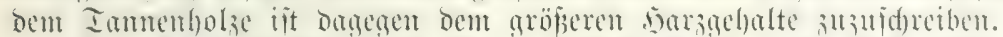

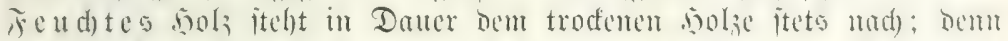

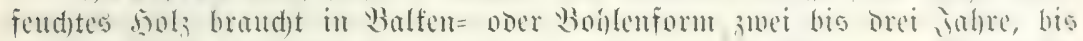

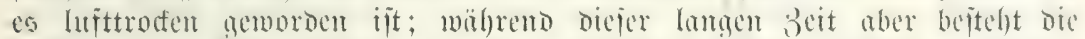

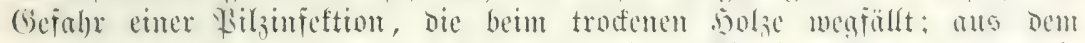

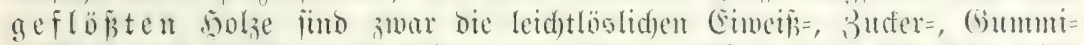

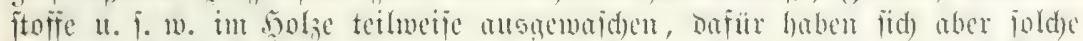

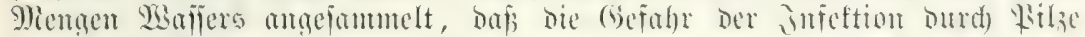

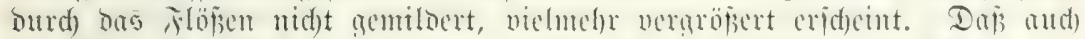

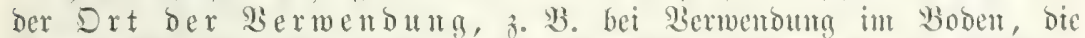

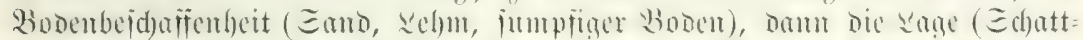

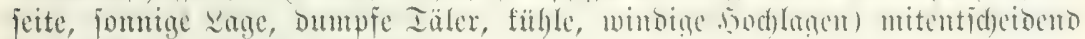
bezüglidy der Dauer fein mülne, liegt nalje.

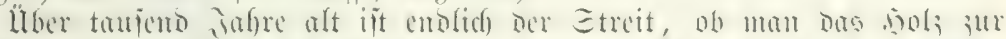

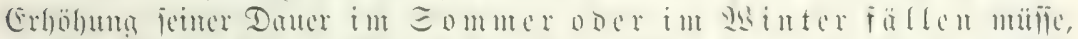

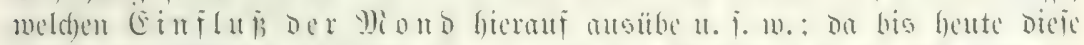

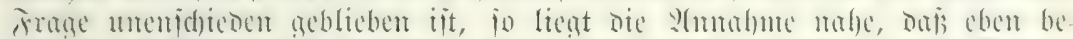

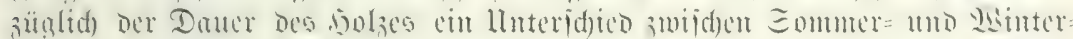

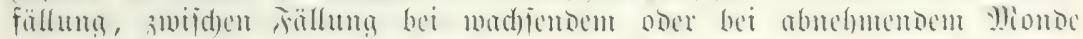

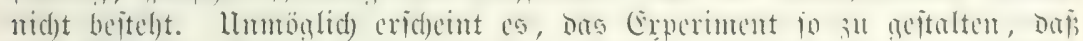

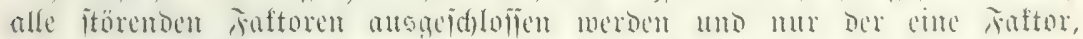
befien Cinflup beitimmt werben foll, übrigbleibt.

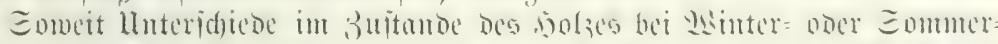

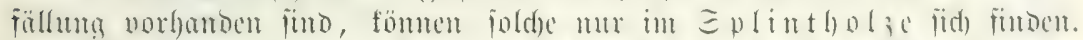

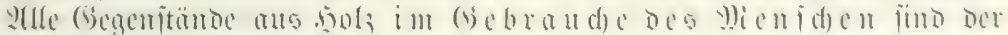
2)

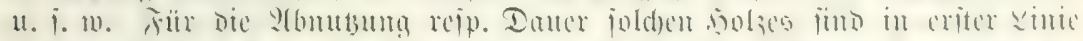

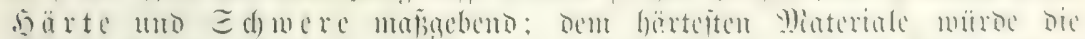

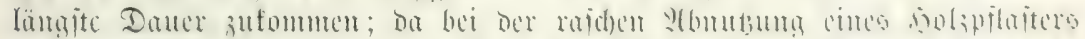

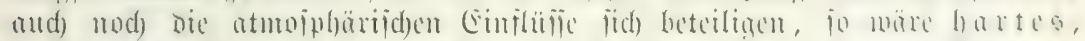

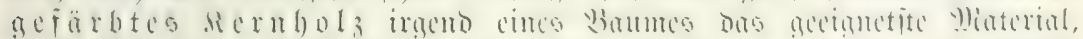

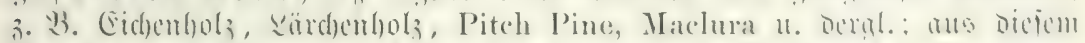

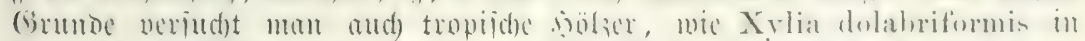

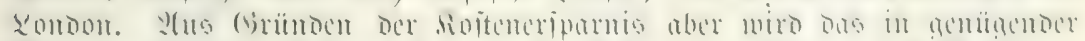

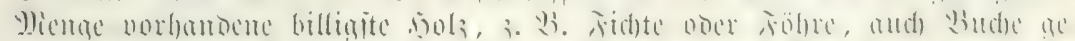

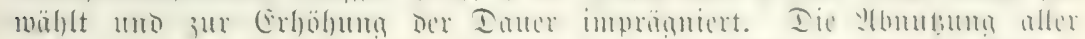

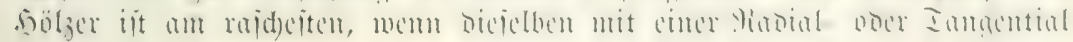


fläd)e nad) sben gerid)tet f̈nd; Da bieje aber bic jdönere Iertur tragen,

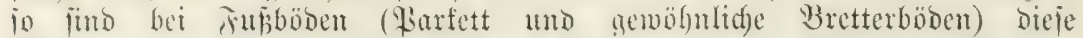

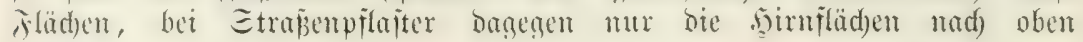
actelirt.

Unter ben Iiexen, weldse bic Daner des bolzes beeinträdtigen, find

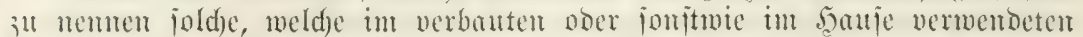

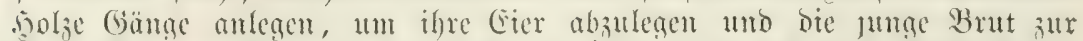

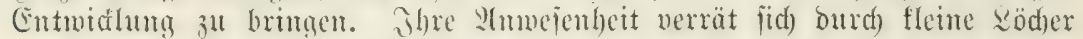

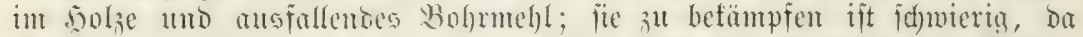

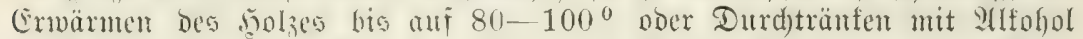
meijt unzulaifing it. Aäfar und ifre sarven, wie Anobium tesselatum und A. pertinax (bie iogenamnte Intenthr in alten Miöbeln), Bostrichus lineatus (aud) idfon im Mohfolze), Dermestes (in Zaubhöliern aumeijt), Limexylon navale (an

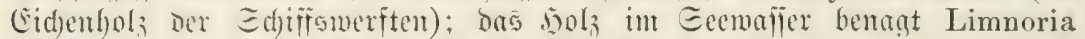
terebrans, cin fletuer firebs; Die Bohrmuld)el, Teredo navalis, Durd)(öd)ert

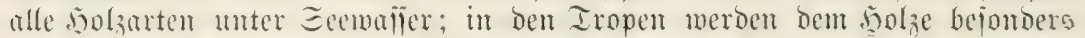

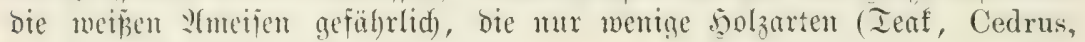
Tun, Sissu, Sal) ${ }^{1}$ ) veriftonen.

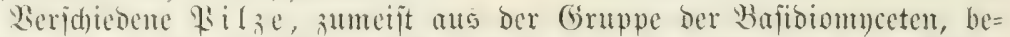

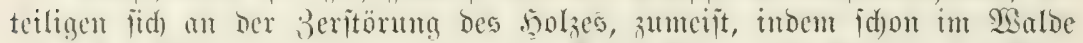

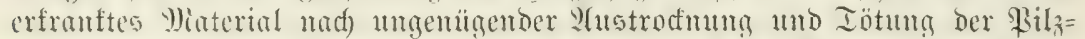
macelien im solas Wermendung findet ober trodentes Miaterial in feuchte Näume zu liegen fommt. Dic 3ahl Der Beritörer bes im bauje ver= mendeten solses ijt fidfer viel gröper, als in ber siteratur befount if̈;

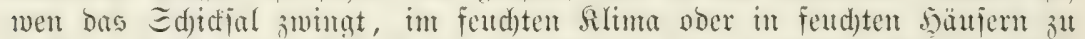

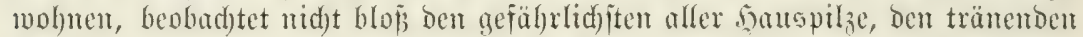

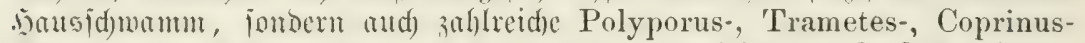

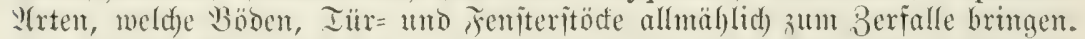

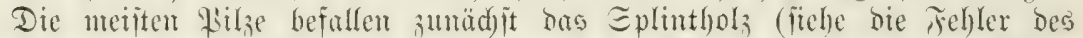
siolzes in Der Tarbe), gehen ban anf das Sientholz über; cintine (Trametes Pini) dagegen leben mur im Siene; die cinen vermandeln bas holz

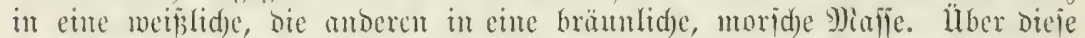

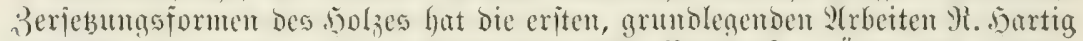
aebradet in ieinen unten sitierten flaifichen Sierfen $^{2}$ ). Über ben gẹähr= lidjen jemo in sauje, Den sausid)manm (Merulius lacrymans), idjrieb

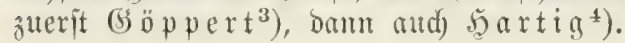

1) Dr. Schlich, Manual of Forestry V. Forest-Utilisation by W. R. Fisher

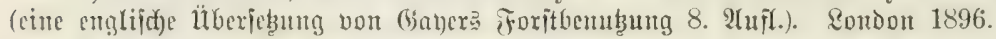

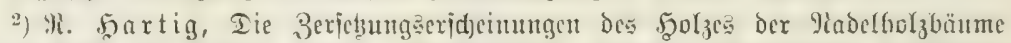
anto Der (Firfe. 21 litfogr. Iafelu. Berlin 1878. Wid)tige Aranfbeiten Der Malo= bäume. Berlist. Refrbud) Dex Baumtrantheiten. 3. 2(ufl. 1899.

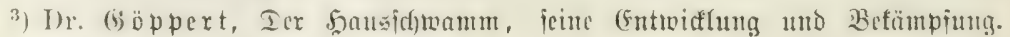
Serauagegebent vou Dr. Wolct. Wręlau 1885.

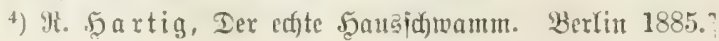




\section{Bic Zja}

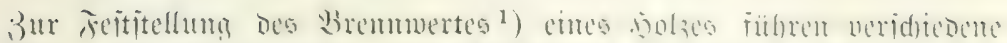

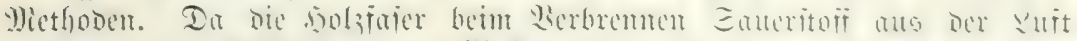

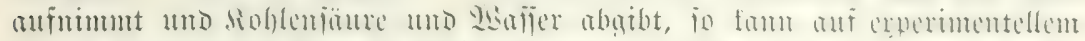

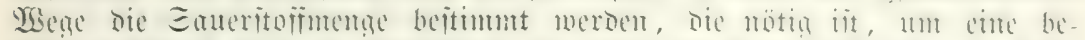

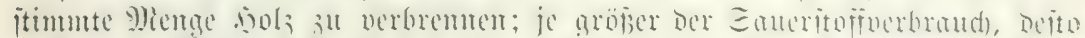

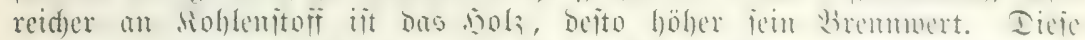

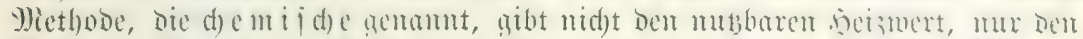

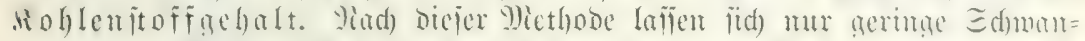

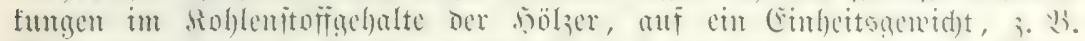

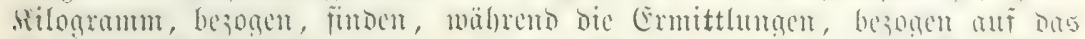

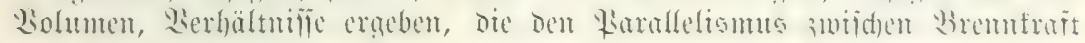
und Didfte (ipezifijd)es (siemid)t) erfenmen lafīen.

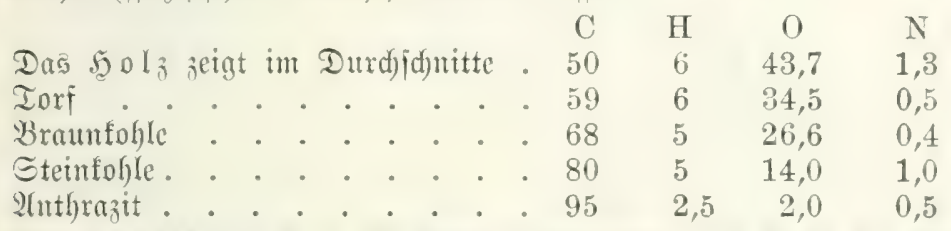

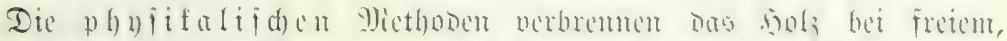

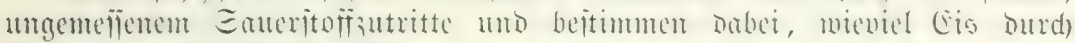

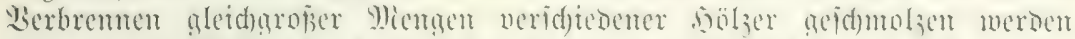

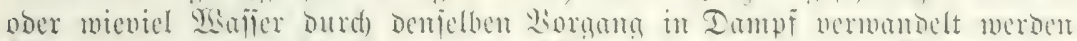

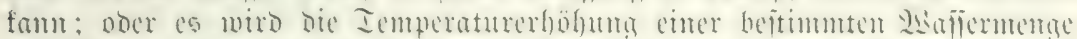
gemeñen, mobet die

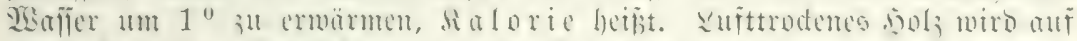

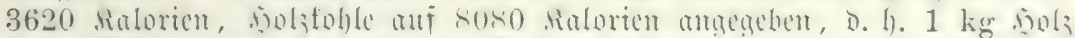

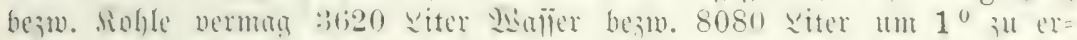
märnten.

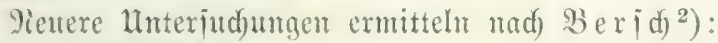

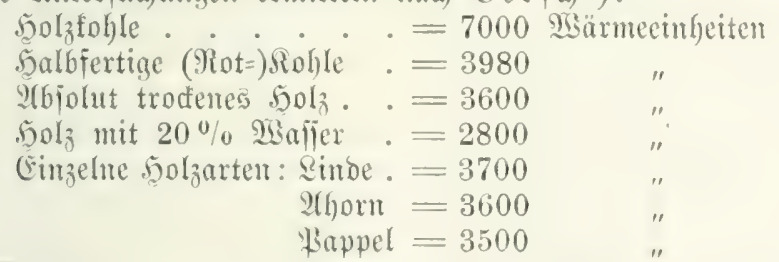

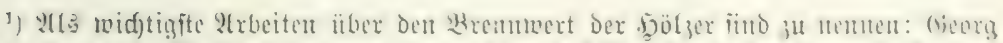

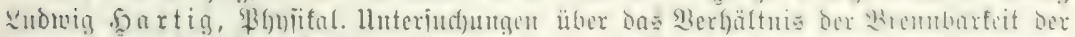

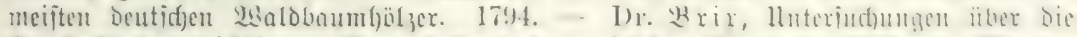

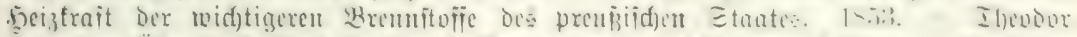

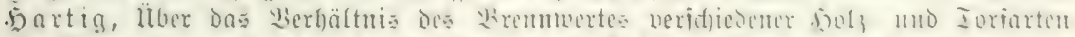

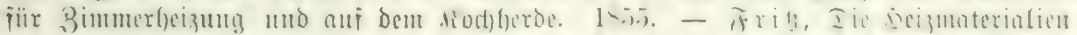

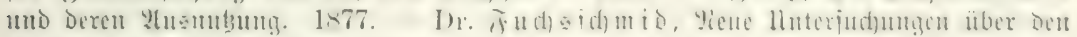

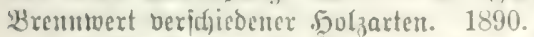

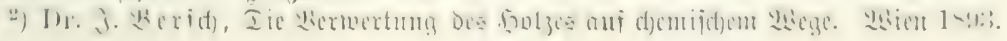




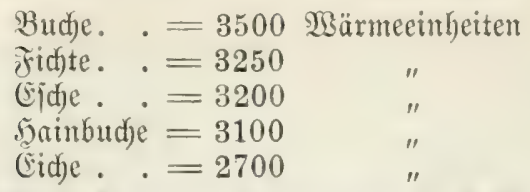

Der Wärmeeffeft in Sialorien, bezogen auf bas (j) emid)t, zeigt, baj

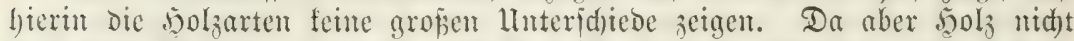

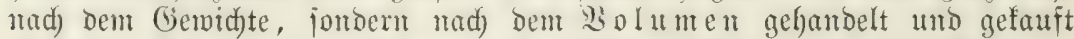
wiro, io haben nur jene Sahlen, bie Den Wä̈meeffeft bei gegebentent Solumen, ๖. $i$. den ipezififden siärmeeffeft wiedergeben, praftifde Bedeutung.

Eebt man den ipejififden MBärmeefieft des reinen Sioflenitofies =

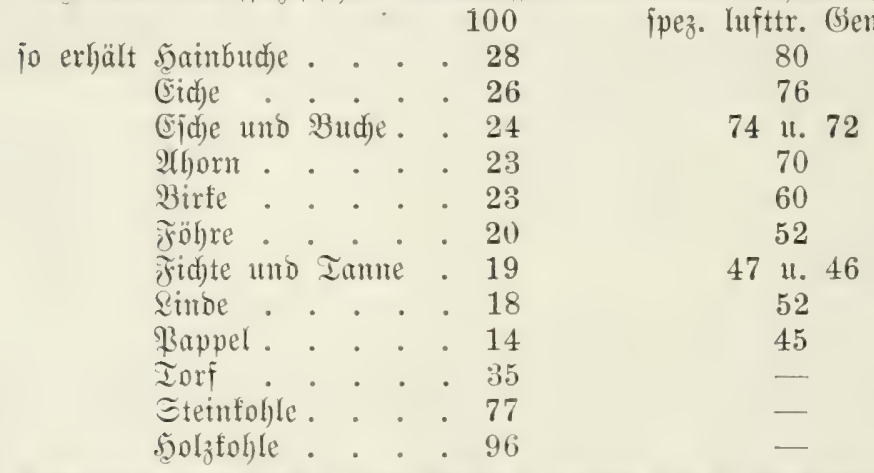

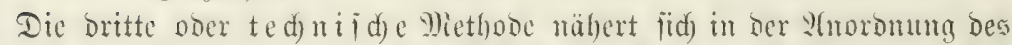

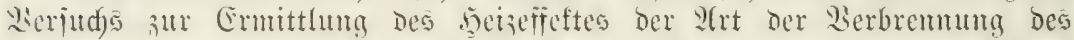

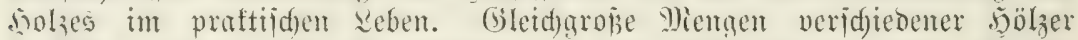
merben in einem Efen oder jeuerungstaume verbrant und babe bie Er= märmum bes :Haumes, in ben ber beizförper iteht, an Ihermometer ober bet Dampfmajdinen Die entmidelte Damprmentace am Mianometer gemefien.

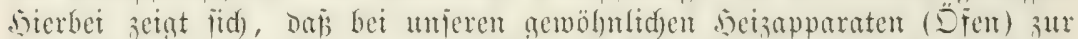

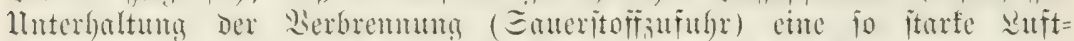

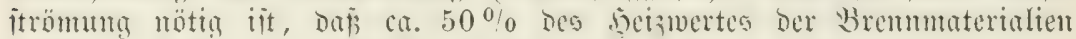
burd) Den Edjormftein entfülurt werbent.

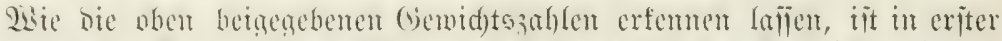

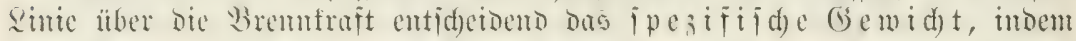
Dos id)merite nols in cinem Banme mie immerfalb Der Banmarten and

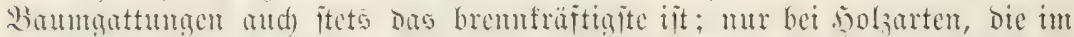

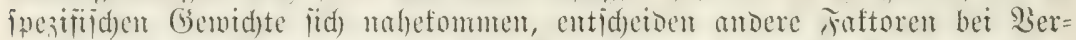

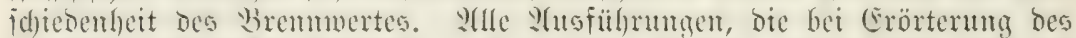

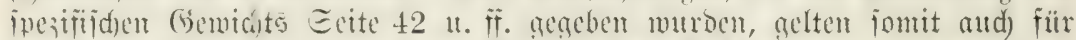

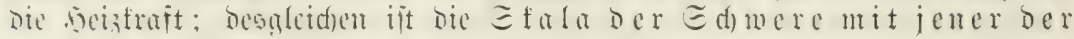
beiztraft ibentijd.

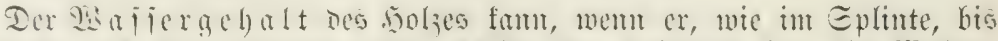

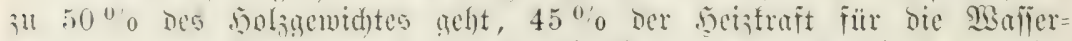

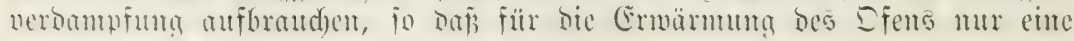

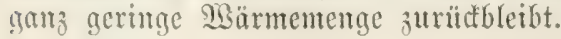




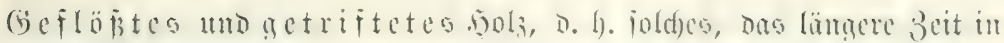

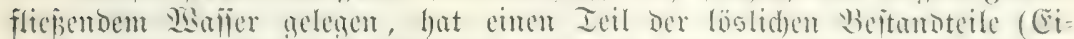
meip, 3ucfer, (berbitoī, (isummi) verloren mo gilt oeshalb als brem:

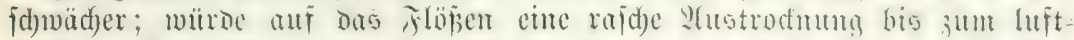

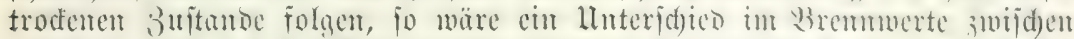

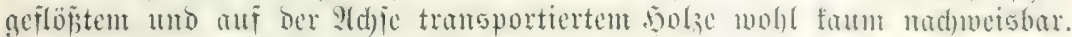

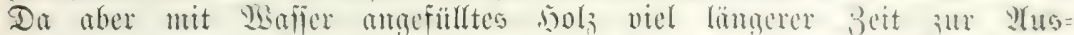

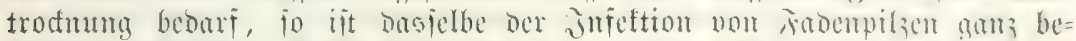

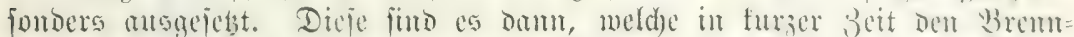

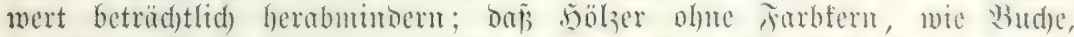

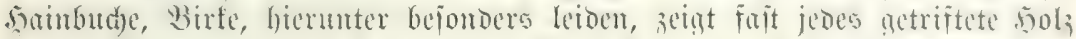
biejer Bammarten; mad) utieren Beobadumgen find as insociondere

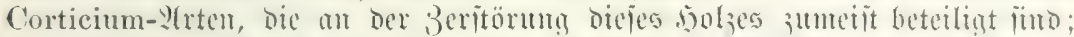

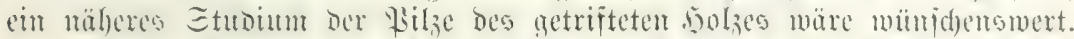

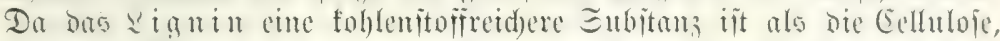

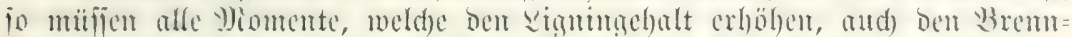

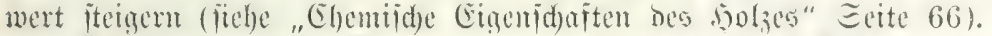

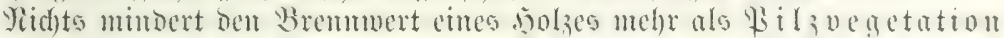
i

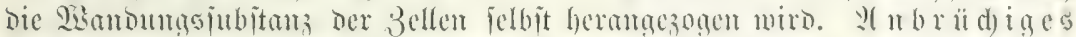

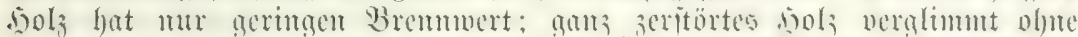

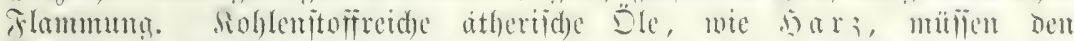

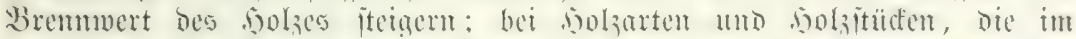

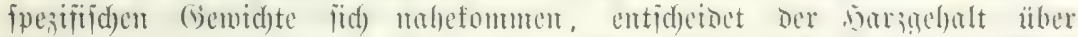

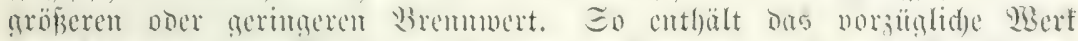

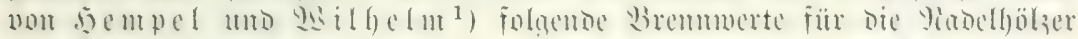
(Butd)e $=100)$ : Sarzgefyalt bon $1 \mathrm{~kg}$ abjol. 5olzund unier. Iluterjucfungen ${ }^{2}$ )

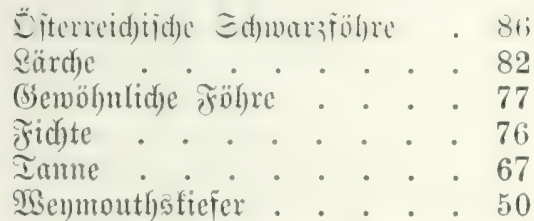

\section{Spezififid. (Betvidyt}

17
60
52
47
46
40

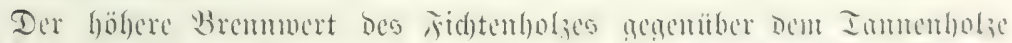

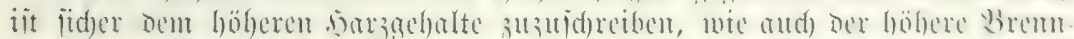

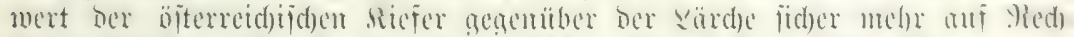

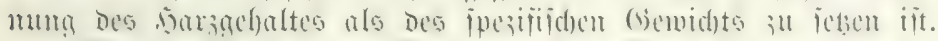

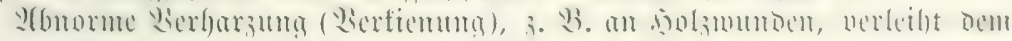

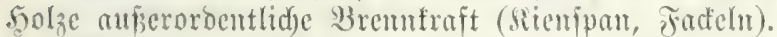

Betulin erböbt Den Geizmert im Solze wie in ber Minte bẹ

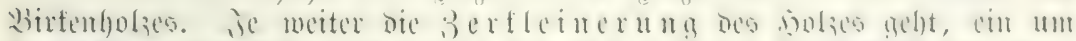

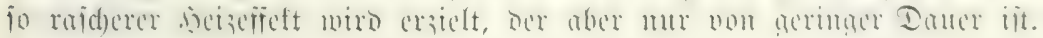

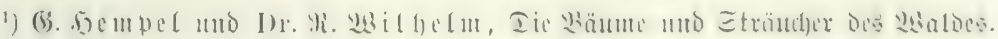

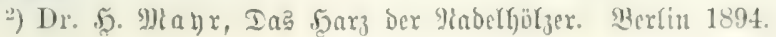




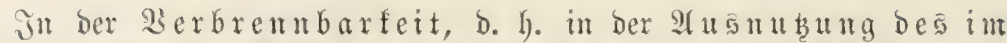

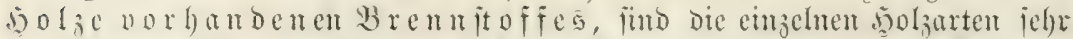

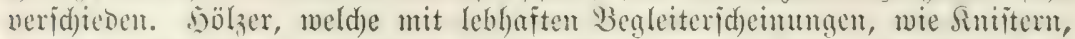
Brad)en, Zirafieln, verbremen (Ëntweiden eingejd)lofiener, erbibter suft

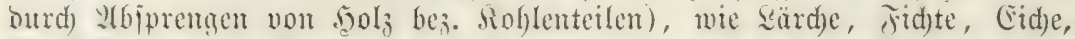
CEdelfatanic, entwicteln einte itart flammende bibe von furzer Damer; $5013=$

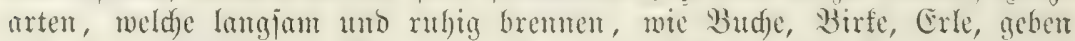
non ber vorfandenen 2isämemenge am meijten an ben seisförper ab;

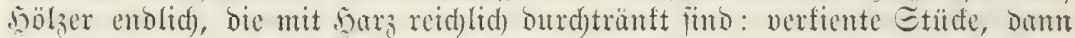

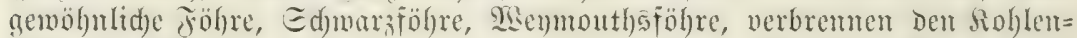
itoff unnollptänbin, bie Fismmen rupen, b. h. ein Ietl bes Brenmertes entweidyt.

\section{Die Bearbcitungafühigkeit Des Golies.}

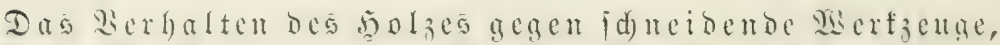
wie Miejfer, S(rt, bohel, hängt zumäd)it von ber Siraftrid)tung ab, indem

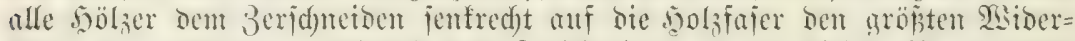
ftand entuegenjeben, mährend bas Beriduetoen um jo leid)ter ijt, je mehr

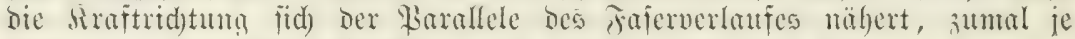

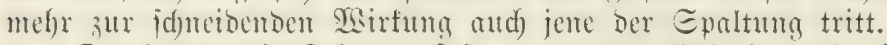

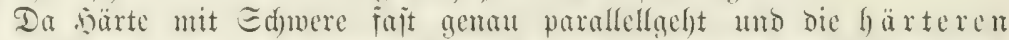

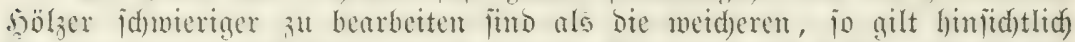

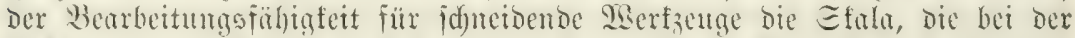
$\Xi$ d) were ber söbar aegeben murbe, wie and alle Bemerfungen über bie

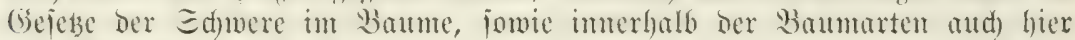
3ur Âmentung fommen.

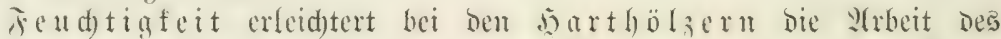

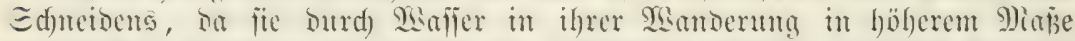
anfgelodert merder, als bierbei die 3ähigfeit 3unimnt, minoert bagegen

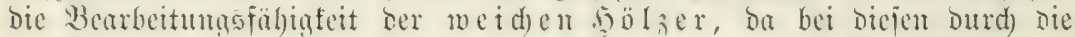
Feudgtigfeit vornehmlid) bie Zühinfeit cine Eteigerung erfährt.

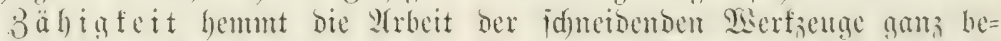

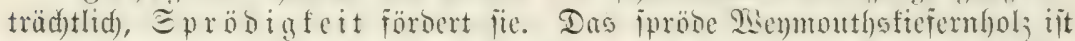

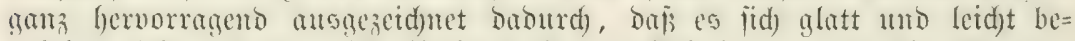
arbeiten läjpt; es übertrifft hierin mohl alle Ulbietineen; mur bie Chamae-

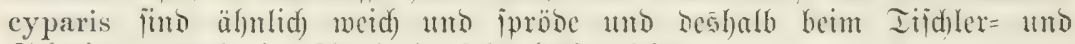
Schreinergemerbe im $\mathfrak{A}$ (uslande jehr hod) geidübt.

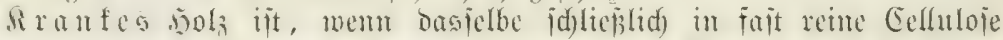
iibergeht, id)mieriger, mem es cinte homogene, an signtur reidge Enbitanz

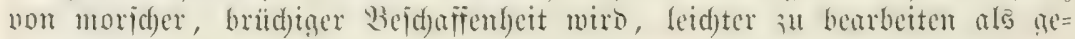
jundes 5012.

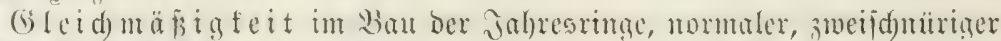

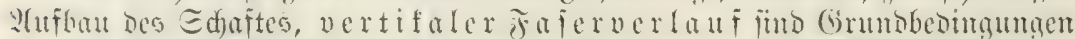

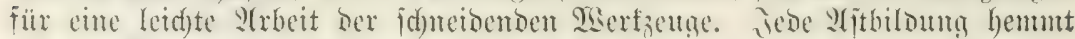

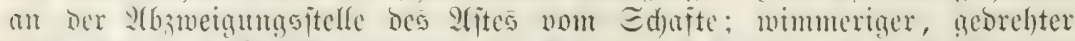

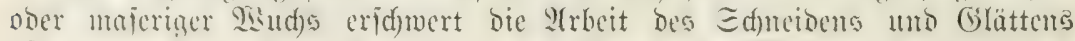

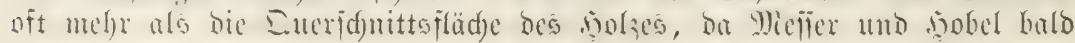




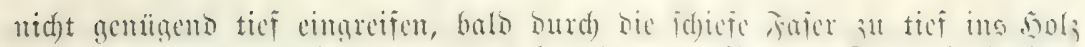

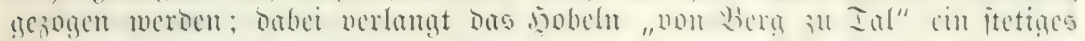
Umorehen des snjtrumentes.

Das Berbalten des Solzes gegen die Gäge ij in wejent=

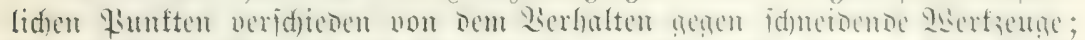

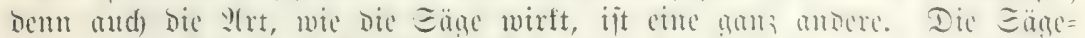

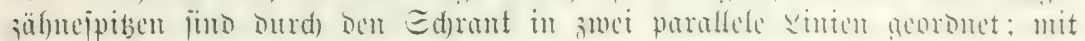

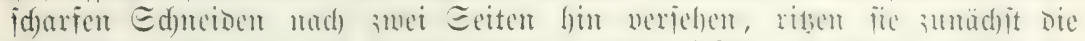

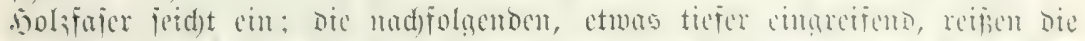

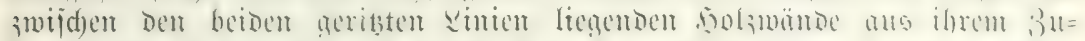

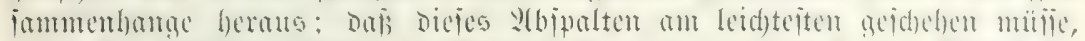

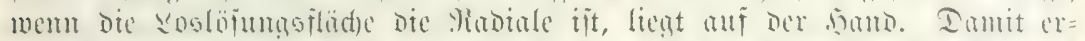

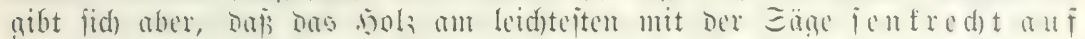

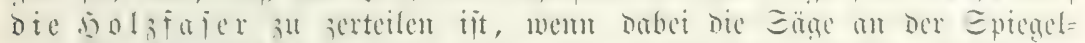

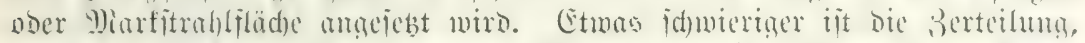

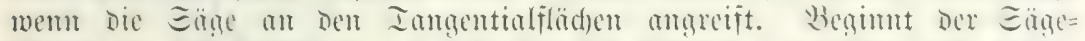

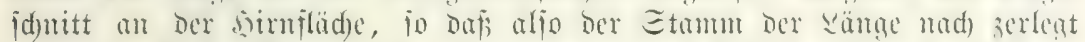

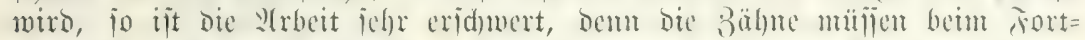

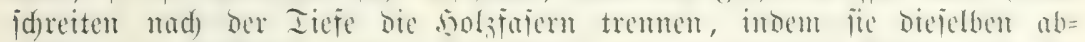

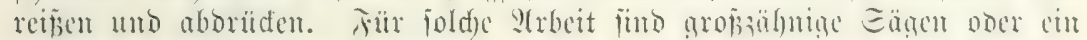
bejondexs meiter Edfrant mötig.

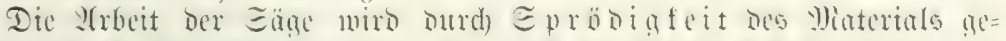

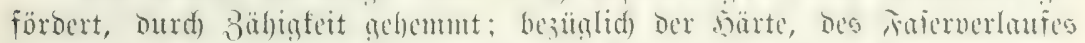

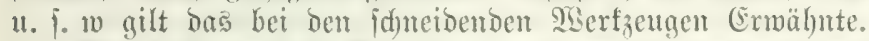

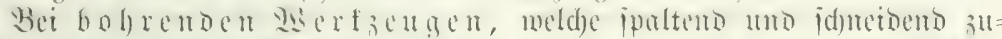

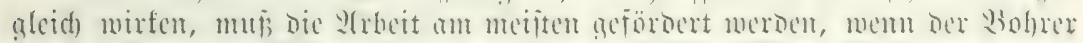

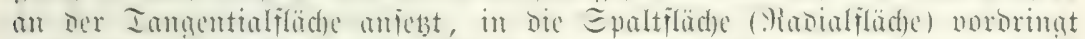

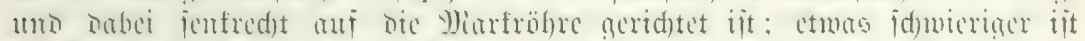

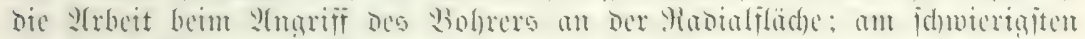

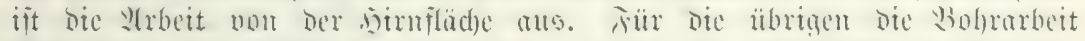

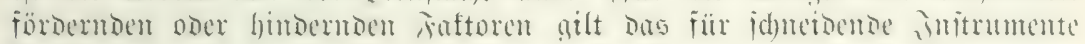
Ẽrmälunte.

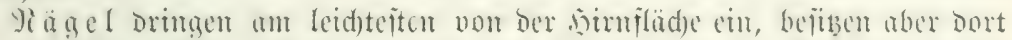

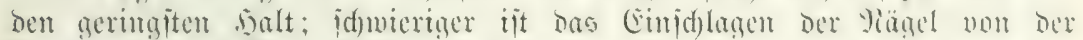

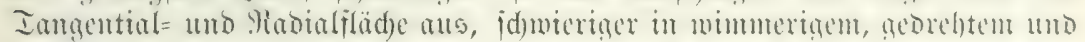
gemajertem Solze. Ed) a a ben verbalten fid) wic Boljer.

\section{Werbalten gegen $\sigma$ deleifen.}

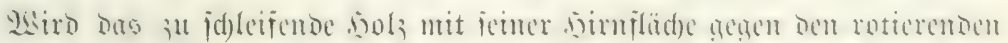

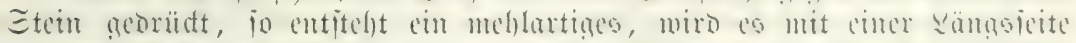

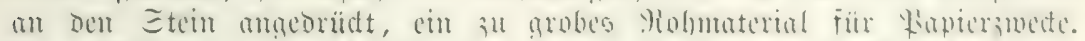

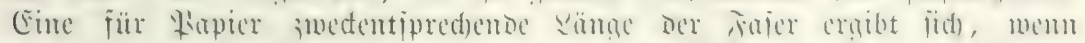

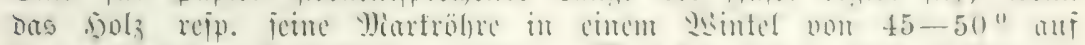

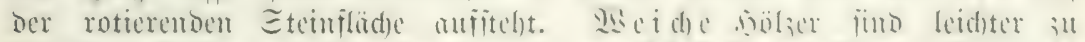

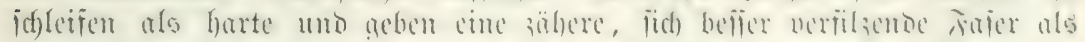

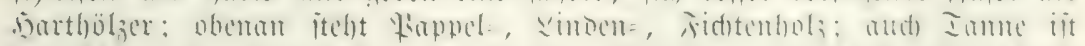

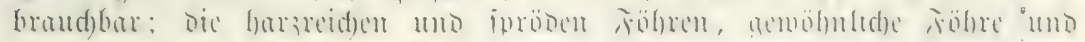




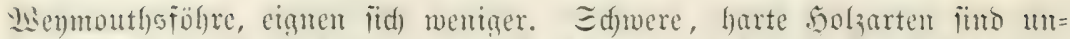

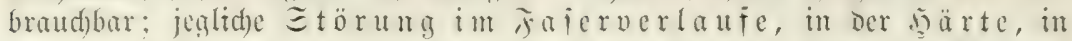

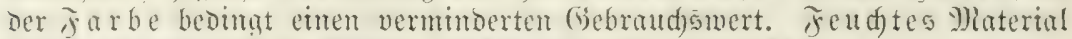

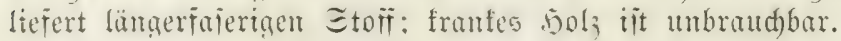

\section{Berlalten gegen $\mathfrak{B}$ olieren.}

Mittelidwere, mittelharte bölaer find bie bejten, politur= fähigiten: Die härteiten und weidjiten soölier iteflen ber beritellung

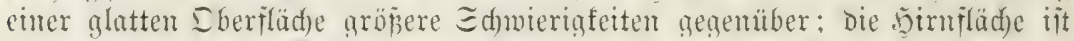
id)meriger als die Mabial= uno Iangentialfläche zu polieren. Sölser mit

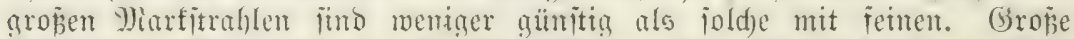

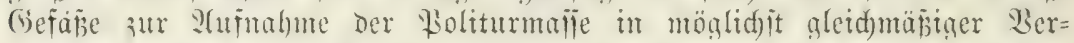
teiluma bedingen hobe Politurfähtgeit, sumal wem bosu nod ein natür=

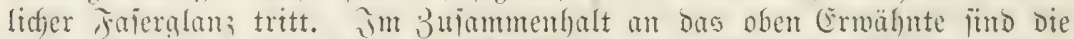

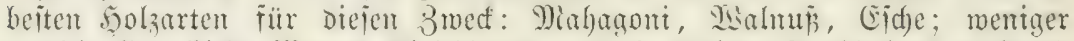

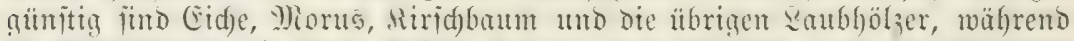

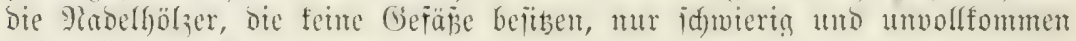
iid) polieren lafien.

\section{Berbalten gegen Bleiden.}

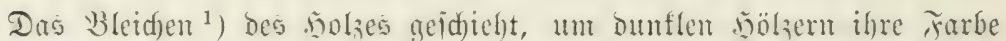

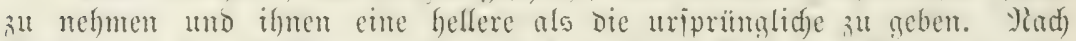

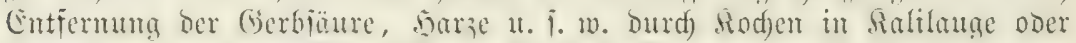

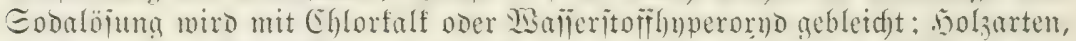

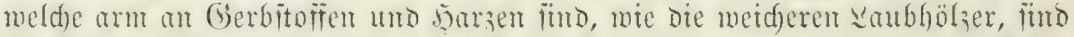

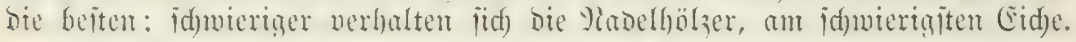

\section{Berlalten gegen Beizen แ\# Färben.}

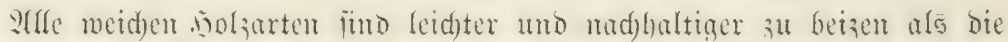

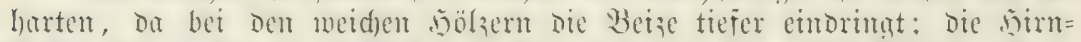

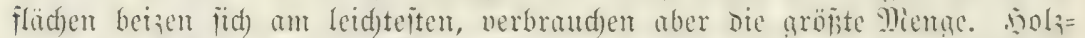

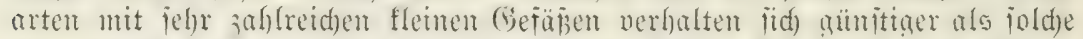

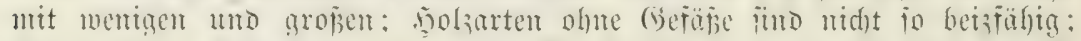

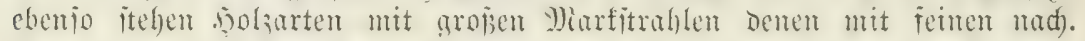

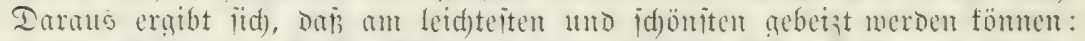

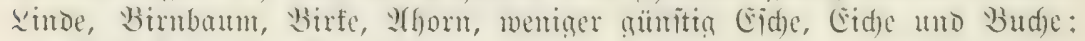
am Ende jtehen bie Madelyölzer.

\section{Berlatten gegen Brenten.}

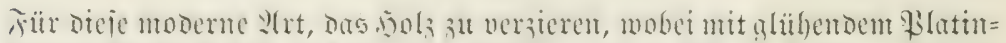

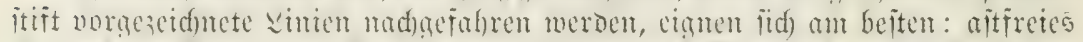

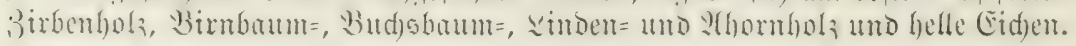

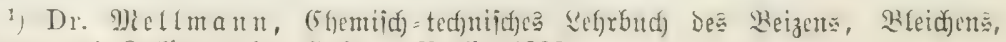
Folieren uno Raffierenz ber Şölzer. Berlin 1899. 


\section{Berbalten acgen Berfoblung.}

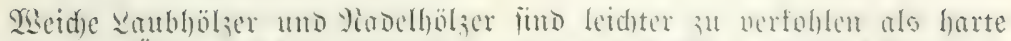

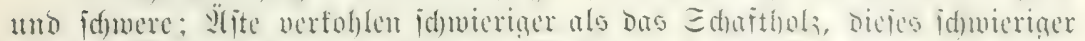
alo das disuralbol; ;

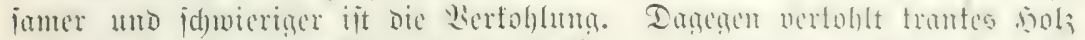

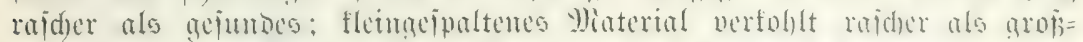

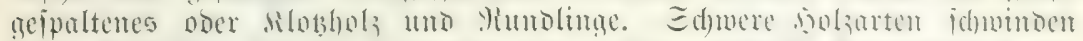

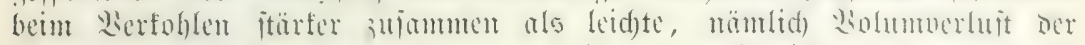

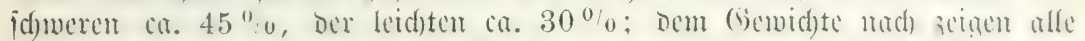

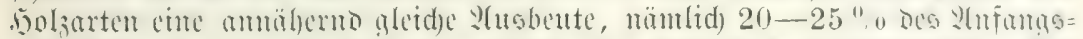

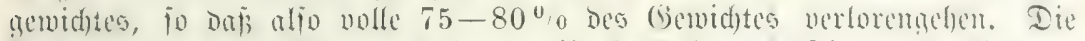

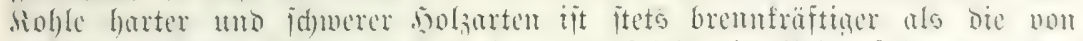
werden nölicut; banad) eraibt jid) non felbjt dic Meibenfolge non ben

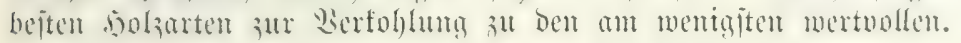

\section{Berbalten gegen ̧̌mpägnierung.}

Das Jmpräunteren hat zmmeijt Den Bued, bie Damer Der nölser su

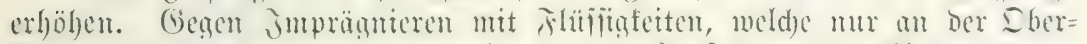

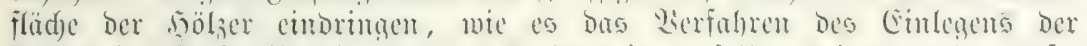

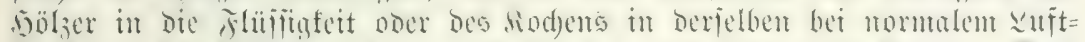

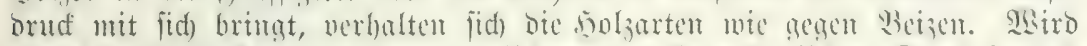

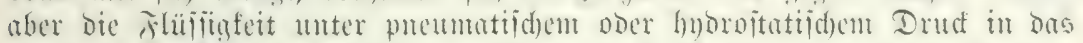

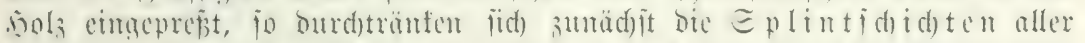

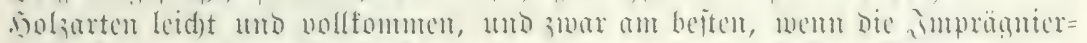

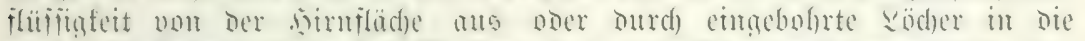

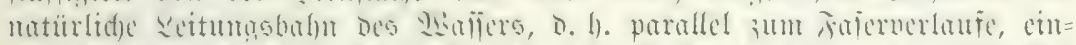

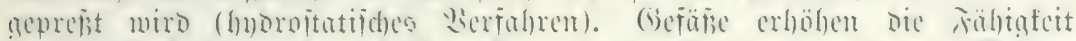

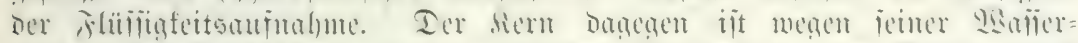

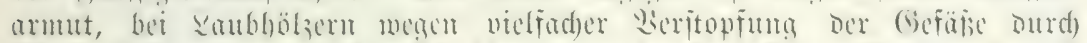

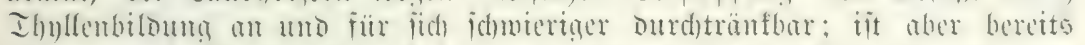

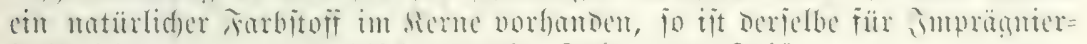

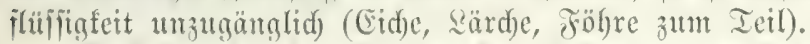

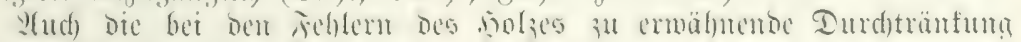

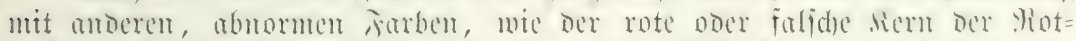

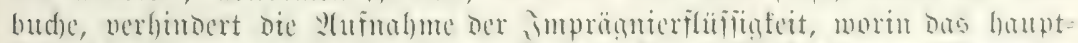

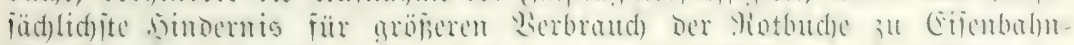

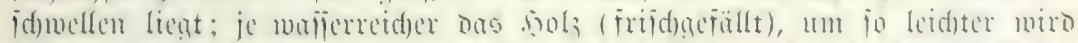

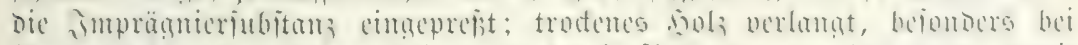

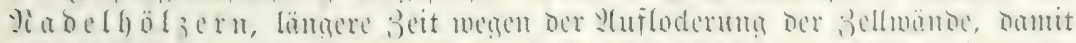

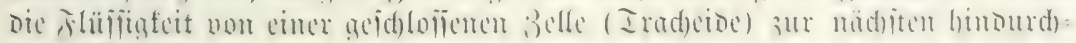
treten fomm.

\section{8. 刃imenfion.}

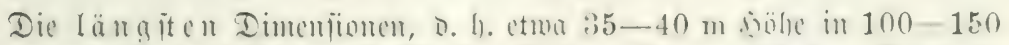

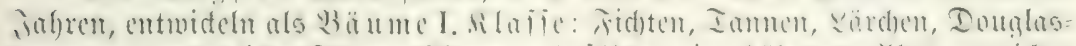

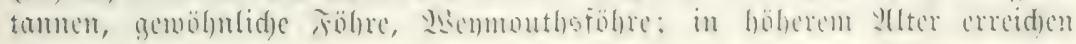




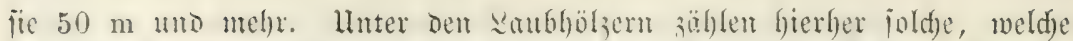
in 100 jorbren ctwa $30-35 \mathrm{~m}$ erzitelen: Das j̈mb Ëidjen, Buchen,

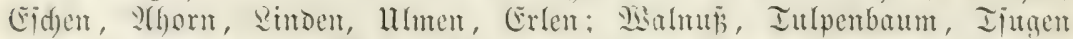
und Chamaeeyparis - VIrten (Pinus rigida, Pinus Banksiana) eben= falle $35 \mathrm{~m}$.

3u ben 3 äumen II. Rla jic mit $20-25$, jelten $30 \mathrm{~m}$ zählen:

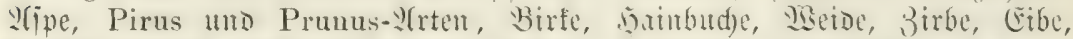
Epirfe (Pinus uncimnata), Dom nifory, Juniperus virginiana.

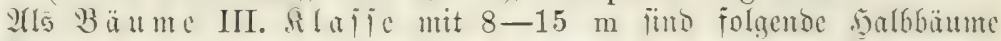
noer (Gropiträud)er ju menten: Juniperus communis, Evonymus, Viburnum, Sambucus, Prunus spinosa, Cornus, Syringa 1t. $\%$. w.

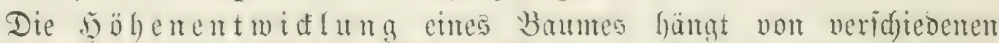

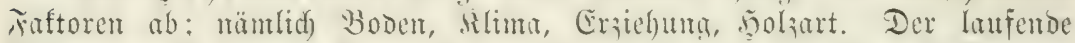

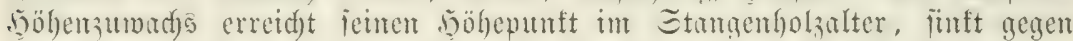
bie baubarfeit hin and fommt bei nolzarten mit jid abfladientoer Mrone zum Etillitanbe, währeno bie bolzarten der vorhin ermälnten

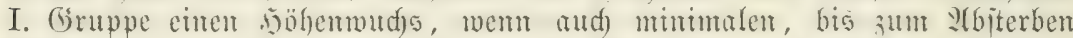

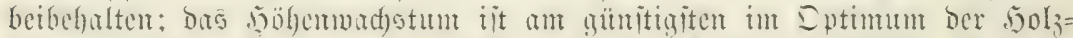

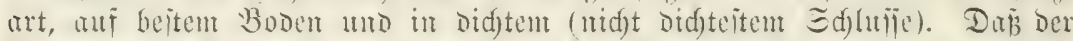

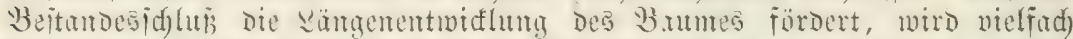
beitritten; In Der jugend mirft der Beitandesjoflü (vou ertremen Fällen

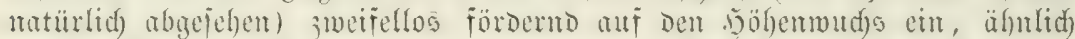

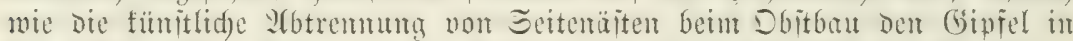

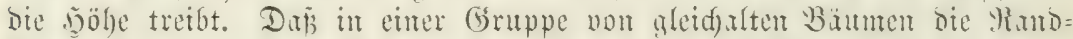

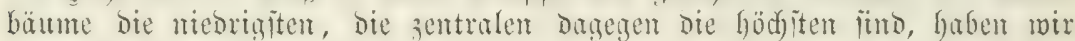
idjon 1890 nad)gewiejen.

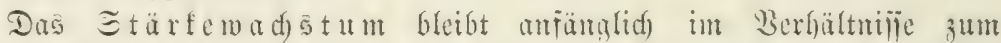

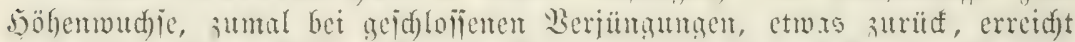
aud) Fpäter jeinen bobepunft und idgliejt erit mit dem Iode ab, Da jeder

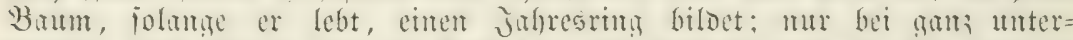

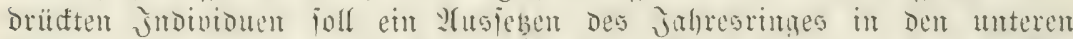

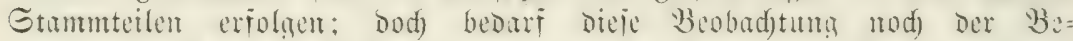

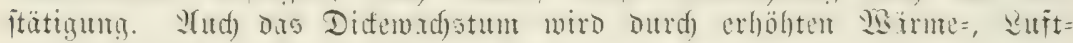
und Shahrungaggenü gehober.

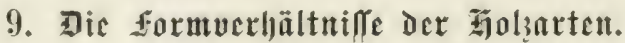

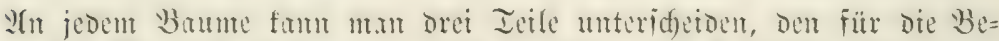
mubung Des Banmes widftigiten mittleren Ietl, Den $\Xi$ (f)a

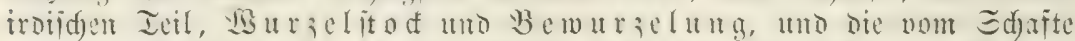

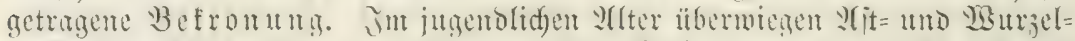

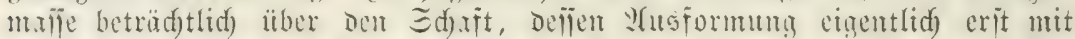

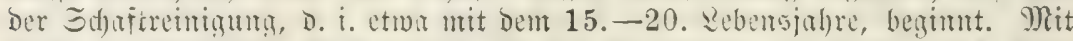

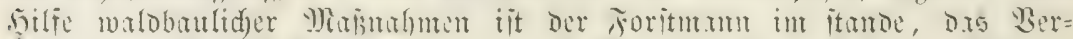

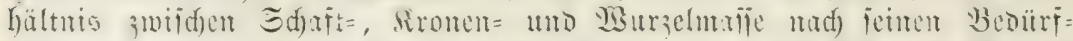

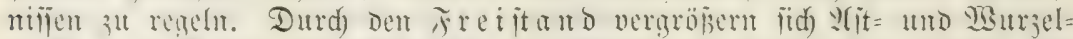

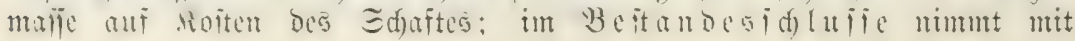




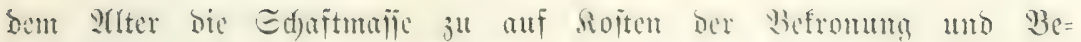
murzelung.

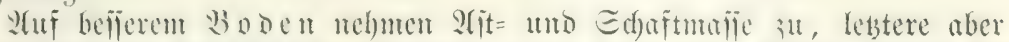

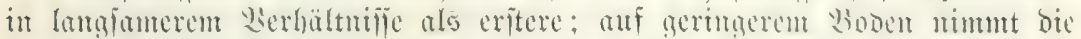

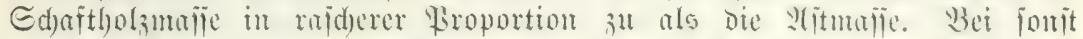

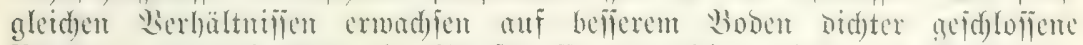

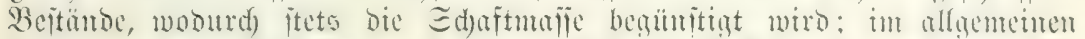

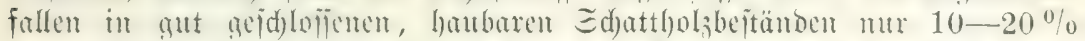

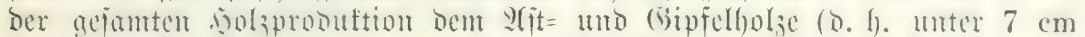

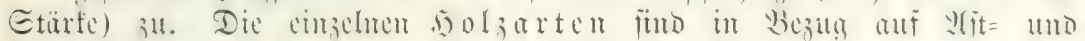

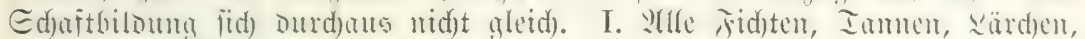

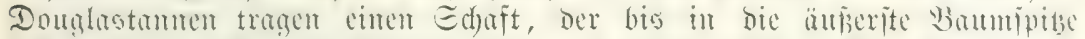

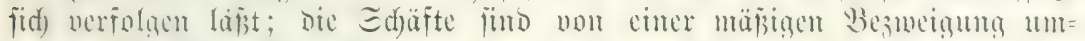

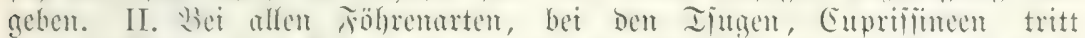

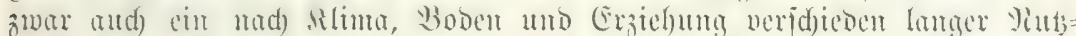

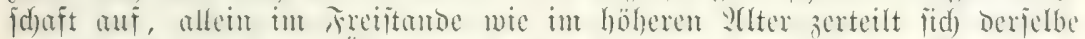

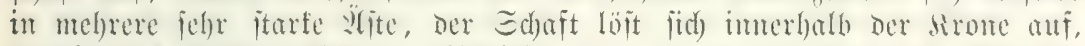

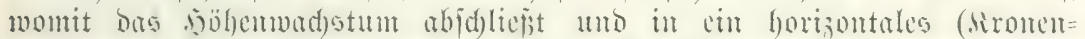

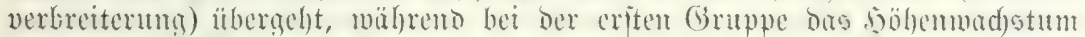

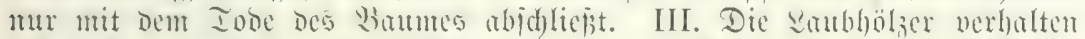

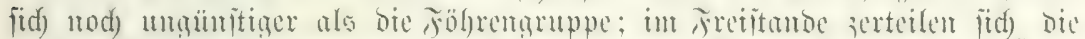

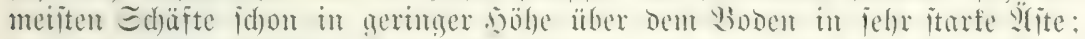

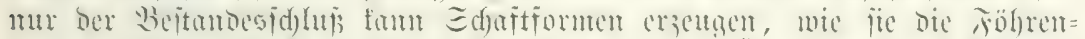

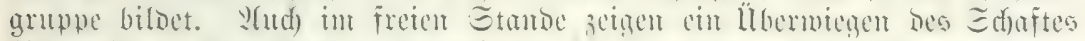
bis meit in die dironte: Eumperede (Q. palustris) Iupenbum (Lirio-

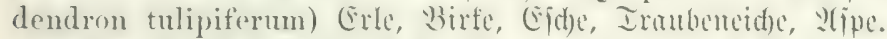

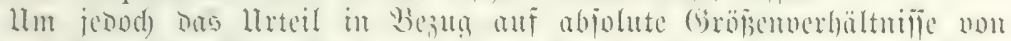

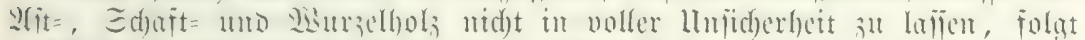

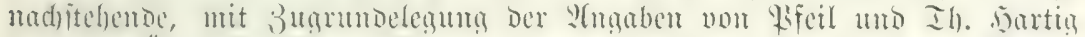

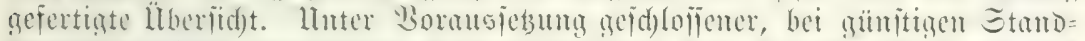

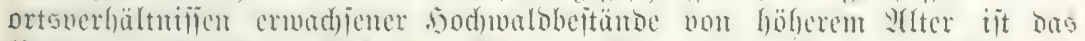

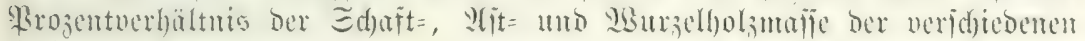
Fुolzarten folgenoes:

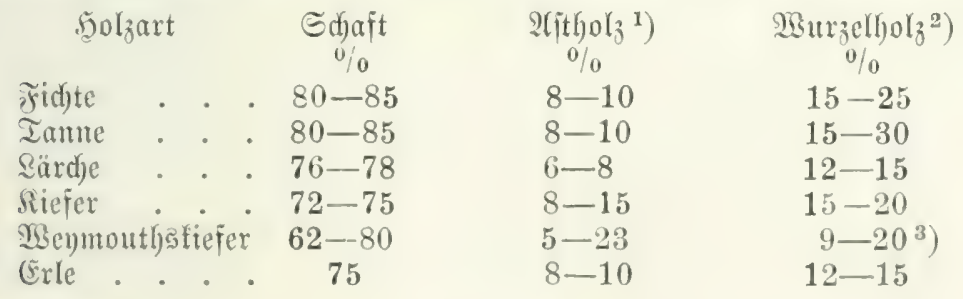

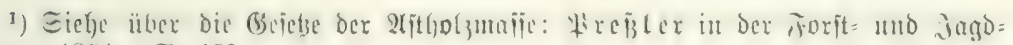
zeiturtg. 1864. S. 460 .

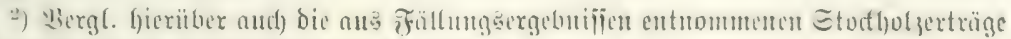

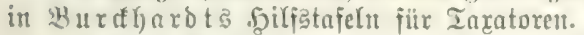

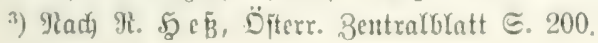




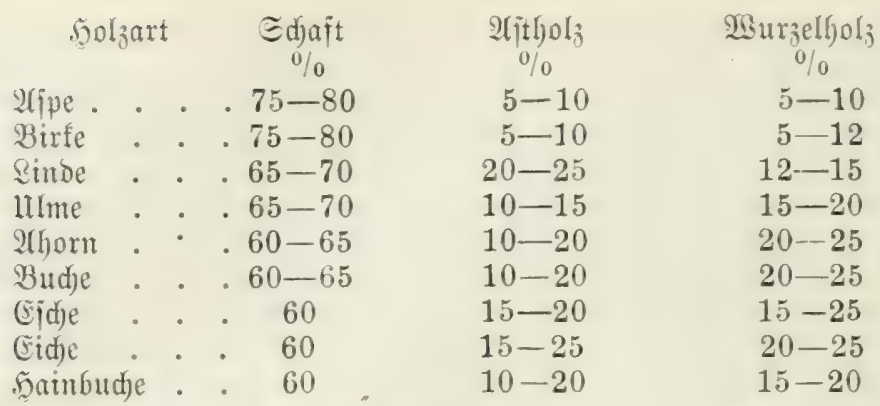

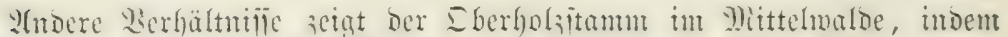

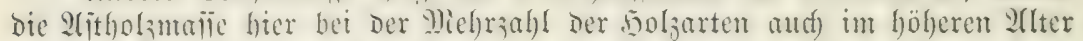

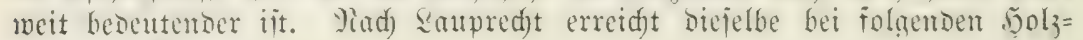
arten im aller von:

$$
50-60 \text { jafiren }
$$

(Eiche . 58

Budje . . 59-60

Ujpe. . 40

Birfe . . 35-40
$60-100$ Jabren

42

51

40

$35-44$ über 100 Jahren:

$18-25$

$28-40$

$25-29$

$34-40$

SEas Die Boll ol zigfeit anlangt, jo itchen ans obiger I. Gruppe Fridjten, Ianmen und Douglastamen oben an: an fie reihen fid) die füm $\bar{f}=$ nabeligen fïbren der Eeftion Strobus. Die Ijugen, ¿ärd)en, jwei= un

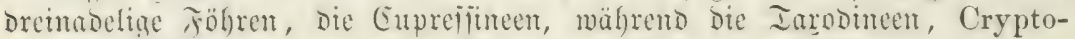
meria und Sequoia sur criten Gruppe gejüblt werben mïlëen.

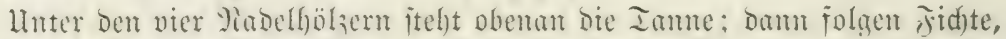

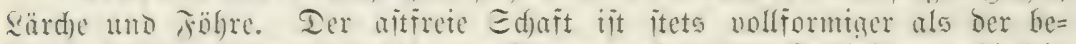

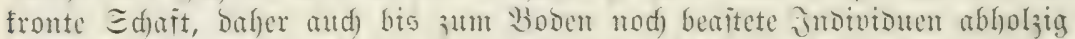

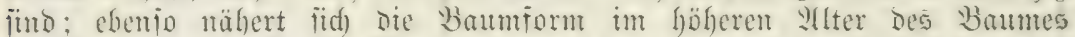

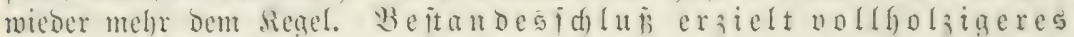

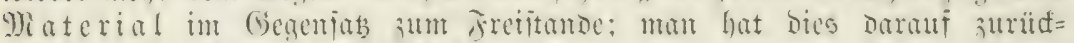

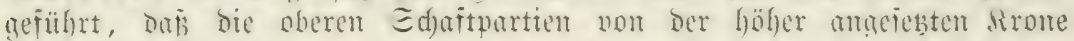
befier cmährt meroen als bie unteren: ambere (2)iebaer, Ed)mari) betrad)ten

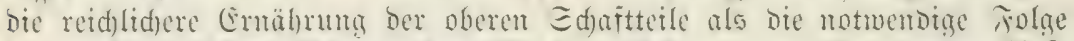

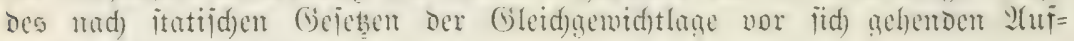

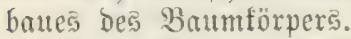

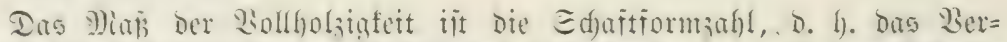

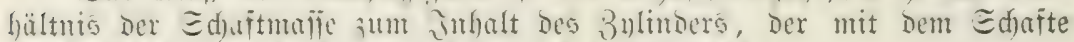

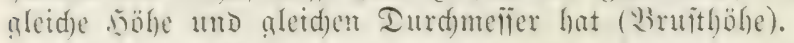

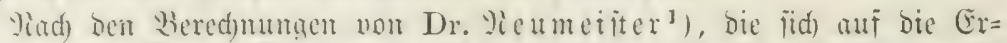

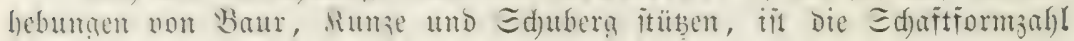
(3ylinder $=100)$

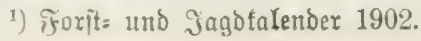




\begin{tabular}{|c|c|c|c|c|c|c|}
\hline Der & Fidute & mit & 20 & $\mathrm{~m}$ & 5ृöhe & $=$ \\
\hline " & $"$ & $"$ & 30 & $\mathrm{~m}$ & $"$ & $=$ \\
\hline$"$ & & $"$ & 40 & $\mathrm{~m}$ & $"$ & $=$ \\
\hline " & Ianne & " & 20 & $\mathrm{~m}$ & $"$ & $\overline{=}$ \\
\hline " & $"$ & $"$ & 30 & $\mathrm{~m}$ & $"$ & $\overline{=}$ \\
\hline " & & $"$ & 40 & $\mathrm{~m}$ & $"$ & $=$ \\
\hline " & Joblere & $" \prime$ & 20 & $\mathrm{~m}$ & $"$ & $=$ \\
\hline " & 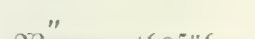 & " & 30 & $\mathrm{~m}$ & $"$ & $=$ \\
\hline " & Mermouthsfölyre & " & 30 & $\mathrm{~m}$ & $"$ & $=$ \\
\hline " & Уैud he & $"$ & 20 & $\mathrm{~m}$ & $"$ & $=$ \\
\hline " & Pink & $"$ & 30 & $\mathrm{~m}$ & $"$ & $=$ \\
\hline & stroe & $"$ & & $\mathrm{~m}$ & $"$ & $=$ \\
\hline & zarate & & & $\mathrm{m}$ & " & \\
\hline
\end{tabular}

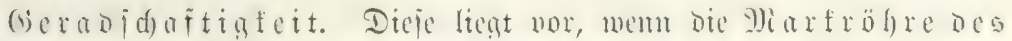

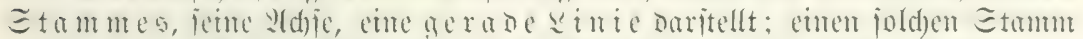

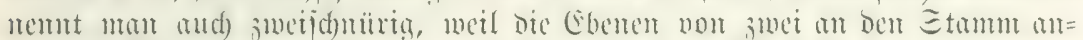

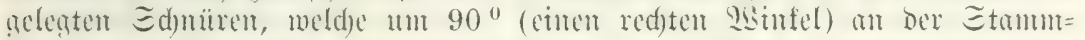

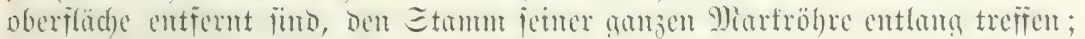

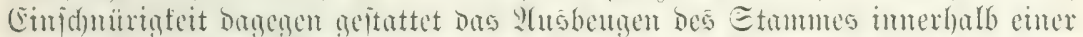

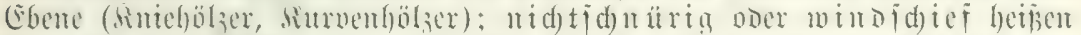

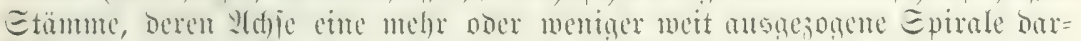
itellt. je mehr cin

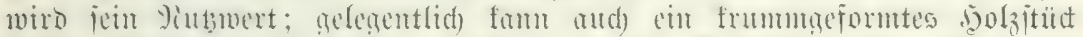

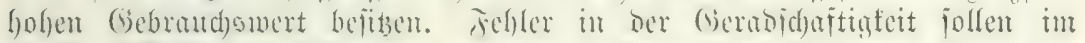

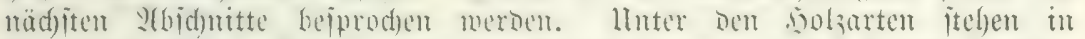

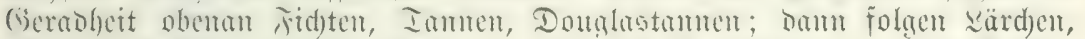

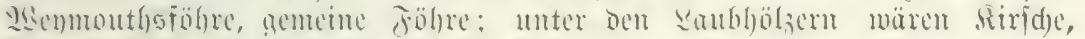

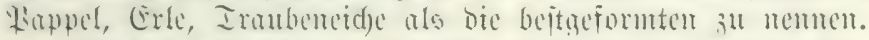

Dolltermigfeit. Die dernbilomm beaimnt bei alfen solzarten erit

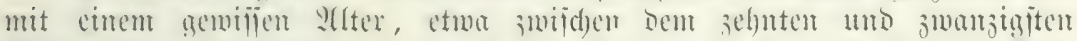

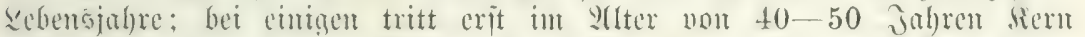

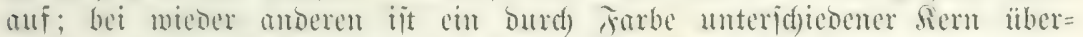
haupt mid)t mad)meisbar; Dïrolinger hat joldye Bäunte Eplintbäume genant.

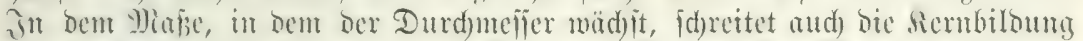

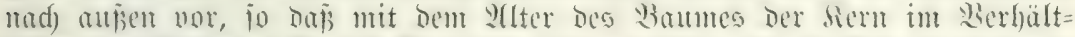
niffe zutr Gejamtmafie bes bummes itetịn mäd)it, Der Eplint bagegen in

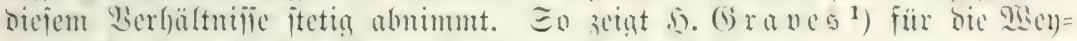

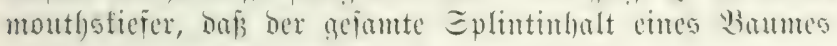
mit $10 \mathrm{~cm}$ Durd)mefjer $37 \%$ ber ganzen 50 lzmafie

aแล่mad)t.

\begin{tabular}{|c|c|c|c|c|c|}
\hline 20 & " & " & $24,6 \%$ & " & $"$ \\
\hline 30 & " & " & $18,2 \div 0$ & " & " \\
\hline 40 & " & " & $15 \%$ & " & " \\
\hline
\end{tabular}

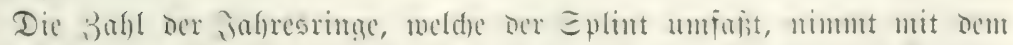

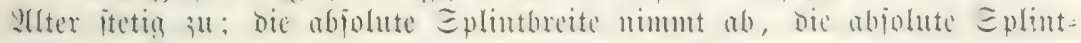

1) G. Pinchot and II. Graves, The white l'ine. 1899. 
Fläd) nimmt 3u. Da ber Siern bent Eplinte in fajt allen CËigenjuajten

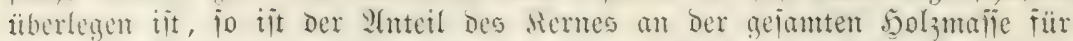

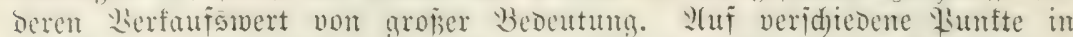

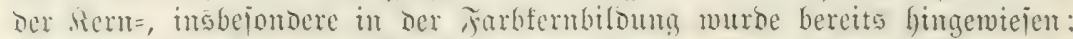

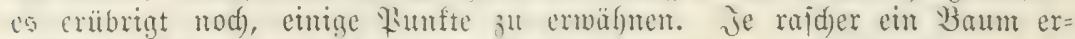
madjit infoloc ge iteigerter 当obenbonitüt, beito breiter it ber

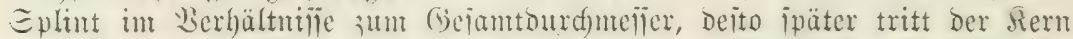

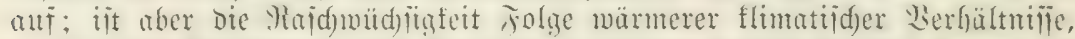

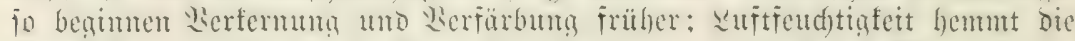

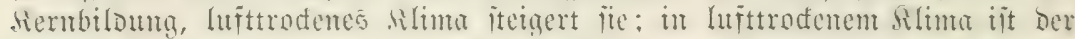

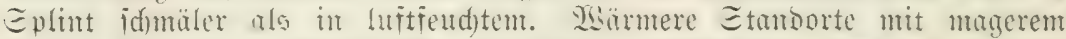

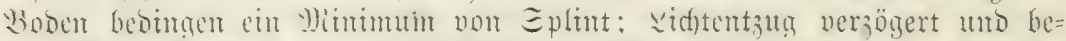

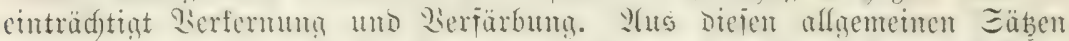

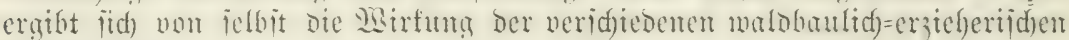

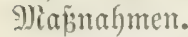

Einen Splint bis zu $3 \mathrm{~cm}$ zeigen: Ëibe, \&ürdhe, Ëidje;

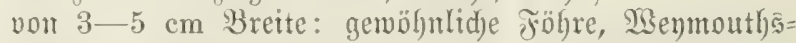
Föhre, Fiddte, Iamme;

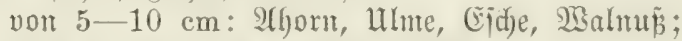

über $10 \mathrm{~cm}$ : bie übrigen \&atubhölzer.

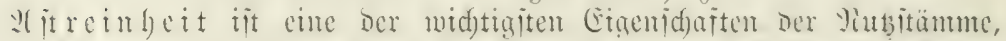

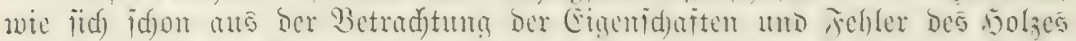

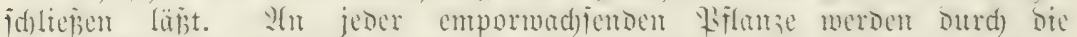

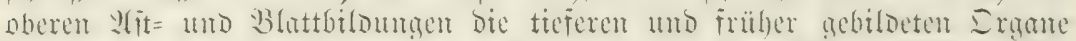

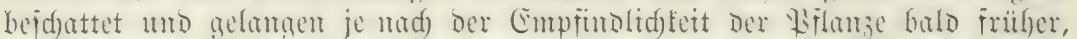

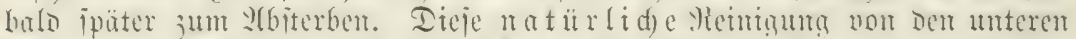

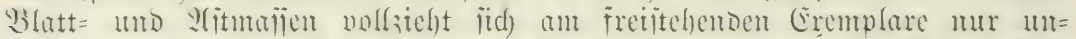

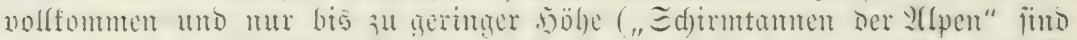

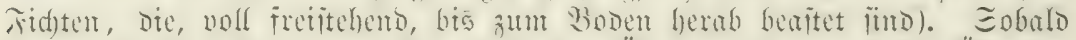

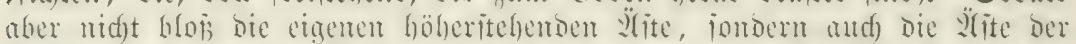

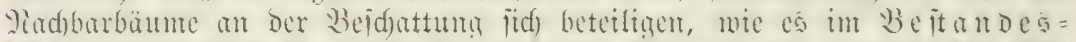

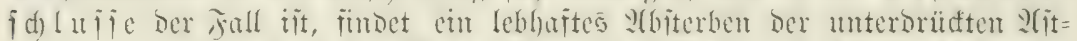

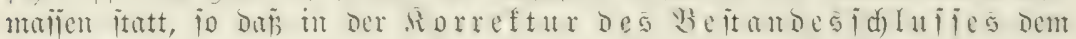

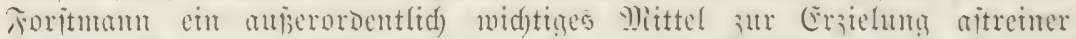

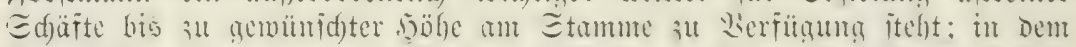

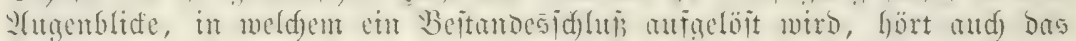

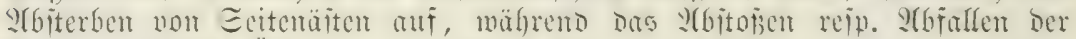

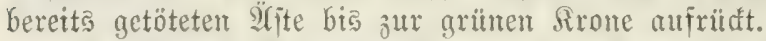

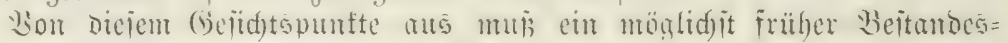

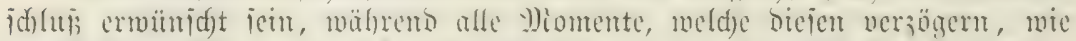

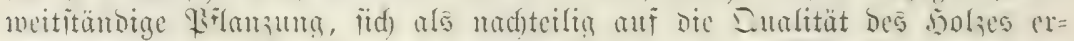

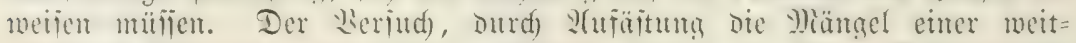

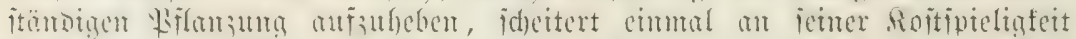

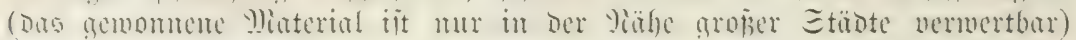
ant an ber (Gefahr, die bem itehenden Etamme ermäd)it.

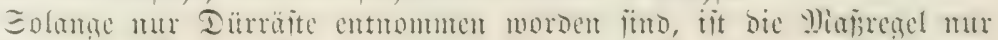

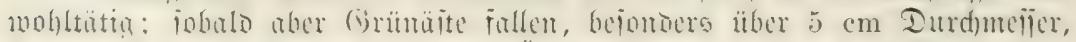

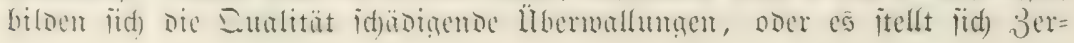




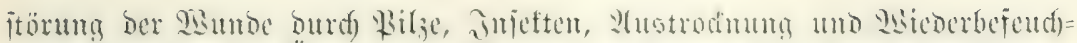

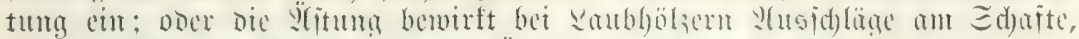

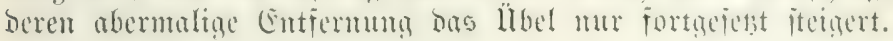

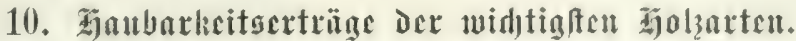

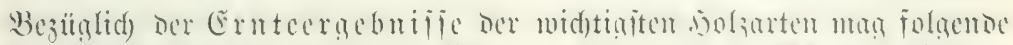

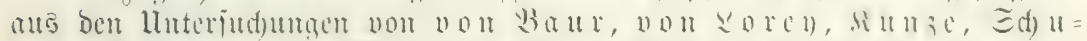

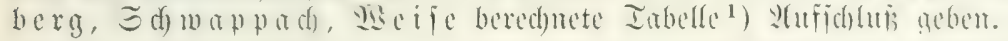

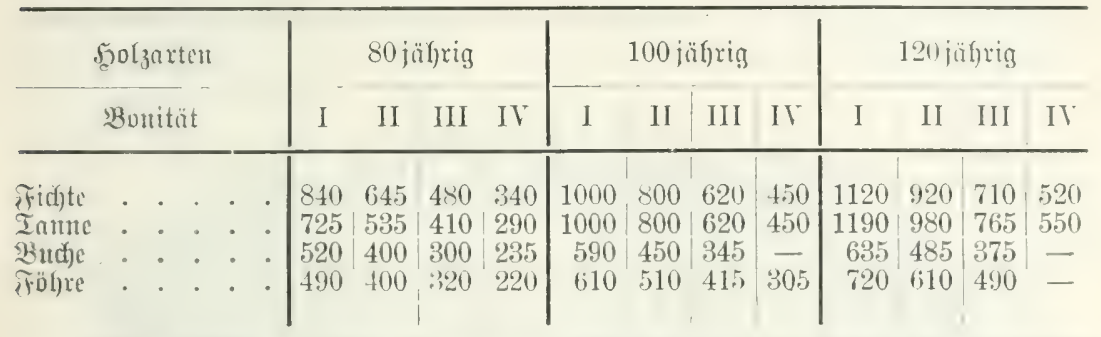

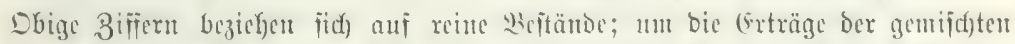

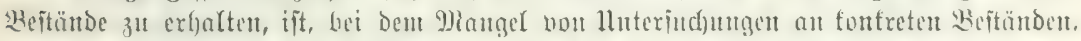

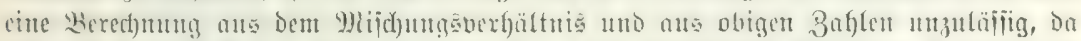

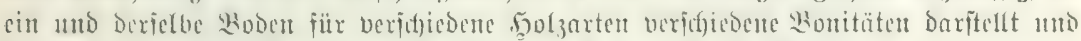

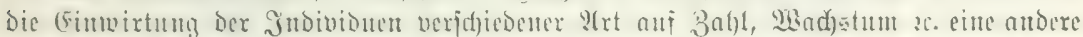

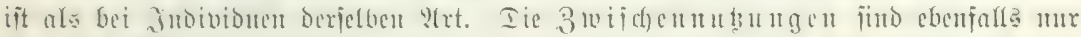

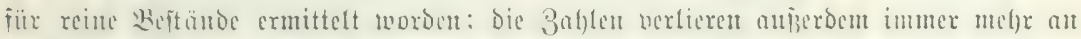

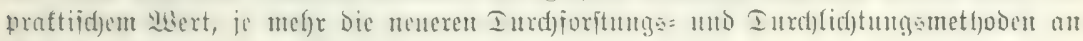
Bobent getvinuetr.

\section{E. fenler Des 甚oliers.}

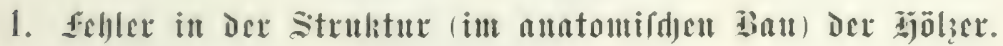

a. Ttburme 3 eld $=$ ub Gewebeformen.

5)äm住

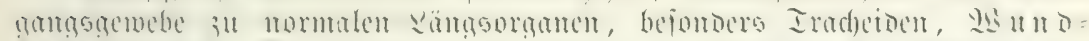

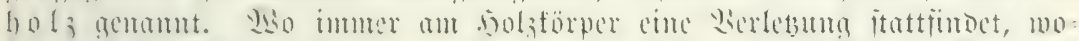

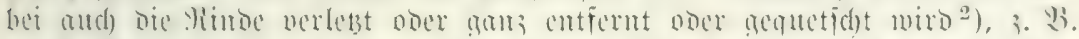
ถurd)

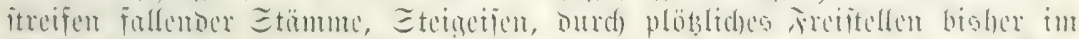

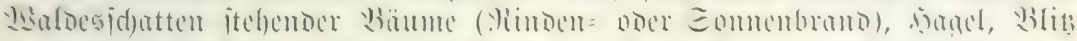

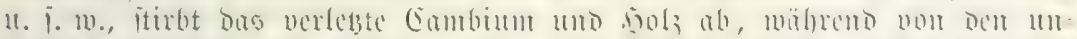

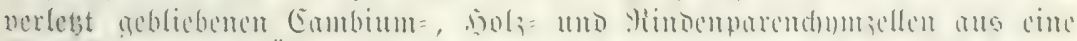

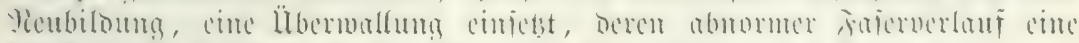

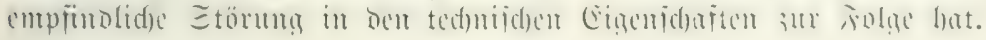

1) Dr. Reumeifter, For to = unto Jagdfolenter 1902.

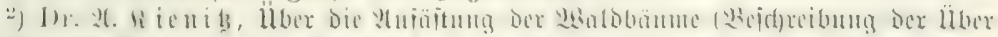

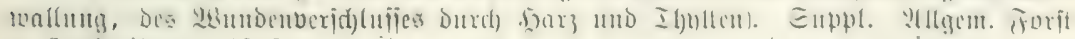
11. Jagozcitung. 1878. 


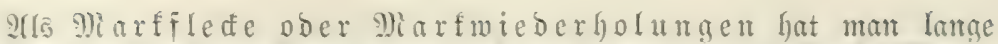

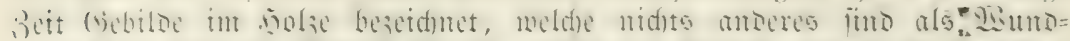

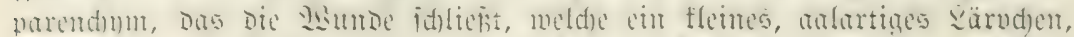

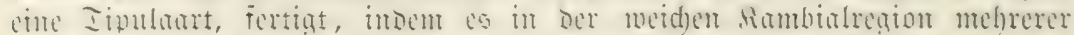

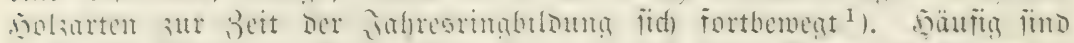

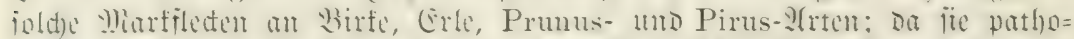

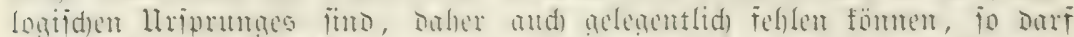

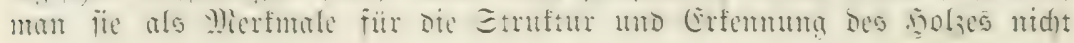
verwertent.

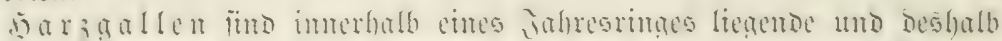

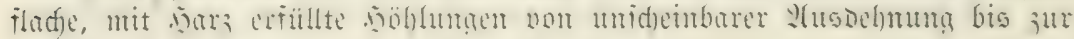

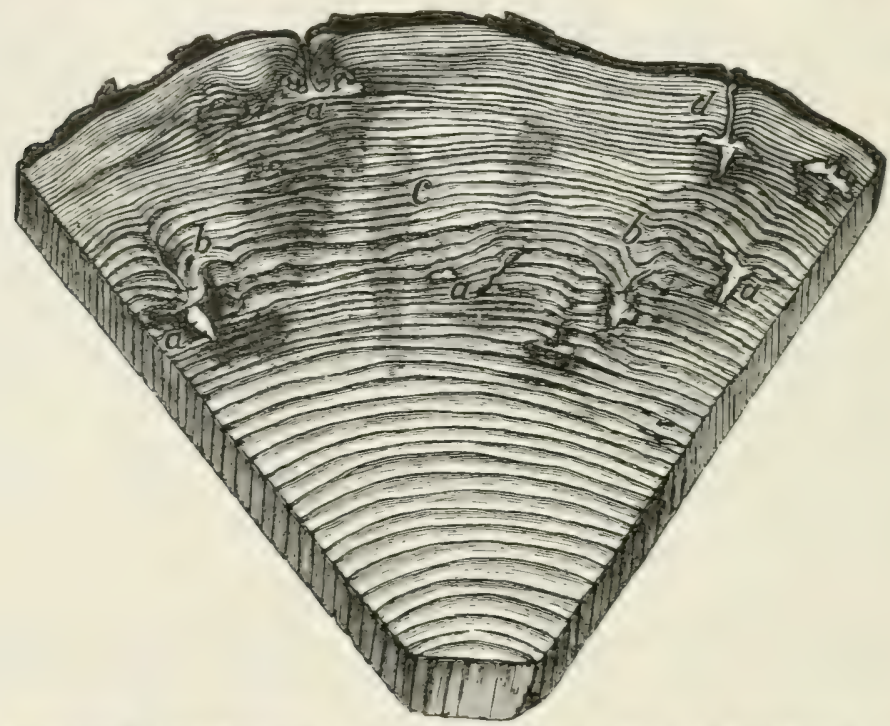

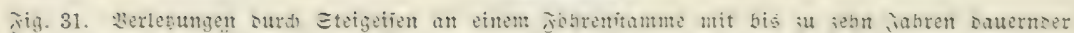
iibermalung; jöbre jum 3weđe deş 3apfenbrediens bejtiegen.

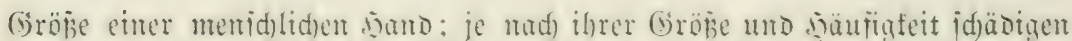

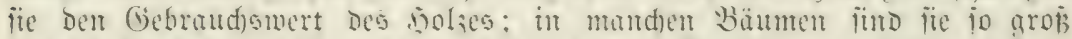

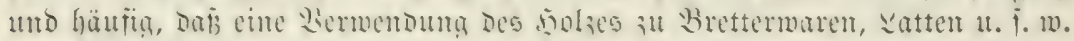
uแz̧นläilitg ìt.

Tie (Entitehum Diejer non uns inerit ausfülurlid) unteriudden ${ }^{2}$ ) ab=

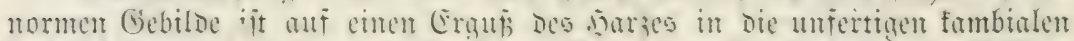

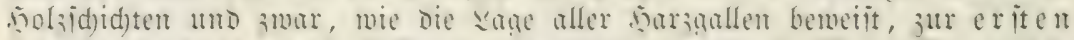

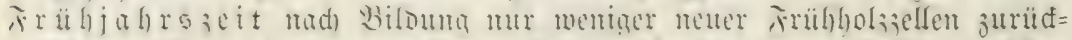

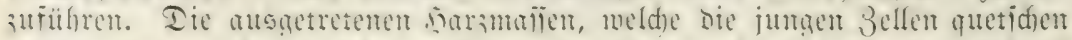

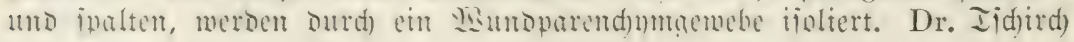

1) Dr. Mi. Ritenth, Iie Entitehung Der Mharfflede. Sotan. Bentralbr. 18E:3.

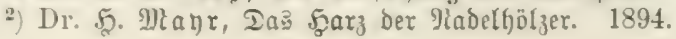




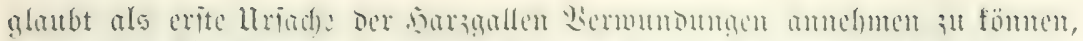

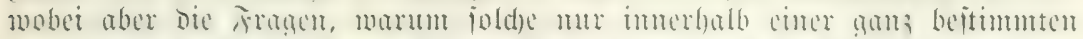

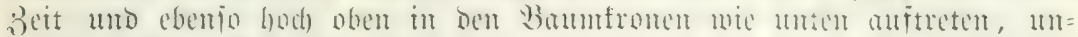

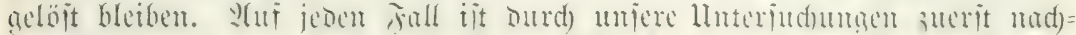

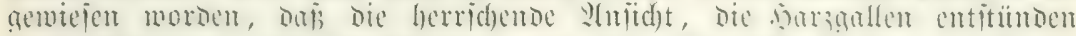

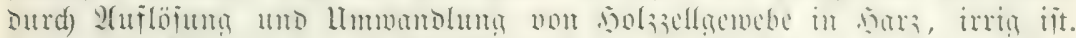

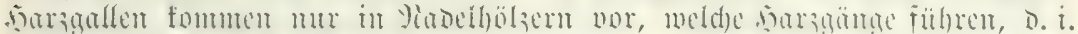

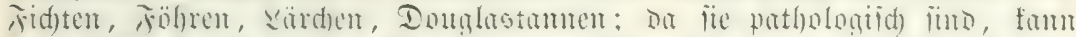

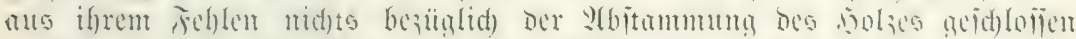

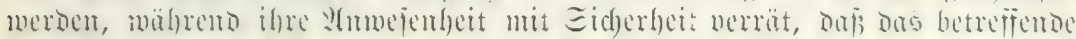

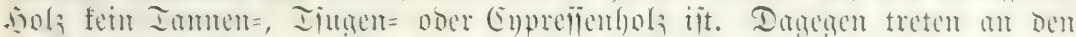

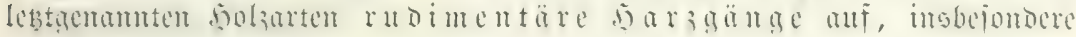
im Mandholze, aud an ein = und mehrjährigen Irieben, ment biejelben Durd) Sagel ober Froit mikgeitaltet werben. Bei ben harzgangïllfrenden solzarten fint abnorme Miengen von Gängen in gewillen Jahrgäntgen, in anderen wieber auffallend ipärlidjes 2utftreten berjelben bemerfenswert.

(5) allenparendy y, bejoubers bei \&aub= hölzern, entiteht unter ber Meirwirfung von Jmieften unb Deren Rarven; an Foritgewädjen verurjadjen Lach-

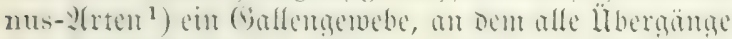
von Parendigm = 3u normalen Belfen zu finden find.

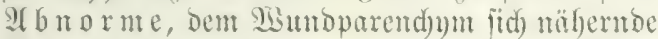
Belfiormen entitehen bei Saub= unb Madel= hölaern unter ber Eimwirfung vou Spätfroit. Sitel= Fad) iit mit ber fambialen Serlebung burd) Epät= fröte bei fid) ftredtenden Irieben aud) cine ausperlic() fid)tbare frümmutug bes Iriebes, balo bogenförmig, bald ipiralig, verbunden; bei bem idjon ins zweite

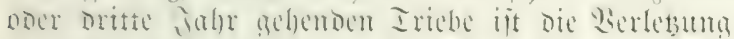
äuBerlid) nidft fidjtbar. Beripätet jid) ber letste

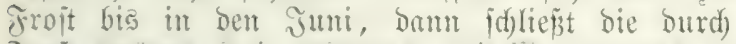

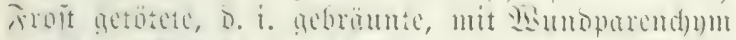
wericheme $\Xi d i d$ t an dic vorbergegungenen joüh=

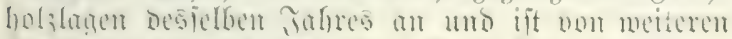

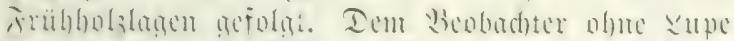

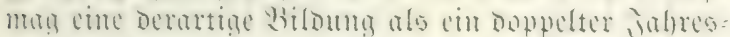

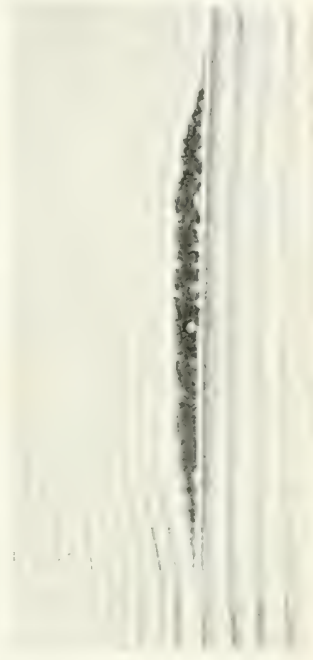

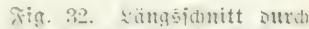
cine sarigalle im jiditen. bolit. Iftginllumbacllen in balbrunben (jruppen (\$) navin.6nm gitgen ben mit sar criallen soblram nor

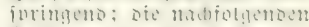

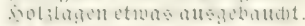
ring erideinen; un, bic wir auf bieje of ro it riuge

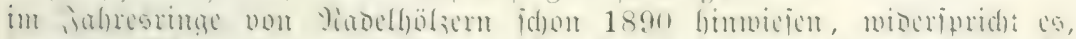

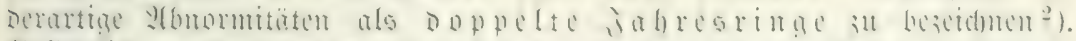

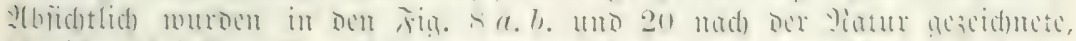

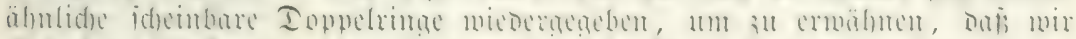

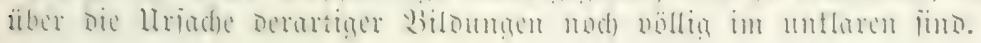

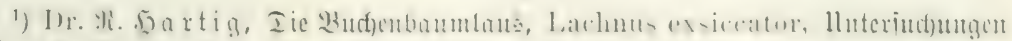

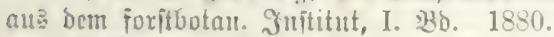

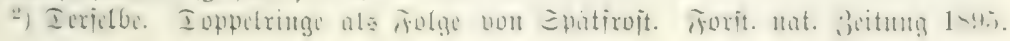


Ĵm wabren Eime fam von כ̧a

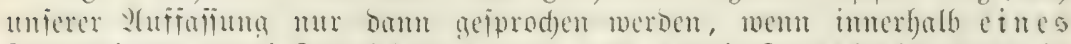

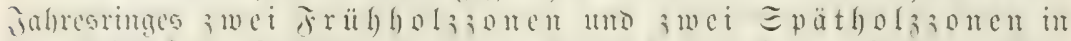

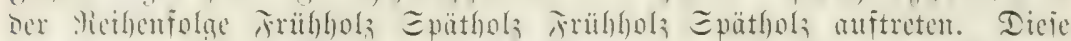

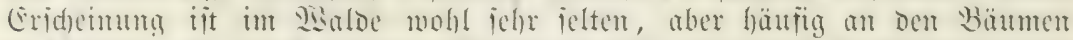
in Etänten, mo Durd) märmere

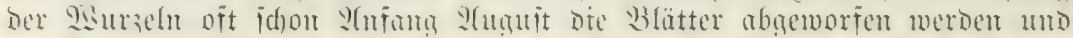

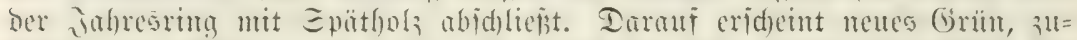

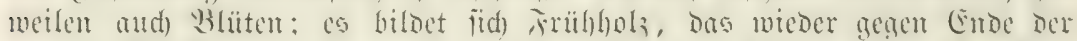
iweiten Lisustumoperione, Enot Eeptember oner Eftober, in Epätholz libergelst, worauf ber Blattabfall folgt.

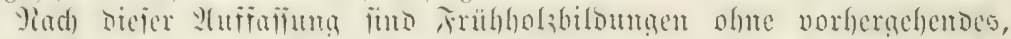

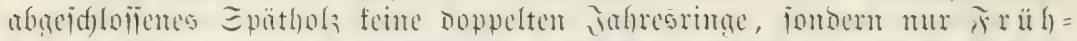

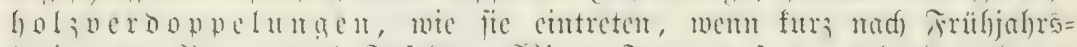

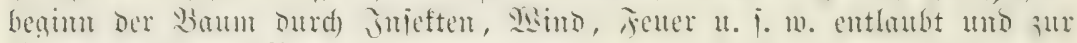
Ẽrzeugutg neuer Blätter gezmungen murde.

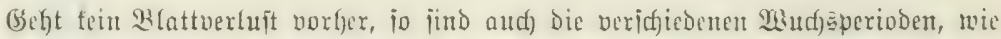
Sohannitriehe, heionber bei (Fidfen, Jiad)triebe in Eeptember bei fräitigen juntgen

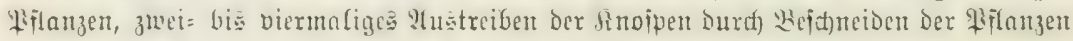

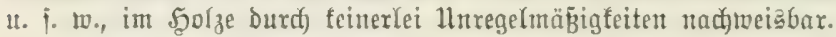

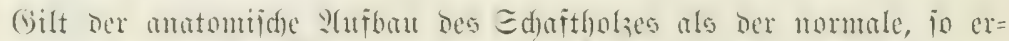

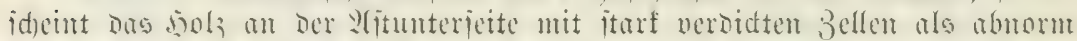

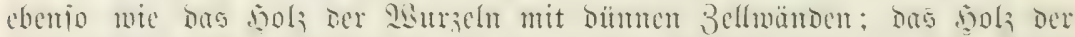

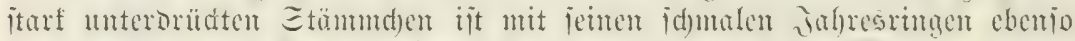
abnorm, wie bos sol; im fetten (Gortenlonse gemadjener Bämme abmorm

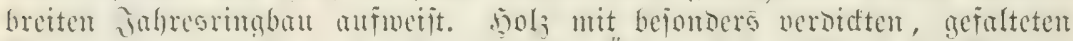

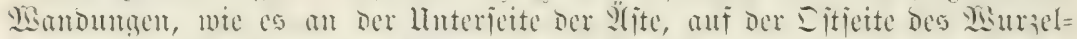

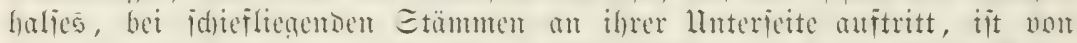

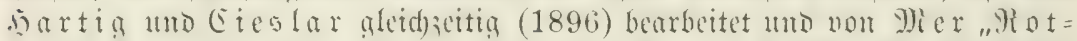

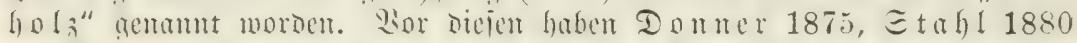

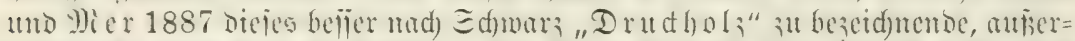

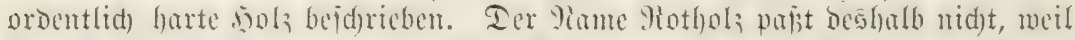

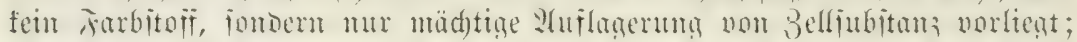

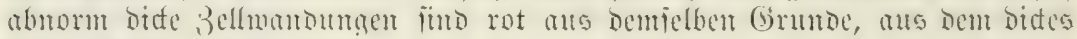
Eั๋ blaแgrün erid)eint.

\section{b. Abuormer Fajervertan}

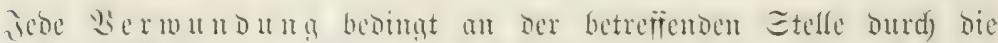

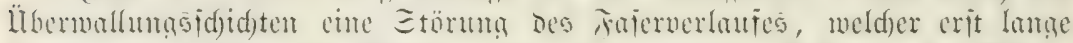

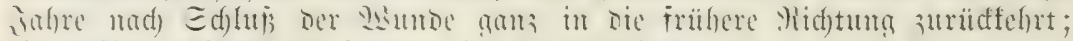
bis bafin erleiben alle Fajern cine 2tusbandyung.

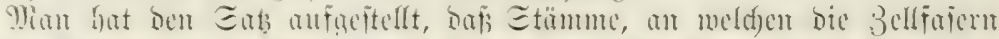

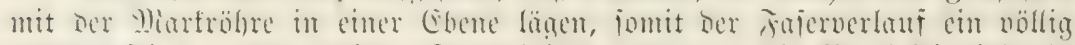

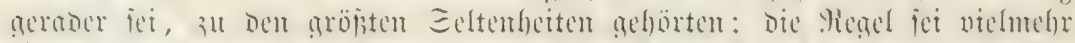

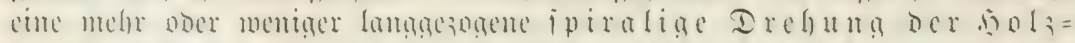

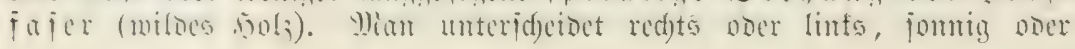




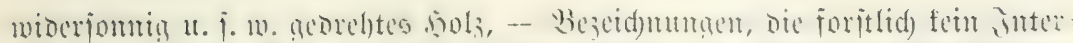

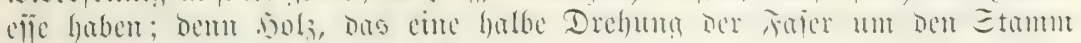
แuf $10 \mathrm{~m}$ anfweijt, iit 3̆u Brrett= ober Spaltware untauglid), mag bie Drefunn nad) redftós ober nad) linf́s gehen.

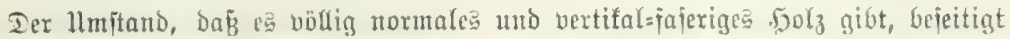

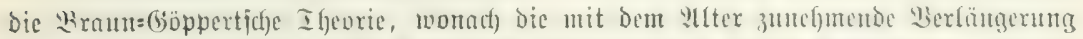

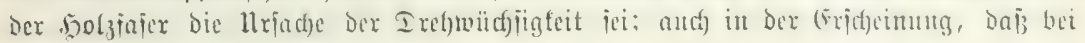
(5ntiftefung Drehwidd)igen folze Die Suerteilung Der Eambium= initialen vorzuģatweife trad) einer Ridytung, 3. B. rectfte, vor fic(f) gef)t, währent bei Bildung gerad= pajerigen 5olzes die Suertrifungen Der Snitialen mady red) te uno linf auftreten (5artig), fömen woir ntidft bie llrjactee, fondern mur die Jolge einer nod) unbefannten Ilrjadje erbliten.

Die Föhre neigt mebr 3ur Drehwïdjigfeit alo Fid)te ober Ianne; bei ber Moßs= faitanic joll nad) Dr. Fen= meifter jeber Etamm, bei Birte feiner georeht jein. Dic Siraris fentut be it inmte sagen, in meld)en bref = muidditges $\mathfrak{S}$ tritt, bas jind 3. 3. jebr iteinge Boben und iominge .̧ärrge; in jold)en D̈rtlid)= feiten Gleiben bie Solzpretic amberen geneniber merflid) 3urüd wegen bes mad) jeder Midstung geminderten (Ge = braudjomertes brehmüdjigen

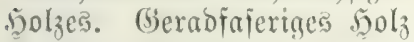
ift fdon am itehenden Baume,

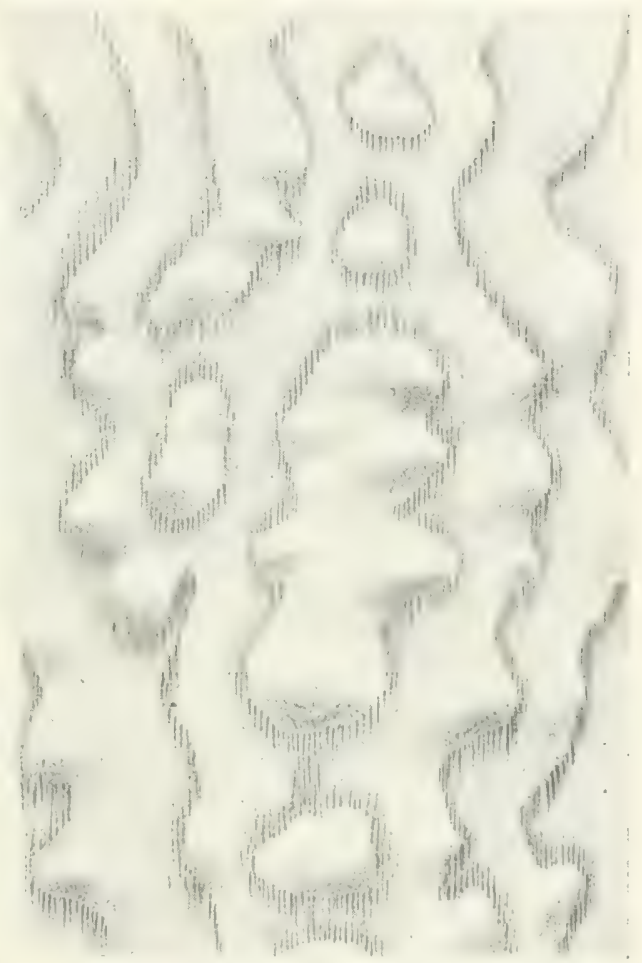

jig. 33. Efarengol; mit welligem faferverlauf; majer artige Etruttur. wie ermälynt, Durd) Den ver= tifalen Berlauf ber Sorfentäler angebeutet; am gefällten uno entrindeten

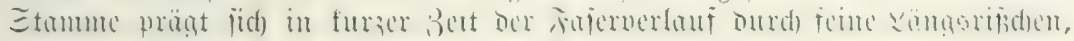
bie burd) $2(u t s$ trodnen entitehen, aus (fiche Fig. $42 a, b$ ).

Welliger, wimmeriger Fajerverla fecinträdtint ben lums=

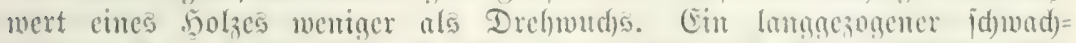

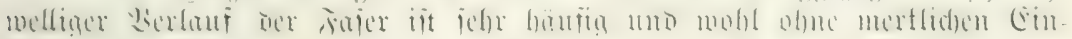

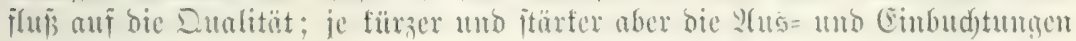

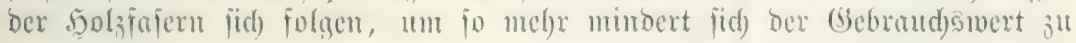




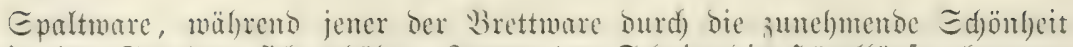

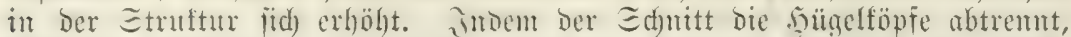

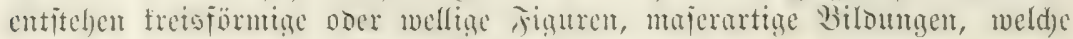
bas Miaterial zu einem Sd)mudfholze itempeln.

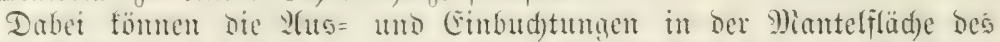

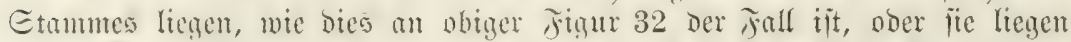

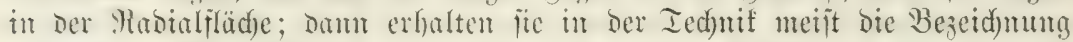

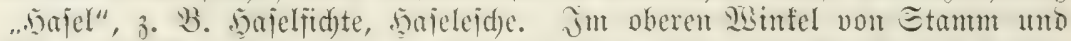

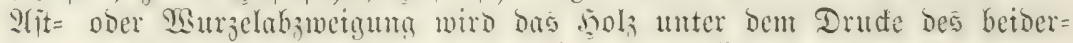
jeitigen Dicfenmad)stums ebenfalla faltig uno wellig.

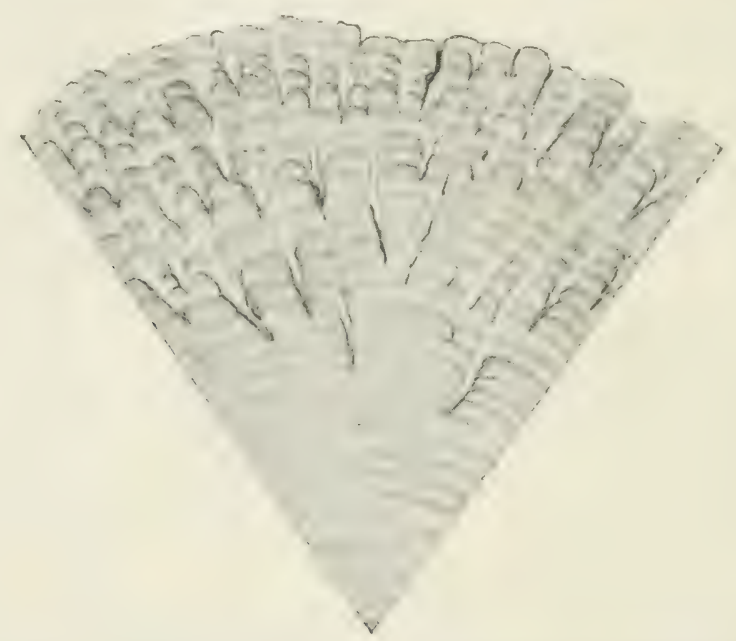

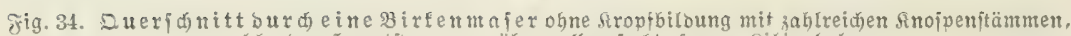
welche ber Srauptitamm 3 u iibermallen fudt, jogen. Silientolz.

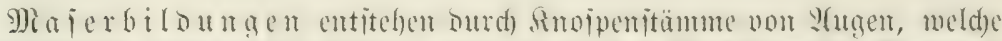

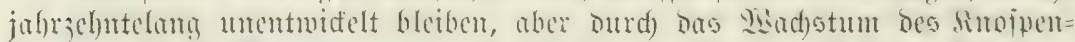

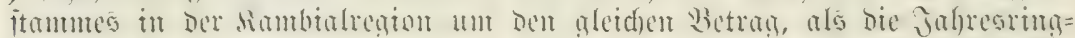

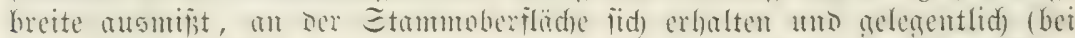

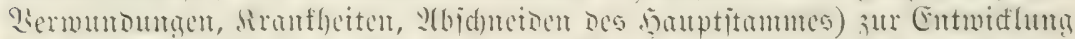

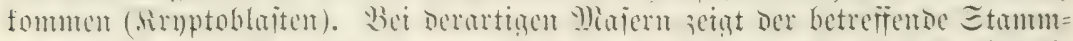

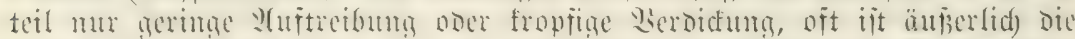

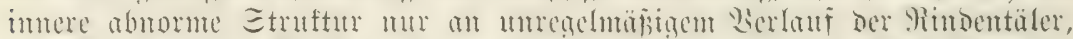

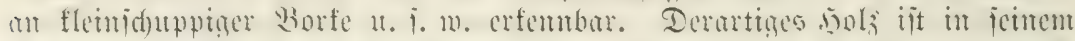

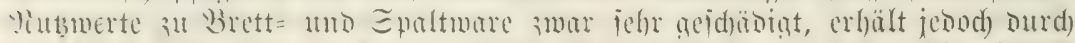

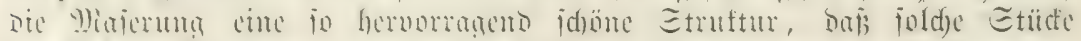

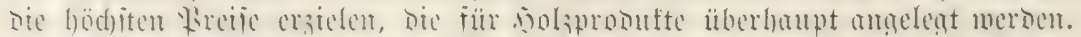

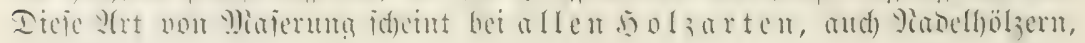
vorzufommen. (Tiç. 33 แnก 34.)

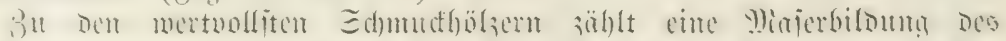

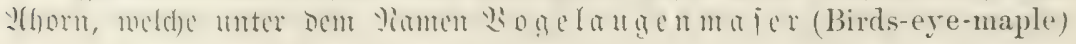




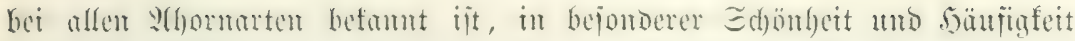
aber am 3udferaforn (Acer saccharinum) auftritt (fig. 35).

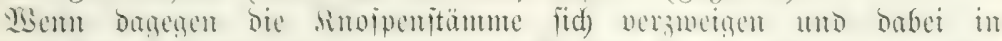

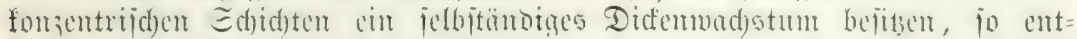

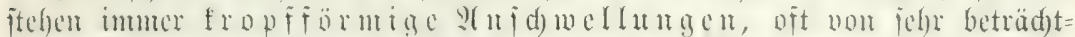

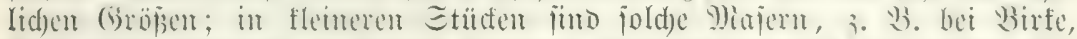

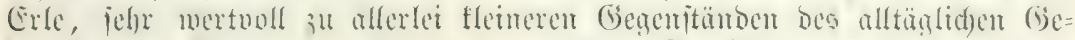

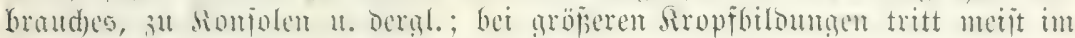
Jutern cine frülyzitige Berjełung auf, bie foldden firöpfen Den Gebraud)smert nimmt. Eold)e Siröpfe tragen aud) öfters Iriebentmidfungen.

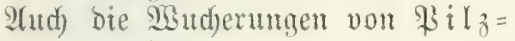
mycelien, wie Aecidium elatinum an Meiñtante, Aecidium giganteum an Föhre, Peziza an Sörche, Aglaospora an Eid)e, fömen Beranlafintug zur fropfigen Inidjueflung des Etammes mit abnormem Serlaufe ber Fajern jein; aber berartige Bildungen find nur juäolid), ba fie ben

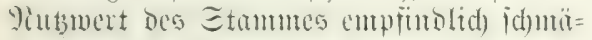
lern und jelbit, wegen ber an ifnen anf= tretenden Berjebumgen, aut nidyt brand $=$ bar jint.

Eine Inidamellumg bes Etammes

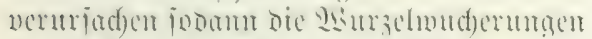
von Viseum album, ber Miffel, ttro Loranthus, Der Miemenblume. Eritere, bie Mifitel, ift bejonders bäufig an Innnen, Föbren, Fidsten und zablreidsen Raub= hölsern. Eie bejibt Rängตmurzeln, weldye, auf der Miantelílädse des Etanumes ver= Inufend, in ihren älteren Ieilen vom Etamme überwadjen werden; von biejen

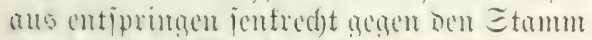

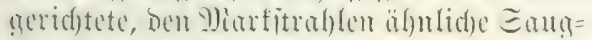

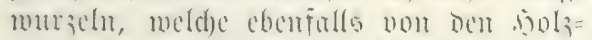

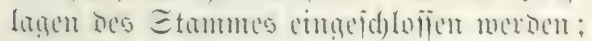

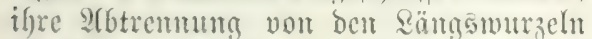

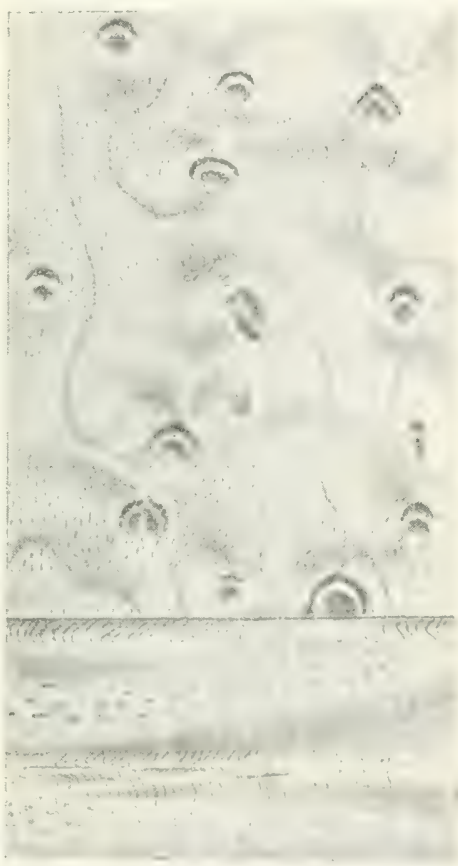

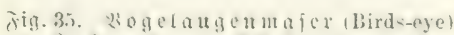
am is uderaborn. Hts siogelangen fino

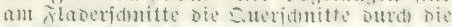

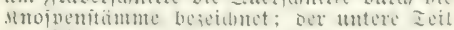

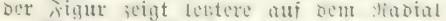

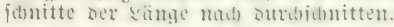

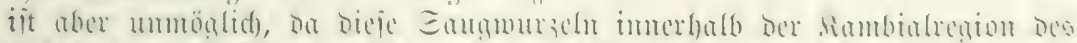

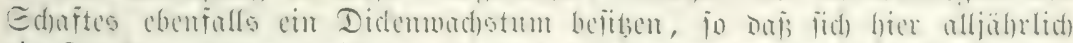

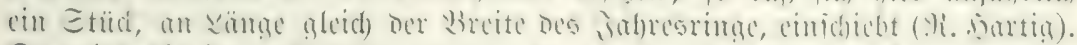

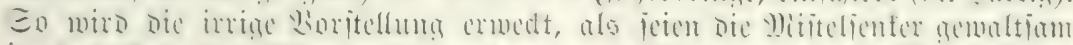

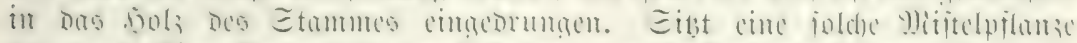

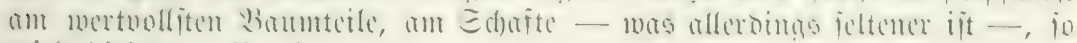
wiro bicjes zu Patybolzzweden unbrandybar (Jig. 36).

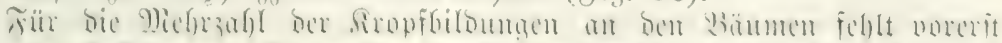

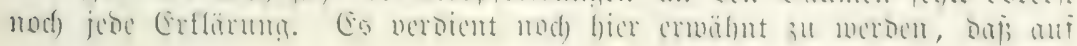




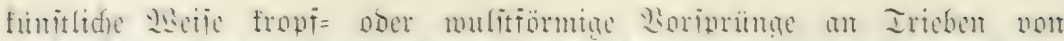

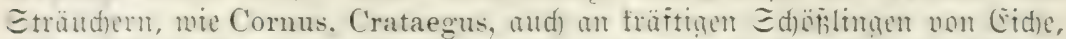

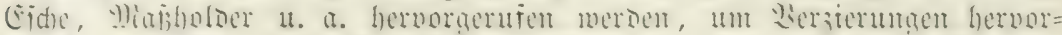

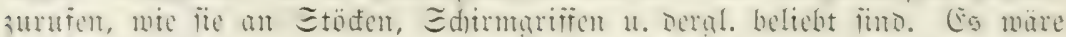

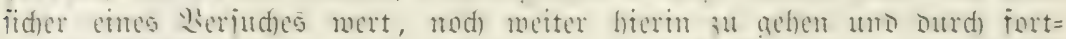

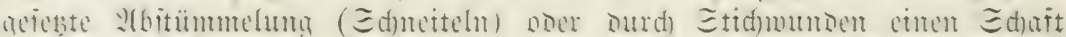

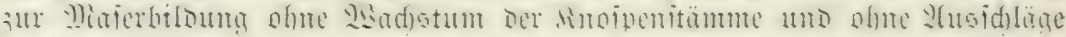
ju veranlajien.

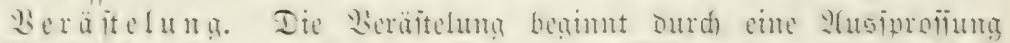

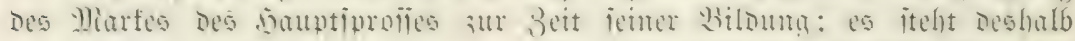

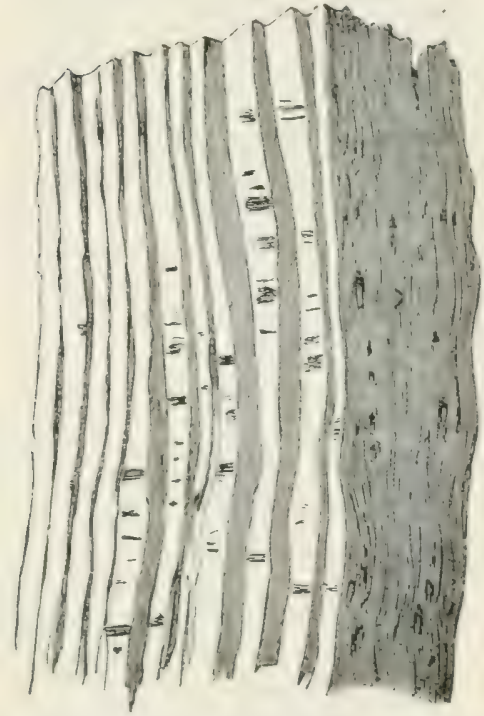

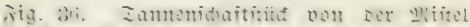

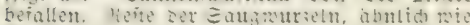
Wartitrablen, in sem netierten vierverlatio an Yasial uno Eangentialidntte ertenntor. jeder ober = mo unteriroijde 2 (it, ber vom bauptitamme absmeight, ourd) jeine Warfröhre mit ber Miarfröhre Dę Mintteritammes in Berbindung. Bet Wiabellöhernt fitsen bie slite mehr ober wentiger quirlförmig angeoronet, jo bab Der 2(bituno ancier Duirle alอ un=

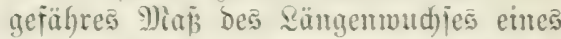
Jahres, bie Zahl Der Eutrle als 2tuhalt bet Der Alterabeitimmung Des Bammes gelten famt. Die wahre Rängstrieb= grenge (9)iarfunterbred)ung) liegt bei jungen Etänmohen höher, bei älteren Etammen (wegen ber jutef aufiteigen=

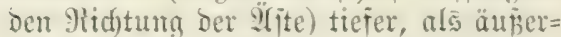
(icd) Der Zlnjats ber Dutrlajte andeutet. (כig. 37 in $M$ M) Marfunterbred)ung oberfalb, nadh Didemwad)ştum bis 4 unterhalb beg äu berliden Qrit= anjabes.) Bet ben Saubhölzers fehlt bie quirlige 2 (norbmung Der ilfite gan ober

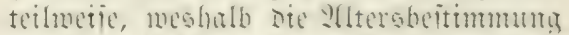
im mejentliden an Dic C̈rmittlum Det Buhl ber iuhrertme antemieicn it.

Die im Raufe ber Jathre angeleaten

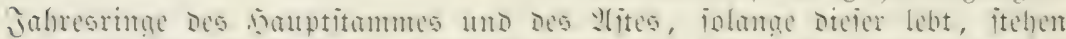

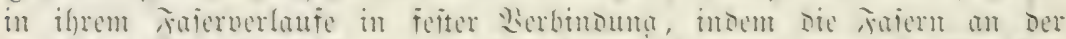
Baits Des

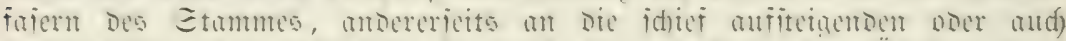

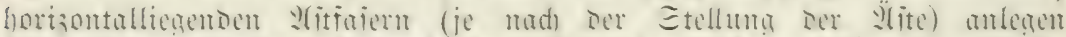

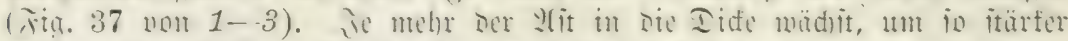

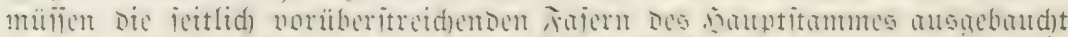

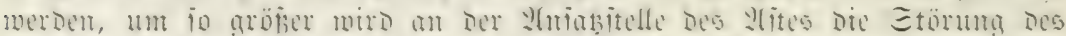

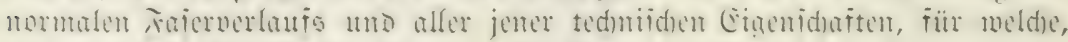

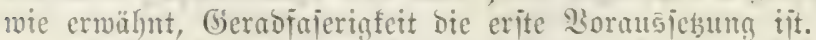

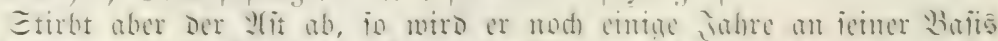

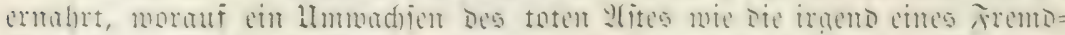

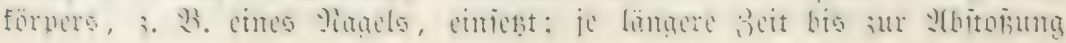




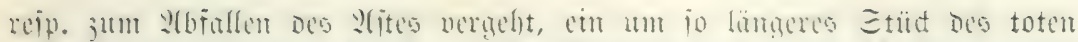

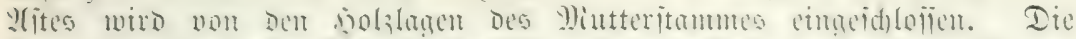

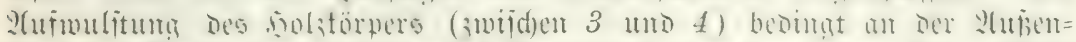

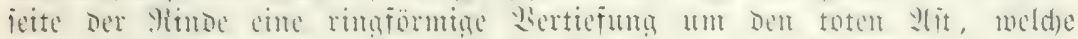

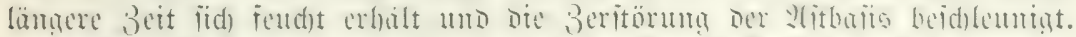

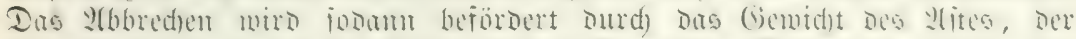

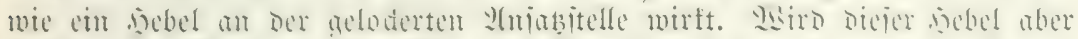

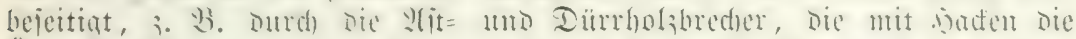

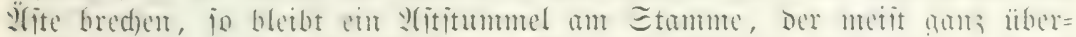

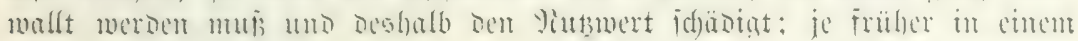

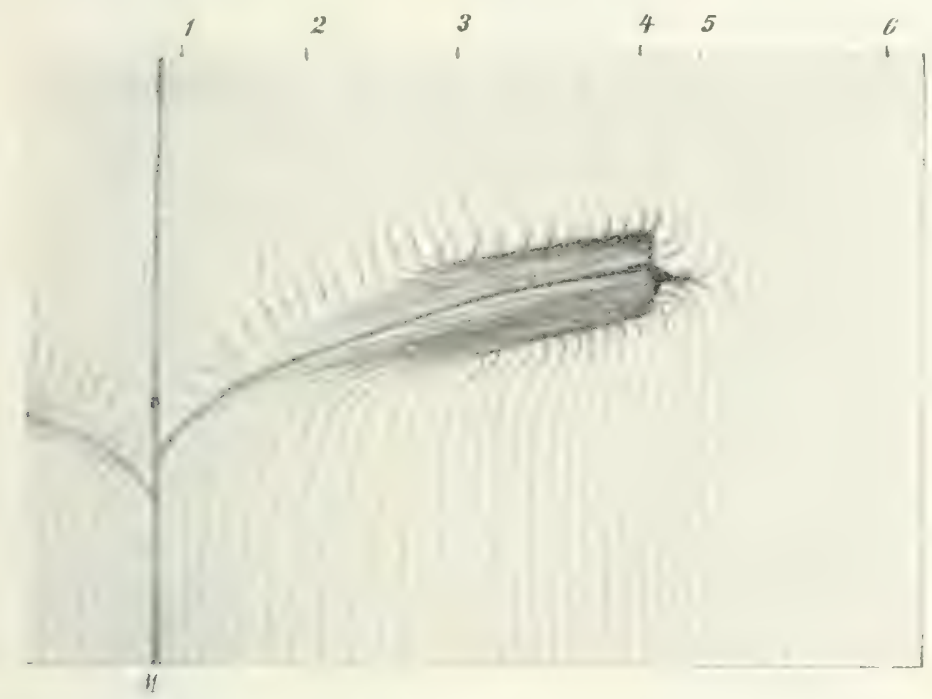

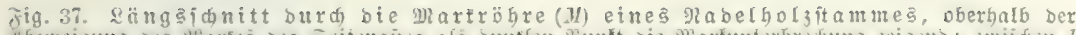

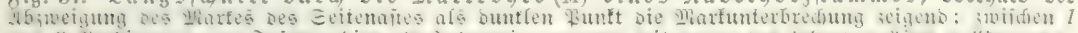

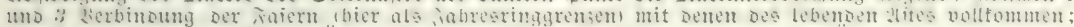
von 3 an 2hit abgejtorben uns l̈berwallung Desfelben bis 5 ; von ba an wieber übergang 3 ur normalen vertitalen 2 noronung ber Fajern unb Jahreagrenzen.

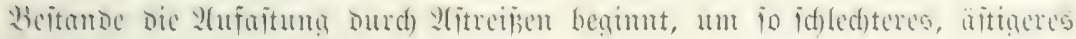

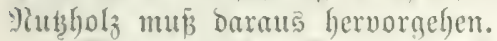

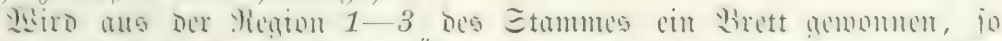

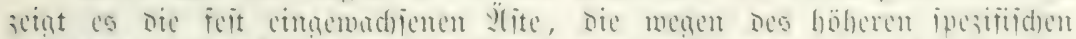

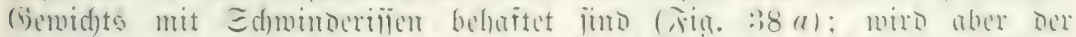

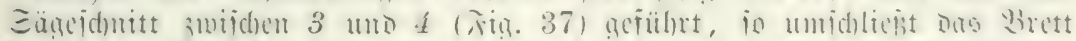

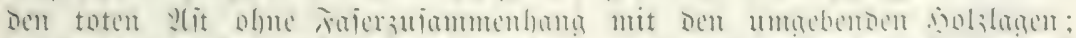

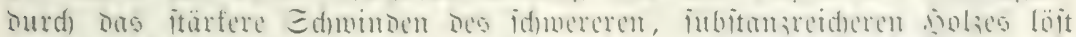

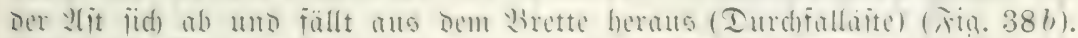

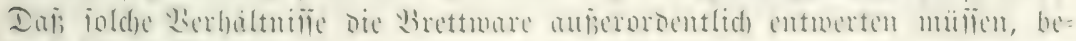
barf teines Bemeities.

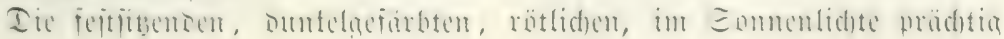




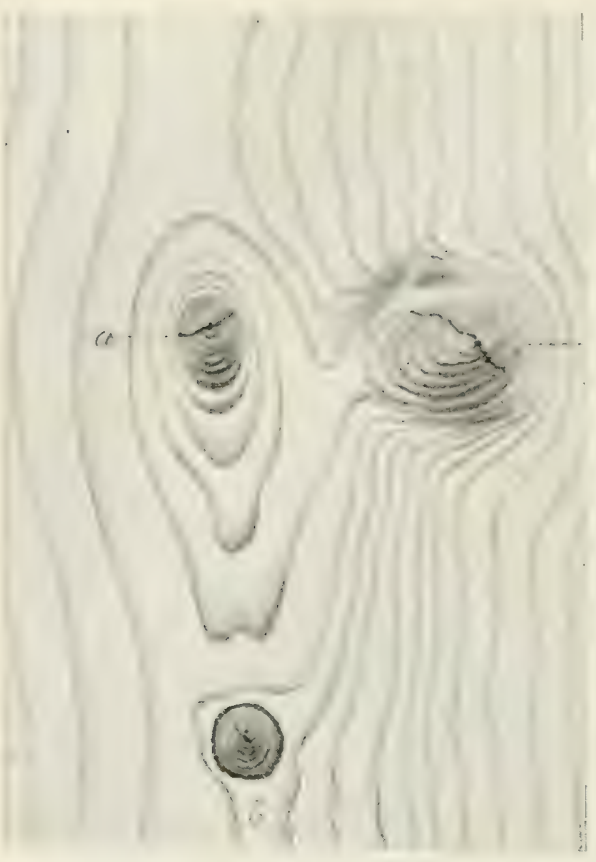

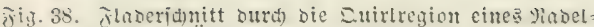
boljbaumes; bie ifite $a, a$ in fejtem Bujammenbange, neben ber Beeinträdtigung bes 9 lubmertes aud ben Bier= wert folder Biloungen seigeno; bei $b$ ein fleiner 3wifuen= cuitalt, als toter :lit ipiter bet cintrofnumg bes brettes beraugifallento.

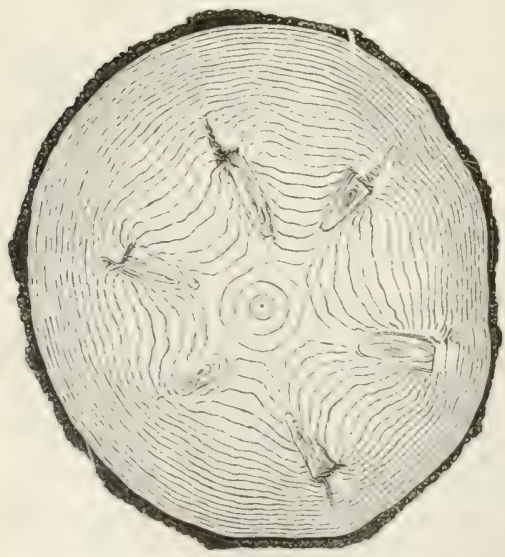

Jig. 39. Duterinitt burw einen Etamm, an weldem fribieitig eine ifitung itattgefmben hat; iumere solalagen tabellos.

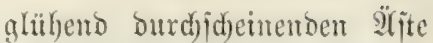
erhöhen für beitimmte Brode (Bertäfelungen) bie Struftux Des Solzes und bamit aud) jeinent 2 bert, bejonders bei särde, Birbe, atth Föhre.

2Gerben bie äfite idfon im jugendidyen 2llter bes Baume? entfernt, fo trägt mur ber imtere Ieil bes haubaren Stammes

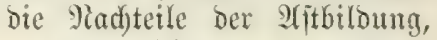
bie um fo fleiner merben müfien, je bidyter Der Beitand geids)lofien war, je mentiger bie Alfte in bie Dide wadjien fomter.

Daraus ergibt jidf aud Deutlid), meshalb gerabe bie äuß̉eriten, ftörungafreien $\mathfrak{S}_{0} \mathfrak{l}_{2}=$ lagen alter Stänme io hod)= mertiges, reintes Brett $=$ unto Epaltholz ergeben (Jig. 39); barats famt aber aud bie empfindlide Sdfäbigutı $\mathfrak{e r}=$ melien werden, die erwäd)it, menu burd) plöbliche Jrei= itelluna cines alten Etammes neuterbinga Sitbiloungen

( $\mathbb{A} \mathfrak{c} \mathfrak{b} c a ̈$ it $\mathrm{c}$ ) bervorgerufen werben.

3 wiejelbildum (Doppelitamm, Doppelferm).

3 wiejelbild ugen entitehen eimmal, ment cine Silanse eintr 3weiten Gitpfeltrieb emporjdiebt, Der an ber Bafis mit bem souptitomme alfmäblid) verwäd)jt, ober inbem zweet poer melyere von 2 tufang an von= cinander getremte Jnbiviouen (Buijd)el= pflamautg) Durde ifre Didemwad)stum zur Beriffrumg und Berwadjung ge= bradjt merben. In ber Megel bleibt ipäter ein Gtamm 3urüd und itirbt $\mathfrak{a b}$; bieje toten 8 wiejel find bie itetige Serlegenteit in ber Durdjforjtungs = praris, went ifre Entfermung fodjon bet Der Sdilagpflege überieben murbe. Entfernt man fie, nadjoem fie bereits $10 \mathrm{~cm}$ Durdemelier crreid)t 


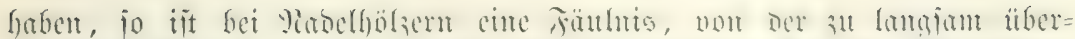

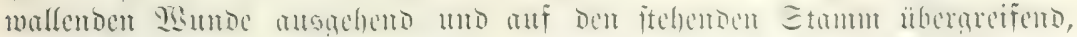

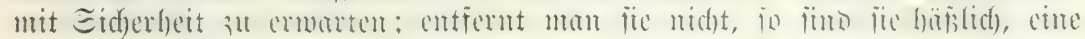
Brutitätte für Injeften. SBerben jie entfernt,

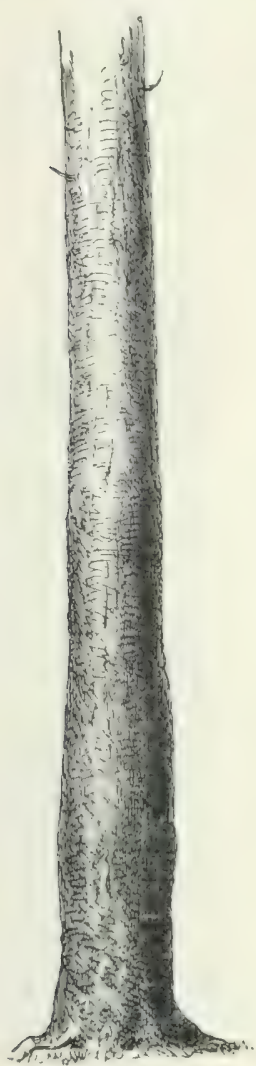

Jig. 40. Bajis eines alten Etammea, bur(f) bie भind (t) i) wiejelftammed ober itarte jeriörung Dutc) Mrotfäule verratenb; an̉bridjig. jo verrät der haubar gemordente Stamm dutrd)

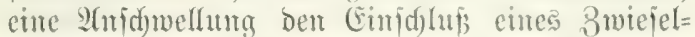
itummels und die Sirntheit Des Edofftes (รig. 40).

Im jugendidfen Altter fund Doppelgipfel vielfad) bie Folge vom Serhut bes normaten

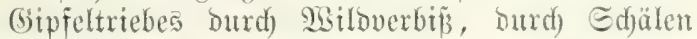
ınto Fegen Des Willoses, ieltenter Durd) Jnfeften

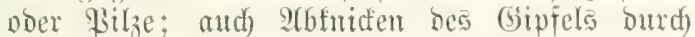
Bögel, Sagel, Sturm, Etoí, Spätroit fom Uriadye eituer Berboppeluna ber Erjatgitufel jein. Da bieje (sefabren den \$iflansen insbejondere anf

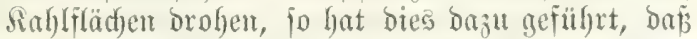

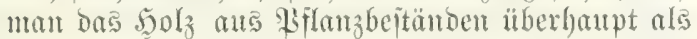
minberwertig gegenüber bem solze von $b_{e}=$

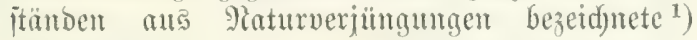
(รัติ. 41).

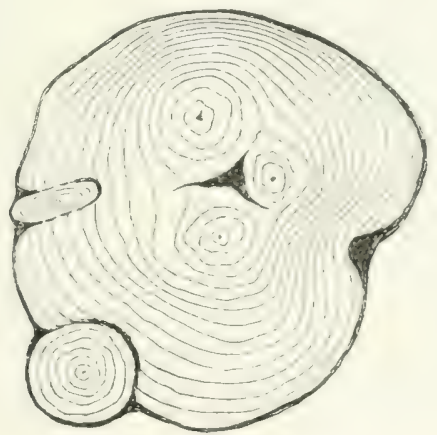

Jig. 41. 2uล ber Bुernad)jung von brei (Sipfern (ein

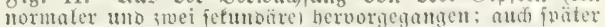
entitanoen Eopnelginfel, welobe an ibrex bafis anf cincu Teil ihrer sänge mit bem Etamme verivudjen.

\section{c. Zerreijung der gefunden Bellfafer.}

Reru= ober Matfifie, Epiegelfuafte, Strableuriffe

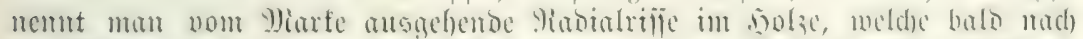

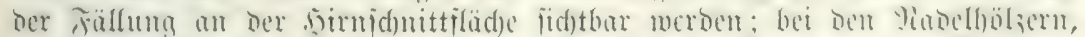

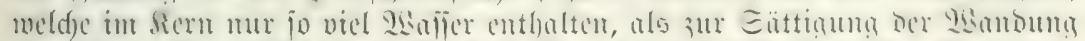

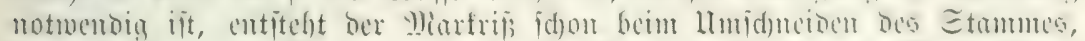

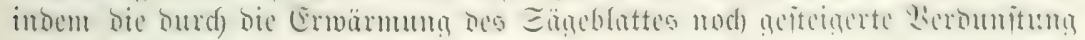

1) Dr. (5. Brąmann in Bante Bentralulatt 1886. 
cin $\Xi$ d)winnen hervorruft, bas in cinem anfünglidg iefr feinen, an ber \&uft

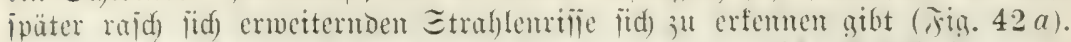

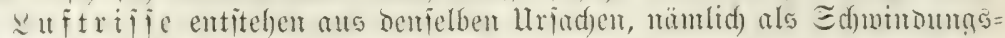

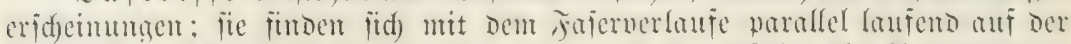

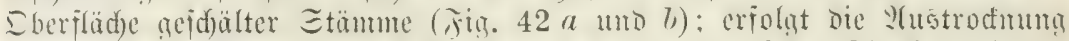

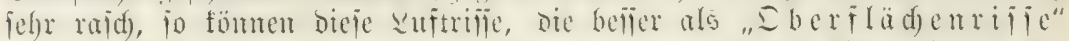

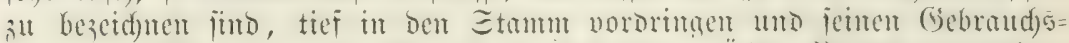

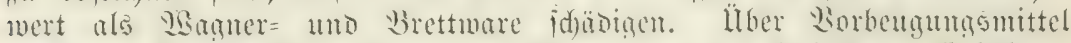

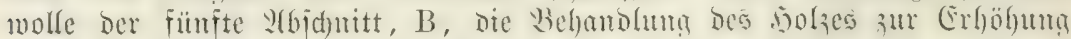
feiner Ëgenidaften, eingejehen werben.

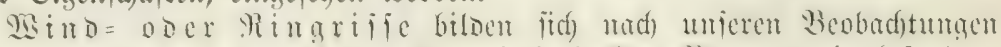

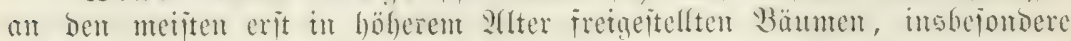
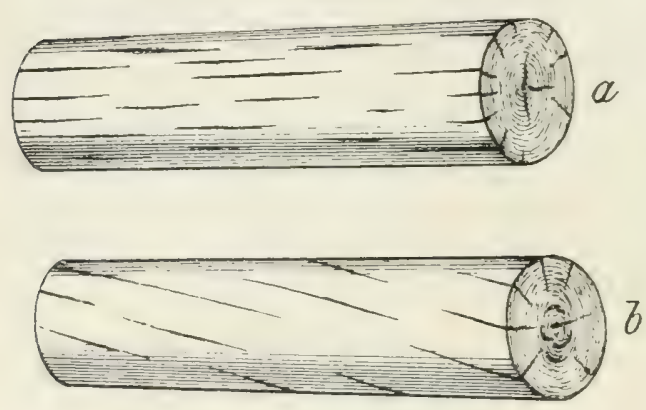

Jig. 4... "getaofajeriger Etamu mit :uftriilen an oer

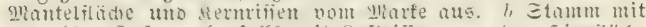
gebregter Jajer, pbenfalls mit Euftrifien, an ber sirniläd) aud) in mit morifien.

an ben Sdjirmitändern in natürlidjen Berjüngutgen. Sie fut hervorgerufen burd) Die itärferen Bemeguntgen Der Stämme bei 23 ind, wo= bei bie Iremmung ber $5_{2} l_{z}=$ lagen eine bem Jahreșringe parallele iit (Jig. $42 b$ ). Dieje Berreipungen finden mur ba itatt, wo ber Stamm auf jeine Jeitigfeit burd) bie Syebelwirfung ber an ber Sirone angreifenden Siraft all meijten beariprud t) ijt, bas ijt ber tisurzelfals แก bas etina $1-2 \mathrm{~m}$ am Sdjafte fidj anjuliejente

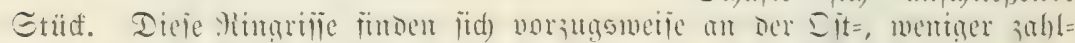

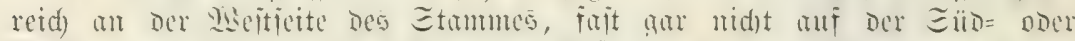

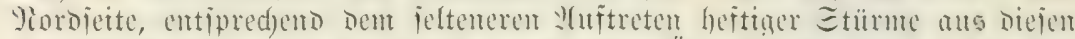

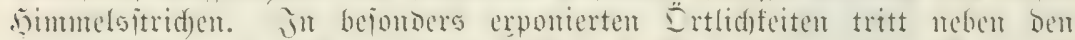

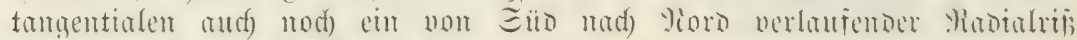
mitten burd) baร M)arf auf (Fig. $42 b$ ).

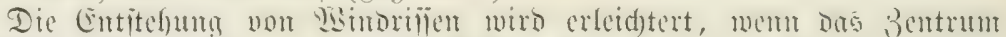

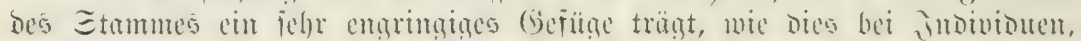

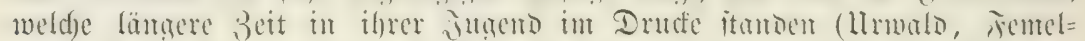

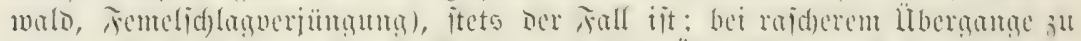

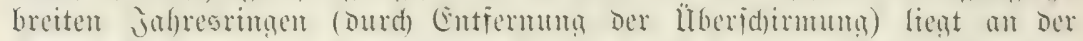
Grenze bes eng=

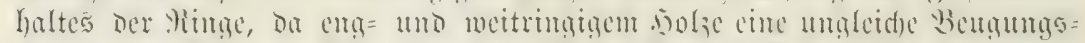

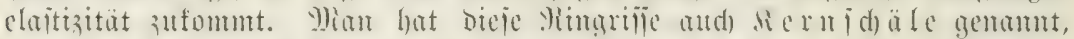

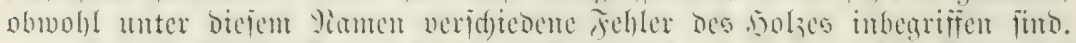

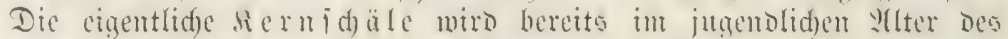

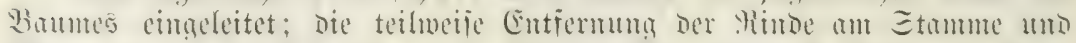

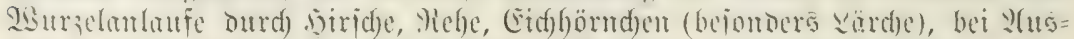

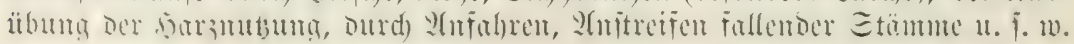




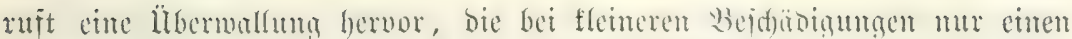

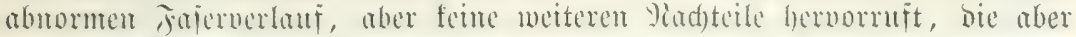

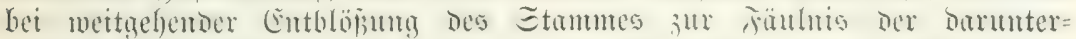

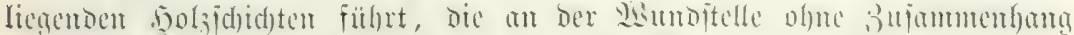

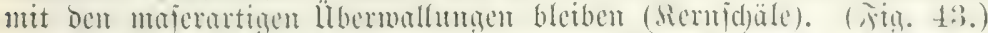

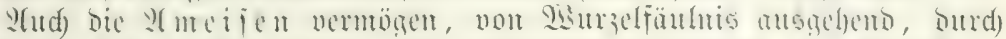

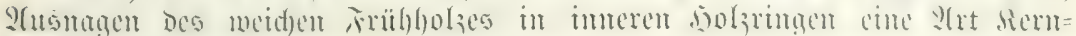
fdjäle herworzurufer.

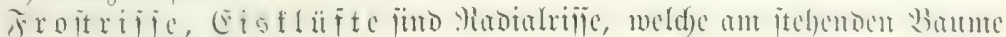

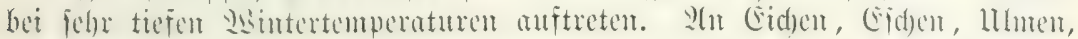

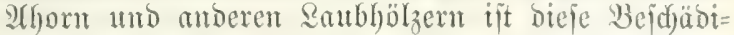

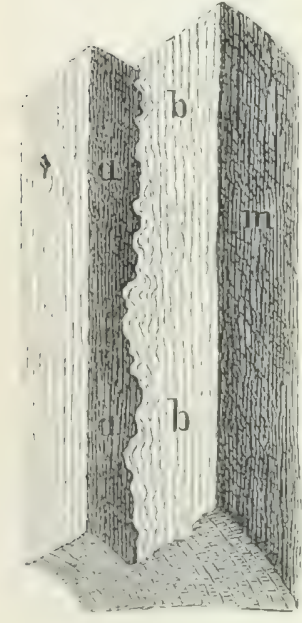

Fig. 43. na vom Motruilbe eimitens gejdülte Flüd)e, ge= brannt; $1, b$ bie barauffolgen= Den If nllmathlit in normalfajtriges Sul; inorgebeno; Etamu ;u Jubzhol s unbraud)bar. gung bäufiger ala an Siabelhölzern. Für bie Ent=

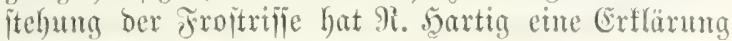
abgegeben, bie allgemetne

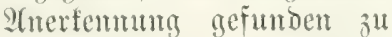
Gaben jdjeint; er erflärt: beim Gerrieren tritt bos

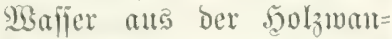
buta ats und zmar um jo mehr, ie tiefer dic Tentpe= ratur finft, bis entolid) in= folge ber 2Ututroctututa Sdjmindrifle entiptehen. Dieje Ertflärung hat Durdé) unjerc Interjudungen feine bese itätigung gefunden; es ipredyen Die Berjudse porvie Das ganze phyjuffalijd)e und medomiche Berbalten Des aefrorenen solzes dafür, baib da

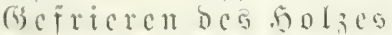
in oc verbleibt; das 2 ufreifen

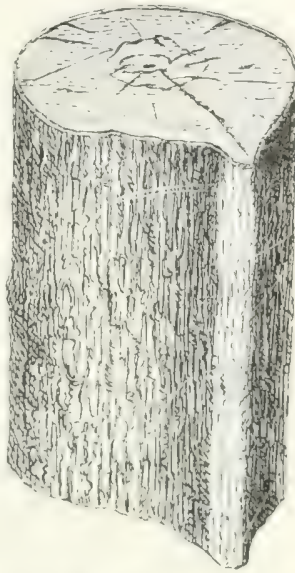

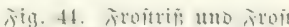
Leive; iibrige Yiac om Eater joutite surth !lastrotnen ent fíanoert. ber Stämme bet jehr tiefen

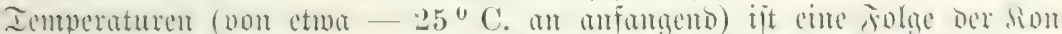

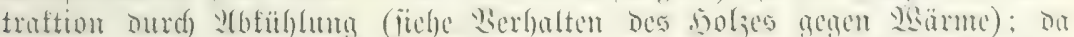

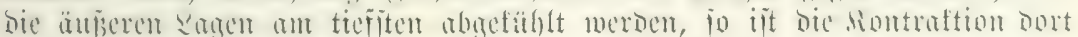

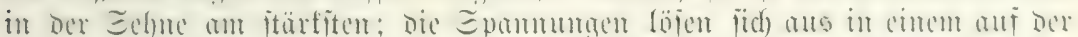

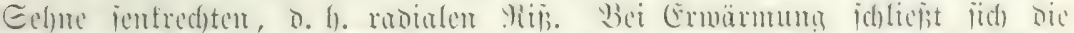

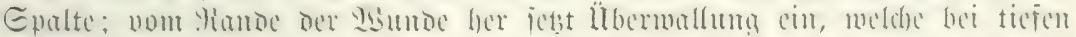

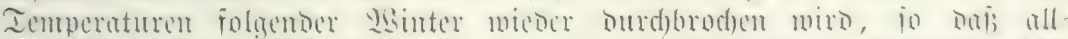

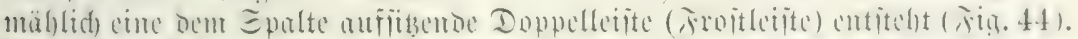

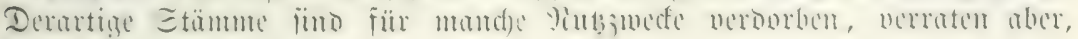
baji jie gut jpaltbar jüto.

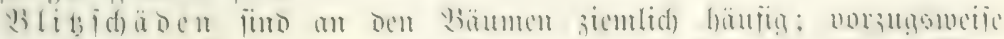

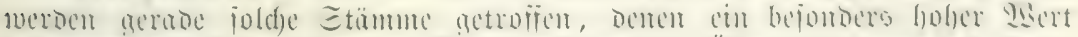

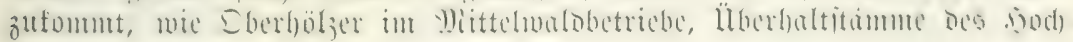




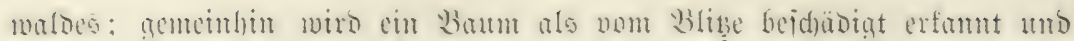

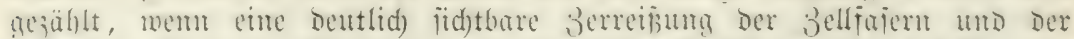

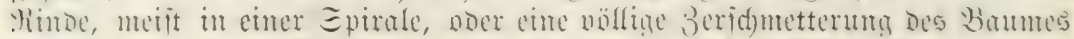

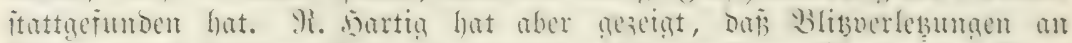

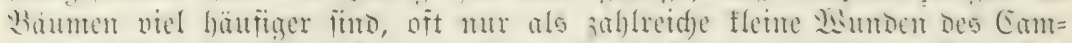
biums eridecinten, interlid) übermallen, aber Dod) bei meiterem Iidemads s= tum aud) äuferlid) fidftbar merom milifen. Vianelhölier iterben meijt jofort

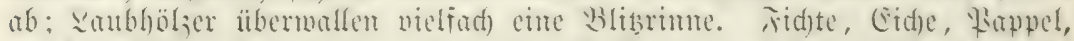

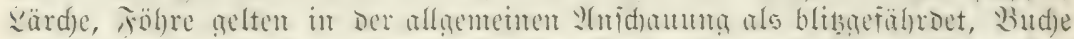

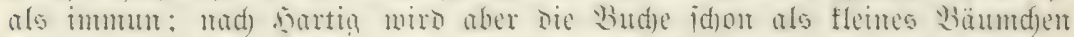

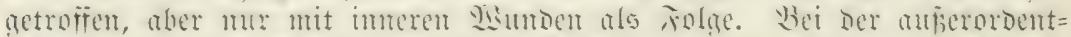

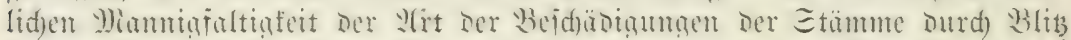

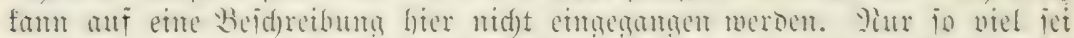

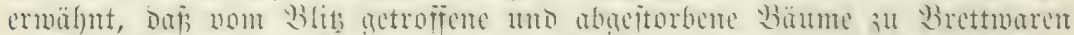

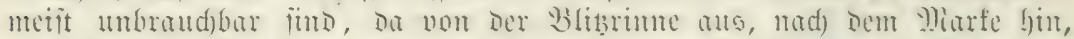

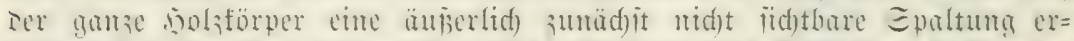
fahren hat, Die aber ipater jid) unlieb offenhart Durd) Serfallen Der bretter.

Unter Den Iieren, melde cine Beritömen ber gejumben nolifajer ver= uriad)en, mären mur jente hier abermalo atijüählen, Deren idjon bet ber

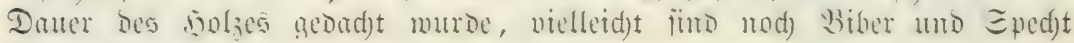

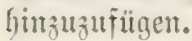

\section{d. Erfrantunger bูolzfajer $\left.{ }^{1}\right)$.}

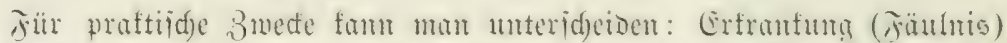

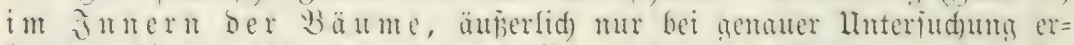

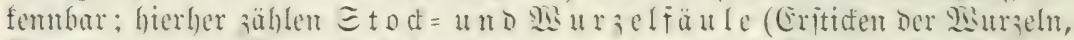

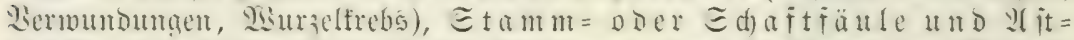

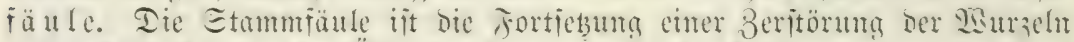

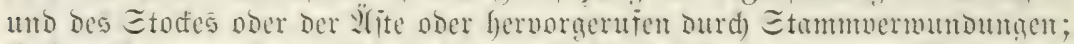

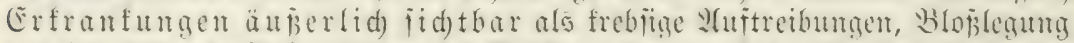

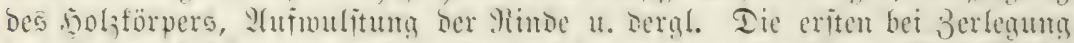

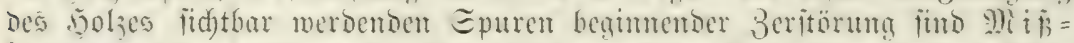

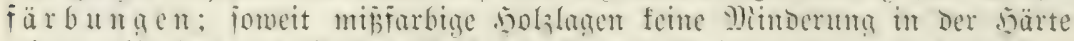

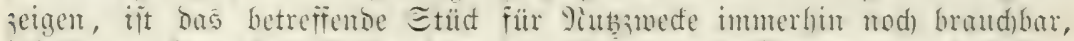

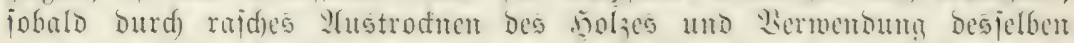

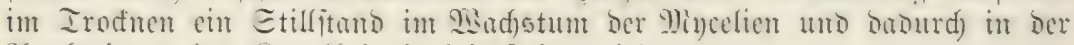
Atubreitung Der Siranfbeit herbeigefüfrt miro.

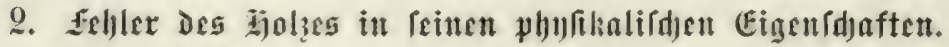

a. Farbenfehler, D. h. V(bmeiduman won Der nomalen farbe bes Eplintes oder diernes, beuten sumeitit anf Erfranfungen und begimmende

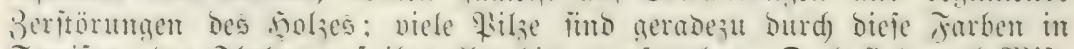

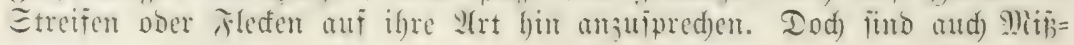

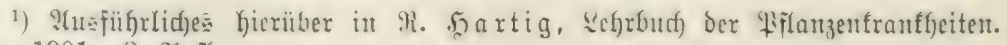
B̈erfin 1901. 3. 2lự. 


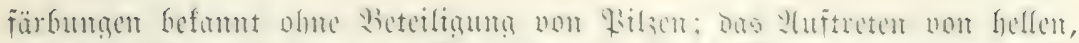

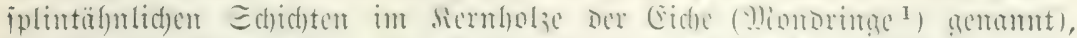
Die idsmad)e (E)

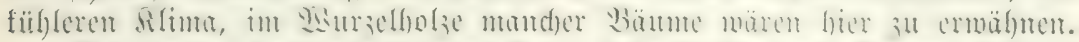

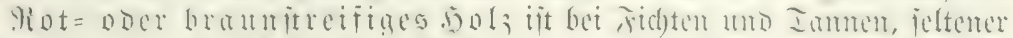

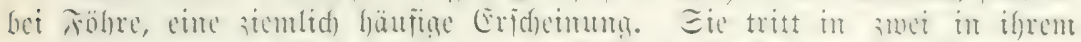

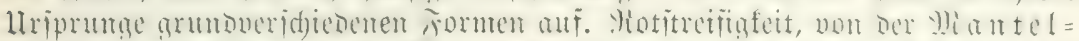

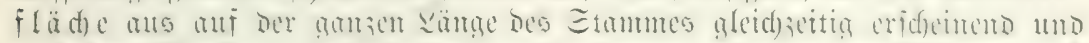

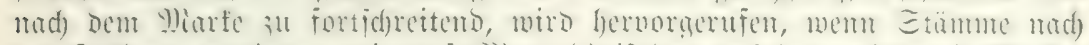

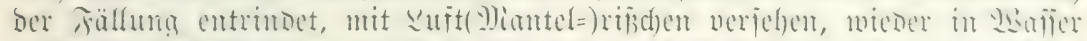

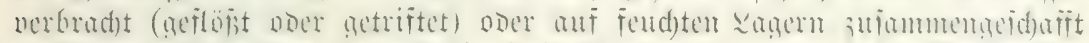

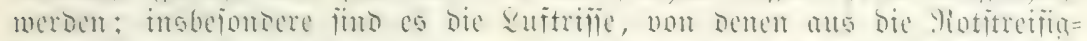

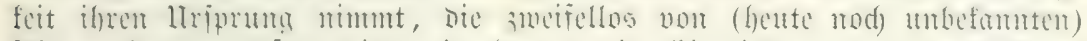

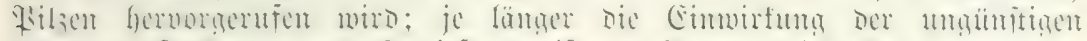

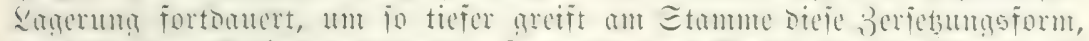
zunäd)it Den Eplint seritöreno. ie nad) Dem (Grade Der Beritörung i it

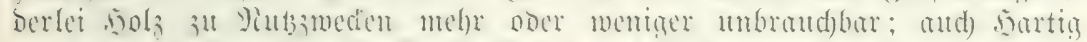

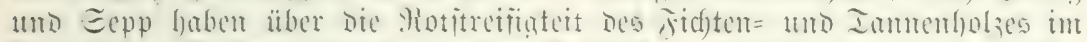

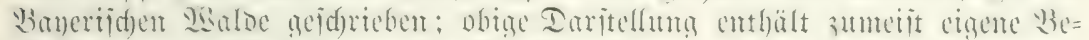

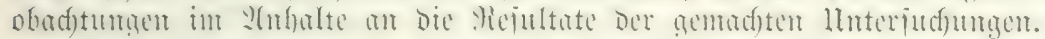

Eilte zweite Form ber Motitreifigfeit geft wou $3 \mathrm{er}=$ ictsug th

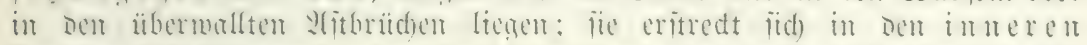

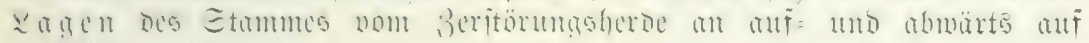
veridjicdene Ränge.

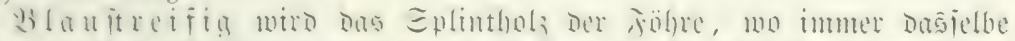

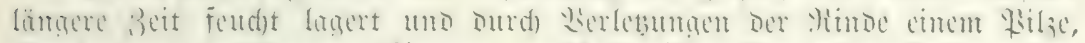

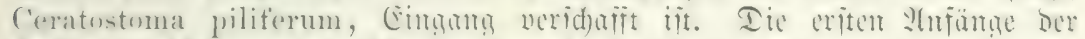

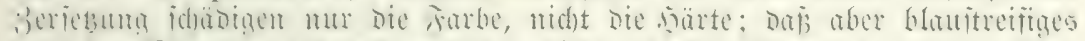

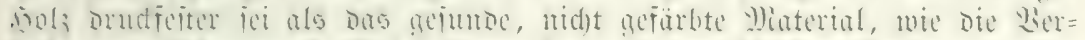

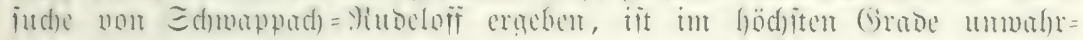
idjeinlid).

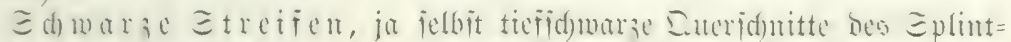

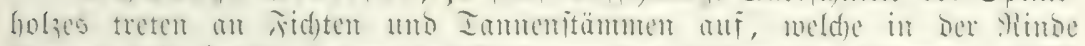

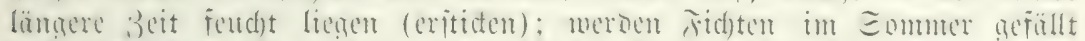

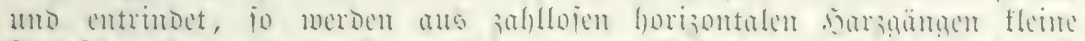

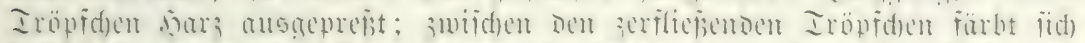

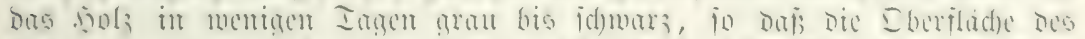

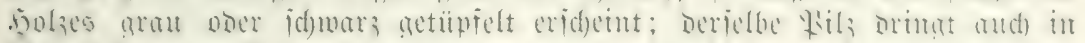

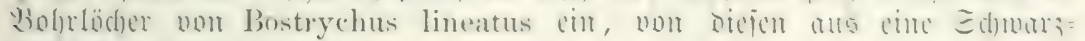
itreifigleit hervormifento.

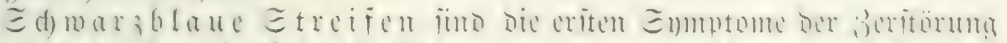

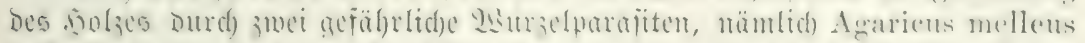
und 'Trametes radiciperda (Polyporus annosus); infde Earifur funden iid) baher vorwiegento im unteriten Edjafteile.

1) Son Boppe und (5. Mter (La Lanure du chêne. Rév. des eaux et forêts

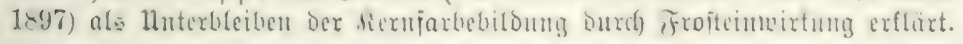

(3) a $)$ er, Foritbenuţung. 9. 2uft. 


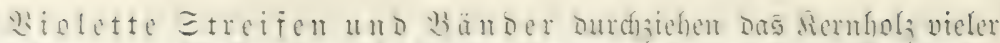

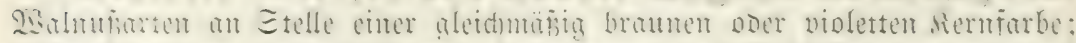

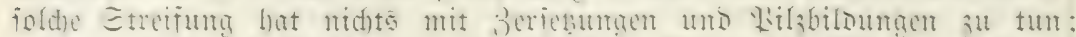

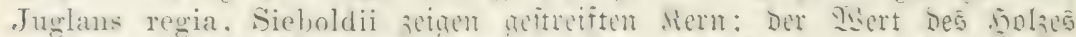

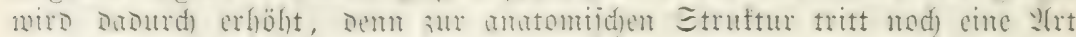
jarbemmajer.

(iva

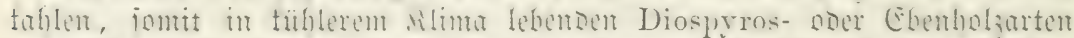

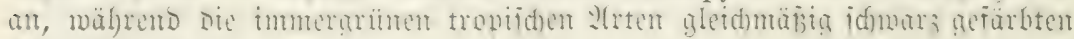
fiern beliken.

(ij)

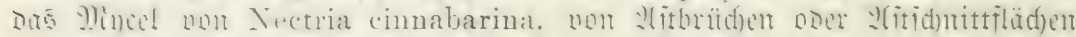

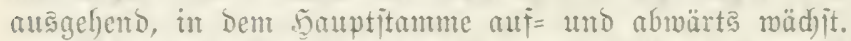

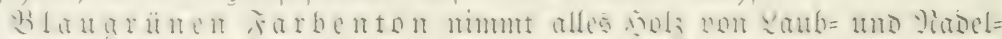

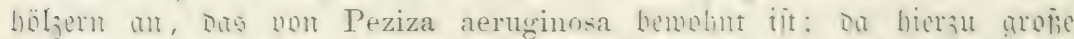

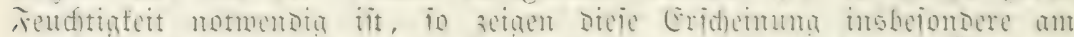

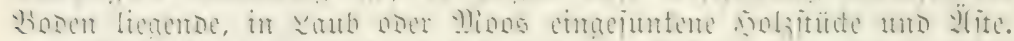

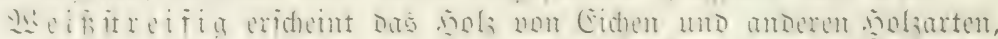

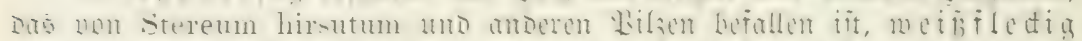

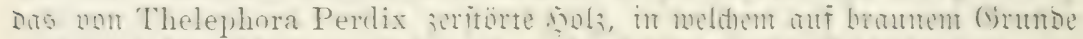

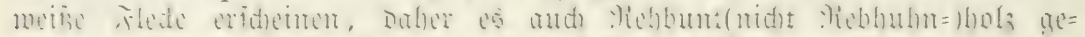

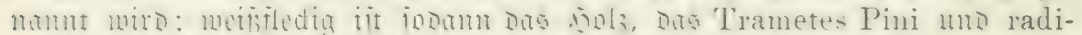

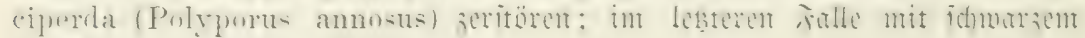
Flectchen aü weipent Grunbe.

Der rote bis grabraune J゙arbitofi im Rerne Der Rot=

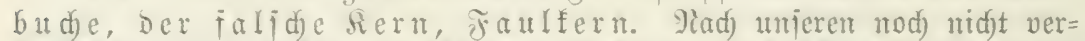

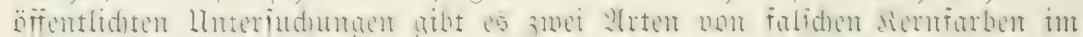

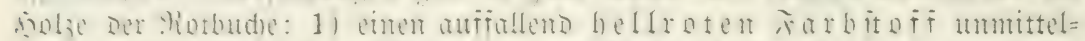

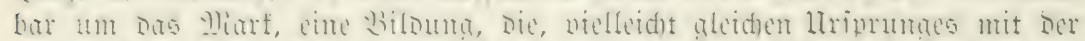

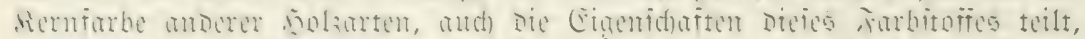

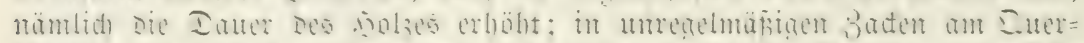

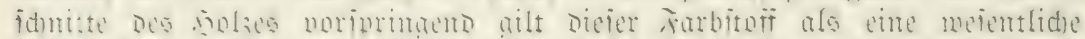

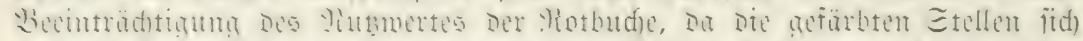

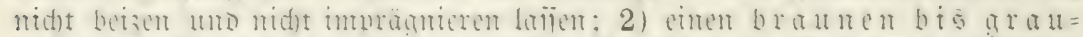

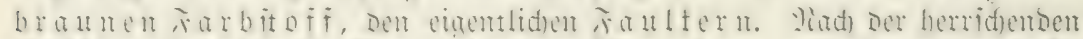

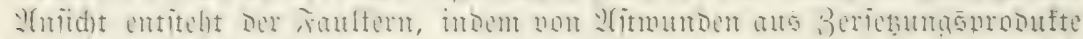

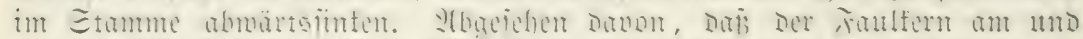

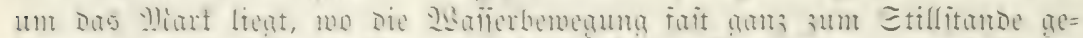
tommen แn Dicictbe

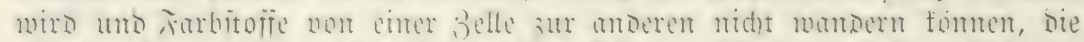

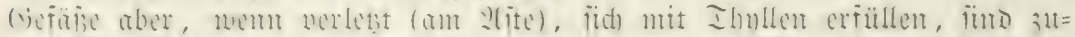

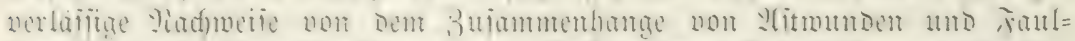

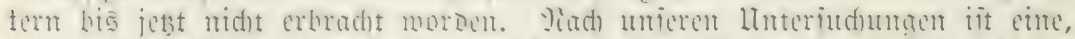

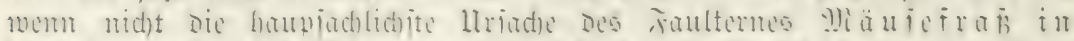

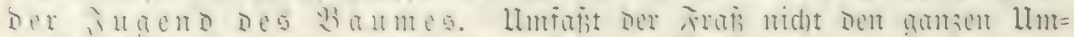

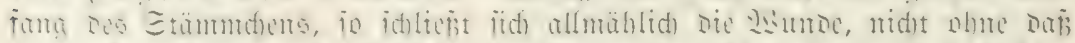

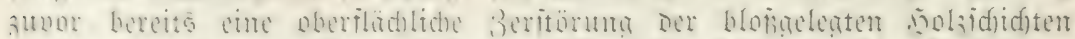

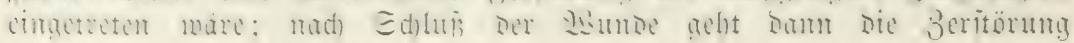




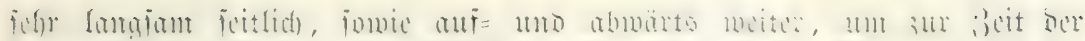

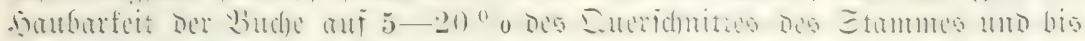

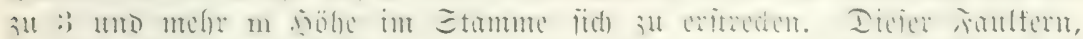

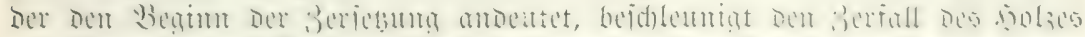

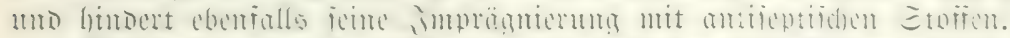

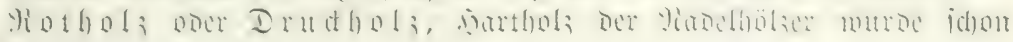

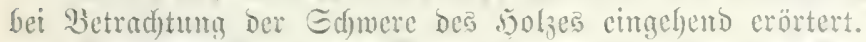

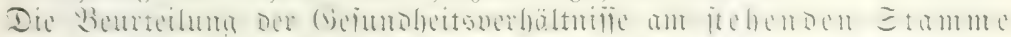

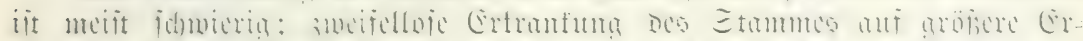

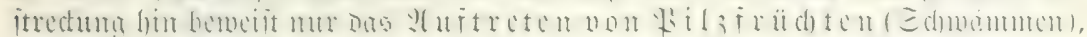

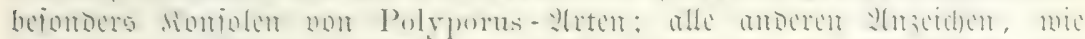

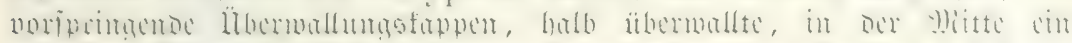

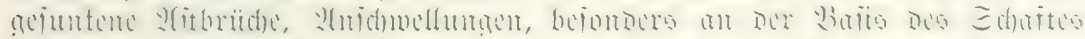

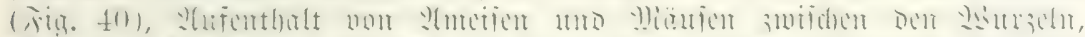

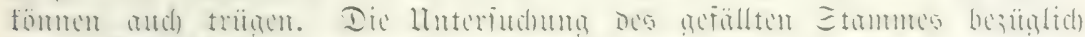

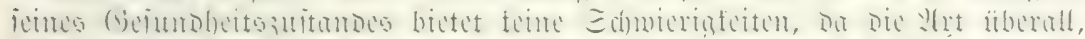

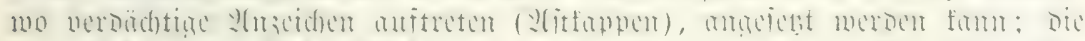

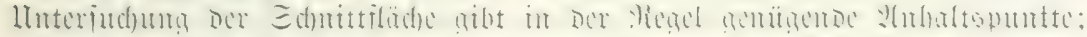

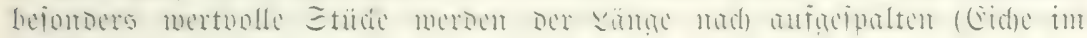
Speijart).

\section{b. Fefler im (berad d e}

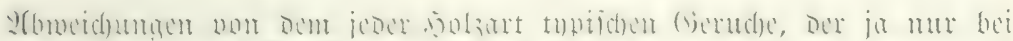

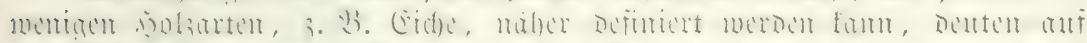

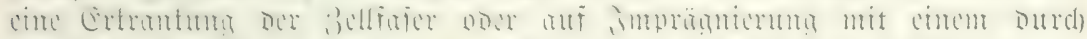

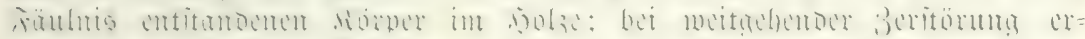
imtert ber (berud) atr Wilse.

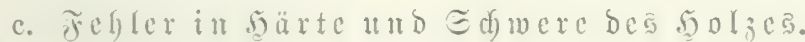

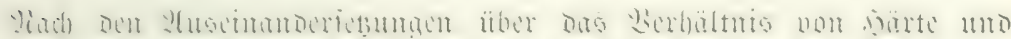

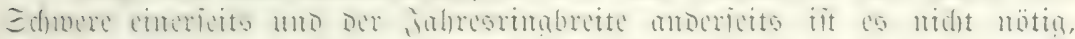

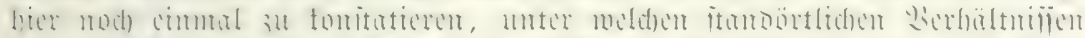

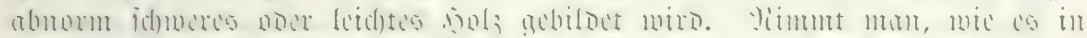

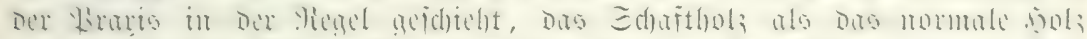

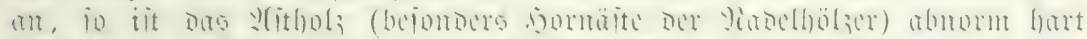

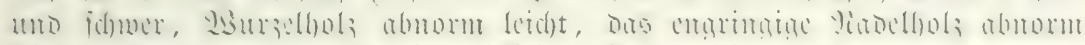

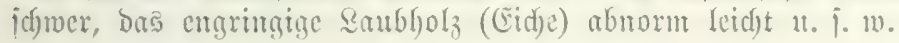

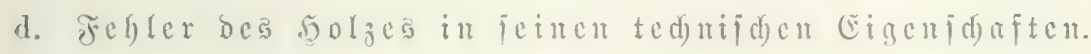

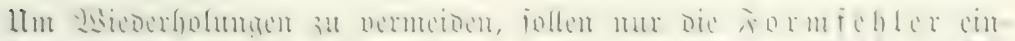

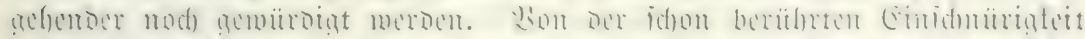

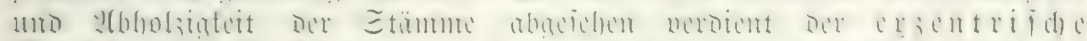

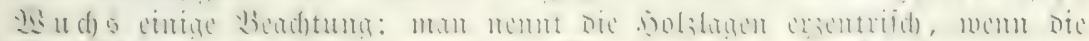

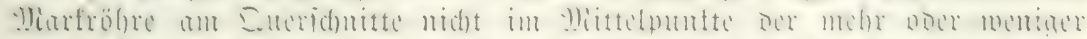

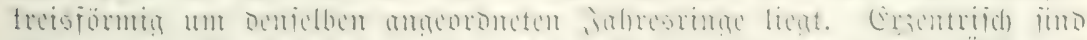

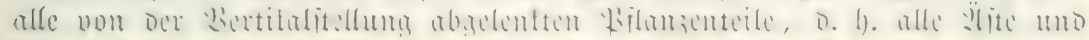




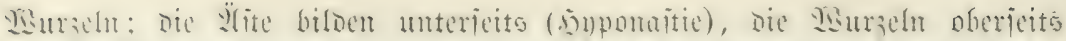

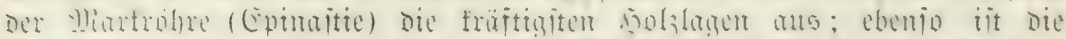

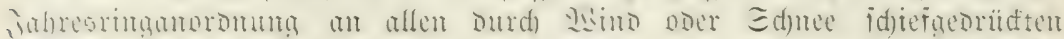

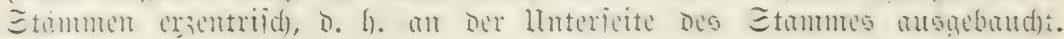

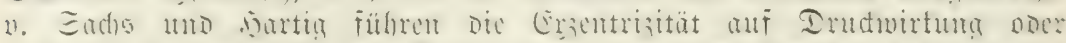

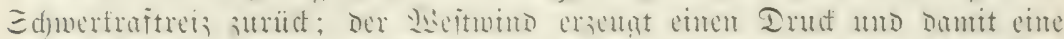

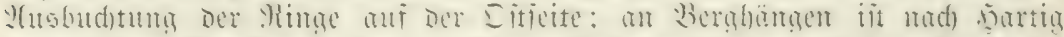

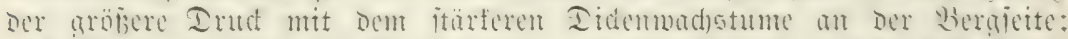

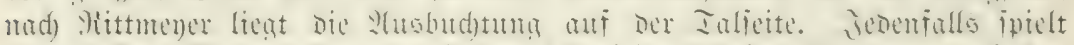

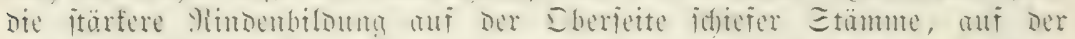

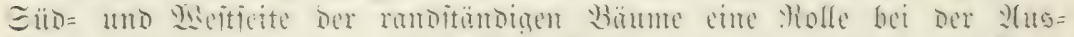

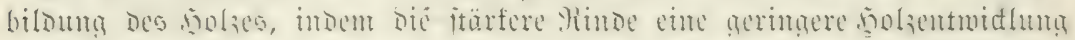
im Gefolge hat.

ङ pan ä

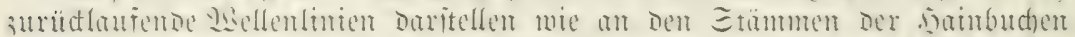

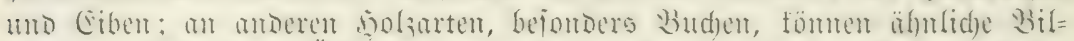

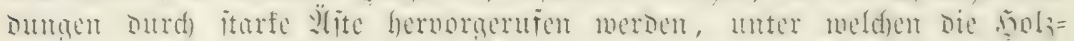

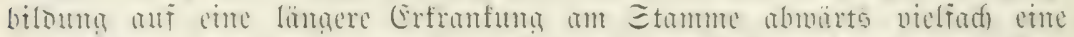

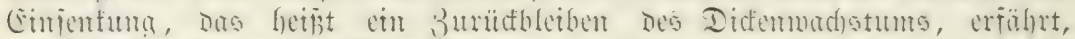

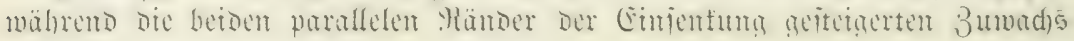
nupweijen.

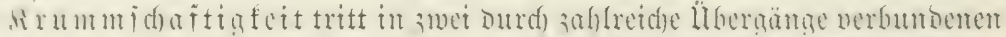

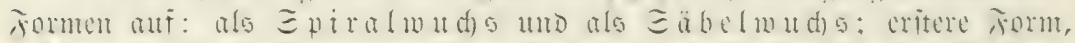

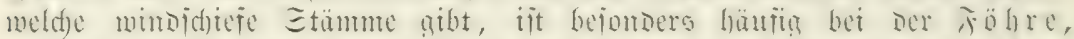

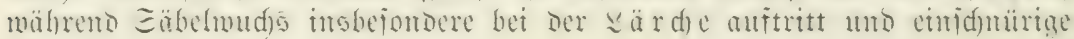
Stämme liefert.

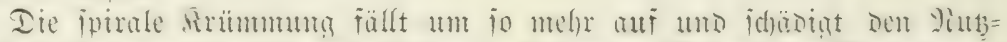

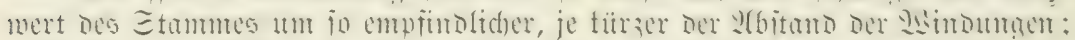

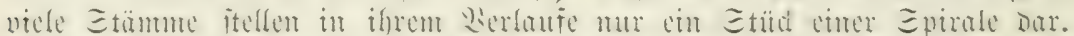

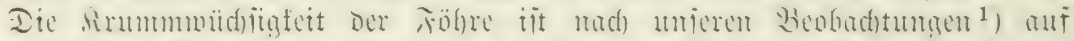

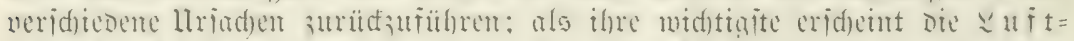

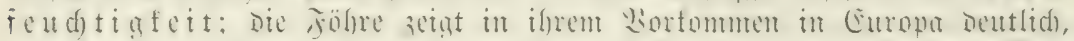

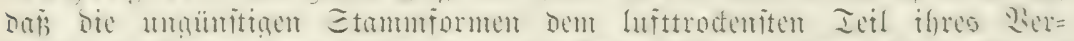

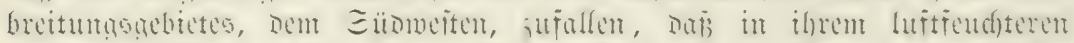

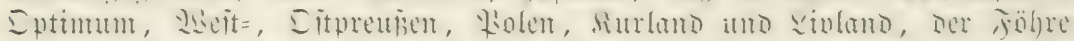

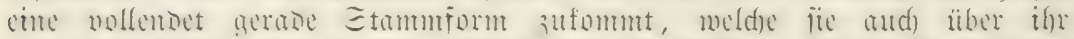

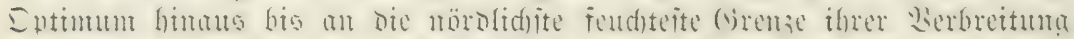

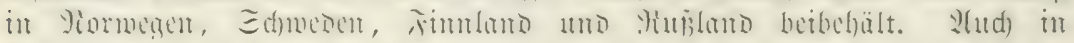

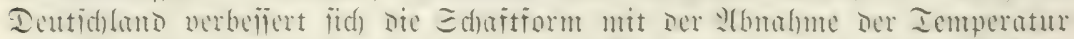
4mD 3 )

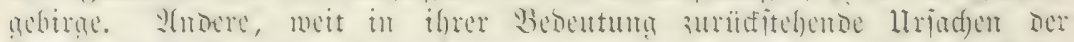

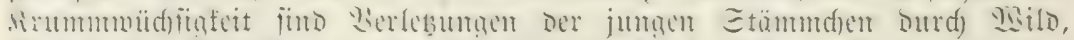

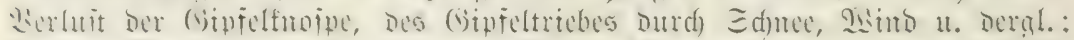

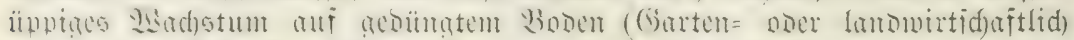

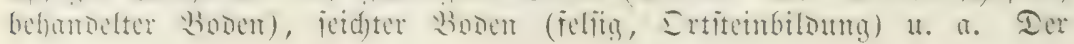

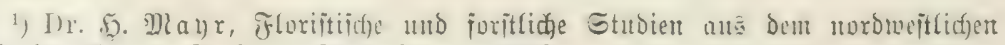

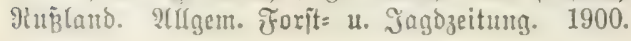




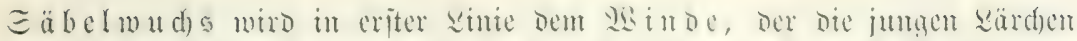

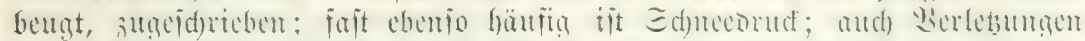

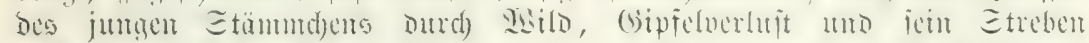

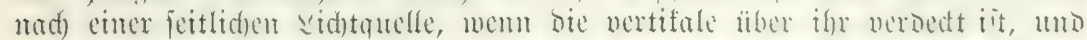

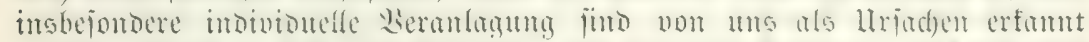

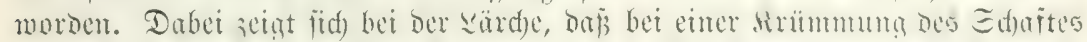

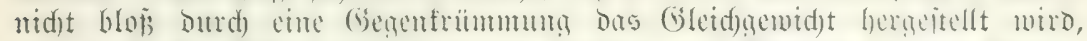

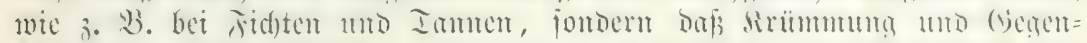

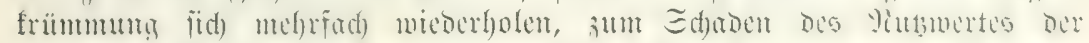

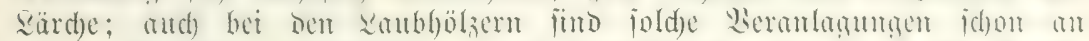

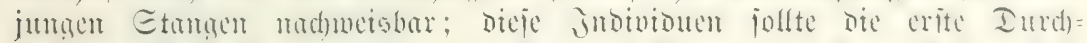

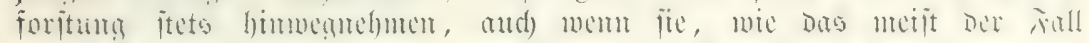

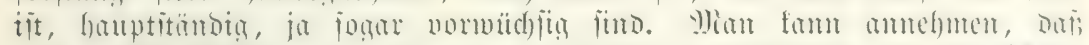

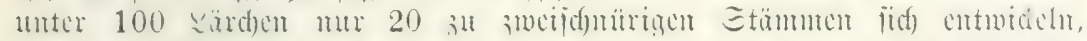

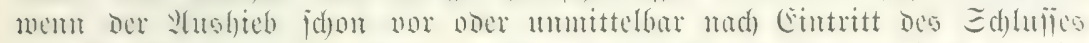

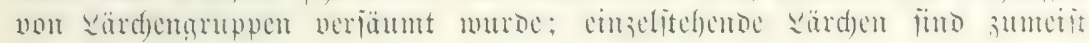
frumtm.

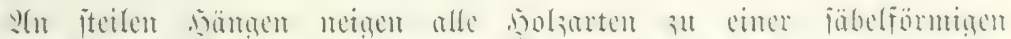

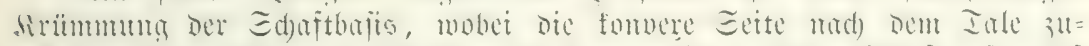

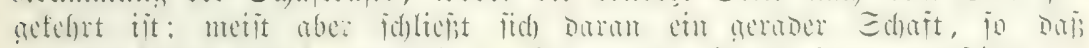

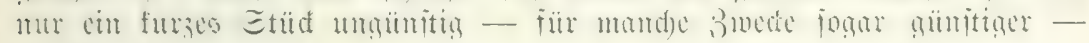
geformt ijt.

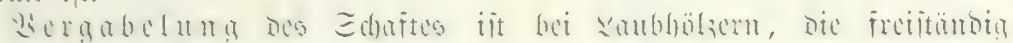

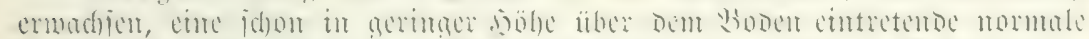

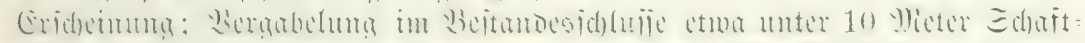

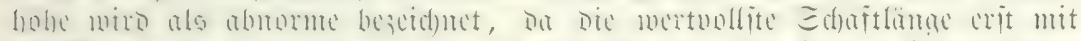

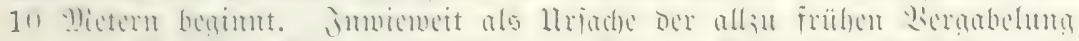

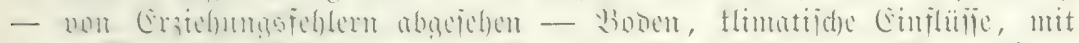

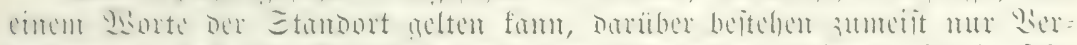

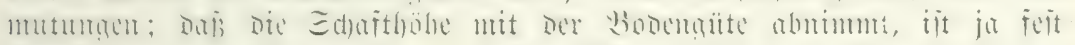

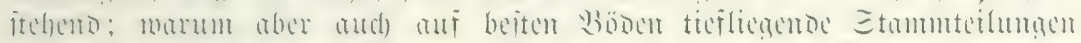

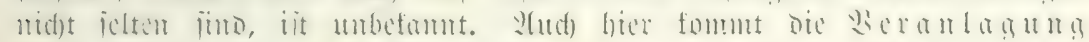

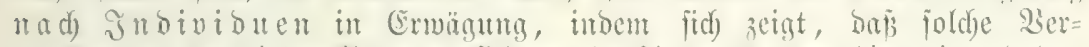

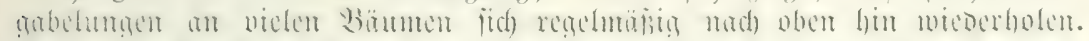

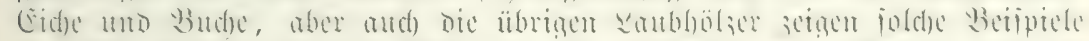

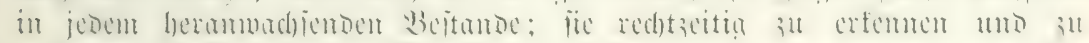

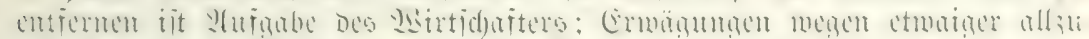

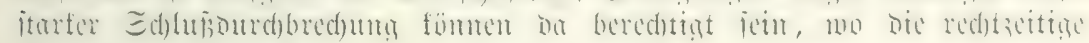
Čntnalume jolder Jnbiviouen veriäumt murbe.

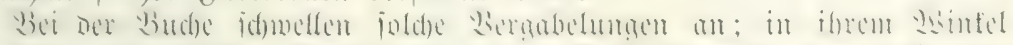

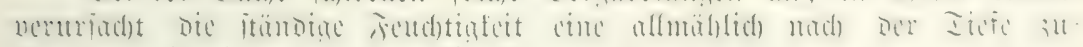

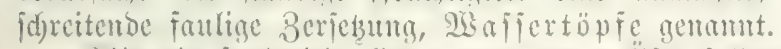

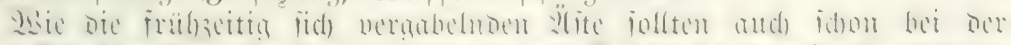

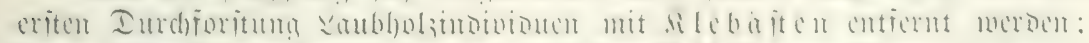

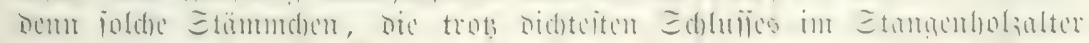

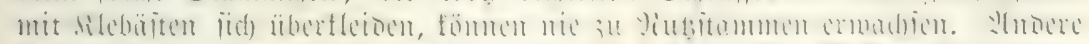

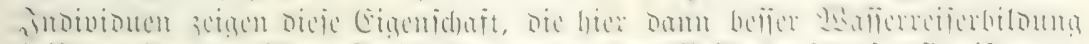

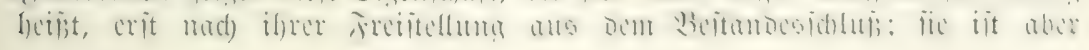




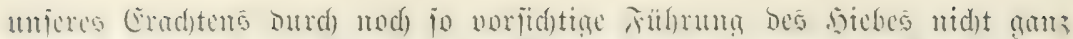

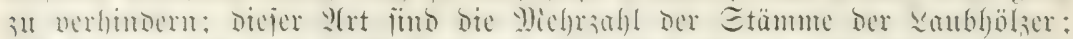

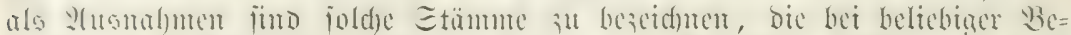

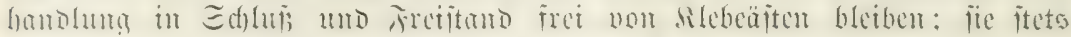

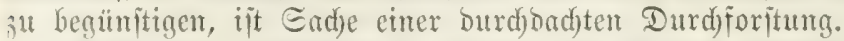

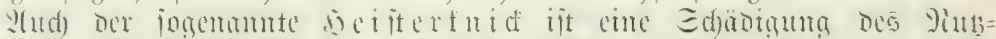

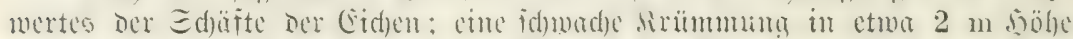

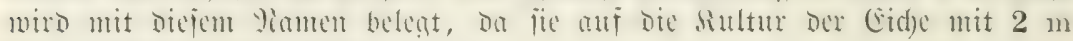
bohen Setitern zurüdgefülnt wiro.

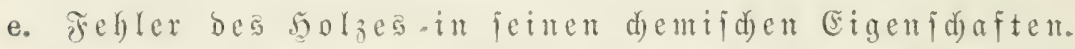

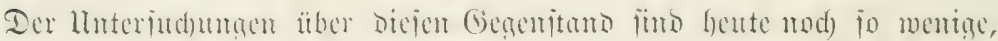

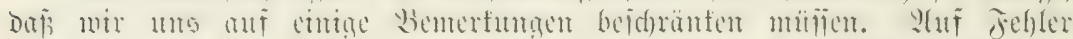

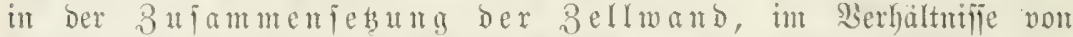
E

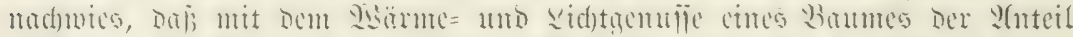

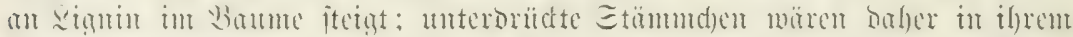

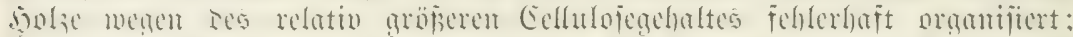

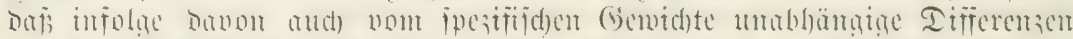

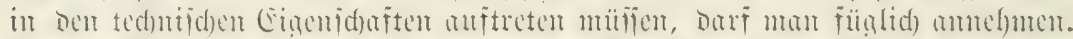
Jn oct

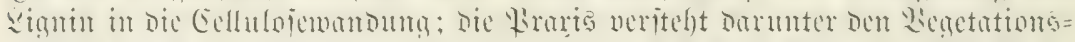

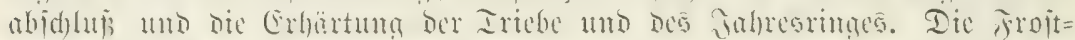

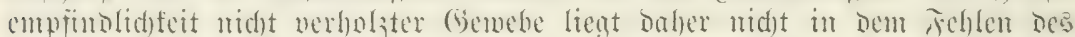

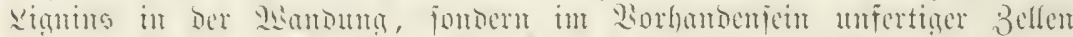

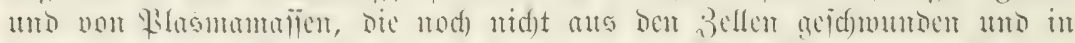

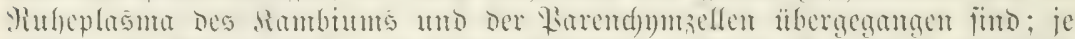

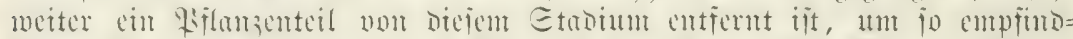

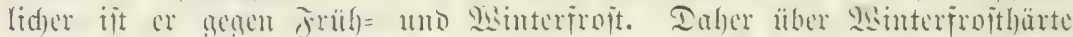

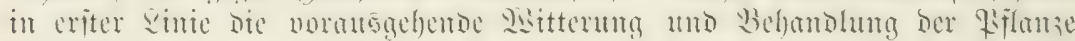
entidjetioet.

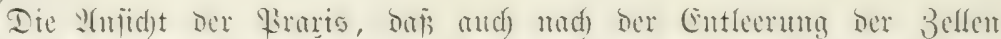

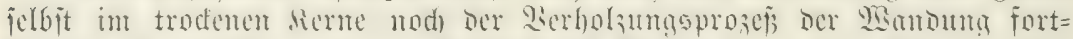

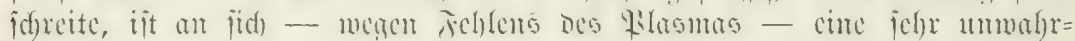
icheinlid)e uto aud bis beute nirgends nadjgerviciene.

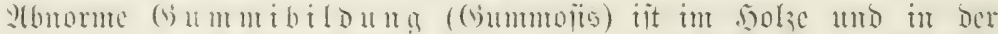

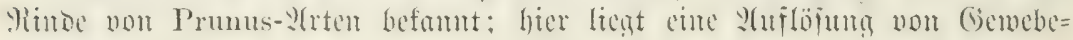
partien vor.

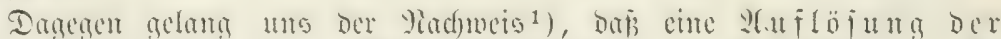

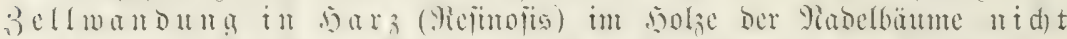

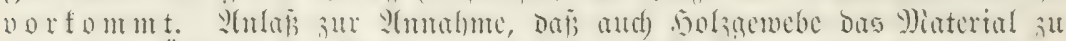

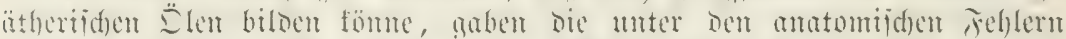

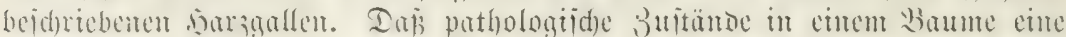

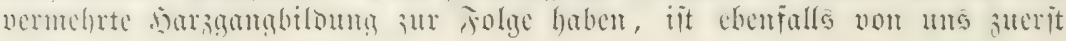

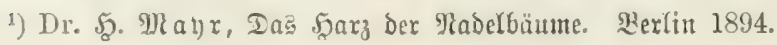




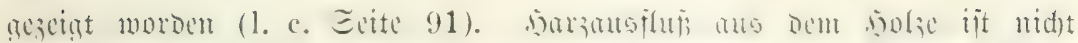

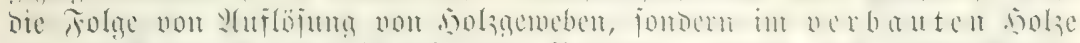

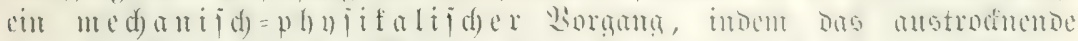
.)

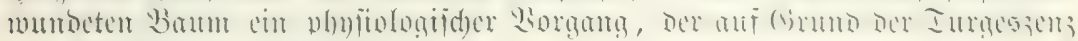
ber Semebe ben Sarzfluis bebingt.

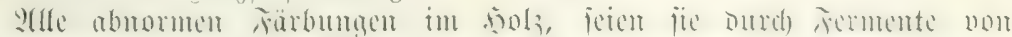

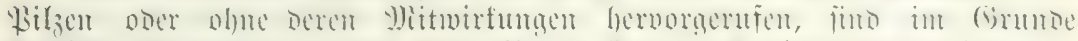

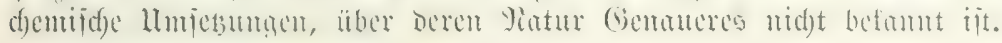




\section{3weiter 2lbjąhnitt.}

\section{Fällum!}

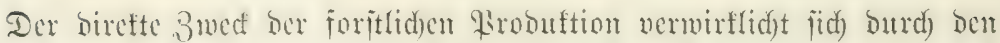

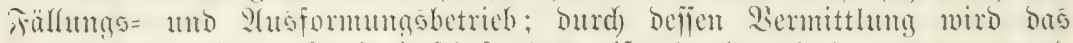

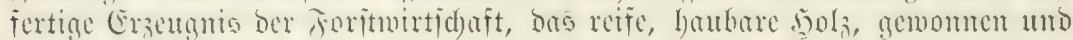
Der Sionjumption ïbergeben.

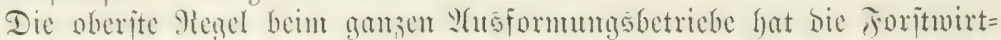

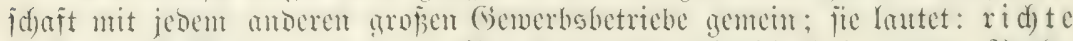

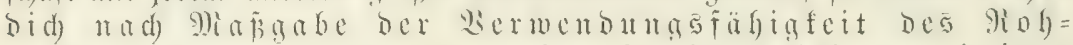
probuftes und, fomeit es olue Beeinträd)tigung beiner

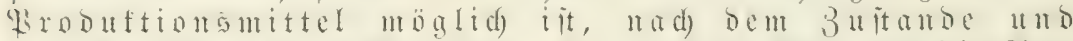

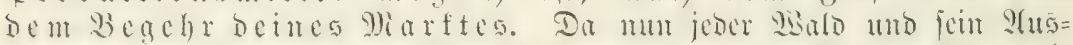

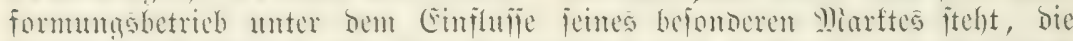

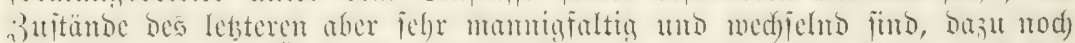

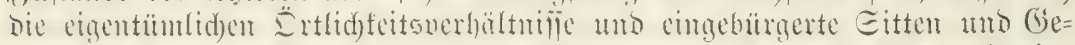

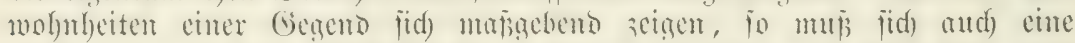

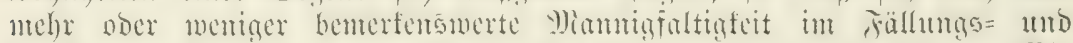

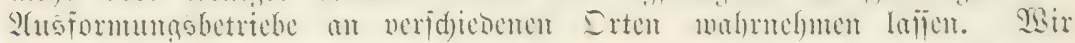

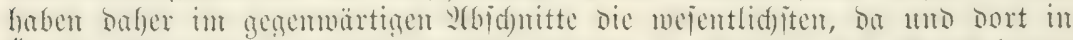

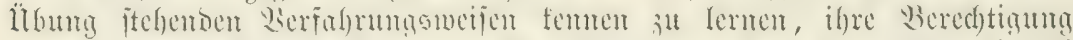

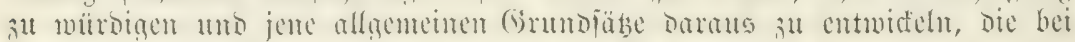

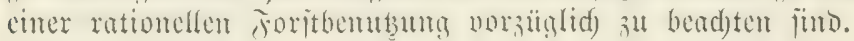

\section{Arbcitgknäftc.}

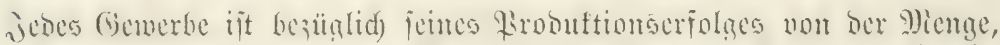

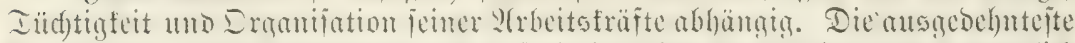

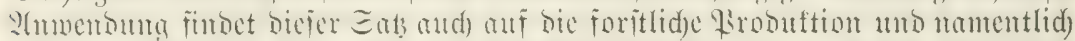

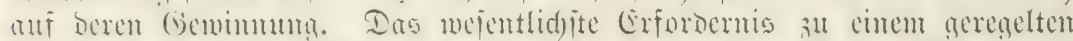

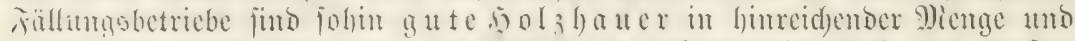

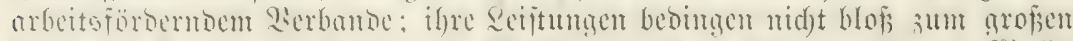

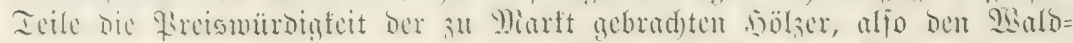

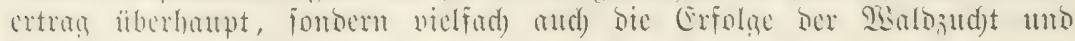
Darbpflege. 


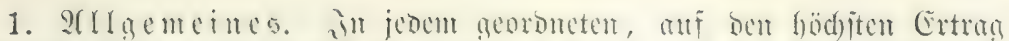

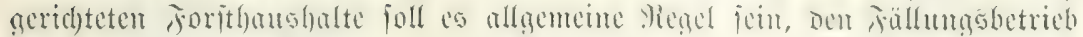

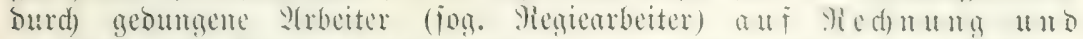

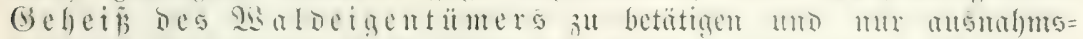

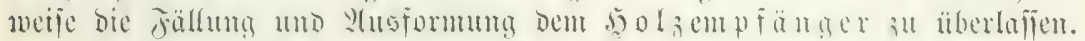

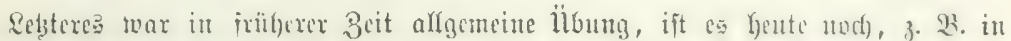

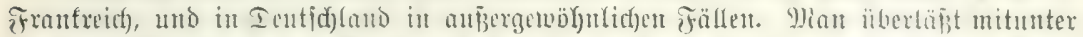

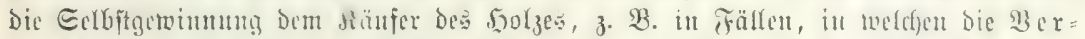

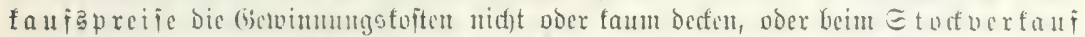

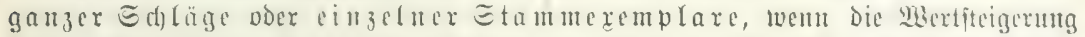

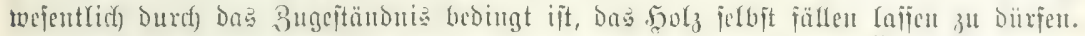

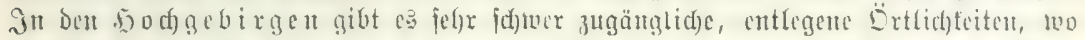

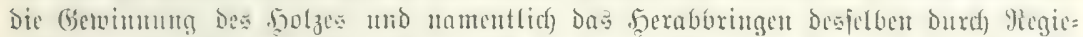

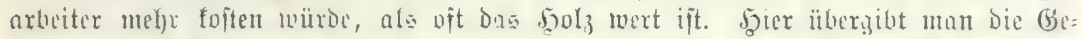

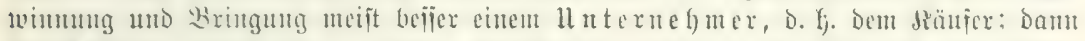

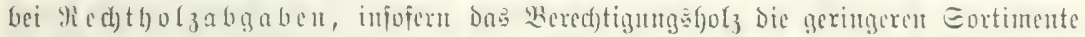

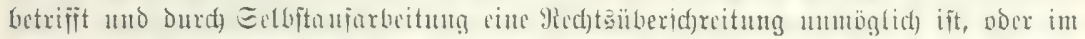

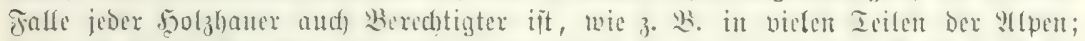

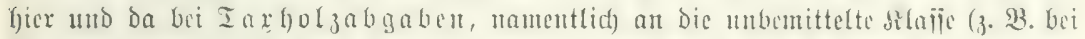

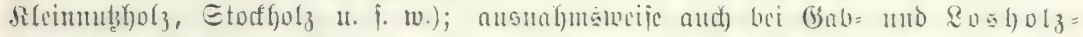

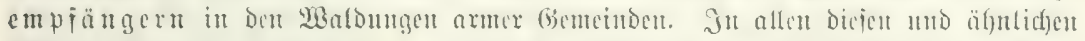

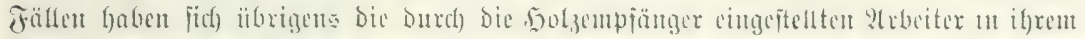

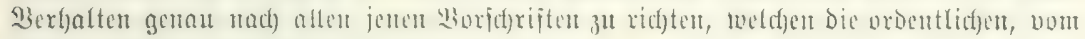
Maldeigentümer Geftellten f̧olzfauer unterlicgen.

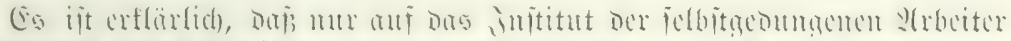

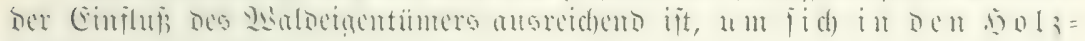

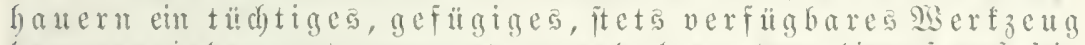
f)

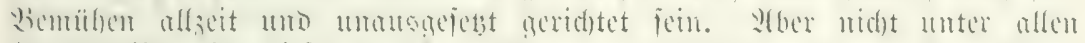

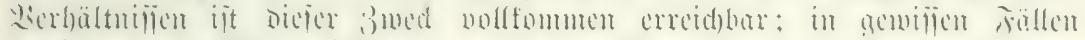

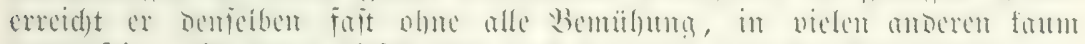

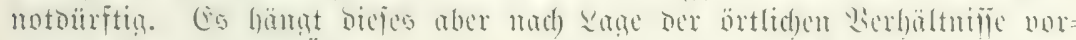

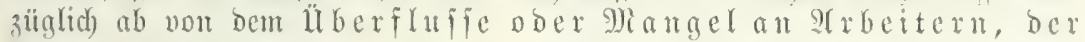
Dauer ber $23 a$ loarbeit mo von ben 3 ugeftändrifien, welde

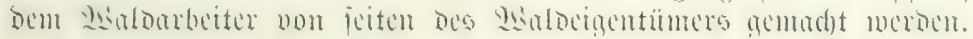

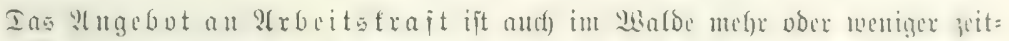

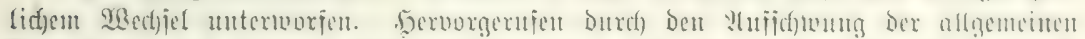

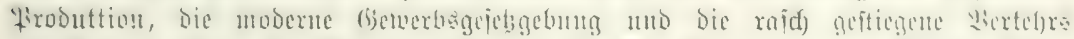

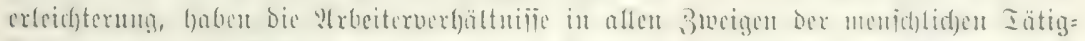

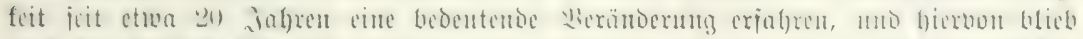

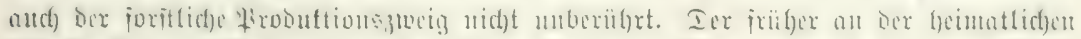

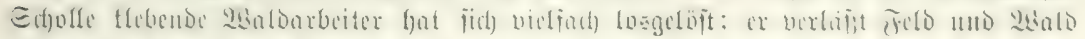

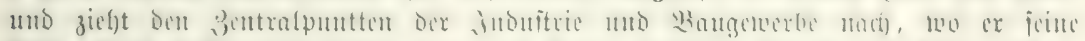

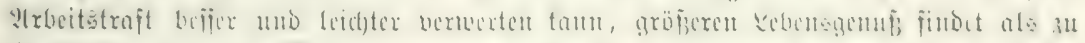

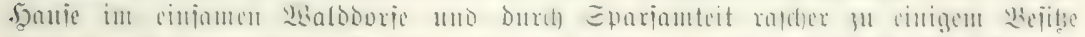

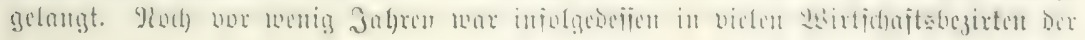




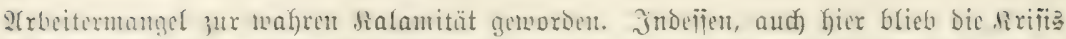

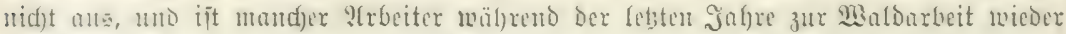
3uriugfgetelyrt.

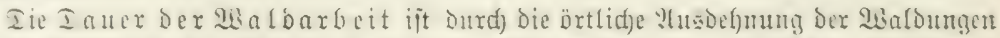

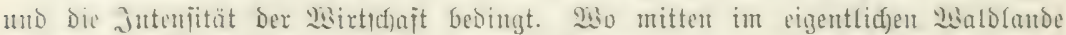

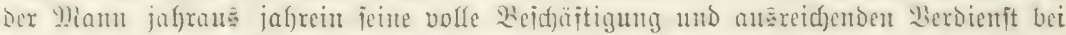

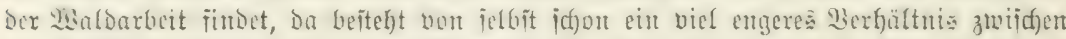

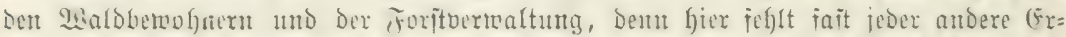

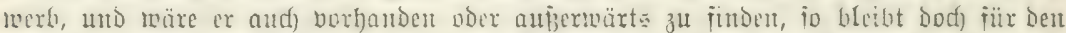

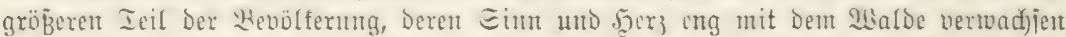

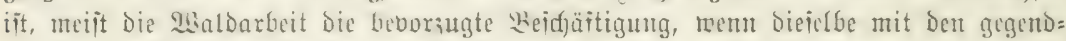

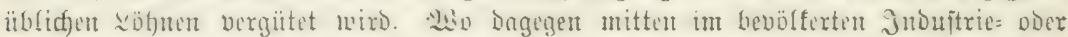

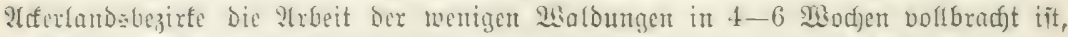

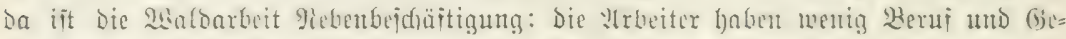
jchif und genügen meijt nux ben bejdyeideniten Anjorberungen.

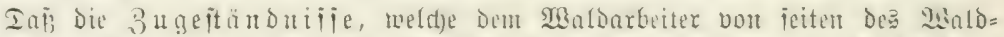

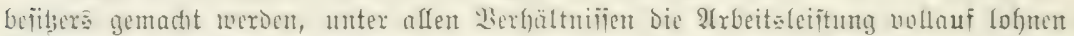

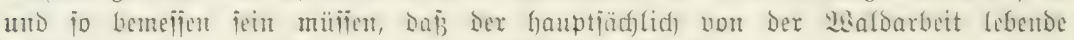

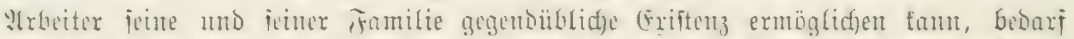

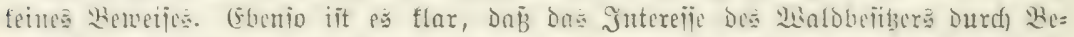

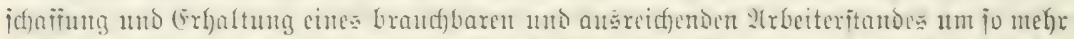

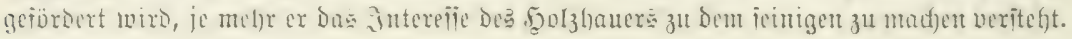

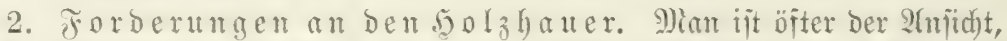

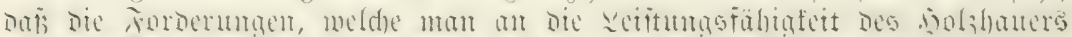

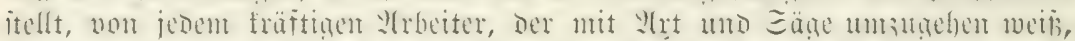

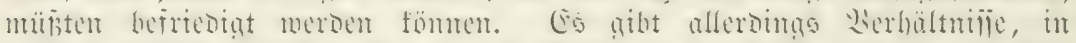

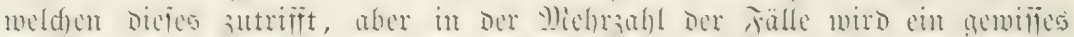

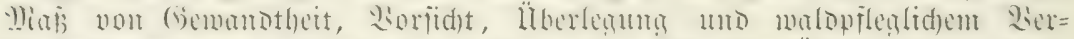

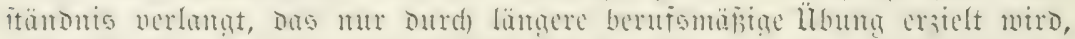

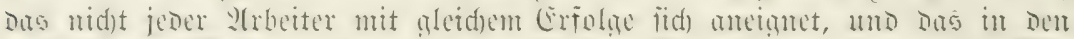

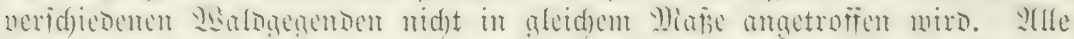

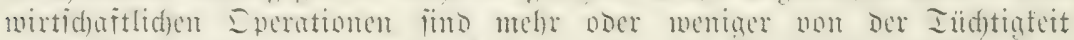

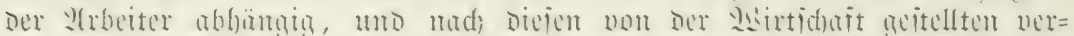

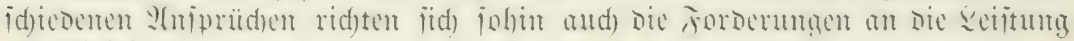
Der 2 rrbeiter.

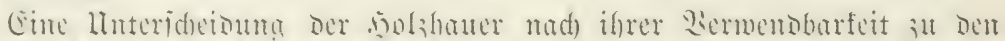

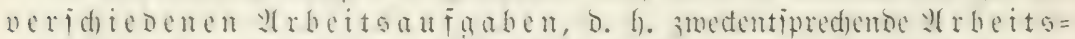

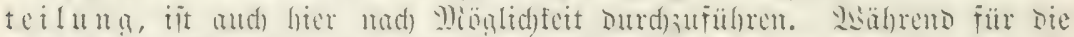

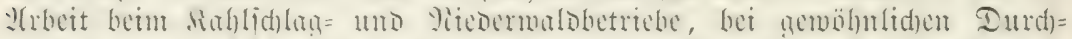

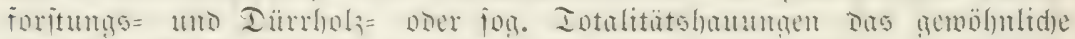

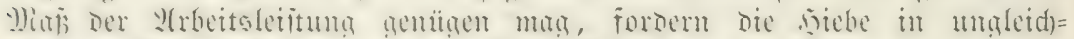

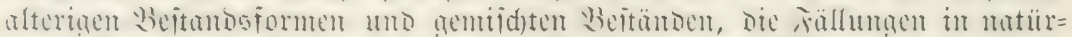

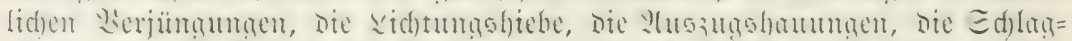

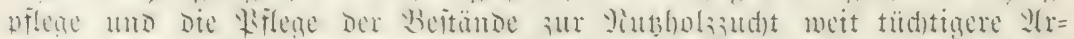

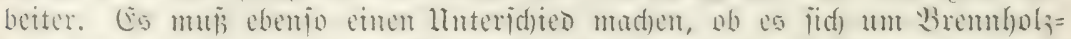

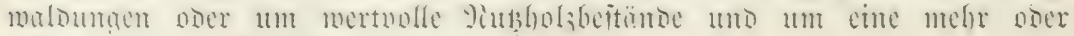
weniger jubtile 9iubgolzaus̃ormung banbelt. 


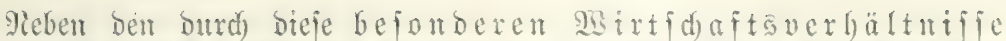

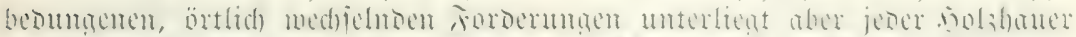

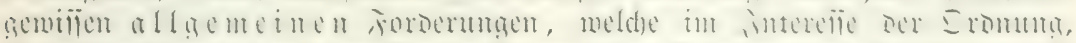

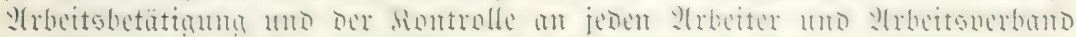

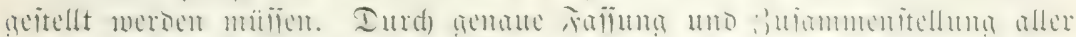

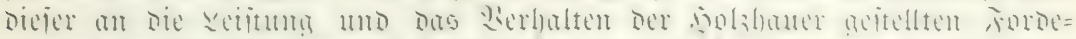

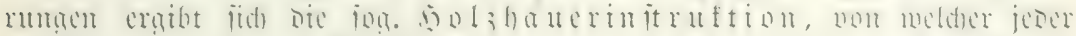

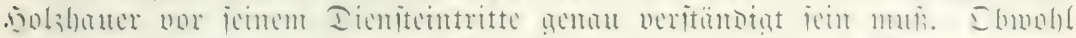

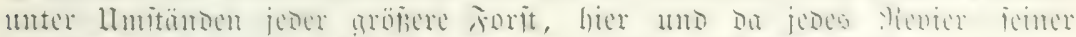

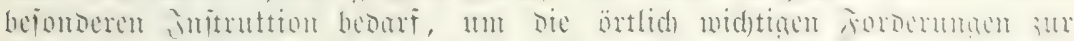

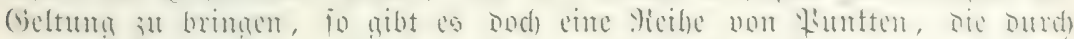

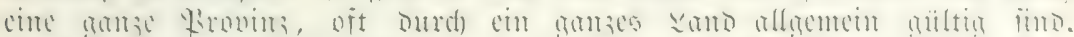

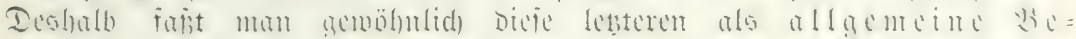
it in

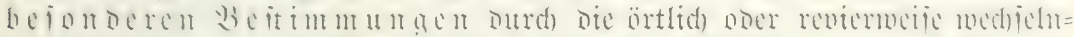

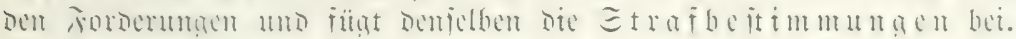

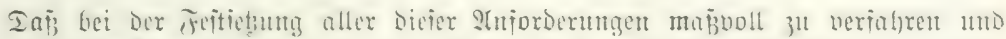

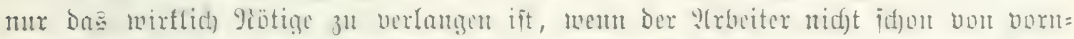

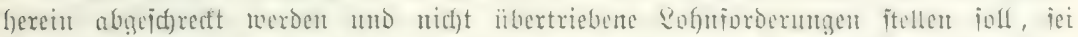

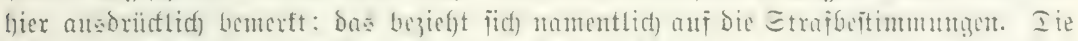

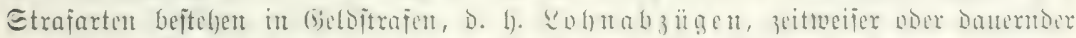

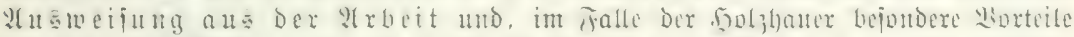

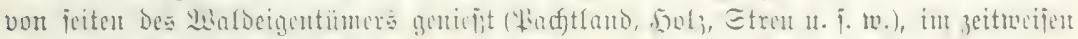

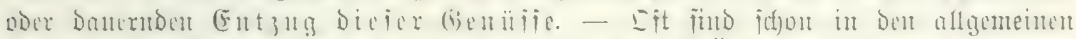

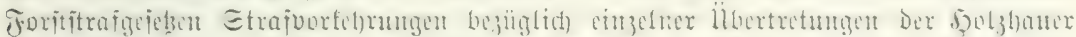

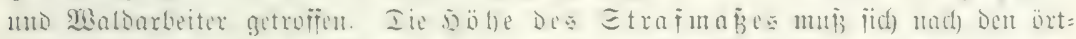

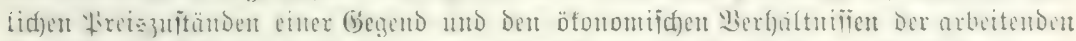

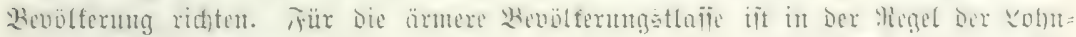
abzug und der (Eutzutg bisher gentifentr

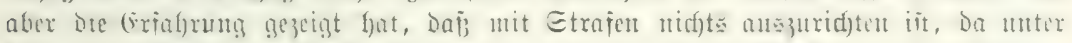

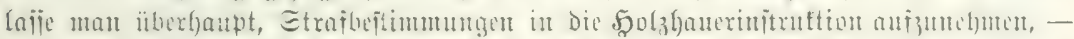

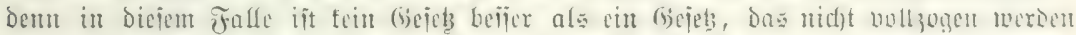

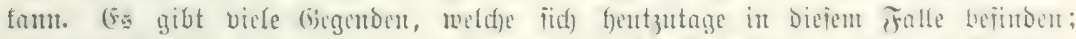

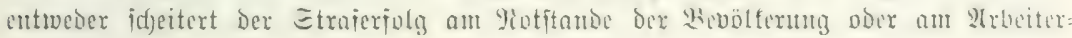
mangel.

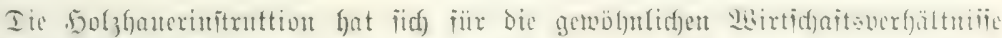

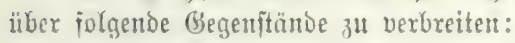

\section{Irlgemciue Bef̂timungen.}

1. Doliegenfeiten Der Solzhauer:

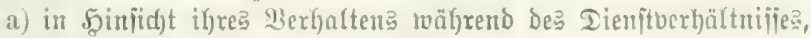

b) in Şinfidgt ber Jällunģăarbeit,

c) in Siuffid)t Der $\mathfrak{2}$ แร

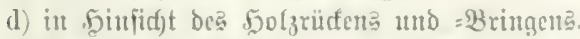

2. Sbliegentyeiten Der 5olzfeber uno Rottmeifter.

3. Sblirgenfeiten Der Bringarbeiter uno Floß̈̈ned)te.

4. Doliegentfeitent ber lluternefymer. 


\section{Beioudere Beitimmugen,}

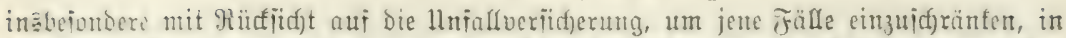

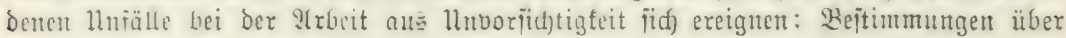

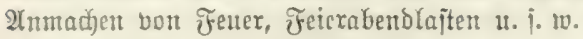

\section{Etraibejtimungen.}

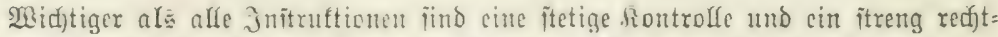

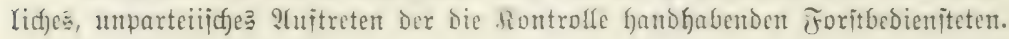

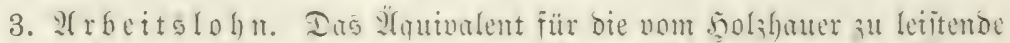

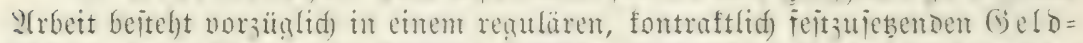

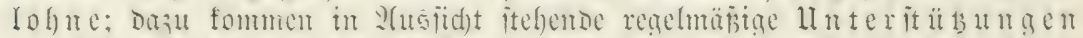

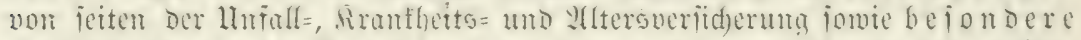

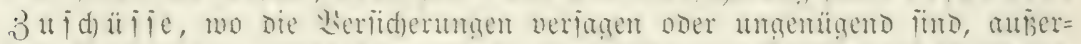

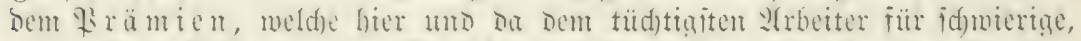

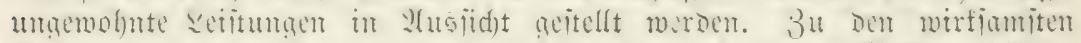

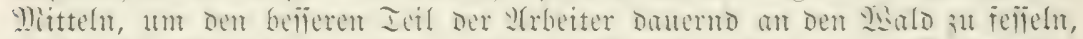

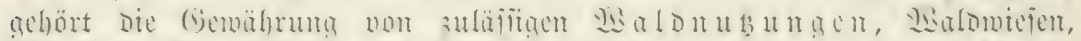

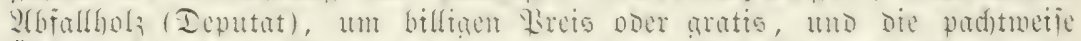
Ïberlamma flemer 些

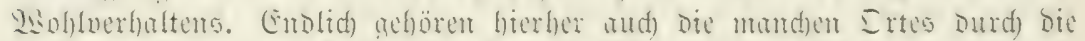

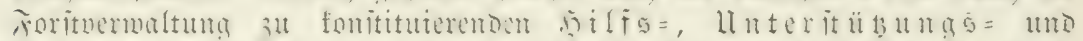

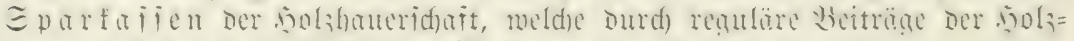

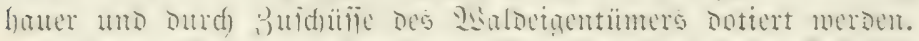

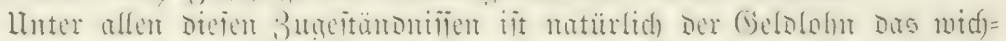

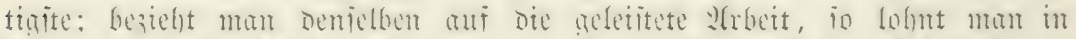

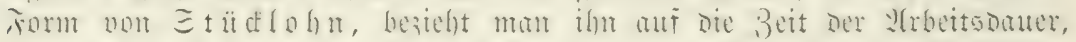

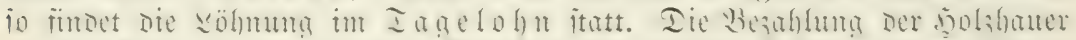

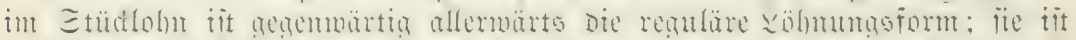

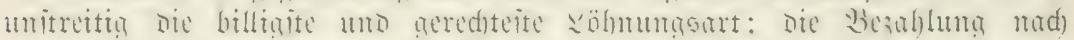

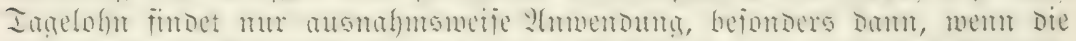

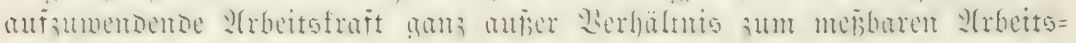
eriolge iteht.

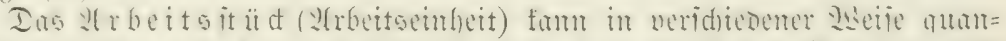

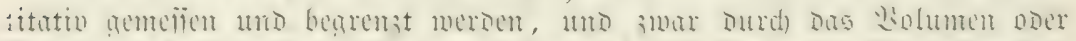

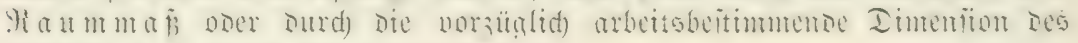

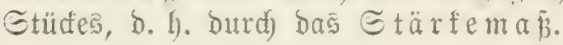

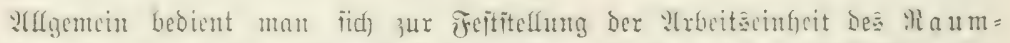

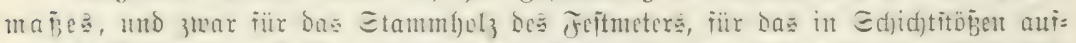

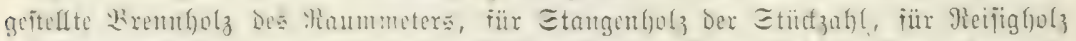

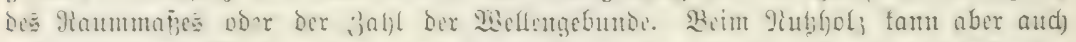

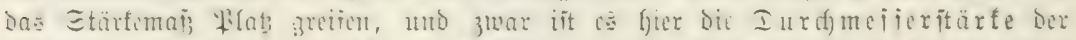

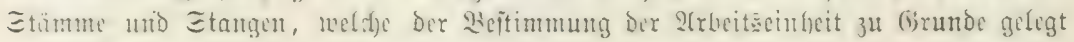
merden faur.

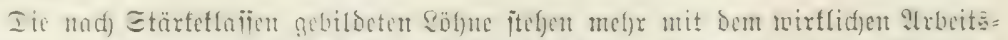

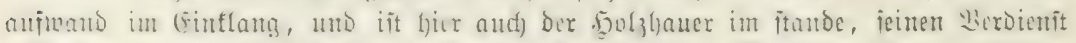

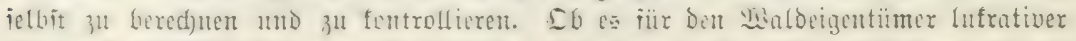

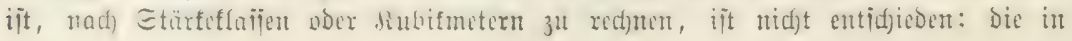




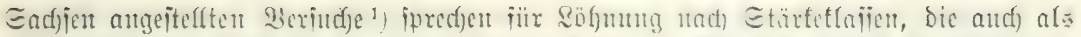

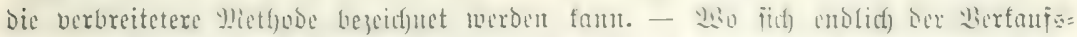

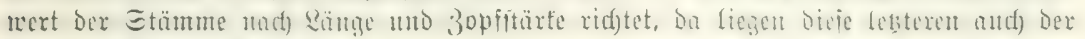
?trbeitaeinfeit zu Girutioe.

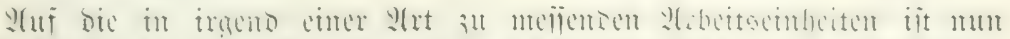

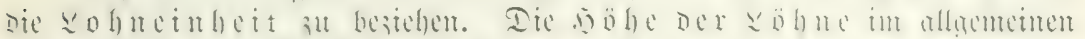

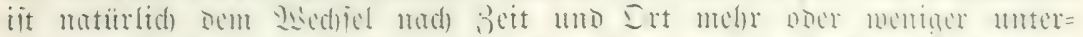

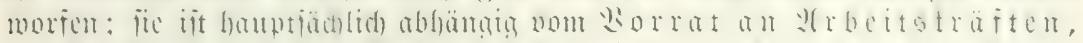

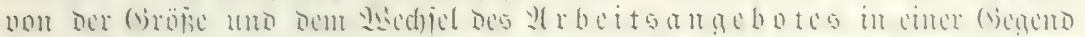

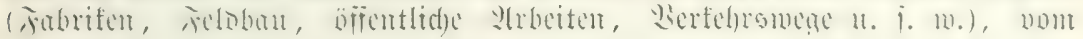

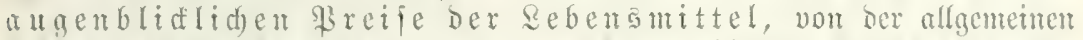
i)

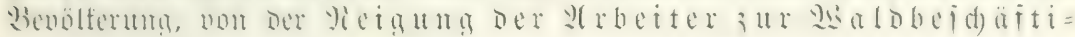

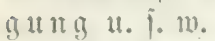

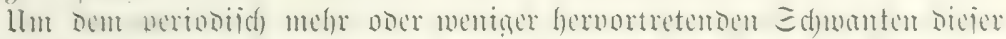

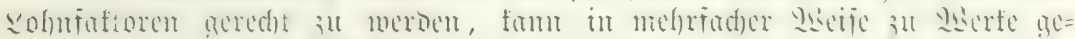

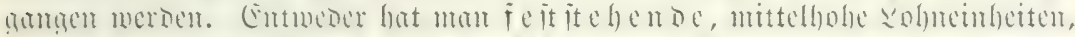

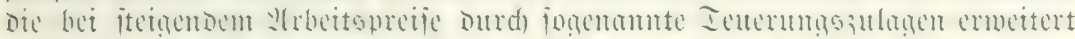

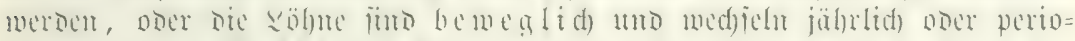

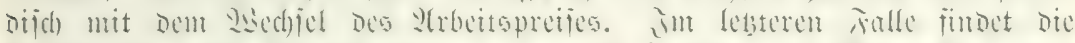

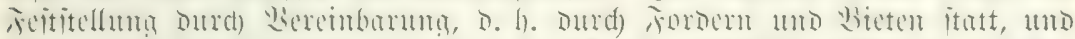

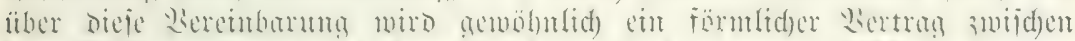

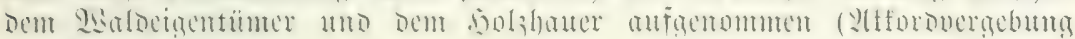
der Đolzhauer(öhne).

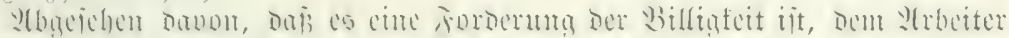
Den ; )

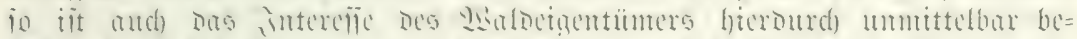

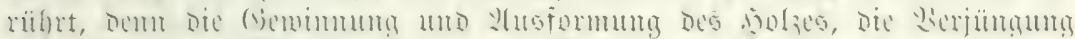

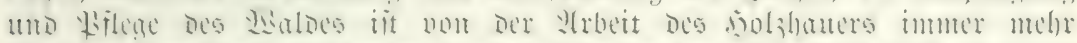

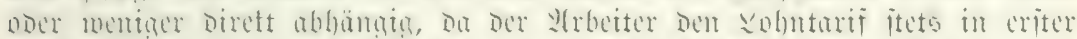

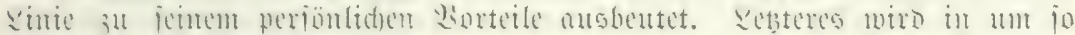

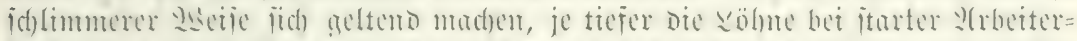

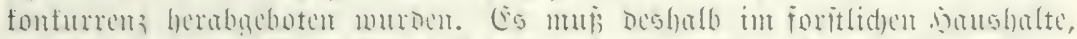

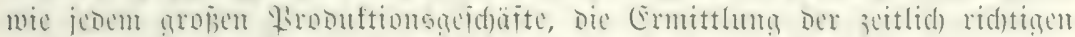

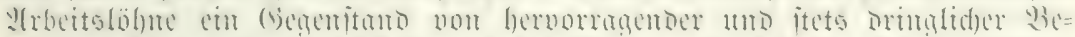

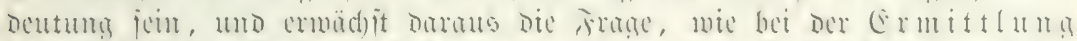

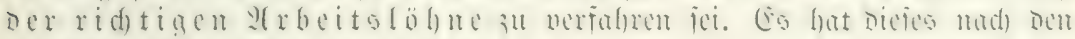
Folgenden (3rumbfäßen zu gejd)eben.

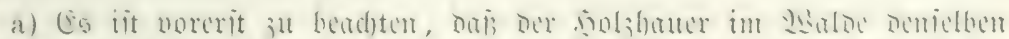

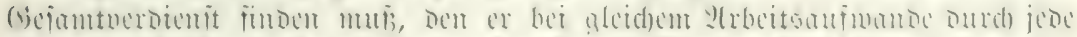

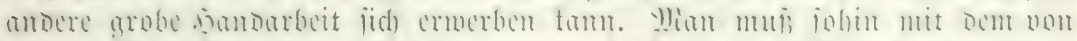

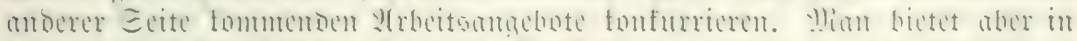

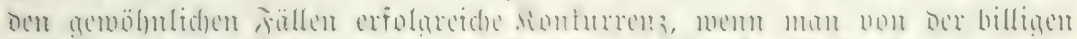

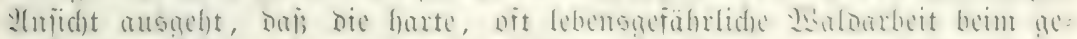

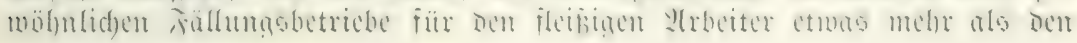




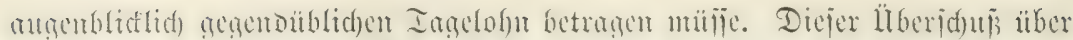

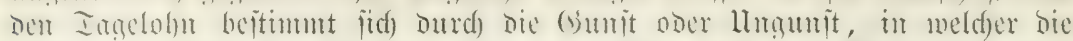

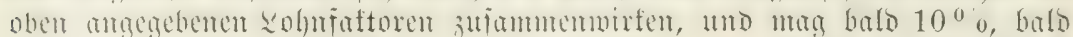

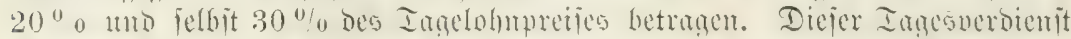
it

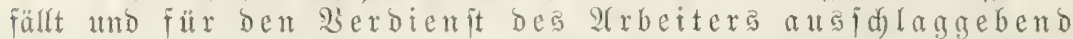

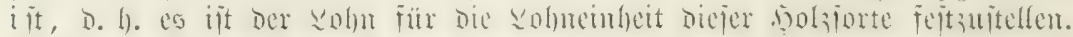

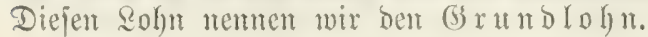

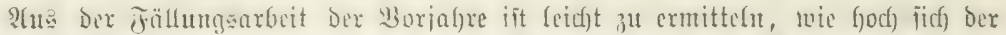

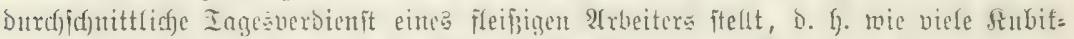
meter ex in einem Iage Gei Durdjof(d)

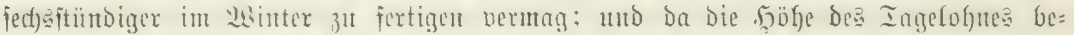
fannt iift, fo ijt

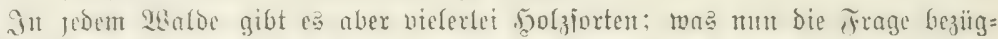

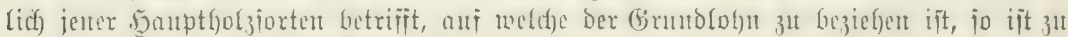

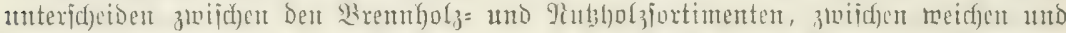

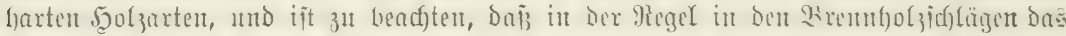

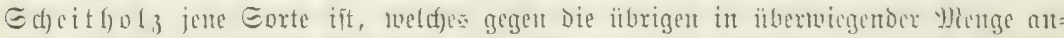

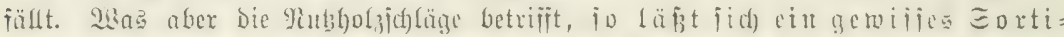

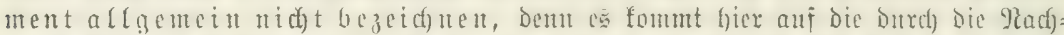

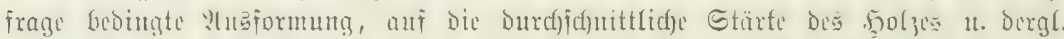
weientlid) an. Indurd) tamn in ber cimen (Begene dor mittelitarfe Eägetlob, in einer

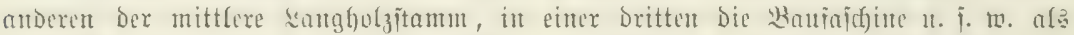

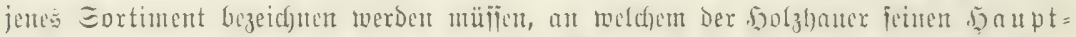

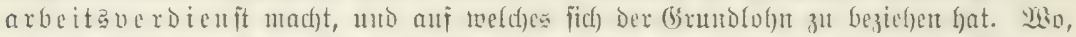

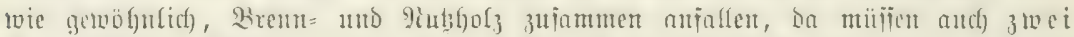

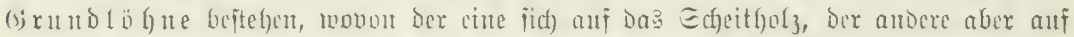

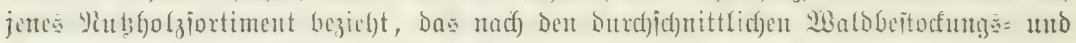
2uăpormu ngăberfältniffen in größ̈ter Menge aufällt.

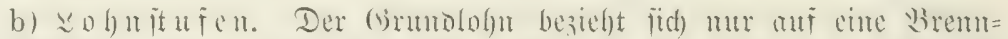

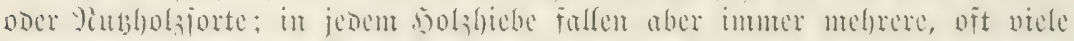

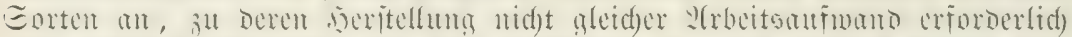

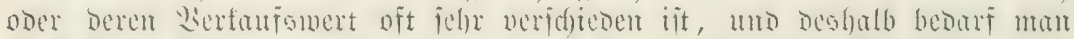

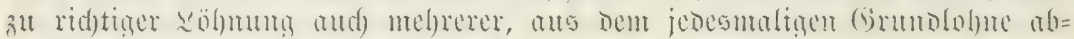

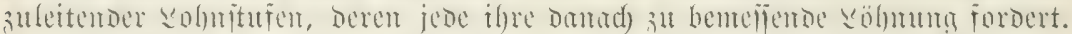

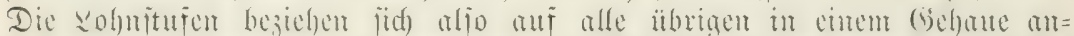

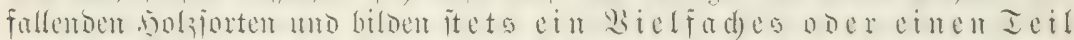

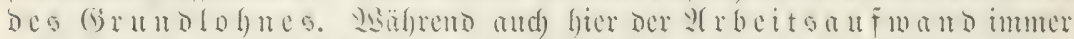

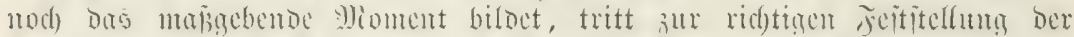

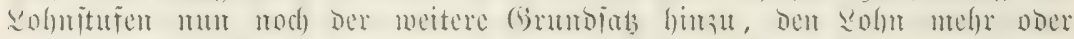

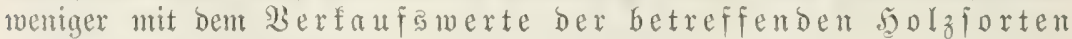
in Bezielung zu bringen.

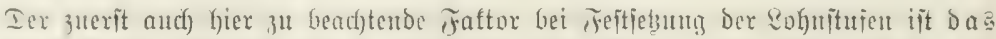

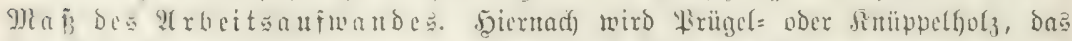

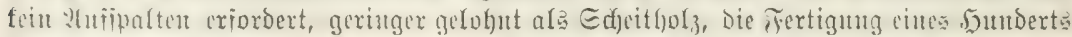

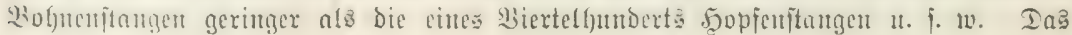




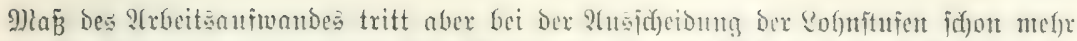

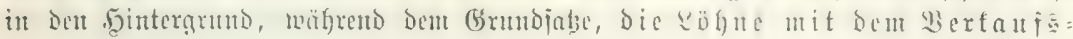

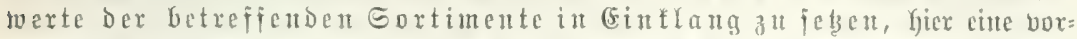

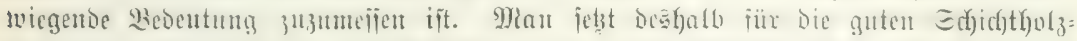

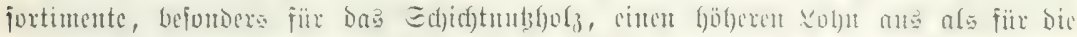

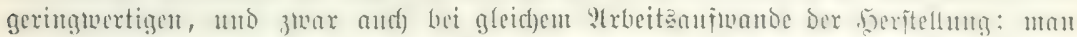

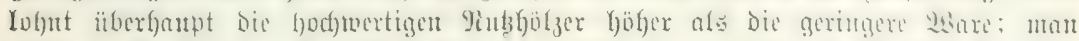

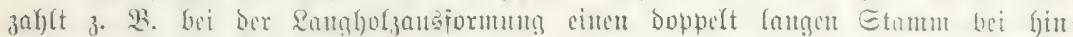

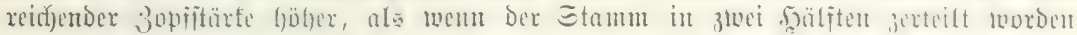

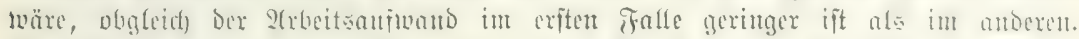

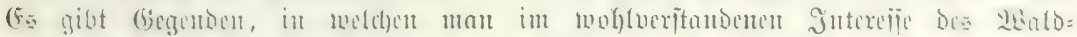

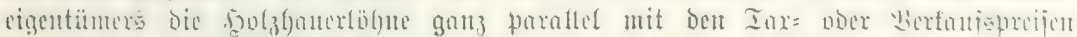

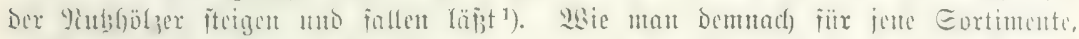

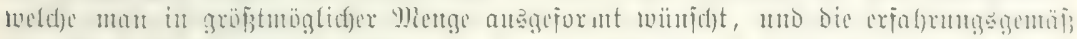

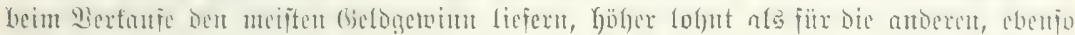

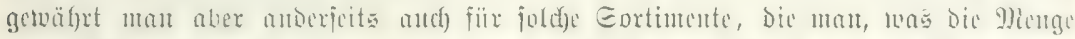

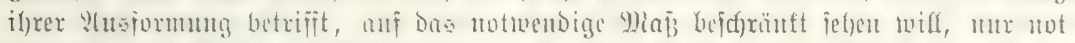

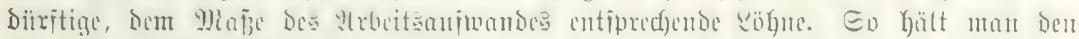

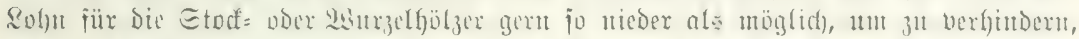

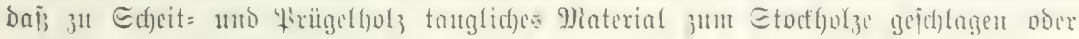
überbaupt viel હtodfold antagefaltent werde.

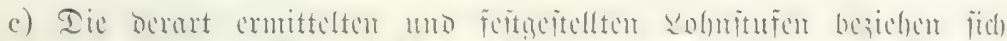

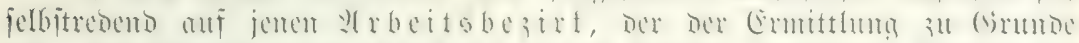

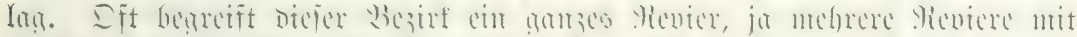

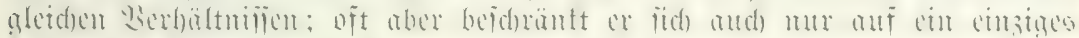

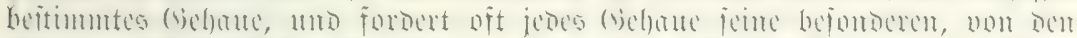

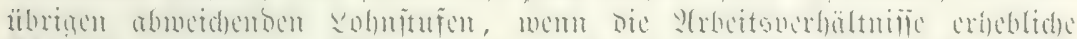

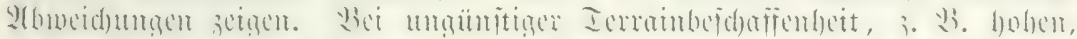

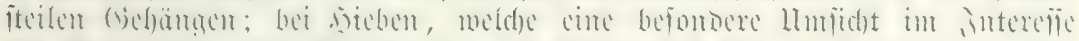

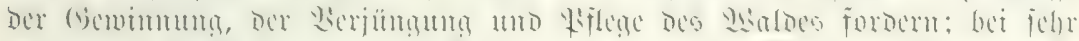

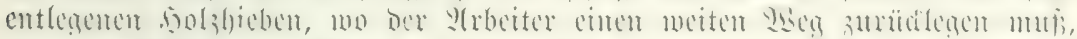

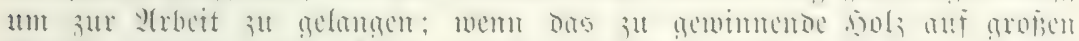

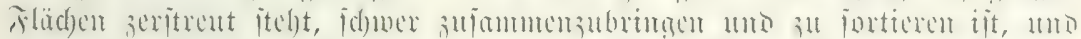

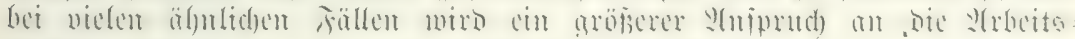
leijumg gemad)t als bei entgegengejeb̨ten Berbältnij̄en.

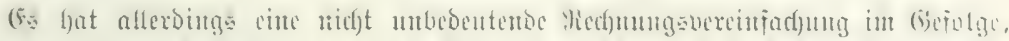

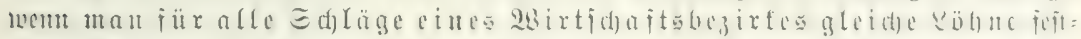

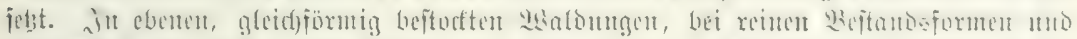

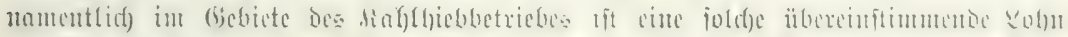
betvilfgum

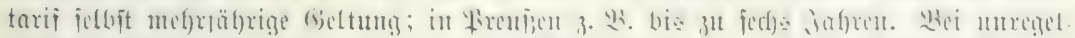

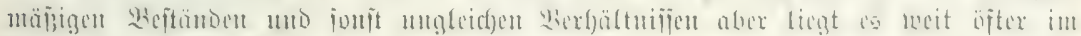

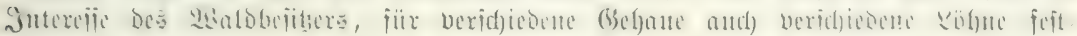

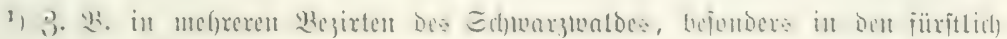
Finitentoergidjen \$aldungen. 


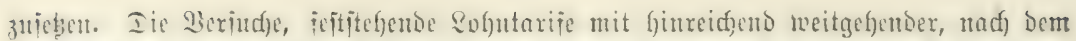

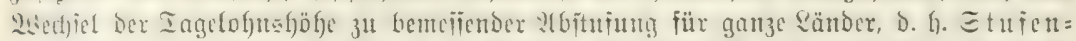

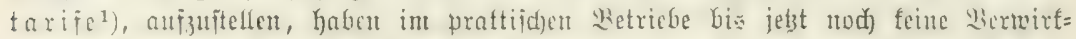

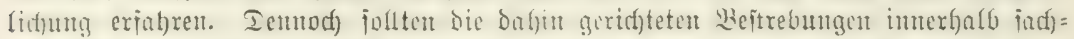

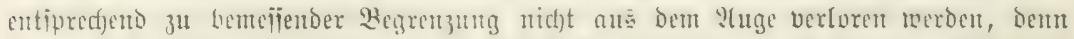

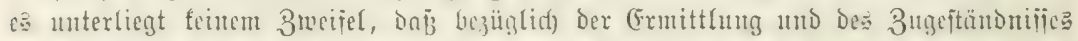

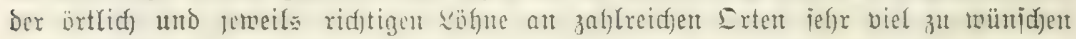
übrig bleibt.

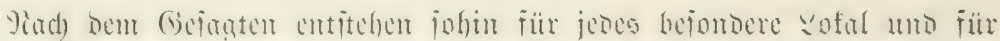

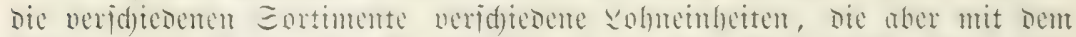

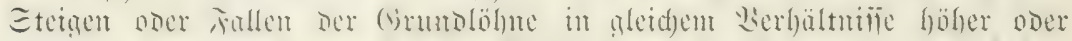

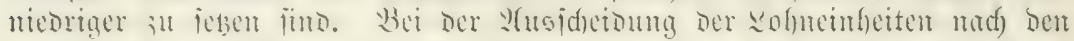

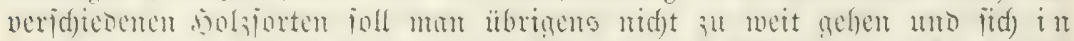

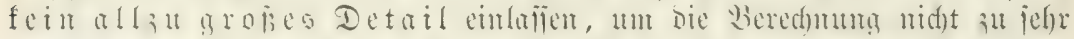

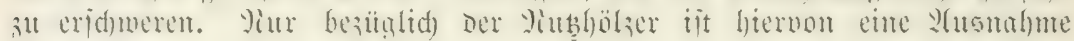
zu madien.

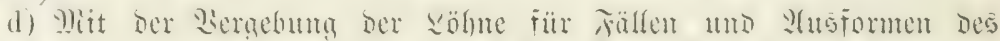

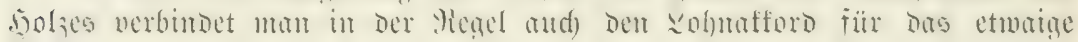
Ẽtrinben ber Etammbölzer, bas Bujammenbrimgen ober

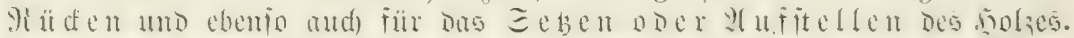

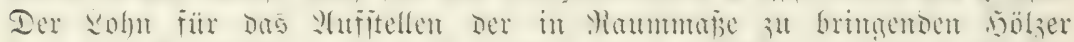

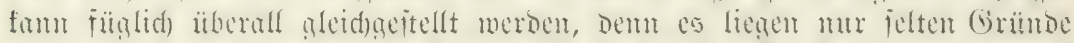

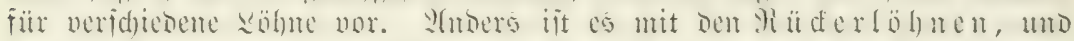

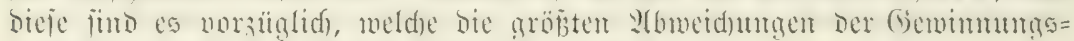
foiten vom mittleren Durdjidnittabetrage bebingen.

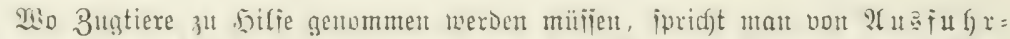

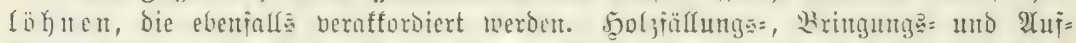

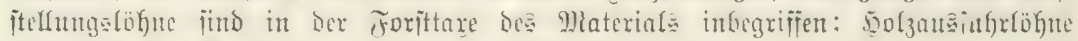

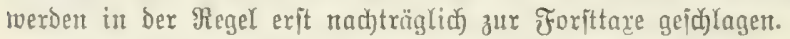

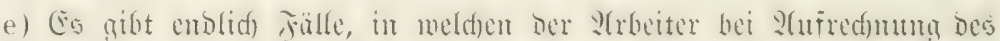

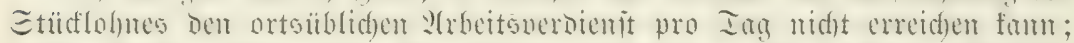

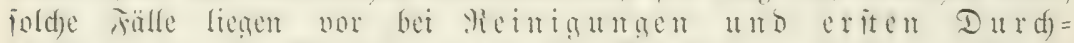

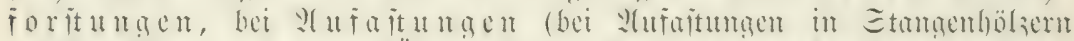

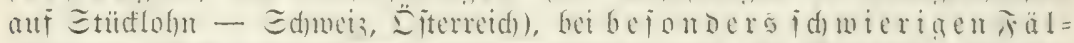

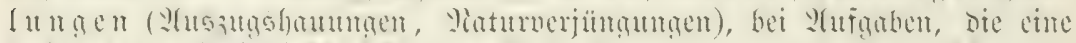

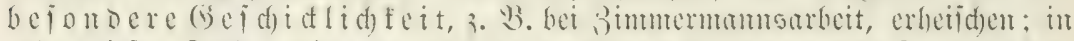

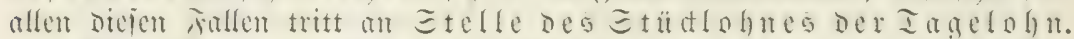

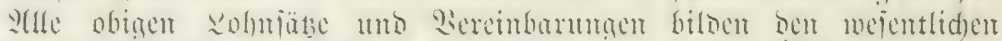

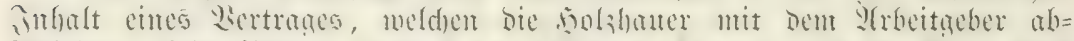

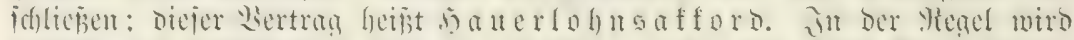

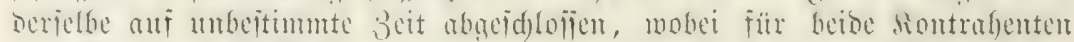

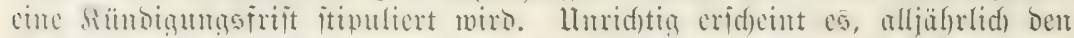

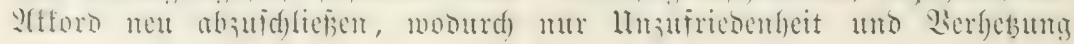

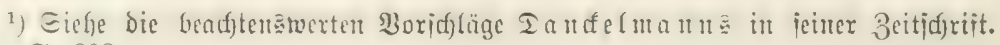
1888. ๔. 203. 


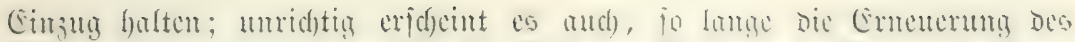

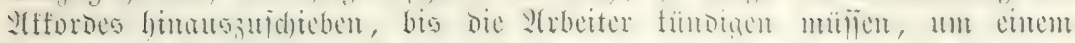

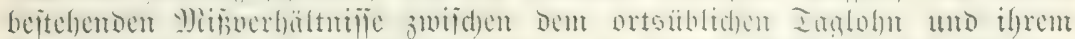

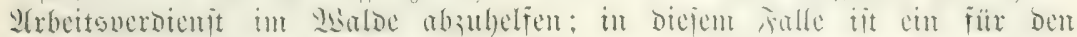

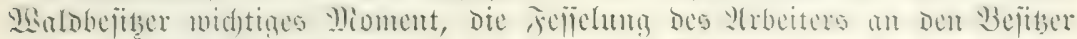
und an ben Malo, verpafit.

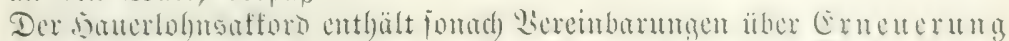
આ 2U id)riften aller $\mathfrak{A}$ rbeiter und Des Irbeitgebers.

4. Drganifation ber bुolghauerjaft. Un bie meijt nad)

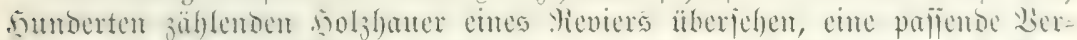

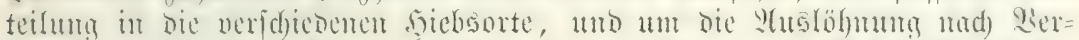

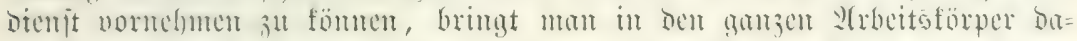

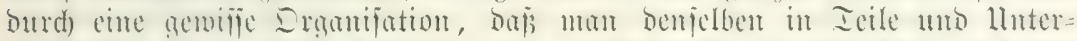

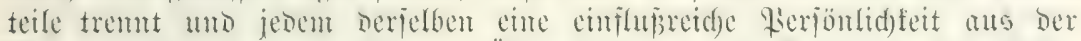

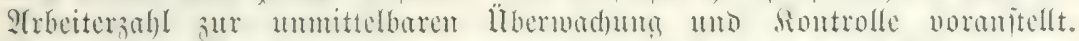

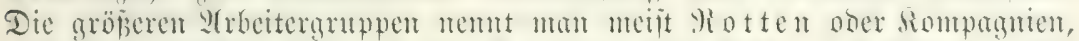

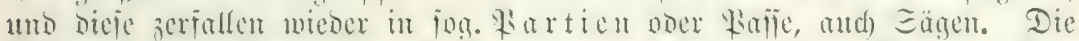

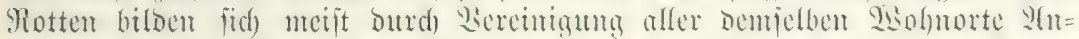

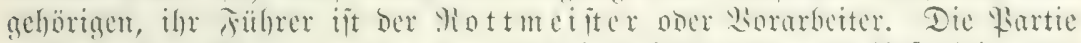

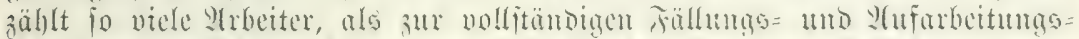

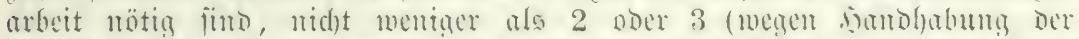

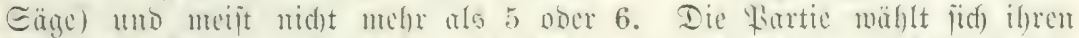

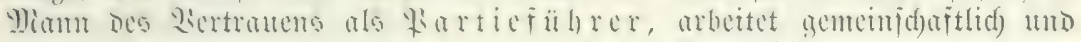
verteilt ben Sobn zu gleidjen Ieilen nad ber Sopfzahl.

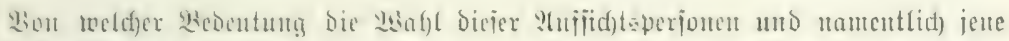

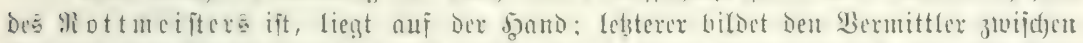

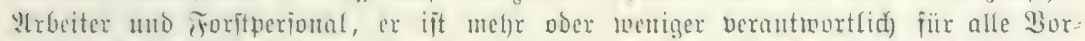

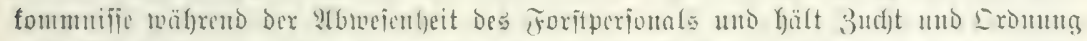

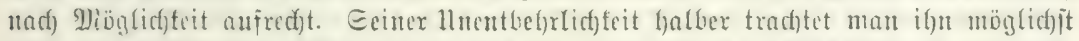

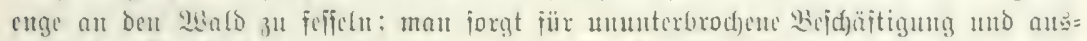

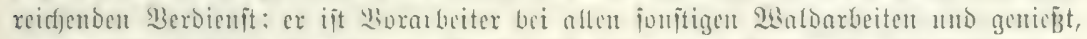

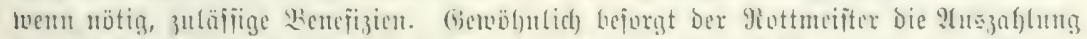

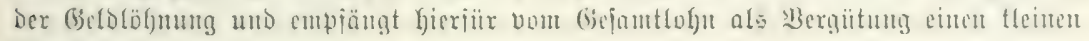

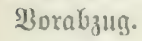

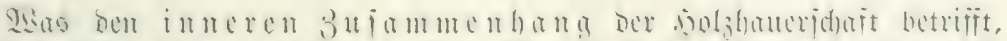

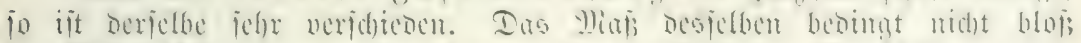

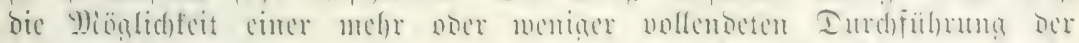

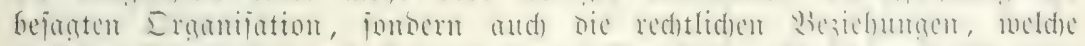

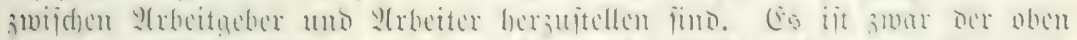

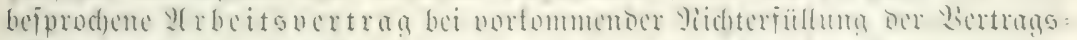

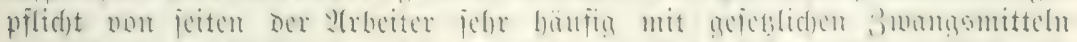

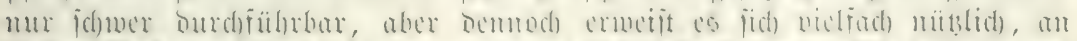

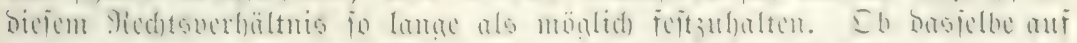

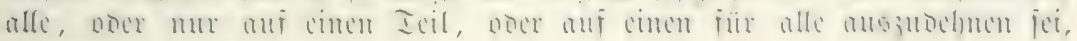




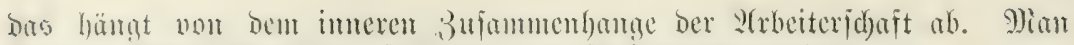

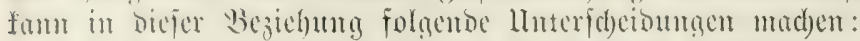

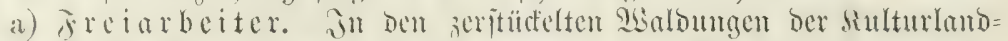

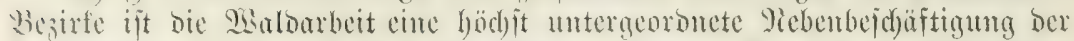

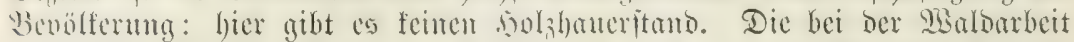

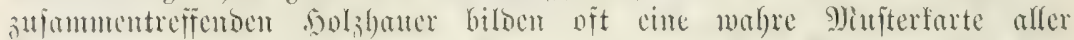

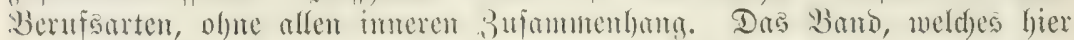

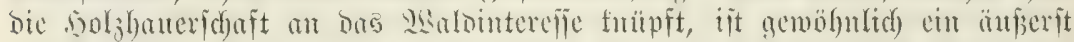

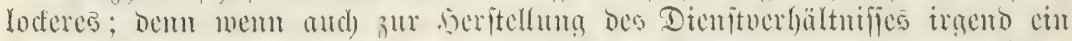

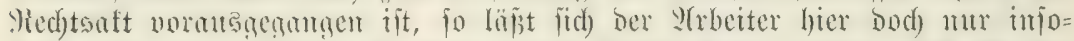

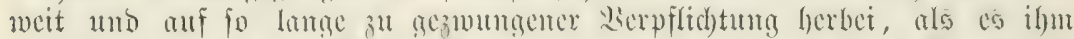

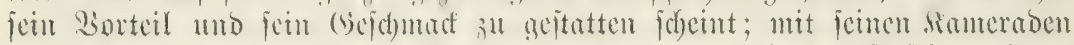

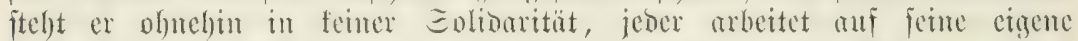

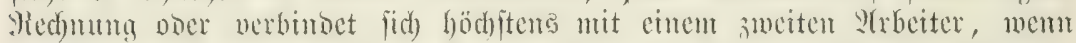

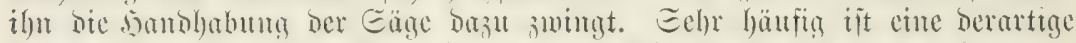

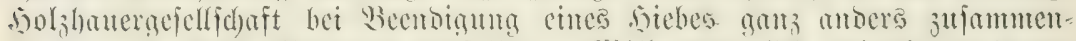

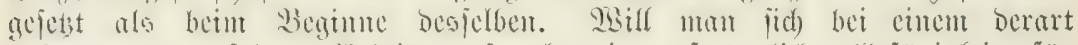

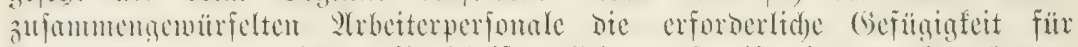

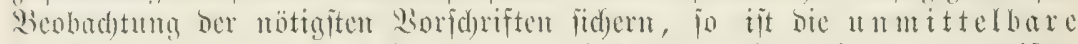

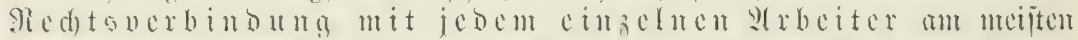
on ber Solzhauerfofaft bie natiurlidyite.

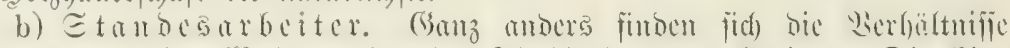

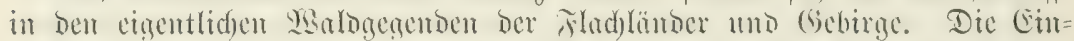

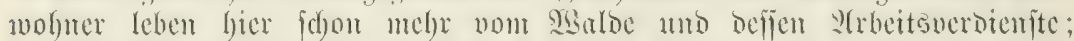

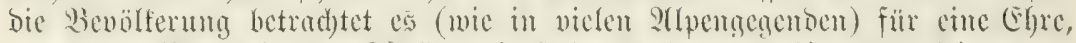
men Der D)

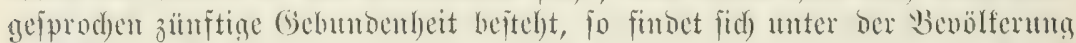

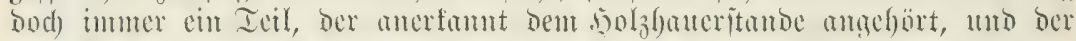

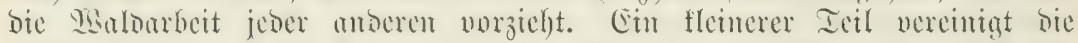

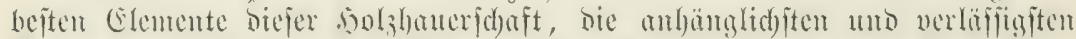

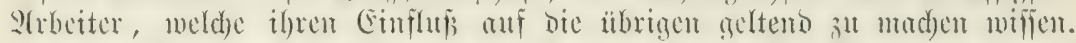

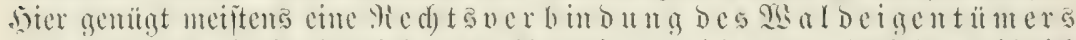

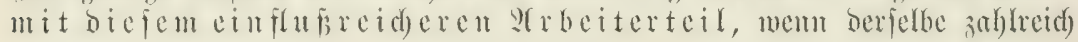
genug beitellt ift.

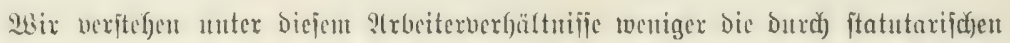

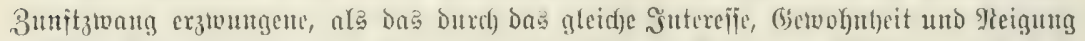

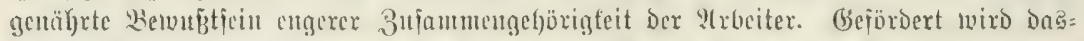

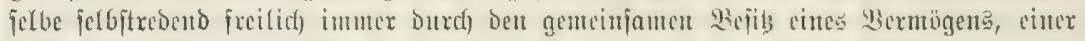

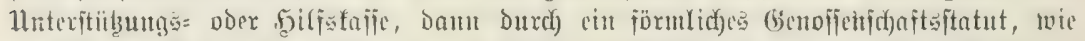

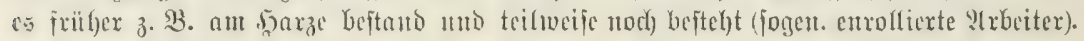

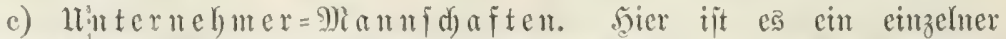

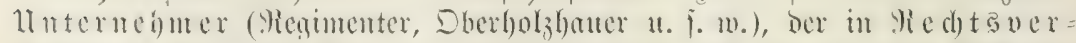

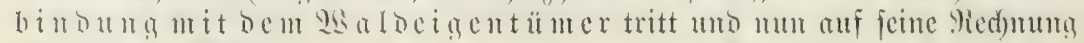

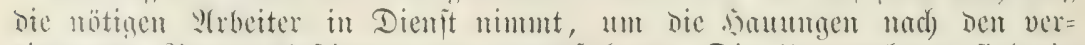

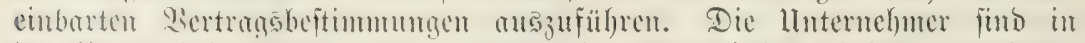

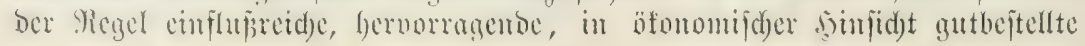




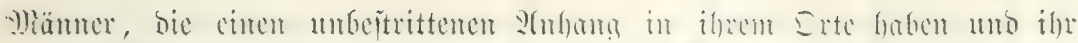

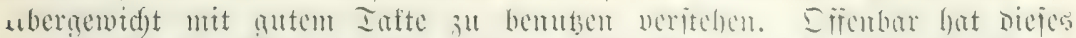

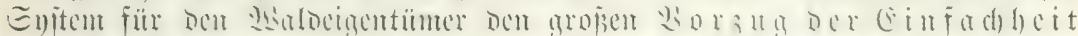

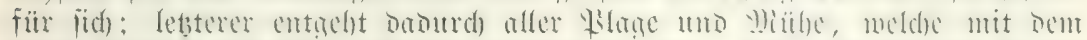

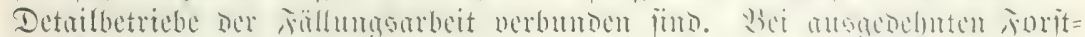

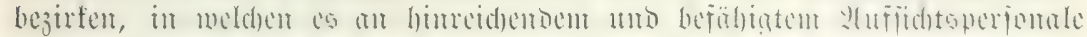

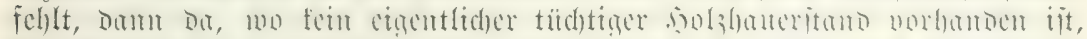

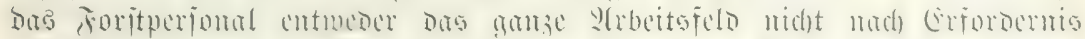
jeble

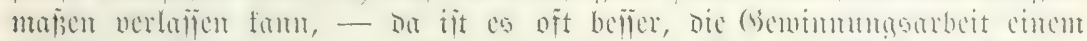

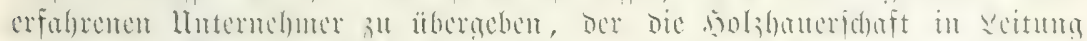

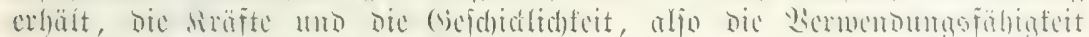
jones consehen

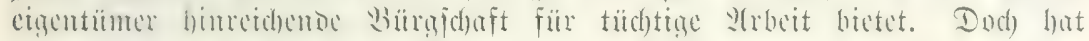
biejes Erjten aud jeine Edjattenjeiten.

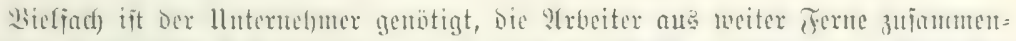

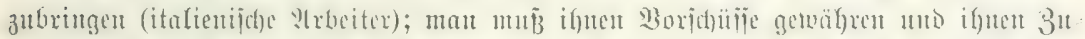

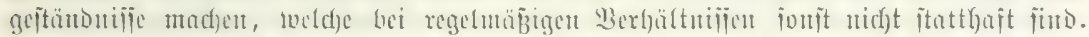

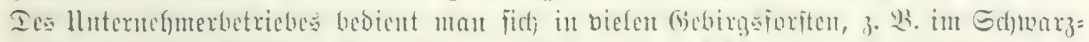

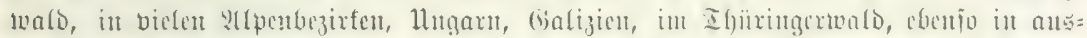

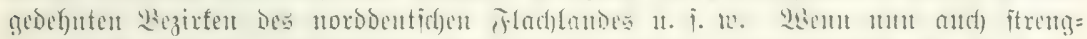

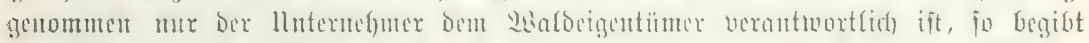

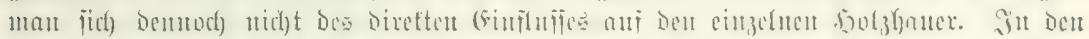

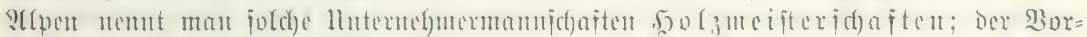

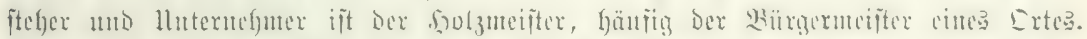

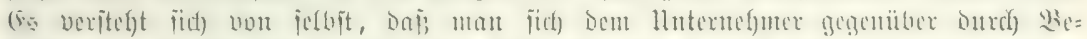

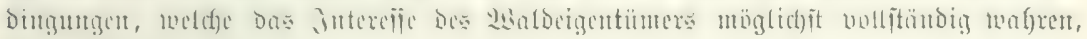
fiderzuftellen Kat $^{1}$ ).

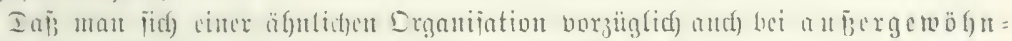

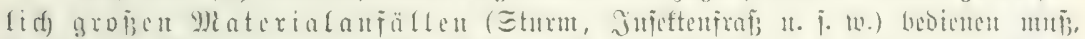

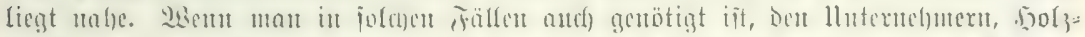

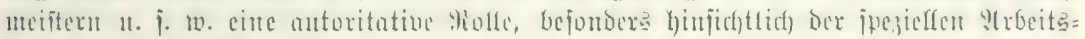

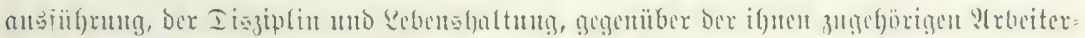

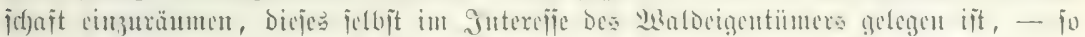

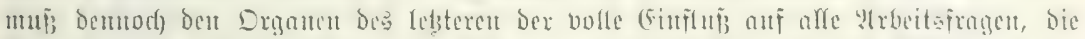

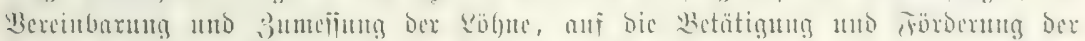

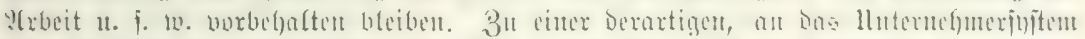

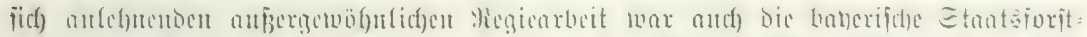

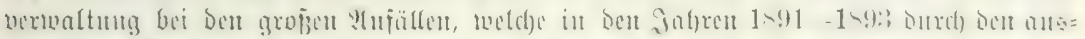

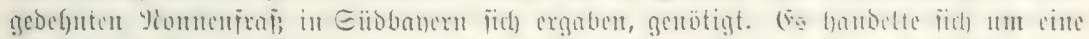

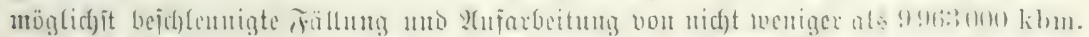

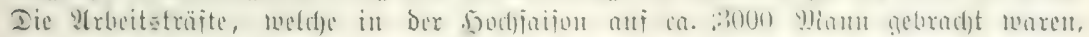

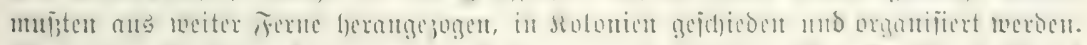

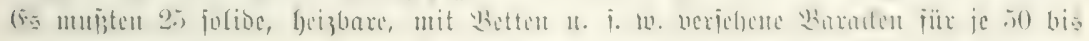

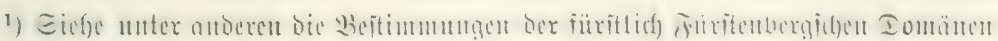
aomiutiftration vom 18. Şuli 1865 und 9. Februnr 1875. 


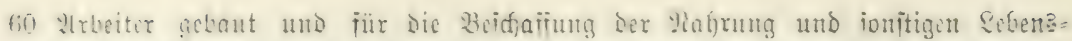

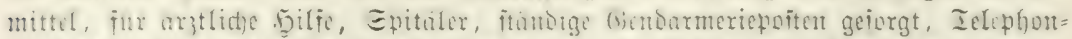

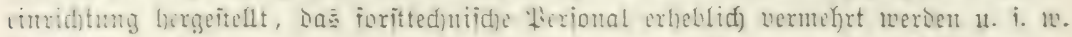

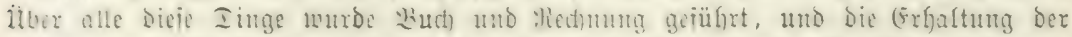

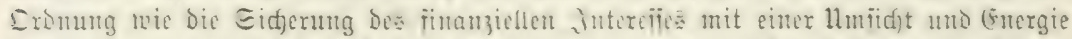
malrgenommen, welde Durd) Den (Explg nom urganijatoriidfen Ialente ber oberitut

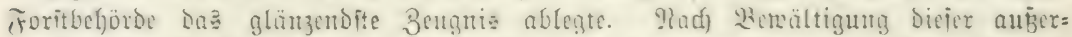

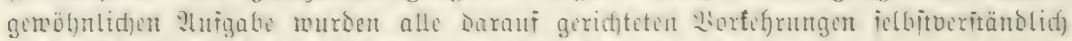
mieder beicitigt, und heute tit feine Epur bavun mefr wahrjunchmen.

d) Etänbige Eöldner ober 9 rrbeiter in mebr ober meniger

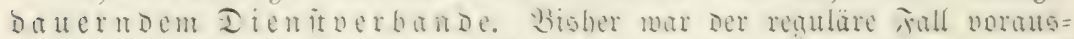
acicts, Dats

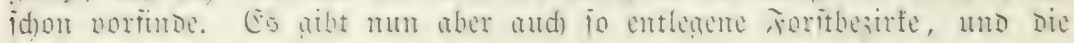

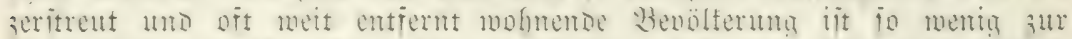

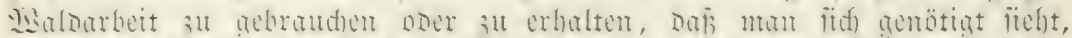

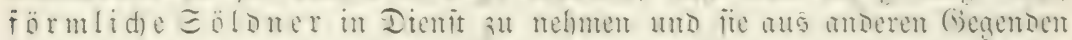
q)

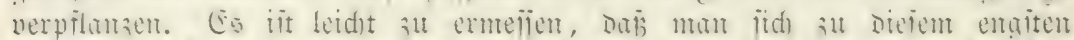

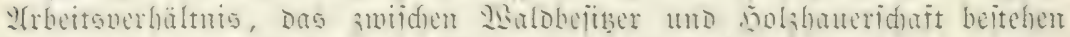

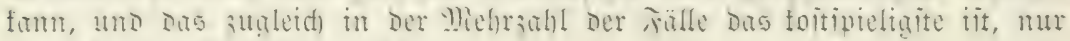
im äuberiten grotialle entid)liefit.

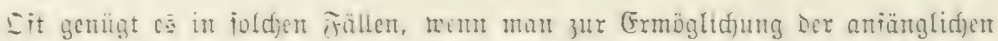

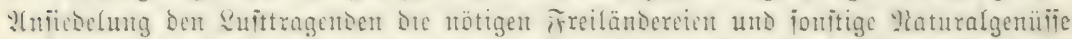

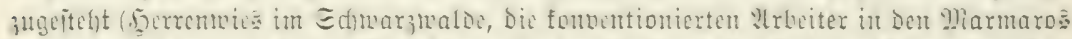

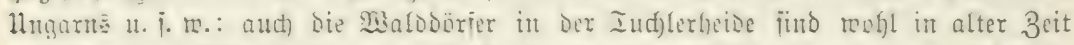

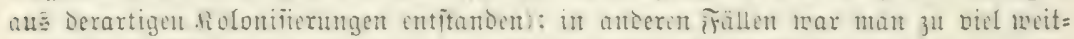

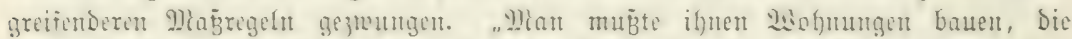

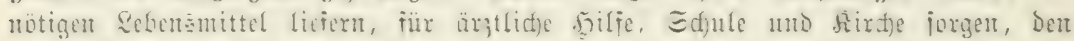

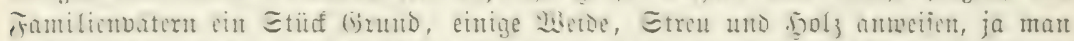

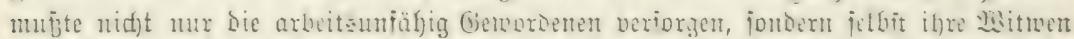

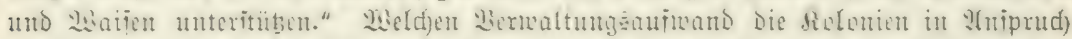

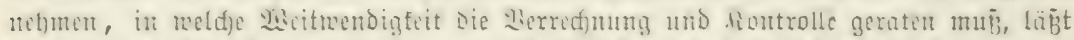

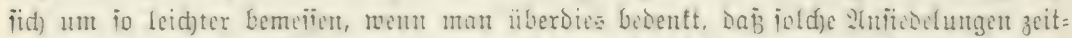

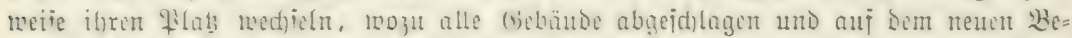
itimmungoorte wieber errid)tet morden mïjen. Iije :lrbeitertolonien fanden fid am

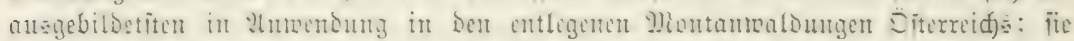

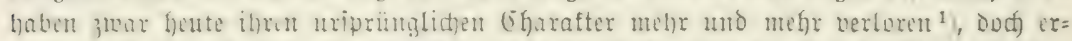

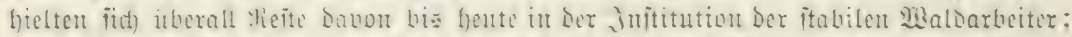

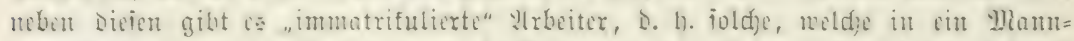

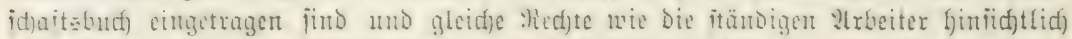

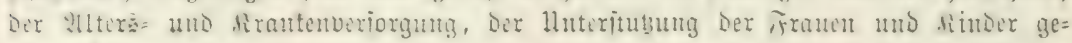
nitient $\left.{ }^{2}\right)$.

\section{Eeite 27.}

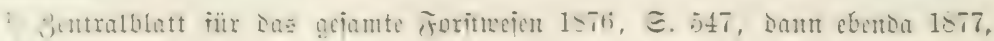

- Iie Etant in 19 ict. 1900. 


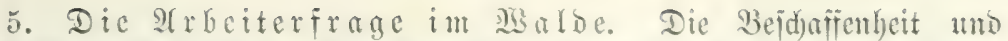

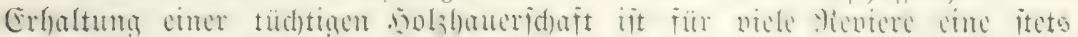

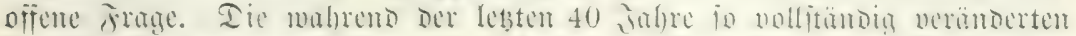

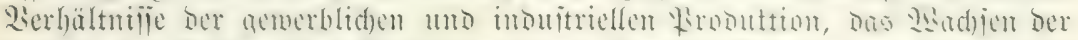

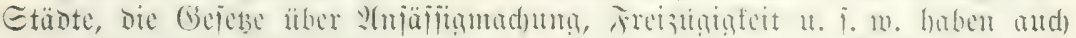

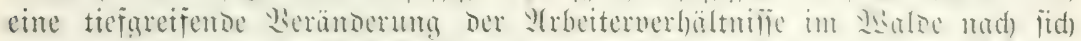

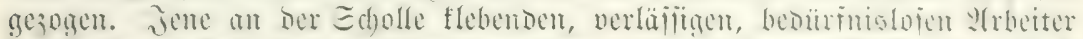

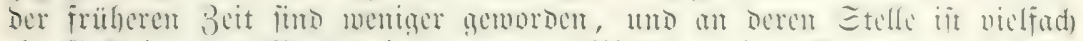

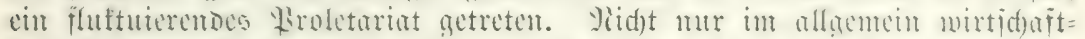

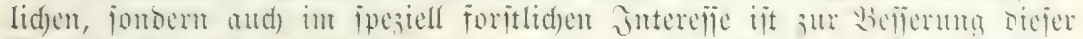

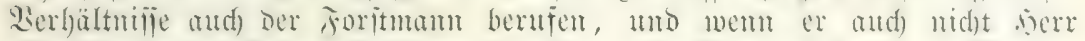

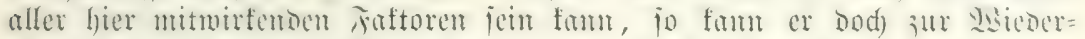

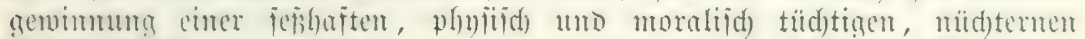

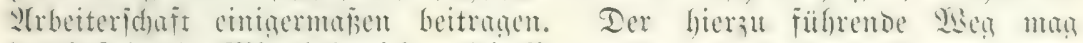
butd) folgento Mittel bezeidnet jeint ${ }^{1}$ ).

a) Dian gemähre (iselolöhne in angemeflener söhe, wie fie ber harten SBalonrbeit uno Den allerwärts aejtiegenen sébensmittelpreijen entipredyen.

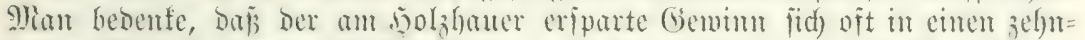

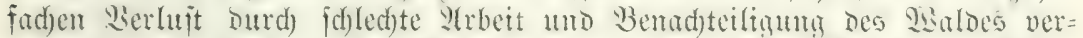

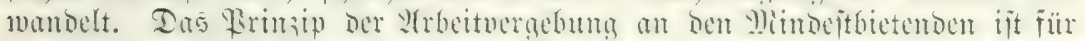

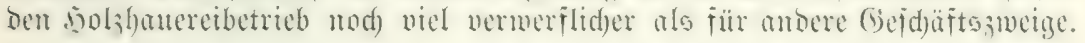

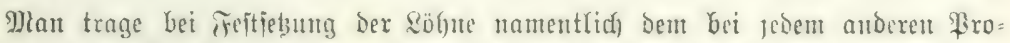

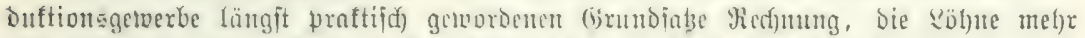

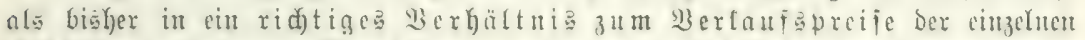

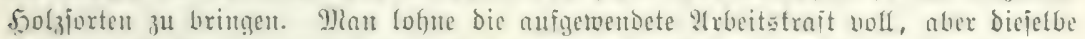

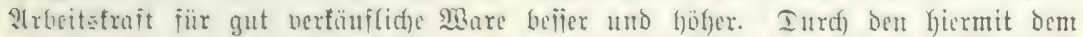

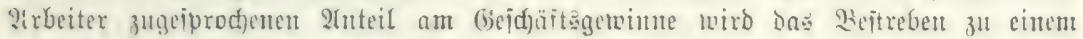

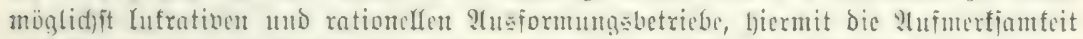

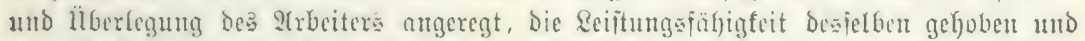

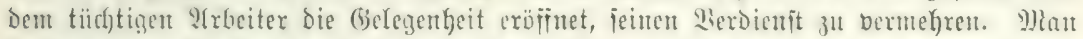

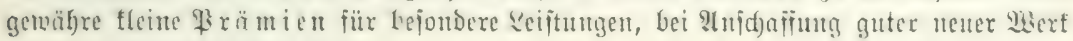
zeuge unt int äfnliduen Frälten.

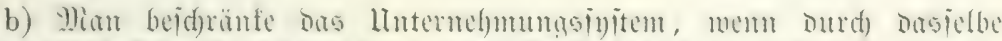

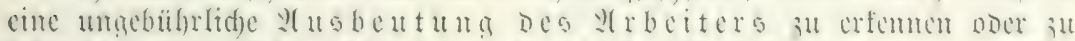

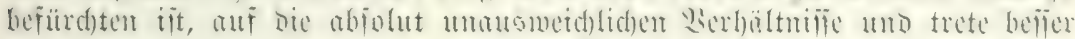
mit bem einzelnen SIrbeiter in red)tlidje SBeziefung.

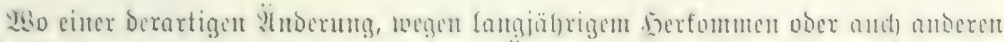

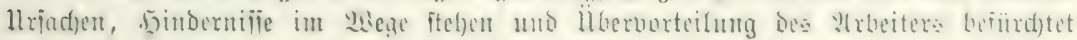

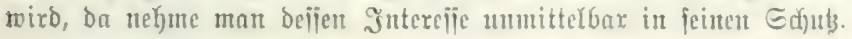

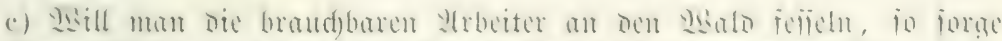

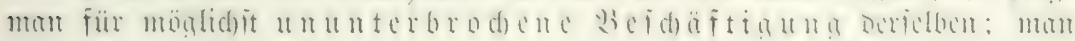

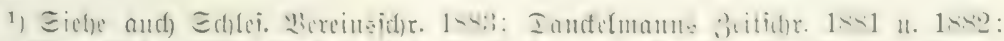

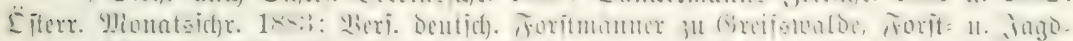

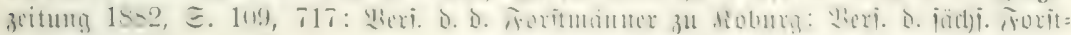

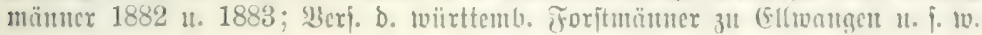




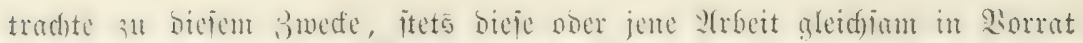

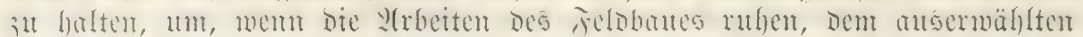

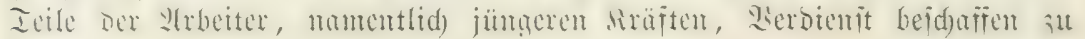
föment.

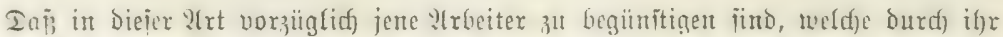

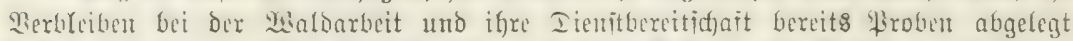

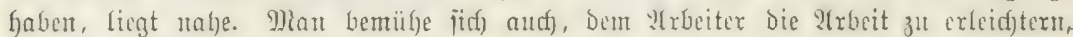

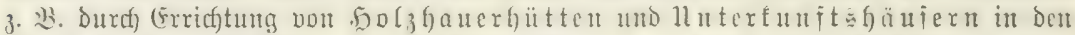

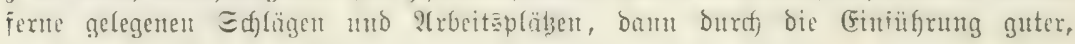
leiftungä̧

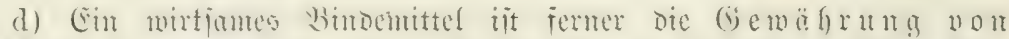

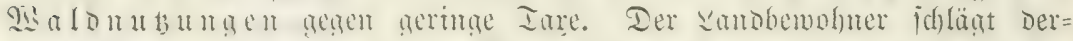

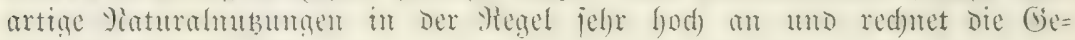
wimumgs̄foiten midjt.

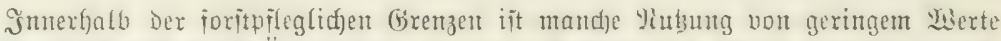

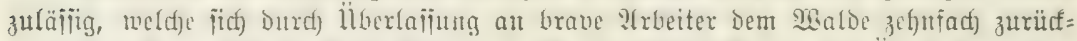

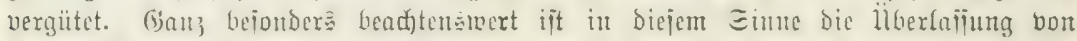

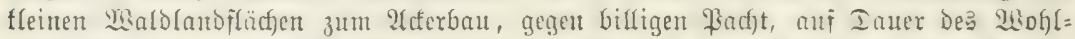

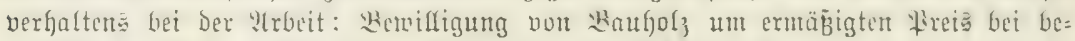
abjigtigtem Meubau ndex nötiger Meparatur von ?trbeitermofmungen.

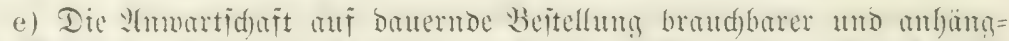

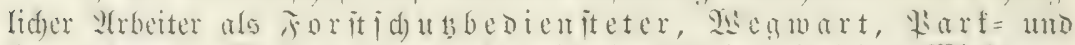

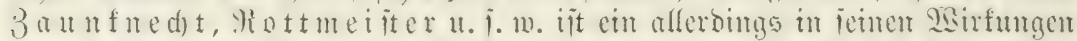

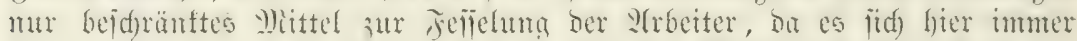

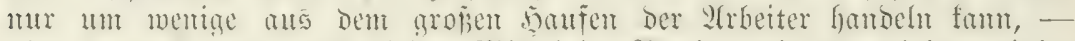

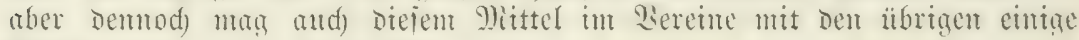
Bered)tigung nidjt abajupredjen jein.

I ie oit jehr mangelfajte Hezah)lung biejer nitderen Iienjtesorgane und bie not=

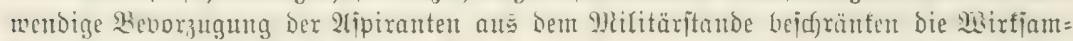
feit diejes Mrittele jefr.

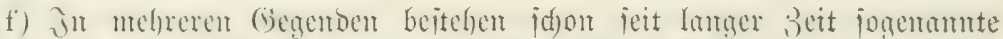
5o!

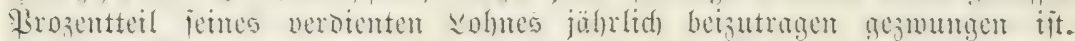

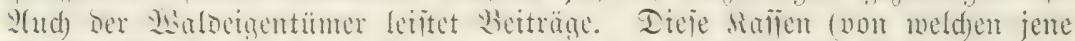

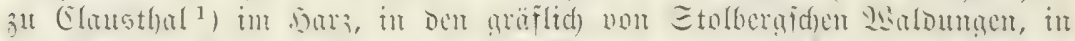

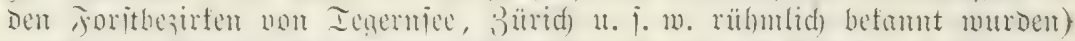

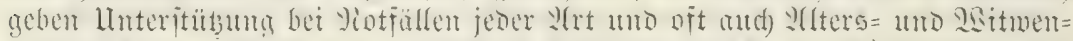

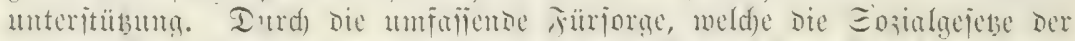

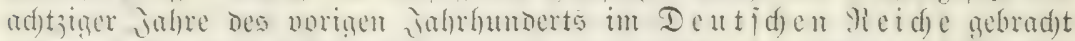

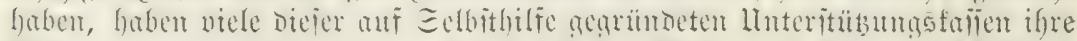

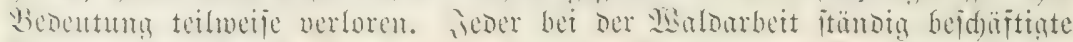

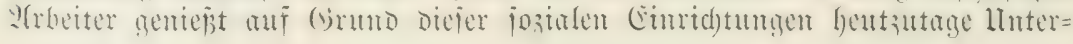

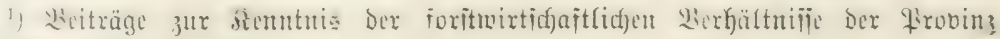
Sannober. 1881. ङ. 55. 


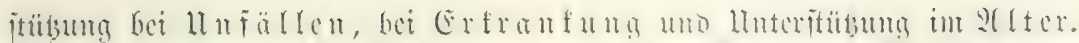

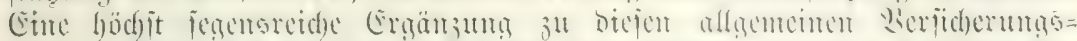

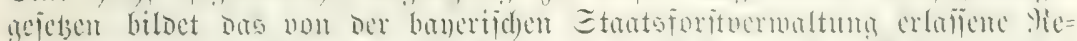

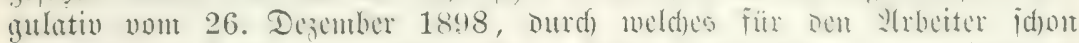

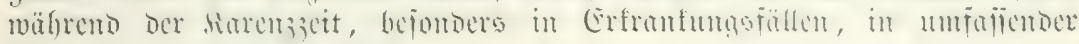
Weije Eorge getroffen wirb.

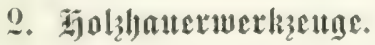

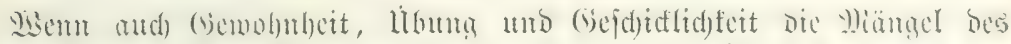

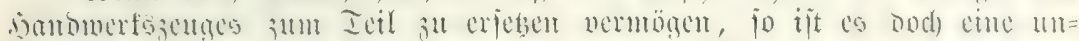

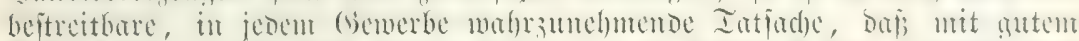

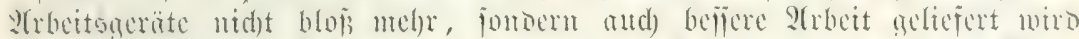

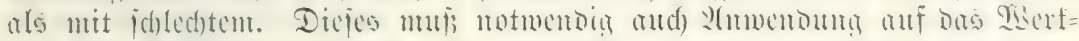

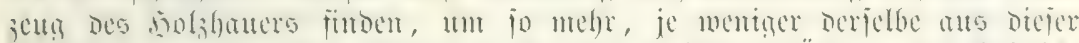

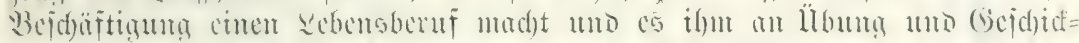

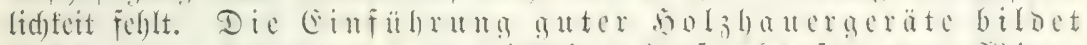

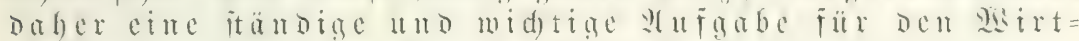

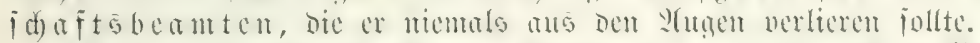

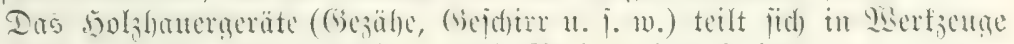
zun , Sauen, Eägen, Epalten uro Roden Des 5olzes.

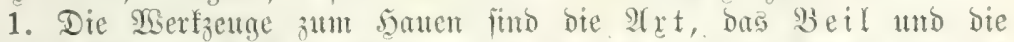

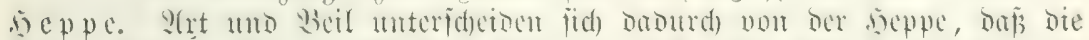

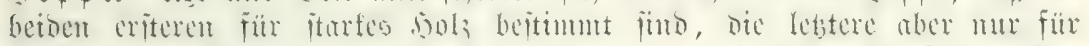

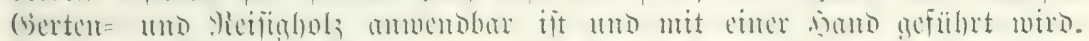

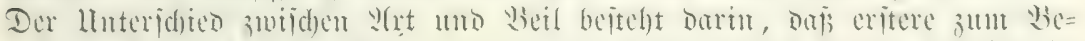

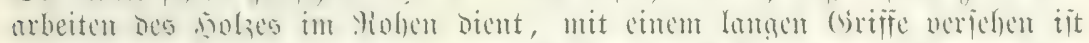

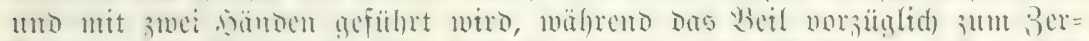

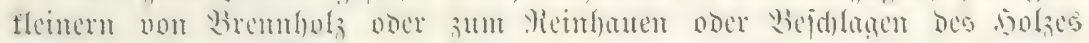

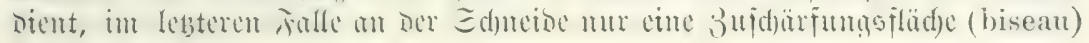
befibt.

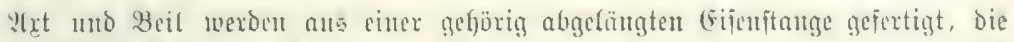

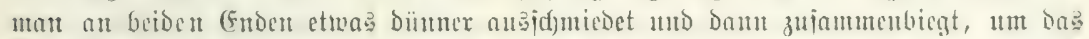

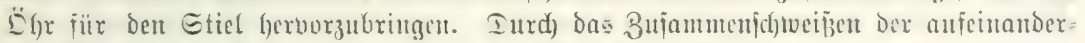

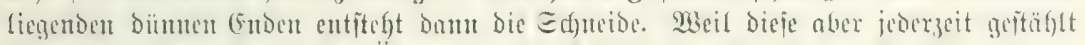

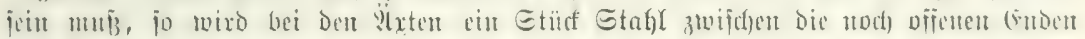

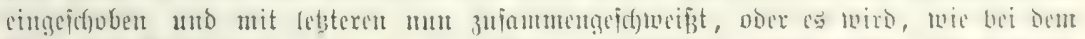

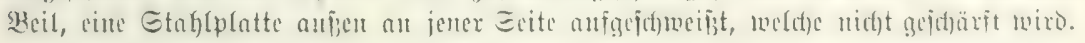

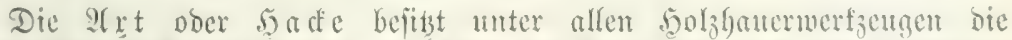

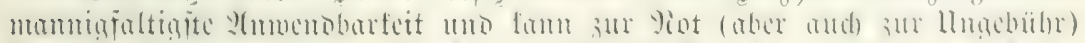

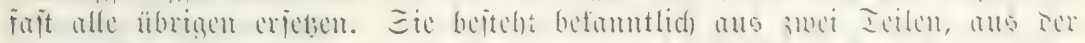

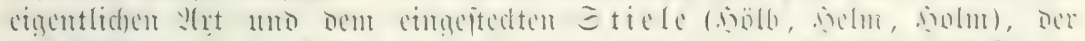

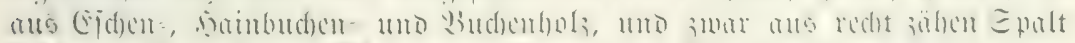

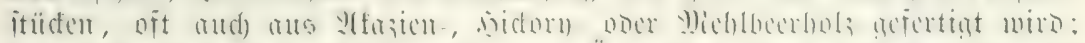

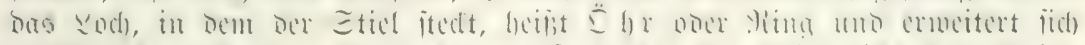

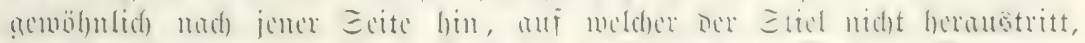

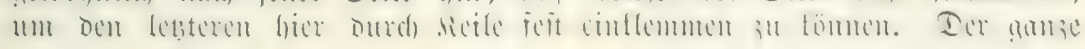




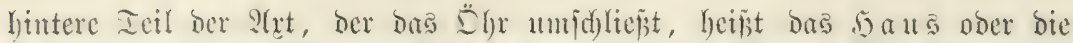
Sonbe, jie ijt an linteren Enoe entmeder abgemölbt ober abgeplattet, im

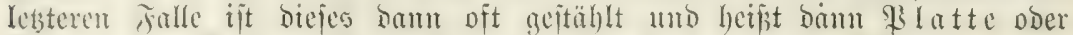
Siaten; ber Sorberteil ber S(rt miro burd) bie beiben Blätter ober TIa angn gebilbet, bie fid vorn zur Sdmeibe vereinigen.

Bon eincr guten $\mathfrak{A} \mathfrak{t}$ fan man im allgemeinen ver=

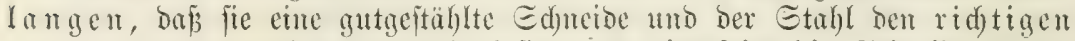

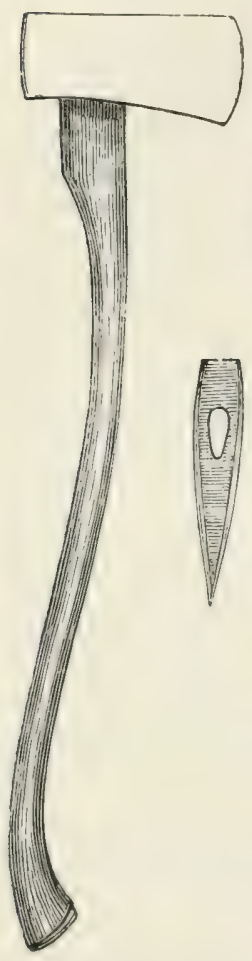

శ̧ig. 45. Wumerifanifice sit. $\mathfrak{S a ̈ r t e g r a b}$ bejitze, um einerjeits bie Sdjueide zu er= halten, amberjeits aber aud) nid)t auszujpringen; was bie form betriffit, fo foll fie einen vollftän bigen Reil baritellen, b. h. Die beiden Blätter follen al’ jtetige glatte Fläd)en, ofme jeden Ilbjab, fid ins Saus fort= jesen. Diejen Bau finden wir bei alfen anerfannt guten S(rten, Deren melyere im folgenoen näher beid)rieben werben. (Den S̈rten mit abjäbigen Eeitufläd)en gegen= über finsen fidd and joldhe mit cingeband ben Blättern.)

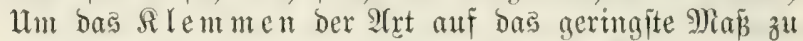

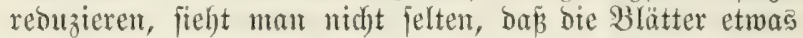
gewölbt find ooer in der Mitte eine fleme Beule tragen. Das (5ewid)t ber 2Art, bam die Stärfe und bas $\mathfrak{B e r}=$ bältnis der einzelnen Ieile ridjtet fid) nadj bem $14 \mathrm{~m}=$

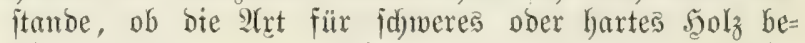
fitimmt ift ober für geringeres und meidjes $\mathfrak{y}_{0} l_{z}$; im

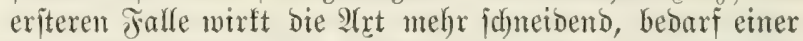

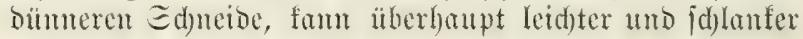

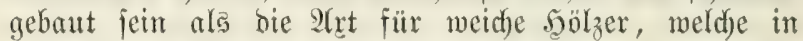
allen Ieilen, bejonders im sauje, ftärfer und breiter ift, aljo einen wirfameren Reil barftelft, und eine bidere, mebr gebrungene Edymeibe hat.

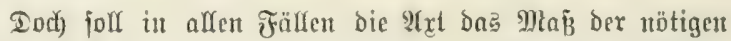

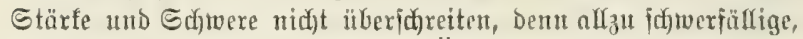

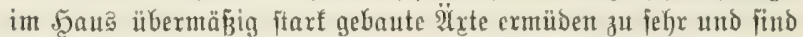

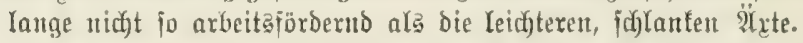

Den Stiel fimbet man bald gerabe, bald gefdumeift, balo liegt ex parallel mit ber Edrneide, balo biegt ex fid) acaen bieje cint, bald mentet er fidf non bicjer ab. (Es tijt fobwer zu fagen, weldje Form und Ridjtung bie

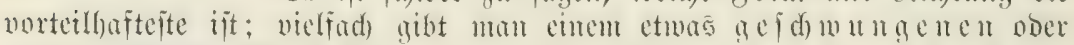

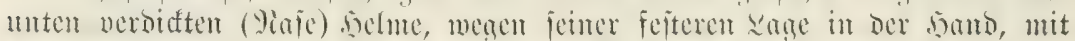

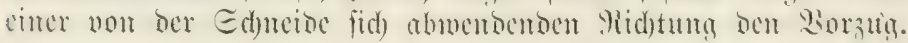

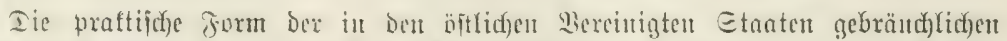

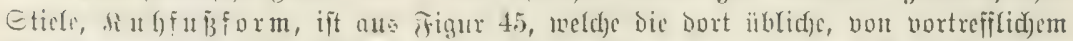

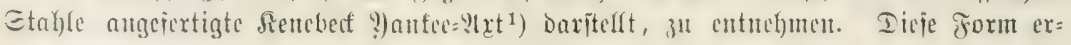

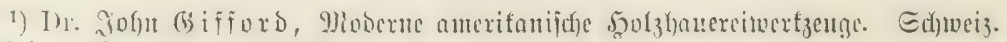
3eitichrift ₹. Forpittwefert. 1900. 


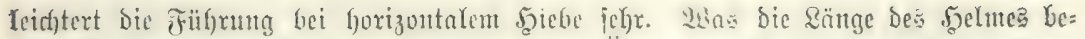

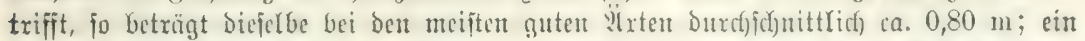

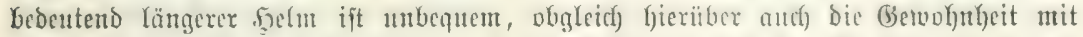

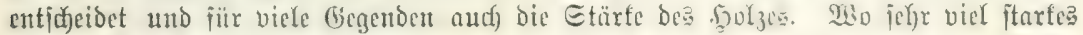

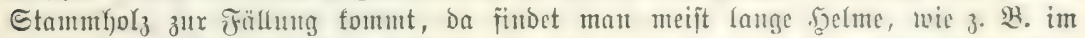

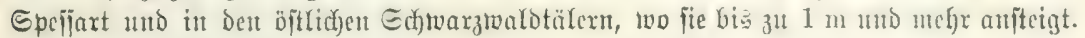

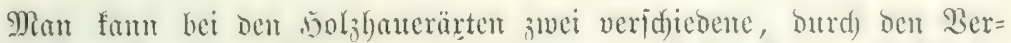

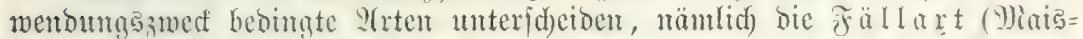

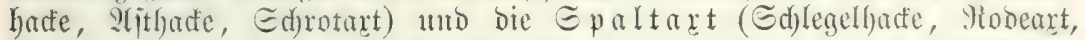

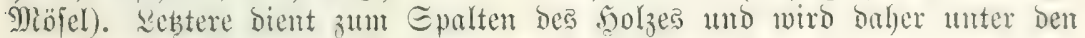
zum Epalten bienenden Miserfzeugen aufgerüfrt werben.

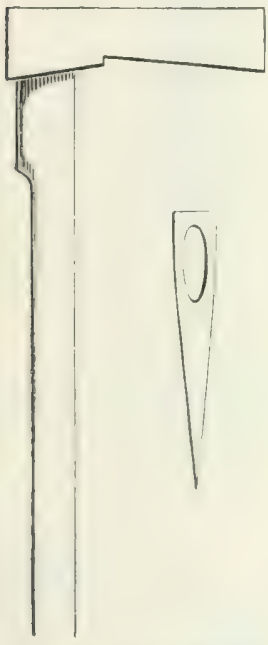

Fig. 46. Gädilifate 2 xrt.

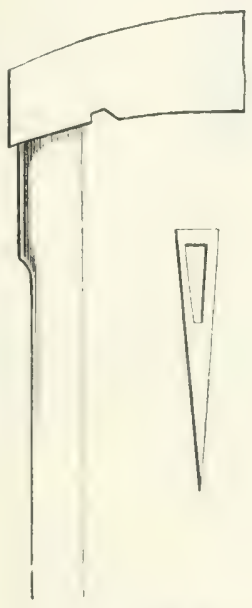

ॠig. 47. 5arzer 2rt.

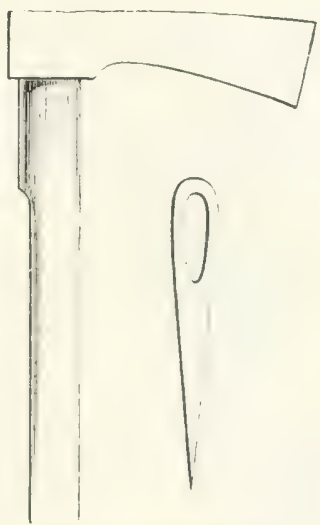

Fig. 48. 3öhmijde 2rt.

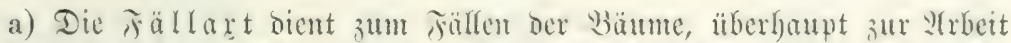

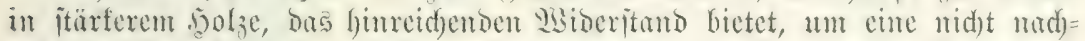

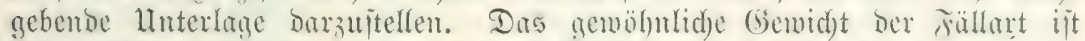

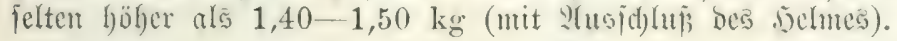

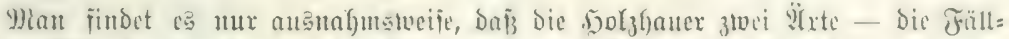

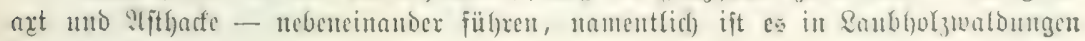
nid)t gęräu(d) (iç).

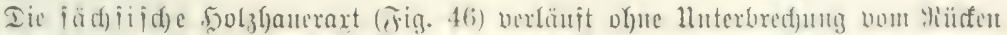

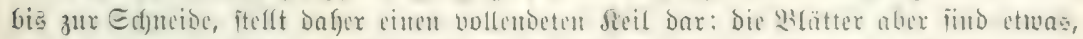

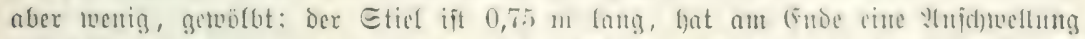

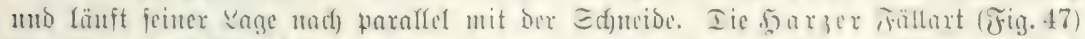

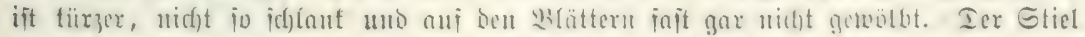

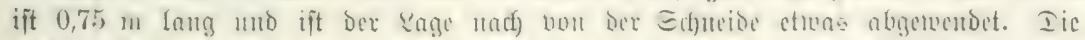

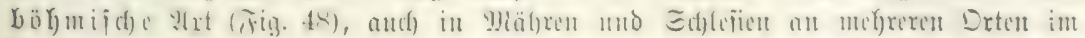




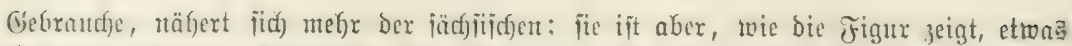
cintuärto gebogen. Der betm ijt meift geraine unD $0,75-0,85 \mathrm{~m}$ lang. Die Fü̆llart

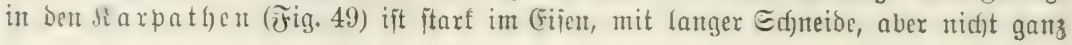

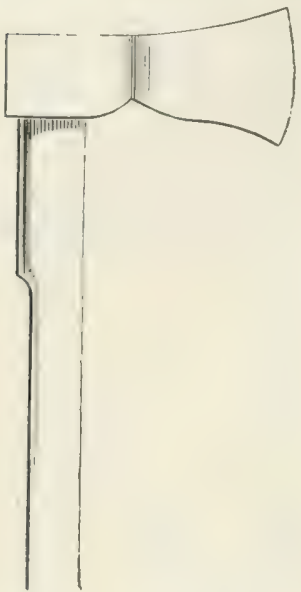

žig. 49. Sarpathent=2rt.

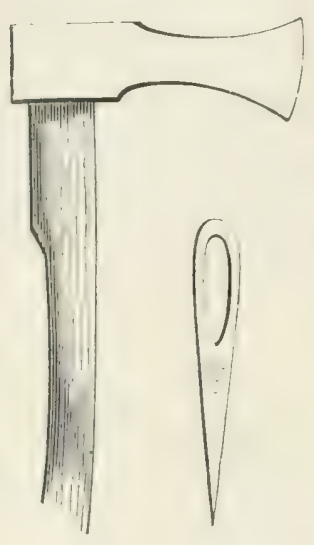

Fig. 50. Norbalpen=21xt.

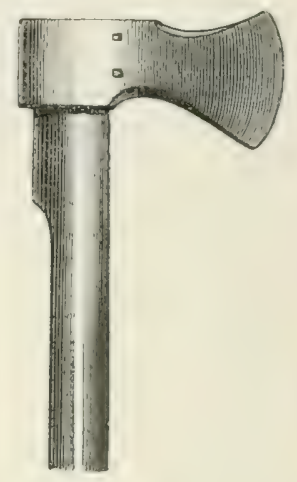

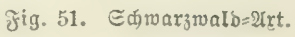

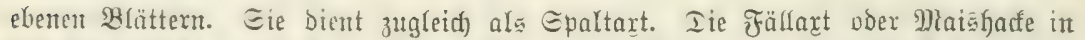

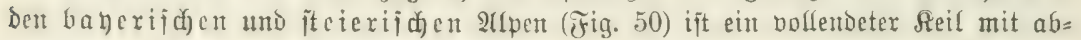

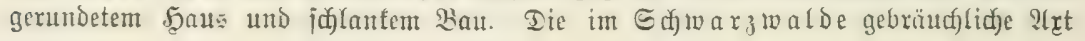

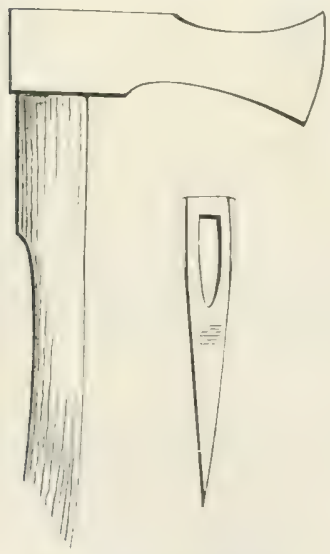

Fig. 52. Rorbalpen=21jthade,

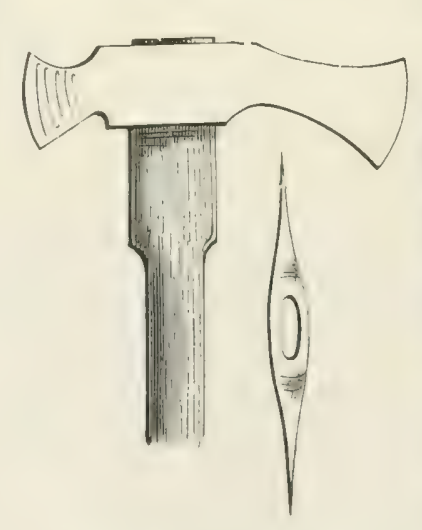

Fig. 53. Torbalpen=Doppelart.

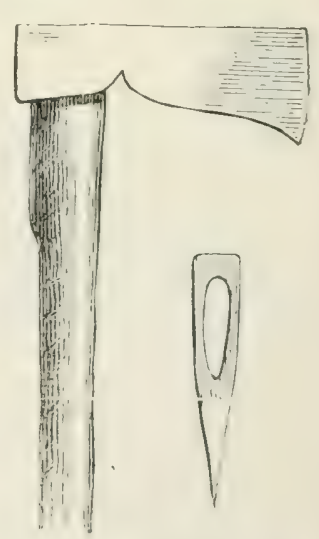

Fig. 54. Thüringer 2(xt.

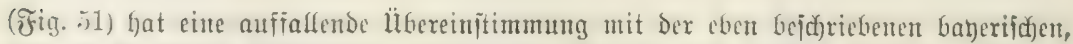

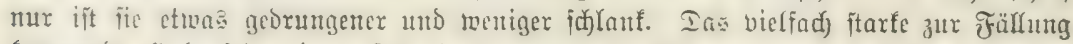

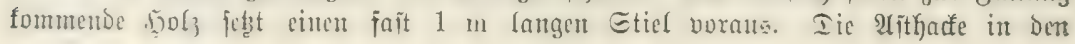




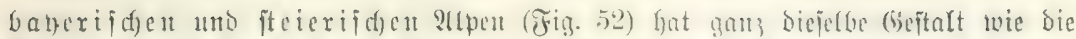

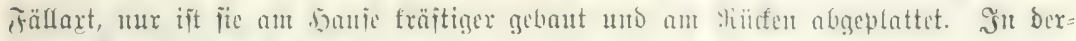

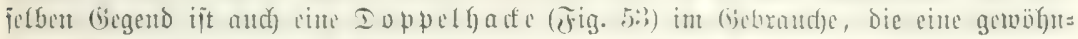

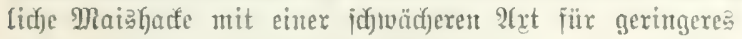
Solz vereinigt; ifgr (Getvidjt beträgt mur $1,40 \mathrm{~kg}$. Dic If) üruger Art (Fig. 54) ftimmt im Bau an meiften mit ber fädjifidjen übereis. Fig. 55 gibt bie form Der ङ übalpen=(italienifden)?(xt twieder, weld)e einen boll=

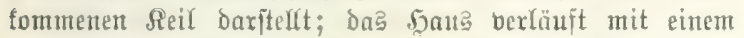
jd)wad)en Minfel in bie Sdfneide; (Gervid)t Der Art (ohne Stiel) $1,7 \mathrm{~kg}$; 2(xtlänge von Sdfneibe zum 9lxtrüdfen

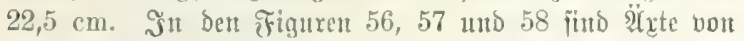
Rothriugen und Franfrud ${ }^{1}$ ) wiedergegebeu, wobei

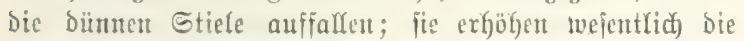
Siraftivirfung, erid)tweren aber bie Fiibrung. Fig. 59, bie

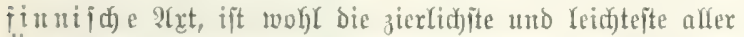
शُxte; vom Sूausanfang bis zur Edyneide nux $15,5 \mathrm{~cm}$ lang, wiegt fïc mur $1,5 \mathrm{~kg}$, wobei bie Jäljte Des (Serwid)t? auf Das Den Etiel Gerablaufende Şau tommt. Die eigent=

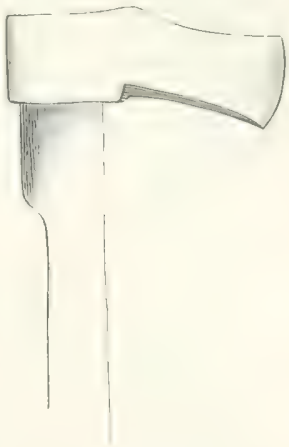
Fig. 55. Siibalpentitalien.)
2irt.

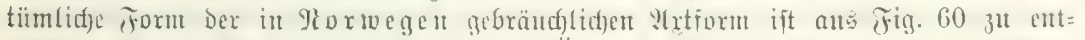

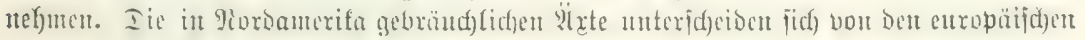

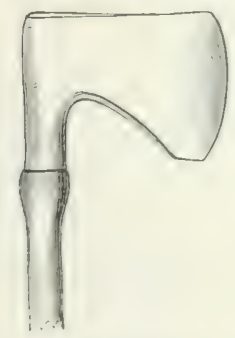

Fig. 56. 21rt bes \{ranjöj. Sanbes.

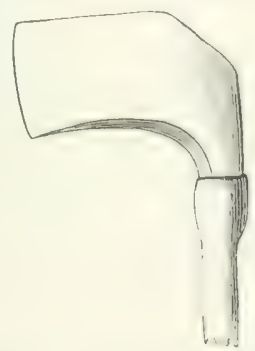

รig. 57. 9xt ber Bretagne.

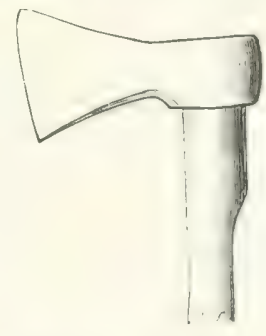

Fig. 58. Rothringer art.

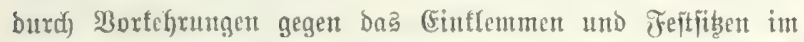
Epalte. Die Ecitenfläd)en finto 3t diejem 3twerfe entweder mit einer ber Witte entlang \aufenden, abgemölbten Sante verfehen

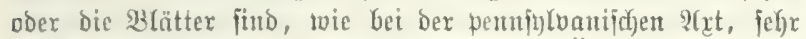

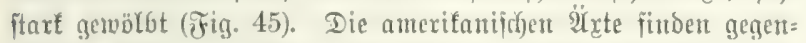

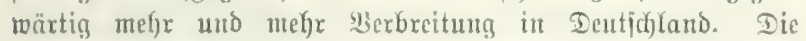
Ed)meide ift aus tomprimiextem Stahl hergeitellt, mubt jidf fait gar nidht ab und licjert jeine Arbcit. Die $\mathfrak{A} x \mathrm{t}$ if nad) über= cinjtimmendem Ilrteile fefr arbeitsföroento und ermübet burd)

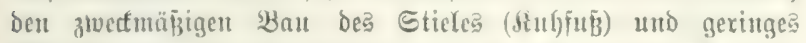

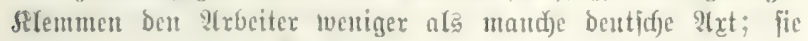

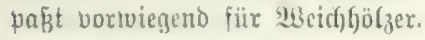

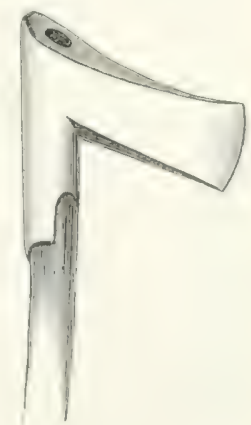
1887.

1) Jad R. Boppe, Cours de 'Technologie forestière. 
b) Dab 3 eil bient zum 3erfleinen Des Brembolace Durd) Epalten und

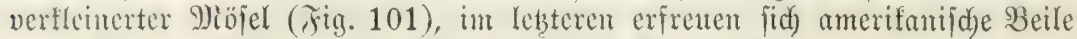
ciner itetigen Berbreitum in ben deutjdyen saubhaltumgen.

Dā 3 reitbeil bient zum Beid)lagen ber Etammbölzer und mird in

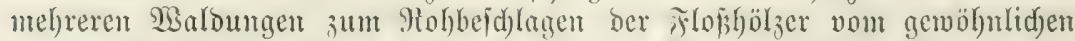
Solzhaner, fonit aber von der sand des Siommerzialfolzarbeiters and 3immermannes geführt.

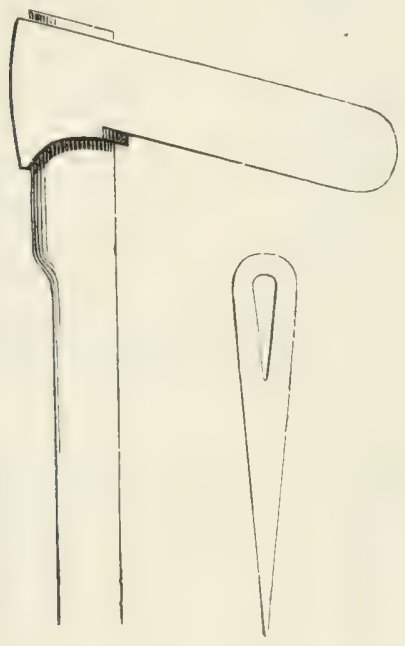

Fig. 60. Norwegifde 2 xt.

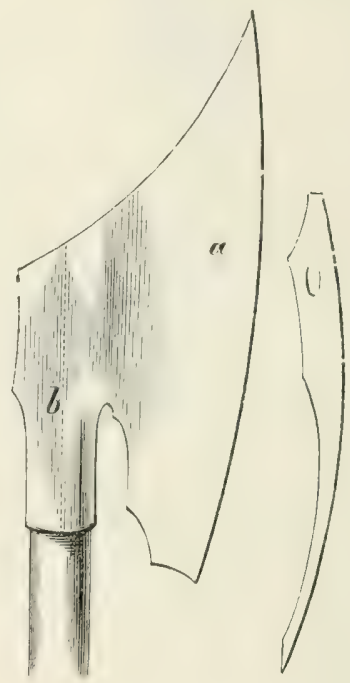

Fig. 61. Wrettbeir.

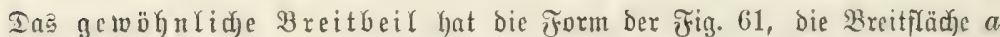

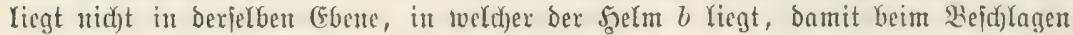

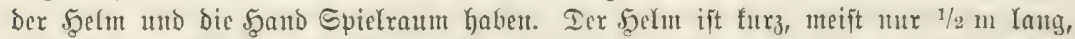
Der Ptrbeiter fteht beim Bejdlagent fe it ü üt farles zum Maldgeforand)e beftimute Form ift die in Fig. 62 grgebene. Beilflüchen

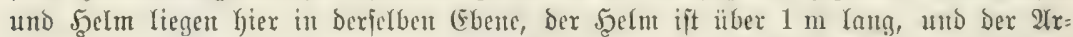
beiter jteht beim Befd)tagen a uf bem Stamme. Diejes Buil ift ntamentlid) im

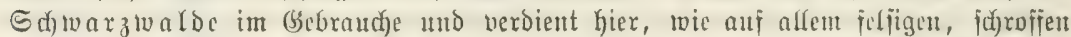

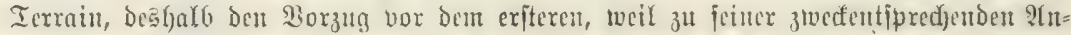

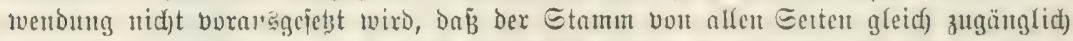

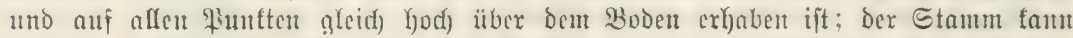

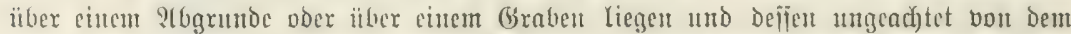

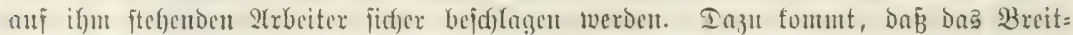

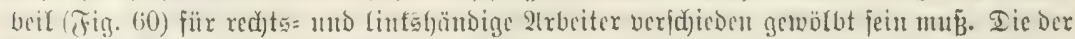

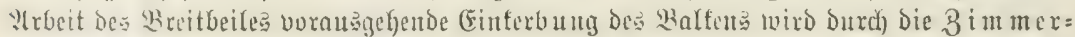
mann hergeftellt. 


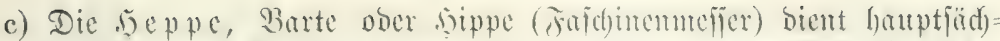

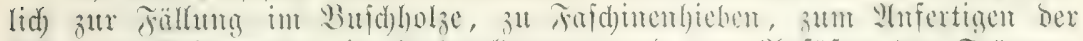

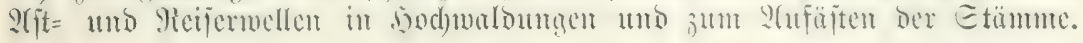

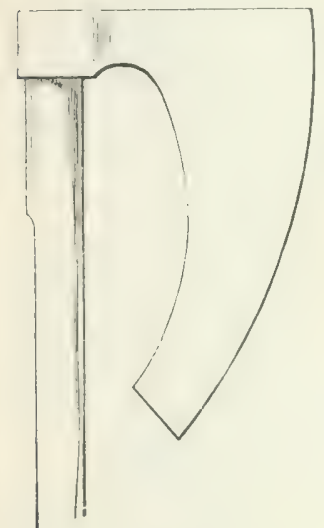

F.tg. 62. Ed)marzwaider 3reitbeil.

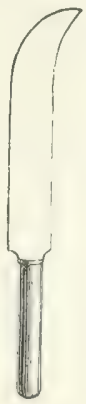

Fig. 63. fig. 64. Seppe, Engl. Faid.=\$liefier.
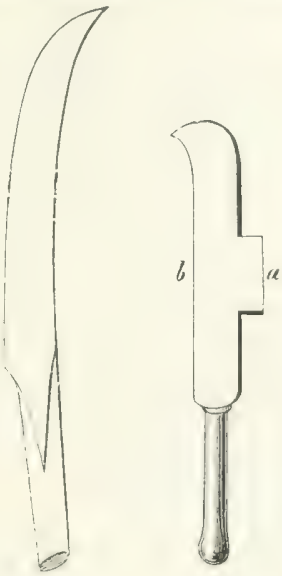

Fig. 65. Seppe.

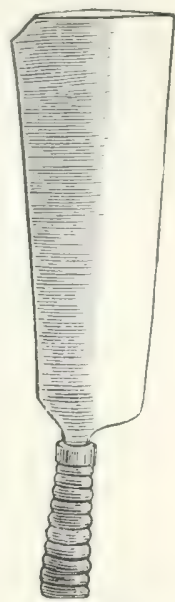

7) $\mathrm{ig} .66$. (5ourvals seppe.

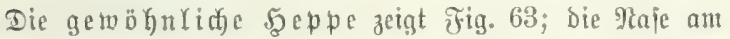
vorderent Ende ift eine bequene Beignbe, da fie beim Wellen=

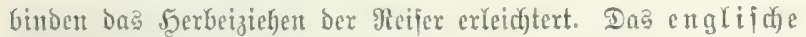
Faidinentmefier (Fig. 64) ijt ganz von (Eijen gebaut; es hat cine fäbcliörmige Gsĩtalt, ift $0,55 \mathrm{~m}$ lang und bei feinem fräftigen Bßau für Das ftärfite Frajdinenholz antwendbar. Fin

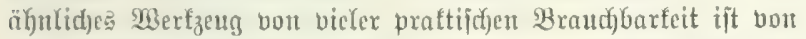
Dex Form wie Fig. 65, e ift im Piüfen $15 \mathrm{~mm}$ ftaxf und hat midjt mux bei $b$, fondern aud in $a$ cine Sifncide zum Durd)=

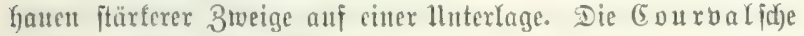
2(ufäjtunģhcppe (Fig. 66) bat cine Ränge von $42 \mathrm{~cm}$ und viegt $1,50 \mathrm{~kg}$; fie ift in ber Mritte am ftärffiten im (Fif̣en, un bie

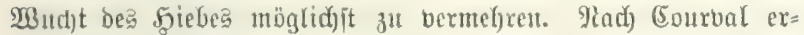

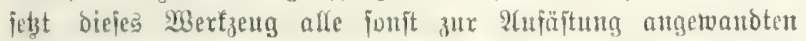
Snftrumente uno virb bon ifm aud) aux 2(bnahme ftarter

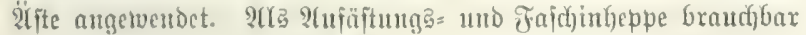
ift jodan die amerifanifide $\mathfrak{B} u\left\{d_{j}=\right.$ oder Dornhaue, Edyabel=

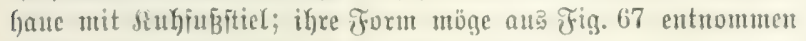
werden; fie twiegt ofne Sticl $1,25-1,5 \mathrm{~kg}^{1}$ ).

2. Die $\left.5 a ̈ g e^{2}\right)$ dient beim 50 hbanerbetriebe vor=

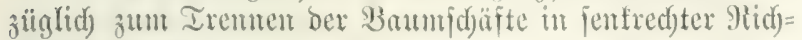

1) 3 bezief)en von S. D. Dominicus \& Göhue in 9em=

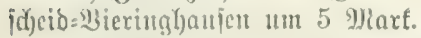

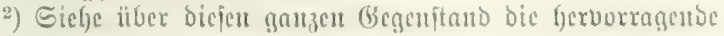

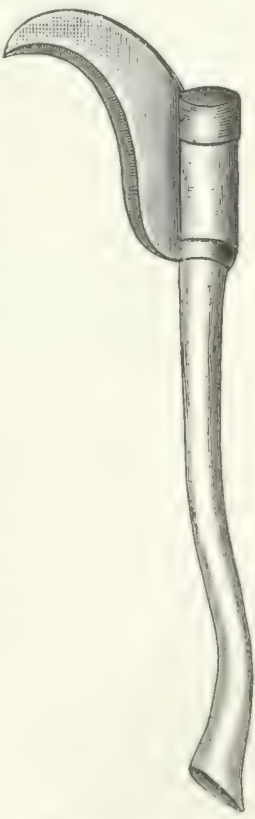

Jis. 67. y(merteanifd)e Dorn= 1t. Edmabelgante. 


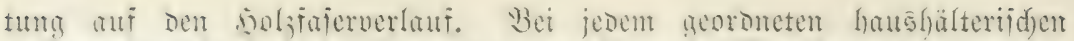

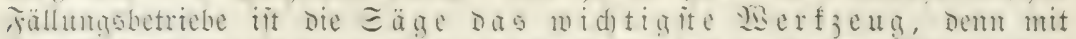
ihrex

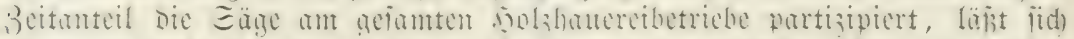

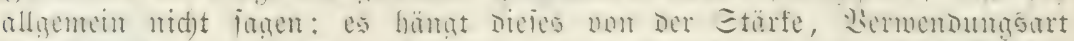

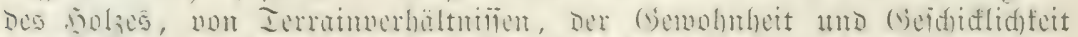

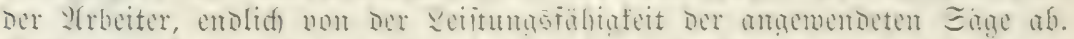

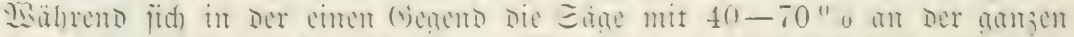

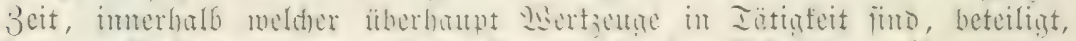

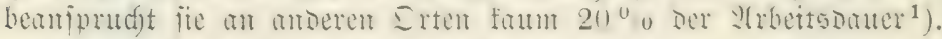

Iie פ⿴囗十 Firtigt, bas gewalgte Eägeblatt mubte dann Durd) faltes bümurn io hart, iteif uno

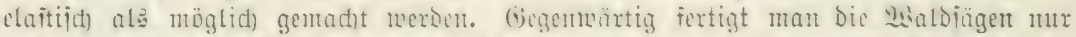
meh) aแ (is u

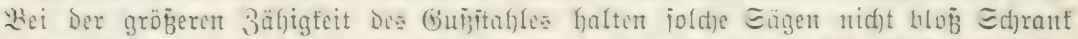

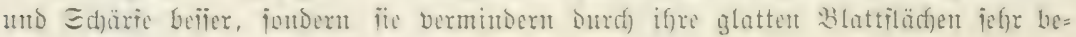
merficidy die Reibung im Edyntitte.

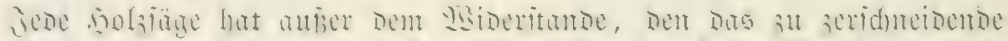

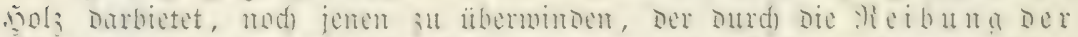
娄

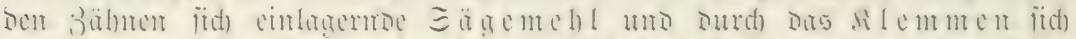

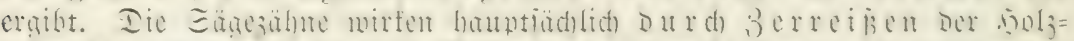

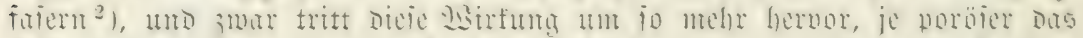

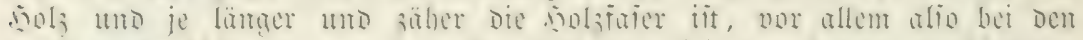

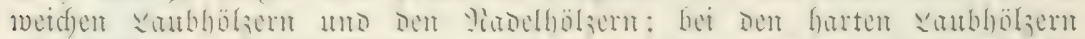

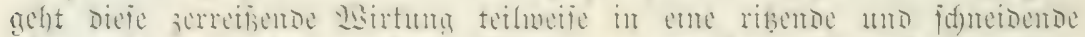

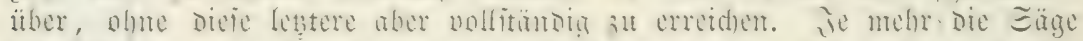

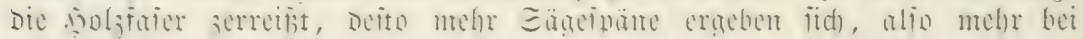
meidjen alอ bei harten f̧ölzeru.

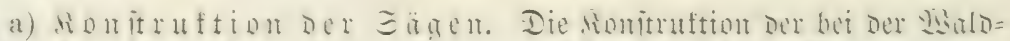

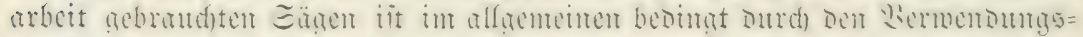

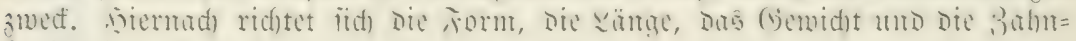
foriturtion Derjelben.

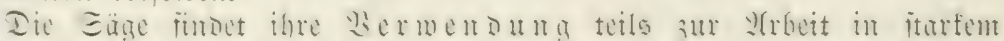

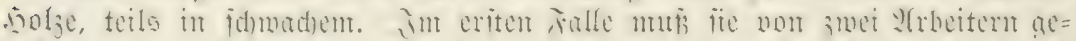

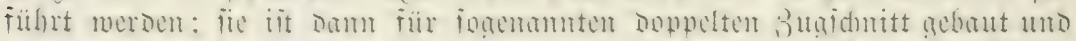
miro cime ; we im

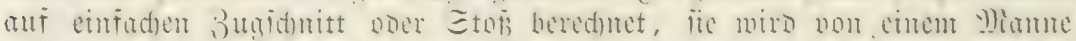

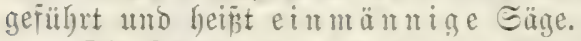

Iic

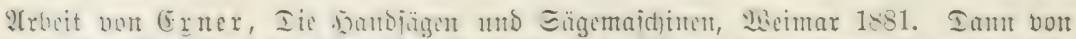

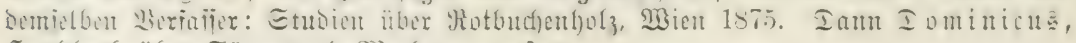
5ुantofudf über Eägen und 23?erfzeuge u. ¡. tw.

1) Siehe Roreh in Forit= uno Jagozeitung. 1874. ๔. 199.

2) Eiche bie 2(rbeit ber Gäge im eriten 2(bjojnitt. 


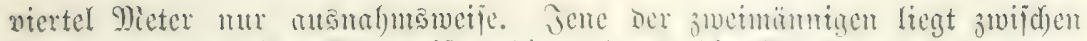
$1 \mathrm{~m}$ unt $2 \mathrm{~m}$; ihre sänge ift bebingt butd) bie Etarte nes solzes uns

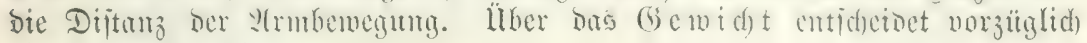
bie Sänge der Säge.

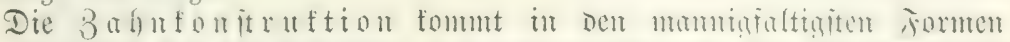

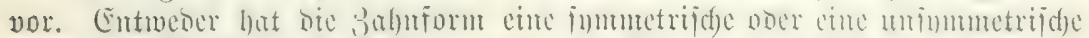

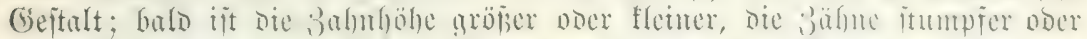

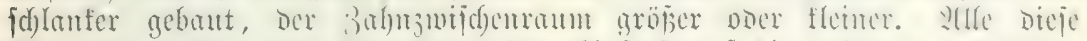

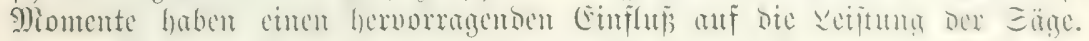

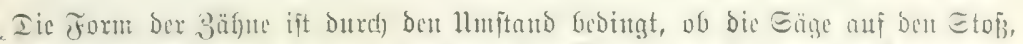

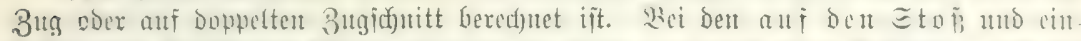

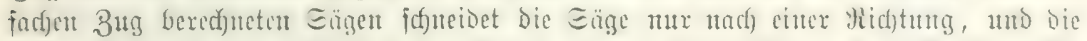

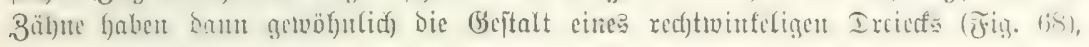

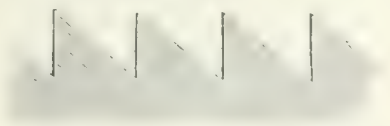

Jig. 68. Riegende Dreieç3̈̆nne.

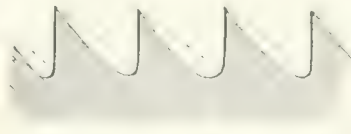

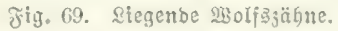

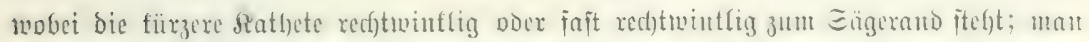

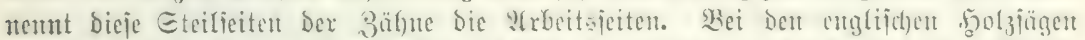

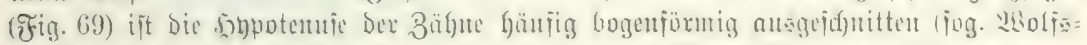

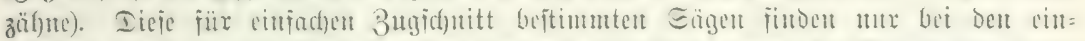

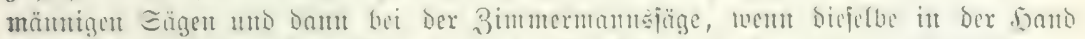

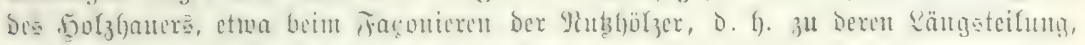

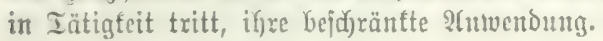

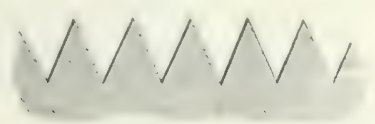

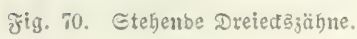

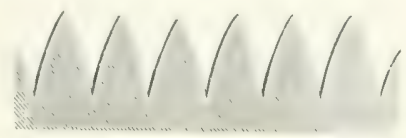

Fig. 71. 3ähne ber 5arjer Eäge.

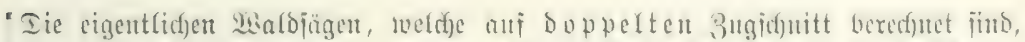

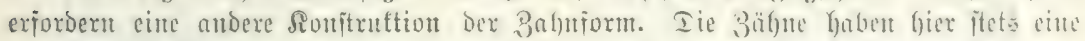

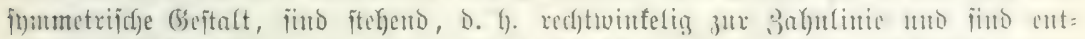

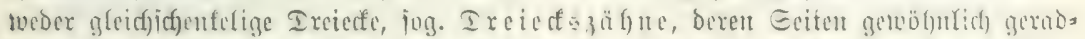

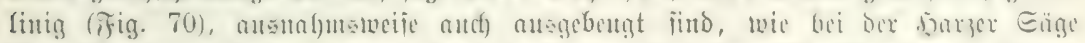

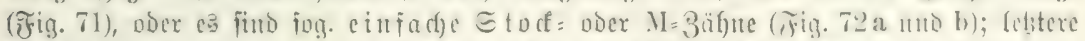

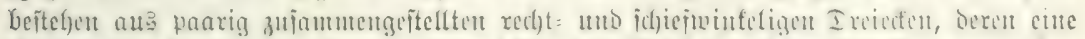

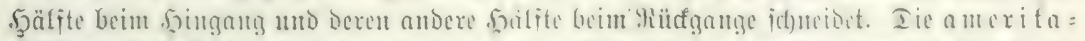

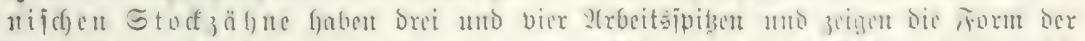

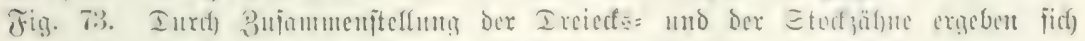
fombintexte Formen bes Barutbejalsce, wie in Fig. 74 .

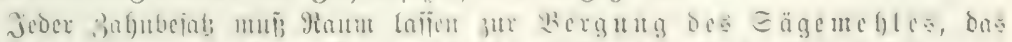

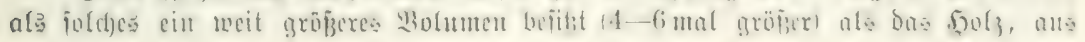




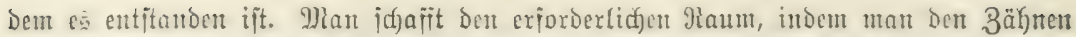

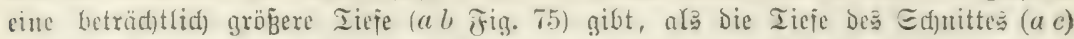

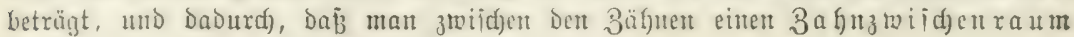

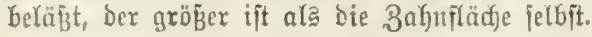

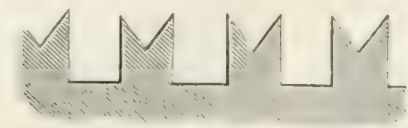

jig. T2a.

Einfadje હtod= ober M-3ähne.

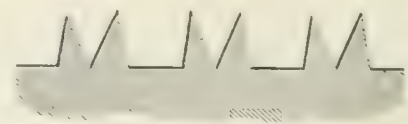

ช̃ig. 72. b.

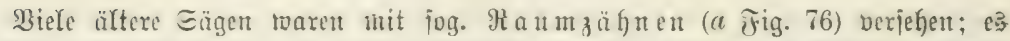

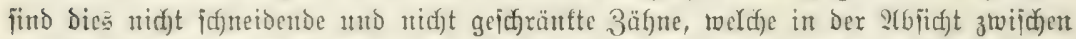

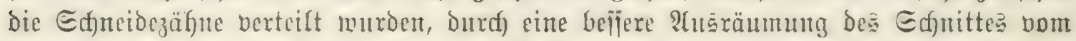

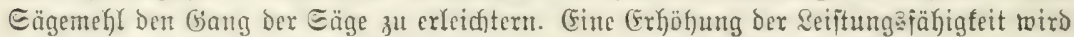

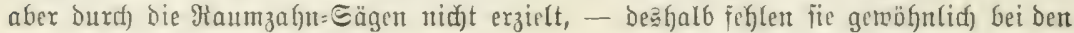

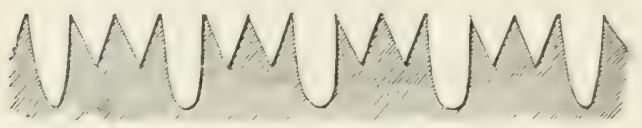

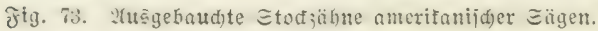

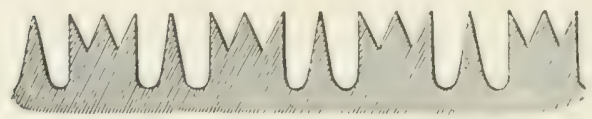

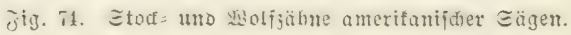
neuteren Sägen. Die ztwijdyen Den fombinierten MI-3äfnen der amerifanifiden Sägen ftehenden einfad)en Dreiectäzähne (尓ig. 74) förmen 3war aud) al⿳亠丷厂 ßaum= zäfne aujgejab̄t werden, bu fie nicht gejd)ränft werden. Man mū fie aber mefye als $\mathfrak{A}$ rbeits= zäfhe betrad,tent, Da ifhre Spitzen in Der allgemeinen Bafmipitzent= Linte Der Eäge Yiegen unto ebentio geidjärft werden wie bie übri= gen 3ähne.

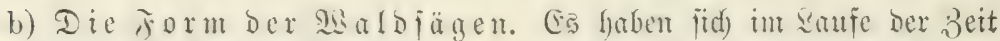
in verjdetedenen Gegenten verfdeteden geformte Eägen cungebürgert, von meldyen bie widjtigeren nadjplgend zu betrad)ten finto.

а) 3 wei

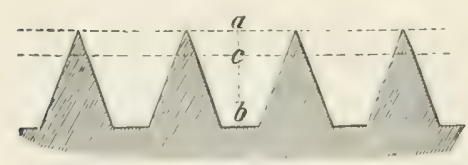

Fig. 75 .

Єägezäbne mit vertieften 3 wịß)nräumen.

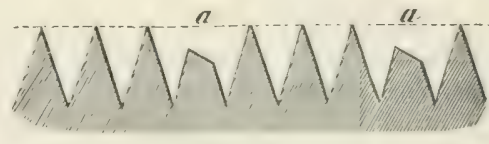

Fig. 76 .

Єäge mit Эiaumžăbrien!

Dic aerabe Dueriäge ober $\Xi$ d) rotjäge: $1,40-1,60 \mathrm{~m}$ lang und $12-15 \mathrm{~cm}$ Blattbreite. Dic sejte find redfuninfelia auf bic Sinte

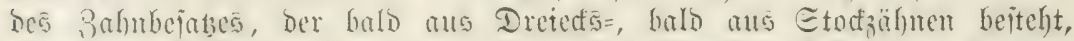

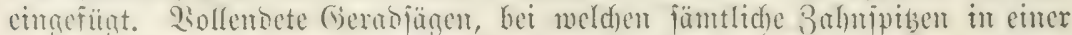

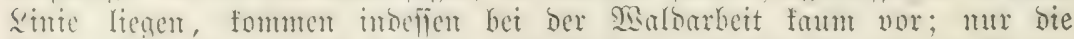

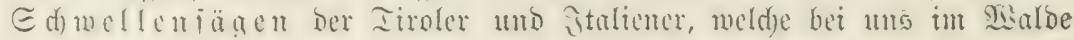




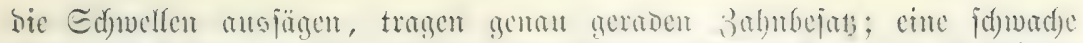

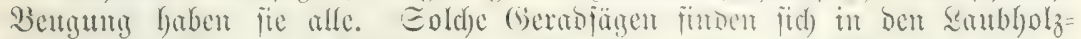

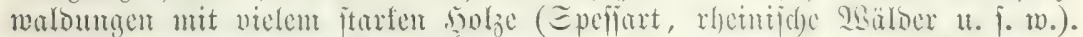

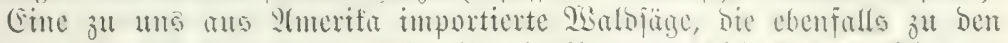

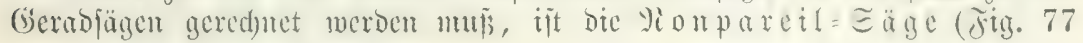

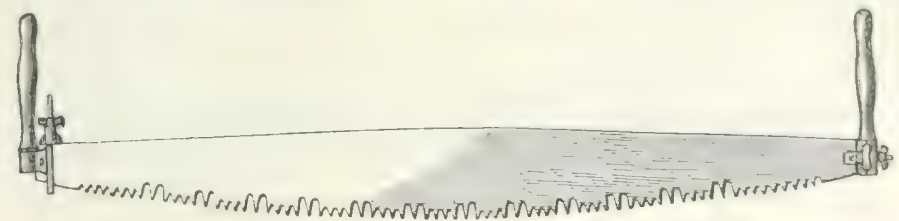

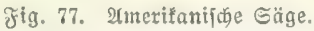

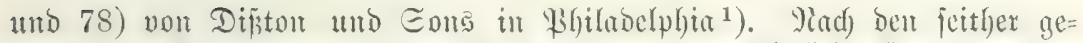

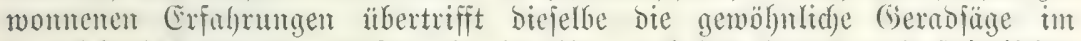
\&aublolze un $35-40 \%$; fic ijt bier aud) der sazzer und jeierifden

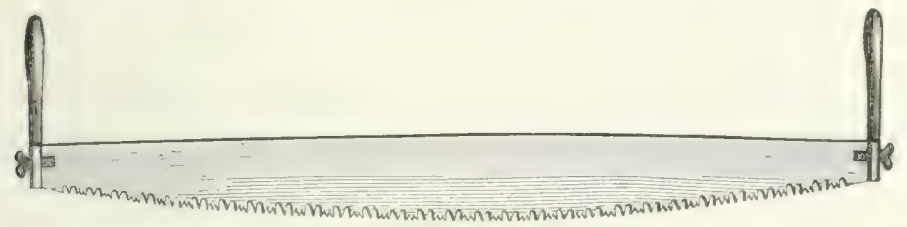

Fig. 78. Amerifaniłøe ভäge.

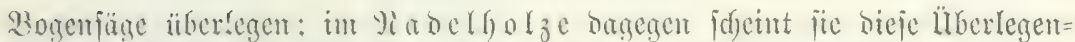

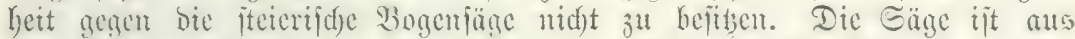
vortrefflidsem Etalle gebout und loat cine jumretde Ëinrid)tung zur $\mathfrak{B} e=$

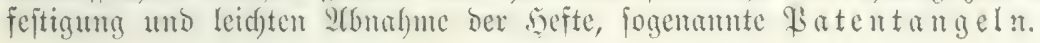

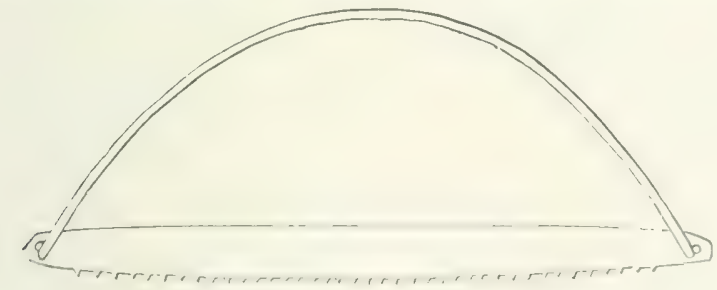

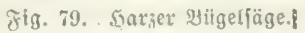

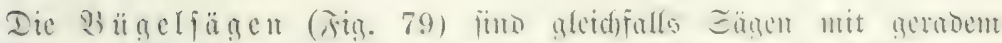

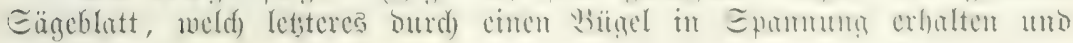

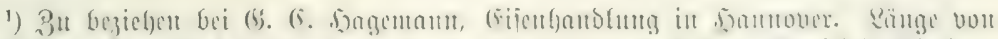

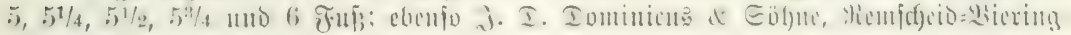
foulett.

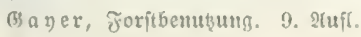




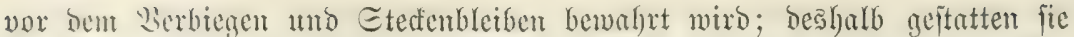
bie :)

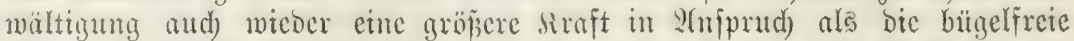
Eäge, bejonders bei Eägeblättern von groper säuge, für weldje fid) der

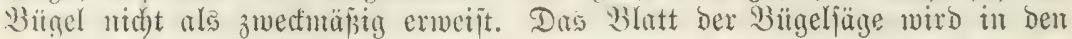
verjotedenften Dimenfinen gefertigt, lyat aber immer Den Eloarafter ber

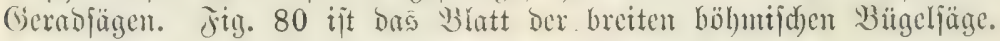

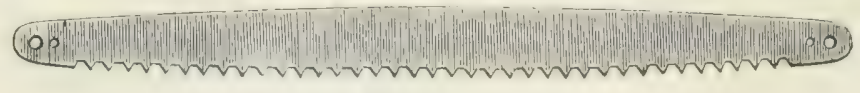

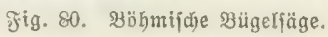

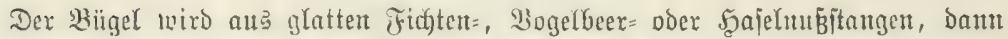

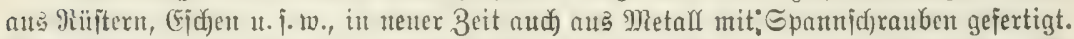

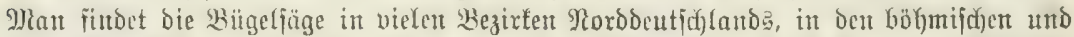

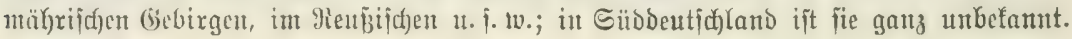

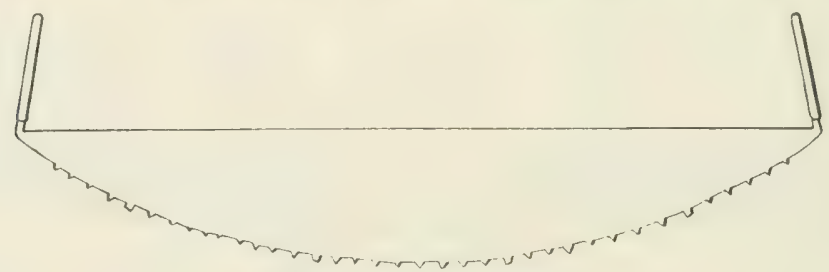

Fig. 81. Tyroler Bogenfäge.

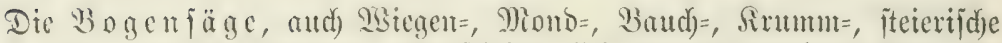

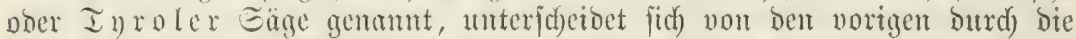

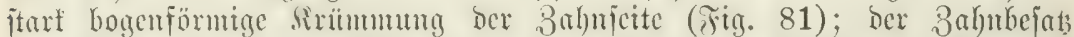

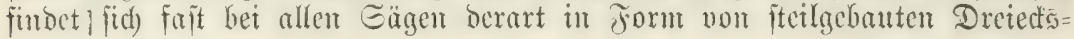

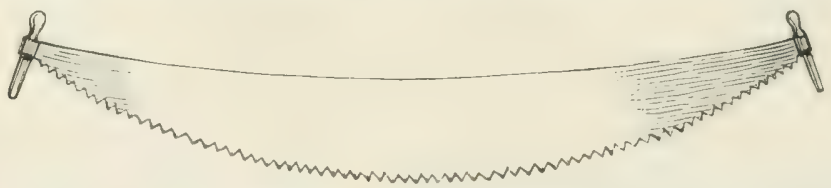

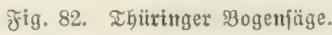

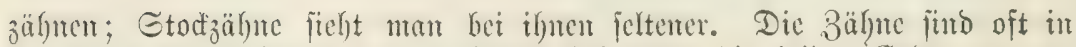
Der Mitte etmes länger unb verfürzen fid) gegen bie beiden entoen öu, wo fie meniger ftart abgenutst merben.

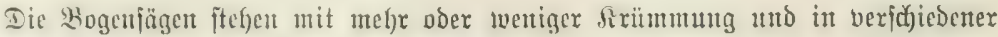

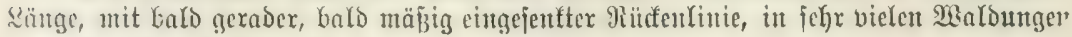
it auggedefrntem (Gebraud ${ }^{1}$ ).

1) Die Inrolex Dogenfüge ift zu beziefen bo Joh. 2iseihuadgt in Mühlent=

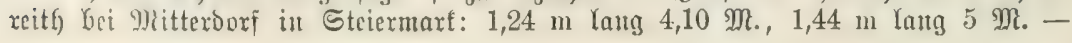




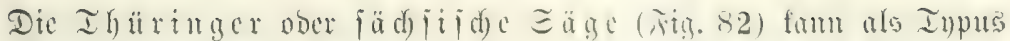

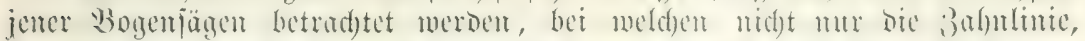

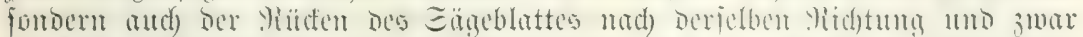

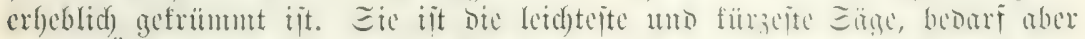
vieler übung zu urfolgreider Jül)runtg.

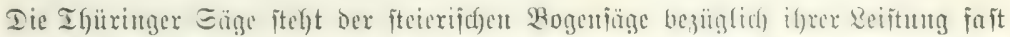

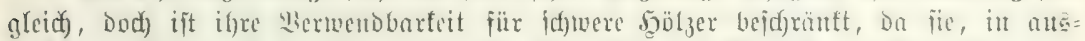

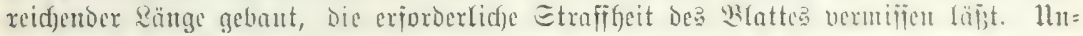

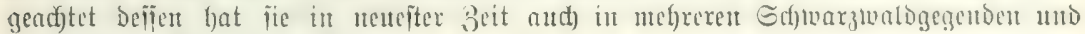
antertwärts cringang gefunben.

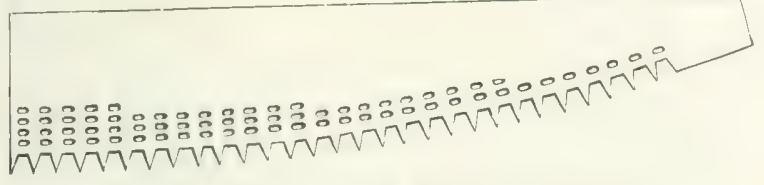

รig. 83. "Non plus ultra ${ }^{*}=$ Eäge von Dominicus.

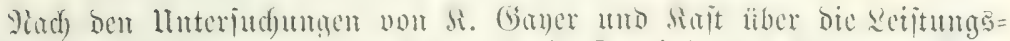

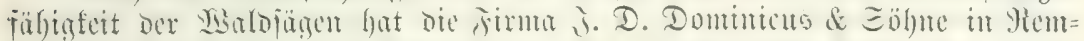

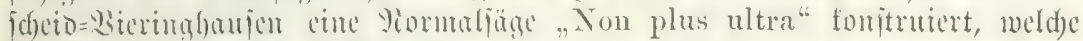
bie Borteile ber iteiertichen Säge mit jenen, welde bie Berforierung bietet

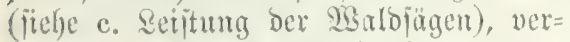
bindet; jie fommt in jedfes eängen von 1,3-1,8 m, wit cinem (5imidfte von $1,45-2,6 \mathrm{~kg}$ utro cintem Freije won 8,5-13 Marf in ben 5uthol (Jig. 83). Ein nötiges 2 (ppertinem jeder Säge find bie $\mathfrak{s e f t e}$ (5ambaben, Gritife, YHughtit). Set den alten Sägen wurben Die eifernen Dorne, über weldye bie hol) len Sefte eingeitedt werben, als be= pornocre Etüde an bos Sänchlatt an=

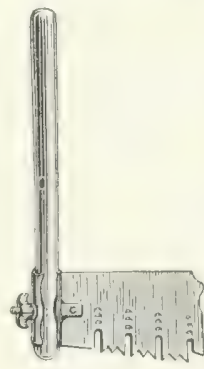

Fig. 84.

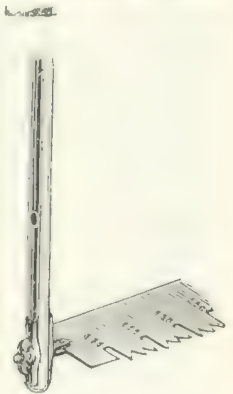

Fig. 85 . gentetet; beffer iftes, wem dieje Dorn=

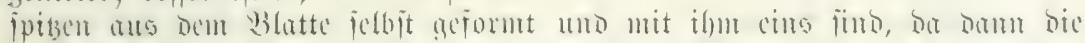

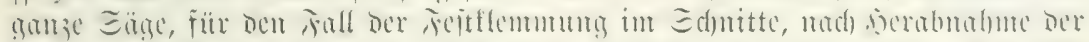

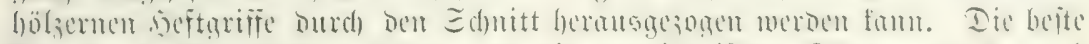

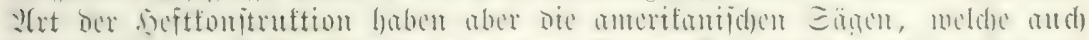

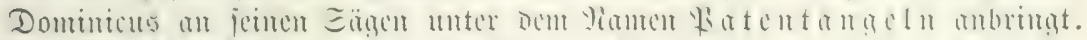

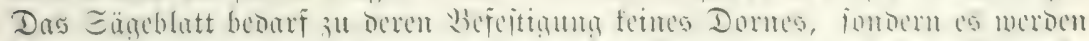

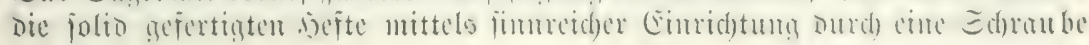

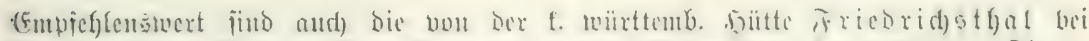

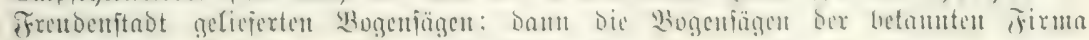

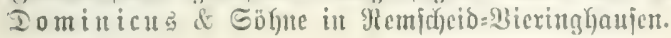




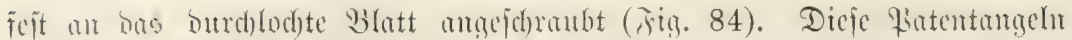

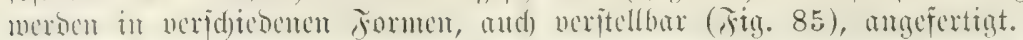

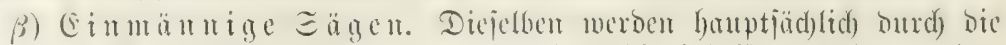

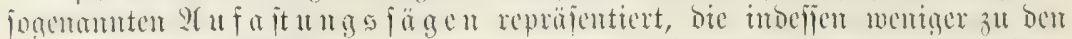

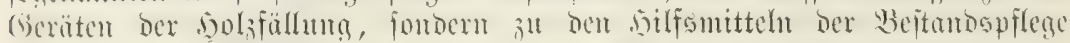

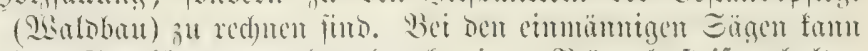

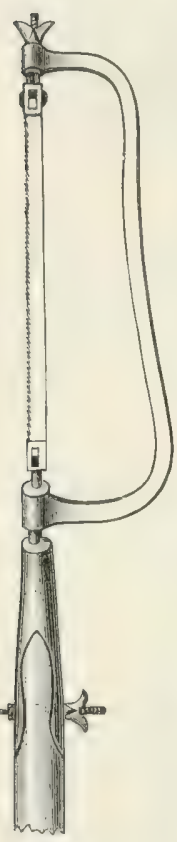

jig. 8i, Thleres juiigelfiage.

Das Eäneblatt entweber ourd) einen 3 ü gel fteif erbalten

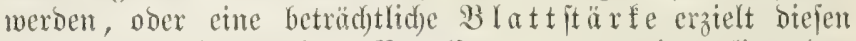
3ived. Die entmänntigen Bügeliägen tragen einen liegenden 3abubefats, an weld)em die 3abujpiben mad) vorn gerichtet

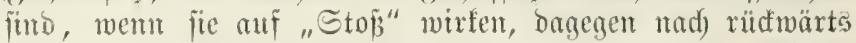

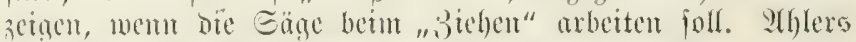

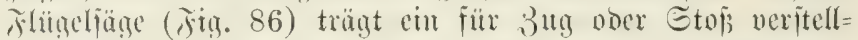
bares Shlatt und einen aus ber Ebente bes Sägeblattes breh)= baren Bügel mit Spammidranbe.

Eimmämnige Sägen ohne Bügel, bie burdf entipred)ende

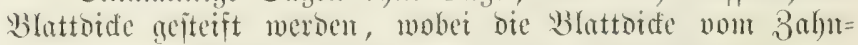

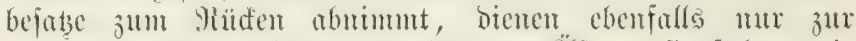

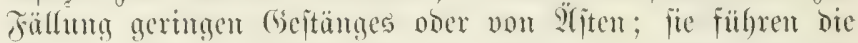

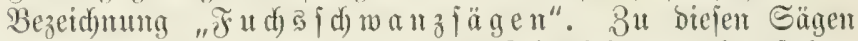
gefört aber and bie in neuerer 3eit bei uns cingefülyrte a merifanijd) Irummjäge (Jig. 87) aแB ber Fabrif

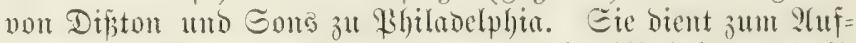
fdunciben nidjt zu it arfer Stämme in 2(bjd)nitte und ijt

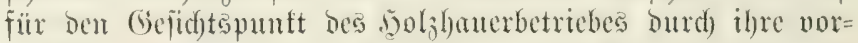

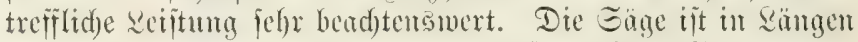

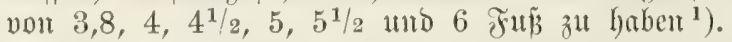

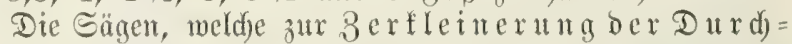
forftugajtangen an eintgen Drten zur Anwendung fommen, fund burd)us mit ber befmuten Eäge bes Ed)remers veraleidgbar; fie find wie bieje in einem leid)ten solzgatter cingefpamt, bas Blatt ift cint gemalytes, büntes Stallblatt,

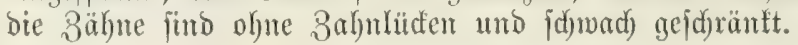

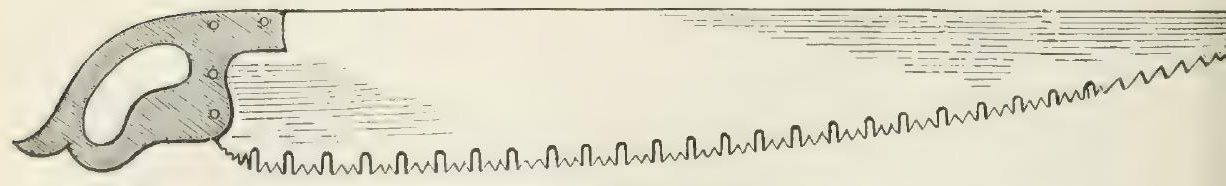

frig. 87 . 2merifanijđe Irummjäge.

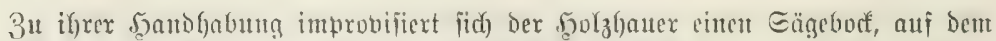

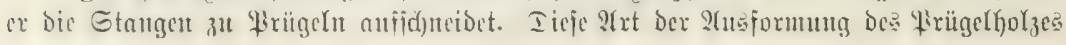

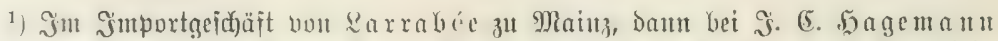

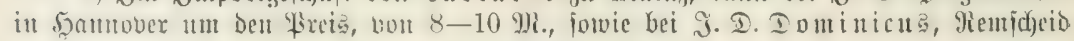
perforiert und nidjt perforiert um 4,40-14,50 9 . 


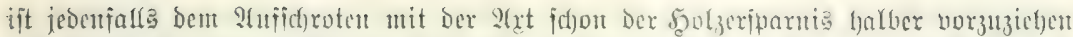

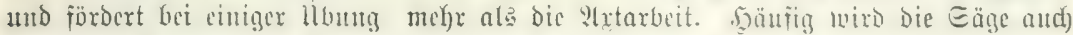
von ztwei 2 trbeitern in 13 etwegung gejebt (Edjitterjäge).

Eägemajd)

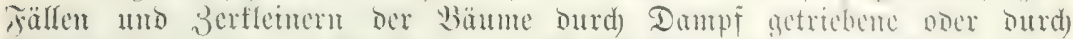

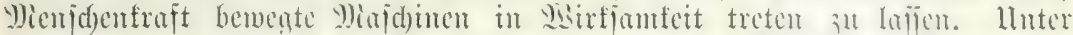

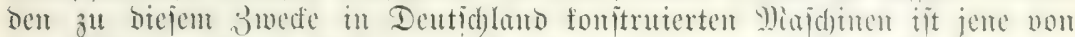

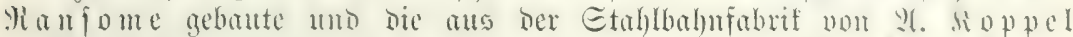

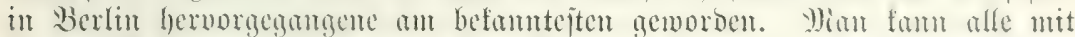

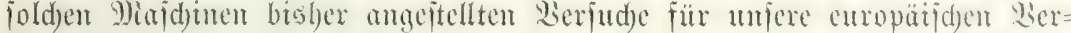

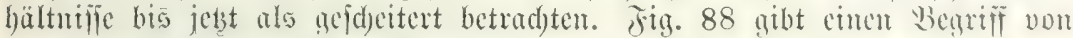
ber Einrid)tung berartiger Borridtutuen.

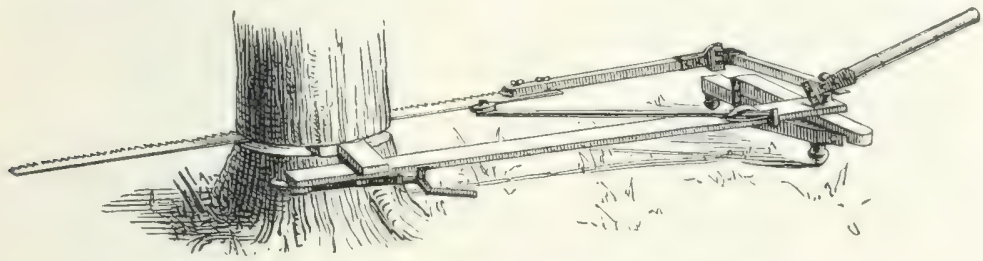

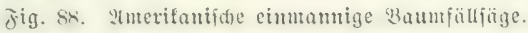

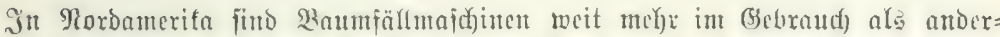
wërts; freilid) Darf man bou Der majientaften Reflame Der Durtigen Fabriten tridgt

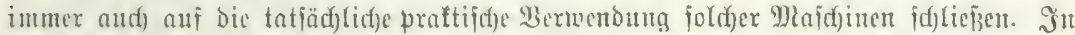

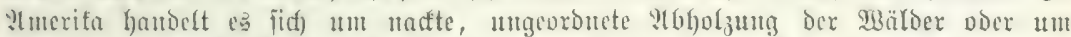

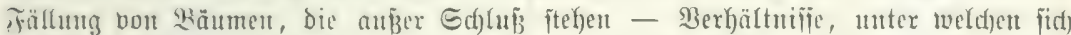

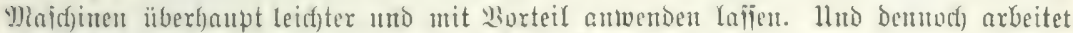

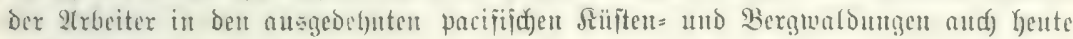
nod) mit ber 2 (xt.

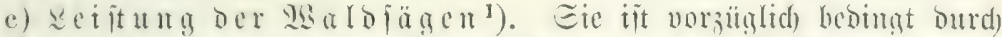

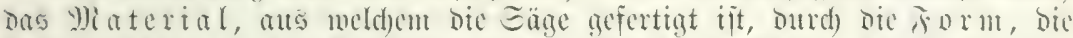

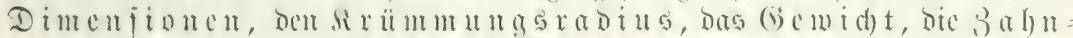

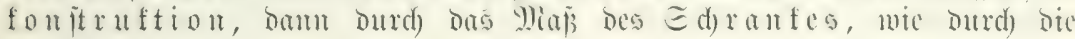

1) Miffib, Euppl. zur Torit mo Jagdzeitung. II. 144. Sinifer, Forit=

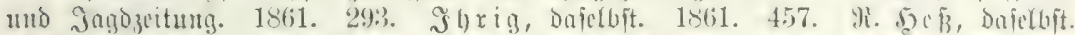

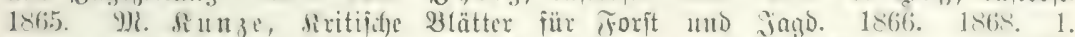

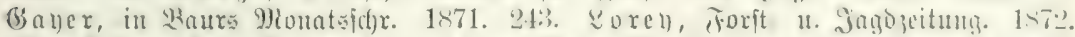

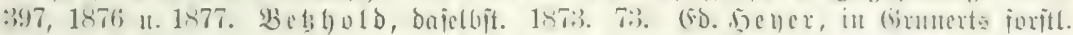

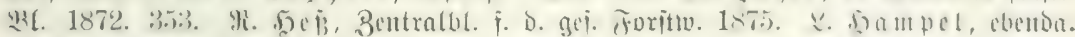

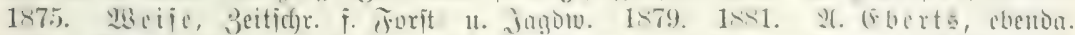

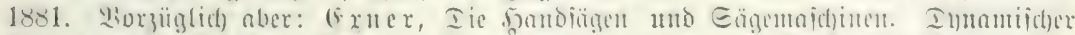

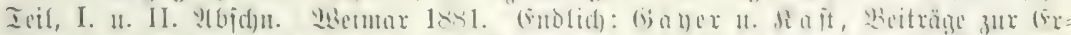

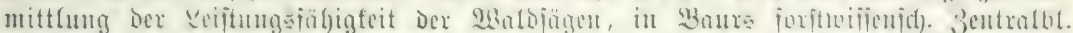

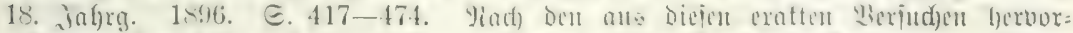

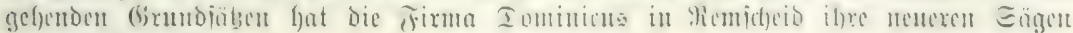
gebaut (fig. 83). 


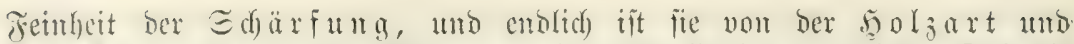

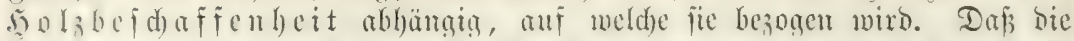

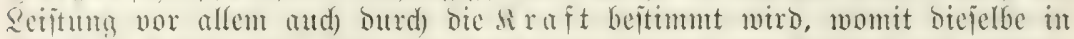

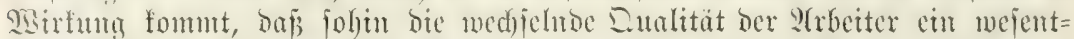

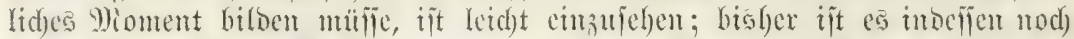

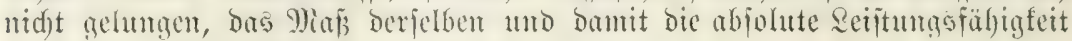
eimer Eäge àl bejtimmen.

Das Material ift injoferu cutidjetidend, als dadurd) ber 5yärtegrad und vout

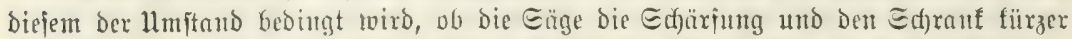

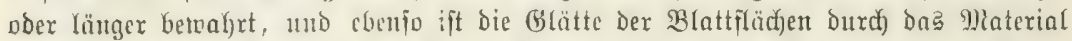

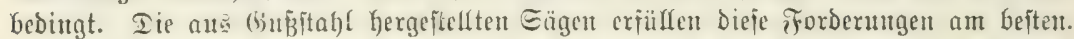

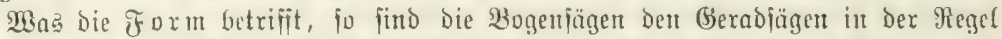

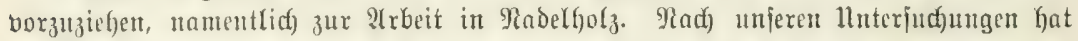

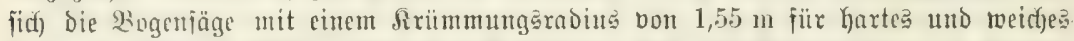

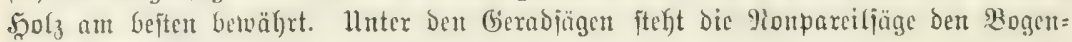
jäget nแm nädffiten.

Iie Arbeit mit Der Bogenjüge ift für den an jie gewöhnten 2rrbeiter leicfter

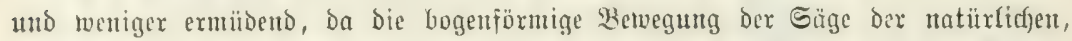

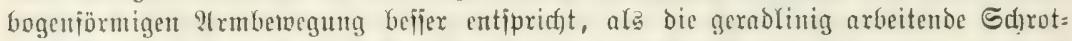
fäge: bei ber eriteren fann Der $\mathfrak{P}$ rbeiter in mełhr aufredfter Etellung verfarren, wäf)reno

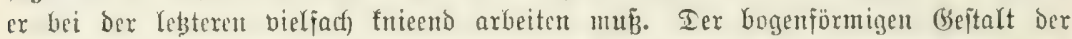
Gäge follte audf) cinte fongrutente bogenförmige Bbetvegung ber Säge entiprecfen. Dieje

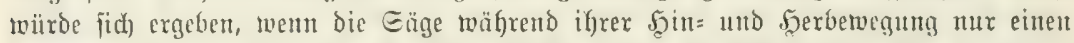

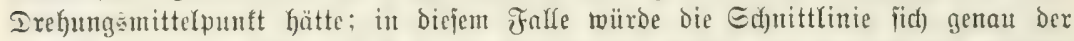

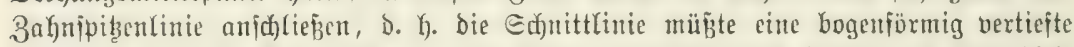
fent. Da aber bie Enge jiff) um zwei Irefungamittefpunfte betwegt, io faun bieje

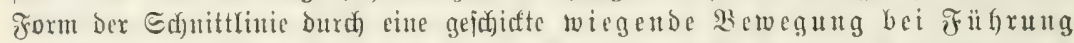
Der Säge moht zum Ieil, aber nidft bolfftändig erreid)t werben. Iie Edfnittlinie

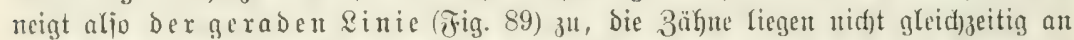

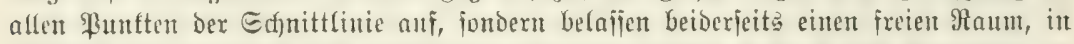

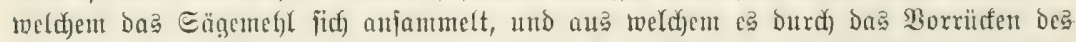

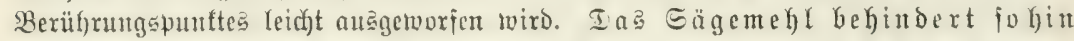
bei Den Bogenfägen ben Gang ber Eäge weniger als bei ber gerabun Sdyrotjäge.

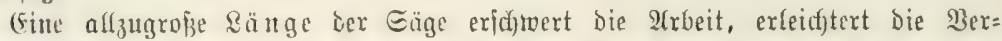

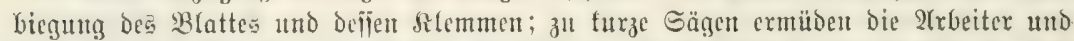

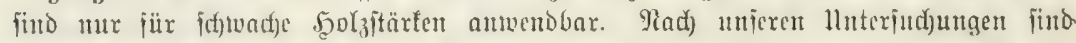

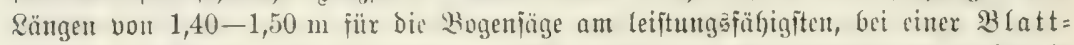
breite von $22 \mathrm{~cm}$ (ohne 3nhubefab). Wab die Stärfe Des Eägeblattes betrifft, fo

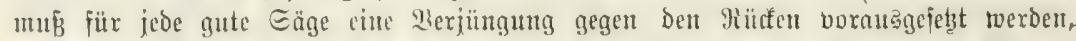

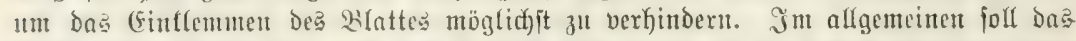

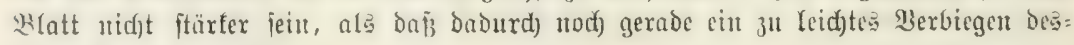
jelfen bermicoent wirb.

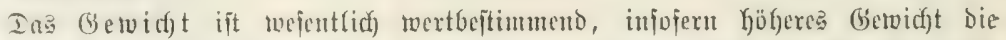

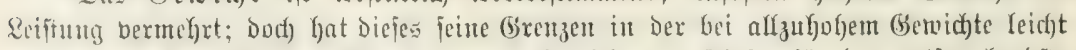

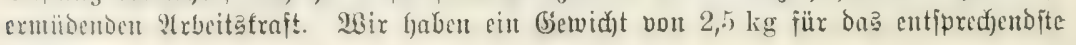
gejunoen. 
Bon gauz herborragendem (Einflufie ift bie 3 af) nfouftruftion. Steil gebaute

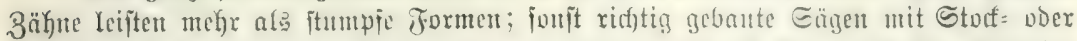

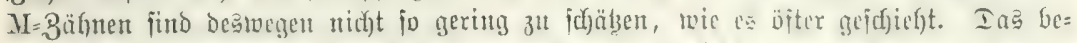

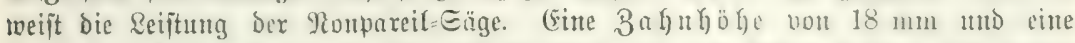

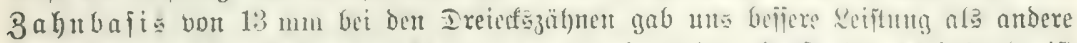

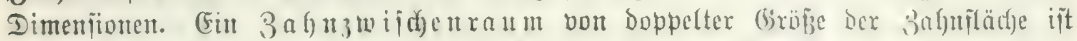

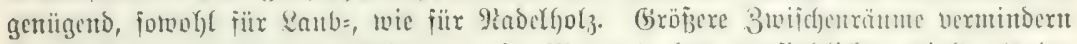

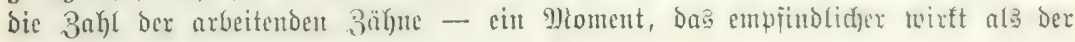

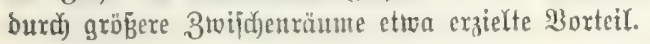

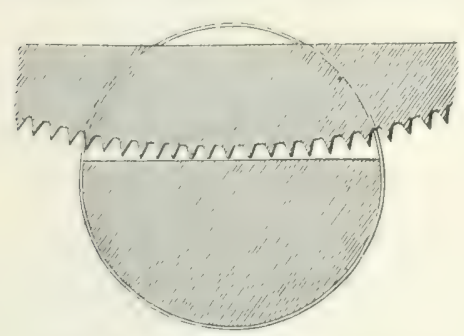

F̧ig. 89. Єđnittlinie ber Bogeniäge.

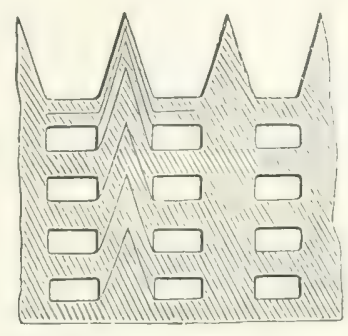

Fig. 90. ßerforiertes ভägeblatt.

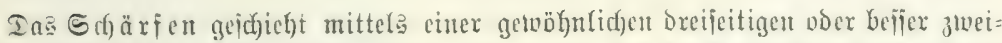

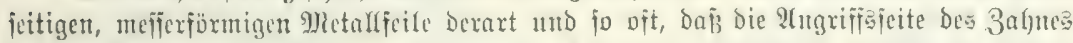

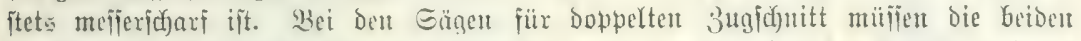

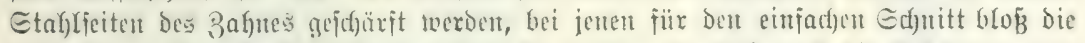

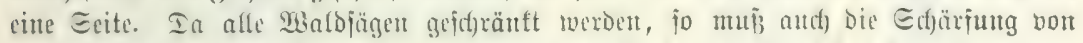

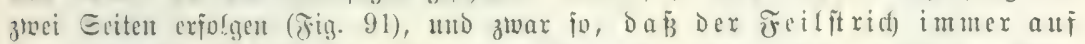

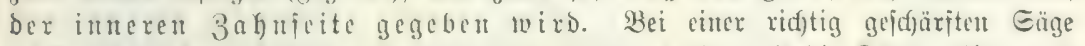

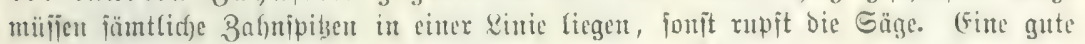
Säge faălt bie Edjärịung 5-6 Tage bei andauernder $\mathfrak{A}$ rbeit.

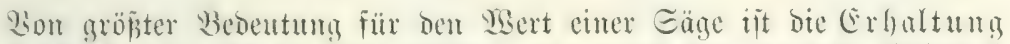

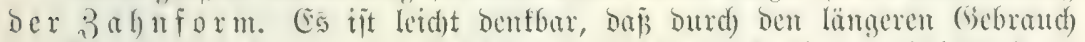

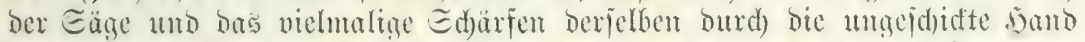

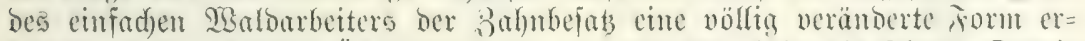

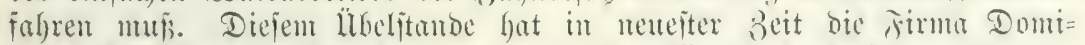

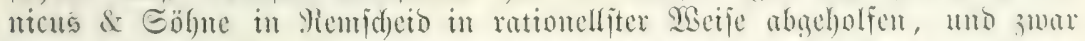

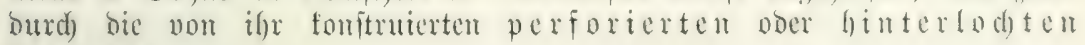
Sägeblätter.

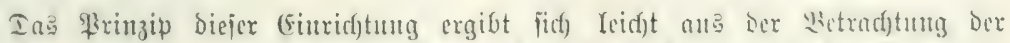

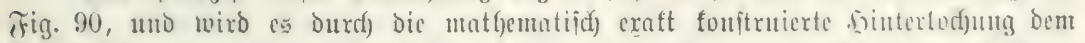

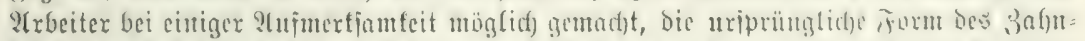

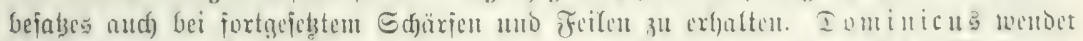

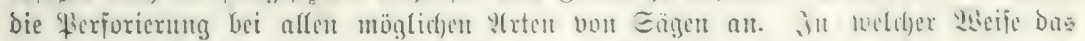

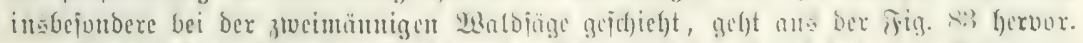

Ins $\Xi$ d) $x a ̈$ uf

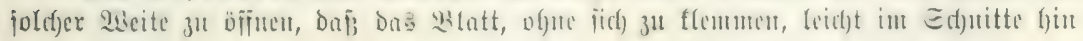




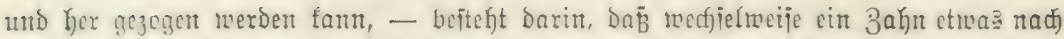

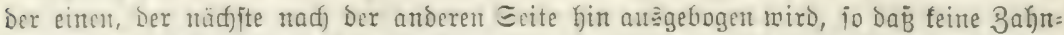

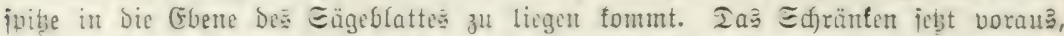

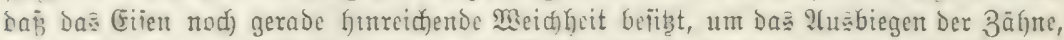

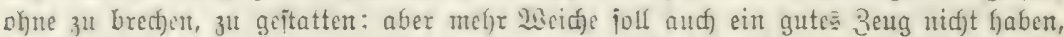
jonft hält bie Eäge tweder bie Edürinung nod den Edrant.

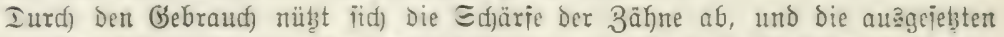

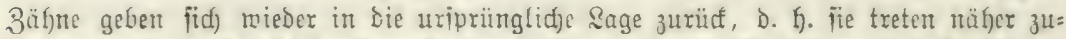

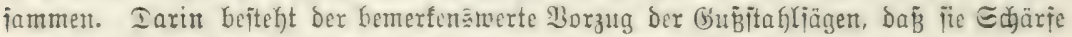

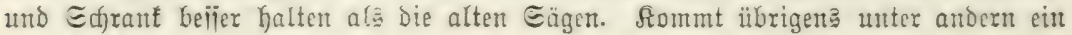

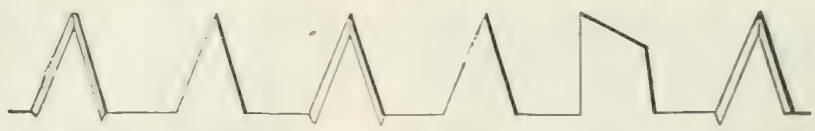

ช̛ig. 91. Gđärĭung ber Єägeзägne.

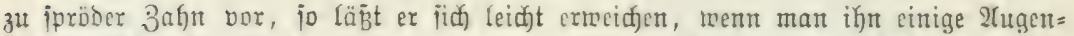

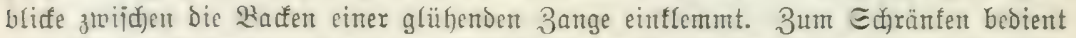

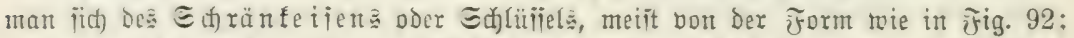

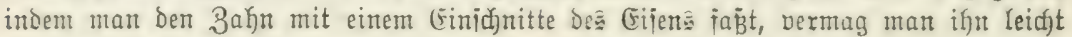

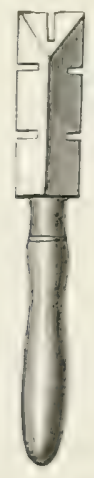

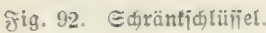

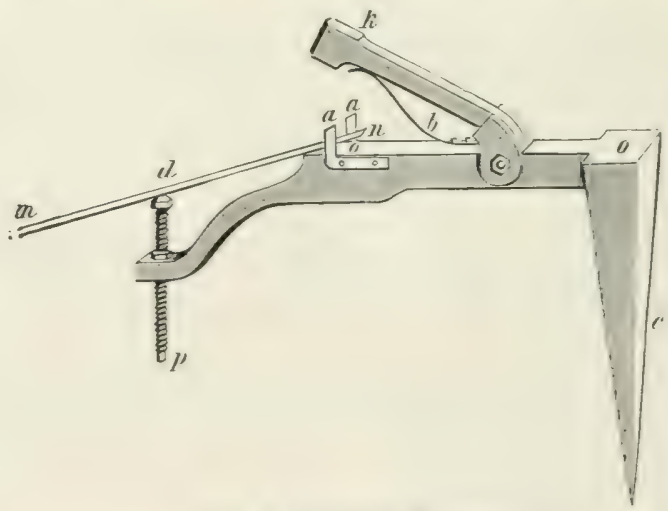

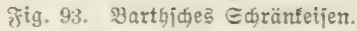

auf Die Eeite zu biegen. Winn Den mandferlet fonitruierten Edyränfoorridftungen

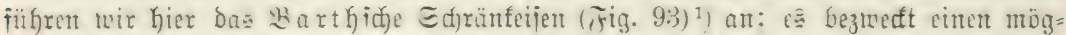

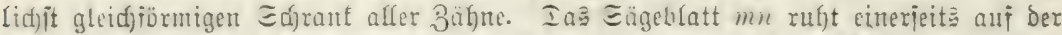

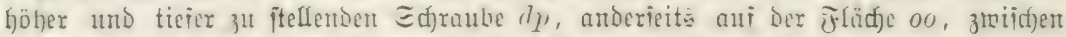

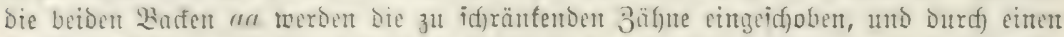

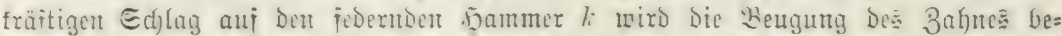
mirtt. Iie ganze liorridfunty nird mittela des eifernen liagels bei 0 in eime jeite

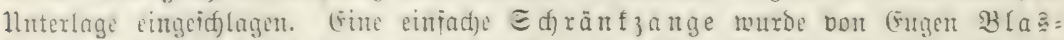

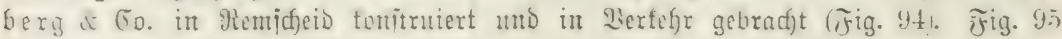

1) Eiełe $\mathfrak{B}$ aur品 Bentralblatt. 1880. Є. 141. 


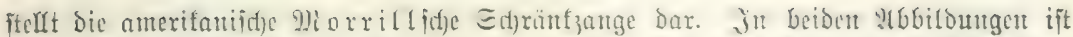

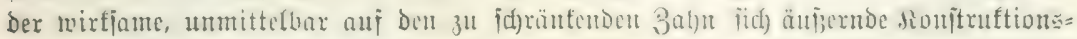
teil (Etō̧bolzen) mit a bezcidgnet.

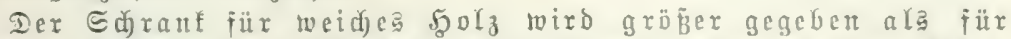

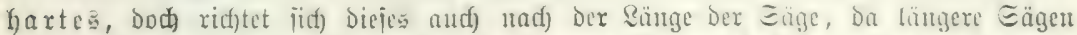

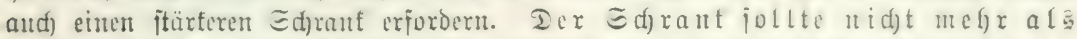

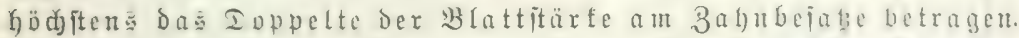

Etatt Des Edyräntem ijt in neuerer Seit in Mmerifa Dos jou. Etaud)en Der

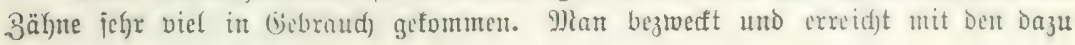

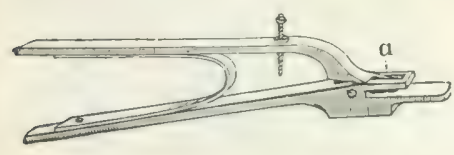

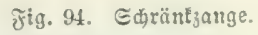

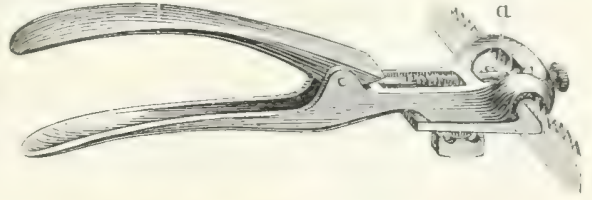

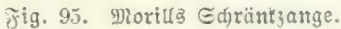

fonitruierten Juitrumenten cine 2uitreibung Des 3ahnes an jeiner arbeitenden Epibe,

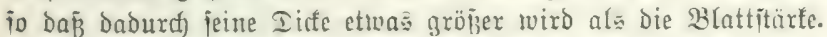

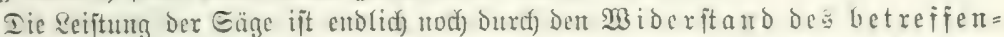

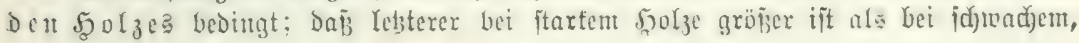

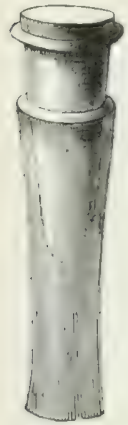

テัig. 96.

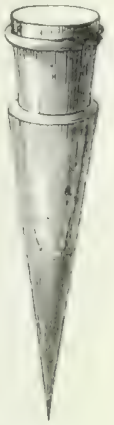

ciferner seil mit bölzernem Stopi.

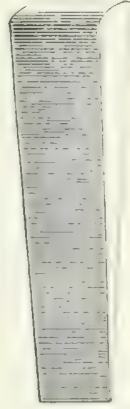

รั)ig. 97. 5)olatet!.

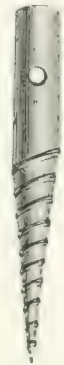

Fig. 98.

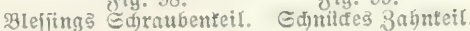

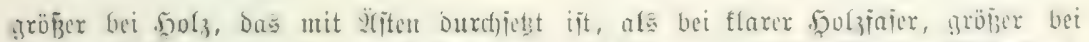

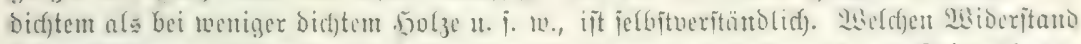

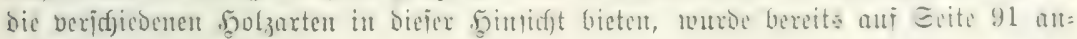
gegebert.

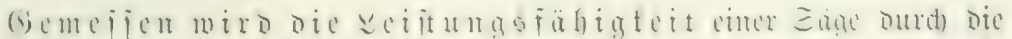

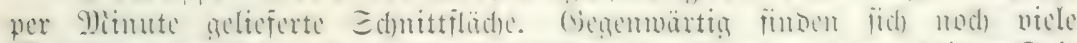

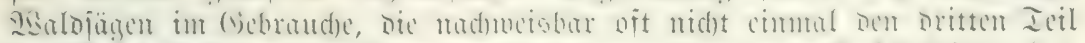

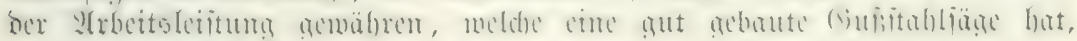
und bie beshalb eme immenje Rraftuergenoung bedngen ${ }^{1}$ ).

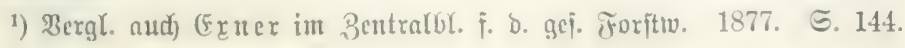




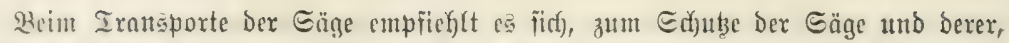

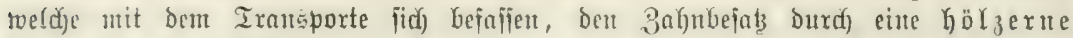
Eägcjueibe zu jidyern.

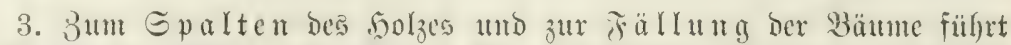

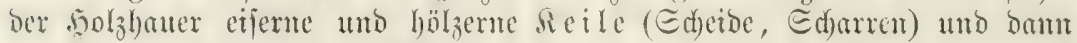
die Epaltart oder ben Miölel.

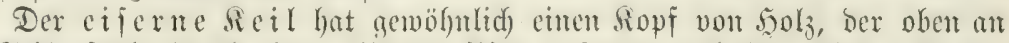
Der Ed)lagfläd)e Durd) cinen eifernen Ming zufammengebalten mitro, um bą Beriplittern Des Siopfes zu verbindern (jotis. 96). D̈fter ijt and ber Seil ganz von Eifen, wo ex Dam zun Eintrethen hölzente Edflügel erforbert,

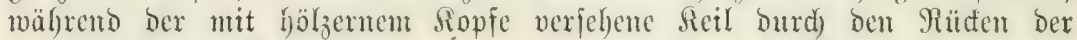
Spaltart eingetrieben wiro.

Den hölzerucu Reil (in Form Der Fig. 97) fertigt fid) Der Syolz=

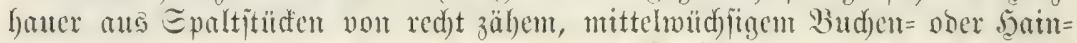
budjentyolz, tretbt oft aud) zur Eidjerung des Sopfes gleid)fallas cinen eifernen Ring ein.

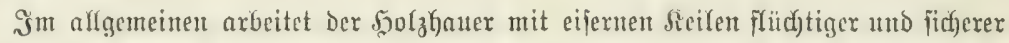

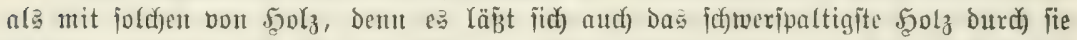

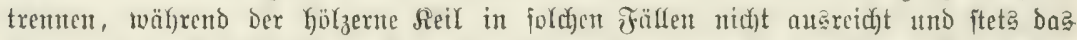

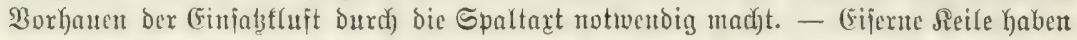

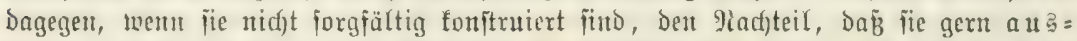
fpringen, Da an Der glatten (Eifenfläd)e Die Reibung weit geringer ift als bei f̧olz=

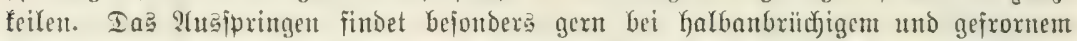

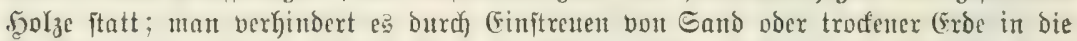

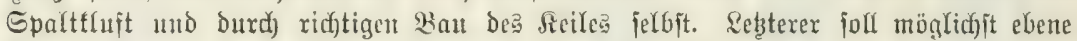

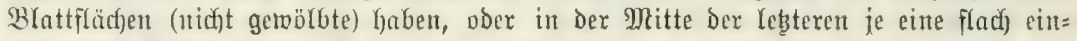
fpringenbe $\Re$ inme tragen $(2 \mathrm{~cm}$ breit, $3 \mathrm{~mm}$ tief), bie unter bem Siopfe anfärtgt uno

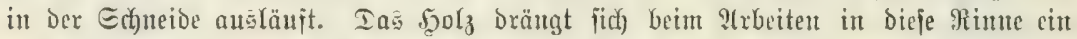

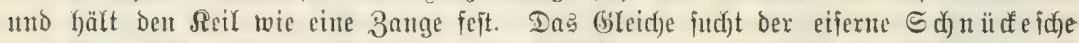

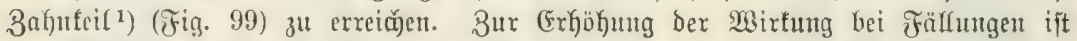

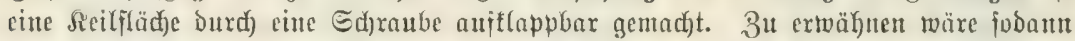

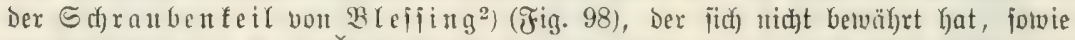

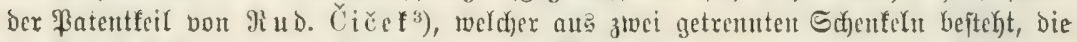

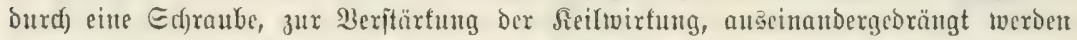

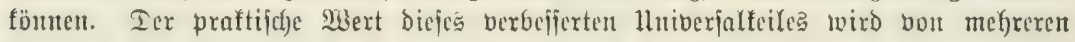
Jorftwirten gerïfint.

Die Spaltart (9)iojel, Edylegelfade, Sicilfane, Seiler) unterfdeciot

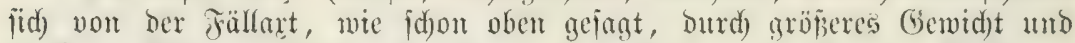

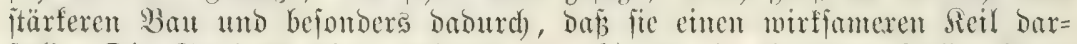
itellt. Dic Epaltät wiegt meifters $2-2^{1 / 2} \mathrm{~kg}$, in cinzelnen fällen jogar $3-3^{1 / 2} \mathrm{~kg}$. Whas die Form betrifft, fo fimmen dic Epaltärte gewöhnlid) mit ber gegendüblichen fällart überein.

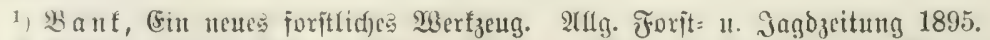

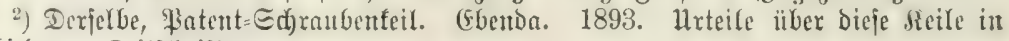
veridjiebenten 3eitjuriften.

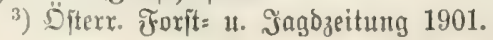




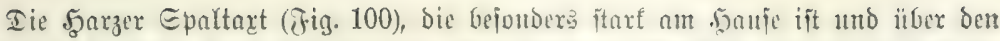

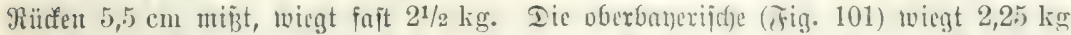

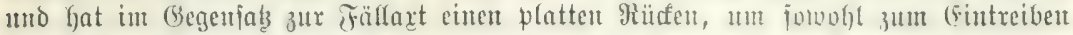

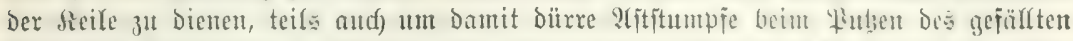
Etamme weginglagen zแ fümten. Fig. 102 zrigt bic Ifjuringer Epaltart; fie gelgört

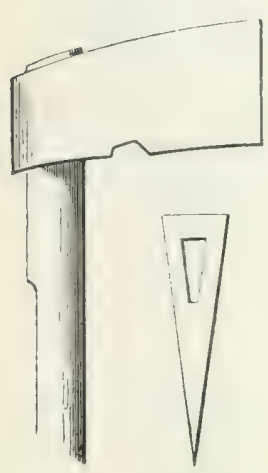

Fig. 100. sjarzer Єd)legelart.

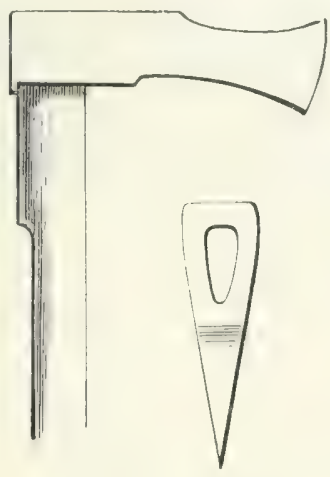

Fig. 101. Zntoler Möbel.

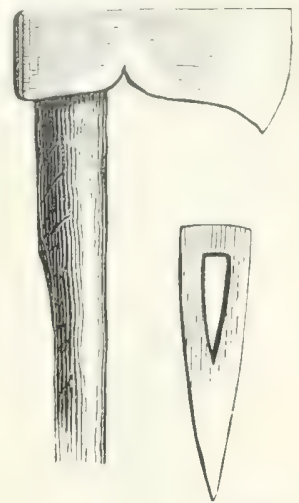

ริig. 102. ₹hüringer Möjel.

mit zu Den fadweriten Reilfanten. Die Frager Epaltaxt (Fig. 103) bildet wohl unter

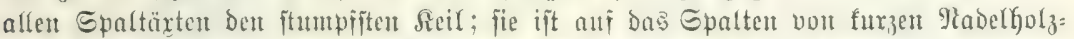

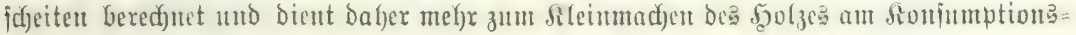

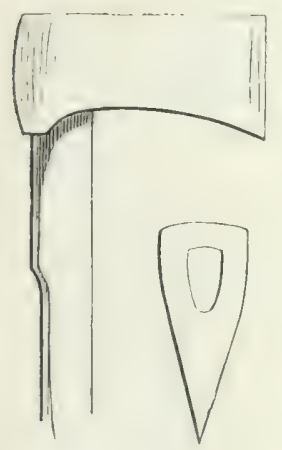

Fig. 103. \$rager Spaltart.

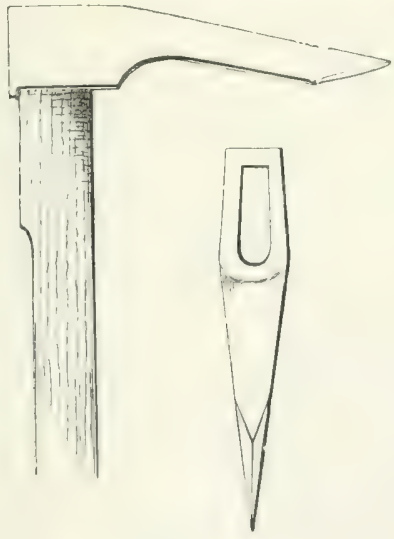

Fitg. 104. Błtener Epißmöfet.

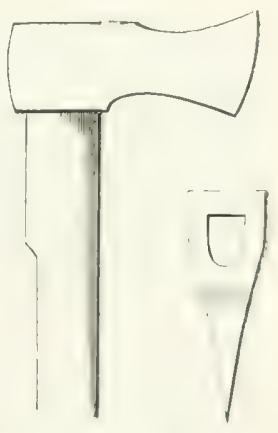

Fig. 105. Edjlefifdje Epaltart.

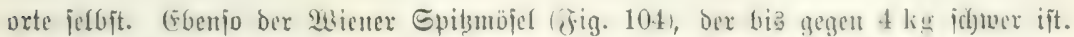

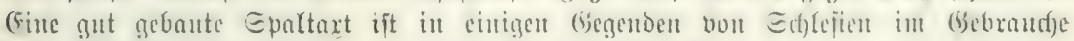

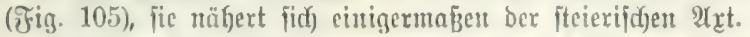

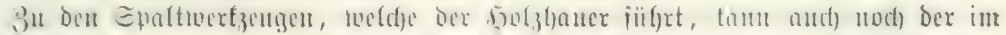

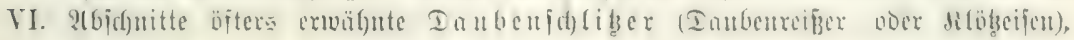


Figig. 2i1, gered)net merben. IIfle übrigen Epaltinjtrumente, jo aud Dic in mefreren

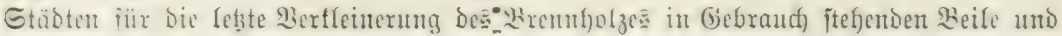

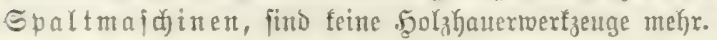

4. Eo cinfad) Die Giğher betrad)teten, jur (Gemimmug ber oberirbijden

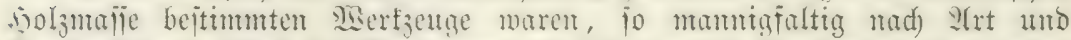

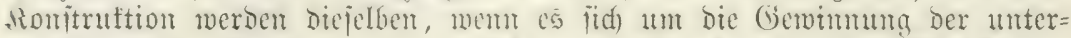

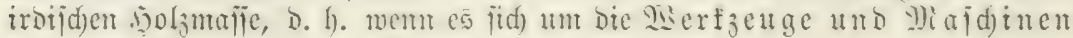

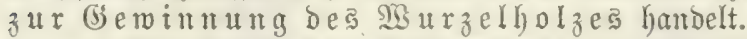

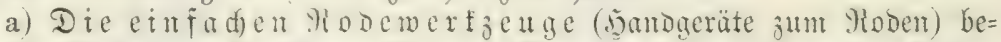

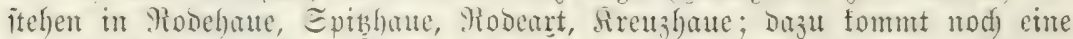
furze Nitegenjüge, Wred)itange, Reile und Die Ziehitange oder jtatt Deren ein Biebjeil.

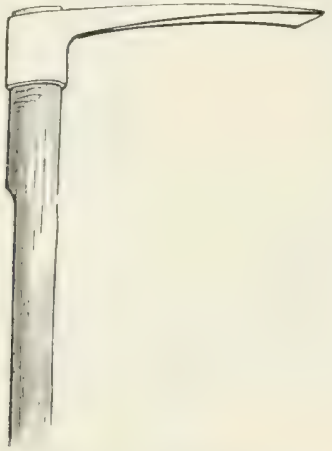

テrig. 106. Mobebaue.

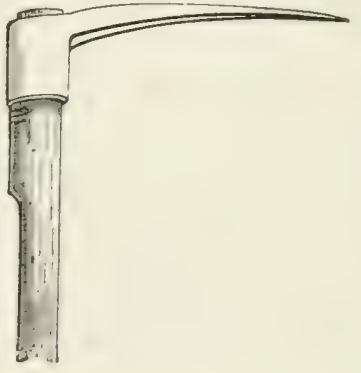

ซ̧ig. 107. Epit̨̧aue.

Iic Mobehaue (Modehade) (Fitg. 106), cine ctma $30 \mathrm{~cm}$ lange und $5-6 \mathrm{~cm}$ breite, iturfe, aut veritählte, an Etiele gut befejtigte baue, bient

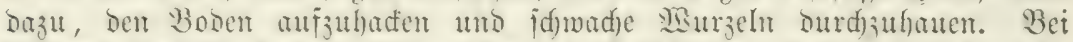

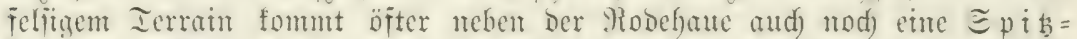
h) a ue jur Sermendong, Die, mie jig. 107 jetgt, itatt in cine idjuale

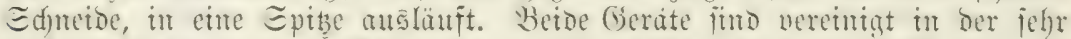

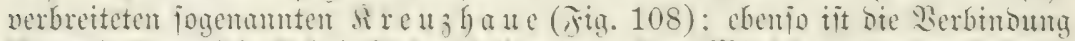

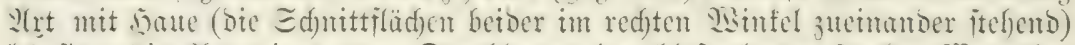

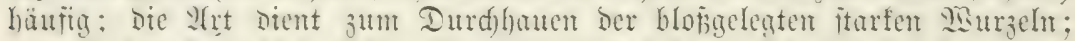

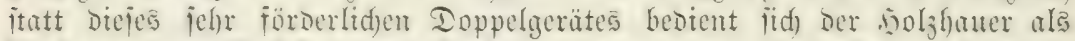

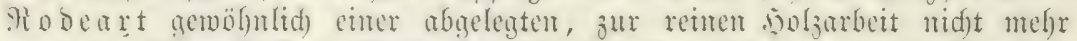

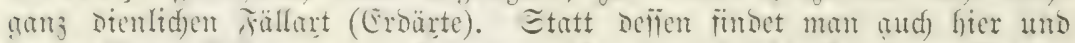

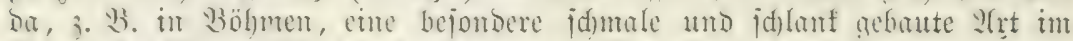
(Webraud)e (rig. 109), Die beadtensmerte Worteile bieten joll.

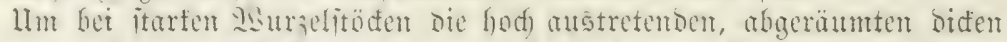

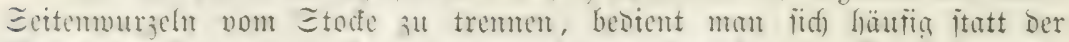

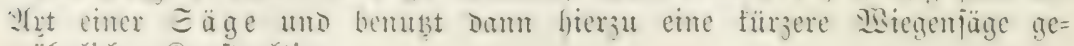
möhnlider Simitruftion.

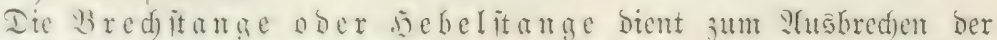

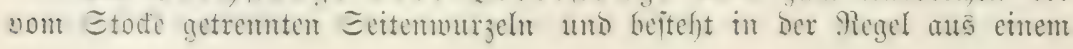




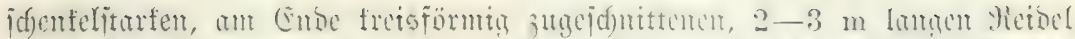

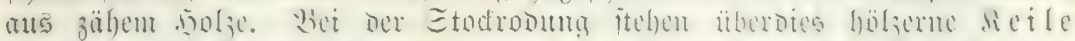

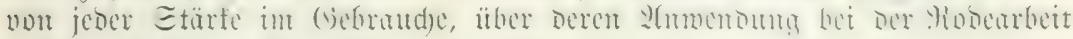
jelbịt bas Alötige bemerft werden foll.

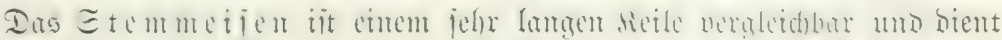

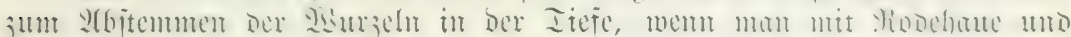

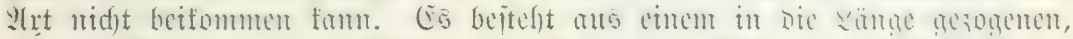

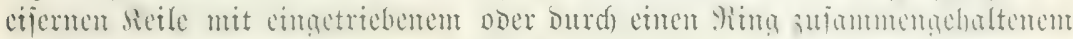
Solzhtopfe.

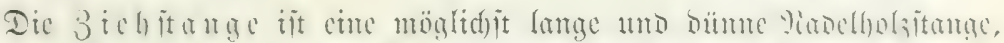

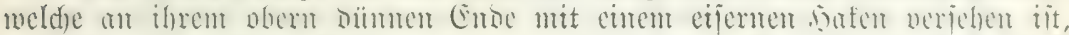

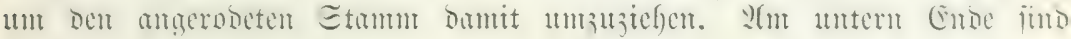

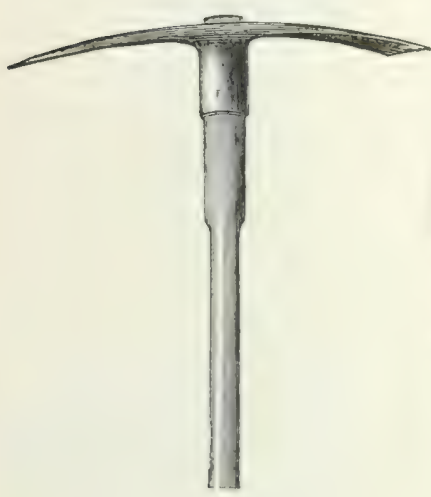

Fig. 108. Sreushaue.

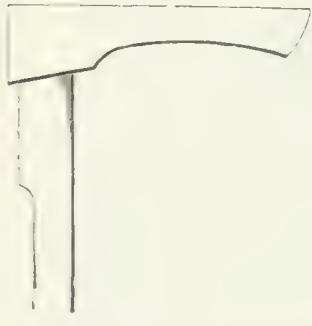

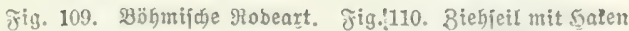
uns sebejtange.

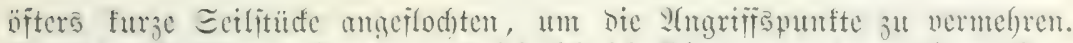

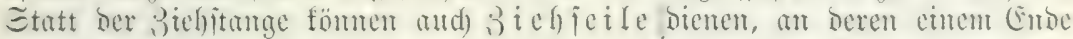
ein eijerner Şaten jid befindet.

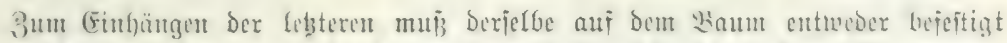
werben, voer man iekt Den shafen loie ani eine leid)te, fintreid)ent langi Etange uno

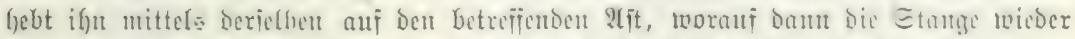

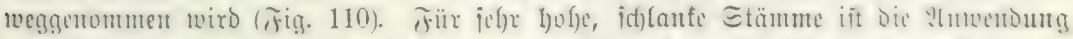

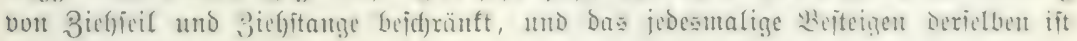
3u zeitraubend.

b) Bur (E)

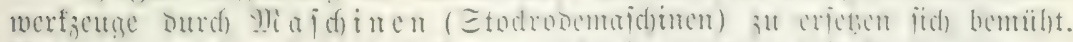

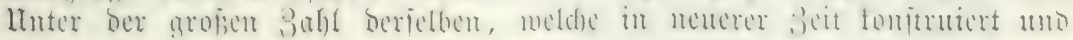




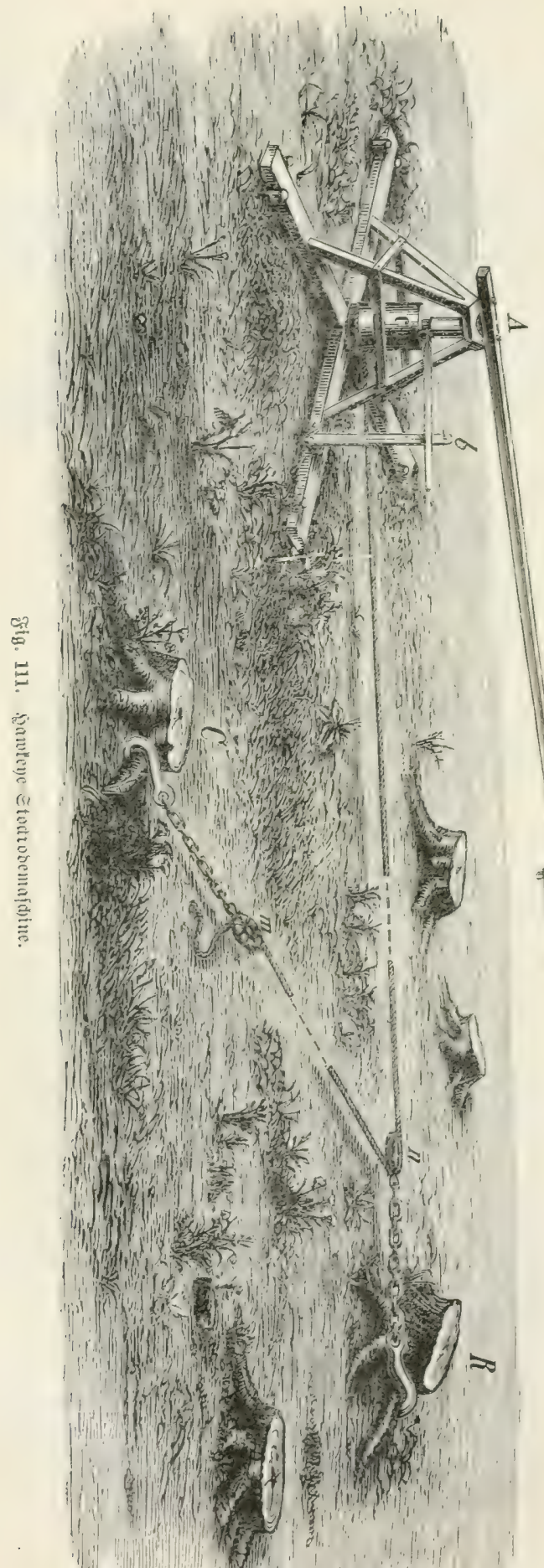

angepriejen murben, fübren mir hier mur bie Samfene=

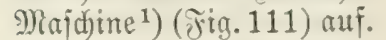
Iuf feiter Unterlage be= findet jidf) eine jenfred)t itehertoe, oben uno unten in Bfanten laujende eijerne Iddje, weldje von einer Irommel $c$ ummantelt iit. Dieje Trommel famm mit ber Adyje in feite Berbin= butng gebrad)t, nad) Bebarf aber aud) burd) ben Scebel $b$ von ifor gelöt werben.

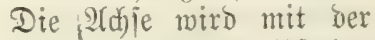
Irommel burd \$ferbe= fraft am Göpel $a$ in lang= jam brehente Servegung ge= jebt, und bamit wiffelt iidf Das an ilgr befejtigte, 160 ₹̛̃ lange, äuperjt biegjame Etabloralifeil mit bem eitren Ende um A bie Trommel auf. Dả Seil läuft pon hier um bie Rolle $n$, weldje Den überaut fräftigen $\mathfrak{A}$ rbeits $=$ hafen trägt, und gelgt von hier nad) Dem fẹten Stük = punfte $C$. Die Entfermung zmijodjen $A$ und $R C$ in Der J̛igu muj man fid) um bas 6-10 fadje er= meitert benter.

Die Samfene=9lajofine hat eine gewaltige Siraft= mirfutg, bie jid) nid)t blös auf bas llmieben des

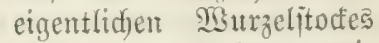
bejd)ränft, jonbern mit biejem aud alle meitaus= itreidenten Seitenmurzeln aus bem Boben ziegt. Sie ift bejonders fitr Pooung

1) 2. \$icper in Miox a. Rf., Deutid)e Foritzeitung 1897. 


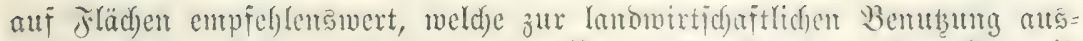

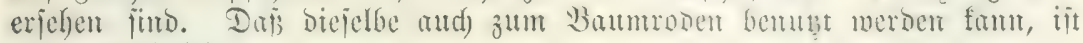
leidjt erifidtlide) ${ }^{1}$ ).

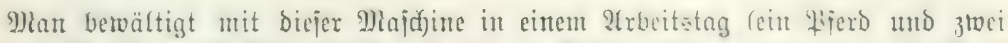

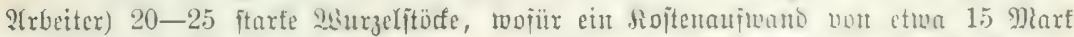

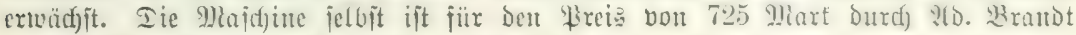

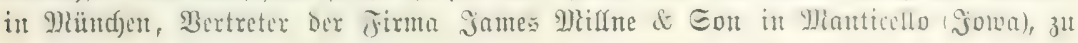
beziełert.

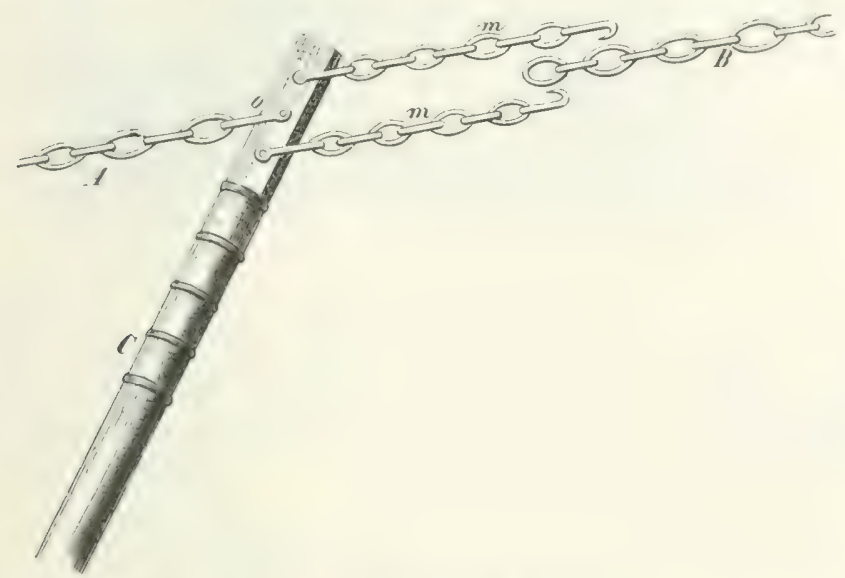

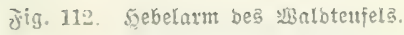

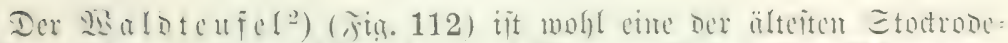

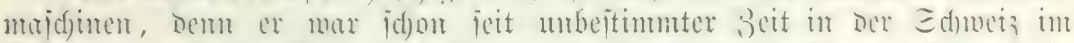

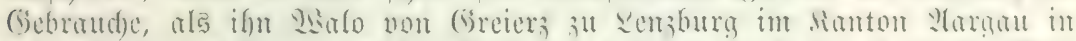

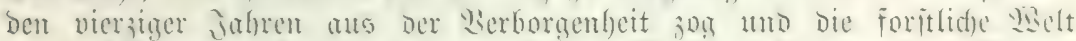

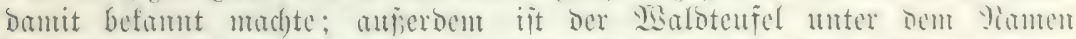

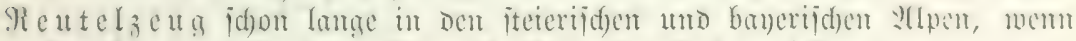
aud) nid)t zum allemingen (isebroude beim Stoctroden, betamt.

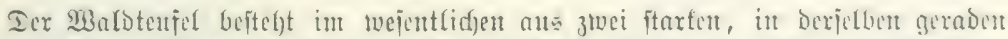

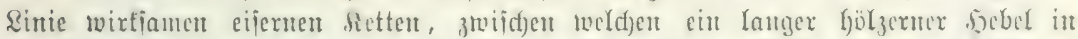

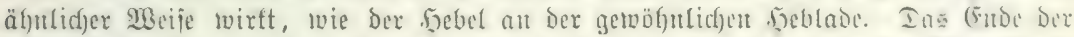

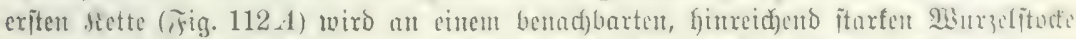

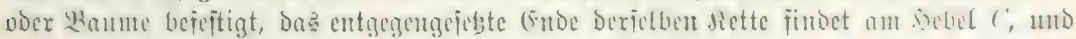

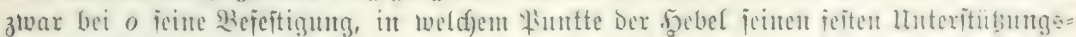

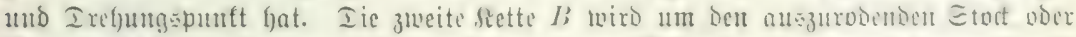

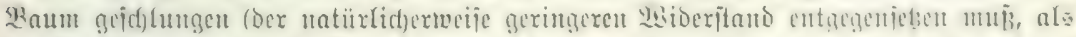

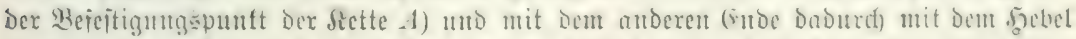

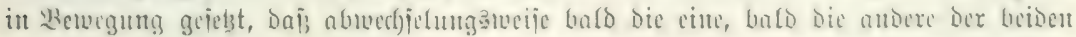

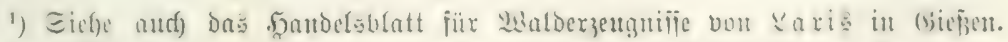
Jahrgartg 1891.

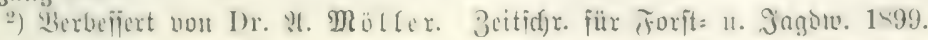




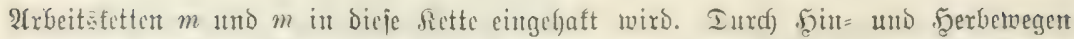

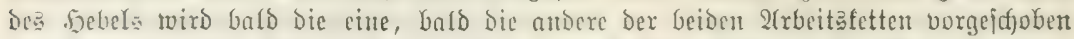
und fant mut mit ifrem feafen um cincu Doer mefrere Finge in ber fiette $B$ lveiter=

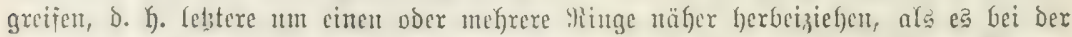

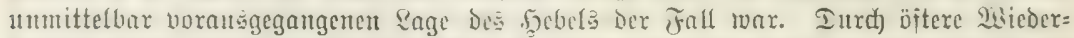
Yjolung Diejer Eperation wird bie Rette $B$ mefor und mefre herbeigezogen und Dex aut

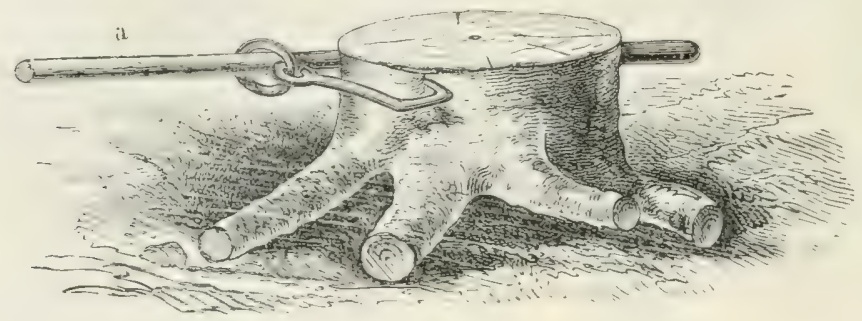

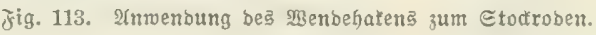

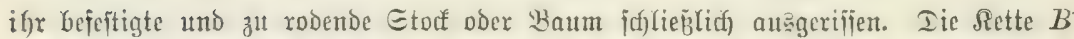

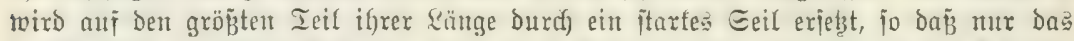

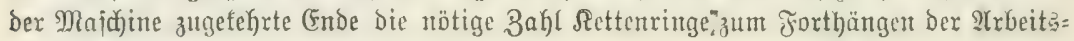
oder 3iehgafent hat,

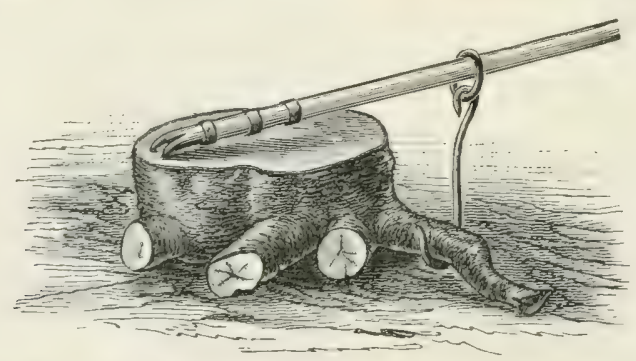

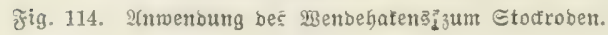

Der İendehafen, ein zu vielpeitiger Bermendung alfgemein 'ge= bräud)lides einfad)es (Geräte, ijt nahezu aud) bie empfehlensmerteite Stoct=

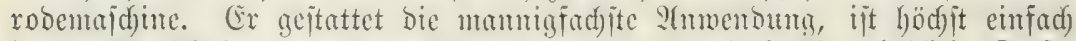

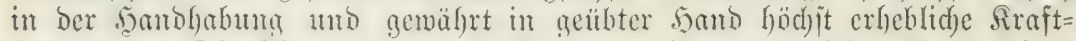

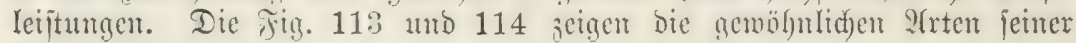
Bermendung.

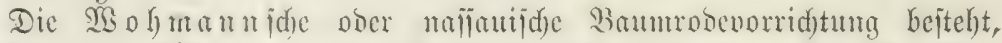
mie Fig. 115 zeigt, ants ciner fraffingen Viabelgolzitange, bie am oberen Ënoe mit einem cijernen Etifte, jum Ëuritofien in ben zut rohenoen Etomm,

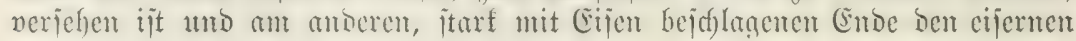

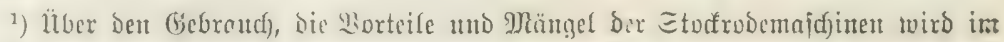
Rapitel über "F̧ol ffällung" gehandelt. 


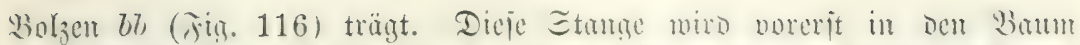

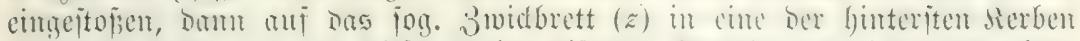

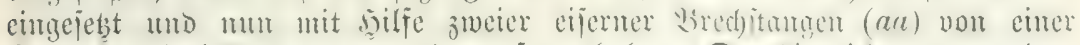

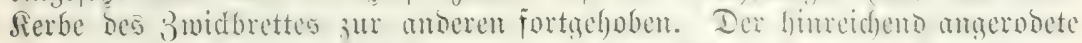

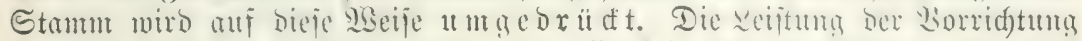

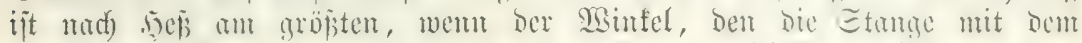
3widbrette bilbet, ungefähr cintem halben Red)ten gleidgtommet ${ }^{1}$ ).

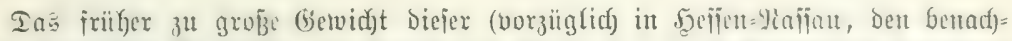

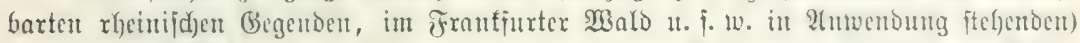

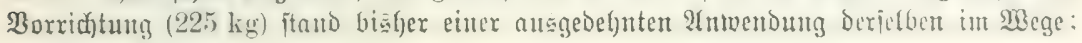

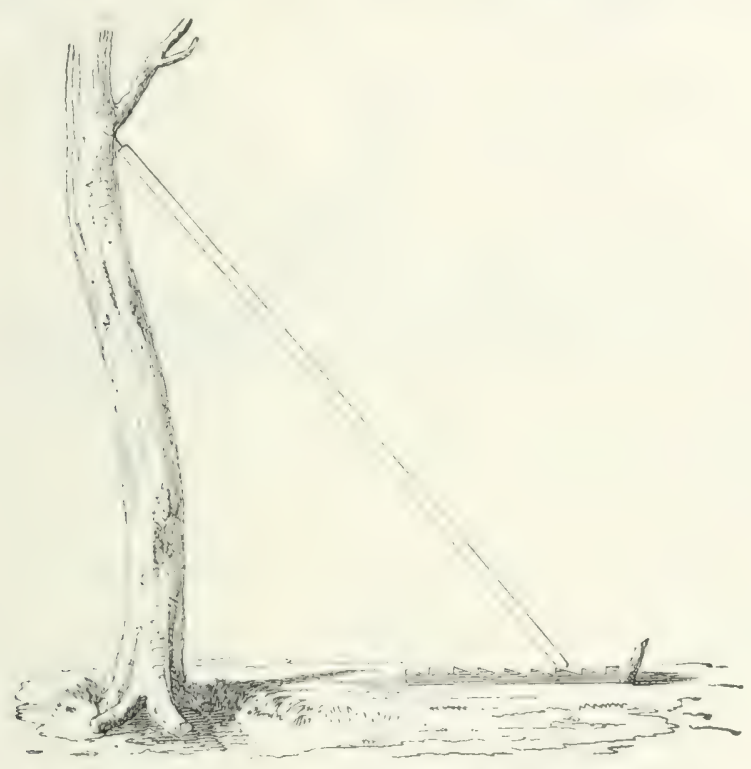

Frig. 115. \$3ohmannide ober nafjauijde ßaumrobevorridutung.

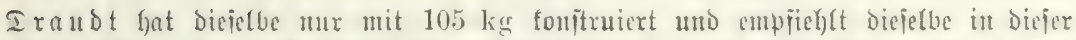

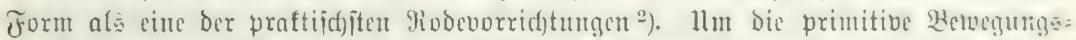
einridgtung zu verheifern und momentlid) an Srait zu fparen, hat snubenfeimer

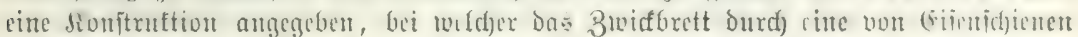

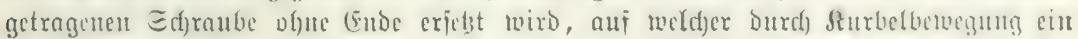

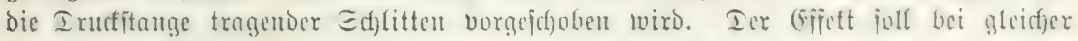

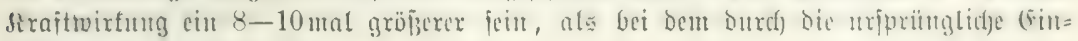
ridutung zu erzictenden ${ }^{3}$ ).

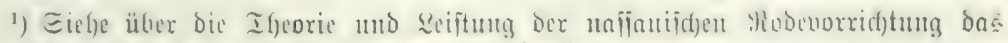
Wiener Bentralbl. f. b. gei. Forittwejen 1879, 2. Şeft.

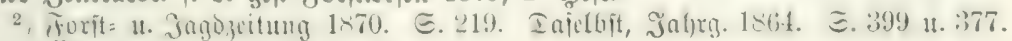

3) S̈Pterr. Zentralbl. 1879 . ธ. 131.

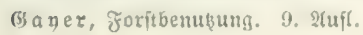


श(uch) bic eiufad)e $\mathfrak{B a g e n w i n b e ~ f a n t ~ m i t ~ g r o p e m ~ B o r t e i l e ~ z u m ~}$

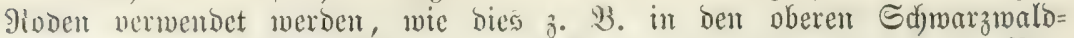
gegentoen ${ }^{1}$ ) mit bejtent Erfolge ber jall ijt. Unter ben mandjerlei $\mathfrak{B e r}=$

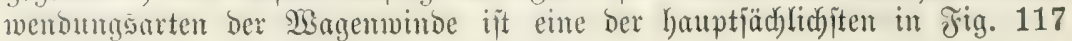
bargejtellt.

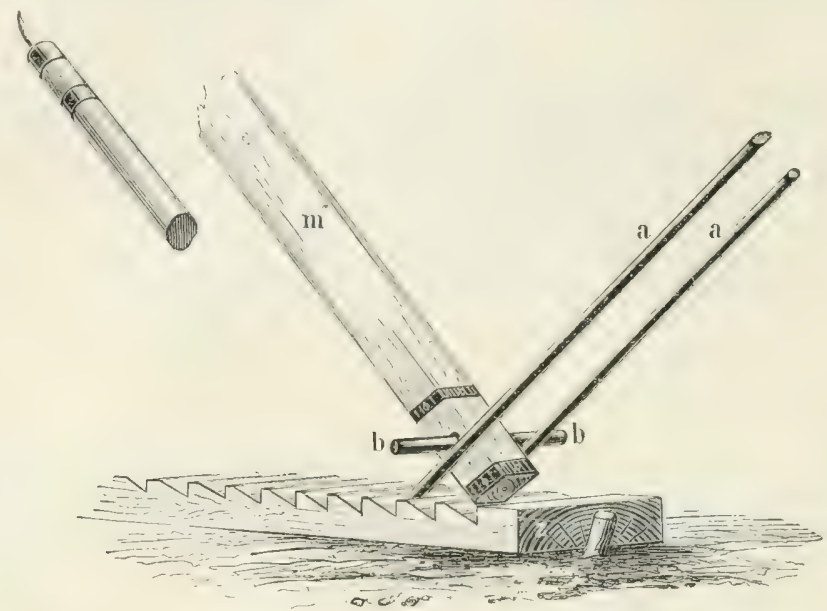

Jig. 11i. Wohmanmide Tobemajaine mit Druditange $(m)$ und 3 widtoot $(z)$.

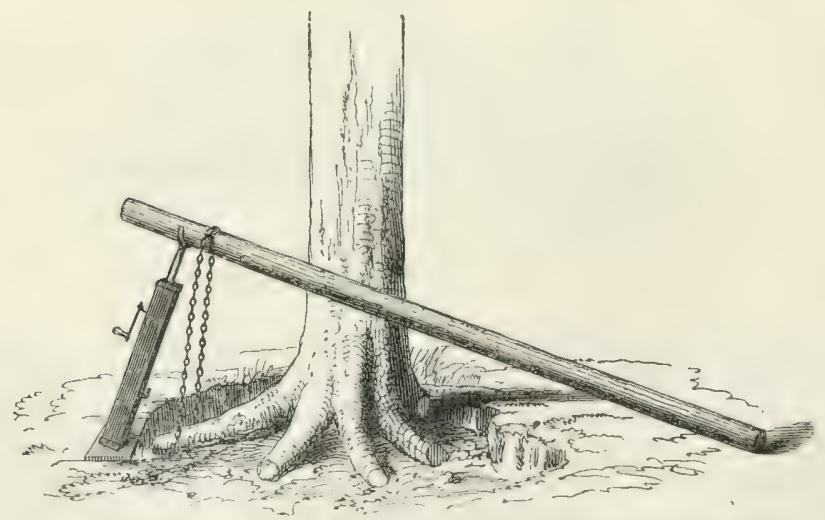

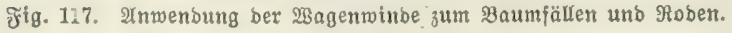

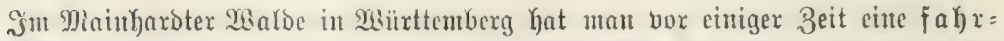

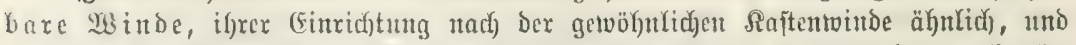
Jtad) Den Darïber getieferten Berid)ten ") unit einem (Exfolge in Antwendung gebrad)t,

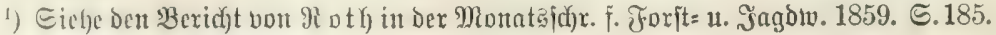

2) Dengler Mtonatajurift. 1862. S. 291. 


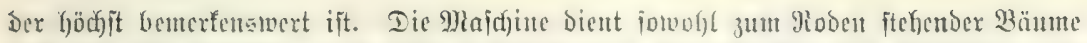

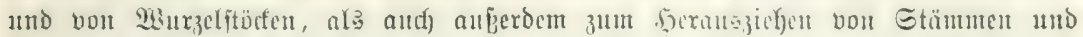

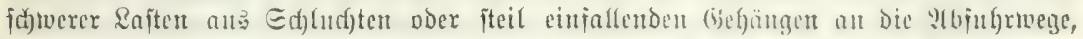

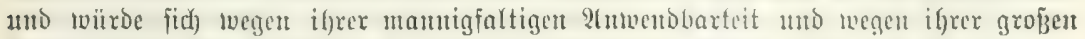

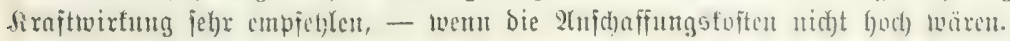

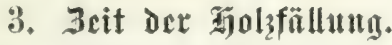

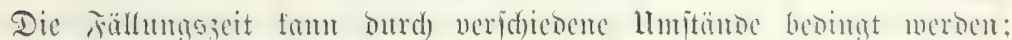

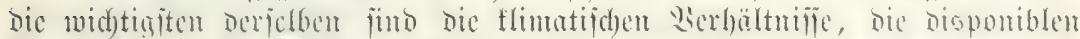

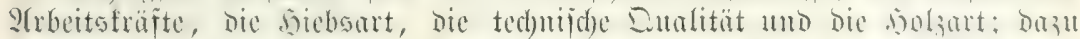
fonmen nod) cintige meitere, burd) Den bejonderen Fall bedingte Wionente.

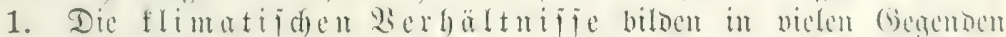

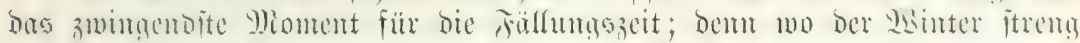

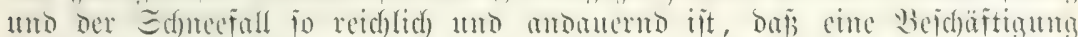

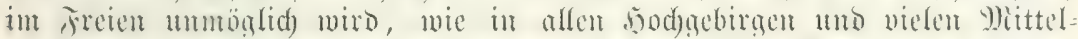

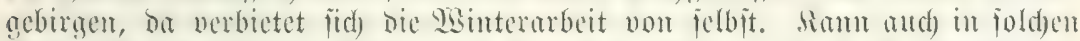

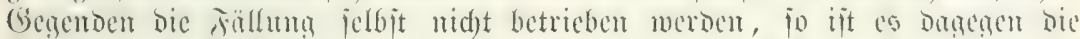

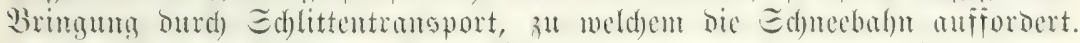

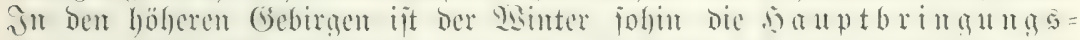

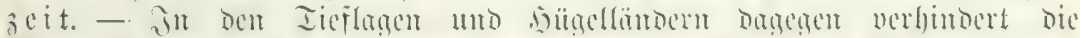

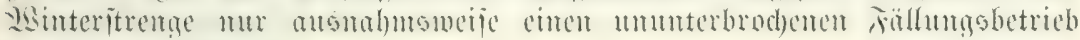
in biejer Jahreszet.

2. Die verfügbaren $\mathfrak{A}$ rbetisträfte. Jn ben meiten Ge=

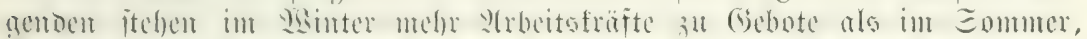

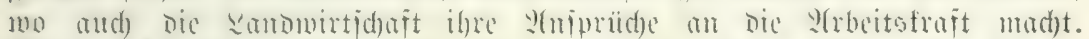

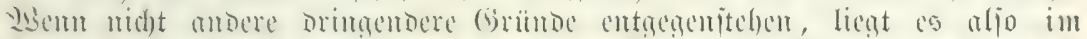

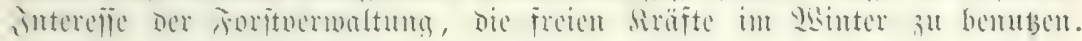

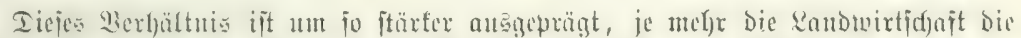

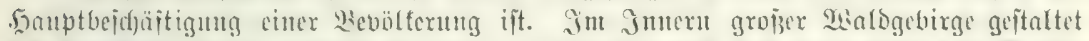

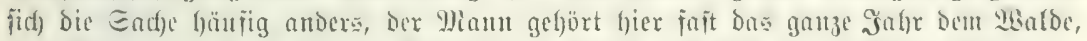

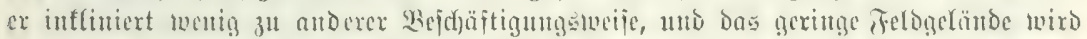

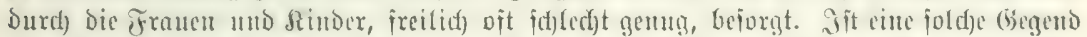

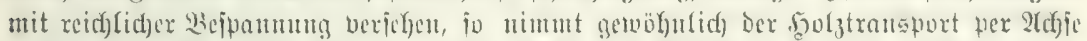

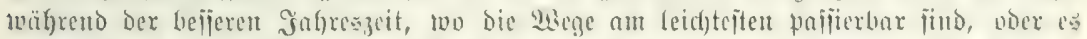

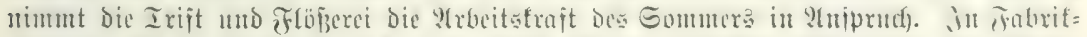

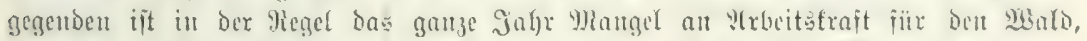

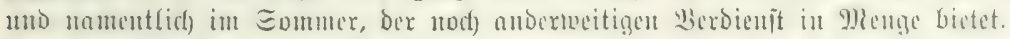

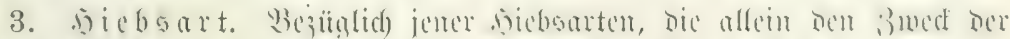

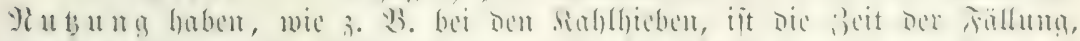

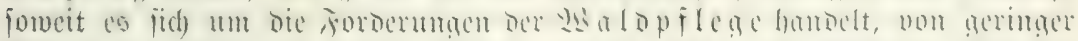

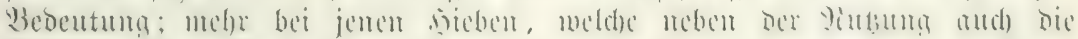

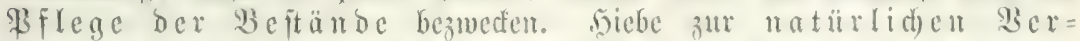
ز

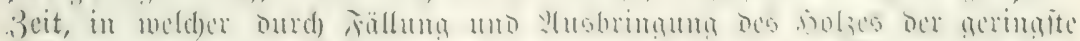

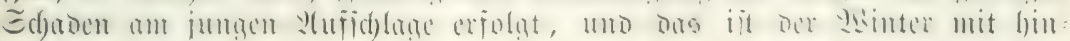
reidyender Schnecbette. 


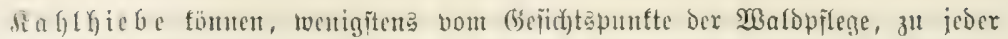

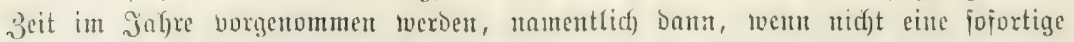
Miederbeitellung Durd Gaat ober Fflauzung zu erfolgen hat.

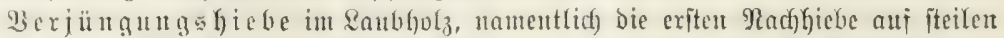

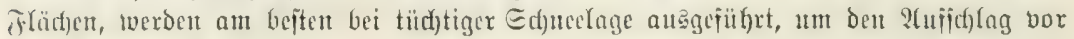

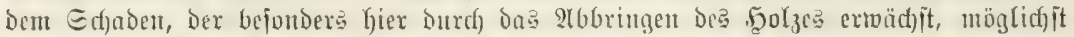
зu bewal)ren. Im Eommer, wenu alfe im (sntjalten und Entwiffelu begriffen ift,

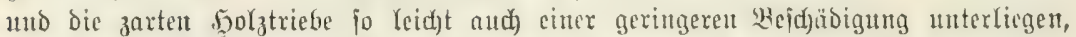

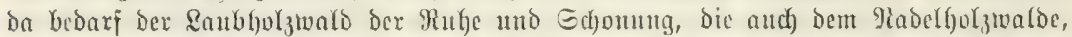
mit matür(idjem Berjüngungagange, wohl tun wïroe, went fic, bei ber meift hohen Winteritrenge dex gröberen Gebirgäfomplexe biefer 2(rt, überhaupt bejofift werden

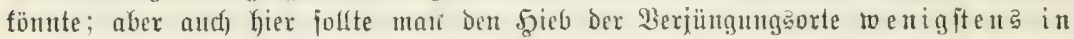

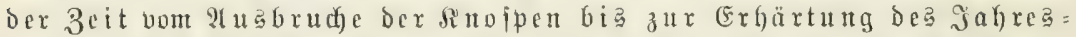
tricbca, b. h. bis $\mathfrak{A} u g u \mathfrak{t}$, a lajien.

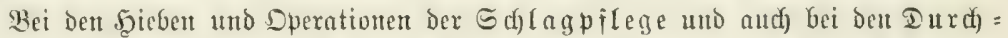

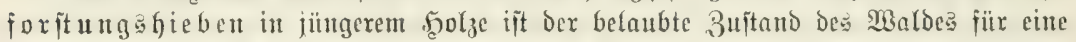

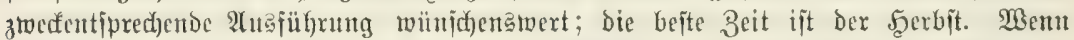

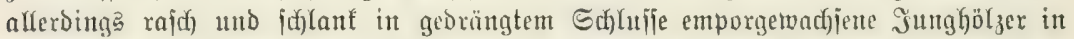
raufer, Durch) Ed)nce und Iuft hrimgefucfiter Sage im Epätferbite Durchjoritet werben,

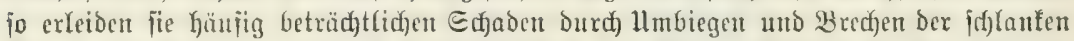
Gerten und Etangen, während bex Früfjafrs̀= oder Eommerfieb ifnen 3eit gibt, im

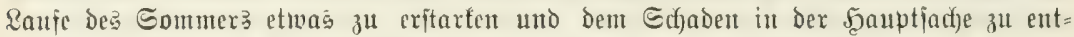

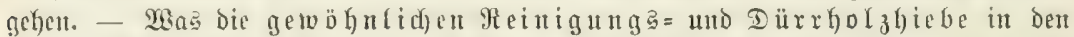
ältexen Beftänben betrifft, jo verjofiebt man biefelben im \&aubhol $\mathfrak{l}_{3}$ gern in ben

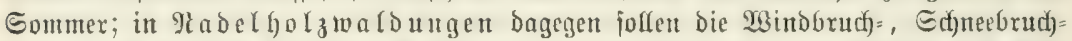
föblzer uno bie fid) zeigenden fiaferbäume womöglidf fofort zur Fäflung und $\mathfrak{4}$

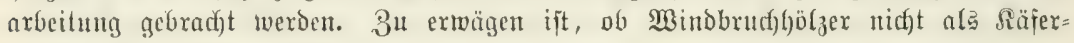
fangbäume Genüb̧⿻ar find.

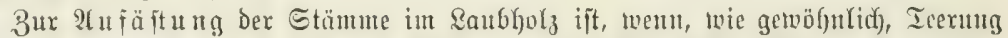

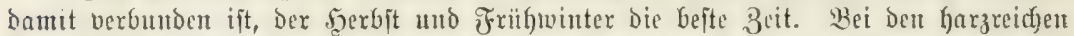

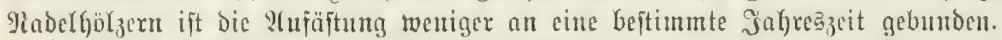

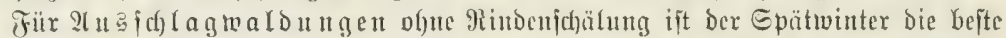

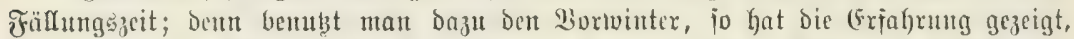

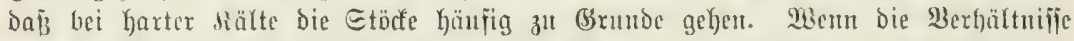

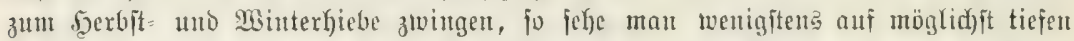

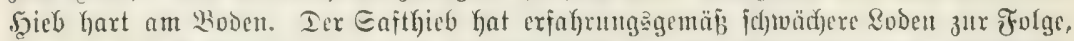

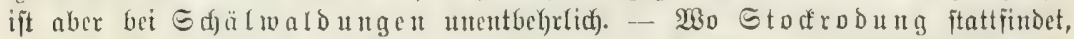
gef(hieht fie getwöhnlich im Sommex; bei gefrorenem Boben ifit fie natiurlich nid)t autiuibrbar.

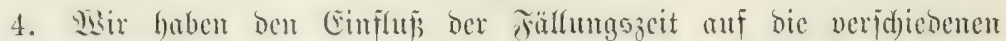

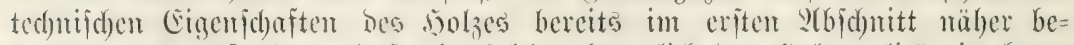

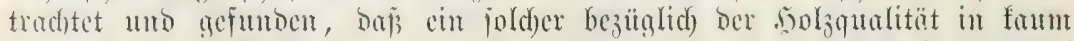

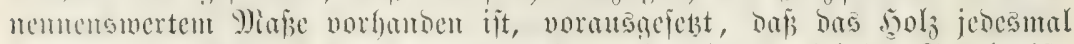

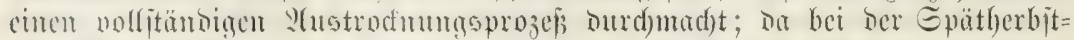

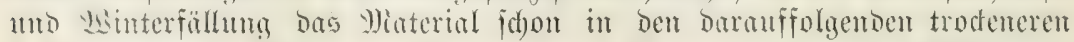

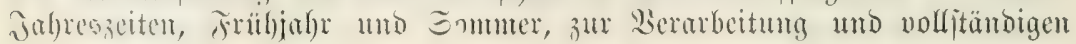




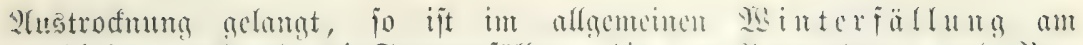

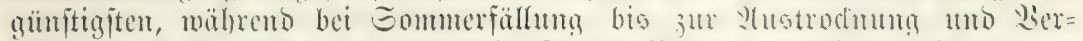

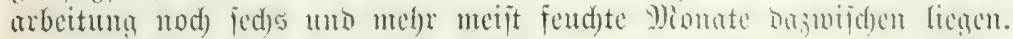

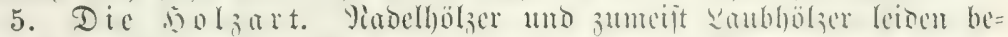

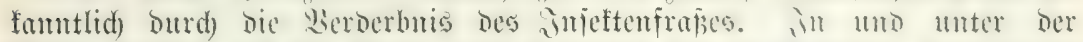

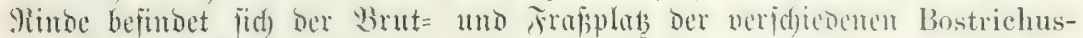

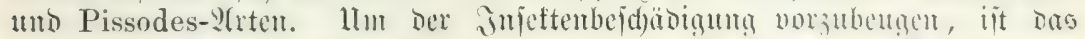

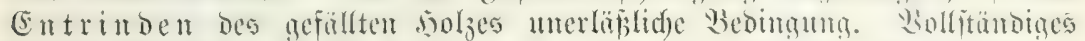

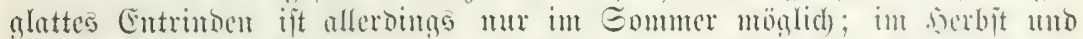

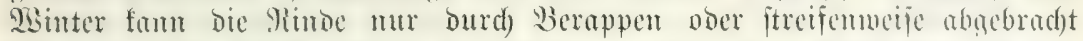
werben, aber biejes genügt vollitändig, jowohl vou (iscied)topuntte der

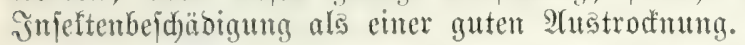

Wirb Das Etammfol

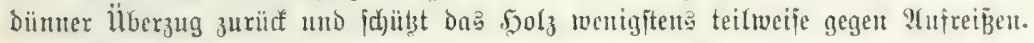

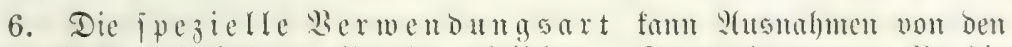

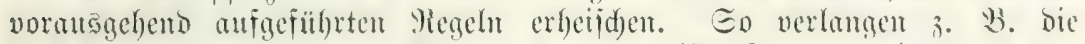
Fabrifation ber gebogenen Wiöbel, Dann aemifje Jntprägnationsmethoden

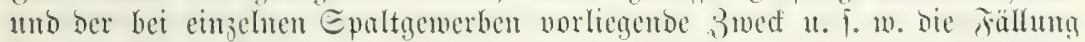

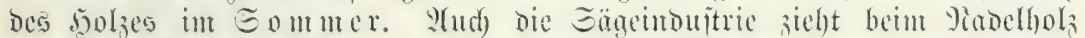

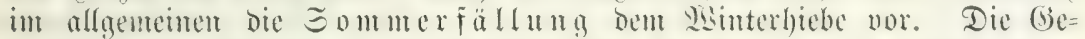

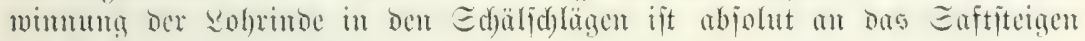
im $\mathfrak{F}$ rüliahr gebunden.

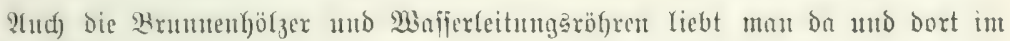
Eafte zu fälletr.

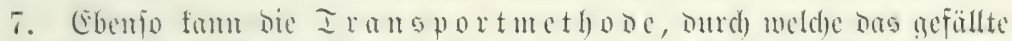

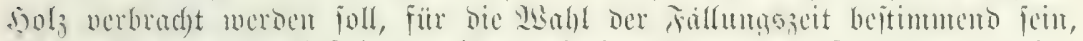

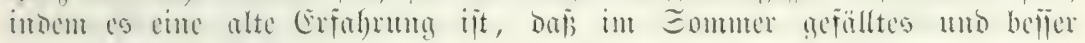

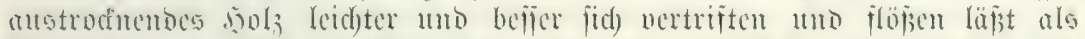

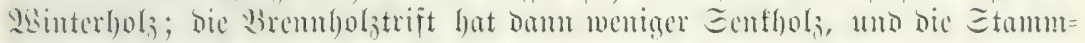
flöpe geitatten eime ftärfere Dblajt.

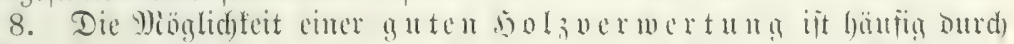

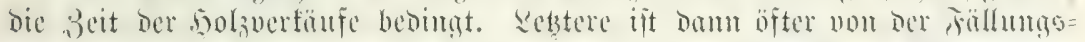

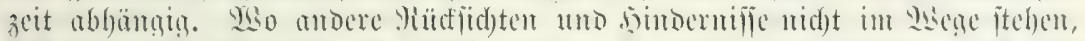

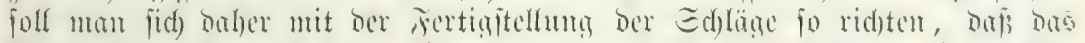

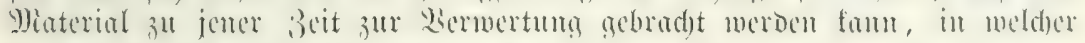
es begehrt und an bejten bezalglt wirb.

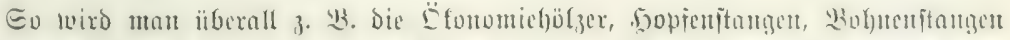

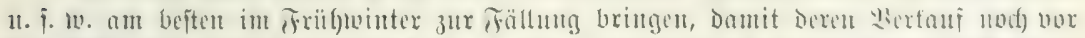

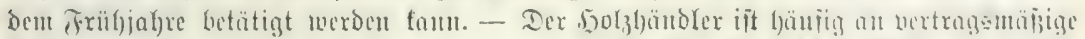

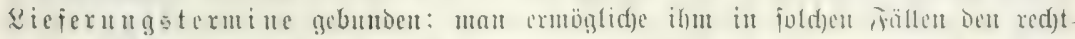

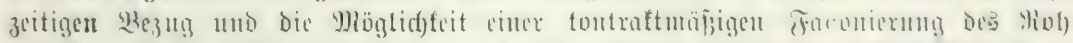

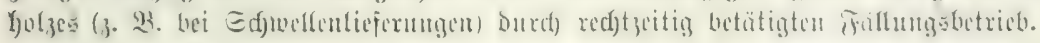

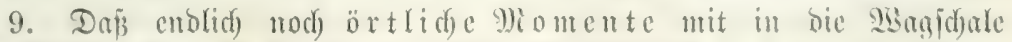

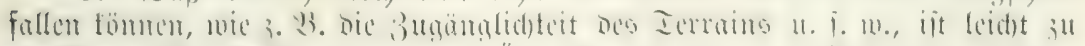

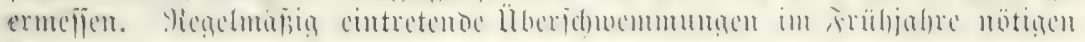




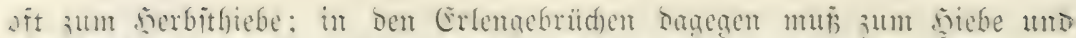

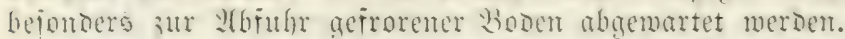

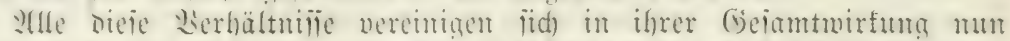

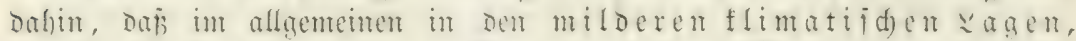
im Iief $=$ und mittleren Bergland, ber ŞGinter als̀ reguläre

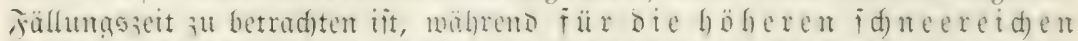

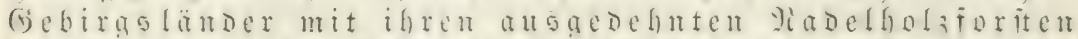

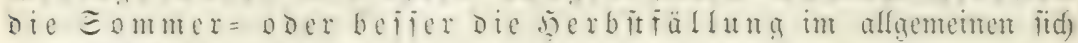
als notmendig ergibt.

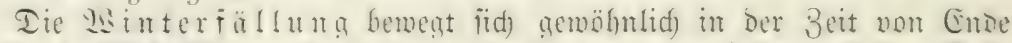

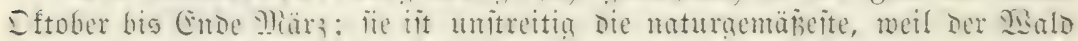

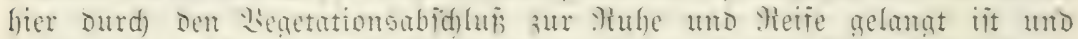

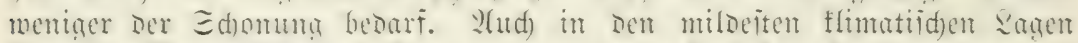

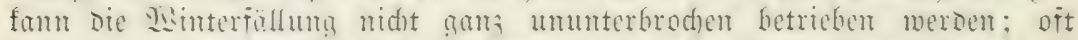

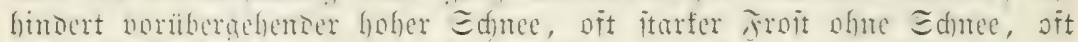
iortacieste mafitalte

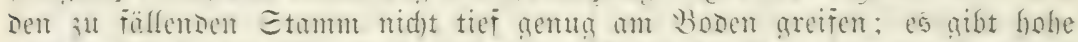

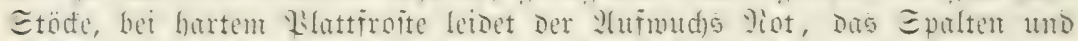

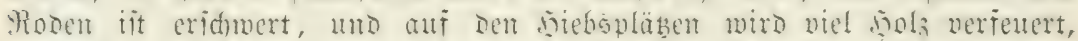

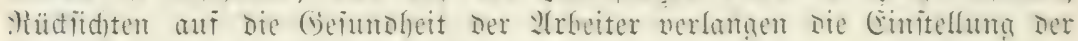
2rbeit bei itetig majier Sitterung.

Mas bie 23erteilung ber einzelnen biebsarten a ti die veridficbenen

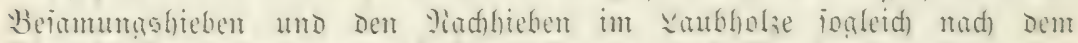

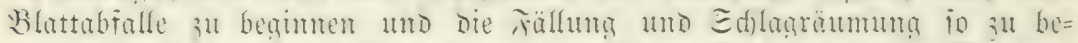

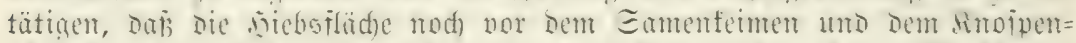

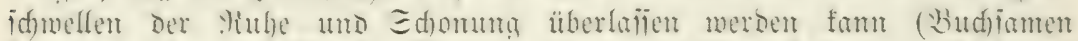

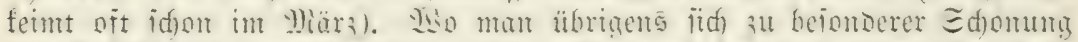

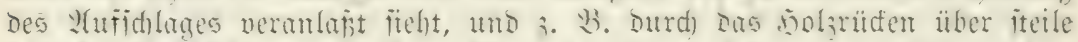

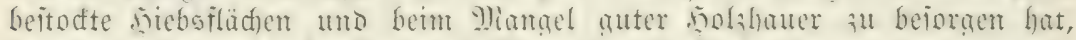

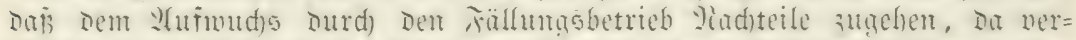

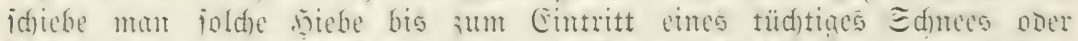

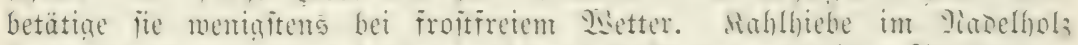

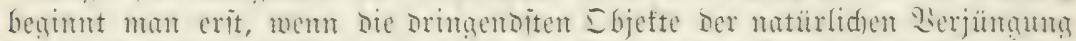

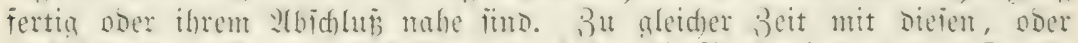

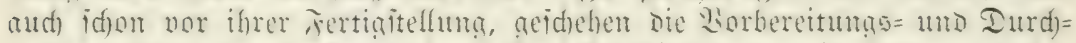

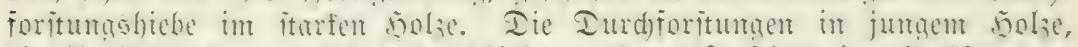

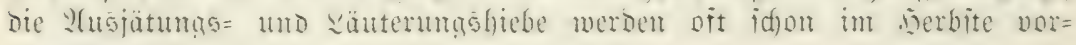
gentommen.

in Mevieren mit heoutentem Miaterialetat mo arojem Worrate an

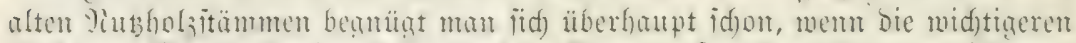

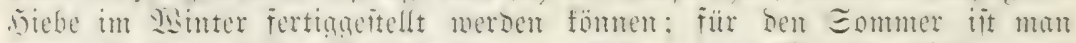

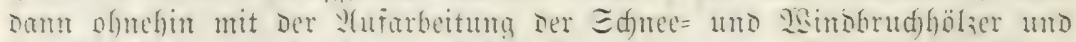

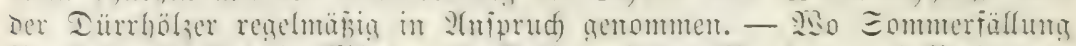

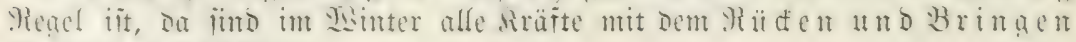
Des solzes bejuäiftigt.

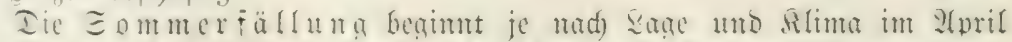

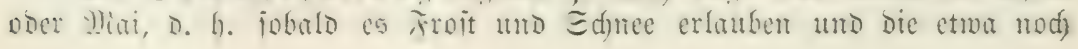




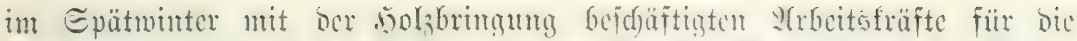

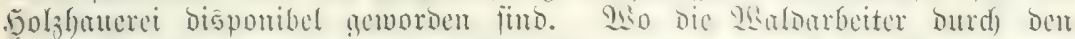

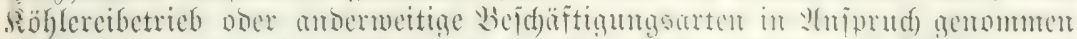

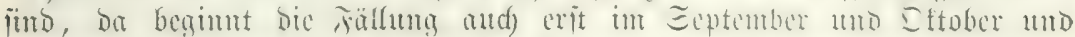
wird fo lange fortgejetst, bis es bie Mittermng verfindert.

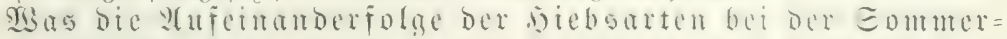

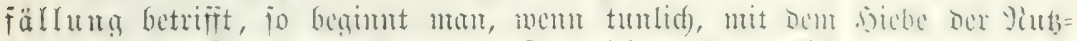

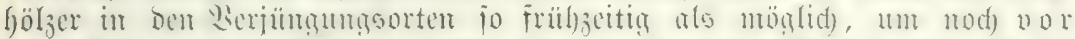

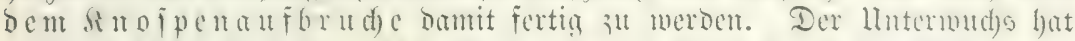

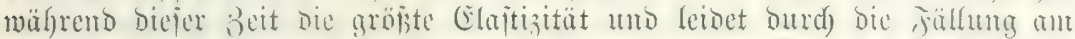

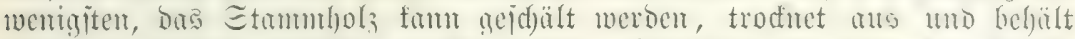

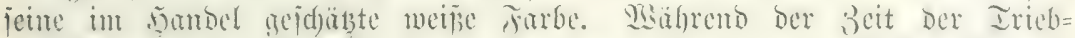

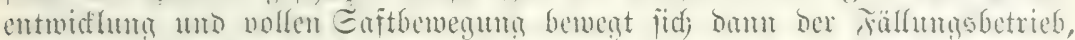

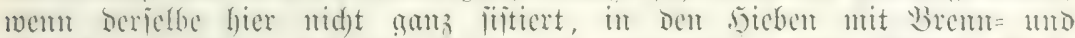

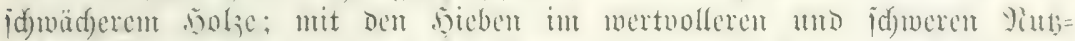

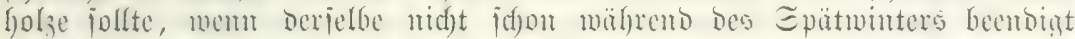
werben fourte, momö̈lid erjt im Eeptember begounen ober bericlbe

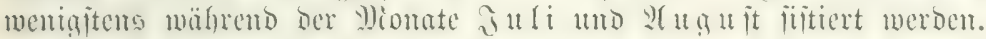

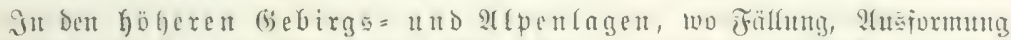

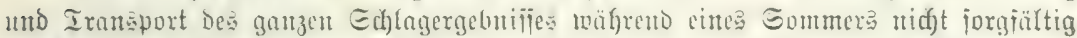

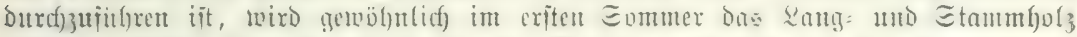

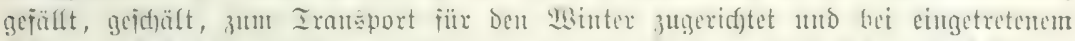

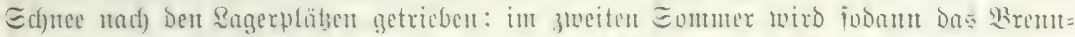

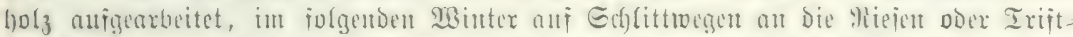

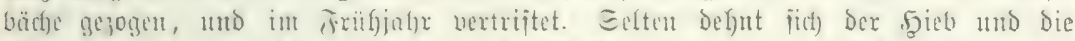

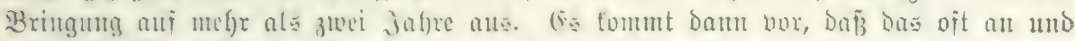

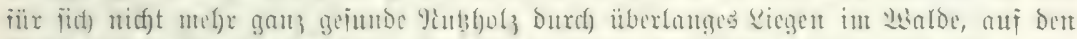

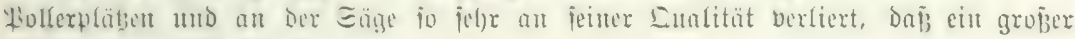
Ieil mur mel)r 2 (uaj)

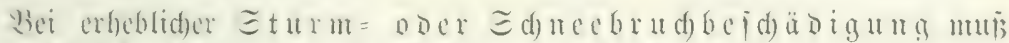

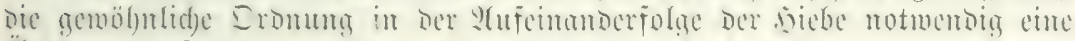

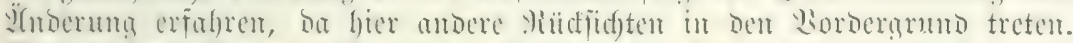

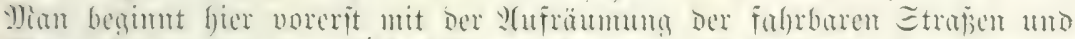
黑ege, bejeitigt bic von liberhältem ober nom Ecitenjtanbe herrübrentom

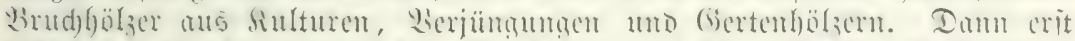

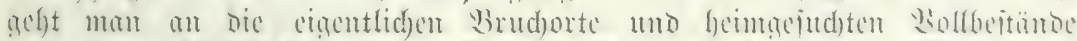

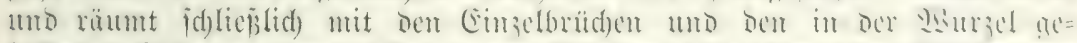

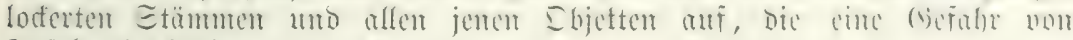
Injeftenbejuäbigung in fid) fidjliểen ${ }^{1}$ ).

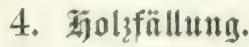

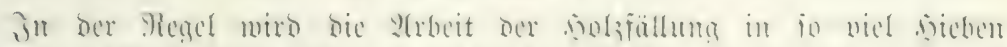

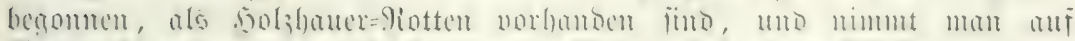

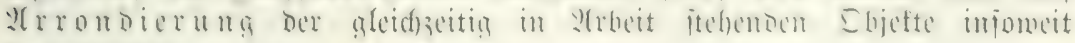

1) Siefoe Burfhardt, 24ว Dem Malde. II. G. 167. 


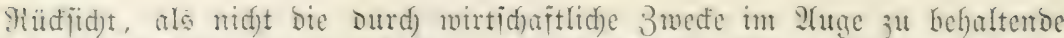

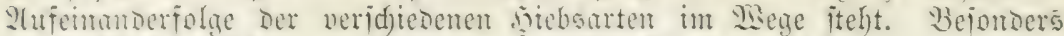

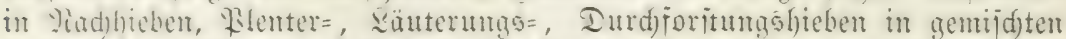

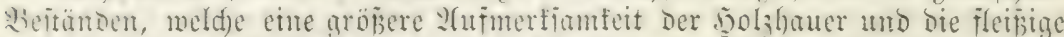

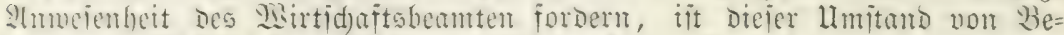

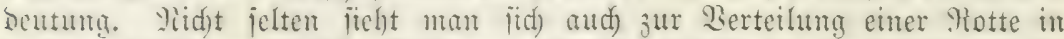

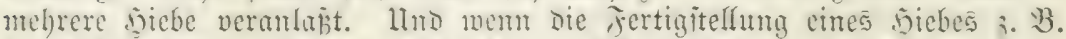

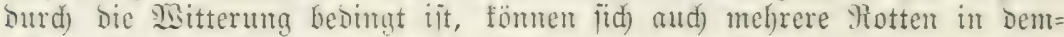
felben Siebe vereinigen.

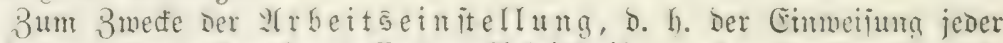

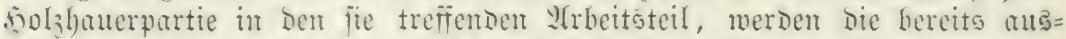

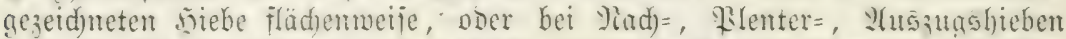
13. †. w. itammmetic in io viel gleid)e Ieile geteilt, als Partien vorhanden

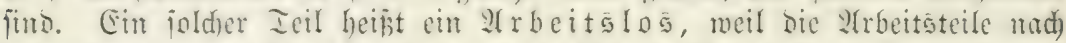

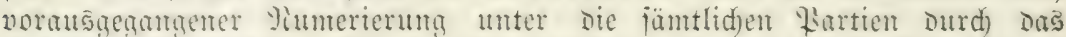

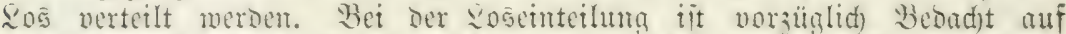

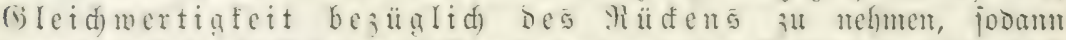

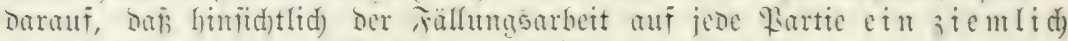
gleider Anteil an arbeit un 3 berbient fommt.

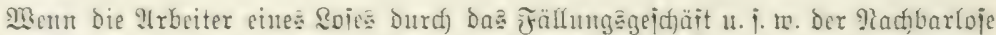
nidgt gefinbert und biter unterbrodfen merben jollen, jo bari man bie soje nidjt zu

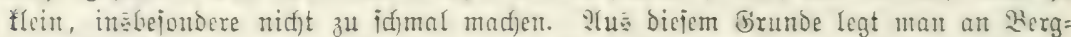

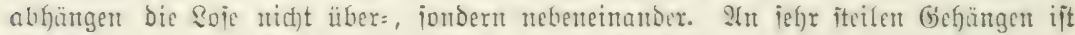

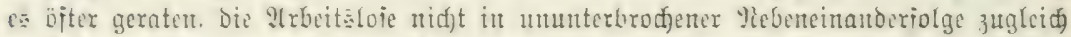
31t beietsen, ionoern vorerit zwiid)en ie zwei Soien bas zmiidenlienende frei zu Lafien,

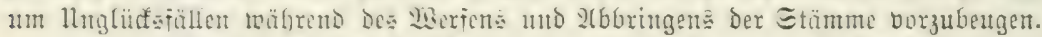

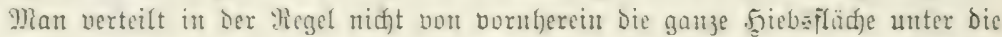
Wrbeiter, fondern rejerviert cine :(nzah) Soie zur nafjolgenten Werteilung an bie

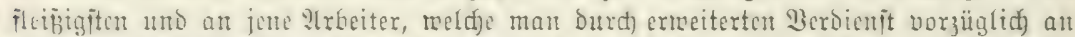

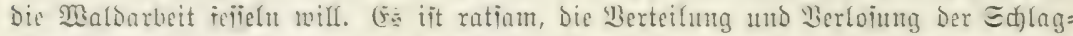

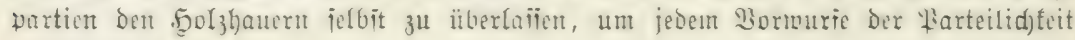
3ut entgefyen.

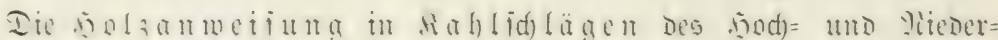

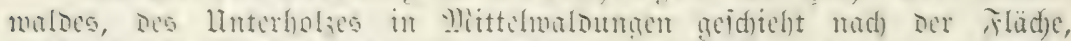

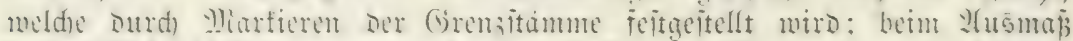

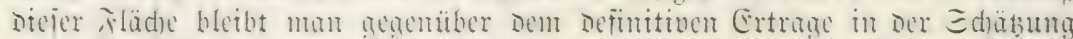

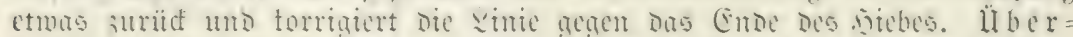

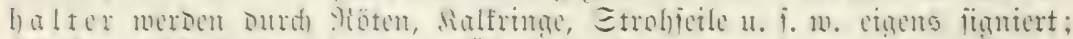

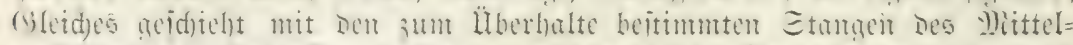

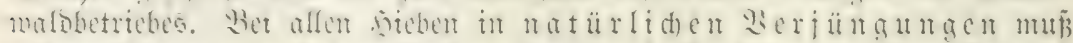

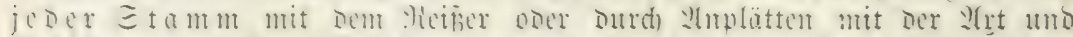

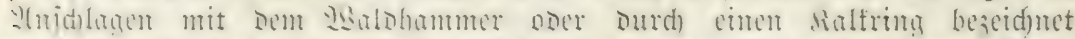

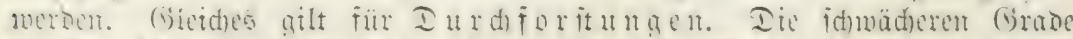

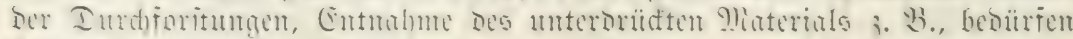

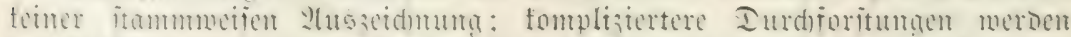
Burd) 


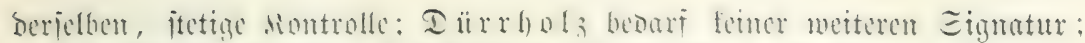

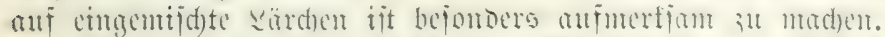

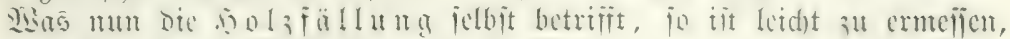

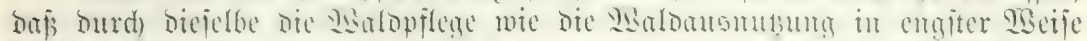

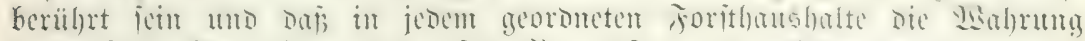

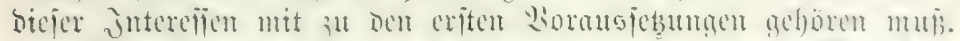

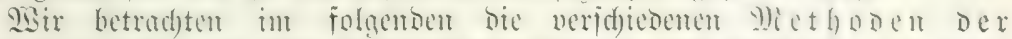
B⿺廴

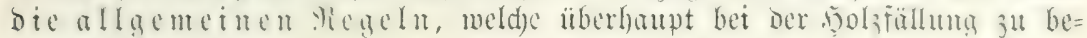
obad)ten find.

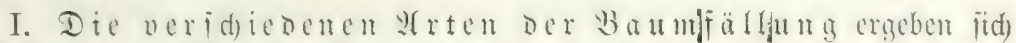

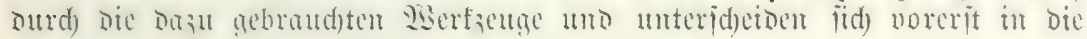
Gewinnung ber oberirbijd)en und die Geminmung Der unterirbijtzen .jolzmaj̈e.

A. Gewinumg ber oberitbifden รัo ว

1. Fällung burd) bie $\mathbb{Z}$ rt allein (umid)roten oder Etämmen Der Bäume). Der îll fällende Stanm wirb jo tief als möglid) am Boben, แ⿰㇒⿻土一 swax von zuvei, einamber gegenüber= itehenden Eeiten mit jilfe ber Fälart angehauen. Die Durd) Die 2rat angehauene Rerbe (Der $\subseteq p a n$, Rerb ober $\Xi$ d) rot) bringt feilförmig mefr und melyr nad) bem Serzen des Stammes vor, bis Derielbe, ber linteritübung beraubt, fällt. Der Span joll itets möglid)it ebene glatte Dänoe seigen und midgt viel weiter jidf D̈frnen, als zum ungebinderten Ëmbringen Der Wat erforberlid ijt; beträgt bie 5öbe bes Epanes (ientred)t an ber

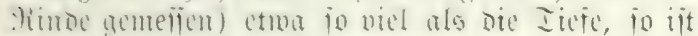
Diejes in ben meijten Fällen genügeno.

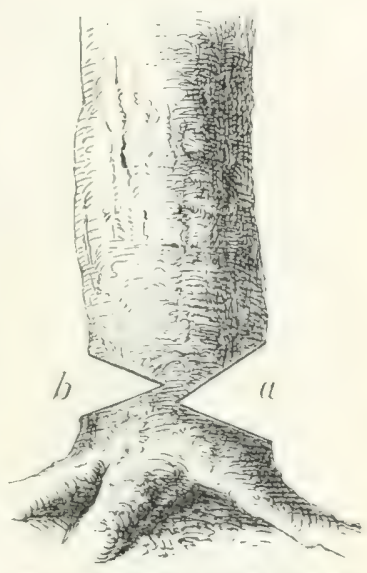

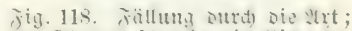
oit Etamm fillt in oic :itiduthy ber serbe a.

\section{Eoll ber Etamm nad) ciner bejtimmten Yidf)=}

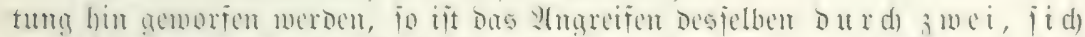
et

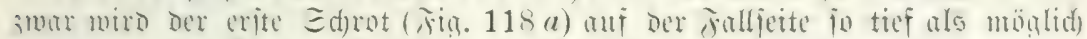

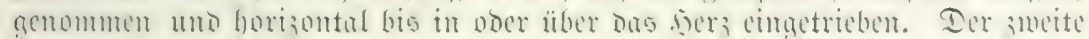
Ed)rot (b) wirD 4m 10-15) cm höher, je mad) Der Etüte Des Etrmmes, be= (3)

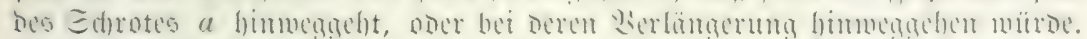

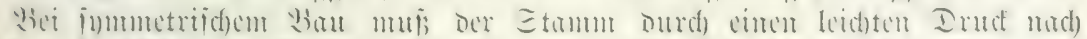

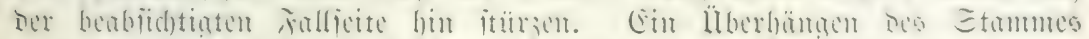

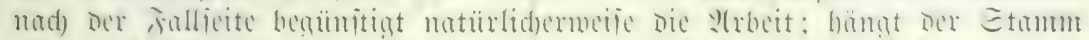

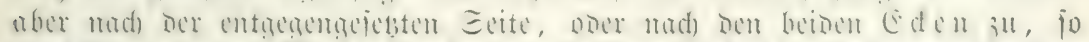

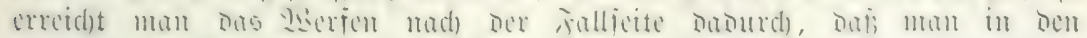

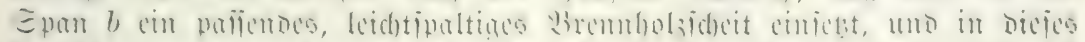

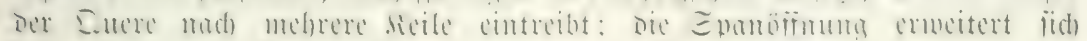
baburd) uto orüdt ben Gtamm mad) ber Fallictite biut. 


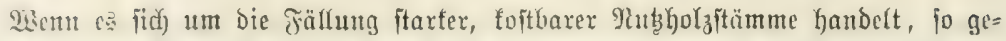

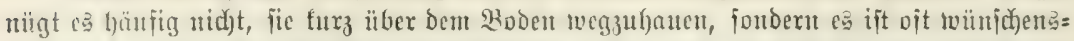

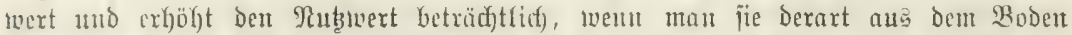

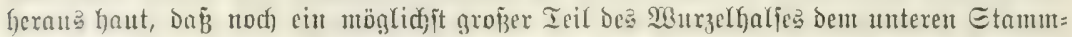
teile beigegeben brcibt. Man greift Dant mit ben Spänen fo tief alz möglida), gräbt

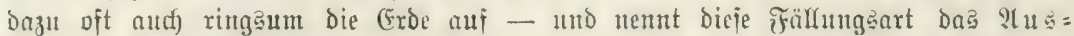
feffel

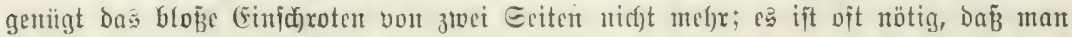

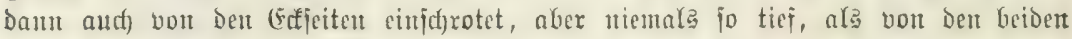
anderen, weldye in Dex Fallinte liegen.

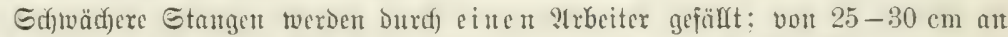

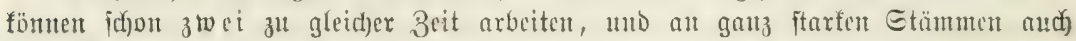
viex $\mathfrak{A}$ rbeiter.

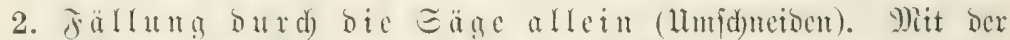

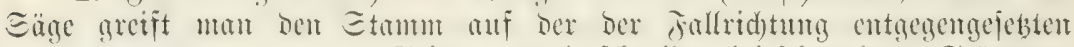

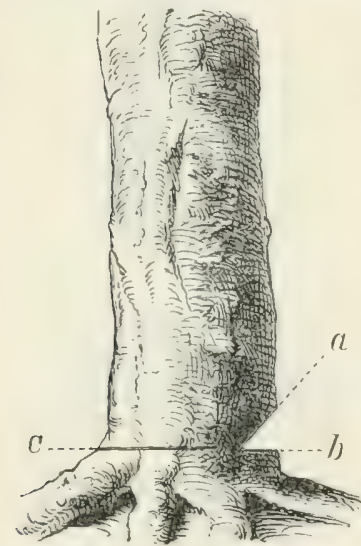

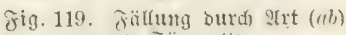
uno Ë̈ge ( $\left.{ }^{\prime}\right)$. Seite an und fodretbet bet fdumäd)erent Stämmen fo tief ein, bits ber Stamm fid) umtoriaden läßst; bei ftarfen Stämmen läpt fid) der Sdyntt obnte Slemment der Eäge über bas Syerz hintats ntdot fïfren, uno treibt man bier linter ber Eäne,

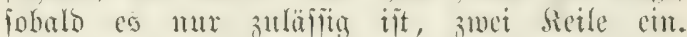

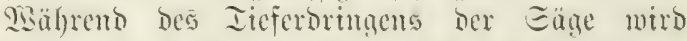
mehr und mehr nadgeteilt, bis ber Etamm Falle fommt.

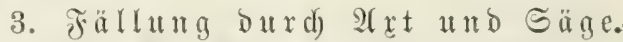
(i)ig. 119). Der Etamm wird anf ber antg= arjehenen jorlfete ticf am Woben mit ber Eäge med) Der simte $b$ angefidutten, mit ber v(rt wird

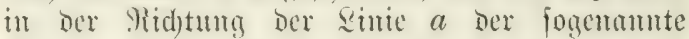
Falferb atsogipaltem, uno foll letsterer nidat tiefer cimbrimgen, als ber fümfte ober vierte Ietl bes Etammourd)mefiers beträgt. Eodan mird

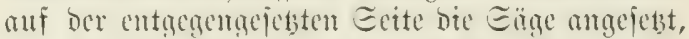
und fobald fid bieje lourreidjend tief in Den

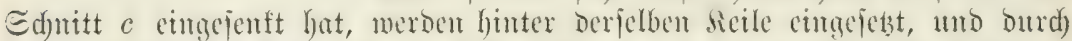

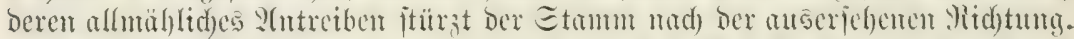

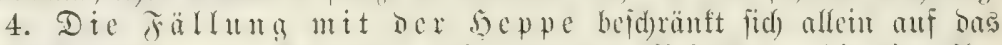

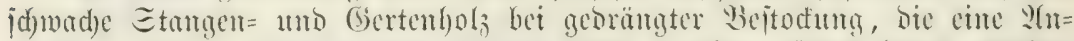

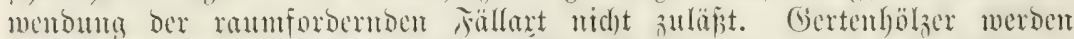

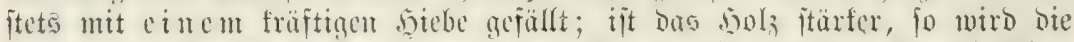

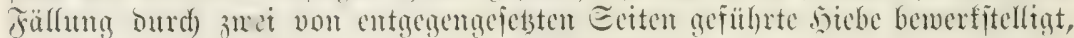
obne daf ein eigentlider Span gelöft wixd.

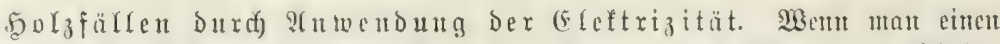

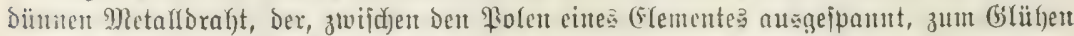

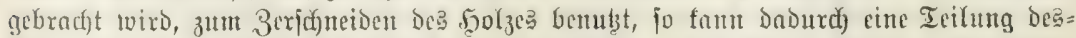

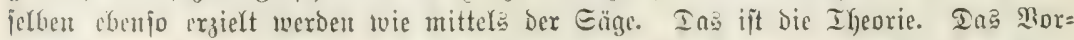

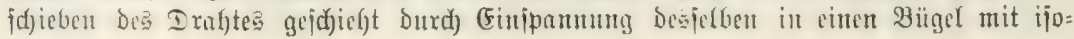




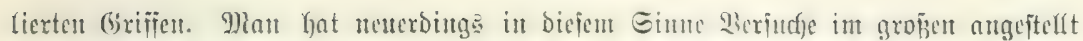

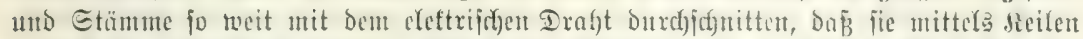

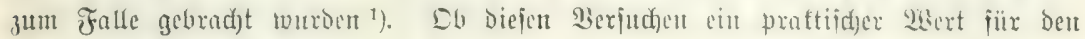
Wald beizulegen ift, mแß dic 3ufunft lehrent.

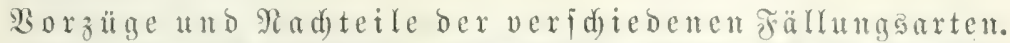

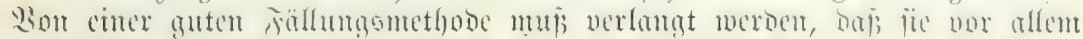

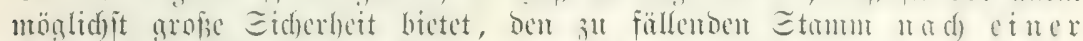

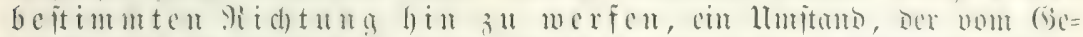

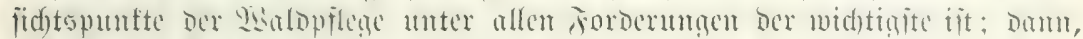

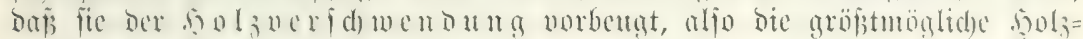

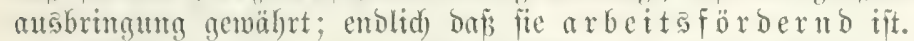

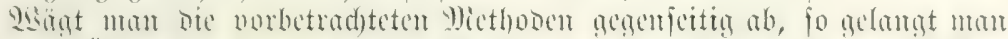

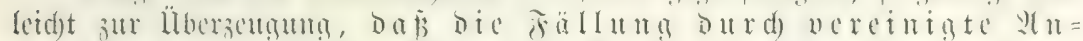
we

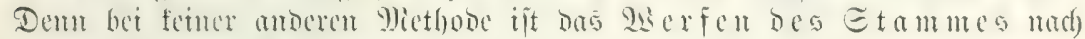
einer befinmten Fallridytung io fidjer als lier.

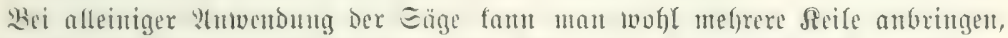

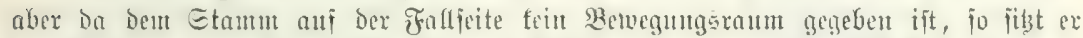

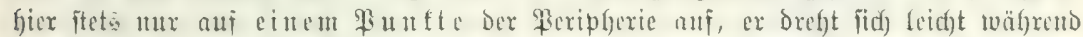

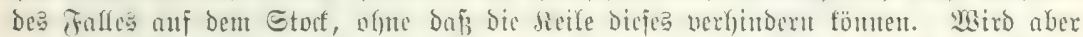

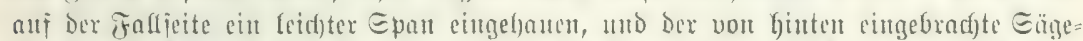

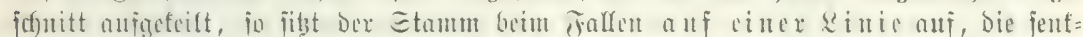

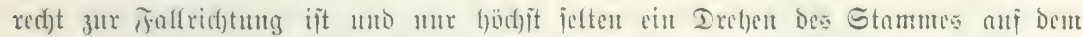

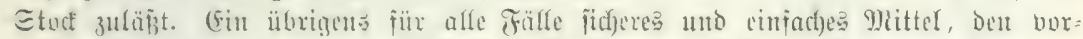

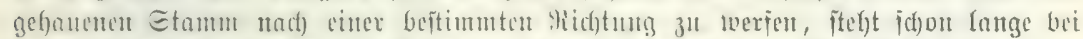

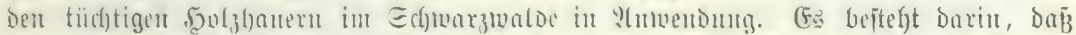

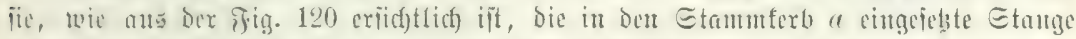

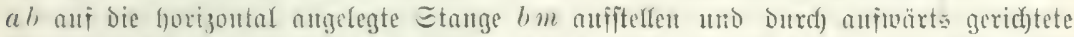

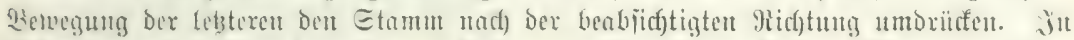

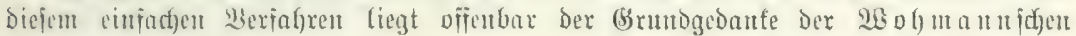
Hodeborricftum

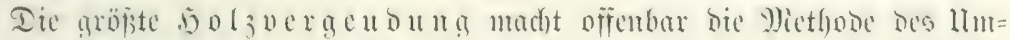

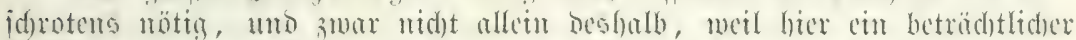

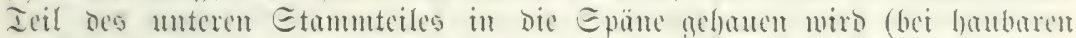

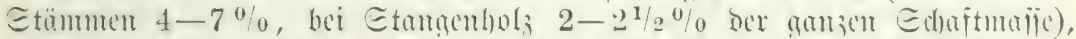

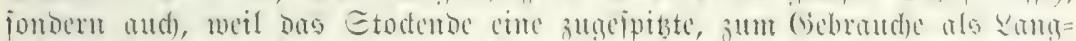

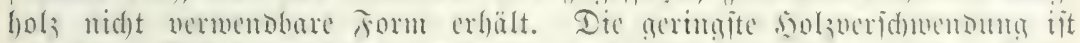

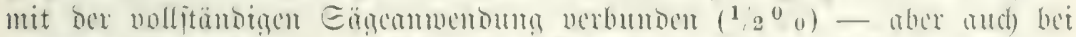

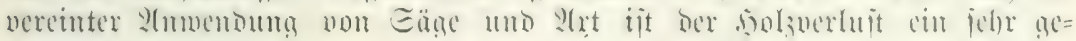
ringer $\left(1-1^{1 / 2} \%\right)$.

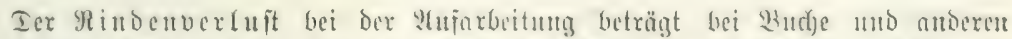

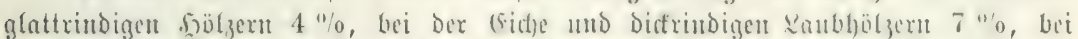

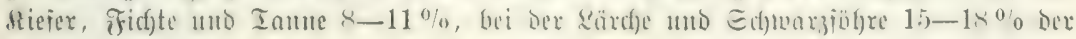

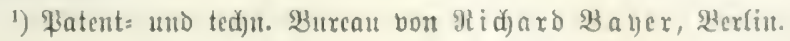




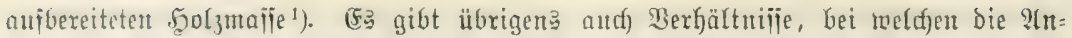
wenoung ber Säge eine grȫere Solzberidnentung herbeizufüfren vermag, afa fic

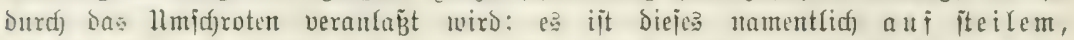
id)roifem, mit Felatrümmeru überbeffem Ierrain ber fall; - wollte mant hier mit der Eäge arbeiten, fo mübten oft bie Etörfe fo hod) belafien merden,

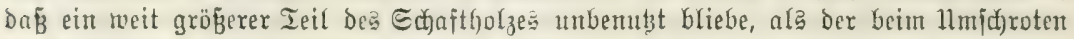

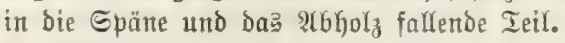

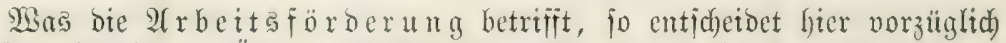
bie Gewohnheit und Übung Der Irbeiter. Yian fam hier mur bie Reitung von $\mathcal{A}$ rbeitern miteinander vergleid)en, die jomohl mit ber $\mathcal{E}(\mathrm{xt}$ als mit ber

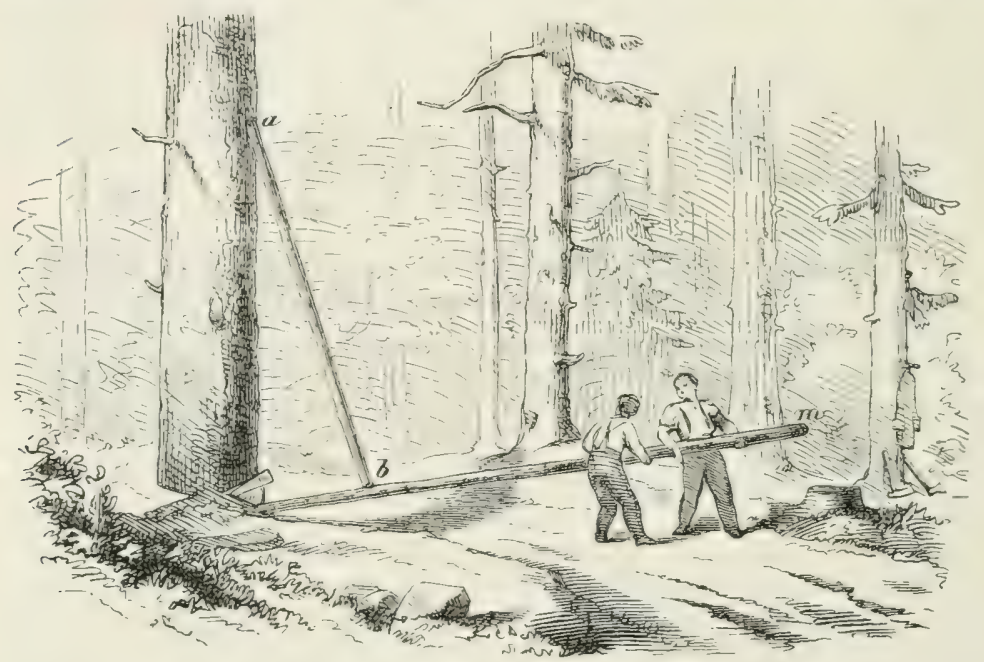

Fig. 120. WSerfen beß Stammes ntttels f̧ebeljtange.

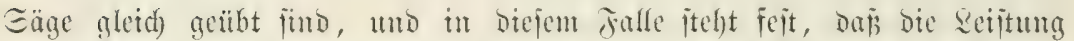

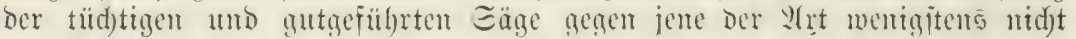
zurüditeht.

Die Jülfung ber Bäume burd) vereiniate

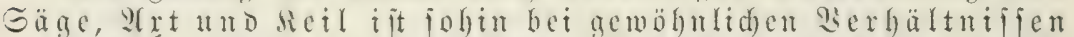
unfreitig bie mirtfdaftlid) fte and jollte überall Ëingang finden, mo nod) ats (isemohnheit bie verid)wenberifde S(rt bes ltmid)rotens bejtelyt. Sic ijt mur allem nidst amembar anf jd) roffem, felfigem Ierratu,

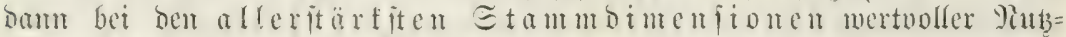

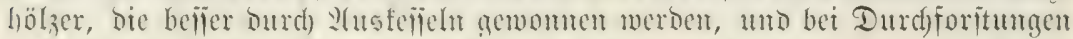

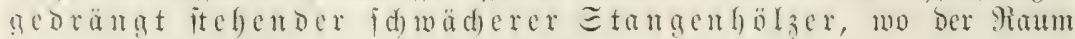
3ux Fül)rung ber Eäge gebridyt.

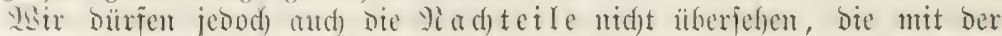

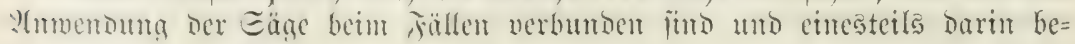

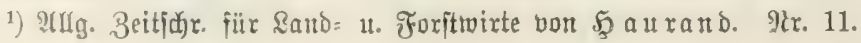




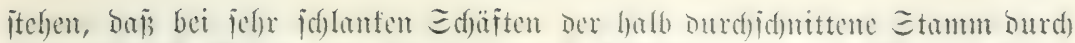

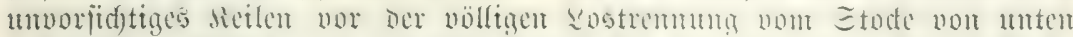

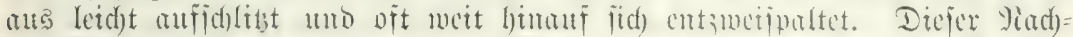

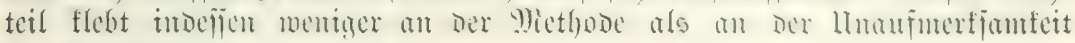
ber 2 trbeiter.

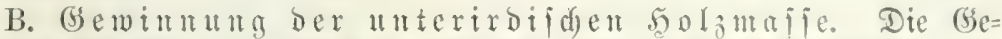

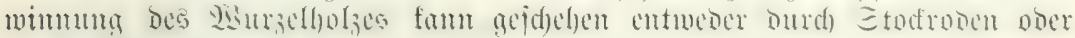
burd) Baumroden.

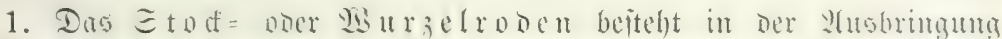

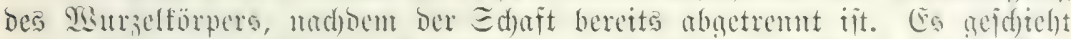

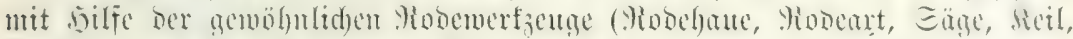

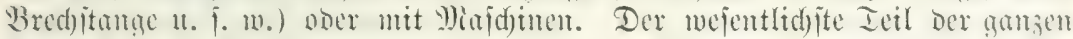

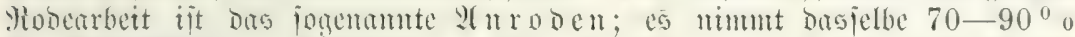

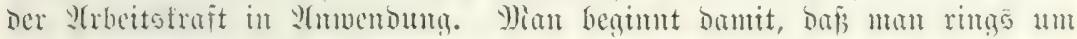
belt Stod herum bie Eroe tweg= räumt mo alle Geitenmurzelı fo meit zu Tage legt, als fich) iffre $2(u s=$

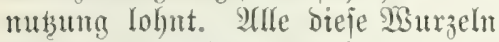
werden bann hart am Marzelitode uno in grö̈erer Entfermutg von Demielben bei \$rügelitärfe (nid)t unter 4 cm Durd)meijer) abotetremt und mit Der Bredfitange ausge= brodjen. Darauf gräbt man ringes=

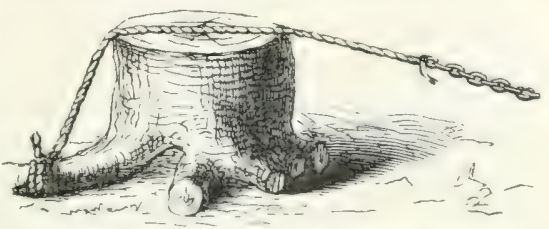

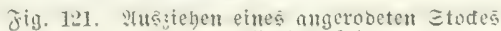
burd) ben saldteufel.

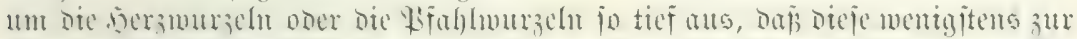

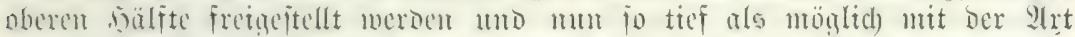

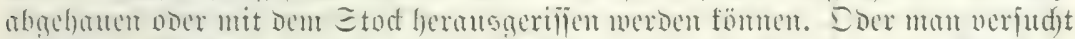

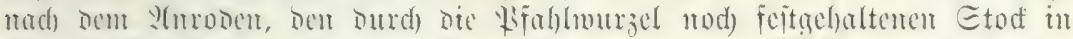

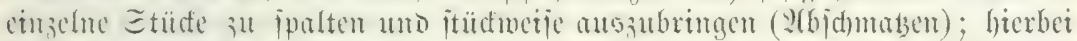

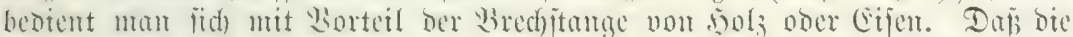

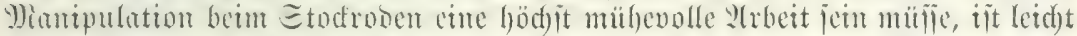

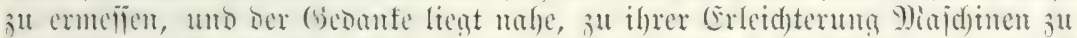

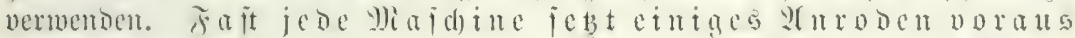

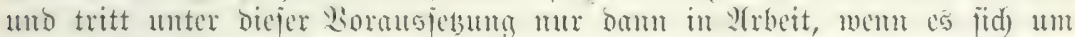

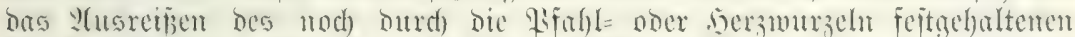

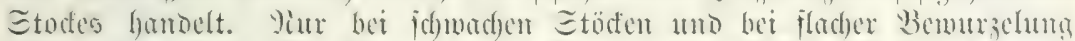

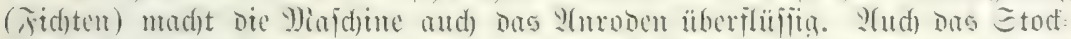

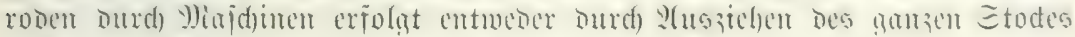

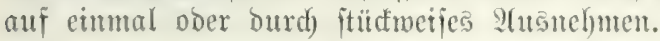

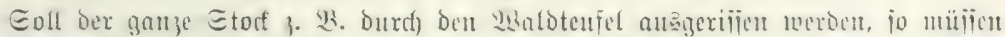

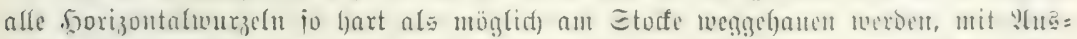

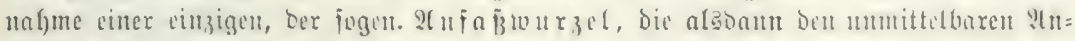
grifïsunft jür bie Mlafd)ine abgibt (vergl. Fig̣. 121).

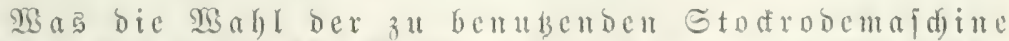

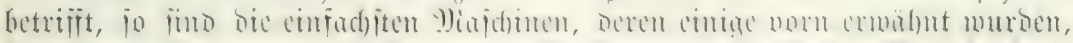

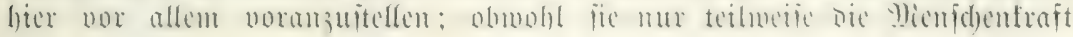




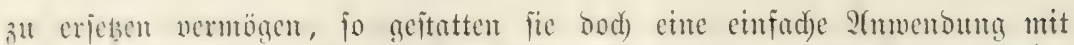

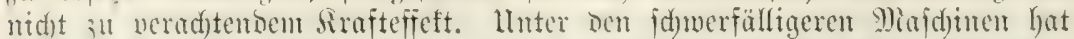

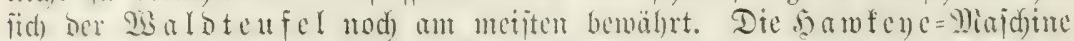

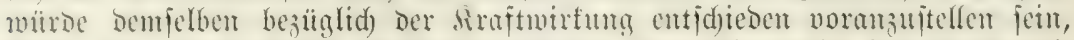

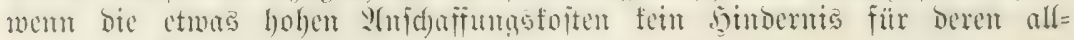
gemeinere Berbreitung mären.

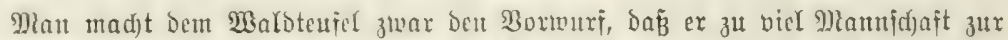

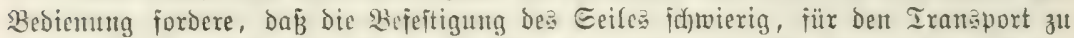

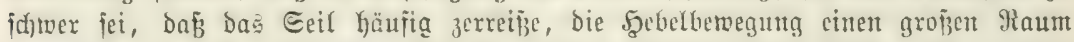

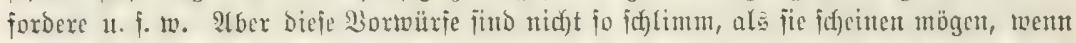

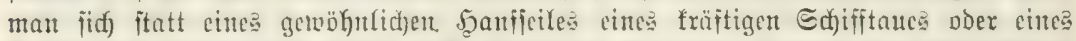

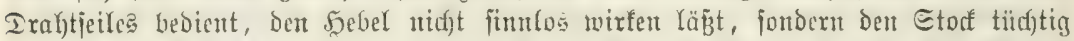

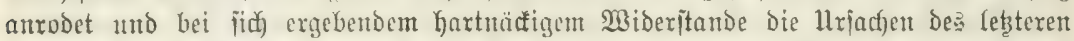

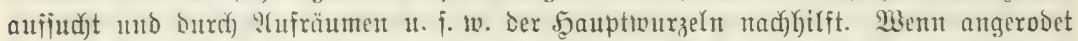

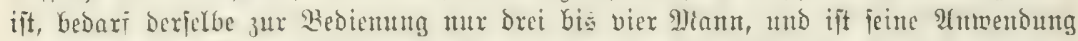
auj idfwerem bindigem Boben im Brgenjate zur gemöhnlidjen f̧andarbeit am vor=

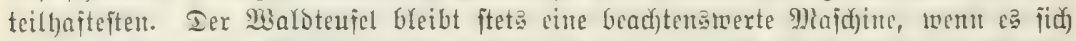

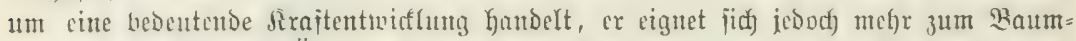

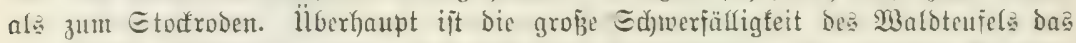

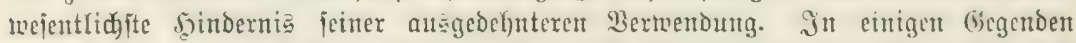
Ed)lcfiten, wo man fid Des Maloteufel mit Sorteil bedient, wiro befauptet, Daf

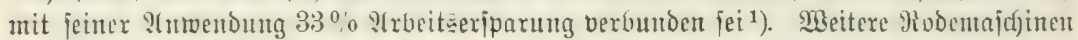

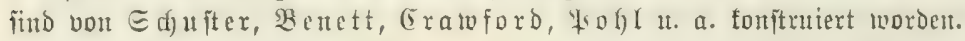

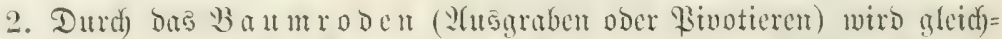

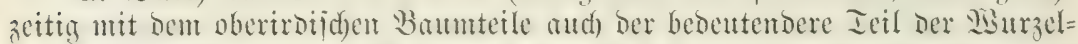

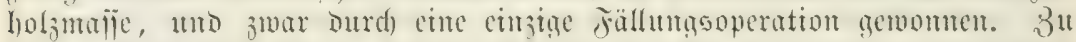

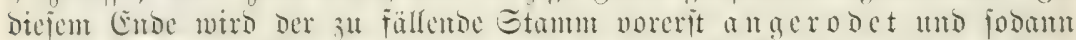

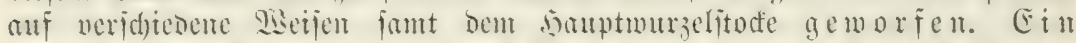

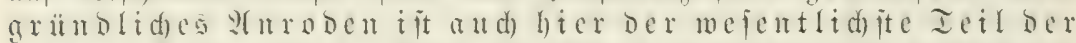
a a

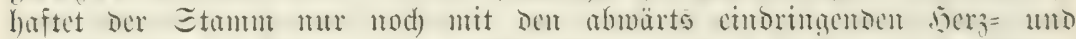

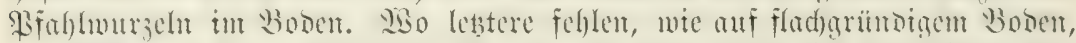

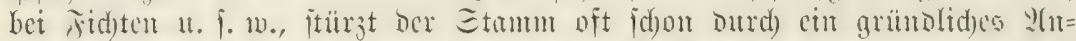

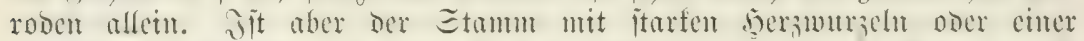

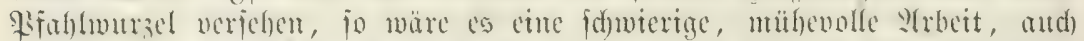

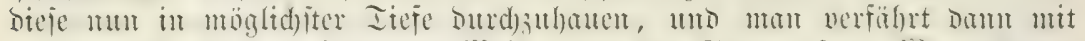

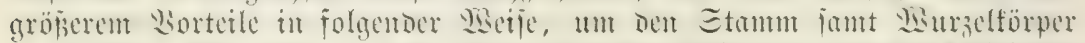

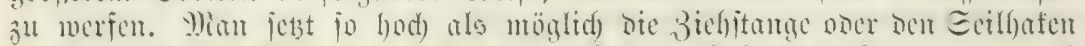

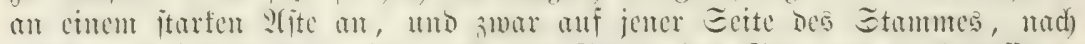

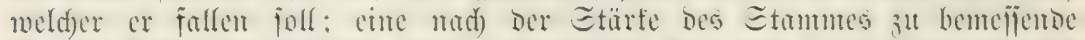

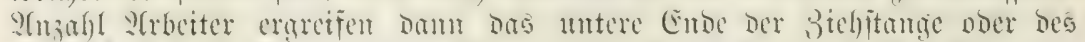

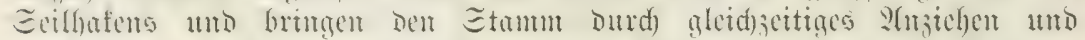

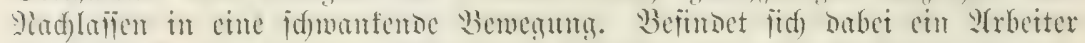

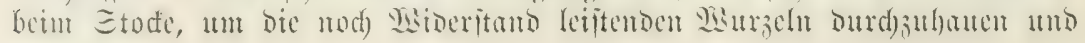

1) Eiefe Merkanblungen 


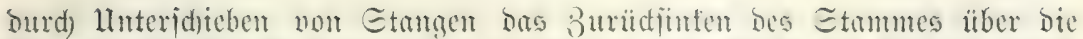

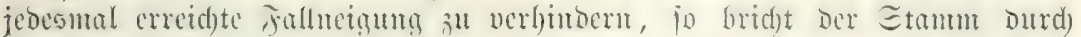

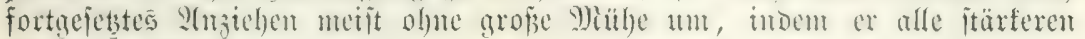
פ̇uzeln herausreibt.

In einigen Drten hat man zum Wiserfen ber macroneten こtämme,

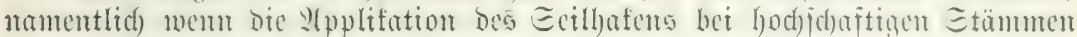

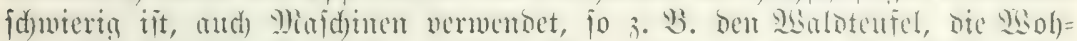

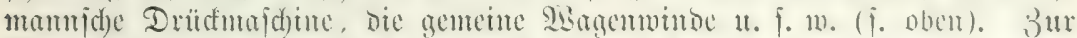

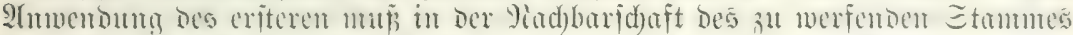

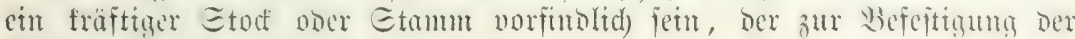
9)(ajdine Dient.

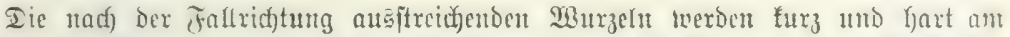

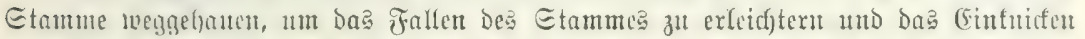

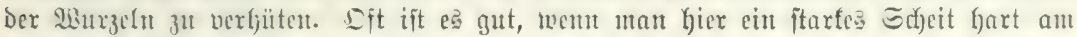

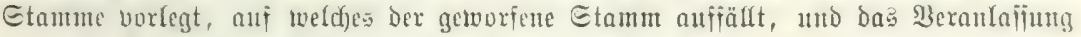
gibt, die Betvurzelung beffer nub Dem Grunbe zu heben.

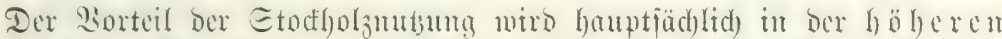
5ol oua

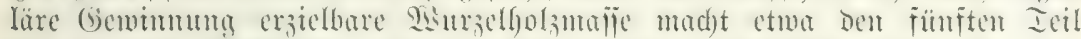

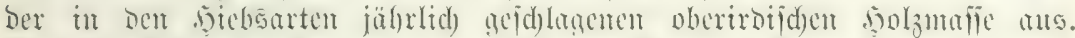

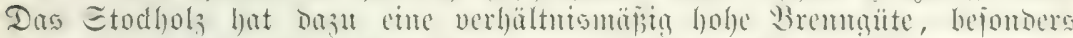

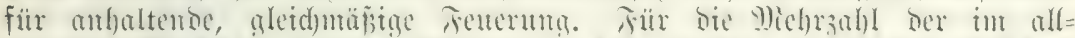

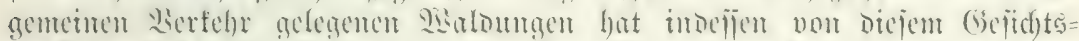

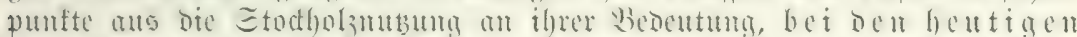

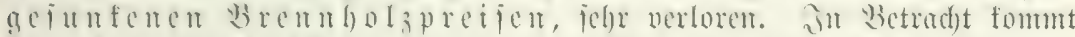

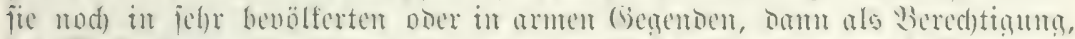

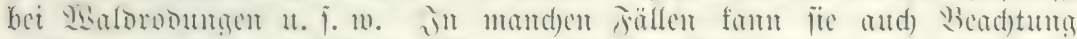

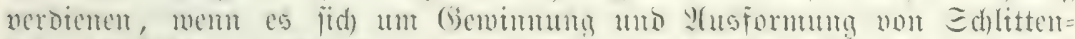

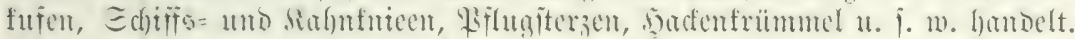

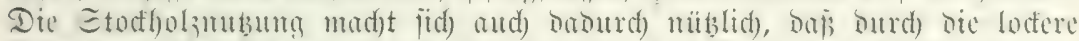

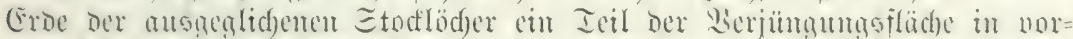

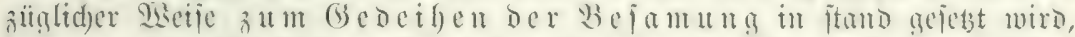

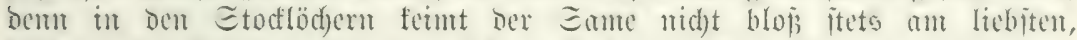

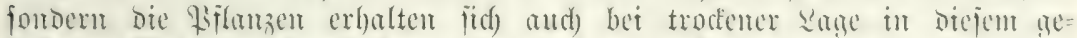

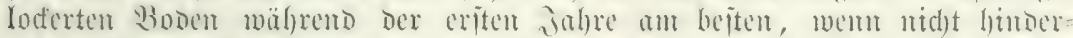

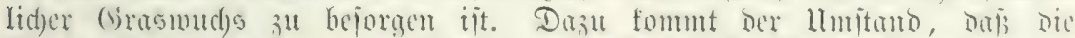

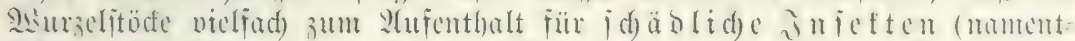

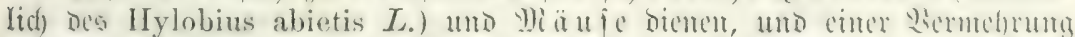

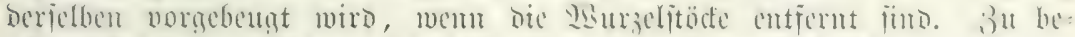

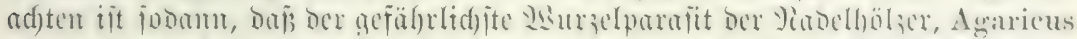

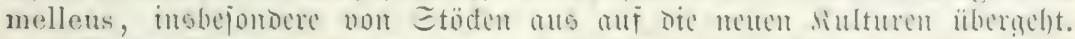

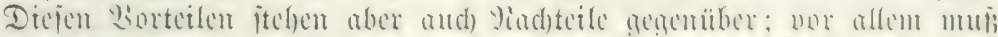

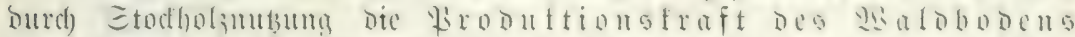

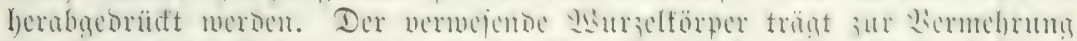

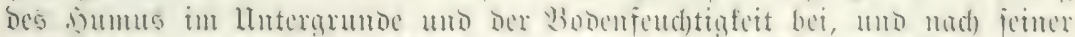

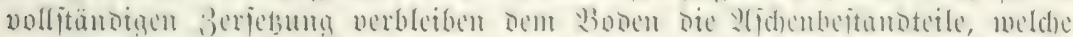

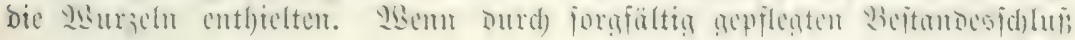




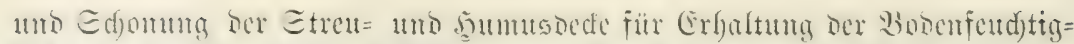
teit gejorat mirs, jo mag biejes, namentlid) anj Den an unb für fids frifderen

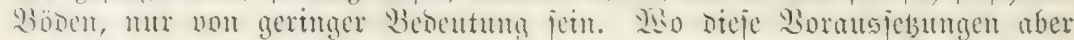

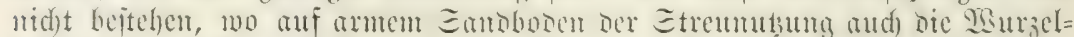

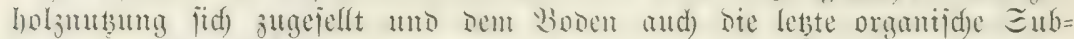

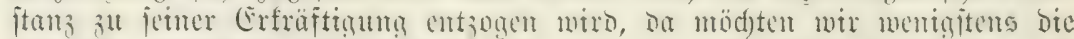

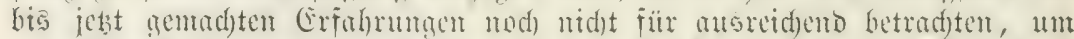

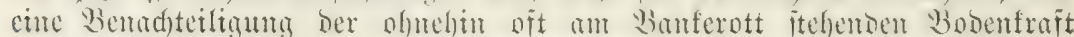

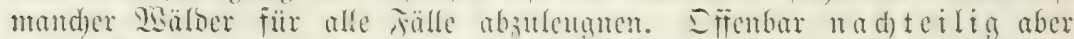

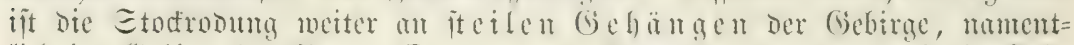

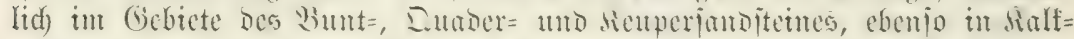

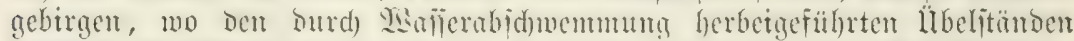

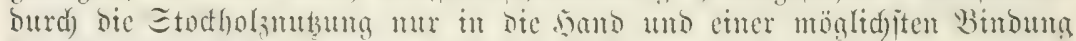
ber Bobenoberfläd)e entgegengearbeitet wirb.

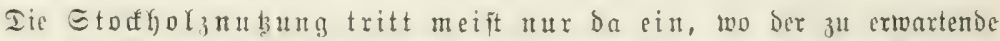

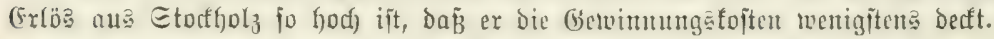

(E) exïbrigt mun nod) die Frage, ob zur (5) ewinnung bes

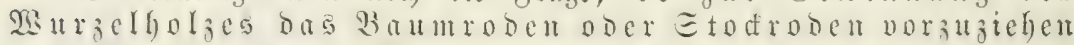
fei? Waut bat über bie Beantmortung bicjer Frane früber viel gejtritten;

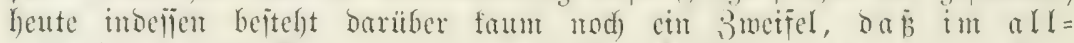

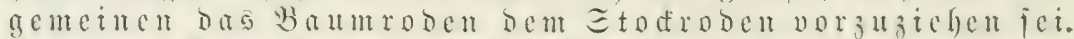

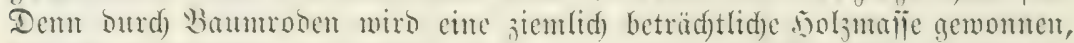

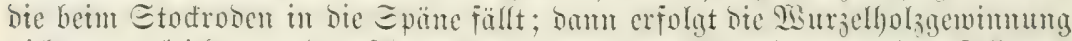
micht mur leidfter mo rajder, jombern aud nollitünbiger; weiter fällt ber

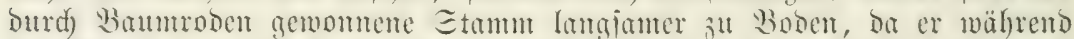

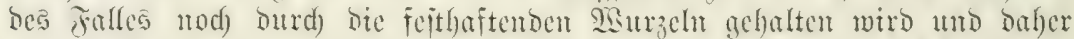

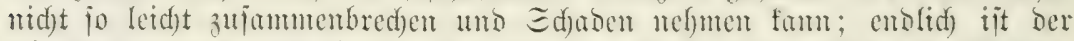

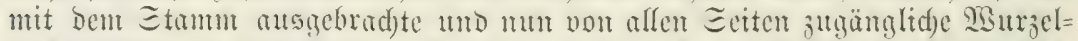

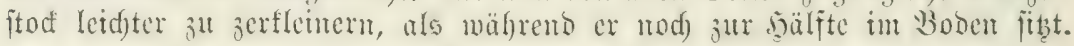

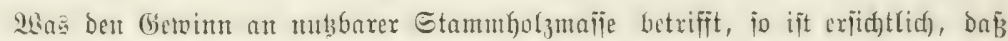

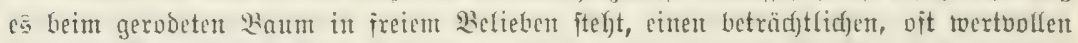

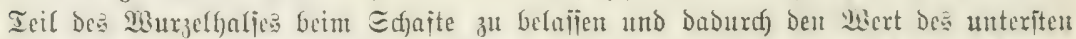

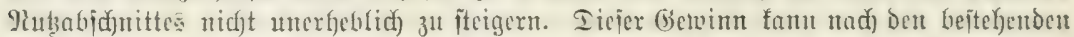

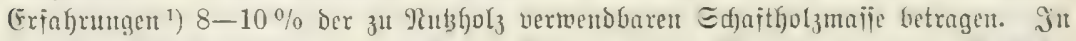

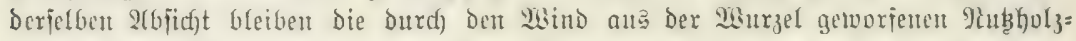

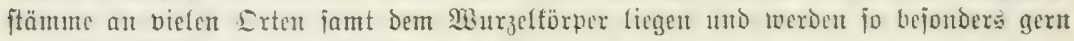

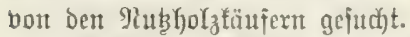

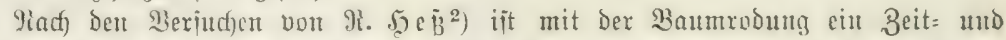

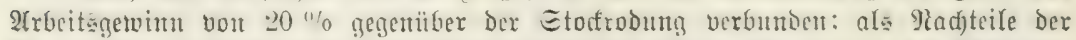

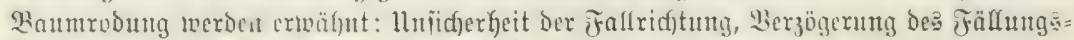

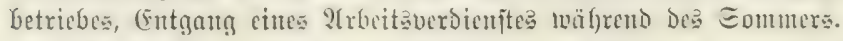

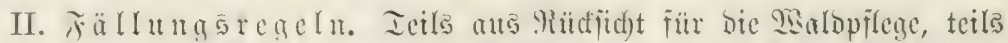

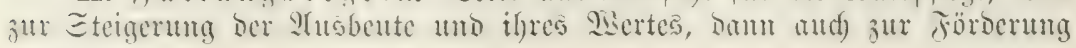

1) Giebe Joritt. Blätter, I. Seft, S. 183.

2) Forft= u. Jagbzeitung 1875; fiehe bajelbit aud 1873 , Є. 140. 


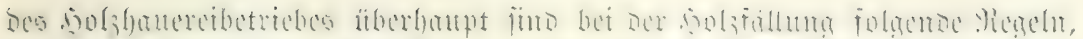

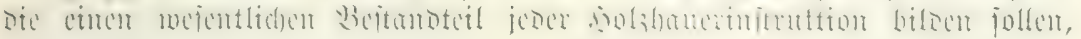
3 il beobad)ter:

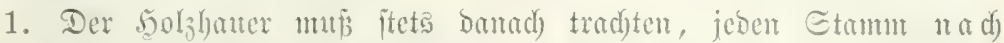

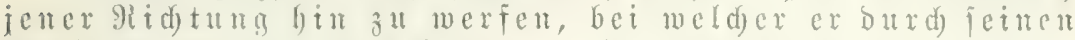

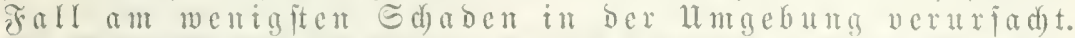

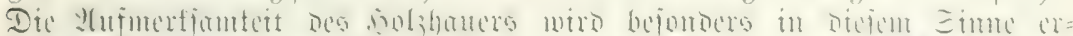

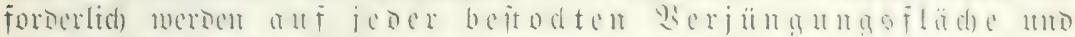

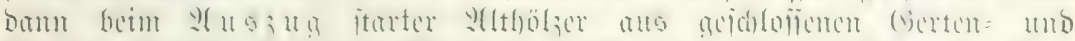

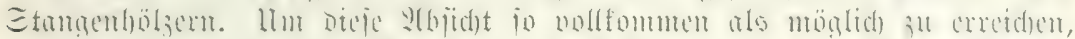

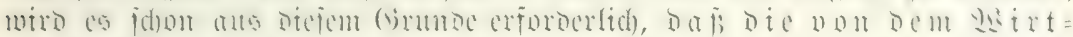
idaftabeanten vorgejdriebenc Färumgart itreng ein=

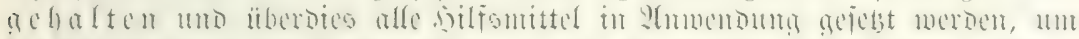

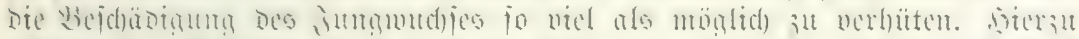

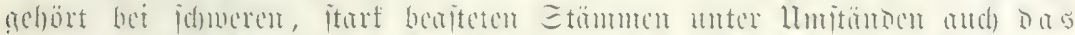

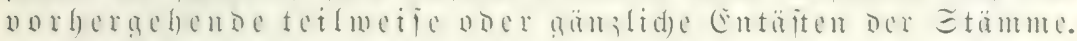

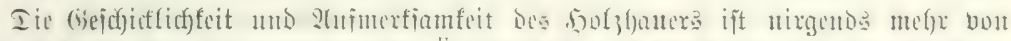

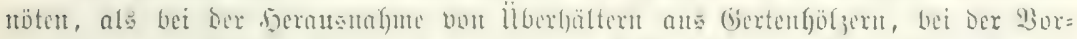

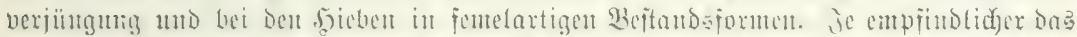

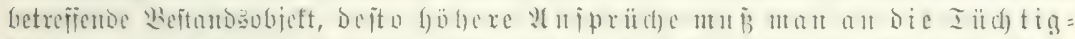

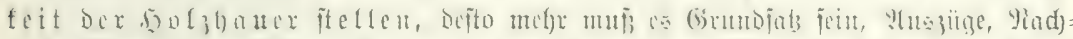

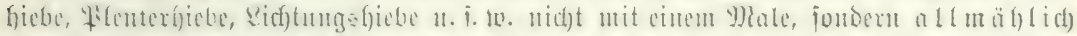

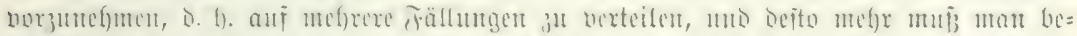

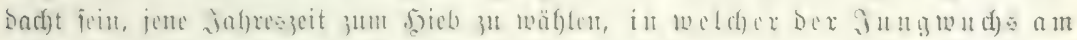
zäleften und am wenigften cmpfindlich i it gegen bie mit Dem Fällungas=

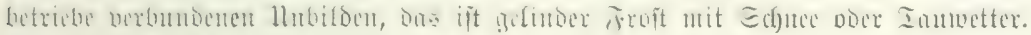

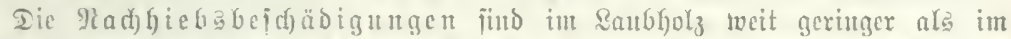

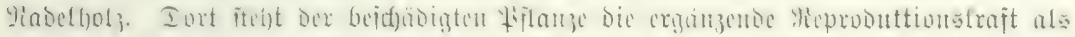

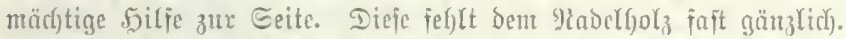

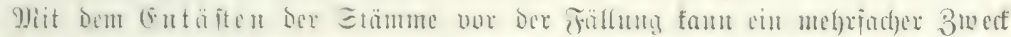

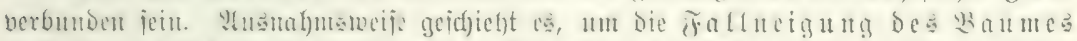

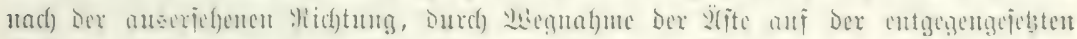

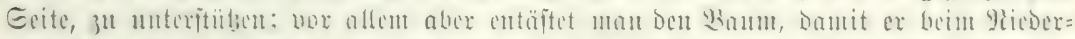

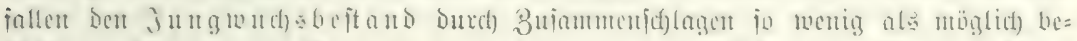

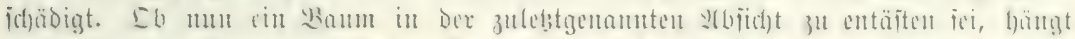

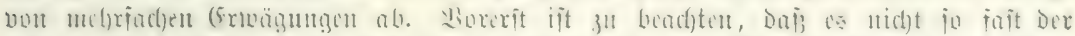

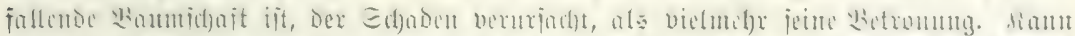

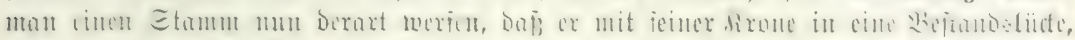

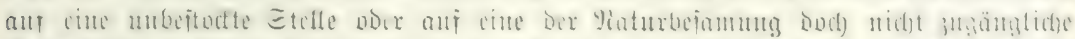

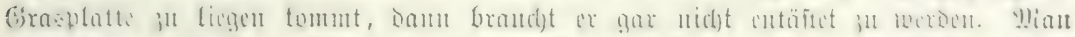

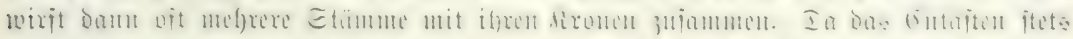

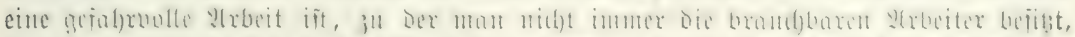

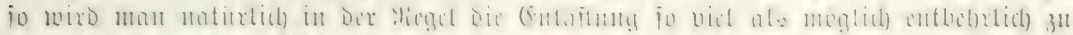

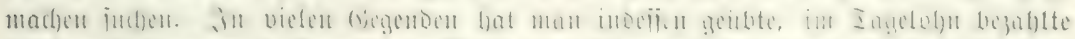
Etriger

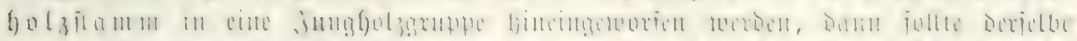

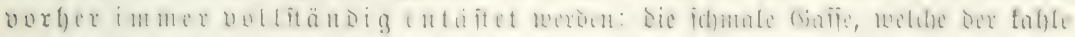




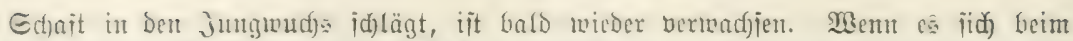

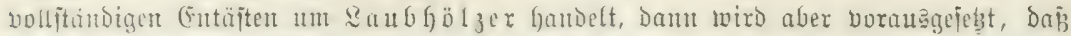

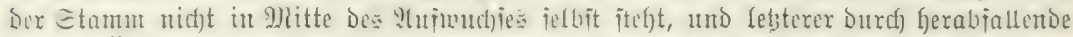

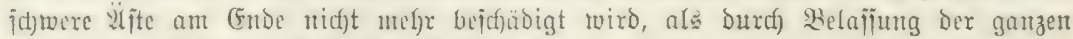

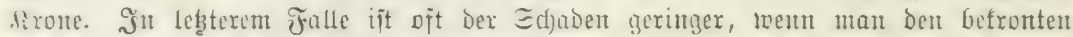

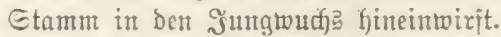

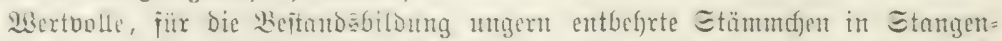

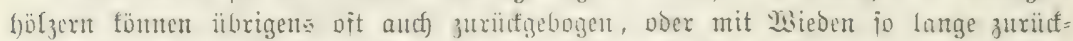

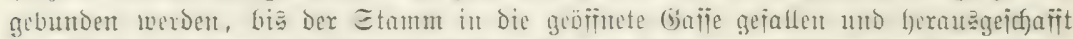

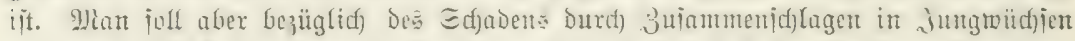

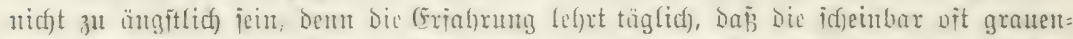

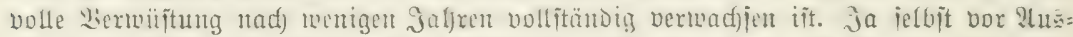

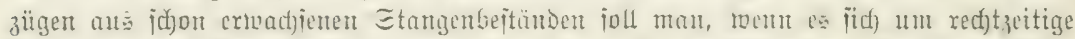

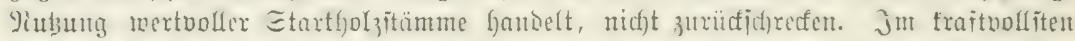

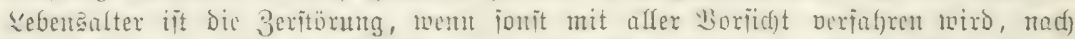

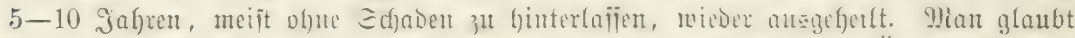

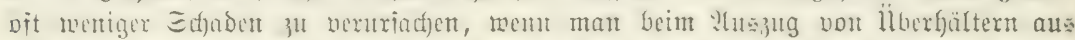

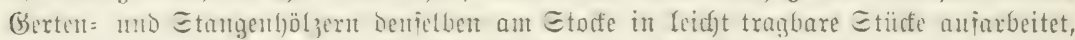

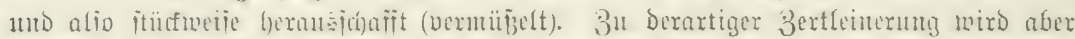

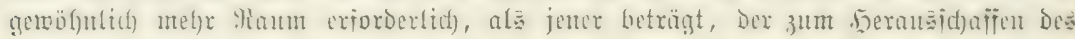
entäfteten Edfaftes nötig gewejen märe.

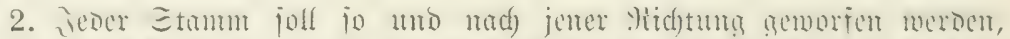

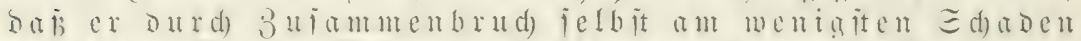

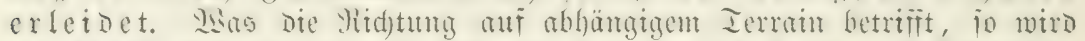

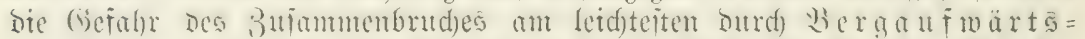

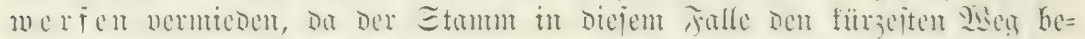

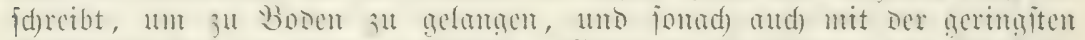

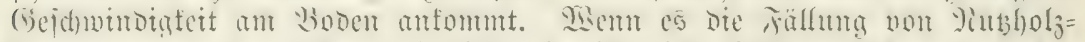

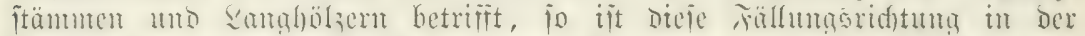
Tequel Die imetentipred)endite, nementlid) Dant, wem Die Etünme ans

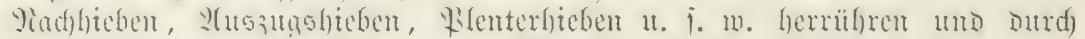

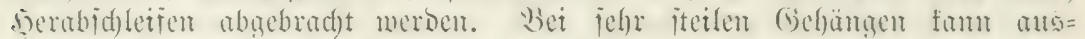

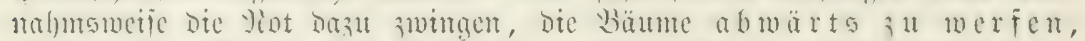

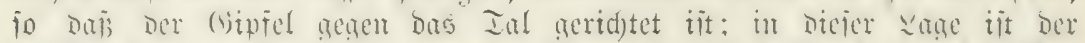

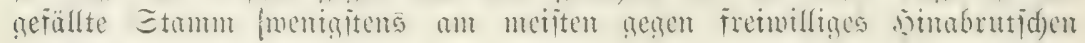
gejidjert.

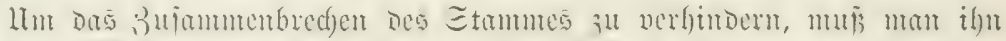

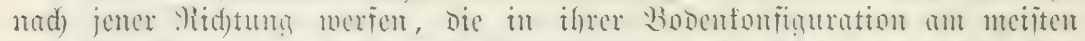

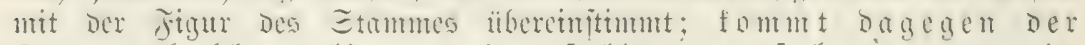
Gtam hobl ou liegen oder fält er a f f heroortretende

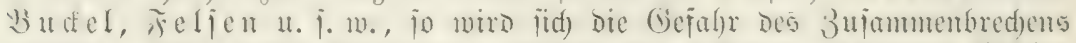

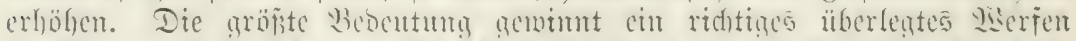

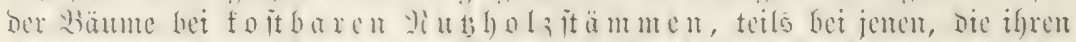

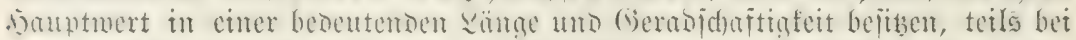

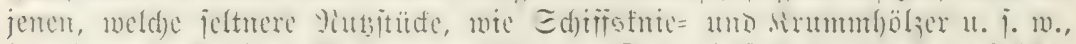

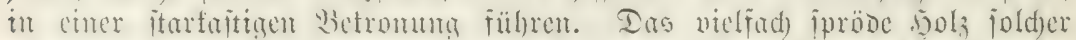

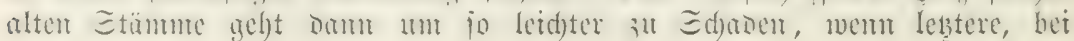




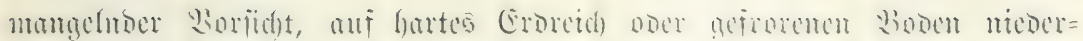

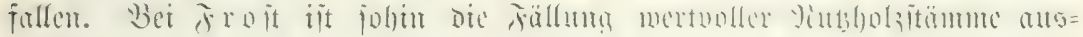
зujetsen.

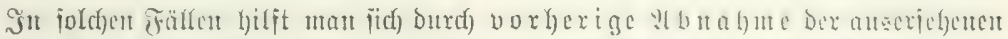

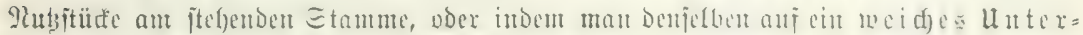

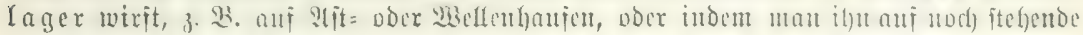

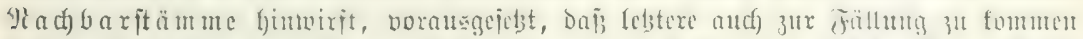

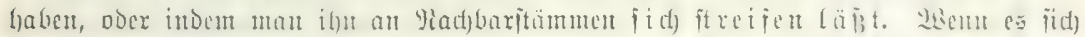

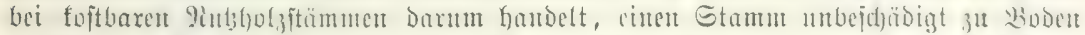

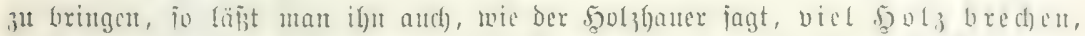

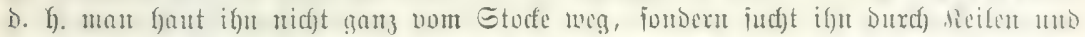

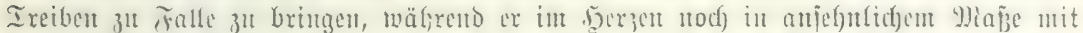

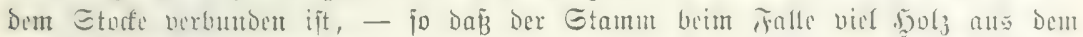

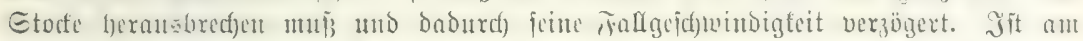

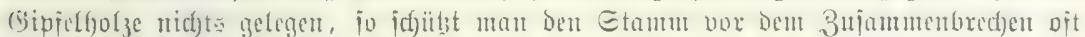

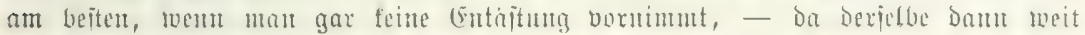

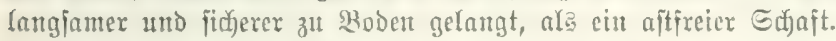

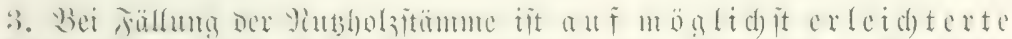

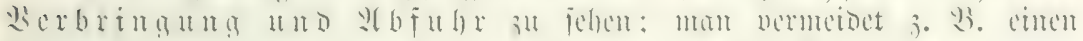

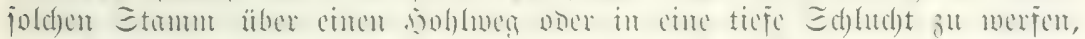

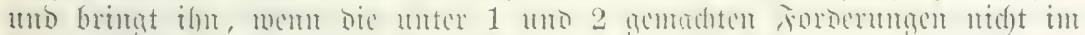

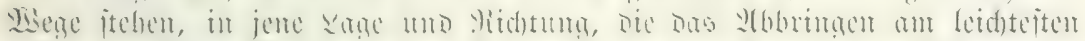

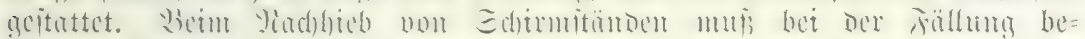

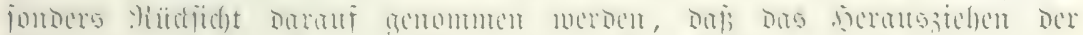

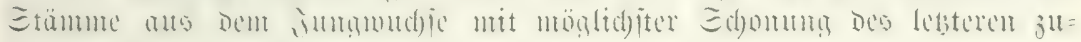
läjïg wirb.

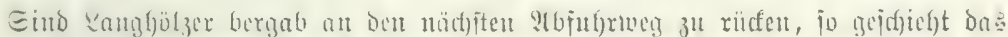

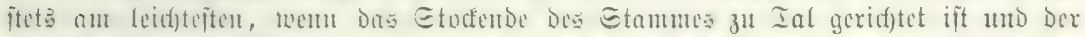

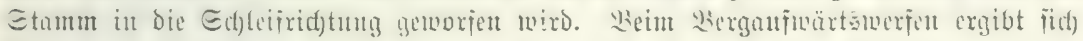
Dieje Rage von jelbit.

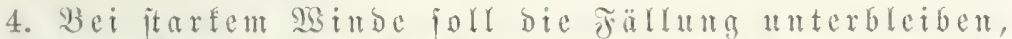

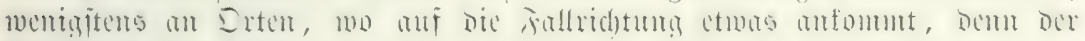

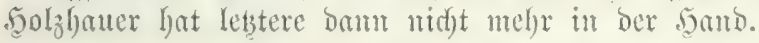

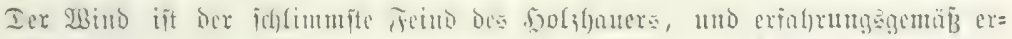

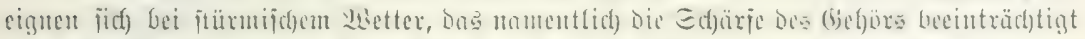

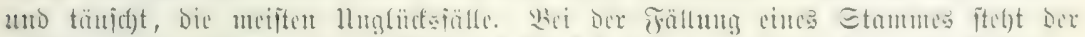

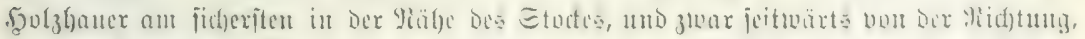

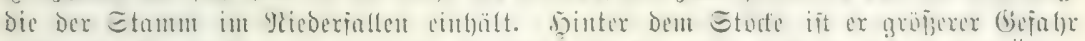

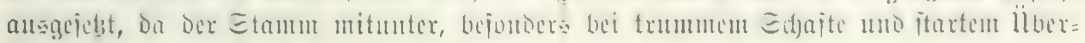
bängent über bent Ctod zuriidrutjudt.

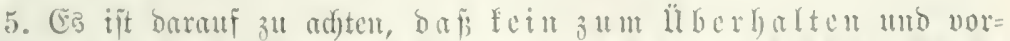

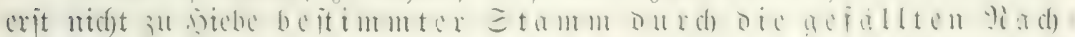
barbäume bejdäbigt ober umacjd) lagen mexde. Circignet fid)

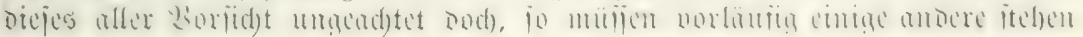




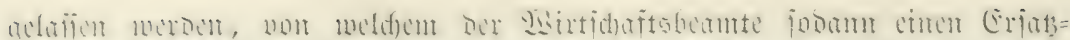

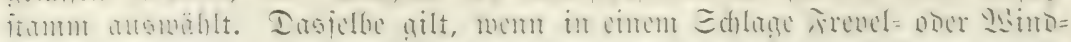

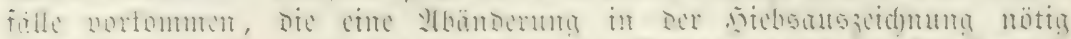

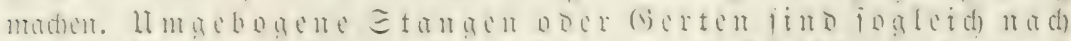
IE glatten bieb aitf Den Stod zut jetsent.

2:

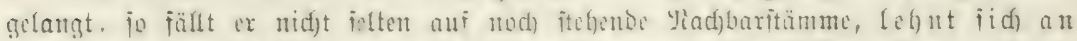

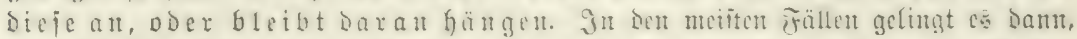

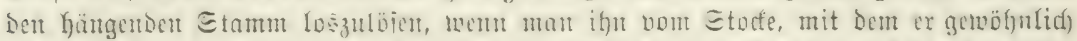

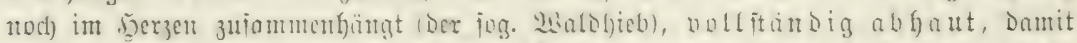

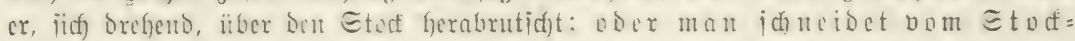

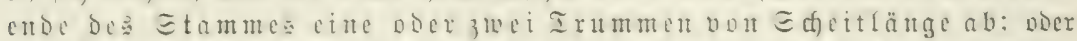

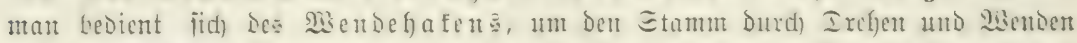

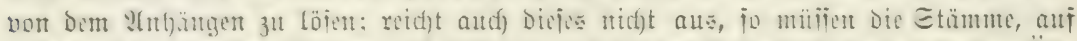

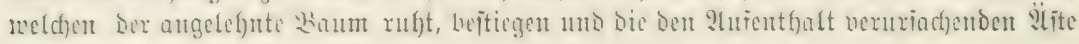
loasgelöft twerbent.

6. Etämme nou üher $15 \mathrm{~cm}$ untem Dutrafuneijer follen itets mit

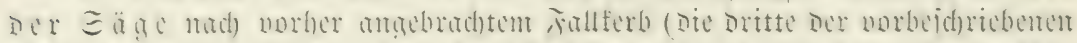

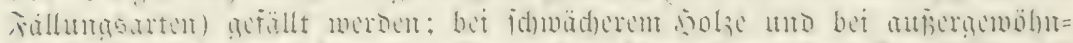

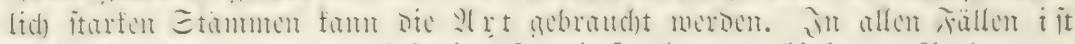

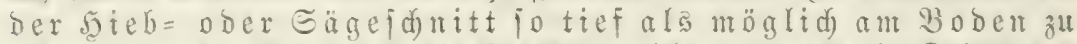

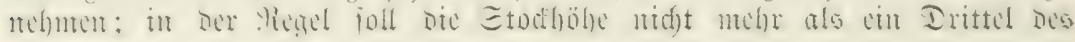
Stammourdymejers betragen.

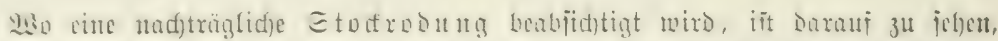

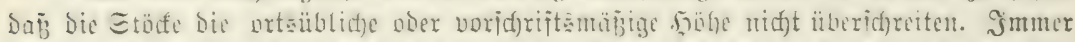

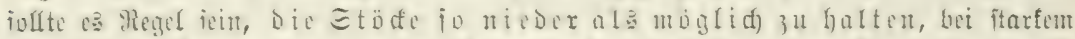

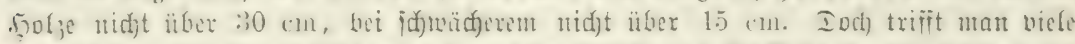

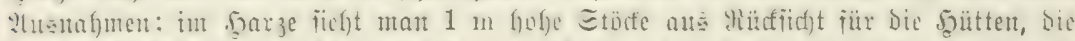

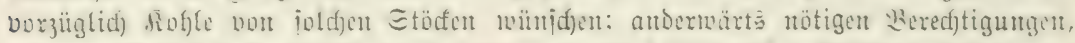

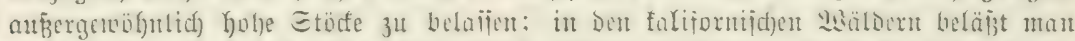

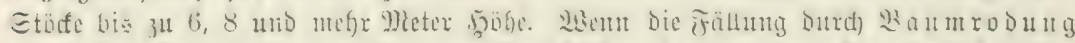

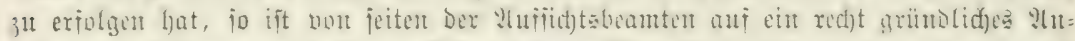

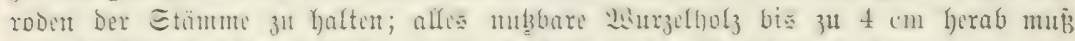

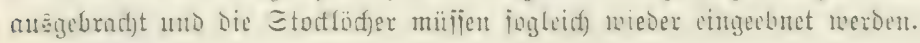

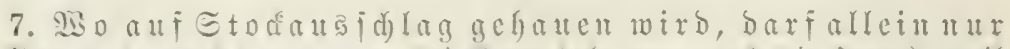
Dite $y$ y

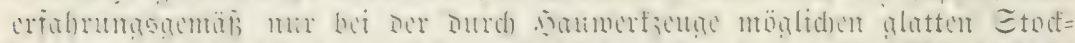

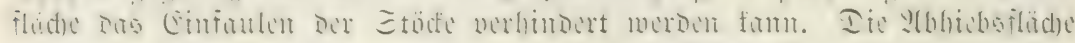
mu aljo glatt gebmen merom, ber Stod barf uidjt iplitterm

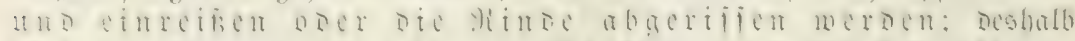
Dür.

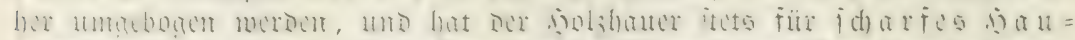

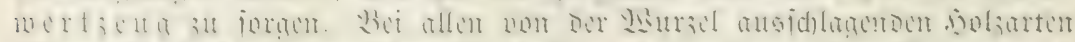

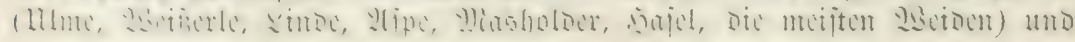




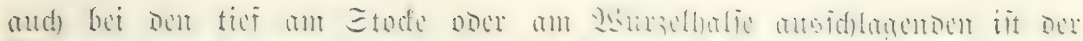

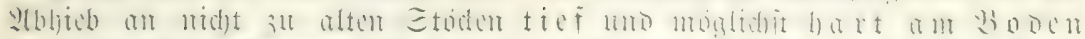

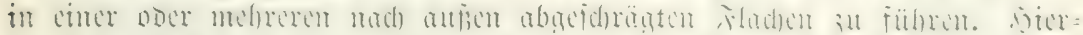

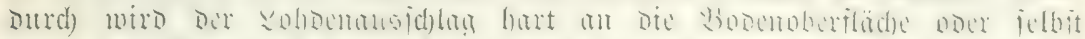

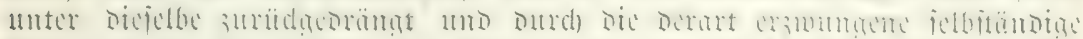

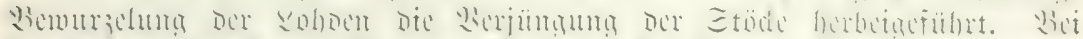

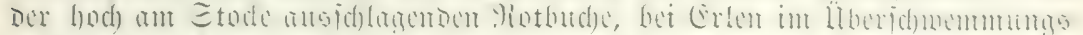

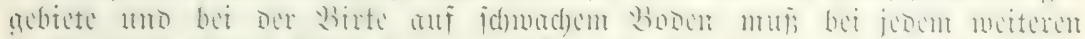

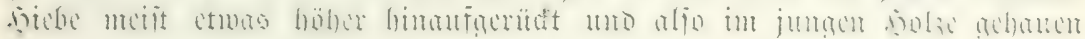
merben.

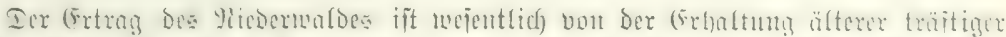

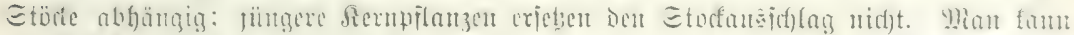

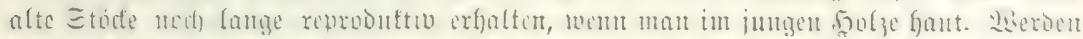

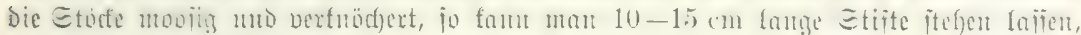

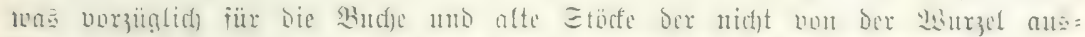

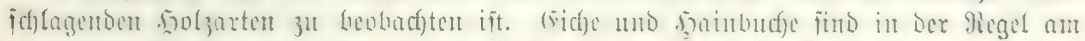

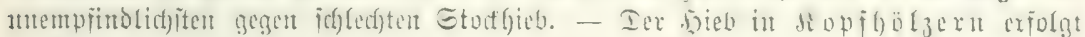
meijt im jungen 50 olje.

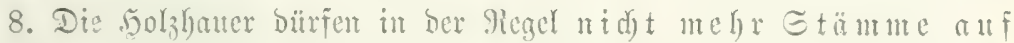

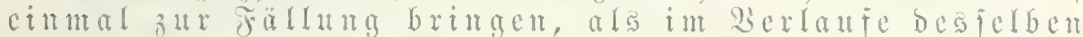

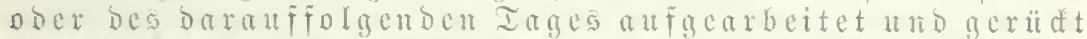
س

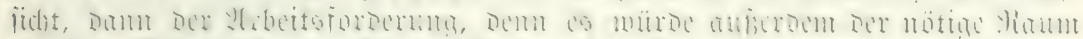

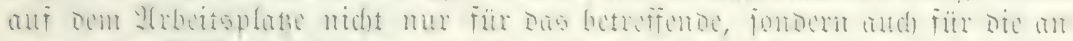

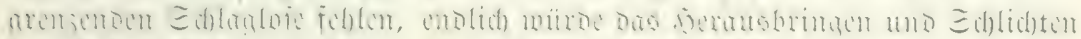

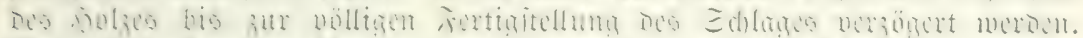

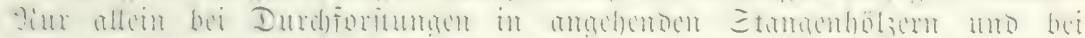

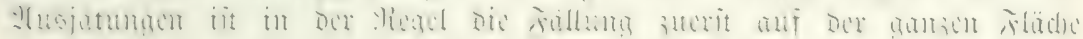

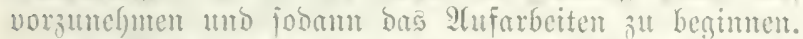

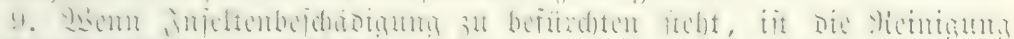

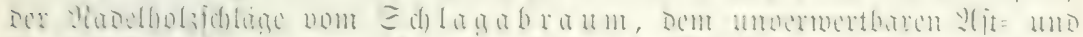

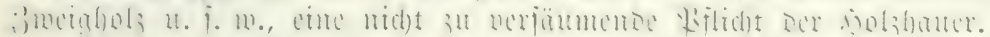

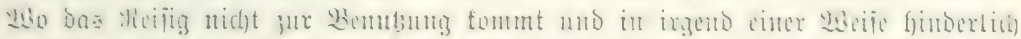

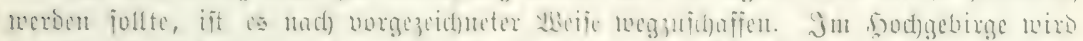

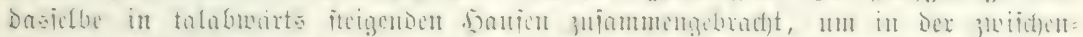

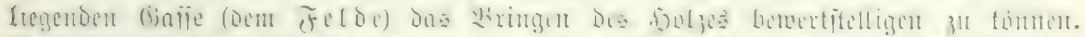

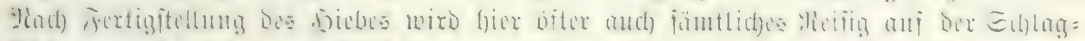

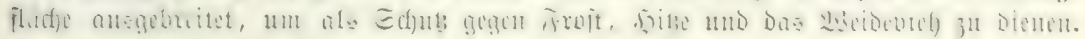
Jut viefu Gegenden wird Meifig und Ed)lagabraum verbramt.

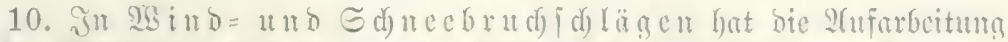

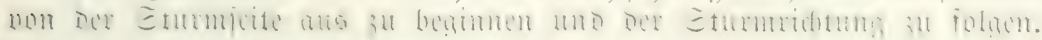

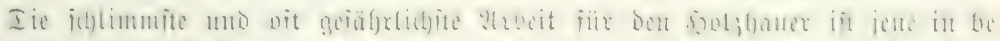

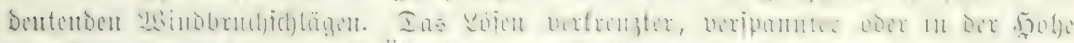

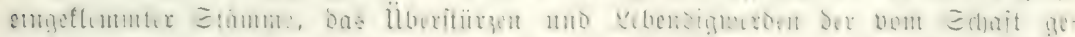

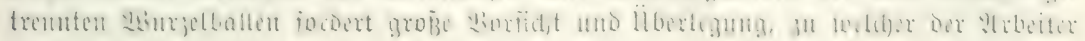
nicft oit geutg aufgejordert werden tauts. 


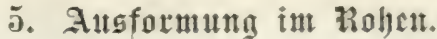

Das Berlegen bes gefälten ba aumes in einzelne, ben

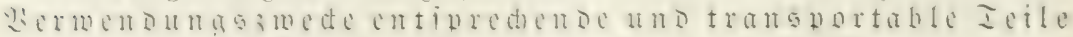
D) 4 r d) bie

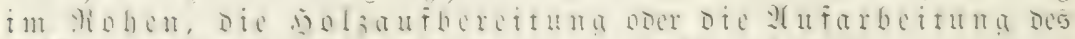

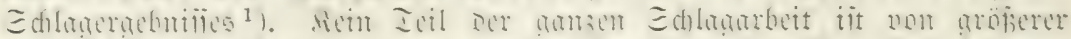

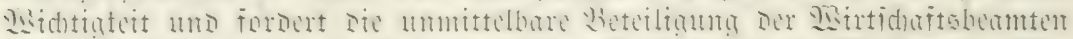

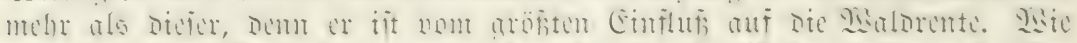

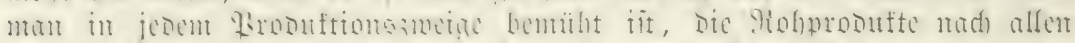

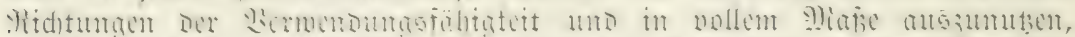

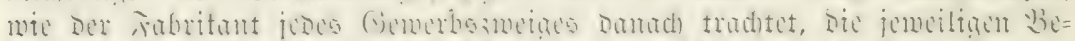

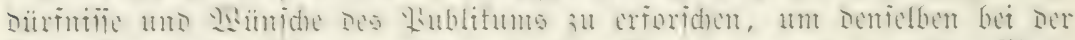

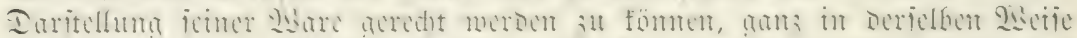

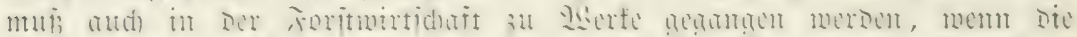

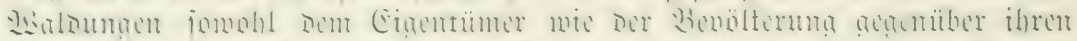

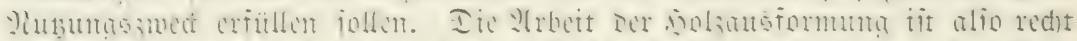

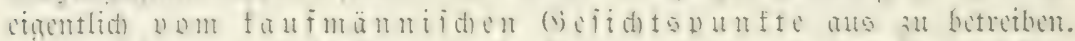

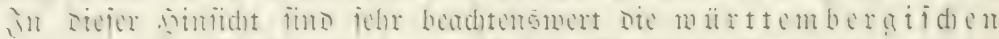

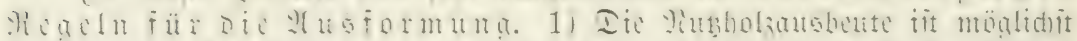

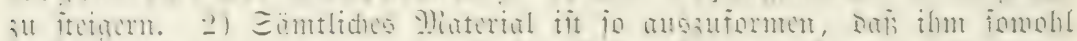

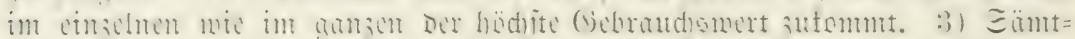

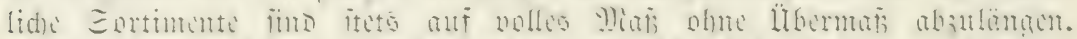

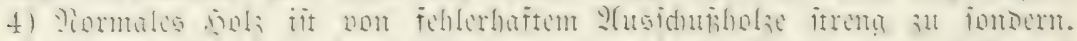

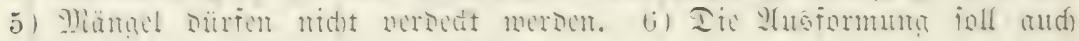
ente äuberlid) gefällige form erbalten.

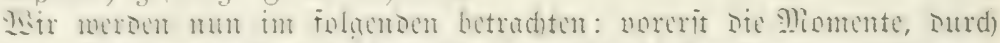

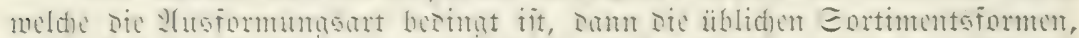

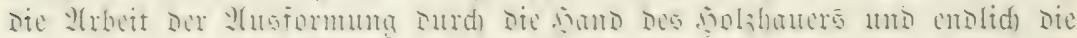

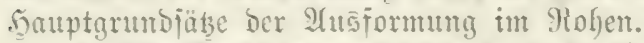

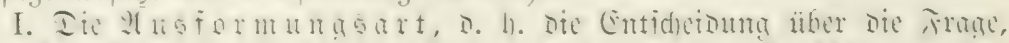

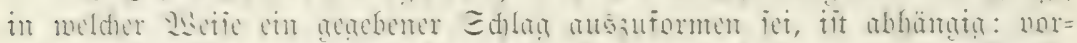

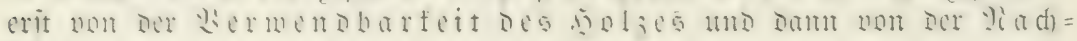
frage.

1. Die Bermenbbarfeit bea Holses bejtimmt jud burd) bie Bolzart, Jorm, Etärte uno Den inneren Buitand ber Etämme.

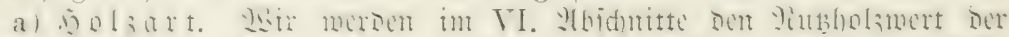

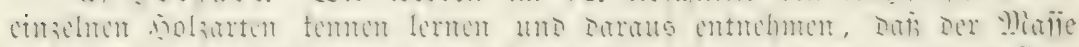

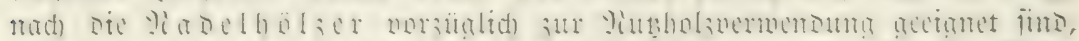

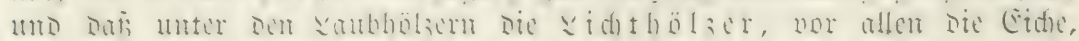

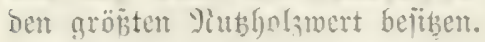

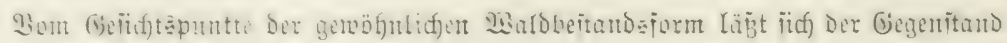

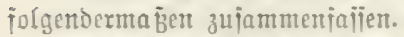

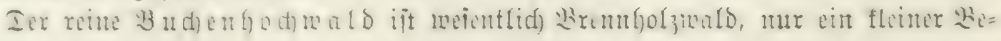

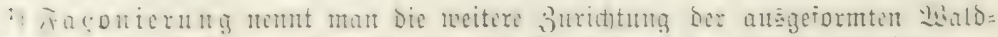

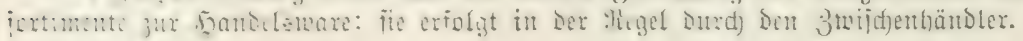




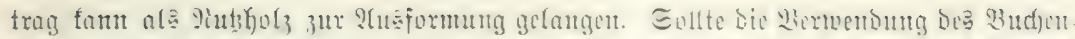

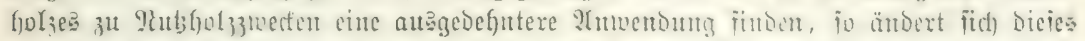

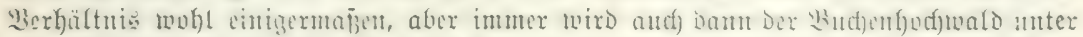

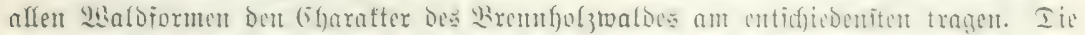

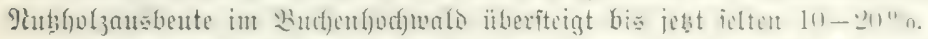

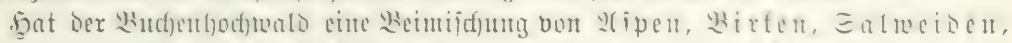

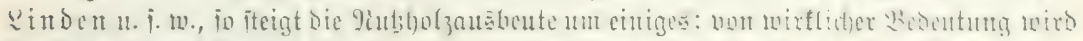

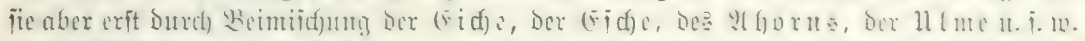

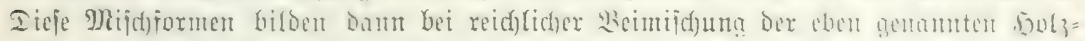

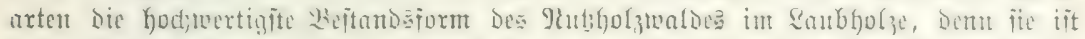

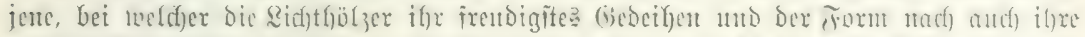

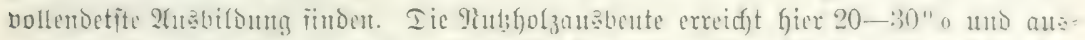

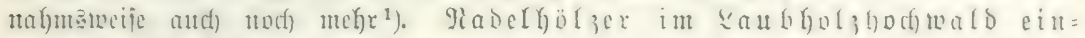

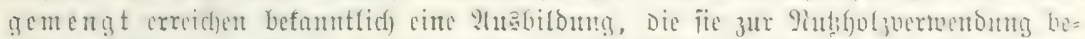

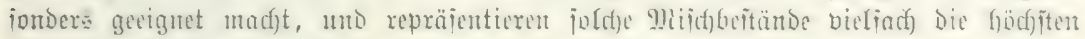
giubliolzwerte ïberhaupt.

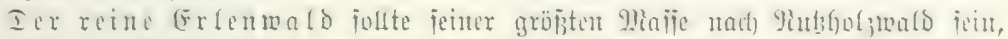

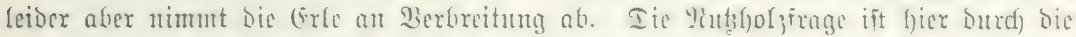

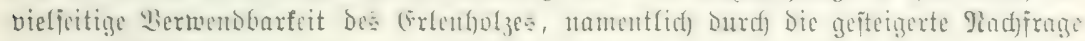
zu Bigarenfiftentiolz, immer bon holger Bebeutung.

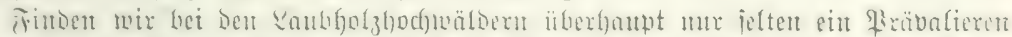

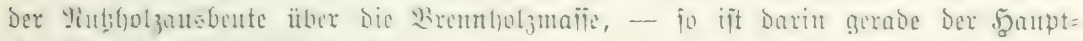

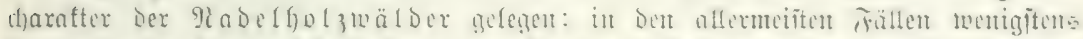

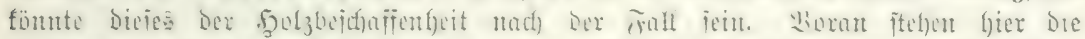

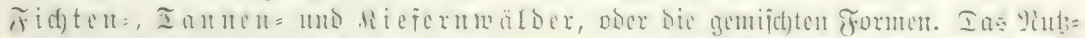

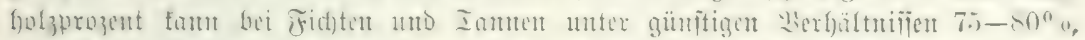

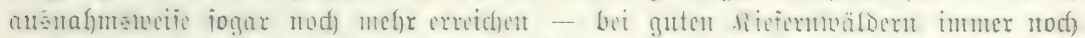

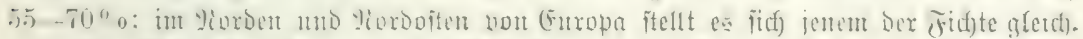

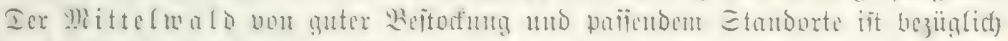

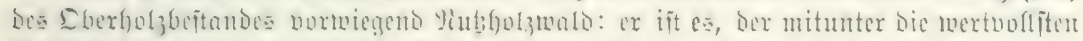

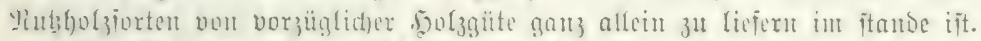

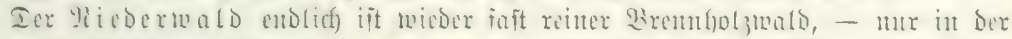

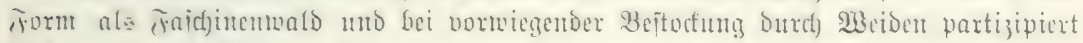
audf) er an ber Nutbigolzausformung.

b) Form ber ङtämmc. Ju ber Regel befäbigen itarfe Dimen=

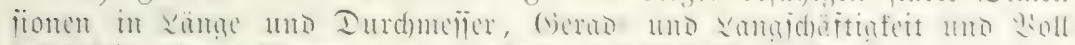

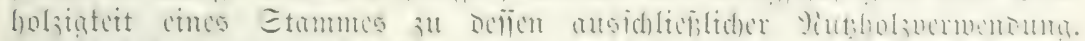

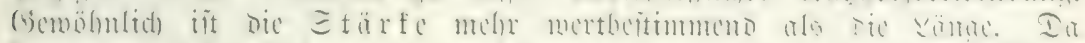

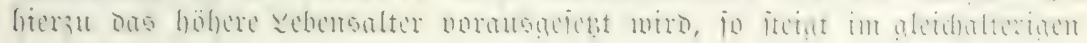

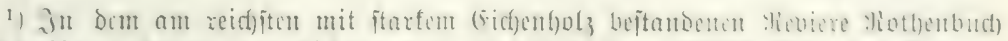

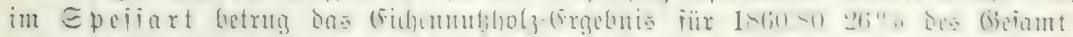

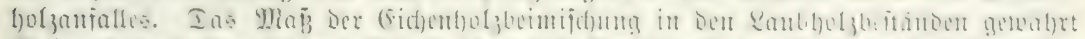

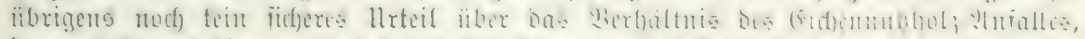

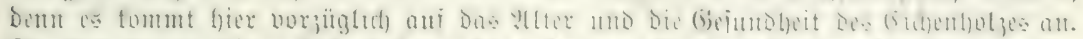

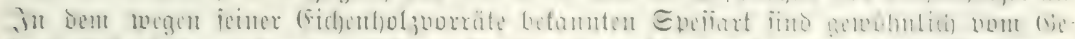

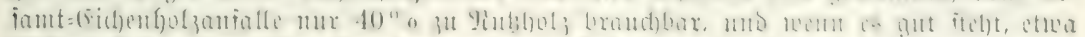
s.)" 


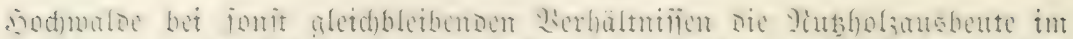

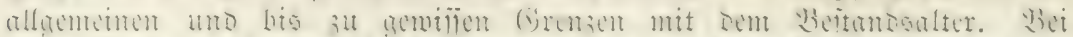

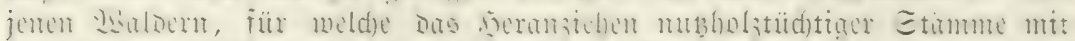

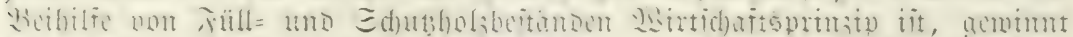

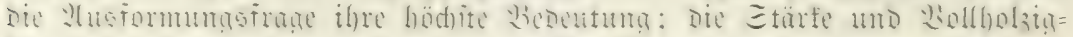
feit ber Etümme erreidjt fier ifr hödjites 9)iaj.

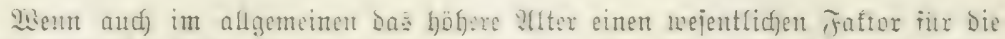

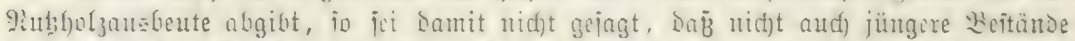

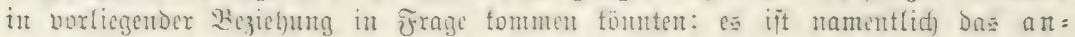
gefende Etangenfol\}= und julbit Das (sertengolzalter, in weldem anf Dem

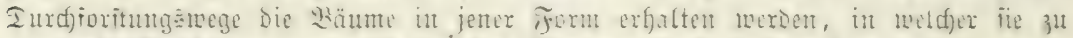

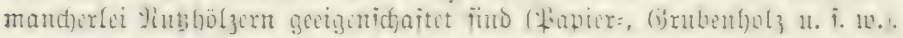

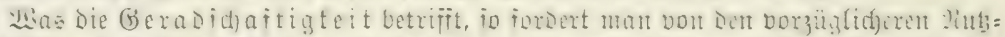

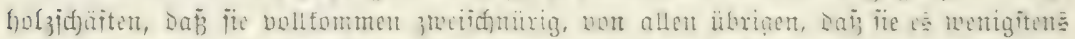

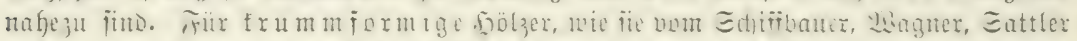

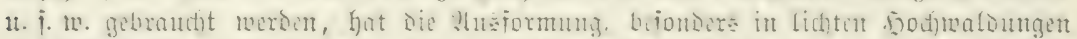

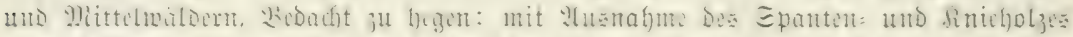
hat indifin Der alfe getwünjden Forment erzeugt twerden fömen.

c) Die inneren (Ëigenidaften ober Gíte und Dualität.

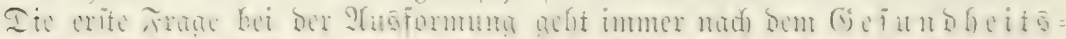

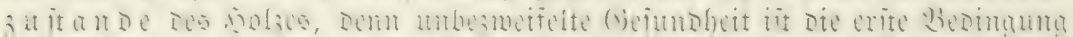

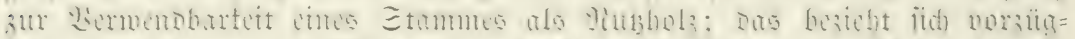

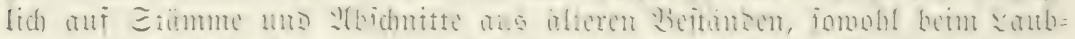

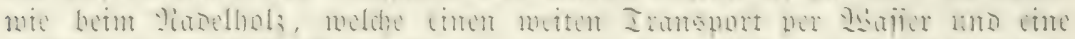

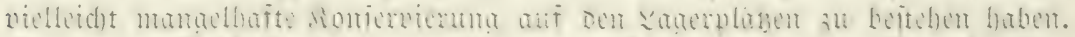

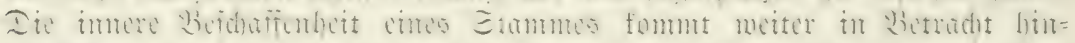

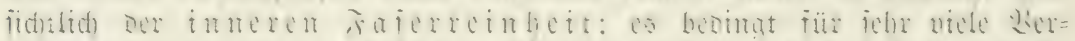

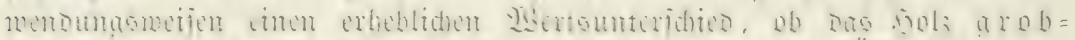

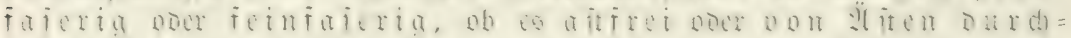

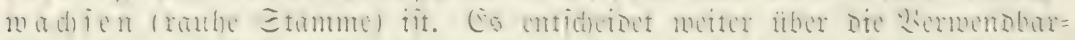

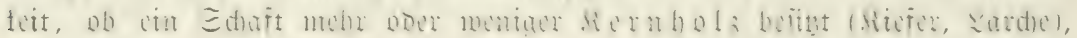

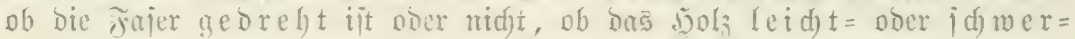
ipaltig̣ ijt, und ob cin Etumm mehr ober mentger vou fierntifien,

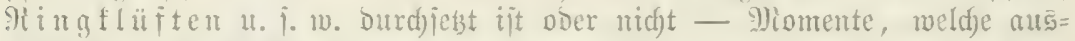
fübrltch iut I. Y(bjd)nitte erörtert mutroen.

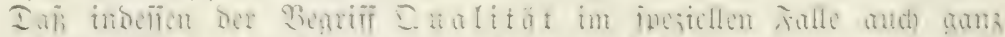

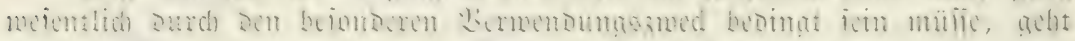

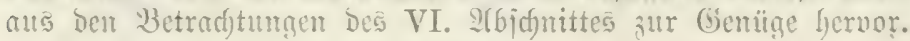

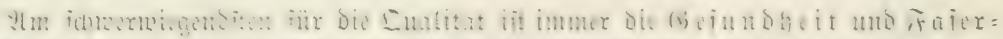

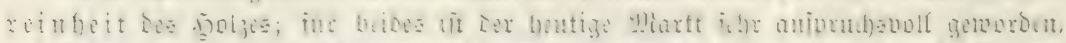

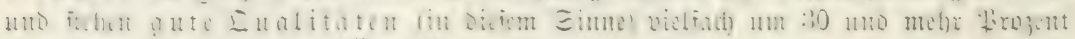

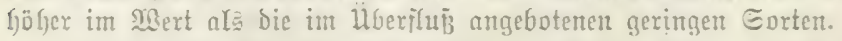

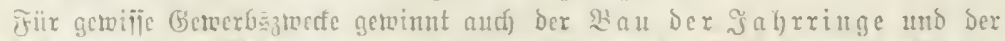

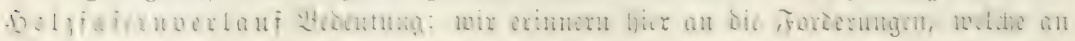

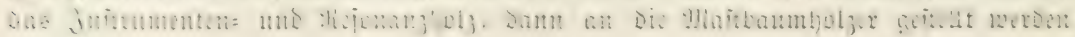




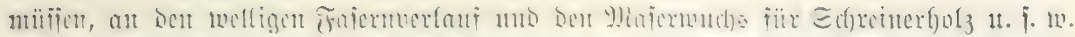

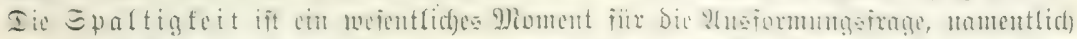

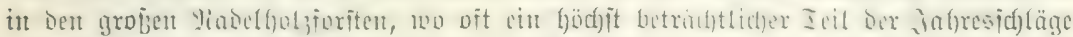

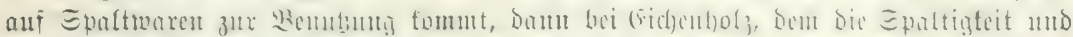

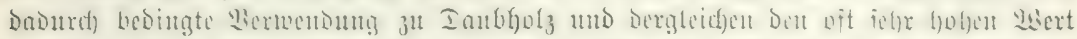

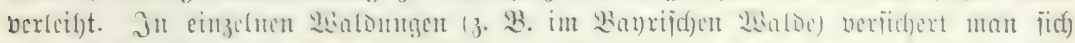

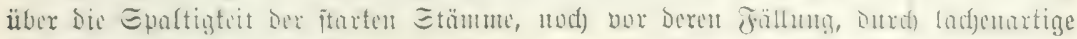

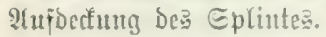

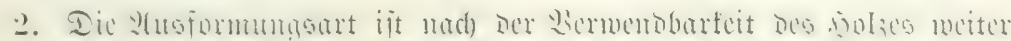

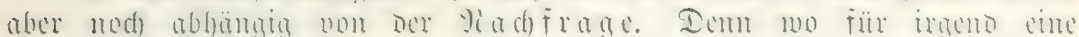

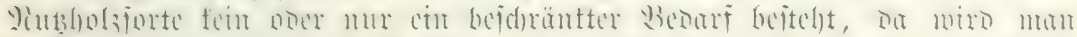

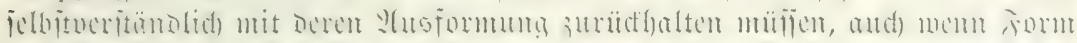

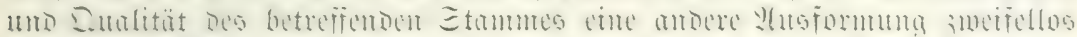

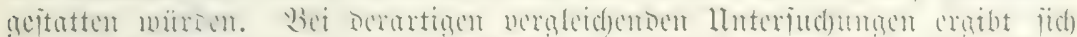

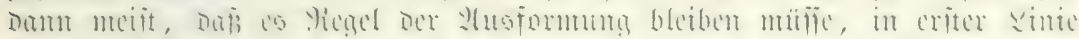

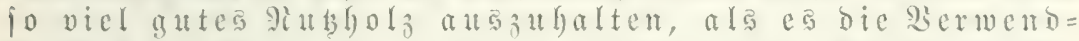

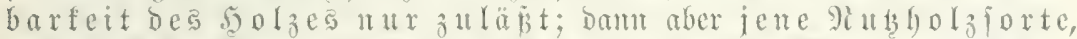

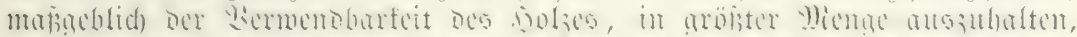

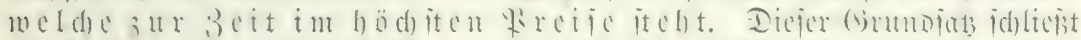

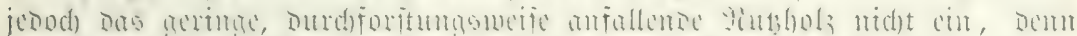

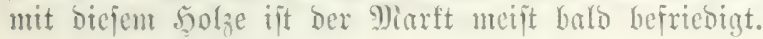

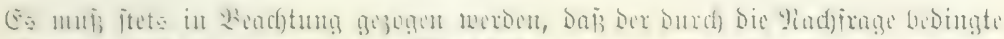

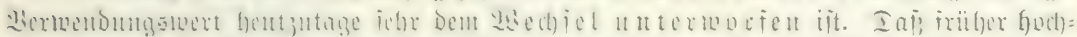

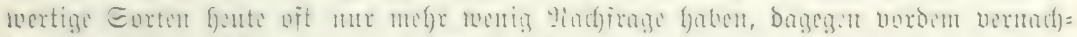

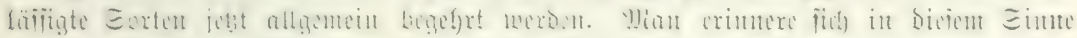

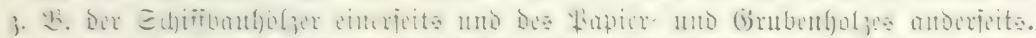

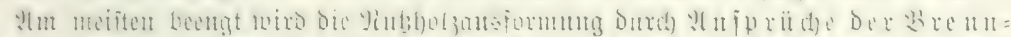

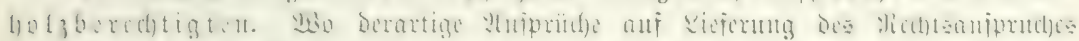

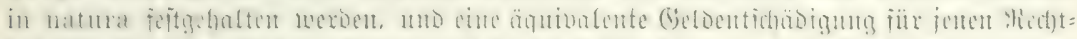

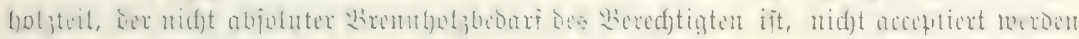

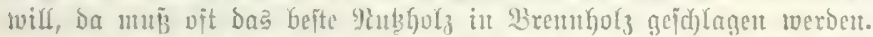

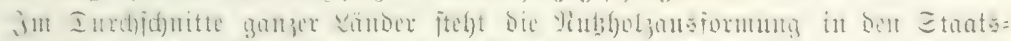

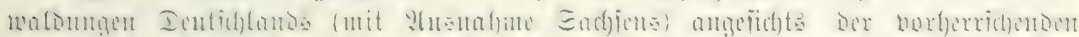

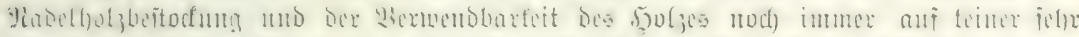

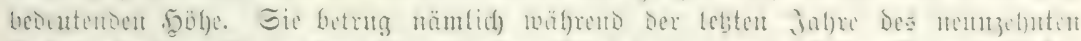

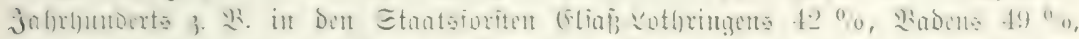

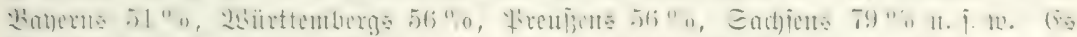

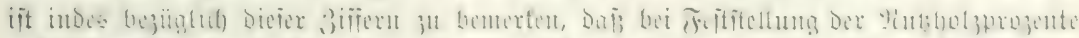

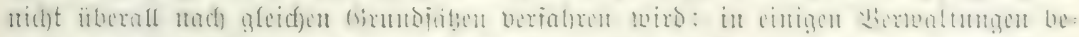

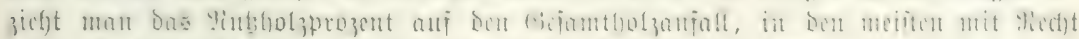

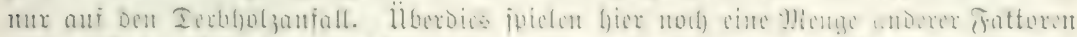

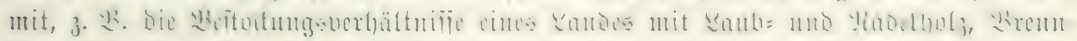

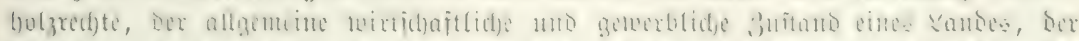

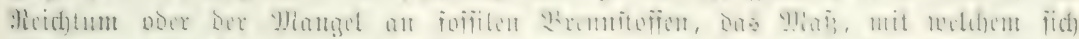

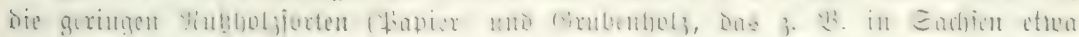

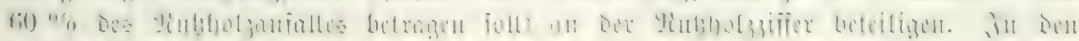

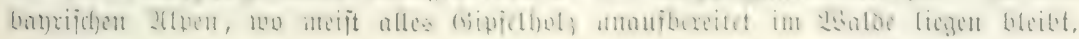




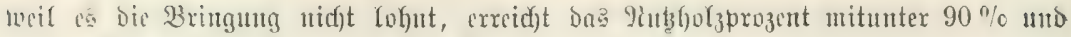

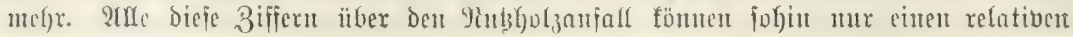
Mert beaniprudjen.

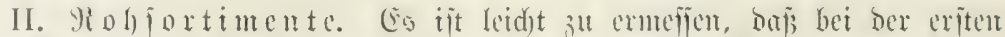

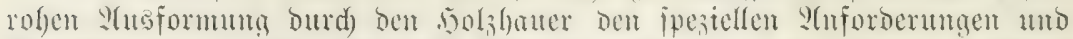

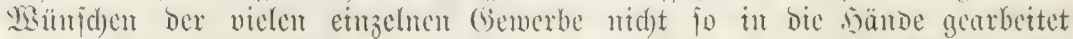

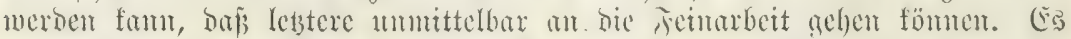

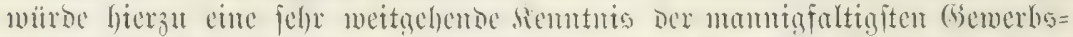

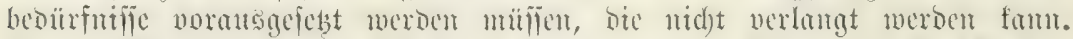

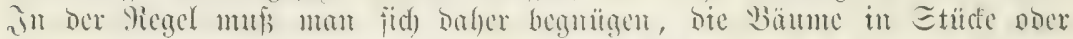

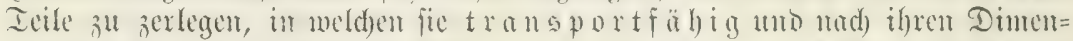

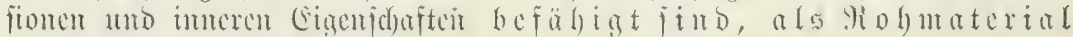
für ein einzelues oder gauze Gruppen vou Gemerbenzu

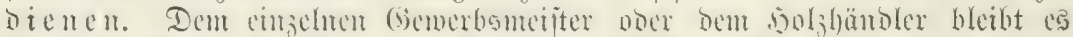

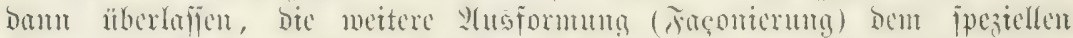

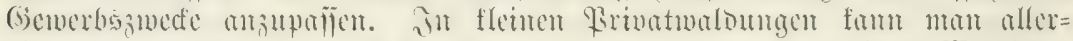

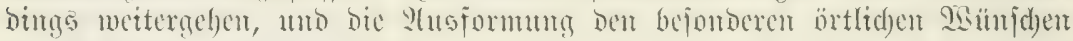
ber 2 tbuelymer jpezicll anpafien.

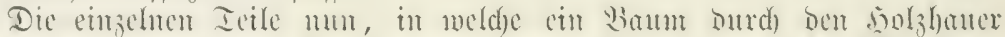
jerlegt miro, ment man Bolifortimente (

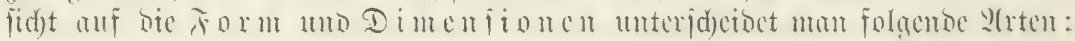

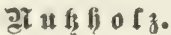

a) Derblool $($ Srobholz

1. Stammlyolz.

2. Derb= Stangentyolz.

3. Edfidftmublyolz.

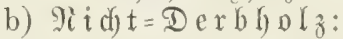

4. Gerten $=$ tno Reifermubholz.

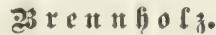

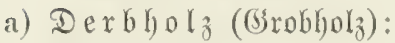

1. Edhetholz.

2. Prügelholz.

b) $\left.\Re_{i} i d\right) t=D_{\text {erb }}$ ol $\mathfrak{l}_{\mathfrak{j}}$ :

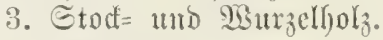

4. Meijerlyolz.

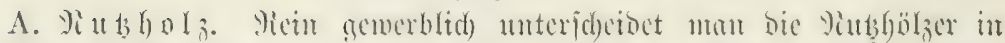

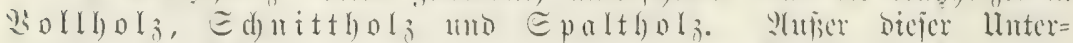

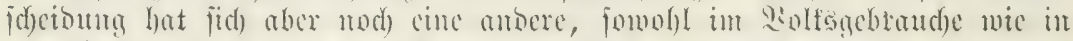

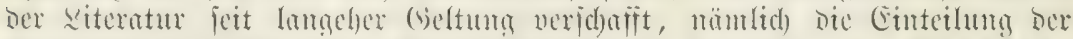

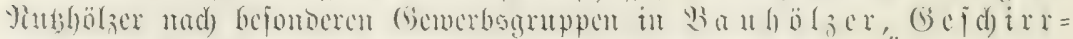

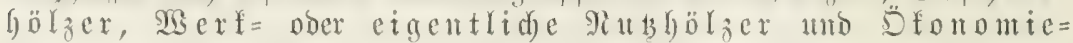

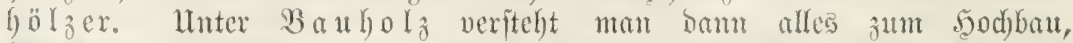

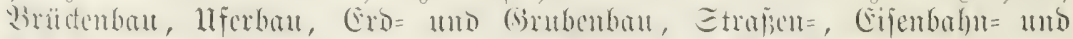

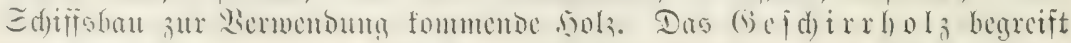

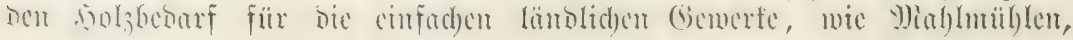




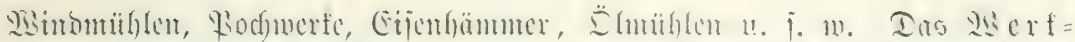

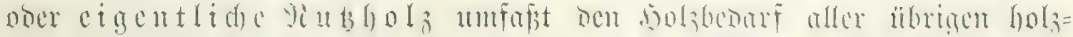

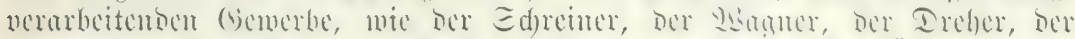

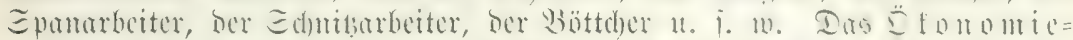

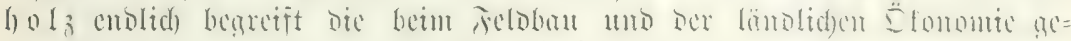

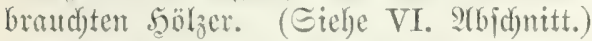

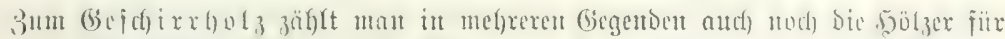

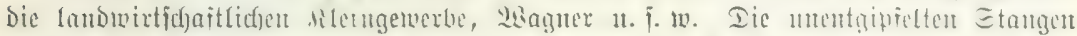

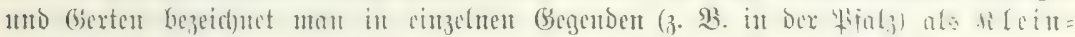

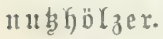

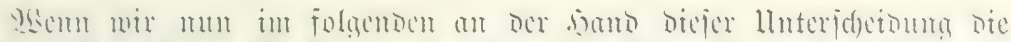

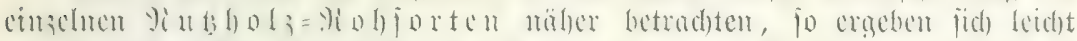

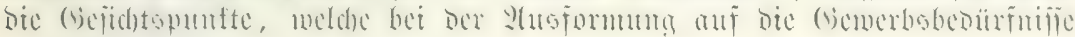
ôl nelumen finto.

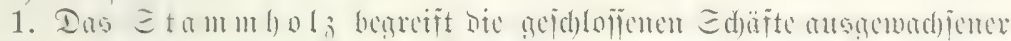

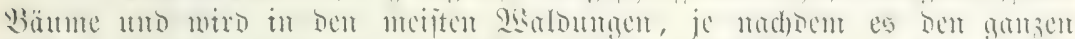

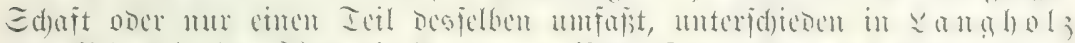

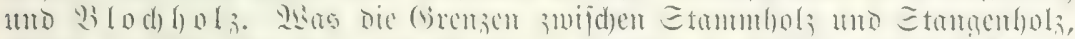

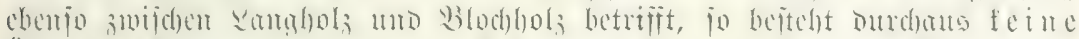

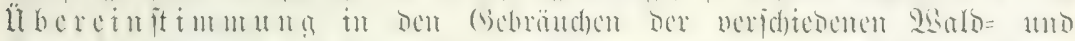

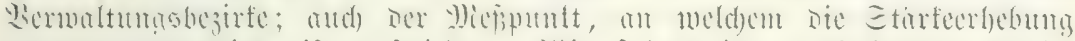

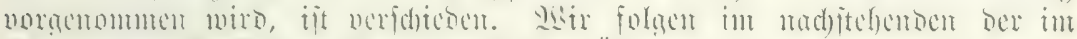

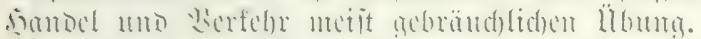

\&anglyolz. Man verjtebt Darunter ben a ft feien entgipfelten ganzen Ed)aft ober ben gröften Ieil bespelben vour hau=

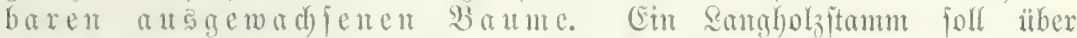

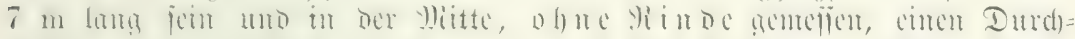

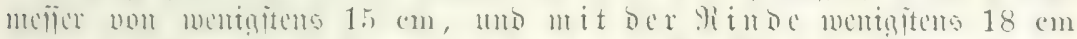

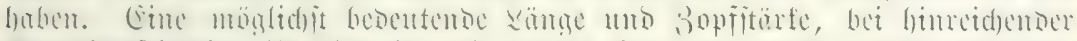

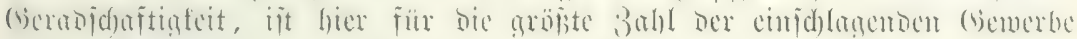
wejentlid) wertbejtimmento ${ }^{1}$ ).

U(ta

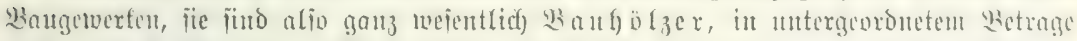

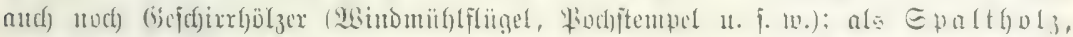

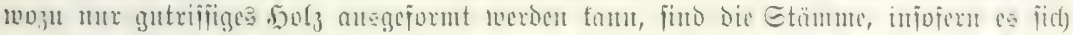

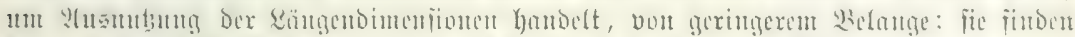

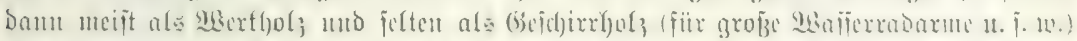

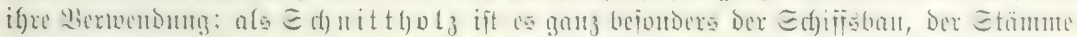

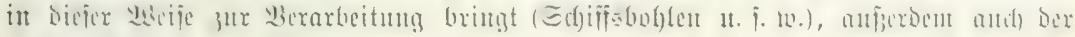

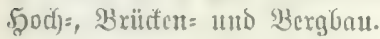

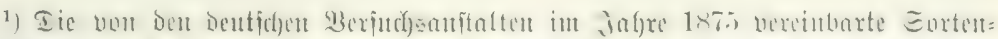

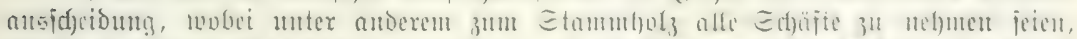

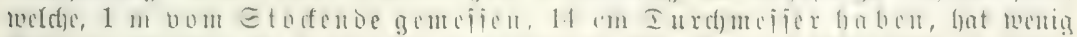

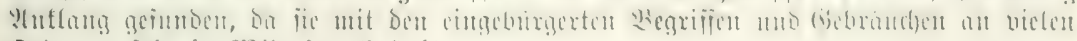

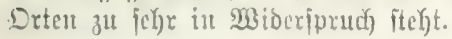




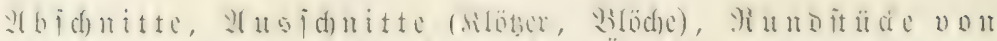

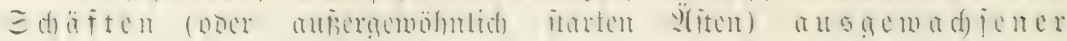

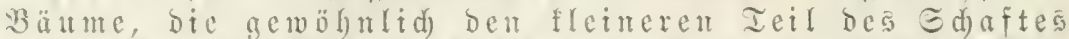

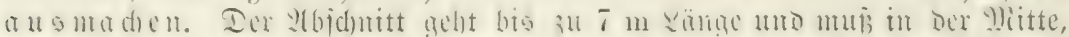

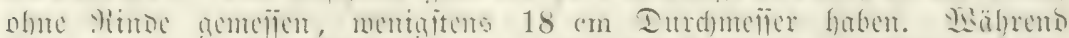

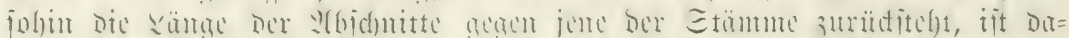

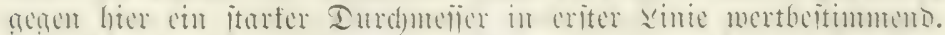

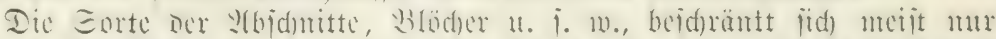

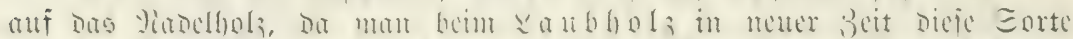

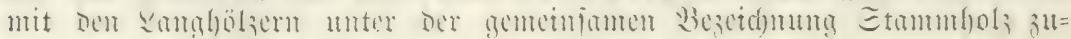
jammenwirit.

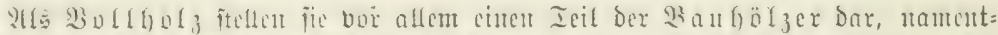

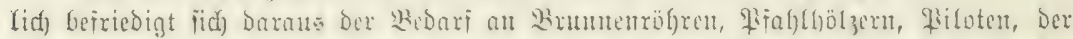

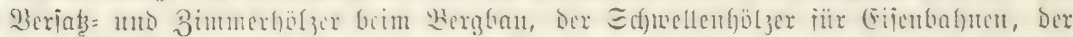

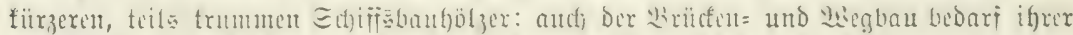

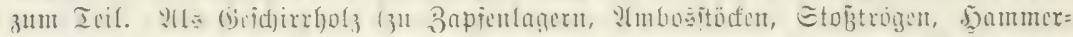

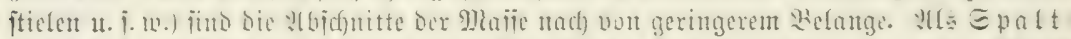

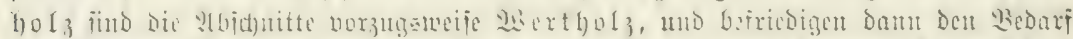

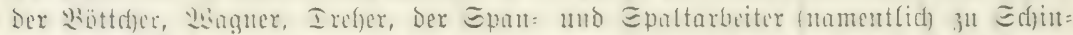

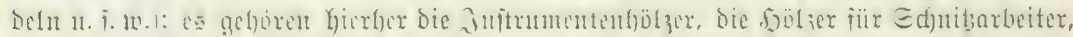

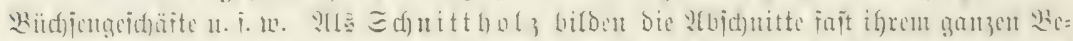

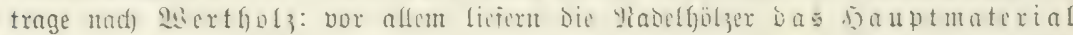

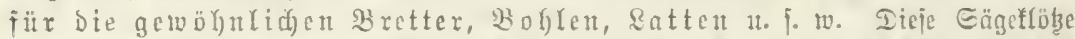

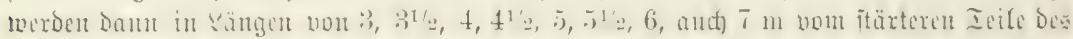

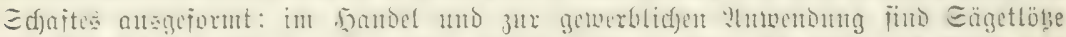

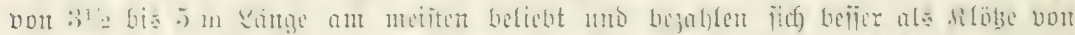

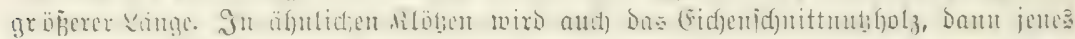

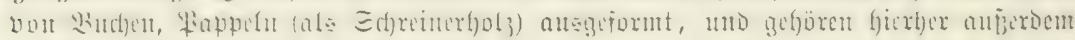

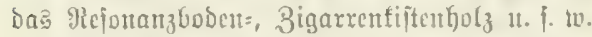

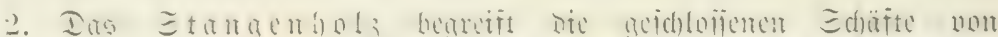

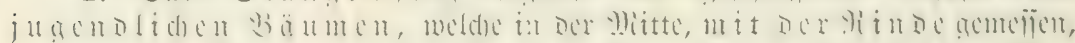

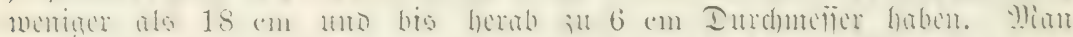

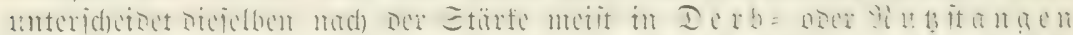

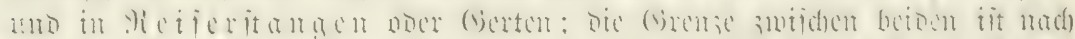

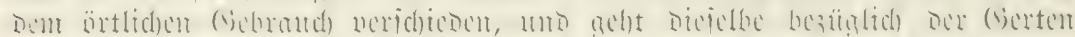

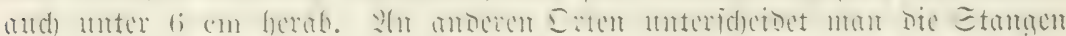
in eutgipfelte, urentgipfelte uno fileiunultangen. arle Etangen merben mit ber ginde gemejen.

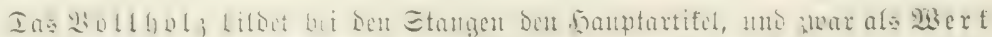

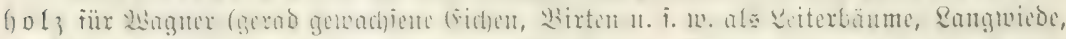

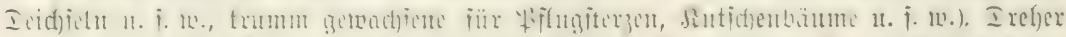

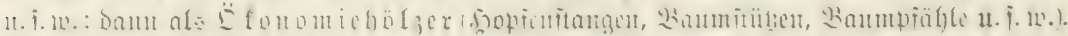

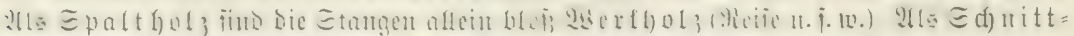

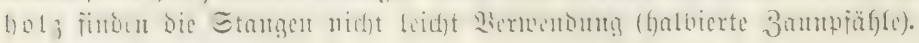

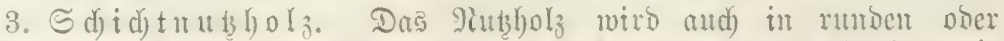

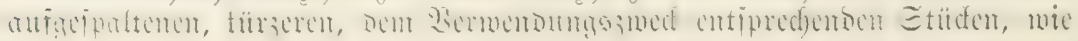




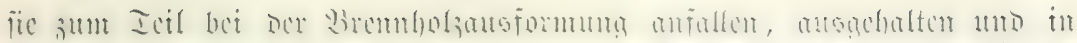

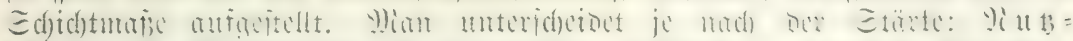

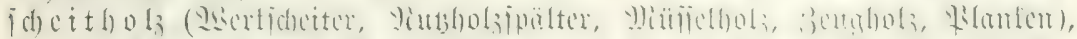

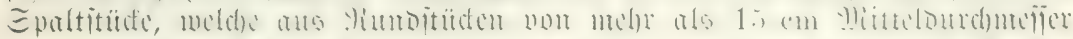

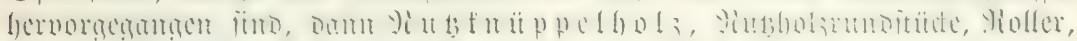

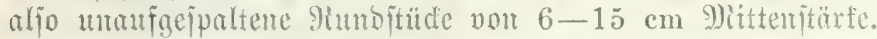

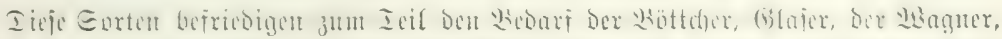

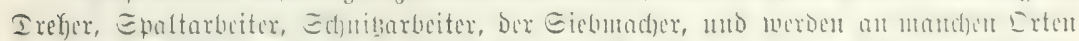

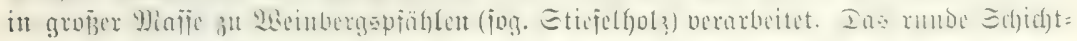

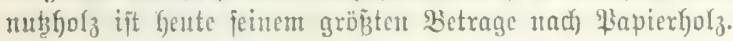

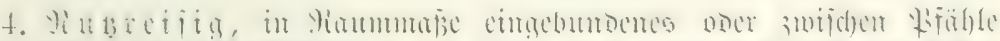

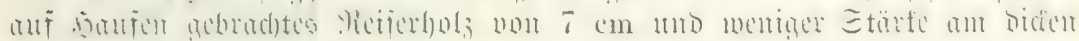
Eัnoe gentilient.

(5. il bieles teils fiemund)

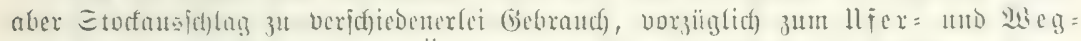

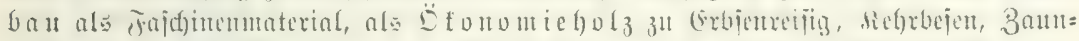

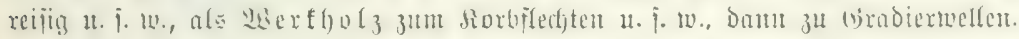

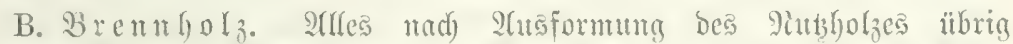

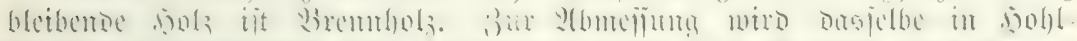

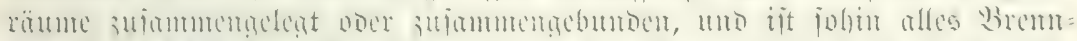

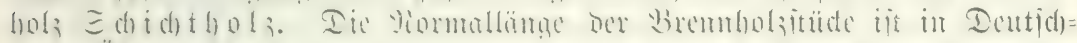

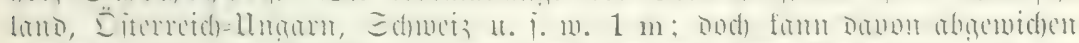

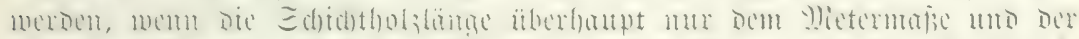

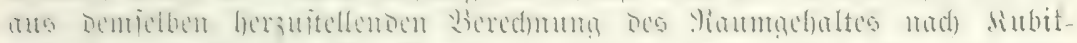

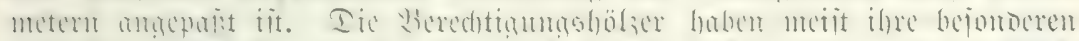

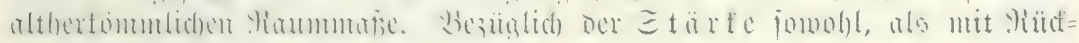
fidgt auf Die Form, unteridgeibet man:

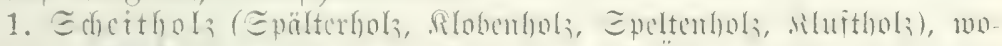

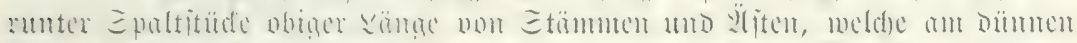

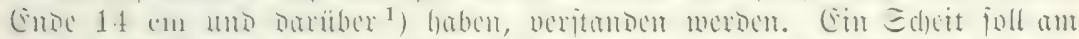

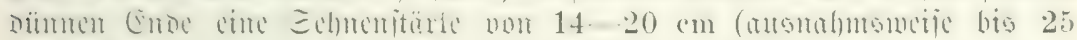
uno $28 \mathrm{~cm}$ ) baben und jets anf but fiem gejpalten feit.

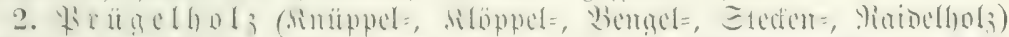

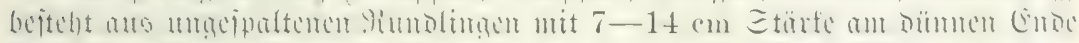

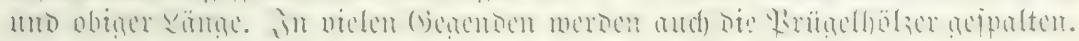

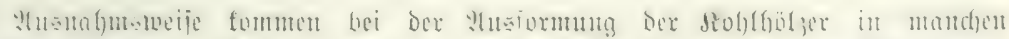

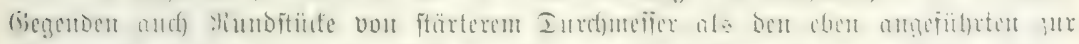

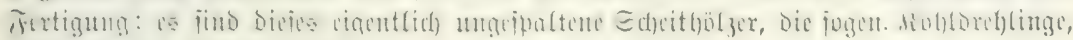
Rohldorillinge, fiohtorumment.

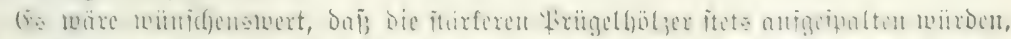

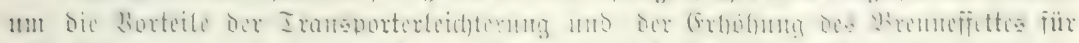

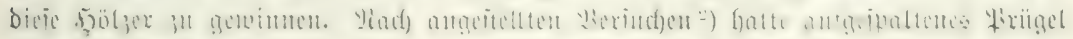

1) Jin ber Edfuciz $12 \mathrm{~cm}$ und bariiber.

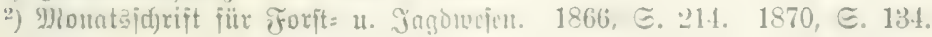




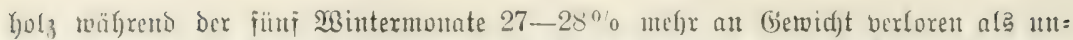

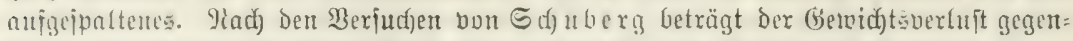

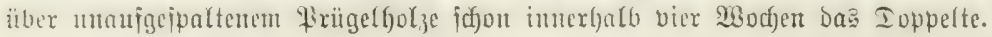

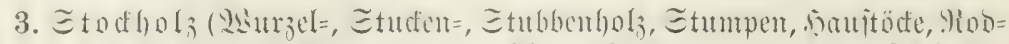

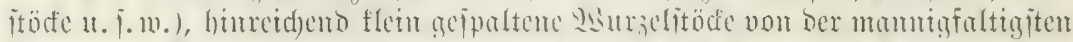

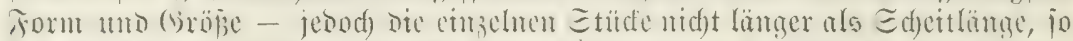

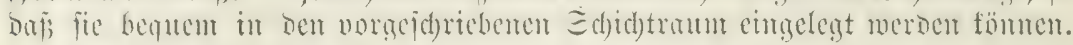

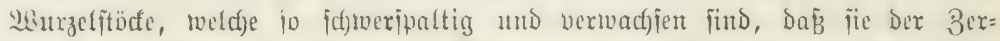

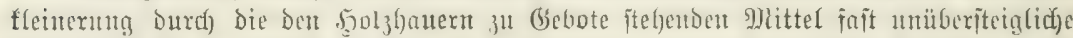

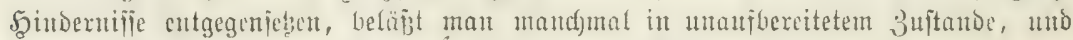

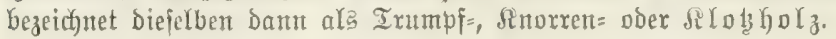

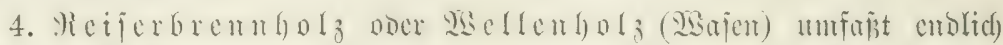
alles nad) 2tugformug ber vorategegangenen Fobjortent nod) übiableibende

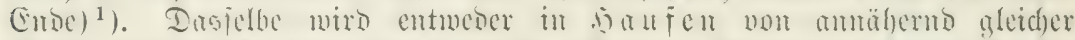

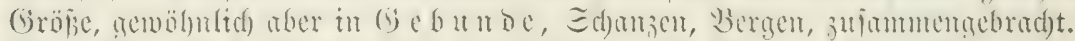

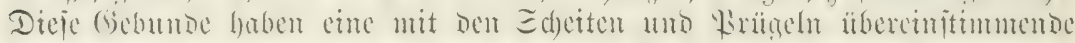

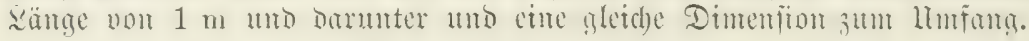

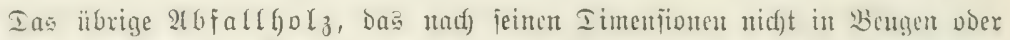

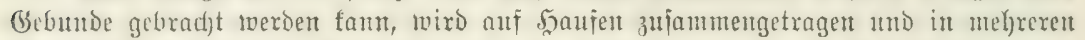

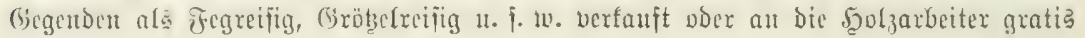
(Deputatholz) oder gegen gerintge $\Re_{3}$ ergütung verteilt.

III. ำ 11 ต

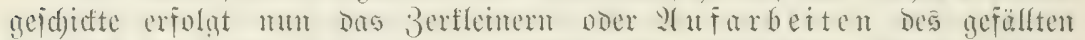

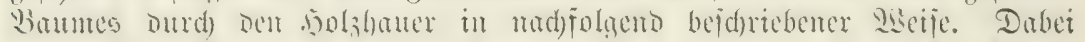

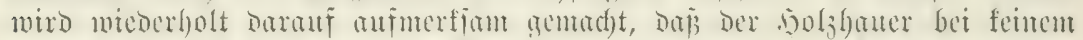

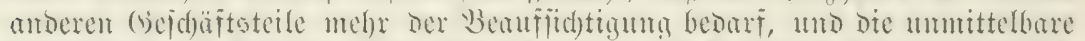

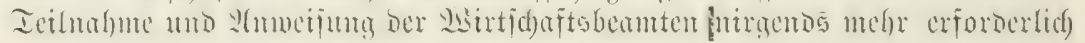

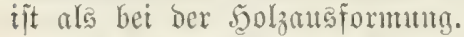

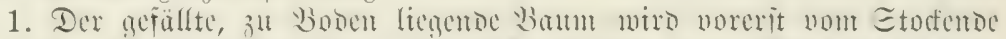

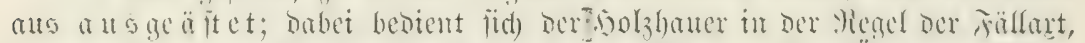

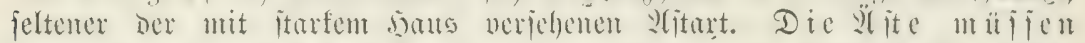

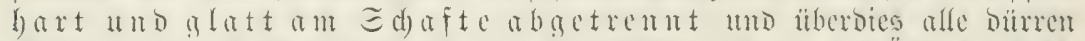

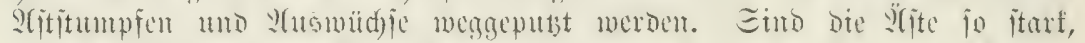

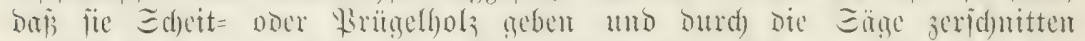

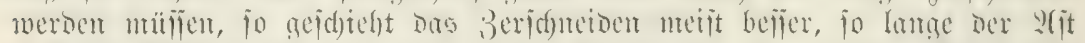

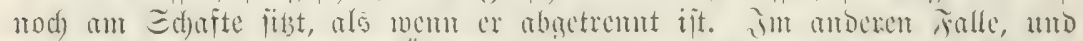

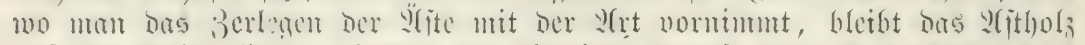

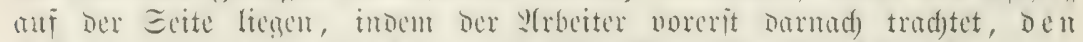

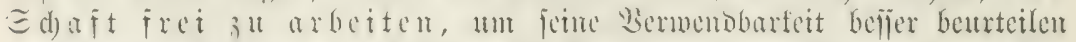

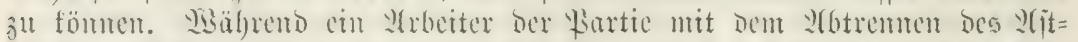

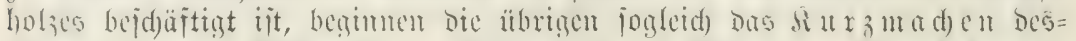

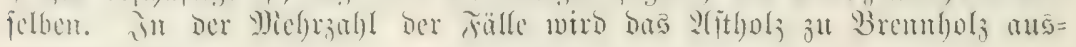

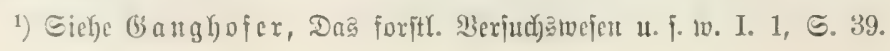




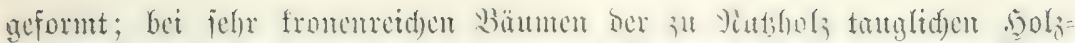

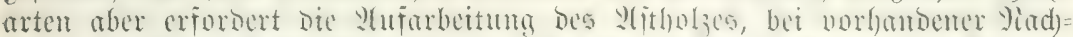

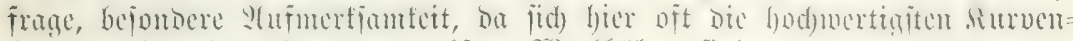
lölzer und andere frmmmgemadjfene Sigerflölzer futben.

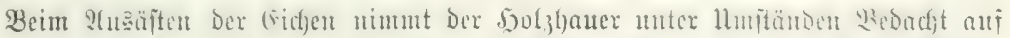

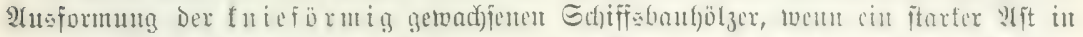

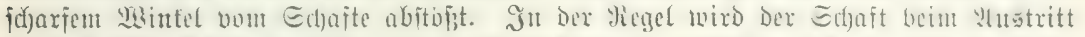

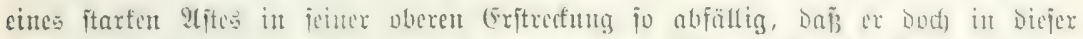

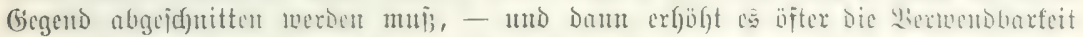

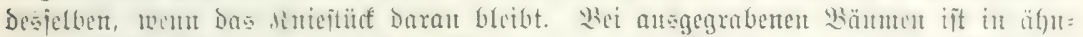

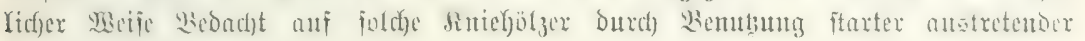
Wurzeln 孔и mełmen.

2. Jit ber Edfaft freigelegt, fo wirb Derfelbe abgelängt, D. f). er

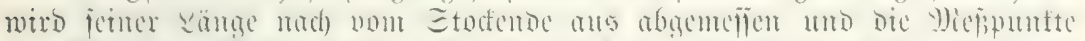

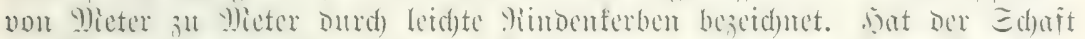

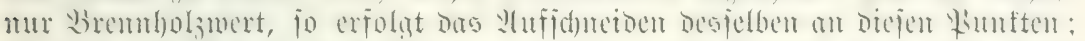

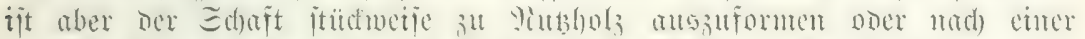

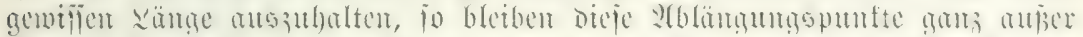

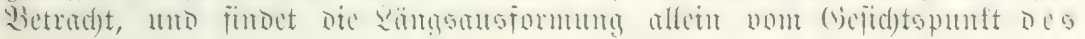

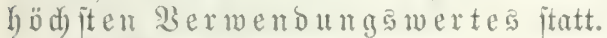

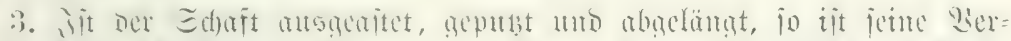

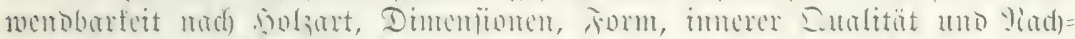

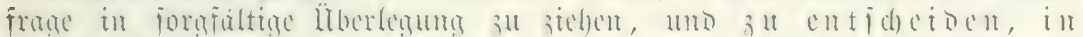

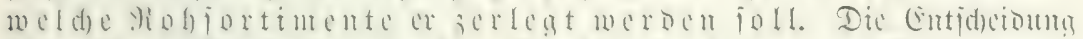

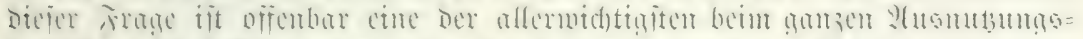

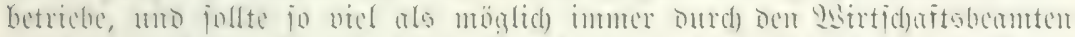

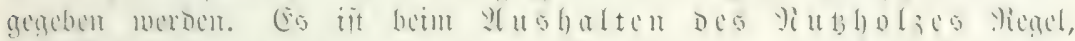
bie 巨d)äfte von ge mä

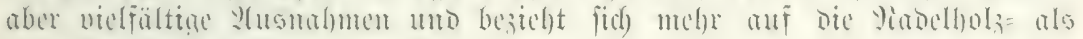

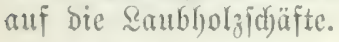

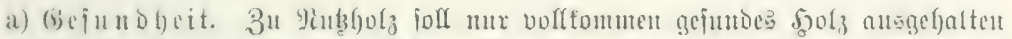

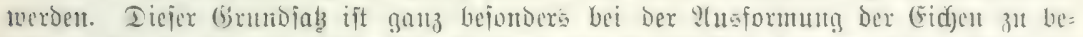

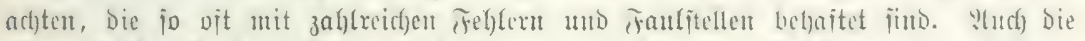

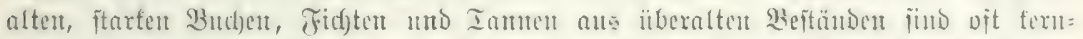

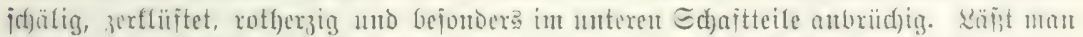

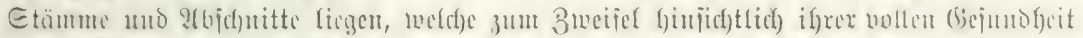

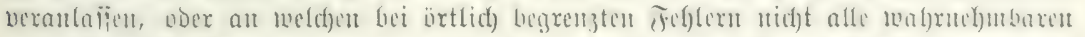

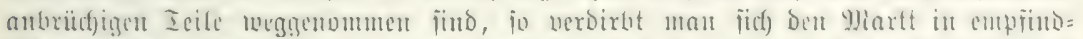

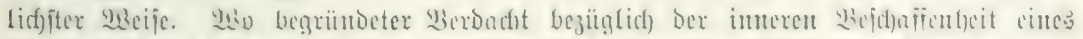

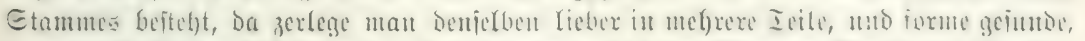

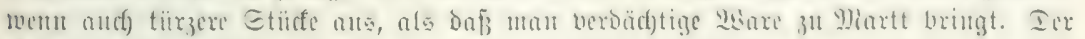

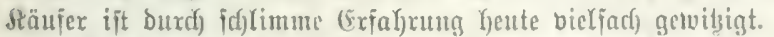

1.) 三 (d) a ft

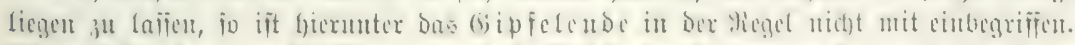

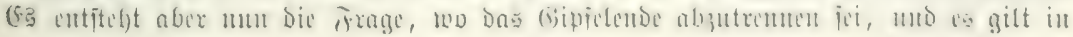




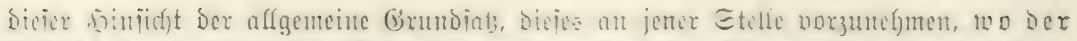

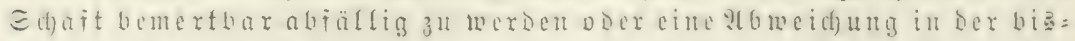
herigen Form und Figur anzunelmen beginnt, wo alpo z. SB. Die obere

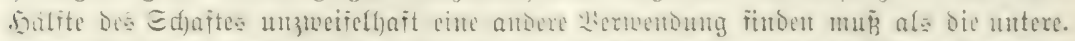

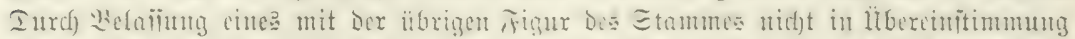

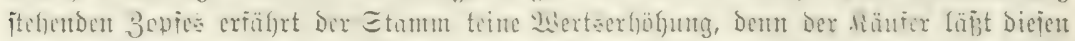

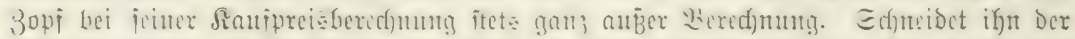

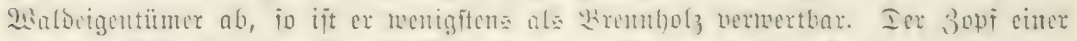

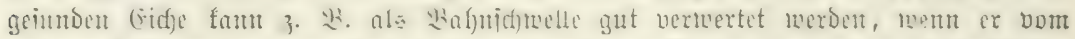

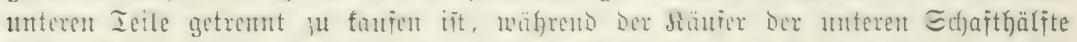

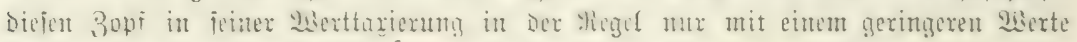
in Injał bringt.

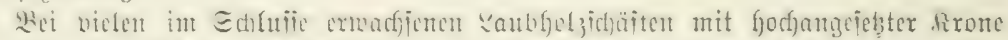

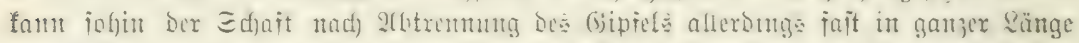

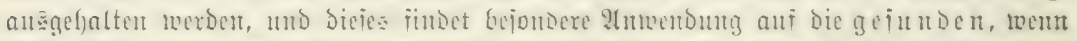

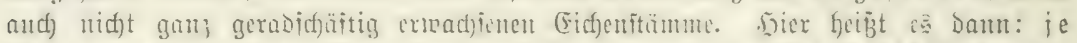

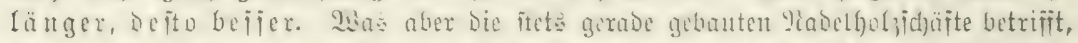

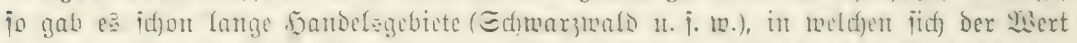

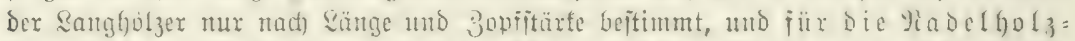

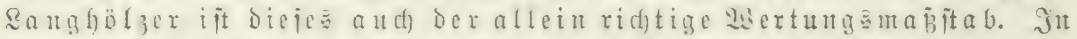

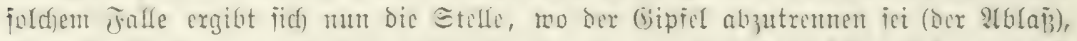

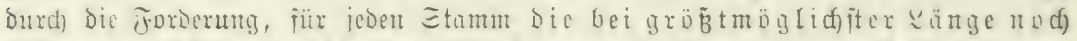

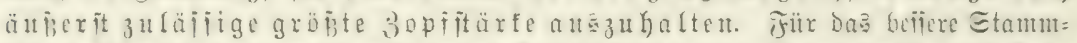
hol\} geft ntan bant meijt utd)t unter $30 p$ it ärfen oun $15 \mathrm{~cm} \mathrm{herab,} \mathrm{und} \mathrm{foun}$ man in allgemeinen als thegel aufitellen, bie Entgipiolung an iener Etelle zat be:

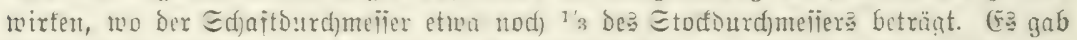

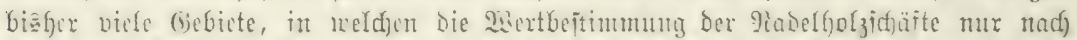

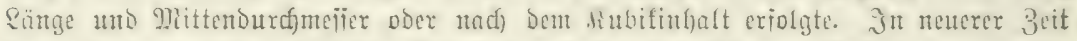

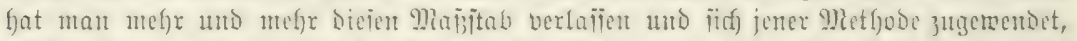

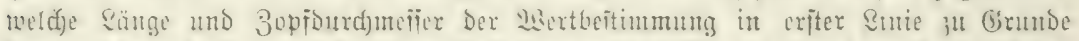

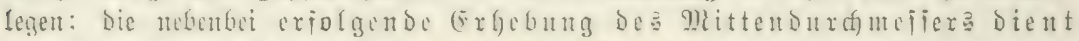

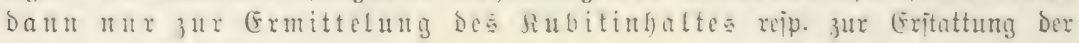
Quantitätäergebnijịe

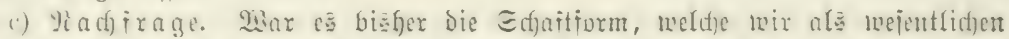

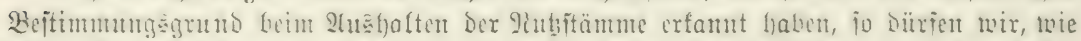

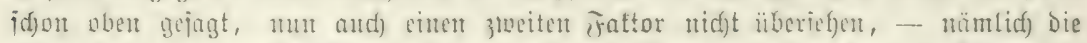

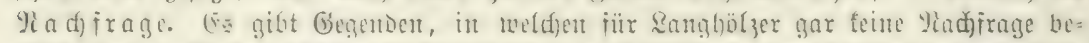

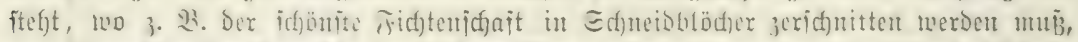

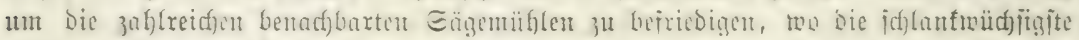

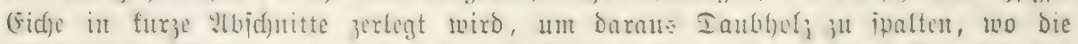

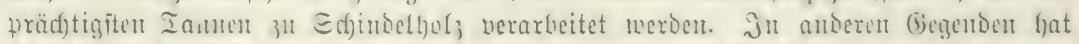

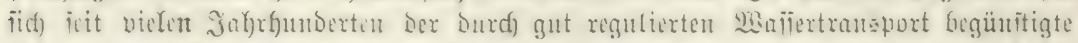

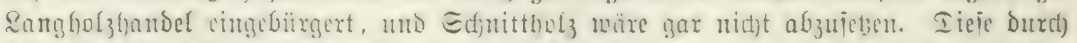

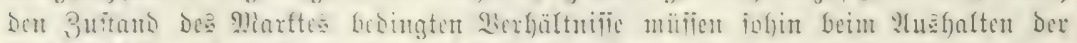

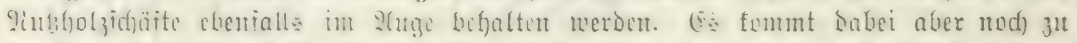

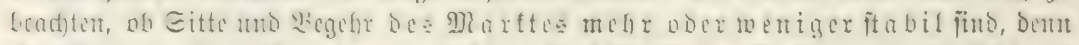

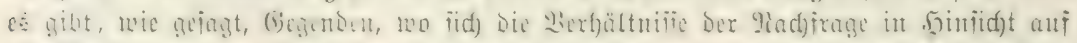

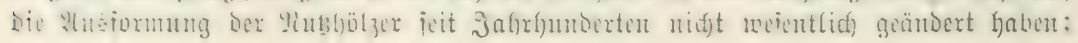




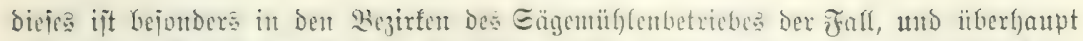

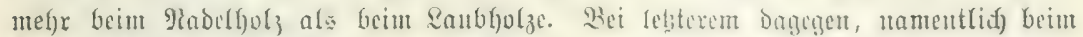

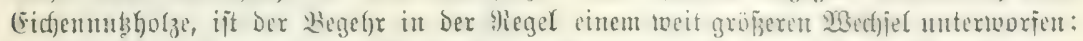

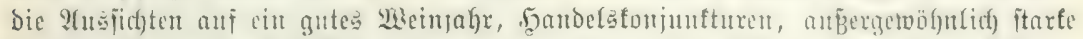

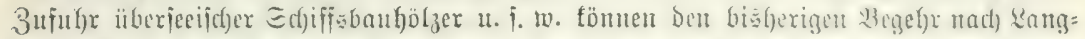

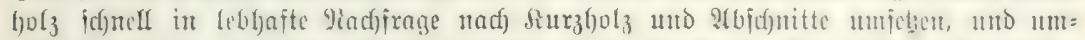

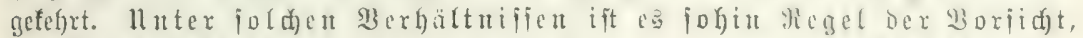

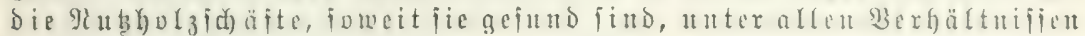

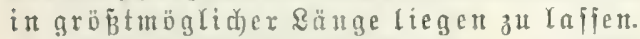

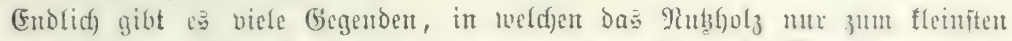

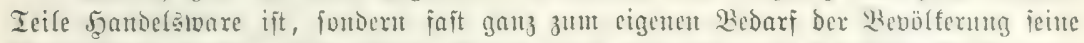

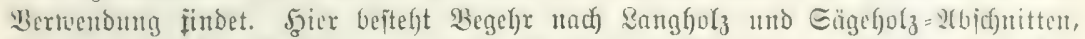

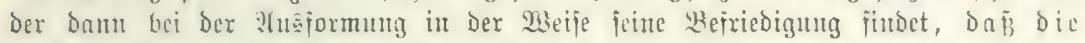
unterite liartie ber Dazu taugliden Edafte in eimen oder zwei Säge=

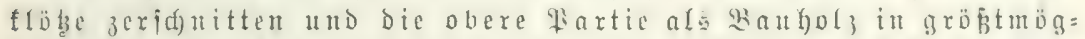

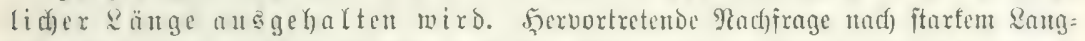

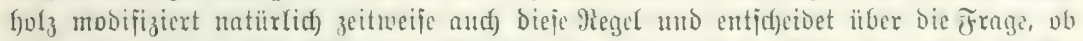

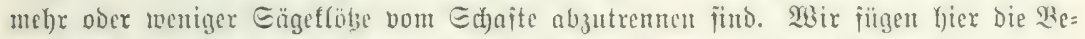

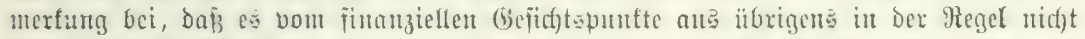

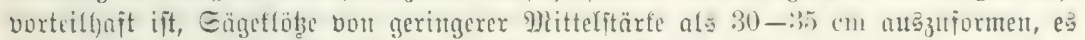

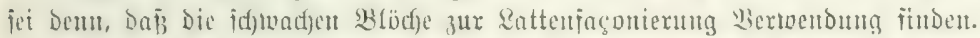

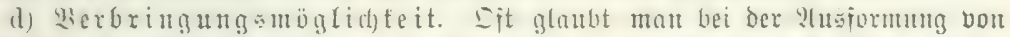

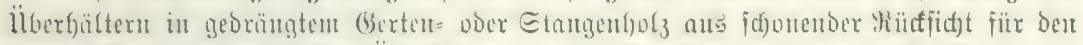
jungen

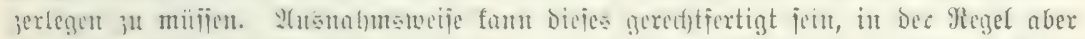

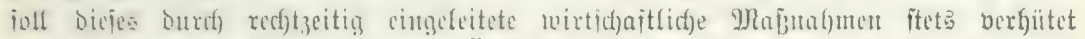
werben; benn woz̆t erzię̧t man bic überhälter?

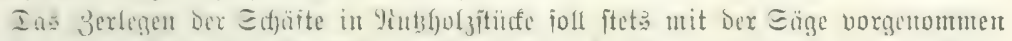

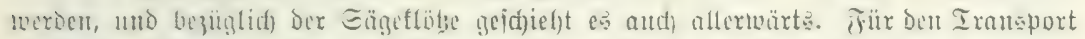

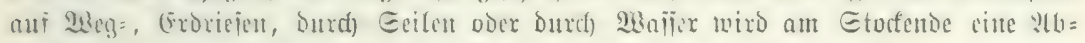

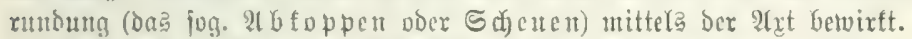

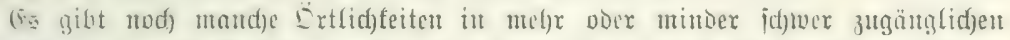

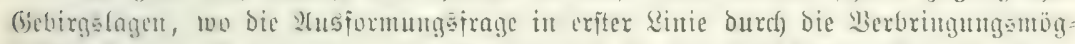

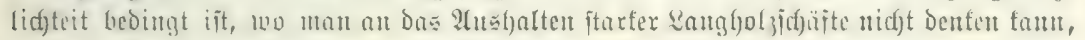
weil if)r 2 tuşbringen utmเöglid) ift. -

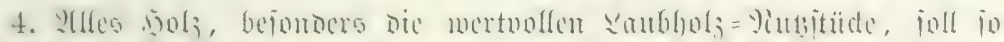

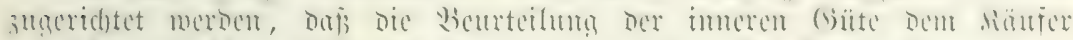

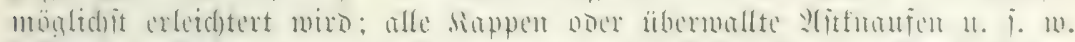

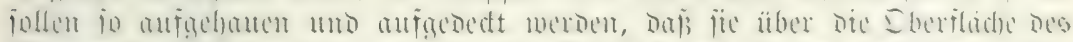

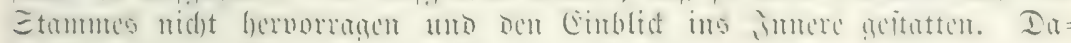
burd) wiro bas Bertrauen bes Siäufers achober.

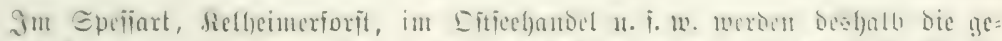

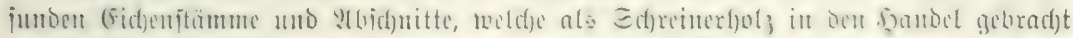

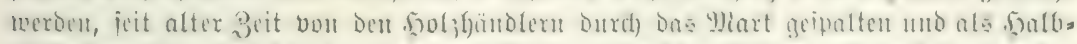

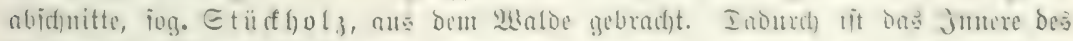
Etnmmes voliftünbigh Glöigelegt.

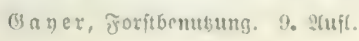




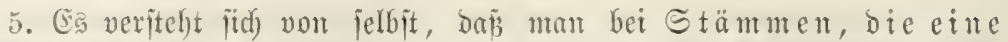

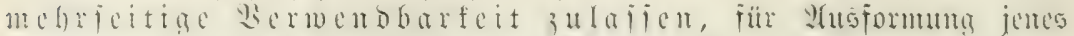
Eortimentes entidacioct, weldyers am höchiten in Pircije jteht.

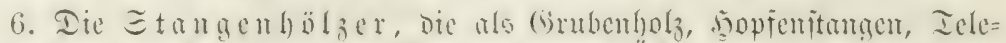

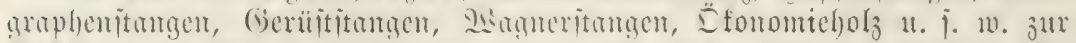

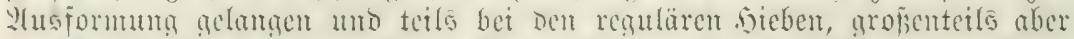

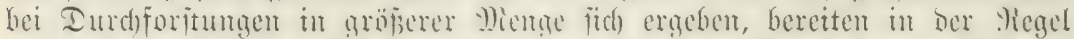

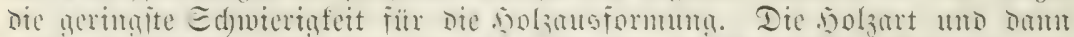

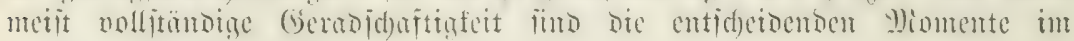
gegebenen Falle.

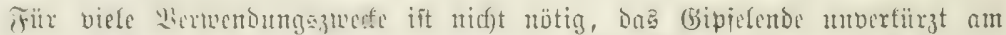
Ed)aite 3 Laffer: Lei Den foupienitangen werben bie sifte uidg)t glatt afigefauen,

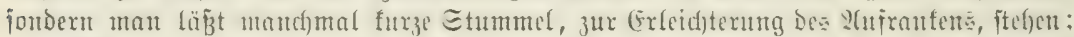

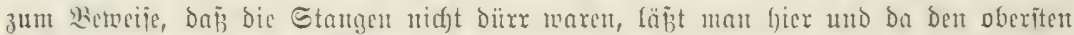

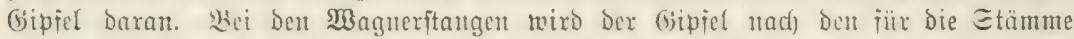

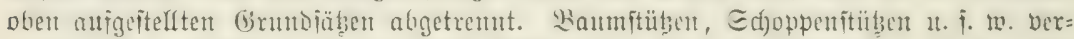

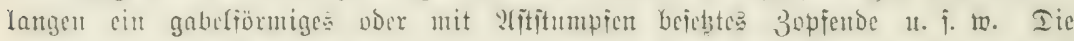

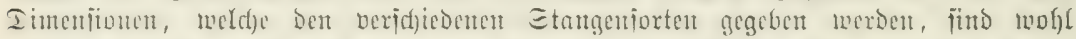

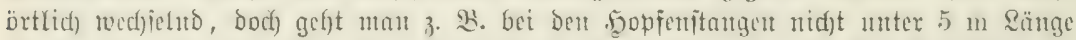

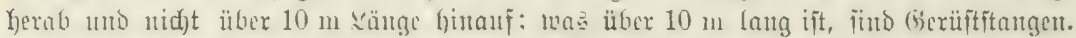

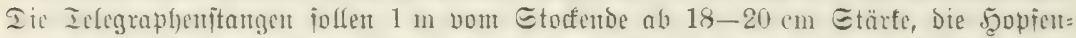
ftamgen 6-12 cm fahen u. f. w. In ber Meget liebt man vou feiten ber fäujer bei

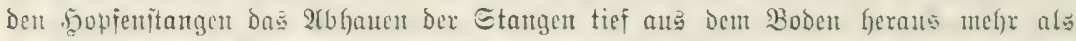

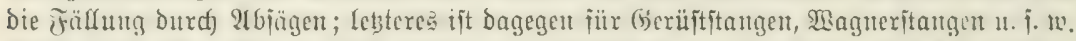

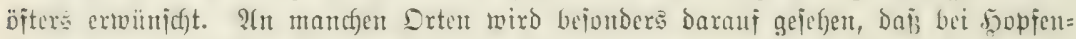
ftangent bas (Froftürf ntidgt weggeidnitten ift.

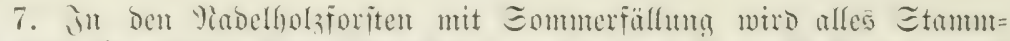

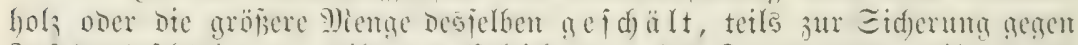

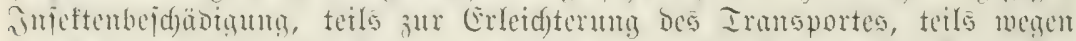

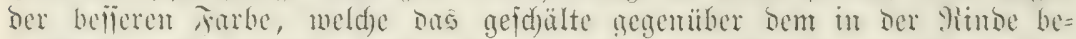

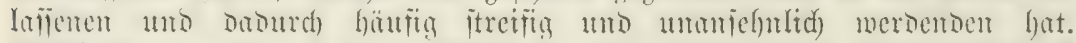

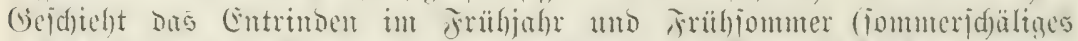

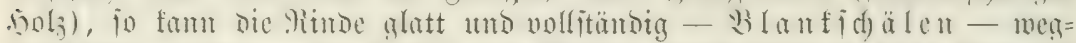

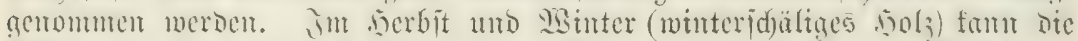

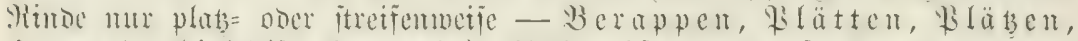
b)

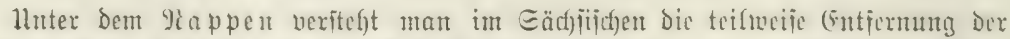

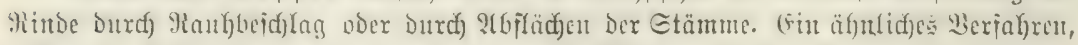

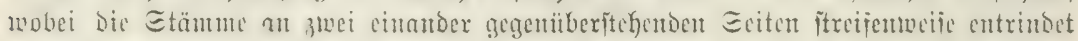

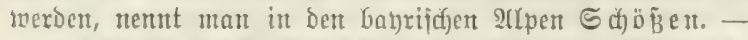

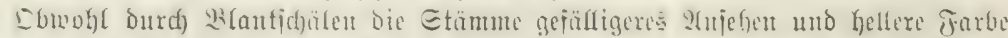

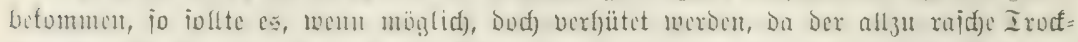

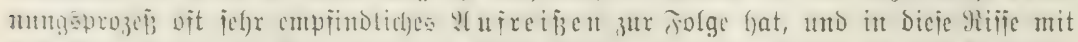

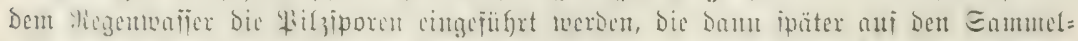

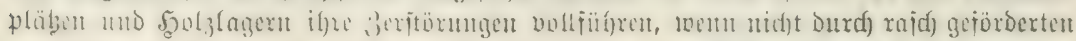

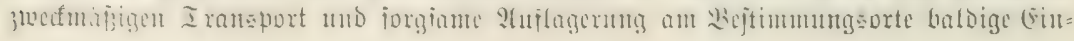




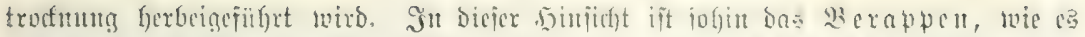

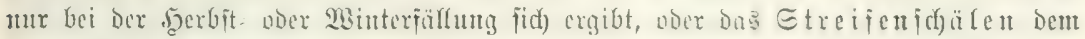
Blantjadjälen vorzuzief)en.

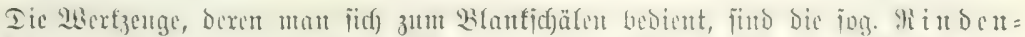

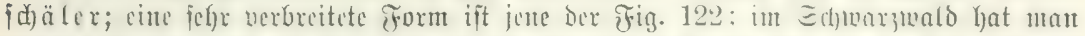

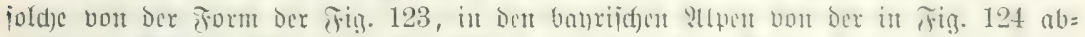

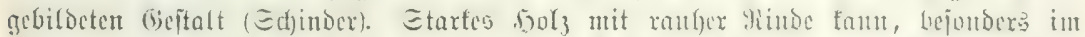

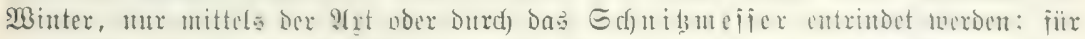

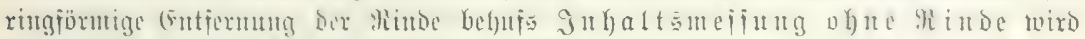

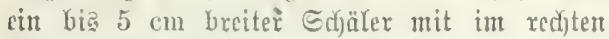
Winfel peitliç) abitebenden Fläd)en benntst.

Fait alfgenciu gebräud)(ich) ijt heute bą Edyälen ber runden Sdjidjtyolzjorten, bejonder:

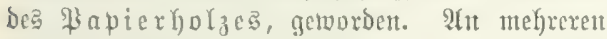
Drten fot man i.t nachabmungstwerter Mibe

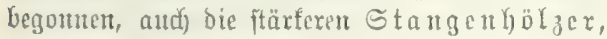
bejondere Sopfentangen, zu eutrinden. 23olfes

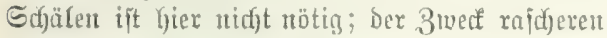
24ustrodinen und Dex Iratsporterleidjterung

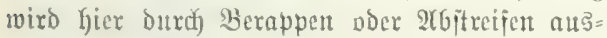
reidjento erzielt ${ }^{\mathrm{x}}$.

8. Daร B̧ren Sdjett= mo Frügelfoly, wird entweder

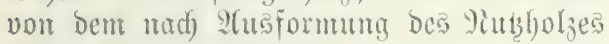

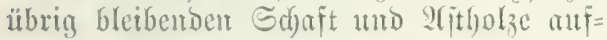
gearbeitet, ober es werben ganze Suenn= bolzbäume baju furzgenadyt, wie bas in Budjenmalbungen vor alfem ber fall ijt. Solde Bremtholzbäume werden ausgeätet, gepust, nad) Sefbertlünge abgelängt uno mun ber Sdfaft und dic järteren sirite in Mundinge (Irummen, Irimmner, Mollen, foimpel, Drehlinge, Dreilinge, $13 a$ lzen u. 1. w. zeriffunitter.

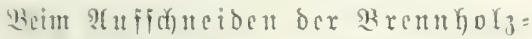
bäume ift Die Bogentiäge namentlid) an Pilabe;

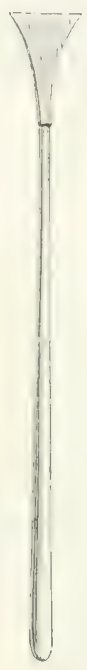

Fig. 122. (jetoübn= licher Vitinosu fdäler.
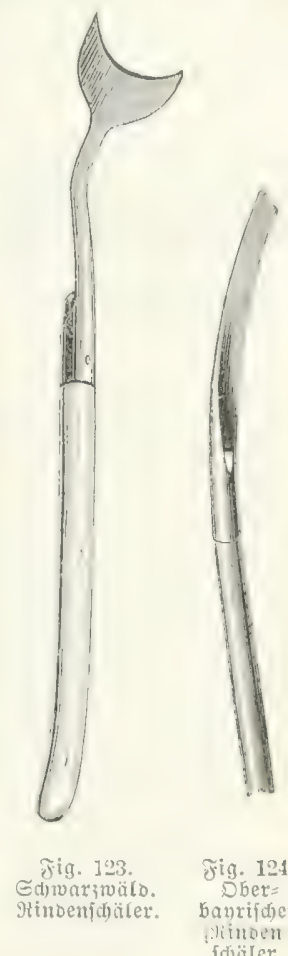

ซig. 124 Dber = banrifuer (litulen jd) jobals daz Gïgeblatt tici gemug engeorungen ijt,

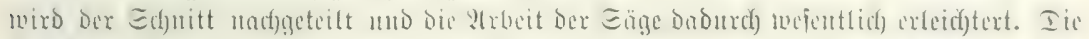

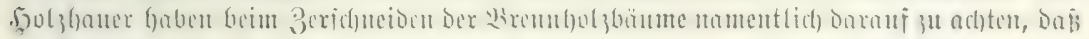

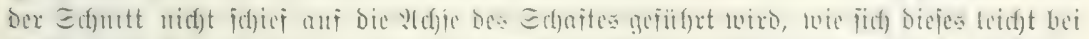

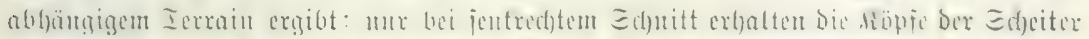

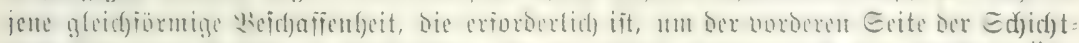

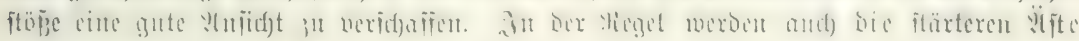

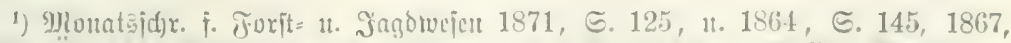

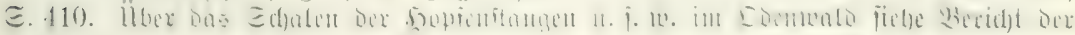

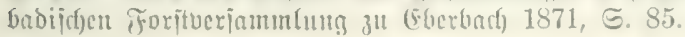




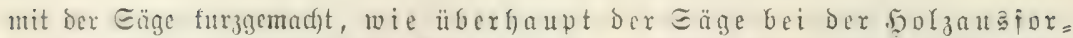

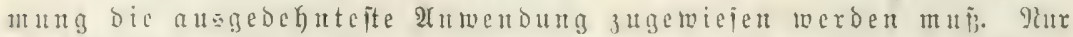

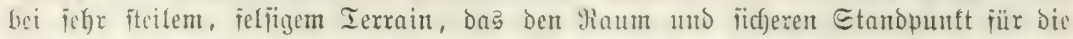

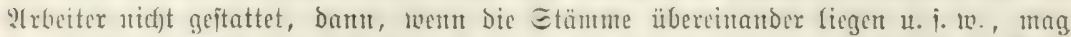

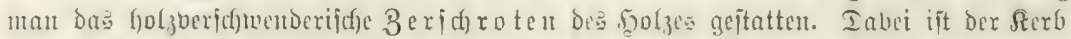

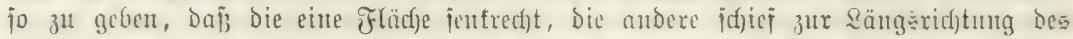
5oolges, wie in Fig. 125, gefiif)rt wiro. Weim Berictroton Der Rremtholzitümme fallen

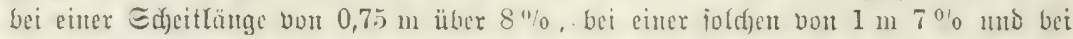
$1,25 \mathrm{~m}$ Edfeitlänge faft $6 \%$ exjafyrungasmäßig ił bie Späne $\left.{ }^{1}\right)$.

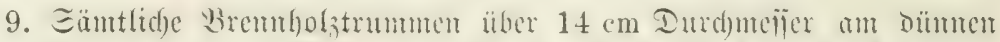

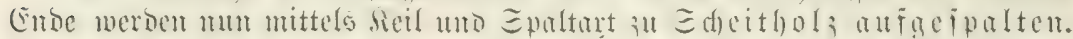

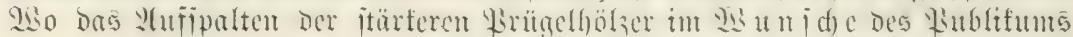
liegt, foll man aud bamit nid)t zurüdhalten.

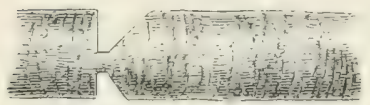

Fig. 125. Serbenbieb beim 3er= idroten bes Etrmmes. In ben reutitidien Rantoen 3 . 3 . wird alles Frügelfoly bis zut $7 \mathrm{~cm}$ herab in ber Megel geipaltert.

Der Reil twird Dabei meirt an Der Stirn an= geicht und bic Dur(f) ifn gebildete säntgatujt mit ber

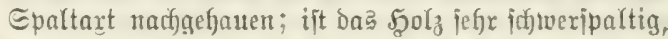

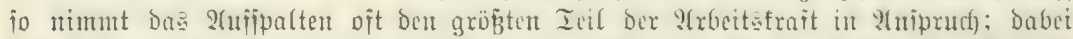

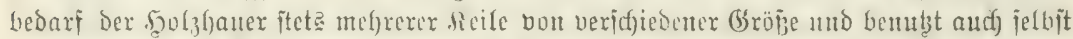

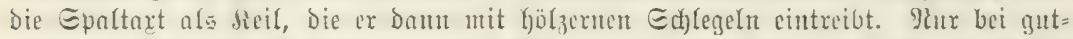

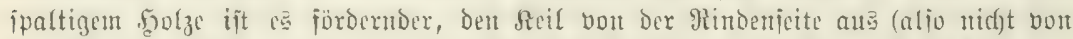

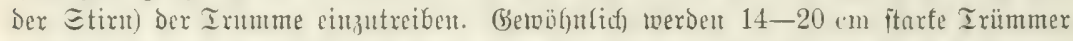

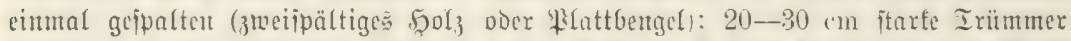

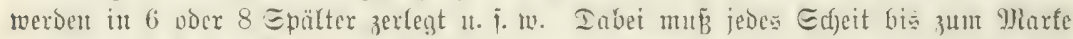

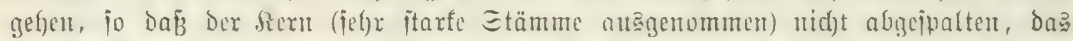

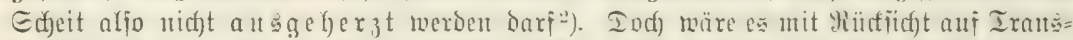

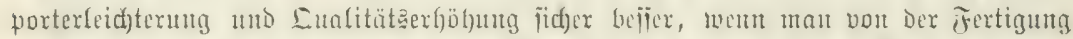
grober Edfeiter ganz abgehen und diciclben bi zu einem mittleren ylaje non etwa

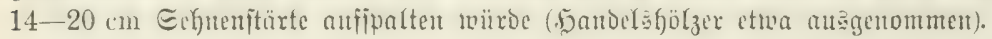

10. Unjpaltige, frotige oder vermajerte Irümmer fömen nicht madt) Ben vorgenebenen Dimenfionen in Epälter zerleat merden; fie bleiben teils

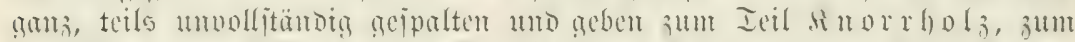

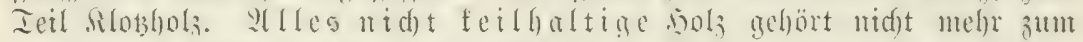

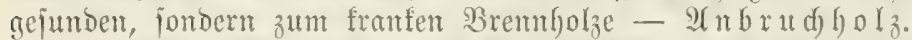

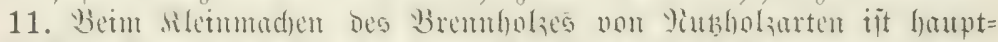

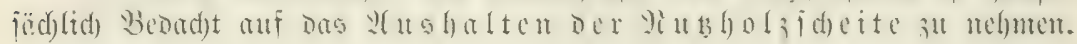

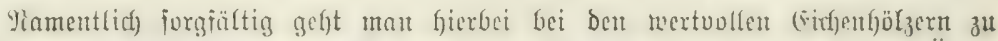

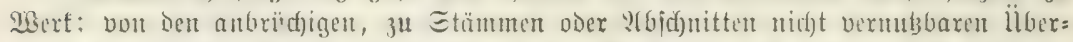

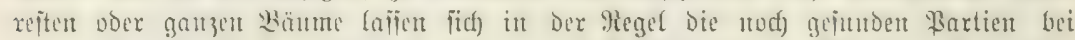

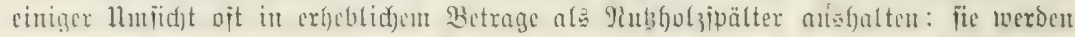

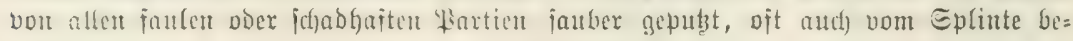

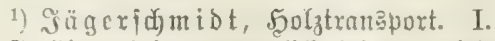

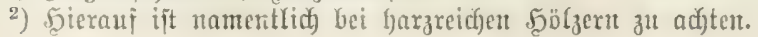




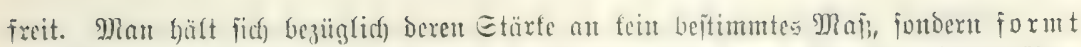

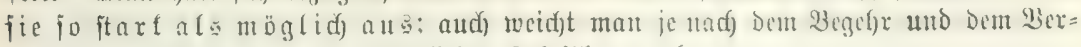

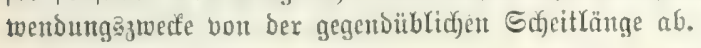

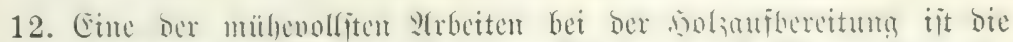

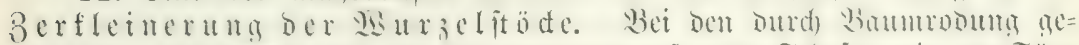

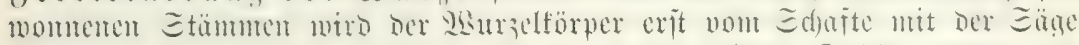

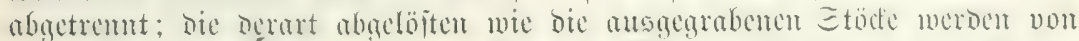

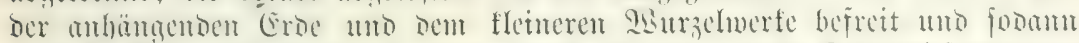

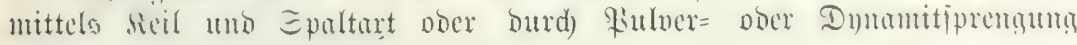
zerfleinert.

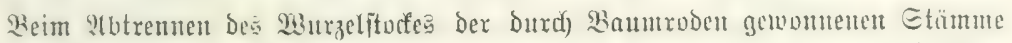

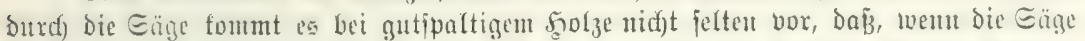

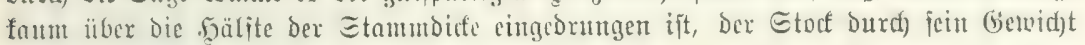

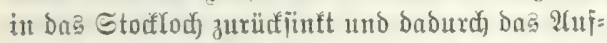
reifen de 巨a)aite herbeifiibrt. Un dieje be=

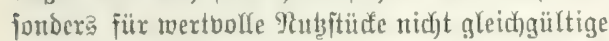
Bejadjäbigung zu verfindern, umppannt man, nack) Brenne dfe, Den Edjaft unmittelbar hinter Dem Sägejodnitt vorexit mit einer Rette, bie Durch rin= getriebene Sieile Don Ediaft feit umichliebt.

Bexteinerung mit dem gewöhn= ridou 5olzhaucrgeräte. Die geringeren Etöcfe biä zแ $7 \mathrm{~cm}$ Stürte bleiben u= gejpalter; 7-14 cm ftarfe werden mit Sieil und Spaltaxt bex sänge nadj cinmal auf= geipalten, ftärfere werden gevierteilt u. 1. 10.; baz

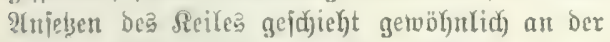
Stirne (2(bid)nittafläd)e) und, wenn man audi) von Dex unteren Geite beifommen mun, immer auf cinem 3ehen (hervortretende Scitenturzeln), weil hier bic Epaltung am Yeichteften von ftatten geft. Dian fpaltet aljo aud) ficx, io weit als irgeno tunlich, itets auf bas glart. Bei jeljx ftarten, verwactjenen Störten nbex ijt biejes vit

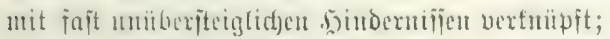

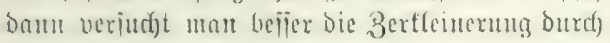

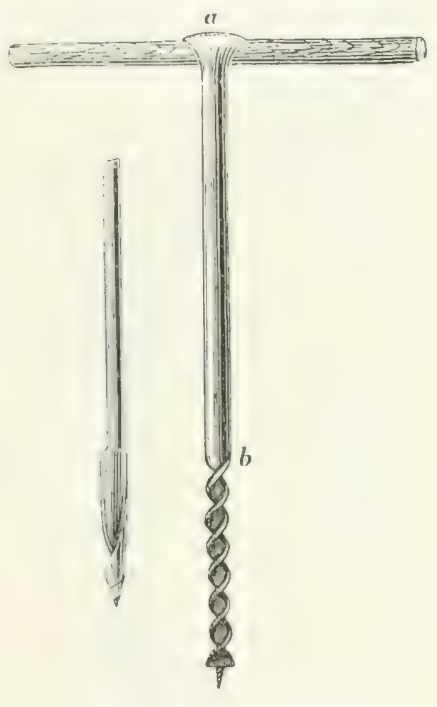

要得. $1: 2 i$

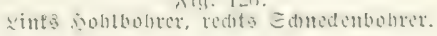

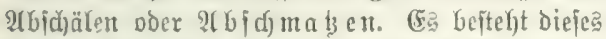

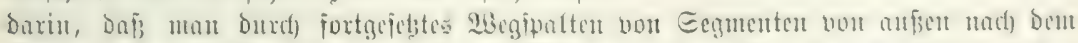

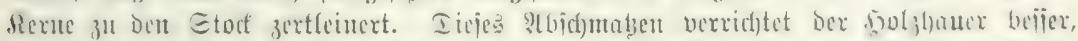

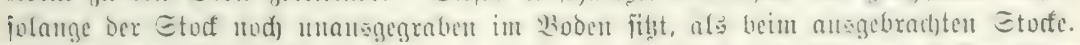

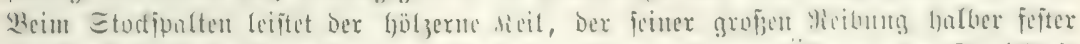

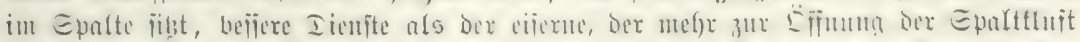

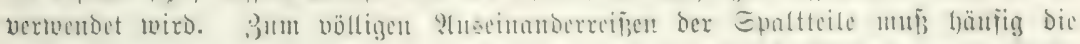

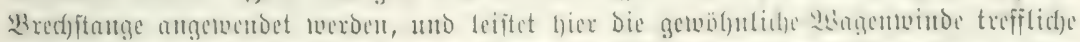

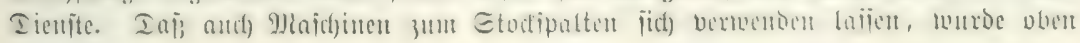
angegeben. 


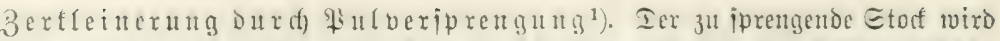

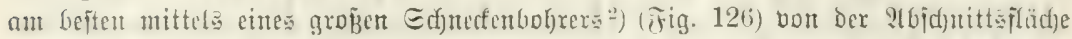

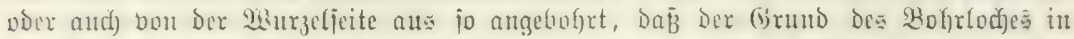

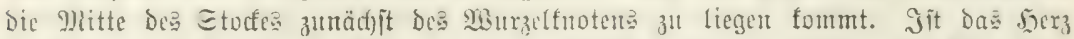

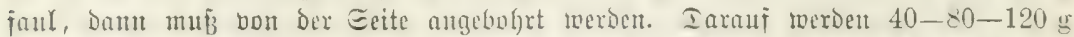

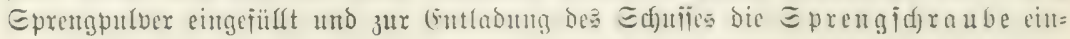

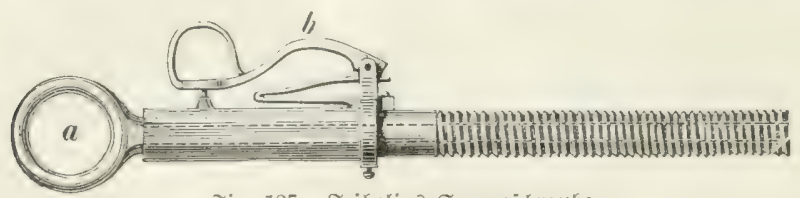

Jig. 127. Fribolins Eprengidraube.

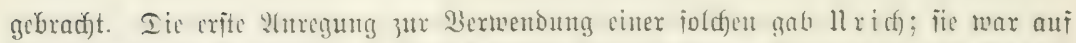

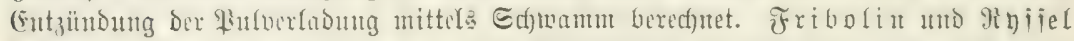

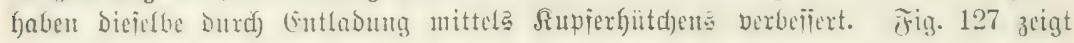

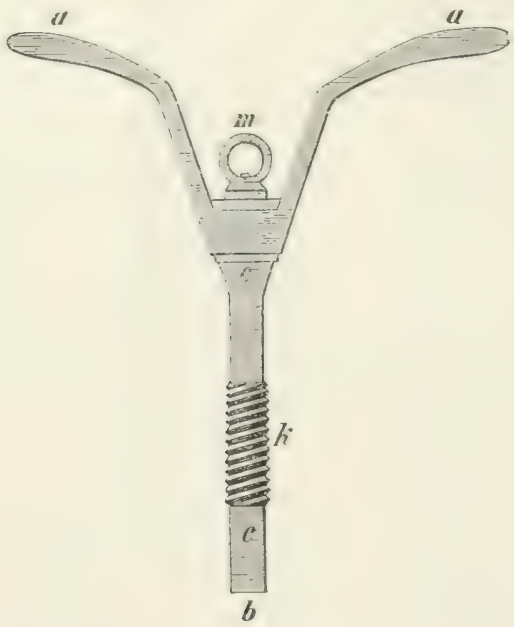

Fig. 128. แrids Zuinbnabel= Eprengid)raube.

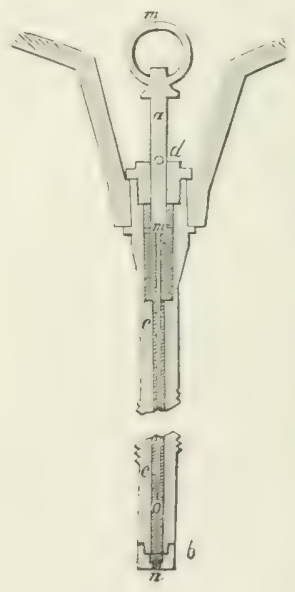

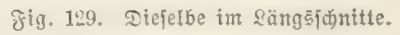

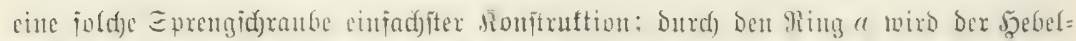

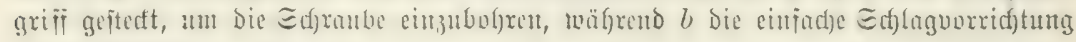

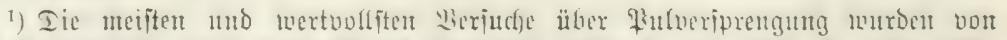

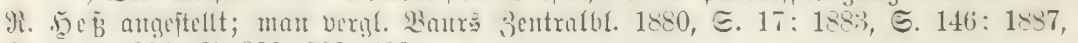
ธ. $511 ; 1892$, ธ. $320,393,433$.

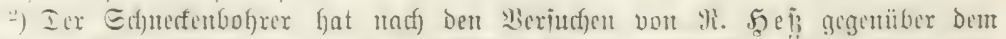

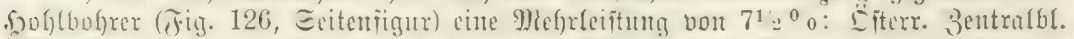

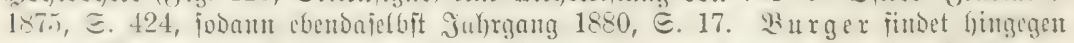

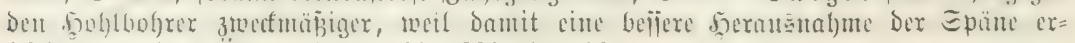
feidjtert inerde. S̈fterr. 3entralbL. 1880, G. 103. 


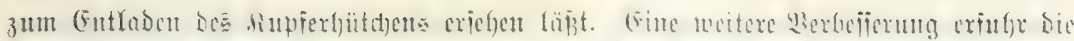

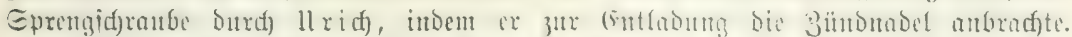

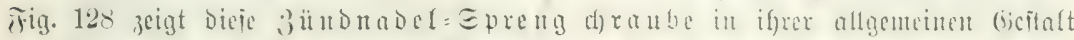

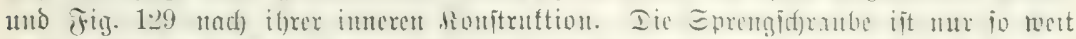

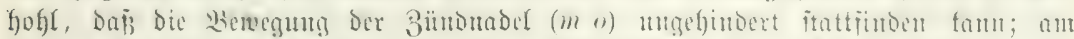

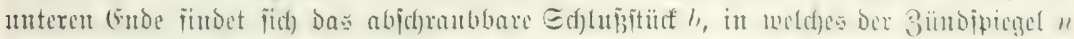

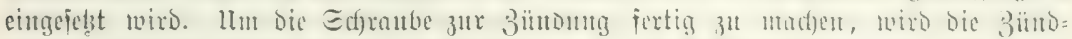

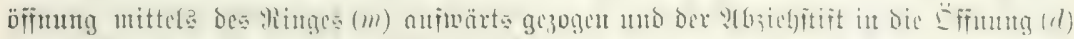

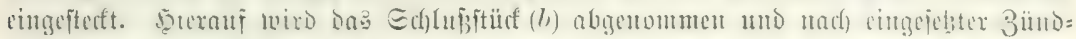

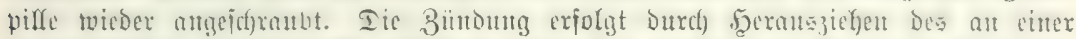

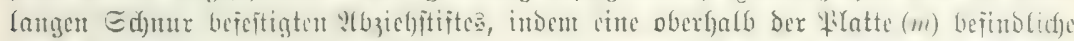

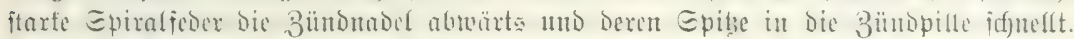

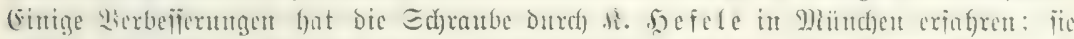

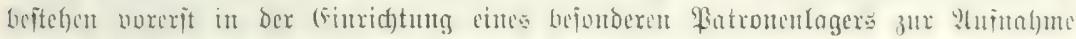

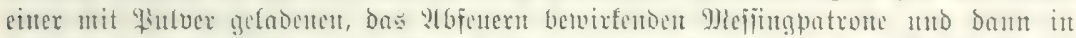

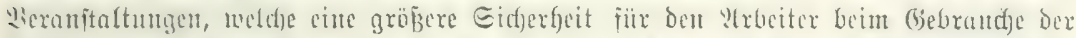

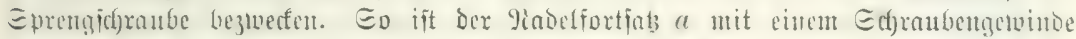

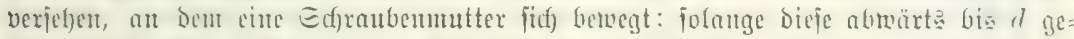

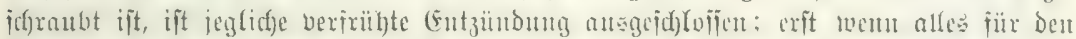

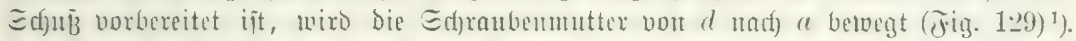

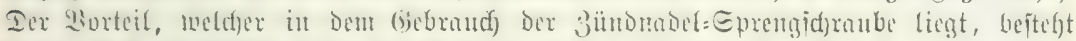

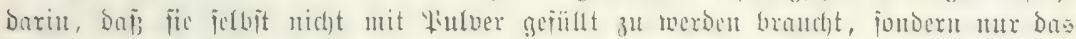

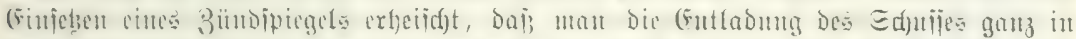

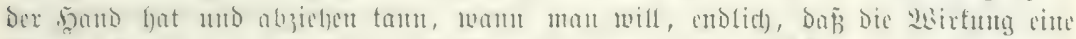

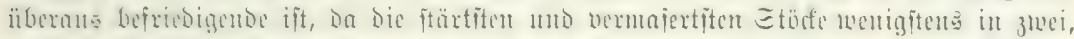
meift ijolierte, häujig aber in mefrx Ieile zerrifien twerben ${ }^{2}$ ).

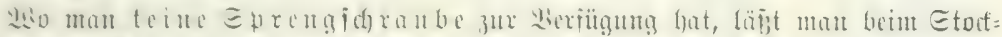

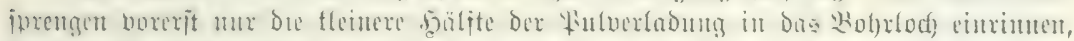

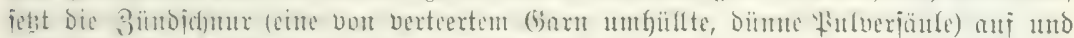

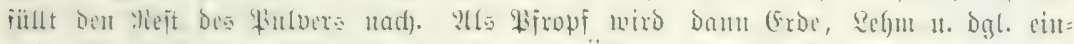

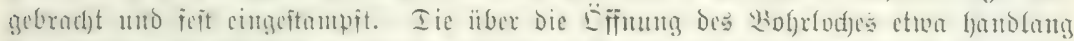

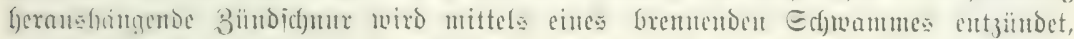

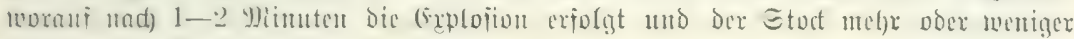

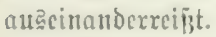

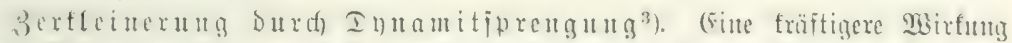

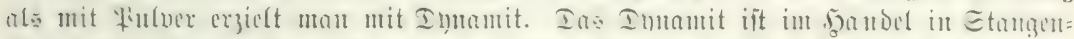

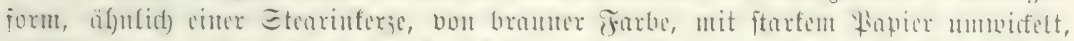

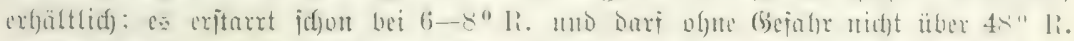

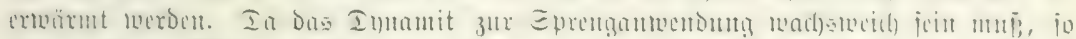
bebri ts im

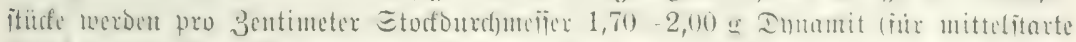

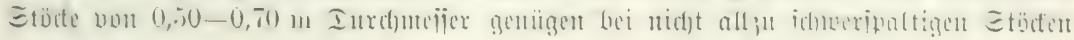

1) शื а ит弓 Bentralbi. 1895. E. 11

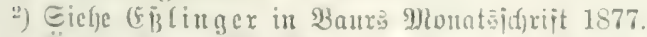

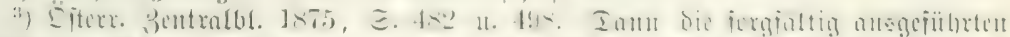

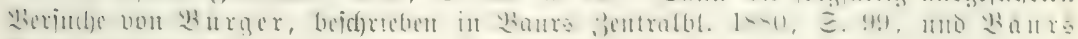
y) 


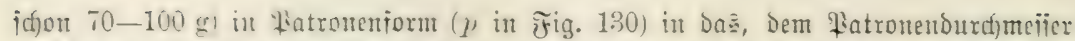

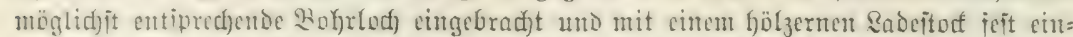

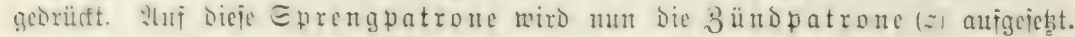
$11 \mathrm{~m}$ Dieie zur 3ündung zu ridften, wiro bie Züntoid)nur vorerit in ein fiir bicien

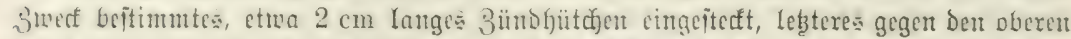

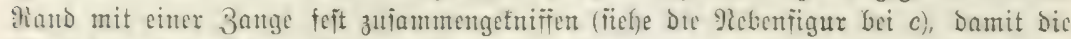

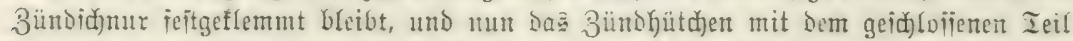
voran fant Bünbid)nur in Dis meidfe Innamitmalie ber 3ünopatrone (nadfoem Der

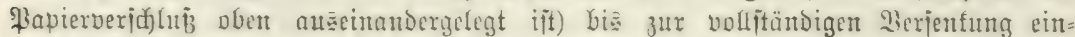

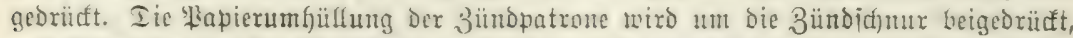

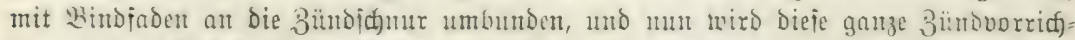

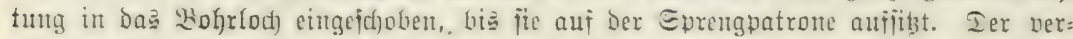

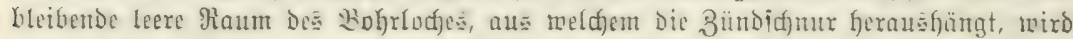

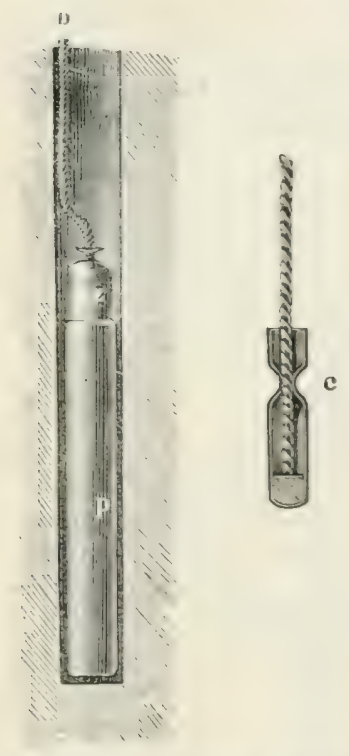

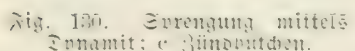

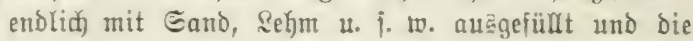
3ünofidnur mit brennendem Edfivamm pder einer 3igarre zur Entladung der Eprengïüllung angezündet.

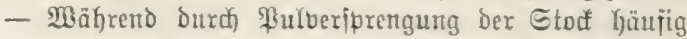
nur aujplabst, wirb er Durdj dą weit fräitiger tvirfende Intramit getoönnlid) in 3, 5, 10 Etüfe zerrifien, bie oit einer weiteren 3erfleinerung nicft mehr bedürfent.

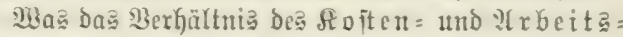

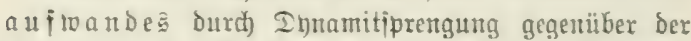
Saltoarbeit betrifift, io habent die Seriudje folgende

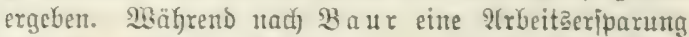
von 36-50\%, ntad) Şam eine juldde von $58 \%$ erzielt twirb, hat $\mathfrak{B}$ urger geiundert, ba $1 \mathrm{~B} 1 \mathrm{rm}$ W3rurzelfyolz von Fidjen 50 PF. Gilfiger, $1 \mathrm{rm}$ Mmurzel= folz von fieien bagrgen um $28 \mathfrak{P}$. teurex zu fteken fommt ala bei ber Sandarbeit. Die $\mathfrak{A}$ nuvendung Des Innamita ift mux bei vollftänoig angerodeten und ganz prei Liegendent Etörfen lofnend; auf ntidt an= gerodete Stöfe jimb bie Sprengmittel nahezut wirfunga los. Finer auşgedehnten ?tntwendung bes Innamita

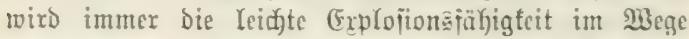

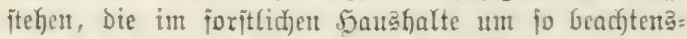
tverter iff, ba ber fö̆lungäbetrieb vielfady im Minter

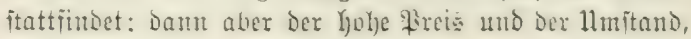

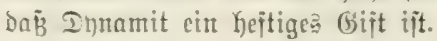

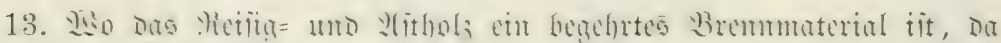

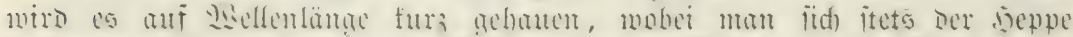

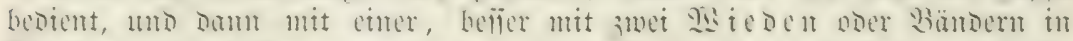

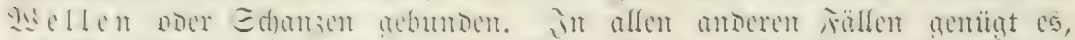

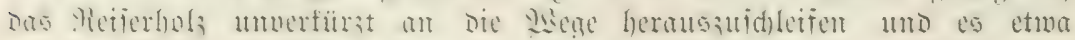

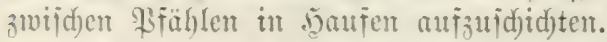

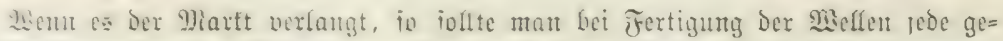

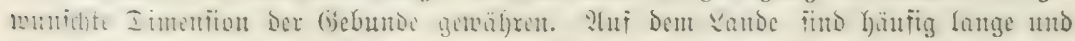

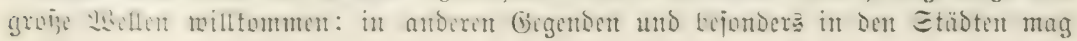




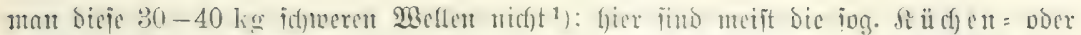

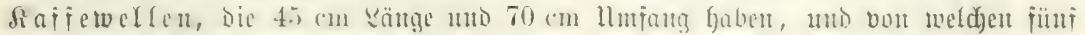
Stïí auj cinte Tormaltuelfe gehen, beliebter.

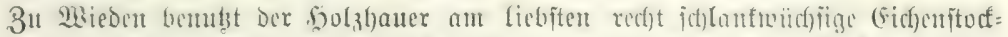

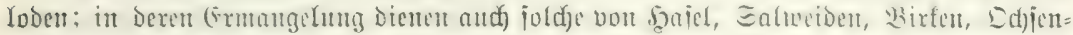

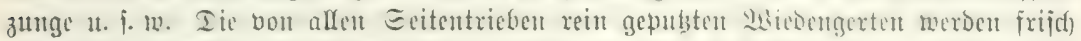

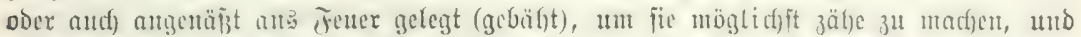
bam am bïmen (5nde, unter jeilartigem 3ujumenbreben, Die Esflinge angebrad)t, burd) weldje bas bidfere (Ente beim Welfentinden gezogen wiro.

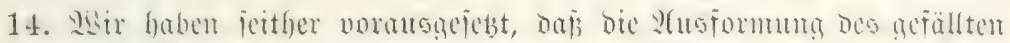

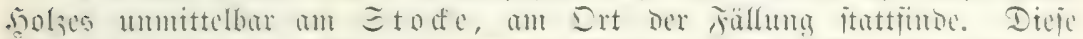

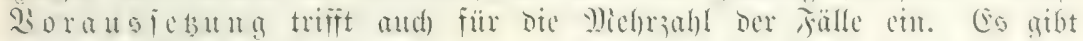
aber aud Serbältuiffe, bei welden es notwendig wixd, bas

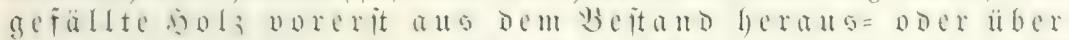

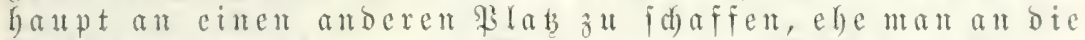

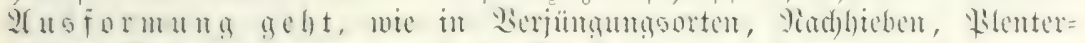

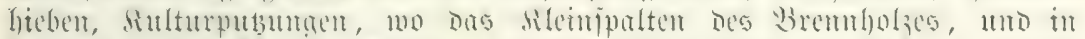

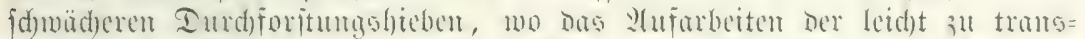

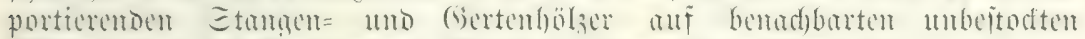

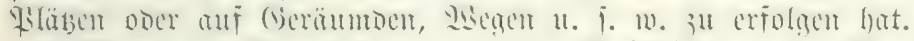

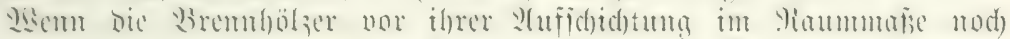

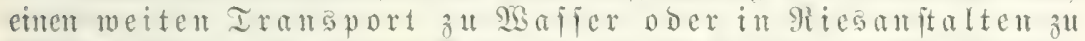

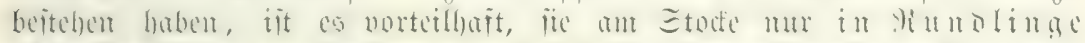

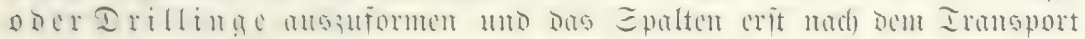
vorzuchmen.

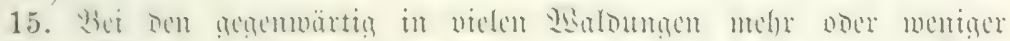

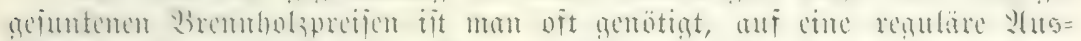

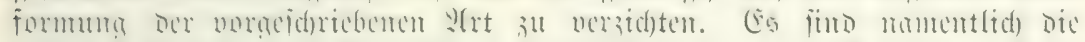

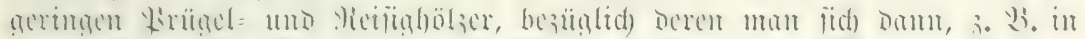

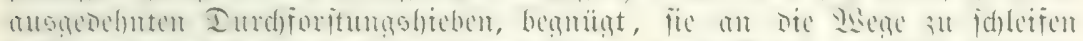

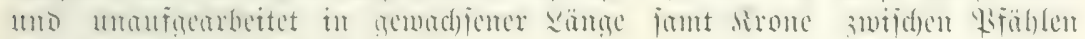

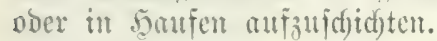

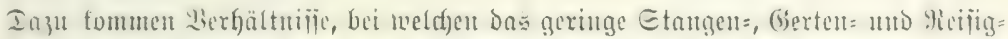

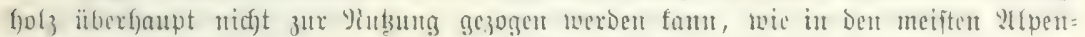

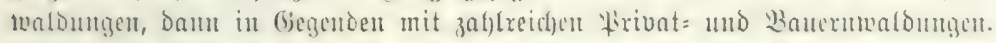

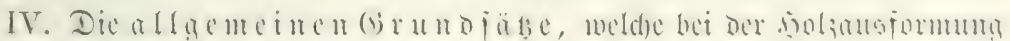

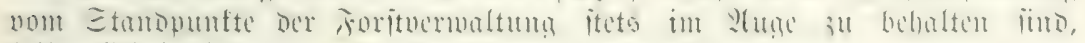

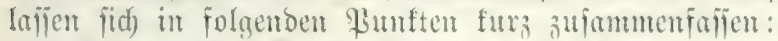

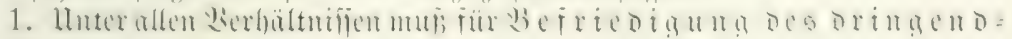

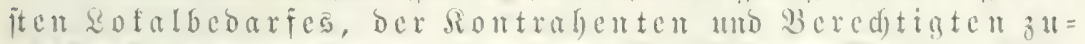

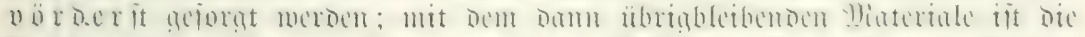

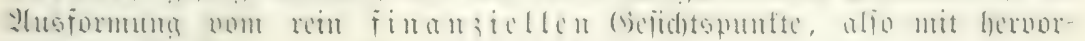

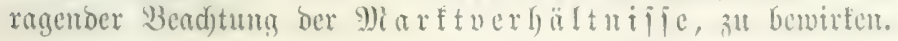

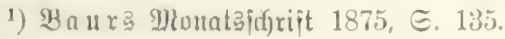




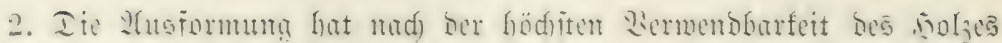

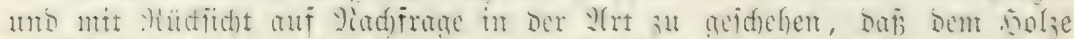
Durd) Die

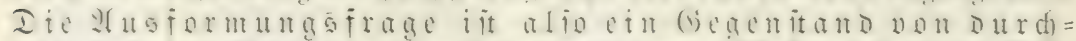

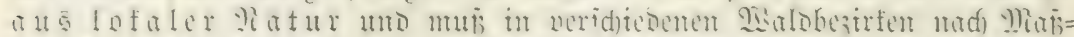

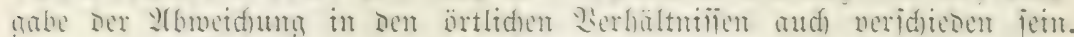

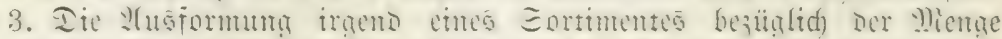

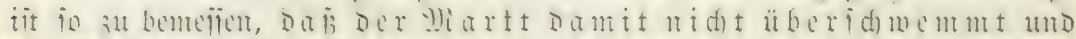

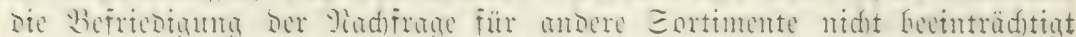

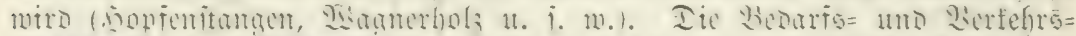

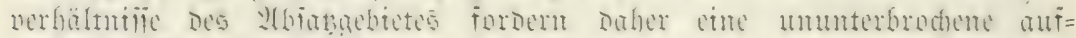
merfiame Berfolgung von jeiten bes Sistriffartşbeantent.

4. Se jeltener und wertvoller die 50 lzer jind, beito un=

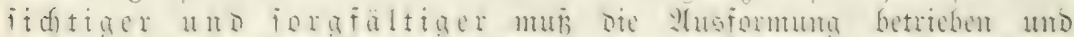
neletet merout. Integ beiteht

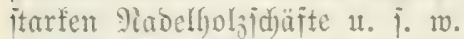

5. Iie und leidjter erreid)t, went jie nad) Eortimentagruppen und Durd) bejondere $\mathfrak{A}$ tbeiterflajjen betätigt merben.

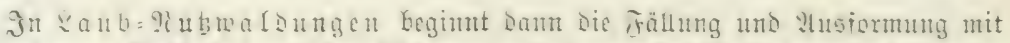

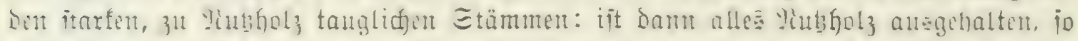

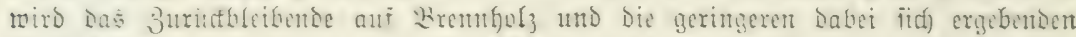

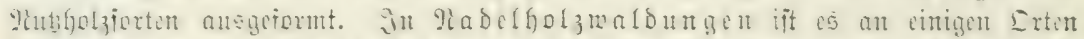

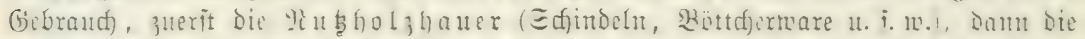

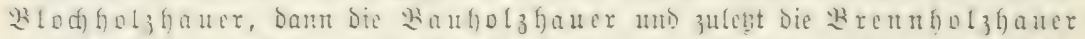

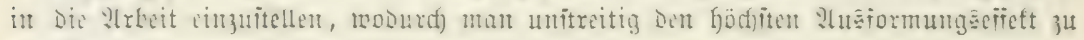
errecicjen im jande ijt.

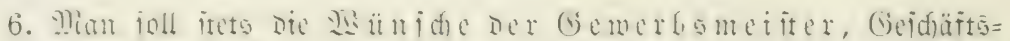

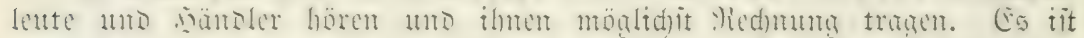

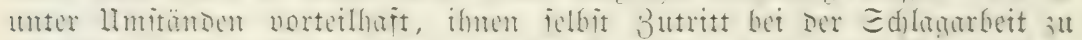

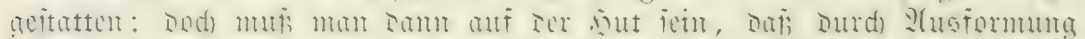

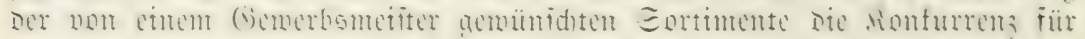
lebtere nid)t beemtrüd)tigt ober gar aufgehoben wirs.

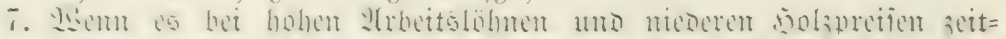

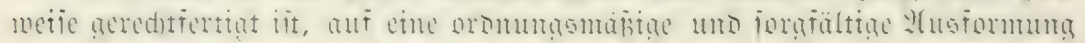

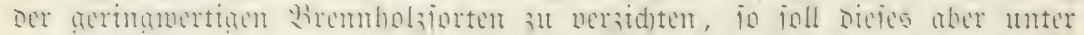

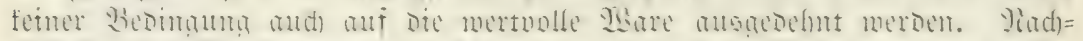

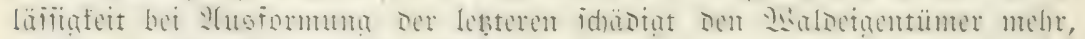

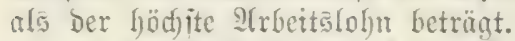

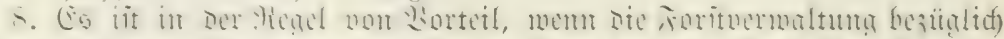

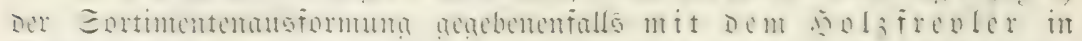

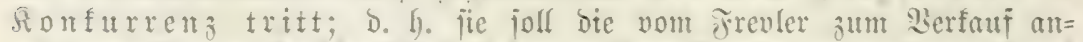

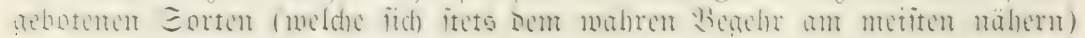

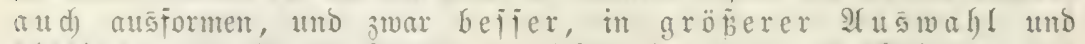

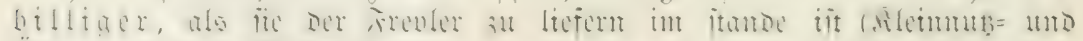

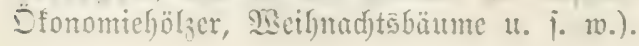




\section{Sorticrung.}

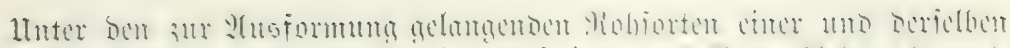

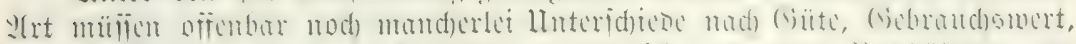

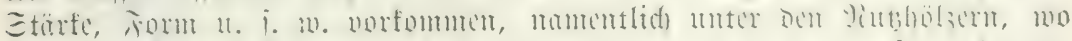

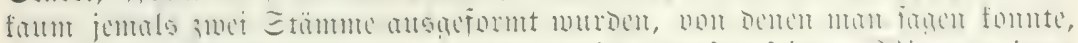

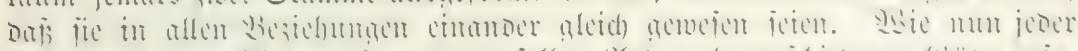

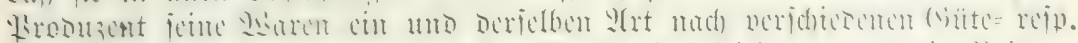

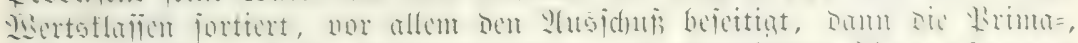

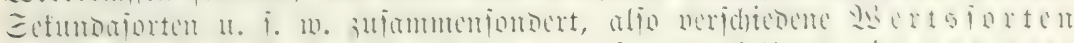

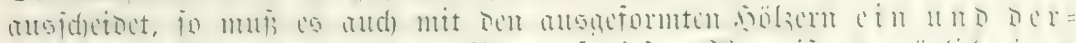

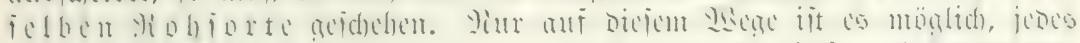
chische 三tüt

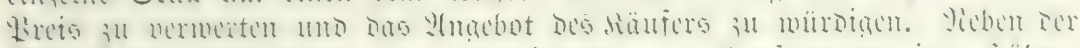

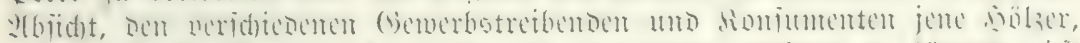
mu meld) ih)

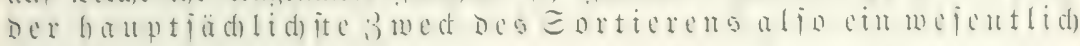
finanzieller.

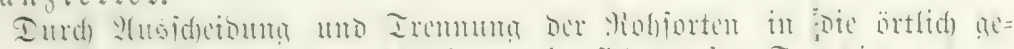

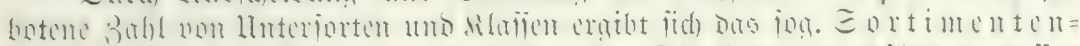

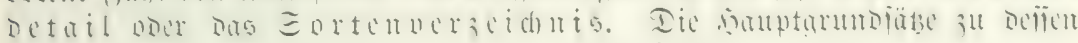
Biloung laijen fich) folgendermafen zujammenfajien:

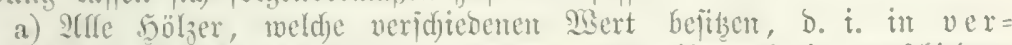
idicesentu Eorten şu tremten.

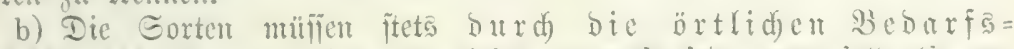

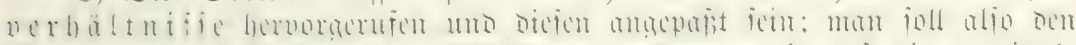

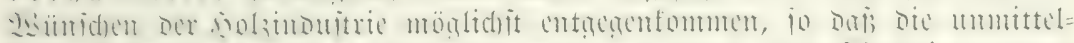

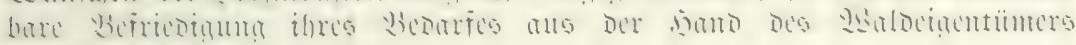
möglid) wirb.

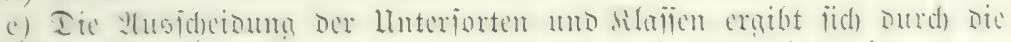
Berjdiebeubert ber Solzart, Etáte, Form, bex interen

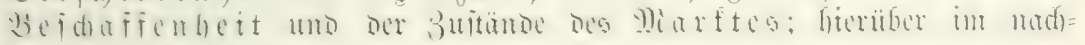
folgenoen dos glähere.

d) Das Eortimentendetail foll nidyt jo weit getricben at do

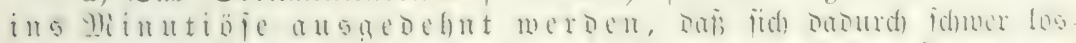

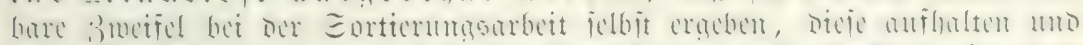

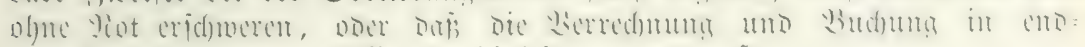
lofe Beriplitterung and $\mathfrak{B e}$ eitmendigfeit geraten müpte.

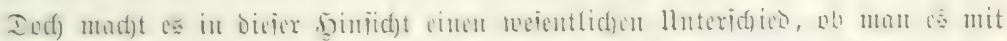

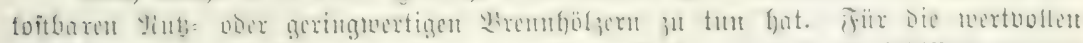

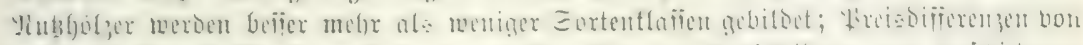

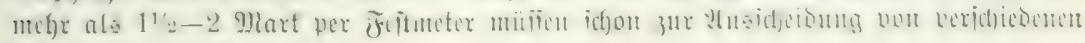
Staijen Berantaijung feitr.

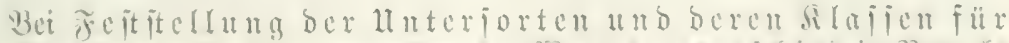

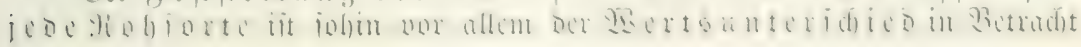




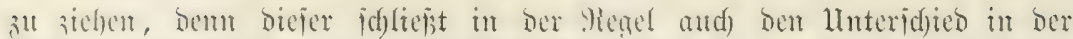

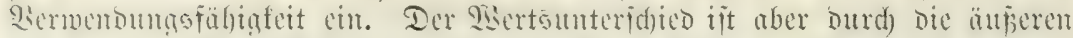

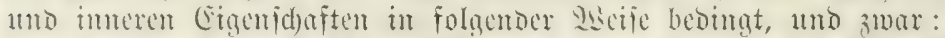

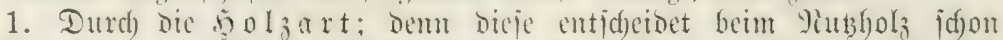

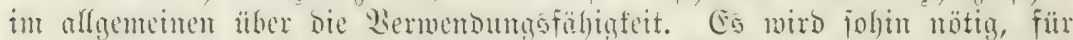

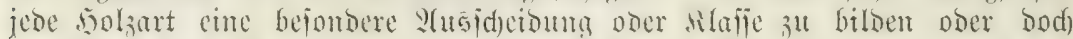

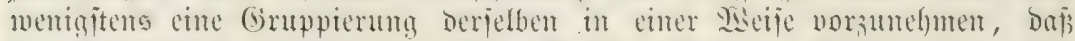

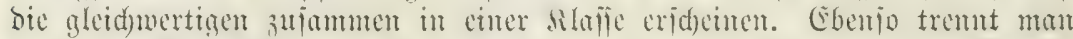
aud) bie brembölser mad) bolzarten uno wirft bei geringem \$(nfalle Göbjtens bie geringwertigen Sorten ăliammen.

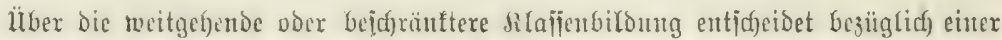

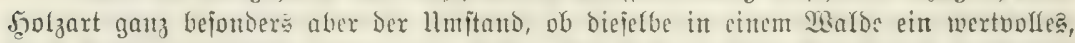
ftarf bertretenes Ebjutt bildet oder nidgt. Eo wird in einer begend mit mertuollent

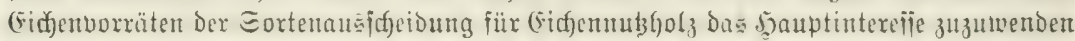

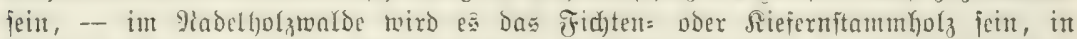

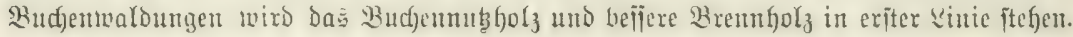

2. Durd) Die Dimeniionen. (Es ijt natürlid), Daj bie meiten

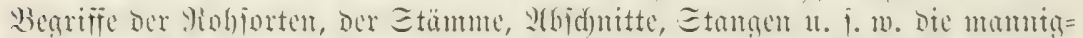

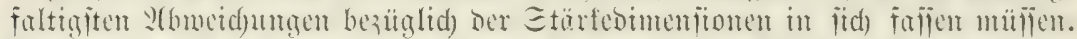

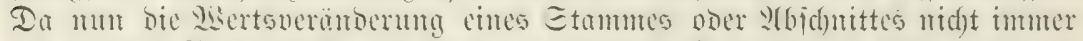

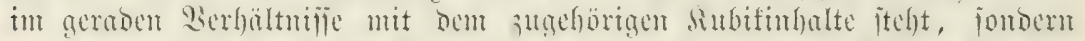

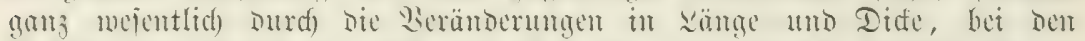

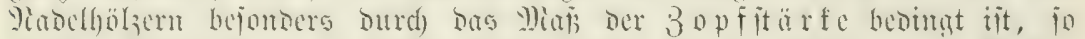

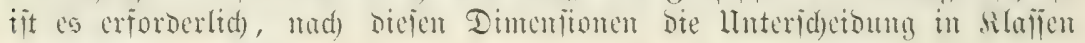
zu bitlont.

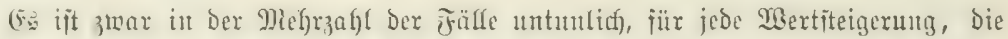

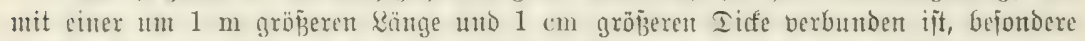

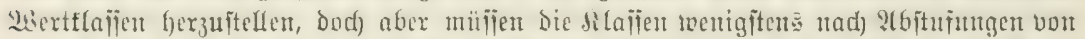

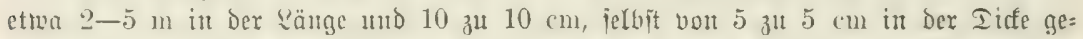

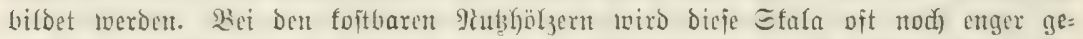

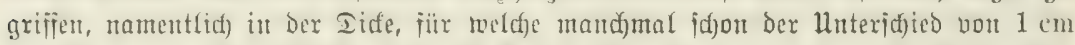

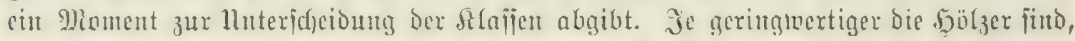
Defto weiter tömten überffaupt bie Rlafiengrenzen geftect twerden.

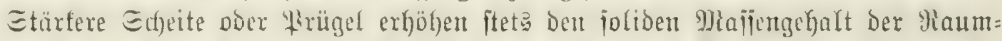

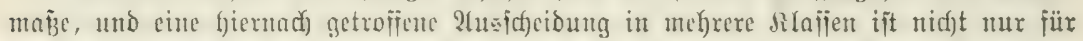

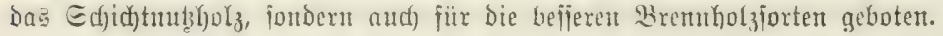

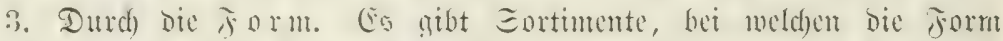

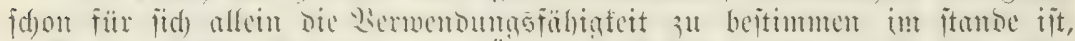

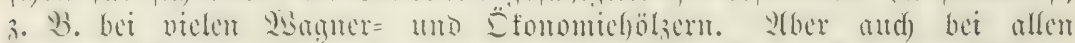

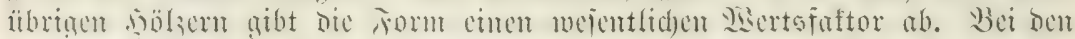

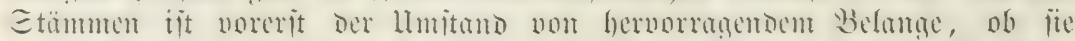

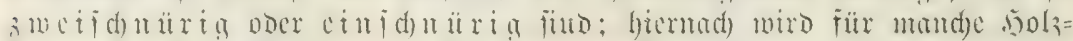

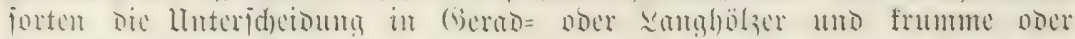

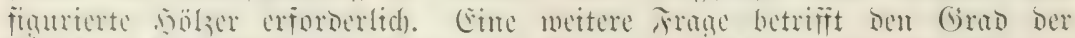

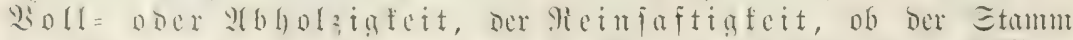

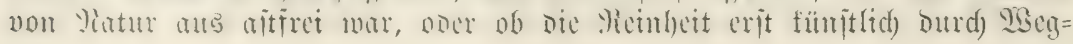




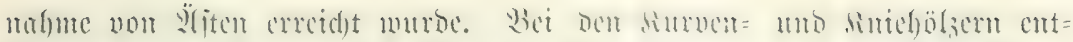

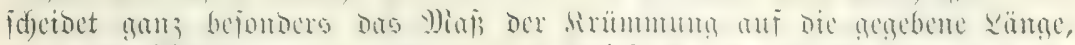

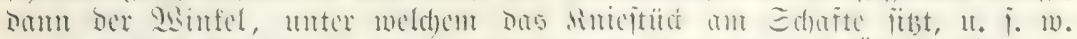

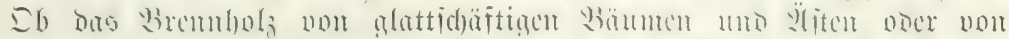

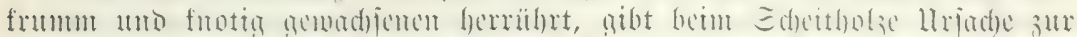

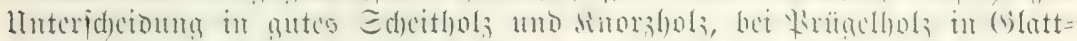
oder Etanacmpriagel ober Afitpriagel.

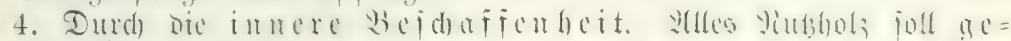

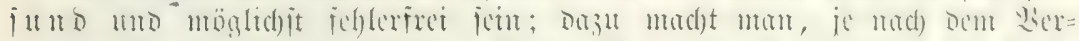

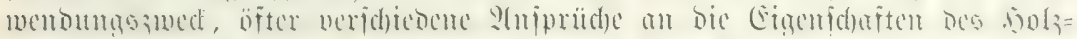

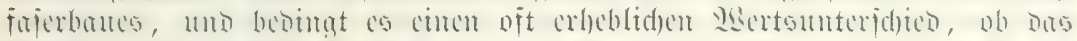

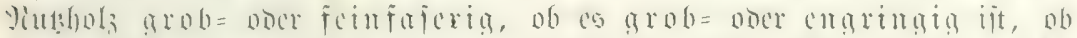

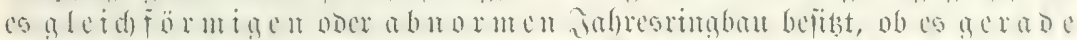

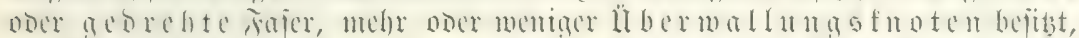

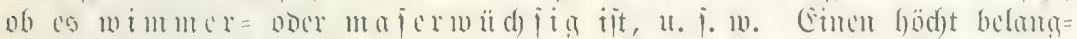

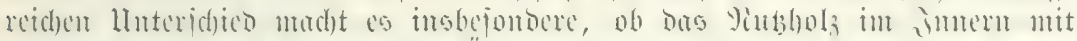

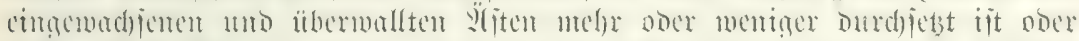

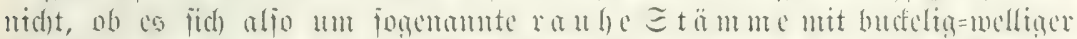

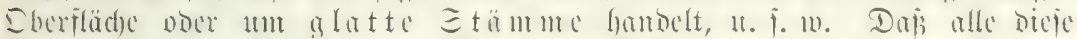

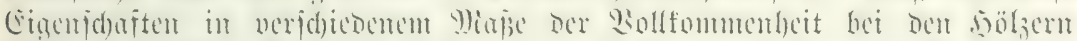

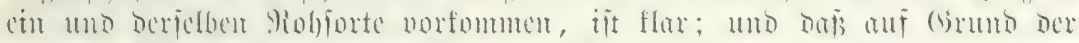

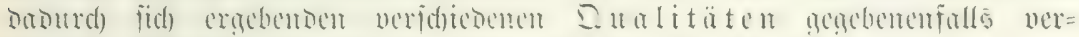

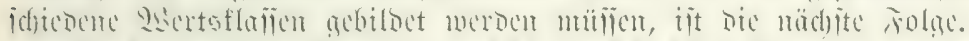

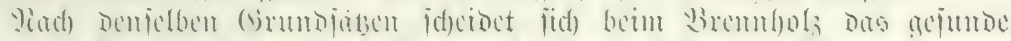
ज) bemertliden Lluterideto in

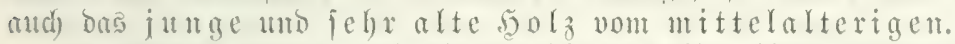

5. (E)

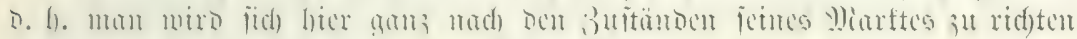
baben, alf bem bie bölzer igren 2(biats füben.

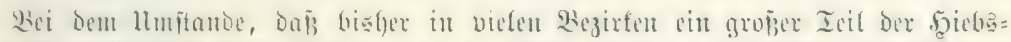

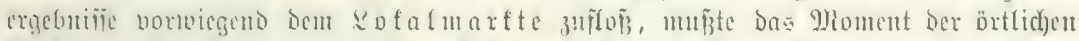

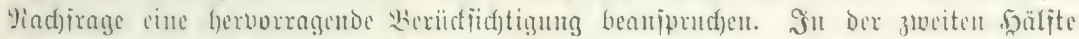

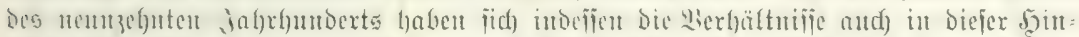

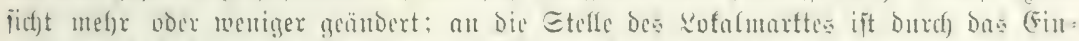

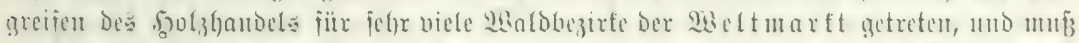

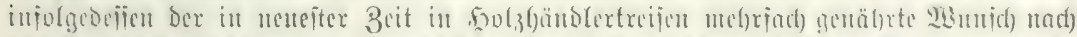

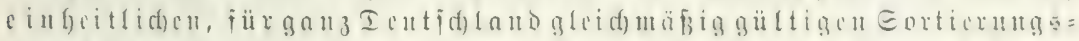

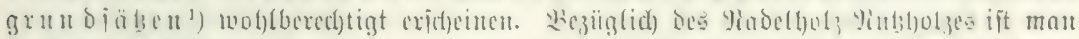

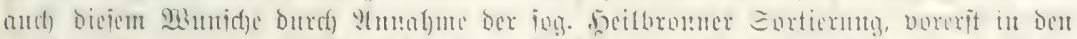

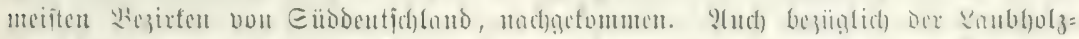

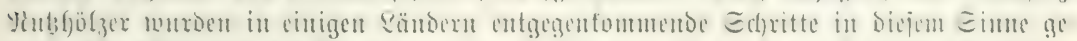

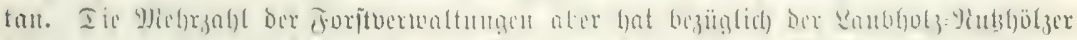

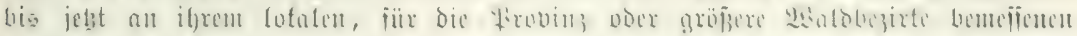

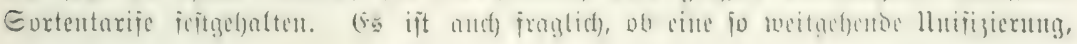

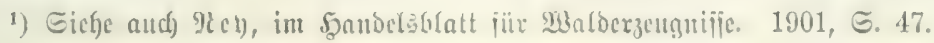




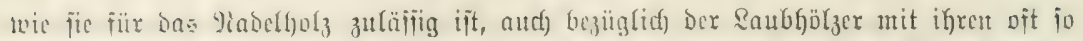

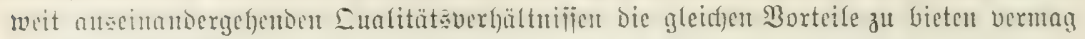
mic beint Iabelfolze.

Ia mun, alggefeben von biejen lebtgenanten Eortengruppen, fait ïberalf cin an=

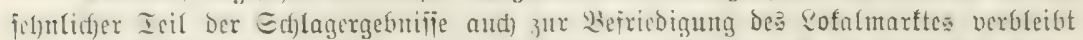

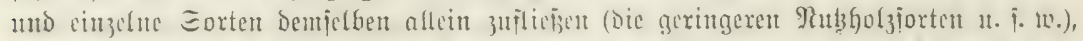

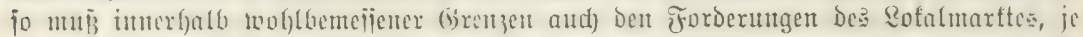

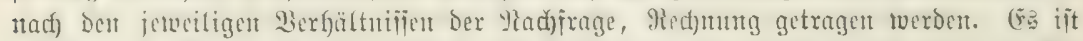

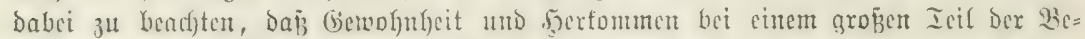

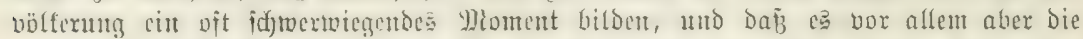

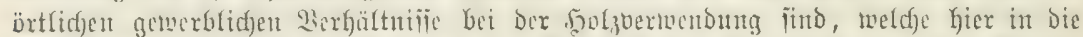

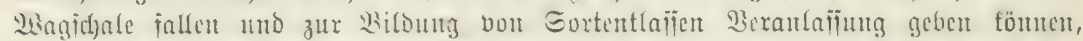

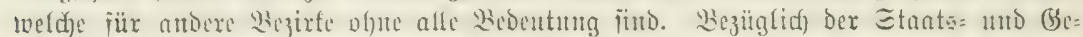

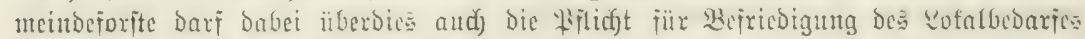
nichit aแ1 Dem 2tuge berlorest werbent.

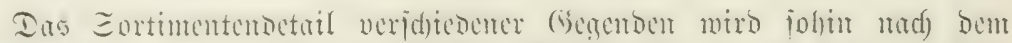

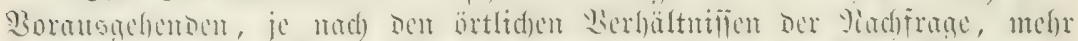

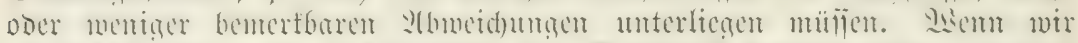

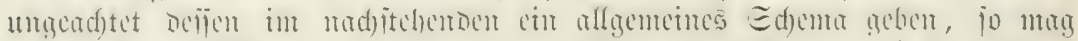

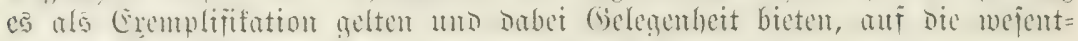
lid)iten Ylonififationen im Eortimentembetatl finzunetion.

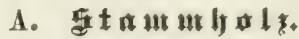

\section{I. $\{\mathfrak{a} \mathfrak{n \mathfrak { h }} \mathfrak{o l}$.}

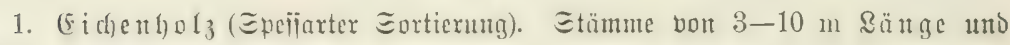
normaler Bejdaffenteit:

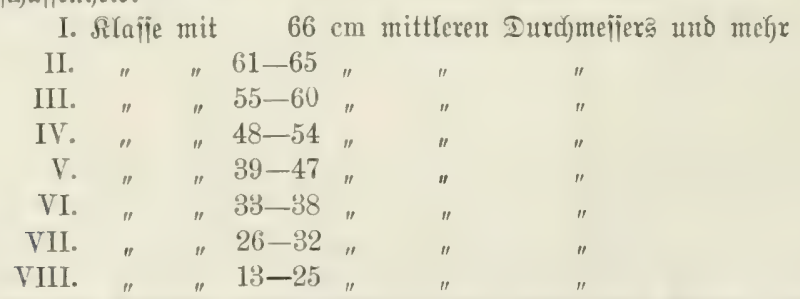

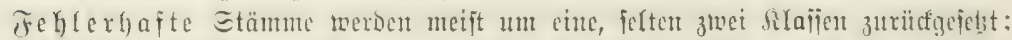

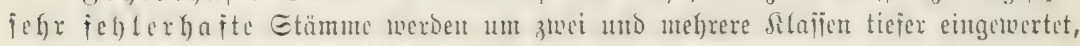
als jie nad) iffen Dimtertiontent einzureifhen wären.

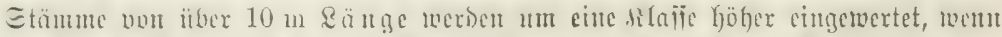

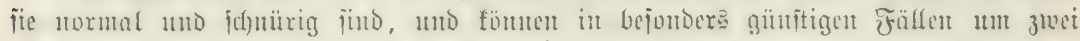

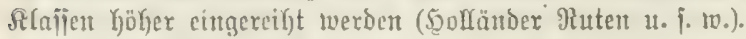

\section{Iiadelgol 3 :}

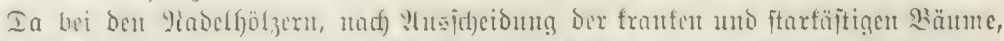

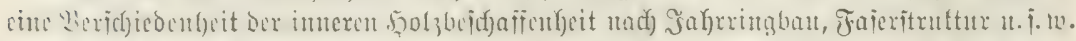

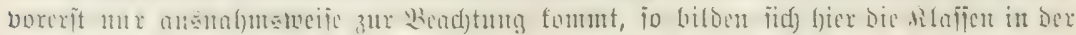

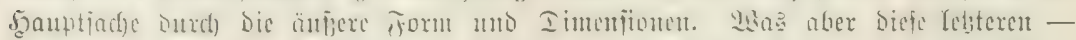

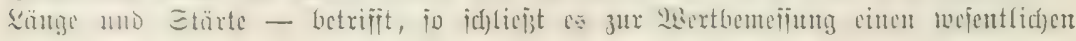




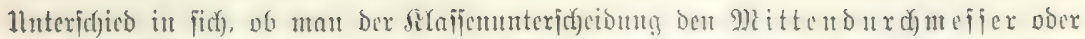

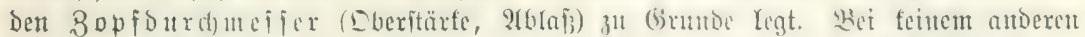

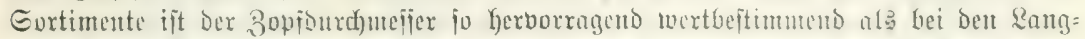

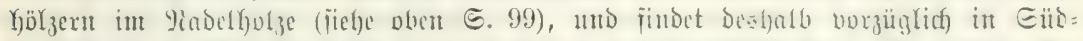

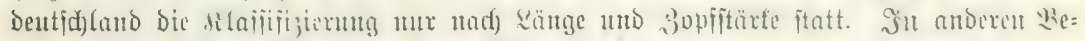

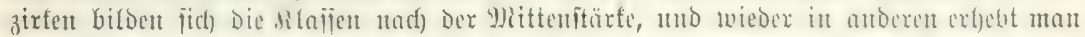

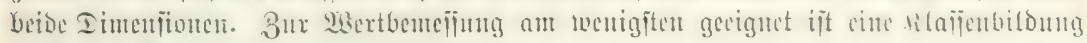
nadid Dem $\mathfrak{R}$ bifiukalt bex Etämute.

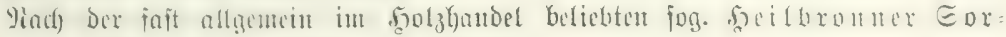
tiexug werden folgende Rlafien unteridjeben:

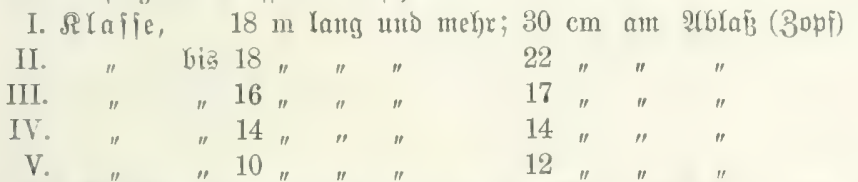

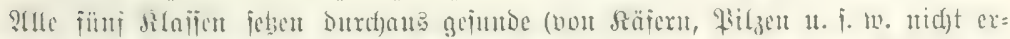

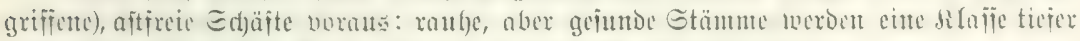

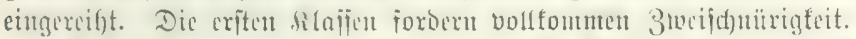

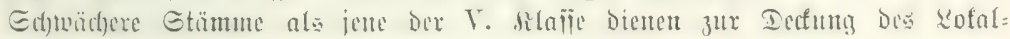

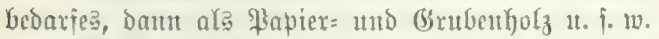

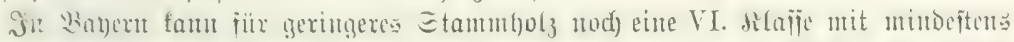

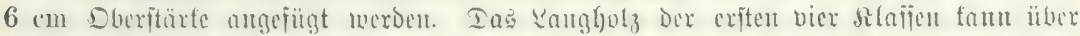

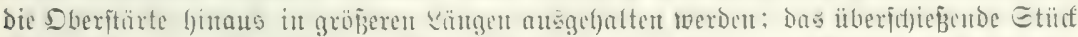

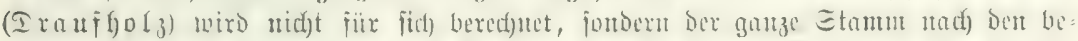

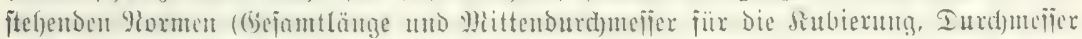

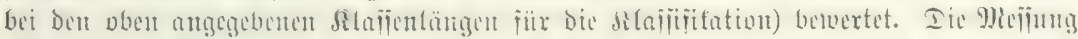
exfolgt ofye gitude.

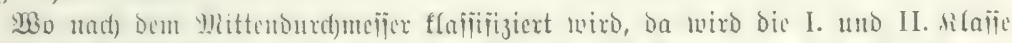

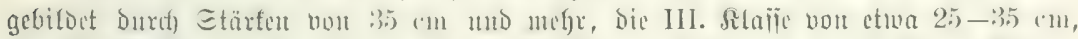

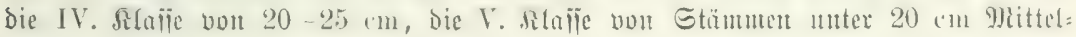
ftärfe n. Ғ. w.

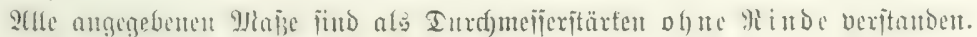

3. ïbrige $\mathfrak{H}_{\text {olzaxtent. }}$

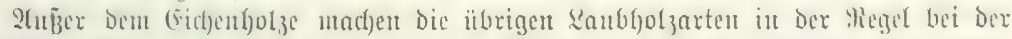

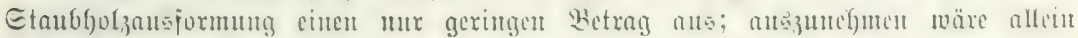

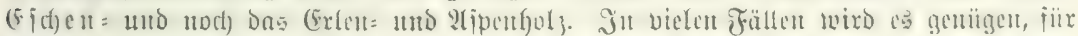

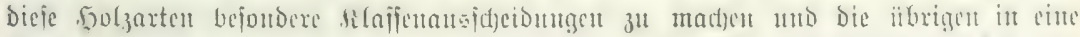

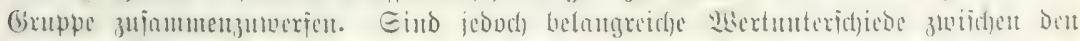

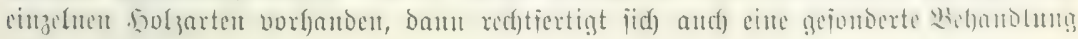
jeber cinzelnen.

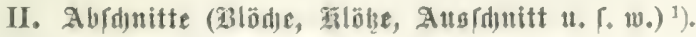

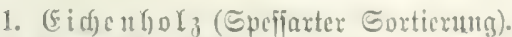

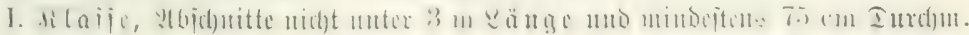

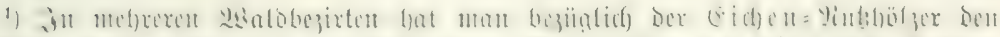

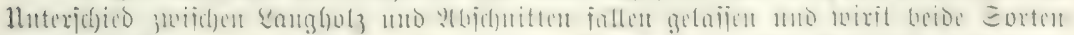

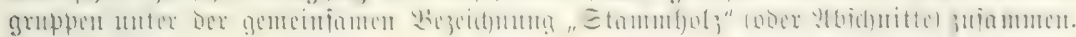


II. Rĩlafic, nidd)t unter $3 \mathrm{~m}$ lang uno $66-74 \mathrm{~cm}$ Durd)mefier.

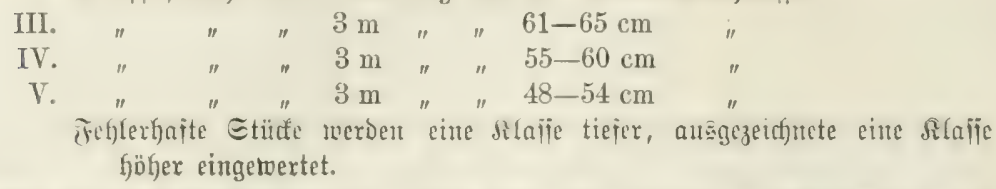

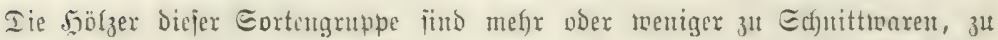

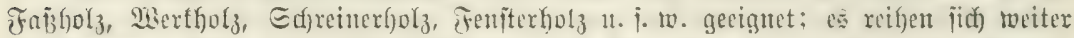

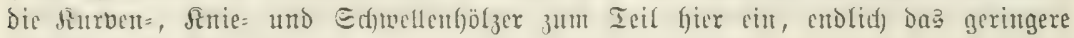

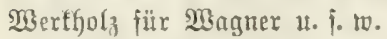

2. Itabelholz (banrijaje Evrtierung).

Epaltmare: Sllifinitte bejtex Sualität, zu Rlabiatur=, Intrumenten=, Edindelffolz und zu feitten Epaltwaren braudfbax.

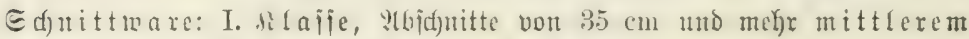
Durchmefier, aftreit uno gerabjajerig.

II. $\mathscr{K}$ Tafie, 2tGjidnitte von $26-34 \mathrm{~cm}$ Durifmefier.

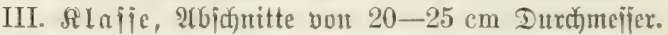

IV. Rla fije, Itbidnnitte unter $20 \mathrm{~cm}$ Durdymeifer.

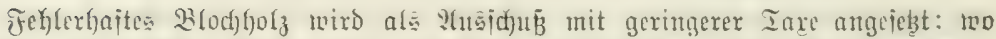

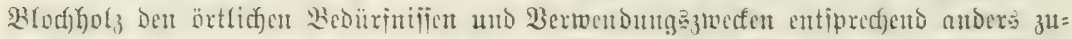

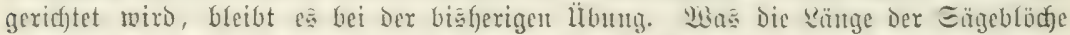

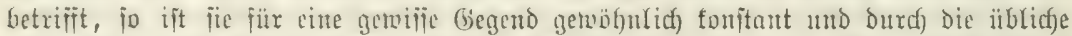

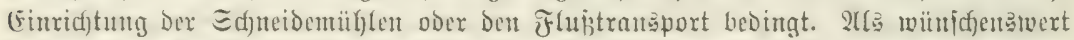

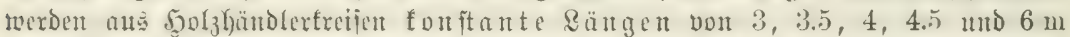

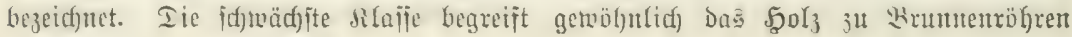
und bergl.

3. Übrige אुolzarten.

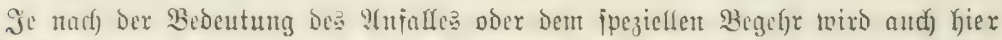

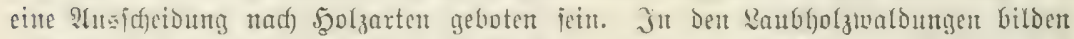

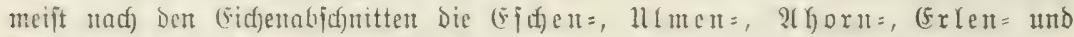

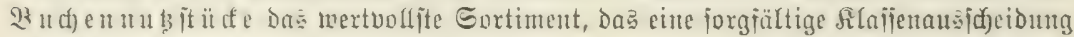
exheifat.

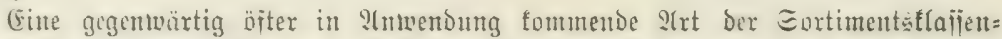

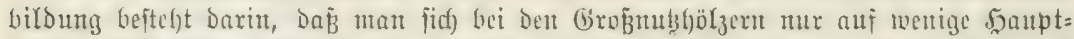

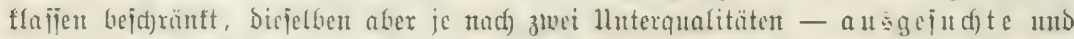

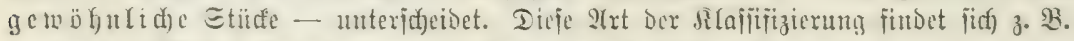

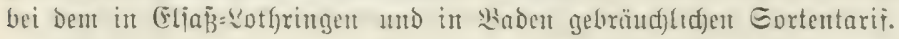

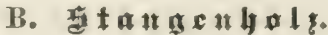

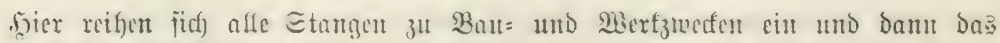

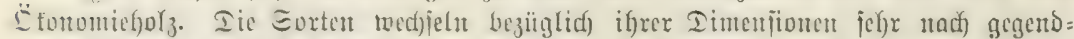

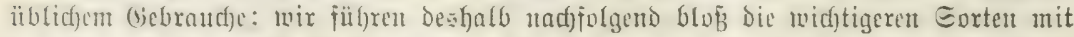

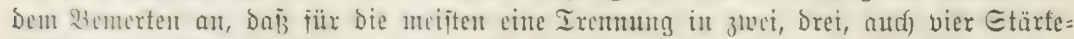
flaijen crforberlid) wiro, namentlicf) bet Den ftïrfiten Eortimenten, mit welden fier ber 2 trijang gemadft wirb. 


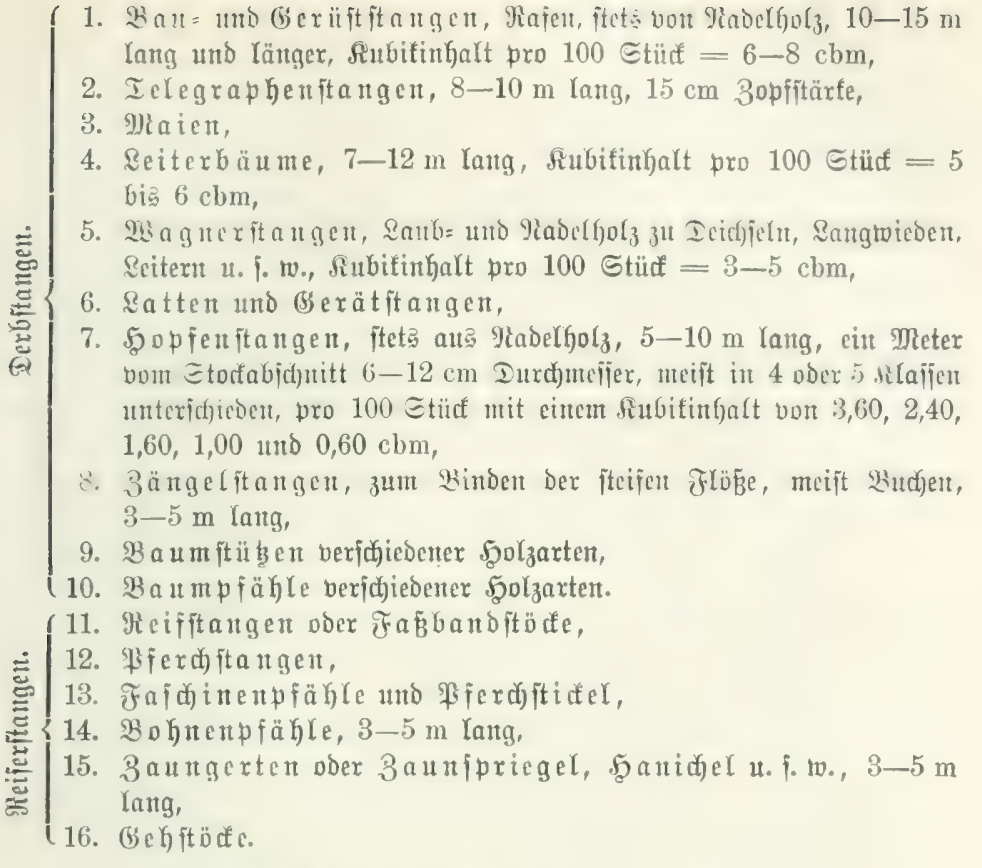

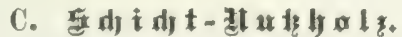

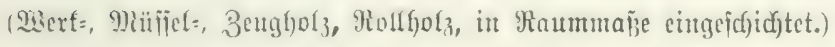

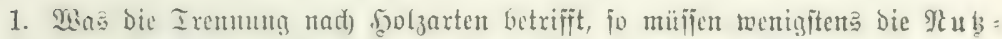

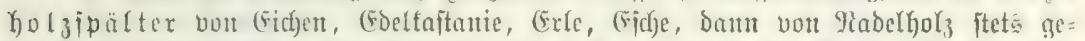

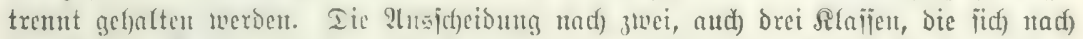

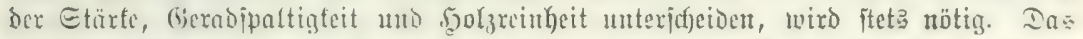

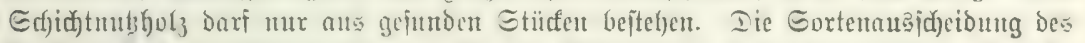

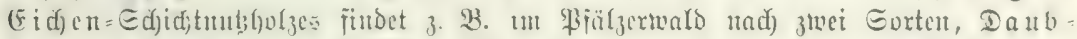

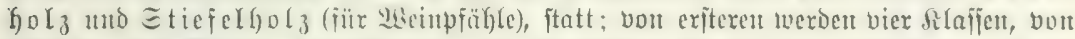

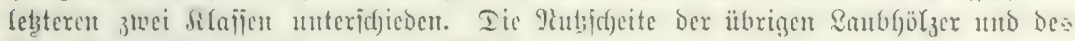
Stabelfolzes físeiden fid in je brei Rlafjen.

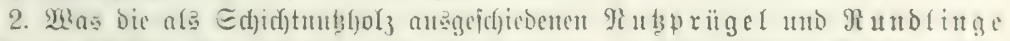

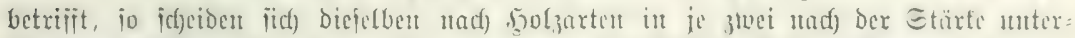

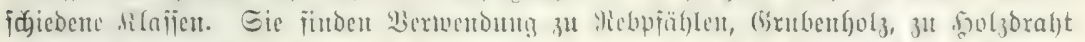

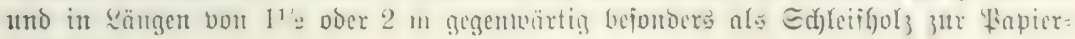
fabrifation.

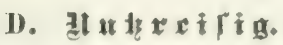

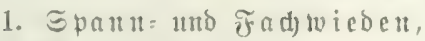

2. (5) etreidebätber,

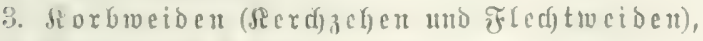

4. Befen= mo (Erbjenteifig,

(B) a v) er, forftbentsung. 9. Ituil. 
5. Trafdineminaterial,

6. (5) rabiertwellet,

7. Defrei门ig,

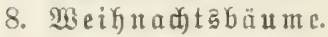

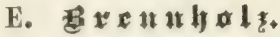

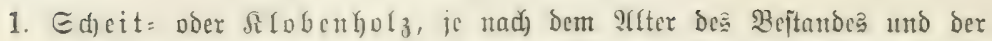

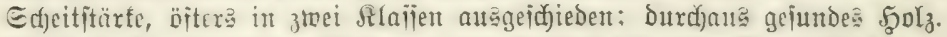

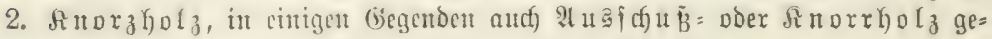
naunt, geiunbes, aber fnötiges, vertvadyjente Sdjeitfolz.

3. $:$ nbrudhol

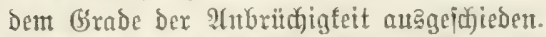

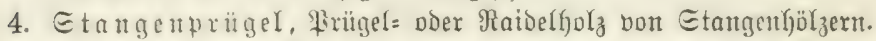

5. If itpxügel oder $\mathfrak{\Omega}$ ü upelhol

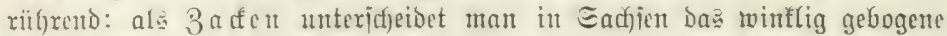

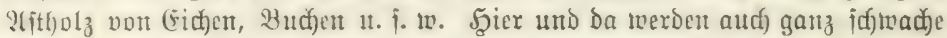
Hritgel ausgerormt, zwifhen 4-7 cm Iurdymeifer, unter Dem 9tamen গtolf

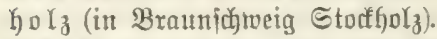

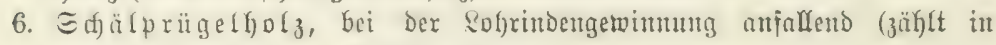

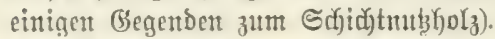

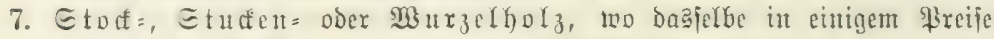

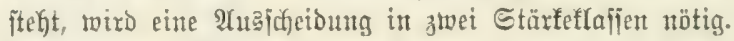

8. Il nipartige $\Re \mathfrak{l o ̈ b e . ~}$

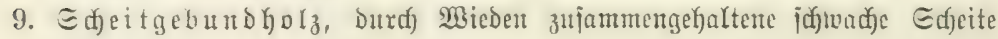
(Sachjictt).

10. Etaugenreijig, audid) zum Ieil Wajen genant, bab unter $7 \mathrm{~cm}$ ftarfe

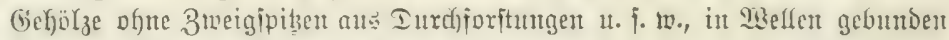
(Etammreifig voer Stammtwajen).

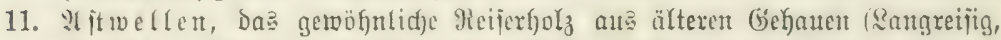
3opireifig, 2(jtreifig, Mbid)lagwajen, A(braumreifig).

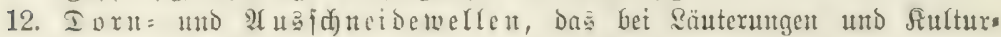

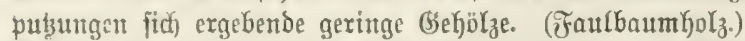

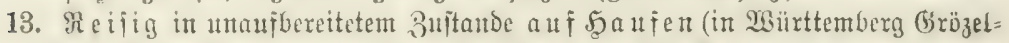

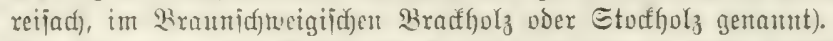

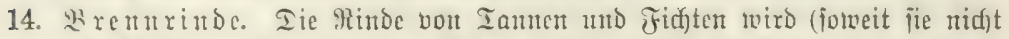
als (jerbmaterial vermertbar iit) an viefen Erten in Brentholzraumabe

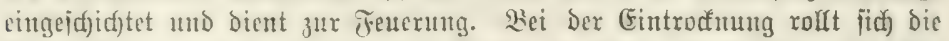
Rinde fuapp 3ujammen und beaniprudft in biefer Form bont geringitent Haum.

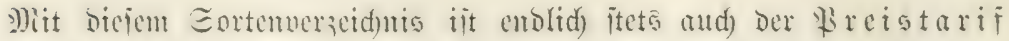

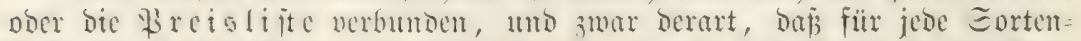

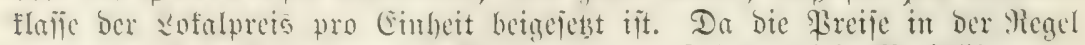

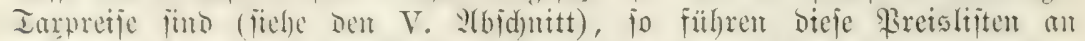

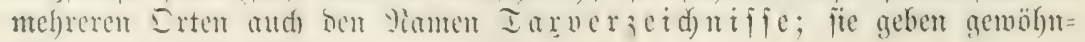
(id) ben Preis infl. (Seminmungafoiten. 


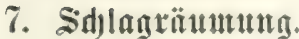

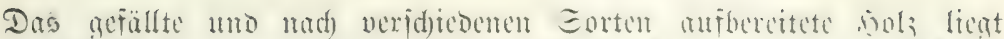

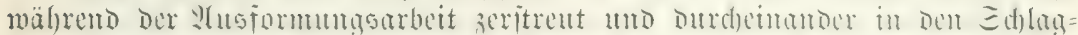

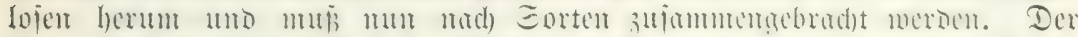

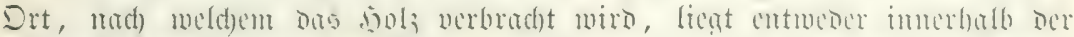

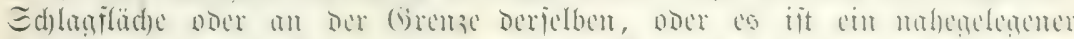

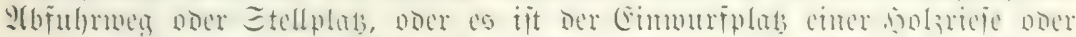

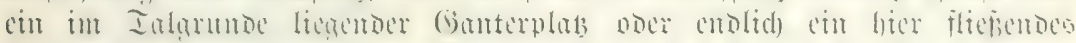

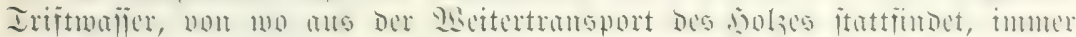

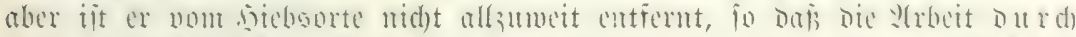

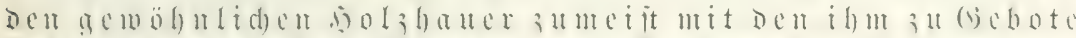

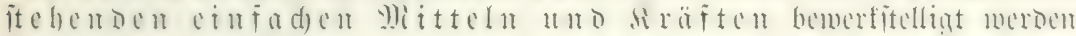

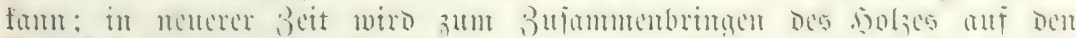

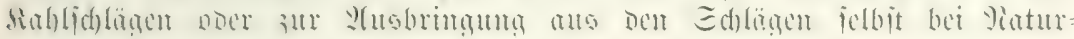
veriünutugen Iiergejpann vermentot.

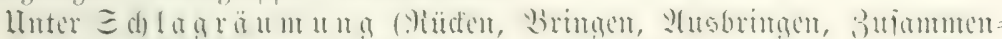

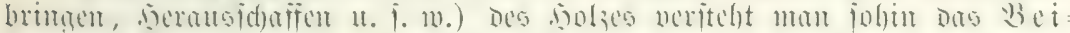
bringen bes ausgeformten Gdalagergebuijies an einen im Sd)lage ielbit befindliden ober nid)t allan weit von ibu

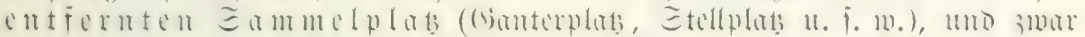
burd) bie cimfadjiten Jittel uno Beranjtaltungent.

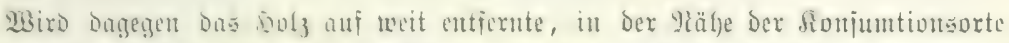

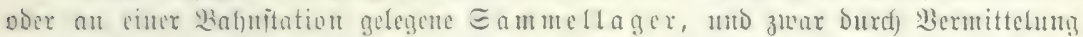

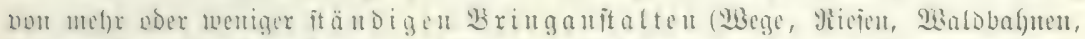

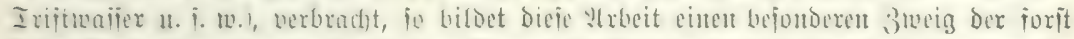

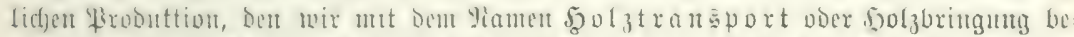

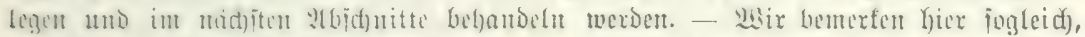

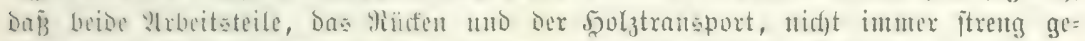

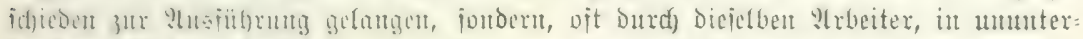

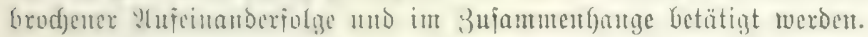

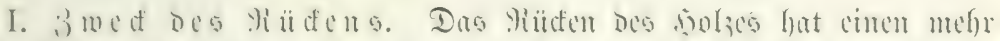

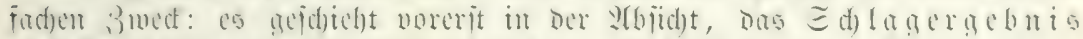

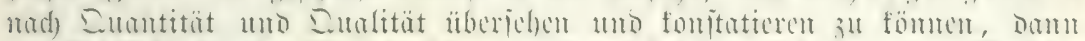

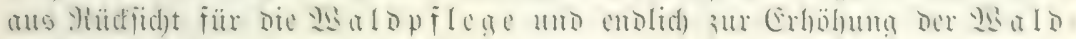
rente.

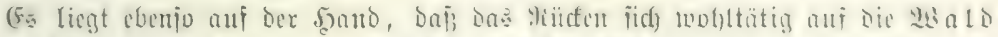

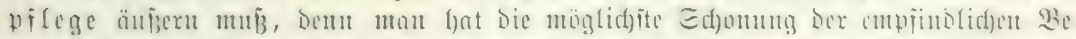

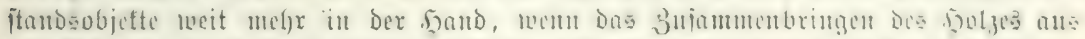

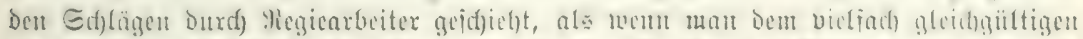

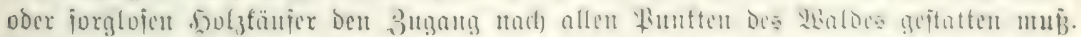

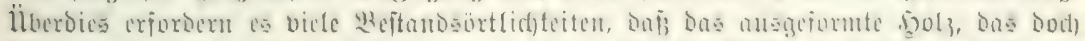

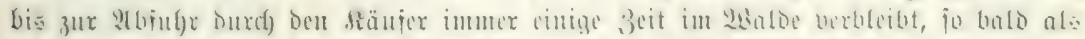

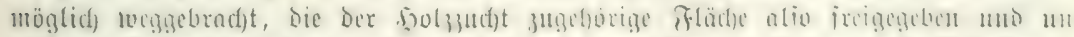

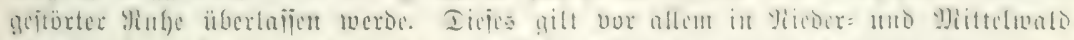

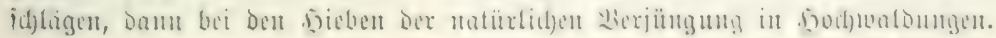




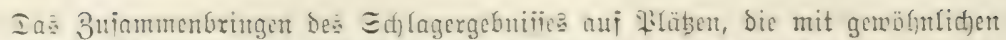

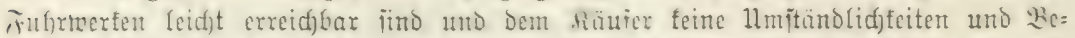

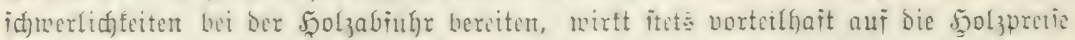
im Eime be Probuzenten, a I

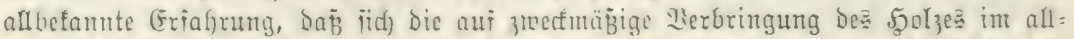
gementen vermendeten fioiten itetz mefriällig bezahlen: und menn aud bie :Irfeit Des Rüdens ïd) gleich) bleibt, ob ïte Durd) Dent Liblbeigentümer ober Durd) Den fiüner bejorgt mird, jo leiptet fie Der eritere bod weit bilfiger.

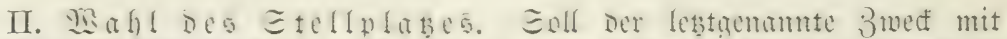

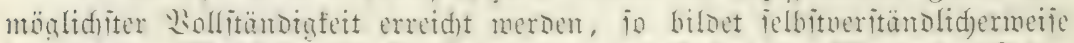

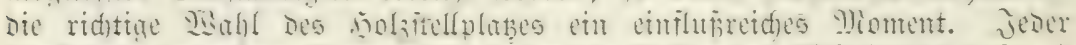

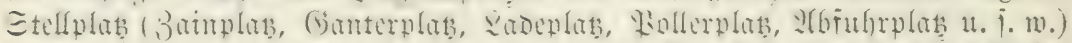

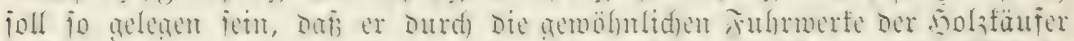

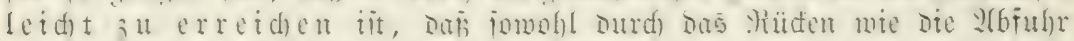

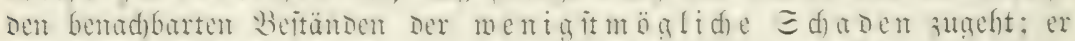
iolf I u itiqu und irei noer mentigitens trode

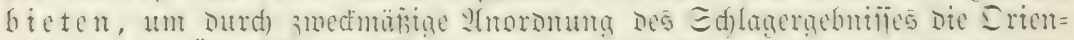

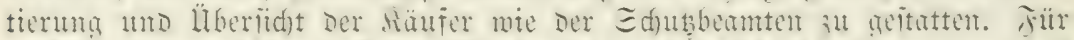

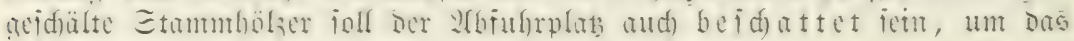
ßeipen berjelben ju verbüten.

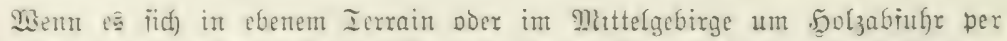

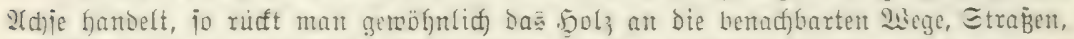
(ijejtelle oder, two Dicje nicht Baum Bieten, neben biejelben in cinen angrenzenden

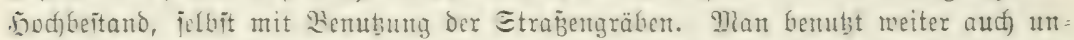

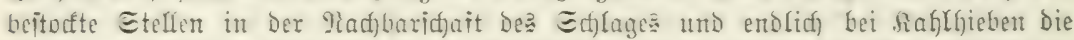

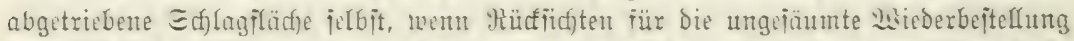

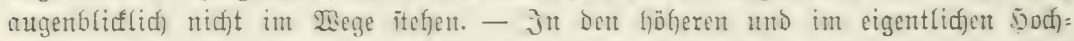

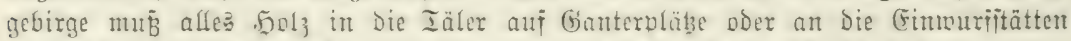

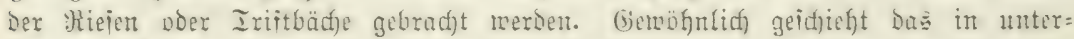
brodjener $\mathfrak{\text { Irbeitajolge. }}$

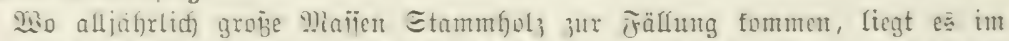

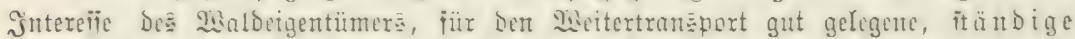
Zagerpläge ju beidaffen, bas Etammfolz in Loferen Gantem auf llnterlagent aui= zurollen und bon ber (Erbjeuctigteit zu ijolieren.

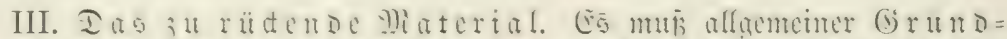

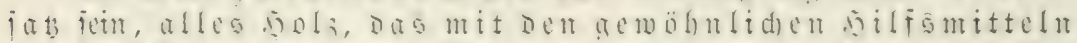

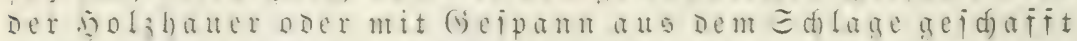

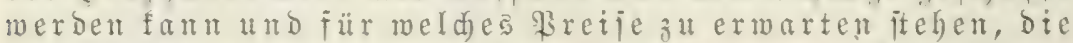

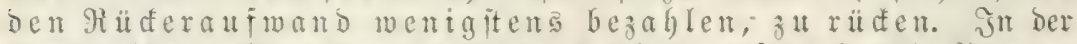

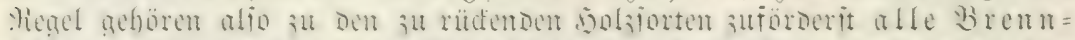
h)

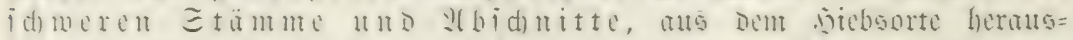

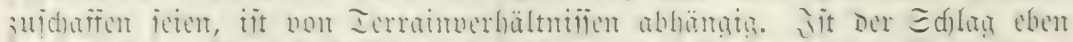

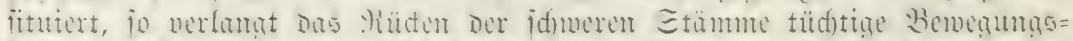

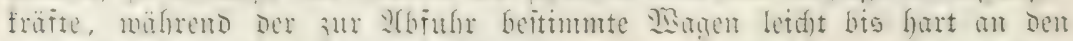

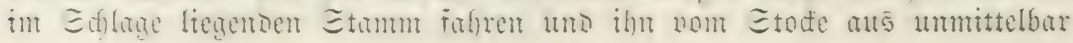




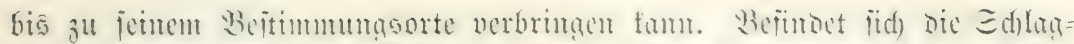

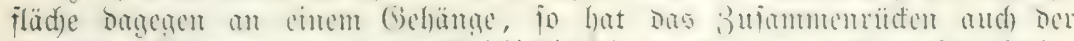

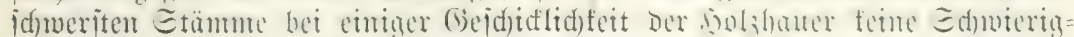

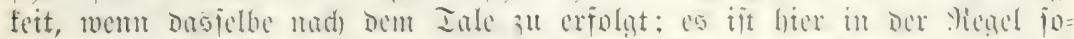

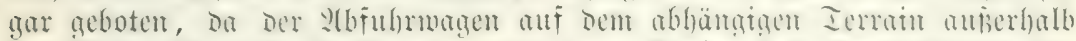

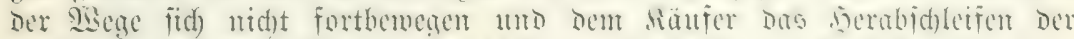

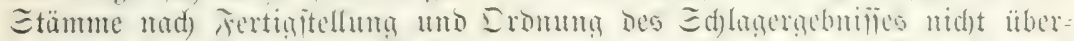
latien werden fum. 诜

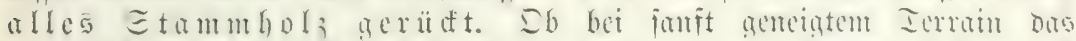

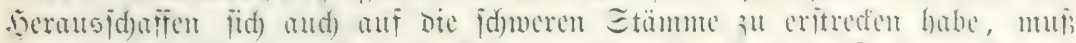

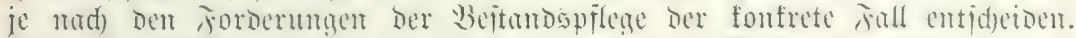

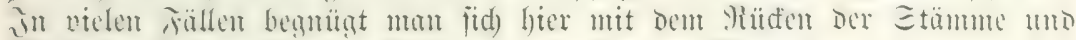

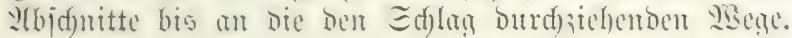

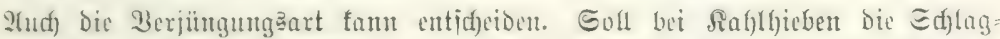

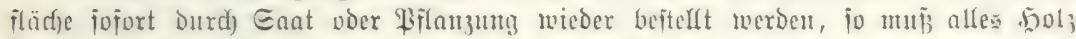
gerüft merben. Bei Der natürliden Ierjüngung ergeben fid) in Den vorerfit nod)

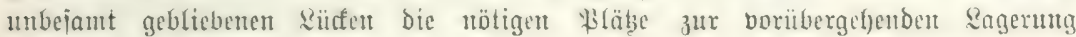
wenigiten der jăberjten Stammbölzer.

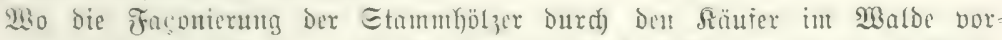
genommen wiro, da jollte nun biefelbe io vid als tunlidg niemals intuerhalb dor E(f)lagîlädje geftatten.

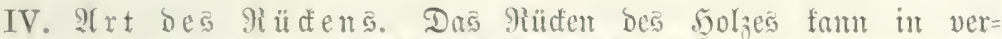

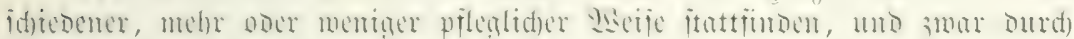

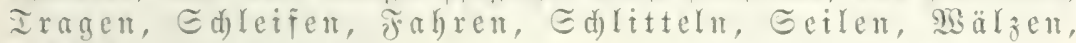
ङdicisen แnD Etürzen.

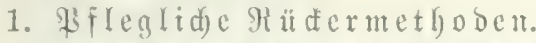

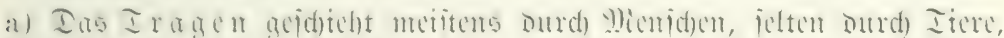

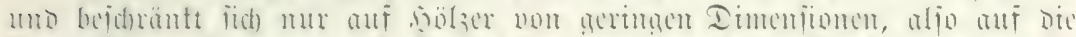

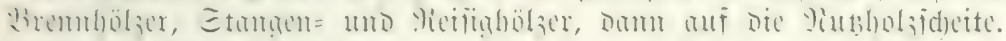

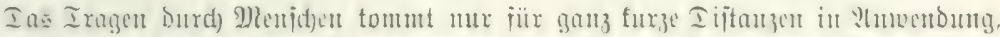

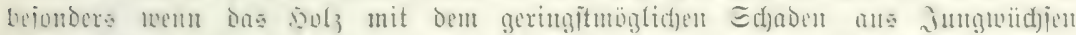

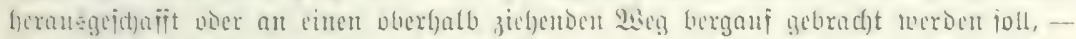

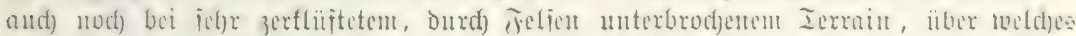

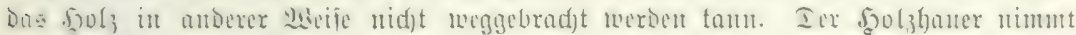

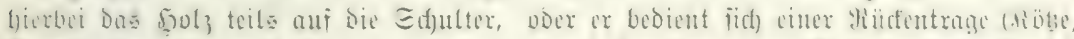

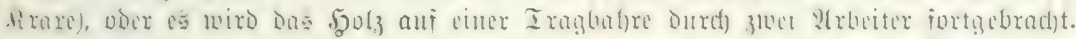

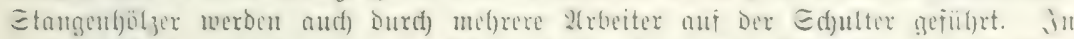

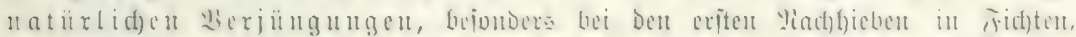

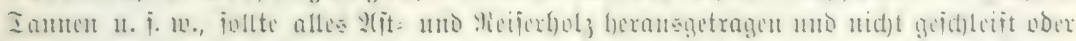

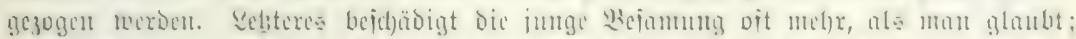

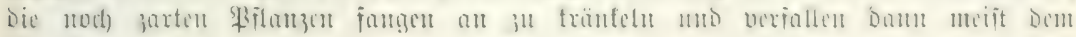
औüijeltäjer.

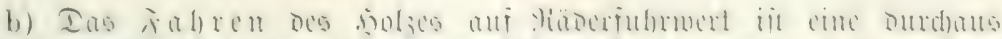

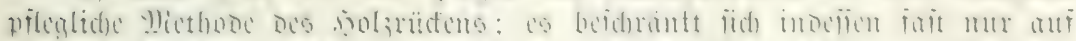

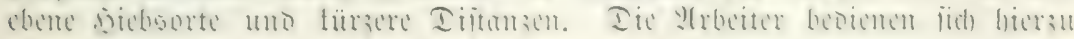




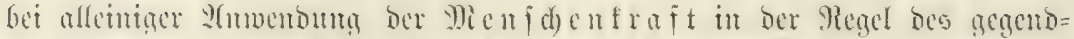

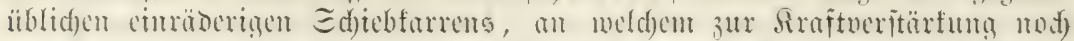

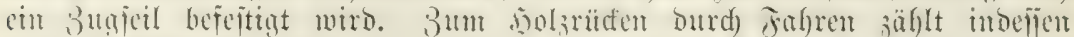

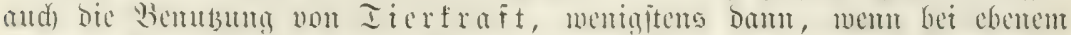

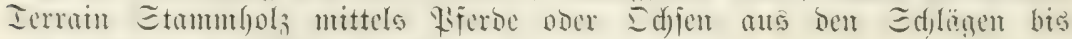
żun näd)jten Geftell z̆ ziehen ijt.

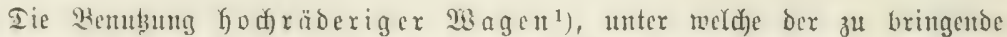

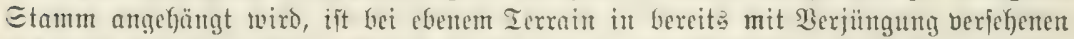

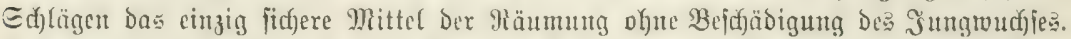

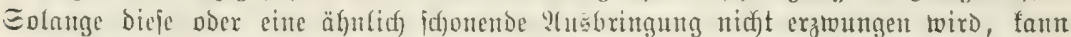
bei rajc)en Räunungen bon feinem (Erfolge ber matürfirfen Berfüngung oder Santen

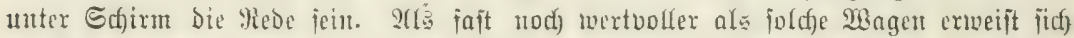

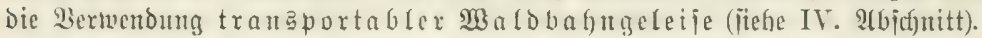

Edfon Der feidjten Förberutg halber terben paliende, offene IFade eingefalten;

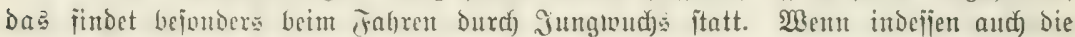

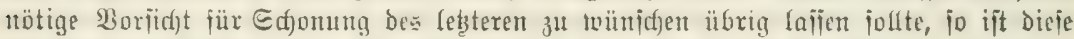

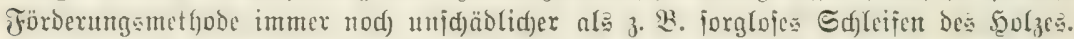

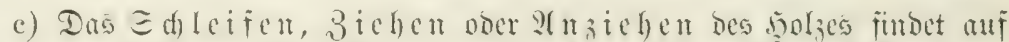

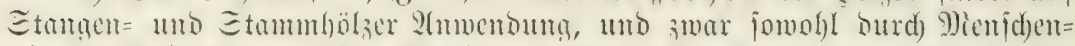

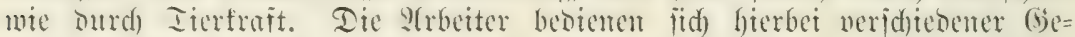

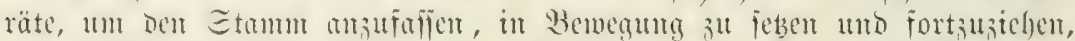

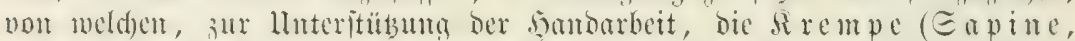

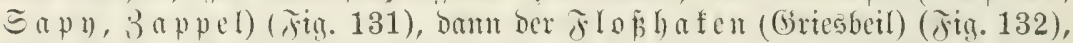
ber (5) riff (siral) jamt giendebafen (jig. 133) und einfade bebel=

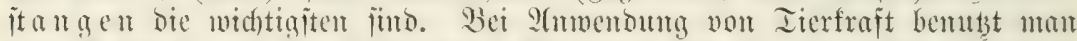

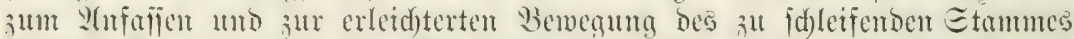

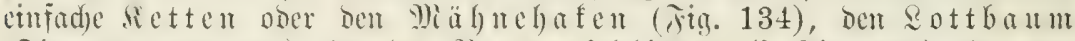

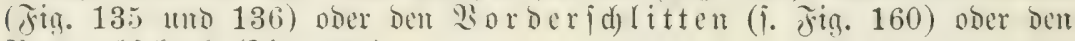

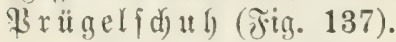

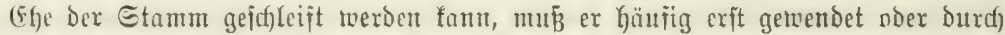

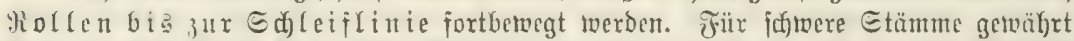

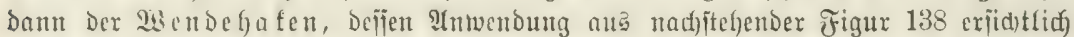

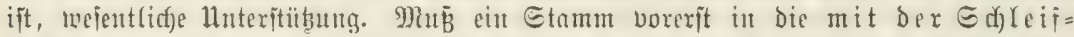

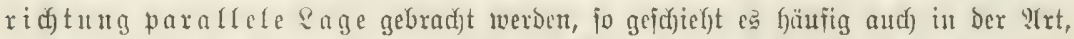

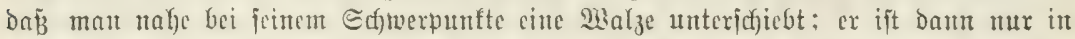

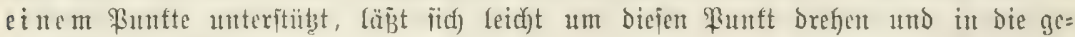
wünict) Rage bringen.

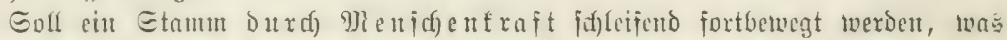

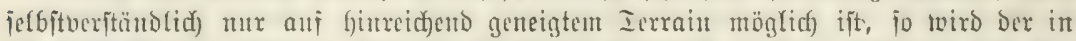
Die Edfleiflinic geluadste, mit Dem Etodenoe tafmärt gerid)tete Etamm von Den

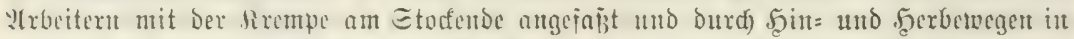

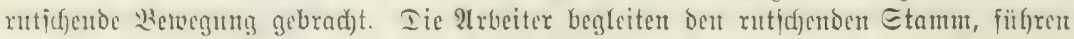

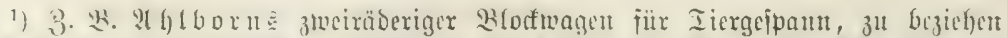

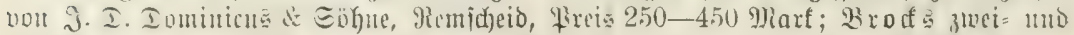

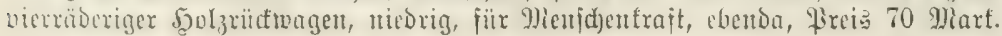




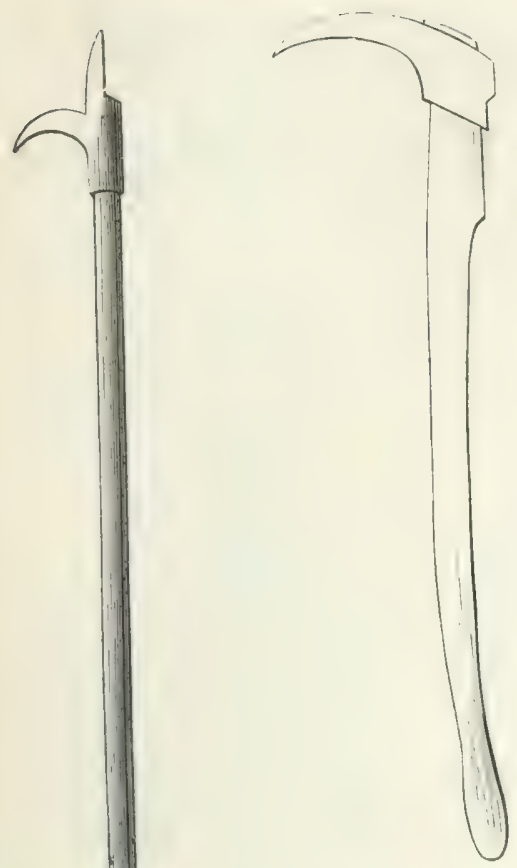

Fig. 131. Sapine.

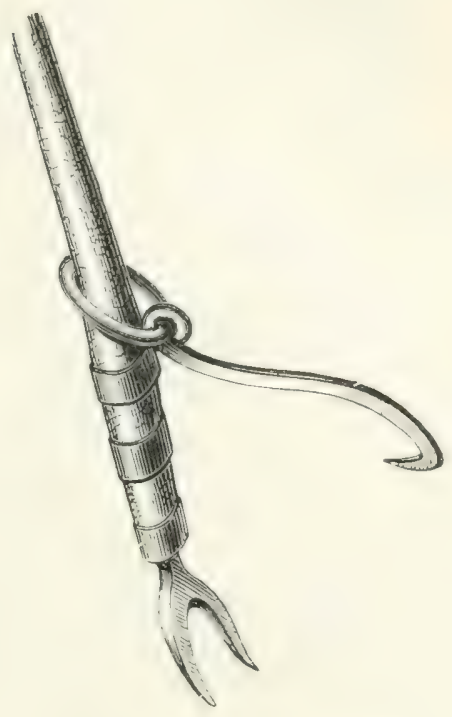

Fig. 133. Wenbehalen uno Griff.

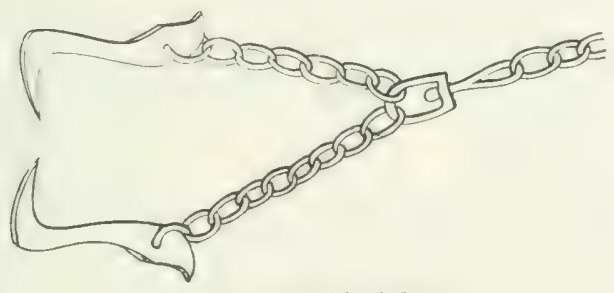

Fig. 134. Mäbrehaten.

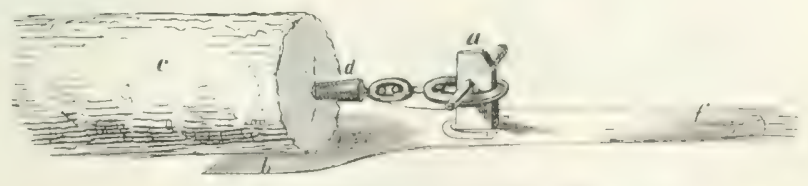

ifig. $13 \%$

slophaten.

Jig. 135. Sottbaum fïr smei Bugtiere.

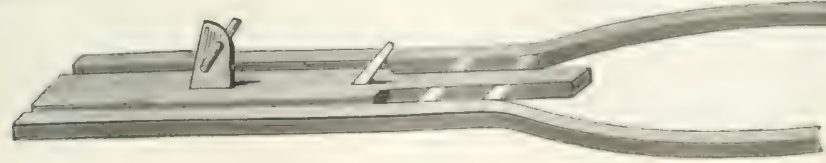




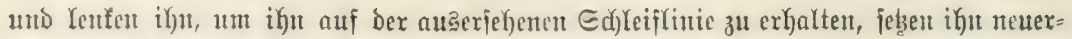

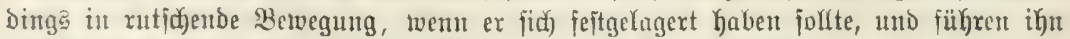

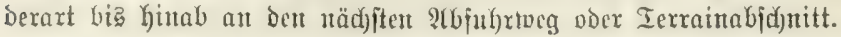

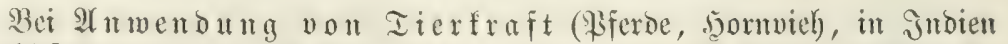
aud) (Elefanten u. f. w.) ijt man nidjt anf blop geneigtes Ierrain bejdyüntt;

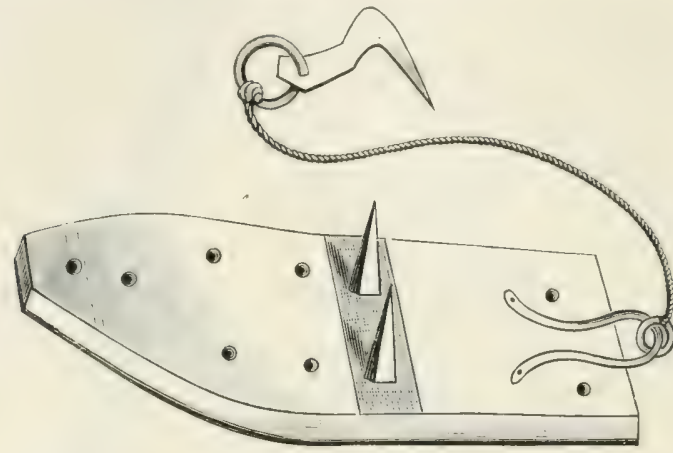

Fig. 137. Frügeljouh.

Das 3iehen gebt anf ebenen ober fanftgeneigten Fläden an beiten. Sier wiro um das Etodende des ă id leifenden Etammes sime cinfadje Ed)leiftette gewuthen, ober man bemust, wie in Den Ullpen, Den

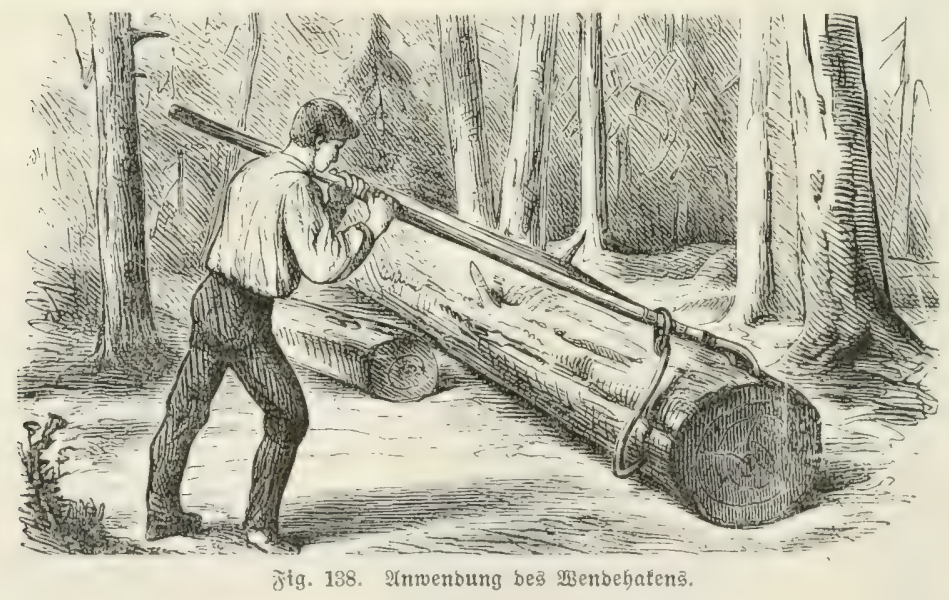

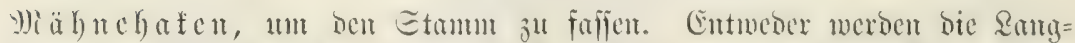

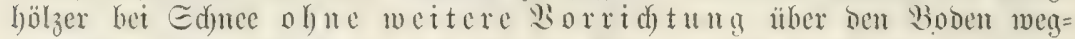

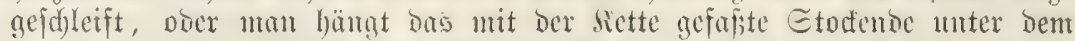

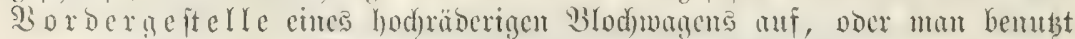

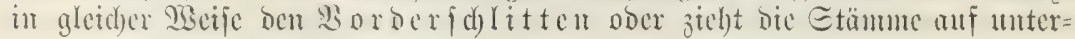
gelegter 9 Salzen heratis. 


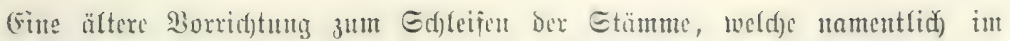

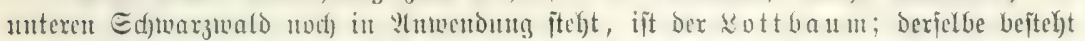

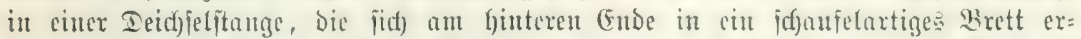
meitert (Fig. 135 fïr zwei, Fig. 136 für eit 3 ugtier). Iiefes joumfelartige Birett (b)

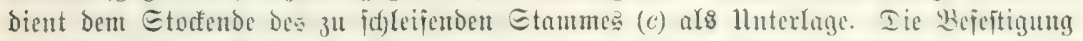

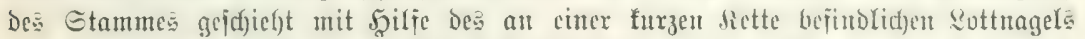

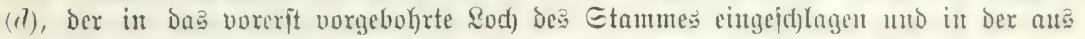
Der Figux erfid)tlid)en :(rt nu jogen. Ramme $(a)$ angehängt wiro.

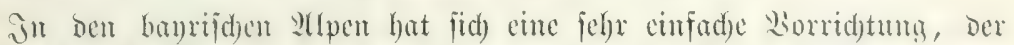
İ $x$ ügelfd)

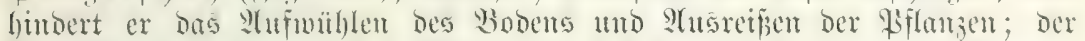

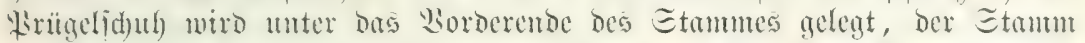
Drüdt fid) in Die eifomen Epiber; jollte ber Edful) beim Irangport fid)

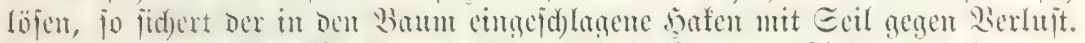

Jn Den metiten MEaldungen ijt Das Ed)leifen ober Bieben Dés Etamm=

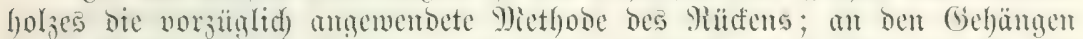

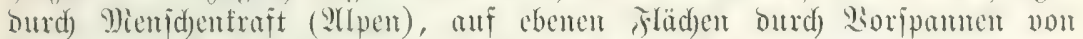

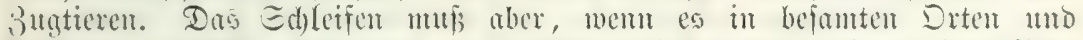

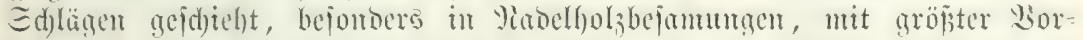

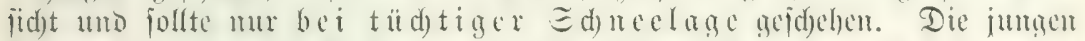

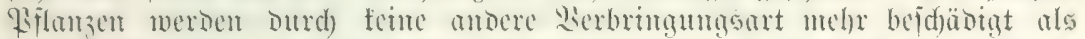

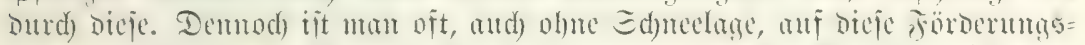

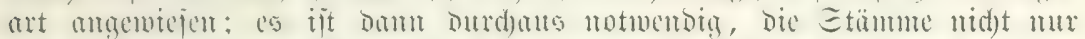

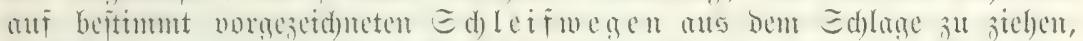

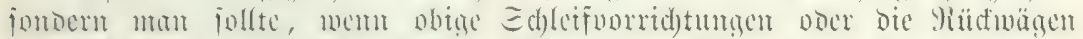
nou

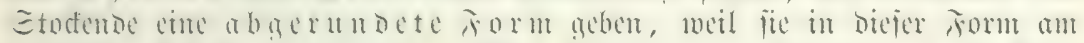
mentaptu $三$ d)

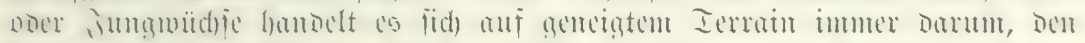

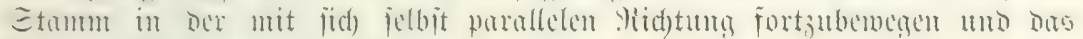
Bollen besierben zu verbüten.

Eoll cil Etamm $f(d)$ i⿺

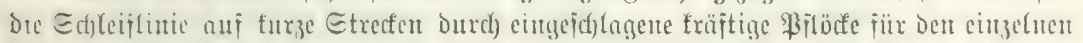

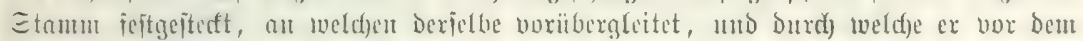

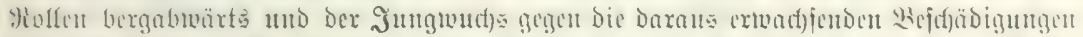

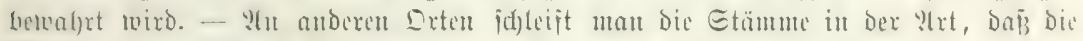

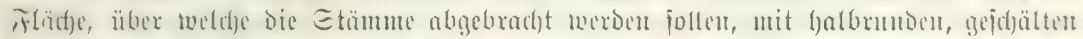

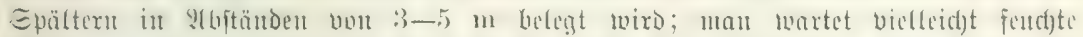

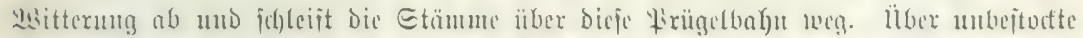

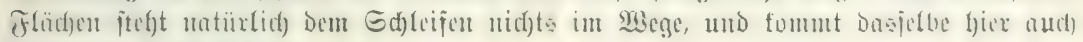
allgemein it $\mathfrak{A}$ șiübrung.

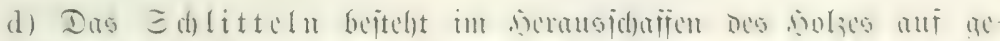

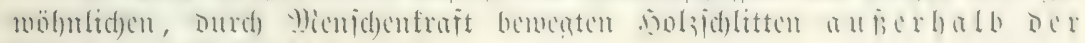
it äル Dịcu

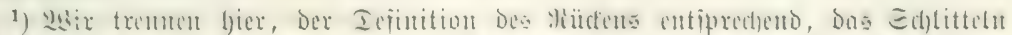
ani, ergalb of 


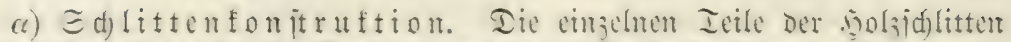

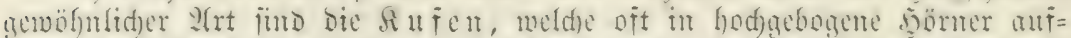

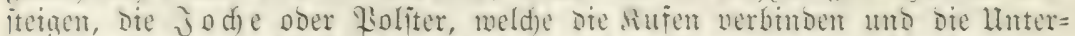

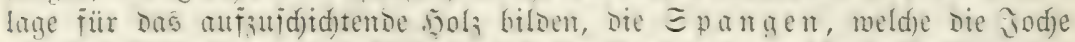

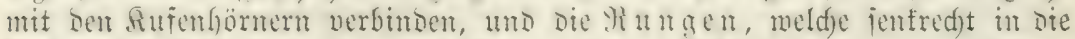

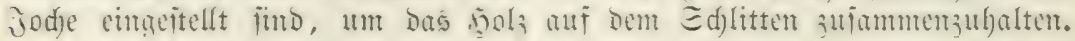

Eomohl alfe Wibldidflitten in iffen mejentlidjiten Ieilen miteinamber überein= Ftimmen, io zeigt Dodf jeder Edfitten einer beitimmten Sandidjait ieine bejondere

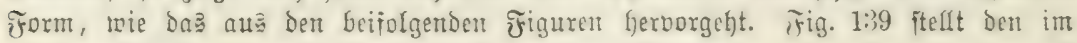

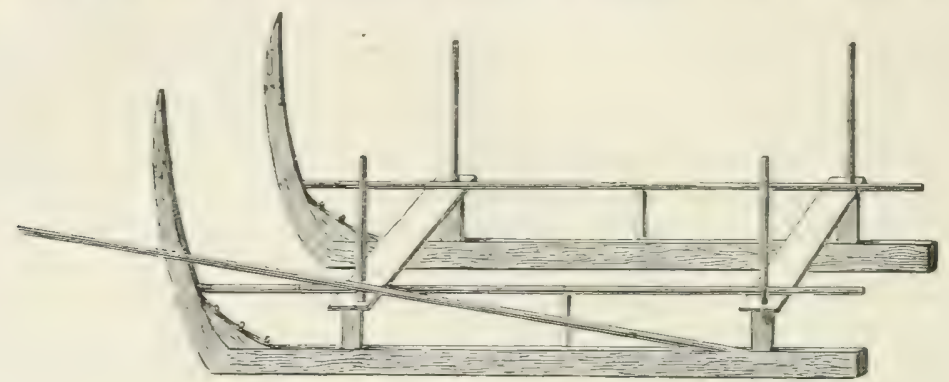

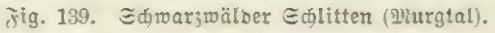

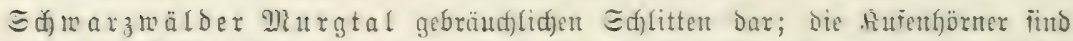
meift angeiduftet und iteigen unter einem itumpien Leren $\Re$ hein= und unteren 2laingegend üblide Edflitten (Frig. 140) hat gar

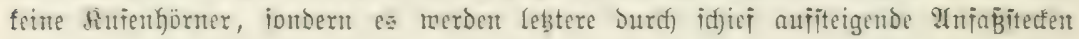

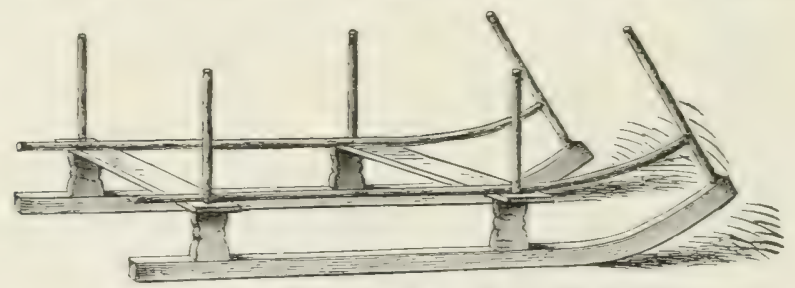

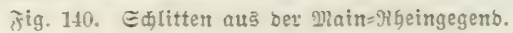

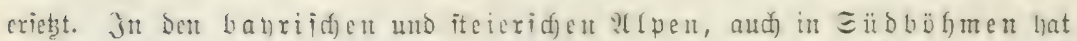

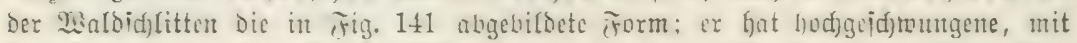

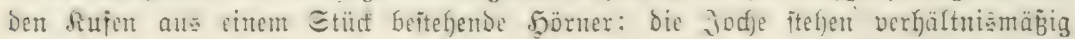

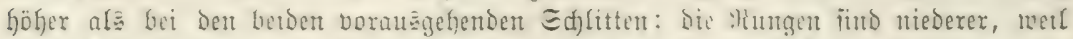

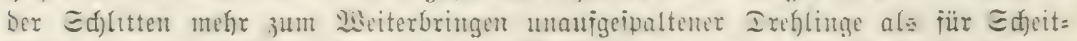

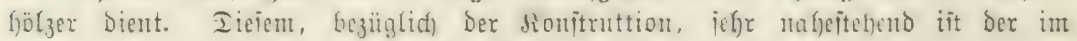

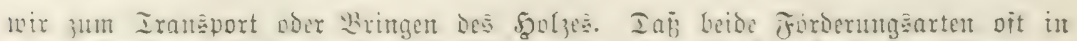

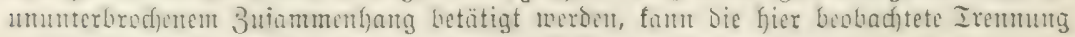

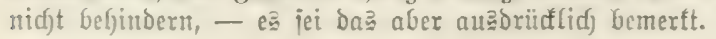




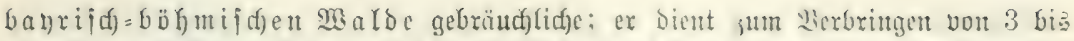

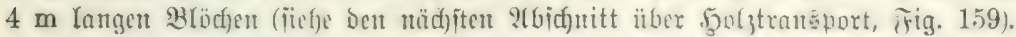

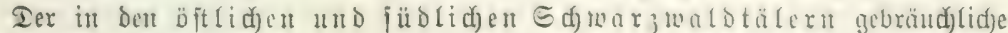

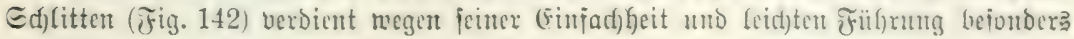

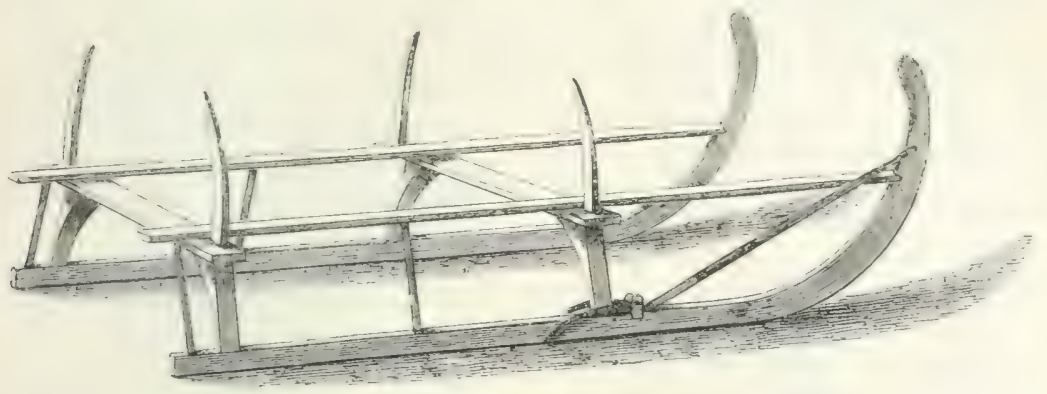

テ̃ig. 141. Alpenjulitten.

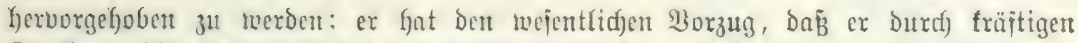
Irucf auf bie vorberen (Enden ber 3utaftangent leid)ter ala jebex nndere gुefentmt twerben

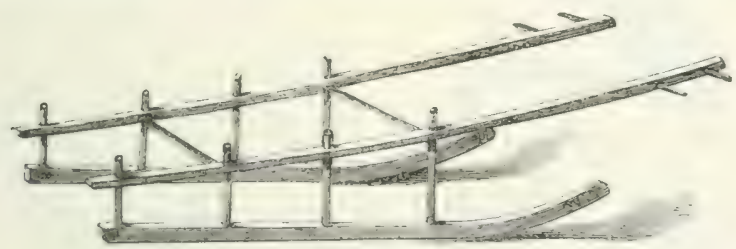

F)

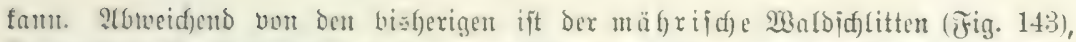

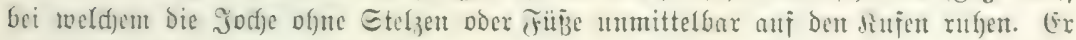

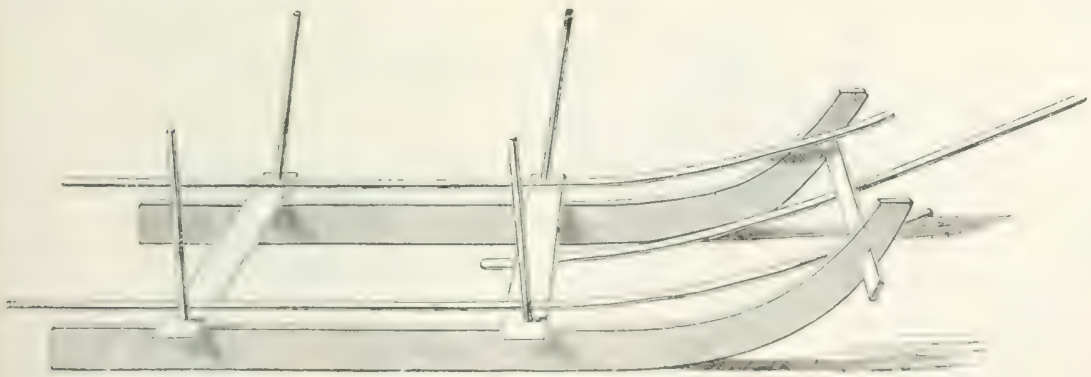

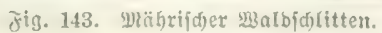

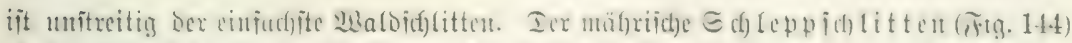

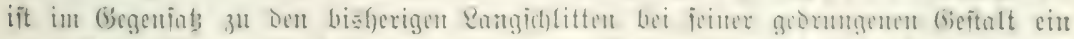

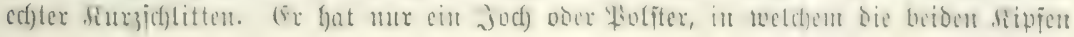




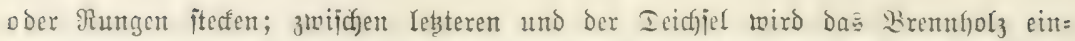

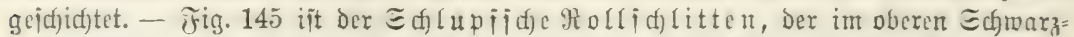

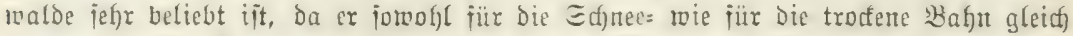

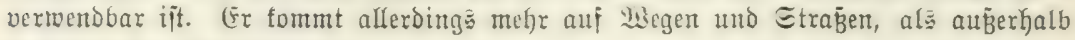
Derielben zur গ⿹ertoendung.

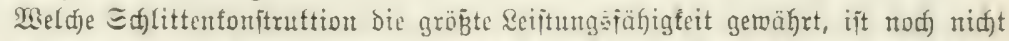

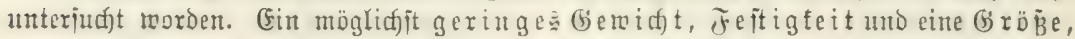

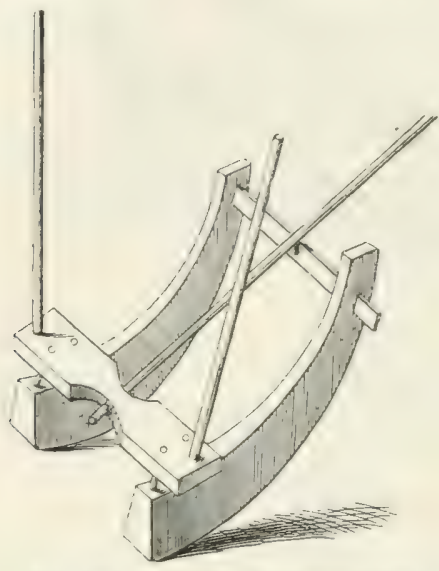

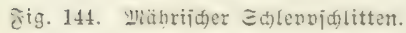
weldye Das 2Luflaben bex bollen, ber $\mathfrak{B}_{e}=$ regungătrait eine? Menjdjen entipredjen= Den Rajt gejtattet, finto wejentlidide Forde= rungen eines tüd)tigen, arbeitäförbernden Edjlitten.

$\beta)$ Die $\mathfrak{A}$ menoung bes Ed)lit=

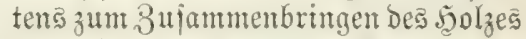
jebt ente benubbare $B$ ab u vor= aแ3. Das Edhlitteln findet zowar ge= möhnlidy auf ber Ednee= ober Minterbabn itatt, mandimal er= folgt es aber aud) auf ber idneelojen oder Sommerbahn.

Mas bie jo ijt in ebenem Ierrain uno bei geringem Ednnee mit gefrorentem Wosen eme bratdbore bahn entweder idjon ïberall vorbanden ober fam

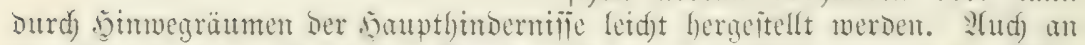

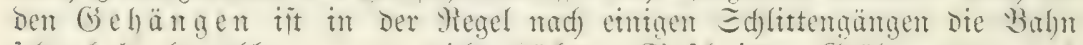
jebr bald brandebar, mem nidjt vöd)er, Cinidurtte, Gräben oder and)

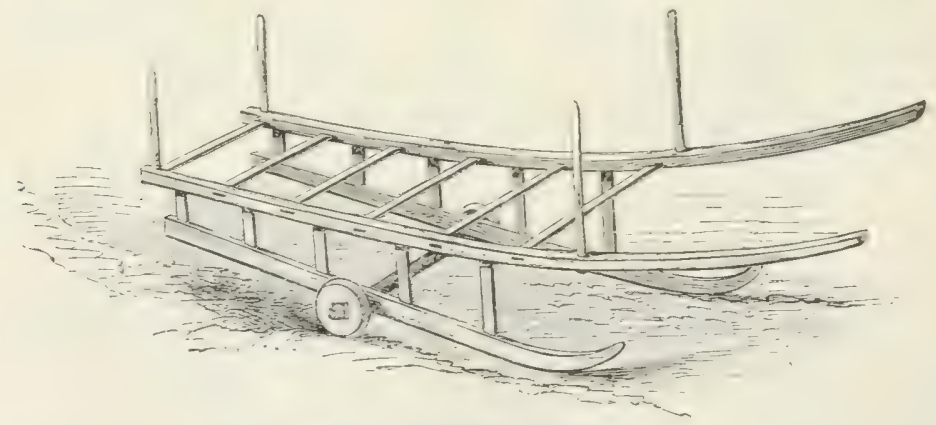

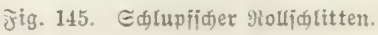

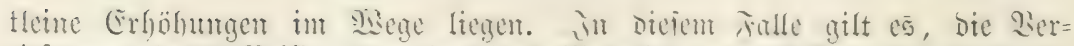

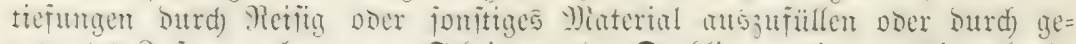
orbutes 3 ujammenlanen vou Edjeitern obor Irehlingen cine vorübergehende

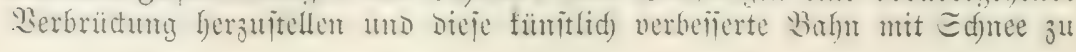




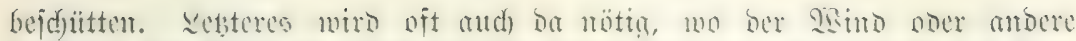

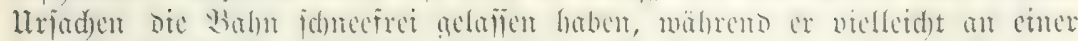

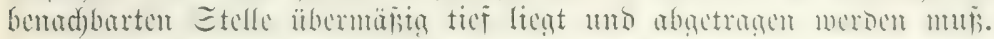

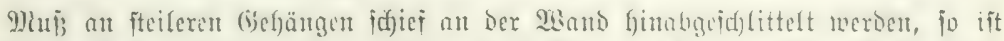

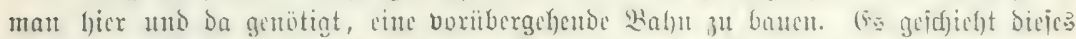
Durd) jogen. Fir

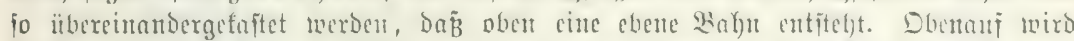

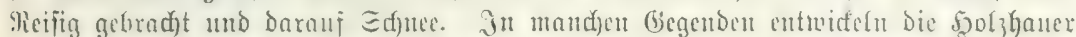

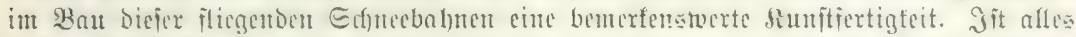

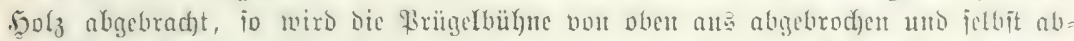

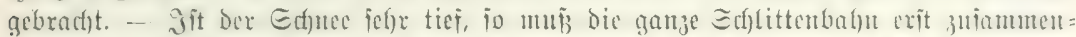

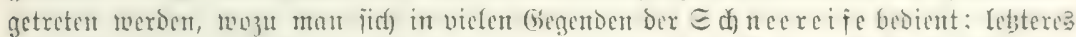

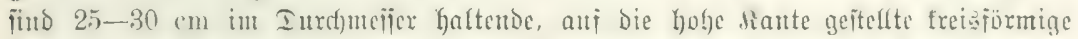

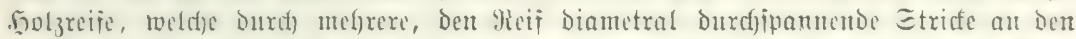

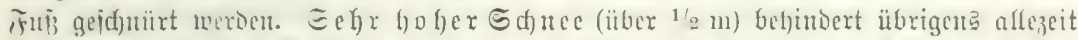

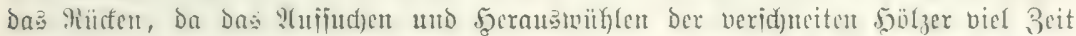

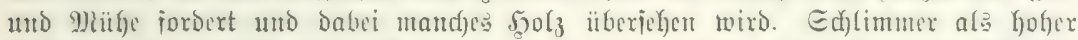

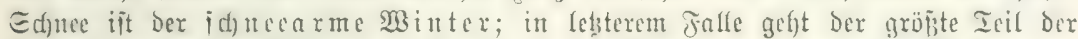

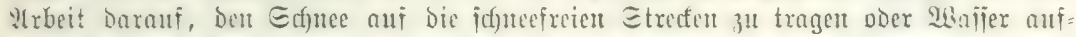

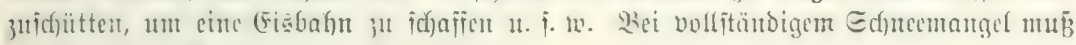
oft ber ganze Röunungąbetrieb jiftieren.

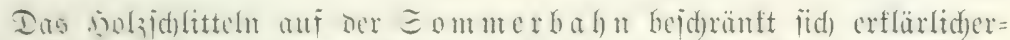

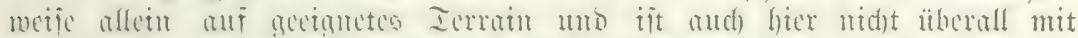

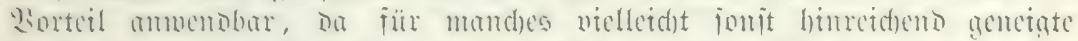

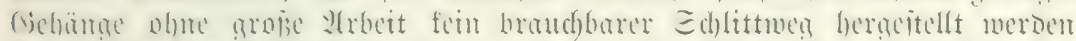

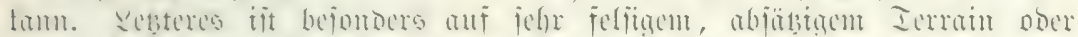

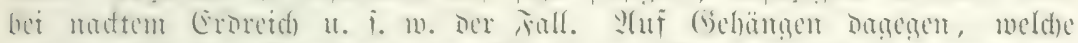

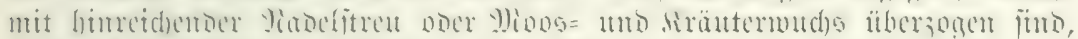

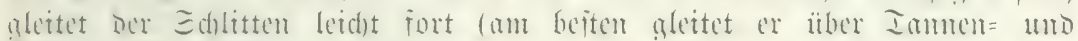

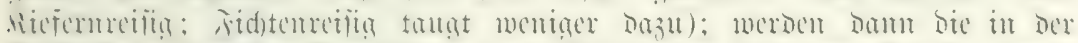

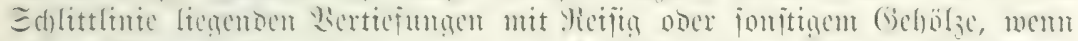

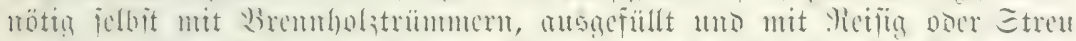

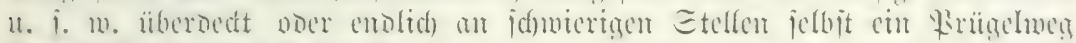

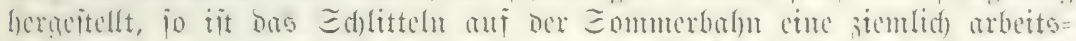

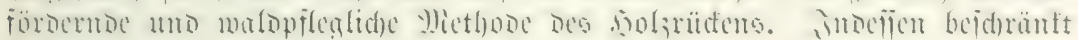
iid) basjelbe immer mux auf furze Dijtanzen.

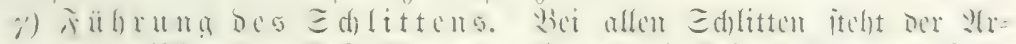

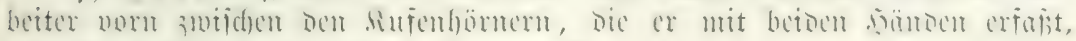

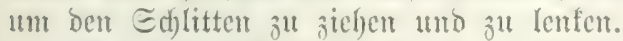

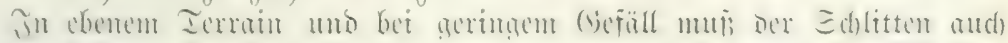

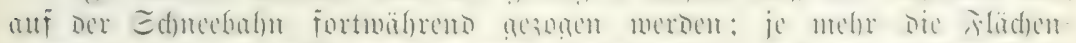

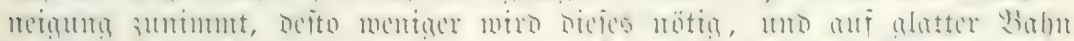

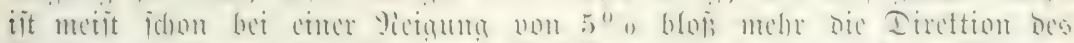

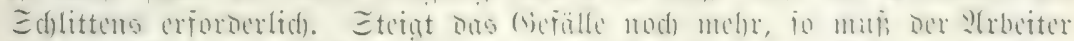

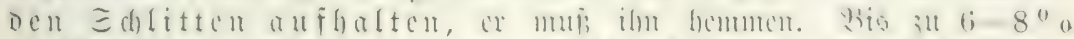

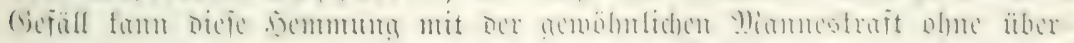

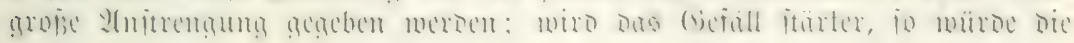


Sdunelligfeit bes Ed)littens aud) bie angeitrengteite Miannesfraft üherwinben;

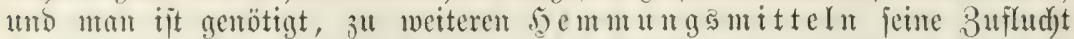

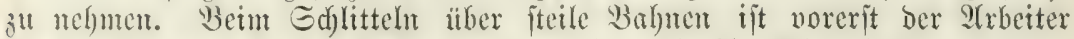

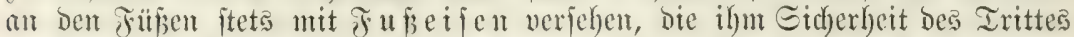

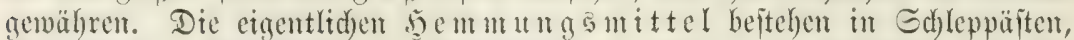

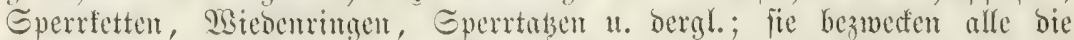

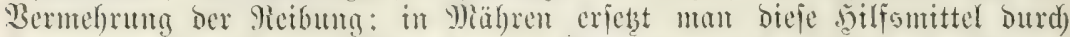

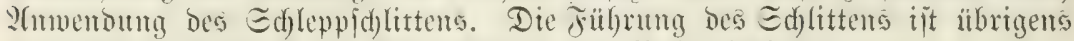

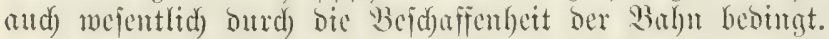

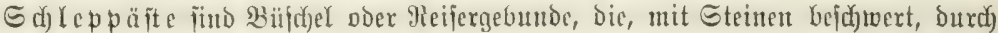

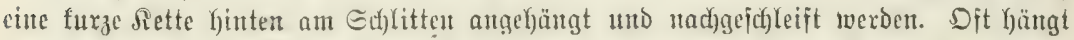

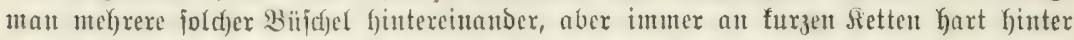

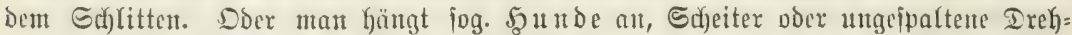

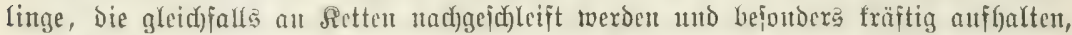

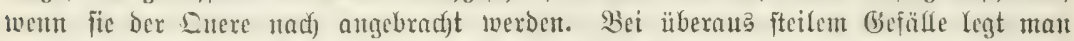

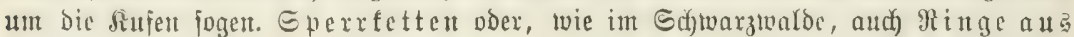

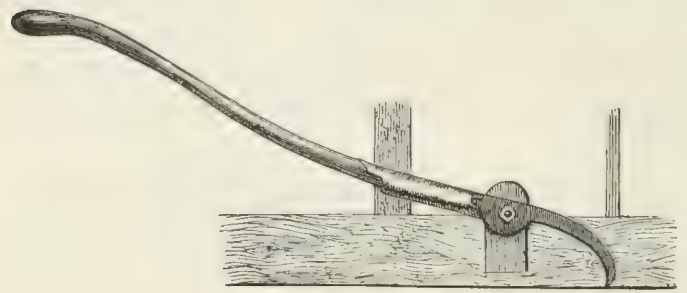

Jig. 146. Sperrtathe. Flo fluteden, bie über bie 尺ufentjörner hinabgeidyoben werbelt, woburdid offentar

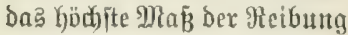
und Semmung erreidyt wiro. Gine bejondere Eperrvorrict)= tung hat Der in Den Arpen gebräuddiche ভdjlitten: auf eitter, meift auf beiden Seiten Dę Sdatitten be $=$ finten fid jogen. Eperx=

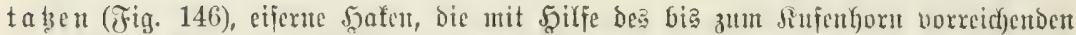

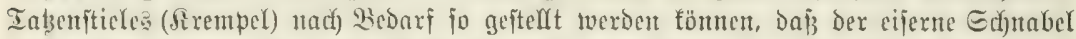

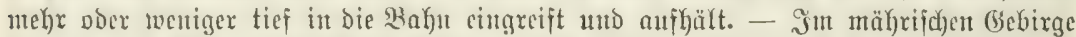

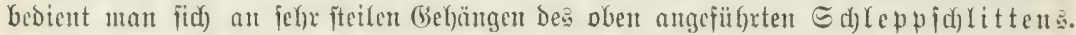

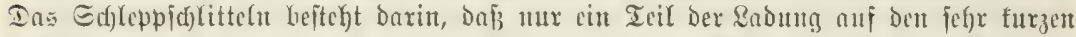

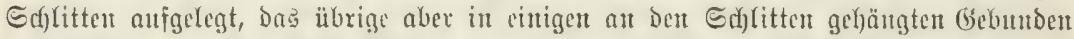

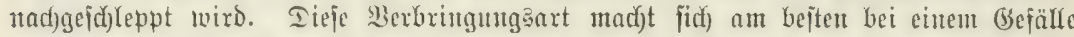
volt $\left.25-30 \%{ }^{1}\right)$.

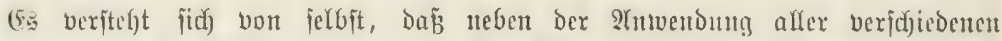

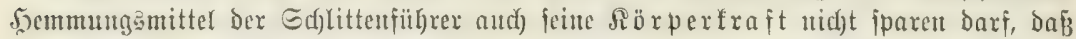

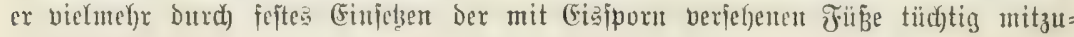
arbeiten habe.

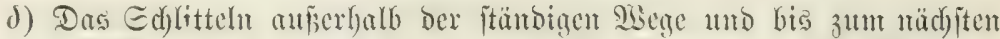

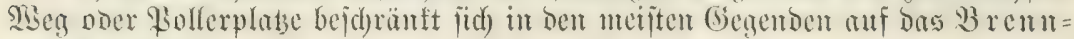

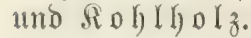

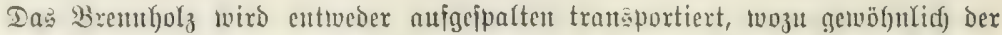
Ed)litten mit höher anfifteigenton Ripfen ausgeriiftet ift, zwifduen weldye bie Edjeiter

1) Siefje das 3entralblatt für bas gejamte Forftucion 1876, હ. 502. 


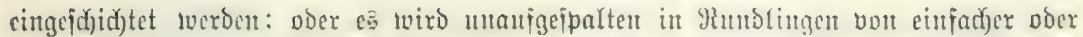
boppelter Edfeitlänge (bie Roh)lhölzer mandfer (Gegenden) gebrad)t, in weld)em Falle

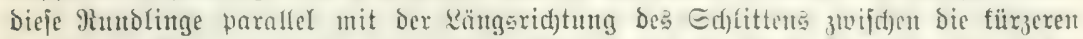

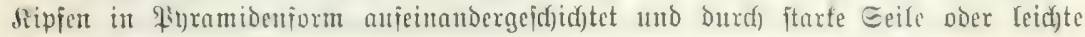
Retten in beiben Fälfen verid)lungen uno feftgehalten twerden.

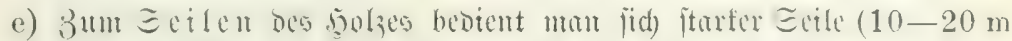

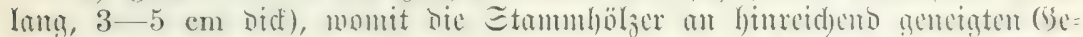

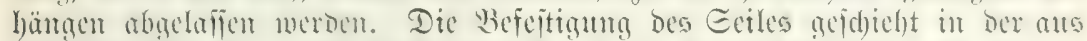

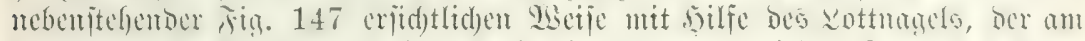

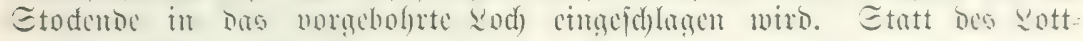
nageles bedient mat fidd) and cines an Seilende befejtigten fitarten eifer $=$ nen Safents, ber in ctue utf ber räbroflädje des Stanmes cingehanene Rerbe enrgejdlagen wird. je nad Der \&age des abzulaijenden Stammes länt man bald bas Stodembe, balo ১aร 3oprende vorausgehen. Scat man ben Stamm berart mit bem Eetle gefapt, fo wird lesteres un einen in ber Jiäbe itebenden Stanm ein= ober mebrmala (je nad) ber Sdywere des - Stammes und ber Ierrainnetgung) gefdungen uno burch allmälylidyes Jiad)lafien des Geiles der Etamm

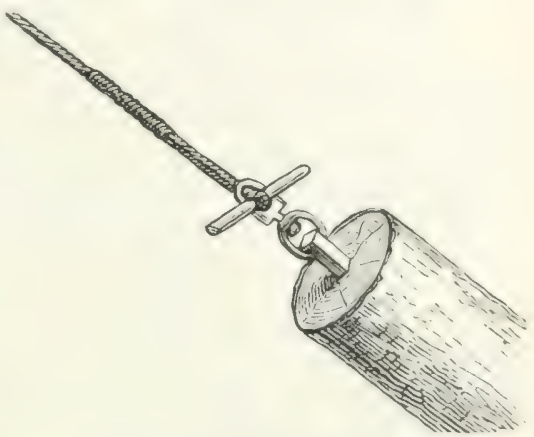

ซึig. 147. Ceilen Des 5olzes.

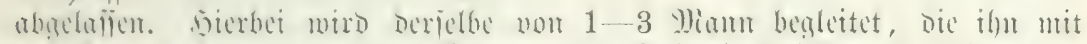

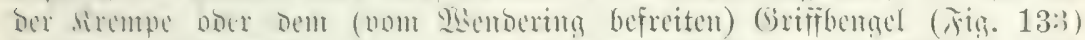
Dirigieren mo 3mijd)en Dem etma norhambenen

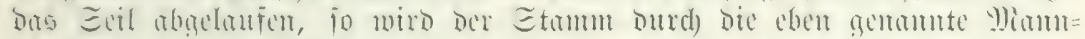

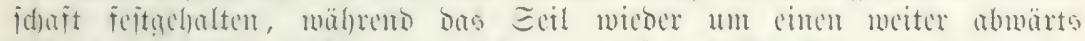

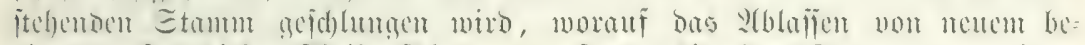

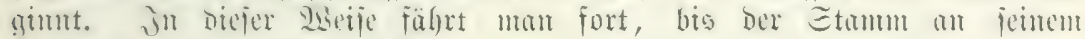
Seitimmungsort angelangt ijt.

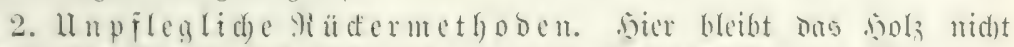

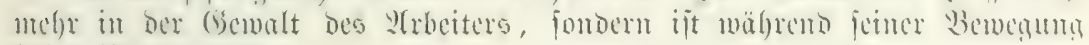
fid) jelbit überlafler.

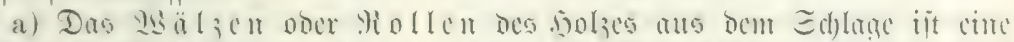

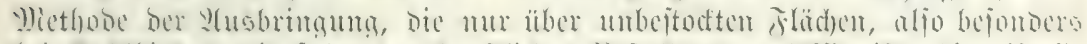

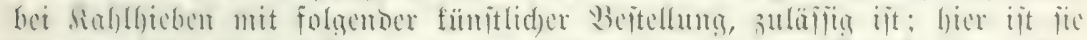

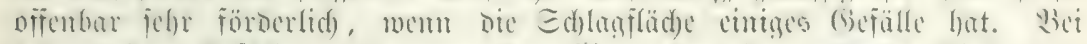

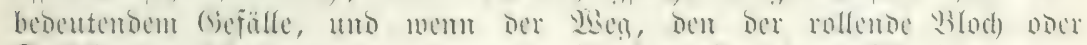

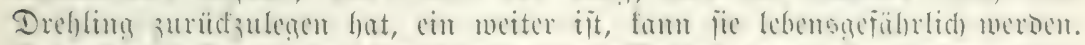

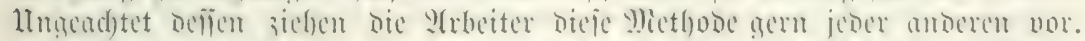

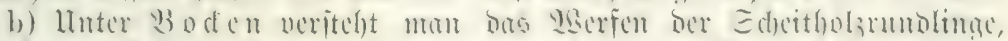

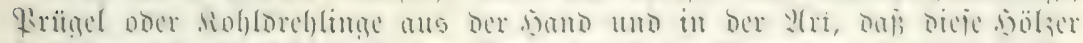

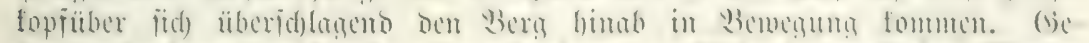

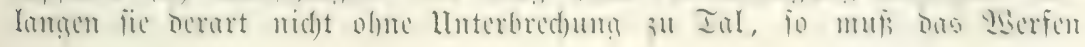




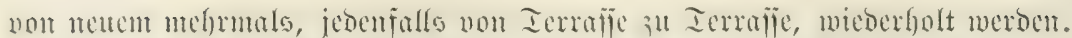

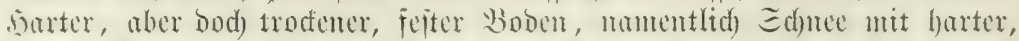

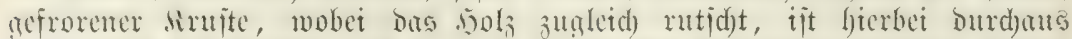

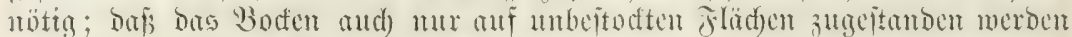
bürfe, bedarf foum ber Ermähnung.

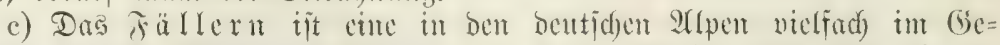

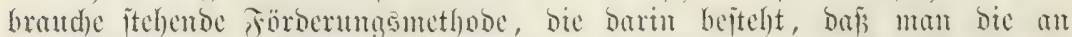

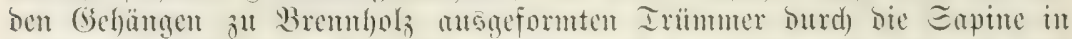

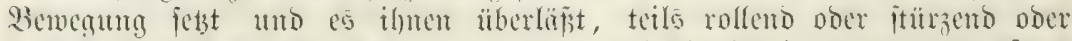

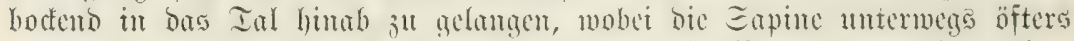

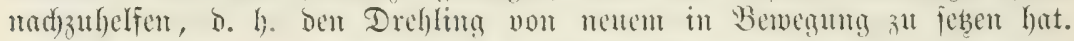

Şier Keiften die in Yangen Rinten Den Edy)Ing hinanfiftrigenden Reifïghaufen

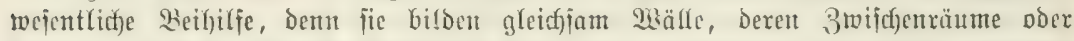

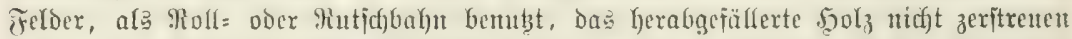
uno ansenantoeriverfon Yafien, pondern es immer zujammenthaften und jammeln. Die

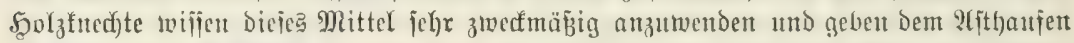

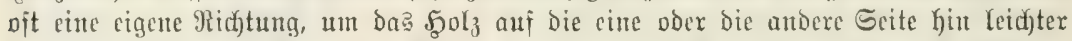

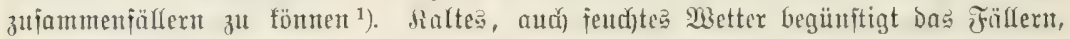
- trodfenes Metter und tiefer Sd)nee find ifm am Kinderlidaften.

d) Inter dem Ed)

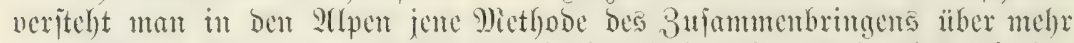
ober wentiger gencigtes Ierrain, mobei bieje solzortimente in eine mit ber

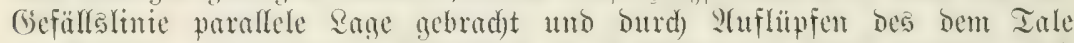

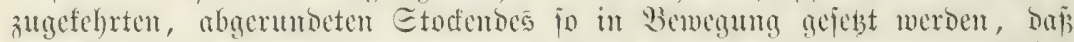
jie, fid) felbit itberlafjer, in biejer Eane bergab gleiten ober rutjejen

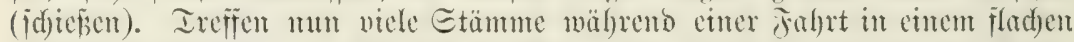

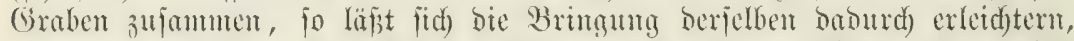

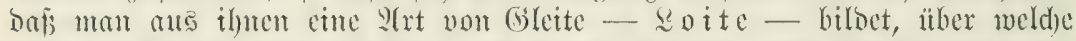

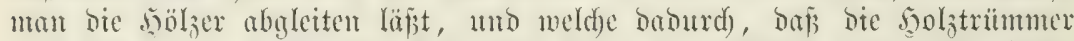

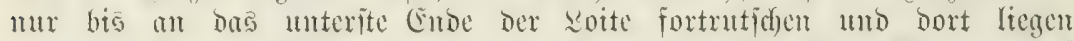
bleiben, jï) von jelbjt comeuert uns verlängert, bis bie lebten Etämme anf

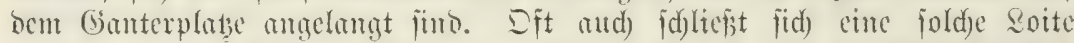
an ben unteren

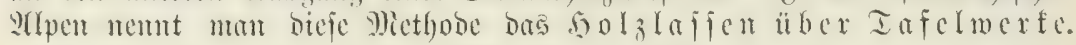

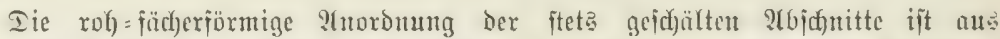
Fig. 148, weldje ein joldjes, cintm Behaute in Torotirol entrommente Iafelwert

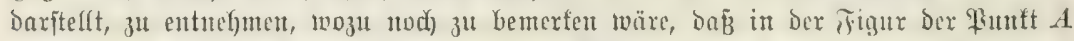

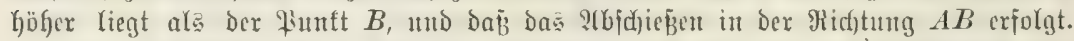

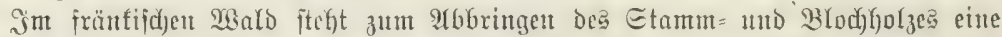

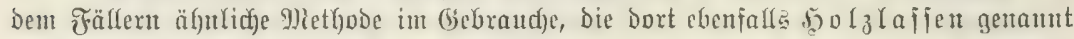

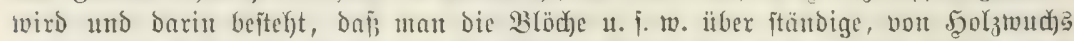

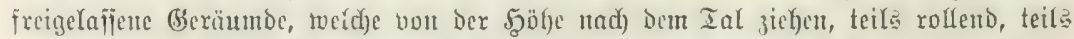

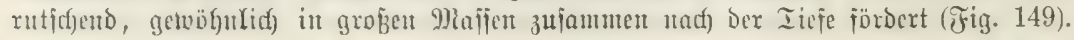

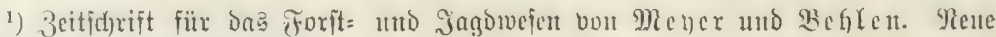

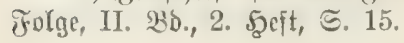




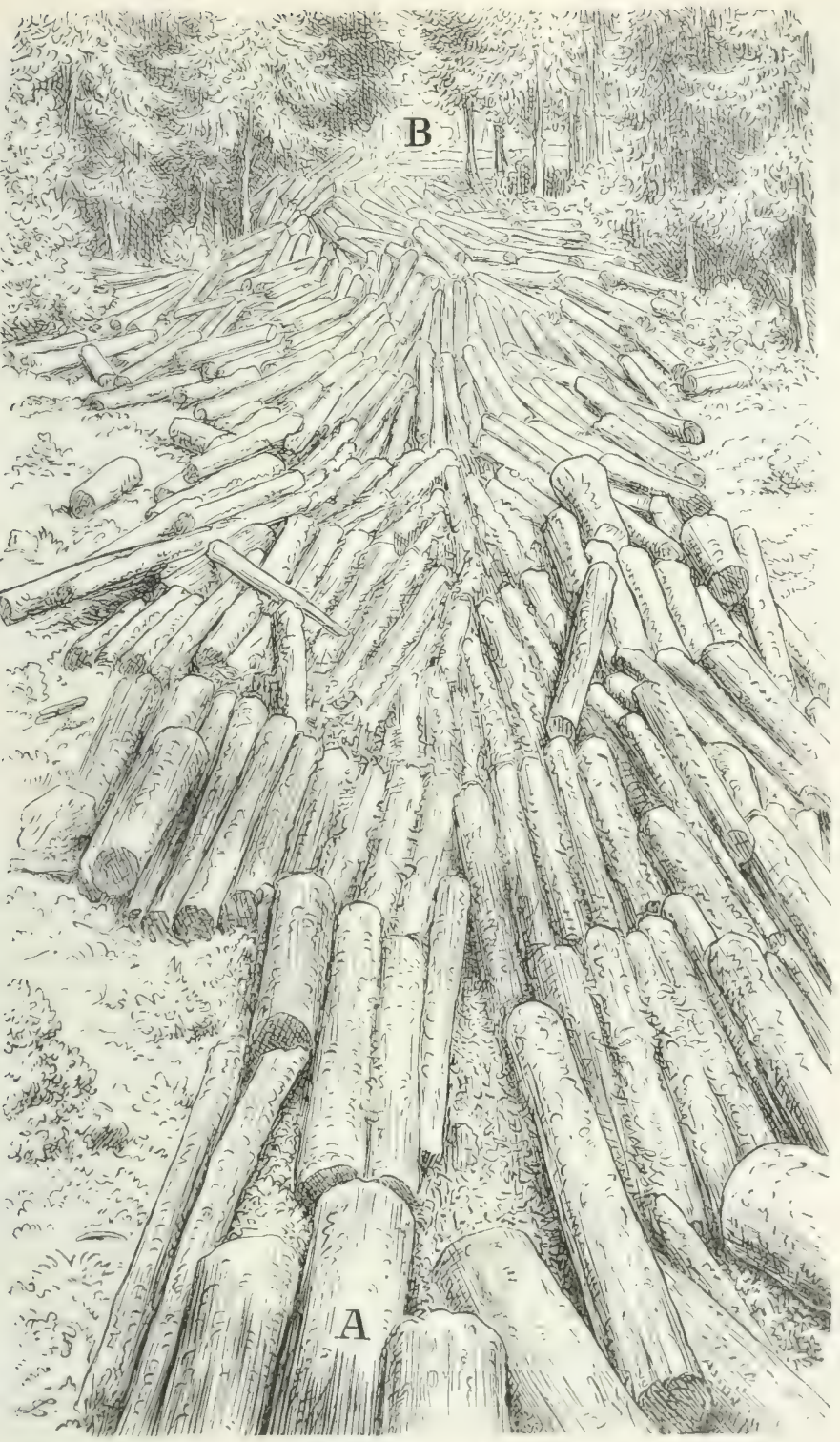

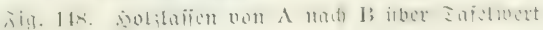

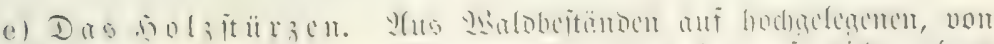

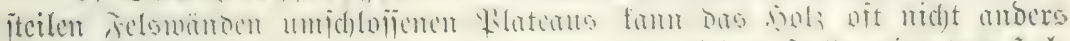

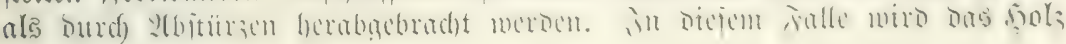




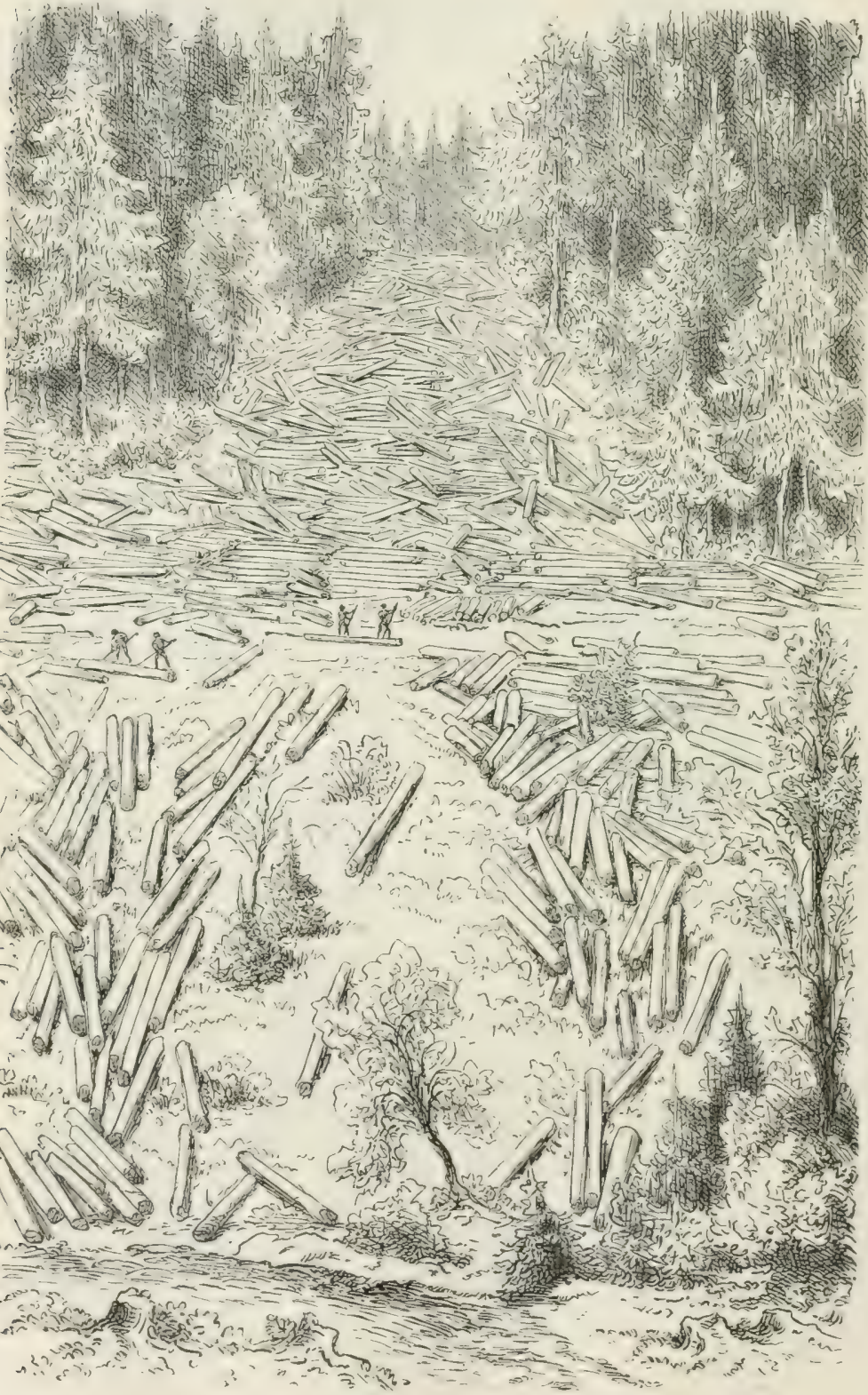

jig. 149. Solzlafien im fränfijànen galde. 


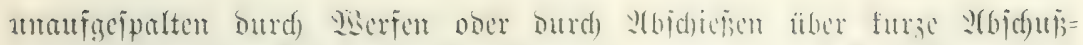

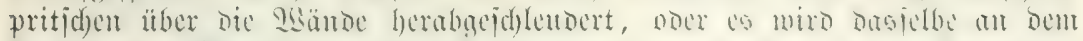

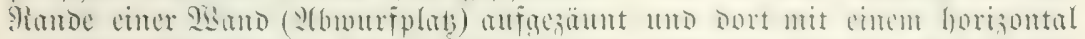

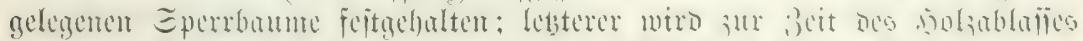

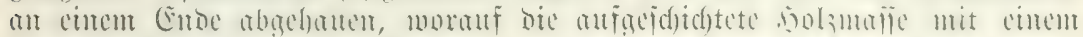

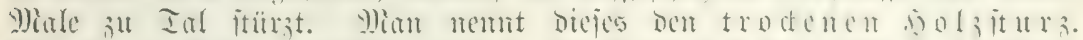

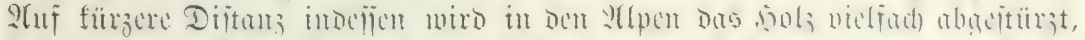

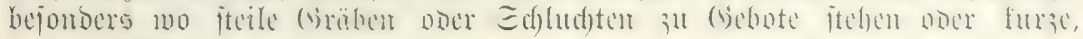
fteile 1 Sänoe.

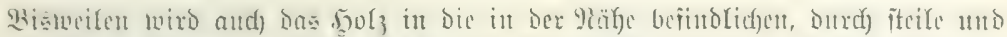

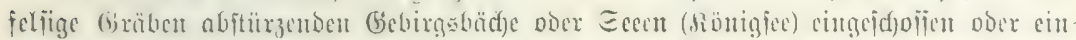

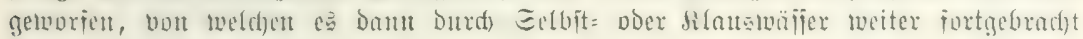

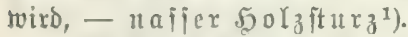

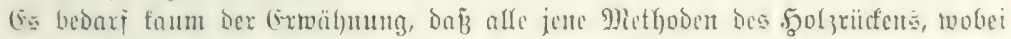

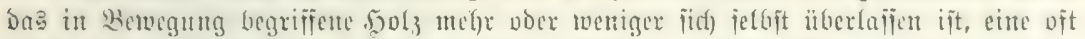

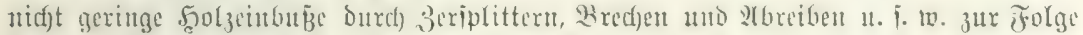

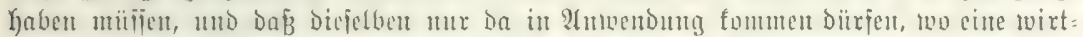

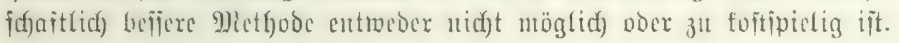

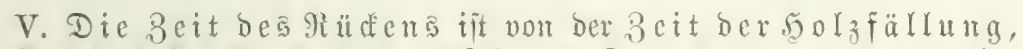

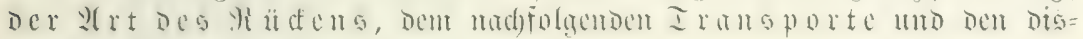
poniblen $\mathfrak{Z}$ rbeitsträiten abläugig.

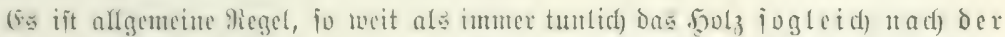

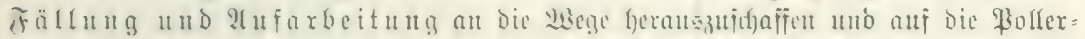

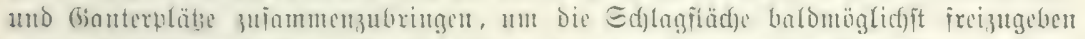

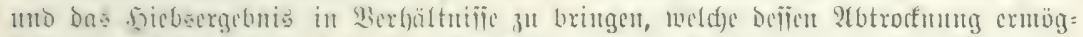

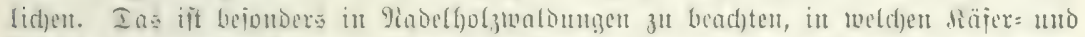

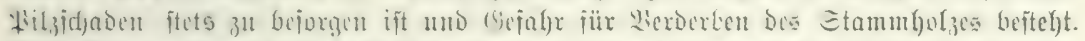

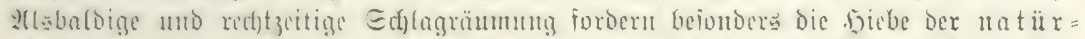

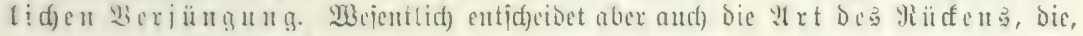

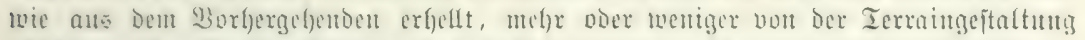

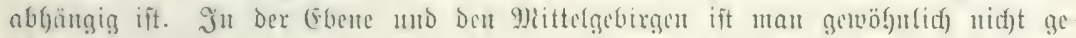

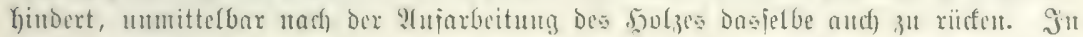

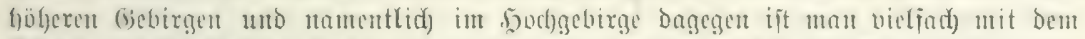

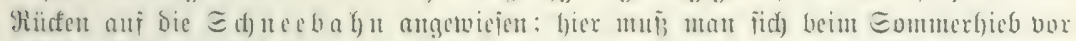

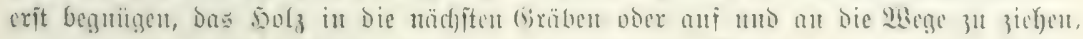
- von wo aus basfelbe Dann im fommenten sisinter bei Edjuee tweiter= verbradjt twirø.

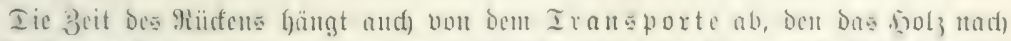

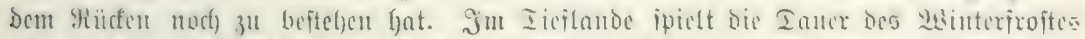

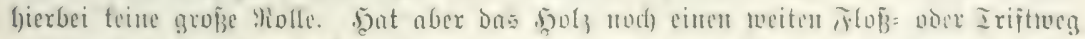

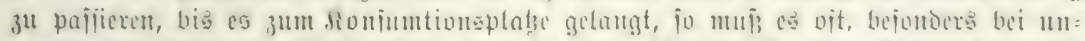

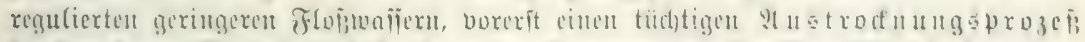

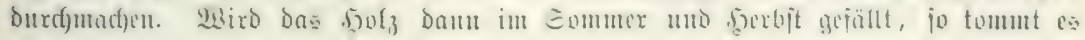

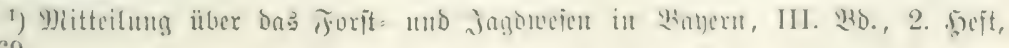




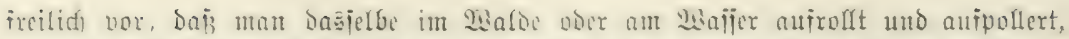

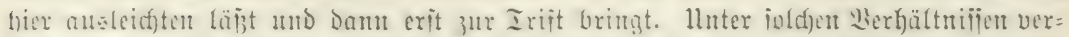

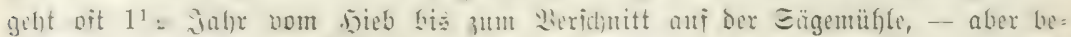

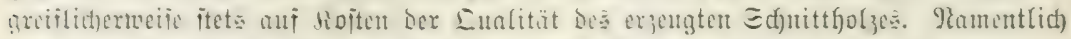

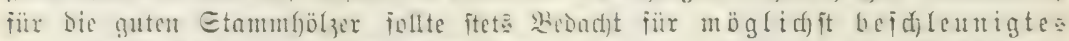

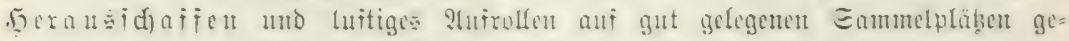
nommen twerden.

VI. Dic allgemeinen Regeln, welde beim Rüden zube= (ad) ten itnd, lajien jid folgendermasen zujammenjtellen:

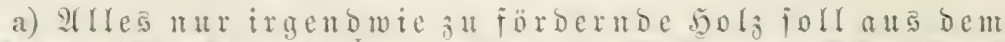

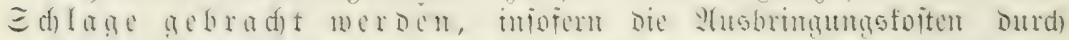

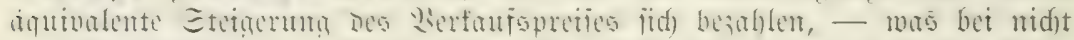

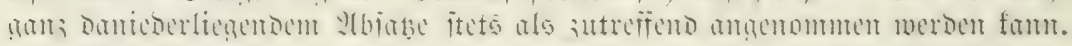

Ganz beiondera find jent bölzer ftet

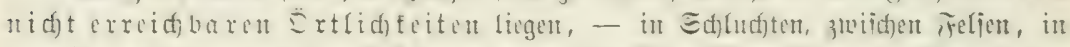

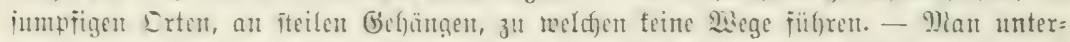

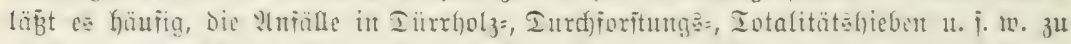

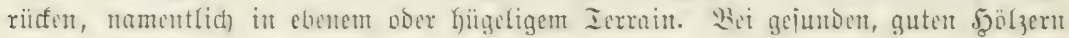

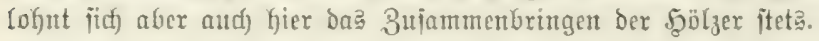

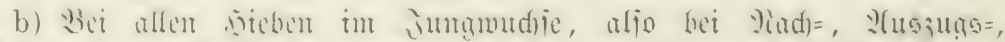

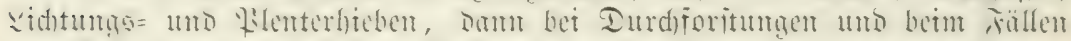

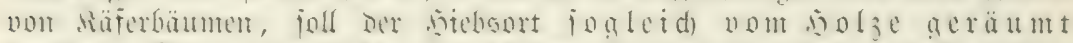

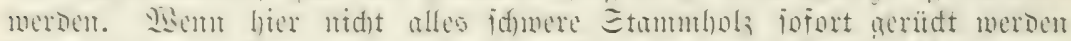

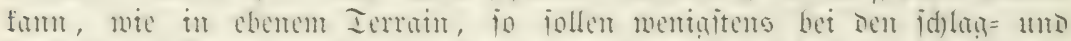

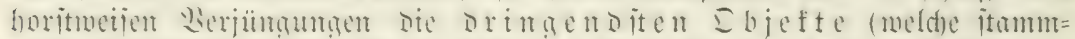

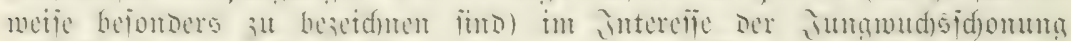

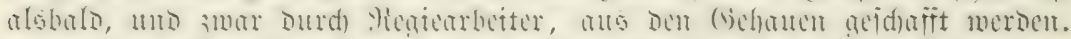

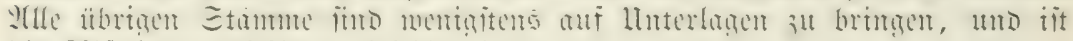

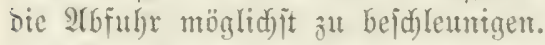

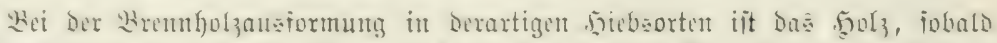

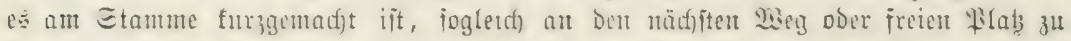
bringen.

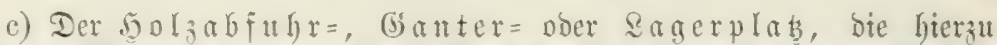

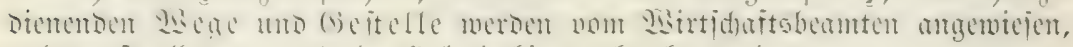

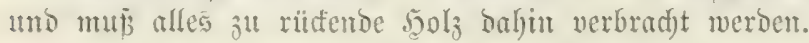

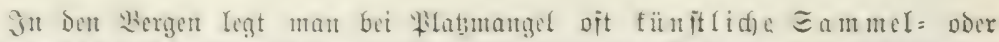

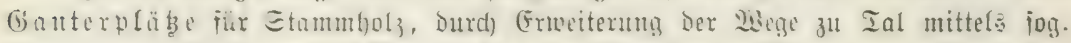

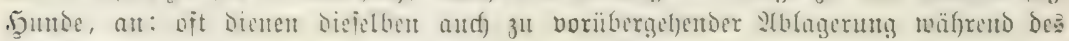
Bringungăbetriebes.

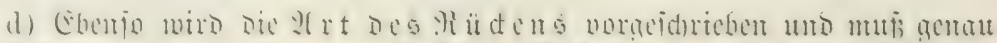

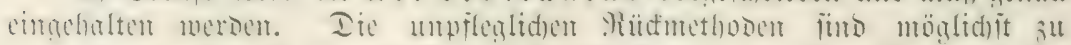

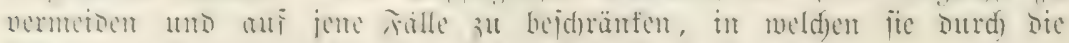

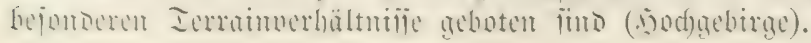




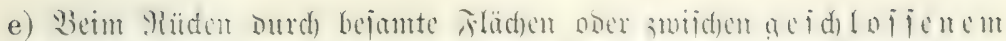

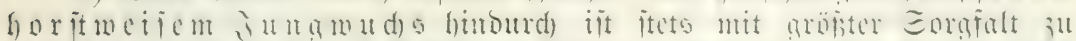

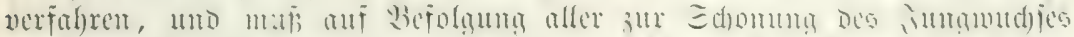

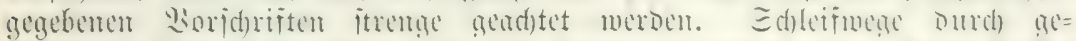

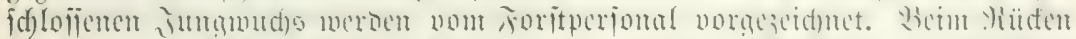

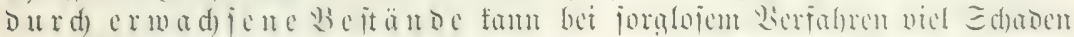

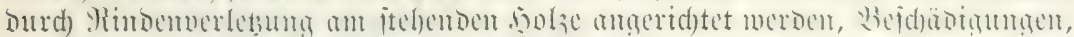

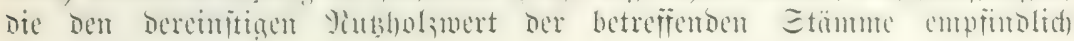
berunterjetsen.

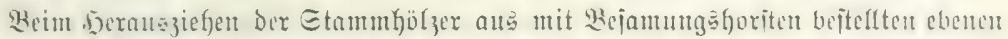

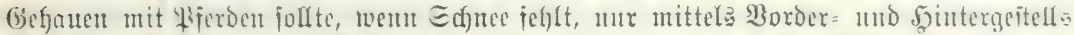
gearbeitet werben, namentlud) in Tabelfolzhejomungent. - "lu Gégängen fït Die

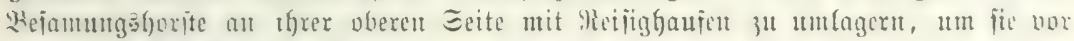

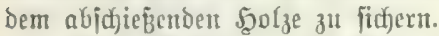

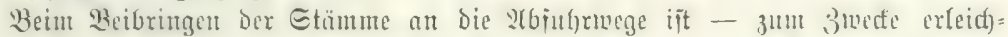

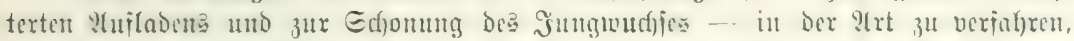

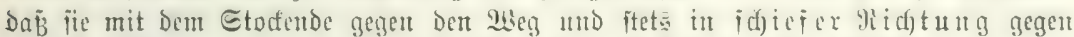
benjelben beigezogen und gelagert merden. Iaranf ift bejonder. ju adjen, Inen die Etämme cinzeln zurifgen jungumud)

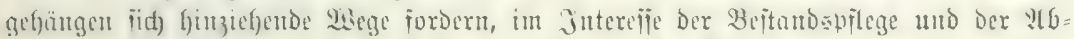

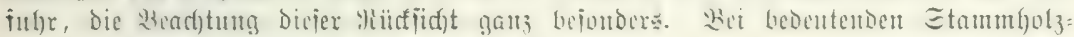
majien belcat man gerndezu die Wege felbit.

In

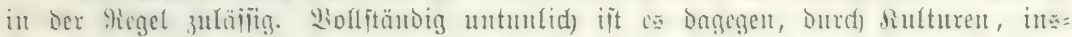

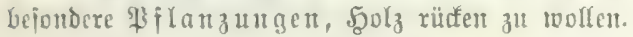

f) Das 3 uammenbringen der Sörex mu is jortiments=

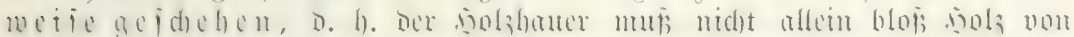

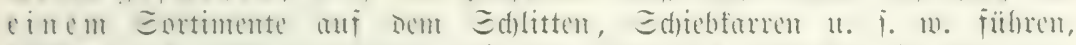

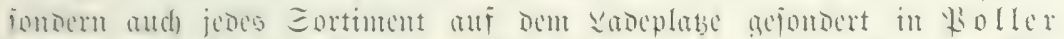

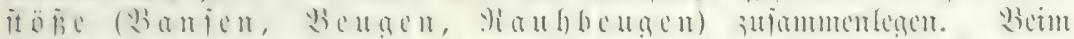
: ex itößze nidgt lebentig merocn.

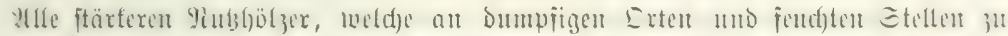

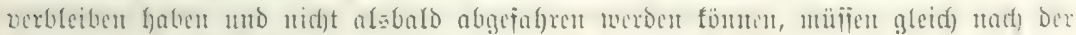
Fälung a ui llnterlagen gebrad)t worben.

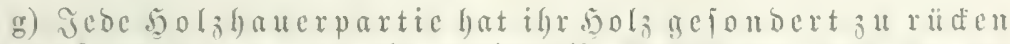

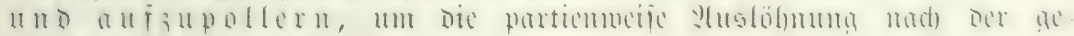
leijeten 9 trbeit bemerkitelligen zu fömnen.

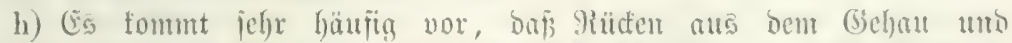

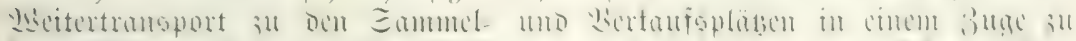

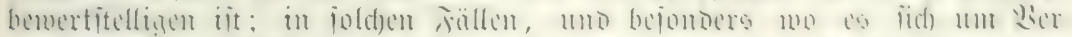

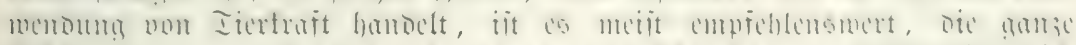

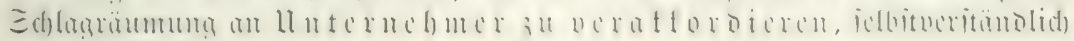
muter Eidferitellung gegen jedartige Gerälyoumg. 


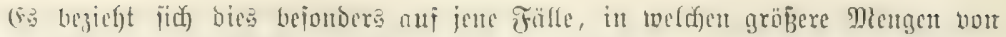

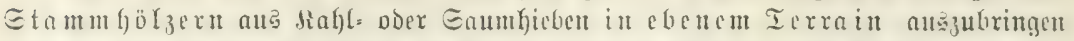

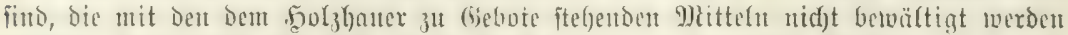

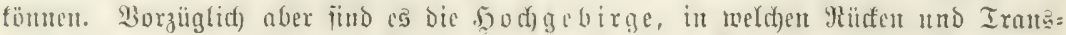

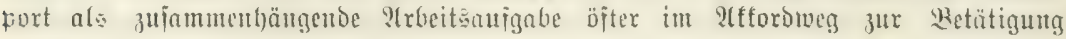
foument.

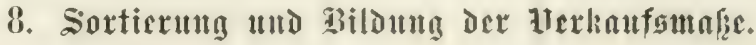

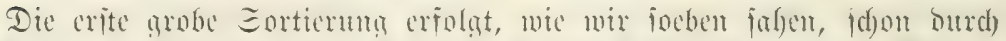

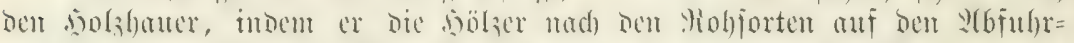

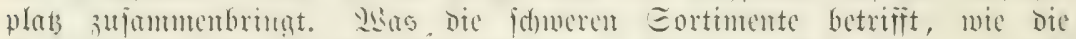

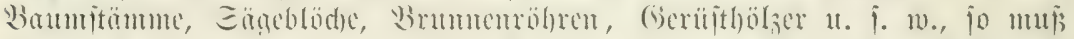

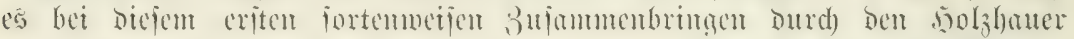

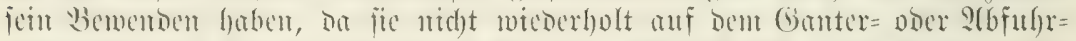

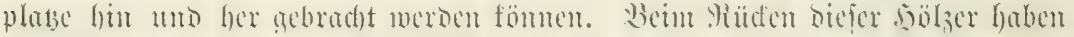

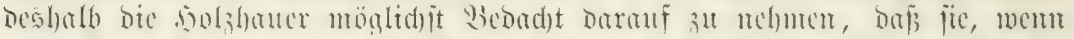

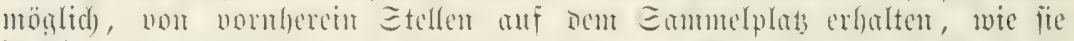

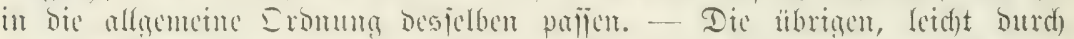

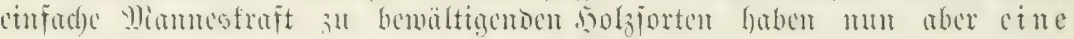
abermalige feinere Sortiexung zu beftelen; es find biejes vor=

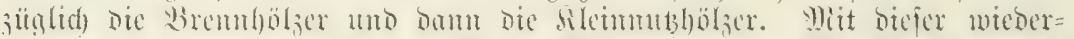

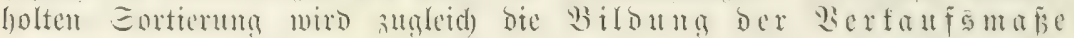
verbunden, D. 6. es wird jede Gorte bergeitalt in fleinere

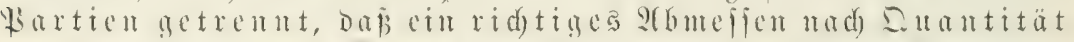
un b a

Dic

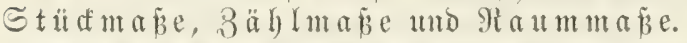

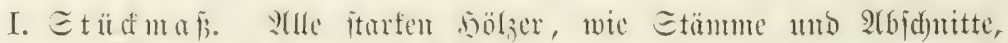

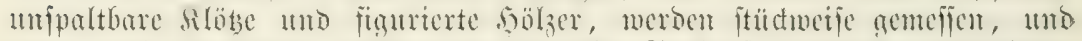

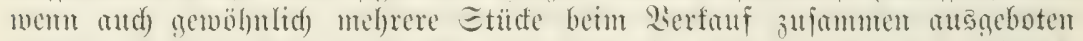

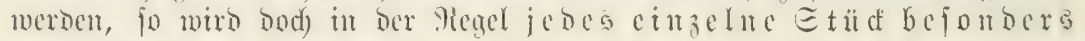
II n fïr jich) gewertet.

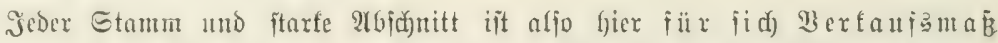

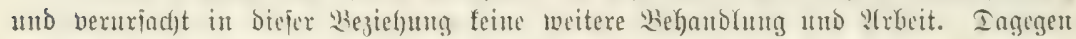

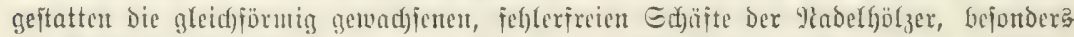

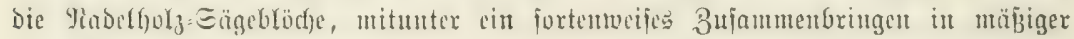
Inzahl weit efer.

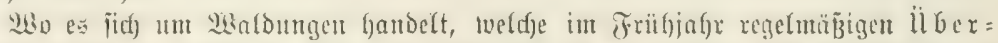

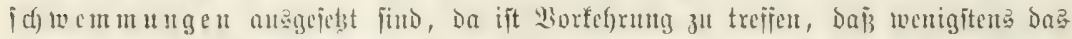

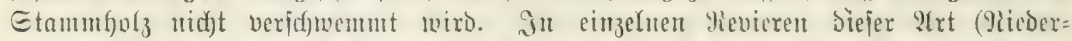

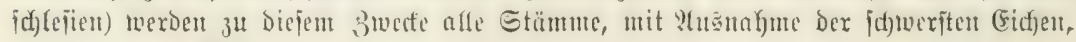
mit Drabt an \$̧iählen angeböngt.

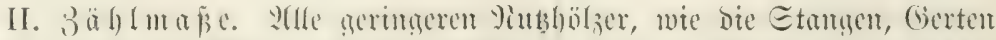

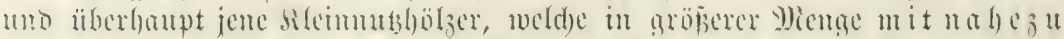

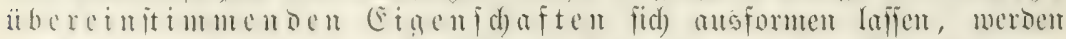

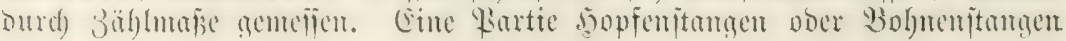




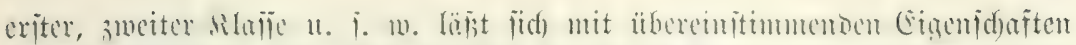

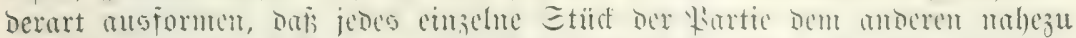

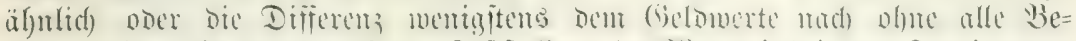

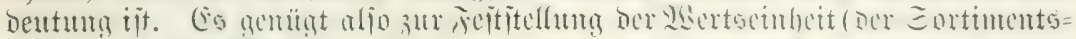

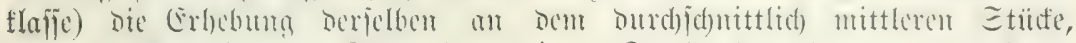

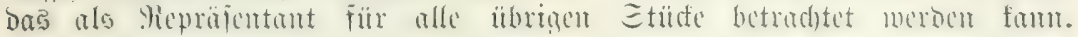
Bei diefen sölzern wix alfo nidyt mebr jebes einzelne

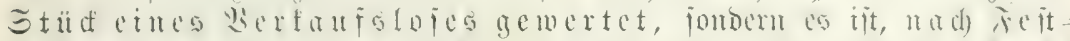
it ôl beftimmen.

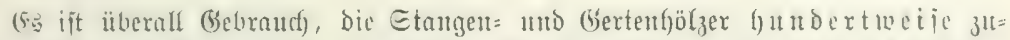
jammenzulegen, wobei mnn jïx bie ftürferen Eorten unb fïr jene, wefd)e d's geringen

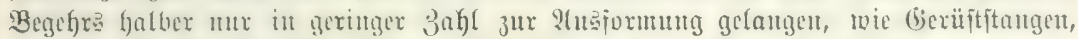

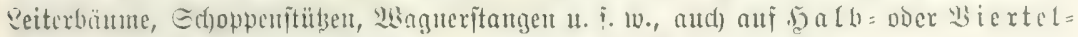

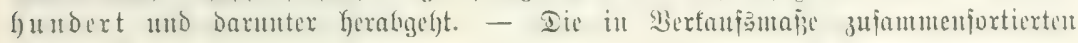

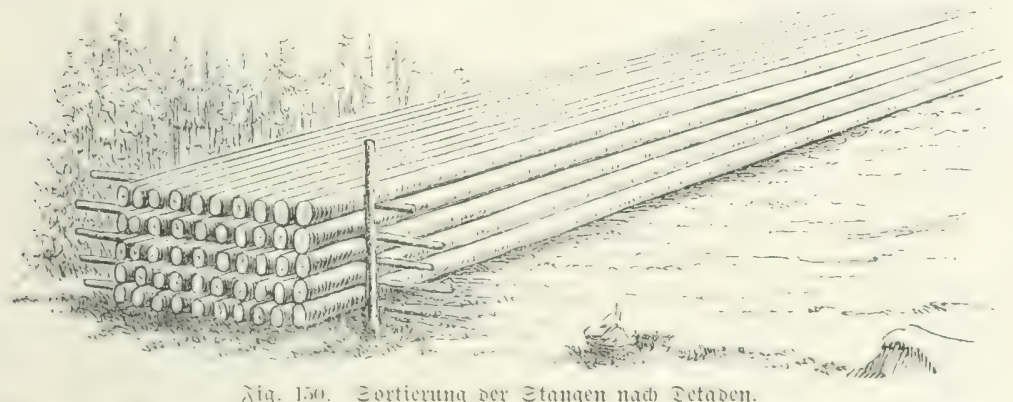

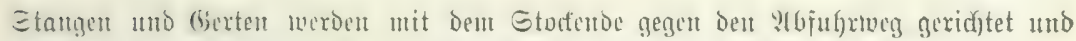

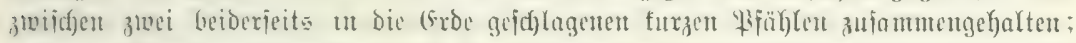

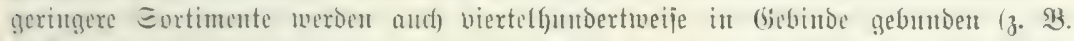

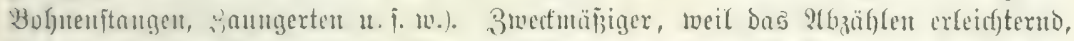

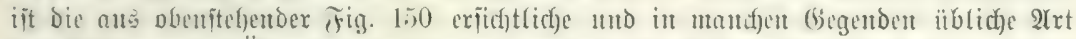

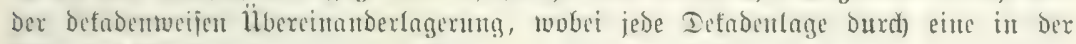

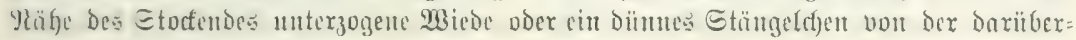
liegenden Raģe getrent miro.

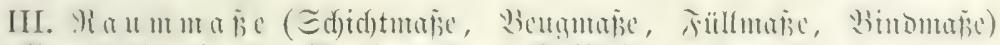

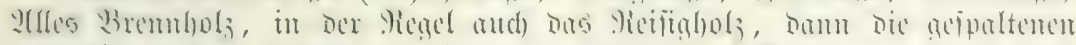

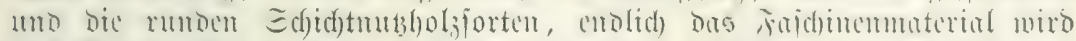

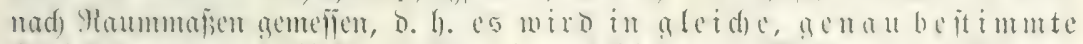

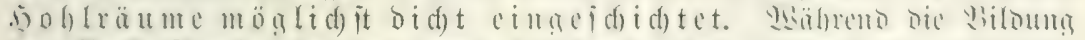

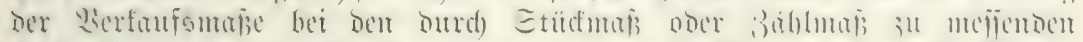

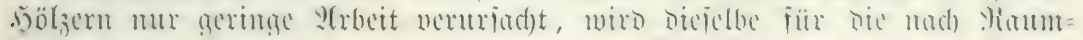

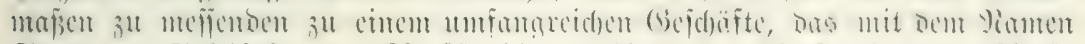

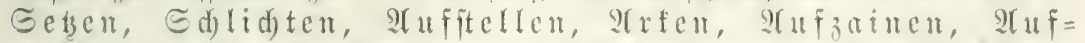

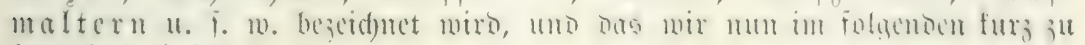
betrad)tert haben. 


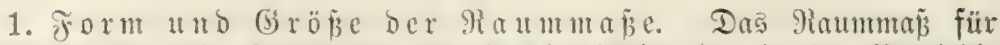

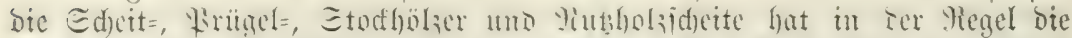

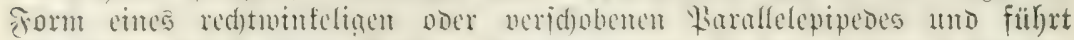

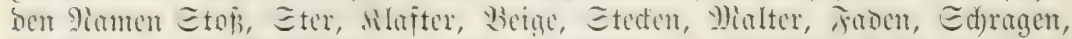

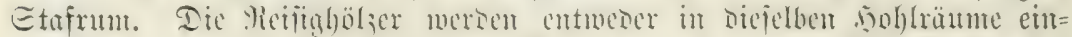

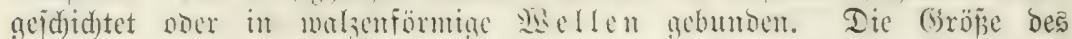

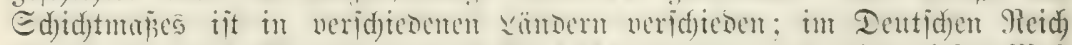

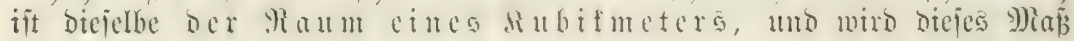
beshalb $\Re$ a um meter (Ster) genant.

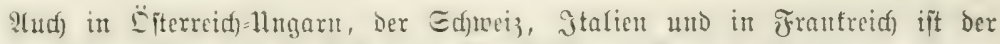

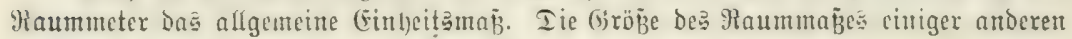
Ränder ift aus folgendem zu entrefhmen:

\begin{tabular}{|c|c|c|c|c|}
\hline & $\begin{array}{l}\text { Ränge bes fqube? } \\
\text { in Mletern ans: } \\
\text { gebrüft }\end{array}$ & 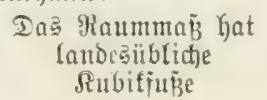 & 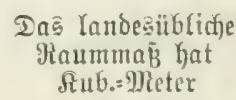 & Ge \\
\hline \multirow[t]{2}{*}{ Dänemarf . } & . $\quad 0,31385$ & 84,5 & 2,6124 & Faben. \\
\hline & & 216 & 6,1161 & Fabent. \\
\hline \multirow[t]{2}{*}{ England } & 0,30479 & 126 & 3,5677 & Faben. \\
\hline & & 128 & 3,6243 & Faden. \\
\hline Edtweden. & 0,29690 & & 7,0664 & Etajrum. \\
\hline 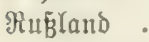 & 0,30479 & 343 & 9,7122 & Subit=ङajdjen. \\
\hline
\end{tabular}

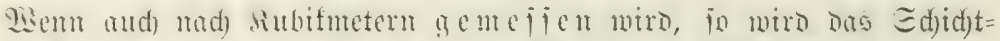

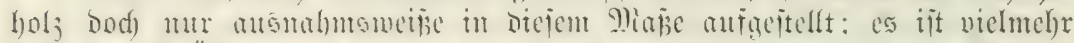

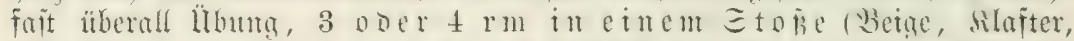

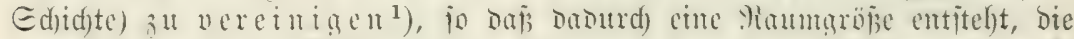

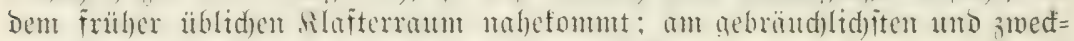

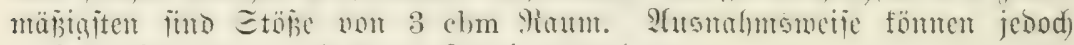
aud Stöpe von 1 und $2 \mathrm{rm}$ formiert werden.

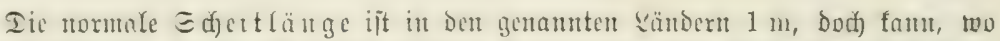

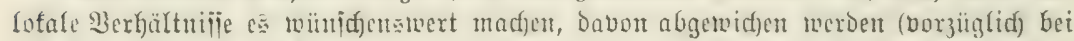

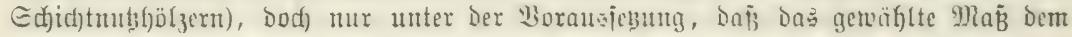

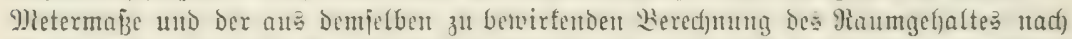
Siubifmetern angepä̈t ijt. Iurd) Die Ect)eitlänge ergiht fïd) Die Iieje Der Stö̈e: bie betoen vorderen Iimenitonen berielfen werden mit

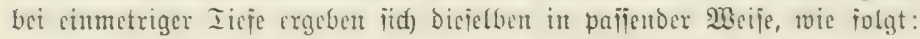

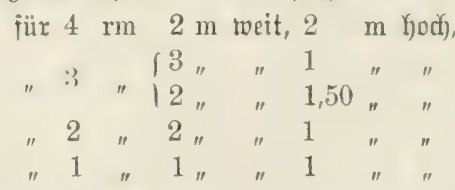

3 holje Etöbe follen vermieben wexden, namentfià) auf geneigtem

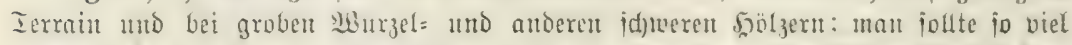

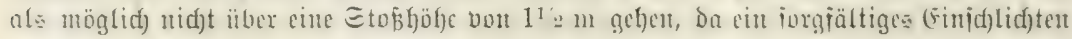

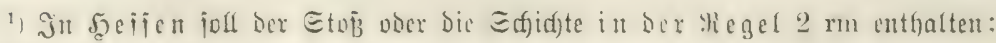
aนติกลhm? 


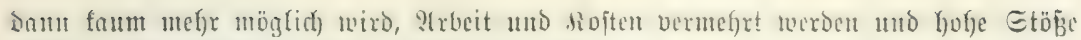
ridjt io gut zujammenthalten als wentiger lyohe.

Ier Mieflentam

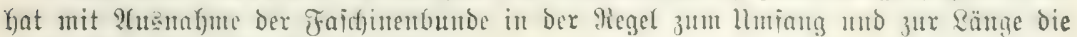
głeidje Dimeniton tvie bie Sd)eitlänge.

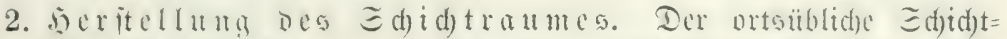

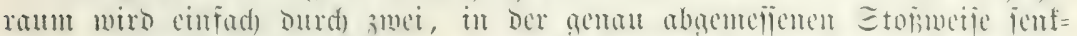

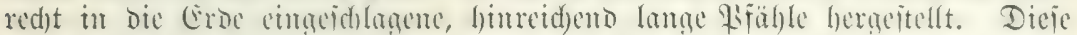

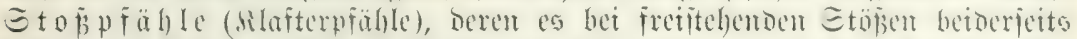

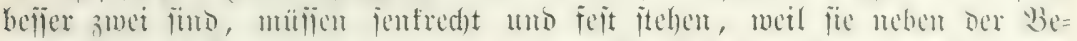

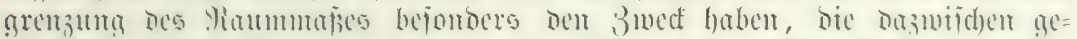

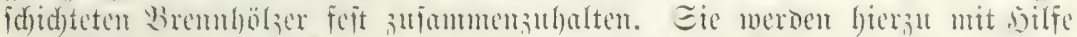

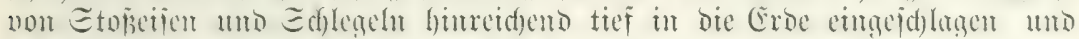

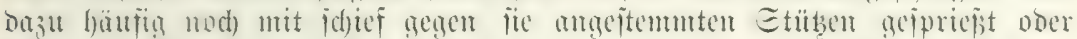

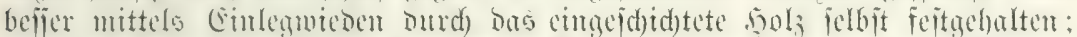

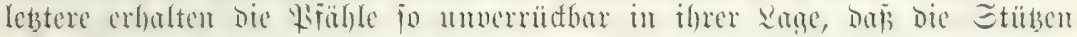

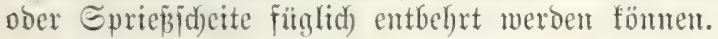

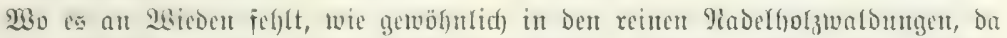

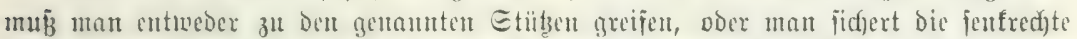

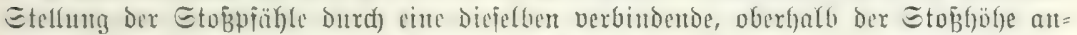

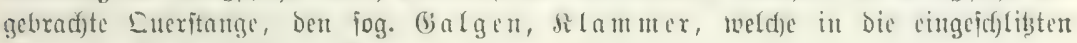
Röpie Der Stop̈pfähle eingetlemmt werden.

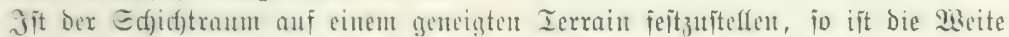

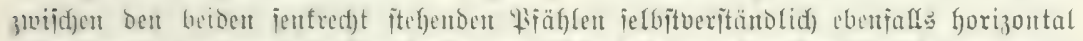

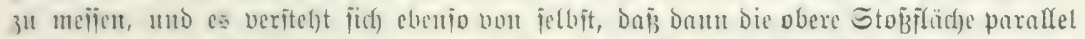

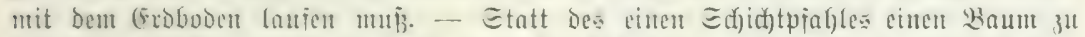

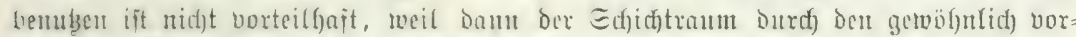

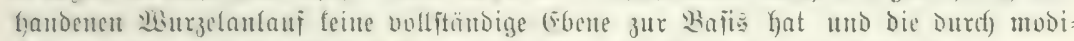

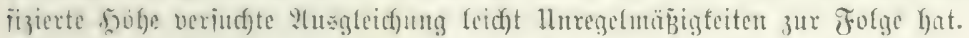

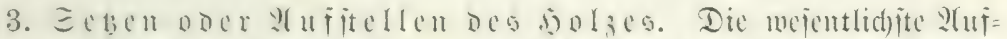

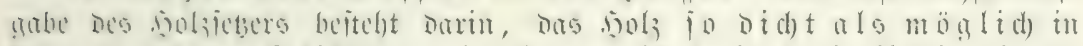

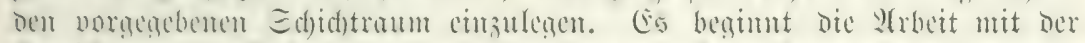

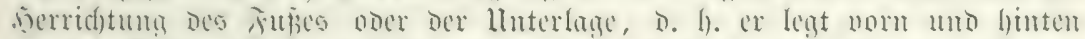

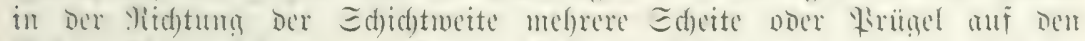

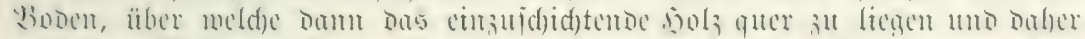

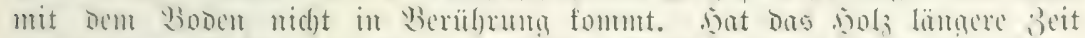

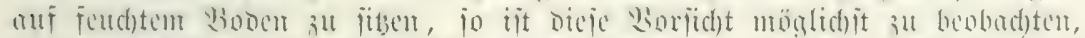

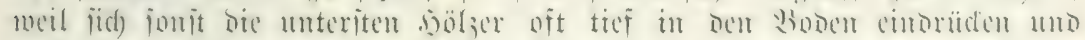

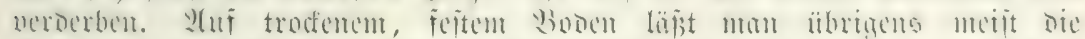

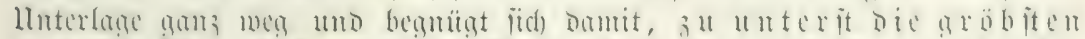

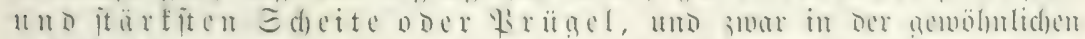

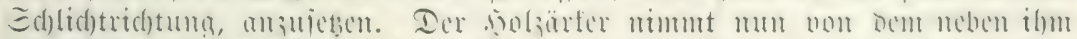

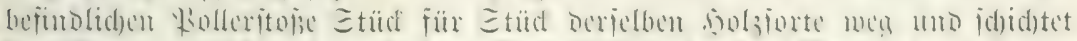

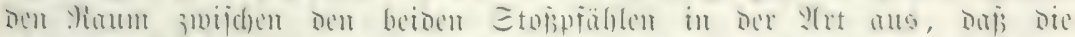

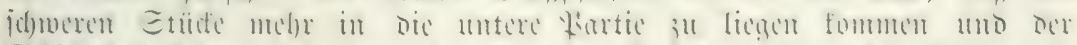

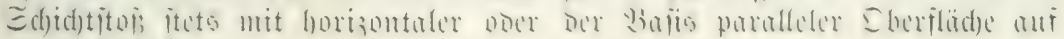
wärts fortjoreitet. 


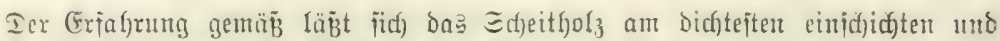

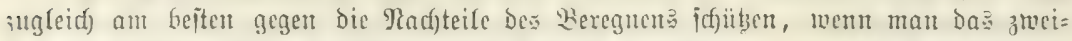

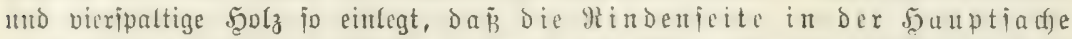
uad) oben zu gefehrt $\mathrm{t}$ jt (Fig. 151), und bas icf)

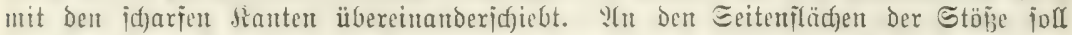

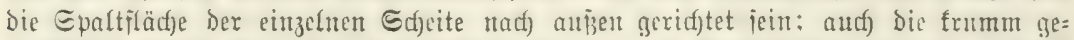
wadfienen Etüfe fommen auj bie Eeite hart an Die Etopipiäfle zu liegen, und ift

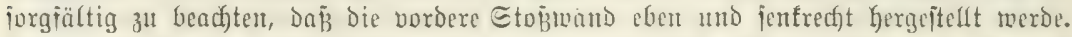
Iamit molid) affe biden (Enden nidft auj bie tine Eeite allein fomment, io iit nad)

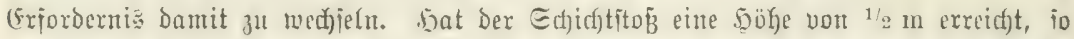

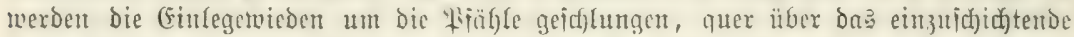

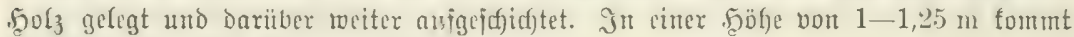
Die ztweite Rage ber (Finlegerwieden.

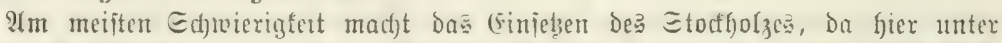
Den einzelnen Etörfen Die wideriprechenoften Formen vortommen. Iis Epaltitiufe

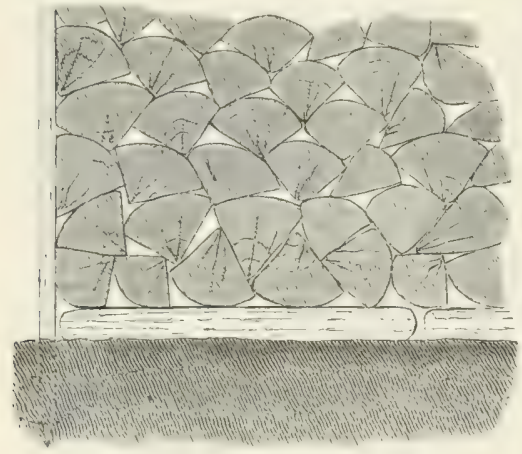

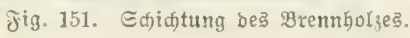
von icfwadjen Stöfen legt mant ftets nach

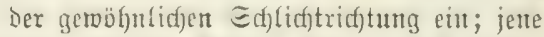

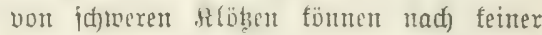
Eromung mefrer gejuidutet rexden, jondern

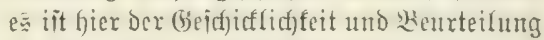
dew Solzjebers überlajien, für jede fic er= gebende Siffnung do paliende Gtủa zu juchen und. fo bidt als möglid einzulegen. Die Durch die groben Etoripälter nicht aus = jüllbaren 3ivijhenxäume twerden ourd,

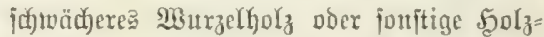

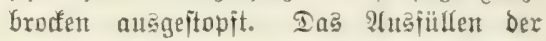

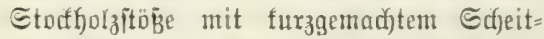
odex $\mathfrak{B}$ rügelfyolz ift bagegen unitattfyaft; eit Etodfyolzito $\bar{B}$ folf nur Etodfhola entfalten.

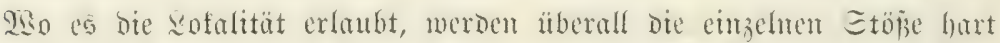

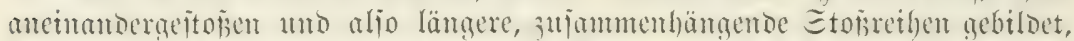

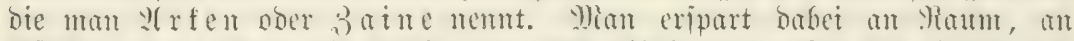

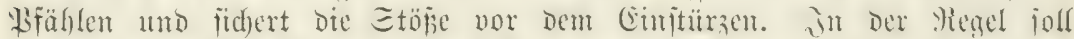

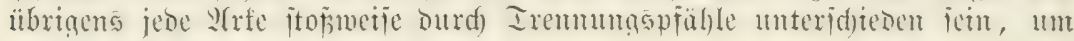

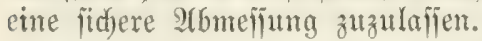

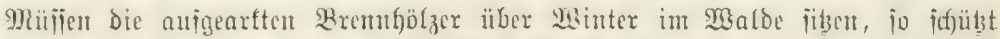
man fite an einigen Erten gegen volftändiges Derid)neien unb Daburd) beranlaptes

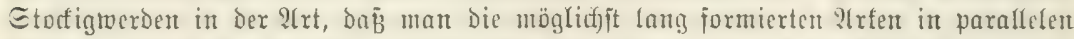

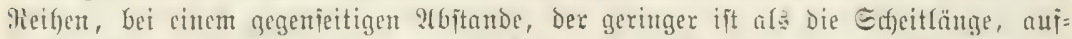

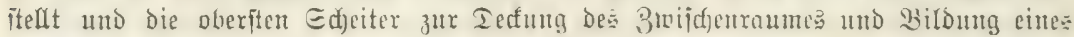
Iadjes übergieł)t.

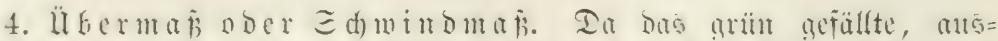

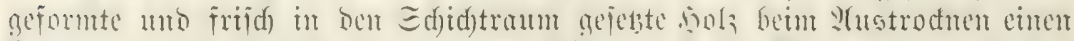

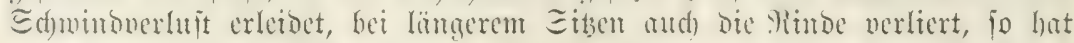

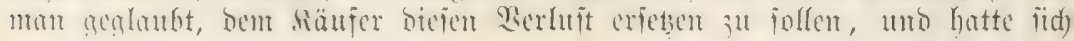




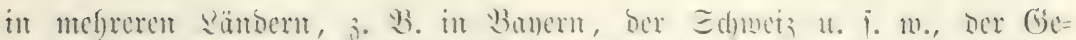

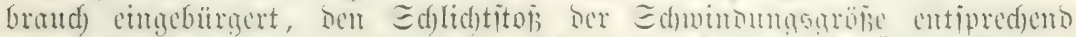

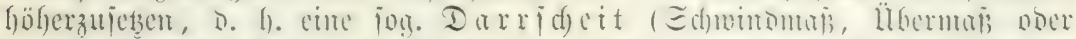

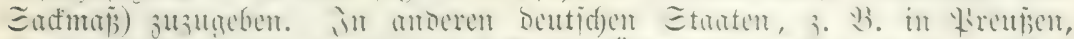

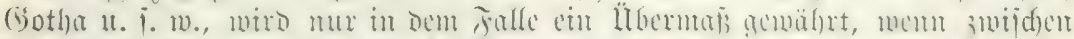

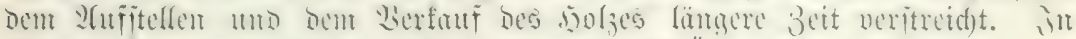

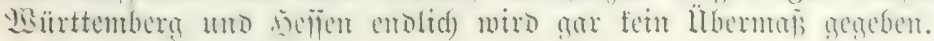

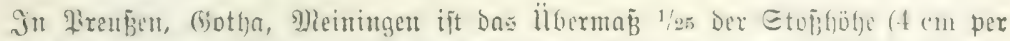

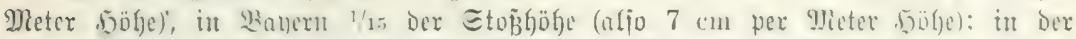

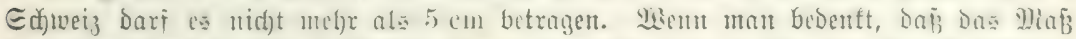

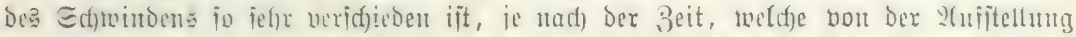

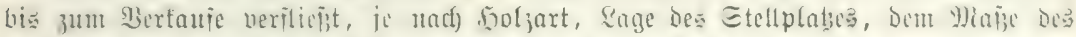

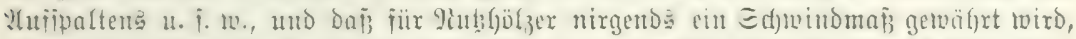

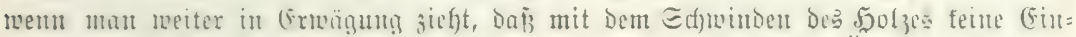

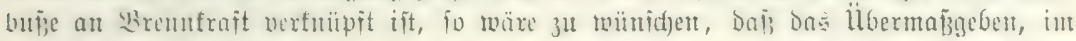

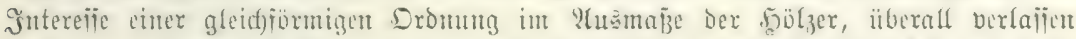

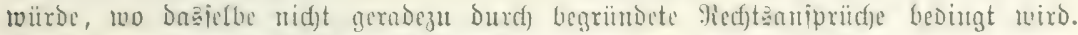

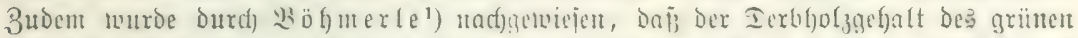

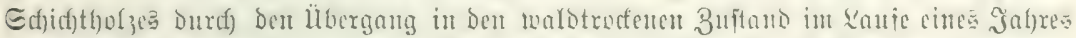

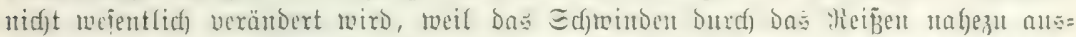

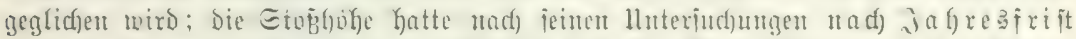

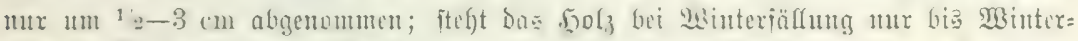

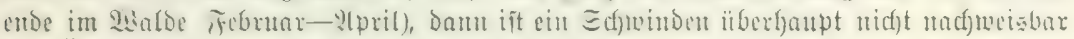

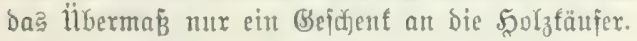

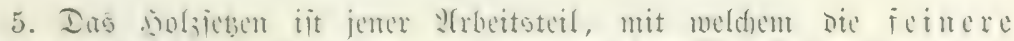

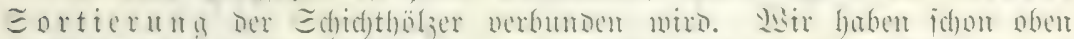

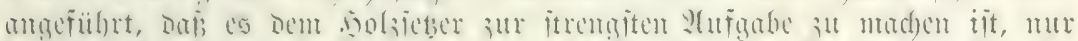
imater ; แi am

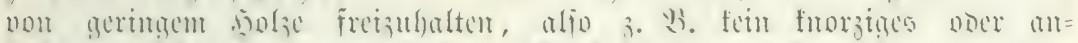

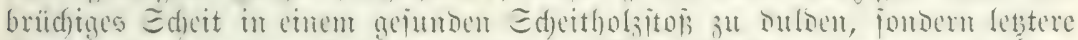

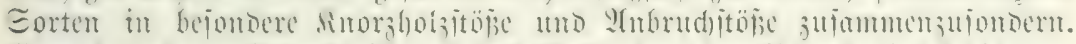

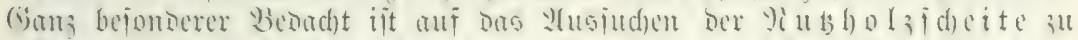

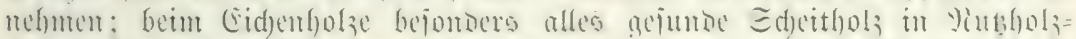

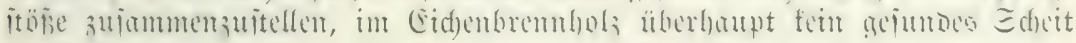
su Dulden.

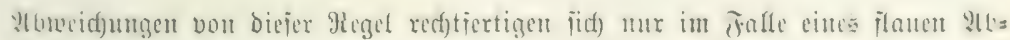
ją̧es jür bie geringen Eorter.

Iie feime :4

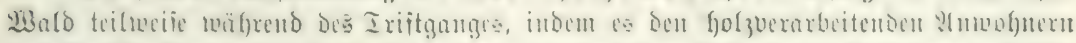

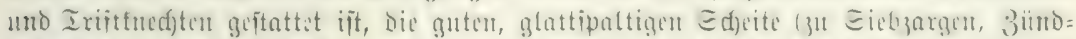

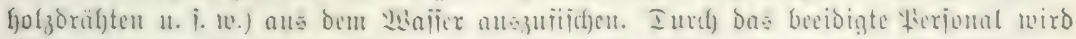
Diejes Solz am llfer aufgeftellt und un Die Sint3golztare verwertet.

1) Ia walbtrodene 5ूot3. Wien 1879. 


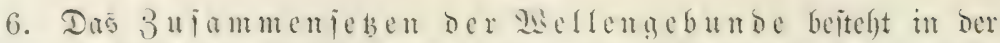

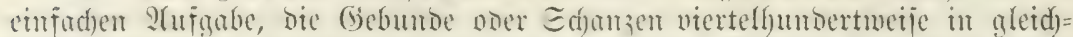
fömiac sanfen sujammenzulegen ober in itelfen. Bielfad) werden biejelben gelegt, es ijt aber bas $2($ ufitellen ber Sisellen für bie Ronjerwation

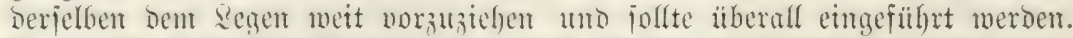

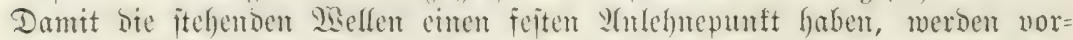
erit brei Gebunde in Pinramidenform gelent und alle ïbrigen an bieje an= gelehnt.

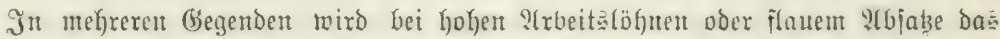

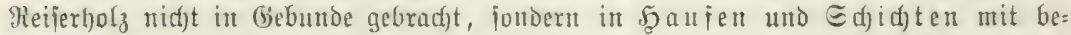

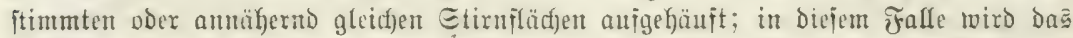

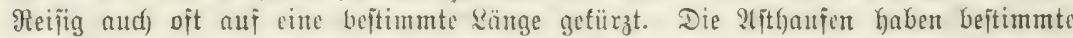

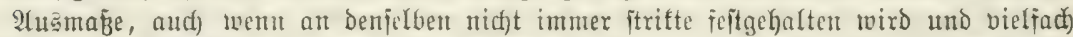

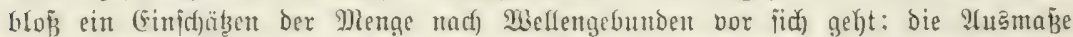

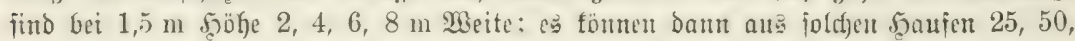

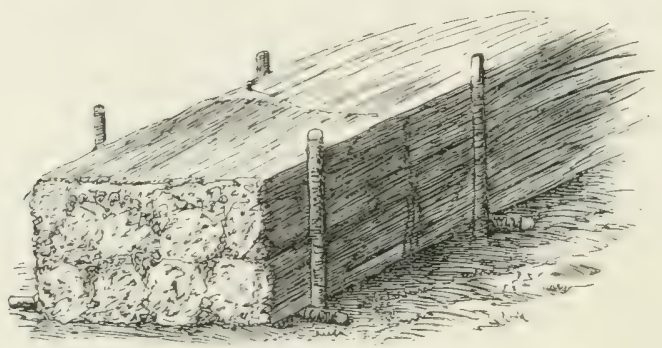

Jig. 152. Reishols in Gebunben.

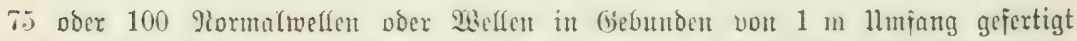

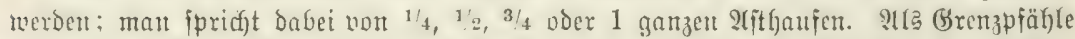

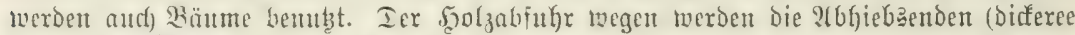
(Enoen) Der silfte nad) einer Eeite, und zwor bem f̧olzabjubrwege zugefefret, fejt auf=

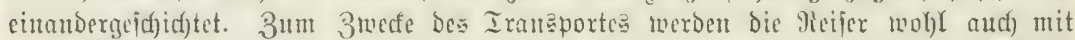

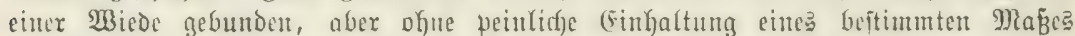

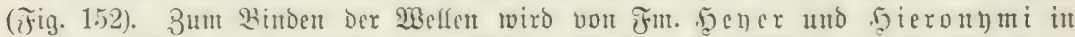

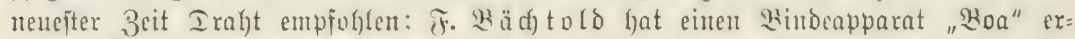

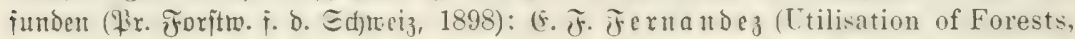

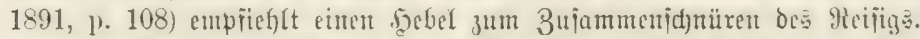

(5.

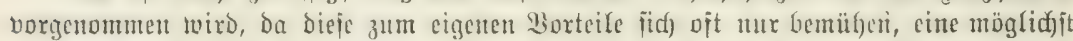

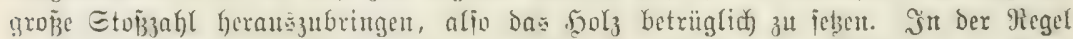

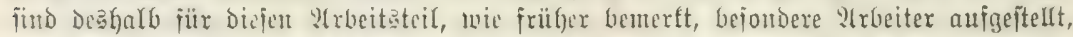

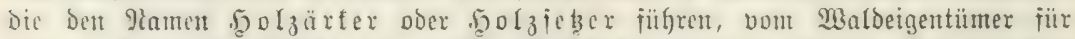

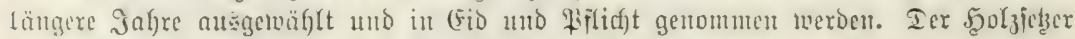

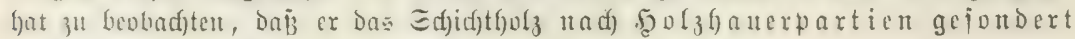

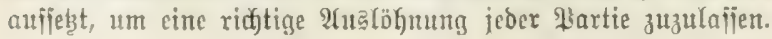




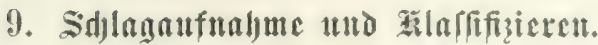

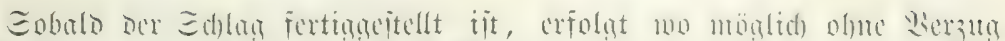
Dic $\Xi$ d) 1 a

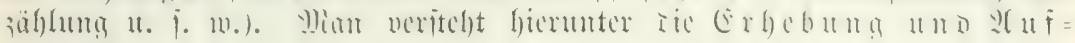
jeid)ung ber (5ejamtholzernte cines Siebes durd) Siou= itatierung aller jener Eigenjadfteu und jaftoren jedes einzelnen Sdylagobjeftes, welde den Geldwert desielben

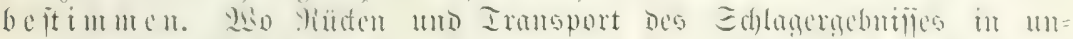

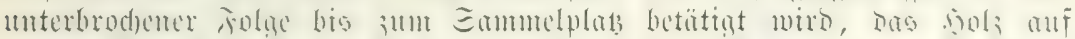

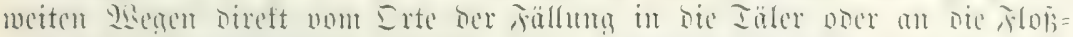

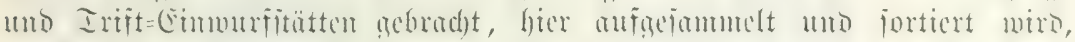

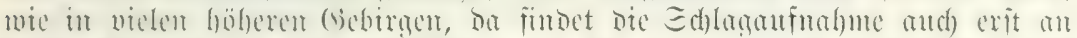

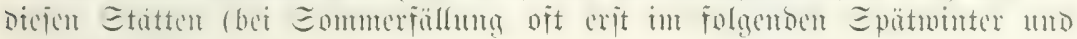
Fribjalyr) itatt.

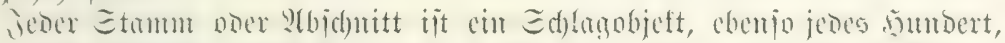

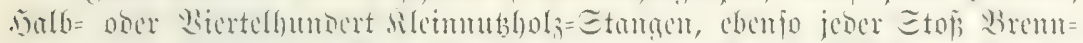

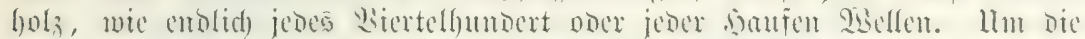

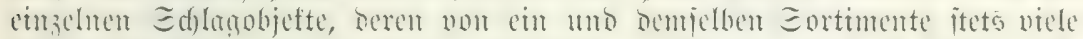

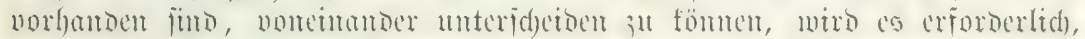

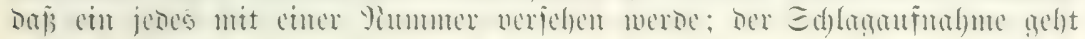
aljo bie giumerierung bea Sdy lages vorber.

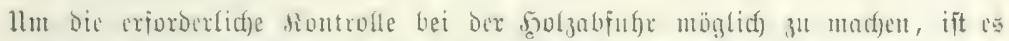

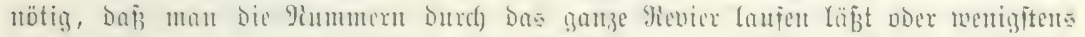

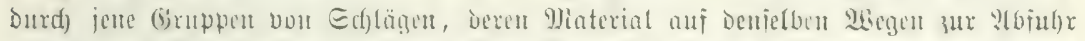

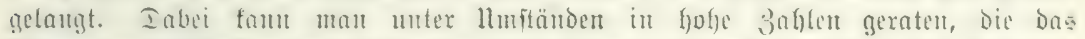

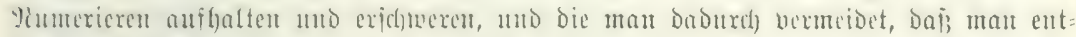

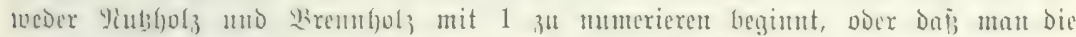

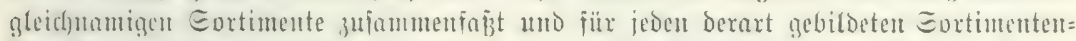

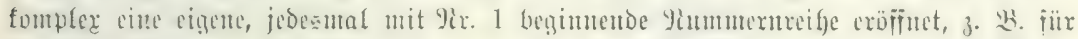

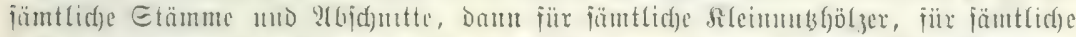

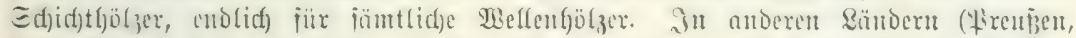

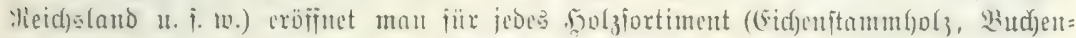
ftammbolz u. j. w.) eine beionbere शzummernfolge.

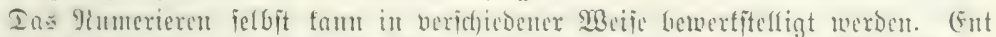

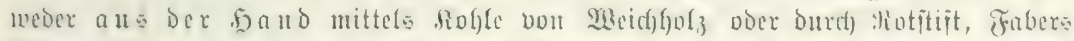

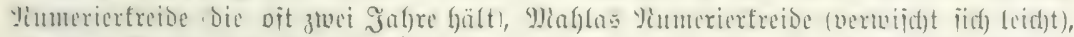

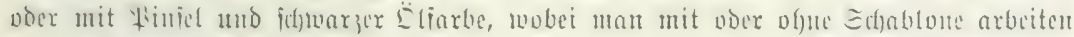

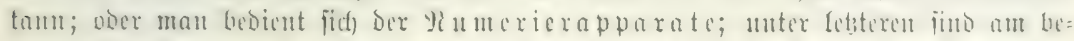

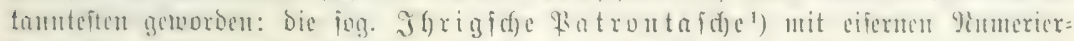

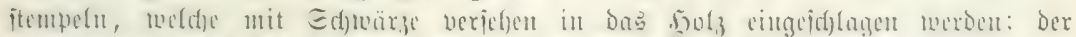

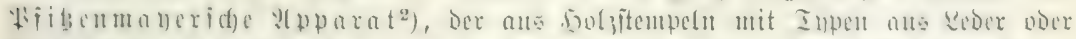

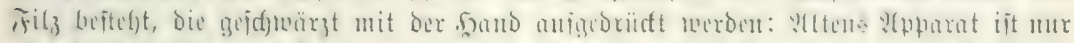

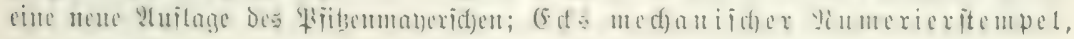

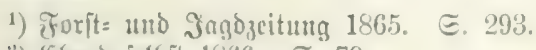

2) Ebendajelbit 1866 . $\Subset .79$. 


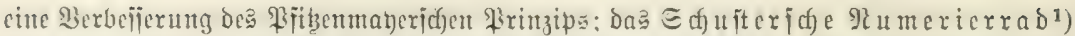
mit Der (unter bem Itamen "Iriumphidflege!" angepriejente) "Numerieridflegel von

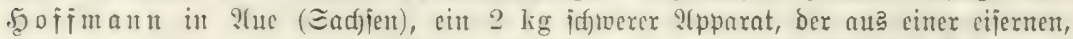

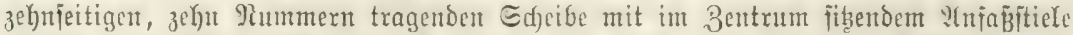

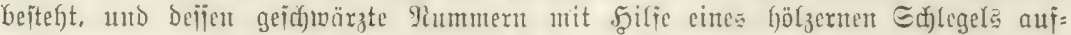

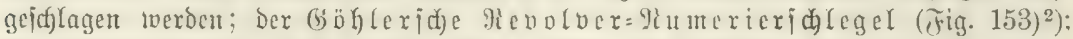

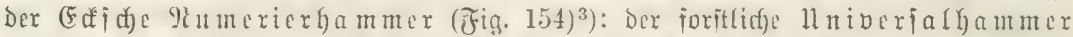

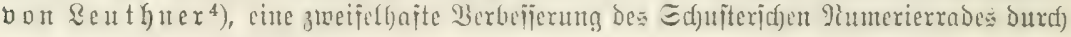

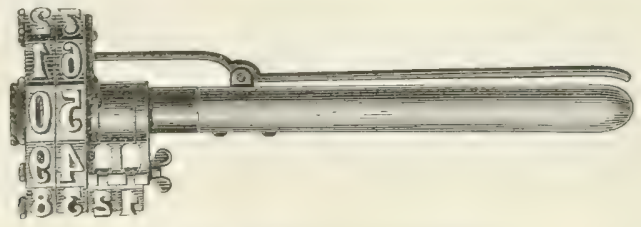

F̂̀ig. 153. Göhlers stumerierjolegel.

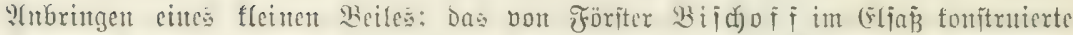

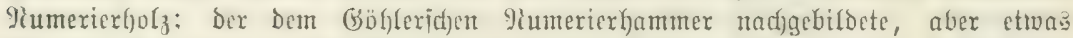

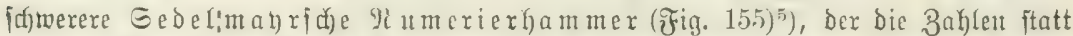
horizontal, vertifal ani Den Etamm amidhlägt, babei afer mit ei nex frant (im (ijegen=
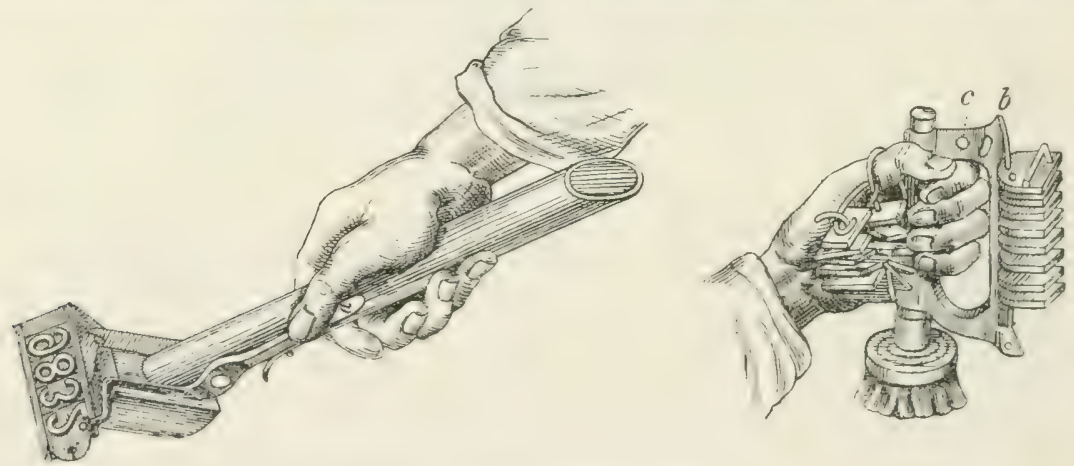

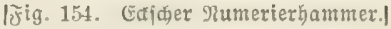

fał zu (söflers I(pparat) bedient werden faun; I uft

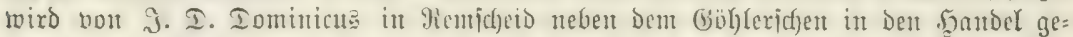
bradgt: er wird in zwei formen (3ah)lent parallel Dem (Griffe und Bahlent quer anj

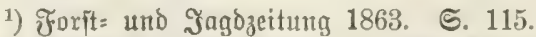

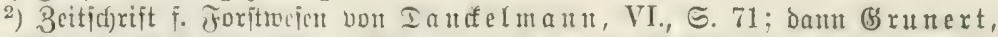

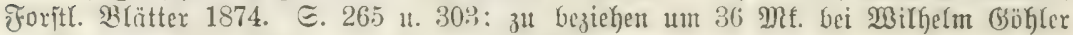

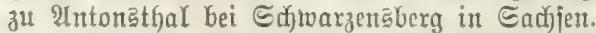

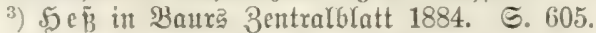

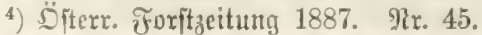

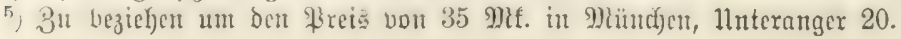




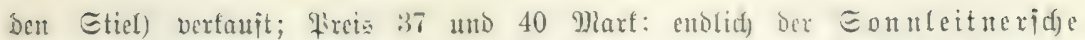

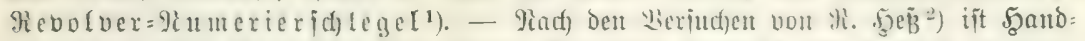

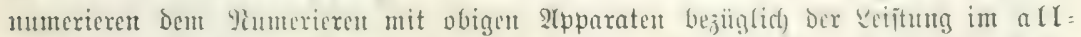

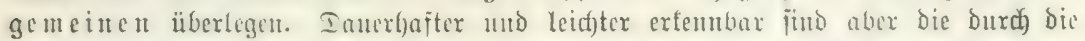

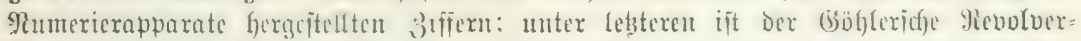
Tiumerieriffegel alfen anderen um $60-65 \%$ ïberlegen; man munerert mit bemjelbu

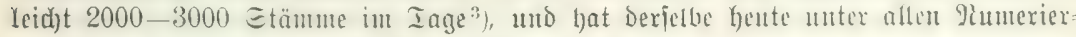

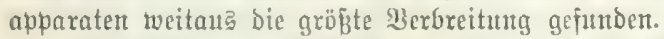

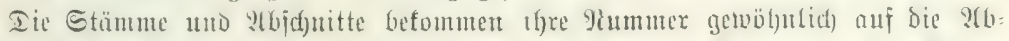

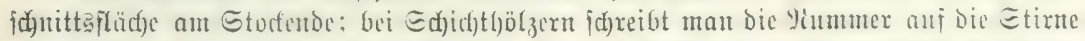

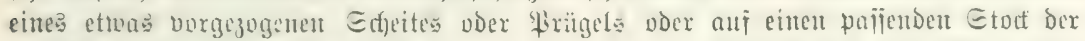

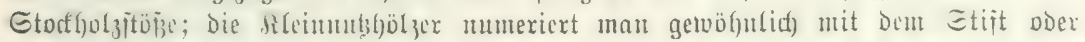

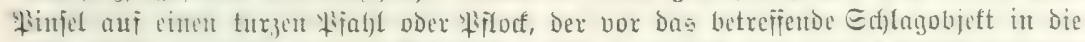

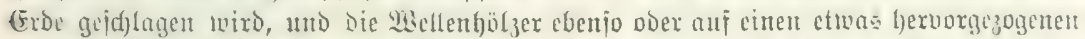

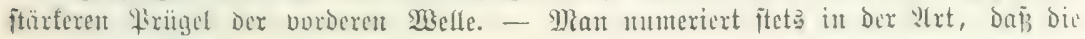

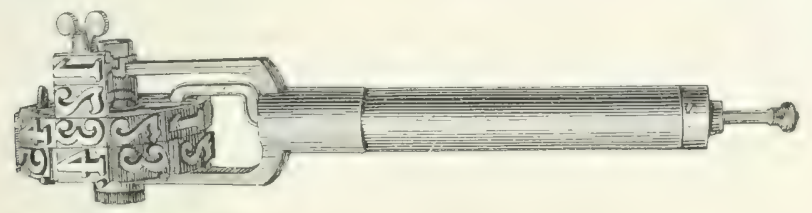

Fig. 155. Eebelmanx Th Tumerterhammer.

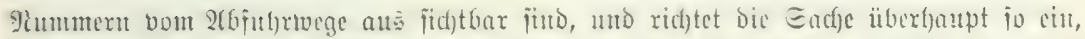

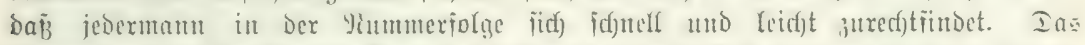

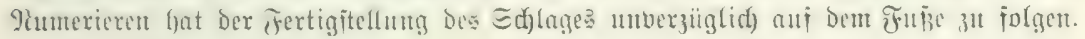

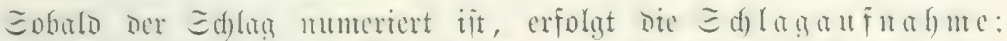

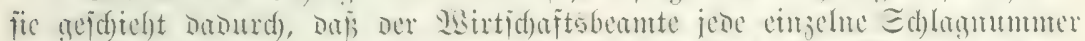

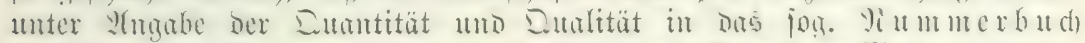

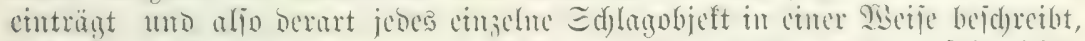

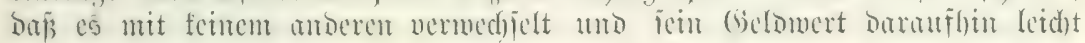
beîtimmt werben famm.

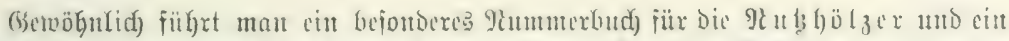

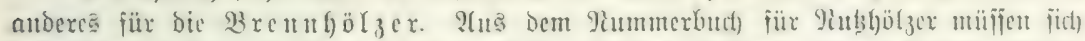

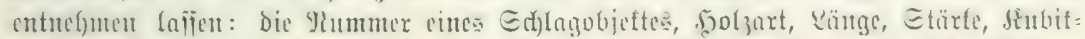

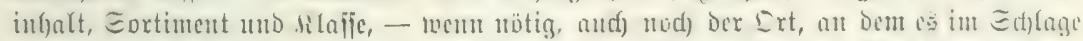

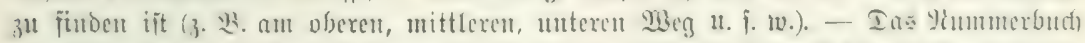

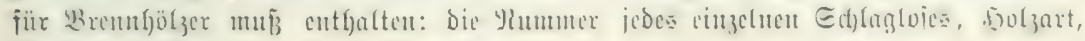
Gortiment, Qualität uno bie Suantität.

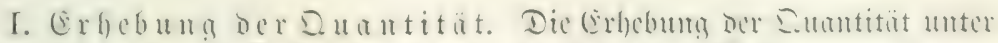

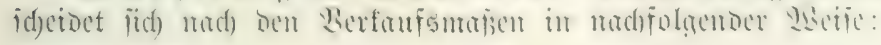

1) Siełe S̈iterx. Foritzeit. 1893. ธ. 158.

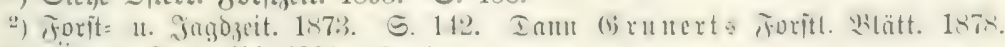
๑. 216 ; Diterx. Bentralbl. $1882 . \quad$ ๑. 1.

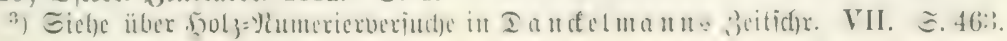


1. Dic 三t ï du

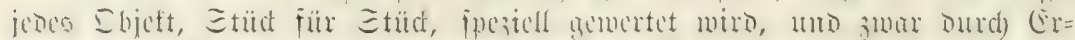
hebum Der Dimenjione

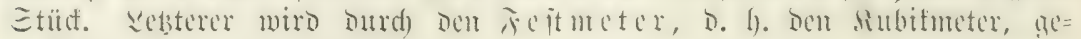
mej̃en and auggedrüdt.

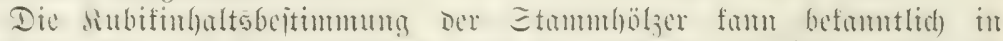

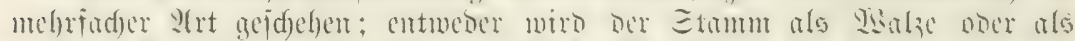

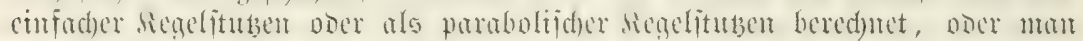

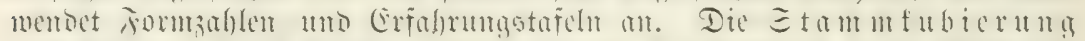

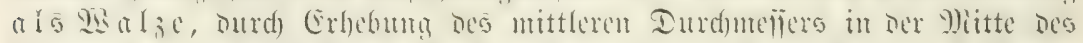

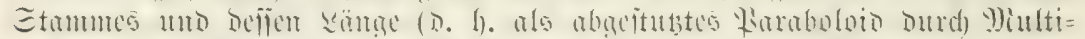

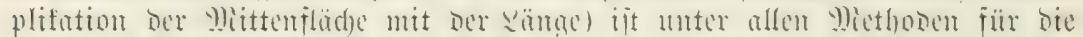

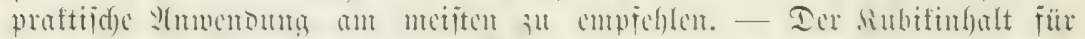

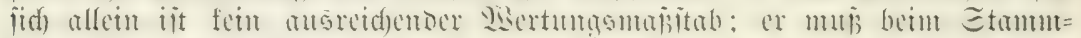

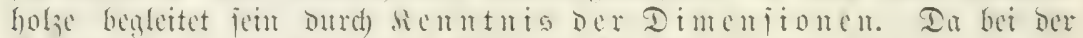

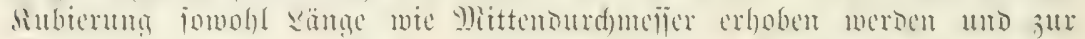

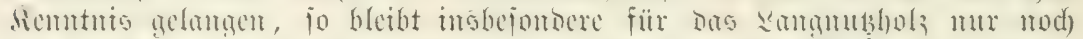

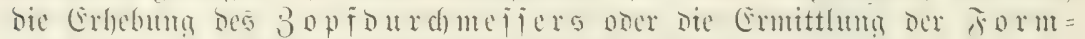
bölce übrig, um alle wertbeftimmenden 9lomente zu fenmen ${ }^{\mathbf{1}}$ ).

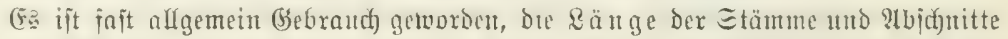

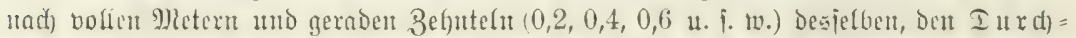
mefiex in ganzen Bentmetern unb ben dibifingalt in diubifmetern mit zuei

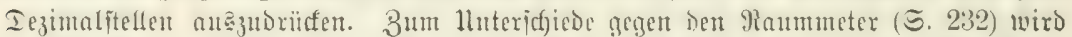

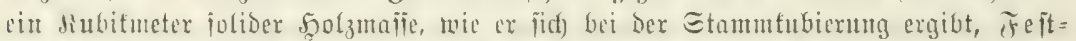

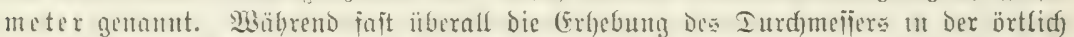
3 bezeidunendon Etammeämitte gejchieht, hat man in einigen Maldungen bei Eäge=

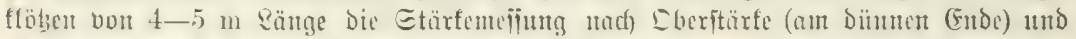

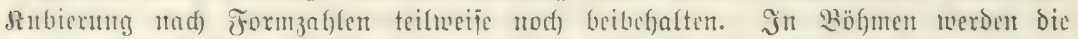

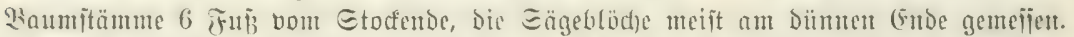

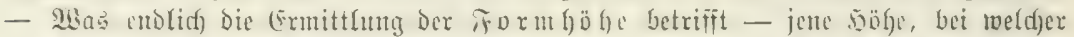

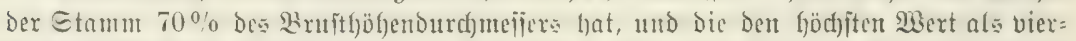

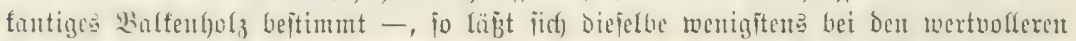

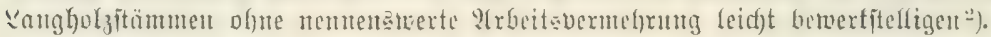

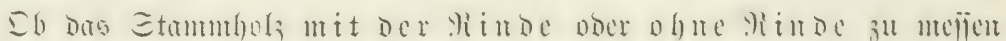

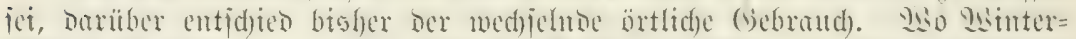

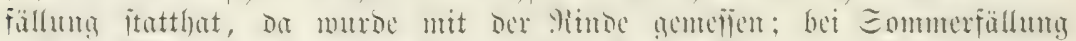

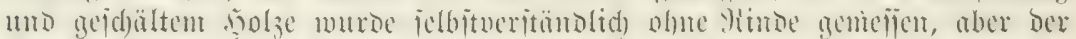

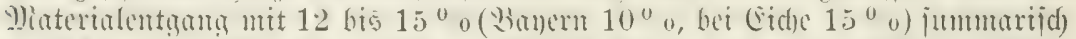

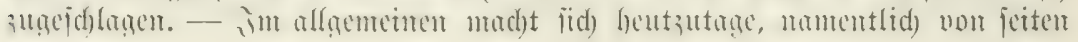

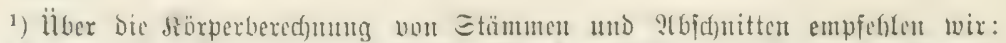

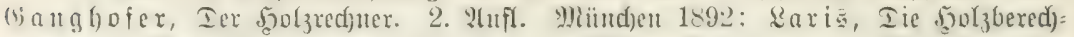

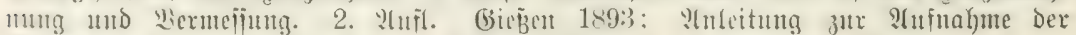

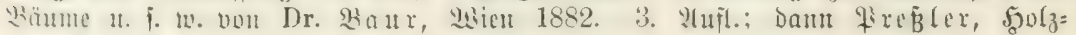

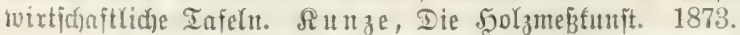

-) Eirbe Die jefr bead)tentwerten Ilnterind)ungen vou \&egnpfuf) in Iandel= mants Beitjdx. 1885, Dezemberheft. 


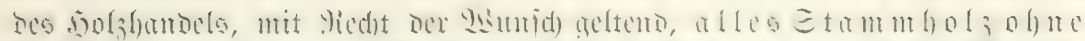

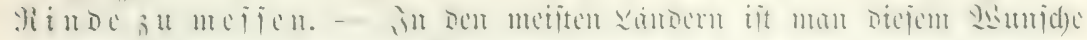
beute and) bereitwillig nadjgefommen.

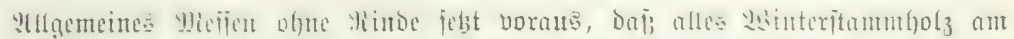

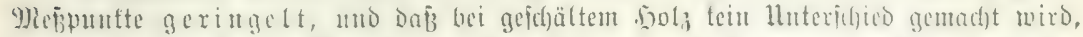

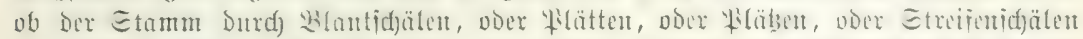

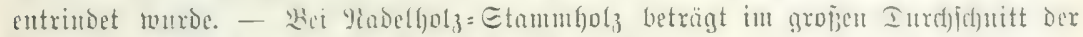

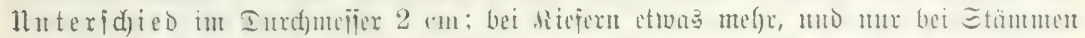

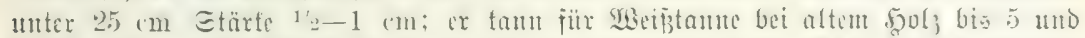

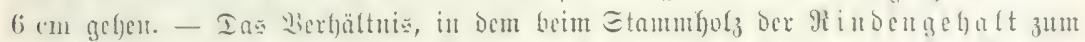

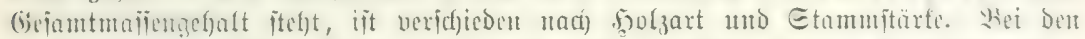

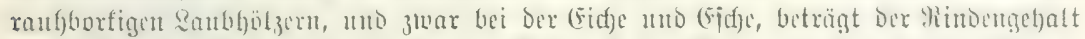

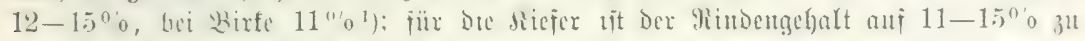

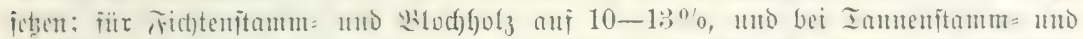

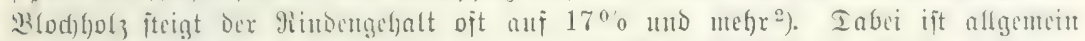

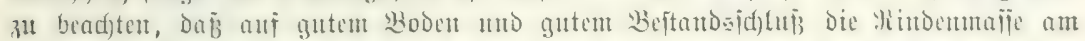

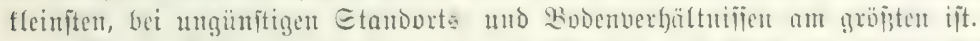

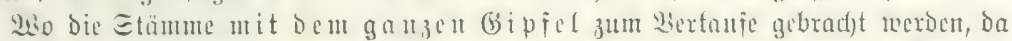

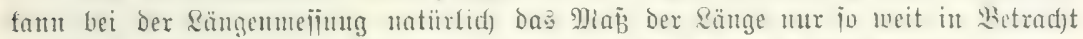

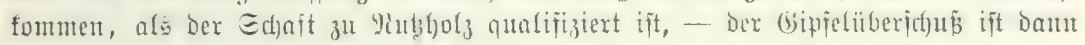
als Brentitola 1t. f. w. anzulprechen.

2. 宩花

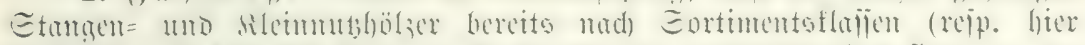

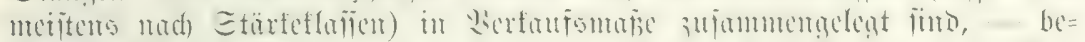

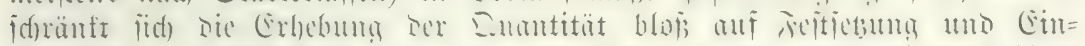

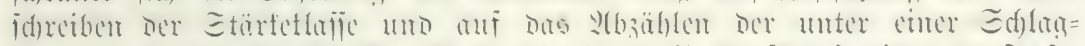

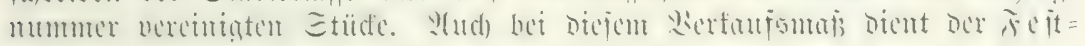
meter als quantitatives Einfeitsmap.

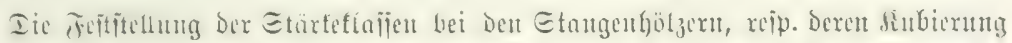

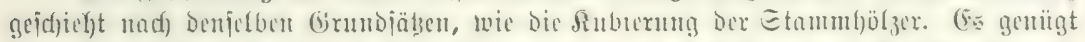

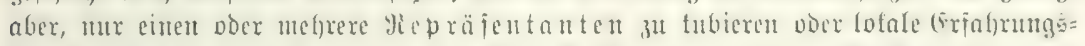

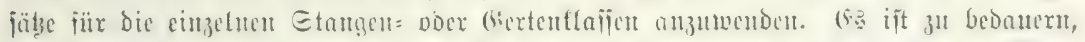

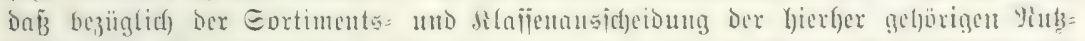

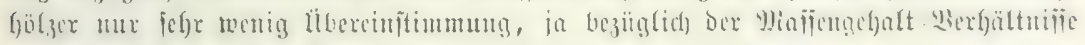

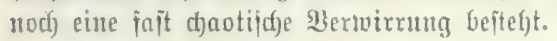

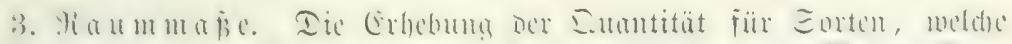

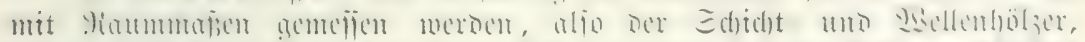

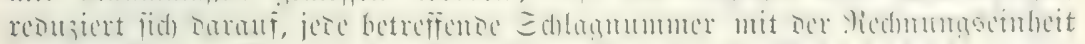

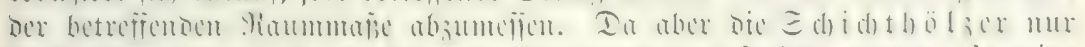

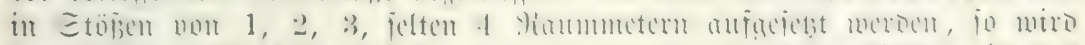

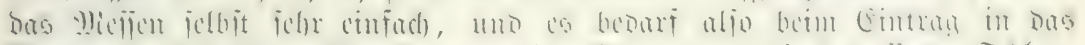

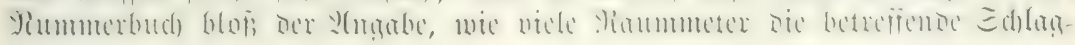

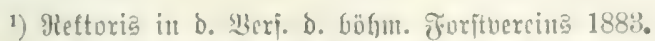

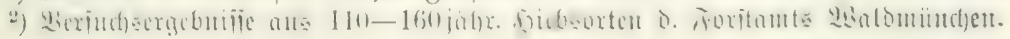




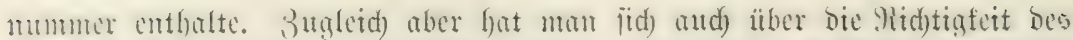

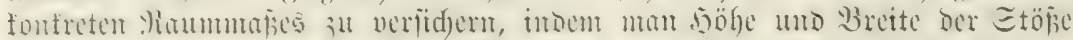

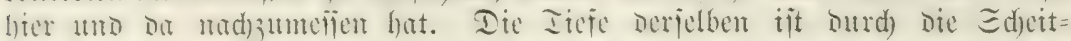

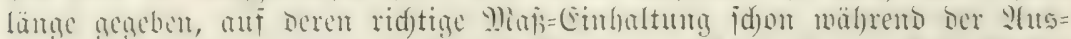

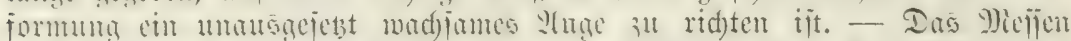

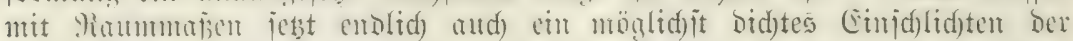

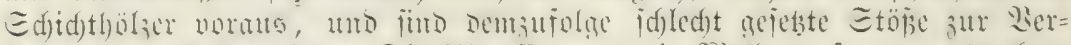

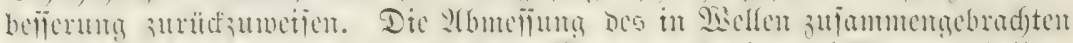

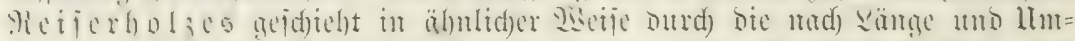

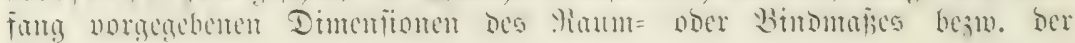
P(ithanfent.

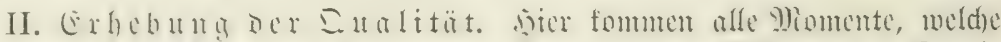

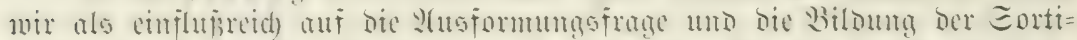

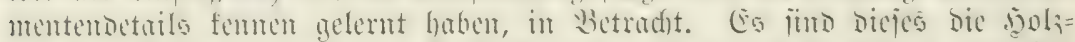

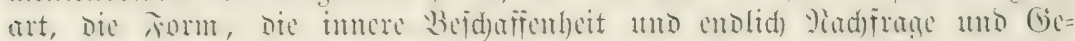

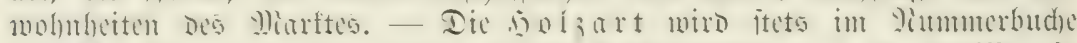

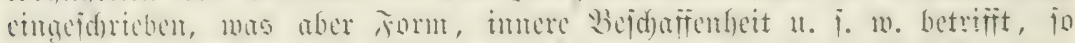

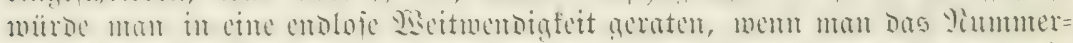

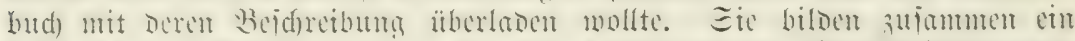

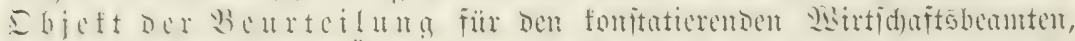

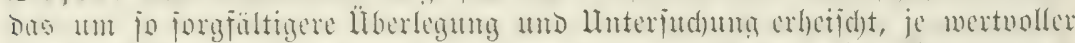

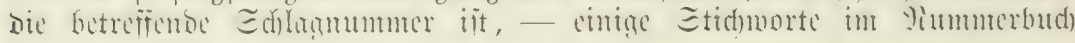
find erminitid)t.

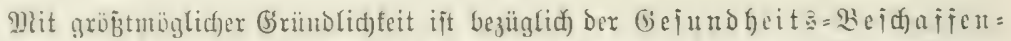

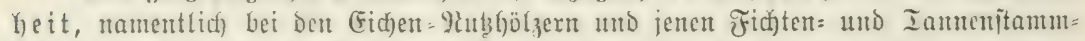

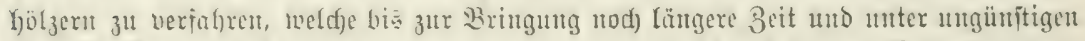

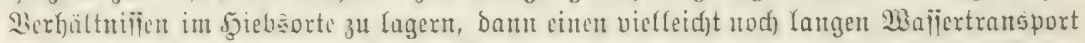

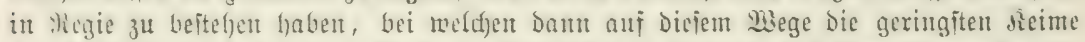

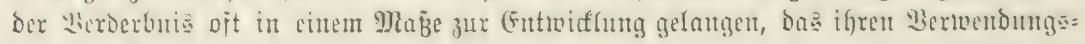
twert afs glutbholz bolfiänoig aufigebt.

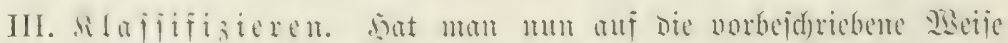

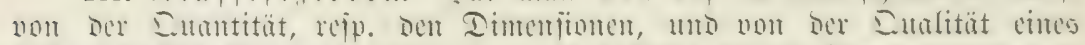

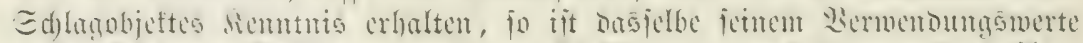

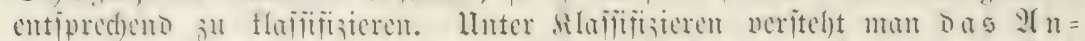

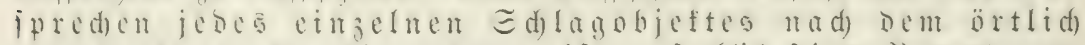

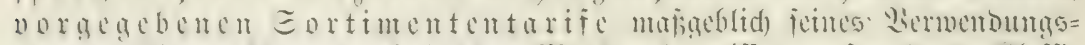

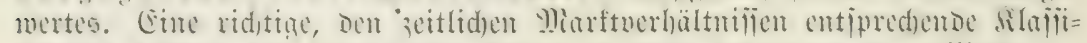

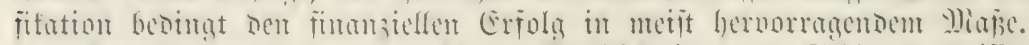

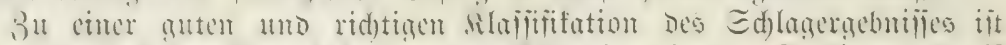

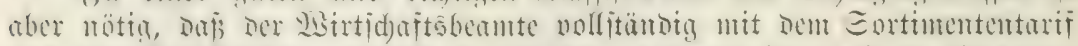

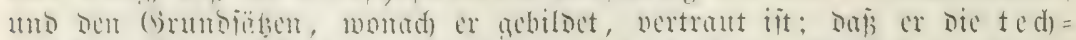
ni dd $_{\text {a }}$ (E)

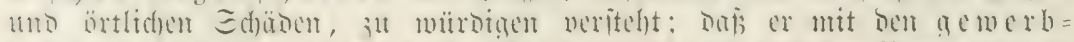

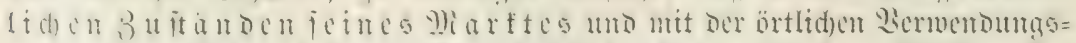

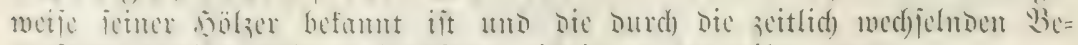

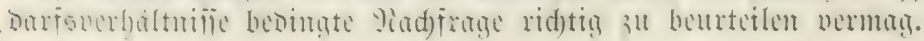




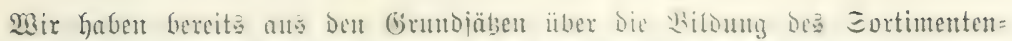

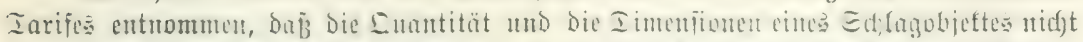

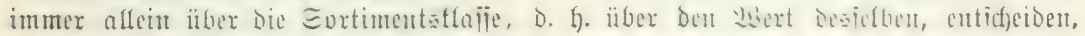

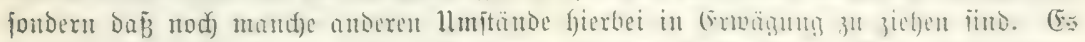

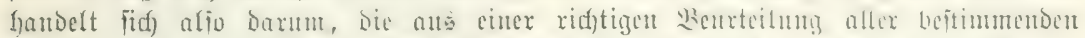

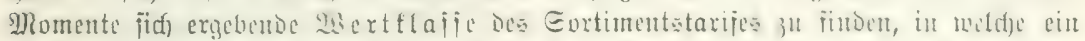

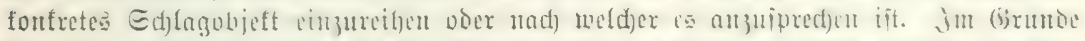

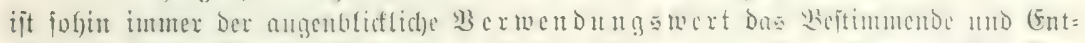

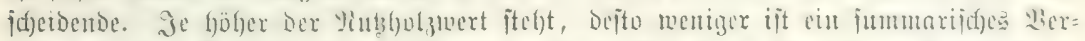

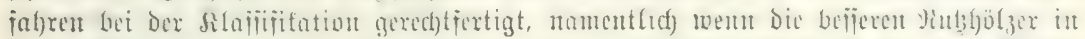

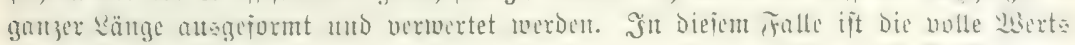

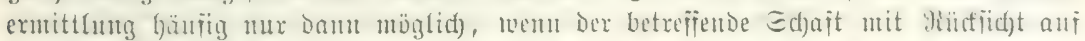

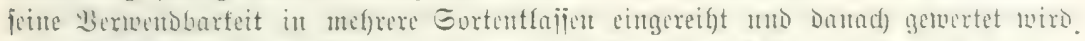

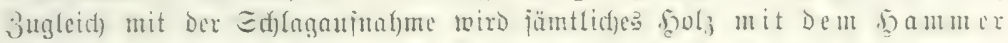

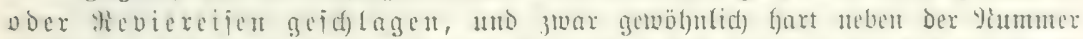

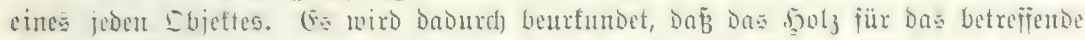

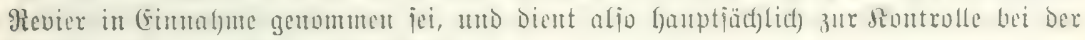

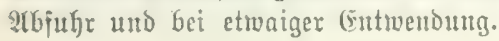

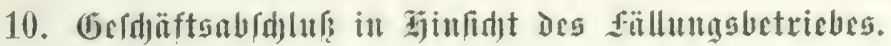

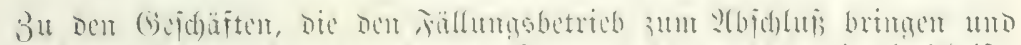

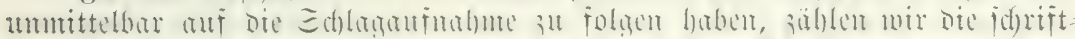

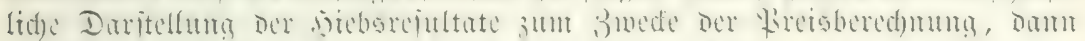

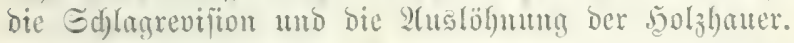

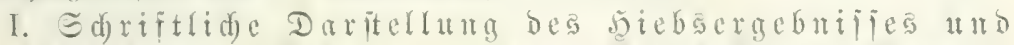

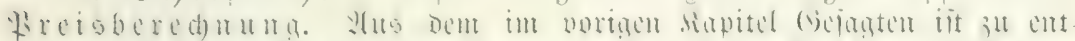

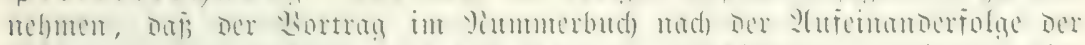

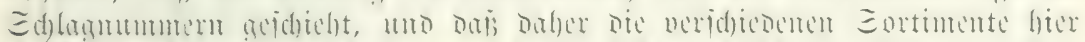

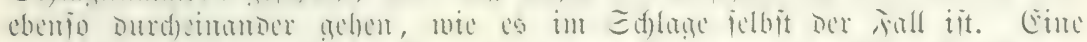

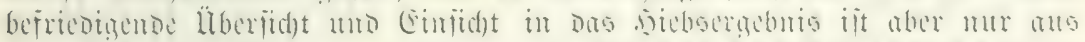

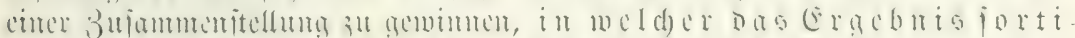

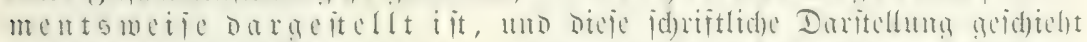

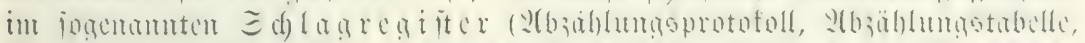
Zuscinteilmas=-

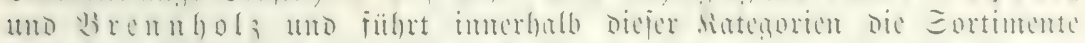

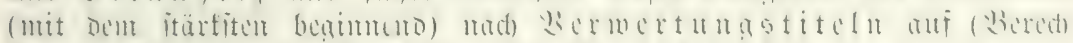

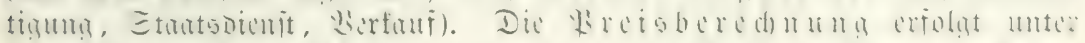

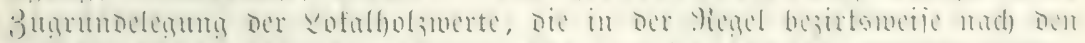
icitlds s

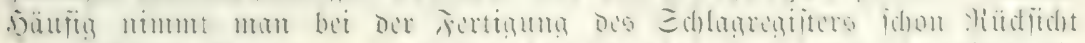

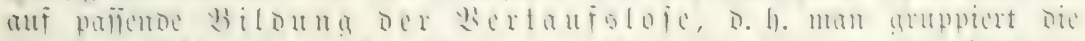

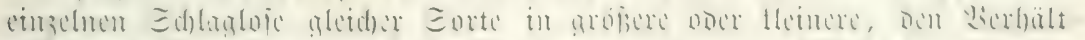
miten des IV. 2(bid)nitt.)

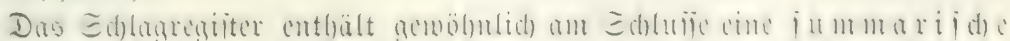
i) 


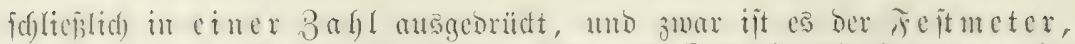

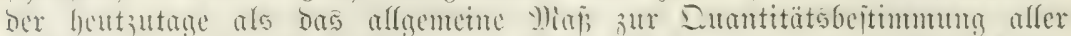

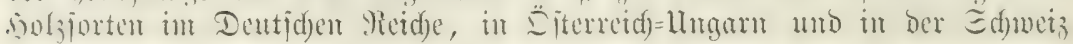
argentommen ijt.

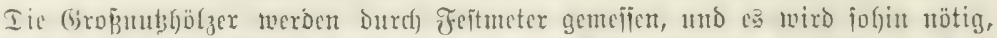

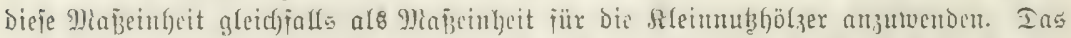

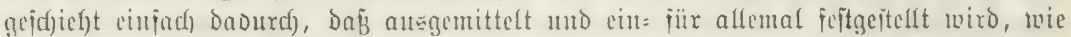

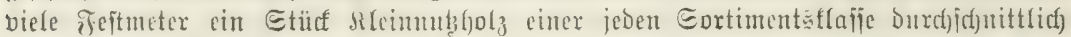
cutbält, odex wie vielc Etüffe ber geringeren Evortimente auf einen Feftmeter gercd)net

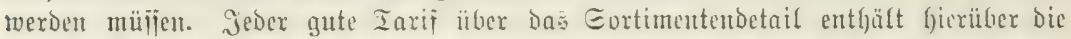

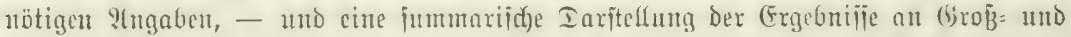

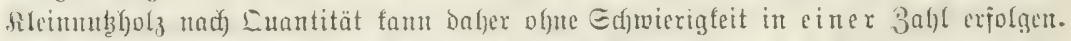

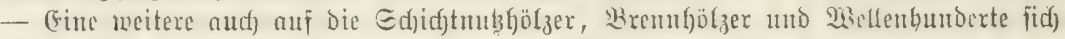

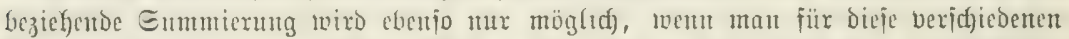
Eortiment

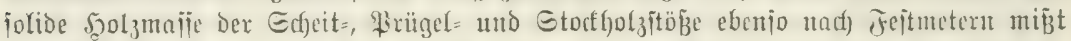

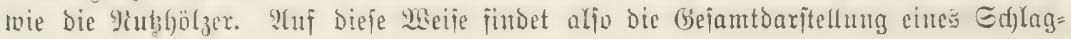
ergebuififes in Feftmetern italt.

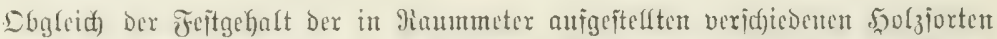

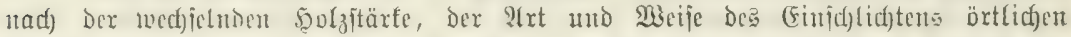

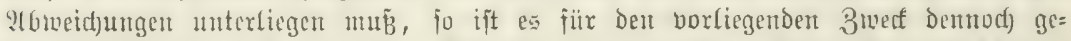

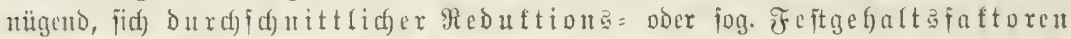

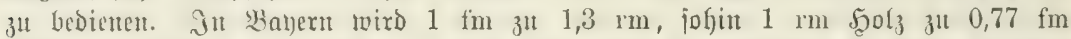
folide Solzmafie angenommen. Tha Dent Durd) Die Deutichen Etaatent gemein= idfoftlid) unternommenen Huterjucfungen baben fid) nun folgende Meduftionsfaftoren ergebent ${ }^{1}$.

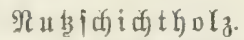

$1 \mathrm{rm}$ stutsidjeite. . . . . . . . . . . $=0,75-0,78 \mathrm{fm}$

1 "פ่uţtnüppel . . . . . . . . . $=0,66-0,72$ "

$\mathfrak{B} \times \mathfrak{e n n \mathfrak { o l } z}$.

$1 \mathrm{rm}$ Edfeitfyol $_{3}$, glatt unb gerabe . . . . 0,72-0,75'"

1 " " fnorrig แnס frumm . . . 0,66-0,69"

1 " Snüppel, glatt unঠ gerabe. . . . . 0,66-0,72 "

1 " " thorrig uno frumm . . . 0,60-0,64"

1 "Reis̆tnüppel, ভtamm= unঠ 2lïtreifig . . 0,47-0,55"

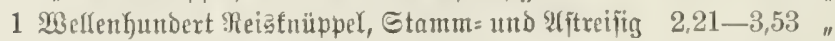

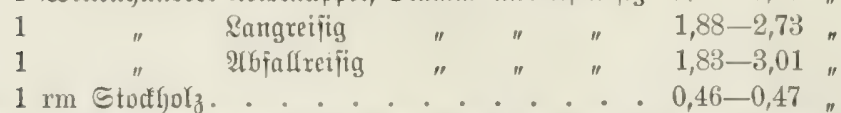

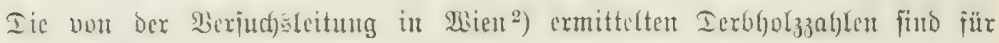
$1 \mathrm{~m}$ Edjeitlänge:

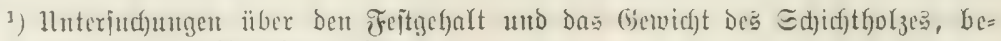

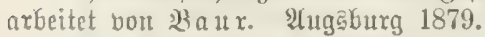
1. Scit.

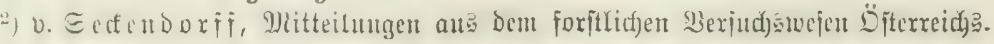




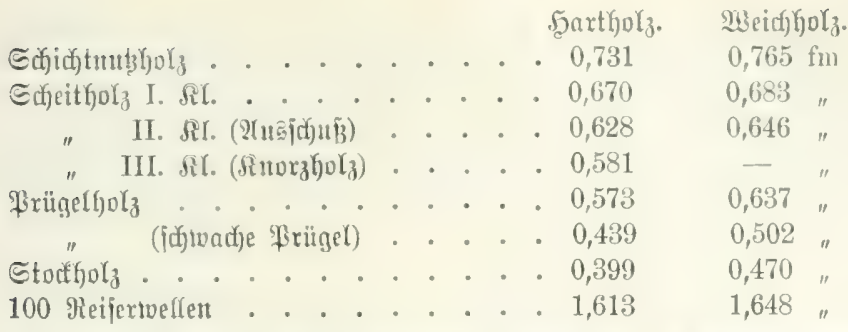

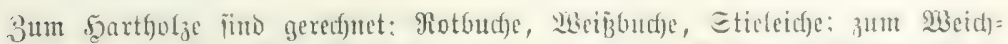

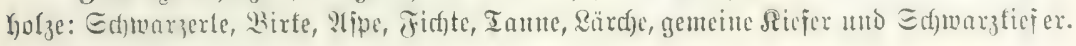

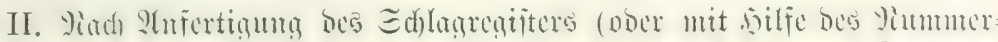

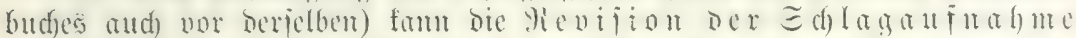

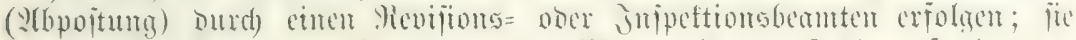

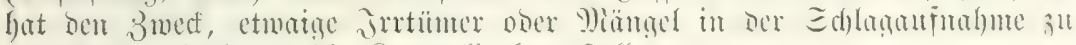
verbefiern, überbaupt bie Sontrofle herzujteffen.

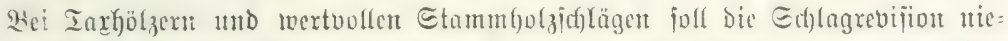

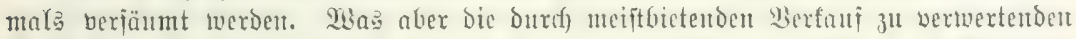

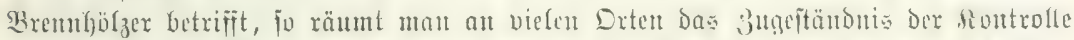

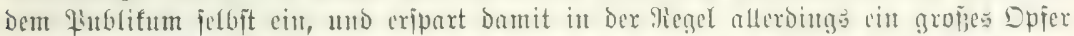

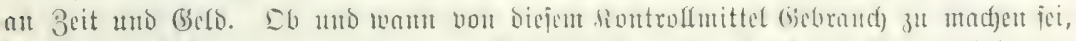

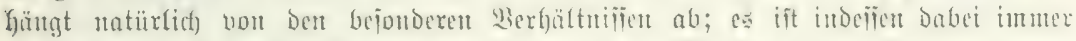

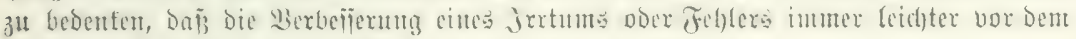

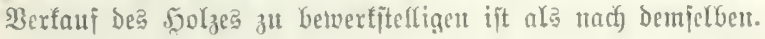

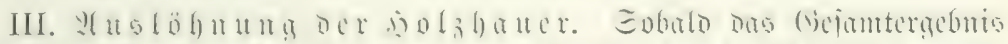

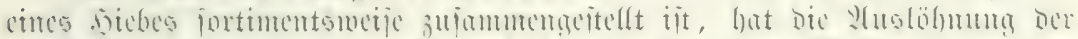

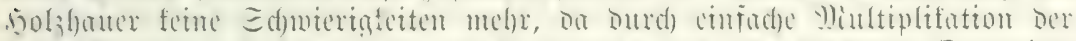

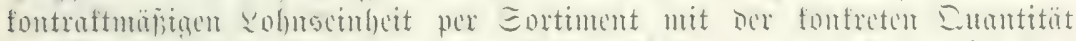

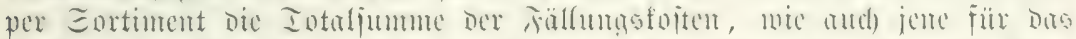

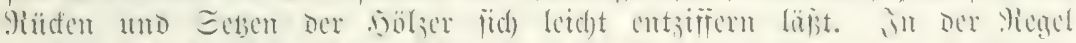

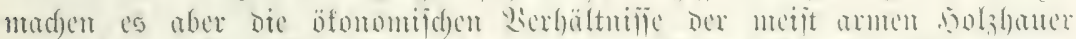

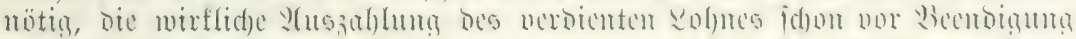

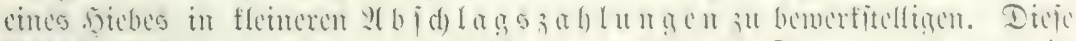

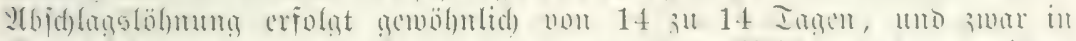

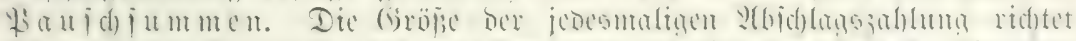

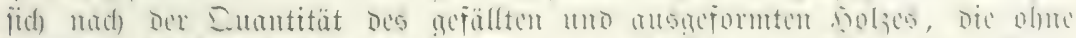

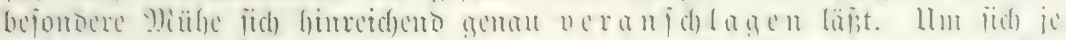

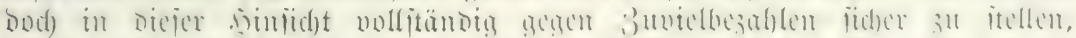

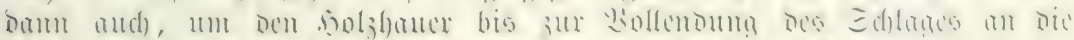

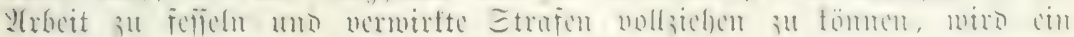

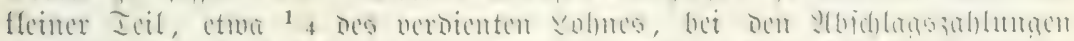

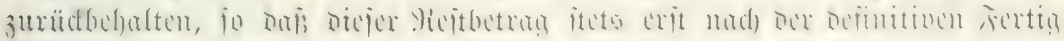

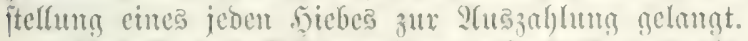

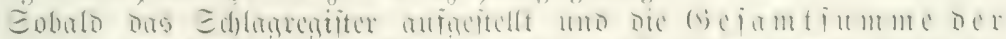
(i) Durd) Die cingeluen : 


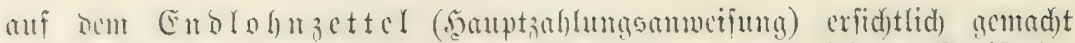

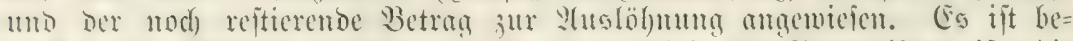

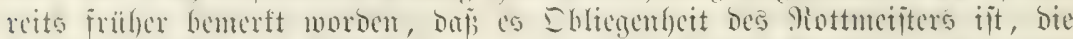

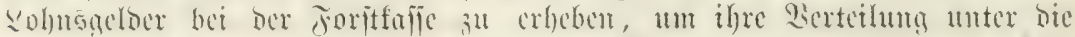

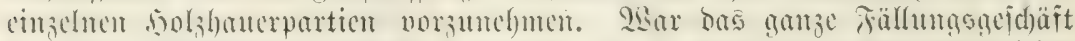

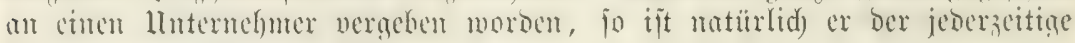
Ěmpfänger Deș \&olnę̧.

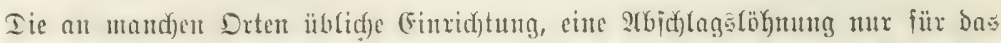

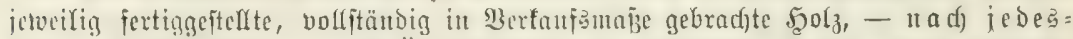

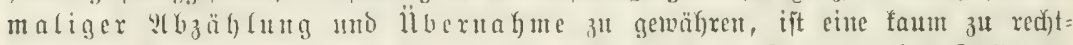

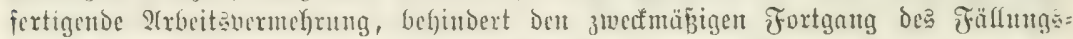

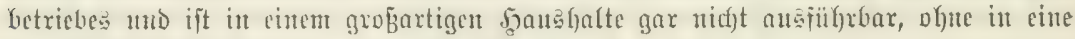

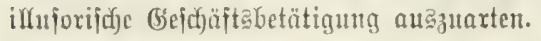




\section{Dritter 2lbjhnitt.}

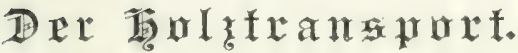

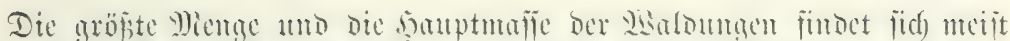

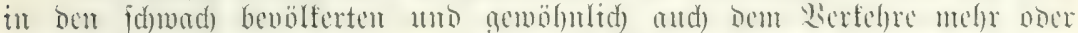

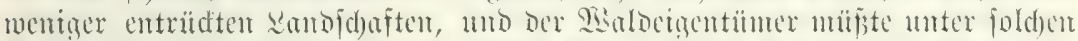

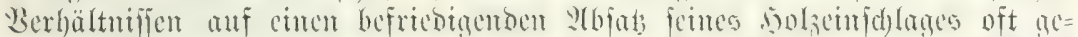

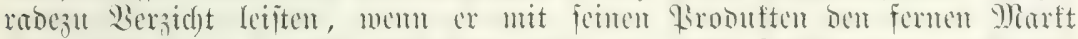

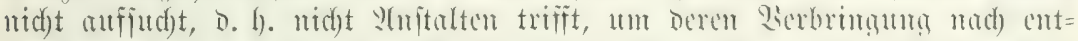

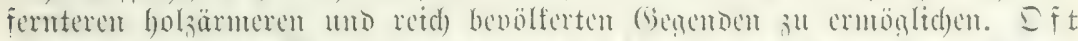

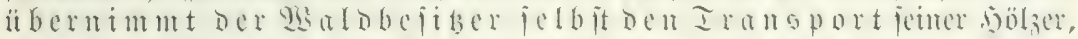

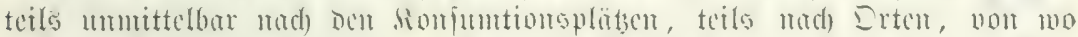

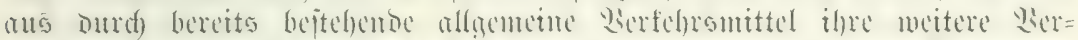

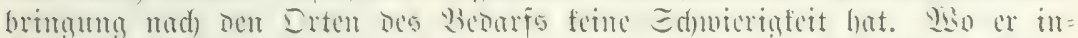

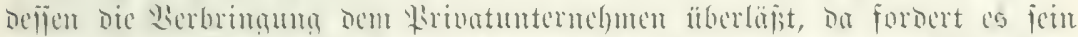

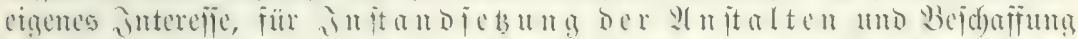

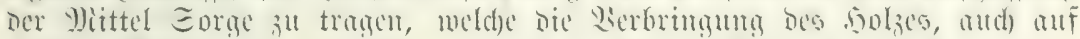

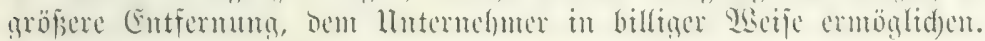

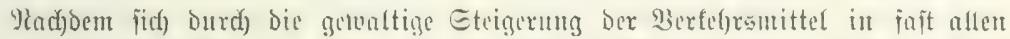

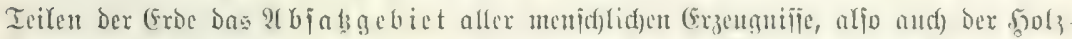

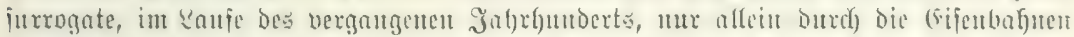

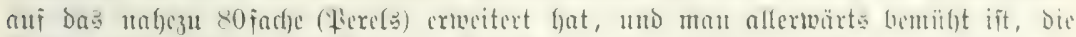

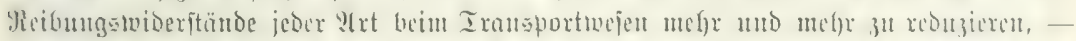

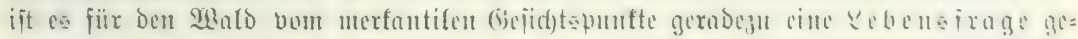

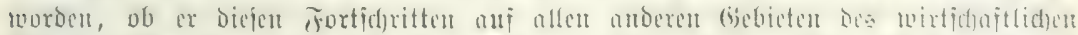

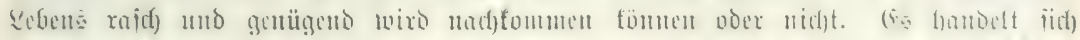

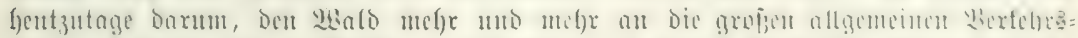

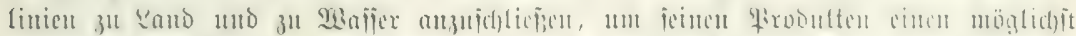

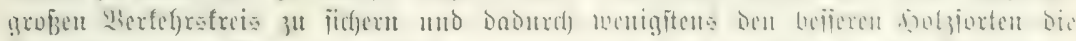

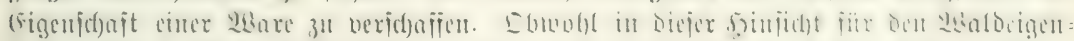

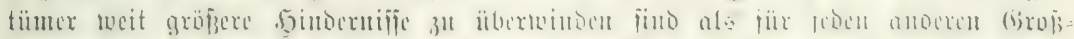

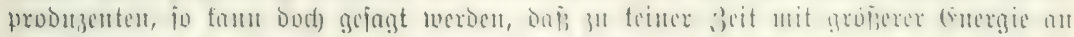

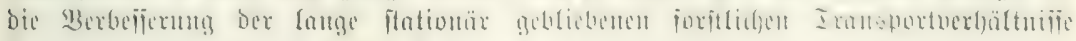
herangetretent wurbe alz it ber Begentuart. 


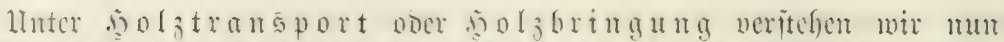

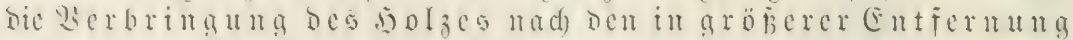
gelegenen Sionfumtionspläben ober Eammellagern, und

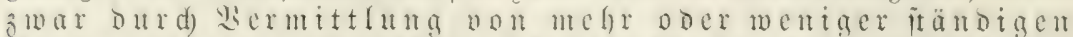
B

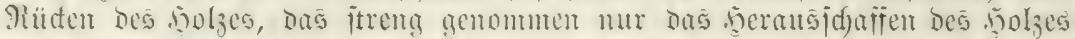

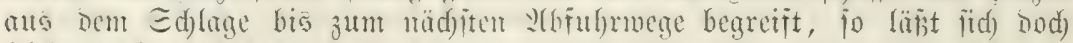

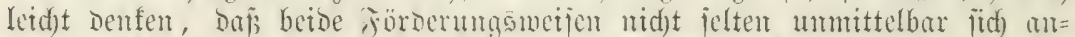

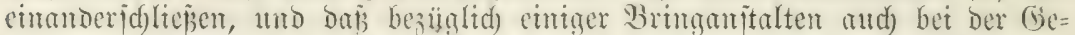

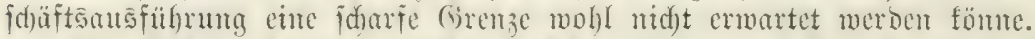

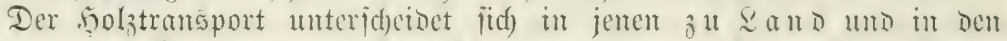

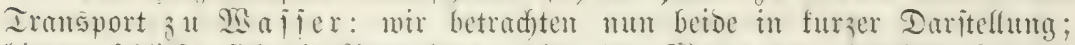

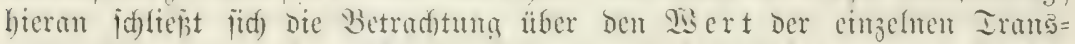

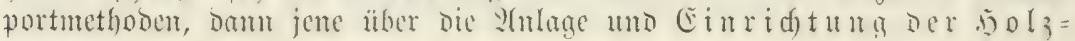
gä refen.

\section{Cirite Ilnterabteilung.}

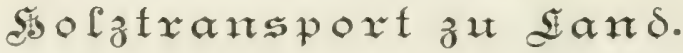

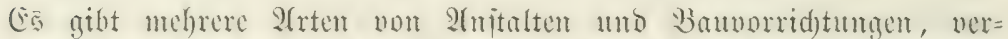

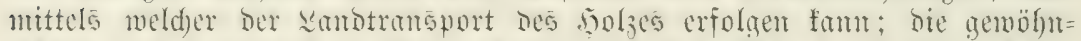

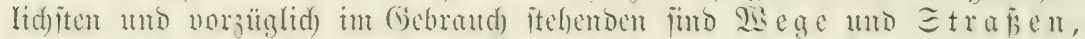

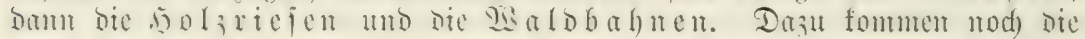

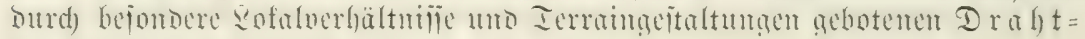
feilriefen uno Bremaberge.

Iex Iariteflung Dex verid)icoenen :Irten Der Solzbringung auj Den gentanten

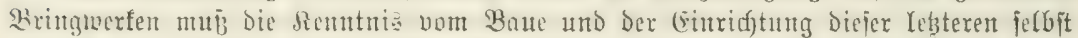

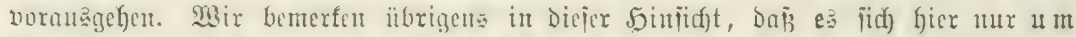

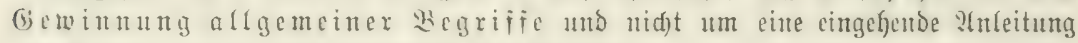

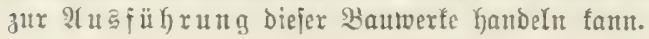

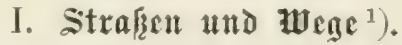

\section{A. B̧au}

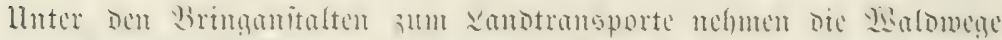

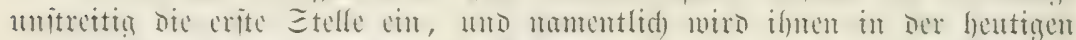

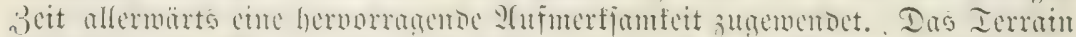

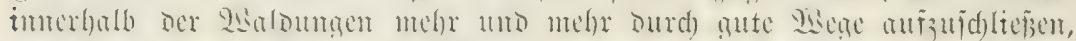
mui; heutiutage ons fortacieste

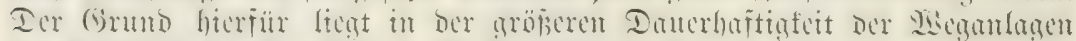

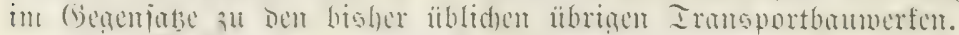

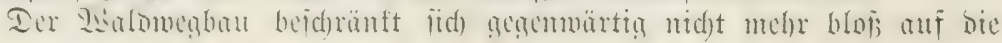

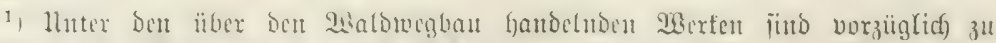

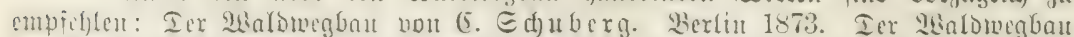

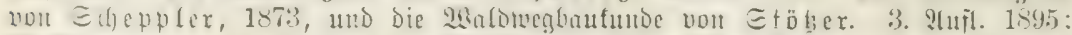

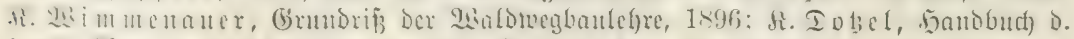

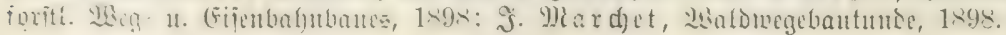




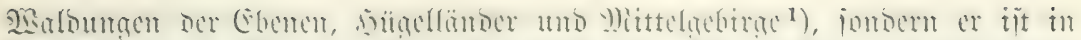

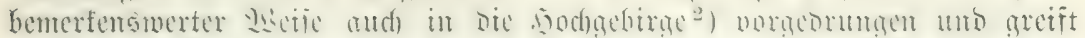

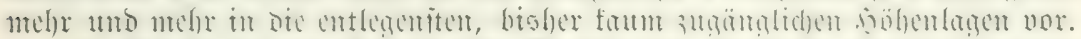

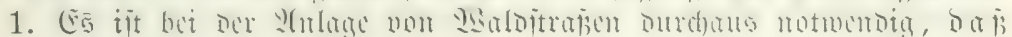
man nad) eitent vorler wohl exwogenen glane verfährt,

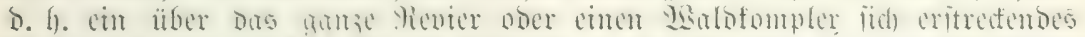

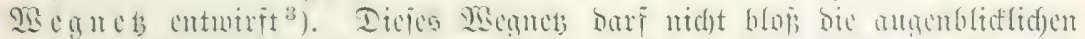

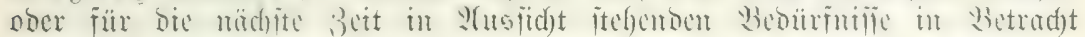

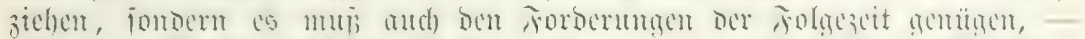

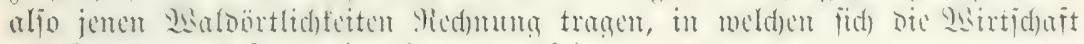
erjt in päteren Dezemien bewegen wirb.

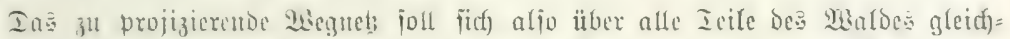

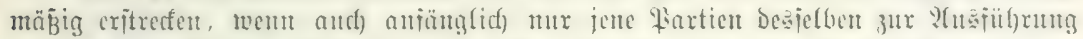

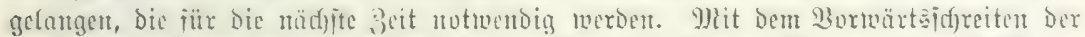

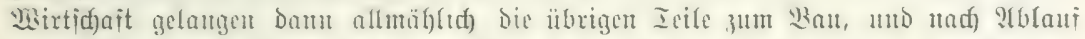

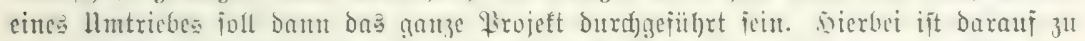

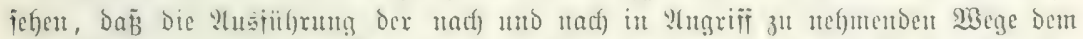

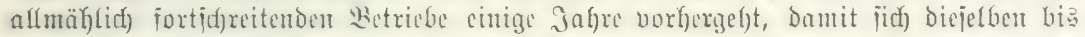

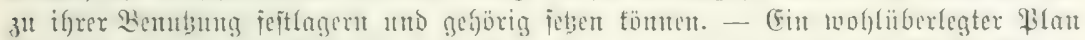

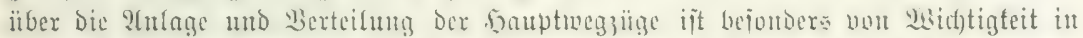

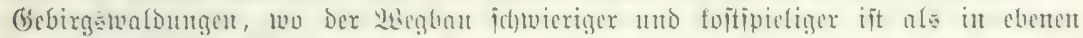

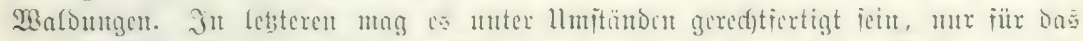

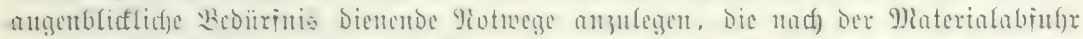

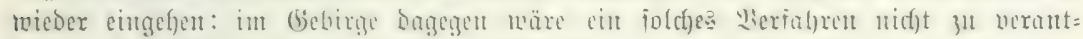

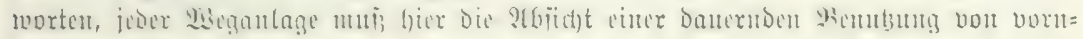
herein at Grumbe liegent.

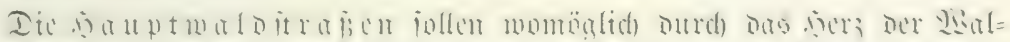

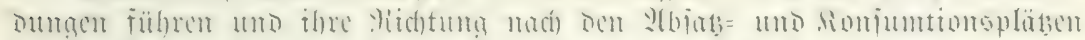

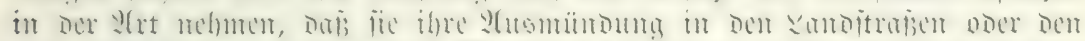

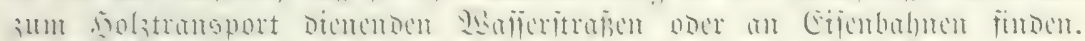
.)

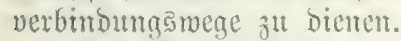

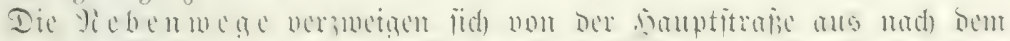

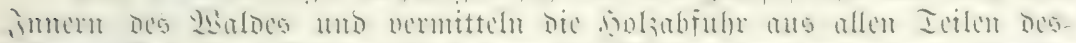

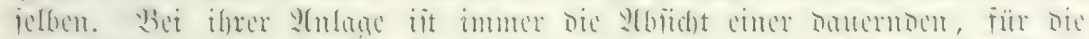

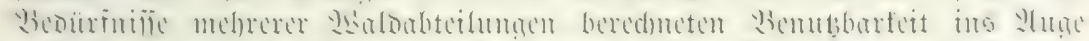

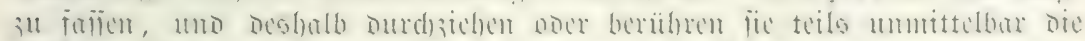

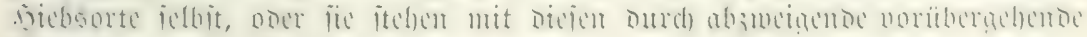
ङtellwege in Werbintung.

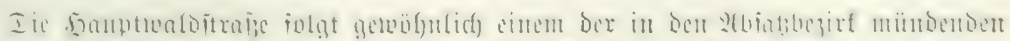

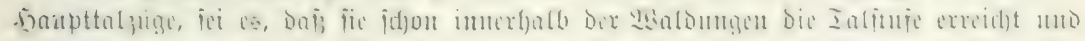

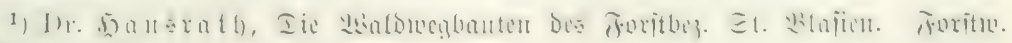
3entralol. 1895 .

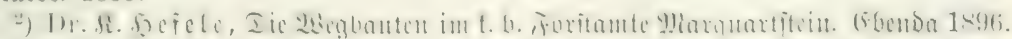

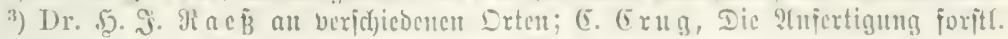
Ierraintarten น. Dic megutetprojeftierung. 1878. 


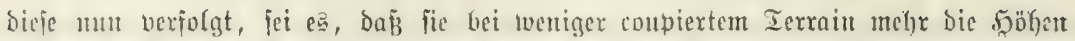

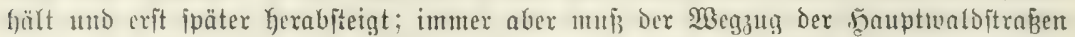
io angeleģt jein, ba

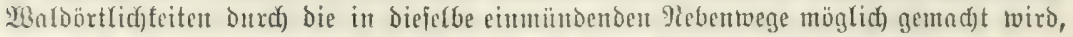

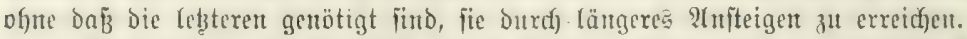

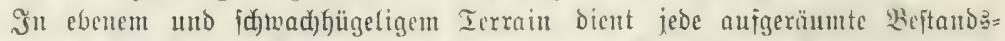

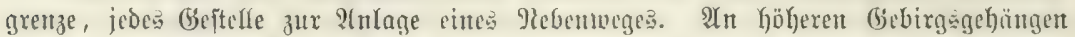

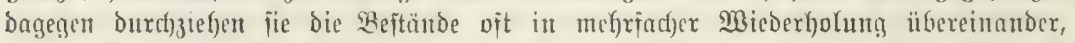

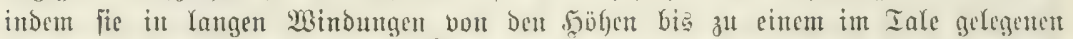

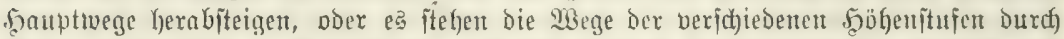

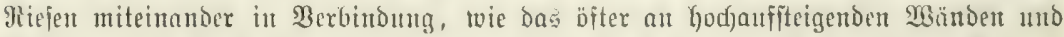

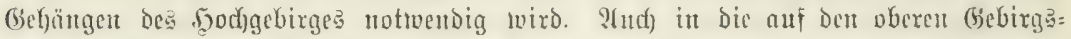
ftufen gefegentu engen Seitentälex, in weld)en bon beiden Gehängen herab bas 5olz

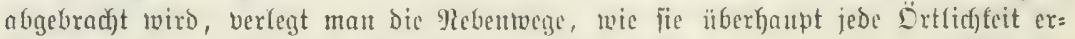

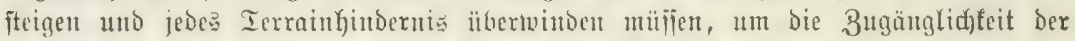

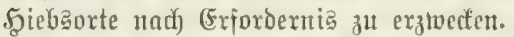

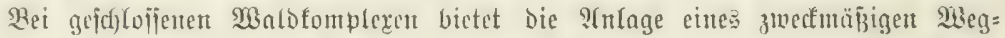

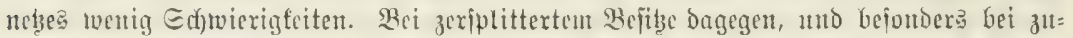

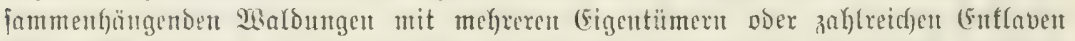

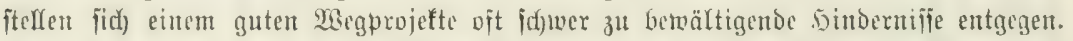

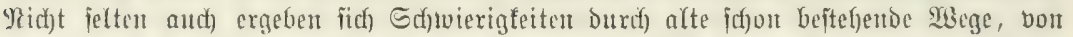

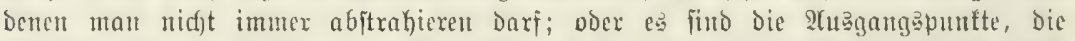
3 tweifel gebären und die Frage offen Yajfen, ob die folid gebaute Malditrabe in gleid)

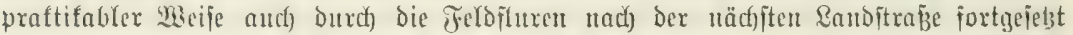

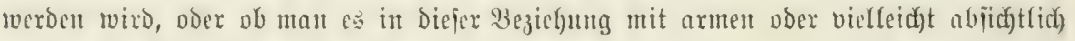
renitenten (Gemeinden zu tun bat.

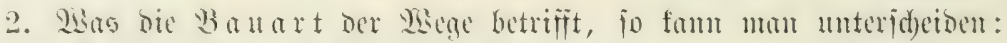
Eromege, Runjtiträ̧en und Bege mit \$olzbau.

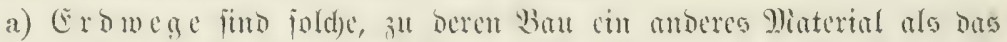

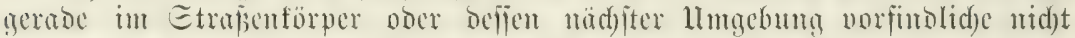

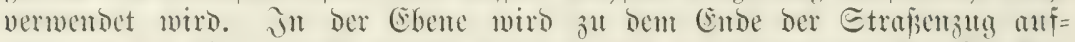

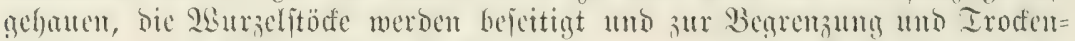

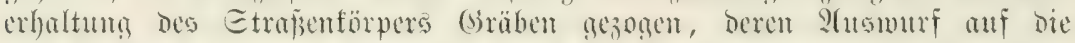

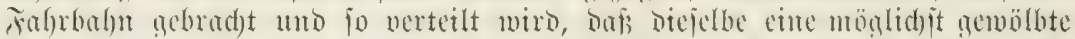

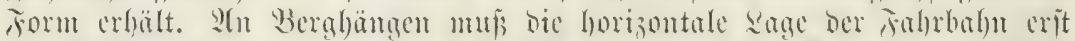

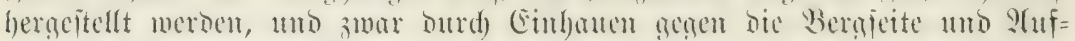

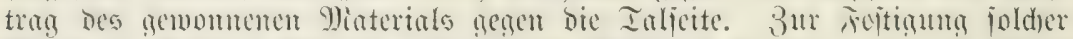

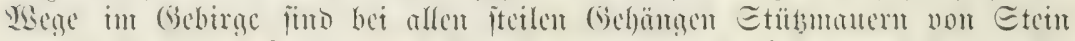

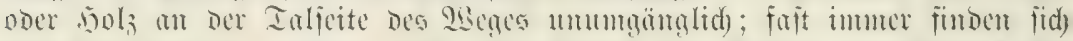

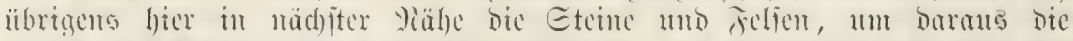

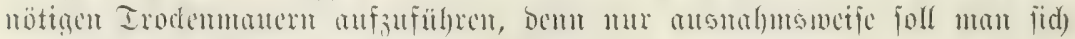

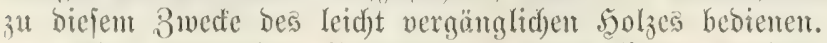

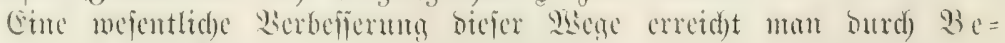

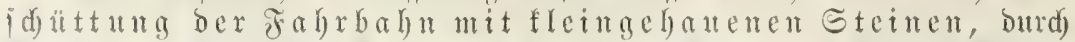

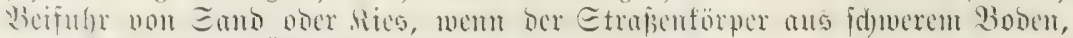

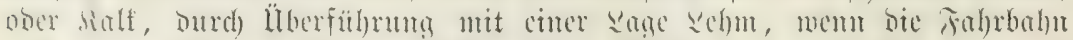

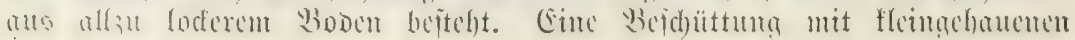




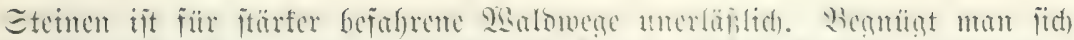

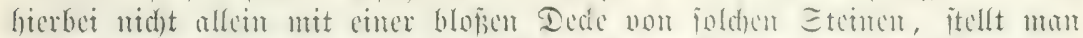

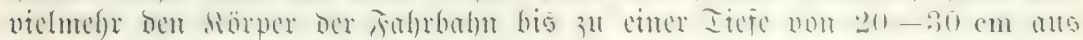

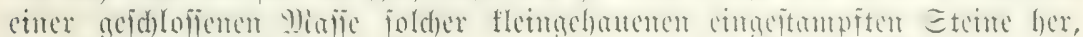

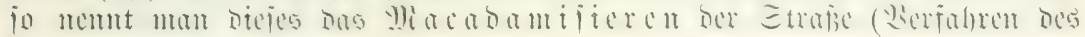
Eัnglänbers Miac $\mathfrak{A}$ (bam).

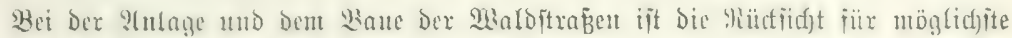

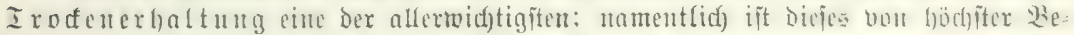

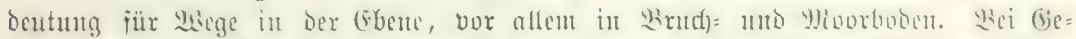

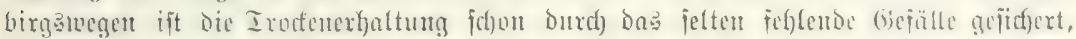

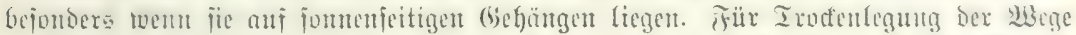

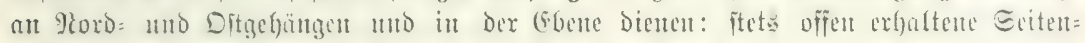

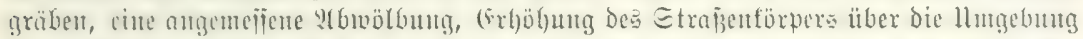

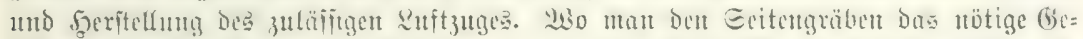

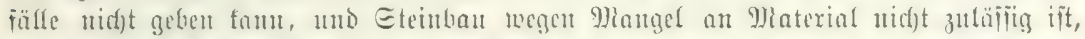

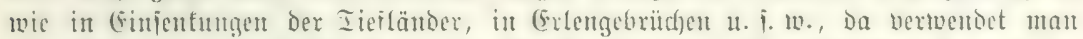

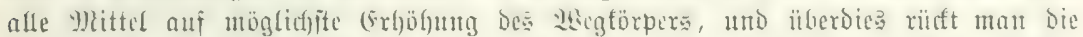

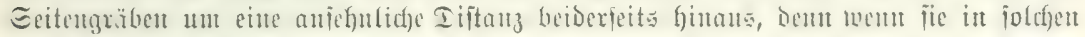

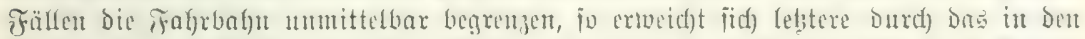

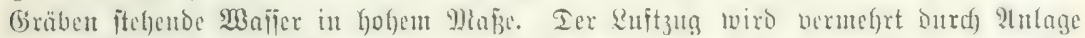

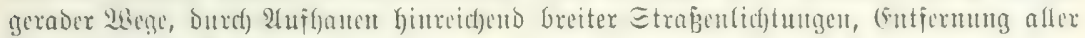
ïberfängenben Mandbäume ํ. f. w.

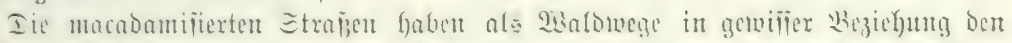

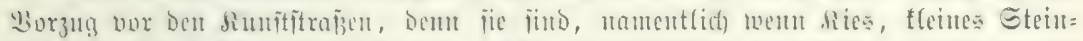

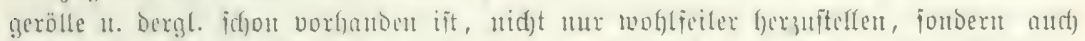

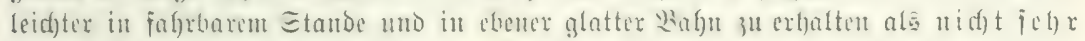
jorgiältig gebaute Sunftłtrāen.

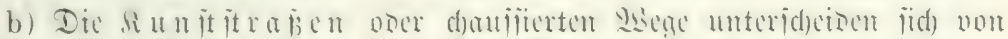

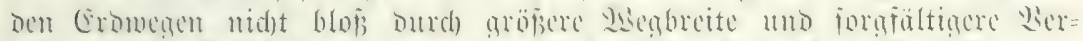

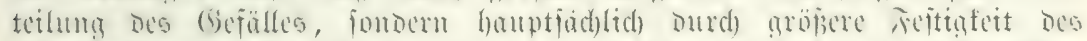

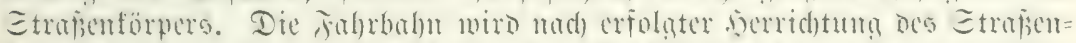

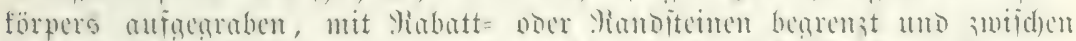

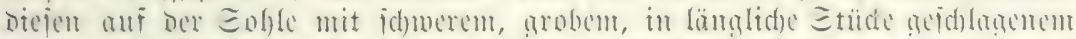

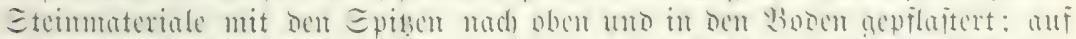

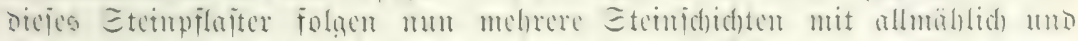

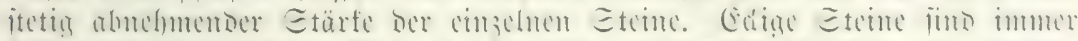

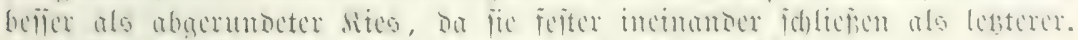

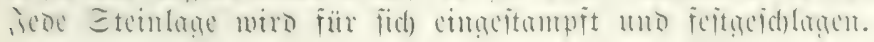

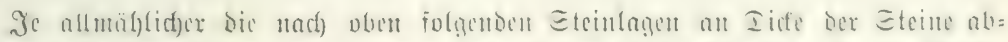

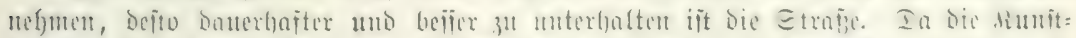

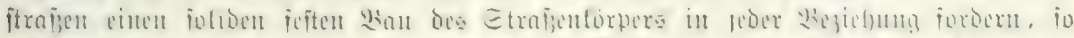

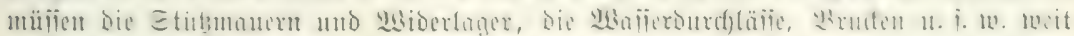

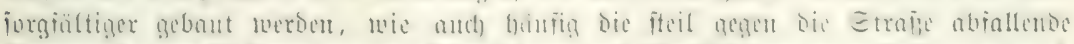

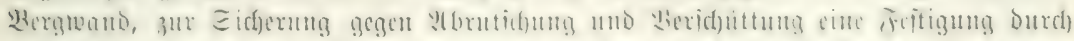

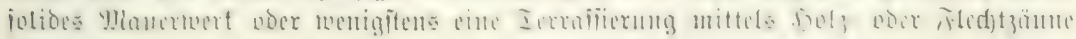
erforbert. 


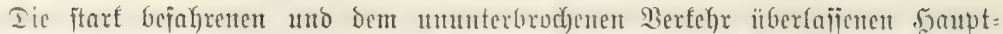

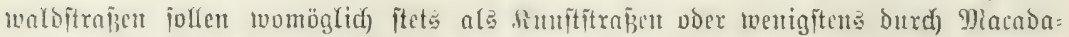

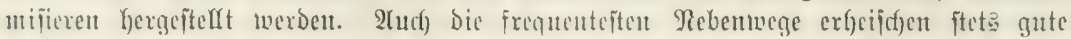

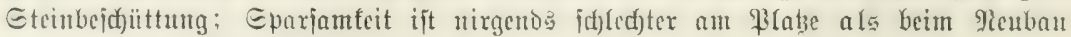
vielgebraudter Waldwege.

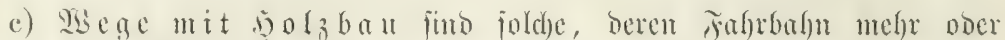

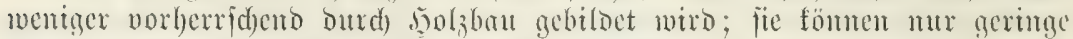
Dater bieten un fund fon beshalb möglichjt zu vermetoen. Doch funbet

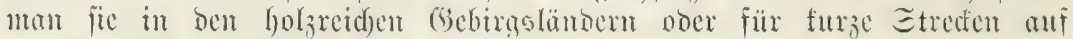

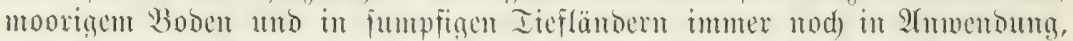

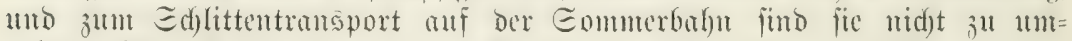

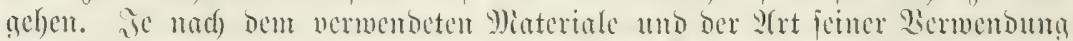

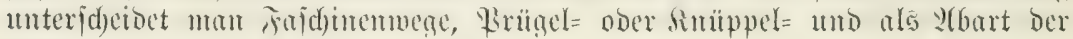
leb̧teren die jogenamnten Gdmmiermege.

Fajef inculuege werben vit auj furge Iiftanz exforberficf, tocun ber Meg itber

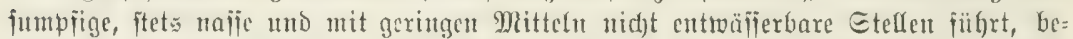
ionder aber beim Begban über naficn Iorjooden, in weldem Der Etcinban fort= wëlfrent in bie Iteje berfinfen ober ber Grabentuburf und Iorjabraun im lofferet

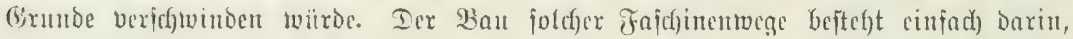

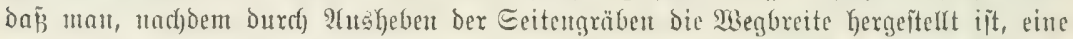

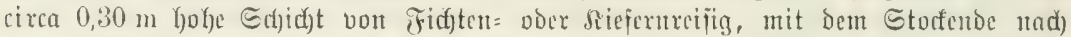

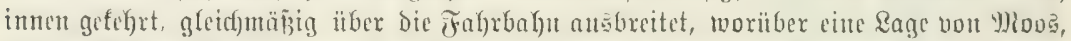

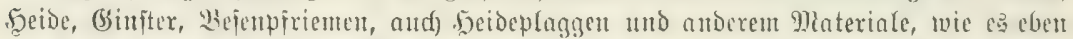

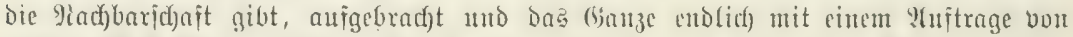

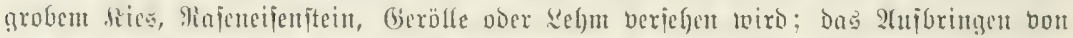

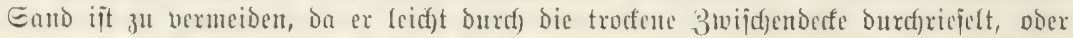

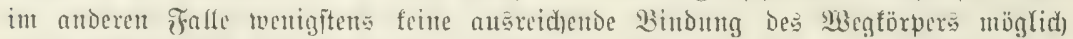
madyt. diant man Dem Eand Dngegen Ion boer ReYm beimengent, fo wirb bie Ber=

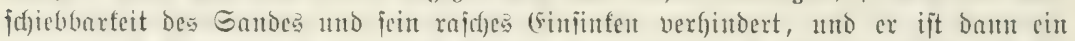

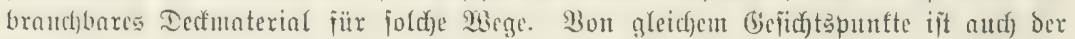

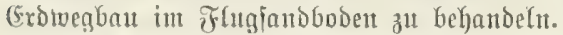

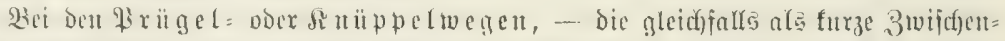

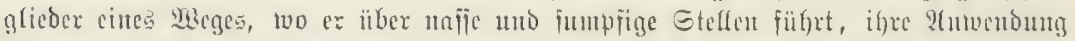
findon, - bildon mittelftarfe Etämme, weta)e am beiderieitigen Hande Der Fafurbafyn

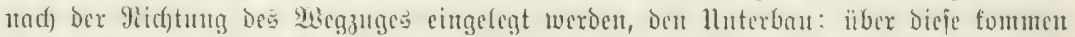

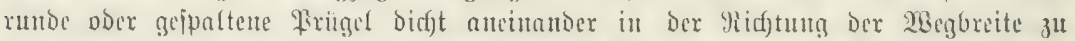

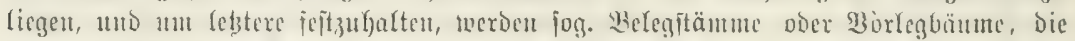

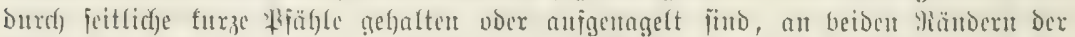

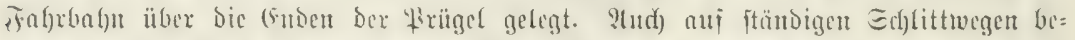

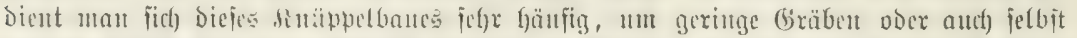

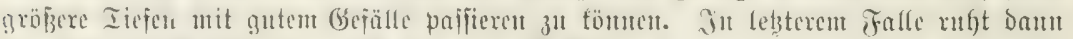

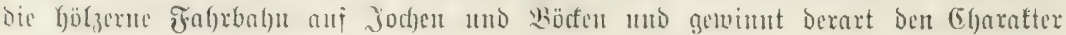

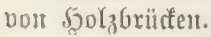

Die $S_{\text {df }}$ ier = oder $S_{\text {df }}$ leiftwege findet man feltenter; fie dienen alfein zum

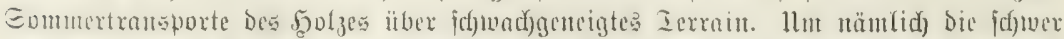
3u

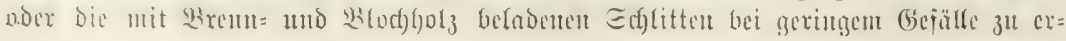




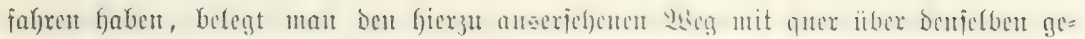

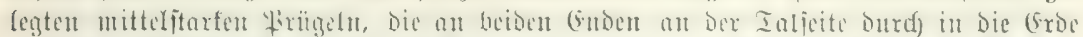

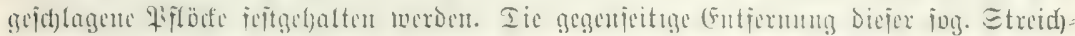

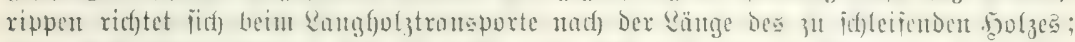

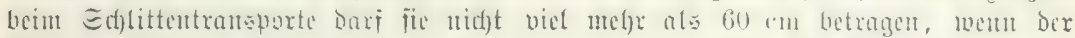

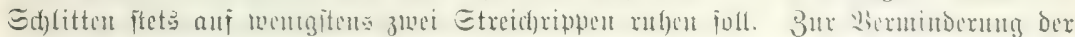

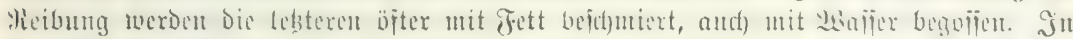

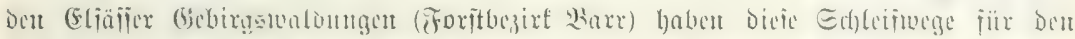
Echlittentransport nod) wor furgem in ausgedelutem (bebrandje geftanden.

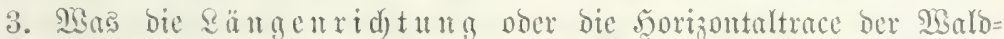

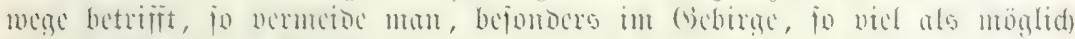

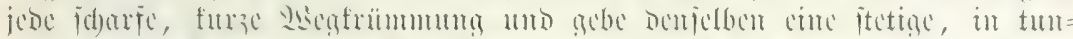

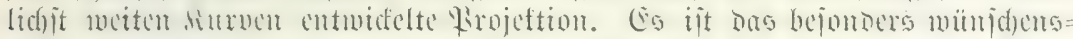

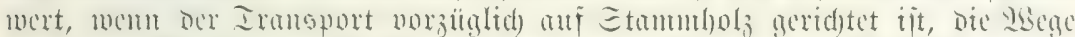

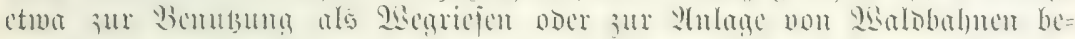
mutst werden jollen.

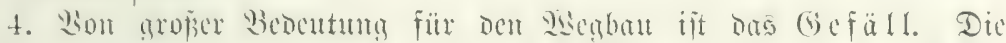

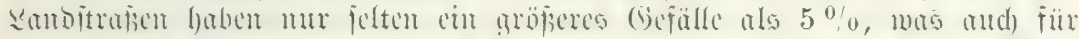

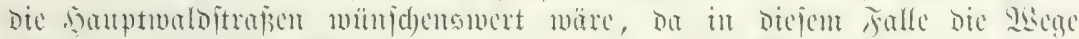

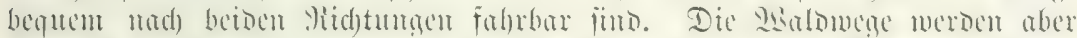

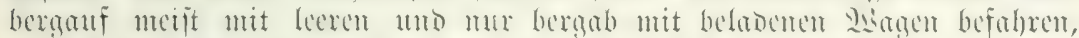

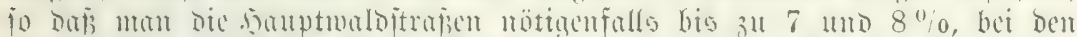

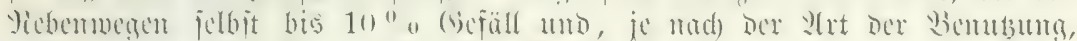

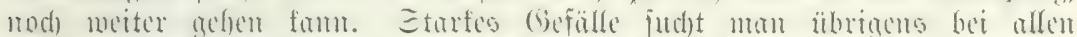

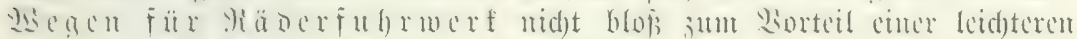

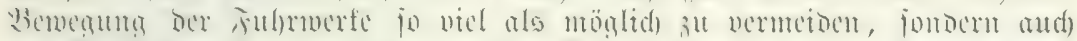

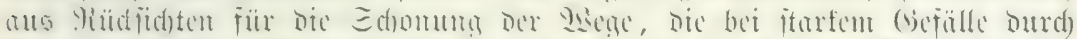

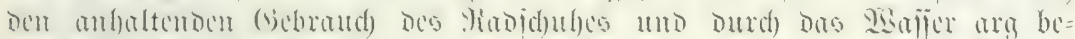

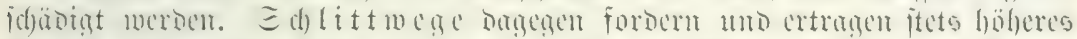

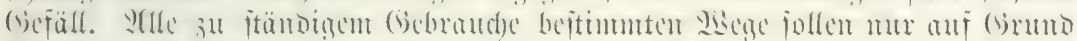
cines forgfültigen 9 i vellement s gebant werben.

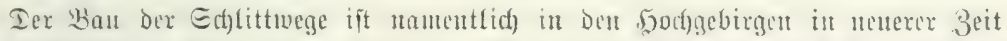

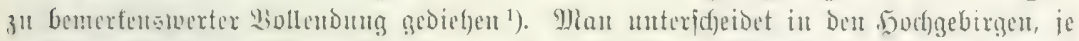

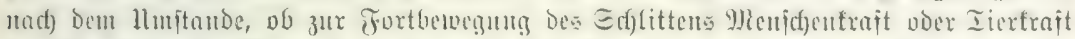

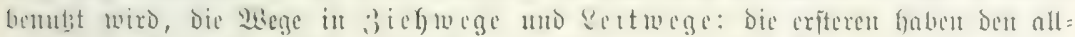

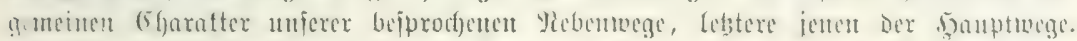

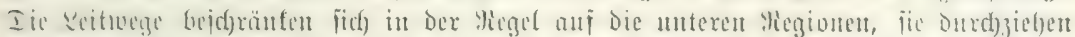

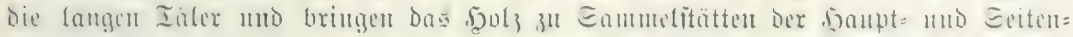

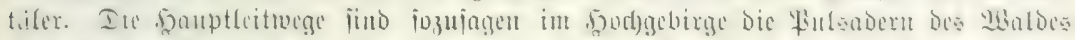

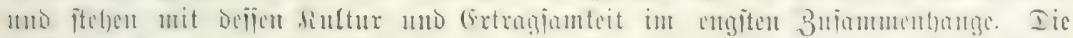

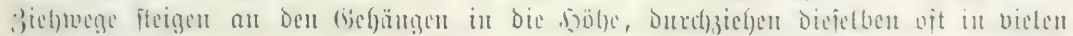

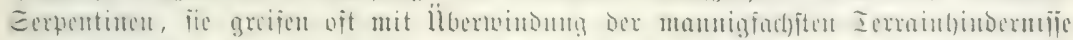

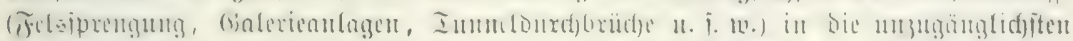

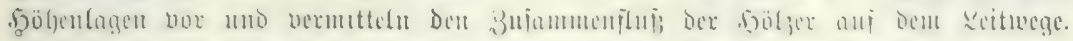

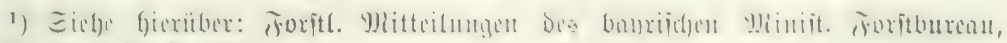
अ. III, 2. Scit, G. 209. 


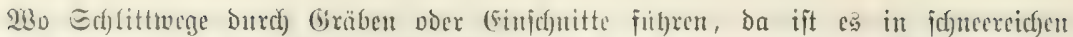

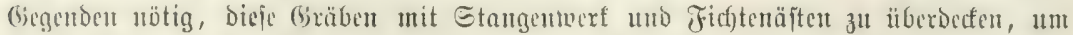

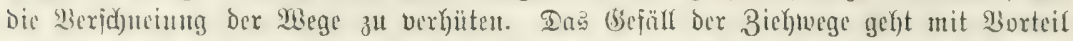

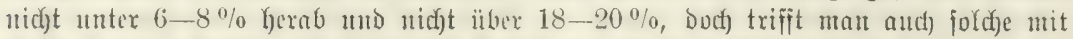

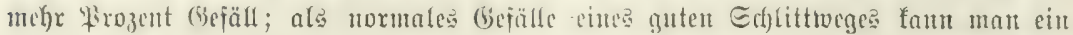

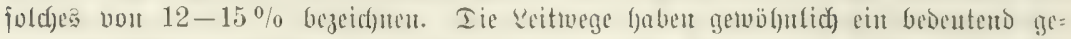

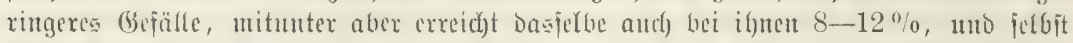

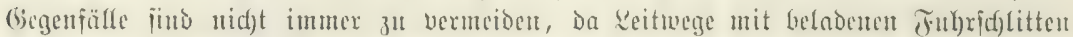

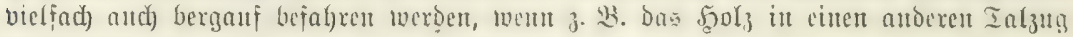
zu bringent ift.

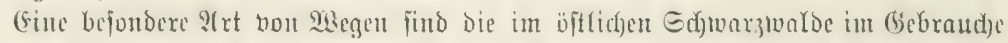

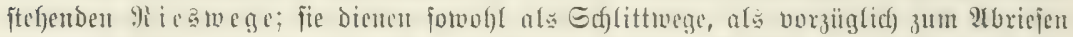
Dex Ranghölzer, and wird hierwon weiter unten beim Ricfenbalt geiprod)en serden.

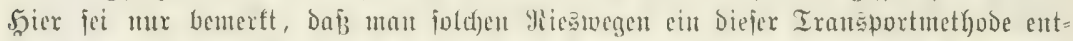

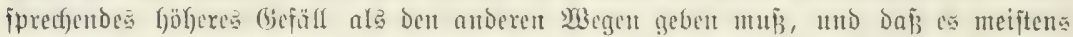
zividjen 9 und $12 \%$ liegt, oit aber aud aui 15 uno $18 \%$ anjeigt.

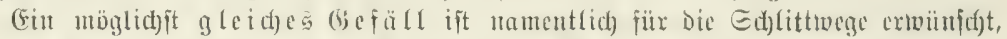

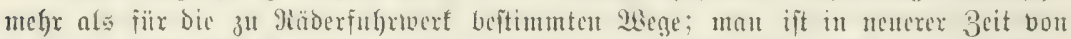

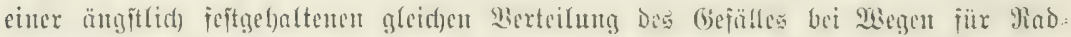

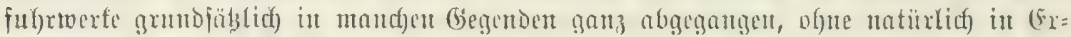

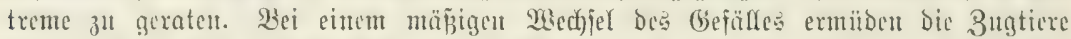

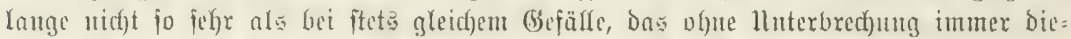
felben 9)

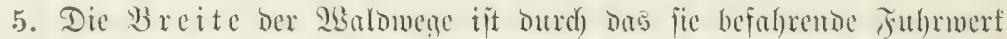

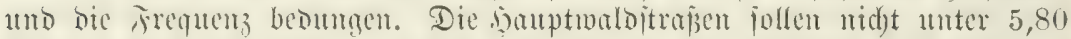

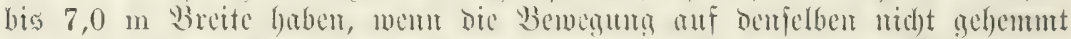

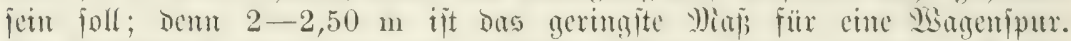

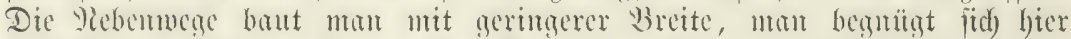

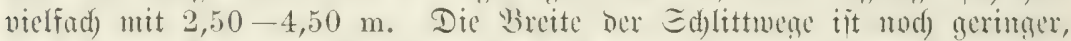
die seitmegc babm gemöhnlid) 2,50-:3,00 m, dic jichmege mu $1-1,50 \mathrm{~m}$

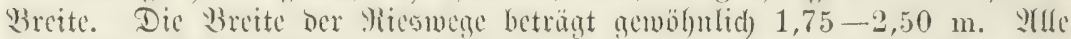

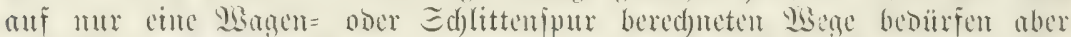

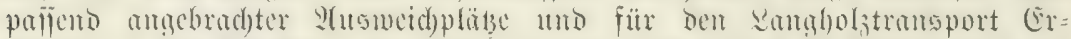

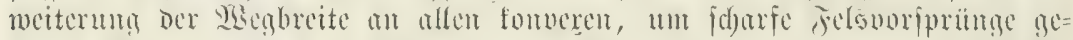

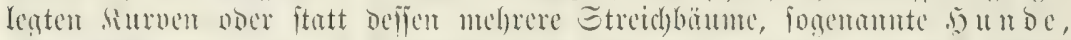

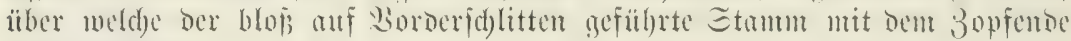
himuegrutfod.

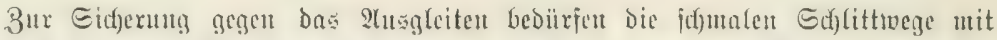

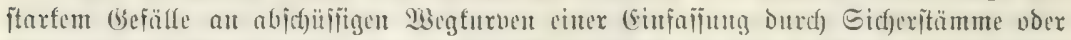

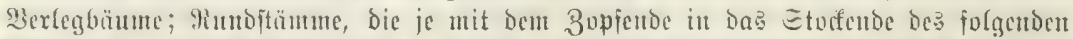

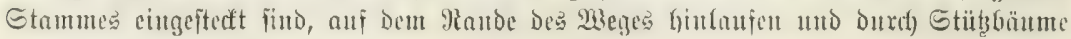
oder ’rähle feitgehalten werden.

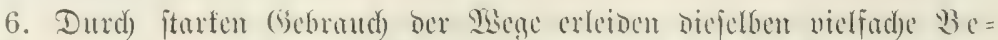

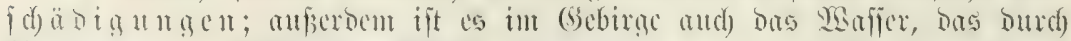

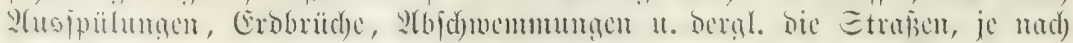

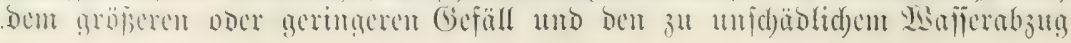




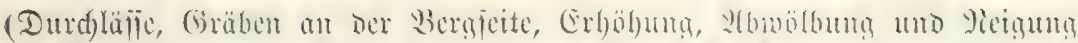

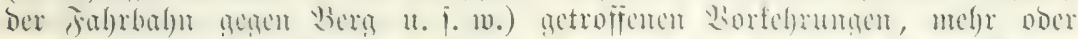

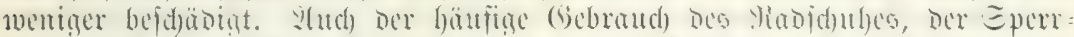

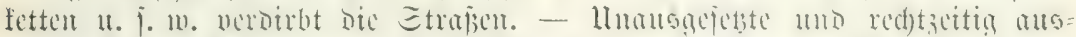

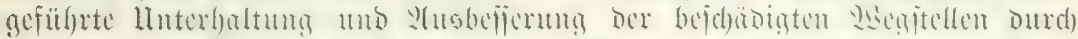

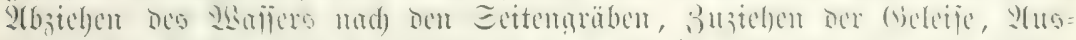

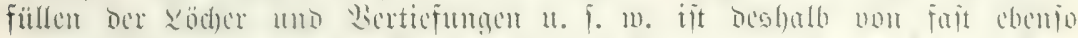

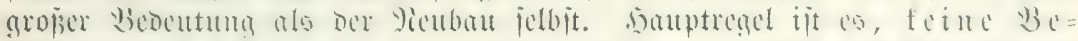
fd) ä bet trodement

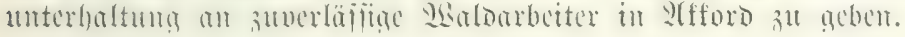

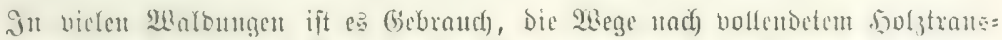

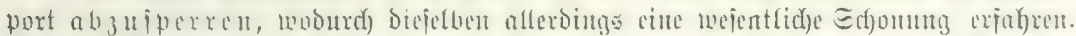

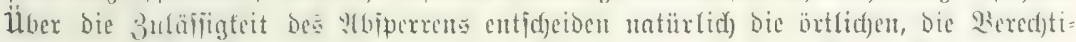

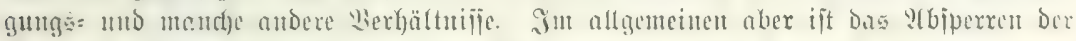

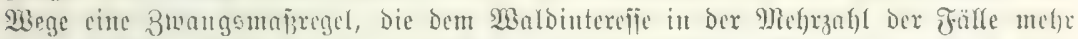

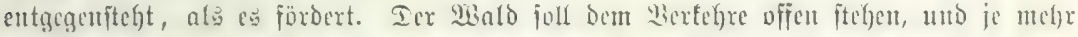

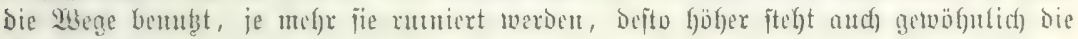
maldrente.

B. 2)

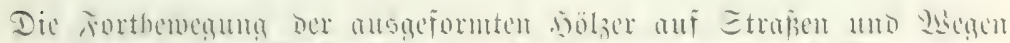

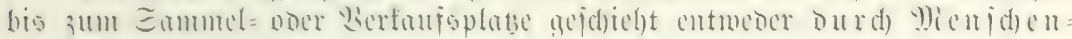
ober but $x$ dierfeft.

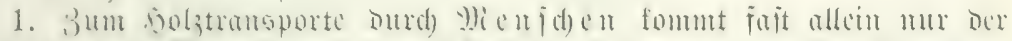

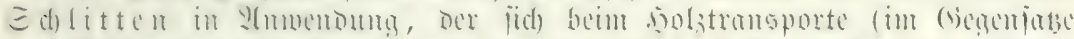

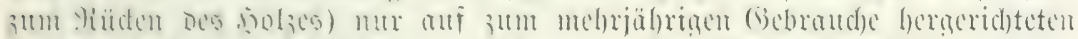
Dodr it änoiga

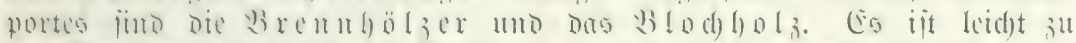

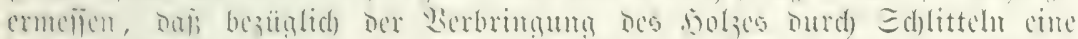

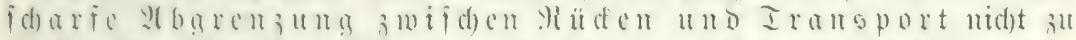

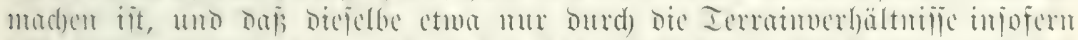

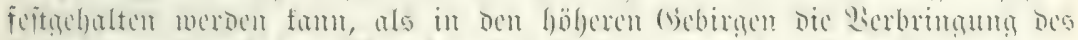

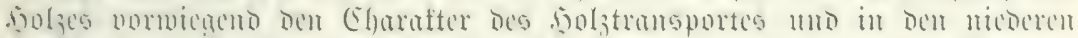

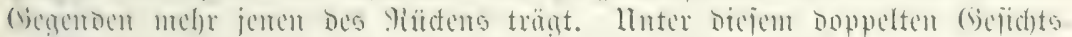

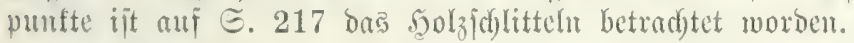

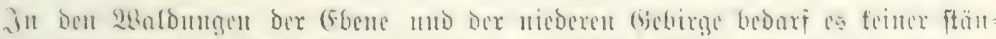

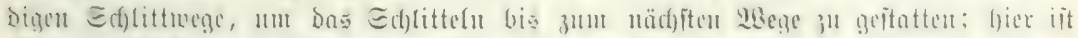

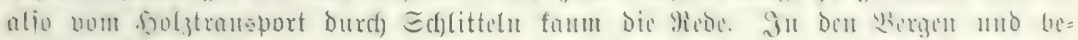

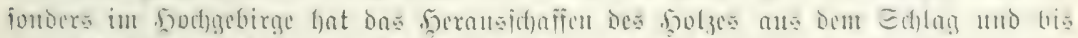

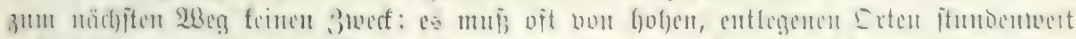

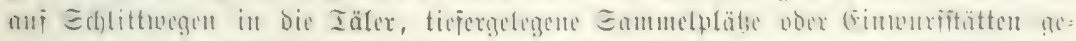

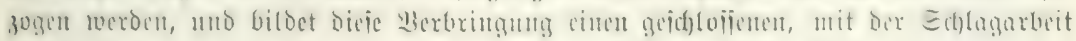

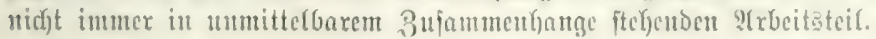

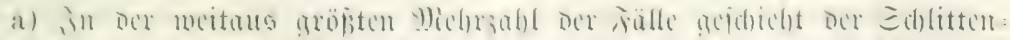

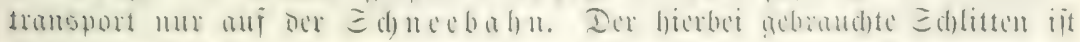




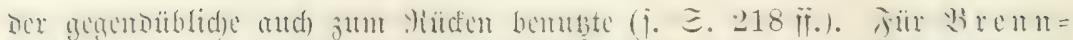

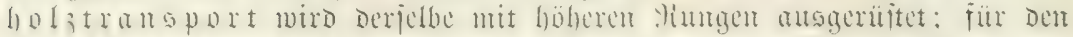
是

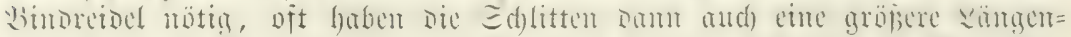

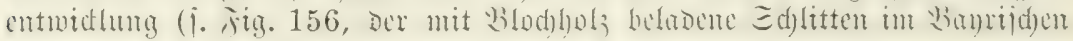
Migalo).

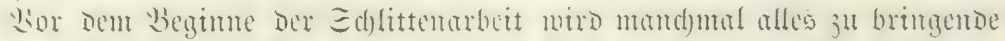

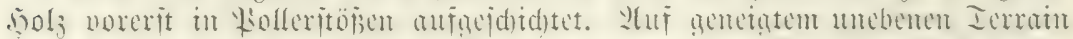

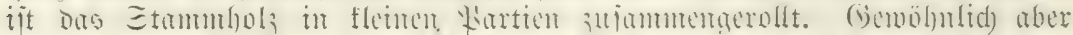

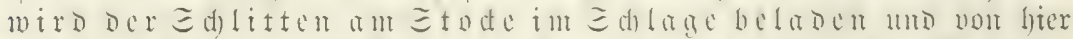

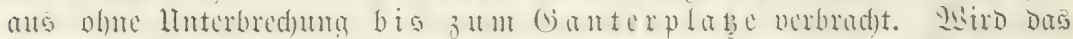

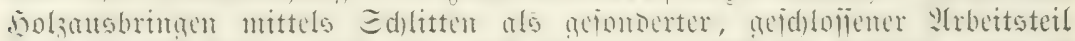

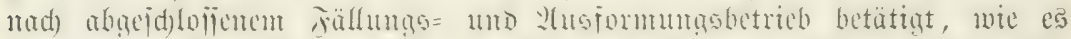

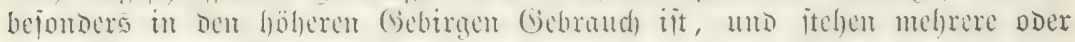

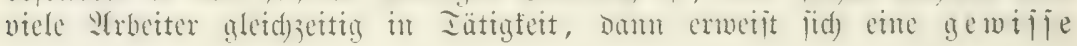

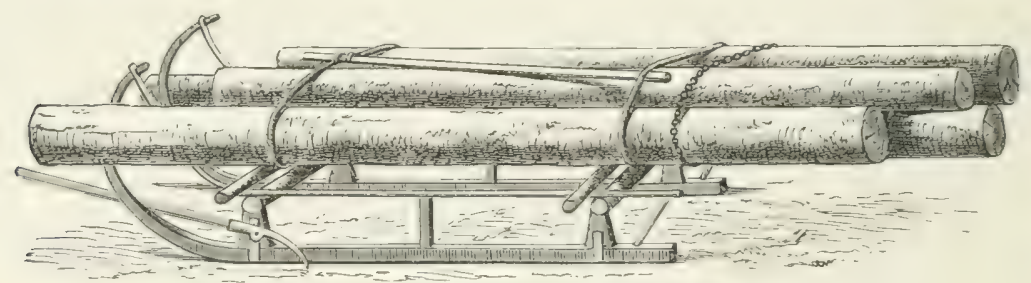

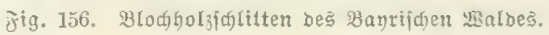

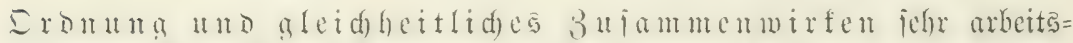
förocmo. Ieshalb mo hejombers mu micocholten Etörmgen norjubagen,

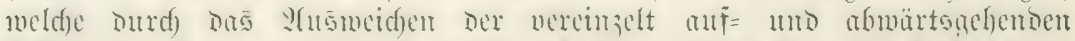

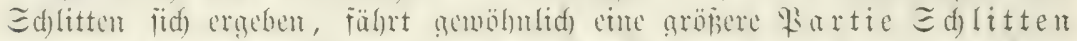
î

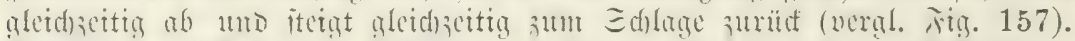

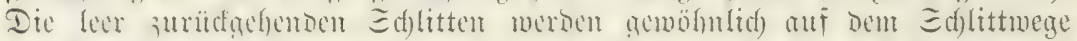

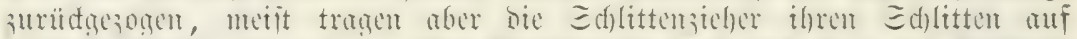

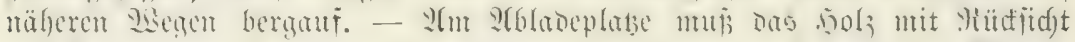

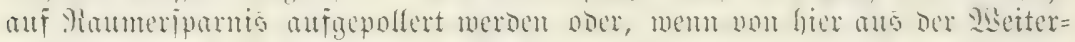

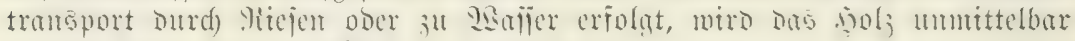
in bie Rieje oder Dag Mafier entugeworfen.

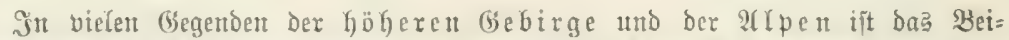

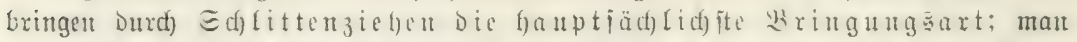

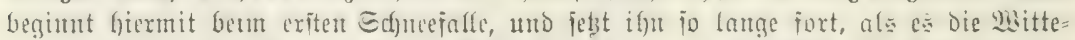
rung erfaubt. उur Unterfunft Der Frbeiter find fier in Der liäbe ber 3iefurege von

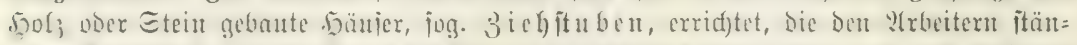

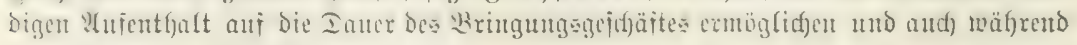

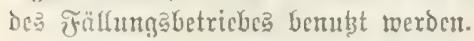

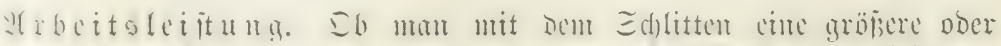

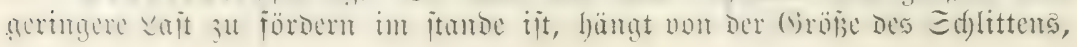




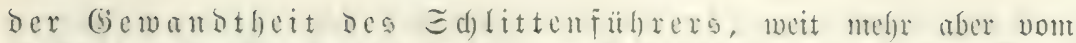

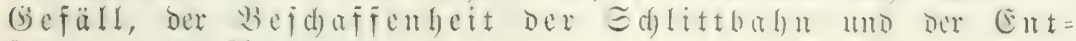
fernu

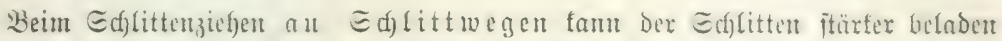

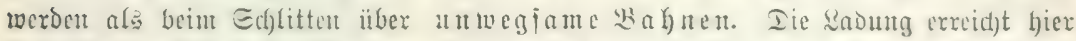

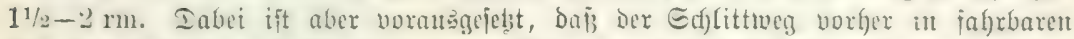

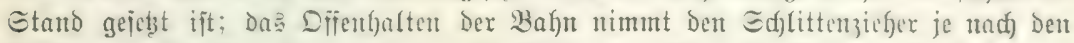

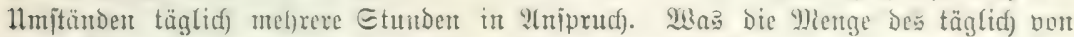

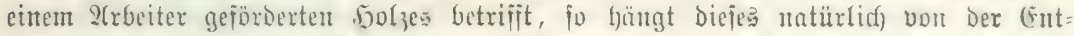

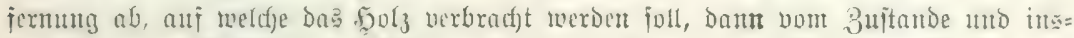

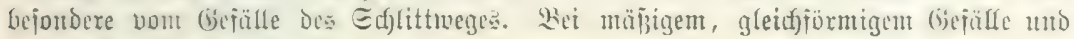

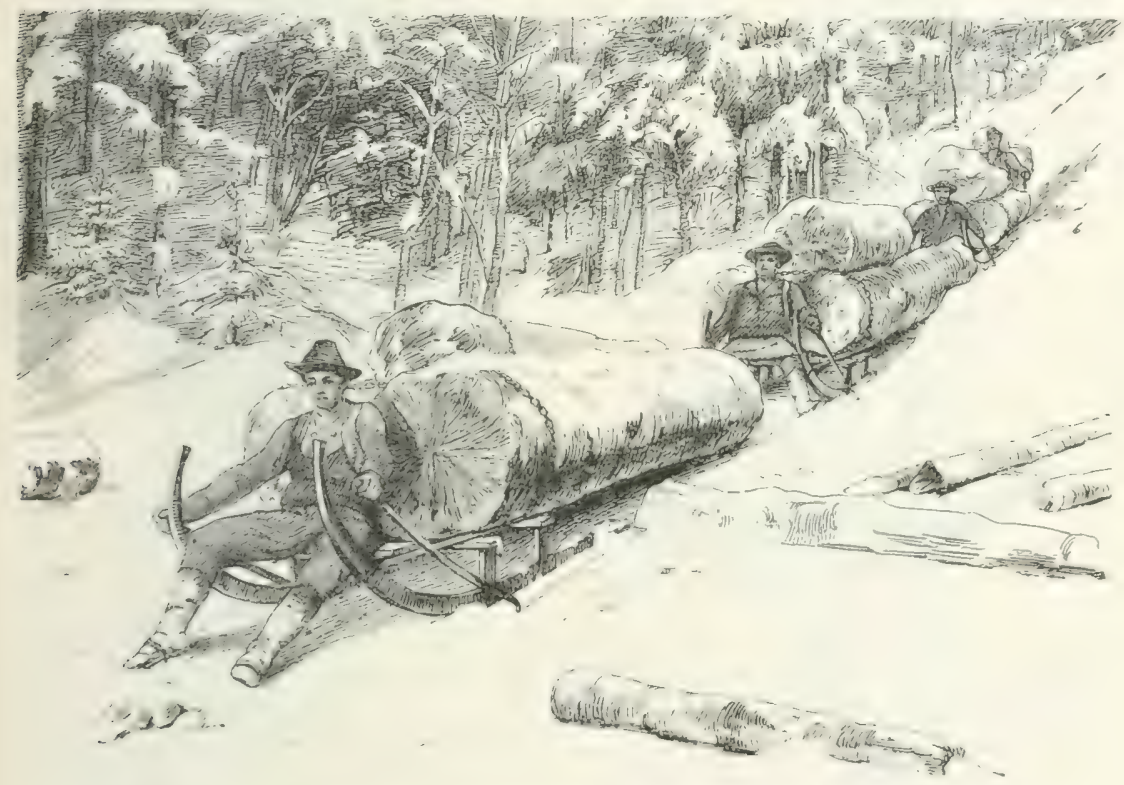

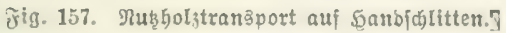

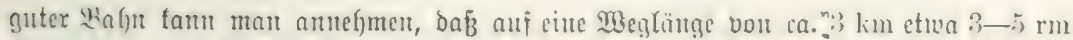

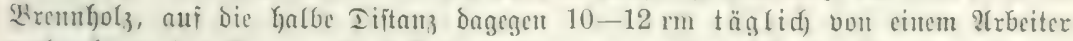

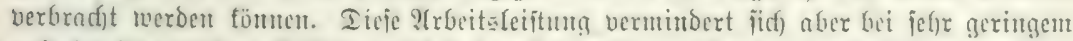

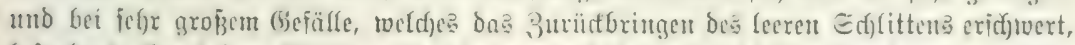

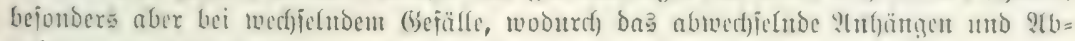
nehmen ber Ed) Ceiff(aftent erforberlid) wirb.

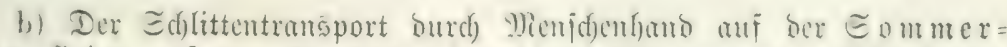

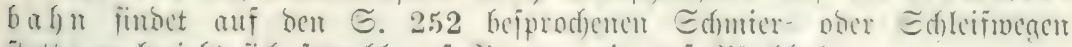

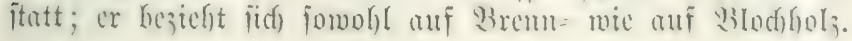

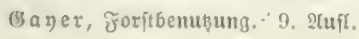




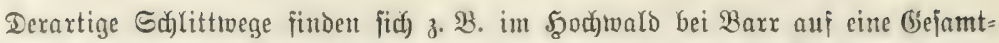

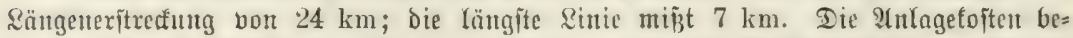

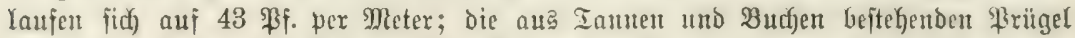

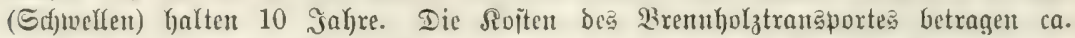

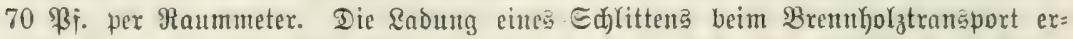
reid)t 2-5 rm; jente beim Stammfolztrambart ic nad) bem Gejälle 3-6 Blodje (Mebmann).

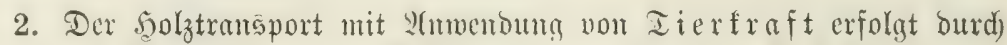

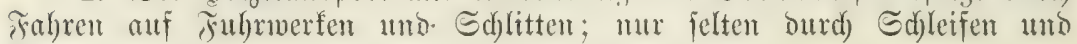
Säumen.

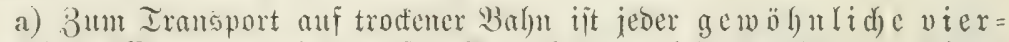
xäberige $\mathfrak{W}$ aģen geeignet; für Brembülzer miro berfelbe mit Leitern gerüjtet, für Etangen=, mittelitarfe Ban= ober Sdynttmublgölzer gef)t ber

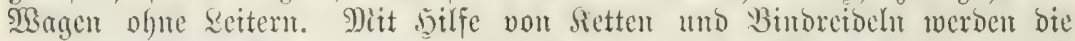

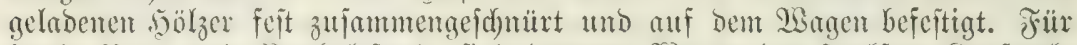

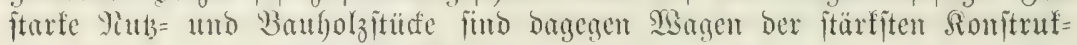
tion erforberlidf), fogenamte $B l_{0}$ d) wagen.

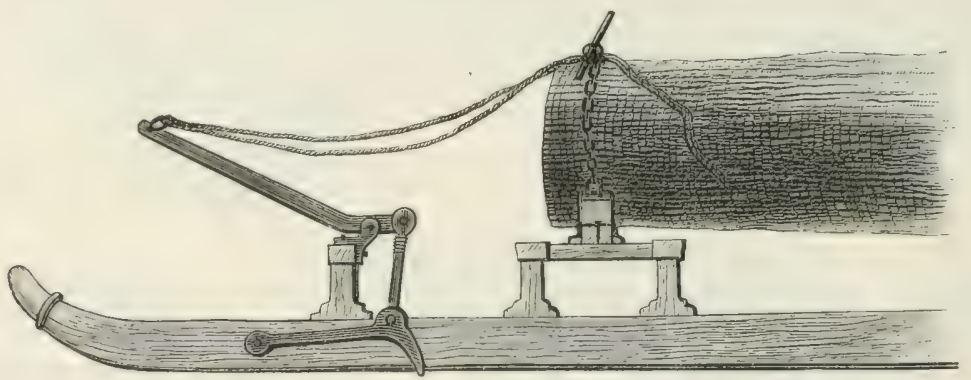

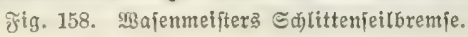

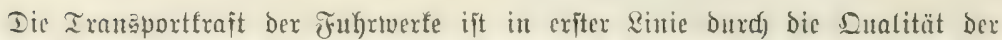

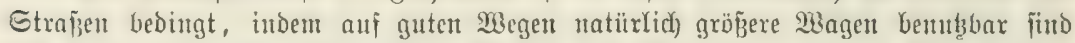

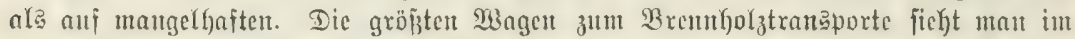

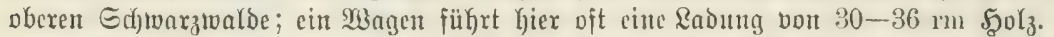

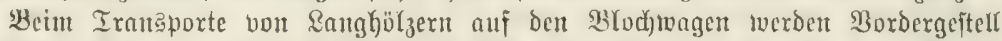

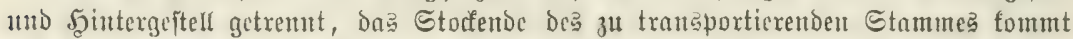

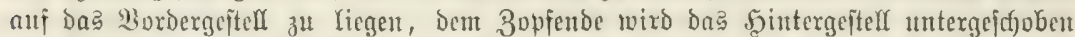

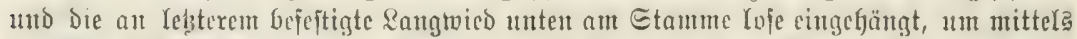

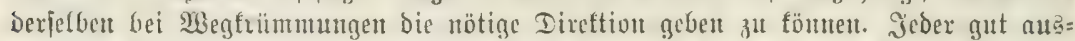

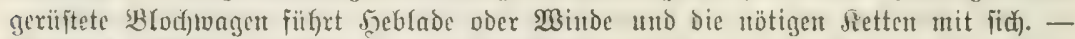

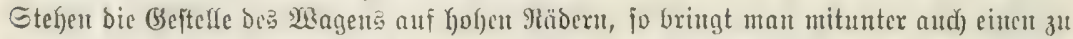
transporticrenden Stamm in hängender \&age unter Don (befteflen an, woburd bas̆

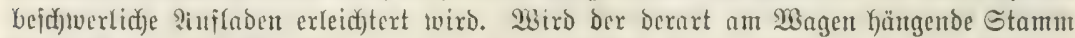

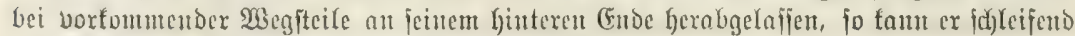

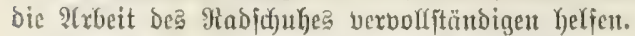

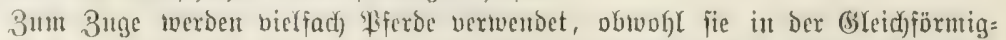

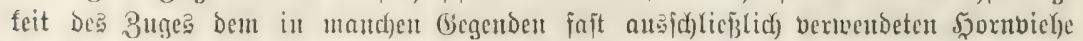
nadiftelen. 

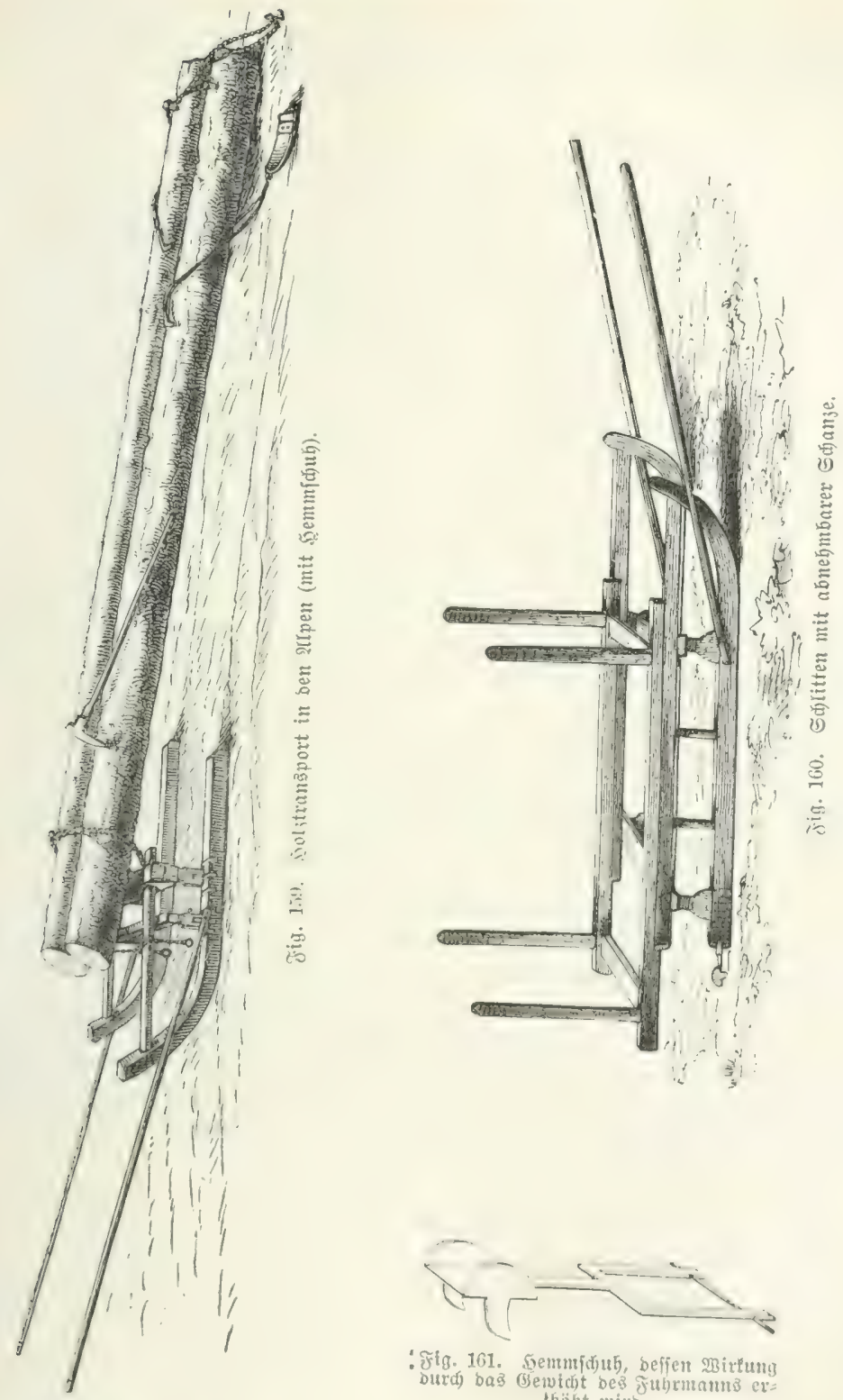

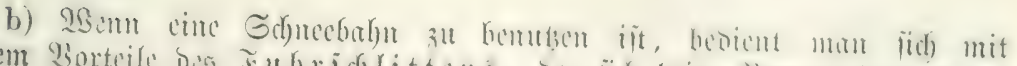

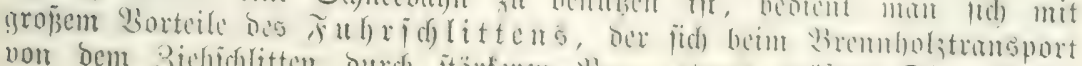

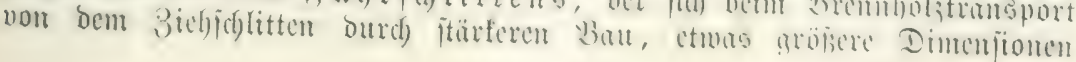




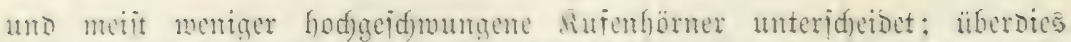

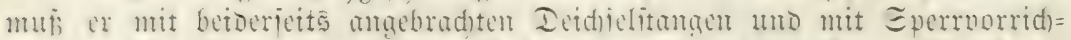

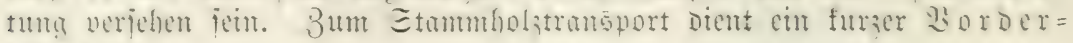
idititen.

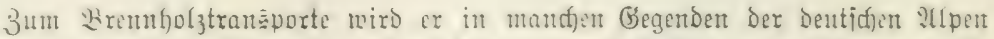
mit Dex iog. Edjanze au

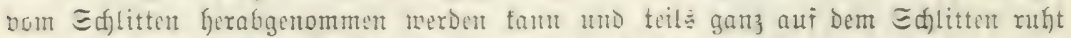
Doer bei ing. Salbifflittett aud) mit dem (imbe nad)geid)leift wiro. 3um Etamm= umo

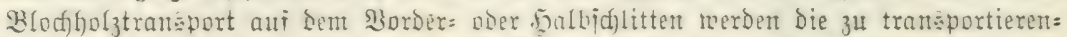

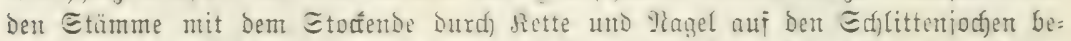
feîtigt und vom Edflitten getragen, wäfremo das 3opiende der Etämme aư bem

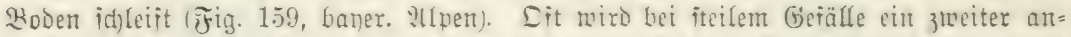

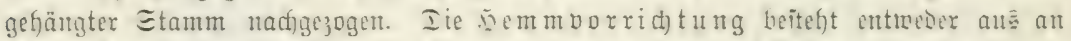

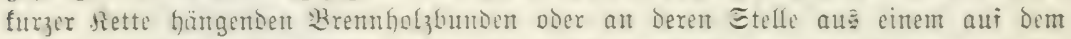

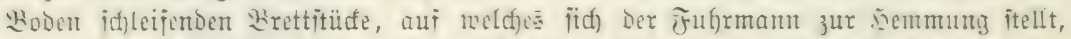

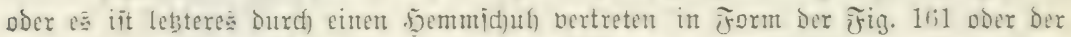

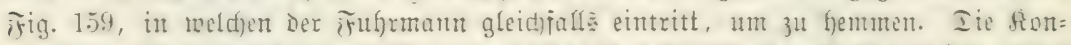
itruttion und 5andhahung Der

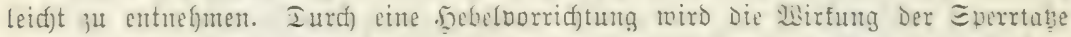

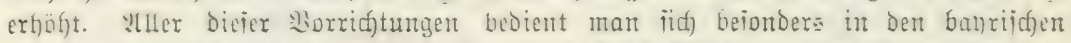

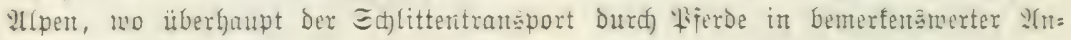
mentoung fteft.

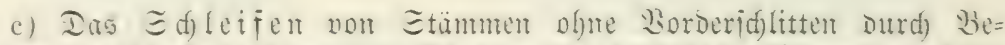

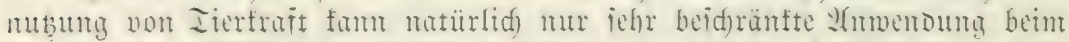

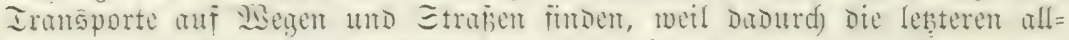

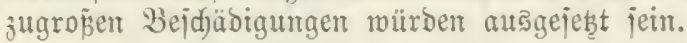

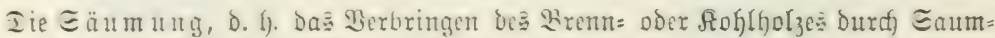

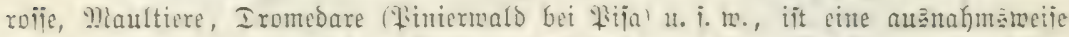

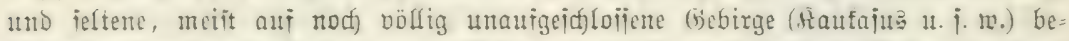

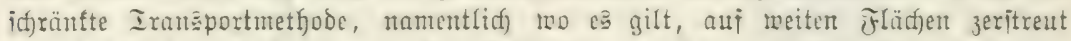

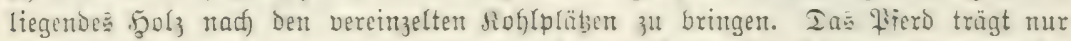
2 3entner, mânento of $7-9$ 3entner 3 utehen im itande ift; aber zur Eäumung bes

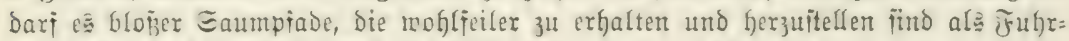

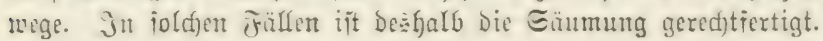

\section{Kitesge}

A. Bau un Činridtung Der Riejen.

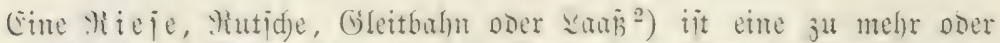

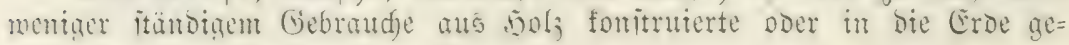

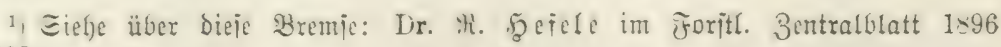
n. 1898 .

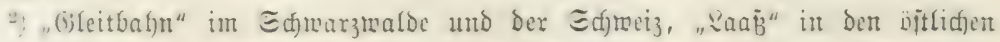
צItpen. 


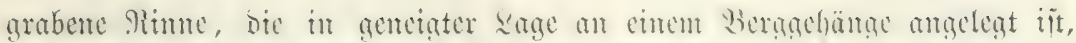

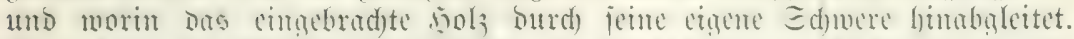

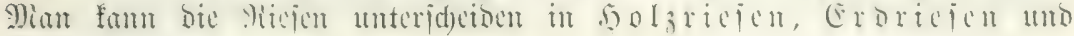
23 egriejen.

\section{50 f $z$ rie $\left(e \pi^{1}\right)$.}

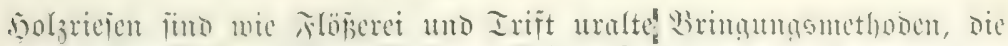

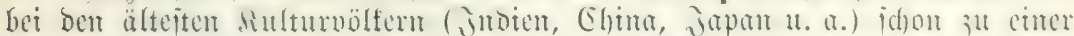

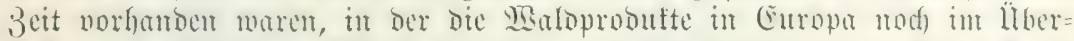

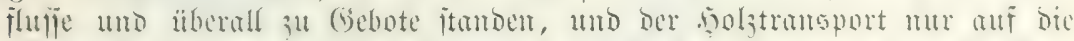

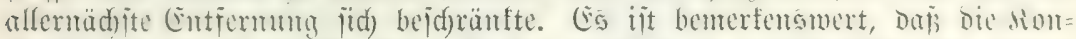

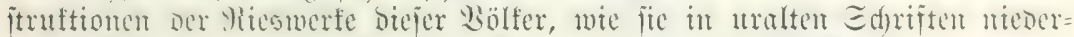

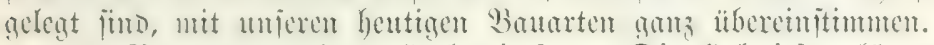

1. Bauarten ber Solzriejen. Die Solzriejen fönnen je nad)

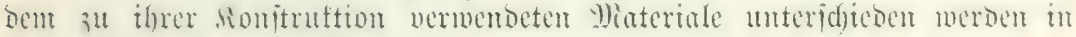
Stammriejen und B̧rettriejen.

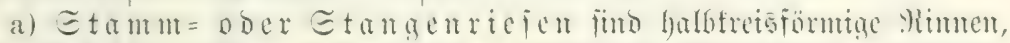

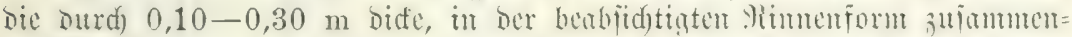

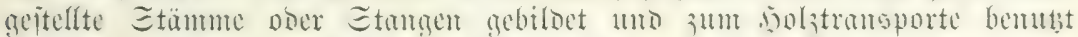

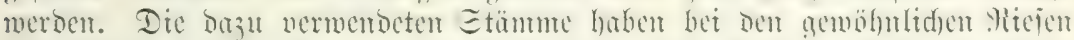

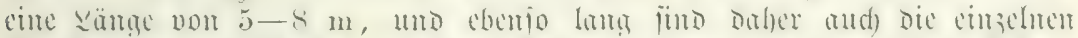

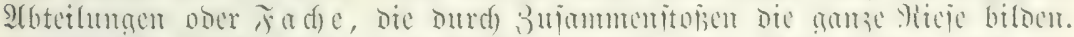

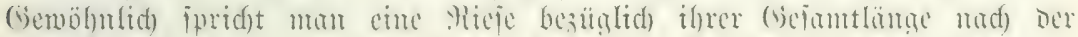

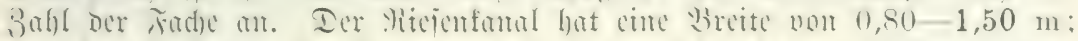

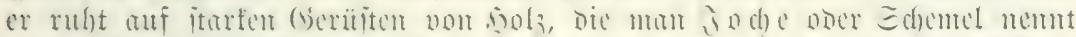

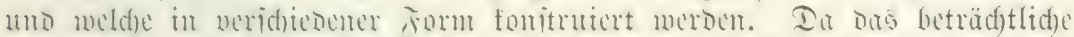

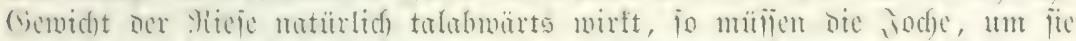

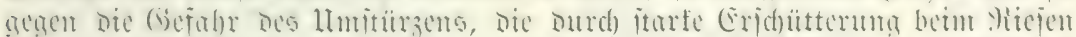

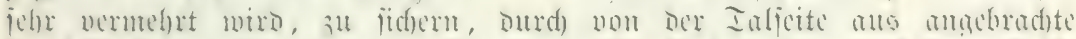

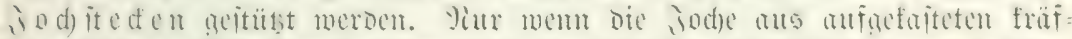

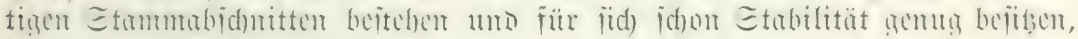
jind bie Jodjiteden entbefrlid.

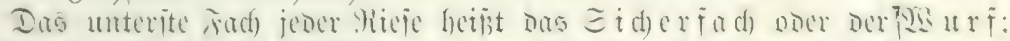

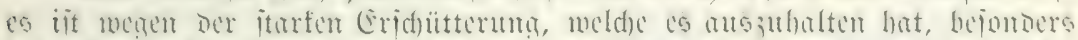

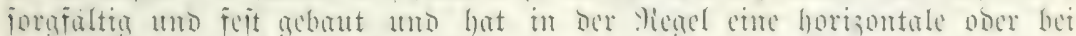

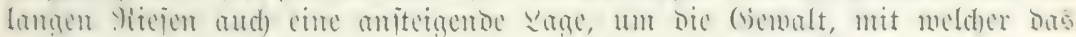

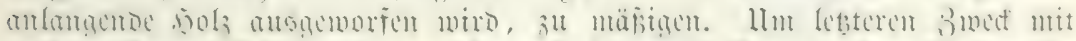

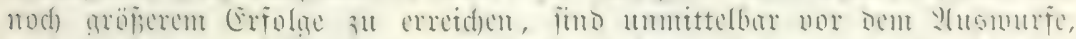

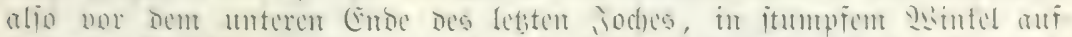

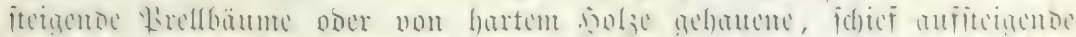

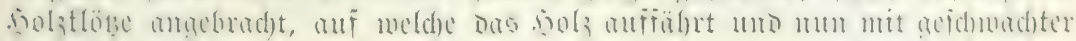
(Gemalt im Wogen auggemorfen wirb.

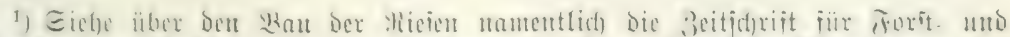

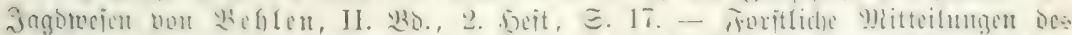

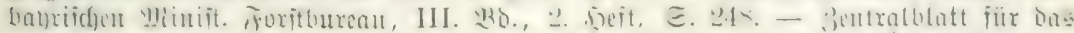

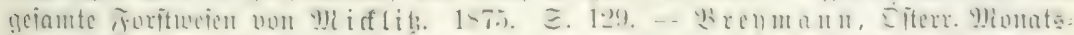

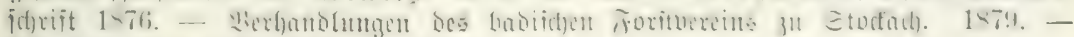

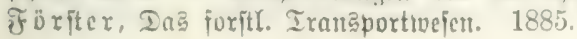




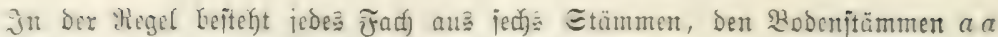

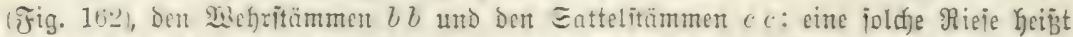
sine gejaftelte Mieje: bei firmmungen hat bie gejattelte ßieje oft nux auf ber rinen Ecite cinten Eattelbaum, mäfrend Der zmeite auf Der inneren Eeite ber Rurve

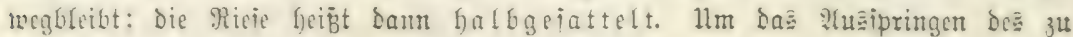

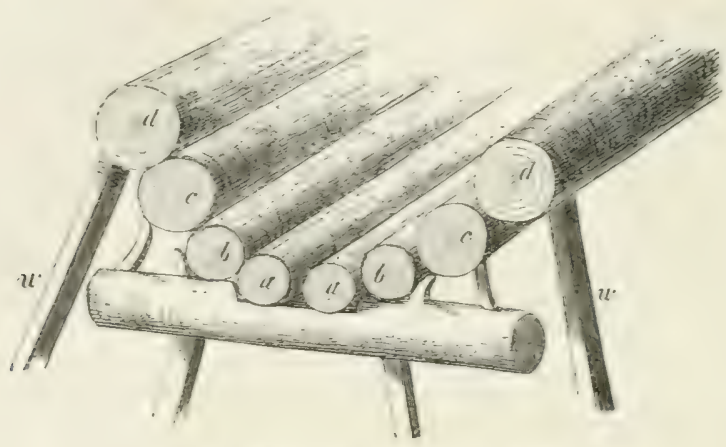

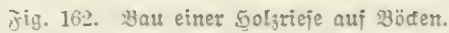

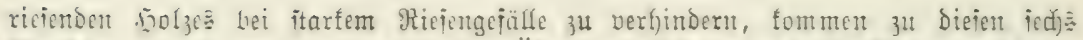
Ries̆büumen nod) zuei meitere, bie iog. Überiüttel $d d$, modurd) bie hicie zur über=

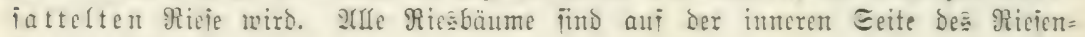
tanale entrindet.
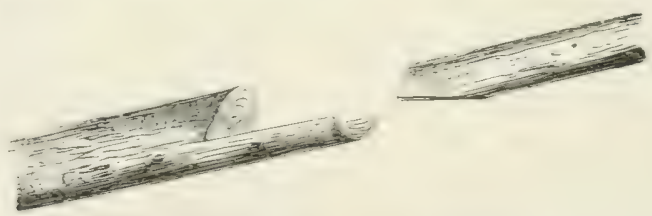

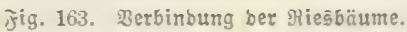

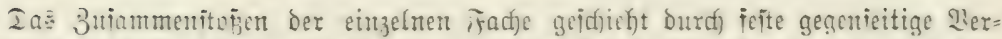

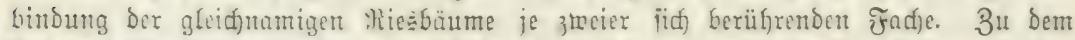

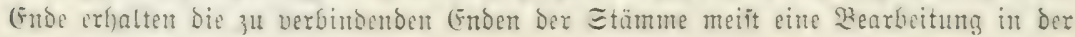

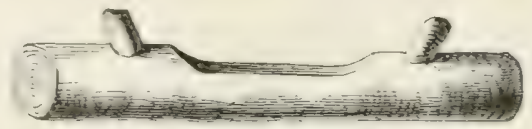

j̀ig. 164. joఢträger.

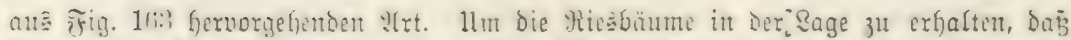

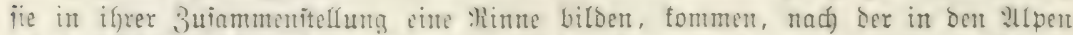

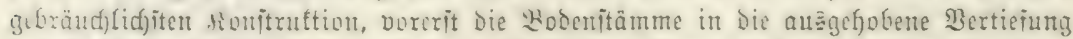

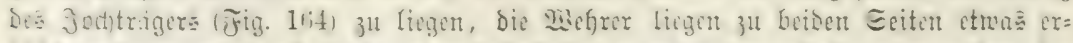

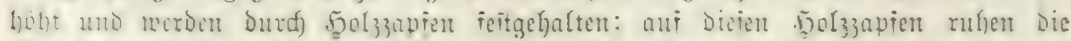

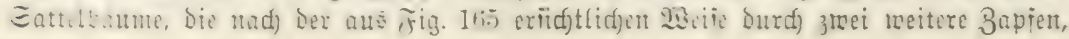




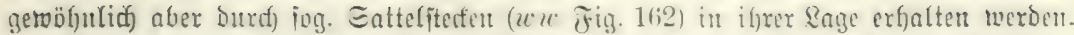

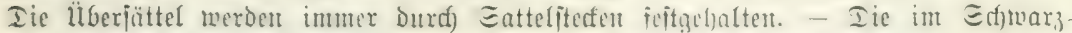

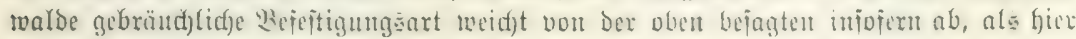

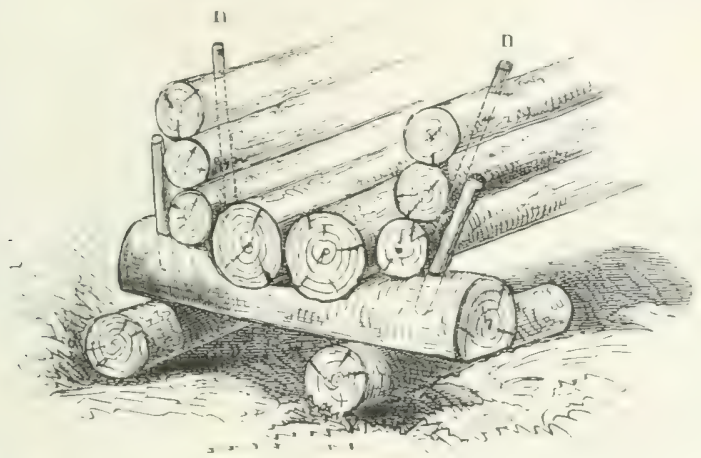

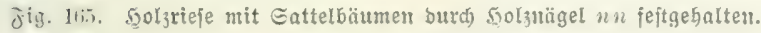

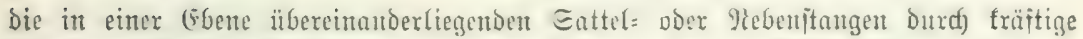

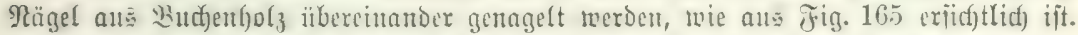

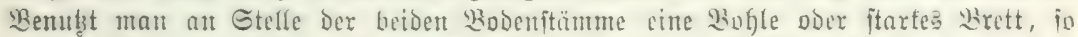

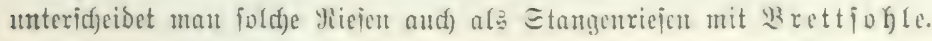

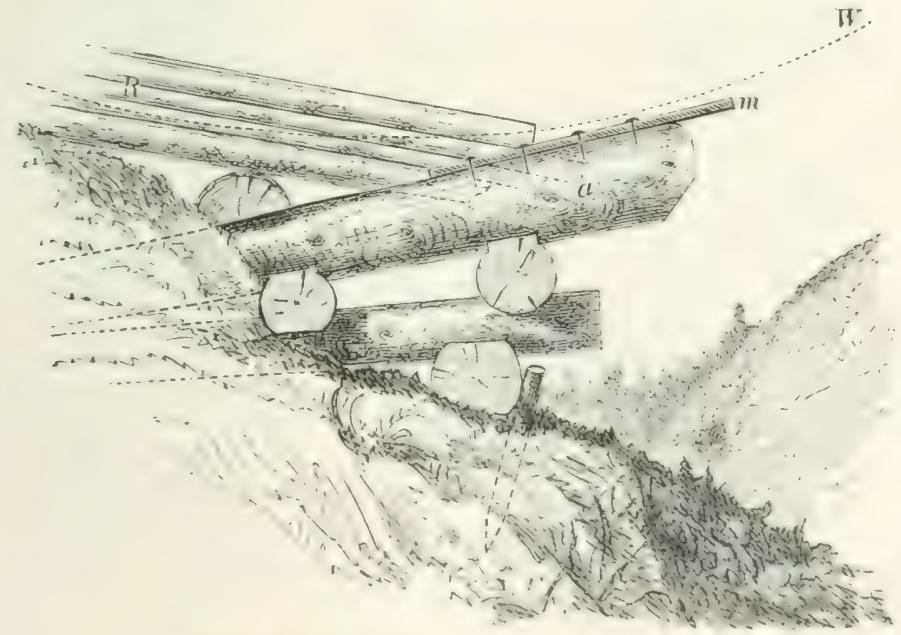

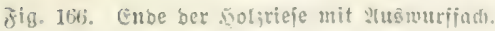

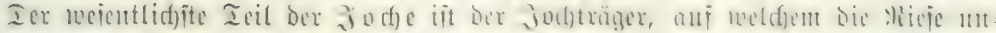

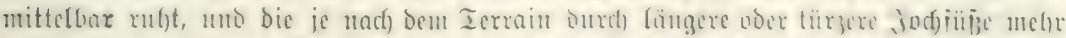

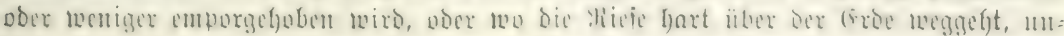




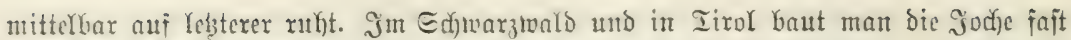

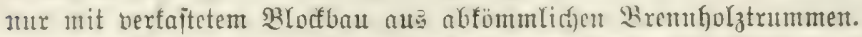

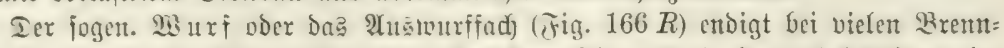

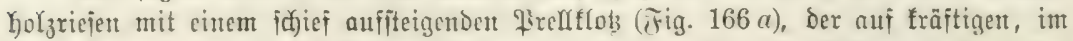
Sivoent veranfertent uto verfafteten Etanmunterlagen ruht. Jm Edymarjwalde trägt

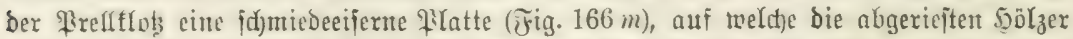

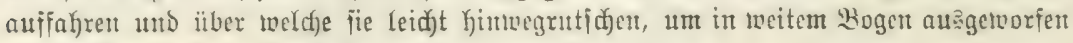
zu twerbert.

एङ

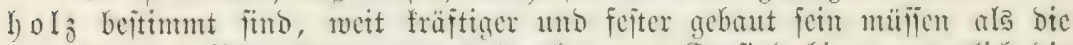
mur für ben Bremholztransport bered)ueten. (Ë fimo hier namentlid) bie

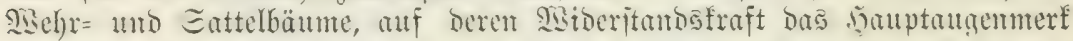

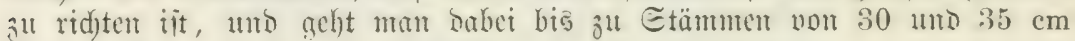
Durd)mefier แno $15-18 \mathrm{~m}$ 'ä̈nge.

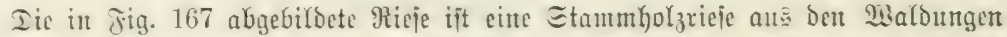

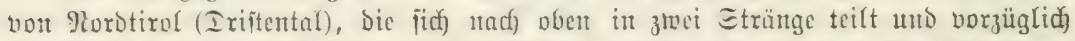

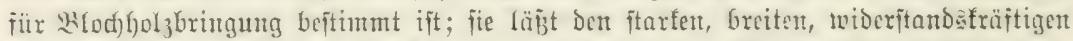

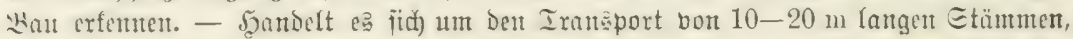

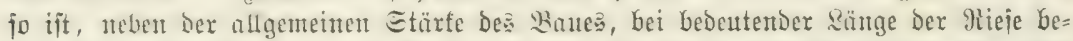

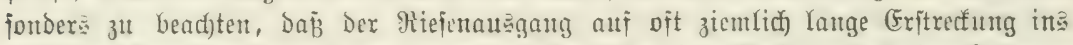

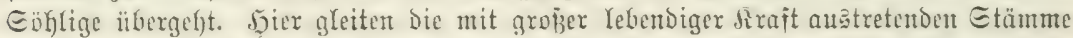
nit nod) $60-80 \mathrm{~m}$ meit über Das jantitgentighte Sorterrain finaus (Ealzfammergut,

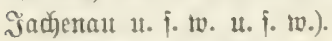

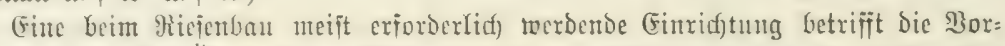

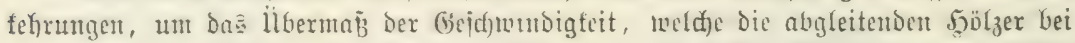

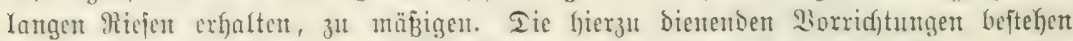

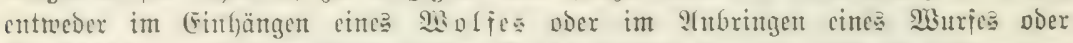

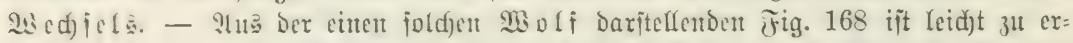

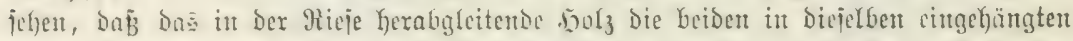

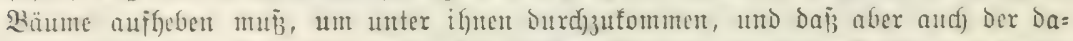

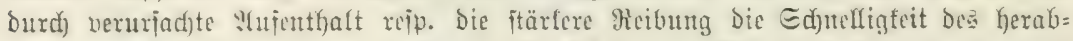

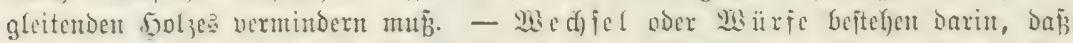

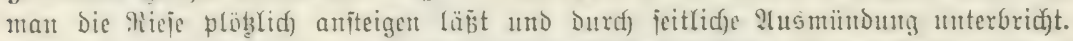

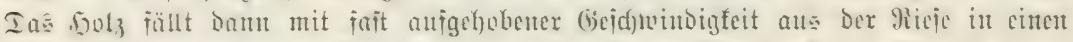

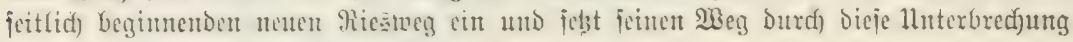
mit verminderter Edjneffigfeit fort.

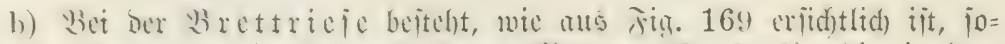

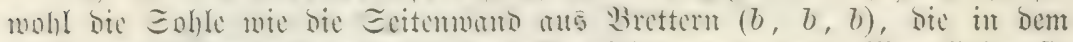

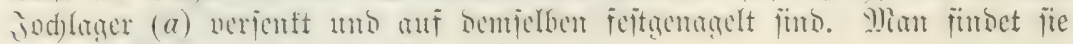

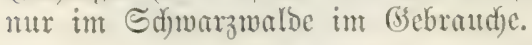

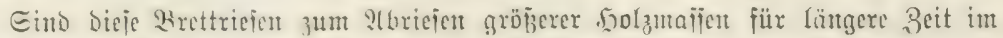

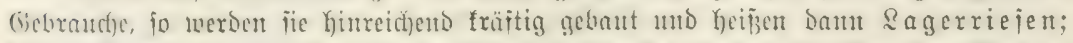
Dienen fie unt zu voribergehenton Irampurtzwecten, Kaben jie ofter Den PIats zu

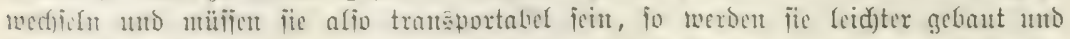

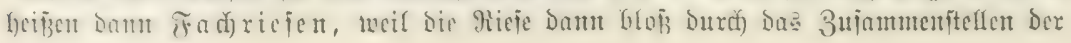




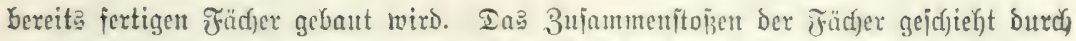

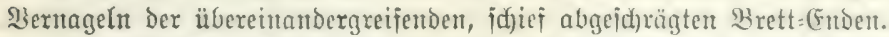

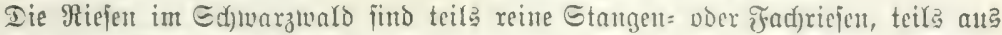

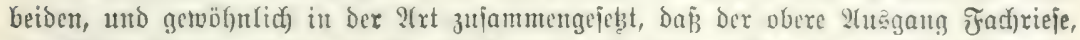
bie Mitte Etangenrieje mit Brettiohle und bie untere Rieientinic reine Etangen= ricie ift.

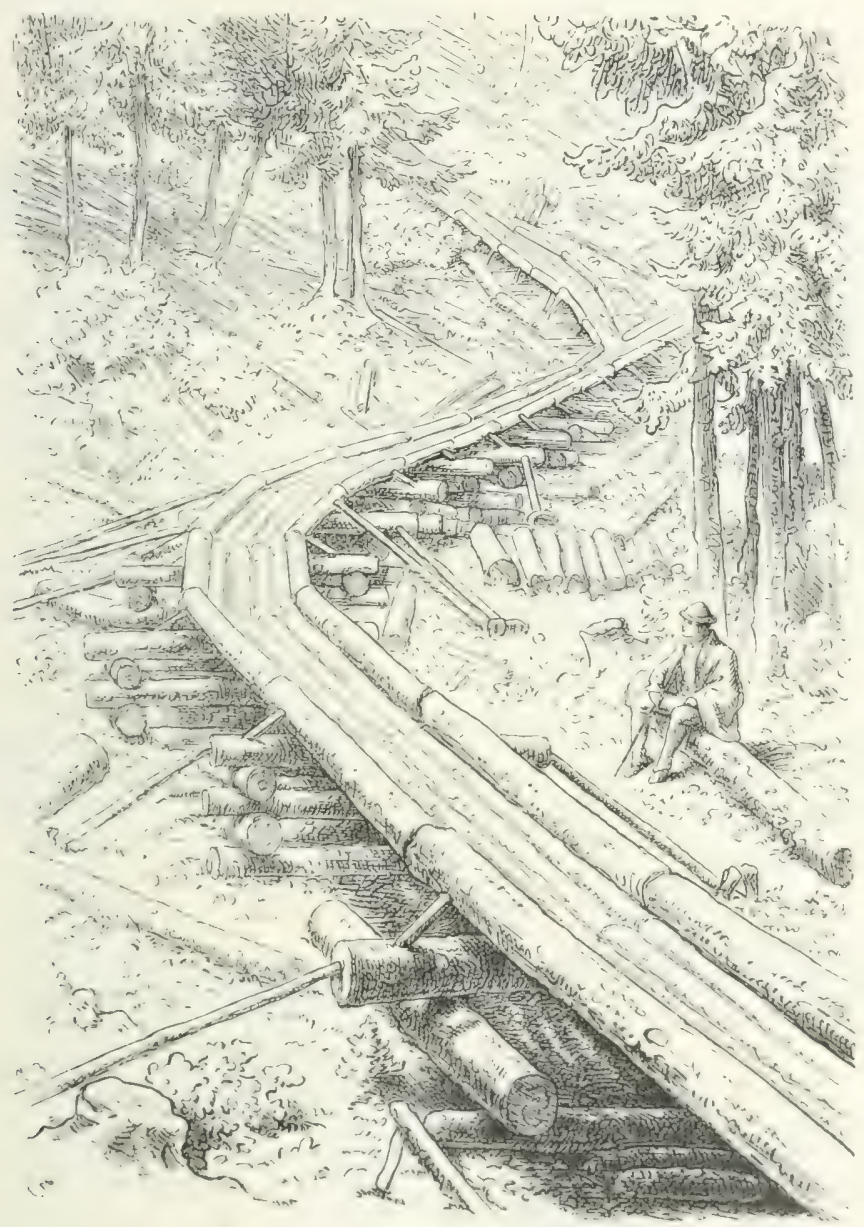

Fig. 167. Etammboliticie in 9lorbtirot.

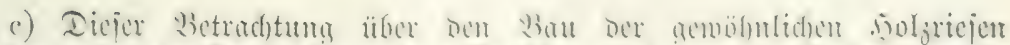

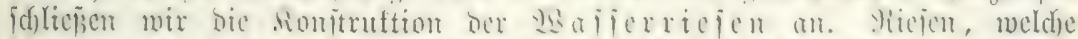

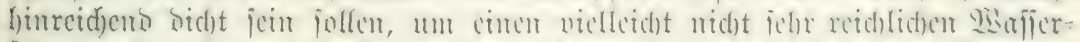

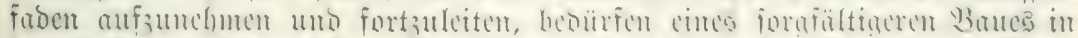

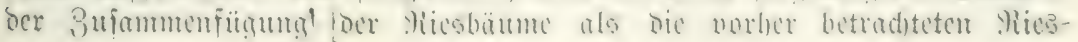




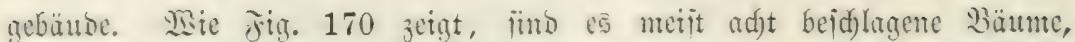

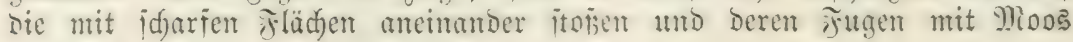
neritopft merben.

Bei furzen Majierriejen und finteidfend ftarfem 23 ajier zieft man viels

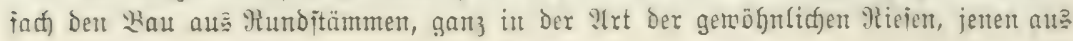

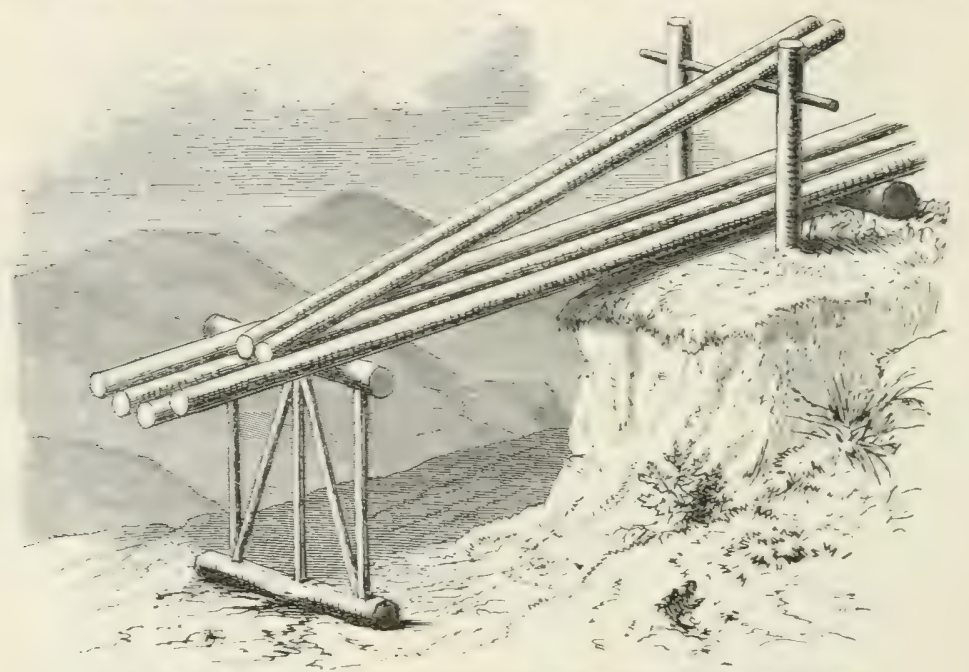

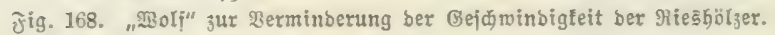

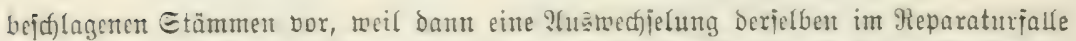

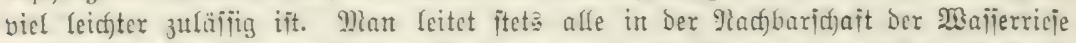

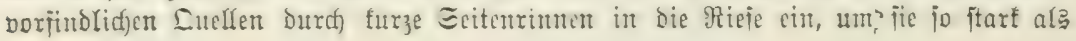

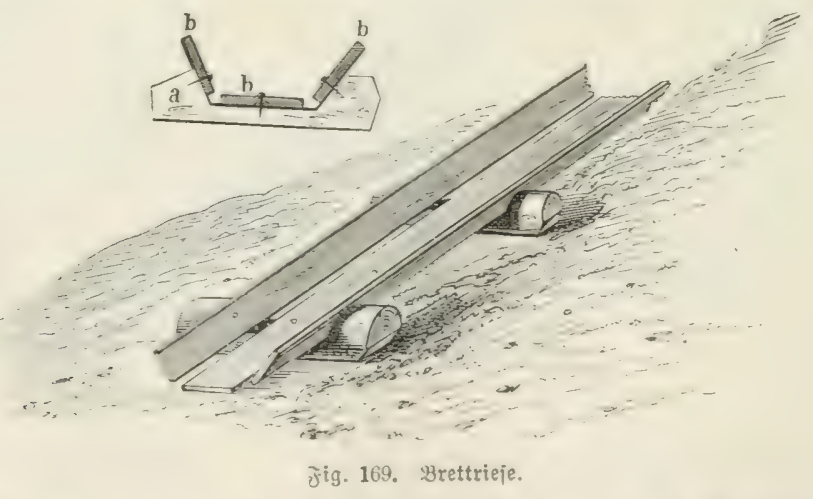

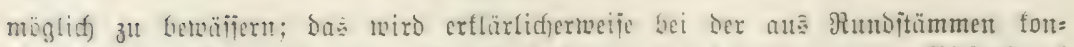
ftruiertin vor allen notmendig. Sm Salzfammergut baut mant Den Miejenfonal

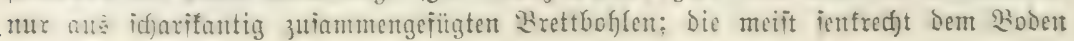




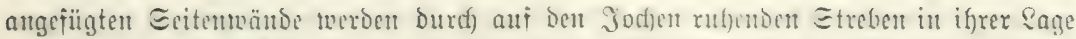

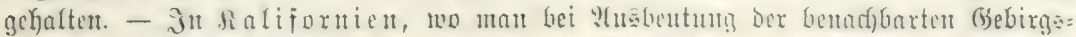

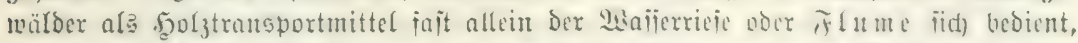

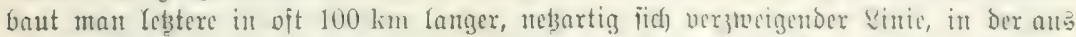

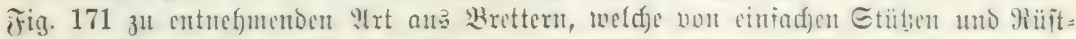

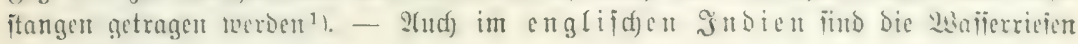

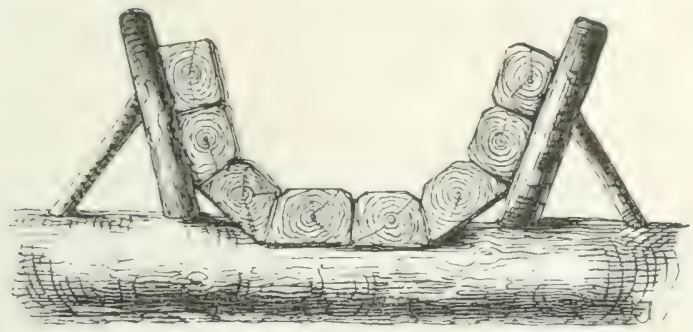

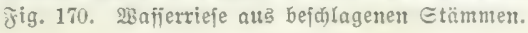

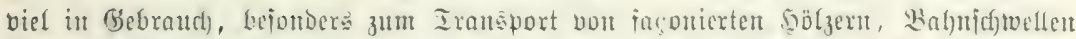

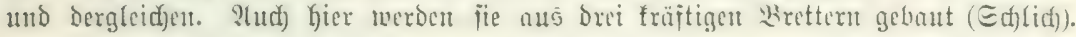

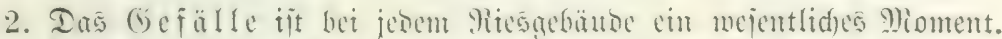

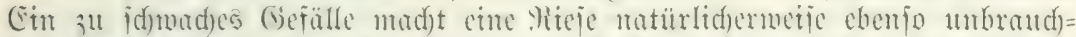

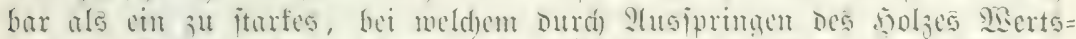

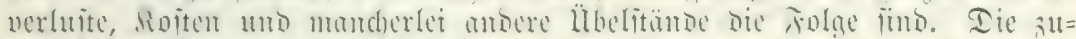

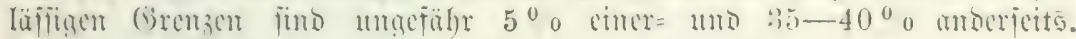
Das einer Mieje zu gebende zmeduärigite (be fülle ridjtet pidf) mu aber nad) ber $\mathfrak{A r t}$, in weld)er bie Mieje ge= braudjt merben joll, und baut nad) ber Stärfe bes zu riejen= bet 50 olzę.

Bezüglid ber $\mathfrak{2} r \mathrm{r}$ ber $\mathfrak{B} e=$

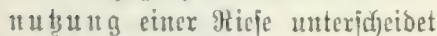

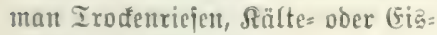
ricjen und Wafjerricien.

Trodeuriejen find joldes,

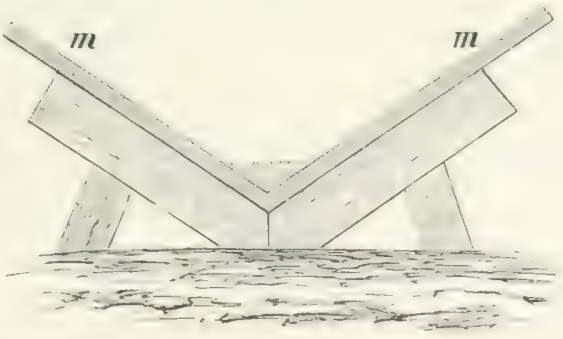

jig. 171. Sialifornifide mafierrieje.

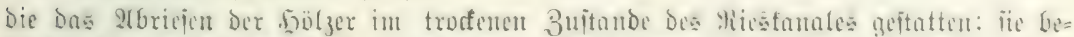

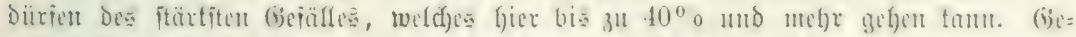

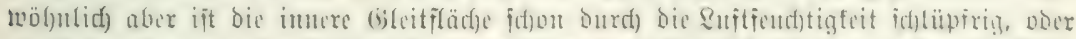

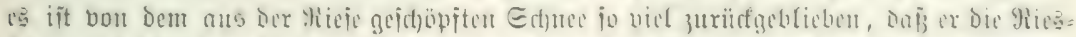
bäume aliglittet, uno alio nut Die time voer andere

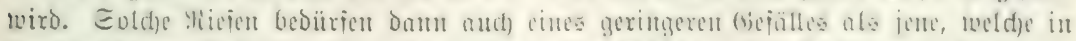

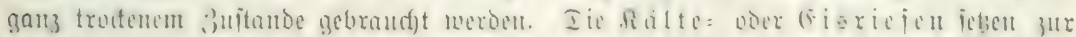

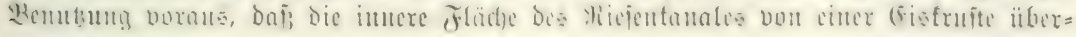

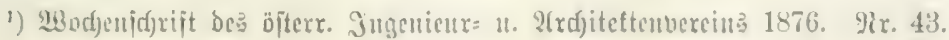




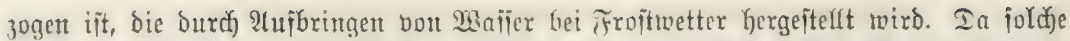

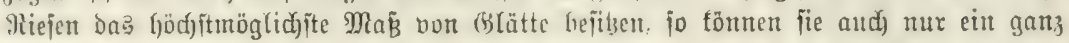

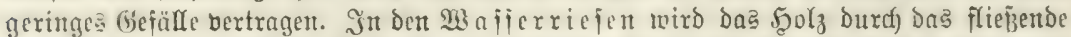

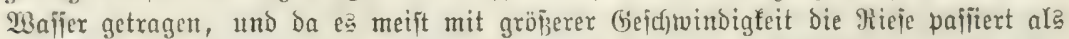

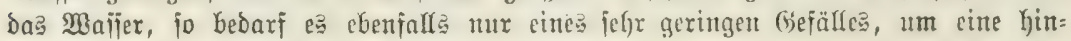

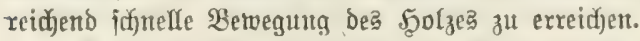

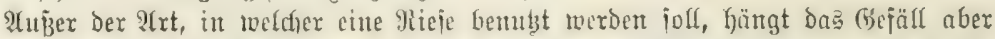
aud vou ber Etärfe bes zu riejenden 5oolzes ab; je nadjoem cine Yieje für

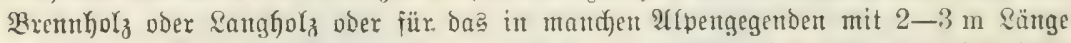

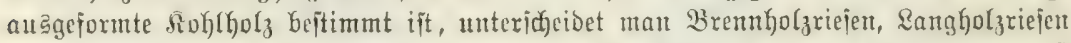

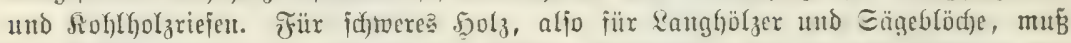

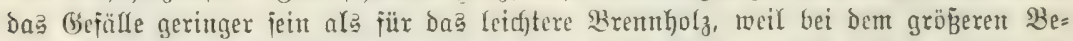

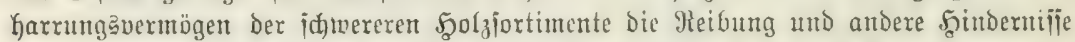

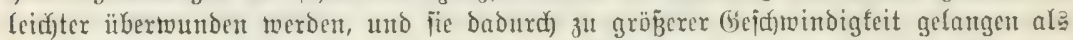

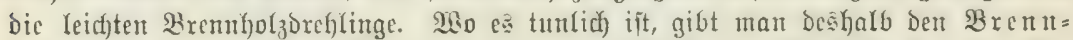

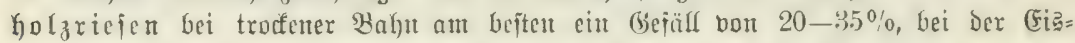

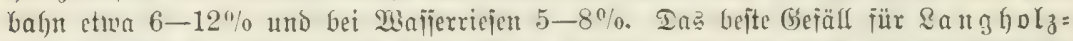

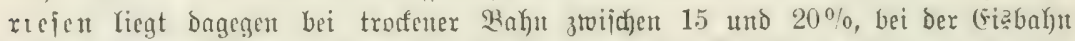

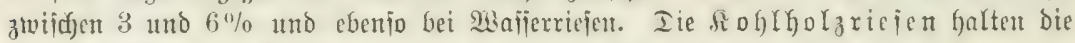

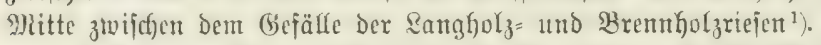

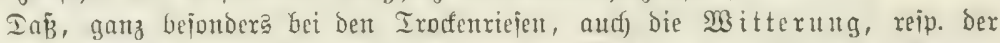

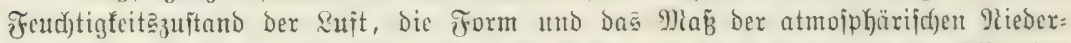

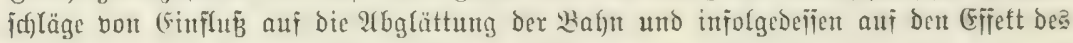

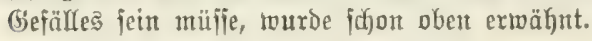

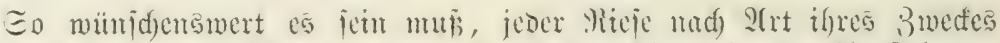

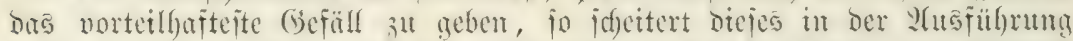

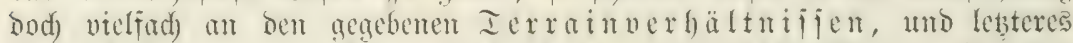

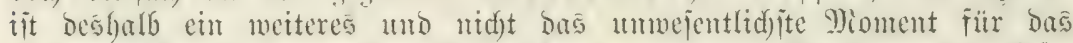

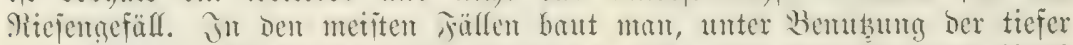

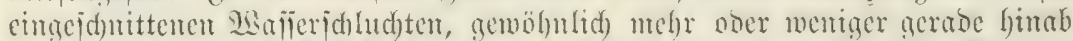

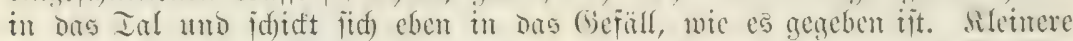

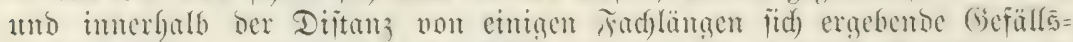

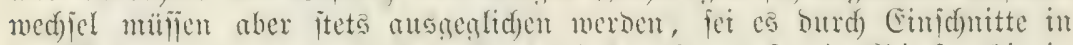

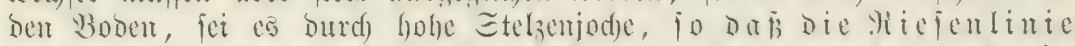

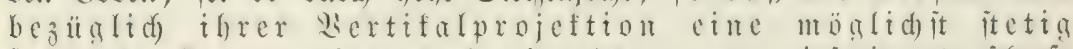

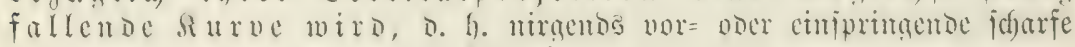
Eifen zwijden ben cinzelnen Fädjern lat.

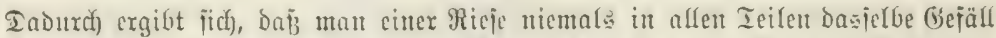

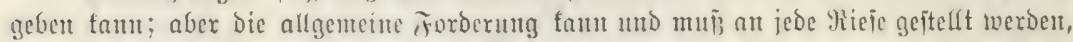

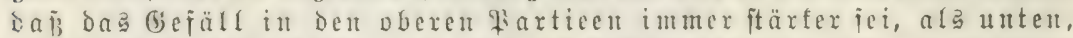

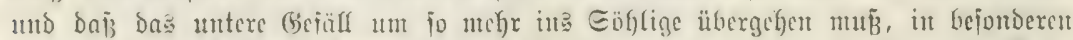

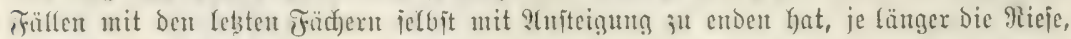

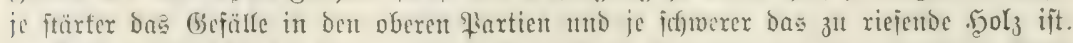

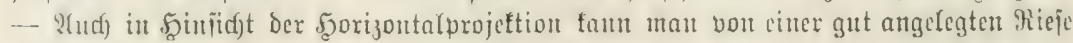

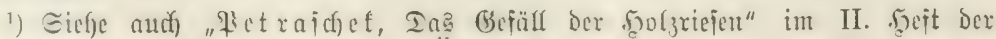
Mitteilg. Der foritl. Derjud) 


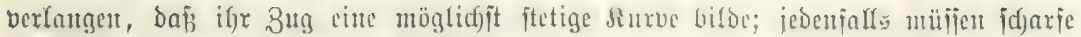

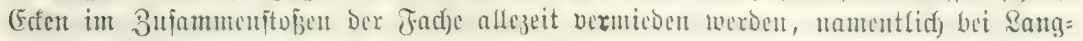
Golzriejert.

3. 5o

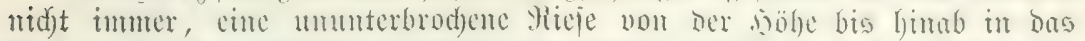

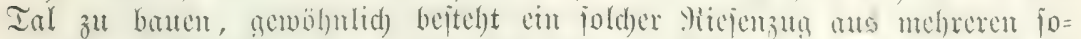

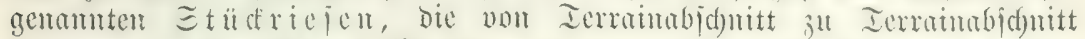

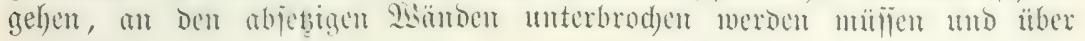

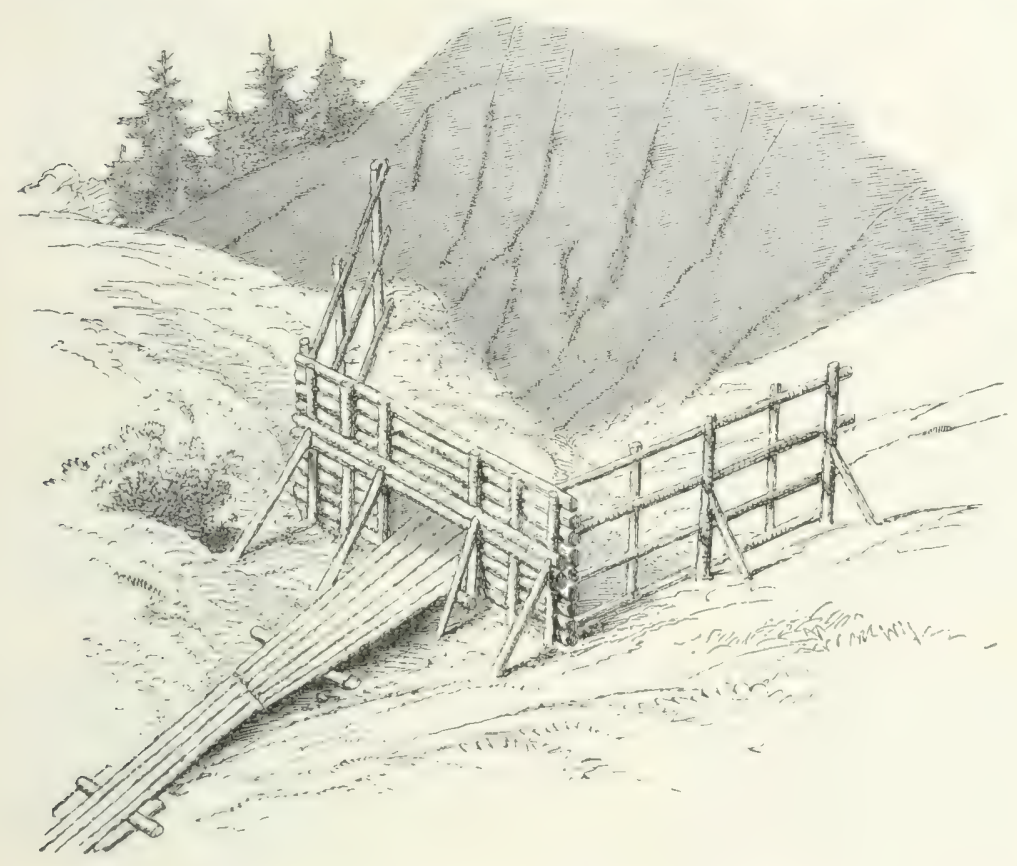

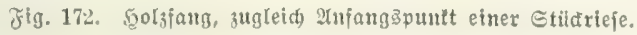

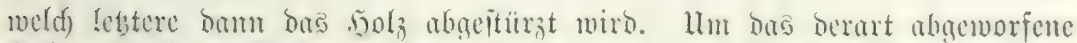

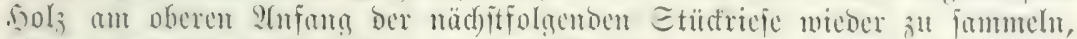

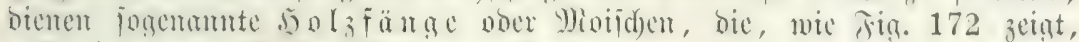
ats cimer non itarfen Etämmen fonftuierten somptmomb beiteben, an

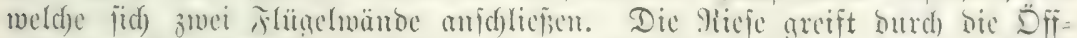

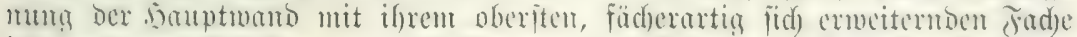

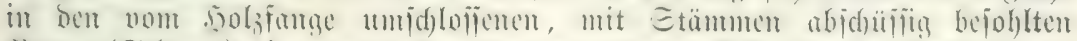

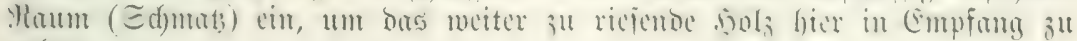
nelymen.

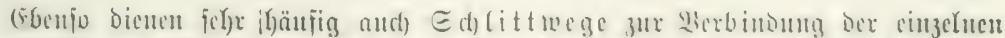

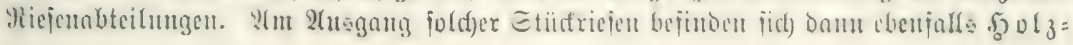


fü॥ge, bic aus fräftigen, wanbartig übercinandergezapiten und geiprię̧ten Gtümmen

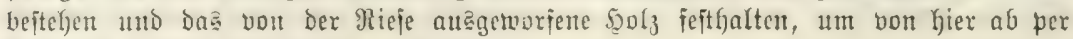
Sdylitten weitertramaportiert zu werden.

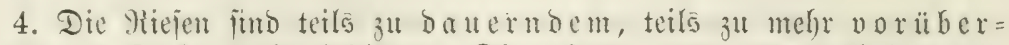

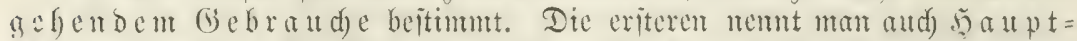

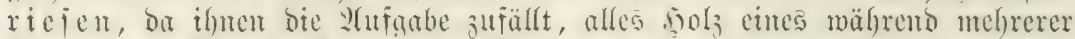

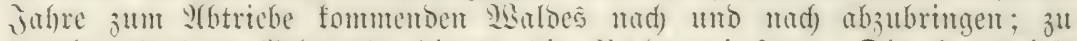

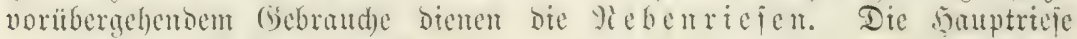

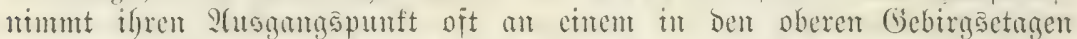
gelegenen nolsfammelplabe, Der die nölzer ants mehreren Zufreitien

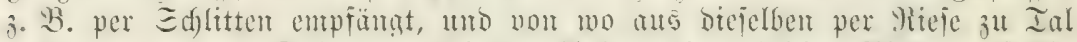

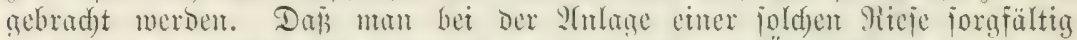

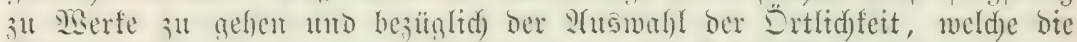

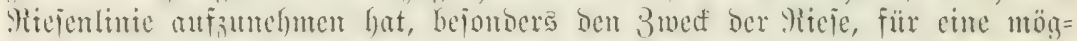

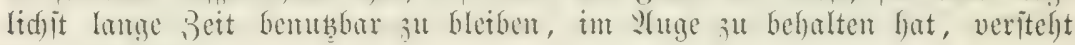
jidf) von jelbit.

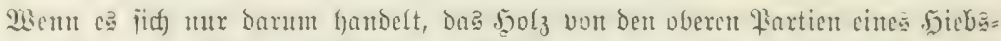

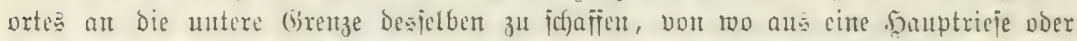

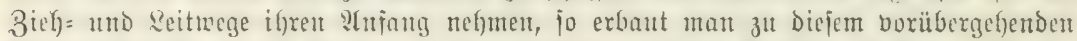

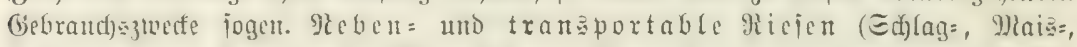

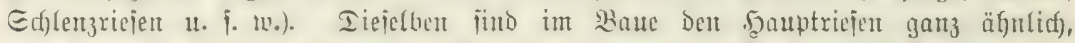

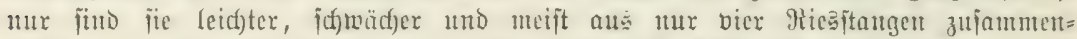

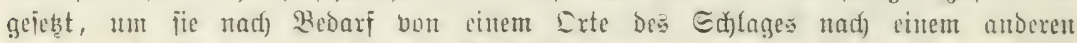

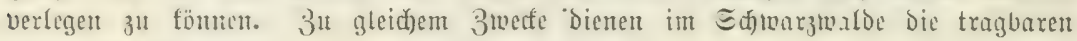
Frad $=$ ober Brettrięer.

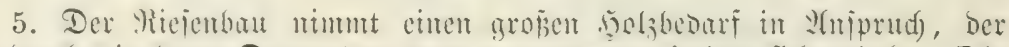

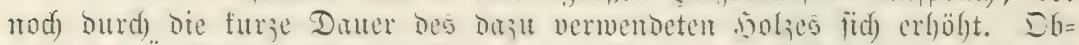

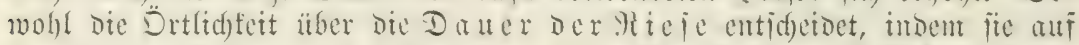

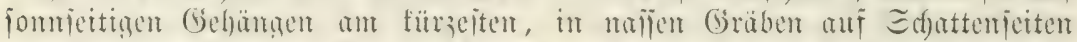

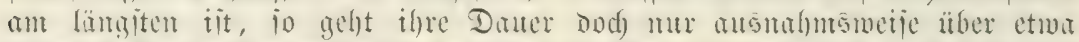

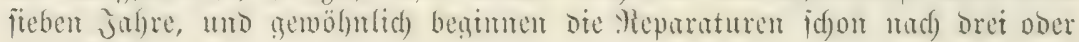
vier Jallert.

Durd) Den Mmitumb, Daß mu früher viclfad) bic Imben; hatte, bie

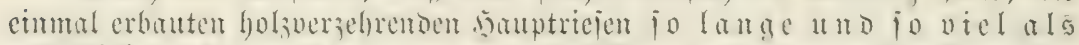
mögli

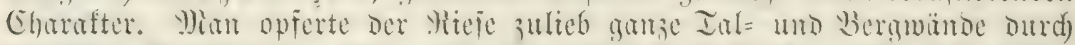

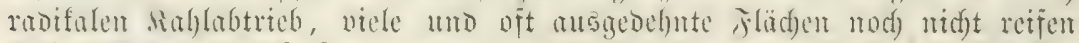

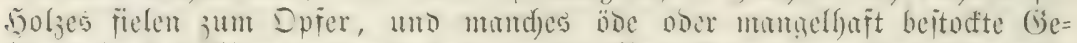
hänge in Den

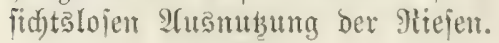

Mlit ber jurtid)reitenden (Erweiterung Des Megbaucs verliert ber Micientransport

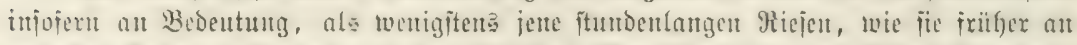

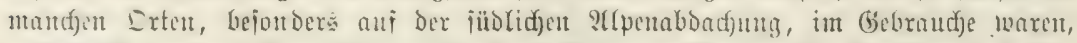

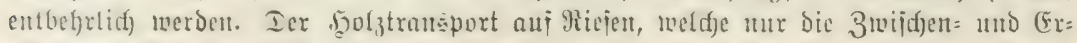

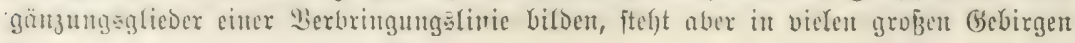




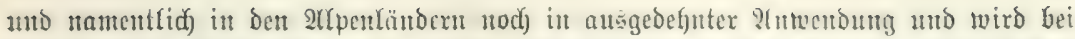
ben heutigen Sgolgpreijen nod) lange nidjt entbel)rt toerden tömen. Die fibnten

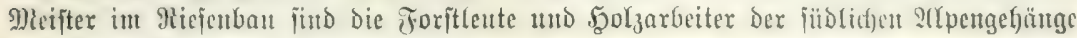
dę Bilfertalez uno Salzfammergute?.

\section{Eroriefent.}

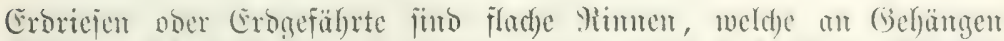

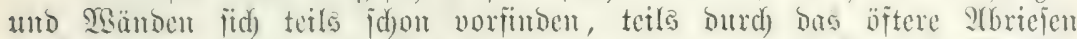

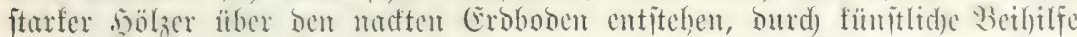

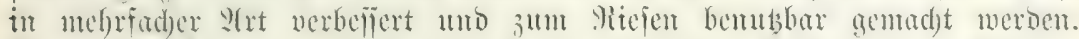

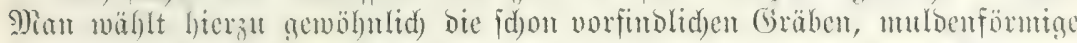

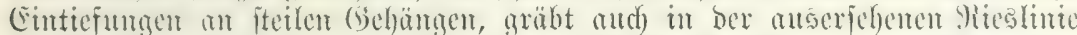

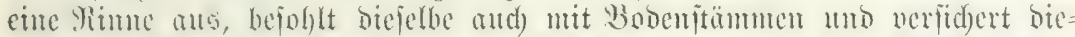

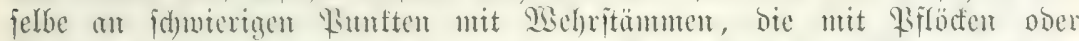

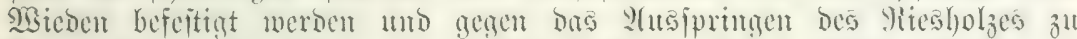

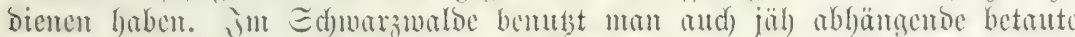

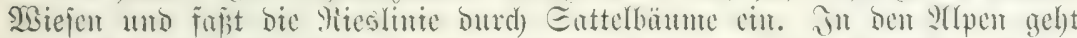

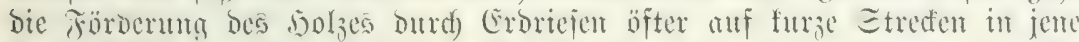

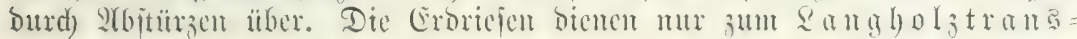
porte.

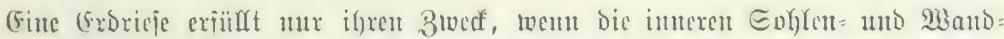

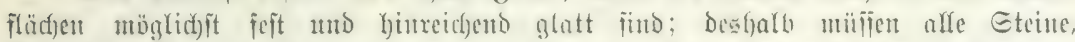

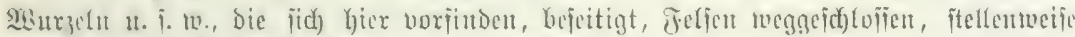

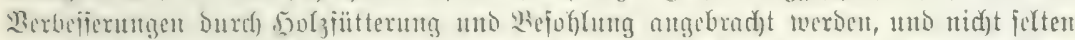

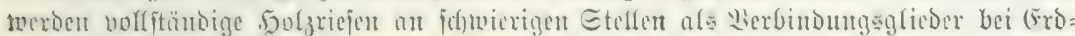
riejent exporberlidid).

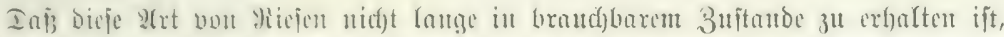

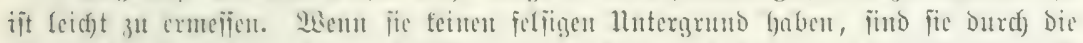

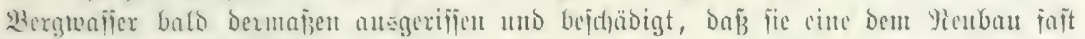

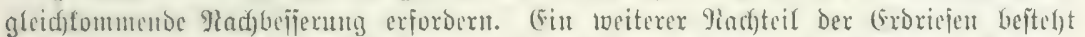

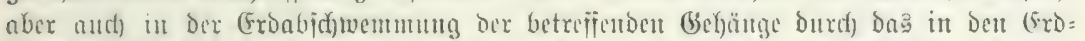

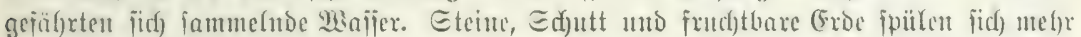

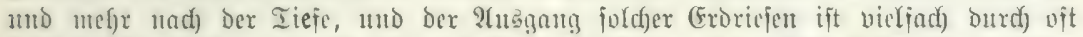

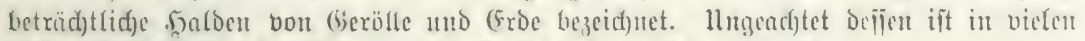

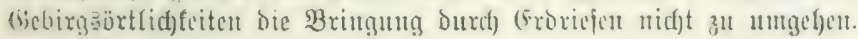

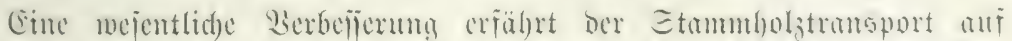

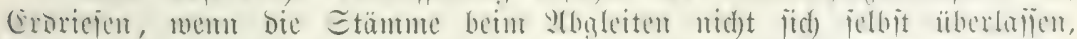

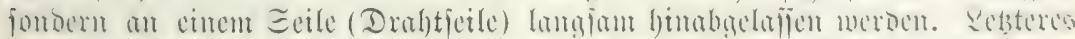

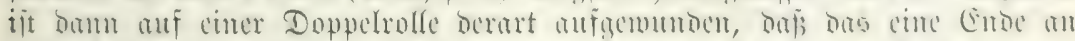

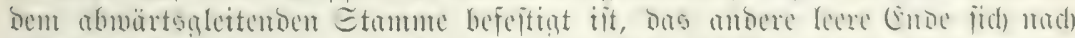

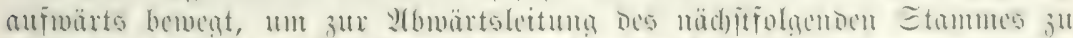

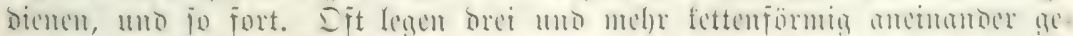

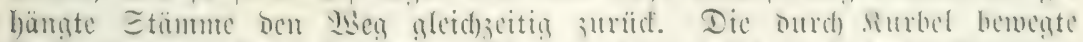

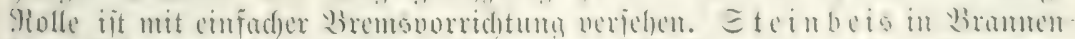

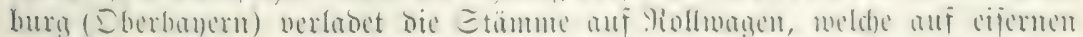
Ed) 


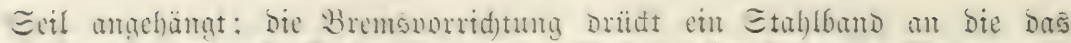

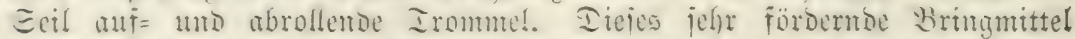

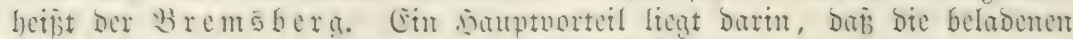

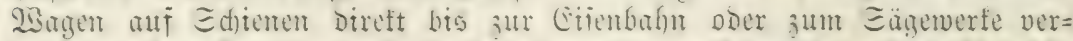

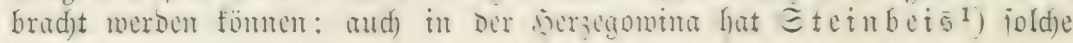
Bremberge angelegt.

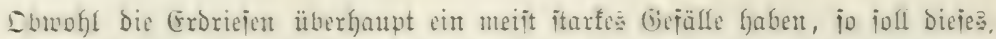

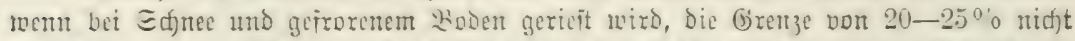

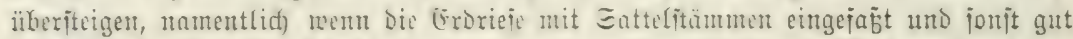

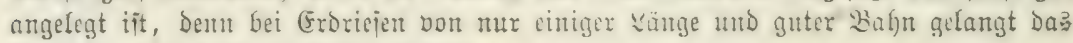
Rangholz jefr bald in jtarfent Eduß.

\section{3. $\mathrm{ds}_{\mathrm{eg}} \mathrm{g}$ iefe th.}

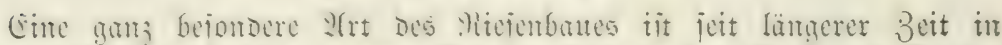

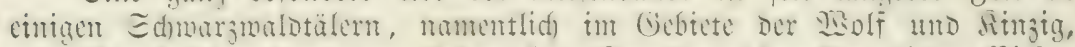

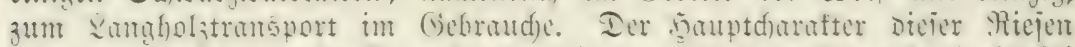
beiteft surin, bus at

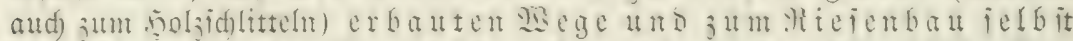

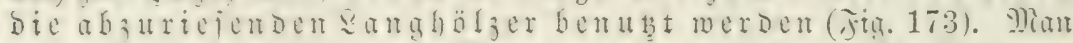

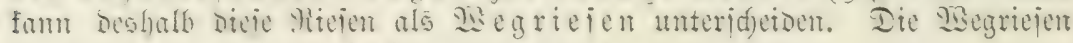
bienen mur zum 2 angholztramborte.

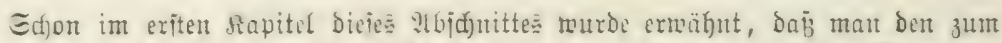
Kieientran port beitimmten, in möglid)it langen zïgigen Sinien angelegten wegen ein

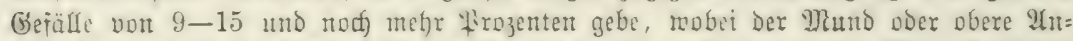

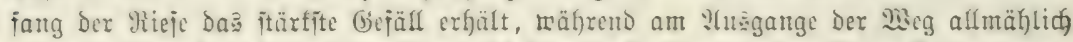
ins Eöhlige ïbergeht. Ebmohl möglidgit geftrafte Rinien obne furze firimmungen

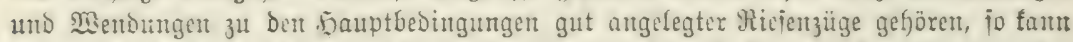

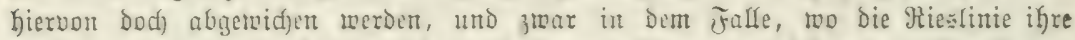

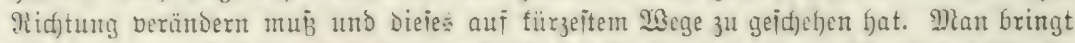

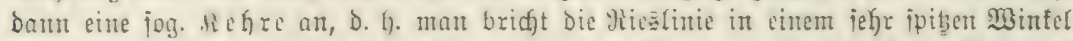
(Fig. 174) und bringt im

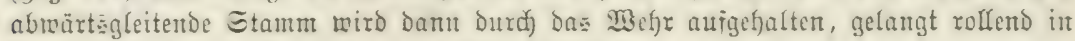
bie Rinie $m x$ und gleitet nun in leb̧terer meiter ${ }^{2}$ ).

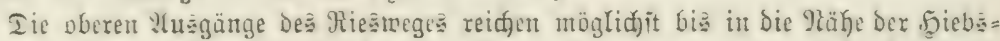

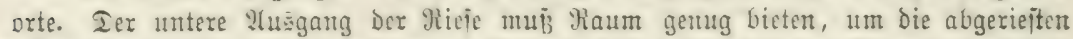

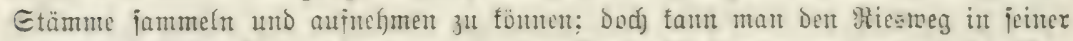

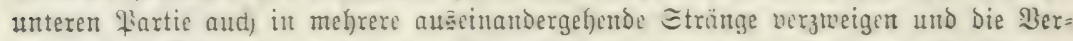

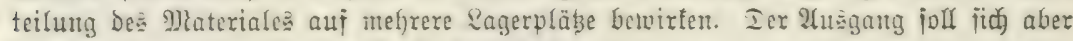
ftets an eine Rand= Doer Majieriträe anjoflieb̉en.

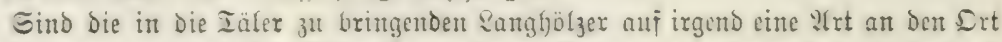

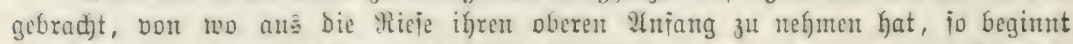

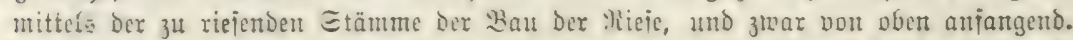

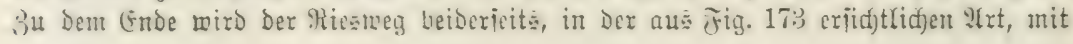

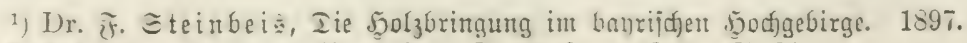

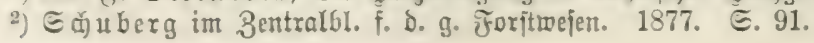




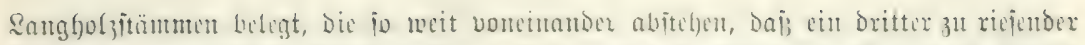

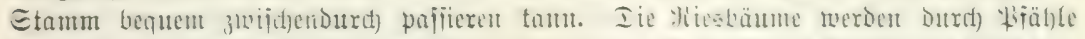

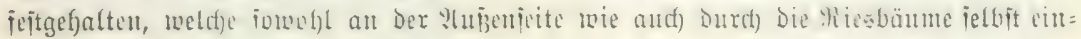

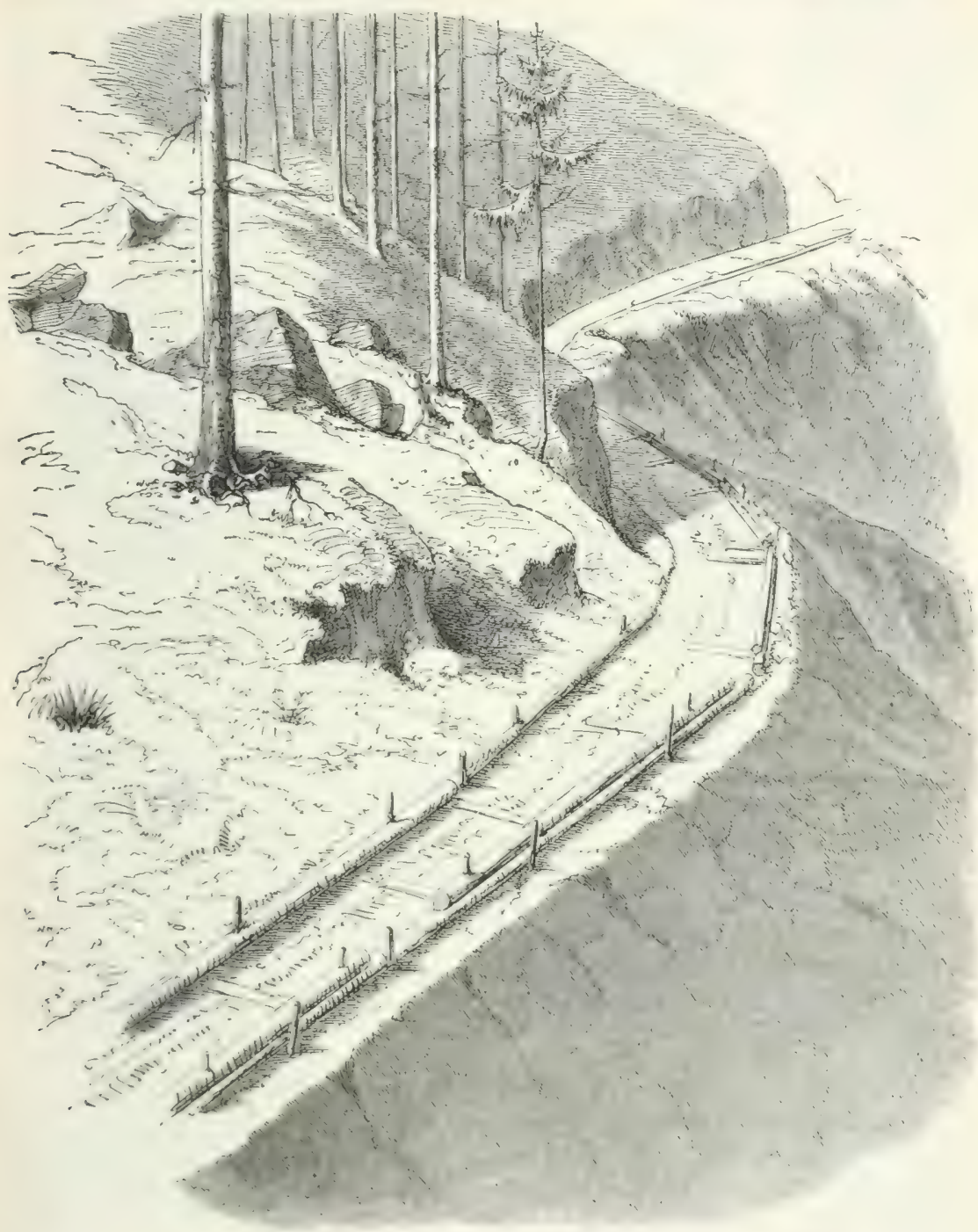

Fig. 173. こd)

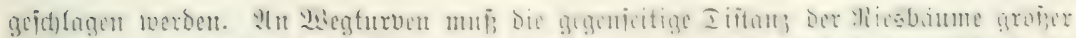

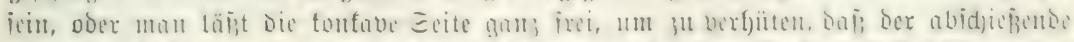

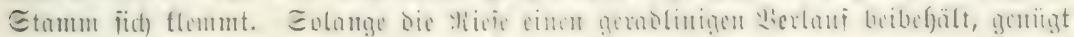




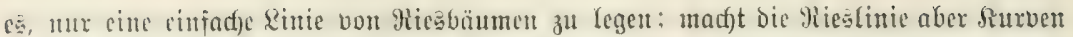

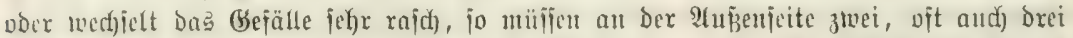

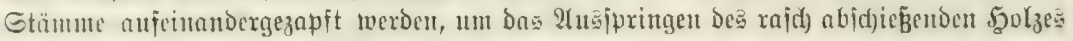
zu verfjüten.

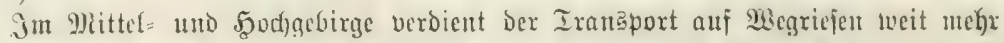

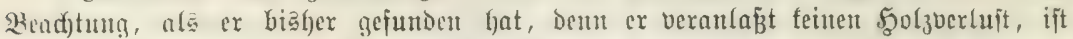
iiberans föroceno, intoem bei cinter Mieülänge non etwa $2000 \mathrm{~m} \mathrm{100-300} \mathrm{Etämme}$

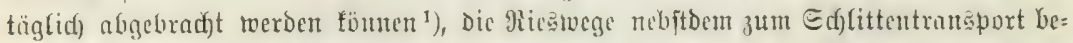

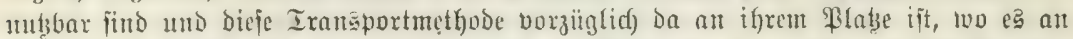

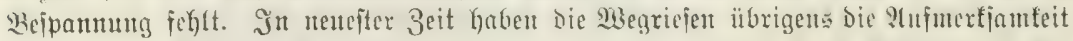

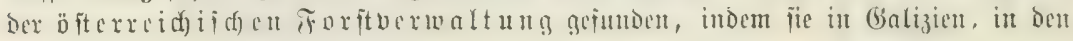

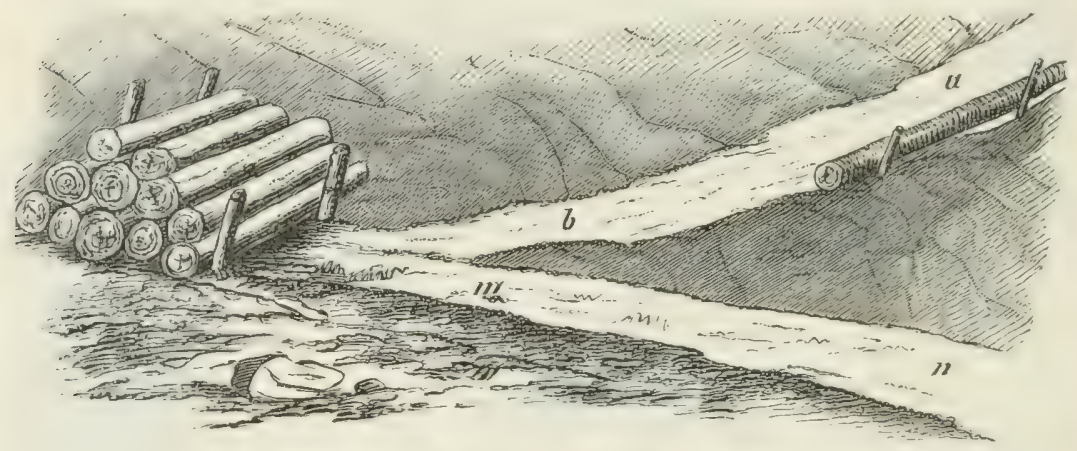

Fig. 174. Sehre ober \$redung ber Hiefe al mit \$rellwehr.

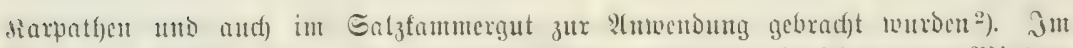

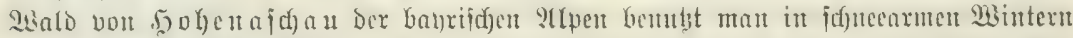

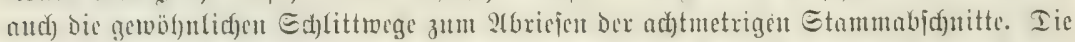

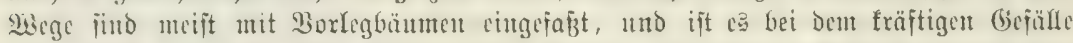

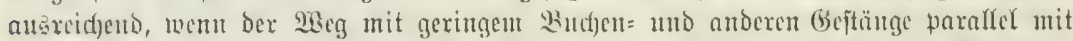

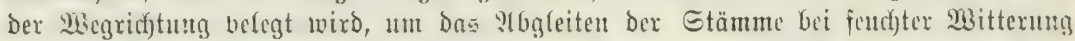

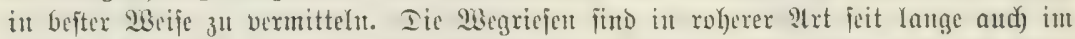

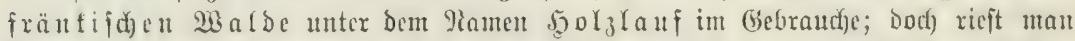

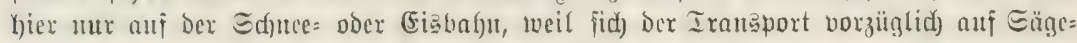
brtödye beid)räntt.

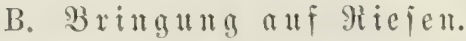

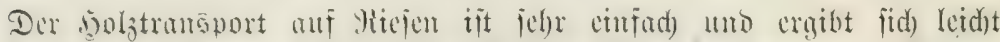

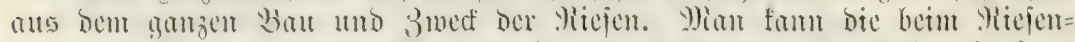

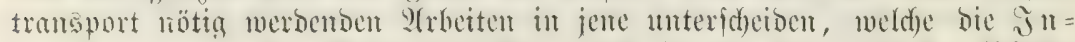

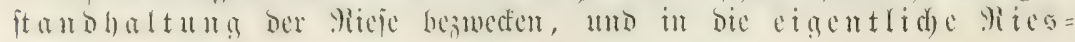
arbeit jelbit.

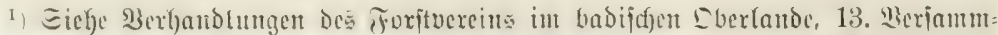
Iung, Є. 144, Dant Die Berjanmlung in Etodfadh), 1879.

2) 3entralblatt f. D. g. Foxituejen. 1875. 


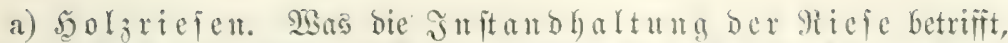

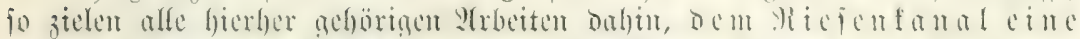

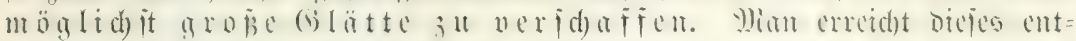

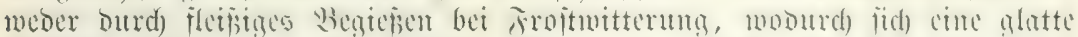

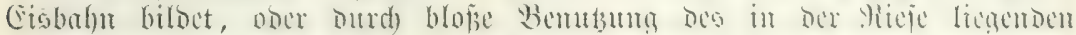

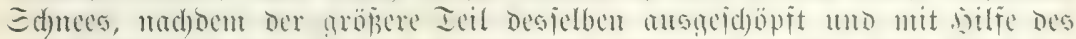

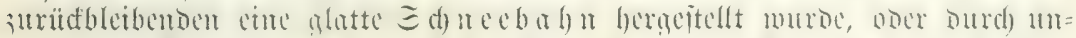

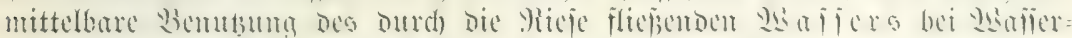

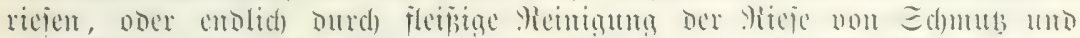

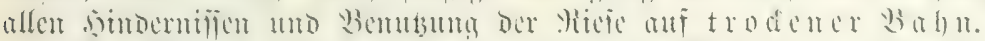

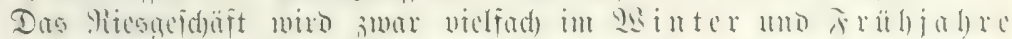

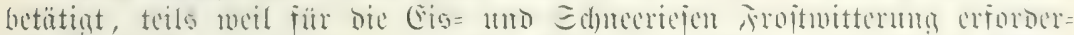

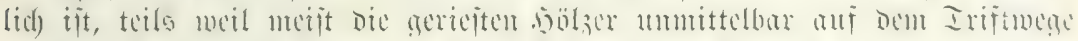

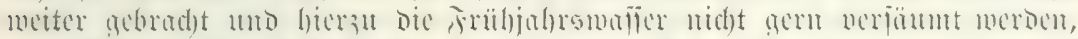

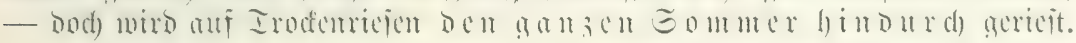

खenu ma bei geringem, oft nux 5-6prozentigem 6efälfe zum Eiariejen ge=

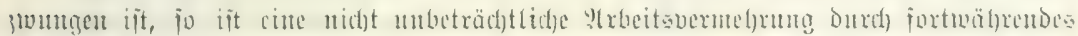

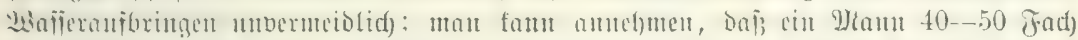

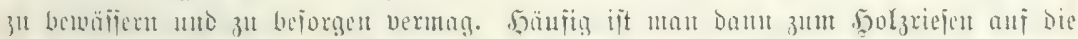

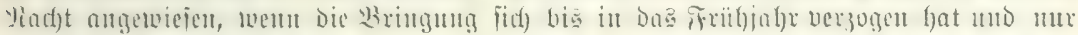

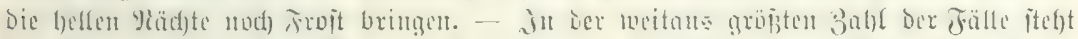

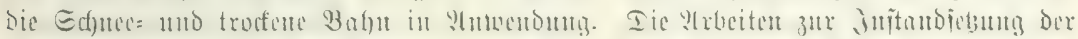

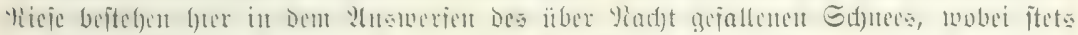

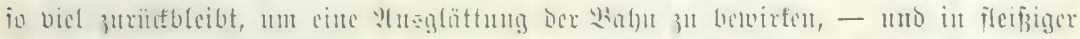

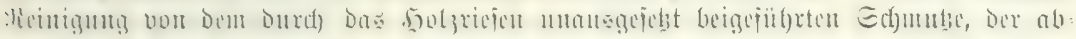

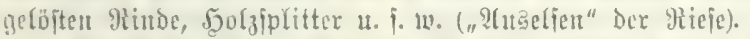

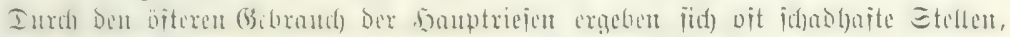

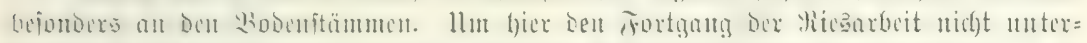

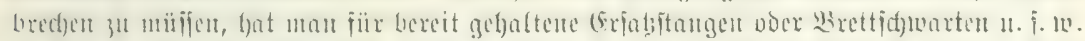

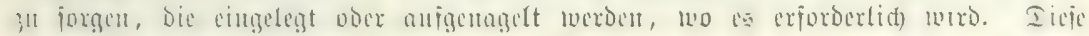

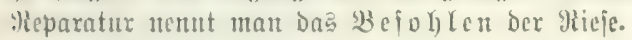

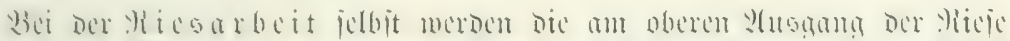

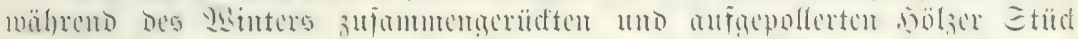

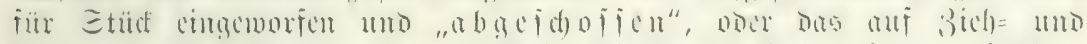

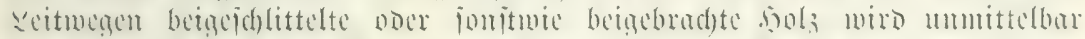

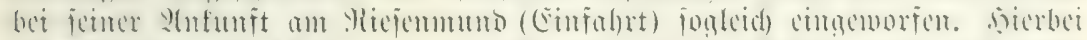

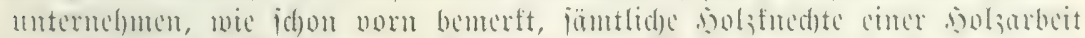

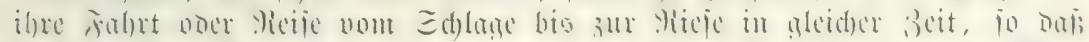

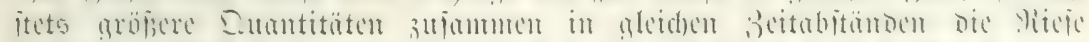

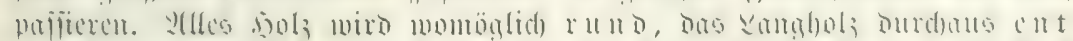

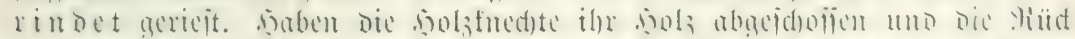

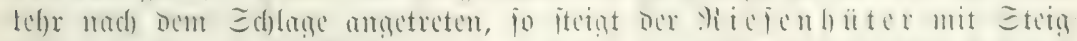

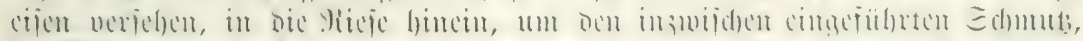

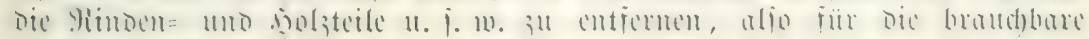

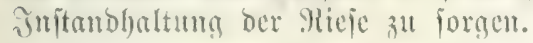

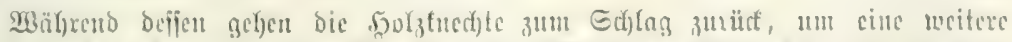

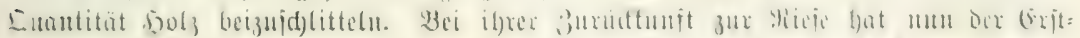




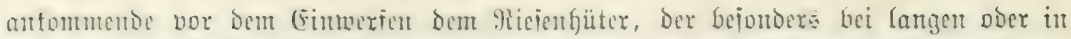

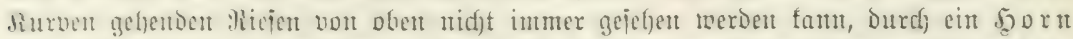

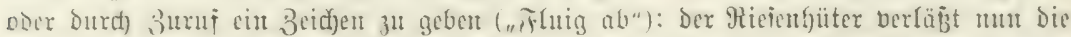

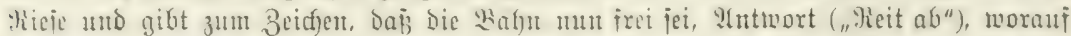

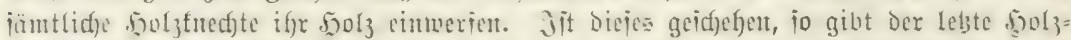

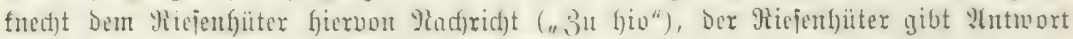

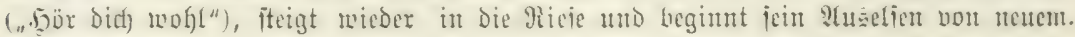
(sîla

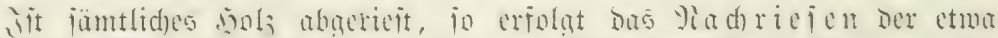

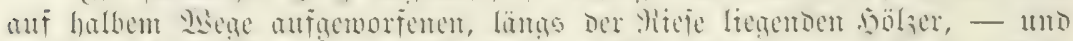

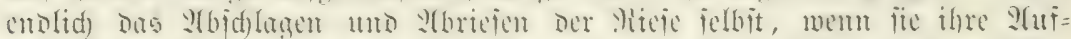

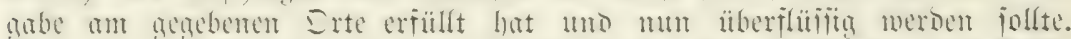

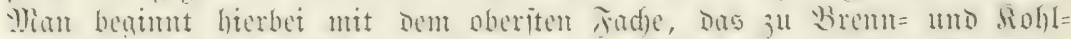

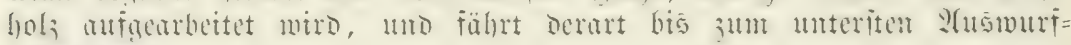
fadje fort.

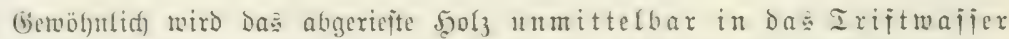

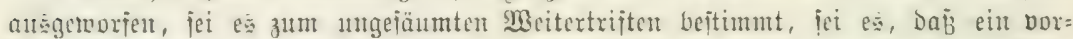

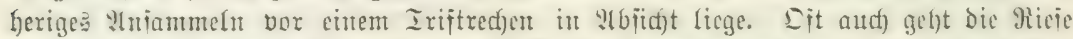

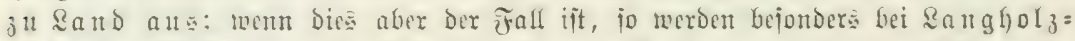

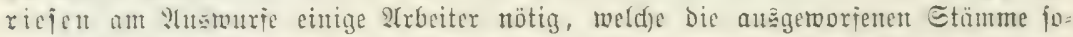
gleid) auf bie Eeite rollen, um Deren Bejdäbigung Durd) bie nadjolgenden ఔu ver=

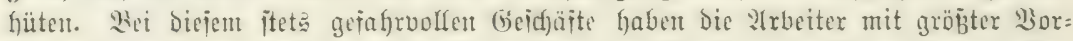

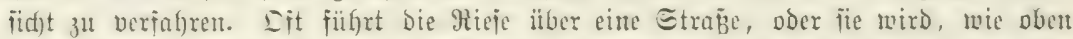

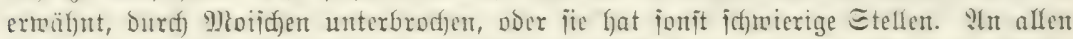
Derartigen Erten müifen bejondere ?Irbeiter auigeitellt werben, um Gefahren für bie llmgebung oder bie Gej̧äjtäförderung zu verhüten.

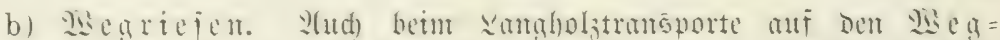

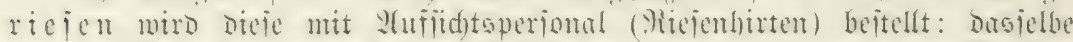

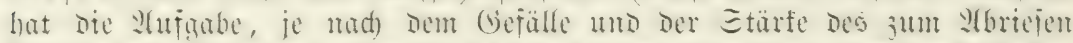

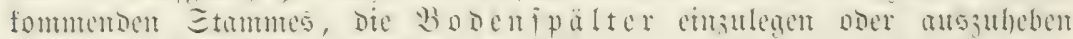

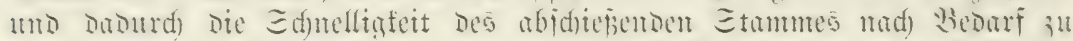

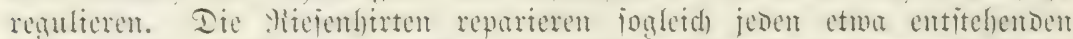

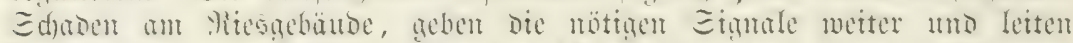

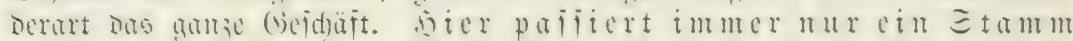

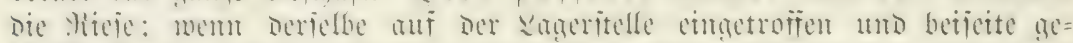

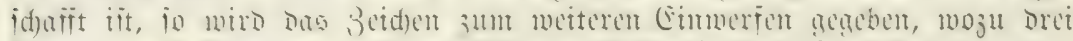

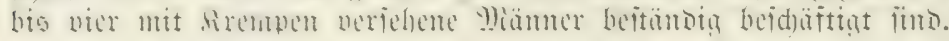

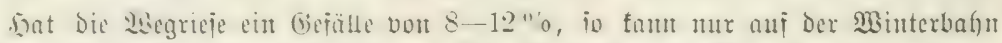

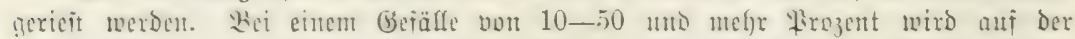

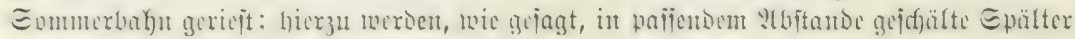

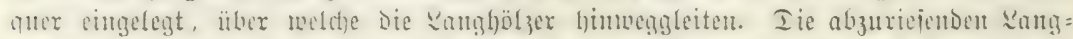

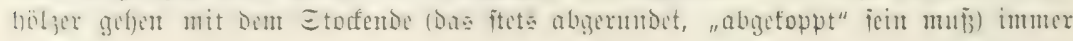
boraus. 


\section{Walocifenbaluen ${ }^{1}$ ).}

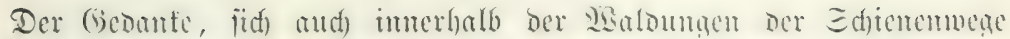

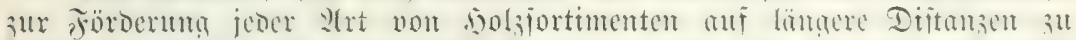

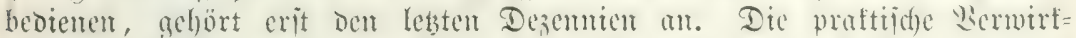

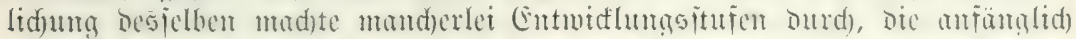

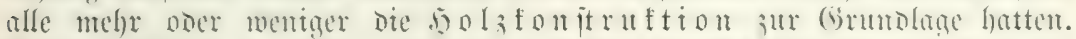

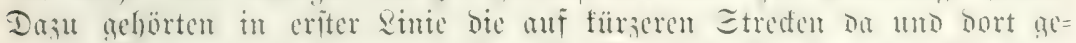

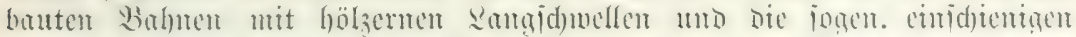

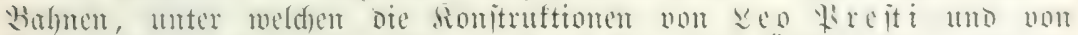

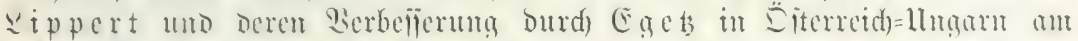

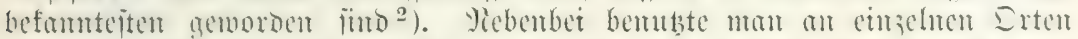

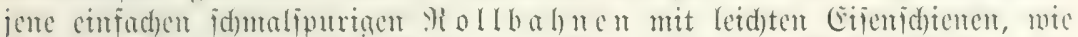

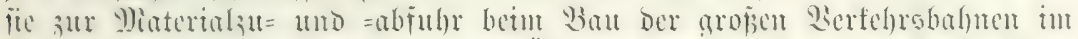

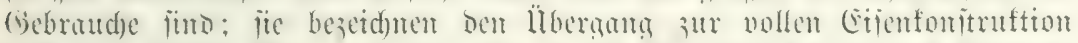

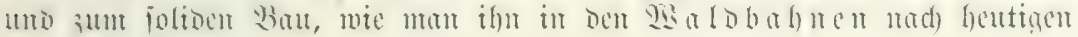
Begriffen findet.

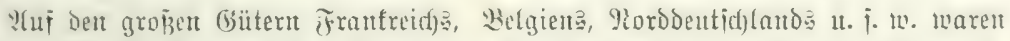

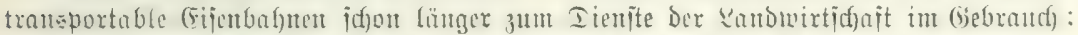
am befantepten waren bie homptruftionu von Iecanbille, Iictrid) u. j. w. ge=

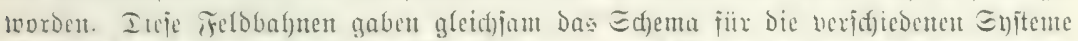

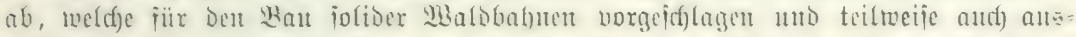

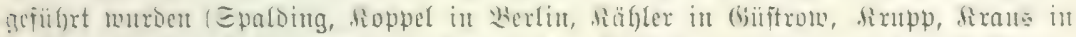

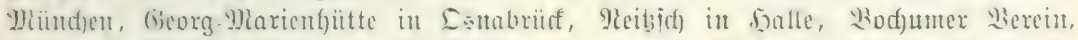

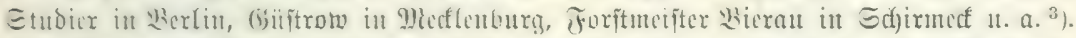

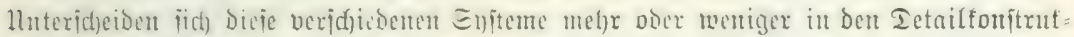

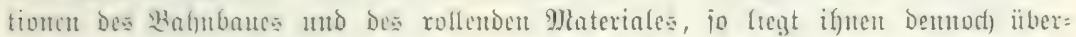

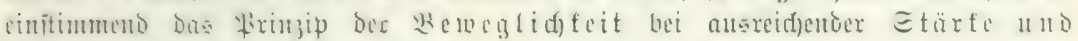
Solibität in ber fiontitruftion aller Tetle zu Grunde.

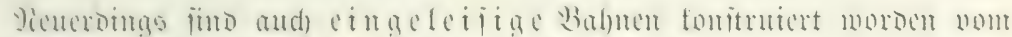
id)weizerifden Foritimpeftor vou Eoulou $\left.^{4}\right)$, Eatlet

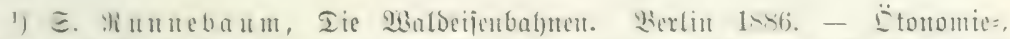

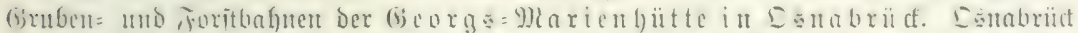

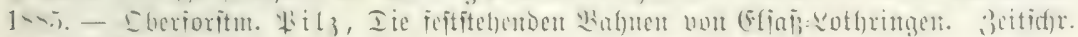
i. ₹. u. Э. 1900.

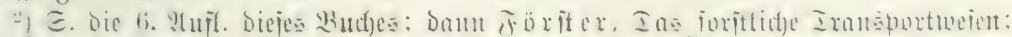

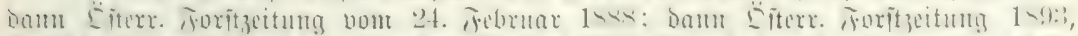

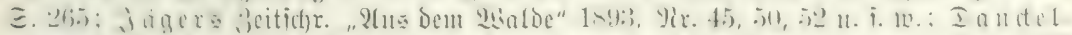

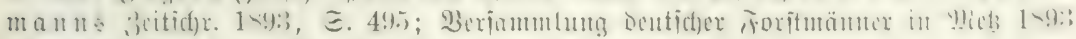

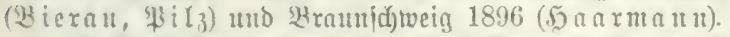

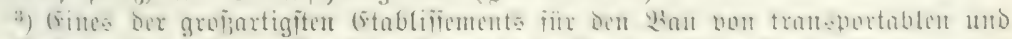

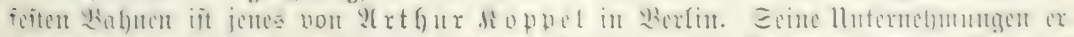

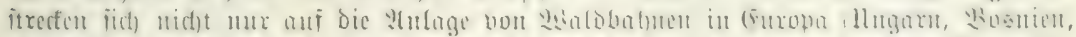

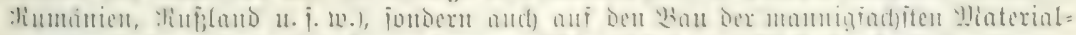

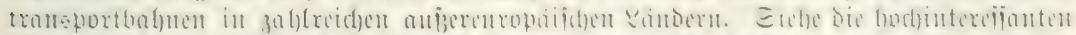

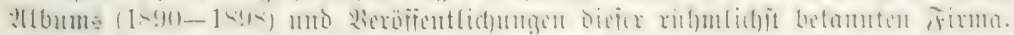

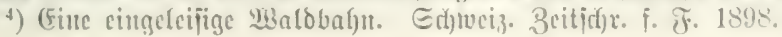




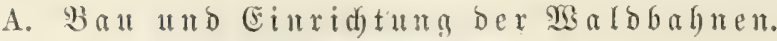

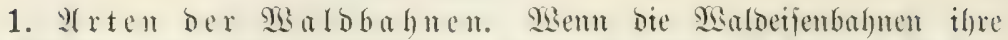

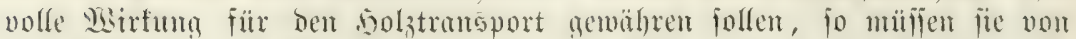

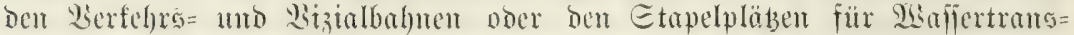

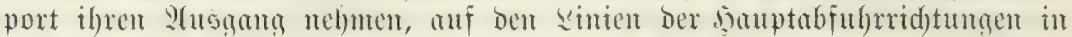

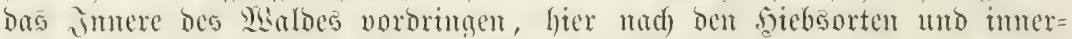

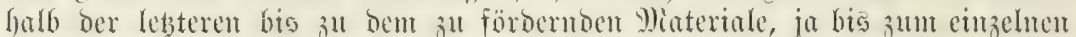
Etamme fid) verzucigen. Siterats ergibt fid), baj ein Ieil ber Etrecten ill

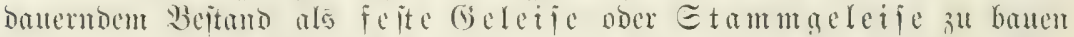

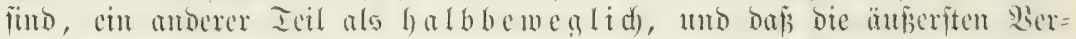

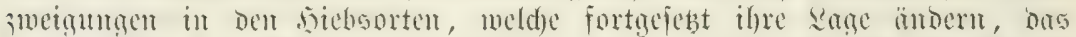

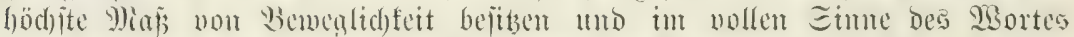

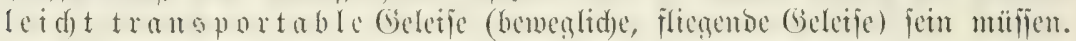

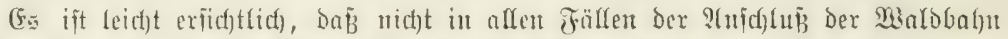

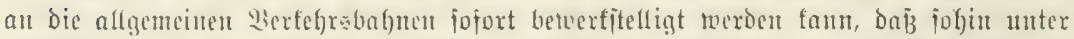

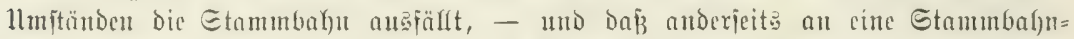

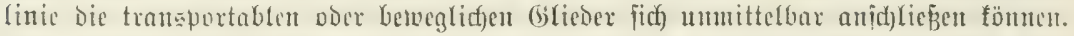

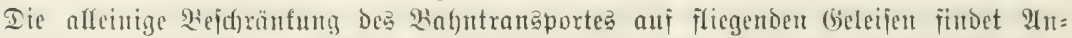

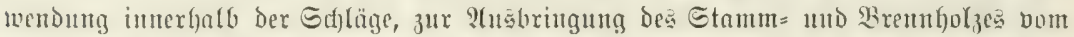

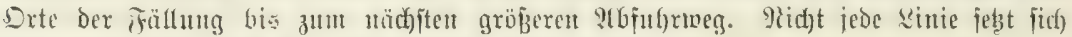
jobiu immer aus den brei veridfiedenen शrten zujammen.

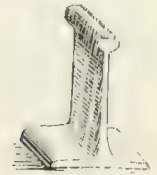

Jig. 175. ediene.

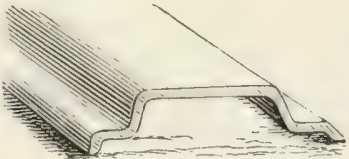

Jig. 176. Eiferne Sd)

2. B⿺a und Ron it $u \mathfrak{t}=$ tion. Wir betradsten fier in all= gemeinen Umrifien bie Irafitierung, die Geletie, das rollende Miaterial und die Rabevorridutung.

a) Irajicerug. Für die Etammgeleife mo die halb= bewerliden (seleife werben wo=

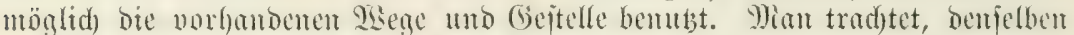

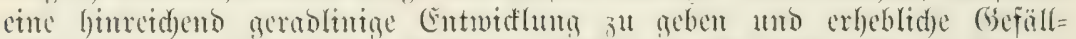

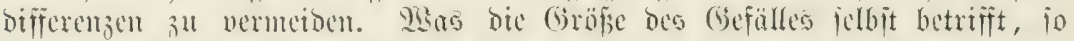
fum basfelbe im liotfalle mohl bis anf 6 ober $8 \%$ anfetgen, aber mat

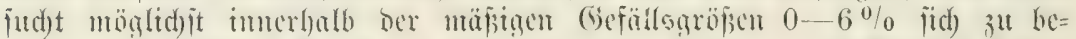

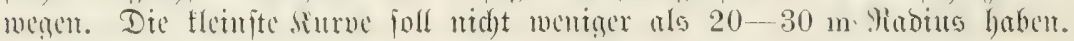

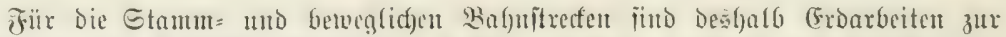

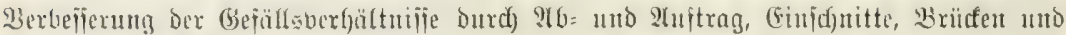

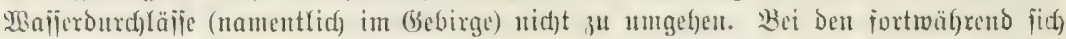

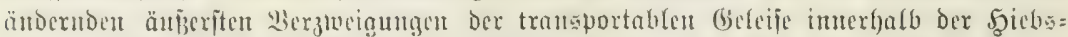

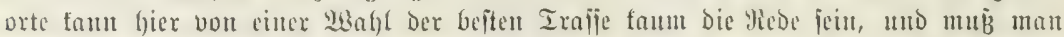

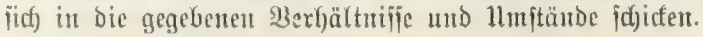

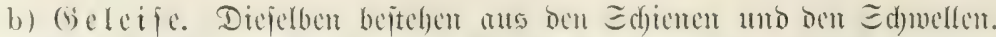

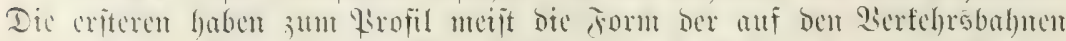

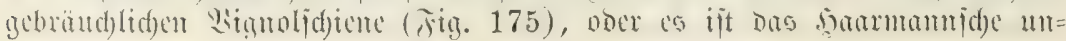




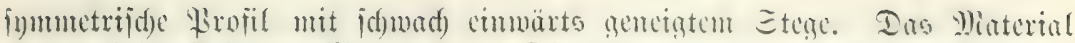

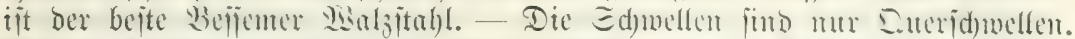

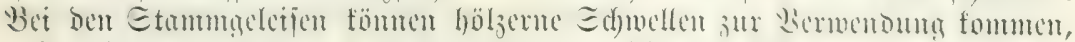

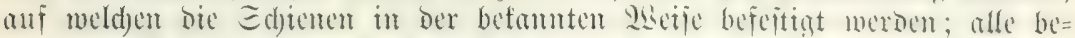

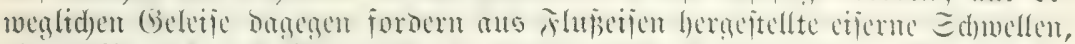

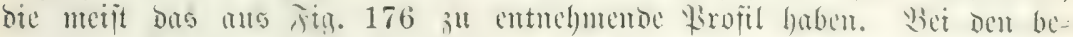

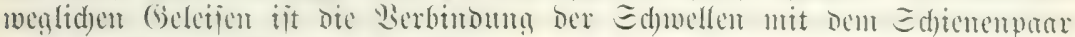

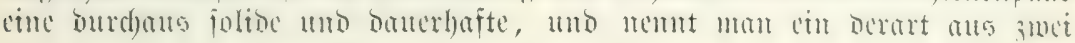

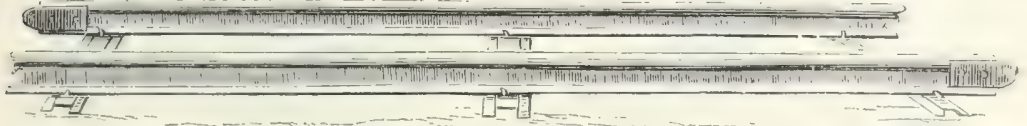

jig. 177. Fad ober jod) aus zwei Sdienen ober brei Edymellen beitegenb.

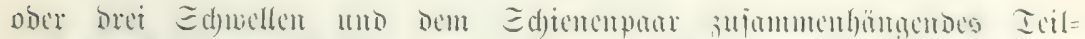

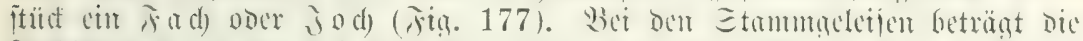

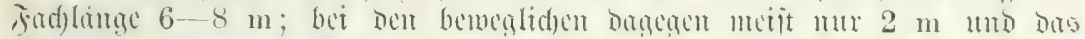

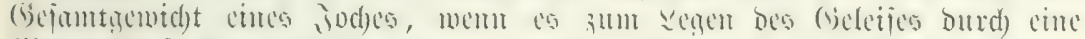

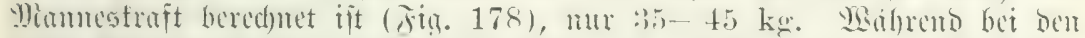

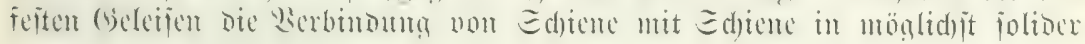

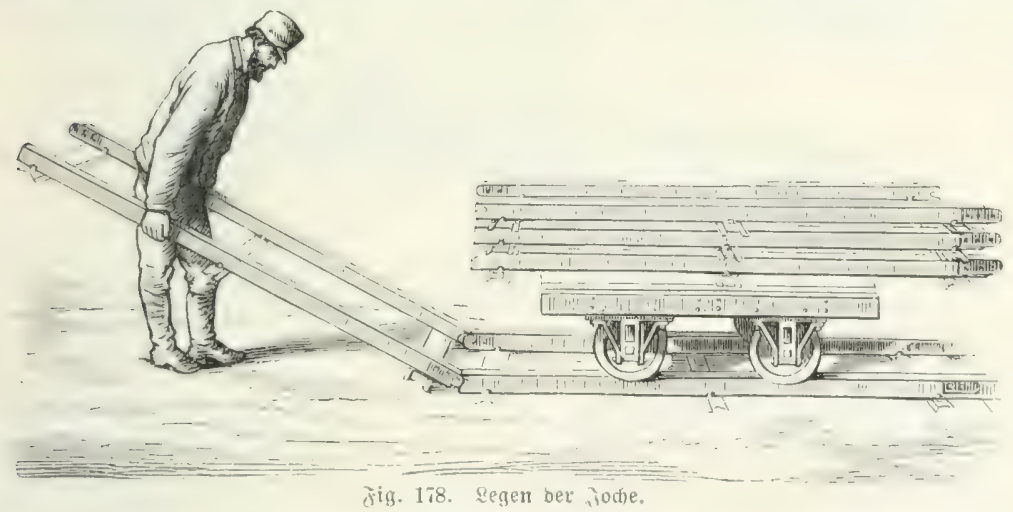

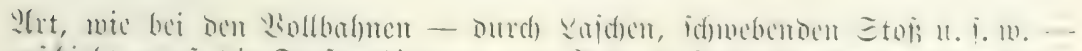

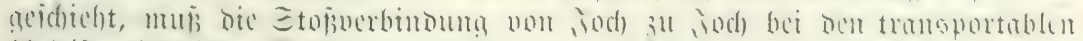

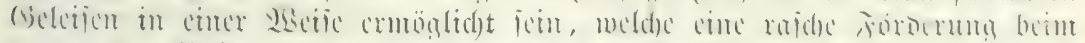

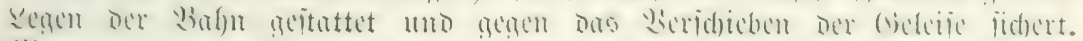

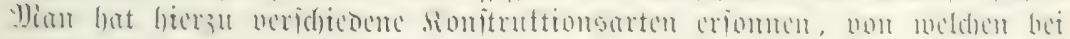

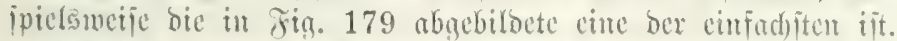

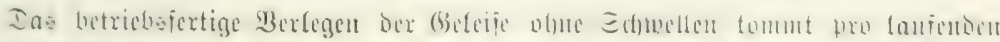

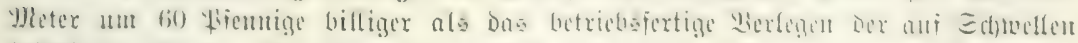

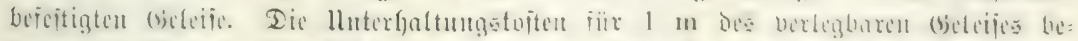

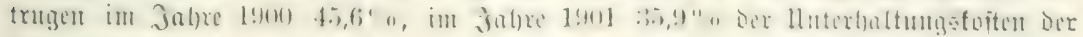
ieften $\mathfrak{B a f}$ )nen. 


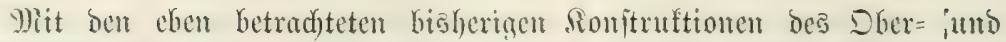

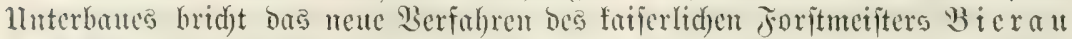

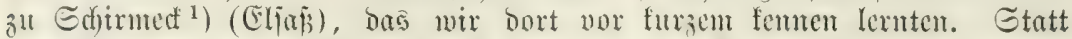
ber Berlegum der Edjenen auf Duerfdewellen fommen lebtere ganz in

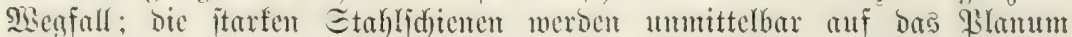
gelent; Die $9 \mathrm{~m}$ lamgen und $16 \mathrm{~kg}$ idumeren Etahlidjienen werben non 1,5

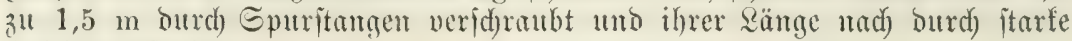
Enfoden befejtigt.
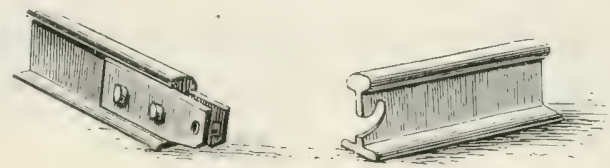

Fig. 179. Werbittoung bet Jodie.

SEas bic ङpurmeite betrifft, fo mutroe cinte foldfe in neuciter 3eit,

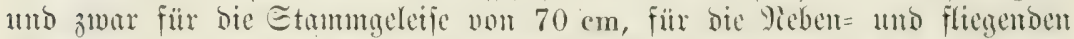
(iseleije von $60 \mathrm{~cm}$ als an meiften entipred)ento erprobt. Dais endid), wie

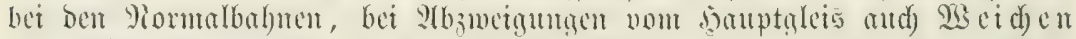

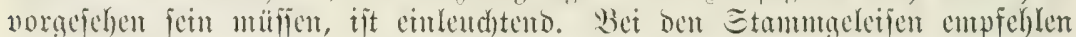
fid) bie befamten Echlepp= ober liedalwetden: fïr bie tramsportablen (Gese=

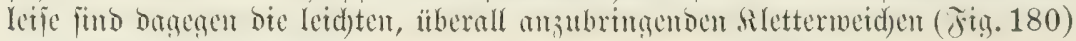
ganz bejonbers gecignet.

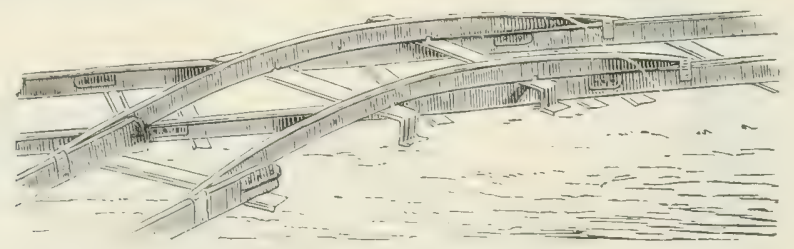

Jig. 180. Mltterweidje.

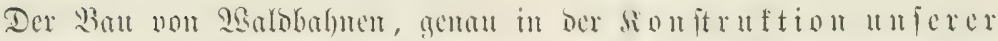

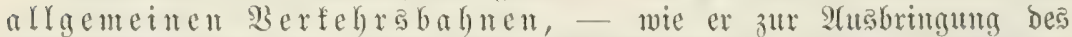

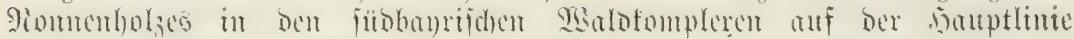
ftattfans, - ijt morerit mod) als cime : betraditen.

Iaji bie Etammgeteife ebenjo Durd) cinzehu Fadje zufammengeftellt werben

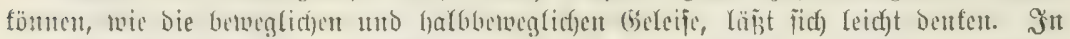

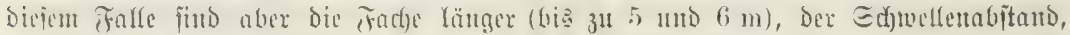

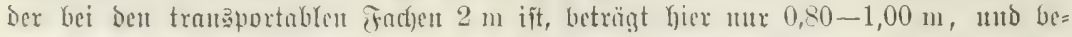

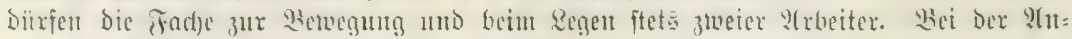

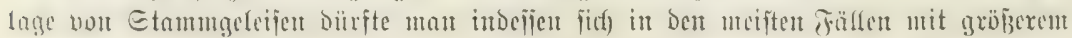

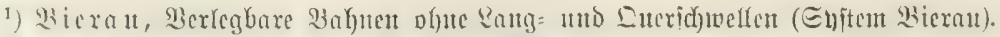

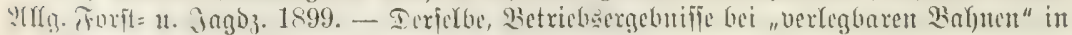

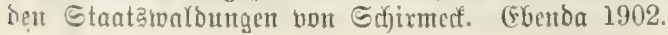




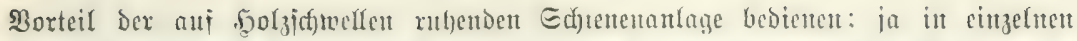
Fällen hat man dic Etammgeleifi ganz nad) Den (brundfäten und in Der ?tet ber all= gemeiten

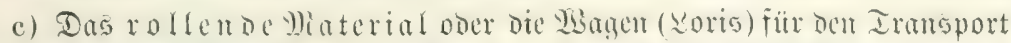

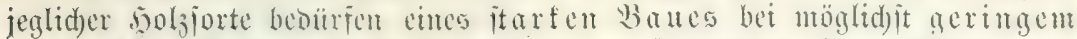

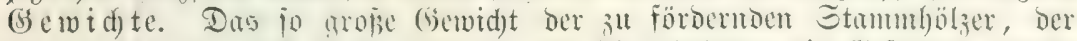

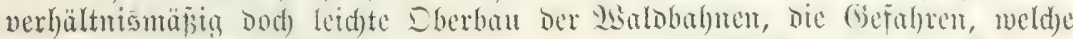

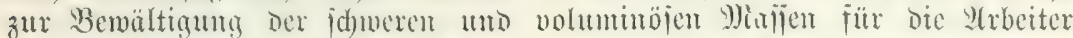

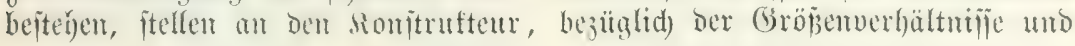

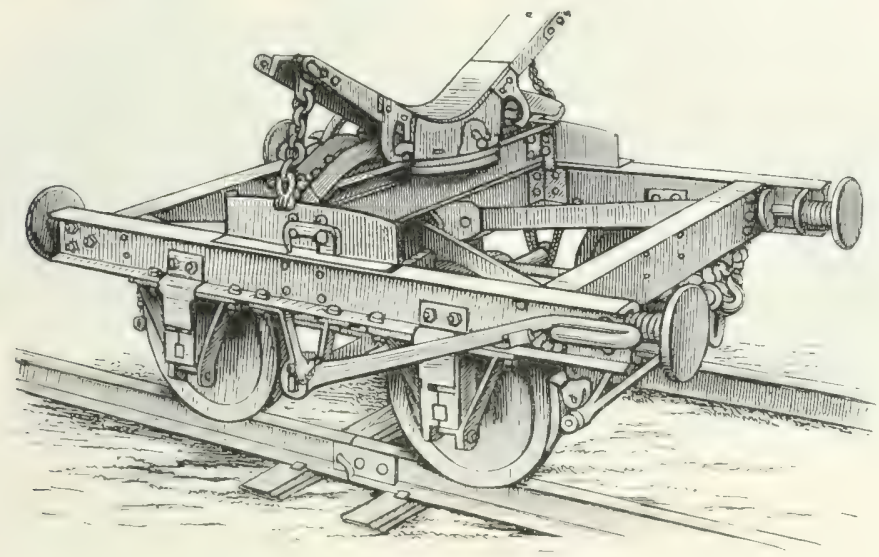

F̌ig. 181. Lsagen für Etammbolstransport.

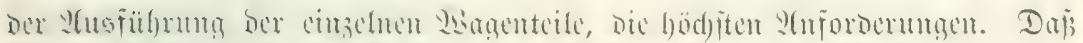

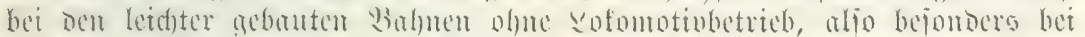

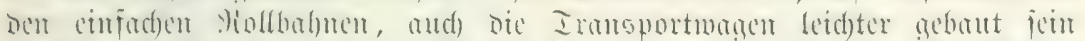

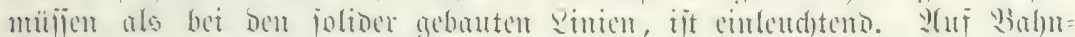

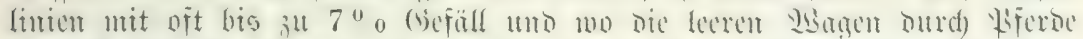

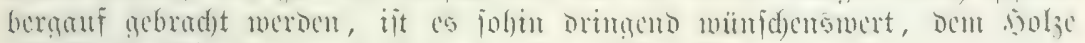

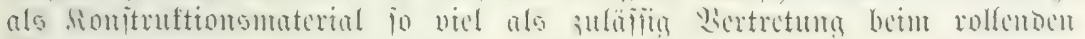
9) Rateriale zu geben.

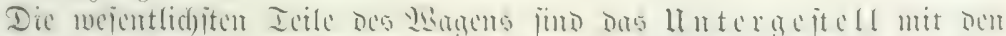

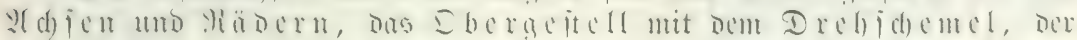

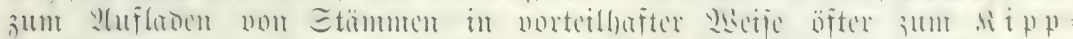
D) verid)

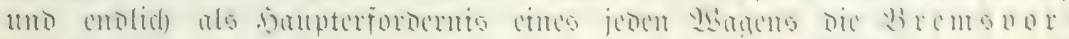

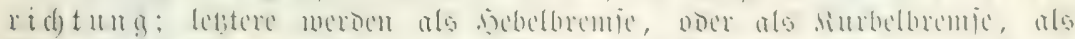

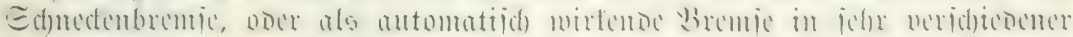
$\mathfrak{A}$ rt gebaut.

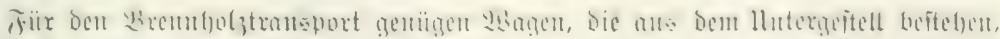

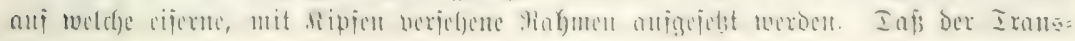




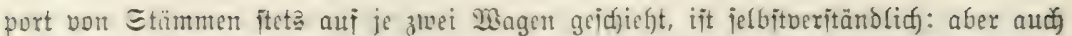
3um Sirmfolztran ober Rangholzłtämmen (Fig. 182) vertonóet.

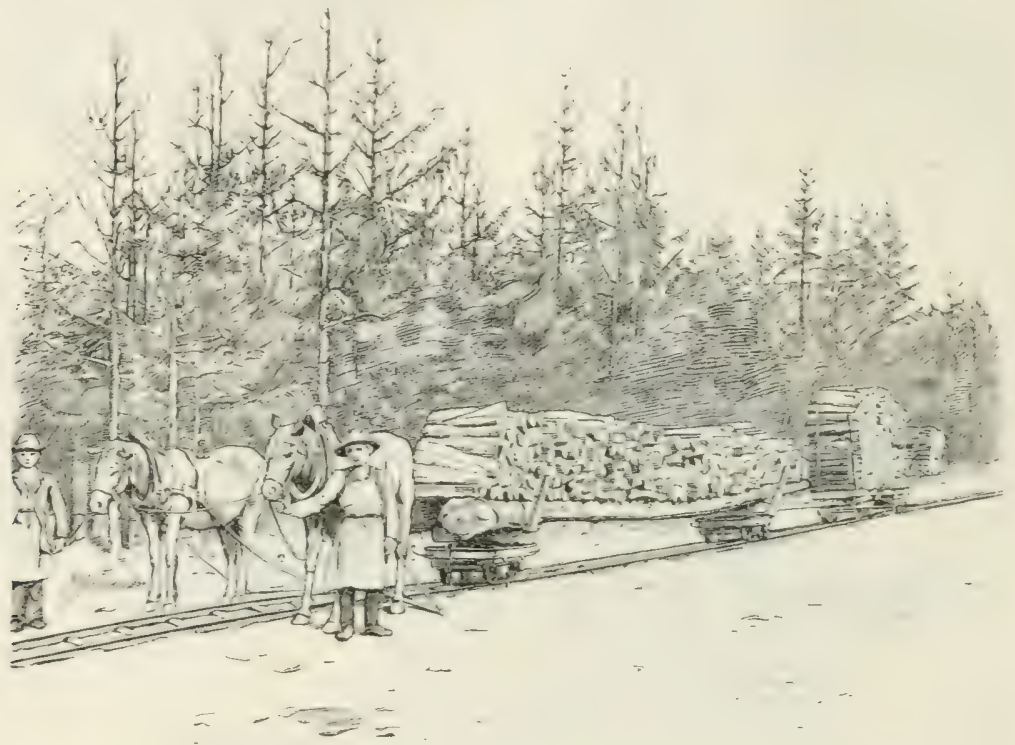

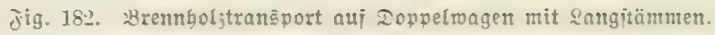

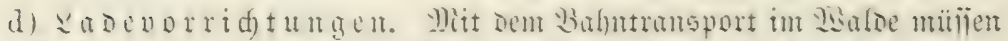

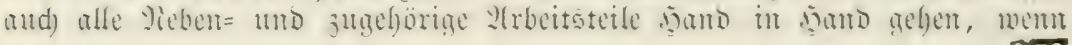

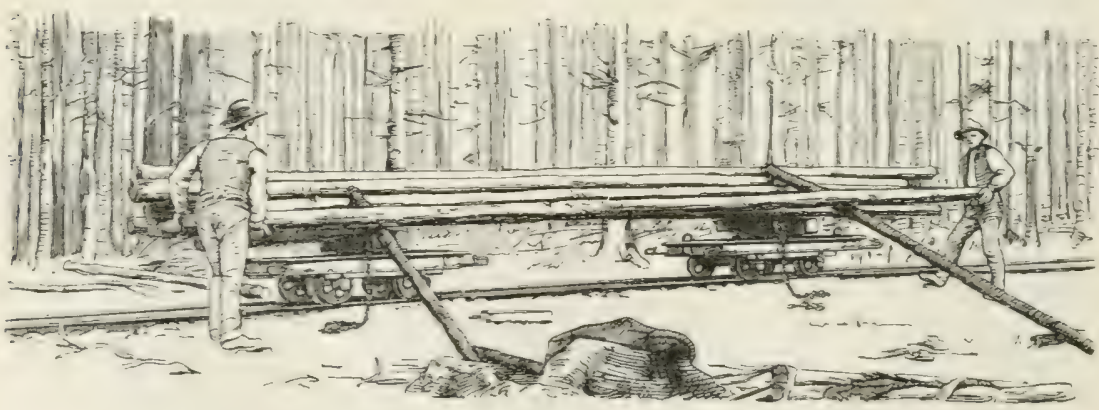

jig. 183. Belaben ber wagen.

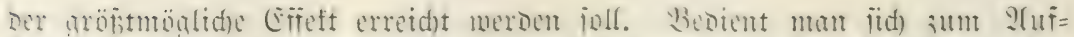

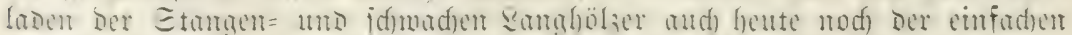

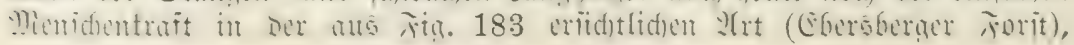




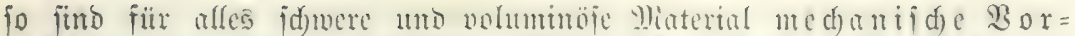
rid)tugen nidjt ju entbehren. S(nfïnglid) half man jid) mit ber ge=

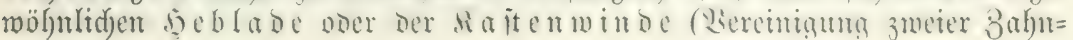

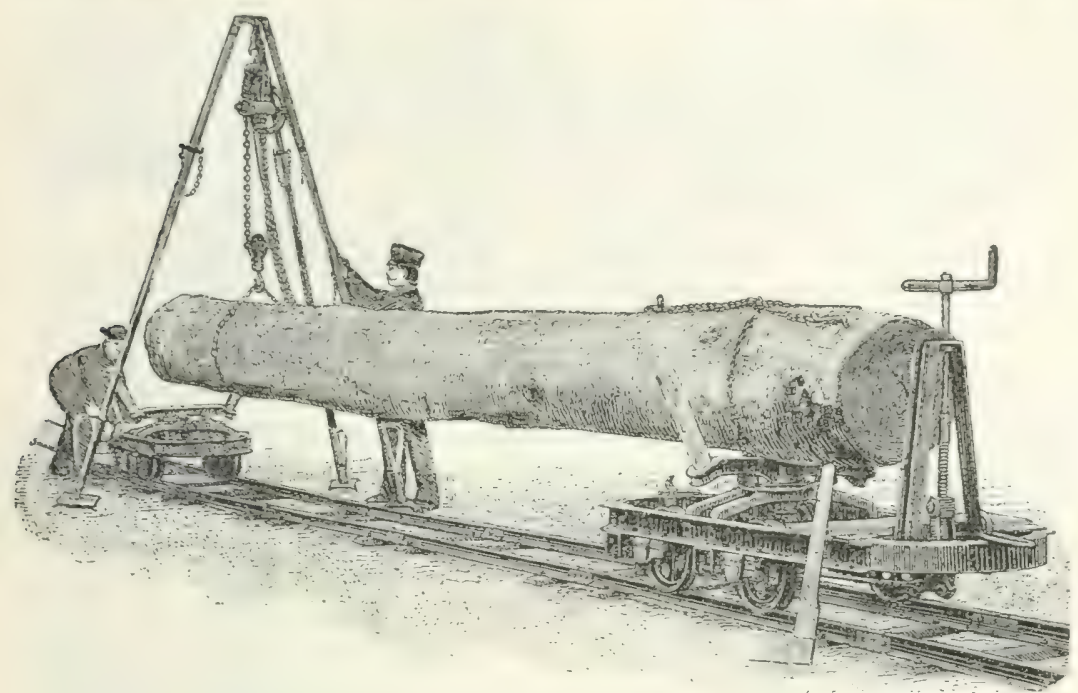

Jig. 184. Werlabung mit bem Srabnen.

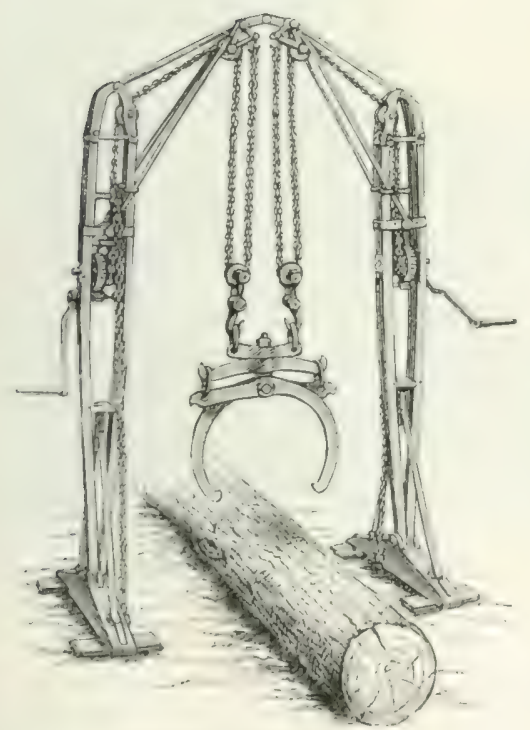

fig. 18:. Ioppeltranuen.

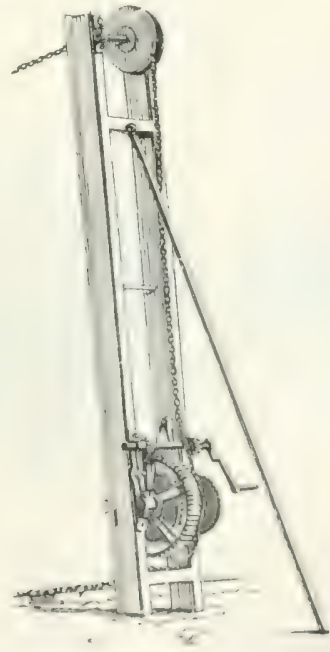

Nig. 18\%. Eeitninbe. 


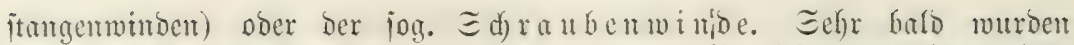
aber ipeziell bem 3 mede angepajte wirfiamere Borriditungen fonjtutert, von weldyen fier als bie widytigiten gentunt jeien: Der Salobahntrahnen

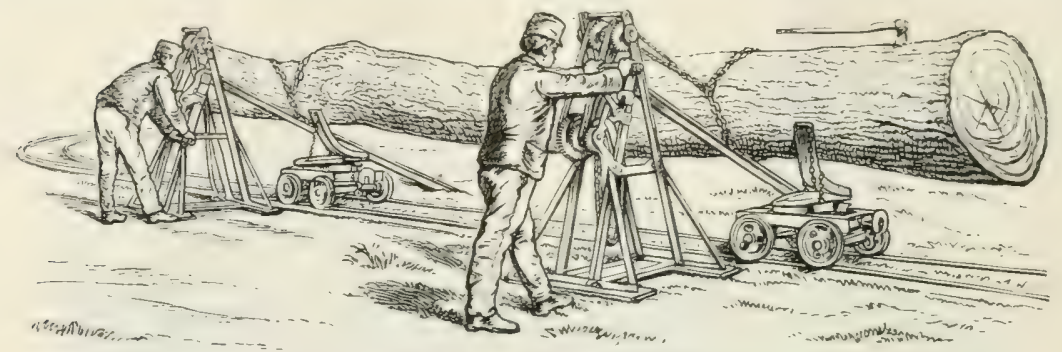

テૅig. 187. Jerlaben mittels bes 2abebaumea.

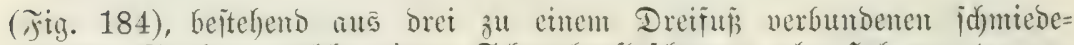
eijerten Sätlen, meld)e cinte Sd)ratbenflajd)enzug als f̧ebzeng tragen;

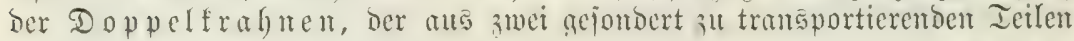

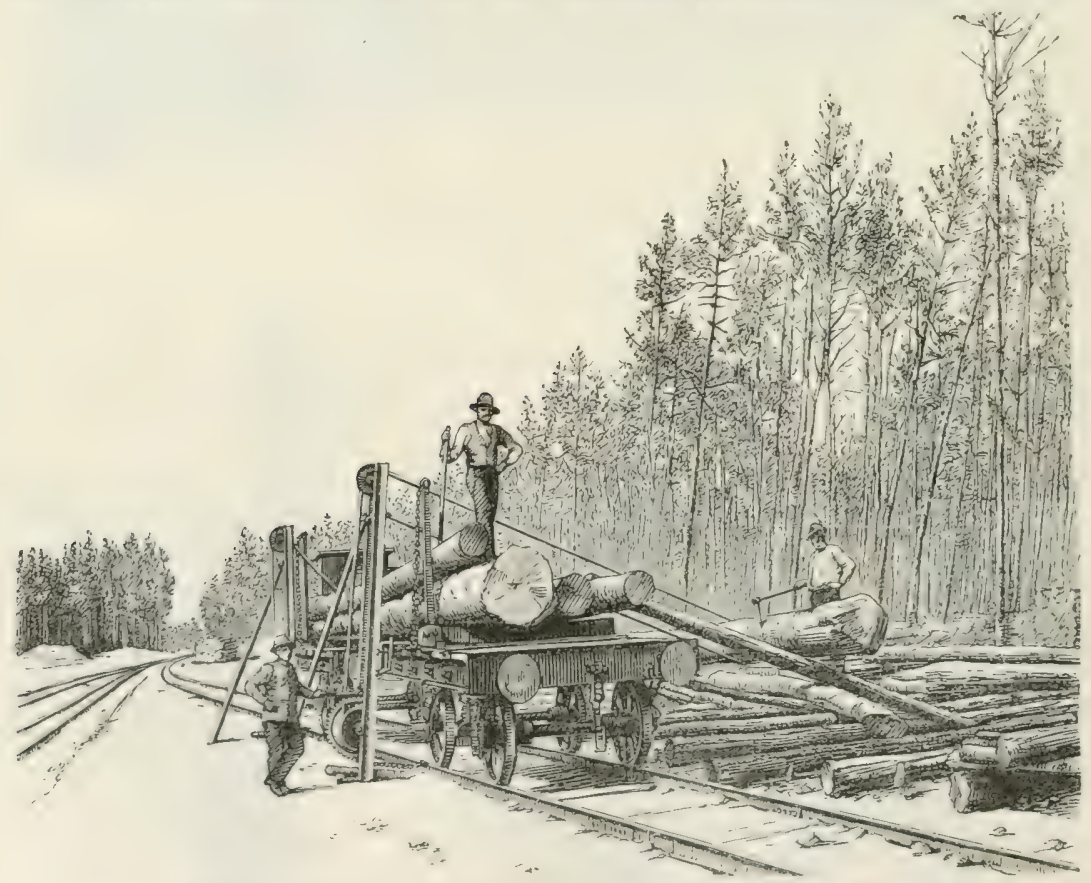

Fig. 188. Serlabet ber Elämme mittets ber Eeil = ober Settenwinbe.

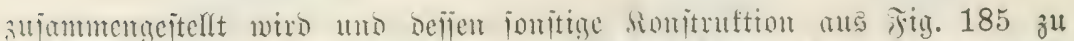

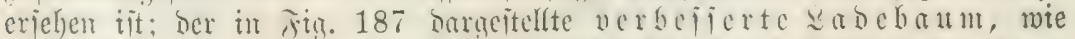

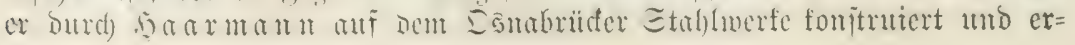




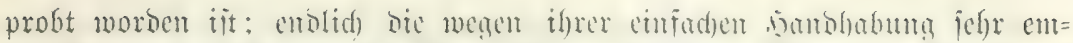

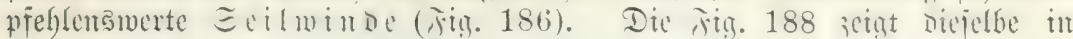
ihrer $\mathfrak{A}$ moendung betm Serladen vou Etammlyolz.

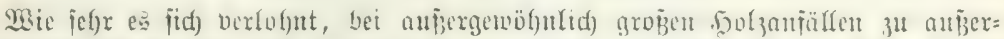

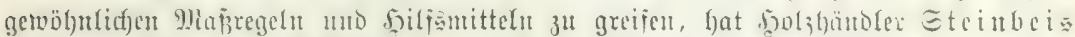

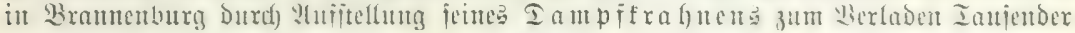

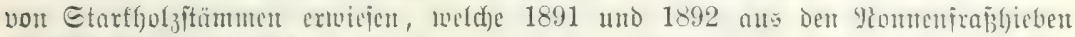

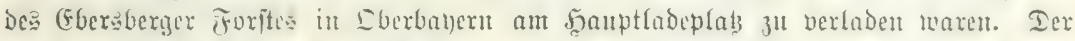

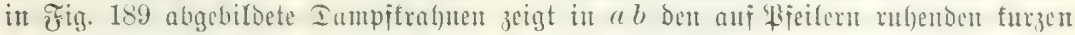

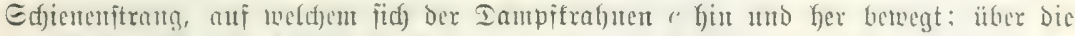

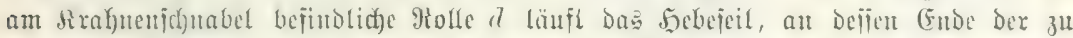

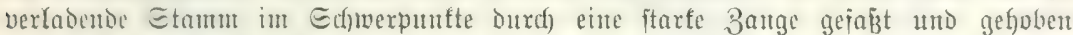
wird. Iurd) furze liüfuärtobemegung Des Inmpiftahuen wird Derjelbe auf Den pafienden Sort Dç Tagents $w$ berbracht.

Wei Dex :(mwendung Dix meiften bicjer med)antiffen Rabeborrid)tungen handelt

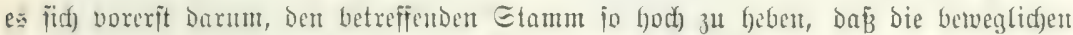
Fadje unter Denfelben gelegt und bie llagen unter Denfelben gerolnt werden fömen;

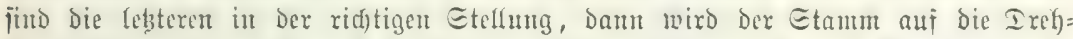
¡d)emeljättel niedergelajien. Ia $\bar{B}$ hejontere Sabevorrid)tungen für Das Brembolz nidft erjorberlidy find, iīt einteudjtend.

\section{B. Betrieb auf den $\mathscr{W}$ aldbahnen.}

1. Benegende Siaft. Se nad) ber Urt Der bemegenden Rraft

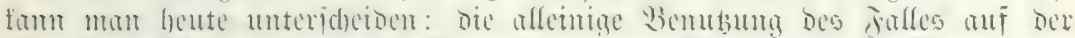
id)

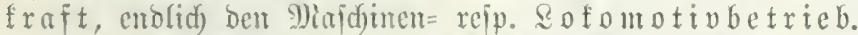

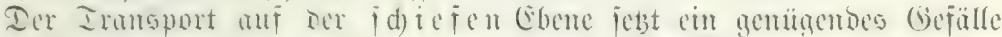

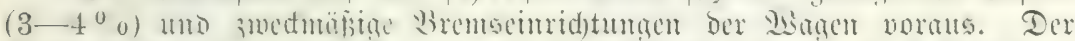

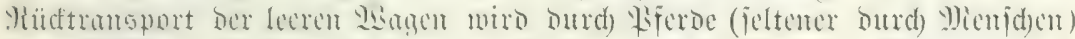

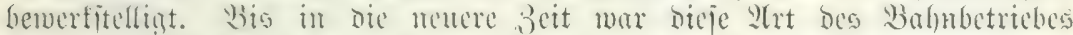

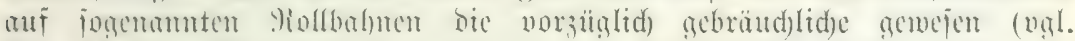

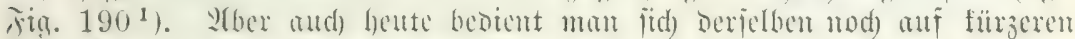
Erituedungen und bei gecignetem Ierrain.

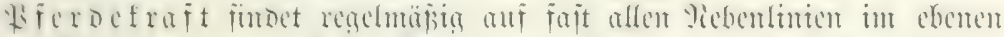

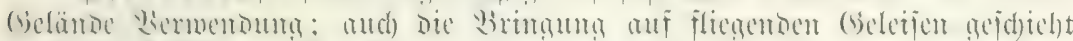

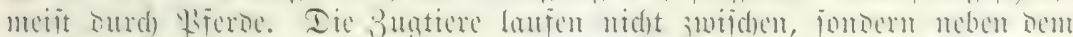
Ed)

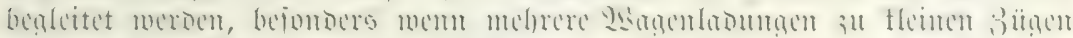

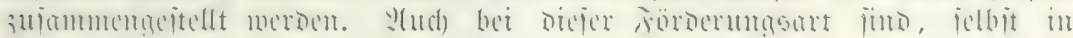

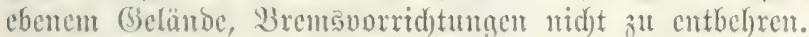

:

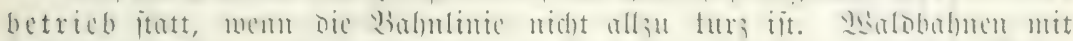

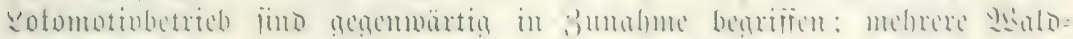

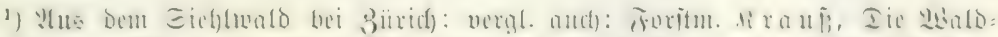

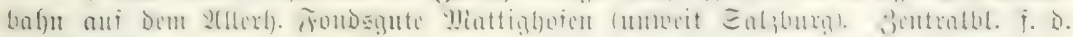
ถูеं. ‡. 1902. 


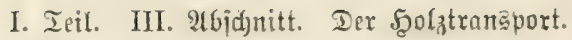

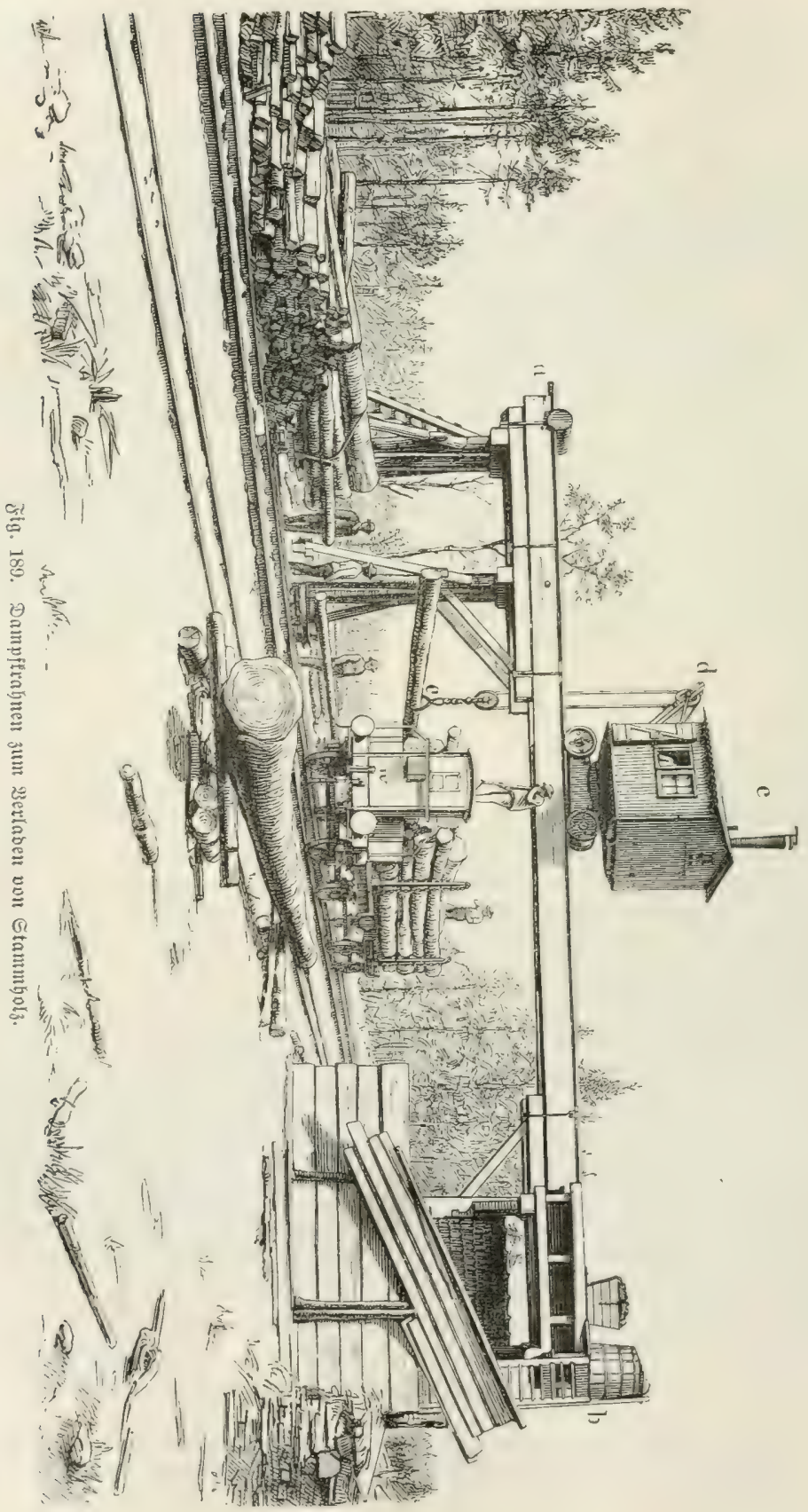




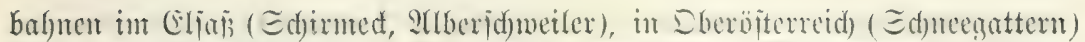

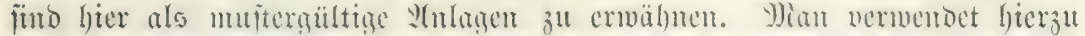

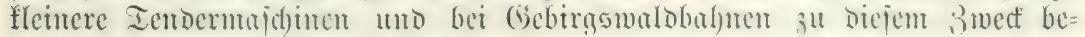

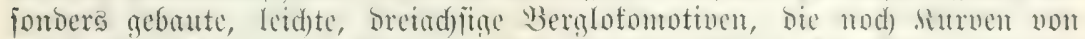

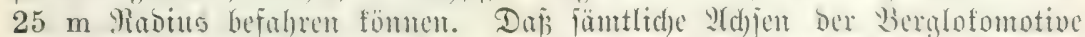

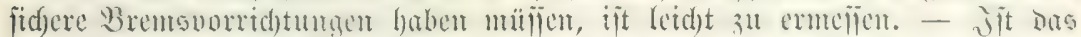

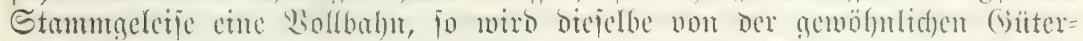

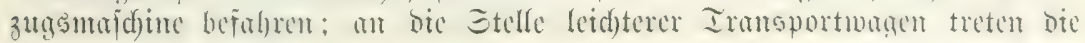

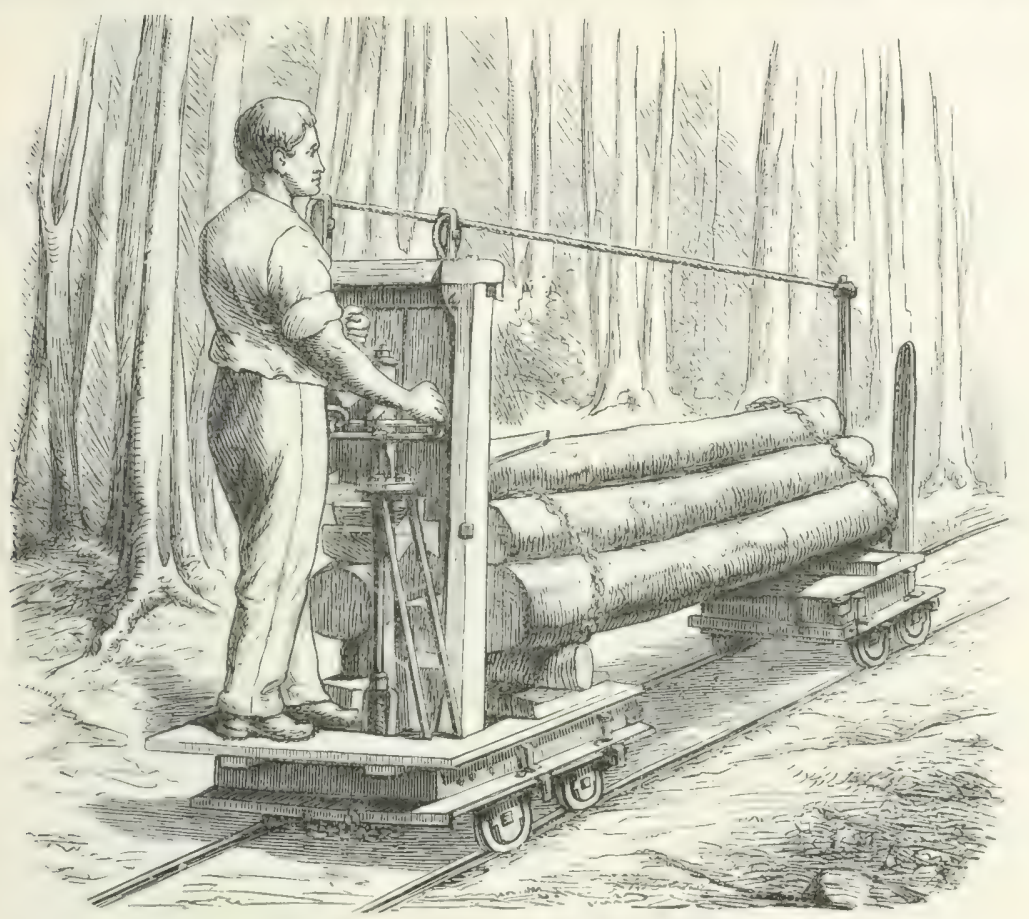

Fig. 190. Solgtransport auf fóliejer (Ebene.

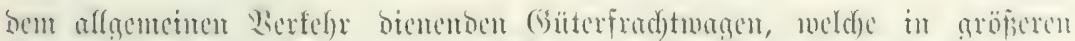

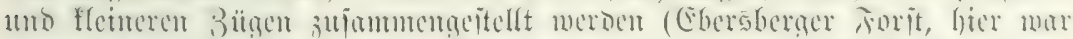

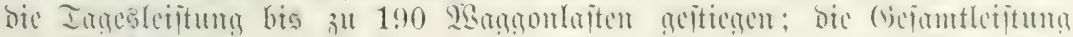

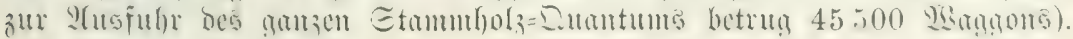

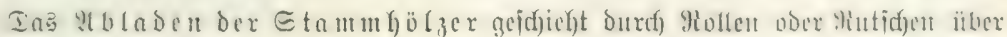

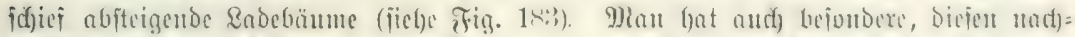

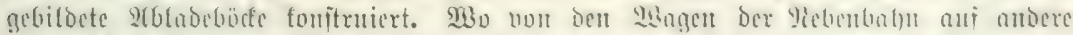

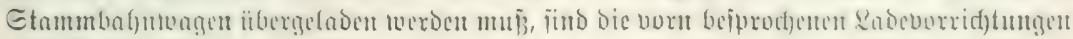
uno dirahnen nidjt au entbehren.

2. Db Dex 是a a u

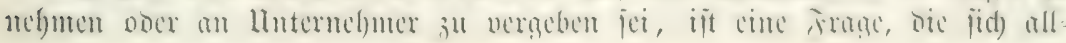




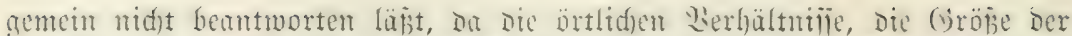

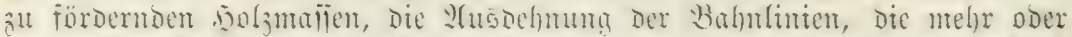

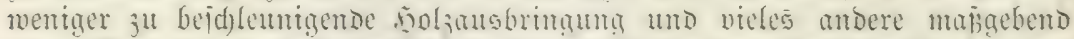

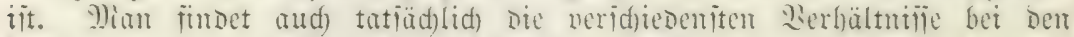

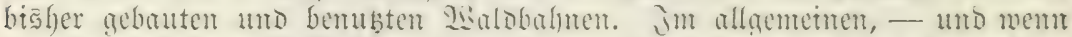

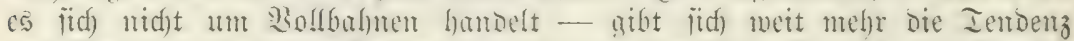

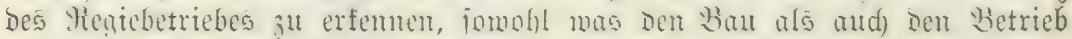

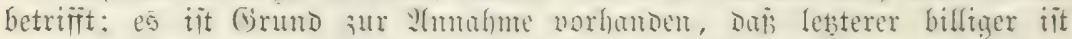

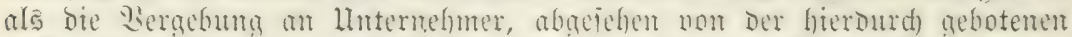

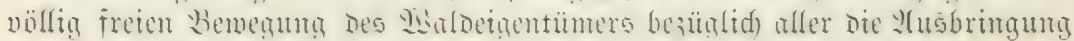
betreffenden Fragen.

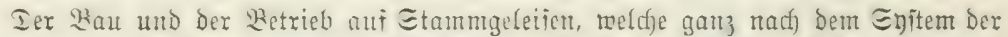

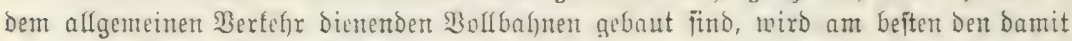

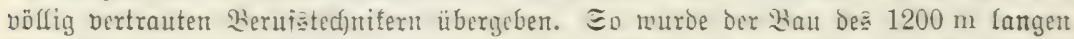
Bollbahngeleites im (Fber Gataillon ausgerüfyrt, und zwar in überaus furzer 3eit.

\section{Etatijifdę.}

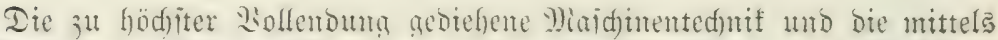
Derielben herbetgeführte wöllige IImmanduma Der Iranoport= uno Berfehrs=

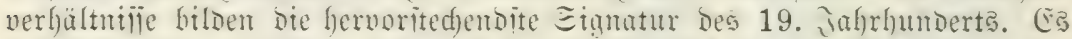

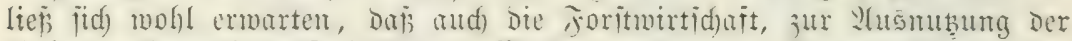

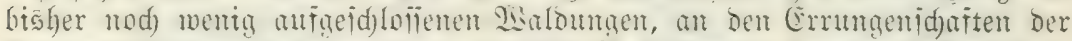

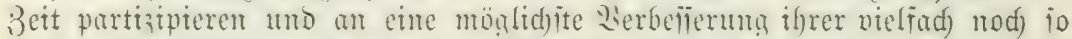

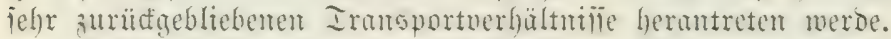

Das Dieje Ermartung aber in Der furzen Betipante non 2-3 Dejentien

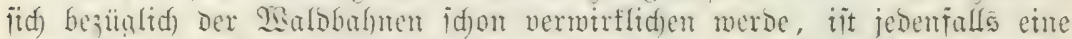

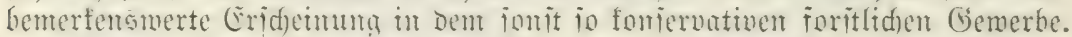

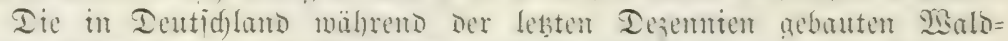
bahmen zählen heute nad) Iutenden, und es aibt finum mehr ein vand, in

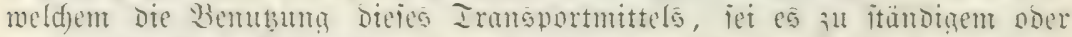

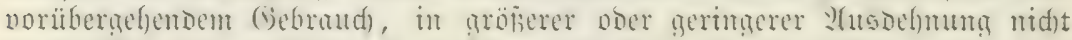

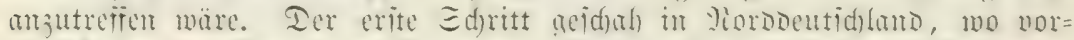

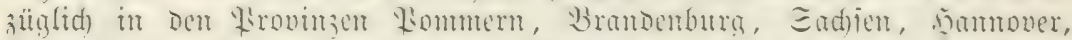

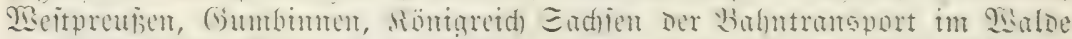

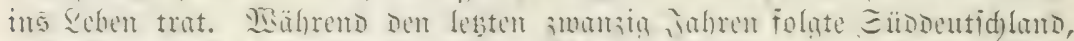

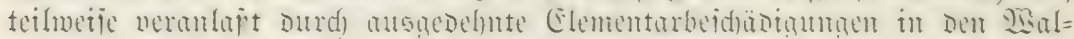

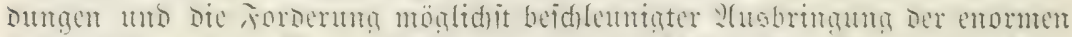
nono!zm

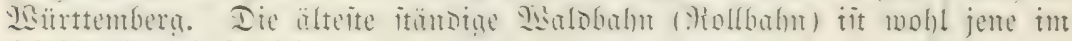
Siehlmald bei Bürid).

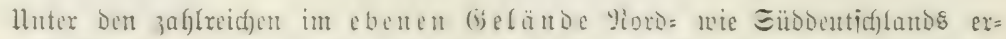

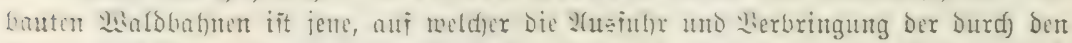

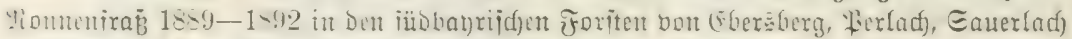

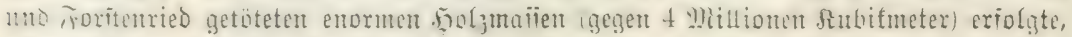

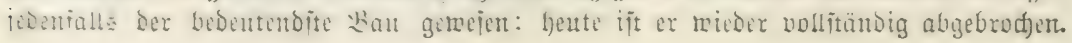




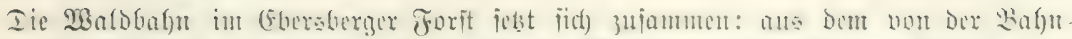

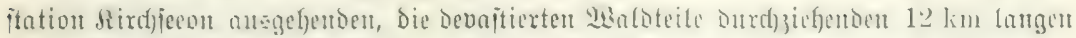

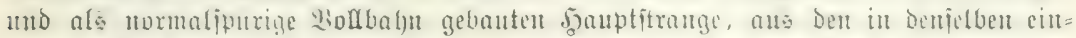

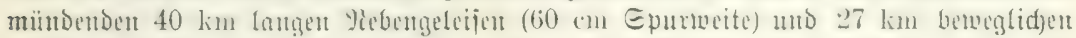

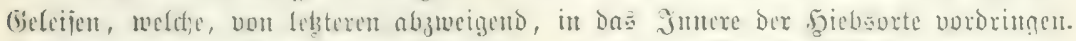

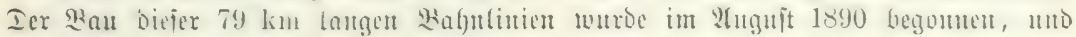

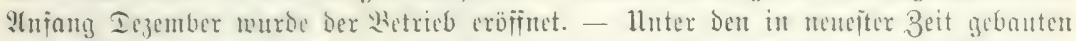

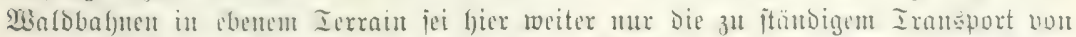

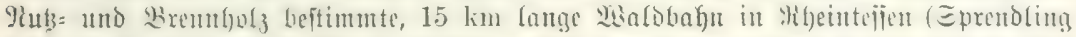

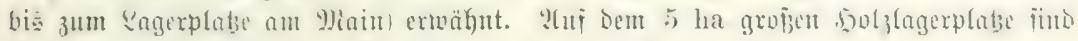
Borridftungen zu bequemer Şerladung in die Edjiffe getroffen.

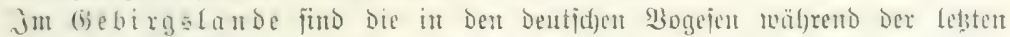

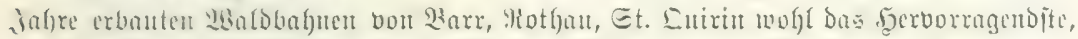

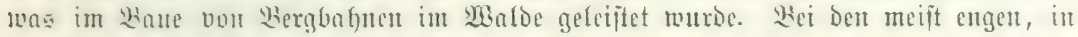

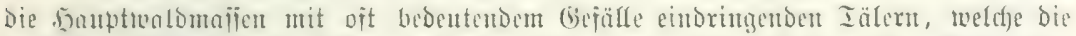

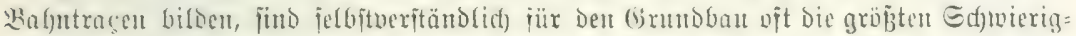
feiten zи

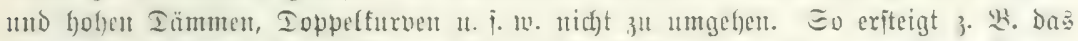

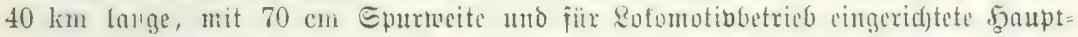
geteije ber Edjirntefer Waldbafyn cint Dirette föbe von $501 \mathrm{~m}$. Weitere $16 \mathrm{~km}$

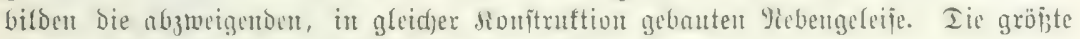

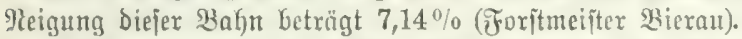

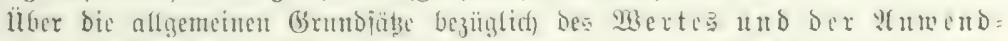

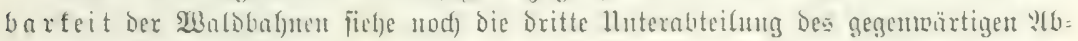
idi)nitt?.

\section{IV. 刃rabtreilticien.}

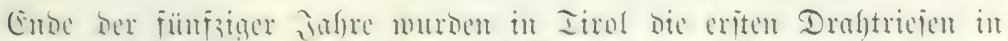

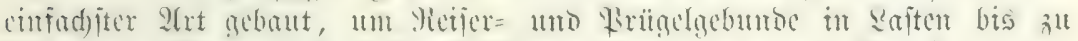

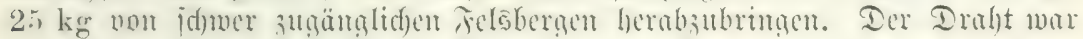

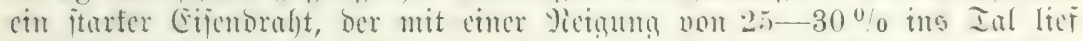

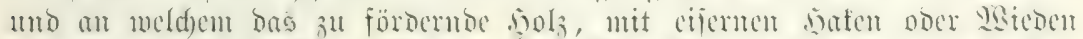

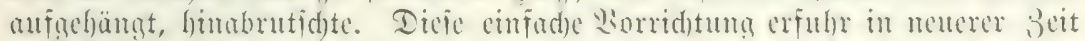

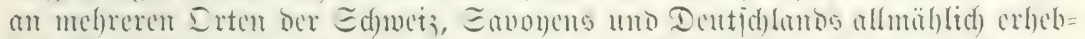

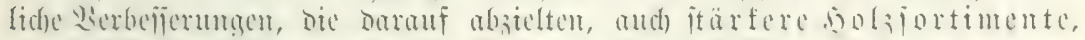

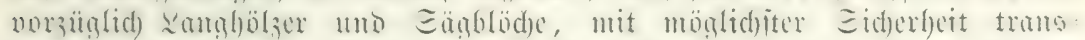

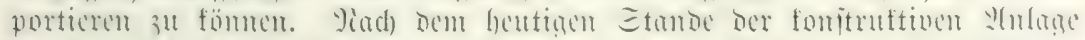

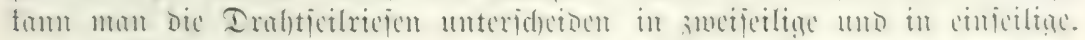

a) Bei ben zweijeiligen Drabtricjen furb zwet etwa $3 \mathrm{~cm}$ bide

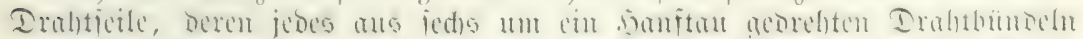

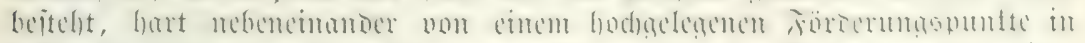

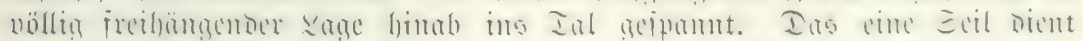

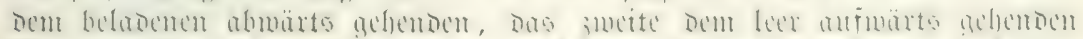

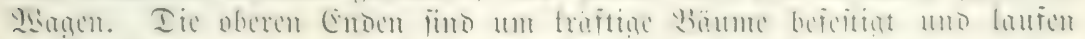

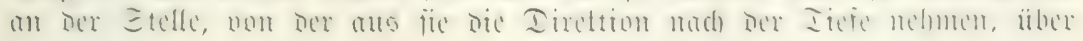

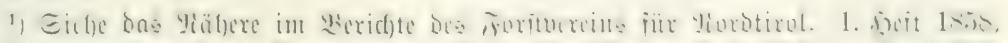

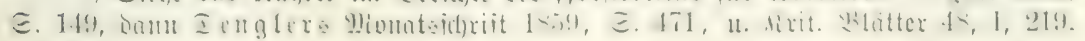

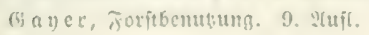




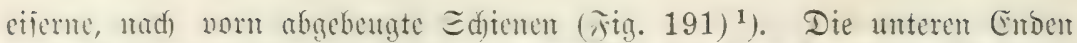
werben über horizontale sisaljen anfacrollt, bie zum Epamen ber Eeile

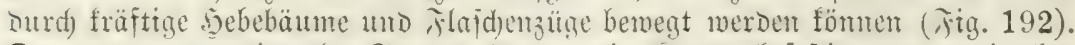
Der zu tranghortierende Etamm bängt mit sietten befeitigt an joet über Dus Eeil wegglettenden Eimfrollen $(a a)$, meldje burd) cine Etange $(b)$ in paliender Entfermung arsemander gehalten werben. Dieje lebtere Bor=

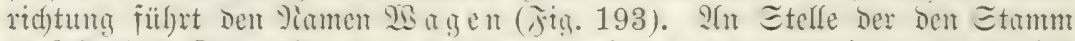
umfalienden Retten hat man mbermärts cime ; angenartige, Durd) eine

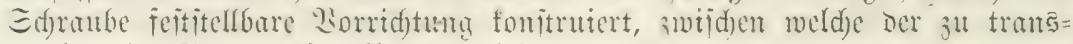
portierende Stamm eingeflenmt mirb.

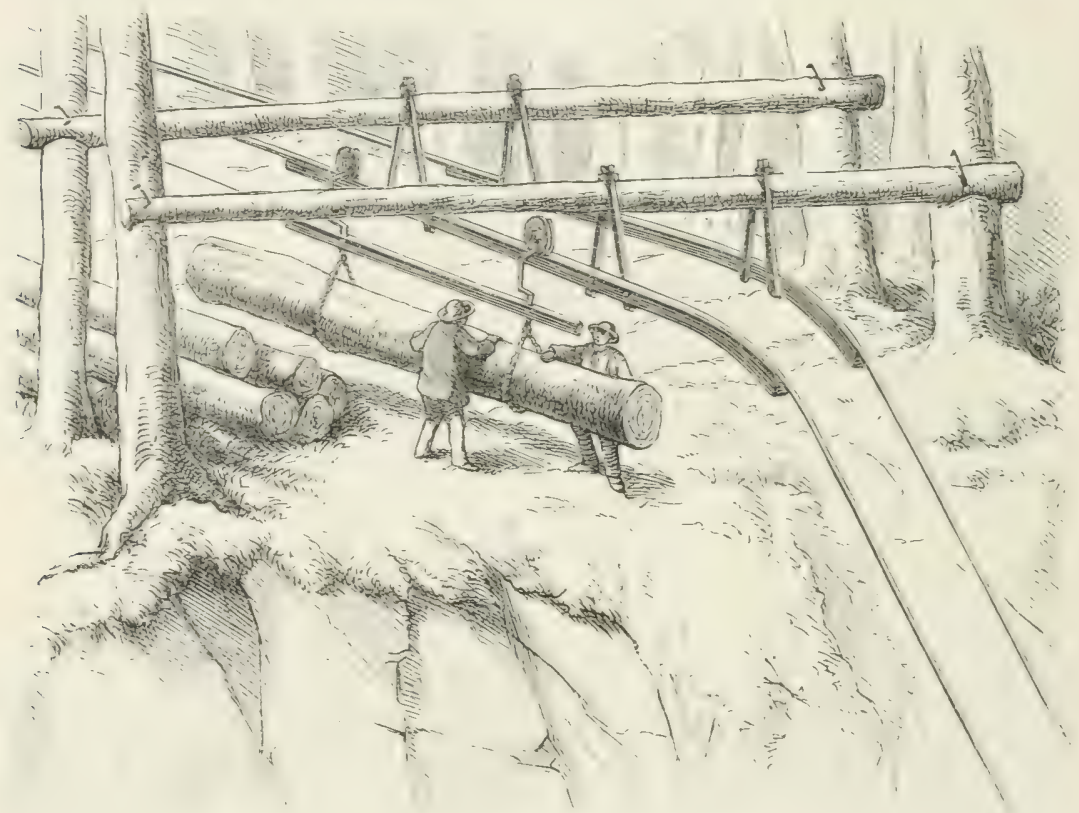

Fig. 191. Drabtietirieje bei Gündtifdrano.

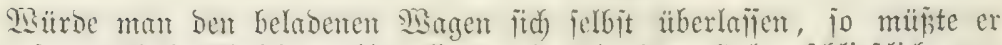

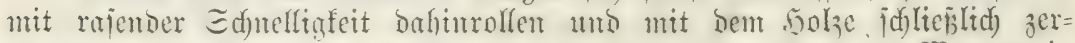

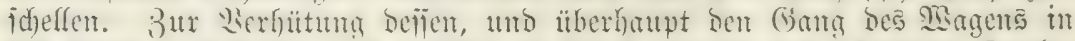

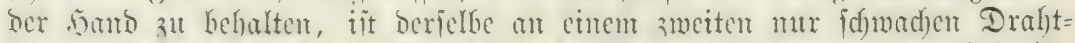

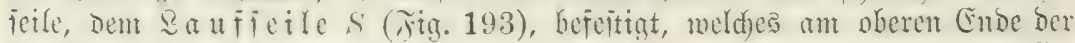

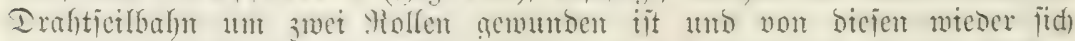
abmürts mendet, um un bem anf bent imeiten Eetle leer heranfgehenden

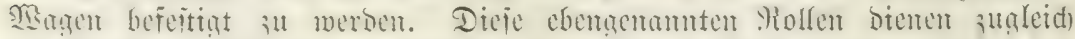

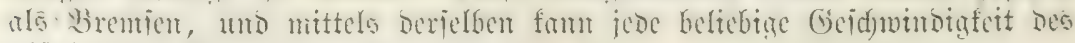
abfahrenden Magents erzielt werben.

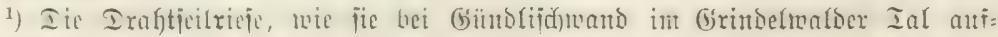
:geftellt war. 


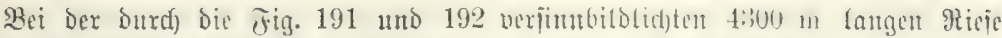

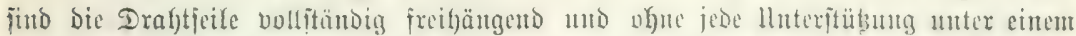

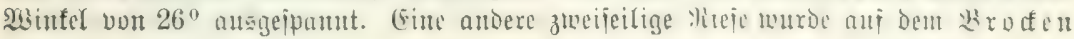

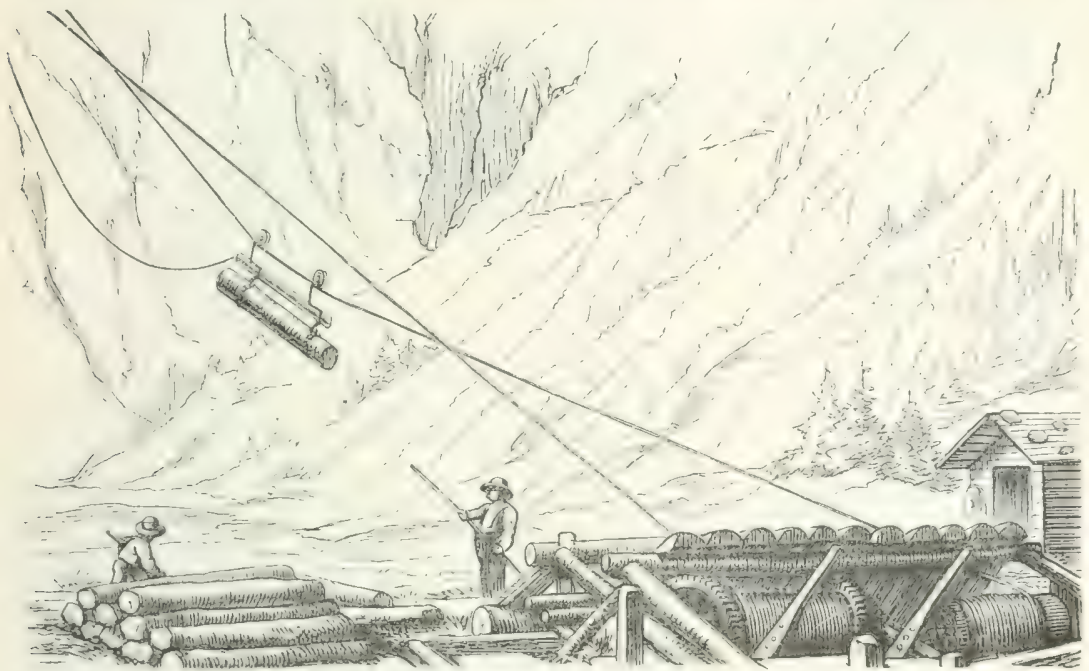

jig. 192. Ituteres Enbe einer Drabtjeitricic.

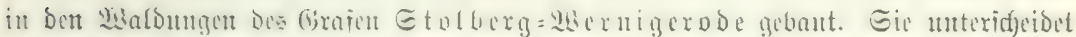

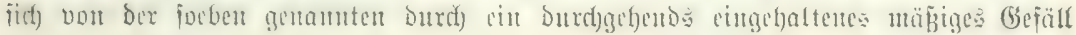

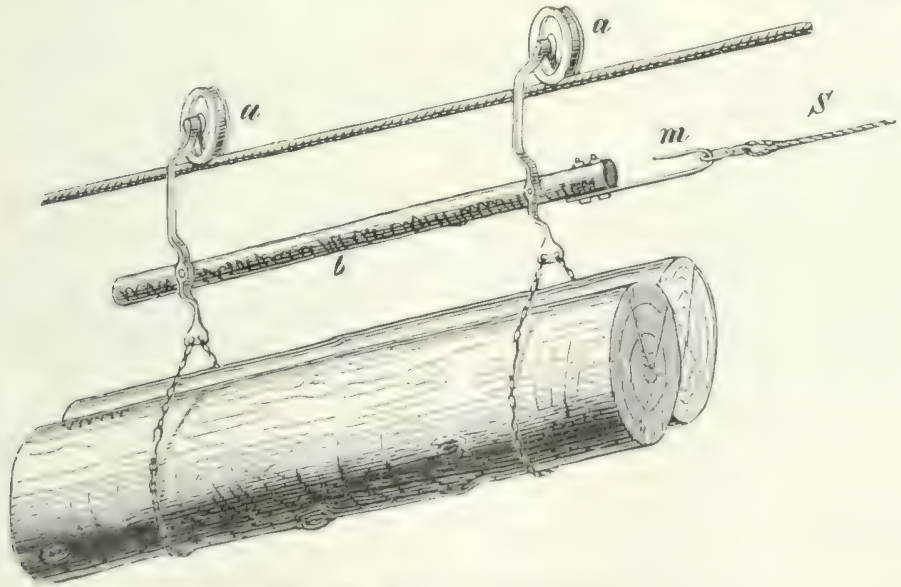

jig. 193. wagen ber Irabticitrieje.

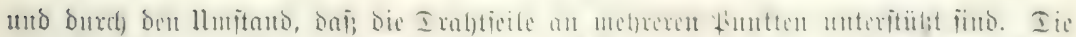

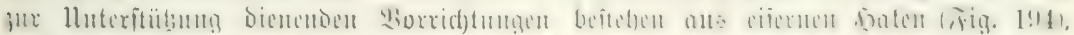

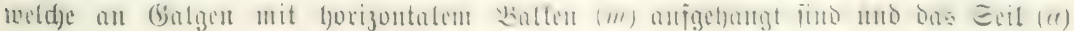




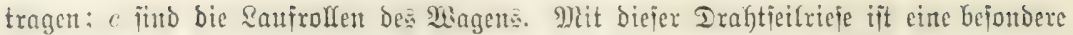

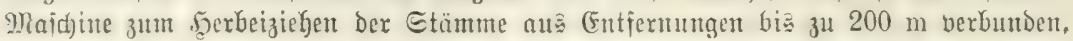

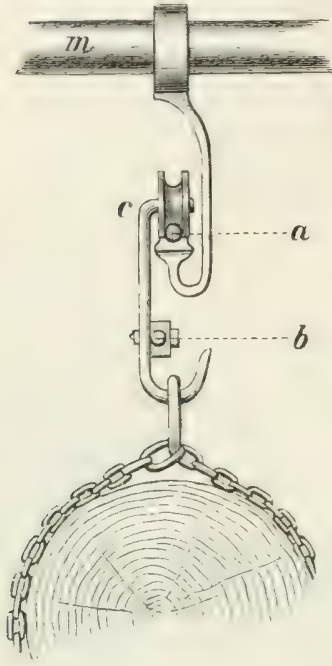

Jig. 194. Weidreibung neben= itebent.

bie aus einter it exhöhter ange angebrad)ten, burd) Surbel zu betwegentoen Irommel befteft, um veldje fich ein am herbeizuld leifenden Stamme Gefejtigte bünte?

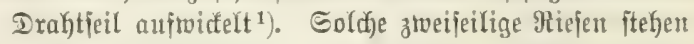

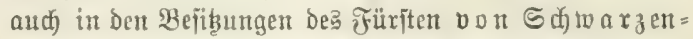
berg im Böfmerwalde im Géfrauche. Die größ̆te ber=

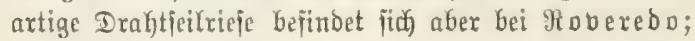
jie ift $8 \mathrm{~km}$ lang.

b) Bei ben einfeiligen Drahtriefen läuft fowohl der belabene wie der leere Wagen auf bemielben Eeil; bie fonftruftive Einridgtung it fonjt vollitändig übereinjtimmend mit jener ber zmeijeiligen Riejen, - und unterjodeidet jids nur burd) bie Borfefrungen, weldye bei $\mathfrak{B e}=$ gegmung ber auf= und abwärtsgehenden Magen getroffen merben müfien. $8 \mathfrak{3}$ leţterem 3 wedte wirb gemöhnlid in ber Mitte bes sauffeiles,

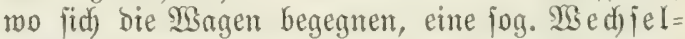
itation angebrad)t; ber auf einem Berüit itebende $\mathfrak{A}$ rbeiter bebt den leeren Magen vom Seile ab und jebt ifn oberbalb bes belabenen, abwärtagehenden $\mathfrak{W a g e n s}$ wieber auf bas Seil,

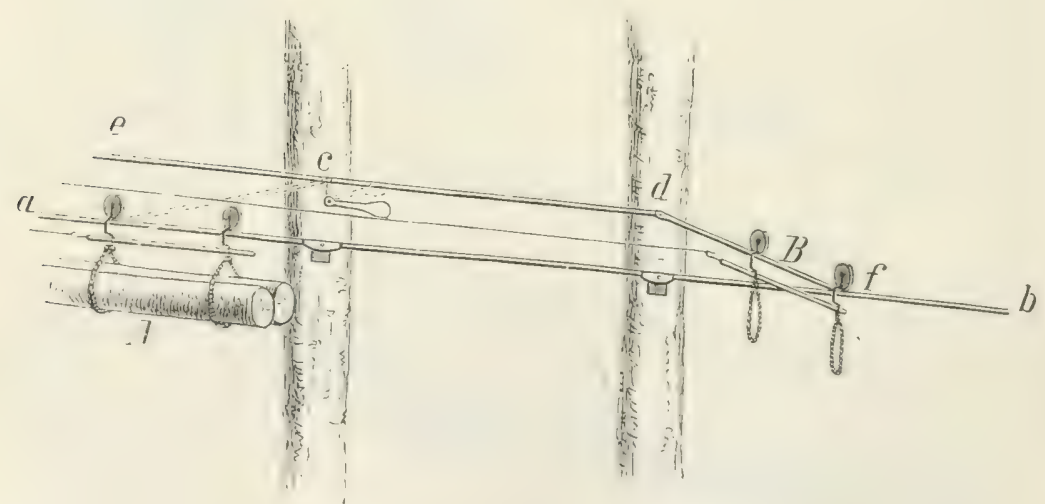

Fig. 195. Bedjelfation einer einfeiligen Drahtrieje.

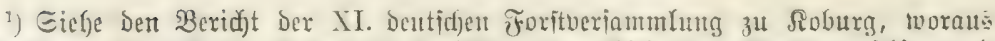

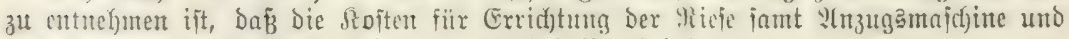
allen allgemeinen Unfoiten fid mux auf 3450 Diaxf belaufert. 


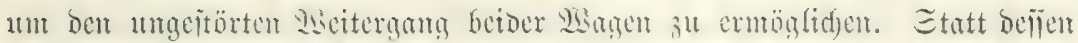

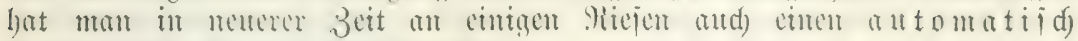
wirfenben 19 ed jel angebrad)t.

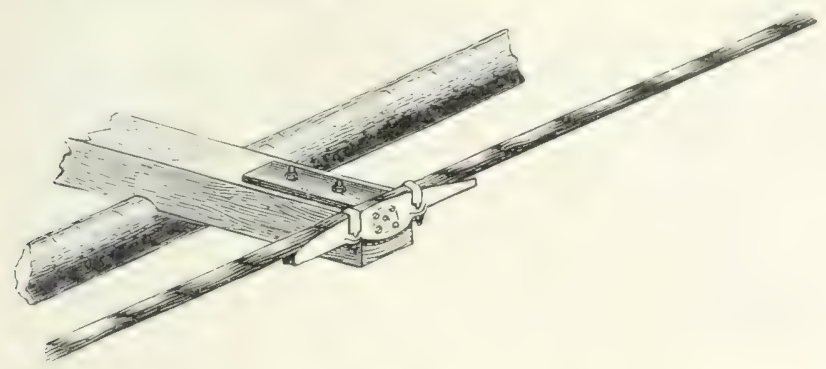

כ̌̃ig. 196.

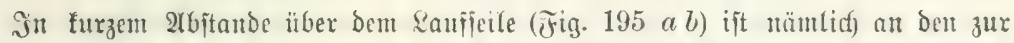

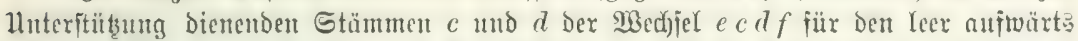

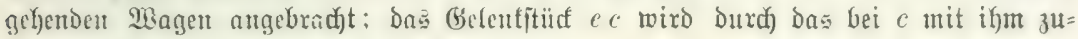
jammenfä̈ngende (Begengewid int in Korizontalex Eage erbaltent, während das Gelentitüaf $d f$ bei $f$ aui Dem Rnuffeil ruht. Dex leer gethende Wagen $B$ jteigt bei jeiner Infunit im \$infte $f$ auf Den Medjel, paffiert Denfelben, indem ex das Gelent=

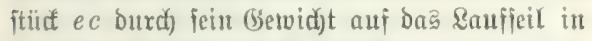
bie Rage ca niederdrürtt, weld) lebsteres ex bann bei a wieder exreic(d)t. Mäfrento Deijent ift Der belabene Magen $A$ unter bem $\mathfrak{B}$ edjel, und nadjoem cr bas Stuicf $d f$ vorübergefyento auj= gefoben hatte, finourd) gegangen. (Eine andere

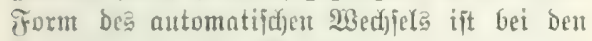

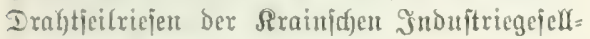
idjaft in 2 (ntwendung gebractft ${ }^{1}$ ).

Die erfte derartige Piefe twurbe im Ed) Iierento bei $2(p u a d)$, Fanton llnter= twatben, geba.! "2); fie hat eine Ränge von $2100 \mathrm{~m}$, und $i_{1}$. Das Geil mit cinem Durd)= d)nittlid)en (Gefälfe von $35 \%$ an zaffreidfen Wunften unteritüżt. Iicje Unterfitiłungen unteridjeiden fid indefien von ben oben $\mathrm{cr}=$

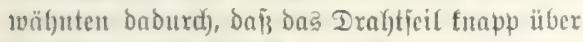
Das (Ende eines jeitlid) vorgeidjobenten horizon=

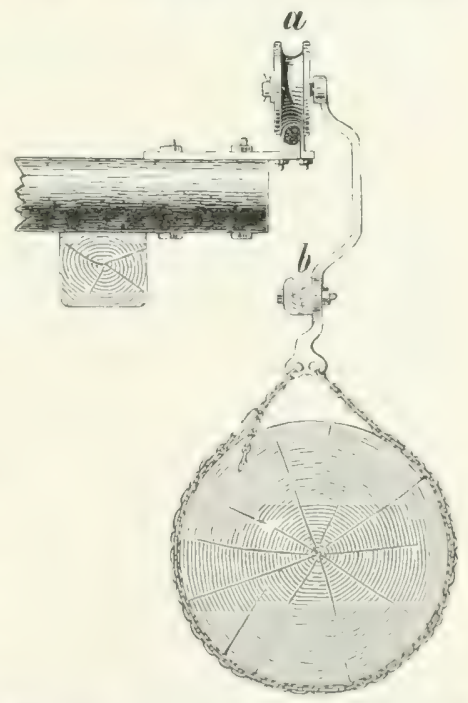

iig. 197. Lnteritiißung bes Drahtietles jur Êrböbung feiner Iragfraft.

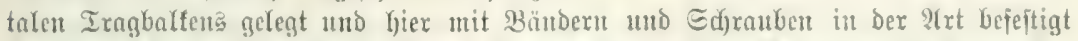

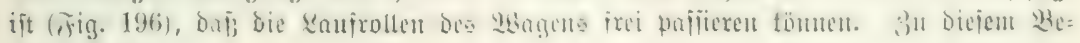

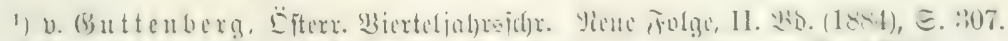

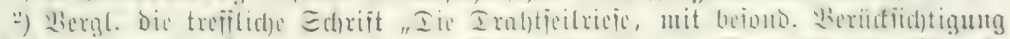

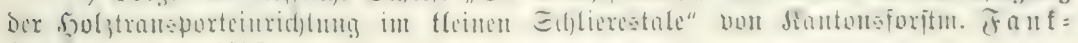
f) aufer. Bern 1872. 


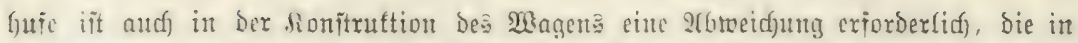

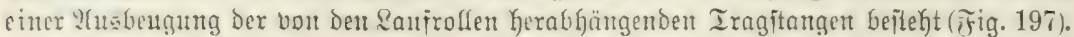

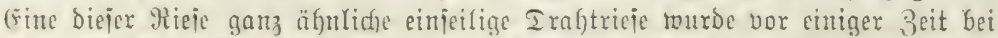
Sarlitein (Meidfenfall) augeitellt, uno cinieiligge Iraftrieien beftefen weiter im

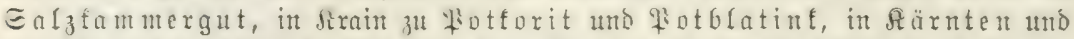
an vielen anderen Srten Der iüblidfen ?llpen. (Fine Der fïfniten Irahtieilriejen ijt über die

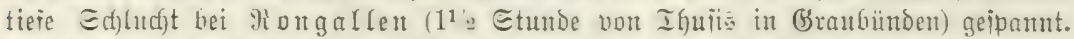

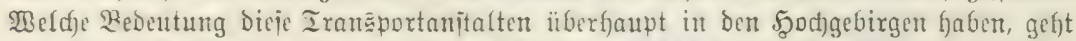

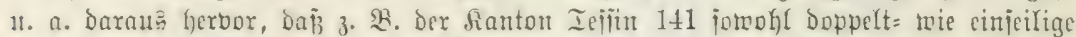

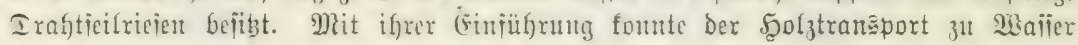
und mittela Şolzriejer jef̧r eingcidgränft toerdent.

8 weite Unterabteilum

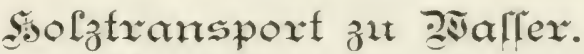

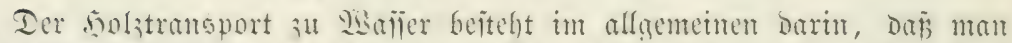

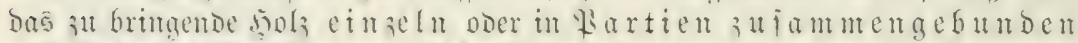

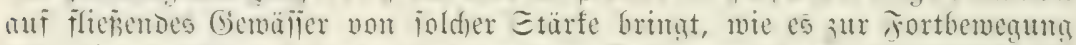

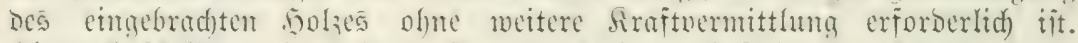
bientad) idsetion wir unicren Gegenitano in suet Icile uno betrad)ten im

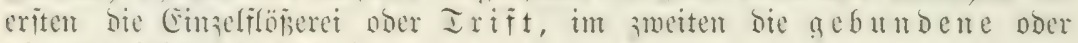
eigentlidye frlöperei.

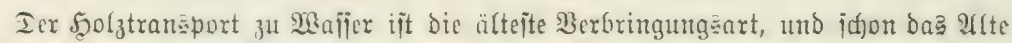

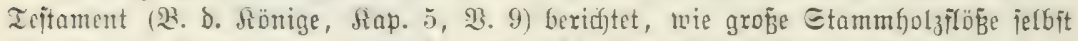

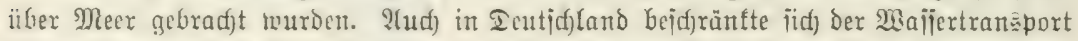

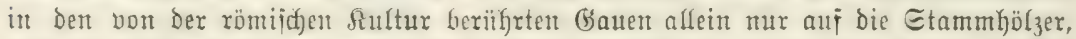

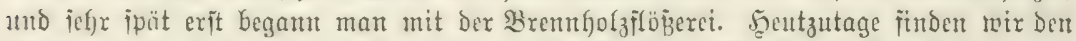

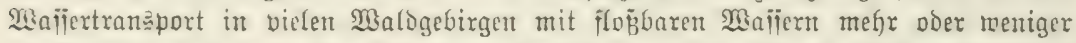

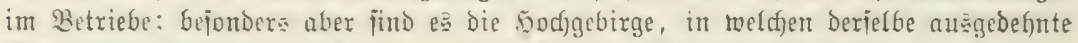

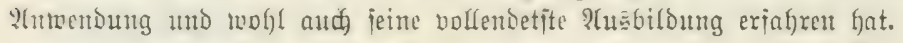

\section{I. (Uxift $\left.{ }^{1}\right)$.}

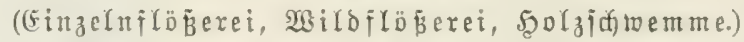

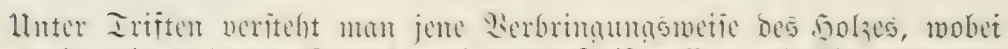

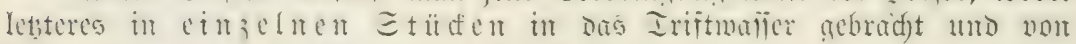
biejem bis an jeinen Bejtimmungsort fortgetragen wiro.

Hnier (begentano hat jidt) in verbreiten: vorerit über bie erforberlid)e

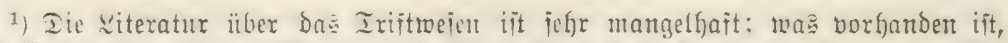

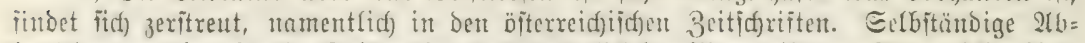

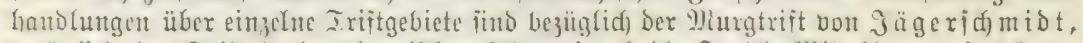

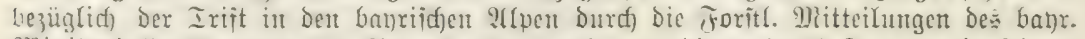

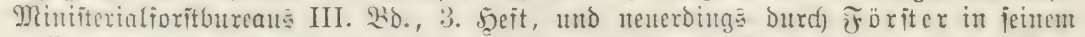

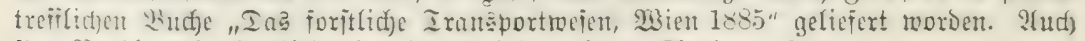

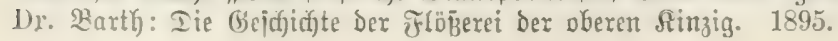




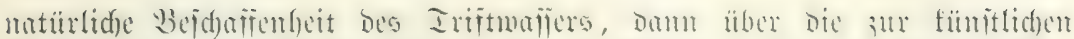

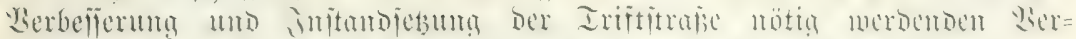

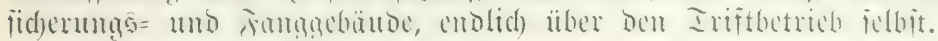

\section{A. Die 3ur Crift exforderliden Eigenflyaften Der Criftetrafie.}

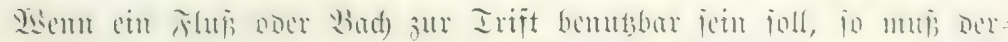

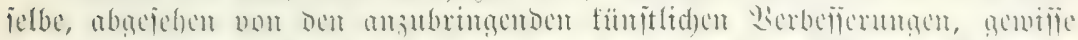

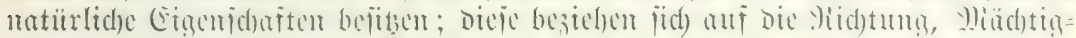

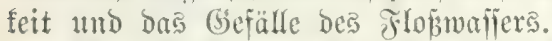

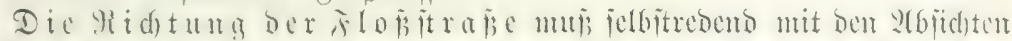

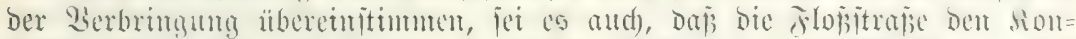

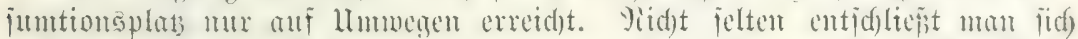

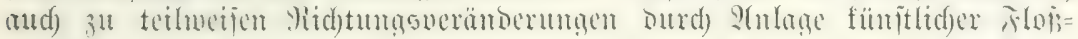
fanäle.

Das geringite Miás bex 3reite ift von ber Ränge des Irift=

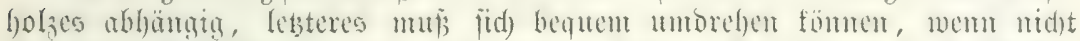

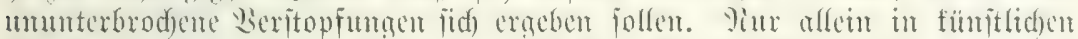

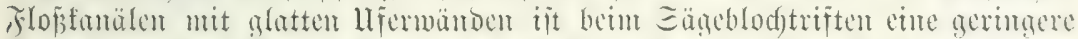

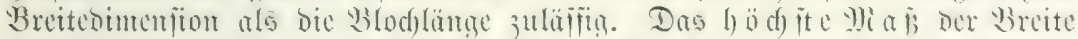

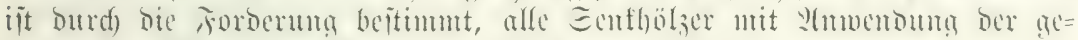

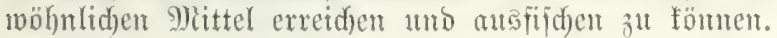

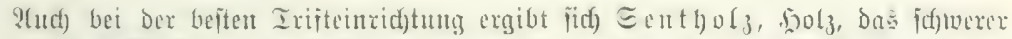

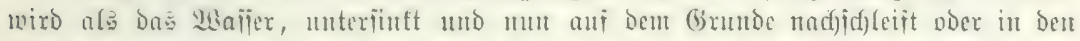

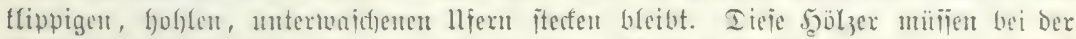

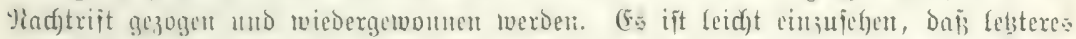

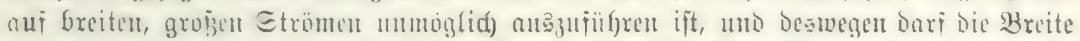

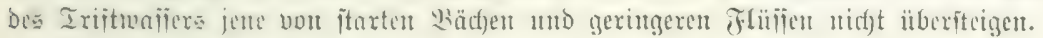

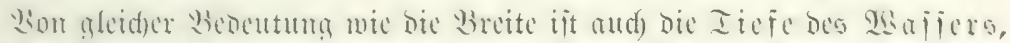

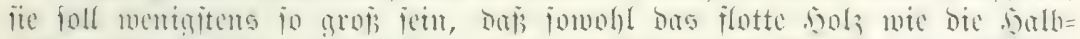

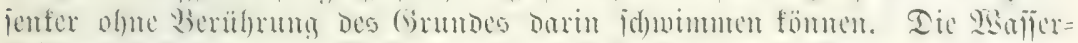

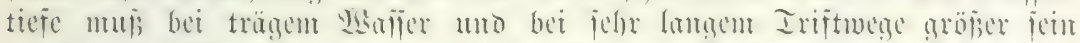

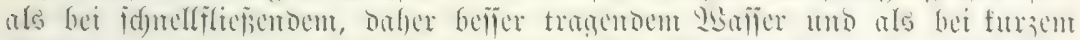

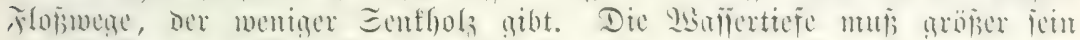

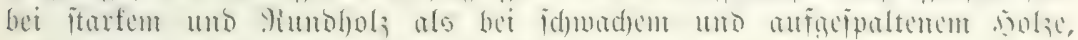
meil letsteres weit leidjter vom

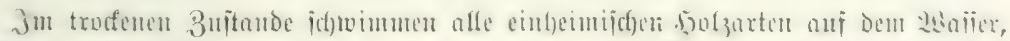

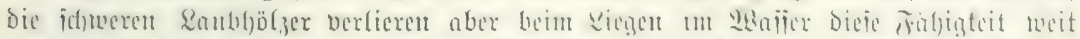

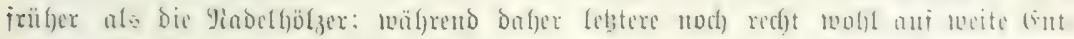

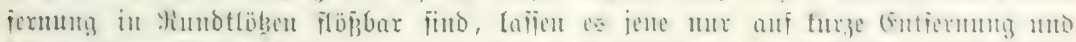

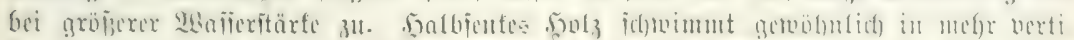

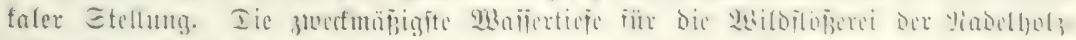

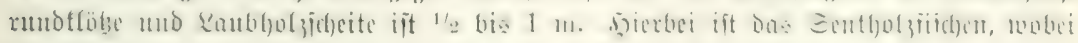

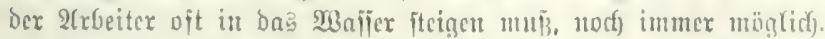

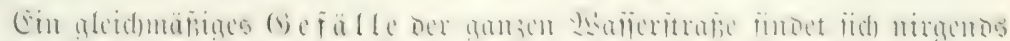

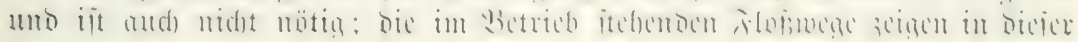




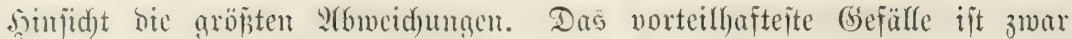

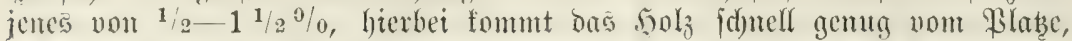
cs findot tein ummäfiges Dräntgen und Ireiben ftatt, das zu Etopfungen

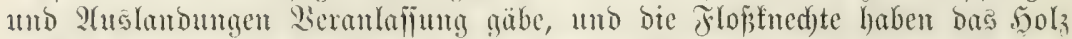
nod) hinreidgens in ber (Gemalt, un es zu lenfen uno bemetïtern zu fömten. Sielfad) aber muis man fid) cin geringeres ober aud) weit ftärferes gefallen

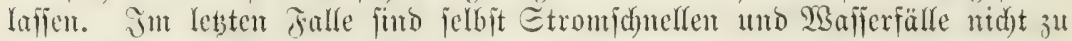
unngehen, wobei höhere Iriftuerlufte nidht ju vermeiden finto.

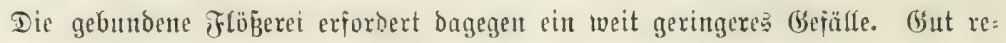

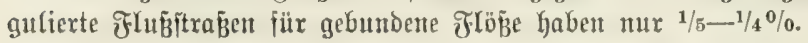

Endid) ift bie Bemtbbarfeit eines Waflers nod) an cime weitere Bor=

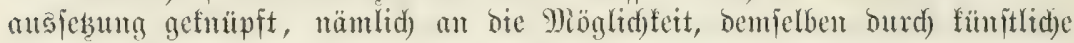

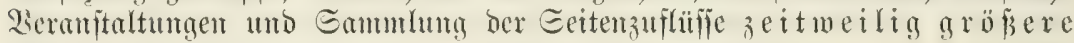

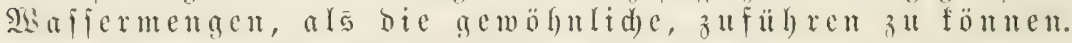

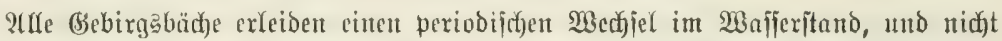

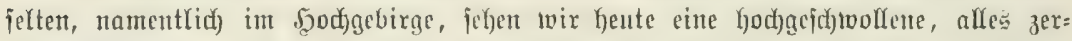

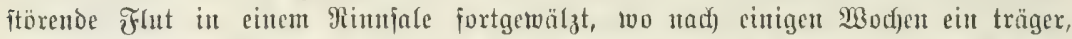

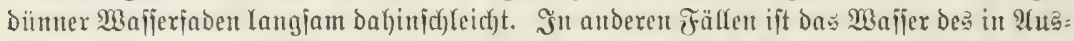

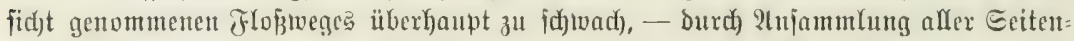

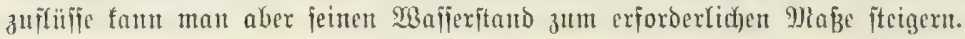

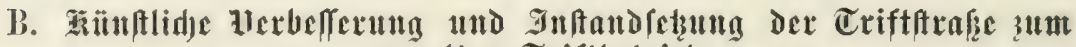 geregelten Triftbetricbe.}

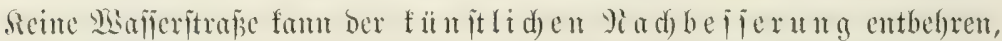

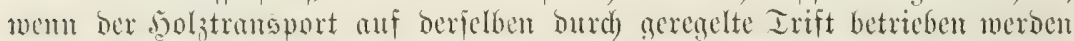

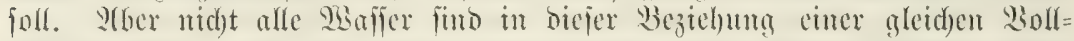

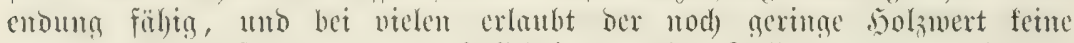

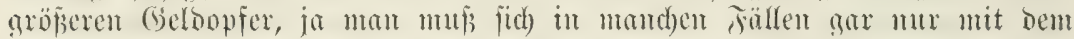

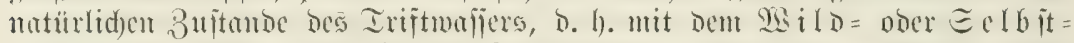

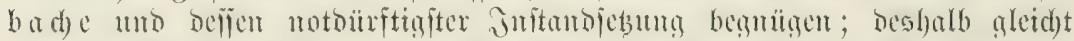

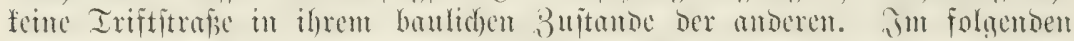

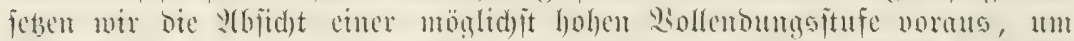

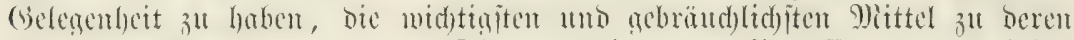

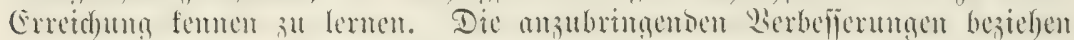

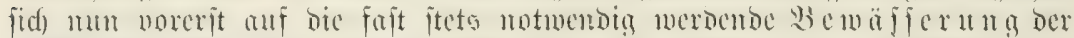

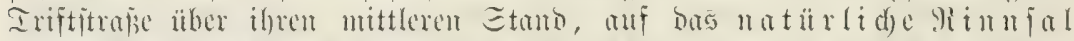

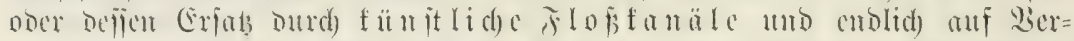

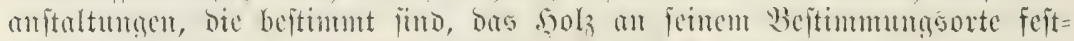
subalten geforist werbes.

\section{B̉ewäfferung bex Iriftitraß̧e.}

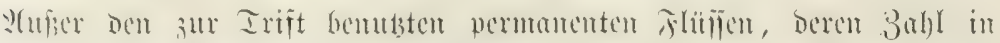

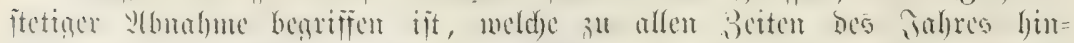

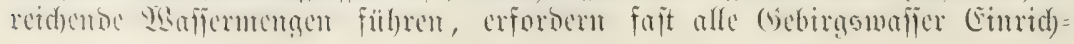




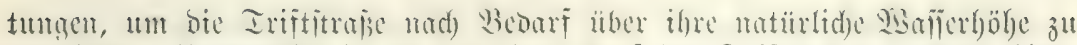

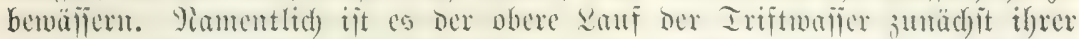

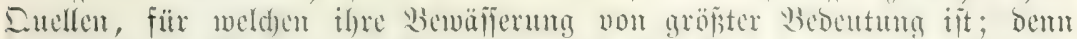

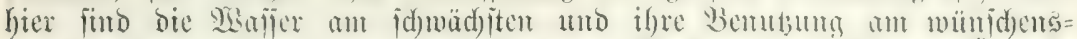

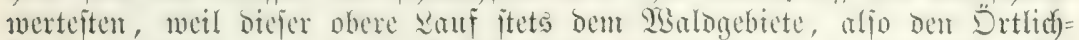
feiten amgefört, non wo aus das bolj weitergebrad)t werden foll. Dic

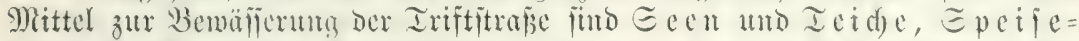

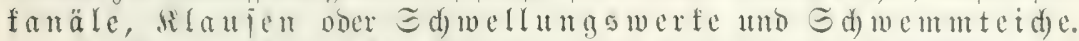

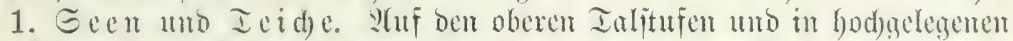

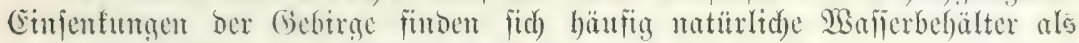

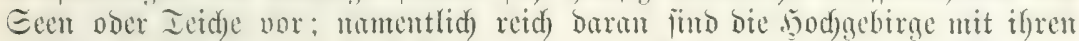

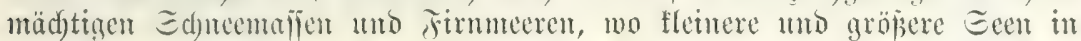
ben quer nerriegelten oberen Etufar der Eettentäler jebr nemöhnlidf find.

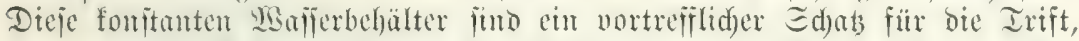

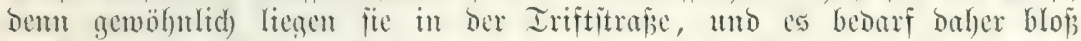

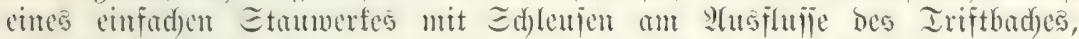

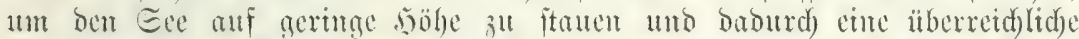
$23 a j \pi$ ermaj̄e find viele Geen zur Irift benubbar gemad)t.

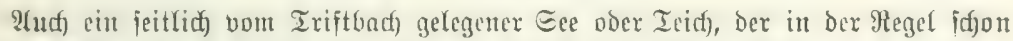

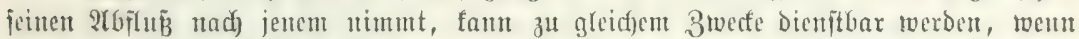

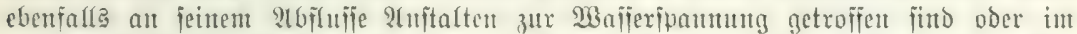

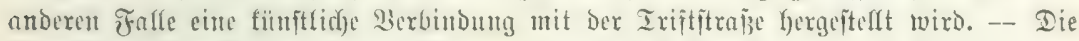

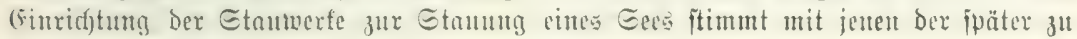
betradftenden Rlaubbaten mehr poer tweniger überein.

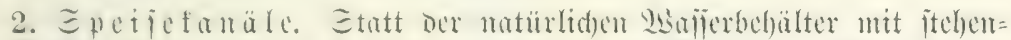

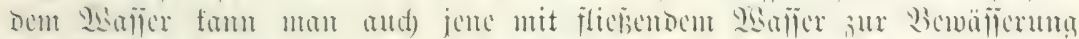

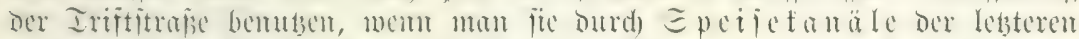

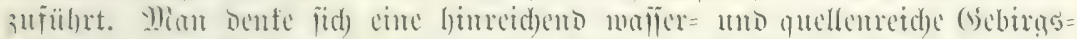

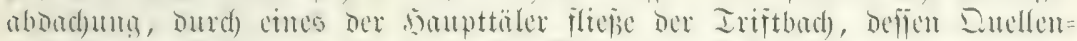

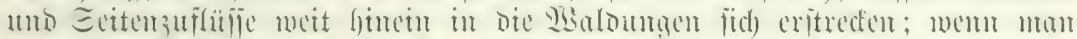

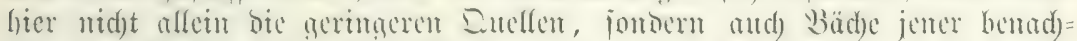

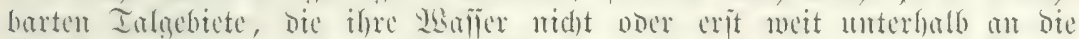

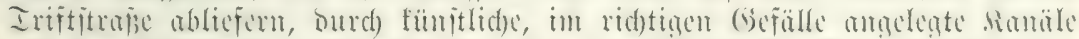

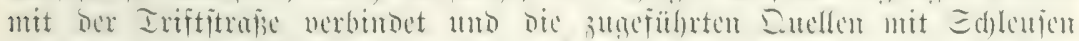
nerielet,

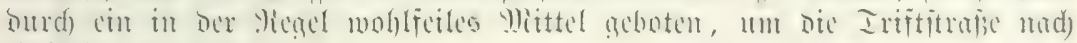
Gefallen zu bewäfĩern.

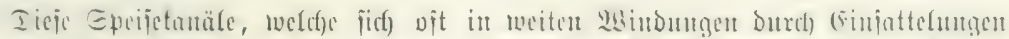

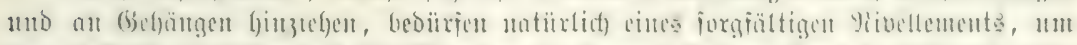

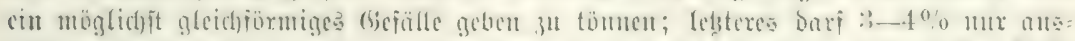

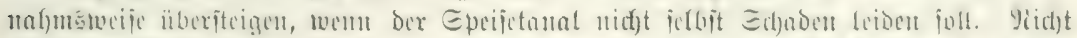

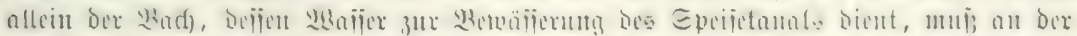

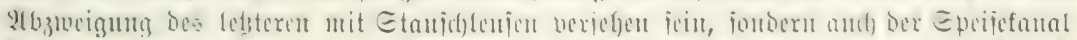

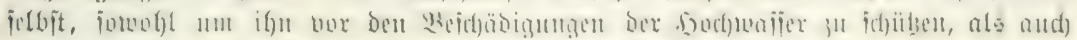

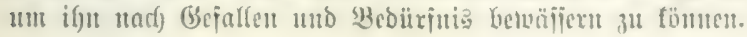


Dian begegnet ber Bemäfjerung ber Iriftiftrabe durch Epeijefanäle mur felten;

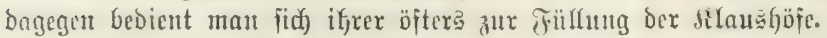

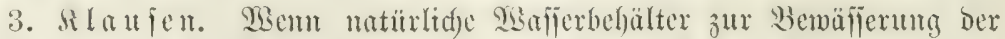
Iriftitraje nidjt zu (Sebote ftefen, io muis man fid) Dazu bequemen, Das

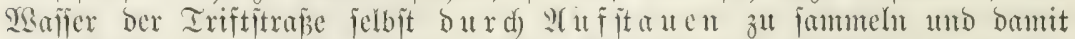

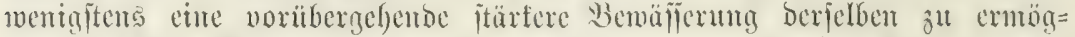

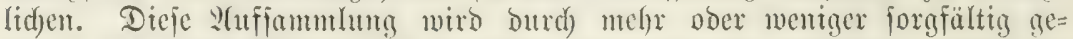
bante, mit ciner 2 Sajierpforte verjebente Dammbanten vermittelt, weldye bas

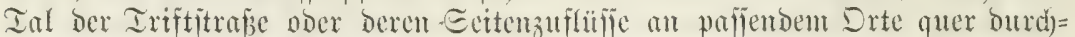

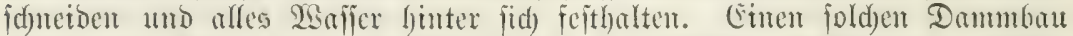
nemt man sila a

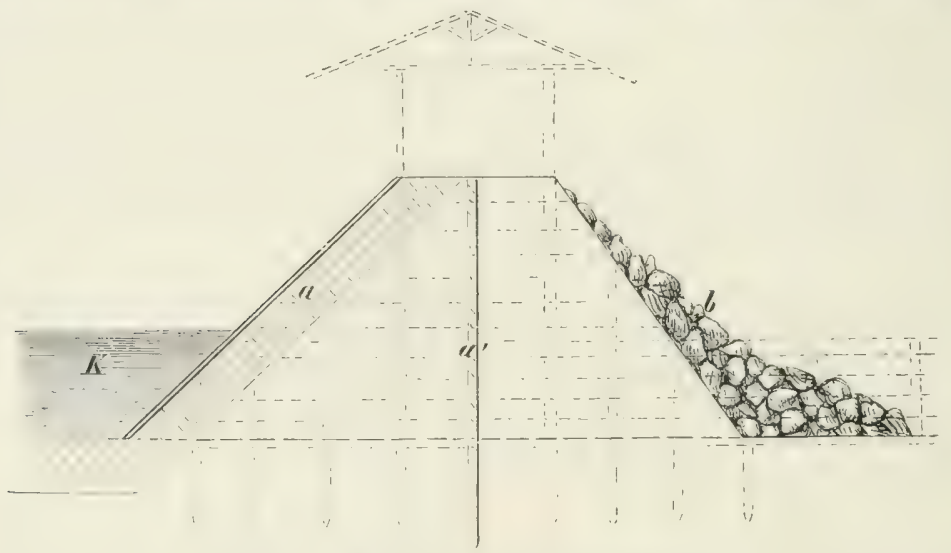

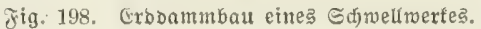

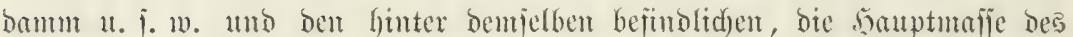

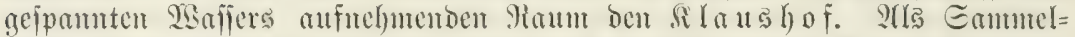
beden bient gewölynlidy) gerabezut ber Iriftbad) felbit von ber silauje anfwärte.

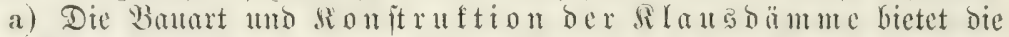

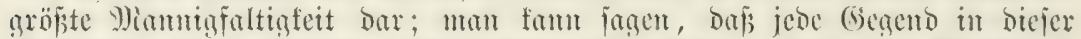

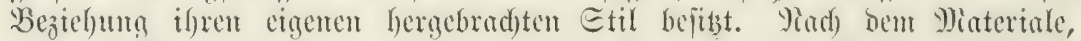

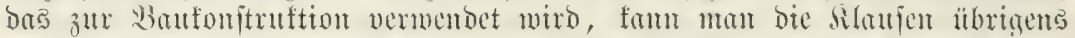

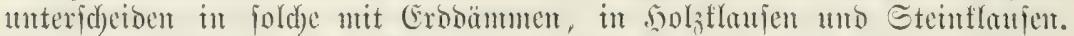

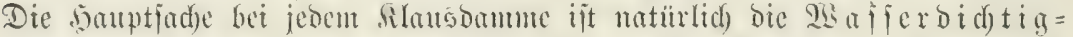
feit; am beiten finto in biefer ninficht bie Etcinflatien mit 3ementạuis, aber and bie (Erboammflation fund immer nod) beffer als reine Dnaber= ober Sholżlaujen.

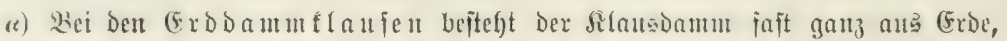

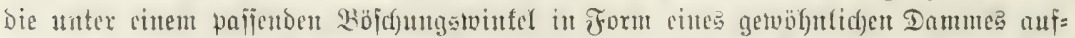

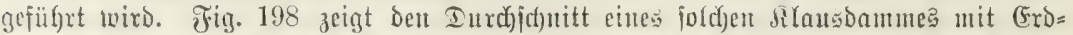

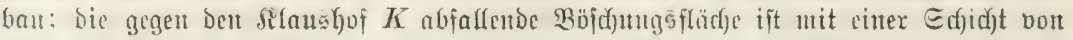

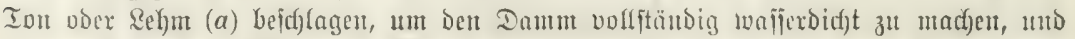

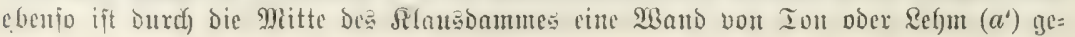




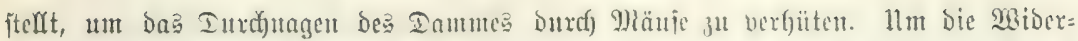

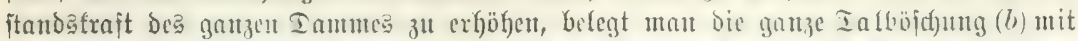

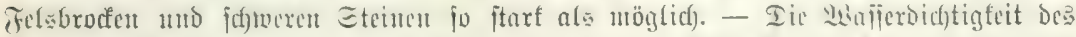

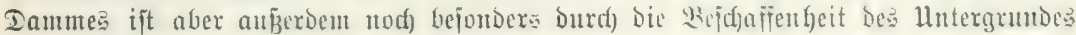

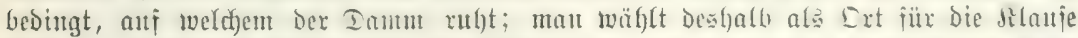

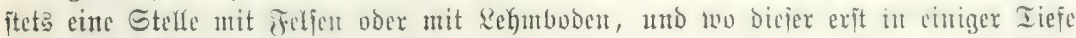
beginut, muis bis Dafiu mit Rehm gebant werden, wobei man wit bie ganze Fun= Dierung in Junern mit Spundwänben begleitet.

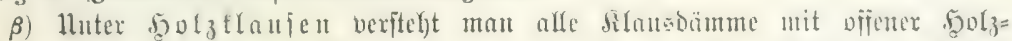

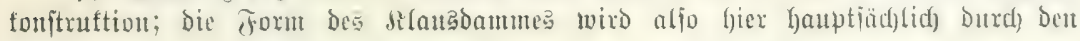

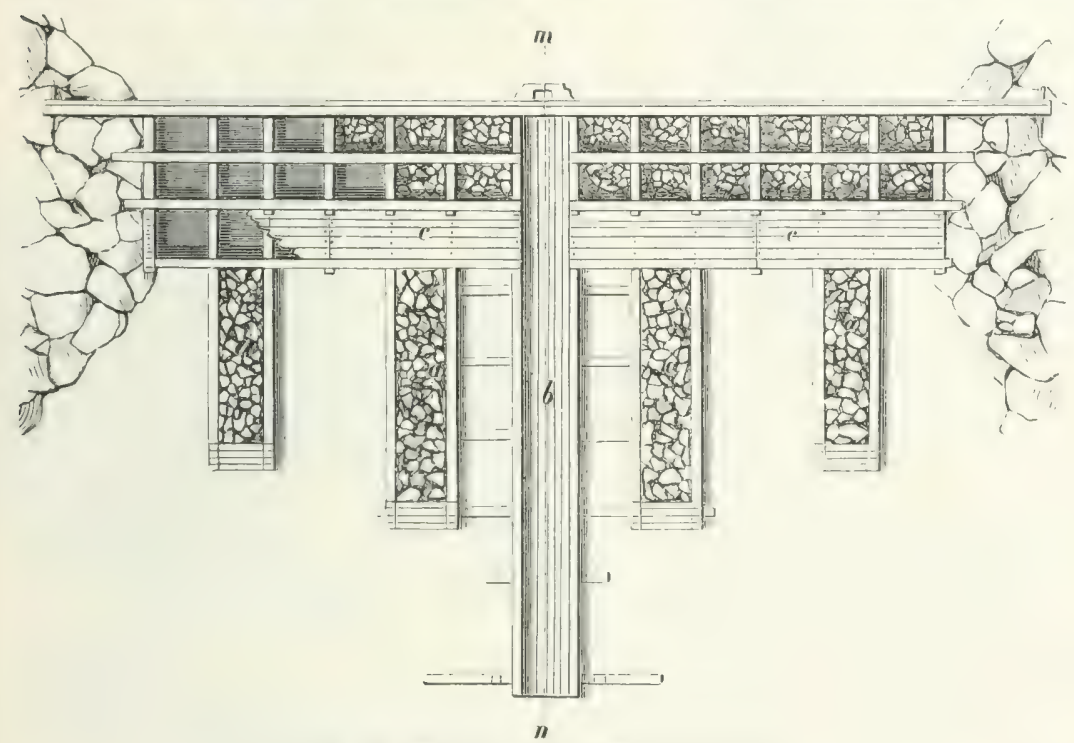

fig. 199. Eteintaftenbau eines Sdymelluertes.

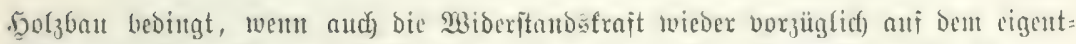
lid)en, mit (sxbe, Eteinen, Felsbructen 11. i. 10. Gergeftellten Iammföper berubt.

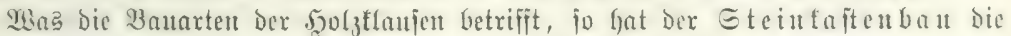

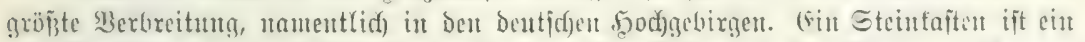

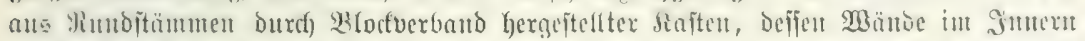

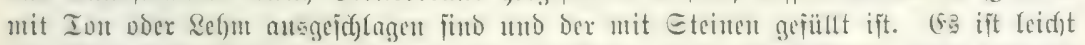

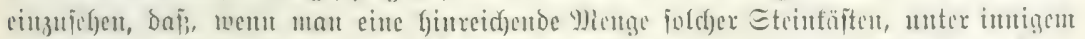
gegenpitigem \$erbande, o. i. mit übergreifenden Etämmen, ancinanderïugt, Dadurt) rin

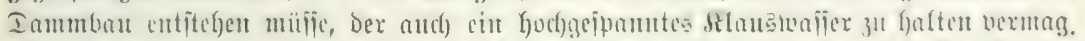

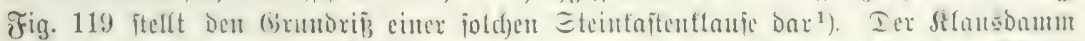

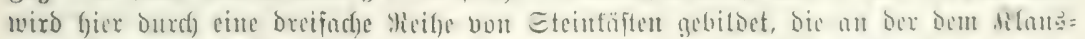

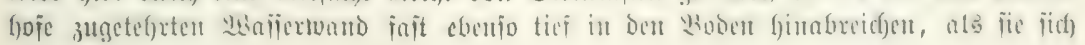

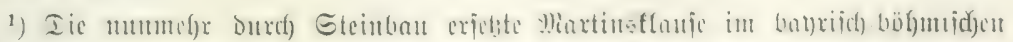
Walbgebirge. 


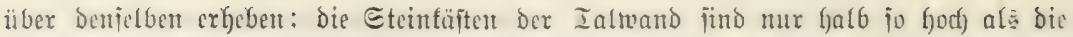
ïbrigen uno burd) cinen 2 retterboden überfteibet. Ier ganze Silaubsamm ijt in ber Viegel überdadyt und Durd) Raufbretter ïber bie gamze Rrone weg gangbar. Hm mu bie

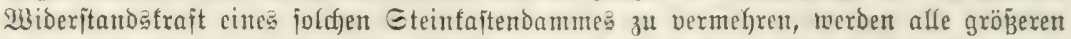

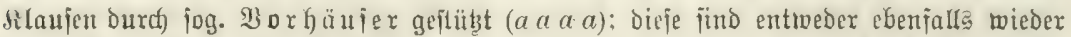
lange Eteinfäjten, ober jie jind ganz aus Eteit in grobem Şauberbanbe bergejtellt.

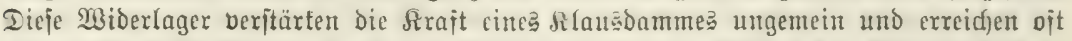

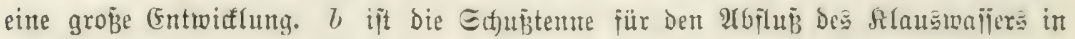
Der Ridjtung $m n$.

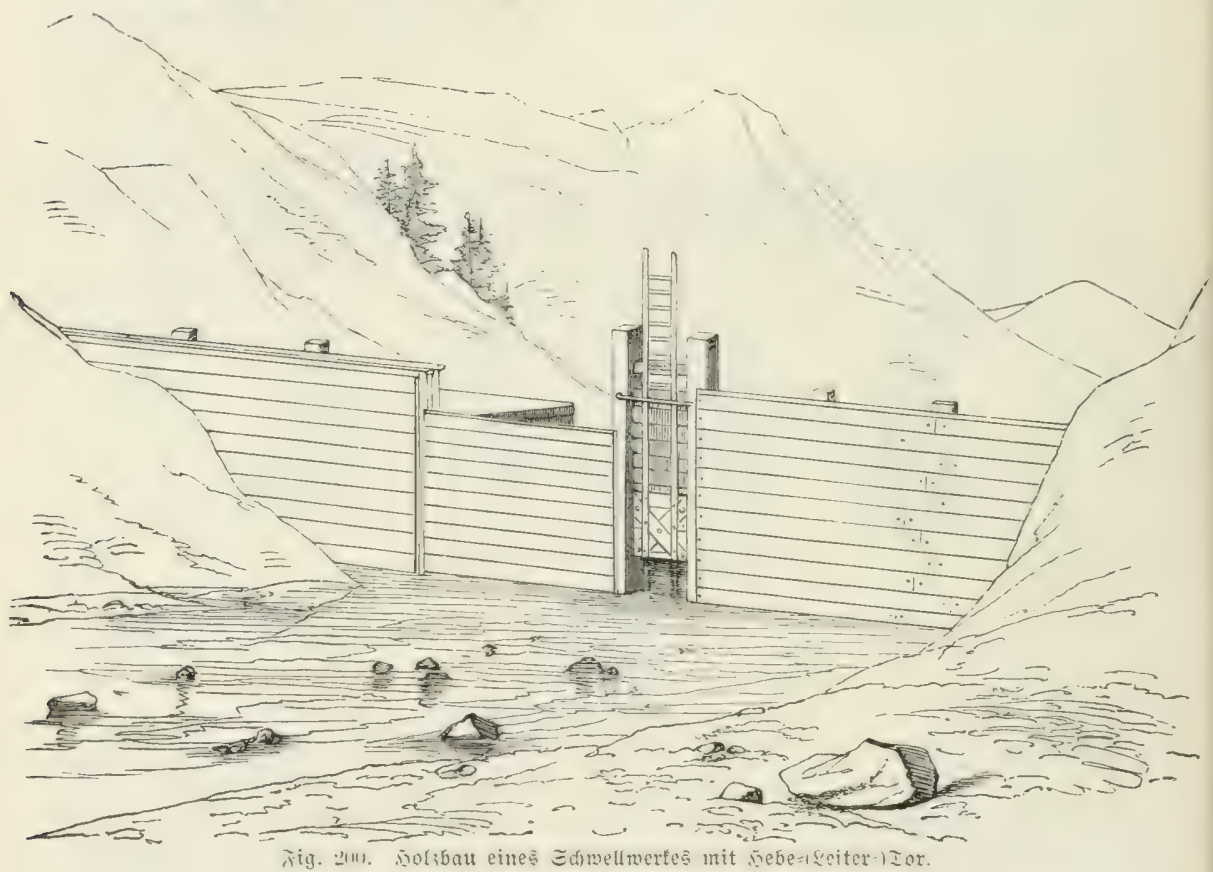

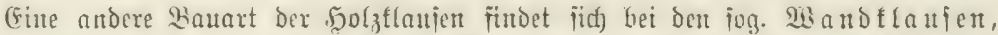

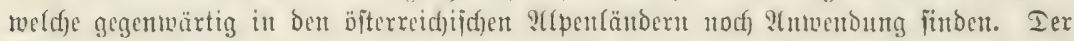

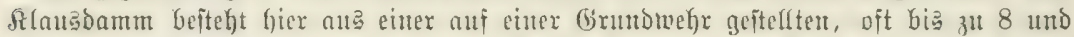

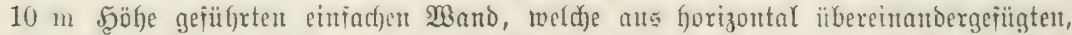

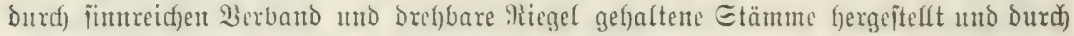

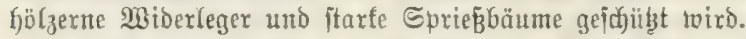

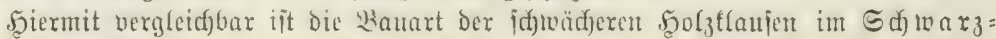

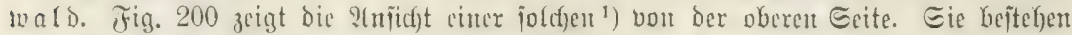

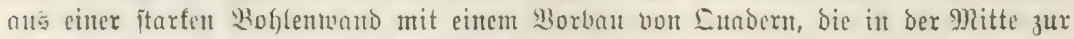

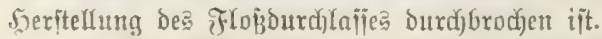

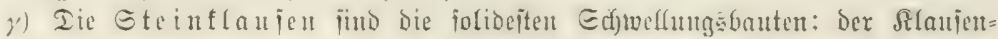

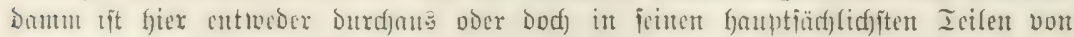

1) In ber 2(b̧add, einem Geitenwaijer Der Wolf. 


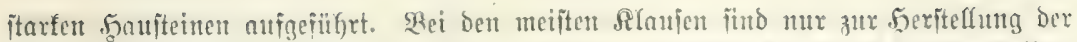

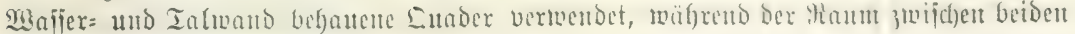
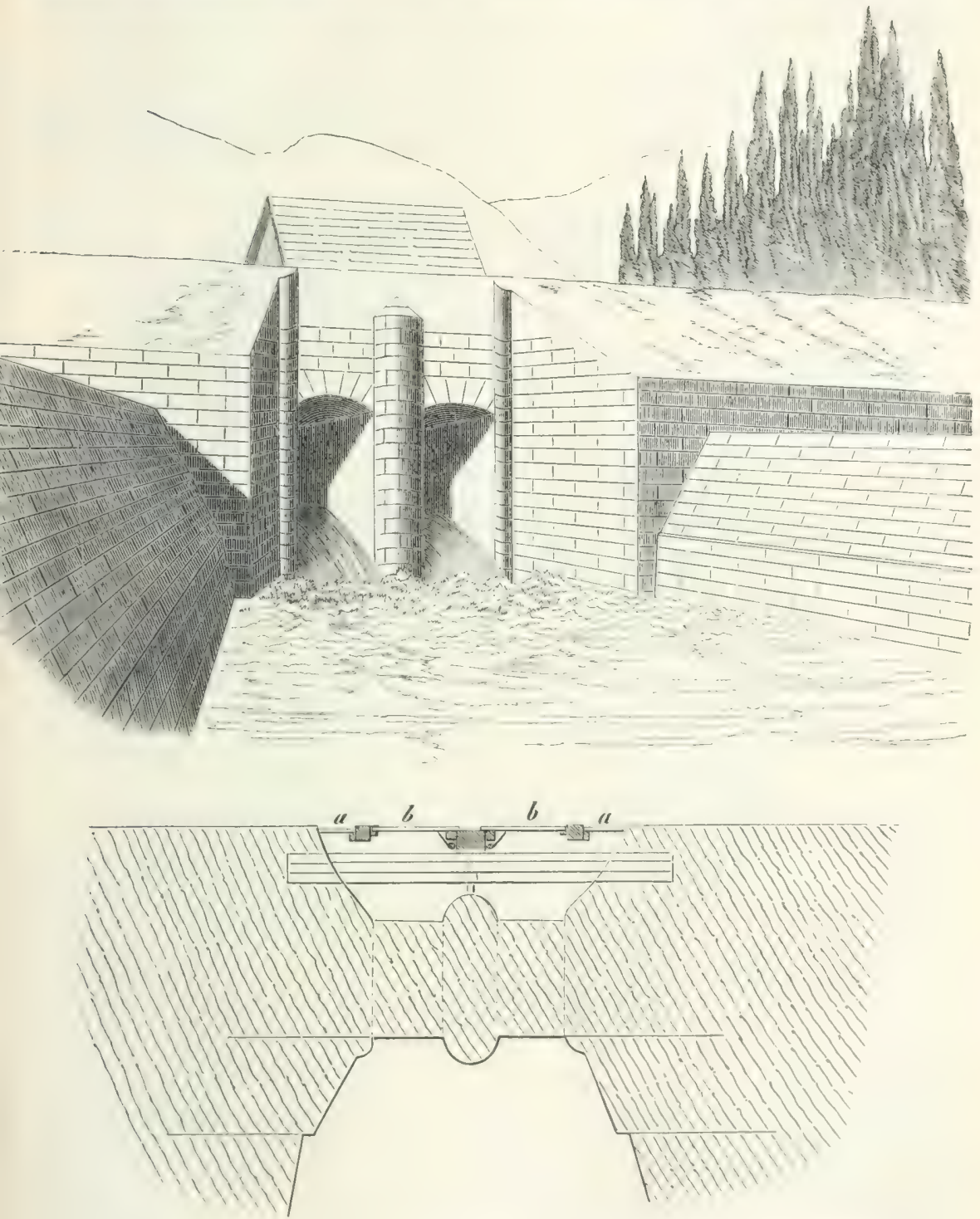

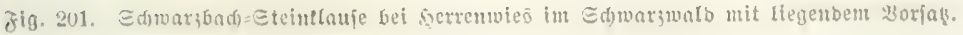

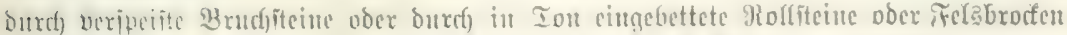
autgejullt ift. Die Mände find bam nad) imen dure) Mbiberfager veritürft. 


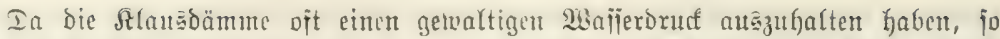
Gaut man fie mitunter in Form cincr regelmä p̈igen fin rbe, Deren fonvere Eeite

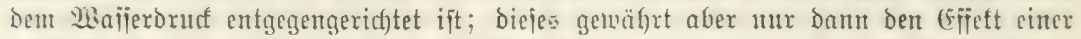

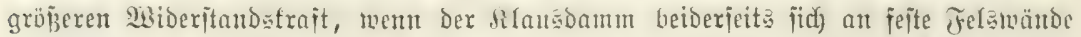

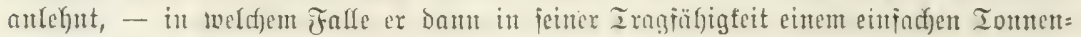
getwölbe zu vergleidjen ifł.

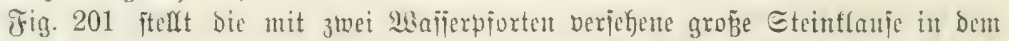

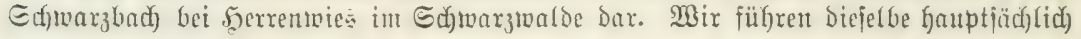

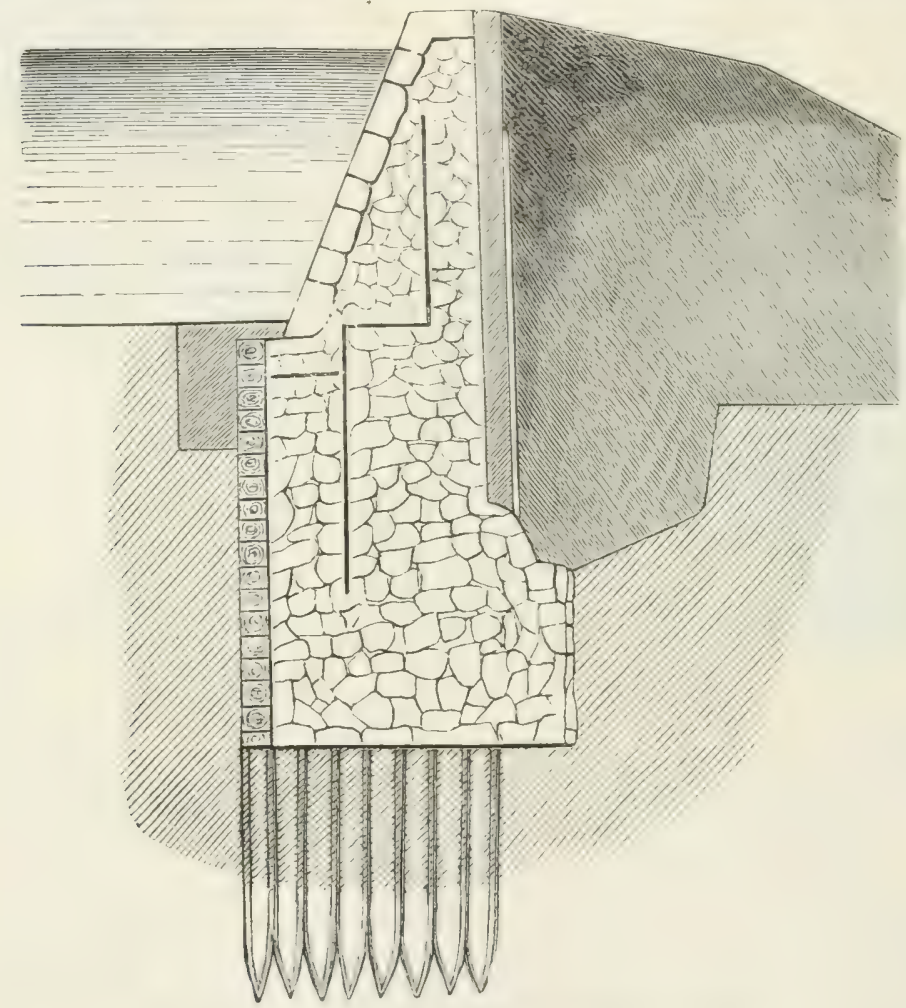

ซ̈ig. 202. Etein= unb Crobammtlauje im Banrijont \$ăbe.

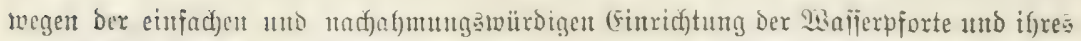

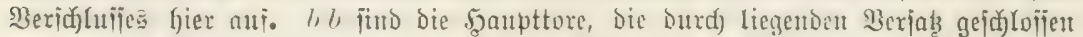

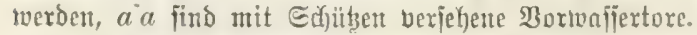

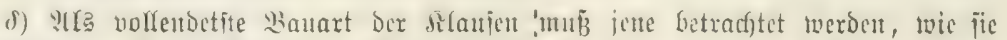

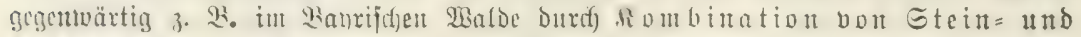

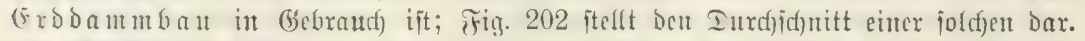

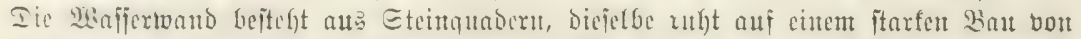

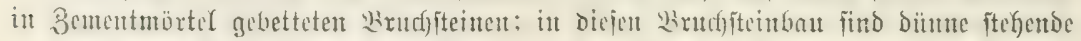

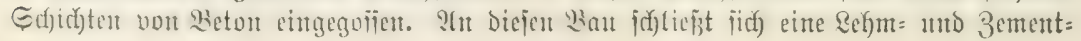


want an, unt bas (ianze wirb Durd) cinen itarten, zu Ial cimpallenden und ans ge=

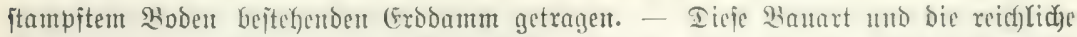

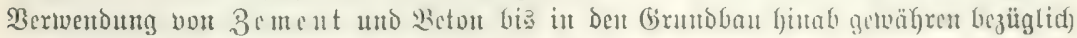

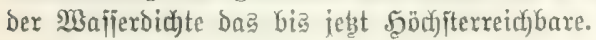

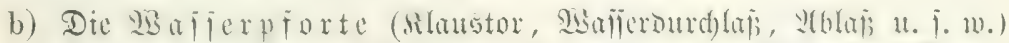

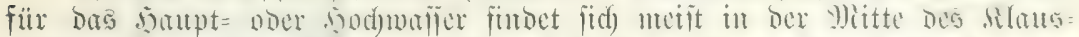

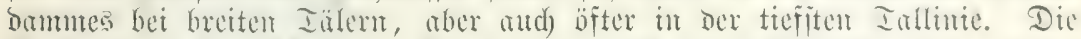

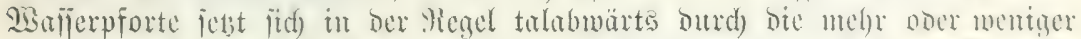

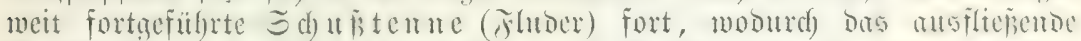

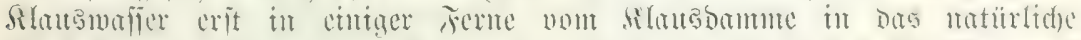

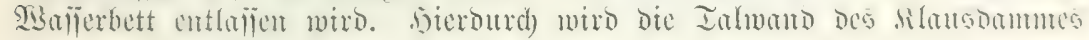

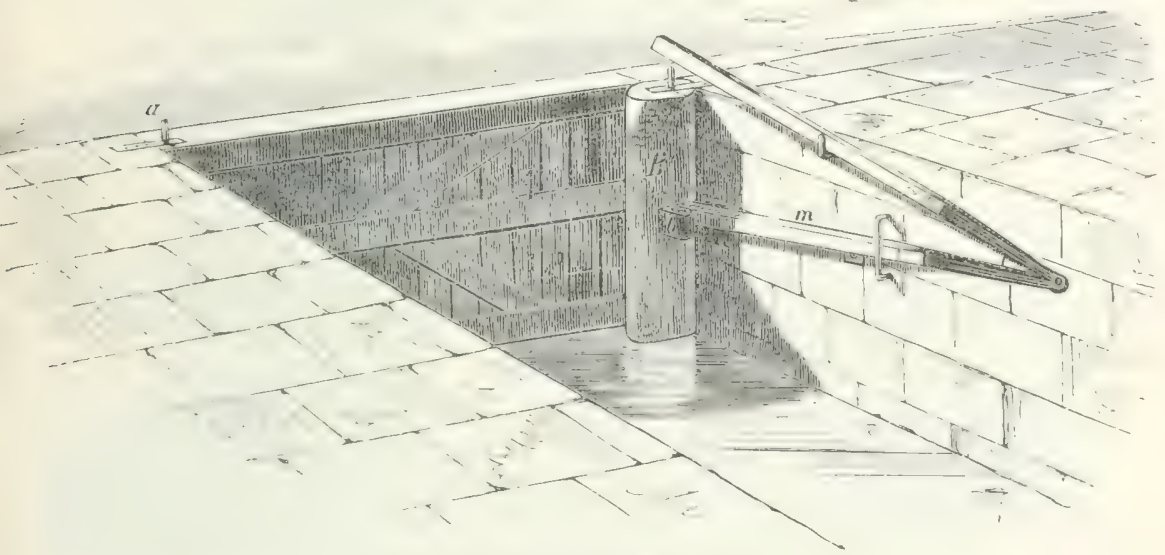

Fig. 203. Ed)lagtor mit Eperrgrünbel.

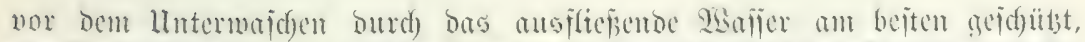

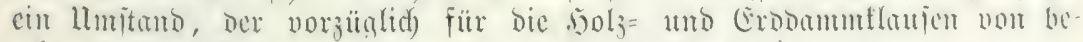
adjtensmerter Bebeutung ijt. (Bergl. Fig. 199 mbn.)

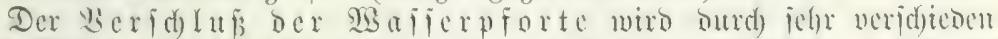

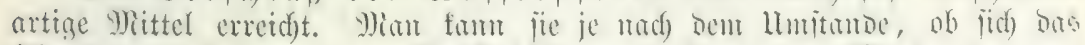

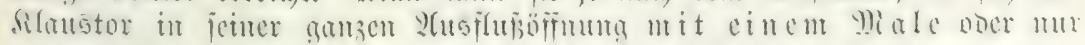

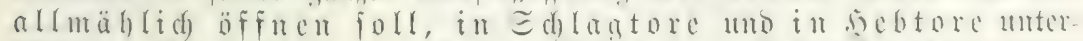
foction. :

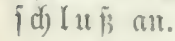

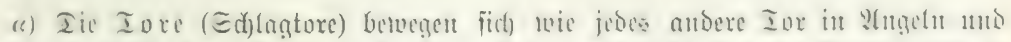

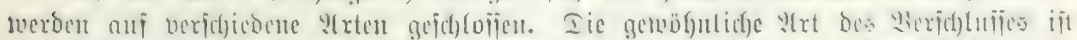

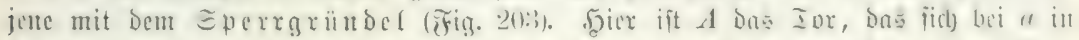

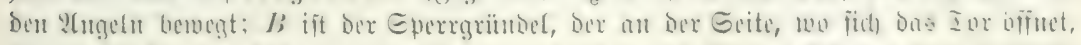

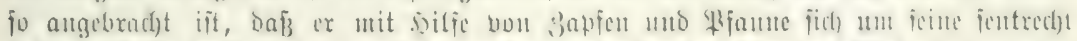

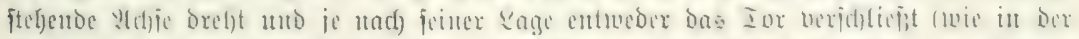

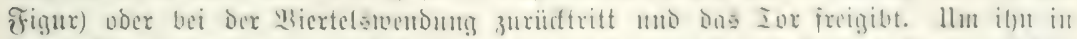

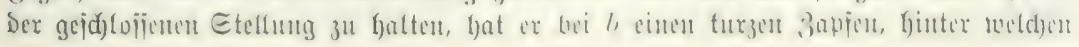




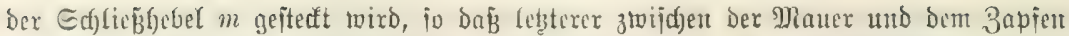

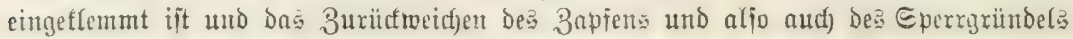

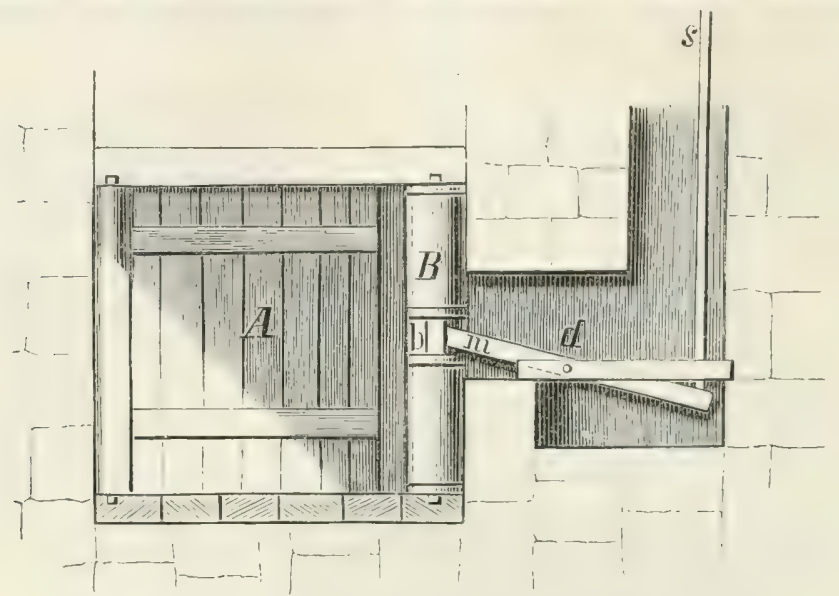

Jig. 204. હdlagtor mit Eperrgrün১elveridglū̄.

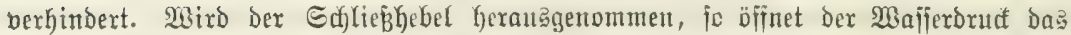

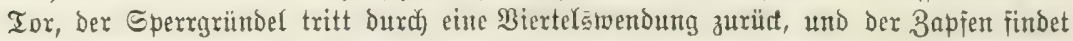

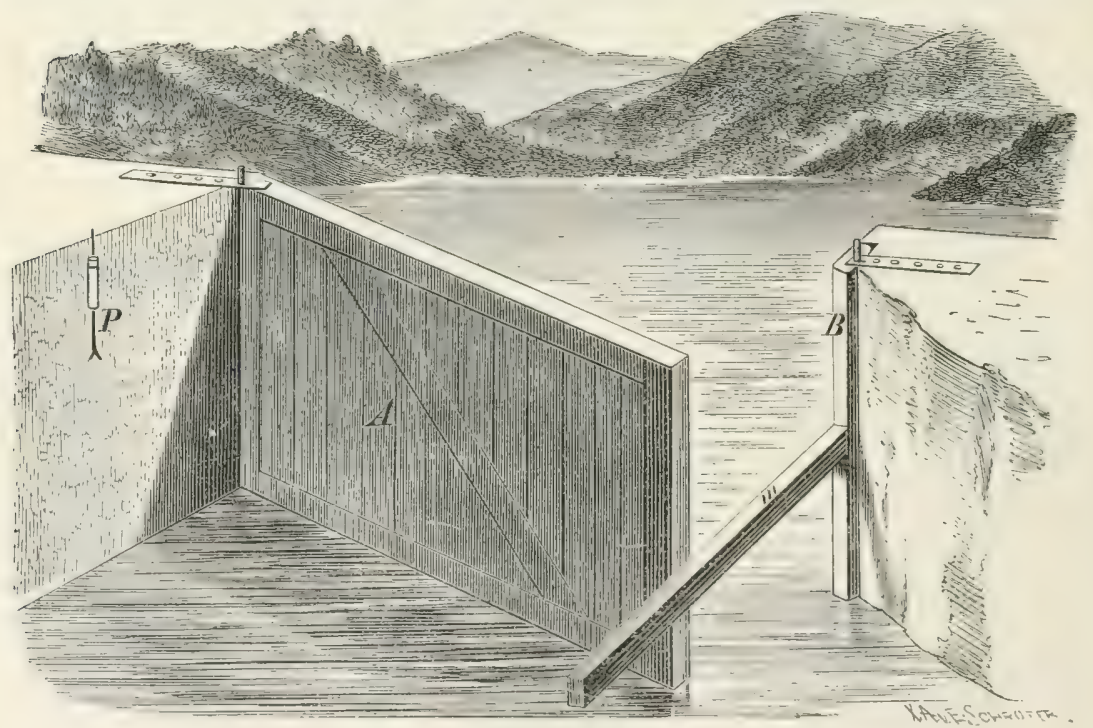

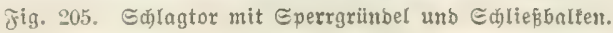

Jlnterfunft in cinem in ber Mauter angebrad)ten Rodje. - Sint Fig. 204 ift Der Edyließ =

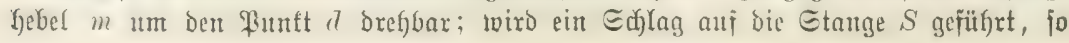




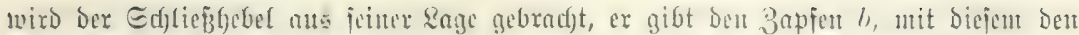

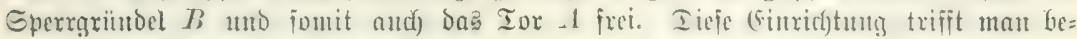
fonder aud bei fodjtwandigen filaujen.

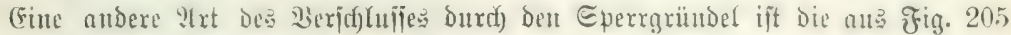

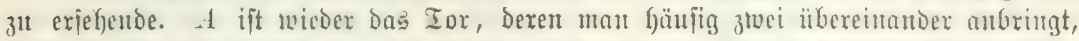

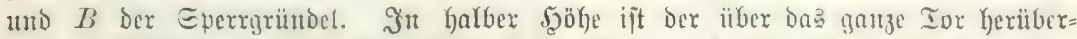

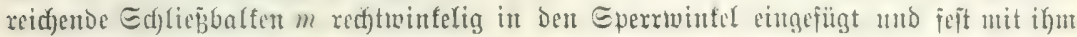

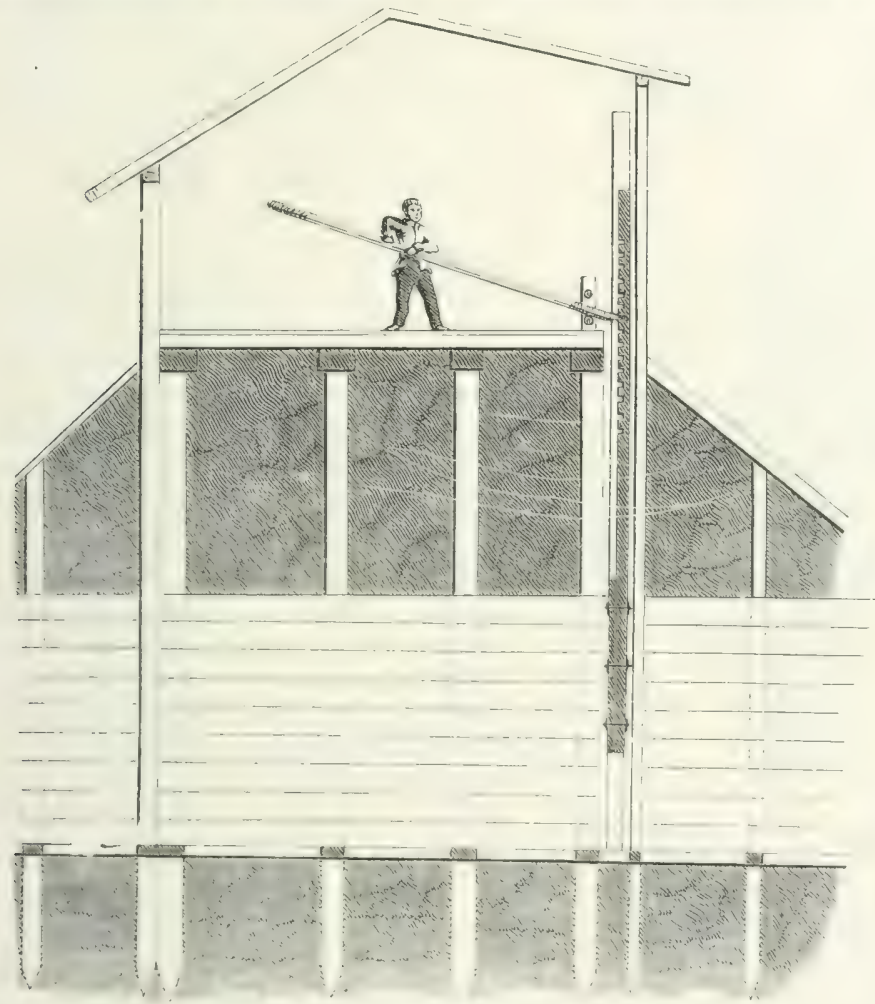

Jig. 206. Erbbammlaufe mit Sebtor.

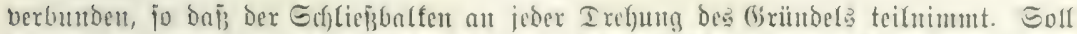

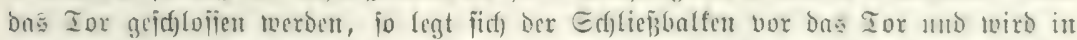

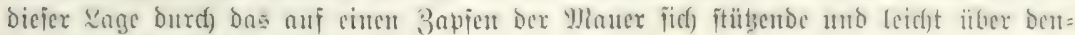
felbent wegidjiebbare Edjlię̧eifen gehalten.

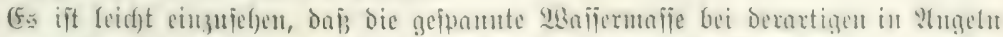

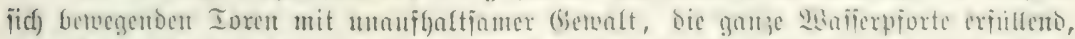

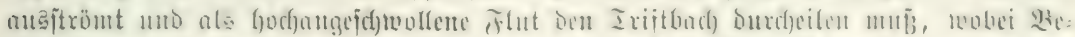

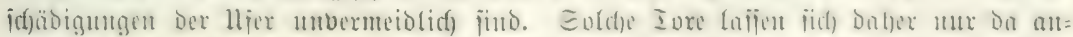

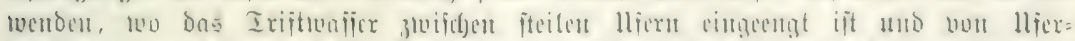

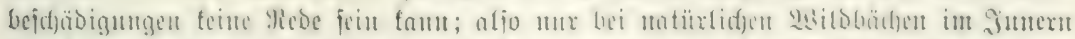

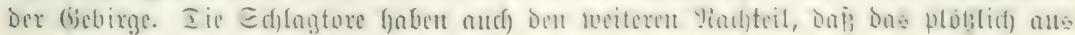




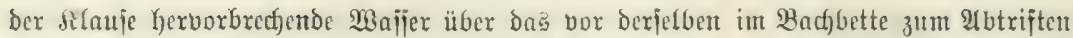

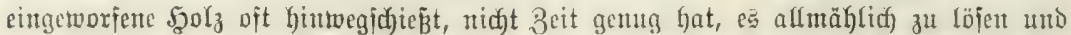

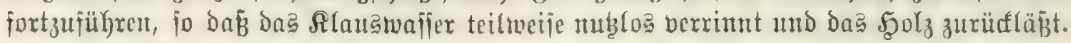

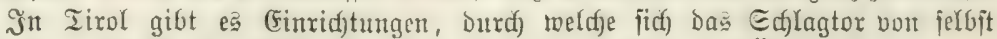

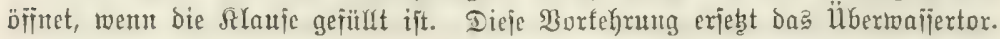
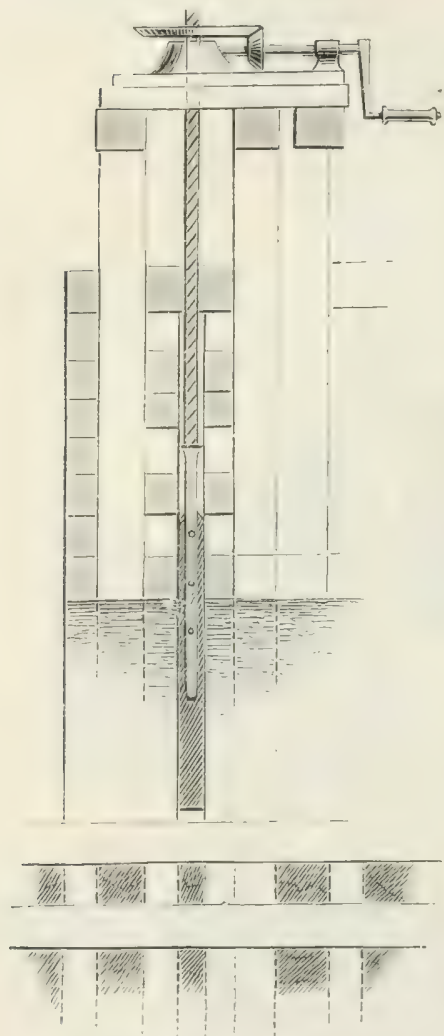

Fig. 207. Бebtor mit Räber = uno Surbeluoriditung.

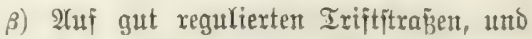

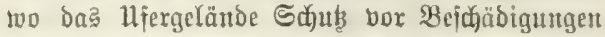
foroert, ba Gedient man fid) ftatt biejer 2 (ngel= oder Edflagtore ber jog. Şebtore, burd) tweldje

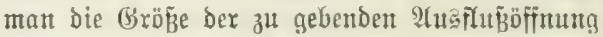

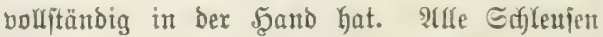
haben Şebture; fie vermitteyt Den Begriff Der Yebzteren am beíten. Für die größ̄erent uno jafweren Sebtore, wie jie für bie Rlaujen ge: twöhnlidi exfordert twerden, bedient mast fid dex

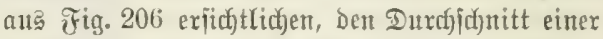
(Exobammflaufe burd, Die Malierpforte baritellen=

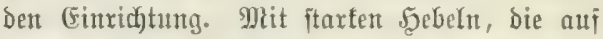
eifenten Ragern ifre Unterftübung finton, greift

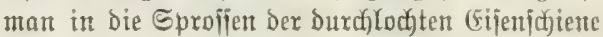
ein, welche fich an ben Edjübenfüulen befindet;

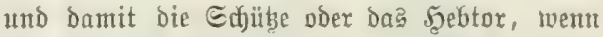

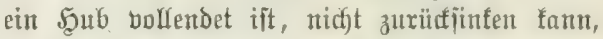
fällt ein nebenbețindlidjer Sperrfafen in eine gezäfnte Stange ein. - Statt Der burdidodjten Eifenjidiente an ben Iorjäulen finDet man öfter

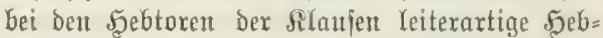

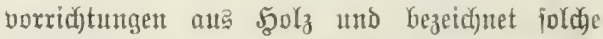
Iore ala Reitertore. Diejer (Finridutung be=

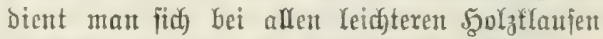

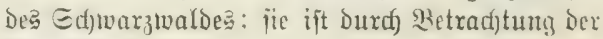
Fig. $200 \mathrm{flax}$.

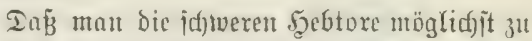
bermeideu jucl)t, ijt begreiffid): Deargals findet man bei neuen (Finridedungen entweder ztwei fleinere Scebtore nebenteinander poer gewöh)t= lidfer meffrexe gegenfeitig ïbergreifende scr)ïben überentantoer, berent jebe jidf in 'ifrer Gejonderen

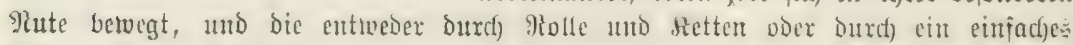
Räbertwert mit אurbelGetwegung gefobent werden.

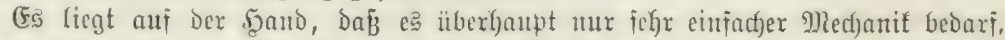

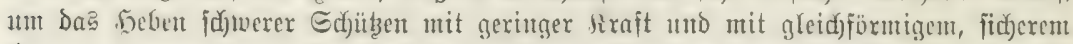

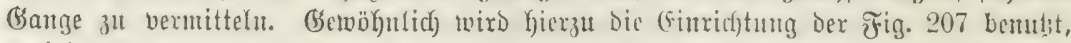

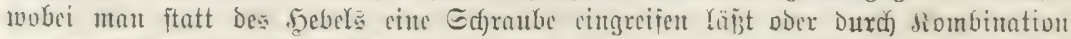

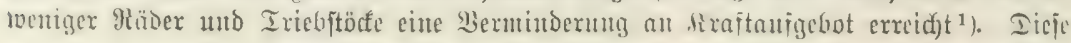

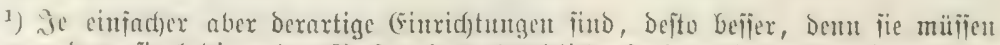

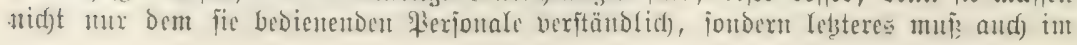




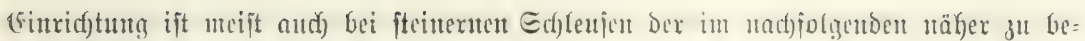

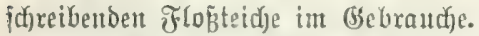

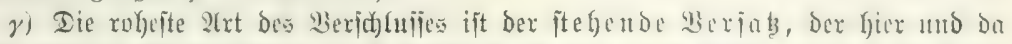

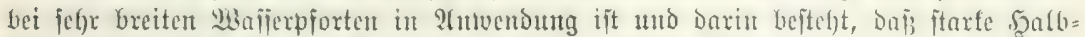

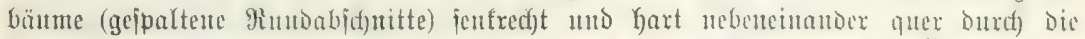

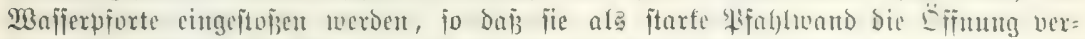

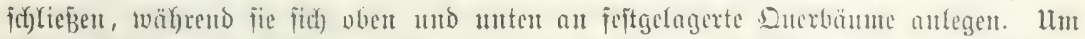

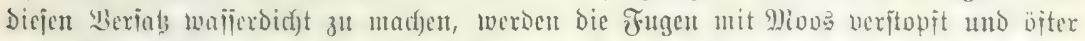

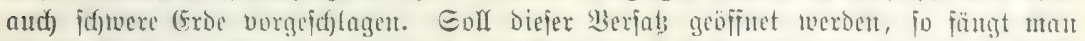

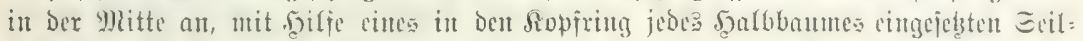

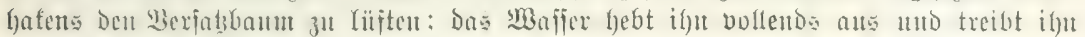

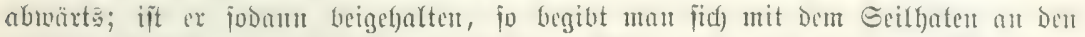

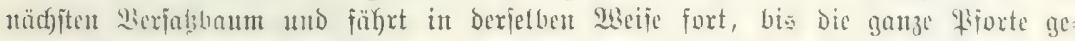
Definet ift.

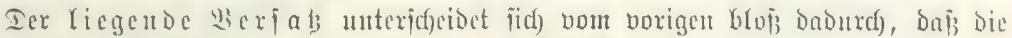

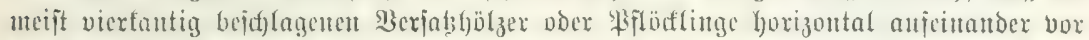

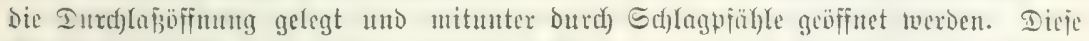

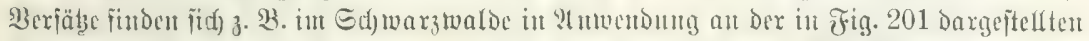

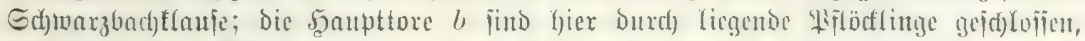

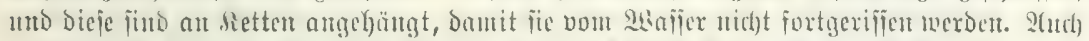

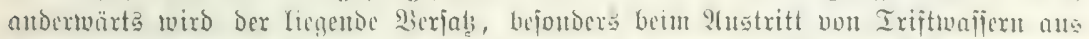
Eeen, hänfig angetroffen. Dit hebt nan aud einen fiflöfling nad) Dem anderen mittels Şatenitangen aแล.

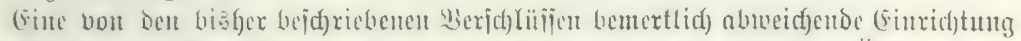
t)aben bie jog. 3ap a

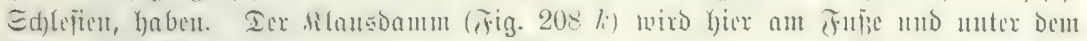

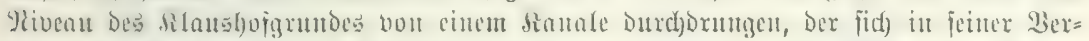

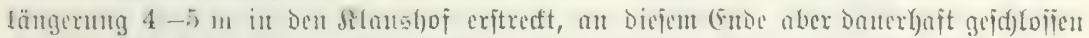

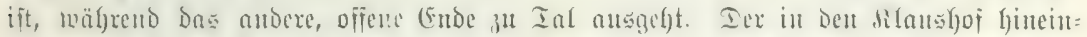

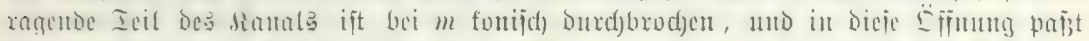

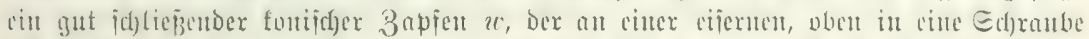

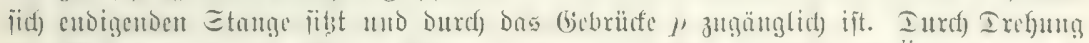

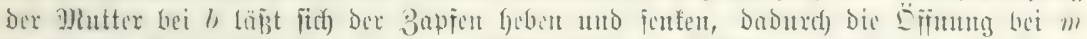

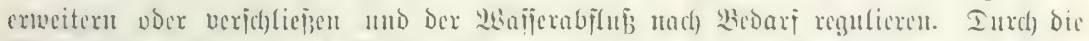

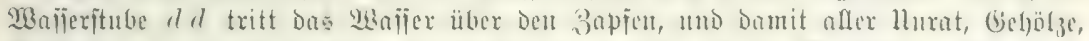

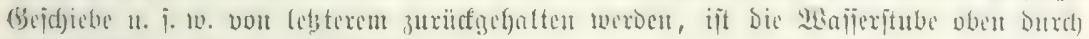
cine Rattenvergitterunģ ïberbactst.

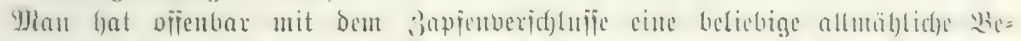

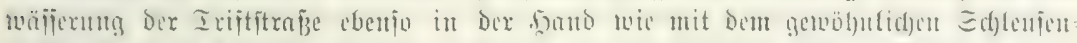

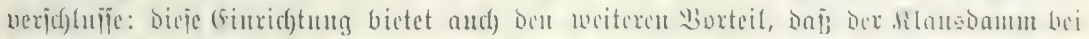

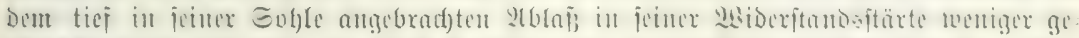

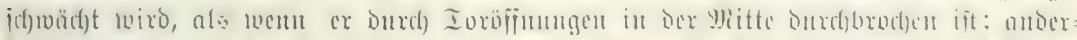

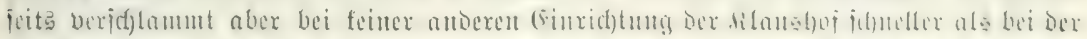

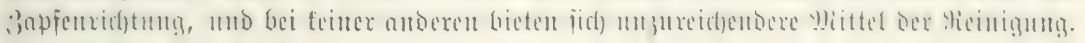

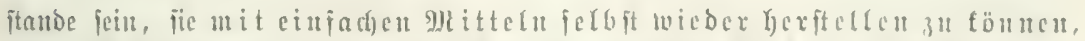

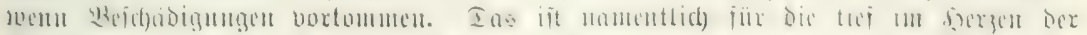
Whaloungen gelegenen berartigen 2 erfe von Sebentung. 


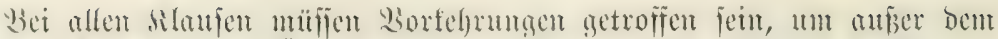

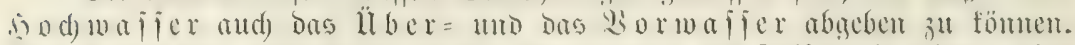

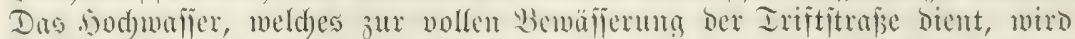

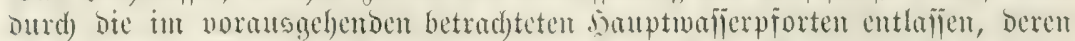

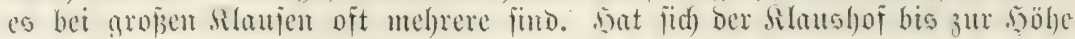
Des silanfendommes gefüllt, io miliste dos gistifer bei weiterent Eteigen

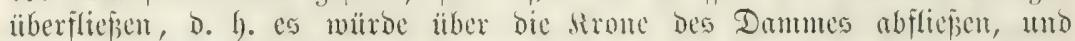

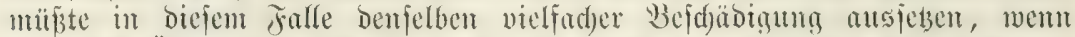

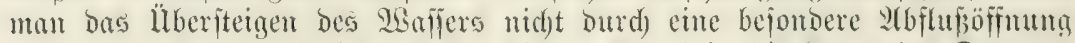

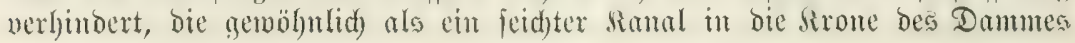

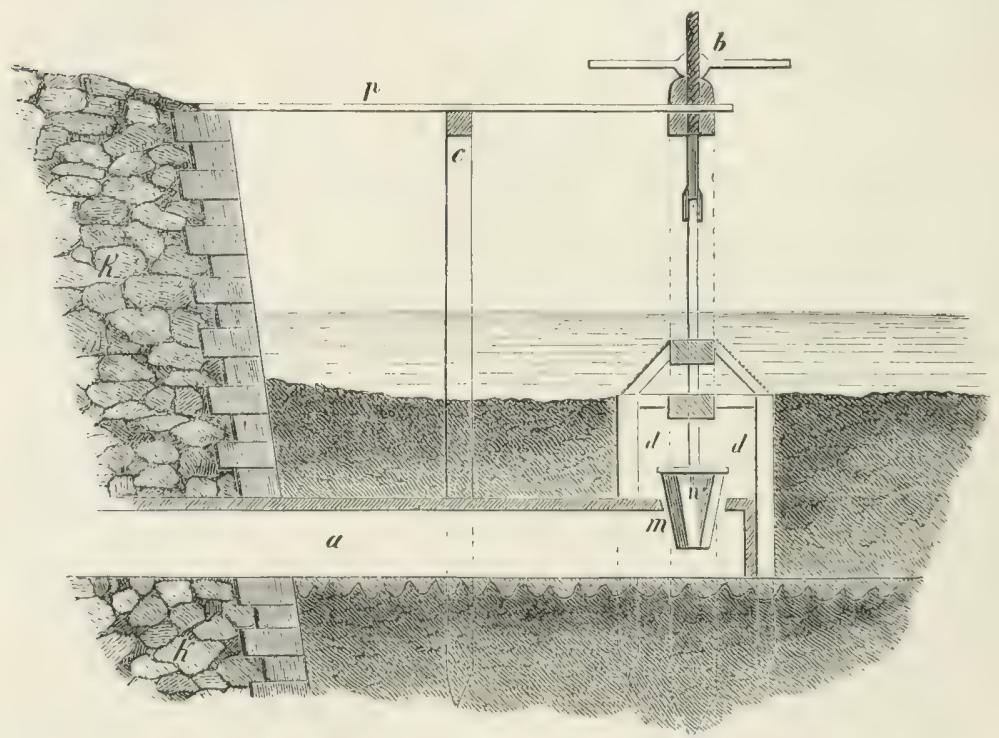

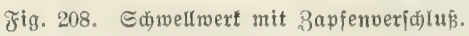

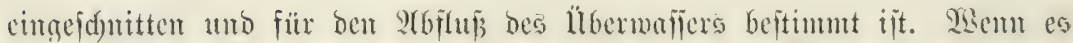

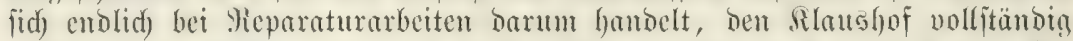

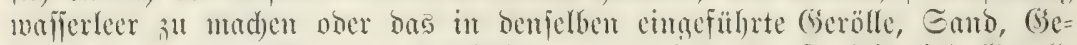

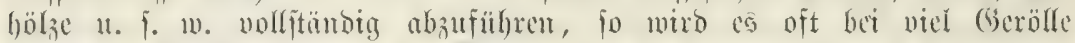

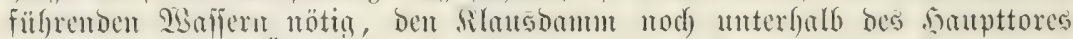

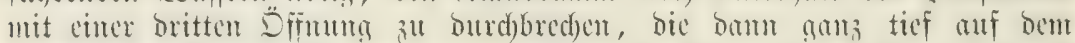

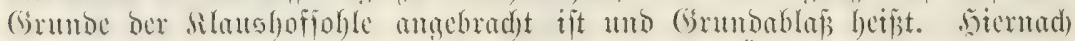

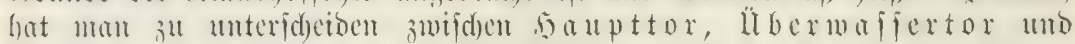

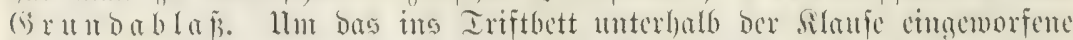

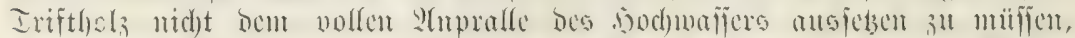

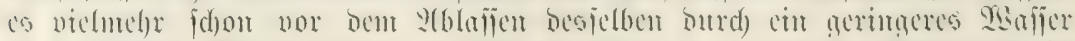

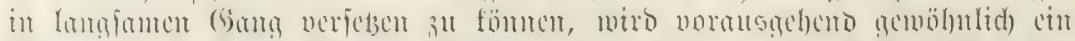

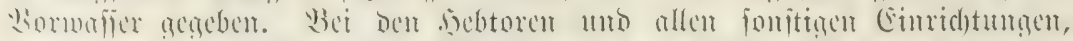

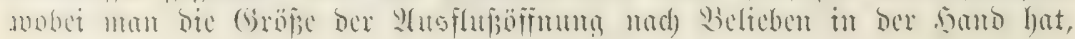




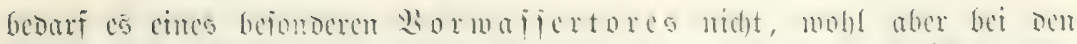

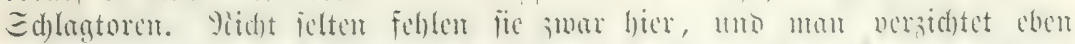

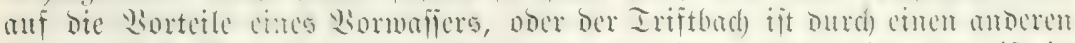

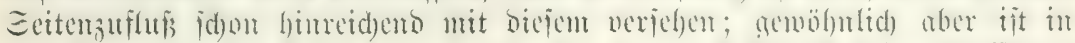

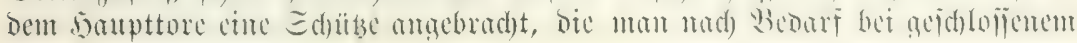
Tore zieben fant.

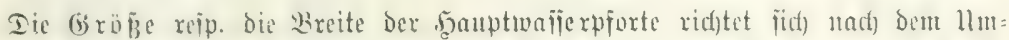

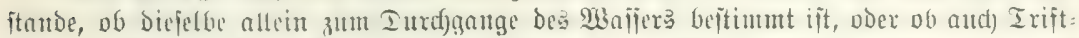

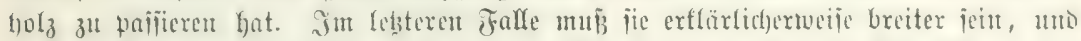

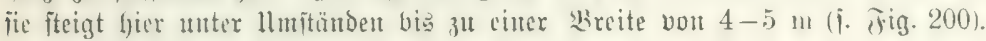

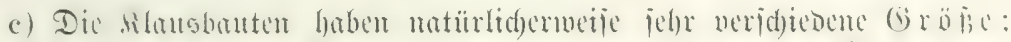

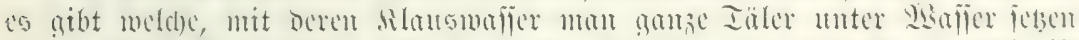

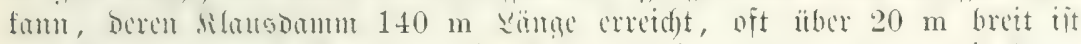

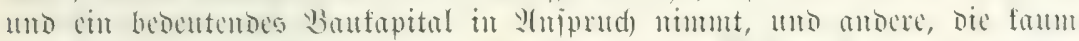

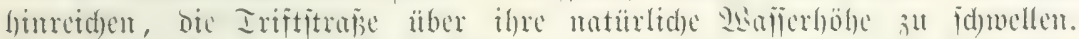

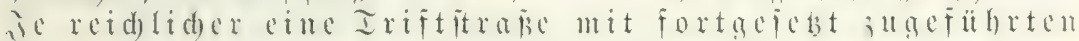
golliteinen und Felfen belaben ift, ub je niebriger ber Sommermajieritand bei groper eänge ber Iriftitrafje ift,

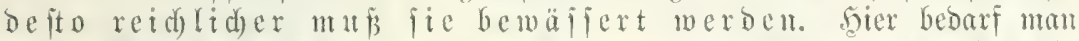

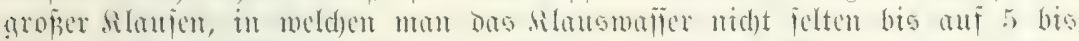

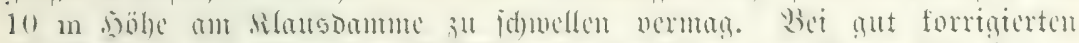

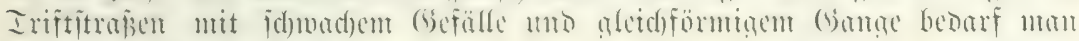
aud) mu fodmäd)erer Silaujen.

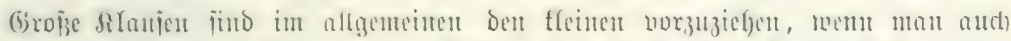

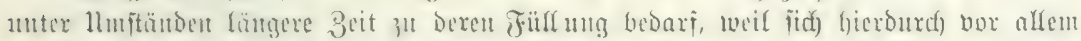

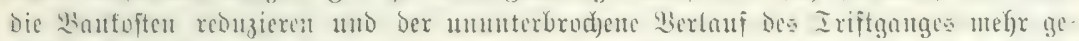

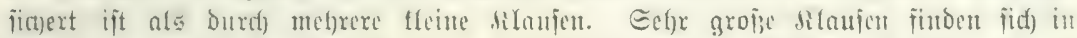

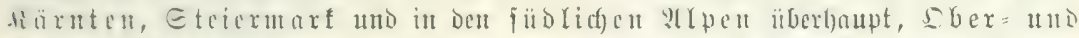

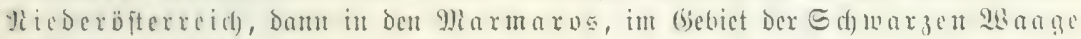
in Hngarn 11. ¡. tw.

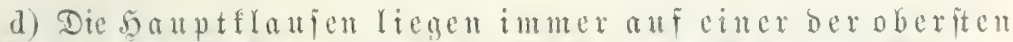

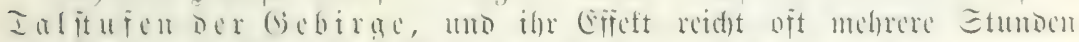

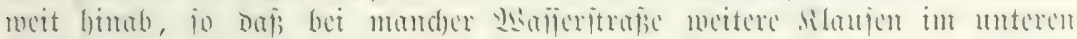

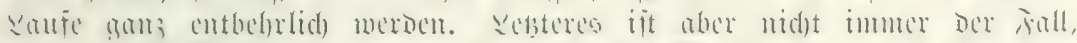

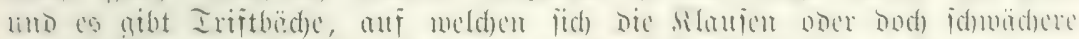

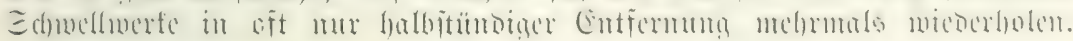

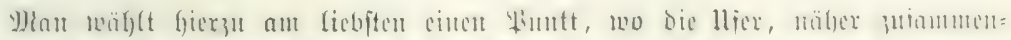

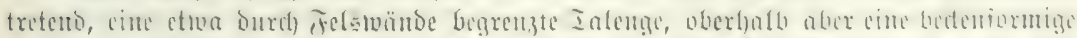

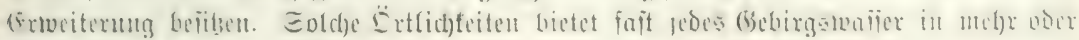

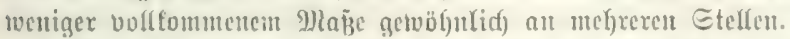

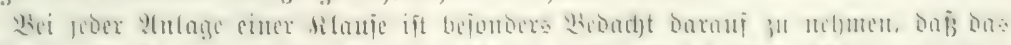

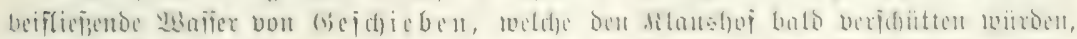

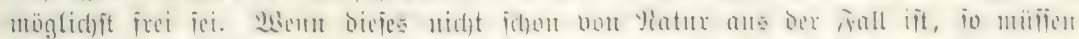

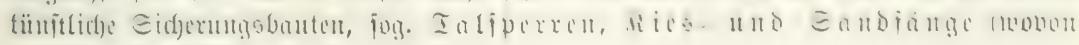
unten bei den Meforen gejprochen wiro), angelegt twerben. 


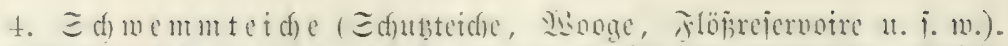

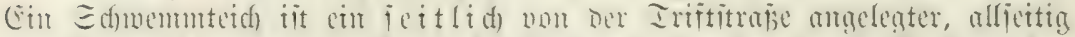

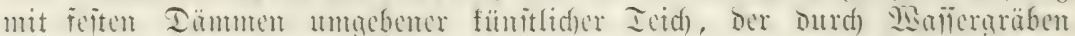

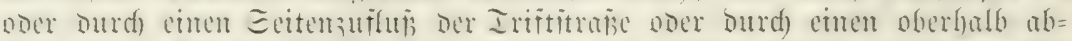

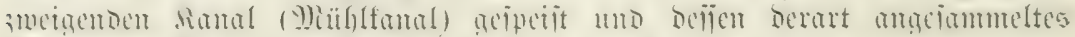

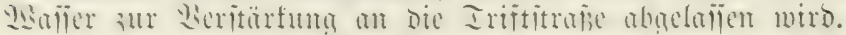

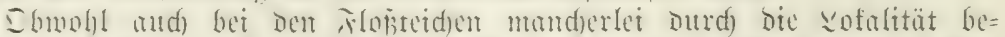

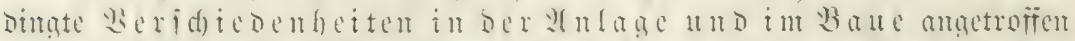

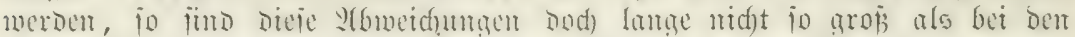

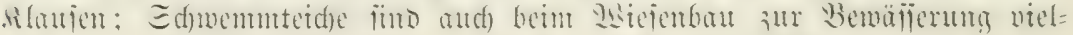
fad) verwendet; ifre fiontruftion ijt bic benfbar einfadjite.

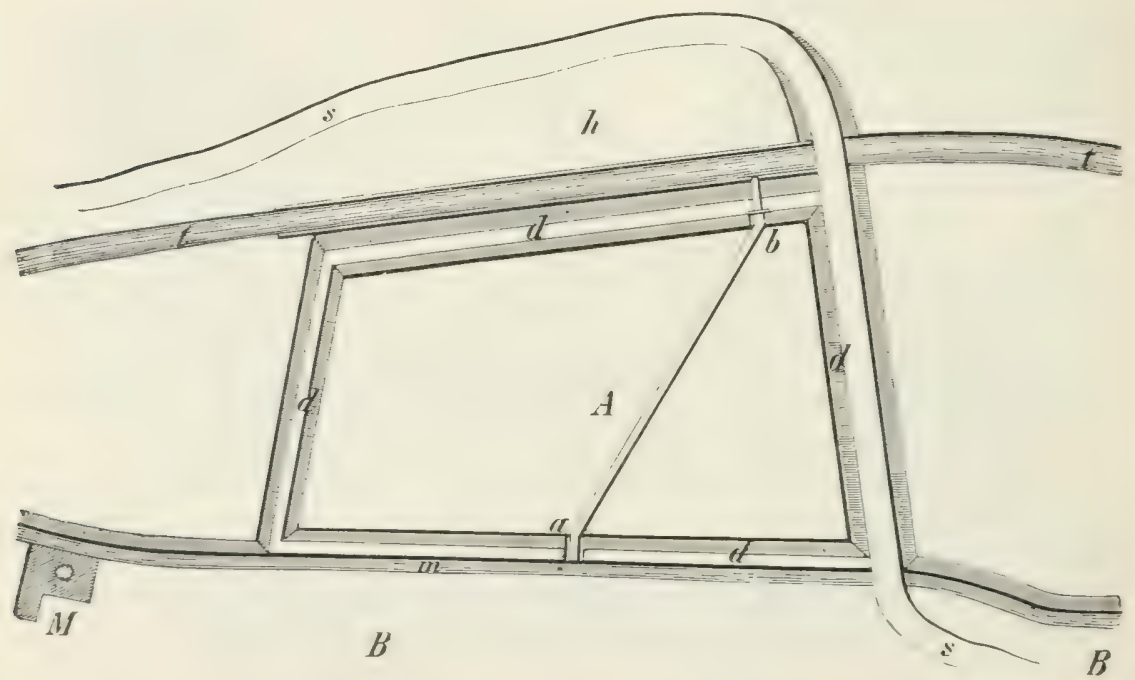

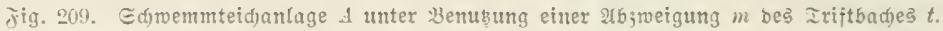

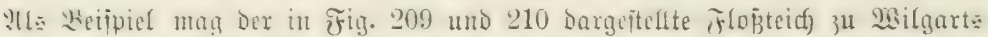

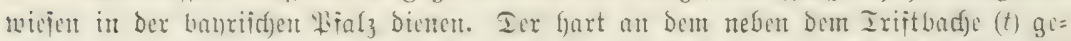

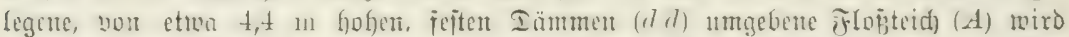

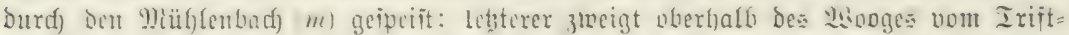

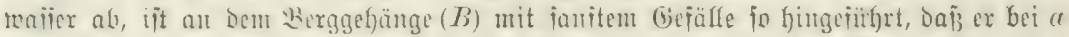

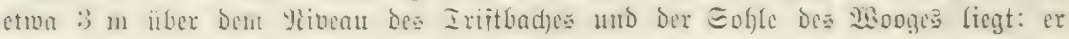
mündet unterfalb ber Mähle $(M)$ wieber in ben Triftbadi ein. Bei $a$ und $b$ find Thaïerpiorten; sie eritere bient zum (Fintritt De

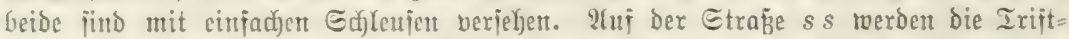

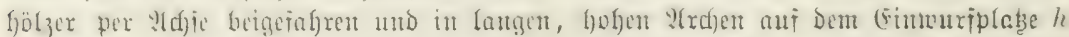

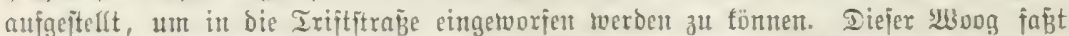

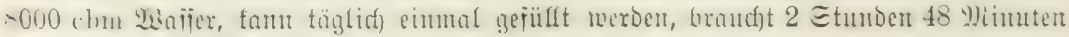

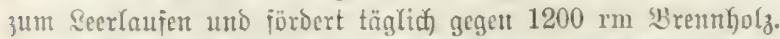

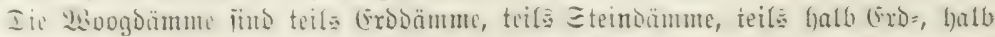

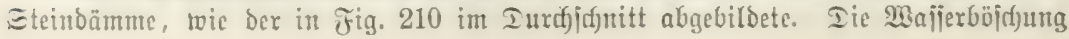




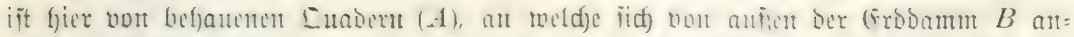

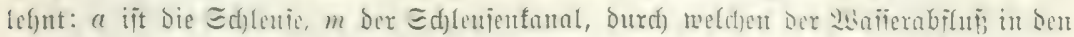

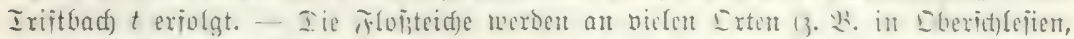

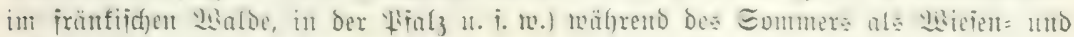
Iderland bentubt.

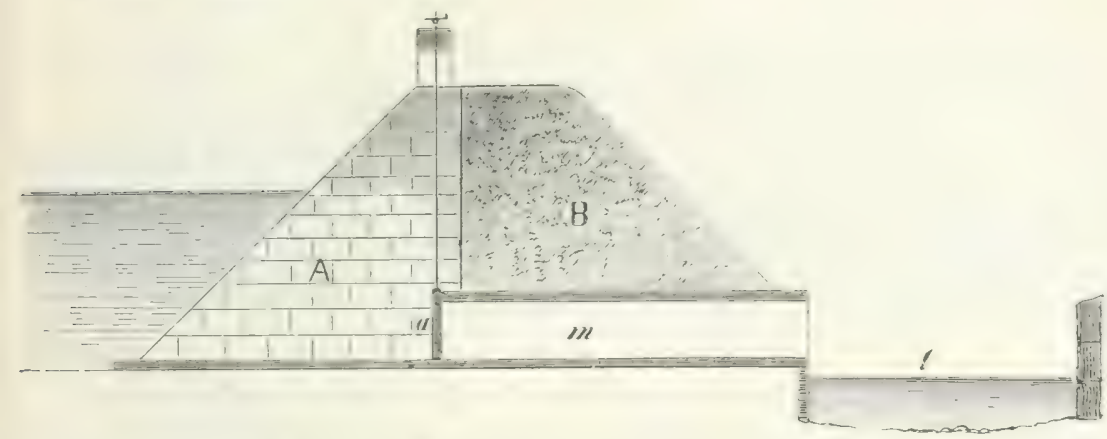

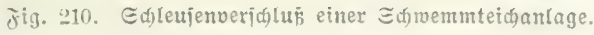

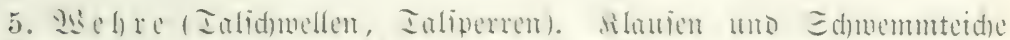

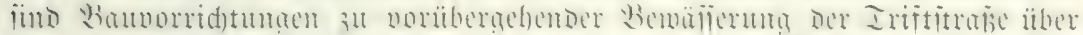

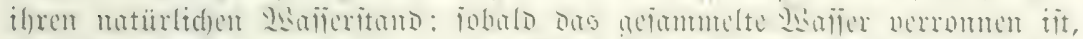

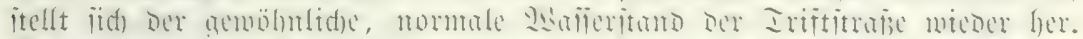

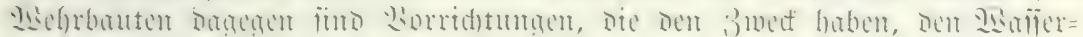
itanto etres flicfienden (Gemäljers bumerno ju

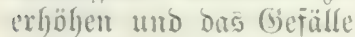
Des̃jelben zu mäbigin. ) Jian bente jidf einen jd)rvadjen, cirrfadjen Damm quer burdy ein Iriftwajier gelegt, ber mit peiner firone ben Tatjeripiegel mefor ober meniger erreid)t ober iiberiteigt, แ⿰亻 zu Deाjeu

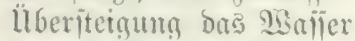

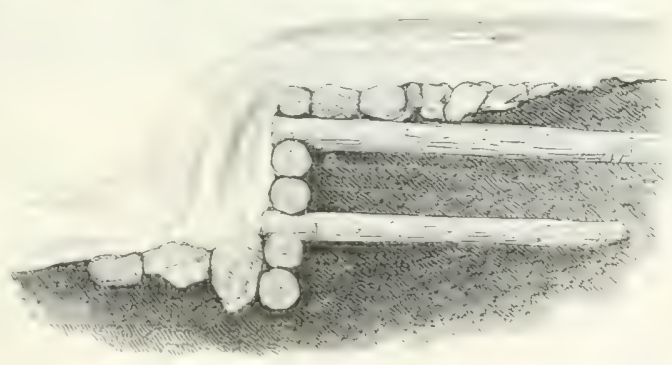

jig. -211. nberfalnetr aus sol;.

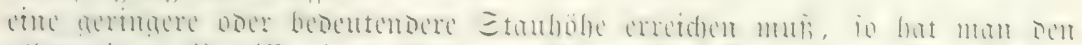

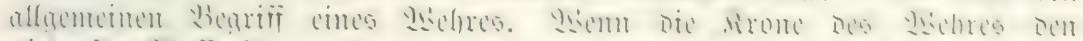

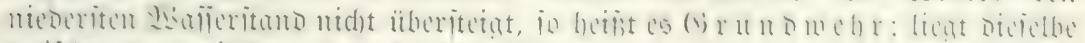

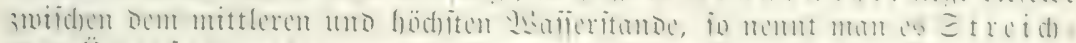

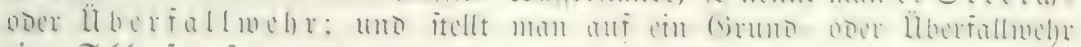

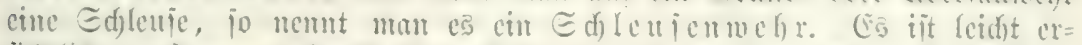

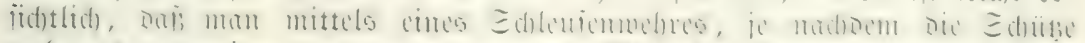

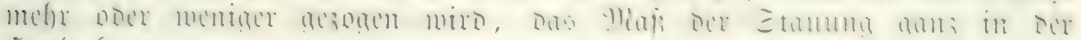
i)and bat.

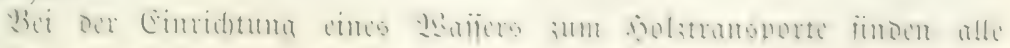




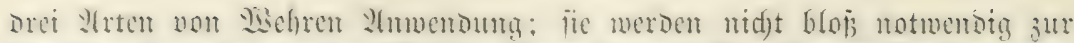

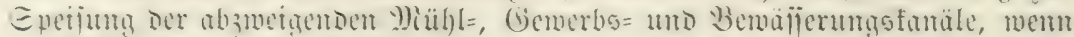

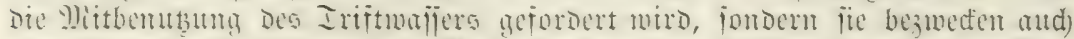

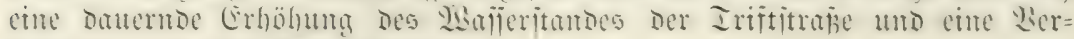
belierung des Ġefülles derielben.

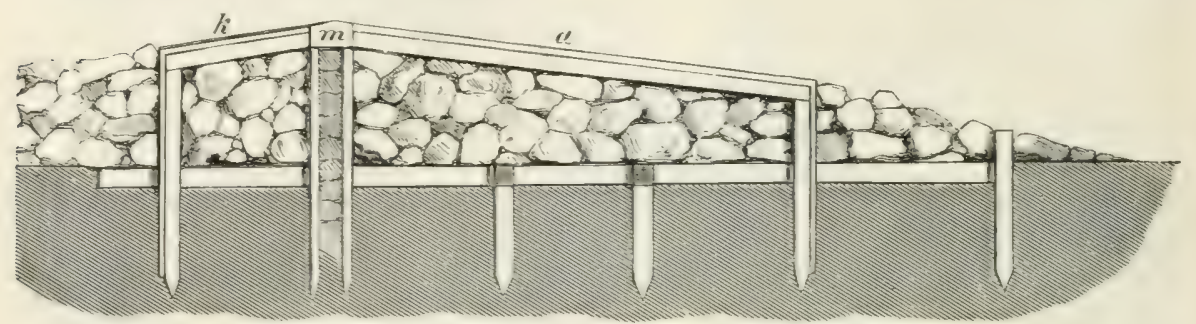

ìig. 2I:. Eueridnitt burd, ein janjt geneigtes überialrwebr.

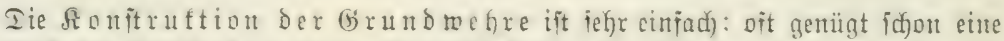

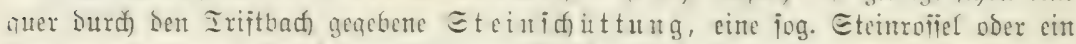

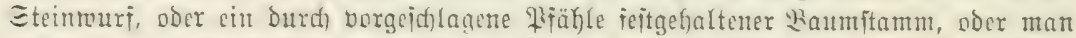

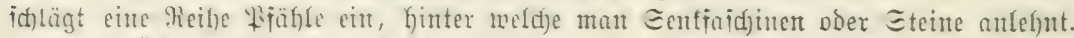

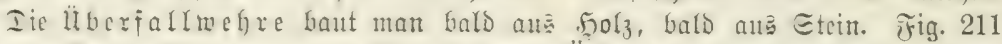

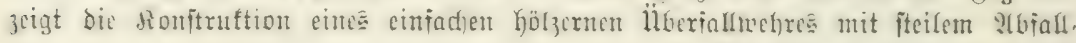

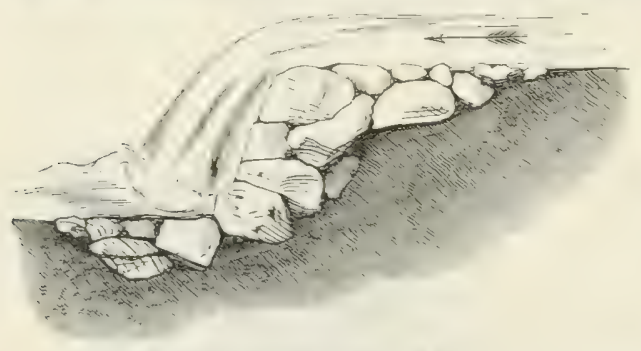

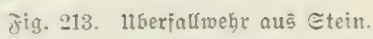
Die テrig. 212 ein joldues mit janjt gencigtem 2(biduñfoden; man nent nümlid) bie jodjieje, mit Epurtoboden veriegene, an ben Fachbaum ( $m$ Fig. 212 ) iid) an=

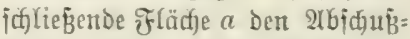
Godert ober das Şinterfluder, bie

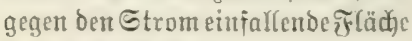

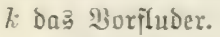

Die fteinernen lïberiallmelfore Find natïrlide den hölzernen weit vorzuzicfen. Eine finteidjento

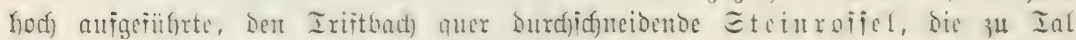

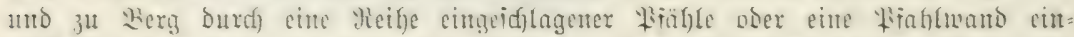

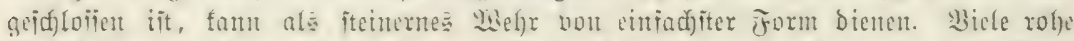

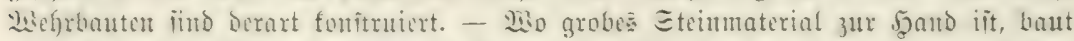

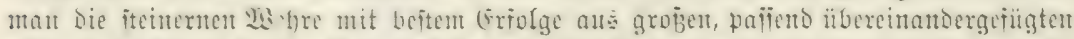

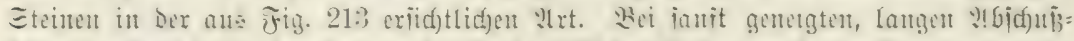

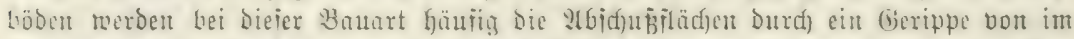

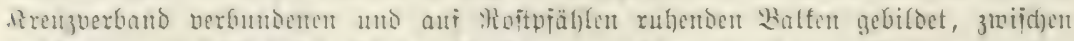

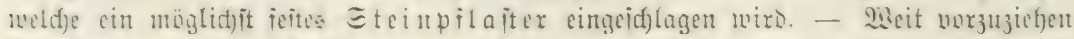

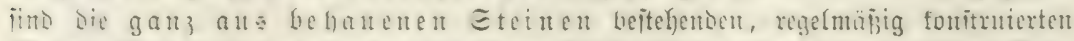

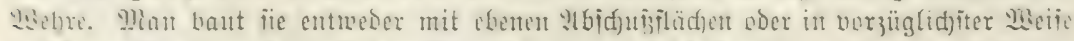

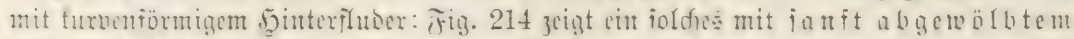

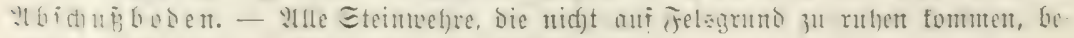

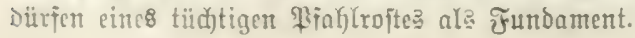




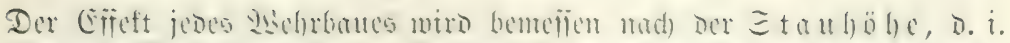

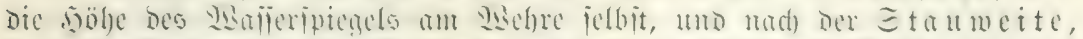

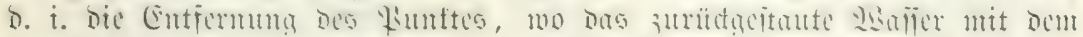

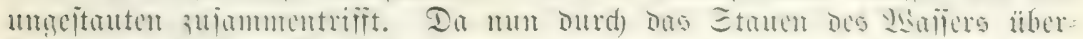
haupt cin höberes

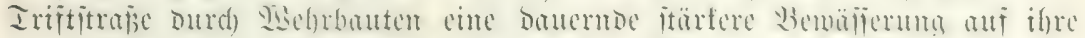

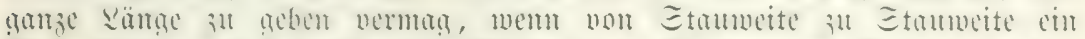

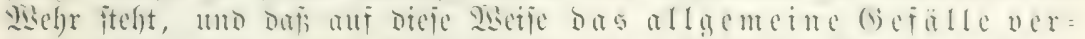

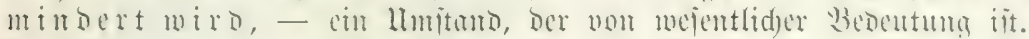

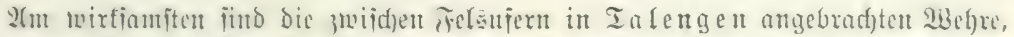

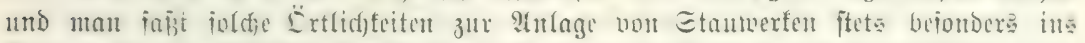

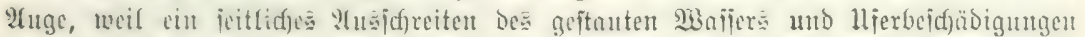

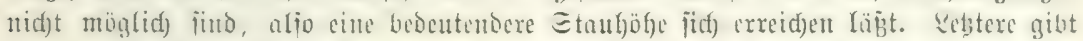

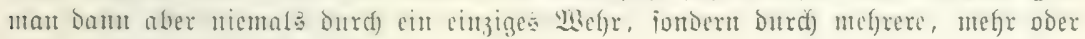
wentiger hart aneinandergeriidfte.

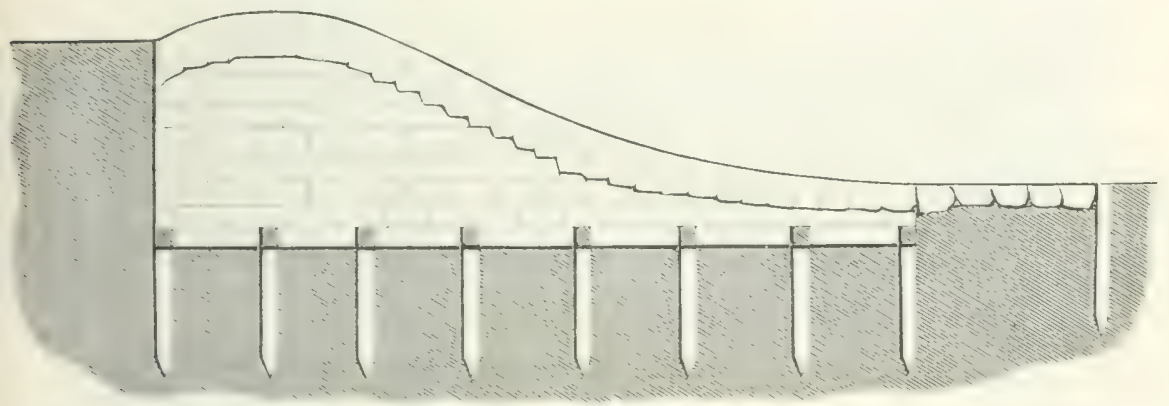

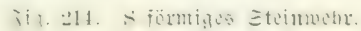

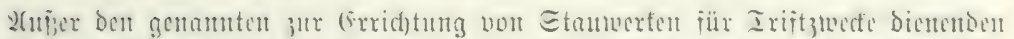

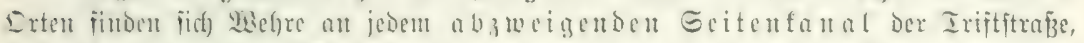

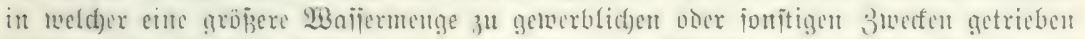

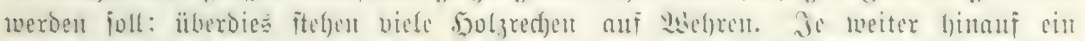

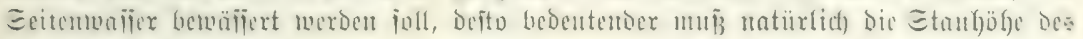
ß̉ebres jein (Irijtfanäle).

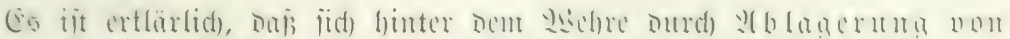

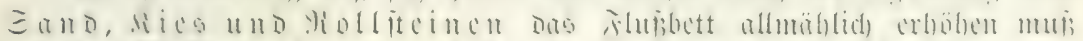
mas bas

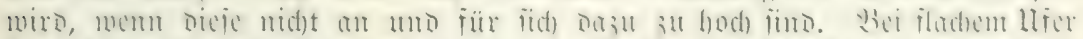

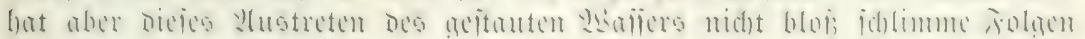

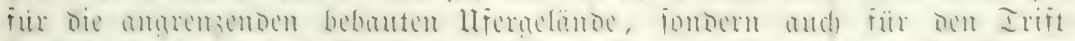

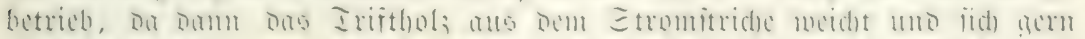

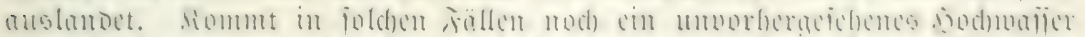

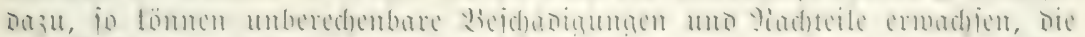

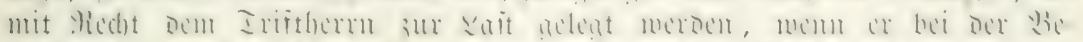

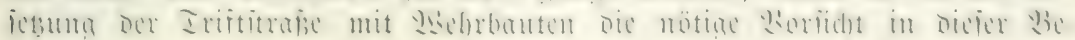




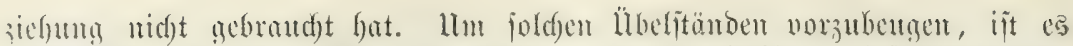

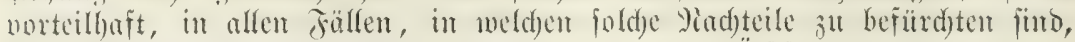

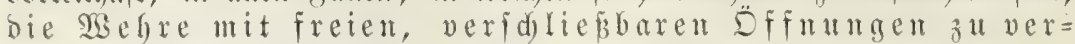
jegen, bie im falle ber Mot geoffnet werben fömen.

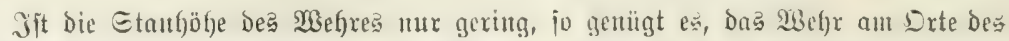

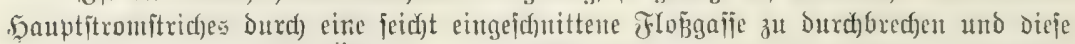

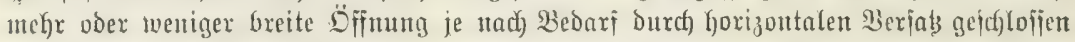

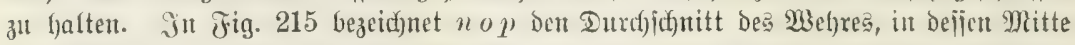

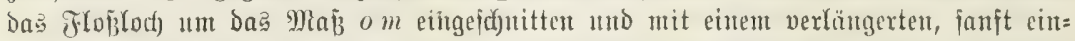

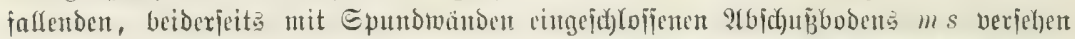

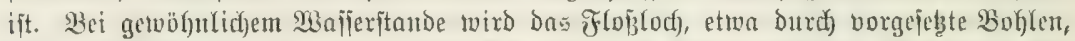

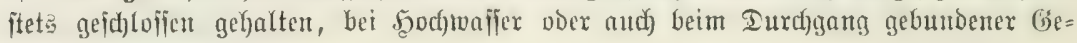
ftöre wiro ę geöffuet.

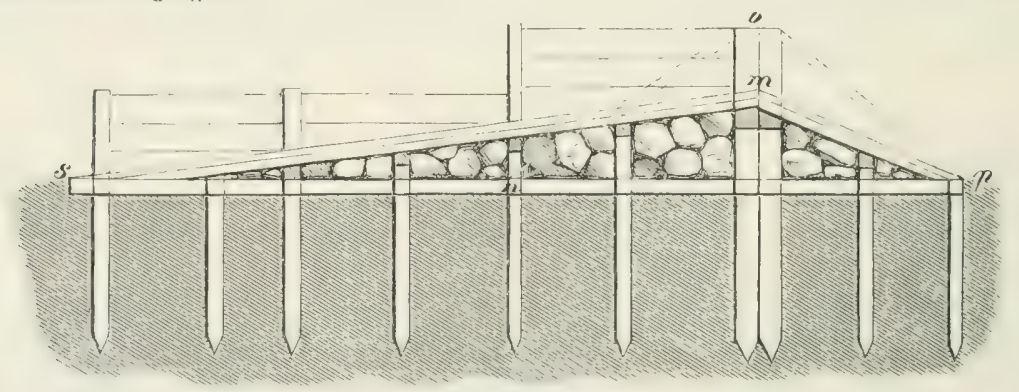

Jig. 215. Etaumehr mit eingejd)nittener Flop̄gafie.

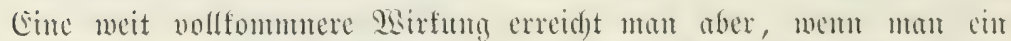

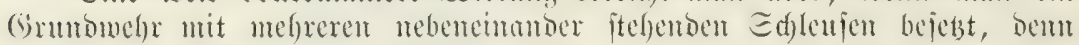

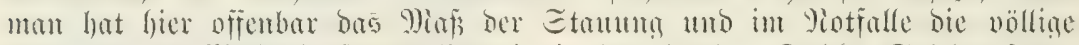

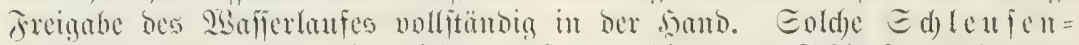

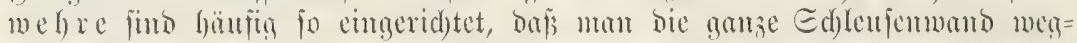

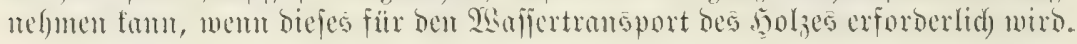

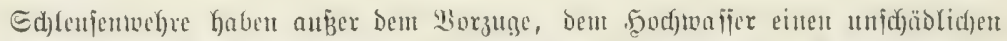

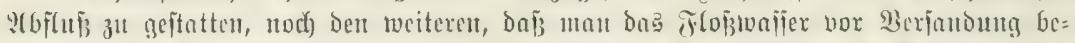

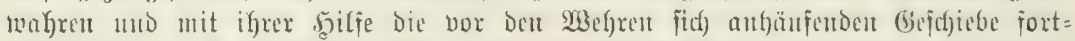

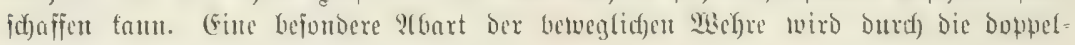

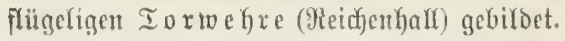

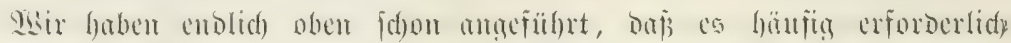

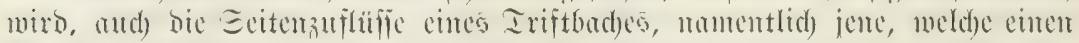
Slaushof fpesion, mit $\Xi$ a

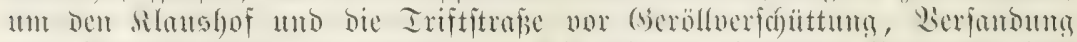

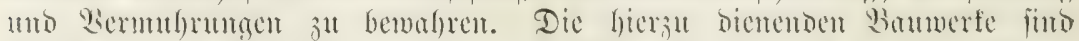

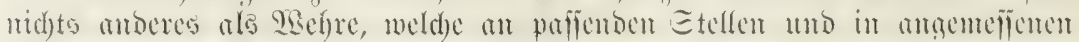

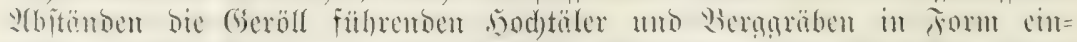

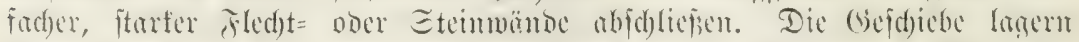

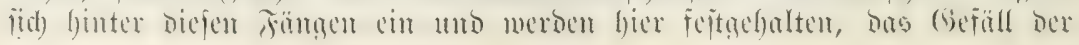




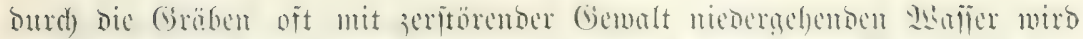

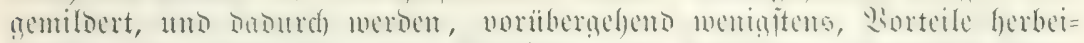

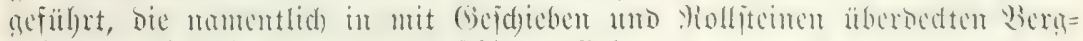
gehängen nidgt hod) gemug amzuid)lagen juns.

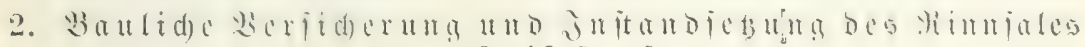
bex Iriftitráne.

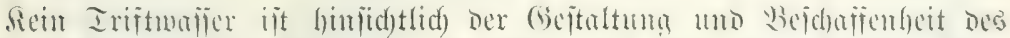

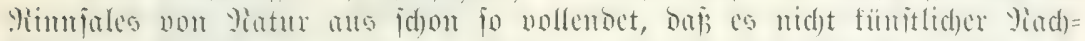

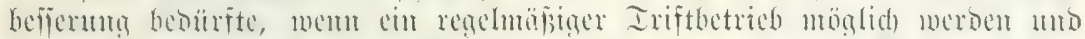

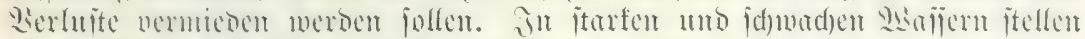

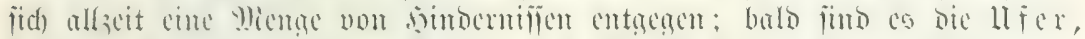

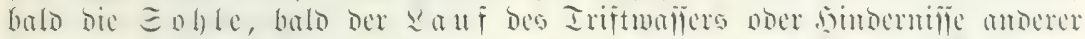

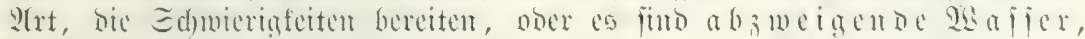

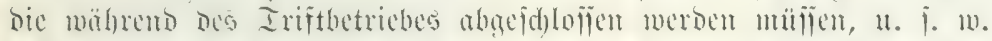

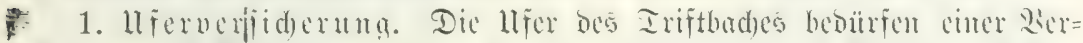

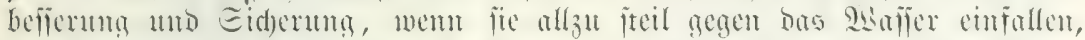

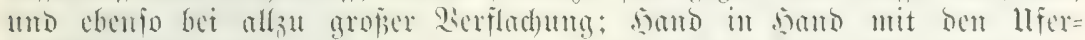

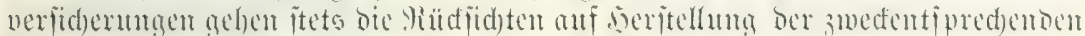
Bormalbreite bes Iriftmailers.

a) Sobe, iteile ober gar fenfredit efinfallende llferfind,

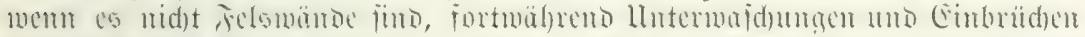

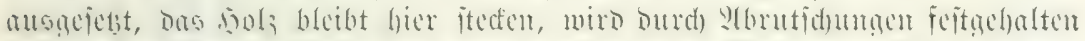

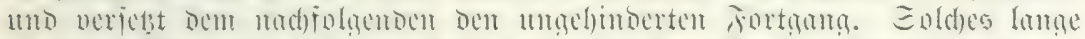

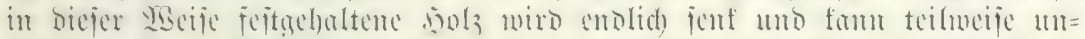

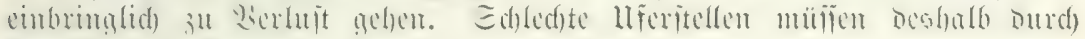
iog. Il ferbed ungen verbefiert merben.

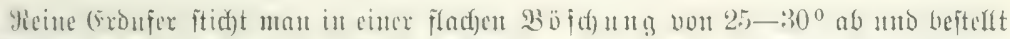

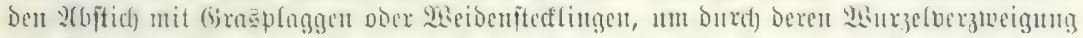

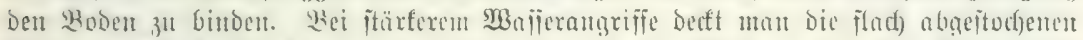

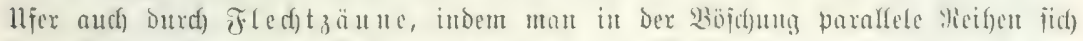

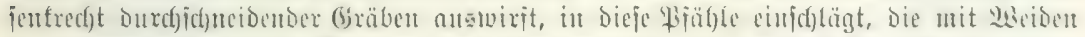

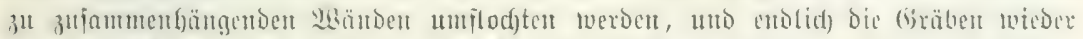

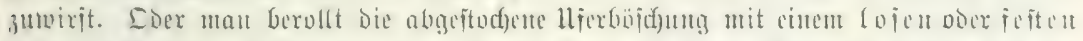

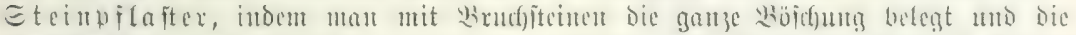

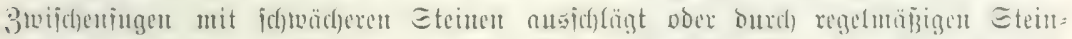

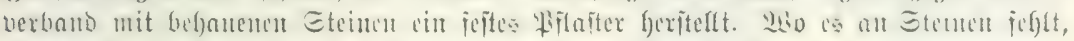

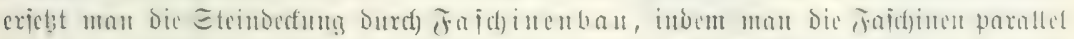

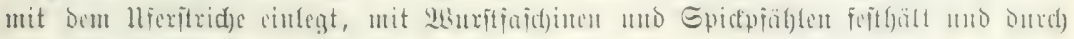

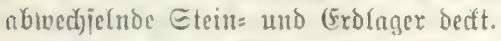

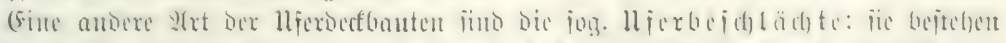

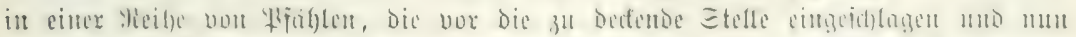

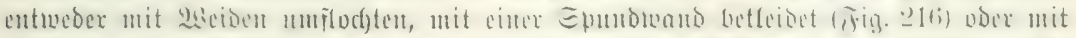

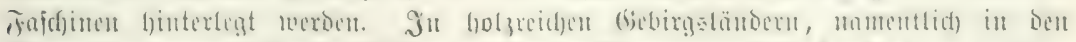

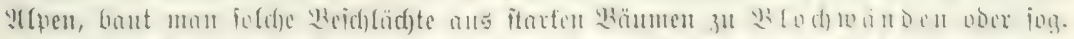

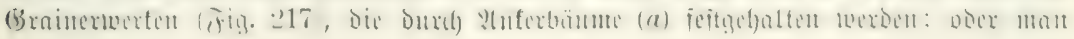


Deft Die llfer surdf Etcinfaitenbau mit iog. Ulerard)en Doer, wie gegenmärtig im

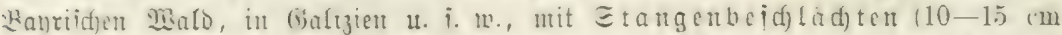
itarfe Etungen, bie mit langen Ylägeln an cingeranmte Pïähle angenagelt Dber, wie

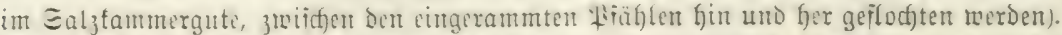
Wher alle bicie bözernou llierbectwerfe iollte man namentlid) in (Begenten tunlid)it

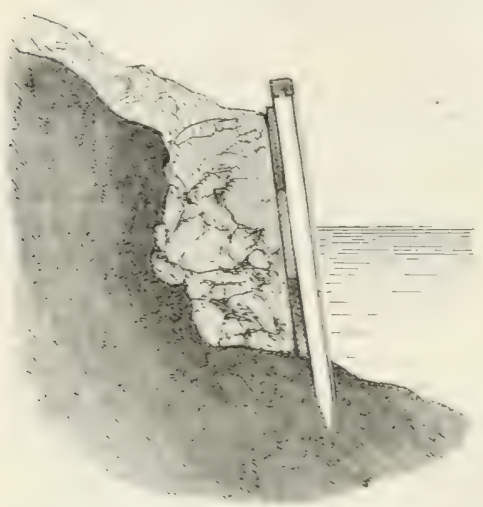

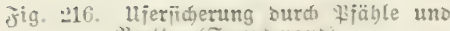
Bretter (ङounomand).

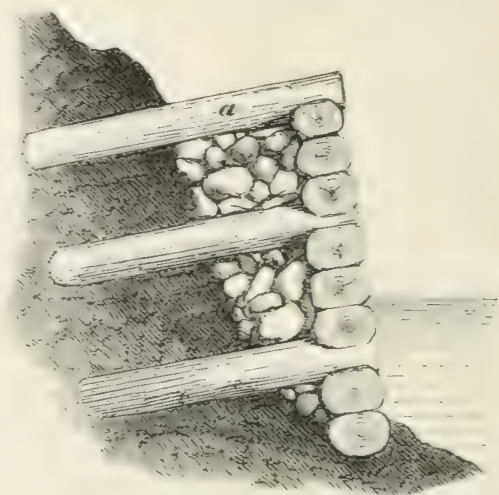

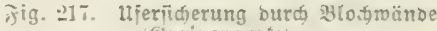
((5irainermerfe).

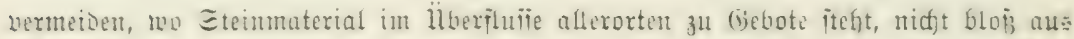

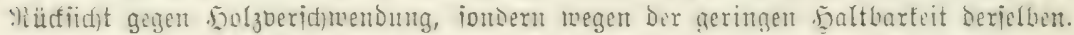

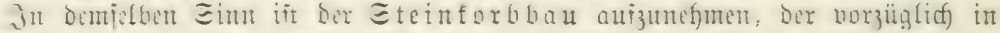
Den Gebirgen Der iüblichen Thenafbact)ung in (sibraudfe iteht. Ier Eteintorb iit

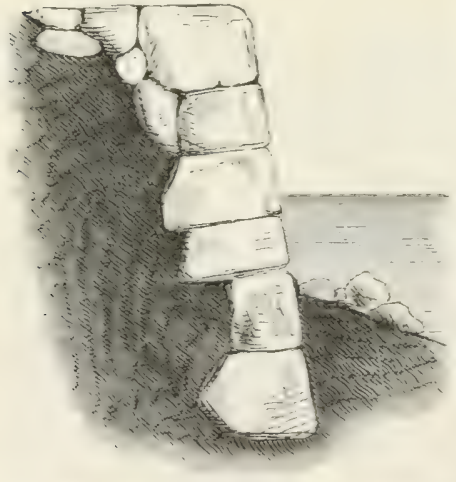

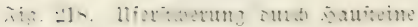

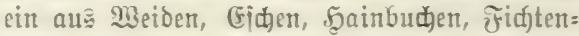
äîten u. j. In. in Geitalt eine abgefitubten Regel geflodftener fort, Der auf ber gröBeren Grimbiläd)e rufft und im Jintern mit Eteinen gefüllt ift; der Storb wirb ant Der Etelle, bie ex zum beabfiditigten Barzloefe cimnehmen joll, gefertigt. 3ur Eidjerung einbrïdjiger $U_{\text {jer }}$ fiellt man mefrere förbe unverbunden in furzen Ubjtänden vor biejelbell ein, ober man ber=

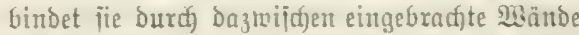
von Brettidjwarten. - Sin Eavonen, im füb. lidjen Iirol u. j. w. bebient man jidf) zur Hier= Decfung audf. Der unten beidjriebenten $\mathfrak{B}$ ö of c mit ftarter Steiniüllung.

Dic vollendetitent llierdecfwerfe pind die

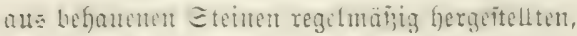

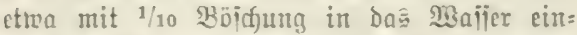

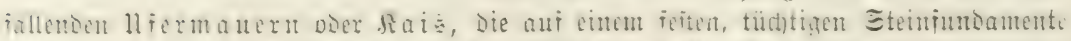

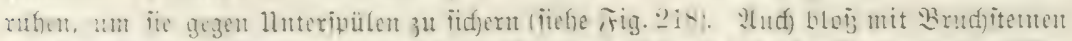

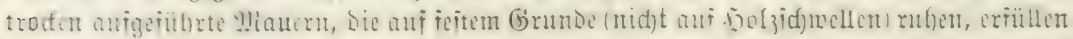

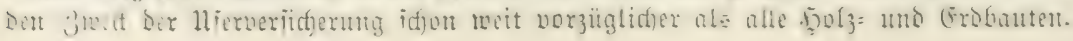




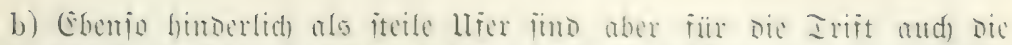

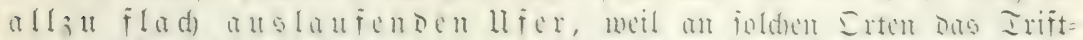

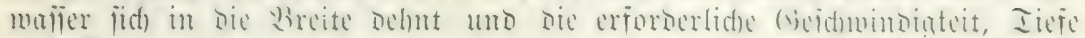

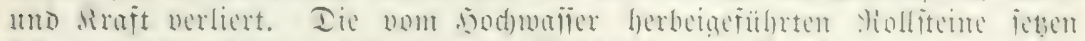

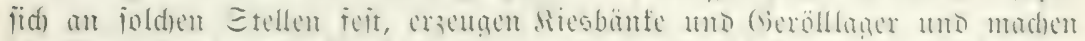

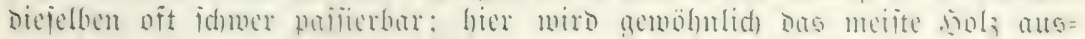

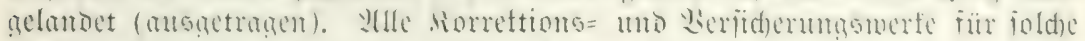

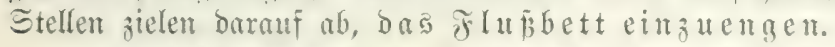

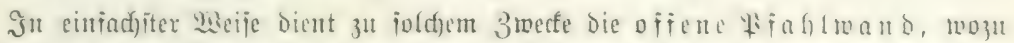

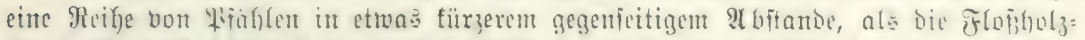

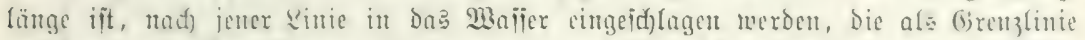

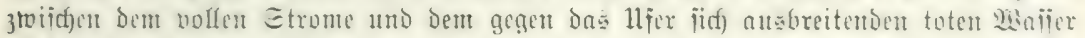

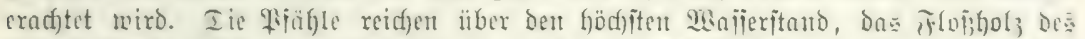

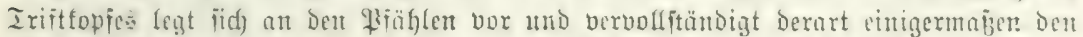

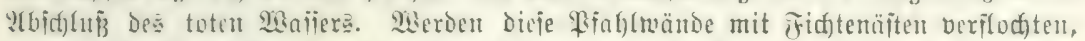

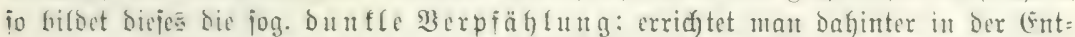

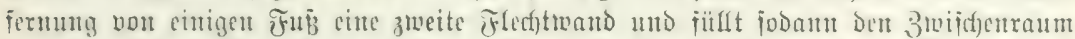

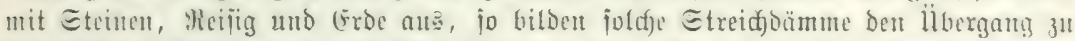

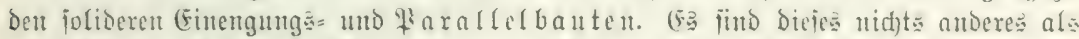
möglid)it dauerfajt aujgẹührte Iämme, moldfe parallel mit bent Etromptricfe in bas

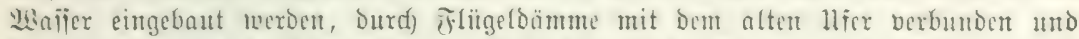

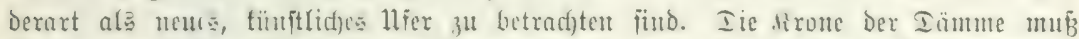

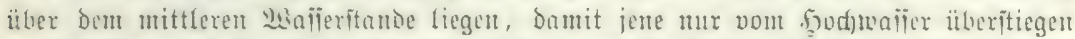

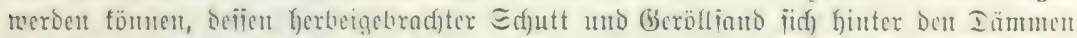

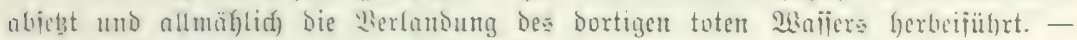

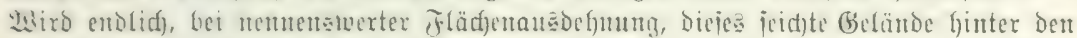
Liaralleherten mit einem Jebse von fid) Durfferenzensen Iämmen verbant, jo entitht

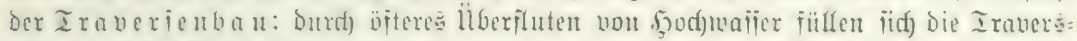

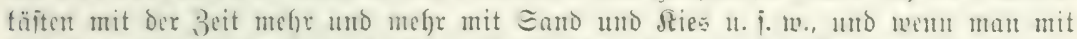
Der (Erhöhung Der Iämune gleidjen Edyritt hält, jo verlandet fid) bas in Wan ge:

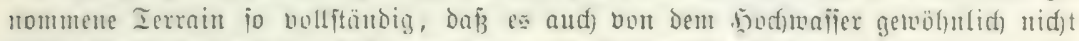

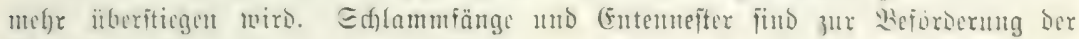
Verlanoung hier nicht minder am Wilabe.

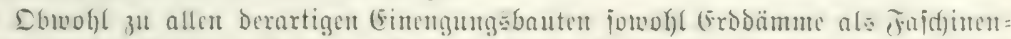

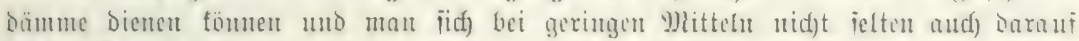

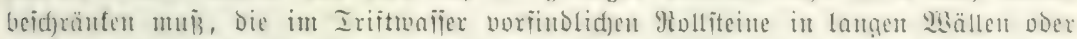

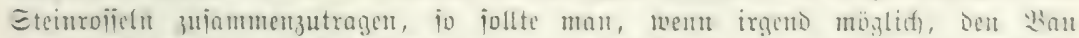

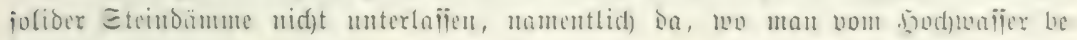
îtäubig zu leiben hat.

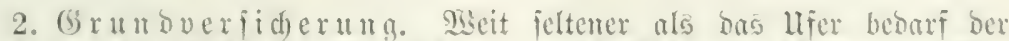

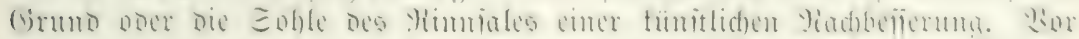

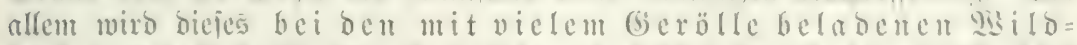

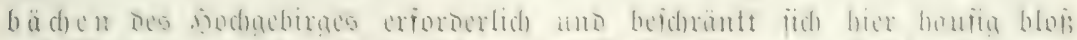
auf ㄴ.

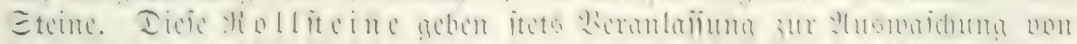

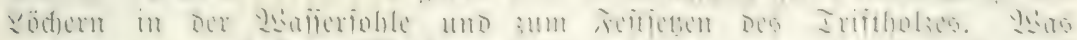

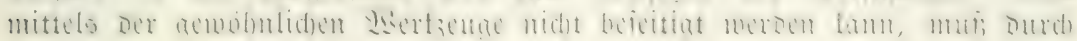




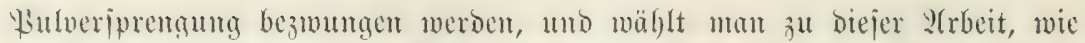

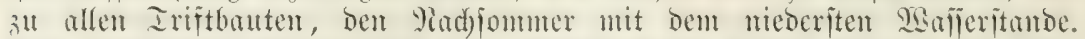

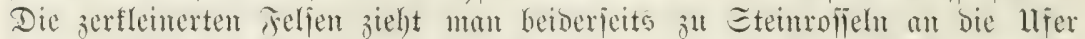

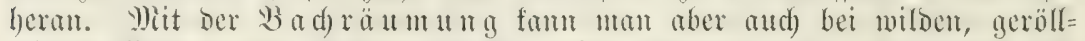

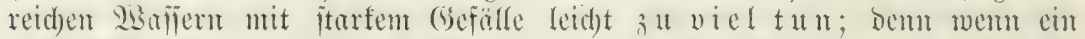

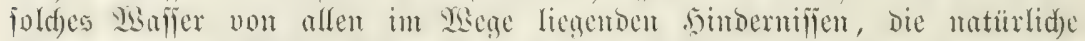

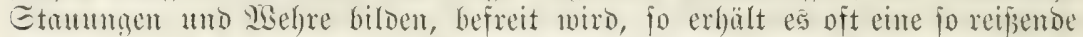

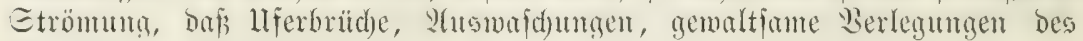
Rimiales u. F. w. Die fdlimme folge firto.

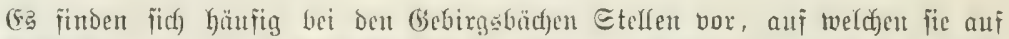

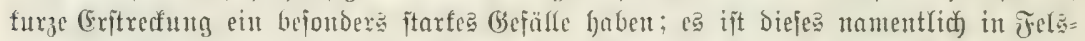

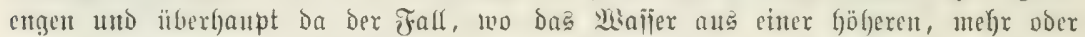
wentger verriegelten Inlftufe in eine niebere herabjteigt. Shier ergebent jid Etrom=

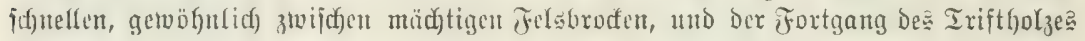

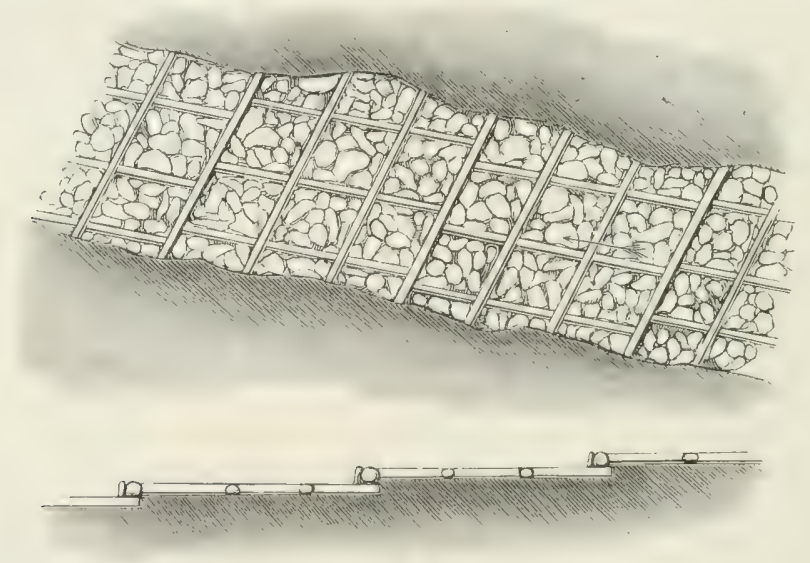

శjig. 219. Berïherung ber Sohle bes Zriftbaches.

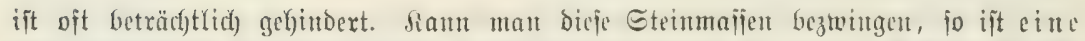

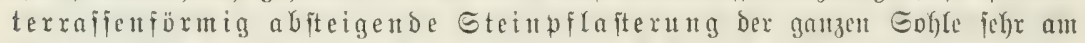

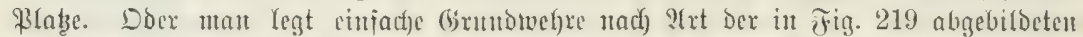

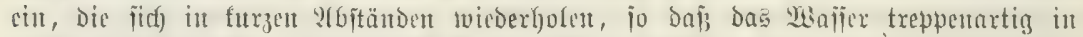

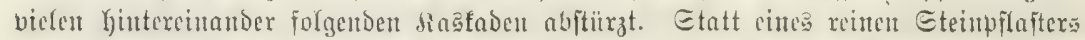

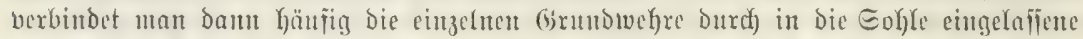

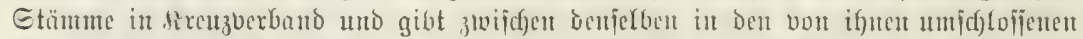

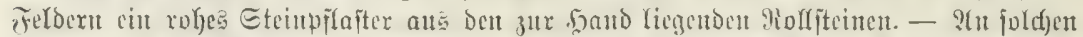

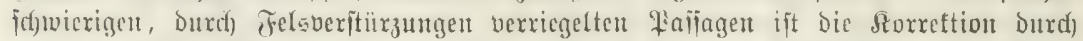

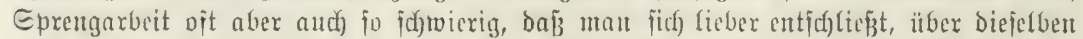

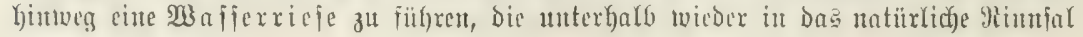
einmündet.

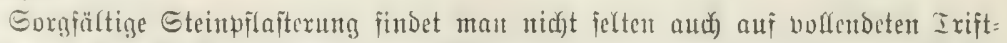

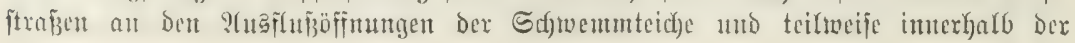
Intsteren jelojt. 


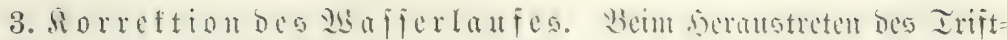

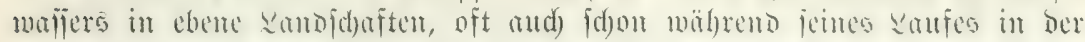

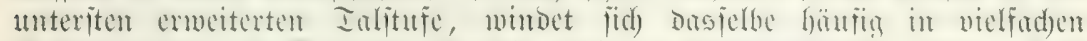

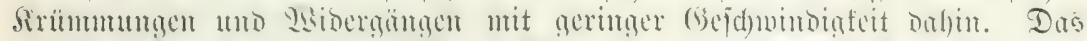
Irifthols bat cinen äberams langen

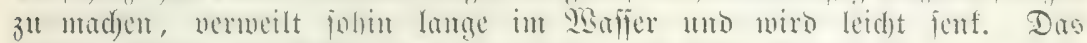

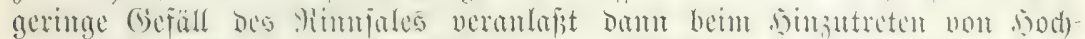

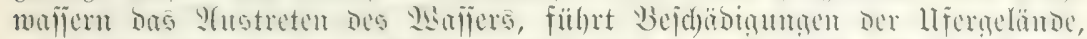

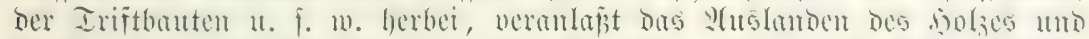

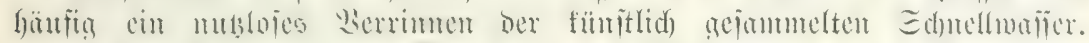

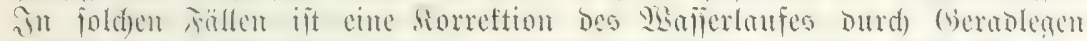

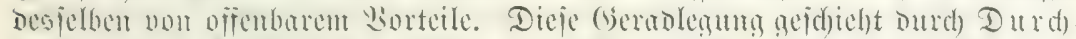

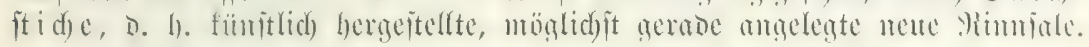

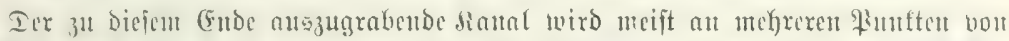
Der Ditte ans begumen und gegen Die Berbindungspuntte mit Dem natïrlidjen

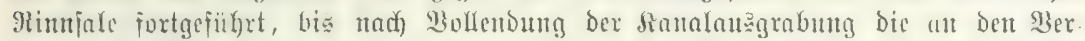

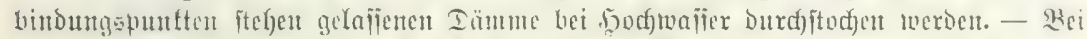

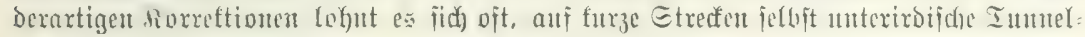

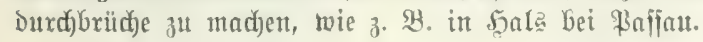

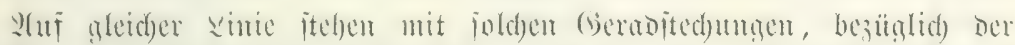

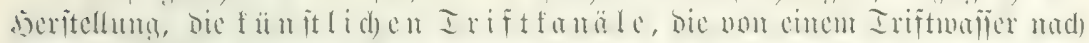

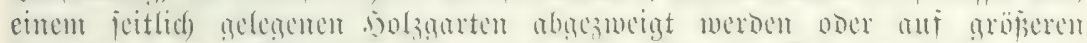

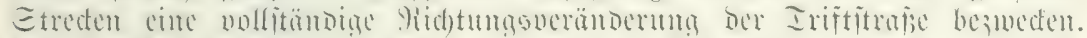

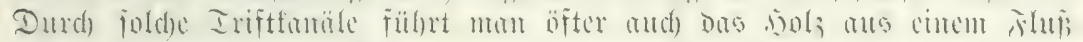
gebiete in ein moeres ïber.

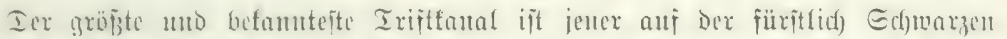

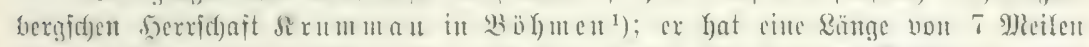

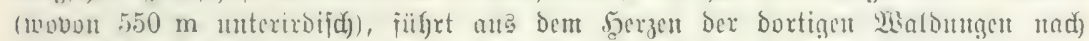

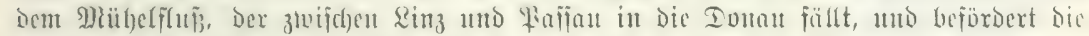

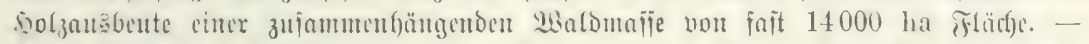

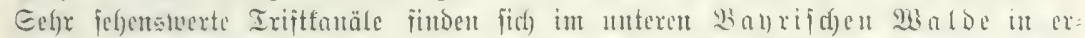

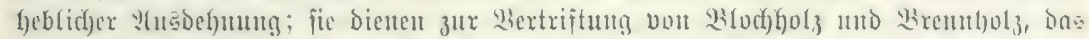

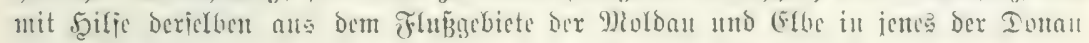
iiberiügrt twiro.

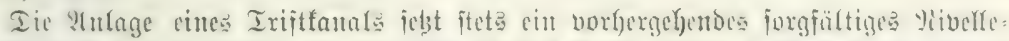

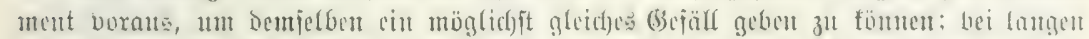

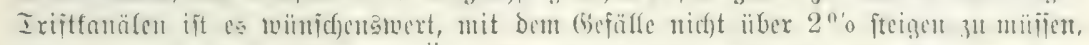

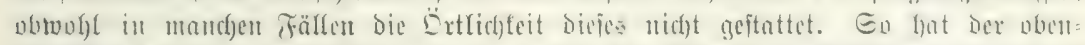

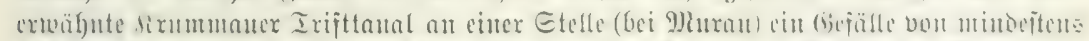

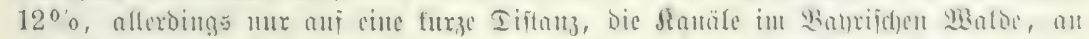

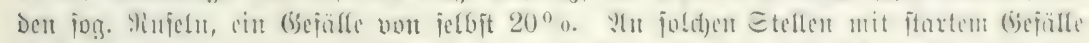

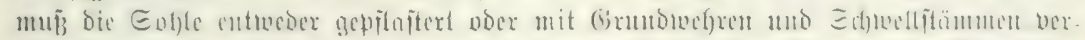

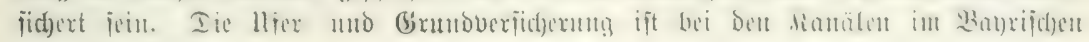

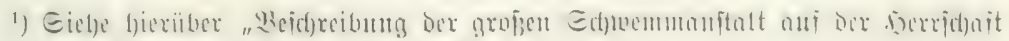
Sirummau in ßöhutr. WBien 1831 bei Gollitger". 


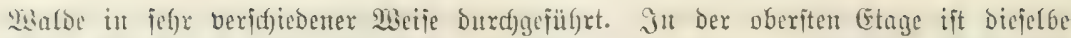

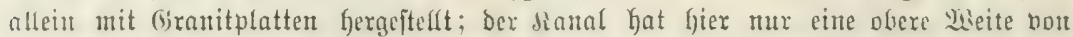

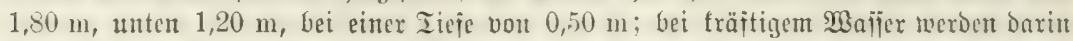

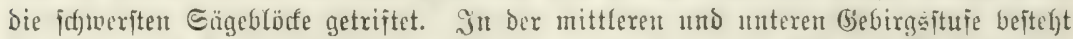

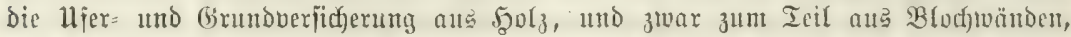

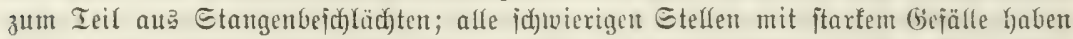
cine Durch fräftige (Erundidfmelfen gebildete jolide Serjicherung ber Ranaljüfle.

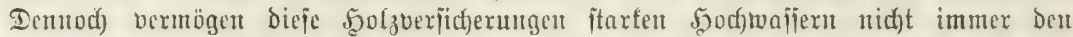

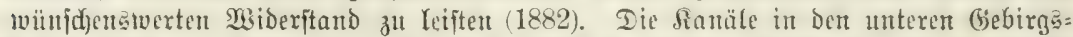

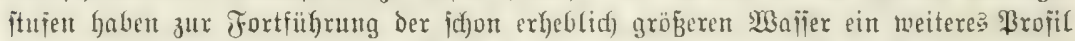
als bie eritgentanten; bie obere Weite ocriclben getgt hier biz fajt $343 \mathrm{~m}^{1}$ ).

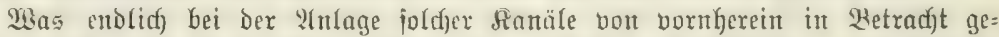

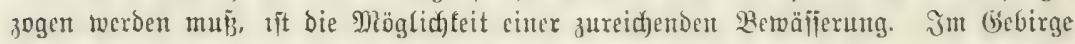

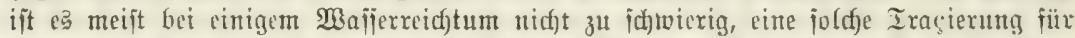
Das ganze Sianalprojeft zu gewinnen, da

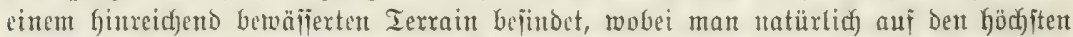

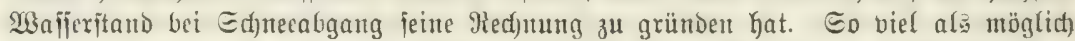
judjt man bann alle ftändigen Gebirgswajer mit Dem Ranal zu Durdjidnneiden und alle ftürteren Suellen in Denfelben cinfufïhren; oder die Ranüle merden, wie im Batrijden Malde, bireft burd) Rlaustwafier geipeijt.

4. Beriaderumg Der Iriftitrafe gegen bas

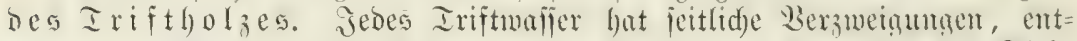

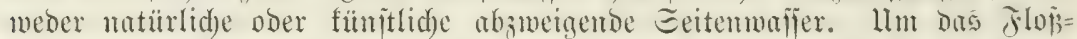

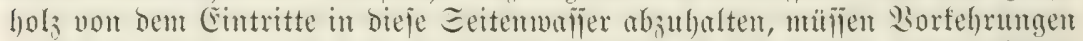

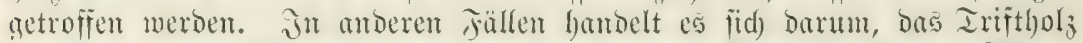
aus dex bauptriftitrabe heram und in cinen Eettenfunal eimaführen,

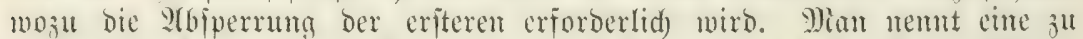

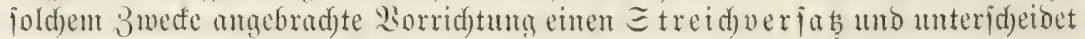
fduminmende und feite Beriäbe und $\mathfrak{A} b$ meis red en.

Wenn man einen gut ausgetroffueten Fichtenitamm mit Wieben am llfer bc=

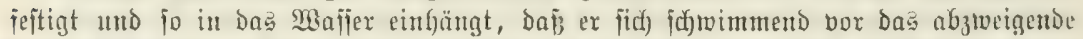

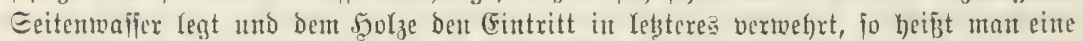

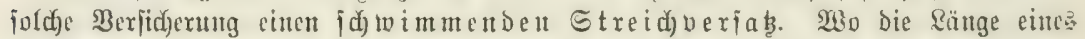

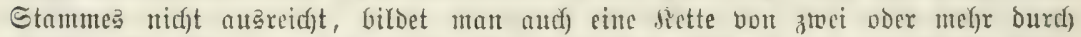
Wieden ober (Eijenringe berbundenen Etämnen (Fig. 220), Yetzterę namentlid), wemu

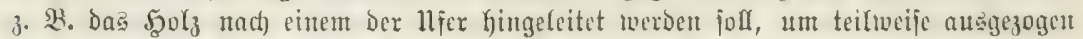

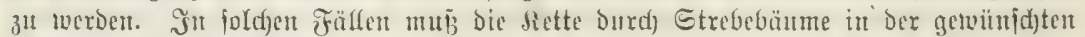
Rage erhalten werden.

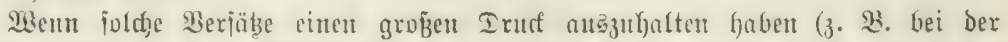

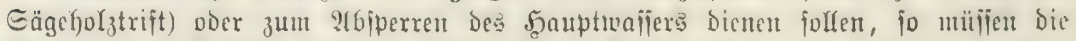

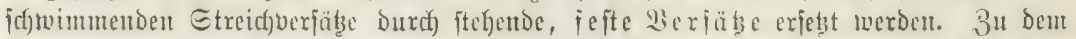

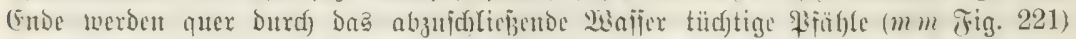

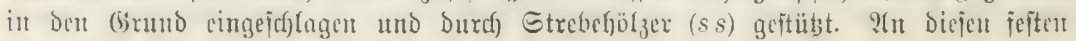

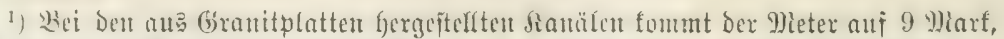

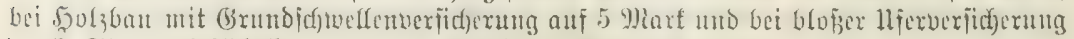
. Durd) Stangenbejd)läd)te auf 2-3 Marf per Mleter (Gampert). 


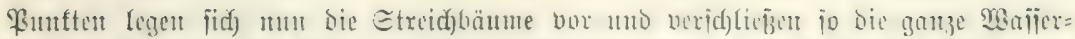

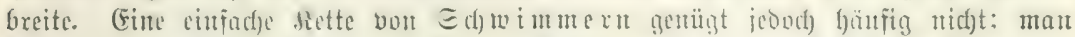

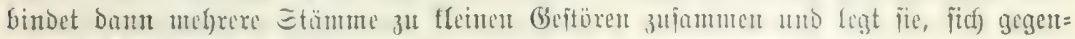

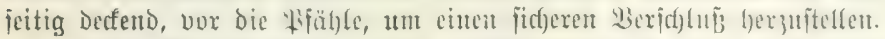

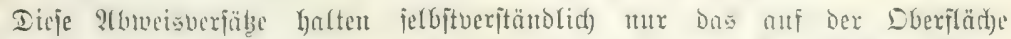

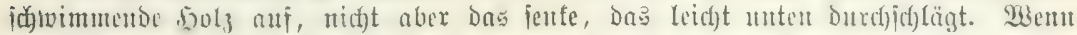

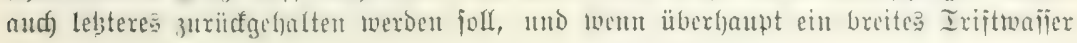

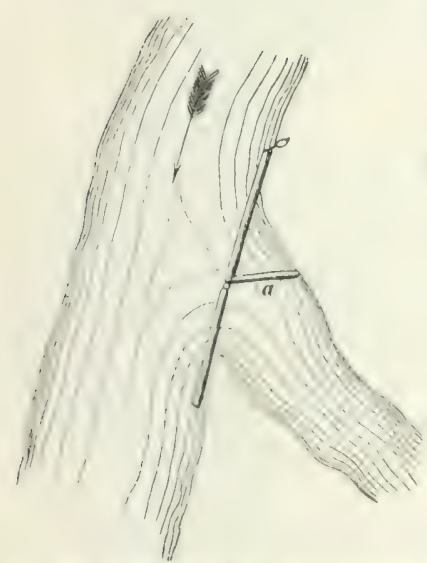

अig. 220. Sdwimmenber Streidverfak.

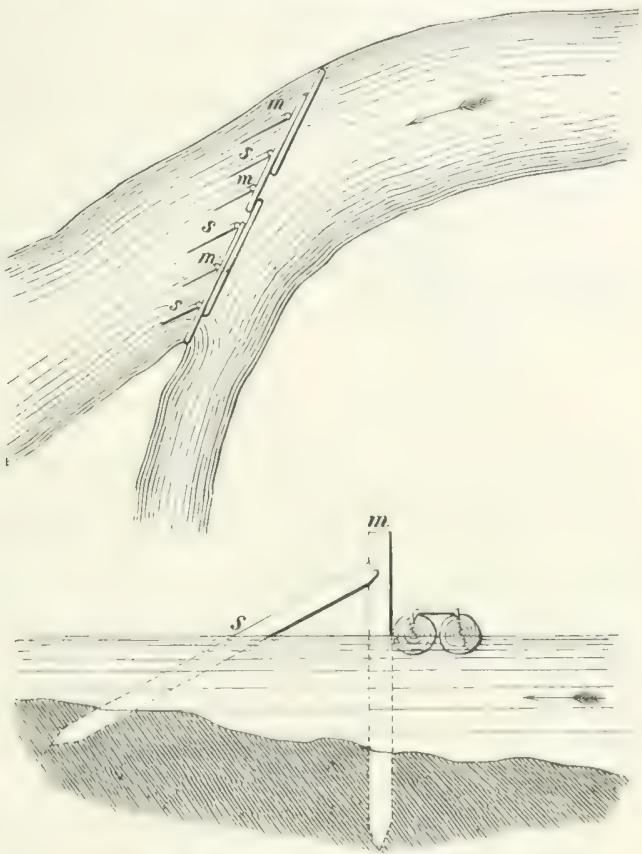

Fig. 221. Feftitehender Etreidinerfaç.

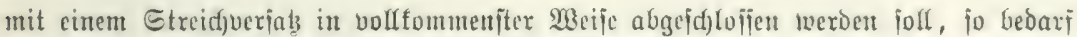

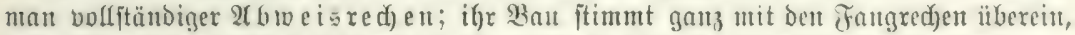
westgalb wir bezïglid) derfelben auf bie unter 3 . folgende Inriteflung bertweifen.

5. 3) $\|$ a

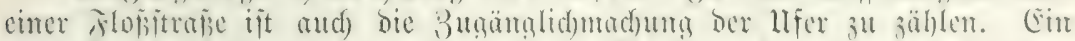

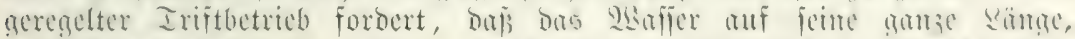

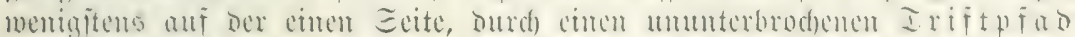

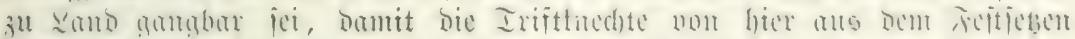
and ? ?

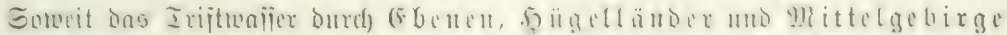

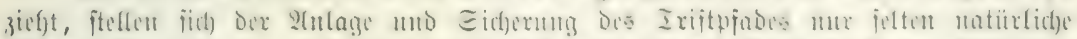

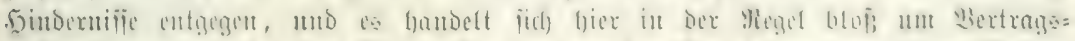

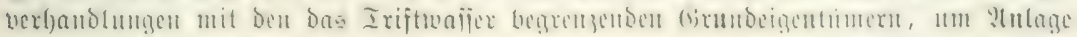




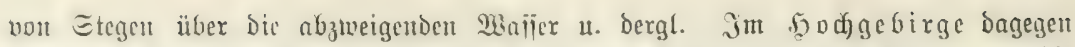

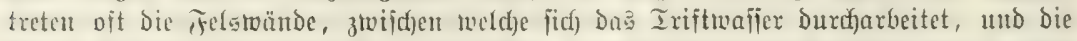

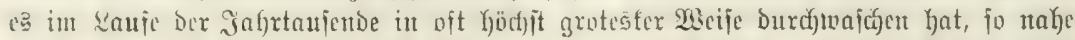

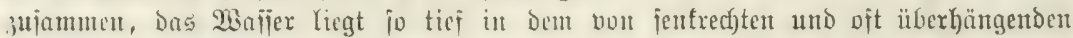

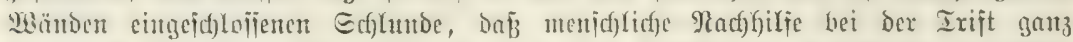

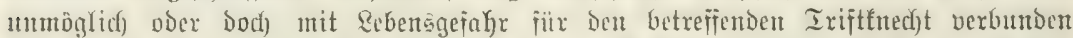

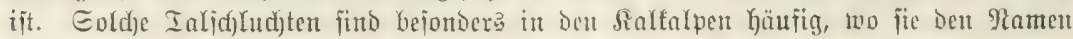

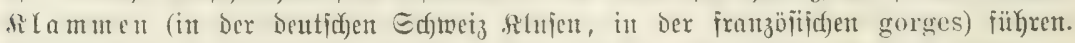

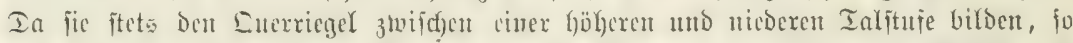

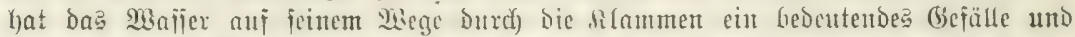

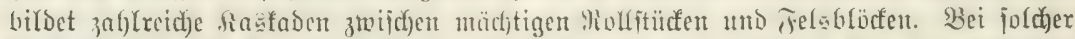

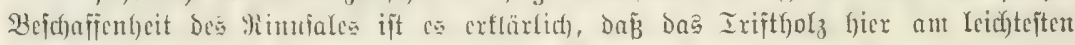

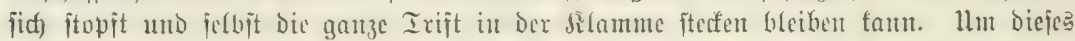

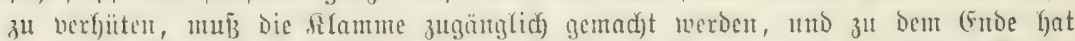
mant viefe dilammen mit hölzexuen (balerien burd)zogen, bie von cifernen difoben

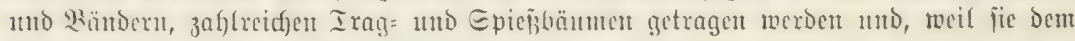
Maijergeiälle zu folgen baben, Durd) Ireppen unterbrodben finb.

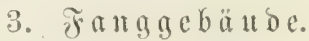

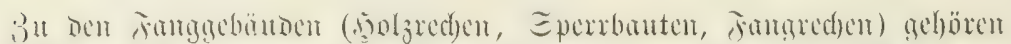

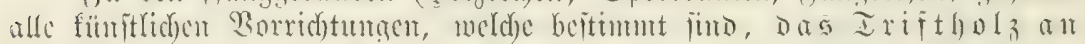
cimem be it im me

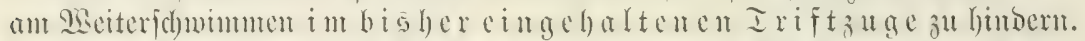

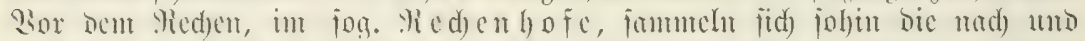
mad) anfonmensen Irifthölzer an, lagern fid lice fejt, uno ment bie Irift

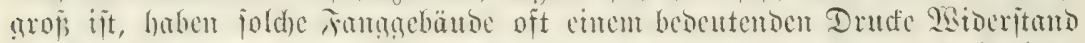

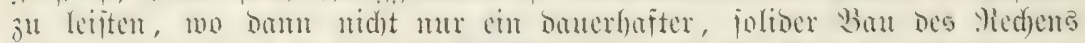

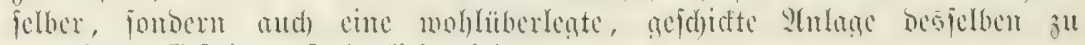
güntigem Erfolge exforberlid) wiro.

(5. gibt Eperbanten bon höd)fit empad)en Lau und geringen Iimenfioncu bi

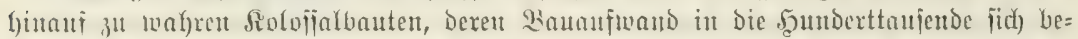

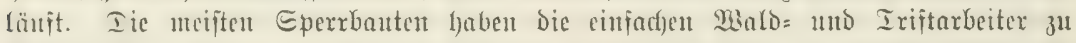

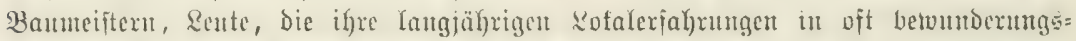

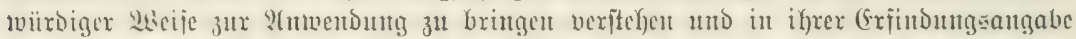

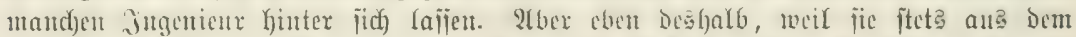

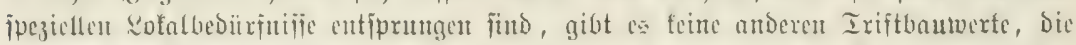

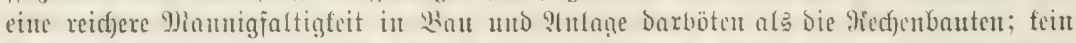

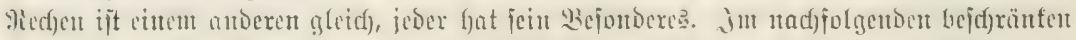

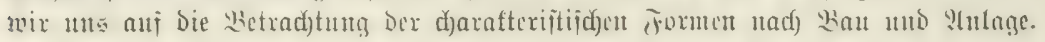

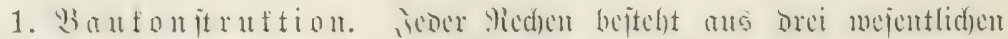

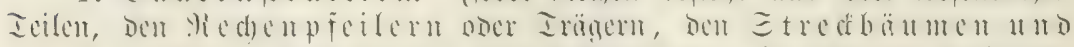

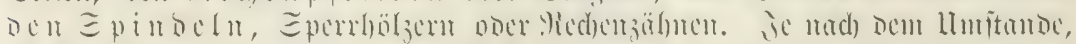

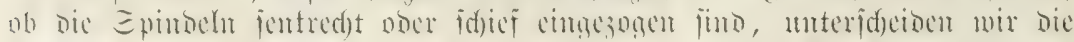

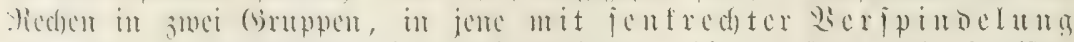

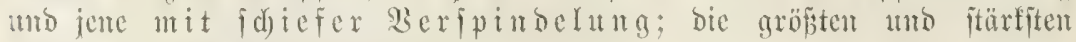
Hedjen gebören bex lebteren an. 


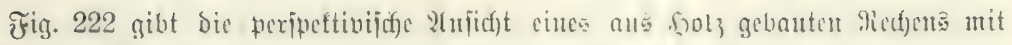

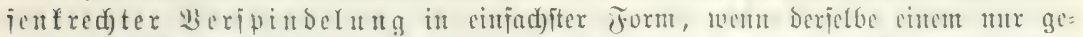

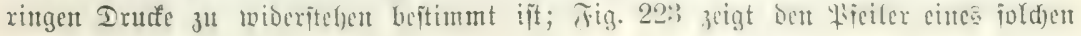

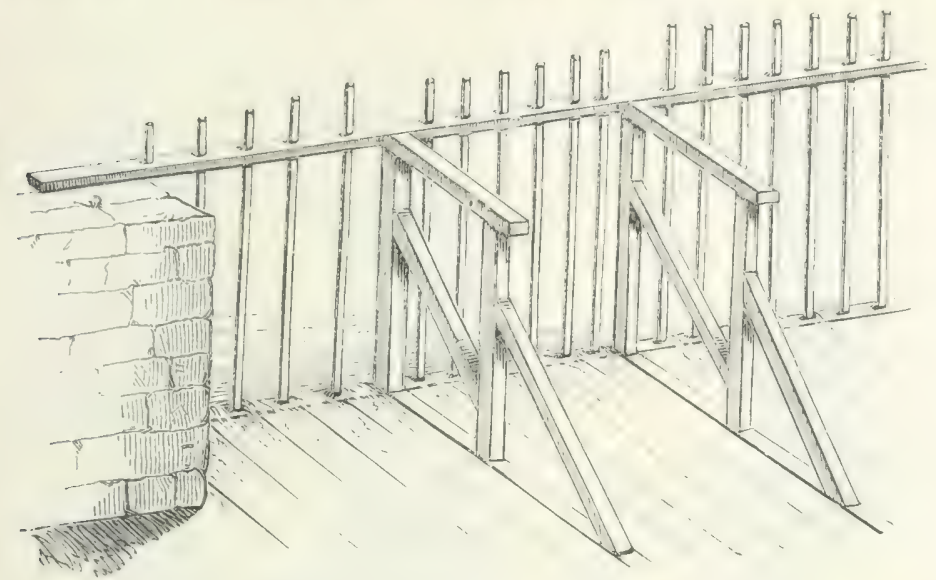

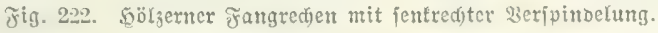

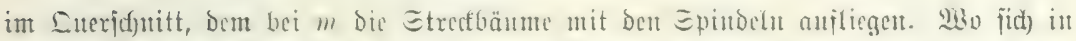

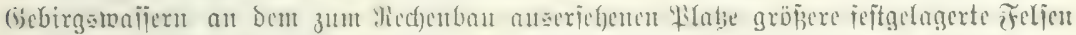

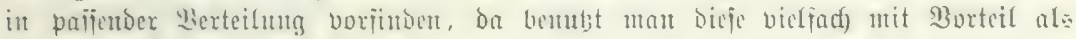

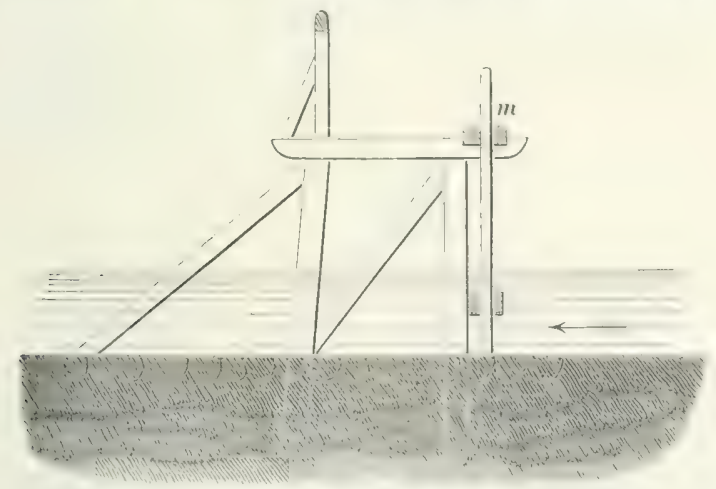

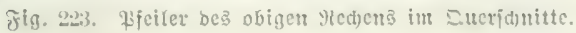

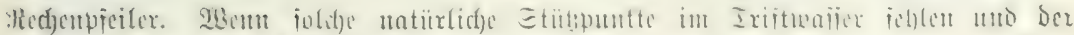

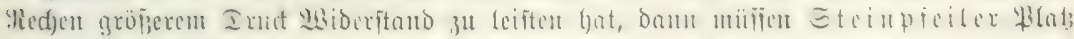
greifen ( (־ig. 224) ${ }^{\text {}}$ ).

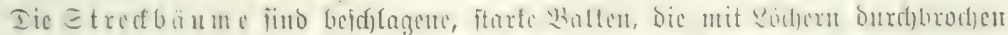
jins, un bie Epindeln onrd)

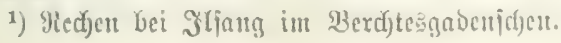




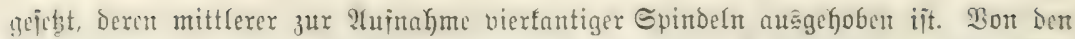
Etrufbäumen legt man Göufig ben unteren hart auf bie Majieriofle ein (Jig. 222): cr tonjerbiert jidi berart am beften.

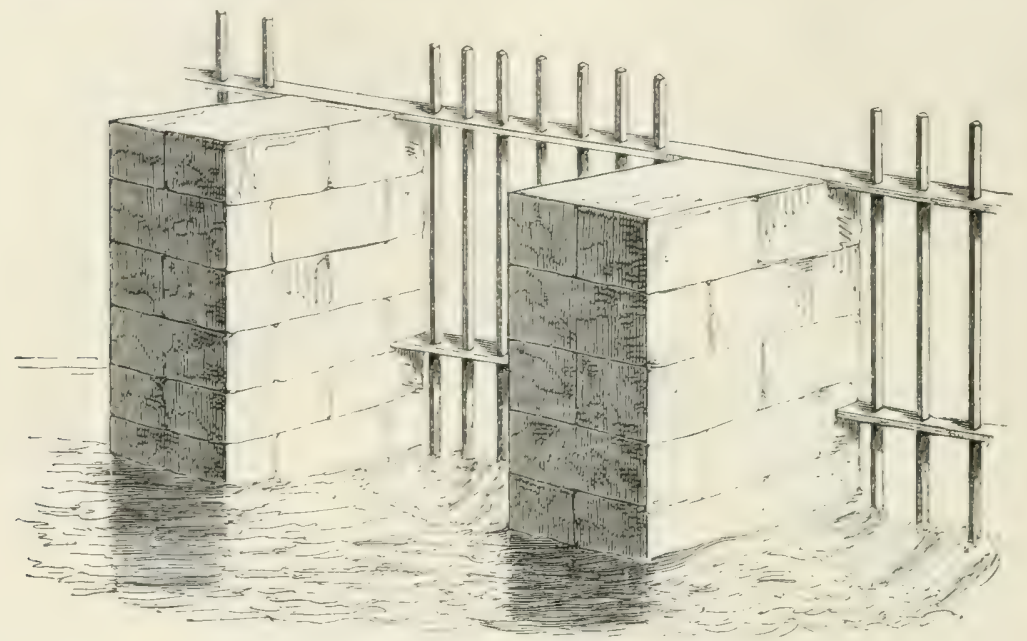

శ̌ig. 224. Fangreden mit ๔teinpfeilern.

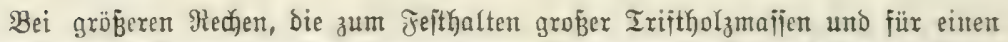
jtarfen $\mathfrak{B a j i e r b r u f f}$ beredynet find, bebient man fïd in Der Regel ber fdjiefen $\mathfrak{B} e r=$

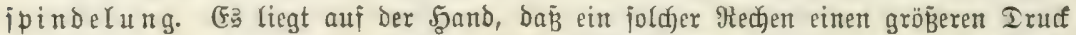

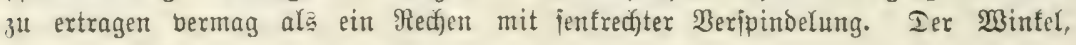

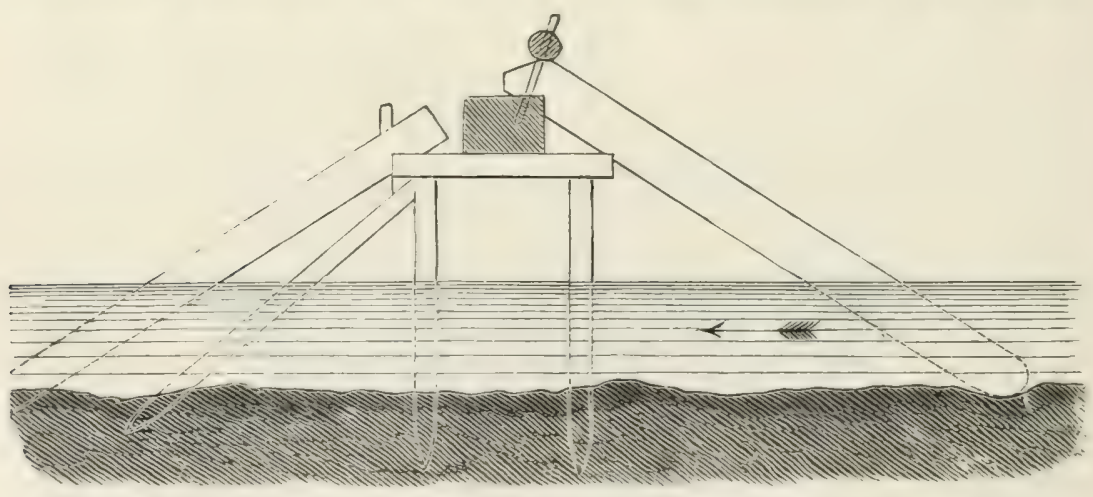

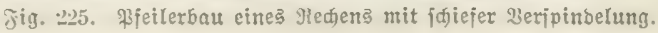

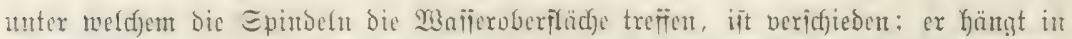

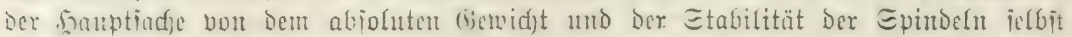

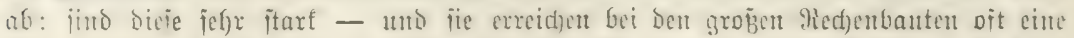

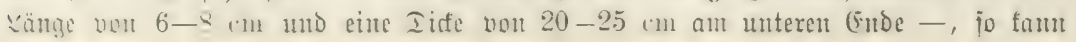




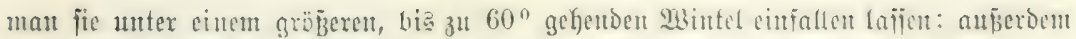

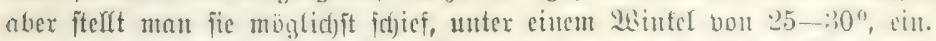

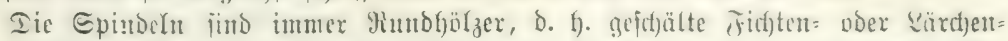

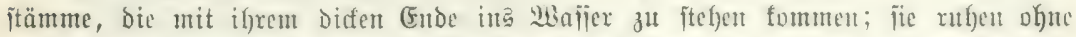
weitere Bejeftiguntg cinfad) anf Der Evhle Des Iriftectes nuf. Quer vor Den Epindel=

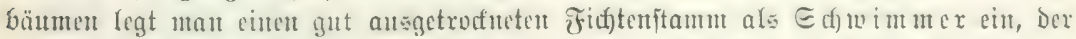
Den Ampraff Des anfommenten Iriftfolzes in Feiner Wirfung nuj Dir Epindelu zu

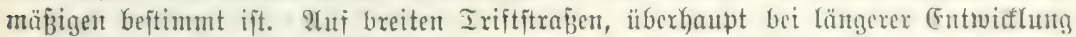

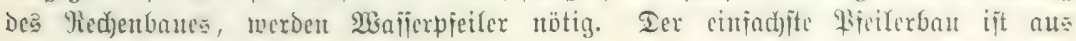
Fig. 225 zu entuthmen.

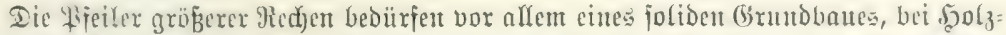

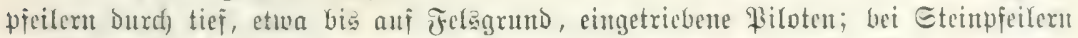

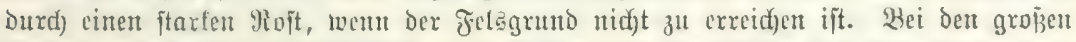
Med)en, wovon bie untenftefyende, Den Ked)en auf bem Regent bei Regensburg Dar=

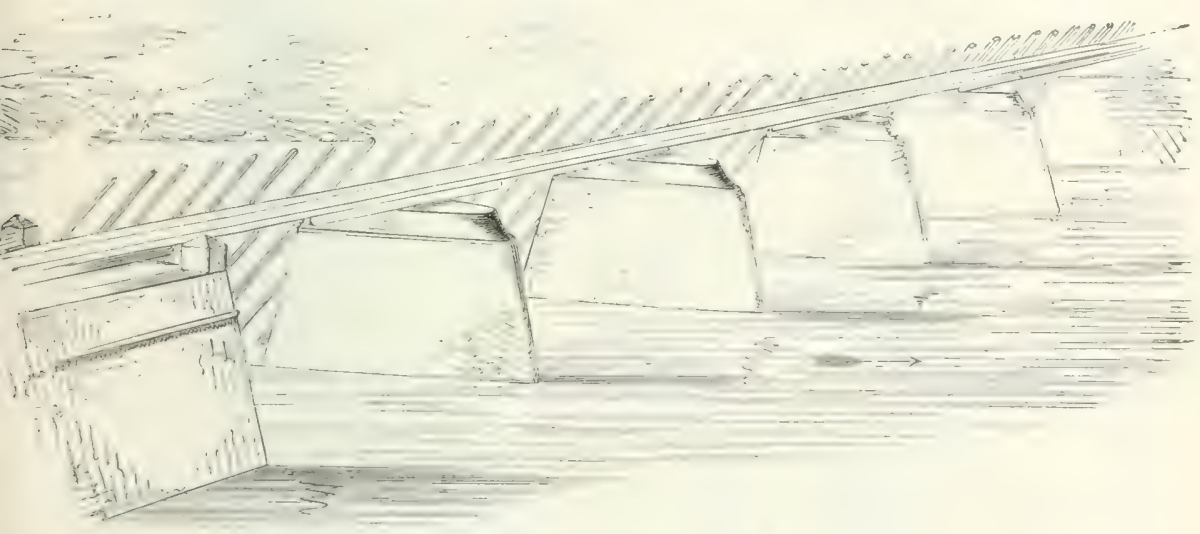

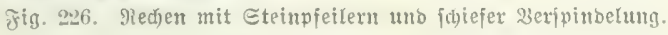

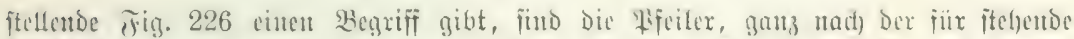

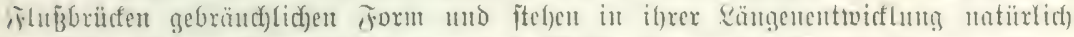

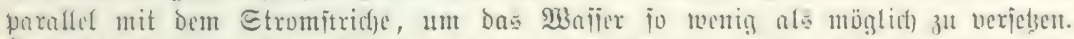

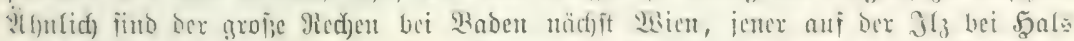

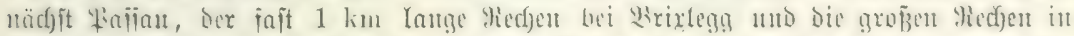

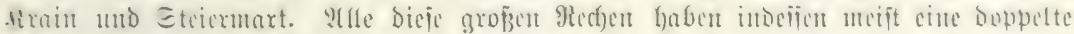
Beripintofung: eime fojicfe und eine gerade.

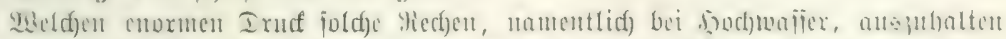

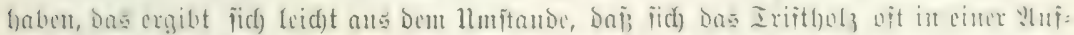

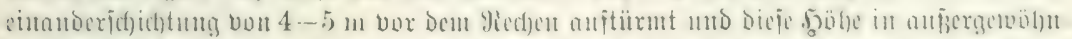

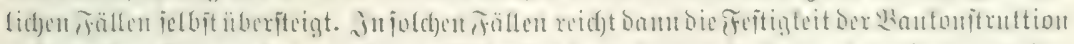

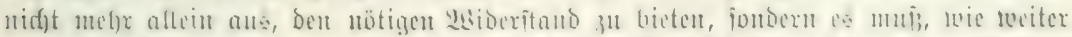

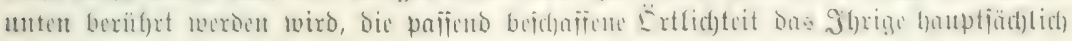
mit Dazu beitragen.

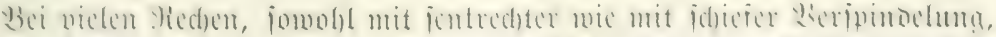

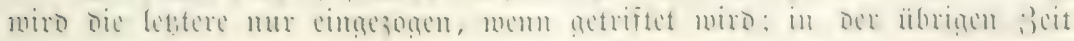




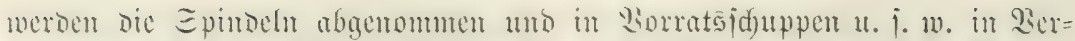

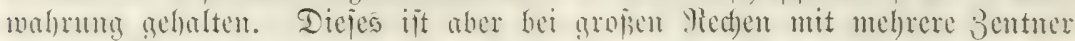

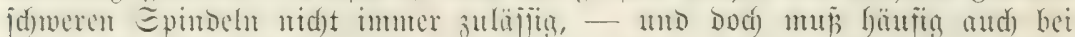
biefen ein Itil Der Eptndeln anfgezonen merben fömen, wem dos Irift=

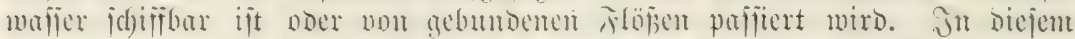

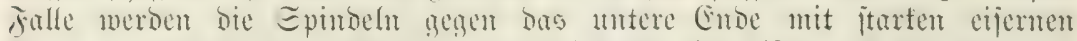
Yingen veriehon, in weldye man mit Ecilhafen cingreifen und Die Epmbeln

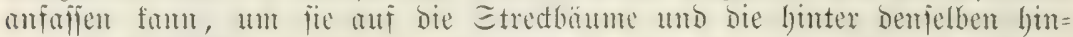

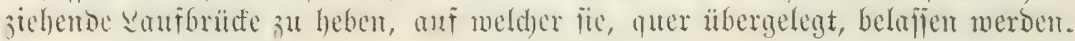
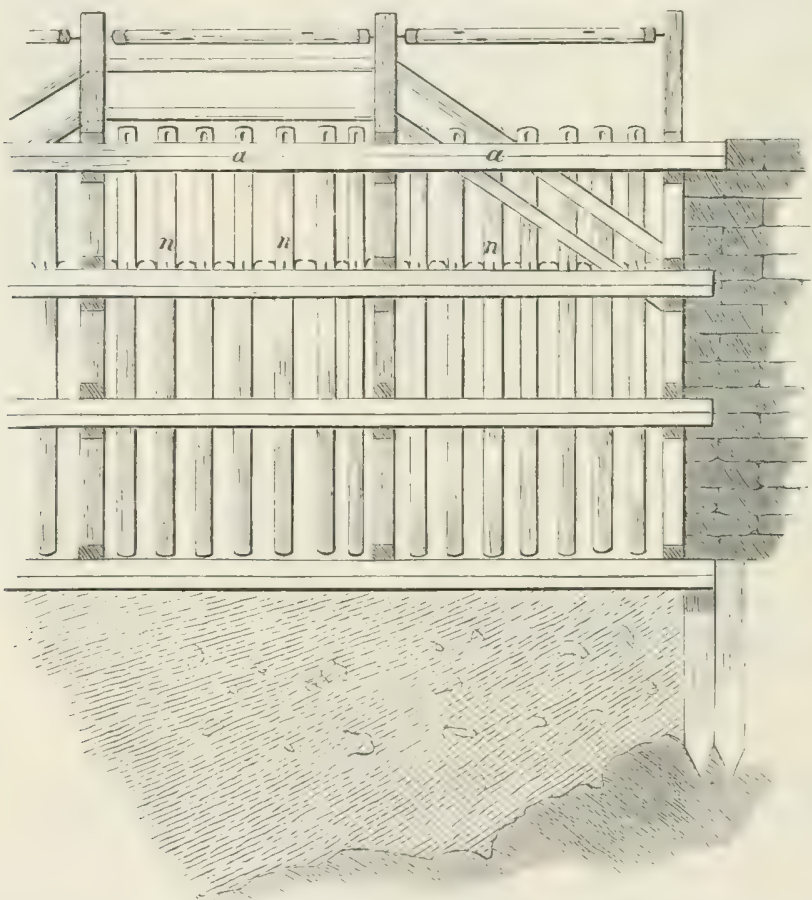

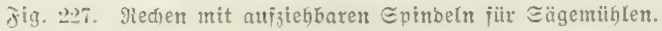

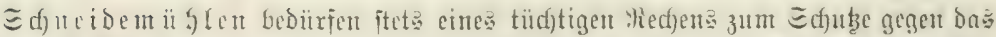

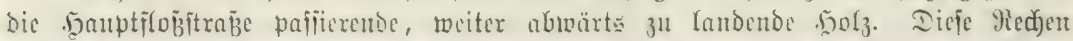

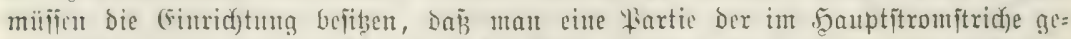

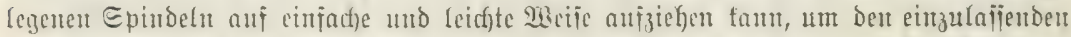

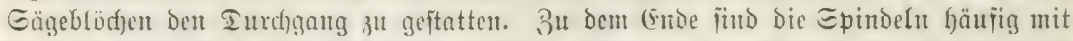

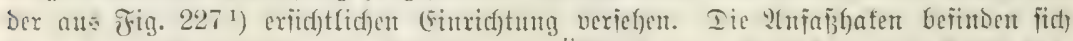

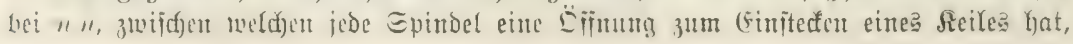

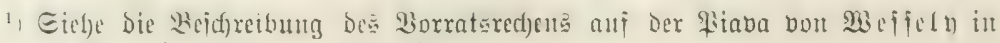
Dex Diterr. Bierteljahrşdjrift. XI. 389. 


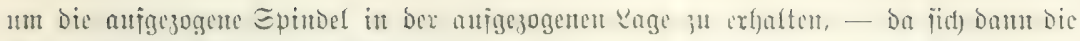
Reile auf Dą Bebälfe $a$ a itüben.

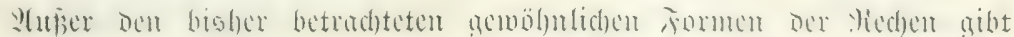

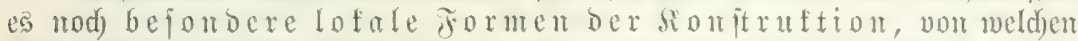

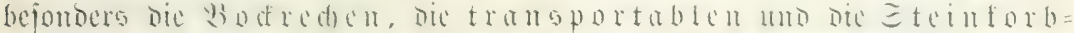

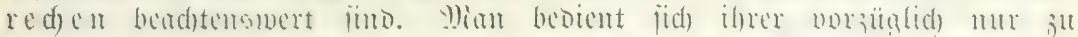

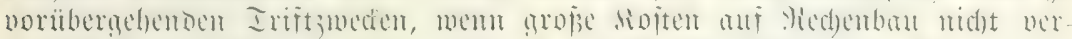

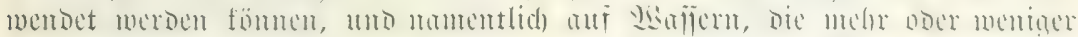

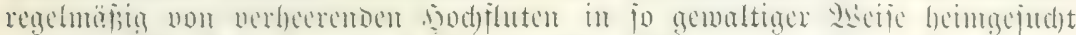

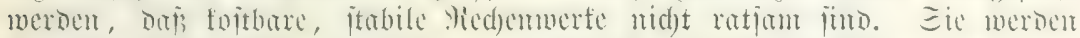

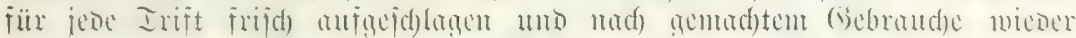

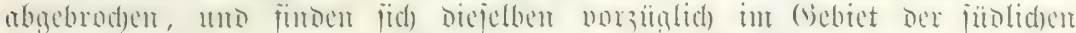

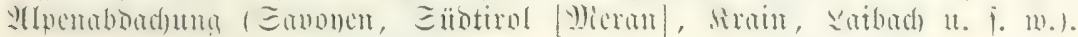

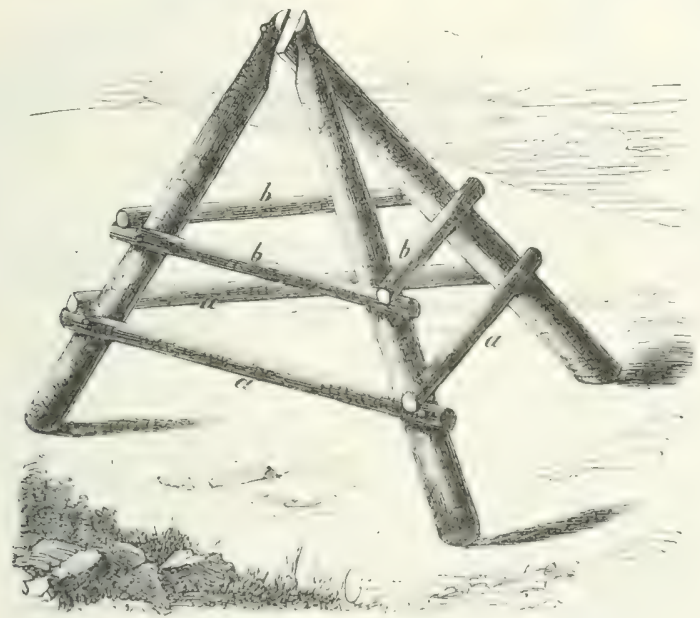

Jig. 2.28. Mectienbor nuล brct jtarten Bäunten.

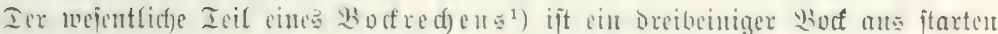

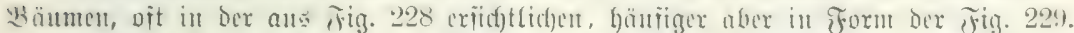

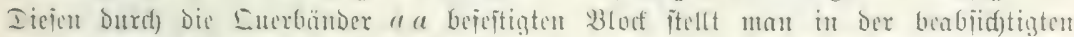

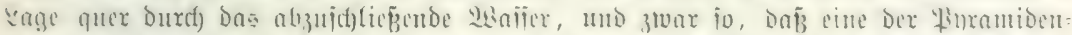

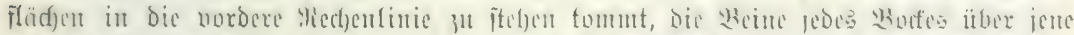

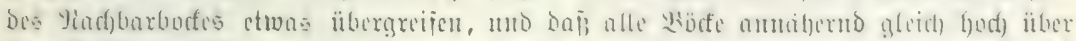

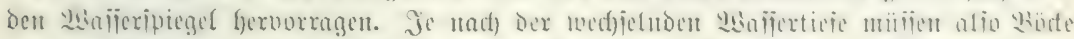

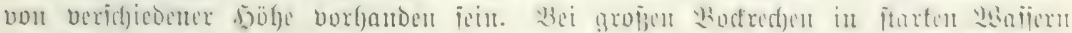

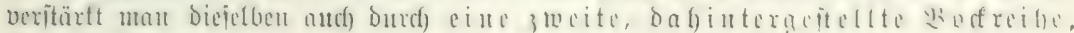

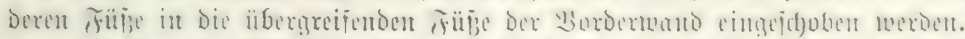

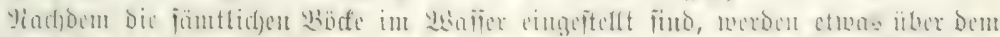

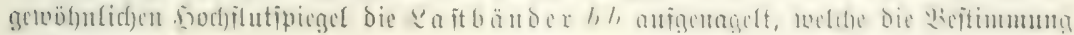

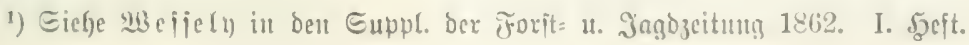




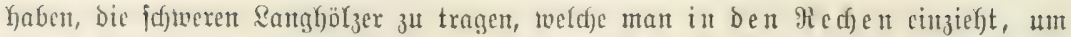

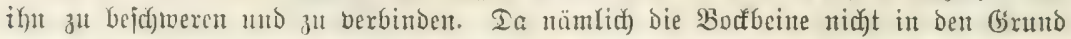

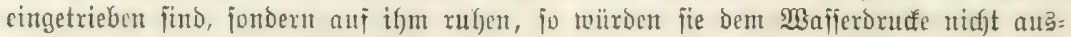

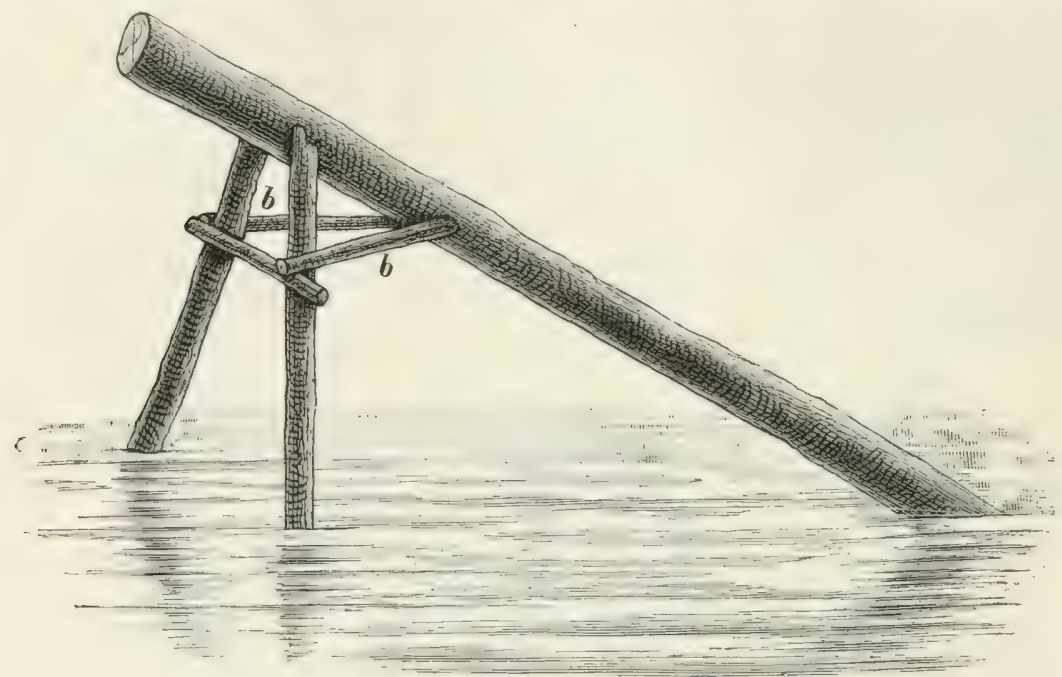

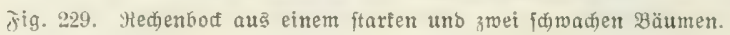

reidenden Miderftand Keiften, wenn nidjt für bic Bela ftung ber Böffe Eorge ge=

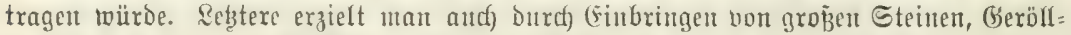

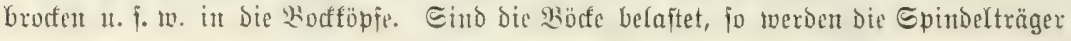

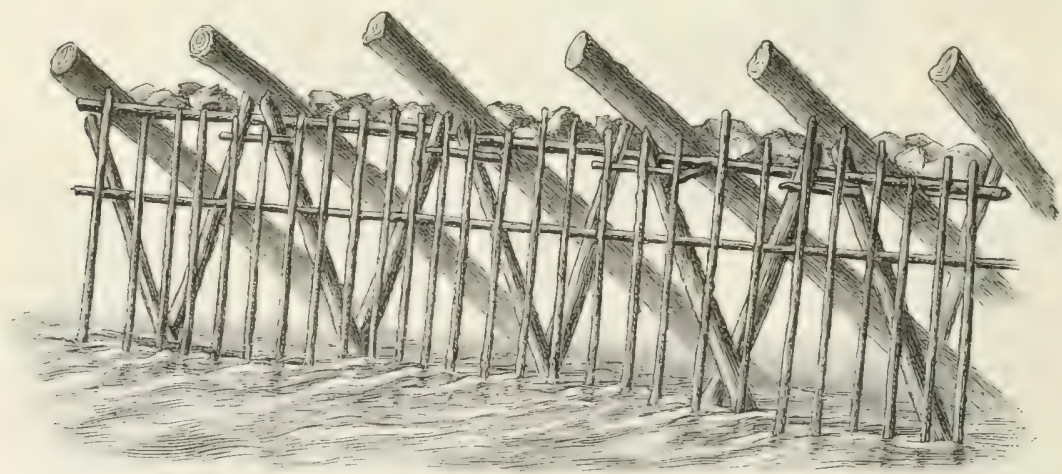

Jig. 230. Jertiger 2odrechen.

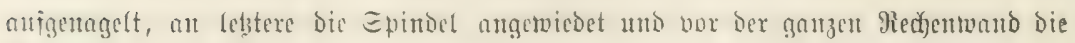
Edimimmer eingelegt.

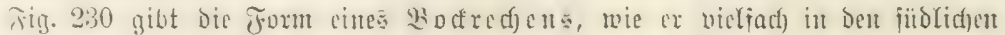
ATlpenländern angetroffen twiro. 


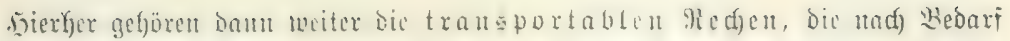

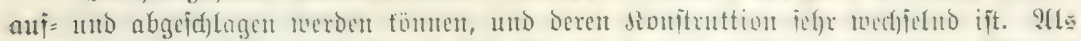

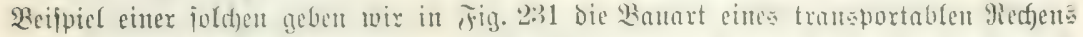

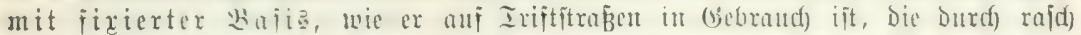

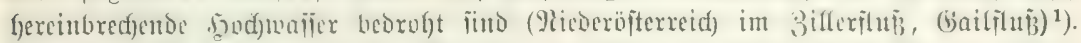

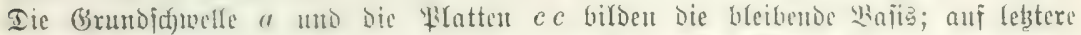

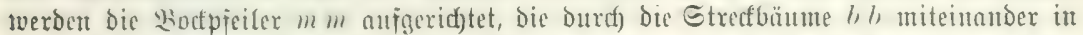

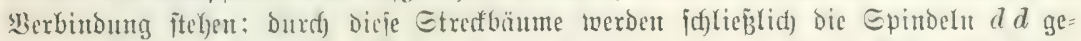

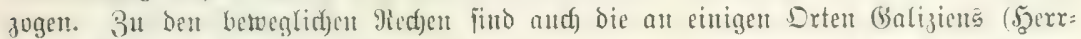

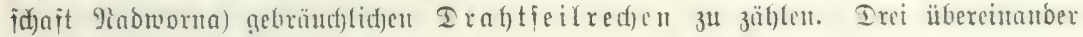

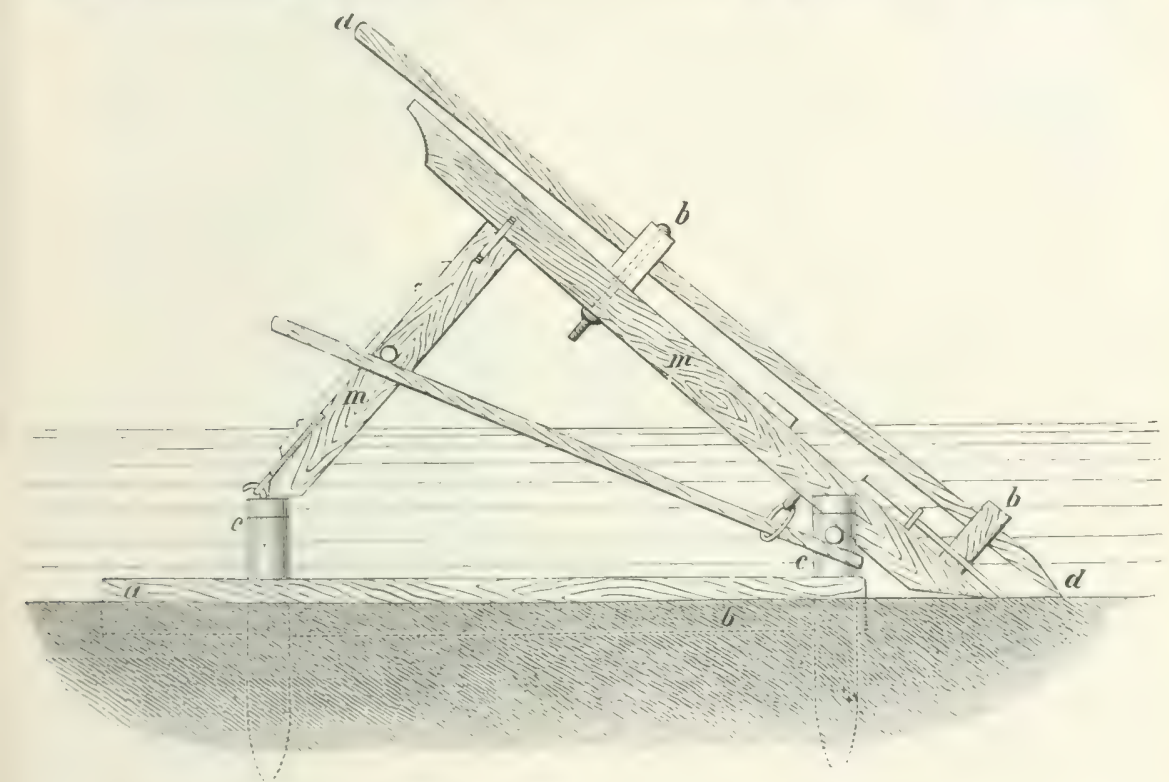

సig. 231. Transెportablex \$odredien.

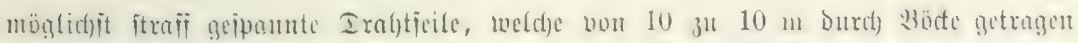
werben, treten hier an Stefle ber Bicilex und Etredfäume").

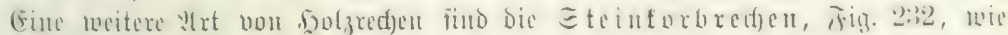

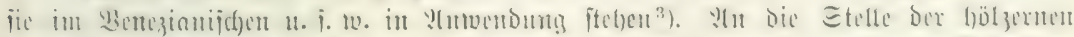

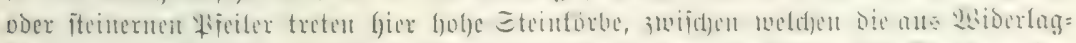

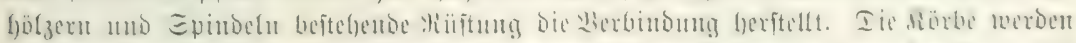

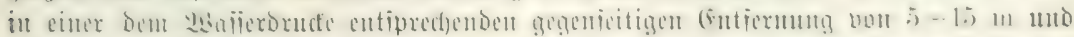

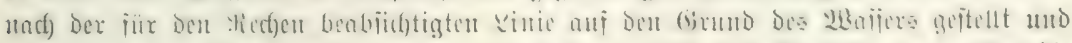

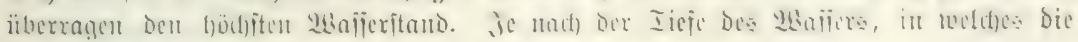

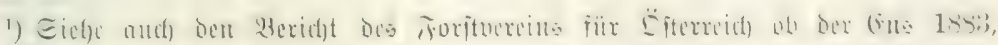
Eeite 105.

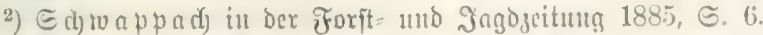

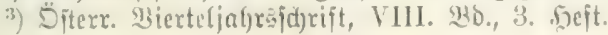


Nibrbe 3 itefen fommen, bebürjen jie de nngefügt wird, wird von Rorb zu Rorb eine "

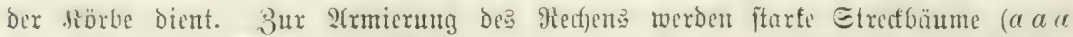

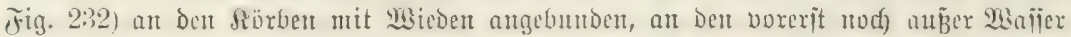

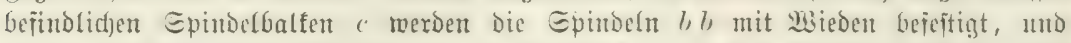

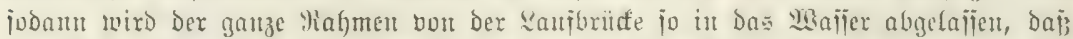
jede Epindel auf bem (brunde anfïtzt. Iie einzelnem Epindeln weroen mut endict)

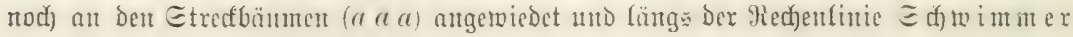
vorgelegt.

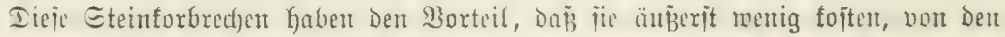
Flofifned)ten jelbit in furzer 3eit hergeitellt und leid)t nadjgebeifert werben fönum.

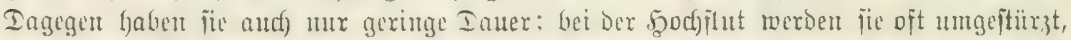

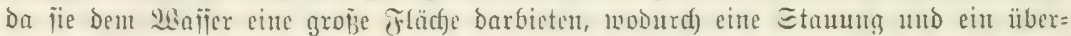

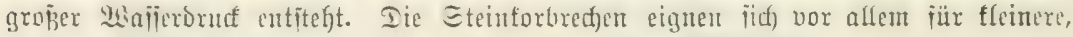

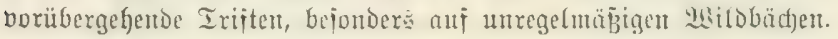

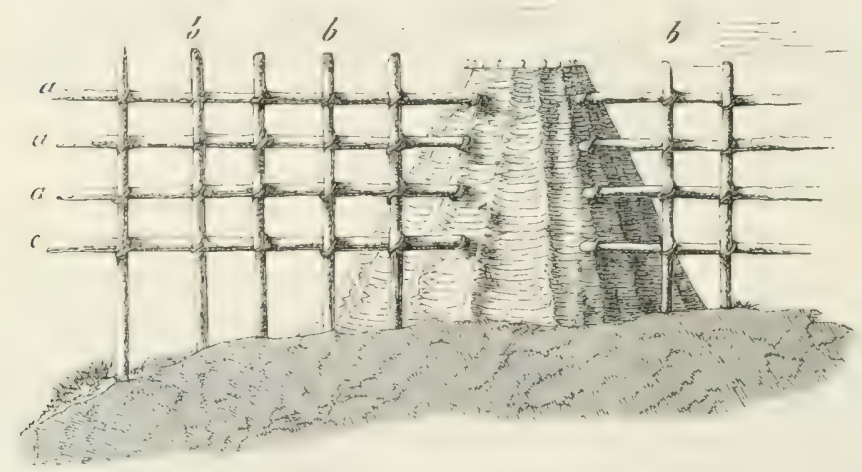

jig. 23:. Eteintorforedjen.

2. Gejamtanlage ber Red)en. Je mad) der Etörfe Dea Irift=

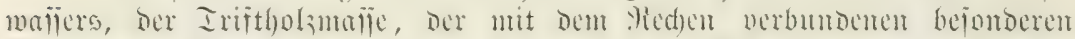

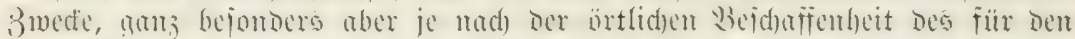

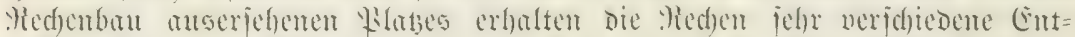

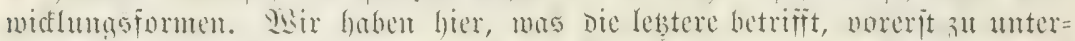

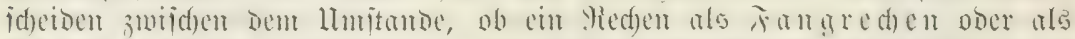

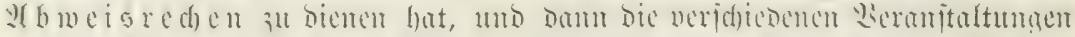

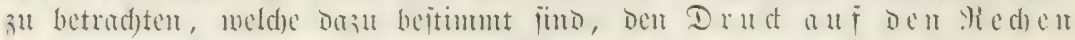

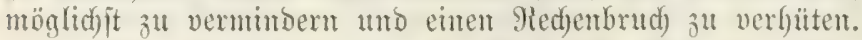

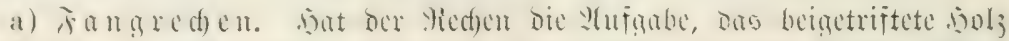

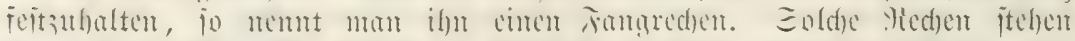

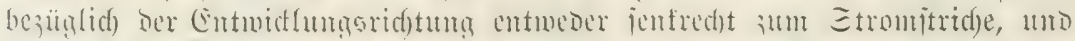

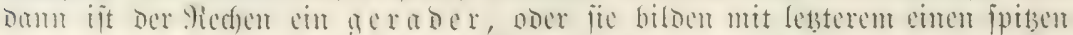

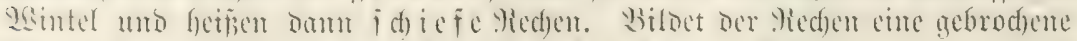

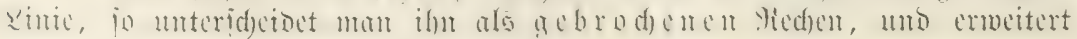




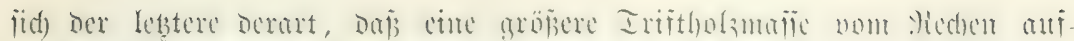
genommen werben fam, id entiftht Der Eadred)en.

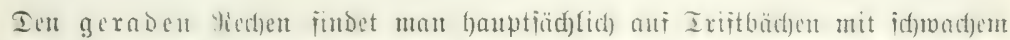

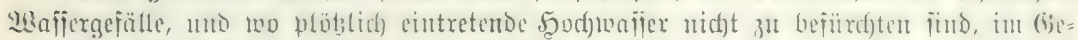

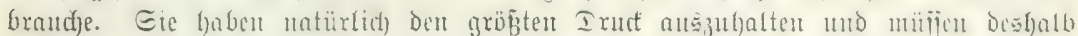

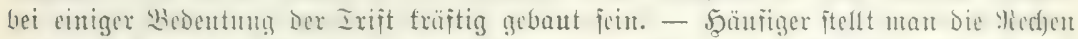
id)

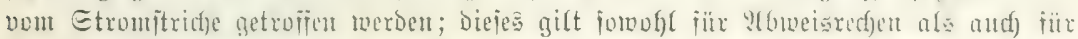

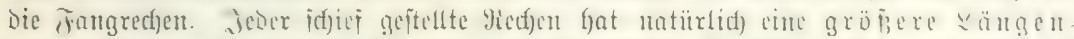

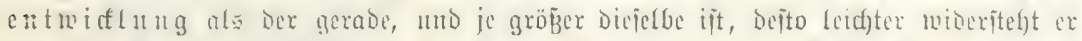

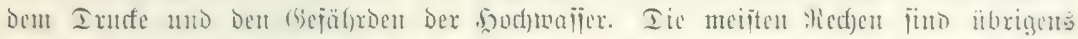

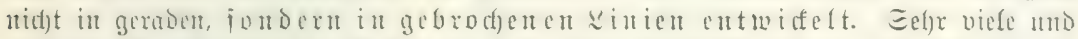

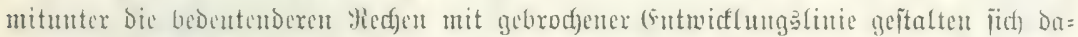

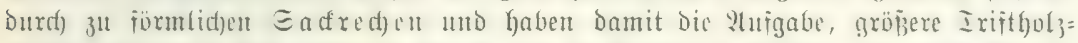

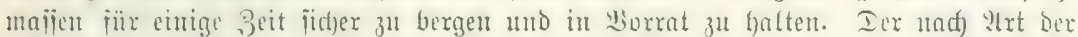

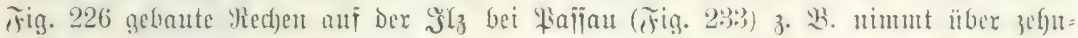

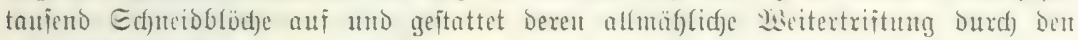
unteriroificien sianal $a$.

b) 将

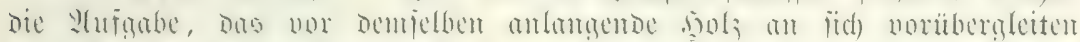

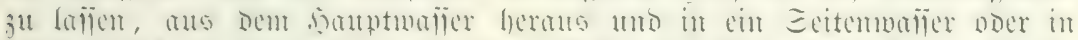

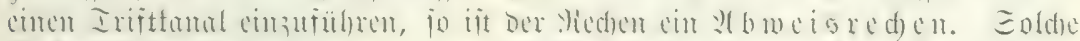

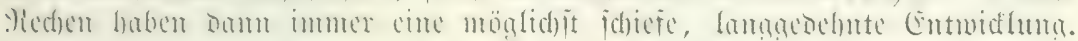

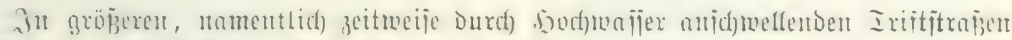

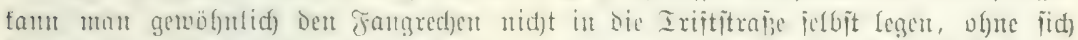

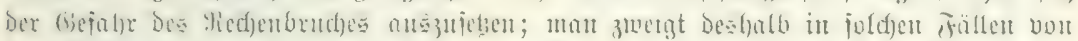

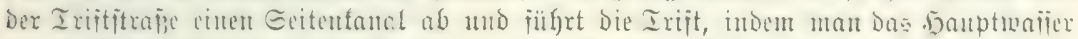

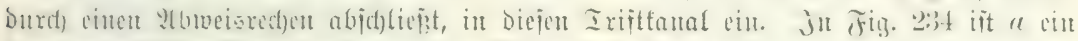

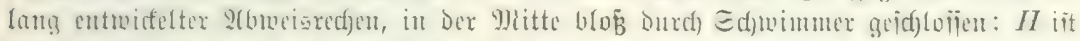

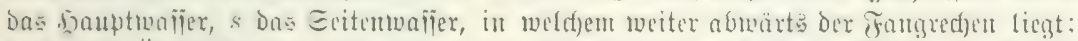

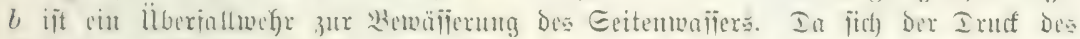

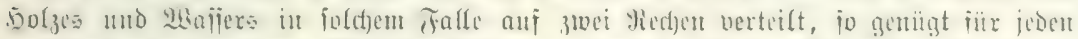

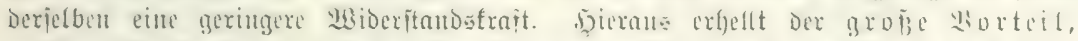

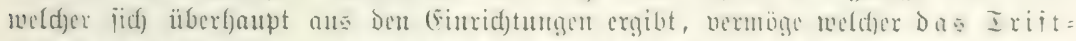

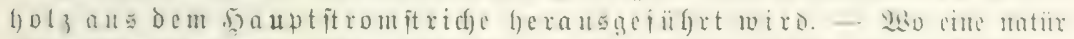

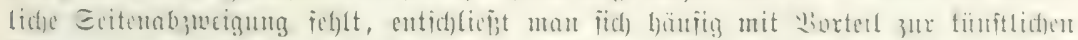

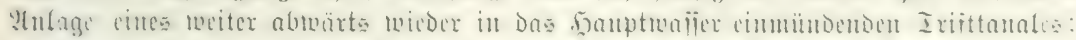

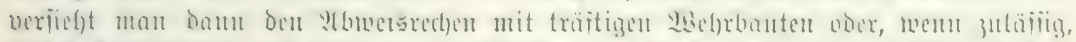

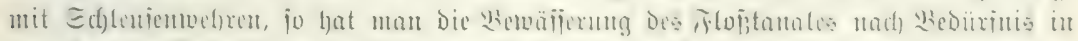

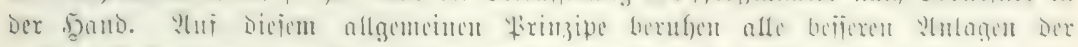

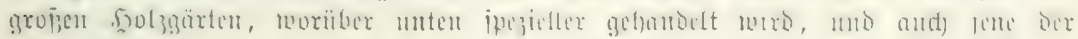
Eq)ncibemühlen.

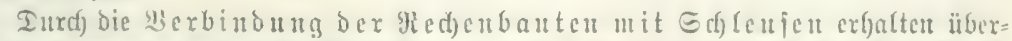

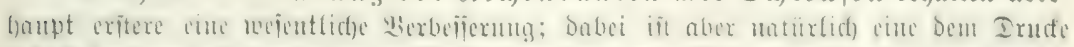

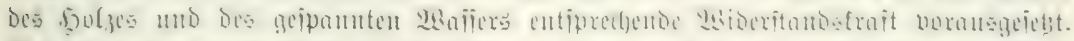

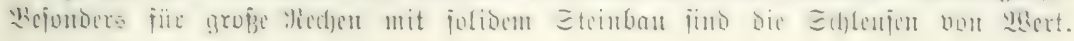




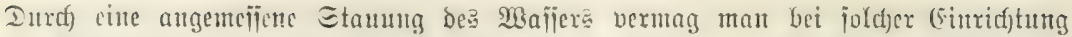

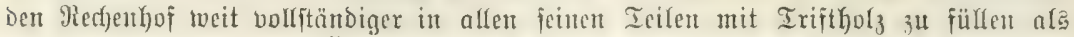

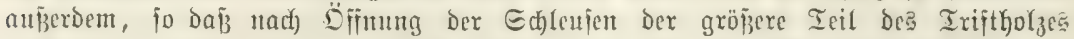
trodfen zu liegen fommt ober bod) leidjt auszulanden ift. Bei ausgebehnten Fang= anlagen ift es bann bon grobem Borteife, burd) Dffinung Der cinen ober ber anderen

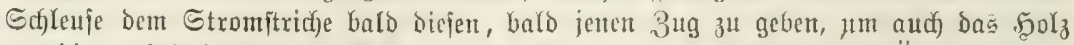

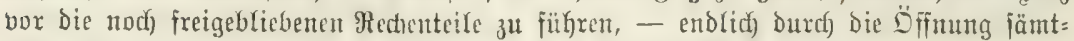

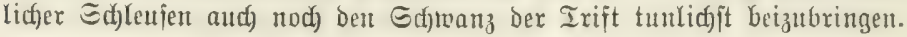

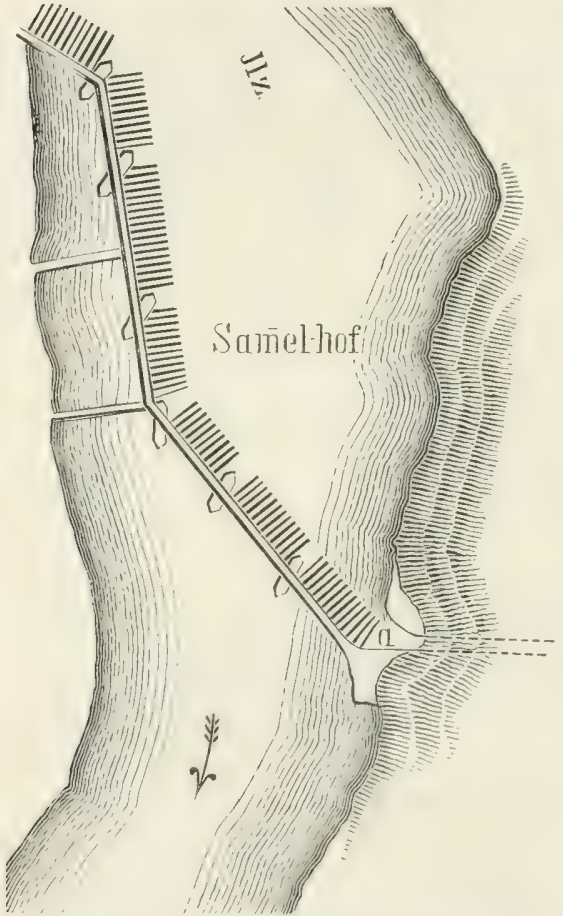

Jig. 233. Eammel= ober Eadredjen bei Waijau.

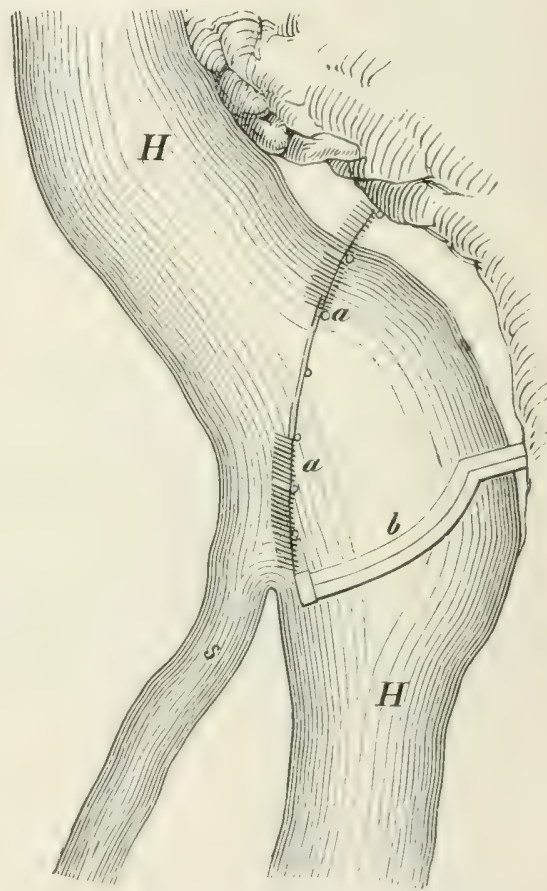

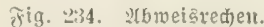

c) 类erm inder

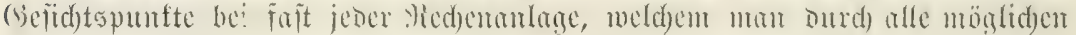
9)ittel nad) Bebari gered)t zu werden bejtrebt fein mur. Diejen 3med er=

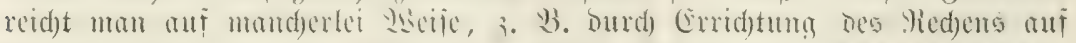

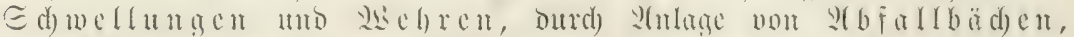

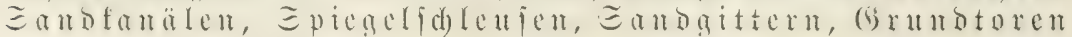
11. f. 10. vor bem Redjer.

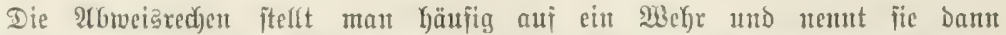

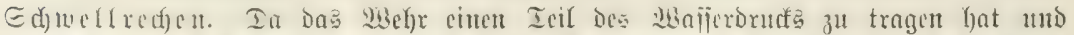

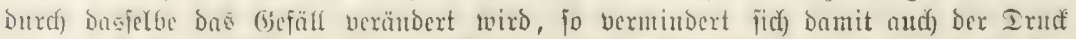

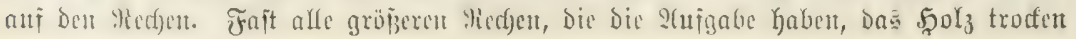




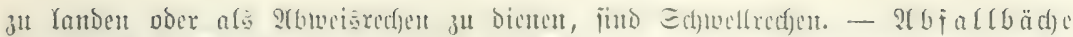

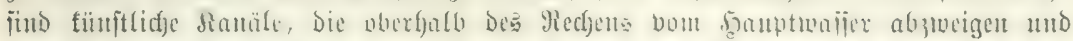

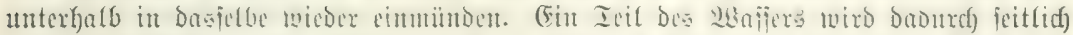

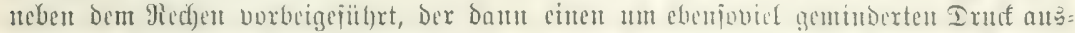

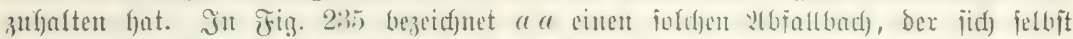

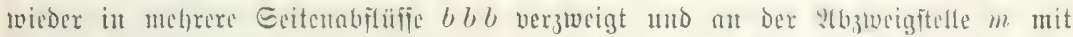

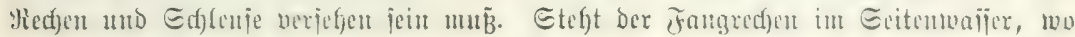

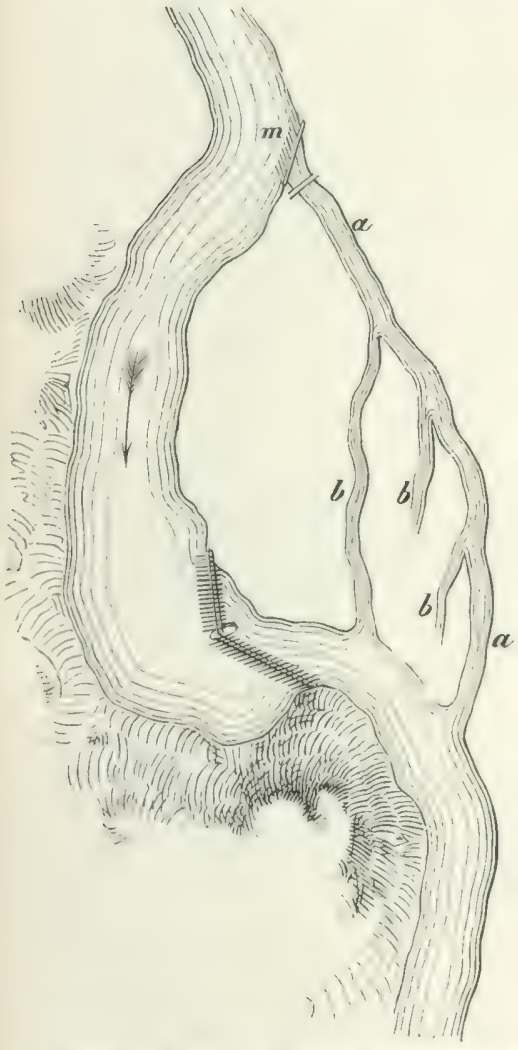

Fig. "235. Kbiallbad a zux Entlaftung bes wafierbrudes auf ben Tangredjen.
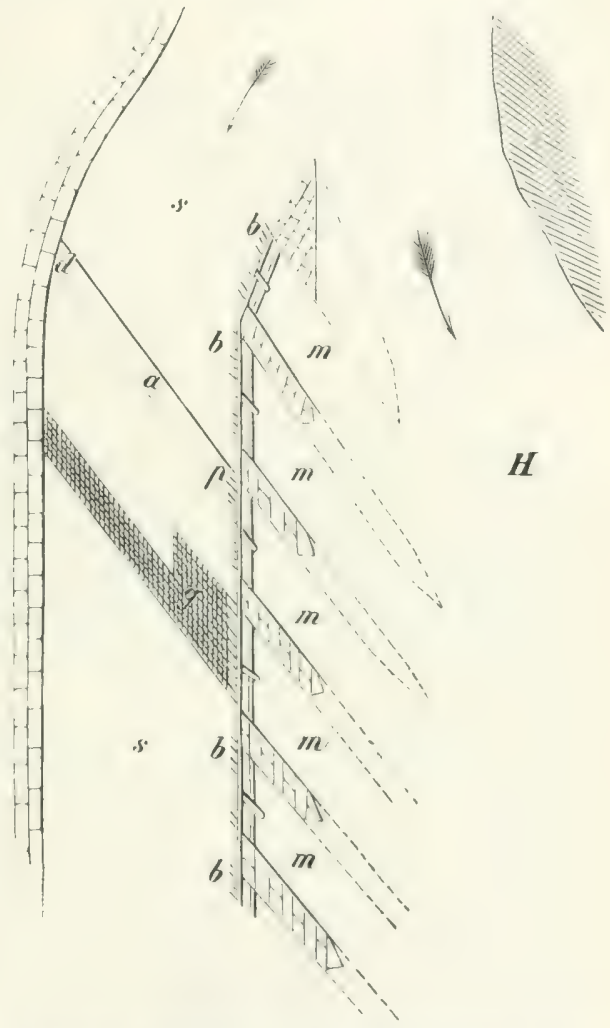

H

Fig. 236. Triftlanal $s s$ mit abfallbäd)en $m m$ uno Eptegerfaleuie $?$.

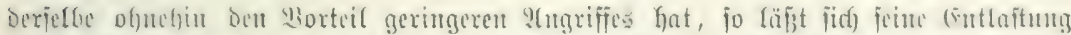

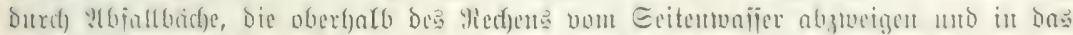

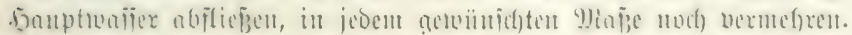

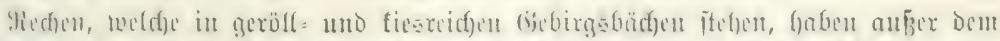

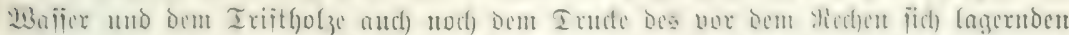

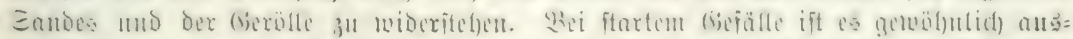

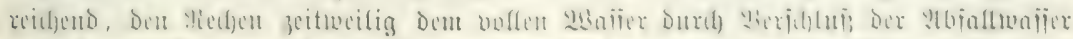

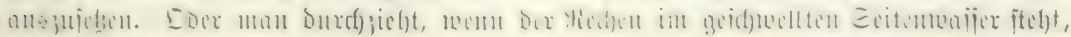


Lenteres mit cincm verienften, itarf gencigten $\Xi a n d f a n a l e$, Der bie eingerührte

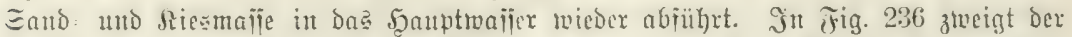

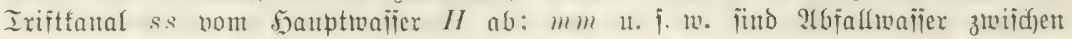

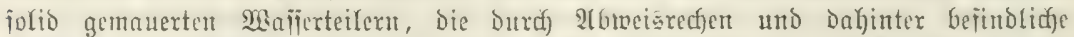
Ed)lcuifu beridyloilen merben tömnen: a jit bex Eandfanal, meldyer bei d mux

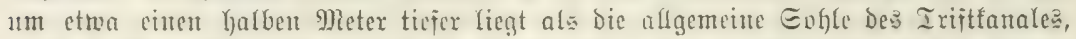

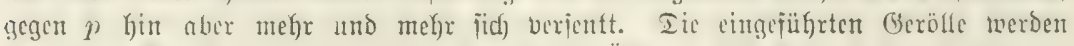

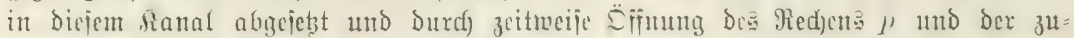

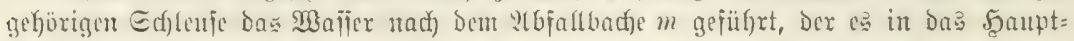
twalier abgibt.

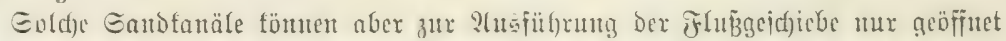
werden, weun gerabe nidgt getriftet wirb. $11 m$ mu aud mäfrend ber Irift Diefe

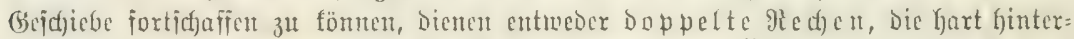
cinamber errichtet futb, in Deren 3 wifdenraum man Durd) Ëfinutg Des eriten Fedfen

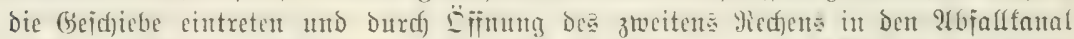

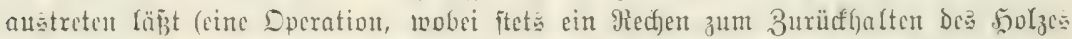

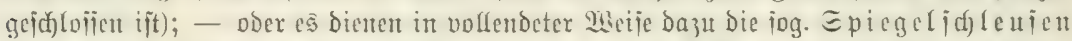

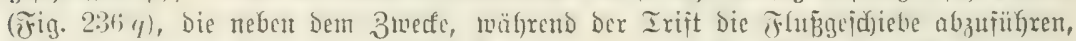

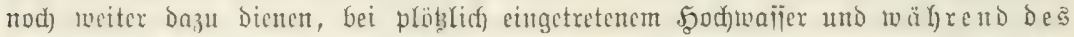
Iriftgange einen möglidfit itaren ieitlidfen Majierabiall zu ge= itatten. Mian Dente jid Den Dben erwähnten Eandfanal Durdy cin hölzernes Zatten= gitter (jog. Epiegel) ïberbeft, unto zwar in ber söbe ber Gokle bes Irifttanale $s$ (Fig. 236), jo hat man Den Begrifi einer Epiegelfd)lenje. Thi Demjelben Primzip bi:

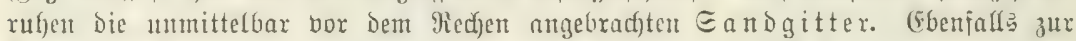

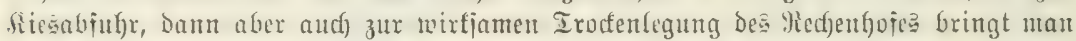

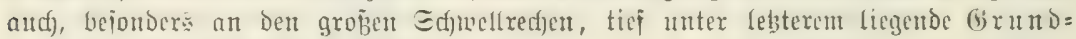
toxe oder (brundabläjie an (Salzfammergut).

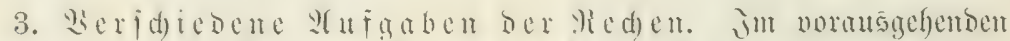

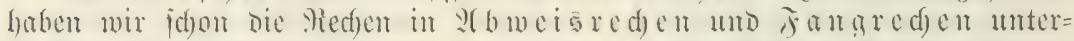

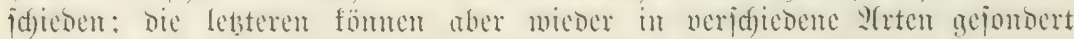

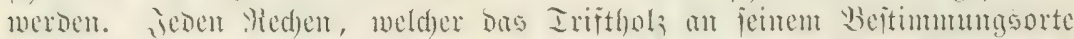

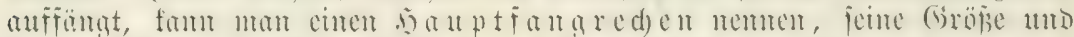

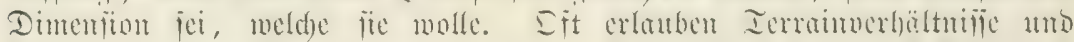

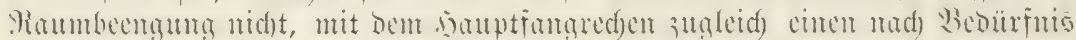

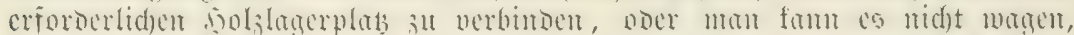

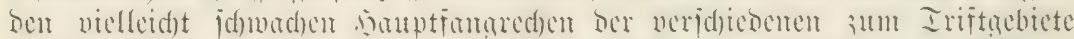

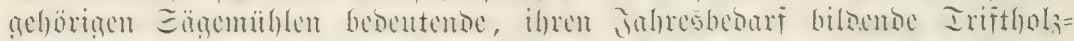

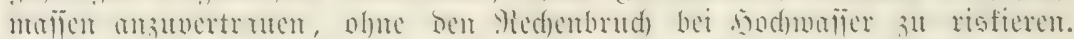

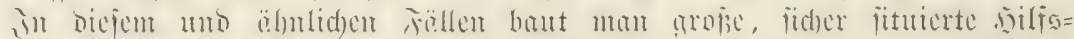

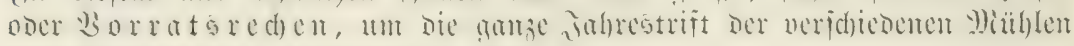
ober Sionfumenten gemeinjam zu bergen.

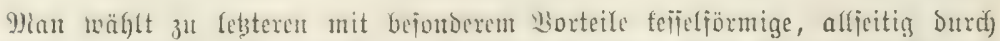

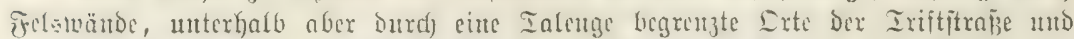

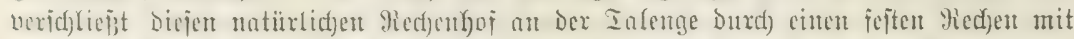

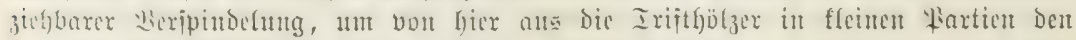
einzelnen Eägemühlen oder Ragerpläben zutrif̣ten zu tönnen. 
Eiter fieht man and eine Irifitrajie mehrmals in midjt allan grofien

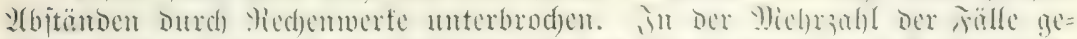

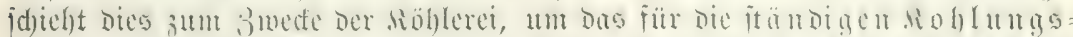

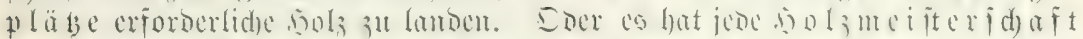

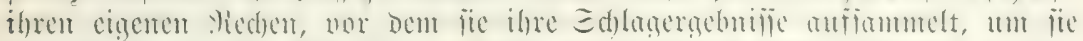

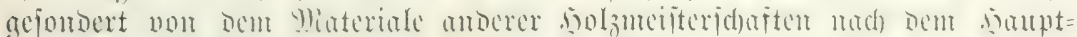

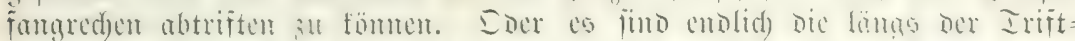

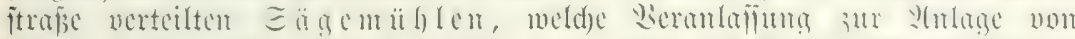

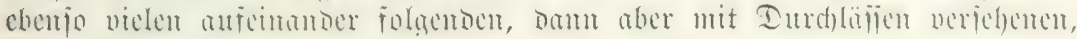
Medjen geben.

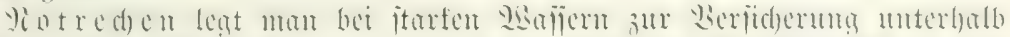

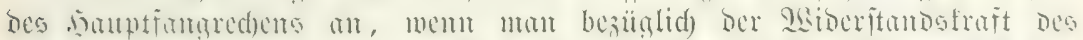

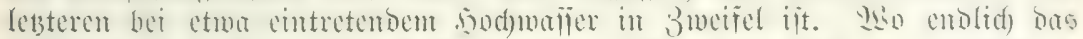

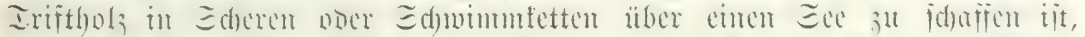

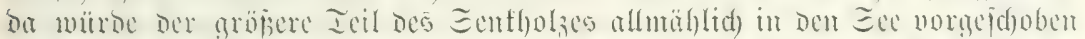

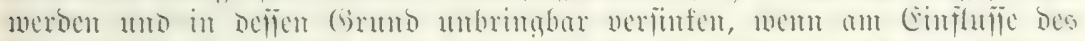

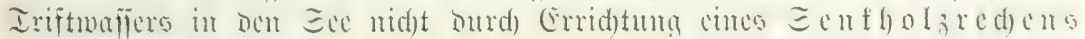
Eorge getroffen ift.

\section{Criftbetricb.}

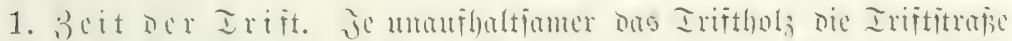

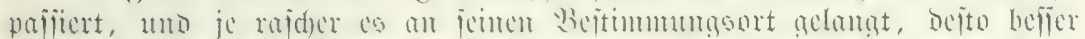

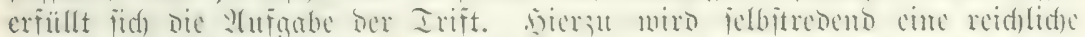

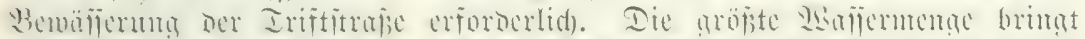

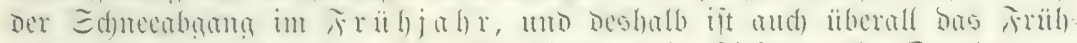

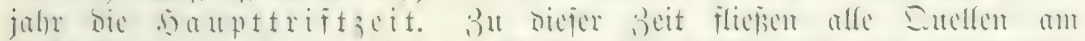

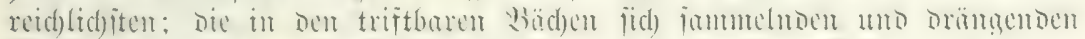

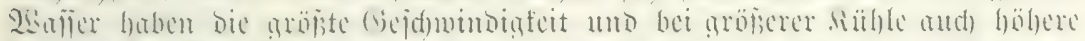

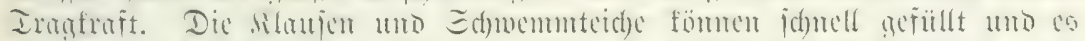

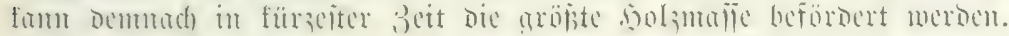

Die Irift auj gröberen, ftändig gut bewäjierten bbebirgabajieru,

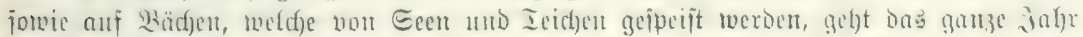

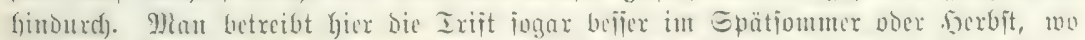

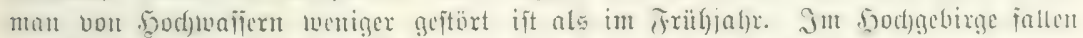

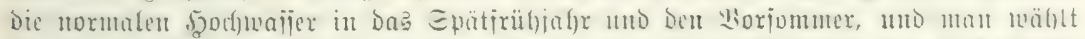

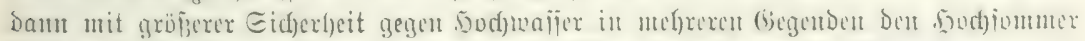

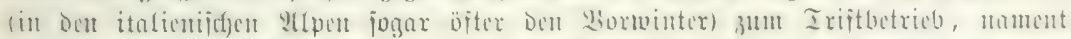

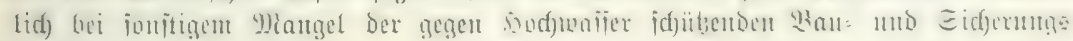
cintrid)tungert.

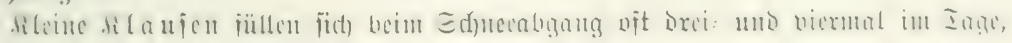
bic grop̃ent bedürfen mełhexer Iage hicrzu.

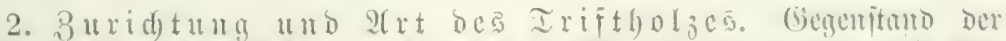

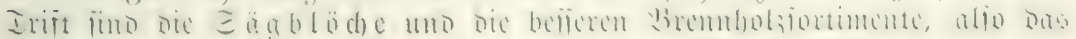

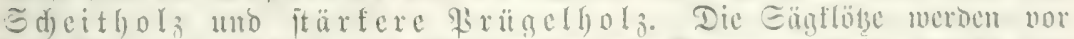

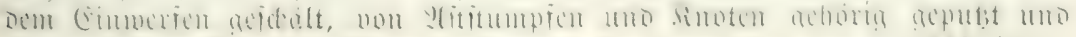

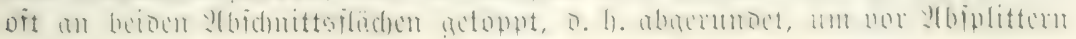




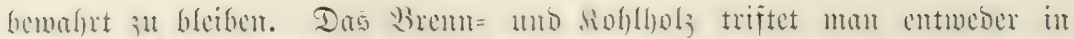
un «

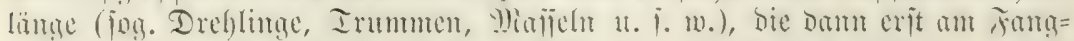

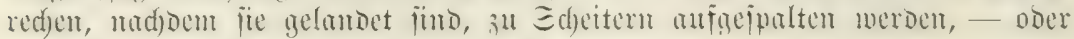
in a

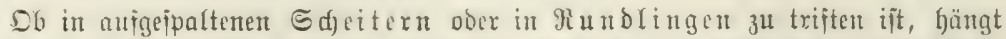

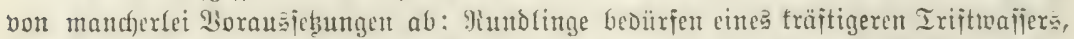

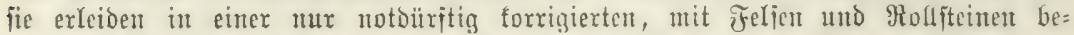

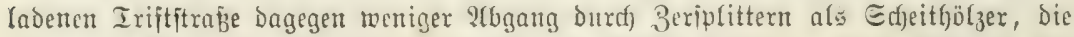

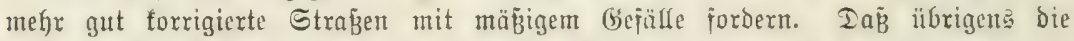

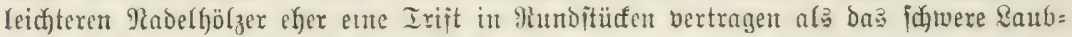

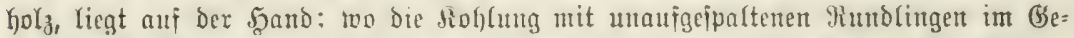

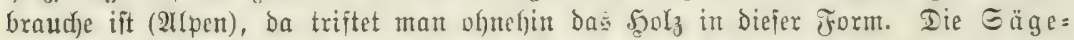

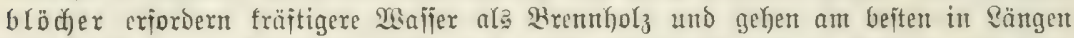
von 3-4 $\mathrm{m}$; in Edyweden trifft man aud Eägeblodje bis zu Rängen von $7 \mathrm{~m}$.

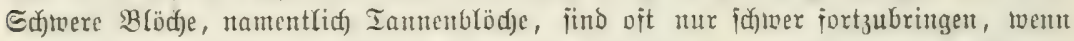
fie nidgt vorker tühtig auggetrofnet werden. İn J̈ndien merden itehende Ieatbäume geringelt, um den Stamm abtrodnen zu lafien und fafwimmï̈higer a exhalten.

Die midutiajte Eperation, welde ïbrigens mit allem Iriftholze vor

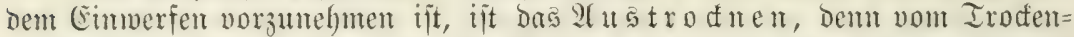
grabe hängt zum grofien Ieile die Mlenge des Eenfholzes und der lebhafte Gang der Irift ab. Das im Eommer gehauene jolz erreid)t fdueller ben erforberlidjen Irodengrad als bas Winterlyols mo cignet fid) bes̆halb be=

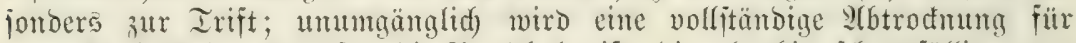

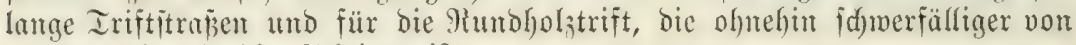
itatten geht als die Sdjeitertrift.

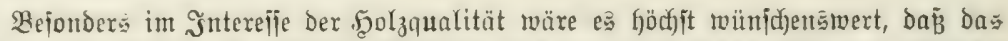
im Eommer gefälte uno gejdälte Blod) folz jo fort nad) Fällung, zur möglidfit

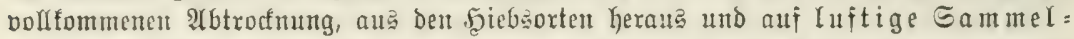
ftellen verbrad)t merbe. Wird ez Dann im Minter an bie Triftbädje gezogen und im Früfiahr vertriftet, jo gewinnt Durd) Den vorauggegangenen Iroffenprozé Der Triftgang.

3. Jutandiejug Der Iriftitrabe und Irift. Wevor mit Dem Eimwerfen mo Utbriften des goljes begomm

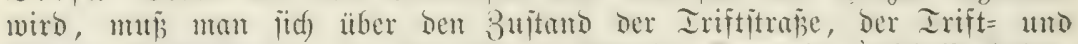

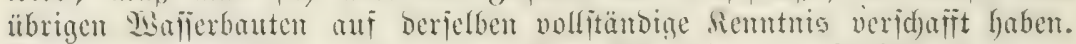

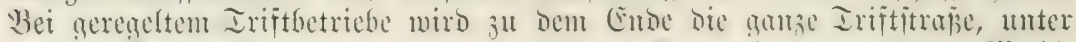

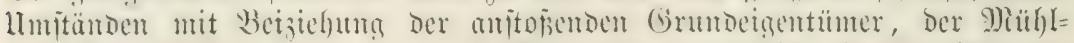

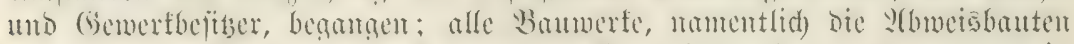

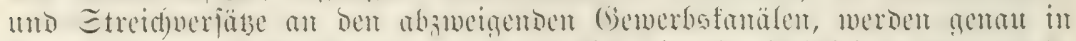

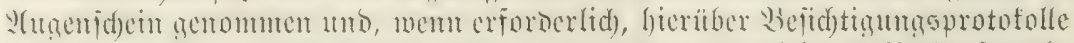

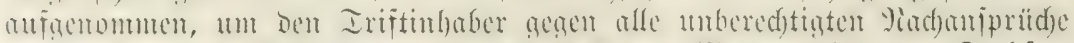

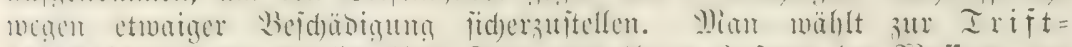

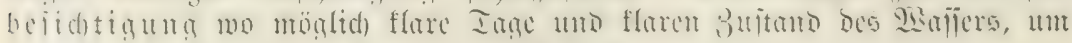
ben Brid audy auf Den Girund des Wafjers zu geftatten. 


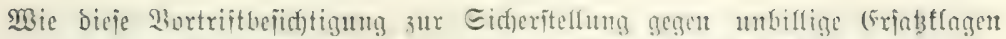

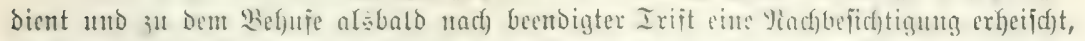

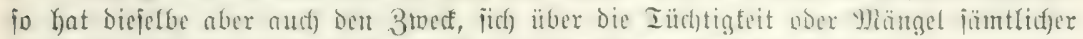

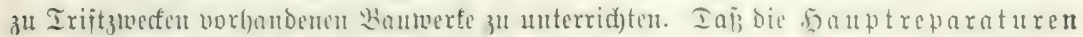
an ben Iriftbauten aber nid)t auf bis Iage furz vor bem Iriftbeginte beriffoben werden bürin, fondern Dicje id)on bei niederem Sknjieritand in Eommer obex Friil)=

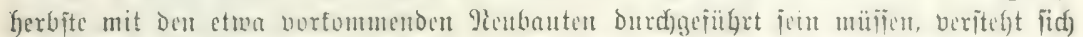

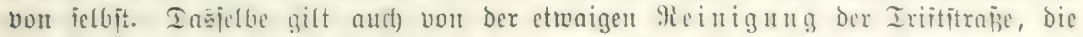

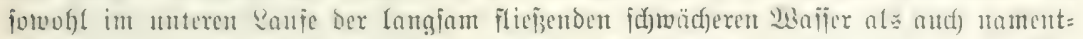

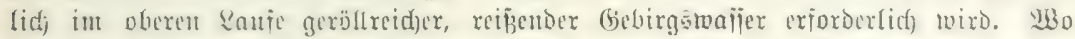
fierzu cine itrefenmeife Irofentegung nötig wird, miijent jür bie Inge ber Iroden:

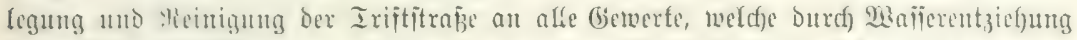

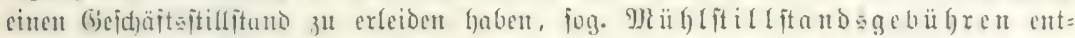

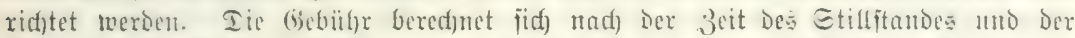

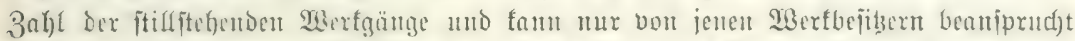

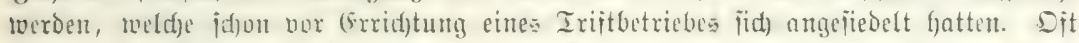

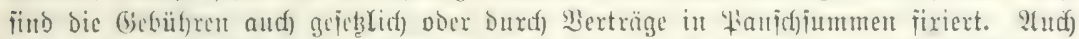

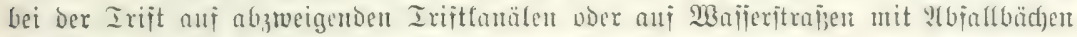
find hier und Da Stilfitandagebübren z山 entrichten.

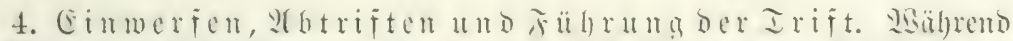

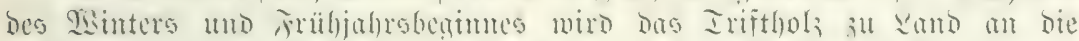

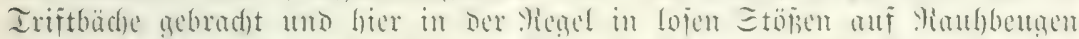

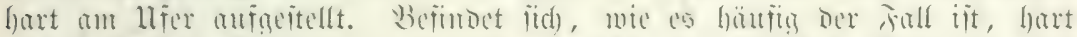

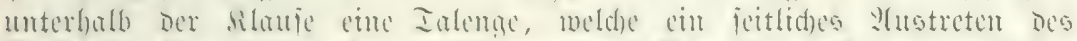

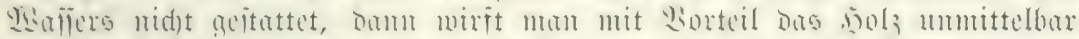

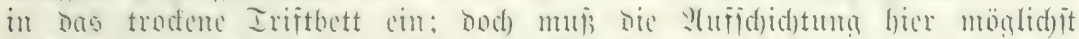

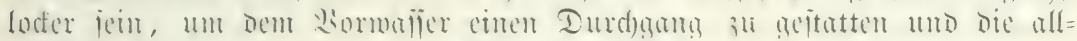
mäblid)e Söfung der Iriftbolzmâfe zu ermöglidjen.

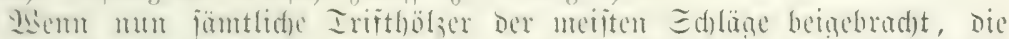

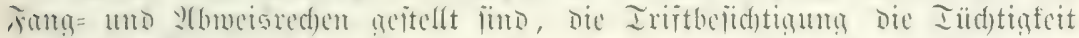

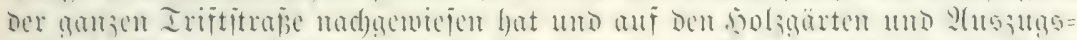

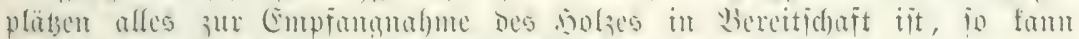

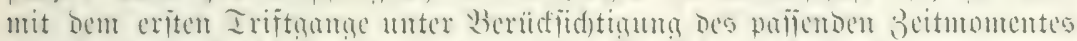

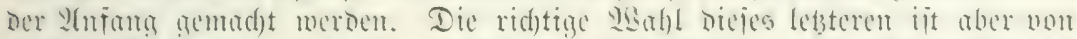

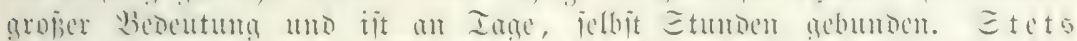

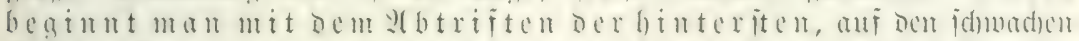

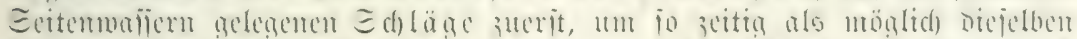

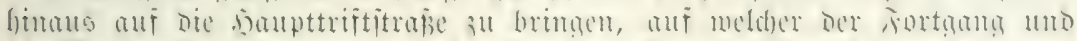

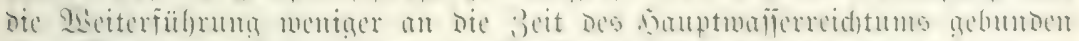

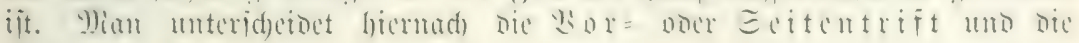
5auptrift.

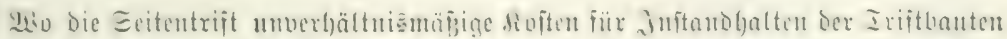

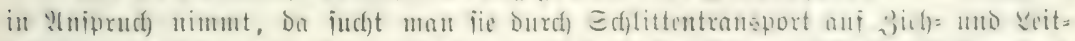

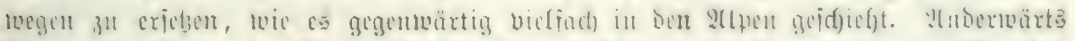

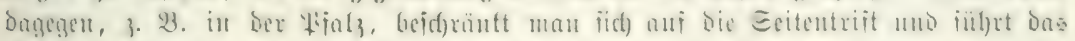

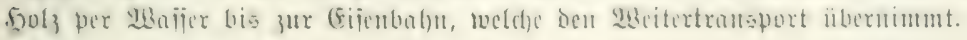

(is a yer, Jorftbenuţung. 9. Qutนf. 


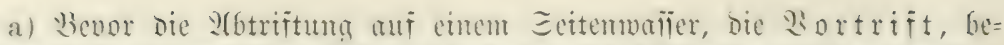

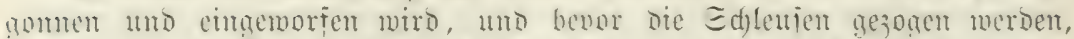

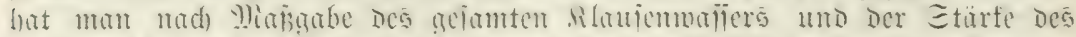

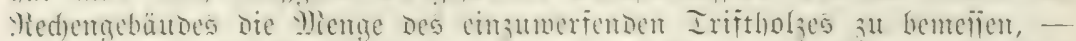

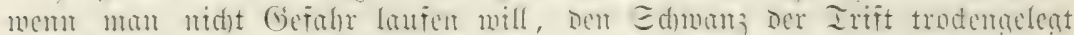

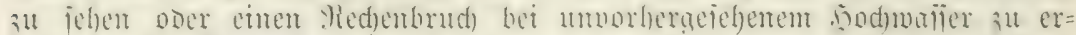

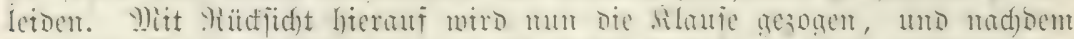

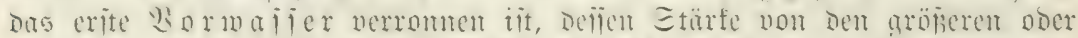

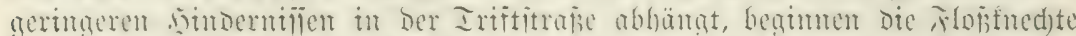

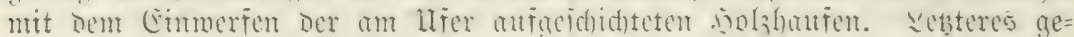

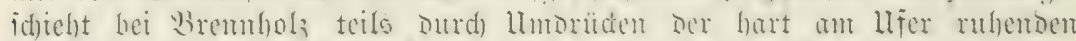

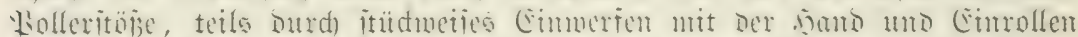

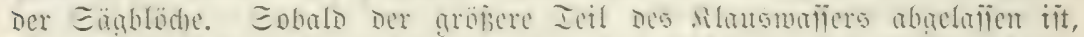

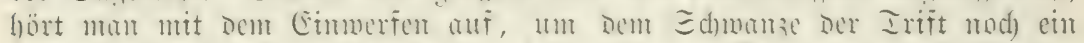

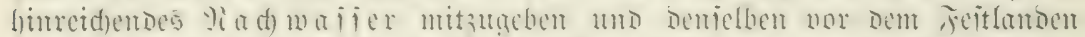

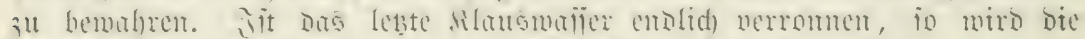

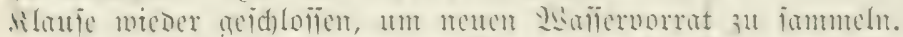

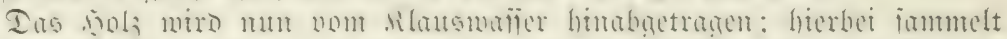

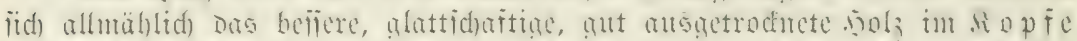

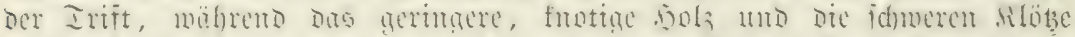

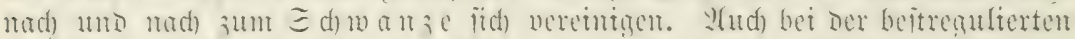

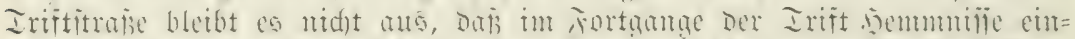

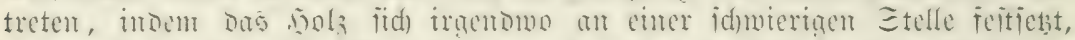

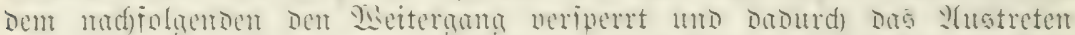

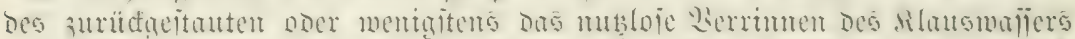

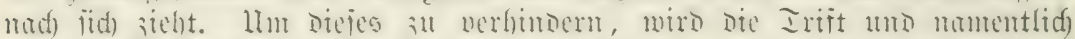

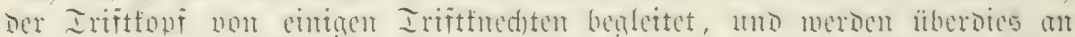

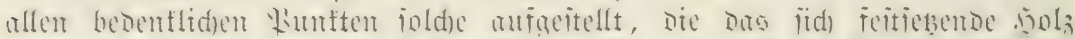

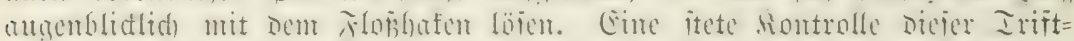

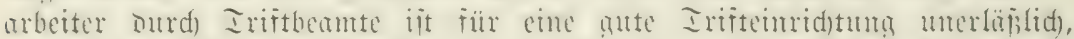

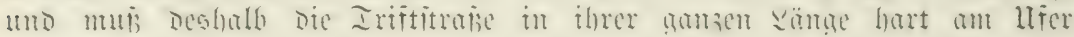
gangbar jein.

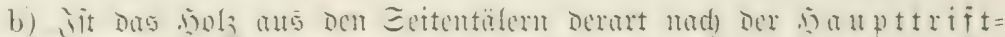

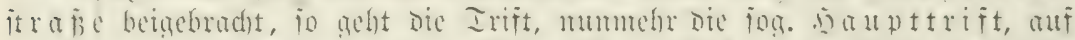

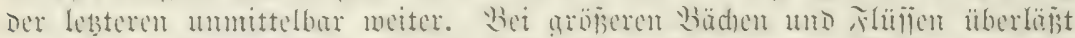

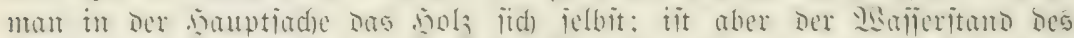

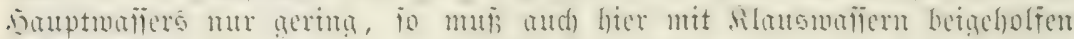
merbert.

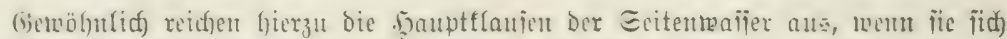

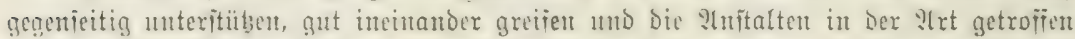

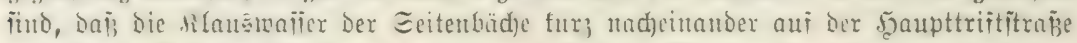

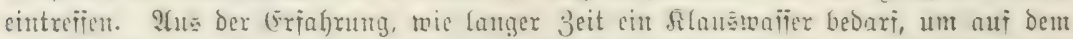

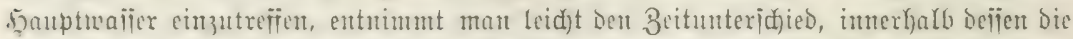

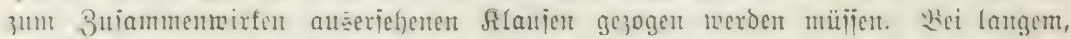

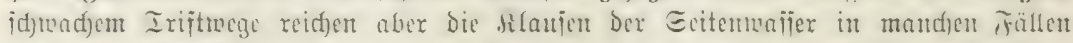

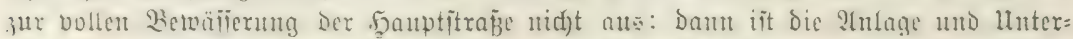

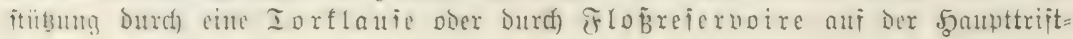




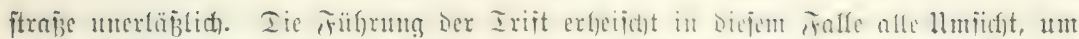

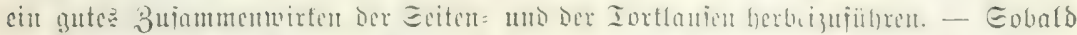

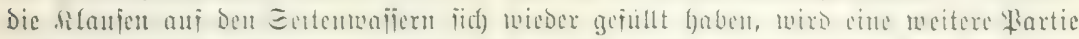

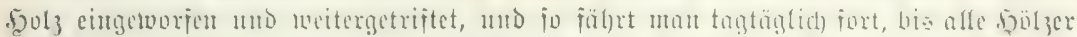

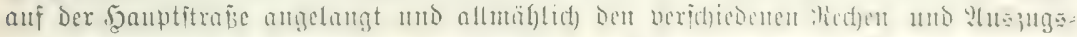

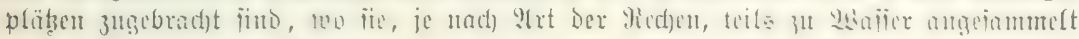
oder jogleid) ausgezogen werden.

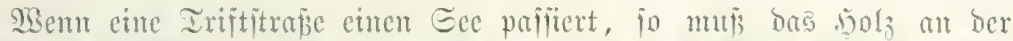

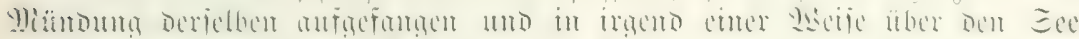

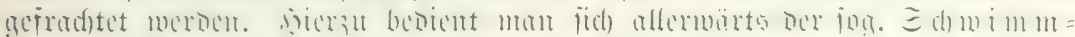

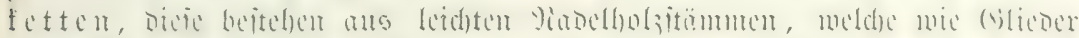

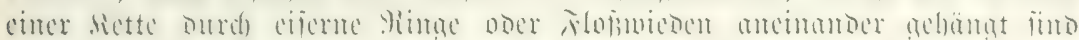

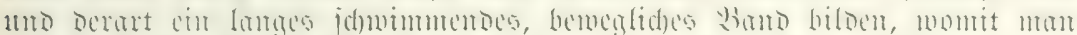

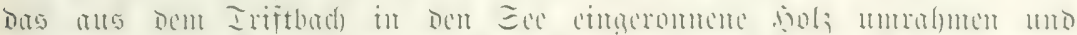

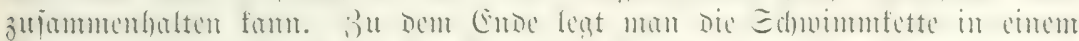

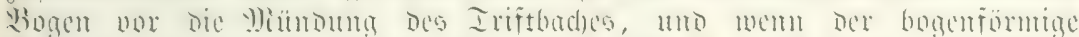

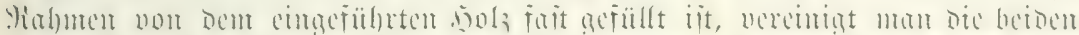

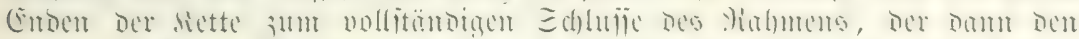

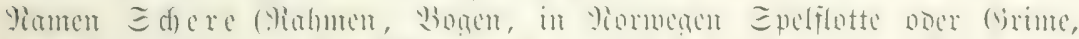

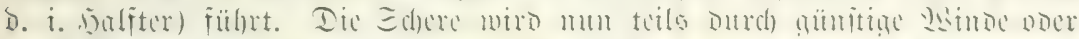

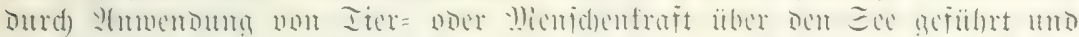

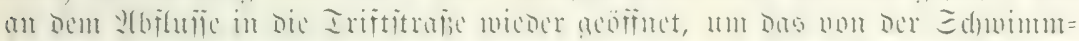
fette umidslofiche Iriftholo in leistere wieber cinzufügren.

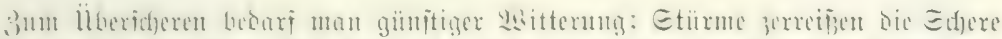

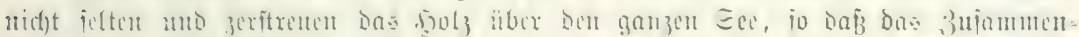

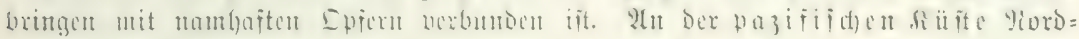

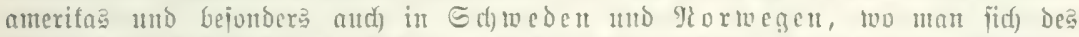

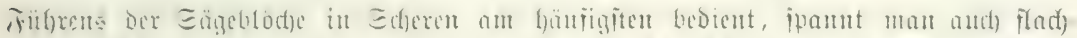

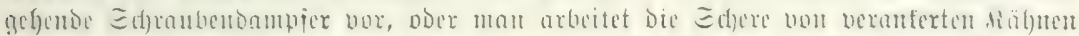

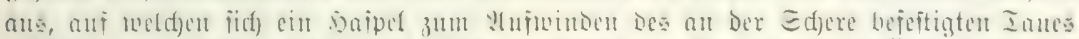

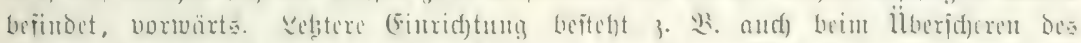

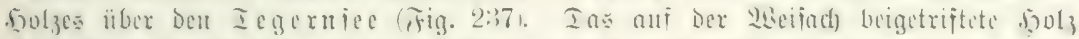

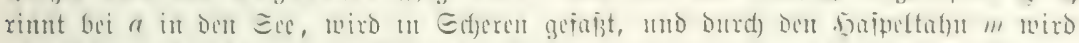

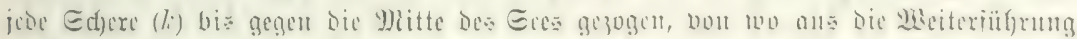

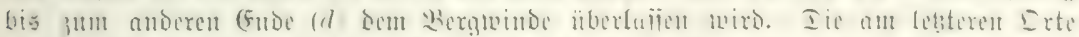

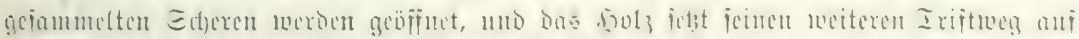

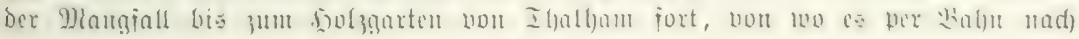
Itändjen gelanģt.

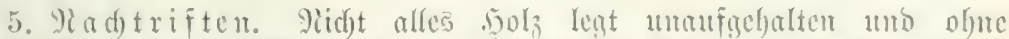
Interbred)un icinen

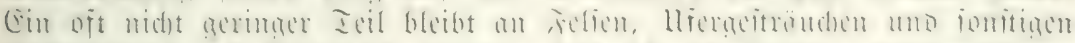

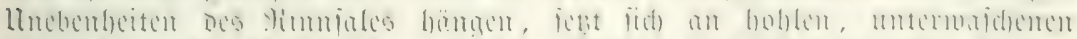

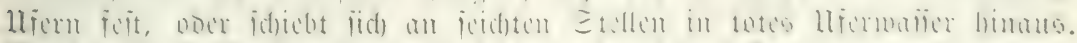

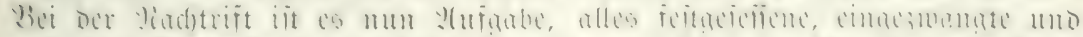

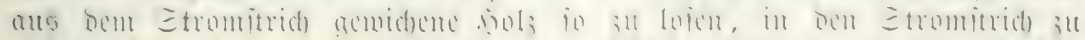

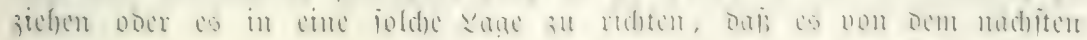




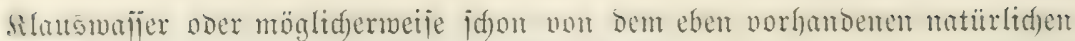
Mafier erfap̄t und weitergejülyt merben fam.

Iieie 9 (rbeit, bie jich) vielfad) bis tief in Dent Eommer finein verzögert, nemt man bas (Eintefren, Beiridjten oder Flottmadfen: man beginnt bamit in ber Fegel uri bei hinlänglidjem Maljervorrate am Thalham oberen (Ende der Iriftifträe, bom (Fin= twuxiplabe abtörta. Sit aber nad) ber= ronnenem Rlaustwafifer Dex Triftweg mux buritig und idjwad, berwäifert, oder vermag man wegen Ungunit ber Bitterung in fin= reidjentoer $\mathfrak{A u ̈ r z e}$ nux geringe Majfermengen in ber flauje aujzuiammeln, io muв man iiđ) baraū bejđränfen, audu nur einen biejer Maijermestge entipredfenden Ieil ber Slact)=

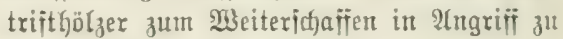
nefmen. Sn biejem Falle beginnt mant mit Dem Finfchren am unteren (Ende ber Irijt=

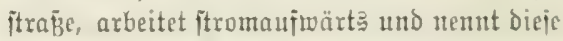
Speration das $\mathfrak{M} b$ bred)en ber Irift.

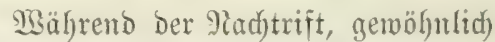
aber exit bant, ment ber $\mathcal{E}_{\text {dywanz }} g \mathrm{e}=$ Görig nadgearbeitet ift, nimmt man einen weiteren Ieil ber Jiad)trift in 2urgrifi, nümlid das Senflol fifden. Mlan fängt babet bet ben Ginteriten $3 u f(u i j e n$ ber Iriftitraiße an und arbeitet bie ganze Flositra范e nad). Die meijte Eenflolzmaile ergibt jid) auf ber unteren Syälfte des Iriftmeges.

Die Menge dea Eentfolzes ijt haupt=

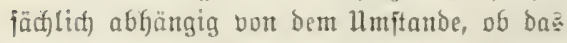
Şolz vor Dem (Eintwerfen sinen mefre oder

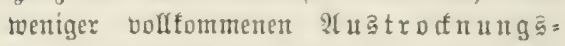
prozeß burdigemant hat, von bem $3 u=$ itande der IriftitráBe, bor allem in

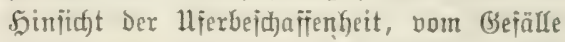
unt ber Iragfraft bez Malierz, von Der Bänge des Iriftwege bom fintwurf= plabic bis zum lied)en, bor Der f̧olzart,

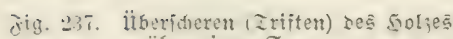
ïber einen Eee. 5ुolzbeidafienteit und Den Dimentonen

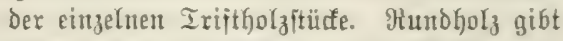

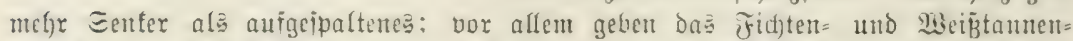

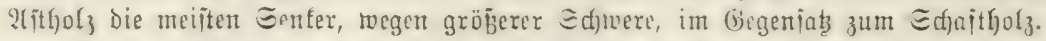

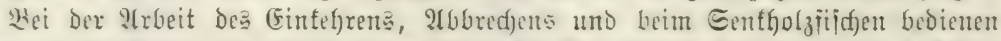

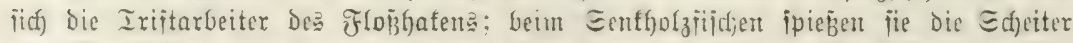

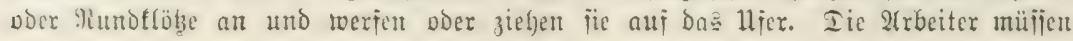




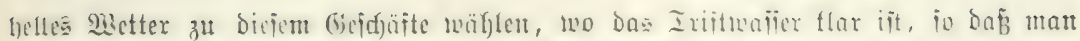

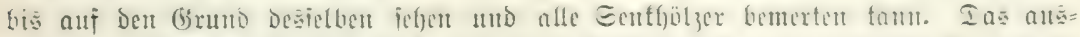

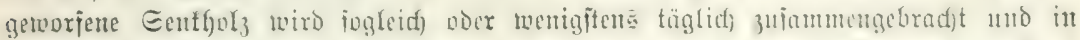

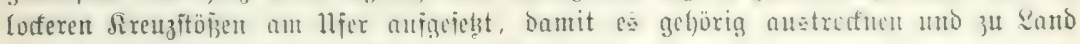
weitergebradjt ober fofort verwertet werben fant.

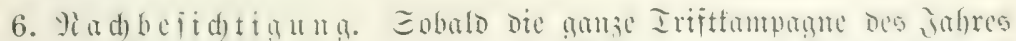

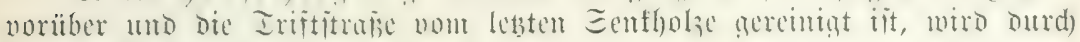

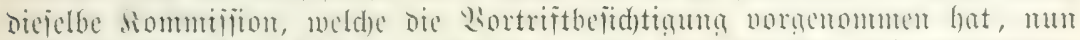

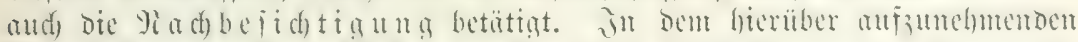

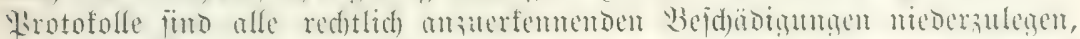

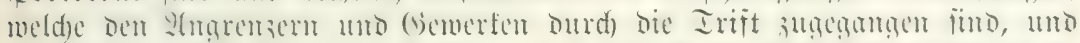

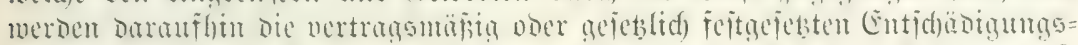

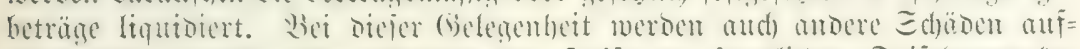

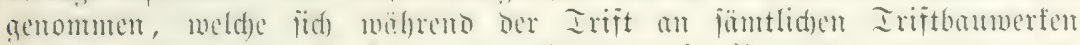
croben baben, um im tommenoen Eommer in Yiparatur genommen ; werber.

\section{Eläleret ${ }^{1}$ )}

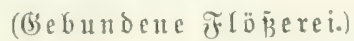

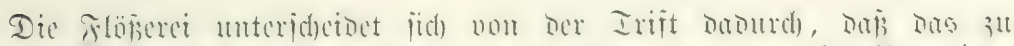

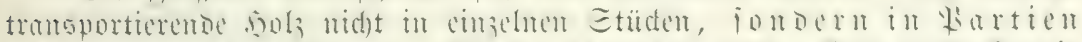
s

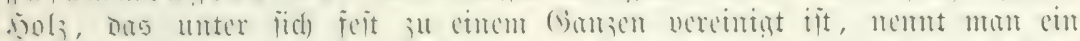

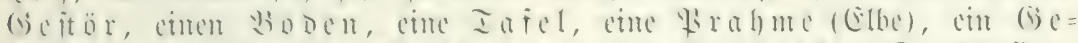

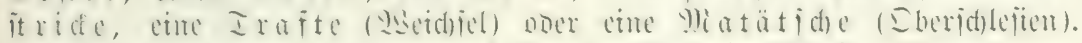
Durd) bie Berbindung mebrerer Gejtöre entịtebt cin Flop.

1. Bejdaffenbeit der Flofitraje. Die Flofferet fetst in ber

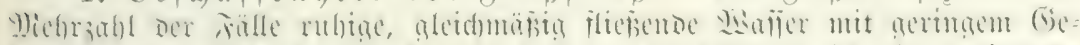

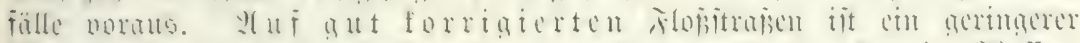

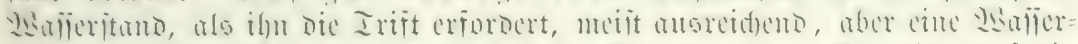

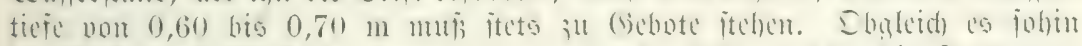

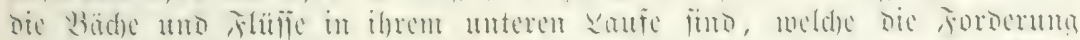

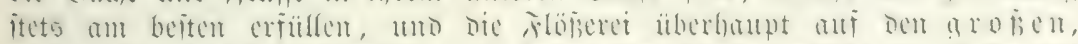

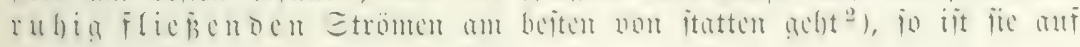

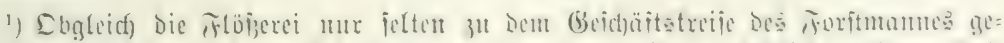

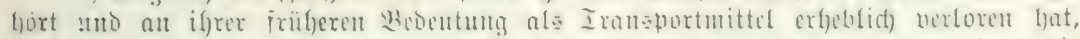

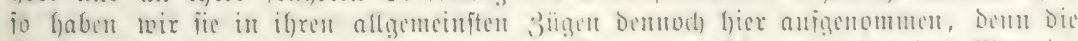

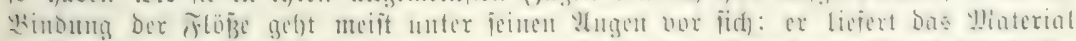

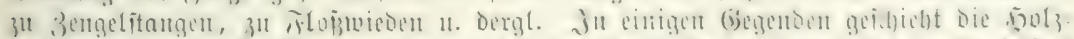

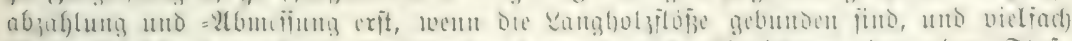

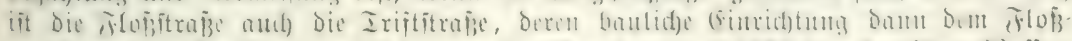

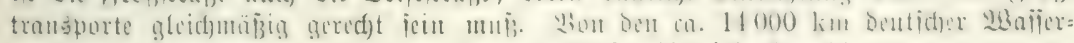
ftrajent werben immer nod) etwa $40 \%$ zum föloferetbetriebe bemußzt.

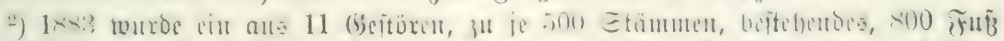

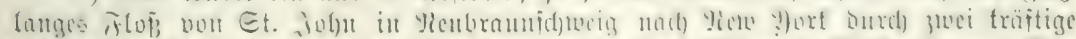

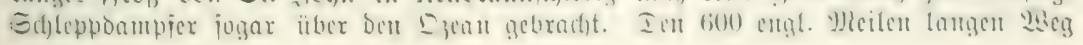




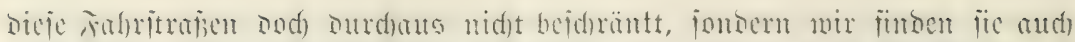

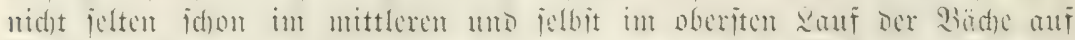
논

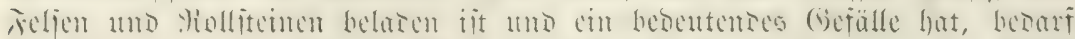

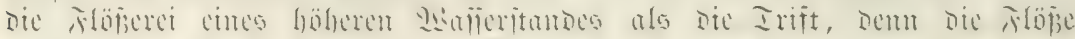

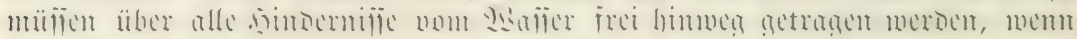
jie midjt zeridfellen and fid anflöfen jollen.

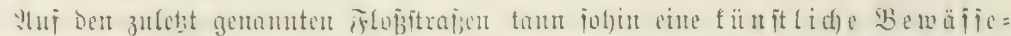

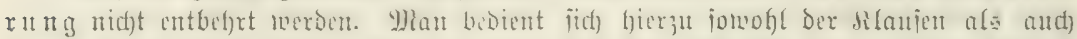

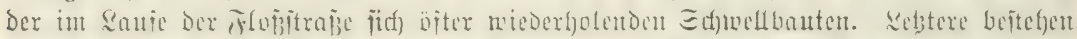

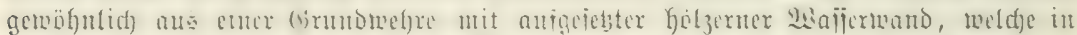

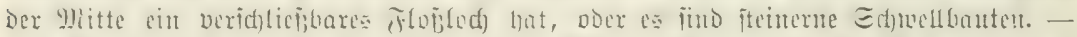

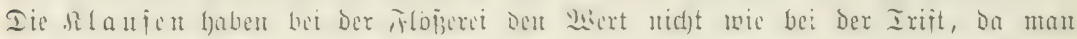

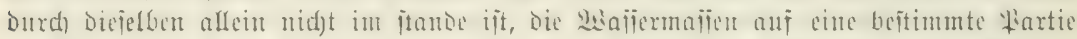

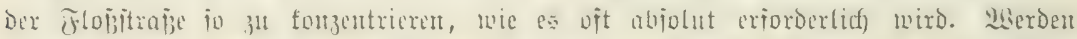

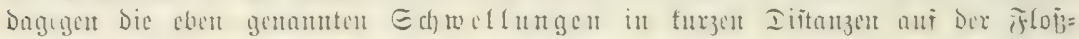

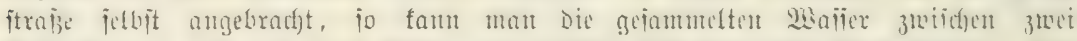

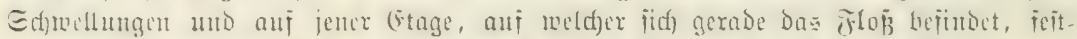

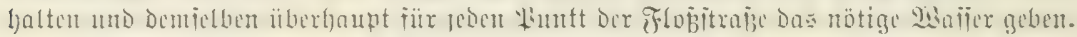

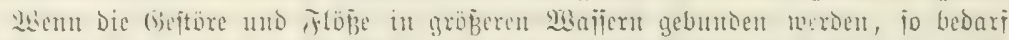

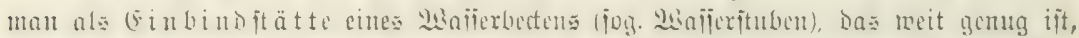

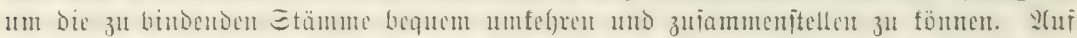

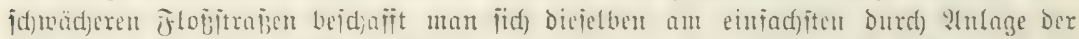

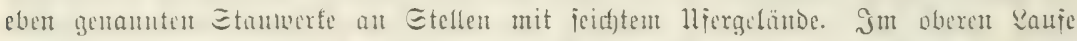

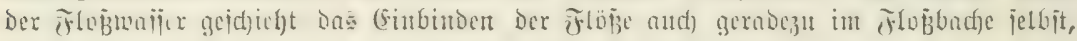
an irgend einer befiebigen Etrlle mit geringem Majijeritande.

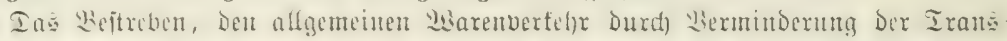

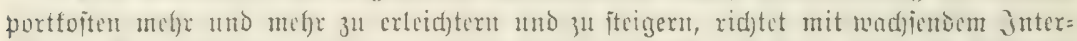

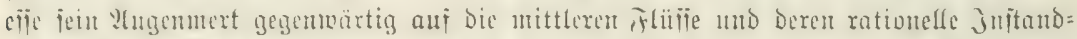

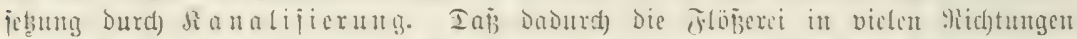

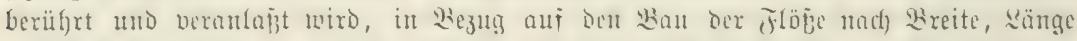

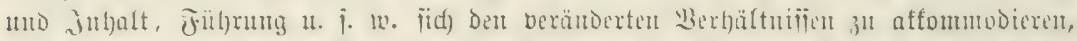

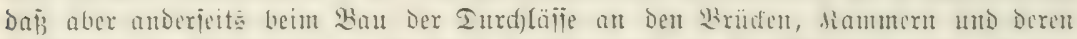

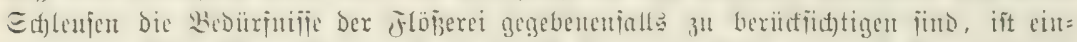

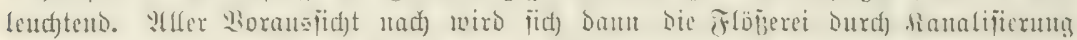

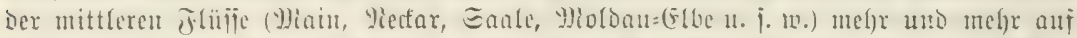

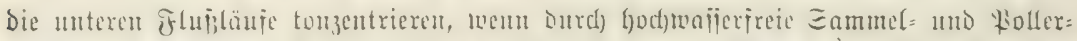

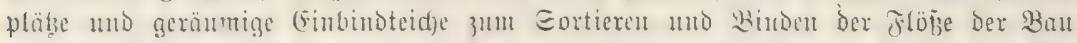

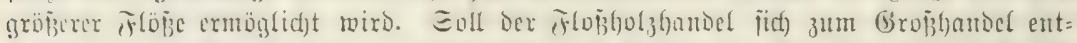

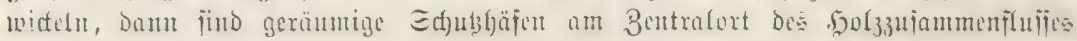
unentbefrlidi).

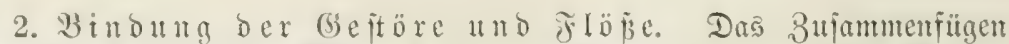

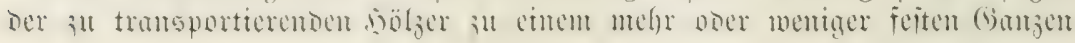

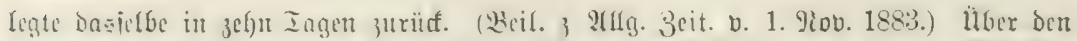

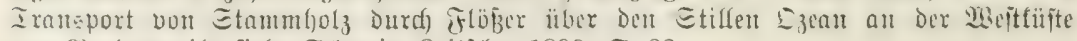
bon SRordamerita jiehe Ed)weiz. 3eitjidfr. 1899, E. 22. 


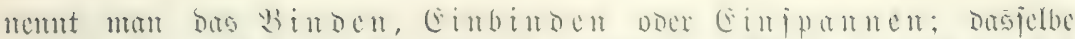

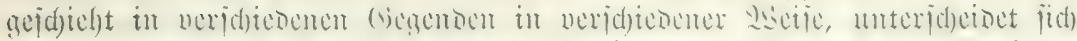

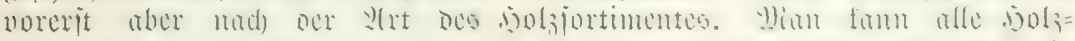

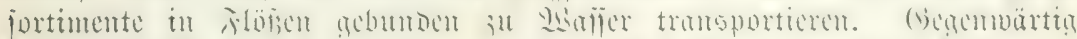
bejd)räntt

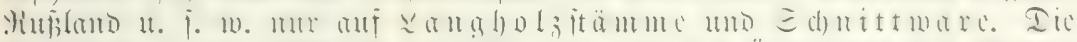

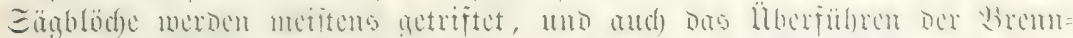

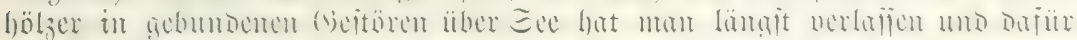

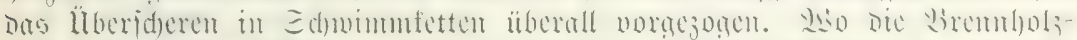

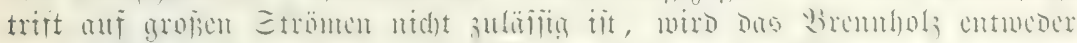

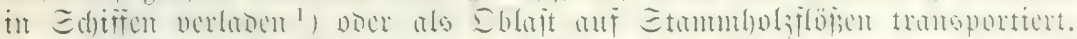

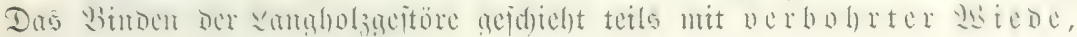
teils burd) Bengelitangen.

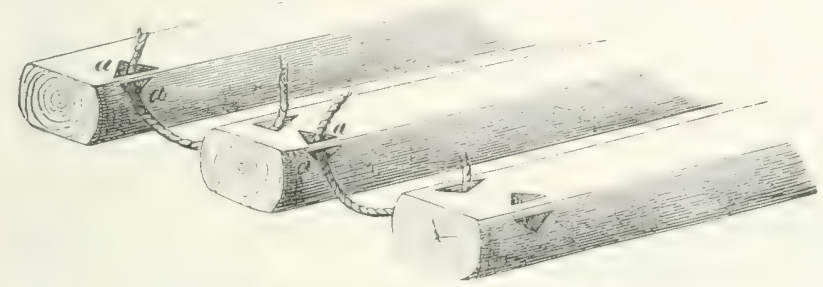

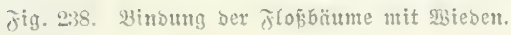

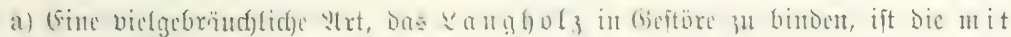

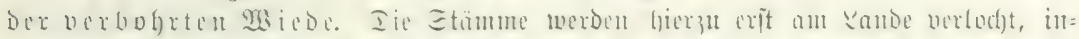

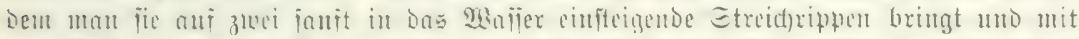

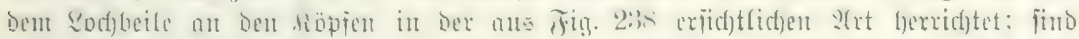

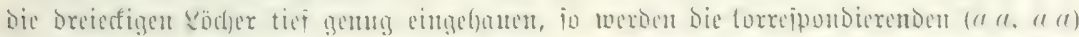

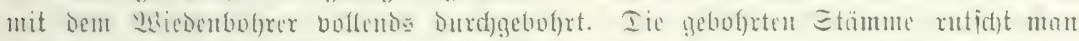

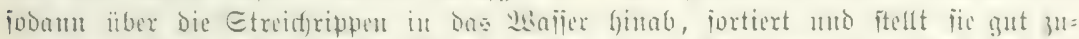

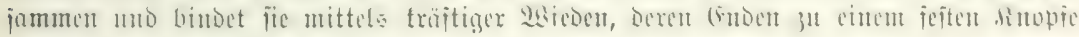
berid)lungen werdert, in (Beftöre zujaumer.

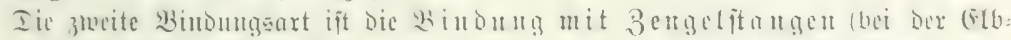

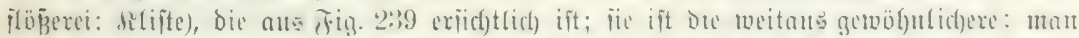

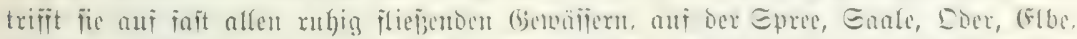

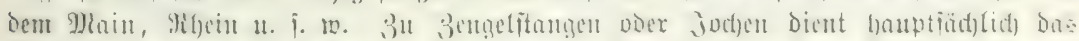

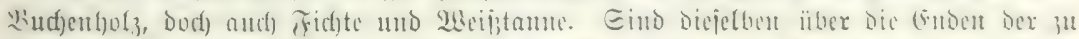

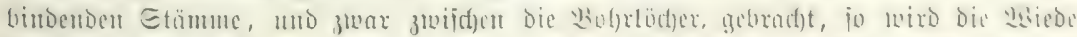

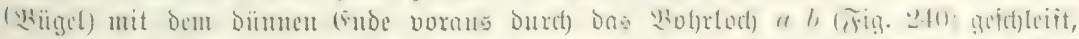

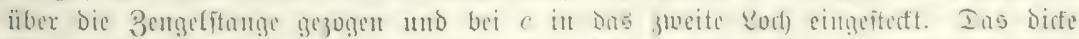

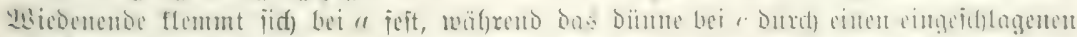

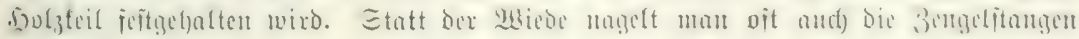

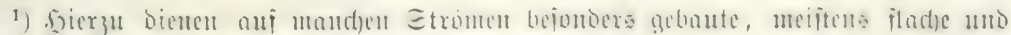

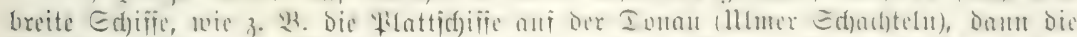

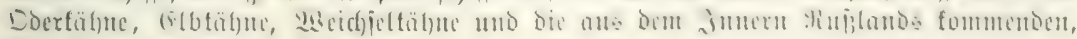
60 - $80 \mathrm{~m}$ lnngen jog. Wittinen. 


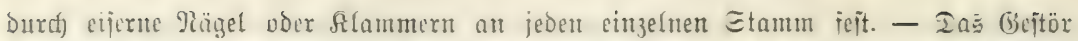

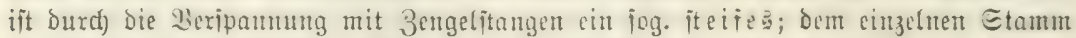
ift fierbet fein jelbittänoiger Betwegunģraum gelaijen.

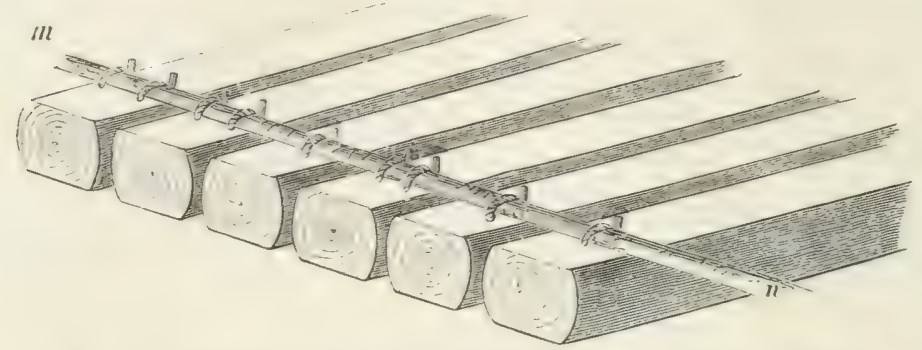

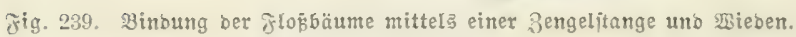

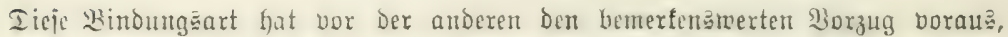

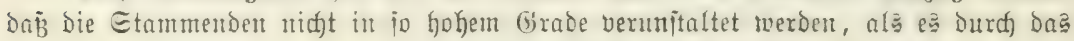

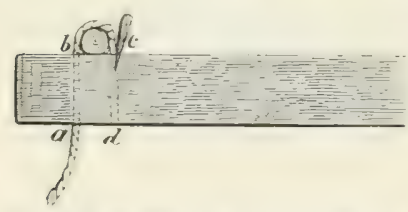

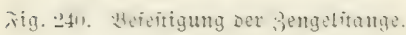
(Finfauen ber weiten Rödjer Der Falf iijt. Sm

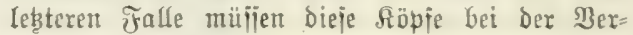
arbeitung Des $50 l_{3} e^{3}$ immer abgeidnitten merden ${ }^{1}$ ), währent bei ber Bindung mit Betgelftangen bå

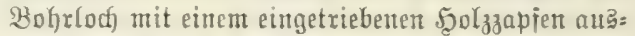
gejïllt wird und ber Ropi Dann zu jeder Şerzim= merung braudjbar bleibt.

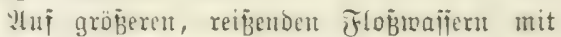

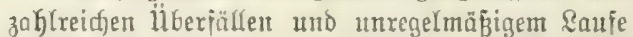

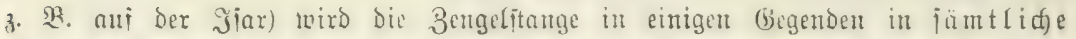

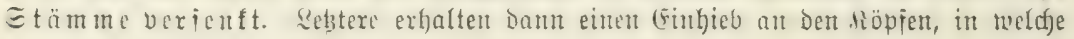

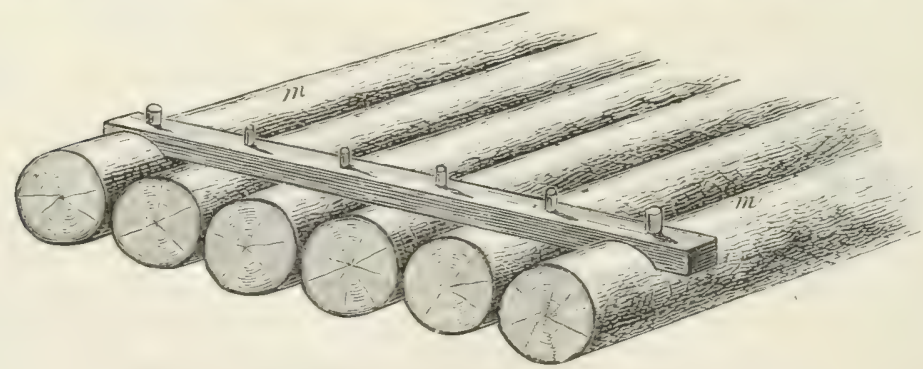

Jig. 241. Werjentung ber 3engelitange in bie Manditümme $(m)$.

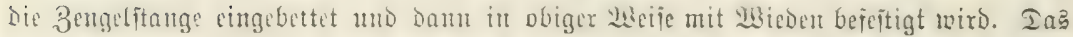

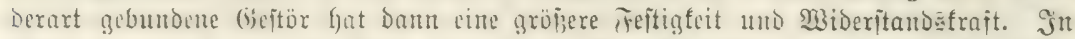

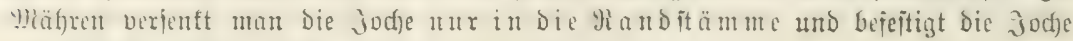

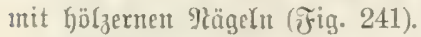

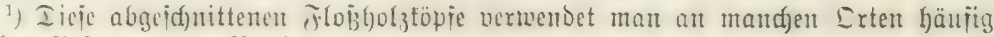
.zur 2 Ut 


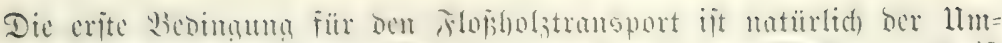

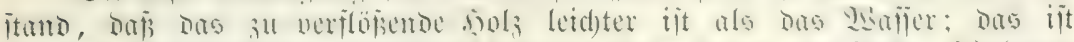

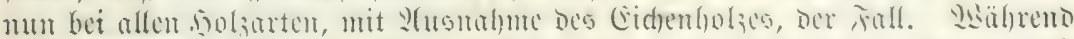

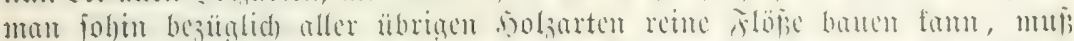

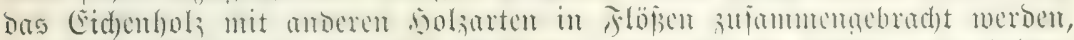

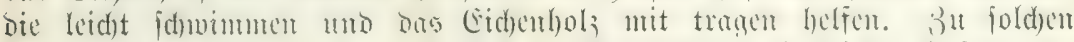

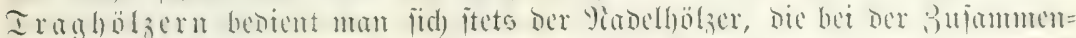

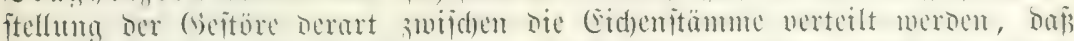

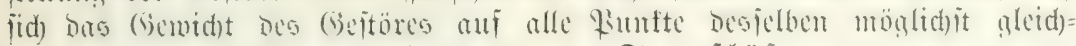

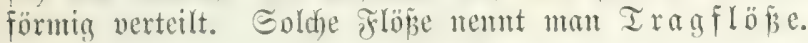

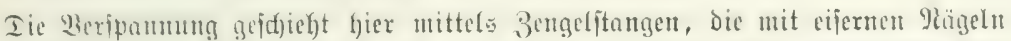

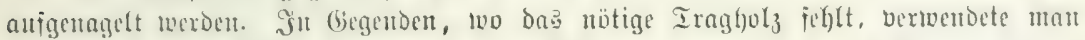

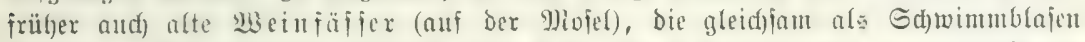

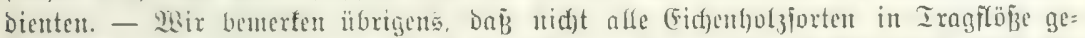

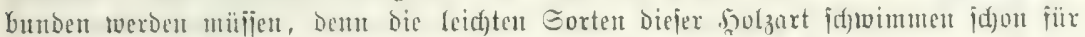

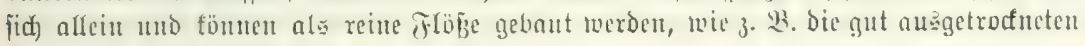
(Eidfentyötzer De Spelfiart.

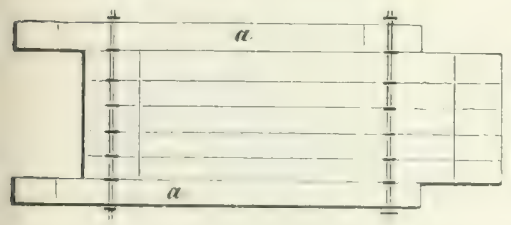

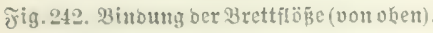

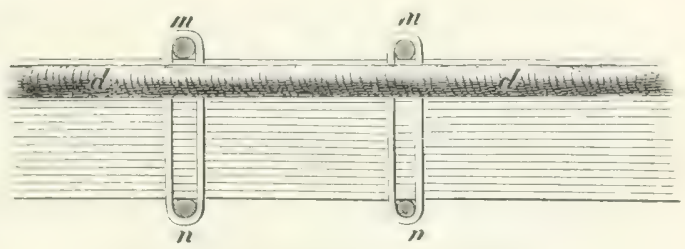

Fig. 243. Seitenanfidt von Fig. 년.

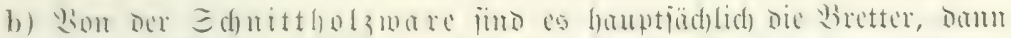

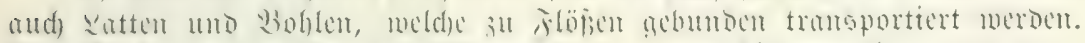

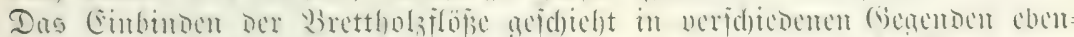

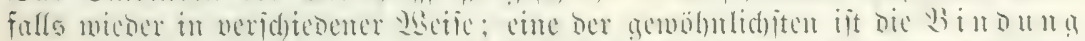

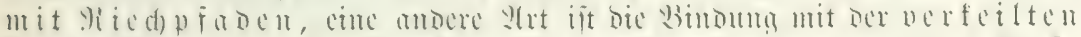
.) id) alten an.

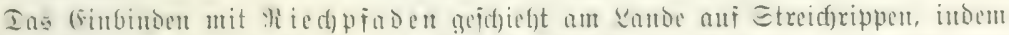

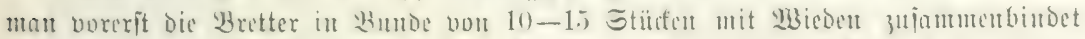

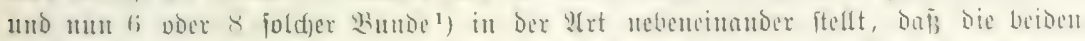

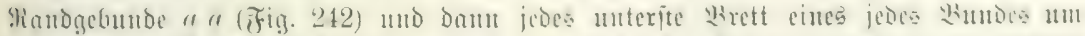

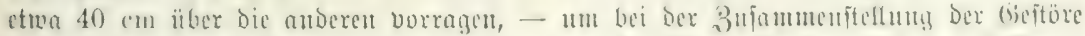

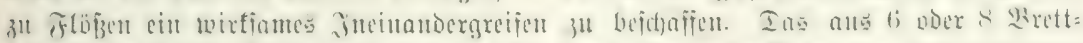

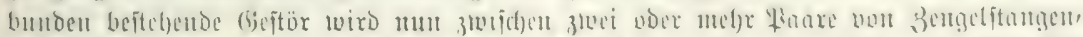

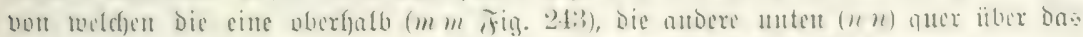

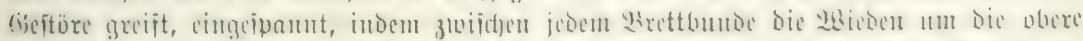

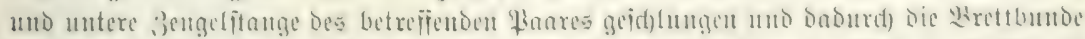

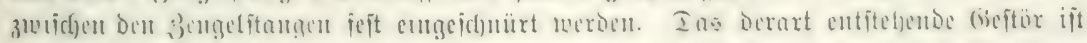
ein bollfoumen fteifer.

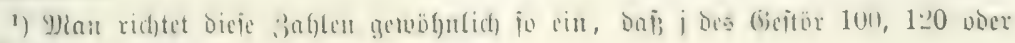
150 şrettex entfjält. 


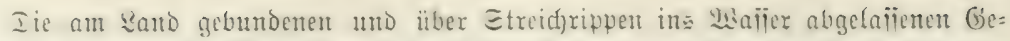

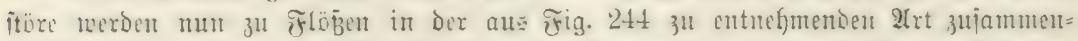

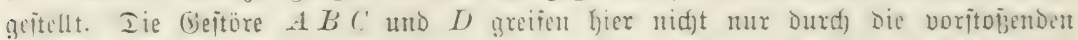

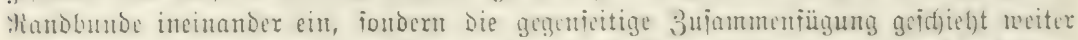

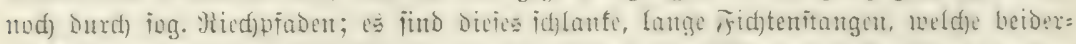

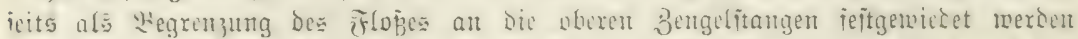

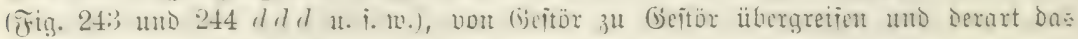

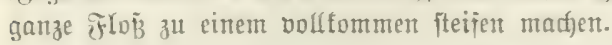

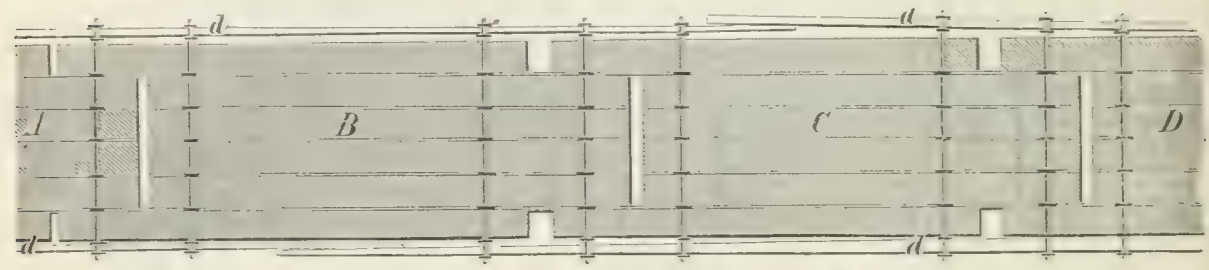

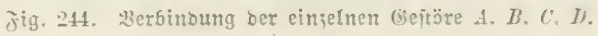

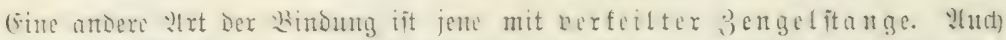

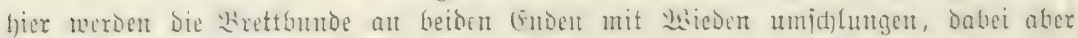

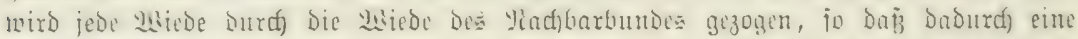

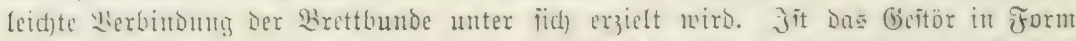

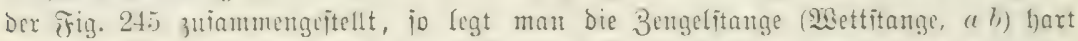

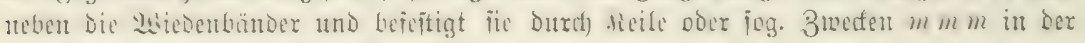
aub der Figur zu entuefmenden 93 eije.

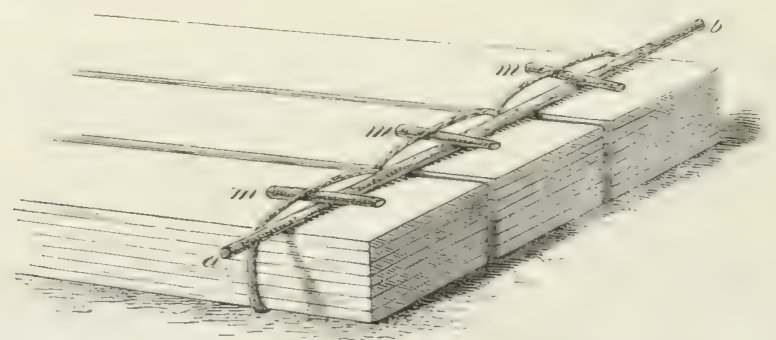

Jig. 245. Sinben eines अeitöres miltels 3engelitange uno Eeilen.

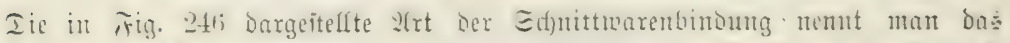

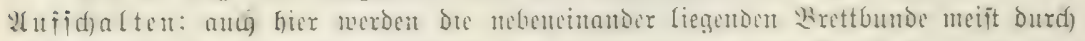

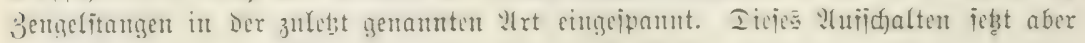
mehyr als Dic anderen Bindungäarten rufige, ticje Mafier voraus.

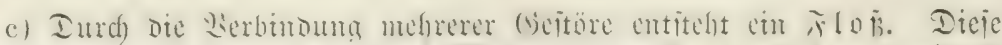

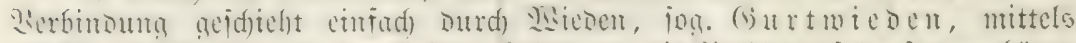

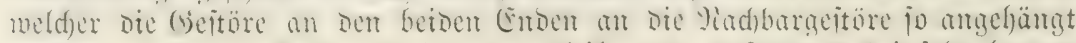

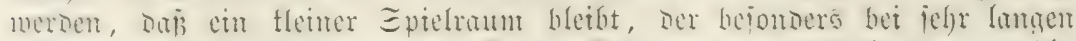

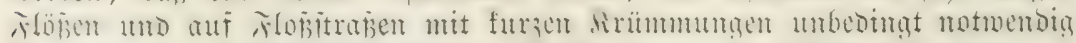

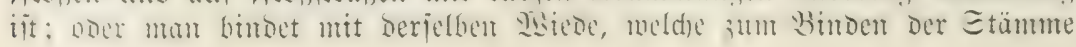




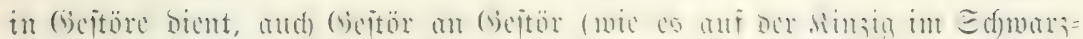

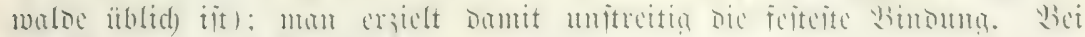

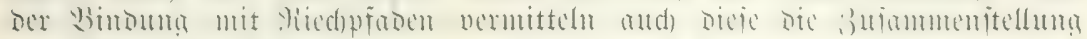

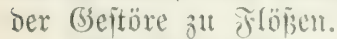

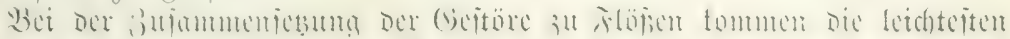

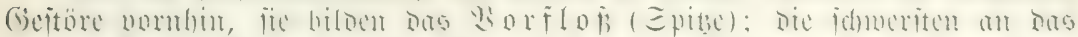

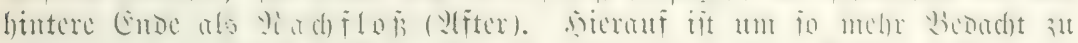

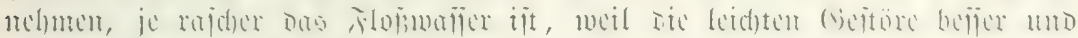

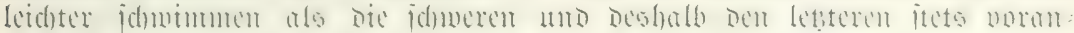

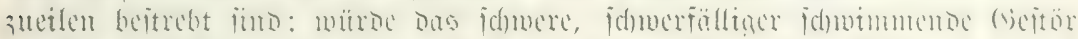

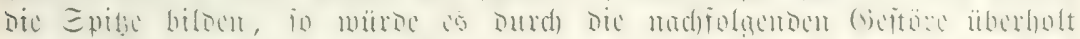

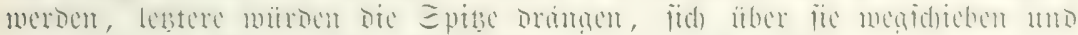
eine geregelte gölfrumg bes (sicjantflofses mmöglid) madjen.

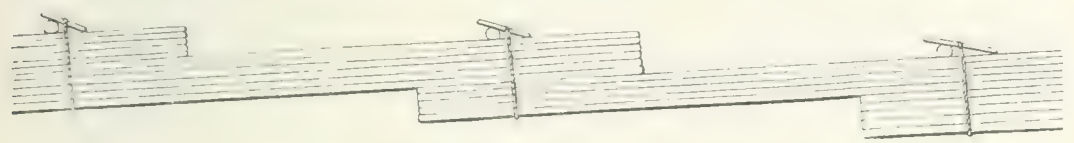

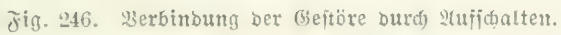

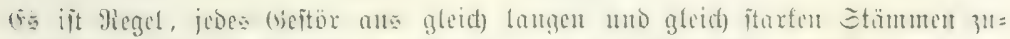

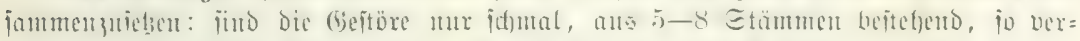

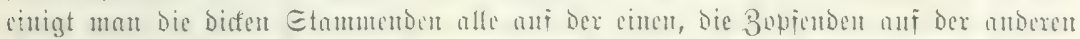

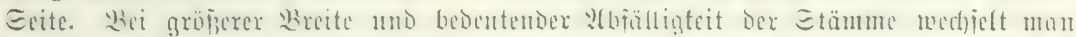

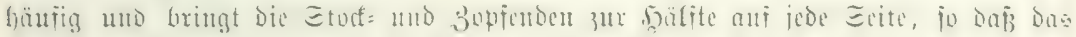

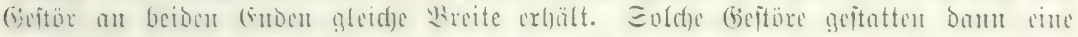

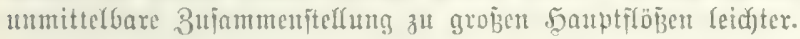

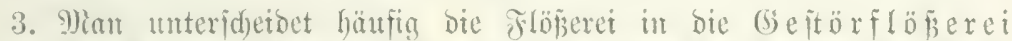
Imo in Dic na

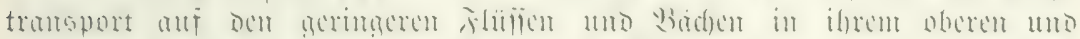

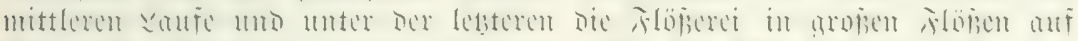

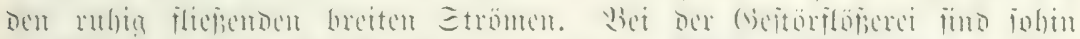

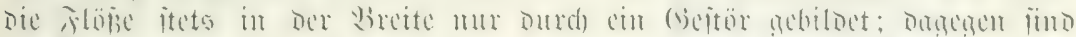

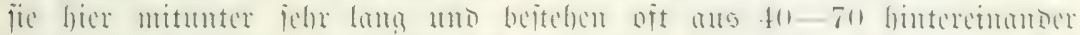

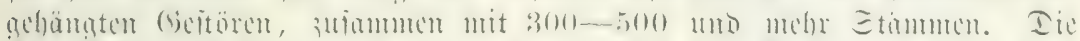
s) $200-250 \mathrm{~m}$ sënge und muxben früber nod) gröjer gebout.

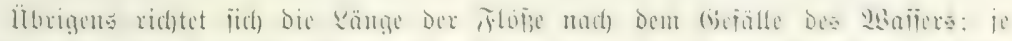

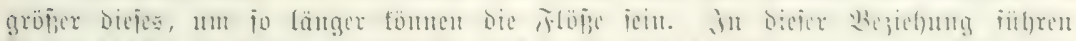

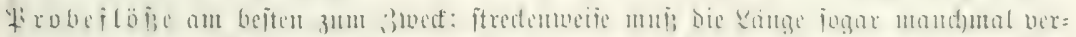

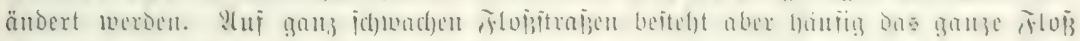
nux auß auß cinem ober wenigen Gejtören.

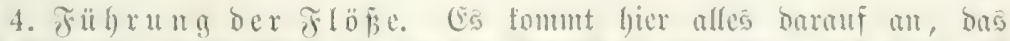

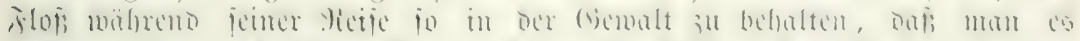

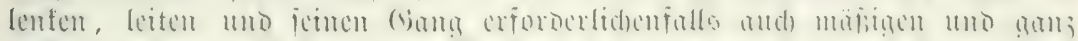

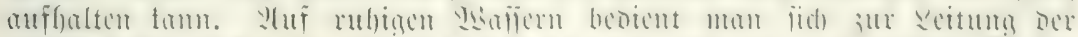

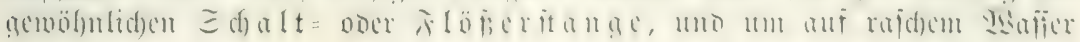




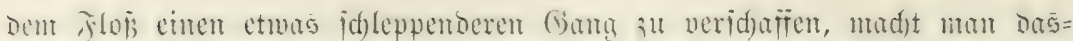

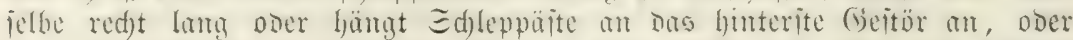
man löit lebteres in einen log. Lisedel (

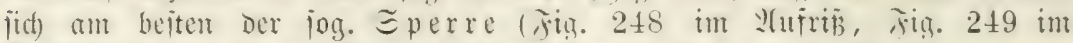

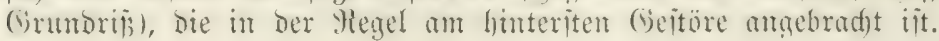

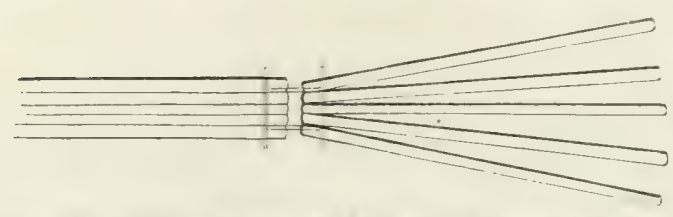

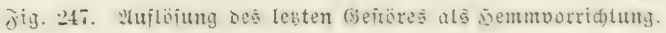

Die Eperre bejteft itt einem ftarten Salfen $(a)$, Der zwifiden ben zwei mit $\mathfrak{K}$ lam: mern ober Mieden ieftgehal= tetrent Eperrriegeln bis auj Dent

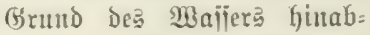
gelailen uno auj biepem in jujiefer Rage fortgeid leift wirb,

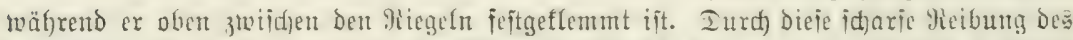

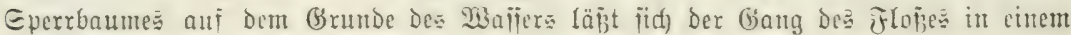

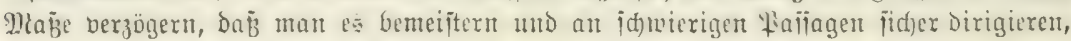

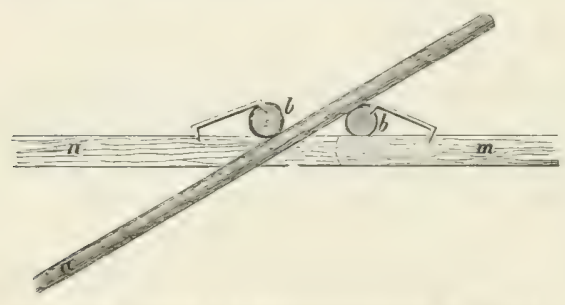

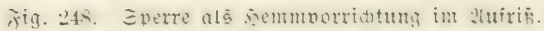
ia jogar anfialten unb lanoen fantu. Range und jujwere Flö̉e auj twildent Majieru mit ftartem Befälle haben

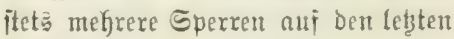
(Beftören.

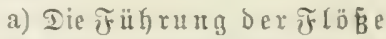

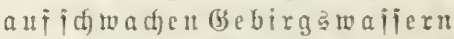
expordert großje Aujmertjamfeit und

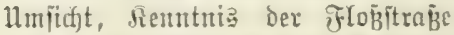
und unberiroliente, tüc(t)tịe II rbeiter. Shamentlich twird bom Flö̈er cine

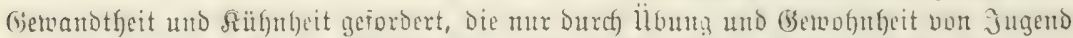

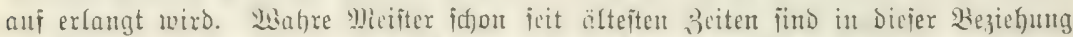

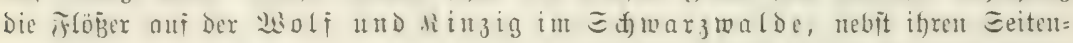

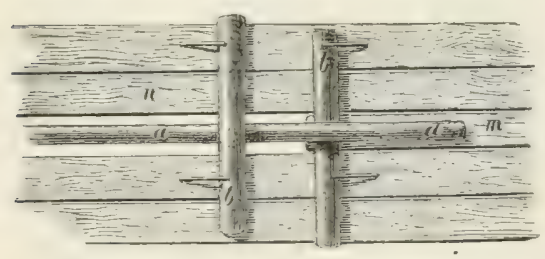

Fig. 249. Everre (f̈ig. 218) im (5runoris. wafiern; obuofld bie fier betriebene Rang=

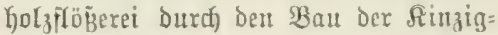
talbahn nakezu aufgegeben ijt, jo fant Diejelbe allezeit als 9 lupter für andere, äfnlicfee Flożtwege Getradjtet werden.

b) Die fithrung ber 5̧aupt=

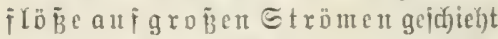
affein Durdy bie Rubèrtteiche, da bei ber größeren Maffertiefe die $\mathfrak{U} \mathfrak{n}=$ wentoung von Eperren u. ogl. nidgt zut= läjiig ift. 2ư bem Mgeine unteriffeibet man bie liuber, bie entweser aus cinem

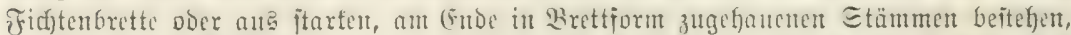

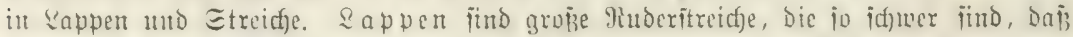

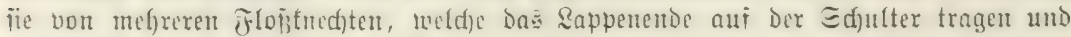

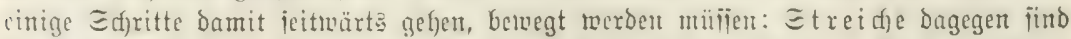

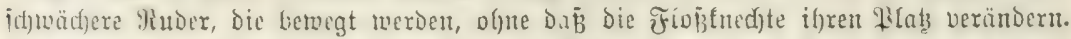

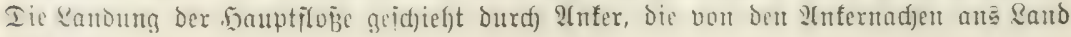
getragen twerden. 


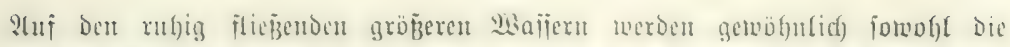

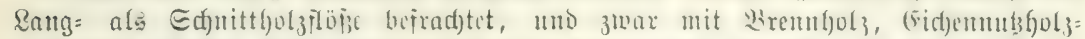

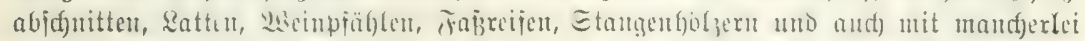

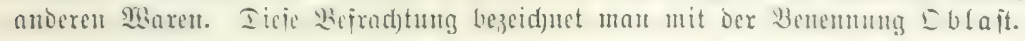

\section{Dritte Unterabteiluma.}

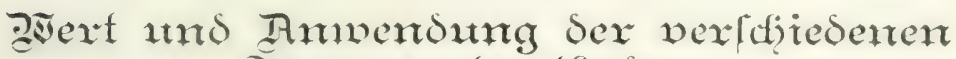 Exarspoxtmethosen.}

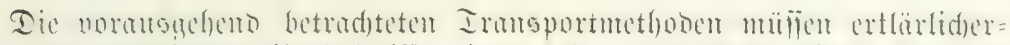

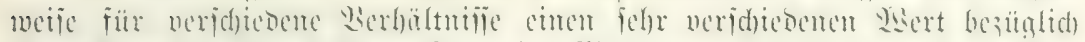
ifrex

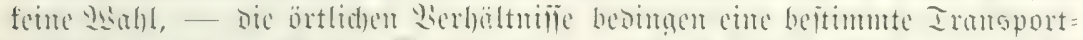

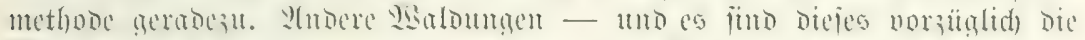

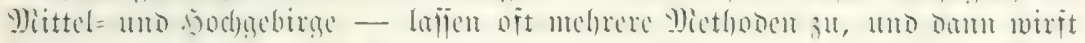

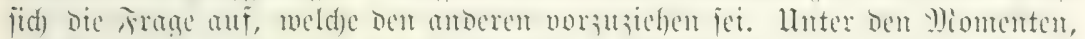

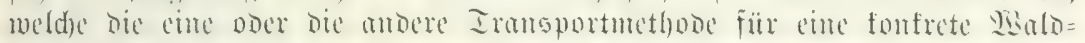

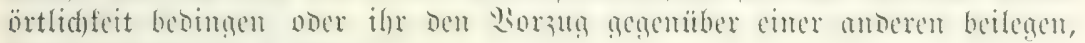
find folgende bie midstigiten.

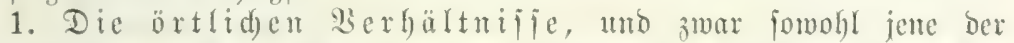

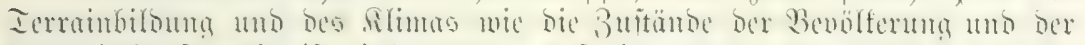

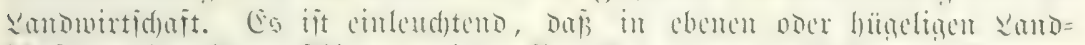

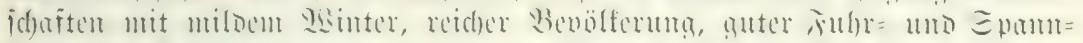

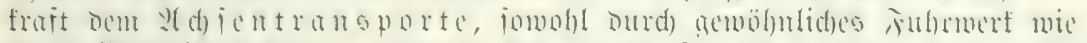

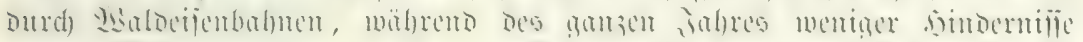

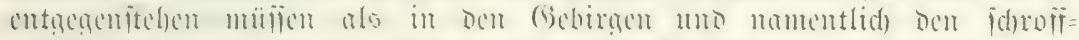

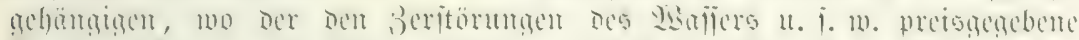

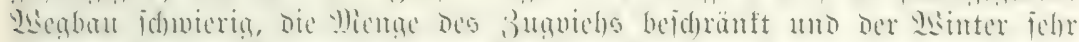

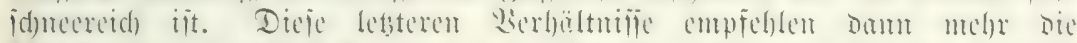

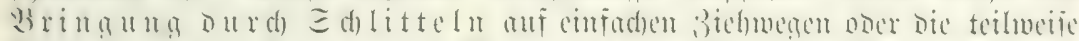

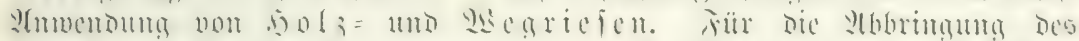

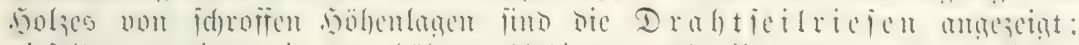

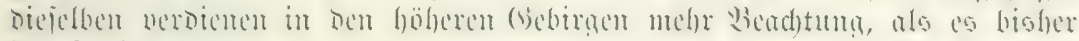
Der Fall war.

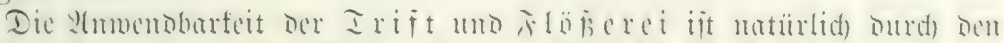

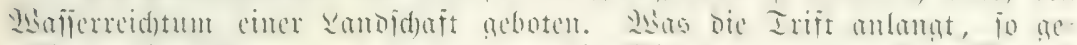

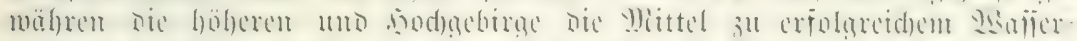

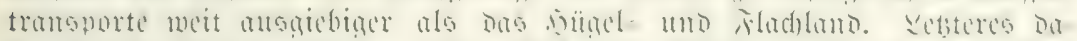

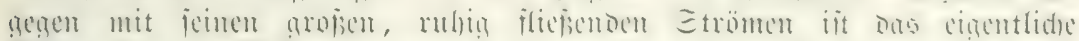

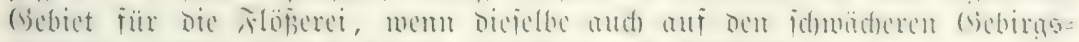

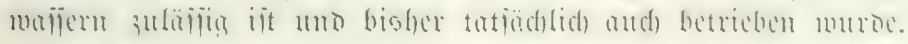

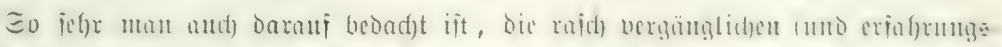

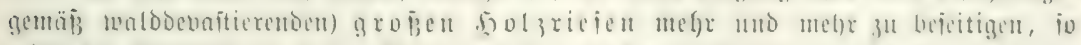

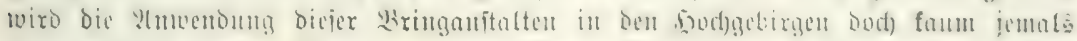

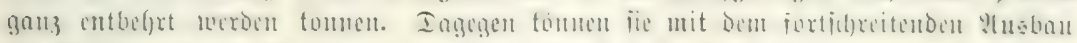

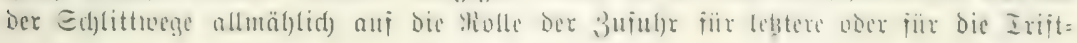




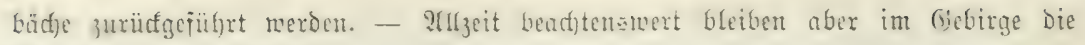
Begriejen jür Rangholz.

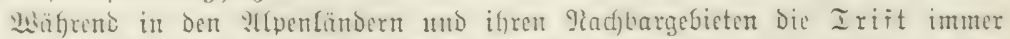

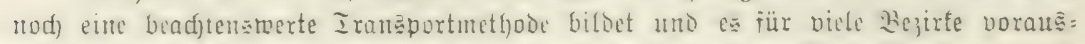

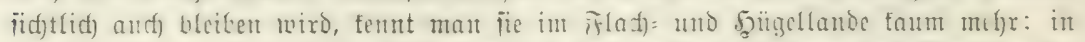

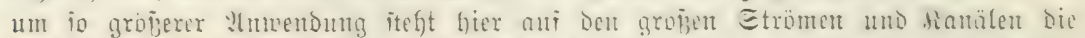

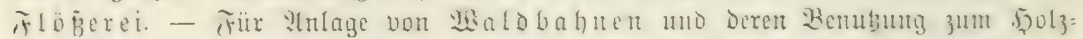

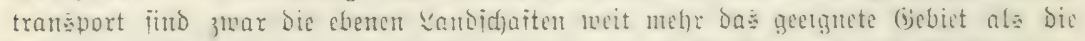

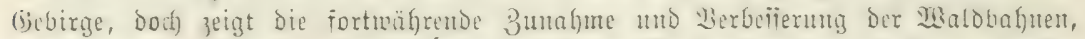

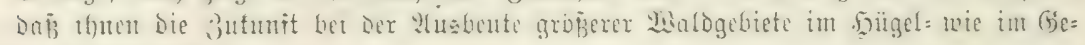
birgs̆lande gefjört.

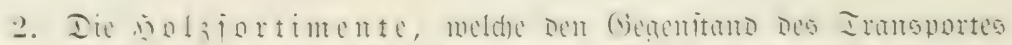

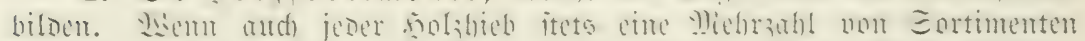

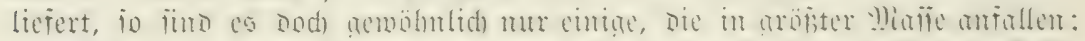

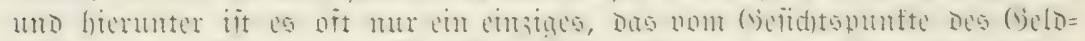

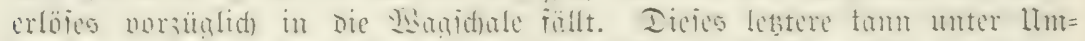

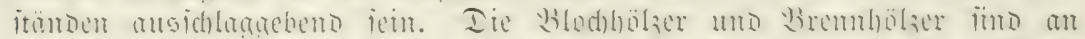

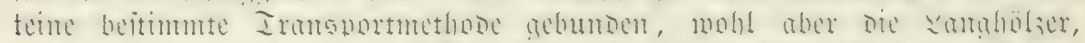

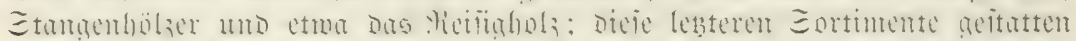

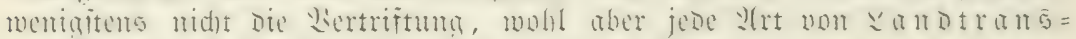

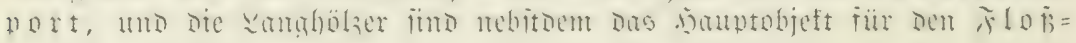
trangport.

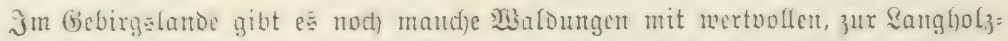
ausiormum qualifizierten Tiubholzmaiten, in meldjen alfe Etammhol, zu :3-4 m

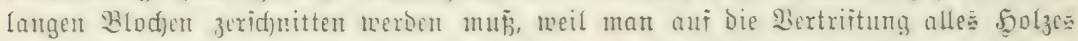
angemiejen ijt ober an biejer Iransportmethode glault ieithalten zu milien.

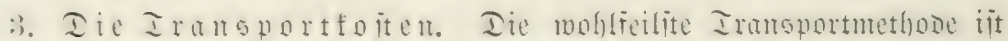

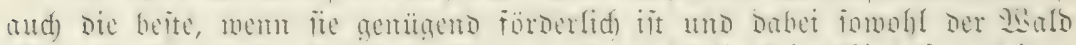

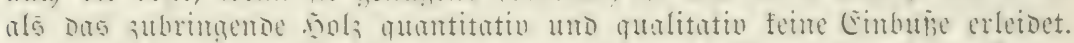

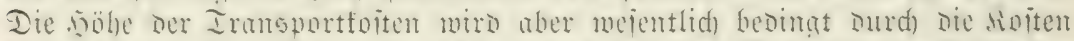

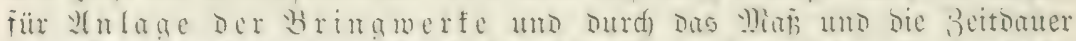

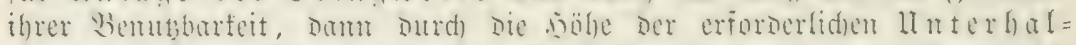

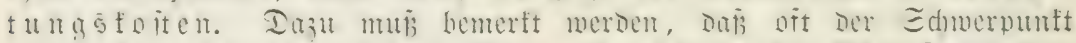

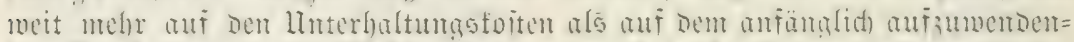

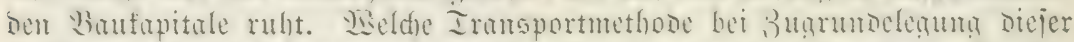

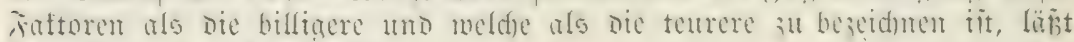
jid) allgemein nidit feititellen.

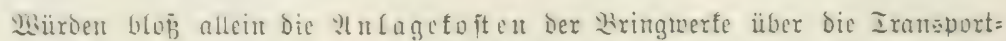

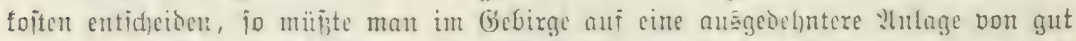

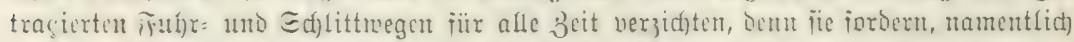

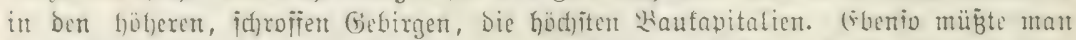

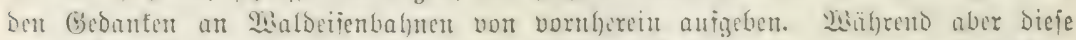

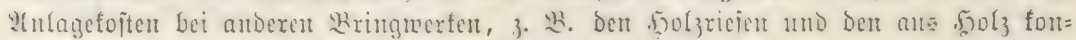
itruierten Iriftbauten, mu gering find, verurjad)en iie Dagegen mitit unverhältmin=

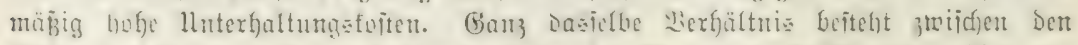

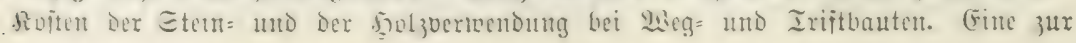




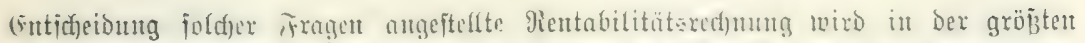

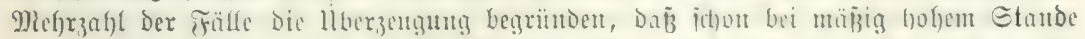

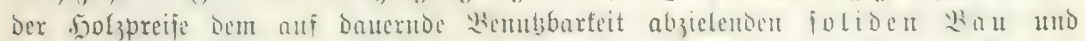

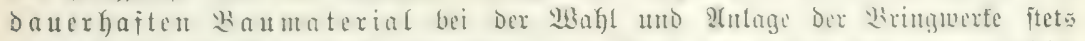

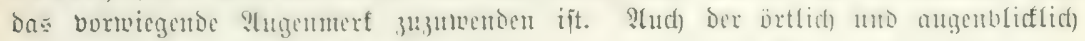
niebere Stand ber Sol apreife für bie wertbolfen Eortimente fant feir

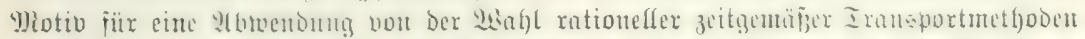

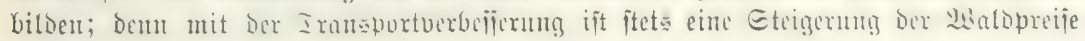
verbunden.

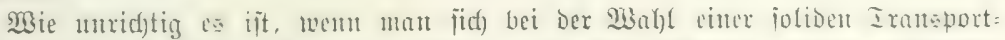

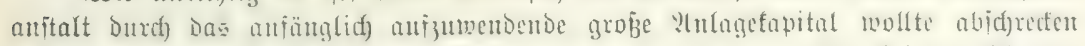

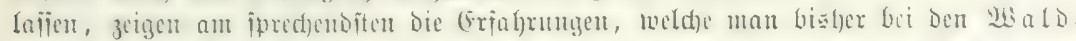

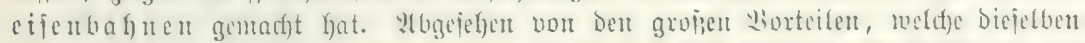

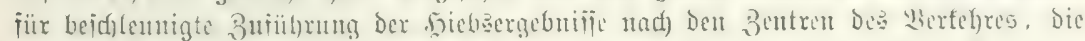

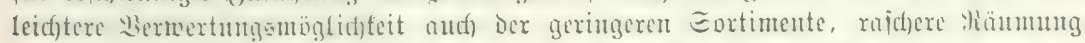

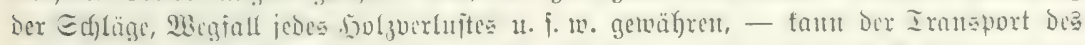

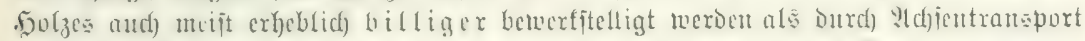

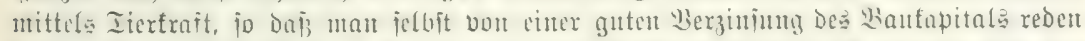

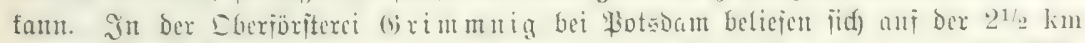

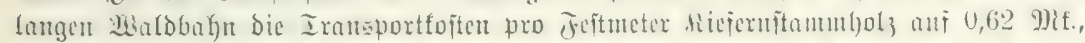

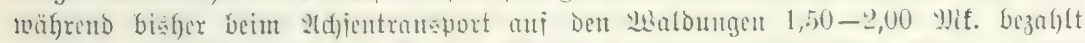

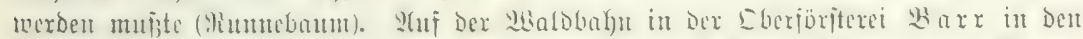

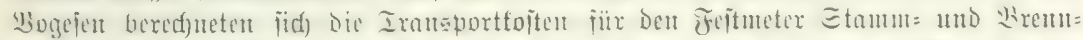

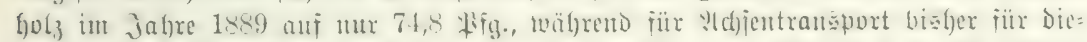

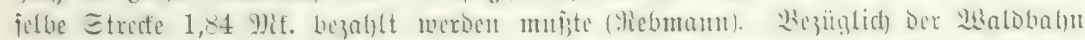

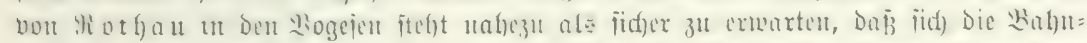

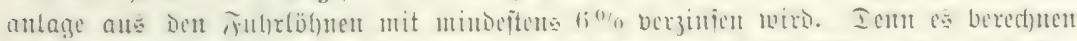

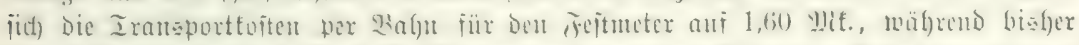

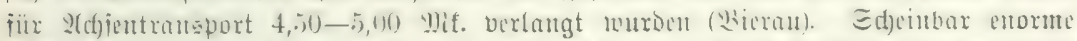

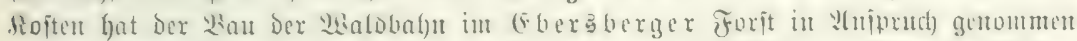

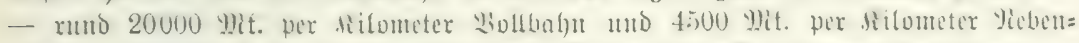

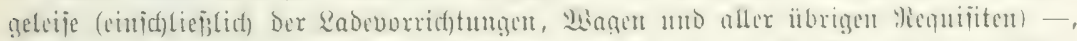

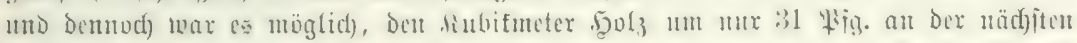

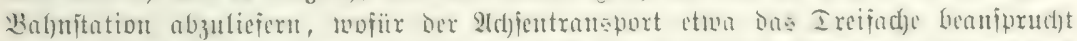

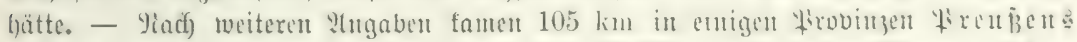

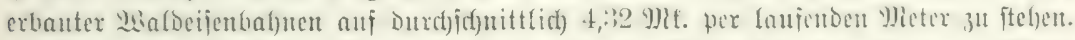

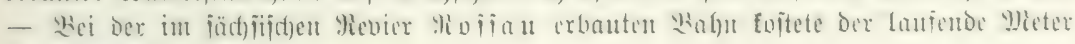
allerding 8,95 ग)(f. $\left.{ }^{1}\right)$.

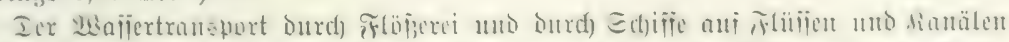

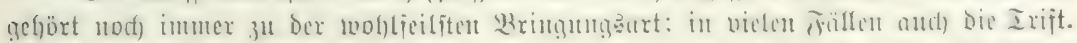

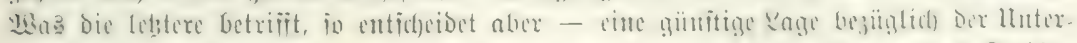

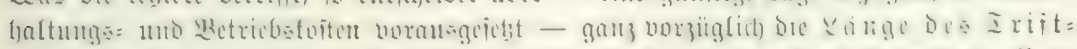

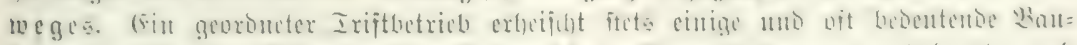

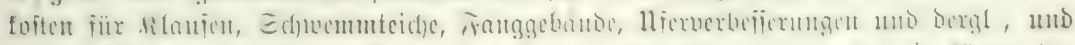

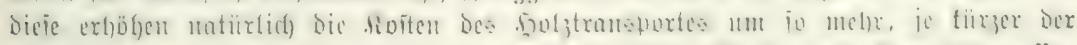

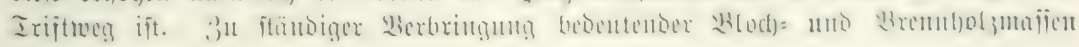

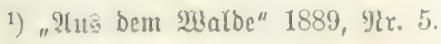


ntad) weiter entfornten Drten ift ongegen Die Irift ftete eine bex wohlfeilften Iransport=

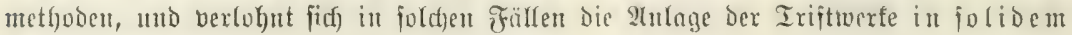
Steinbau.

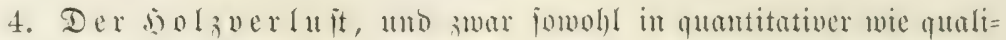
tativer Şinfid)t.

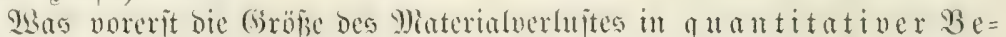

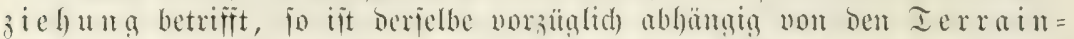

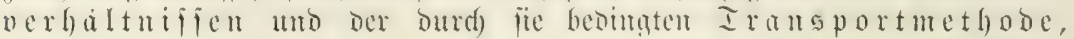

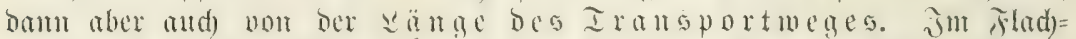

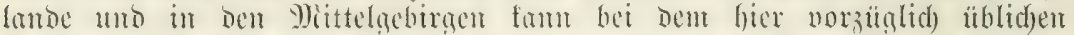

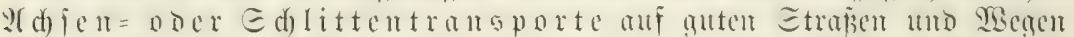
unb ebeno anf ben 2 as a

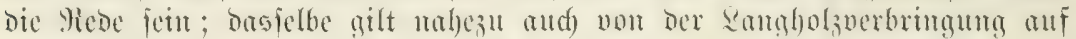
rgegriefen. Atud gibt es gut regulierte Iriftitrafen mit

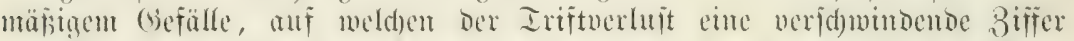

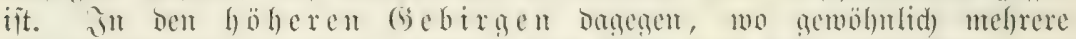

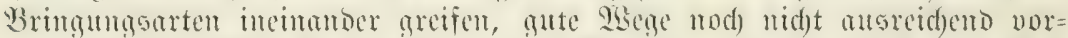

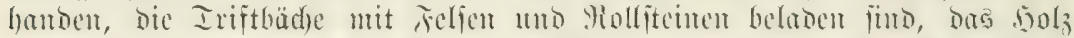

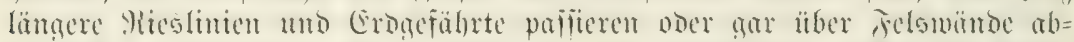

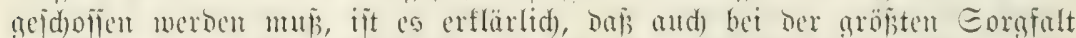

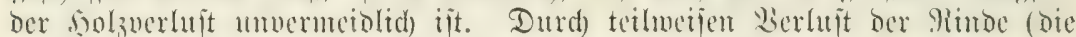
fïr hanbare soblace $10-15 \%$ ber (isefantholimafice beträgt), melgr abor

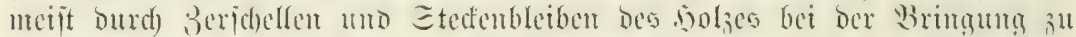

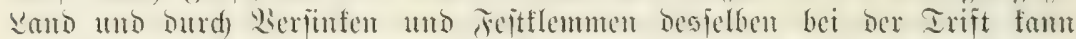

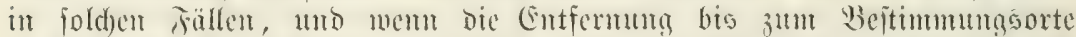

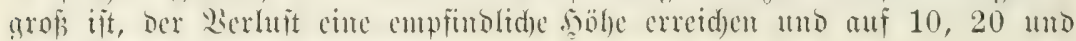
jelbit mehr Brozente aniteigen.

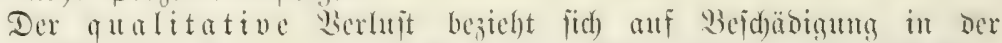

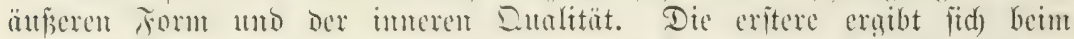

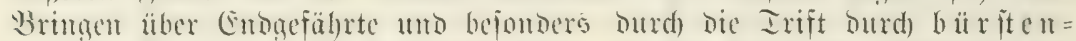

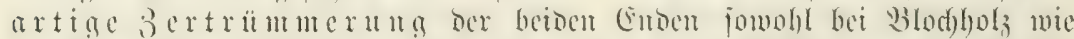

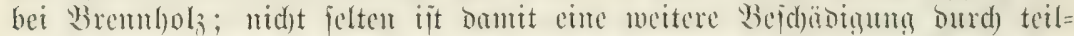

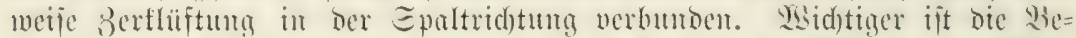

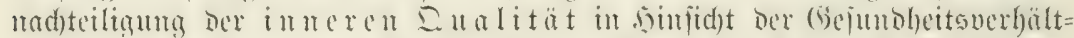

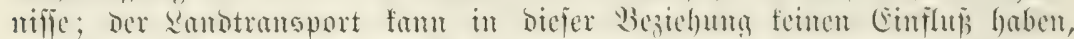

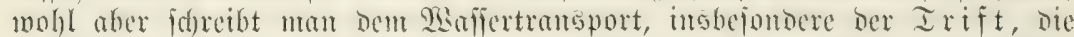

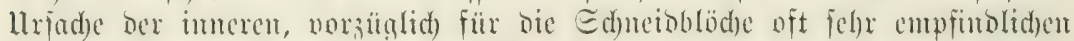

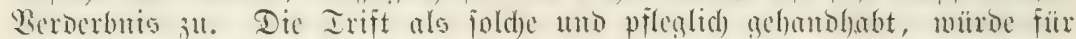

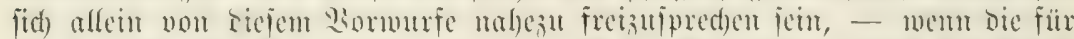

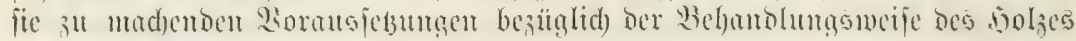
immer realijierbar wären.

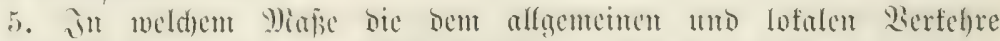
biencmoen (E)

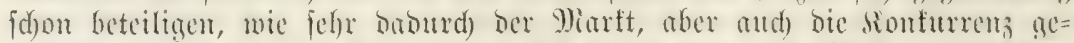

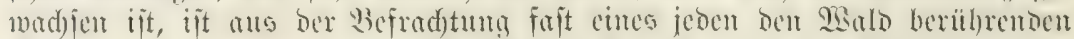

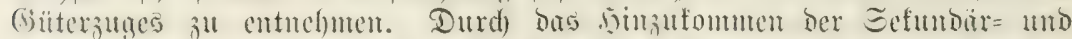

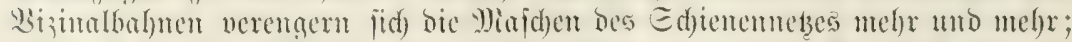

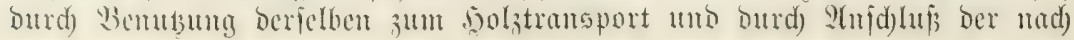




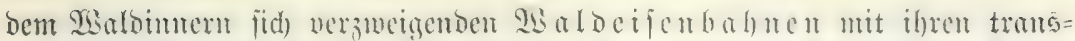

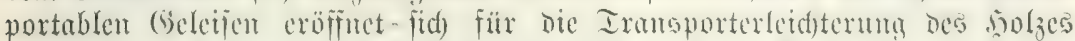

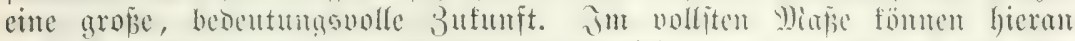

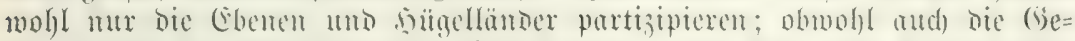

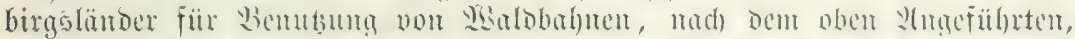

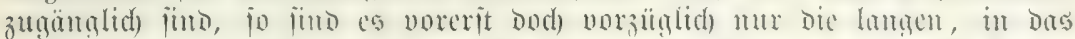

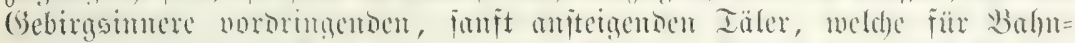

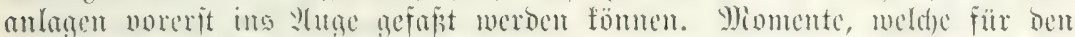

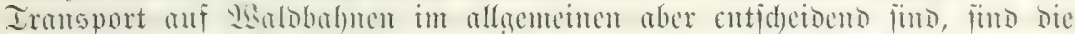

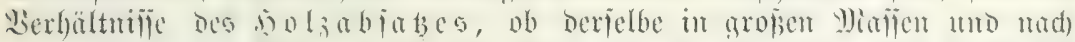

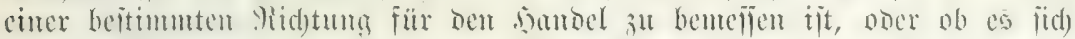

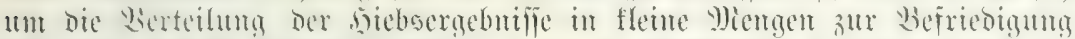

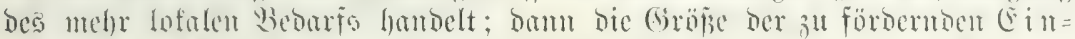

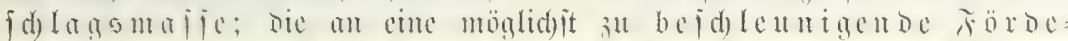

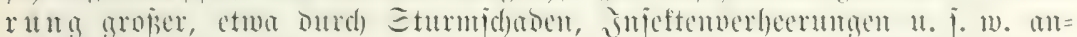

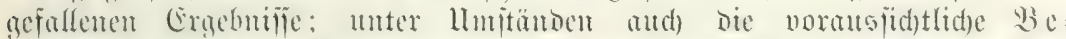

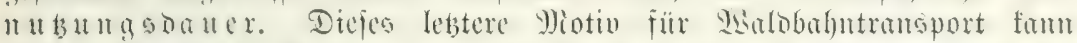

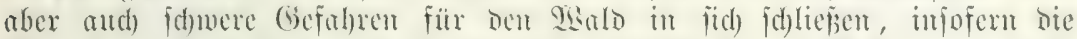

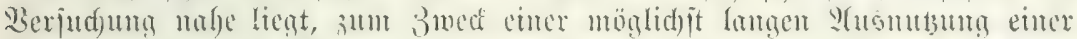

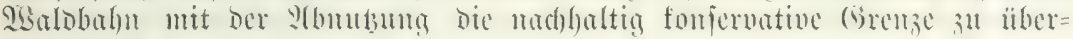
(d)reitert.

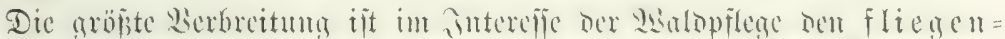

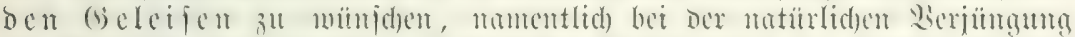

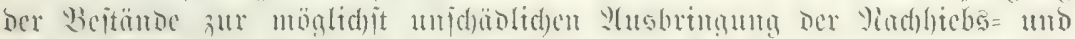

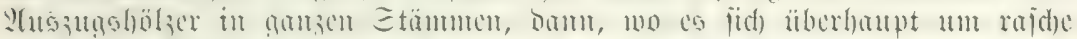

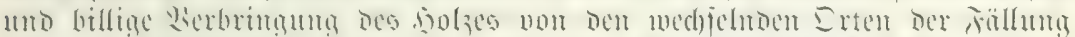

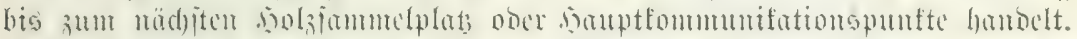

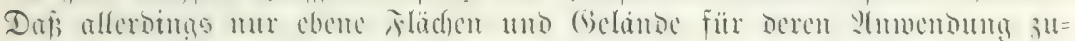
gänglide finto, ift einleudstento.

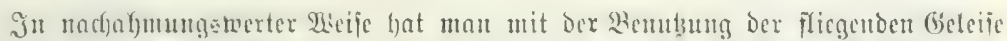

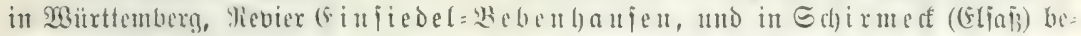

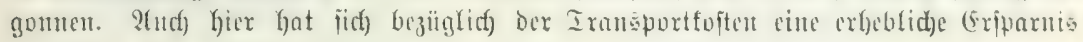
gegenüber Deul Fuffrtransport ergeben ').

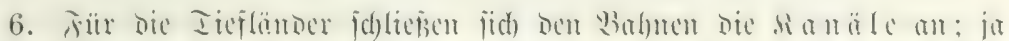

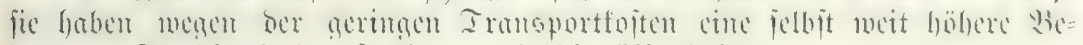
bentung für bie Solzuerfradtung als dic Eifmbabnen.

Mait weld)er Energie die Erweiterung des Raunalutbes in Tieflande der

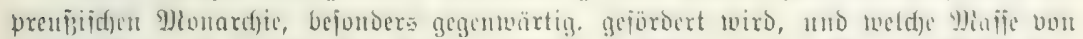

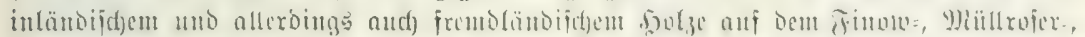

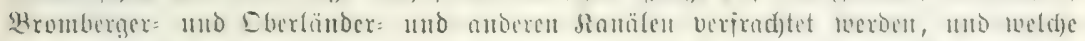

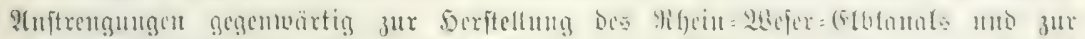

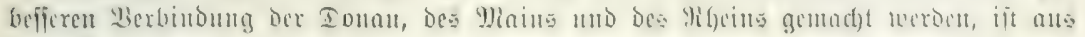
Den öffentlidjen sillattern befanut.

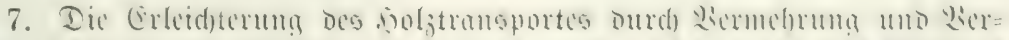

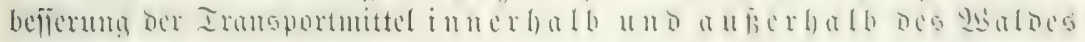

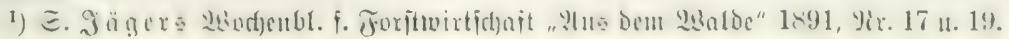
(5) a $y$ er, forftbenusung. 9. खufl. 
iit für lebteren foute zux bremenoen sebengfrage gemoroen. Dic forit=

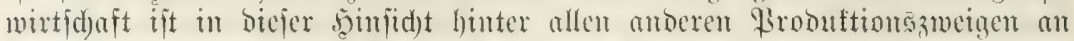

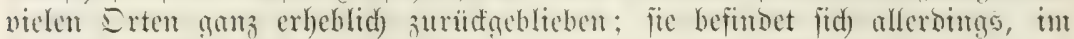

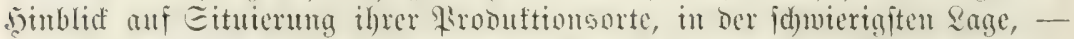

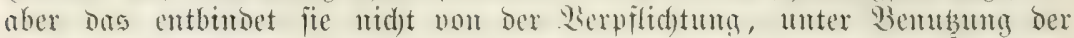

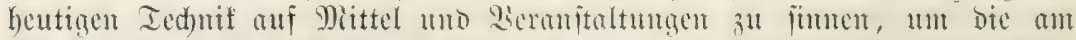

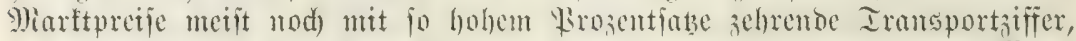

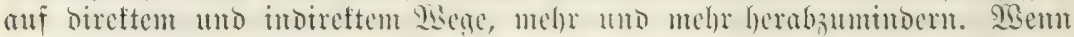

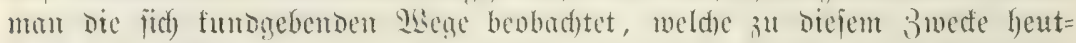

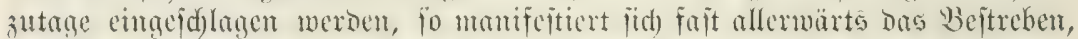

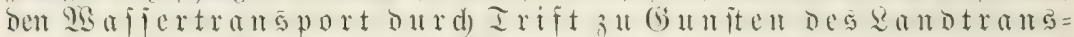
portes einzufdränfen; es beiteht überall die Tendenz, an die Stelle ber Irift mehr ub mehr ben $2(d)$ fentransport a uf $\mathfrak{B}$ egen ud $B$ alfuentreten zu rafien.

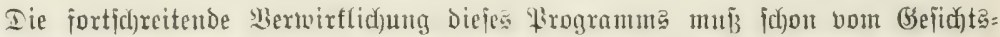

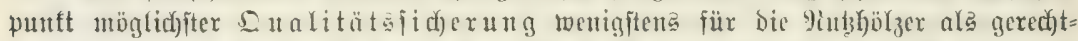

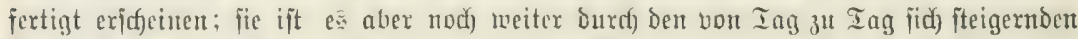

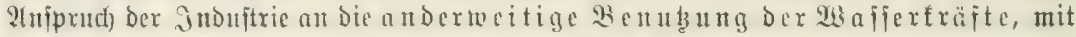

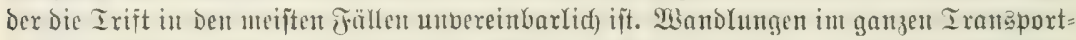

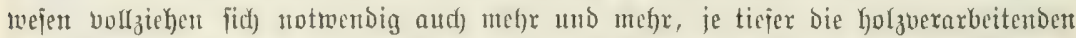

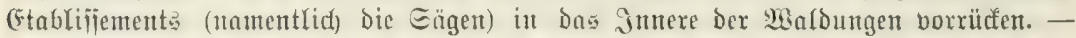

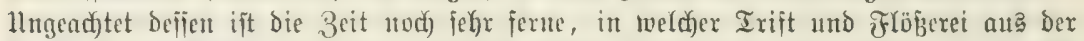
Meifye ber forftlidfen Iranaportmethoden völlig verfd)wutoen feit werden, $-j a$, für mantd)e Giegend twirb fie nie ganz entbefyrt werben fönnen.

\section{Bierte unterabteilung.}

\section{Şol’ägäxten.}

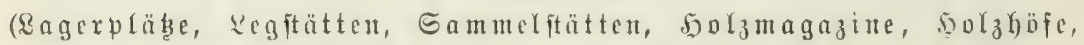

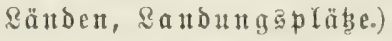

Unt bes burd) irgend cine Irmsportmethobe verbrad)te bols in ge=

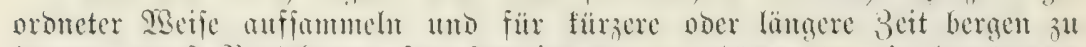

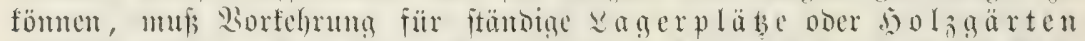

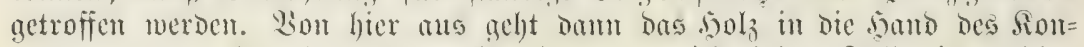
fumenten oder sänolers ïber. CEs gibt zmar nidst felten sälle, in weldyen

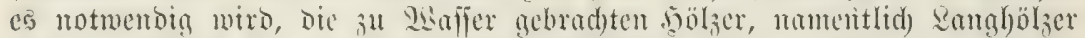

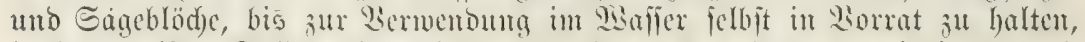

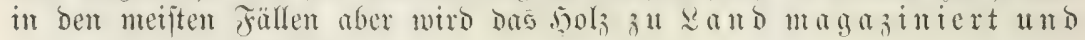
troden a uf bemahrt.

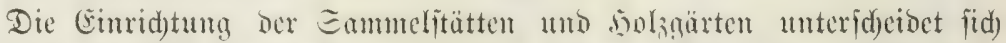

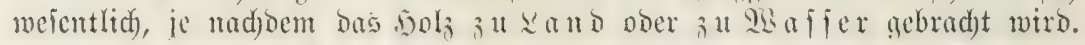

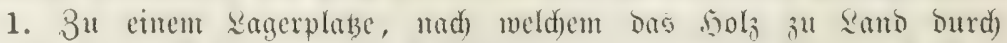

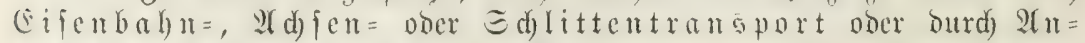
; tehen verbrad)t wird, ift jeber troden gelegenc, hinreid)ent Maum bietente uno burd) Fubrwerf zugänglid)e \$lab̨ geeignet. 


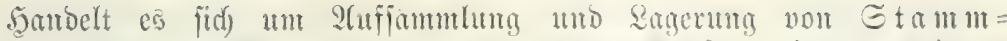
f)

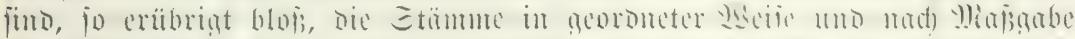

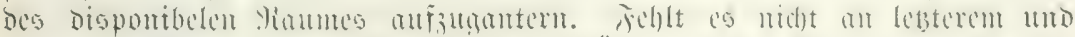

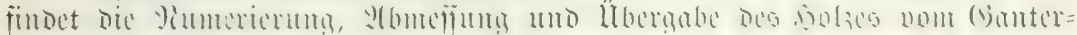
platbe ates itatt, io acid)

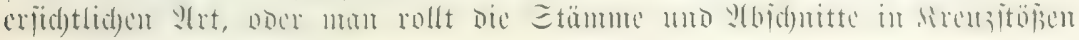

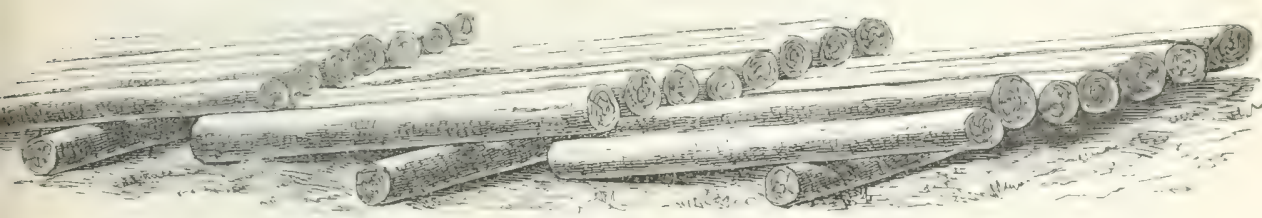

Jig. 250. Stufgantern bes Etammholzes.

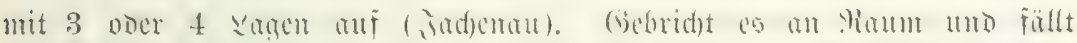

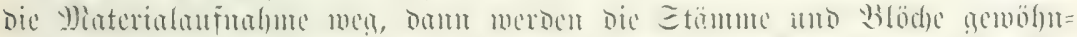

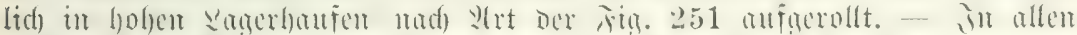

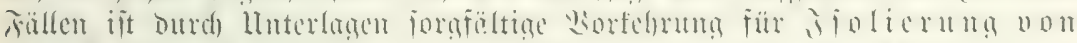

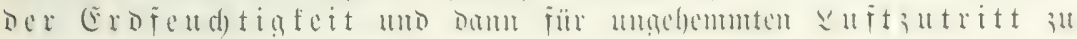
treffer.

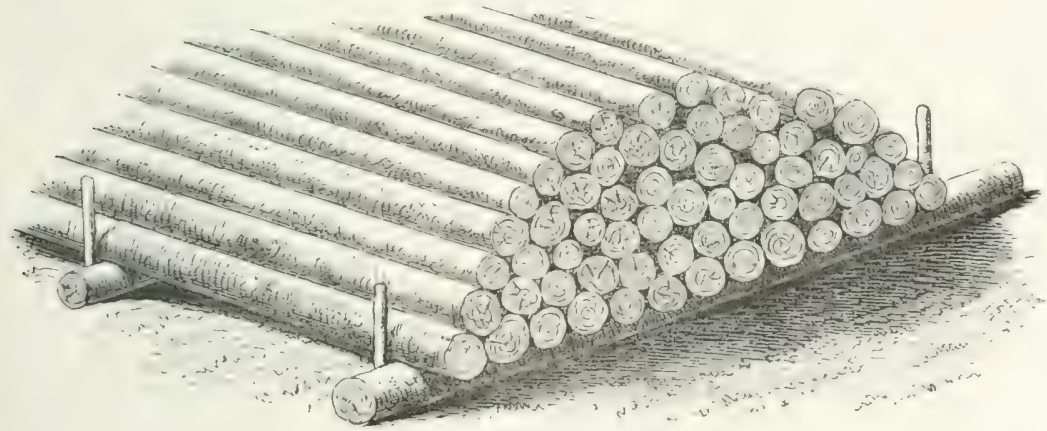

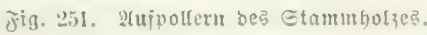

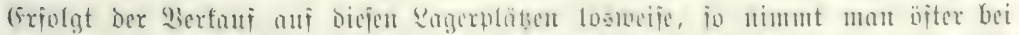

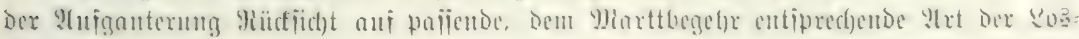
biloung.

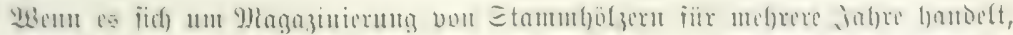

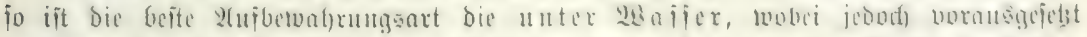

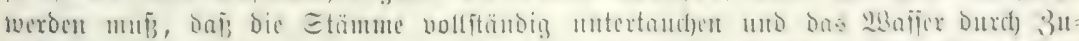

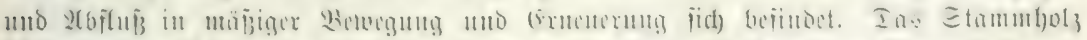

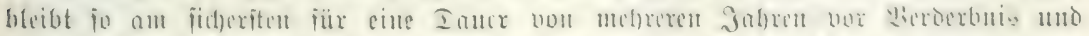

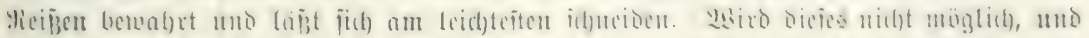

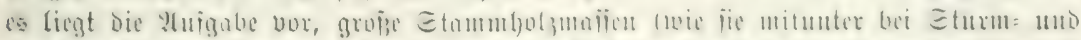

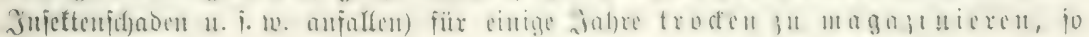




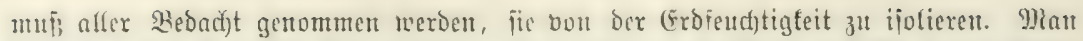
brimgt zu dem (Ende bie Etammbölzer auf llnterlngen, in ichattige, nicht bun tronfenen

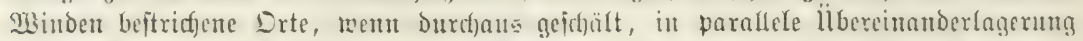

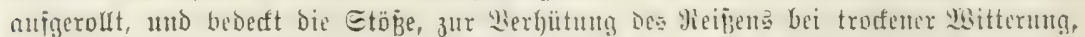

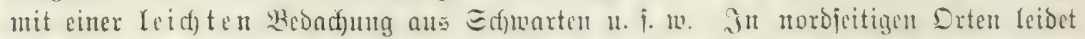

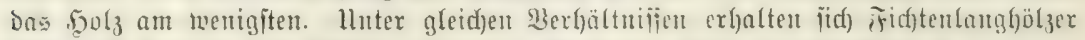
befier als Ianmm und fitim: Enugholy

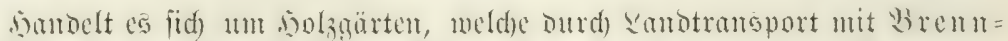

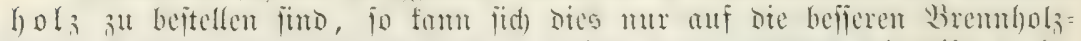

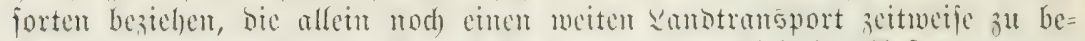

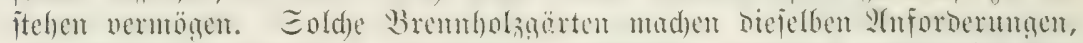

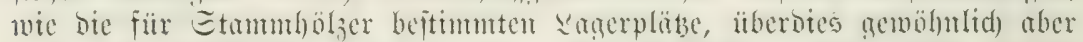

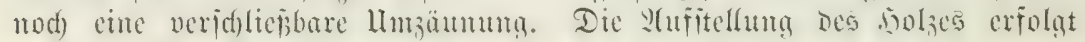
mad) Denfelben (brumbiäsen mie in Den Durd) Irift foumerten (bitrten.

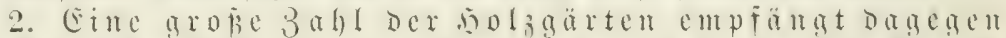

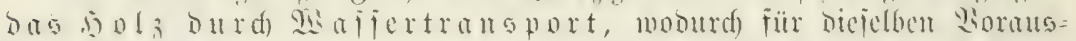

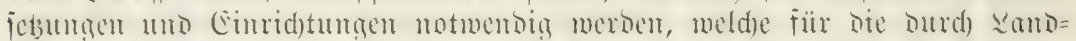

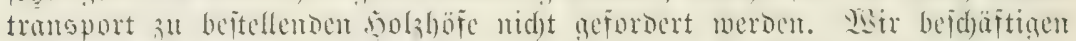

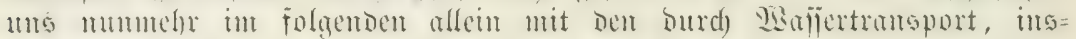
bejombere Durd Irift verjorgten .5olzgärten.

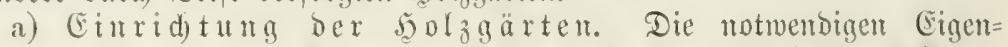

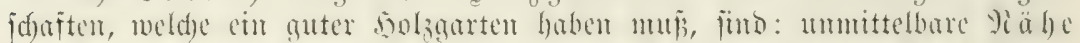

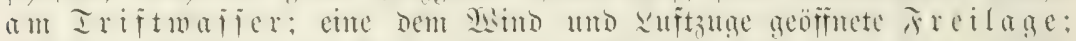

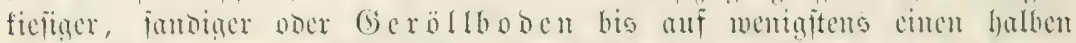

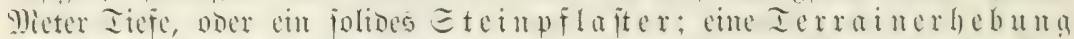

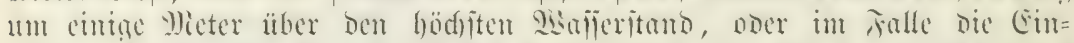

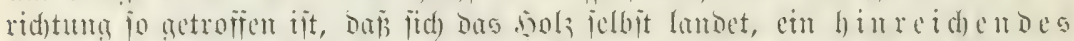

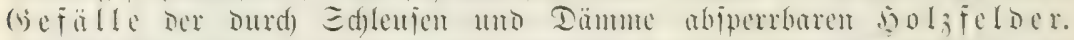

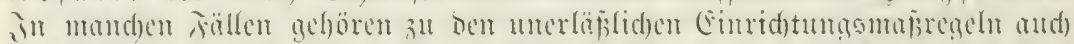

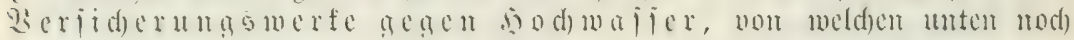
gehandelt werden wird.

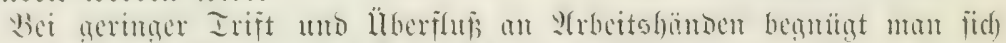

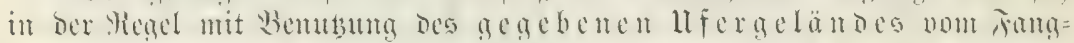

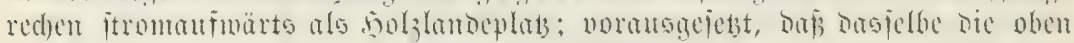

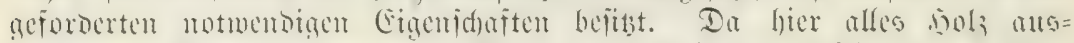

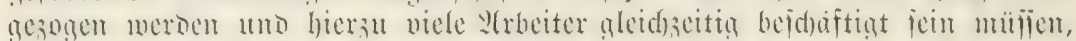

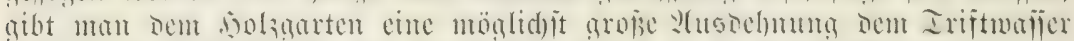

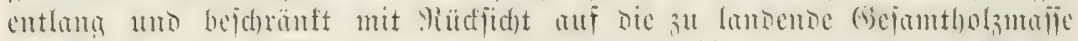

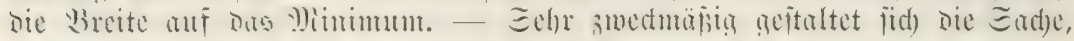

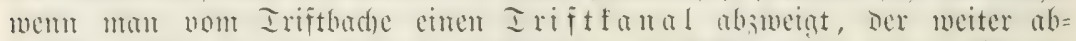

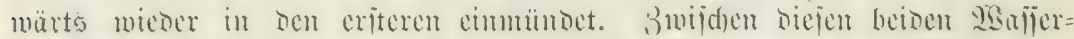

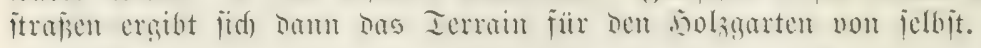

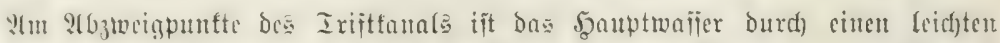

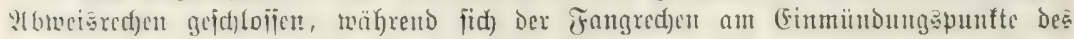

1) Eiche die gelegentfid) ber Eturmbeidyöbigungen in Eadjien gemad)ten (Ex= fahrungen im Ifaranoter Jahrbudf 1873. S. 172. 


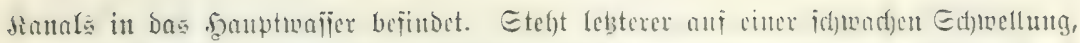

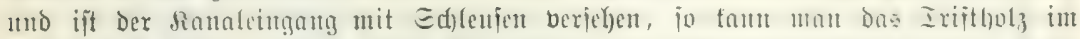

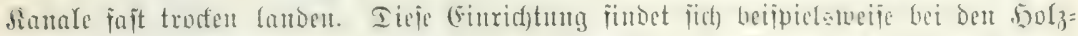

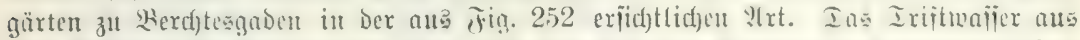

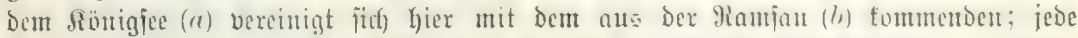

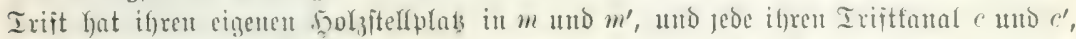

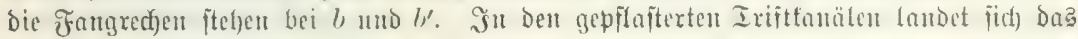
fुolz fait trocfen.

Dit zmeigen vom Iriftfanale Eeiten= fonäle ab, bie nad) allen Ieilen bes jolz= gartens zieben, fid fäntlid) in sampt= fanale wieber vereingen $1 m$ mit biejem in bie Iriftitrabe cimmümoen (9)iäbren, D̈iterreidjifd $=$ Gd)lefien 11. 1. 10.). In jolden Fällen verteilt fid) alio bas Irift= bo!z und bas \$gaffer in viele Germme, und Der Drud auf Edyleufen mb Reden, mit weldyen jeber Geitenfonal am $2(n=$ fange und Ende verjeben fein mufs, ift möglid)it gering. Itm in lester sintiddt alles $\mathfrak{B}$ unjobare ju erreidjen, mo bei unermartet eingetretenem Sodjwajier

Redhenbrübe and anbere Sialamitäten zu vermeiben, veriegt man ben 5aupttrift= fanal uno nad Umitänden den Iriftbad) jelbit mit श口falläd)en.

2uf diejes Prinzip, das Ixift $=$ bolz aแร dem 5auptwajer beră zufïbreu un oas jelbe ourd) Ein= fïhrung in die veridiedenen Felder des jolzgartems mög= lidf zu verteilen, hiermit alfo aud den Kedyendxud zu ver teilen, endid bie $\mathfrak{A} x$ beit bes 证 zu erfparen, grünen fid) die befjeren

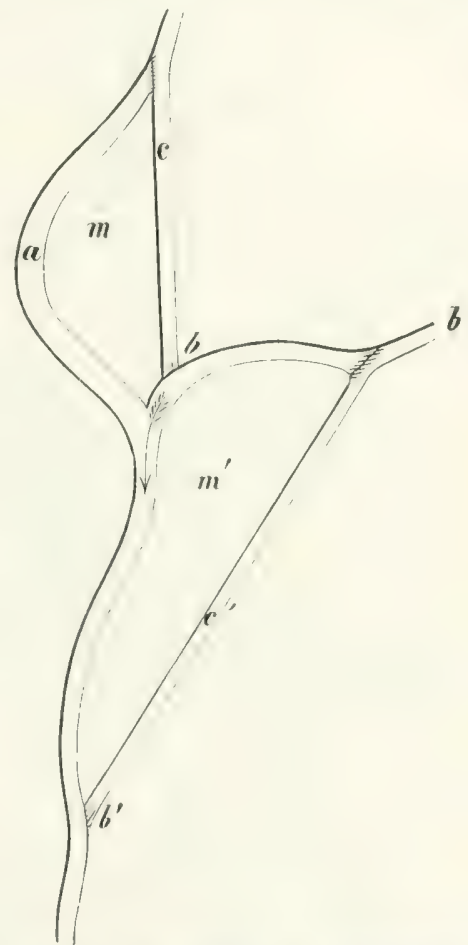

(j) pläben $m$ uns $m^{\prime}$.

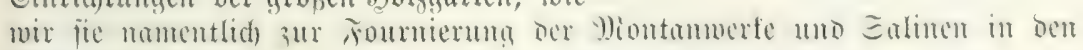
Ulpen fitben.

Ul[

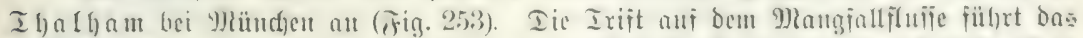

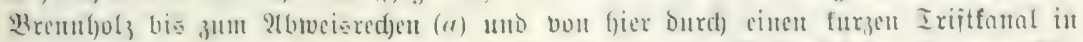

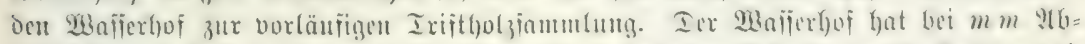

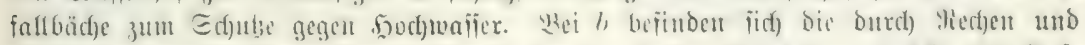

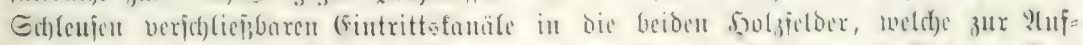

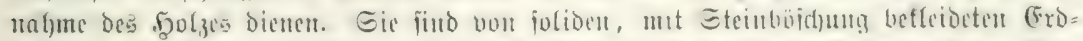

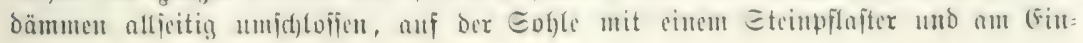




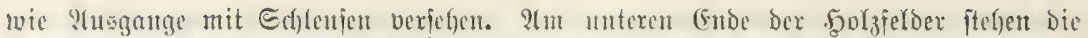

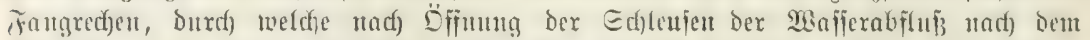

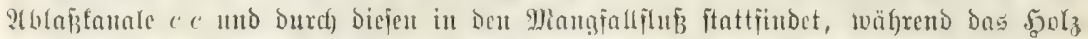
vor Dem Mect)en liegen breibt. - Mittelö Dicfer (sinridgtumg ift

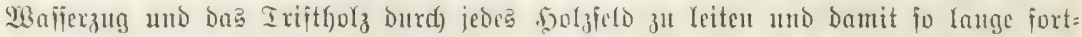

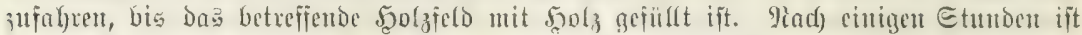

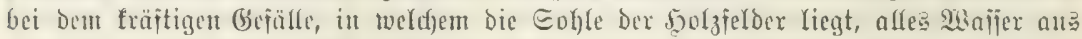

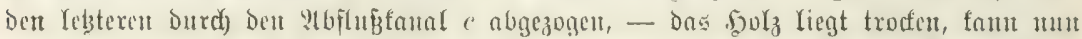

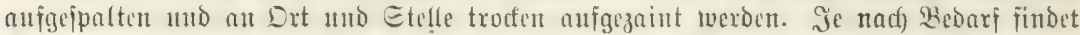

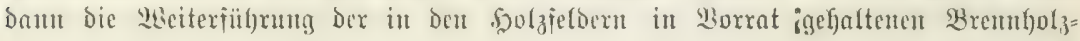

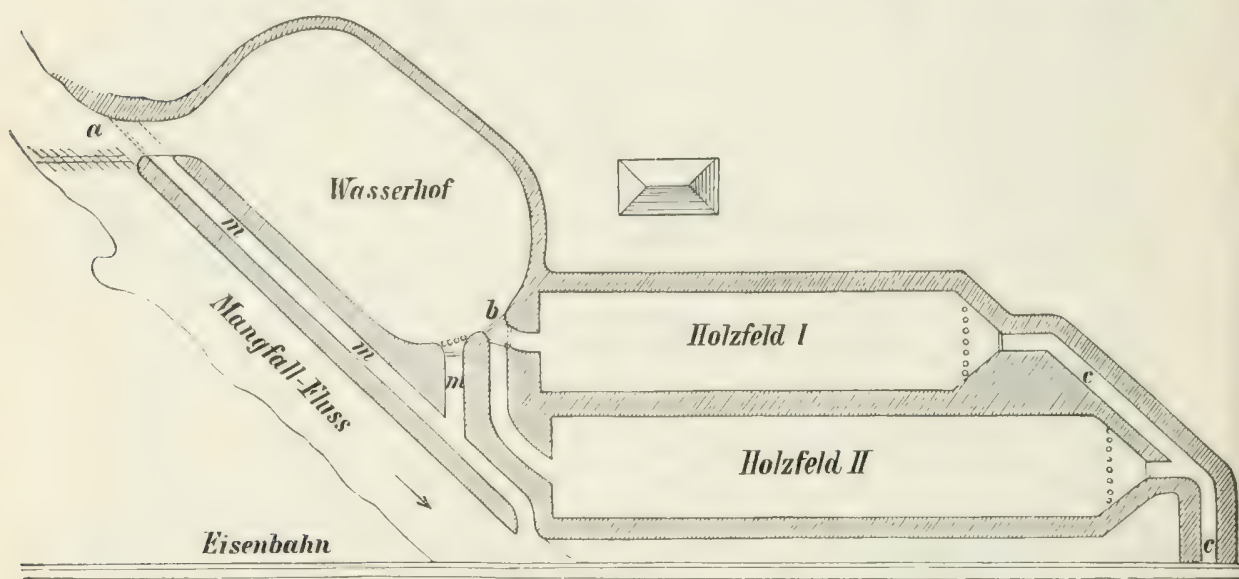

jig. 253. Cinridatung bes 5ुolygartens in Thalhan bet Diünden.

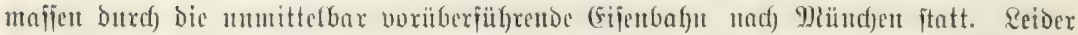
tourbe biefer Şot waffer ftart bejaübigt.

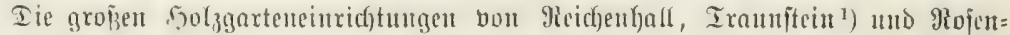

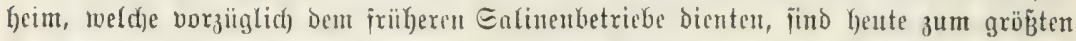

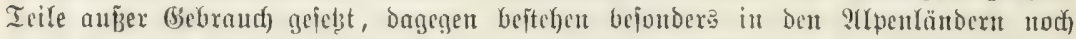
biele frolzgarteneinridftunģen, weld)e, woht werigger grobartig unb ausgebefut, auf

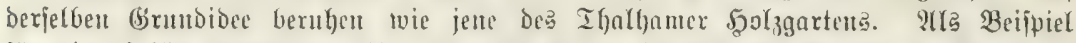

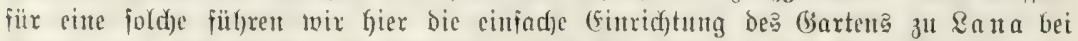
Meran an. Iex zwifchen Der Felfentenge $R R$ (Fig. 254) in Daz Borfand eintretende

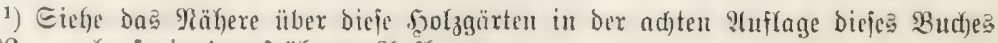
ङ. 392, - ebenjo in Den iritheren 2 ufflagen. 


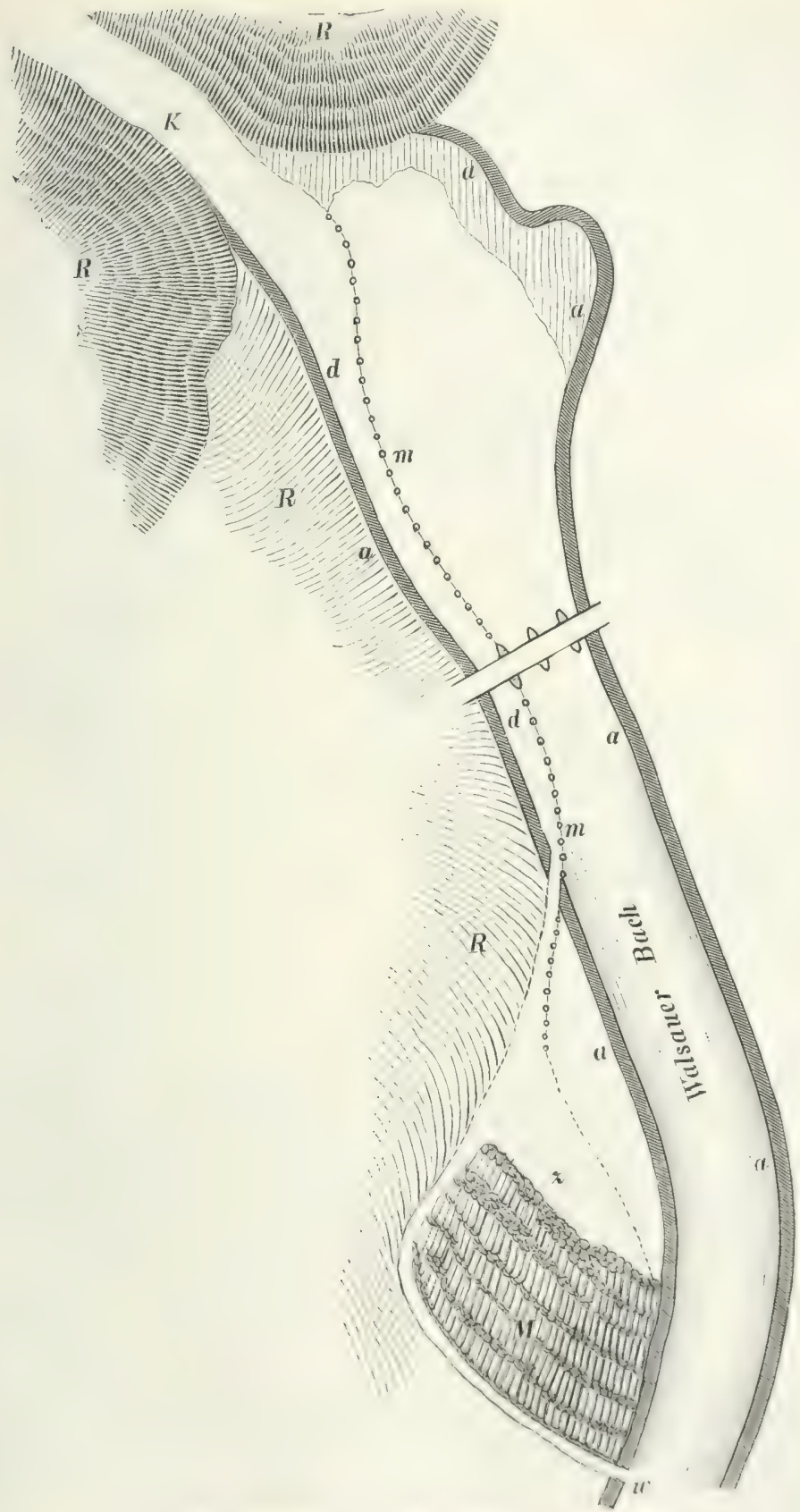

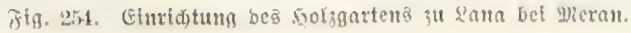




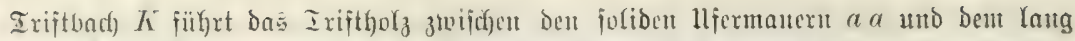

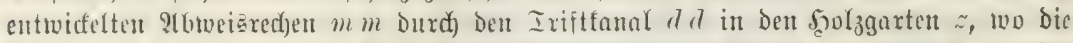

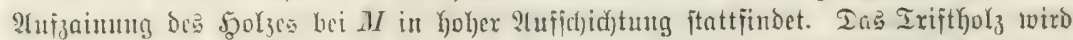

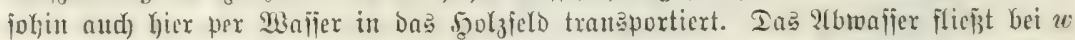
in bent Iriftuact) zuriücf.

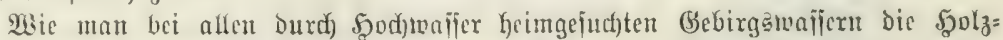

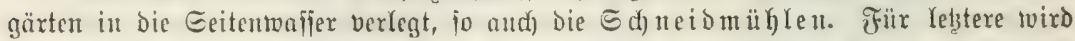

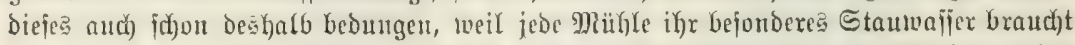

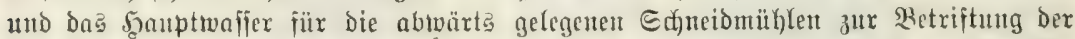

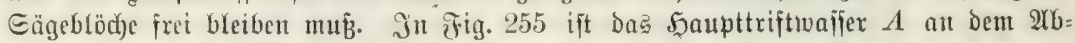

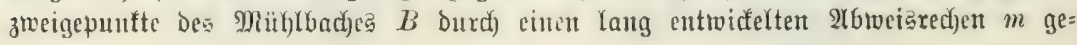

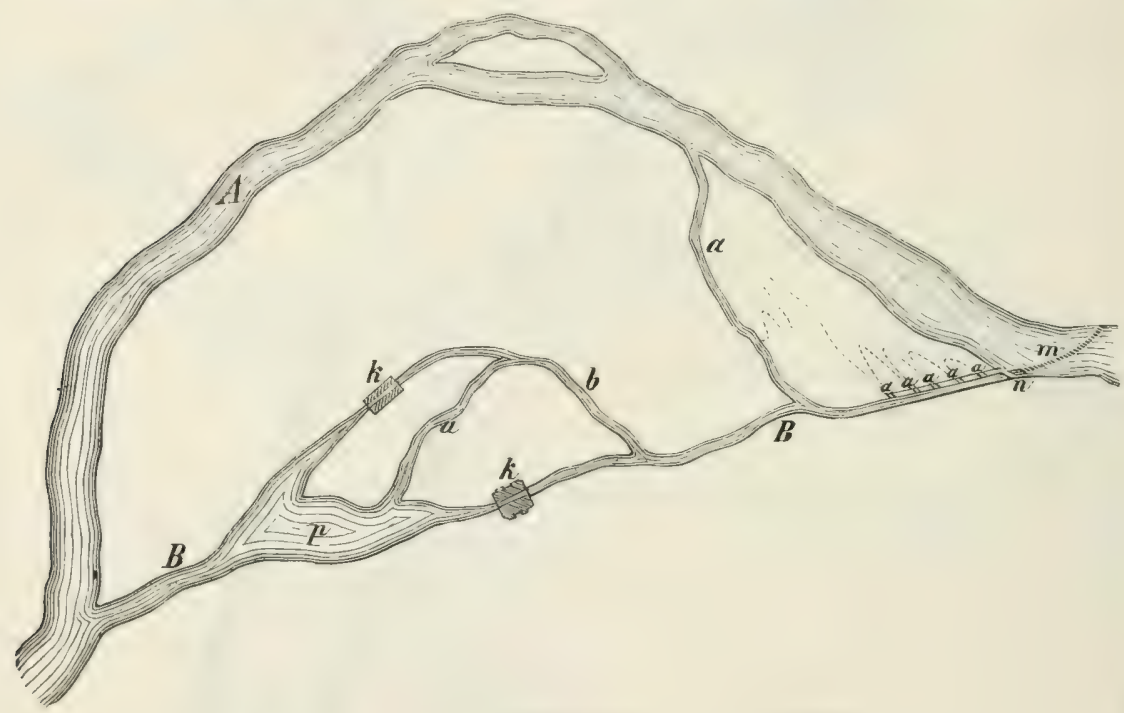

Fig. 255. 2nnlage von Edneibemihlen $k k$ im Iriftgebiete.

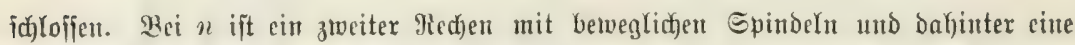

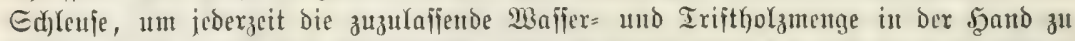

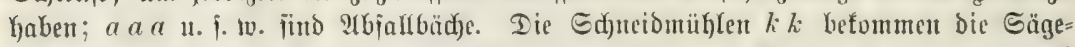

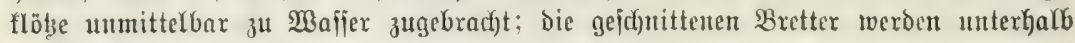

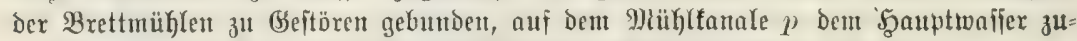

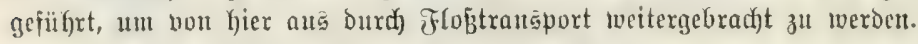

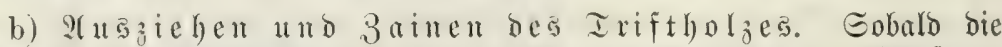
Ixift nor bem fangred)en anlangt, maiflen alle STuftalten zur Empfang= trabue des solzes in ber 2 rt getroffen feir, Dafis basfelbe baldmöglidjit aus

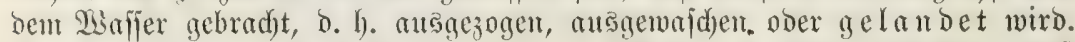

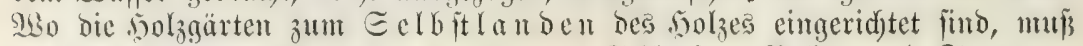
Das :Trbeiterperiontal an bie betreffenden Ed)lenfen, Med)en und Iore ver=

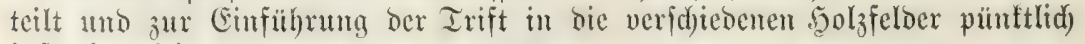
inftruiert jein. 


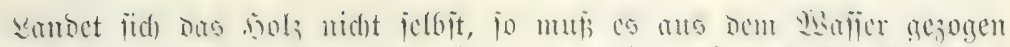

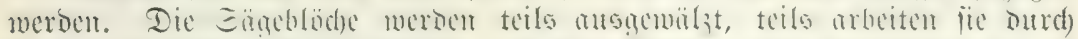
Dampf betrichue

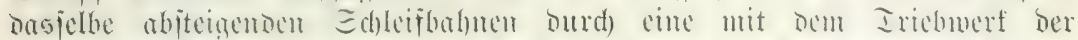

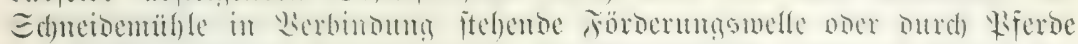

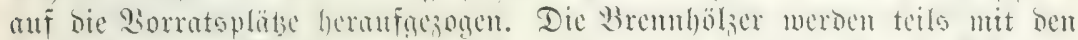

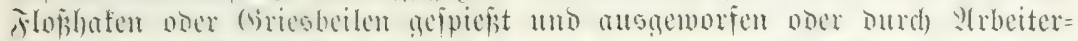

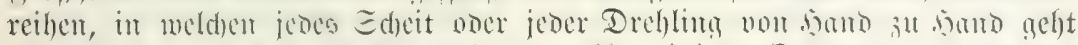

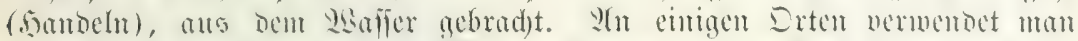

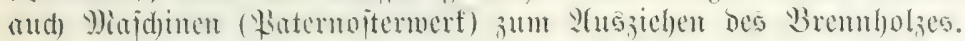

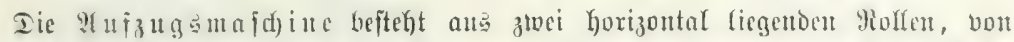

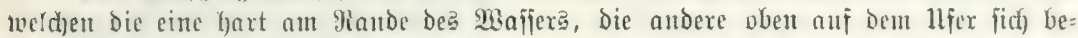

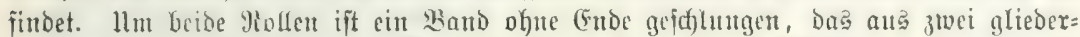
tecife miteinanoex verbundenen Retten beitegt uno in turzen श(bitänden mit auirecht

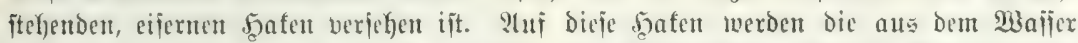
genommenen Syilzer gelint, Durcf) llmbreben Der pberen Rolle wird bie Rette in fort=

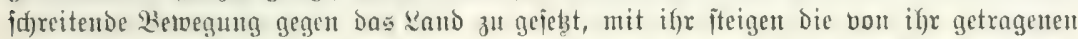

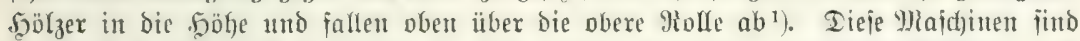

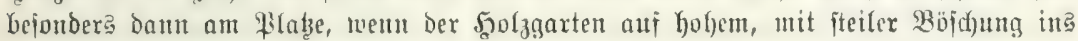
Iriftwafier abfallendem 11 fer liegt.

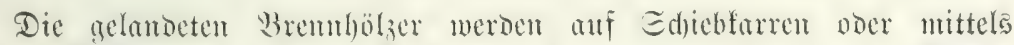

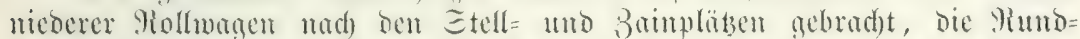
linge vorerit mod) ;u Edeiten afgeipalten, mo mu a

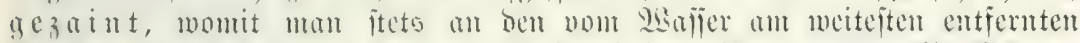

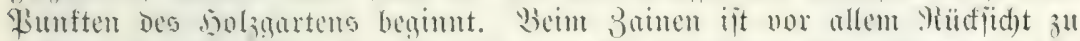

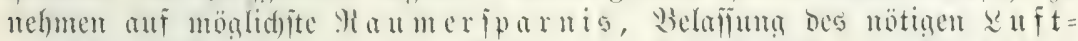

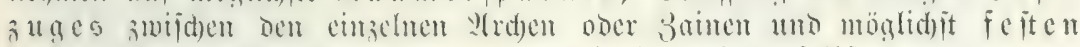
ud foliben a ufbau ber Wrenuborzarden jelbit.

3u Dicjem Ende fteflt man dic Birentuolzzaine in tangen sinien, in ber

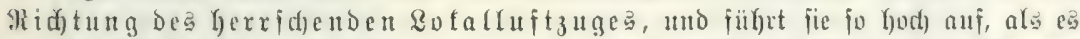
mit den Forderumgen ber Etabilität vercinbarlidg ift. Selten jebor(j) geht man mit

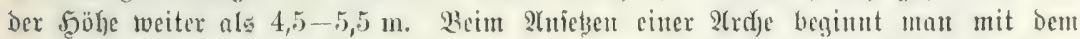

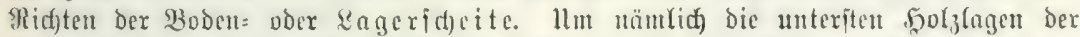
3aine fo weit als möglid) vom Roben entfornt zu halten und fie Daburd) vor qualita=

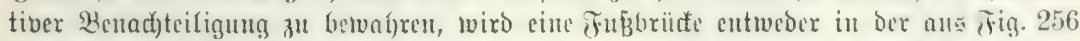

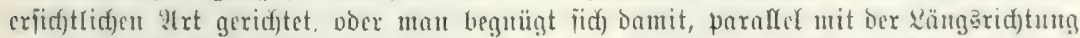

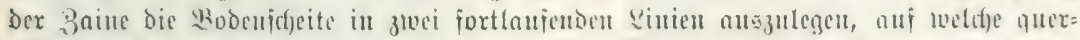

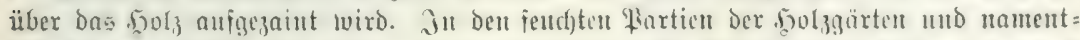

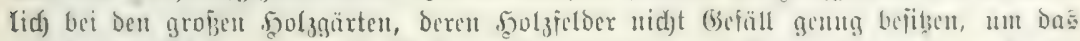

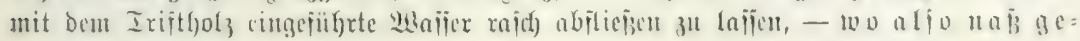

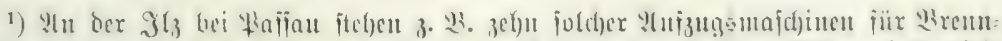

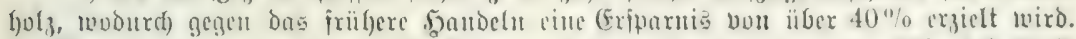

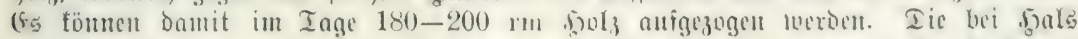

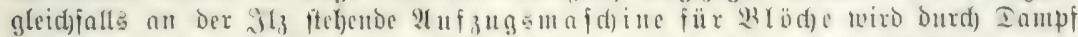

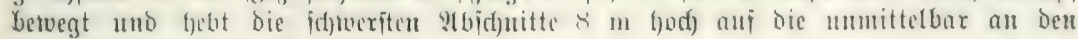

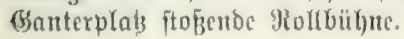




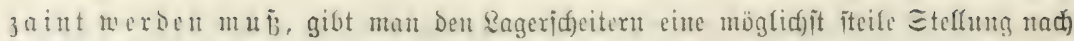
2trt ber Fig. 257.

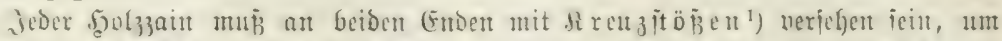

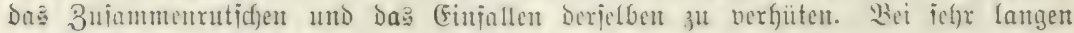

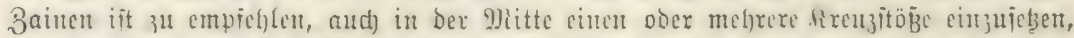

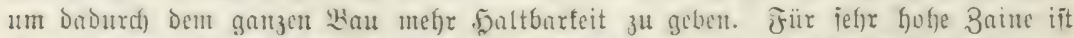

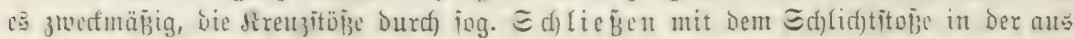
Fig. 258 expid)tlid)en 2 xt 3 uerbinden.
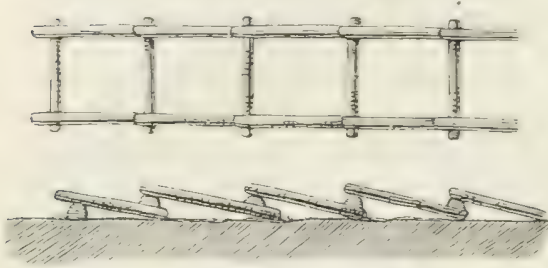

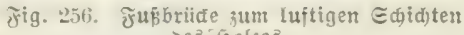
Des: s)olzes.

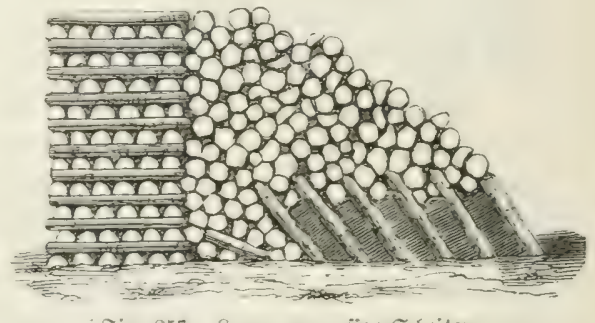

rig. 25i. Ragerung naijer @đeiter.

3mithen ie zwei nebeneinander Ginlanfenten .5olzzainen foll geringiten Falle ein 3wififenraum bou $0,80 \mathrm{~m}$ belnijen werden, um Dem Euitzuge 3utritt zu gejtatten.

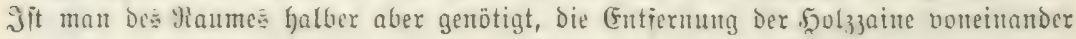

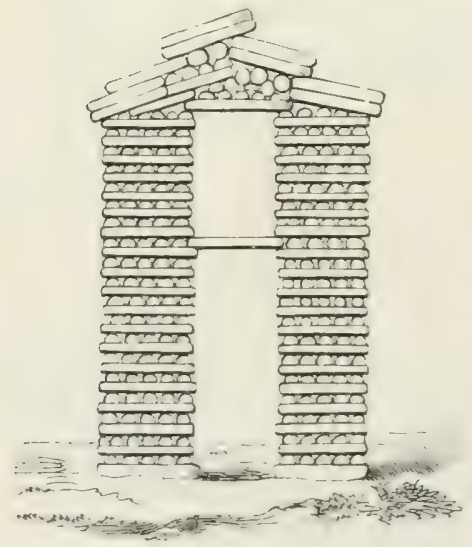

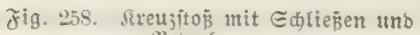
Bebad)ung.

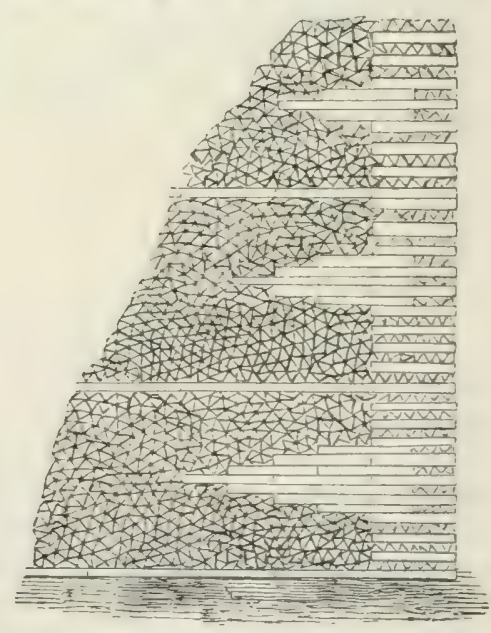

Fig. 259. Berbinoung von freuz= unb ฮdlidtito bei bohen 3ainen.

nui biejes Taib zu reduzieren, und mirb babei fod)gezaint, jo verbindet man ie ztwei

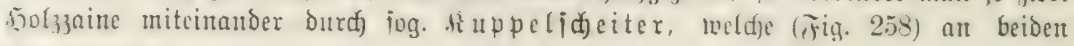
๔. 150

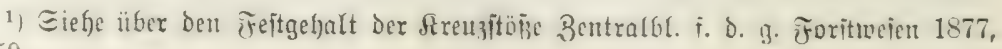




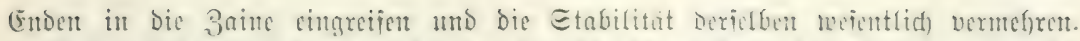

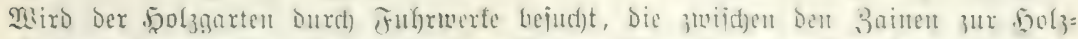

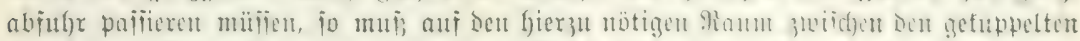

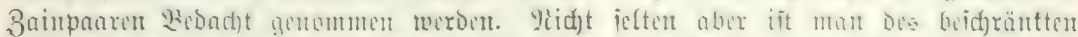

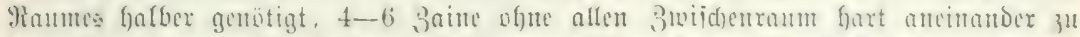

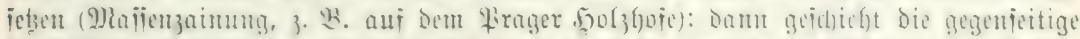

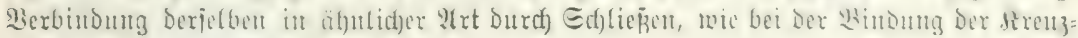

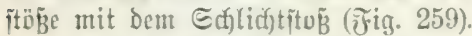

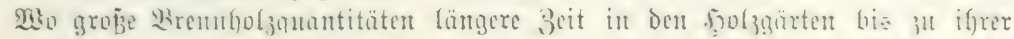
Werwendung magaziniert becibm, hat man an mefreeren Erten Die iog. Ia (t)=

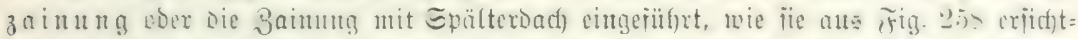

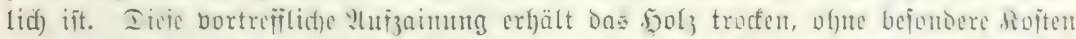

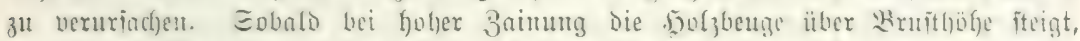

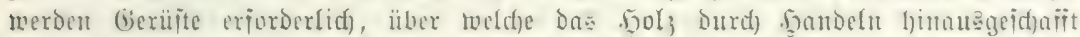

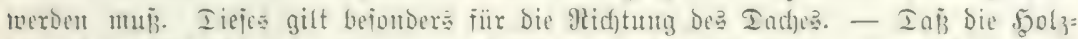

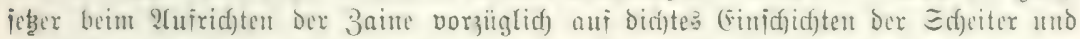

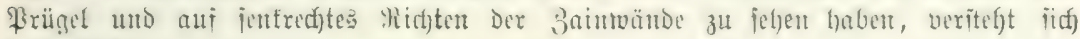
yon felbit.

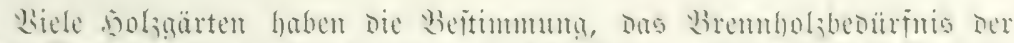

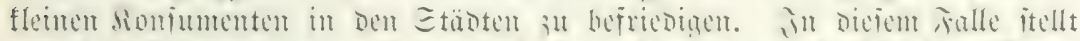

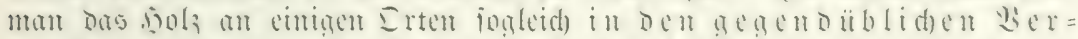
fa

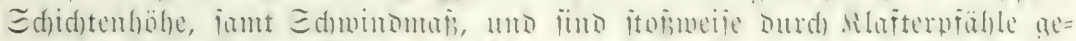

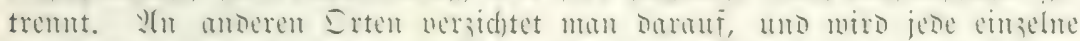

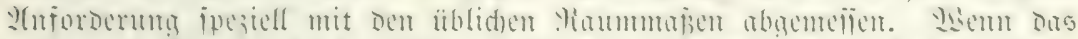

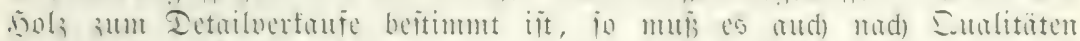

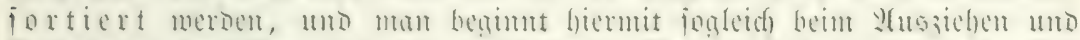

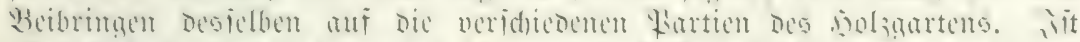

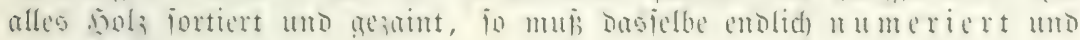
abgemefien werben.

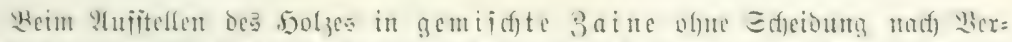

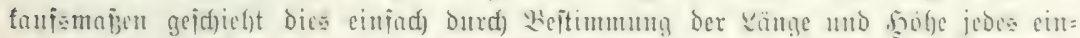

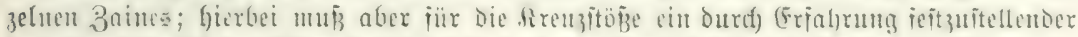

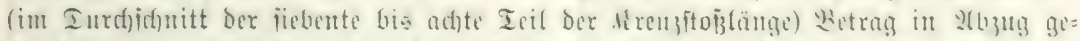

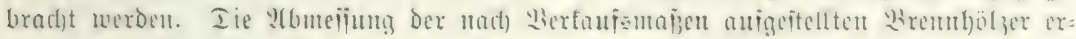

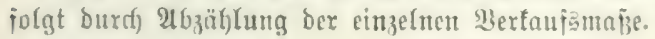

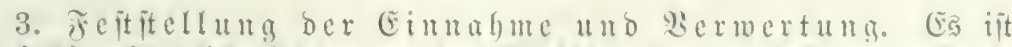

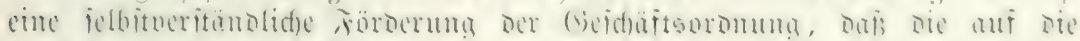

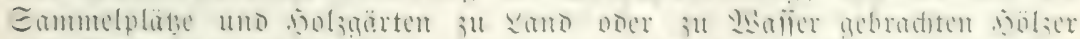

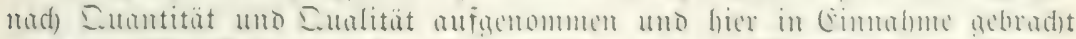

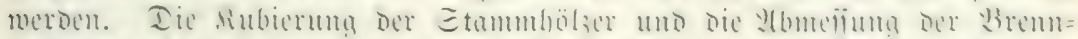

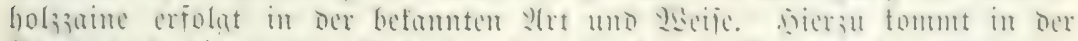

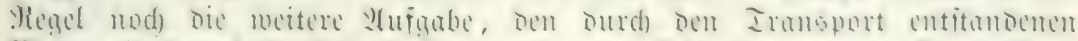

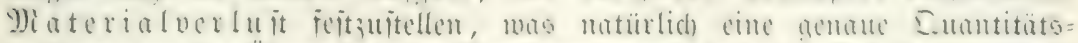

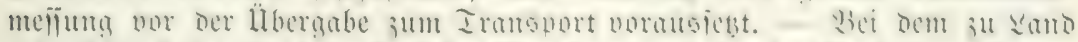

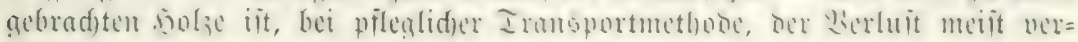




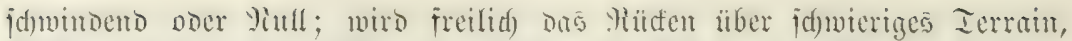

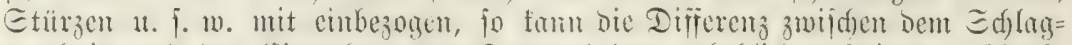
ergebnis und ber (Ëmahme an Eammelplabe erbeblid) antetgen. Ebenfo

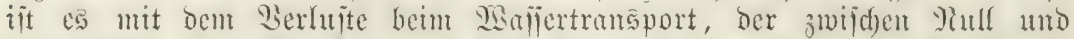

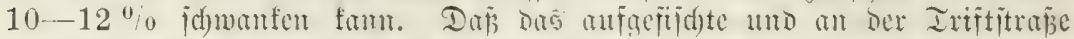

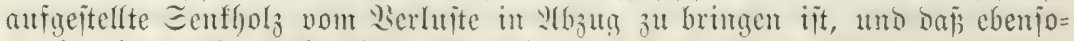

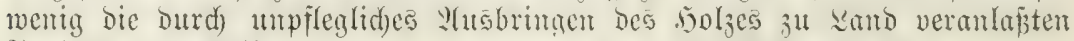

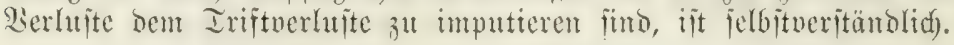

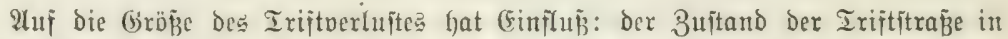
baulidyer Beziefung, Die Ränge Derielben, Die 2tut und Bepiffaffentheit, Dann ber

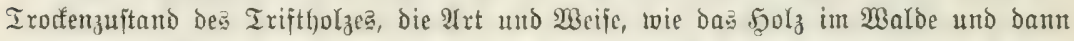

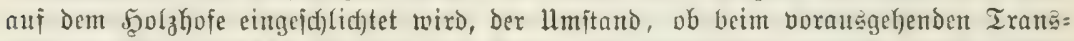

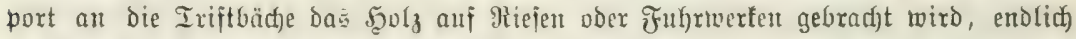

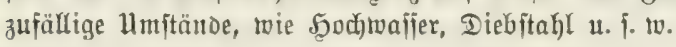




\section{Dierter 2lbichnitt.}

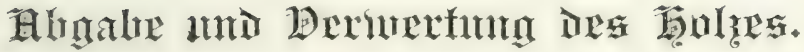

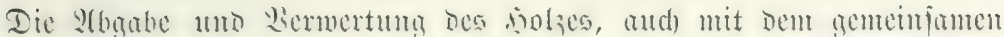

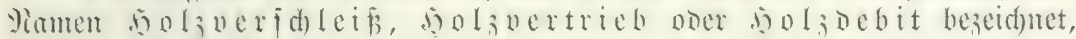

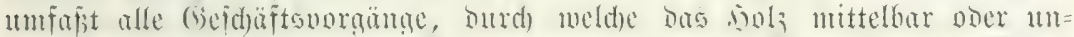

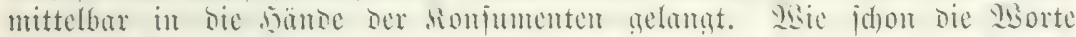

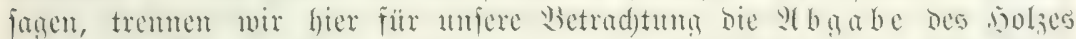
nou oefien

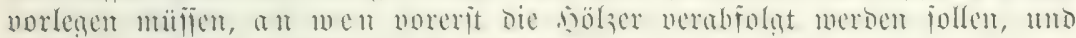
bann, wie bieles geidechen foll.

\section{A. Aggabe Ses Solizes.}

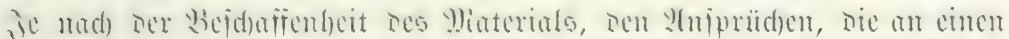

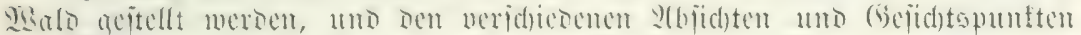

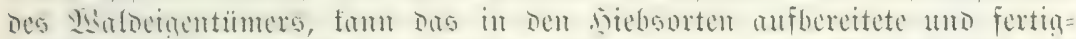

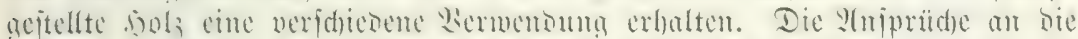

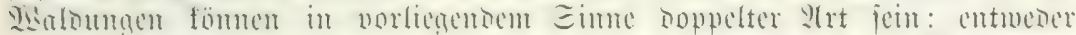

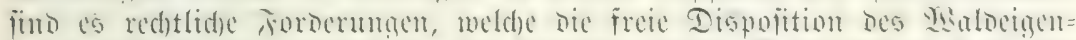

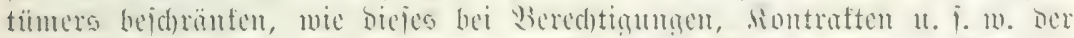

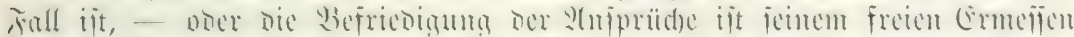

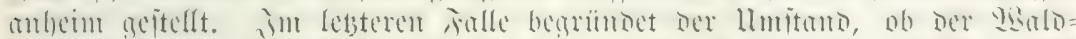

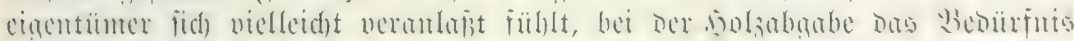

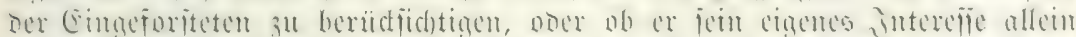

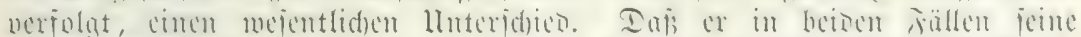

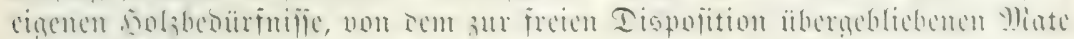
riale, vorerit berïdfidstigen wiro, weriteht jich von felbit.

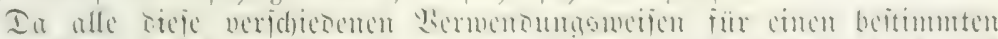

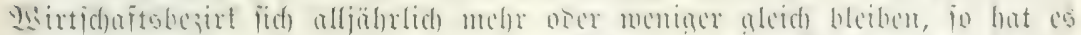

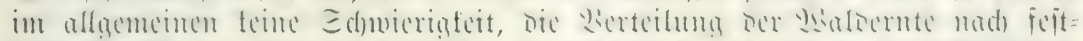

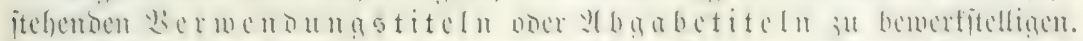

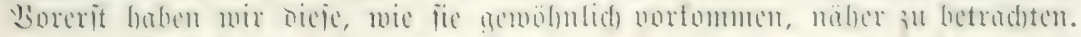

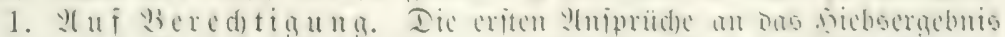

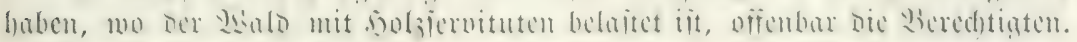




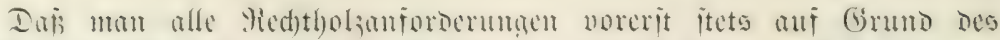

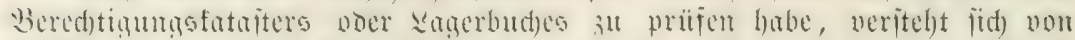

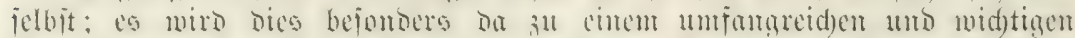

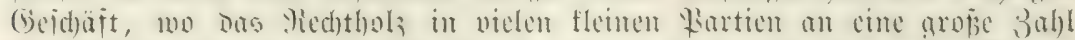

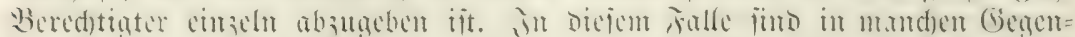

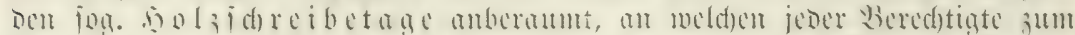

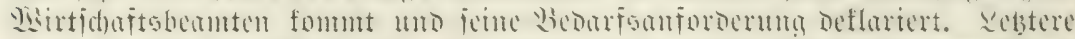

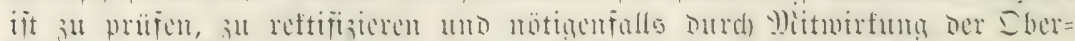

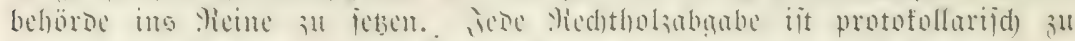

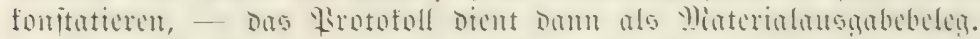

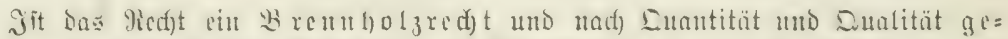

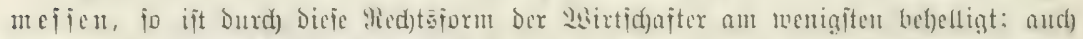

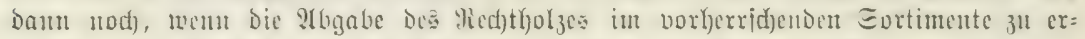

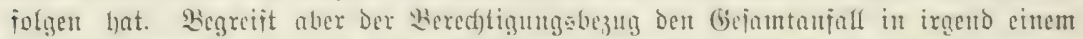

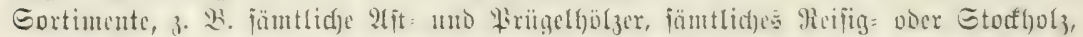

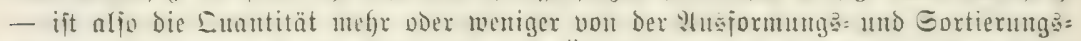

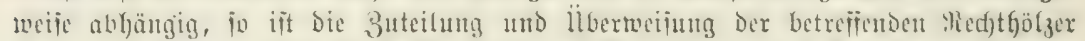

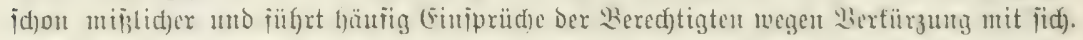

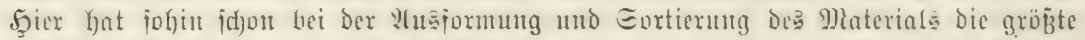

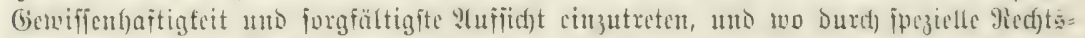

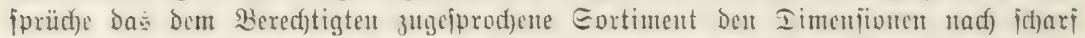

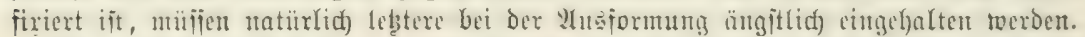

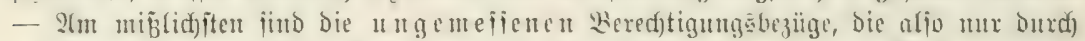

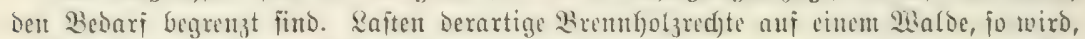

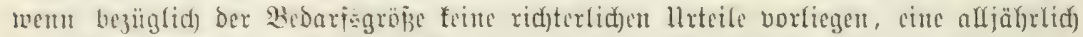

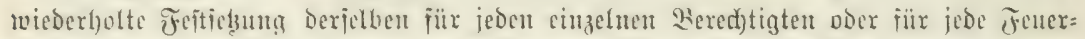

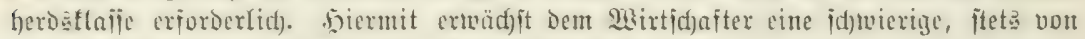

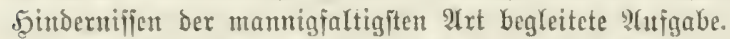

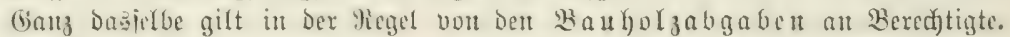

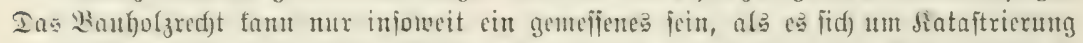

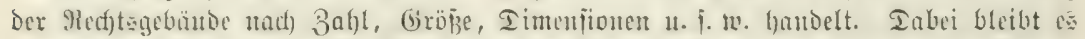

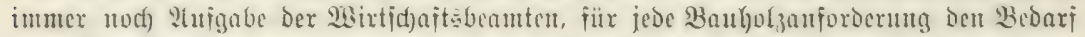
für Peparaturen voer glubauten nad) jeder Hidgtumg forgfïltig zu fonftatiexen.

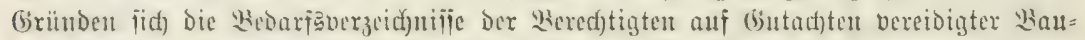

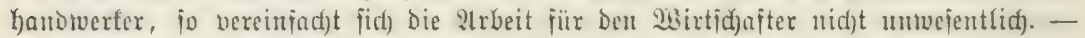

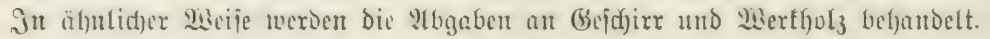

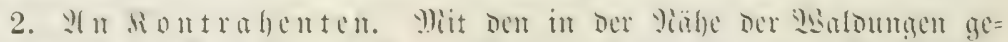

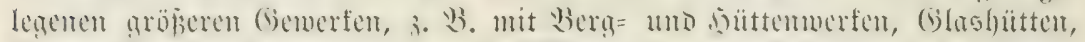

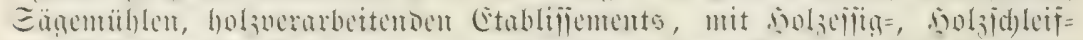

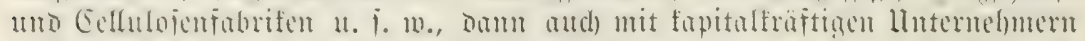

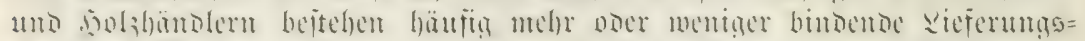

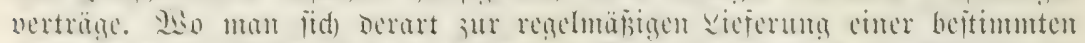

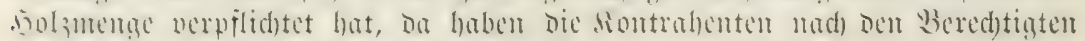
die näd)jen senprüd)e an bic bolzernte.

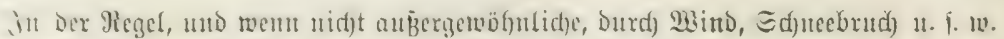

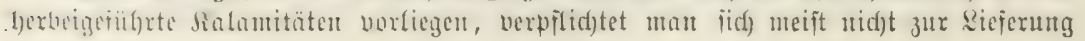




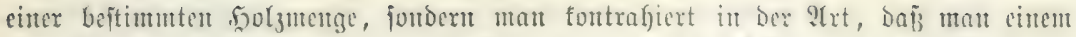

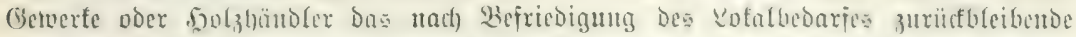

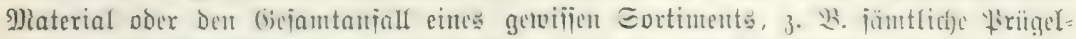

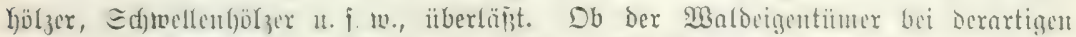

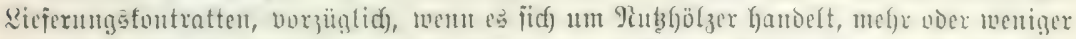

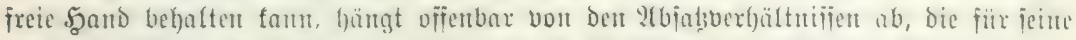

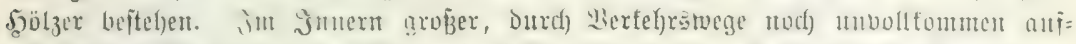

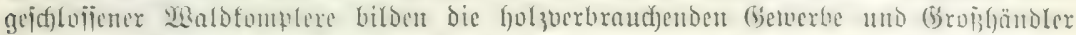

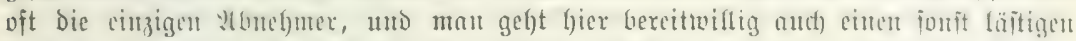

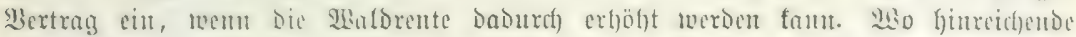

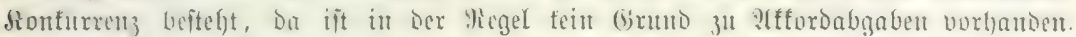

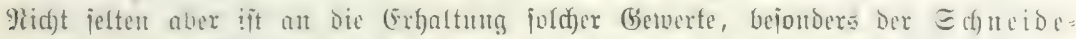

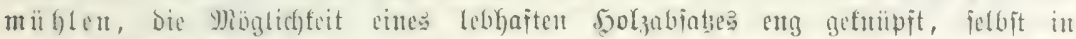

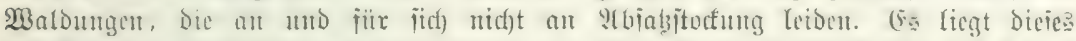

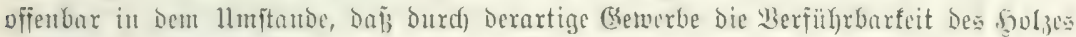

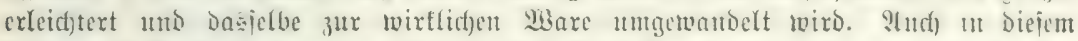

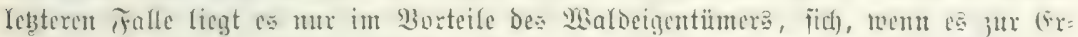

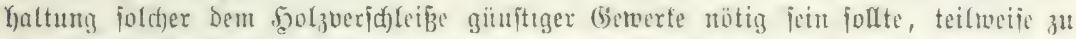

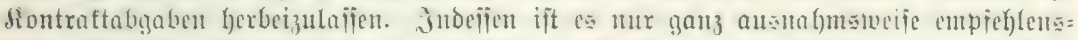

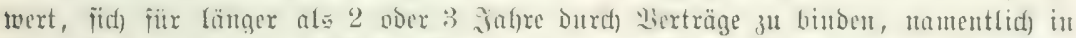

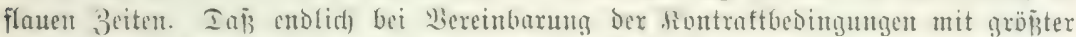

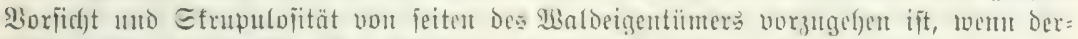

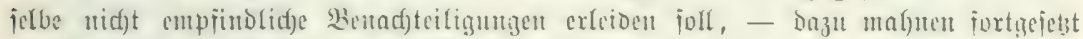

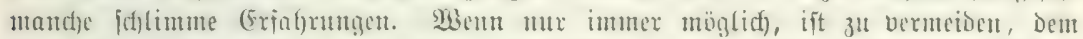

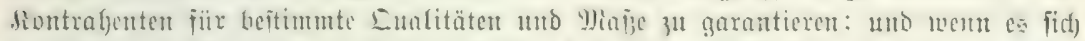

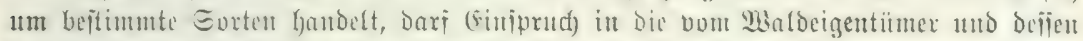

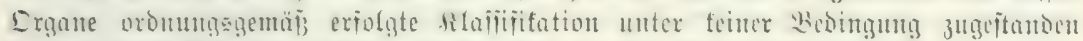

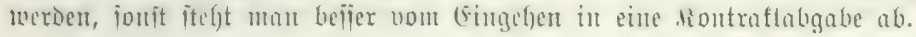

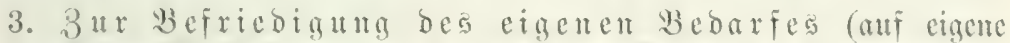

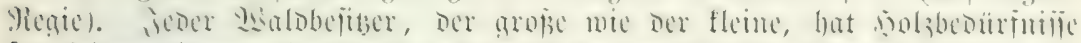

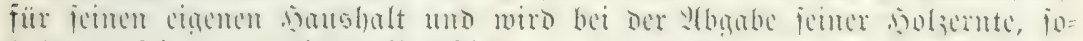

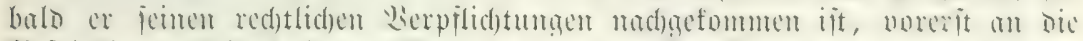

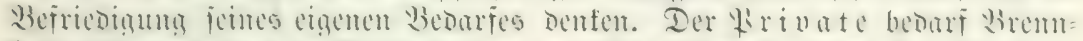

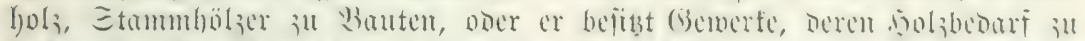

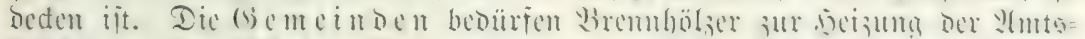

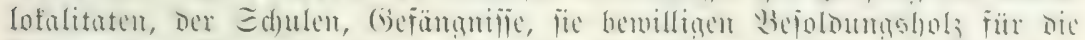

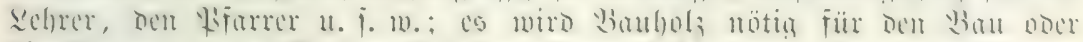

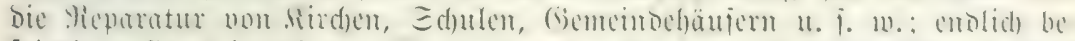

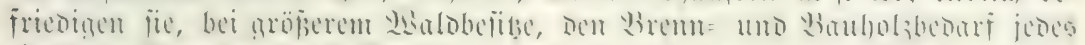

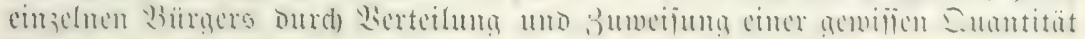
(3) $a b=$ oder 20 a $b$ ol 3 .

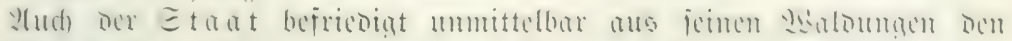

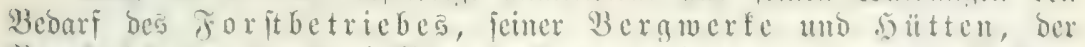
Wa gerväbrt er aud Deputathöl ser.

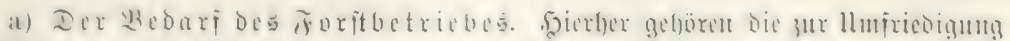

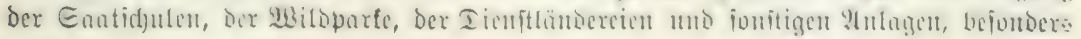




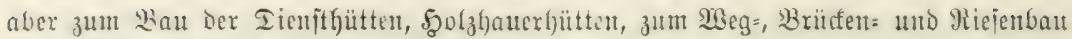

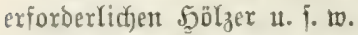

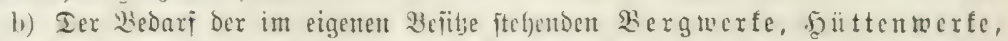

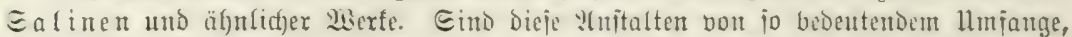

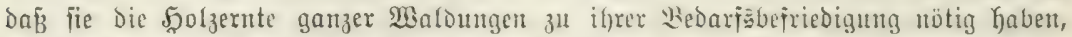

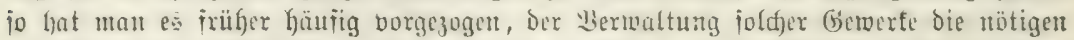

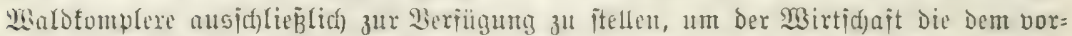

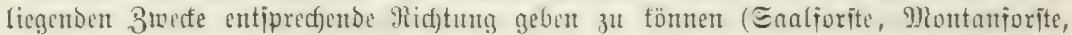
Mejervatiorite). Die Eriahrung hat aher gelefhrt, Daß̉ derartige Zuteilung ganzer waldo= fomplere an Mlontantwerfe nid)t jum Frommen Der Wafoungen ansidglägt (in einigen

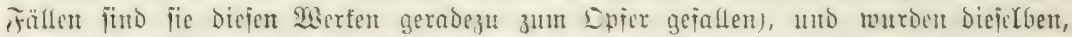

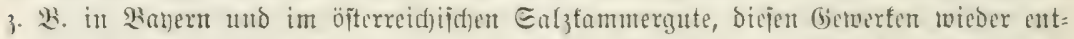

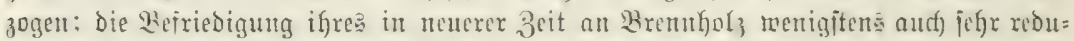
zierten

c) Ier Wedarf Der sisubeförde, namentlid) für Fluphuerbauten, (sijenbahn=

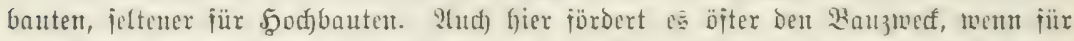

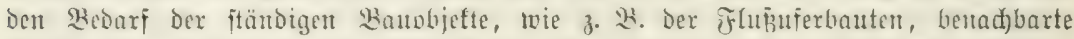

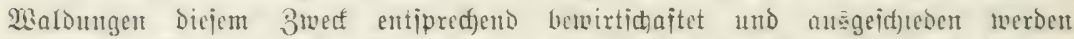

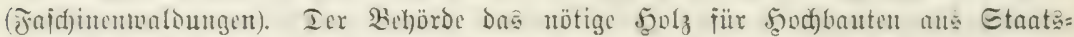

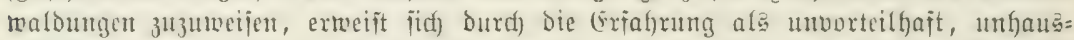

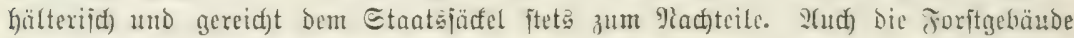
find hier nidjt auลgentumment.

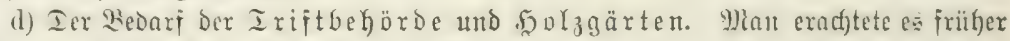

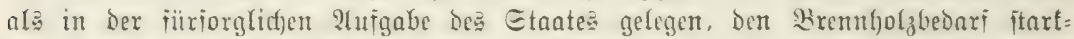

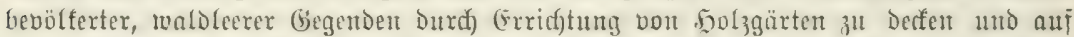

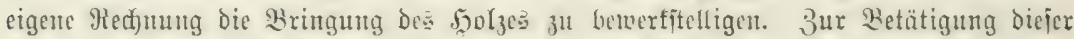
Hufgahe waren meift bejondere Iriftbeförden beftellt, und criolgte bie Ithgabe ber

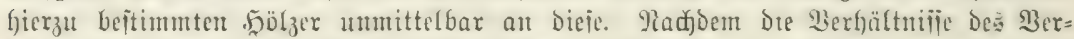

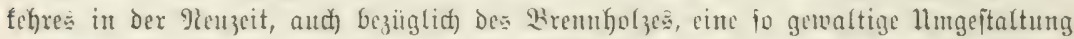

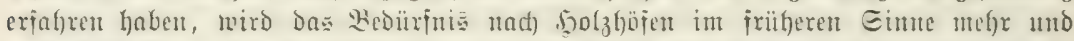

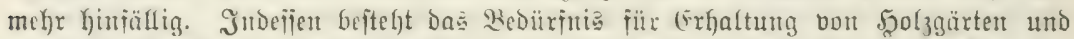

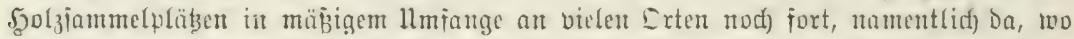
mohlfeiler Irifttramaport zuläifig ift.

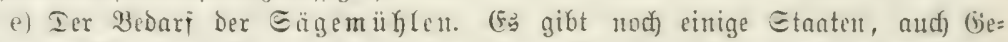
meinden, weld)e eigene Brettmiiflen bejiben, Deren Betrieb unter ciner von Der Forït=

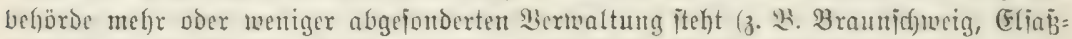
Rothringen, bie Frovinz frannover, Die Etabt shaben=

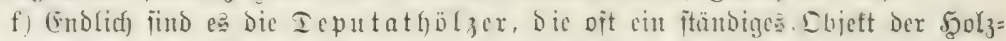

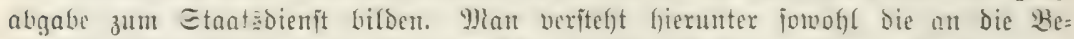

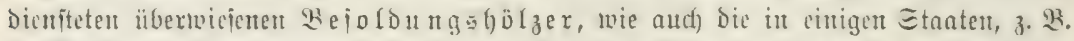

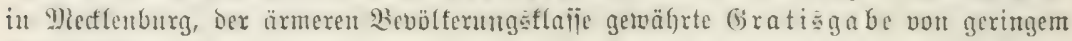
Brenntiolz.

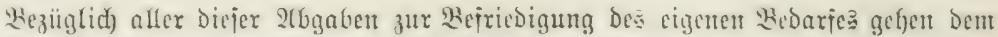

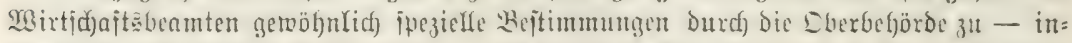

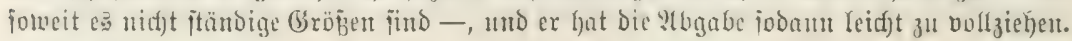

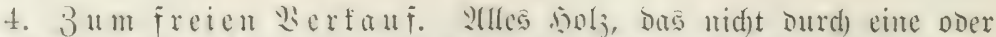

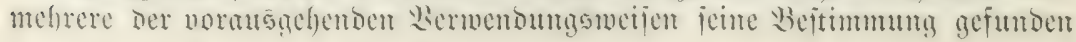




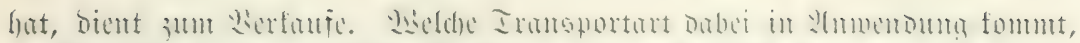

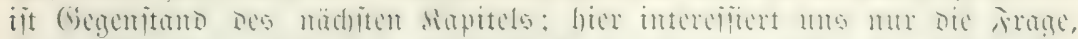

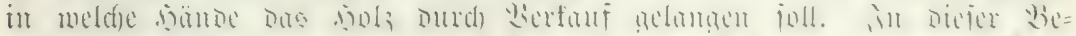

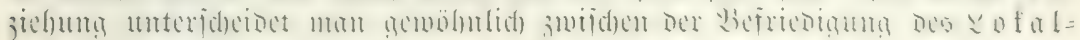
bedarfes und der loggabe des bolzes für ben bandel.

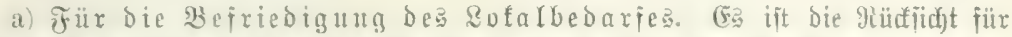
Den $Є$ d) ub und Die

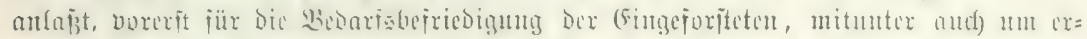

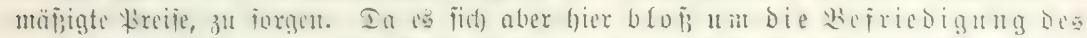

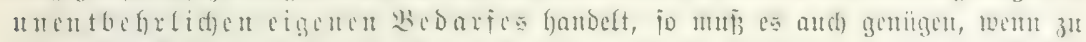

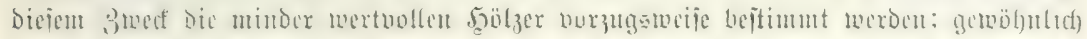

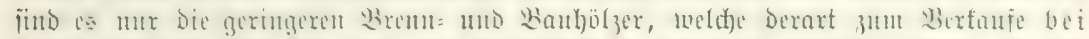

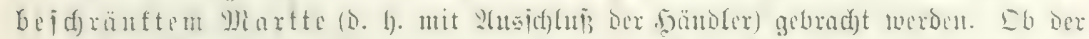

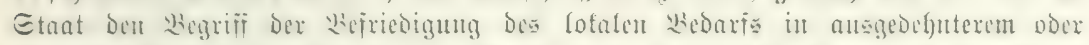

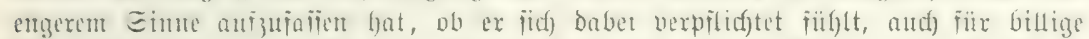

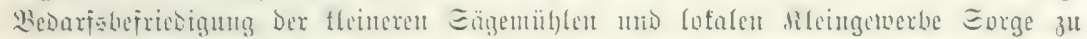

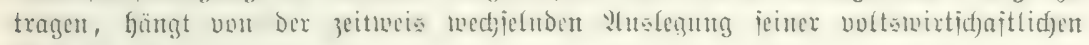
Zlufgabe ab.

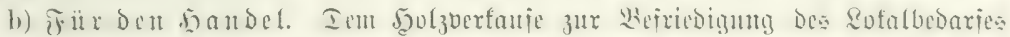

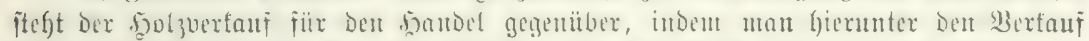

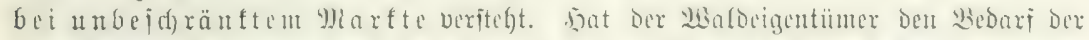

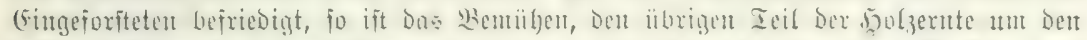

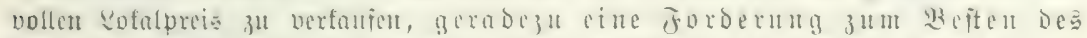

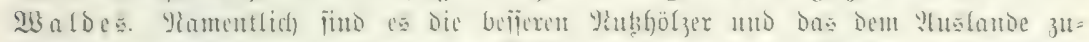

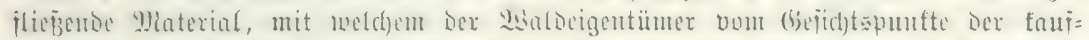

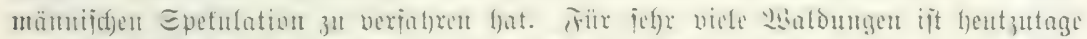

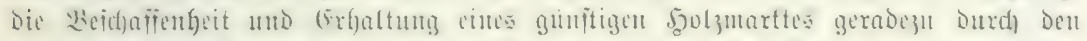

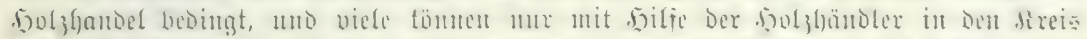

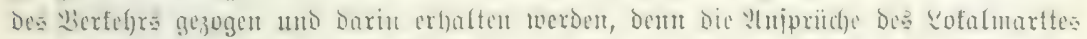

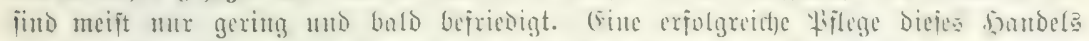

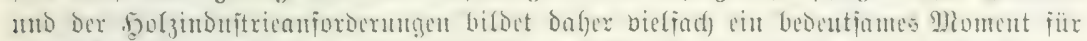

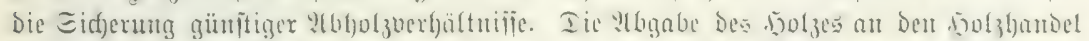

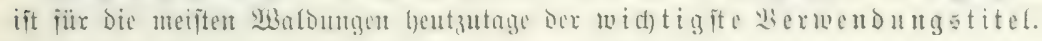

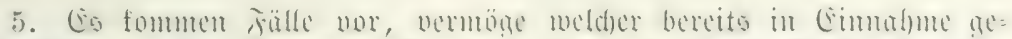

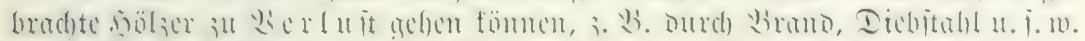

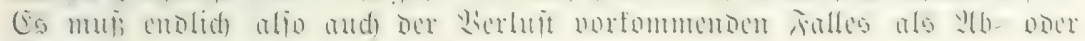
2(utgabetitel betrad)tet werben.

\section{B. J̈exwextung Ses Solizes.}

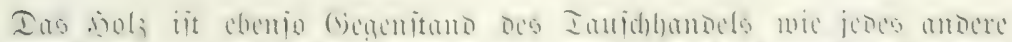

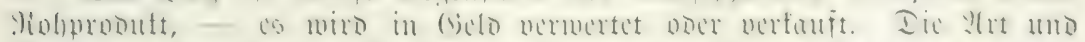

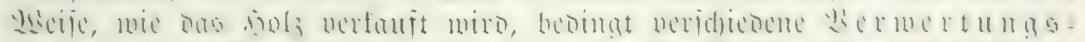

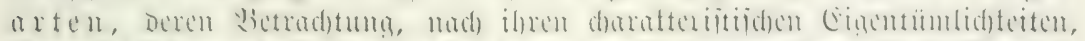

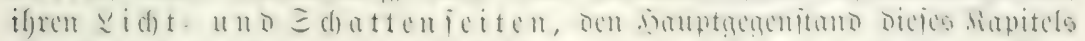

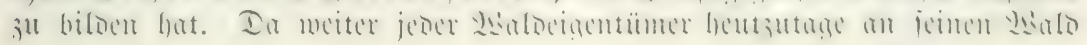

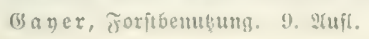




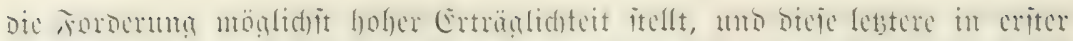

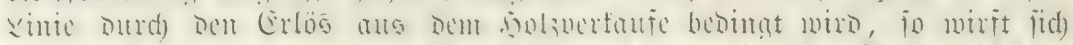

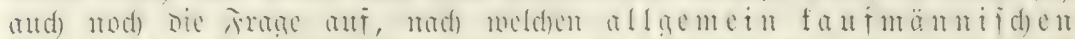
(i) ren of bejtü̈glid) ât crreidjen.

\section{a. Dic Icrucetungarten.}

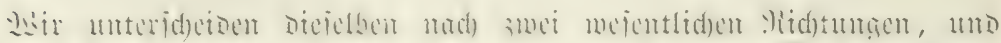

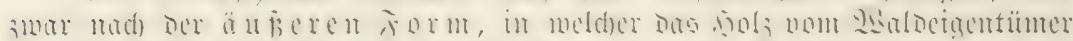

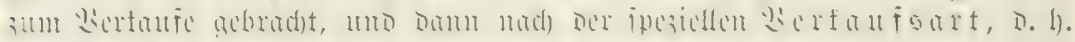
mad) ber QYrt ber Breisbildumg.

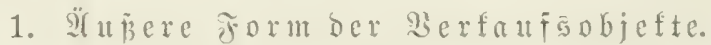

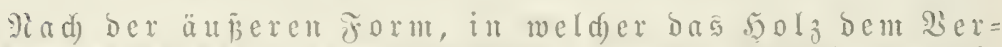
f

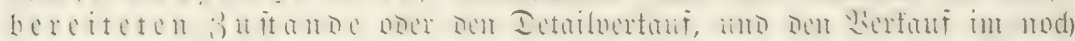

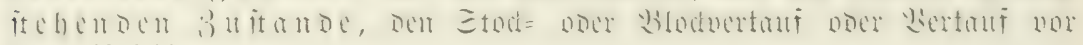
bent CEimjditng.

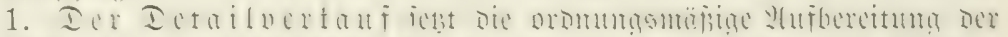

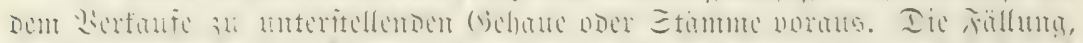

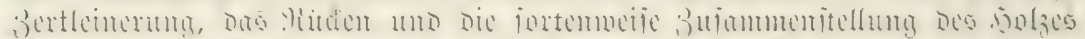

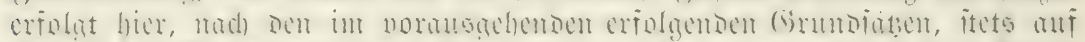

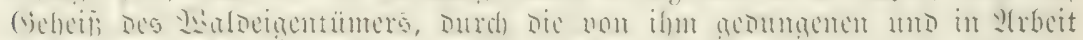

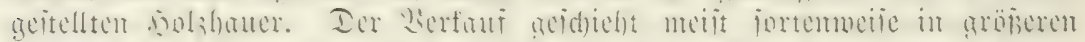

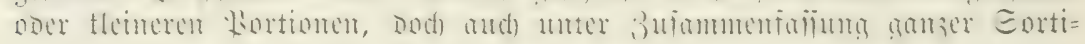
mentsanfülle, je nad) Der Bernvertumģart.

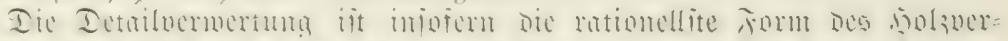

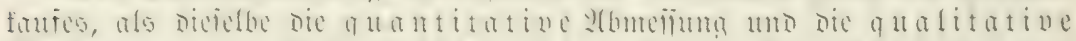

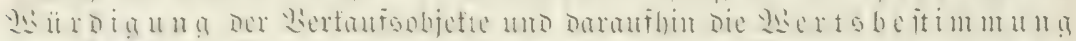

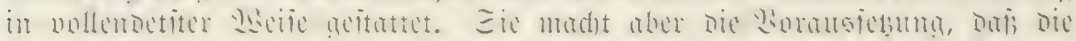

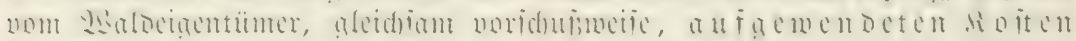

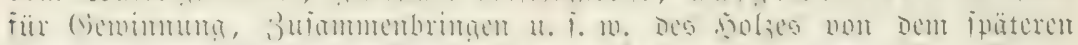

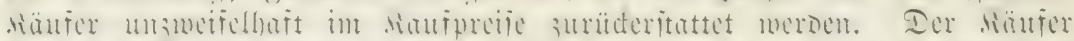

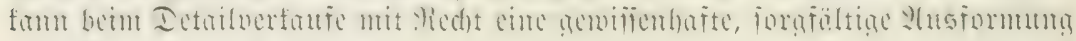
unb Eortienung verlangen.

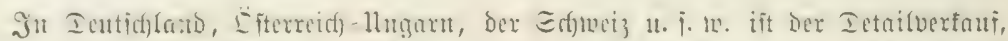

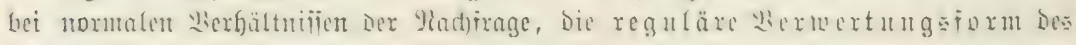

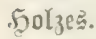

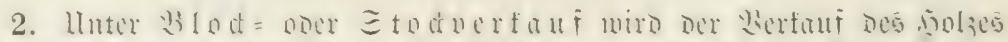

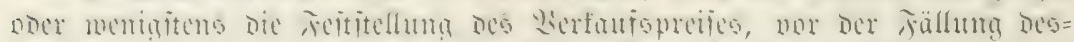

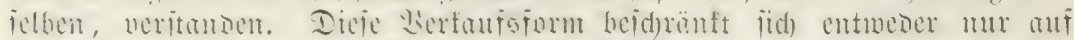

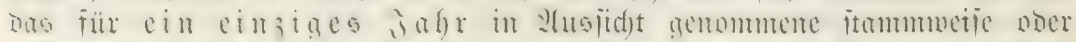

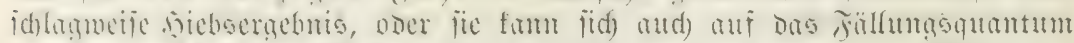

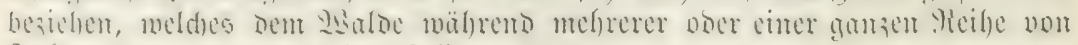
Jahren entnommen merben poll. 


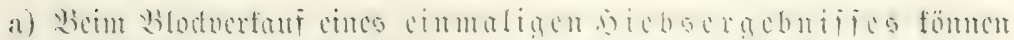

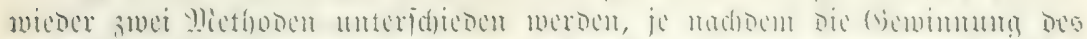

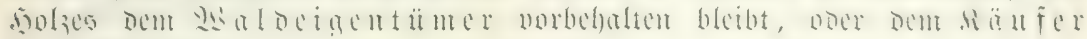
¿̈berlaffen wiro.

a) Der teirweije ober halbe $3 \mathfrak{l}$ do de extauf (vente par unités

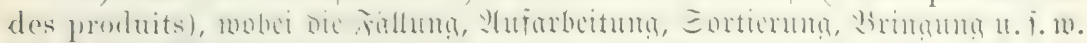
Durd) Bur

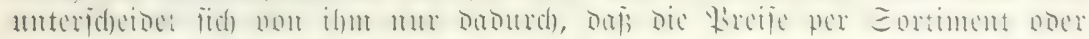

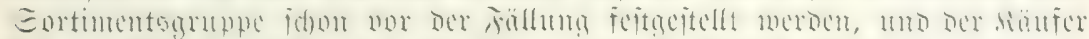

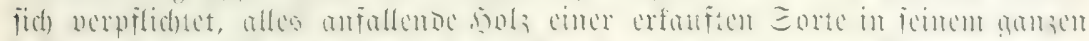

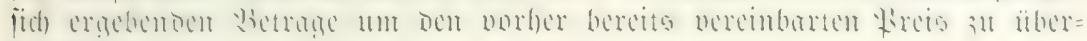
nebmen.

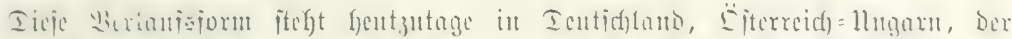

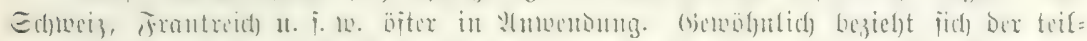

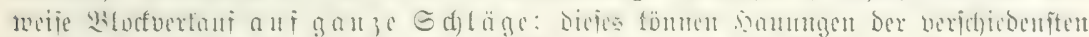

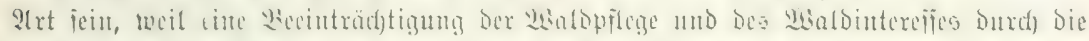

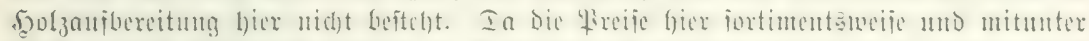

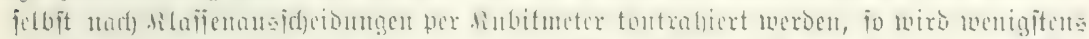
cine ammaterno ridgtige $三$ (d)

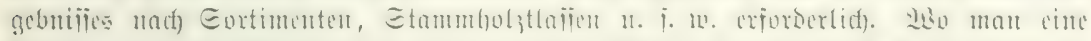

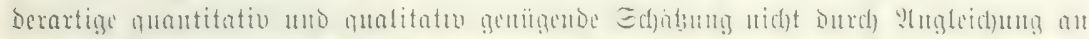

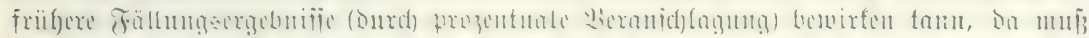

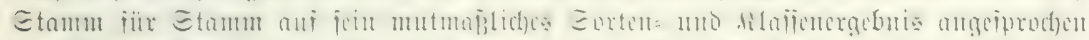

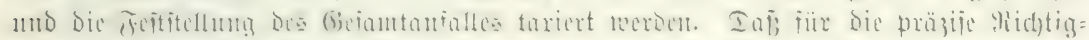

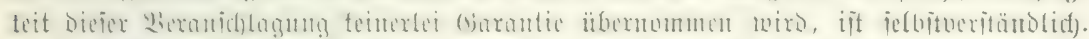

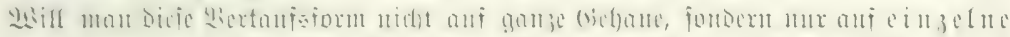

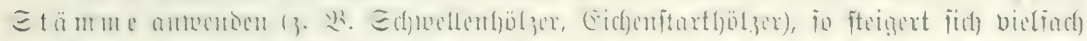

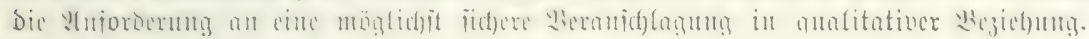

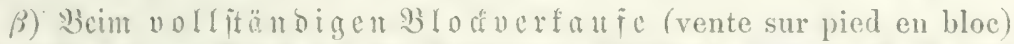

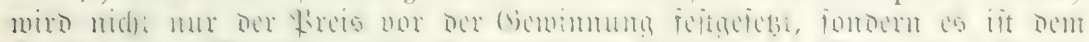

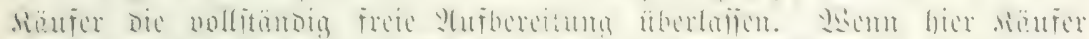

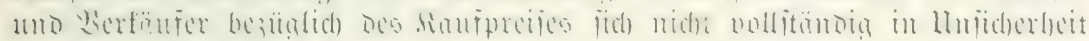

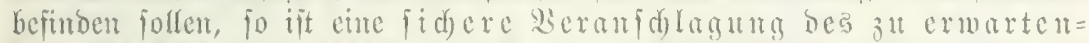

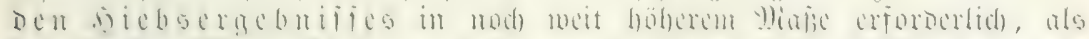

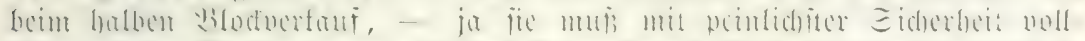

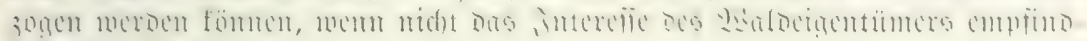
(idi) Sot leioen foll.

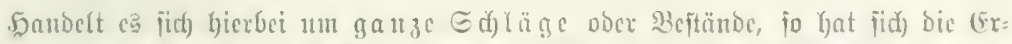

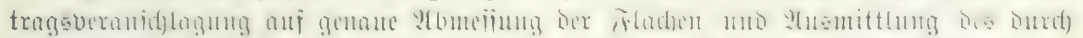

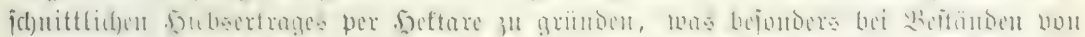

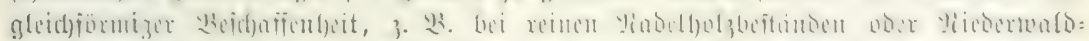

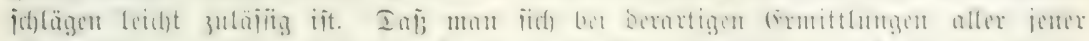

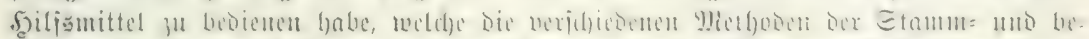

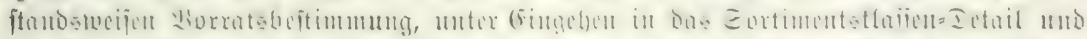

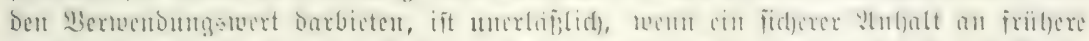

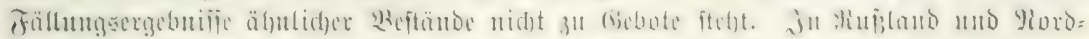

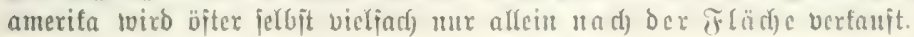




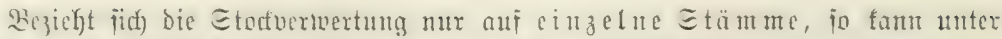

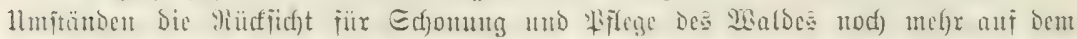

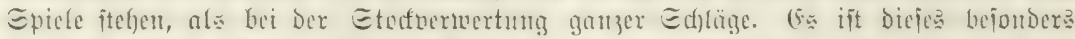

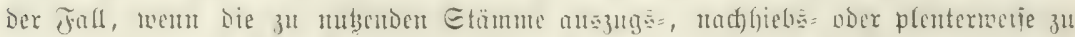
ģeminnen

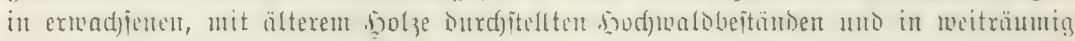

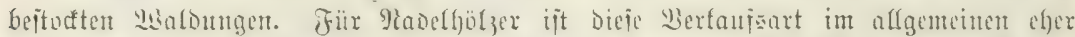

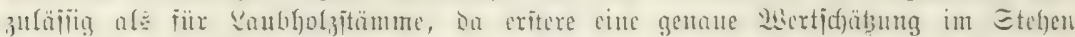

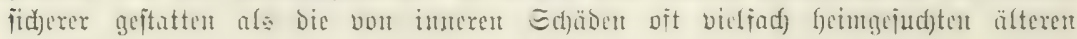
saubjölzer.

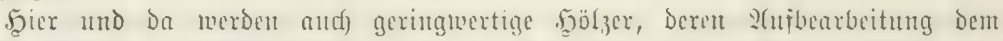

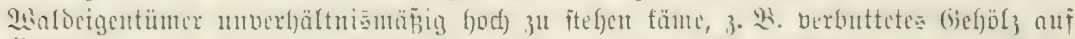

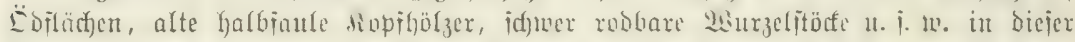

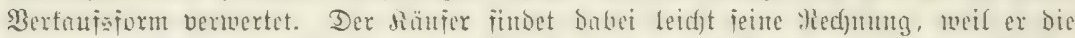

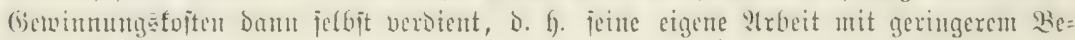
trage itt 2lnjat britgt.

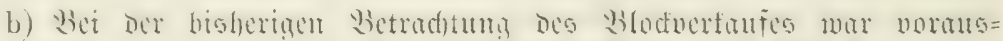

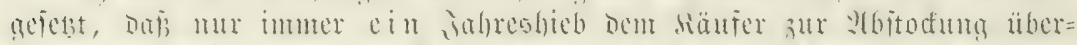

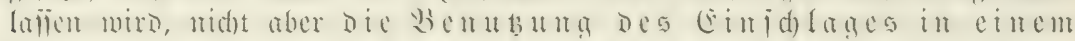
$23 a$ lde für megrere gafre ober längere geitperioden. Diefe

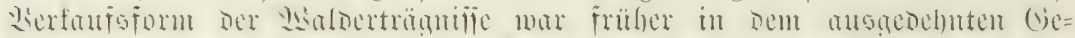

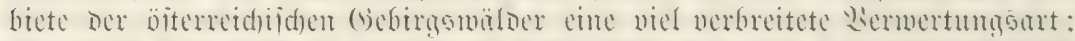

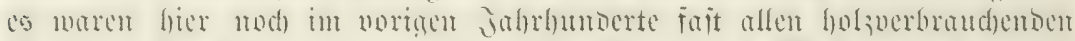

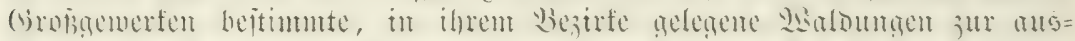

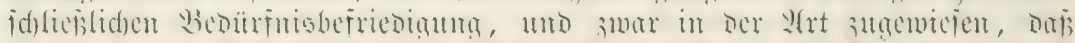

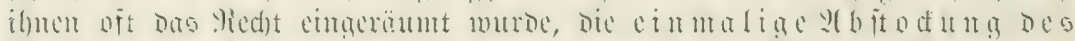

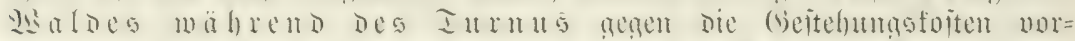

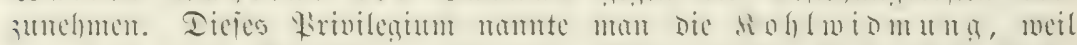

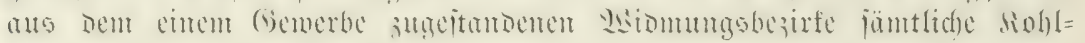
erzanguifje an jenes abgeliefert merben mupten.

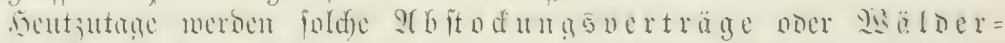
nex 1 a

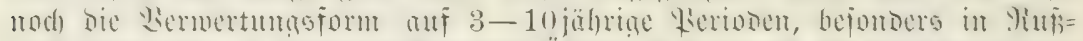

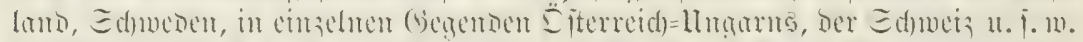

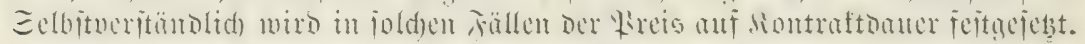

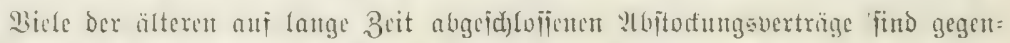

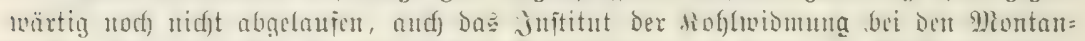

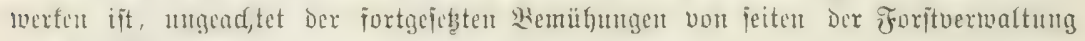
und Dex Maldeigentüner, nod\} nidgt völlig übertumben.

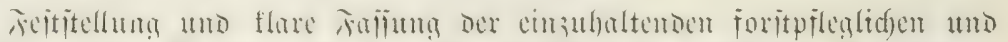

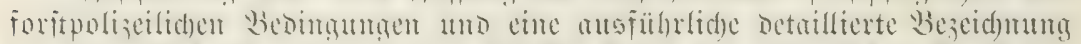

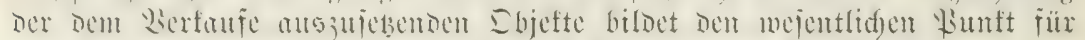

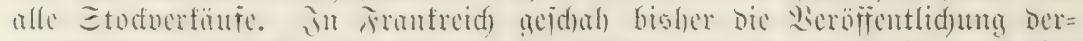

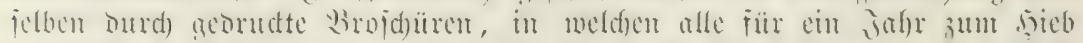

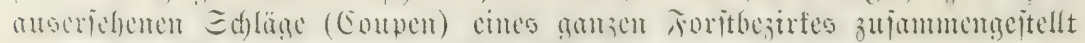

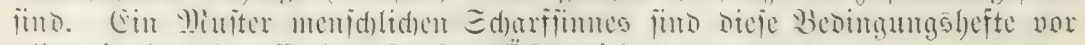
allem in Den betrefienden Foriten D̈iterreidj. 


\section{Berfaนfa}

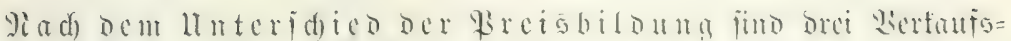
arten möglid), manlid) ber freifüntoige Sertaut.

1. Berfanf und Iaren ober feiten Iarifpreifen. Sisem

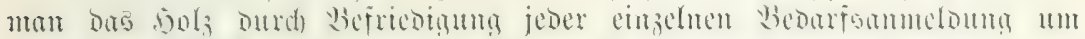

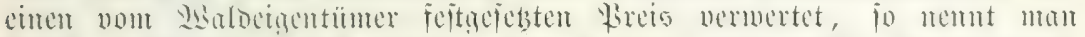

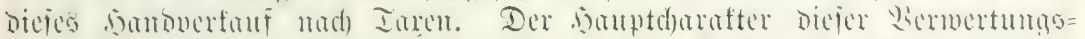

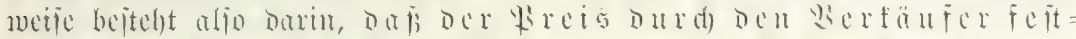

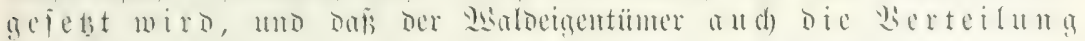
Dex Solzer ente unter bie cinzehten Sonfuntenten fid vorbehält.

a) Ermitteluma Des Iar =, Iarif= oder Reviexpreifes. Unter

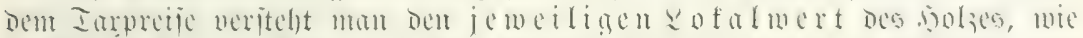

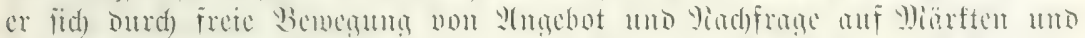

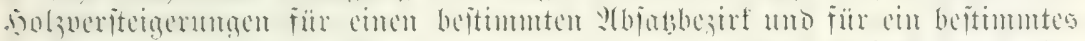

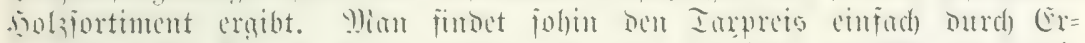

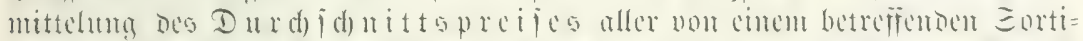

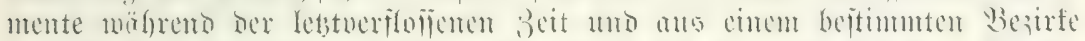

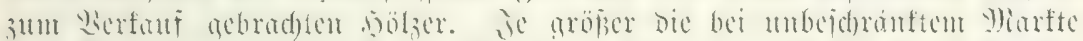

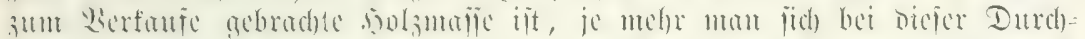

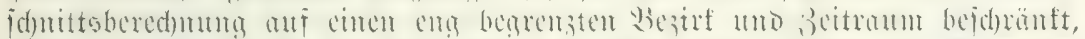

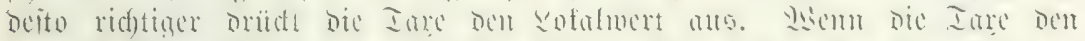

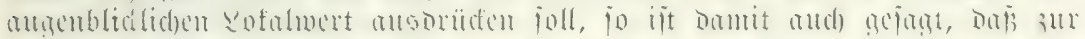

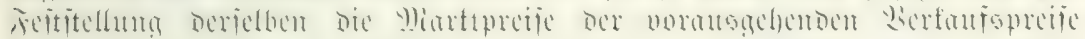
nidjt immer alfeir majaebend jein fömen, - jontorn daß in 3eiten

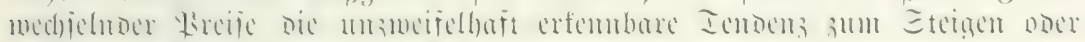
Fallen berfelben billige Berüdidetigung an erfabren habe.

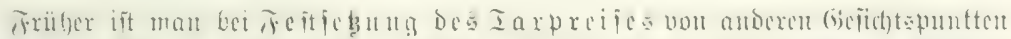

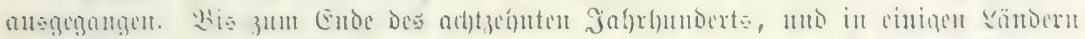

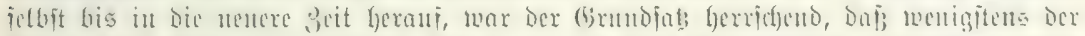

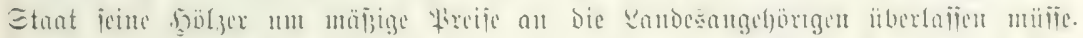

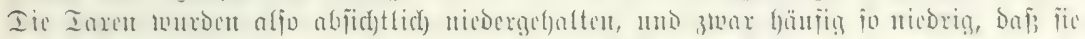

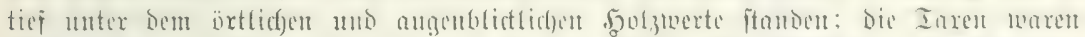

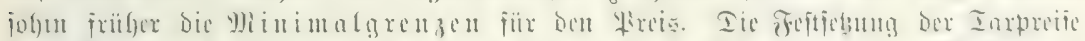

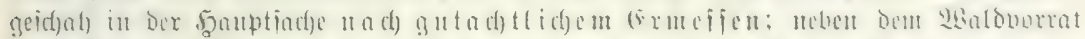

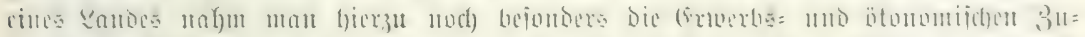

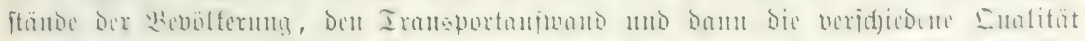

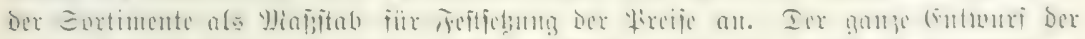

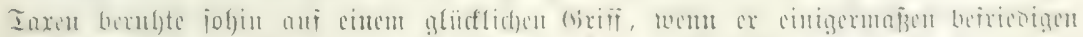

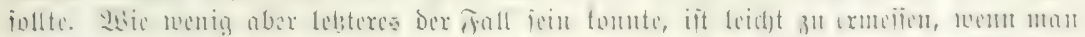

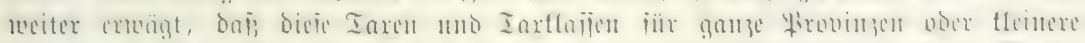

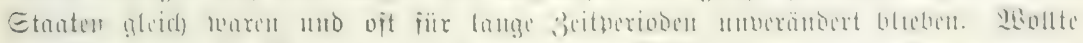
man Den h)

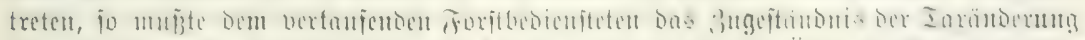

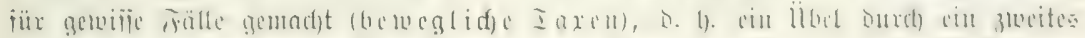

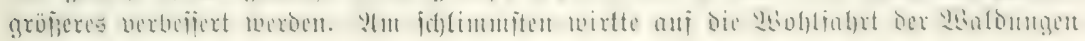




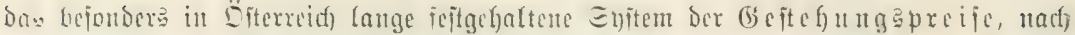

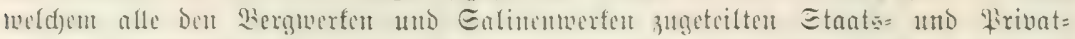

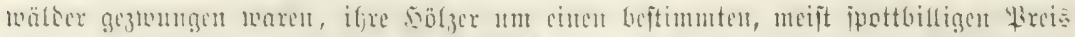

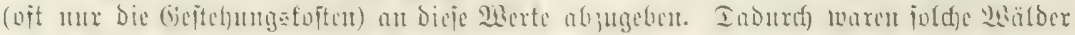

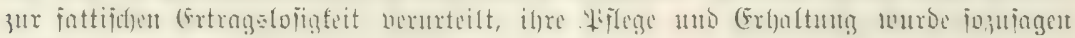
rünberific) verfjindert.

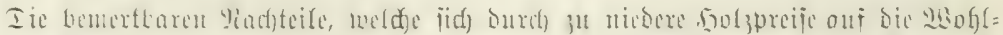

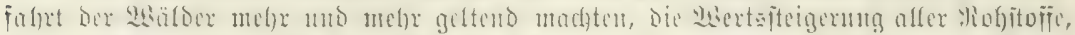

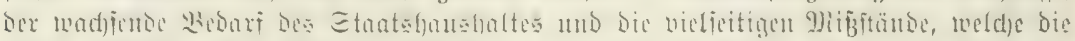

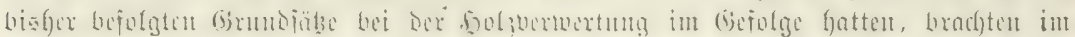

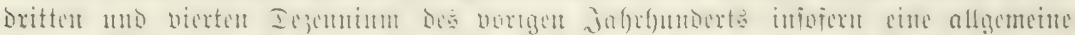

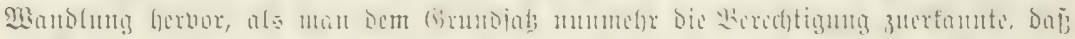

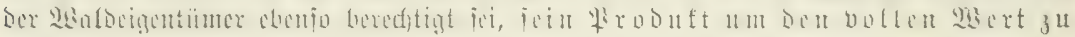
verfaufen wie jeber andere broduzent.

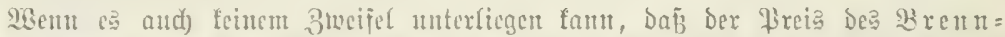

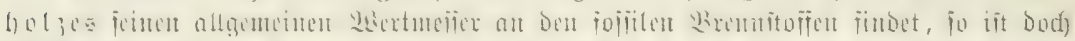

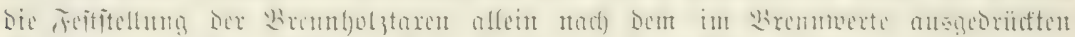

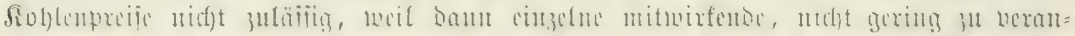

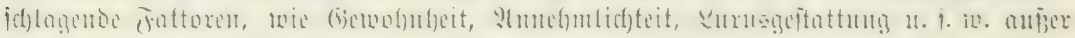
Beatjtung beciben miirben.

Is"

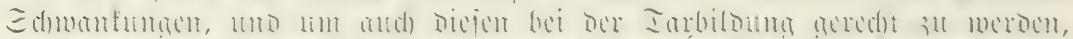

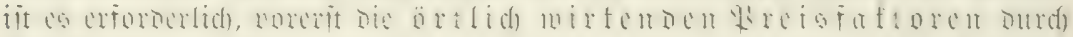

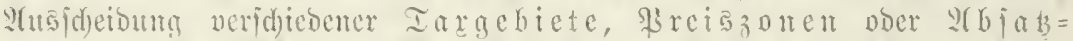

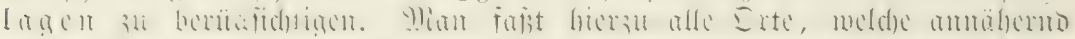

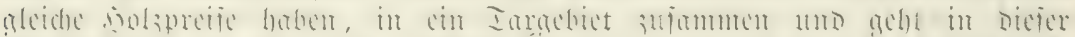

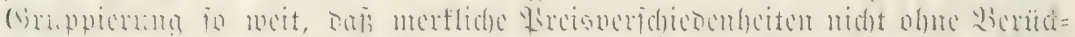

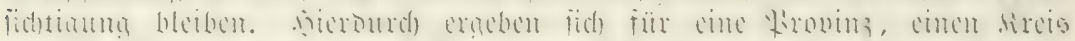

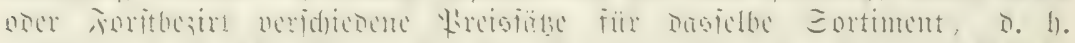

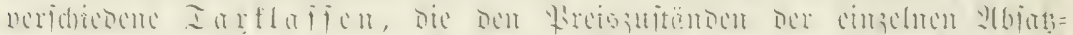

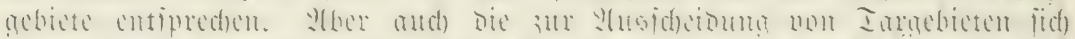

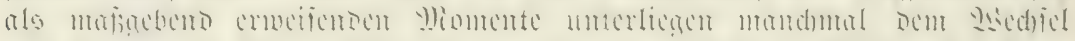

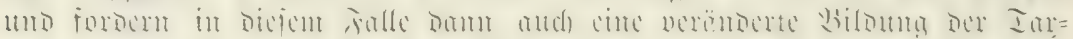

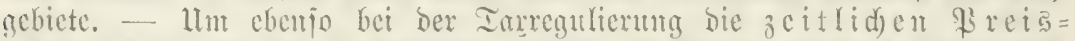

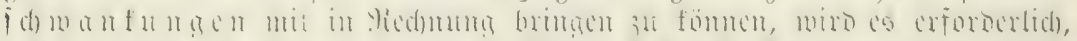

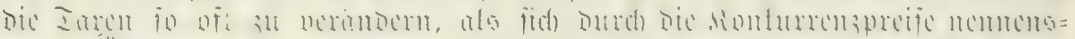

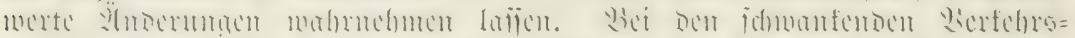

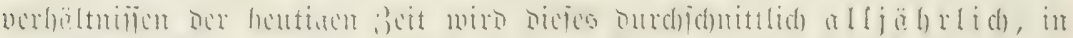

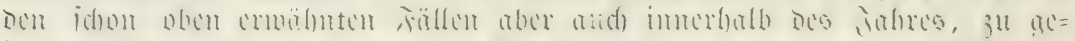

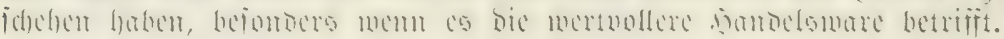

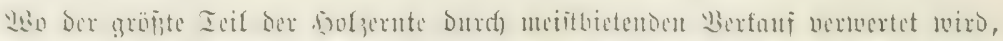

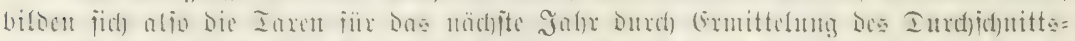

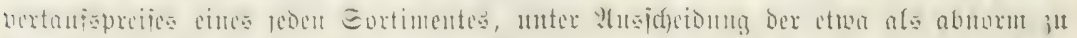

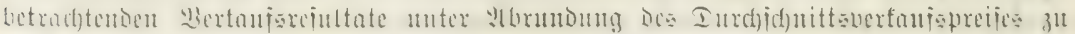

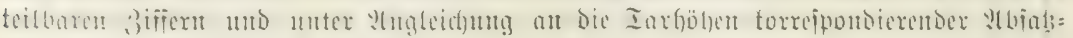
lagen Dex angrenzenden Forjtbezirfi.

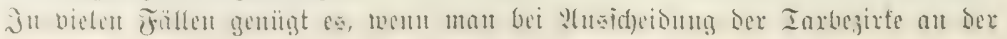




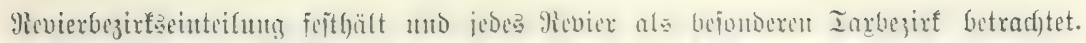

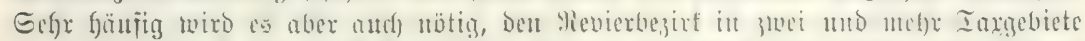

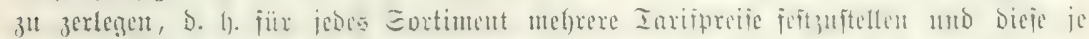

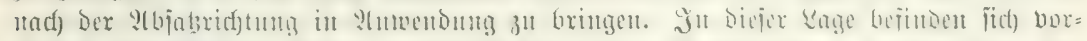

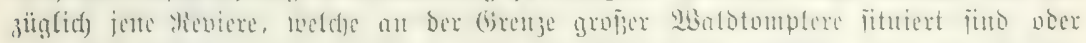

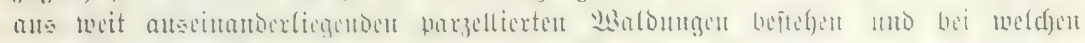

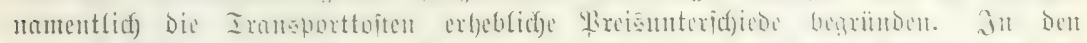

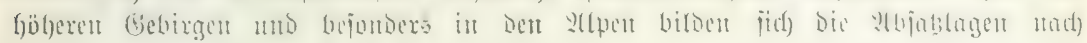

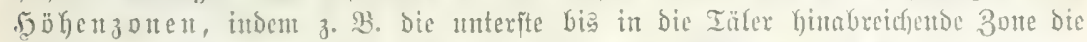

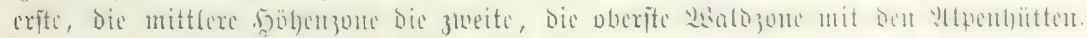
Rajert U. F. W. Die Dritte Mbjatzlage begreift.

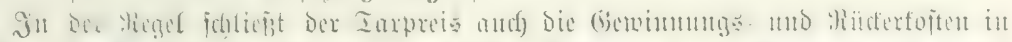

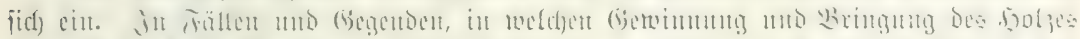

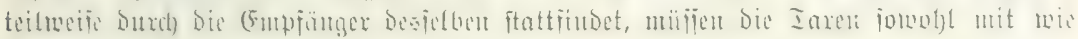
Dfue bieje Merbungâfoften aufgeitent werden.

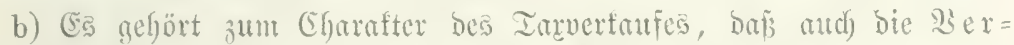
teiluma dex solzerute unter die fiom jumenten durd) den

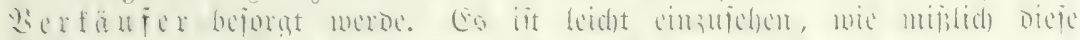

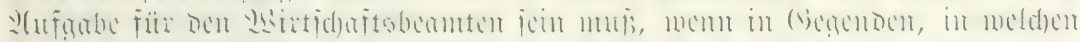

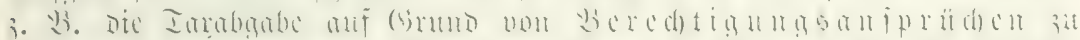

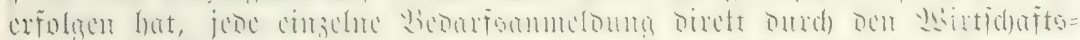

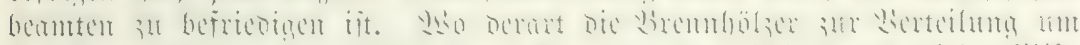

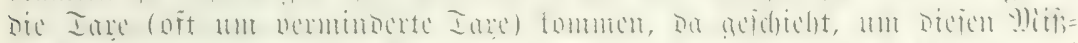

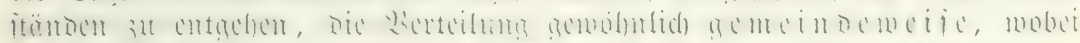

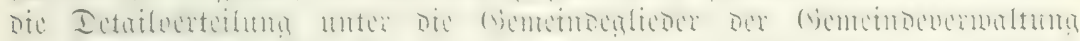

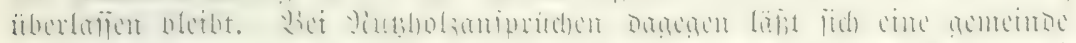
metic,

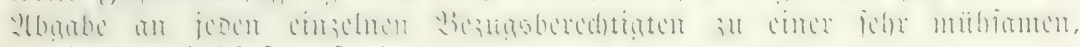

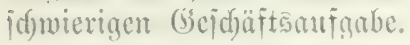

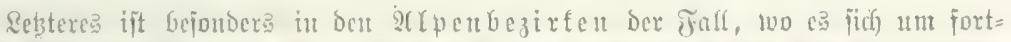

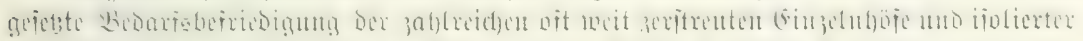

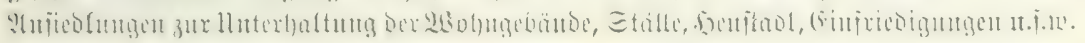
bandelt (Gier meijt (bratibabgaben).

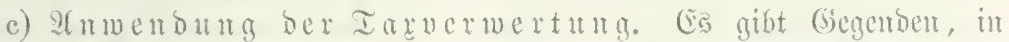

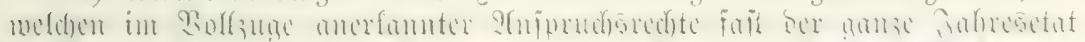

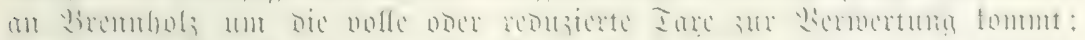

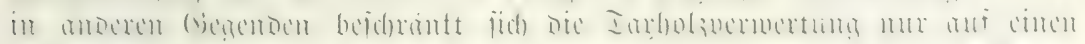

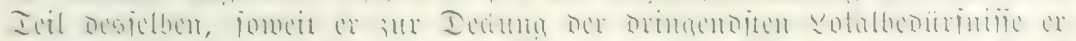

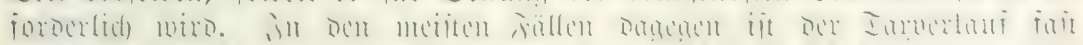

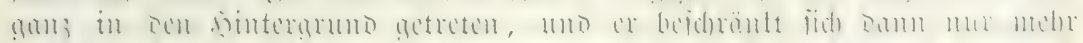
«

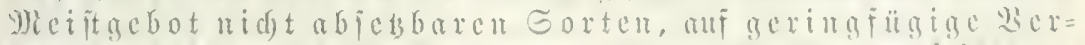
I 1 «

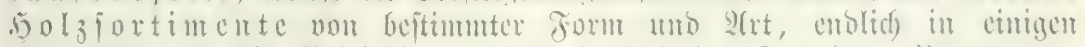

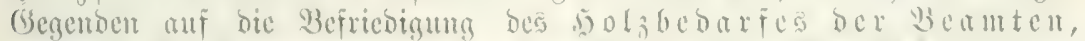

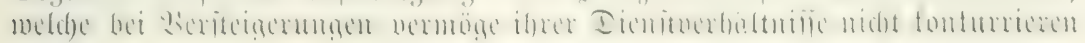
fömกาเ 


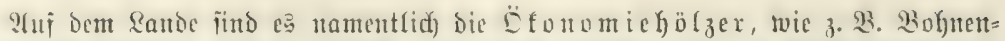

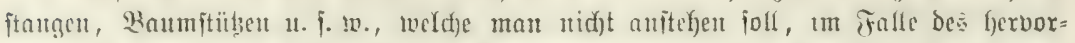

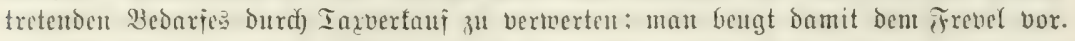

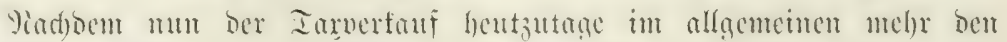

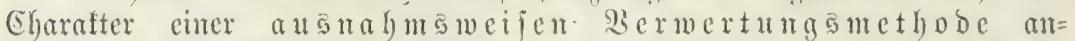

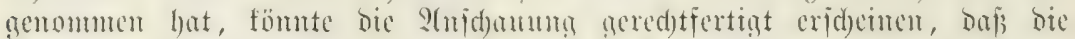

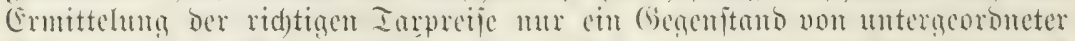

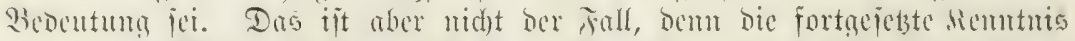

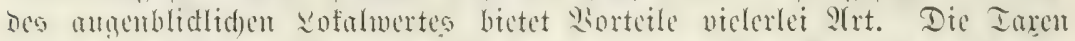

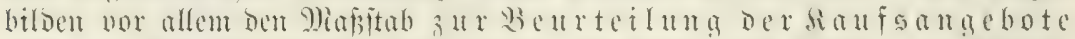

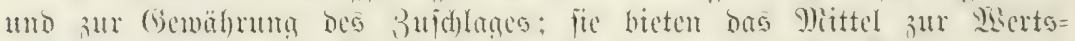

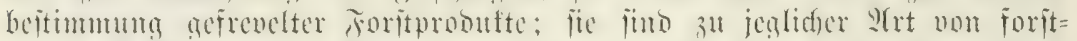

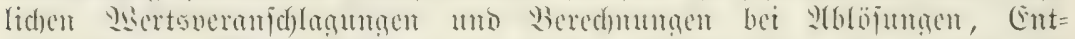

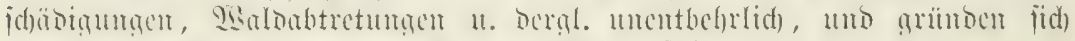
jd)lief̈lid) mand)e (5tata = uno Buogetzal)len auf fie.

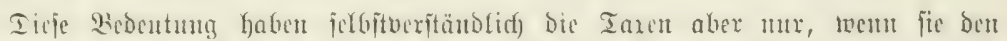

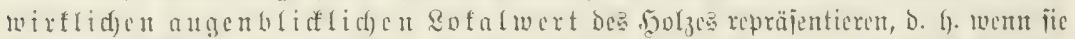

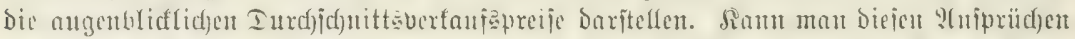

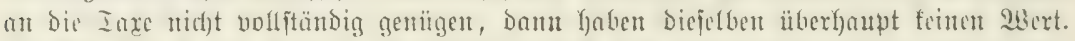

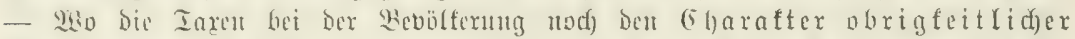

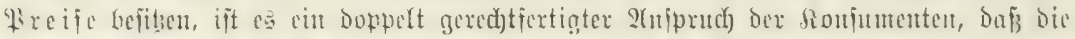

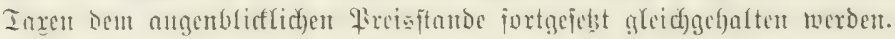

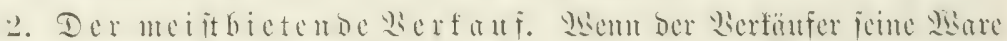

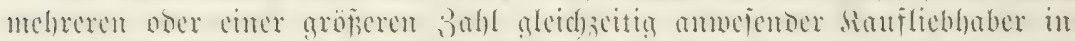

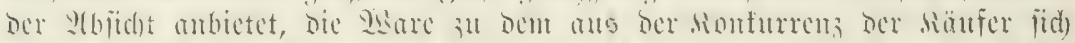

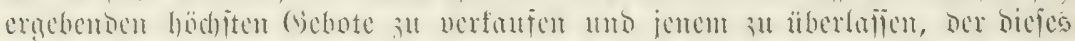

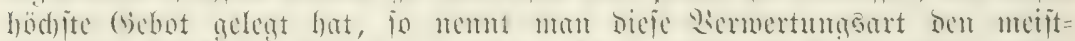

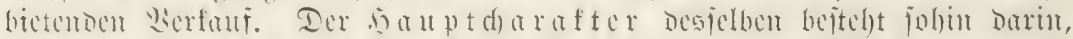
Da

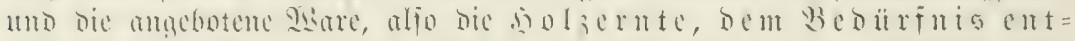

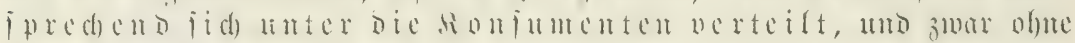
8utut des 9Galdeigentümers.

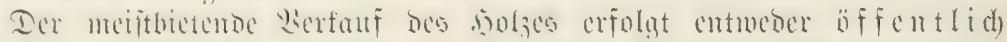
แ แル

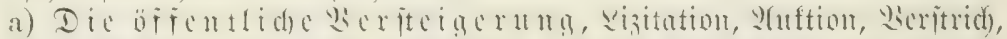

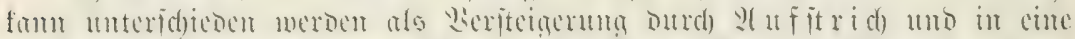

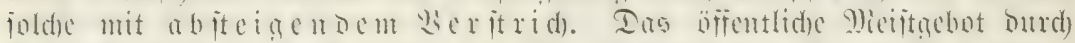

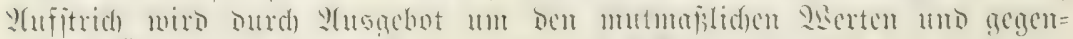

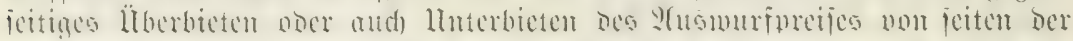

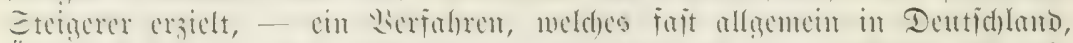

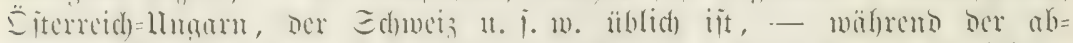

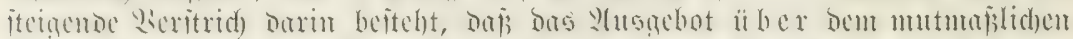

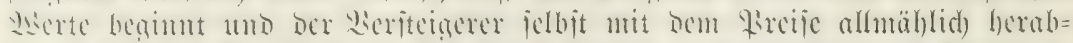

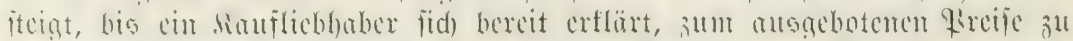

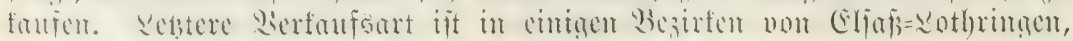

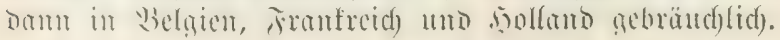




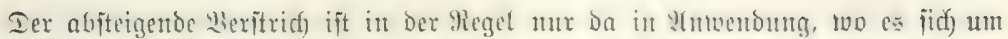

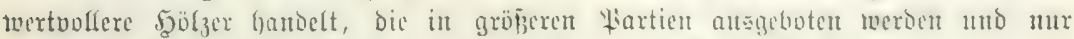

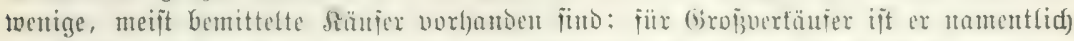

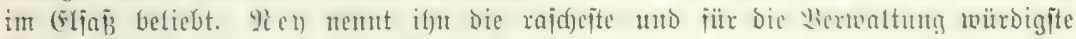
Diethode.

a) Gejdyäf

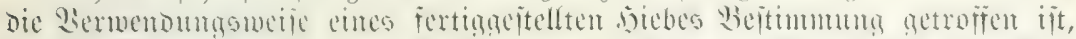

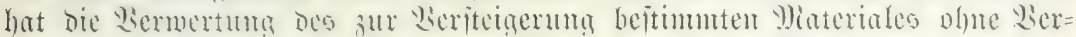

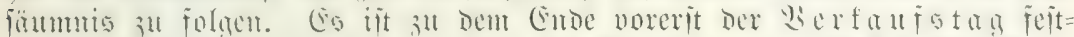

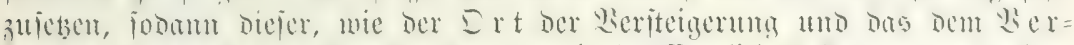
faแ

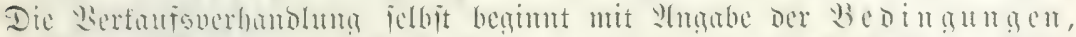

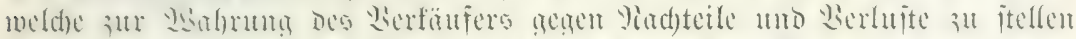

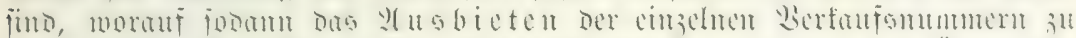

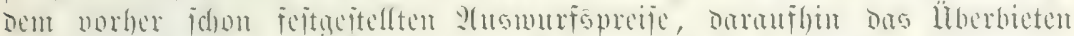

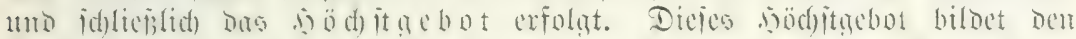

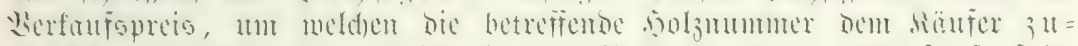

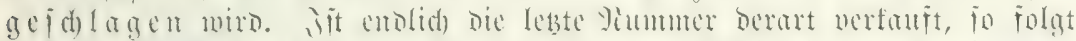

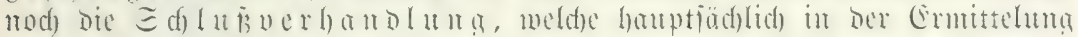
bes Gejamterlöfes per Gortiment mo in ganzen bejteht.

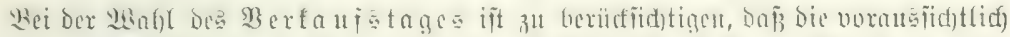

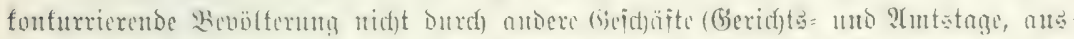

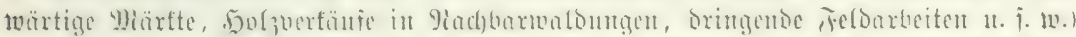

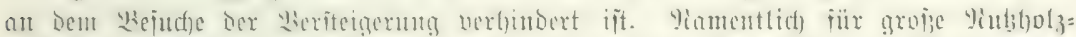

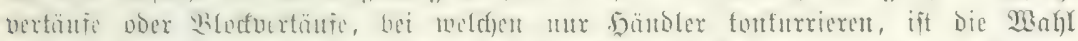

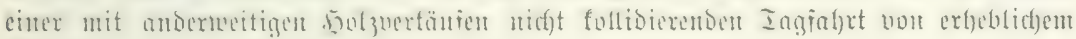
Belang.

Der Drt Der SBerfteigerung ift nicht gleidguiltig für Den (Exfolg. S)lan

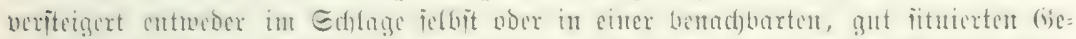

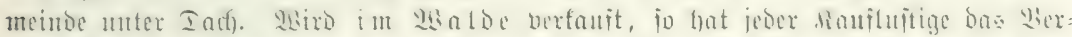

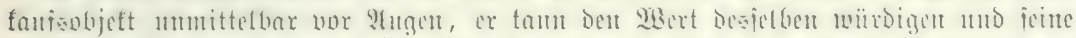

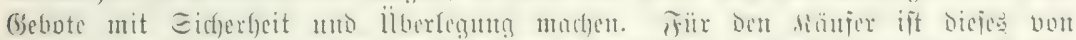

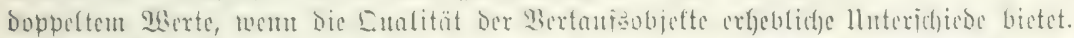

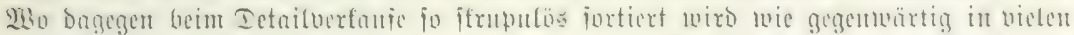

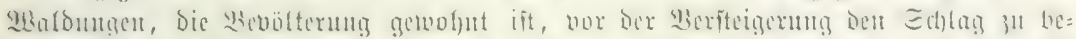

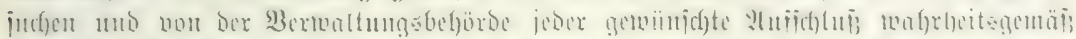

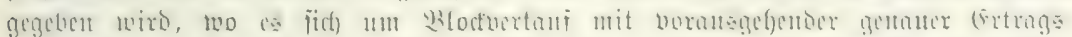

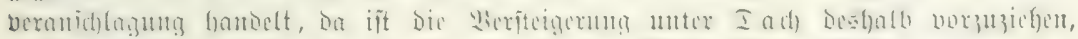

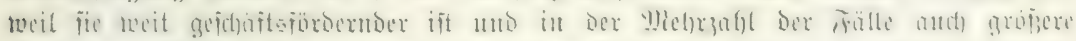

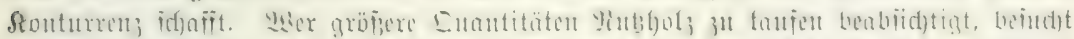

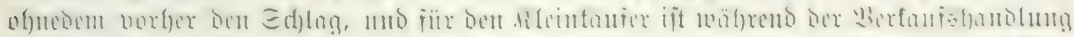

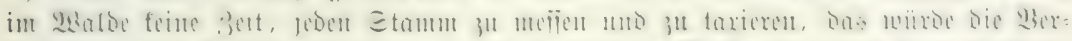

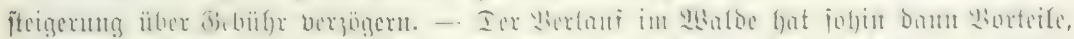

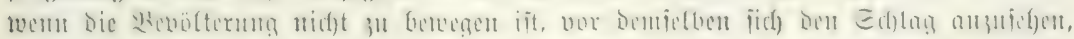

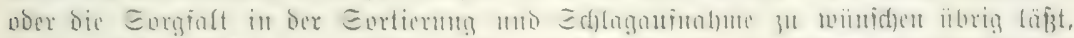

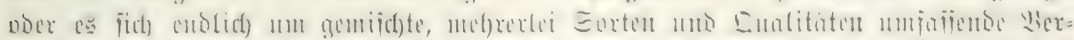

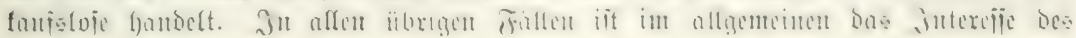




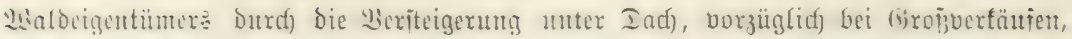 mehr gemahrt.}

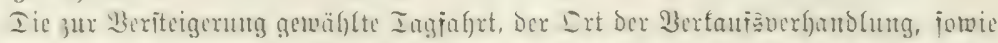

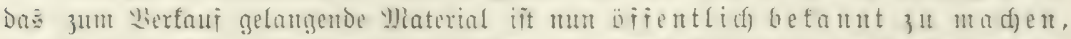

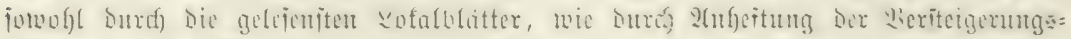

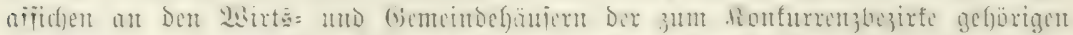

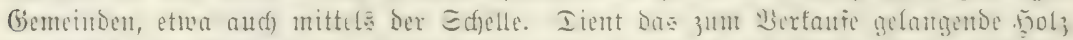

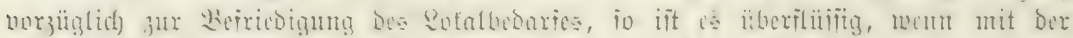

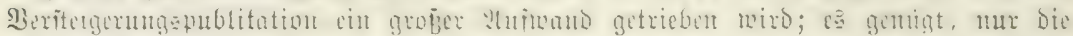

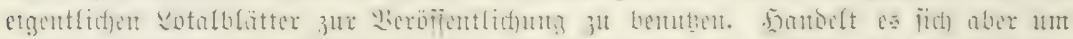

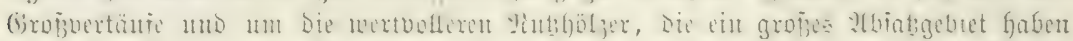

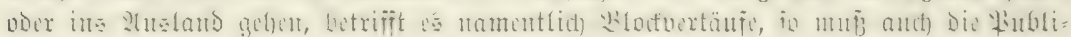

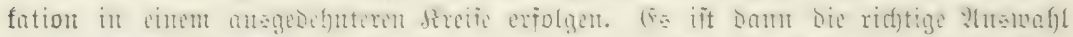

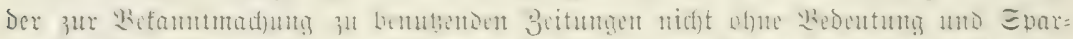

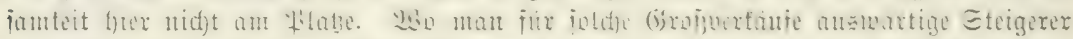

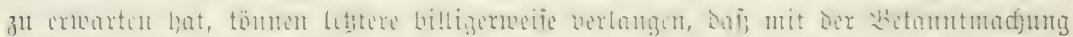

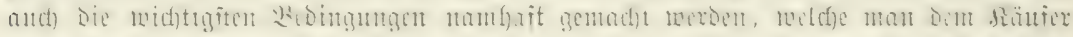

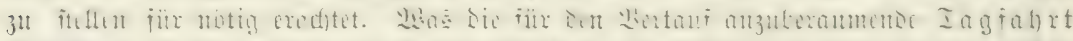

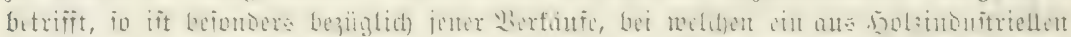

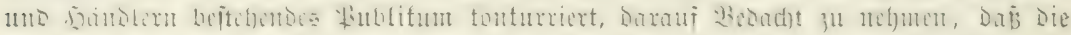

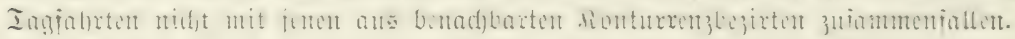

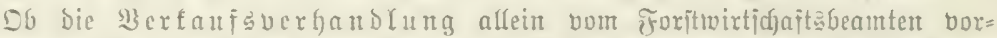

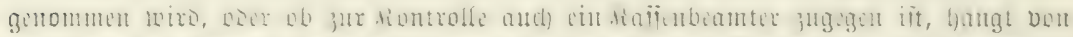

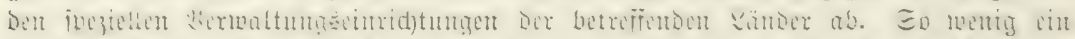

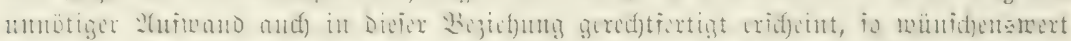
ijt

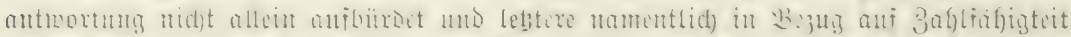

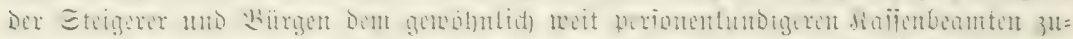

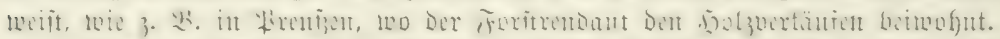

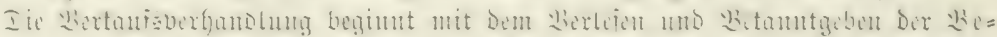

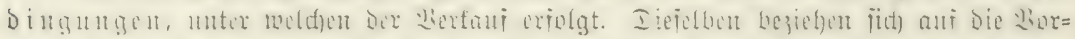

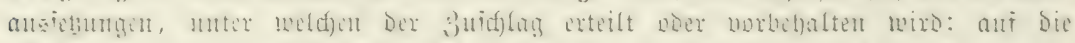

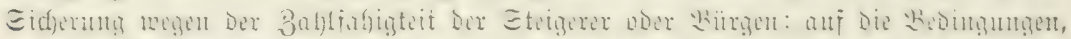

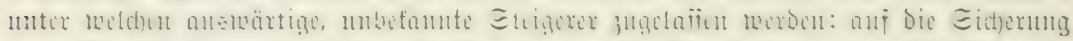

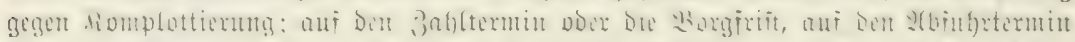

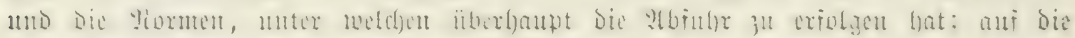

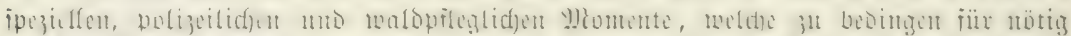

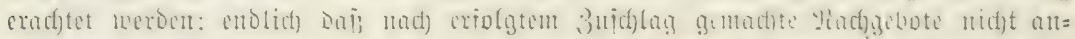
gentommen merden.

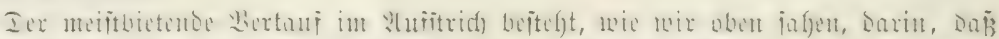
Dos

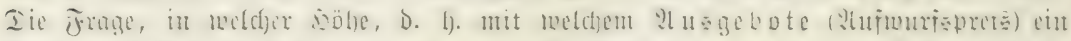

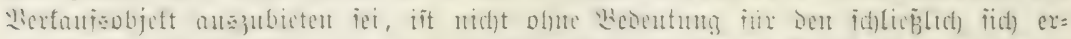

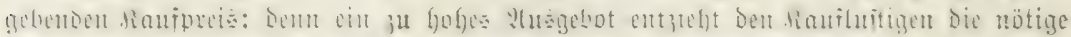

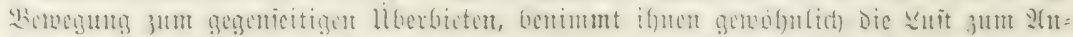

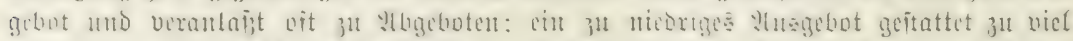

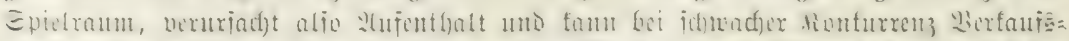

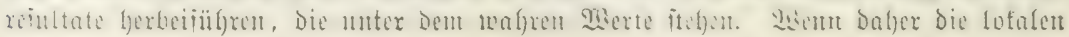




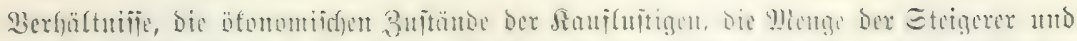

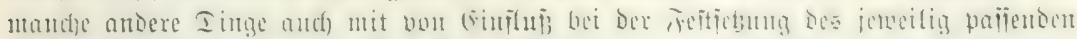

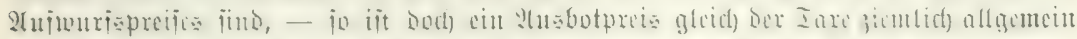

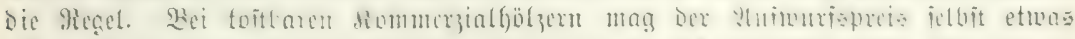

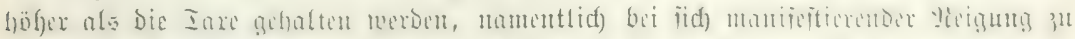

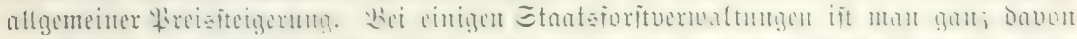

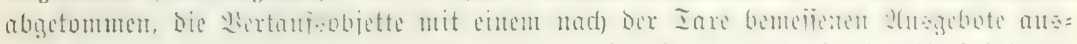

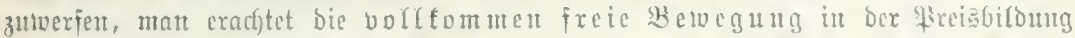

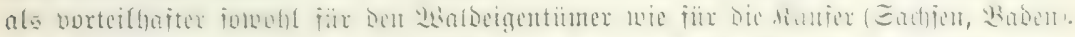

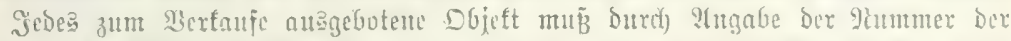

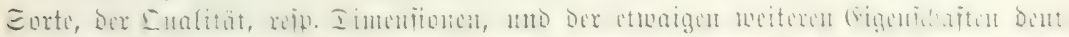

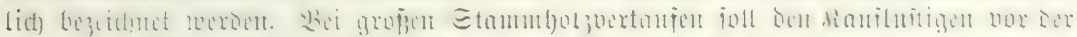

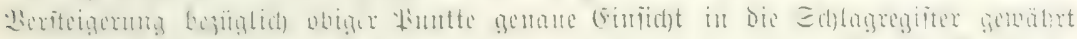

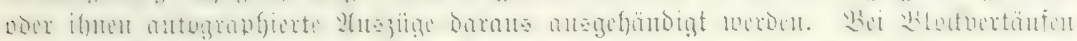

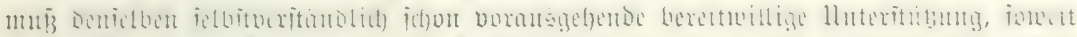

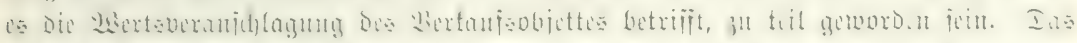

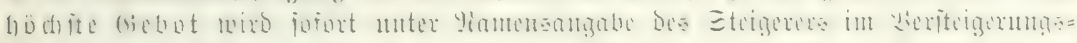

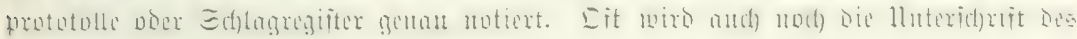

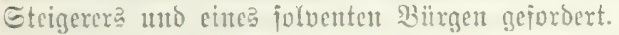

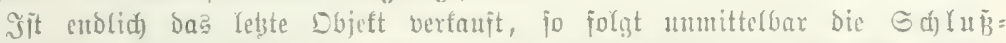

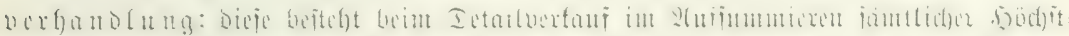

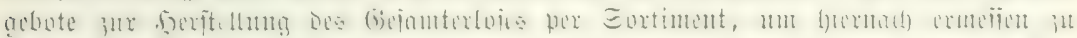
fömen, ob bex defintitive 3 ufd lag fogleid) erteilt werden fam ober vorbefalten

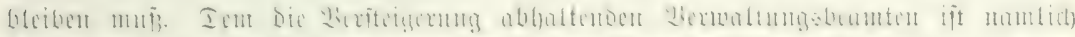

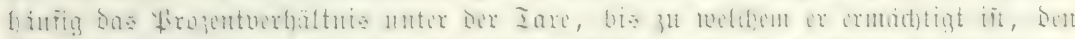

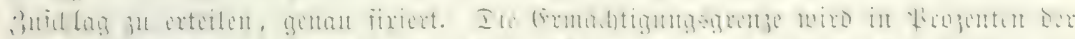

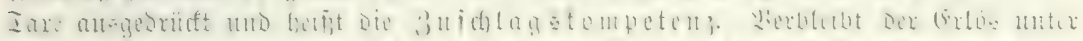

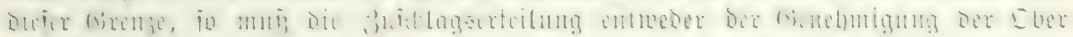

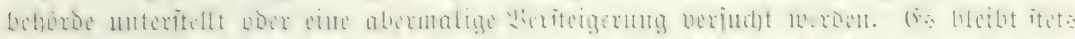

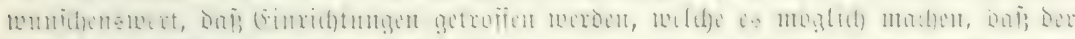

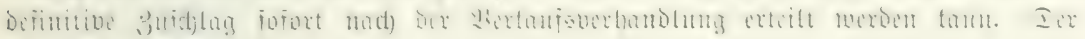

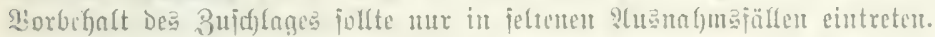

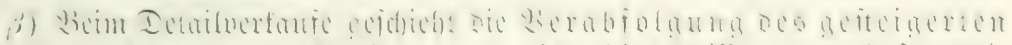
s) ol:

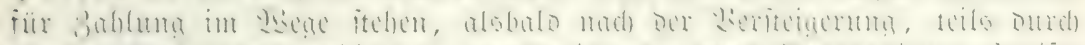

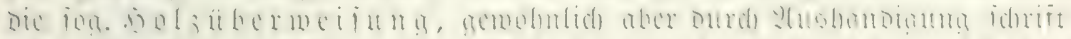

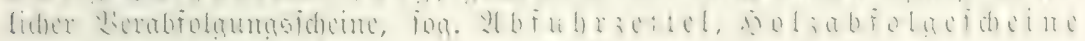

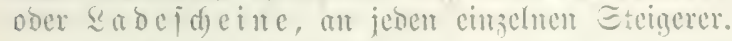

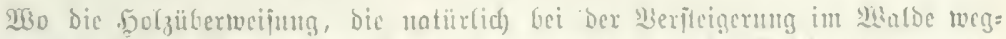

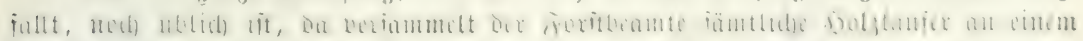

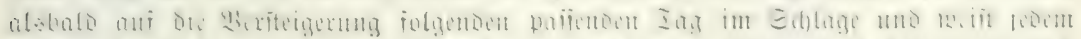

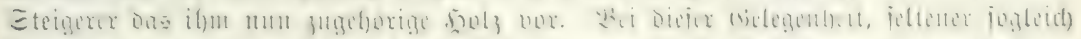

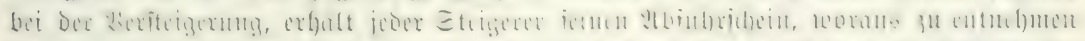

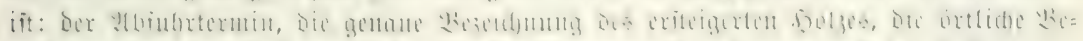

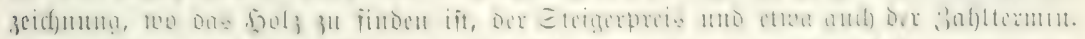

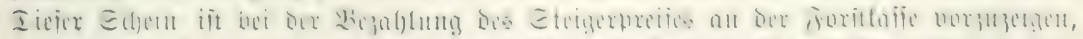

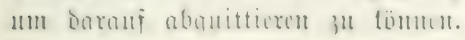

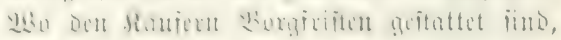




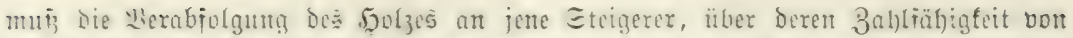

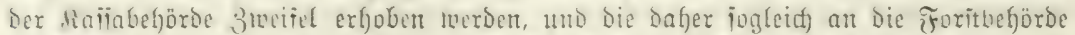
nambait zut mad)en ïno, bi zum Thad)weis der mirflid) erjolgten Bahlung aui

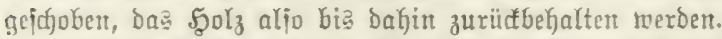

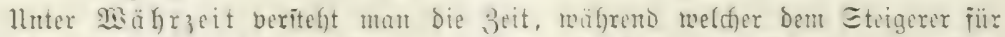
vollitändige (Exhaltung jeines eritigerten nolje burd) Die Forithelörde gerantiert

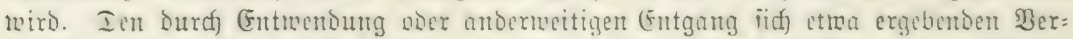

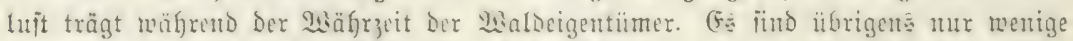

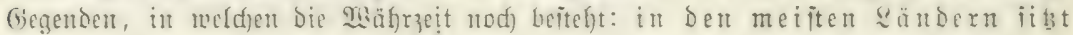
ba

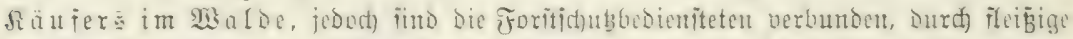

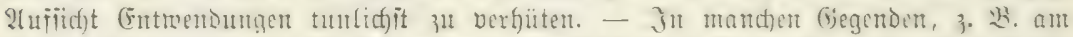

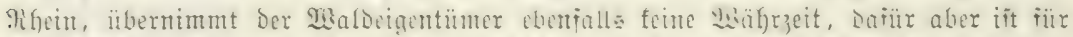

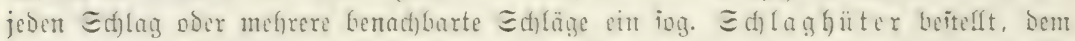

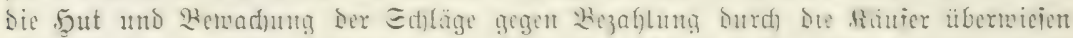

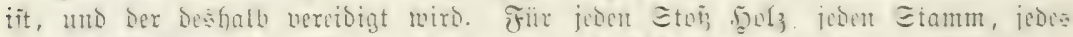

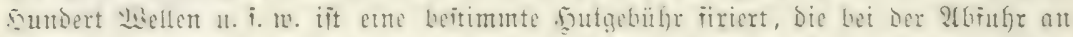

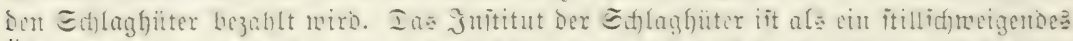

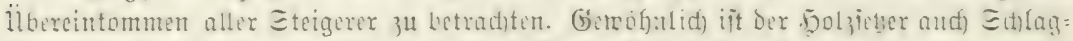

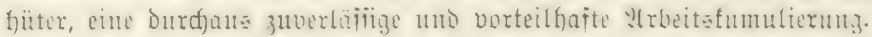

b) Die gefeime Beriteigerung ober Eubmifitou bejtebt

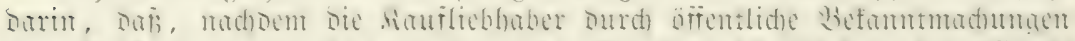

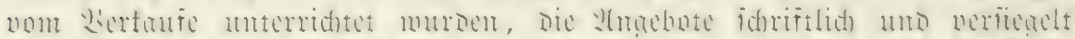

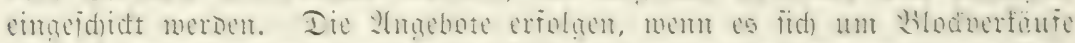
handelt, cutmeder in a limfiac (E)

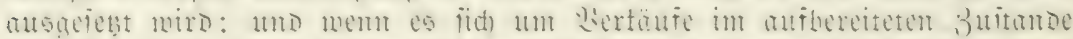

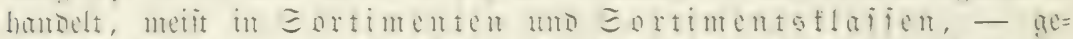

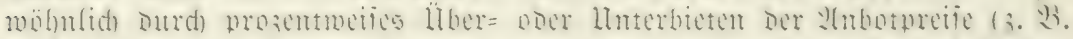

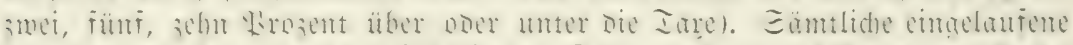

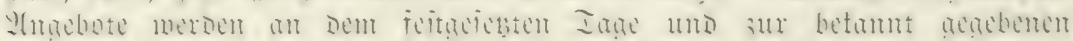

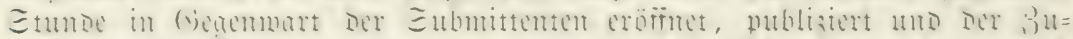

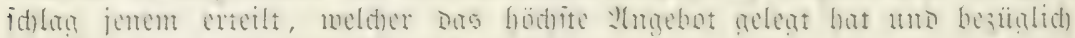

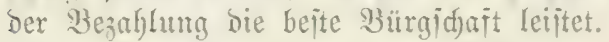

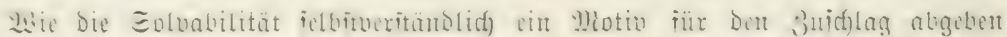

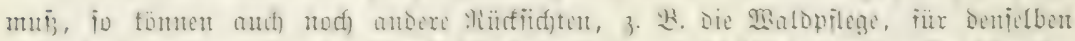

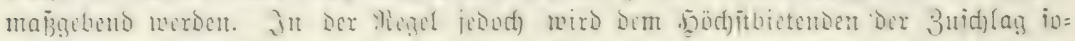

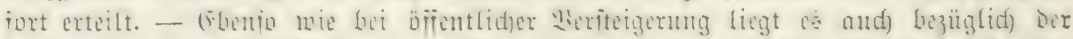

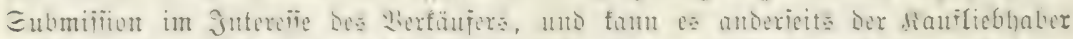

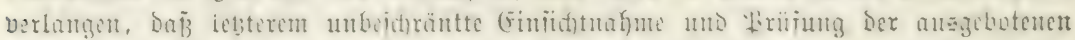

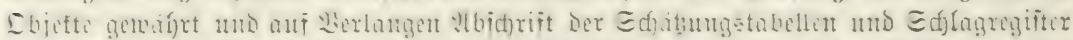

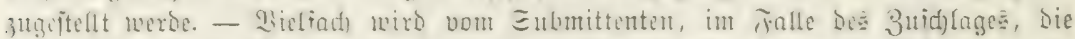

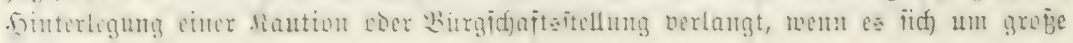
Sojten Gandert.

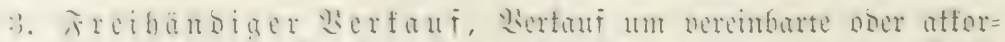

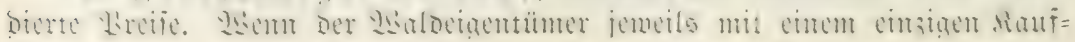




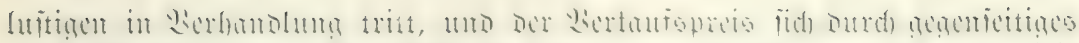

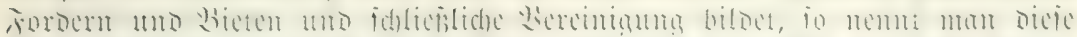

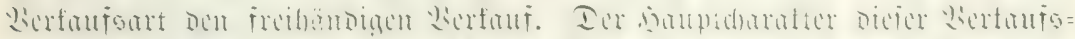

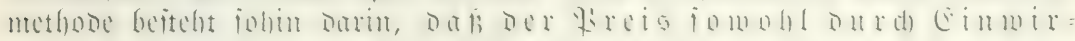

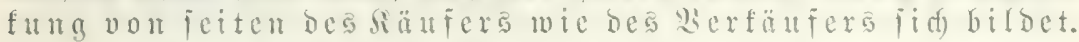

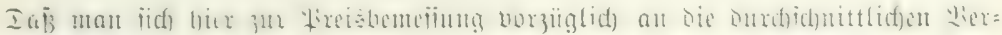

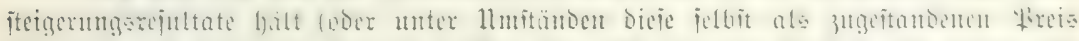

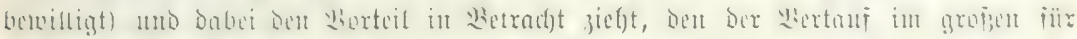

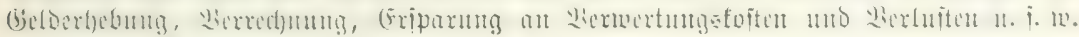
Gat, liegt in ber Slatur bor Eache.

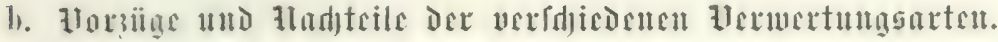

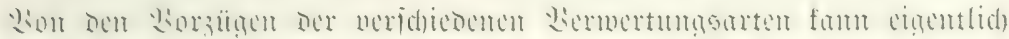

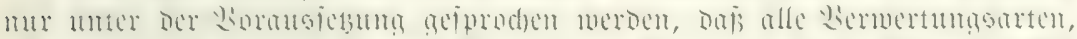

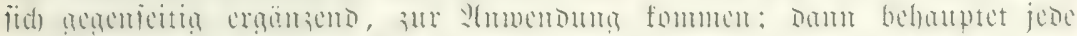

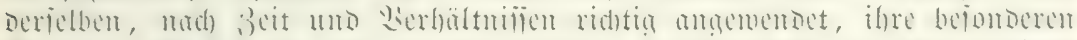

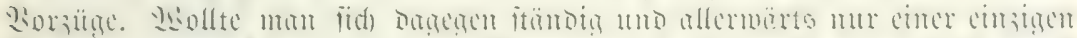

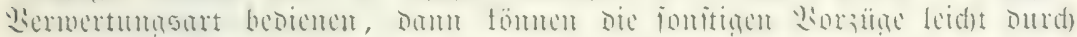

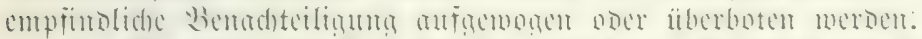

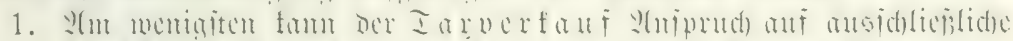

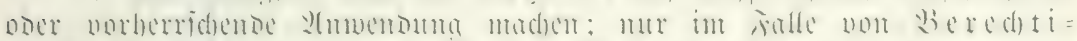

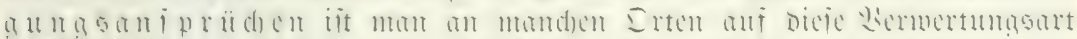

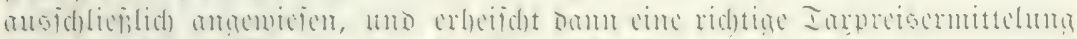

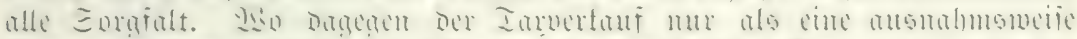

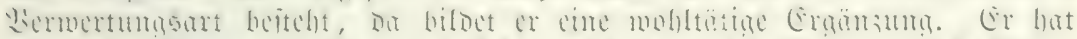

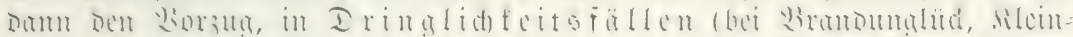

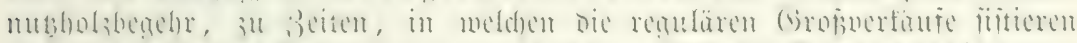

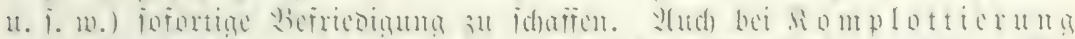

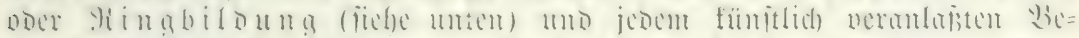

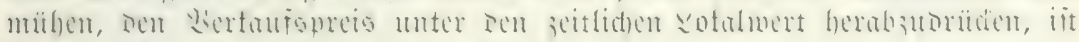
burd) rajden Iaxwertauf häufig gabilfe geboten.

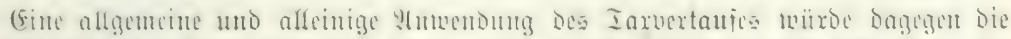

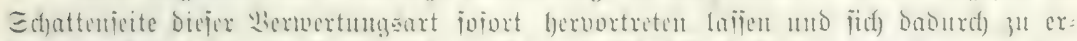

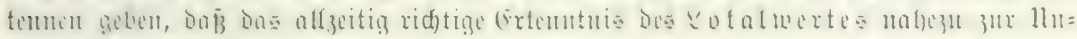
mögliff)tcit toỉrbe.

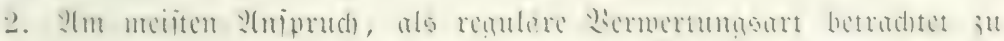
merben, lat bex öffeutlide meifbietende

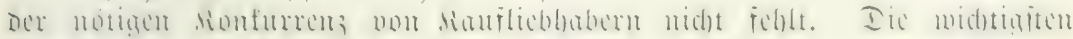
Dorzüge und Vad)teile bicjer Bermenbumgart find folgenoc:

a) Weim Detailuerfanfc. Dic Diorzüge Des meitbetenden

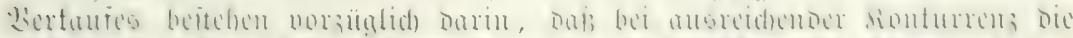

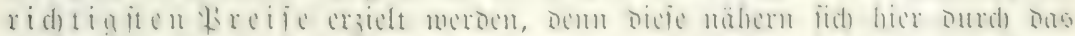

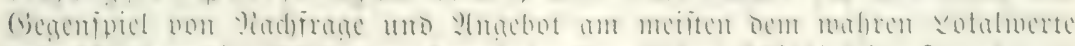

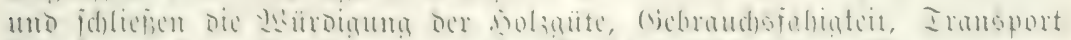

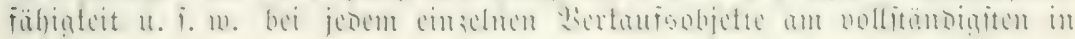




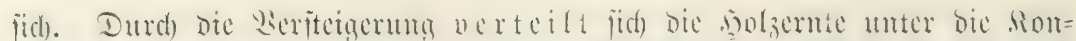

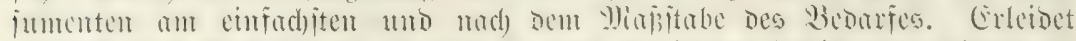

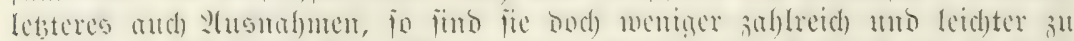

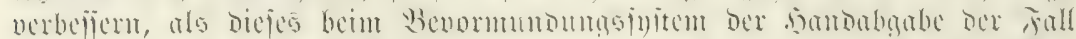

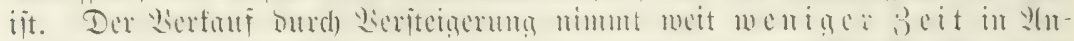

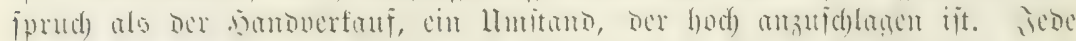

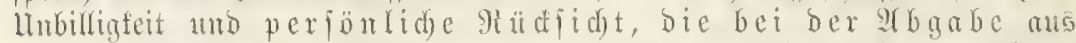
ber bant fo leidft unterläuft, ober bod) als foldbe aud bem ebren=

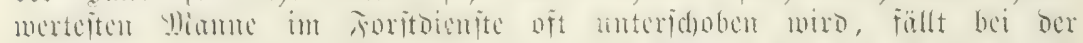

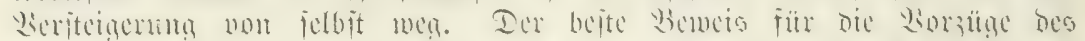

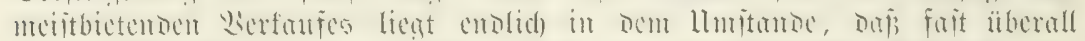

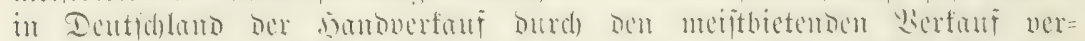

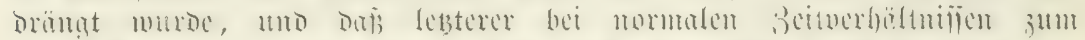
b worben ift.

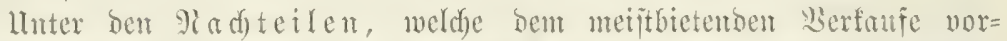

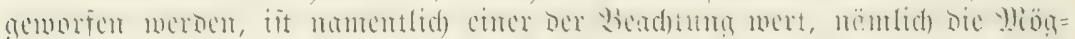

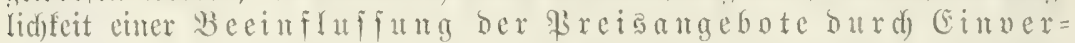
jt

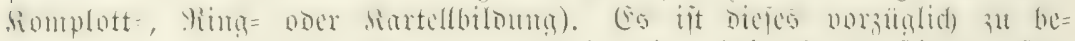

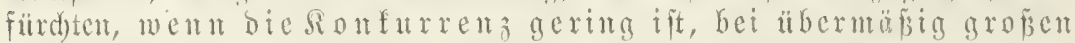

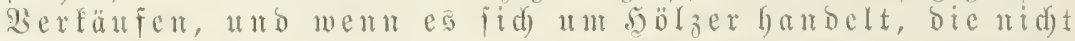
jeberuan faufen

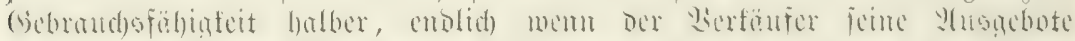

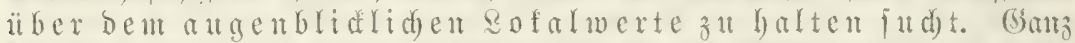

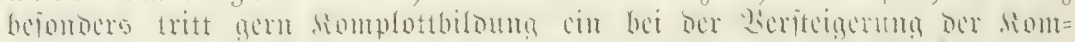

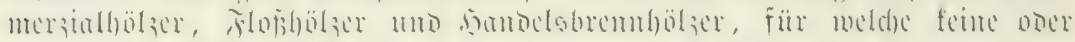
mu fochade lofale Sonfurenz beftelst.

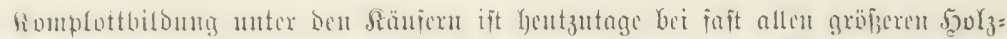

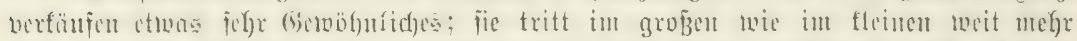

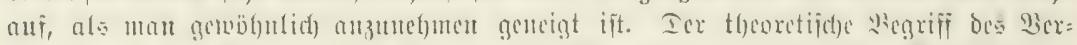

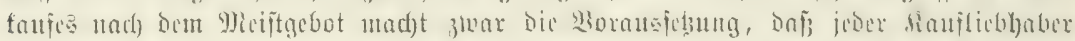

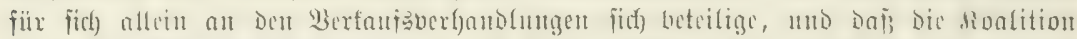

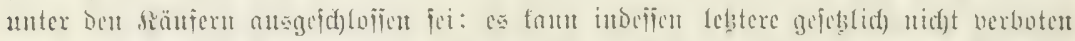

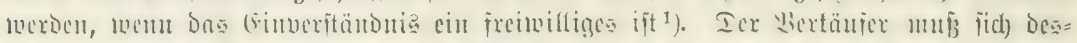

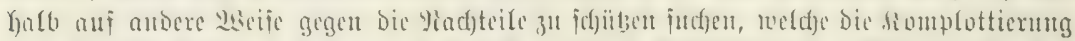

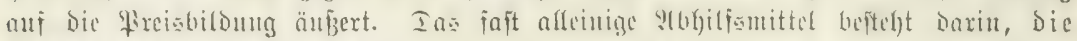

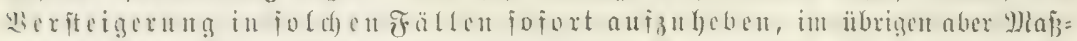

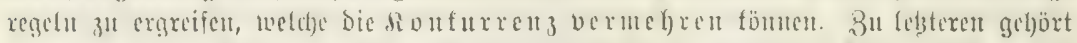

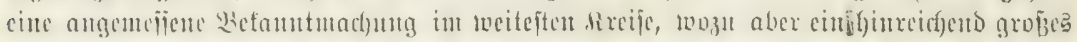

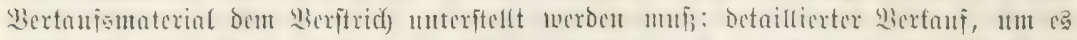

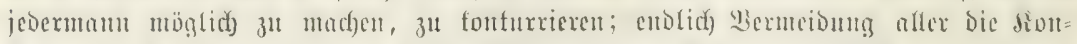

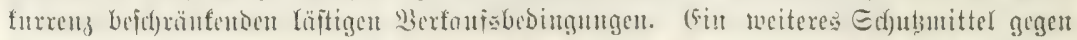

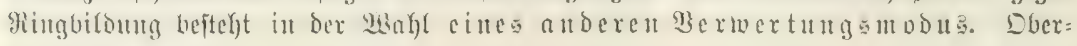

1) gridgt bic siomplottbiloung ift gepetslich berloten, fondern wem jemano einen anderen am Bieten burd) Drohuta u. j. to. berfindert. 


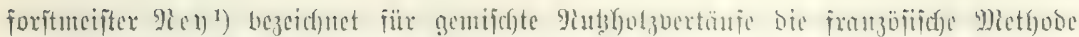
de münolidyen ?tbgebotes als bie befte gegen Atingbildung.

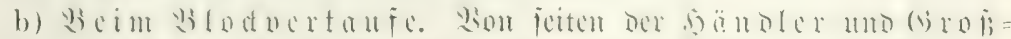

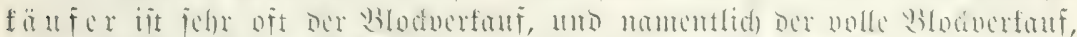

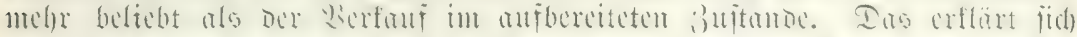

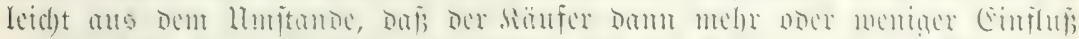

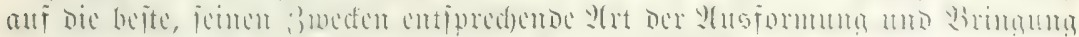

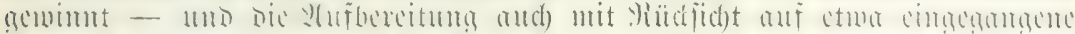

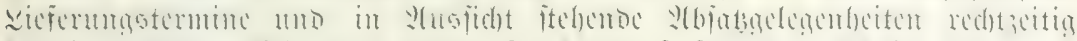

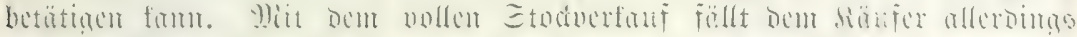

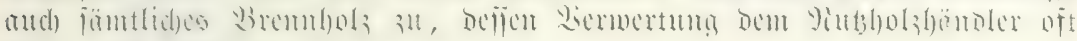
Yätig mo fdumicrig ift.

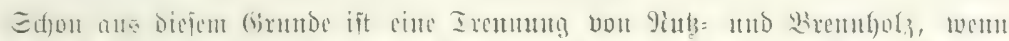

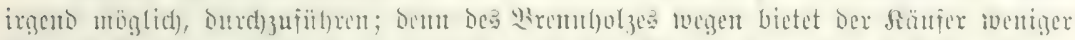

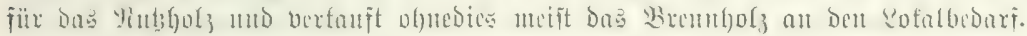

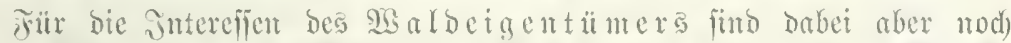

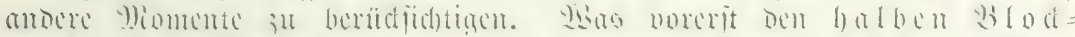

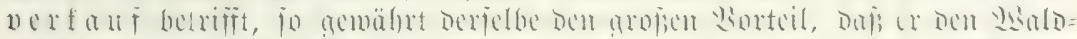

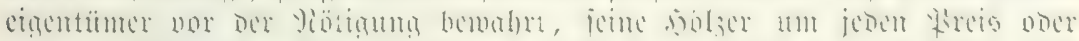

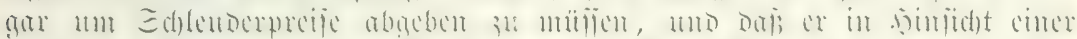

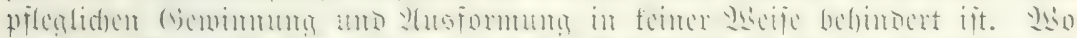

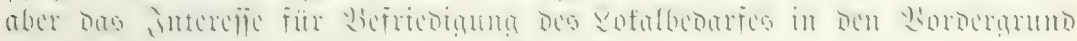
tritt, Do form bieje Berfontfart nidgt genüigen.

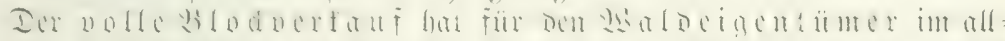

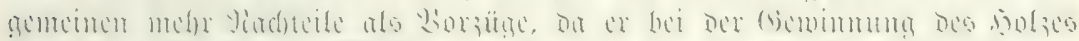

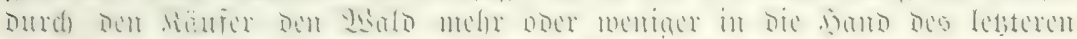

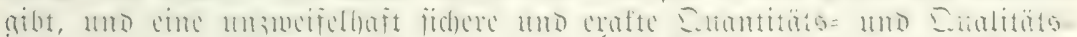

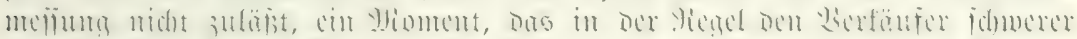

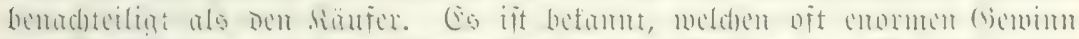

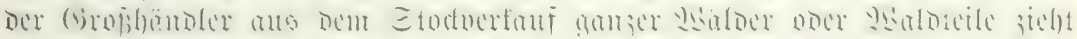

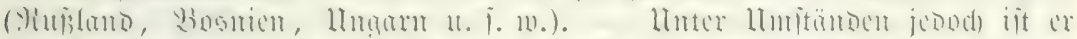

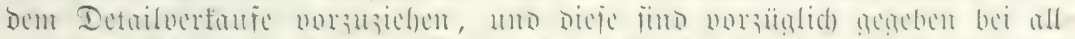

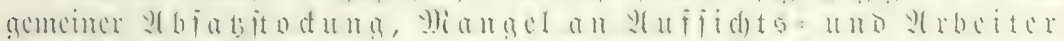

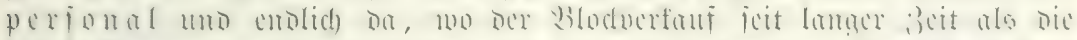
üblide

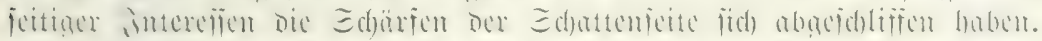

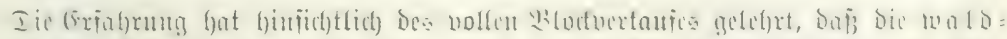

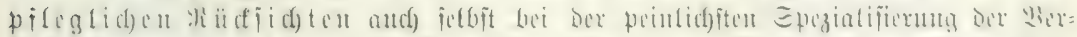

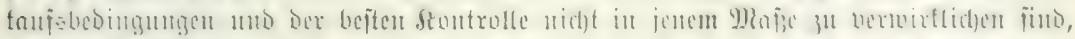

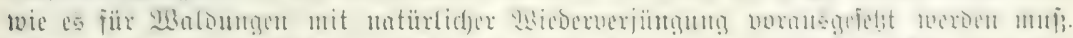

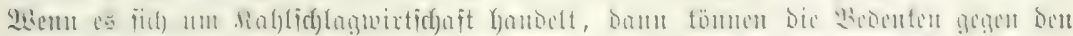

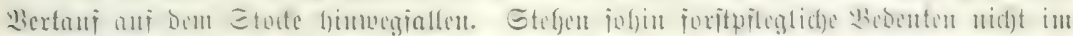

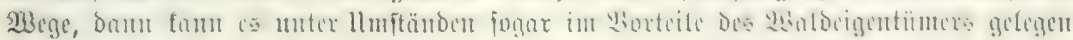

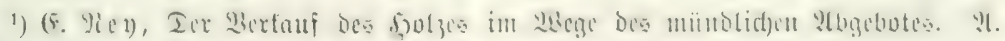
๖. 3 3. 1900. 


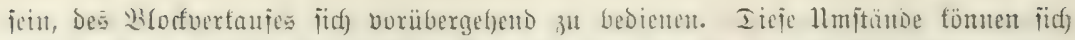

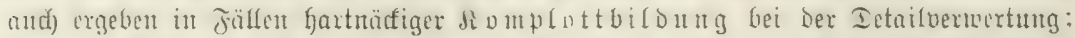

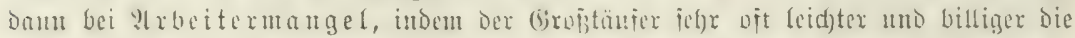

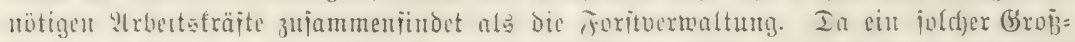

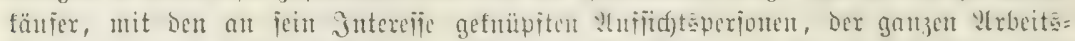

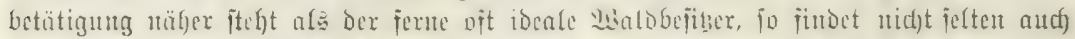

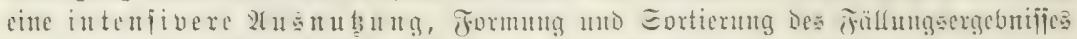

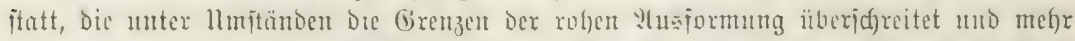

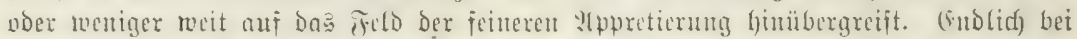

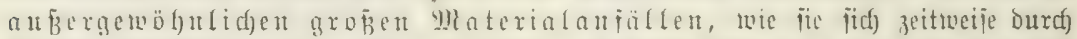

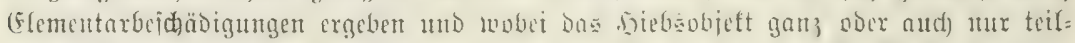

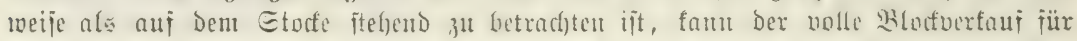

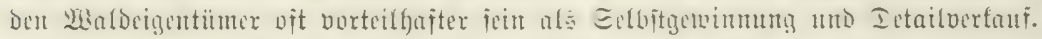

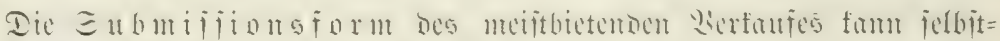

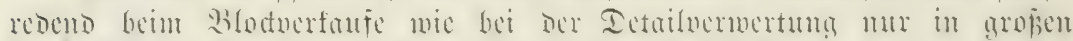

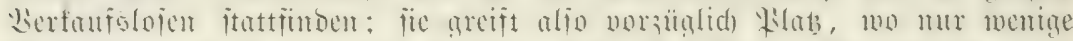

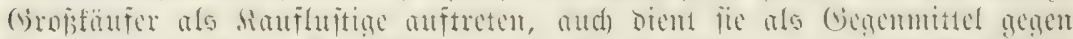

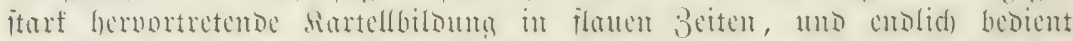

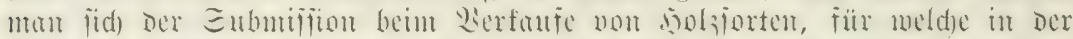

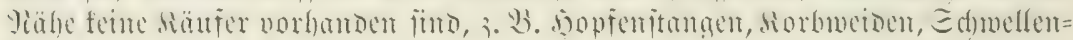
fölzer t. i. w.

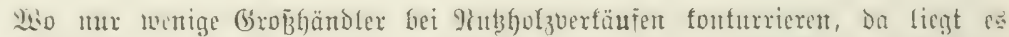

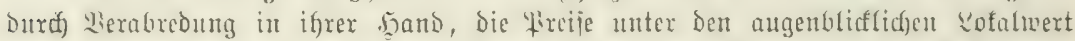

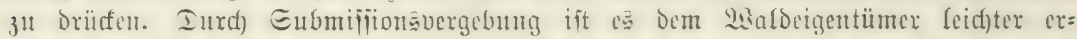

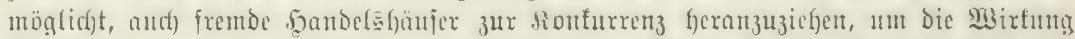
Der fiomplottierunty teilmeije zu parnfnjierm, - it Der Regel alferobitgs mur vor= iibergethento.

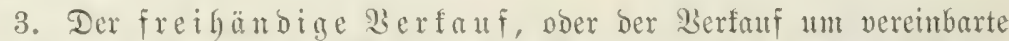

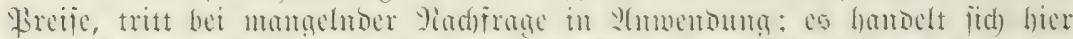

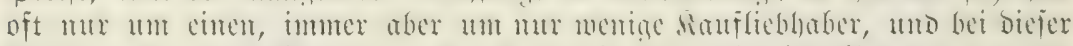

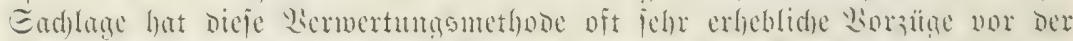

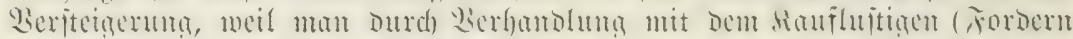

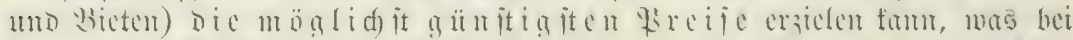

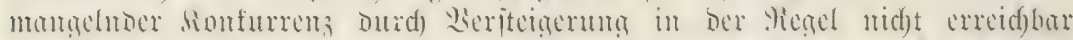
ijt.

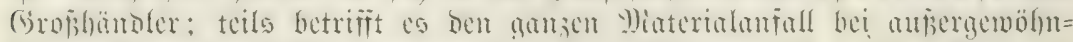

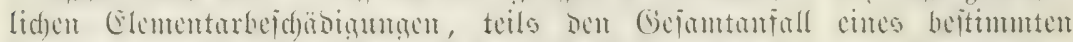

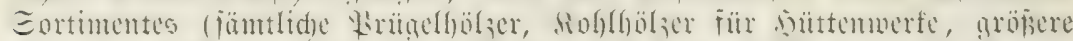

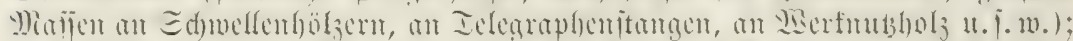

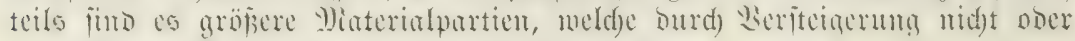
nidjt atm ben Iarpreis abjebbar waren.

Ier Freif)ändige Serfanf hat foute in cinzelnen (jegenden eine benerfensmerte

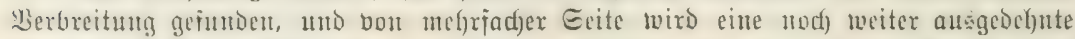

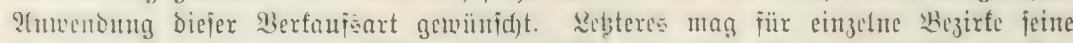

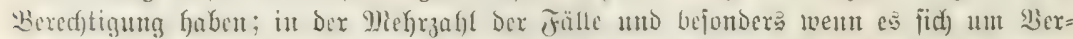

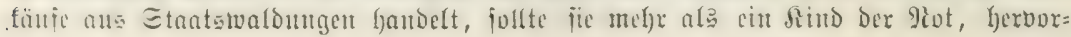




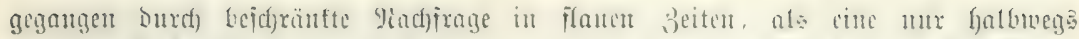

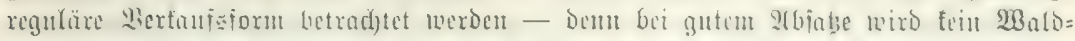

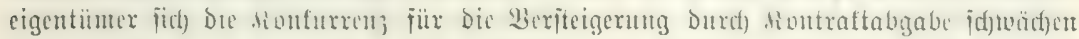
wollen.

\section{c. Iinufuämuifd) Gefidjtspunkte iu Aumcudung auf ioliveruertung.}

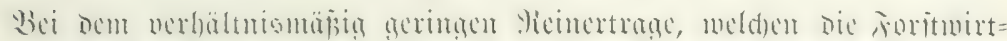

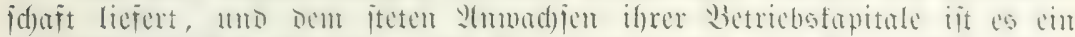

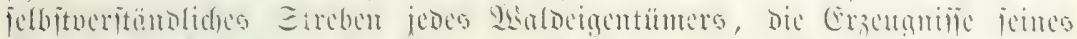

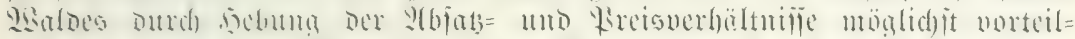
hat ; nexucten.

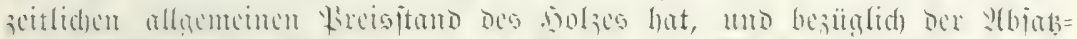

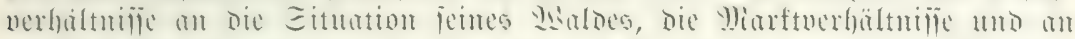

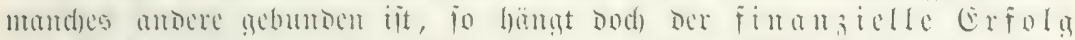

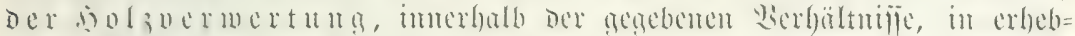

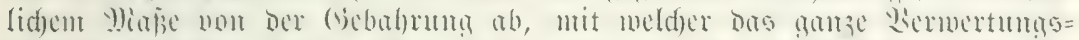

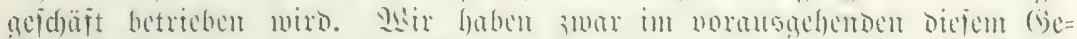

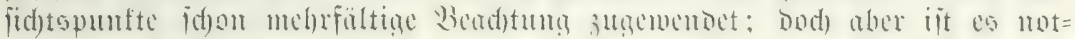

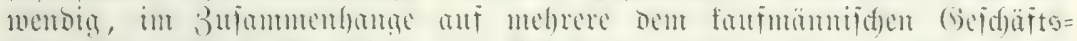

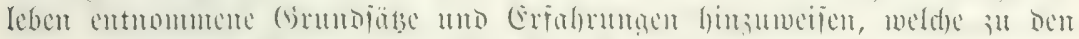

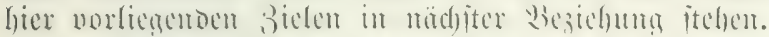

1. iो a 1 g

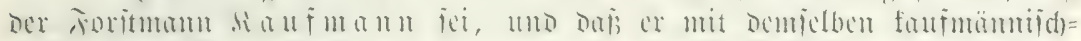

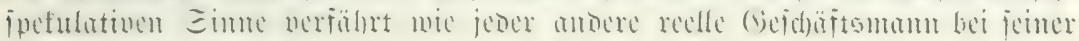
Sroouftenverwertumg.

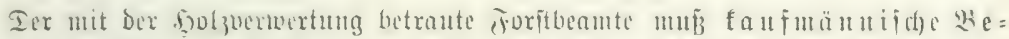

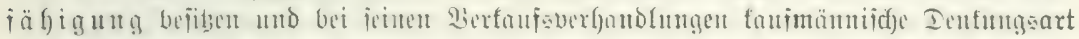

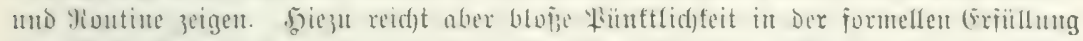
und Weobaditungen ber etwa gegebentu Iienjtenboridgriften nidgt aus, ben formelle

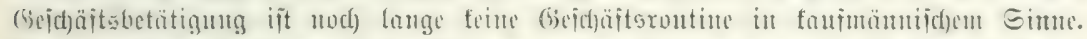

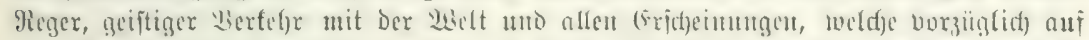

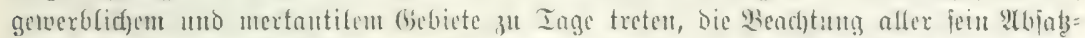

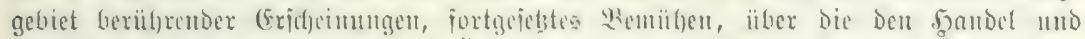

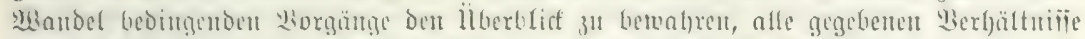

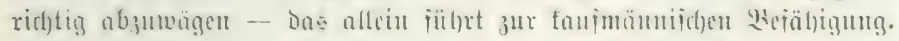

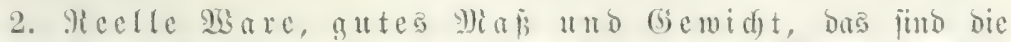

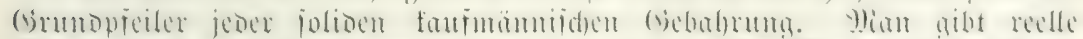

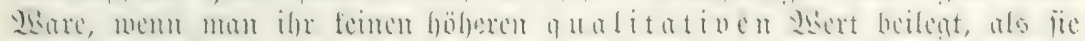

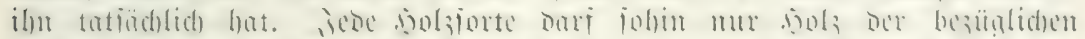

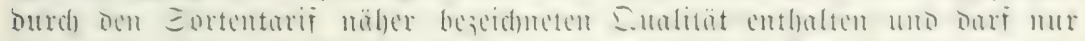

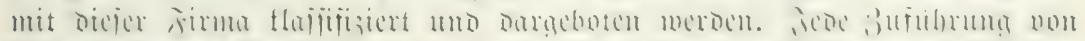

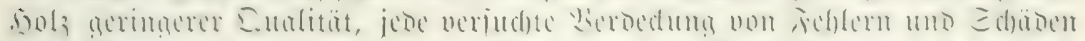

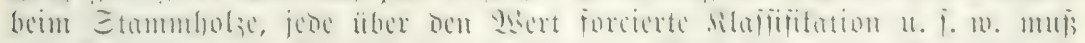

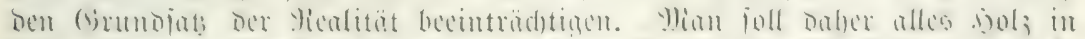

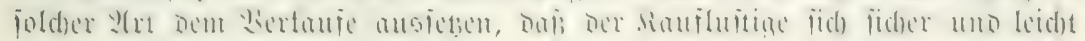

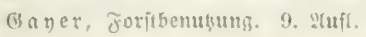




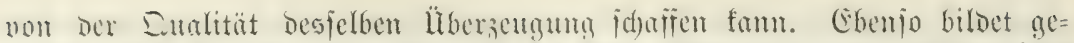

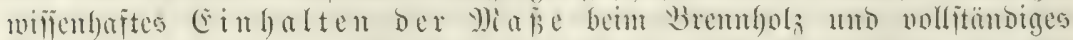

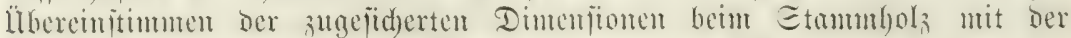

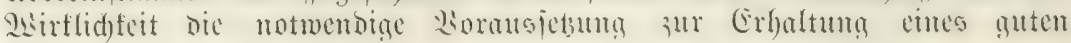
Rrebites.

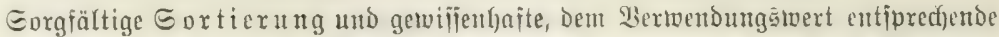

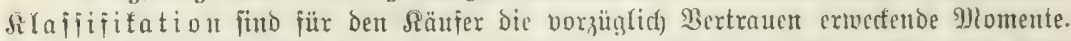
Iazu gefjört weiter aber eine ridjtige Shifoung bo Eortentarifes; autf) Diefer fant

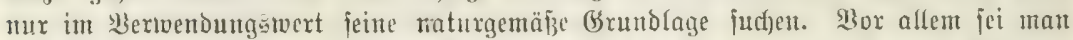

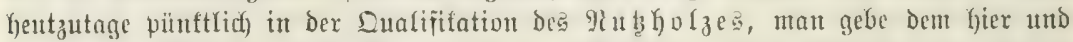

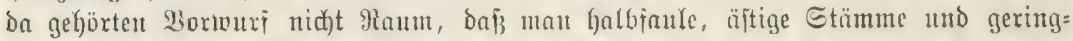

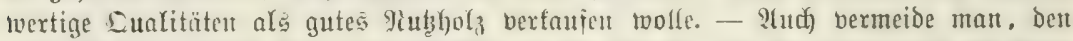

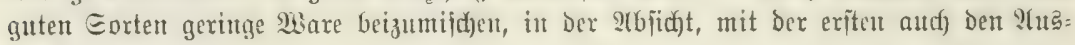

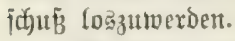

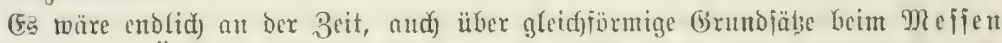
Der Dimenitonten Z̈̈bereinfunft zu treffen, - namentlid) wärest beim Etammforze bas

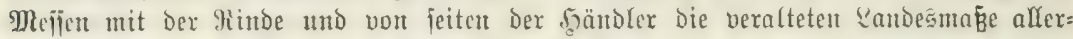

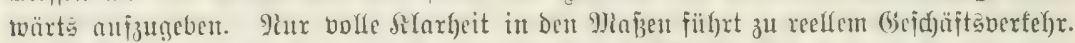

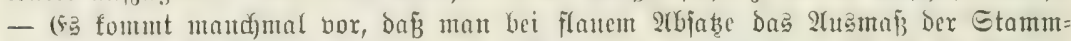

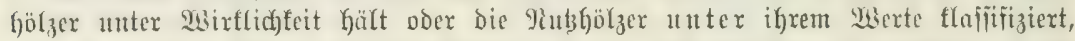

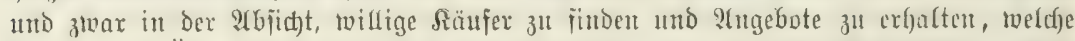

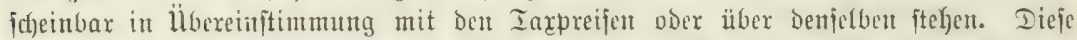

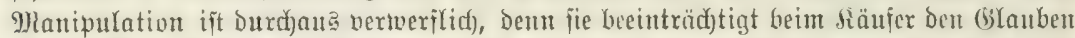

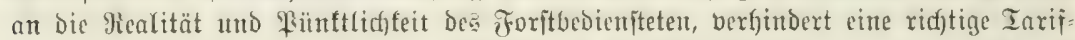

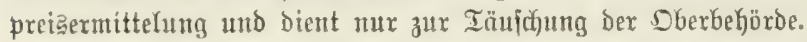

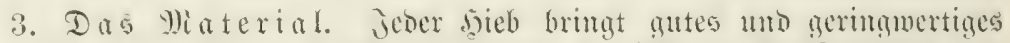

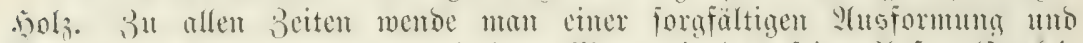

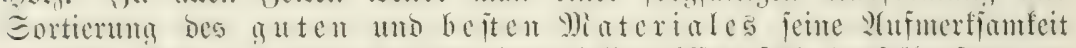

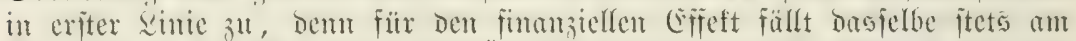

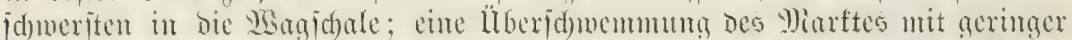

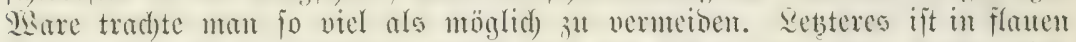

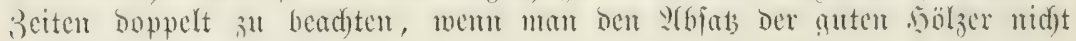
empfunolid) beeinträdhtigen will.

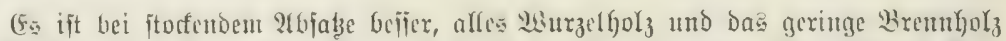

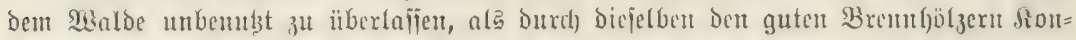

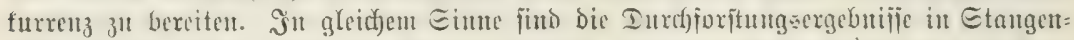
beftäutoe anf

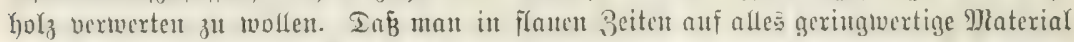

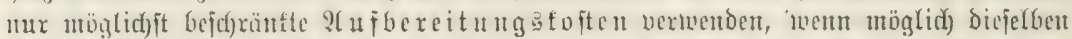

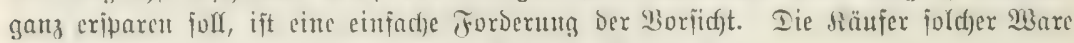
verrid)ten bieje 2lrbeit billiger und nach) ifrem (bejd)madfe.

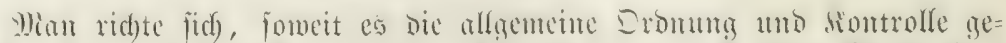

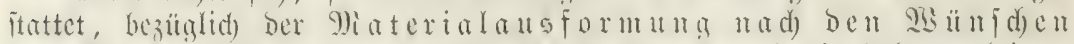

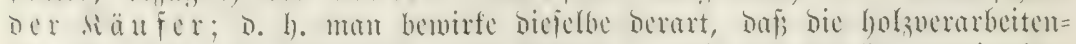

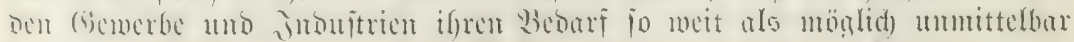

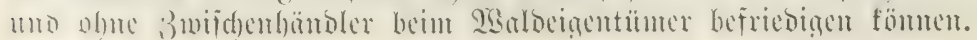




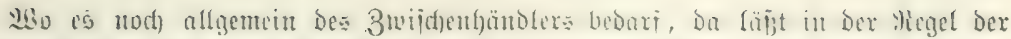

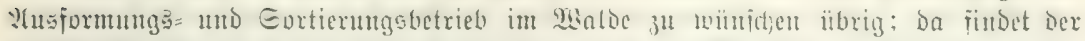

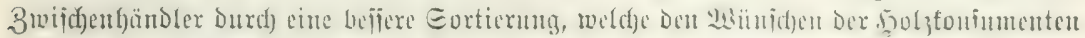

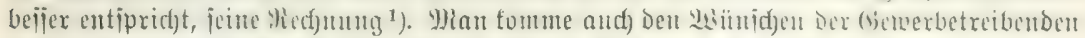

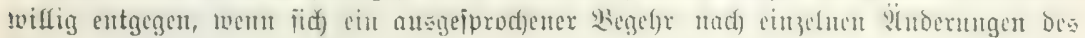
Sortimentendetails zu erfetmen gibt.

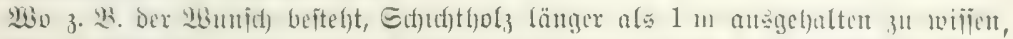

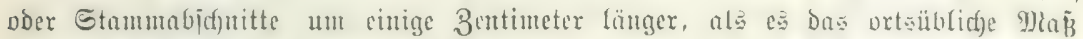

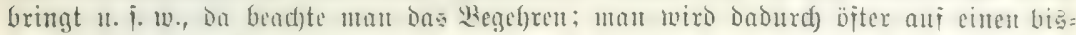

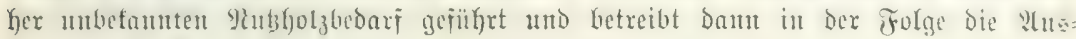
formung im Einue des Yetsteren.

4. 9yart, $\mathscr{U}$ bia

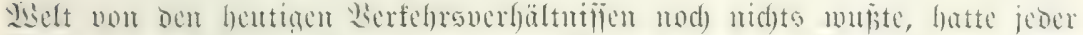

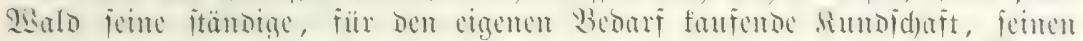

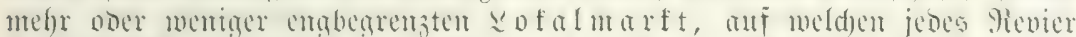

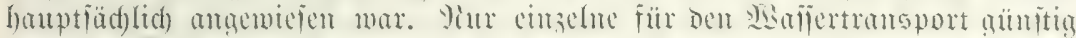

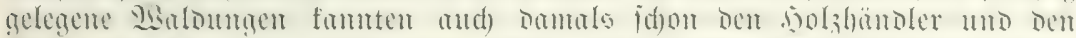

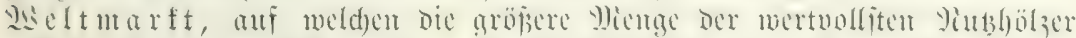

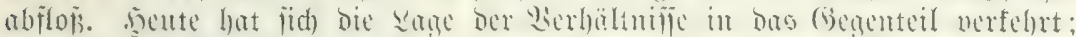

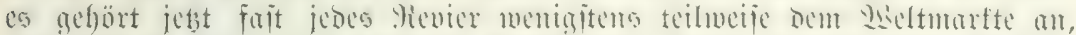

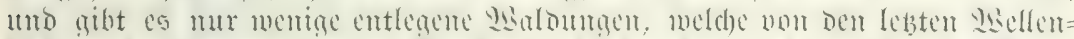

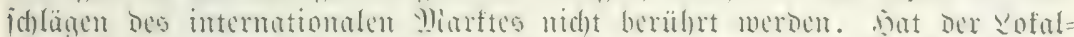

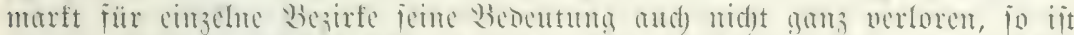

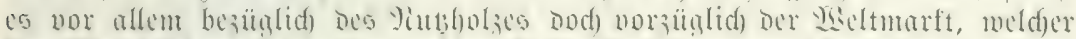

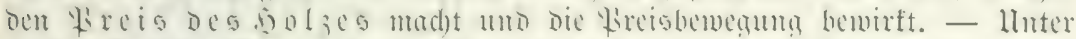

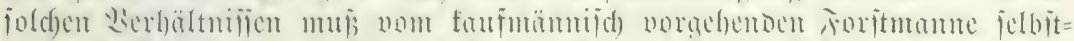

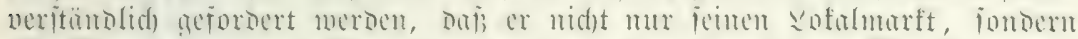

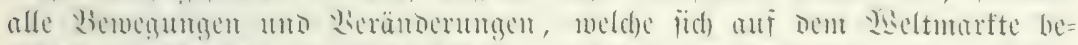

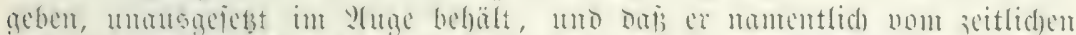

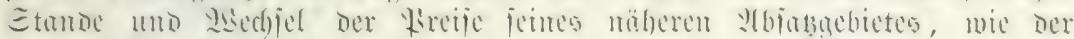

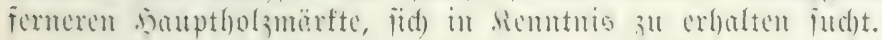

Iicicu an Den Foritucrwaltungsbeanten geftellten Forberungen miingten fid bei

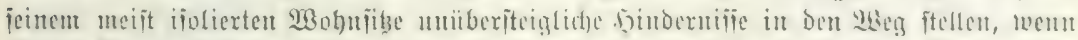

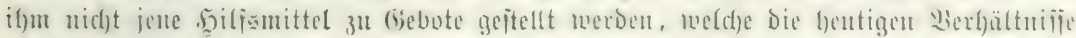

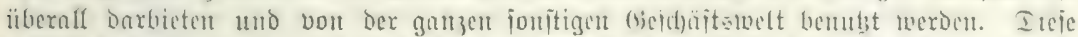

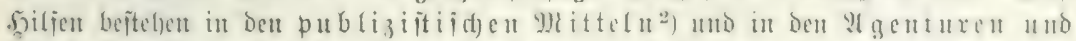

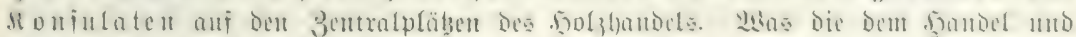

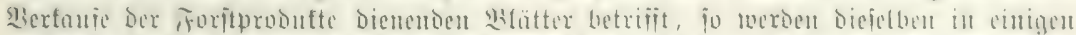

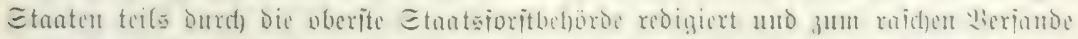

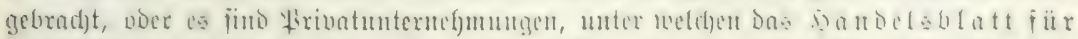

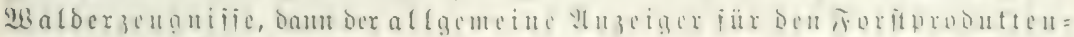

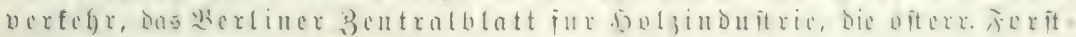

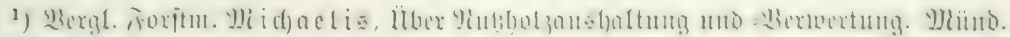
.5 eite 1900.

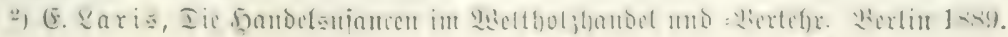




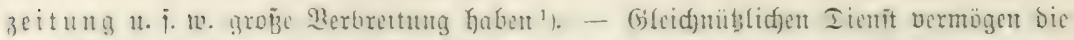

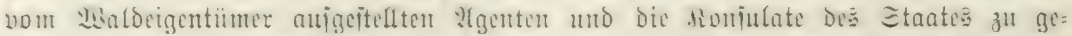

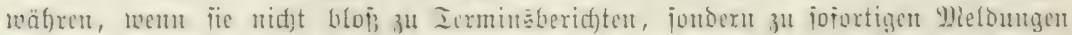

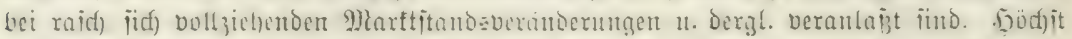

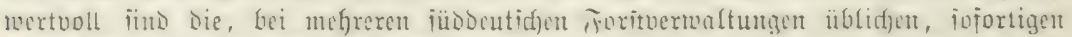

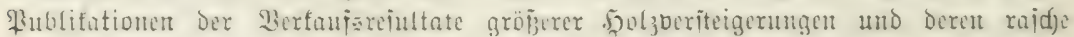
Berjenoung in bic intereffierten Foritbezirte.

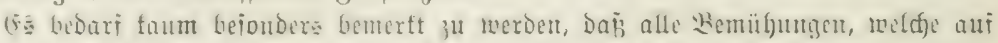

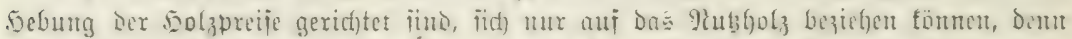

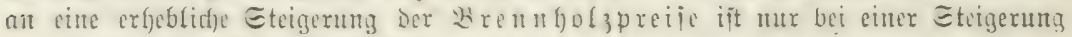

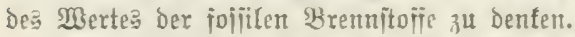

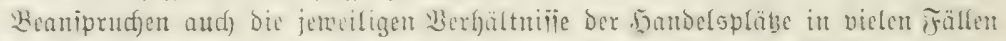
Dos :lutgenmert Des falfulierenden Foritmumes in hervorragender M̉eiti, io Dari er Dod) nidft unterlaijen, icin Jntereije aud) Der (Ergaltung und Erwa iterung ieinc: Sotalmarftes zujumben. Wio hol zuerarbitende (Semerbe, namentlidf)

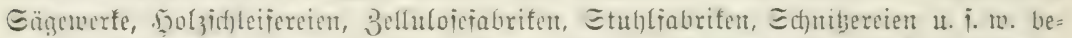

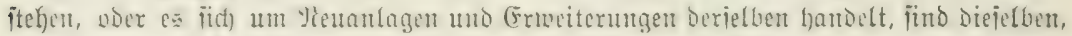

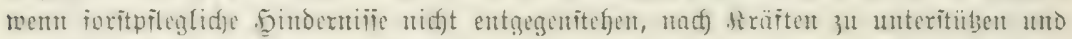
in ifrem bुetriebe entgegentommeno zu föroern.

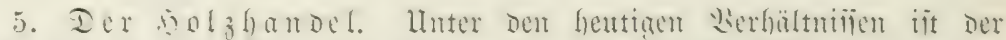

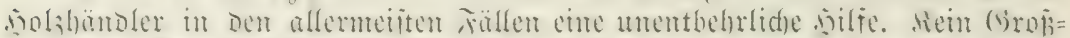

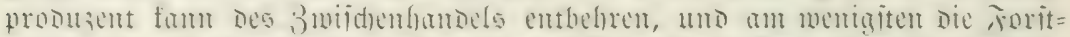

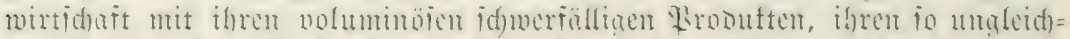

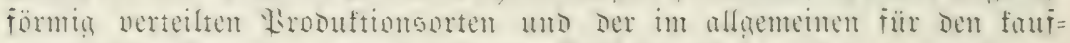

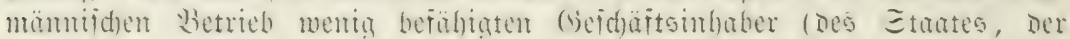

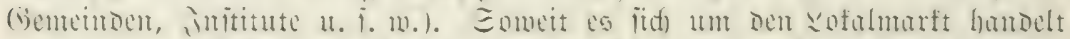

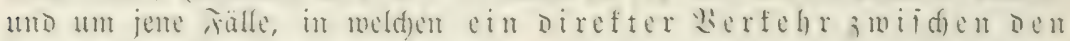

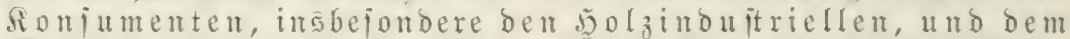

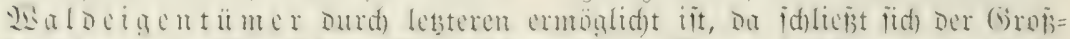

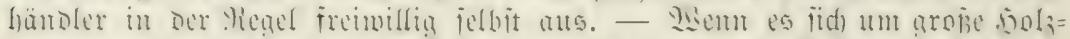

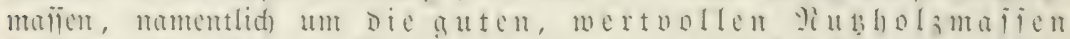
fomdelt, vor allom in

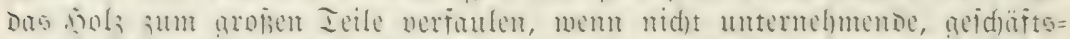

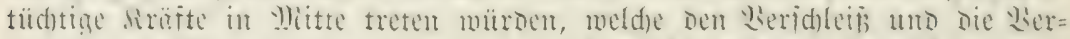

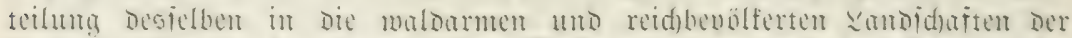

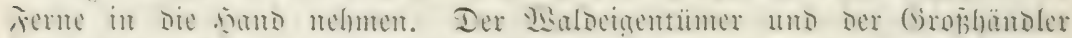

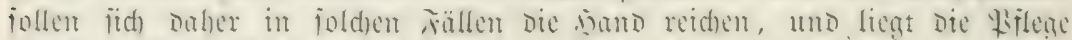

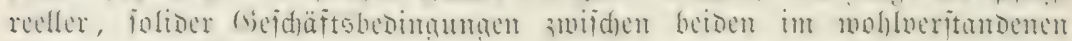

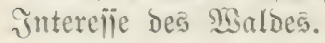

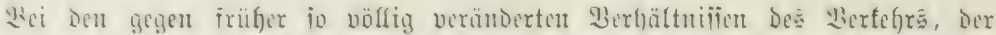

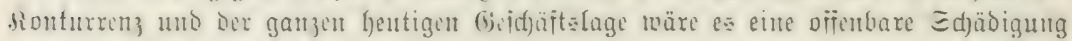

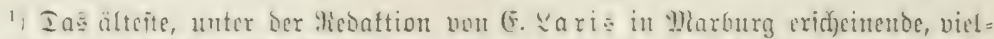

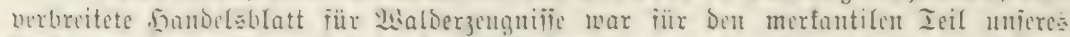

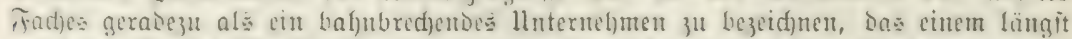

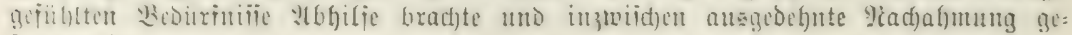
junden hat. 


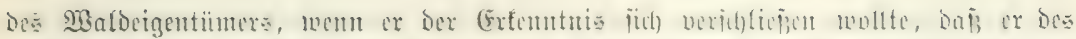

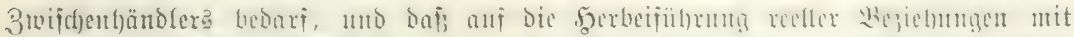

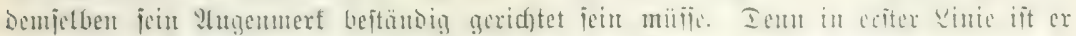

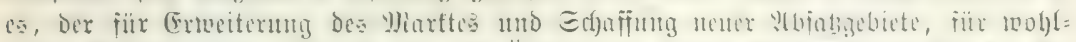

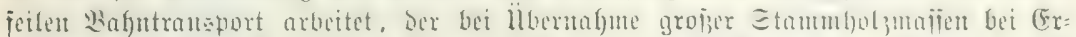

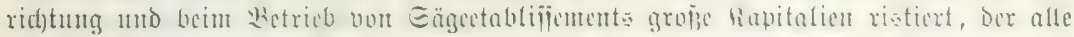

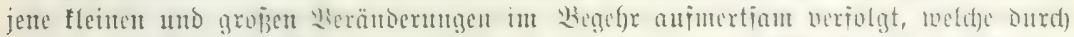

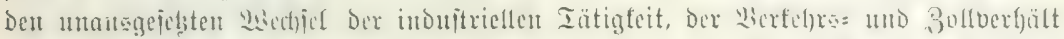

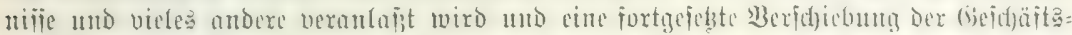

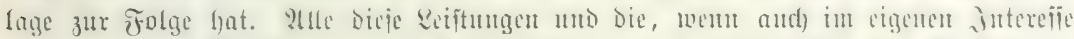

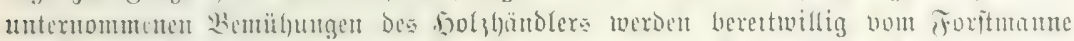
ancrtant. Eollen fid ater iene wïnj(f)

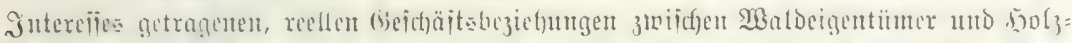

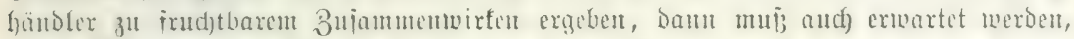

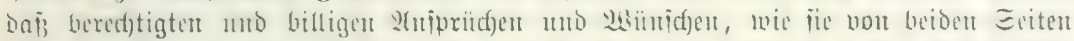

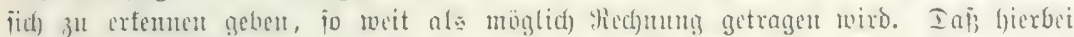

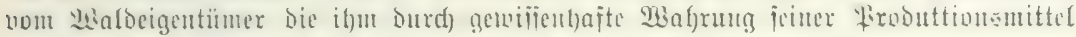

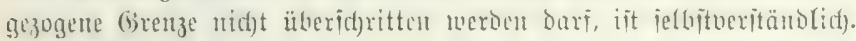

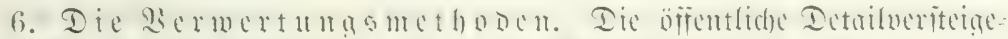

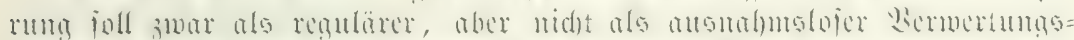

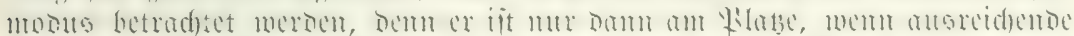

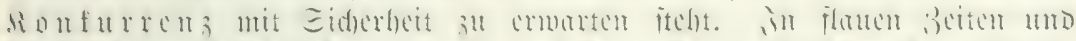

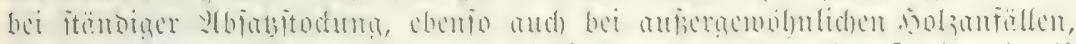

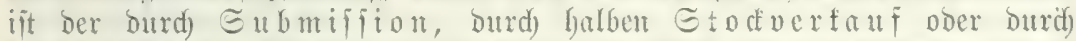
irciban o

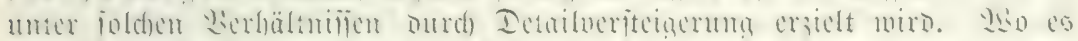

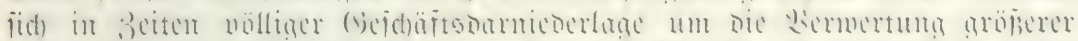
s)

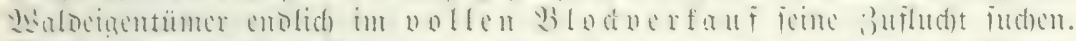

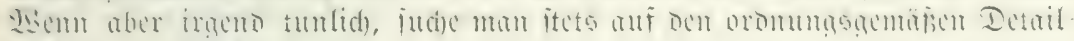
werfout zurüctzufommen.

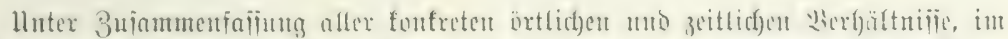

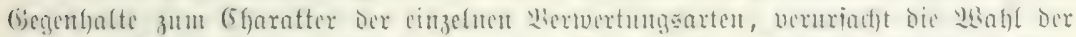

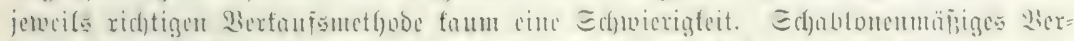

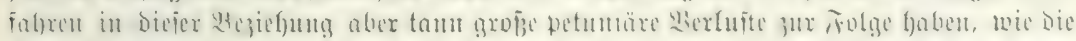

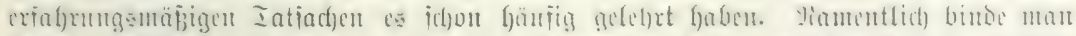

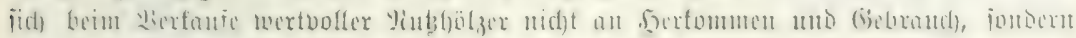

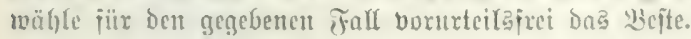

7. Beit bes Derfantes. Dic Beit bes gröfiten Werfebres ip̃t

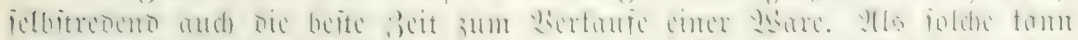

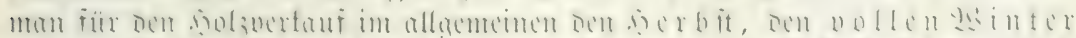

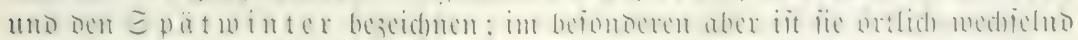

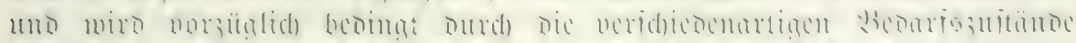

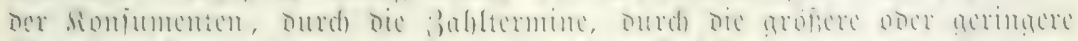

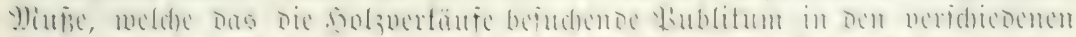

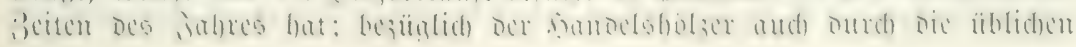




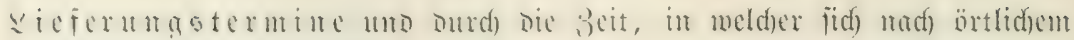
Sertommen Fefte glarftpreije bilben.

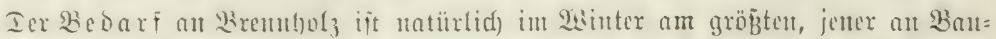

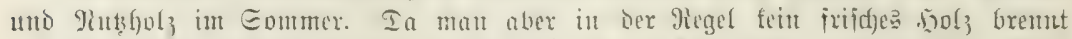

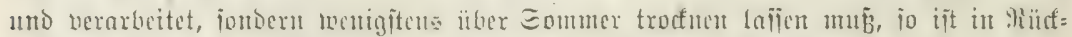

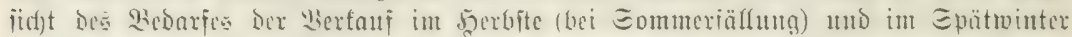

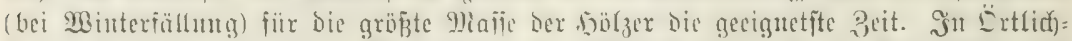

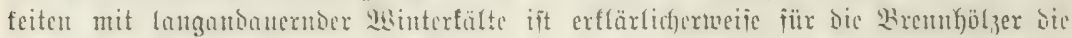

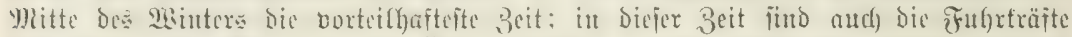

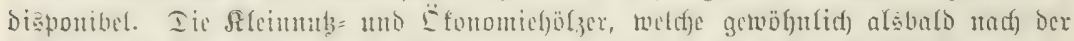

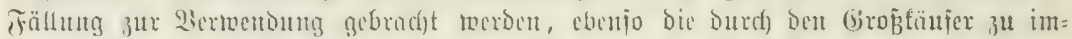

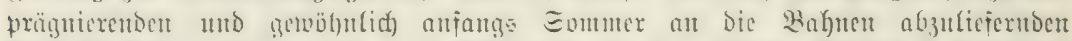

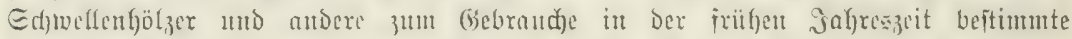

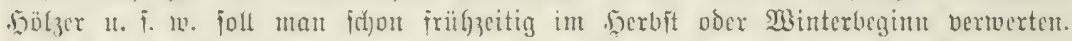

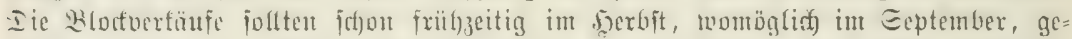

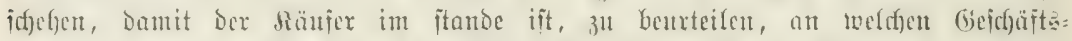

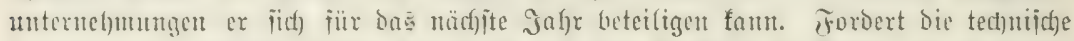

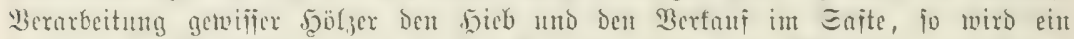

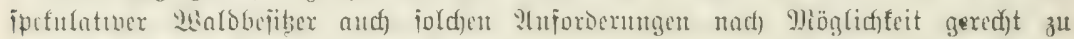

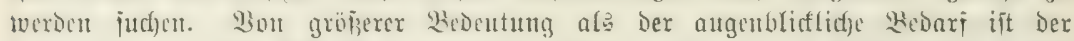

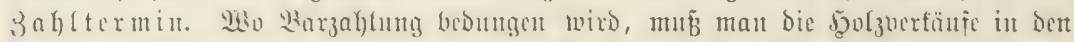

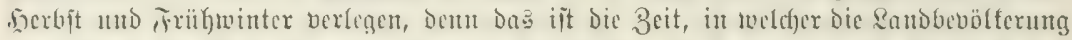

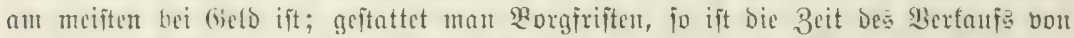
giringerem (Einfluīe, infofern fie bcm 3ahltermin, Der gewöhnlif) am beften auf ben

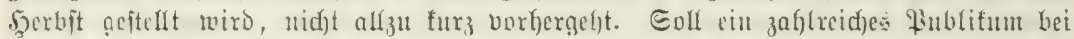

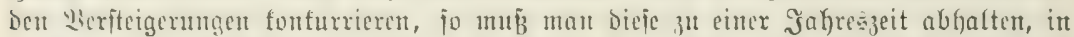

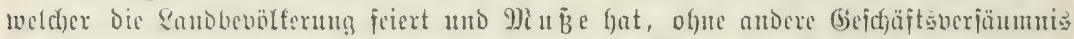

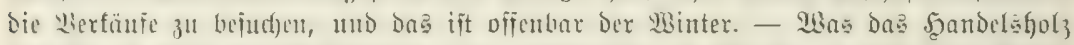

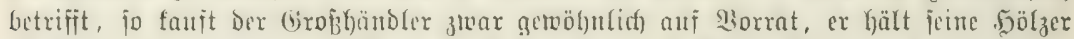

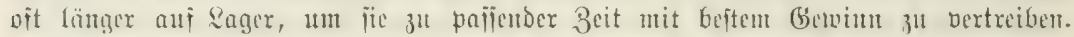

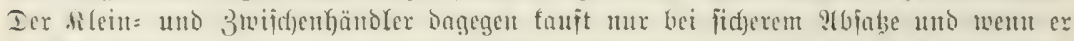

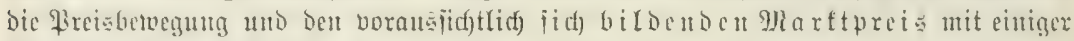
Sidjerbeit beurteilen fant.

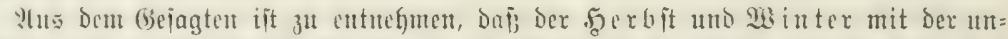

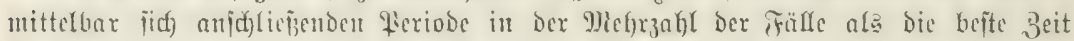

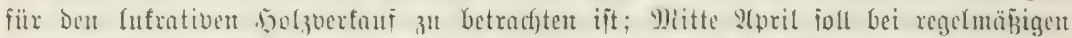

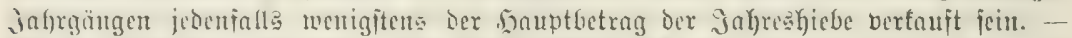

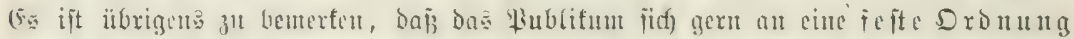

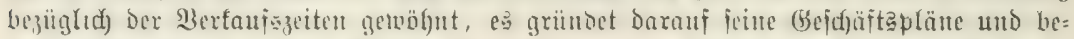

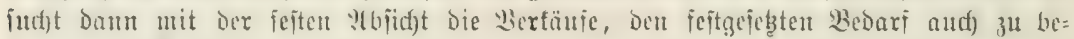
friediger. (Sinorr.)

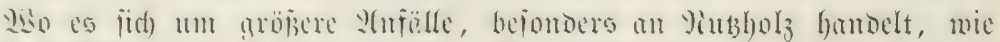

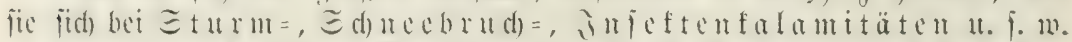

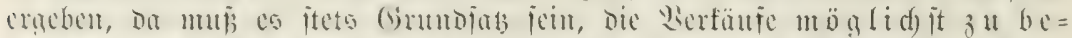
id) leu

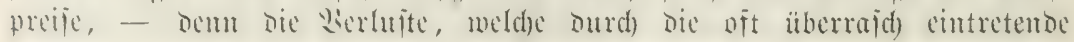
jolzuerderbnis broben, find in der Yegel gröper alo leztere. 


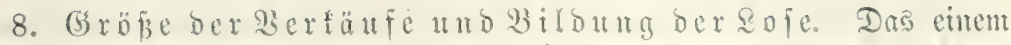

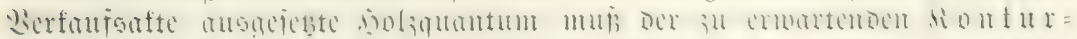

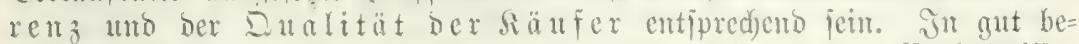

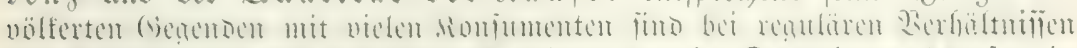

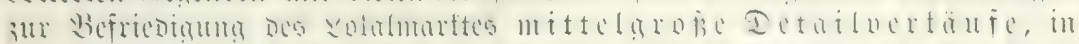

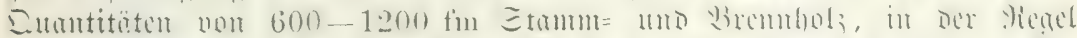

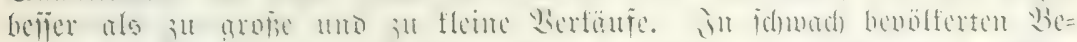

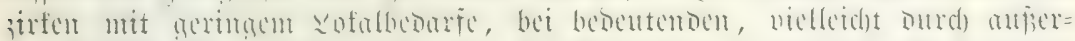

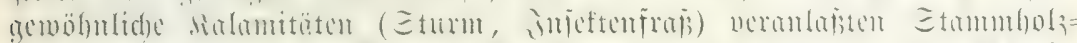

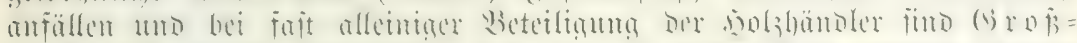

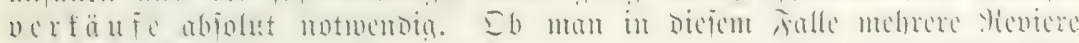
mit ibrem

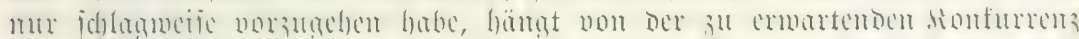

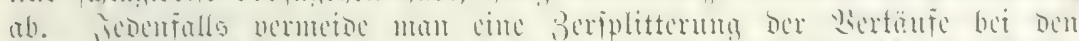

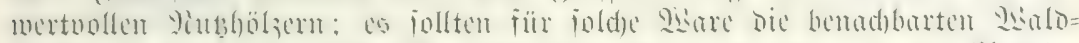

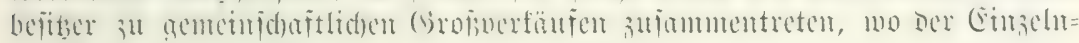
anfall mar gering ît.

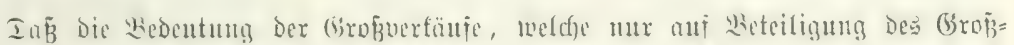

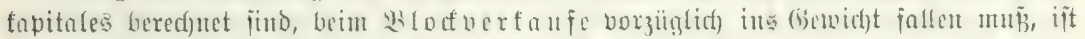

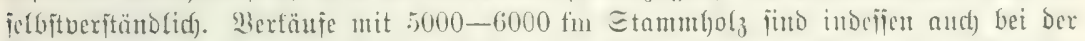

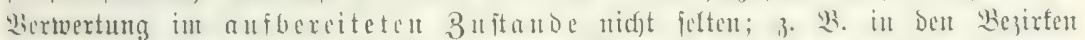

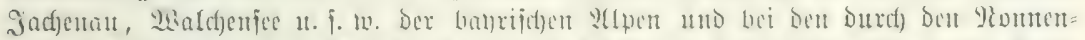

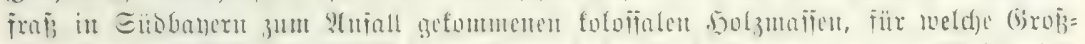

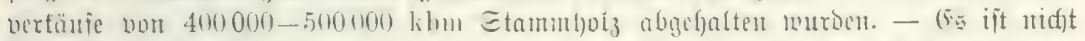

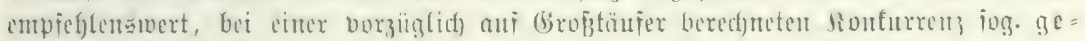

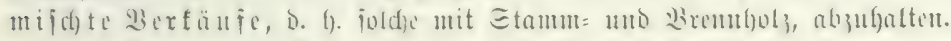

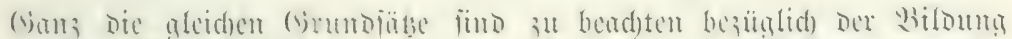

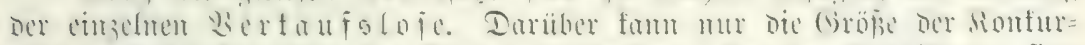

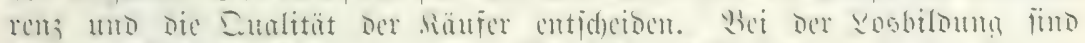

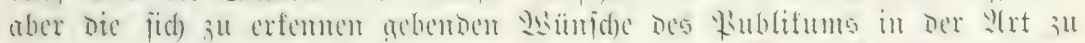

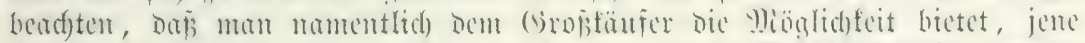

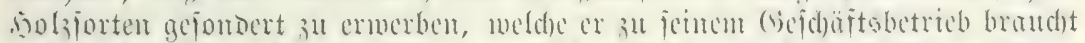

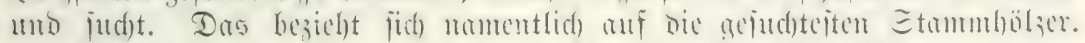

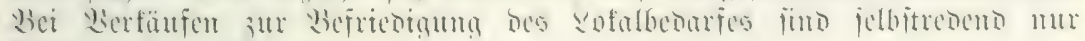
fleine soje zuläfigg.

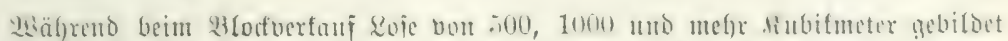

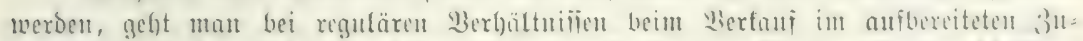

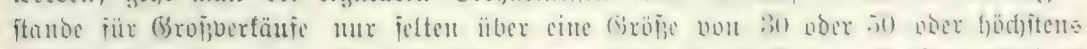

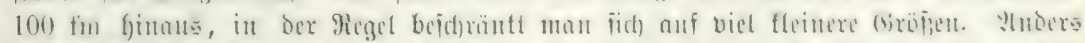

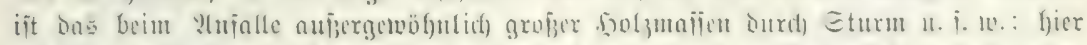

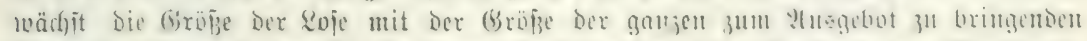

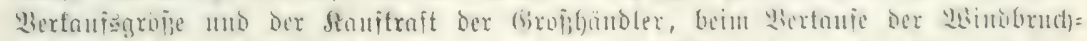

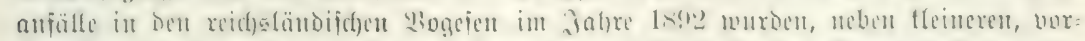

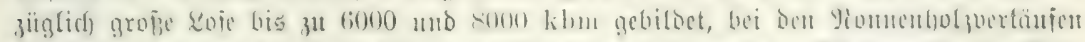

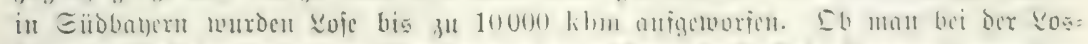

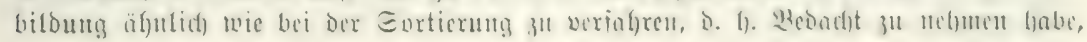




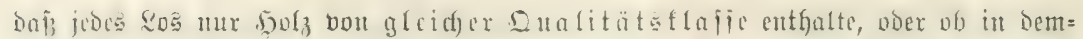

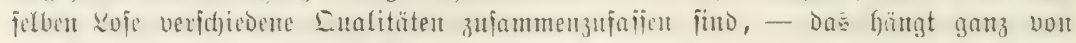
Der Menge unt Suafität Der Raufliebraber ab.

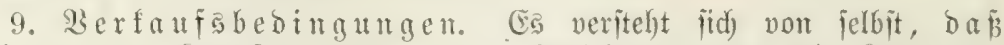
läpige, dem Säufer unbequeme B̉ebingugeu die Sonfur=

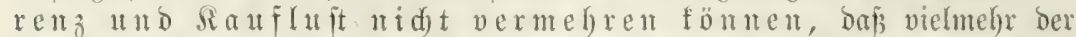

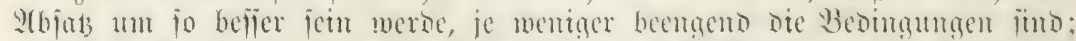

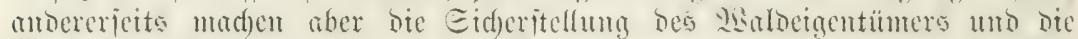

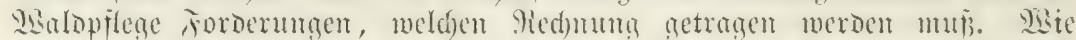

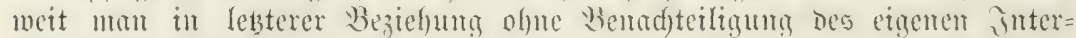

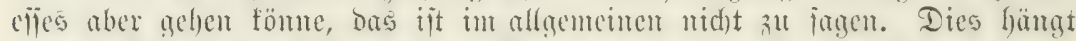

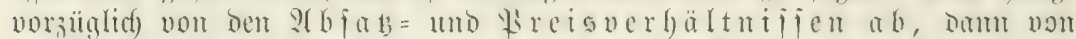

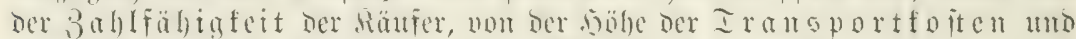

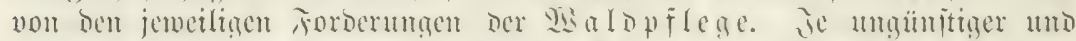

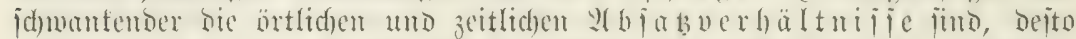

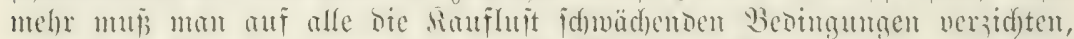

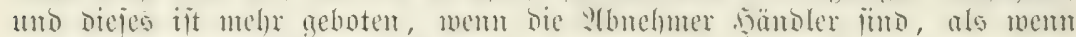
bas Solz bem sofalmarfte zuflient.

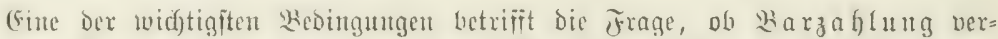

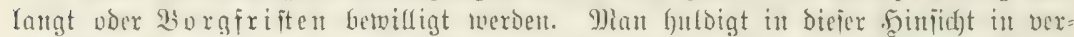

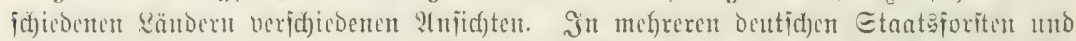

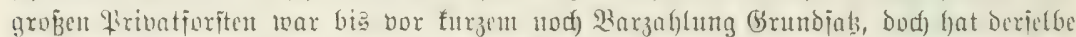

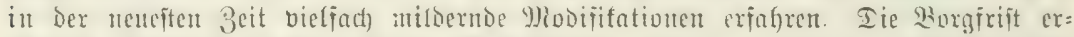

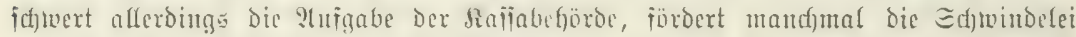

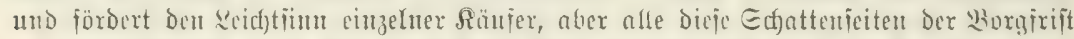

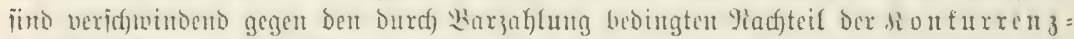

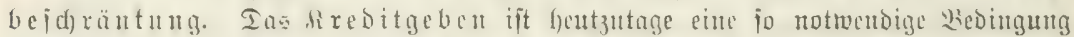

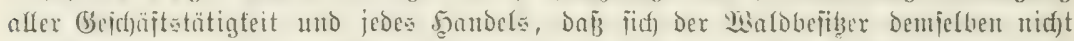

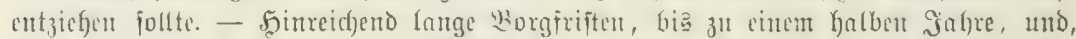

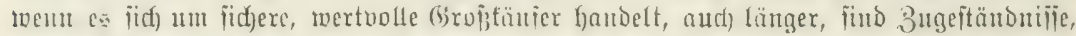

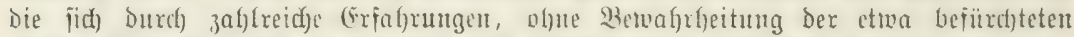

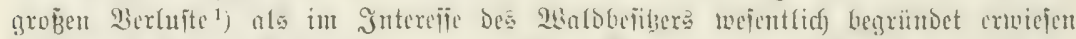

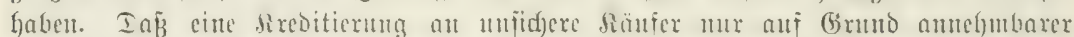

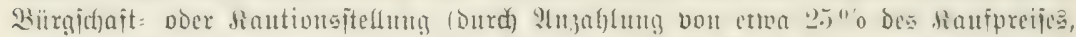

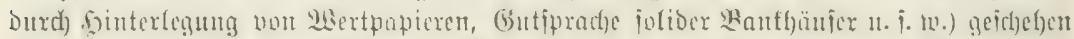

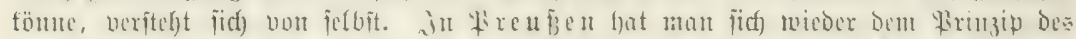

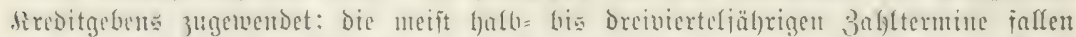

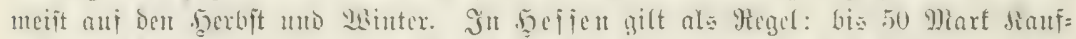

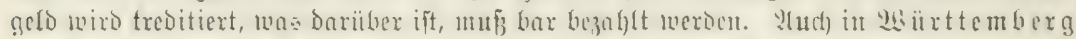

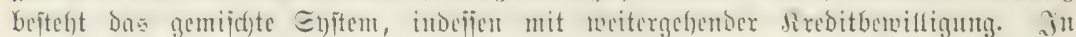

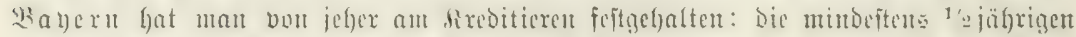

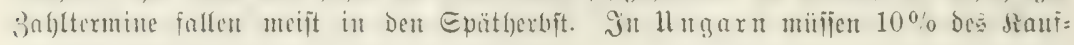

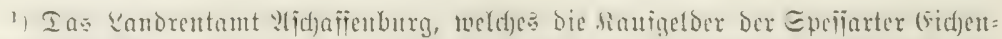

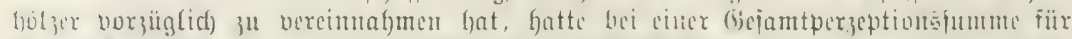

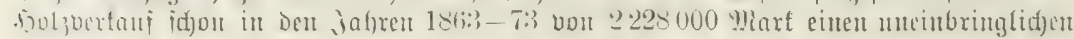
D̈erluft von mux 27 Mlarf. 


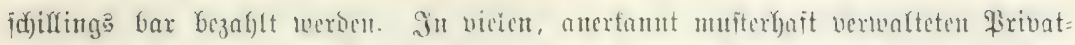

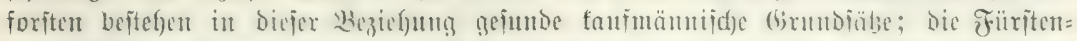

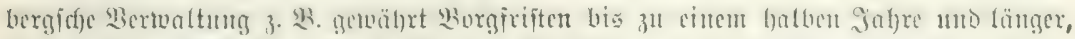

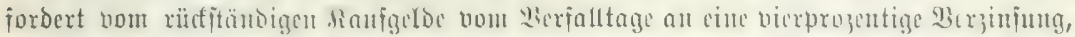

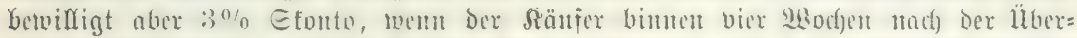

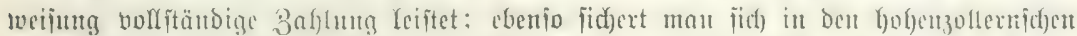

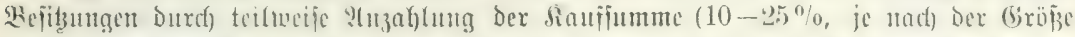

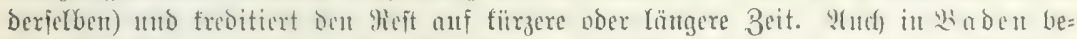

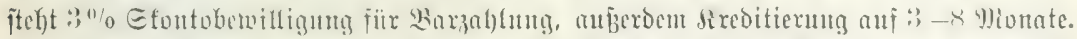

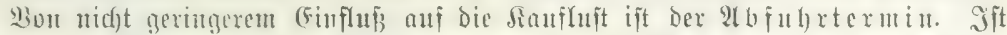

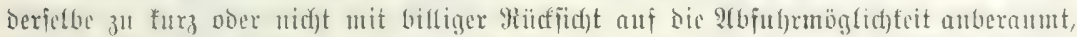

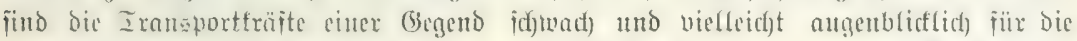

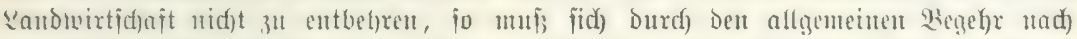

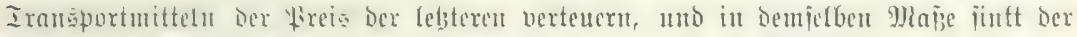

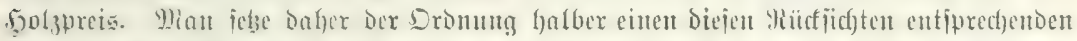

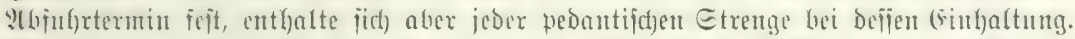

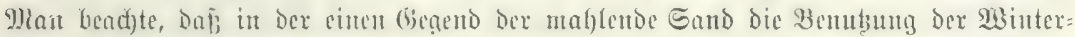

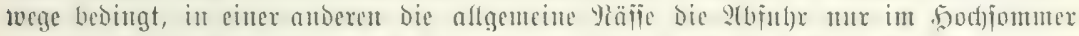

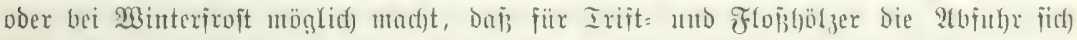

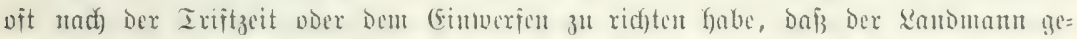

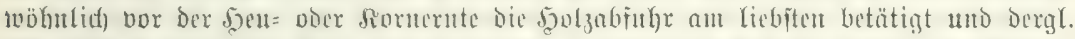

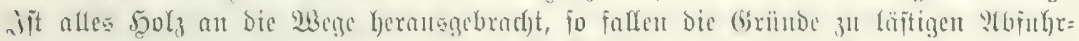

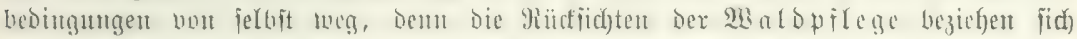

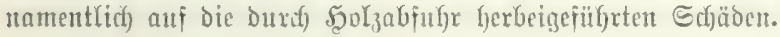

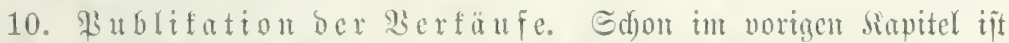

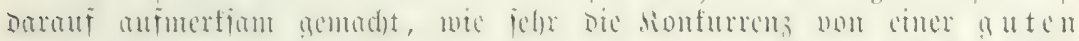

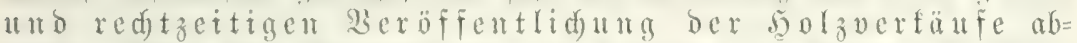

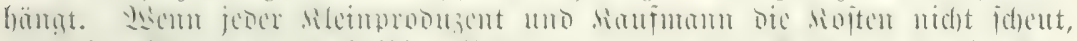

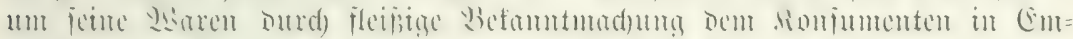

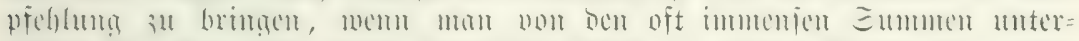

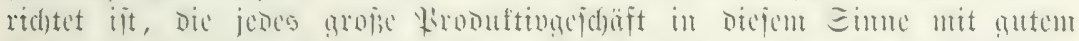

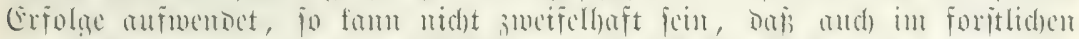

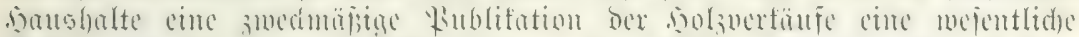

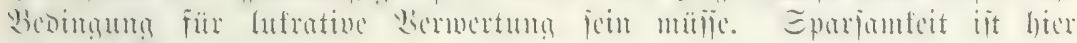
ofïenbar şerluit.

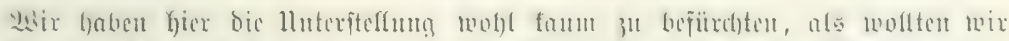

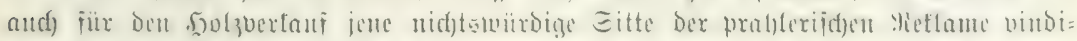

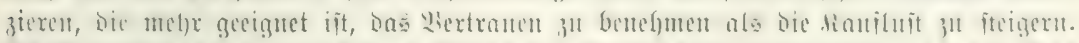

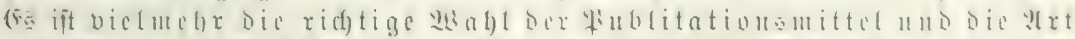

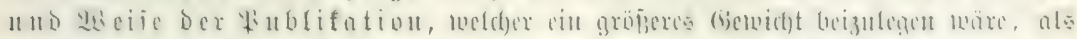

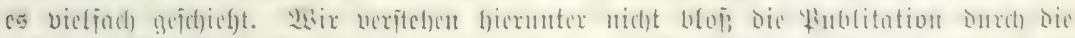

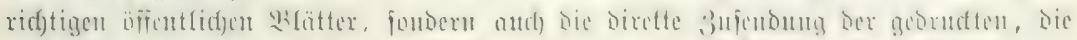

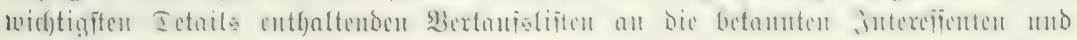

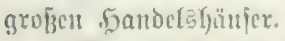

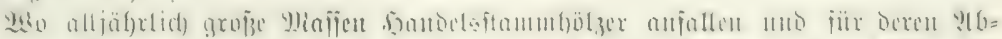

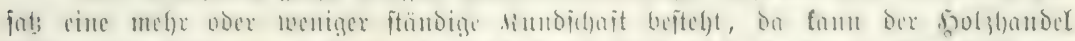

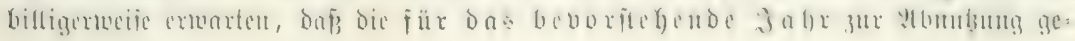




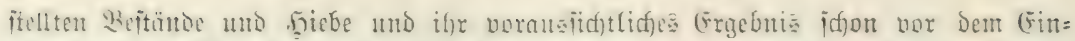

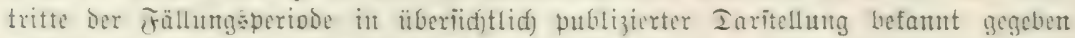
werben, Damit ber Rnufluftige ieine etmaige Beteilignng an Ierminlicierungen und

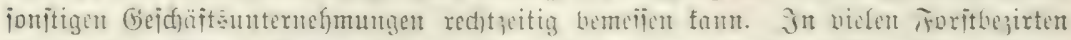

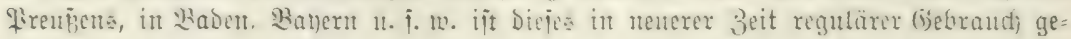
morben.

11. Die Ixansportan italten. Son weldem Einfup Der $3 u=$ it

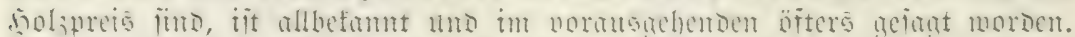

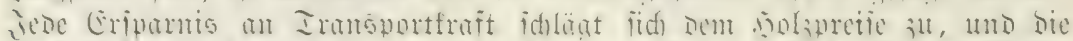

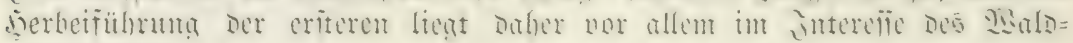
etgentümer⿳亠

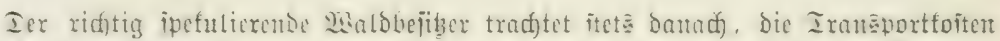

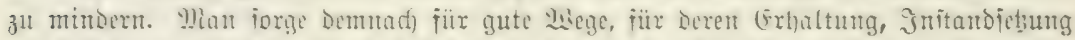

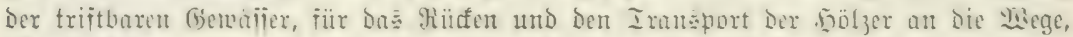

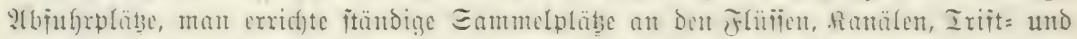

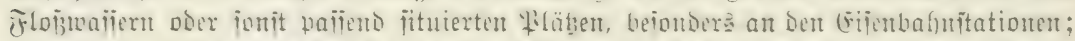

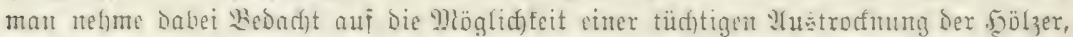

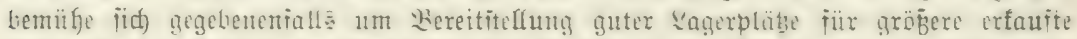

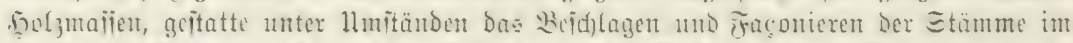

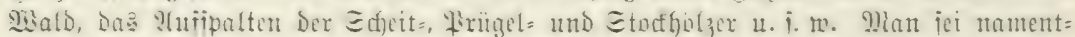

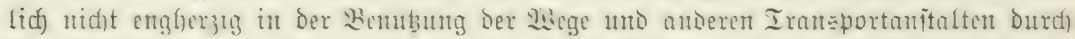

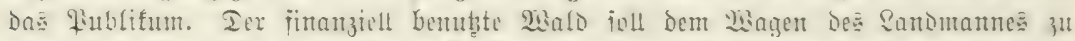

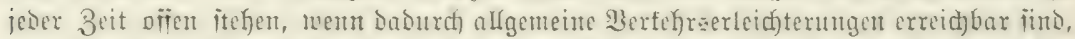
Denu mu Dadurff jieht man Den Mard mit in Den allgemeinen fireis De Berfebr Gorcin. Iic föheren isegunterfaltumgstoften renteren io gut wie das wegbau= fapital jelbit.

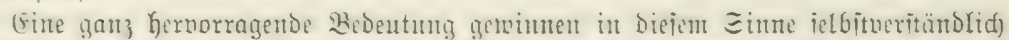

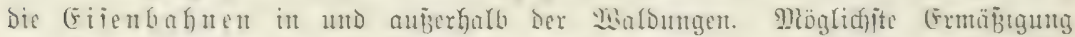

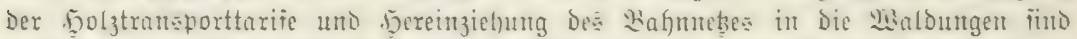

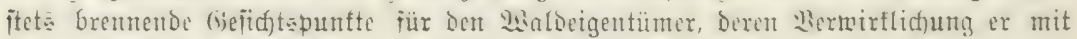
allest אräjten und im Berein mit Dem Solzhandef zu eritreben hat.

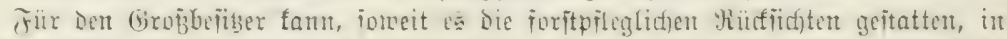

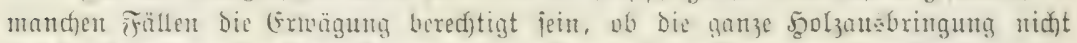

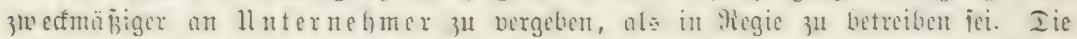

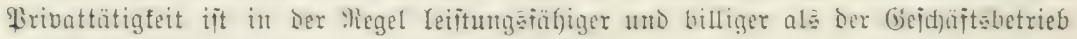

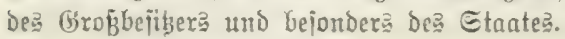

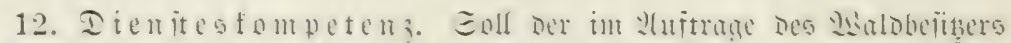

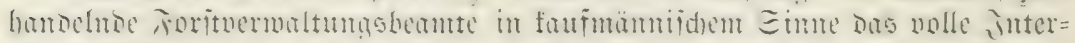

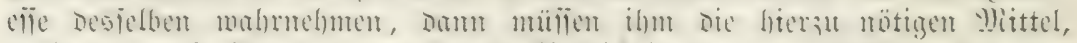

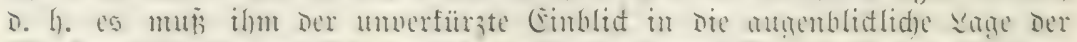

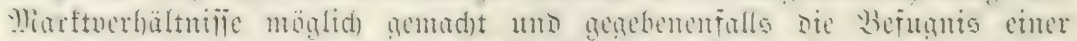

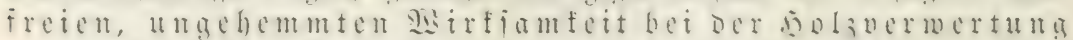

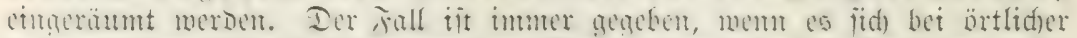

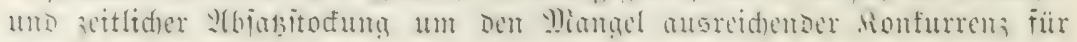
die öfentlid)e Detallveriteigerung hatbelt. 


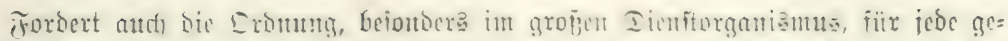

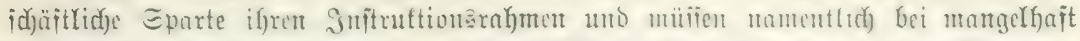
organifiertem hiontrollopparcte ber form Dpier gebradjt werden, io tradjte man

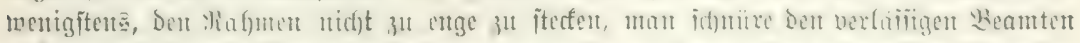

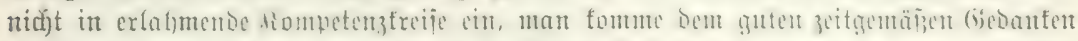

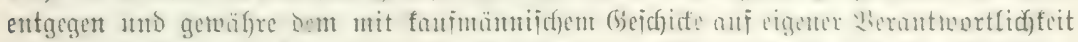

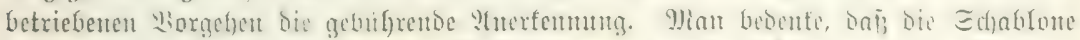

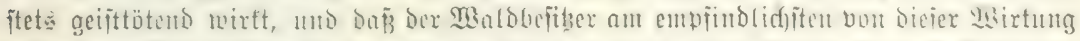

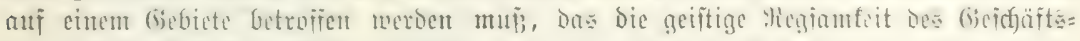

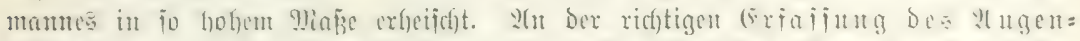

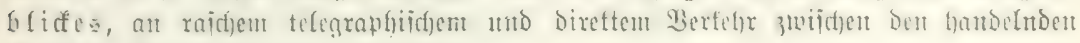
ßexjonen härgen Kentzutage Iaujente. 


\section{fünfter 2lbichnitt.}

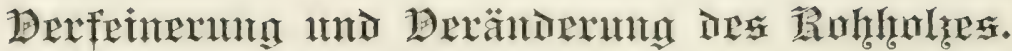

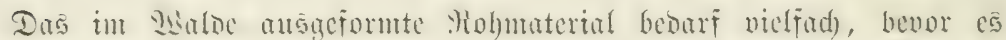

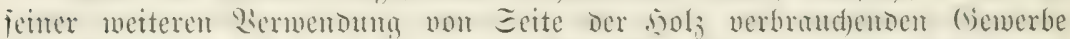
juacfül)st meroen fam, nod) einer meiteren

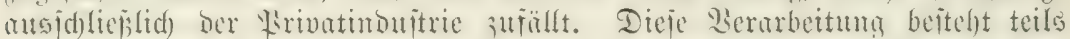

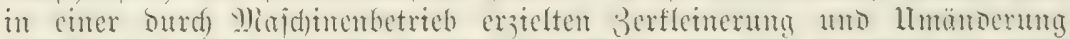

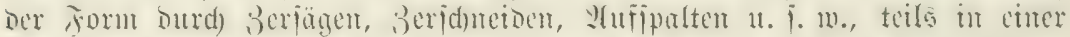

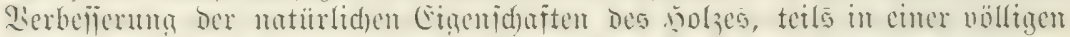

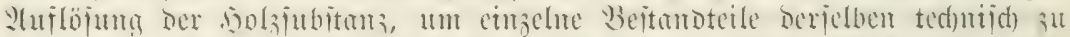

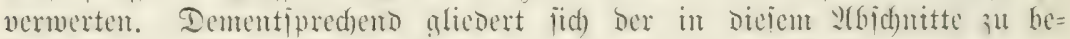
hanbelnoe Stoif in folgente Gruppen:

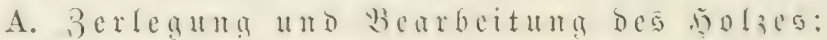

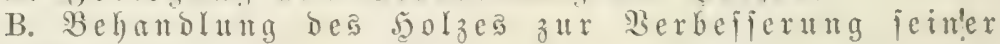
Eigenfdaften;

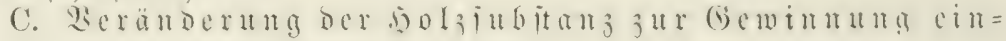
zelnex Bejtandeile des jolzes.

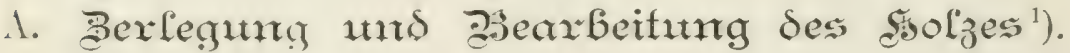

Die Trane, ob ber

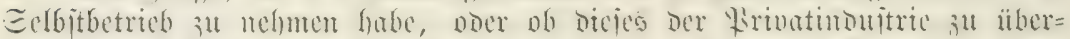

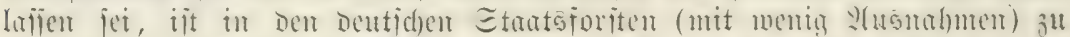

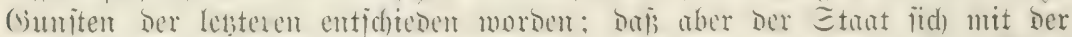

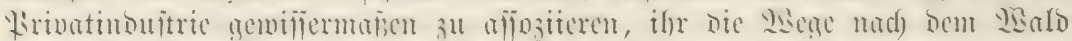

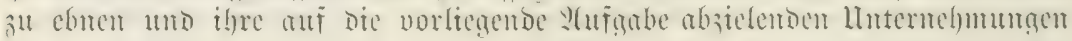

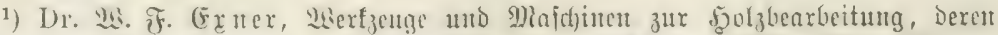

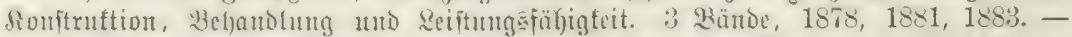

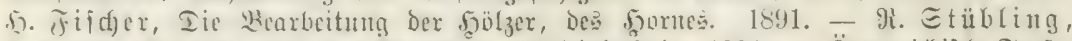

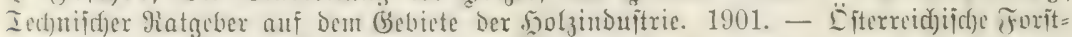
unt) iagozeitung fteft obenan unter allen forftlidjen Beitid)riften, twas bie sebfano=

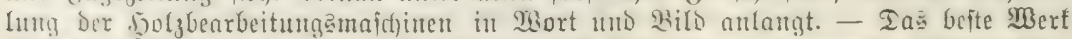

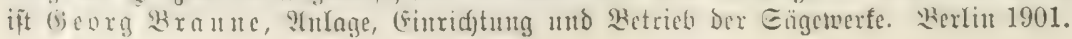




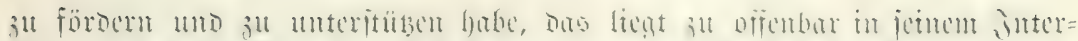

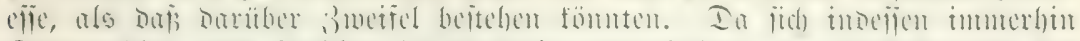

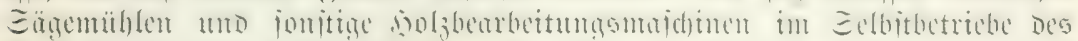

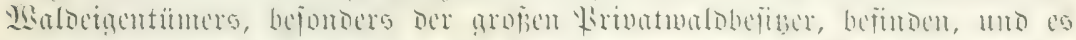

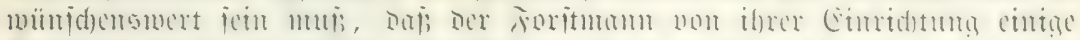

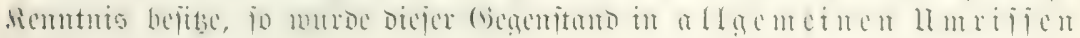
loier anfgentmmen.

\section{Eันี้}

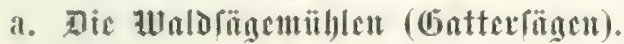

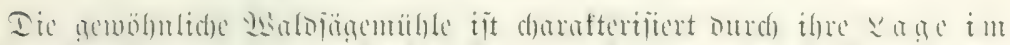

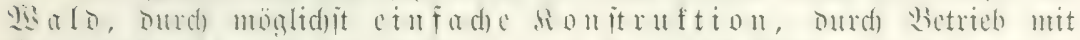

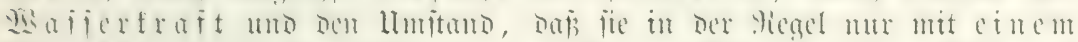

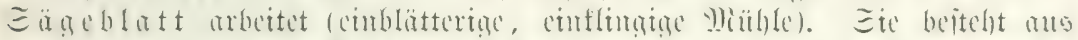

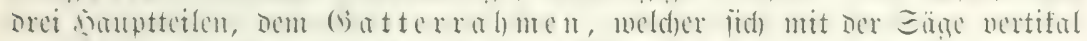

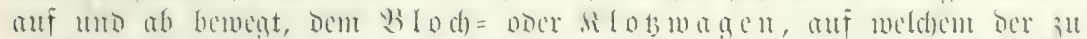

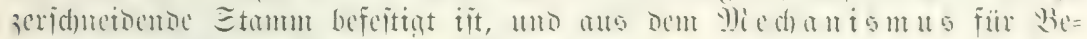

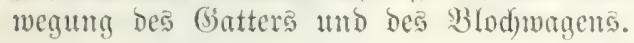

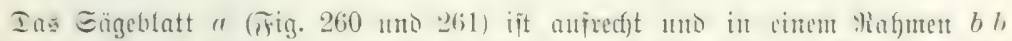
bem Eägegntter eimugepant, mo fetstere betwegt jids mit der Eäge an ben

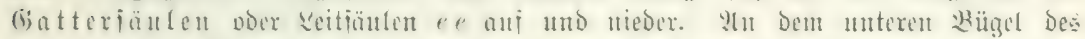

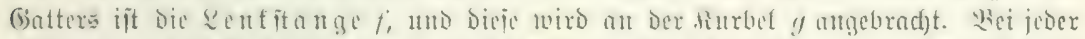

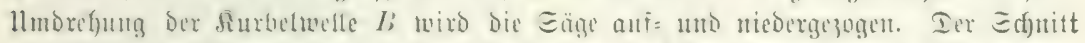

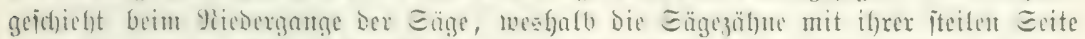

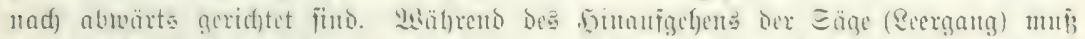

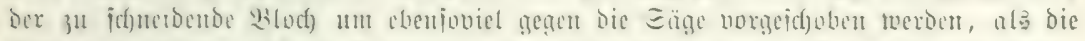

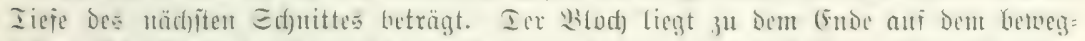

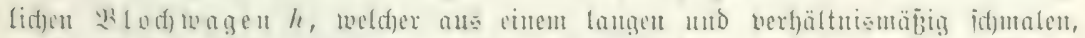

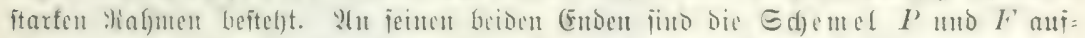

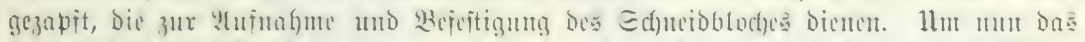

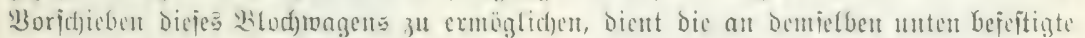

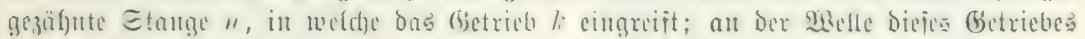

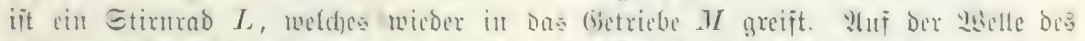

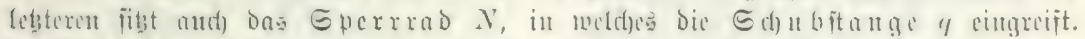

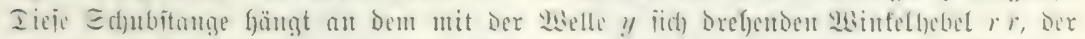

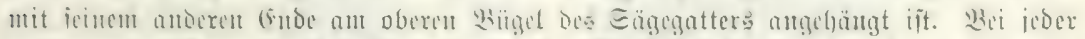

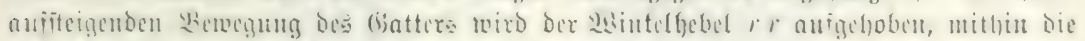

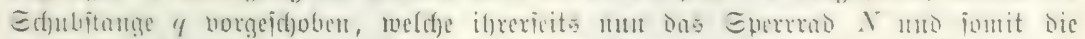

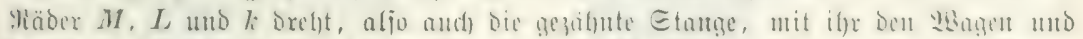

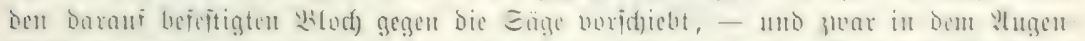

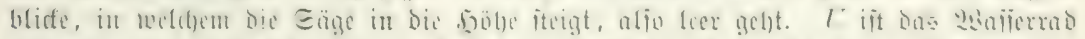

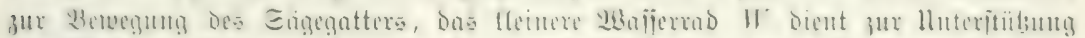

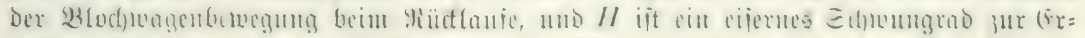
zichung ciner gleichpïrmigeren Betvegung int allen cimgetnen Icilen.

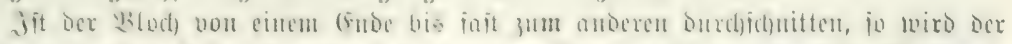

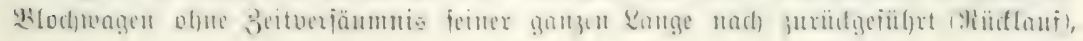




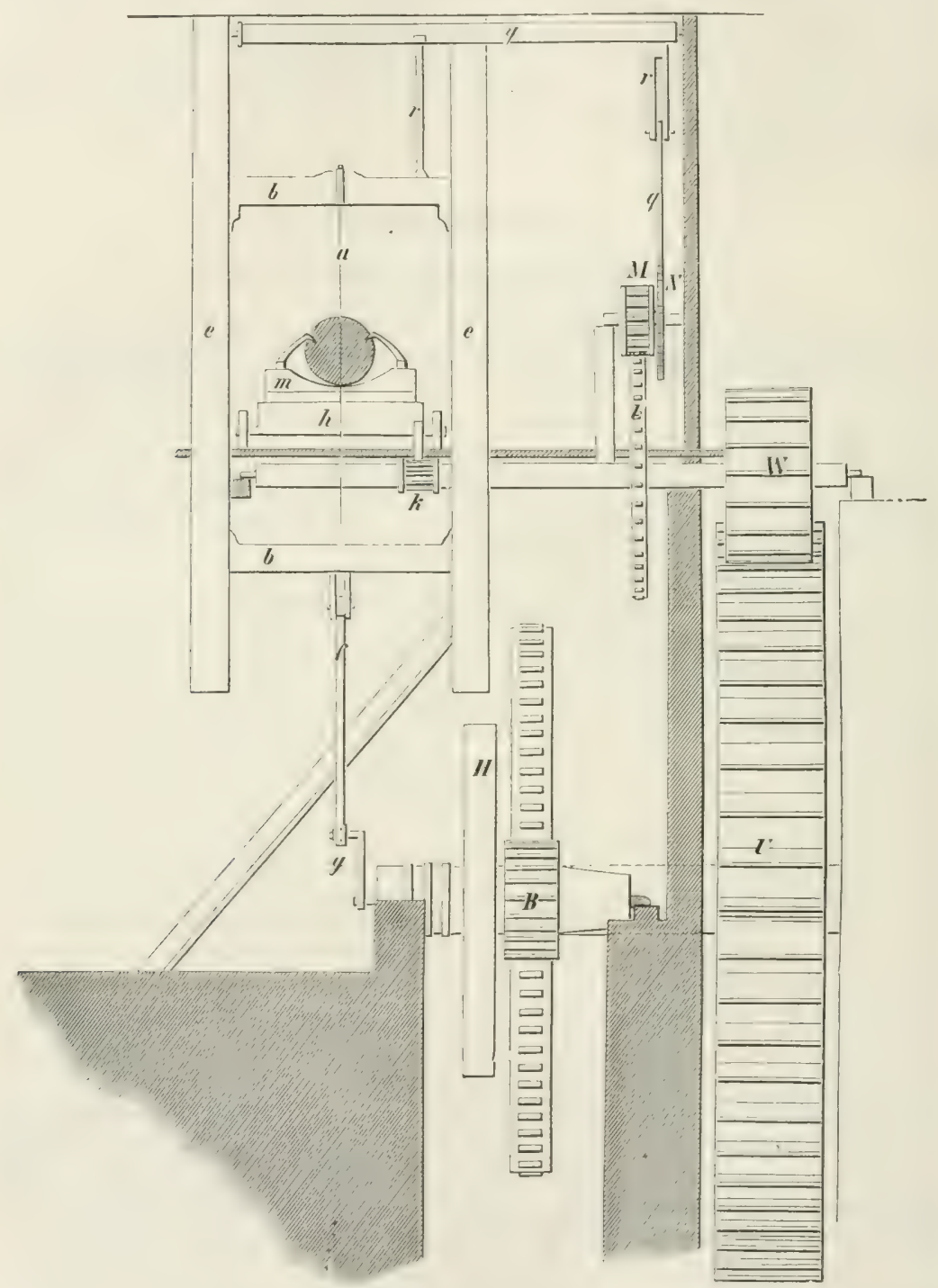

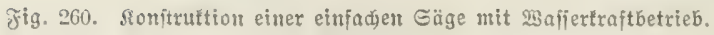

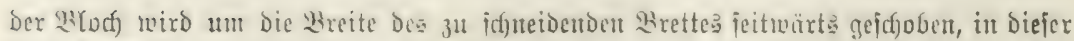

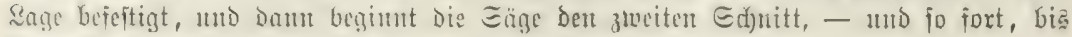
fämtlidje Edjnitte fertig fino. 


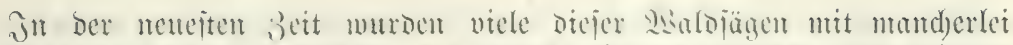

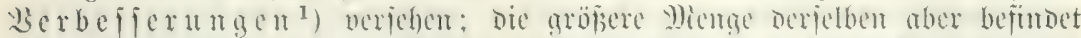

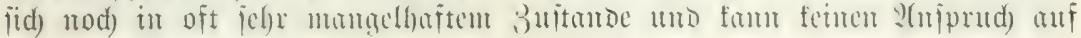

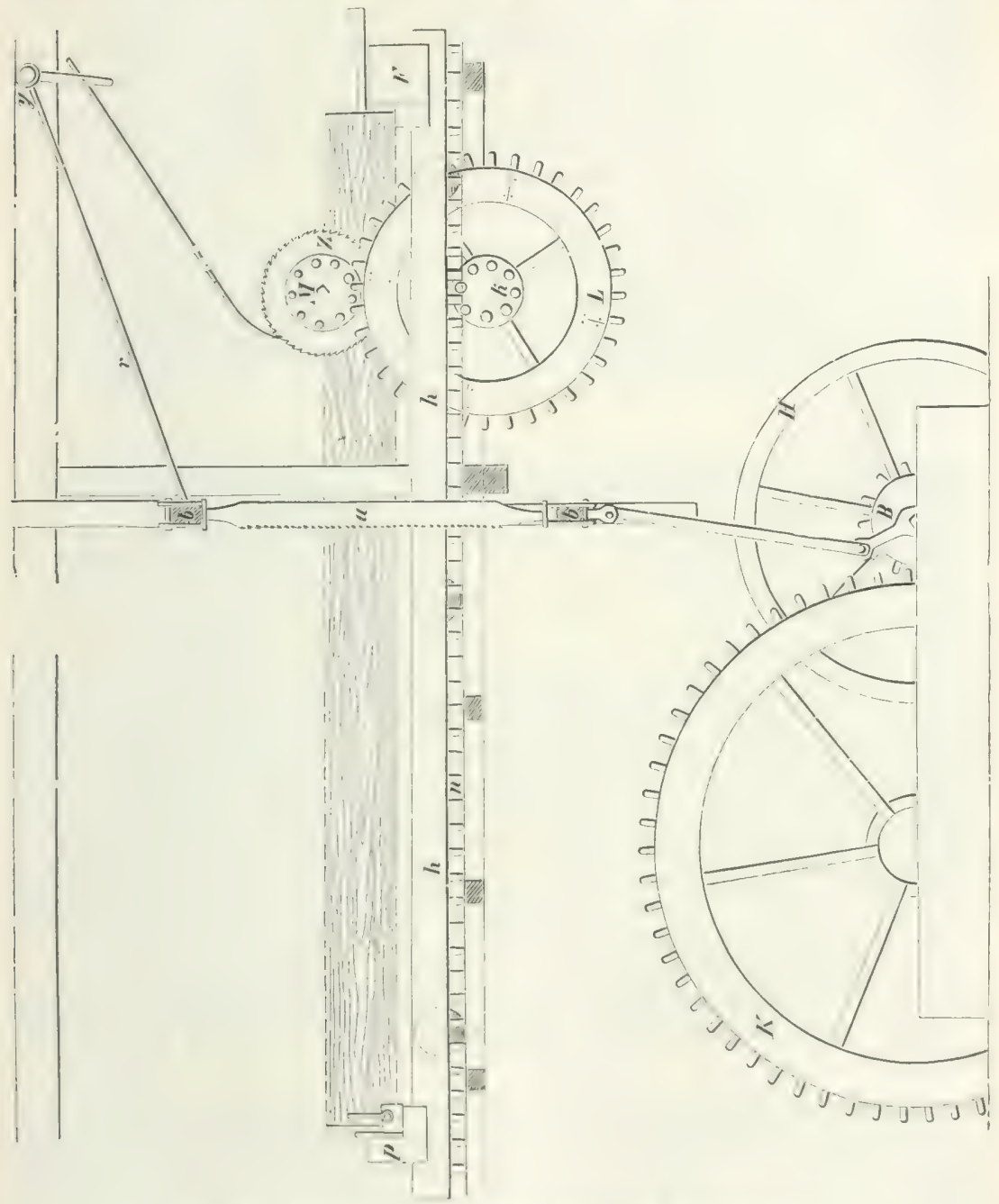

Fig. 201. Sonftuftion einer einfadyen Sïge mit פ3affertraftbetrieb.

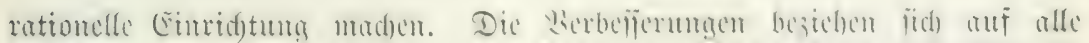

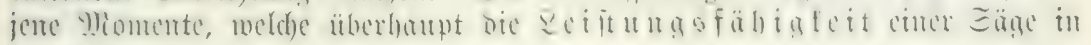

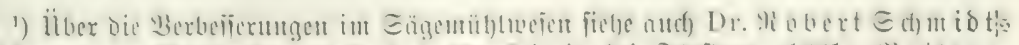

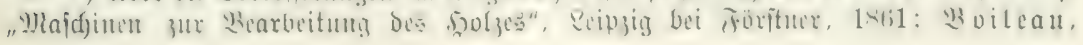




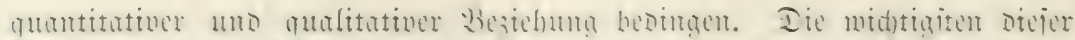

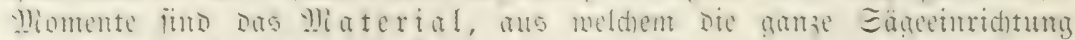

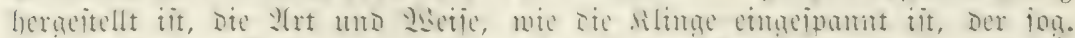
2)

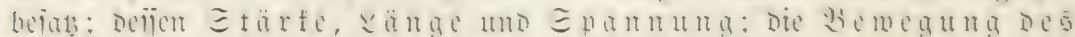

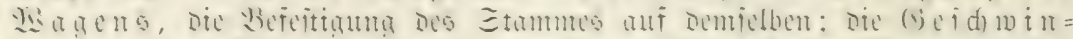

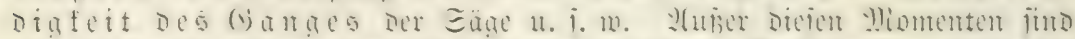

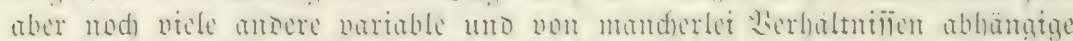

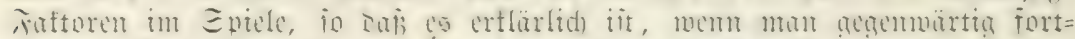

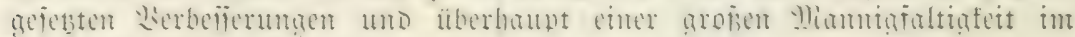
¿ägemiiblenmejen begegnet.

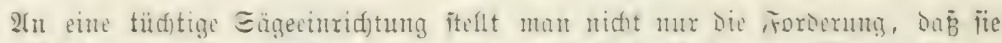

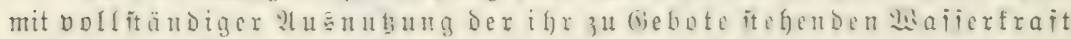

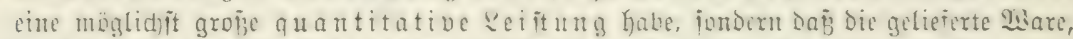

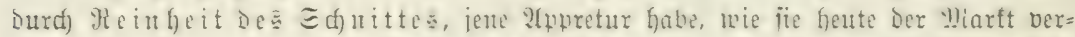

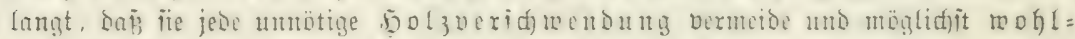
jeil arbeite.

1. At on it ruttionsmattrial. Eollu Die ganj a mühlın dic völiuge Etabifitat haben, io müïen bie einzelnen Merfteile aus volumi=

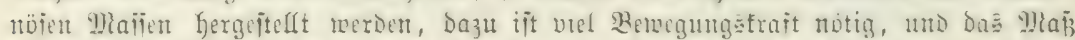

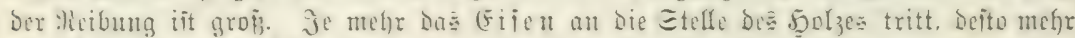

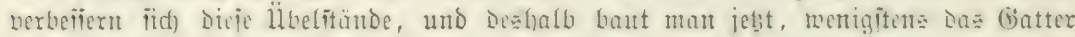

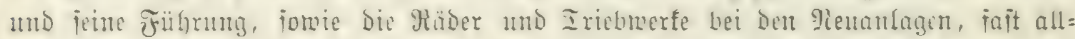
gemein au (Eijen.

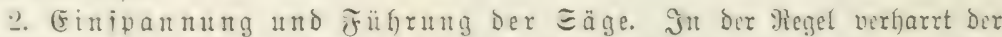

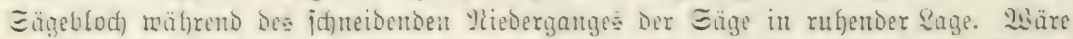

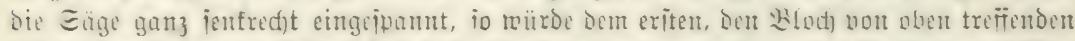

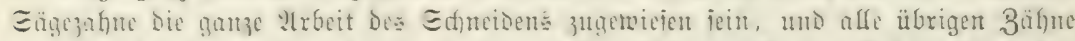

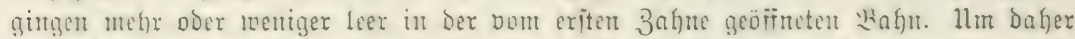

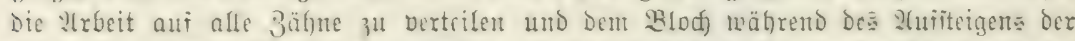

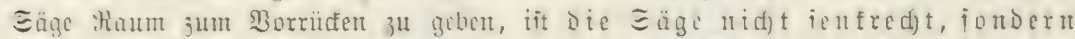

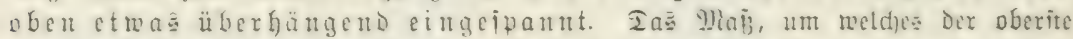

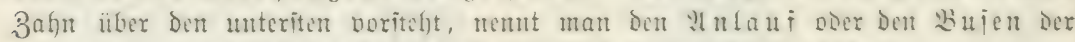

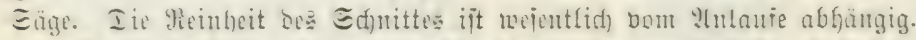

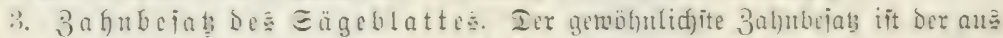

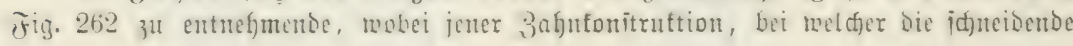

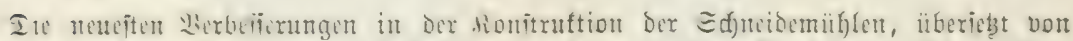
(5. Fromberg, Enedinburg 1862 : W

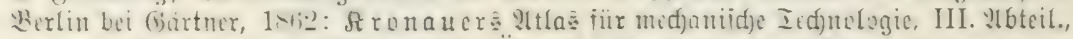

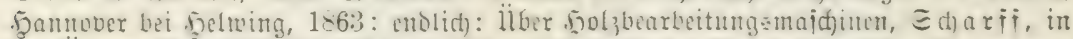

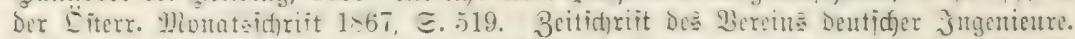
Iedurids:

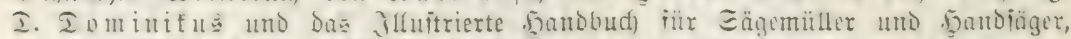

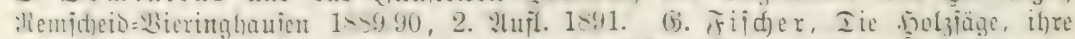

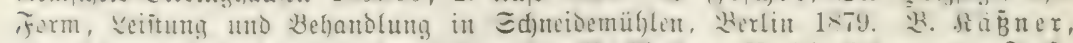

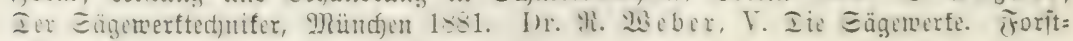
milienichaitliches Bentralblatt 1884. 


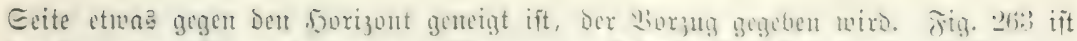

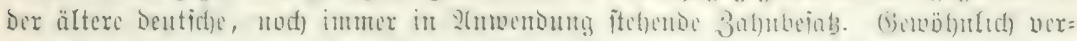

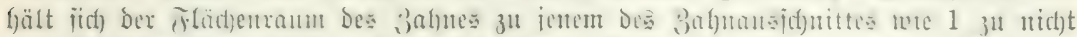

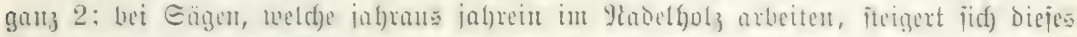
Serfältniz twie 1 zแ jaft 3.

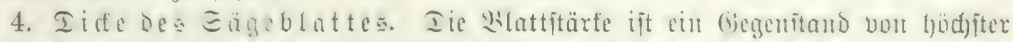

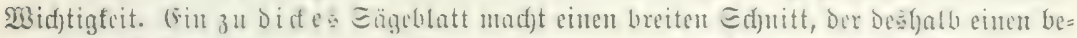

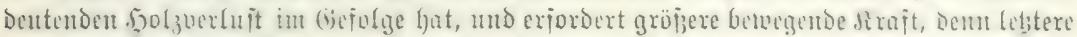

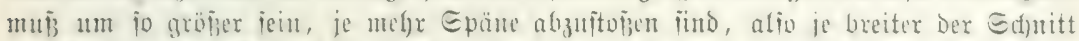

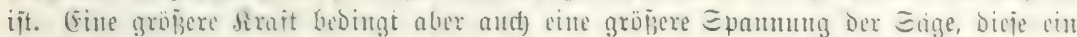

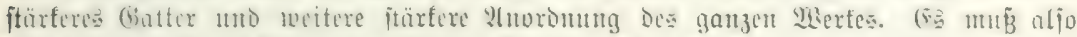

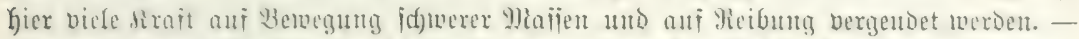

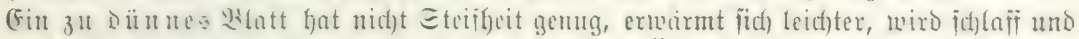

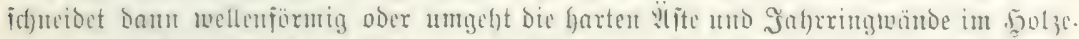

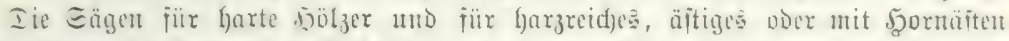

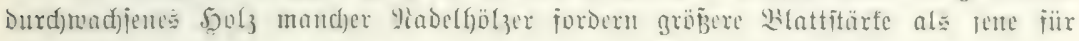

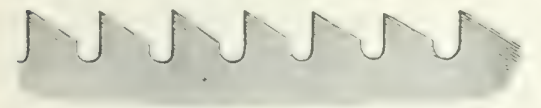

Fig. 262. Bahnbefab ber Єägent gewöhnlidjer sonitruftion.

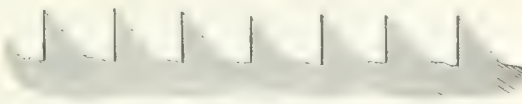

సig. 263. Q̈ltterer 3ahubejas ber Eägemajobinen (Whalojägemïblen).

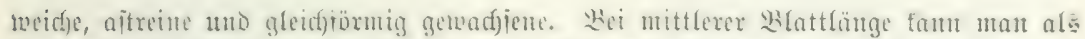

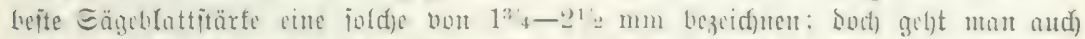

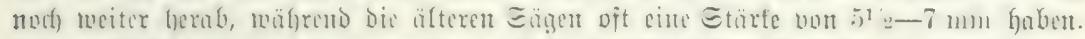

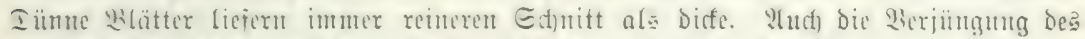

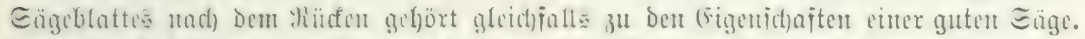

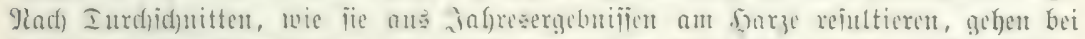

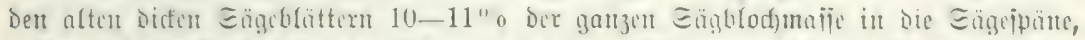

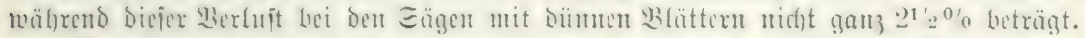

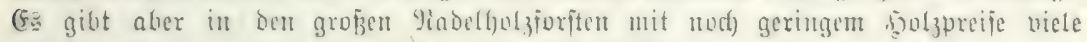

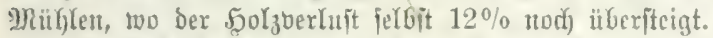

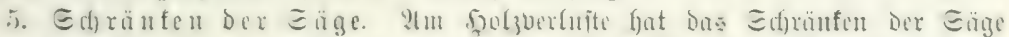

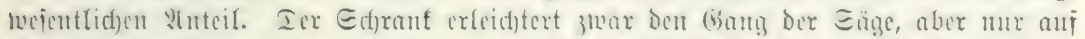

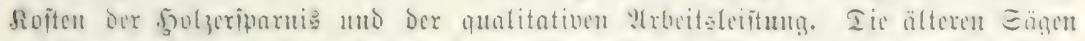

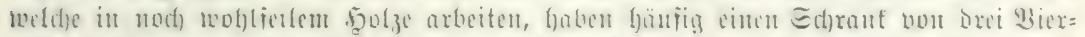

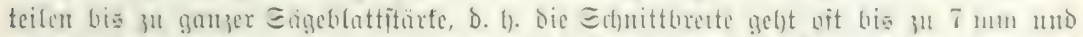

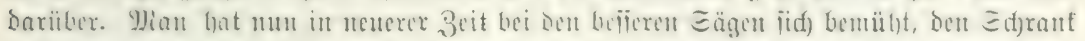

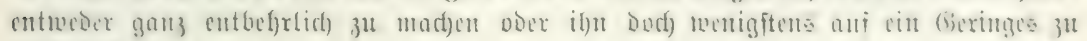
bcjd)ränten.

6. Räuge bes Gägeblatte. Die Ränge Der Gäge hängt vout ber Gtürfe

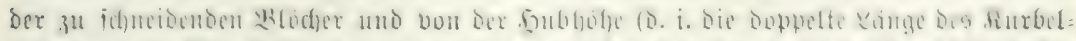

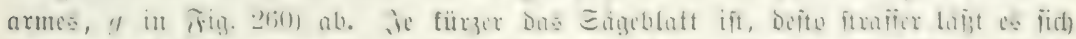

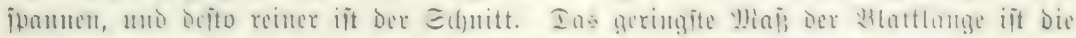

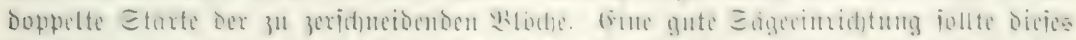

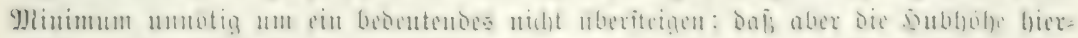

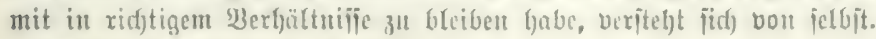




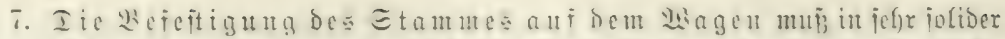

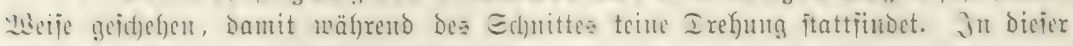

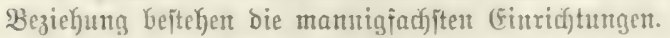

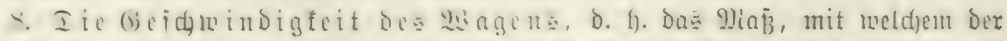

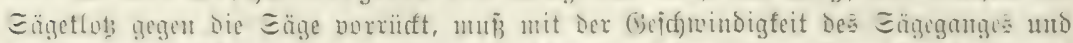

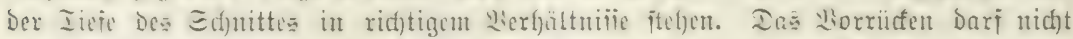

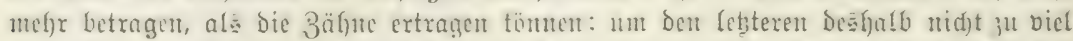

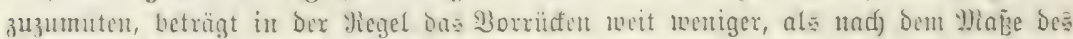

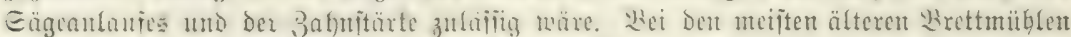
Liegt Die Inji des Ednitte jwijd) 6-1:- mm: bei ben neneren Ë̈gen iteigt or

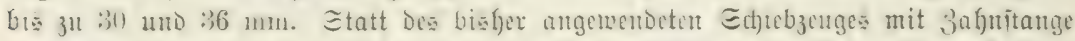

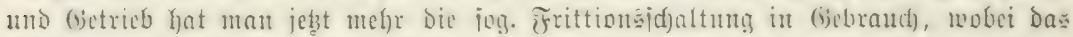

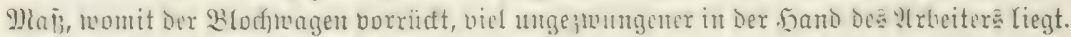

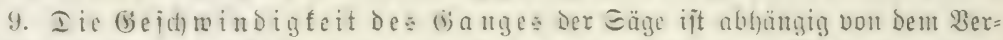

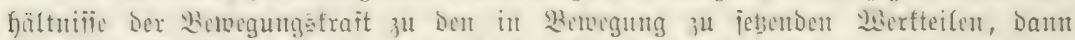

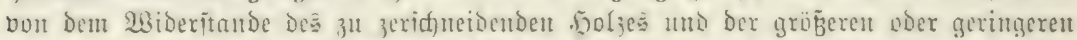

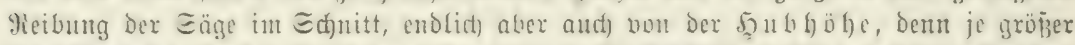

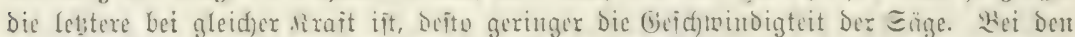

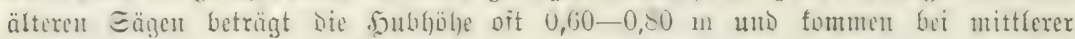

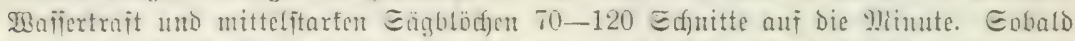

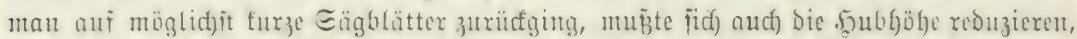

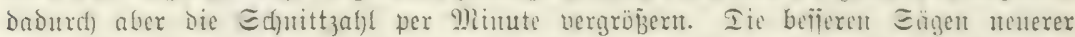

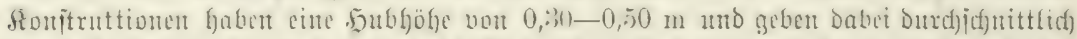

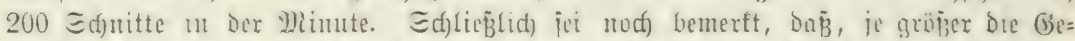

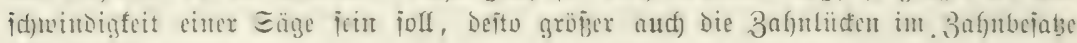
jeist müījen.

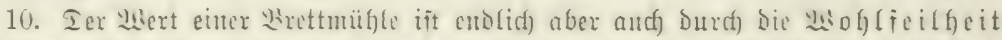

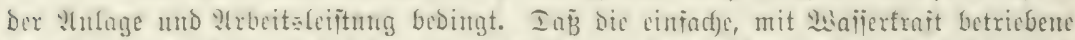

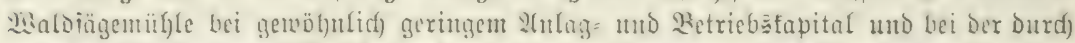

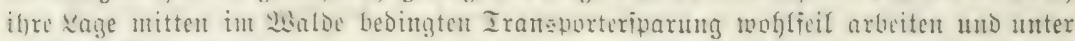

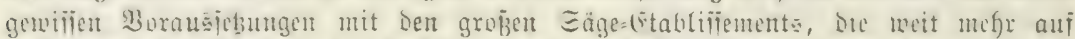

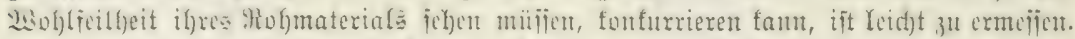

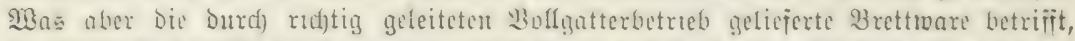

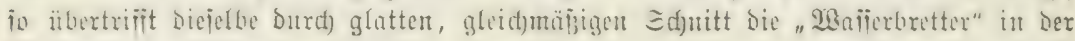
פ)

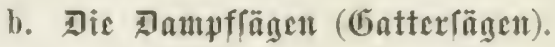

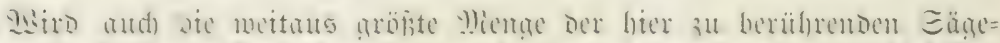

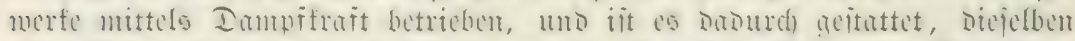

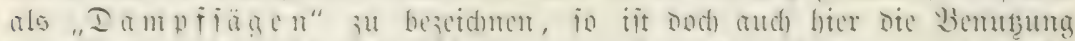

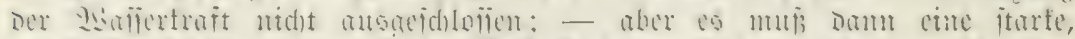

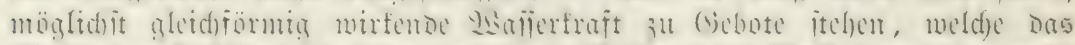

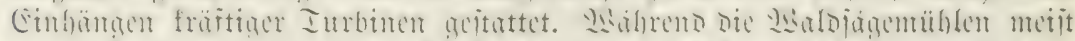

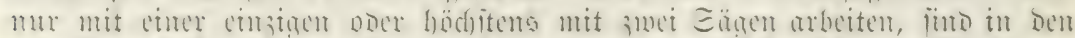

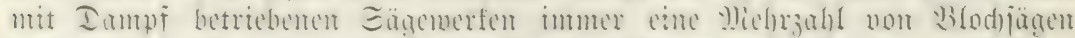

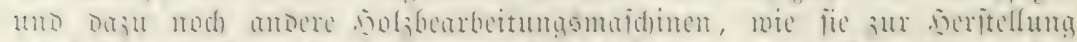

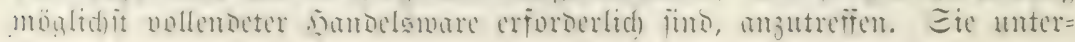




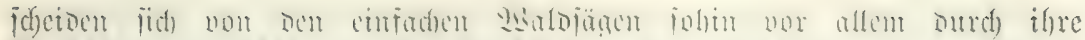
y) a

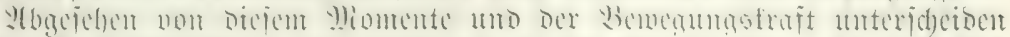

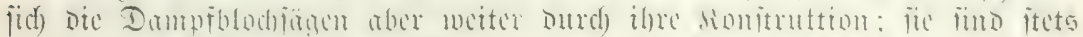

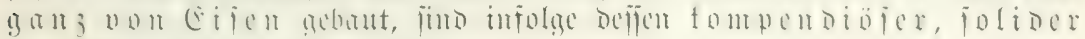
in Dent Detaibauc, baben cine gröbere Stabilität umb Sidfer = beit im Gange, die Reibung

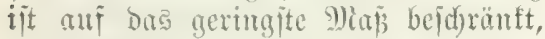
und endid gebieten fic liber che meit gröbere diraftuirtug. Dieje gröbere Siraft mird bet Den Dampfiägen nod) insbejonbere Daburd) vermertet, daf; man in der Regel melnere, bis zebn Slätter und mefr un bas Gatter fpamnt, Die fobiu gleidgeitig arbetten und bas 3erlegen eines Sägeblodjes in Bretter in einem Sunge ermögliden. Da hier

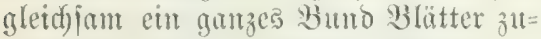
fanmen arbeiten, merben foldhe Singen

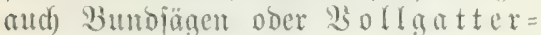
fägen genamnt. Whas den Siraitaut $=$ warb ciner Bollgatteriäge betrifit, io red)met man bet gewöbulidgen ber

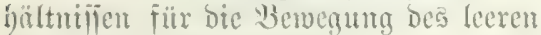
Gatters brei PSferdefrafte, fïr bie eriten vier Blätter etre \$Ferdefraft uno für jedes weitere Blatt eite Galbe Bjerde=

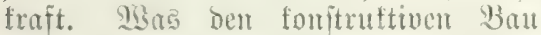
Diejer Ë̈gen betrifit, jo berulft ber= felbe wohl immer ati bem cinfad)en

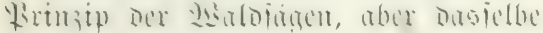
ift fier ourd) die ingenieuje bimit ber Majdinentednif in ciner Metic ner= wirtlidft, wie es ber Ienoenz möglidfit grofser seîtung mit möglidjit menig Siraftarfuand entipridst. Bei Deu Fort= wäbrenoen Berbefierungen, weldyc fid) in biejem (Gebiete fajt täglidf) ergeben, แ⿰ Den mamigfad)e Spezialanfgaben, für welde dic Gigen bejtimmt futro, iit es aber bentbar, baj; die mamigy= faltigiten dionjtruttionsabueid)maen bei Den cinzelnen Jiafduenfobrifen beiteben mïijen ${ }^{1}$ ).

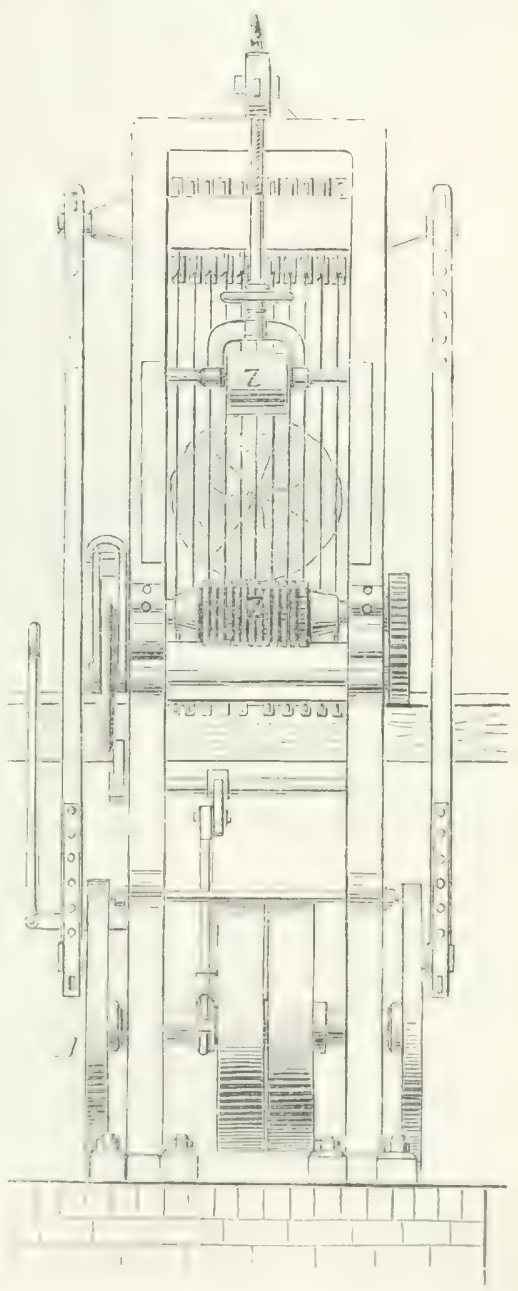

कig. 261. Sonftruttion ciner Dampfïige mit Wlollgatter.

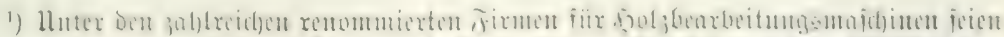

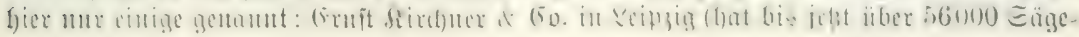




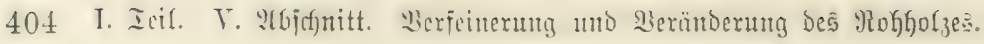

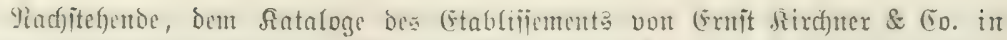

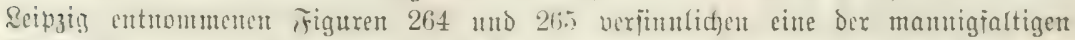

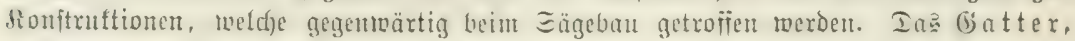

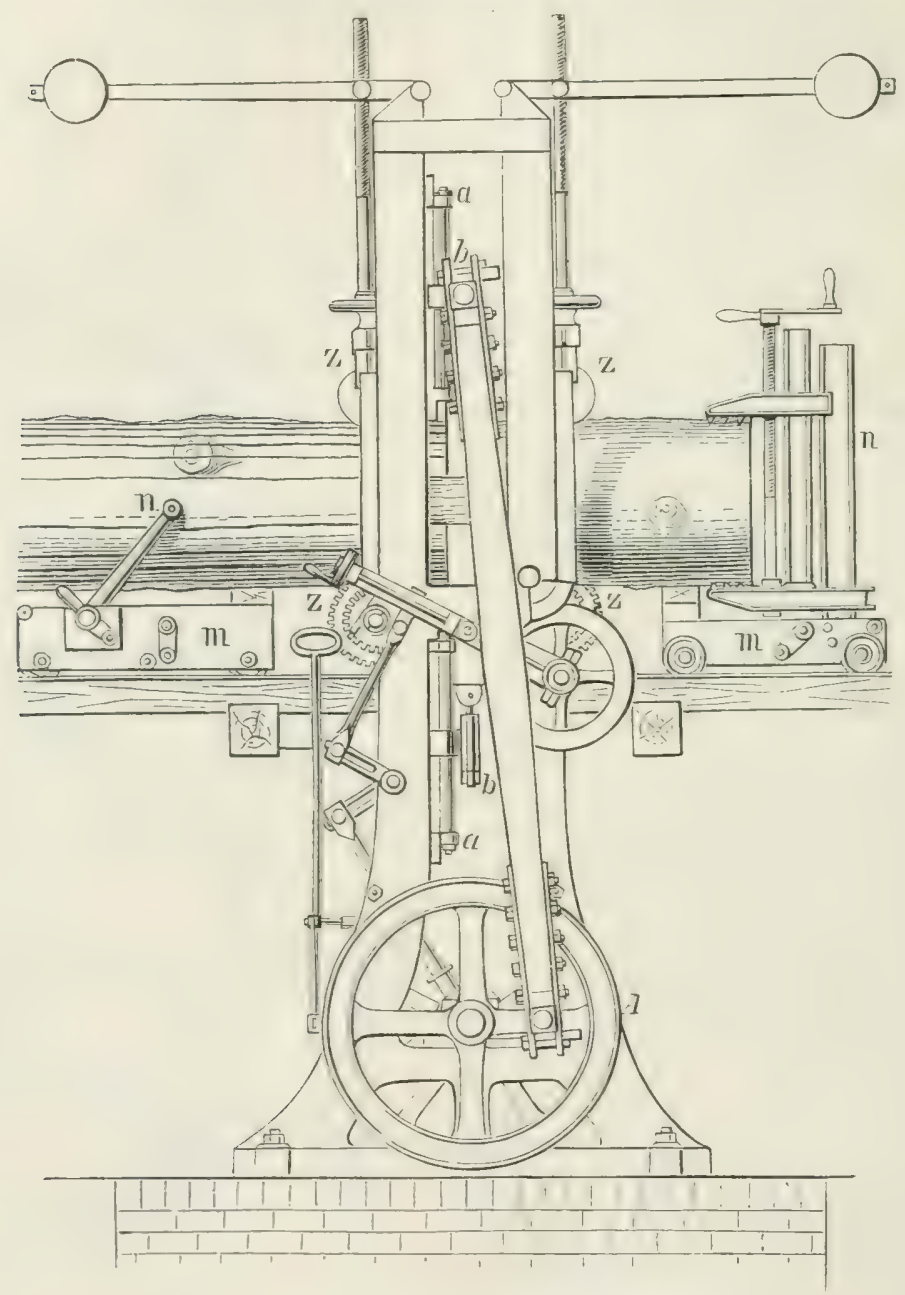

Fig. 265. Sonftruftion einer Dampfiäge mit Mollgatter.

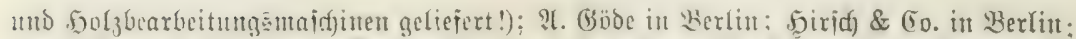

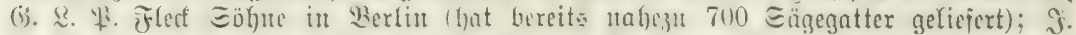

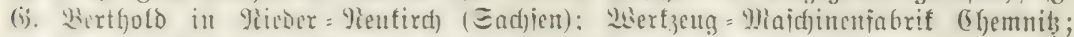

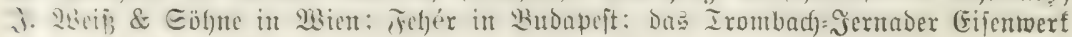
it Hngarn uno biele andere. 


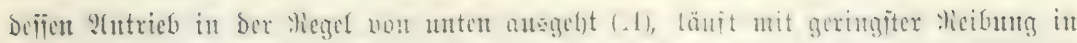

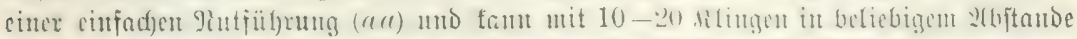

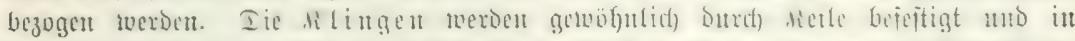

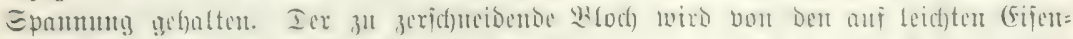

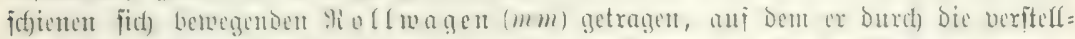

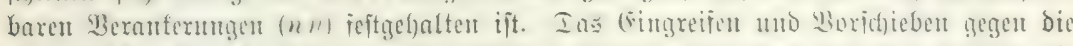

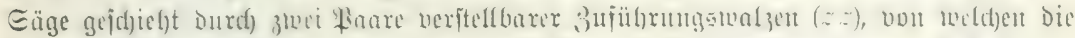

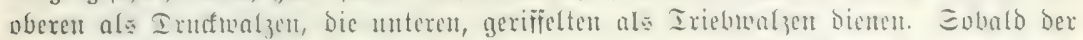

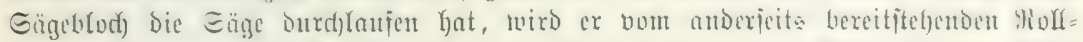

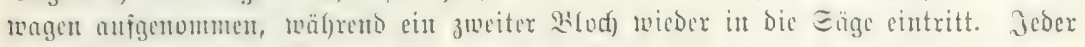

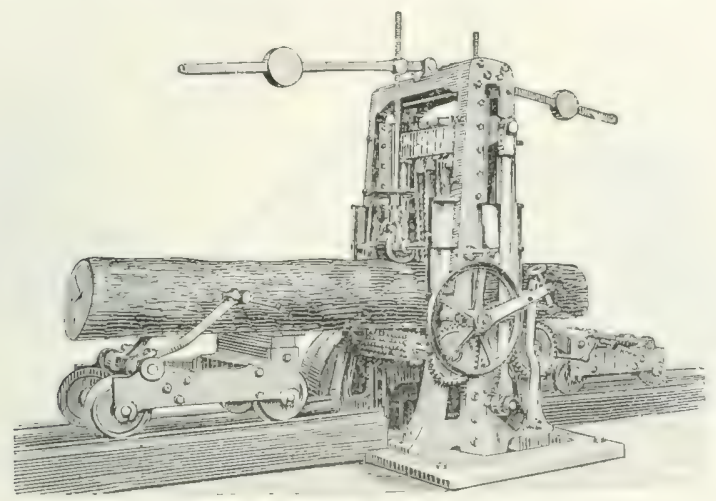

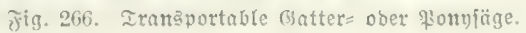

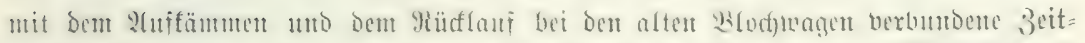

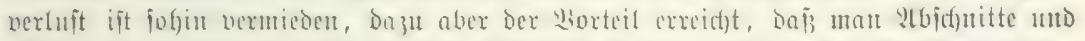

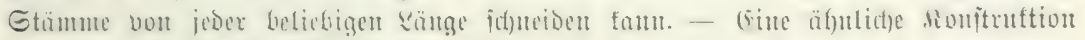
zeigt in perpeftivijder 2 (nfid)t Fig. 266.

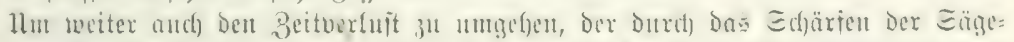

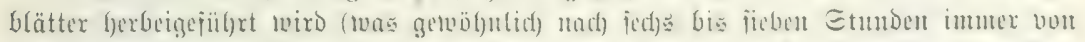

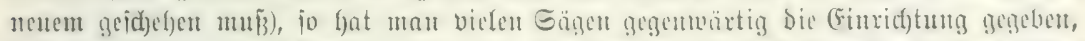

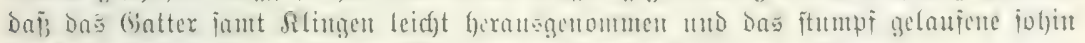

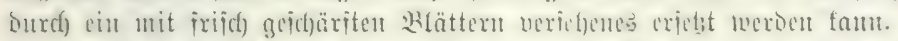

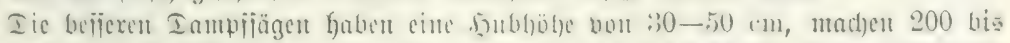

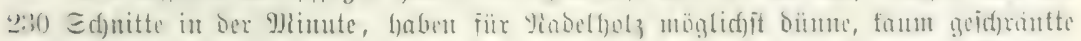

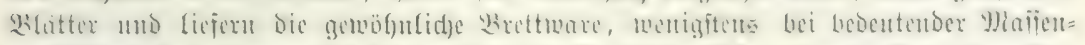

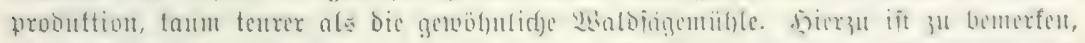

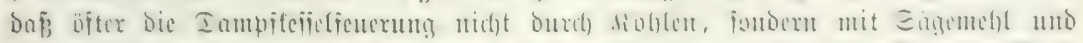

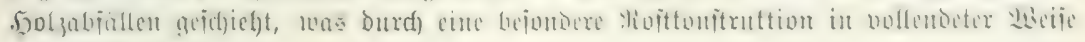
ermöglicft wirb.

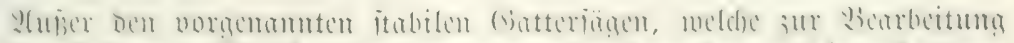

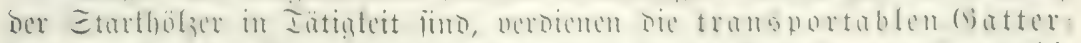

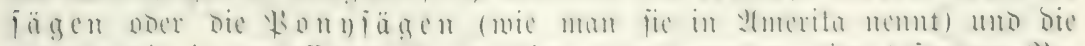

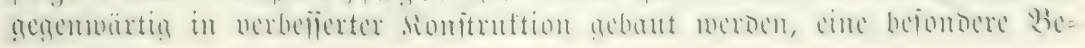




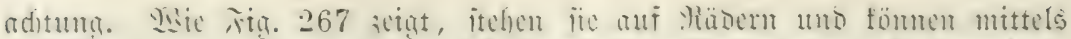

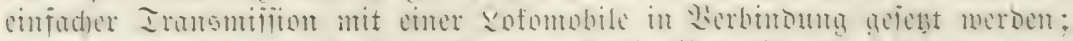

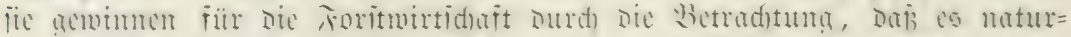

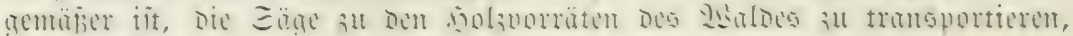

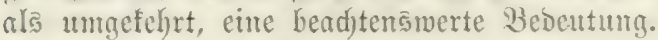

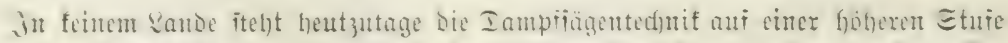

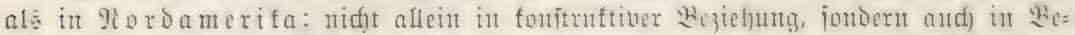

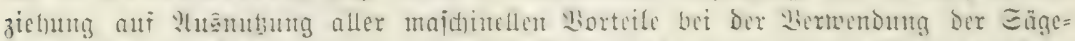

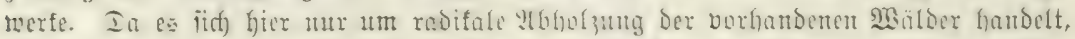

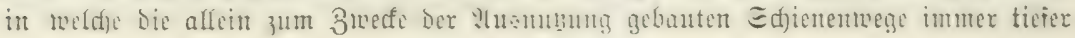

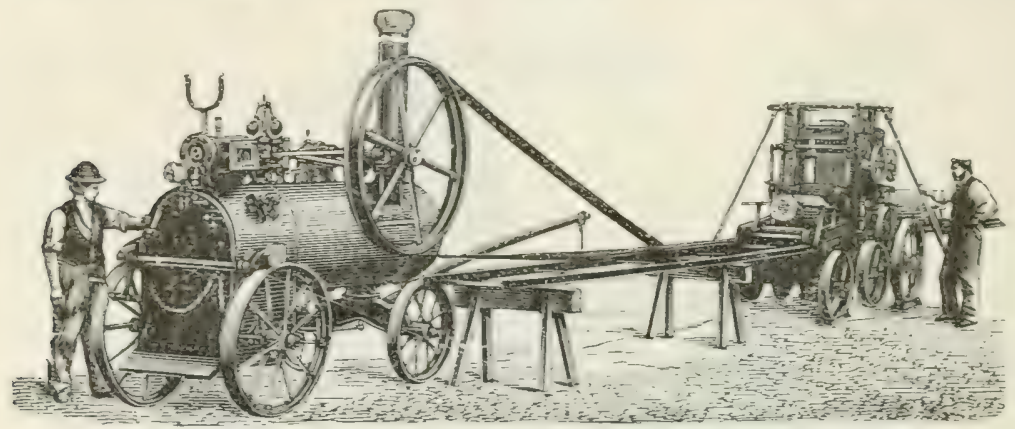

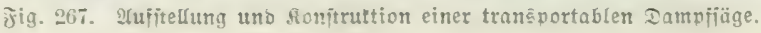

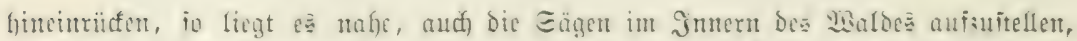

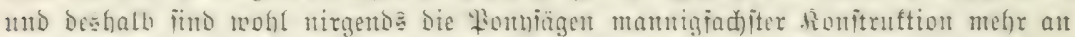

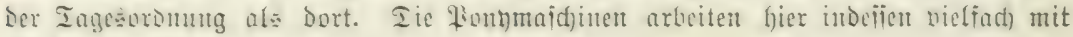
3irfularjägéblāttern.

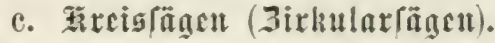

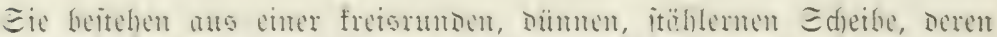

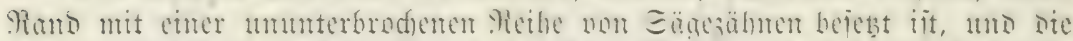

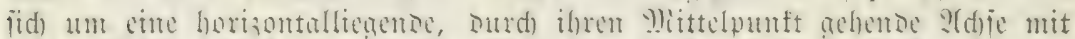

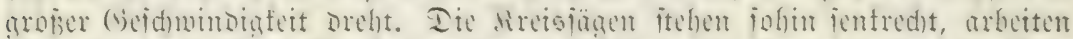

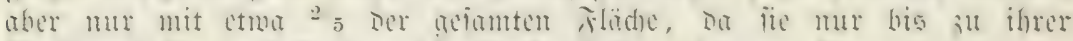

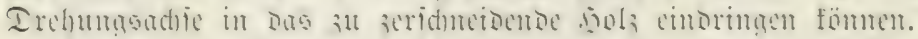

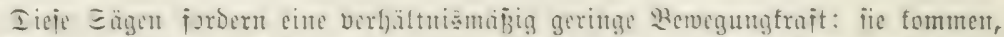

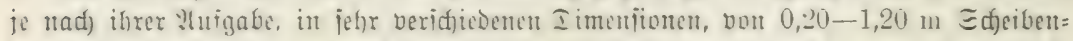
Durd)meilier, vor, uno fiernad) medfielt bie

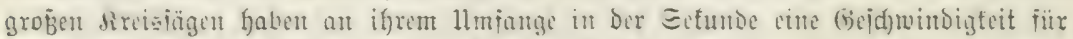
Garte $50 ̈$ żer vont $15-20 \mathrm{~m}$, für meidfe vont $20-30 \mathrm{~m}$.

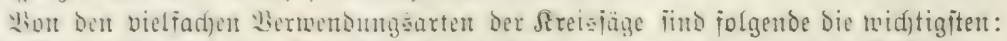

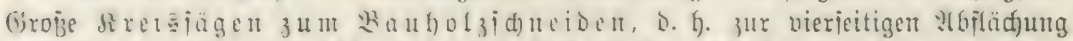

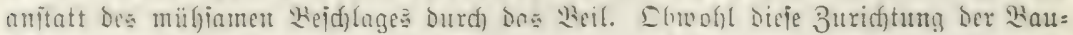

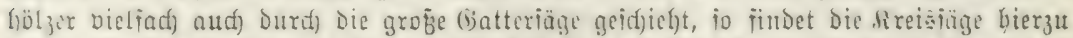

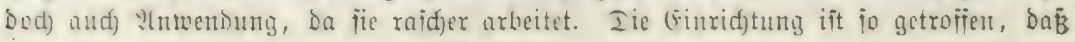




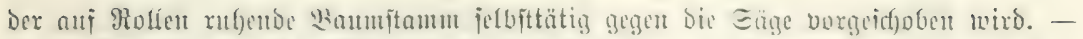

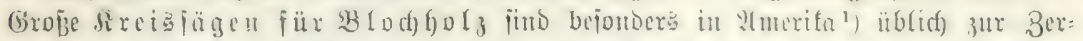

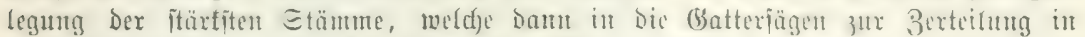

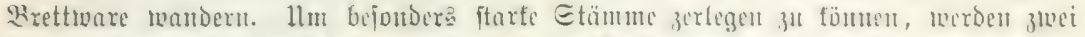

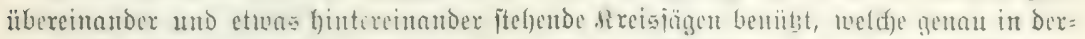

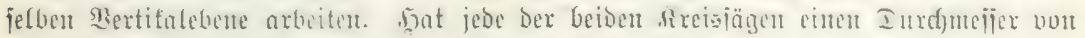

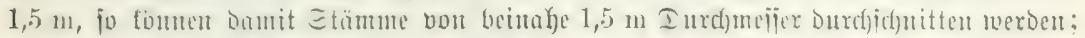

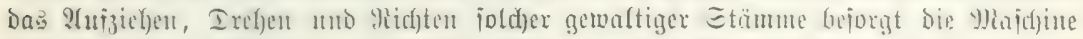

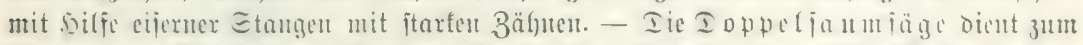

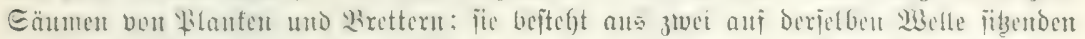

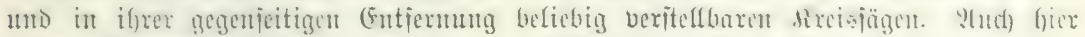

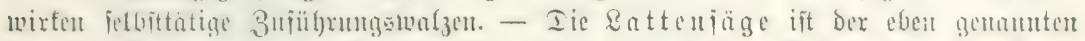

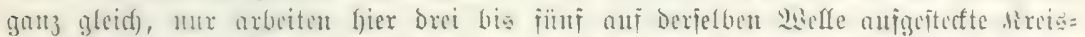

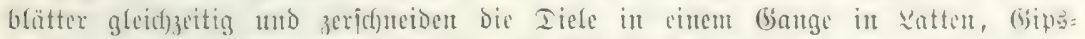

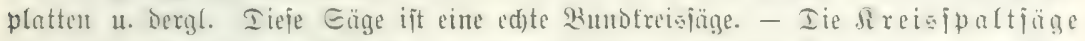

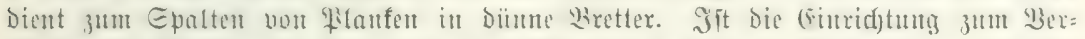

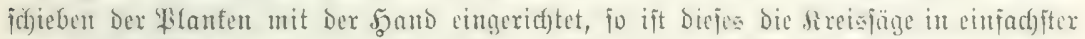

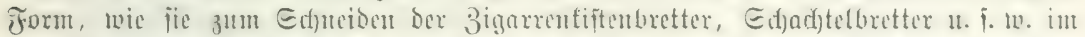

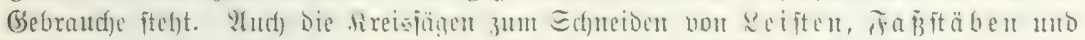

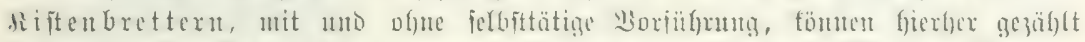

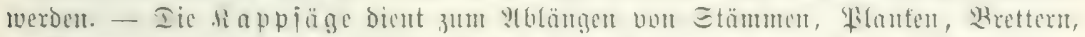

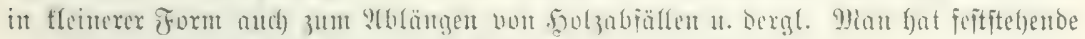
uto tranapprtable (5inrid)tungen im (bebraud).

\section{Bandrägen.}

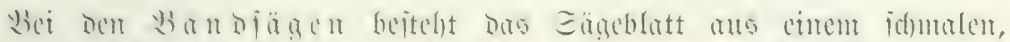

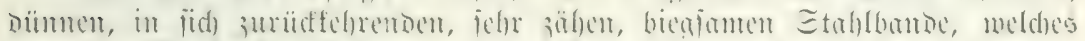

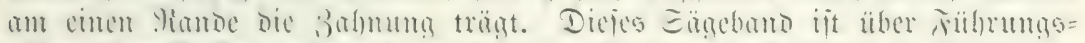

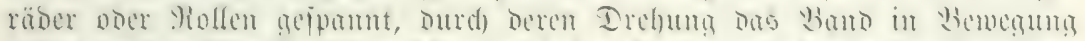

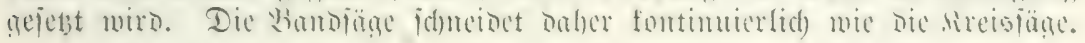

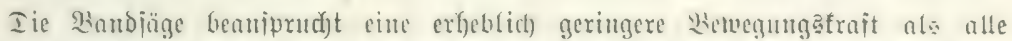

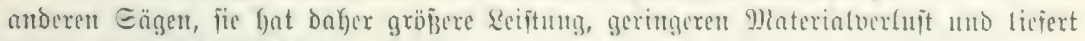
glatte, feine Ed)nittfläd)ent.

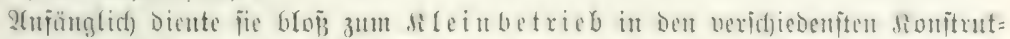

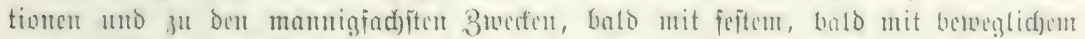

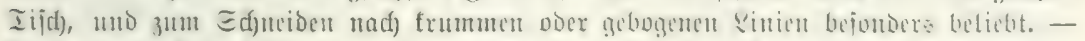

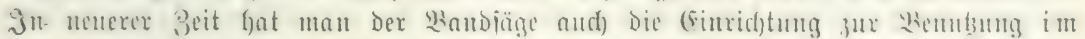

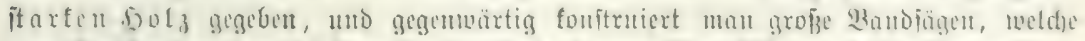

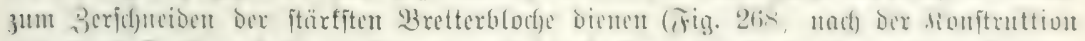

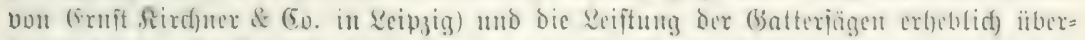
bieten jollen. Jn ?tmerifa betrad)tet man bie Wandiüge als bie ll niverialiäge der $3 u \neq u$ t .

1) Dr. 5ु. Manr, Waldungen von STorbamerita. 1890. 


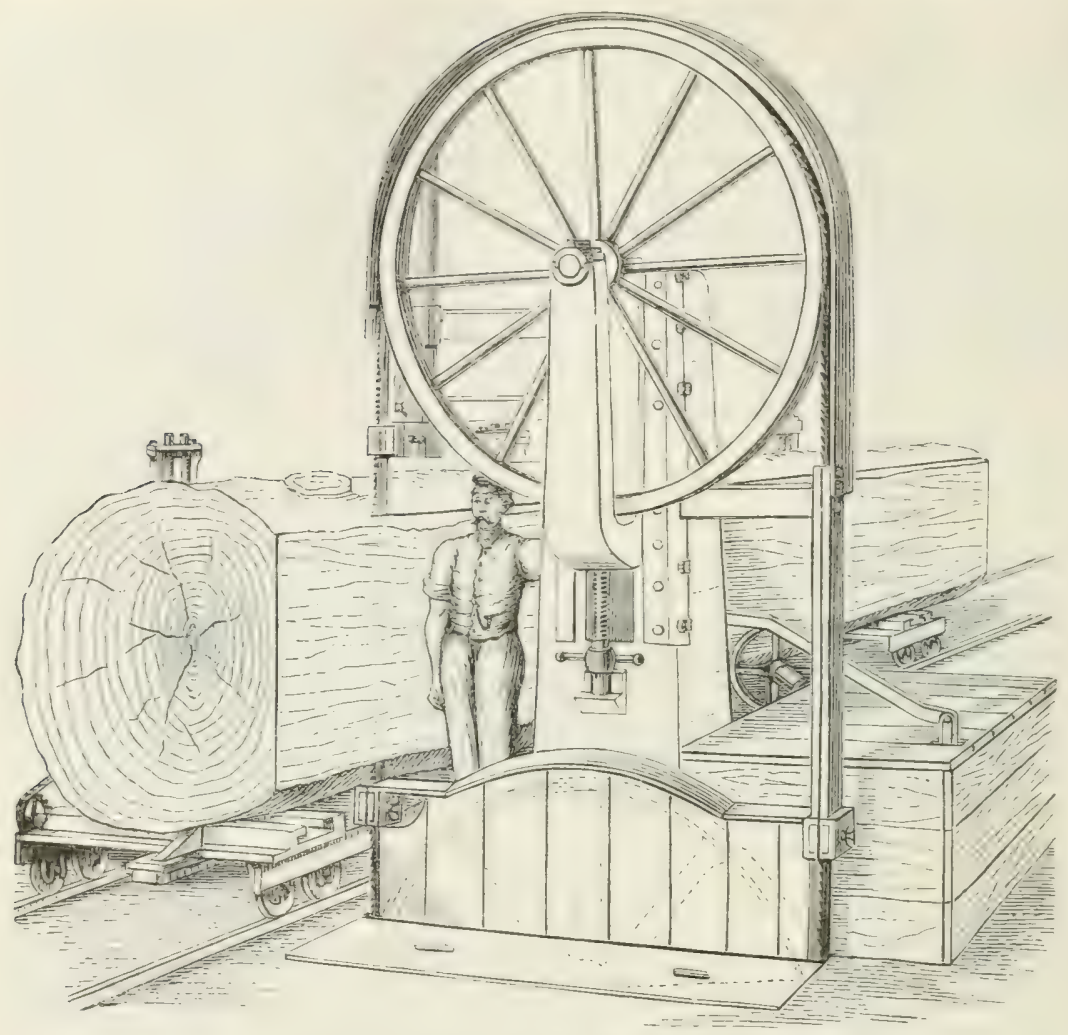

J̃łg. 268. Sionjtruftion einer Banofügemajøine.

\section{e. fournicxfägen.}

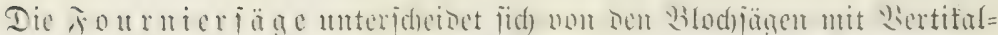

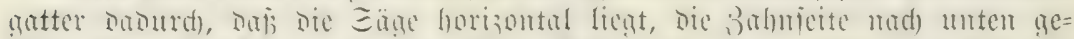

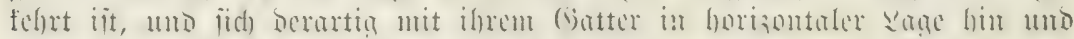

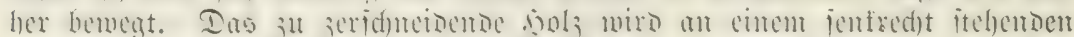

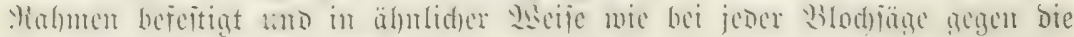
Säge, aber vout unten mad) oben, vorgejdjoben.

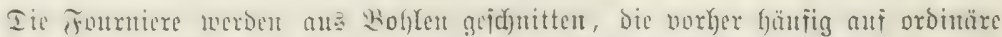

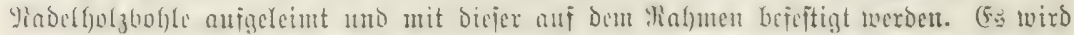

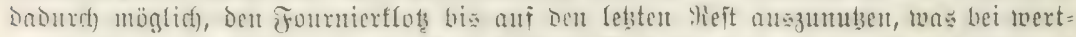

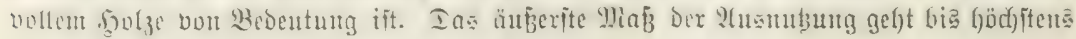
jieben Stï Grautdfbare Fourniere auf $1 \mathrm{~cm}$.

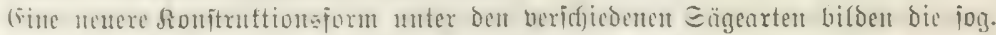

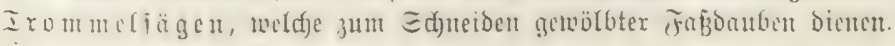


Bezüglid, ber O

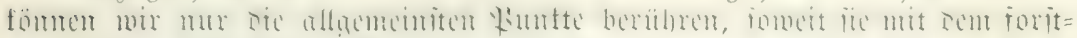
mämijofen Jnterefic in Bezichung iteben.

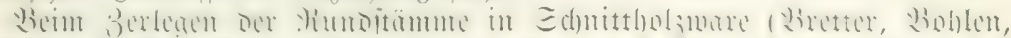

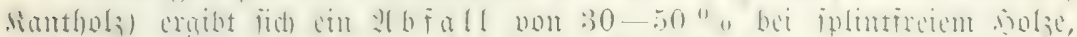

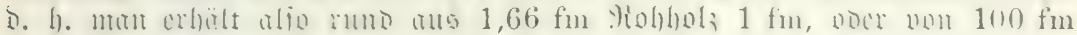

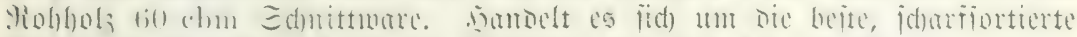

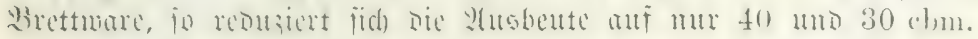

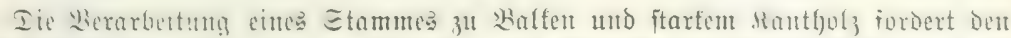

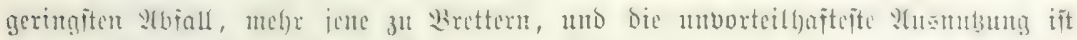
jene zu iptint= und marfireien Boften und \$lanfent.

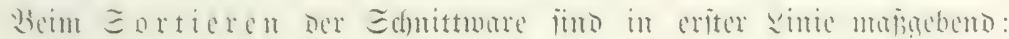
die Gejundbeit, dic Dimenjionen, die Sornäite, der Umitand,

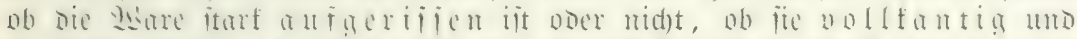

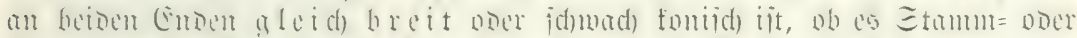

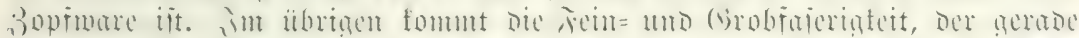

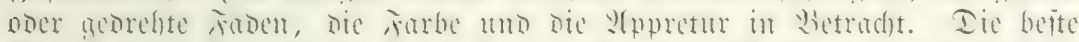

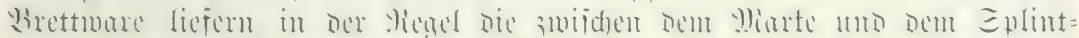

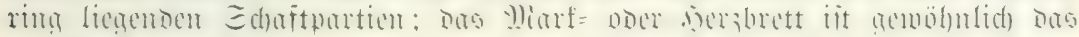
id)led)teite.

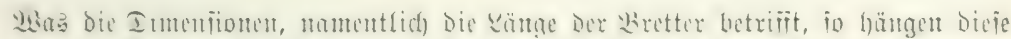

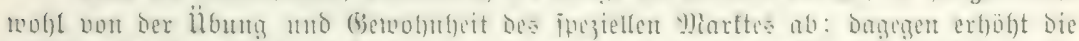

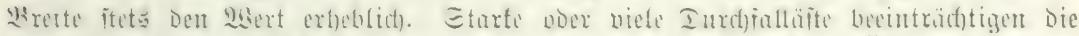

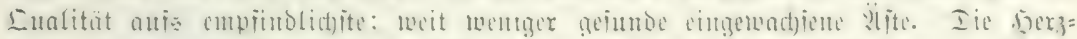

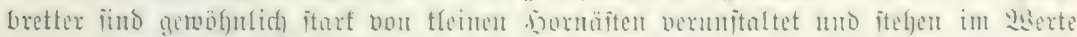

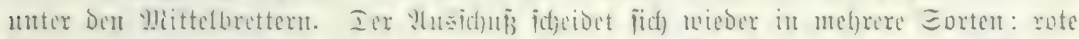

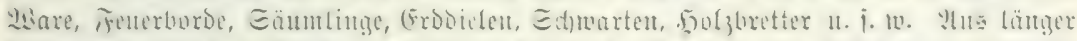

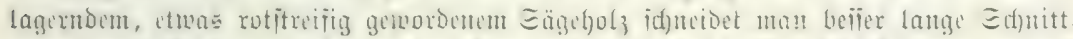

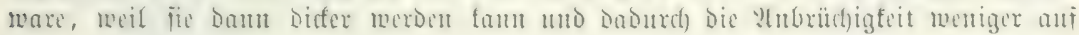
Die Sberilübe tritt.

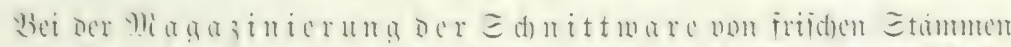

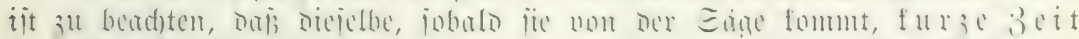

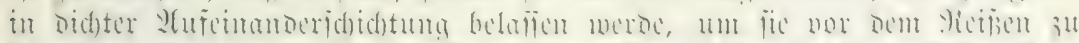

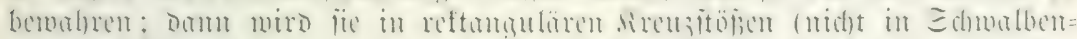

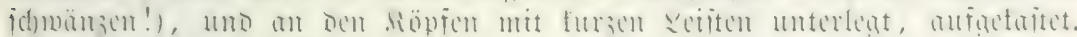

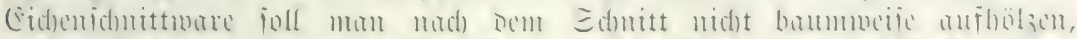

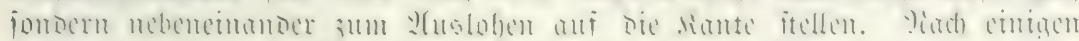

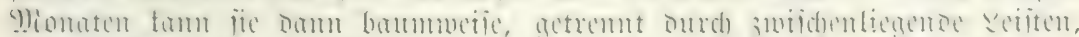

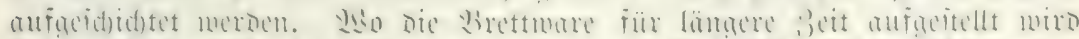

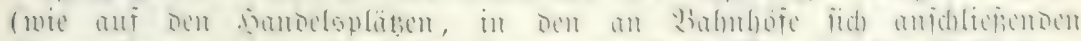

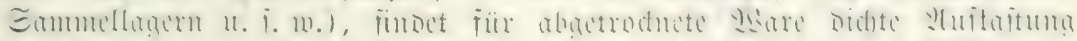

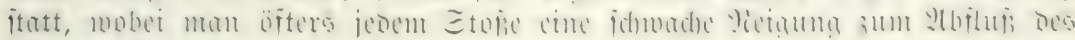
Regemual̄ers gibt.

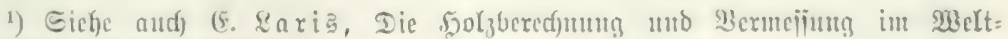
bolzbandel u. i. w., III. Ieil. 


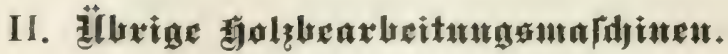

\section{a. Fournierbobel.}

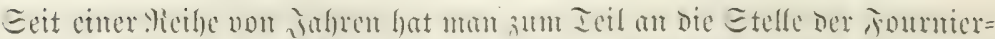

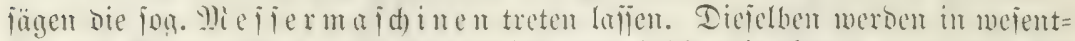

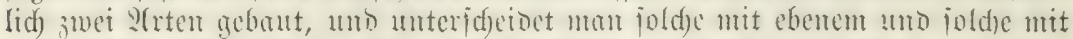

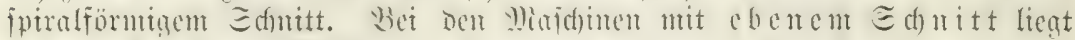

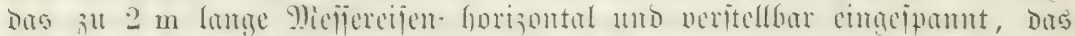

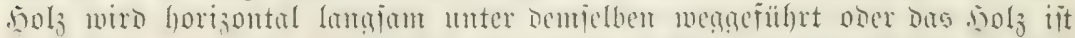

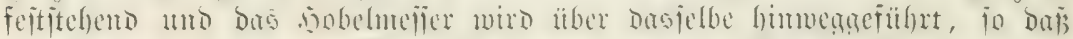

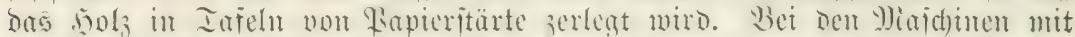

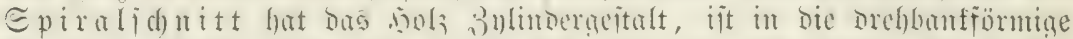

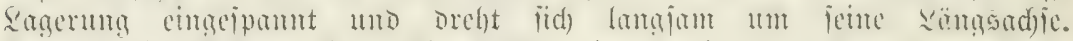

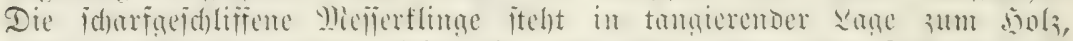

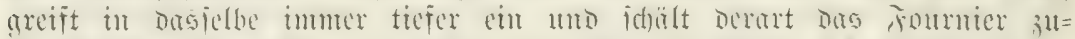

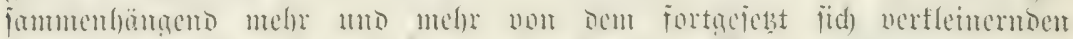

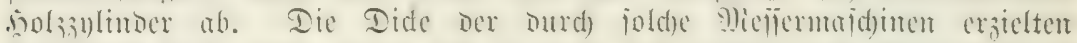
Foumiere fum leidst herob bis $3140,25 \mathrm{~mm}$ achen, uno foumen Dafher 40 Edurtte auf̃ ben 3entimeter.

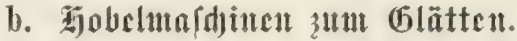

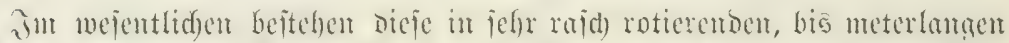

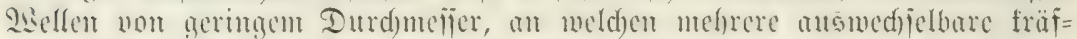

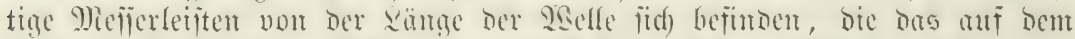

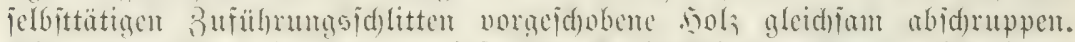
Eic merben heute in ben mamigfad)iten sonjtuttionen gehaut; teils bienen

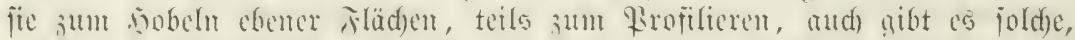
meld)e ein Ed)nittitüd mif allen vier Eeiten in einem (butge hobeh, und

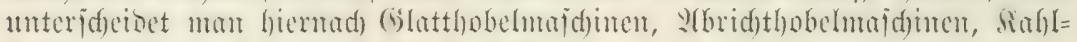
hobelmajditnen, Fïgemajditten แ. j. w.

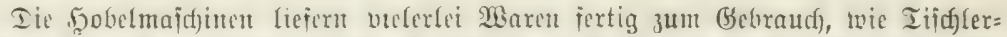

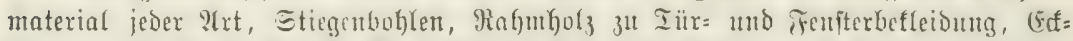

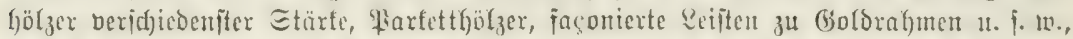

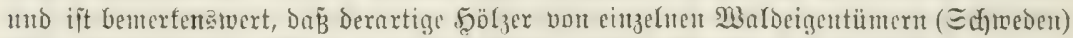

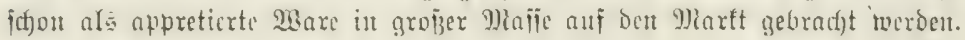

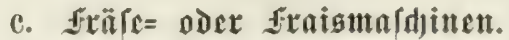

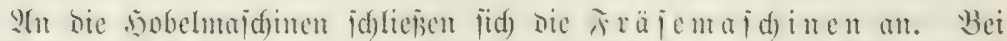

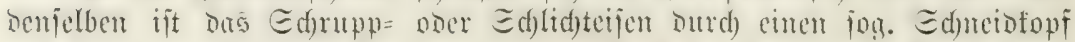

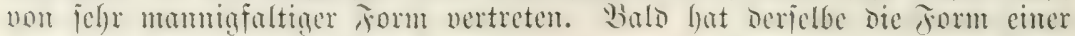

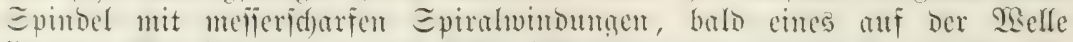

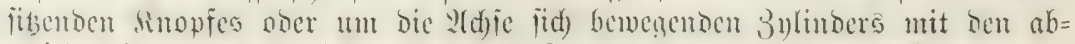

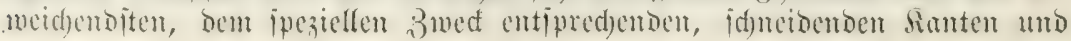




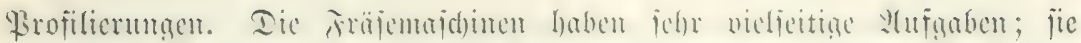

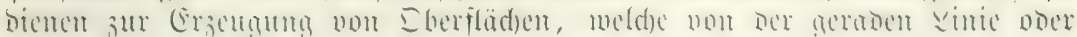
ber Ébene melyr ober meniger abweident.

\section{d. Foliwollmaininen.}

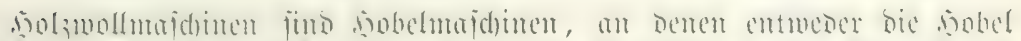

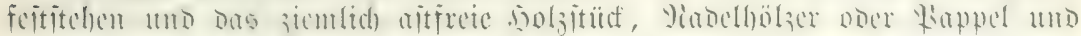

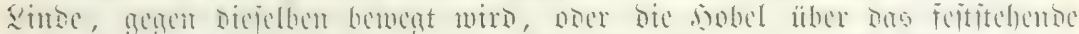

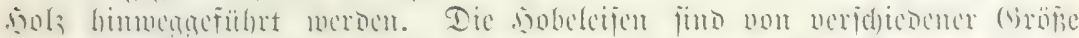

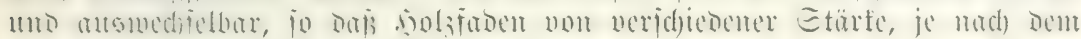
Sermendunģ3mecte, gefertigt werben fömen.

\section{e. Jolzorahtmafducu}

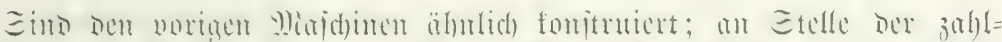

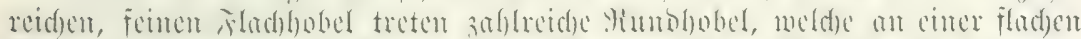

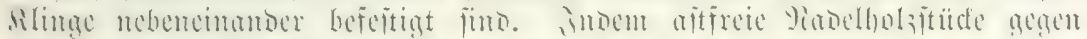

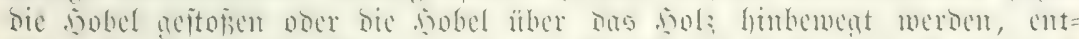

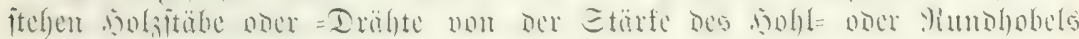
und vou ber Ränge bes Solzitüdes.

\section{i. Ejoląbiegemardjinen.}

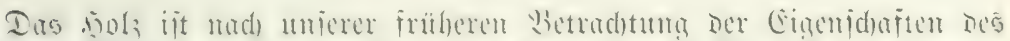

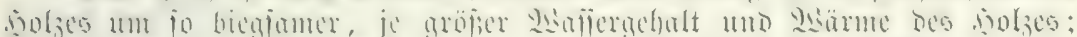

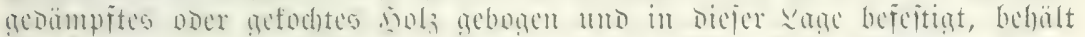

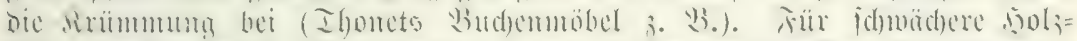

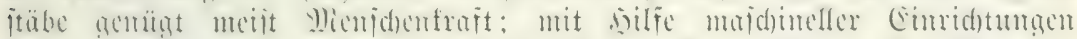

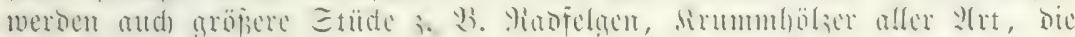

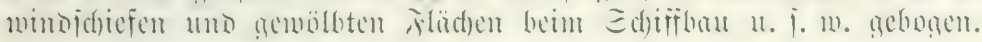

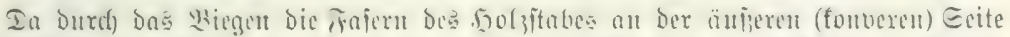

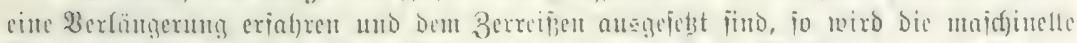

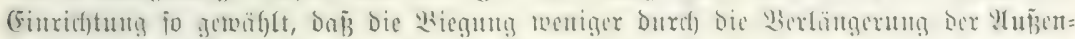

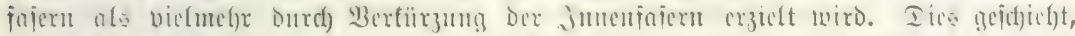

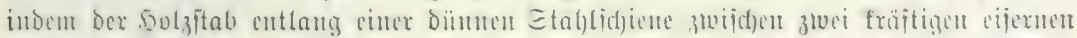

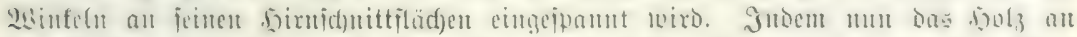

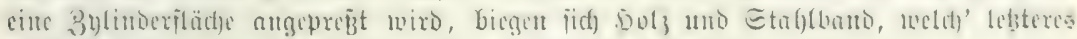

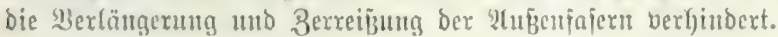

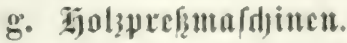

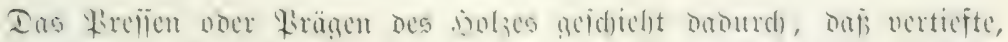

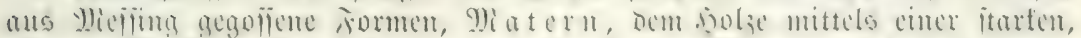

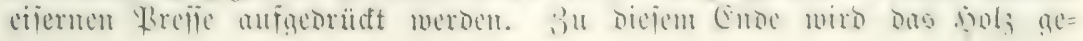




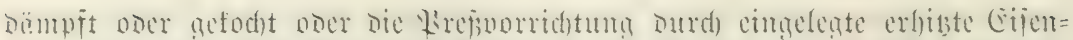

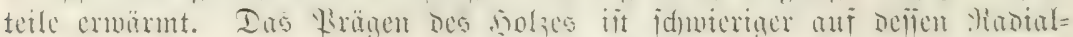

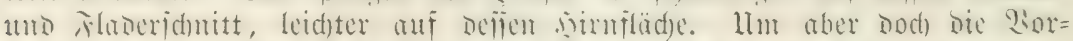

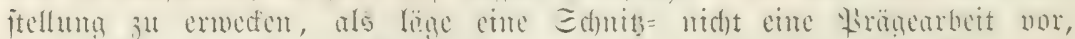

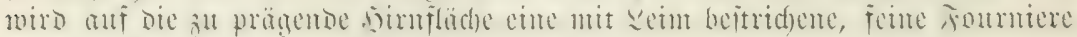
anfgelegt.

Mrrben ftürfere - $3 \mathrm{~mm}$ - 5od

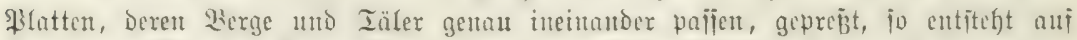

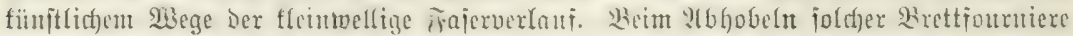

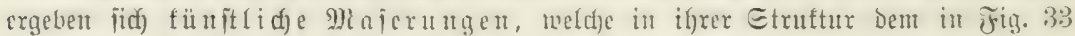

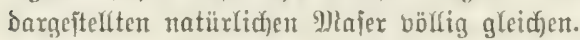

\section{h. Folz̨id)}

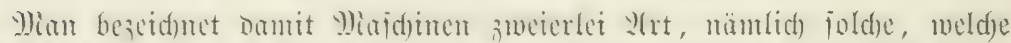

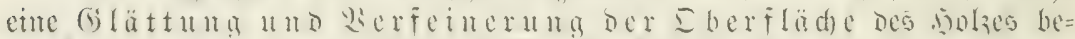

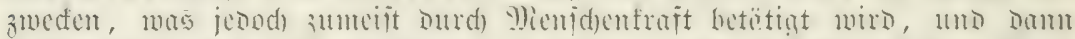

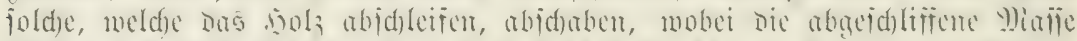

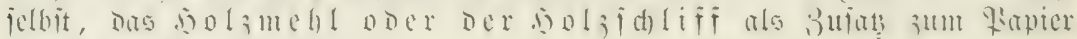
3wed ber Bearbeitung ijt.

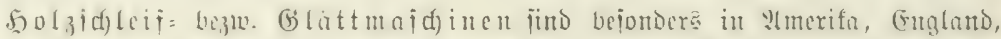

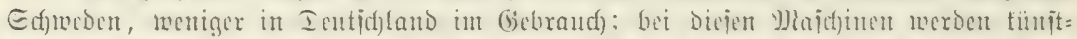

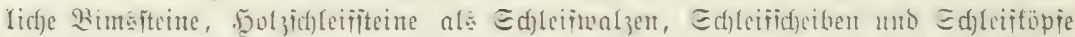

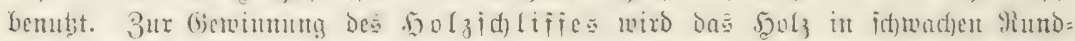

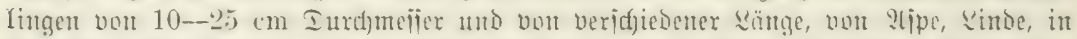

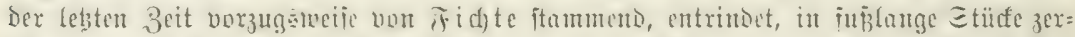

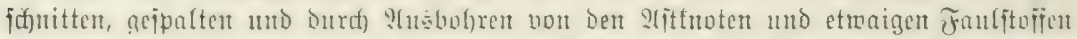

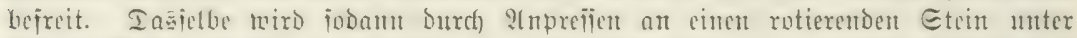

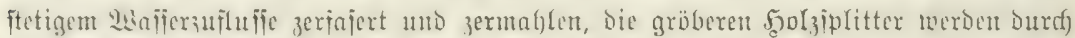

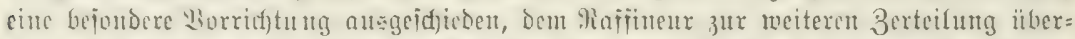

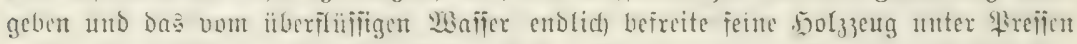

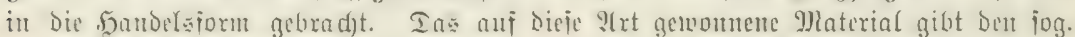

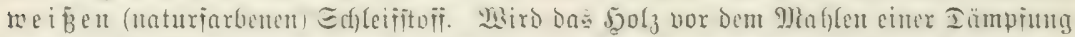

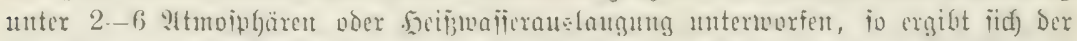

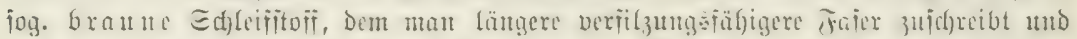

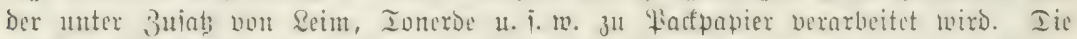
eriten sol

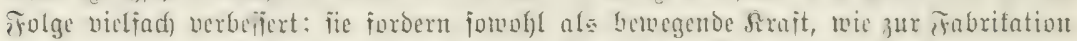

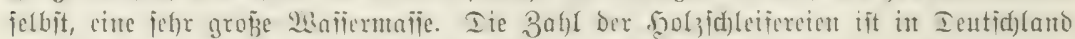

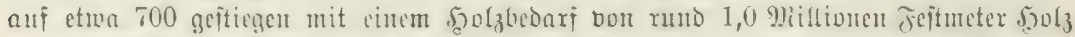

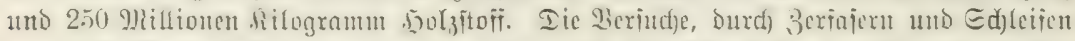

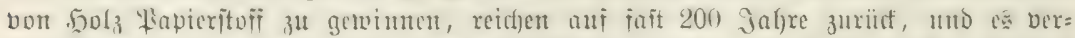

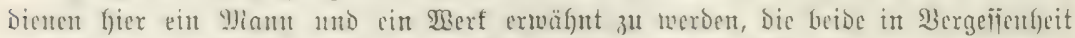

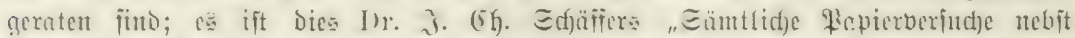

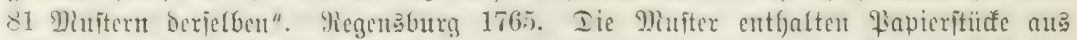

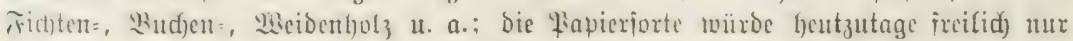
Factpapier feit. 


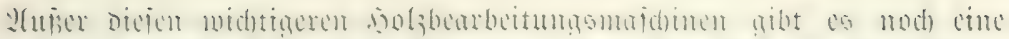

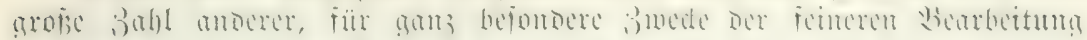

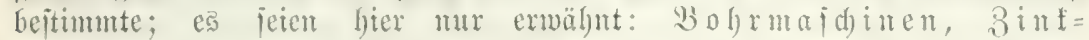

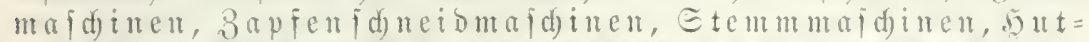

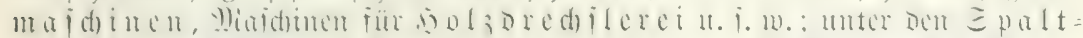
maj (h)

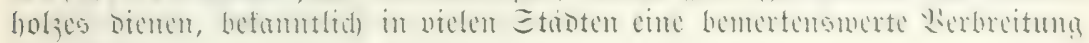
gefunden.

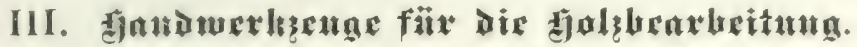

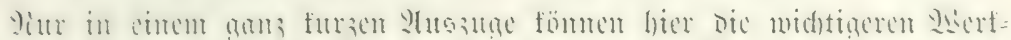

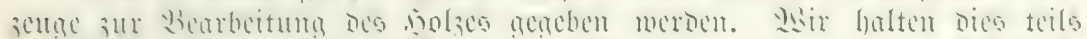

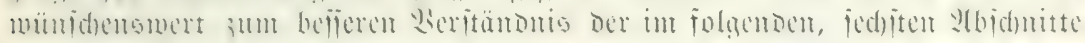
gequenen

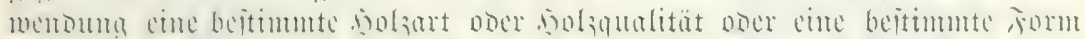

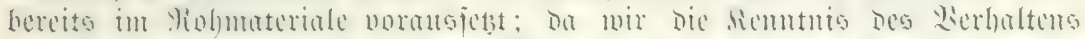

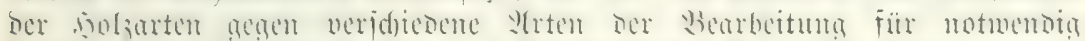

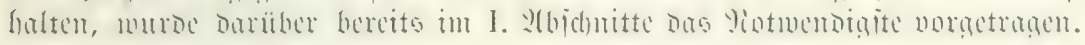

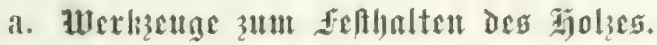

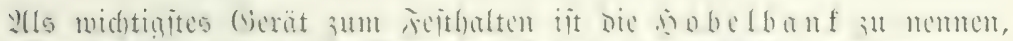

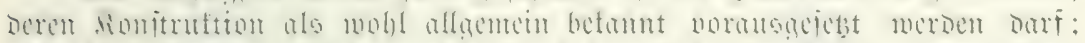

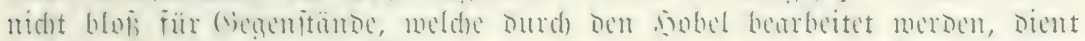

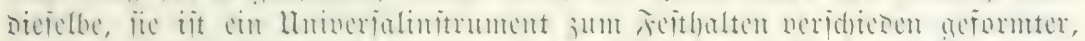

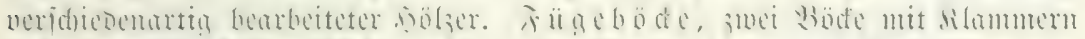

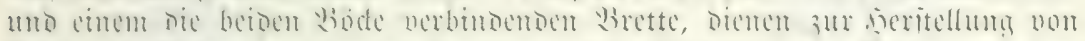

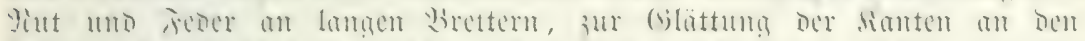

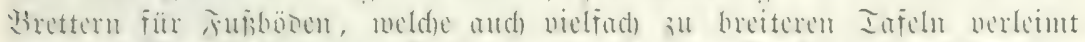

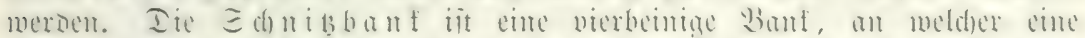

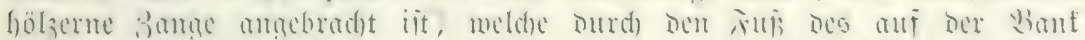

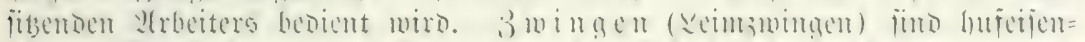

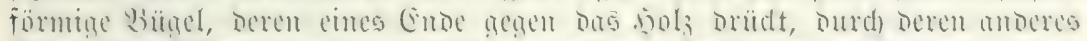

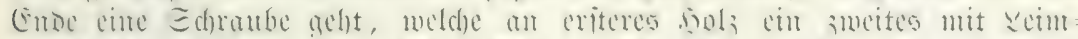

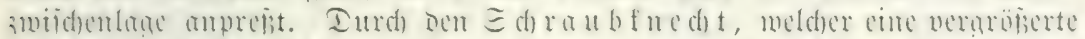

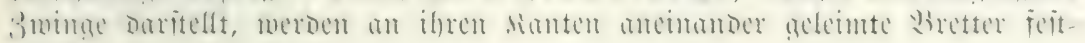
georitit (geleimte Iafeln).:

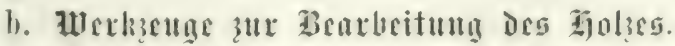

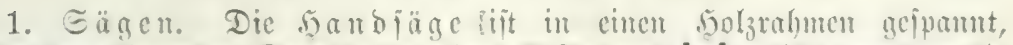

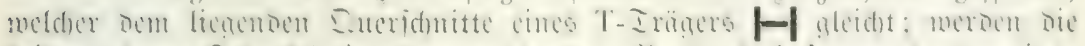

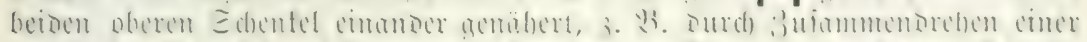

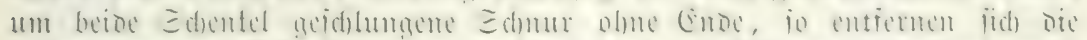

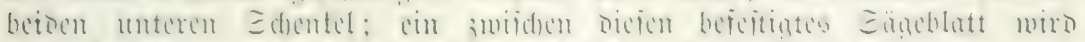

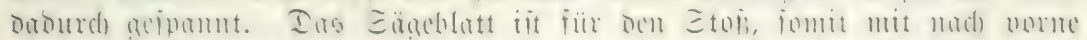

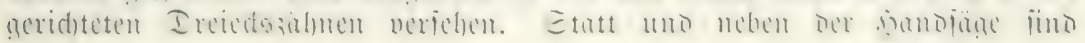


vielfad) Die ìu (t)

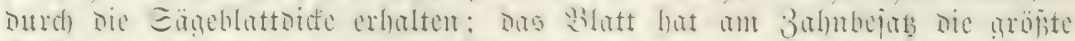

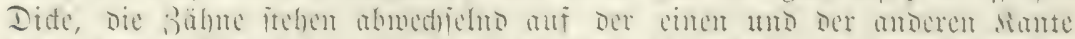

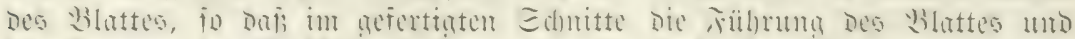

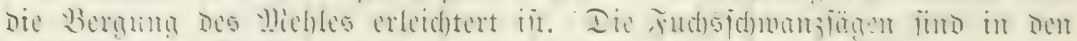

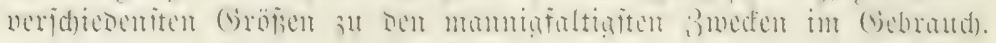

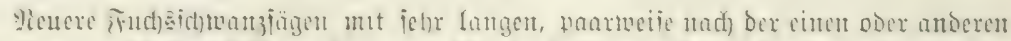

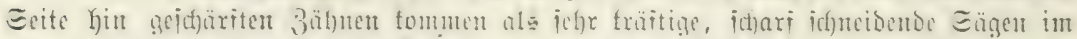

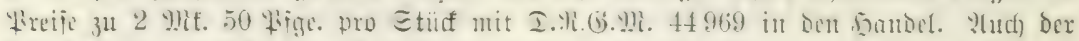

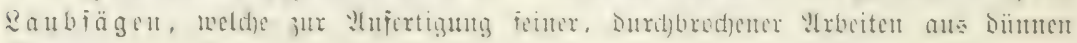
SBretten bicnen, möge Yjier gebacht fein.

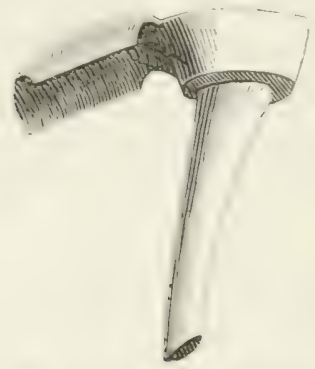

jig. 269. ¿erel sur Bearbeitung von ijoglifüdien.

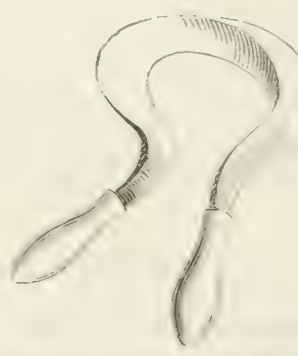

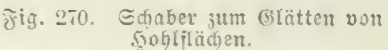

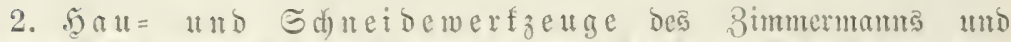

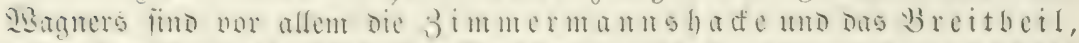

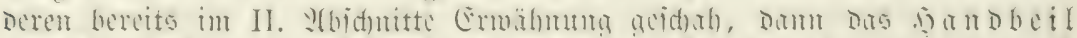

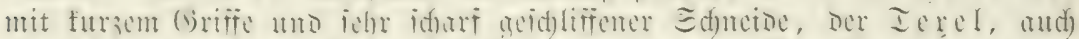

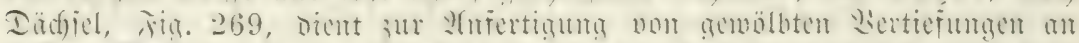

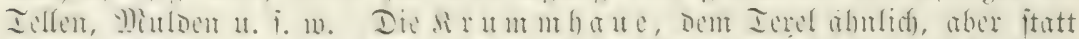

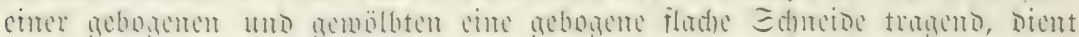

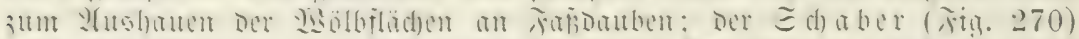

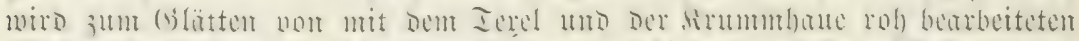

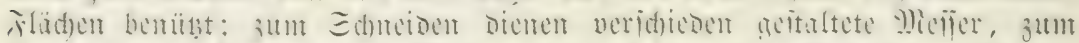

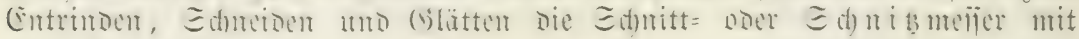
żwei らanogrifien.

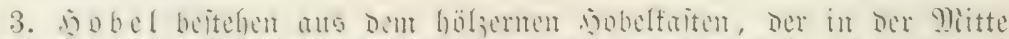

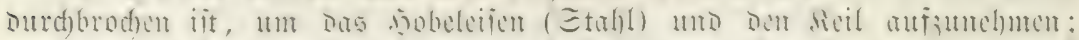

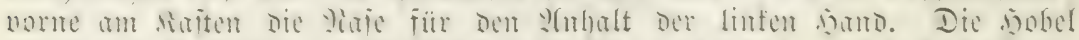

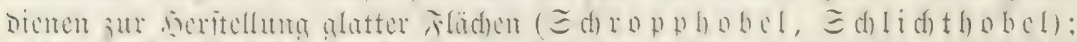

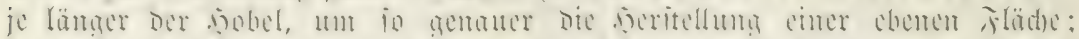

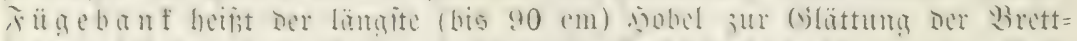

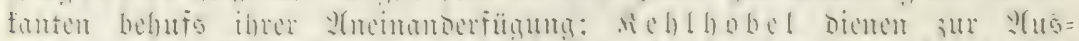

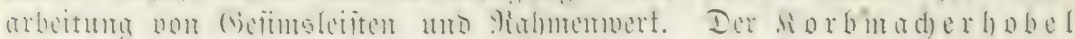

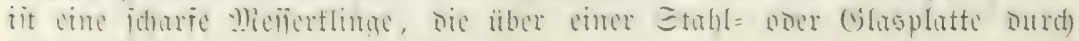
eite neritellbare Sdyrabe bejejtigt ijt. 


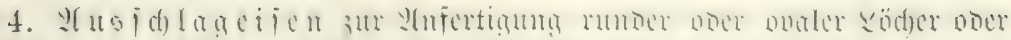

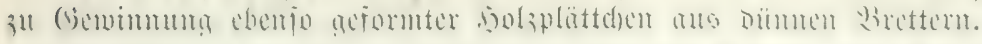

5. Epaltwexfaenge füb vor allem bas silöb= ober filöbeifen

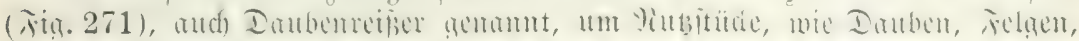

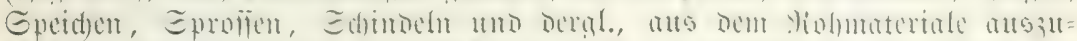

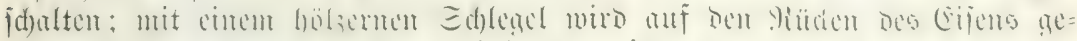

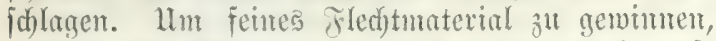
merben bie Meidentuten ber Sänge nad) anf = geipalten; Kierzu werben am bicten Ërbe Der Rute 3-4 Sdynitte angebradyt; in biefe wird ber Reijer mit jeinen 3 ober 4 Sdneiden eingejtedt unD raid) bis zum anderen (Ẽoe Der liute gefülyrt.

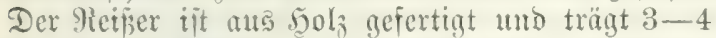
in einem Bunfte zufummentopende Edfueiden

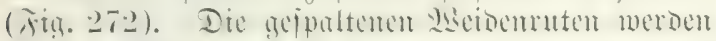

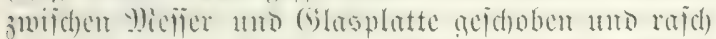

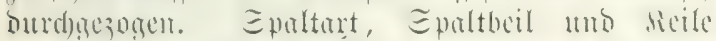
wurben bereits im II. 2(bjd)nitte bejproden.

6. Stentm = und Stidfwerfzeuge fund bas Etemmeifen

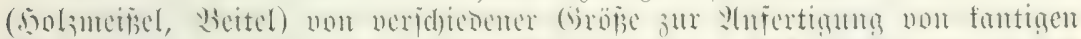

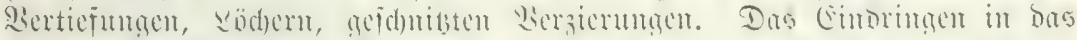

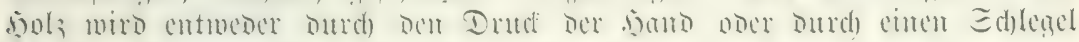
bewirft; bie Sdnteide iit entweocr eben, ober ein

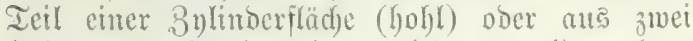
(jeltenter brei) in einem (oder smei) rediten sinfel miteinander verbundenen eijen gebilot.

7. Majpeln, holzfeilen von fladjer, Galbrumber, vier $=$ uno breifantiger ober rumber Form von grobem uno feinem Siorn bienen zum

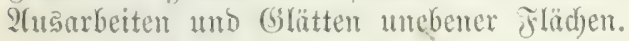

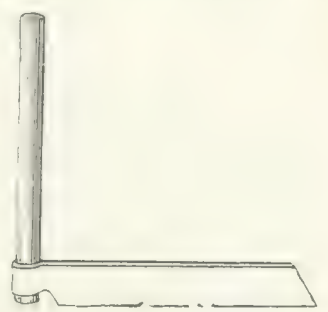

xig. sis. htib voer mibseijen.

8. Bofrex fommen in brei formen bei

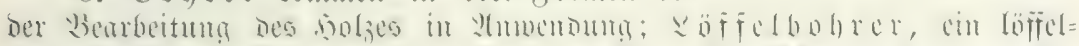

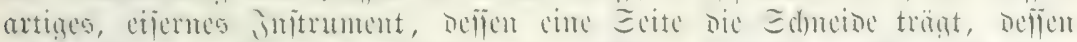

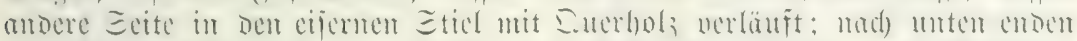

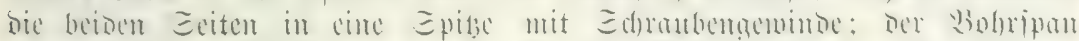

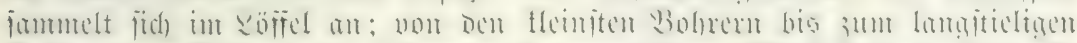

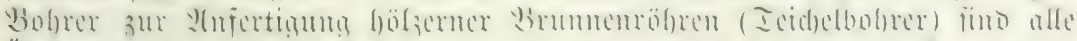

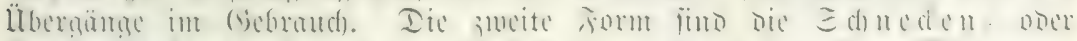

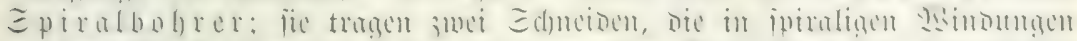

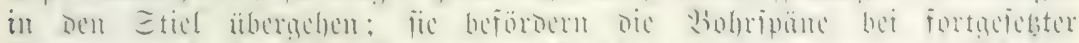

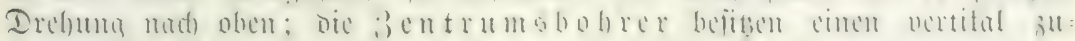
geppisten fammeln fich zmiidgen Etid und Bohrlod) ant.

9. Die Drebbant. Eime lorizontal liegende Epindel wird burd)

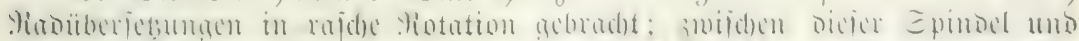

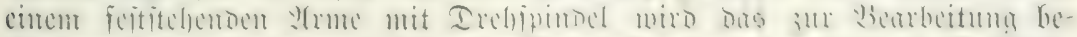

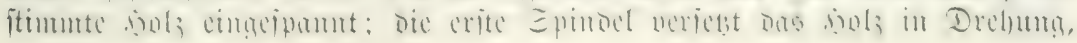




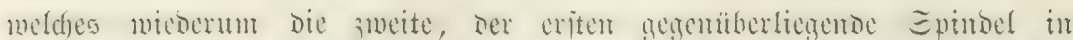

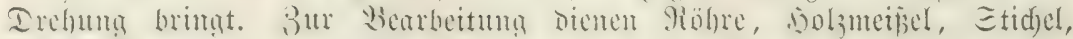

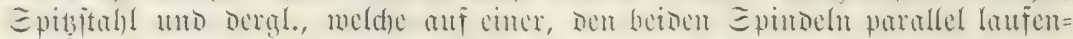
ben, aljo borizontalen, eijernen ङdjiene anfgelegt merben.

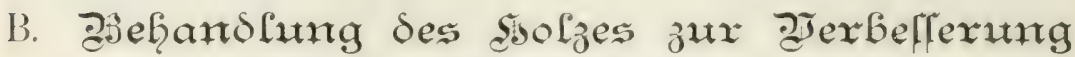 reinex (Eigentichaften ${ }^{1}$ ).}

ìll eriten :

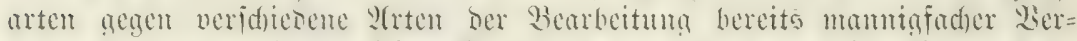

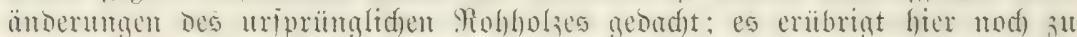

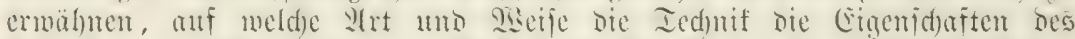

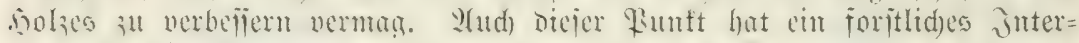

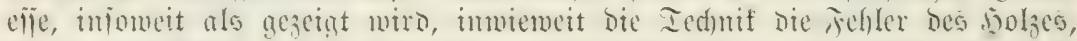

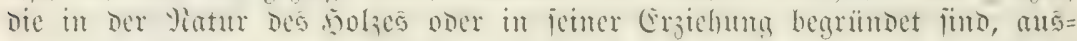
jugleidjen vermag.

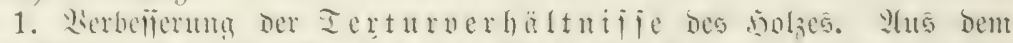

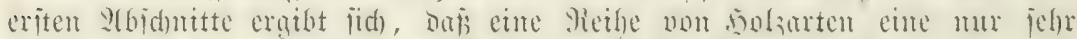

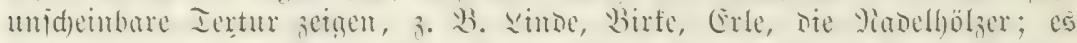

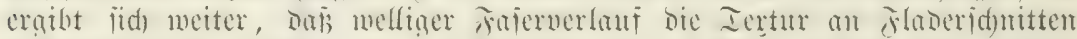

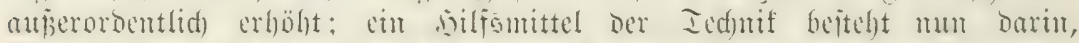

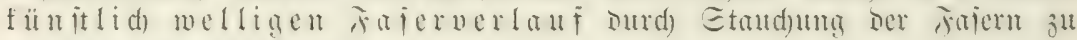
erzielen; fiebe Geite 412.

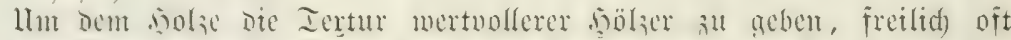

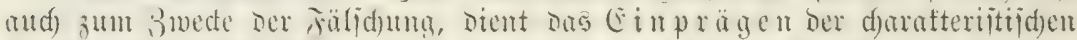

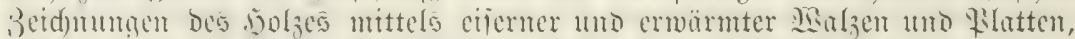

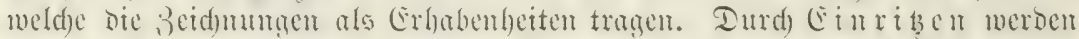

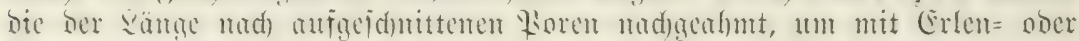

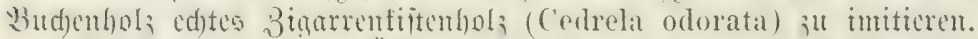

(veht cinte Tärbuna, Elforbenantrid) u. Deral. vorans, fo miro bie ge=

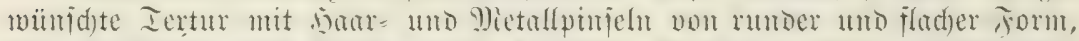

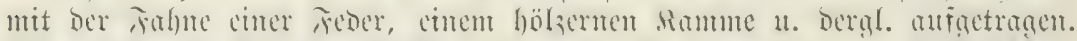

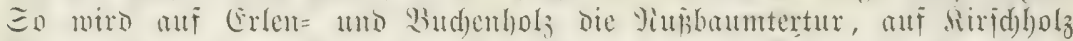

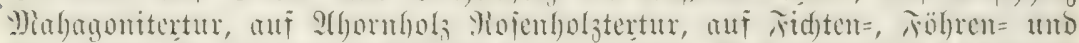

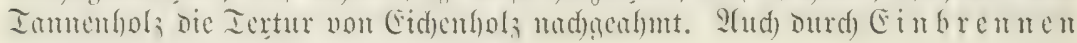
wirb eine fdönere Tertur erzielt.

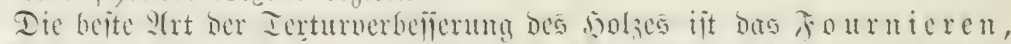

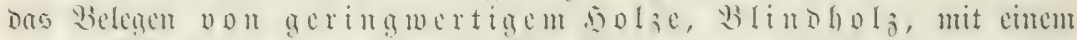

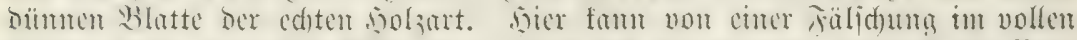

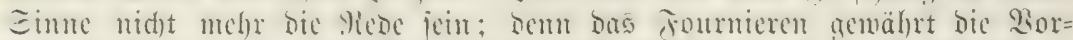

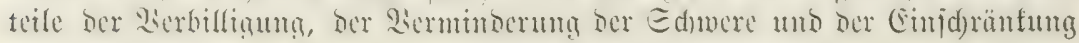

1) 5. E

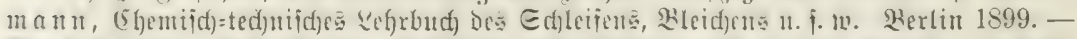

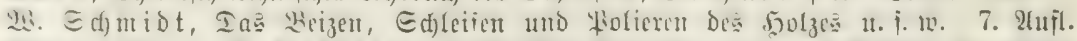

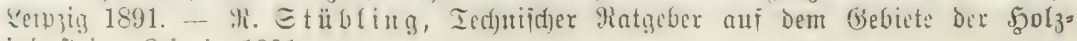
induitrie. Reipzig 1901. 


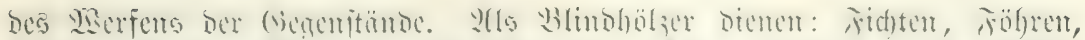

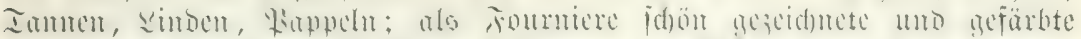

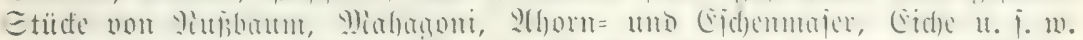

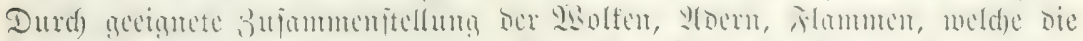

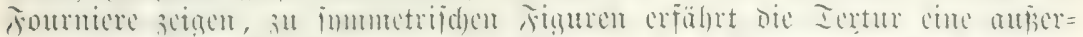

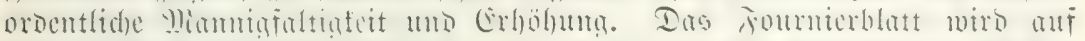

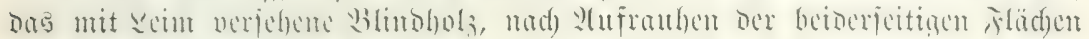
mit bem Epishobel, anfgeprejt.

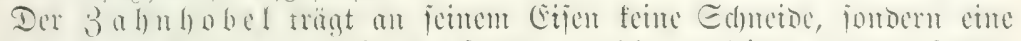

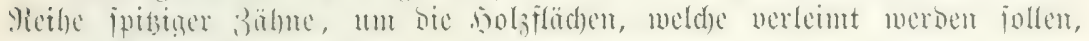
anfatruthen (รourniexe).

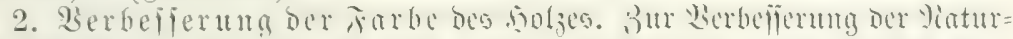

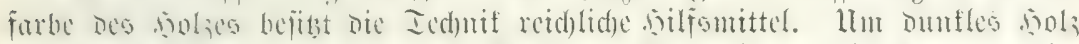

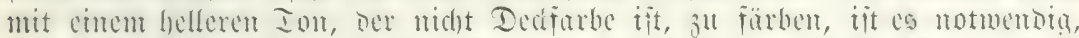

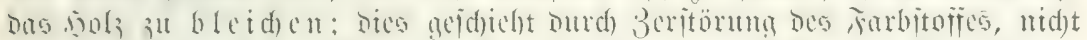

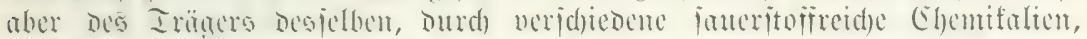

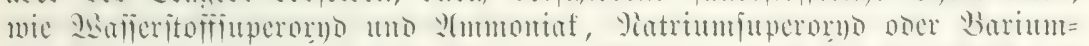

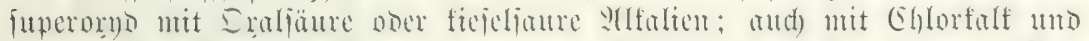

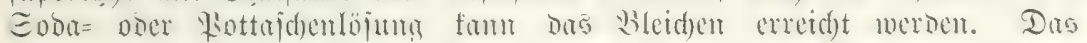

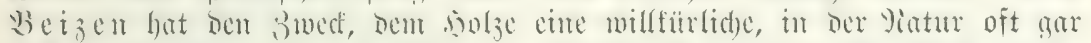

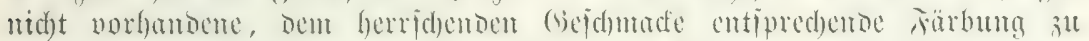

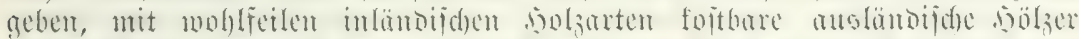

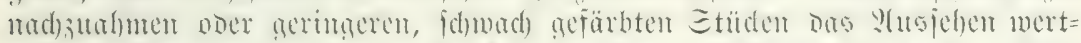

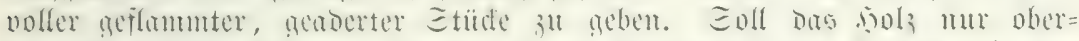

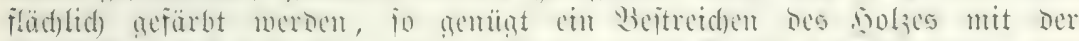

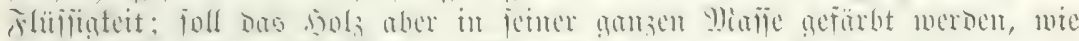

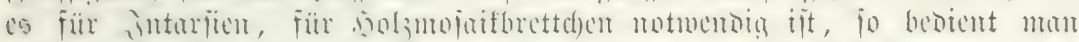

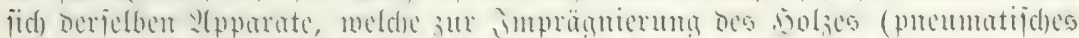

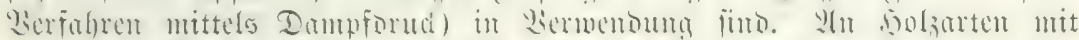

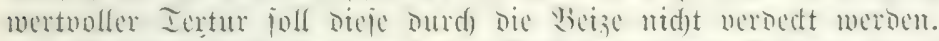

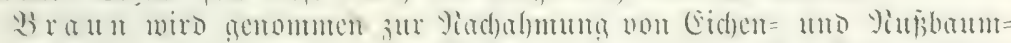

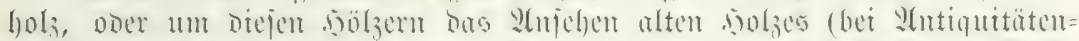

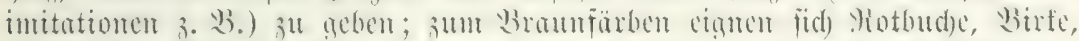

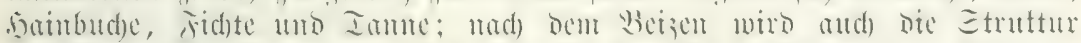

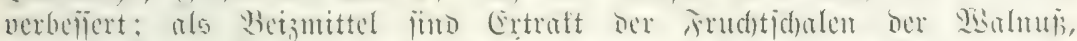

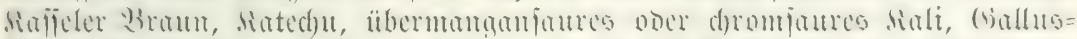

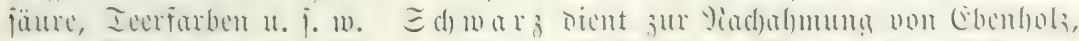
moju

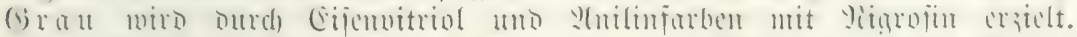

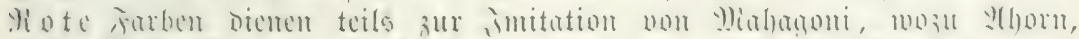

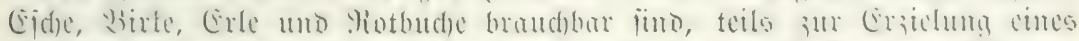

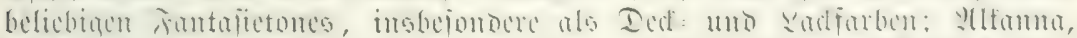

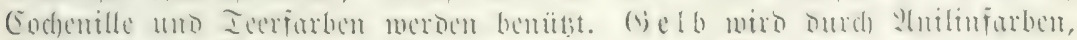

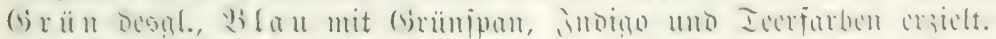

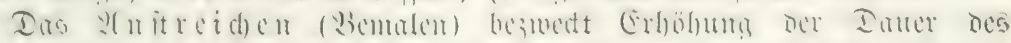

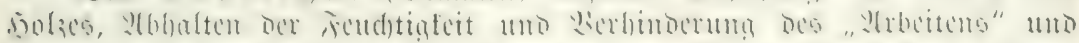

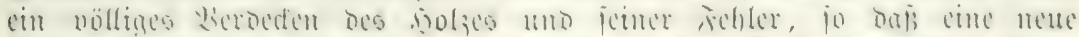

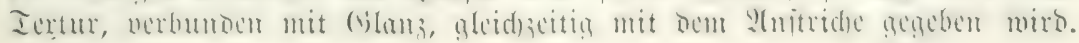


Eoldye Decffarben werben gewomen burd) Bujammenreiben von fialf $=$ umb

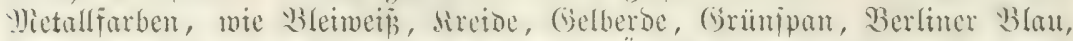

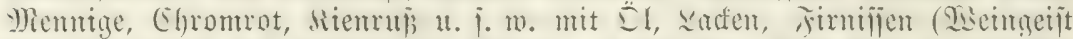

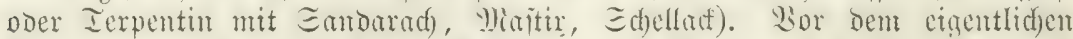

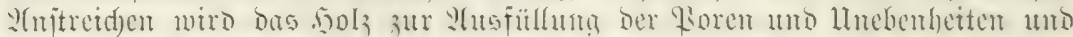

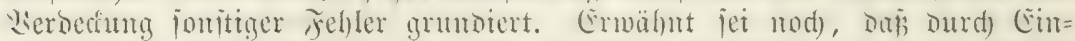

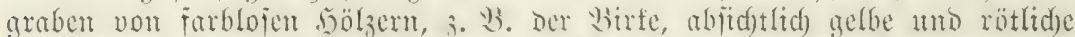

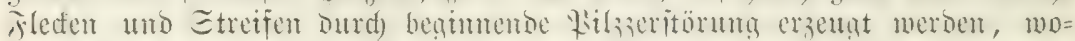
Durd) Das sols in jeiner Fürbunç verbeliert uno für Dredjilererbecten er= meidjt mirb (Japan).

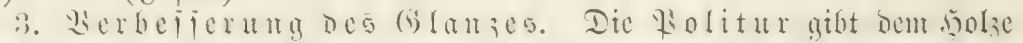

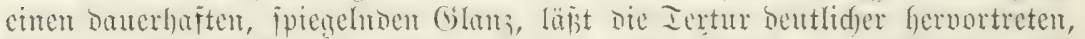

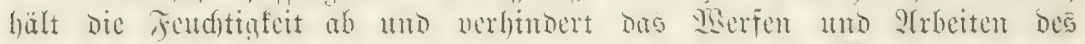

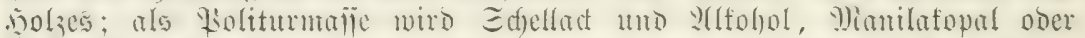

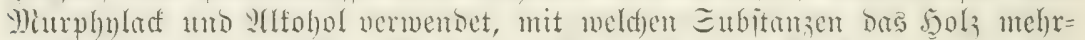

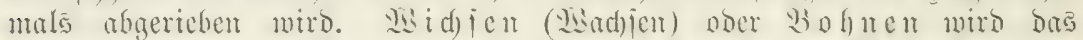

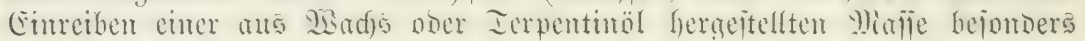
anf Ëidempartettbönen genamt: Das

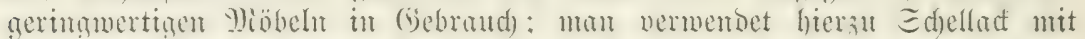

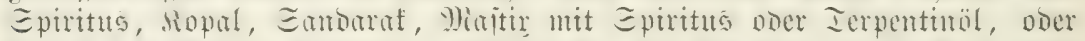

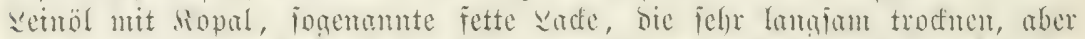

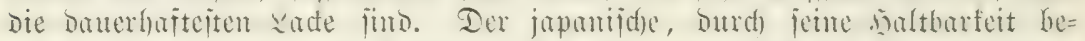

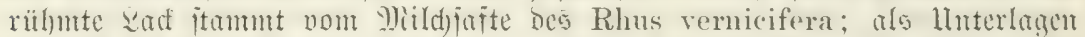
Für bie bejten zactwaten bienen Chamaeryaris und Magnolia-ñölict; für

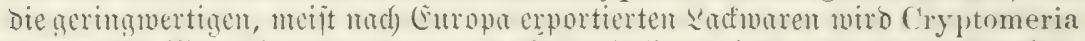

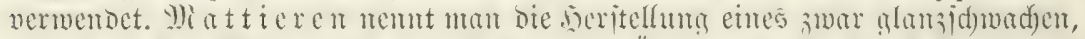

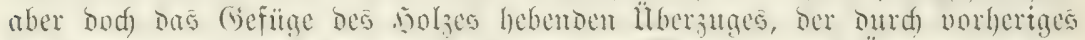

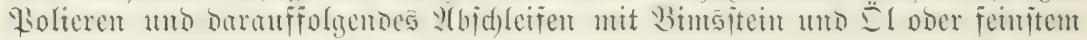
Sandpapier bergeftellt mirb.

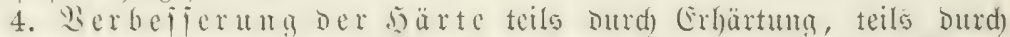

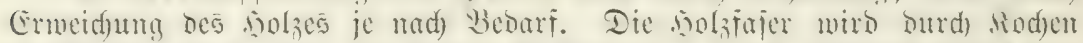

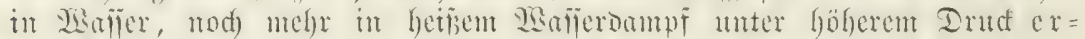

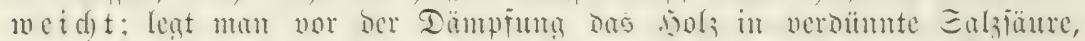

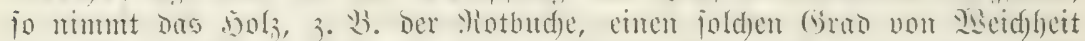

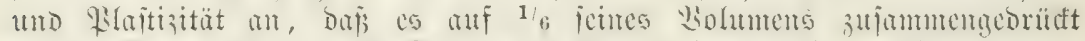

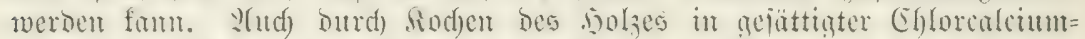

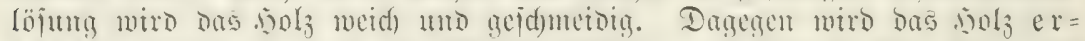

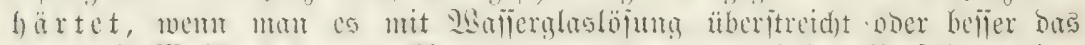

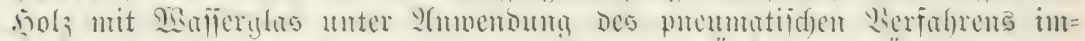

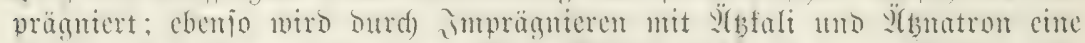

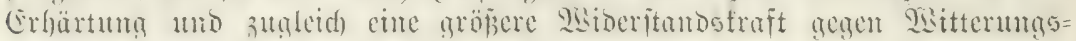
einfliifie erzielt.

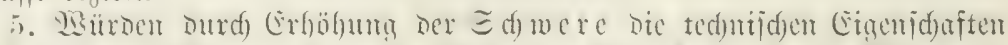

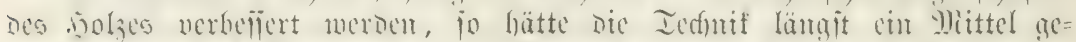

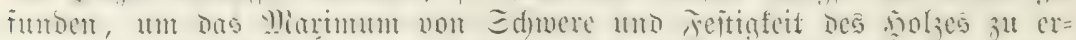

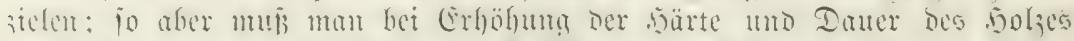

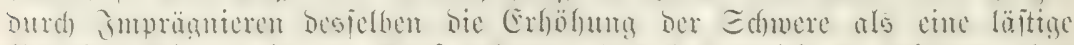

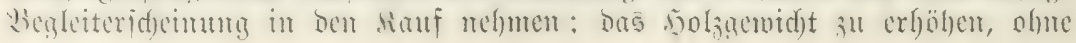




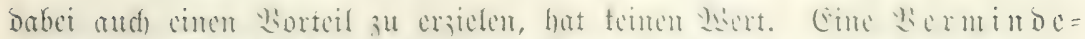

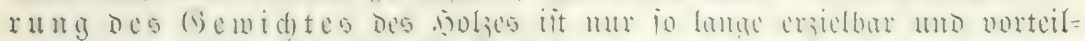

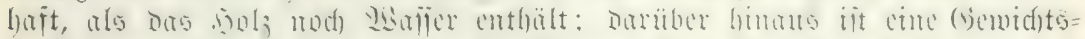

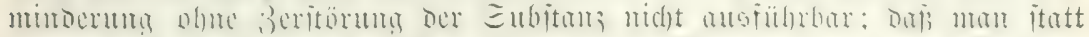

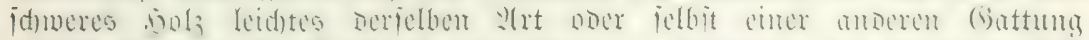

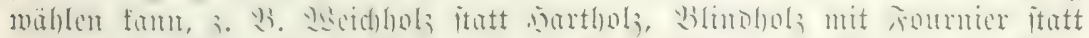

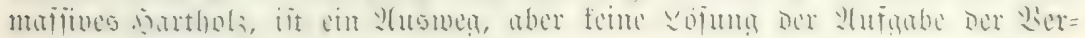
belierung des .jolsgewidjtes.

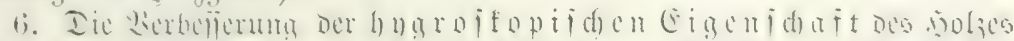

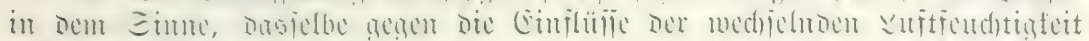

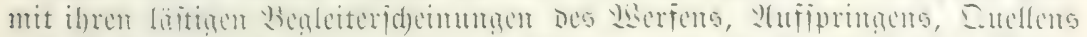

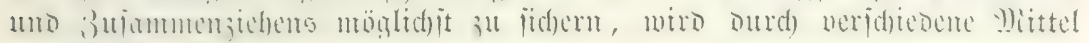
amgeitrebt.

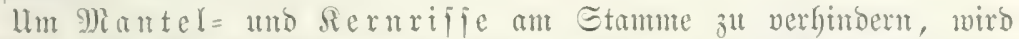

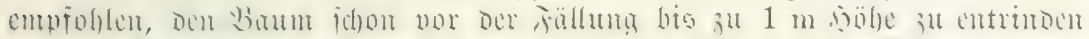

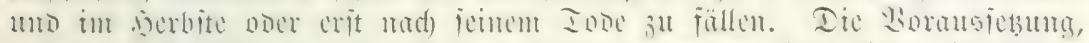

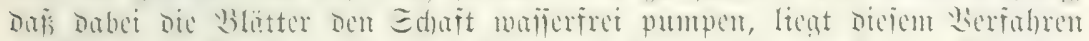

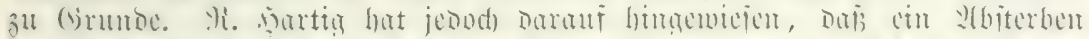

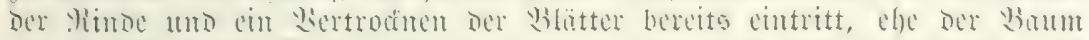

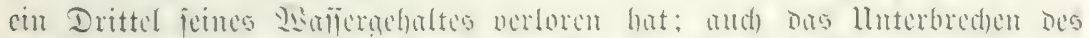

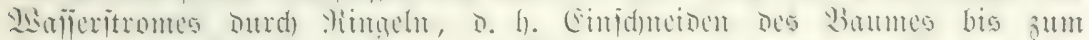

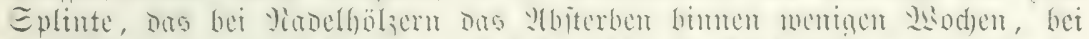

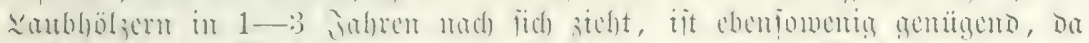

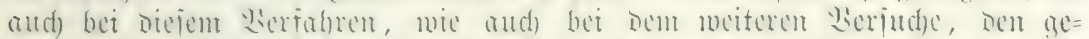

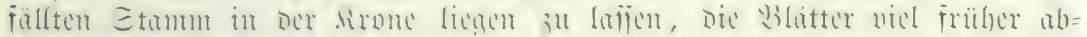

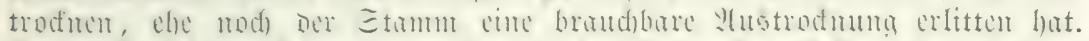

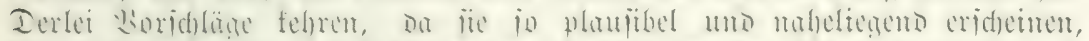

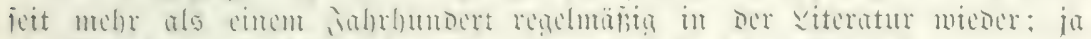

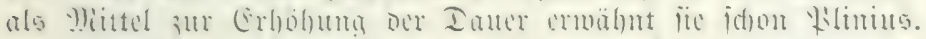

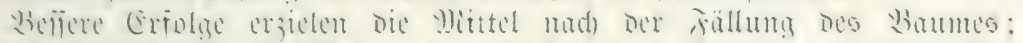

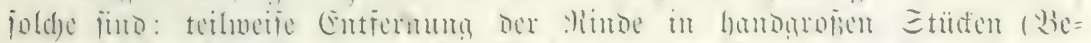

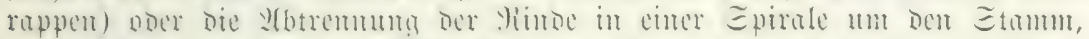

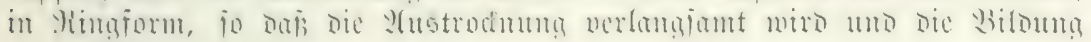
von Mijien unterbleibt.

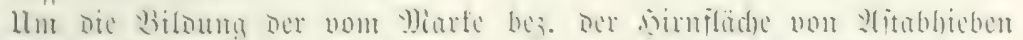

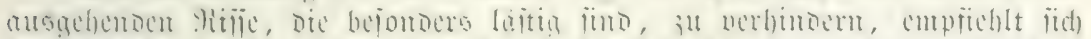

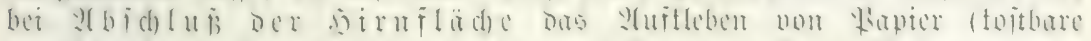

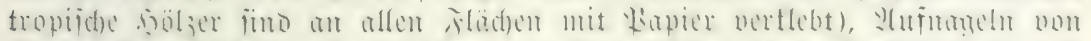

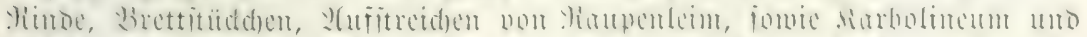

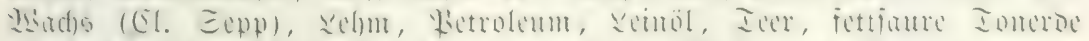

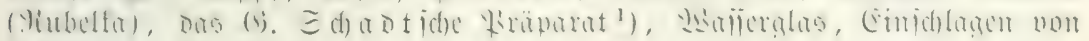
S-förmigen Silammern $1 t$ a.

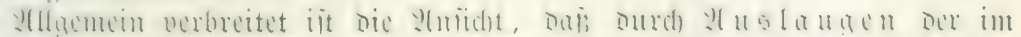

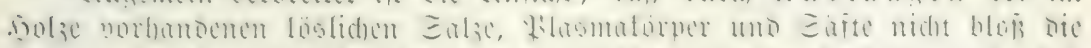

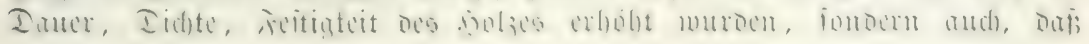

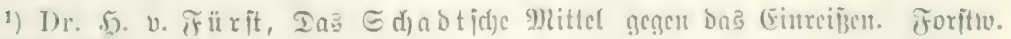
3entralbf. 1899. 


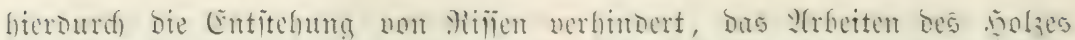

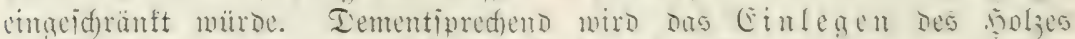

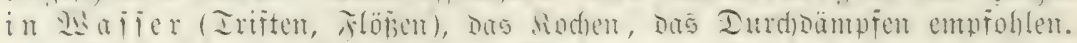

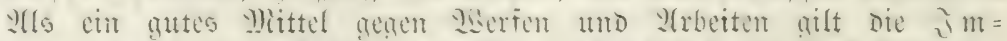

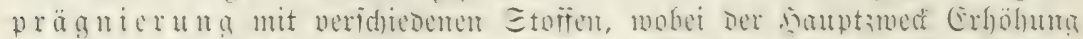

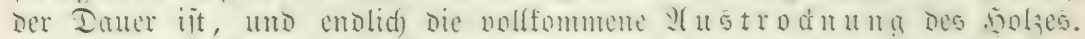

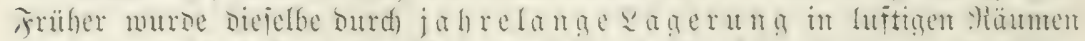

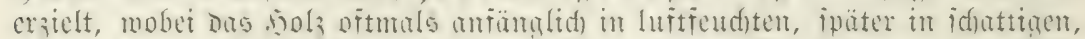

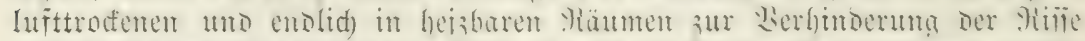

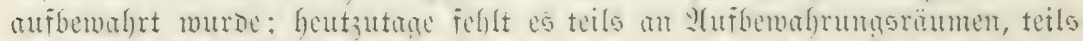

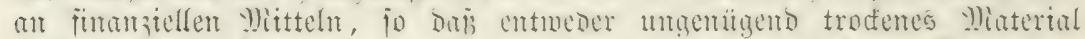

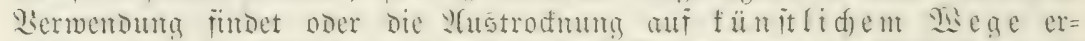

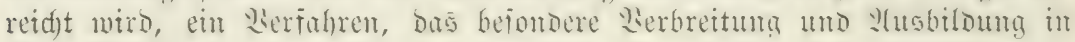
2fmerifa gejumben bat.

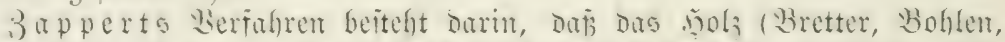

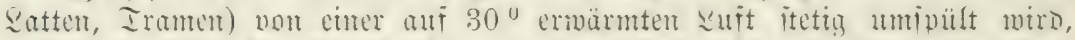

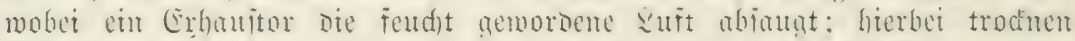

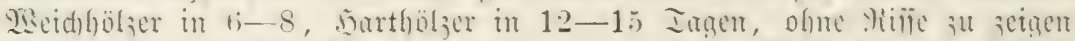

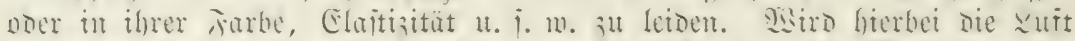

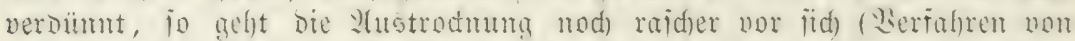

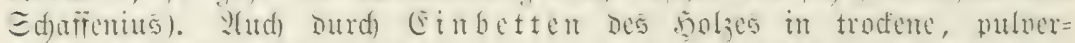

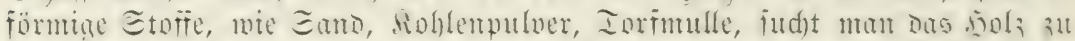

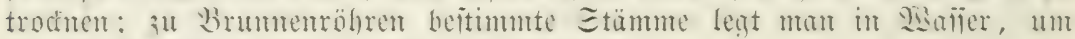

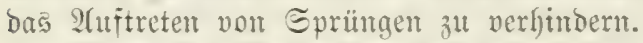

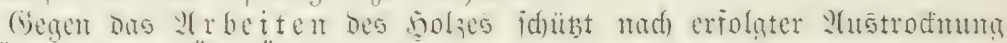

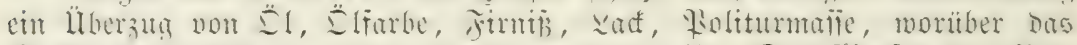

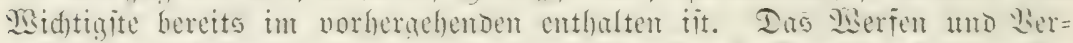

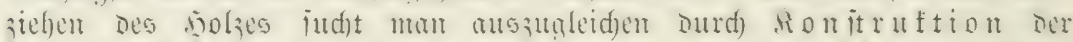

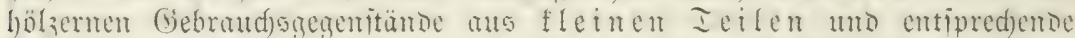

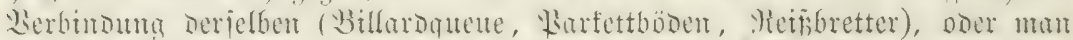

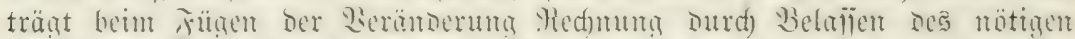

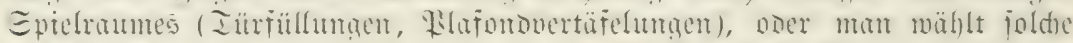

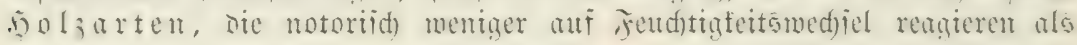
andere.

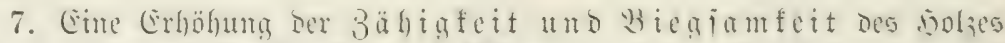

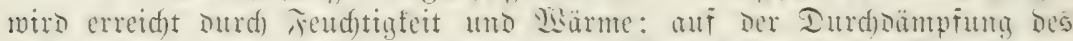

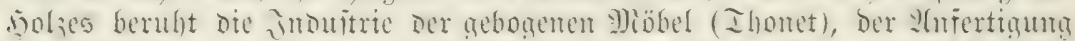

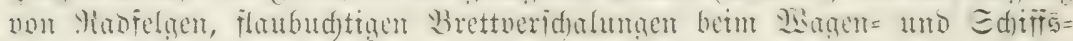
bau u. Dergl.

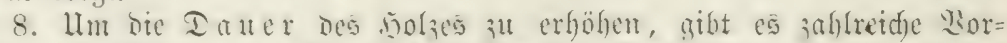

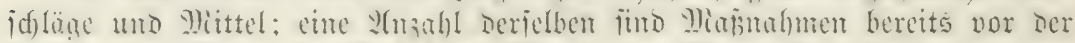

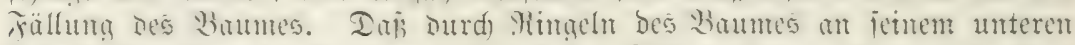

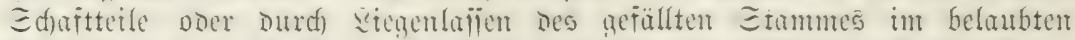

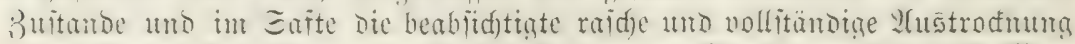

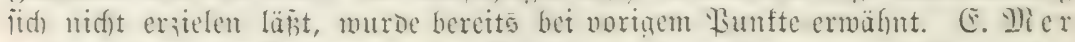
nerlangt mun bie Entformun Der Minne in einem Minge unmittelbar unter

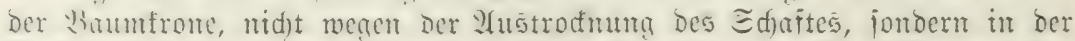

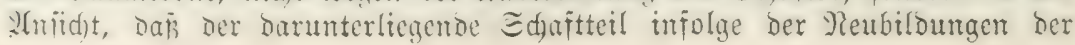




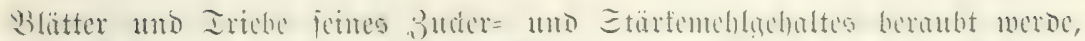

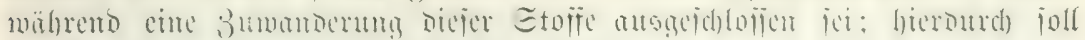
Die Dauer Des Б口olzes fid) wejentlid) exböben.

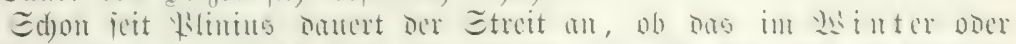

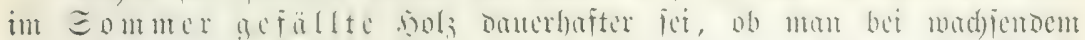

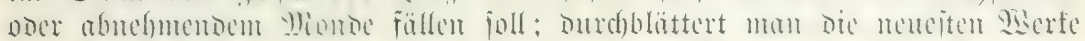

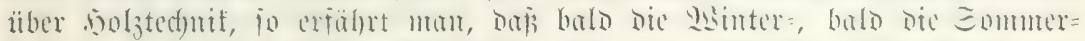

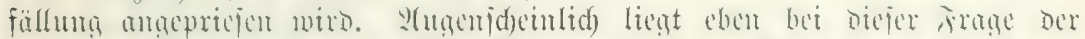

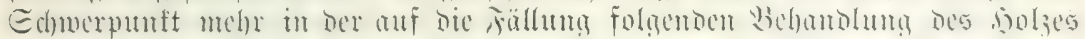

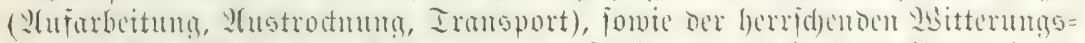

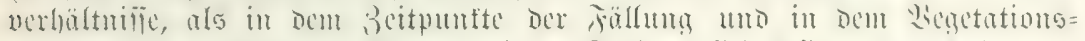

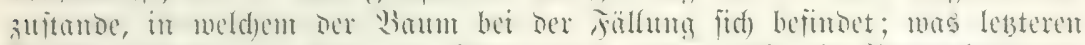

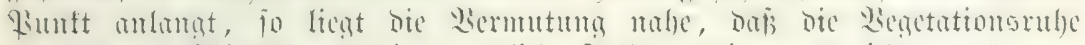

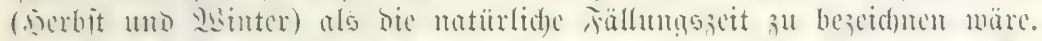

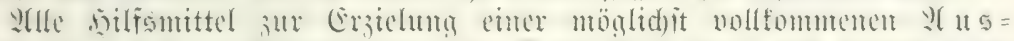

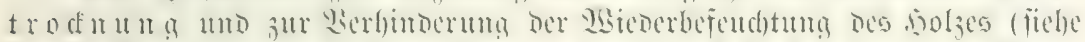

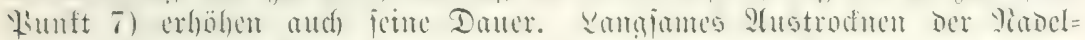

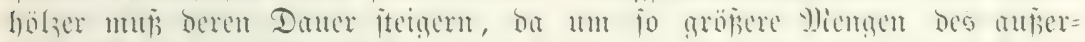

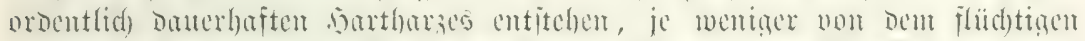

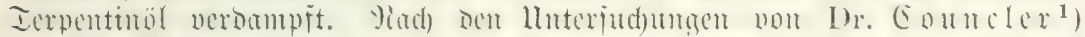

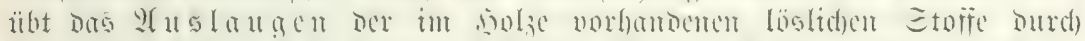

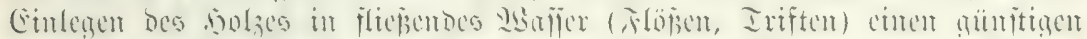

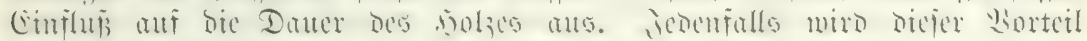

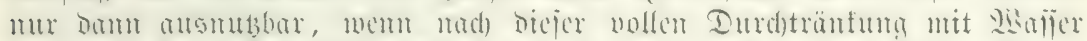

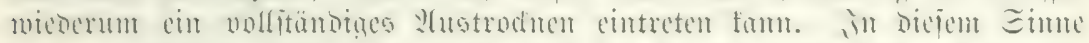

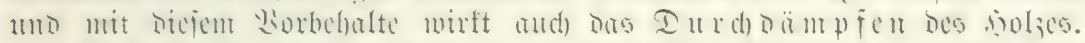

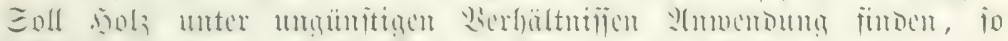
cmpfichlt

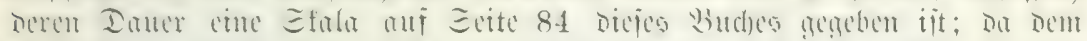

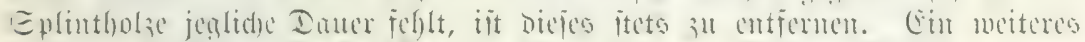

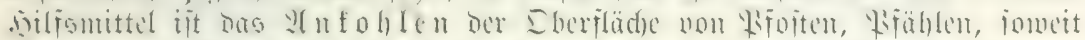

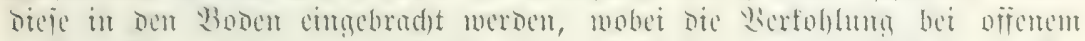

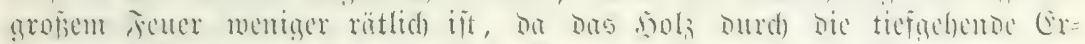

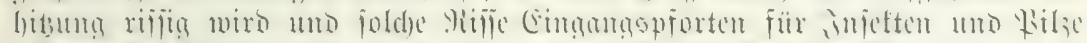

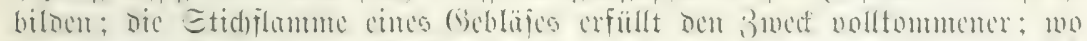

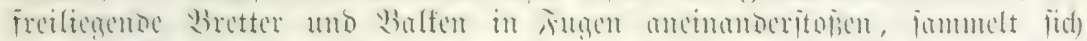

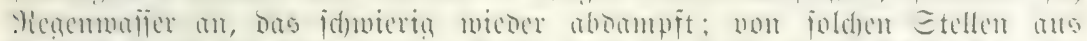

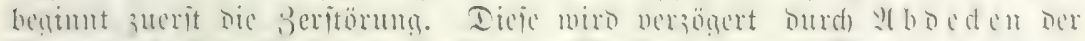

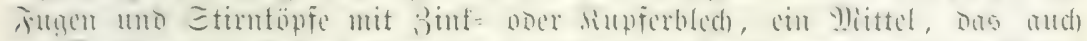

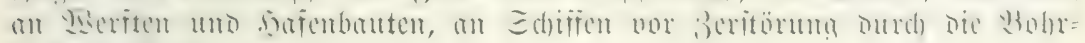
muidjel jưütst.

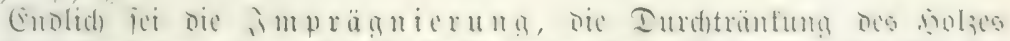

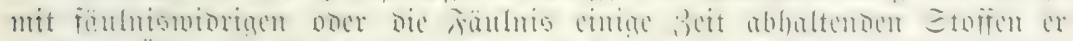

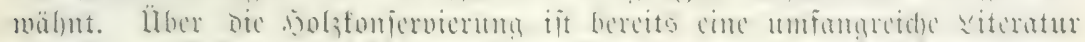

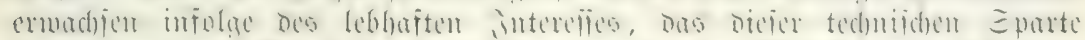

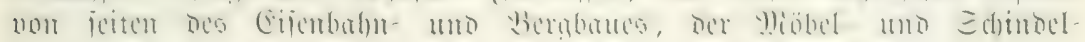

1) Dr. (5оuncler, Mlündener foritt. Sacfte 1897. 


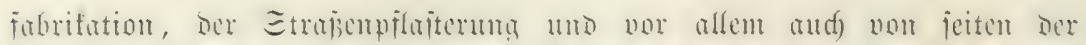

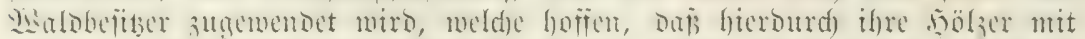

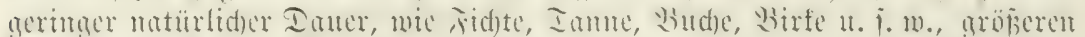

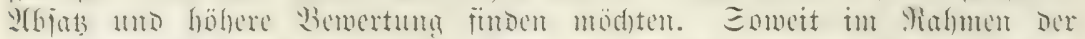

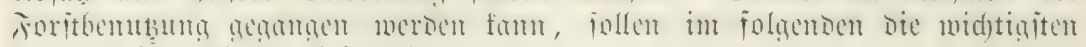
Jmprïgniermethoben beiproden werben.

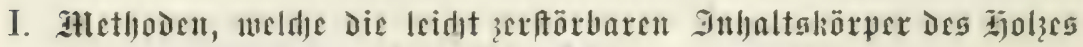

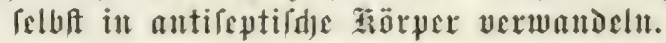

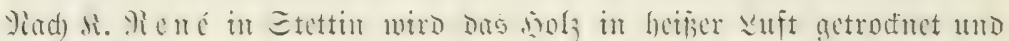

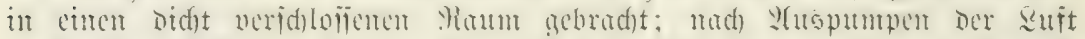

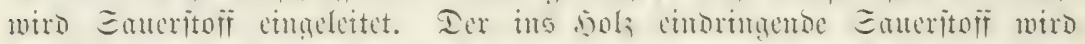

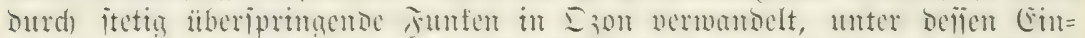
mirfung Die rajd) jeritörbaren Eäfte Des noljes ju Ierpenen und direojoten oribieren.

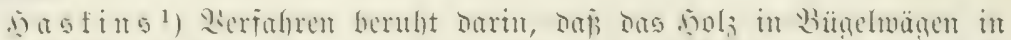

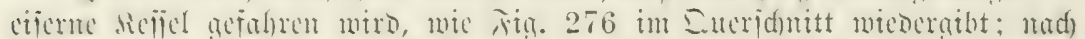

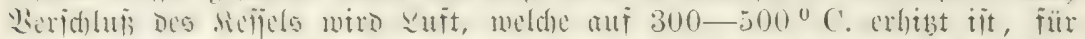

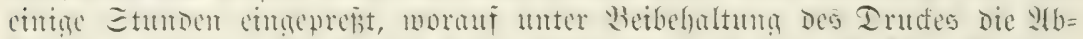

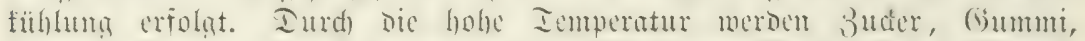

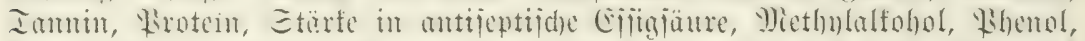

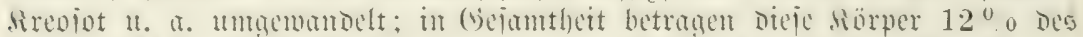

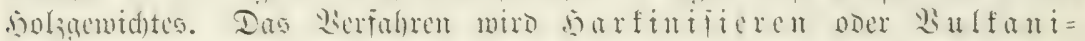
jieren gentunt.

\section{Itlethoden, weldje Meben Dem 3ellfafte aud die iut \$olic vor= bandenen, lögliden, Iridjt icrftörbaren Iuljaltshöruse entfernen und an ilje Stelle ciue antifeptifdıe Subfan briugen.}

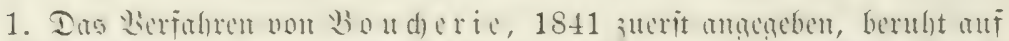

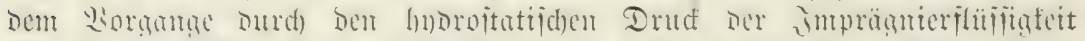

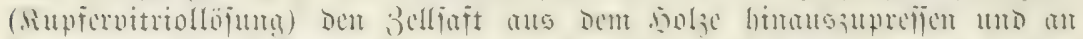

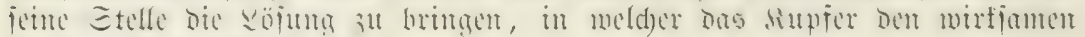
Beitaroteil Daritell.

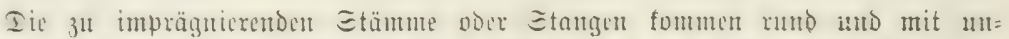

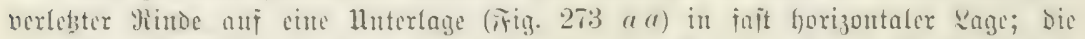

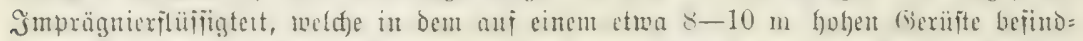

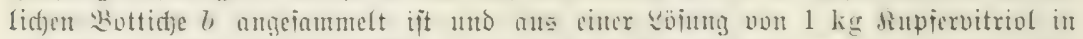

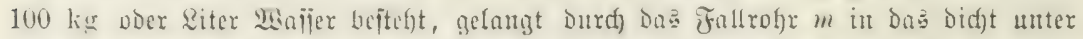

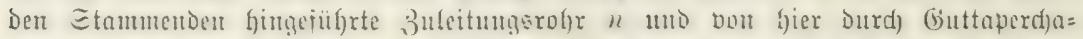

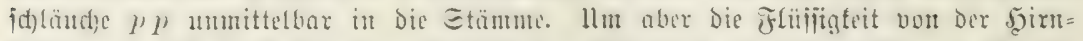

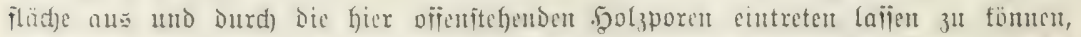

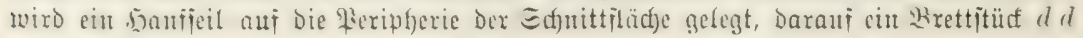

Viad) Grady, Revue des eaux et forêts 1896, gihüht bie firioritüt giner: 


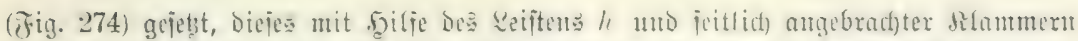

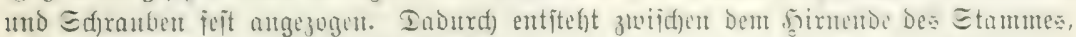

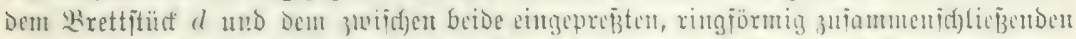

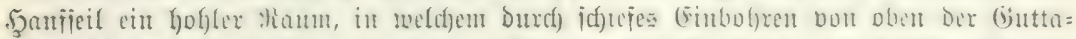

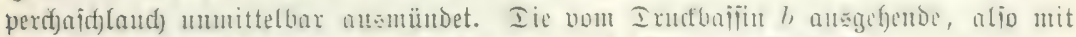

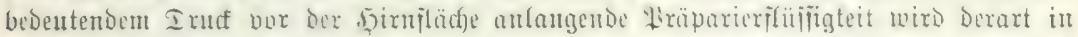

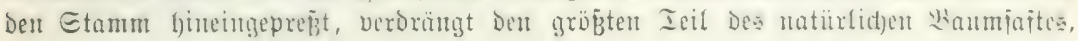

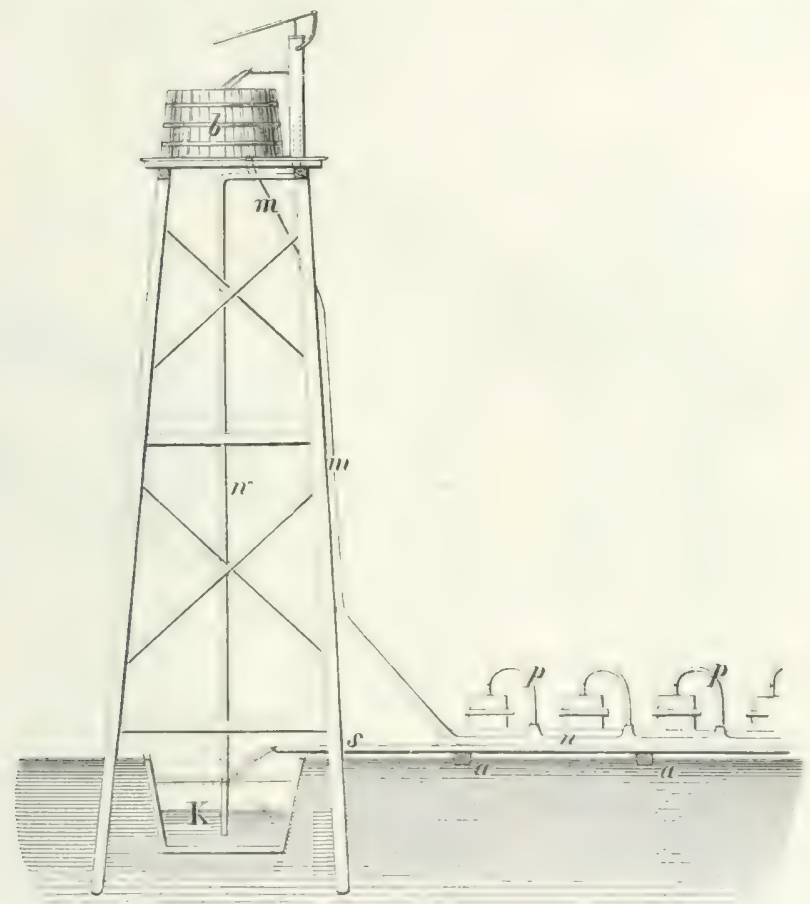

Jig. 273. Jmprägnierung Dutd) hybrojtatiforen Drud nad) Boudjerie.

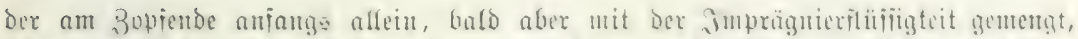

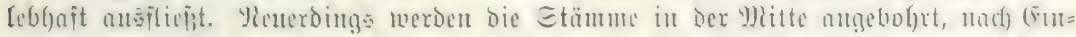

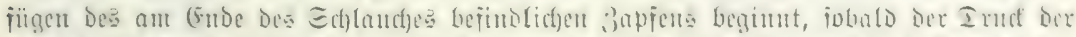

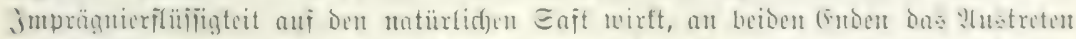

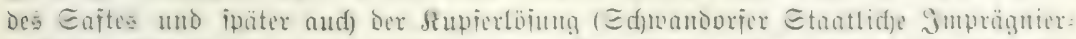

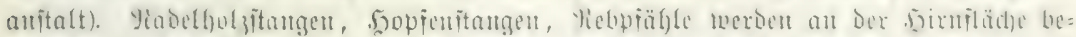

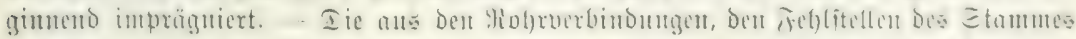

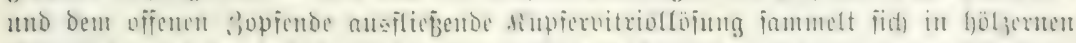

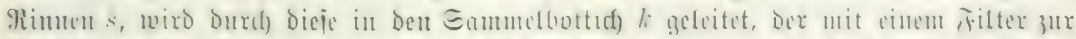

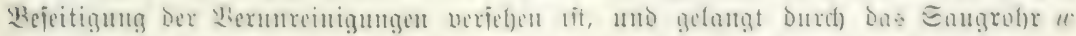

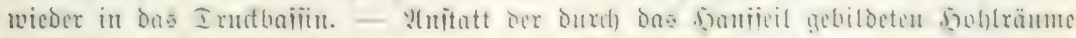

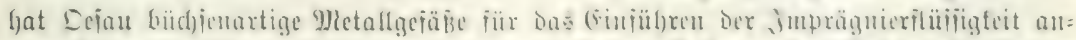

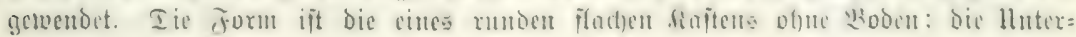




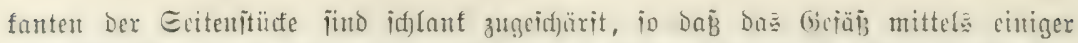

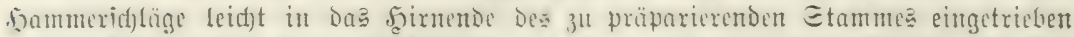

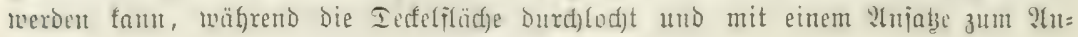

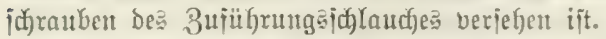

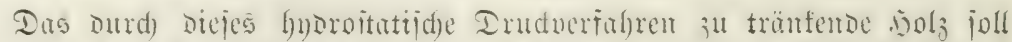

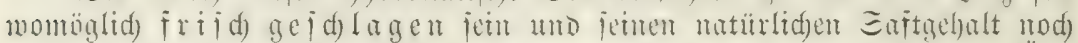

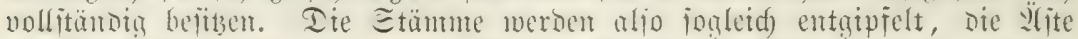

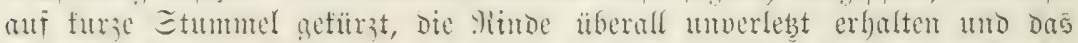

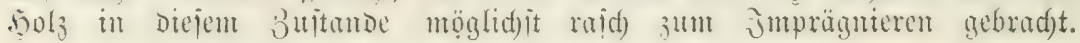

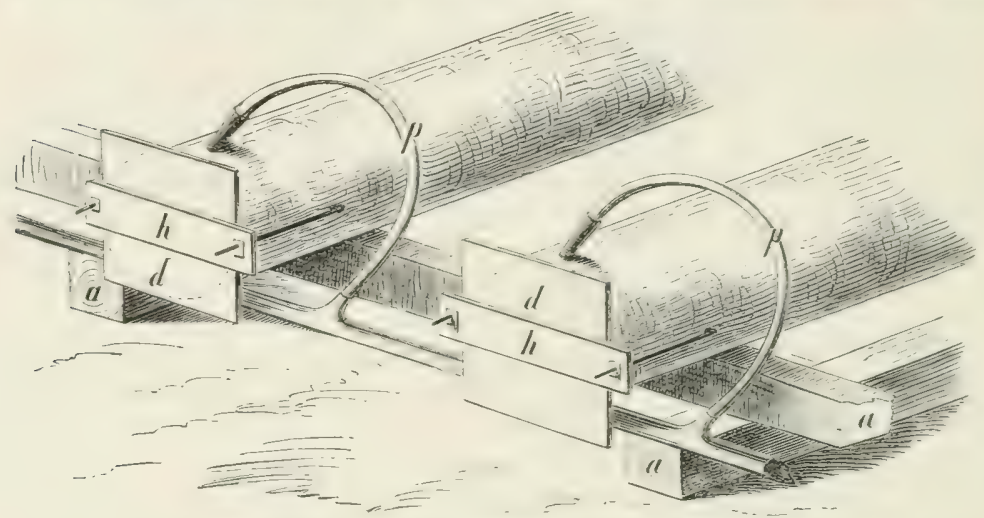

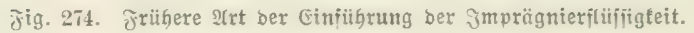

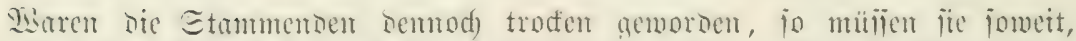

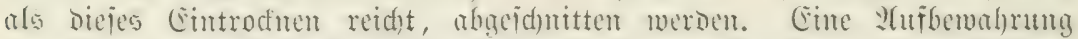

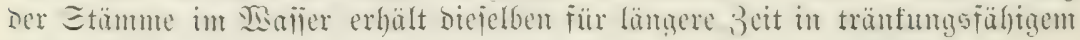
8 intande.

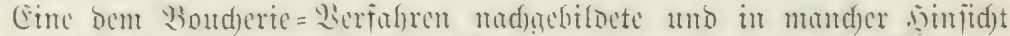
nerbejierte : (pplifationsmethode i

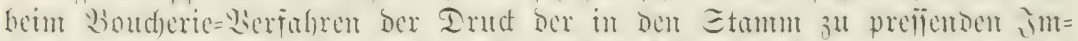

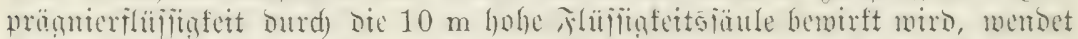

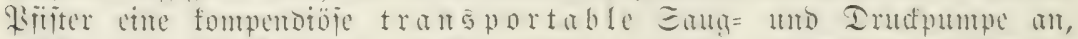

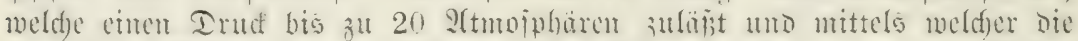

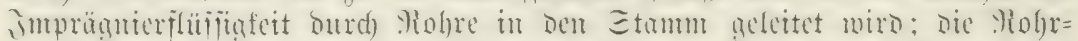

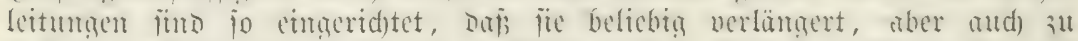

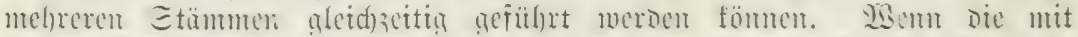

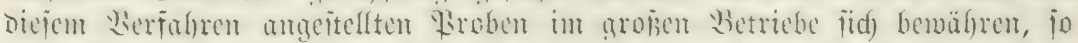

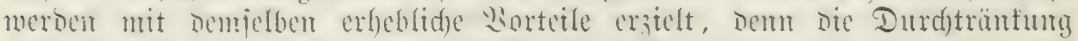

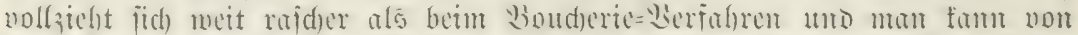

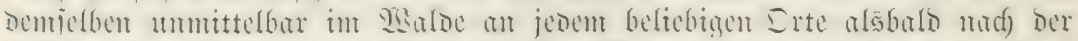

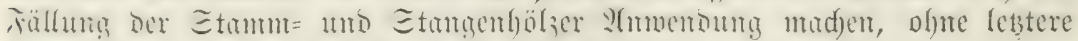

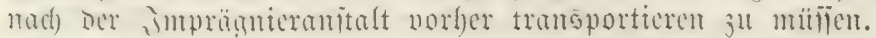

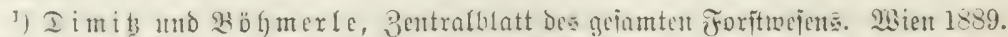

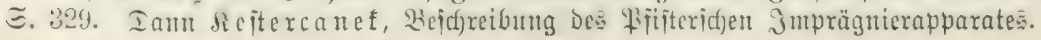




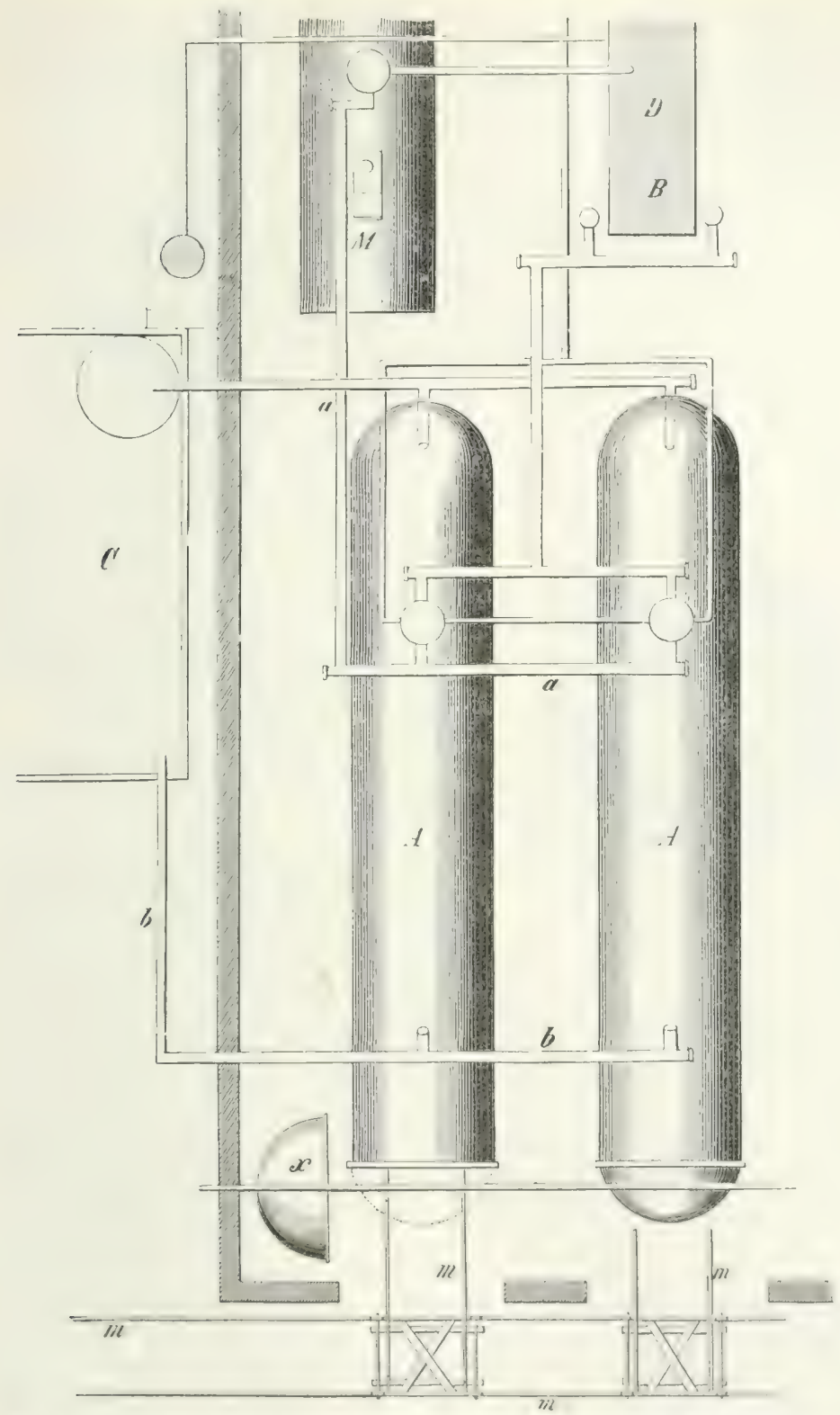

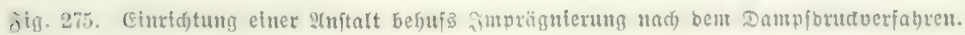

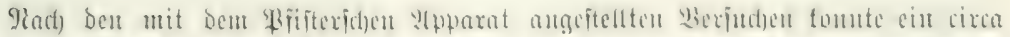

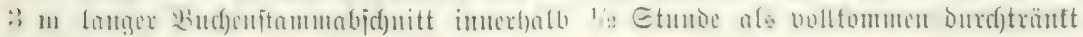


crad)tet werben, Dabei ergab fid), Daßj Stammitüfe mit Rindenverlebung und Q̈iften frinertei f̧indernis für bie Jmprägnierung bieten. Firifter hat audf bem am fopie

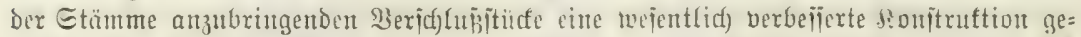

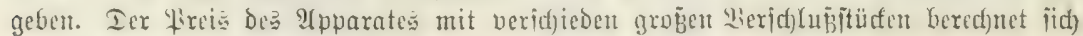
aนT 2000-3000 Grulben D̈. W.

2. Das Dampforud = oder pueumatijde $\mathfrak{B}$ erfalden von

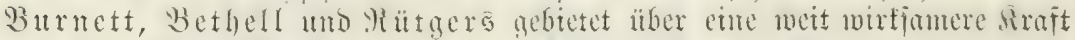
mo über be

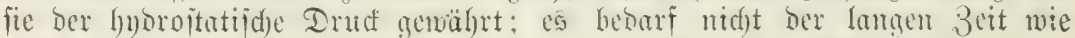

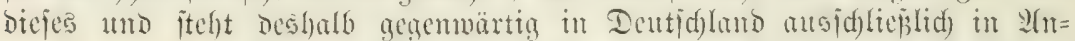

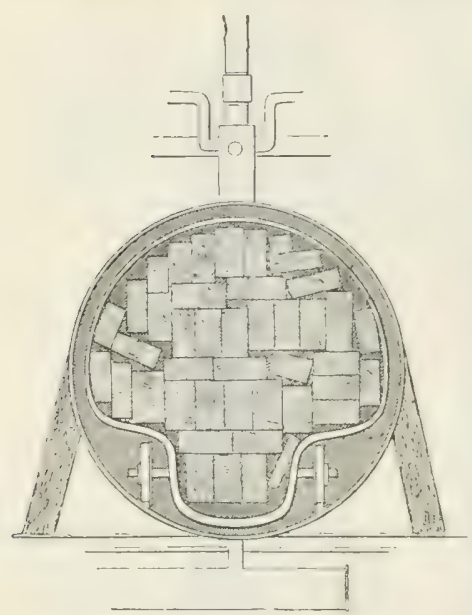

jig. :-76. Eueridnitt outd seliel uno wendung, wem ę jidf um Jujeftion vou Ehlorzinf, Gasteer, 5olzelitgläure, Gijen= orudul u. i. w. Ganbelt.

9Gäbrend bas hubroitatijac Drud= verfalren ben vorber vollitändig be= rimbeten 3ujtand des Solzes vorausjetst, merden die ३u impräguterenden 5eölzer Gier für die Serwendung fertig z ubereitet, aljo vierfartig abgefläd)t, die $3 a b n j$ brwellen ridytig abgelängt und zugerid)tet u. 1. m. in gropen Rejieln ber Bräparierfluffigfeit aţgejest, die mit jtarfen Dampiorud bei einer Iemperatur von $50-90^{\circ}$ C. in Das 5ूolz eirt= geprefst wirb.

Die zu präparierenben ร̧ölzer werden jo Dicht als möglich) auf bie Magen geladen (Fig. 276) und auf Den Bakngeleifen (Fig. $275 \mathrm{~mm}$ ) in Die Aefiel (A.A) eingefütrt. Eind Die Selfel Derart volftänoig gefüllt, fo twerden bie in bie= ielben fïfrenden Edjicnenbahnen unterbrod)en, Der fiejielfopi $(x)$ vorgerollt uno ser ficjel

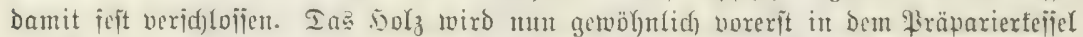
Der $\mathfrak{I}$ ämpi

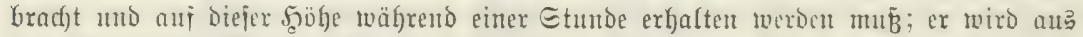

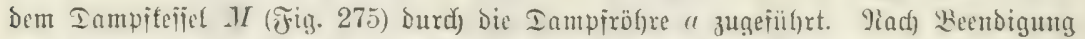

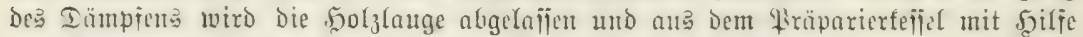

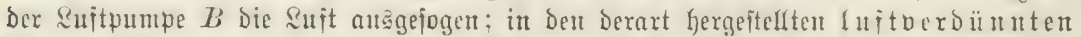

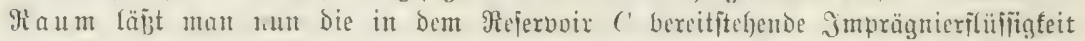

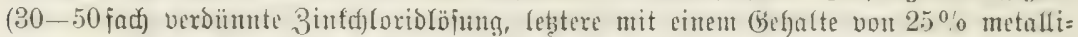

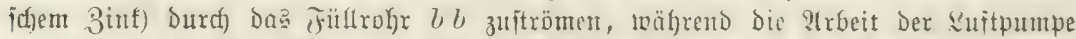

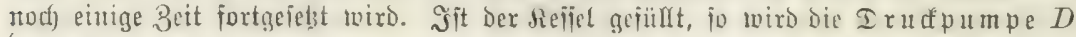

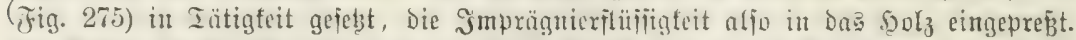
Die arbeit der Druffumpe wiro mit cinem Irufe vou circa 6 2tmophären mährend

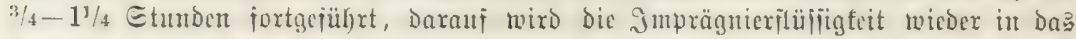

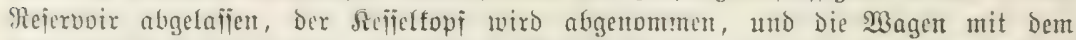

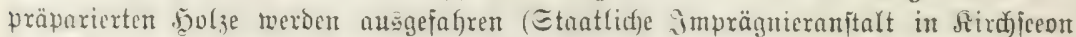
bei $\mathfrak{M}$ (ünḋenen). 


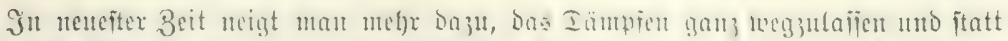

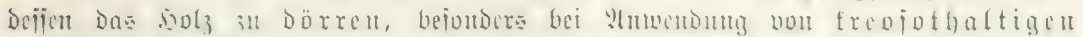

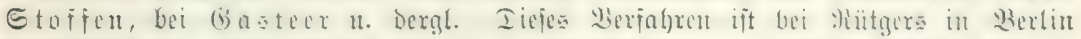

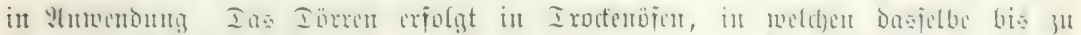

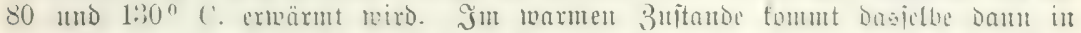

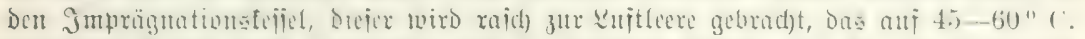

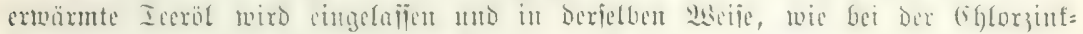

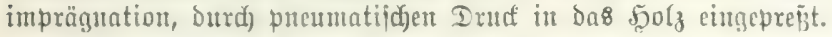

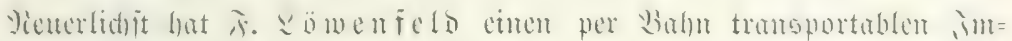

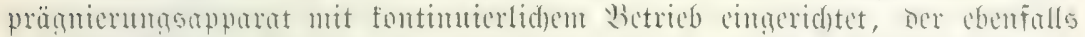

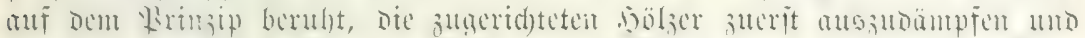

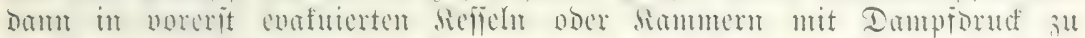

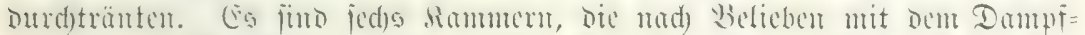

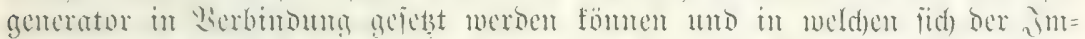

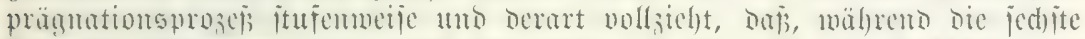

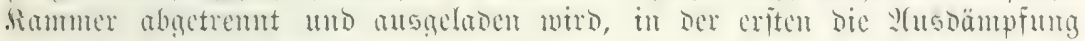
vor fidf) gebt u. ¡. m.

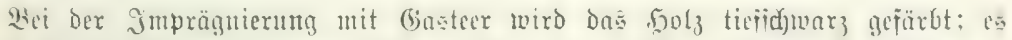

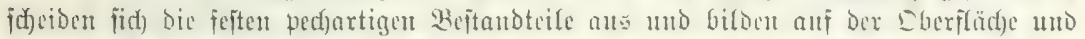

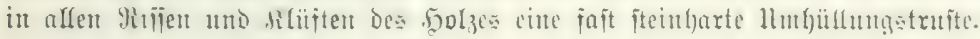

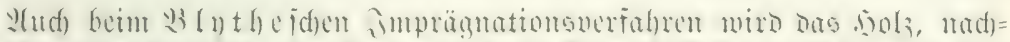

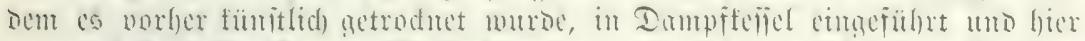
comen hohen Drut nom

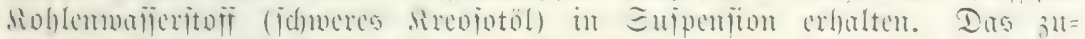

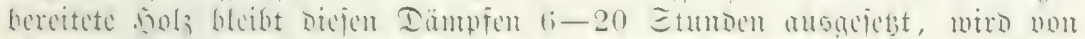

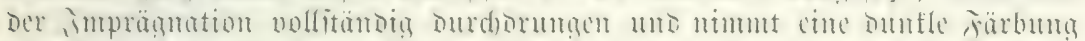

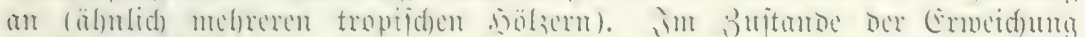

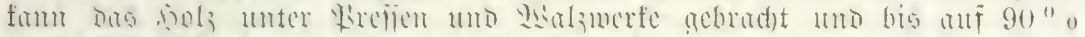

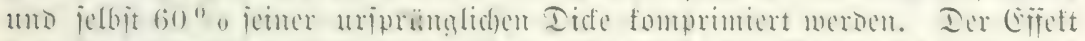

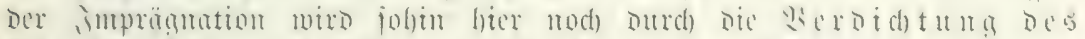

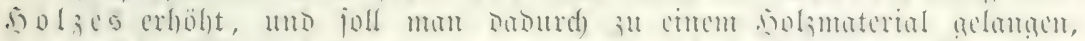

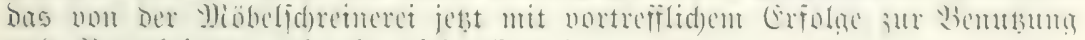
แnd Werarbeitung gebrad)t mird (Ermer).

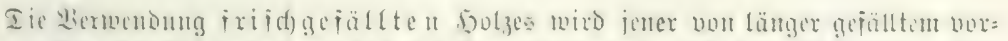

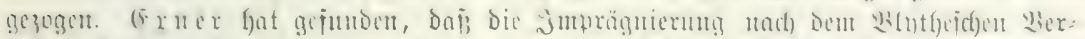

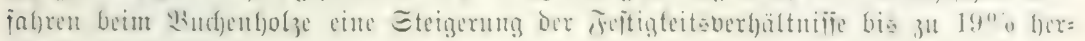
beiiüifren fam.

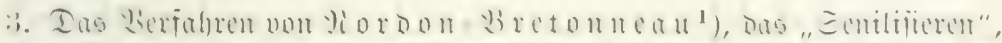

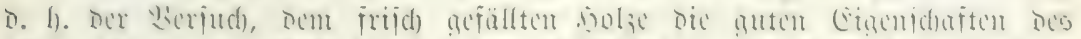

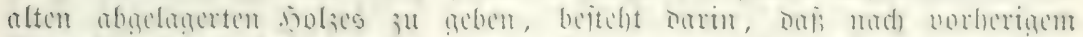

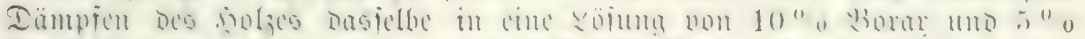

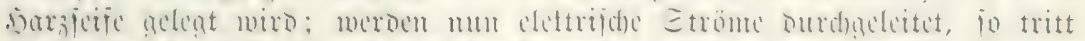

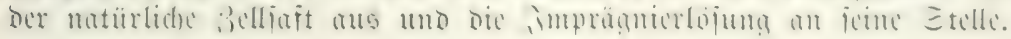

1) D̈iterreidjijdye Foritzcitung 1899. 


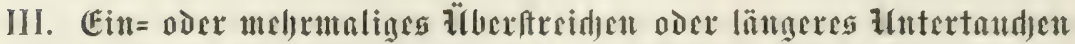

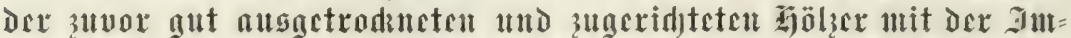 prägnicrflüfrakcit; als lobtere lomut in Anwendung: Rreolot,

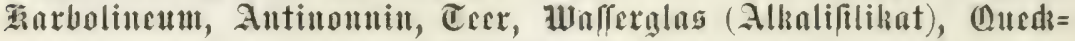 fillucrdjlorid.}

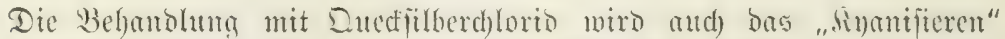

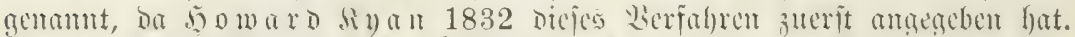

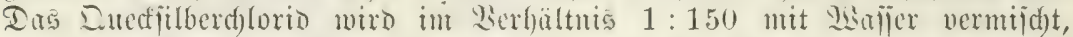

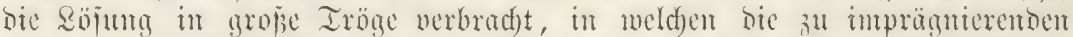
Ed)wellen, Bifähle, Idlegraphentangen n. 1. w. bis 10 Iage untergetandyt

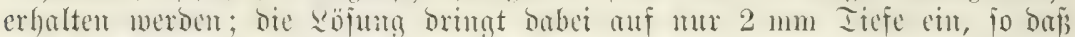

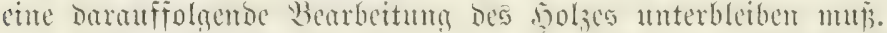

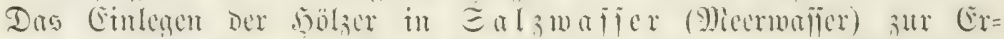

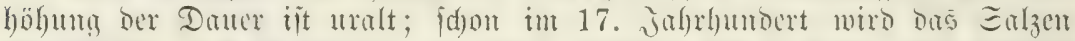

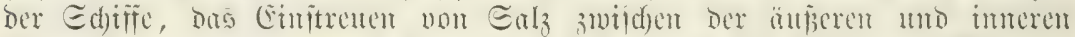

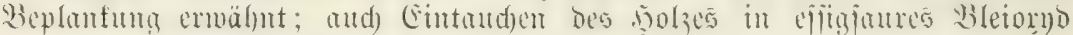
oder Eijenoryd jei ermähnt.

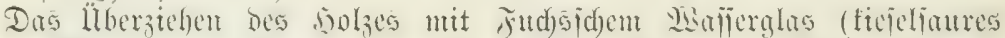

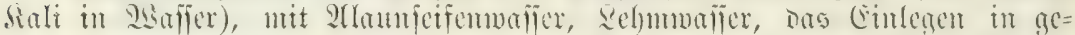

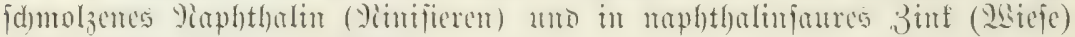
erzielt ebenfalla eirige Eriolge.

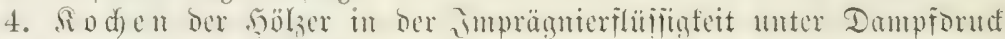

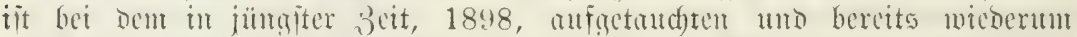

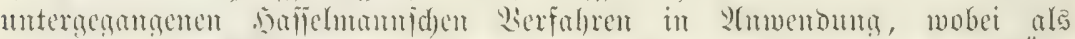

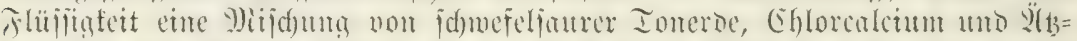

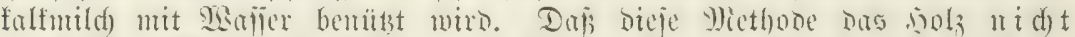

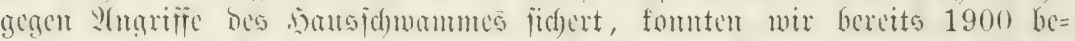

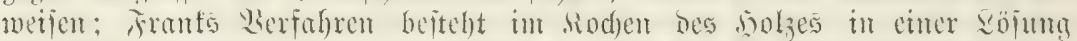

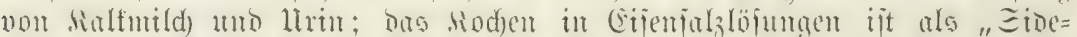

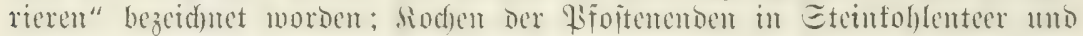
Seitreuen mit Eand empfichlt Siubelfa.

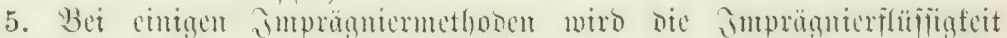

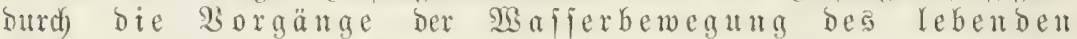

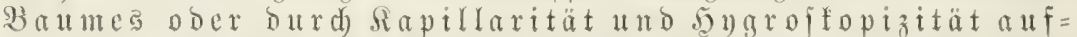

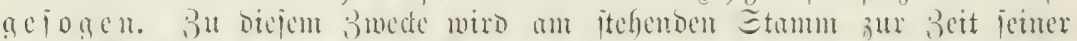

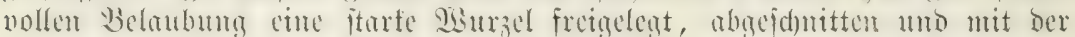

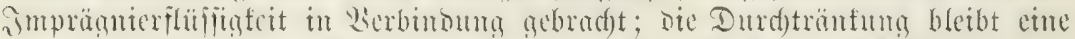

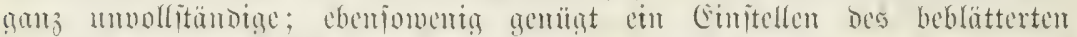

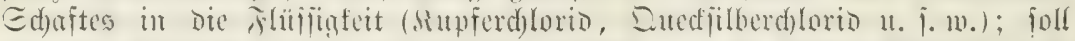

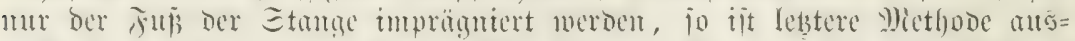

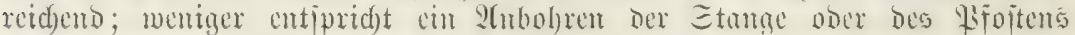
uno Cingießen ber Fliiffitgleit.

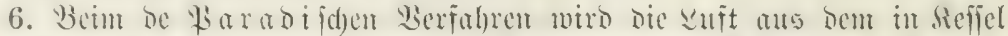
gefarbrenen bolze atsogepumpt, woratf $D$ ämpfe non Sireojot und Siarbol=

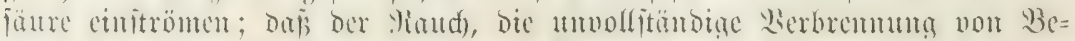

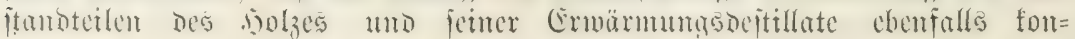




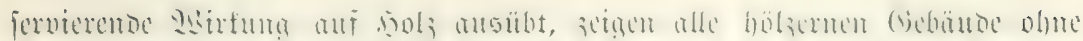

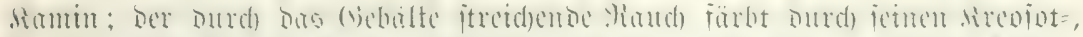

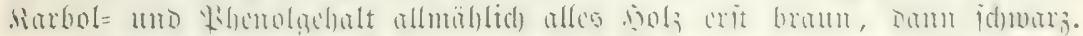

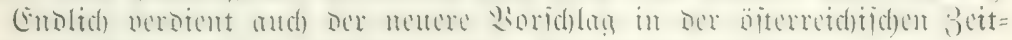
id)rift für Joorit = แno Jagowefen, 1896, Wead)tumg, woutud)

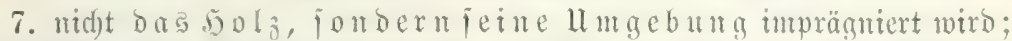

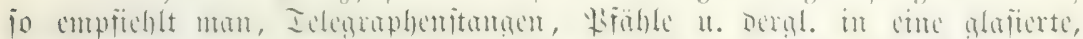

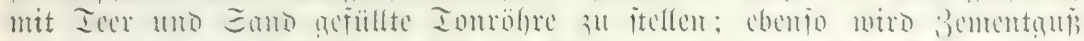

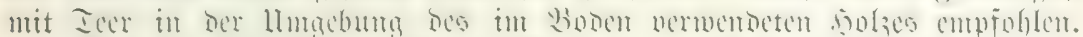

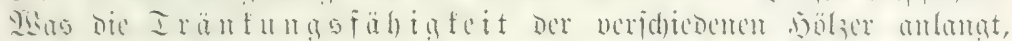

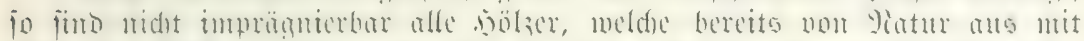

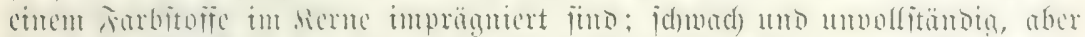

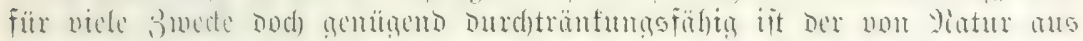

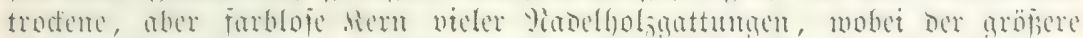

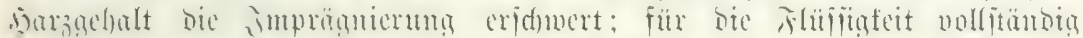

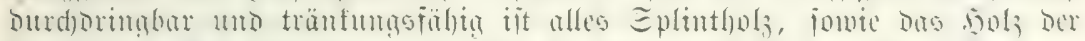

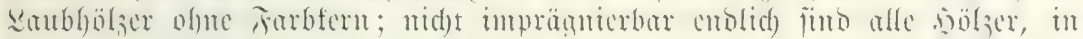

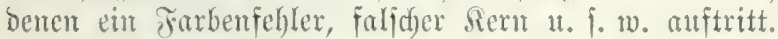

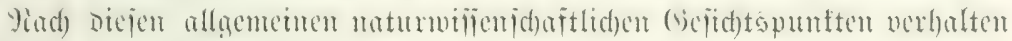
fich bie 5olzarten, wie folgt:

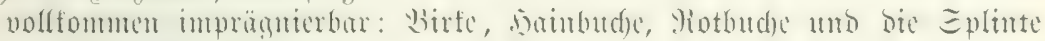
jäntlidjex solzarten ;

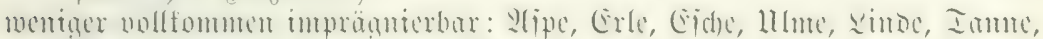
Jidyte, Föhre, İenmoutheföhre;

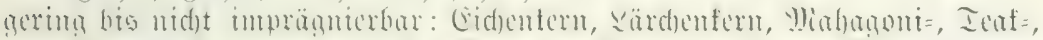

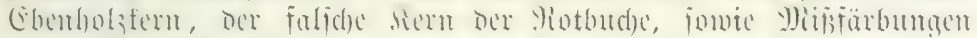
aller 2let im bolze.

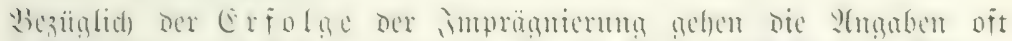

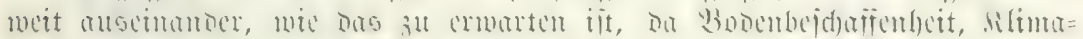

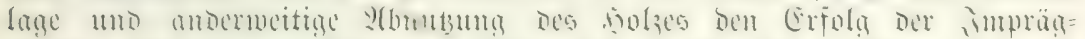

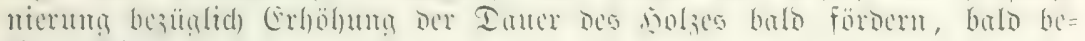
einträd)tigent.

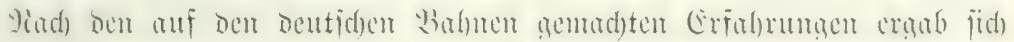
folgendes, $\left.{ }^{1}\right)$ :

Binfd loris und Dampforud

(Eid)enid)mellen, Durd)jdynittlidye Dauer

Riefernjofruellen,

Budjentdumelfen,

8 inf d) L o r i D burd) Eintulidjen

Fidjtenjd)wellen, Durd)juduttlidje Dauer $\quad 6,6$

$19-25$ Jabre

22,8

$13-15$

Sixeojot mit Dampforud

Eidjenidfuelfen, Durd)jduttlidfe Dauer

19,5

Zud)enj(f)rellen,

18,0

Si p fervitriol, eimgeprebt

Sitefernjduvellen, butdjodntttlide Dauct 16,0

1) Drgan fïr Dic Fortid̄)ritte Dę (Fifenbahnuejent. 1880. 
Si p pervitriol, gejotten

Sitefernidyellen, burdff(d)ittlide Dauter 14,0 Jabre

Rupfervitriol, burd) Entautden

Riefermidyellen, burdjidnuttlidje Daner 13,9

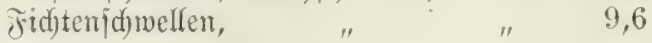

Padi) anderen $9(n g a b e n$ maren

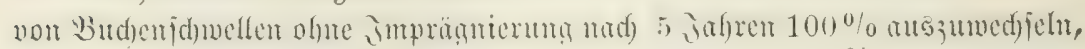

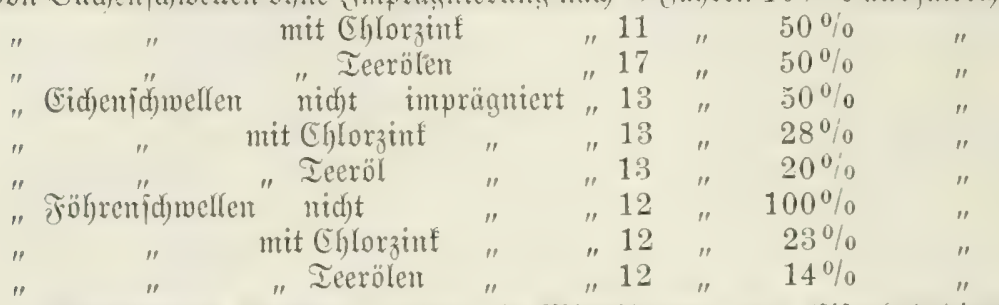

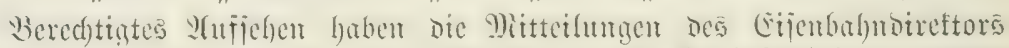

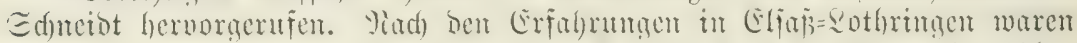

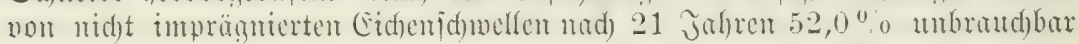
mit Ieeröl

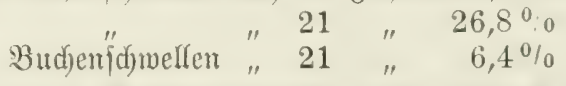

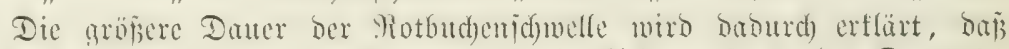

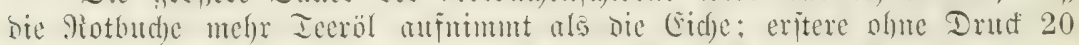

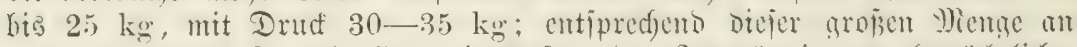

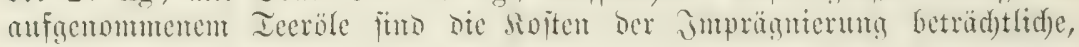
nämlid):

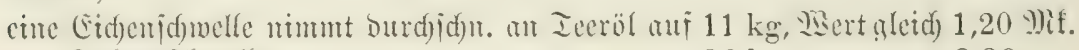

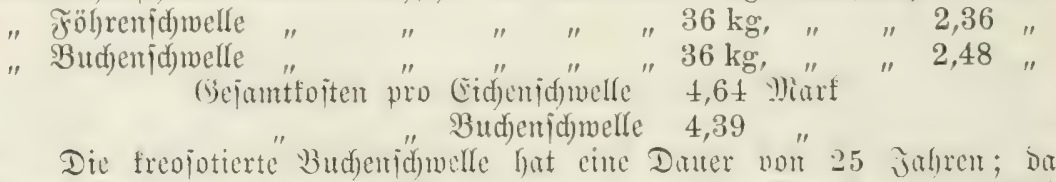

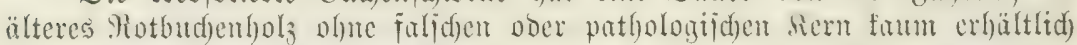

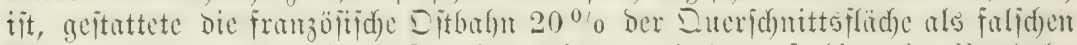

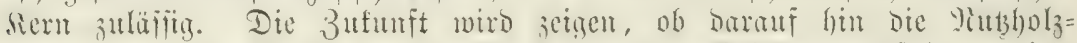

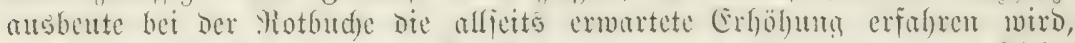

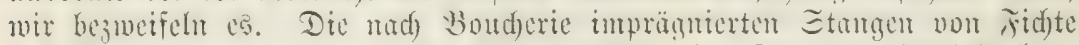

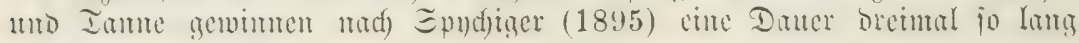
als bie ratürlidse.

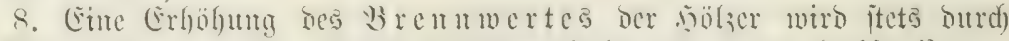

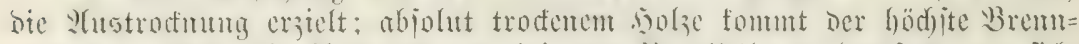

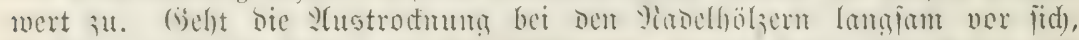

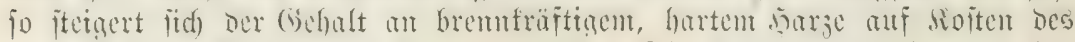

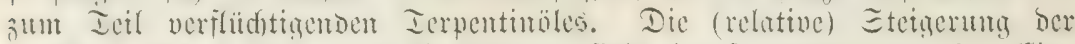

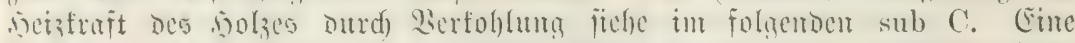

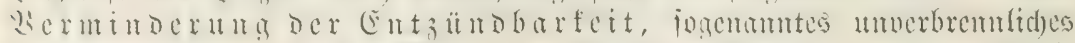

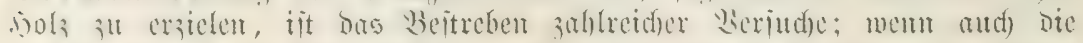

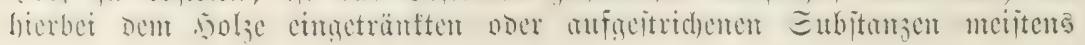




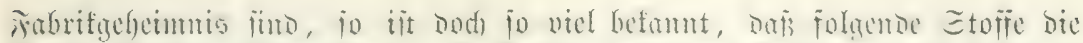

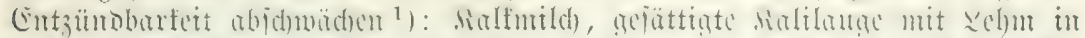

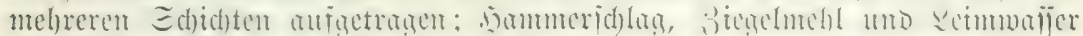

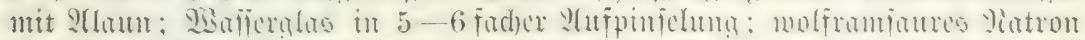

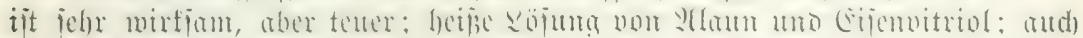

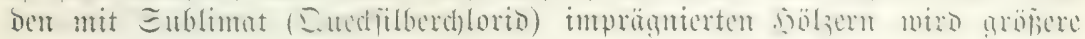
Fenerbeitündoigfeit zugeid)rieben.

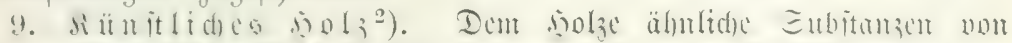

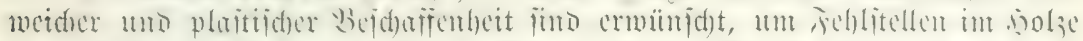

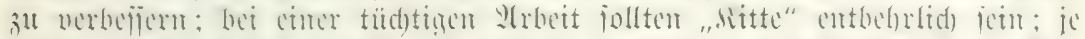

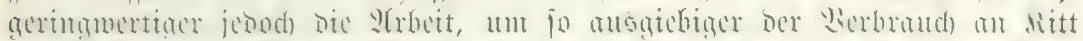

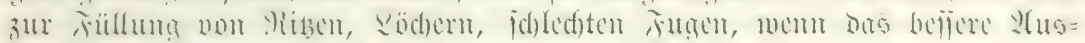

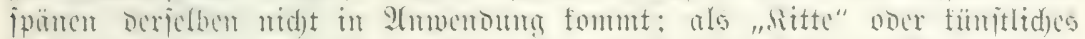

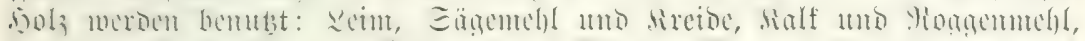

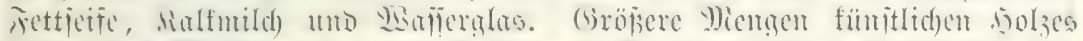

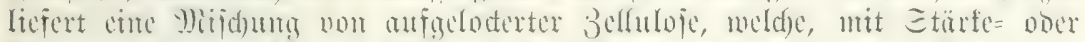

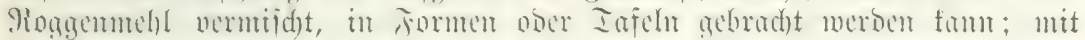

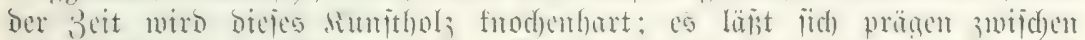

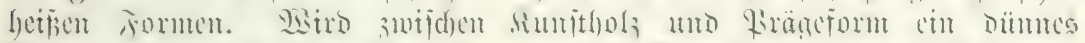

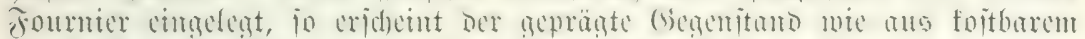

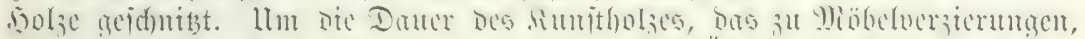

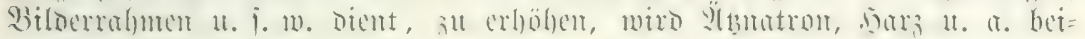
gemijidit.

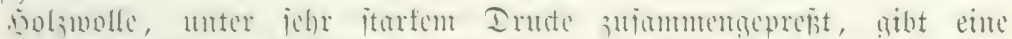

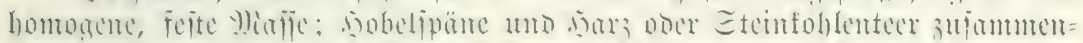

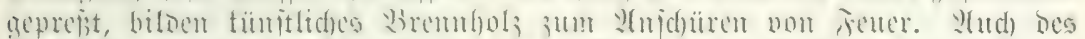

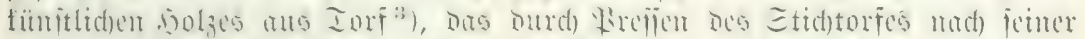

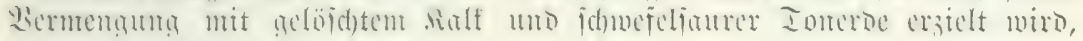
fei furz gedadjt.

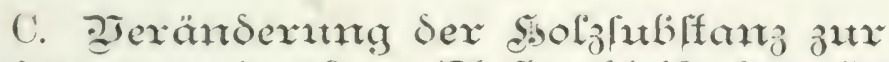 (Senvinnturg einzelnex Żeltandteile Ses solzes.}

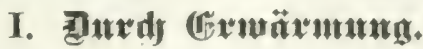

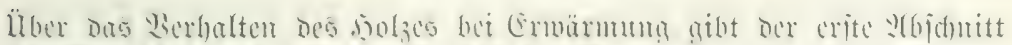

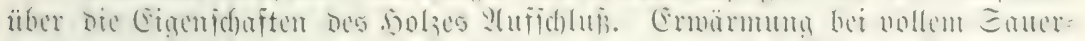

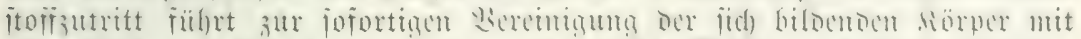

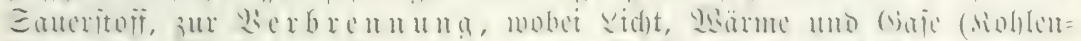
füure oser

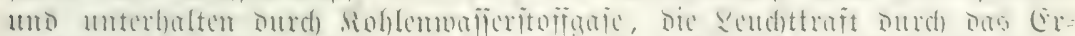

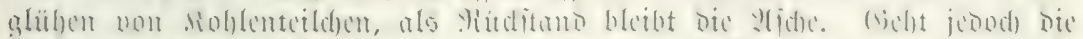

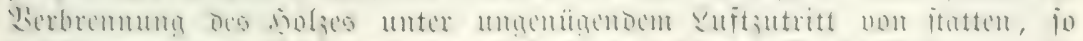

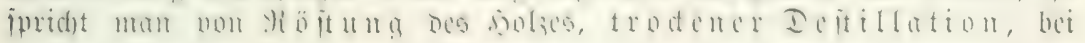

1) 5. Fijucter, Iic \$earbeitung ber 5özer. 1891.

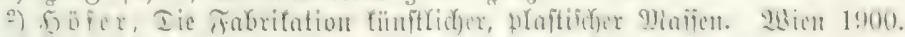

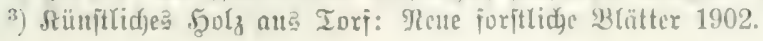




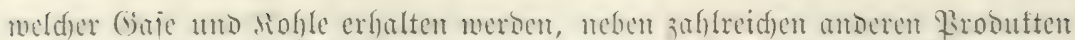

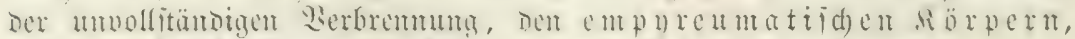

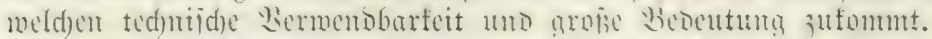

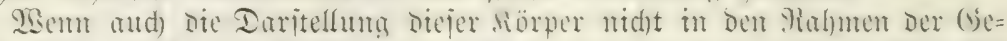

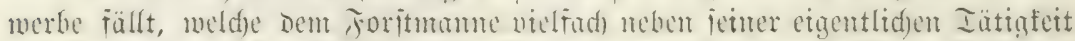

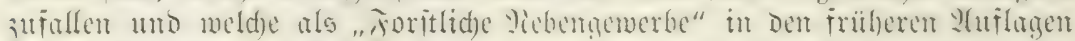

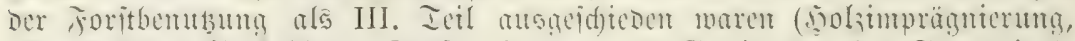

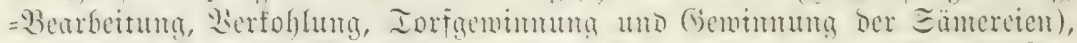

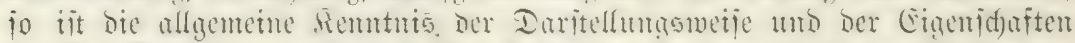

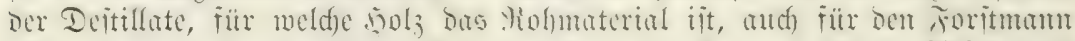

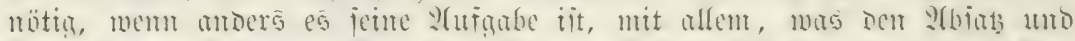

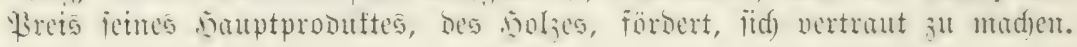

\section{Die Beftillntion Deg Jolizes.}

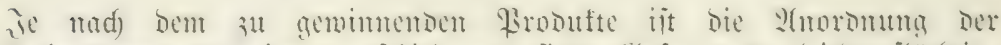

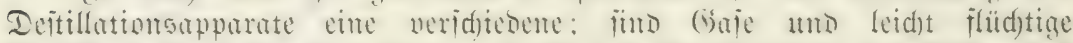

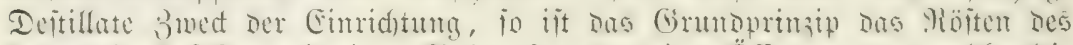

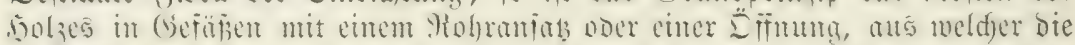
Frobutte in (isas= ober Dantiform ansitrimen, un in ber siul)Inorlage

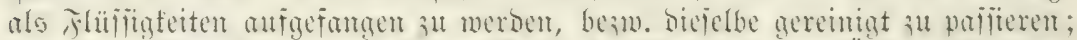

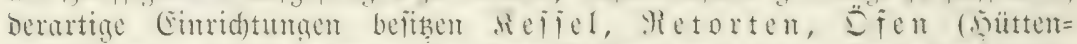

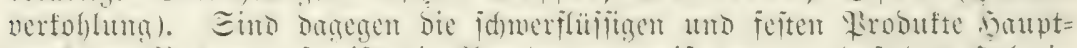

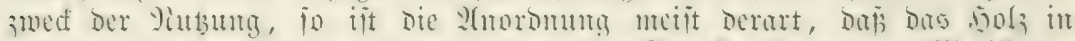

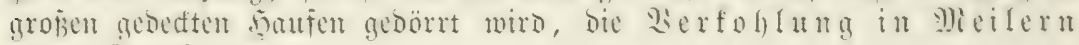
ober (siruben:

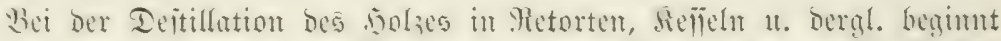

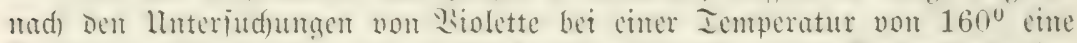

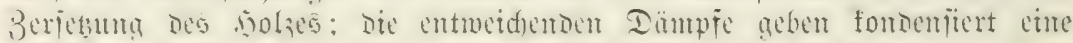

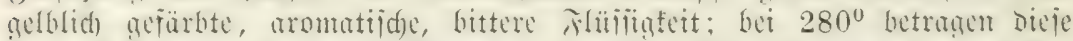

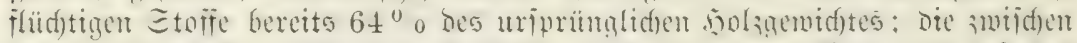

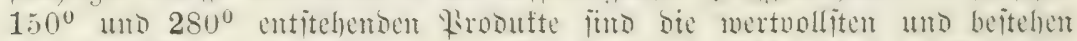

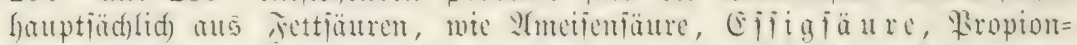

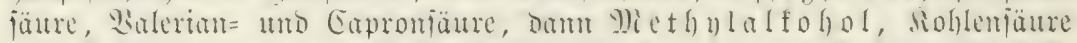

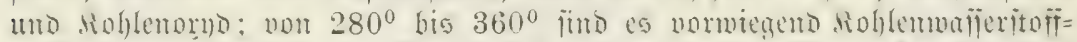

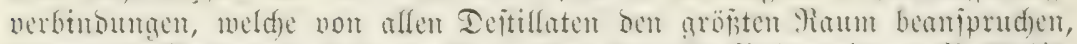

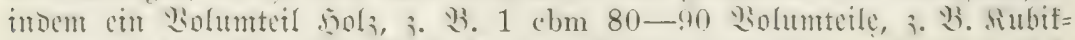

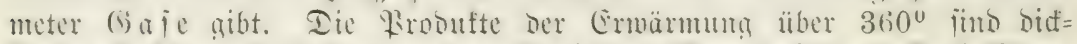

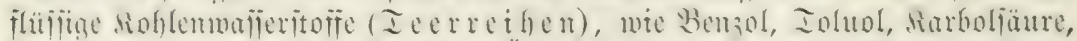

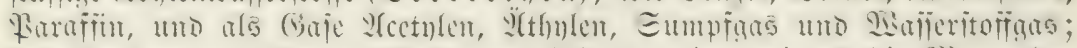

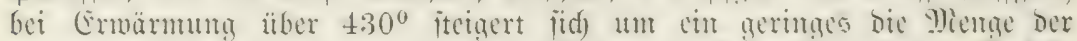

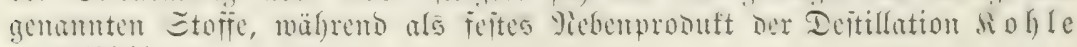
zurüdbleibt.

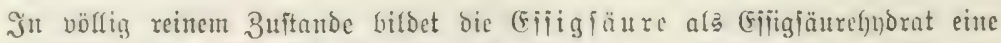

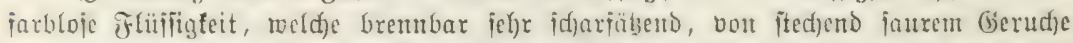

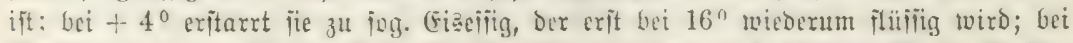

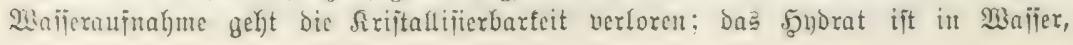




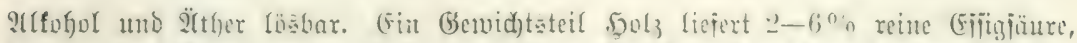

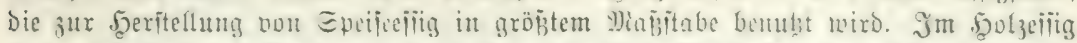

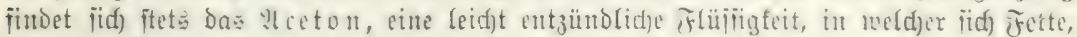

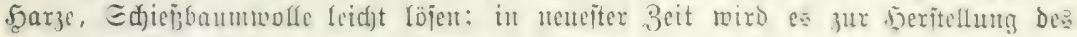
raud) lojen \$itbers vermendet.

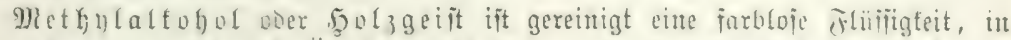

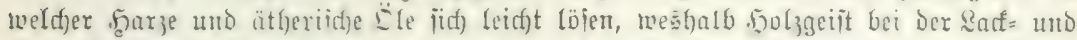
Firniäbereitung von grober Hebentung ift: Durch weitere Ieftillationen gereinigter Solzgeift dient zur ?nfertigung von Ieerjarbent.

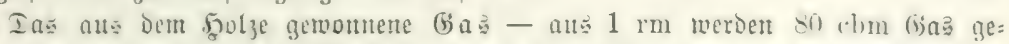

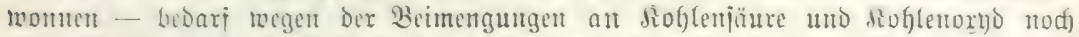

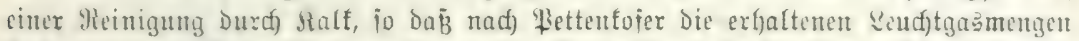

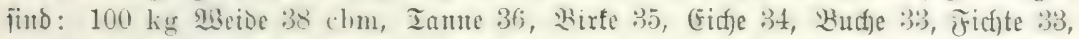
Sürdfe 32. Ias jol3 licjert Demuad) rund $2^{1}$ umal jo viel Reud)tgas als Eteinfohle,

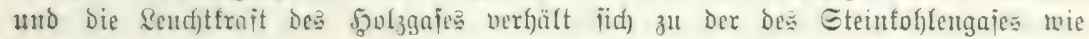
$118: 100$.

9lad) Broillard (Revue des eaux et forits, 1900) ift cs 9). Ridfé gelungen,

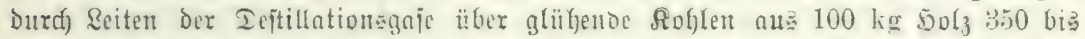

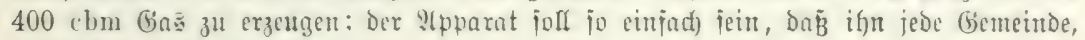
jelbjt Farment benuben tömment.

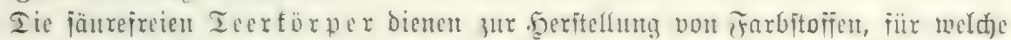
biaher Eteinfohlenteer zumeift benutht murde: Die fäurehaltigen Ienre (Rrcojot und Starboliäure) fino itnrte Intifoptifa; bei gewöfntider Imperatur ieñte Bepitandecile

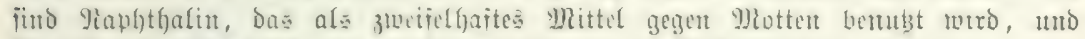

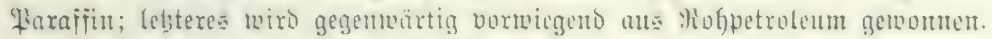

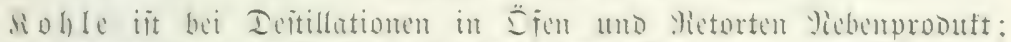

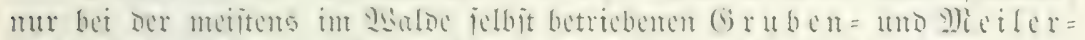

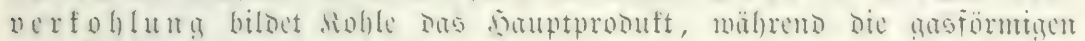

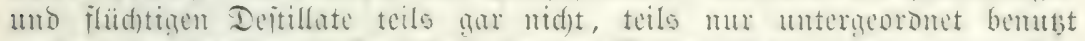

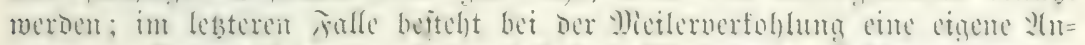

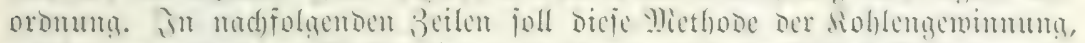

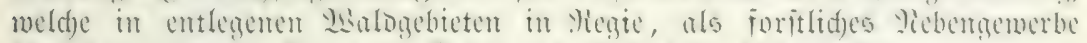

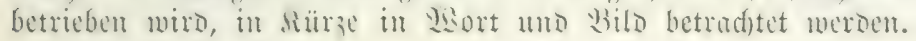

\section{A. Berfoglung in itehendengeilern's).}

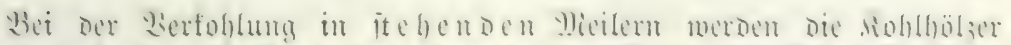

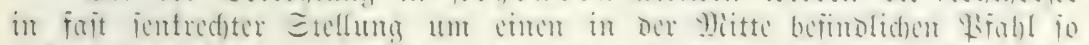

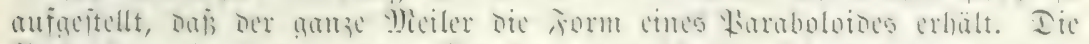

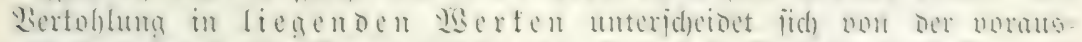

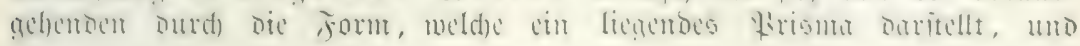

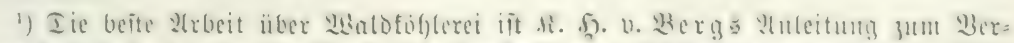

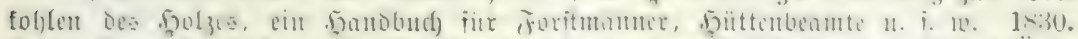

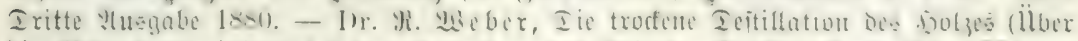

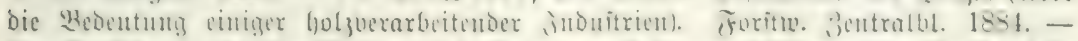

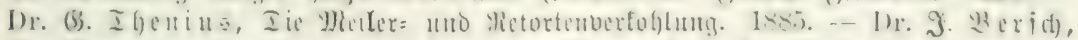

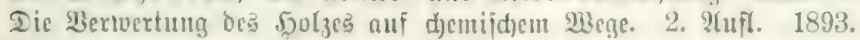




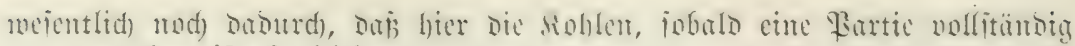
gar geworben ijt, jogleid) ausgezogen werben.

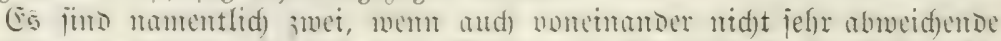

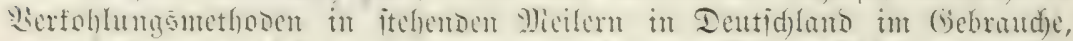

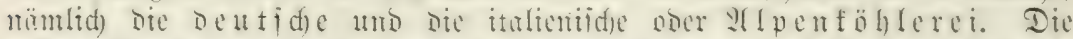

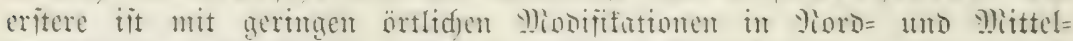

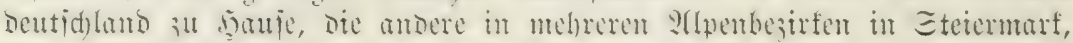
Iirol, Sieberöfterreid) ntud zum Teil Dberbanern.

\section{a. Zeutfde כerk̂fitungsmetfiode.}

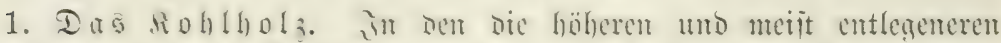

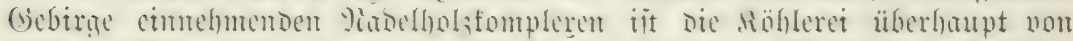

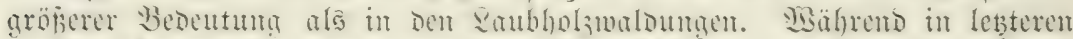

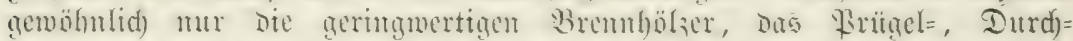

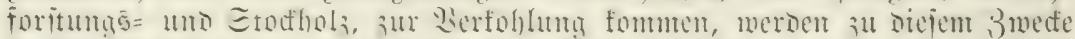

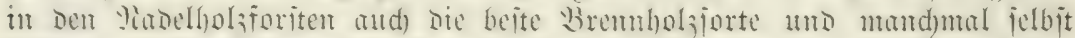

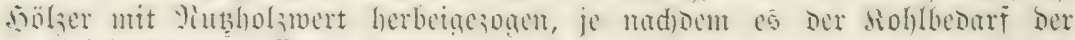
孔 befriebigenden aserfe forbert.

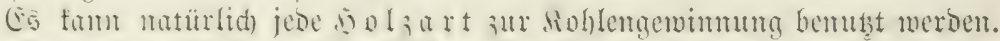

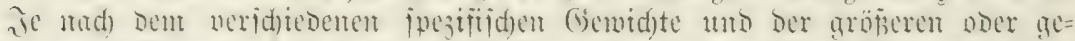

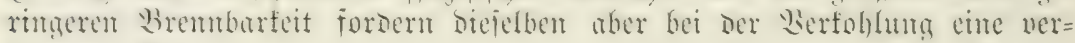
idjebene Bebanolung.

Mian ridjtet Die Meeifer Deäfalb in Dor Megel nur aus einer Fुolzant, unto wo

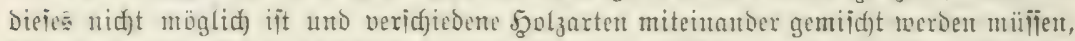

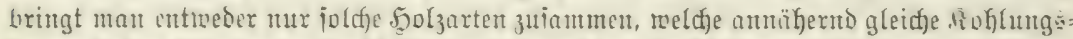
Dauer faben (Dic harten Raubfölzer, - bis weid)en Raubföljer, - Birfe, (F̈rle, Mlforn,

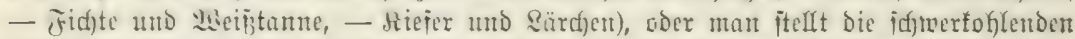

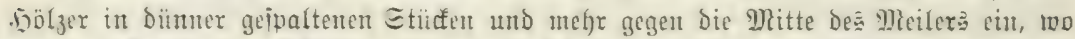

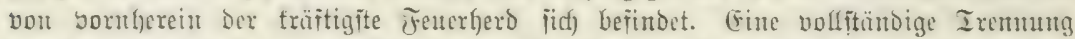

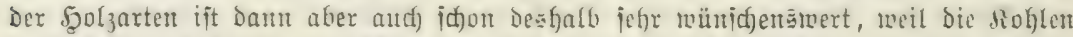

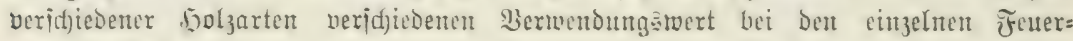
gemerben beitben.

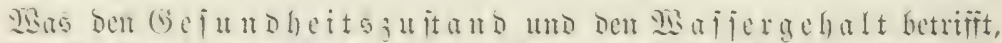

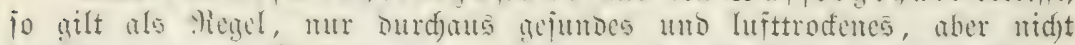

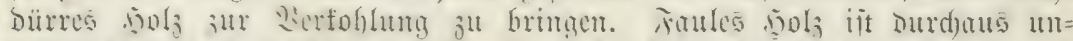

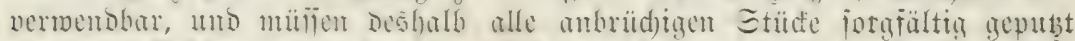

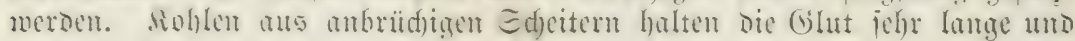
finto Dit Berantafïung z̧u Bränben.

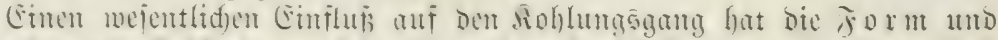

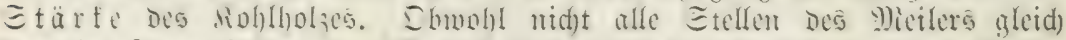

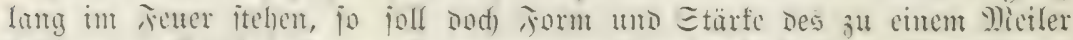

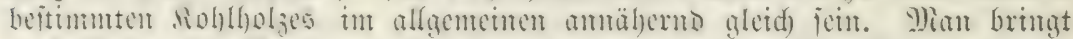

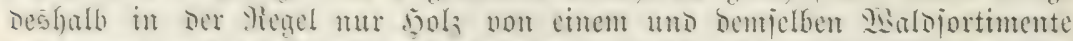

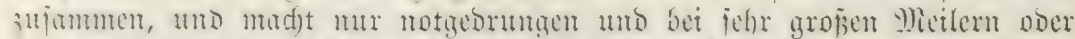

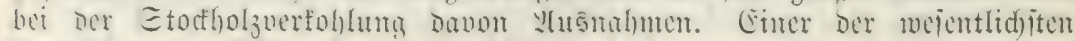

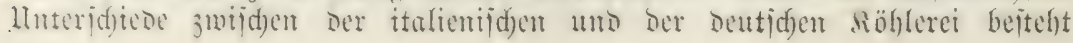




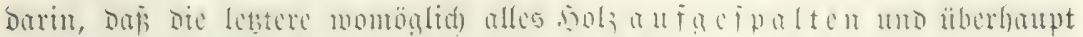
mit geringeren Dimenjionen zur Berfoldum aubformt.

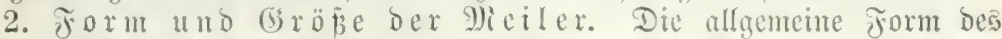

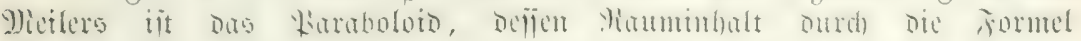

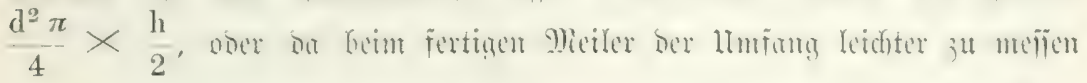

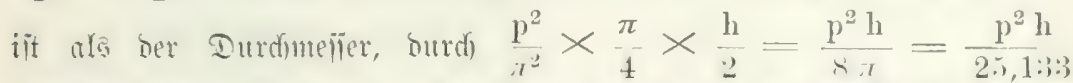

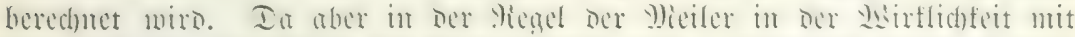

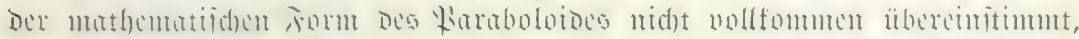

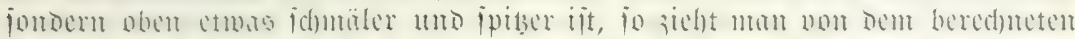

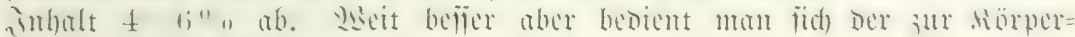
bered)mung ber 9) Beiler bered)meten Tajeln ${ }^{1}$ ).

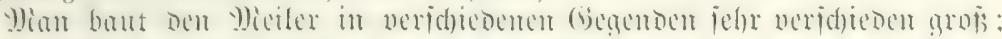

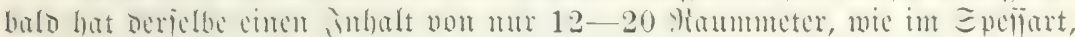

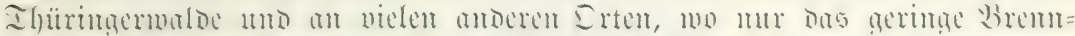

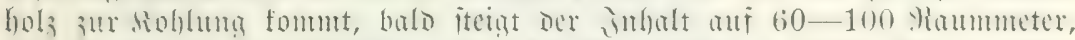

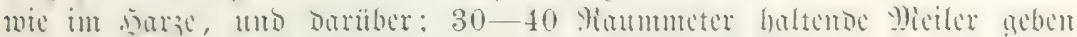

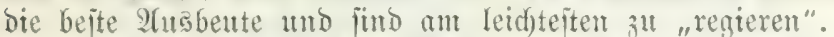

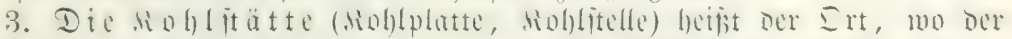

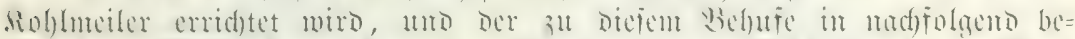

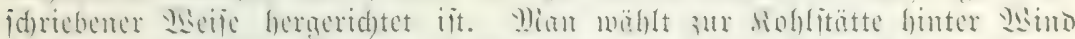

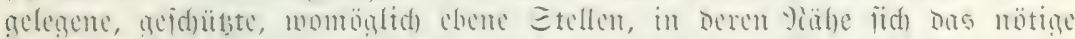

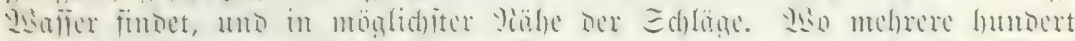

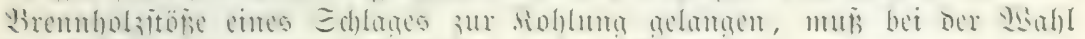

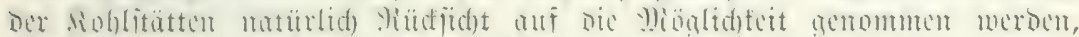

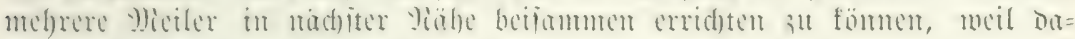
Durd) die Sioften fid exbeblid) mindern.

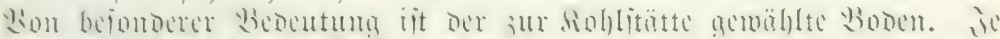

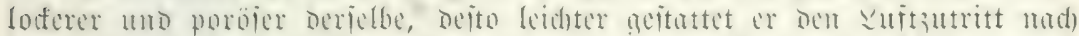

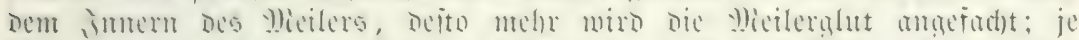

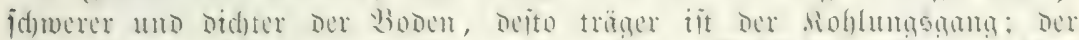

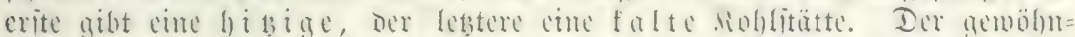

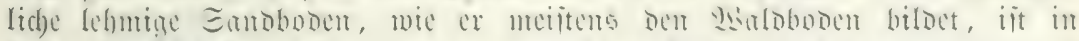

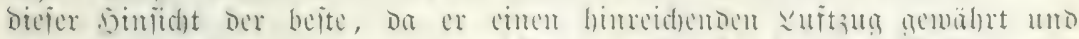

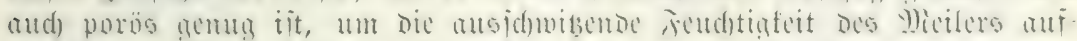

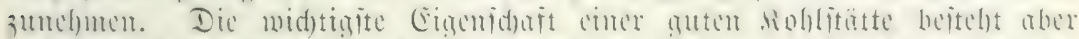

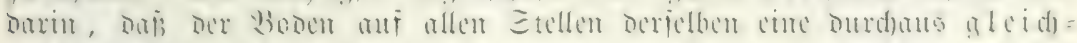

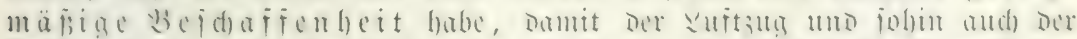

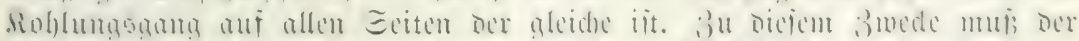

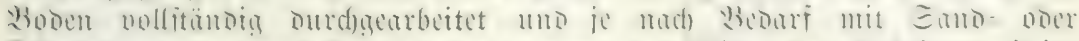

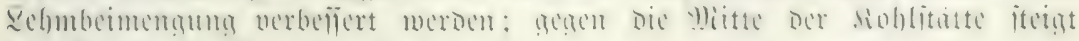
Der Woben an (?) ?nlauf von $20-30 \mathrm{~cm}$ ).

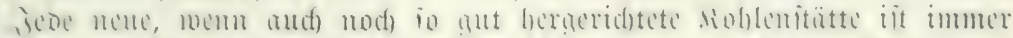

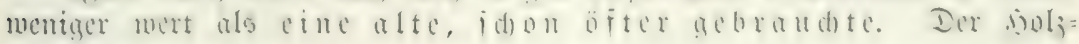

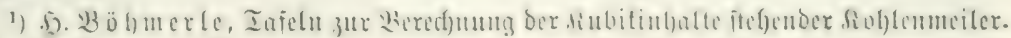
Bertit, 13. Waret), 1877. 


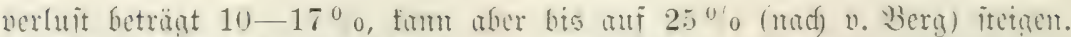

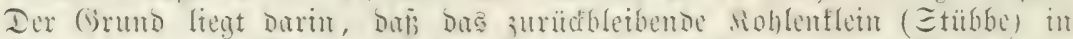

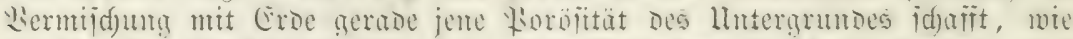

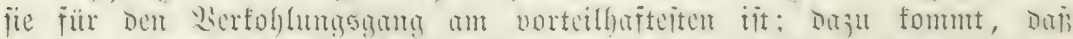
Etübbe aud) Dus bejte Dedmaterial fïr Den Metiler biloet. Ieşhalb jud)t ber siobler immer die alten hiohlplatten wieder zu bemuben, und lieat hierin

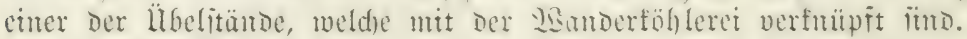

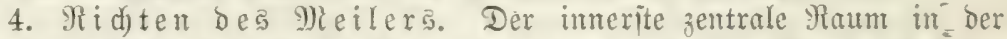

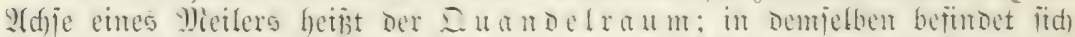

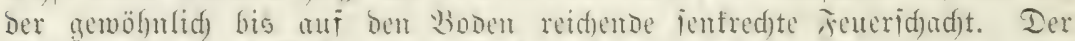

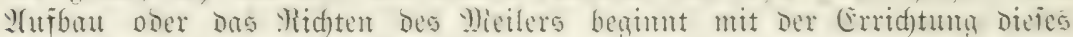

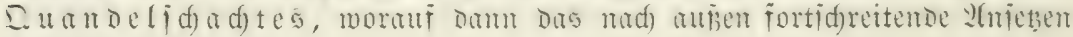
bes Solzes folgt.

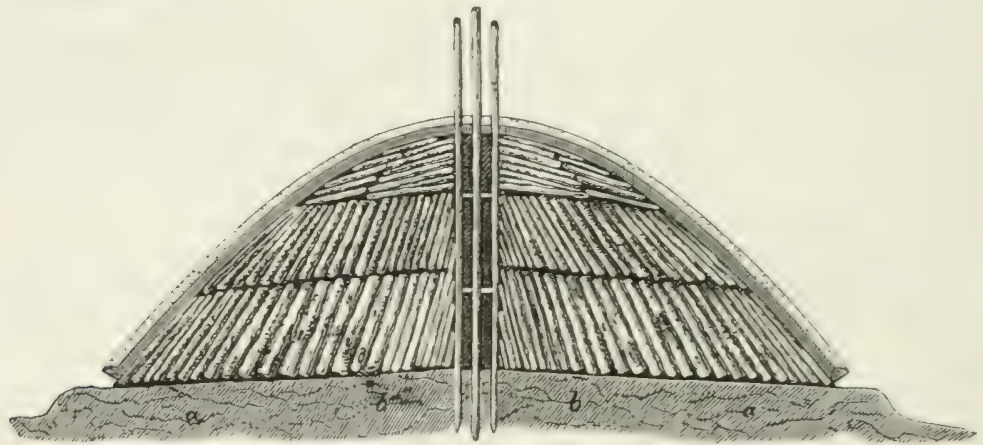

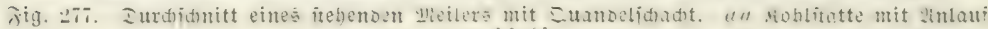
gegen $b\}$ bint.

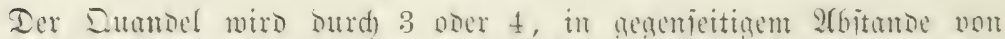

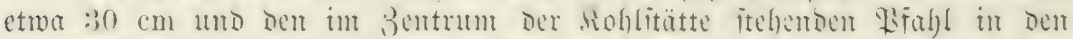

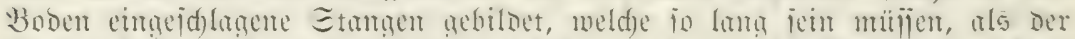

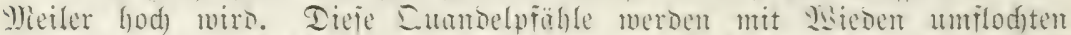

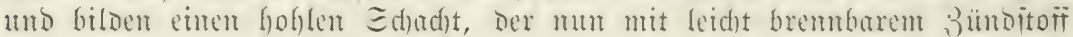
angefüllft wirs.

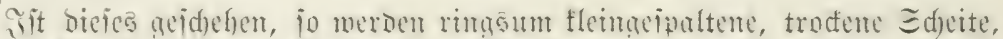

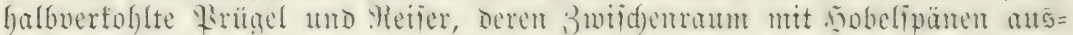

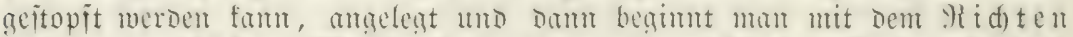

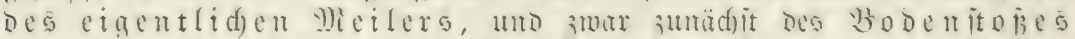

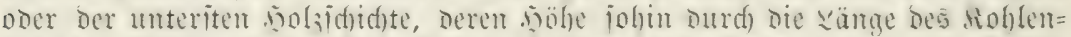

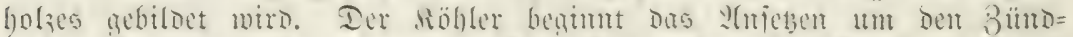

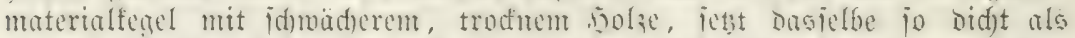

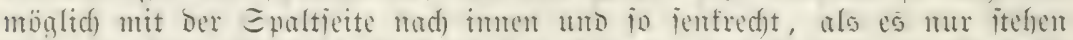

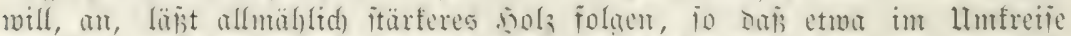
Des halben Iiometers bus itürfite id)werfohtende nols ïd) befunbet, und

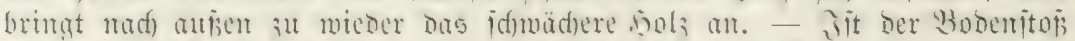

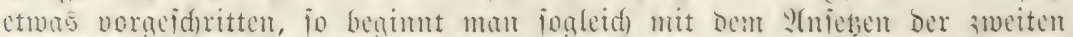

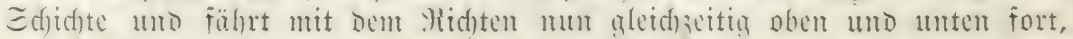
bis ber Sleifer jeinen beitimmten Umfang erreidjt hat. 


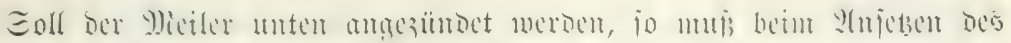

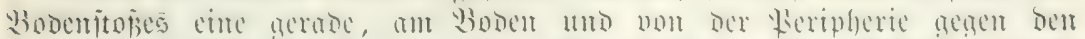

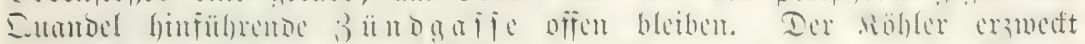

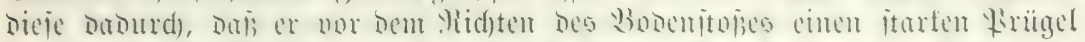

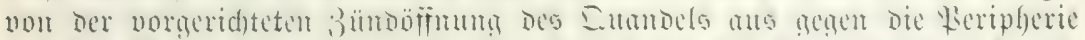

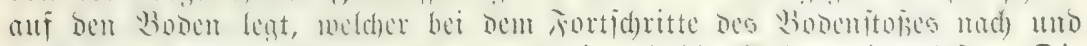

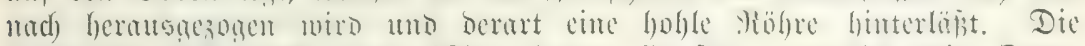

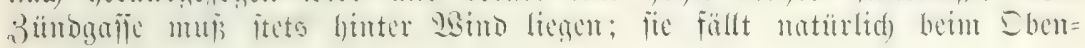

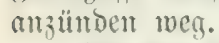

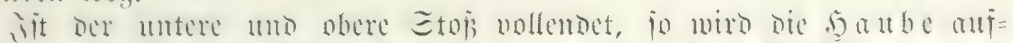

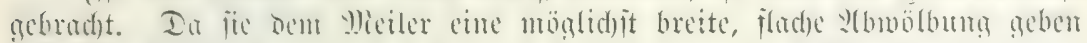

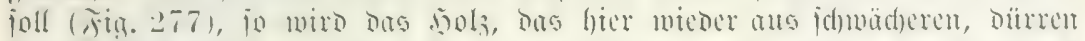

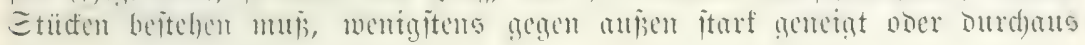

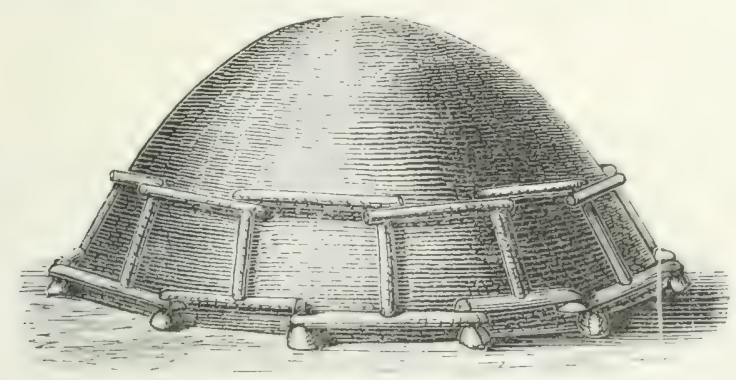

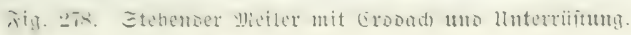

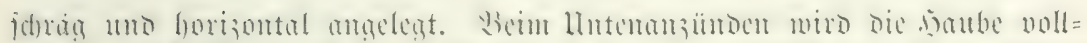

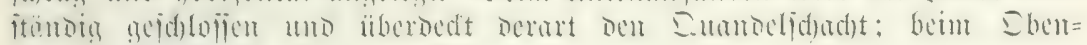
anzünben bleibt ber letztere erflärlicherweije offen.

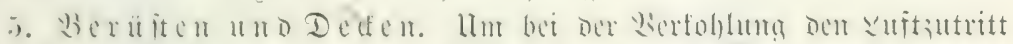

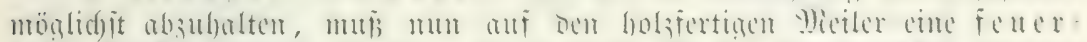

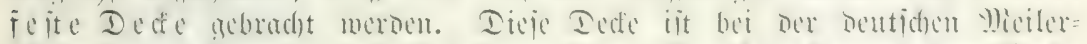

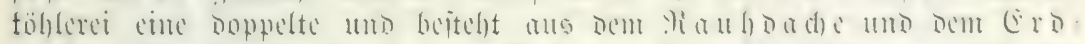

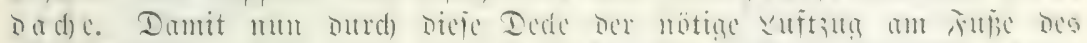

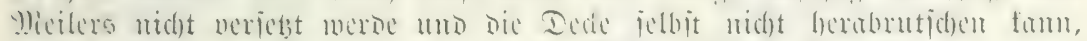

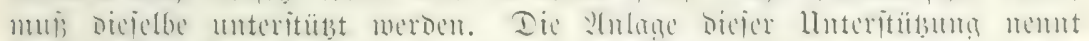

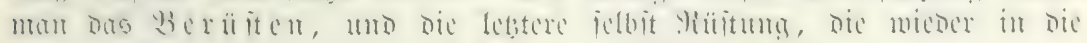

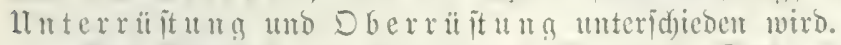

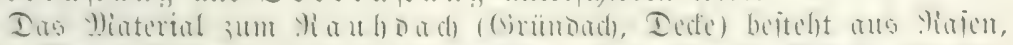

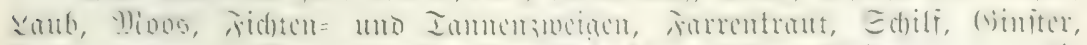

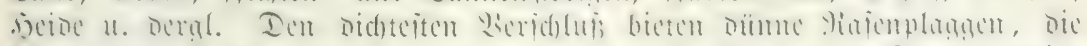

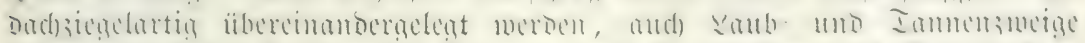

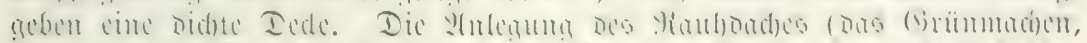

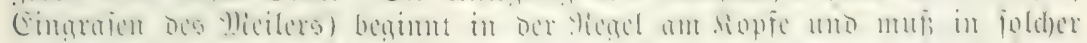

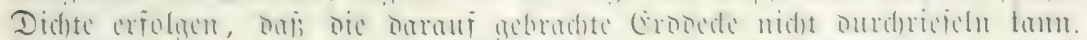

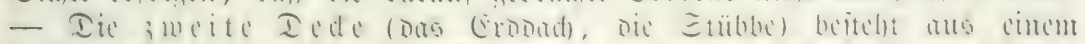

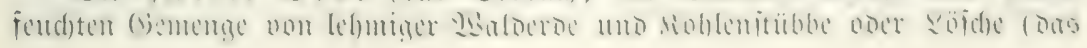




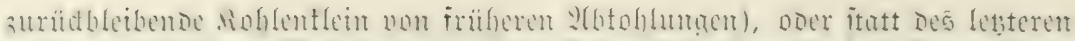

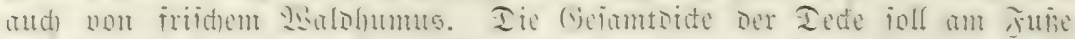
$0,7 \mathrm{~m}$, am flopie $0,3 \mathrm{~m}$, am Eumbel nod) weniger betragen.

3it Der Mieter bemorien, io wiro der

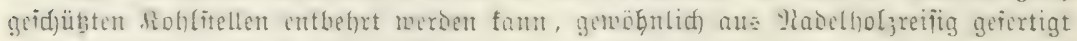
utto mindeitens io fout ala ber Meifer iein muts.

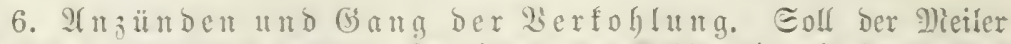

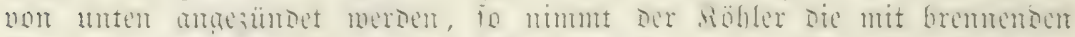

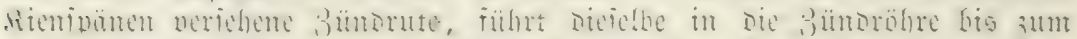

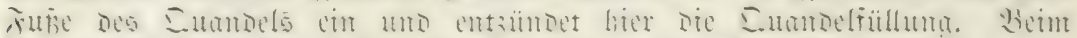

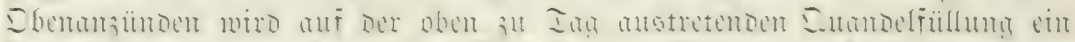

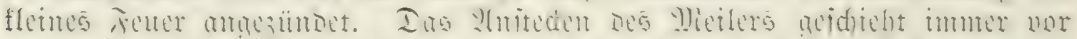

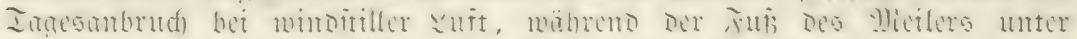

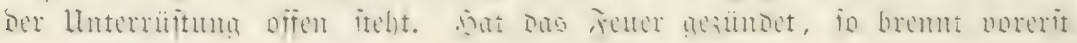

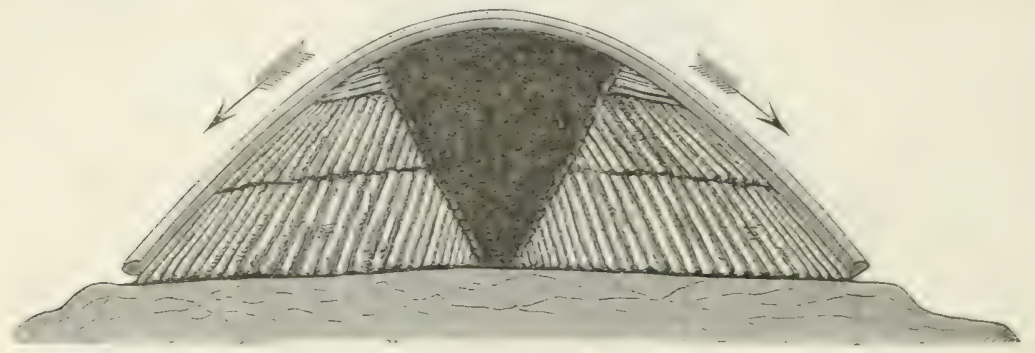

jig. 279.

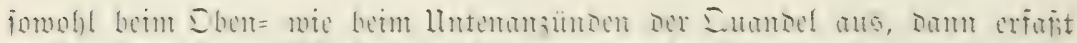

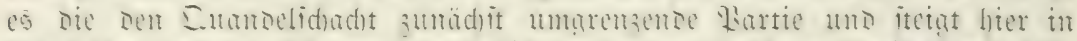

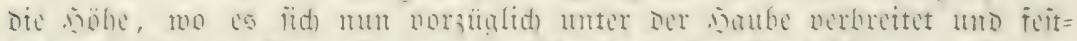

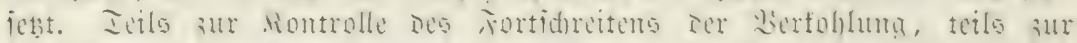

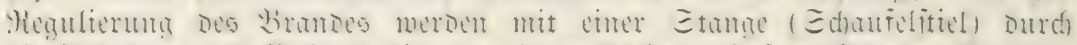

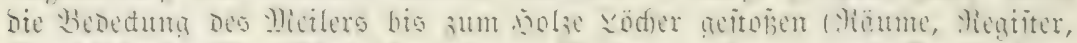

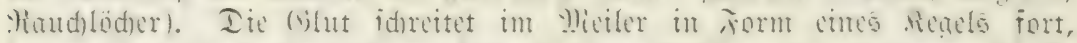

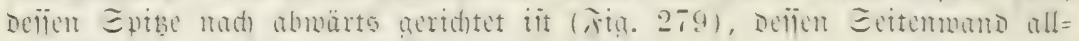

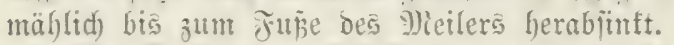

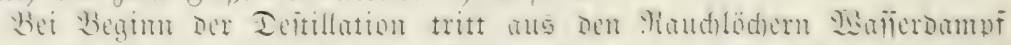

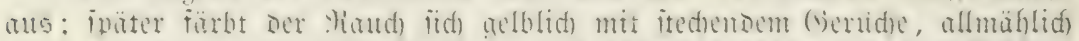

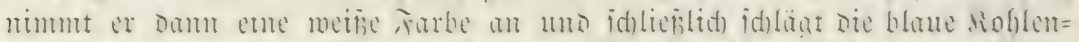

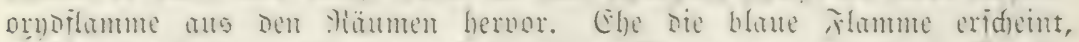

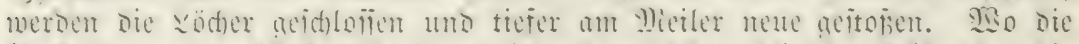

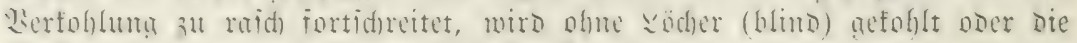
Dede veroidfet oder jelbit mit Migajer begoijen.

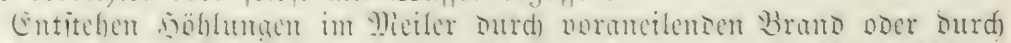

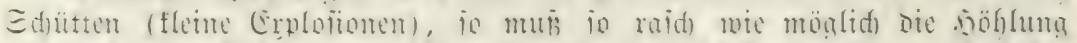

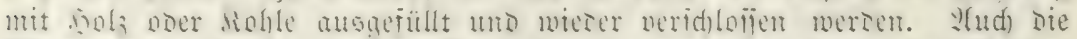

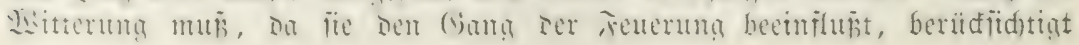




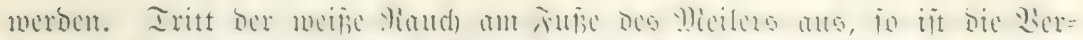

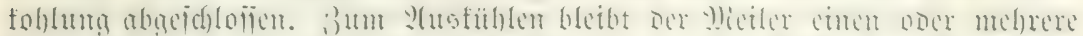

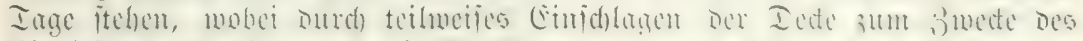

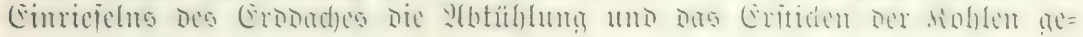
förbert wirb.

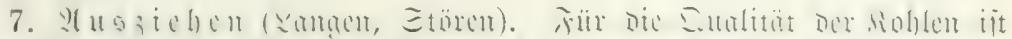

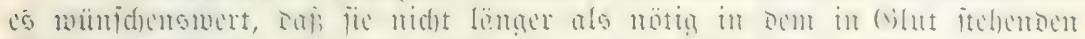

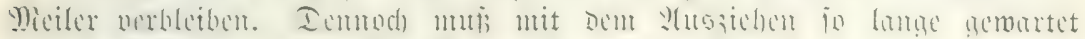

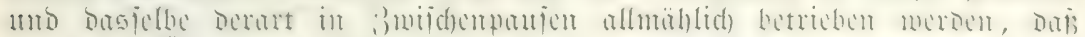

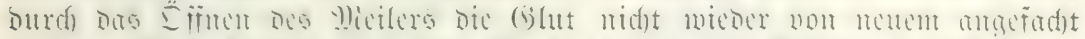

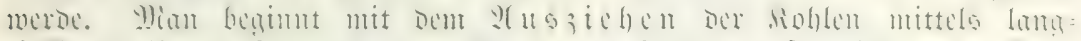

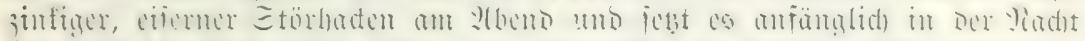

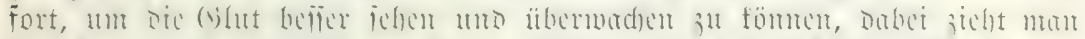

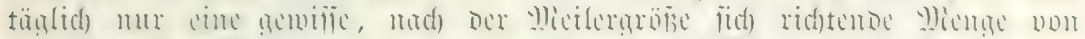

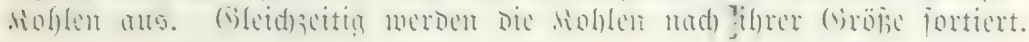

\section{b. Afpentiöliferei $\left.{ }^{1}\right)$.}

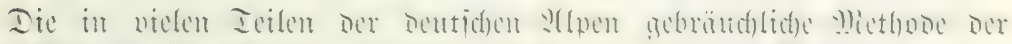

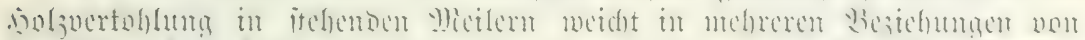

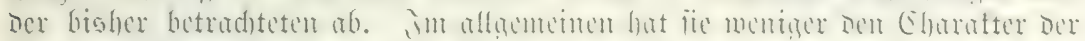

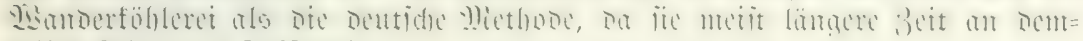
jelben \$labe, an Iriftred)en,

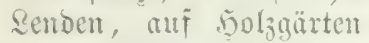
ober am J゙uje weitläufiger 2Balogebänge betrieben mird.

Das 3ur Dertollumg

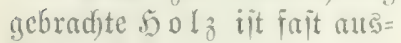
jolf licislid) Yiabelfols, vorzüg= lid) Fidjten, weniger Rärdse แnD Iame, bas in ber Megel unaugeipalten in Munblingen oder Dreblingen von $2 \mathrm{~m}$ Sänge verwendet wirb. Die Síblplatte wird möglidjit feit und ganz in bex oben betrad)teten $\mathfrak{2}$ rt lergeridjtet, mur befommt jic feinen গัulauf, do biejer ourd) die jog. S)iciler = brï de erjest wird.

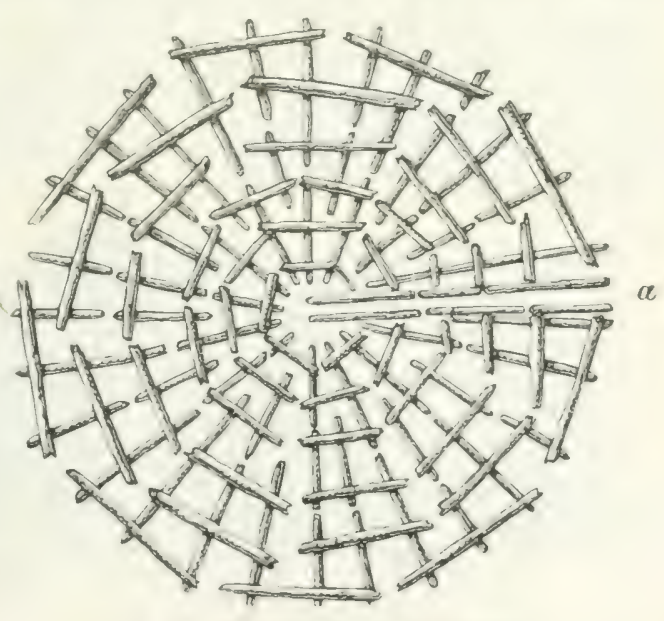

j)ig. 2su. Meilerbride ber Mpentöbleret.

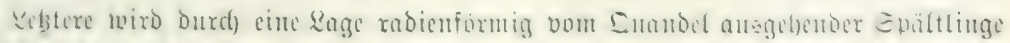

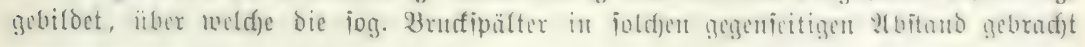

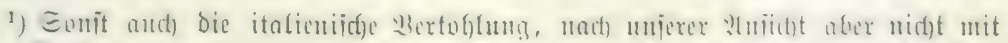

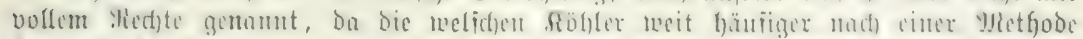

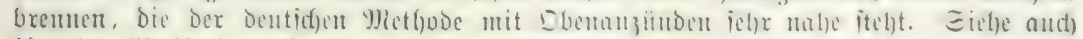

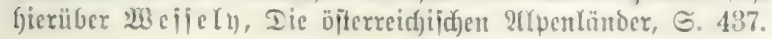




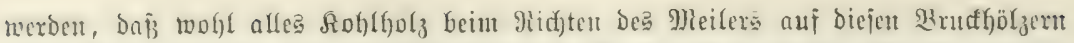

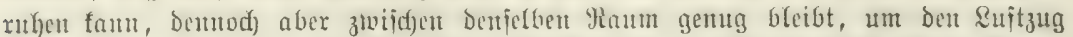

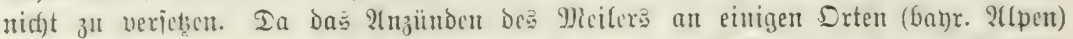

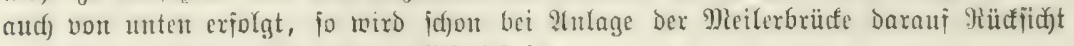
genommen, wie aub Fig. $280 a$ exfid)tlid ift.

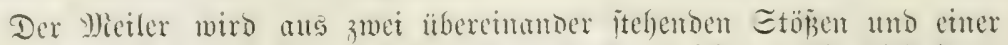

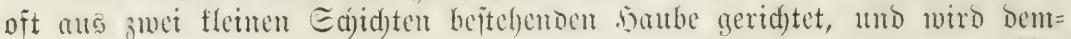

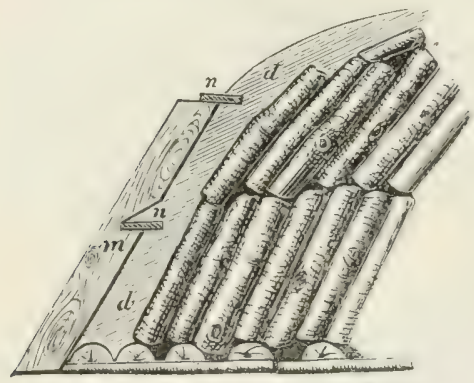

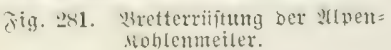
nad) $5-6 \mathrm{~m}$ hod). Möglidyit bid)tes $2(n=$ jeben ift bier ein Şauptangentmerf bes Röhlers; größ̄ere 3 mijd)enräume werden mit Sluftholz ausgebrodt. Was die Meilergröbe betrifft, io iit biejelbe in ber Regel beträd)tlidjer als bei ber Deutidjen Sioblerei, obwobl man gegen= märtig Die itbergropen 9)ieiler mit 1500 bis $2000 \mathrm{cbm}$ verlaijen lyat.

Das Deden und Berwerfen bes 9)ietlers geid)teht hier im allgemeinen itürfer alo beim Deutichen Wiciler. 230 man bas motige Biaterial sutm Cimgrajen (zur Raubdecte) zur 5and lyat, wird

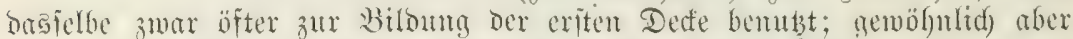

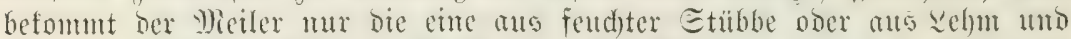

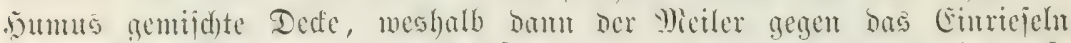

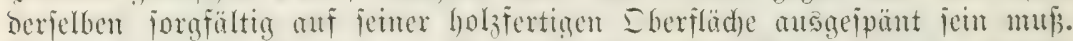
Damit bie Dede anf Dem mit $60-70^{\circ}$ cinfallemben Mietler fejthalte, merden bejonbere Rüiturgen angebradjt.

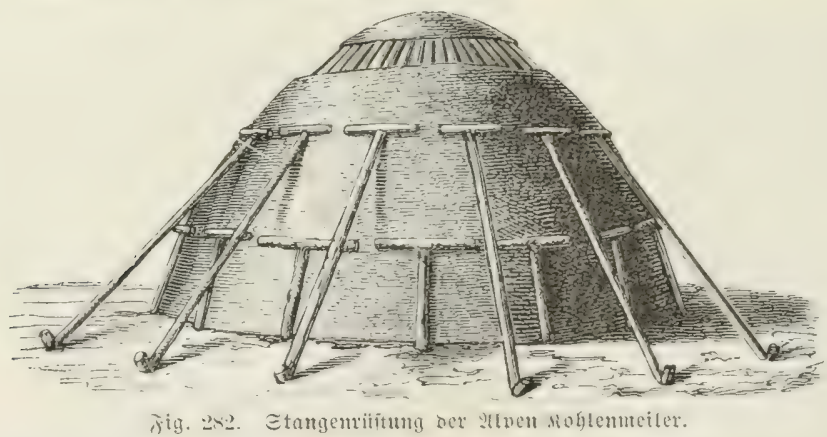

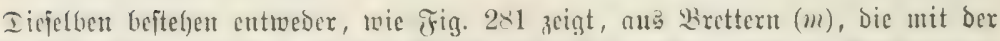
f(f)arfen Sritenfante ringsum an ben Meiler angelehnt werben, und bie Beftimmung

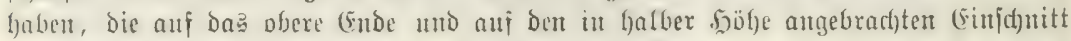

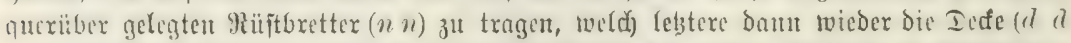

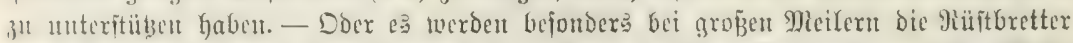

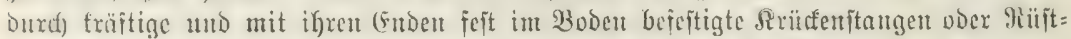

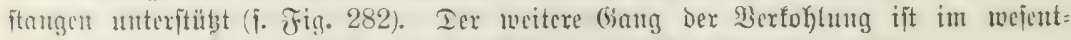

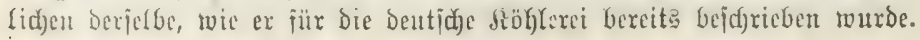




\section{B. Sertolutug in liegenden graeten.}

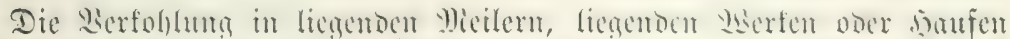

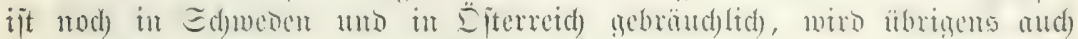

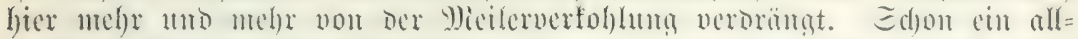

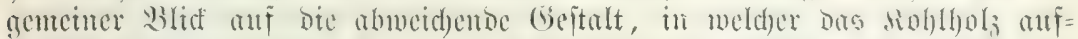

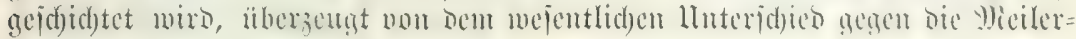
verfolgluig.

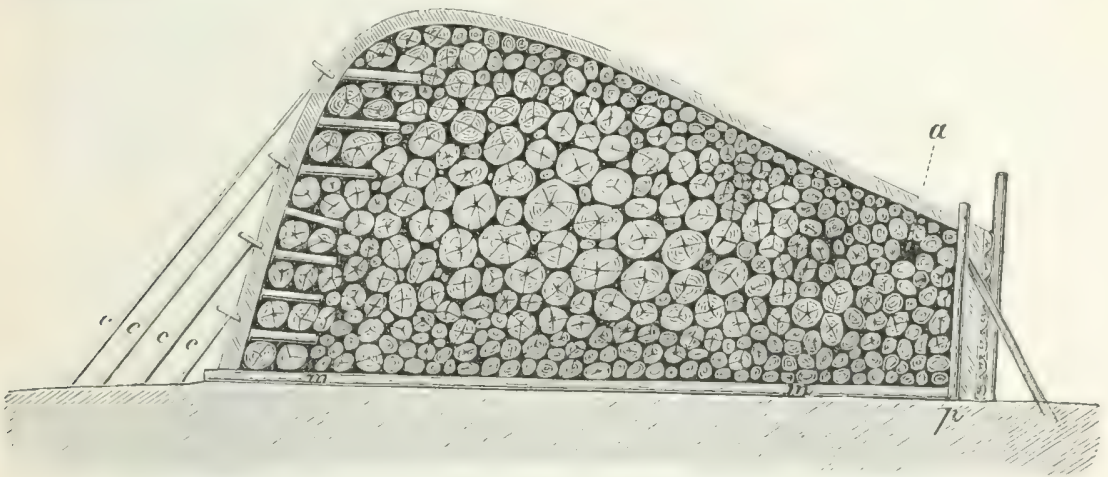

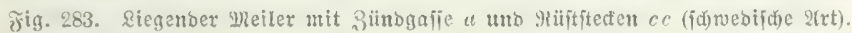

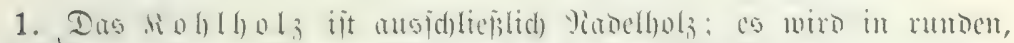

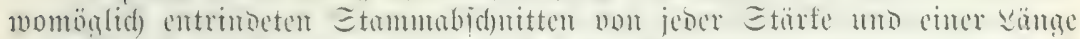

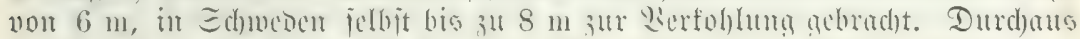

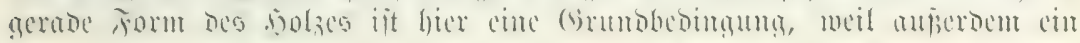

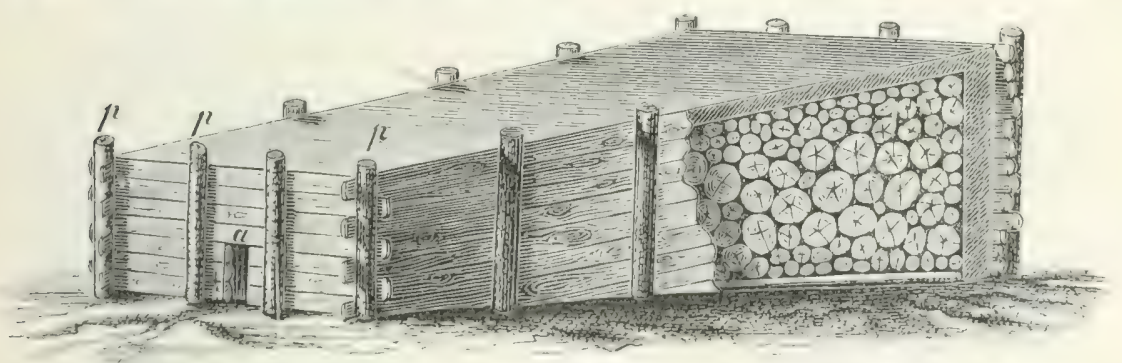

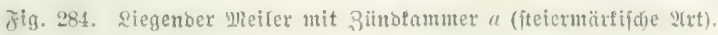

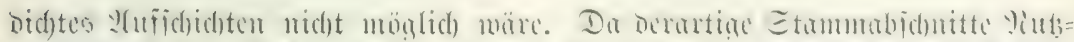

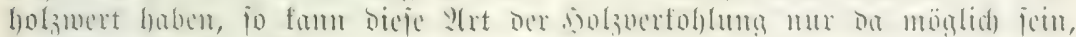
wo eben gar feit Mitubolabegehr beftebt.

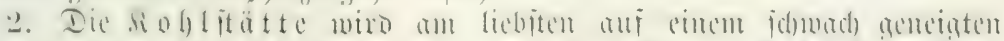

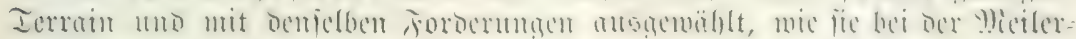
verfoblum gentad)t werden.

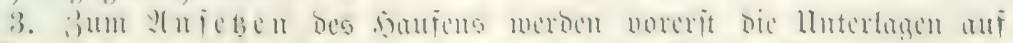

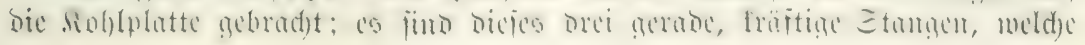




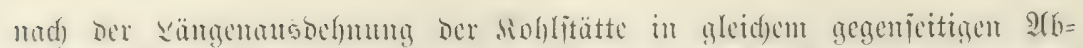

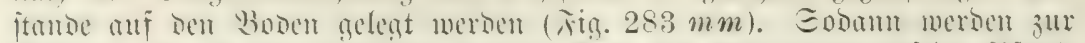

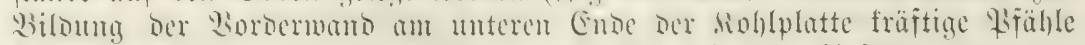

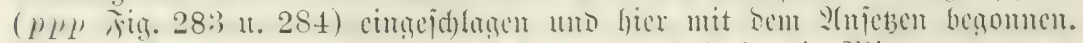

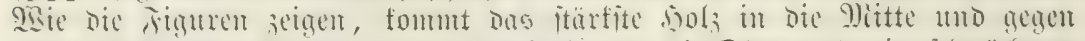

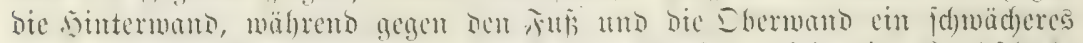

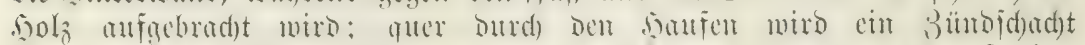

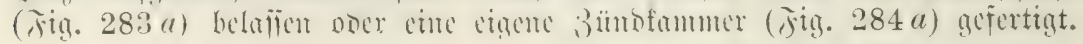

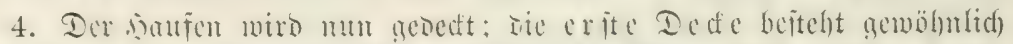

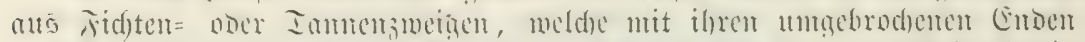

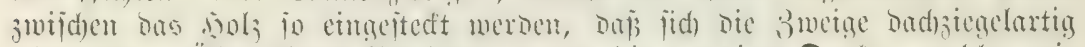

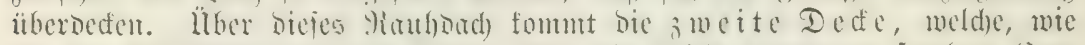

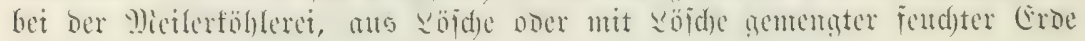
beiteht.

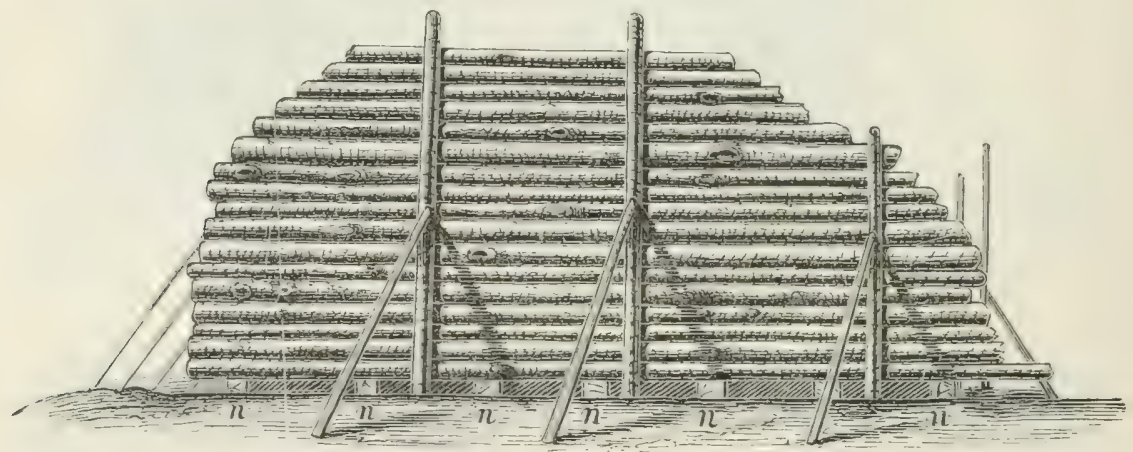

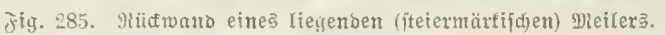

Iamit Diejc Böid)c an ben ientrecten Eeitentünben balte, werben letstere in ciner Entiermung von 15-20 ('1n an Den beiben ?angiciten uns an Der Siorbericite

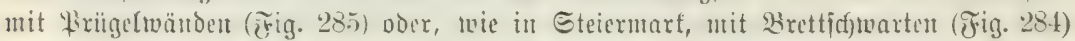

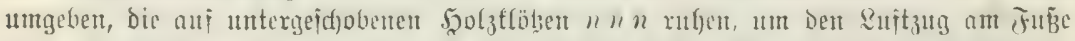

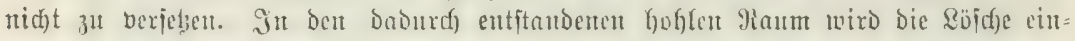

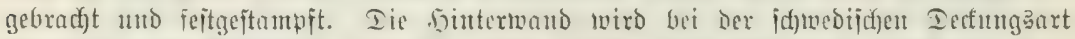

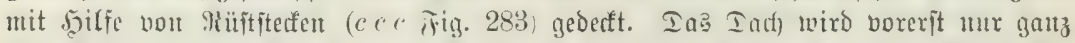

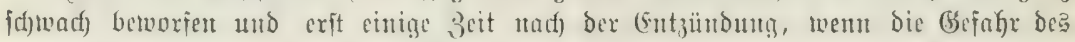
Edjüttente vorïber ijt, ftörfer mit Röjd)e befadjofien.

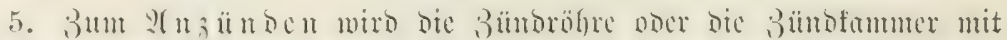

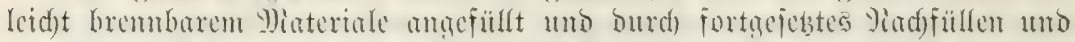

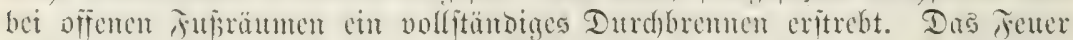

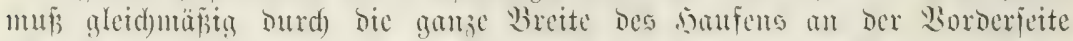

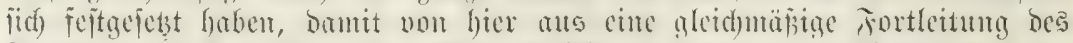

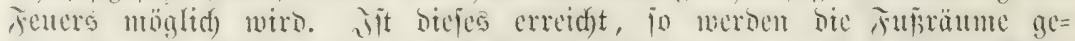

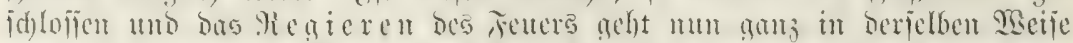
Durd) (Ëmjted)en won Mäumen auf Dem Dad)c (in Etciermarf and) burd) bie

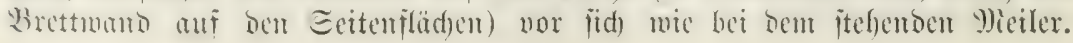




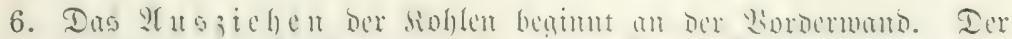

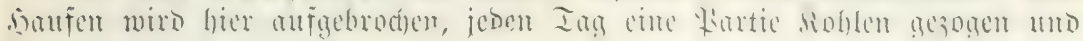
bam roieber zagemorfen.

\section{Die Grubeuverfoldum.}

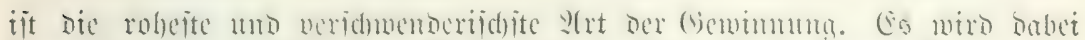

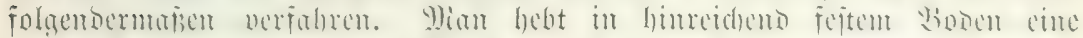

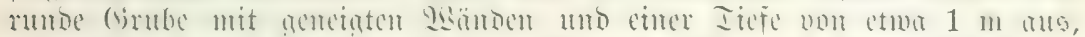

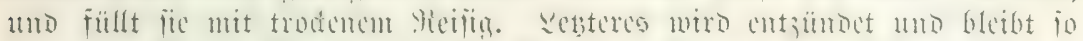

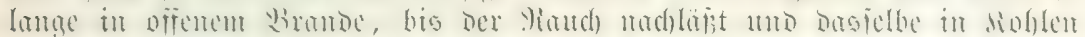

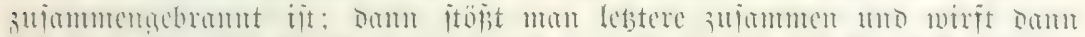

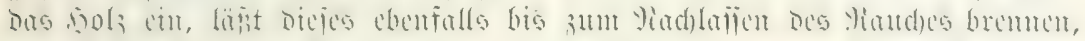

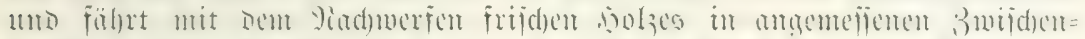

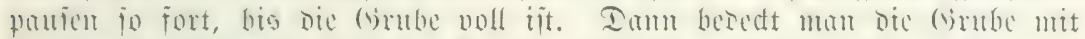

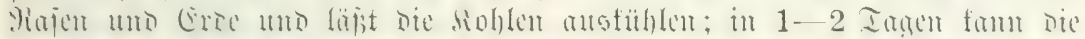

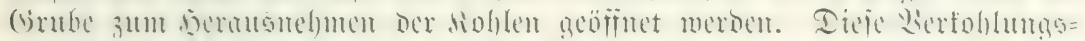

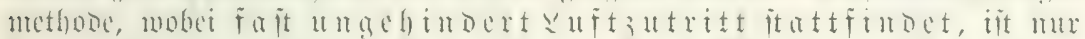

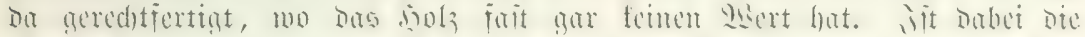

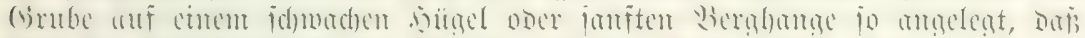

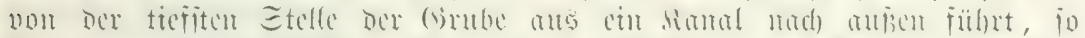

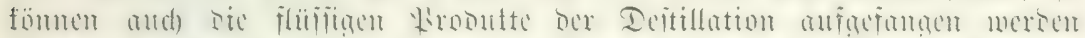

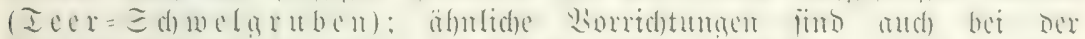

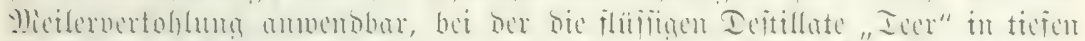

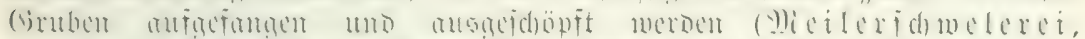

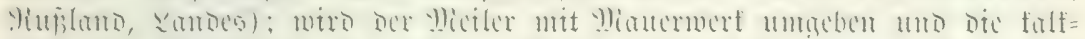

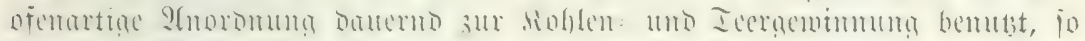
nent man dies $D \tilde{f} n=$ ober süttenfd)welevei (Sandes).

\section{Siolfena sabute.}

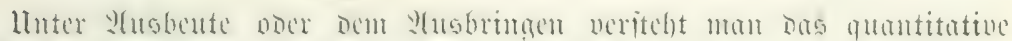

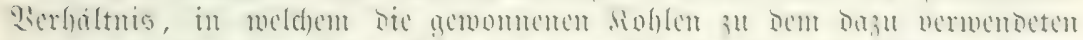

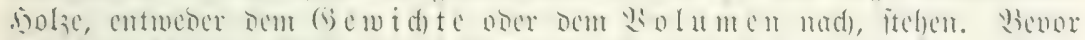

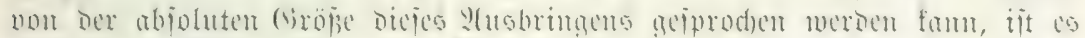

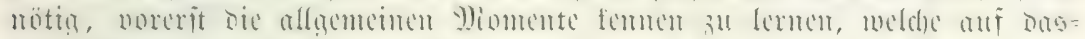
jelbe cinflü gaben. Ės gelören bazu:

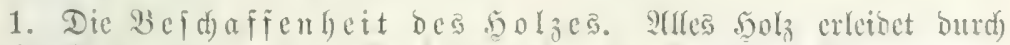

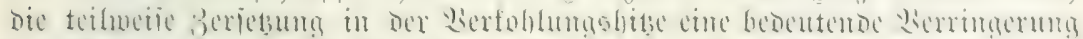

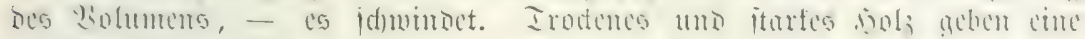
gröfere Sioblenaublute.

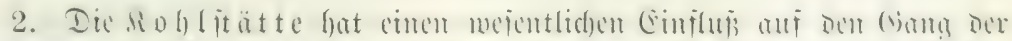

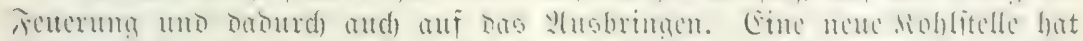

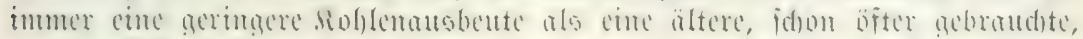

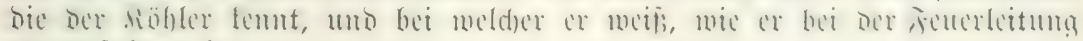
3u verfabren bat. 
(Fine ungleid) treibende fiohlplatte hat itet anf Der cinen Eeite grö̈eren fiofylen= verbrand als anj Dex anderen und beshalb aut) geringeres 2 asbringen. Faft jede in

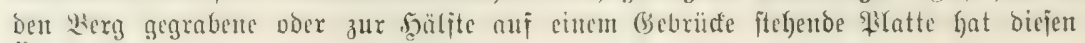
ث̈̈Gelftand.

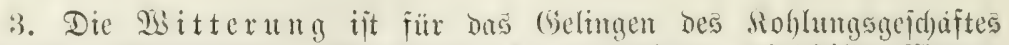

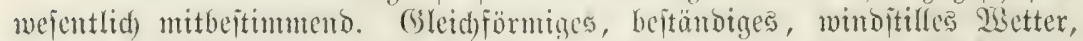

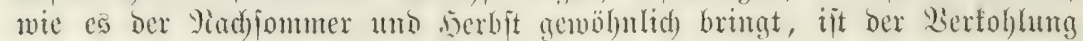
ant zuträglid)îten.

4. Der Feuerungsgang. Cin langfamer und forgfältiger

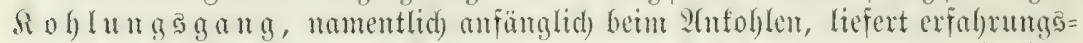

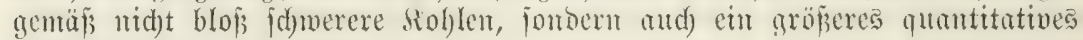
Aนabringen.

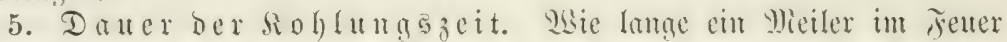

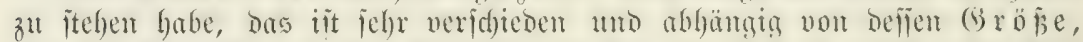

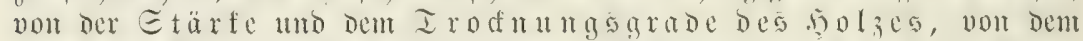

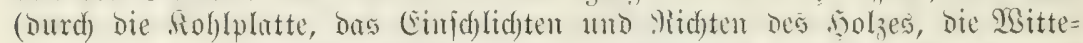

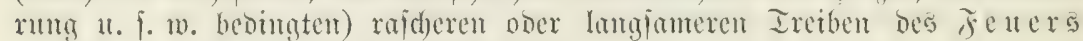
und von mandfen anderen Yebenumitänden.

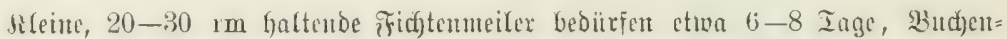

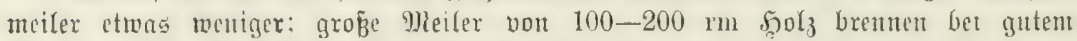
Metter etwa 4 Wodyen, bei fdr)(ed)ter Mitterung 5-6.

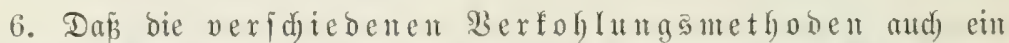

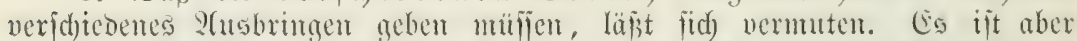

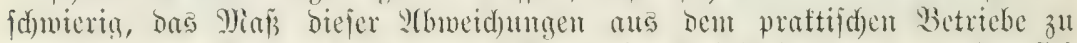
cutnebmen, weil biex su vielerlet, Fattoren in Epiele find, won weldsen fid)

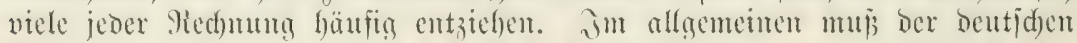

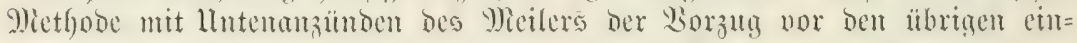
geräumt merben.

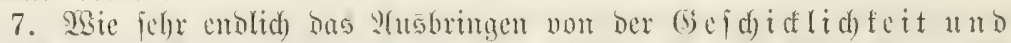

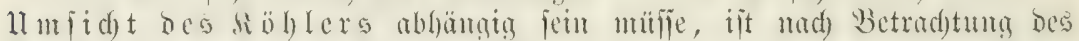
Borangehenden von jelbit einleudjent.

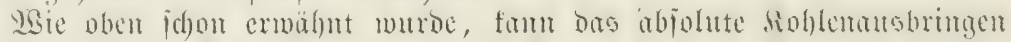

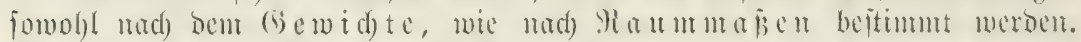

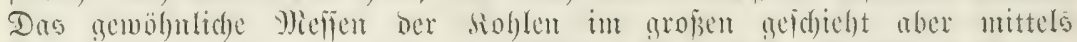

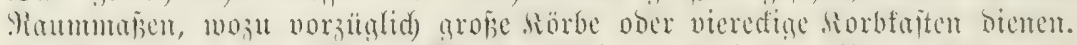

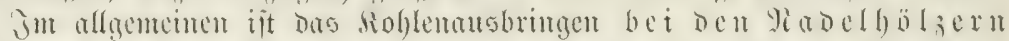
(s)

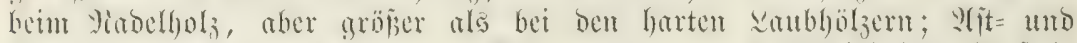

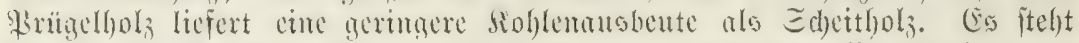

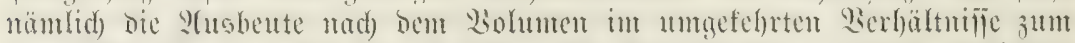

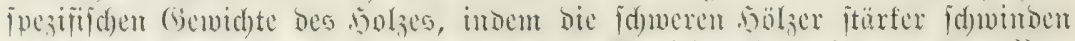

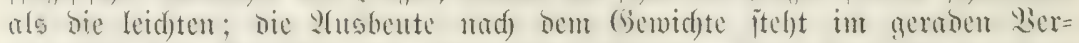

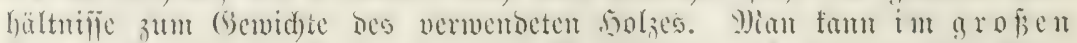

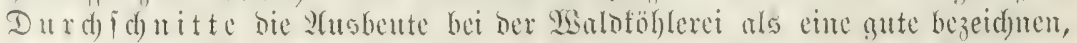

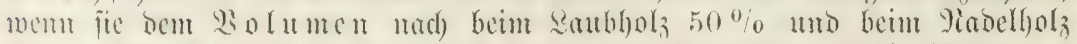

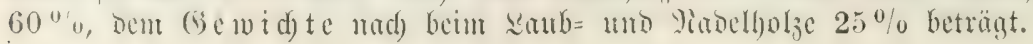




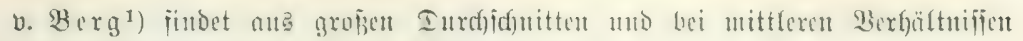
aller einwirfenden Fattoren folgende 2äbeuteprozente:

(Gemicht in Frozenten Solumen in Frozenten
1. Wei Butfen=
$5 \cdot 2-.56$
2. Birfenidueithol . . . . . . . 20-21
$65-68$
3. Riefermidgeitfoly . . . . . 22-25
$60-64$
4. Fid̄tenj(d)eitholz . . . . . . . 23-26
$65-75$
5. Fid)tenftodfol . . . . . . . 21-25
$50-65$
6. Fichtentnippelfyolz . . . . . . 20-24
$42-50$

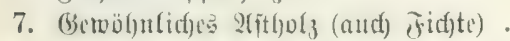
$19-22$
$: 18-40$

Daid) oren ${ }^{2}$ ) in (Eisteben fand in jeinen Sexpucten folgende Mifultate:

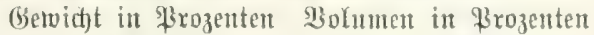

(Eidje 21,3

71,8

Motbudje . . . . . . . . 22,7

73,0

खeiß̄budje . . . . . . . . . 20,6

57,2

Birfe

$20 ; 9$

68,5

Föbre

25,0

63,6

\section{E. Sortimente.}

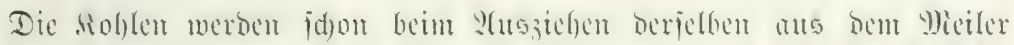

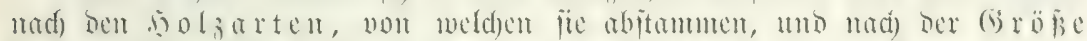

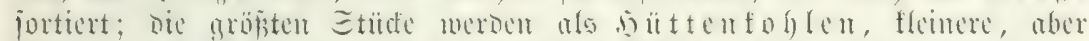

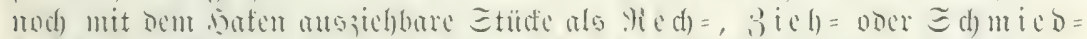

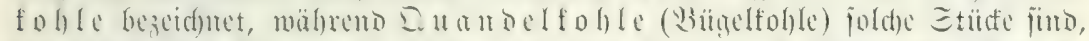

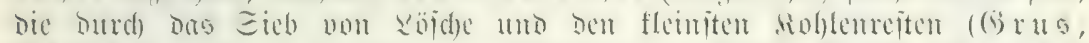

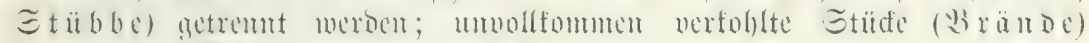
Dicnen , fleimen Mieilern verfohlt.

\section{F. Eigenfdiften ber golztolle.}

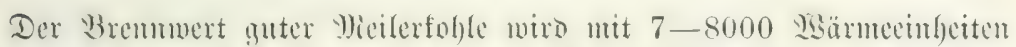

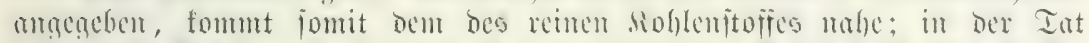

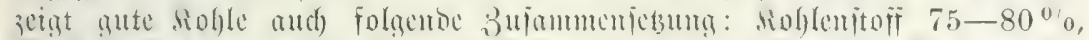

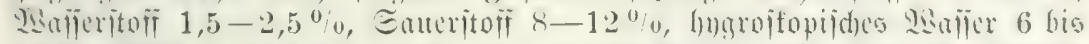

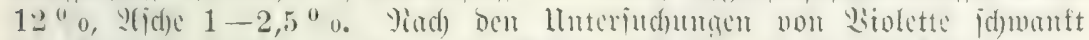

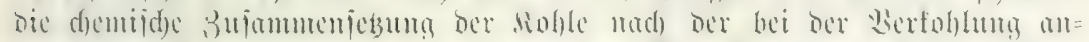

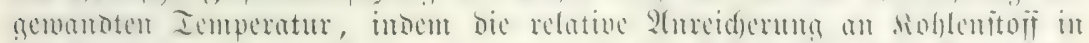

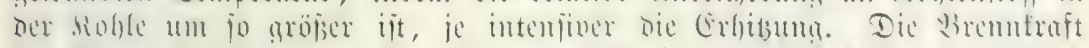

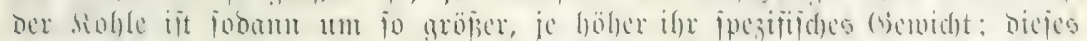

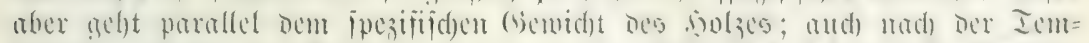

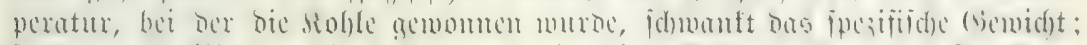

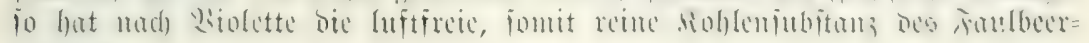
baumes

1) भ. a. D. Є. 184.

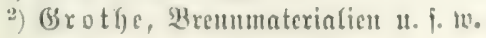




\section{bei $350^{\circ}$ ein ipezififictes (Servidyt von 150 , " $1025^{\circ} "$ " " 184 , " $1500^{\circ} "$ " " " 187 ;}

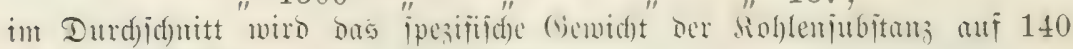
bis 200 (Mafier $=100$ ) angegeben.

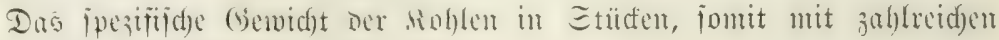
Sufträımen, beträgt naćd) Salifenfrał

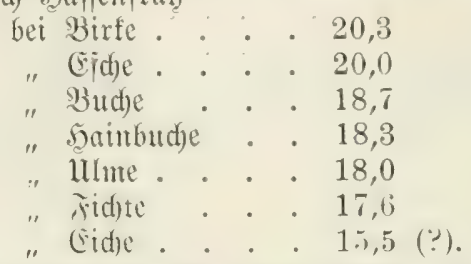

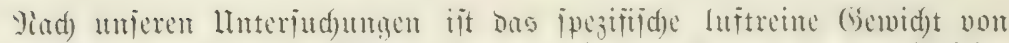

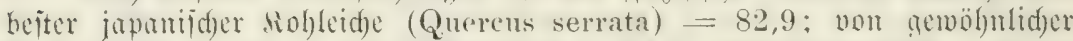

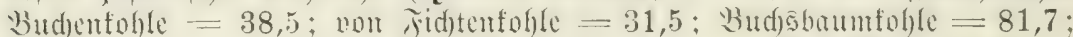

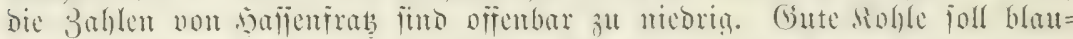

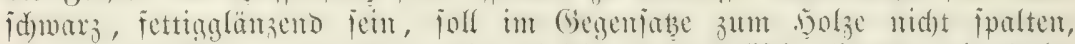

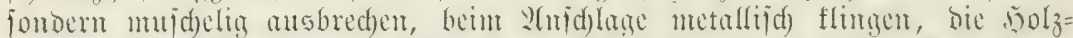

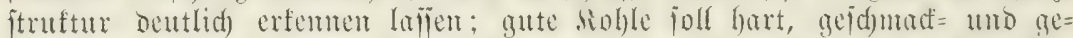

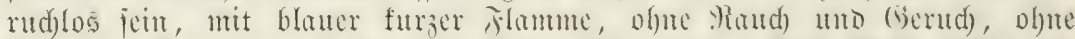

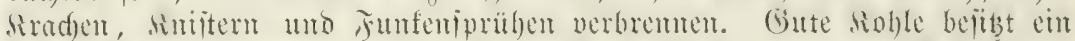

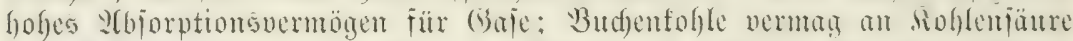

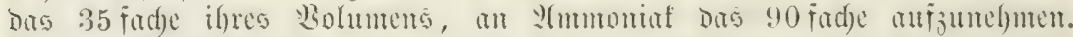

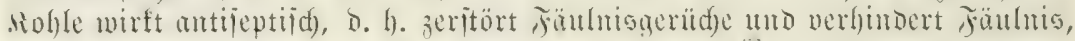
und bejust jelbit eine ganz auperorbentlidje Dauer.

\section{2. 刃ag Jerbrennen Des folics.}

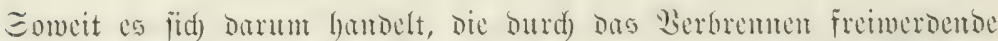

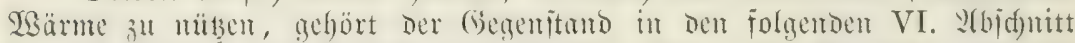

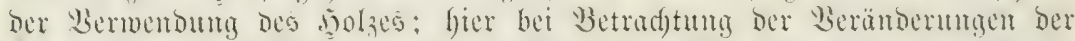

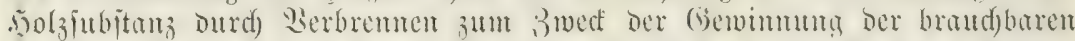

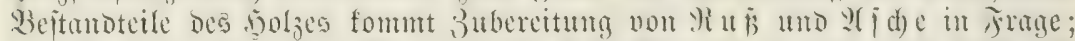

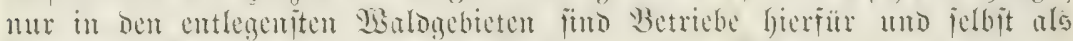

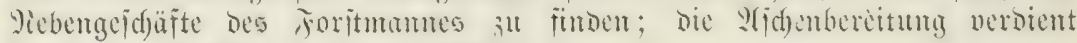
jebod) bie Beadytung allex Foritwirte.

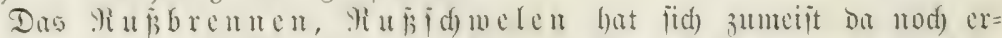

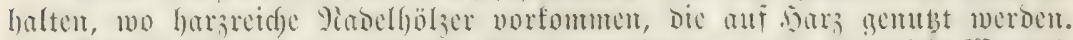

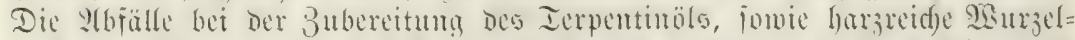

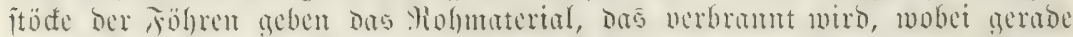

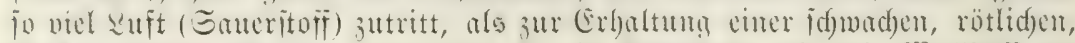

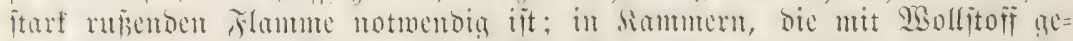

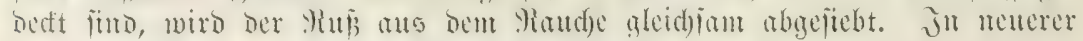
3eit wiro Ruí aug Steinfohlenteer bereitet.

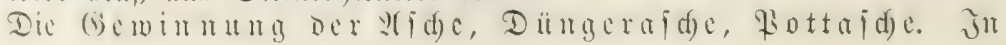




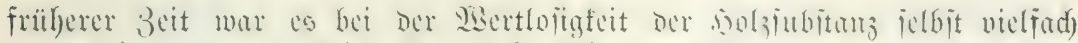

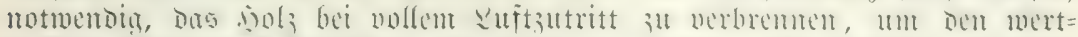

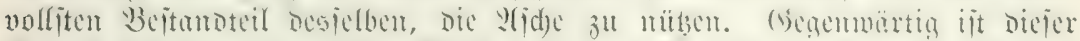

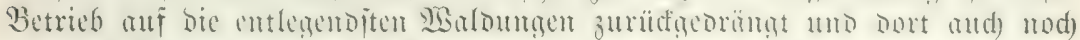

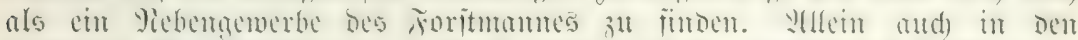

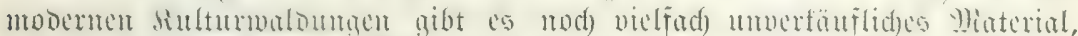

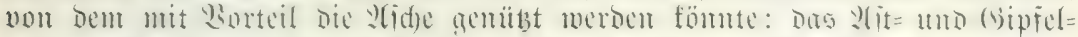

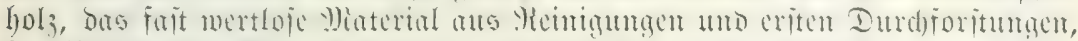

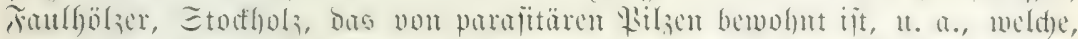

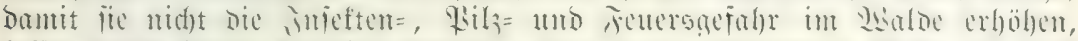

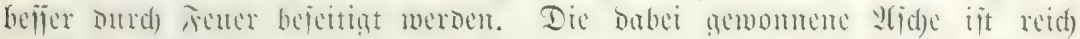

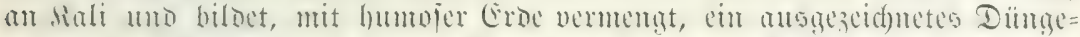

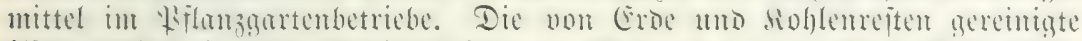

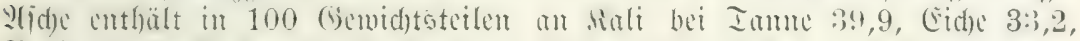

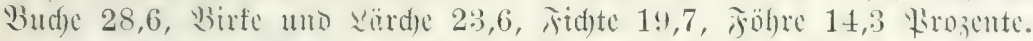

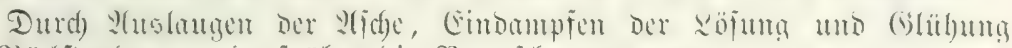
bes Müd ftandes murbe früher bie Bottajde gemomen.

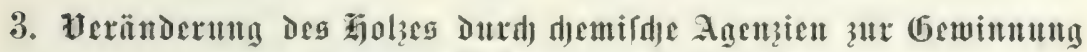 sinz̨luer Geftandtrile Des}

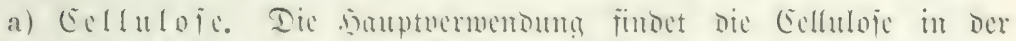

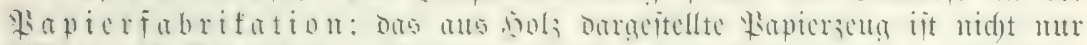

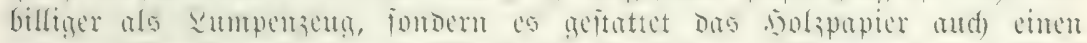
remeren Dut und geringe :

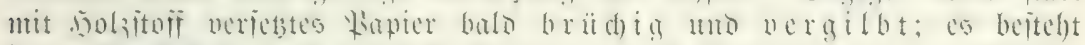

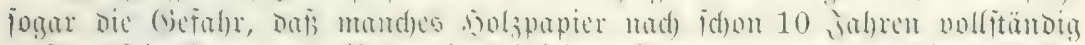

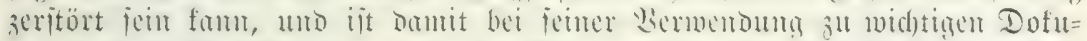

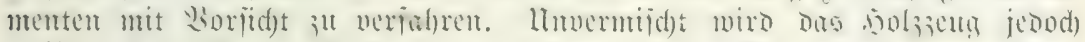

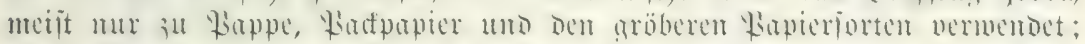

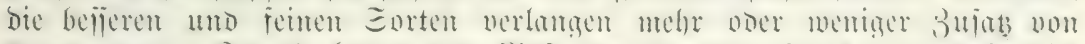

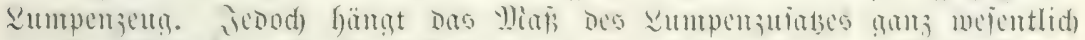

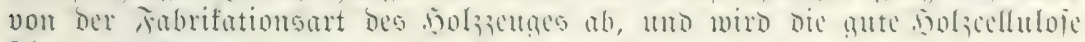
id)on als (Exaja für Sabern betrad)tet.

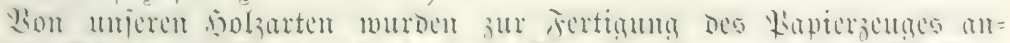

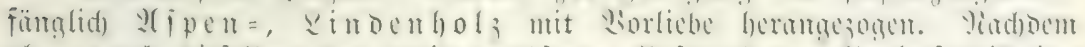

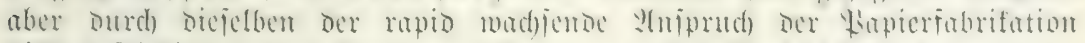

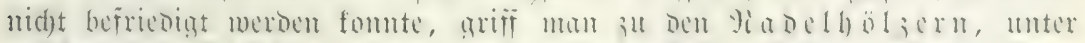

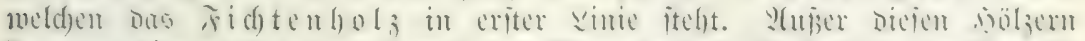

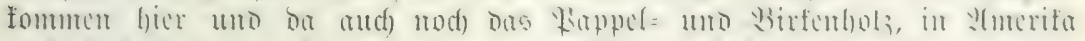

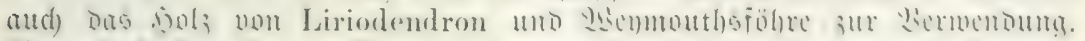

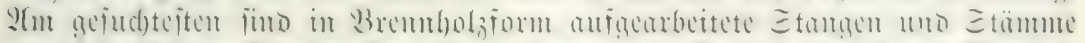

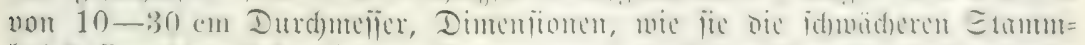

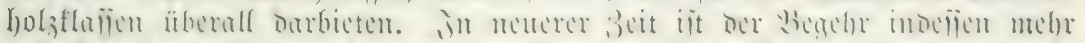

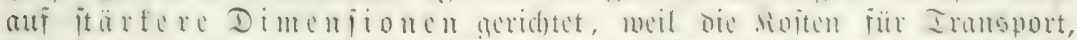

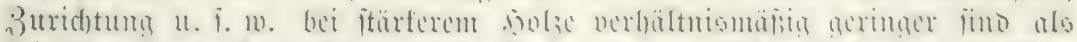

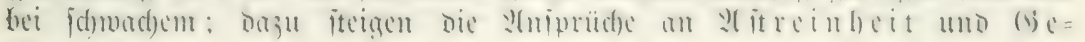




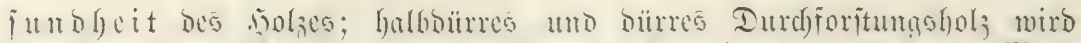

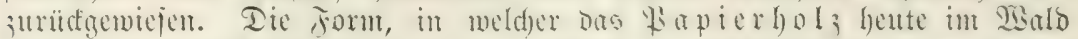

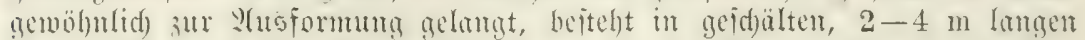
Munditüden von $10-30 \mathrm{~cm}$ Etärfe, meld)e in Maummaken cingeidjid)tet werben.

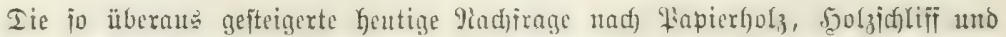

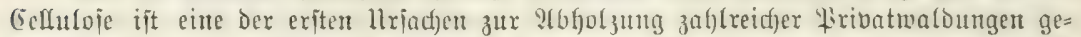
worDen, Da aud) mitteliftarfe Stammholzbeftünde Dem Wedarfe voliftündig genügen.

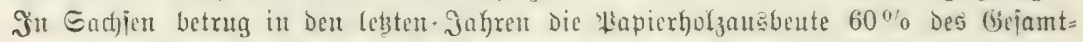

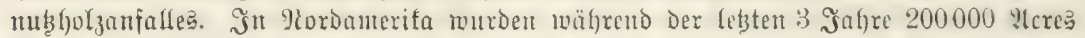

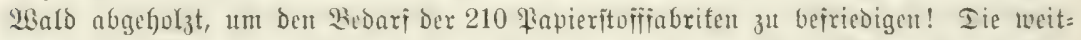

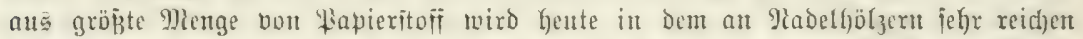

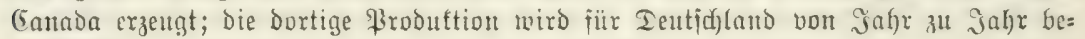
brohlidjer.

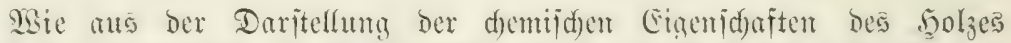

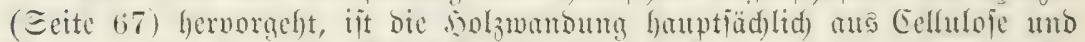

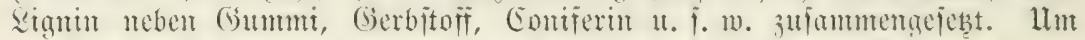

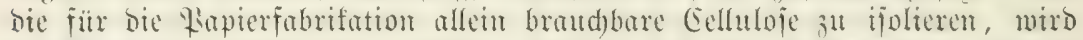

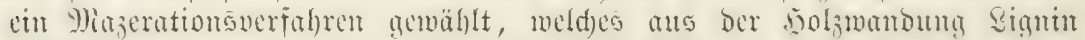

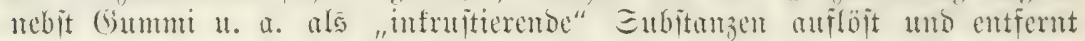

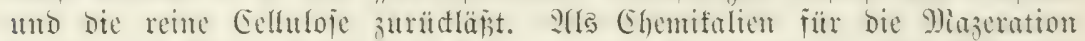

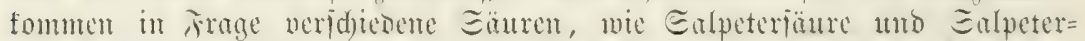

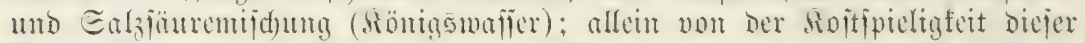

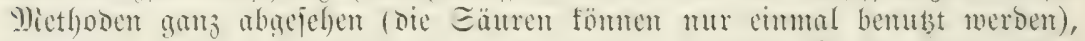

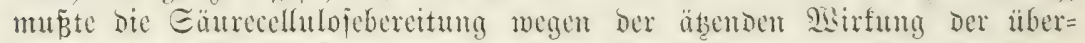
bies giftigen Gaje anfgegeben werben.

Die sefbandlung mit $\Xi$ alziäure greift audf) bie (Sefluloje an und verwandelt

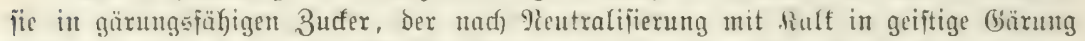

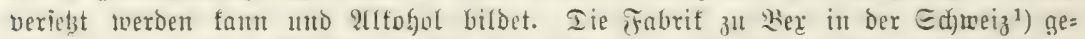

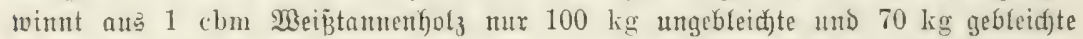
Eefluloje.

ע̈

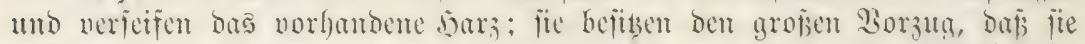

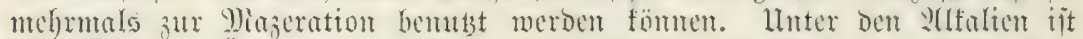

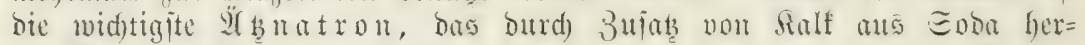
geitellt miro.

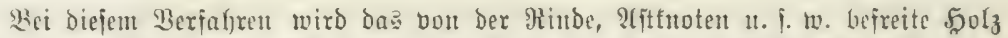

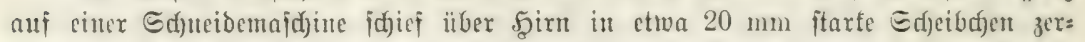

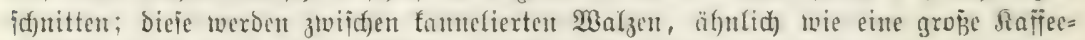
majcfine wirfento, in fleme Epfitter zerrififon, Die munther $2 \mathrm{~cm}$ lang unt $5-8 \mathrm{~mm}$

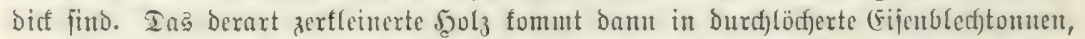
bie in einen langen, horizontal liegenden Iampifefiel gefafren werden. Sit Der

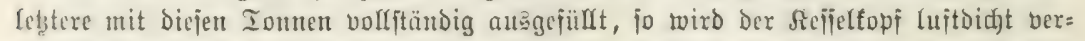

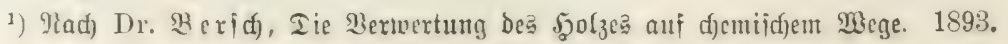




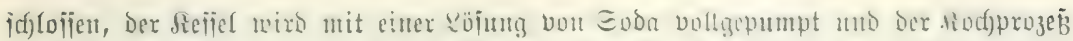

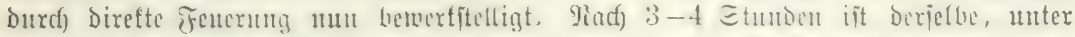

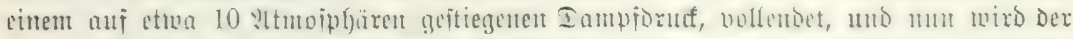

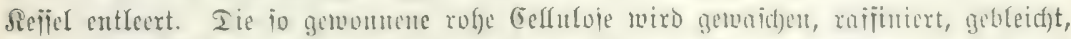

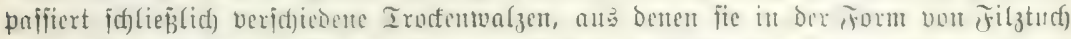

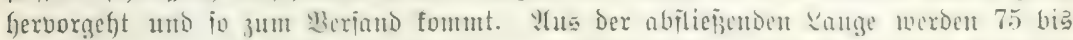

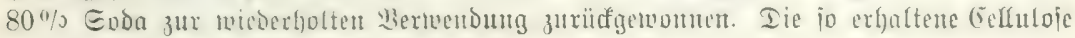

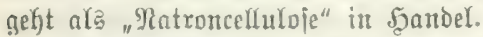

In neuciter 3ett neigt man mefor zum Berfafien des 9latronweriahtens und 3ux

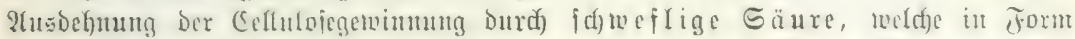

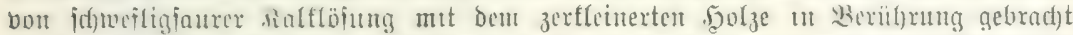

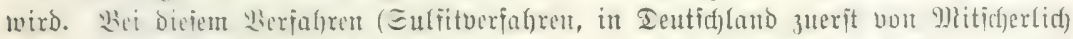

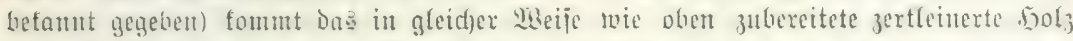

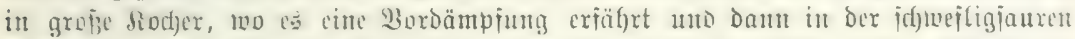

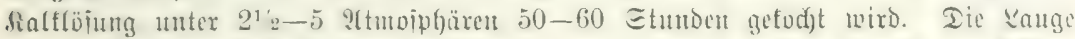

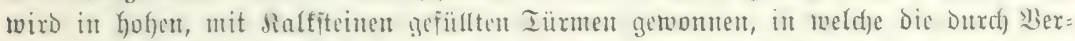

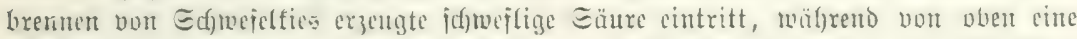

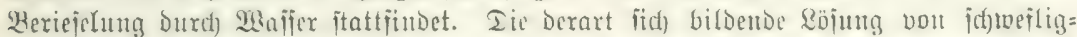
faurem Salf fammelt jith unten in Bafijus. Iex aus Dem liod)er fommende Etoff bilbet rötlidgelbe, weid)e Wrofen, bie unter Etampitu zerbrüct, gewaid)en und ge=

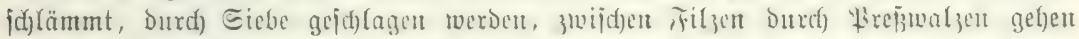
und meift in dieiem 3uitand zur \$eriendung gelantgent.

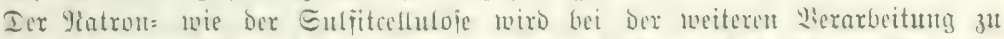

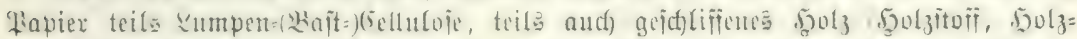

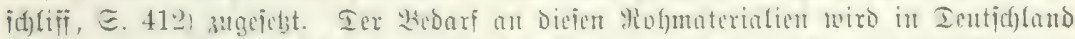

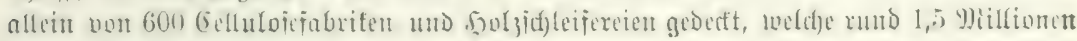
Feitmeter $\mathfrak{S}_{0} \mathfrak{l}_{3}$ berarbeiten.

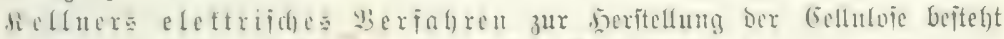

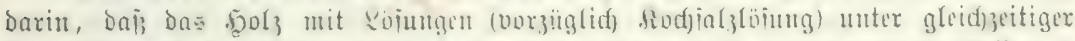

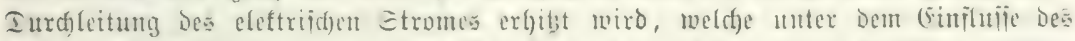

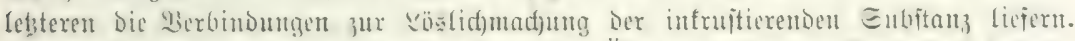

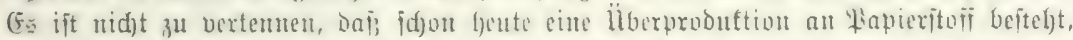

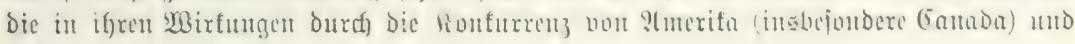
afien nod) verjtärft werden bürfte.

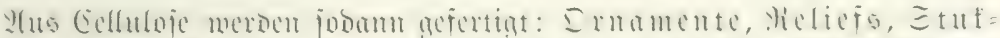

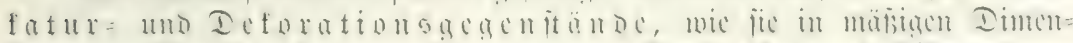

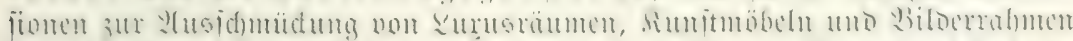

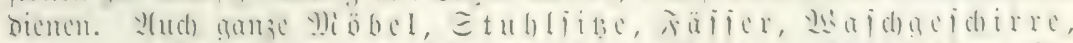
(E)

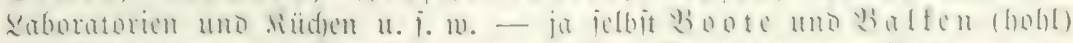

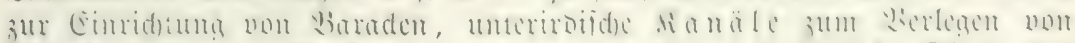

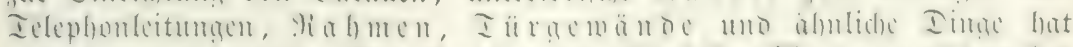

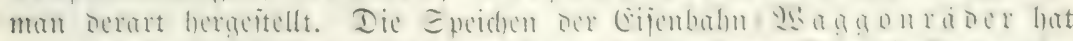

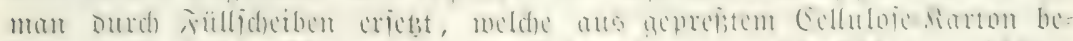

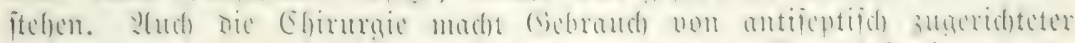

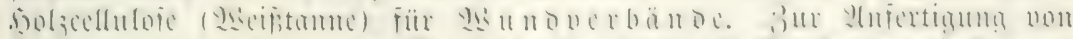
i) $i m m e x t c p i d e n$ und 


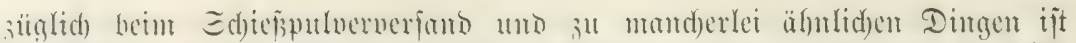

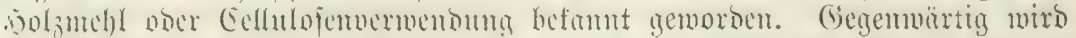

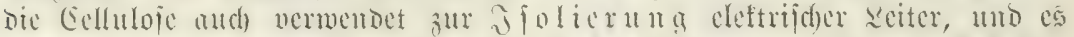

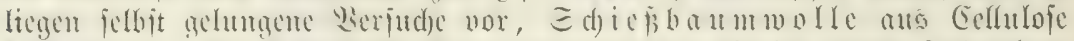

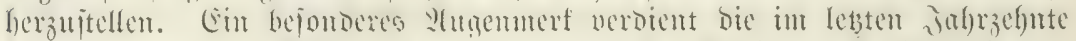

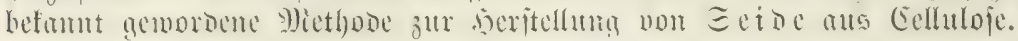

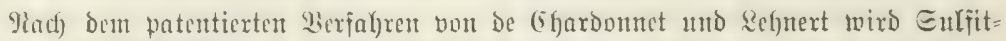

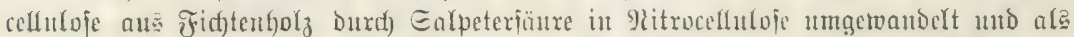

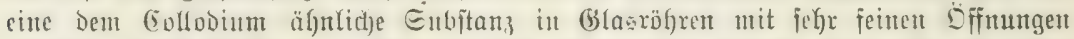

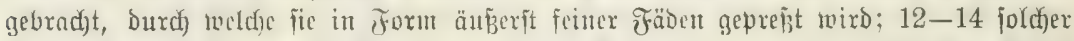

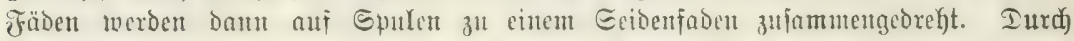

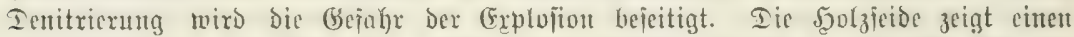

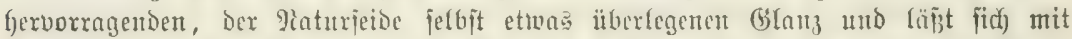
Reichtigfeit betiebig färbent. Iie in Den Yebten Sahren io billig uno fo betiebt ge= morbene gexingere Seibe ift woht zumeift auts $\mathfrak{S D O F}_{3}$ hergeftellt.

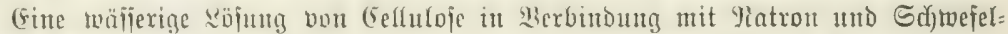

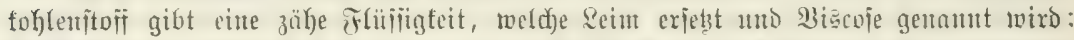

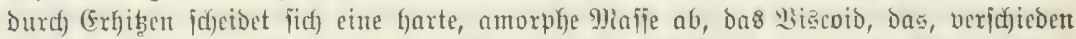

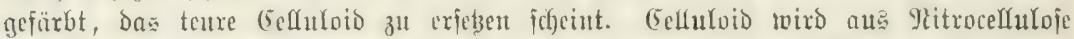

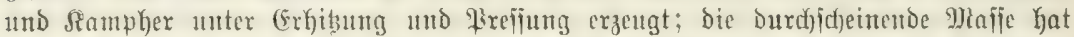

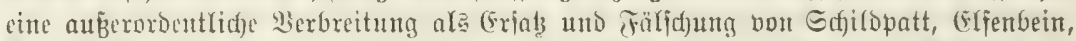

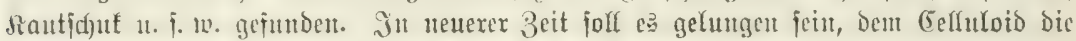

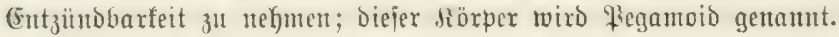

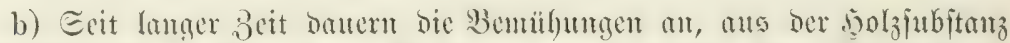
gärumgofäliggen 3 uder ub

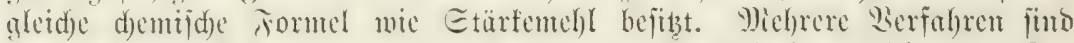
in ben lebten jubren angegeben woroen, weldhe sols in zerfleinertem $3 \mathfrak{u}=$

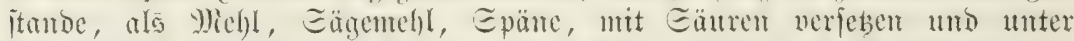

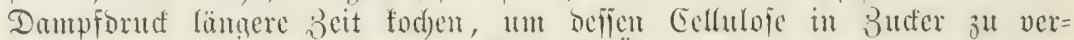

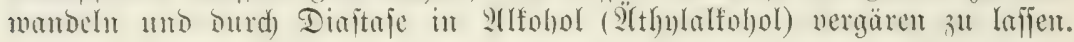

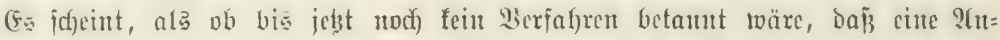

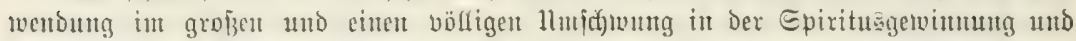

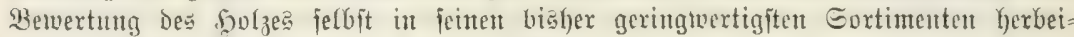

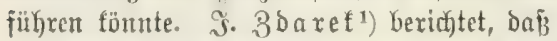

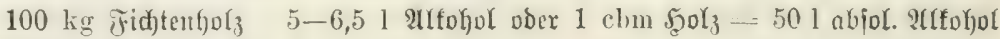

100 "Iantentyolz $4-5$ " "

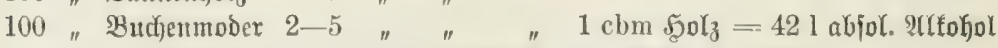

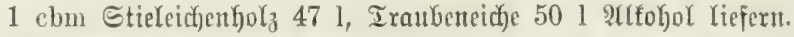

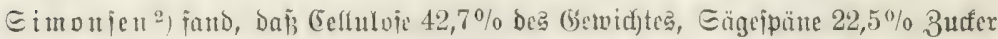

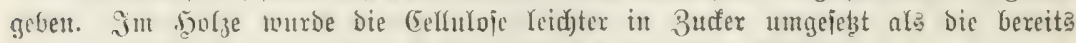
ijolierte Eeflulofe; $100 \mathrm{~kg}$ Eägejpänte gebent $6,5 \mathrm{~kg}$ reitrent $9 u$ fohol.

1) S̈îterx. Foritt= น. Jagozeitung 1895, 1896, 1899, 1900.

2) Bentralblatt für 2 gerifultur 1896 . 


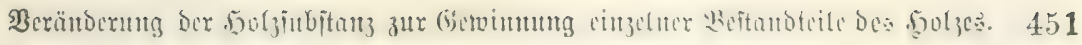

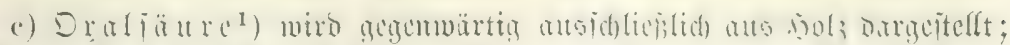

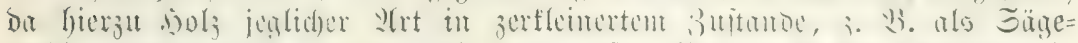

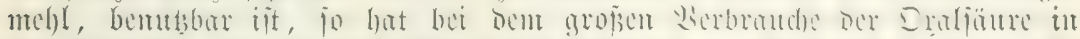

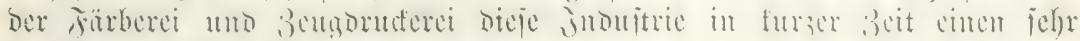
bead)tentsิwerten 2 (uffd)wung genommen.

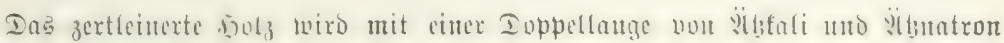

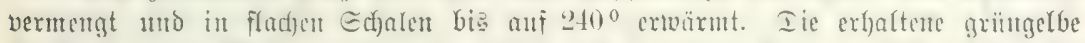

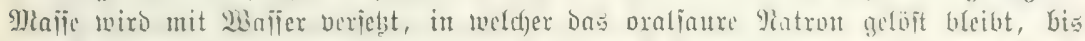

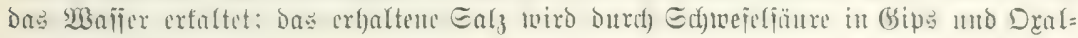
jüure zertegt.

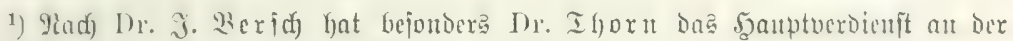

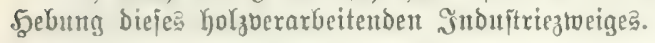




\section{Sechiter 2lbichnitt.}

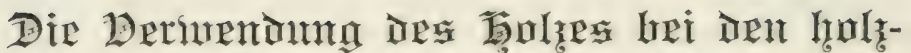 trexbrattigntien (femerben.}

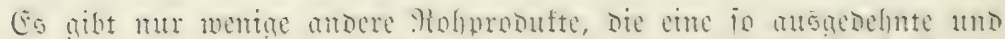

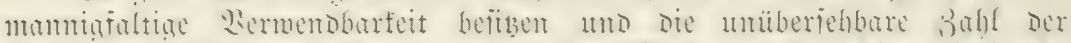

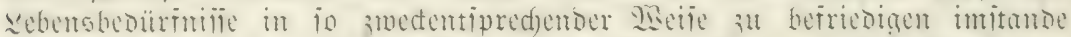

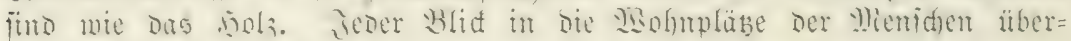
sengt fiervon zur Gienüge.

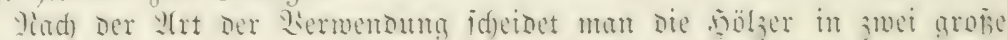

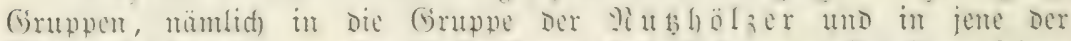

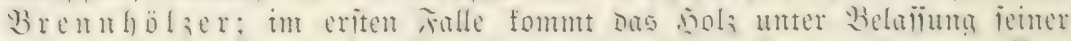

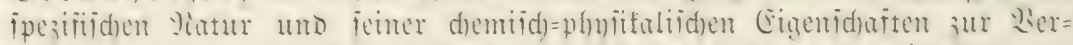

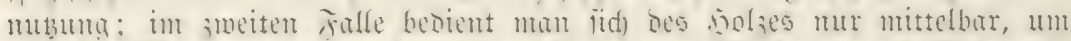

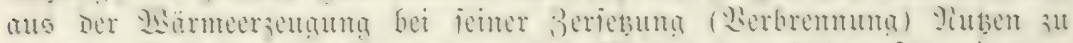

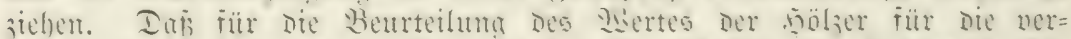

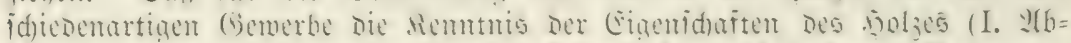

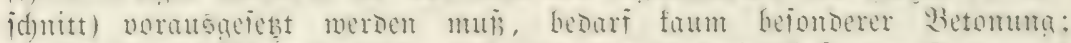

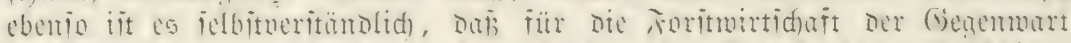

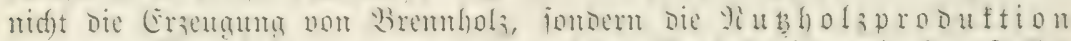

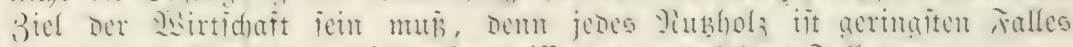

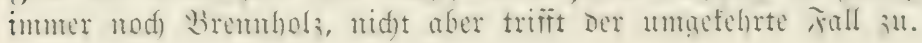

\section{(E) rite unterabteilum

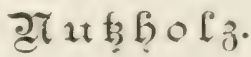

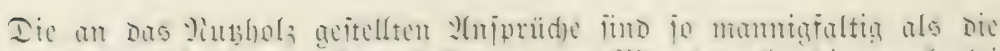

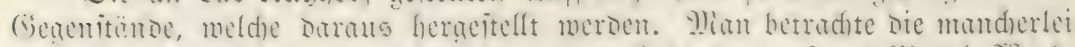

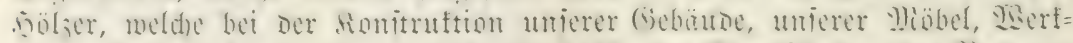

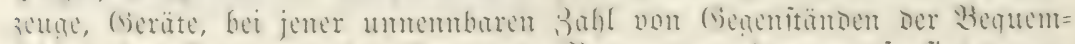

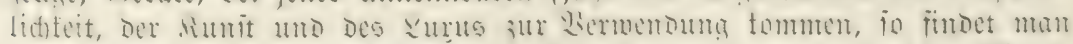

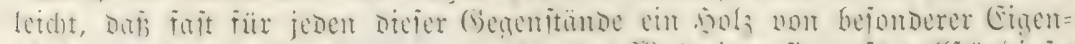

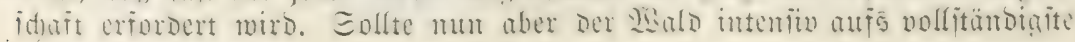




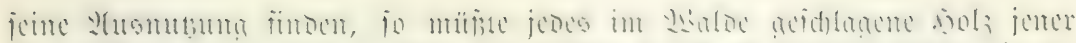

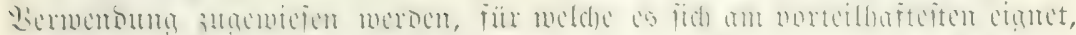

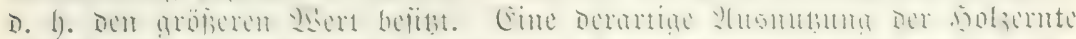

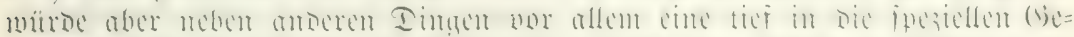

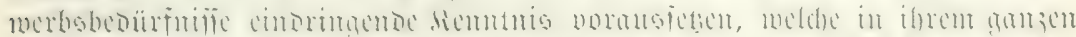

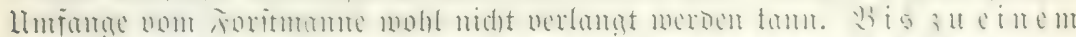

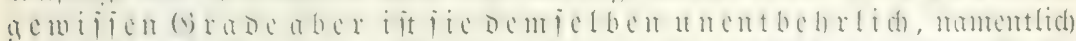

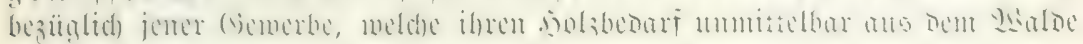

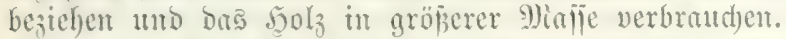

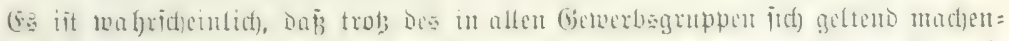

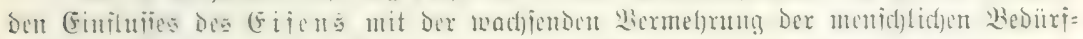

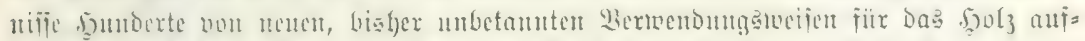

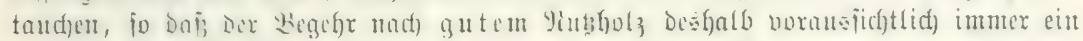

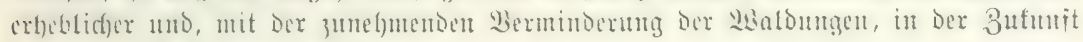
fogar ein fid fteigernber Gleibent wirb.

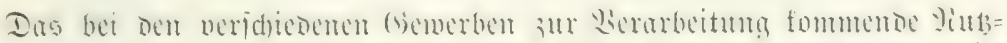

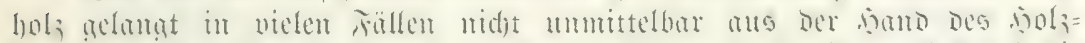

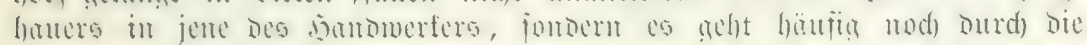

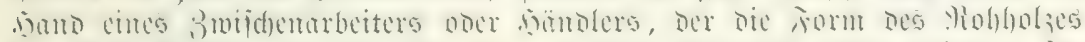

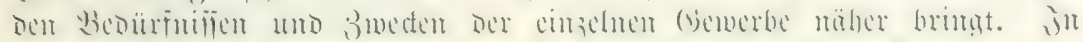

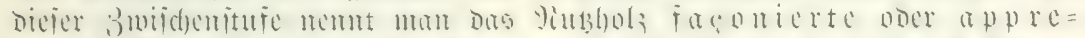

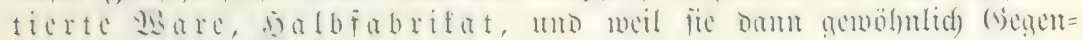

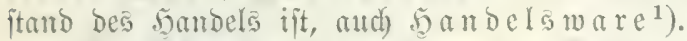

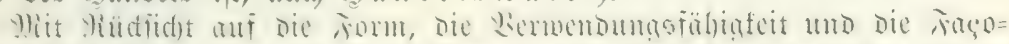

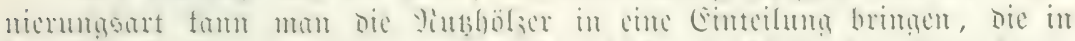

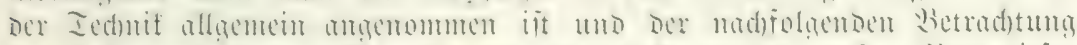

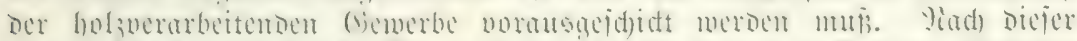

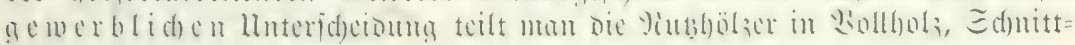
holz uno Epaltholz.

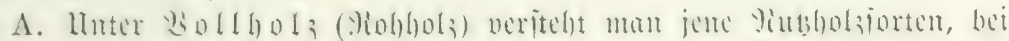

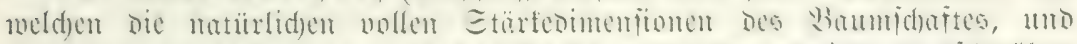

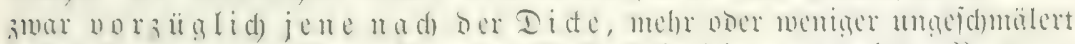

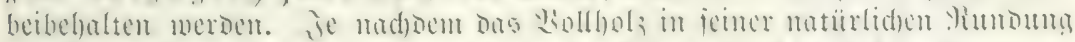

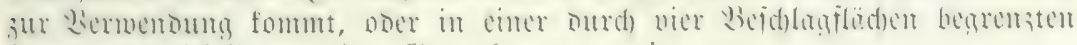
Frorm, unteridoeidet es ber Gewerbamtam meiter

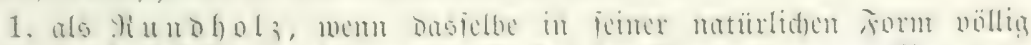

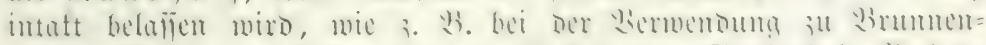

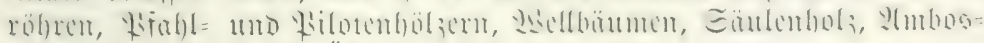

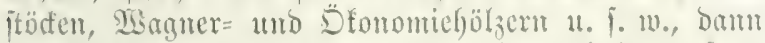

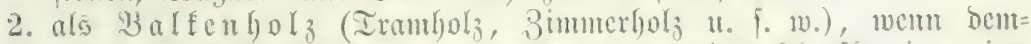

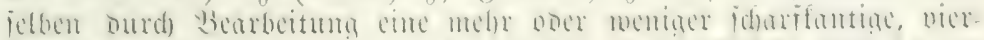

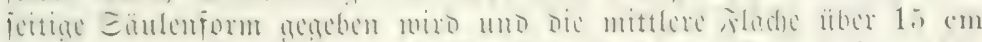

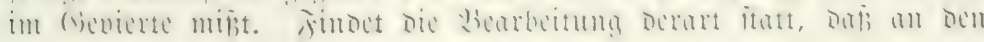

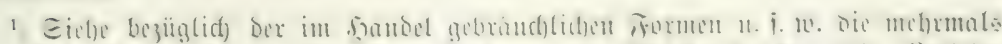

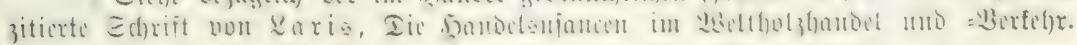
(J)ię̧ก 1889. 


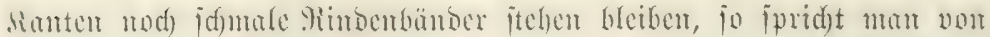
wabufantigem ober wald =, and fdalfantigem Sollholze

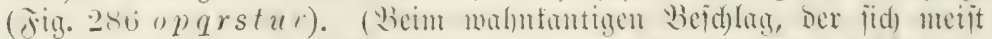
mux ati imet Drittel ber Etommlämge vom Etodembe ab feid)räntt,

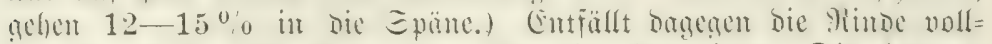

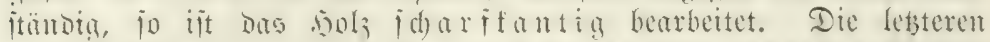

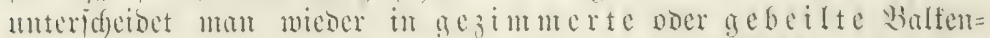

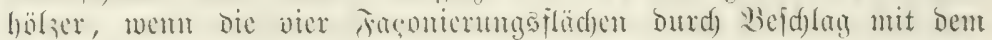
Breitbeil hergejtellt wutoen, uno in befäumte ober befägte

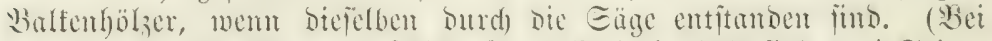

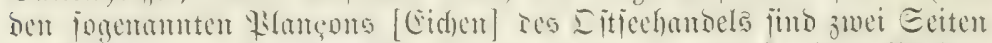

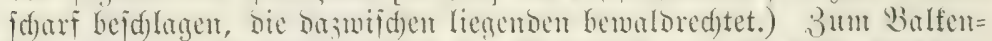

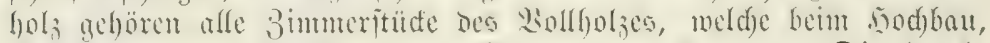

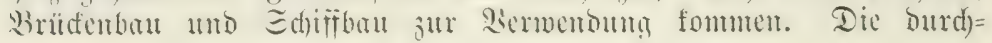

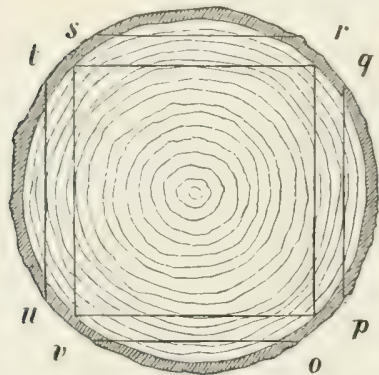

Fig. 286. Wुafutantiges Wollhol mit Minbe, (d)arffantiges obne Minde.

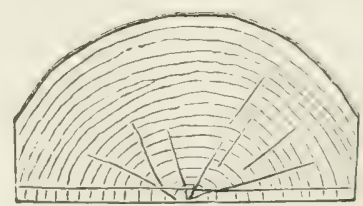

Fig. 287. Etïđbolj, Durd) Epaltung uno Abfanten bervorgegangen.

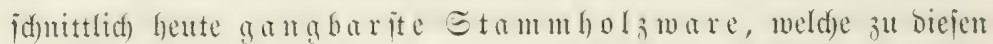
3imeden Sermenoung findot, wiro ans Stämmen gemonmen, weld)e ca. $18 \mathrm{~m}$ sänge แno etma $22 \mathrm{~cm}$ mittlere Etärfe $(30-35 \mathrm{~cm}$ i๘ Brutitgöhe) melien;

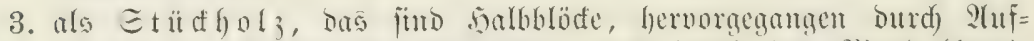

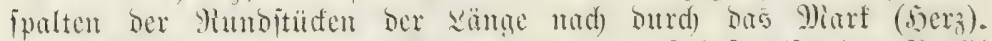

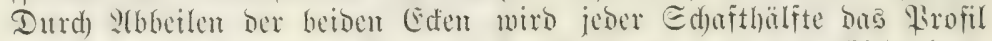

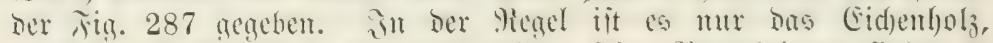

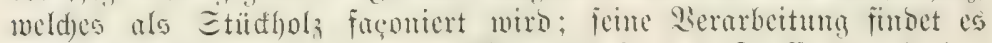

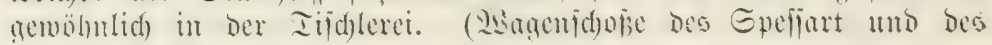
Ditjeehandels.)

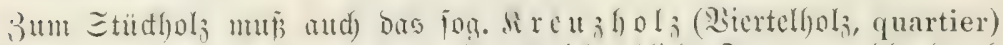

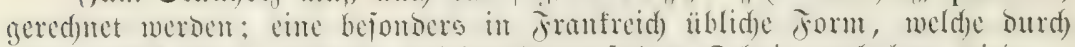

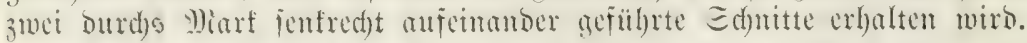

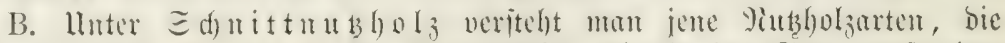

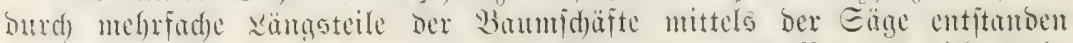

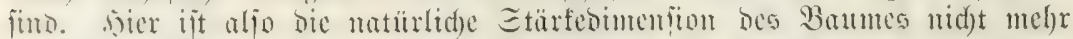

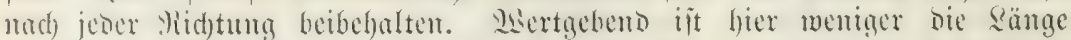

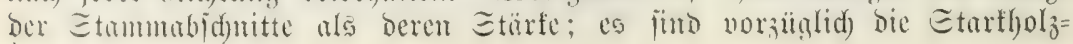




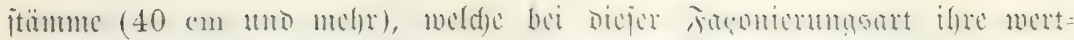

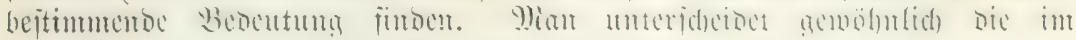
bandel vorfommente Ed)nittlolzware in folgender $\mathfrak{A}$ (rt:

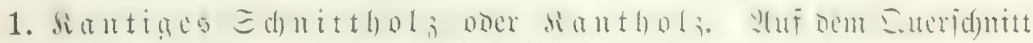
quabratif(a) oder fait quadratifa) (Jig. 288).

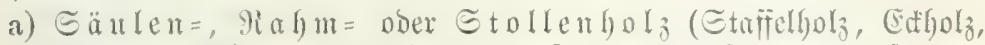
Maldmidjentel), 2,5-6 m long; 5 auf $5 \mathrm{~cm}, 6$ auf $6 \mathrm{~cm}, 7$ auf $7 \mathrm{~cm}$, 7 auf $10 \mathrm{~cm}, 7$ aนf $12 \mathrm{~cm}, 10$ auf $10 \mathrm{~cm}, 10$ aนf $12 \mathrm{~cm}$, 12 aแf $12 \mathrm{~cm}, 14$ auf $15 \mathrm{~cm}$ ftart; burd) Eämģteilutg itärferex

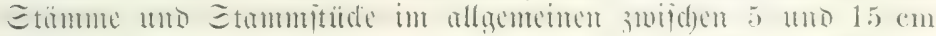
itarf und $2^{1 / 2}-6 \mathrm{~m}$ lang, aud burd) Berjoneiden der Boblen hergeitellt.

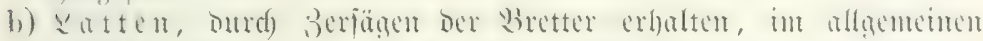
unter $5 \mathrm{~cm}$ ftarf́, $3-6 \mathrm{~m}$ lanţ, gewöhnlid) $2-3 \mathrm{~cm}$ bid uno 4-5 cm brit. Mian unteridetiont Dad)latten, 2s:urfatten, Macin= Iatten, Epalierlatten, Gipishtaten u. 1. w., je nad) den Etärfen=

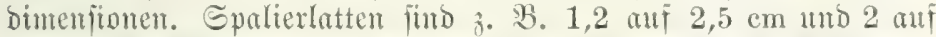

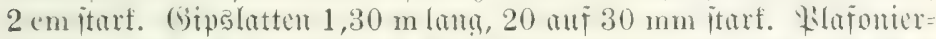

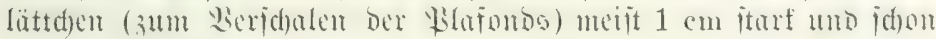
mit $30-50 \mathrm{~cm}$ Eänge vermentbar. Sierfer gerbören audf bie façonierten Reijten.
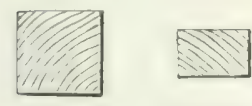

foig. 288. Sinthälser.
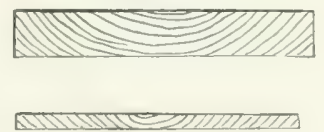

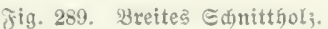

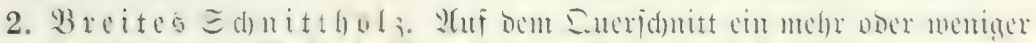

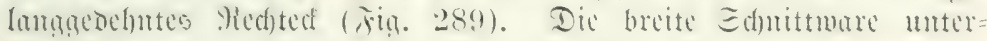

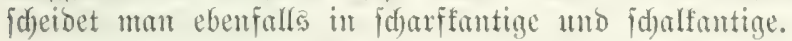

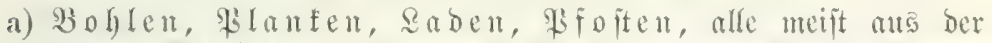

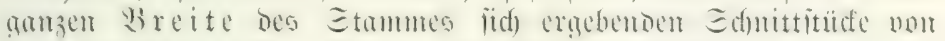
2 und mehr 3oll ${ }^{1}$ ) Didfe. Sie furd gemöhnlid $3-6 \mathrm{~m}$ lang,

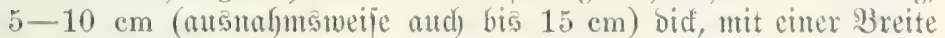
zowijgen 20 und $35 \mathrm{~cm}$ und mebr. Salbe Bohles mit ofit mur 8-10 cm 3reite. Die Wohlen werden ans ben beiten Ieilen bes Etammes gejdutten.

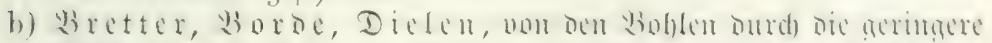

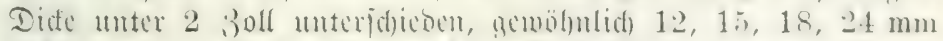

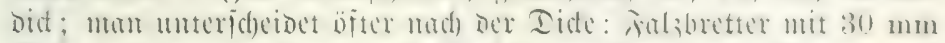

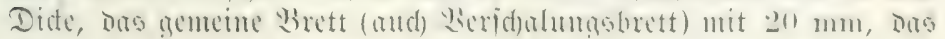

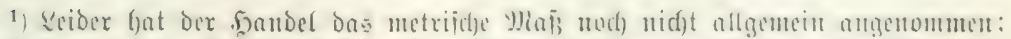

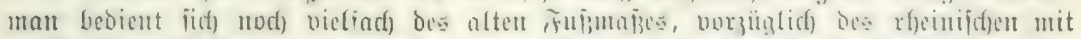

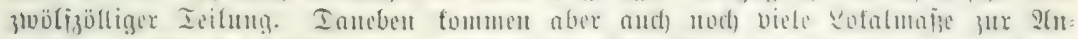

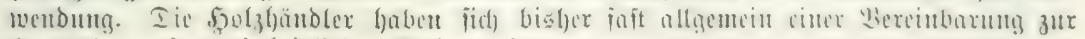

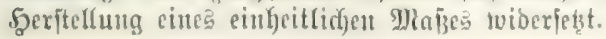


Iafelbrett mit $18 \mathrm{~mm}$, (Eid)en=Iifd)lerbretter in Franfreid) bis herub 3 u $12 \mathrm{~mm}$, Edjadtelborbe 4-10 $\mathrm{mm}$ Dide. Die Sänge ber Bretter ijt in neridfedenen Gegenten veridjeden; im Sandel miro meift nad) folgenden seingen gered)net: $3,3,5,4,4,5,5$

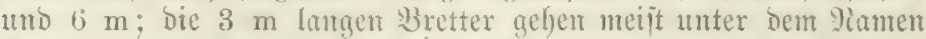
Sanalborde. Die Breite ber Bretter ituft jich im Santol folgendermajen ab: $14,15^{1} / 2,17,19,21^{1 / 2}, 24,26^{1 / 2}, 29,31$, 33 unb mehr cm. Die gröbte Miafie ber von heutigen Marft begefrten Bretter jutro jolde nit $20-32 \mathrm{~cm}$ Breite. Die gute

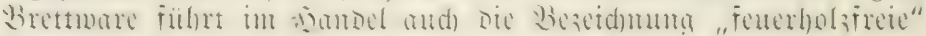
Mare.

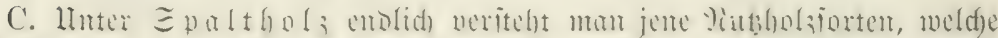

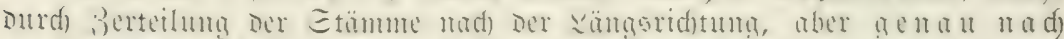
be m

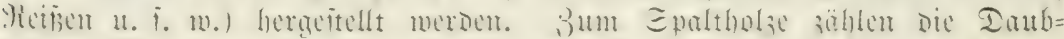

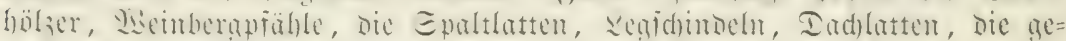

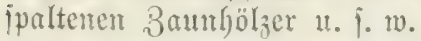

Ins Epaltfols unteridecidet iid) in ictner tedfutidgen Sibrmendbarfent vom

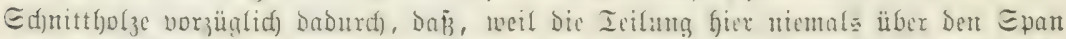

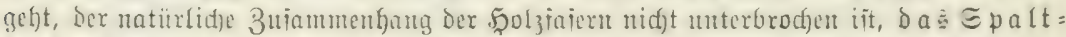

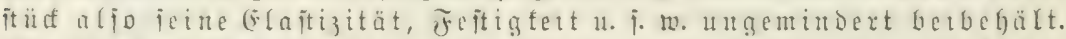

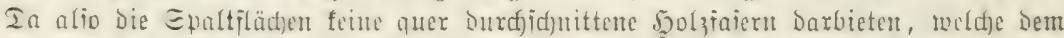
(Findringen ber Foudtigfeit (jelegenfeit geben, io it Epaltfols aud) meniger bem

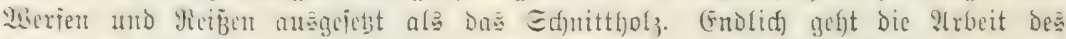

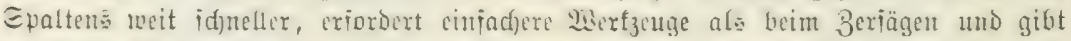

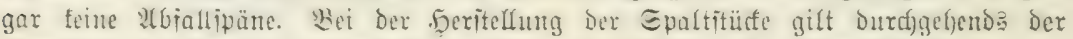

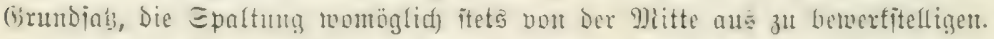

in folgentem betradten mir mun bie Yinthholinermendung bei ben wid)tigeren holzoverarbeitenden Gemerben felbit.

\section{Verwendun Deg folieg beim fodjuat.}

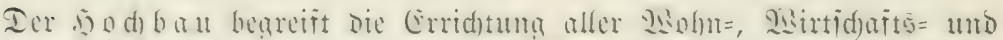

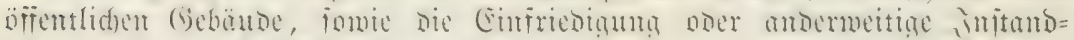

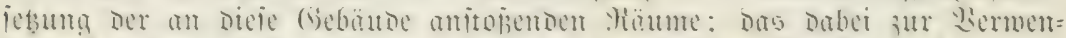

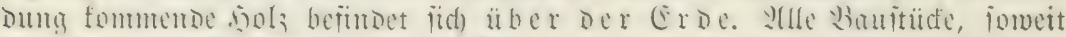

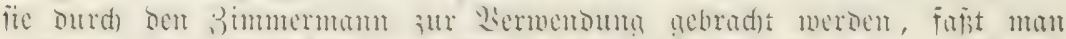

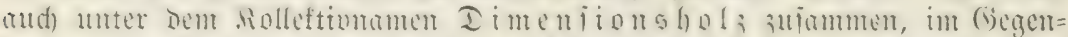

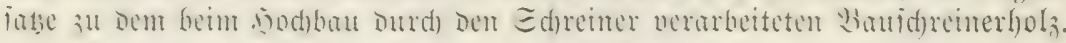

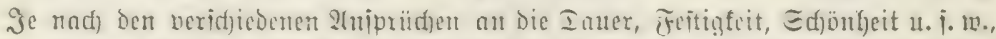

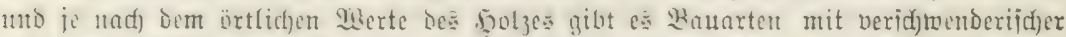

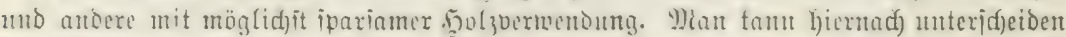
Dent SB(offbau, Fadj)bau utnd Stcinbau ${ }^{1}$ ).

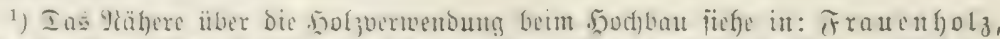

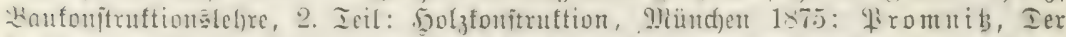

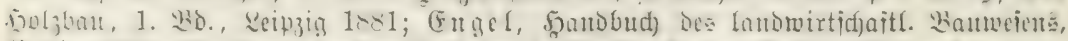

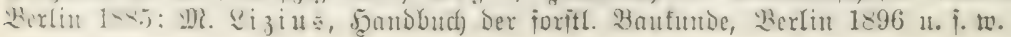




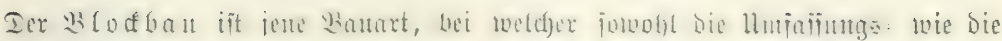

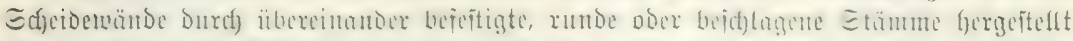

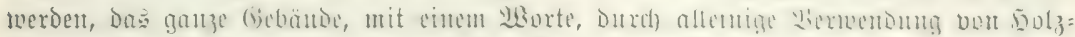

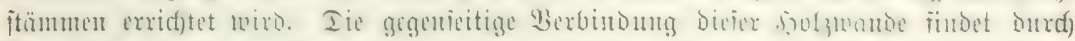

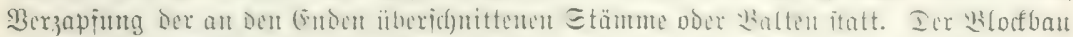

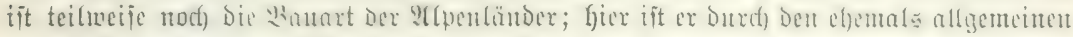

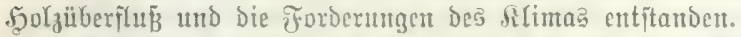

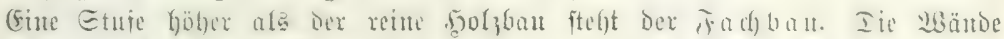

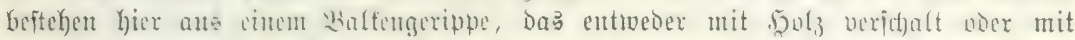

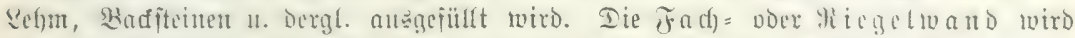
an folganden weicnt!id)en

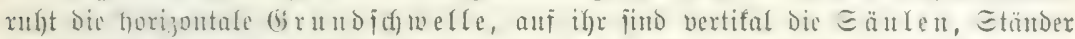

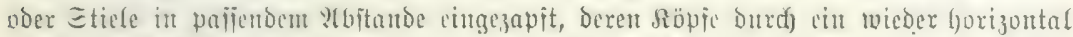

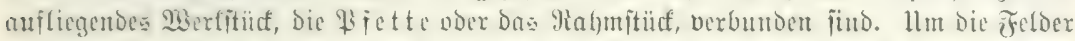
3)

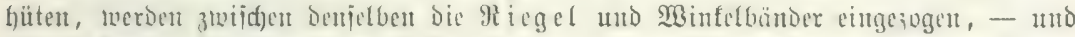

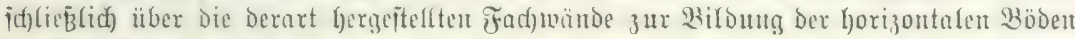

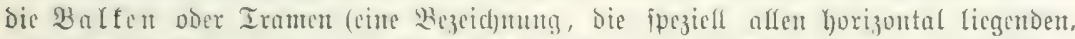

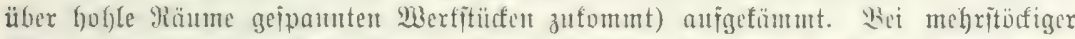

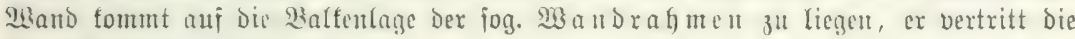
Grundichtwelfe in Den oberen (5tagen.

Im Mittelalter wurden fait alle, jelbit bie gröjten (bebändo anb Fach)ban her=

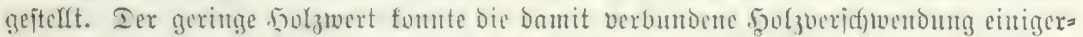

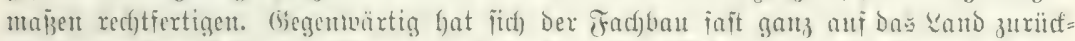

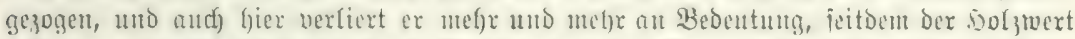

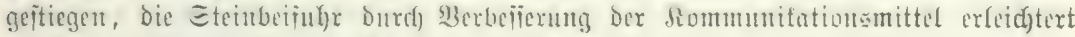

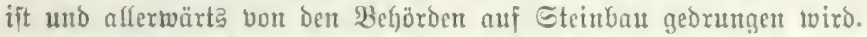

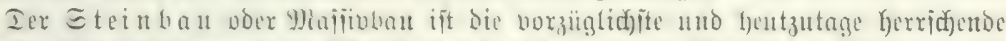

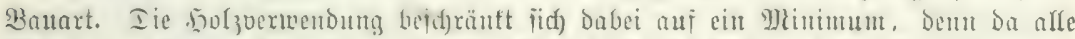

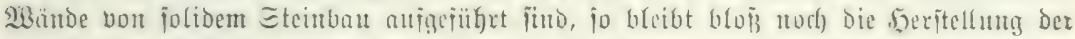

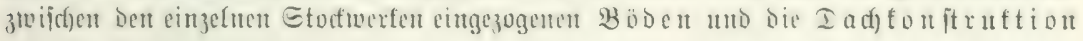
für Den Scolzbnu übrig.

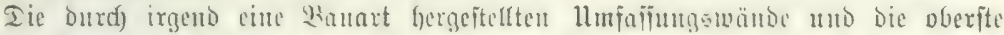

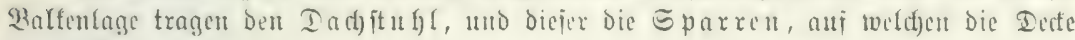
unmittelbar aujliegt.

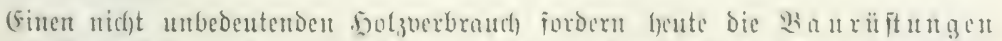

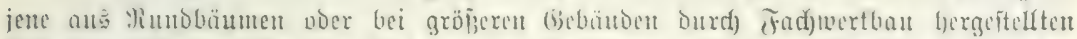

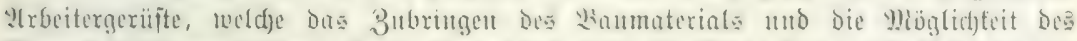

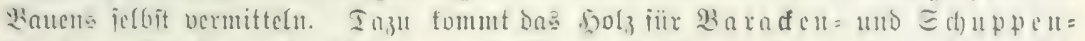

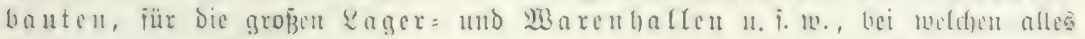
Fad)baubols zux פertvendung fommt.

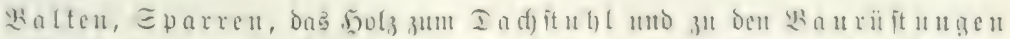

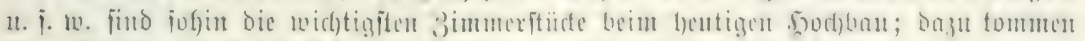

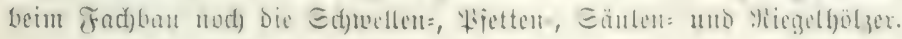

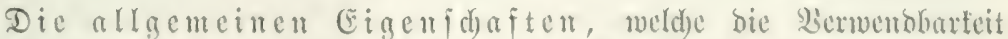

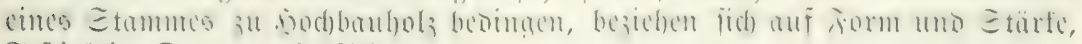
Foftigfeit, Damer un Edyucre. 
a) Jorm und Stärfe. Sbmohl für gemijie 3medfe (z. B. für

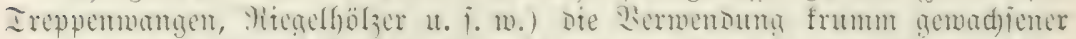

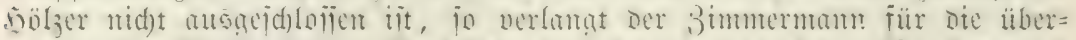

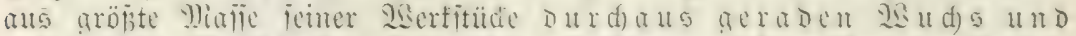

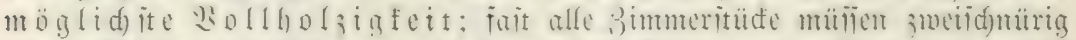

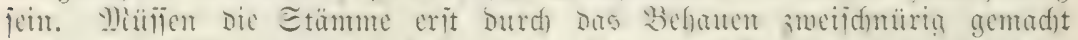

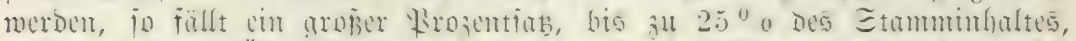

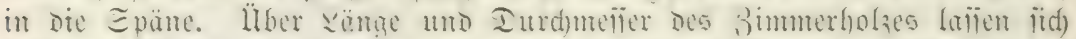

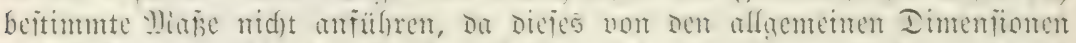

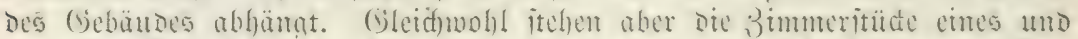

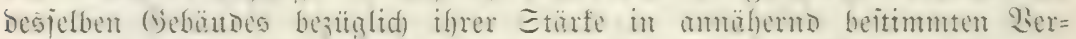

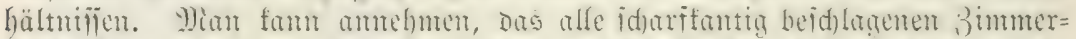

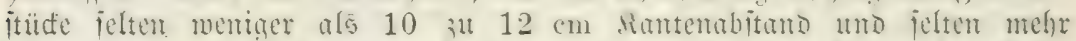

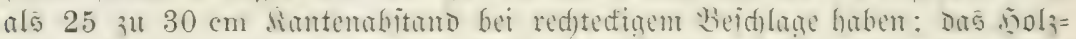

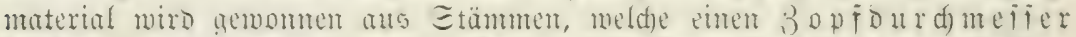

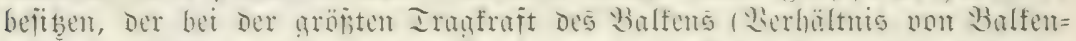

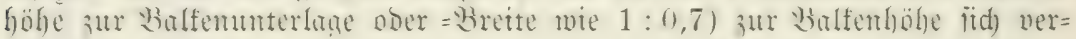
hält wie $1: 0,82$.

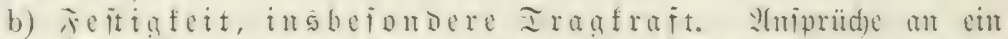

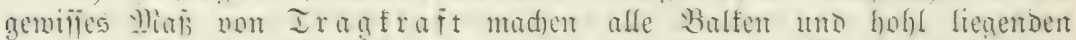

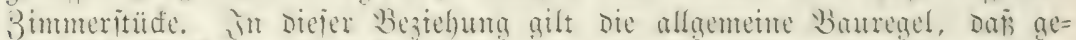
möbnlide balfen non ;irfa $15-20 \mathrm{~cm}$ cinc frete Enamun von $4-5 \mathrm{~m}$

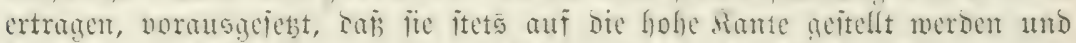

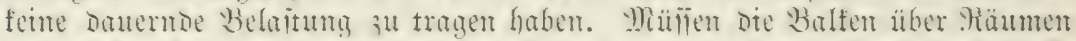

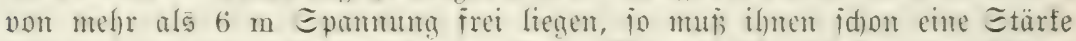

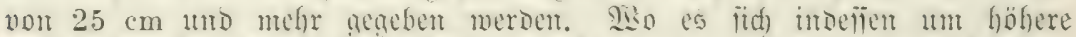
Iragfraftmajic uno Direfte belajumg aud) bei germger Epommeite hambelt,

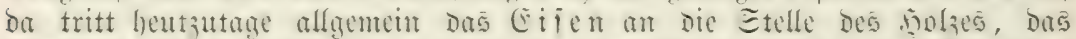

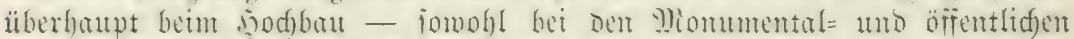
Gebäuden, mis bem cinfaden Prinathan in Den Etästen, mit añ Den Sande - madjente Serwendung findet.

Iie rïrfmetende Fejtigfeit jür bie jenfred)t itehindon 3immerfïcfe fommt mur

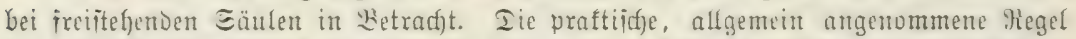

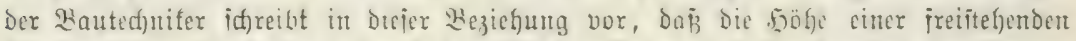

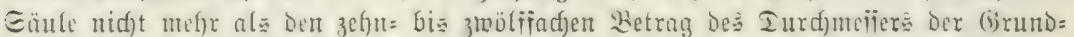

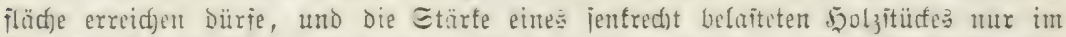

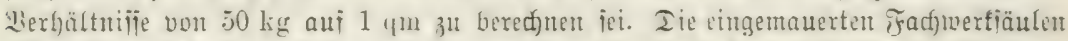
teilen ifre 2lugabe mit Dem Gejamtmanterwerf. Freiitefende Ectulen madjt man übrigen gegentwärtig faft mur mebr von (Fijen.

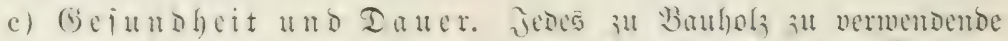

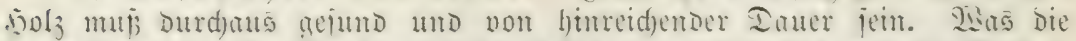

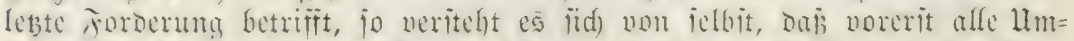

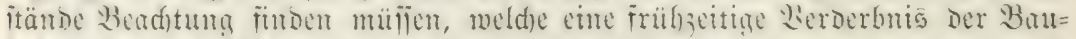

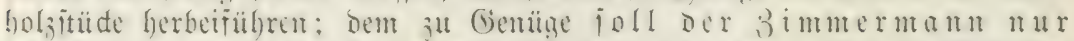

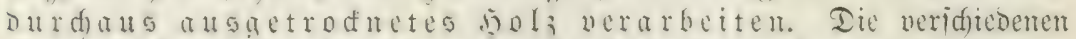

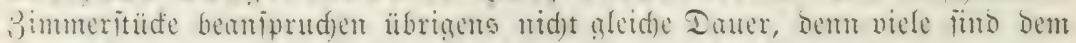

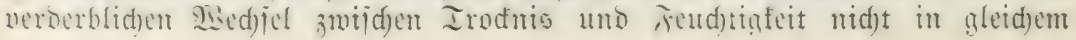




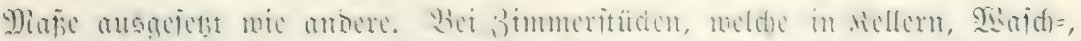

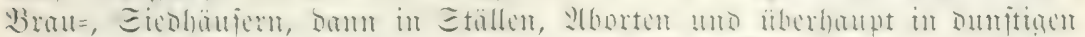

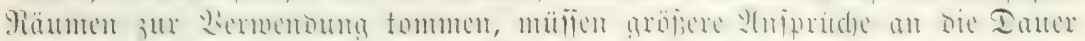

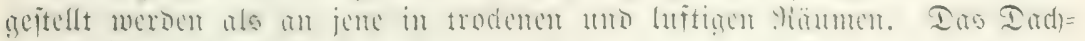
holz zälilt zut ben leżtgentanten.

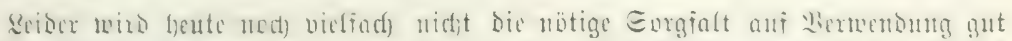

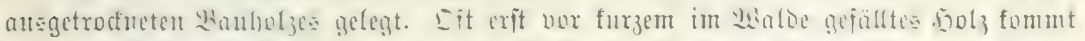

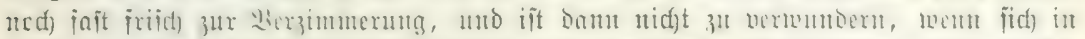

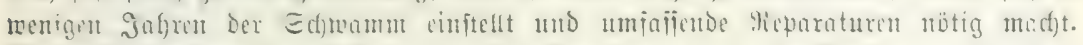

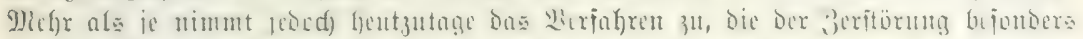

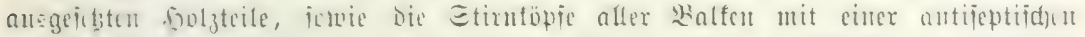

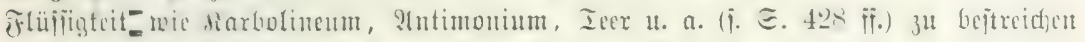
Dober boll ăt imprägnieren.

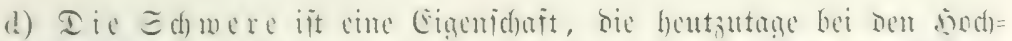

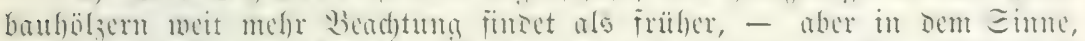
ba

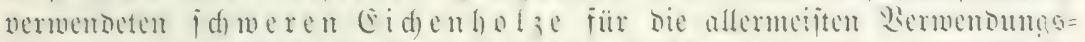

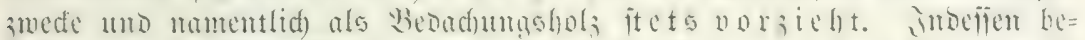

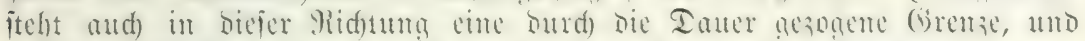

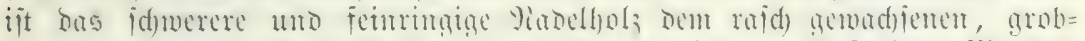

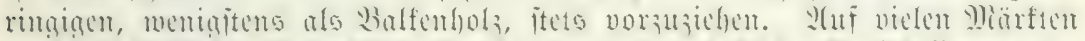

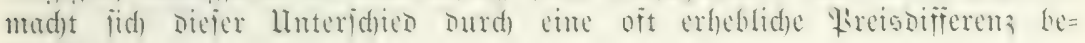
merfbar.

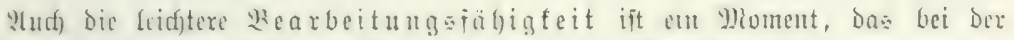

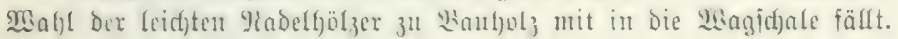

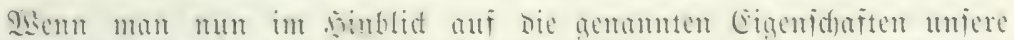

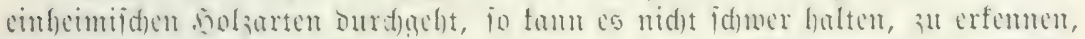

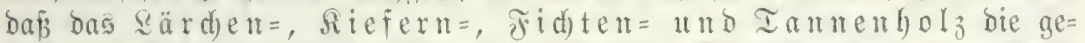

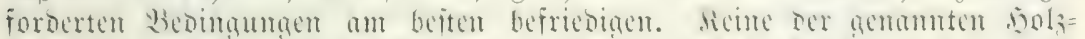

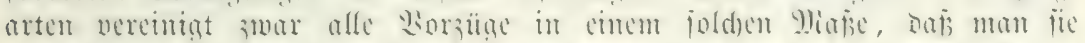

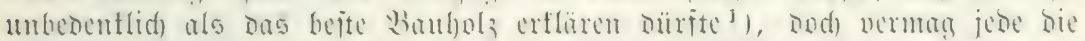

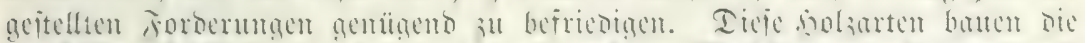

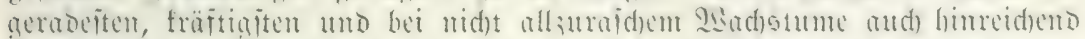

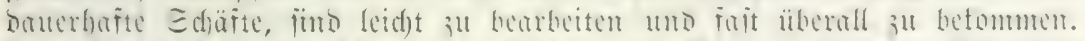
Ins (゙)

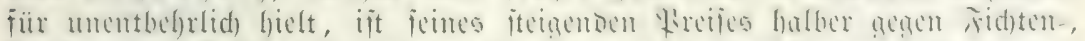

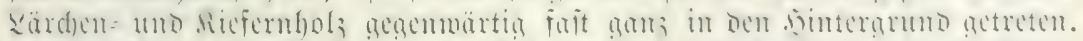

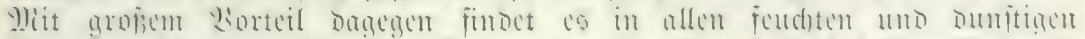

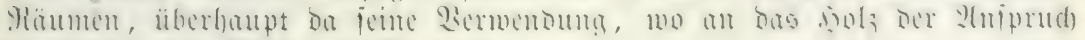
größntüöglidjer Dauer geitellt wird.

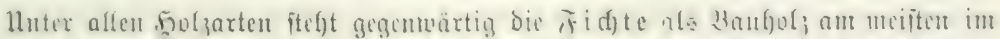

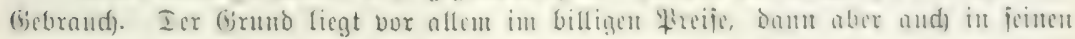

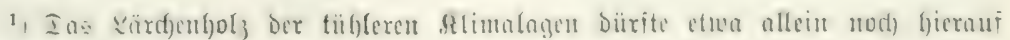
2(niprud) madjen. 


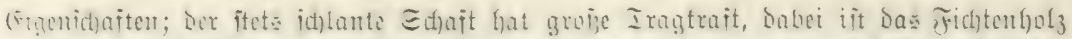

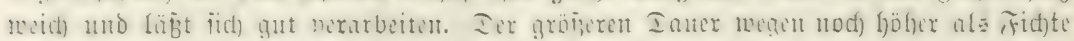
iteht Dor

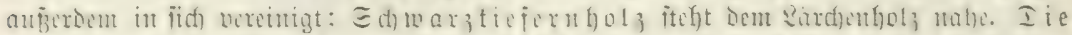

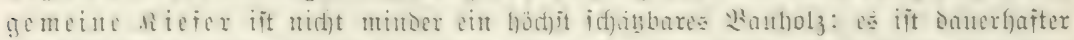

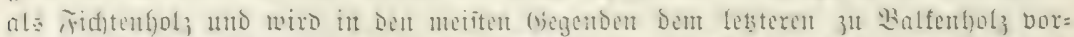

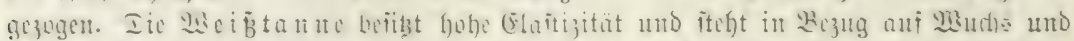

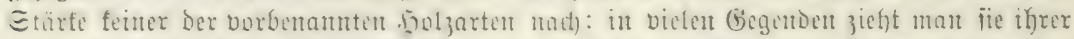

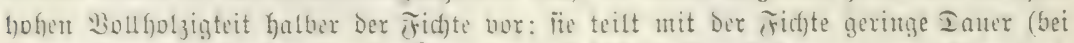

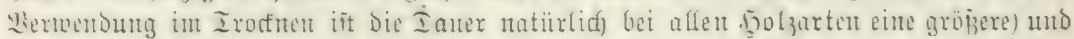

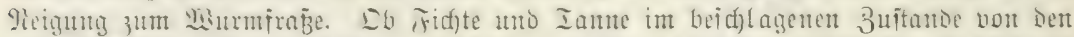

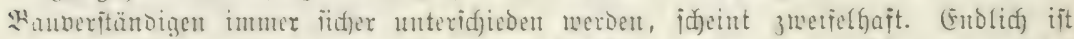

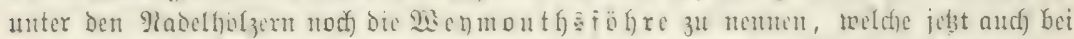

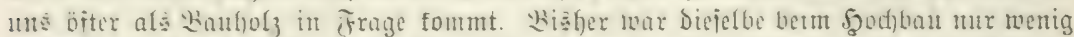
belicbt: man id)reibt if)r cine jeffr geringe Ianer und wenig Iragtrajt zu, iolange

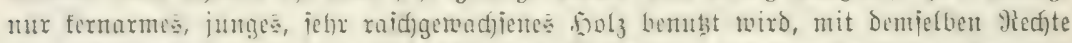

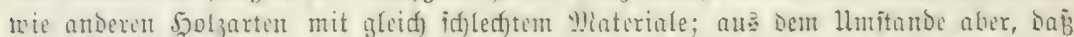

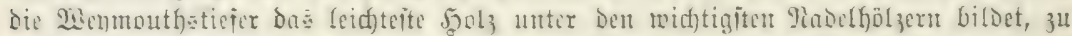

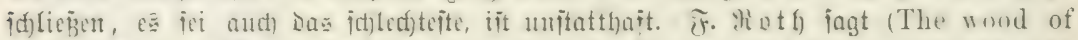

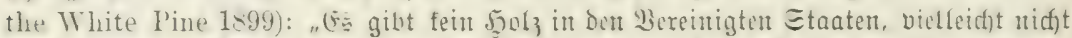

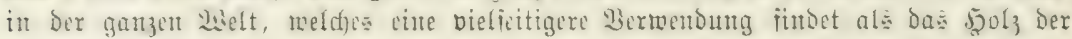
Whet)moutfogïhre."

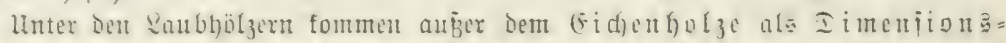

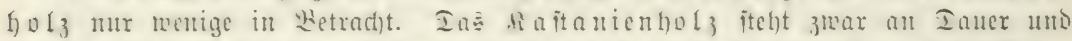

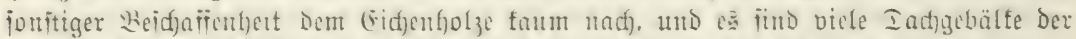

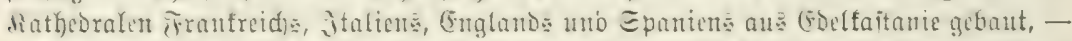

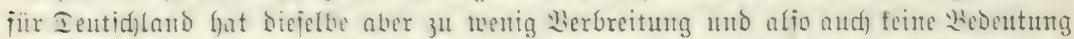

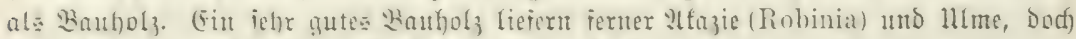

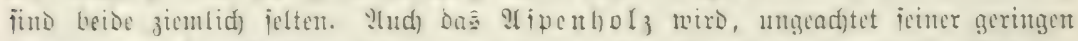

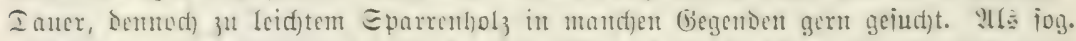

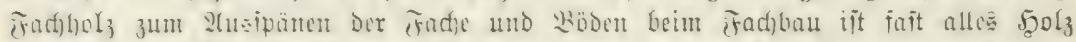

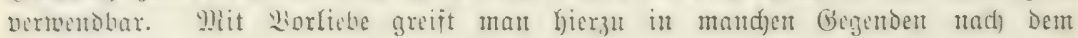
2iduentolze.

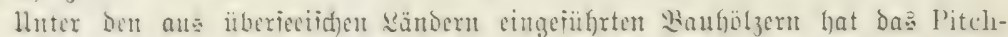

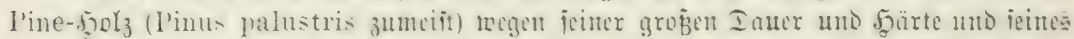

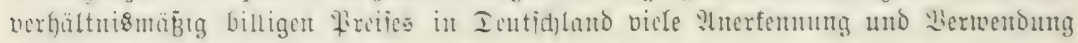
gefunoen.

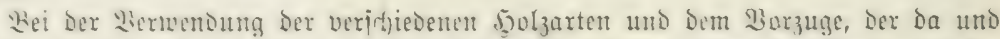

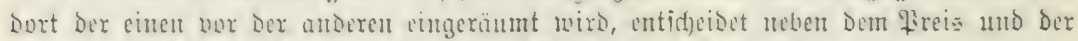

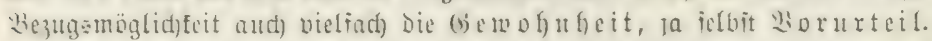

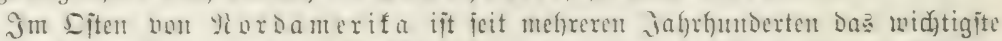

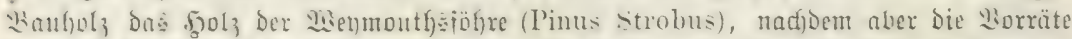
Baran iiff allmäflid) exichopfen, fommen Taxolium distichum und bie früfer ver=

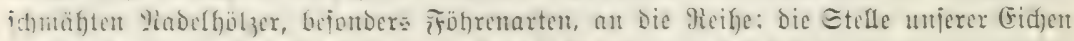

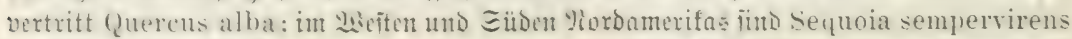

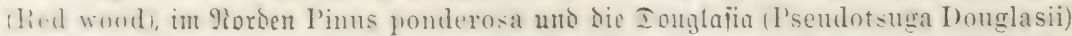

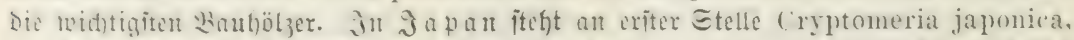

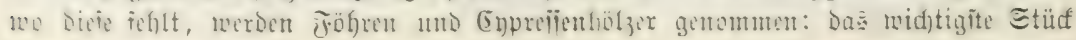




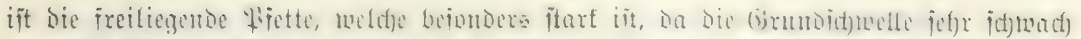

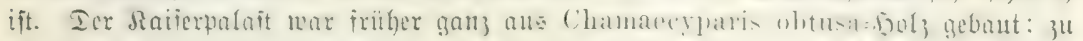

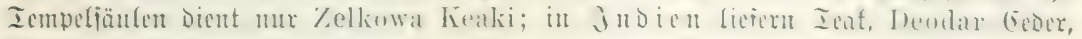
Pinus excelsá uno Sál (Shorea robusta) Dą Geĭte Baubolz.

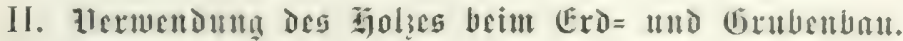

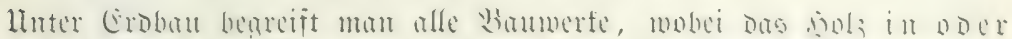
unte ถe

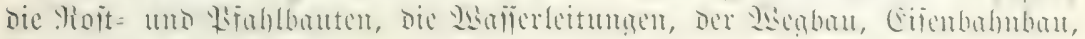
Bergbau u. ¡. เw.

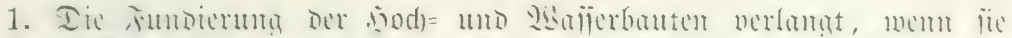

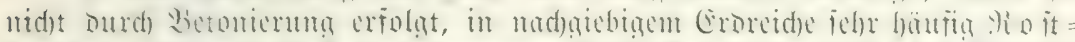

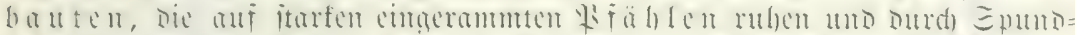

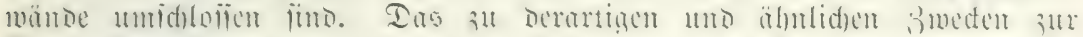

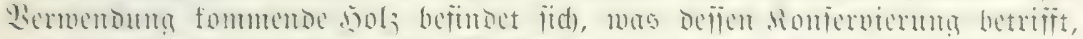

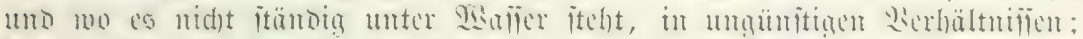

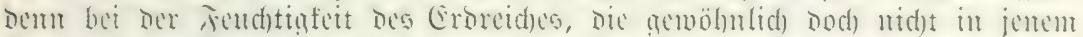

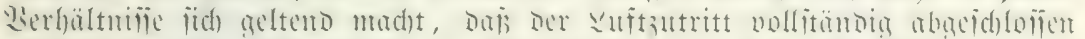

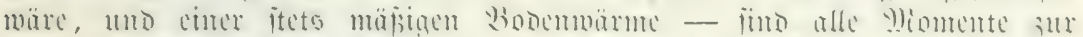

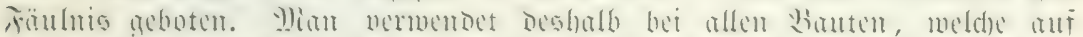

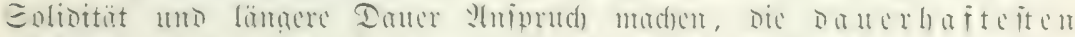
.

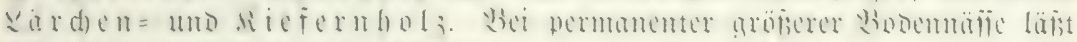

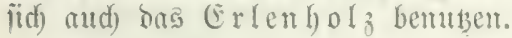

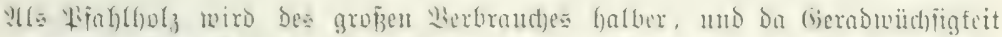

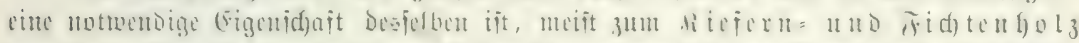

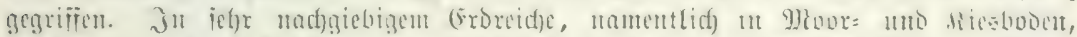

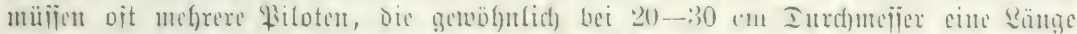

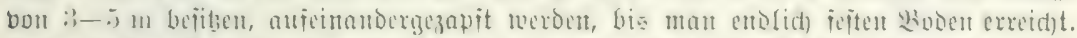

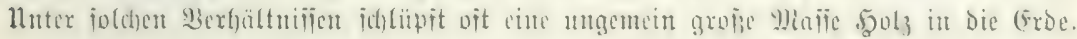

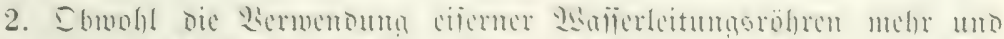

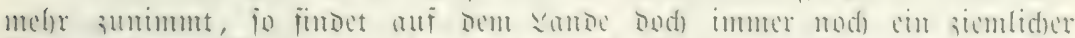

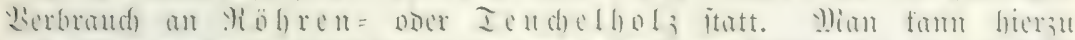

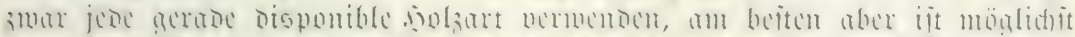

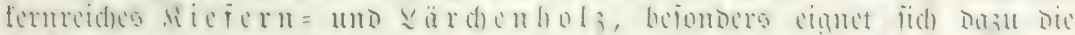
E (h)

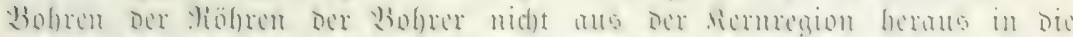

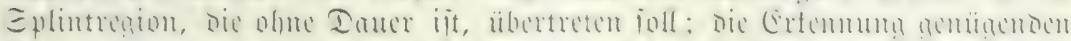

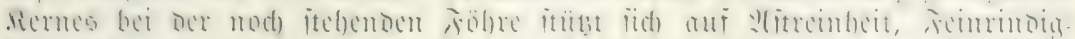

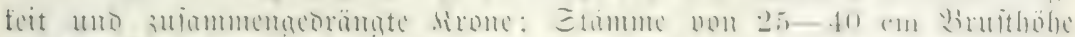

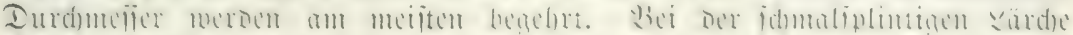

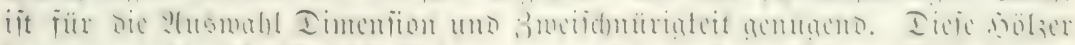

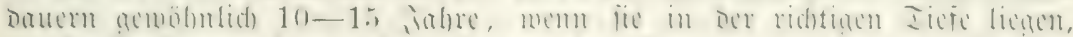

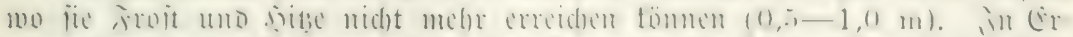

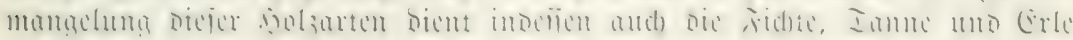




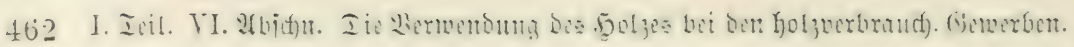

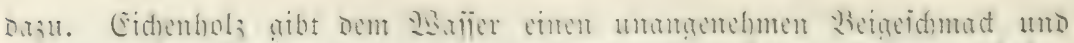

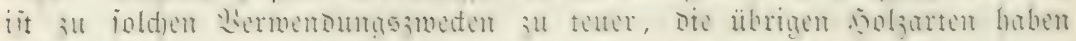
ju wentig Damer.

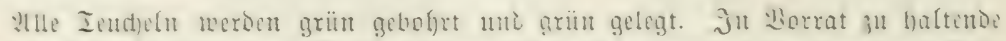

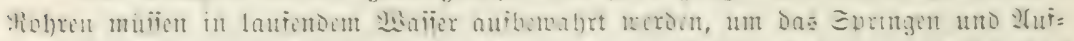

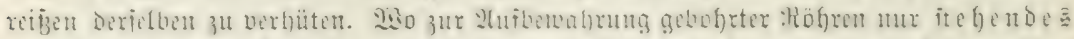

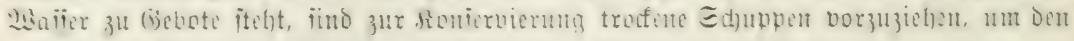

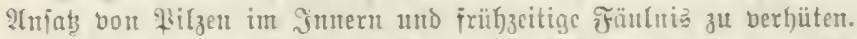

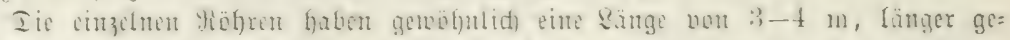
möhnlid) nidft, weil ite jonit nur idfuer zu bohren fins. Iis Lumbitirfe mad)t man

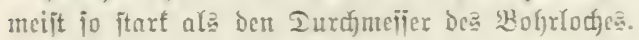

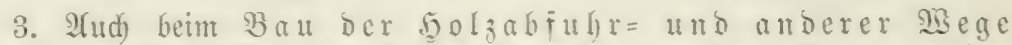

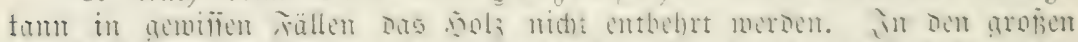

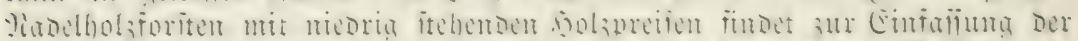

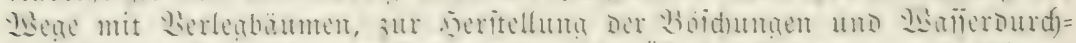

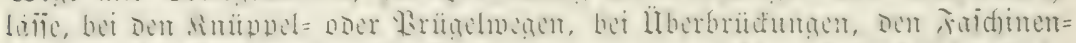

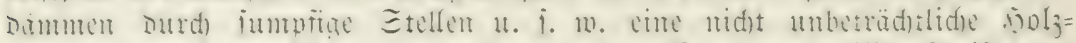

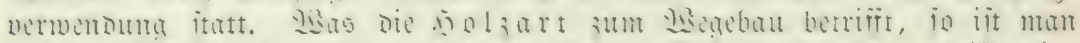

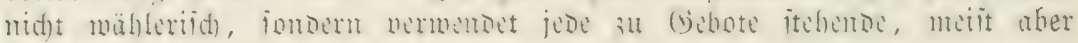
习习⿱

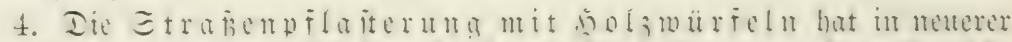

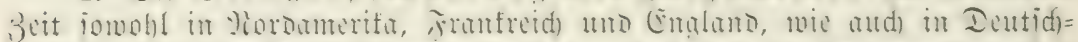

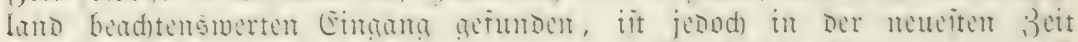

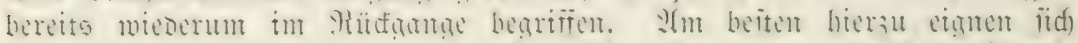

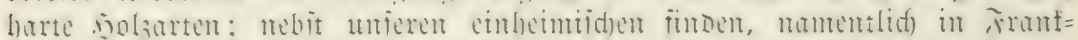

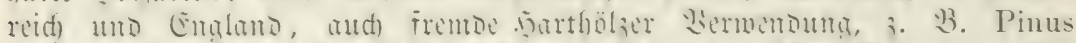
palustris (Pitch Pine) mo ninthölier am Dentropidam diolonien. Der

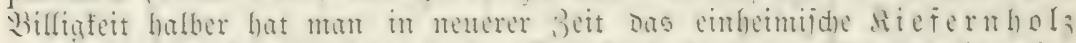

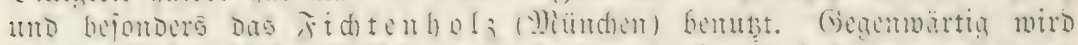

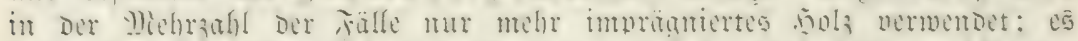

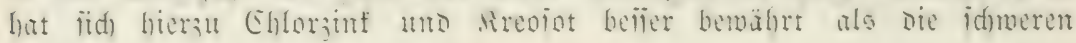
Ieeröle.

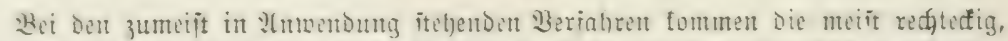

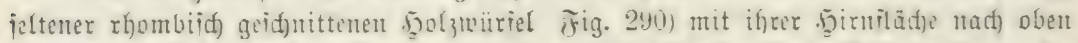

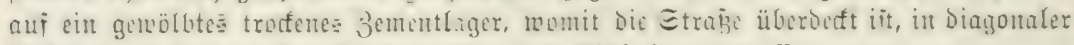
Ridgtung zu iteken. Die Fugen merden mit 2tiphalt auggegoijen.

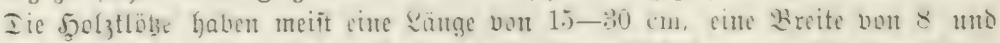

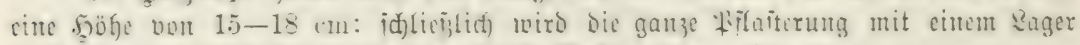

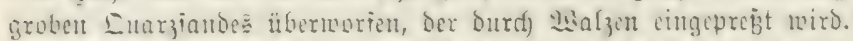

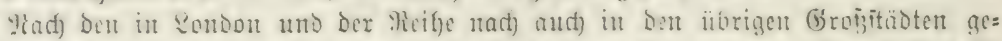

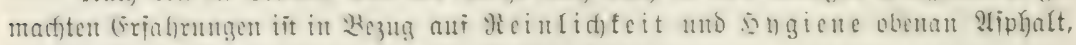
Daran reifen fid) (Sranit bezm. Eteinpilaiter, Jeols:

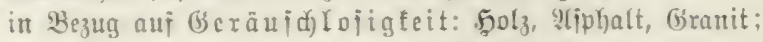

" Iauer: Eranit, Uaphalt, Sgol3:

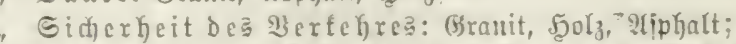

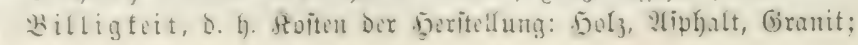


in Bezug auf Eeidytigfeit ber geparatur: (Granit, 29phalt, 5ुol3:

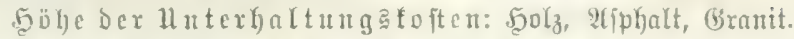

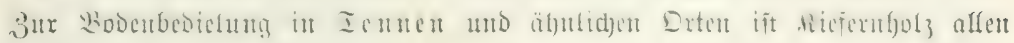
anoeren 5ूolzarten vorzuzief)en.

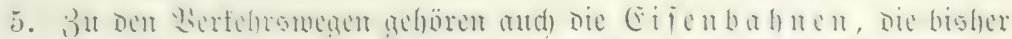

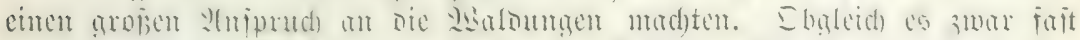

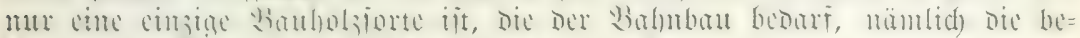

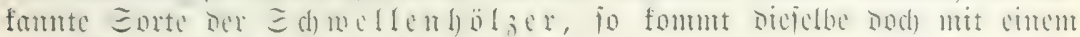
höd)it bebentenben Dunutum in Frage.

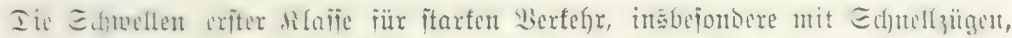

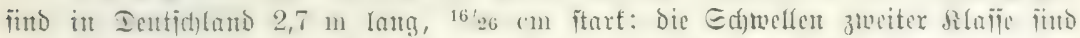

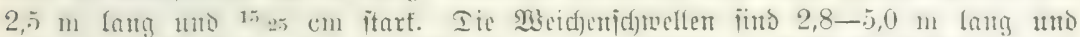

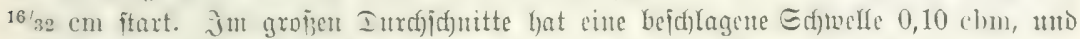

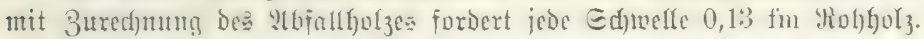

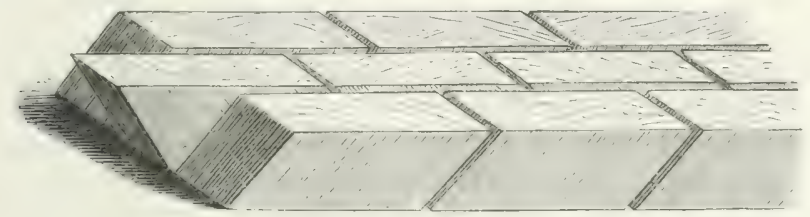

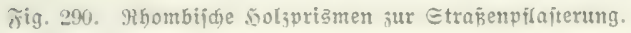

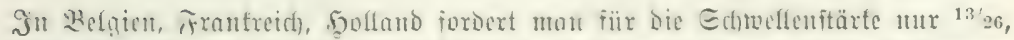

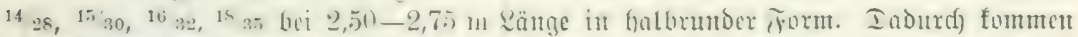

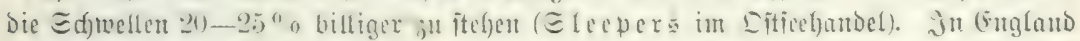

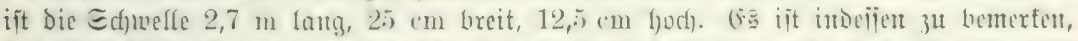

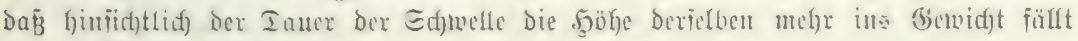
als die Breite.

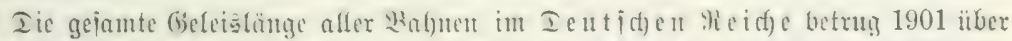

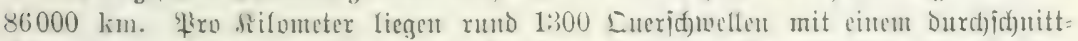

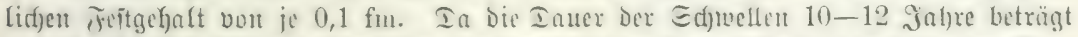

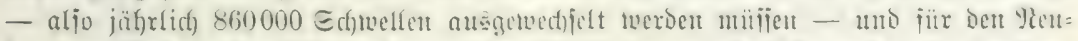

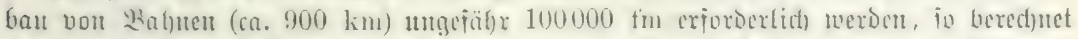

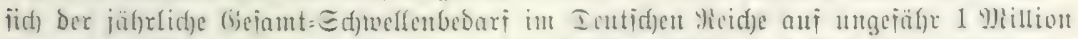

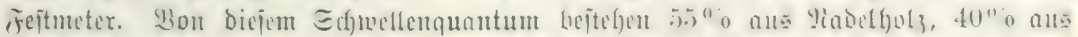

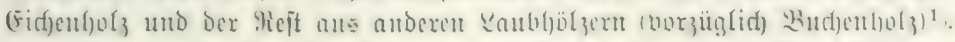

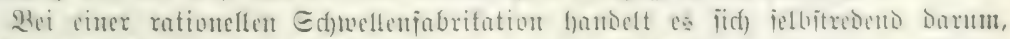

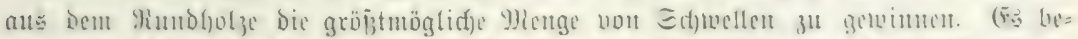

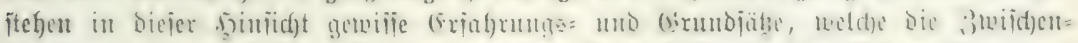

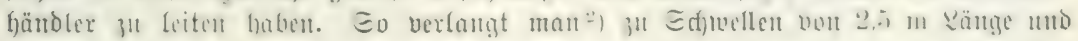
$16 / 24 \mathrm{~cm}$ Etr̈rte

1) Meue jorjtt. Shlätter $1902, \Im .6$.

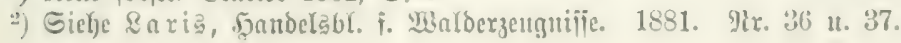




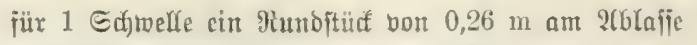

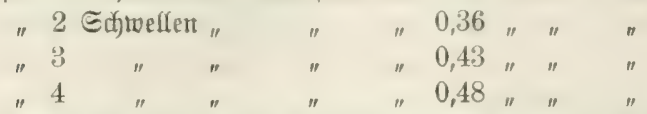

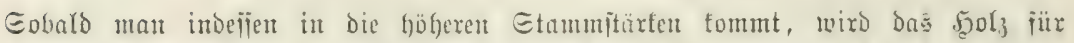

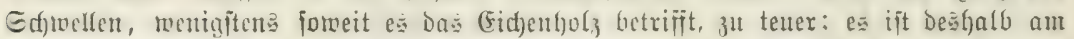
vortcilfafteften für den Sुolzhändler, dic geringeren Etürfen (bei (Eid)en Die Etämme

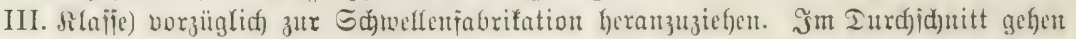
bei ber Ed)rollenfabrifation $30-40 \%$ in die Späne.

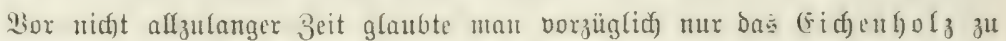

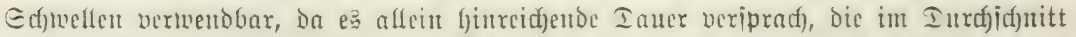
10-16 jafre beträgt: meben Den (eid)enfolze verwendete man nodf Das engringige

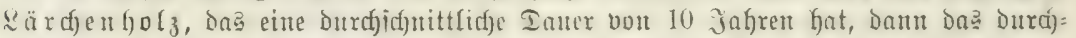

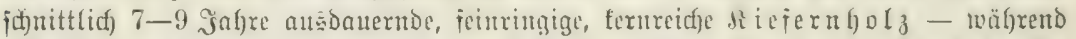

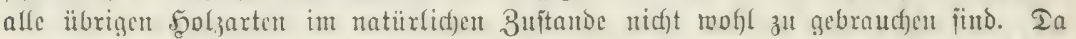
aber bie heute nod) vorhandenen curopäifden (Fid)enfyolzoorräte nidft im entfernteiten

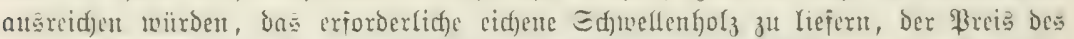

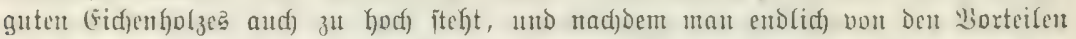
Der Jmprägnierung fimreidjende (Exjafrung gemacht hat, wendet man fid) neben bem

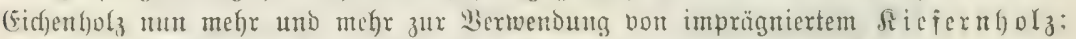

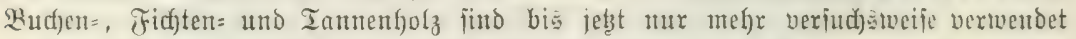

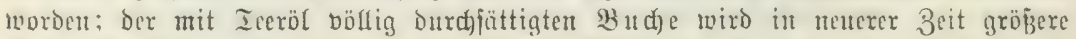
2tumerfiamfeit gezollt (jiche vorausgefenden 2lbidjutt). 2(ud) mit Der Wermendung

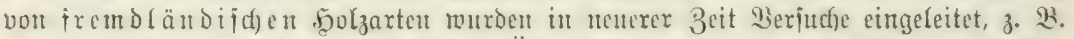

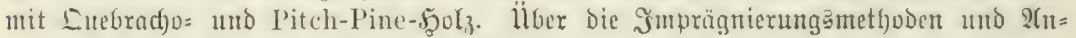
gaben liber bie Dauer ber Exfwellen p̈ehe vorigen 2 bichnitt.

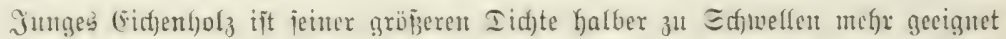

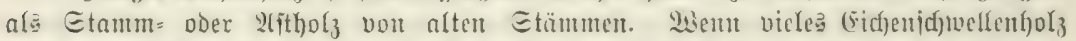
jeitf)er nux cine geringe Iauer zeigte, jo if̈ Das vorzïglich Dem llmitande zuzuj(f)reiben,

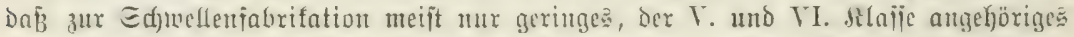

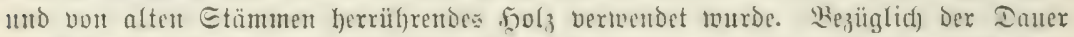
Der Ed)wellen tommt übrigen fehr viel auf Die Rettung, D. १. auf bie Reidjaffentheit

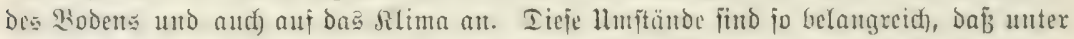
günitig̣en fionftellationen biejer Faftoren and ein nid)t imprägniertes, fonit gering= Dauerndes Sgolz lange unveroorben auszulyalten vermag.

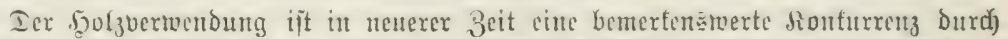

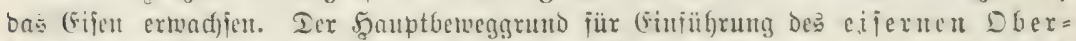

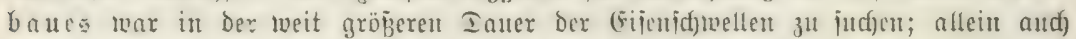

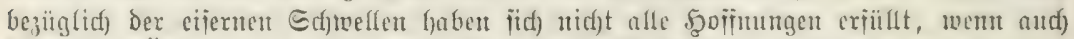

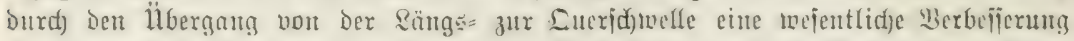

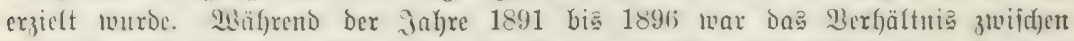

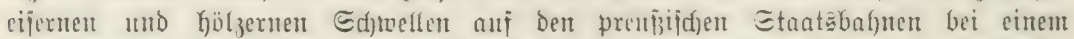

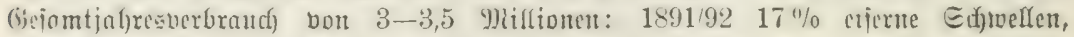
$18929320^{\circ \prime} 0,18939414,8^{\circ} \%, 18949525,8^{(1 /} \%, 18959625,9^{\%} \%$. Won Den höl3ernen

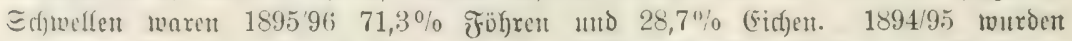

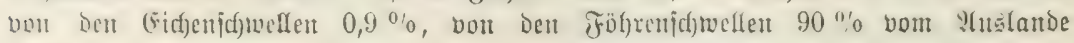
bezogett. 


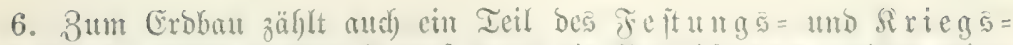

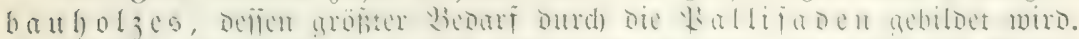

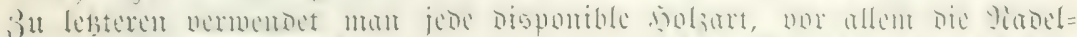

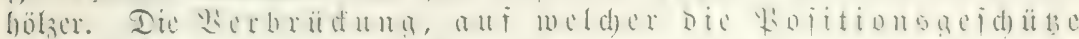

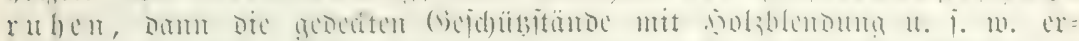

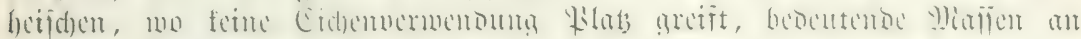

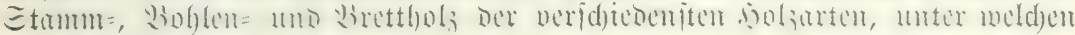
Das Cidjent= anto Sieferutholz obenan jtelyt.

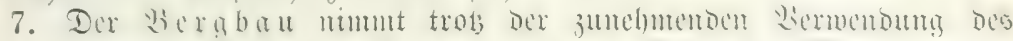

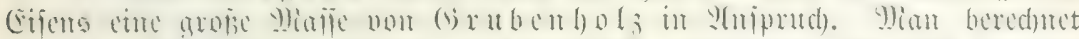

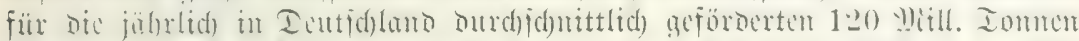

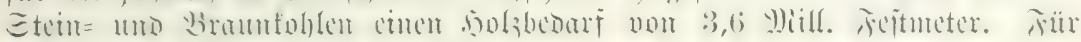

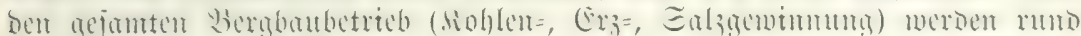

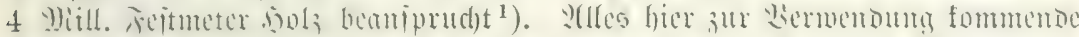

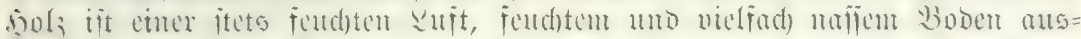

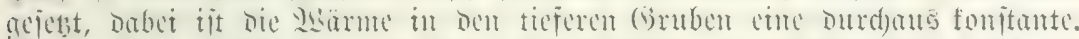

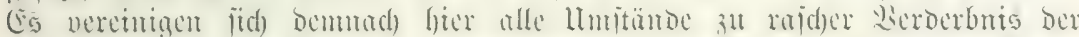

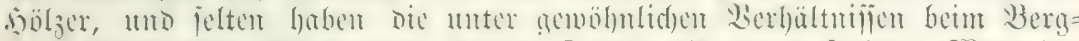

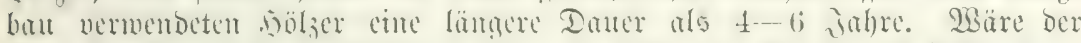

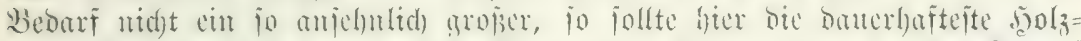

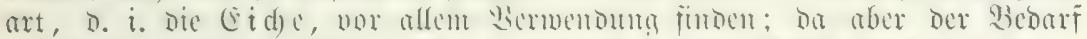

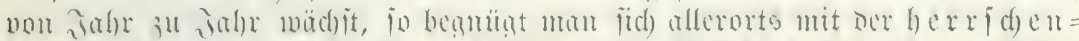

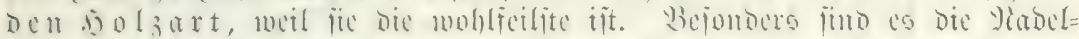

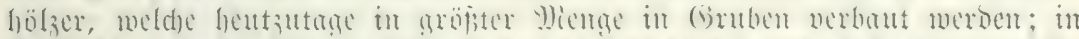

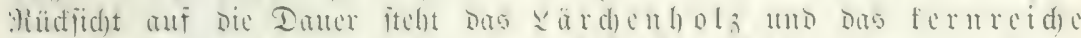

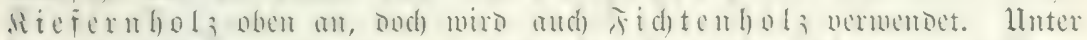

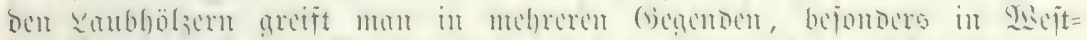

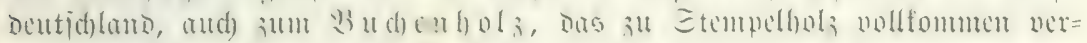
menobax ijt.

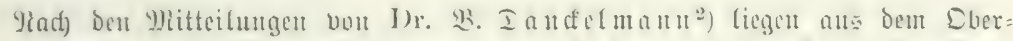

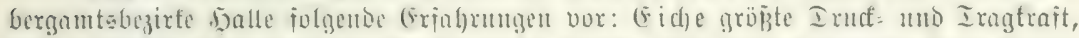

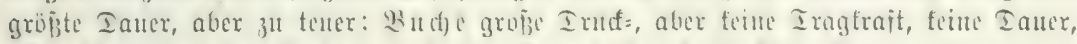

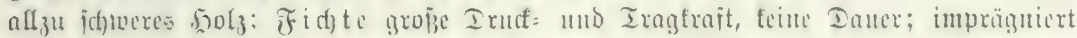

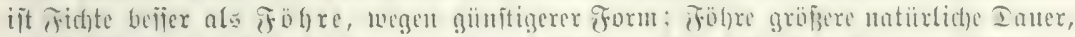

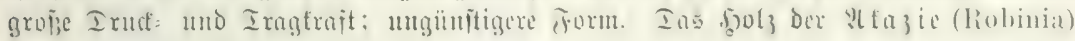
fommt bem (Fidjentyolze gleidf, ift aber teuer.

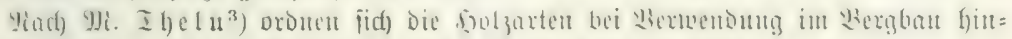
fidtlid) ber Iragfraft: Robinte, finijidtlid) Der Dauer: (Eid)e

\begin{tabular}{|c|c|}
\hline If(f)urt & F̈brfere \\
\hline (Eidge & Erte \\
\hline Sudfe & Ejofe \\
\hline Innue & Mobintie \\
\hline (Ejd)e & 2tyorn \\
\hline llime & llfuc \\
\hline
\end{tabular}

1) Sicue forftt. BHätter 1902 , E. 6.

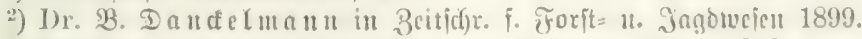

3) Notice sur les étais des mines en l'rance. Paris 1878. 


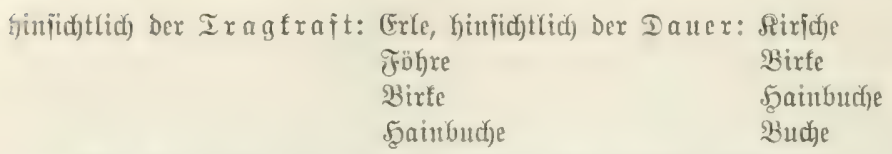

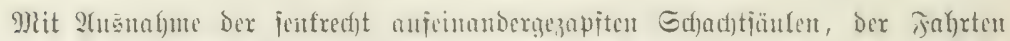

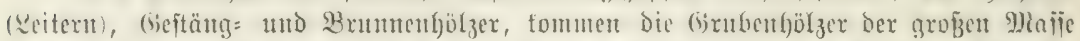

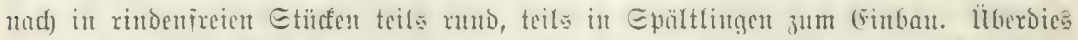

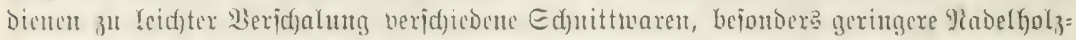

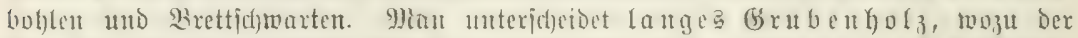

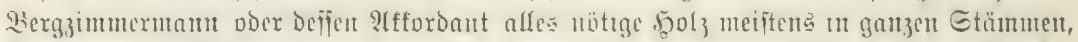

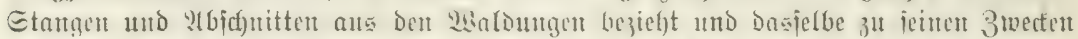

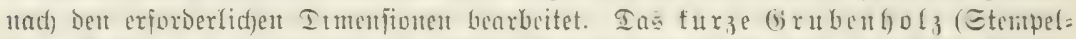

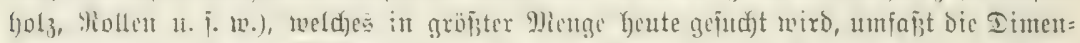

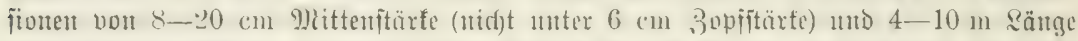

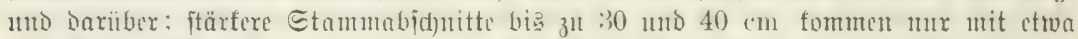

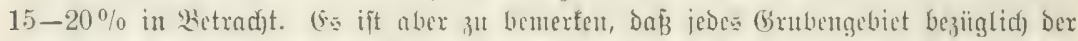

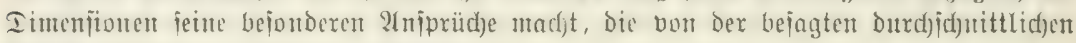
Stärfe indefien mux tweniģ abrocidjent.

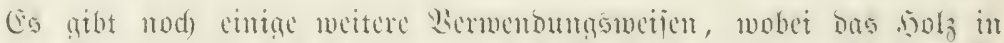

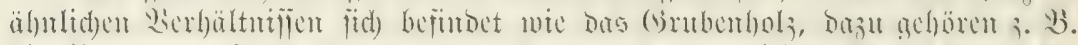

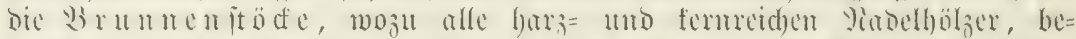

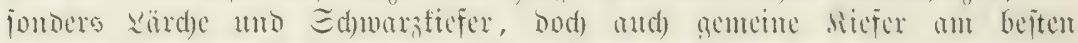

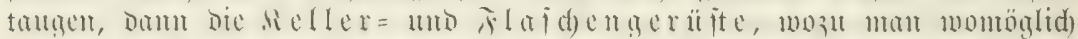

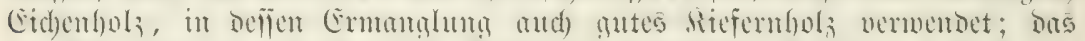

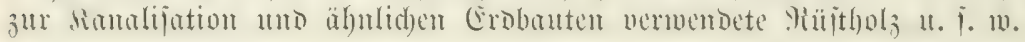

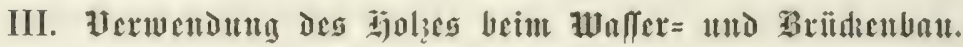

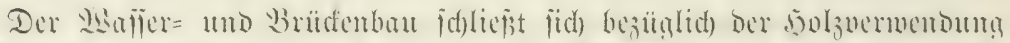

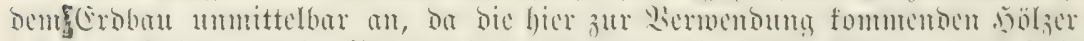

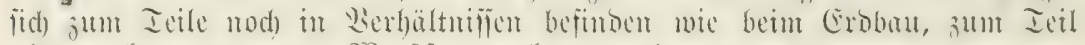
aber aud) ganz unter 93 a jlex verbaut werben.

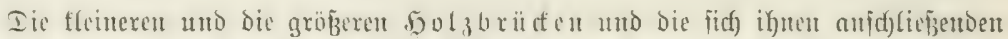

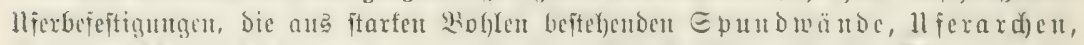

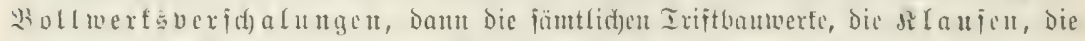

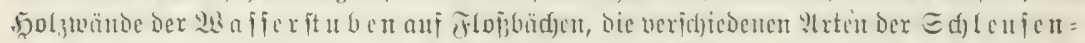

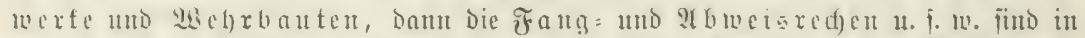

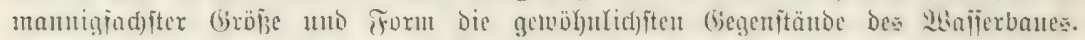

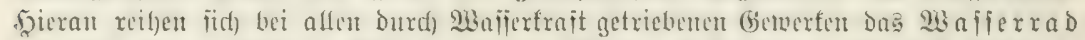

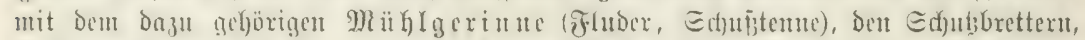

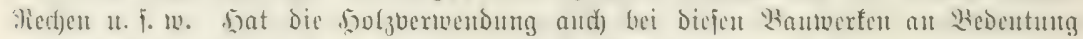
vertoren, nachoem in

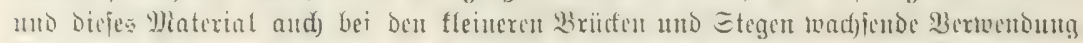

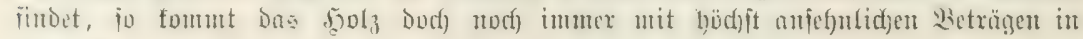
Wetradjt. 


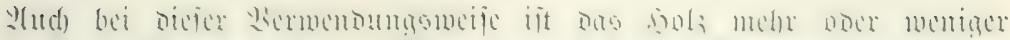

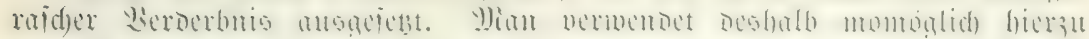

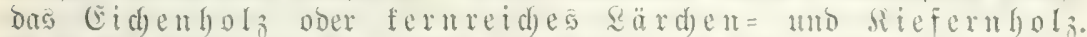

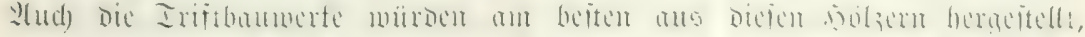

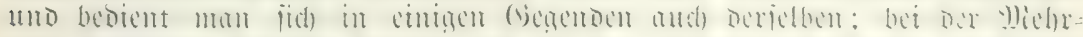

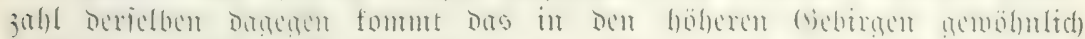

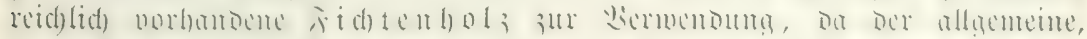

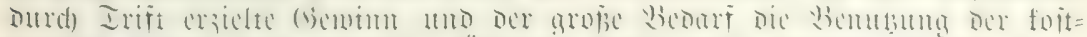

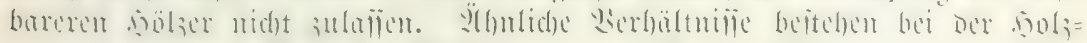
mermendum ;

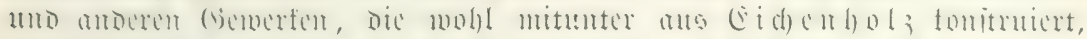
an ben meifen Drten aber ans siefern=, \&ärden= und felbit ans F゙ $\mathrm{i}$ d) $\mathrm{t}$ en hol bergeitellt werden.

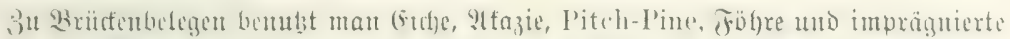

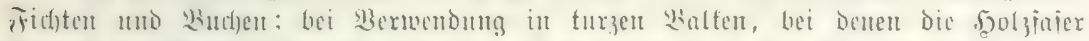

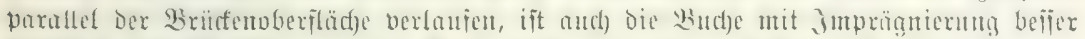

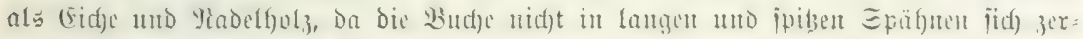
jojiejert und zerjajert.

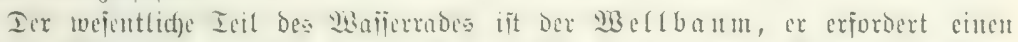

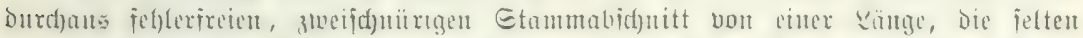

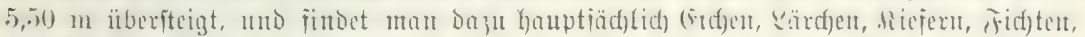

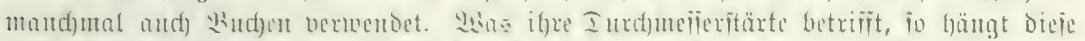

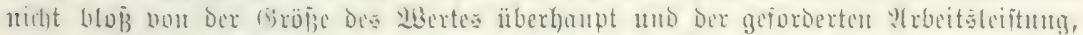

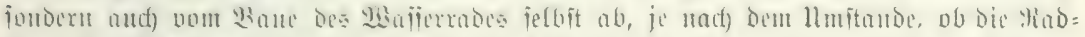

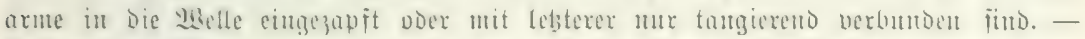

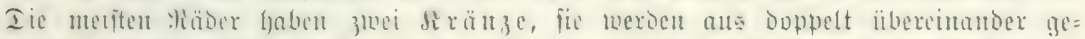

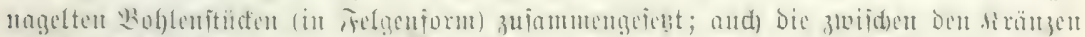

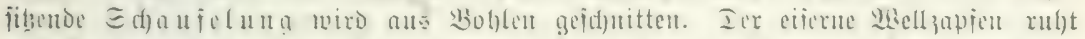

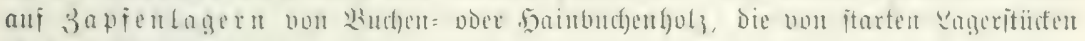
((5id)en, Stiefern, 2ärdúcn u. Dergl.) getragen werben.

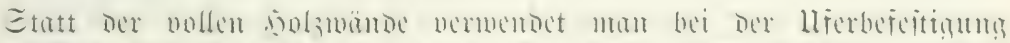

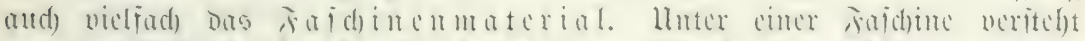

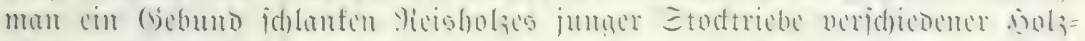

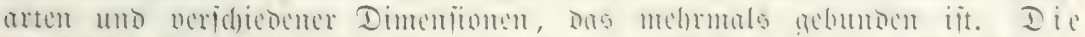

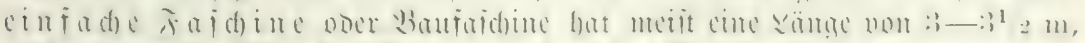

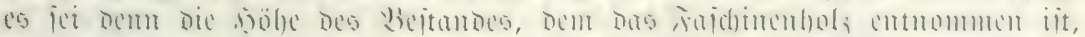

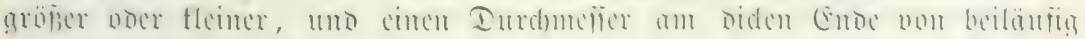

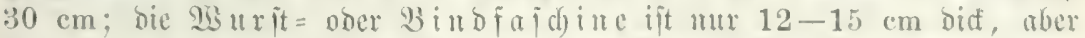

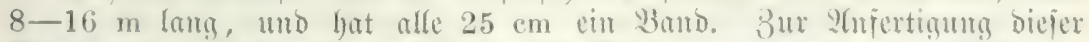

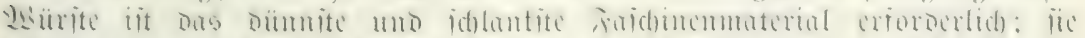

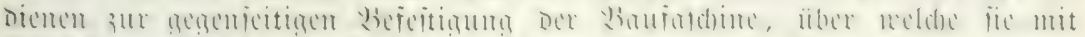

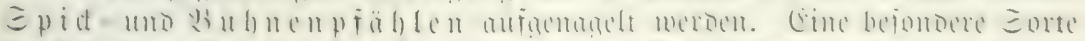

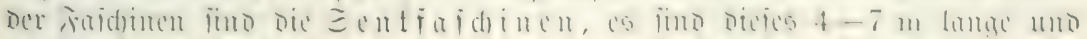

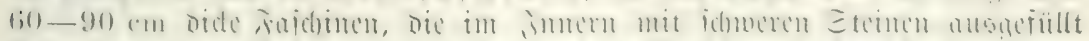

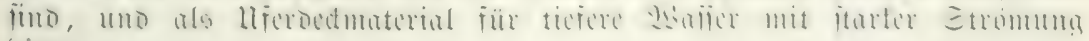
dienter.

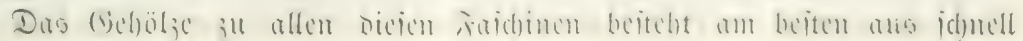




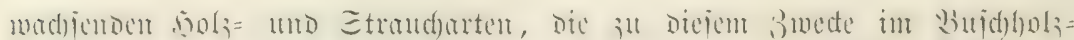

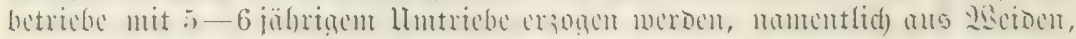
wic Salix fragilis, S. alba, S. rubra, S. amygdalina, S. viminalis,

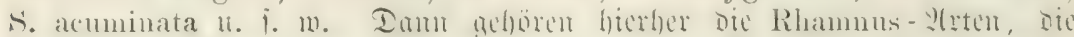

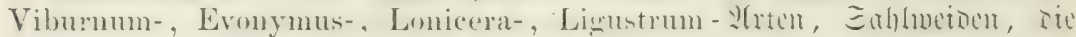

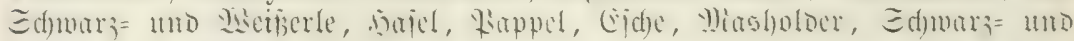

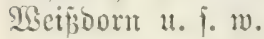

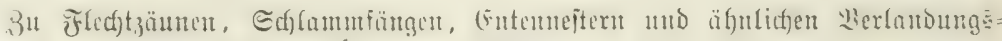
anlagen bienen vorzilglidj die verjdiedenen $\mathfrak{B}$ e idenarten.

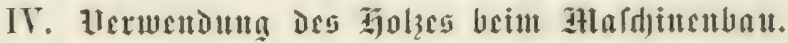

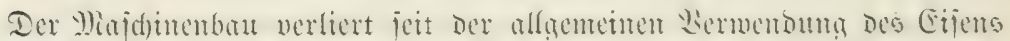

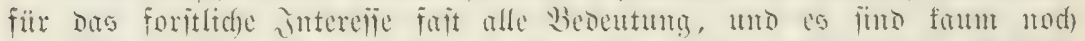

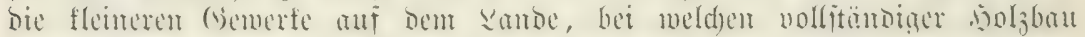

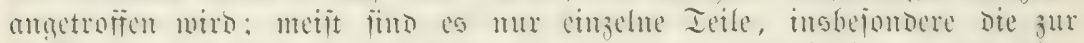

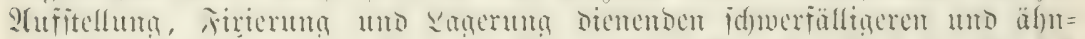

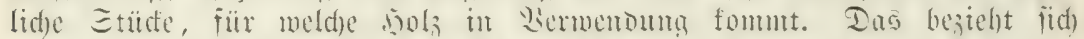

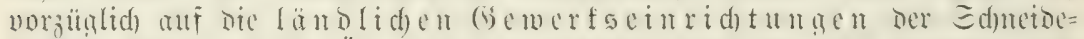

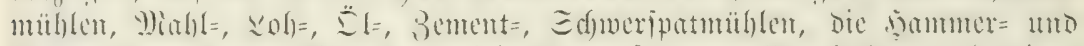

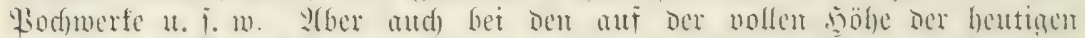

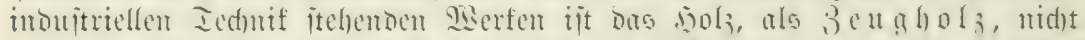

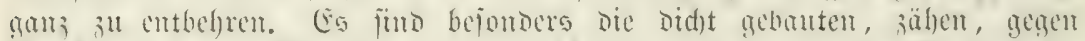

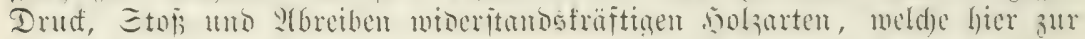
Inwendung fommen.

In nllen berartigen burd) Wafjerfrajt getricbeneu (bemerfen ijt Das Maijerrab

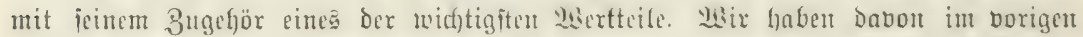
rapitel griprod)en. Sm ausgedefnten Flact)Lande treten an die Etelle Des Wiafier=

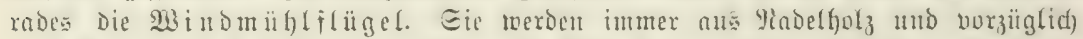

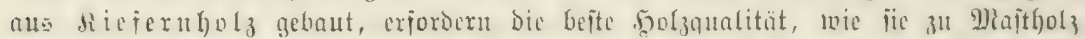

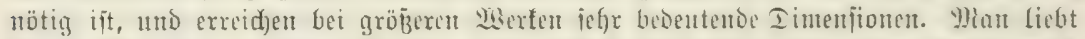

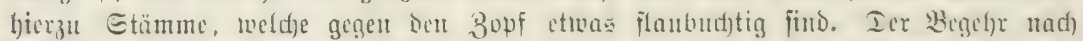

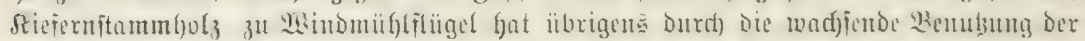
Dampitrait mertlid) nadjgelafien.

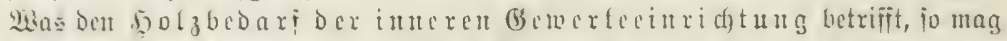

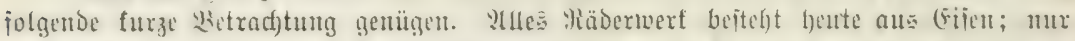

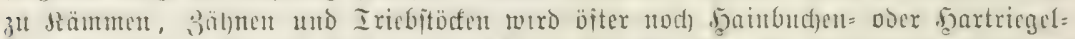

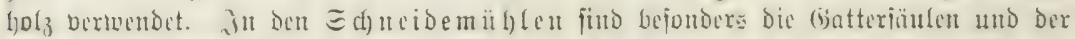

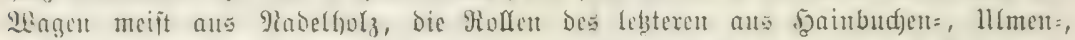

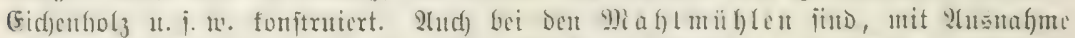

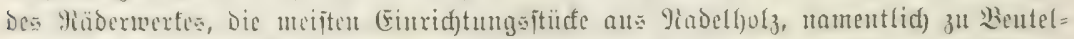

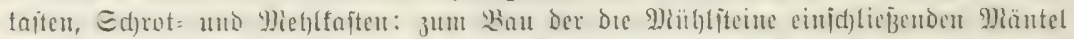

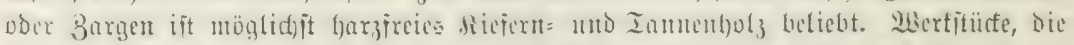

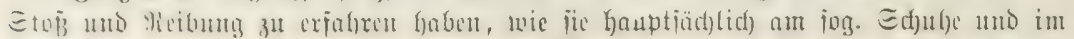

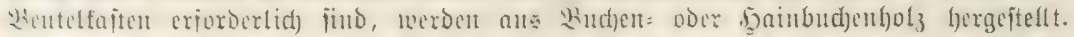

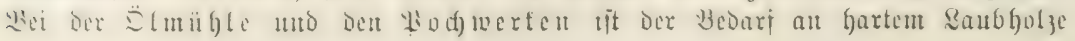




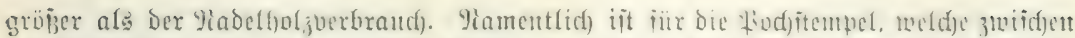

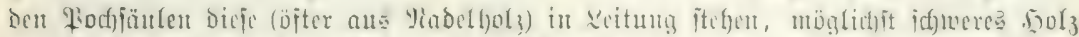

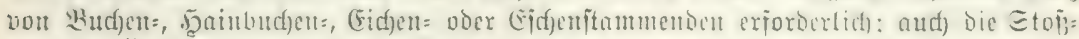

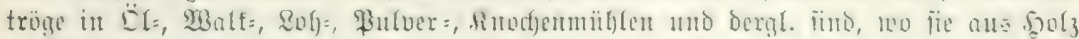

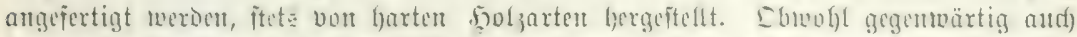

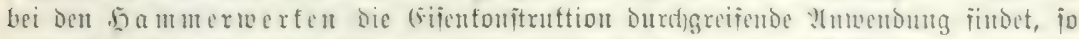

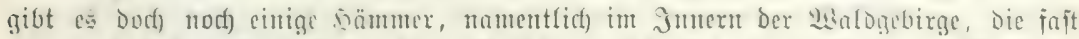

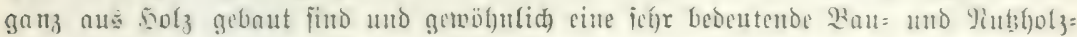
majie, bejonders harte Şölzer, in Injprud) nefment.

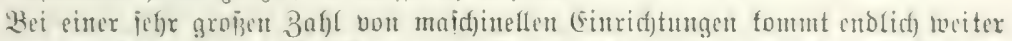

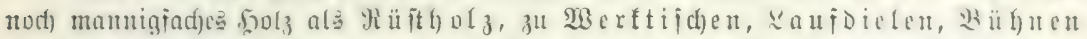

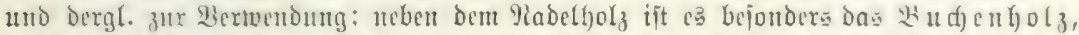

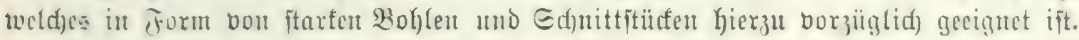

\section{Zlerwendแn Deg Golics beim Sidjiffuau.}

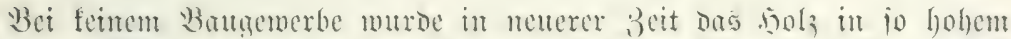

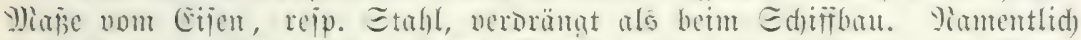

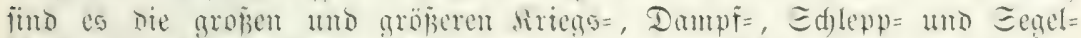

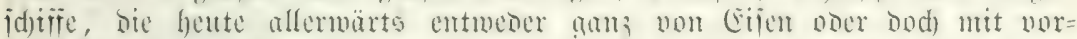

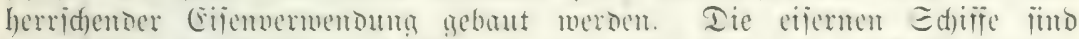

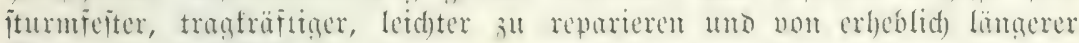
Dauer alo Solzidgtife $\left.{ }^{1}\right)$.

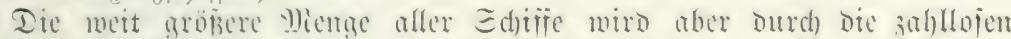

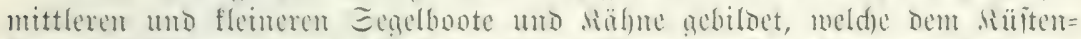

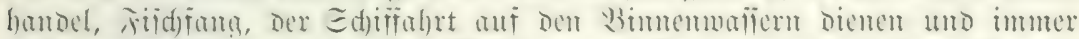

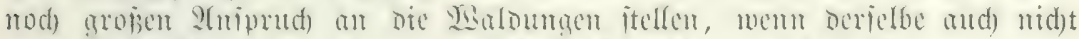

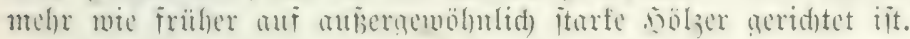

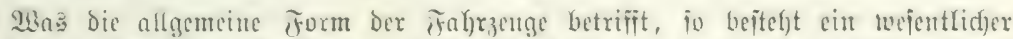

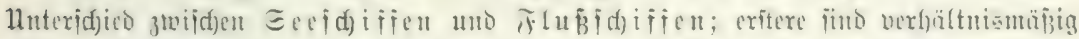

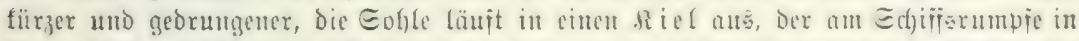

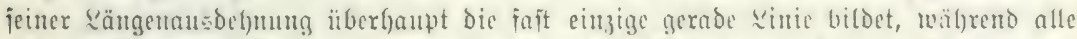

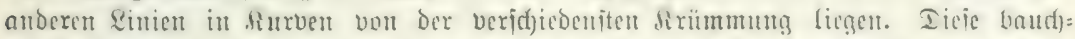

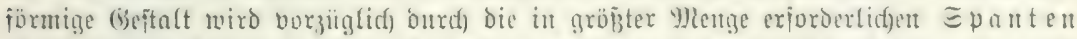

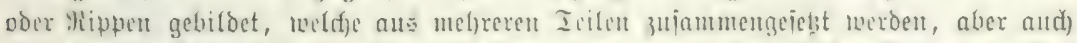

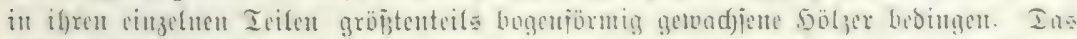

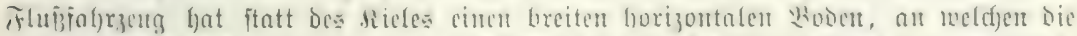

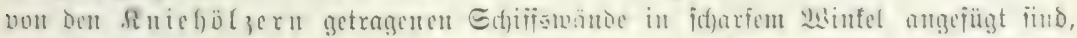

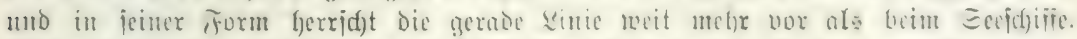

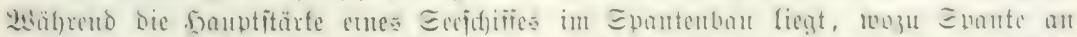

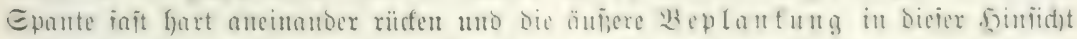

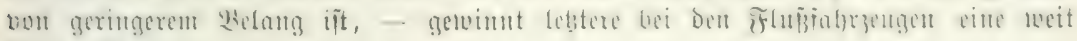
f)öhere Bebeutung.

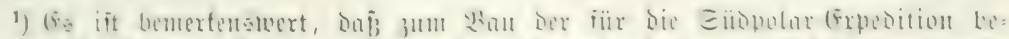

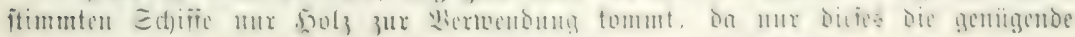

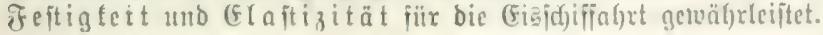




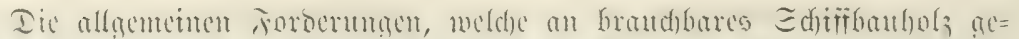

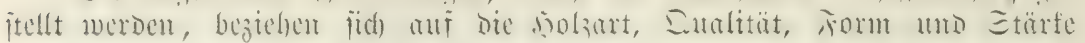
bes Mohntaterials.

1. Solzart und Solzaualität. D Die widgtigite Solzart beim

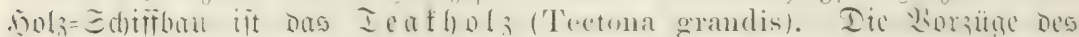

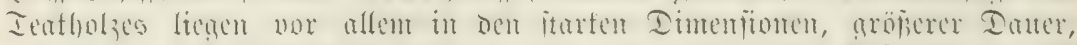

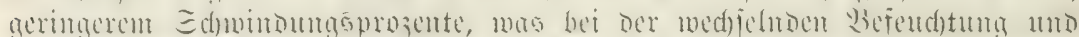

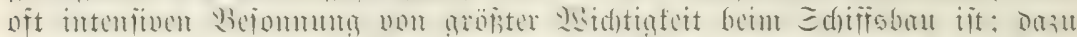

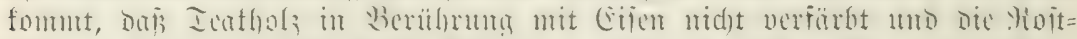

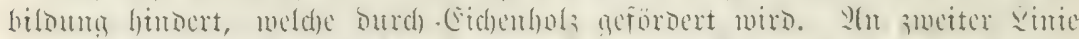

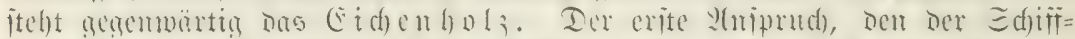

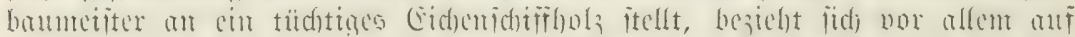

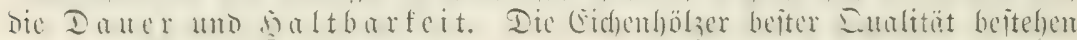
mur aus $\Omega$ ermbolz, Gaben breite, überall gleidnäbig gebate

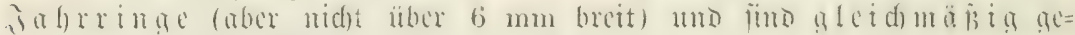
färbt, vou frifdent (Gerbjäıtegerud).

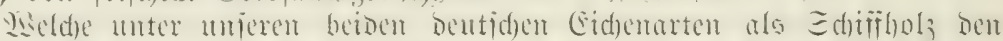

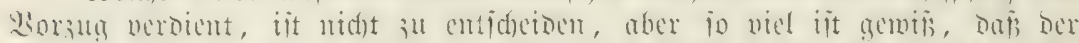

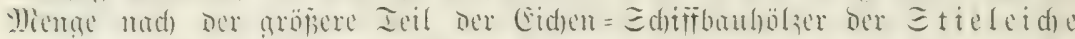

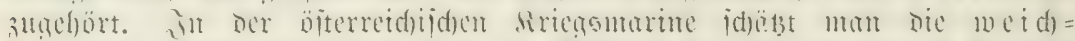
b) ar a

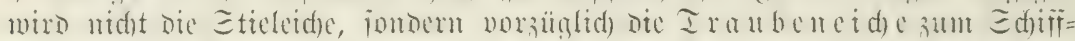

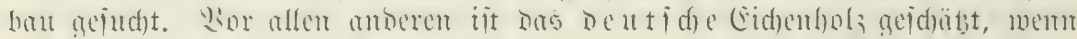

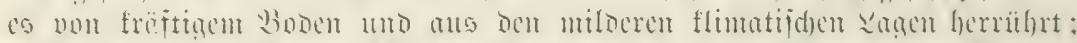

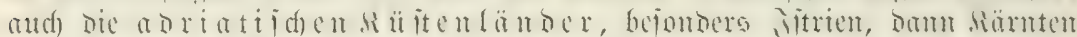

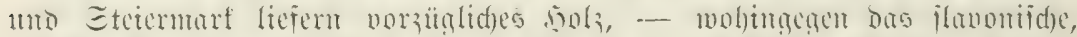

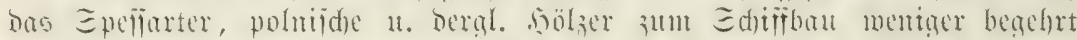

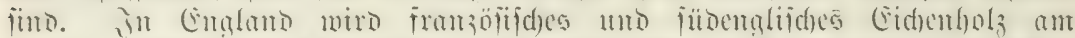

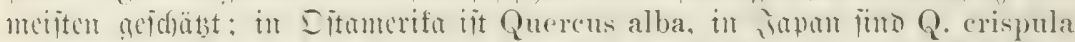

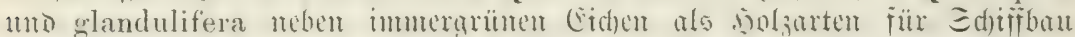

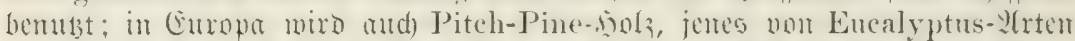

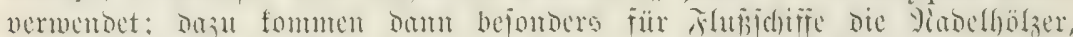

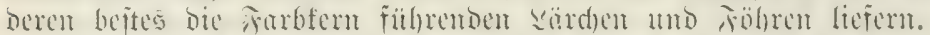

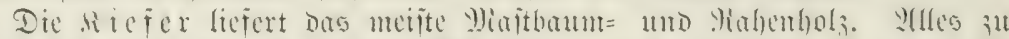

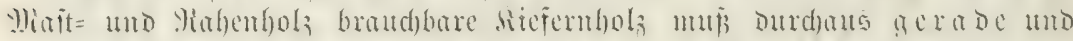

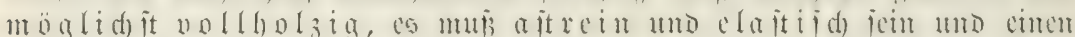
f) inteideuben un burd) alle Stammteilegleidförmig ver=

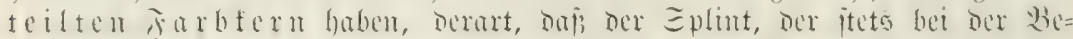

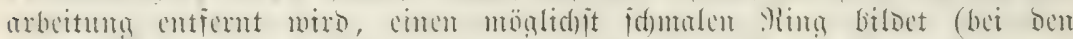

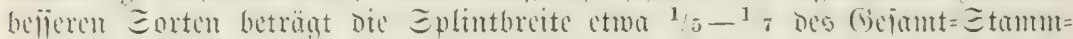

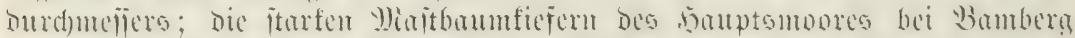

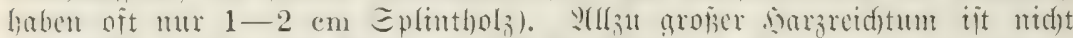

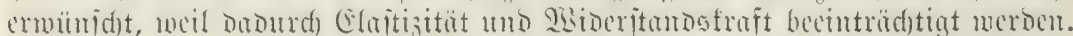

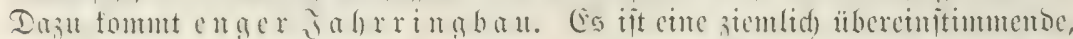

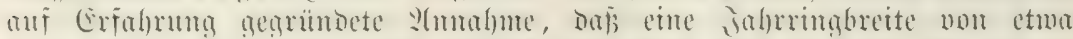

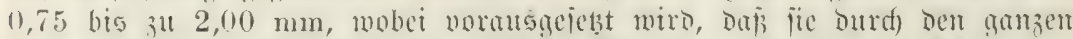

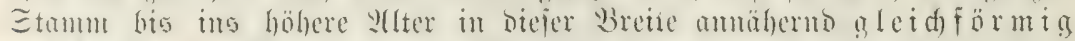
(I) 


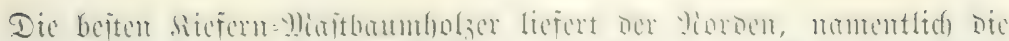

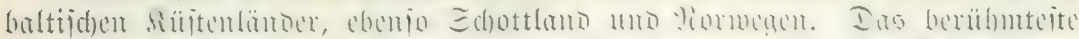

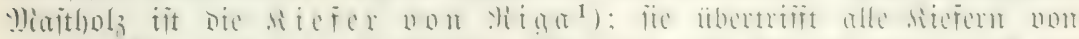

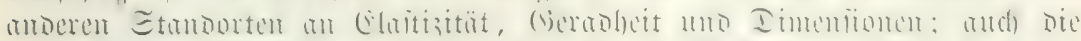

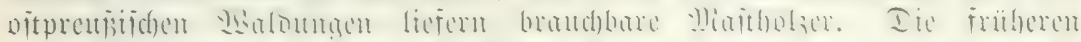

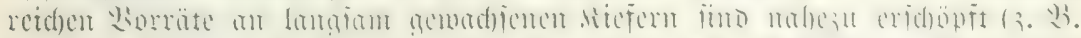

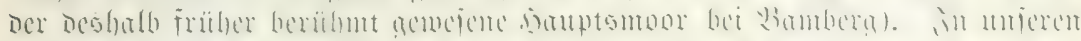

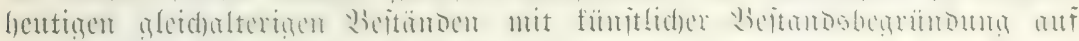

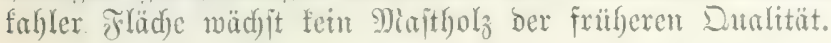

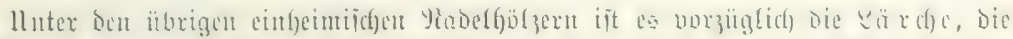

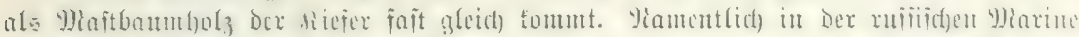

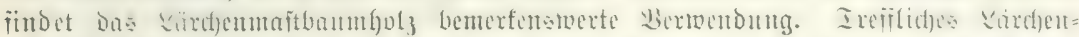

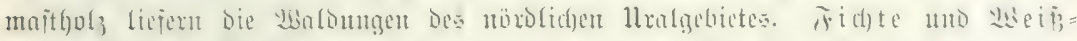

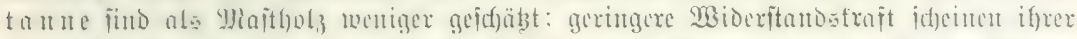

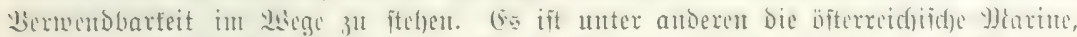

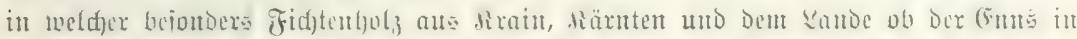

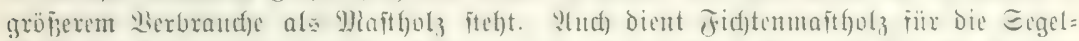

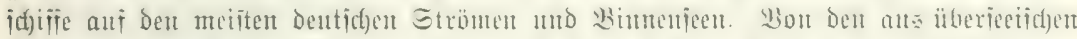

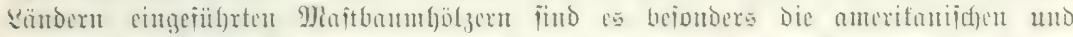

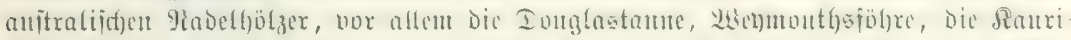

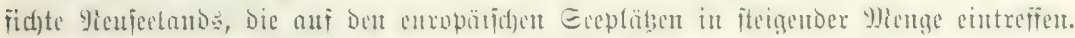

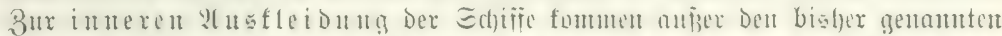

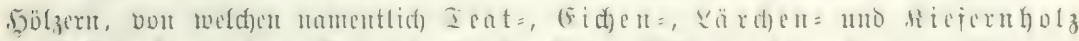

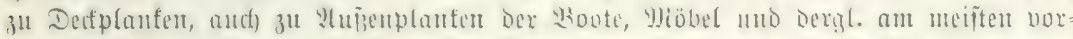

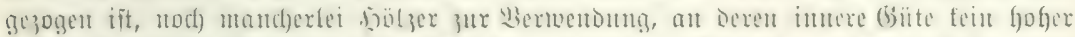

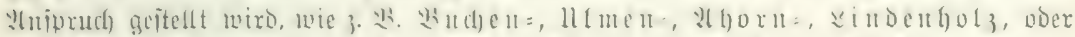

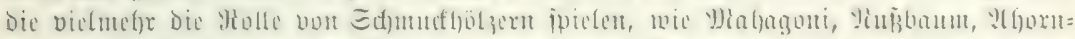

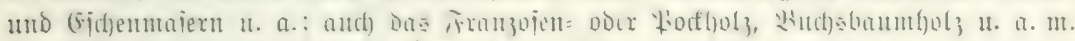

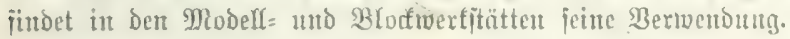

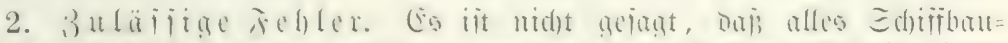

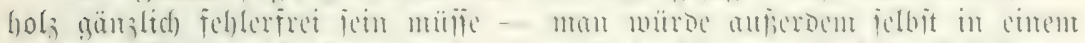

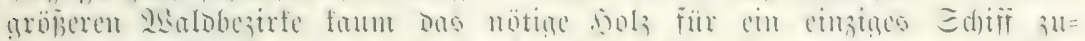

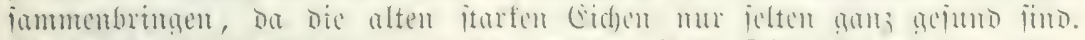

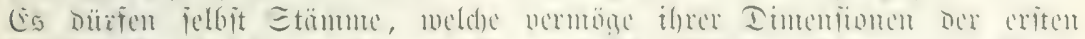

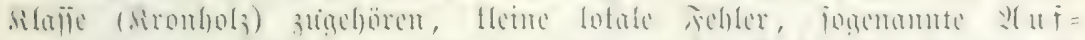

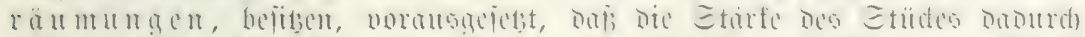

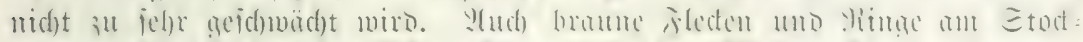

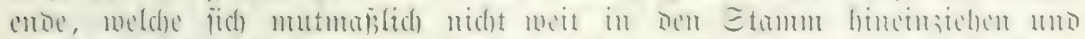

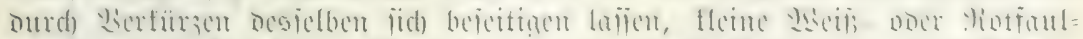

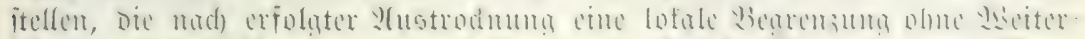

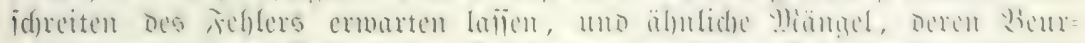

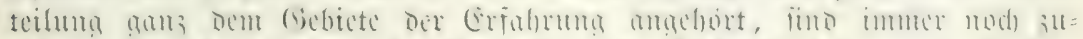

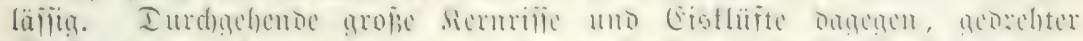

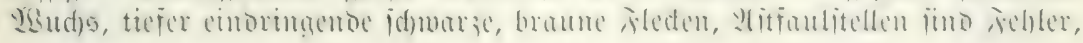




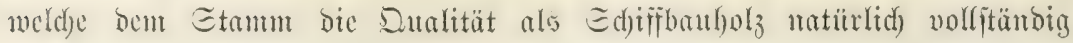
bentelmen.

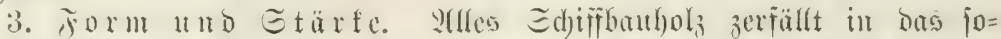

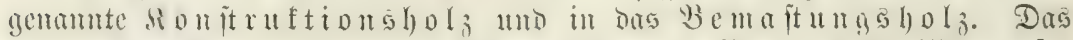
critere benteift alle sölzer in fidh, weldye zum Bame des Edjiffsrumpfeś

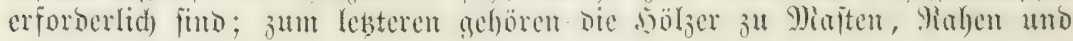
übrigen Eegelitangen.

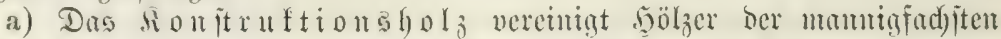

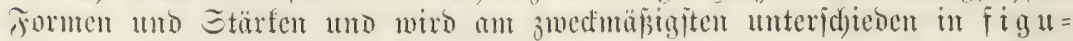
riertes jola umb \&anghola.

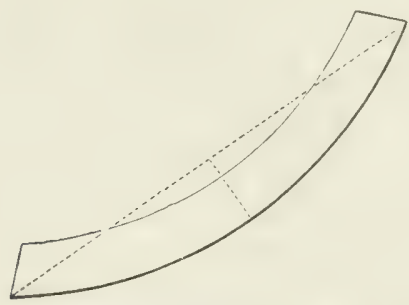

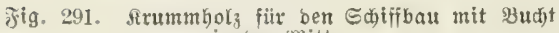
in bet sitte.

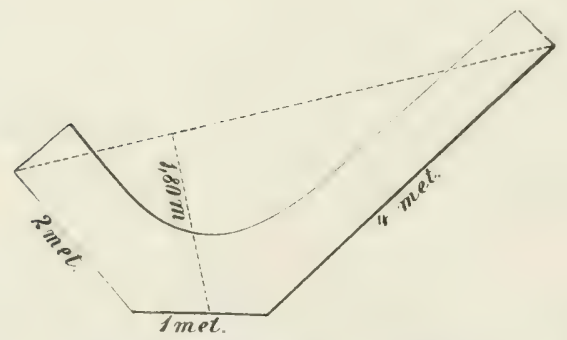

Fig. 293. Snieholz für ben Sdiffbau.

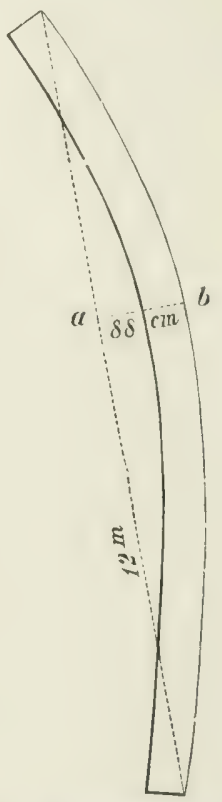

Fig. 292. Srummbolz fïr Den Sdytifban mit $2 u d$ t $1 / 3$ vom Enbe.

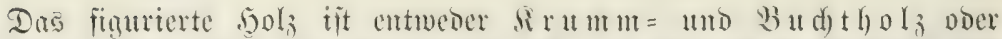

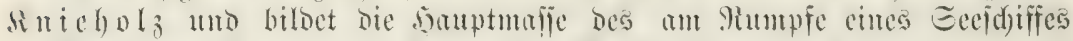

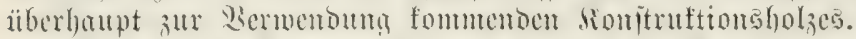

Die meijten Br.

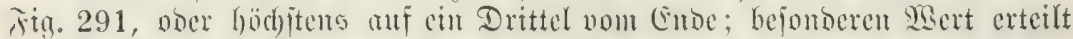
sie Butht cimem Etammitüde, mem fie aegen ctu Drittel vom diden (Enoe fidf befiutoct, wie Fitg. 292.

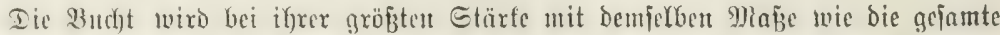

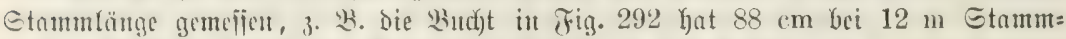

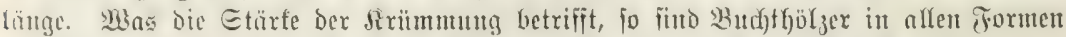

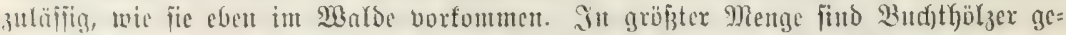

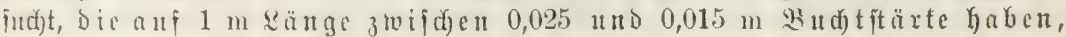




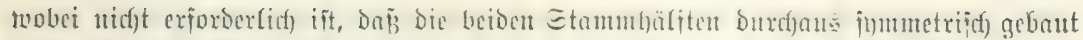

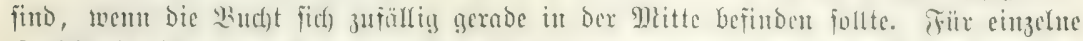

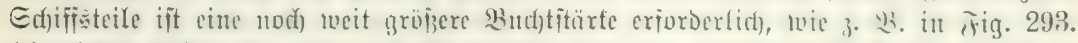

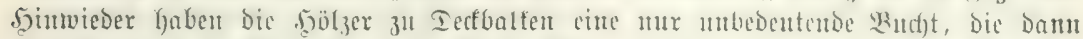

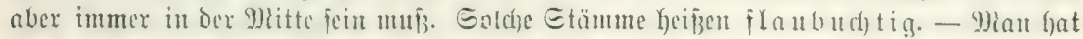

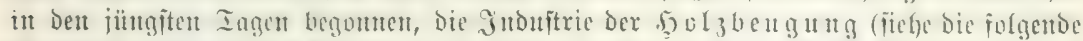

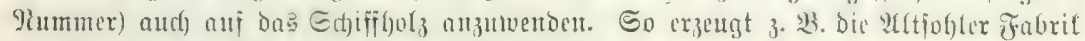
von Swoboda in Altgarn gebogene Erfiffbaubölzer.

Dic d

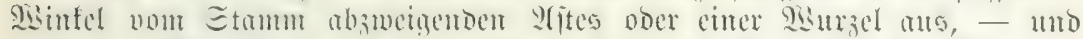

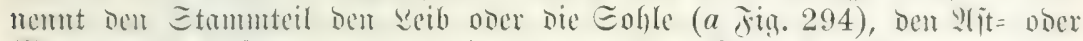

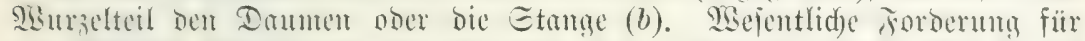

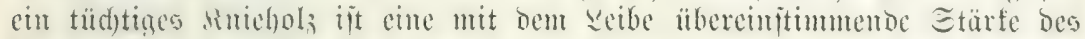

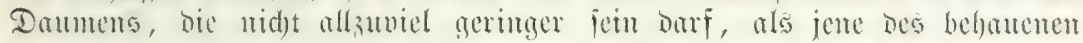
ฉeนต้อิ.

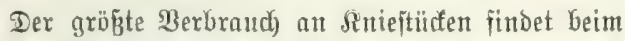
Bau ber Flubfalfrzeuge ftatt; wiro 3u diejem 3redt aud) ein geringerer $\mathscr{A}$ uprud) an bie Gtärfe gemnd)t

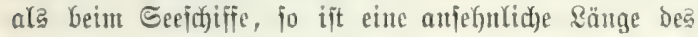
Reibes (ber bei Seejuiffifnieen in ber ßeget mur bas Doppelte ber Daumcnlänge Getragen foll hiex von um

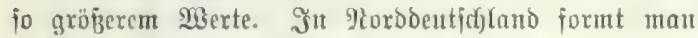

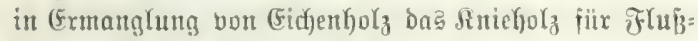
fäl)ne aud) aus ftartäjtigen Riefern au巨, bie auberbem mur in Srennfolz gejd)lngen twürocn. Erjahrungz: gemǟ̄ Goben foldhe Siahntuice cine Dauer bia zแ 10 Sabren ${ }^{1}$. Yud Sudjenlyolz farm hiexzu פer= tvendung finden, wenigitente im Edfifisimern. In

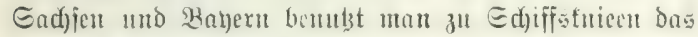
untere Stür von Fidj)tenichäften mit Daran befindidjem

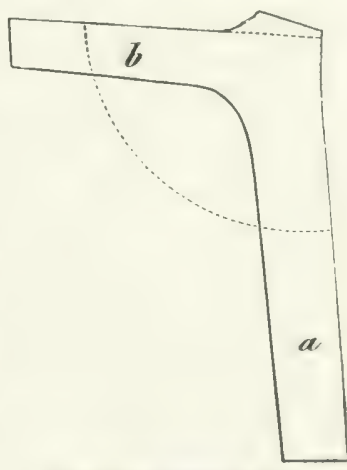

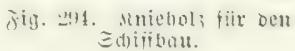

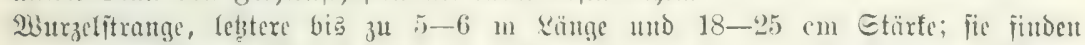

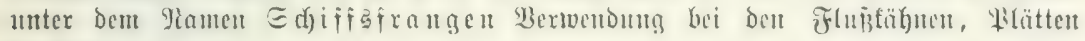
u. bergl.

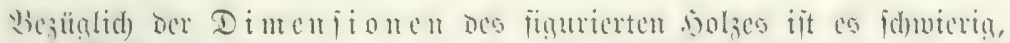

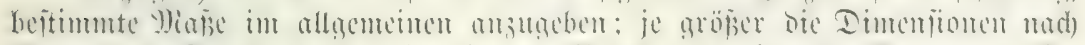

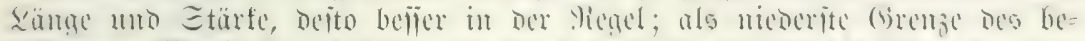

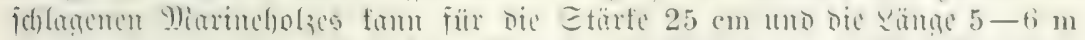

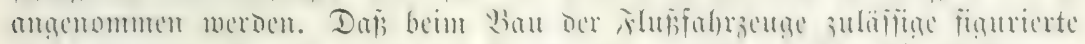

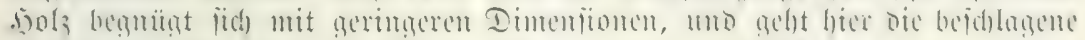
Etärfe Der Sincitücte für Siäbne bis sul $0,10 \mathrm{~m}$ herab ${ }^{2}$ ).

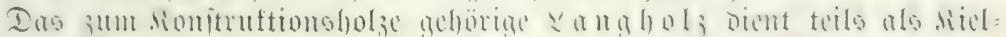

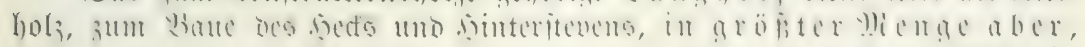

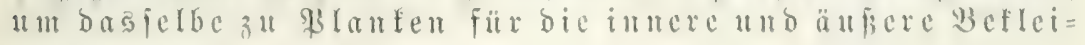

1) Forit: und Эaģozcitung 1867, G. 4.

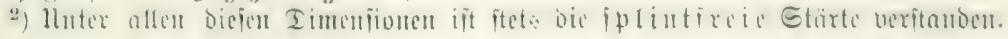


i) 11 t

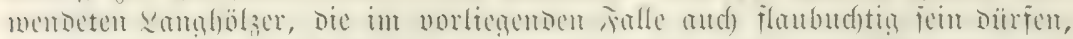

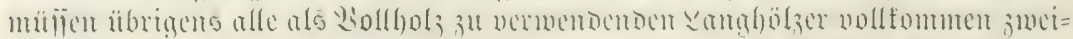

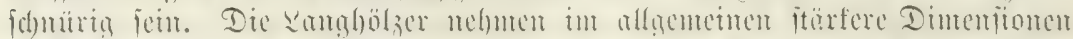

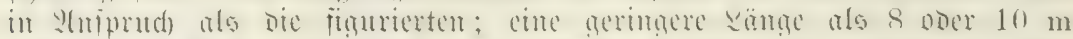

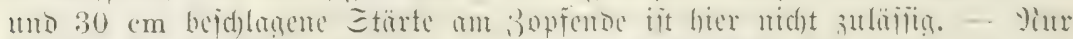

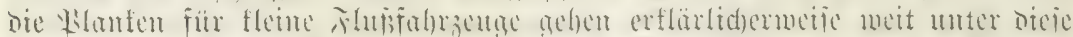

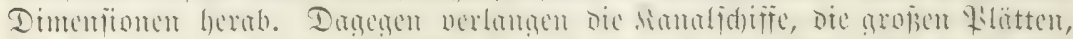

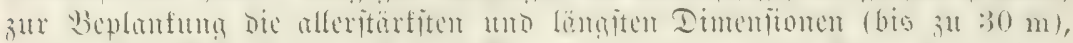

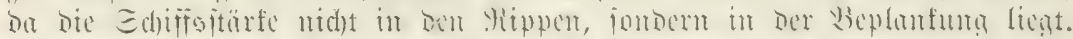

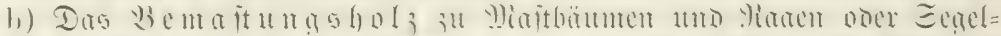

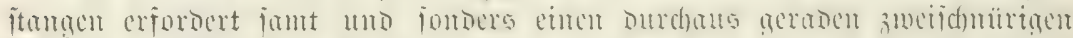

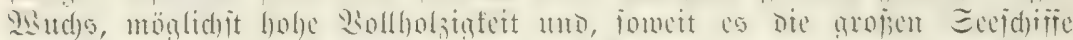

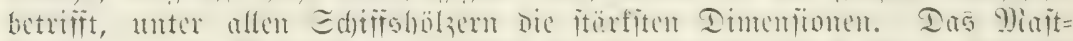

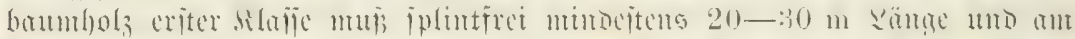

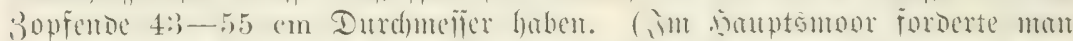

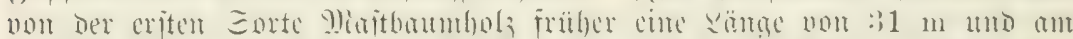

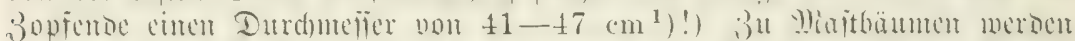

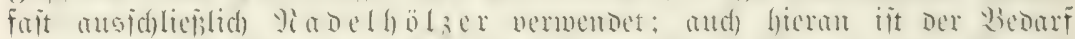

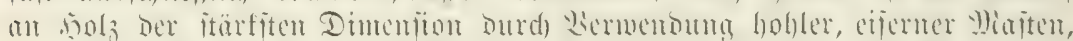

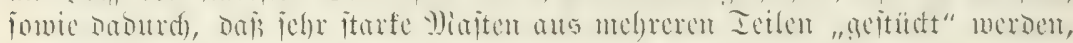
gegen frïber zurïctgegangen.

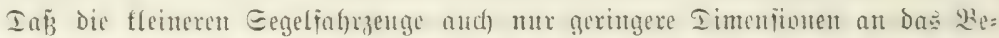

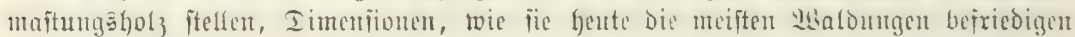
fönnen, bedarf faum ber (5xwäfnung.

4. SBefriebigung ber. Sdyifflorzbedüruffe. Someit es

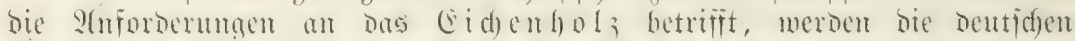

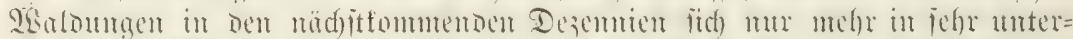

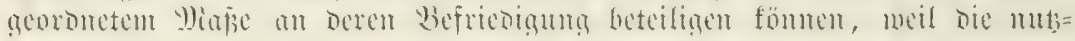
baren Sorräte heute jehr zajammengeid)muben futb.

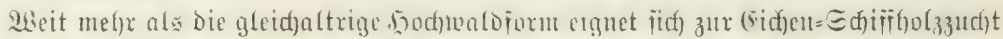

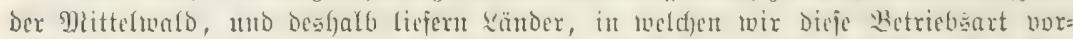

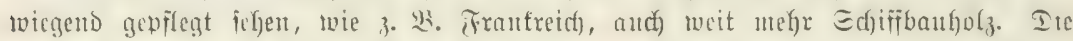

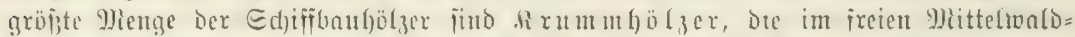

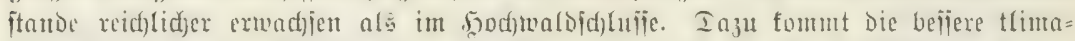

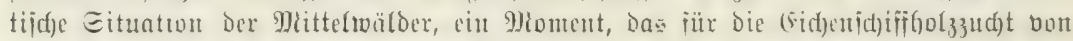
herborragendem (Finflun auf bie innere Dualität be 50 olzes ift.

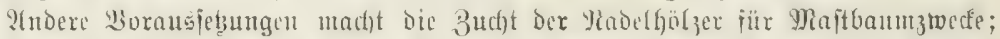

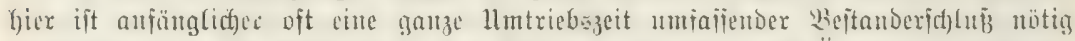

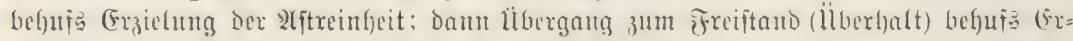

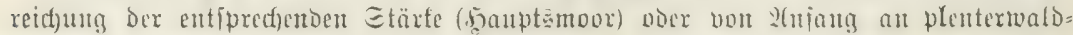

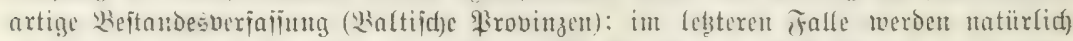

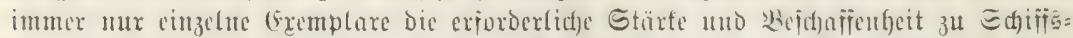

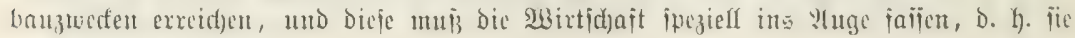
muв individualifieren.

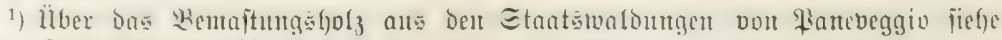
Wiener 3intralblatt 1883, 巨. 633. 


\section{Folsucruendun bei Der Tifdjlerei.}

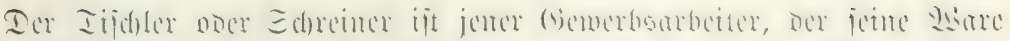

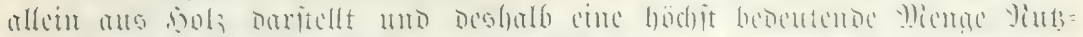

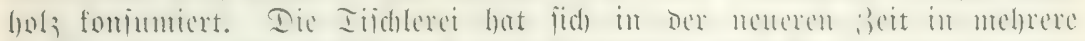

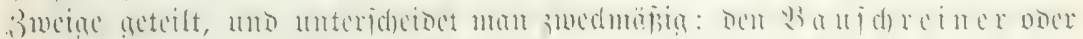

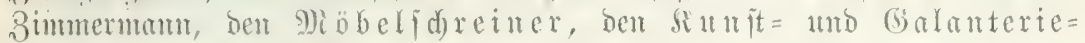

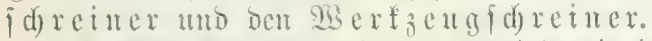

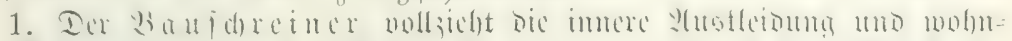

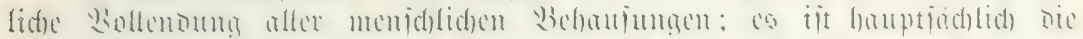

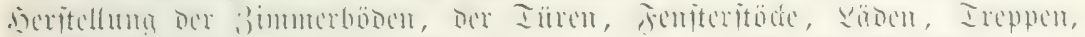

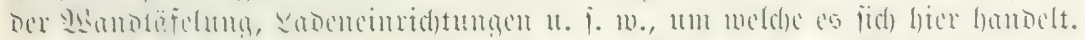

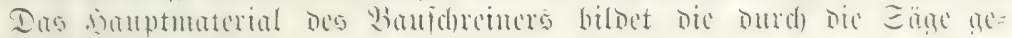
lieferte $ఠ d$ drittholzwarc, worzüglid) bic breiten, aber and bie fantigen Sdynttbölzer. Sh Gtelle ber roly von ber Gäge

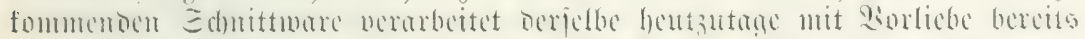

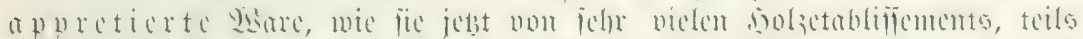

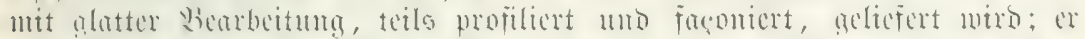

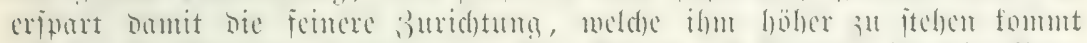

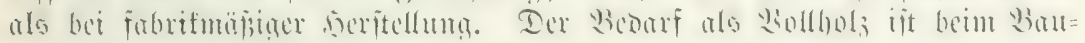
joreiner mu cin geringer.

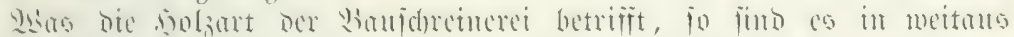

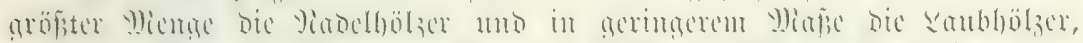

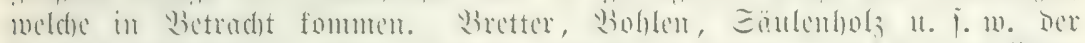

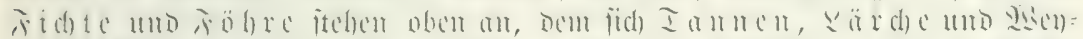

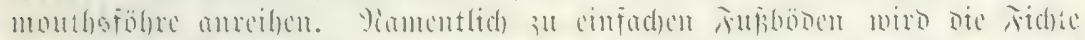

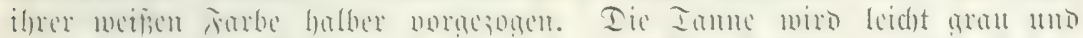

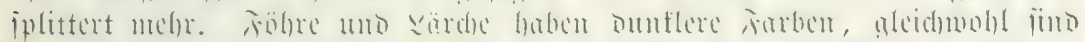

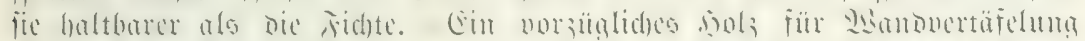

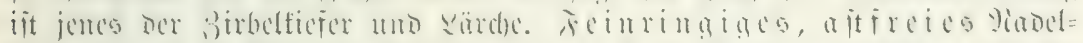

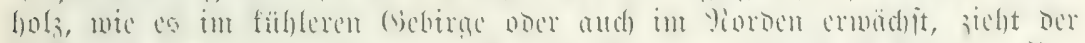

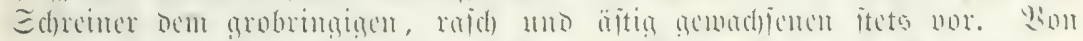

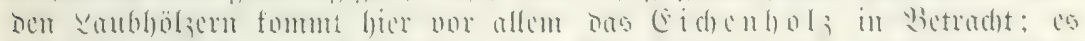

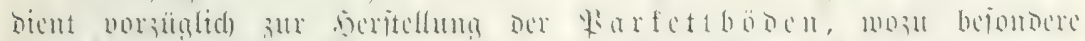

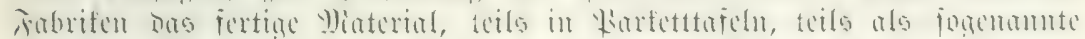

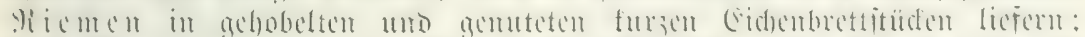

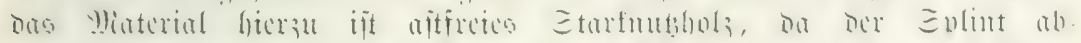

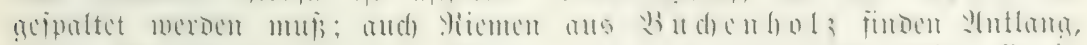

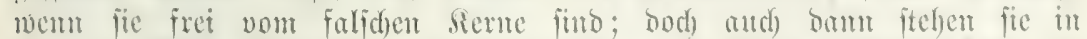

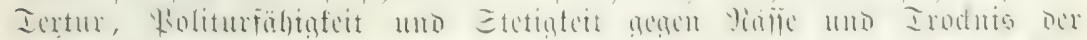

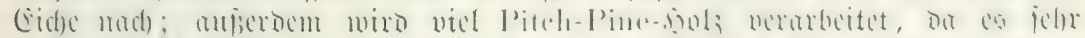

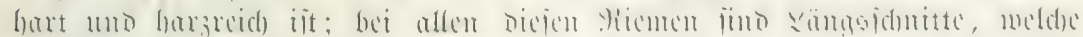

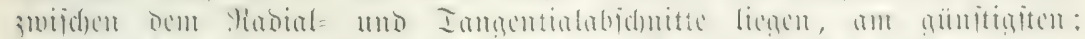

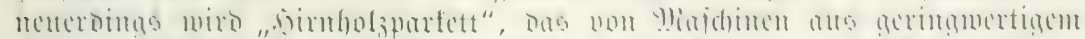

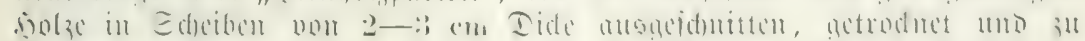

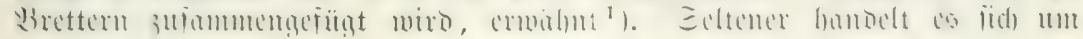

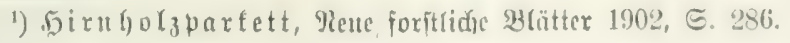




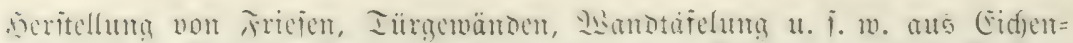

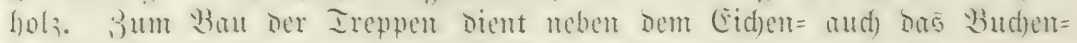
holz; zu Iurugeräten wirb Efdien bolz vermendet u. i. w.

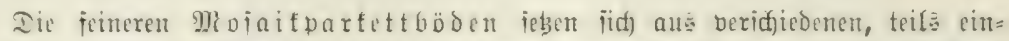

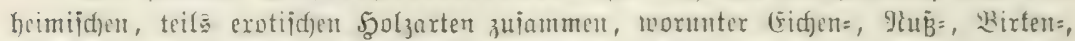

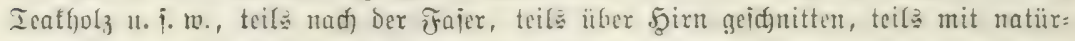
lidjer Farbe, teila gebeizt, bie Snauptrolle fpiclen.

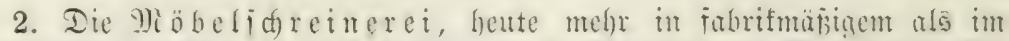

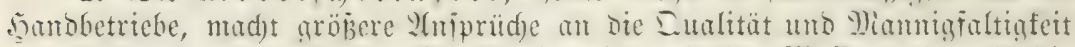

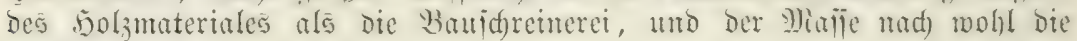
gletchent wie bieje.

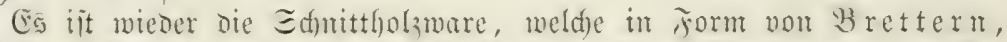

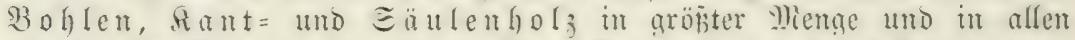

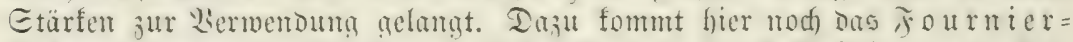

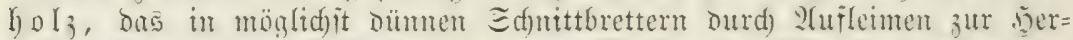

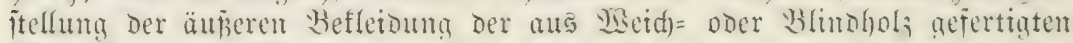

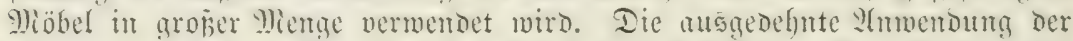

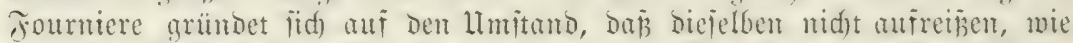

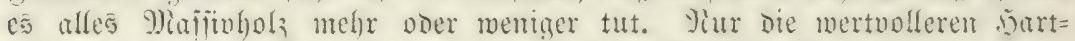

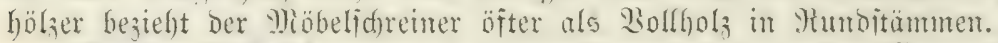

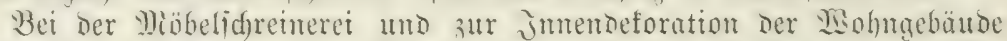

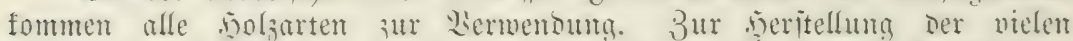

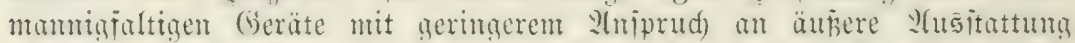

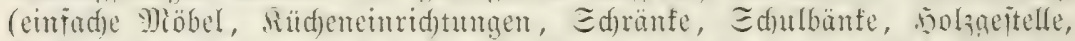

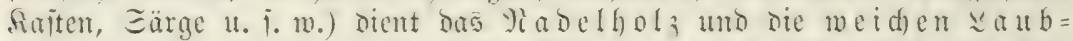
h) D zarten; entweder werden diefe Iinge gam aus Diejen nolarten her=

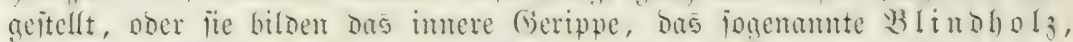

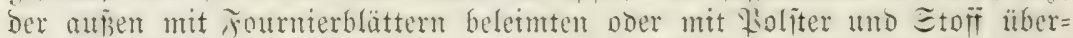

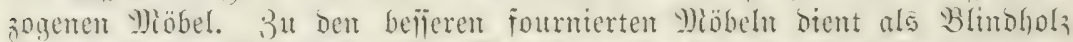

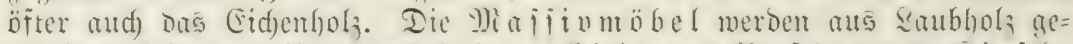

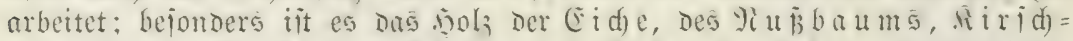

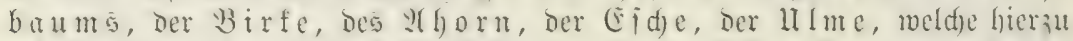

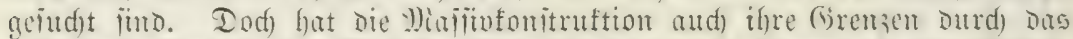

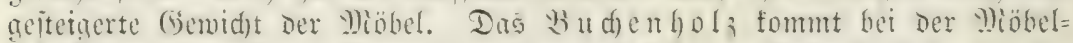
fabrifation äberall 3ur Bermenoma, mo es fid) um Ietle handelt, bic ber

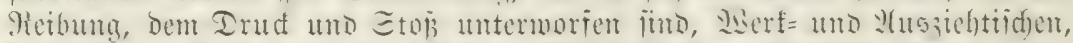

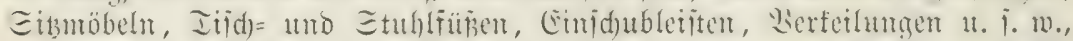

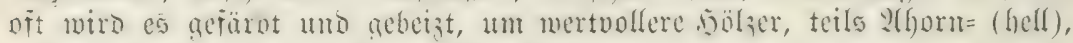
teils Siū́baumbolz (ounfel), nad)zuahmen.

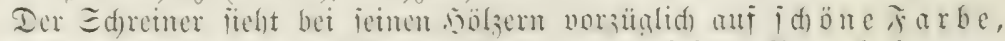
gute Iertur, reine a fifreie Fajern, leidyte Bearbeitung,

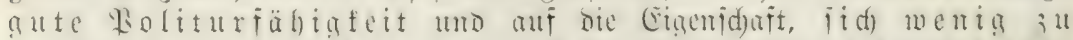

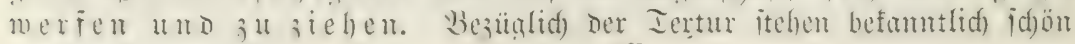

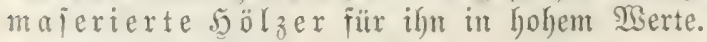

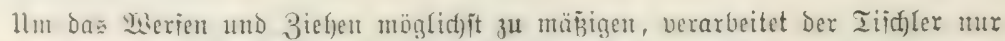

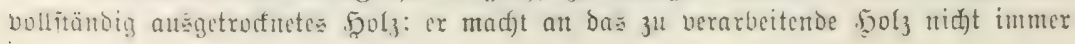




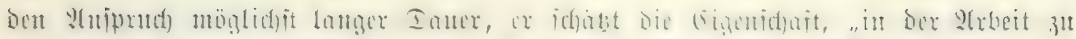

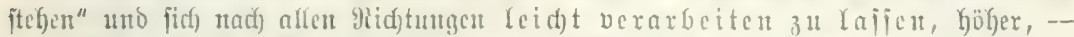

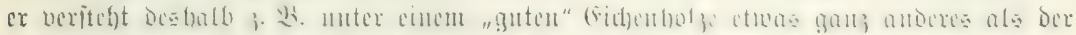

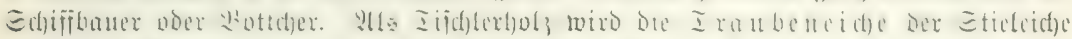

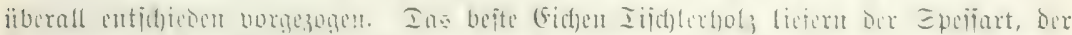

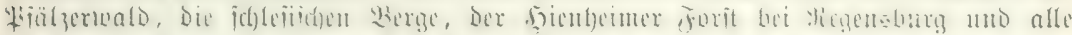

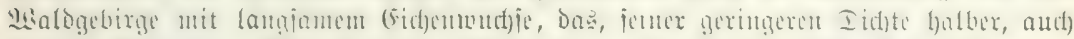

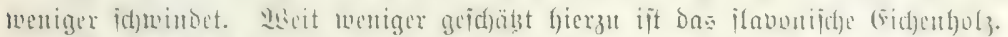

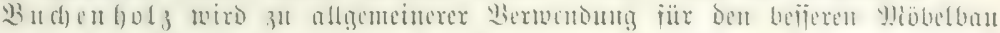

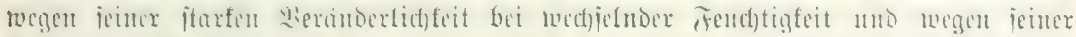

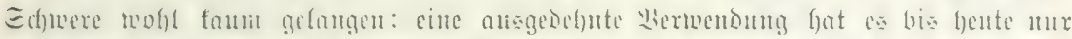

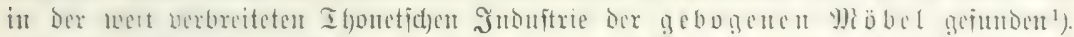

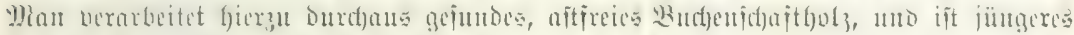

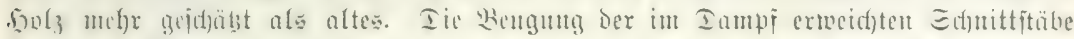

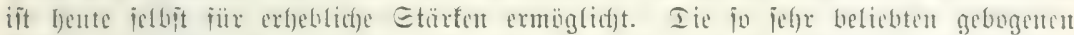

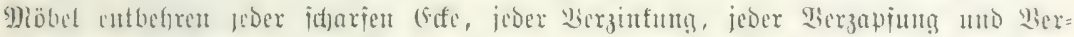

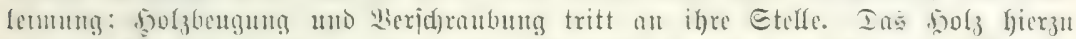

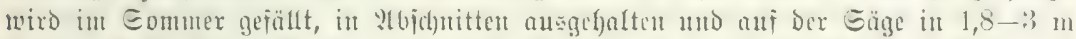

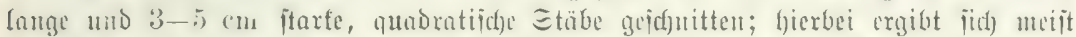

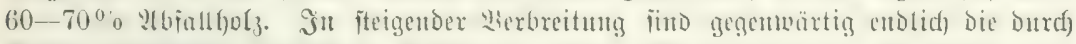

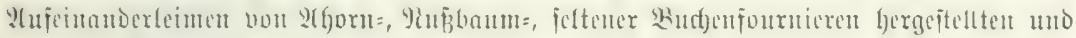

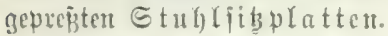

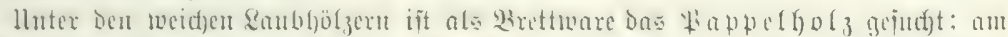

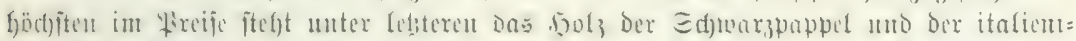

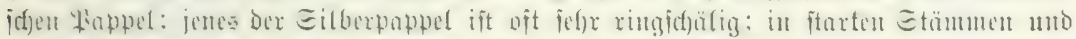

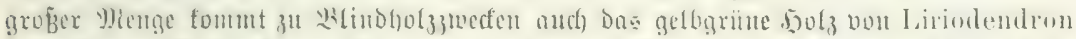

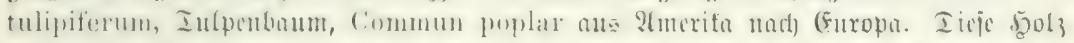

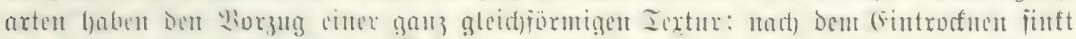

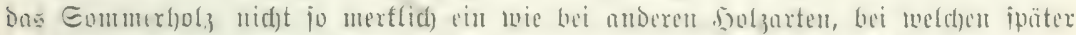

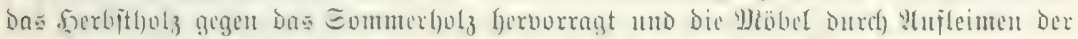

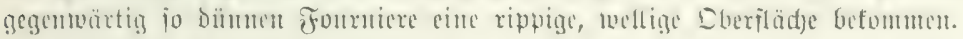

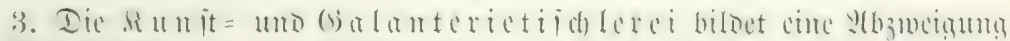

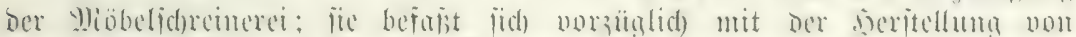

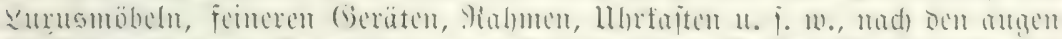

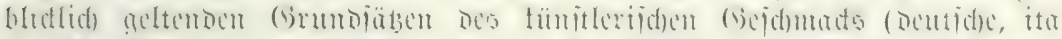

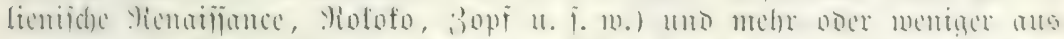

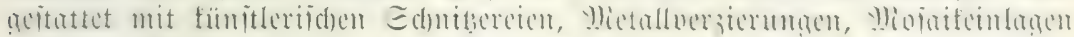
17. i. w. (Woule $=$, Cortura =, 5olabumbarbeiten u. \%. w.).

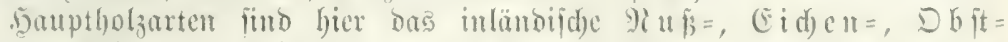

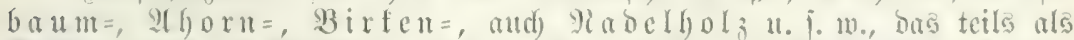

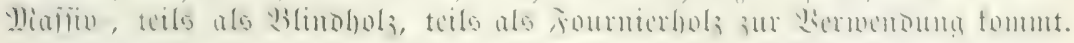

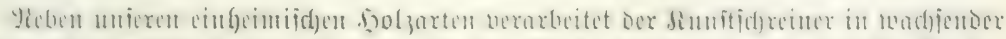

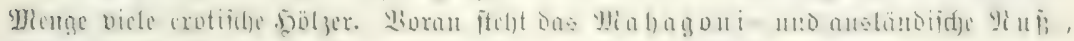

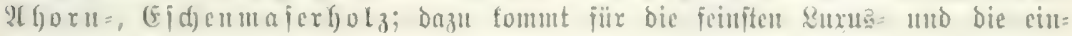

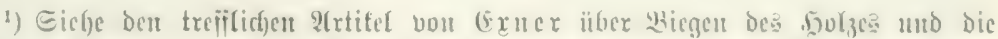

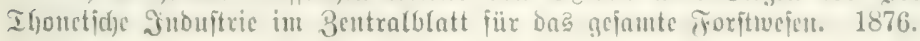




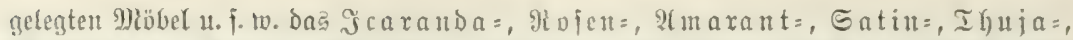

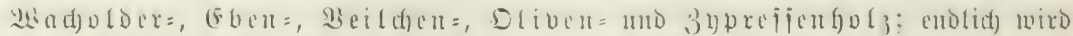

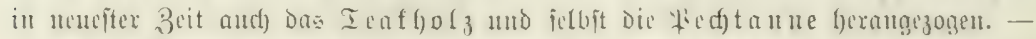

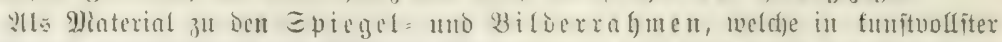

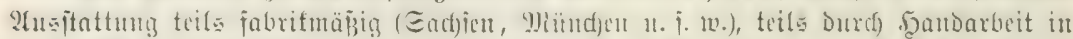

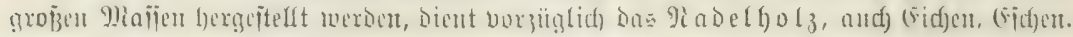

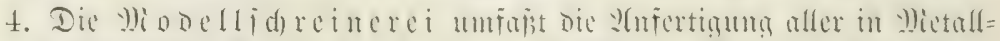

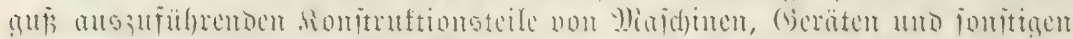

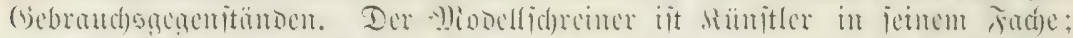

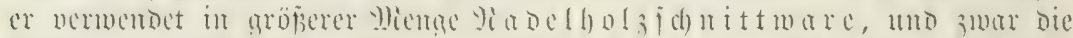

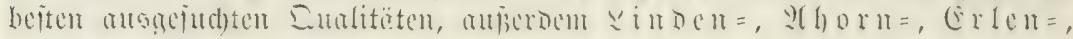

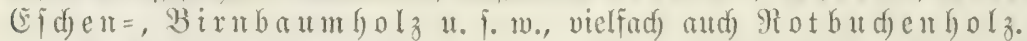

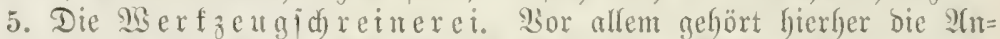

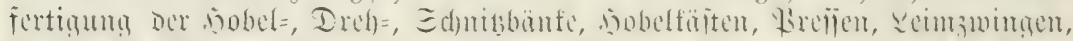

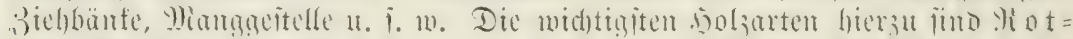

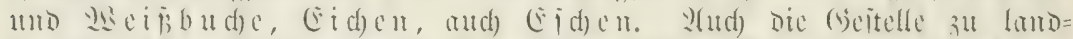

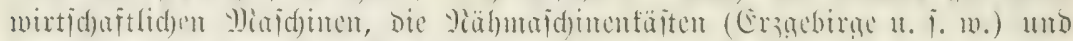

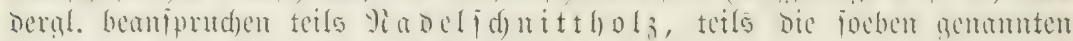
5olzarten in nidgt unbeträd)tlidjer Mienge.

6. (smblidy mären mod) mandjerlet ambere $\mathfrak{A b z w e i g u n g e n ~ b e r ~}$

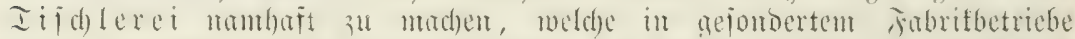

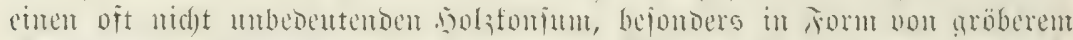

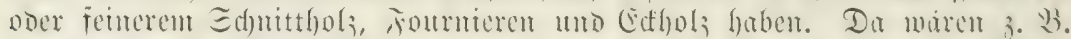

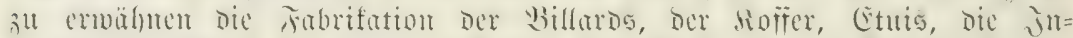

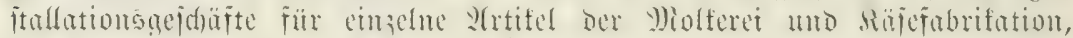
Die Mollabenfabrifen ๓. . m.

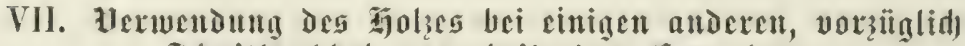 Sdunttutisljol verarbcitenden Gewerben.}

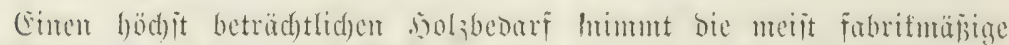

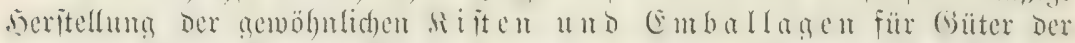

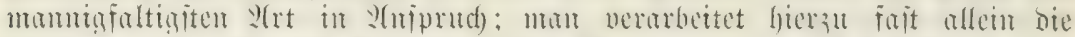

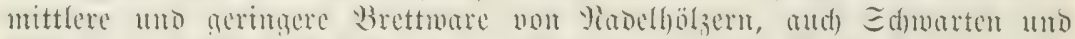

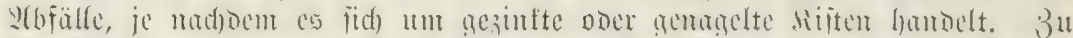

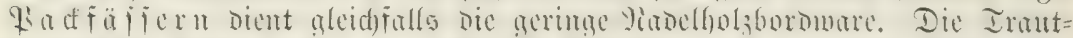

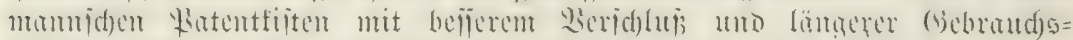

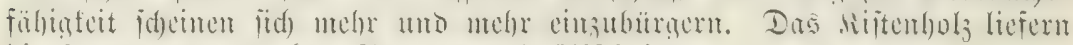

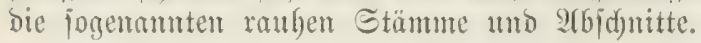

3u ben fleinexen fiftden, tweldfe zur Berpactung bon Galanterie=,

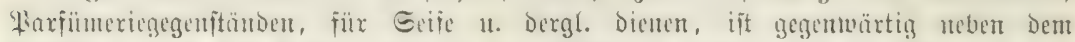

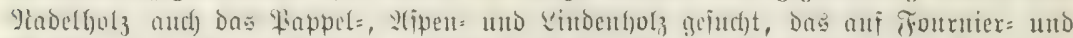

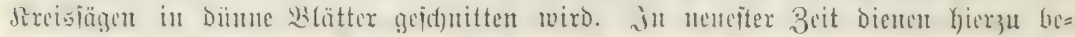

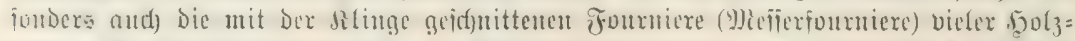

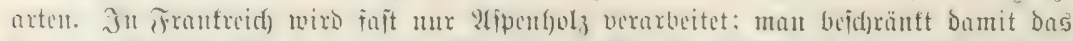

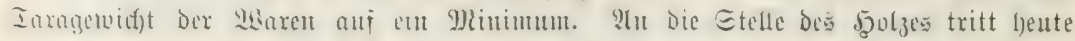
vielfad) $5013 p a p p e$, aud (Eijentbledf). 


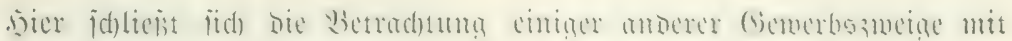
vorzugameifen Edfuttholiverbraude an.

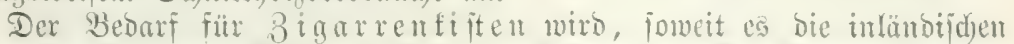

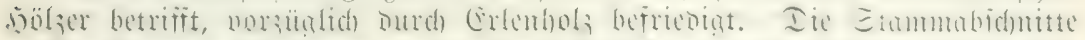

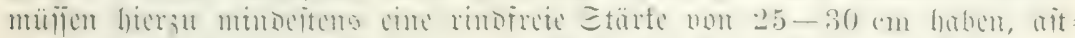

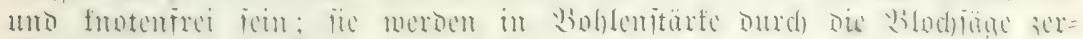

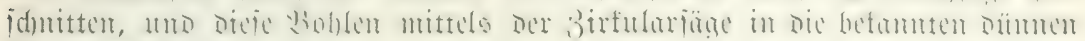
Bretturen zerlegt.

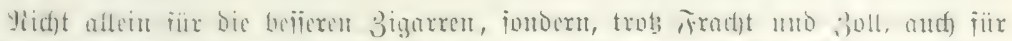

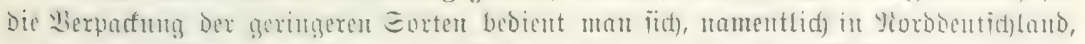

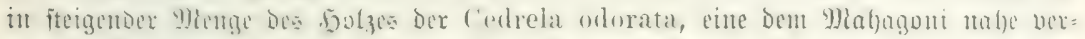

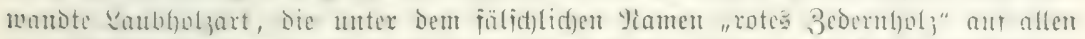

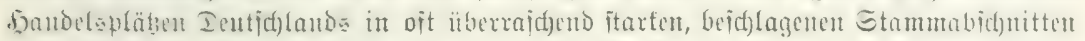

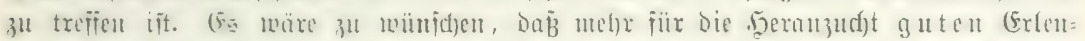

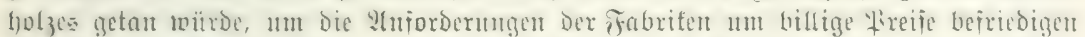

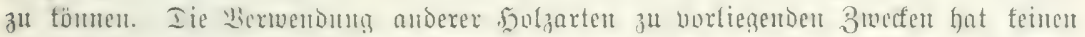

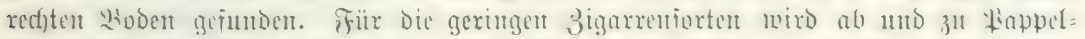

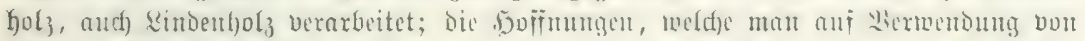

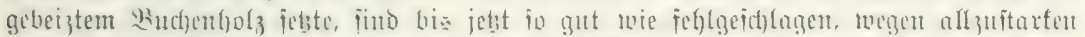

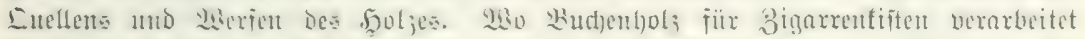

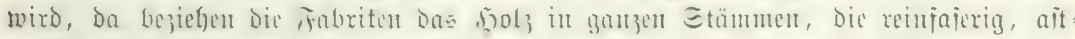
uno fnotenjee jein müpīen.

$3 u 3 i g a x$ ren= Midelformen, bie bazu beitimut find, den ge=

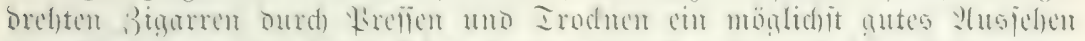

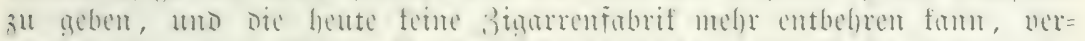
mende mu zum

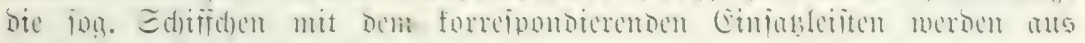
Mot = ober geiß̈budjenlyolz gefertigt.

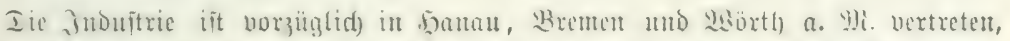

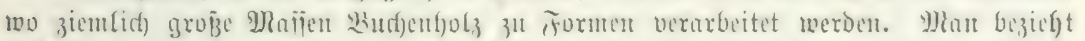

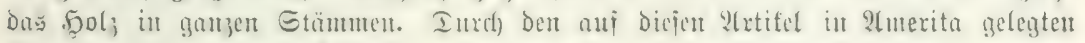
(Einjul)rgolf hat bieje Sndujtrie in nenerer Beit fintrag erlitten.

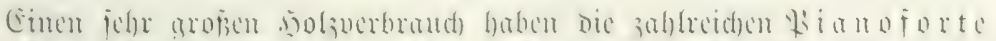

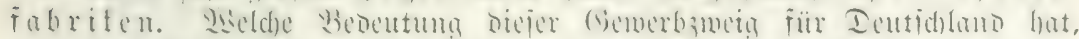

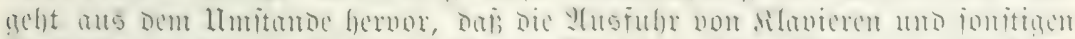

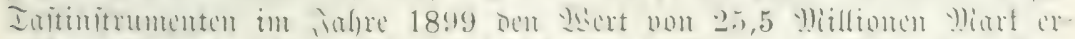

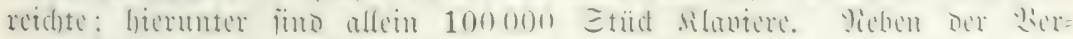

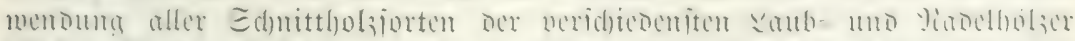

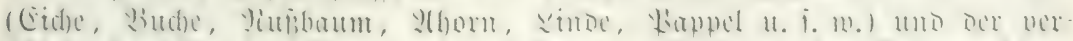

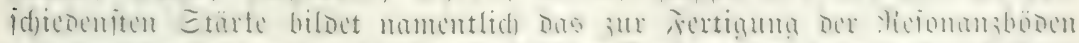

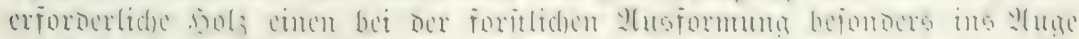

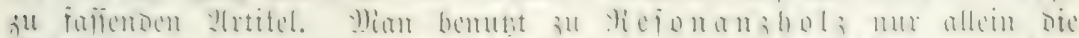

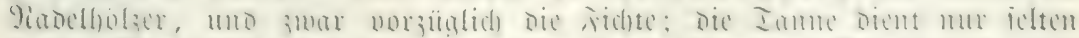

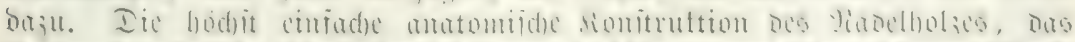

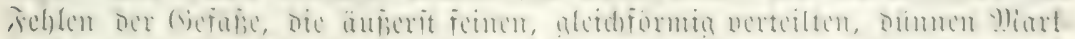

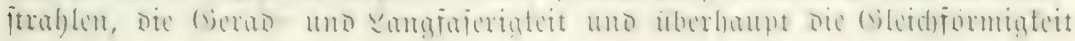




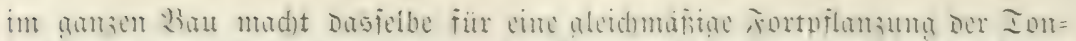

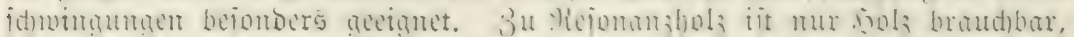

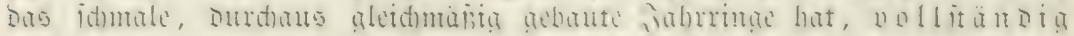

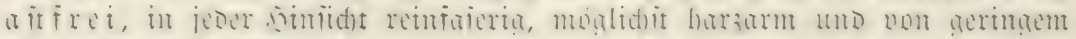
ipeziïidjen Gemidg)t $(0,40-0,45)$ iit.

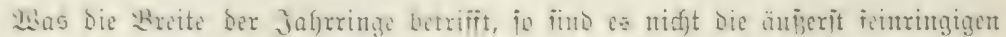

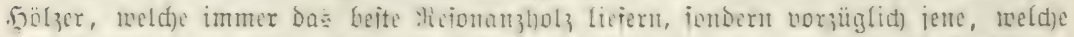
eine Ringbreite zmifiden 1,5 und 2,0 mun haben uno bei melffen Die Epatfol\}=

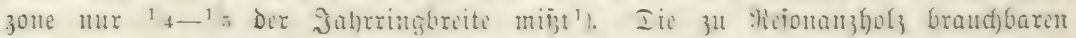

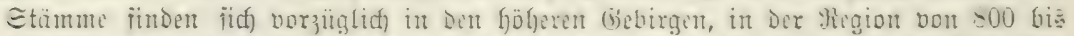

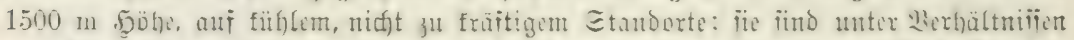

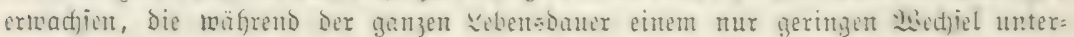
morien maren, in fener, in ber Jugend balb geidjloifenen, ipäter aber räumigeren Etellung, wie ite die berichiofenes formen des Femelmalos bieten. Ias meite

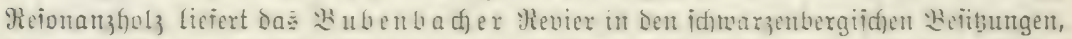

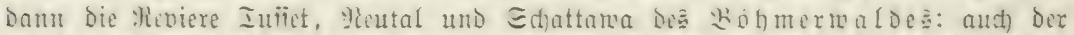

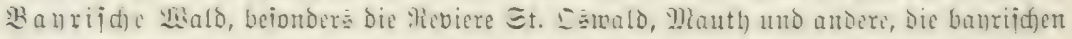

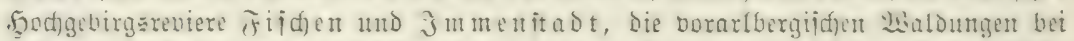

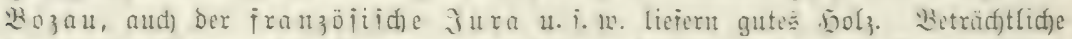
Euntituten Reionanzhol3 fommen gegenuärtig audf über Remberg an Galizicn, jelbit ans 2merita. - Iie zu Rejomamzhol, ausgefaltenen @tammabichnitte merben aui

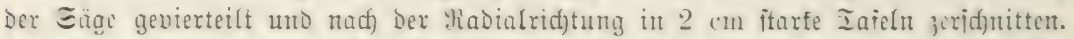
Bann getrodnet, geiäumt, glattgehobelt uno nad) Ionföhen iortiert. Vieneroing hat man veriud)t, Das Rejonanzhol3 Durd) cin füntt(id)es Eurrogat ju erieben, Das Durd)

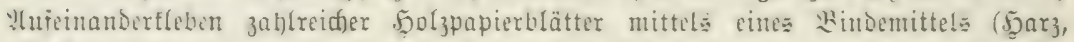
छdellnd, Gummi u. i. m.) und unter fireipen in beliebig grojen filaten her= gejtellt wiro.

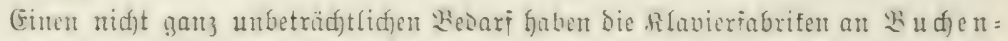
fol3 in Form bon :3-7 ('m itarten Iielen: iie begefren namentlid) Durd)aus rein:

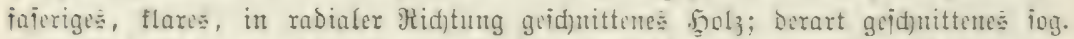

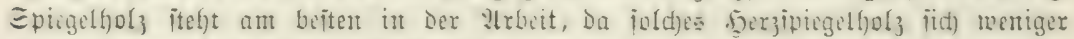
3ithe und werie als anderes Buchentolz.

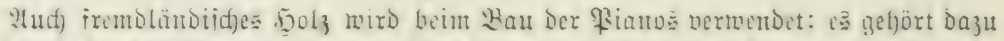

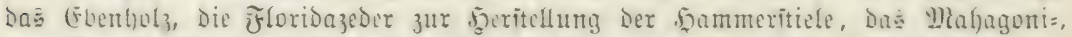

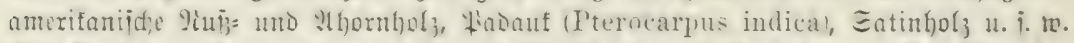

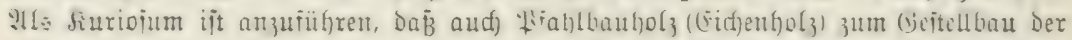

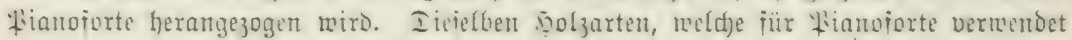

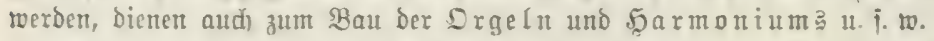

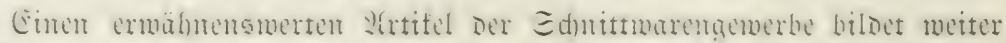

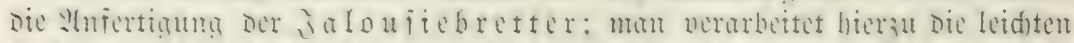

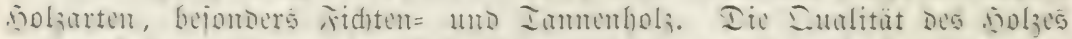

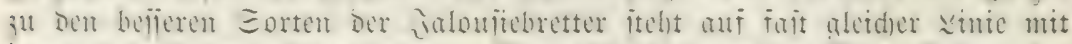

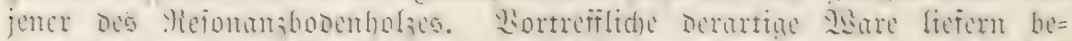

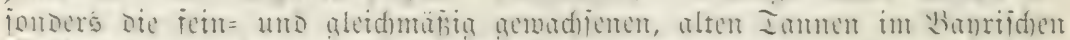

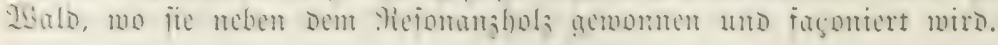

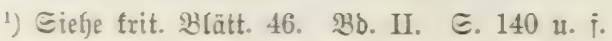




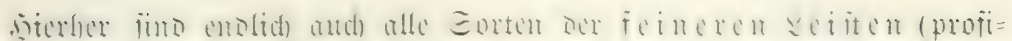

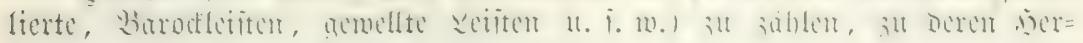

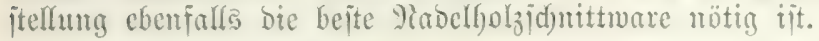

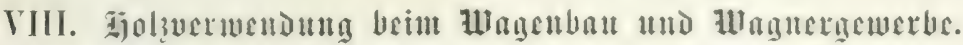

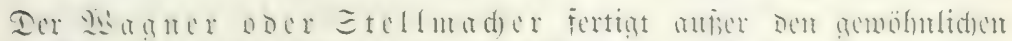

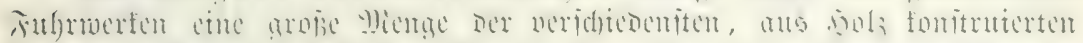

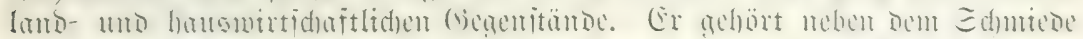
aแf Dem

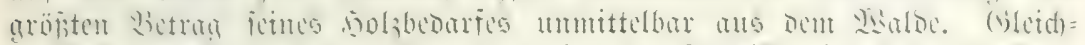

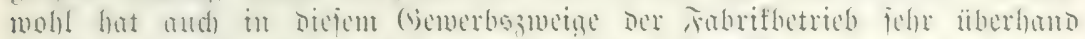

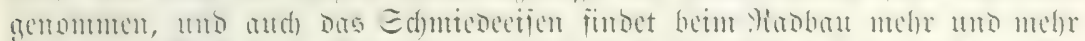

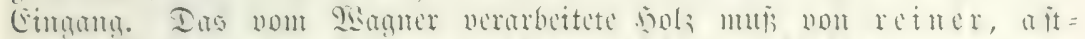

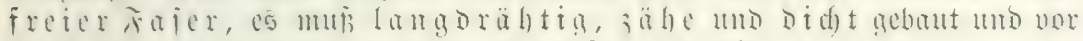
allem frei von Fehlern un Faulfleden jein.

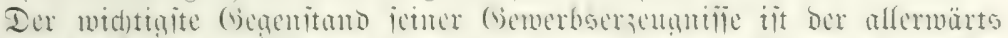

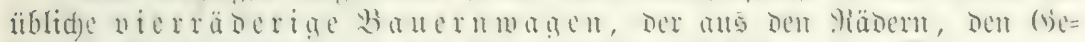

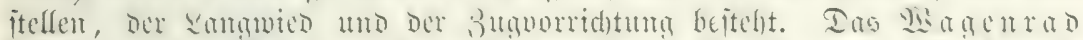

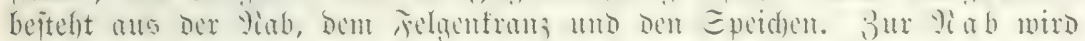

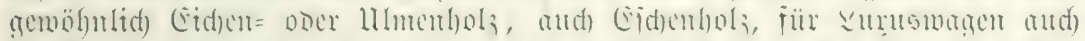

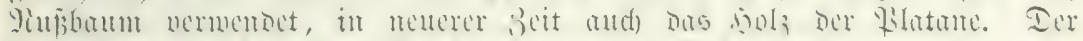

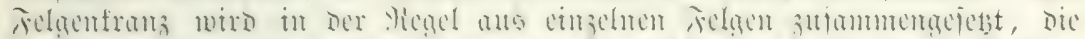

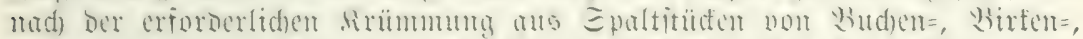

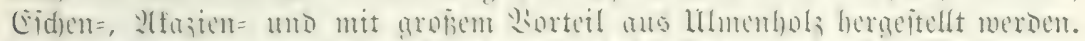

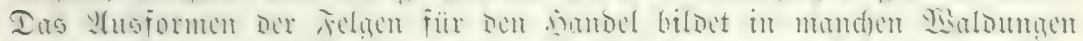

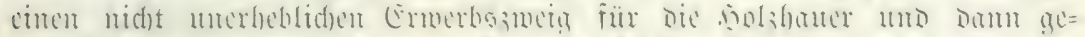

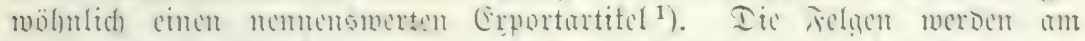

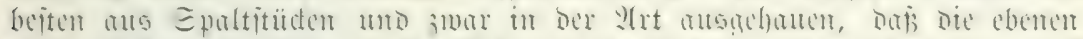

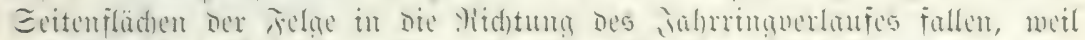

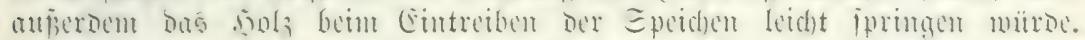

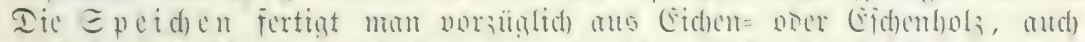

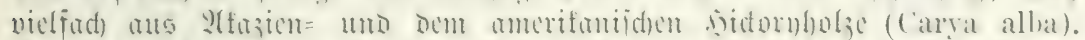

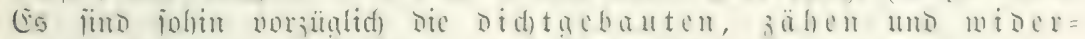

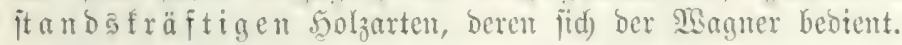

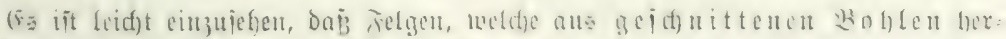

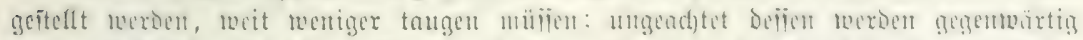

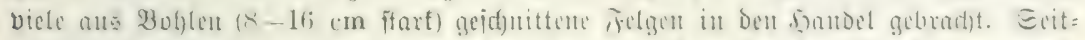

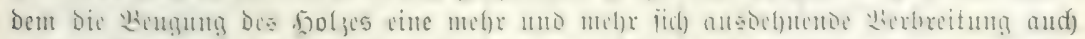

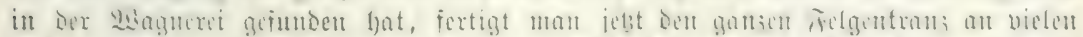

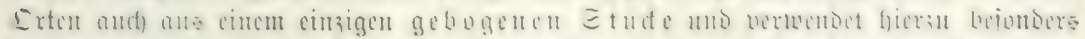

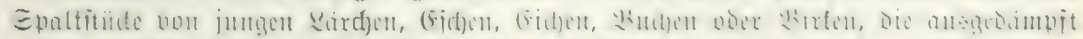
ạbugut werten Des Fetgentranze veriventoet.

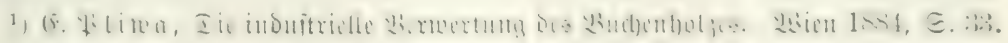

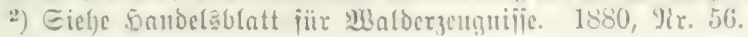

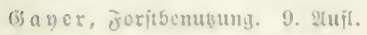




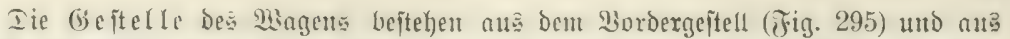

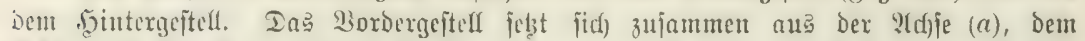

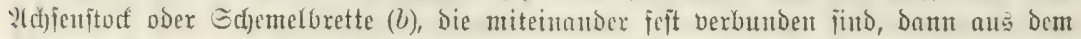

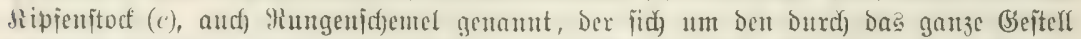

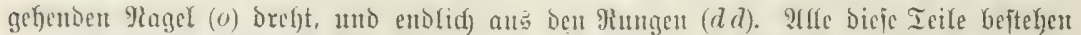

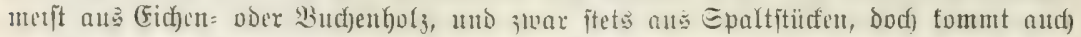

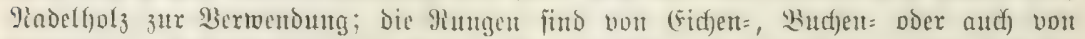

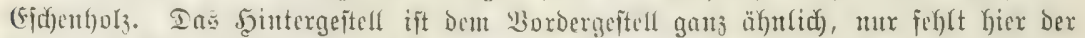

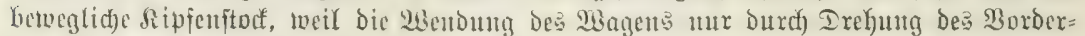
geitellz betwirt wiro.

Ia Şorbcrgeftell ift mit Dem Şintergeftell burch) Dic Rangluied (Rangwagen,

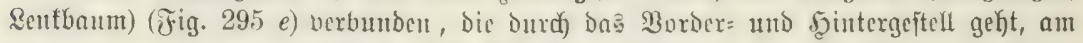

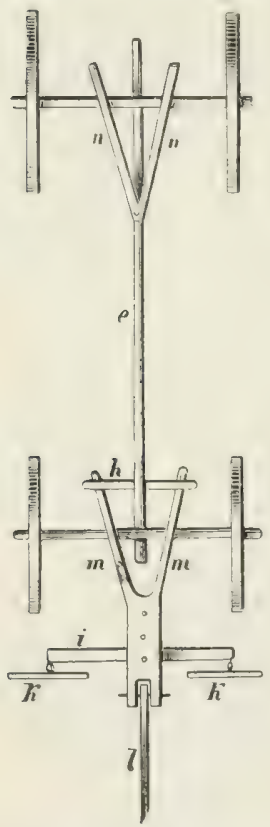

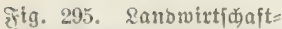
lider झagen, von unten. eritexen Durd) Den Ragel (Fig. 296 o), am Yebteren Durd) bas jog. Metter $(n n)$ unbetweglid mit diefem Sintergejtelle ber: Gunden ift. 3ux Rangivied verwendet man eine (Fid)en=, SBirfen= ober (Fichenjtange, zum Wetter ein gabelförmig getwad benes (Eichentiolz.

Die 3 guoxridutung Gejteft aug Den Deidjelarmen (Fig. $295 \mathrm{~mm}$ ), wozu man entweder ein gabelförmig ge=

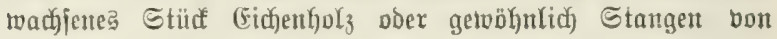

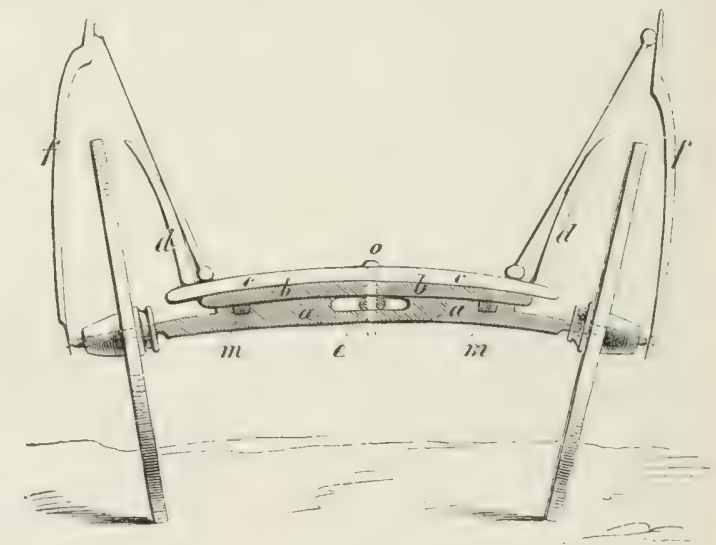

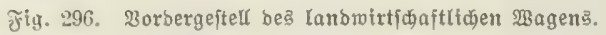

(5id)en, (Ffden, Birfen burd) 3ufammenfügen in bie exforderfiche Figux bemutst, -

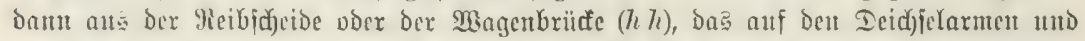

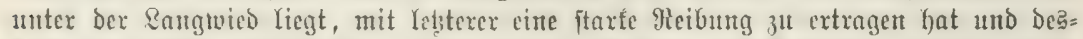

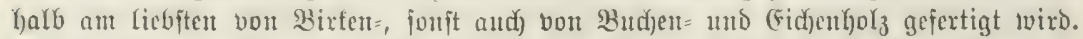

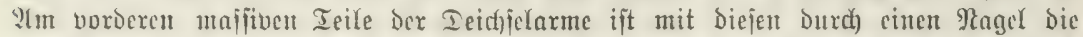

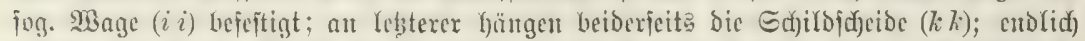

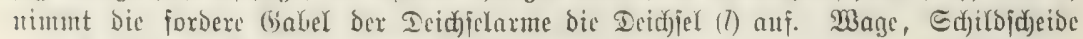

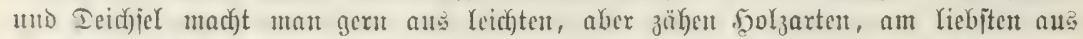

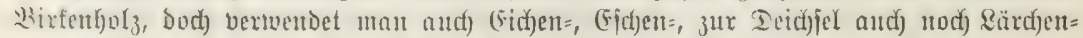
and Fidntentholz. 


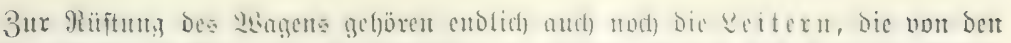

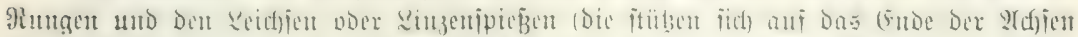

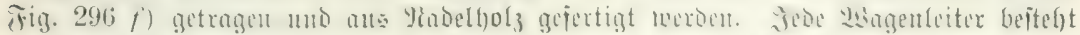

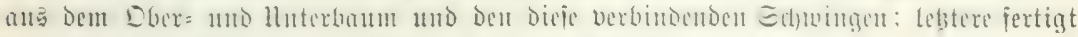

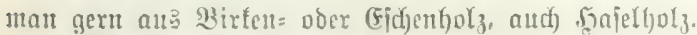

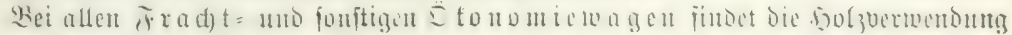

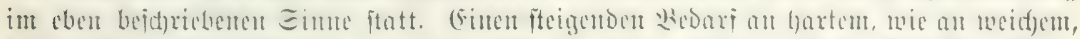

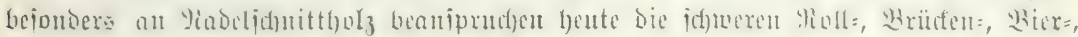

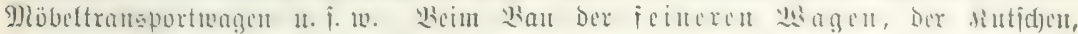

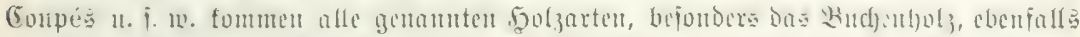

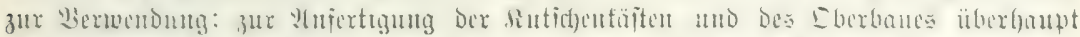

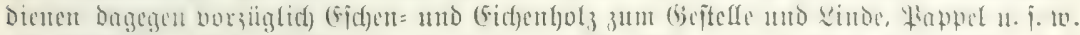

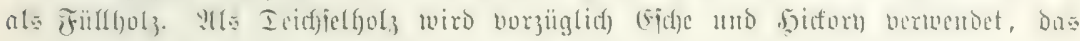
belte aber ift Do: jog. Ranzenhol (Guatteria virgata).

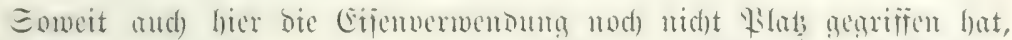

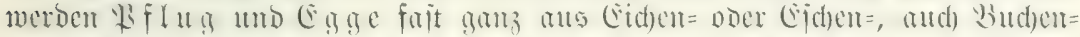

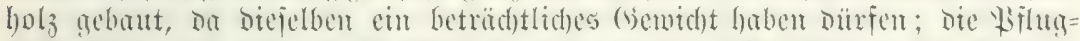

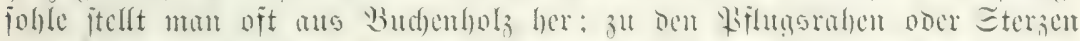

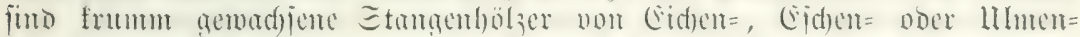

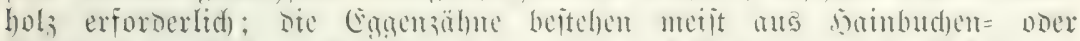

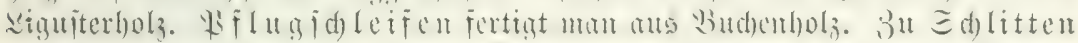

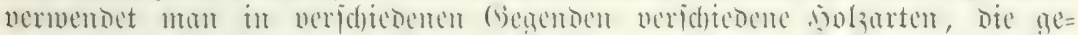

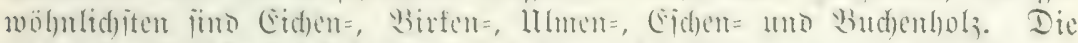

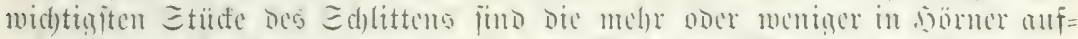

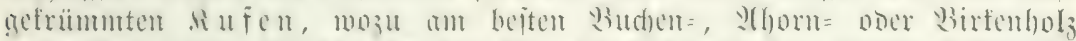

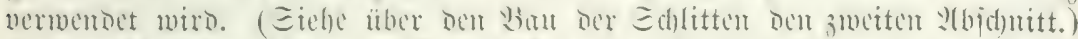

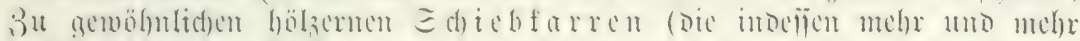

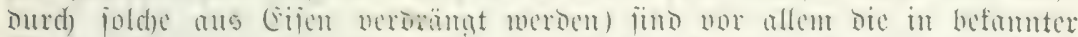

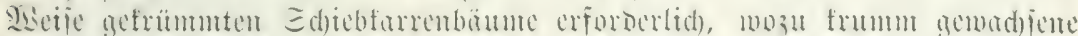

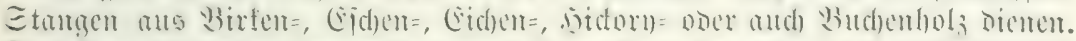

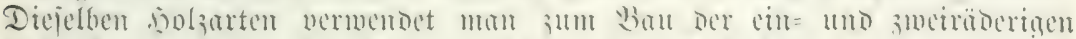

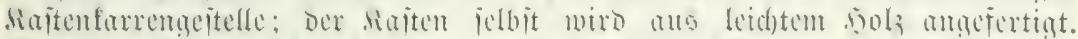

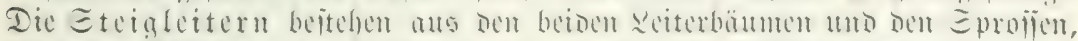

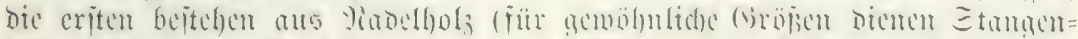

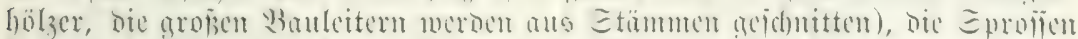

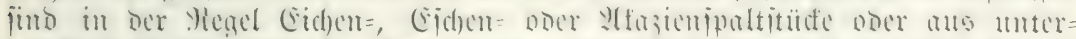

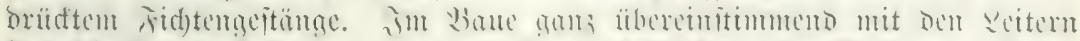

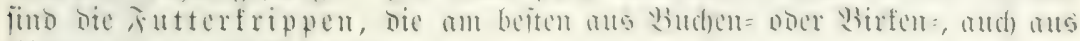
(Eidjenlolz bergeitellt werden.

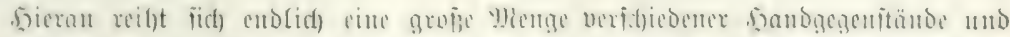

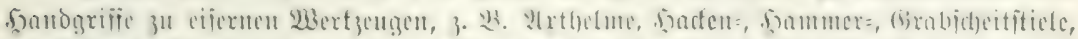

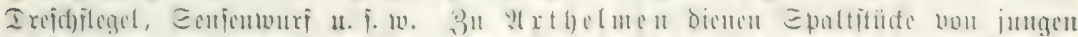

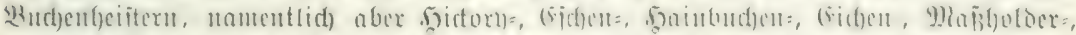

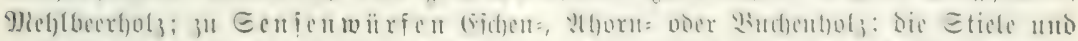

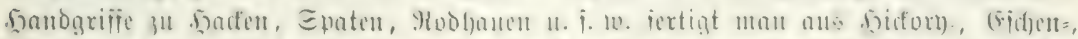

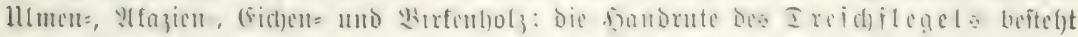

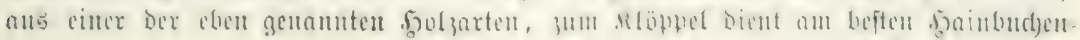




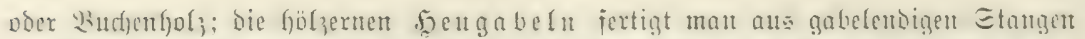

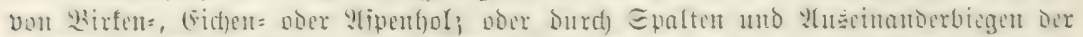

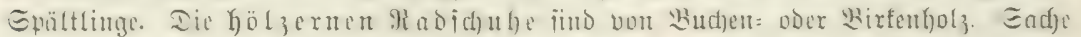

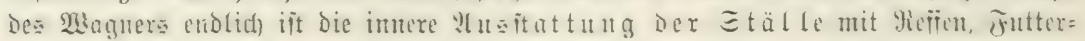
barret u. i. tw.

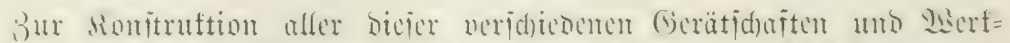
itude nerarbetset Der 2E

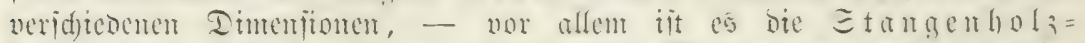

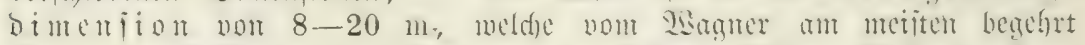

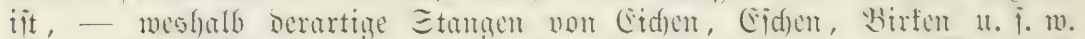

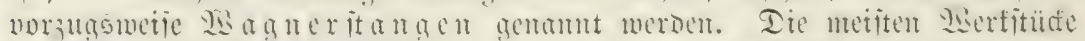

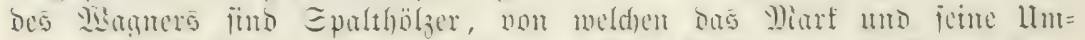

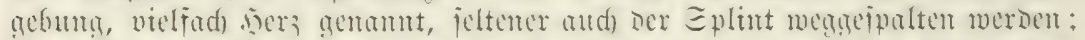

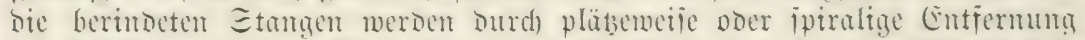

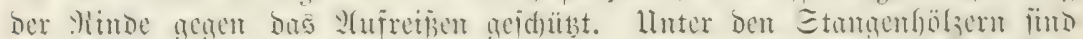
bie f $\mathrm{r} u m u=$ =

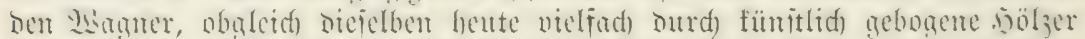

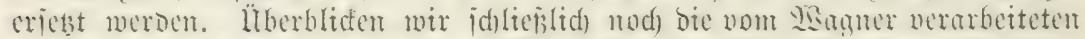

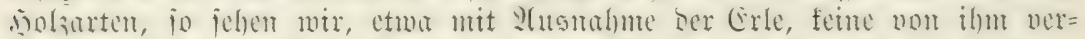

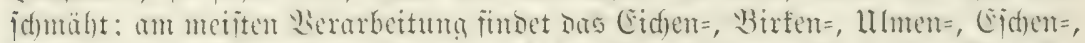

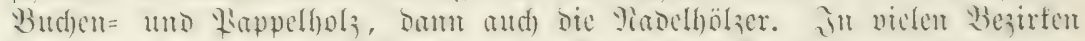

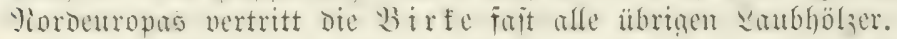

(Fin jofre gutę Magnerfolz ift unitreitig audf) bas llfmenfolz (in cintgen Erten

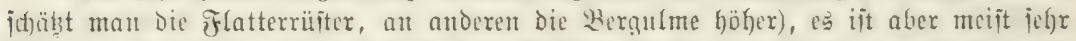

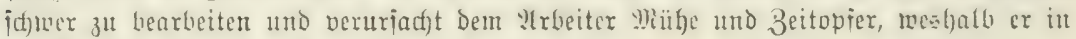
Der Segel nidjt gut auf başfelbe zu ipredjen ijt. -

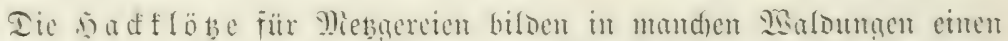

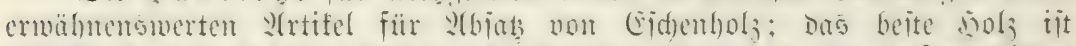

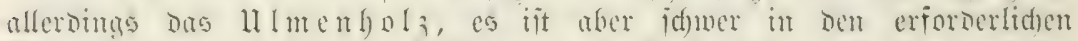

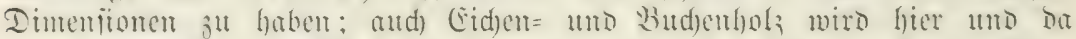

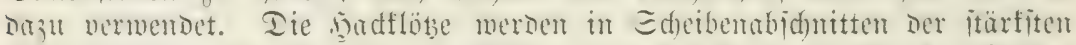
Dimenitumen, bei $25-30 \mathrm{~cm}$ Dide, von Etoctembe Durdum afjumber Etämme autgeformt.

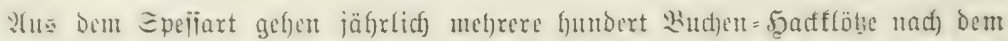

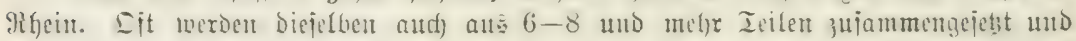
mit eijernen Rrijen gebunden.

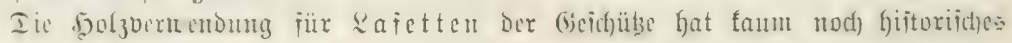
Sintereïe.

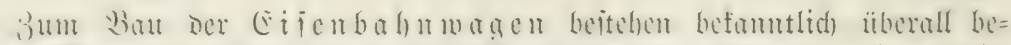

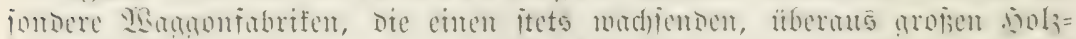

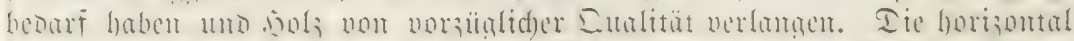

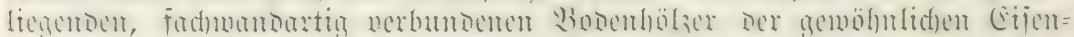
batmmange ( (E)

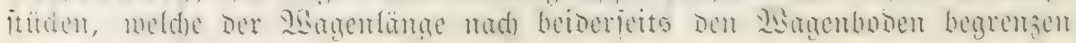




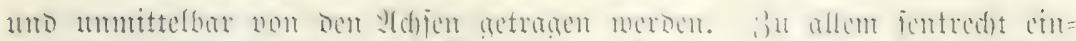

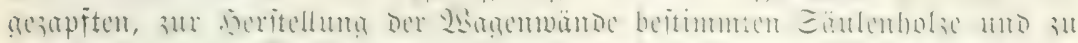

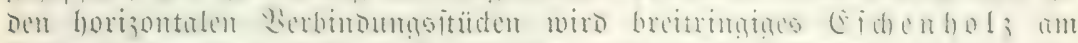

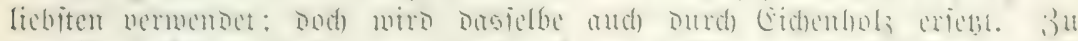

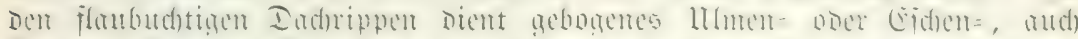

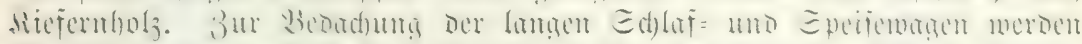

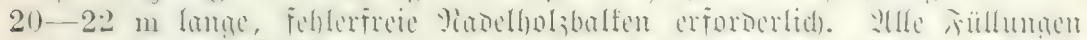

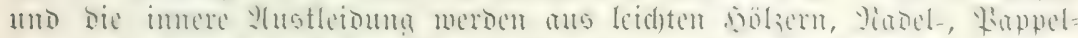

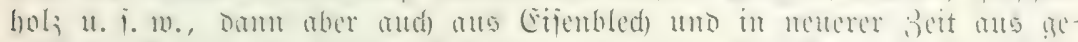

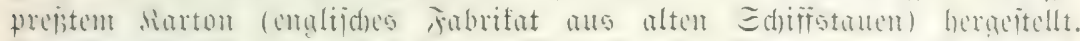

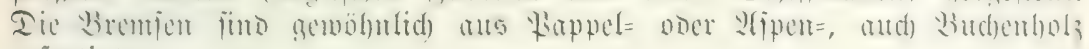
gefertigt.

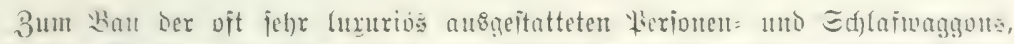

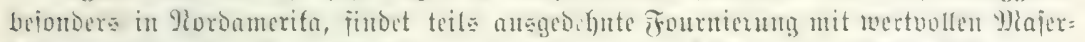

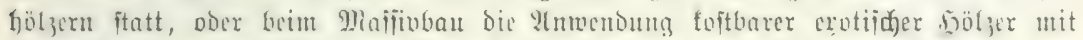

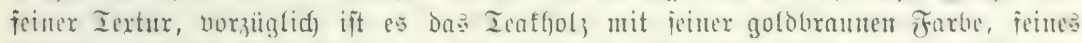

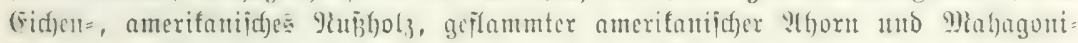
holz u. a.

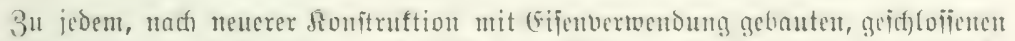

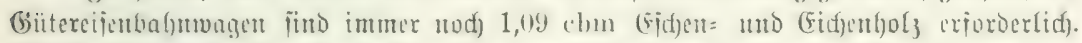

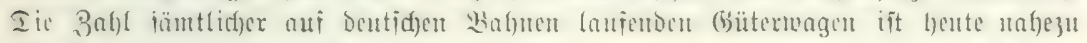
300000 , Gierunter ca. $35 \%$ gedecfte $\mathfrak{B a g e n}$.

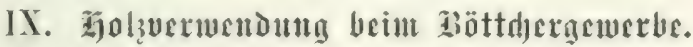

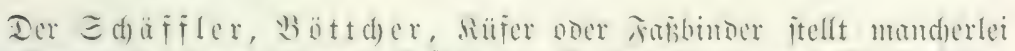

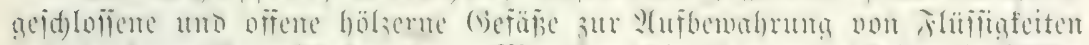

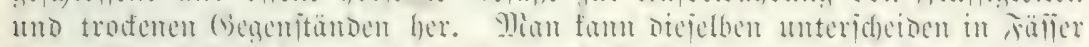

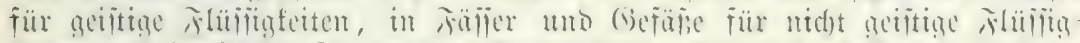

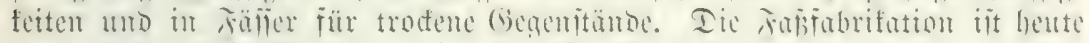
zum gropen Ieil Gegenftand indutrieller Brobuftion.

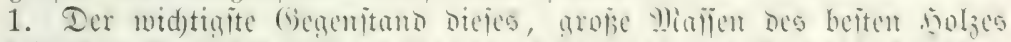

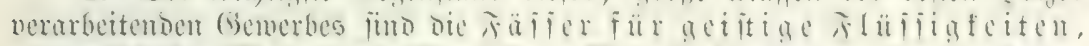

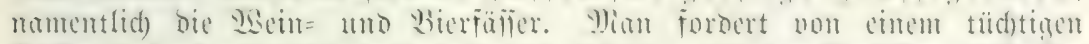

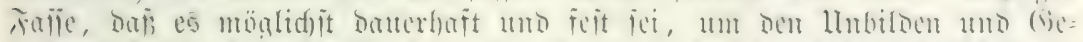

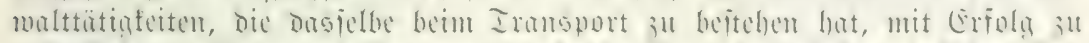

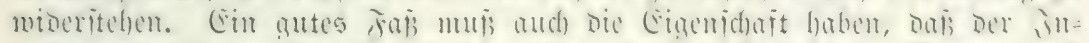

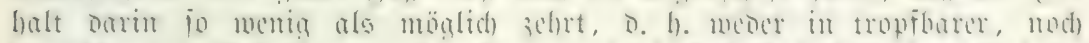

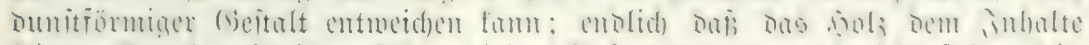

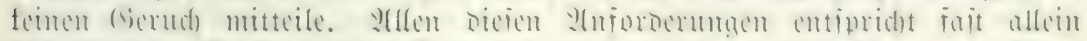
Das shola Dex (E)

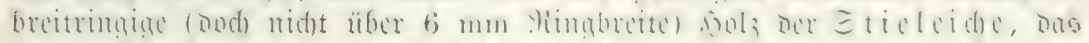

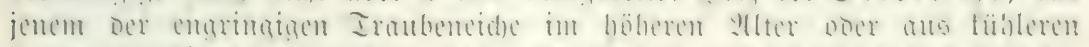

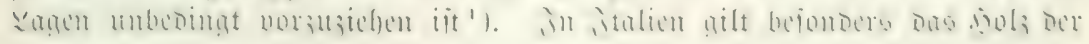

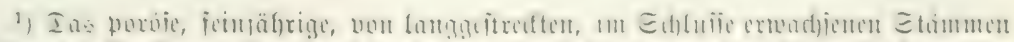

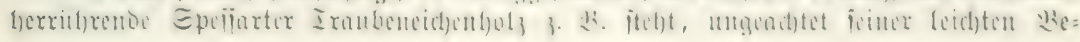


Zlfa;

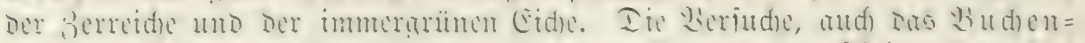

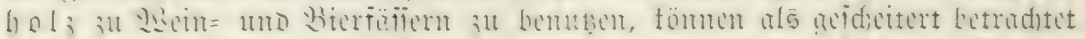

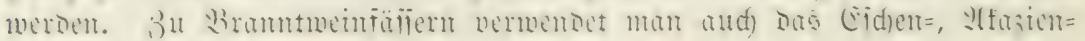
und Bogelbeerbolz.

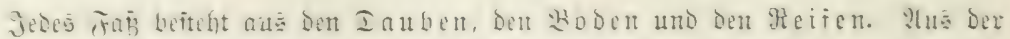

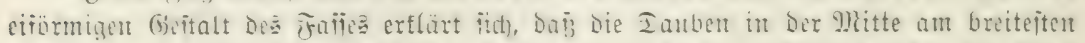

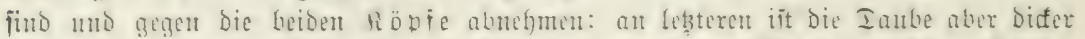

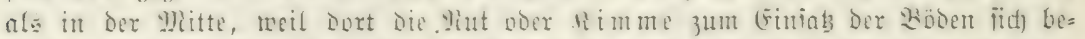

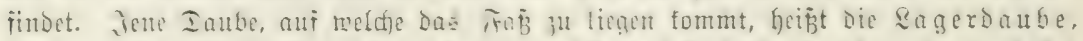

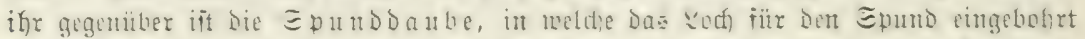

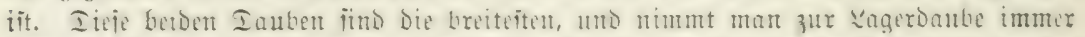

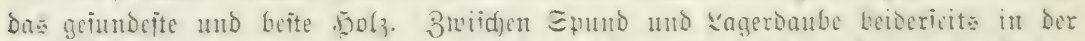
Ditte liegen bie Gefrbauben, alle jubrigen feiben wedfieldauben. Ier Woben

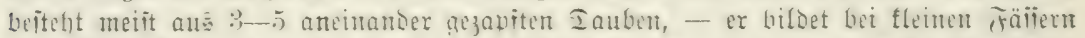

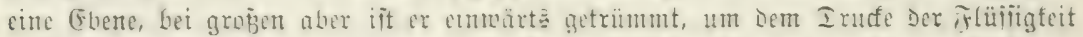

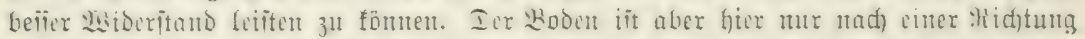

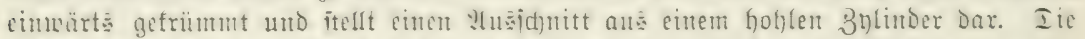

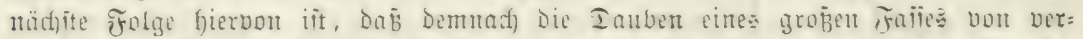

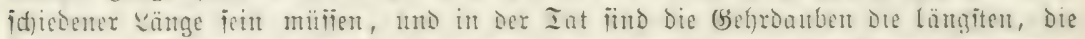

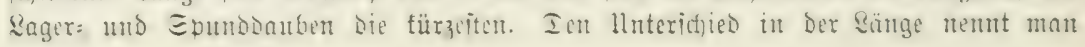
die Gebr.

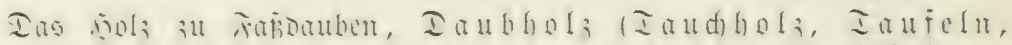
는 a

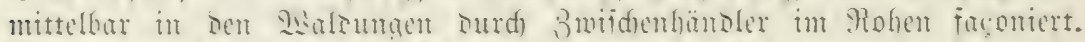

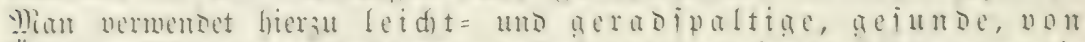

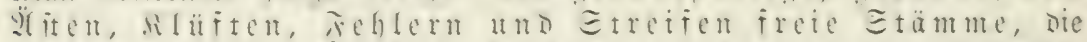

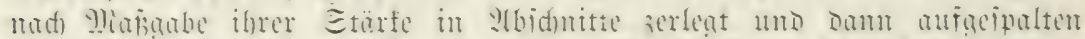

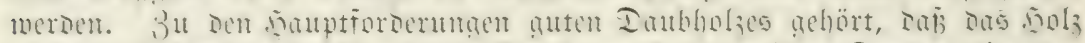
₹

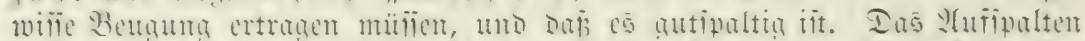

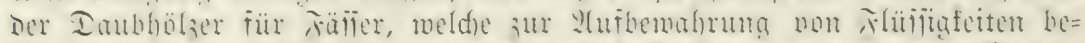

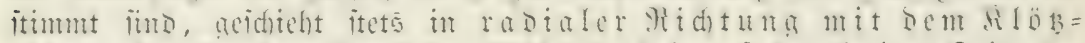

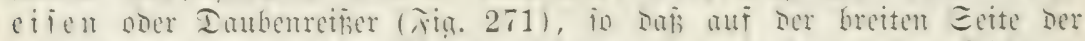

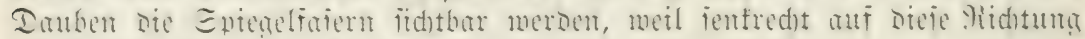
die Durd)lajungsfäbigfeit bes Dolzes am geringiten iit.

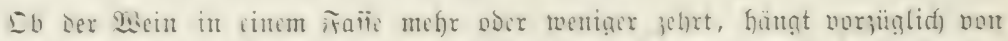

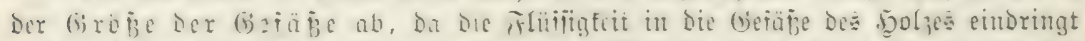

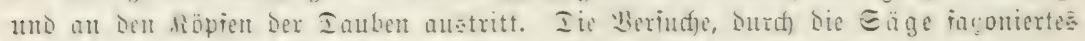

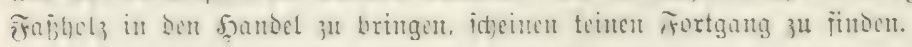

Bei ber Façuterung bes Eideubablolzes verfübrt ber

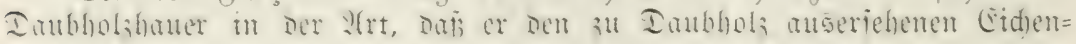

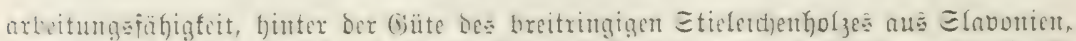

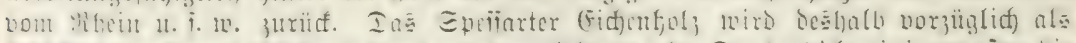

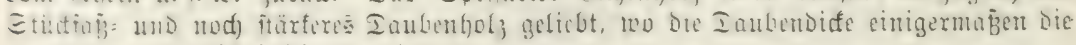
mangelnoe Solzoidatigfeit zu erieben vermag. 


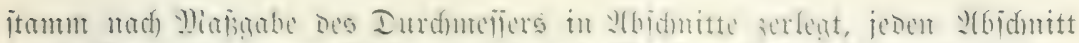

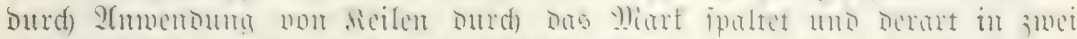

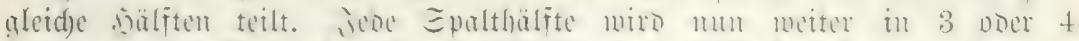

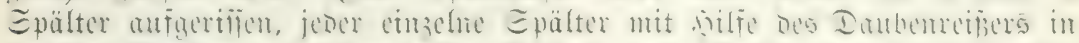

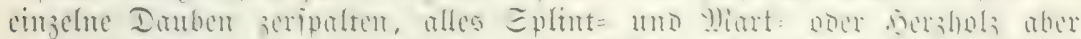

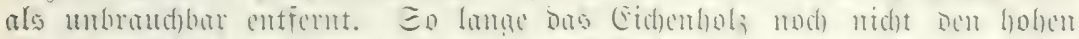

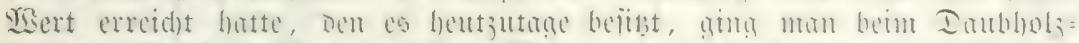

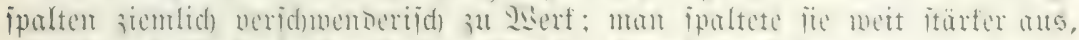

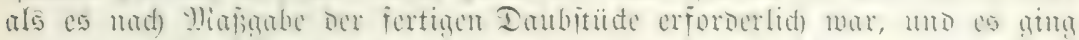

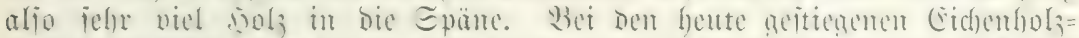

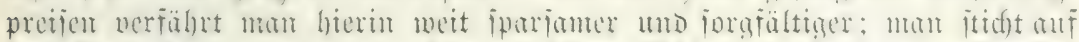

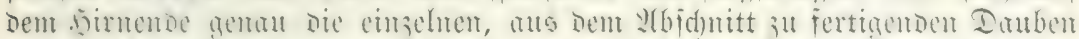

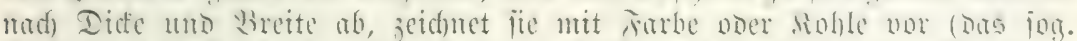

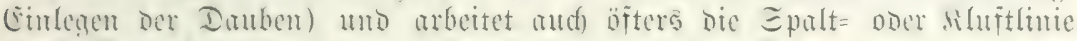

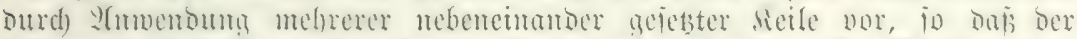

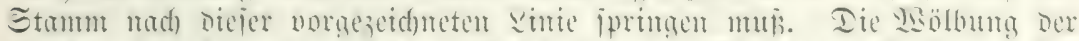

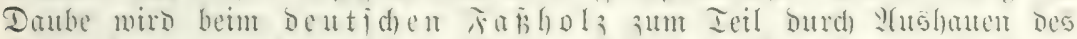

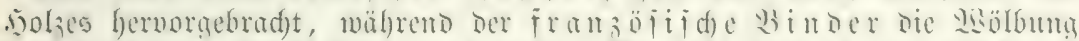

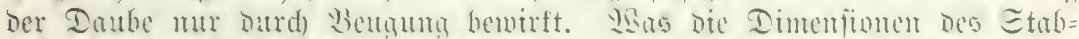
holses betrifit, io ridften jid) diejelben mad) Der Etärte Des $\Xi t a m m=$

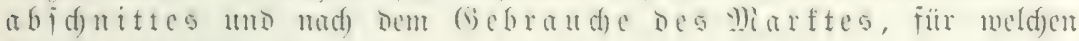
basilbe beitimmt ijt.

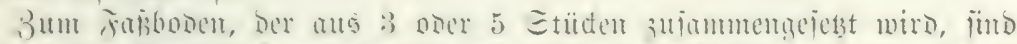

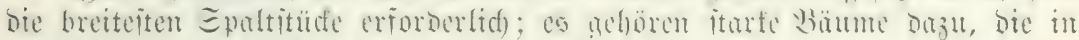

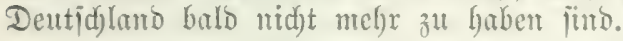

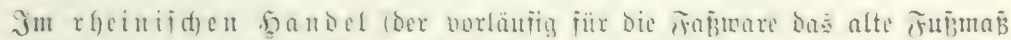

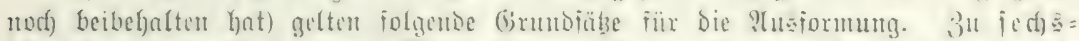

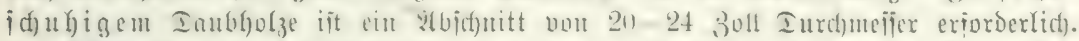

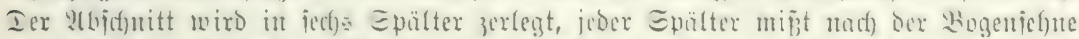

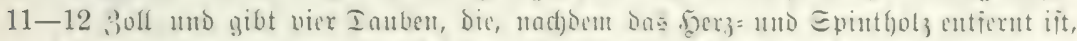

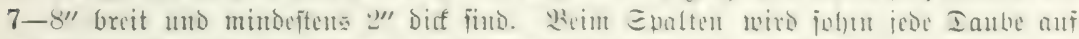

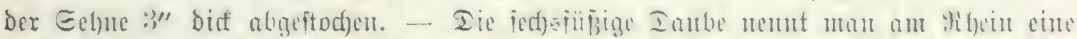

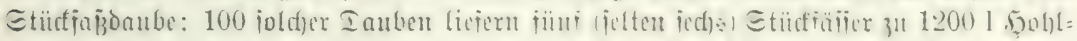

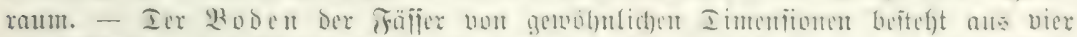

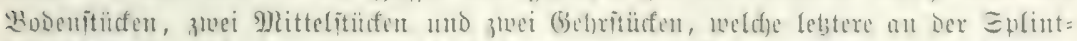

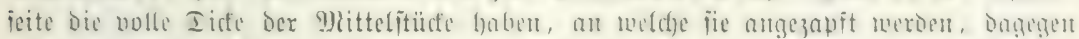

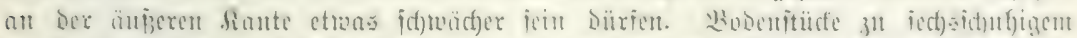

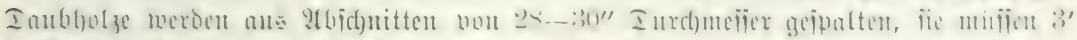

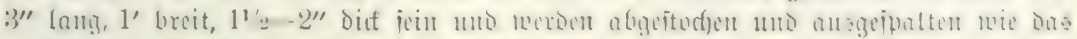

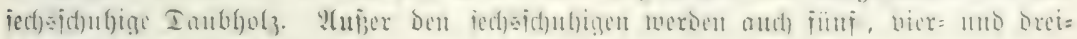
id)ufigge Iauben ausgeformt.

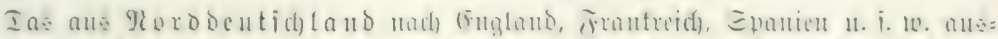

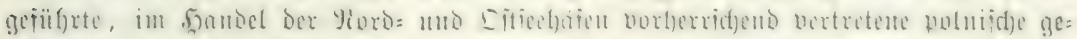

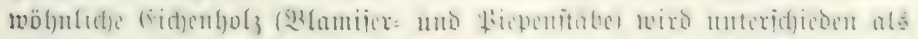

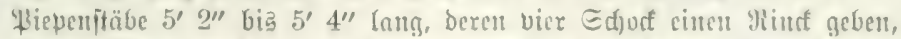

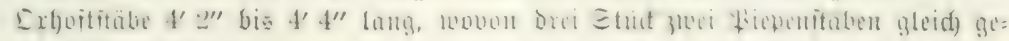
red)utet werden, 


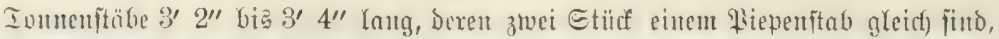

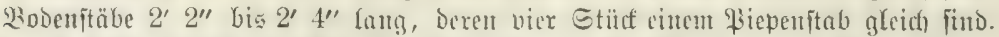

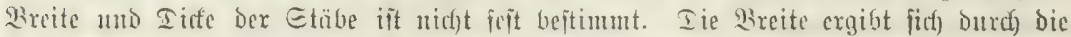

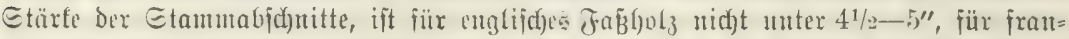

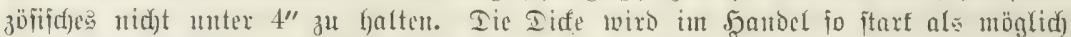

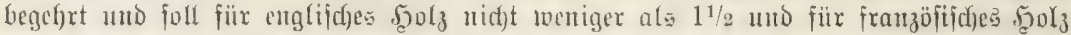

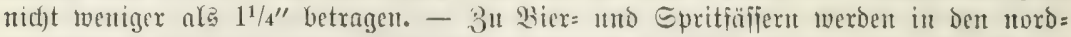

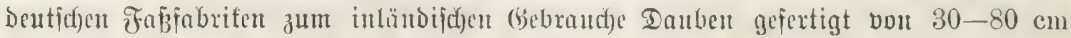
Ränge, 6-13 cm Breite mit Etärfut an fopfe ztvific)en 30 und $50 \mathrm{~mm}$.

Die Scouptländer für Fafibolzprodution find hente fixontien, Slavonien,

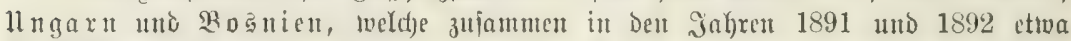
26 Millionen Fap̧oauben produzierteıt. Ier Yeidfteren Bearbeitungäfägigfeit halber

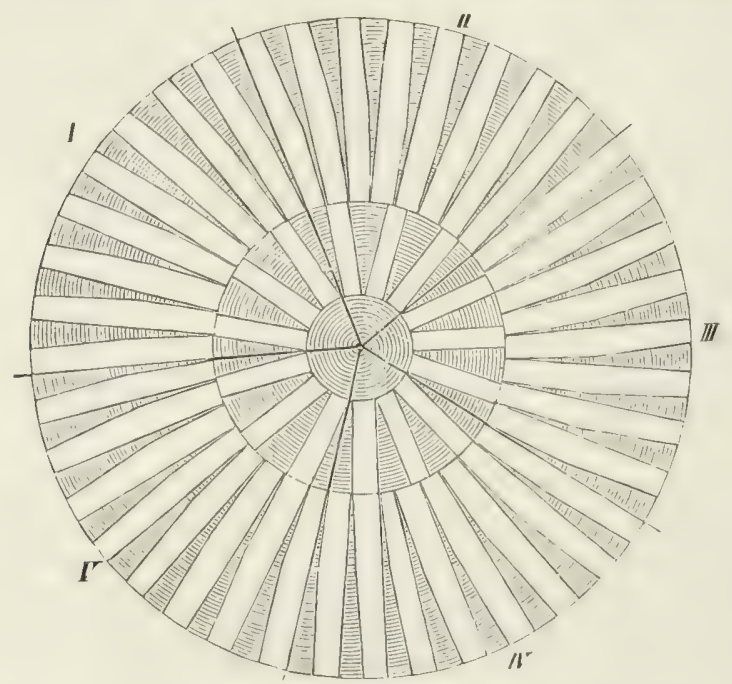

Fig. 297. 2(bftedjen ber Dauben an ber firnflïdje eines Eidjenitammes.

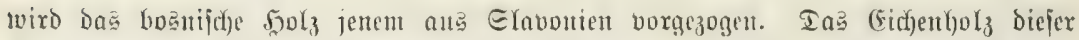

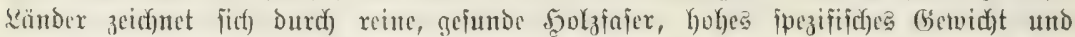

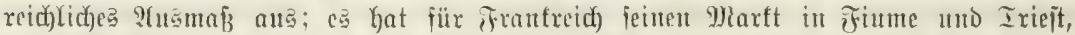

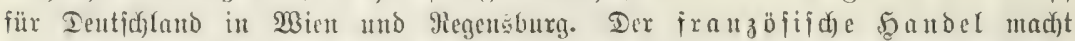

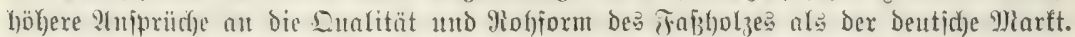

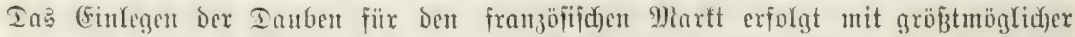

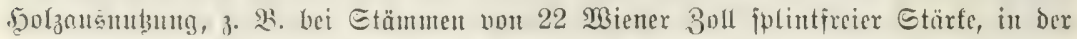

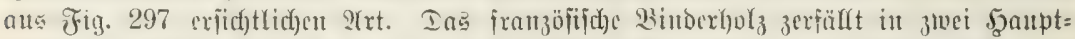

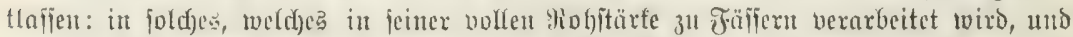

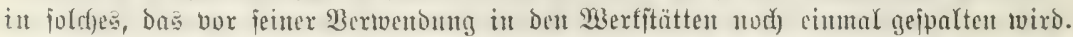

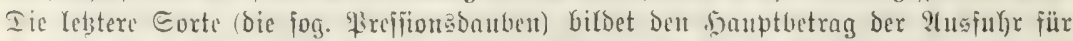

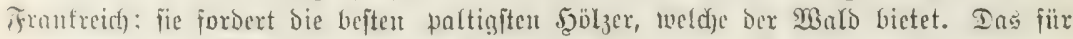

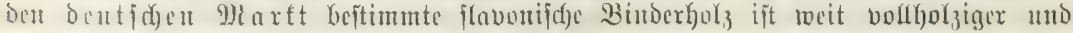

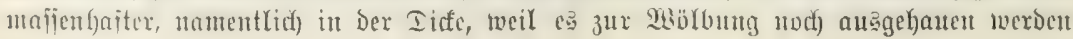




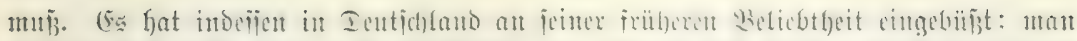

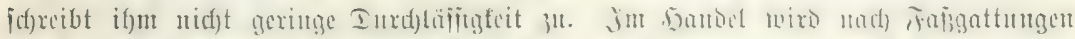

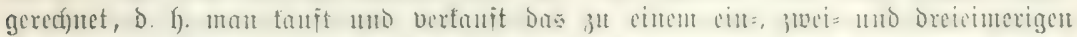

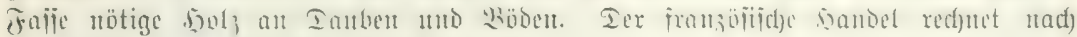
5numberten ber betreffenden Daubenforte ${ }^{1}$ ).

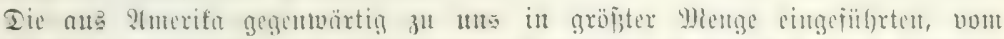

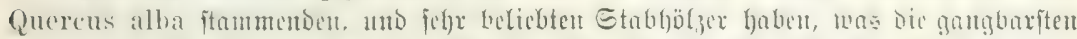
Eorten betrifit, Ë̈ngen vont $54-56,44-46,36-38,30-32,24-263011$, cine

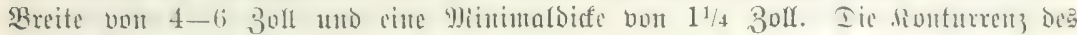

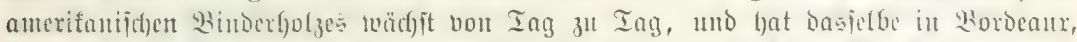

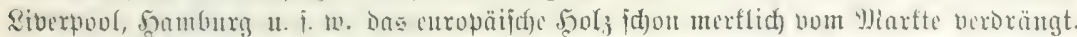

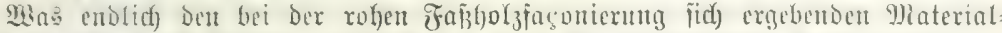

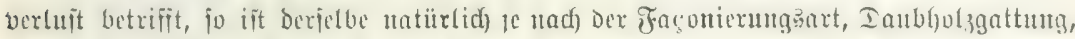

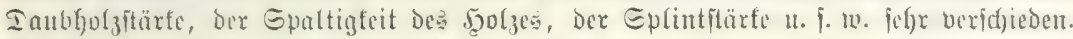

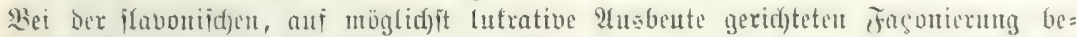

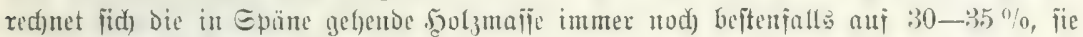
fteigt felbit bis 45 und fait $50 \%$.

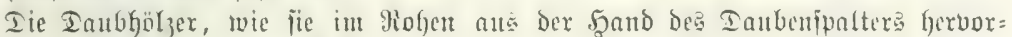

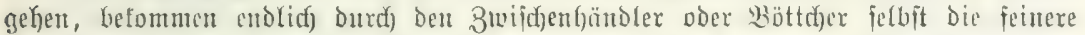

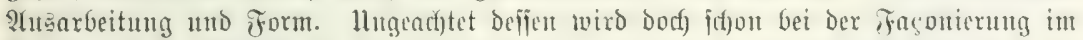

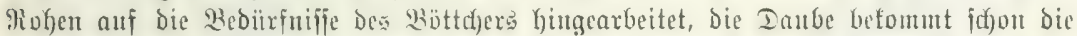

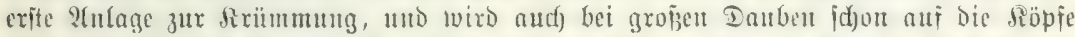

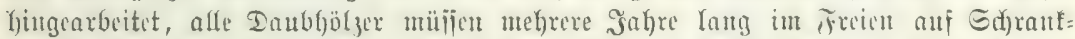

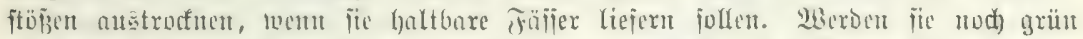

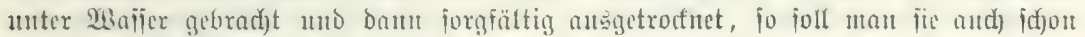

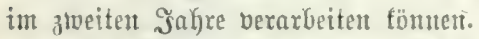

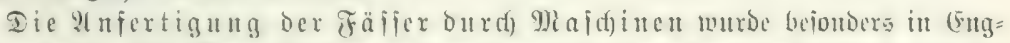

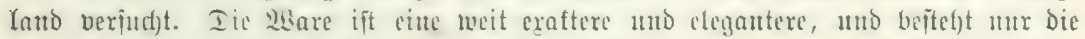

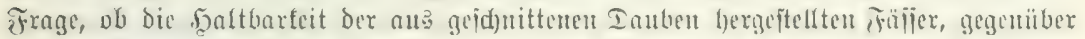

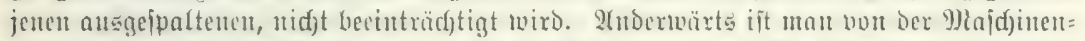

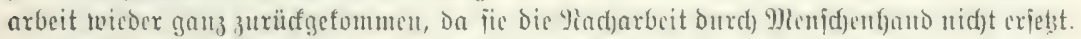

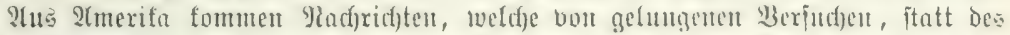

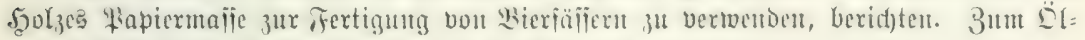
export find foldje Fälifer fdjon länger im Gébraud).

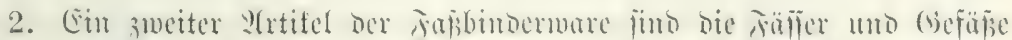

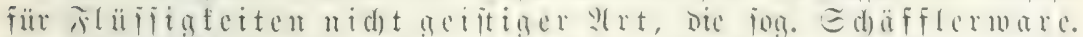

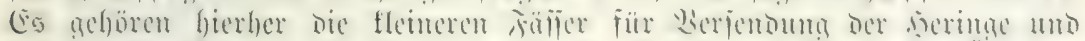

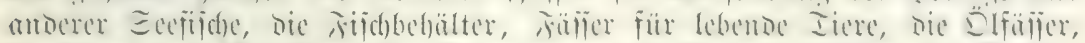

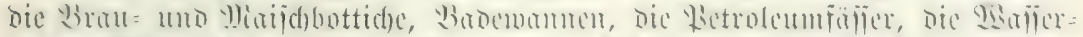

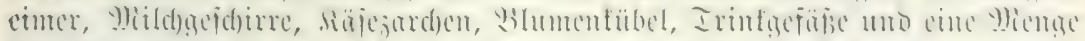

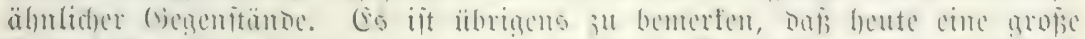

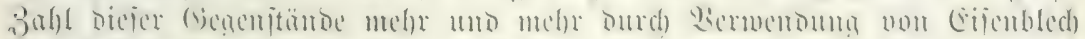
hergeitellt werben.

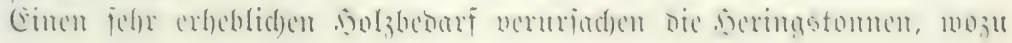

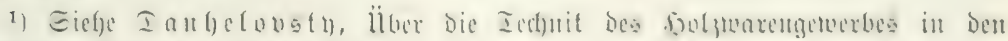
¡favonijof)en MäLderı. Wien 1873. 


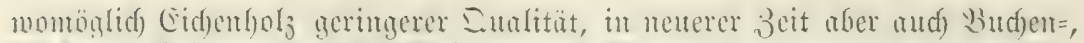

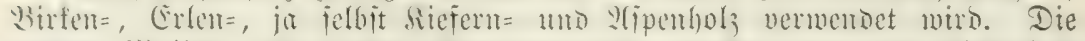

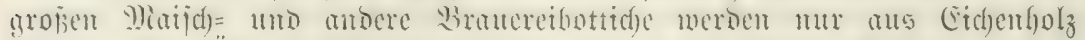

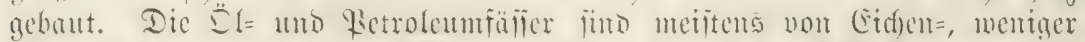

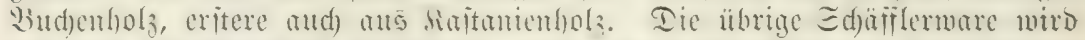

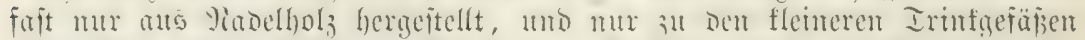

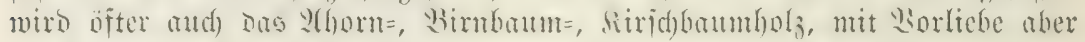
Madjolder $=$ und 3 irbelfolz vermentet.

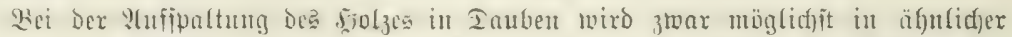

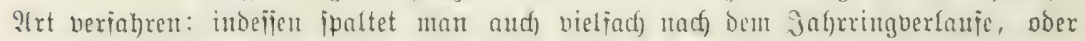

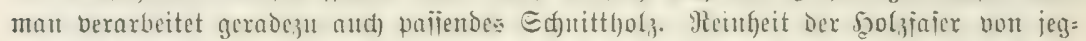

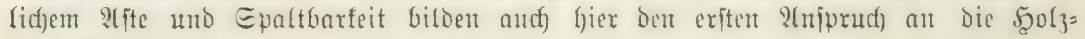
beidjaffentheit.

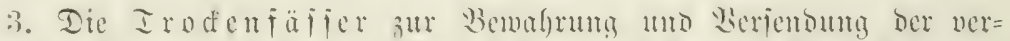

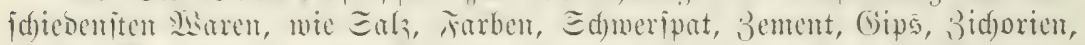

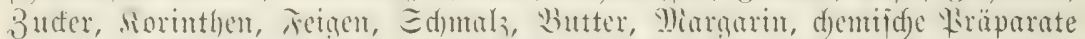

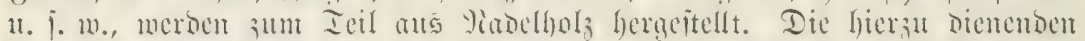

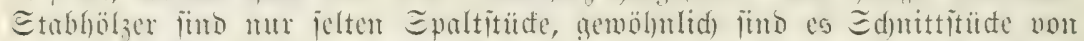

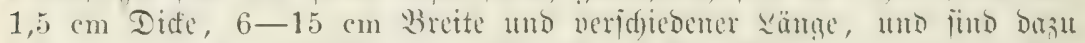

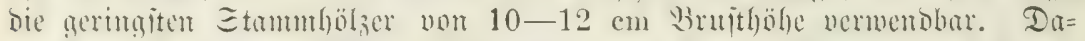

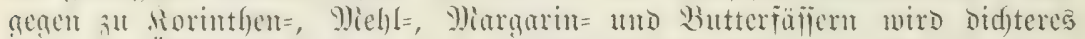

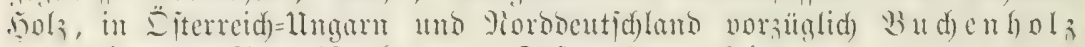
ber geringeren Stammftärfen zur "Jạtage" verarbeitet.

Iie :Infortigung Der Irofenfäilier exfolgt gegenuärtig meift fabrifmǖ̄ig im

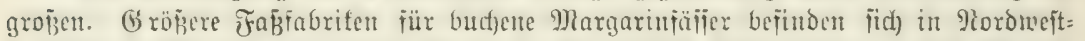

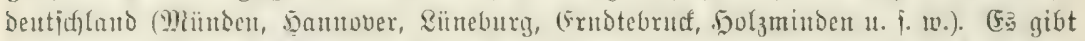

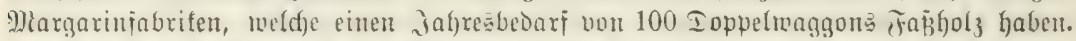

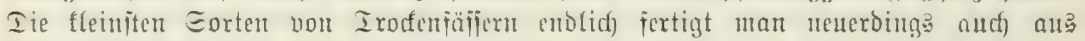
Papiermafife mit Defel und B̉oben bon $\mathfrak{S Z l}_{3}$.

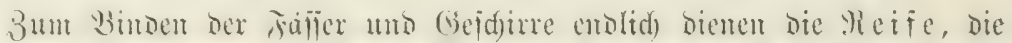

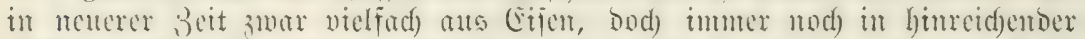

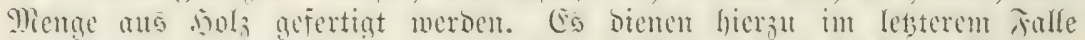

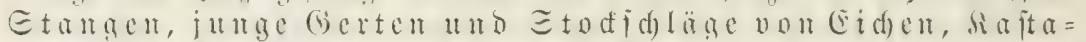

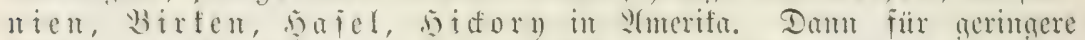

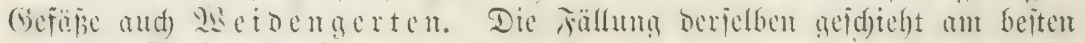
vor Dem Raubausbrudje.

Iic Meififtangen twerden mit ber şippe fauber geputst mo von allen sïften und

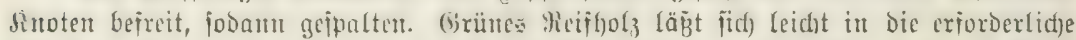

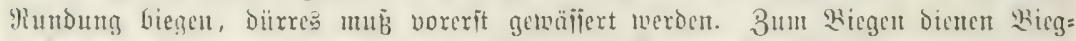

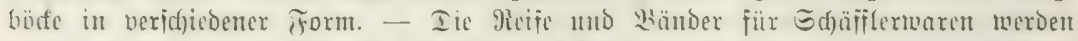

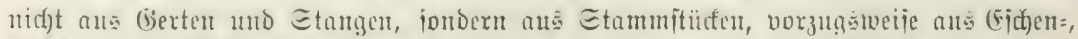

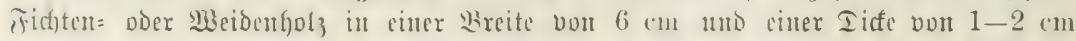

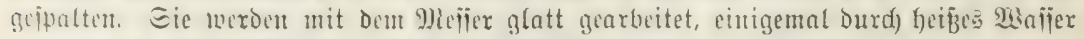
gezogen und baut ïber ein runbes $\mathfrak{S}_{0} \mathrm{Ol}$ gebogen. 


\section{Zjoliveruendun bei den übrinen Spaltmarengemerben.}

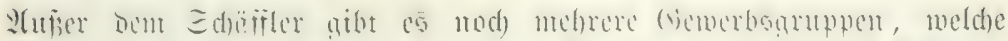

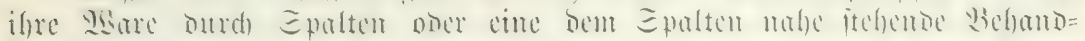

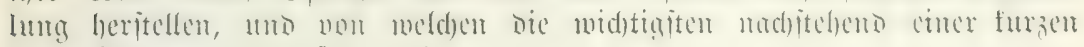
Betrad)tung unterworfen werben.

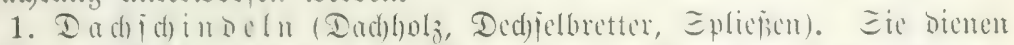
.

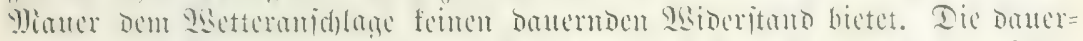

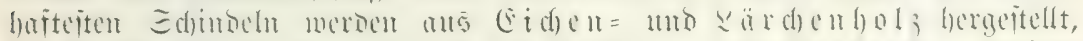

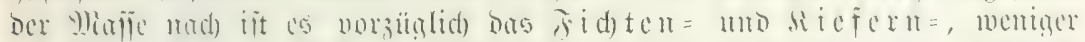

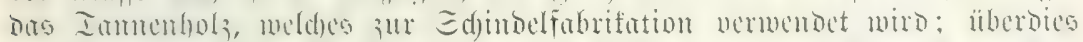

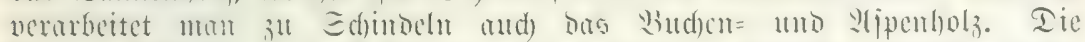

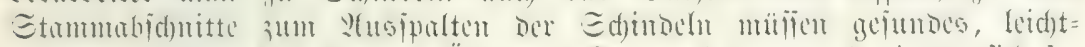

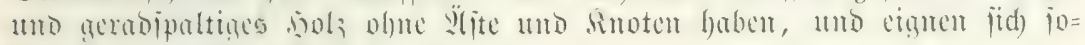
Giu vor allem bie unteren Ieile ber Stämmiduäte Dazu. Für Die Durd Mlaidjinen bergeitellte Sdintiblware find Sölzer von geringerer Meinfeit und Gpalt= barfeit eher vermenobar.

9) (an fertigt die Gdjindeln in jefre vexfofiedenter Gröbe au, je nad) Der थrt und Weife ber Dad)= eindeffung. Die gerwöhnlirfften Iäd)er find bie fog. Sa d) ardäd)er; fie find meift breifad) eingededt, b. Y. von jedor Exjindel fteft mur ber oritte Ieil zu Iage aus (Fig. 298); fie find bie daucrhafteften und

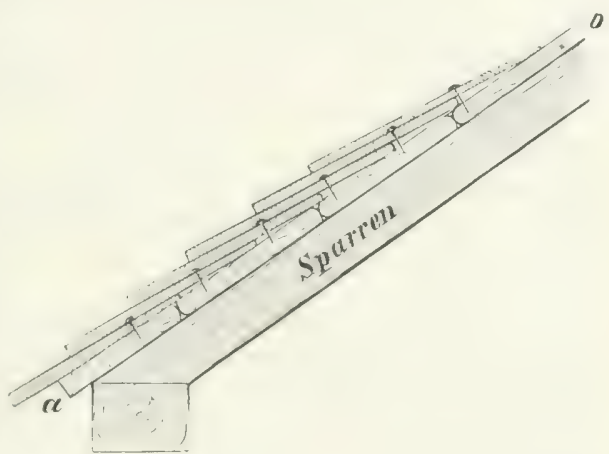

Fig. 298. Lagerung ber Edinbeln bet breijader Defung. walieroidteften Däd)er. Soldje

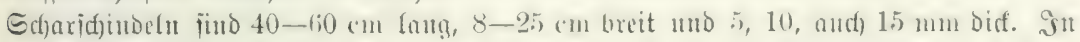

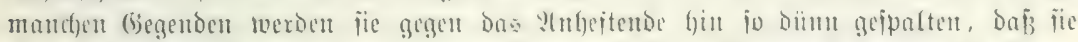

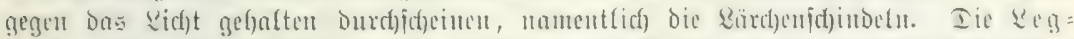

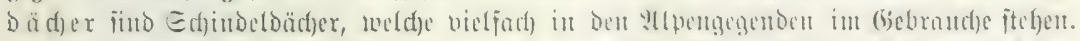

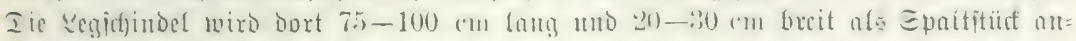

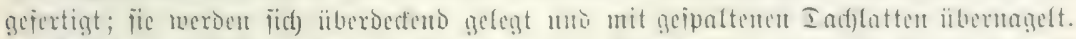

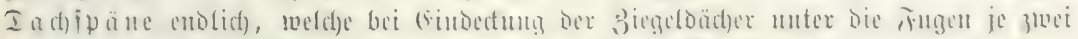

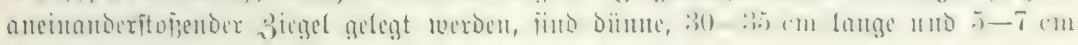
breite Epäme.

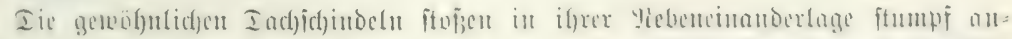

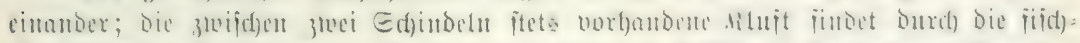

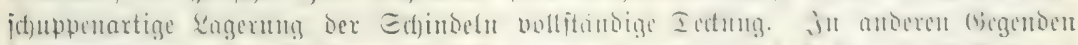

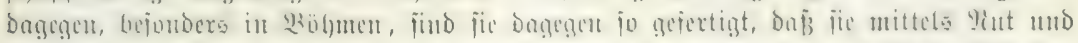

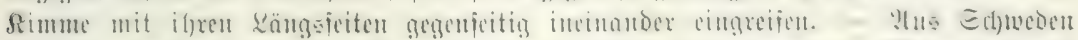

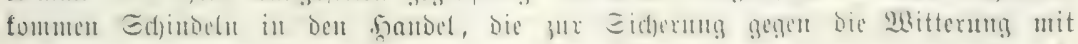

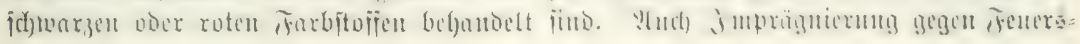




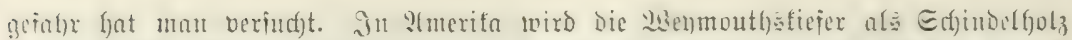

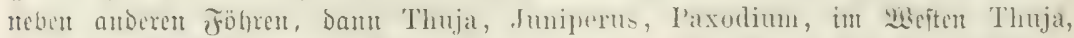

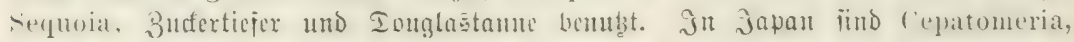
Tanga neben ben Iannen Erjindelfölzer.

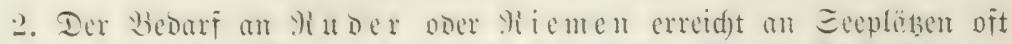

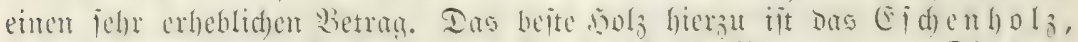

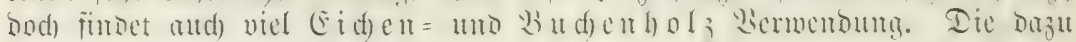

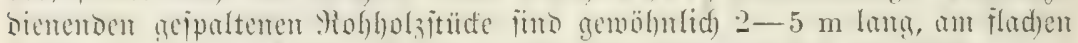
Enoc 10-12 $\mathrm{cm}$ breit und am viertintigen こticle $6-8 \mathrm{~cm}$ iturf.

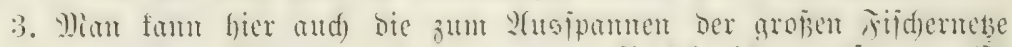

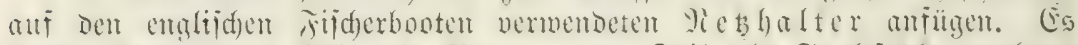

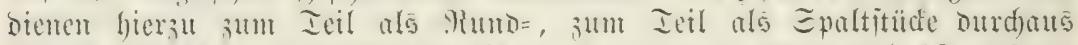

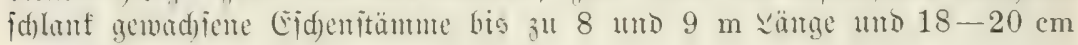
3opfittärf́e.

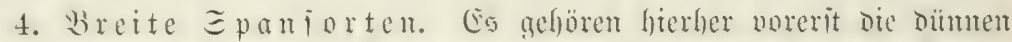

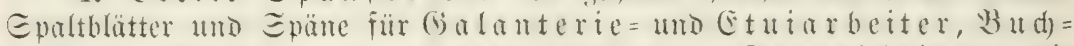
binder, $\Xi d$ uter, ju Epiegetbelegen, Degenidecton, die

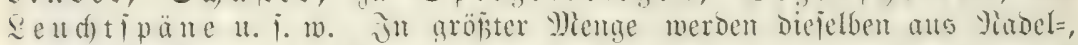

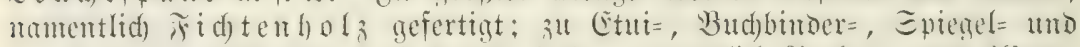

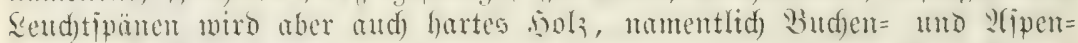

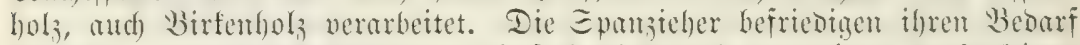
3um Ieil ans Etammabid)ntten, vielfad) aber and) ans remen, gutipaltigen Y) ub = uno Brembolzidjeiten.

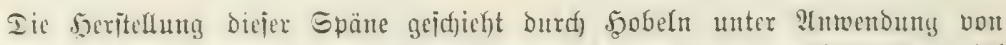

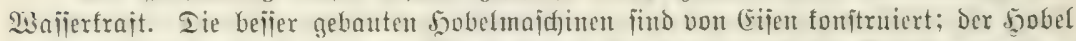

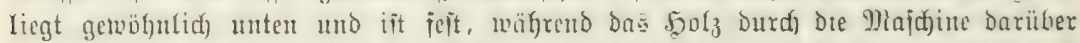

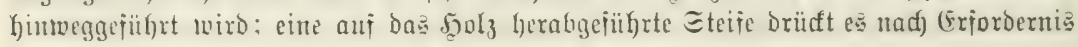
auf ben 5ober.

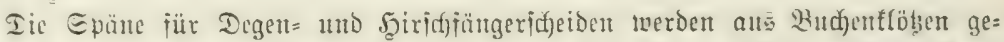

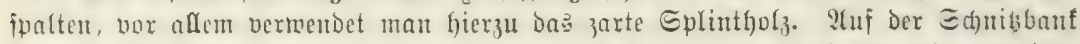

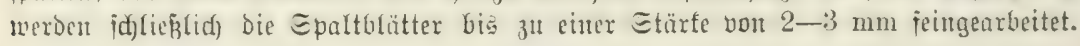

3u ben breiten Examprten aehören wetter bie nolatapeten, bie

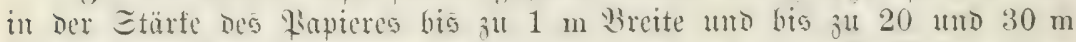

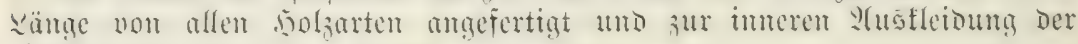
Mohuräune verwendet werden.

Ier entrindete Etammabidnitt wird auf brionber fonitruicten Irebüntent Durd) cinc vom Eupport getrageme, mel)r und meffr vorrïfente, bis meterfange sitinge von Der f'rripherie aus angrgrifion und in einem zufammenhängenoen Epantunte

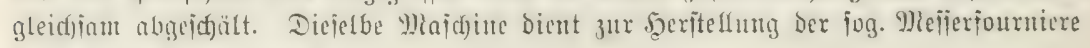

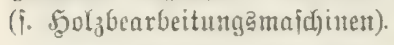

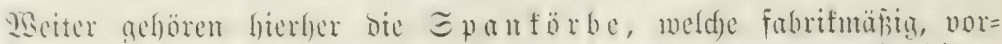

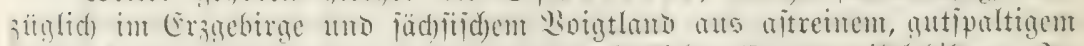

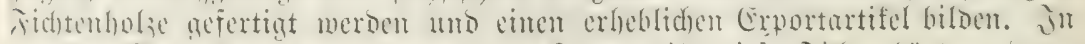

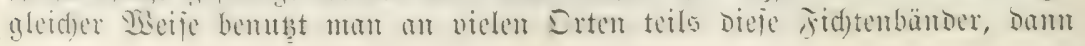


mad) folde nou : Som maen, Siobert, Miaten, Iapeten u. i. w.

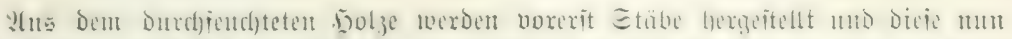

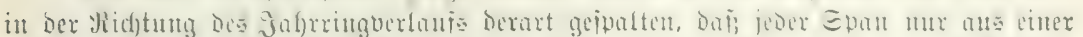

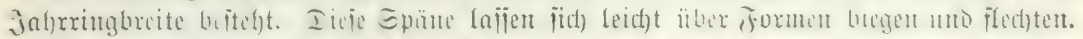
Iie Jुamburg=

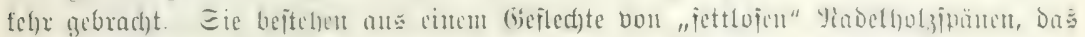

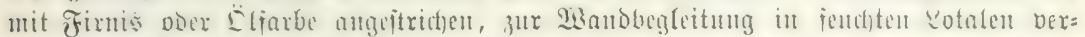

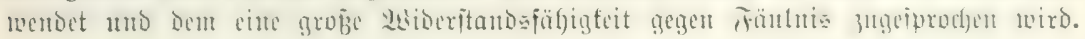

Die 3argenjpäne für Gicbe, Räjeformen werben aus gut=

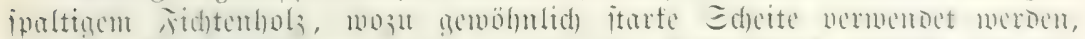

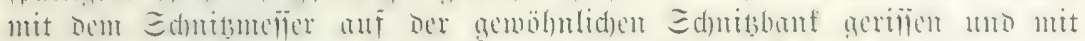

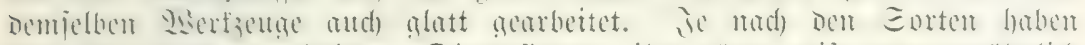

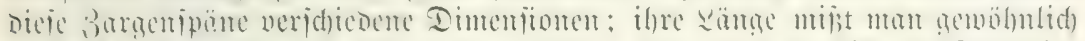

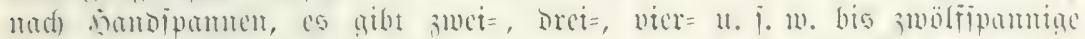

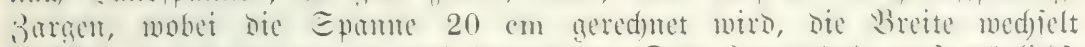

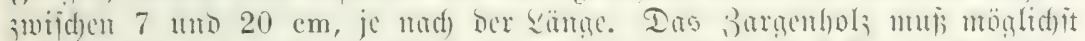

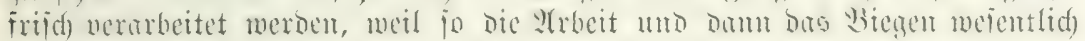
erleidjtert wirb.

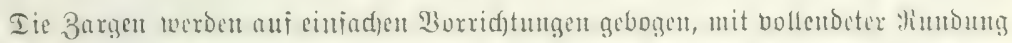

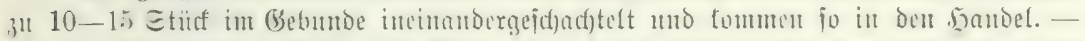

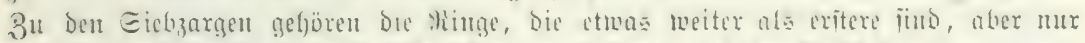

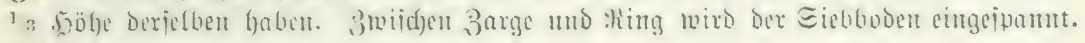

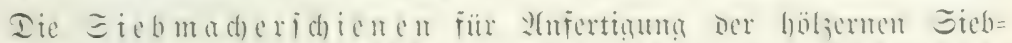

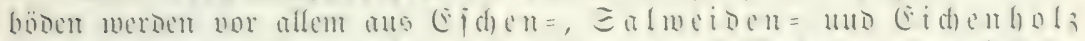

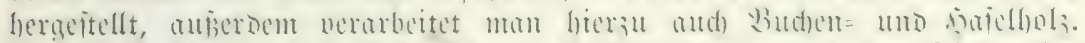

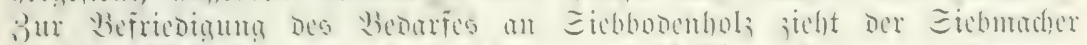

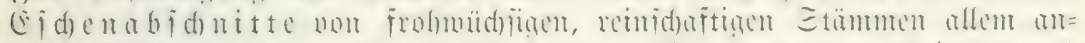

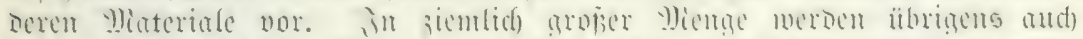

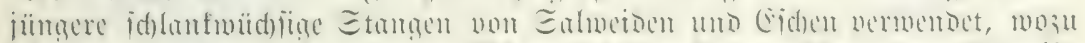

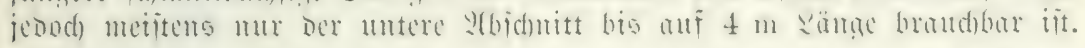

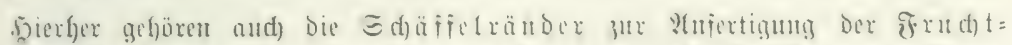

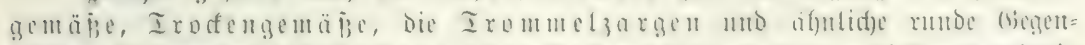

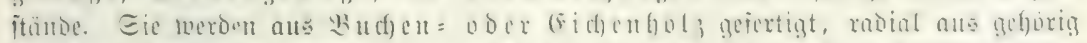

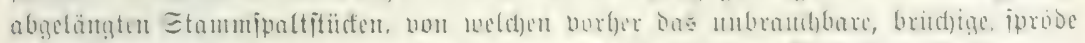

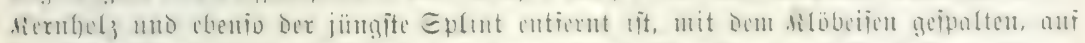

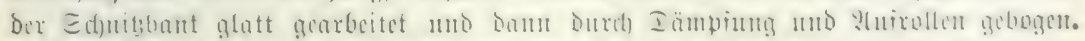

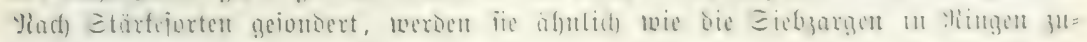
fammenģeid)adfetel und fo in ben Şandel gebrad)t.

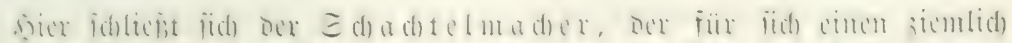

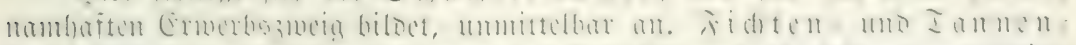

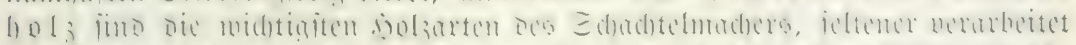

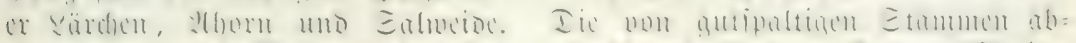

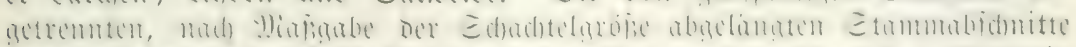

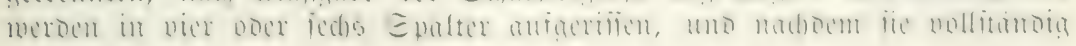




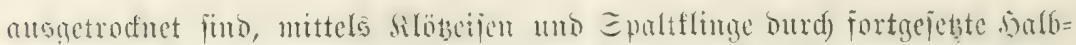
tcilumg in Epaltipäme von erforberlicte Etärte mafgeriñen.

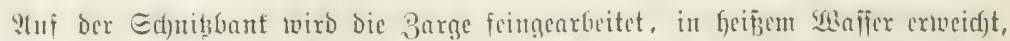

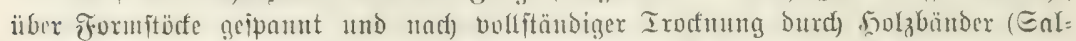

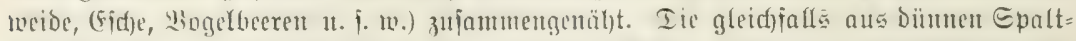

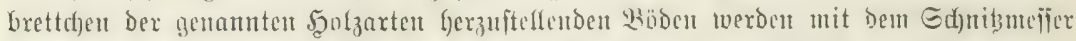

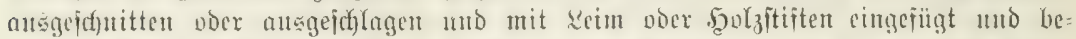

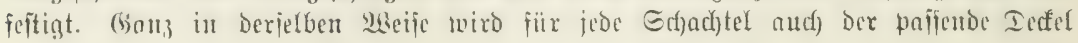
angefertigt.

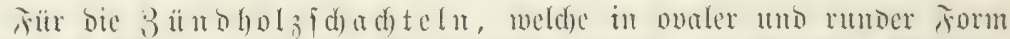

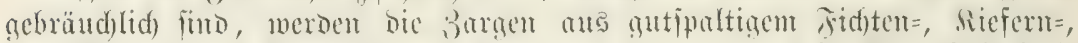

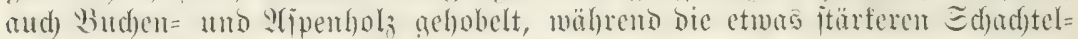

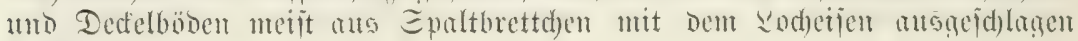
merben.

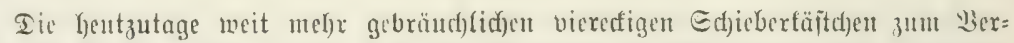

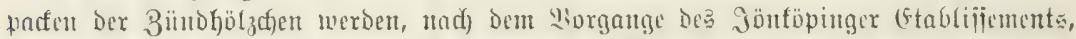

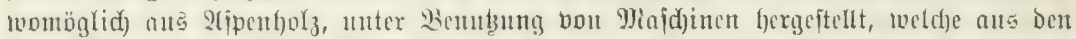

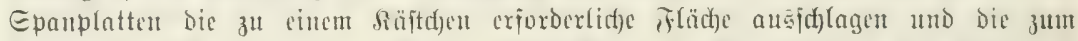

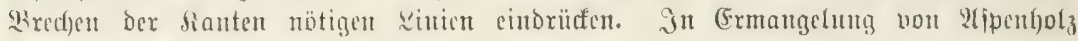

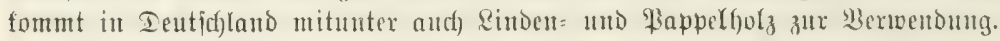

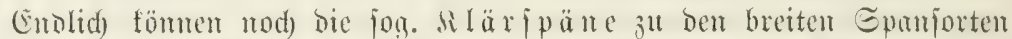

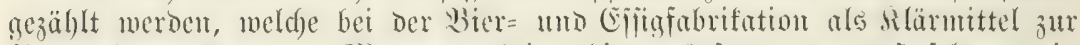

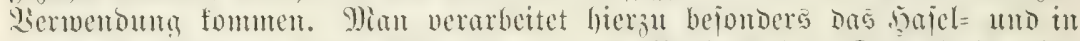

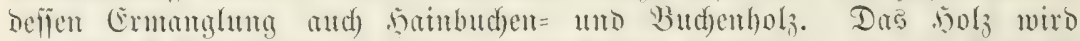

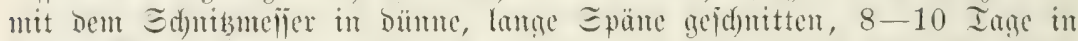

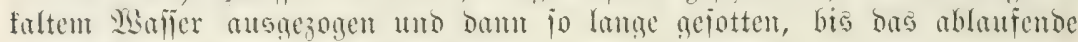
Mafler feme Färbung mehr zeigt.

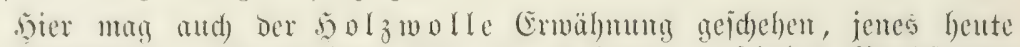

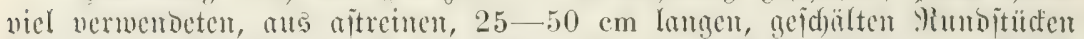
hergeitellten Fabrifates, bas als loctere, fraufe, elajtidde ylajie, an Etelle

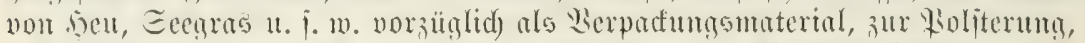

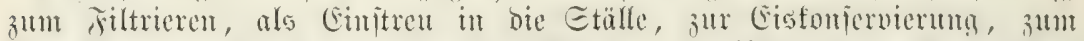

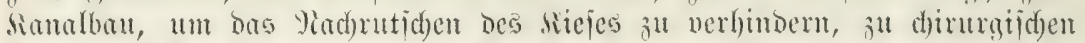

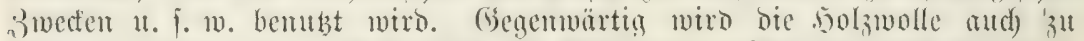

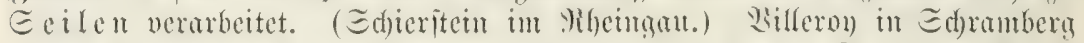

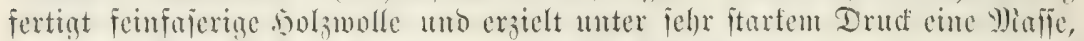

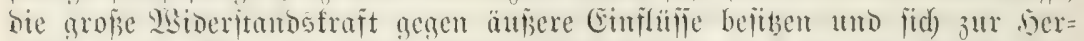

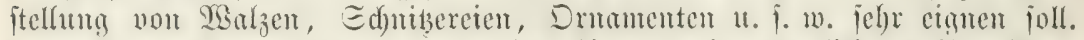

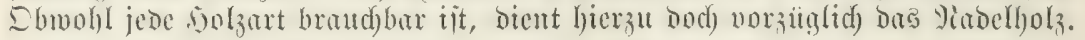

5. Die xunden Gpanjorten. Mian zählt hierzu die Binfel=,

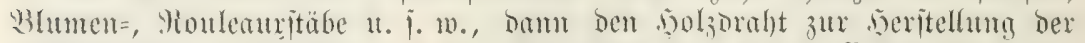

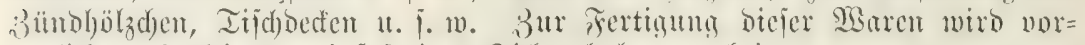

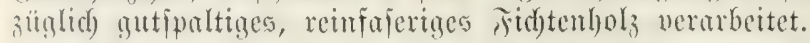

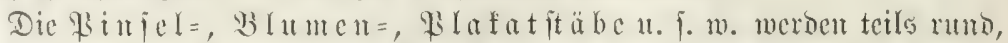
teils balbrumb, teils bual, teilo vierectig, and gerippt in allen Etärfen bis 


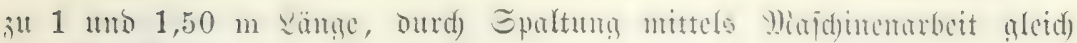
aนร bent hohent gezogen.

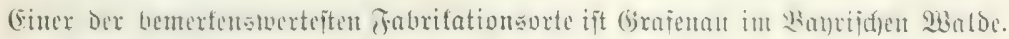

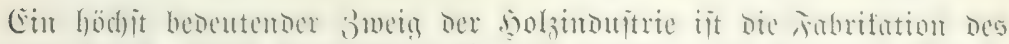

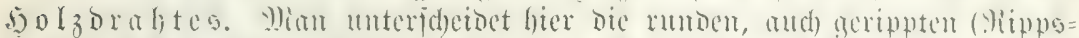

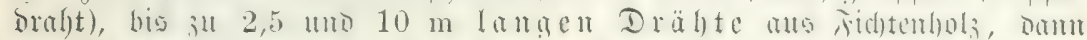

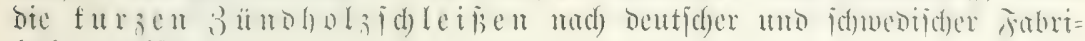
fitionalueife.

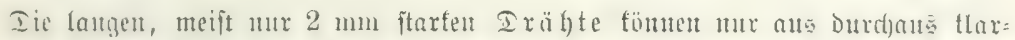

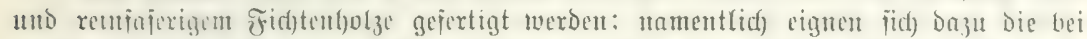

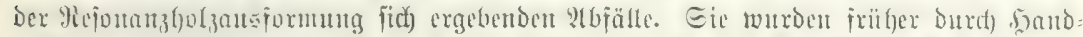

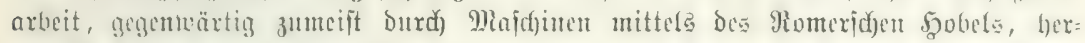

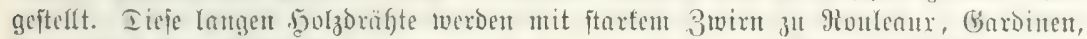

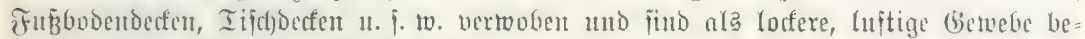

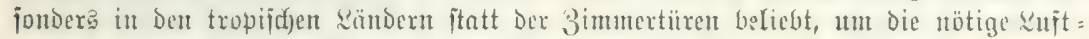
exteucrung aurdy bei geid)lojientert Tïren zu vermittelt.

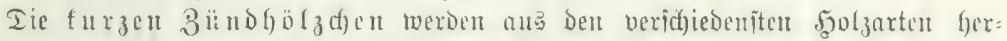

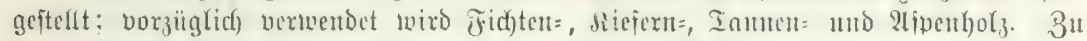

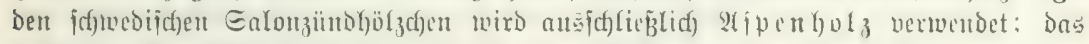

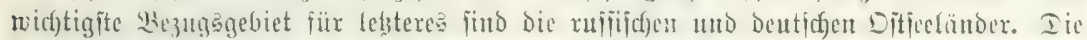

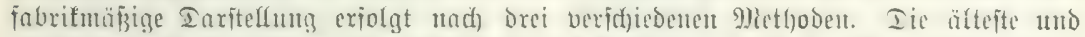

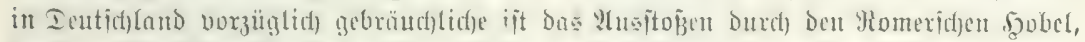

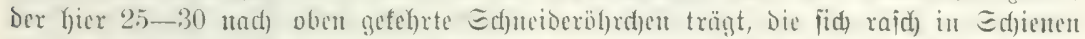

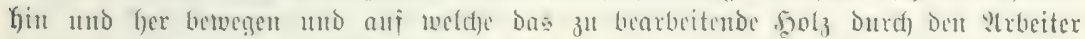

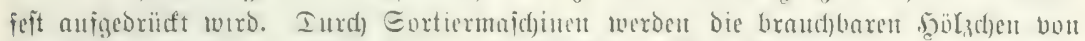

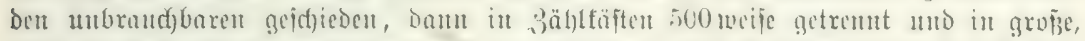

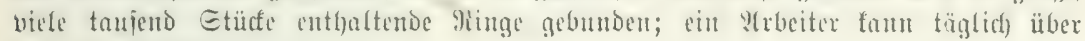
200000 Etuid jertigen ${ }^{1}$ ).

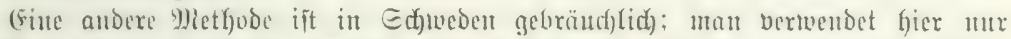

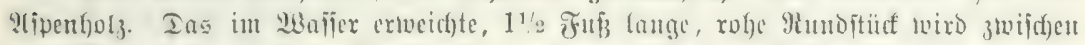

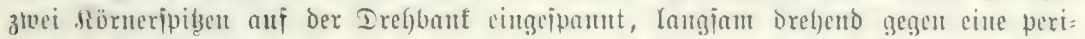

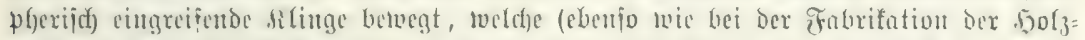

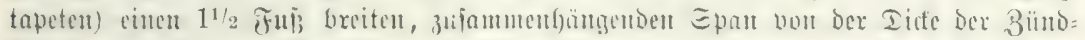

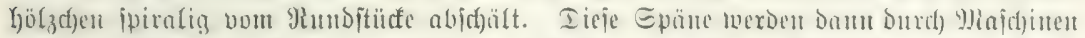

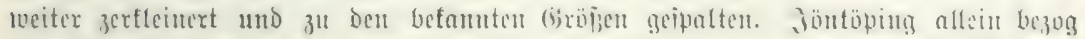

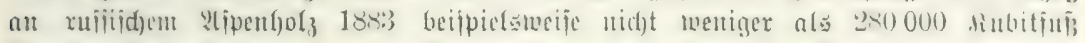
Stammholz.

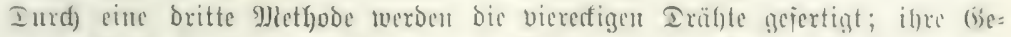

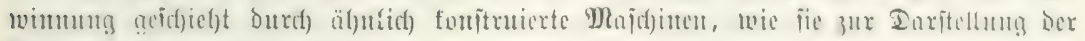
Şolzlwolle furrz ertoälnt twuroen.

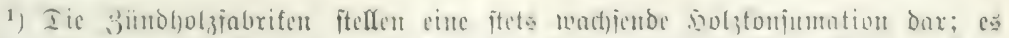

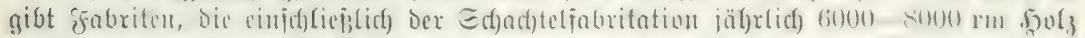

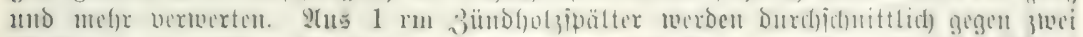
ग)

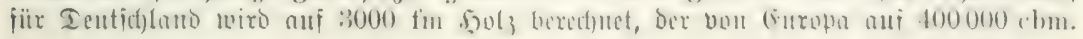




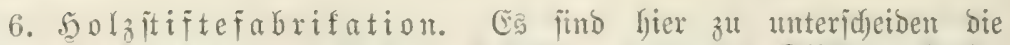

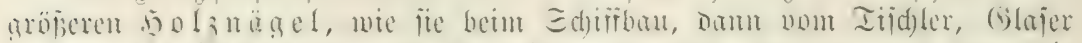

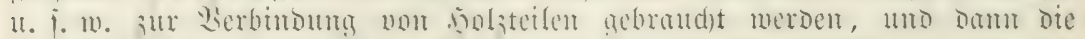
joug. $\Xi$ d) $u$ h mad a eritifte. Eomeit (s itd) un Die criteren, 10, 20, 40

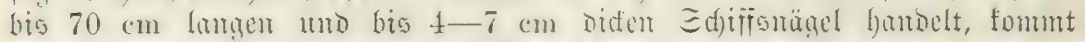

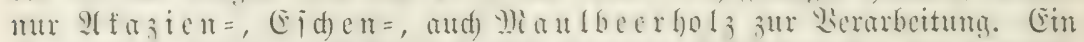

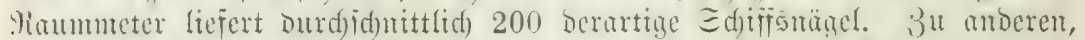

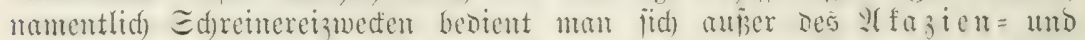

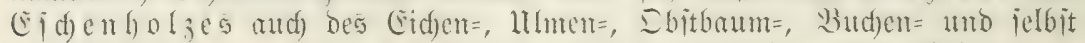

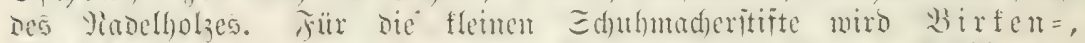

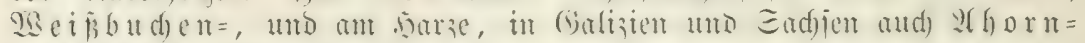
$\mathfrak{h o l}_{\mathfrak{z}}$ bierzal verarbeitet.

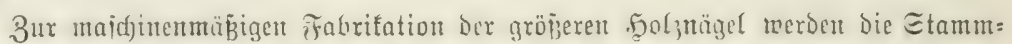

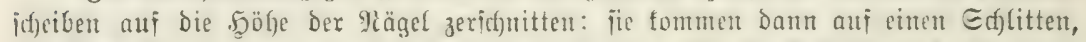
Der jie ruffweife gegent die Epalttlinge boridfiebt. Sit bie Edfeibe nad) Der einent

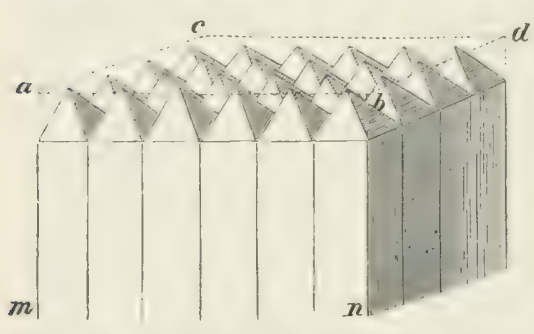

jig. 299. Deritelung oer こd)ubmadieritipte. Ridftung geipalten, bann wiro fie um a $90^{\circ}$ gedreht und nady ber anderen Ridf: tung geipalten. Die Epaltitücte werben

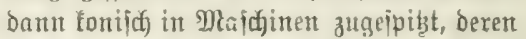
Mlefifer fich mit Buführumg ber Etäbchen mehr uno mefir nähren.

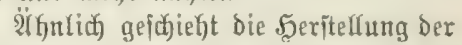
Sd)ufmadiexfitifte; nut erfolgt hier bie 3ulföärung Der vierfantigen 5ृotzitüưe zuterft, unto ztwar burd) Sobeletugriffe in Die Nidgtung ab (Fig. 299), Dann in ber

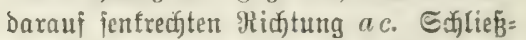

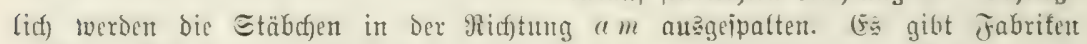

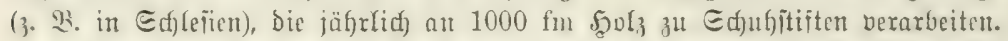

şier iit and bie $3 a$ huftoderfabrifation anzurethen: es Dicuent Dozu bie

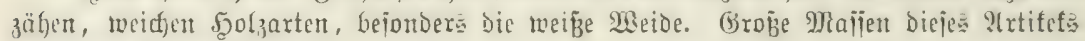
werben 3 . $\mathfrak{B}$. in $\mathfrak{M e i p e n j e l}$ angejertigt.

7. Bur Bleijtiftabrifation liefern bie Deutiden nolzarten cin mur geringes Duantum Mohmaterial, ba hicrä vorzüglid) Das pogename

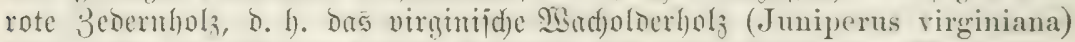

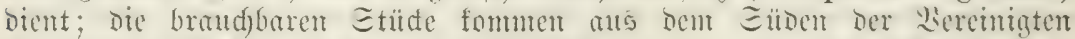
Etanten; Dod) benubt man sur bolsfajum Dex acringen. Etiftnualitäten

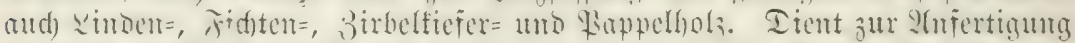

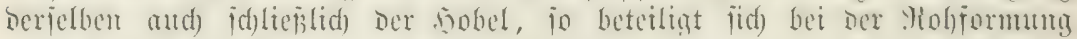
vielfad) aud der Epaltprozep.

8. Die geipaltenen Juftumententölzer bienen zur Sion=

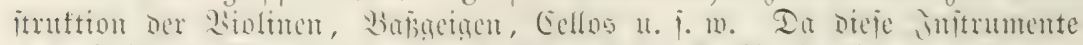

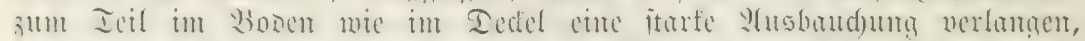

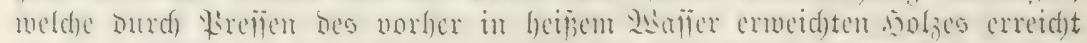

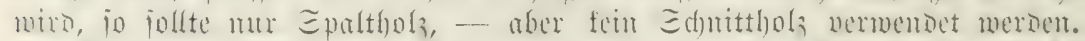

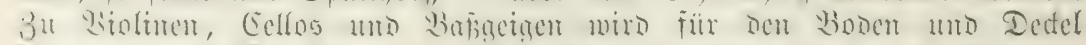
分i d) $t$ c 


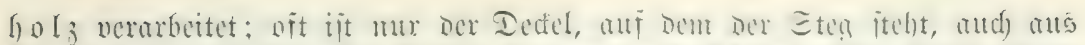

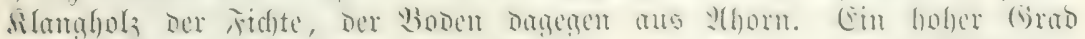

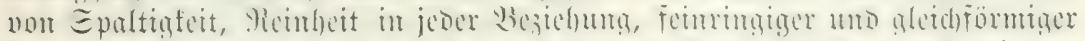

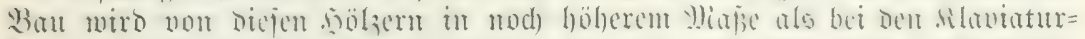

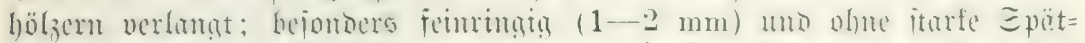

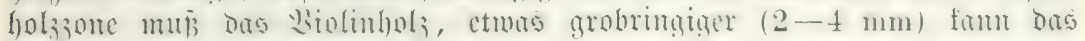

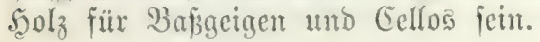

Эe höfer ber Ton, befto enger folf ber Jahrringbau fein. - Dieje fein=

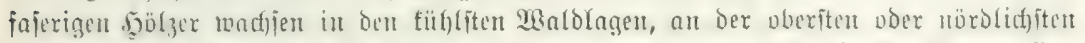

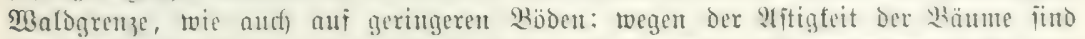

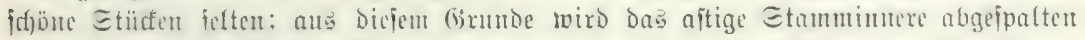

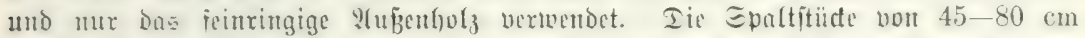

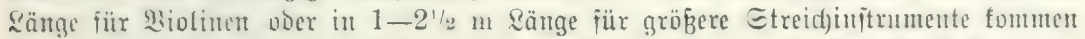

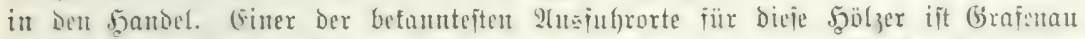

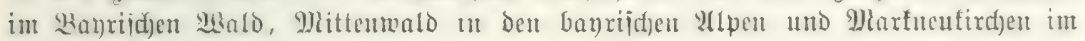
füdjitidfen Sogtland.

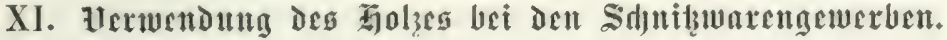

Ulnter bom Viamen $\Xi$ d) nitsarbeiter fömen wir cine Wionge hamb= werter zujummenfajien, bie jid) alle mebs ober mentger bei ber sertigung

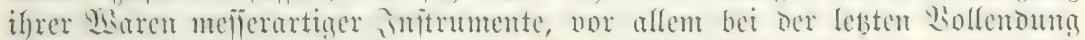

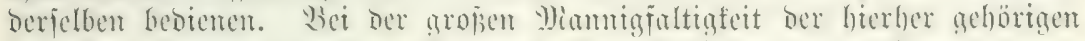

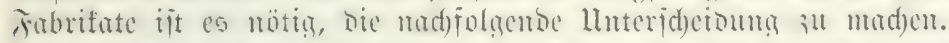

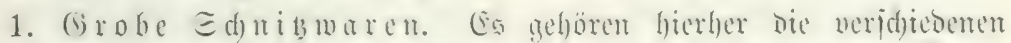

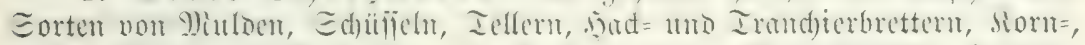

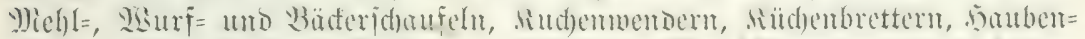

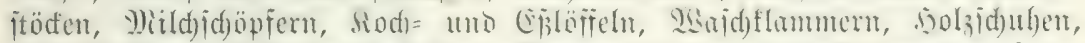

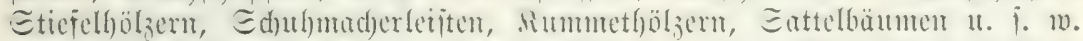

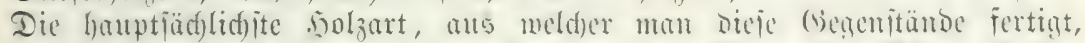

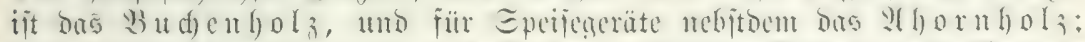

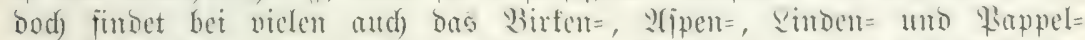

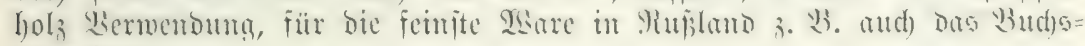
baumbolz.

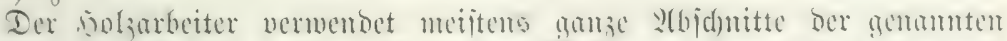

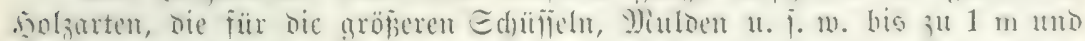

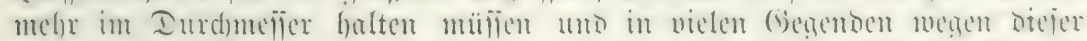

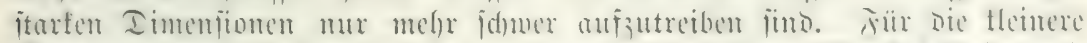

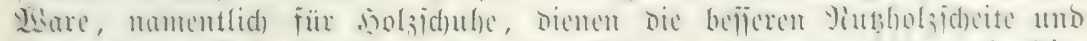

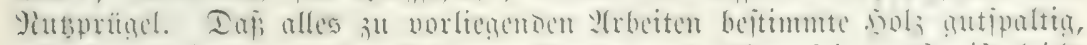

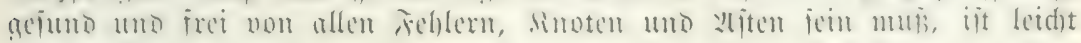
zu ermefīen.

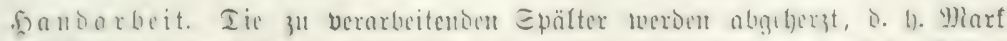

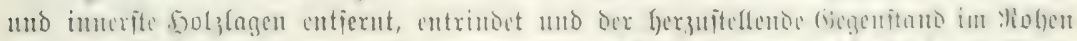

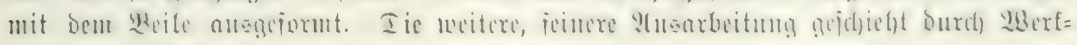


3enge, Die Dex Form Der Gerzultellenden Ware entipredfend gebogen find, und morunter

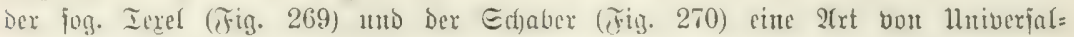
injtrumenten bilden.

In newerer 3eit tritt Majefinentearbeitung immer mehr an bic Eteffe bex

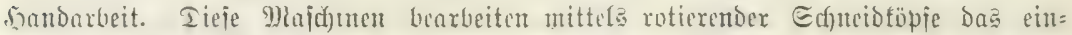
geipante jonlzitüf nach einem vorgegebenes cijerntu Mobelle, und ztoar mit einer

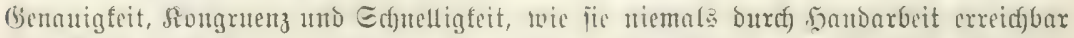

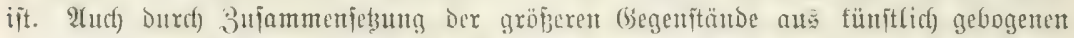

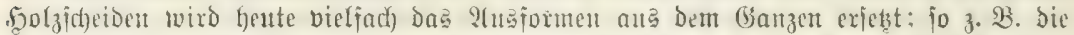

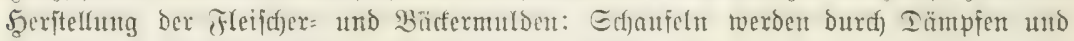

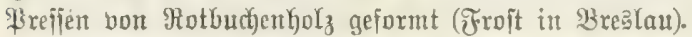

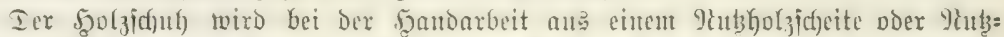

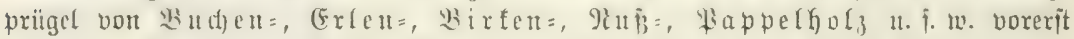

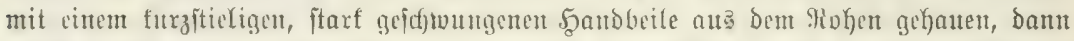

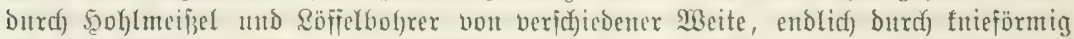

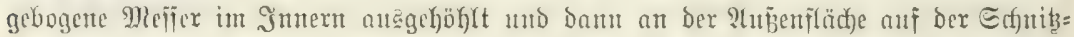
bant fein gearbeitct. Gtänme von $60-70 \mathrm{~cm}$ अrujtgöhenftärfe merden von ben Şolafidulymadyern am liebitent vermendet.

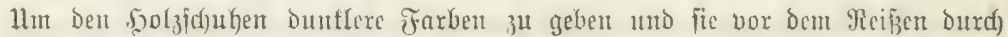

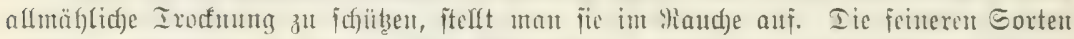

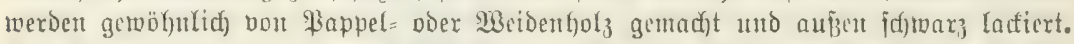

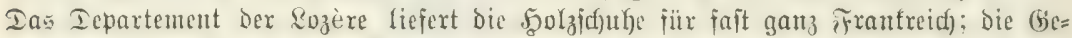
fautproduttion lieträgt dajelbit jäfrlif́ gegen 600000 ßaar, movon ungefähr bic Sä̈lite augigefübrt roird ${ }^{1}$ ).

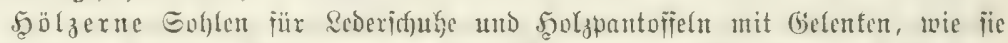

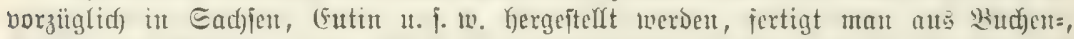

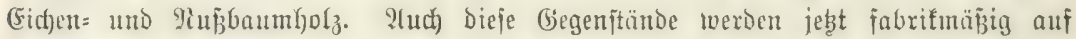
Majudinen verjertigt.

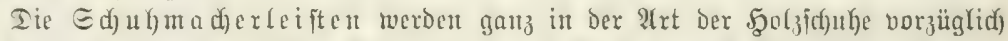

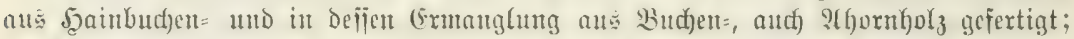

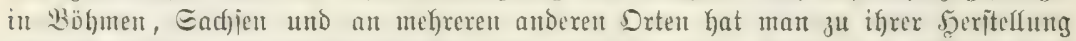

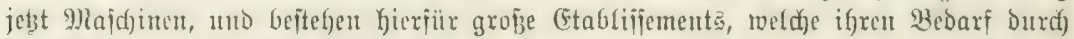
Die bejten Stammbolzjorten befriedigen.

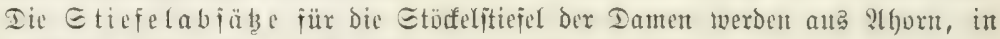

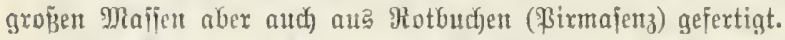

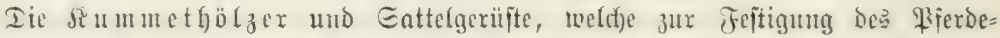

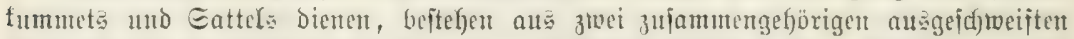

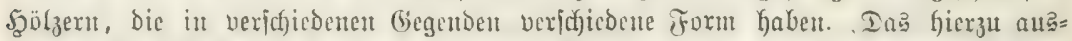

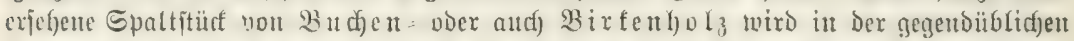
Form ausgelyanen und Dann burdh bie Eäge in ftnrf fingerbicfe, für Sattelfolz in

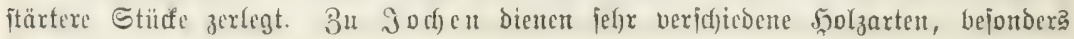
sirfe, Budje, (Eid)e.

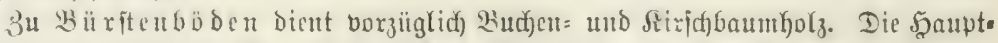

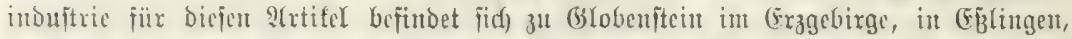
Dam зu Iobtenau im obern Єd)warzwalde, wo der Wert dex aügefüfrten Mare аuf 5-600000 2lef. veranidi)lagt เoiro.

1) Bałyr. Inoujtrie= u. Ǵetwerbebr. 1882. 


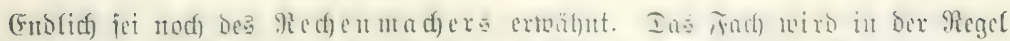

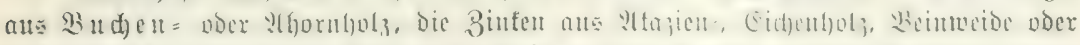

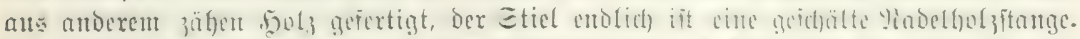

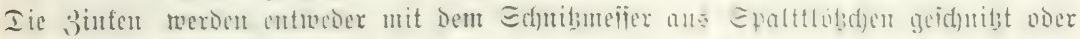
zur Föroerung ber 2(rbeit burd) cin Sodjeijen geid)lagen.

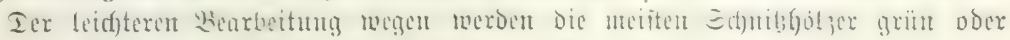
wenigitents nidft ganz bürx verarbeitet.

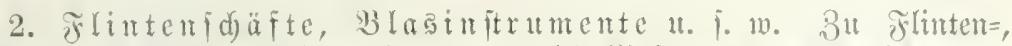

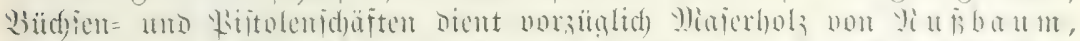

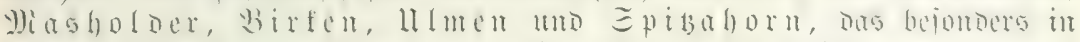

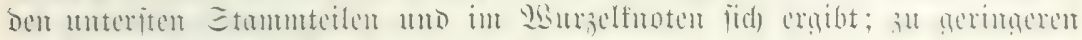

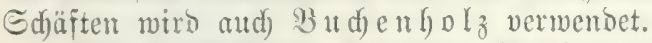

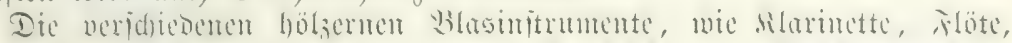

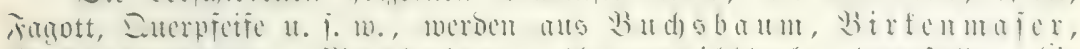

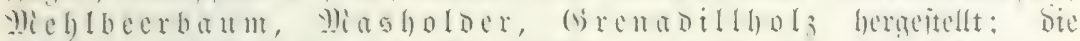

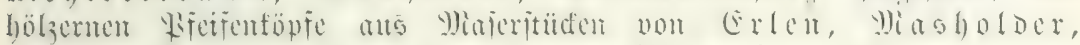
Birfen, $\mathfrak{H}$ orn uto Erica arborea (Brubère).

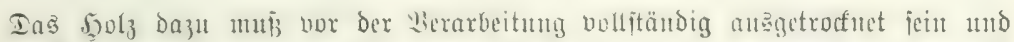

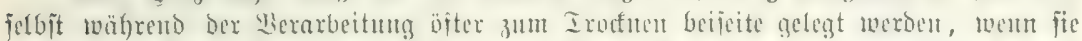

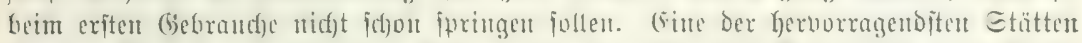

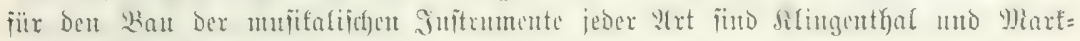
teutirdyen im (Erzgebirge.

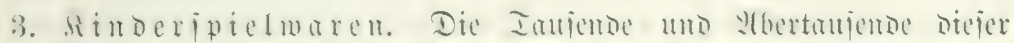

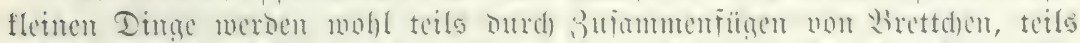

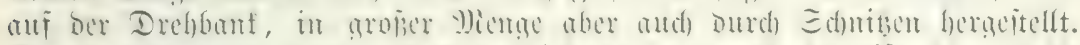

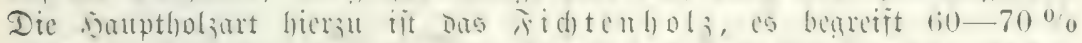

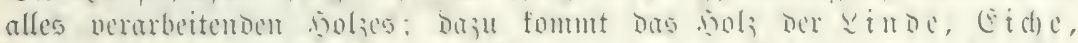

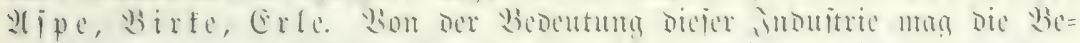

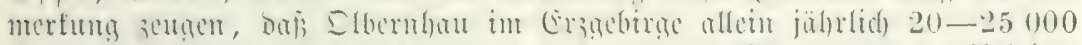

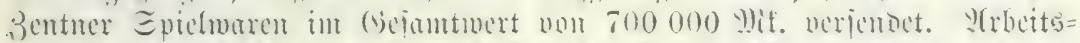

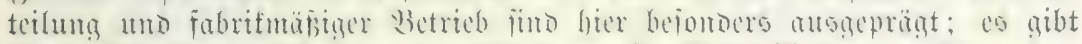

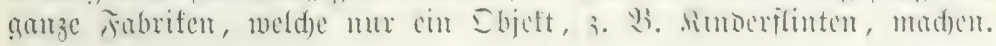

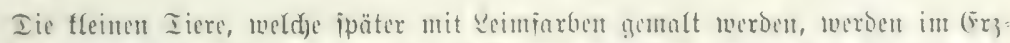

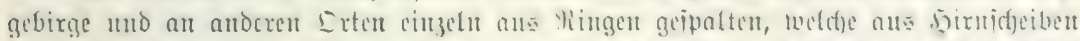

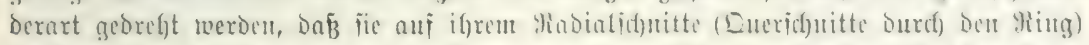

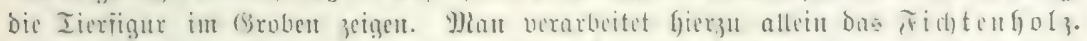

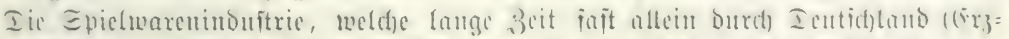

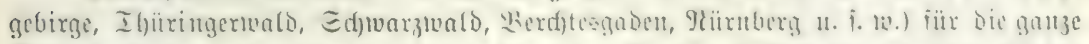

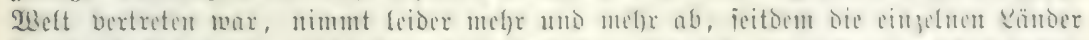

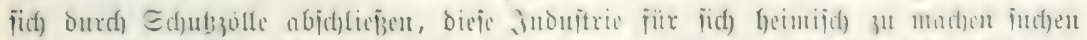

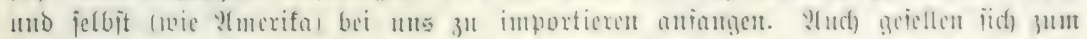

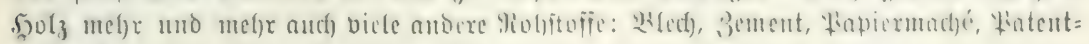

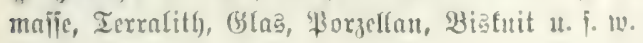

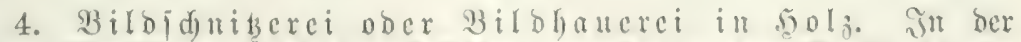

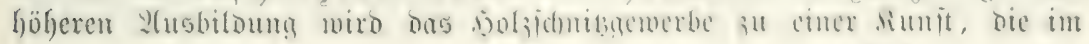




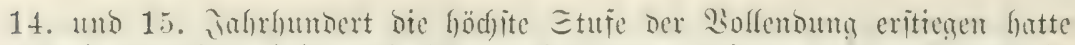

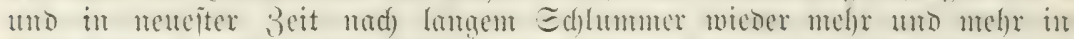

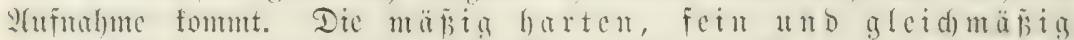

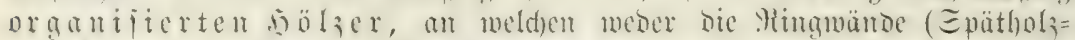
jonen), nod) bie Epiegel (Wharfitrahlen) iehr iturt herwortreten, cignen jid)

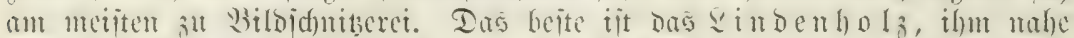

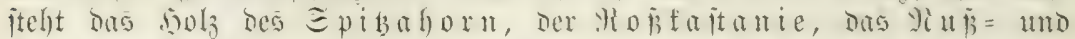

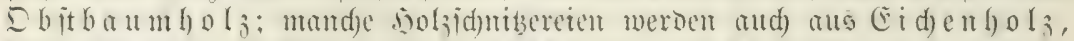

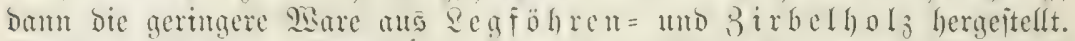

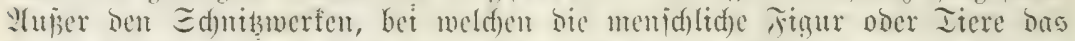

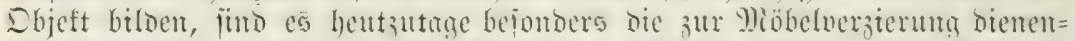
Den Entumente, ober es finto tomplett acidntibte surusmobel, Evicigel=

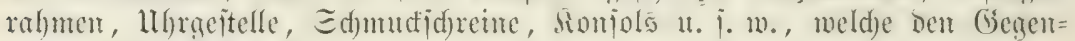
ftand biejer sinduftrie bilden.

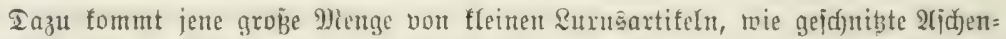

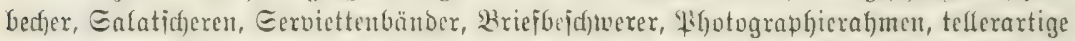

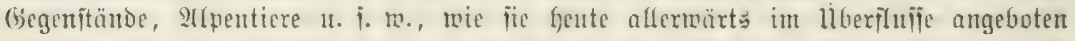

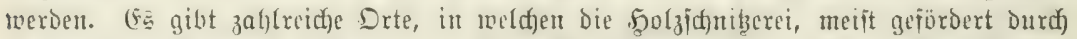

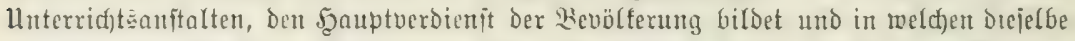

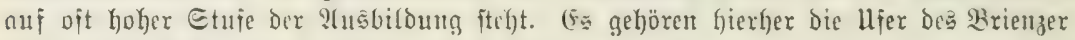

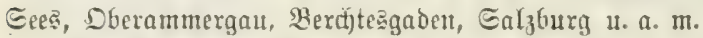

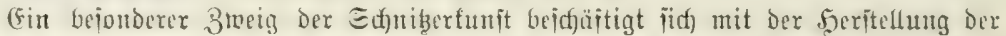

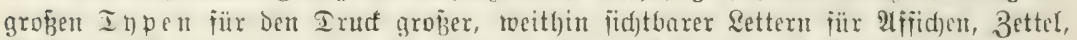

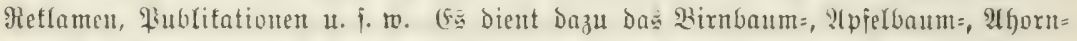

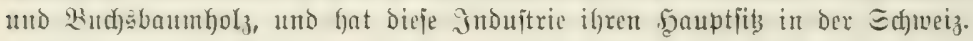

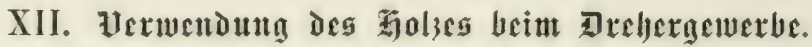

Der Dreher judd bejombers barte, mit gleidjönmiger Iertur ver=

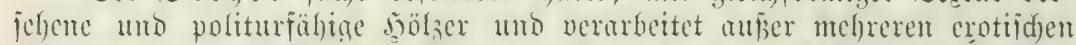

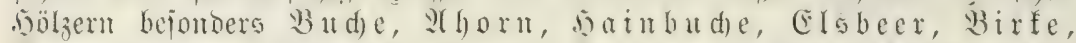

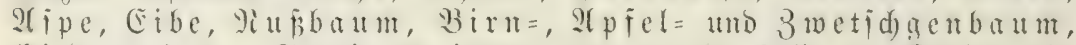
(Eid) c u. 1. 10. Eomeit cs immer mur angeht, itellt Der Dreber jein Fabrifat aus Epalt $=$ und id)wäd)eren Gumbitüder her, uno befriebiạt baher

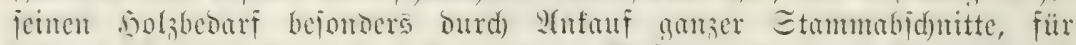
Heinere Gegenitänoc aud) aus gejumben silafteripältem und Etangen bis zu $5 \mathrm{~cm}$ Durd)melier uno weniger.

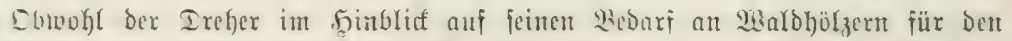

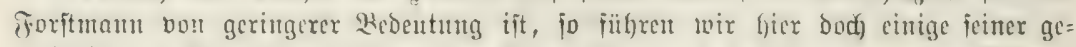

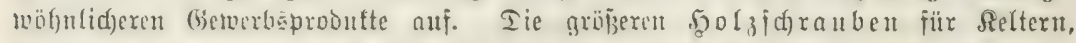

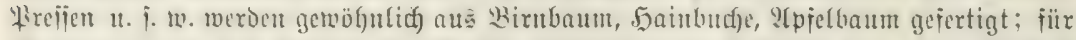

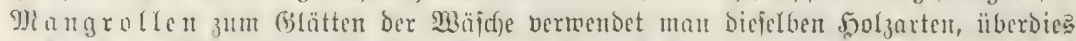

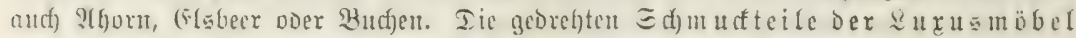

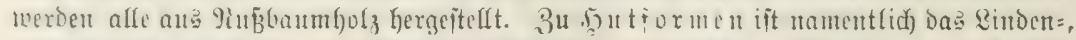

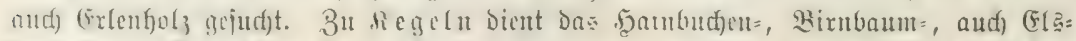

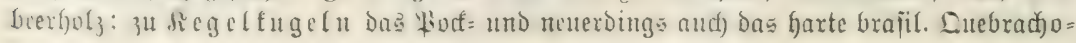




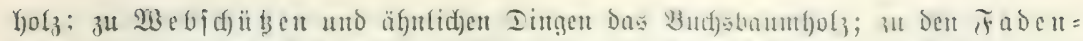

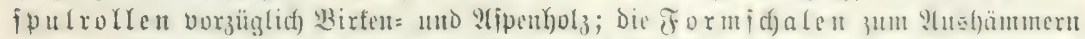

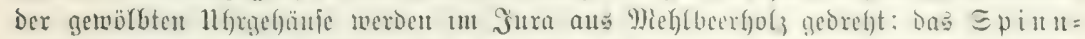

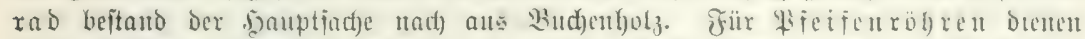

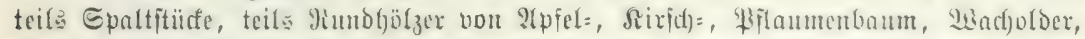

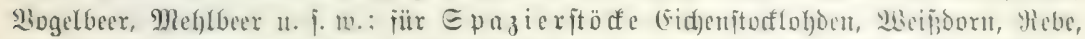

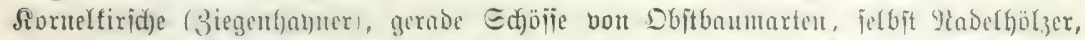

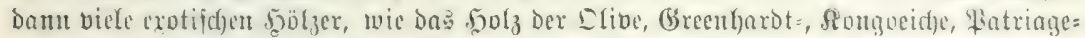

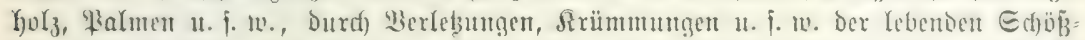

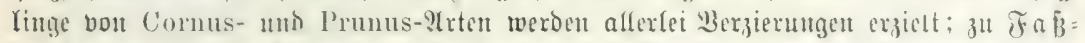

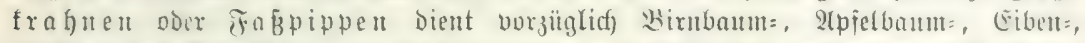

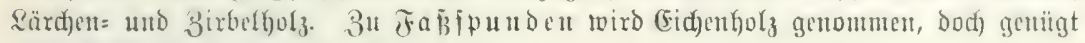
audid) Fidutenfoly geringiter Sorte.

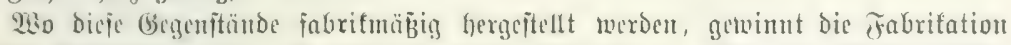

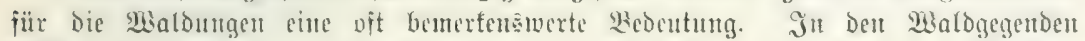

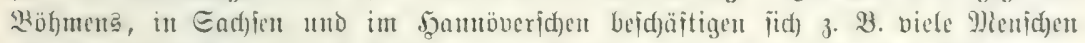

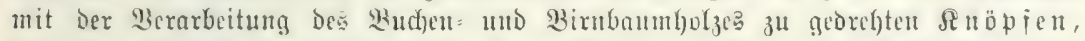

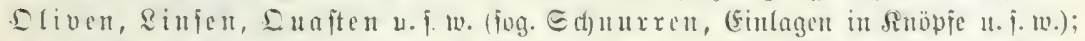

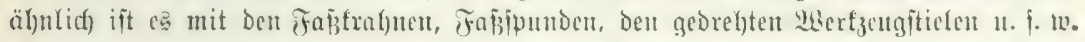

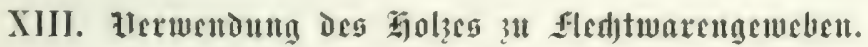

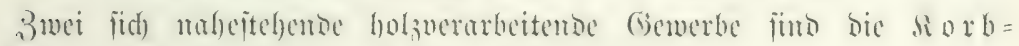
fled)terei und bie 50 z z weberei oder Eparterie.

1. Der Sorbfed)ter fertignt sorbmoren in allen (sejtalten mo

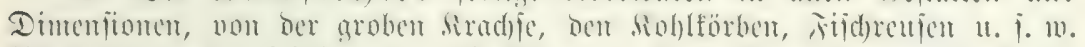

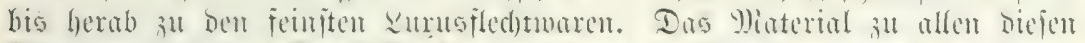

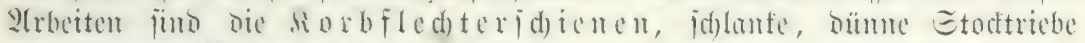
nerichedener Wecionuten, bejouters on Salix viminalis, purpurea, rubra, amygdalina, Lambertiana, pruinosa u. i. m., mu felten mernen Yuten

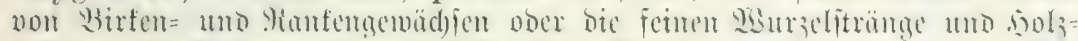

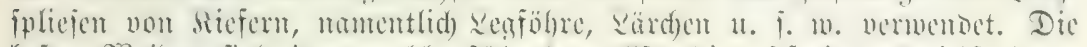

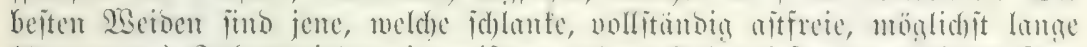
$(2-2,5 \mathrm{~m})$ jabrestricbe mit weipem, sübem solze licfern; an einem Erte

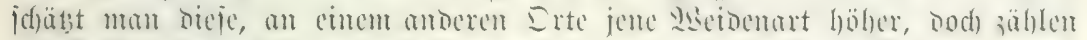

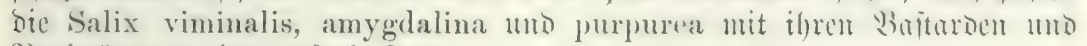
Barietüten zu ben gejuct)tejten.

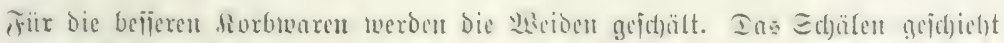

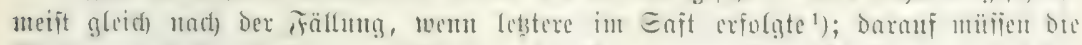

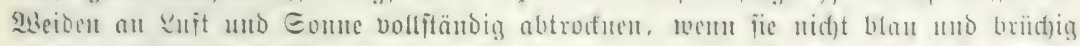

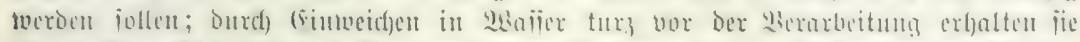

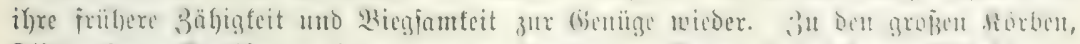

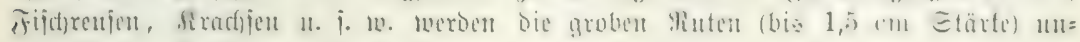
geidjalt, aber friich verarbeitet.

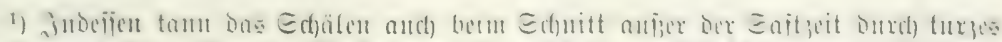

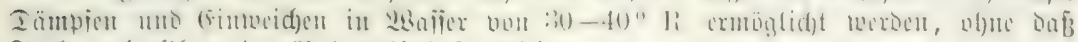

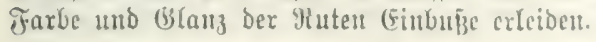


Iic gröberen forbwaren weroen an ganzen, ungepaltenten Ruten gefertight bie

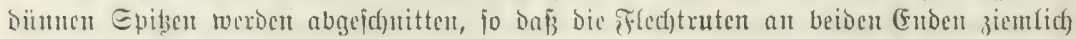

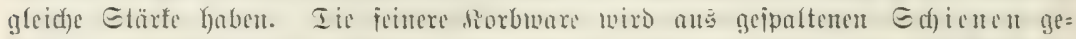

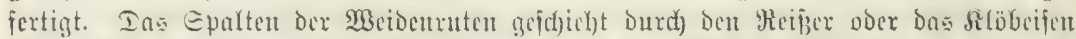

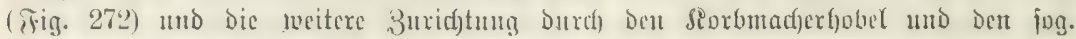

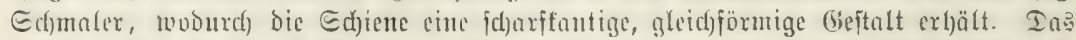

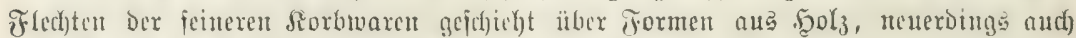
a

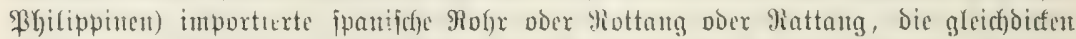

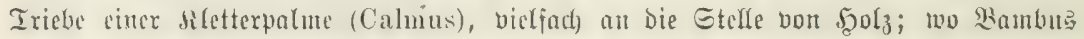
wäd)ft, ifjt biejex bą befte J̈lecd)tmaterial.

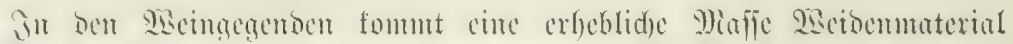

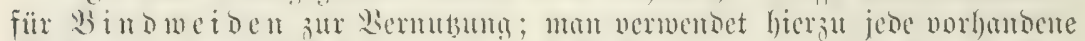

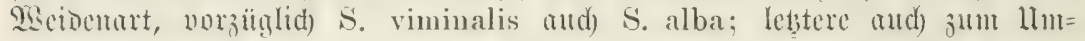
ipinmen der fä̈reife.

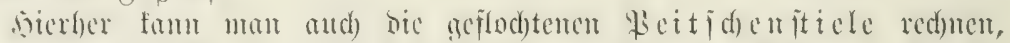
woju man teils Gerten, teils Epaltitude mon (Ej bolber $=$, Salwe ibentolz verwendet.

Mian formt norerit meterlange Epaltrutur von $2-3 \mathrm{~cm}$ Diffe aus und fpaltet

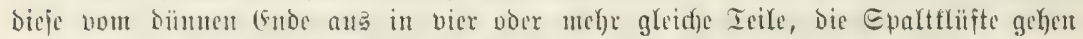

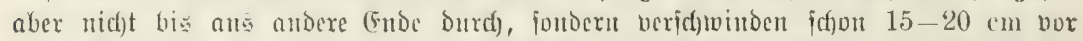

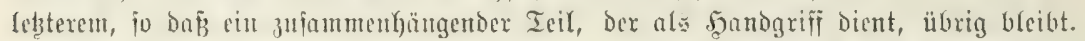

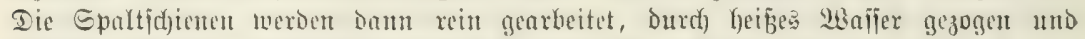
enblid) geflodsten. E(f) lieblith niro der şandgrifi germbet uno glatt gearbeitet uno Dกక Ganze jorgiältig getrodnet.

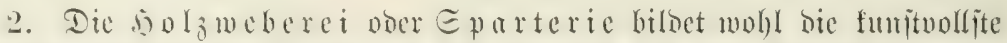

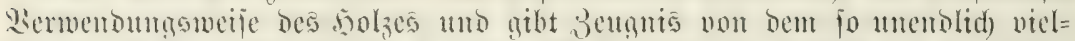

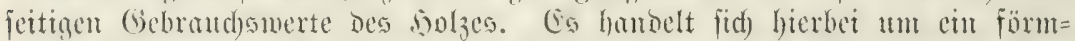

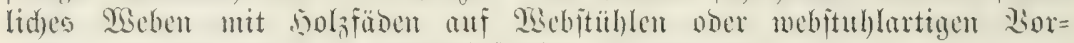
rid)tungen zux Seeritellutg mannigfaltiger Gegenitämbe.

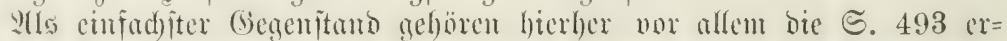

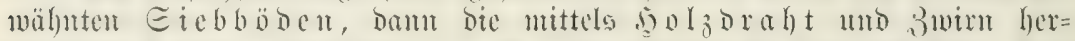

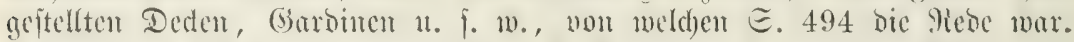

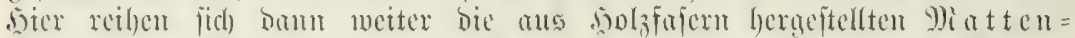

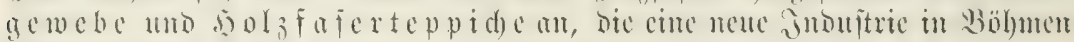

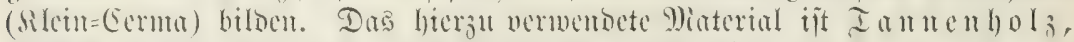
meldes in $40-60 \mathrm{~cm}$ lamge sajerjtränge zerleģt miro, bic Dam au fpagat=

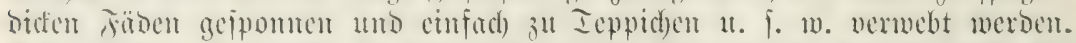

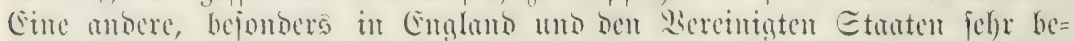

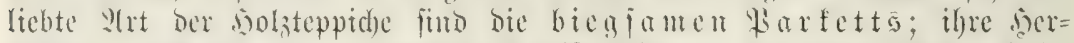

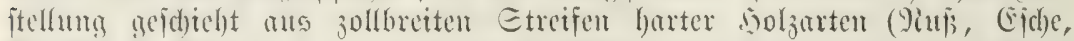

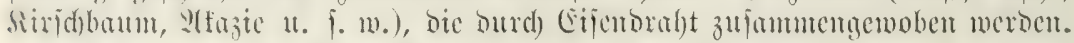

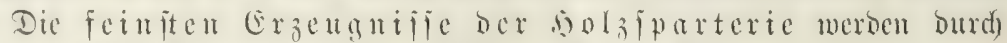

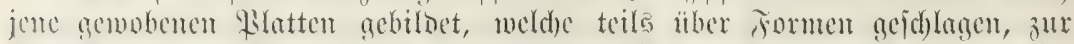

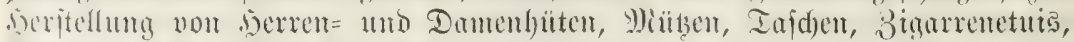

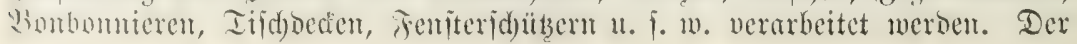




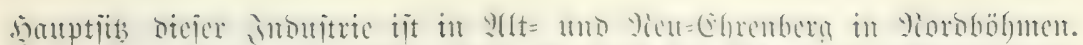

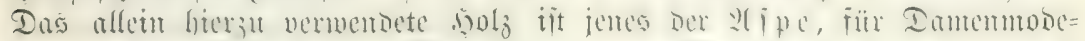
büte atud) viclfad) Fitd)

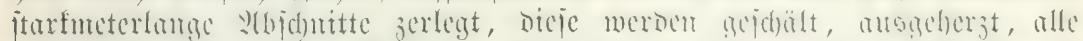

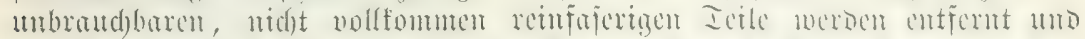

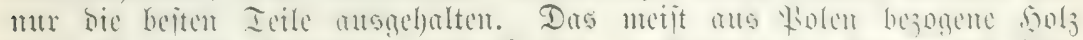

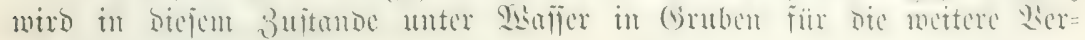
arbeitung anfbewalgrt.

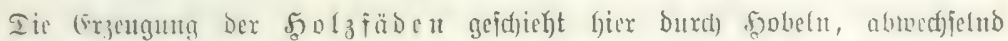

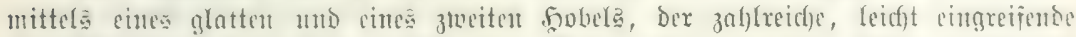

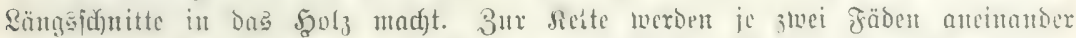

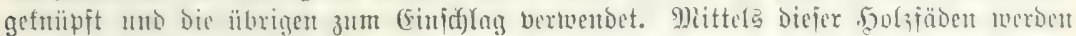

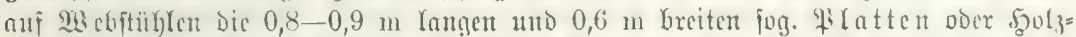

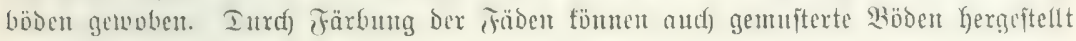
werben.

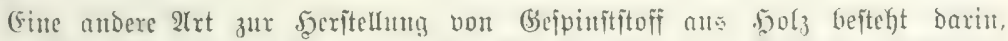

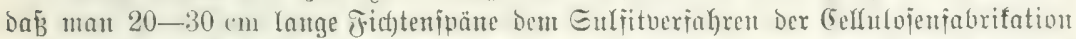

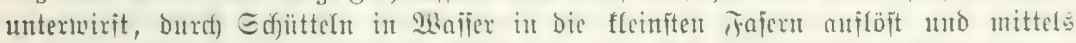

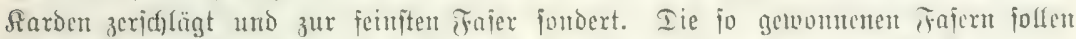

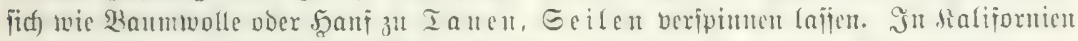

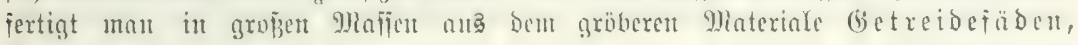
Matteu u. f. tw.

\section{XIV. 刃ex (Öhonomicholz̨conef.}

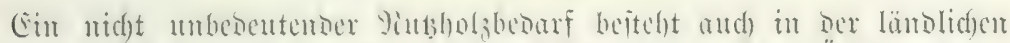

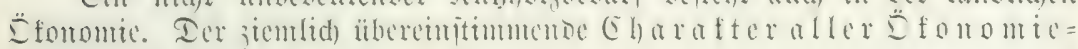
hölzer beitelit darin, baj fie mely ober wentiger ganzrob

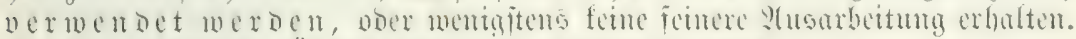

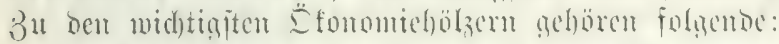

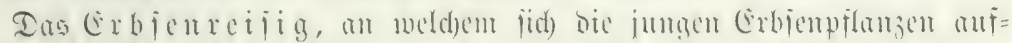

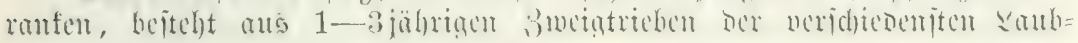
unb Rabelhölzer von $1 / 2-1 \mathrm{~m}$ \&änge.

Iit es furb $2^{1} a-3 \mathrm{~m}$ lange, unten ctwa : $\mathrm{em}$ bide Etangen, moju man

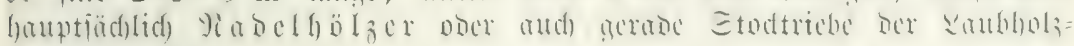
arter verwentoet.

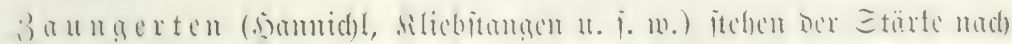

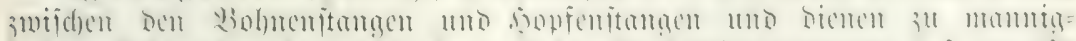

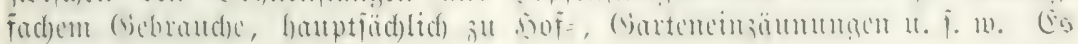
bienten hierău mur bie Miabelfölzer.

Iic s) 0 f f

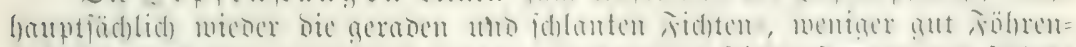

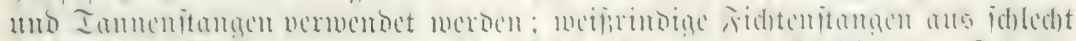

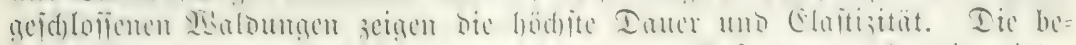

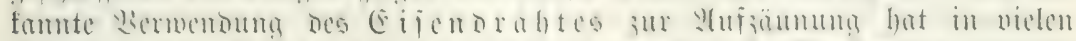

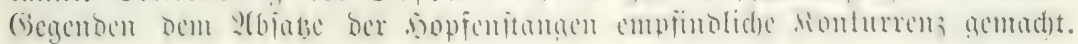




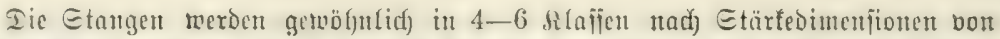
5-12 m Särge un 6-14 cm unterem Iurdjmeifer jortiert. Ier befieren (Frfjaltung wegen sverden bie Şopfenitangen gemöhnlicf entrindet.

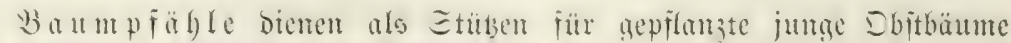

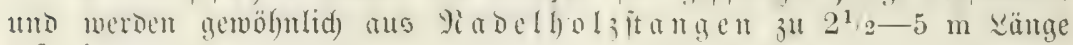
gefertigt.

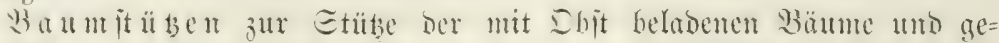

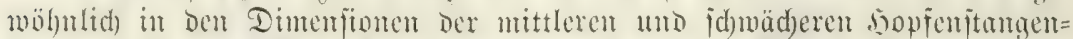

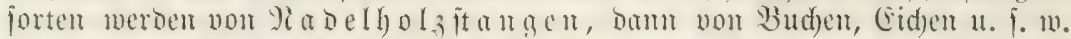

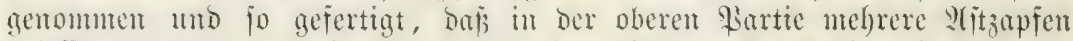
belafien werben, um in ber bierdurd) aebildeten Gabel die mit Ebjt be= labenen $\mathfrak{A}$ ite einlegen uno aufitüben zu fömen.

Dic Deinpfäble, weld) jenfred)t neben bem Yebftod eingeitedt und an meldyen Die Rebitangen angebunden werben, bejteben gemöhnlidg ans ge=

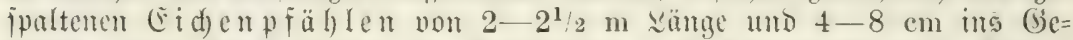

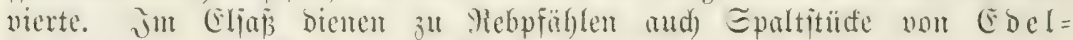
fa fta

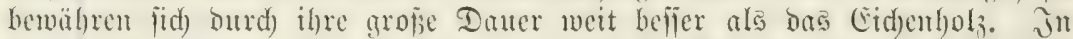

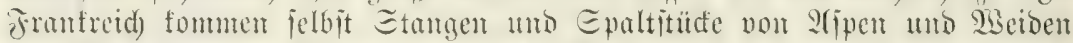

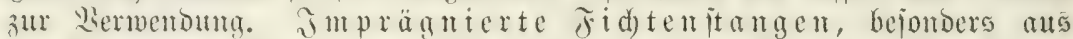

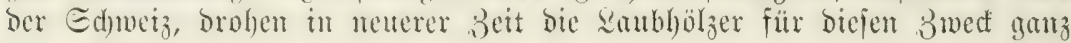
zu verorängen.

Wo de Rebent ichr nieber und mefre in die Breite alb itt bie \&ünge gezogent werben (fiammerbau in Der 'Hifalz), die ganze 5ुolzzäunung über Winter aljo belafien tvird, Da bedari man aud) Daucrfajtere Winterfölzer, und fant Dam mur bą (Eid)en=

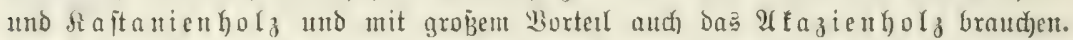

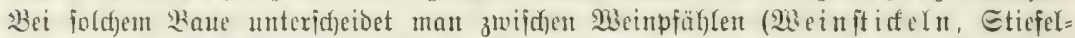
hol3), Die in Reifen jentred)t in bie (Eroe gefd)lagen werben, und Den $\mathfrak{B}$ ingert balten, bie in forizontaler Rage wou rinem Meinficfel zum anderen befeitigt jïn. Lie eriteren find $1 \frac{1}{2}-2 \mathrm{~m}$ lange und fräftige Epälter, Die Balten find $3-4^{1 / 2} \mathrm{~m}$ lange Epaltlatten, dir nus gutipaltigen Etümmen mit dieil uno Epaltflinge anj: gerifien weroen. Iit wingertibalfen werben jetst and Durch (Eifendraht erjebt.

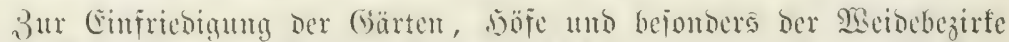
iu ben :

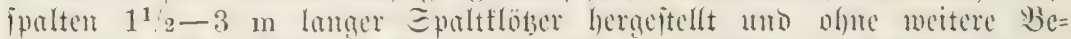

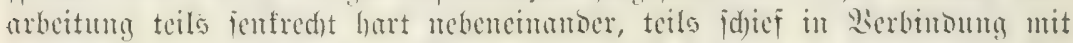

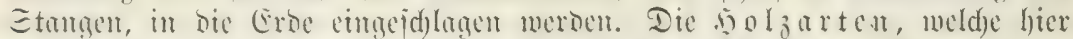

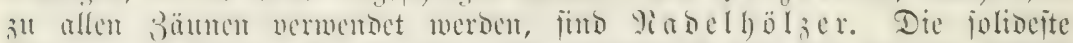

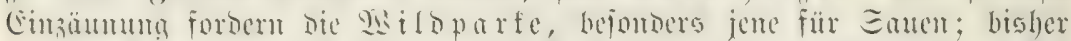

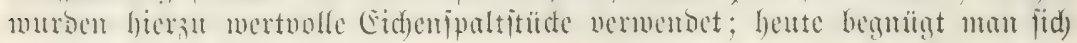
aud) mit Siabelgolzipälten.

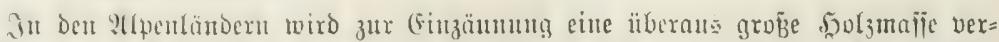

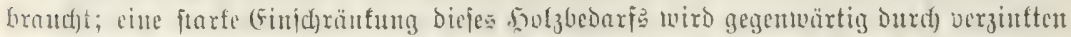

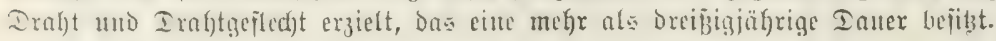

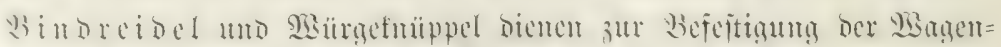

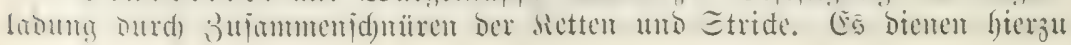


gewöhnlid) (Eidhen=, ฟैirfen= oner fadmäd)ere Etangentüde von veridjebener Sänge.

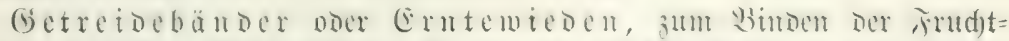

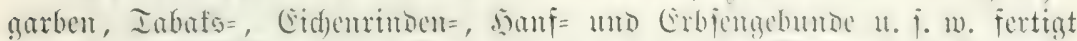

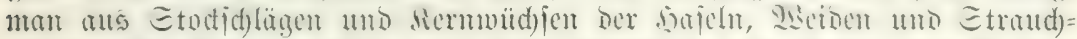

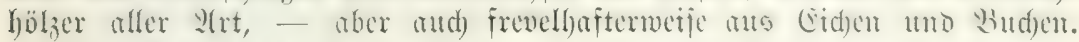

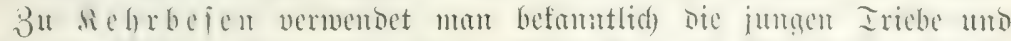

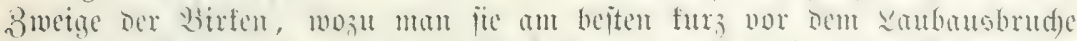

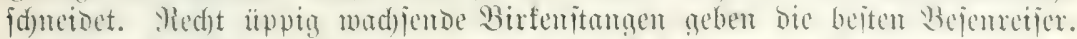

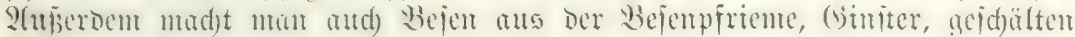
Weidenruten 1t. i. w.

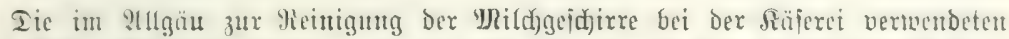

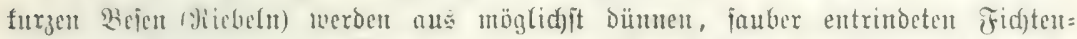
z'weigen uno cintm interen fern von Dünten, nacten f̧eibezlveigen (L. herbacea $L$.)

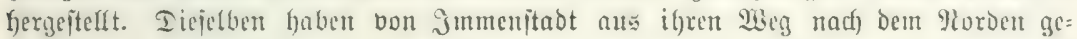
funden.

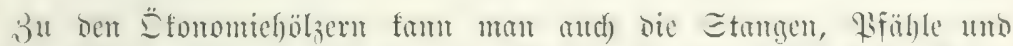

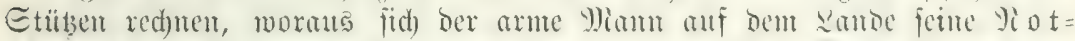
(d) oppen mit cigener samo und in burdans rober sonitruftion baut.

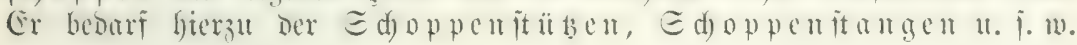

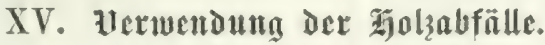

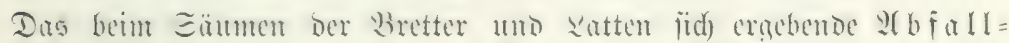

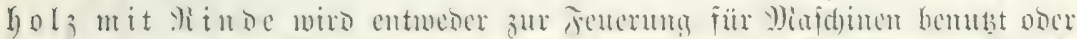

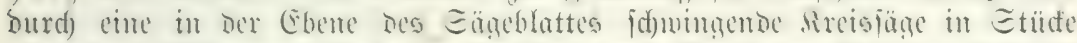

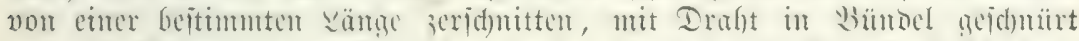

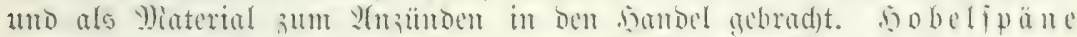

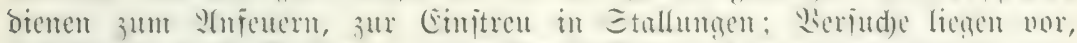

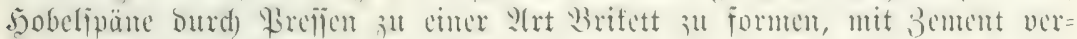
mengt eine 2 (rt Ẋnlolith Darzutellen.

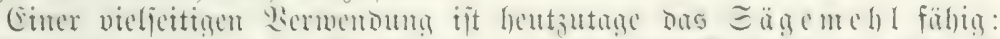

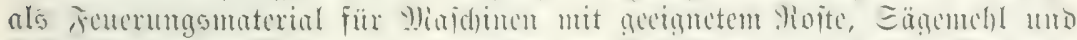

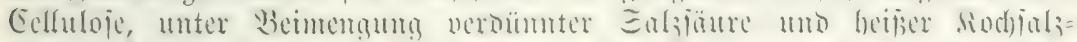

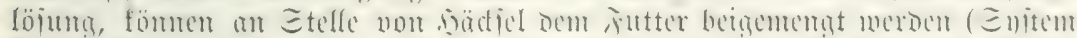

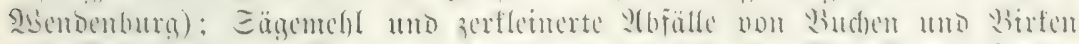

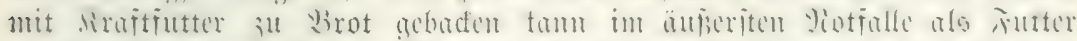

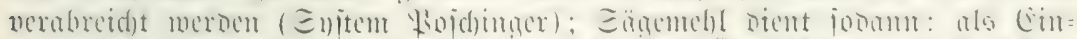

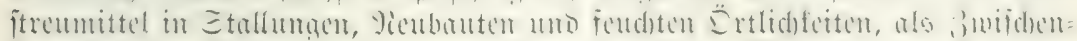

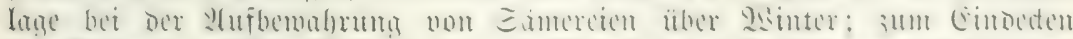

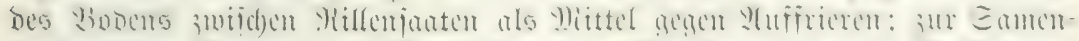

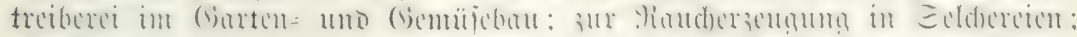

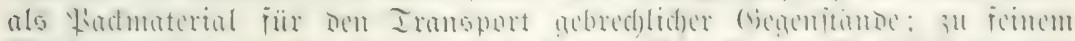

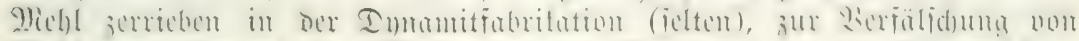

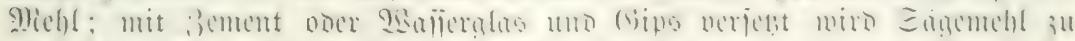

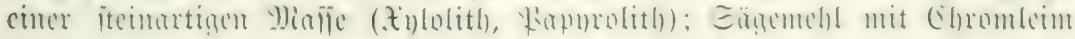




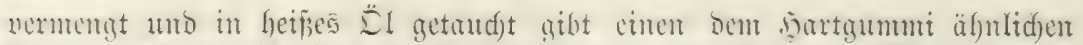

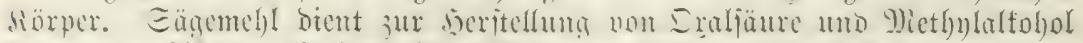

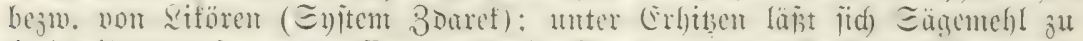

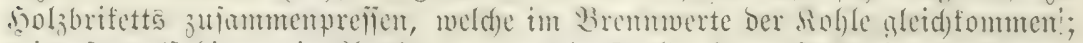

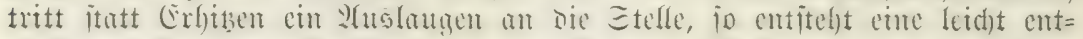

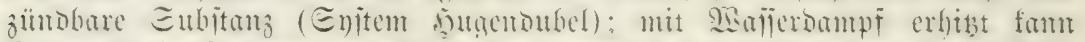

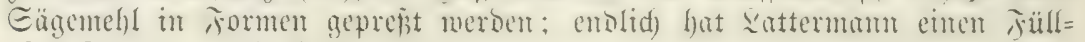
Dfen für Eägemehl fortitruiert.

8 weite unterabteilung.

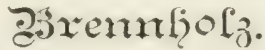

1. Folzulerband in ber $\mathfrak{A} b$ id t, bie babei frei werbende

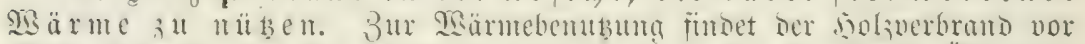
allem ftatt bei Der ङ

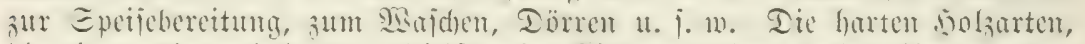

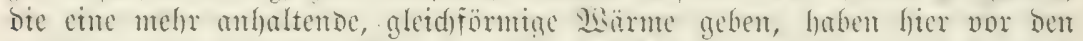

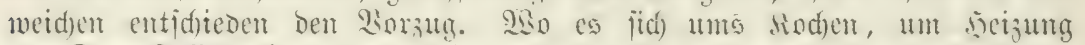

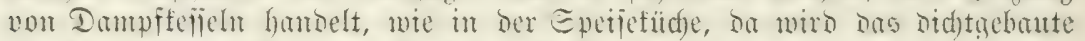

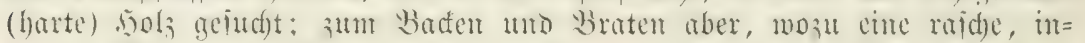

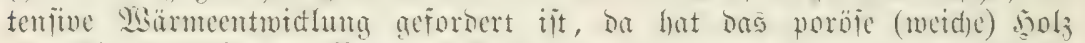

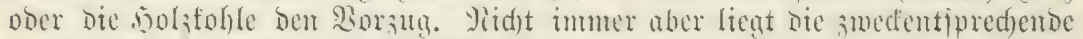

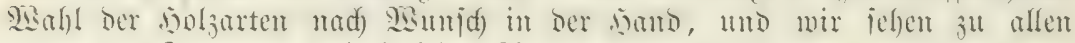
genaunten Feutungen $\mathfrak{S g l}_{2}$ jeber 2 rta vermentet.

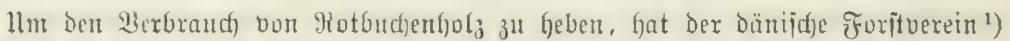

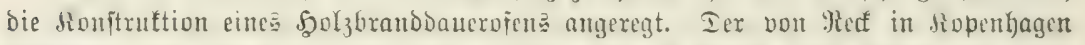

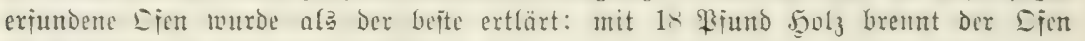
36 Etunden bei breimaliger Füflung.

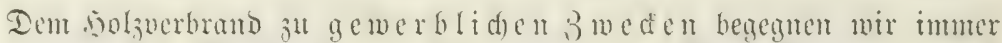

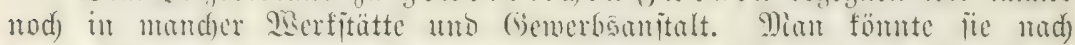

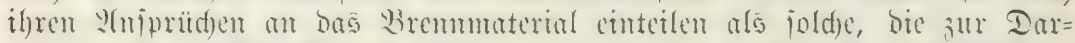

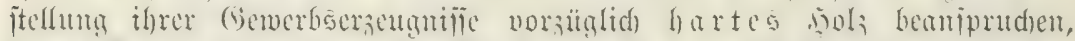

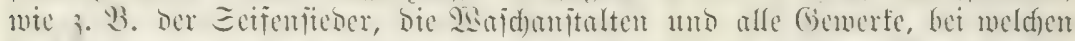

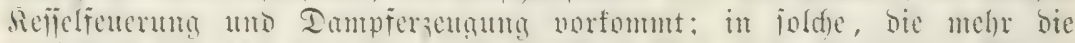

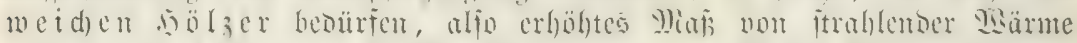

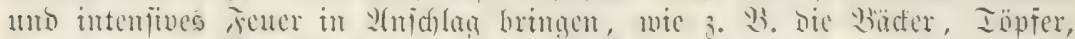

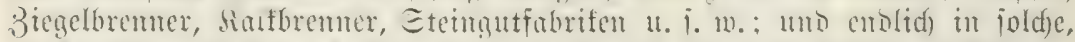

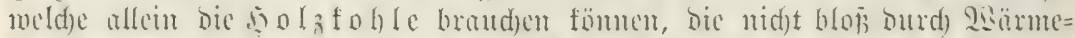

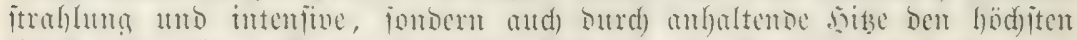

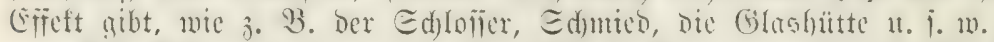

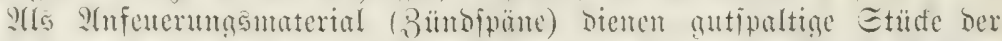

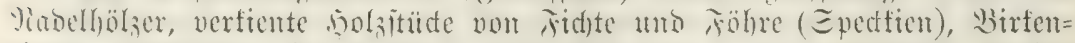

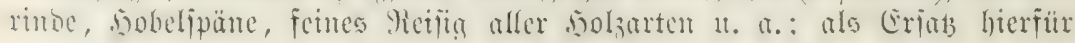

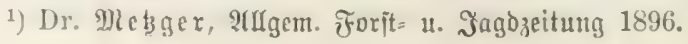




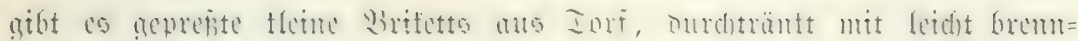
barem Stoïe.

Siter wäre aud ber Rejefolznutzung zu gêdenten, ba bas ge=

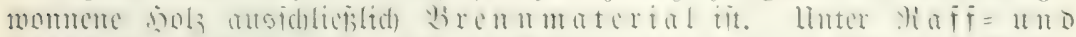

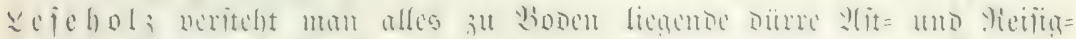

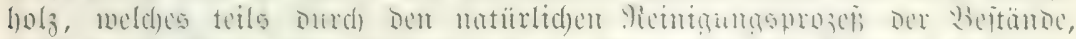

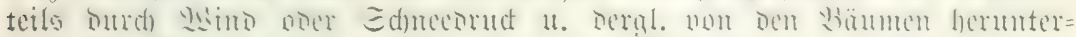

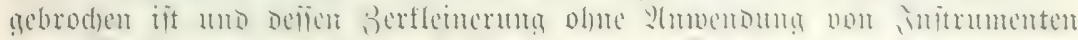

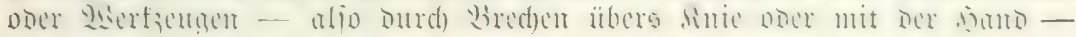
erfolgen fam.

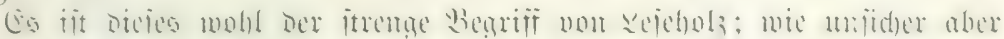

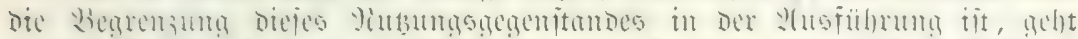

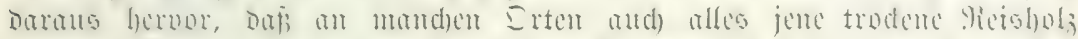

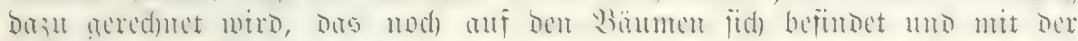

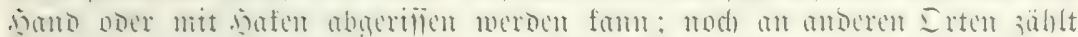

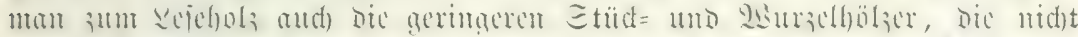

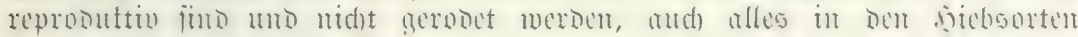
i)

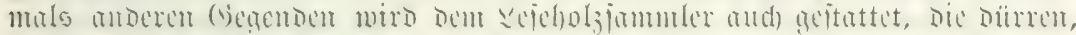

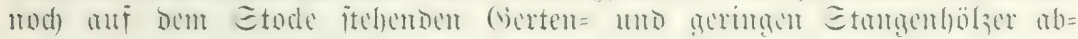
zubauen แ⿰亻丨 jidf) anzucignen.

Die (boutu

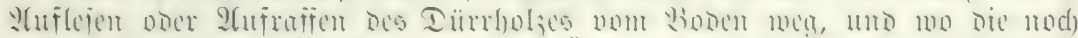

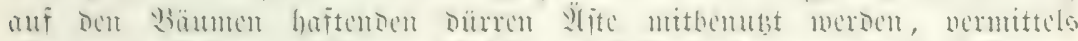
vijermer แ

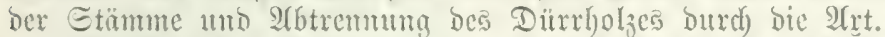

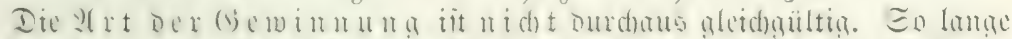

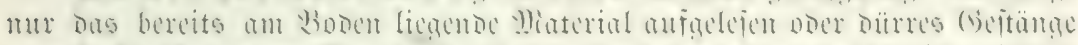

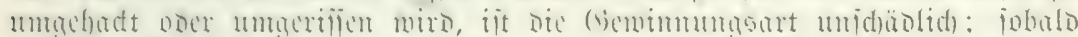

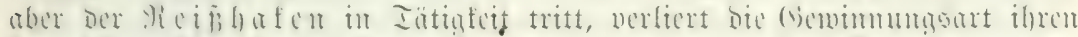

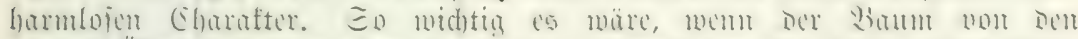

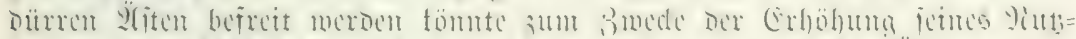

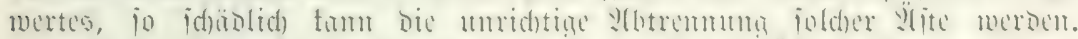

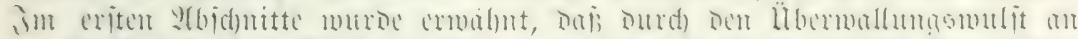

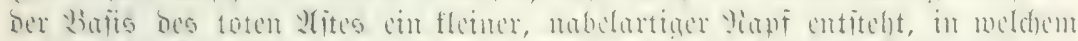

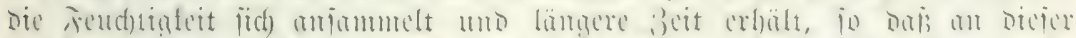

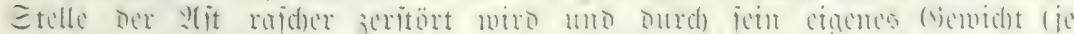

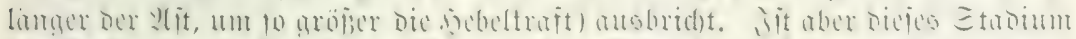

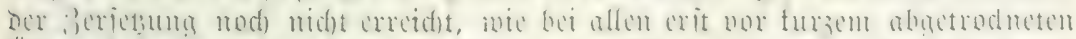

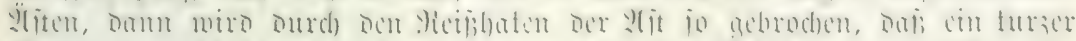

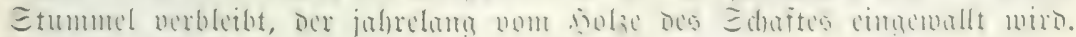

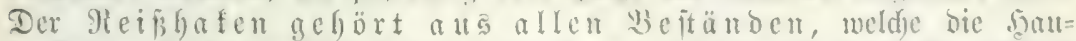

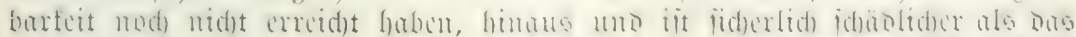

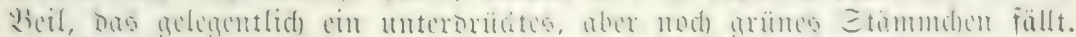

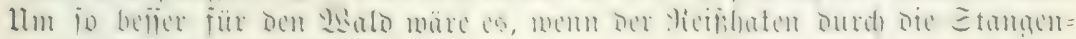
jäge crjebt weroen fömnte.

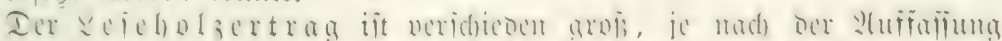

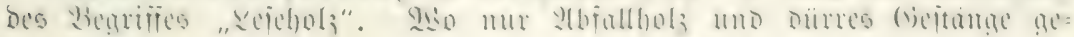




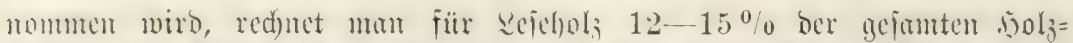

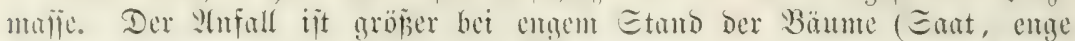

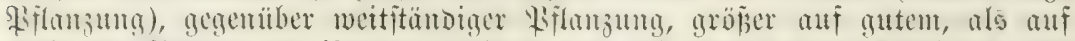

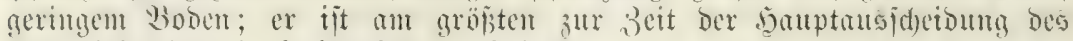
Siebenbejtandes, D. i. im Etangenfolzalter.

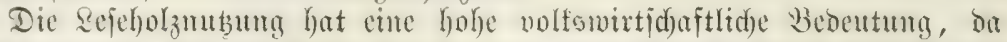

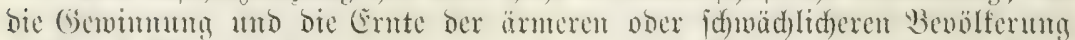

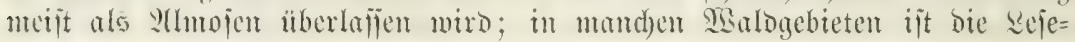
lolzmutzung eine Berect)tigung.

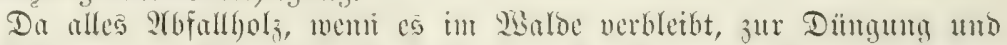
Durd)lïftung des Wobons heiträgt, fo follte bie Jiubung auf geringen ober fd)meren, feud)ten Büben unterbleiben; allein bie erböhte Teutergefabr

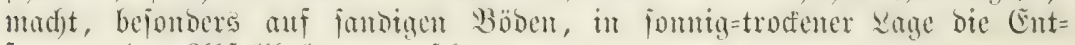
fermung des atbrallgolzes wïnjdensmert.

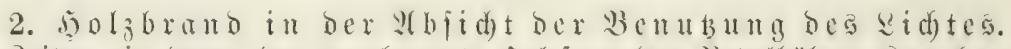

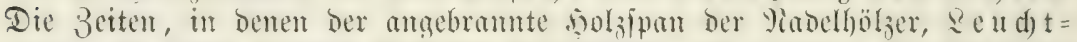

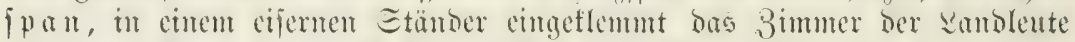

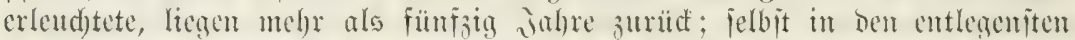

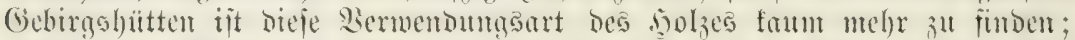

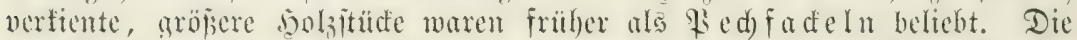

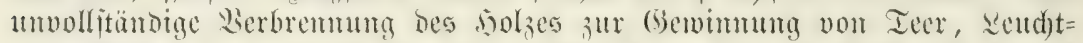

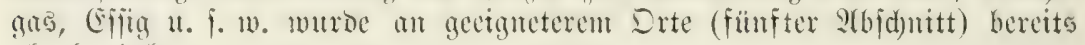
abgebandelt.

\section{Dritte unterabteilung.}

\section{Die J̈exwendung lebendex ב̇flamzen obex ¿flianzenteilie.}

Die Bumertung non lebenoen Piflanzen uno Biflanzenteilen ijt cine

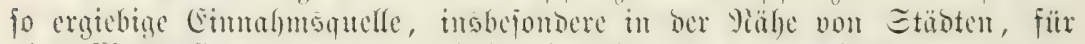

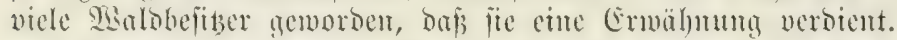

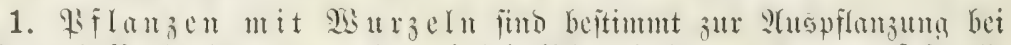

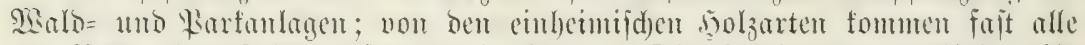

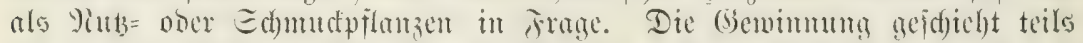

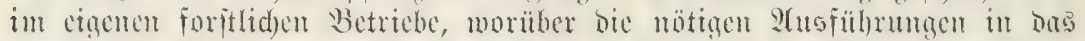

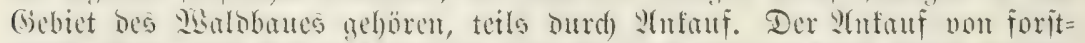

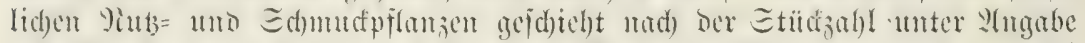

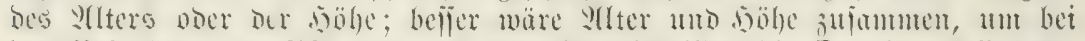

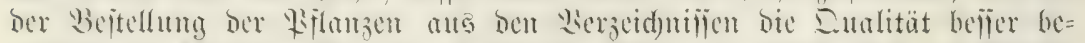

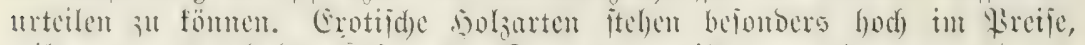

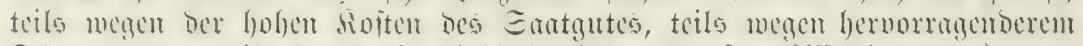

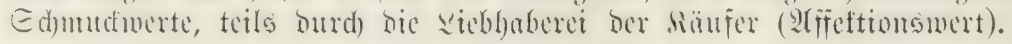

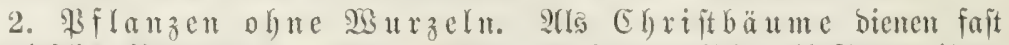

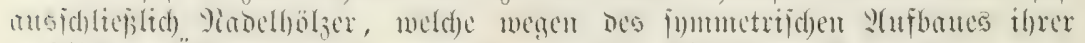

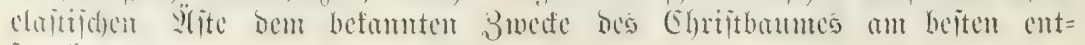
ipredjent. 


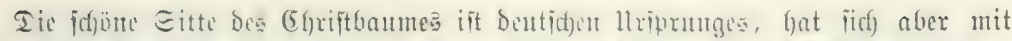

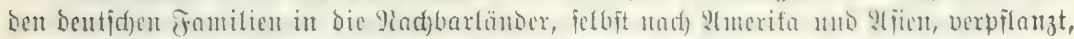

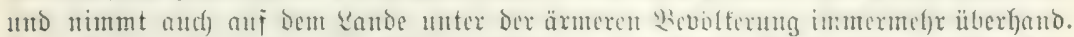

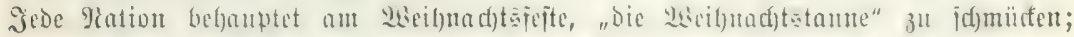

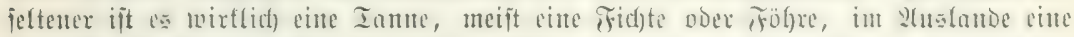

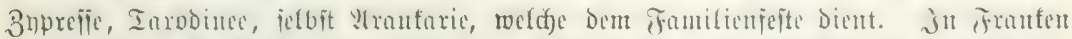

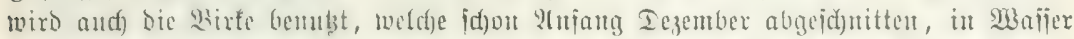

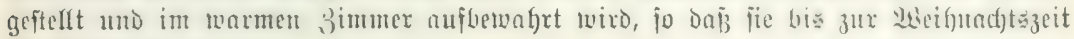
fïch) begrünt.

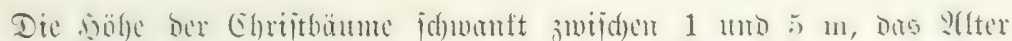

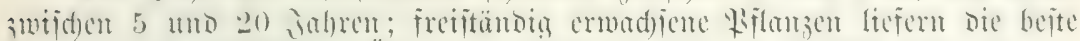

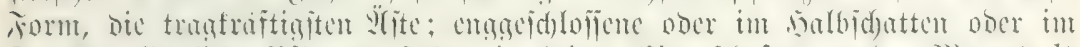

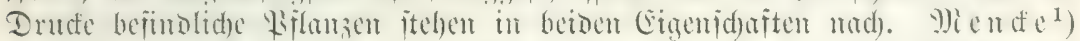

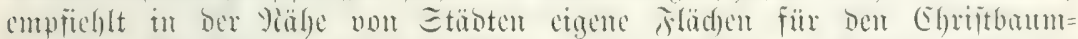

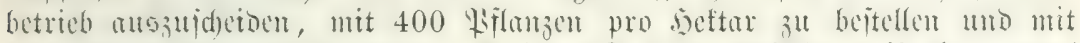

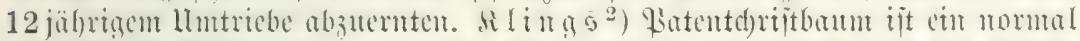

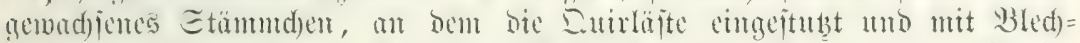

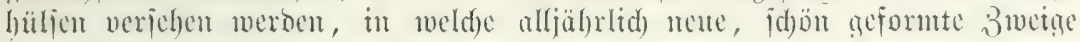
eingeftedt werden föment.

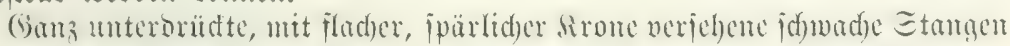

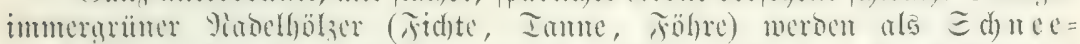

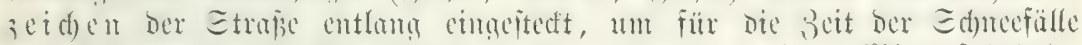

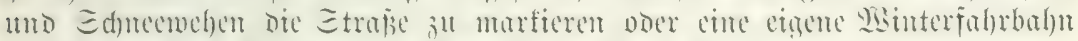

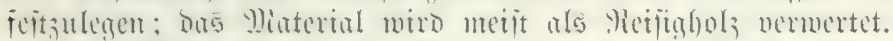

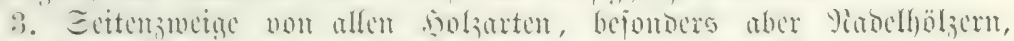

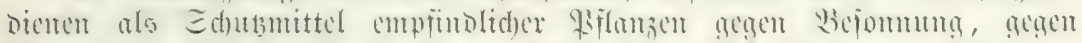

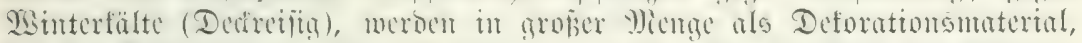

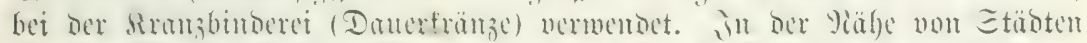

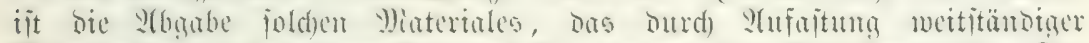

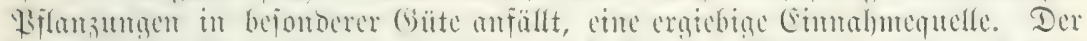

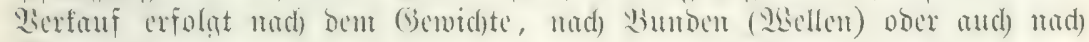
Magenladunger.

\section{Bierte lnterabteilung.}

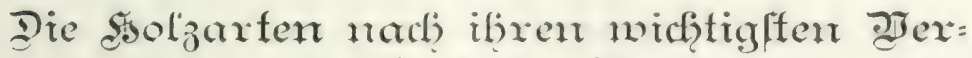 wertoungsweilen.}

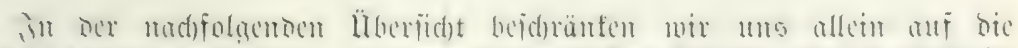
ขึ and) cinc :

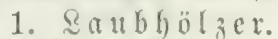

(Cid)

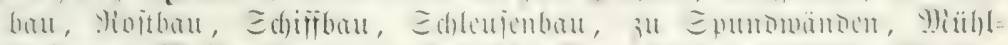

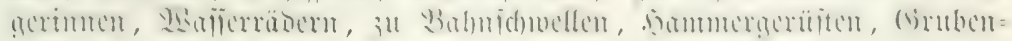

") Diterx. Forjt: แ. J̄ngozeitung 1901. 


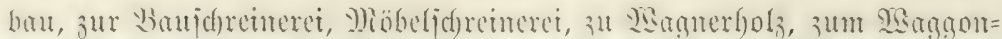

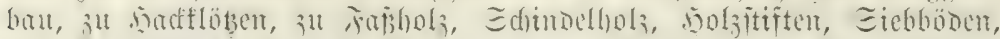

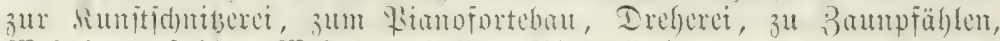

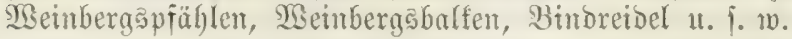

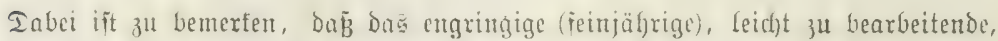

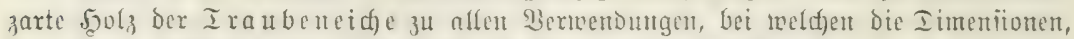

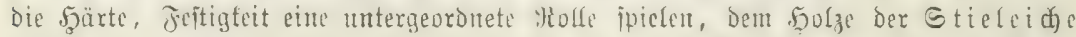

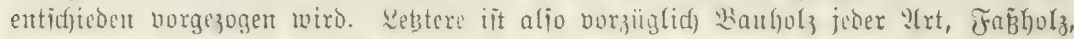
Wagnerholz, Spalthols u. i. w.

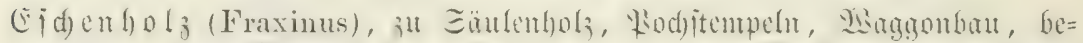

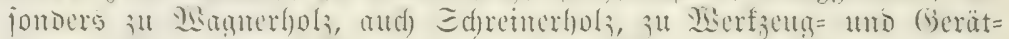

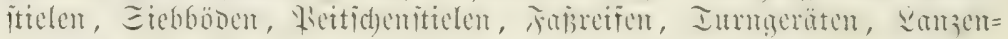

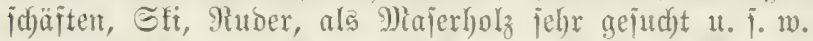

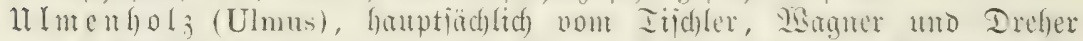

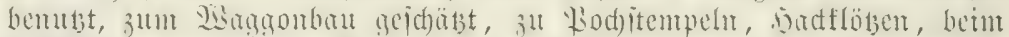

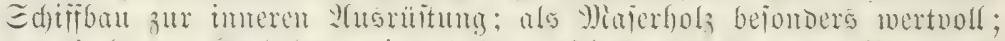

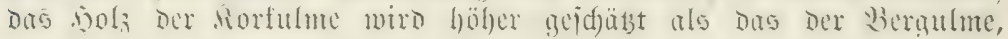
und diejes höher als das der frlätterriijter.

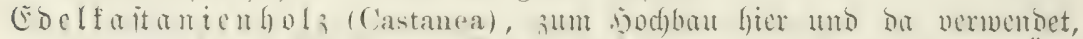

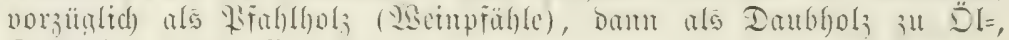
Sorintbent=, aud) Meinfüinern.

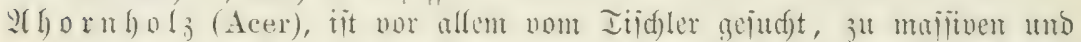

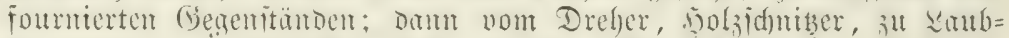

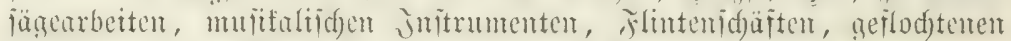
Beitidenitielen; Miajer beionders wertuoll.

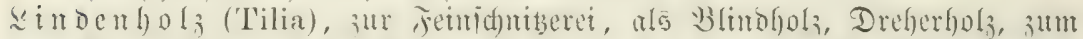

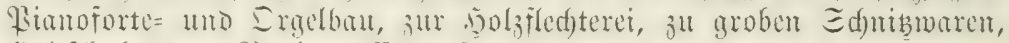
Solziduthen, zu Bapierma

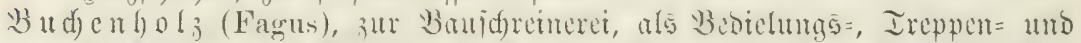

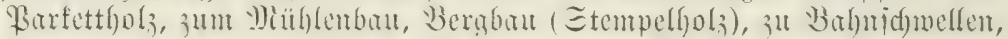

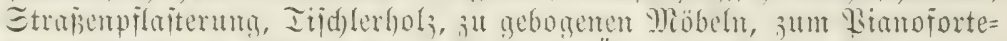

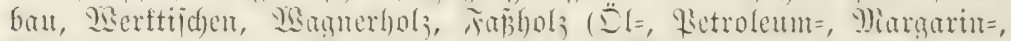

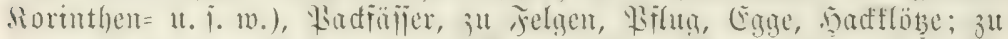

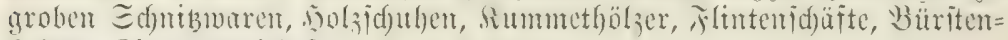
böben, Bigarrembidelformen แ. ¡. m.

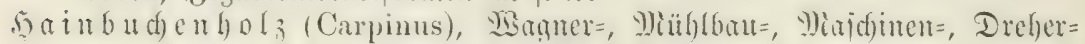

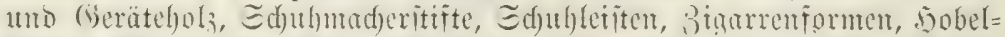

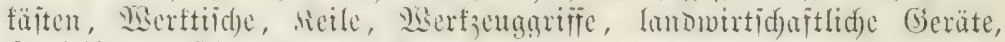

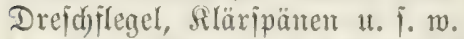

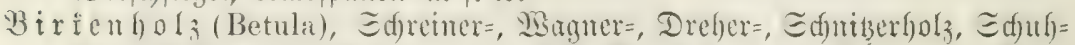

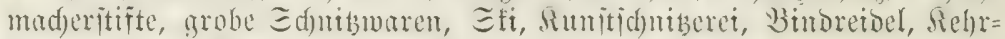

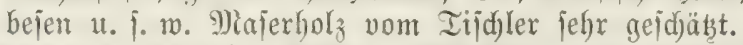

CErlengo!z (Alnus), Erobau, Bergbau, zur Bebichng feud)ter Erte,

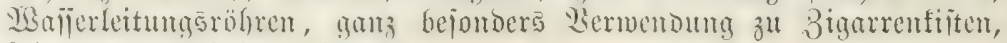
jeltener zu Sdunibarbeiten.

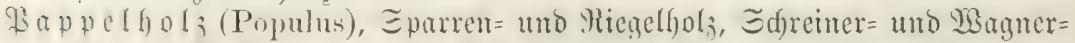

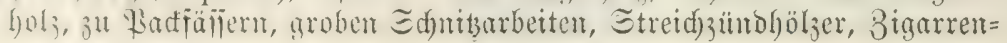


fijten, Dopucloumen

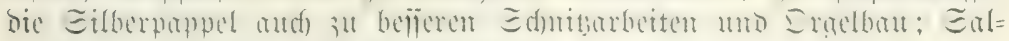
weibe zu Sicbböben, Fled)teridjienen.

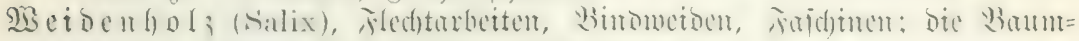

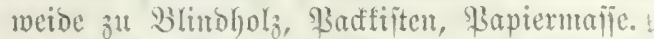

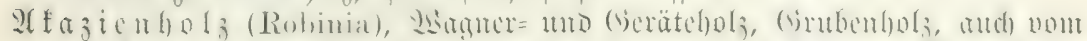

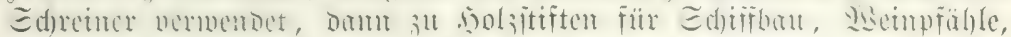
(Serät= uno 93erfzeugitiele, aud) vom Dreher verarbeitet.

(E) Iifd)ler verwenbet, aud) zu Edjnizmaren.

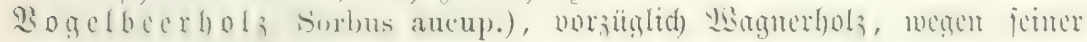
hoher 3äbrgfeit.

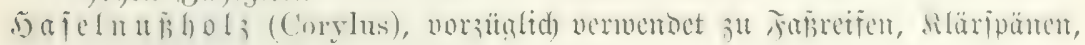
Sicbböben, aud) für Tijd)ler braudbar.

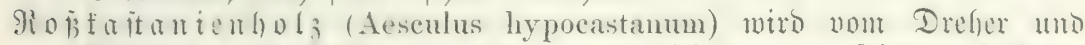

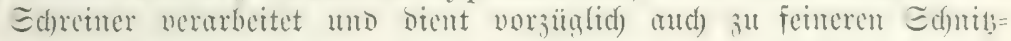
warent.

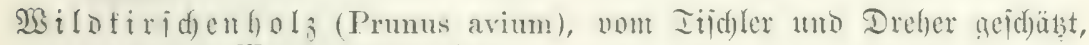
aud) vom Maganer verwendet.

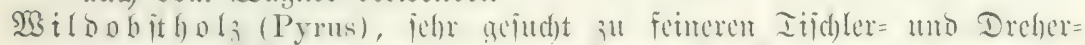

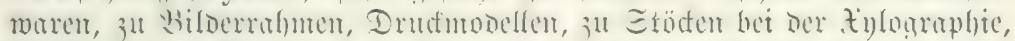

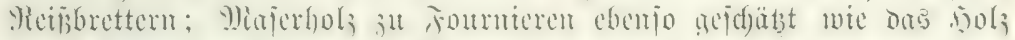
bes fultivierten 2 tp fel= utro Birnbaumes.

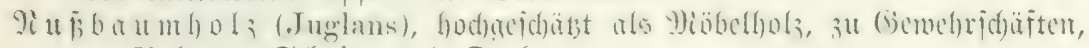
zu Mahmen, Sdyith= แnD Dreherwaren.

2. Miabeltiölzer.

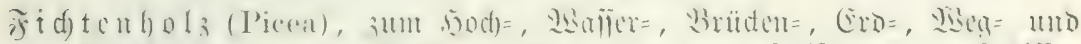

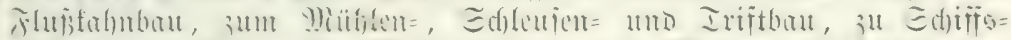

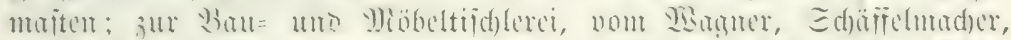

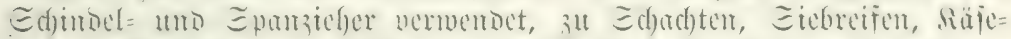

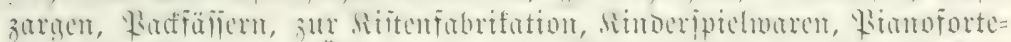

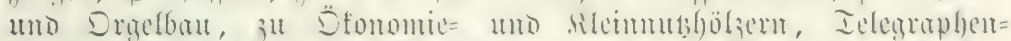

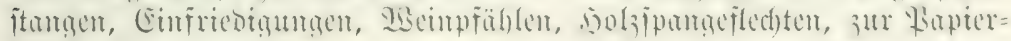
fabrifation t. ๆ. w.

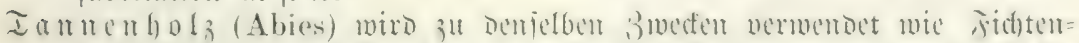

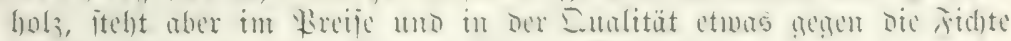
3urüd; findet uberdies aud) im 93 afjer Berwendutg.

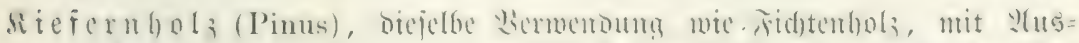

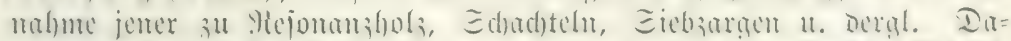

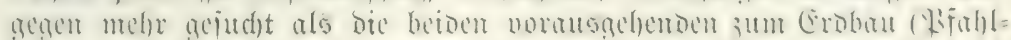

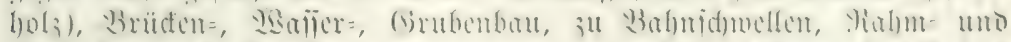

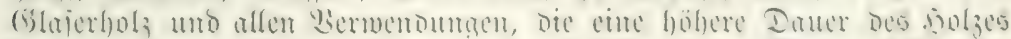

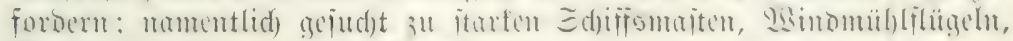
Hahen, Ieudjeln, zur Etrẩenpflaiterutg.

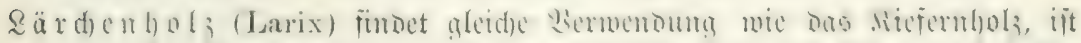

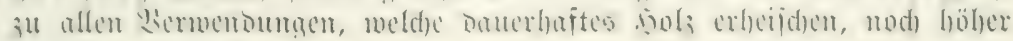
geiduäżt al’ bieję. 


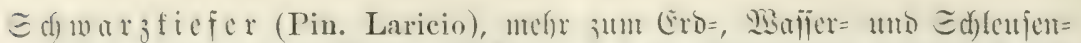

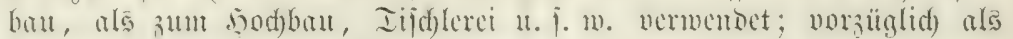
Ieudel $=$, Epuntwand $=$, Filotentolz u. \%.w.

Jirbelfiefer (Pin. Cembra), jur Ed)äflermate, Ed)nibere, Epielmaren=

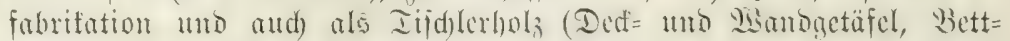
gejtellen) fehr gejudyt.

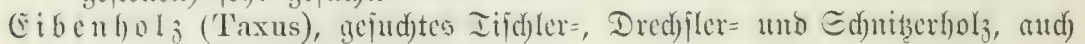
zur Sdjäflerware jehr beliebt.

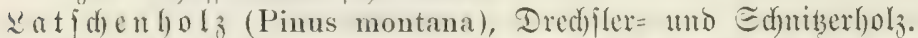

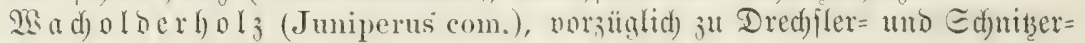
warelt gejudjt.

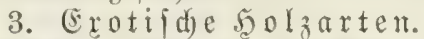

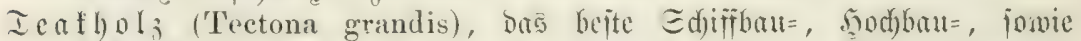

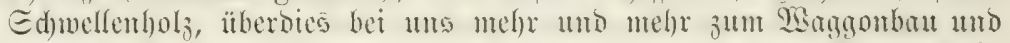

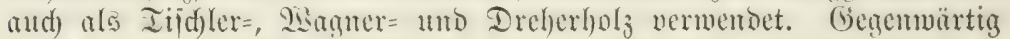

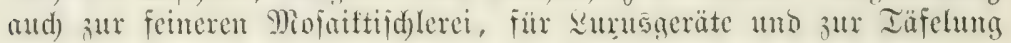
ielhr beliebt.

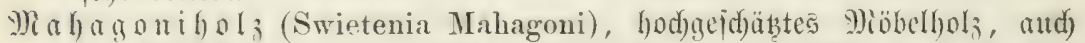

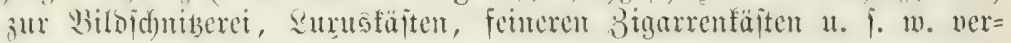
wendet.

bi) iticlen u. . m.

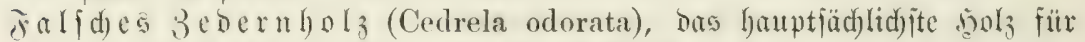
Bigarrenfiftchen, Zuder = und Gemürzfiften $u$. $1 . \mathfrak{m}$.

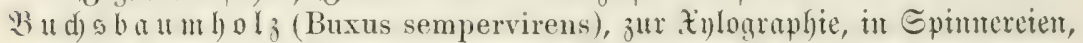

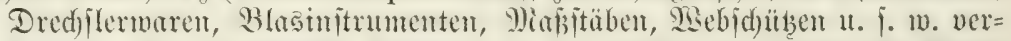

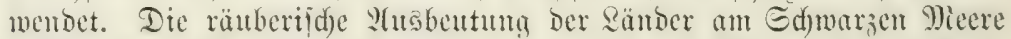

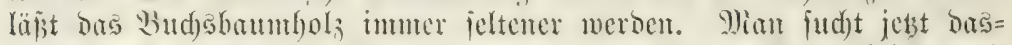
felbe Durd) wintertahle Diospyros- and Ilex-9(rten, Siormelfirid)e uno Sd)warzoorm ju furrogieren.

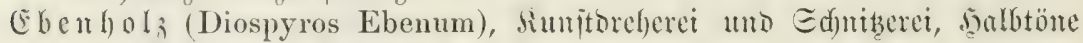
für \$ianoforte, Mieflerbefte ı. f. m.

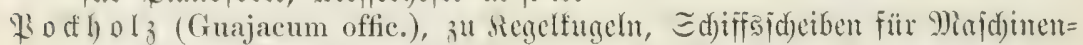
suede, bet ber Puluerfabrifation zu Meibfugeh in ben rotierenden Trommeln benutst.

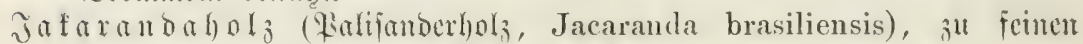
Dreherwaren, eingelegten Mlöbeln แ. f. w.

Rofenlol z, zu eingelegten 9)iobeln.

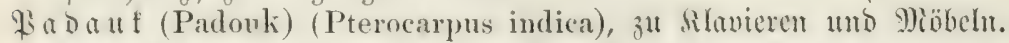

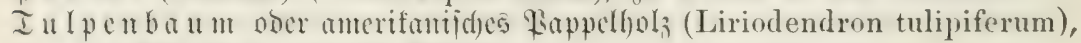

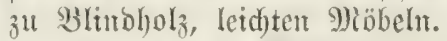

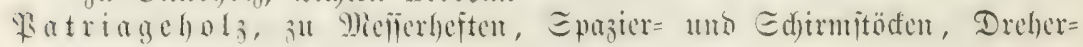
waren It. \%. w.

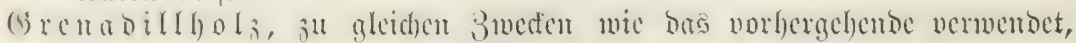
bam zu Blasinftrumenten (Flöten).

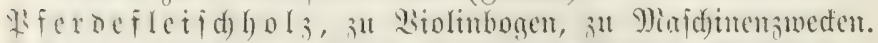

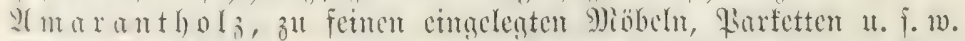

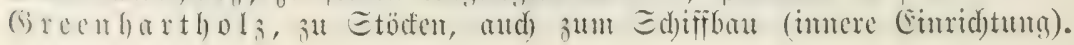




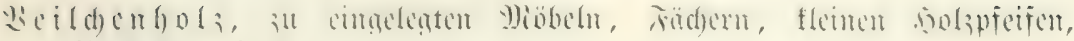
Barfett u. i. w.

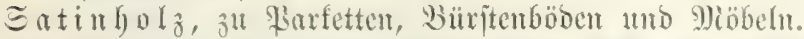

Elivall)

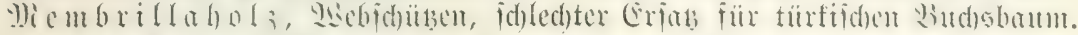

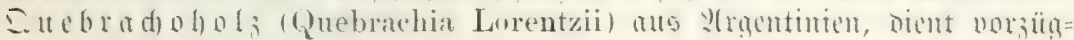

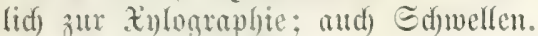

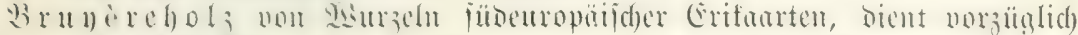

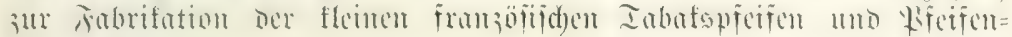
töpfer.

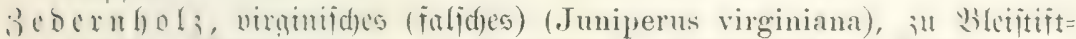

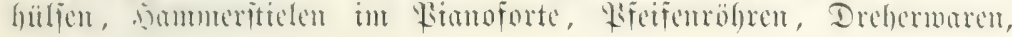
and) zut feineren Iifd) (eret.

P'iteh-Pine (jur. Pitsch Pein) (Pinus palustris sumetit), Dimenjimes=

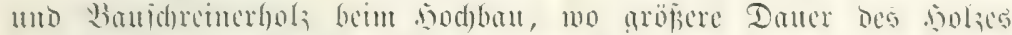

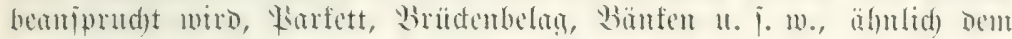

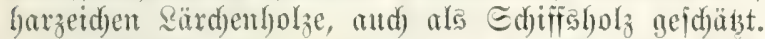

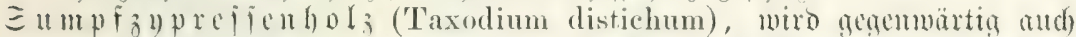

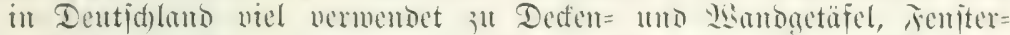

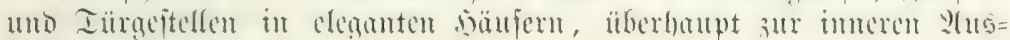
fleioung.

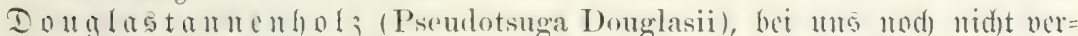

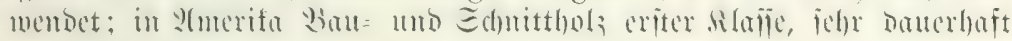
wie Rärdese.

Yamiont)ol; (Chamaecyparis Lawsoniana), in :Herifa Edjutttholz; wegen hoher Dauter zu safenbauten.

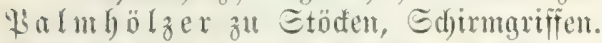

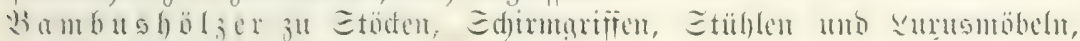
Jled)tarbeiten, Nippgenenitänden. 



\section{ฮెweiter Teil.}

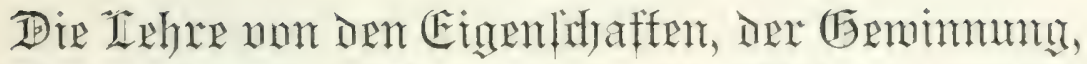

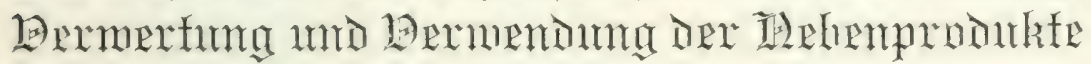

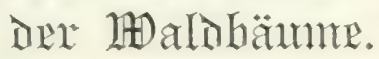





\section{Erjter 2lbjh̨nitt.}

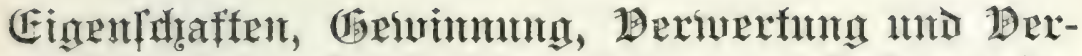

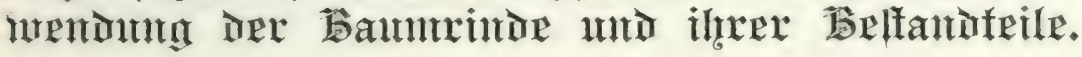

\section{A. Rratontifie Eigentidgaften Sex Zinte.}

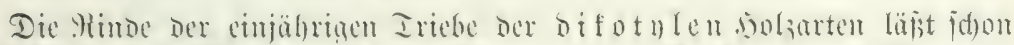

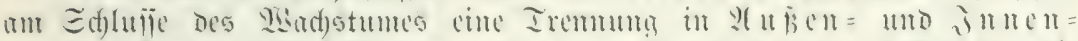

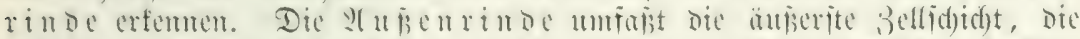

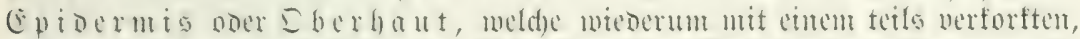

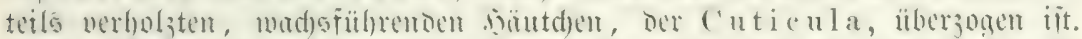

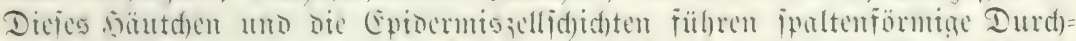

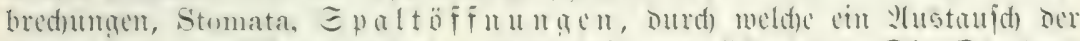

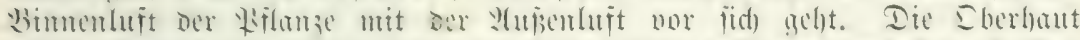

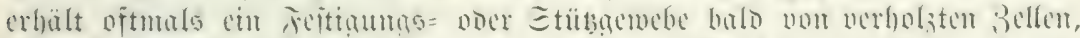
Hypoderm. balo pon Bellen mit quellbaren skmoungen (Collenchym).

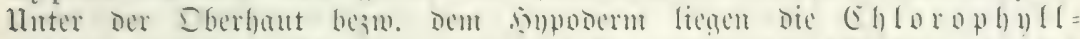

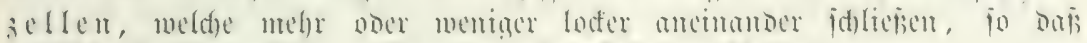

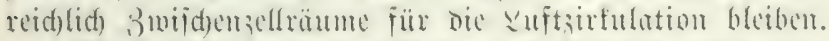

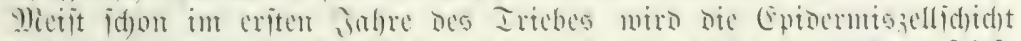

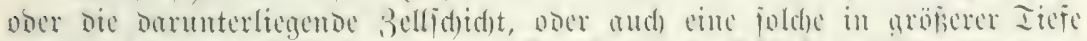

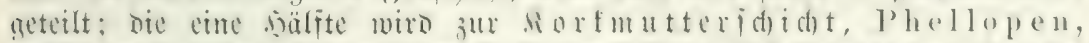

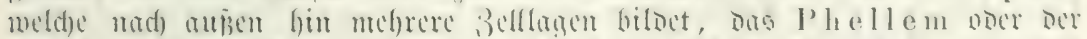

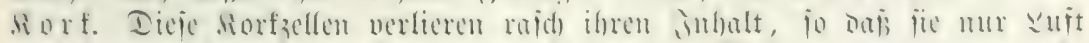
enthalten, verforfor ifre Drimabar.

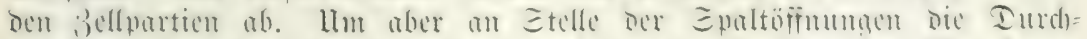

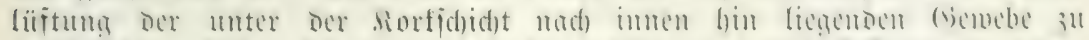

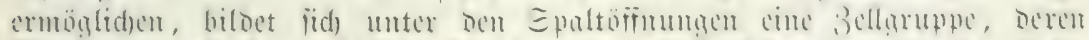

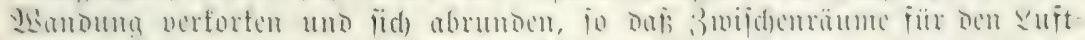

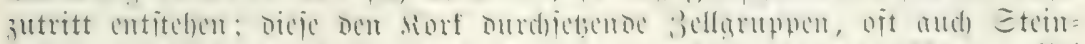

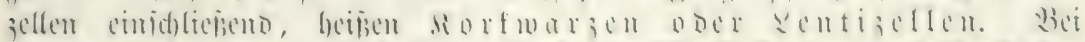

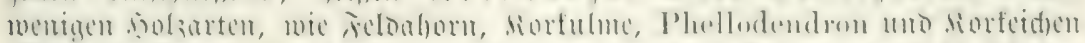

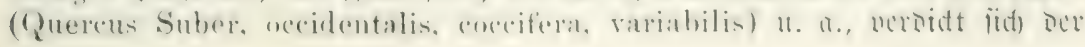




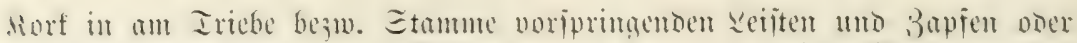

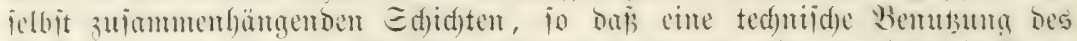

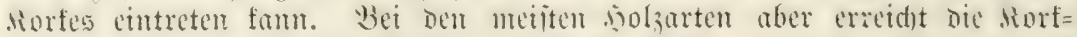

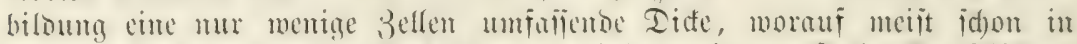

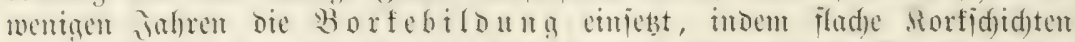

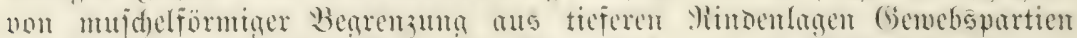

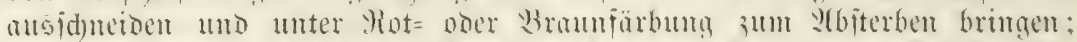

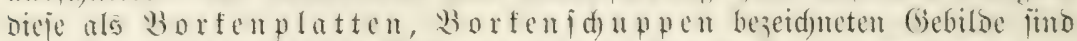

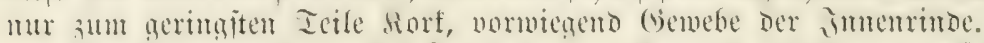

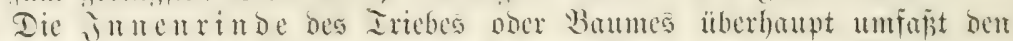

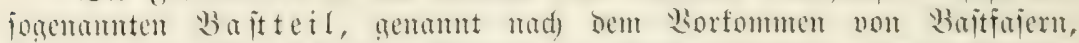

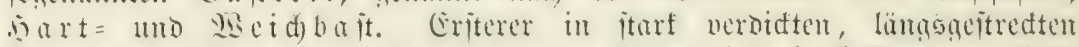
Bellen ausgebiloet, liegt balo in emzelnen Bellen, balo in Bellgruppen, balo

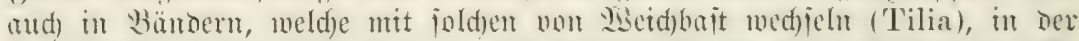

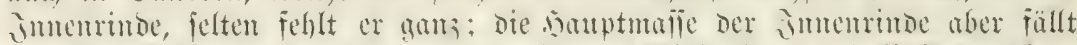

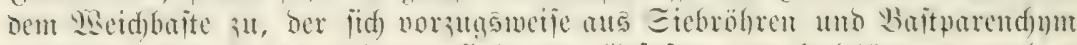

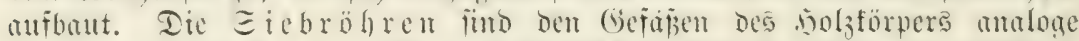

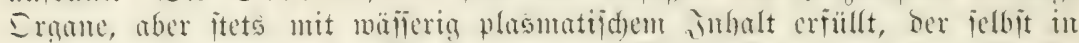

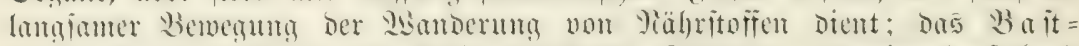
Ha

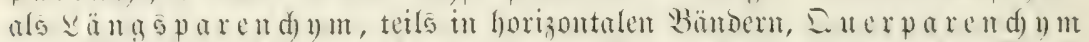

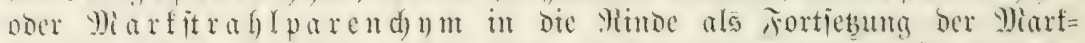

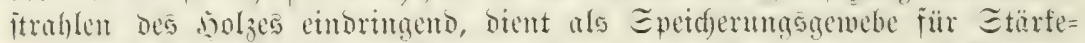

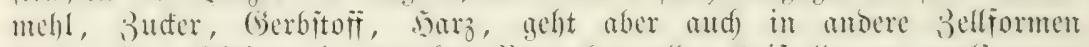

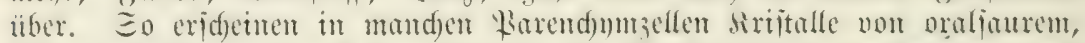

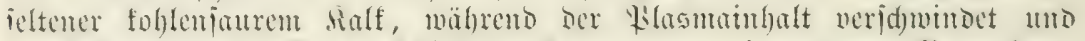

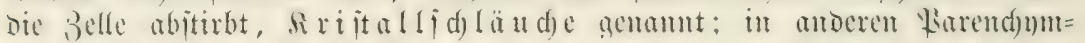

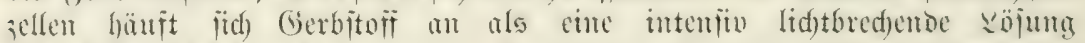

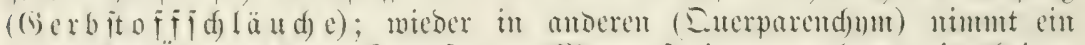

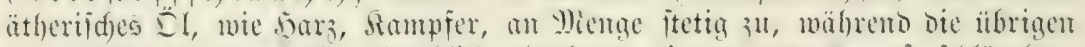

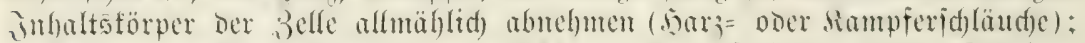

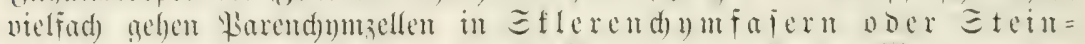
zellen

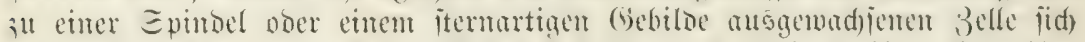

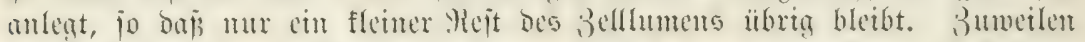

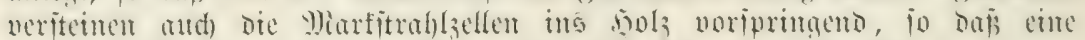

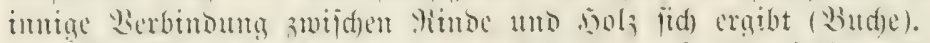

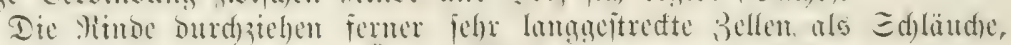

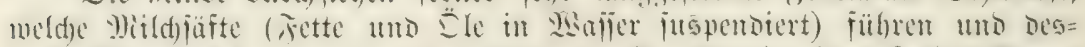

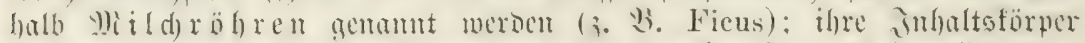

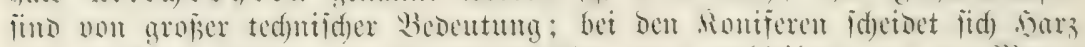

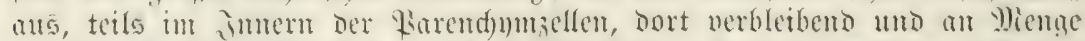

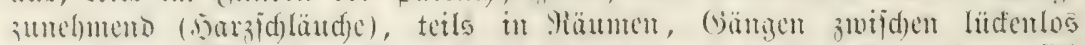

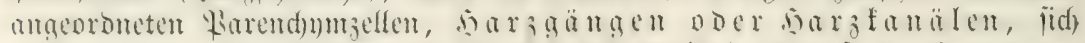

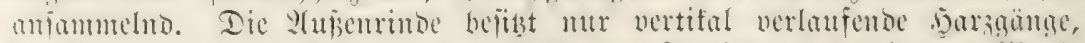

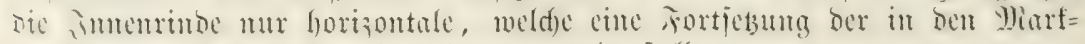

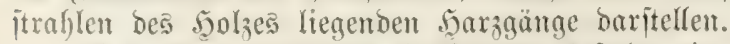

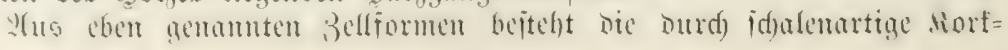




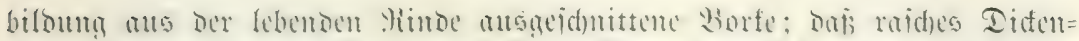

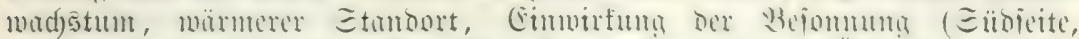

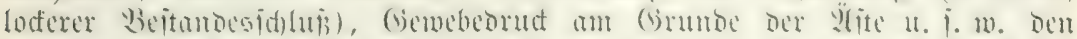

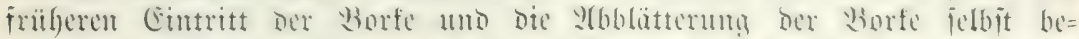

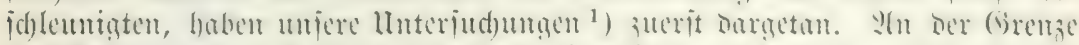

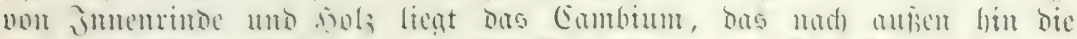

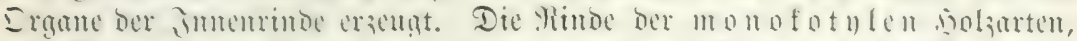

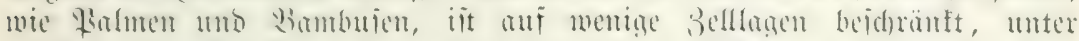

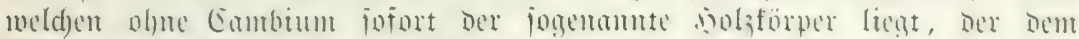

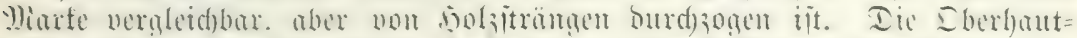

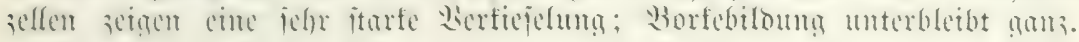

\section{B. Die chemildien, phwlikalifdien und tectirildient

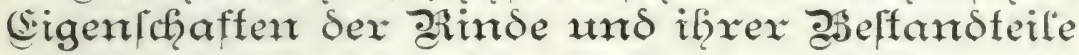

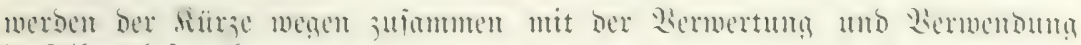
derielben befprodien.

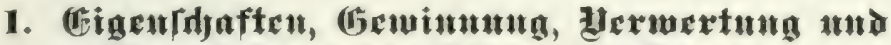

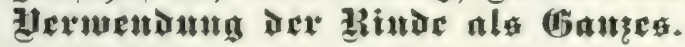

Dex jugcu, gr

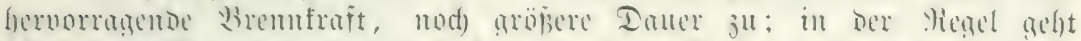

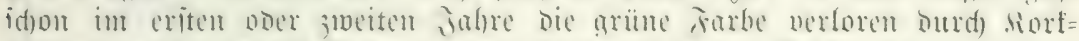

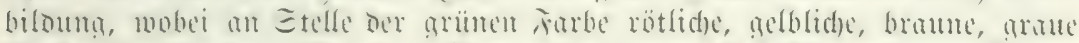

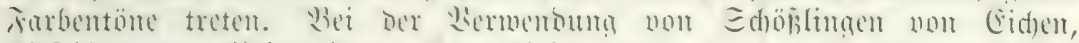

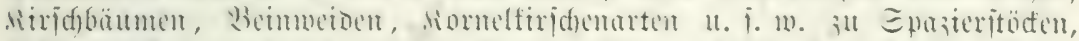

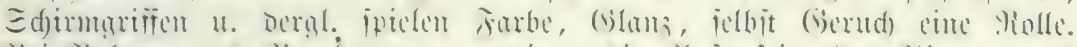

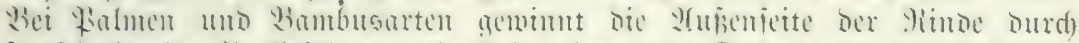

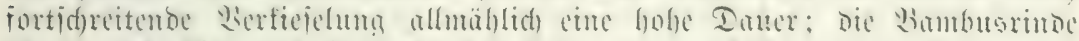

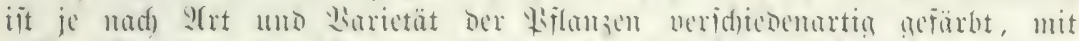

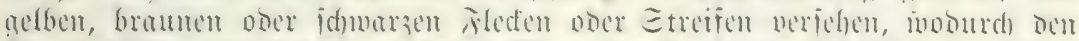

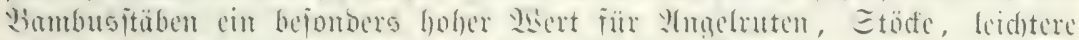

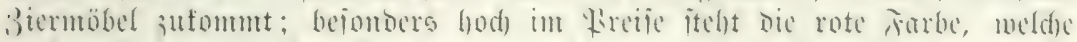

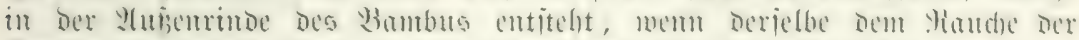

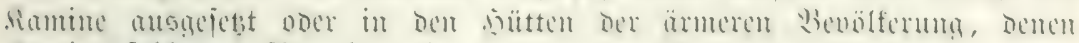
diamine feblen, aufbemalyrt wirb.

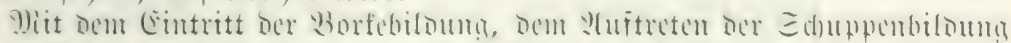

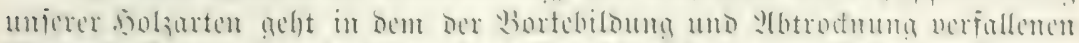

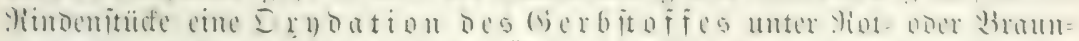

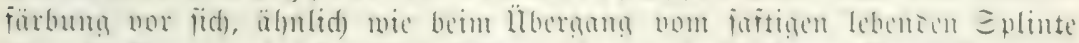

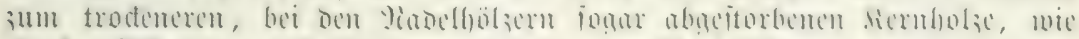

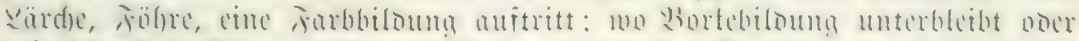

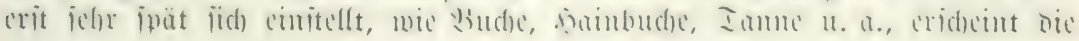

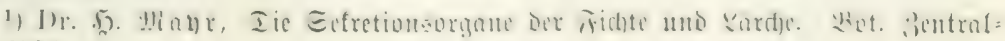




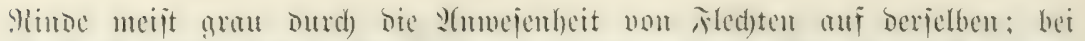

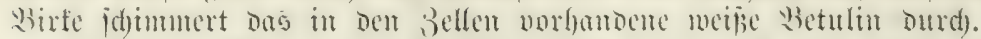

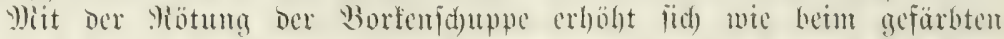

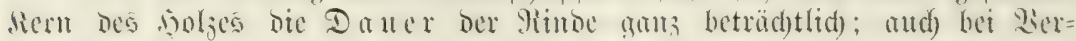

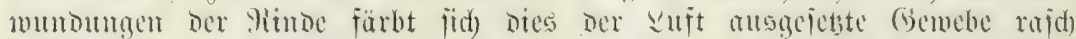

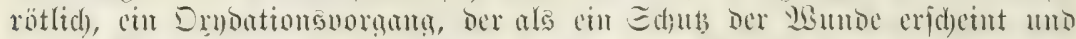

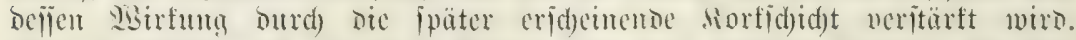

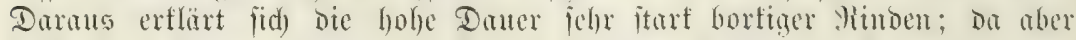

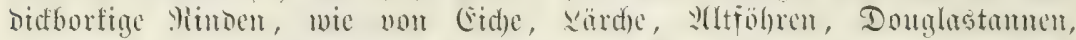

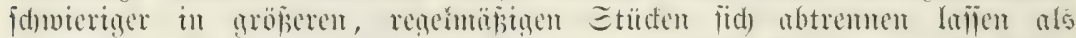

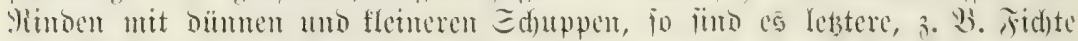

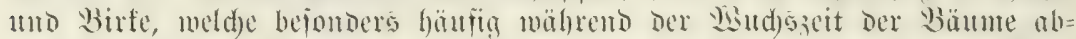

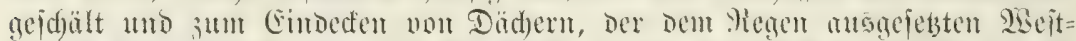

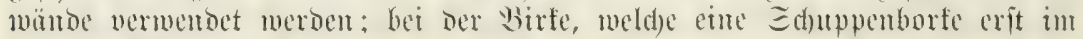

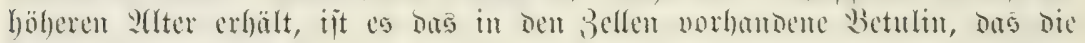
lobe Dauer ber Rinde bedingt.

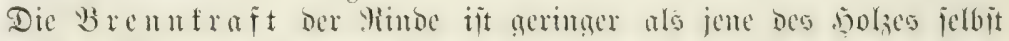

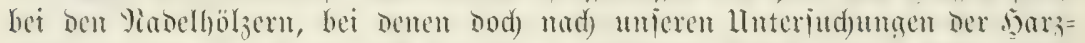

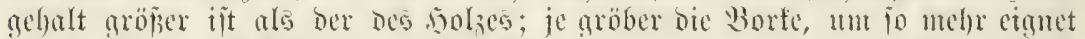

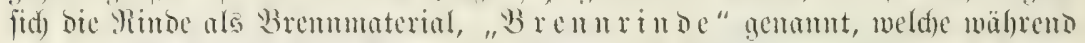

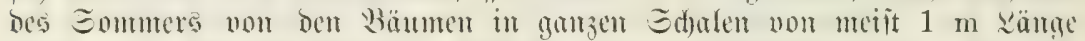

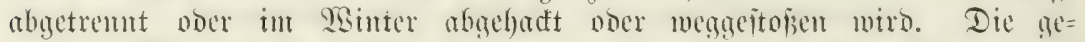

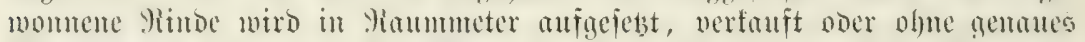

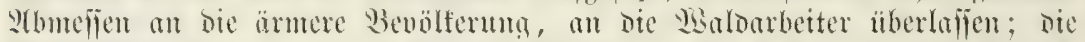

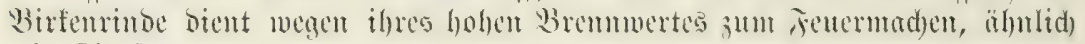
wie Sitripar.

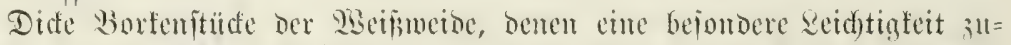

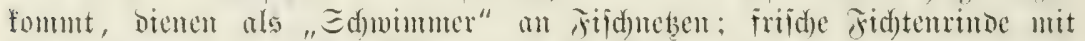

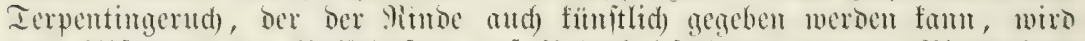

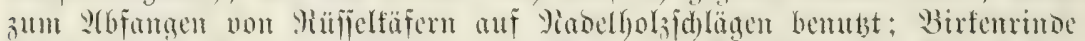

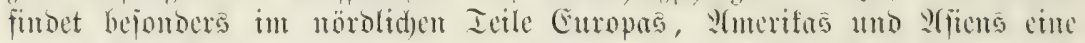

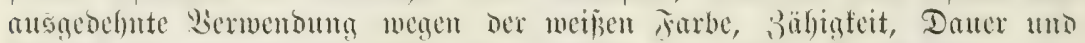

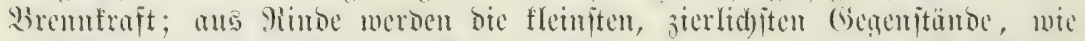

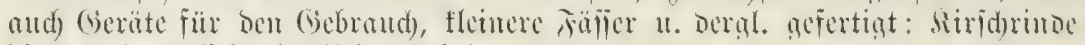
bient gelegentlidy als Sdymutrinde.

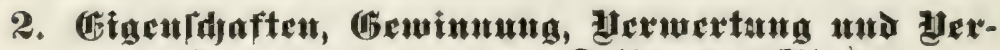

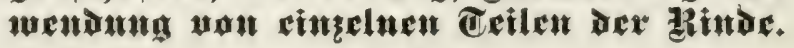

\section{gic (Gerbftoffe ${ }^{1}$ ).}

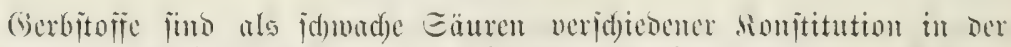

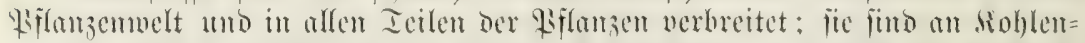

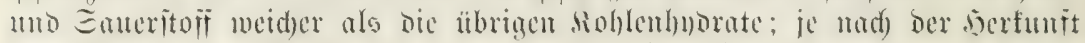

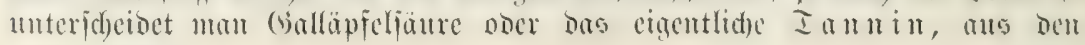

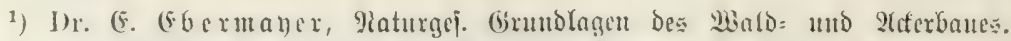

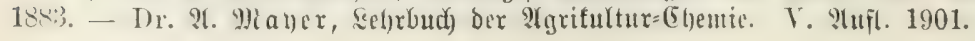




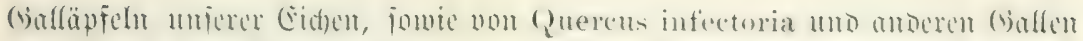

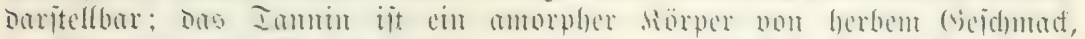

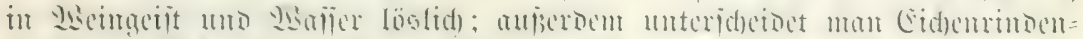

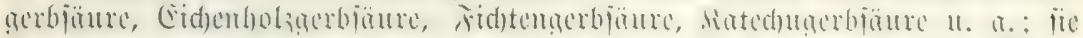

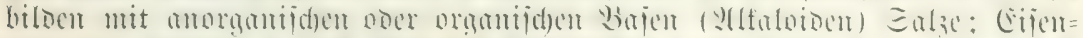

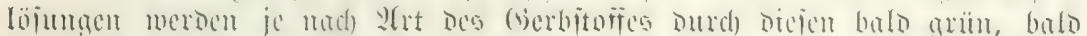

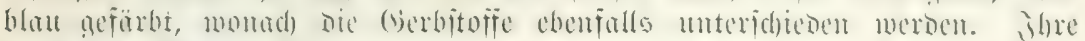

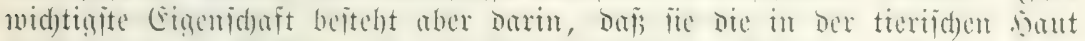

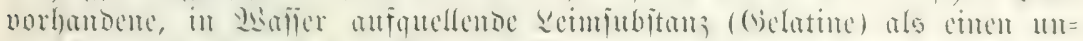

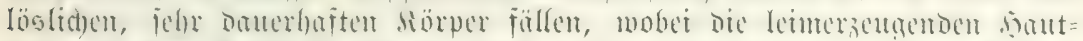

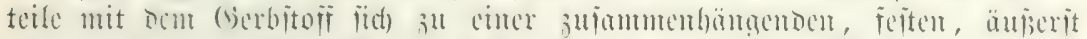

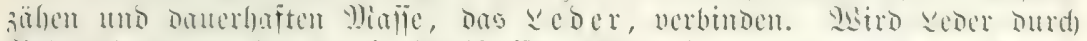

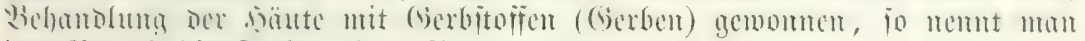
Den Srozen die Soly= ober Rotgerberei.

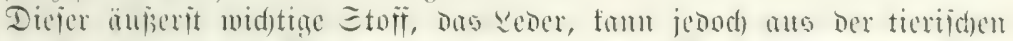

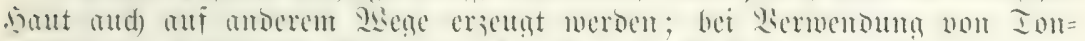

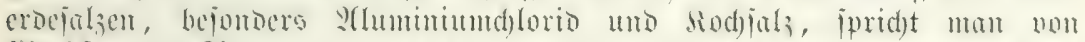

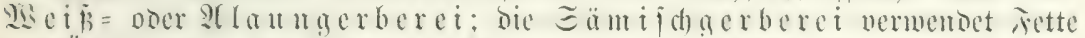

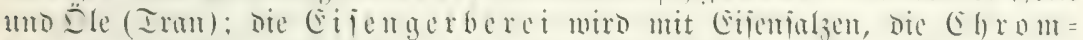

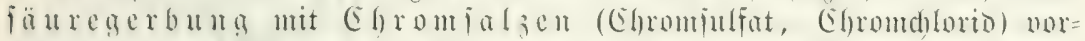

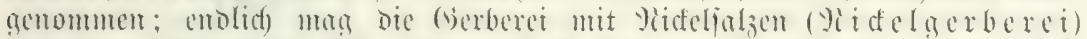

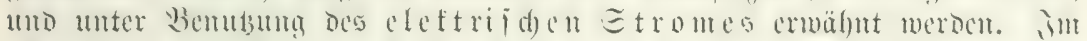

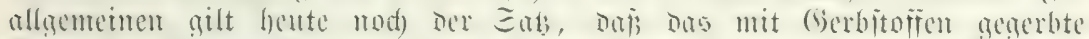

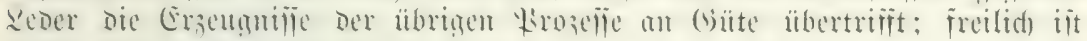
dicjes bejte Reder nud das teuerite.

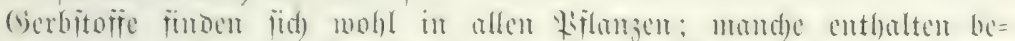

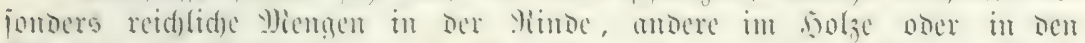

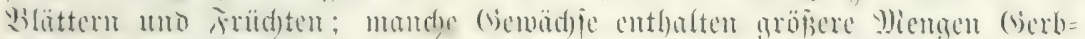

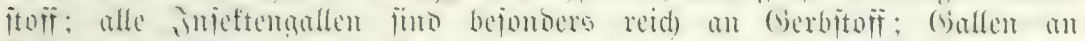

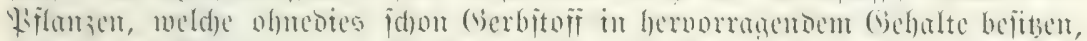

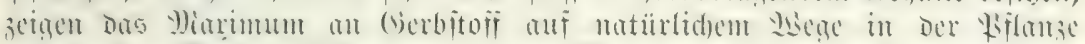

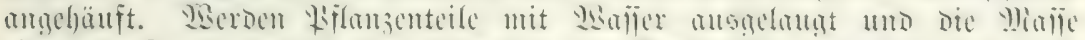

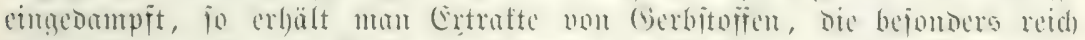

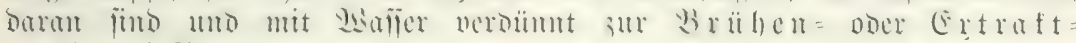
gerberet Berwenturg füben.

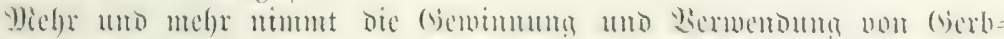

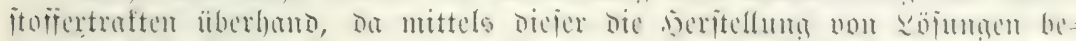

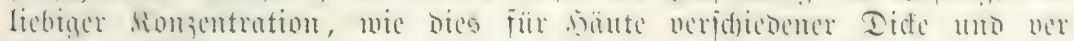

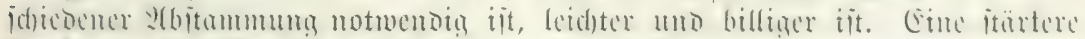

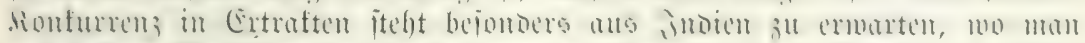

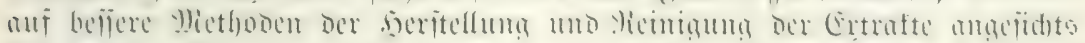

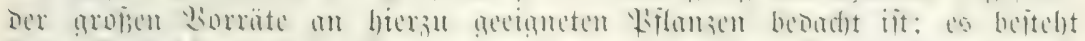

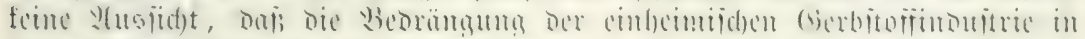
ber näd)iten Butunft nad)lafien werde.

Die widstigiten Gerbuaterialien fitmmen von folgenton

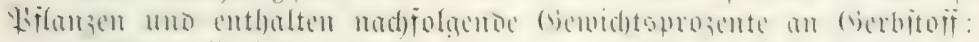

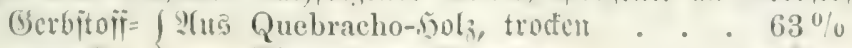
cretratti $\{$, Rhizophora llamele. 


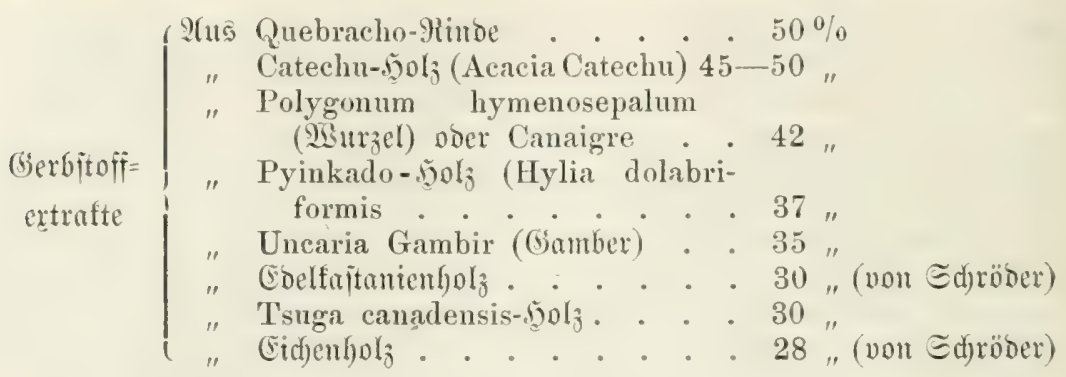

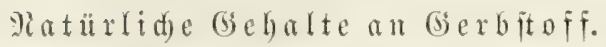

(E)mejiad)e (bullapfel (jap. Gobaishi), impeftentallen an Rhus semiolata

Nimoe won Rhizophora Mangle (ano Deutid)=Eitufrifi) . . Trillo, Die Eduppen Der Bedder (Dalonea) von Quercus Aegylops utto macrolepis.

Minoppern, Gallen an Den iruditbed)ern non Quereus pedunculata,

Cerris 11.

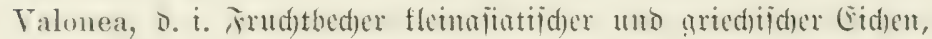

Quereus Aegylops u. a.

$70 \%$

Dividivi, Edjoten von Caesalpinia coriaria. . . . . . 35

Rhizophora Mangle und mucronata-5ol3 . . . . . . 30

(anaigre, Sisurich non Rumex hymerophyllum (von Edyrober)

Myrobalanen, jrüdte von Terminalia ('hebula, bellerica u.

Quebracho-ñola (Quebrachia Lorentrii. Loxopterygium L.) .

Eid)enfoiegelrimbe beiter Dualität

gimbe von 40 jähriger eitde.

Garobille, Rinde vou Quereus coceifera : -

Bablah, Ed)oten von indifd)en $2\left(\mathfrak{f}_{3}\right.$ ien . . . . . . . 17

Vimo von Quereus densiflora und Pirea Engelmanni . . 16,5

'Tsuga Mertensiana .

15,1

Quercus Ilex

Alnus glutinosa

14,6

Pseudotsuga Douglasii .

13,4

Terminalia tomentosa (Indicr) . . . . . . . 13

, Tid)tenrinde von 25 jährtgen Etämmen

Rintoé vout Casuarina equisetifolia.

Tsuga canadensis . . . . . . . . . 10

2llteidentrinde.

Yinde non Meiserle 
Minto vou Quercus rubra Ulmen

Edelfatante

Datidic (balläpicl (cyips-(ballen an vilättem)

Himbe von Quercus Cerris

$4,6^{0 / 0}$

4,5

4 ,

$+$

4 ,

4

3,5

Mofifaitanie

(eid)e

Bude

särdoe

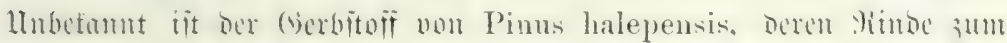
Gierben bient.

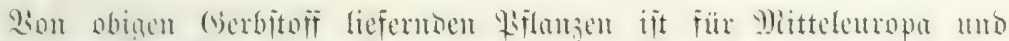

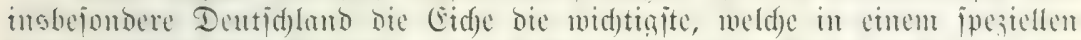

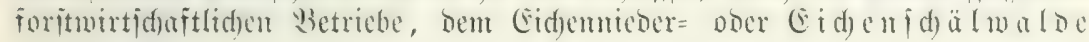
genubgt miro.

\section{Dex (serbitoff ber Jungeidentube 1 ).}

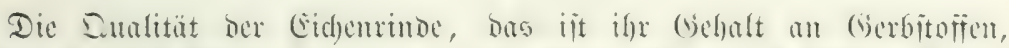

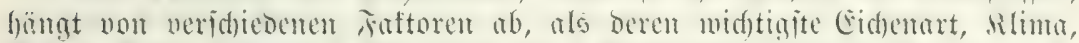

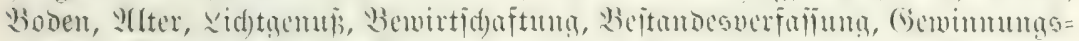

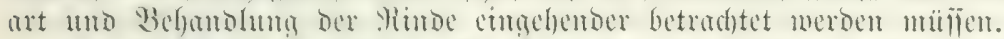

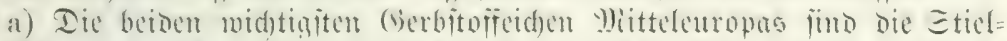
cidfe (Quereus peolumenlata) und dic Irubencidec (Quereus sessiliffora):

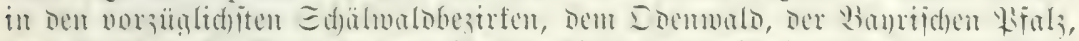

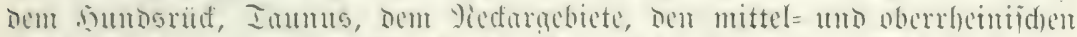

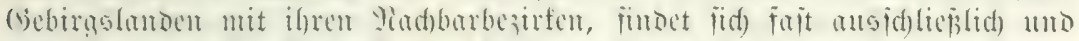

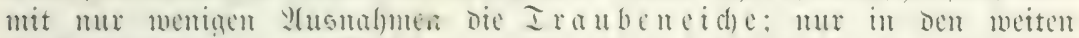

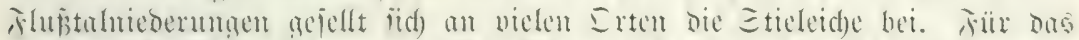

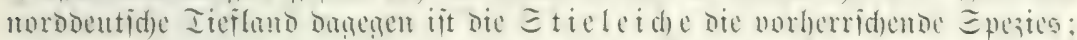

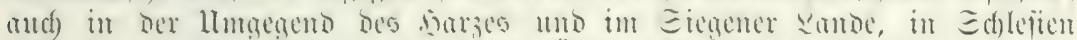

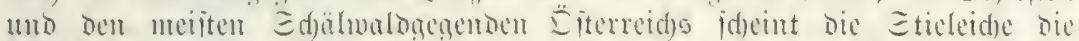

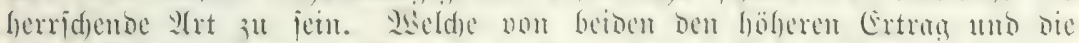

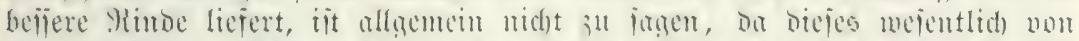
bem llmptambe abfämet, ob Dic ipe;iclle

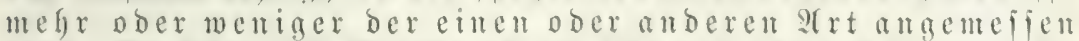

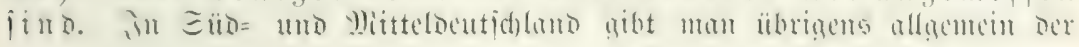

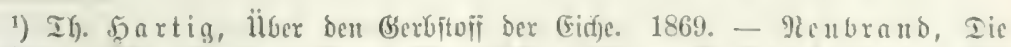

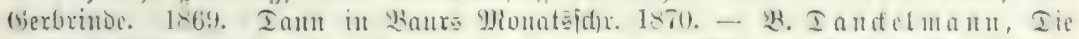

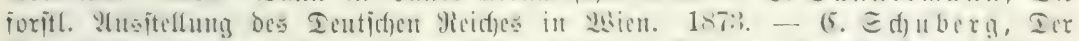

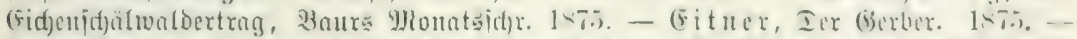

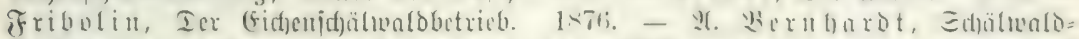

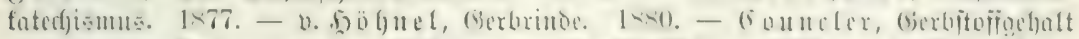

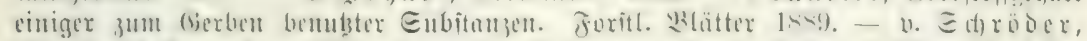

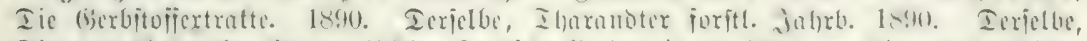

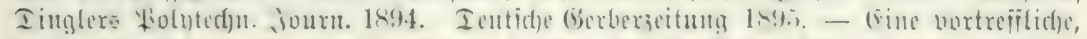

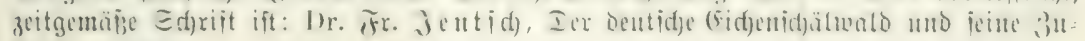
futıt. 1899. 


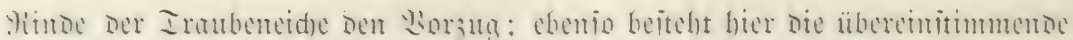

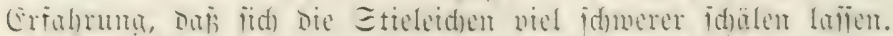

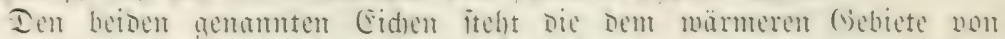

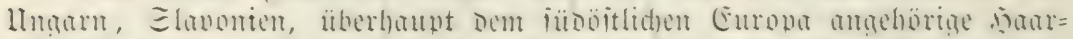

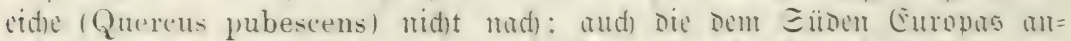

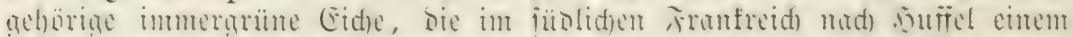

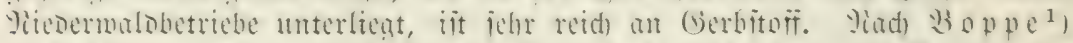
mirs Quercus Tozza mit aleidem \&onteile bemuts: Quereus Cerris. Dic

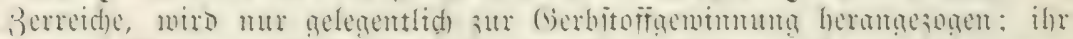

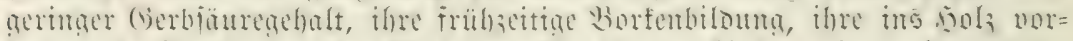

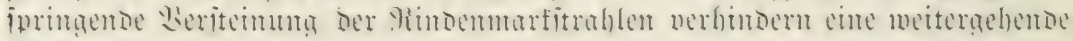
germentoug.

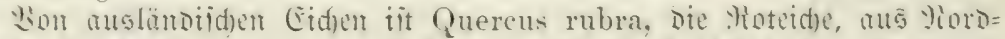

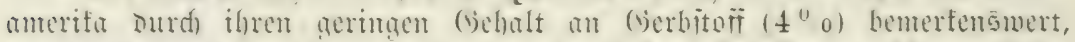

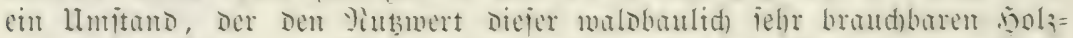

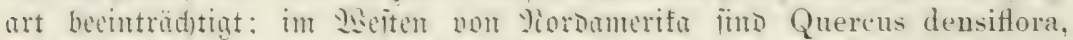

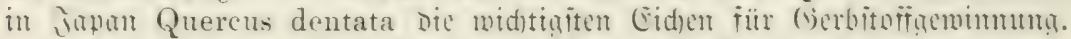

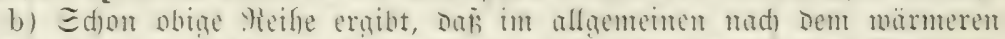

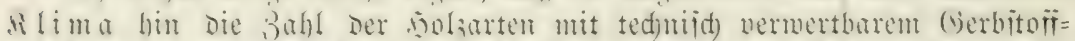

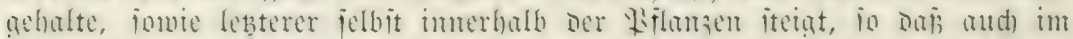

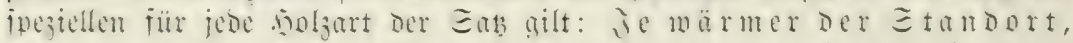
un jo reider it ber Gebalt ber gitube un bes golzes an

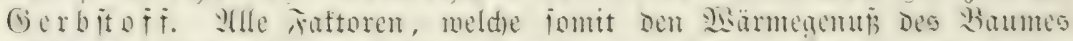

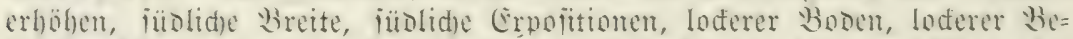

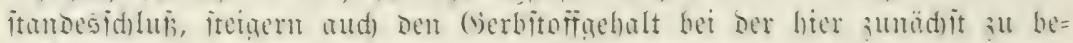
trad)tenben Cidbe insbejonbere in Der Minbe.

3u ben lieiten Edälmalobezirfen Icutidfando gefört Das milde I a gebiet

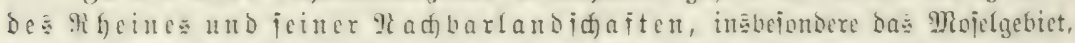

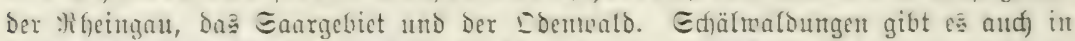

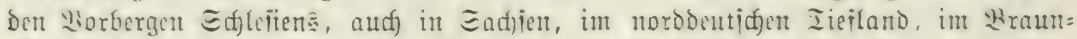

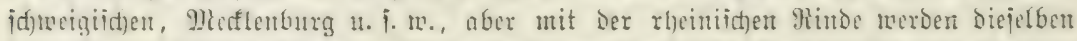

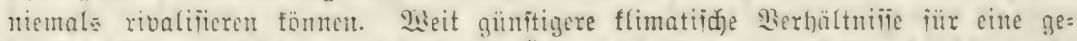
Driflid)e :Hindenzud)t bieten viele Bezirfe Ëiterreid)

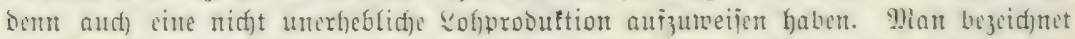

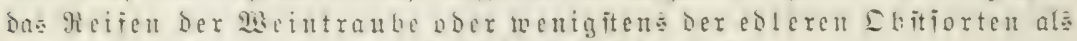
flimatiod)e besingung für cine gebeiglid)e (Fid)enlohproduttion.

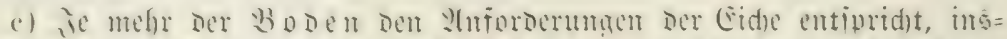

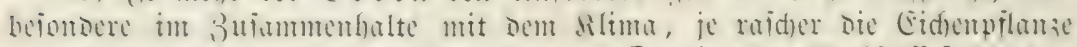

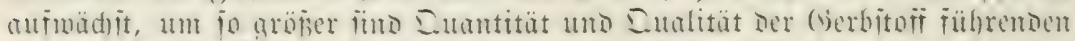

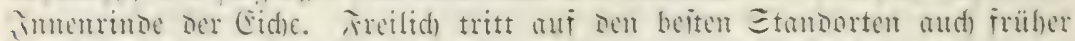

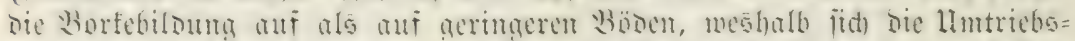

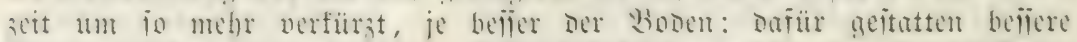

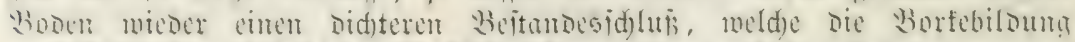

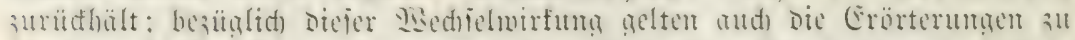

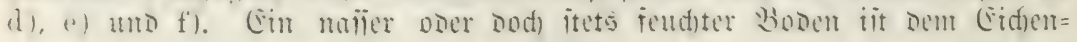

1) L. Boppe, Cours de Technologie forestière. 1887. 


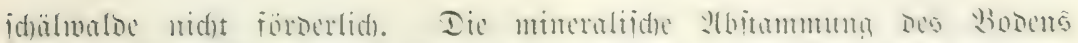

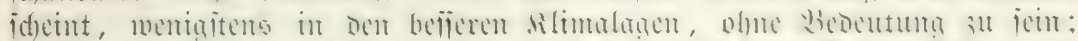

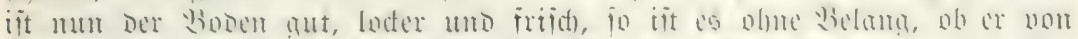

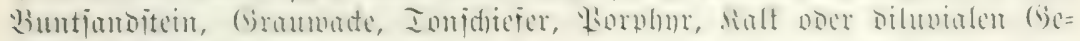
bilbert abjtammt.

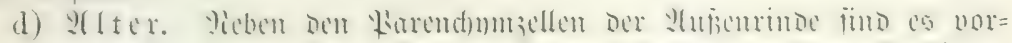

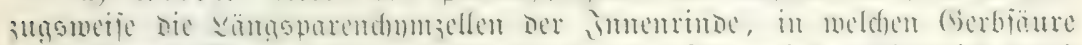

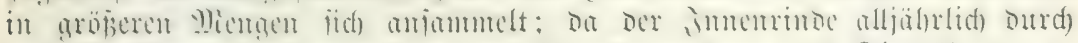

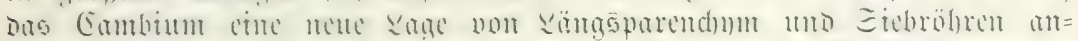

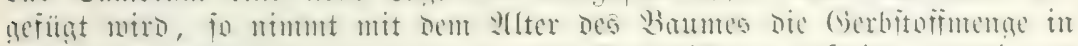

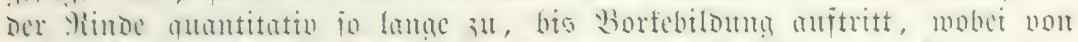

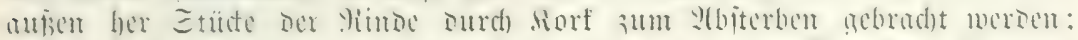

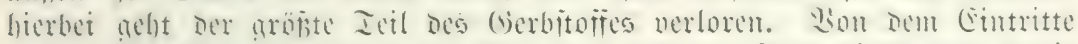

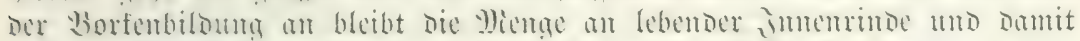

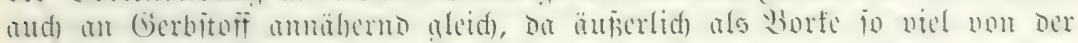

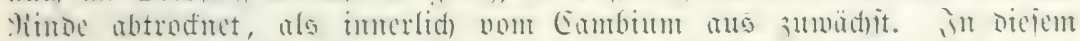

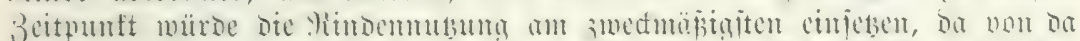

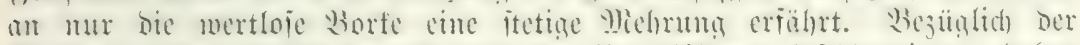

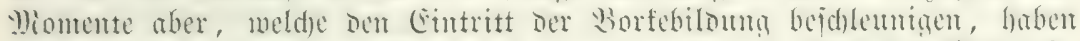

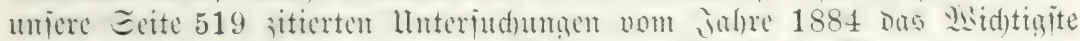

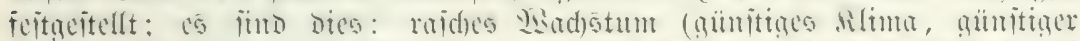

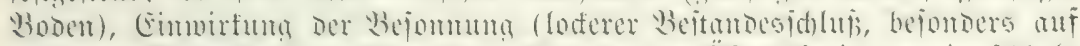

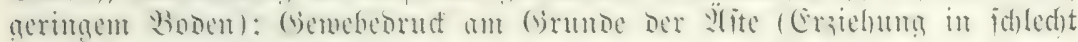
geid)loijenen, ajtigen Beîtänben.

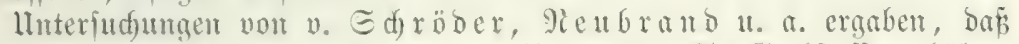
25 jüfr. bejte Cidjenrinbe bis zu $21,0 \%$ Gierbitoif enthält,

40

80

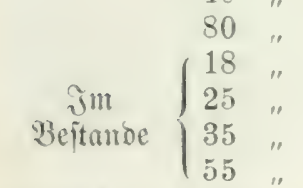

Freīteheno, $\{55$

unterorïut $\{55$

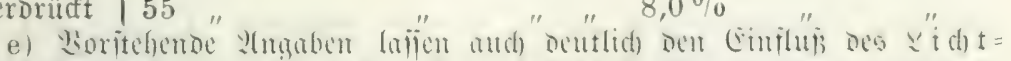

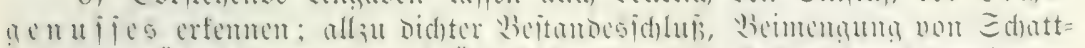

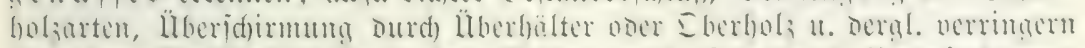

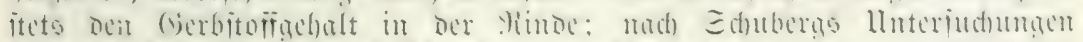

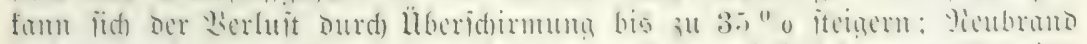

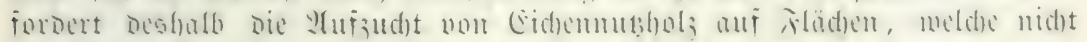
ber Gerbitof̈genimumag gewiomet jüb.

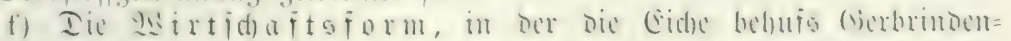

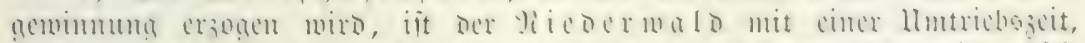

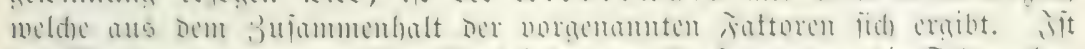

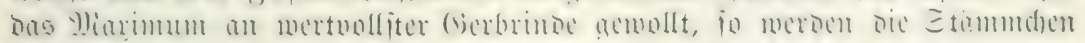

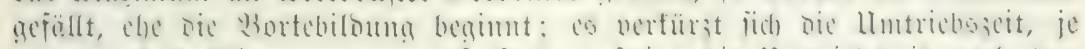

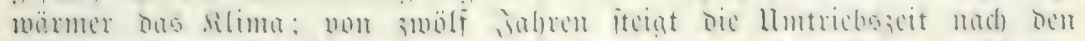

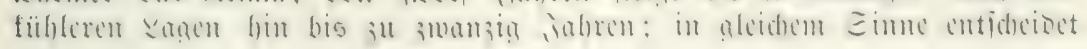




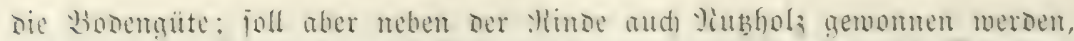

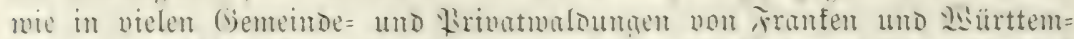

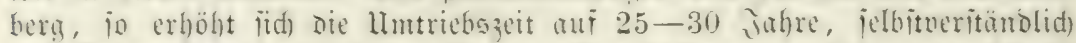

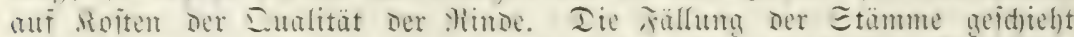

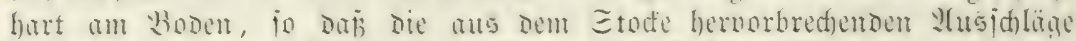

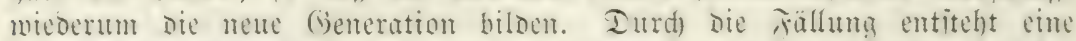

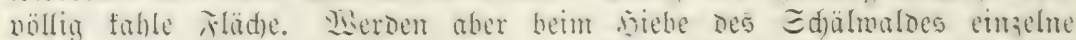

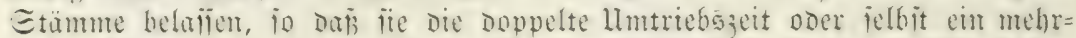

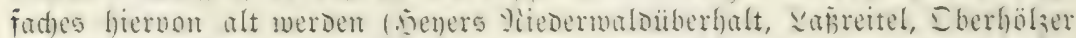

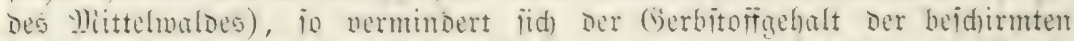

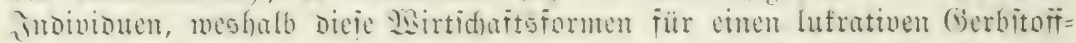
betrieb ungeeignet jüb.

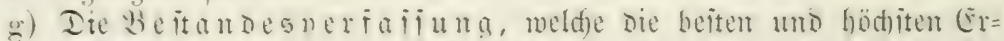

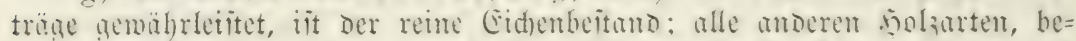

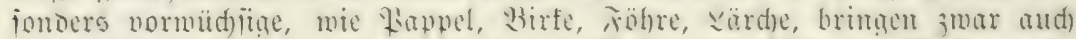

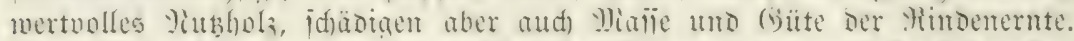

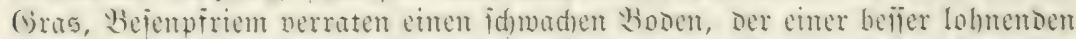

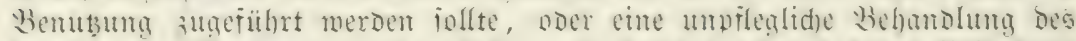

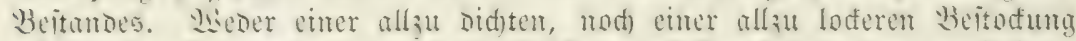

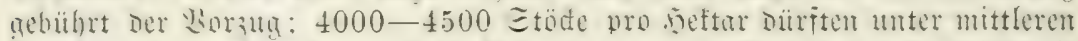

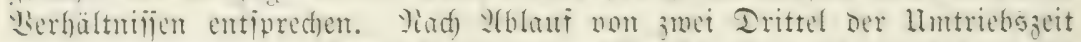

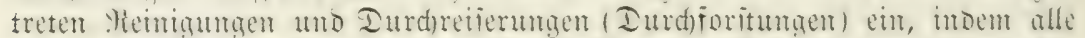

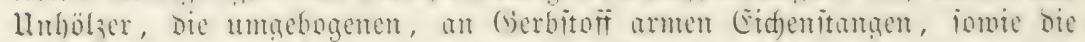

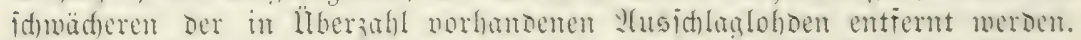

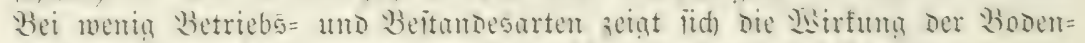

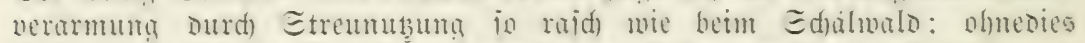

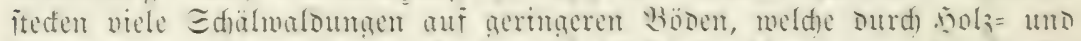

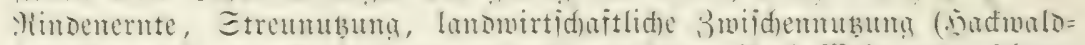

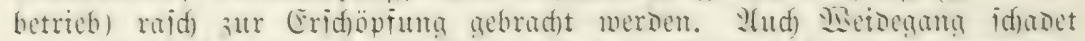

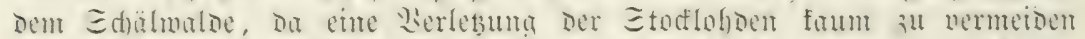

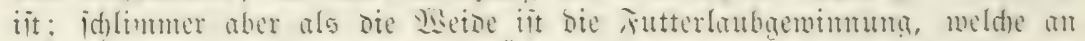
eirigen Drten an 9)ittelrbein in llbung ijt.

2lle genanuten llmitünde enticheiom über ben Gehalt Der Rinde an Gerbitoff. iomeit bie firobuftion in Frage fommt: aus Den vorliegenden zaffreidfen Gerbiüure=

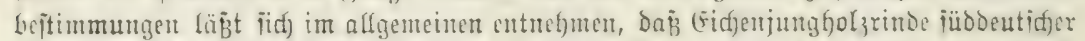

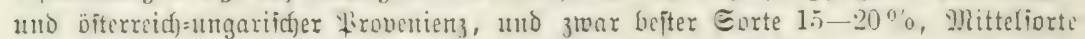

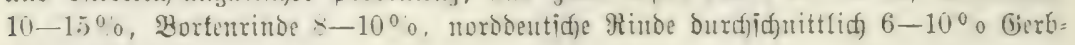
jüure entfortten.

沗 aud) bie (5) w

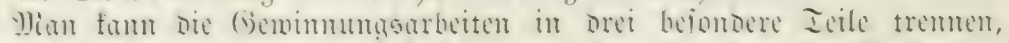

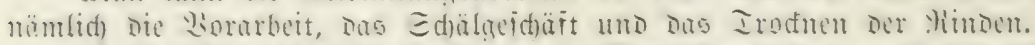

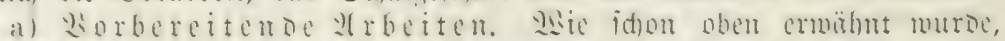
firnot

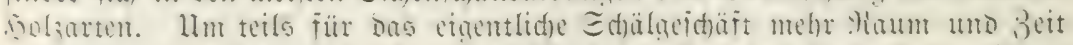

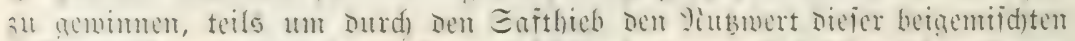

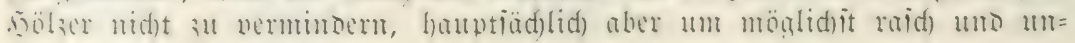




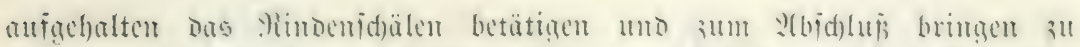
fömten - miro in Des ;

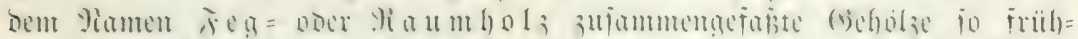

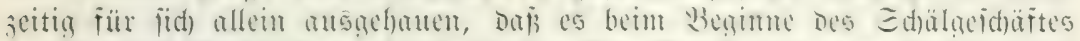

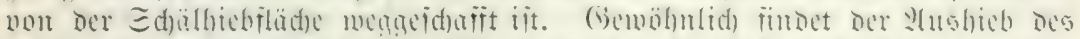

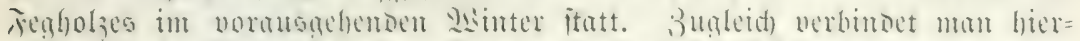

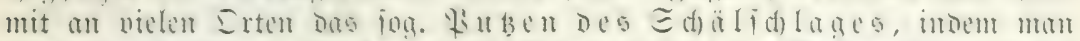

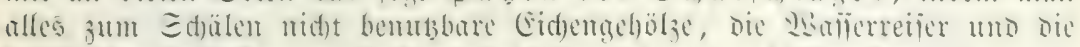

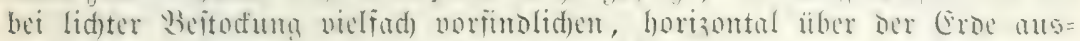

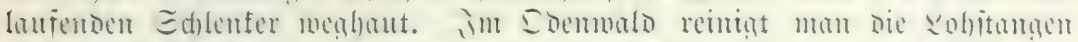

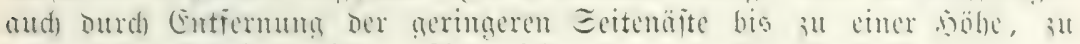

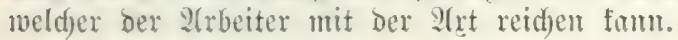

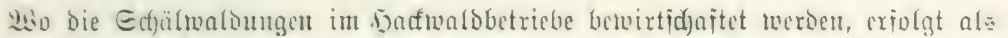

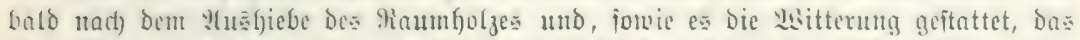

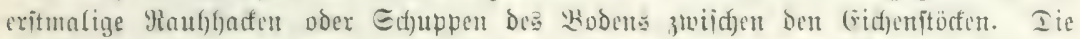

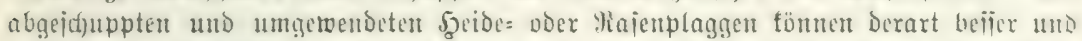

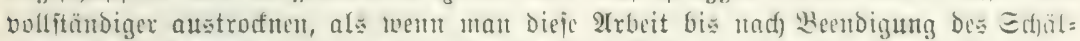

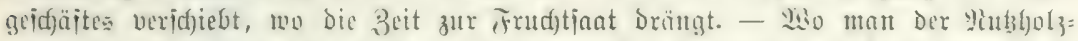

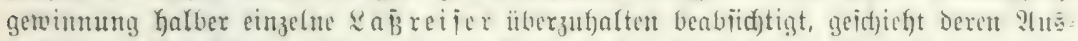

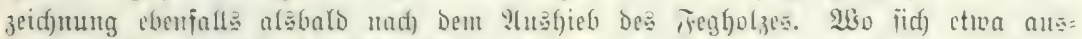

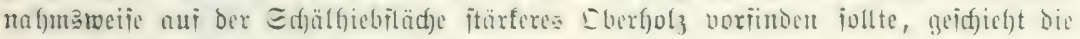

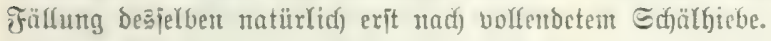

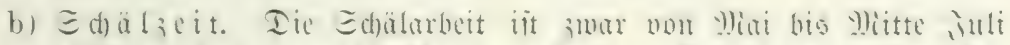

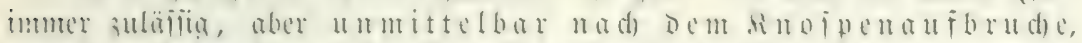

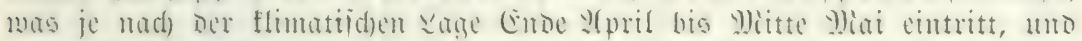

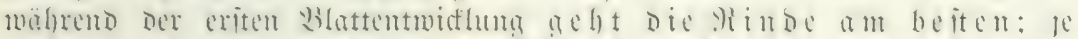

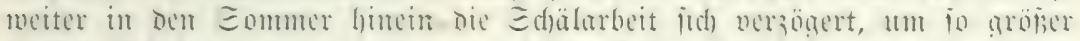

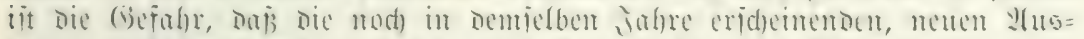

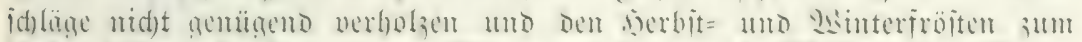
Epfer fallen: féd)te, marme

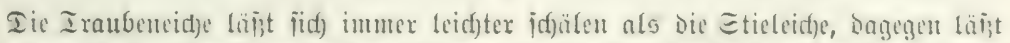

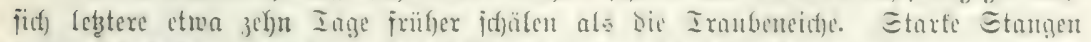

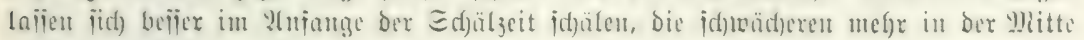
und gegen (Ende derielbeu.

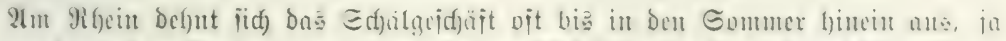

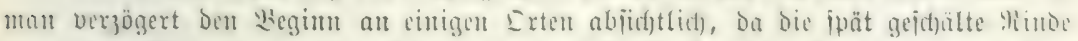

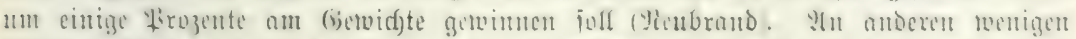

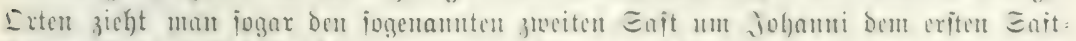

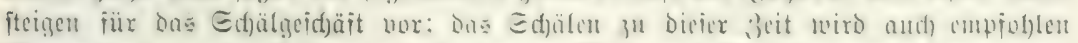

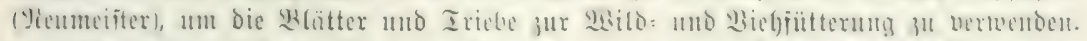

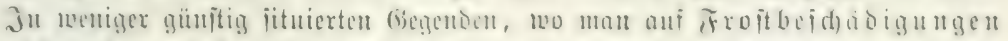

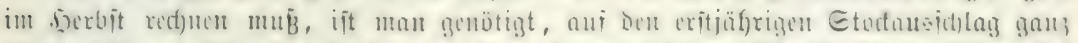

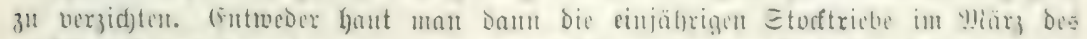

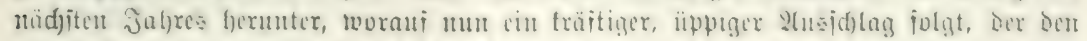

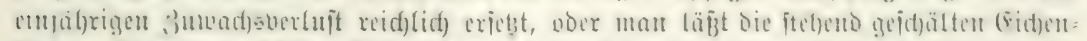

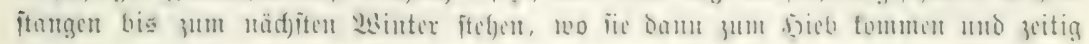




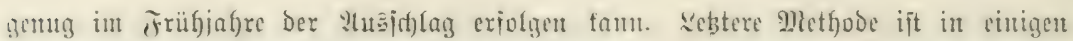

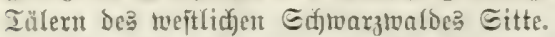

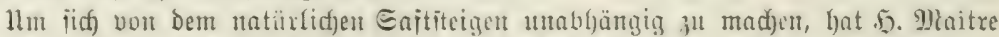
in Fari bie Ermeidung ber Kinden mitel Ia mpi mit gutem Eriolge ver=

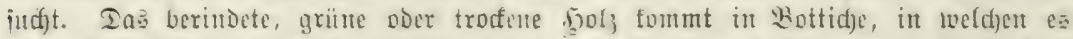

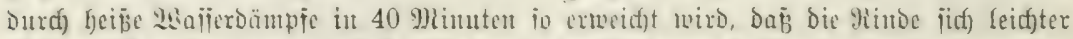

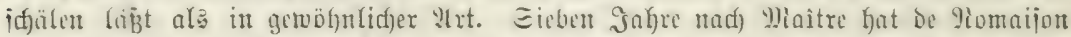

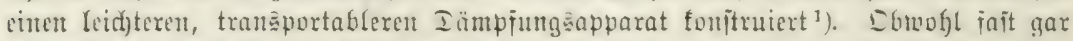

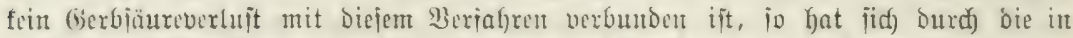
Pari angejteffen Beriudye und (Erjafrungen Dod) ergeben, Dab bie fümitlid) cntrindete

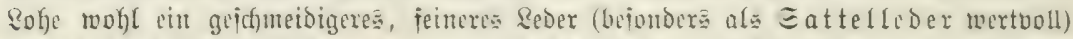

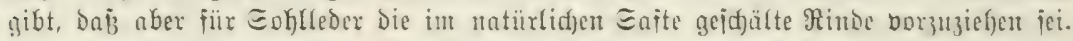

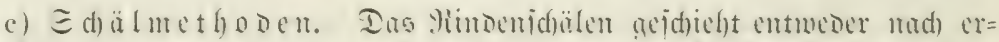

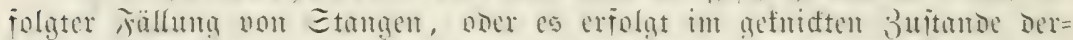

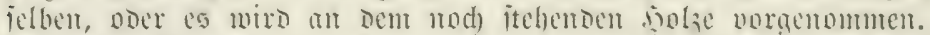

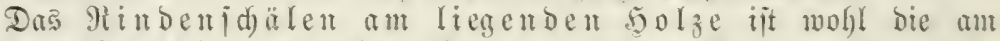

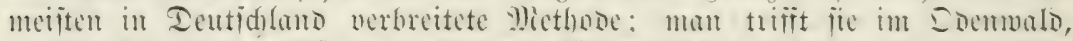

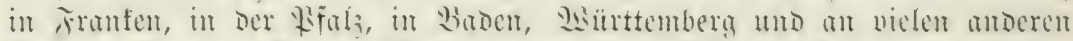

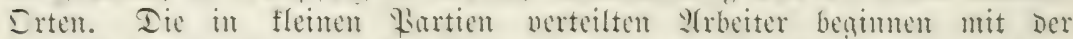

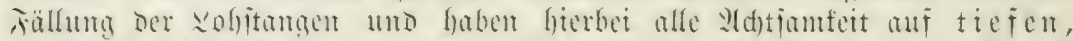

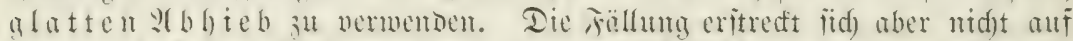

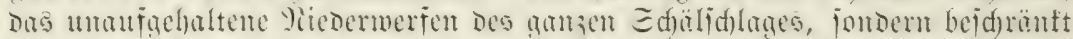

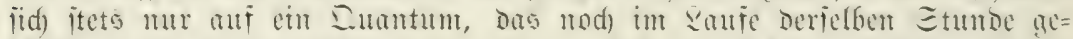

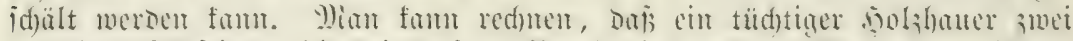

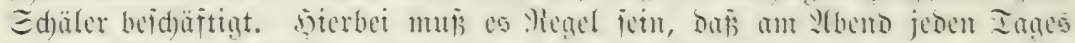

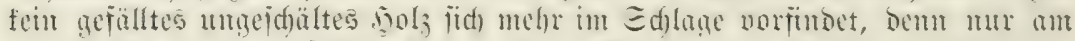

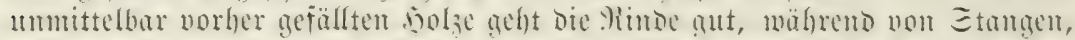

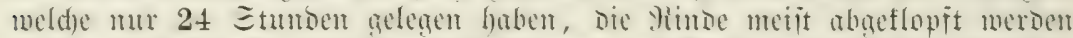

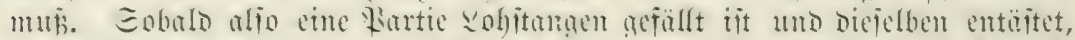

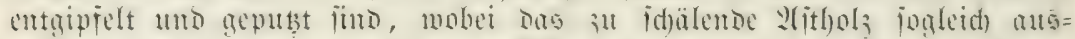

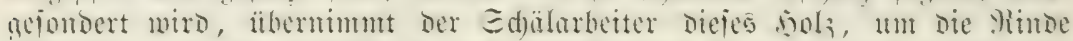

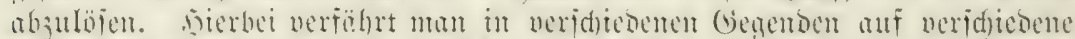

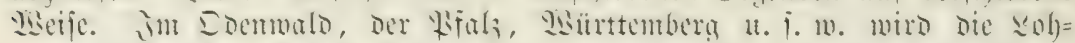

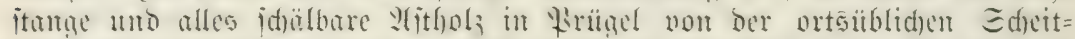

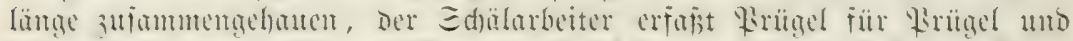

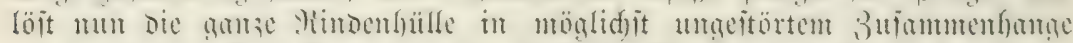

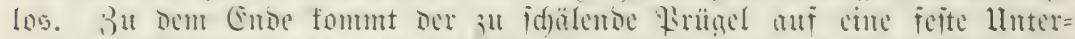

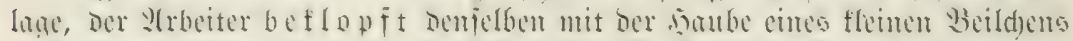

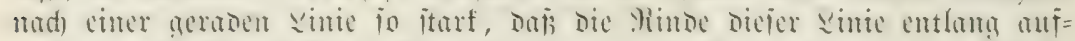

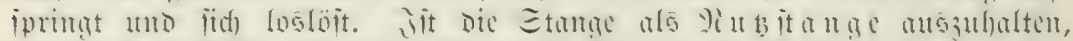

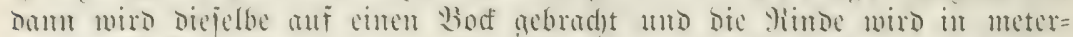

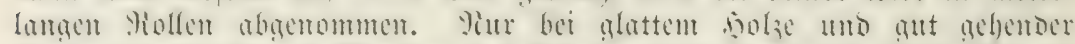

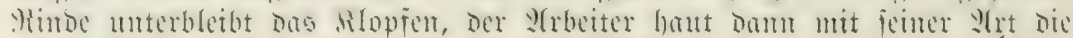

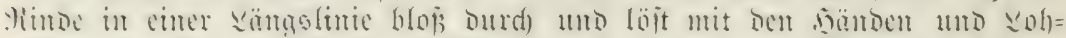

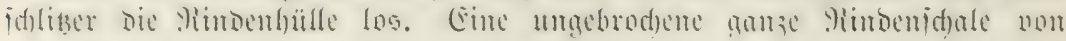

1) H. Nanquette, Cours de Technologie forestière de L. Boppe. 1887. 
ortsüblider 玉 S d) a le 11. i. w.

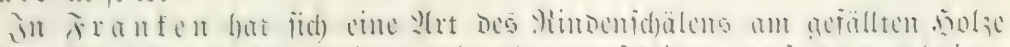

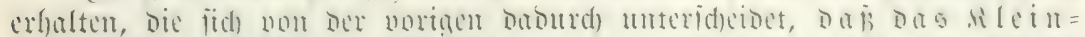

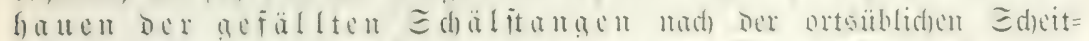

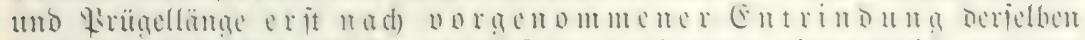

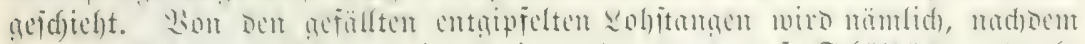

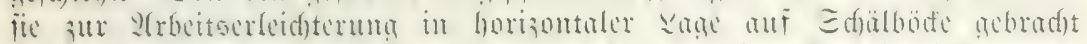

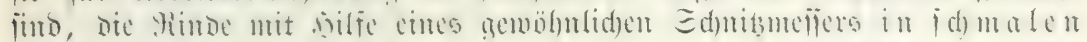

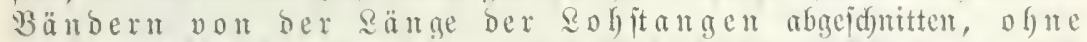

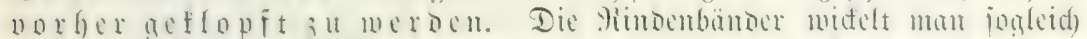
iu jog. jammen und uberläjt jie jo bem Irodnen.

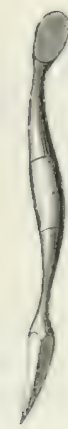

j̀ig. 300. Soblöiel.

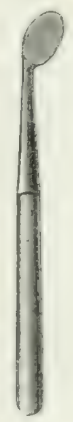

rig. 301. Dillenburger sohlöifel.

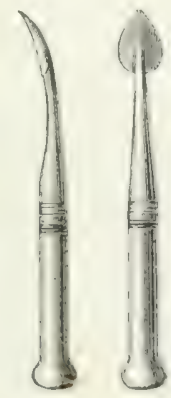

fig. $30^{\circ}$. Mohmannder Röfier.

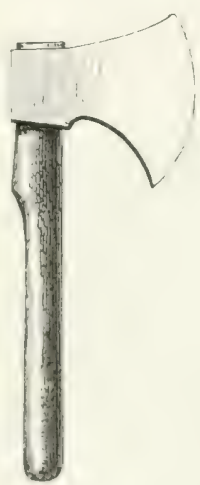

jig. 303. Eberbadier Beir.

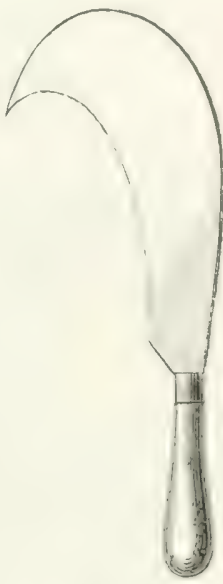

jig. 304. Mohmannide sieppe.

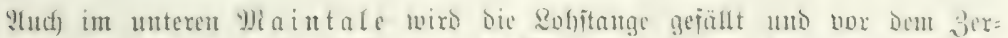

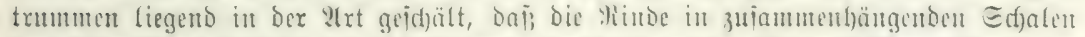

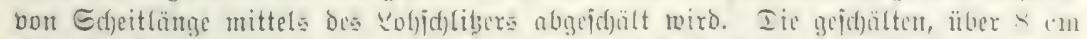

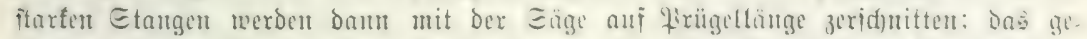

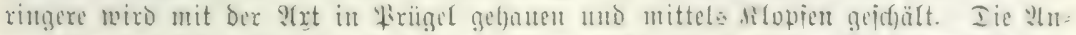

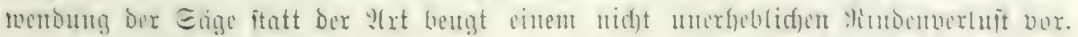

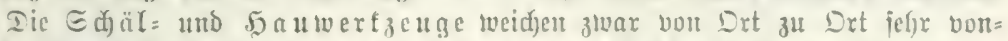

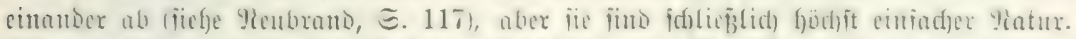

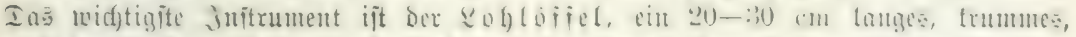

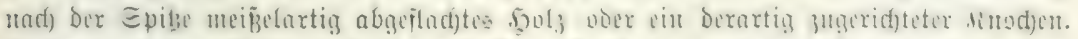

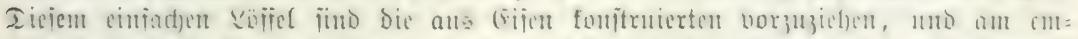

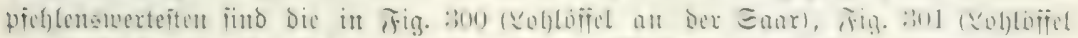

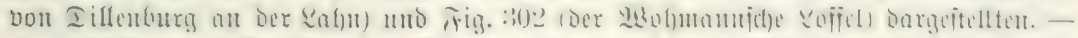

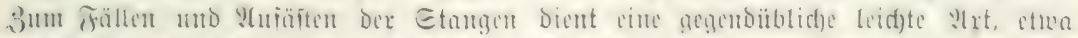

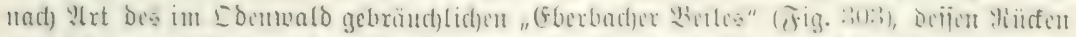

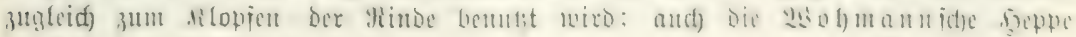




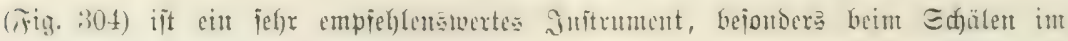
jtekenden 3uitande.

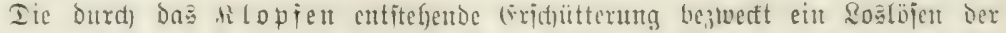

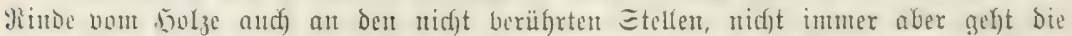

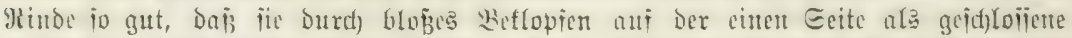

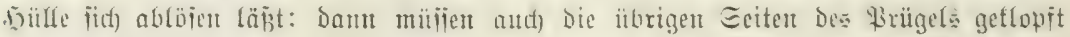

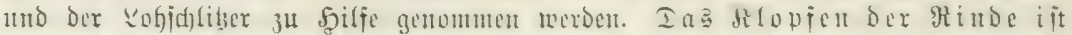

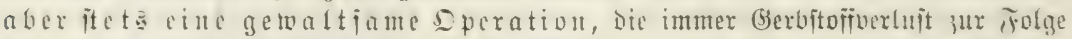

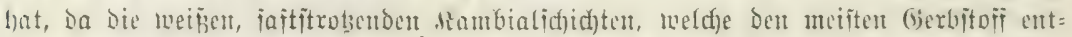

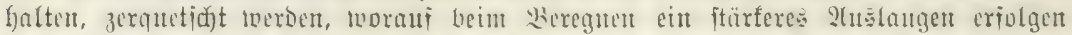

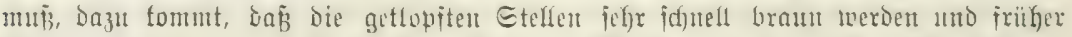

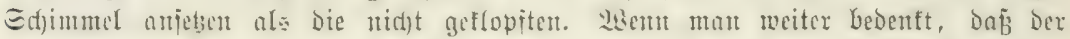

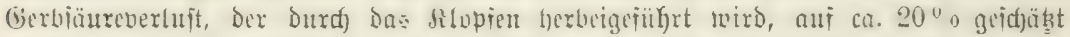

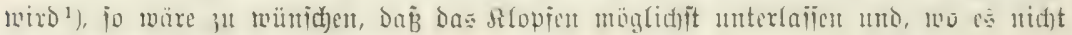

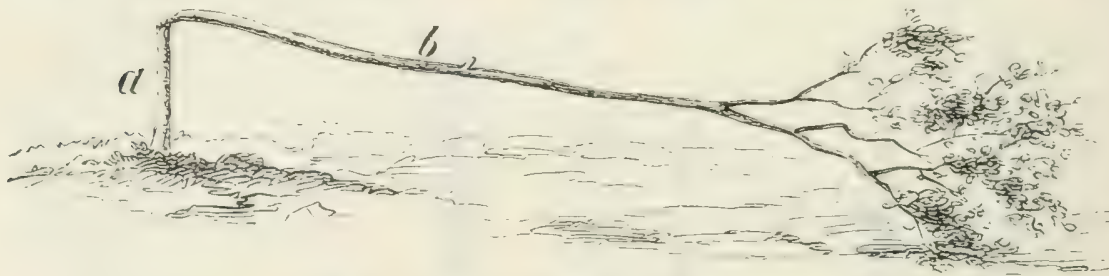

Jig. 305. E(t)älen ber Minde am gefuidten Srolje.

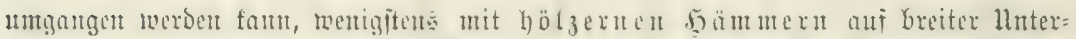

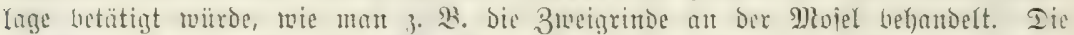

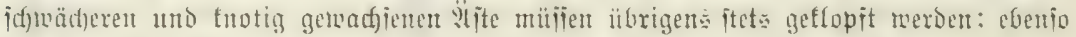

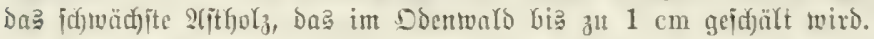

Das Kindenjüblen im gefuidten Etande ber Etange ijt

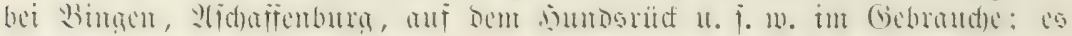

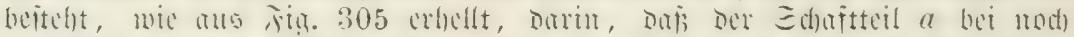

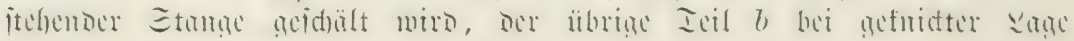
Der Stange.

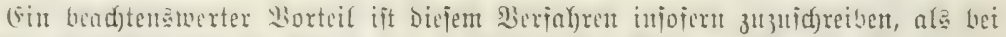

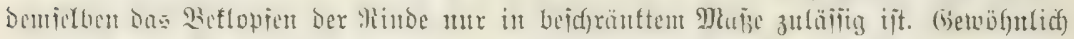
mirb fier die linde in fangen Etreifen und ganzen Edjalen, wie beim polgenden Beriahren, abgelöit.

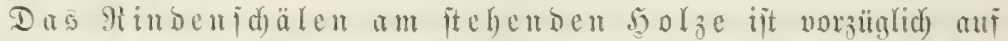

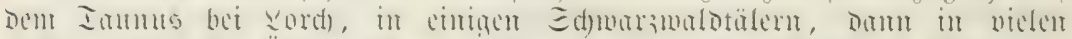

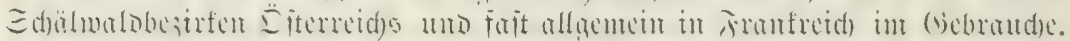

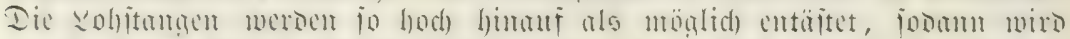

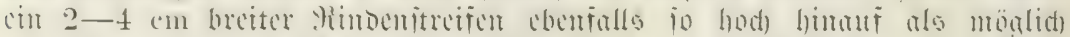

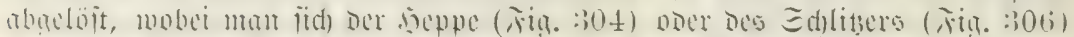

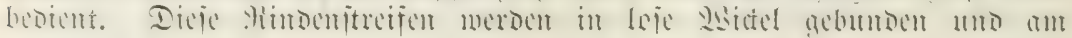

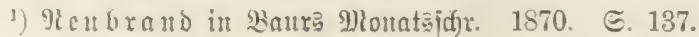




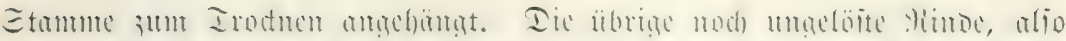

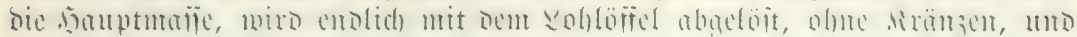

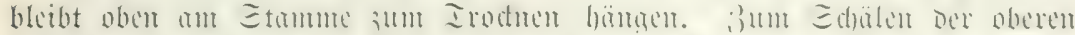

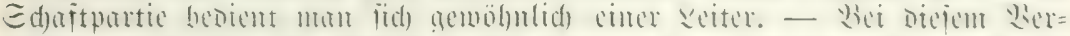

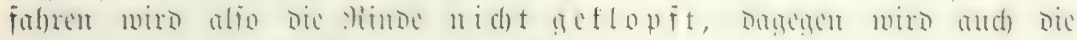

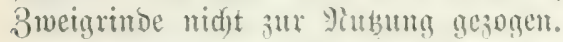

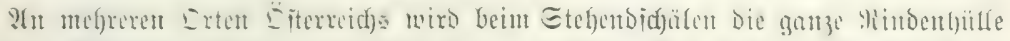

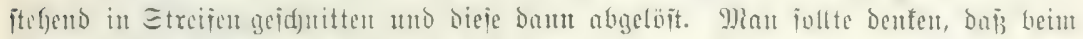

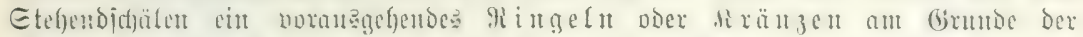

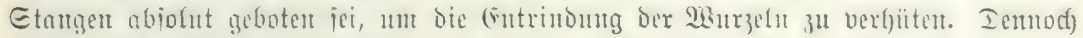

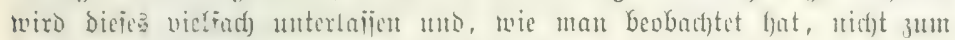

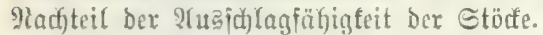

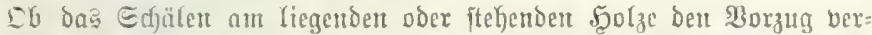

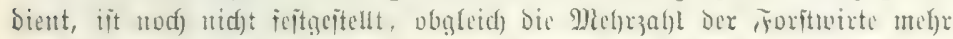

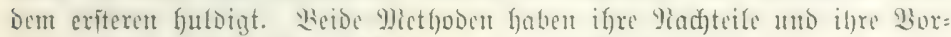

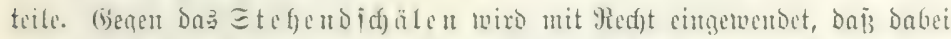

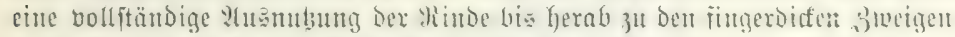

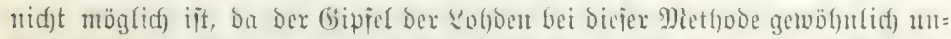

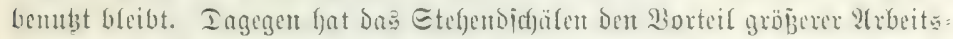

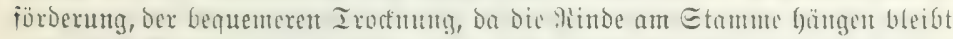

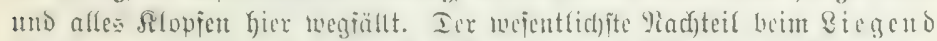

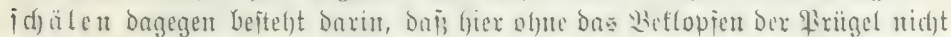

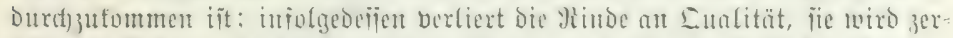

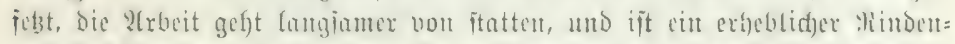

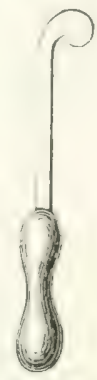

itit. : 3+11i Yinoent fillitis.

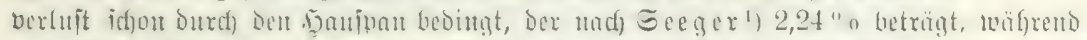

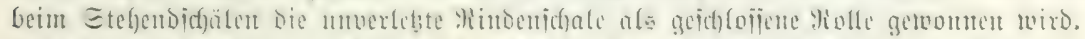

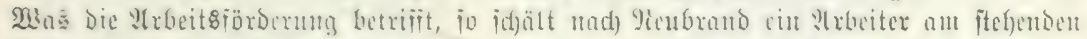

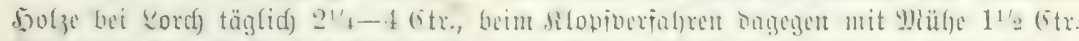

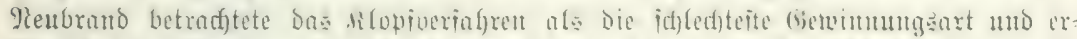

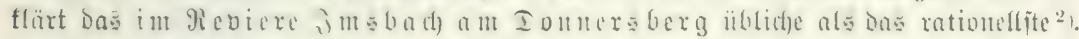

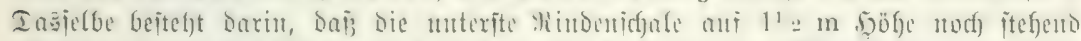

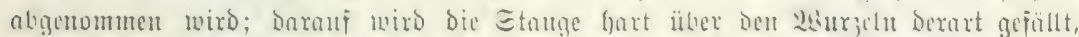

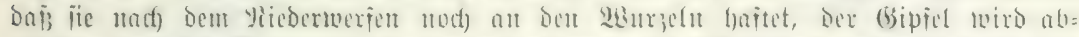

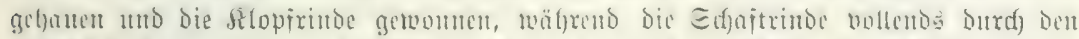

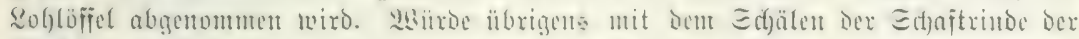

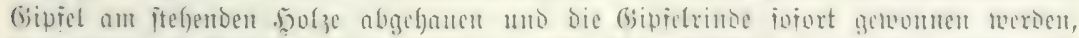

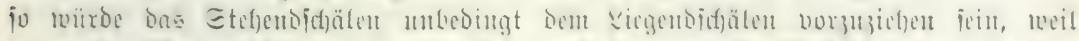

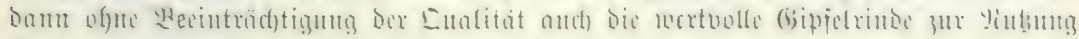
gebradjt werben tann.

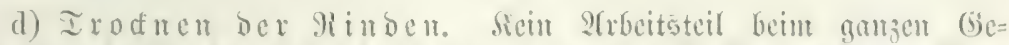

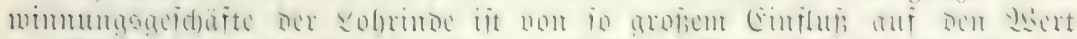

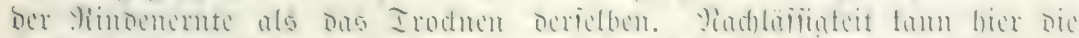

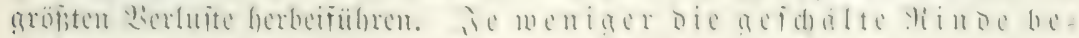

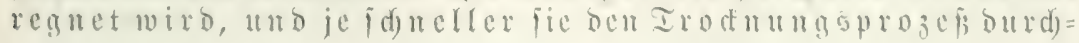

2) Eiche jeine mefrerwäfnte Edjritt. E. 14:3. 


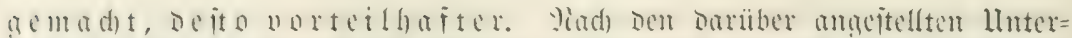

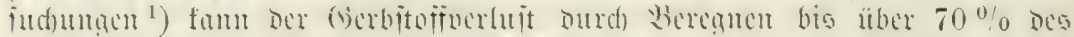

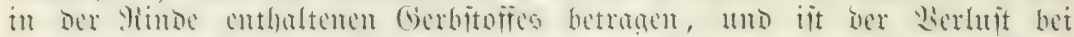

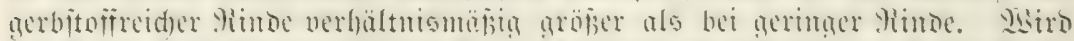

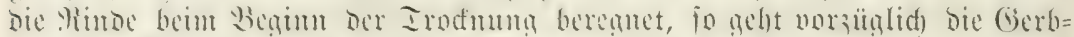

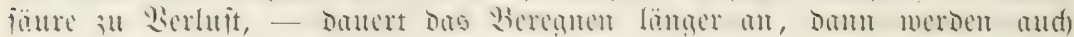

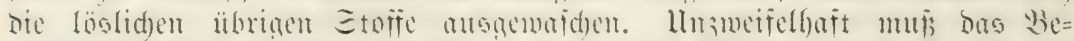

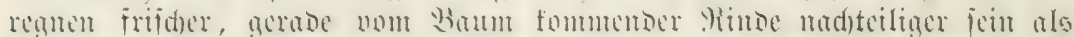

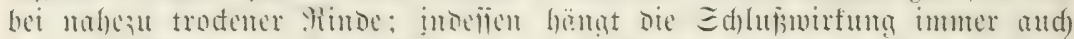

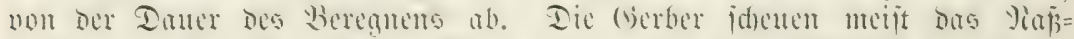

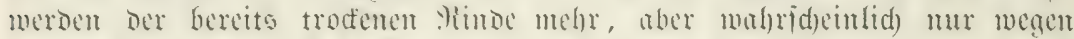

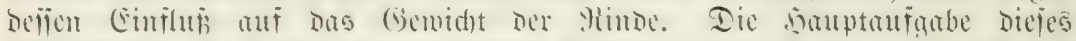

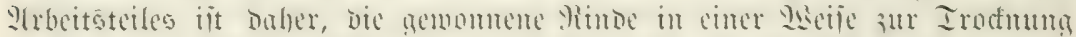

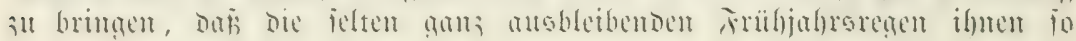

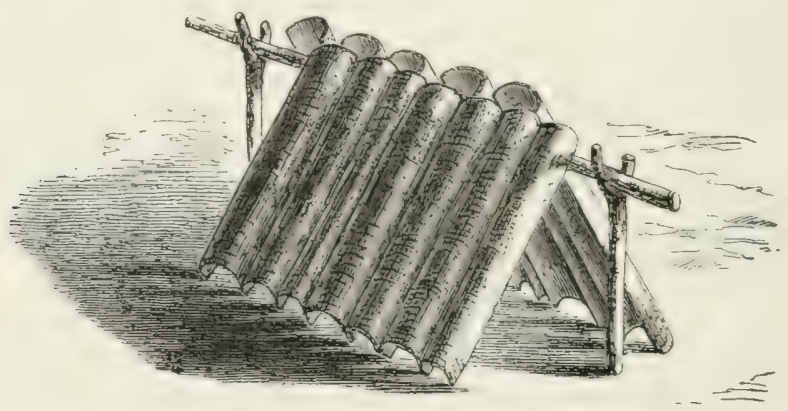

Fig. 307. Irodnen Der Hinbe auj Etangen.

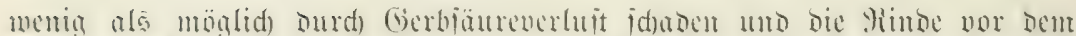

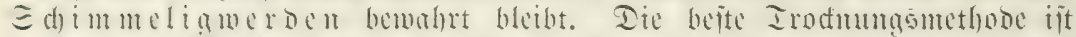

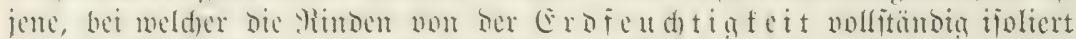

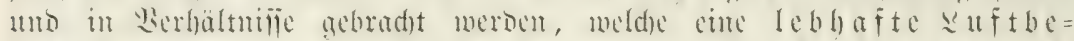
itreid) แ

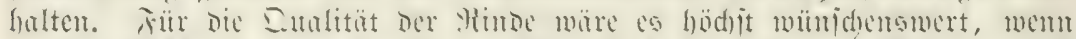

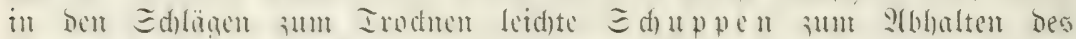

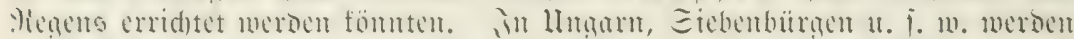

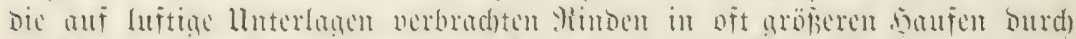

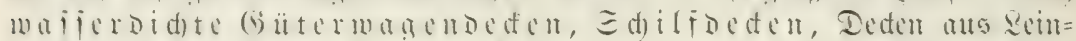

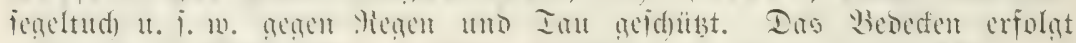

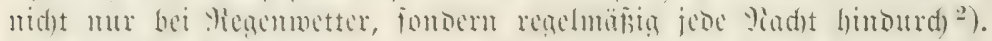

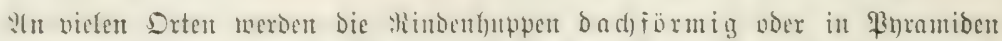

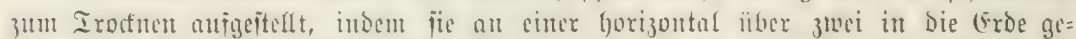

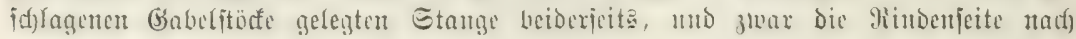

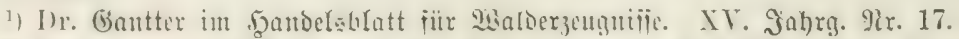

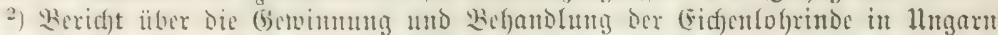

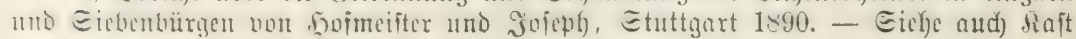
in Baure Gentralblatt 1892. ङ. 477. 


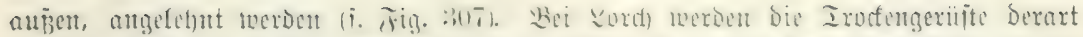

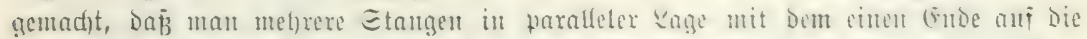

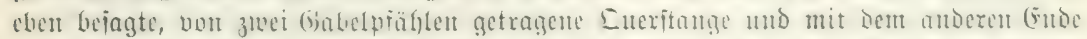

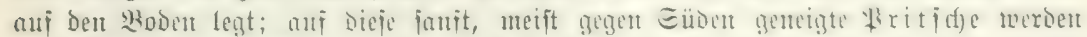

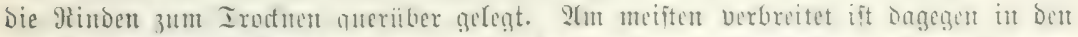

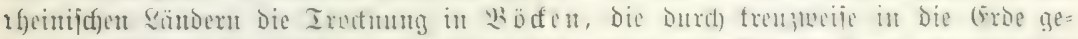

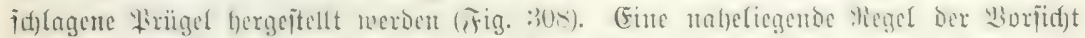

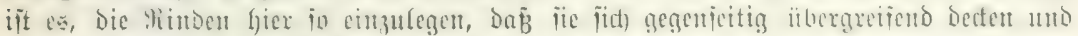

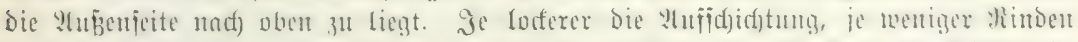

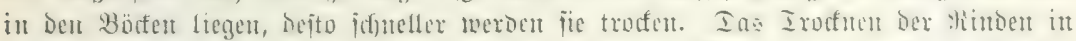

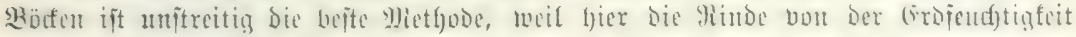
am unabłängigîten ift.

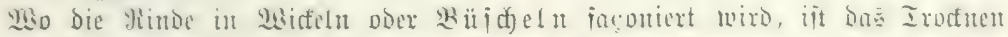

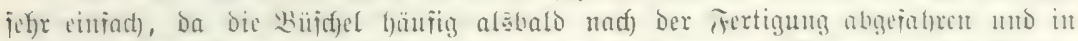

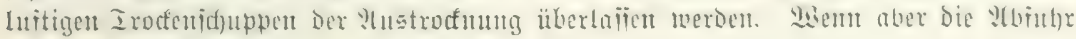

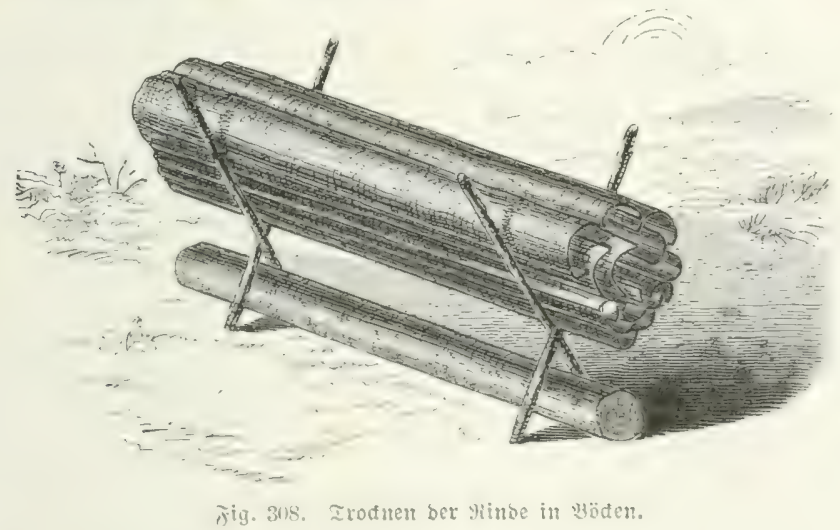

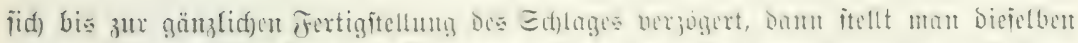

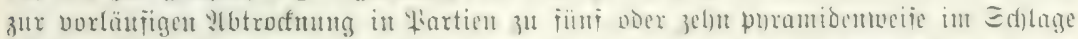

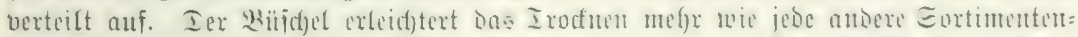

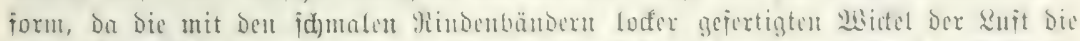

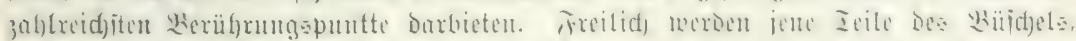

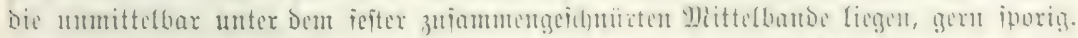

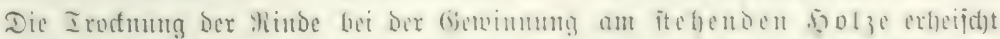

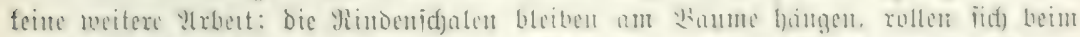

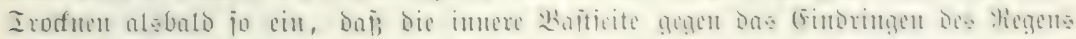

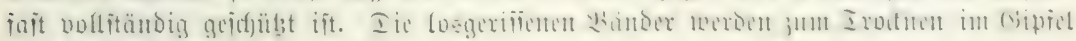
ber itefjenden Etangen anjgeljängt.

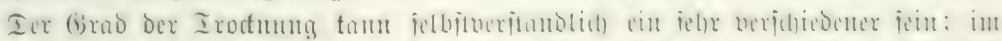

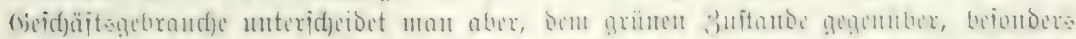

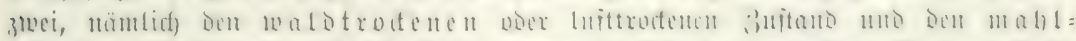

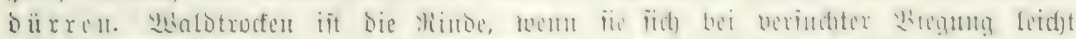

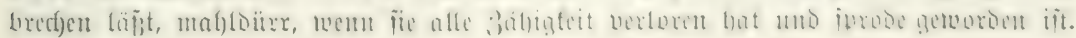




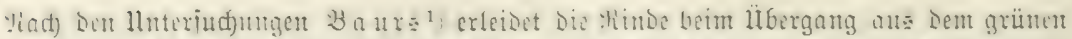

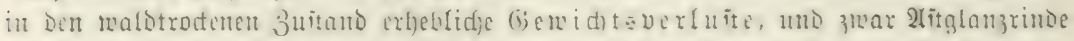

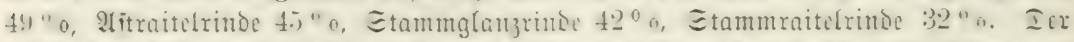

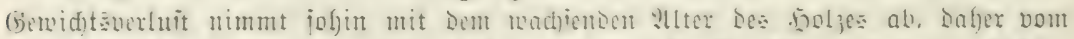

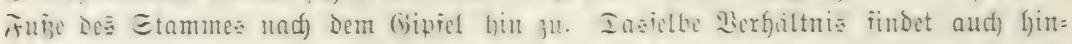

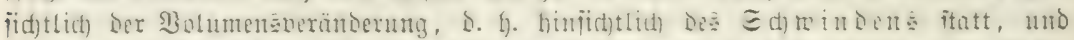

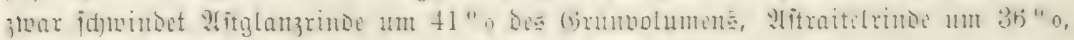
Etammglanzrinde um $34 \%$, Etammraitefrinde um $21 \%$.

Heim libergange Des malotrodenen in Den mahlourren 3nitand betringt ber (je:

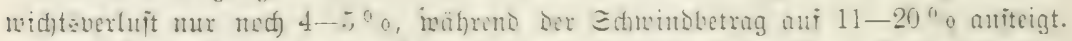

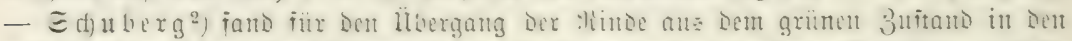

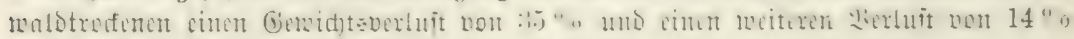
beim übergang De malotrocenen in Den mahloïren 3ütand.

\section{a. Sorticrma und Bildun Der Zlerkatgamatis.}

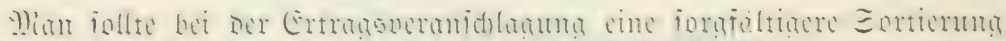

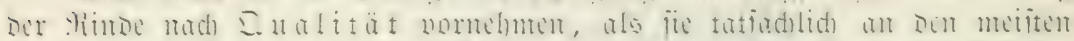

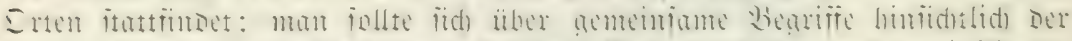

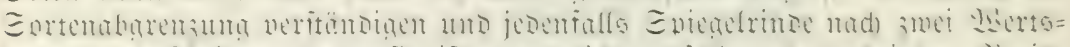

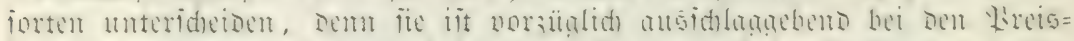

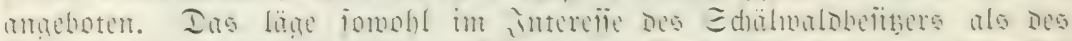

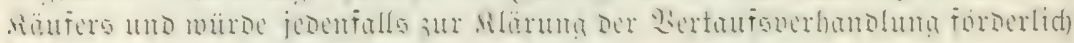
beitragert.

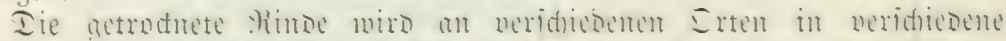

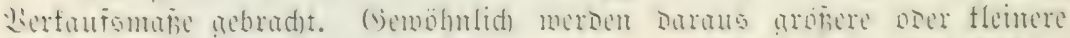

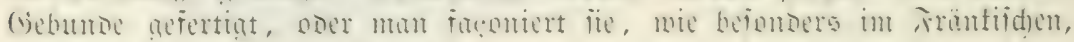
ii Büijol ober geidelgebunde.

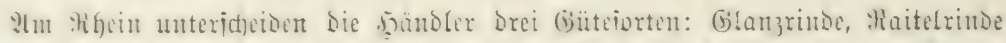

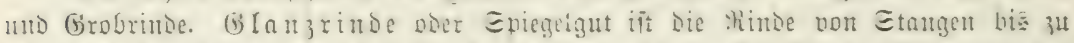

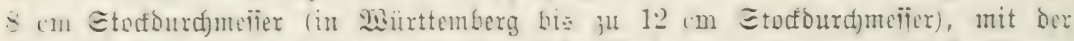

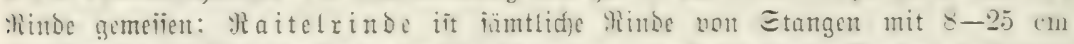
Iurd)meiter (in wïrttemberg non 12-24 (m), - aud) bie glatte Jimbe de Gipipel=

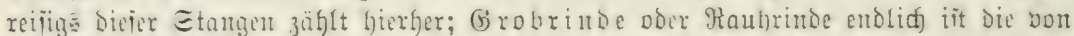

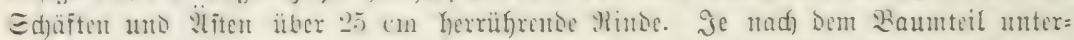

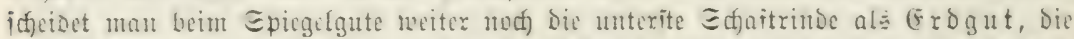

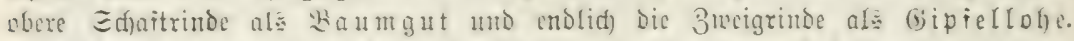

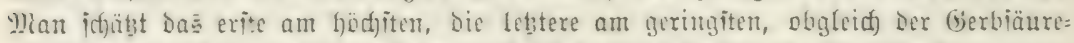

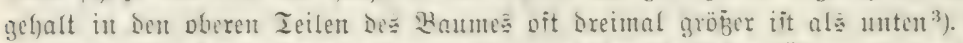

Tie thindengebunde merben ie nach ber örtliden libung in veridfesentent

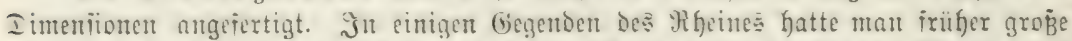

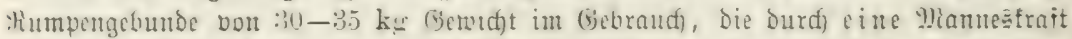

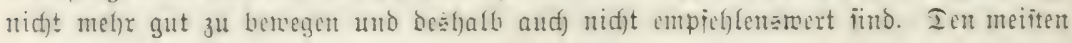

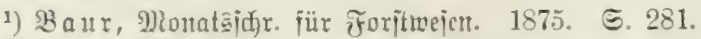

2) B̉aur Plontatijidy. a. a. D.

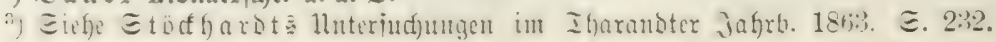




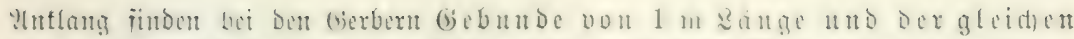

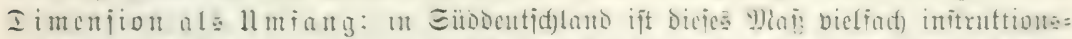

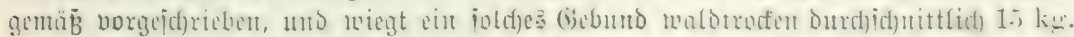

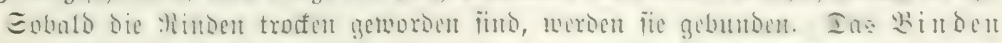

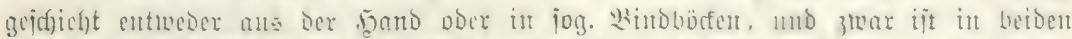

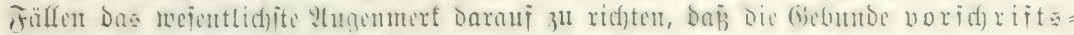

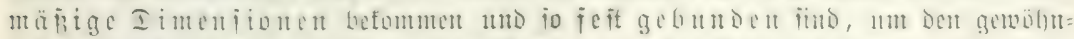

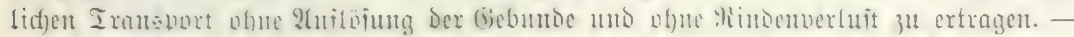

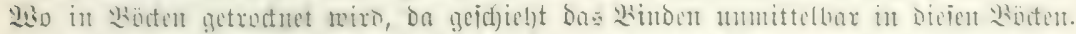

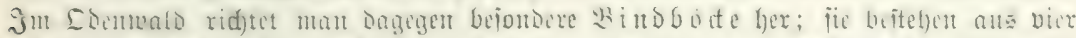

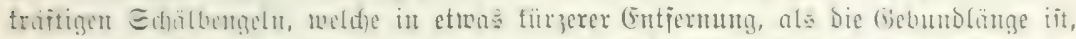

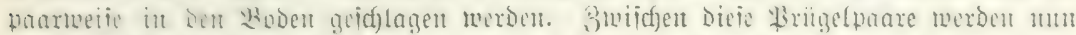

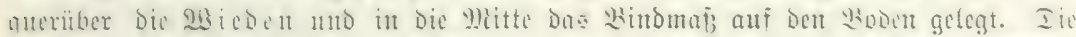

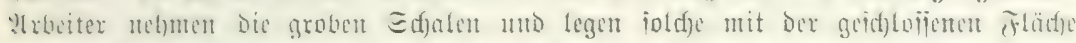

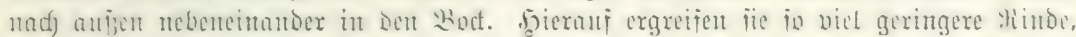

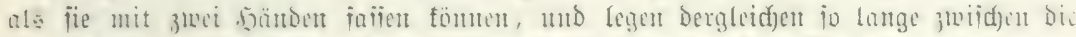

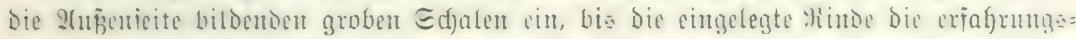

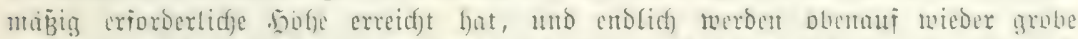

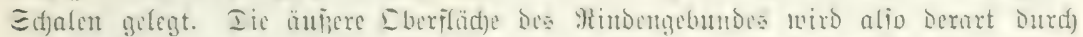

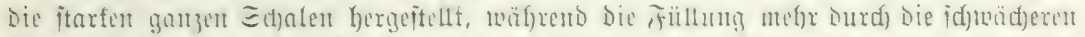

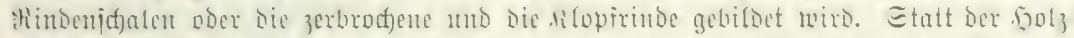

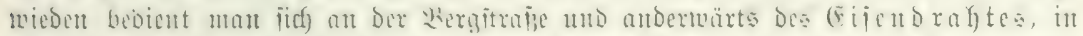

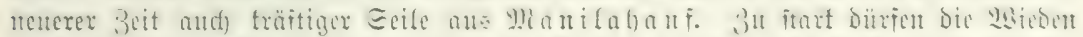

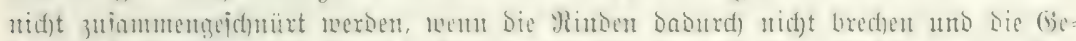

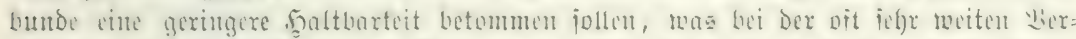

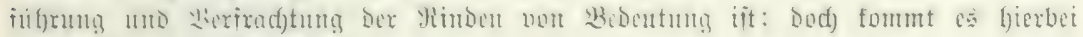

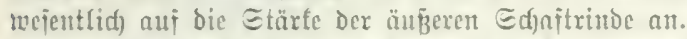

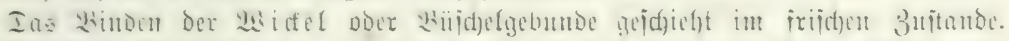

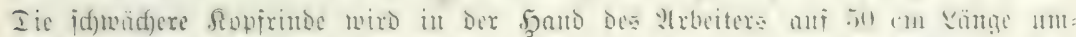

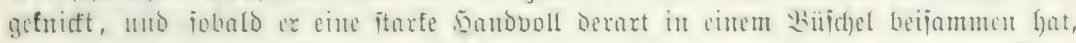

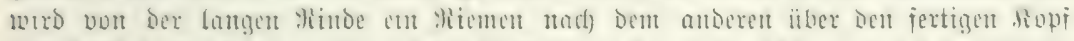

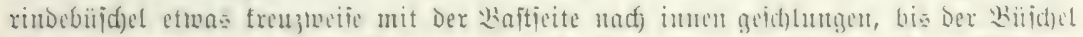

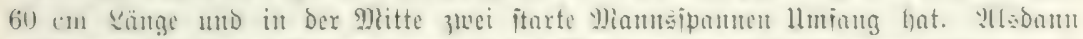

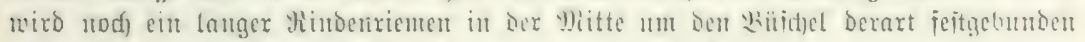
unঠ umichlungent, Daß berielbe nidft auseinander fallen fant.

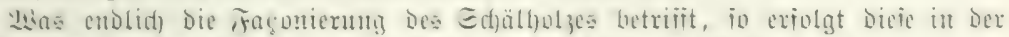

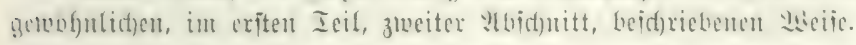

\section{b. Verwertun Der foljtidden.}

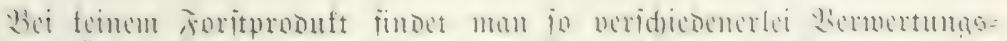
meifon

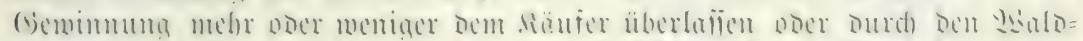

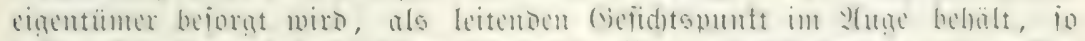
lajen

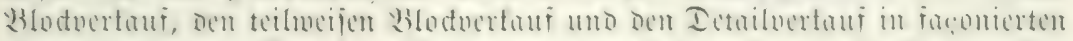

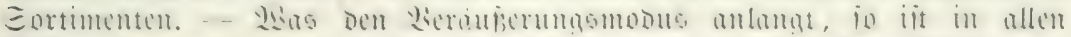

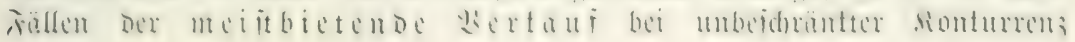




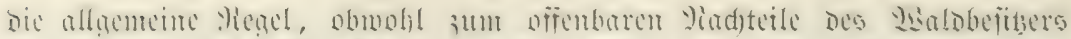

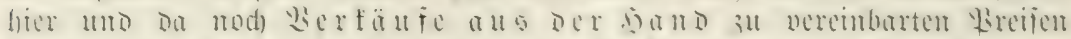

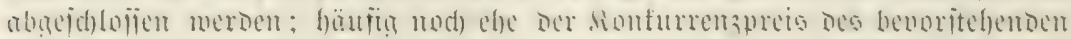
Jafres befount geworden iit.

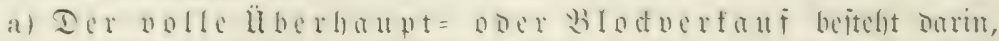

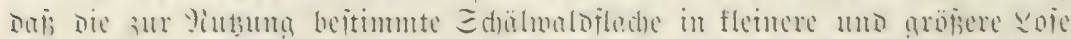

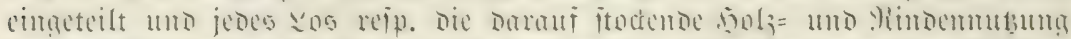

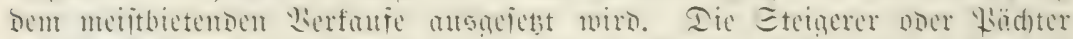

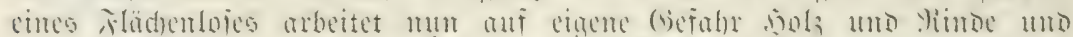

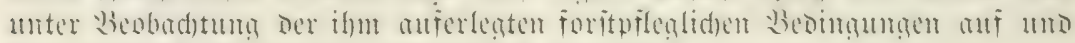

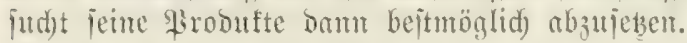

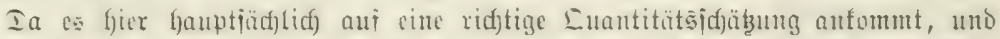

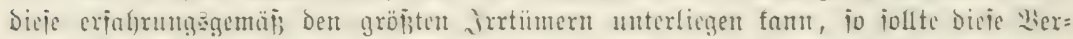

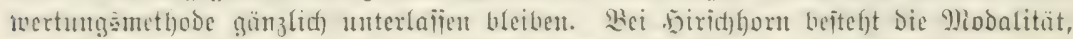

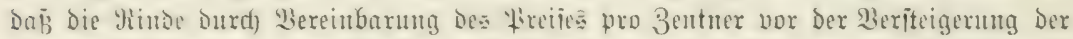

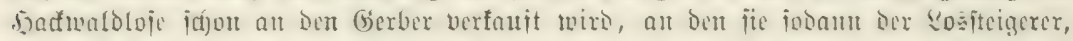
weldjer Die ßindengeminum bejorgt, verabjolgt.

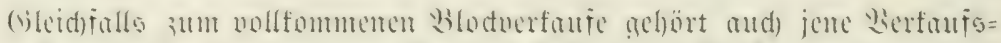

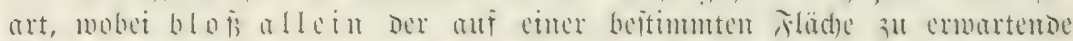

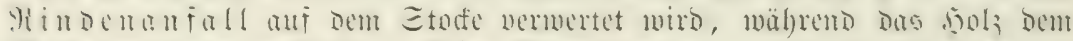

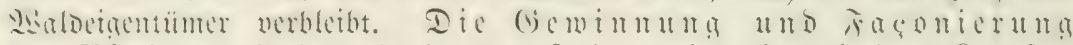
ber Minde un bes folzes erfolgt aber burd ben Säufer

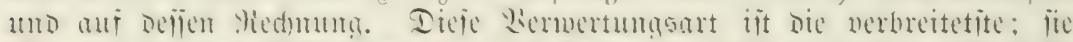

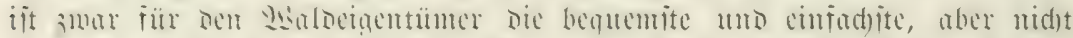

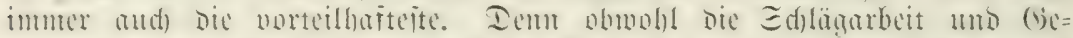

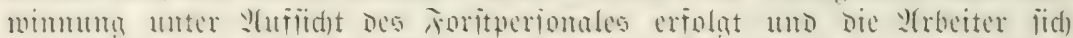

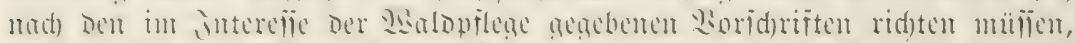

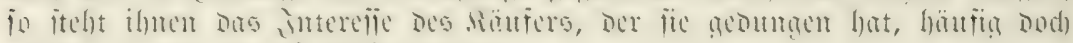
näber ato bas bes

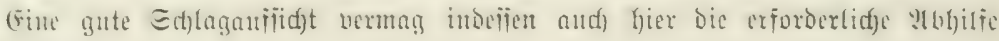
zu bringett.

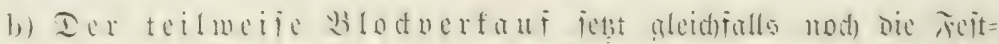

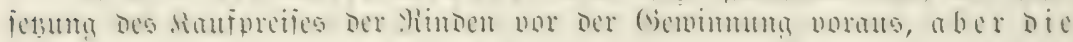

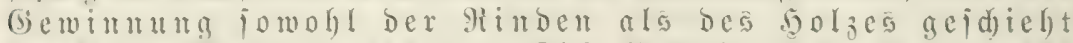
Durd Den

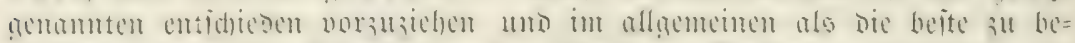

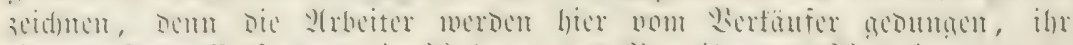

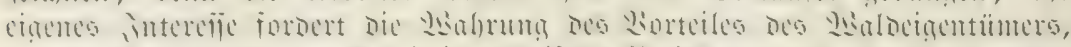

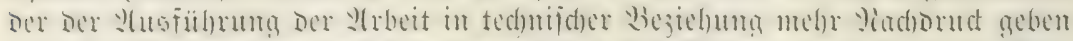

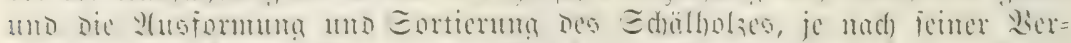

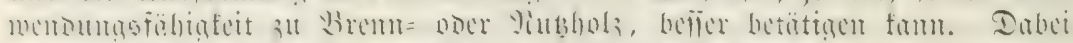

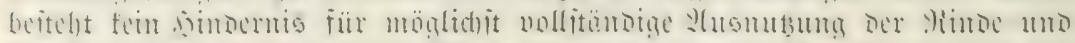

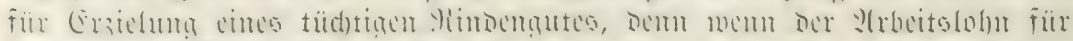

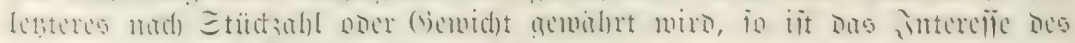

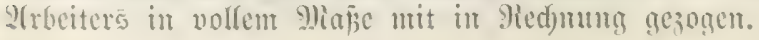




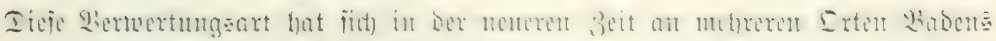

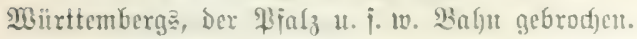

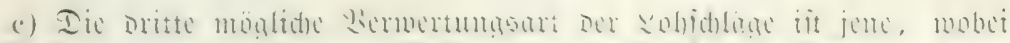

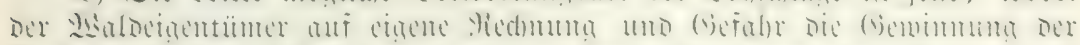

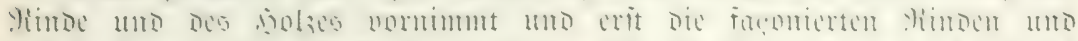

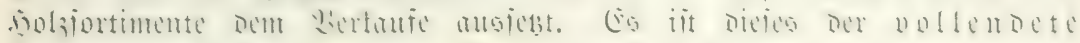
Detailverfaut.

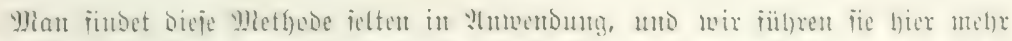

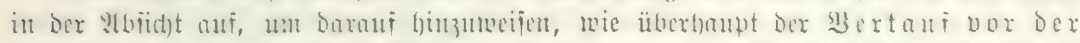

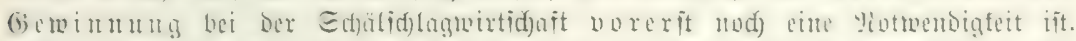

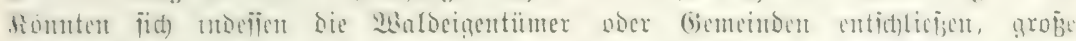

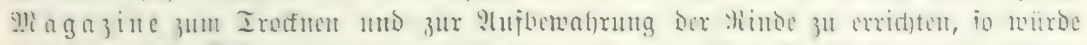

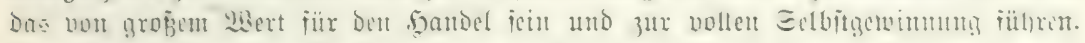

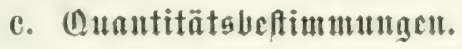

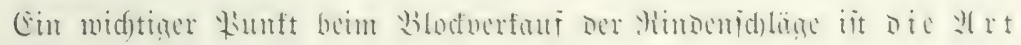
แ

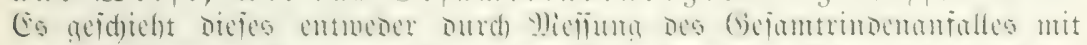

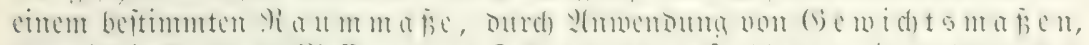

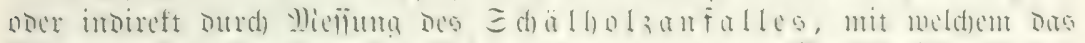

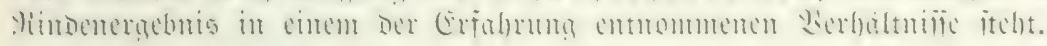

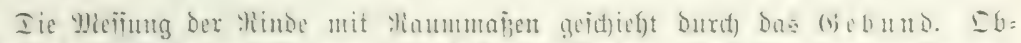

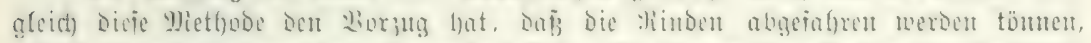

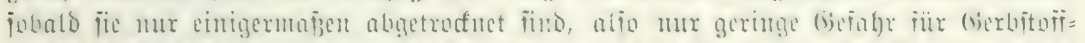

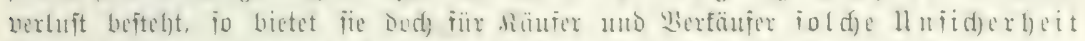

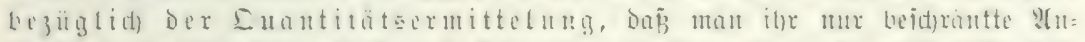

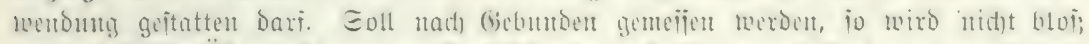

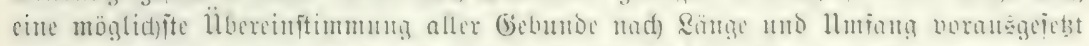

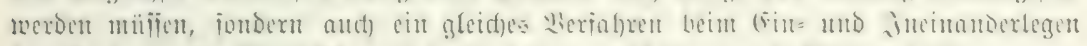

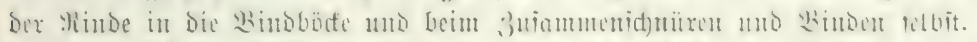

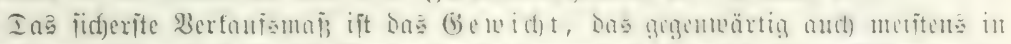

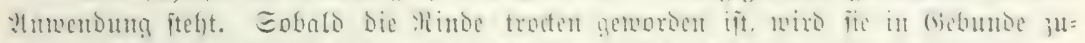

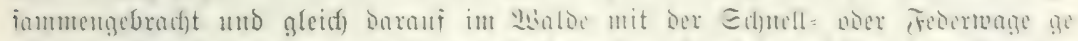

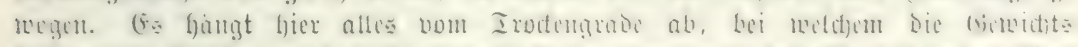

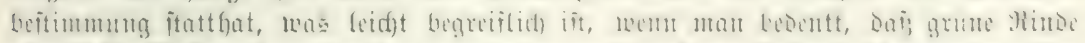

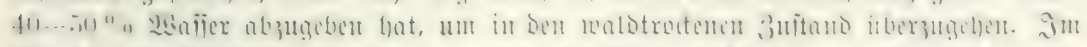

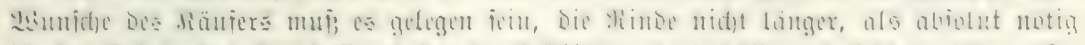

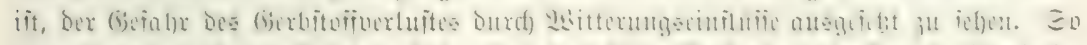

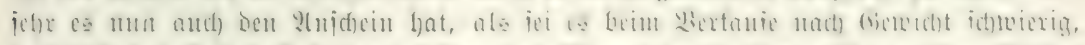

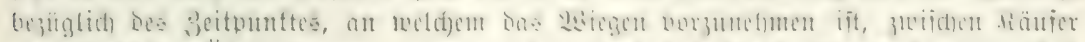

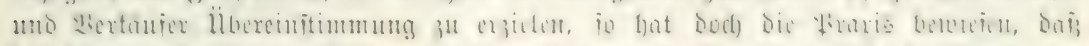

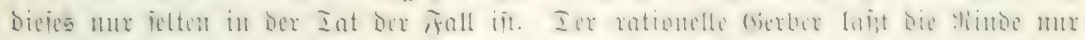

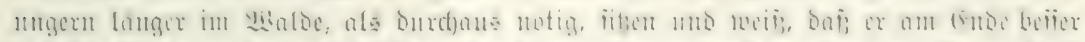

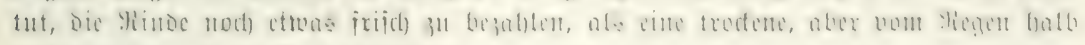
anşgetvajc)enc Minde geimzubringen. 


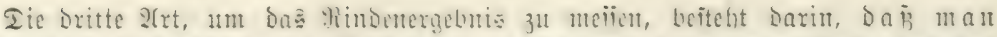

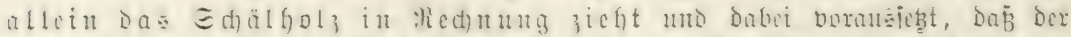

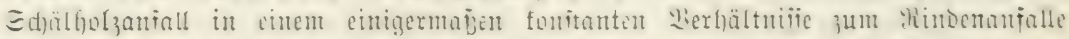

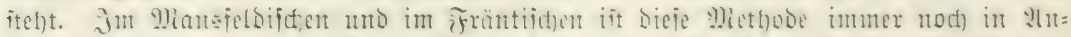

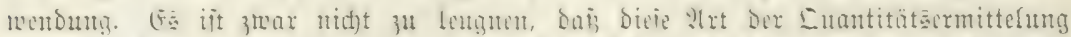

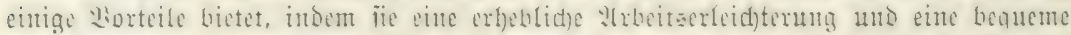
(beid) ät

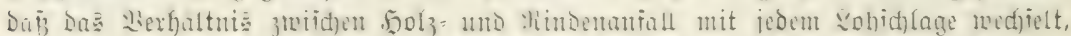

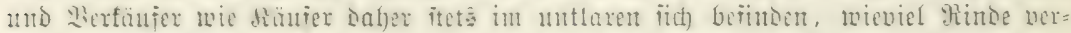

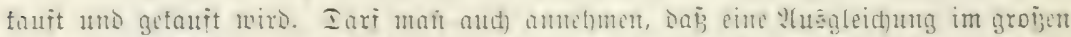

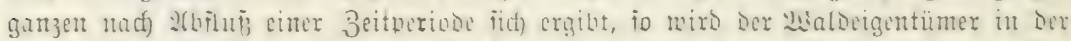

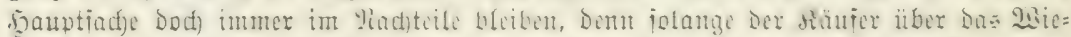

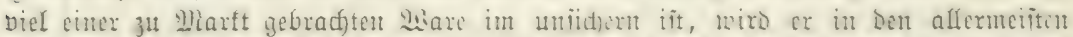

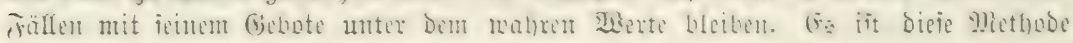
johin bie rohejte ?trt Der Duantitätâermittelung.

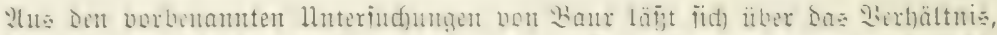

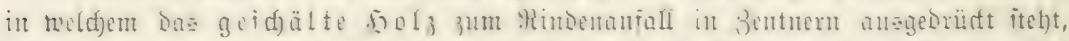

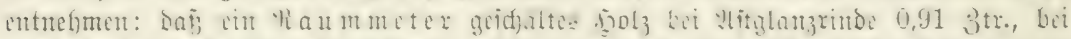

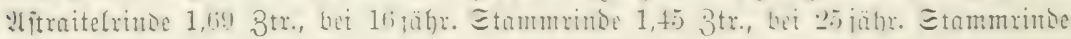
1,95 3tr. gibt u. i. w.

\section{d. Erträge Des Eidjen}

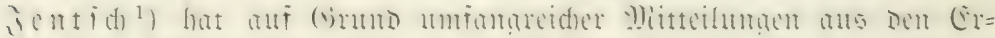

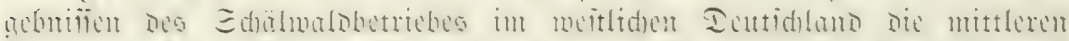

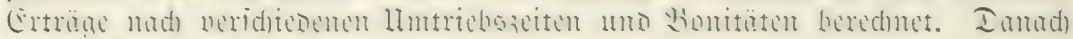
trifit pro beftur ein $\mathfrak{R}$ in denergebuis

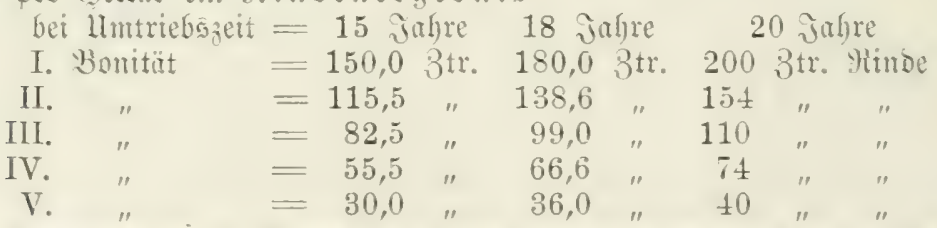

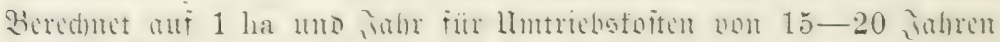
löbt fid) Der Mlaterialertrag folgentomaben Fejtitellen:

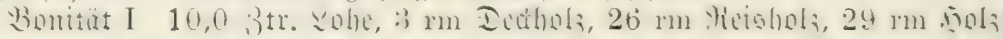

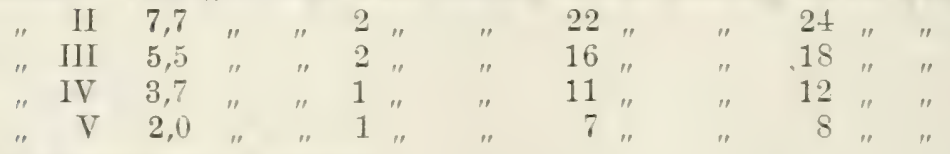

9. Bern $\left.\operatorname{Brot}{ }^{2}\right)$ nimmt

Fü Bontiat I 10,0 Bentnex sole แnd $7 \mathrm{fm}$ ตัol

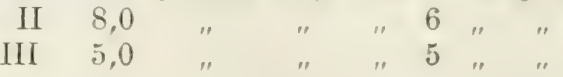

1) Dr. Jentid), Ier Deutidge (Fid)enidfälmals und ieine Zutunit. Berlin 1s99.

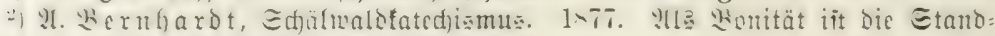
ortäbonität, ๖. G. Boden uno Rlima, berftanoen. 


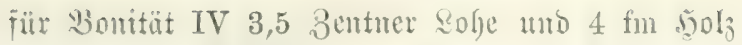

$\mathrm{V} 3,1$ " " 4 " "

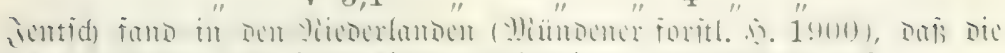

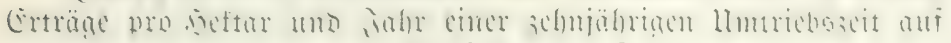

I. Sonität 11,7 Bentuer

$\begin{array}{lll}\text { II. } & 9,1 \\ \text { III. " } & 6,5 \\ \text { IV. " } & 3,9 \\ \text { V. } & \text { " } & 1,3\end{array}$

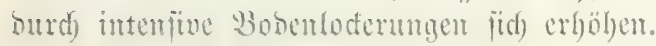

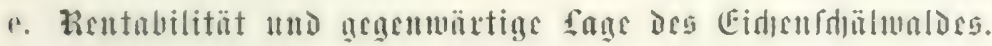

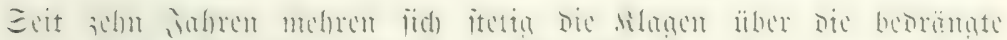

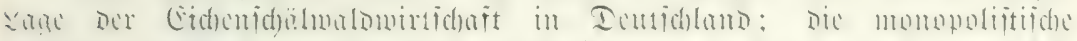

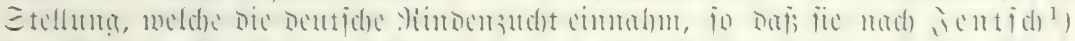

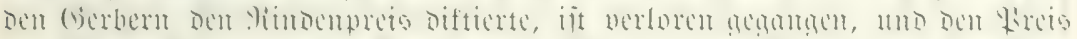

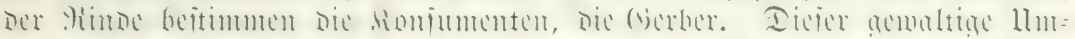

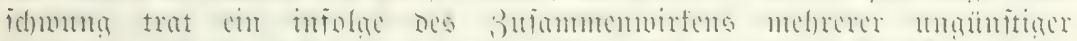

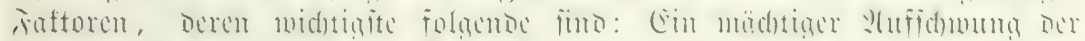

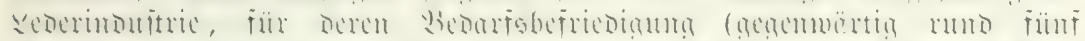

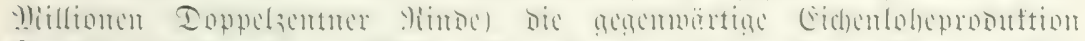

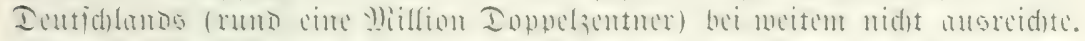

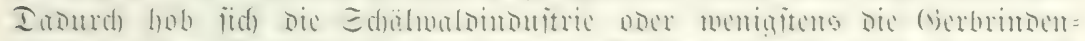

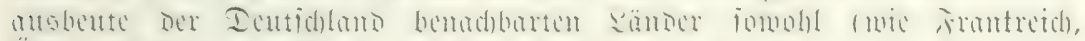

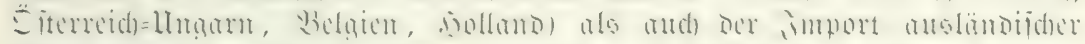

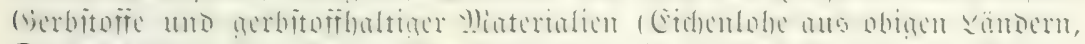

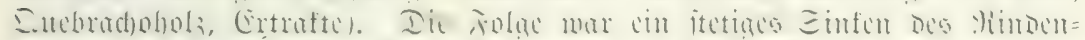

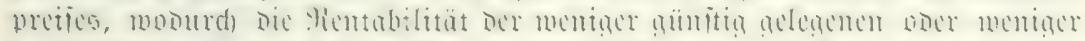

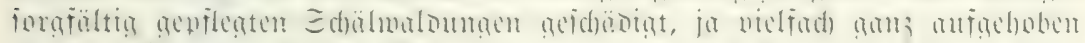

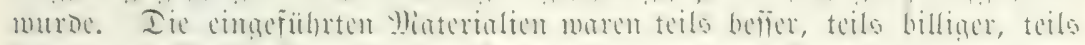

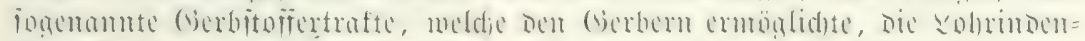
noer brubengerbere

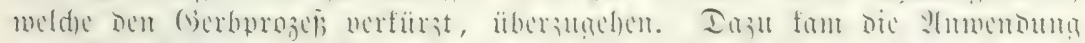

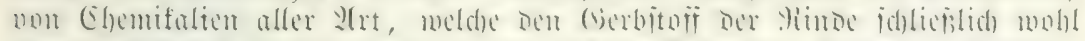

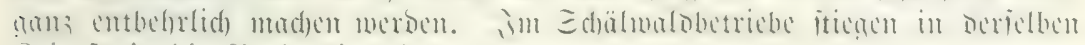
Beit itetig bie Wrobuftionsfoiten.

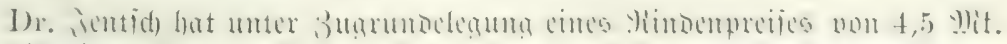

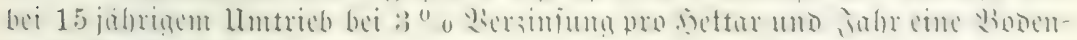
rente bered)net von

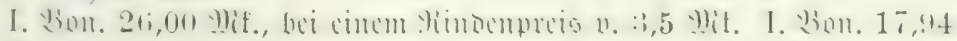

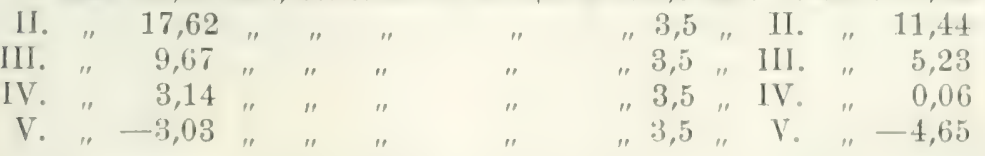

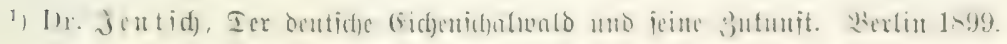




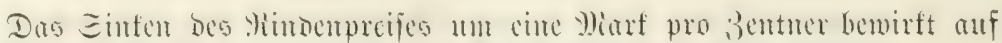

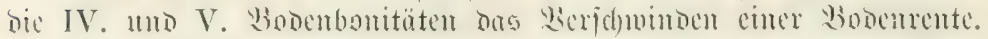

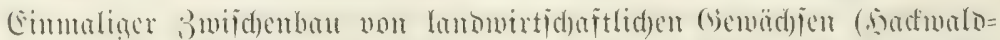

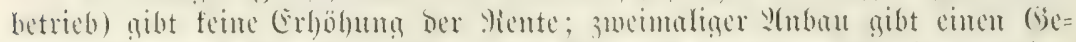

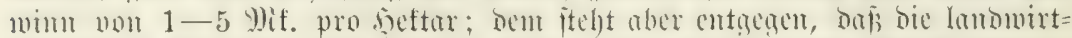

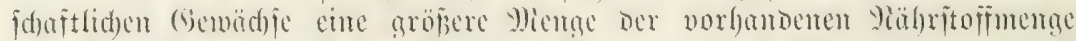

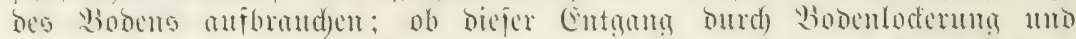

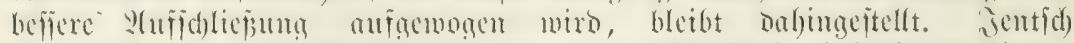

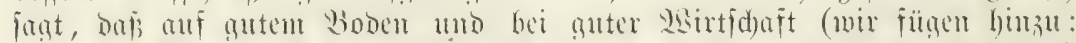

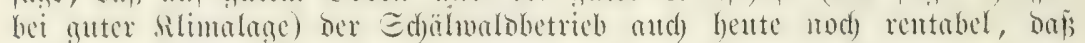

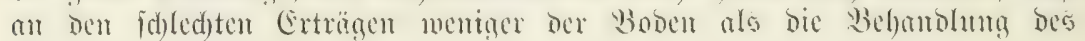
Edjälmaloes fduld jei.

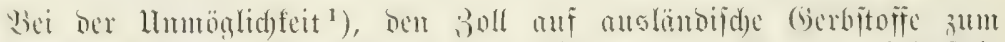

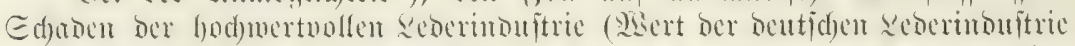

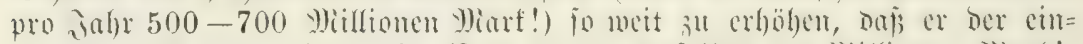

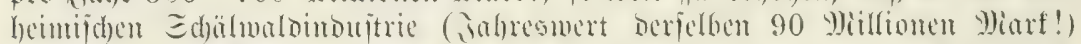

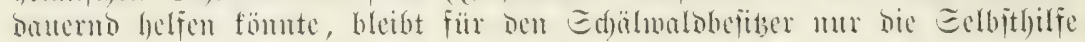

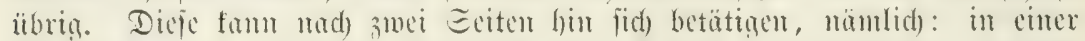

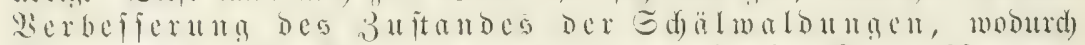

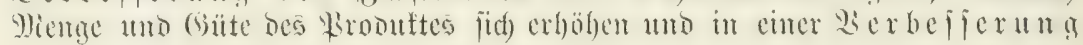
ber Érute ud i fres Berfaufes.

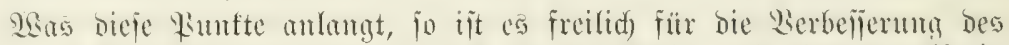

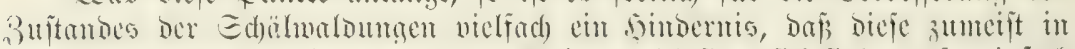

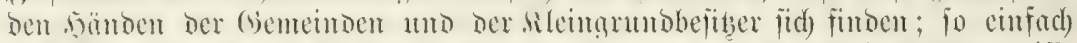

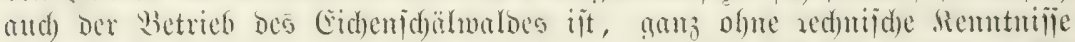

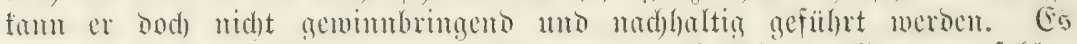

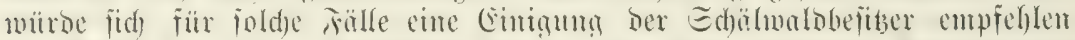

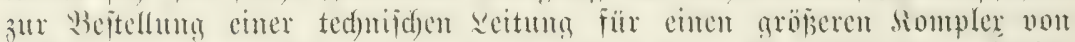

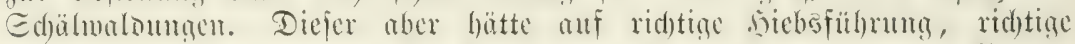

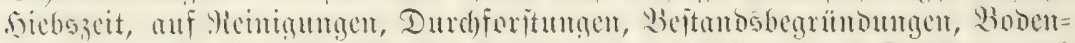

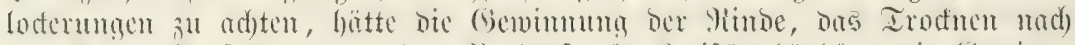

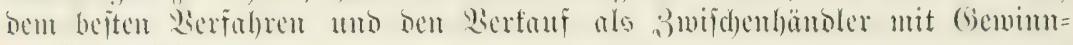
anteil zu bejorgen.

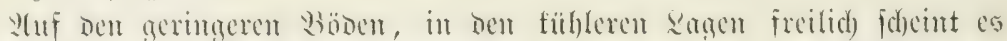

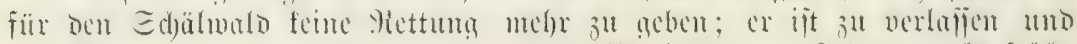

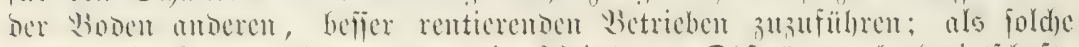

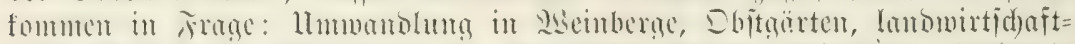

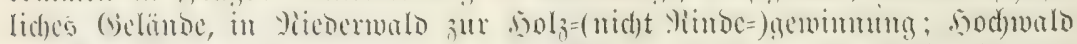

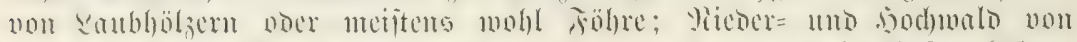

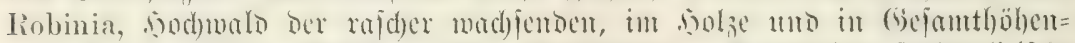

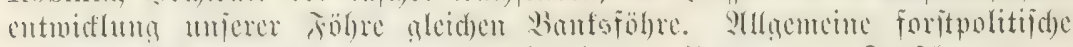

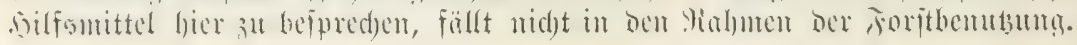

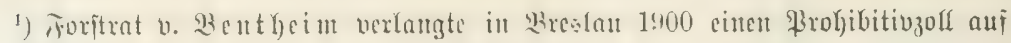
Sucbradjo. 
Der Gerbitoff der atteidentindo

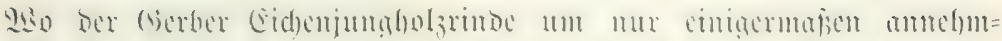

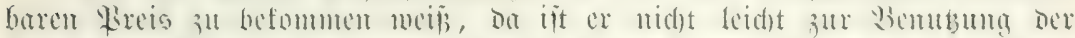

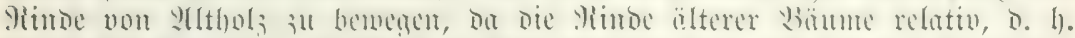

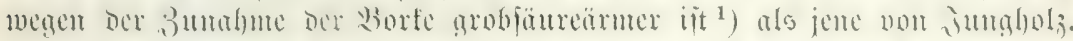

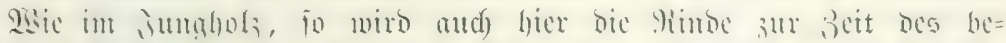

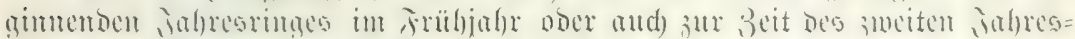

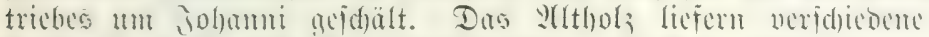

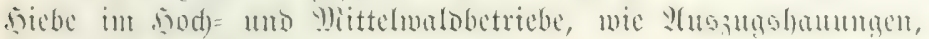

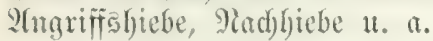

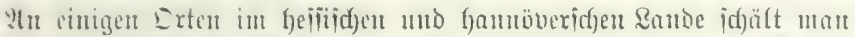

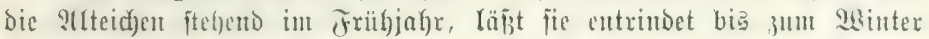

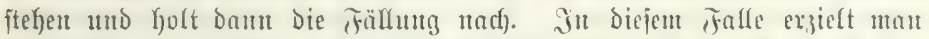

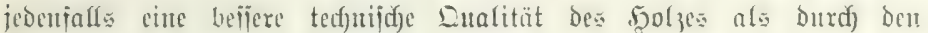
Eaftriéb.

Jn ber Megel wird bie alte Rimbe a m gefällten

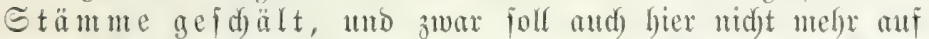

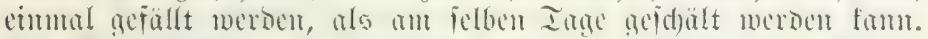

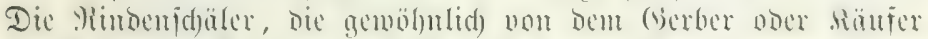

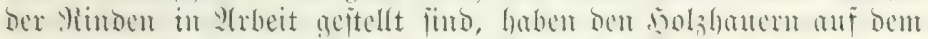

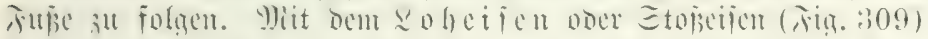

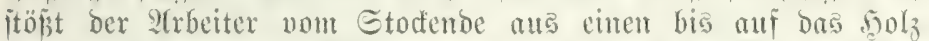

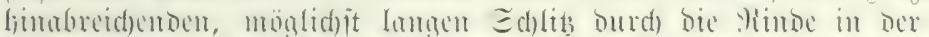

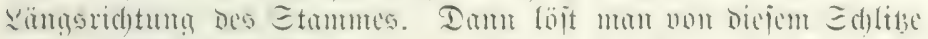

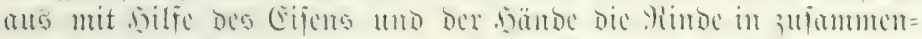

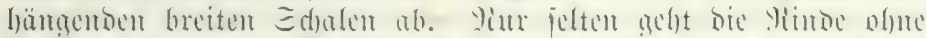

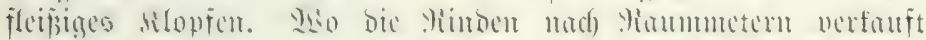

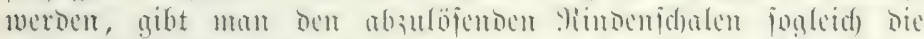

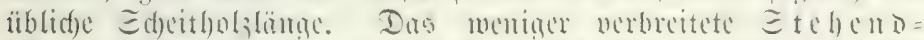

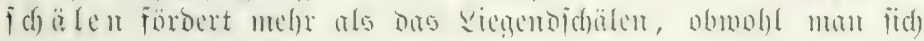
babei ber Seitern bebienen mui.

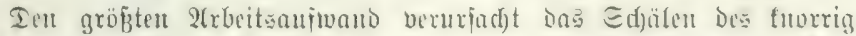

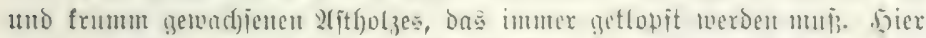

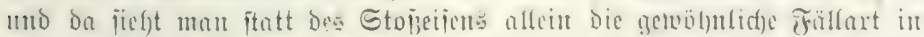

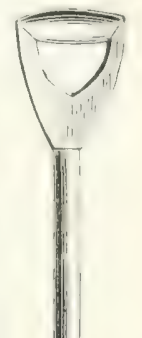

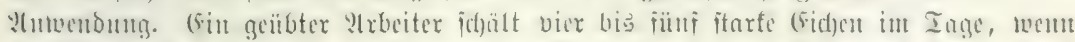

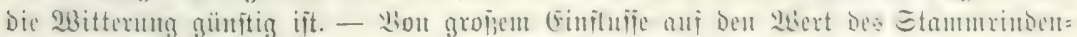

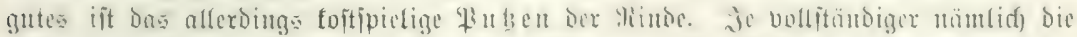

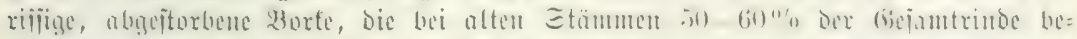

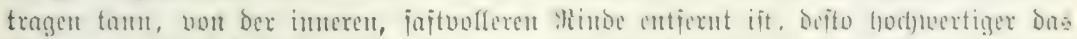

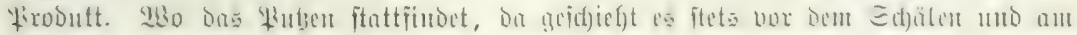
beiten am nod) itebenden Gtamme.

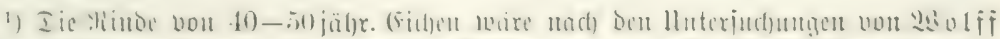

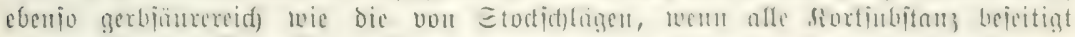

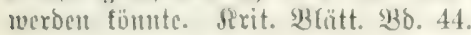




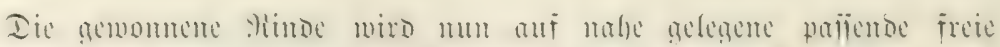

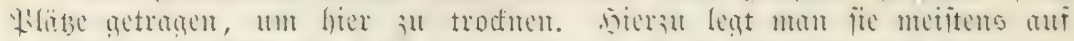
cimfade Etmugengeriate horizontal mo mit oer Eplimticite mad) unten iu,

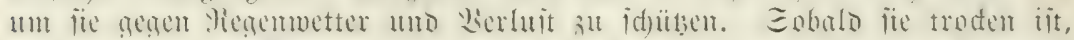

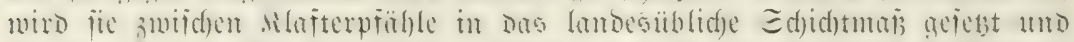

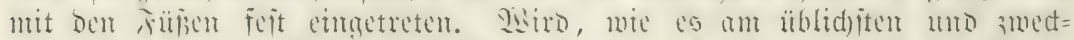

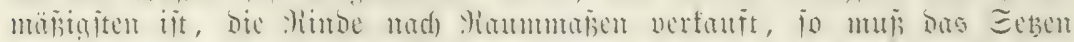

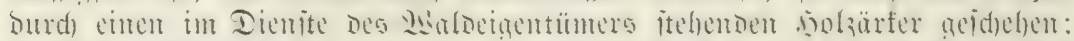

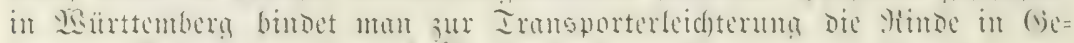

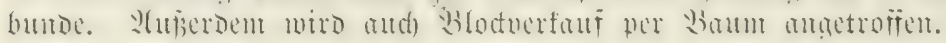

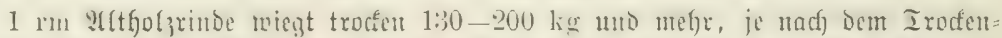

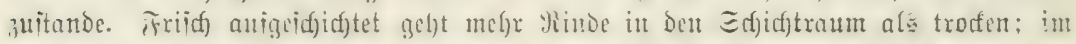

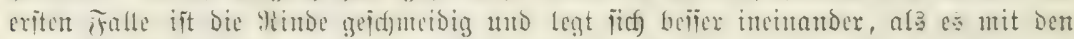
ipröben, zujammengerolltest Iroctenichalen möglidi ift.

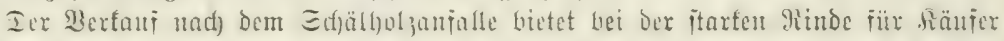

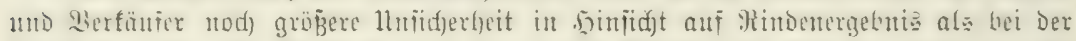

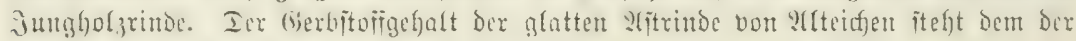
Sungeidfetr foum nact).

\section{Der Gerbitofigehalt ber Fid tenrinbe ${ }^{1}$ ).}

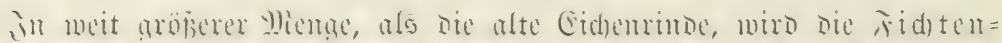

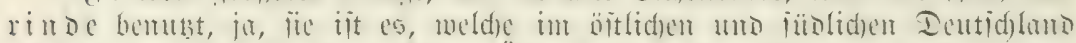

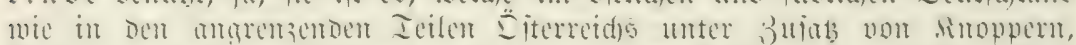

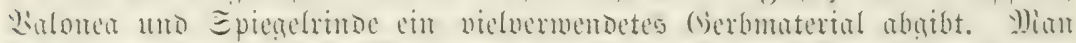

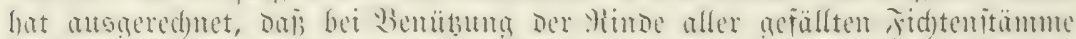

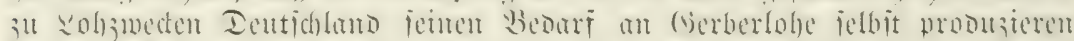

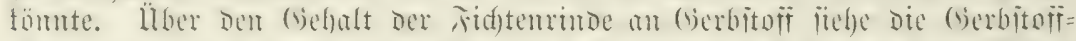

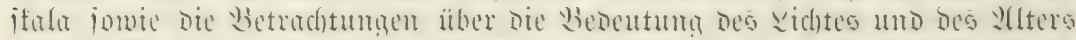

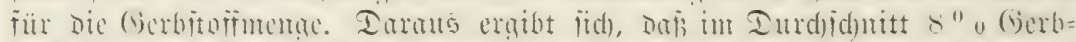
itofigehalt fïr Die velffït) fam jesod) ma ;

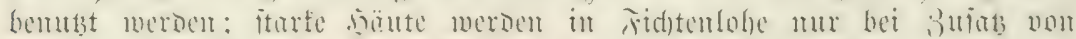

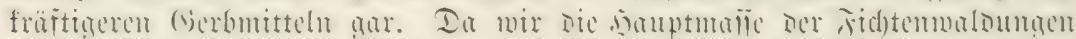

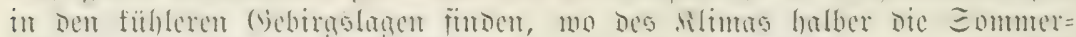

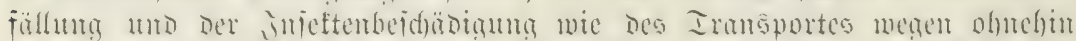

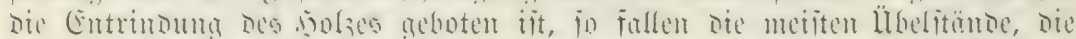

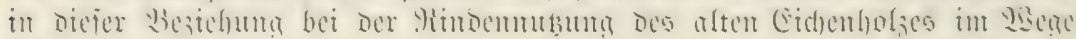
iteber, weg.

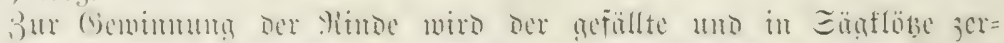

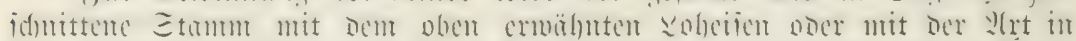

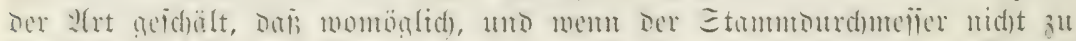

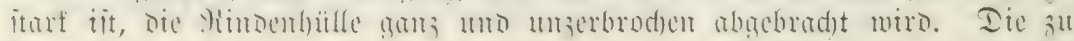

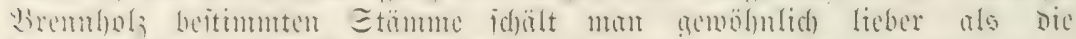

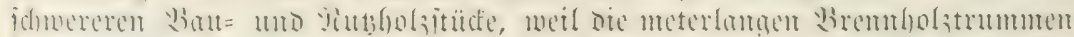

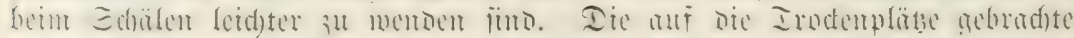

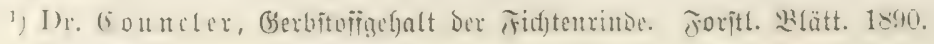




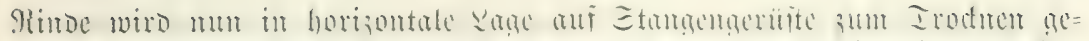

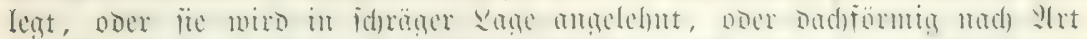

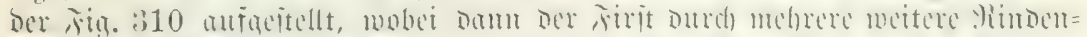

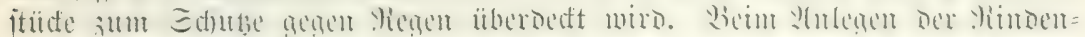

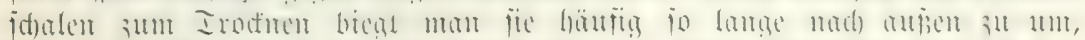

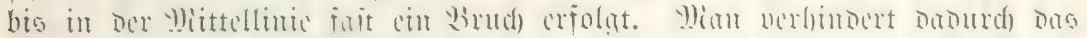

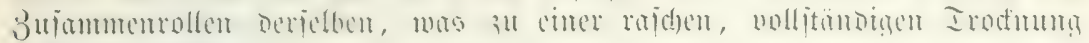
nid)t föroerlid) ijt.

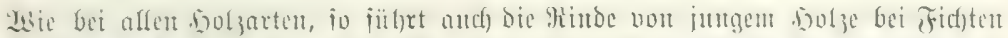

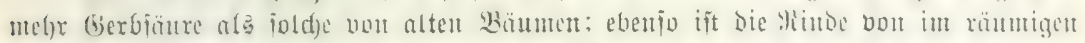

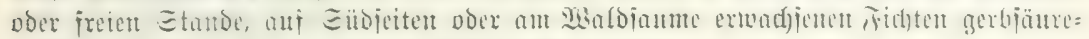
reidjer ala jene bon ben entgegengejetsten Standorten.

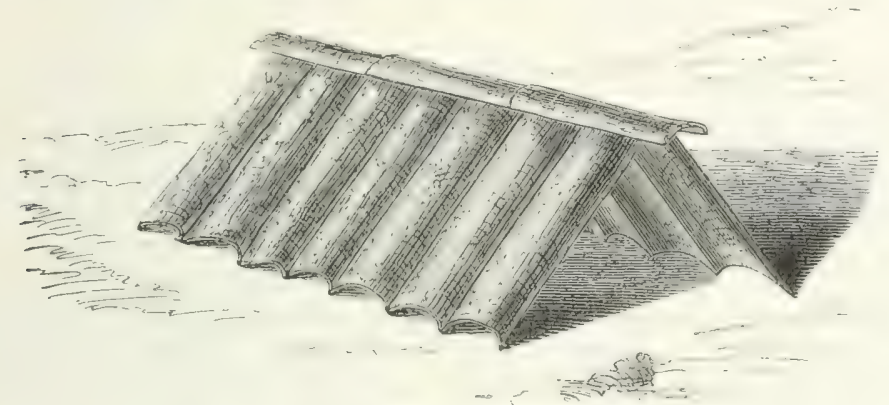

jig. 310 . Irodtuen ber Minbenjchalen bei ser Fiđte.

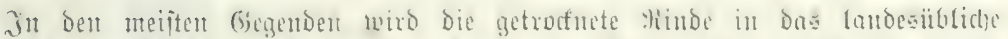

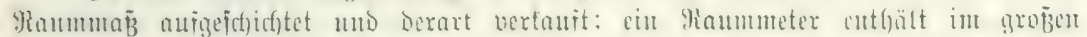

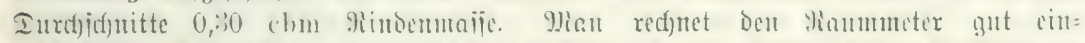

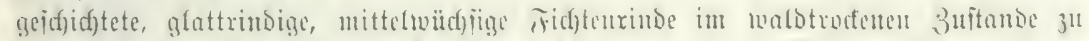

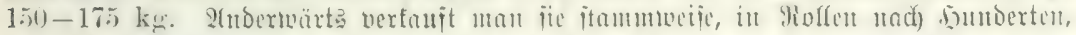

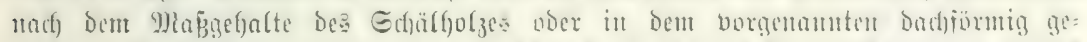

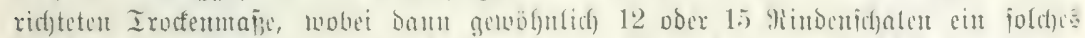

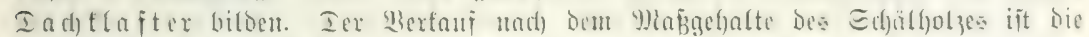

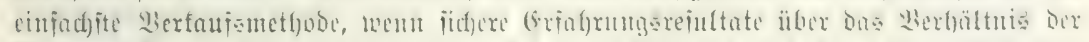

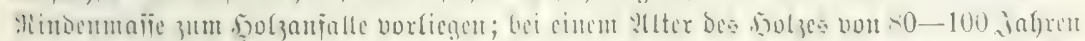

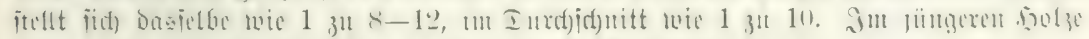

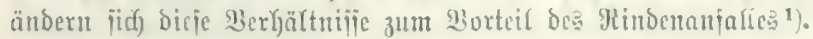

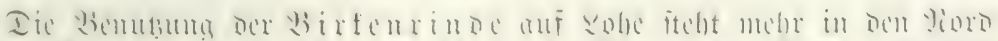

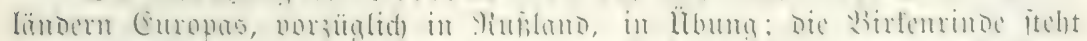

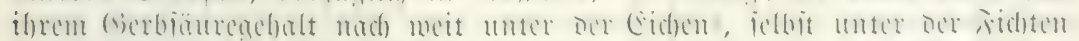

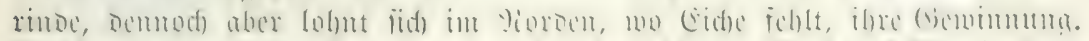

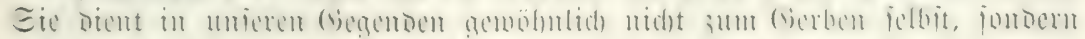

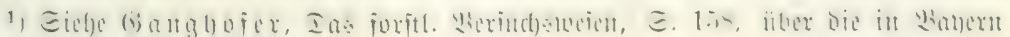
angeftelt(ten Jidjtenidfǘ(veriudje. 


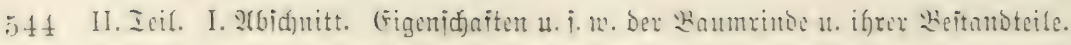

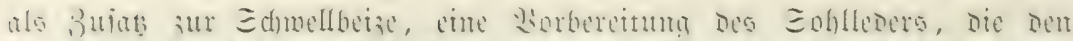

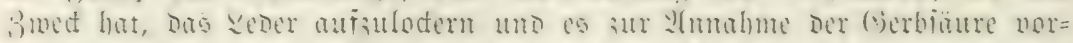

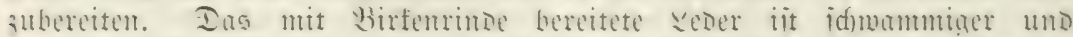

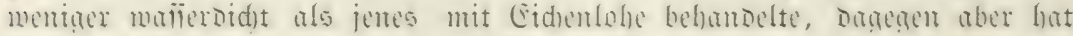

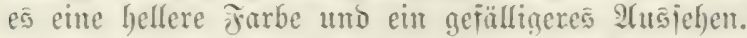

Gemonnes miro Birfenrinde ebenio mie Die (Fid)enrinde: fie geht aber meitents

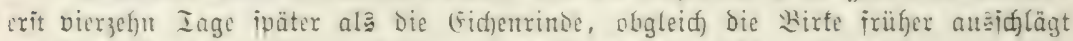

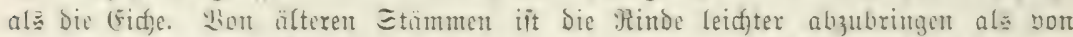

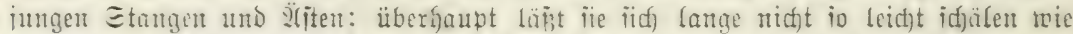

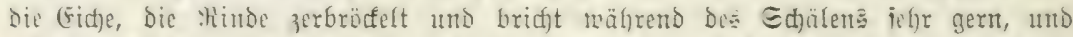
müïen beahalb gemöhnlid) höhere (beminmugälöhne zugë̈id)ert merben. - Tad) Den ipärlidfen (Extragseriafnrungen, meldje uiber bie Birfenrinte befannt ïno, fommen bei

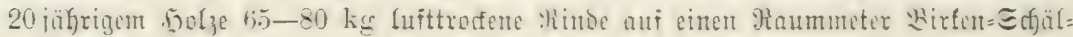
prügelkolz $\left.{ }^{1}\right)$.

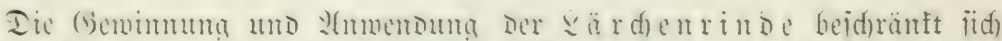

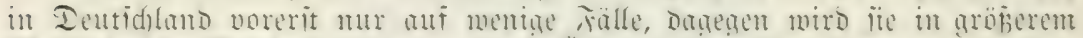

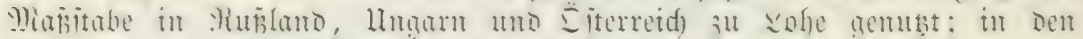

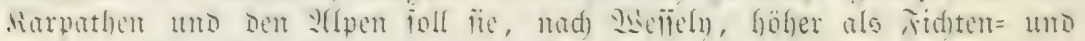
Birfenrinde gejchäbt jein.

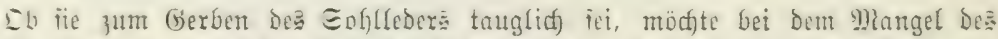

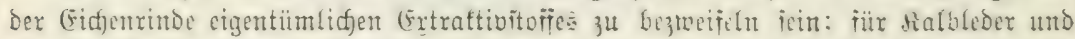

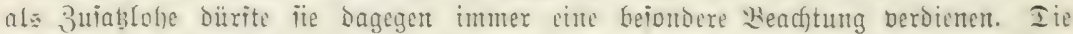
Vürd)enrinde lä̈̈t ala bie (Fid)e und geht audh leidgter als lebtere.

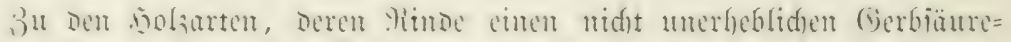

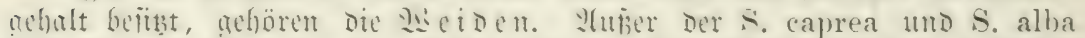

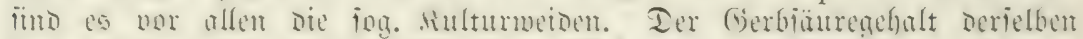

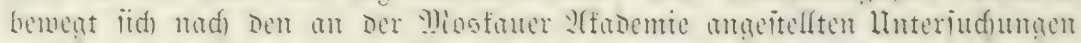

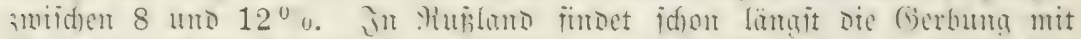

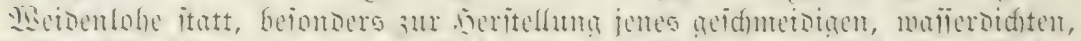

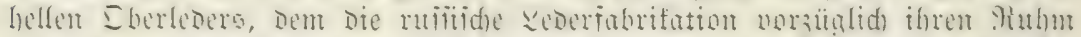

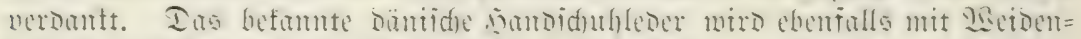

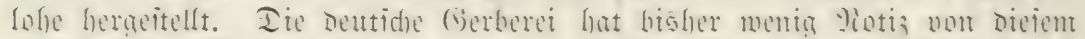

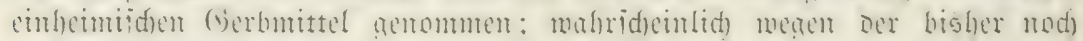
geringen Froduftion.

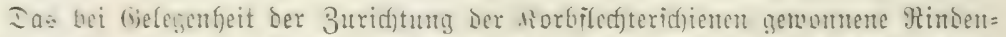

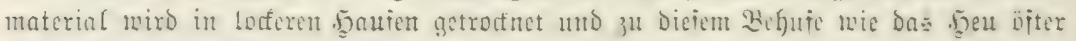
gementidet.

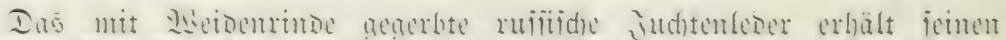

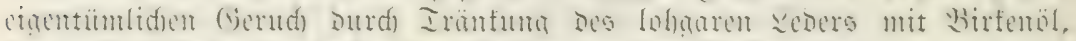

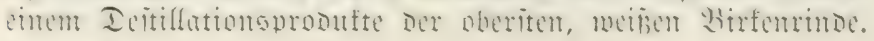

1) Eiege greubrand a. a. L. E. 218. - Eouncler, Beitidgr. i. Forjt=ut. Jagormeien. 1884. 


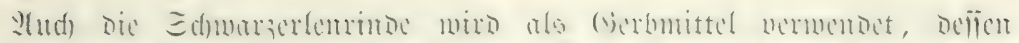

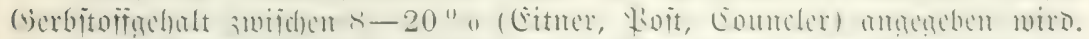

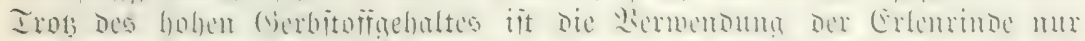

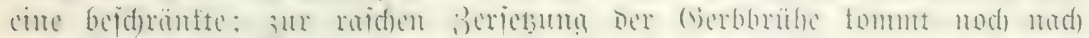

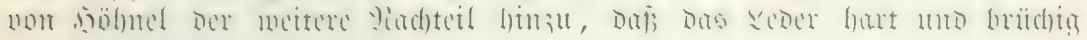
wiro uro fich Dutufel färbt.

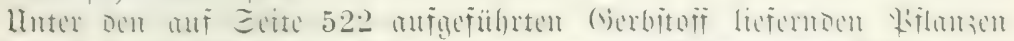

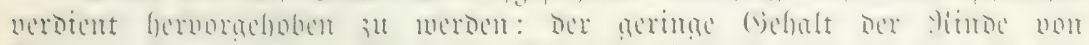

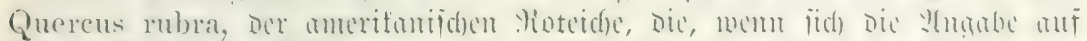

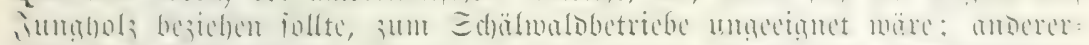

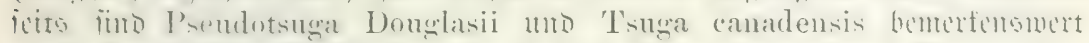

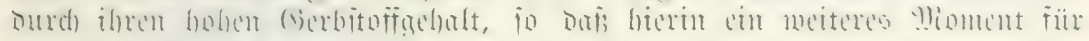

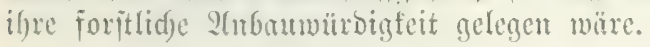

\section{Cellulore.}

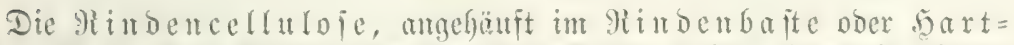

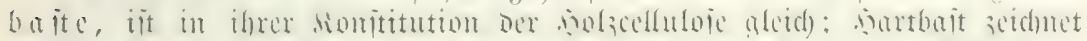
itd) sen

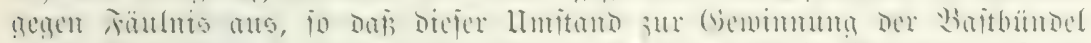

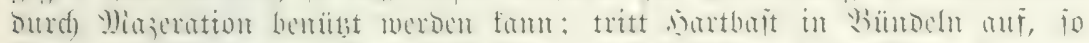

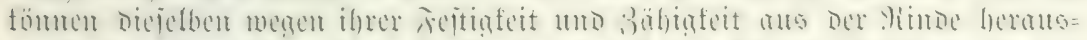

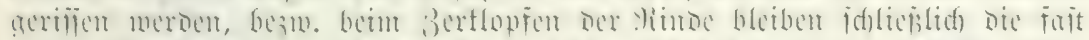

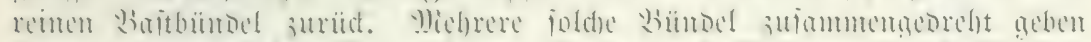

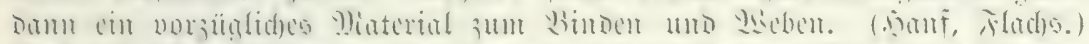

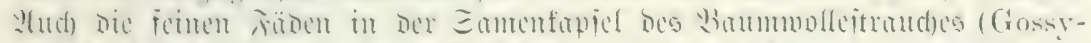

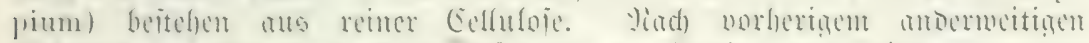

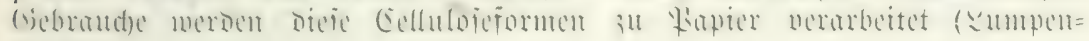
porpier).

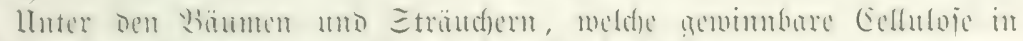

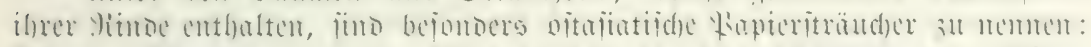
Edgeworthia, Broussmetia, Wickströmia, Daphno, skimmia u. a. Edoe-

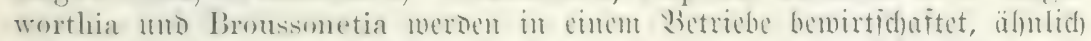

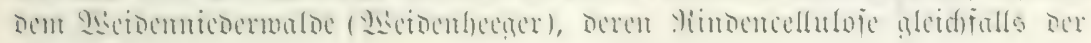
Hapierbereitung bient.

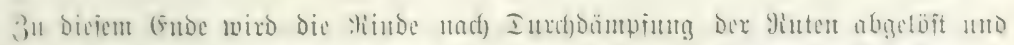

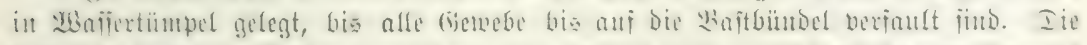

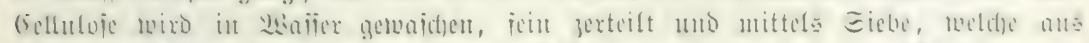

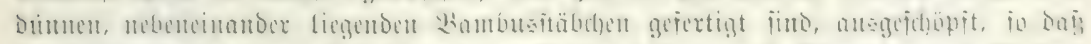

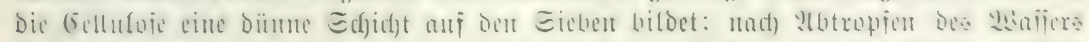

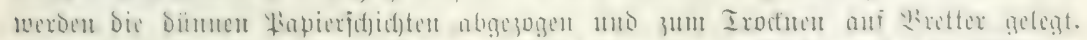

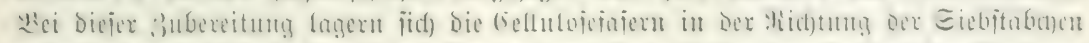

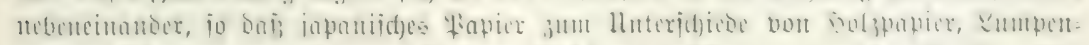

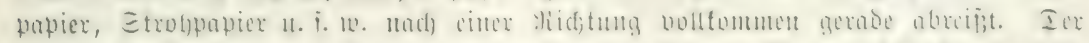

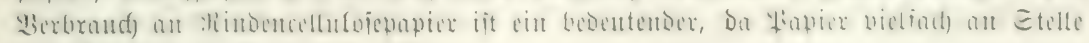
you Betueben in 5auzhalte tritt. 
Ilnter Den

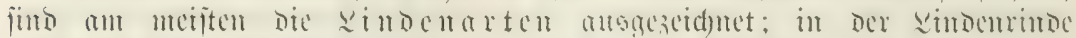

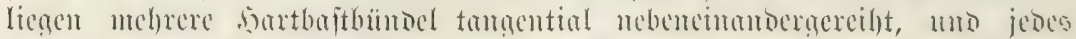

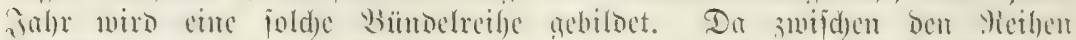

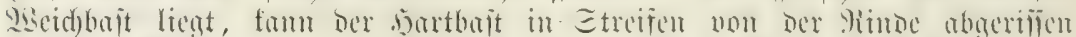

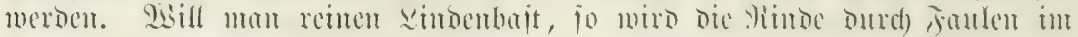
Mafïer mazeriert, mobei bie Baitbündel zarïdbleiben.

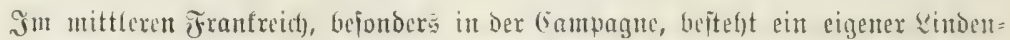

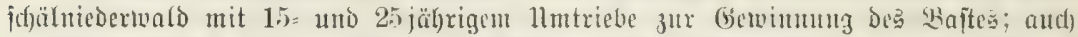

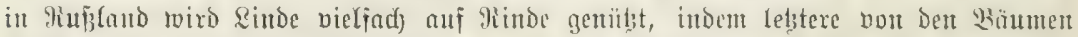

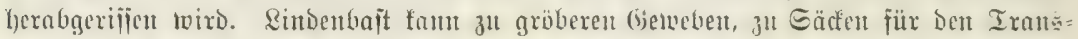

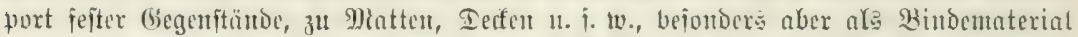

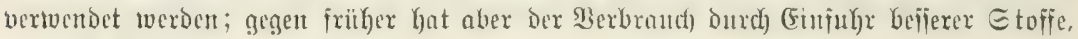
twie ber Maffiafajer, nggenomment.

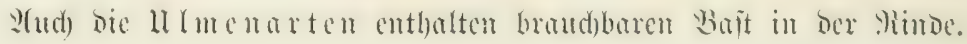

\section{䄈ork $\left.{ }^{1}\right)$.}

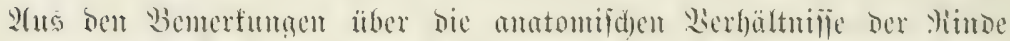

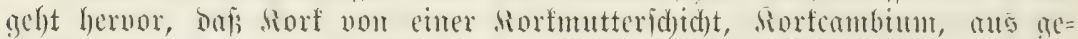

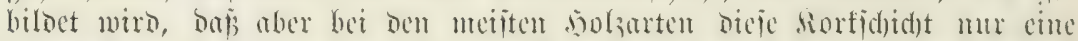

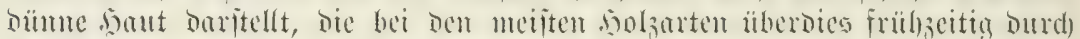

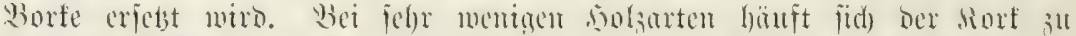

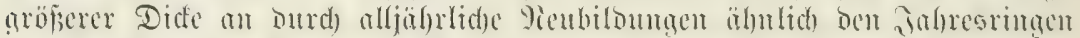

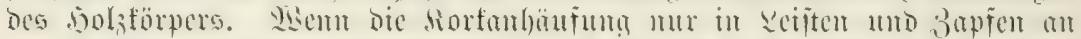

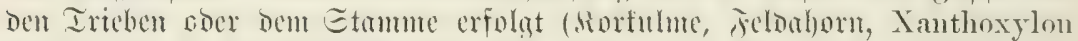

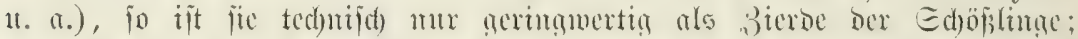

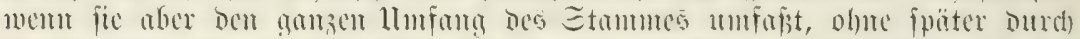

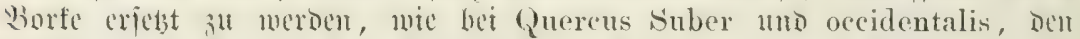

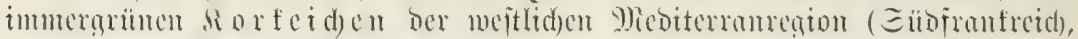

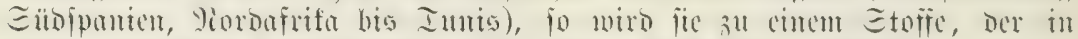

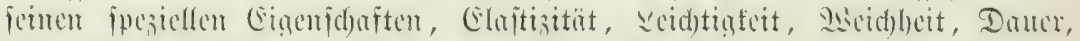

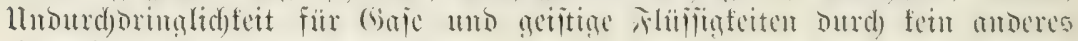
9)iaterial voll eriest merben famm.

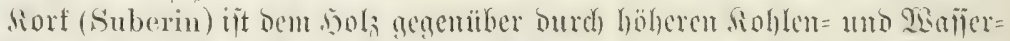

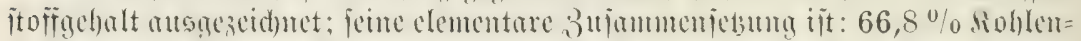

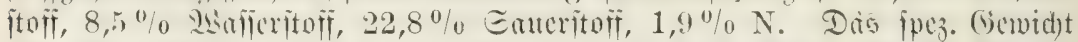

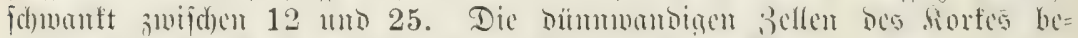

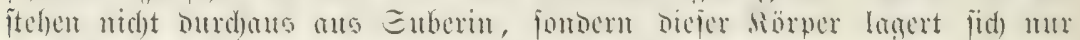

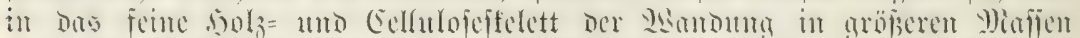

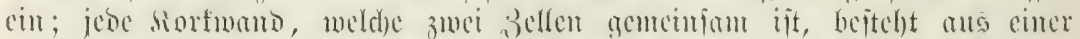

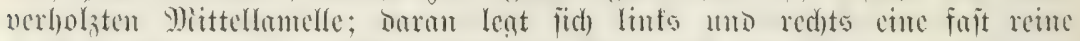

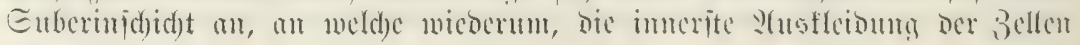

$\left.{ }^{1}\right)$ Lamey, Le chêne-liège en Algerie. 1879. - Boppe, Cours de

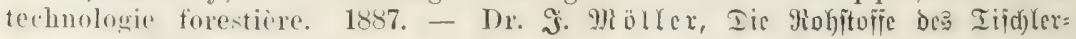
getwerbes. II. Icil. 1884. 


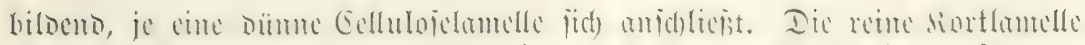

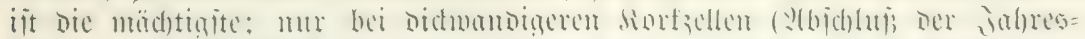

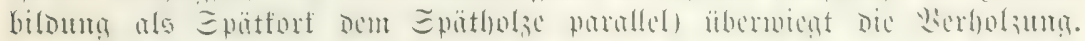

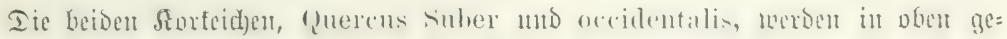

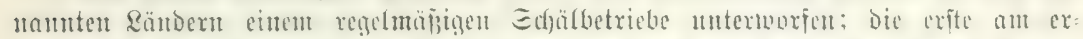

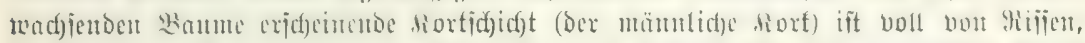

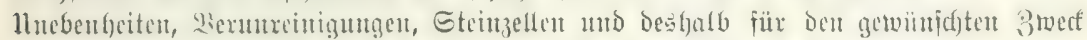

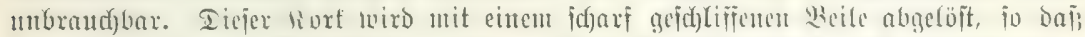

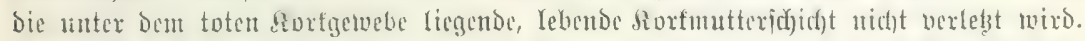

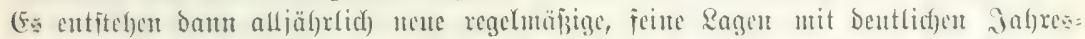

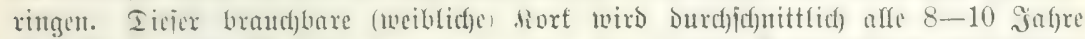

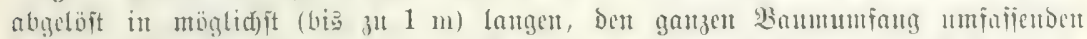

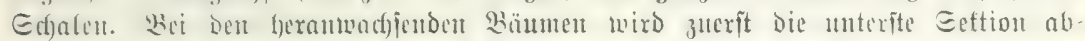

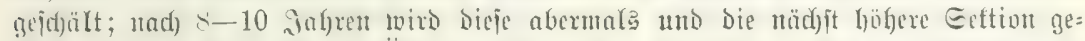

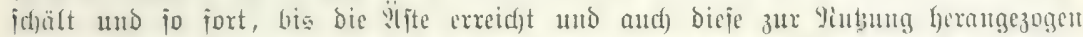

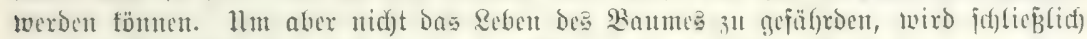

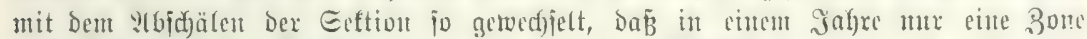

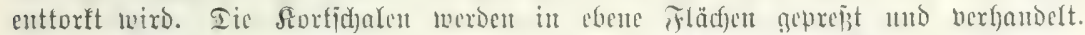

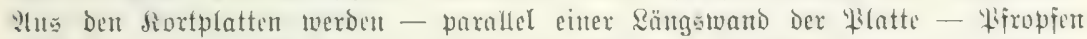

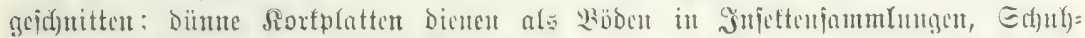

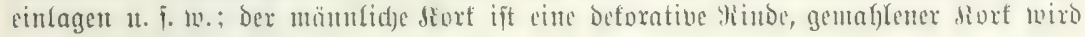
зux Serjtellutig von Rinoleum verwendet.

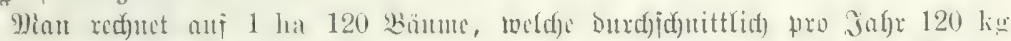

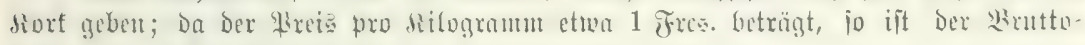
ertrag pro Şettar Siorfwaldungen 120 Fre?. pro Iafr.

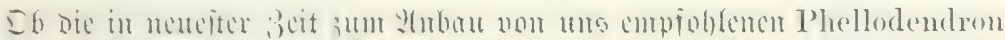

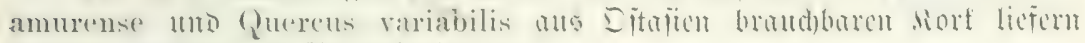
merben, mitifen erit Serfudje Dortut. 


\section{อ̄weiter 2lbjęnitt.}

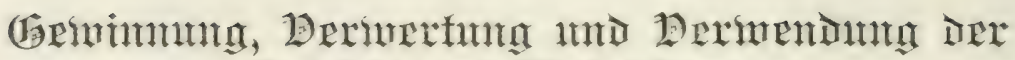

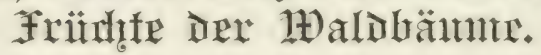

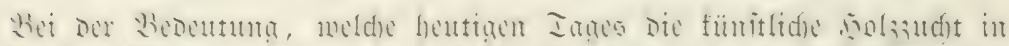

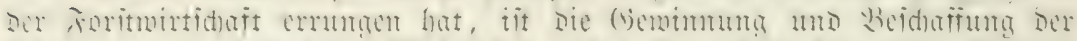

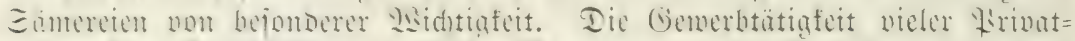

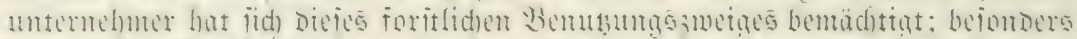

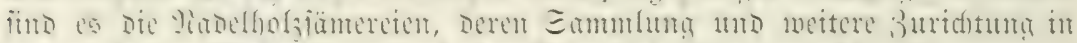

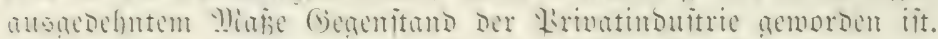

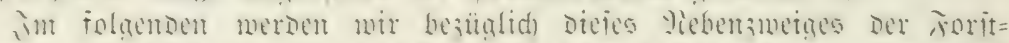

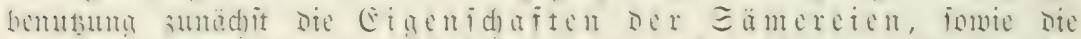

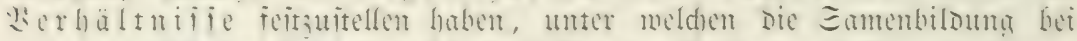

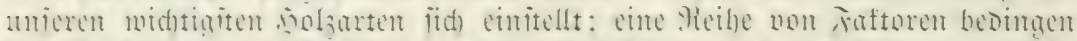

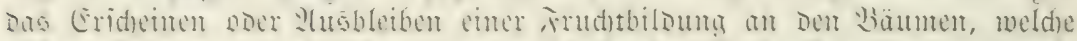

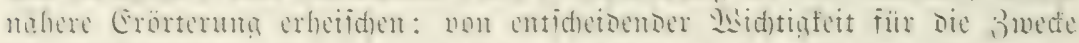
Der Eamenernte ijt bie Beit der ভamenreife und bē̄ ভamen=

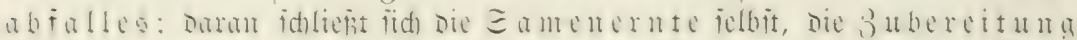

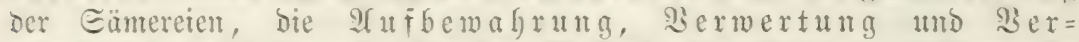
me Elbereitung แ. ก. .

\section{Die ntoxphologilifien Eigenthaften ser Sömexeien.}

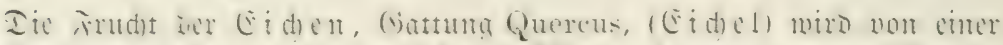

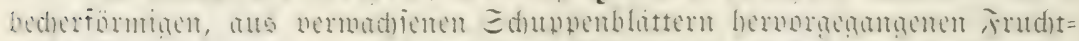

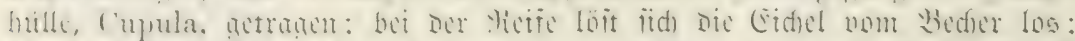

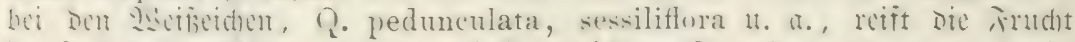
im, iahre sert

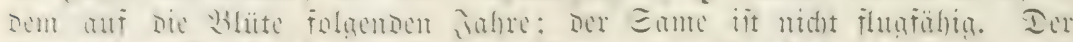

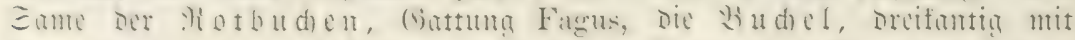

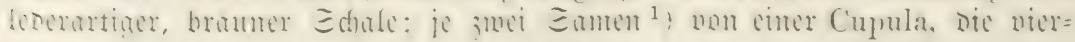

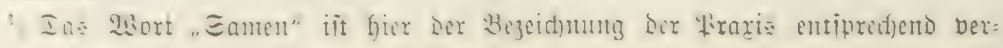




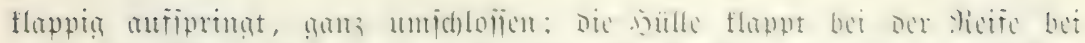

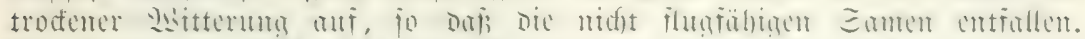
Ier Eame Dex (E)

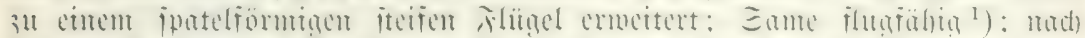

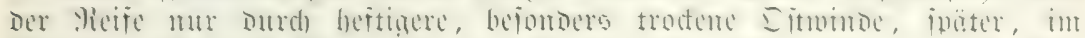

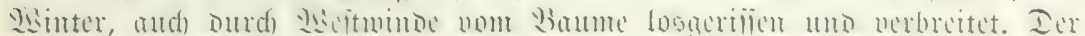

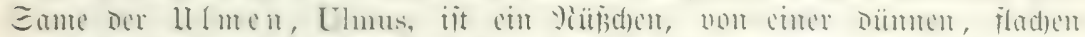

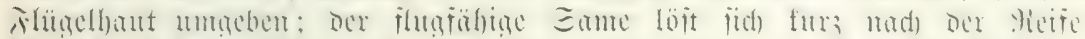

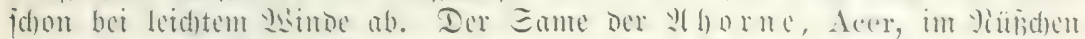

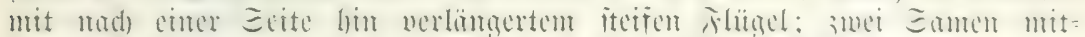

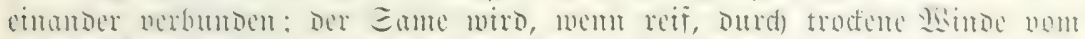

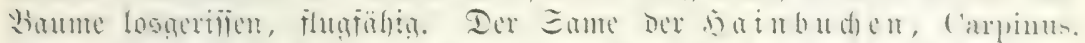

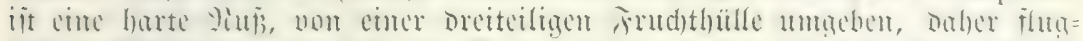

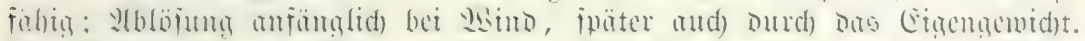

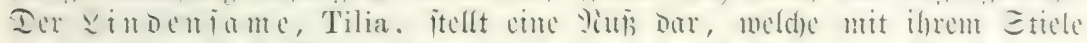

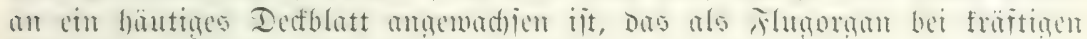
gBinben Dem Eanten Flugäbigfeit verletht.

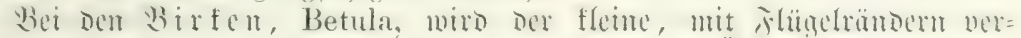

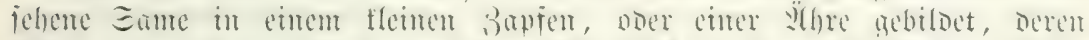
Ed)uppen mad) ocr Vieife jerfallen (

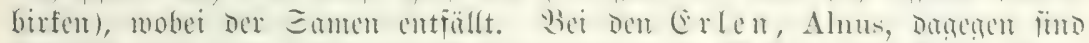

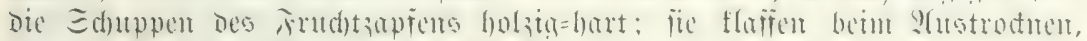
morauf ber platte tleine, faum flugfähige Eame entfällt.

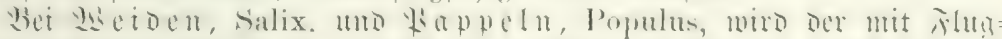

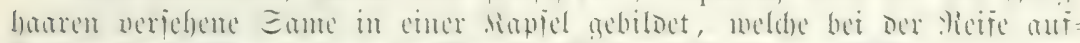

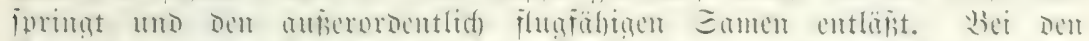

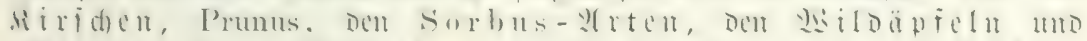
=

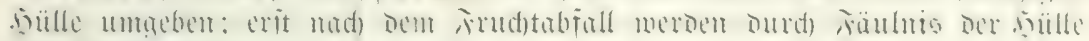
Dic Eamen frei.

Die Édelfaitanie, Castanea, bat cinen gropen Eamen, dex won

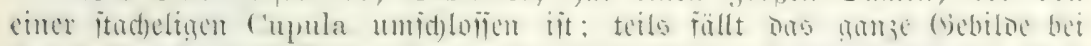

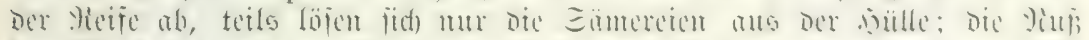
Der umid)lofien, weld)e bei der Sietfe ansemondertlappt.

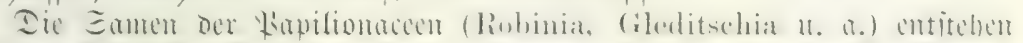

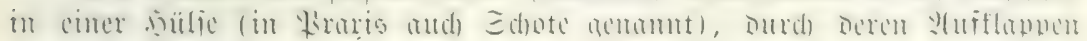
bie nidyt flugfäljigen Eamen entiallen.

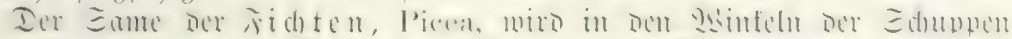

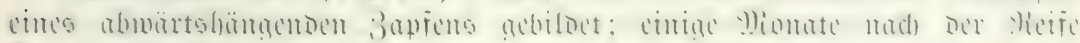

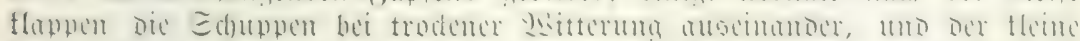

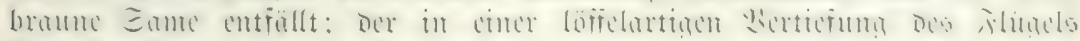
liegende Eame it flugfülig. Der Eame dex Ianucuaten, Abies,

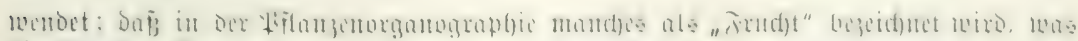
die Praris "Gamen" nenut, joll nicht verjobiegen werbur.

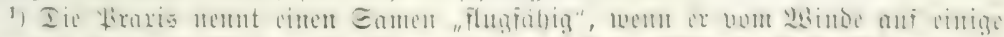

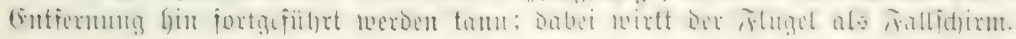




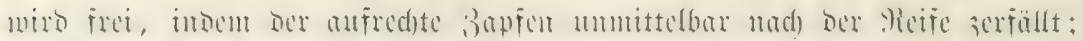
ber Eame ijt an einer Eeite mit bem Fllügel feit vermadjen.

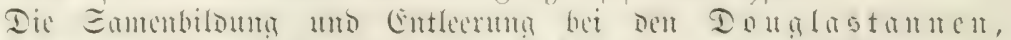

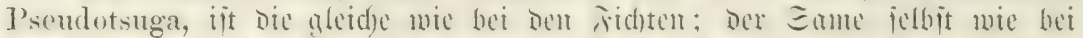

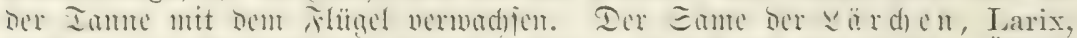

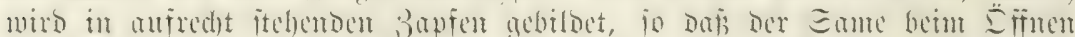

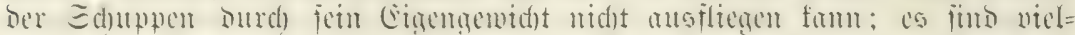

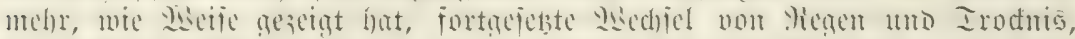

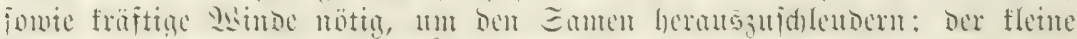

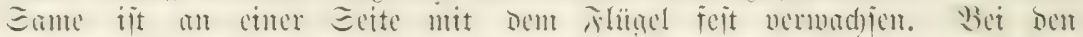

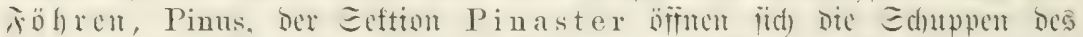

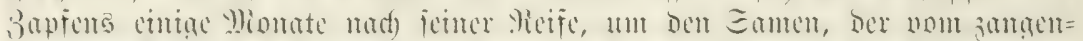

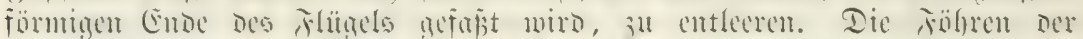

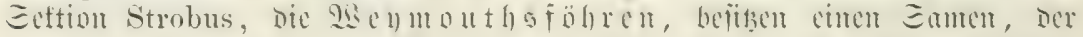

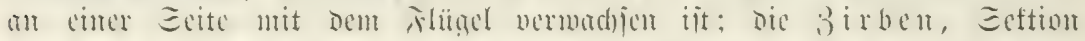

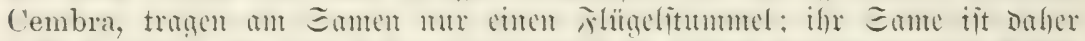

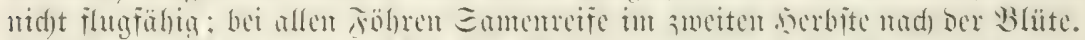

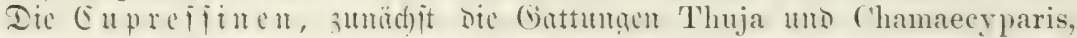

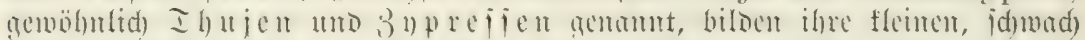

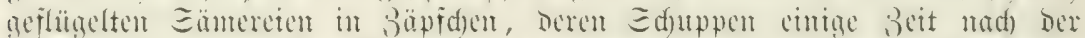

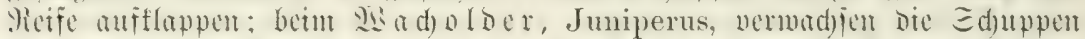

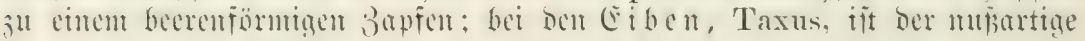
Eame von emer fleijdigen, roten Seille (Arillus) nmgeben.

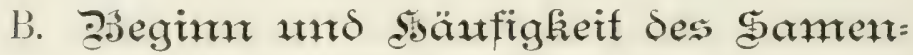 extxägmilles.}

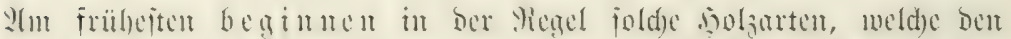

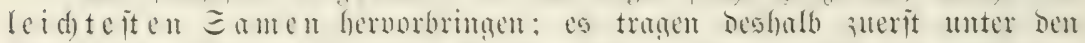

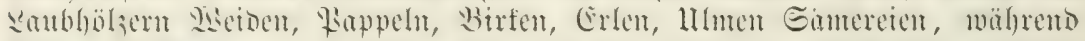

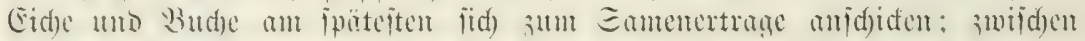

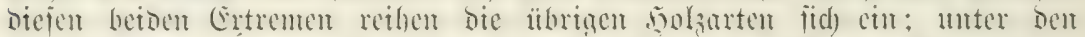

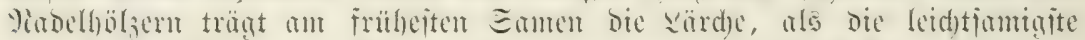

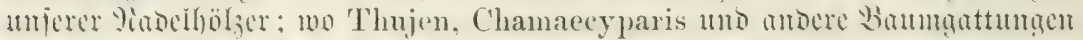

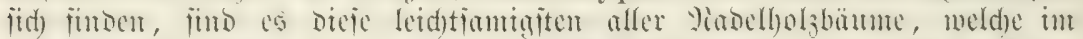
jugemblid)

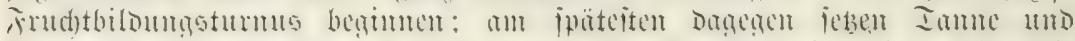

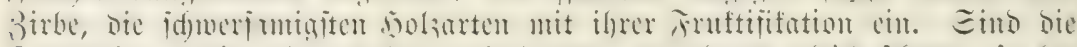

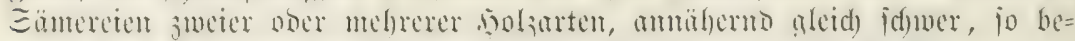

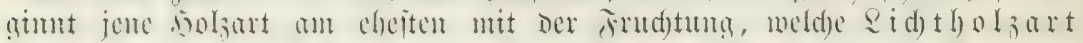

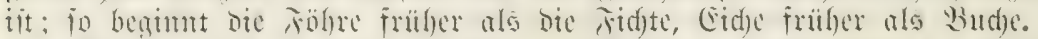

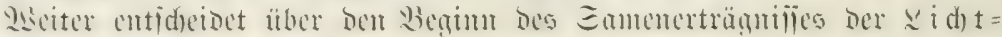
(1)

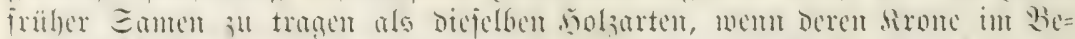

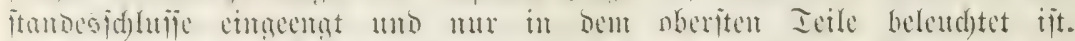

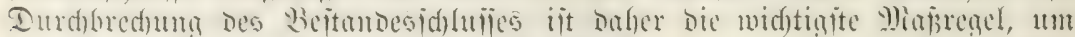

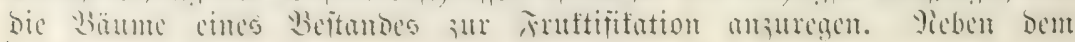




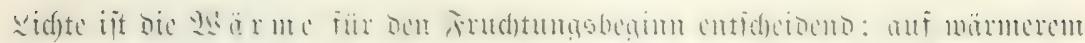

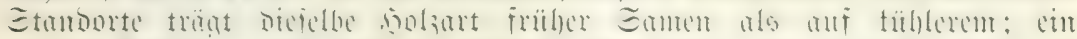

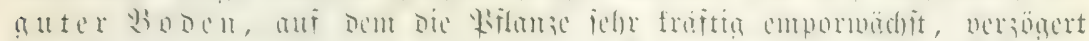

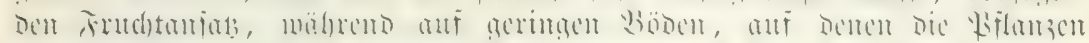

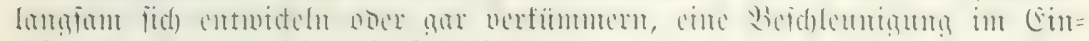
tritt ber glambarfeit jidf cintellt.

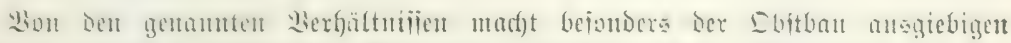

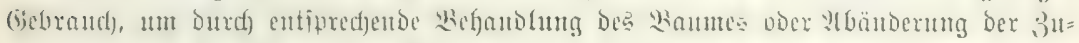

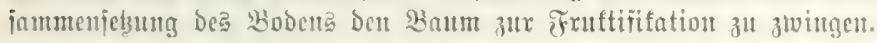

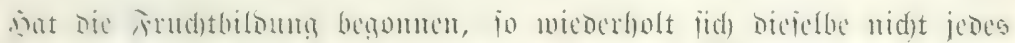

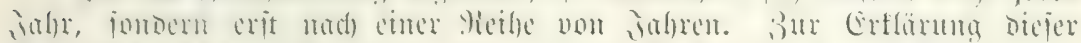

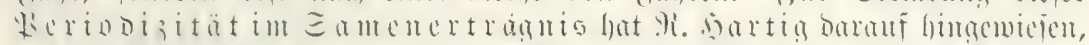

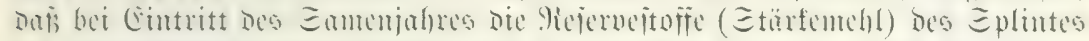

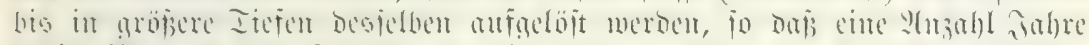

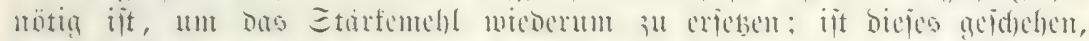

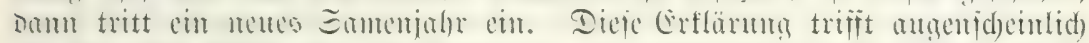

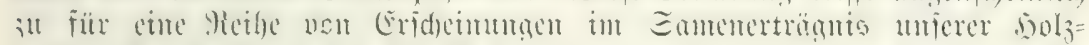

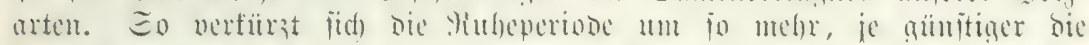

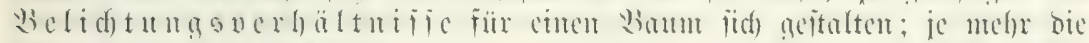

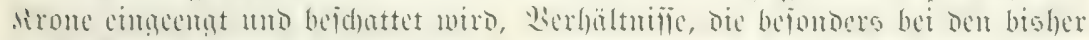

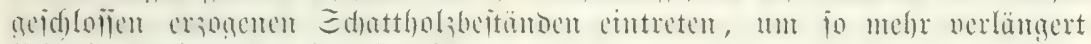
iid) Die Seriobe Der Frudfutrulbe.

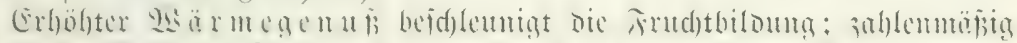

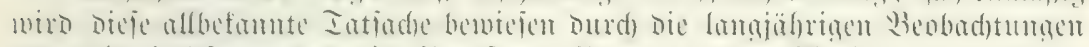

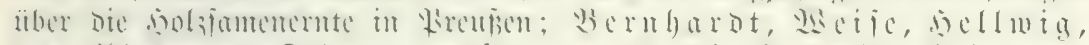

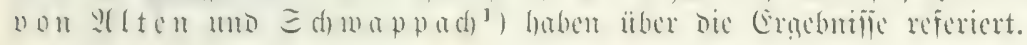

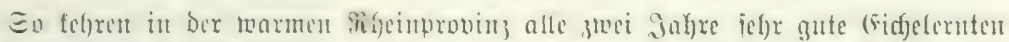

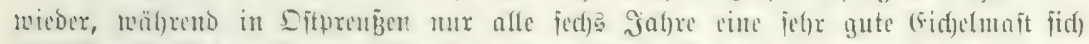

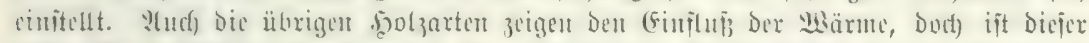

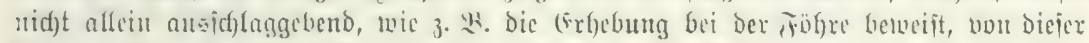

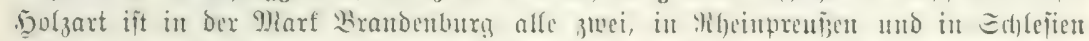

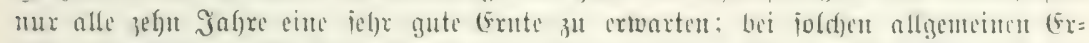

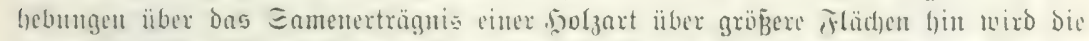

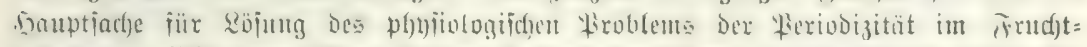

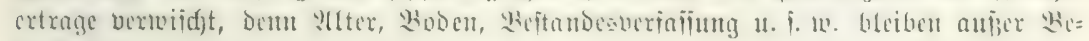
trad)tumg̨.

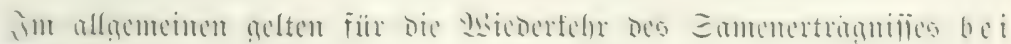
cin un bempelben jubividu

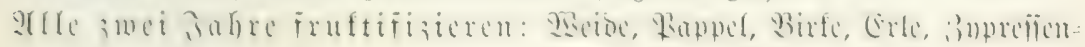
artes, ll!me, Fölux, sürds.

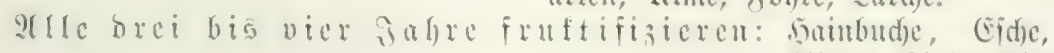

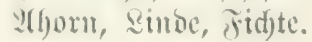

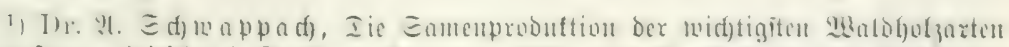

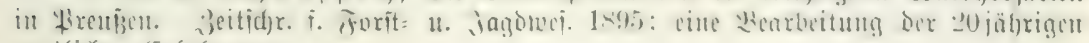
amtlidgen (Exf)ebungent. 


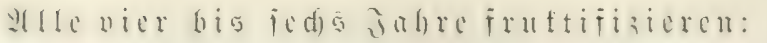
[ed) 5 bis $3 \mathfrak{e l}$ n
Inume, itrke, c゙od= faitanie.

Ẽidje, Budde.

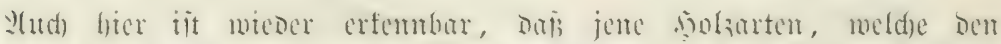

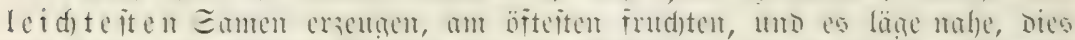

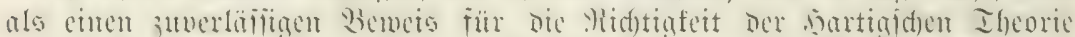

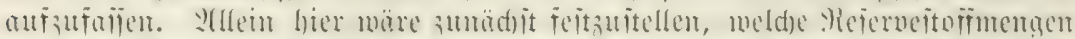

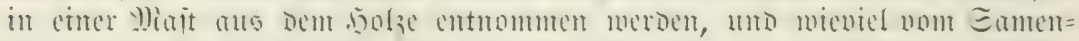

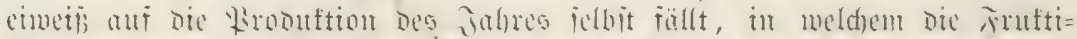

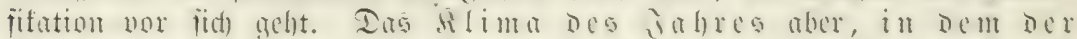

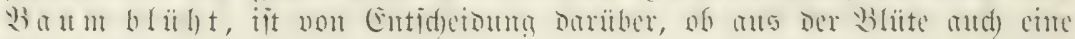
Ærudt)t wird.

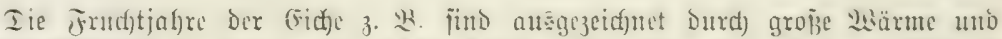
Irodnis (Meimjahre); jolgen zuei joldge Jahre aufeinander, wie 1892 und 1893 , io

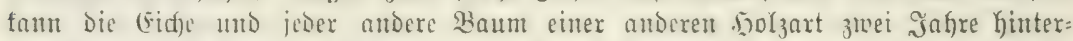

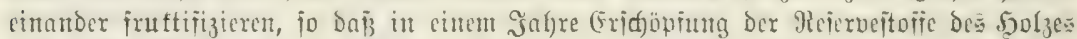

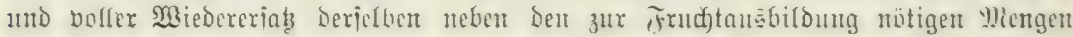

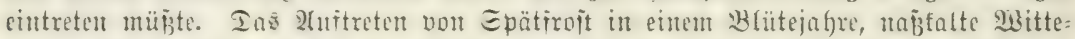

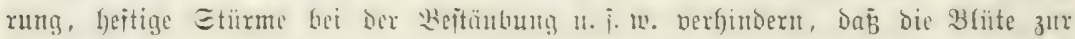
Frutht wirb.

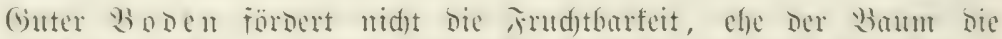

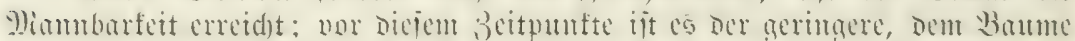

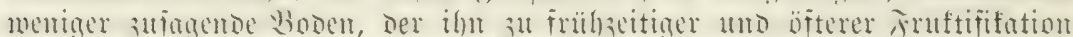

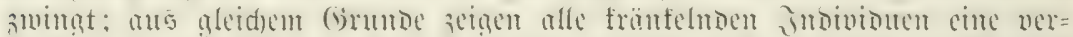

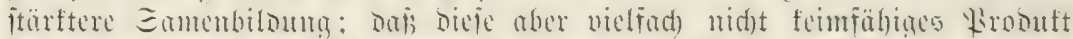

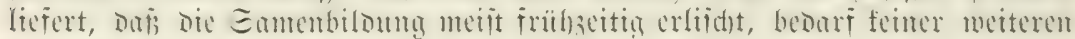
Crörternugen.

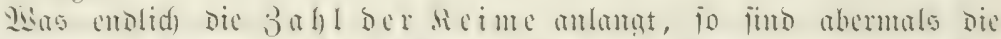

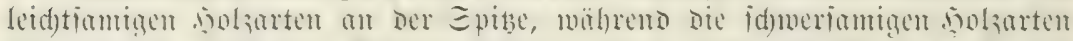

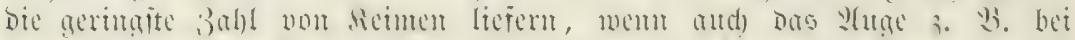

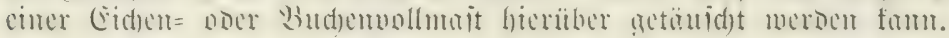

\section{Die Samenxeife mtro Sex Samenabfall.}

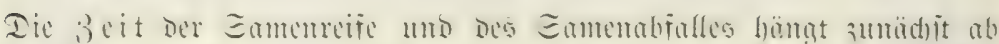

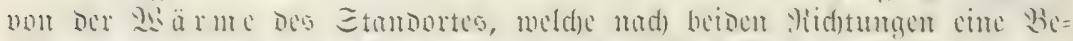

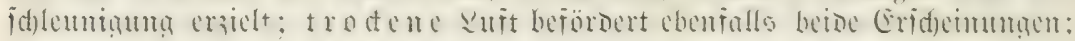
im allgemeinen aber fom folgender Eamenfalentoer gelten:

(Iabelfe $i_{0}$ näd)itte Geite.)

\section{Die Santenternte.}

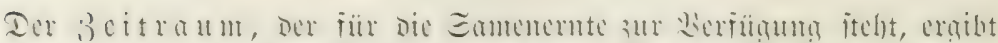

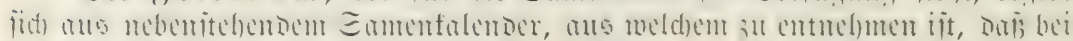

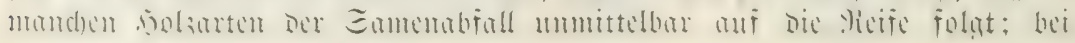




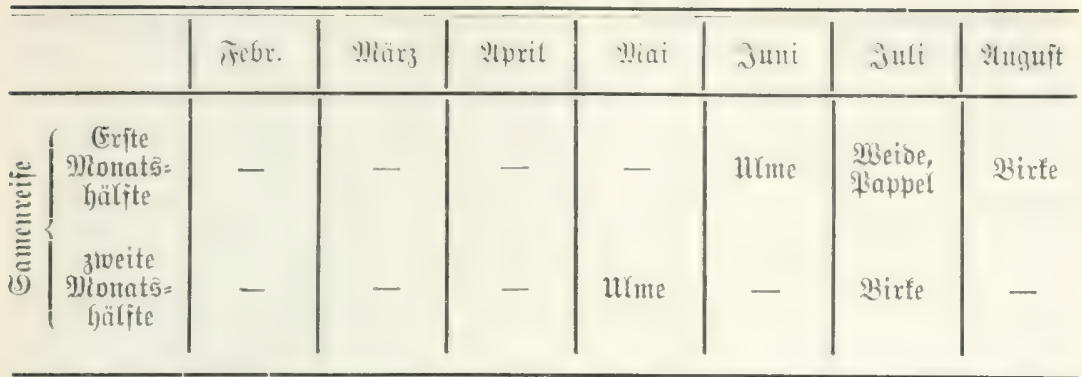

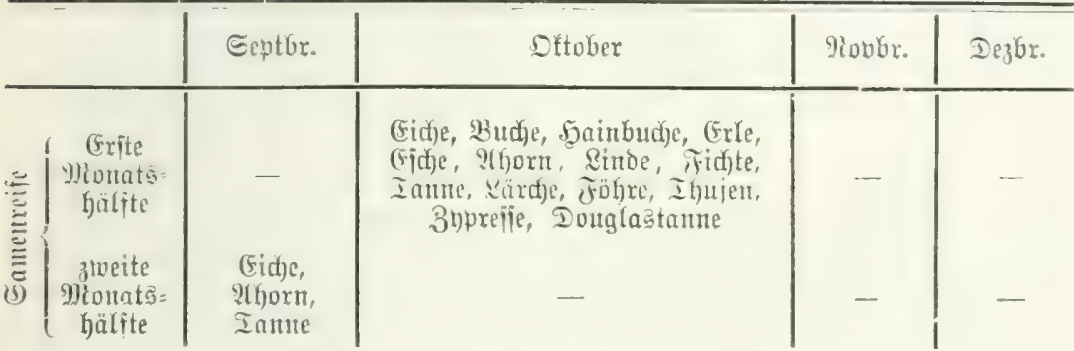

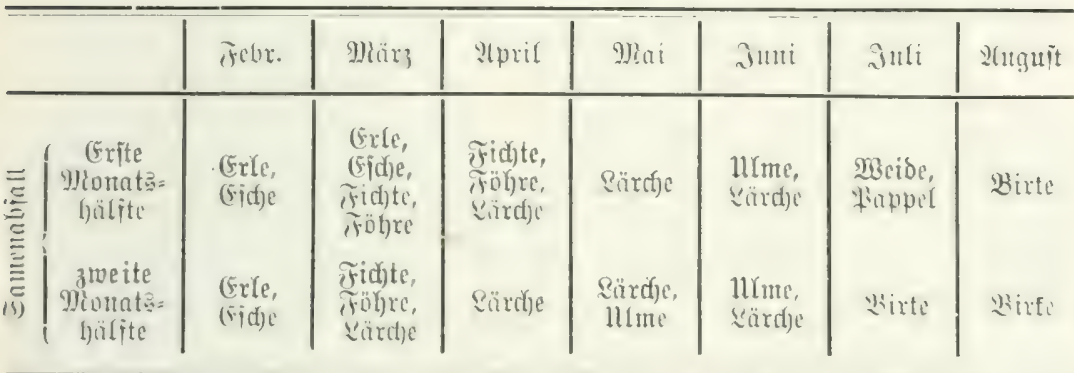

\begin{tabular}{|c|c|c|c|c|}
\hline & Eeptor. & Dftober & 9rovbr. & $D \mathfrak{e}\} \mathfrak{b x}$. \\
\hline 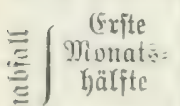 & - & 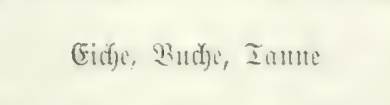 & $\begin{array}{l}\text { Ifoorn, } \\
\text { Pinde, Gicter, } \\
\text { 5ainbudie }\end{array}$ & 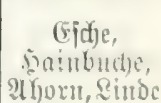 \\
\hline 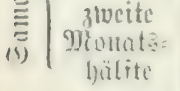 & - & 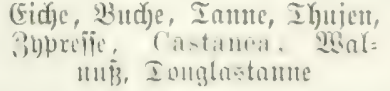 & Iipiellon & (ivide, (5rte \\
\hline
\end{tabular}

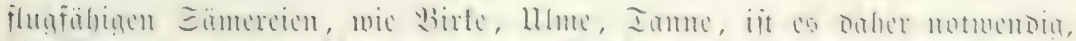

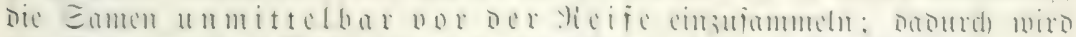

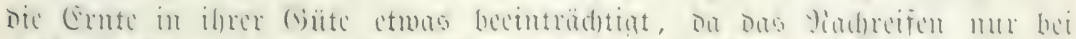

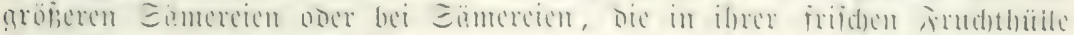

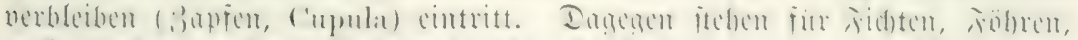

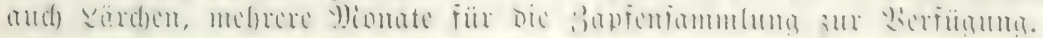




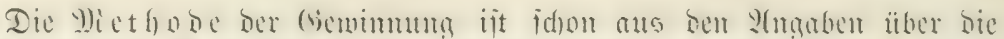

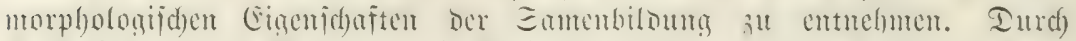

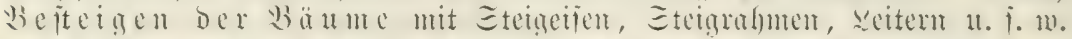

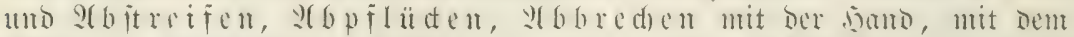

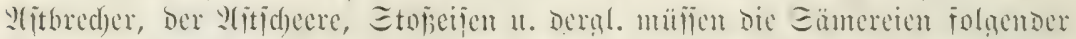

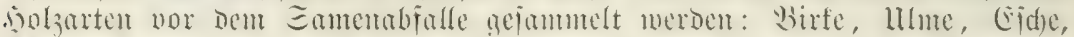

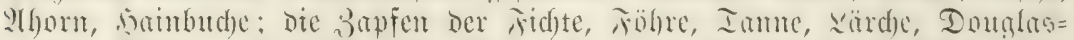

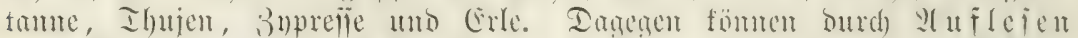

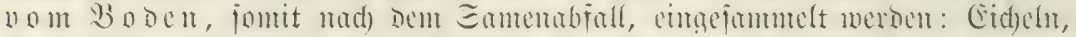

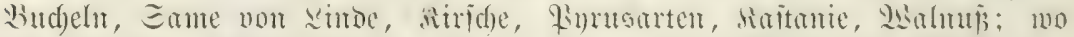

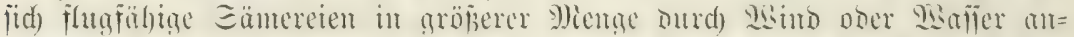

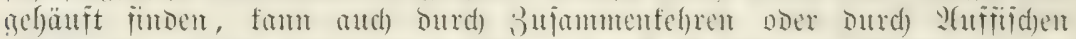

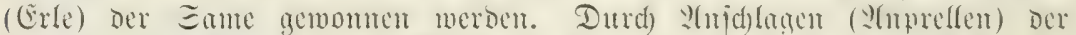

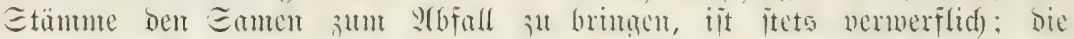

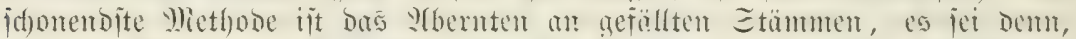

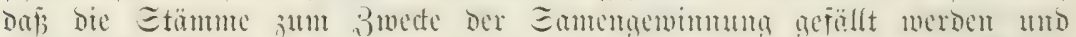

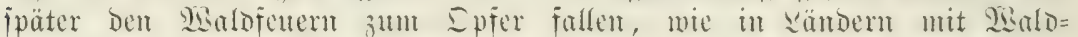

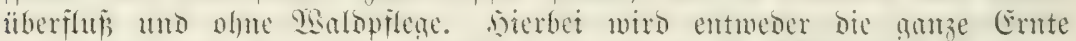

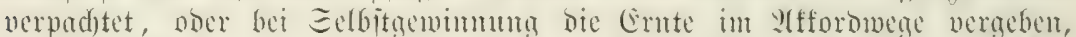

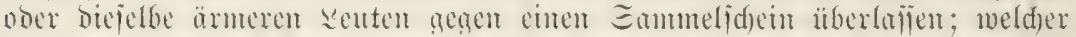

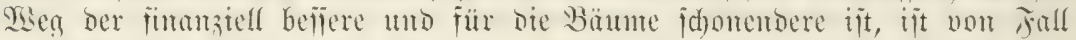
zu Fall benteilen.

\section{E. Die Buxichtutng Sex Sämexeien.}

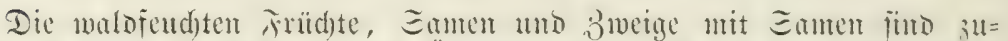

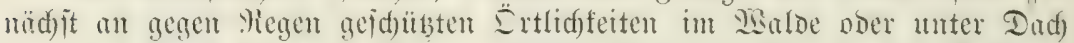

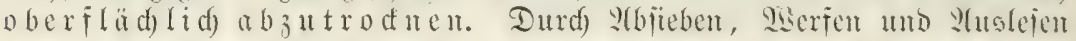

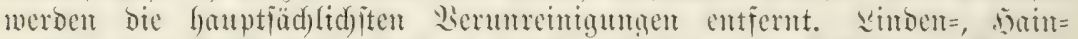

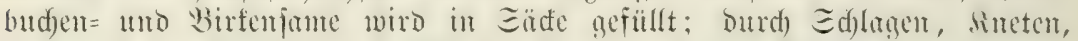

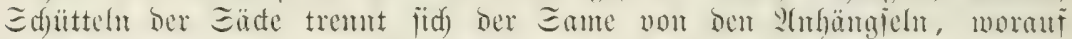

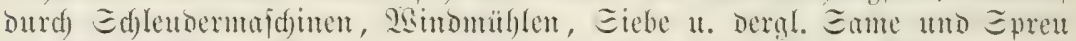

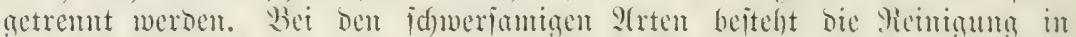

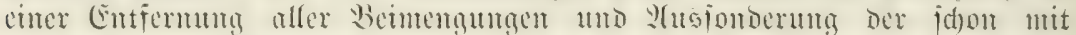

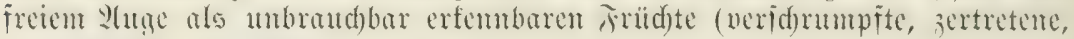
von Jinfeften Durdjbohrte u. Dergl.):

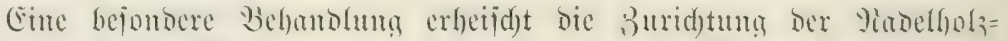

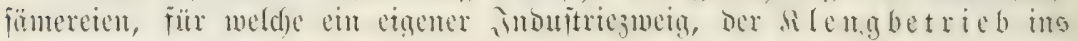
seben getretent iît.

\section{F. (Eintrichtung Ser Silenganlfalten ${ }^{1}$ ).}

\section{Sommendarten.}

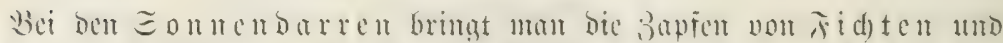

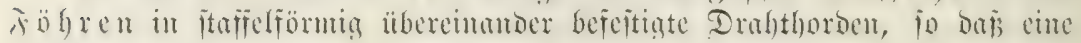

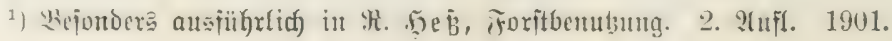




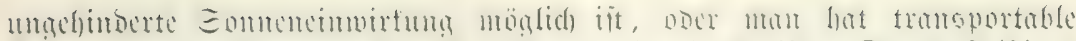

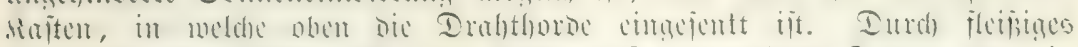

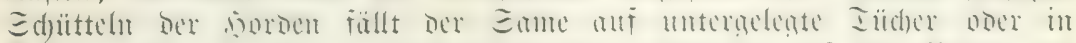

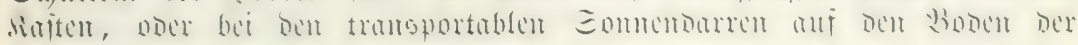
Siajten jelbit.

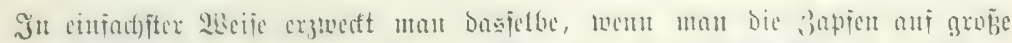

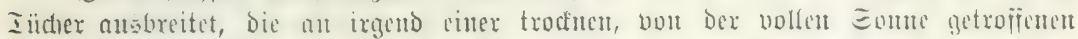

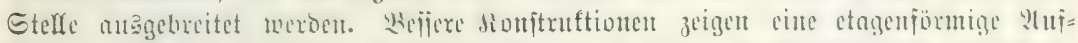

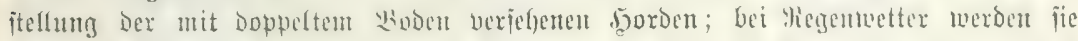

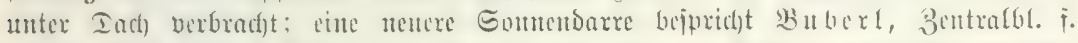

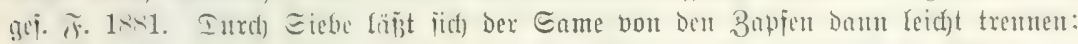

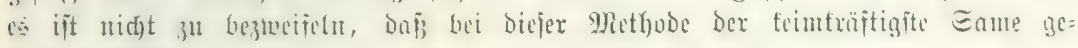
twontten wirb.

\section{2. fenctomen.}

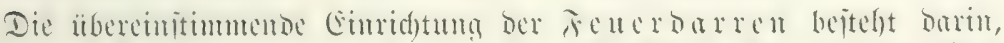

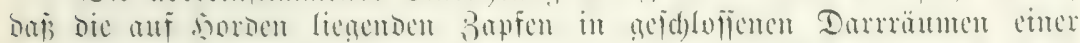

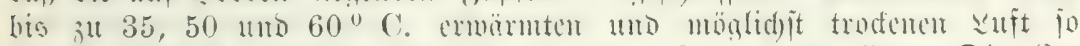

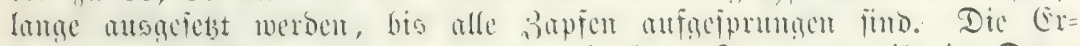

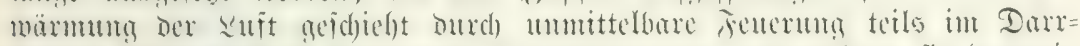

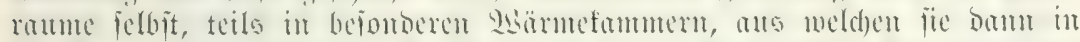

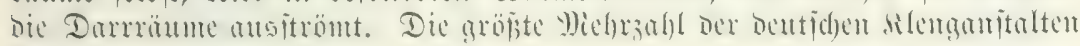
jut Fenerdarren.

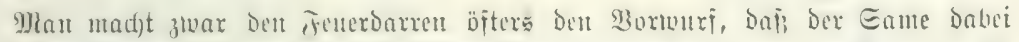

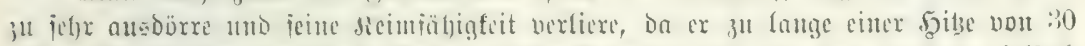

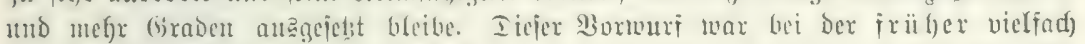

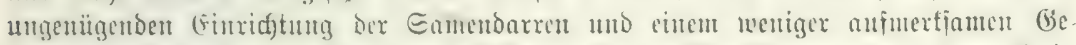

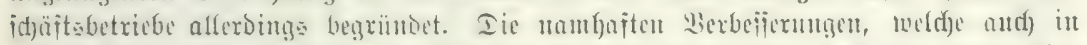

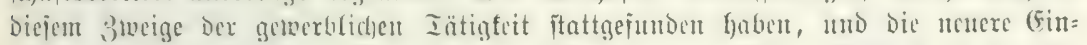

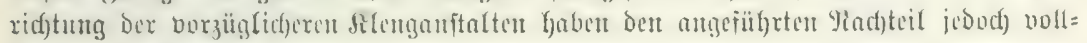
itän๖ig übertvunden.

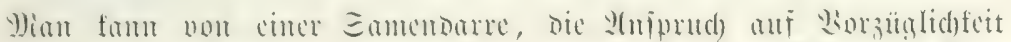

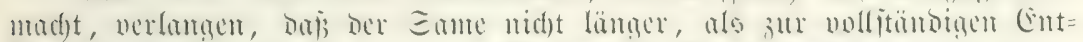

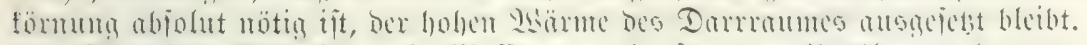

2.

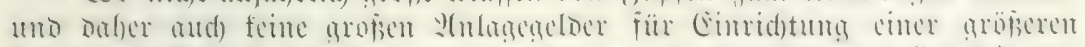

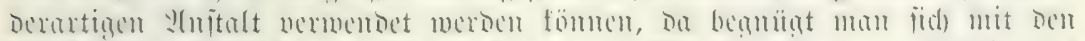

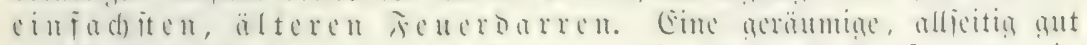

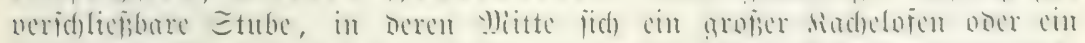

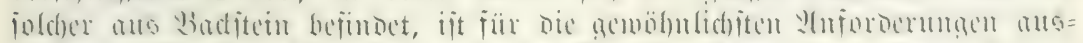

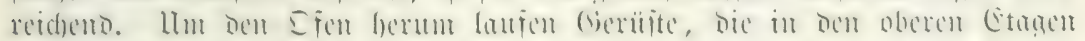

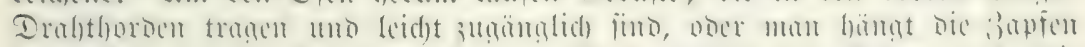

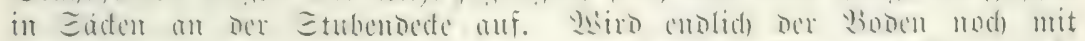

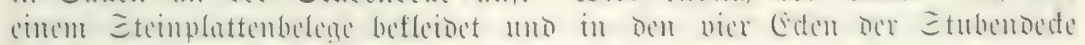

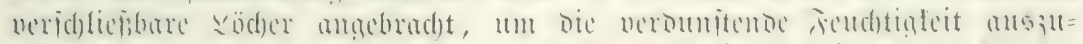

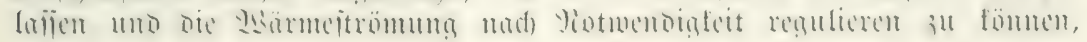




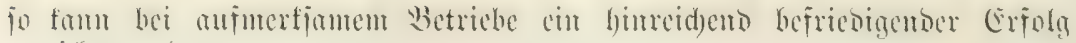
erreidjt werbert.

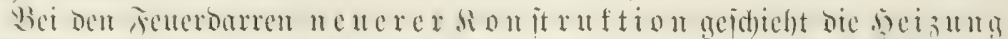

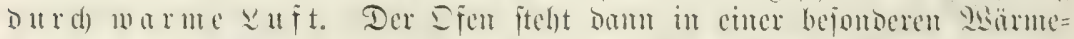

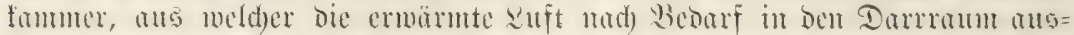

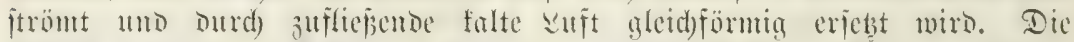

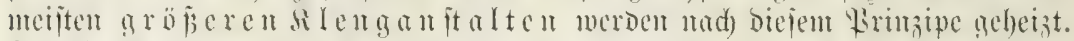

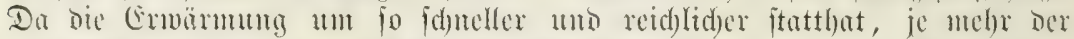

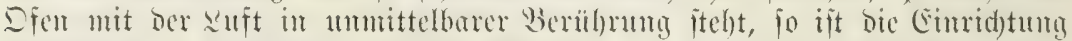

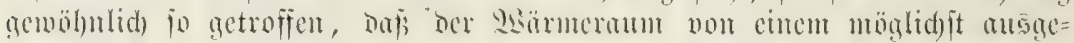

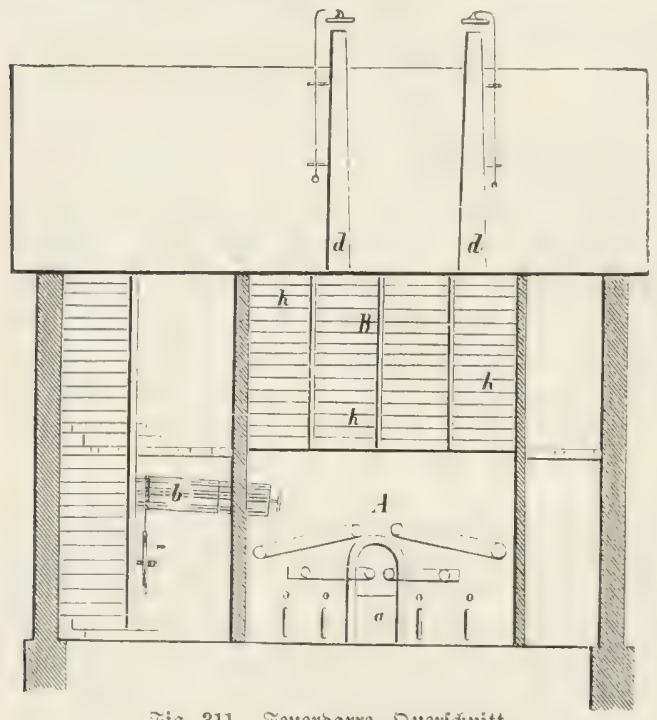

Jig. 311. Feuerbarre, Dueriduitt. befuten Enfteme von cifer= แen Viähen Durd)iogen mird, bie erit nad) vielen Syin= und MSiedergängen in Den अind fong emmümben.

a) Eamendaren mit bewegliden 5or Den. Der Sauptctarafter Dicjer Darrent liegt bariu, bafs bie leidgt ants bolz fon= itruierten f̧orden bemeglid)

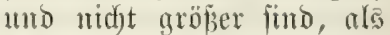
Dap fie Durd) Miammesfraft leidft bemältigt werben fömen, bafi bieje 5yorden it fitrzeitem 2lbitande über= cimanter und gewöbutid) munttelbar ïber bem jeuer= raume auf Ragen aufac $=$ itellt finto. श(us lebterem fömen fie zur Fïllumg แแ⿰ beim $9(6$ lecren leidyt beraus=

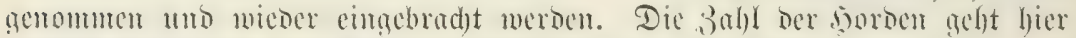
je nad) Der (Gröfie ber Injtalt ïberbaupt, bis zu tamient.

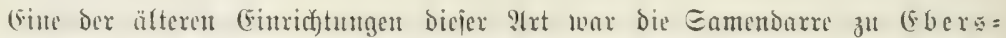

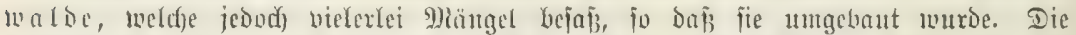

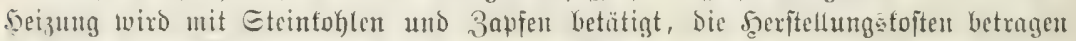

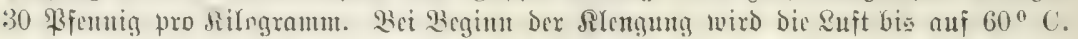

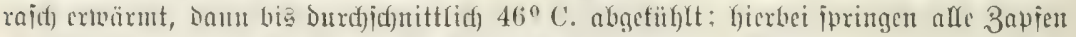
gledd)mäß̄ig auf und Die Iaucr Dex Iörrung twiro auf adf)t Etunten abgetiirzt. (Beit= idfifift fïr Forit = u. S. 1900.)

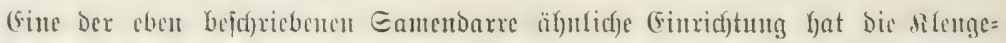

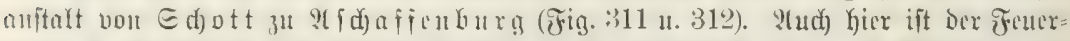

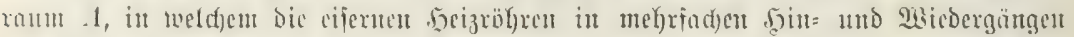

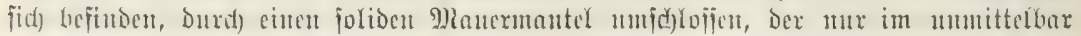

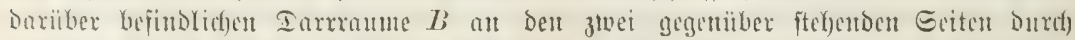

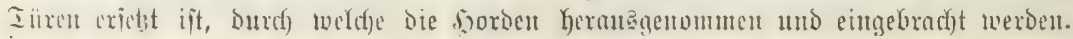




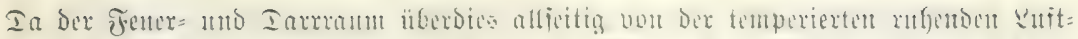

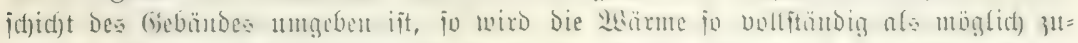

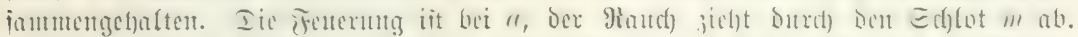

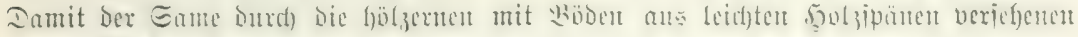

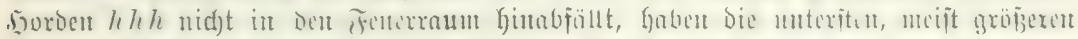

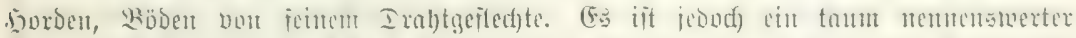

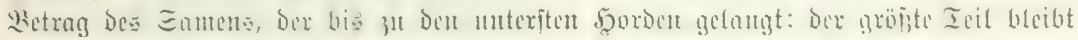

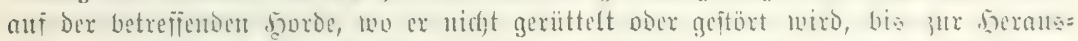

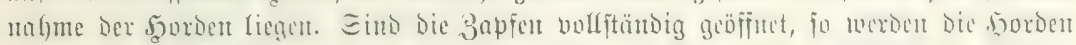

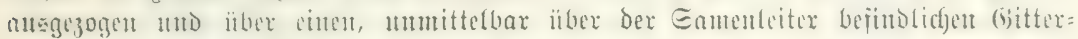

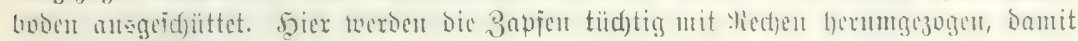
jic fid bolfftănoị entteeren.

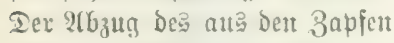
Fid) entwicfeluden Dumites ge= idfieht Durd die beridaließ̧baren Edflüudf)e $d d$; Der Butritt Der fripden Suit in ben Feuerraum Durdid) Die Rödjer 000 .

Dieje Sdy ottidfe einfadie Gamendarre fam alg Ilypu zaff(reidjer, namentlidy ber im \$rivatbetriebe befinolidjen :tat= itnltest biefer sirt betrad)tet werben. Ganz ähnlidy finto bie silenganitalten Feter $\sigma_{\text {d d ot }}$

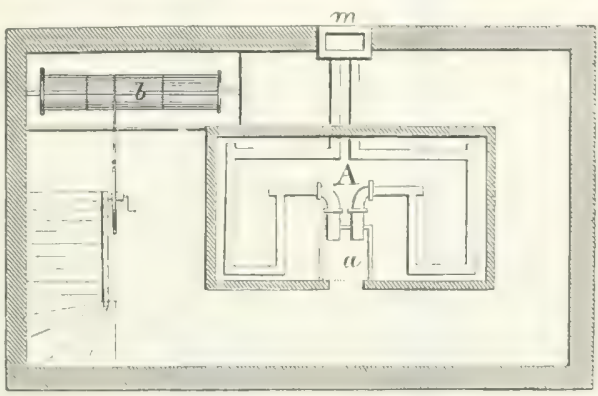

Fig. 312. Femerbarte, Gumbrif.

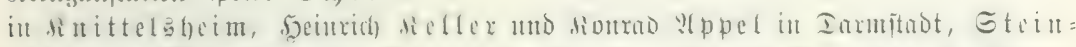

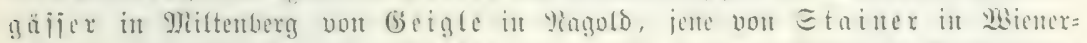

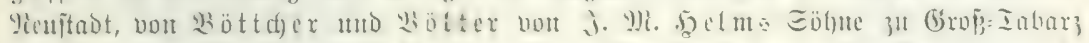

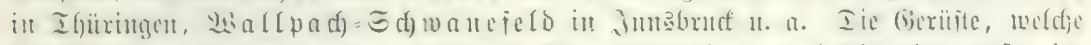

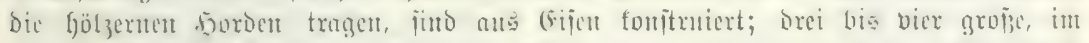

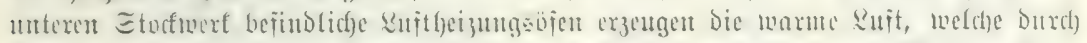

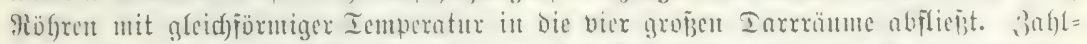

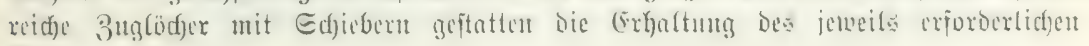
23ärmegrabe弓.

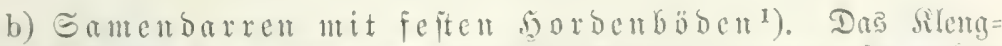

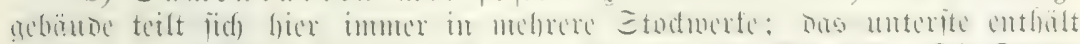

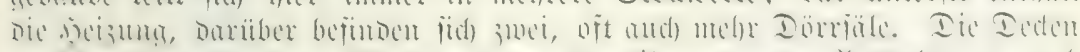

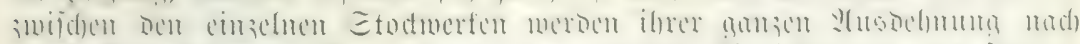

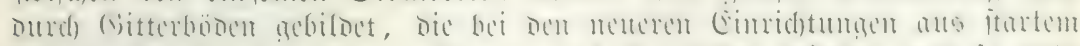

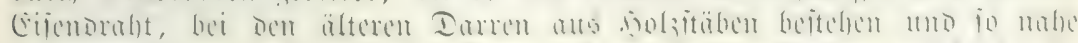

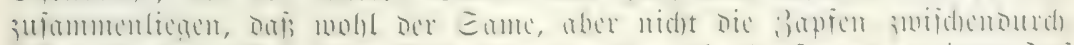

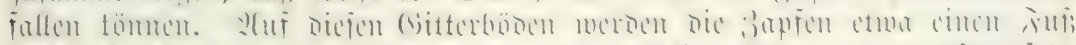

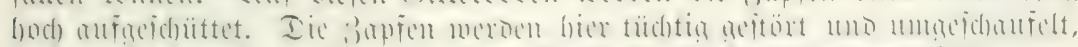

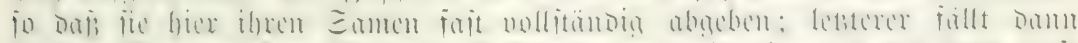

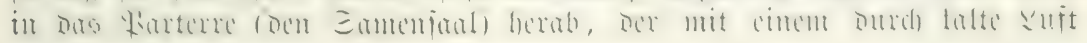

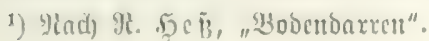




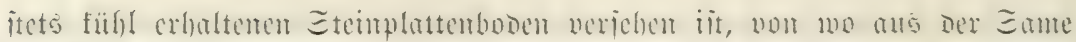
id)liep̧lid) ausgezogen wiro.

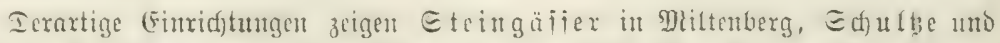

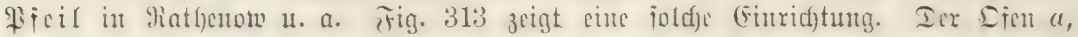

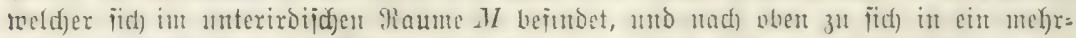
fad) getciltes Enjtem non höhrn (bl) verengert, wiro non cinem tuppeliörmig ab:

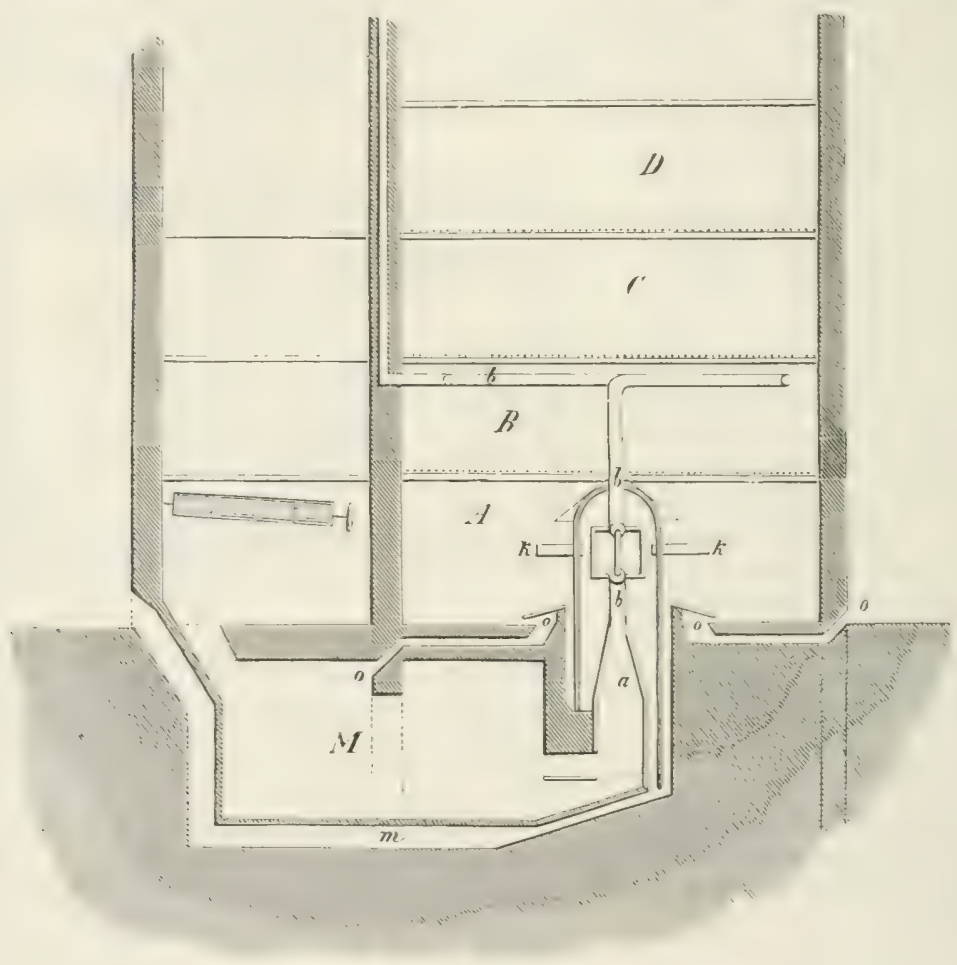

₹̛ig. s13. Eamenbarre mit fejten șorbentöben.

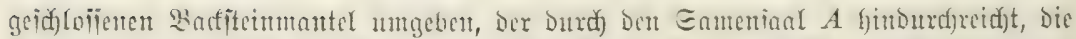

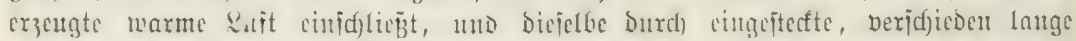

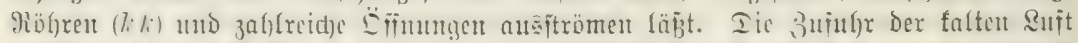

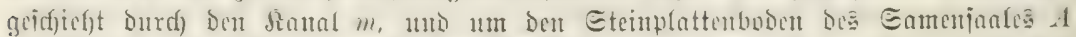

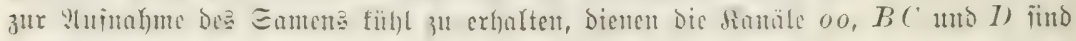
Dörrị̄le.

c) Die Irommeldaren. Cine non ben bisher bejuricbentr

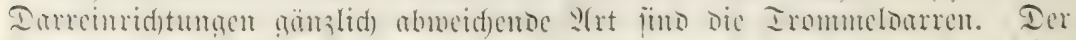

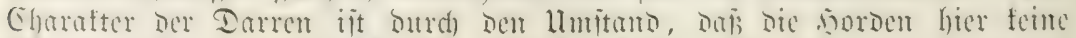

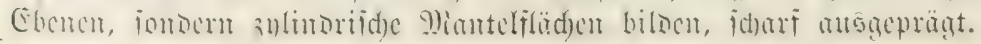




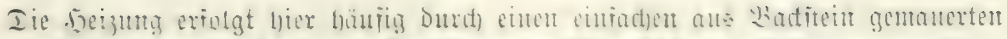

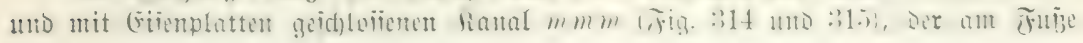

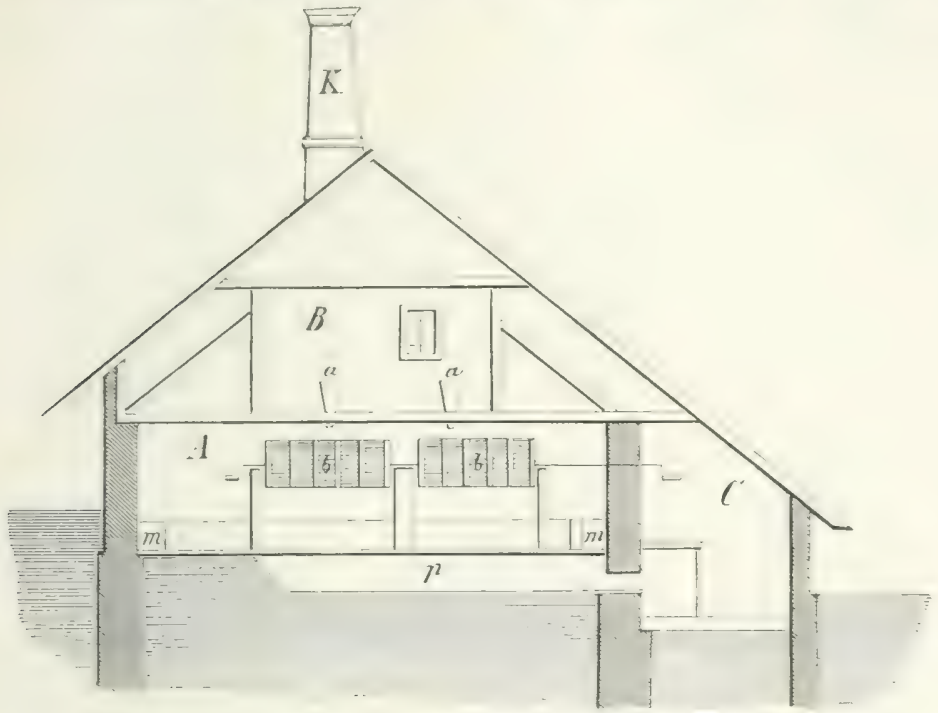

Jig. 314. Tronmeloarre; Sueridnitt.

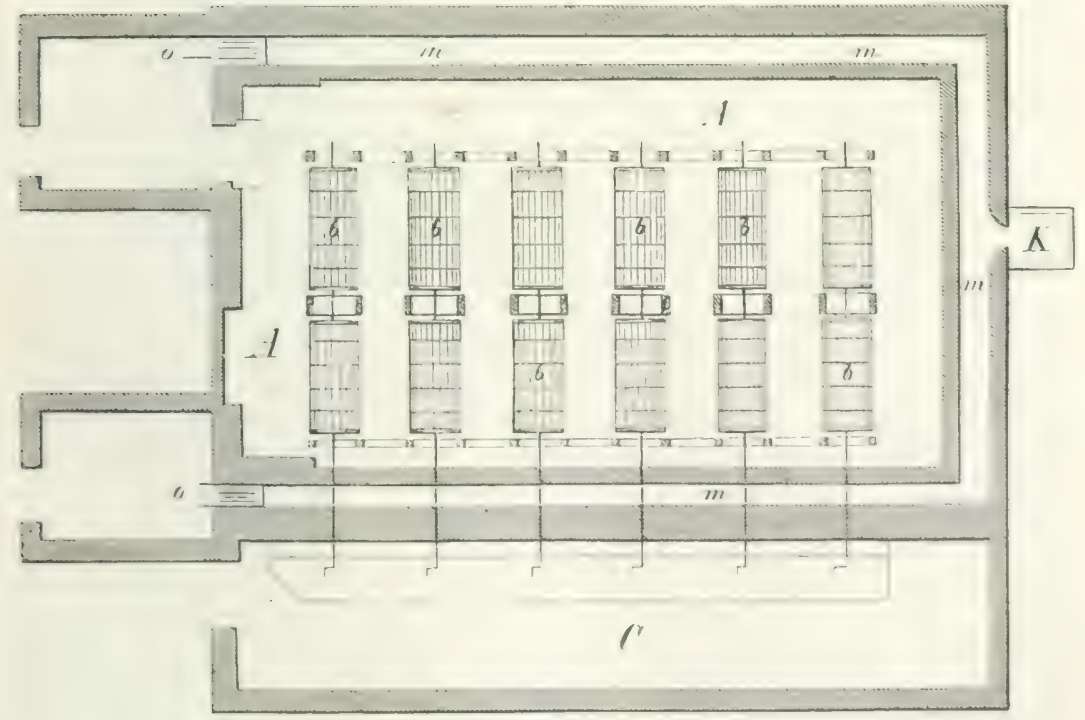

Jig. 315. Trommelbare; ("sunbrip.

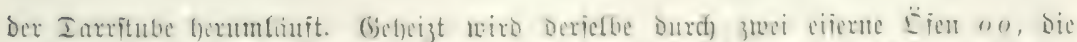

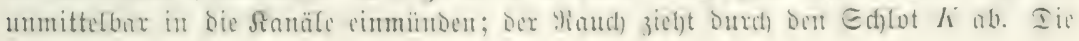




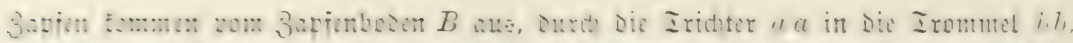

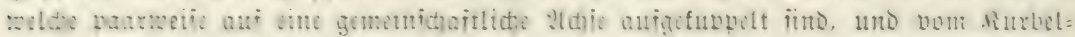

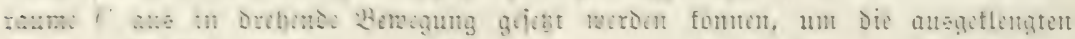

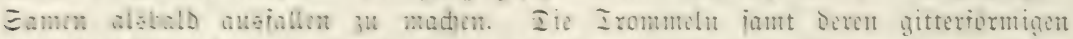

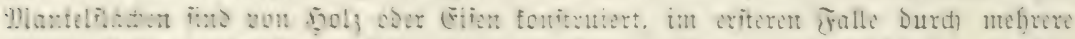

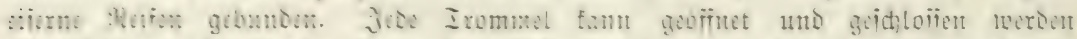

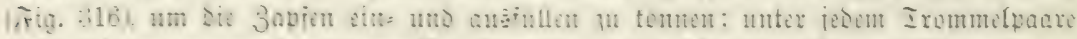

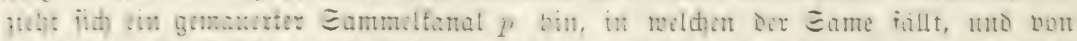

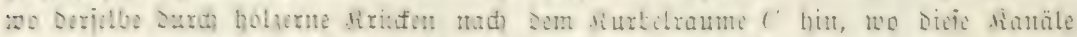

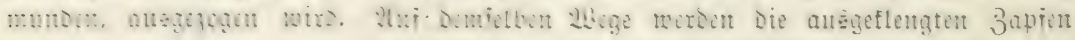

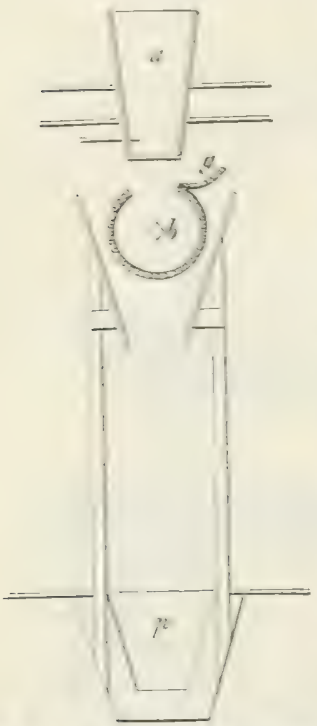

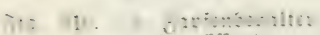
b) ¿rommel (gejïnet).

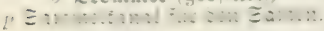
aügeïffrt. - Ia alfe Miertelitunden Der furbler bie Irommeln in Bewegung jebt, io gelangt Der Eame in möglidjit furzer Beit in bie füblen Sammeltanäle, no er iogleid auşgezogen wird und aljo Der Şibe Deß Iarr= raume nidjt länger ala nötig anz̈gejebt bleibt. Iie

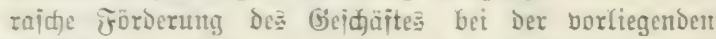

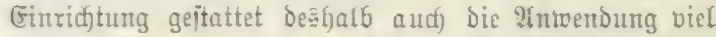
föherer Mämegrade in Dex Iarritube. Jad) Den biä= ferigen Friafrumgen leipten Die Irommeloarren übrigen nidft mefre al Die Darren mit gemönnlidjer jorben= einridtung, uno jieft man lebtere vielfad) bor. Irommel= Darrert jino in Betrieb in ( $\operatorname{arolath~(Ed)Lejten),~in~}$ Bᄂantenburg (Conrad Irumpī), in Millerz= Gauiert.

\section{3. 刃aนıfDaren.}

Bet ben Dampiodaren gejdjebt die Čr wärmung Der SuT̃t in Dem Dorbenram Durd) bie

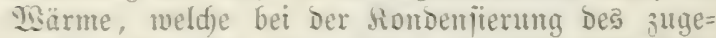
leiteten Dampfes Frei wird. Jin Dem auperbalb

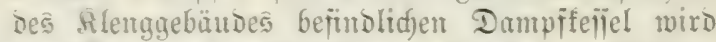

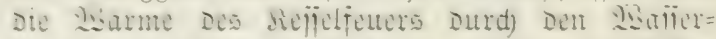

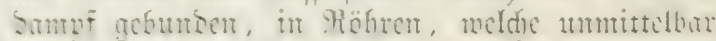
unter ben DorDen binichen, in DampFe beigefïlnt,

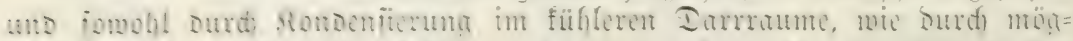

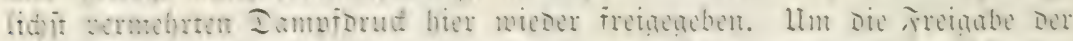

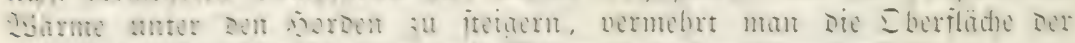

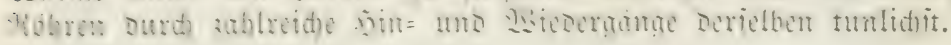

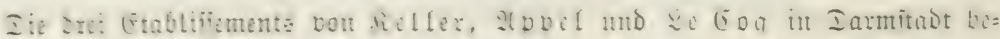
jisen aud mach Diejem Prinjipe fonptruierte Iarren.

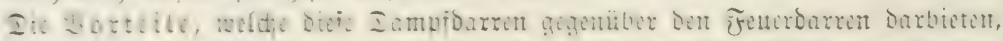

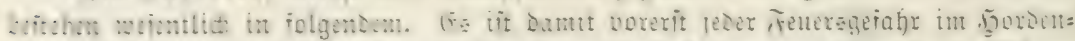

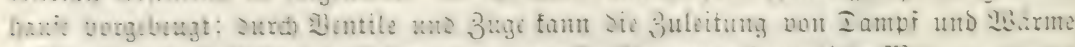

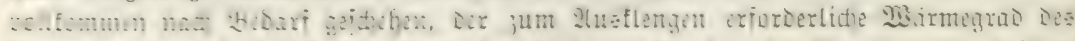

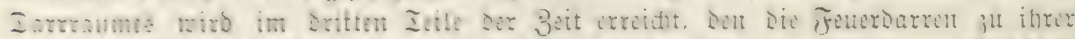

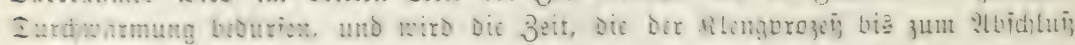

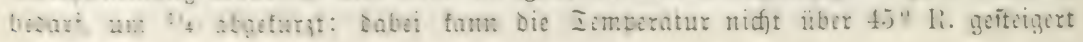




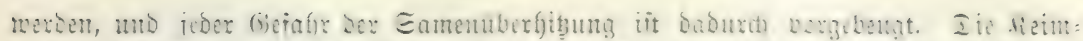
wrobert Helfere ergeben s-

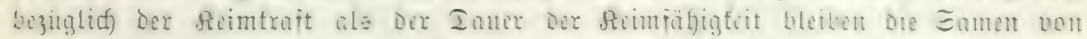

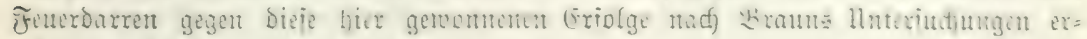
Geb(id) 3uxücf.

Die Jenerung ijt beim B̉etriebe Der Eamendare, mebr ato

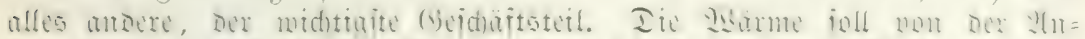

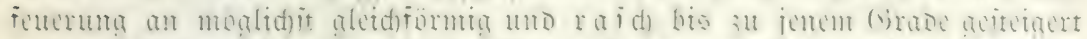

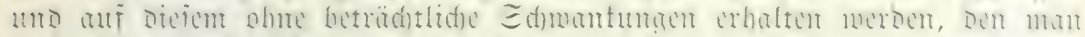

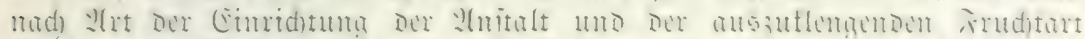

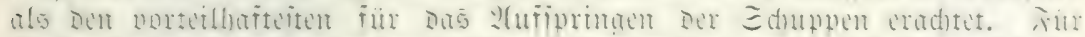

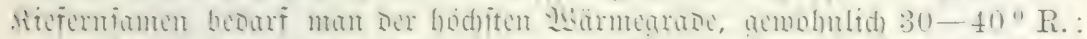

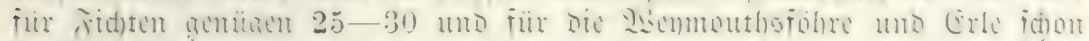
$15-20^{\circ} \mathrm{R}$.

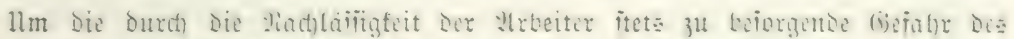

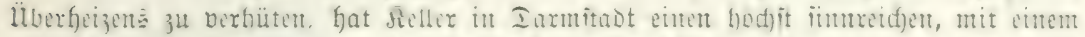

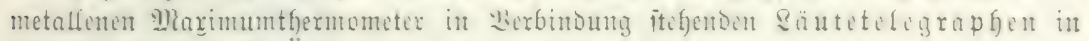
Intwendung, Der jede lïberheizung im Comptoir anzeigt.

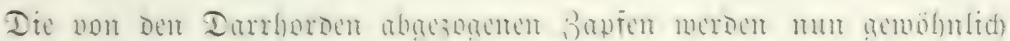

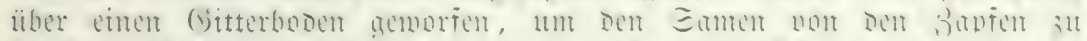

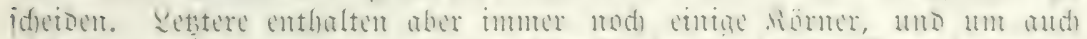

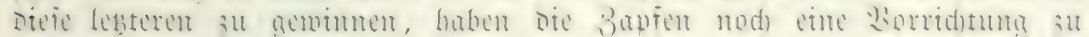

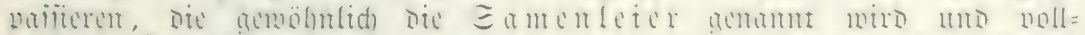

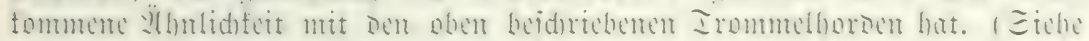
aud, 6 in frig. 314.)

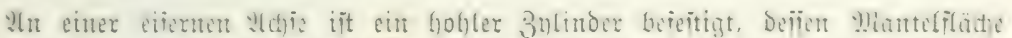

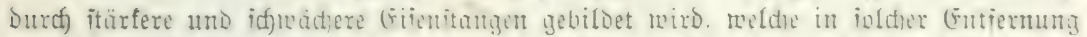

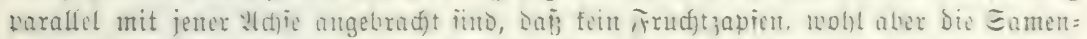

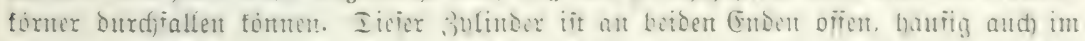

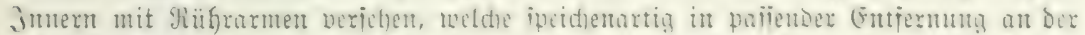

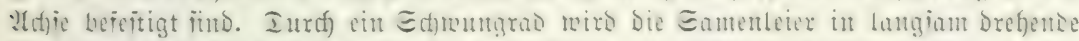

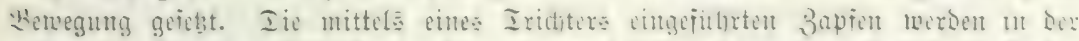

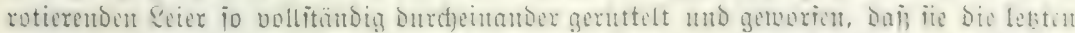

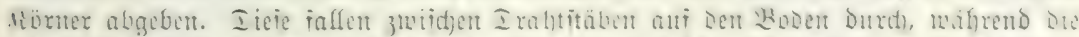

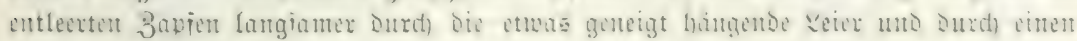
3weiten Iridfter in ben Eammelraum für bie lcerent 3apjen jałen.

Ins C゙nt

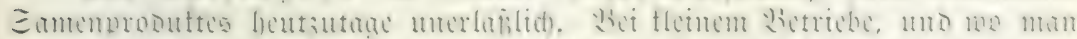

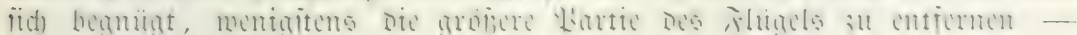

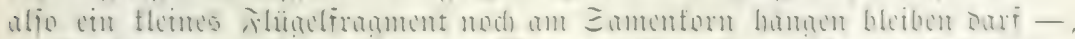

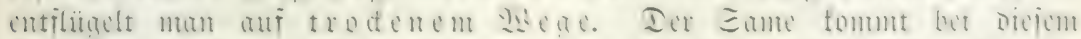

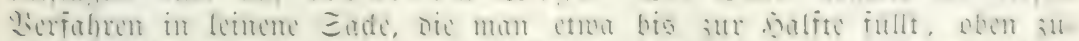

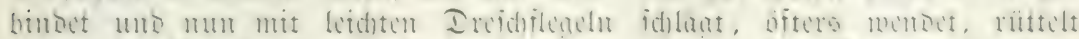

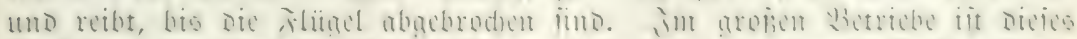

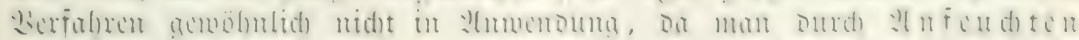

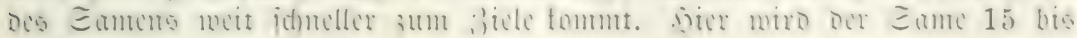
(B) a yer, frorttbenub̧ung. 9. 2tuif. 


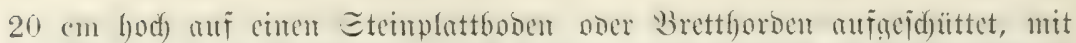

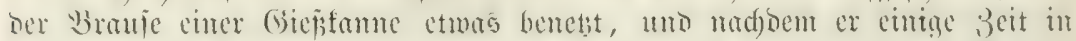

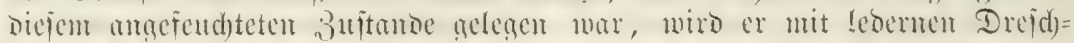

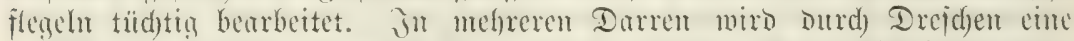

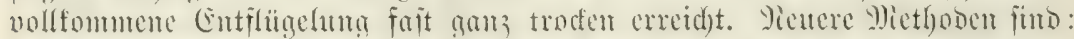

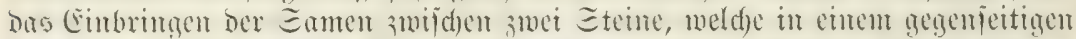

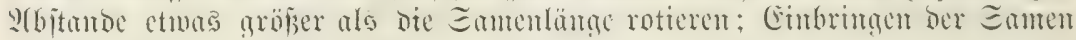
in eine Büritentrommel (Detadjeur).

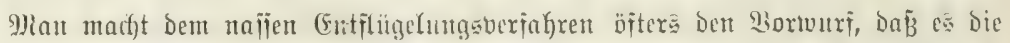

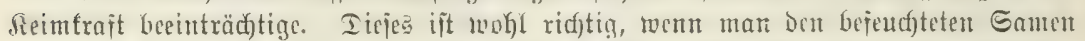

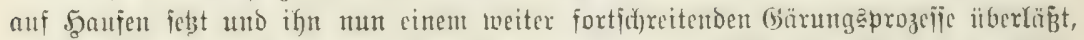

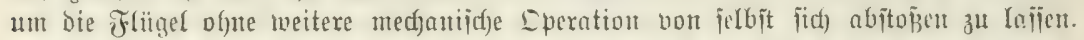
Werfäfort man aber, twie vorfin angegeben wurbe, D. G. läpt man c

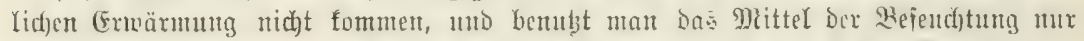

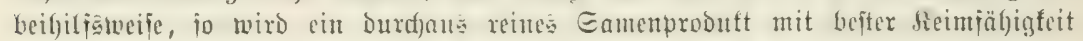
erzielt.

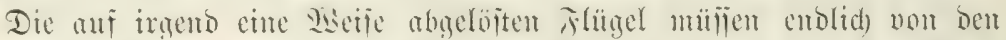

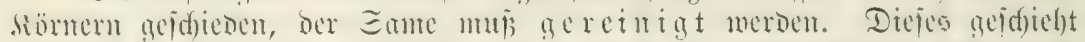

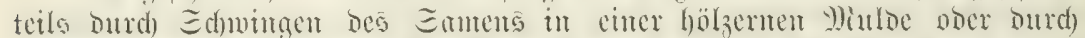

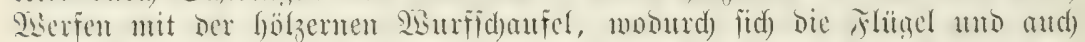

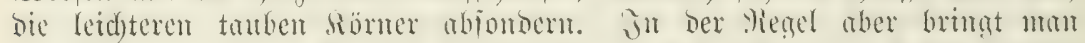

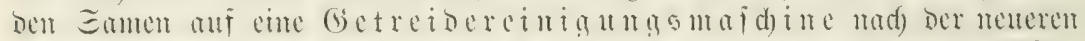

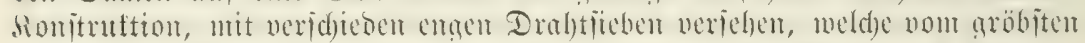

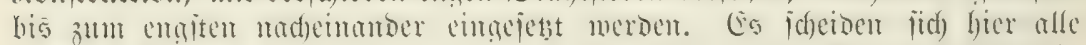

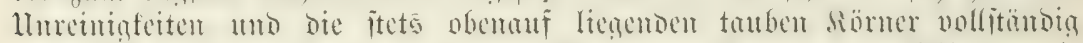

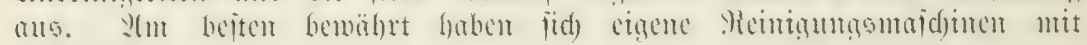
9)iotorbetrieb.

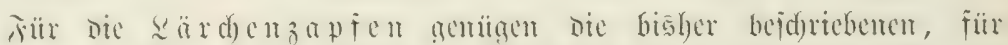

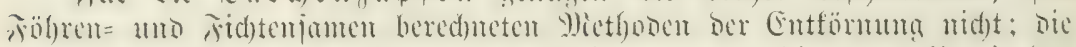

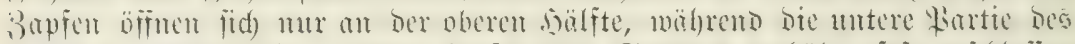

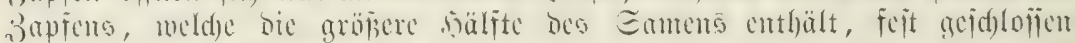

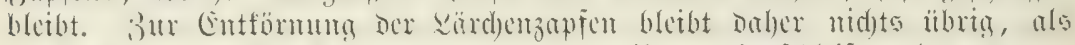

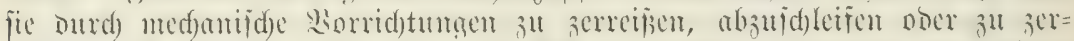

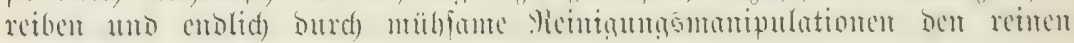
Eamen abjujderiden.

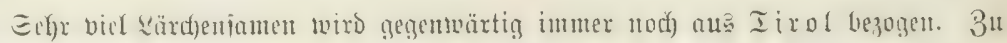

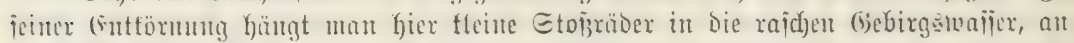

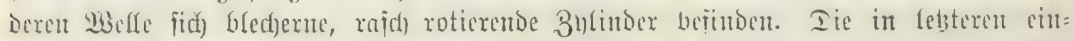

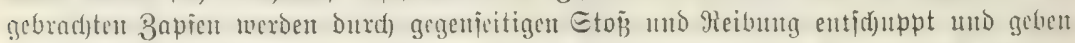

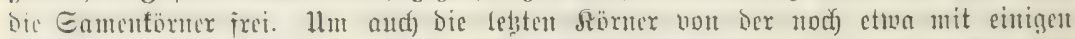

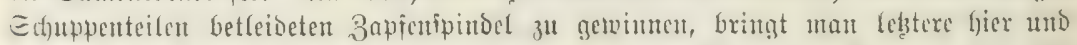

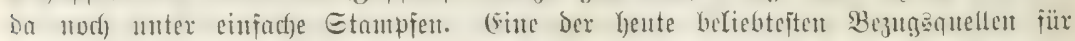

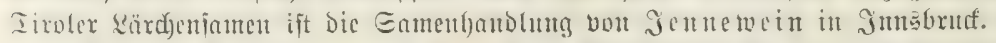

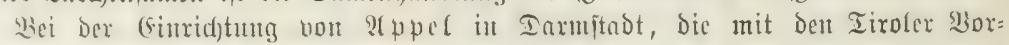

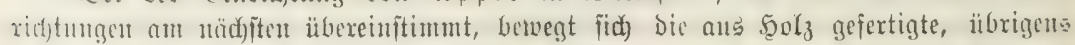

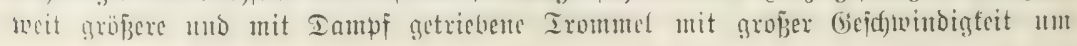




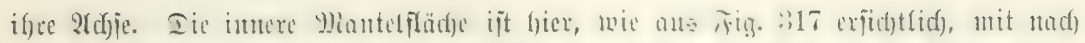

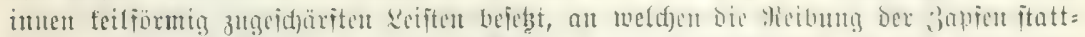

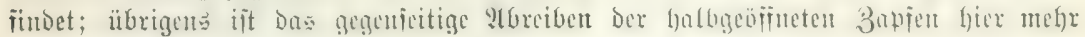

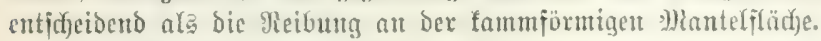

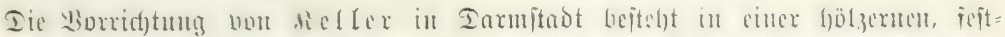

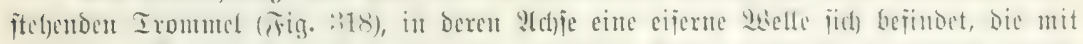

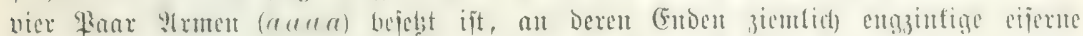

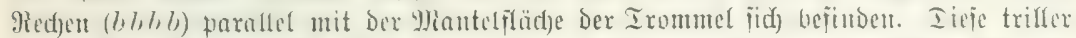

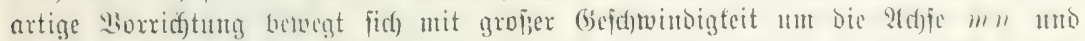

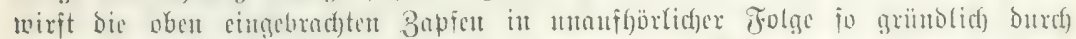

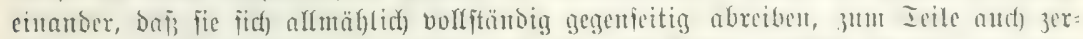

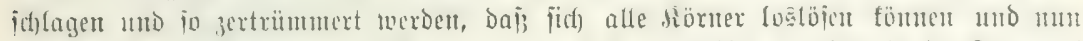

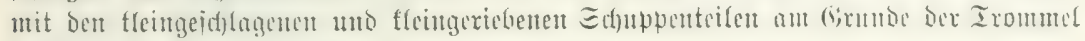
iid) aufiammelu, too fie bant ausgezogen merben.

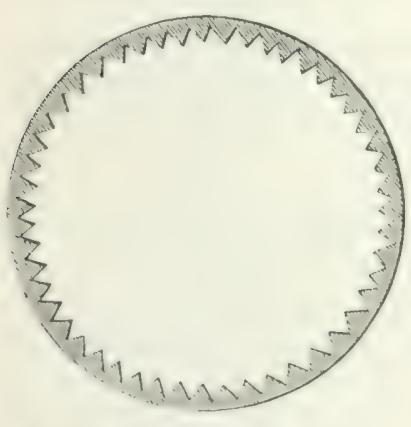

Jig. 317. ₹romutel mit gejühnter

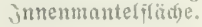

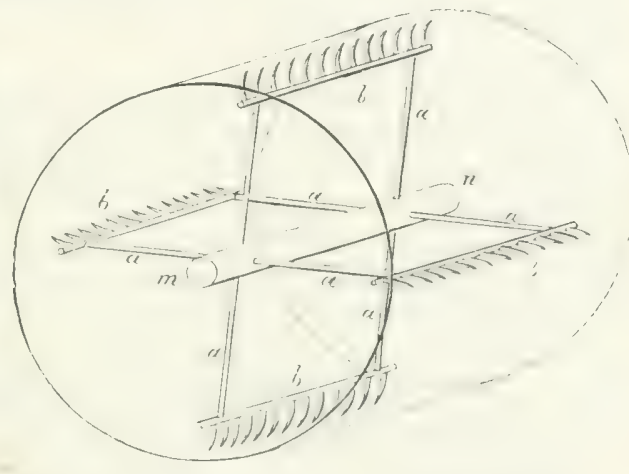

Jig. 318. Itommel, in berem ismeren cijerne Hedjen rotieren.

Der auf irgend etre gatic ats ben Bapfen gelöpte Game ift mit s)oli=

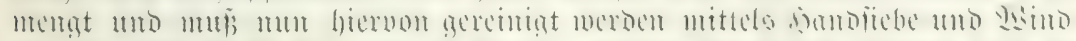

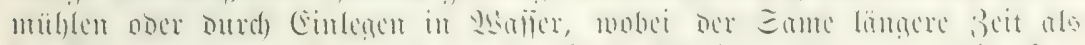

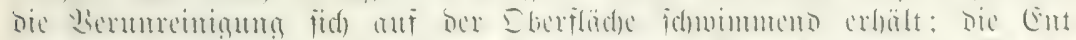

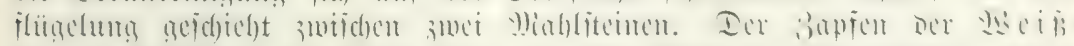
t

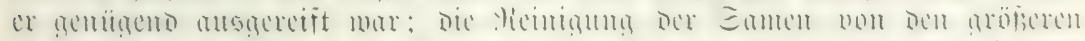

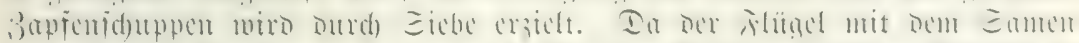

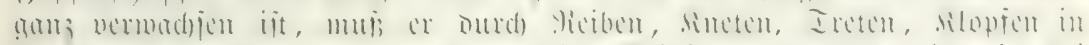

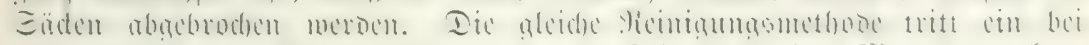

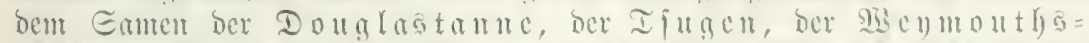

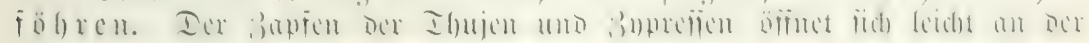
Somme; dic flemen Gamen werden burd) Eicbe geremint. 


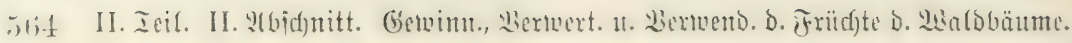

\section{Ausbuts.}

Eb man mon simen bejtumnten E.

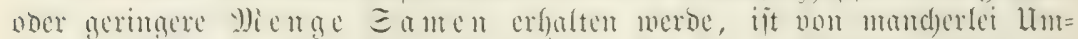

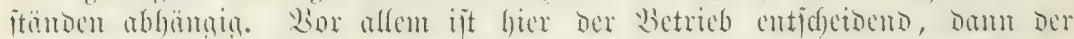

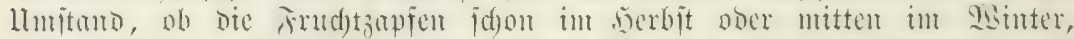

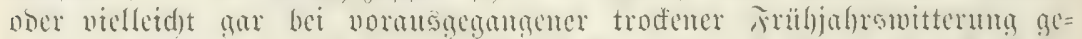

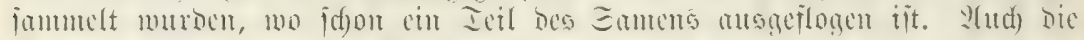

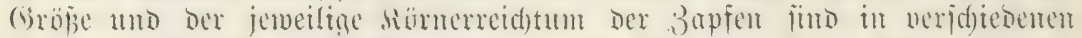

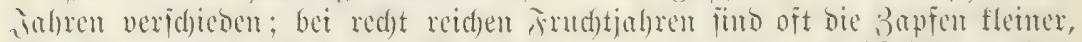

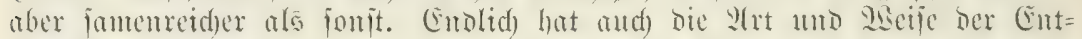

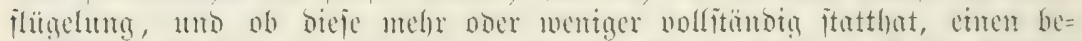

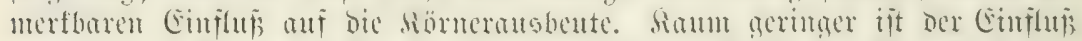

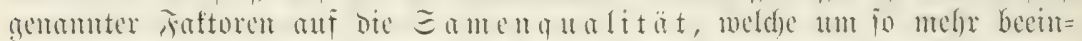

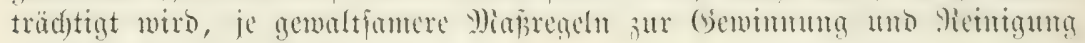
exforberlicf) werbent.

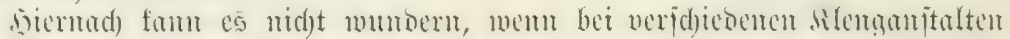

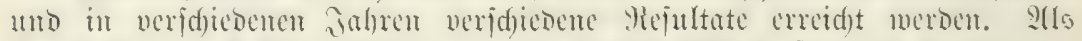

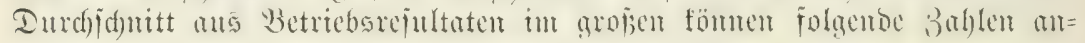
genommen werden.

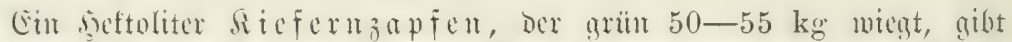
$0,75-0,90 \mathrm{~kg}$ abgeflügelten Emmen. Cin siter trocterer, abgeflügelter mo retmer Sieferniame wiegt $500-510 \mathrm{~g}$.

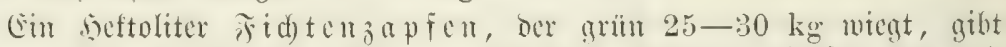
$1,23-1,70 \mathrm{~kg}$ abgeflügelten こamen. Cin siter trodencr, abgeflügelter und reiner fidjtenfamen miegt $560-570 \mathrm{~g}$.

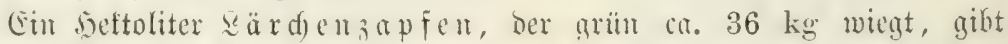
$1,80-2,70 \mathrm{~kg}$ abgeflügelten Gamen.

Eiu jeftoliter I a $1,50-2,25 \mathrm{~kg}$ entflügelten Gamen.

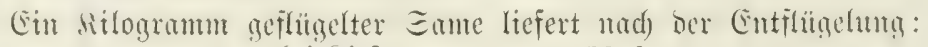

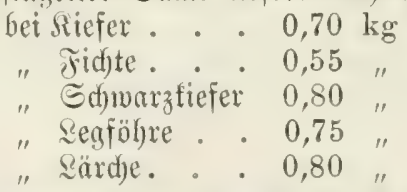

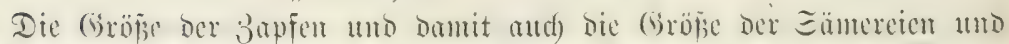

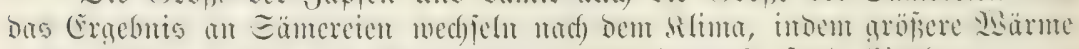

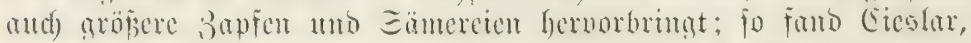

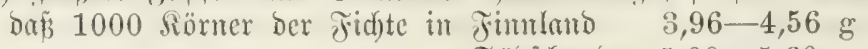

$$
\begin{aligned}
& \text { Südidmeden } 5,00-5,60 " \text { " wiegent. } \\
& \text { Dentid)land } 7,59-8,60 " \text { wuid }
\end{aligned}
$$

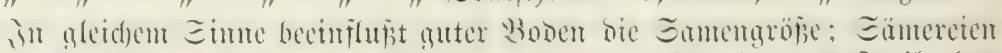

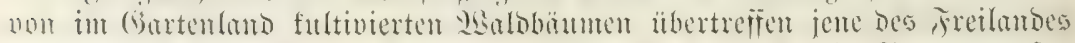

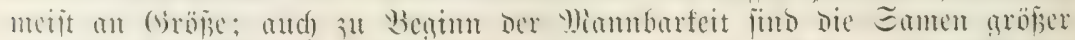

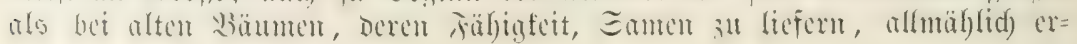




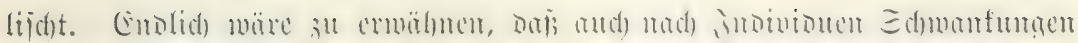

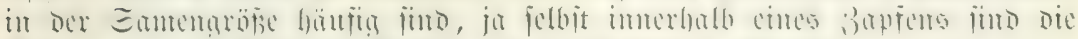

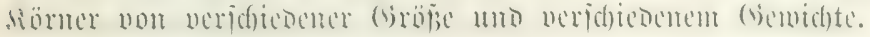

\section{G. Die Rutflienabiraturg Sex Göntereient.}

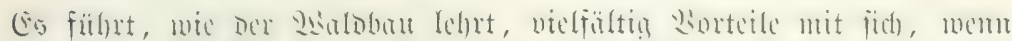

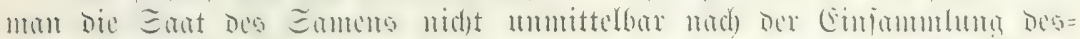

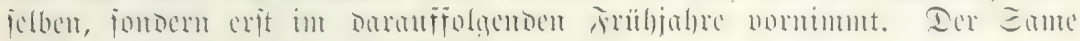

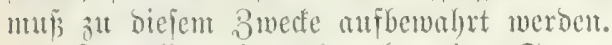

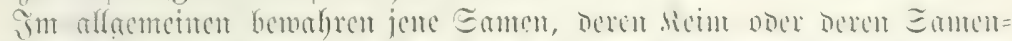

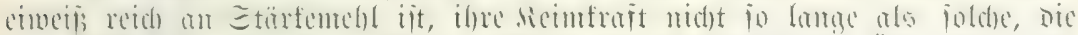

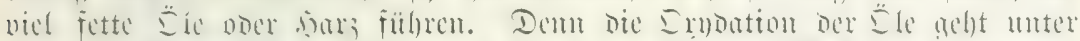

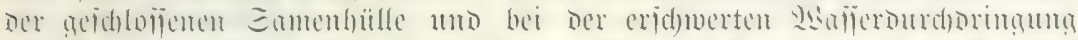

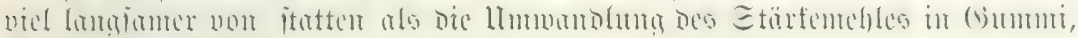
Dertriu und Bucfer.

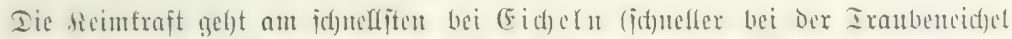

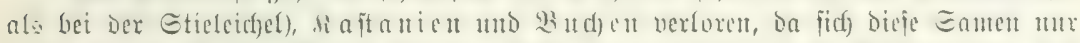

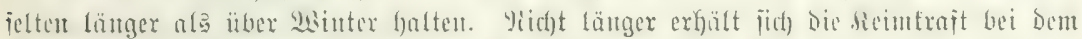

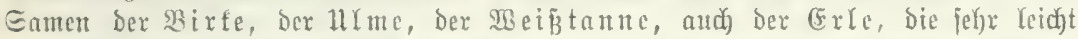

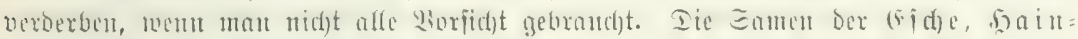

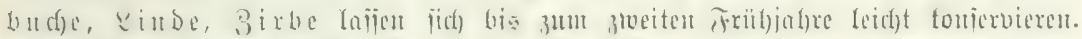
In :

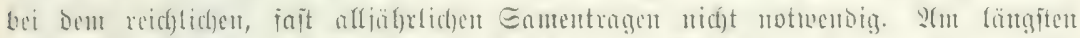

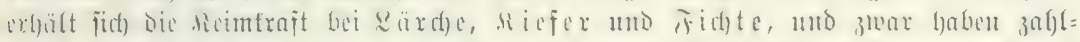

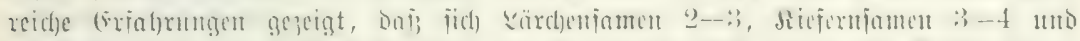

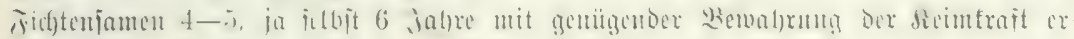
f)alten laifen.

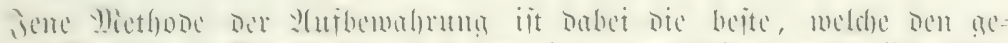

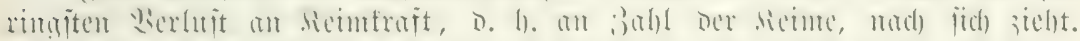

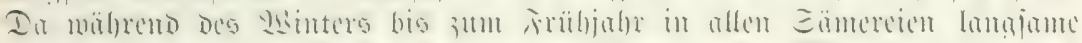

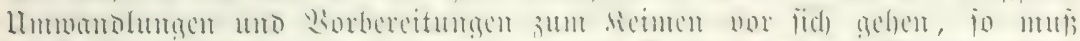

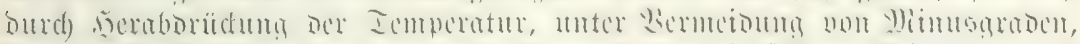

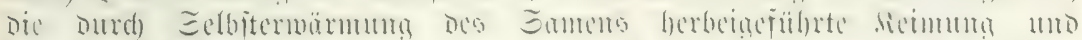

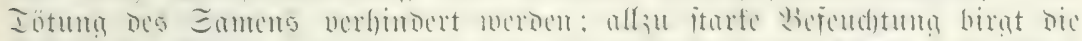

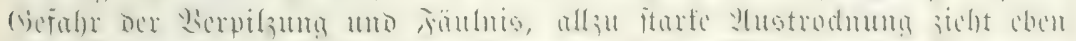

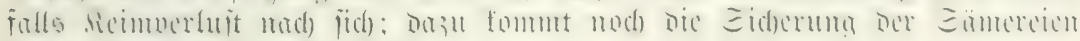

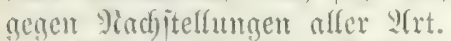

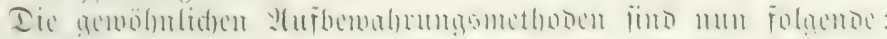

a) 2 uf

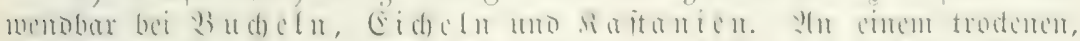

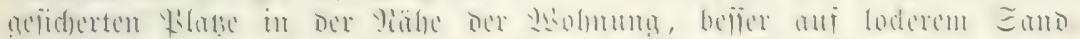

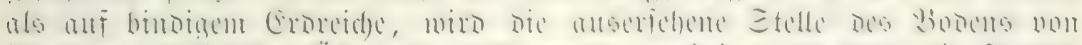

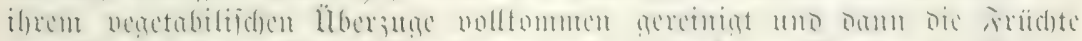

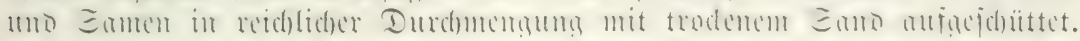

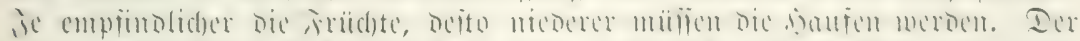

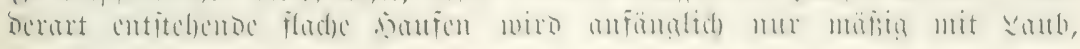




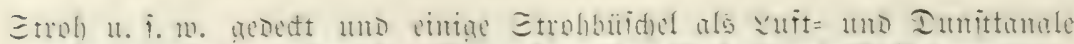

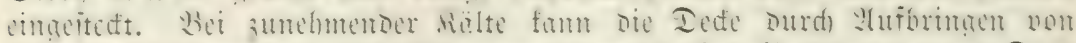

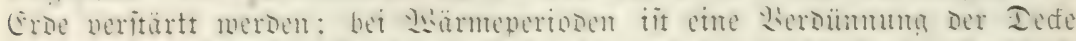

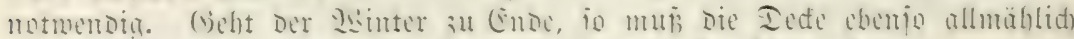

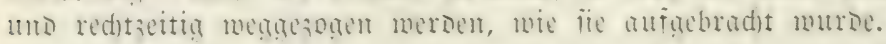

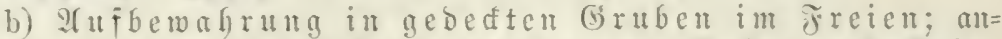

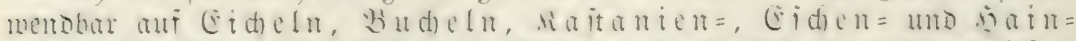

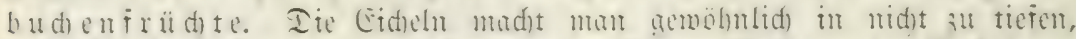

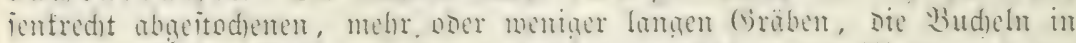

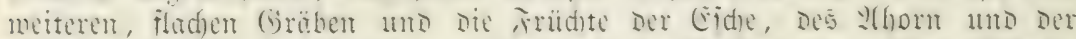

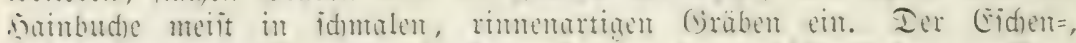

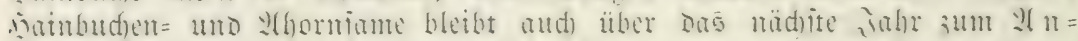

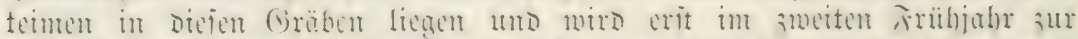

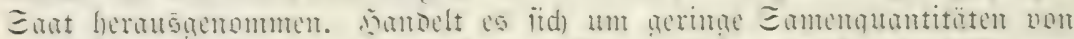

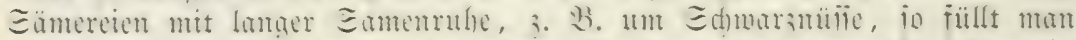

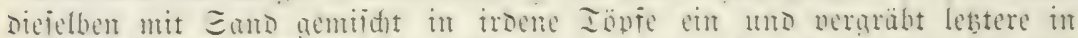

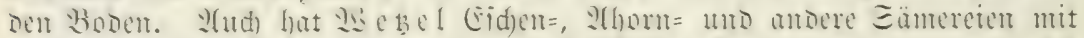

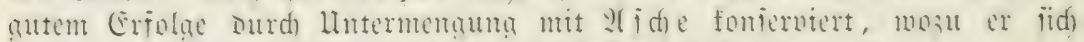

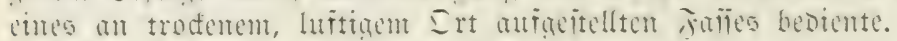

c) $\mathscr{Y} u$ F

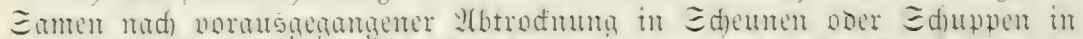

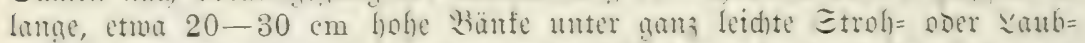

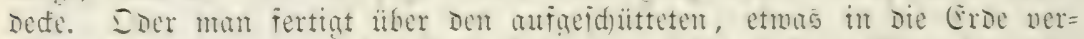

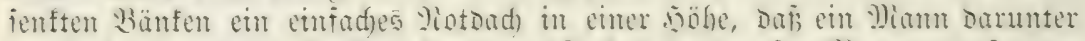

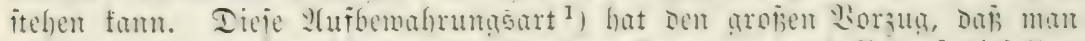

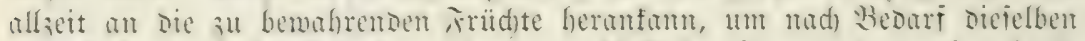

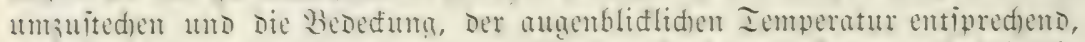

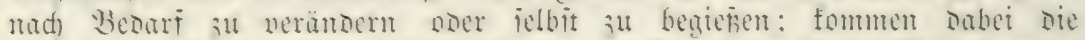

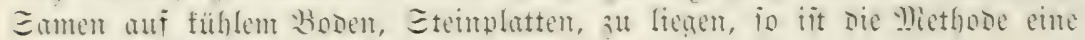
vorzüglidje bejonders für Budjeln.

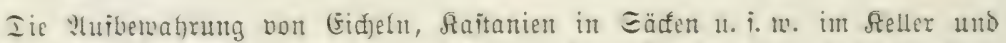

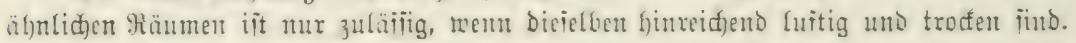

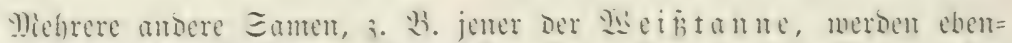

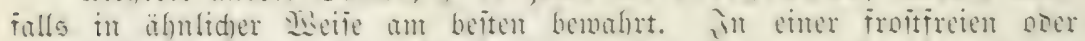
mentalitenos nid)t tiē

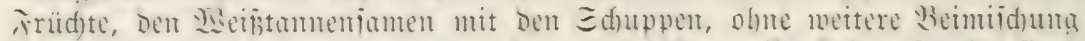

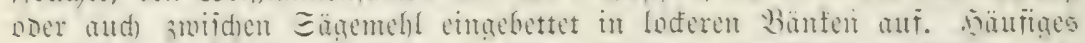

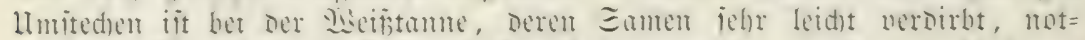

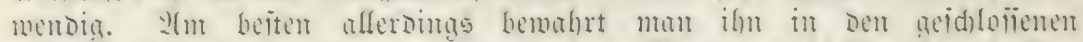

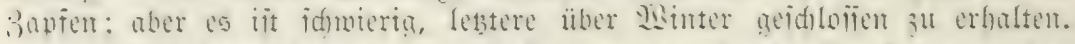

d) 诜

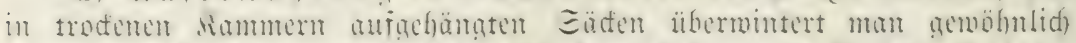

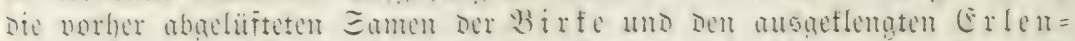

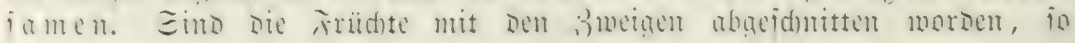

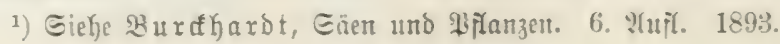


bimoct mant sicic in thane Siammerit aut.

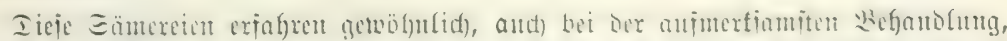

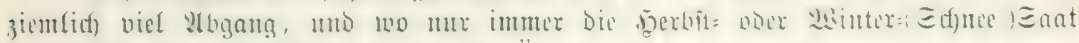
3uläjïg ift, Da abîtraljiert man bon der lïbervinterung vollitündig.

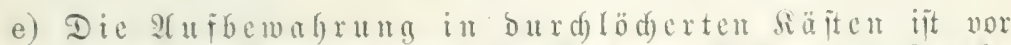

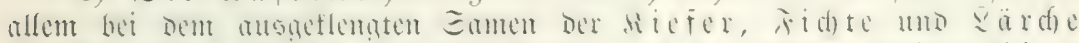

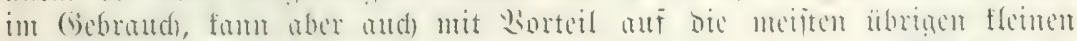

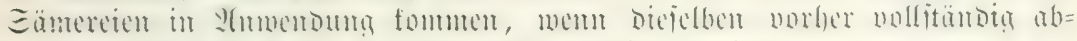

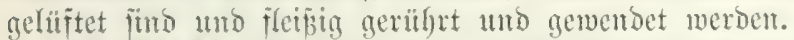

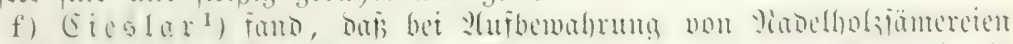

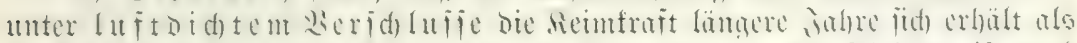

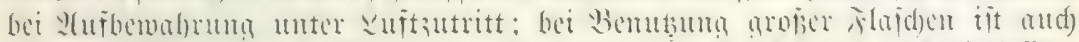

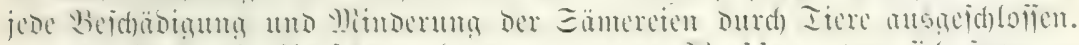

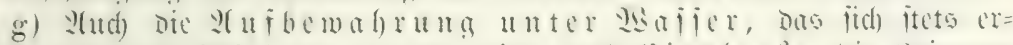

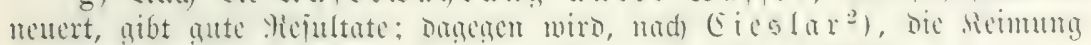

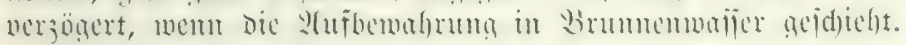

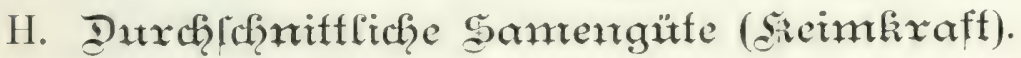

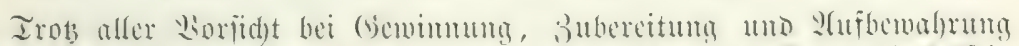

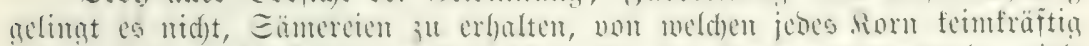

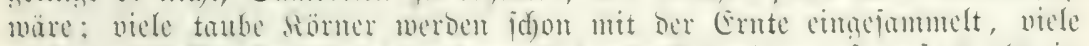

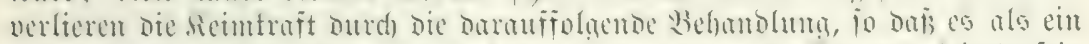

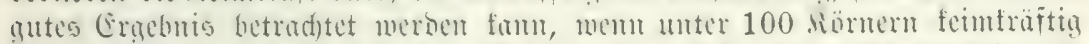

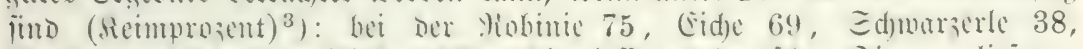

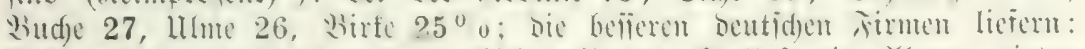

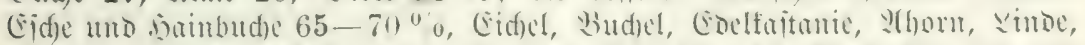

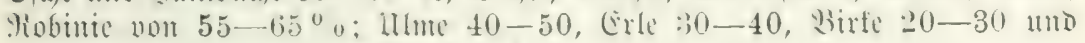
TSeide und Bappel $5-10 \%$ Siemtraft.

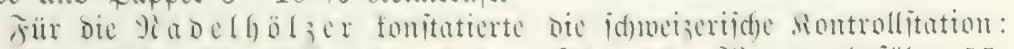

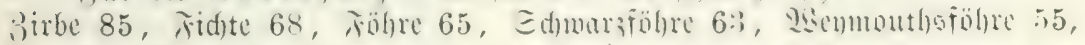
Douglas̄tame 48, Eärdye 38, Iamme $27 \%$.

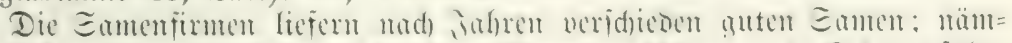

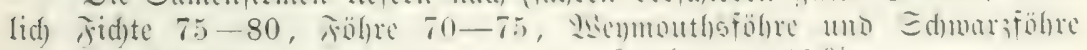
$65-70$, Iame $55-65$, Birbe $40-50$, sürdje $30-40 \%$.

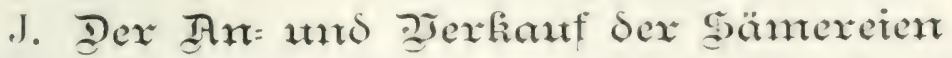

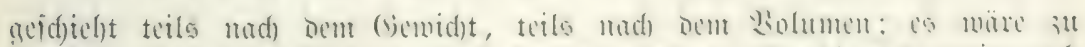

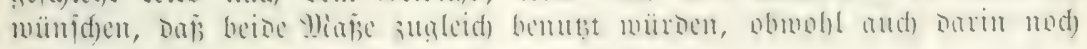

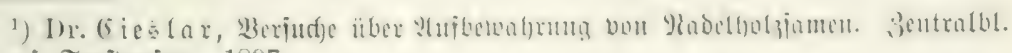
i. ๖. gej. Foxitmejeแ. 1897.

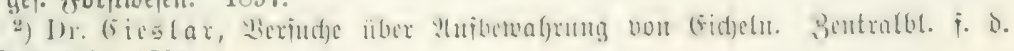
ถุe. Forjtivej. 1896.

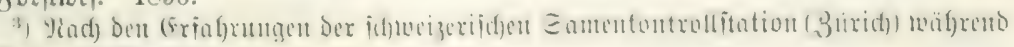
Dex Jaf)re $1876-1894$. 


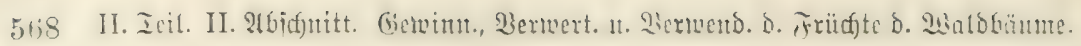

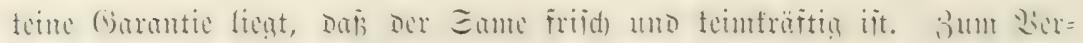
gleidje von Gemidgt uno Яaummâ; jei folgenbes benterft:

11 Eid)eln

1 , Budjels

1 " (Ẽd)enfame

1 " Iformiante

1 " Ulmenjame

1, Birbeln

1 " Töbremante

1 " Jidjtenjamte

1 " Rärd)enjame

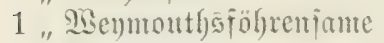

1 , Metistamemame

1 ." Douglastantenjame

1 " Rampons 3yprefieniame

Der Iranaport der werben siiten empfohlen.

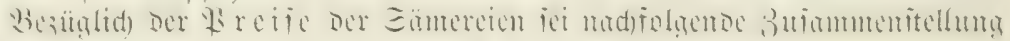

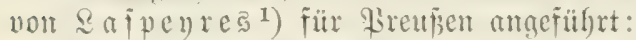

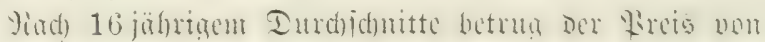

\begin{tabular}{|c|c|c|c|}
\hline & (Eid)eln . & . & 15,7 \\
\hline & Budfeln . & & 21,36 \\
\hline & ๔d)warzerle & & 0,86 \\
\hline & Sseiperlen & . & 1,62 \\
\hline & Birfen . & . & 0,60 \\
\hline & Föfren & . & 4,4 \\
\hline & Jicsten & . & 1,7 \\
\hline & Zärdjen. & . & 2,4 \\
\hline & Innten. & & 0,7 \\
\hline
\end{tabular}

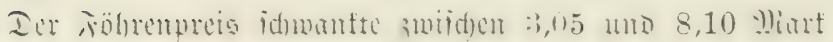

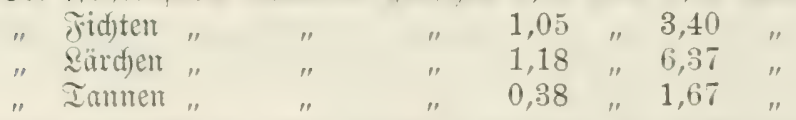

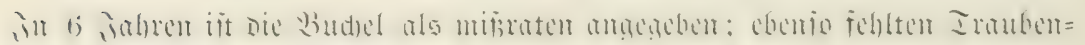

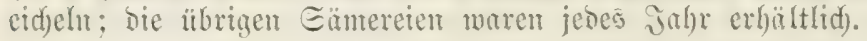

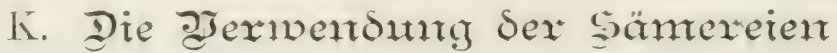

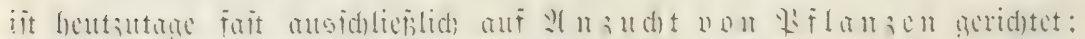

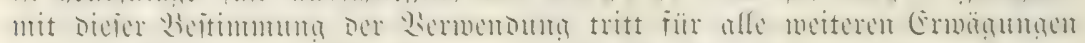

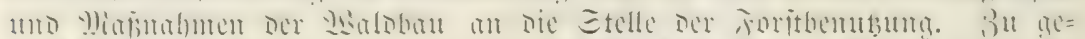

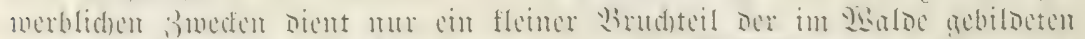

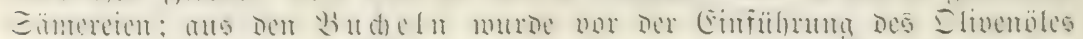

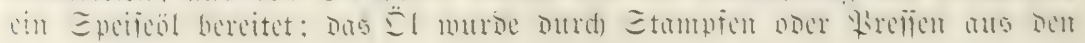

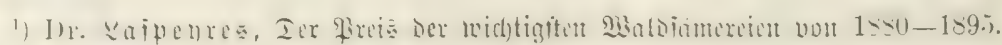

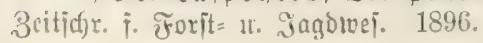




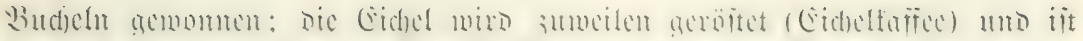

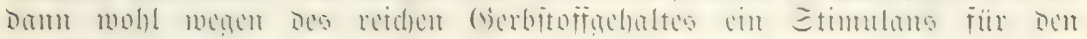
Wirgen.

in

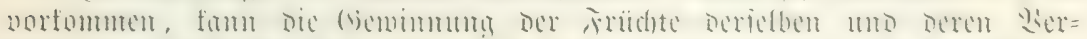

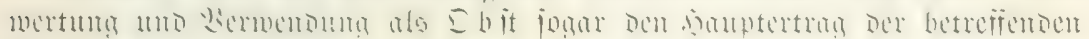
geardungen boritallent.

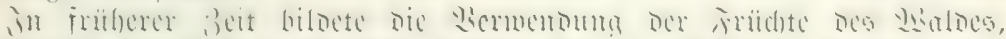

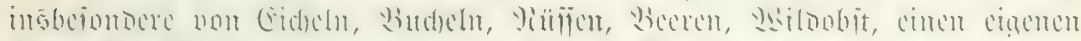
Bucta Dex 然alom

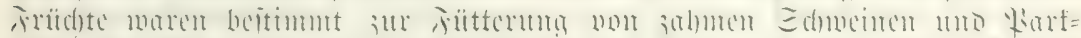

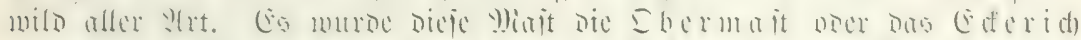

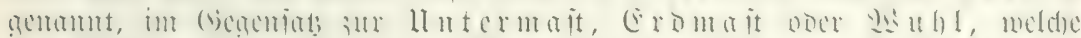

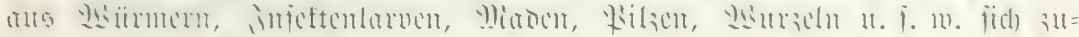

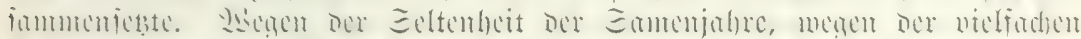

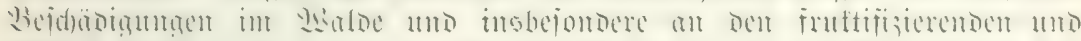

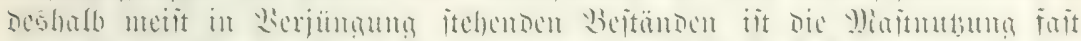

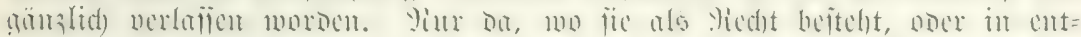

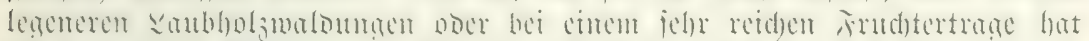

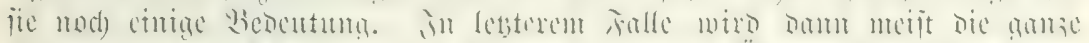

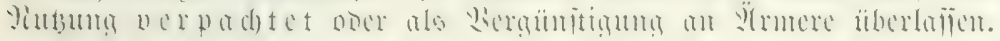

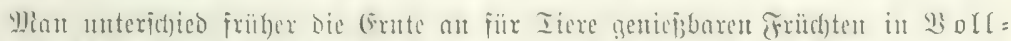

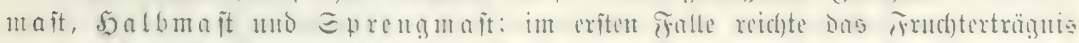

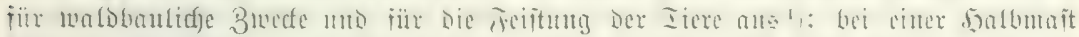

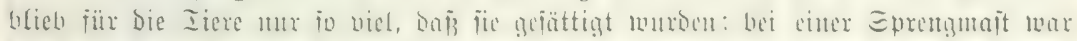

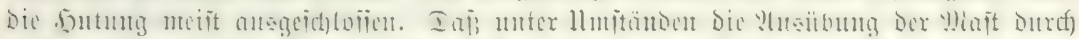

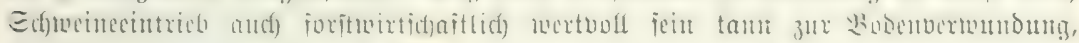
Snjeftenvertilgung u. j. w., fant foicr mur geifteift weroen.

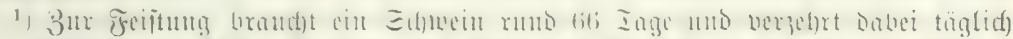

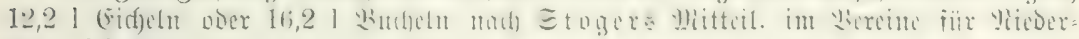
D̈iterreidf, Etetermart 11. †. 11. 1895. 


\section{Dritter 2lbichnitt.}

\section{(6)

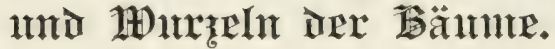

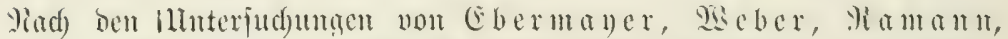

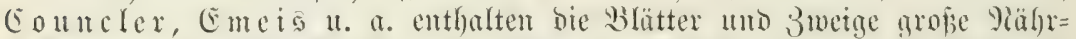
itoffmengen an itiditofifaltigen Eubitangen, soblebubraten mo Mimeral= farzen. Bei Berwendutg ber 3weige und Blätter ju jutterzweden $\mathbf{1}$ ) jtellen

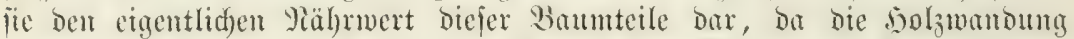

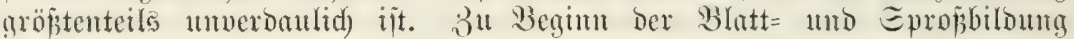

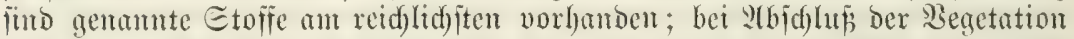
tritt Der gröpte Ieil berjelben aแs den fid) verfärbenden Blättern zurüd

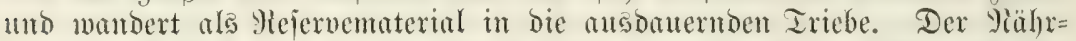
wert der Blätter mo Iriebe hängt fomit junäd)it ab von dex Beit Dex

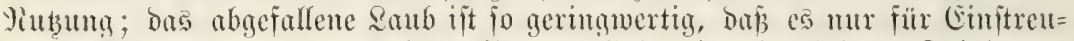

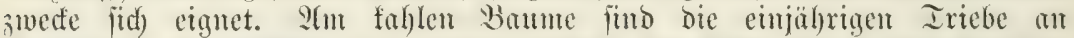
Futterwert bie reidjiten; von ba an nimmt ber Wert ab in bem Lerbält= nifje, in bem ber solzanteil zax gejamten 9lajic mädjit; $1-2 \mathrm{~cm}$ bide

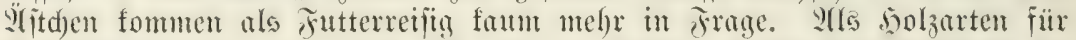

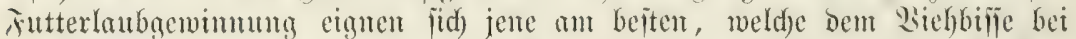

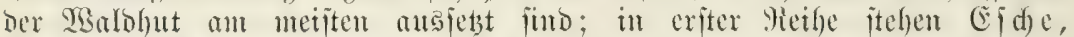
Ifapel, 2Seide (bejombers S. alba, Caprea, vitellina, pentandra),

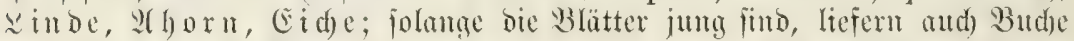

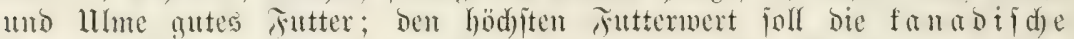

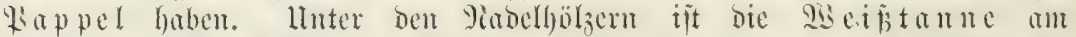
metiten acfudst; iclbjt bie Fid)te wird vermendet, an mentaiten bie

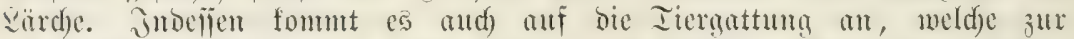
Finterumg in Frage iteht; Dem Siegen mb Ed)afe nelmen jedes saub=

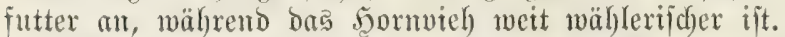

Jian red)net $150 \mathrm{~kg}$ sambfutter ofme 3meige, $125 \mathrm{~kg}$ mit 3meigen

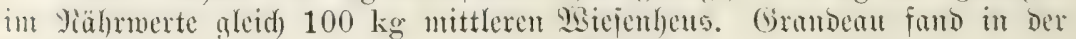
Irodenfubitan einjäiriger Iriebe obne B̈lätter bei

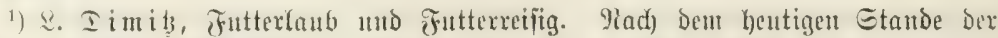

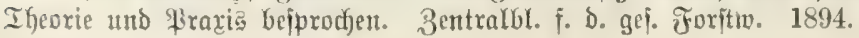




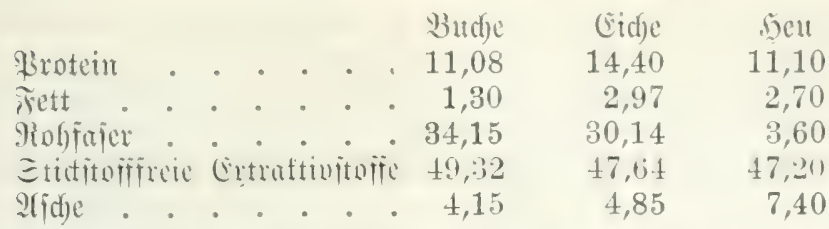

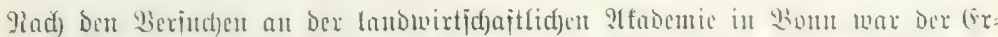

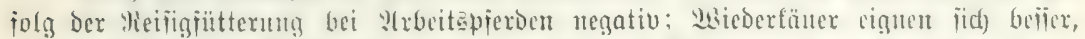

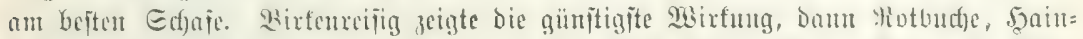

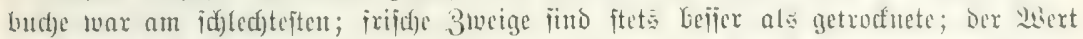

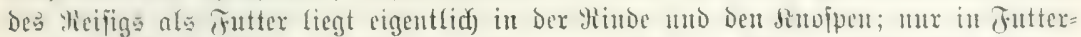

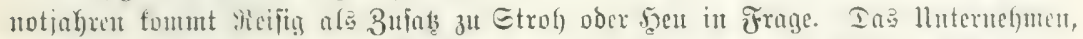
Das mit dex IInfextigung von Jlajd)

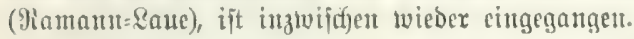

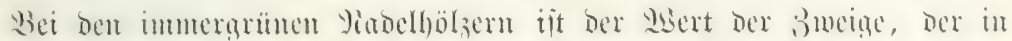
ihrent

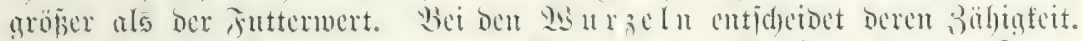

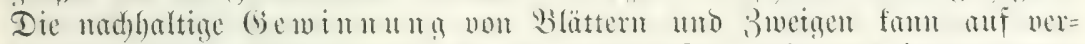

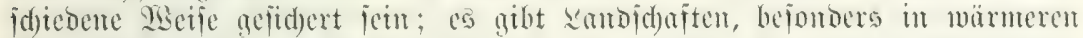

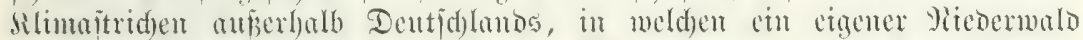

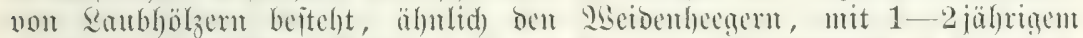
Intriche; in anderen (begenden ift cin Etammansfd)lagbetrieb in (bebrand),

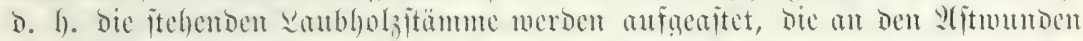

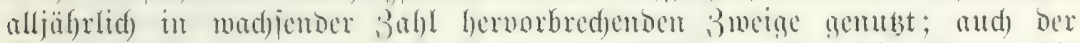

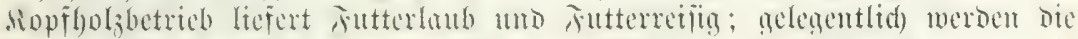

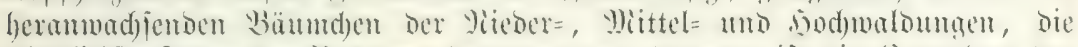

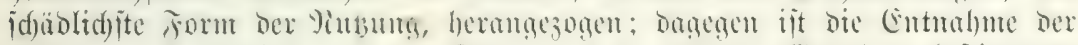

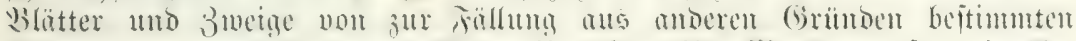

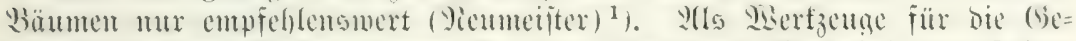

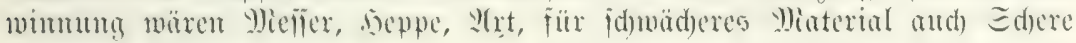
3) nemen.

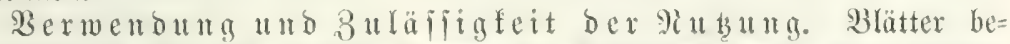

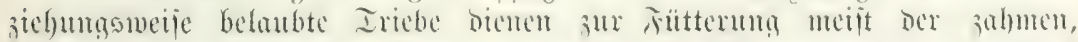

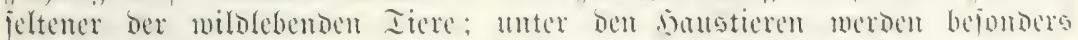

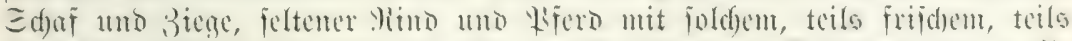

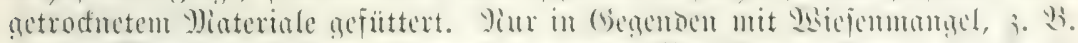

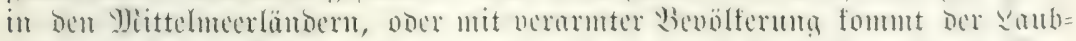

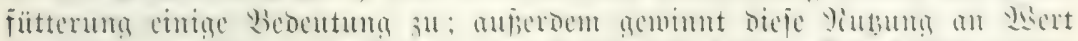

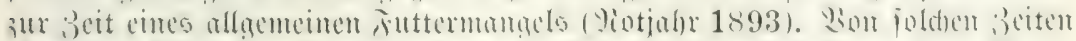

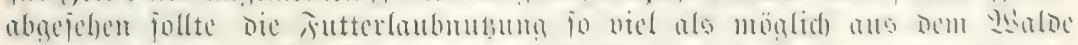

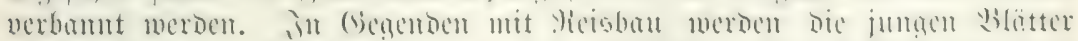

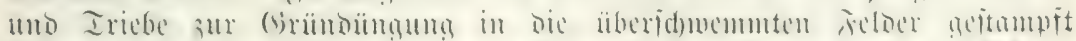

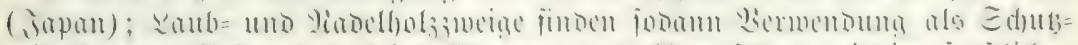

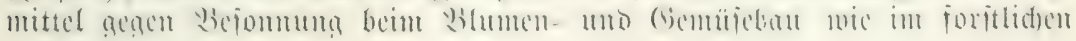

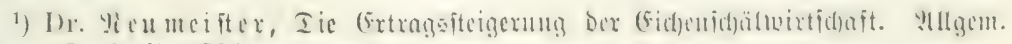
Forit $=$ 11. Jaggozeit. 1893. 


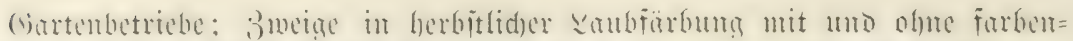

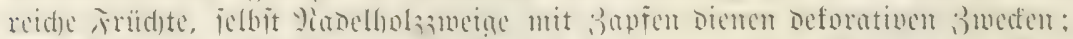

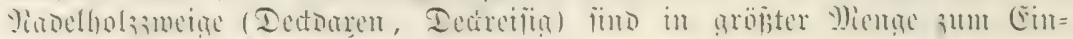

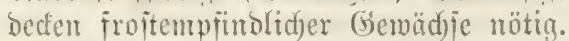

औ)

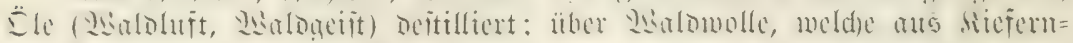

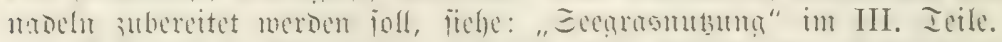

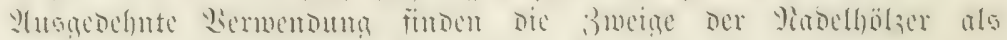
grün $\mathfrak{2}$ it it reu (Gadfitren, Edheitelitren, Daritren, Daren).

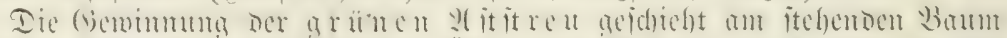

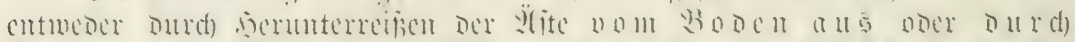

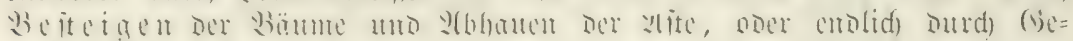

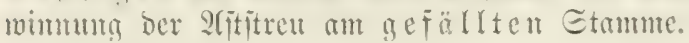

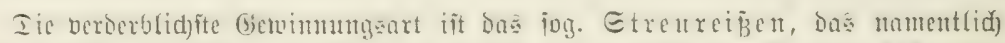

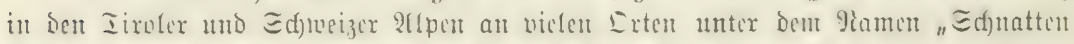

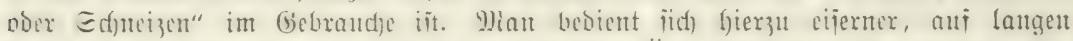

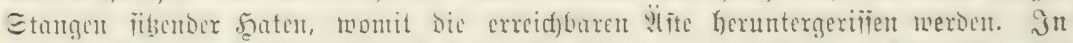

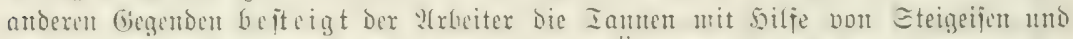

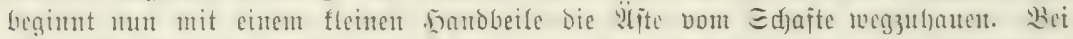

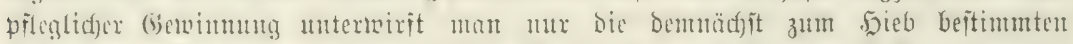

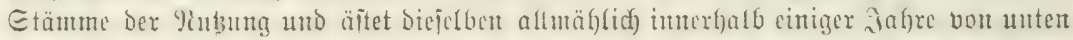

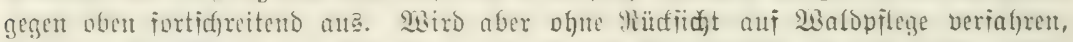

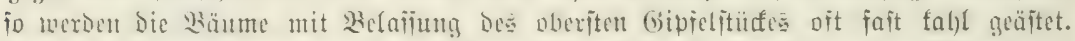

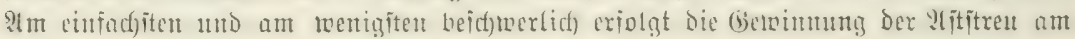

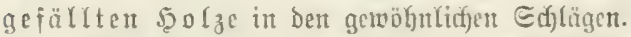

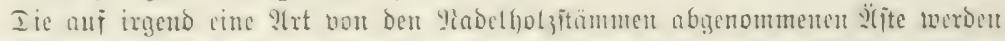

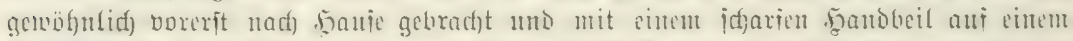

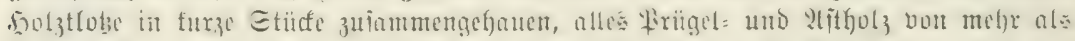

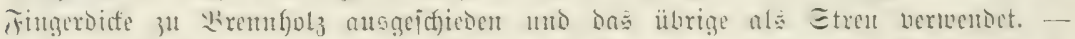

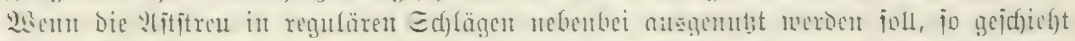

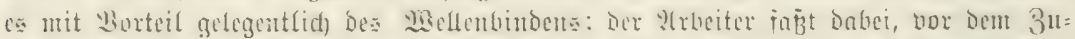

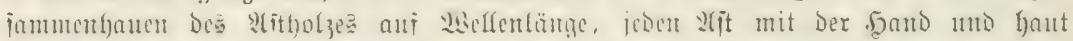

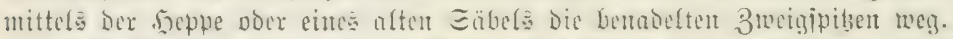

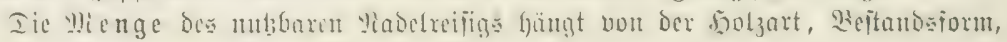

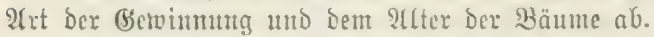

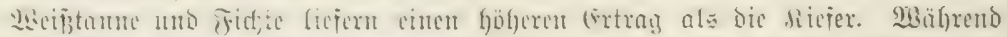

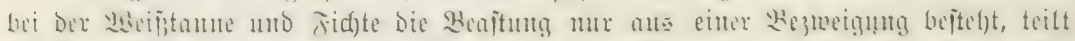

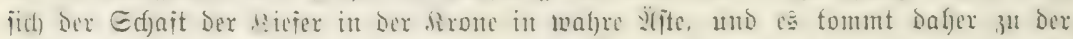

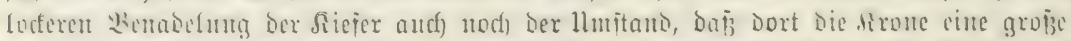

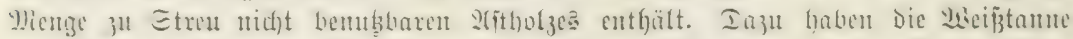

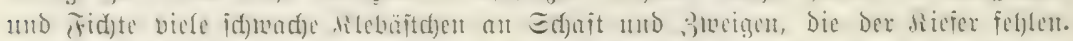

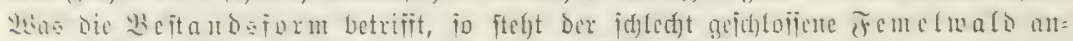

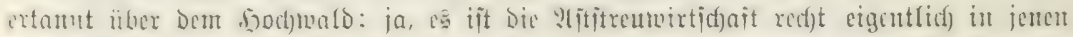

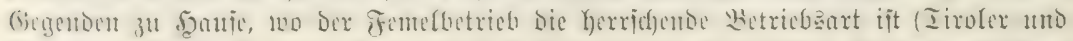

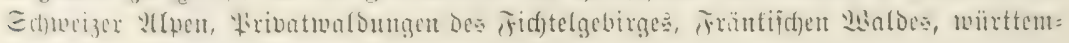

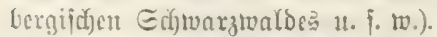

Sive 


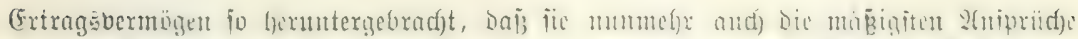

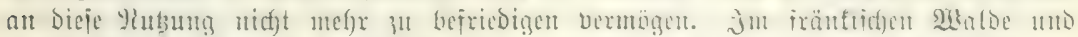

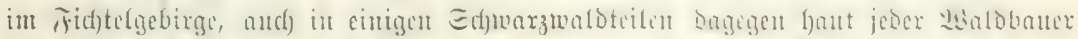

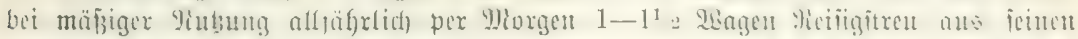

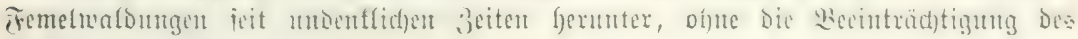
Jadjhalte? zu befürditeu.

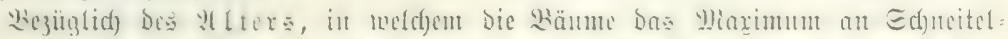

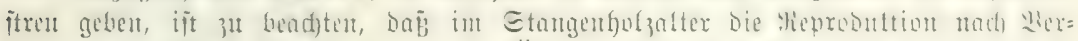

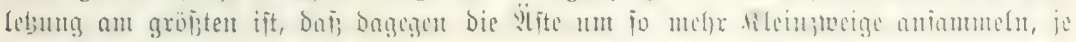
älter fie werden.

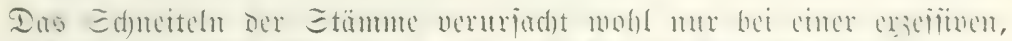

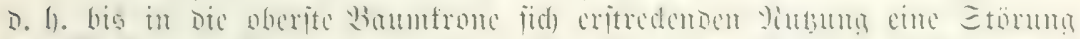

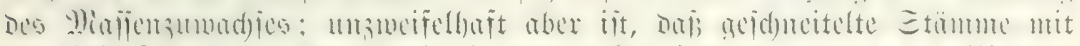

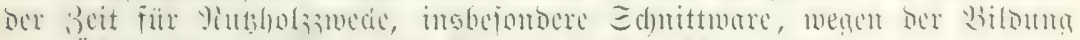

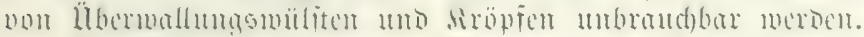

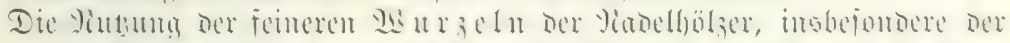

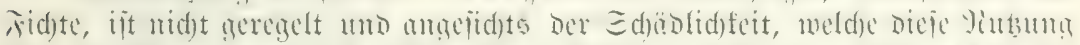

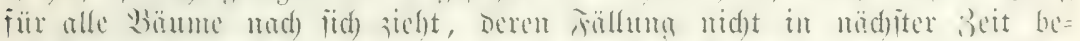

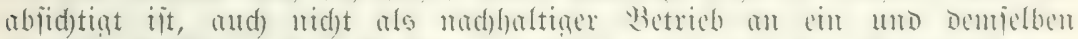

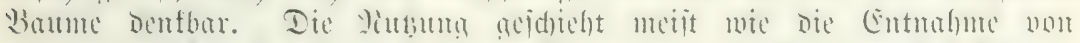

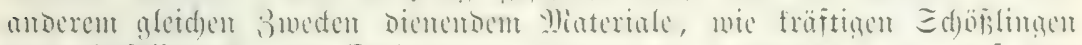

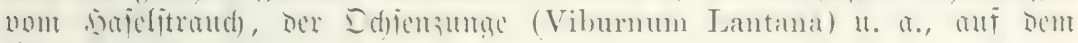
खigege des Frevela.

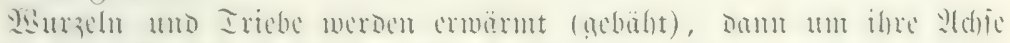

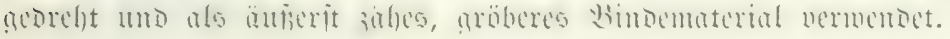




\section{Dierter 2lbichnitt.}

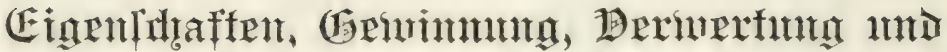

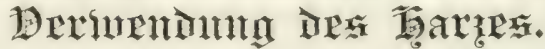

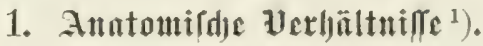

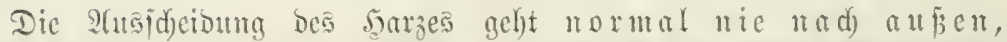

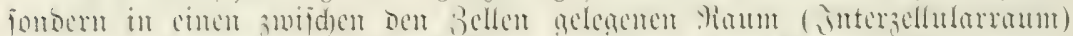

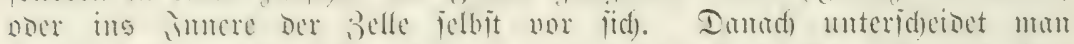
ज)

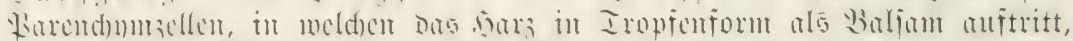

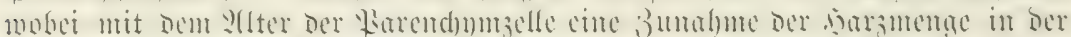

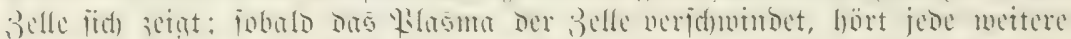

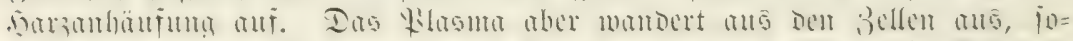

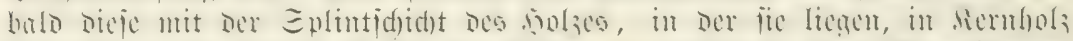

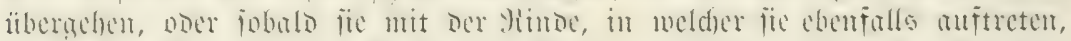

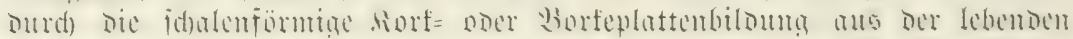

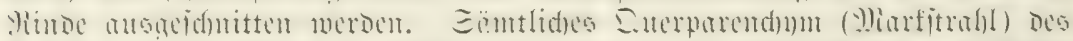

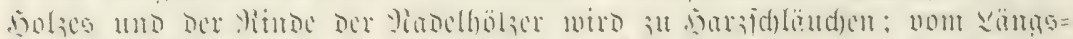
furendif)m fül)

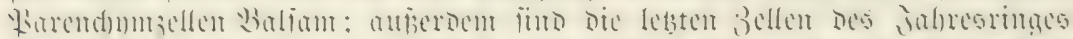

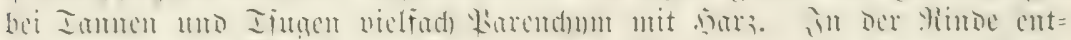

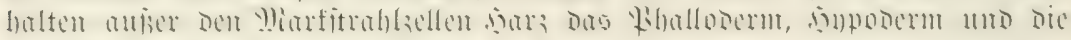
Ed)ließ̈zellen ber Epaltöfinmugen.

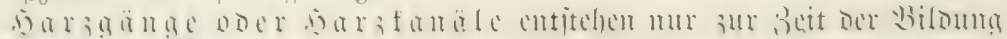

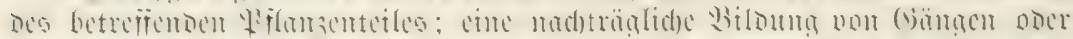

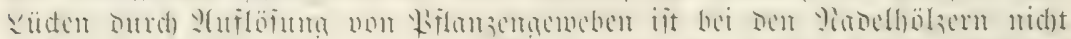

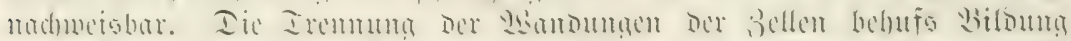

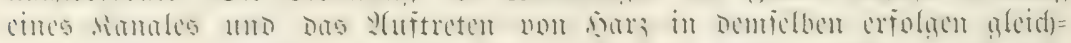

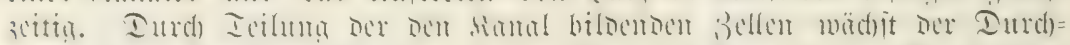

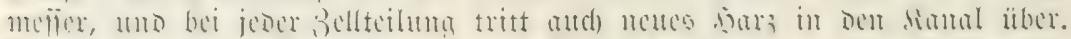

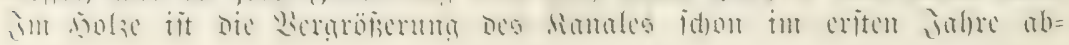

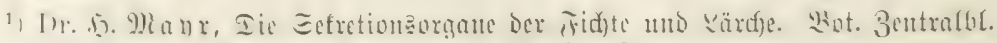

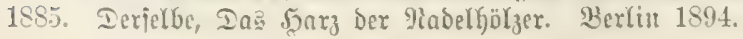




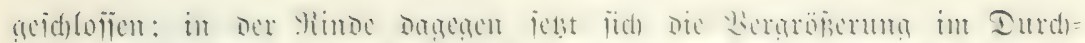

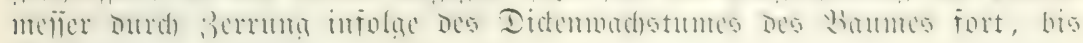
Borfebildoung cimpebt.

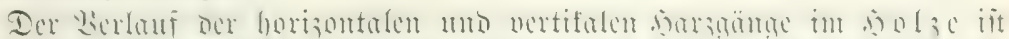

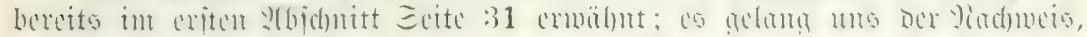

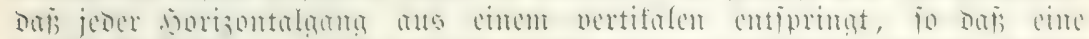

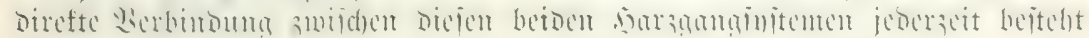
( Jigur 319).

*4)

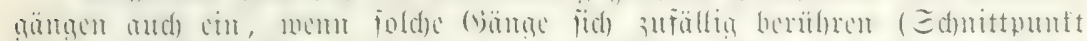

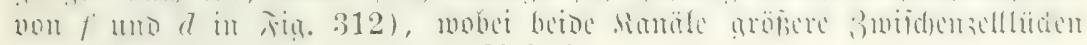
anpucifen (F̃ig. 320, punttierte sinten).

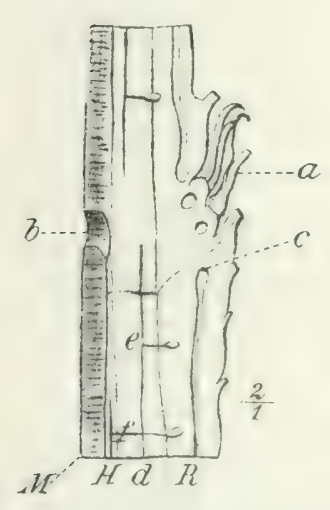

Jity. 319. Girenje smeier Jidstenjafres. 1riebe. " Begim bes Kinbenganges des lepten iabres, b vtartunterbredung, $r$ Enbe Des Minbenganges Des voraus=

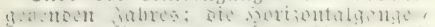
mo $f$ entipringen aus ben Lertifalgangen.

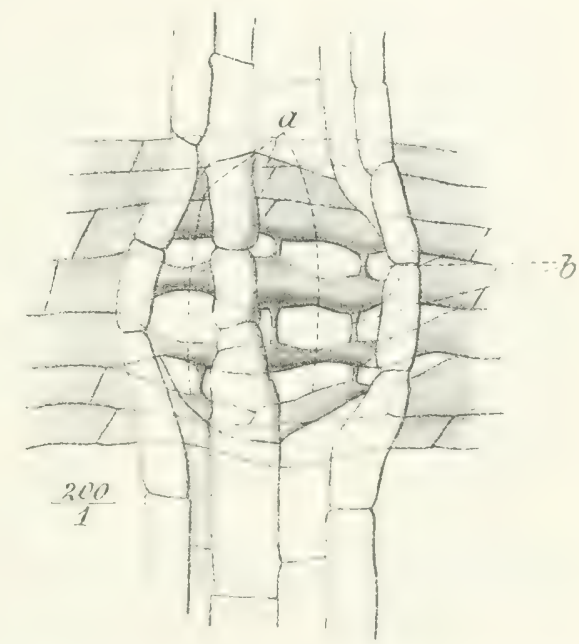

Fig. :20. Die interjelularliafen bes vertifalen, 1 jene

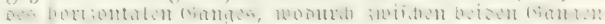
Jerbinbung bergeftell ifit.

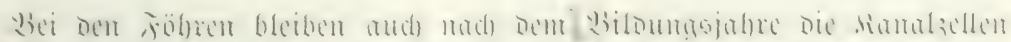

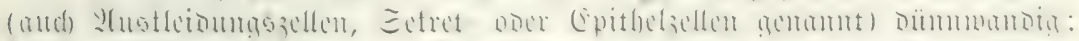

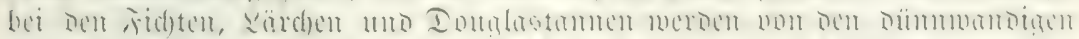

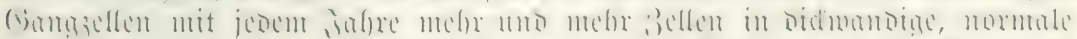

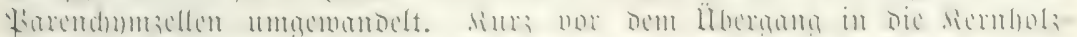

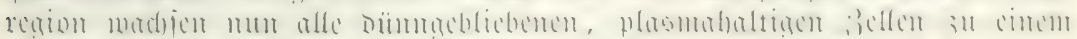

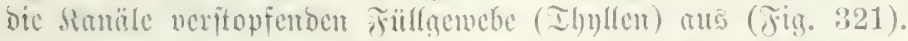

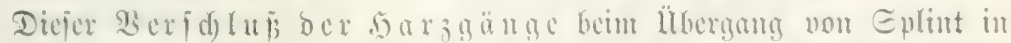

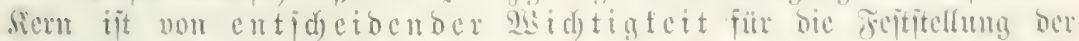

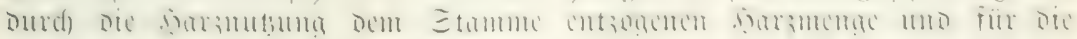

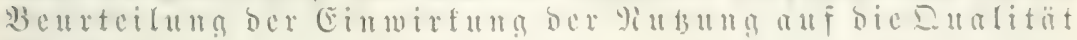

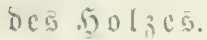




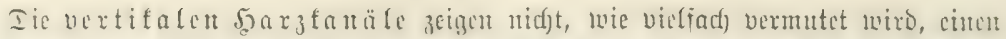

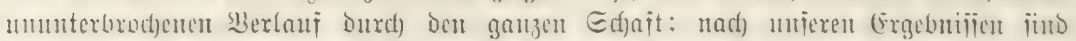

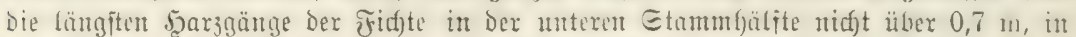
Dex vberen nicht

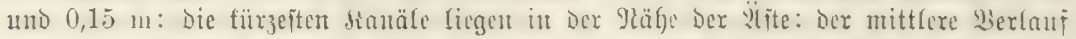

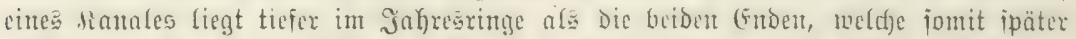
gebildet weroen ale Die Mitte Des Ranales. Siele Gönge enden mit Dem Solzringe

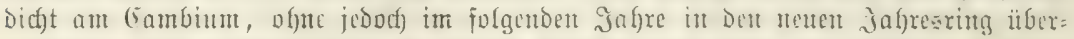

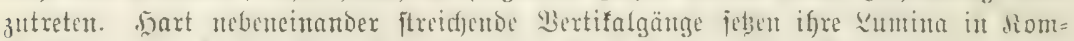

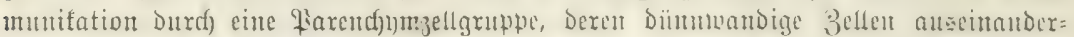

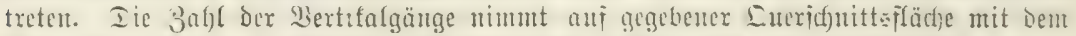

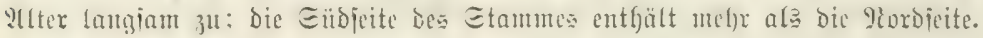

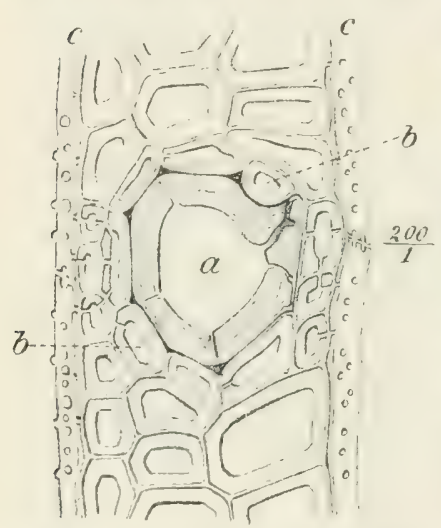

Tig. 921. Euerfuntt burfh einen kertifal gung, Der Dutd) :Iuswathen eimer jelle (a)

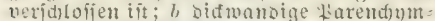
jelfen; cr whartitablicllen mit Etarte uno ingriontron.

Die Forizontalgänge find ftete eng= fumiger als bie vertifalen; fie liegen in ber Mitte der Marfitrahlen und exjtreffen jicf) mit Diejen nody in bie Rinde, wo jie blind endigen; ifre 3ahl ijt jebr groj, an Ficften fandent fich

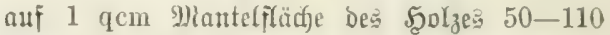
Gänge; unteriter uno oberjter Edfaftteil ent=

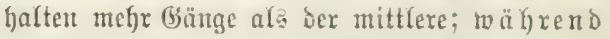
Dex Şegetation dic lü denloje fiambialidid in cin

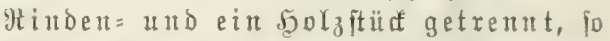
Daß̉ Dab Sarz aub Dem einen nid)t it Den anderen Teil paffieren fant; erit mit ber neuen Jahres:

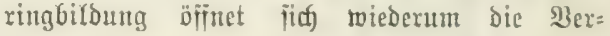
bindung.

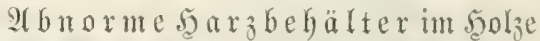

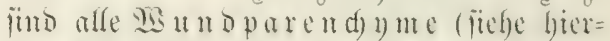
über Є. 99): jolders Gemebe cutiteld teils ämijerlid) uid)t jid)tbar, wie bei sroitmunsen, Duetid)mumben, teils aud) fidytbar als über=

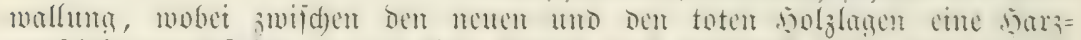

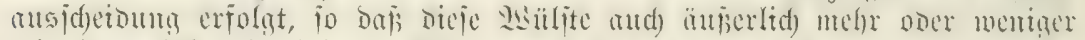

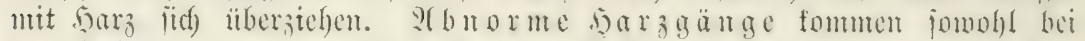

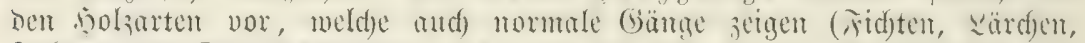

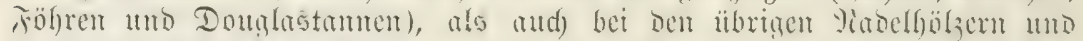

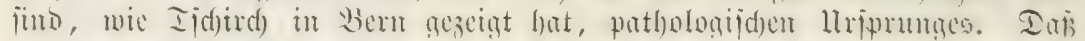

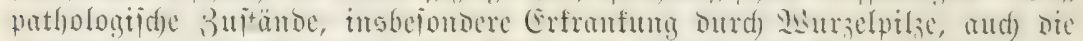

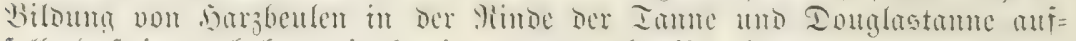
fallemb fteigert, haben wir bereits 1893 nadumeifen fömten.

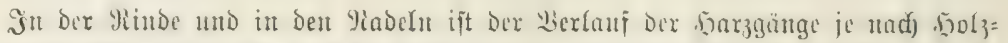

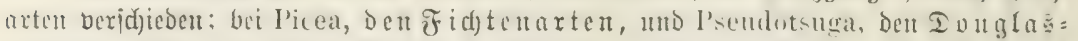

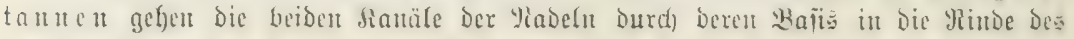

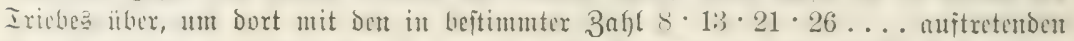

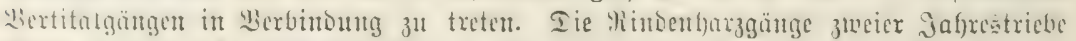

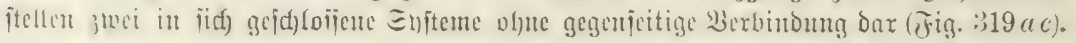




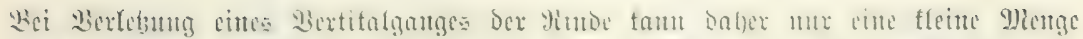

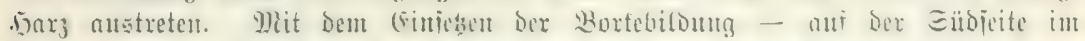

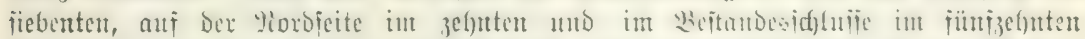

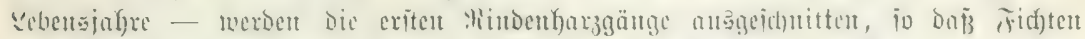

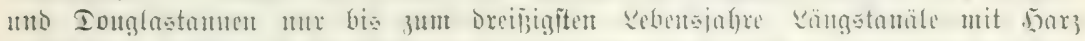

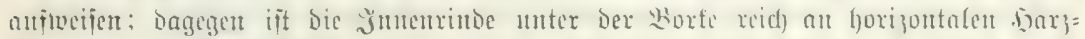

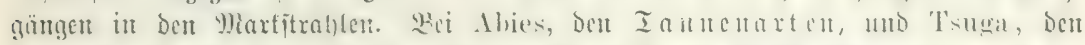

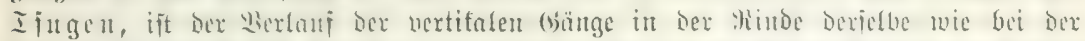

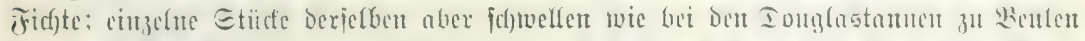

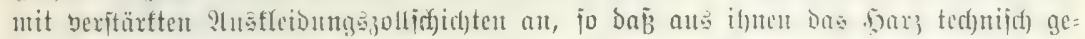

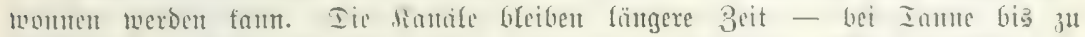

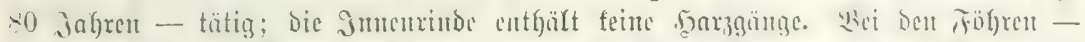

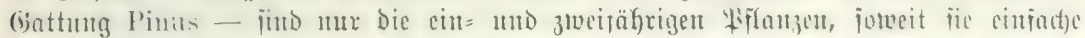

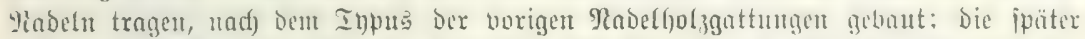

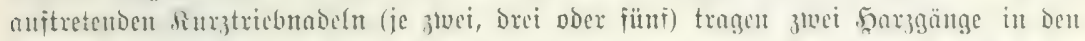

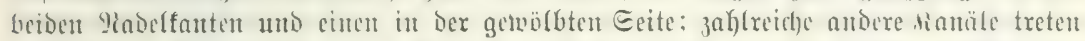

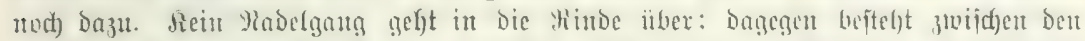

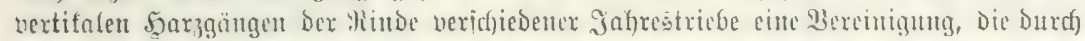
Das Iidfuwad)ätum Dex Suirläjte jdyon iriifzeitig unterbundu wiro: anjeroen be=

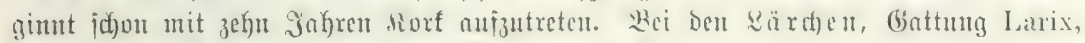

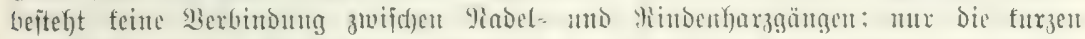

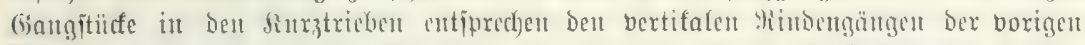

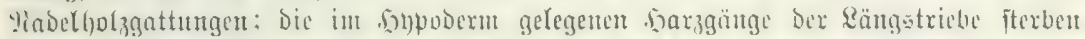

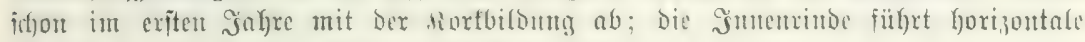
dianïle wie Die Fidften, Föhren uno Doughastannen.

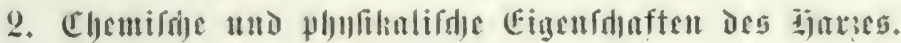

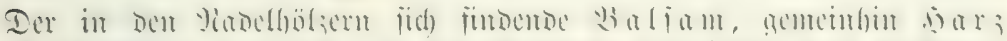

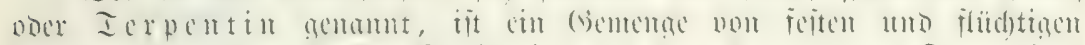

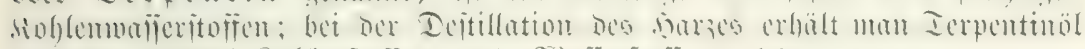

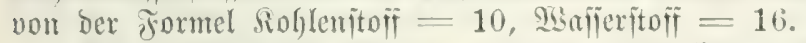

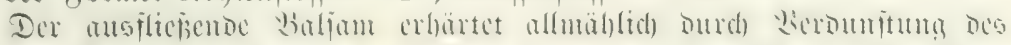

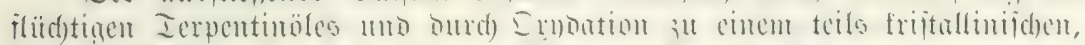

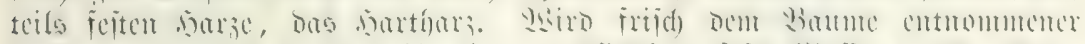

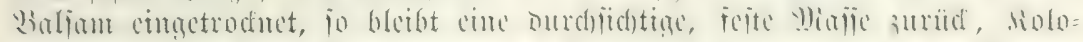

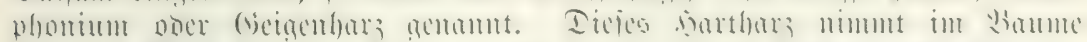

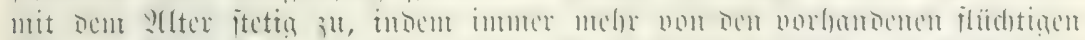

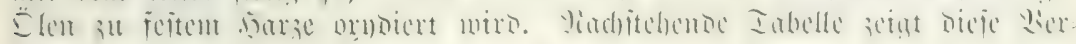
änberumg bentlid) für Fidfte uno jöhte.

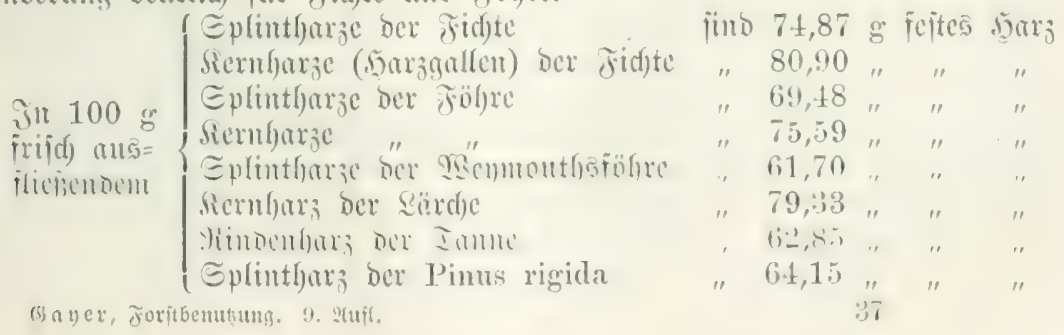




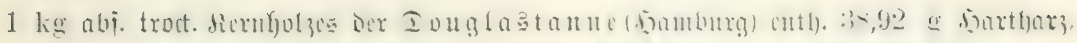

\section{1 \\ 1 \\ 1 \\ 1} $\Omega a ̈ r$ dfe (bal)r. 5yodjebente)

Föbre (Donautal)

Mctmouthä̈rore(Babern)"

(Torbamerifa)

Pitch-Pine (Pine palustris) " 82,78

\section{5,88}

52,40

67,04

78,76

(Rorbamerifa)

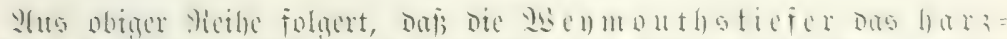

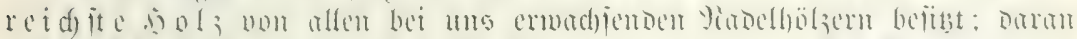

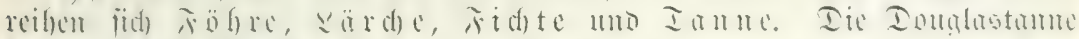

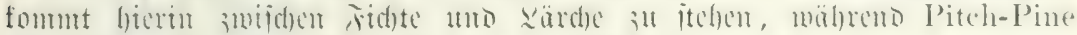
alle obigen Jabelgölzer an Sarzmenge ïhertrifft.

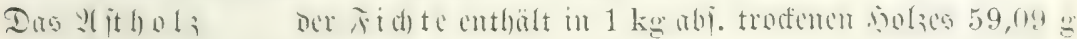
Murzelfol $\mathfrak{l n}_{3}$

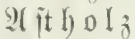

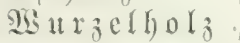

" 1

98,57

44,00

58,35 ,

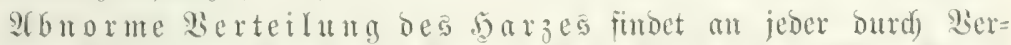

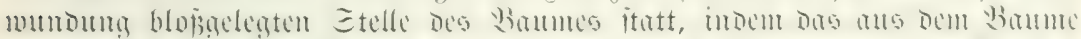
ansegerefte nari bie

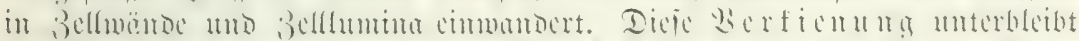

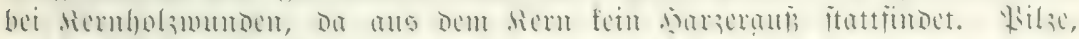

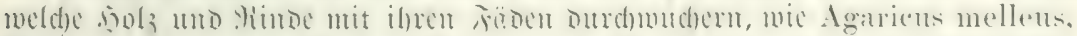

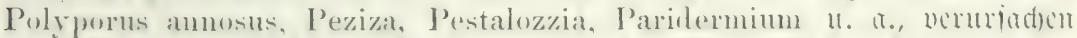

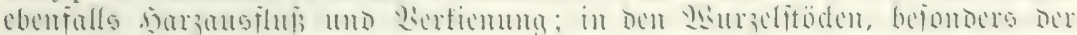

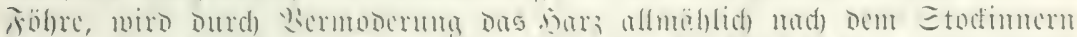

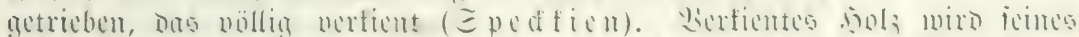

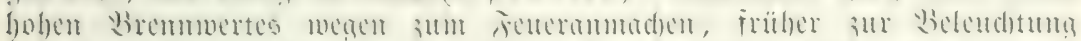

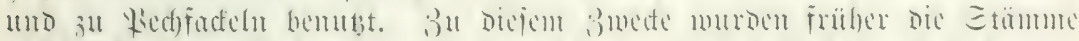

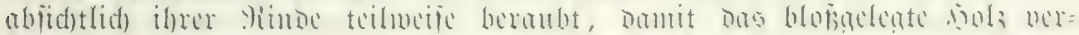

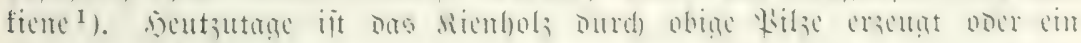
Viebenproduft ber 5arzgewinuma.

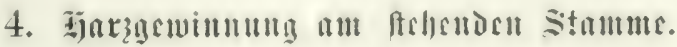

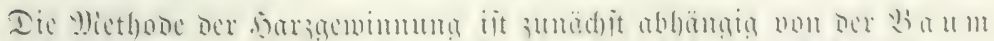

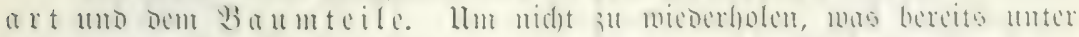

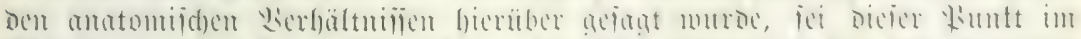

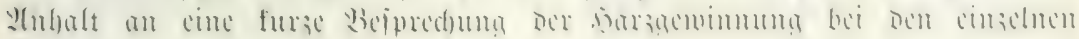
Selzarten cribälunt.

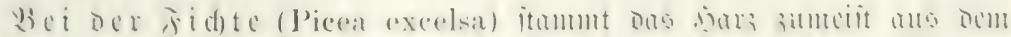

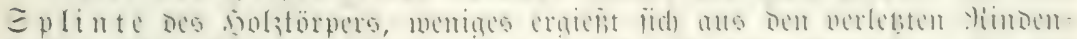

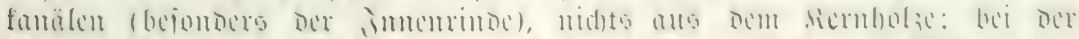
Sorramen beiteht cin

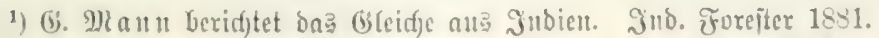




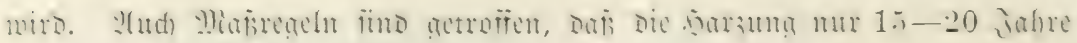
nor Dent T(btriebe begimnt ${ }^{1}$ ).

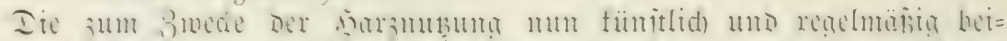

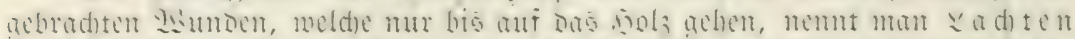

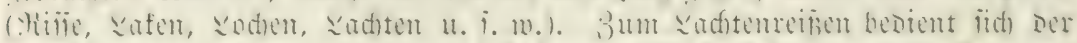

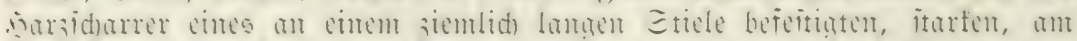

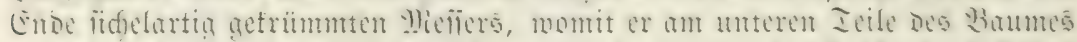

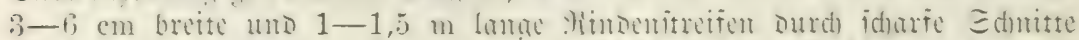

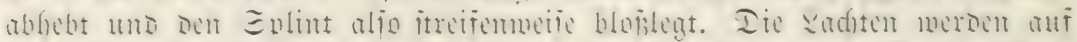

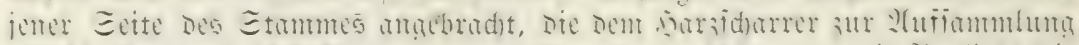

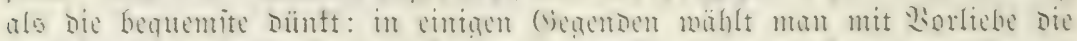

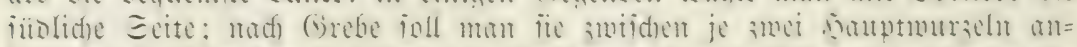

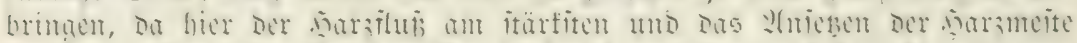

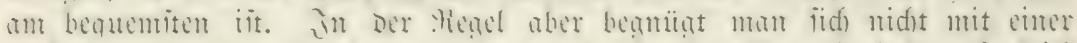

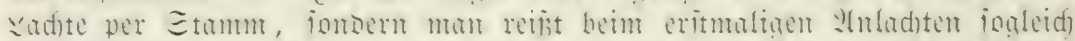

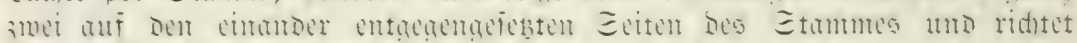

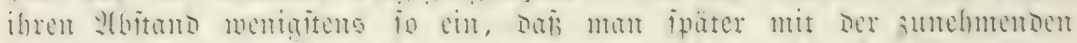

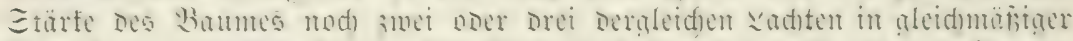

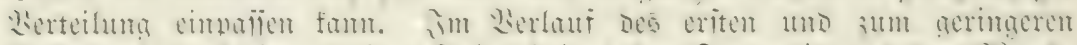

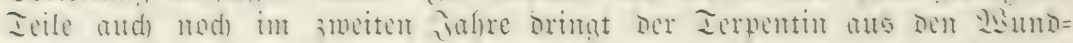

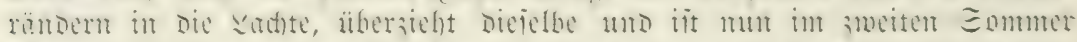

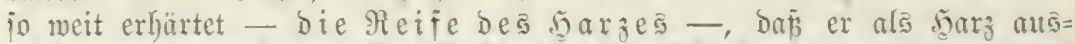

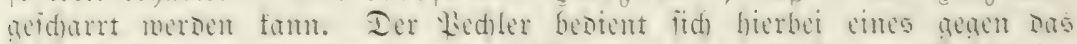

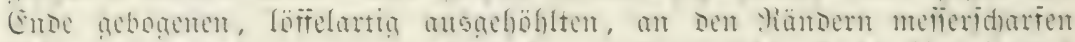

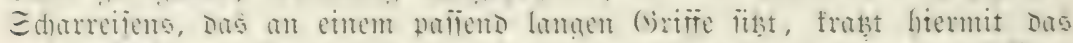

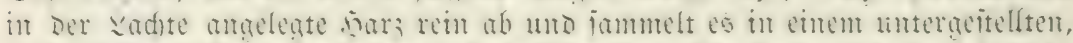

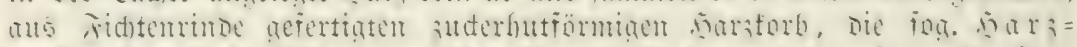

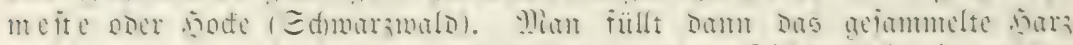

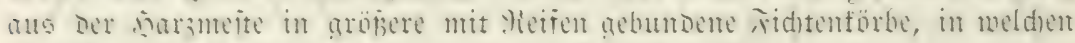
es jeit zujammengetreten uno Dam abgejahren miro.

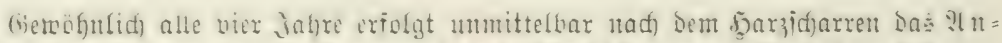

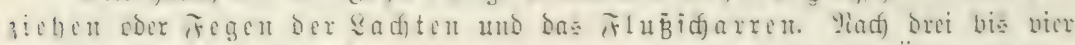

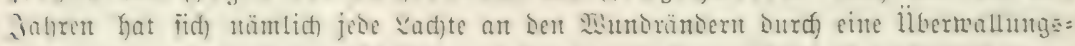

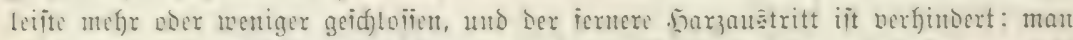

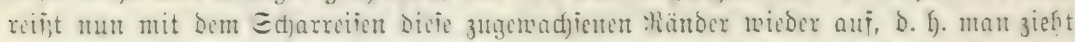

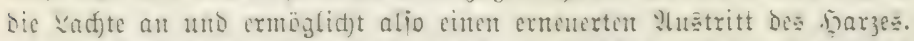

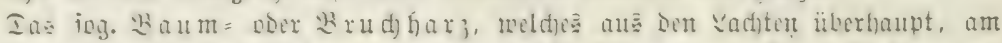
rimiten ans ben jüngeren Sadjten, gemonnen wirb, iit bas mertuollere. Ins gering=

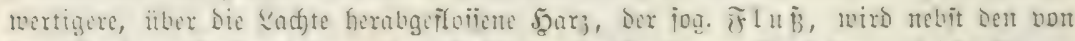

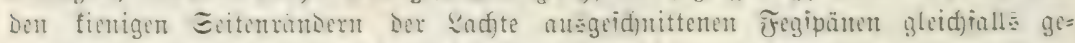

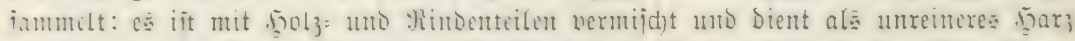

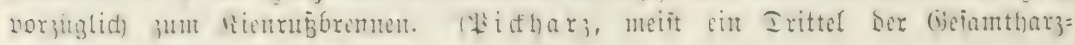
auแ่ใน้อ.)

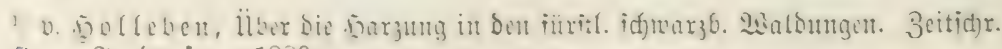
i. Forjt= น. Jagowsier. 1880. 


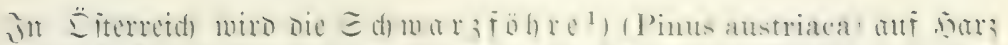

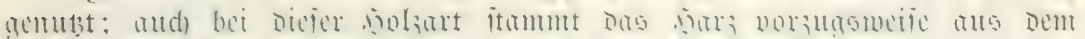

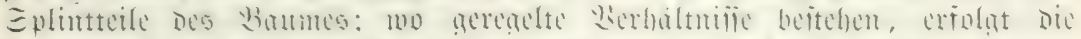

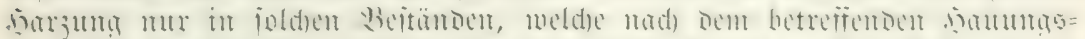

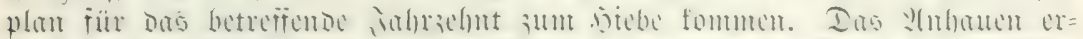

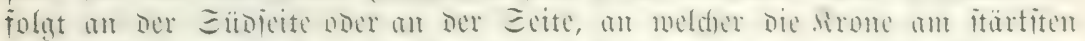

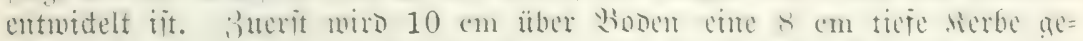

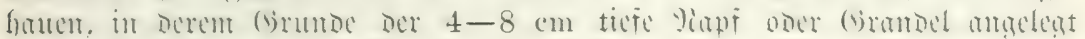

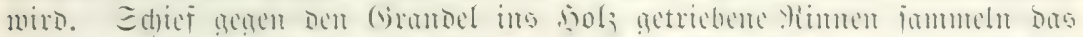

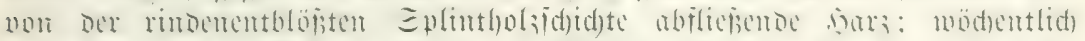

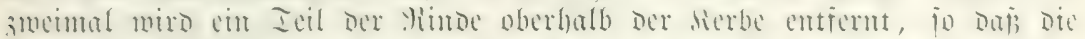

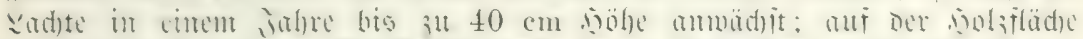

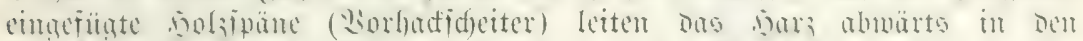

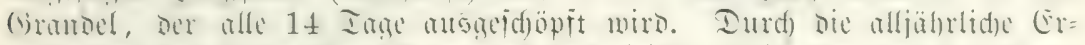

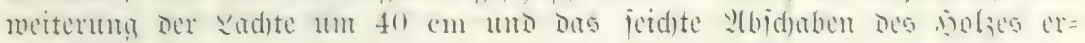

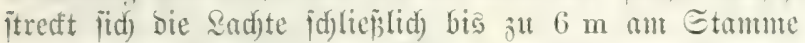

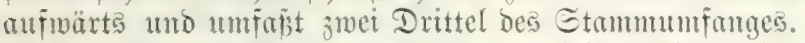

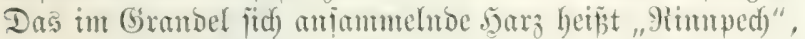
Das vou Der Rad)te abgefrabte barz Das "Edyarped)". Die Jarzmulung an Der Geeitrand maritima) im jüDweitlid)en Franfreid) it bereits vielfad)

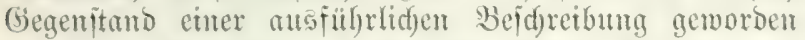

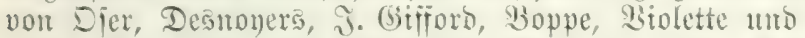

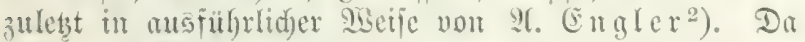
Sidjt und Märme, wie früber gezetgt, bie jax̧biloung föroern, io werben dic Weitünde frafitig Durd)foritet, fo oaj jodon mit Dem 15. und 20. Debengjabre un Srivat= maldungen, in Etantimuloungen mit dem 30. bis

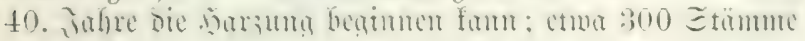

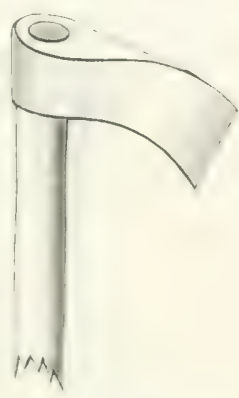

jig. 322

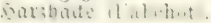
pro Seftar werben amsgemählt als dic beiten Etümme,

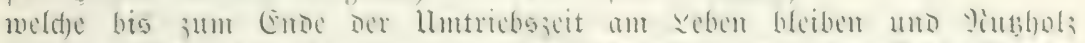

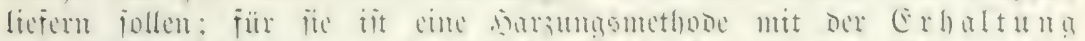

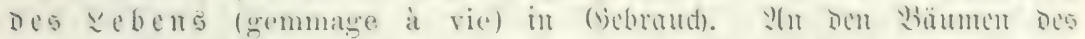

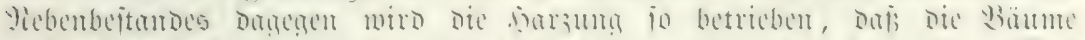

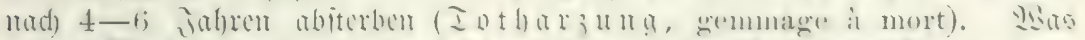

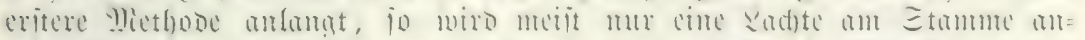

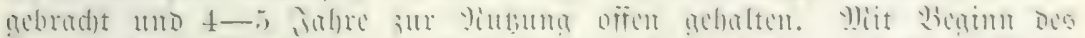

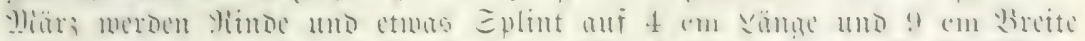

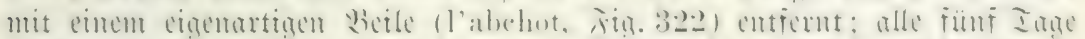

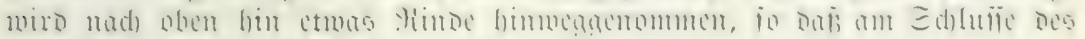

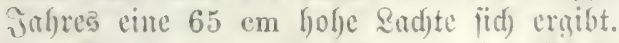

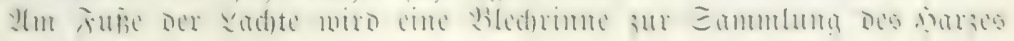

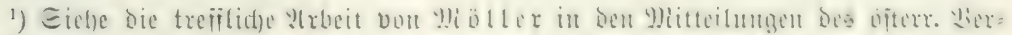
ind) walde. Beitid)x. F. Forit = U. Jaģowefer. 1875.

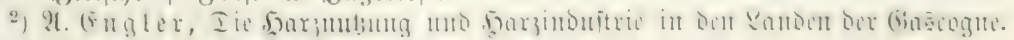
Edfueiz. 3eitidir. †. Foritucicu. 1902. 


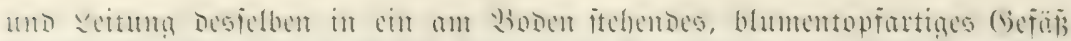

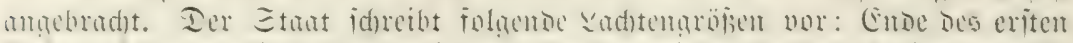

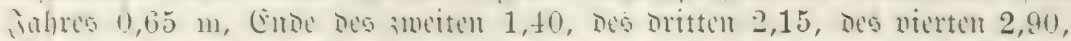

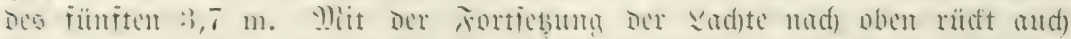

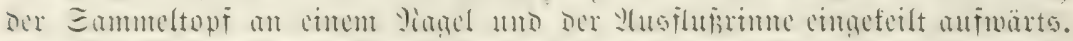

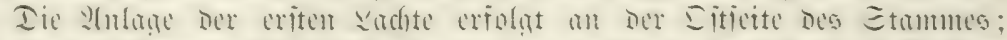

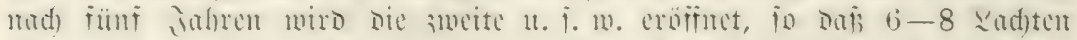

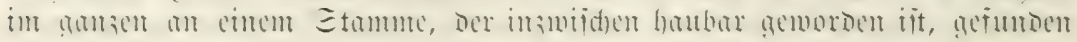

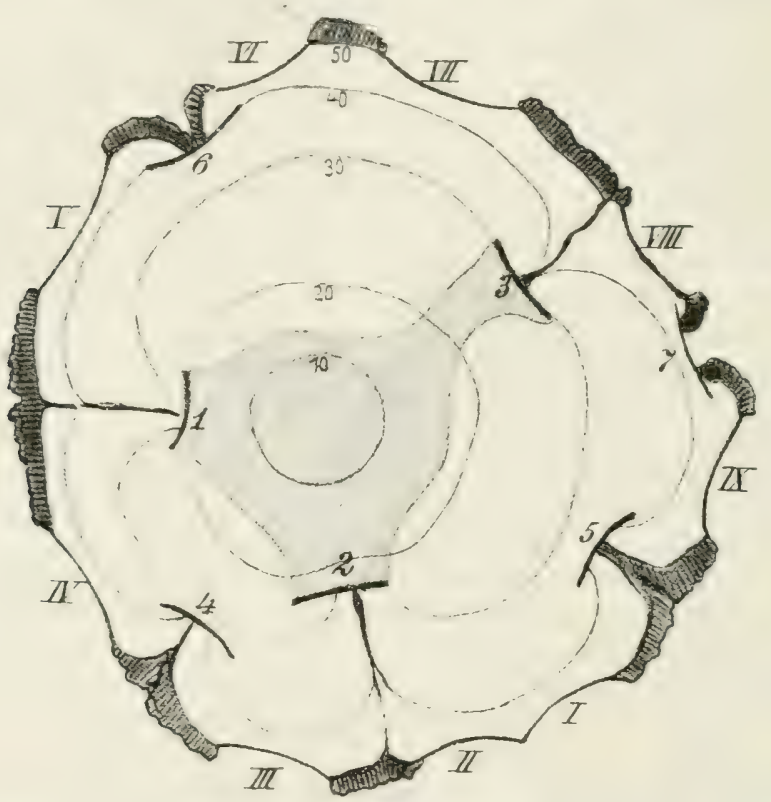

Fig. 323. Eneridnitt burd) einen Etanm ser Eeejtanbjöbre, welde anfänglid mit exhaltung bes

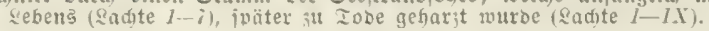

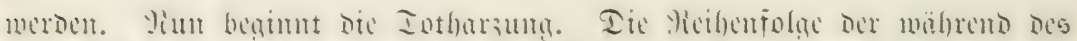

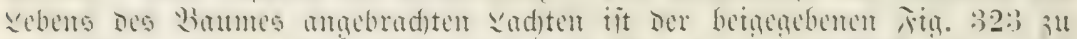

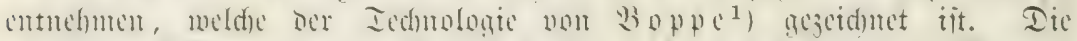

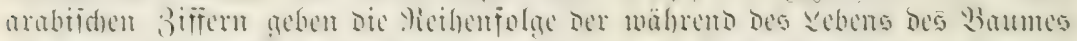

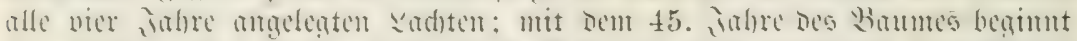

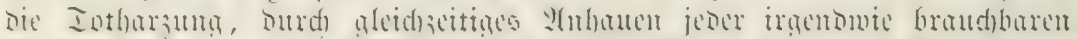

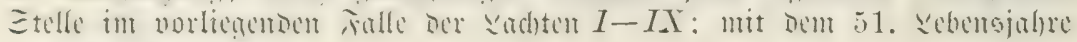
itarb ber Etamm ab.

Das barzen ber langutbeligen Föbre (Pimus palustris ober

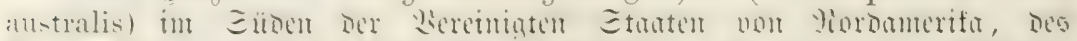

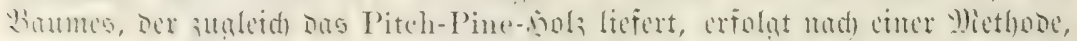

1) Boppe, Technologie forestière. 1887. 


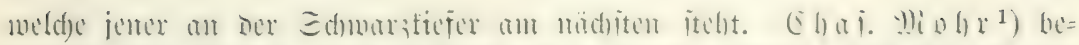

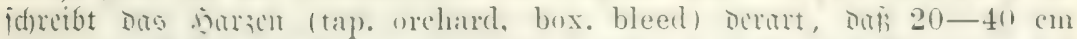
Hiber Dem

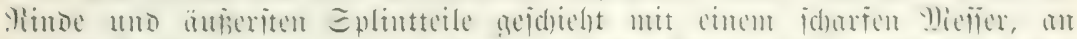

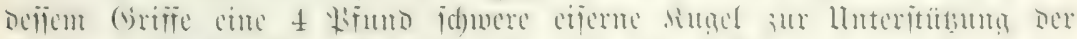

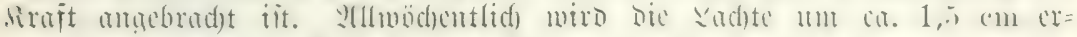

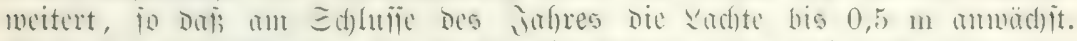

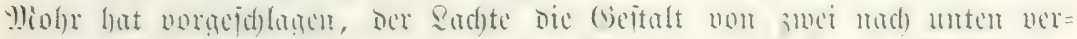

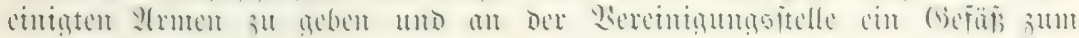
2tbfangen Des 5arzes anfzubängen.

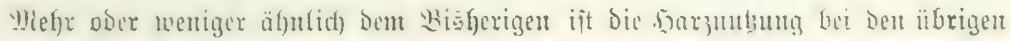

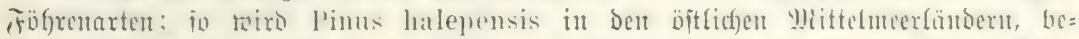

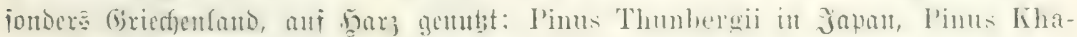

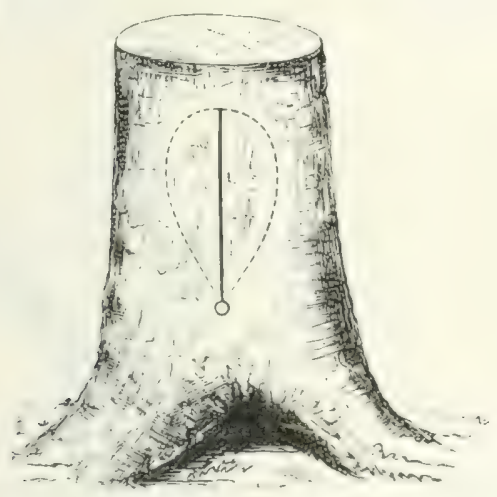

jig. 3:4. Inlage ber 2adjte unter ber Yinbe

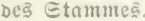

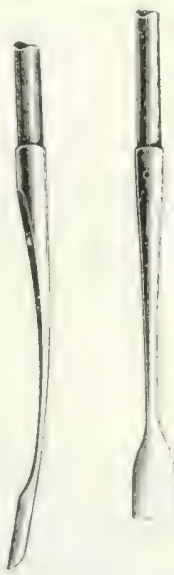

jig. 325. Edüleiten зu teit= weifen ?tolöjung ber tinde.

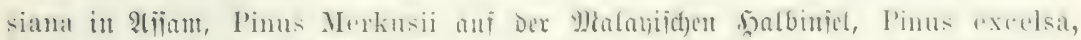

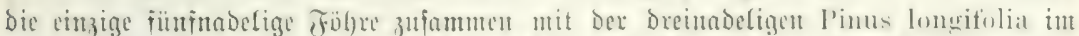

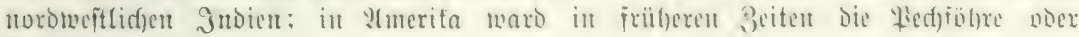
Stect)föf)re (Pinus rigida) bemutst.

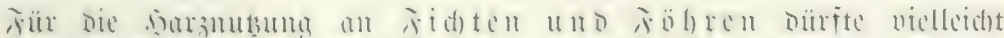
folecuse ne

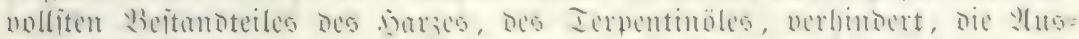

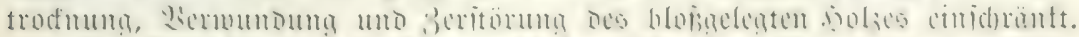

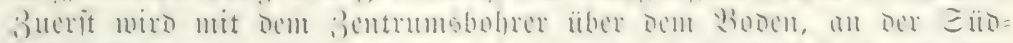

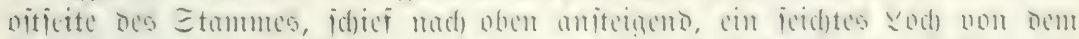

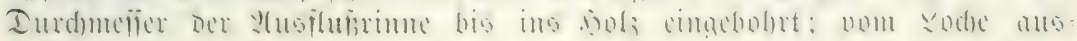

1) Dr. Ch. Molur, The timber l'ines of the Southern United States. 1897.

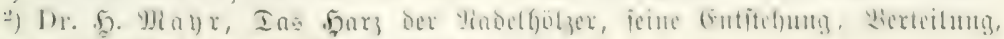
Bebcutung and Belvimumg. Bertin 1894. 


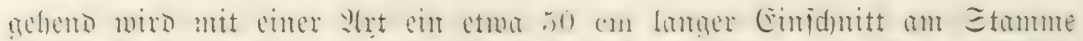

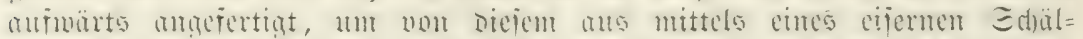

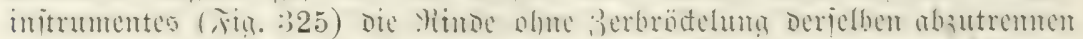

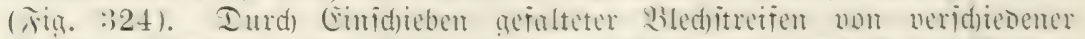

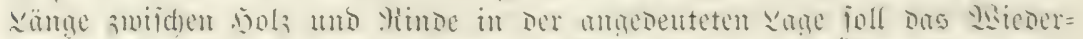

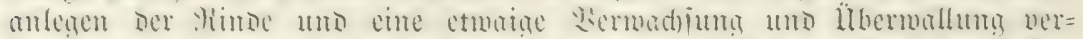

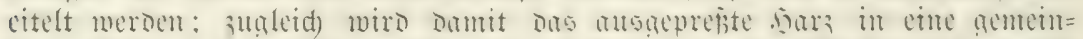

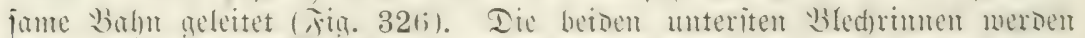

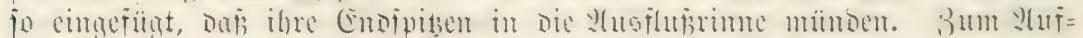

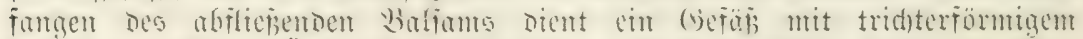

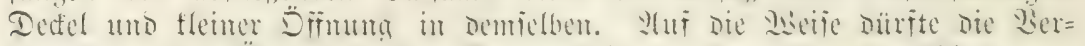

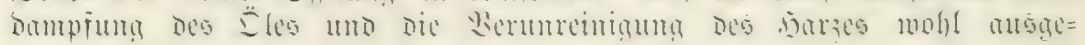
jod)loilen pein.

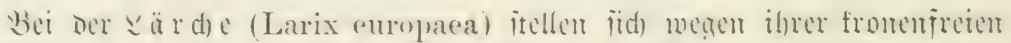

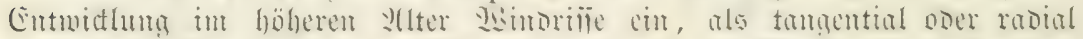

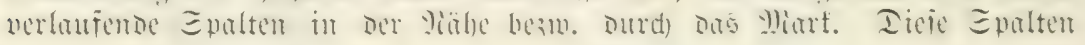

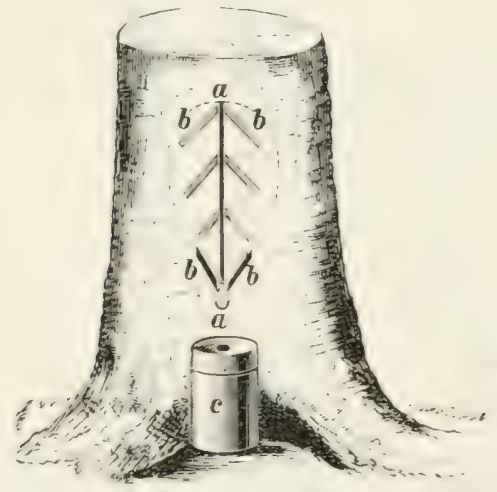

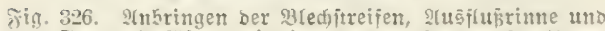
bes હammelgeïñę bei einer neuen sarjugsmetbobe.

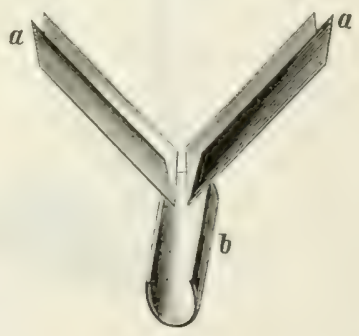

ปig. 327. a a Buleitungs̄rinnen, $b$ กแริ= iิupirinne.

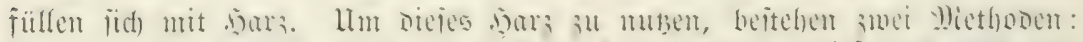

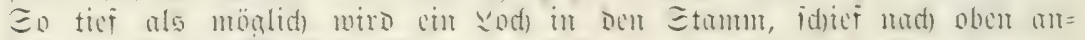

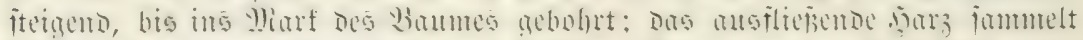

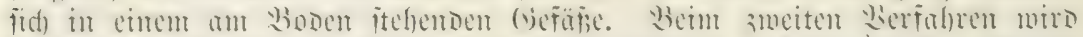

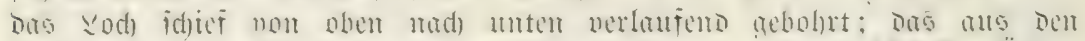

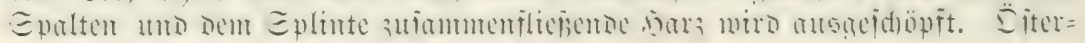

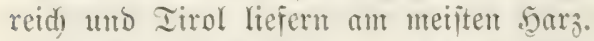

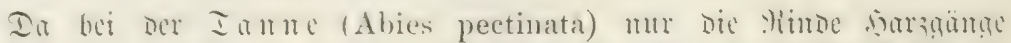

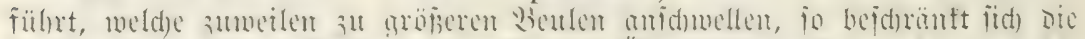

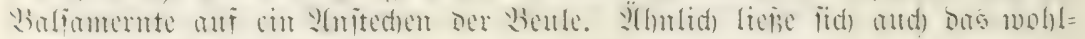

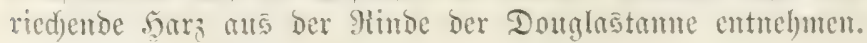




\section{Augbute.}

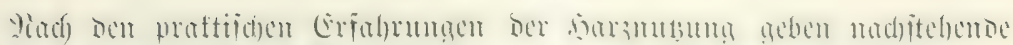

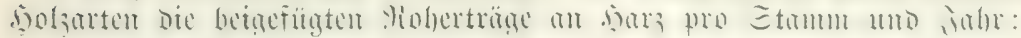

\begin{tabular}{|c|c|c|}
\hline Pinus & Rhasiana . & 7,0 \\
\hline 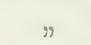 & Merkusii . & 6,0 \\
\hline$"$ & palustris. & 4,2 \\
\hline$"$ & maritima. & 3,0 \\
\hline$"$ & longifolia. & 2,5 \\
\hline$"$ & $\begin{array}{l}\text { austriaca } \\
\text { (alte Stämme) }\end{array}$ & $\begin{array}{l}2,1 \\
3,8\end{array}$ \\
\hline & excelsa . & 1,2 \\
\hline Picea & excelsa . & 0,5 \\
\hline
\end{tabular}

Die 2lbuthme

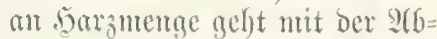
nafme an sionte bes Silimas genau parallel.

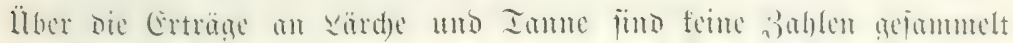

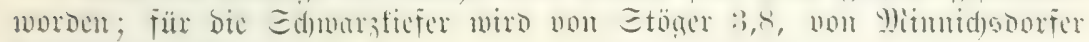
$4,9 \mathrm{~kg}$ angegeben.

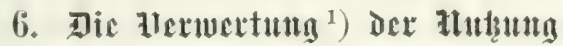

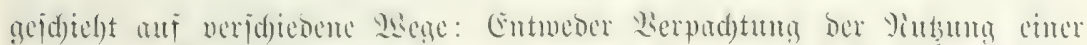
bejtumeten

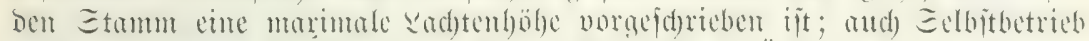

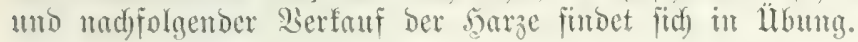

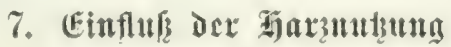

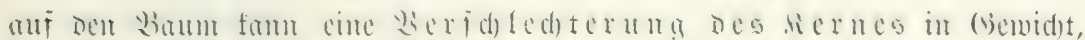

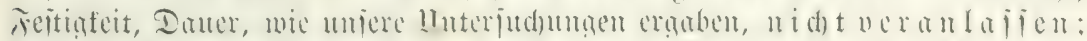

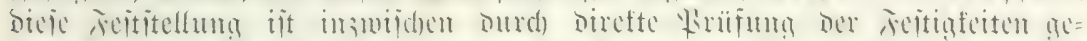

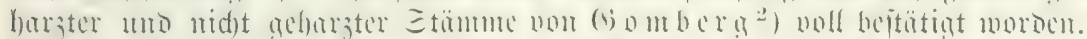

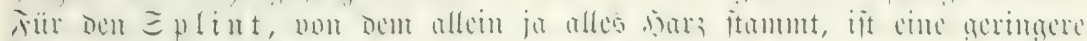

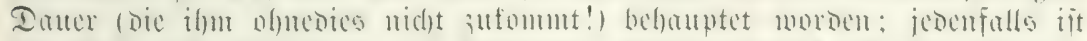

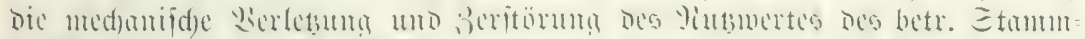

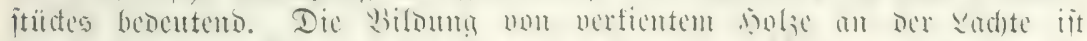

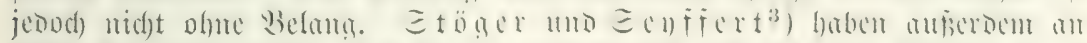

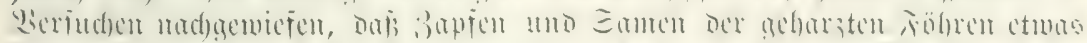

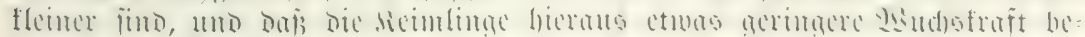

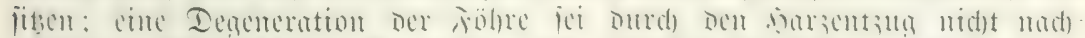

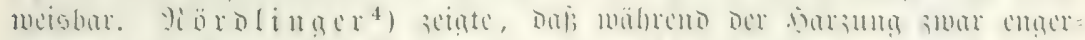

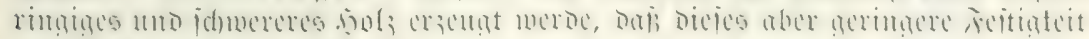
wegen bes welligen fajerverlatfes zeine.

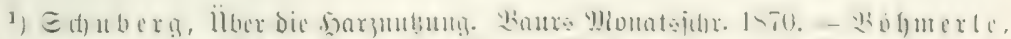

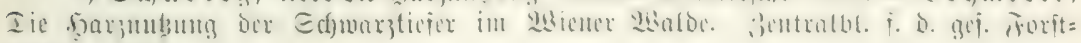
weicu. 1883.

2) United States Department of A griculture. Forestry Division 13ull. 8. 1893.

3) Bentralblatt fiir bas gejamte Torituelen. 1879, 1885.

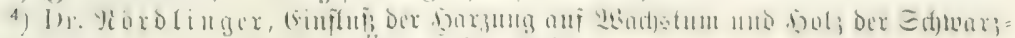

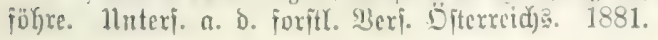




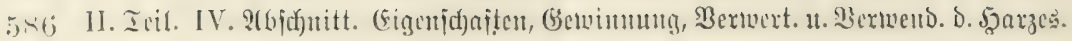

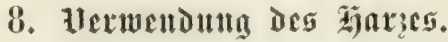

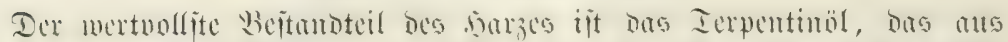

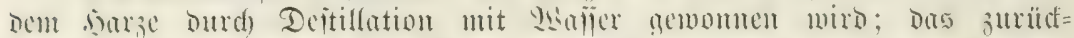

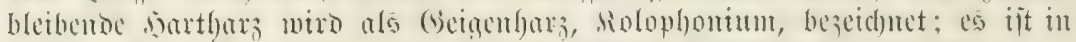

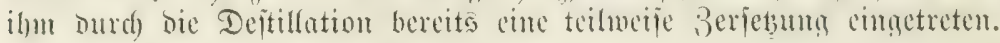

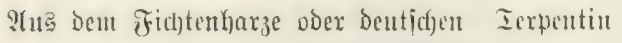

" Franzöfiticten

" amerifanifident "

" venezianifichet "

" Etrap̆butrger

" famadijuchen."

" ölterreidjiijden " (ฉärodc)

(Iantme)

(Tsuga)

(Pinus austr.) " werben $20 \%$ Ierpentinöl $25 \% \quad$ " $17 \% \quad$ " $25 \% \quad$ " $33 \% \quad \quad \quad "$ $18 \% \quad$ " $25 \% \quad$ "

getwounet.

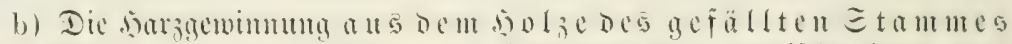

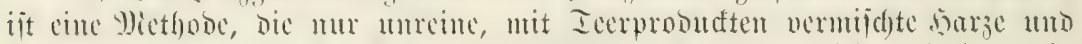

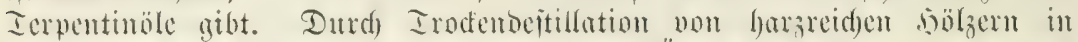

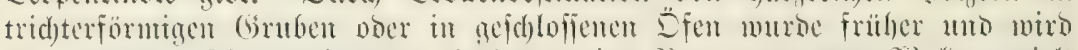

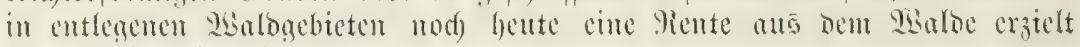
( Ieerid) welerei).

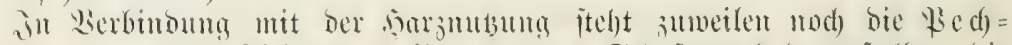

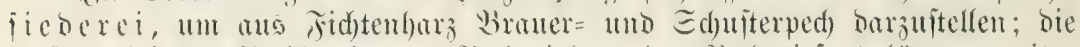

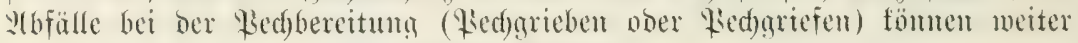
jux $\operatorname{sienxubbereitug~bemut~merden.~}$ 


\section{fünfter 2lbishnitt.

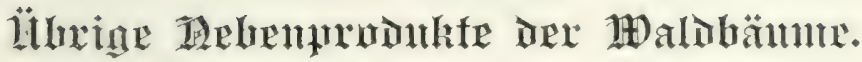

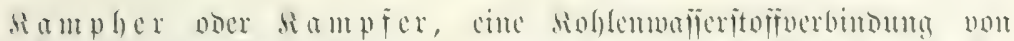

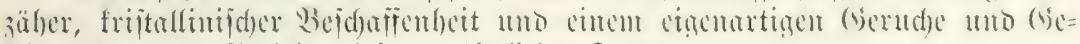
fdymadfe; er verfliidgtigt bei gewöhnlidger Iemperatur.

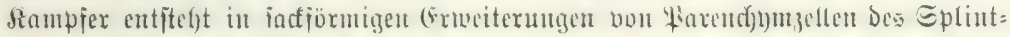
Golzes und anderen Ieflen Des Sampierbaunes, Cimnamomum ('anphoral; in Siern=

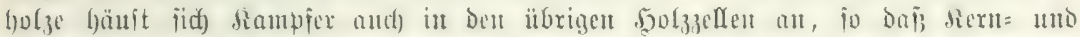

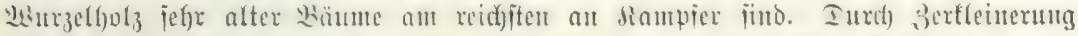

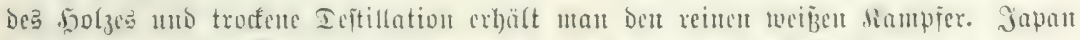

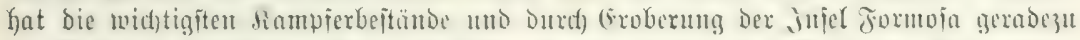

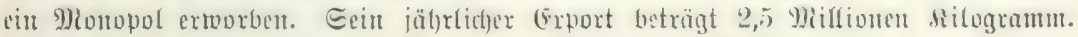
Dryobalanops Camphora auf Bonne liejert ebenfall Rampjer.

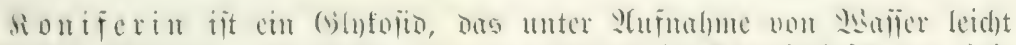

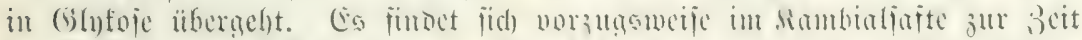

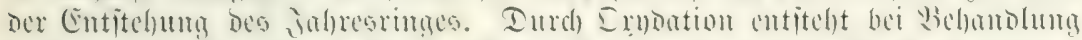

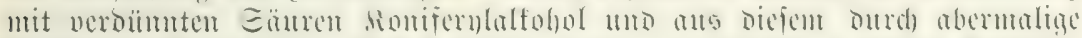

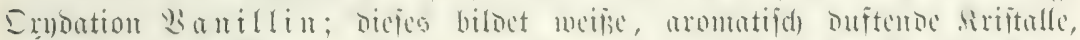

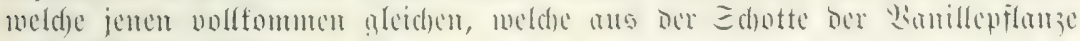
antigefdeteden werden.

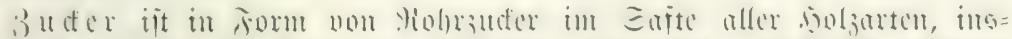

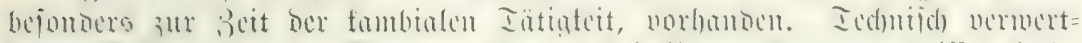

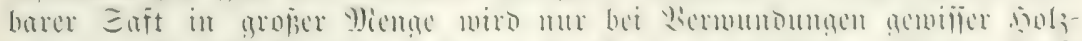
arten, i. 出. Des

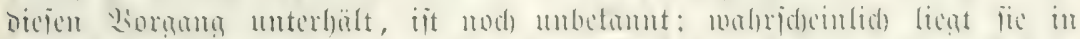

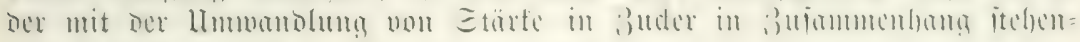
ben Iurgeszenz bes ganzen Eplinttörpers.

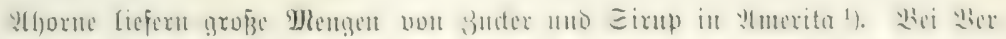

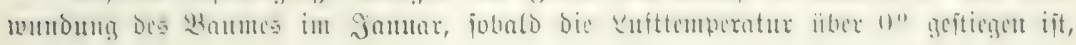

1) Stad) Dr. John G ifford, l'ractical lorestry 1902, jüfrtidf 25 Jlifronten Silogramm Buter uno 11,4 Jillionen \&iter Girmp. 


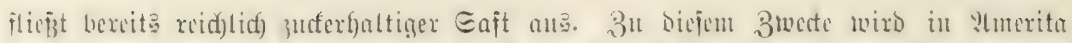

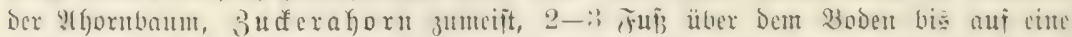

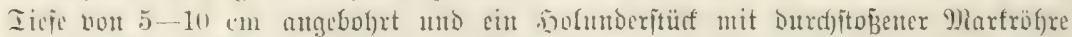

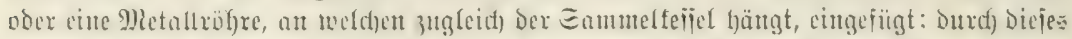

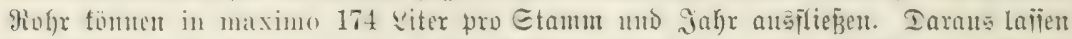

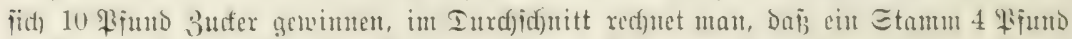
3uder pro jafre gibt. Ier Eaft wird jeden Mlorgen geiantult; mit Dem Blatt=

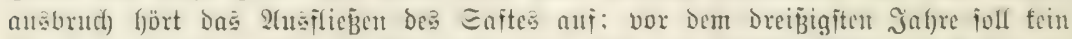

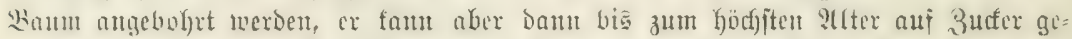

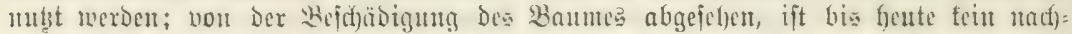

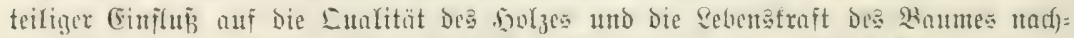

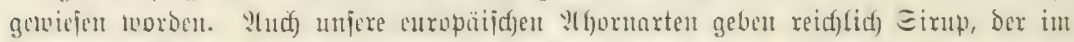

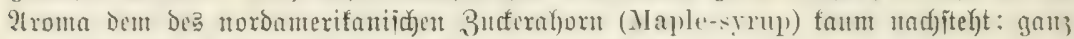
Gejondex twüroe Kierzu Der Bergahorn fitch eignen.

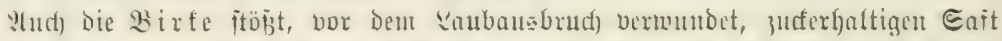

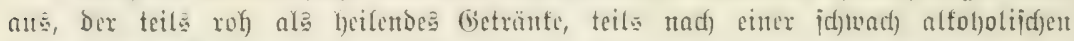
Gärung ale "Birtentwein" genoijen toiro.

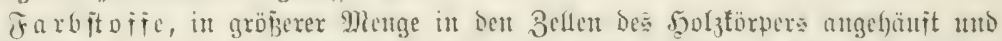

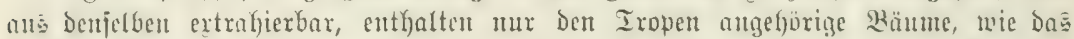

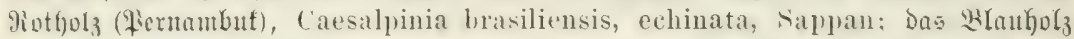

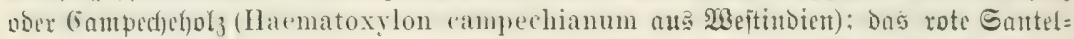

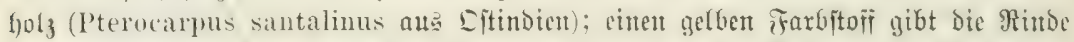

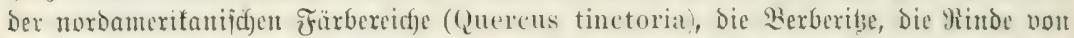
Maclura aurantiaca (Morbamerifa), Phellodendron ammense (Sitapient): cime

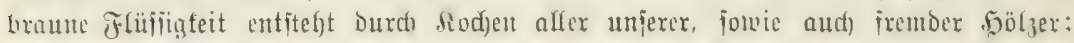

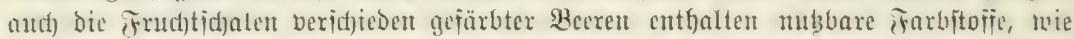

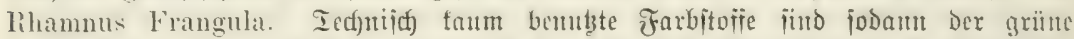

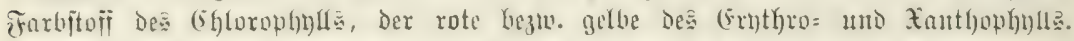

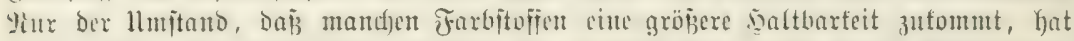

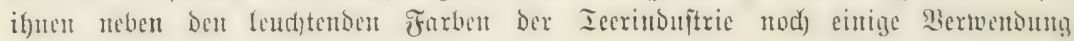
gejicfert.

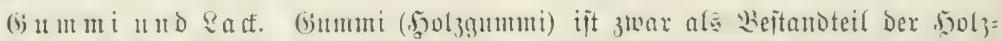

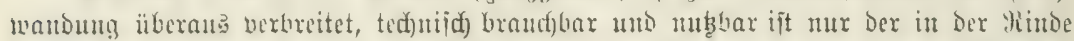

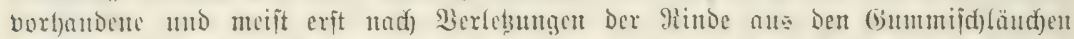

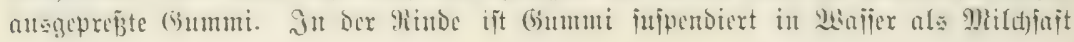
vorijanden.

Q $x a b i j d$ c

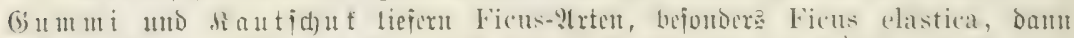

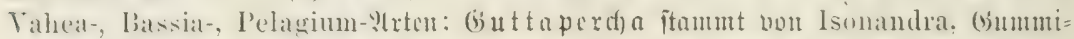

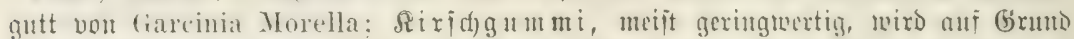

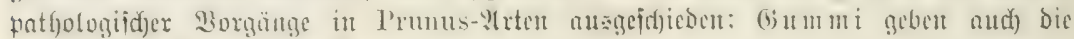
auptralifiden Eucalyptus-arten.

Zeimartige Etofic enthalten bic Fribde von Viscum album (Pogelleim);

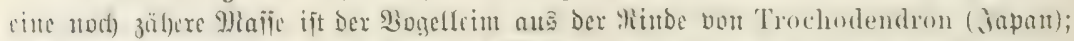

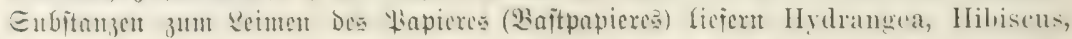

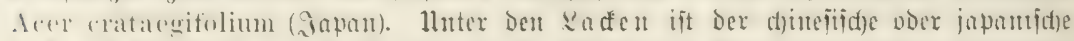

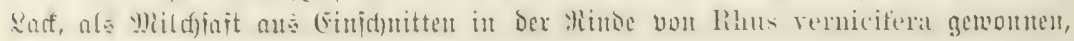
ber beribmteite. 
Ele, Fette und

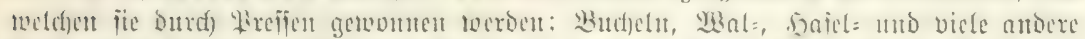

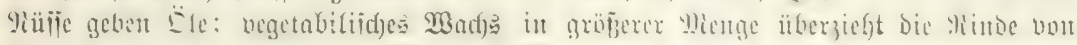

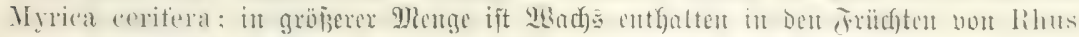

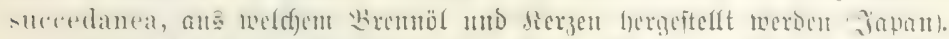

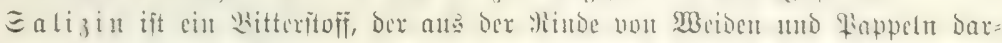

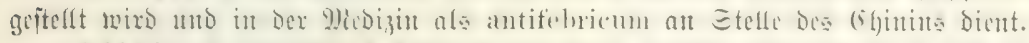

(if)

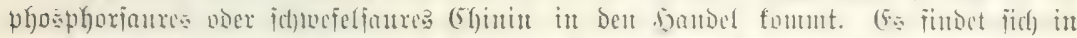

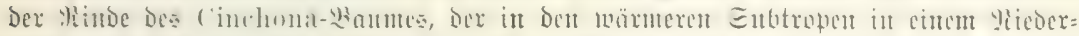

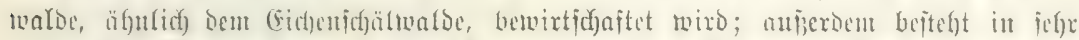

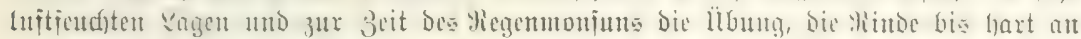

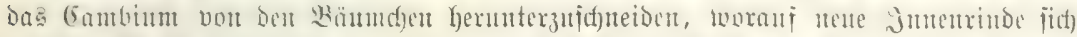

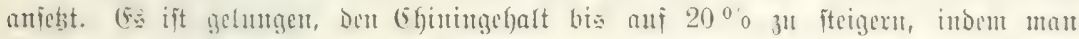

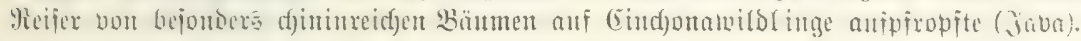





\section{Dritter Teil.}

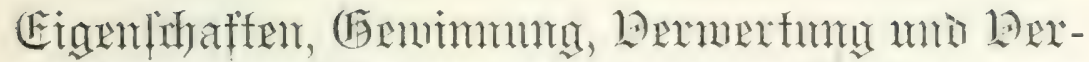

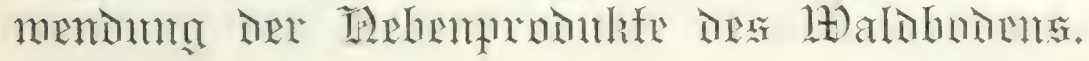





\section{Erjter 2lbjhnitt.}

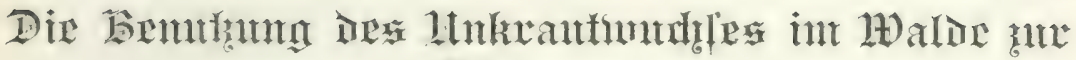 Fitfferung.}

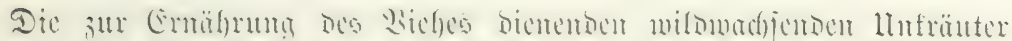

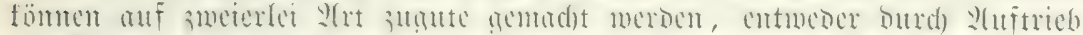

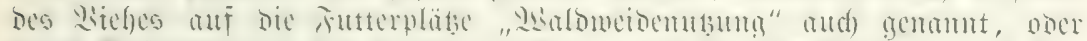
Durd)

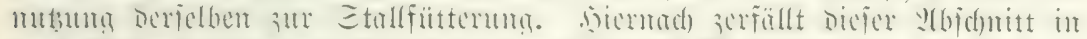

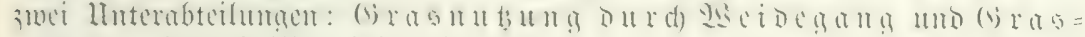

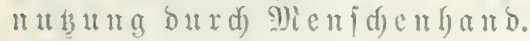

\section{Ẽrite 2lbteilung.}

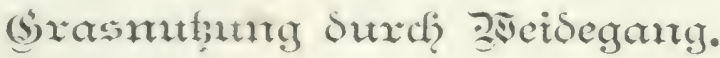

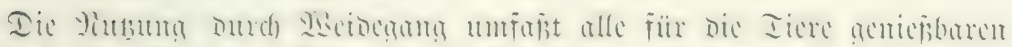

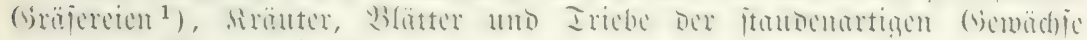
und ber foritlichen Sulturpflanzon.

1. Die Nienge an Futter biejer ?lrt lüngt $a b$ :

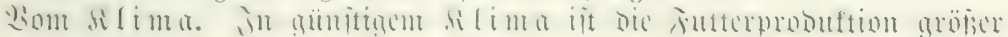

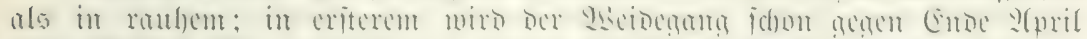

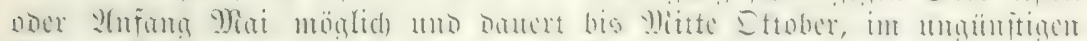

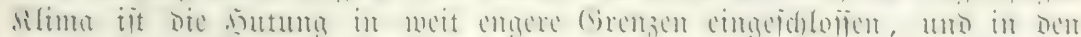

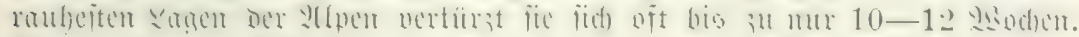

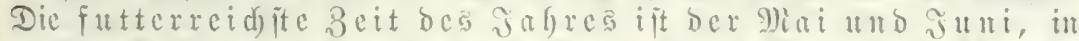

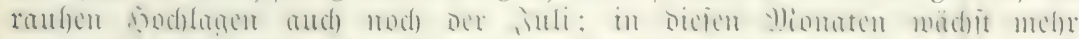
Jutter ala in ber ganzen übrigen Beit 3üanmengenommen.

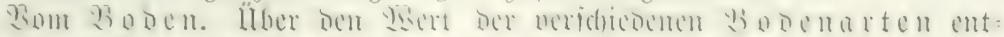

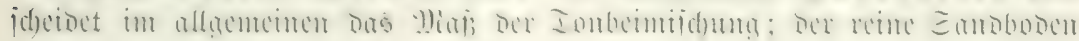

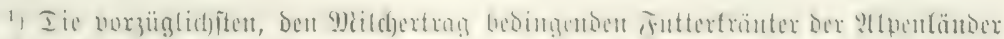

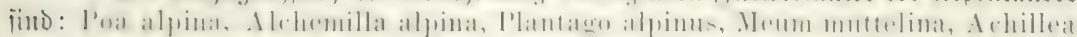

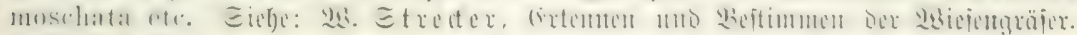

3. शิufl. 1900. 


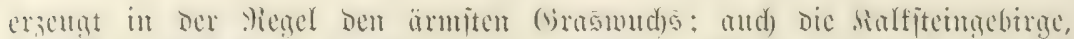

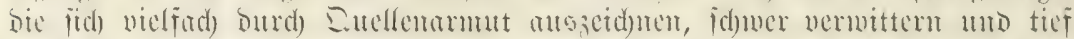

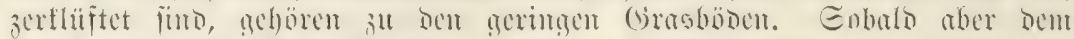

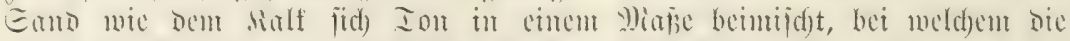

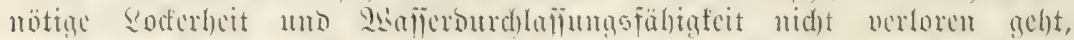

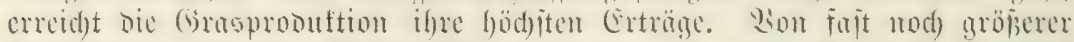

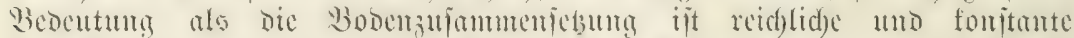

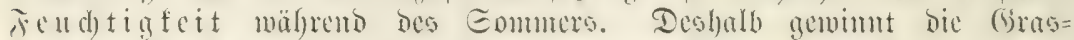

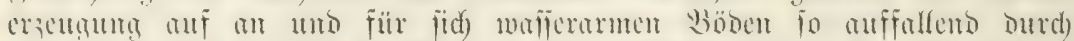

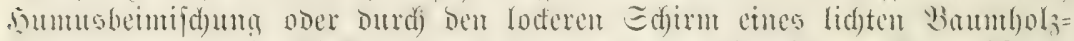

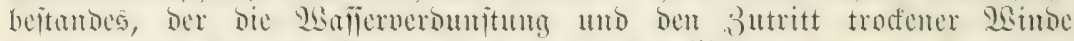

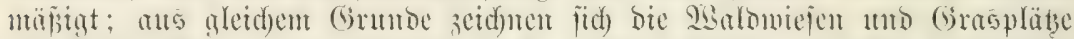

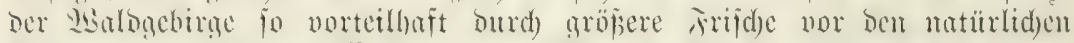

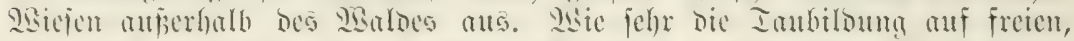

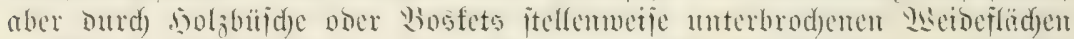

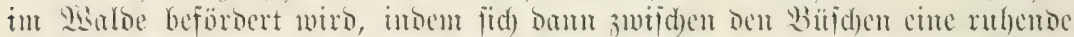

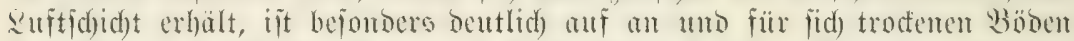

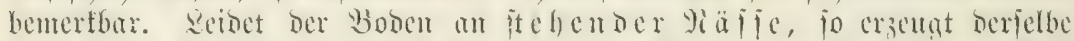

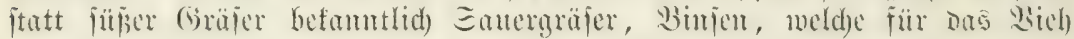
ungeniefbar find.

Wom

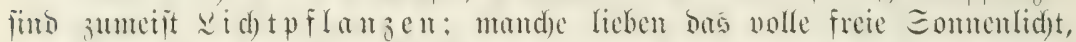

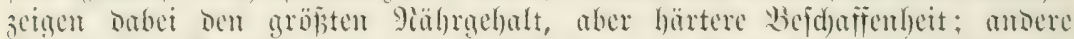

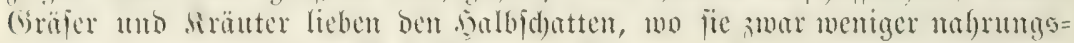

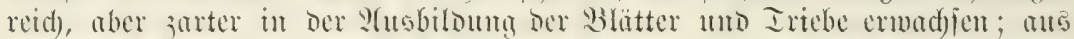

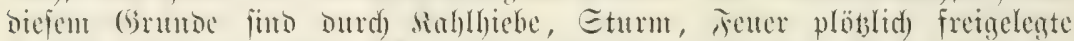

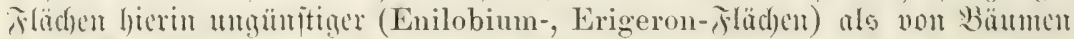

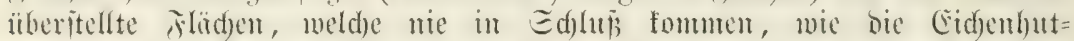

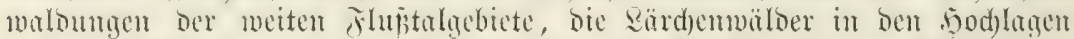

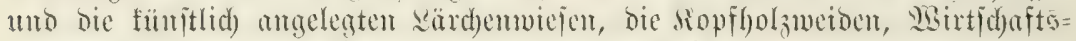

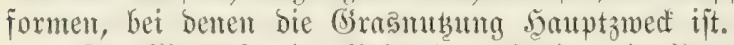

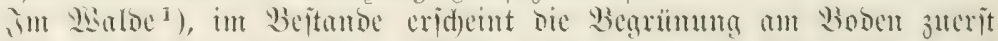

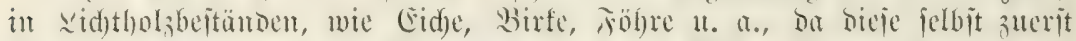

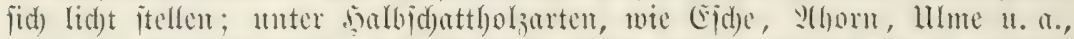

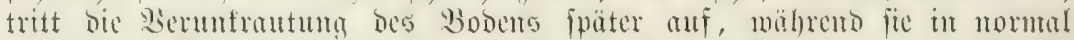

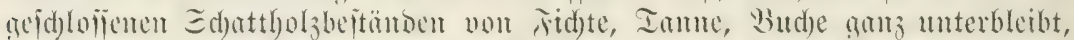

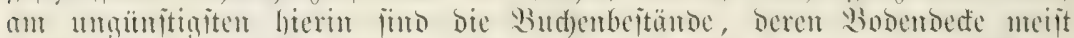

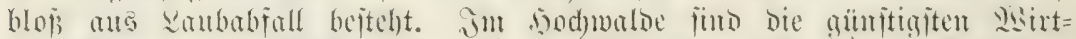

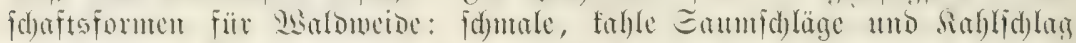

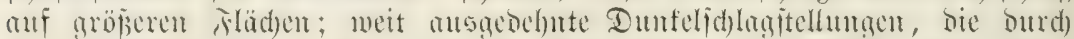

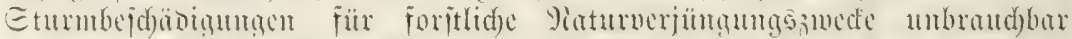

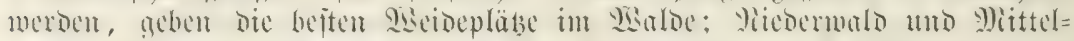

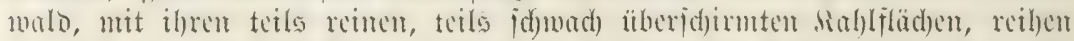

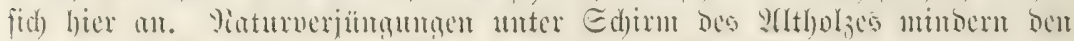

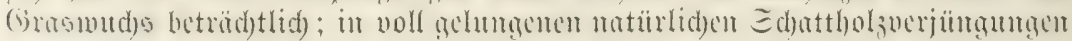

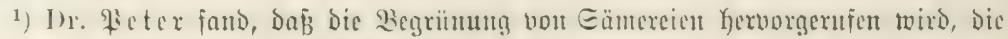
зwanzig und mefre Jakre im Bobent gernht haben. 


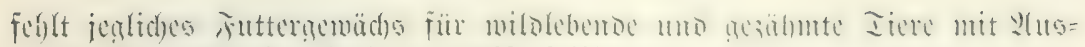
nafyme Der foritliden Siulturgewädje felbit.

2. I ex 然

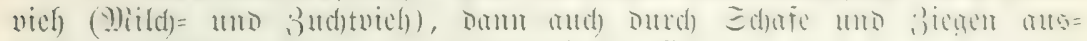

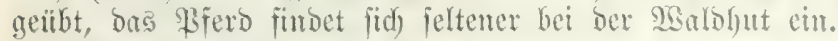

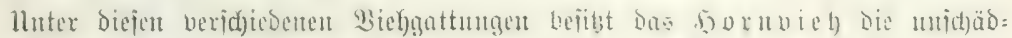

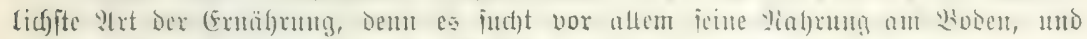
jo lange ifm ein gejunder (ista

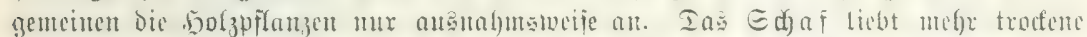

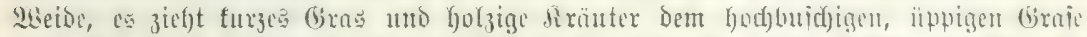

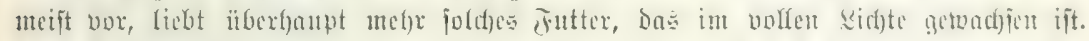

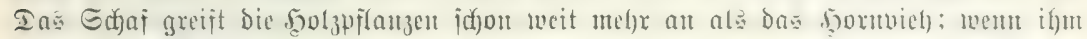

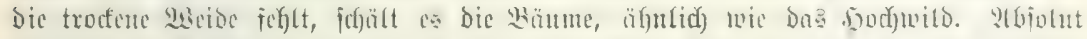

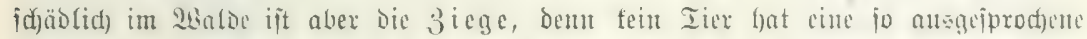

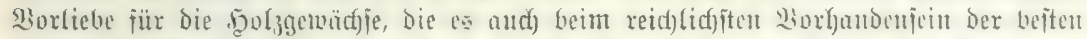

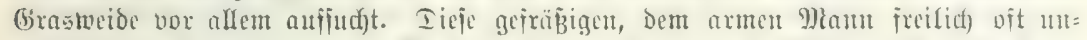

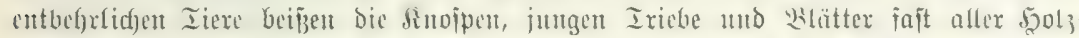

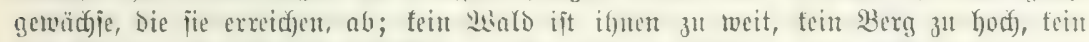

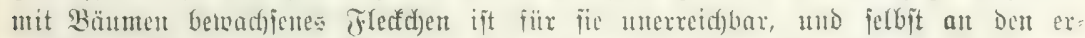

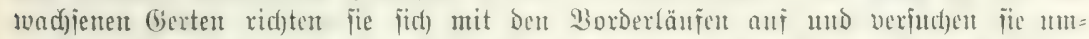

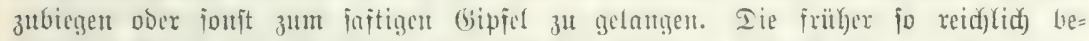

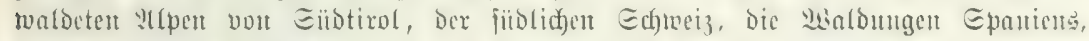

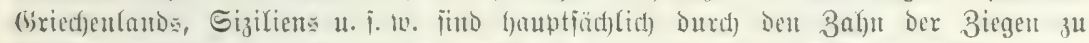

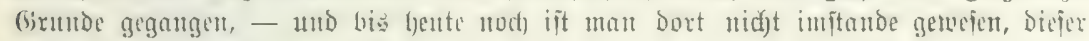
Ralamität eine Grenze zu jetzent.

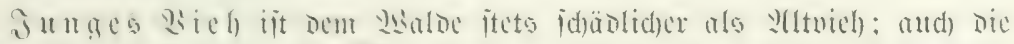

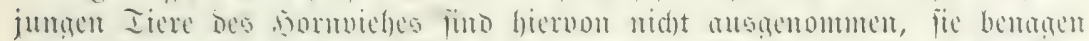

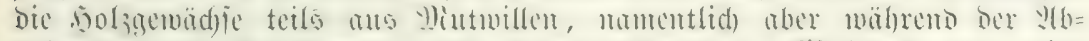

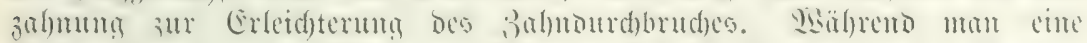

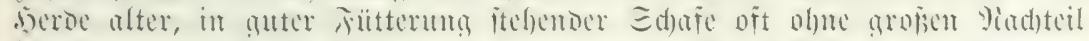

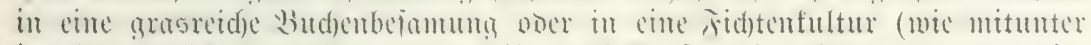

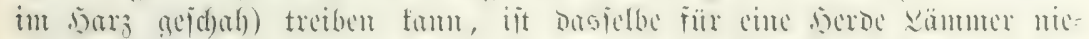
malอ zutäfifig.

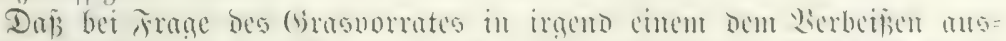

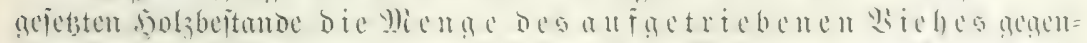

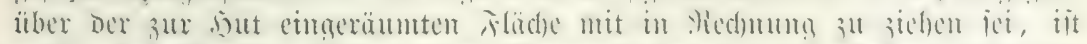

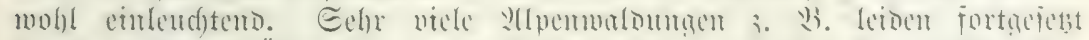

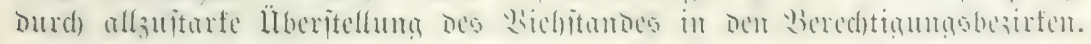

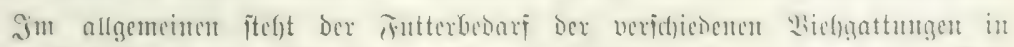

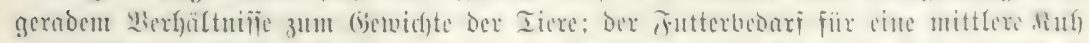

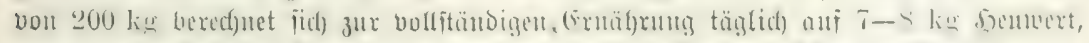

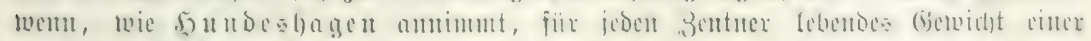

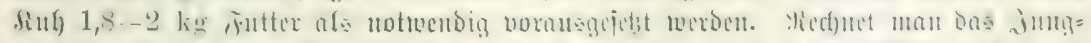

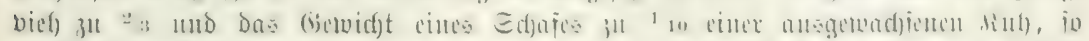

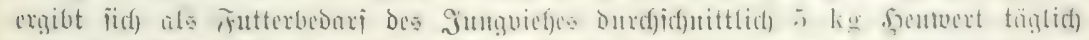

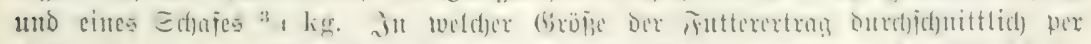

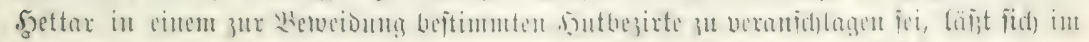




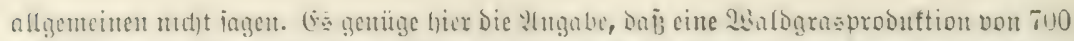

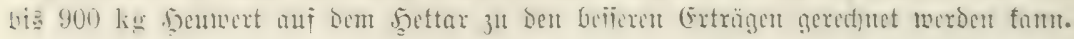

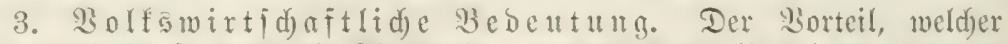

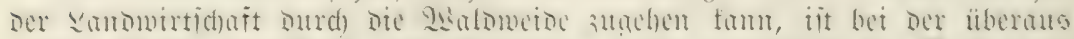

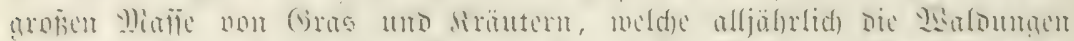

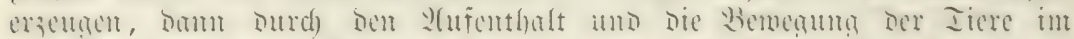

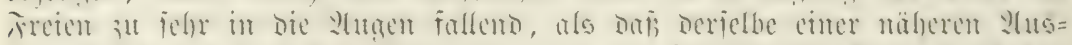

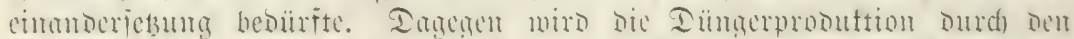

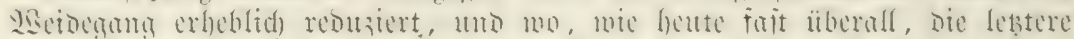

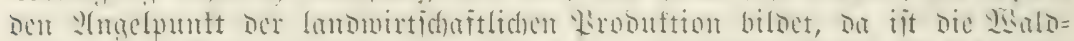

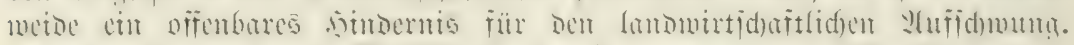

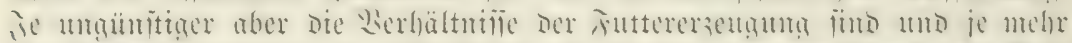

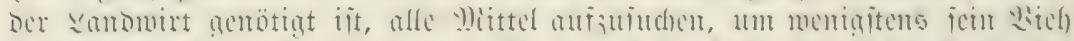

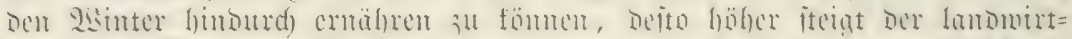

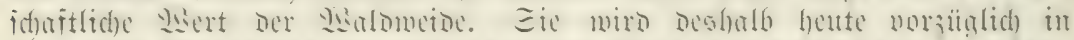

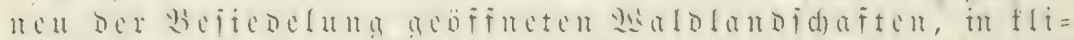
matifd un a

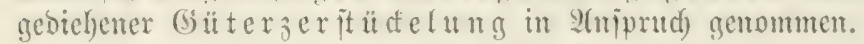

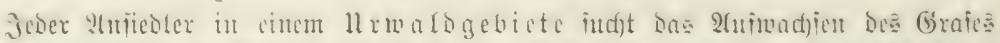

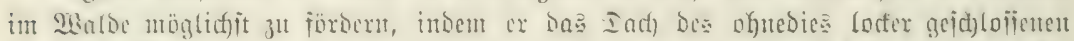

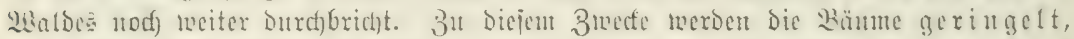

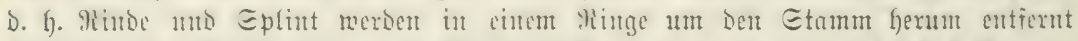

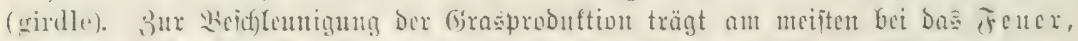

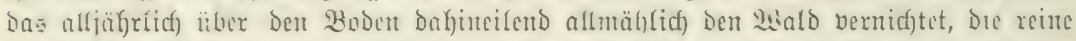

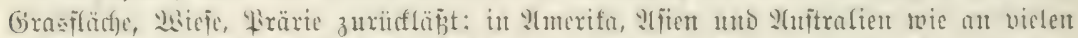

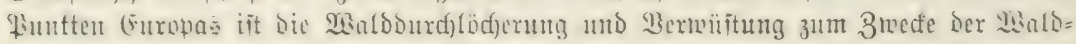

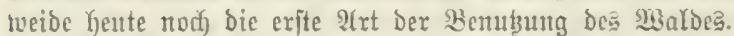

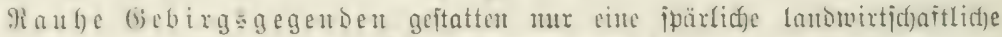

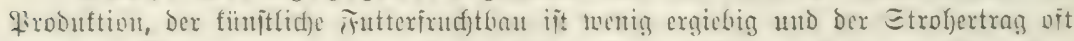

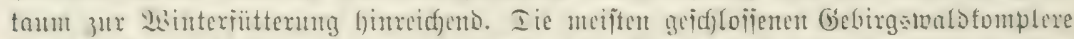

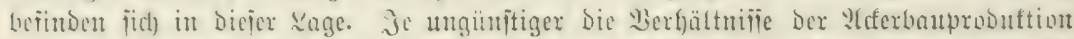

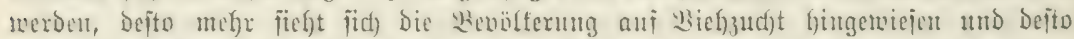

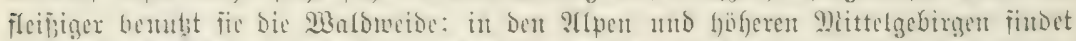

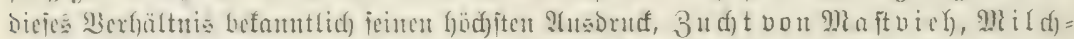

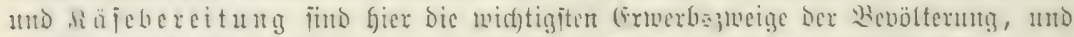

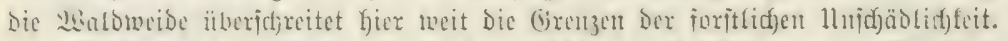

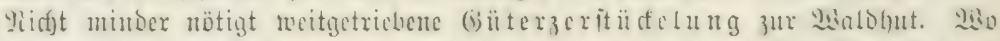

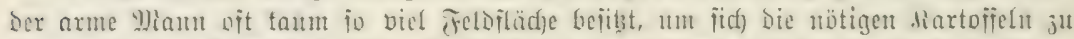

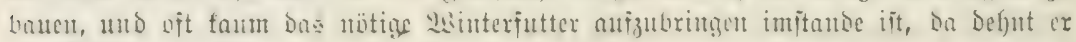

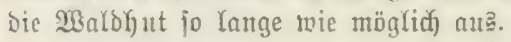

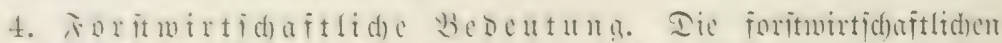

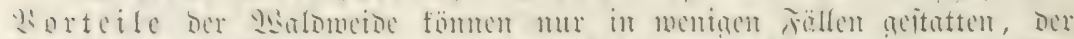

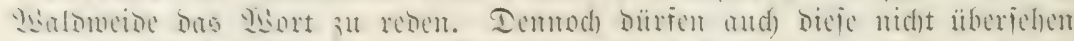

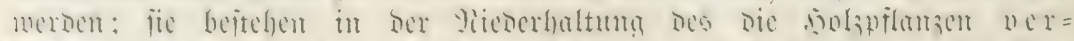

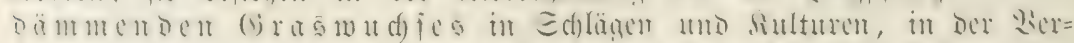

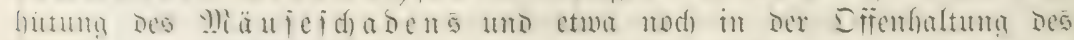

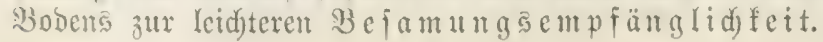




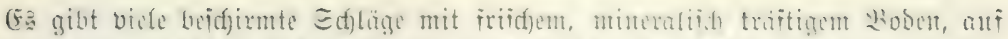

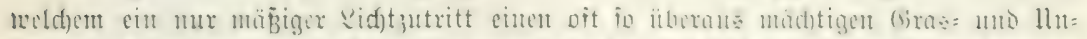

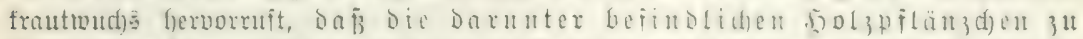

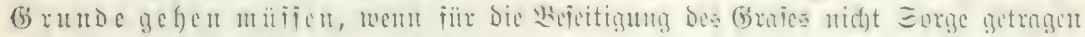

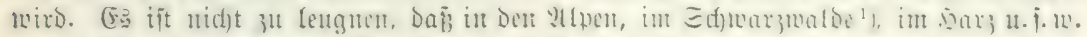

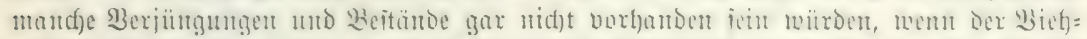

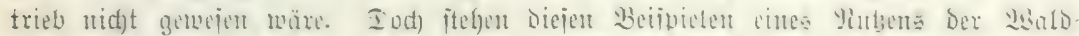

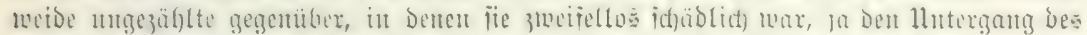

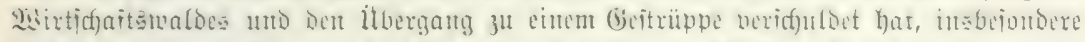

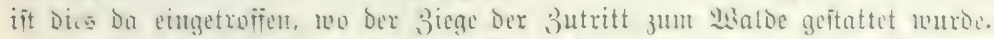

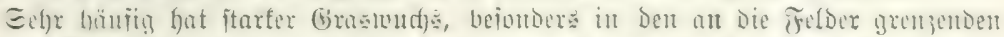

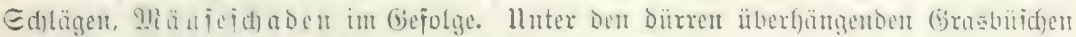

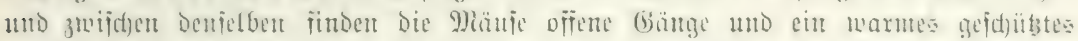

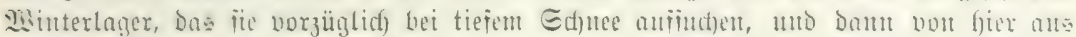

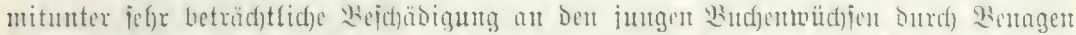

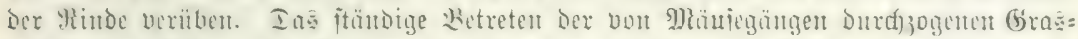

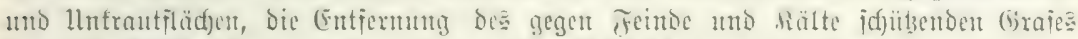

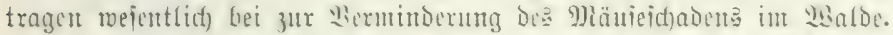

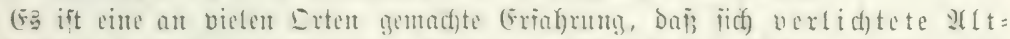

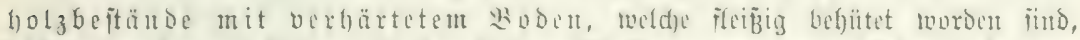

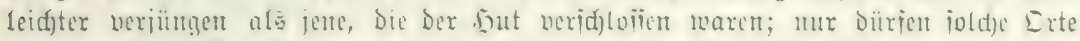

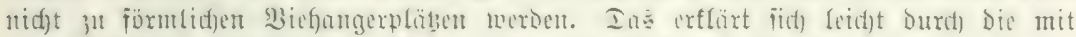

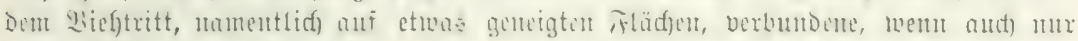
mä̉ige Bodenvermundung.

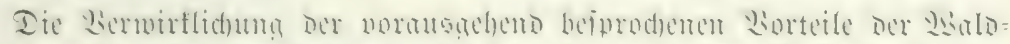

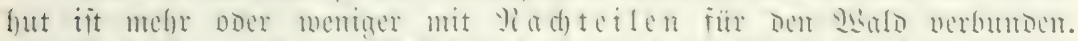

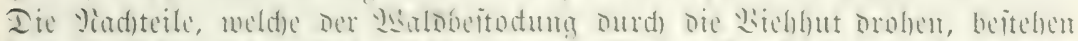

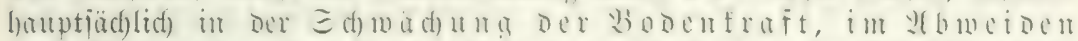
या D

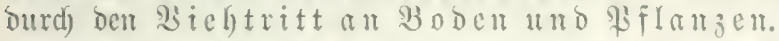

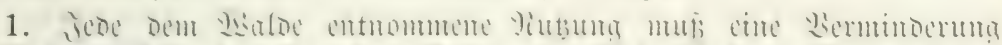

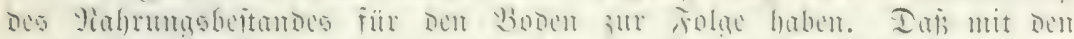

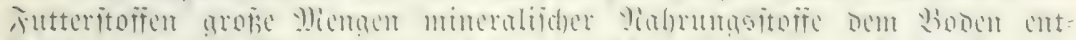

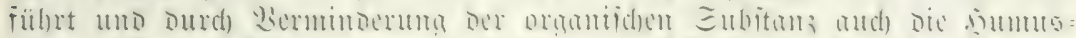

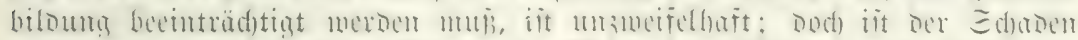

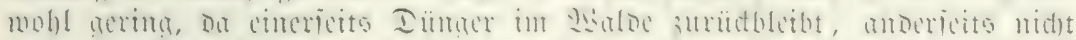

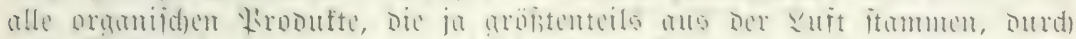

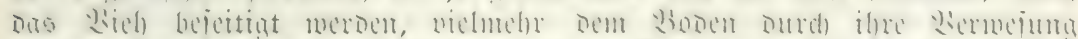

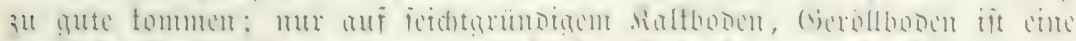

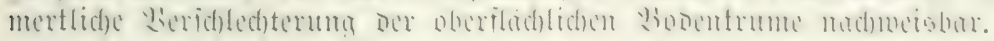

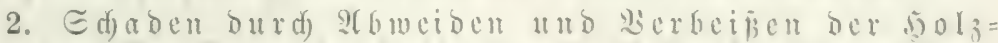

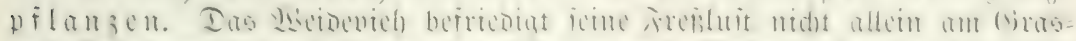

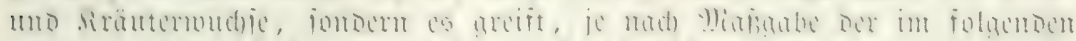

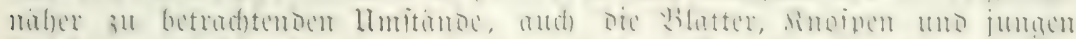

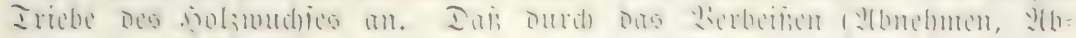




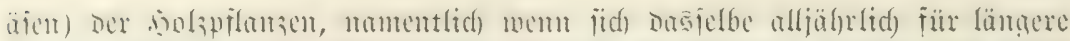

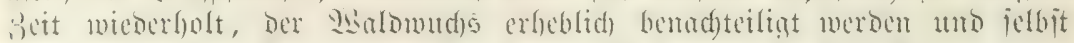

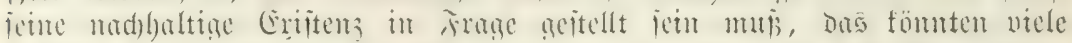

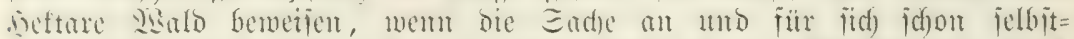

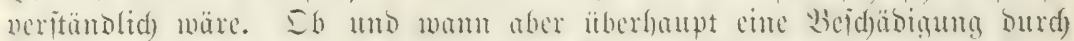

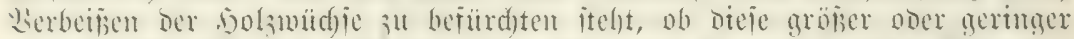

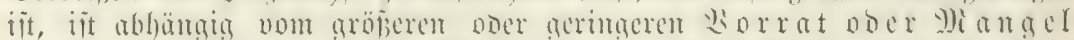

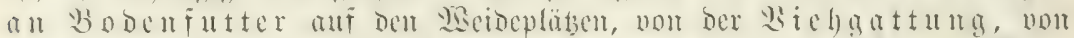

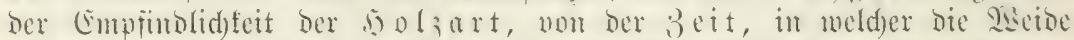

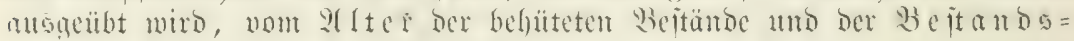
form, weldier lebtere unteritellt fiulo.

Futtervorrat. (5) veriteht fid) am (5nde von jelbit, ban, wenn Das auj=

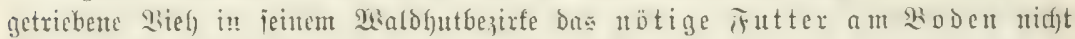

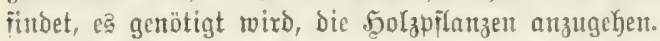

Bon gan; hervorragender SHedutung anj bie Edjäblidfeit des 96aldviches für

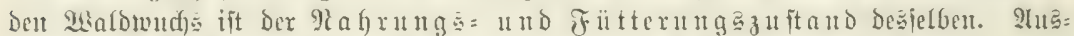

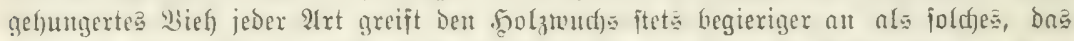

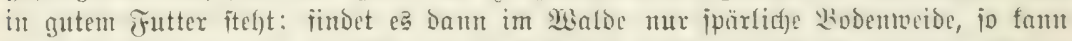

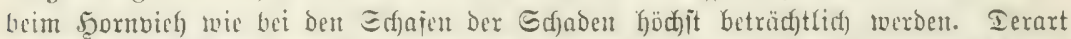

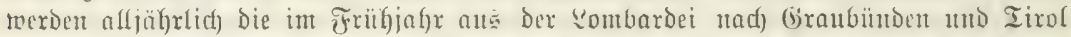

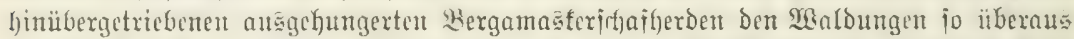

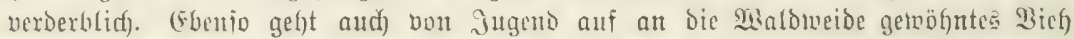

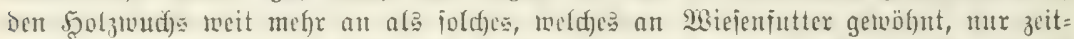

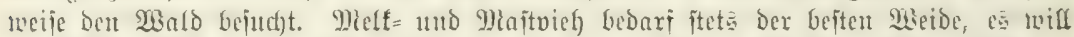

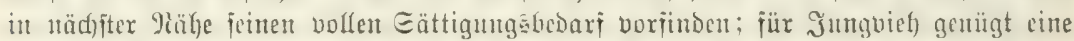

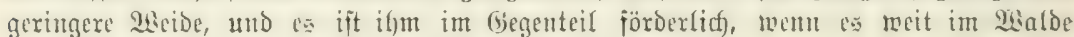

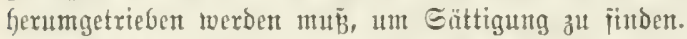

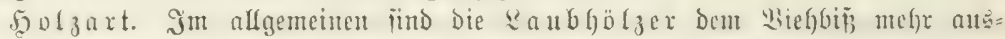

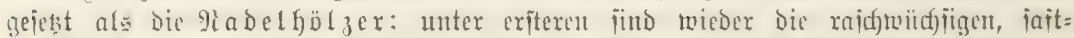

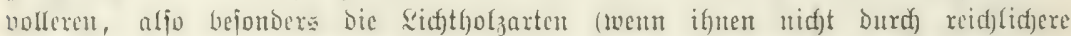

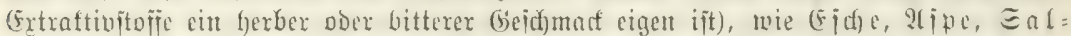

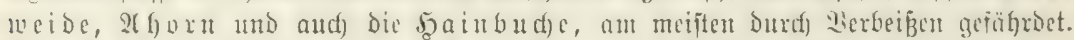

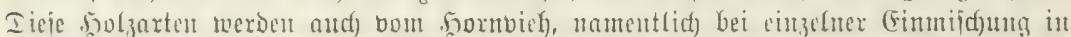

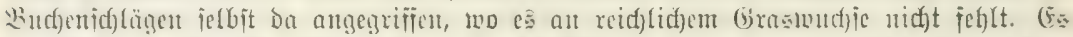

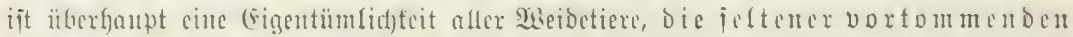

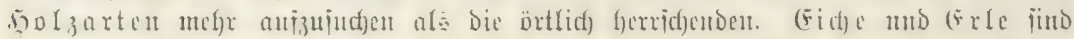

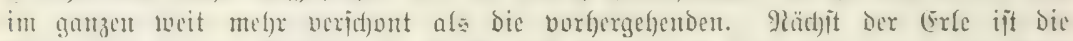

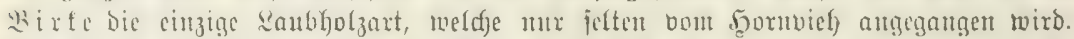

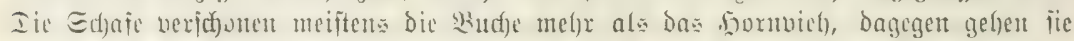

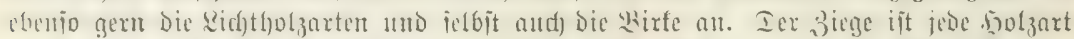

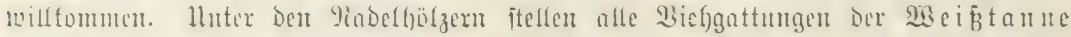

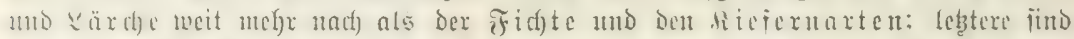

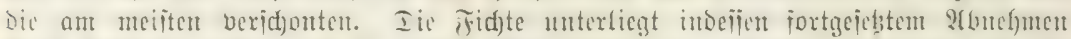

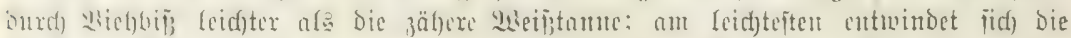

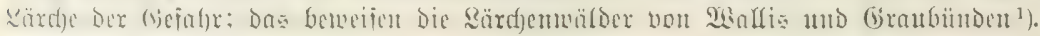

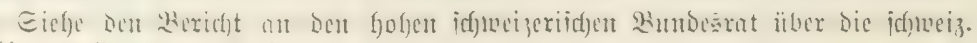

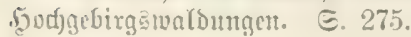




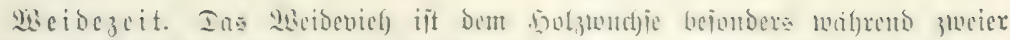

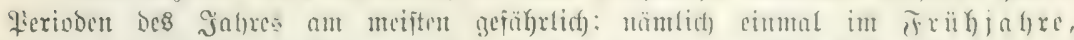

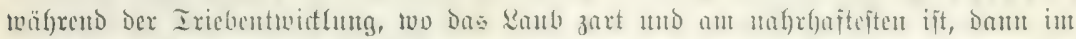

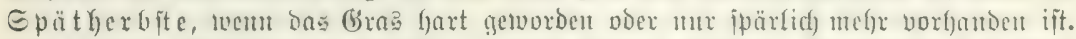

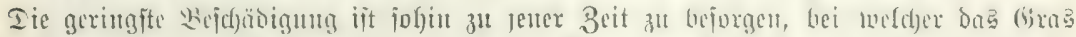

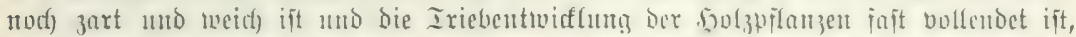

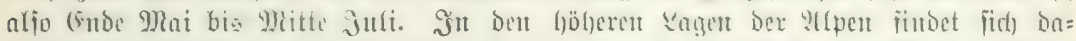

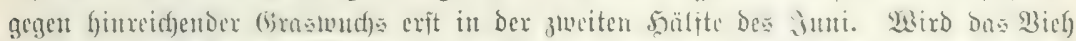

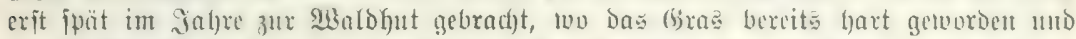

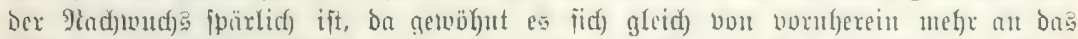

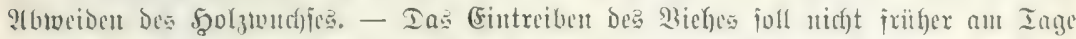

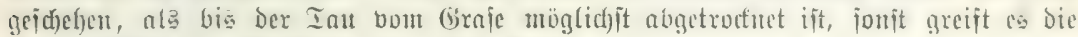
5olzgewädje an. (5eradeio bei najiem Metter.

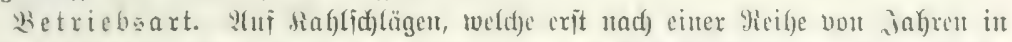

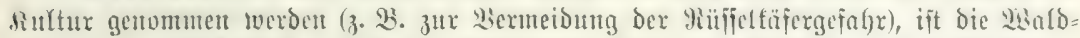

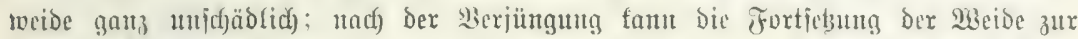

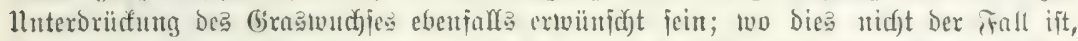

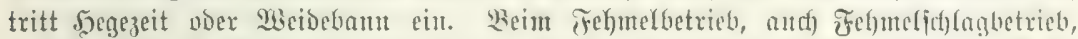

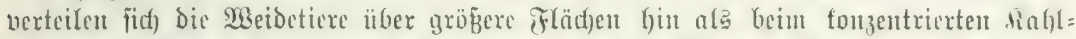

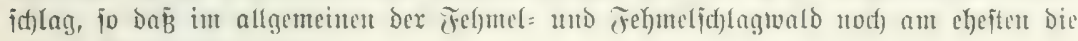
läitige Waldweide exträgt.

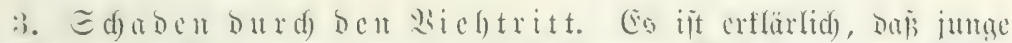

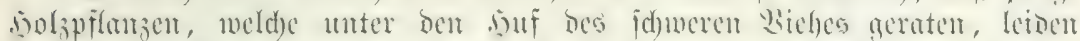

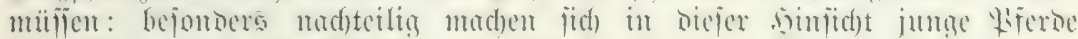

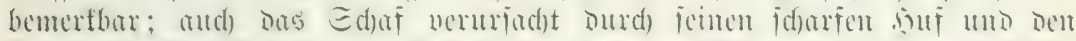

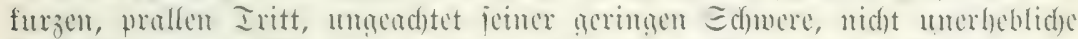

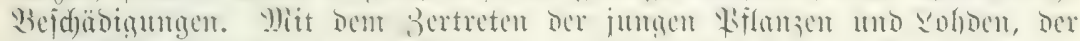

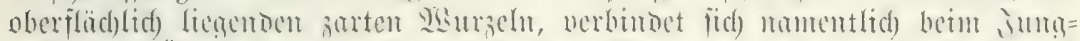

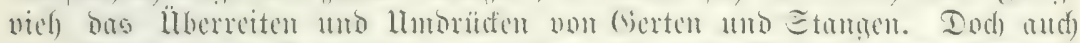

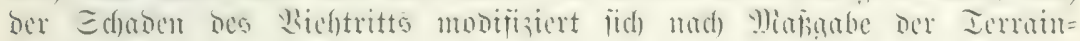
neigung.

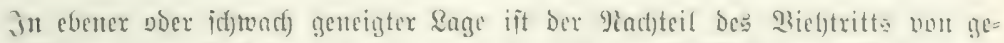

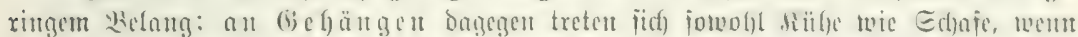

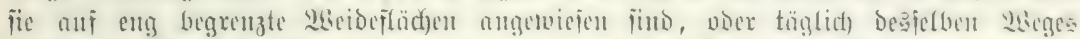

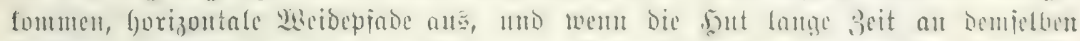

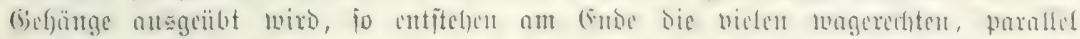

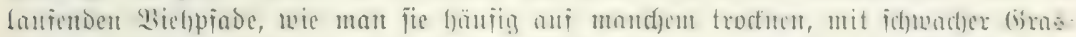

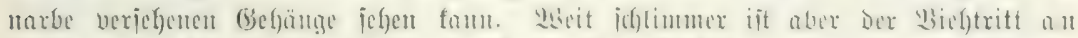

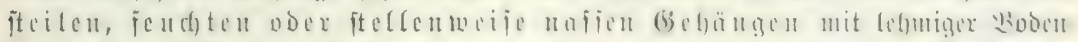

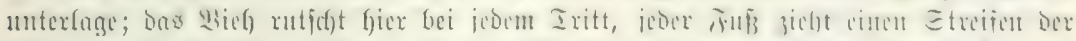

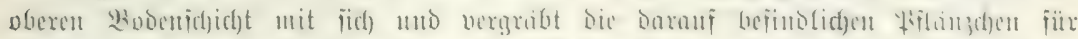

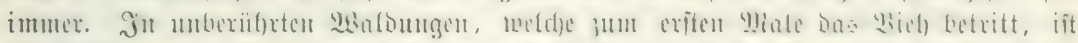

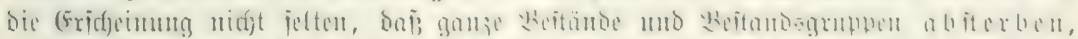

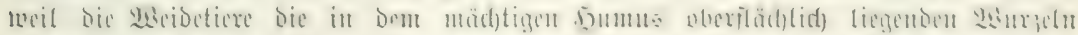

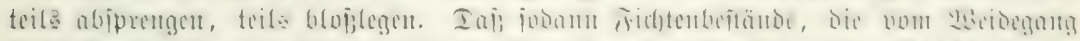

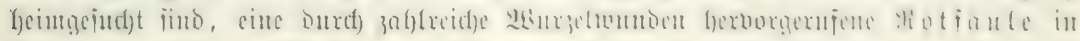

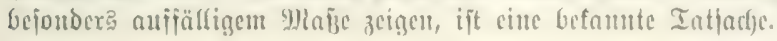




\section{Bweite abteilum.}

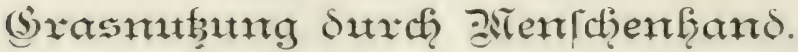

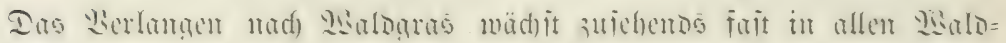
bezirfert.

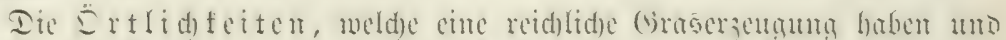

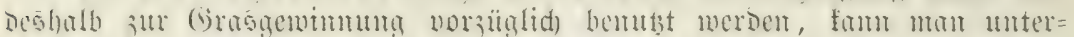

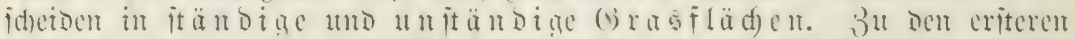

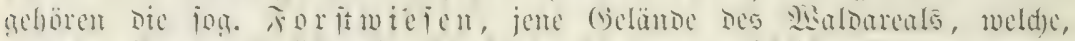

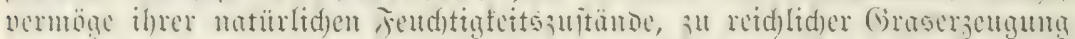

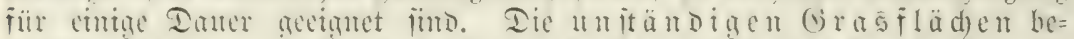

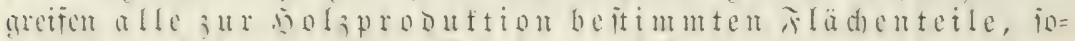

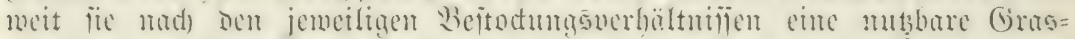

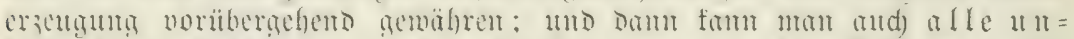

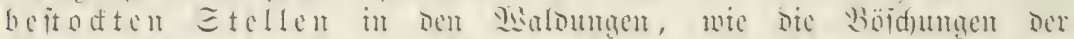

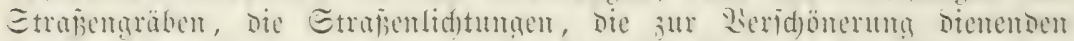

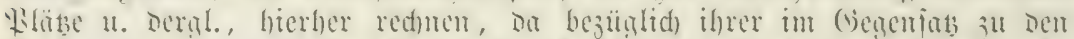

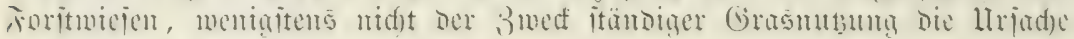
Der Difenerbaltutg iit.

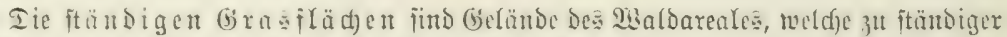

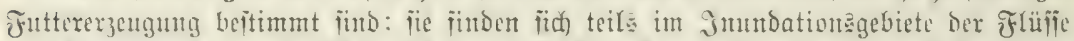

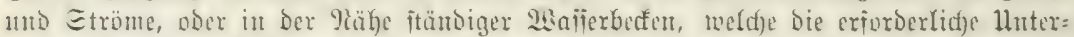

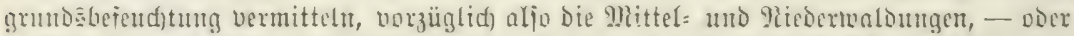

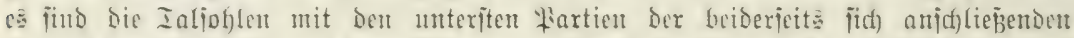

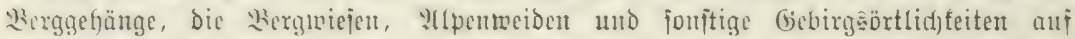

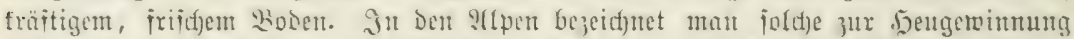

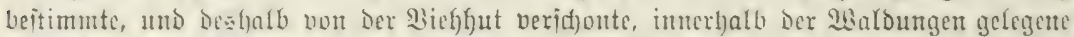

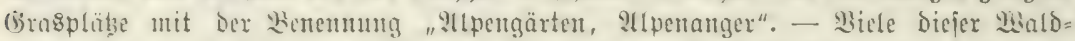

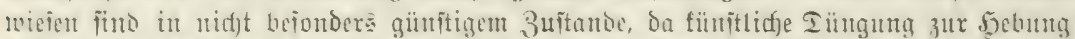

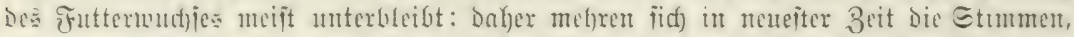

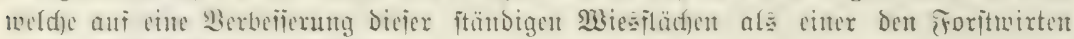
आfallenden :Hufgabe Gintweifen.

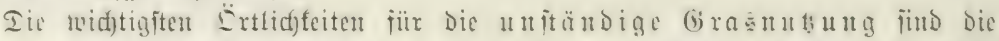

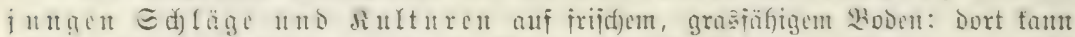

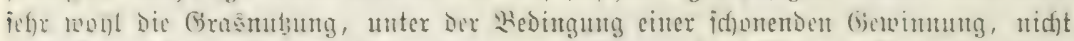

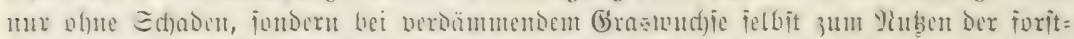

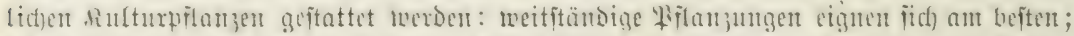

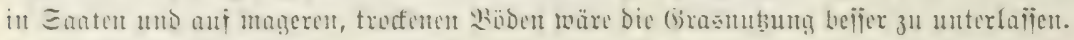

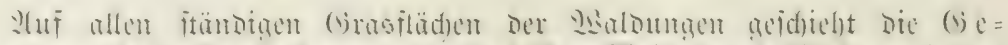
minn

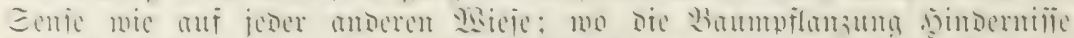

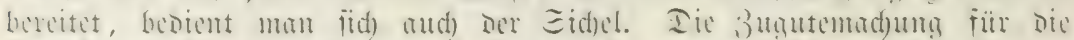

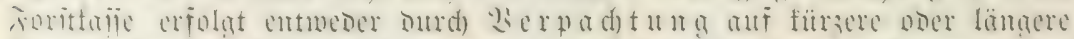
Inter noce Durd) grengten fläd)enlojen. 


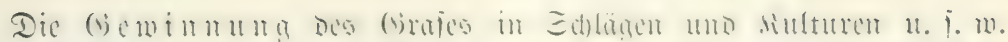

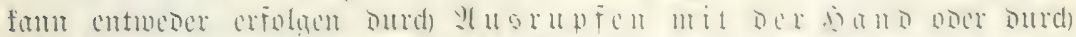
Q⿱

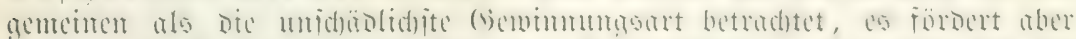

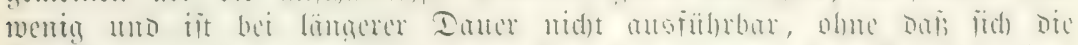

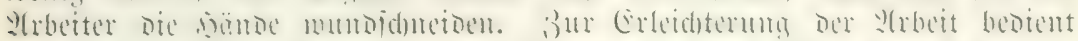

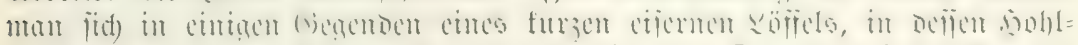

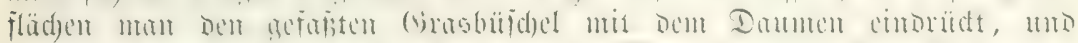

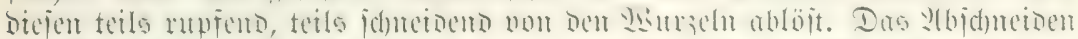

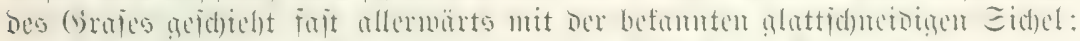

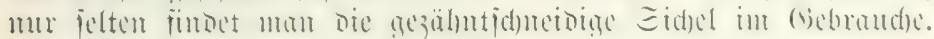

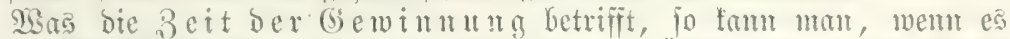

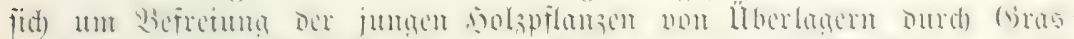

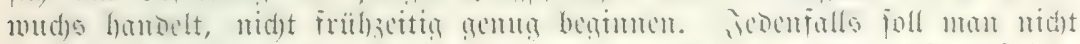

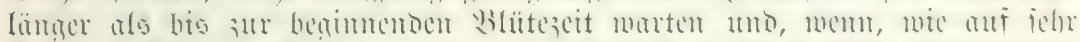

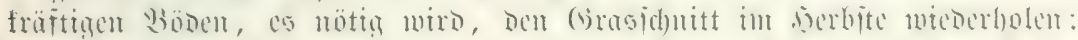

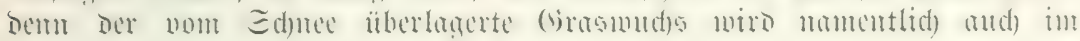
Şinter ben jungen \$ffanzen gefäbrlid).

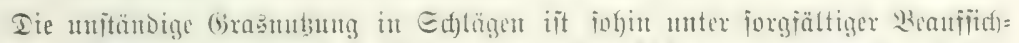

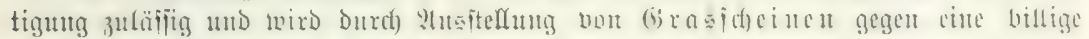

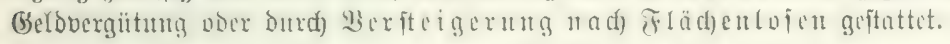

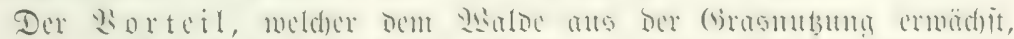

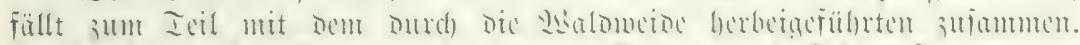

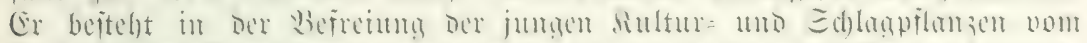
Yiad)teile Des 专c

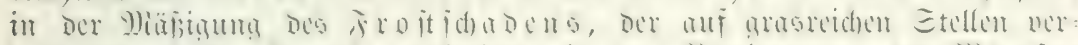

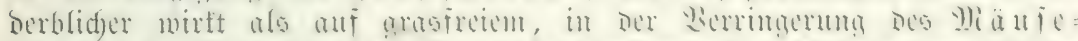

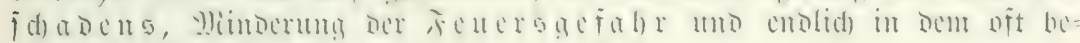

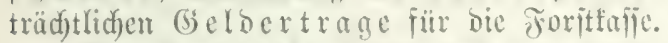

Die viad)teile licagen

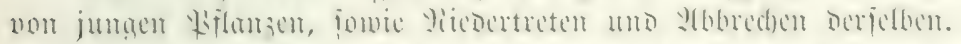

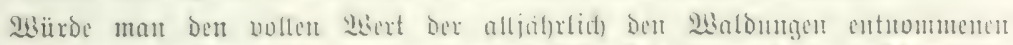

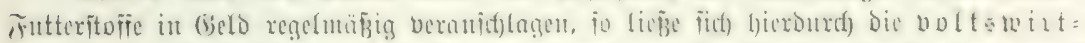

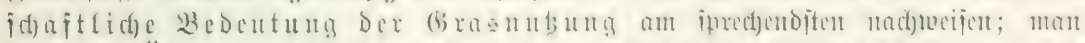

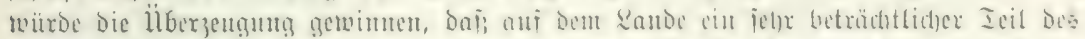

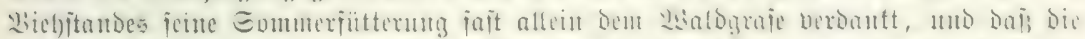

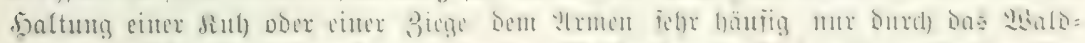

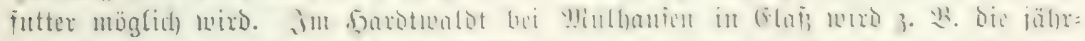

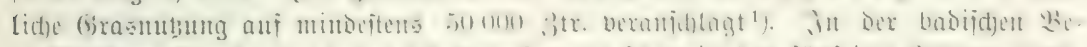

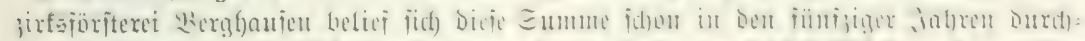

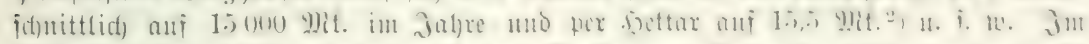

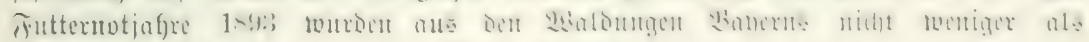

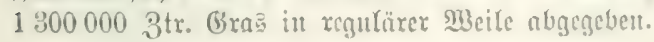

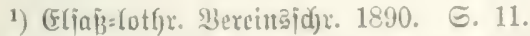

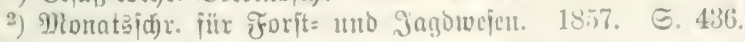




\section{כ̄meiter 2lbjḩnitt.

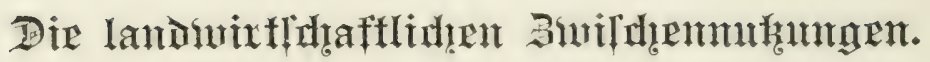

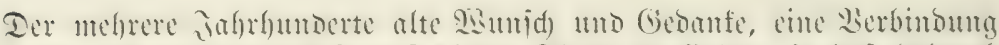

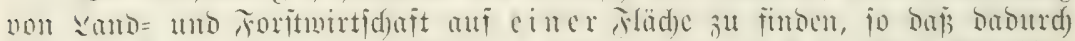

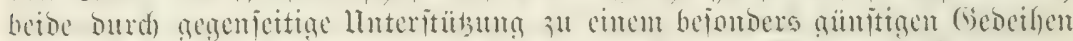

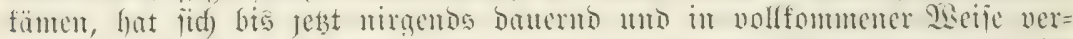

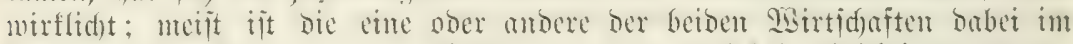

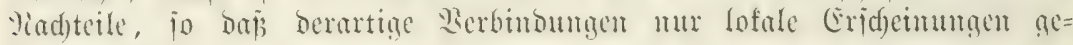
blieben finto.

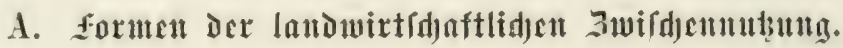

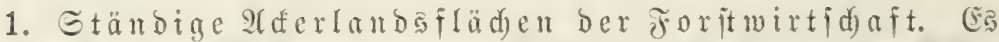

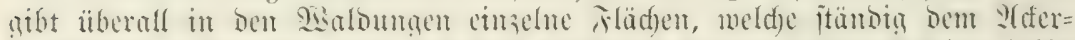

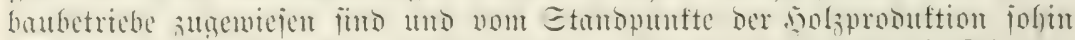

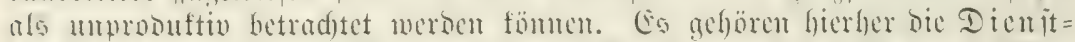

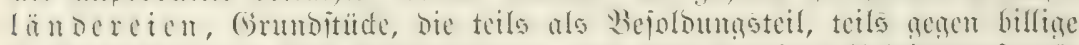

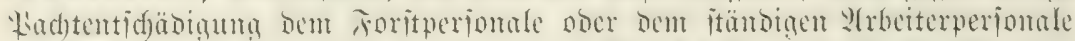

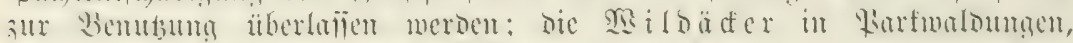

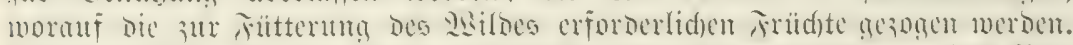

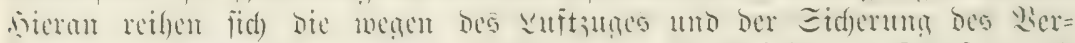

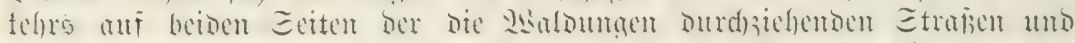

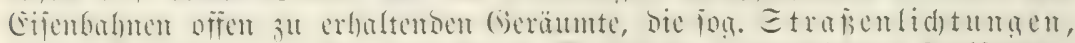

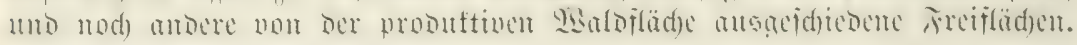

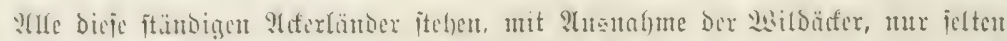

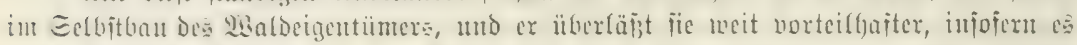

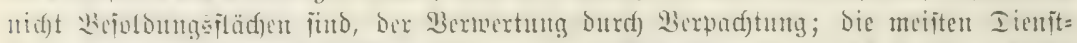

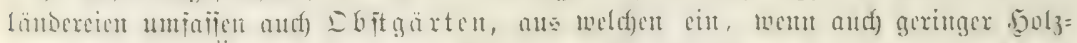

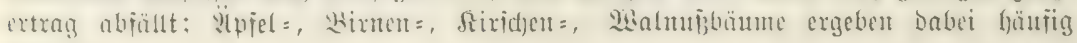
Tiutsigotz.

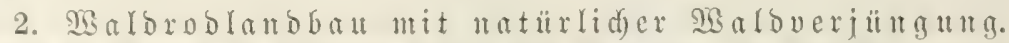

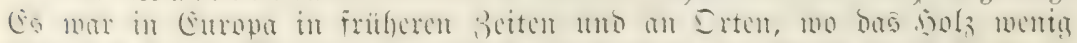

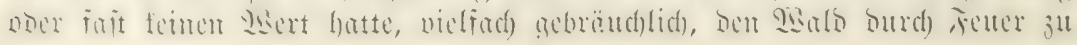




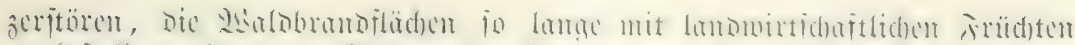

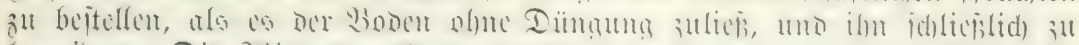

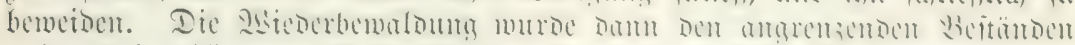

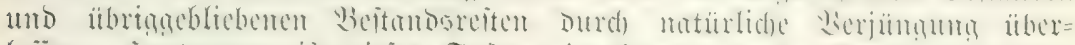

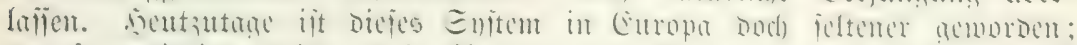

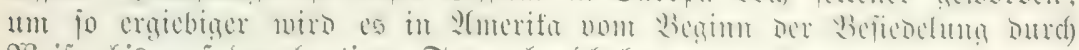

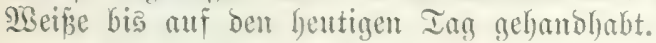

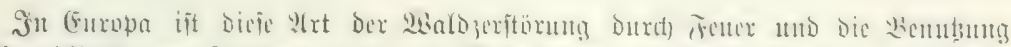

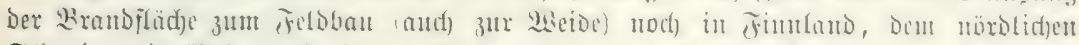

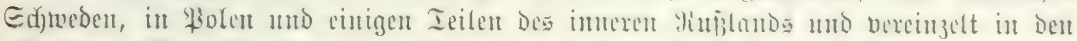

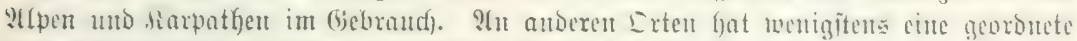

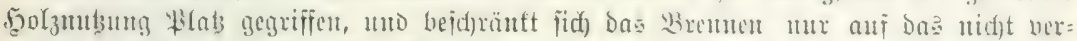
wertbare $50\left\{_{3}\right.$, Dou Etraut)toud)

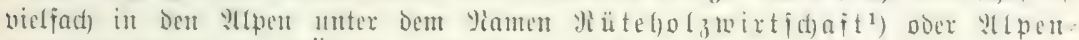

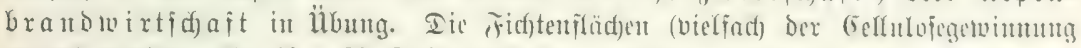
wegen) weroen alle $10-20$ Gahre intholyt, gervoct, gebramt, cinige Safre zum

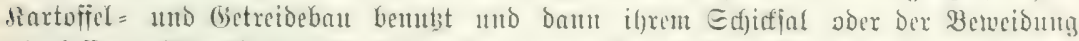

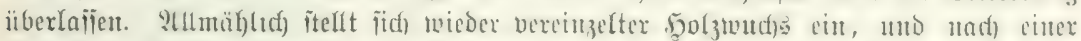

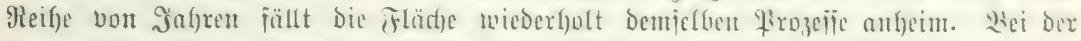

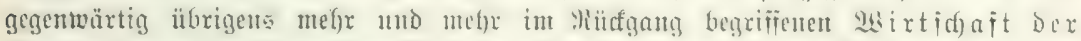

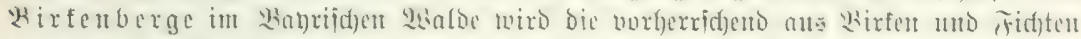

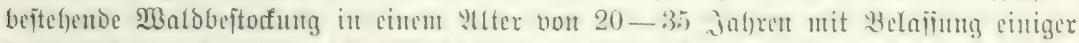

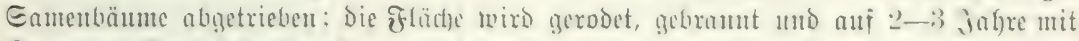

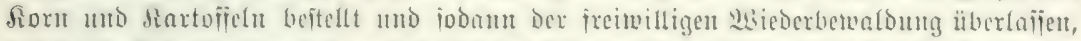

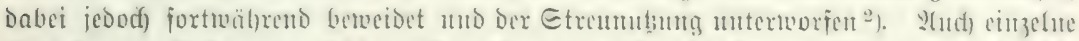

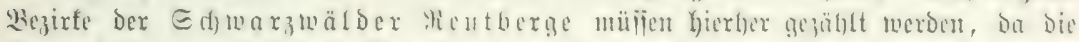

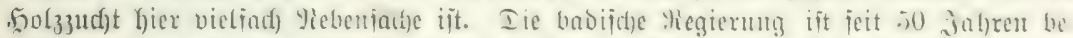

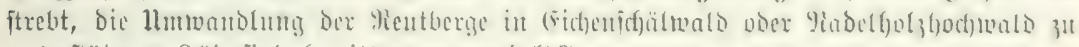
unteritiiben. $8 \%$ jind bereits umgetwandelt ${ }^{3}$ ).

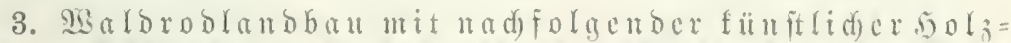

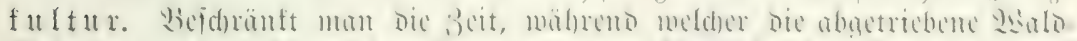

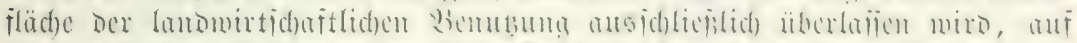

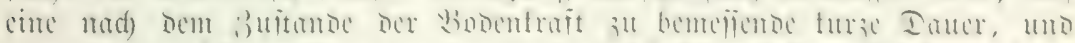

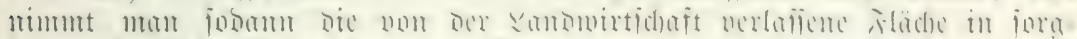

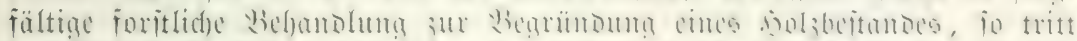

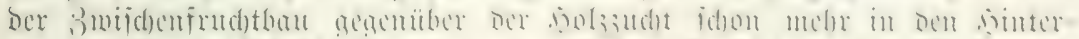

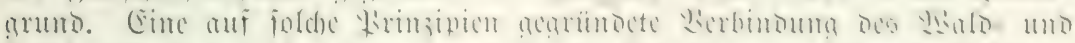

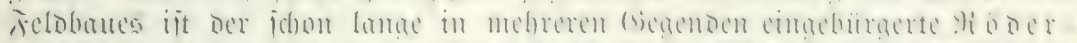

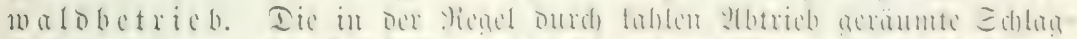

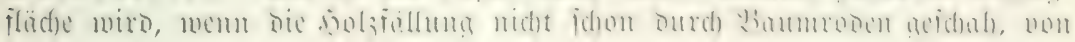

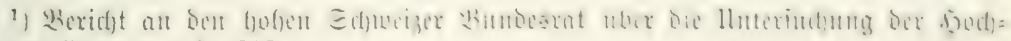
gebirgătwaldungen. G. 268.

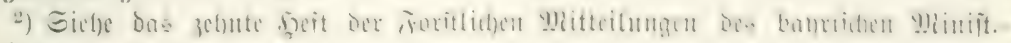
Foriturureau. ธ. 45.

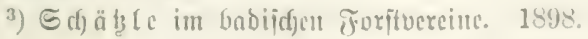




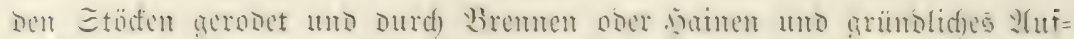

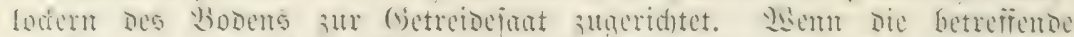

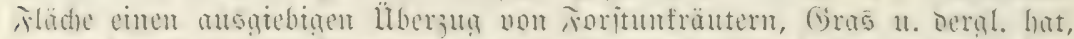

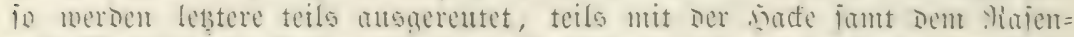

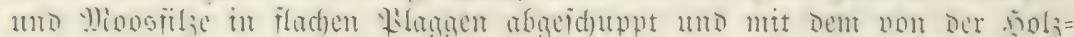

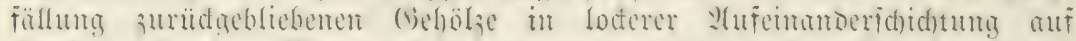

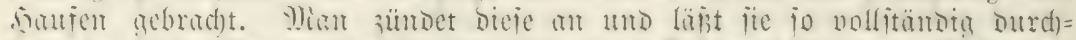

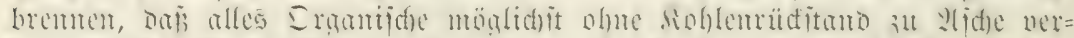

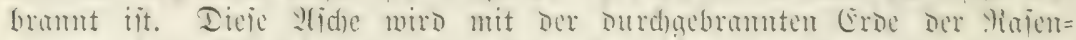

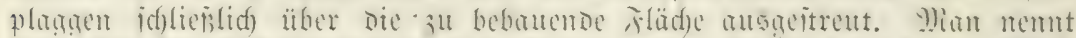

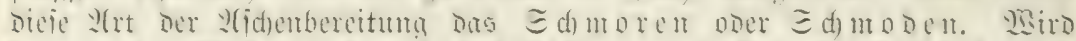

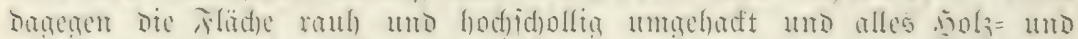

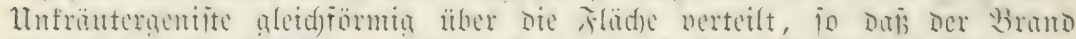

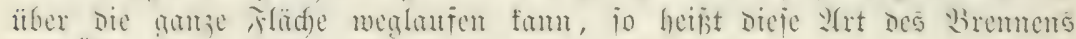
des überlanbrenten ober Sengen.

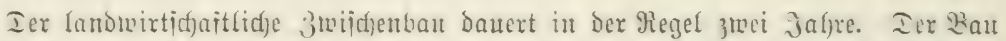

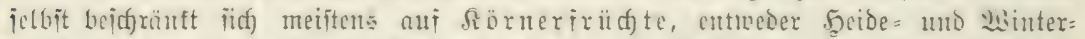

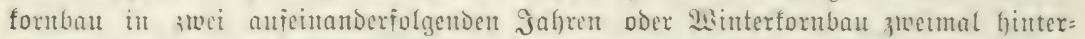

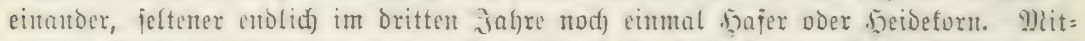

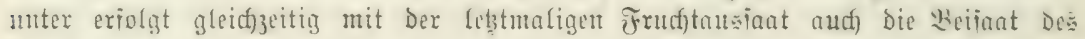

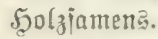

Thobermaloban fommt audf nod) in mandferfet anterent forment uor. Eo meroen

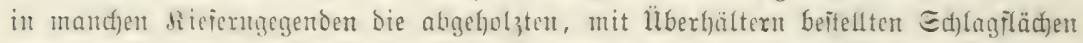

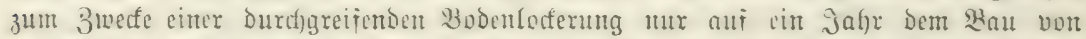

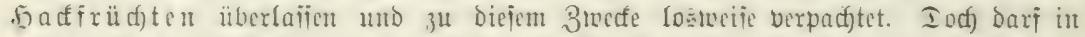

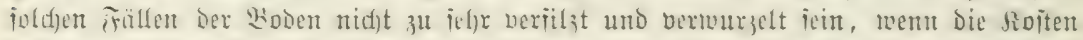

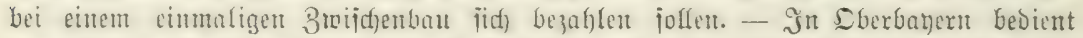

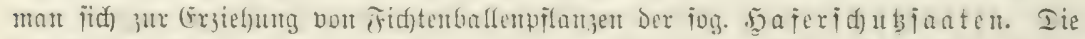

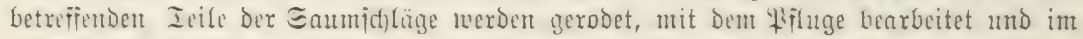

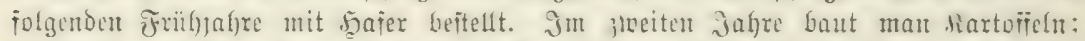

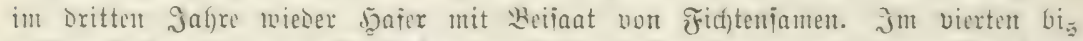

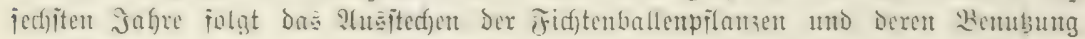

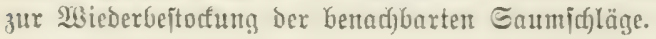

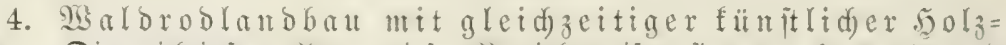

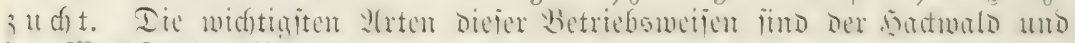

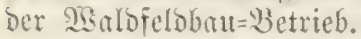

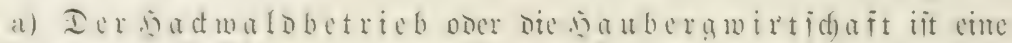

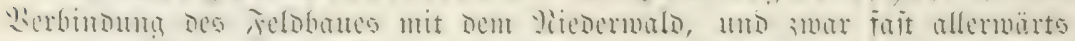

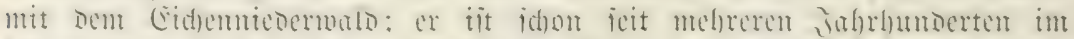

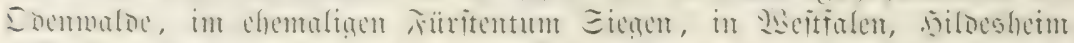

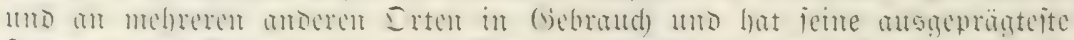

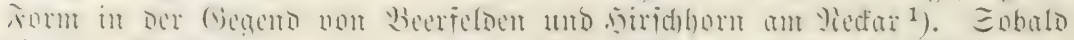

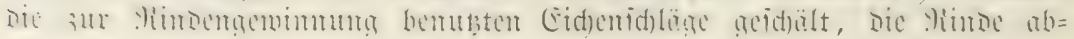

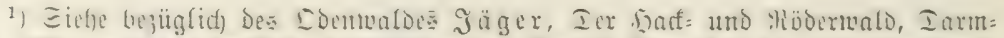

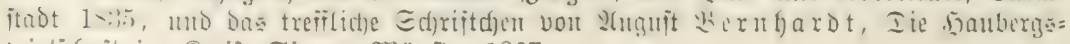
wirticfait im Strcipe Eiegent, Mänjter 1867. 


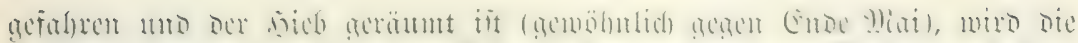

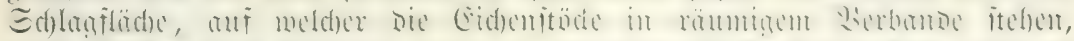

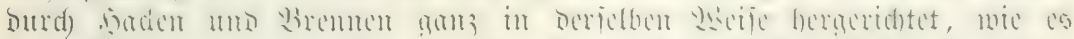

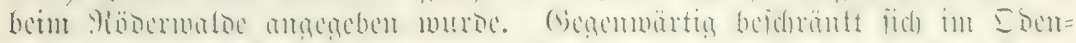

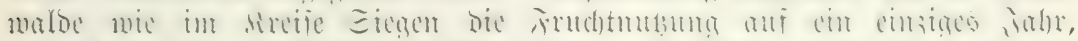

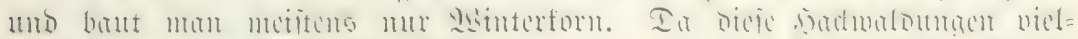

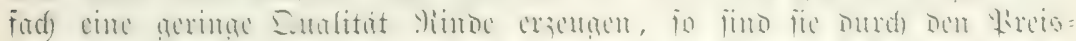

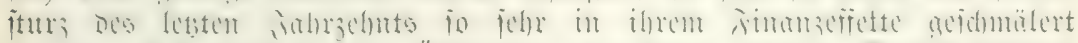

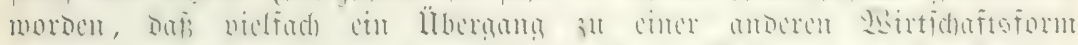

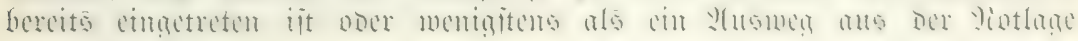
empfoblen wird.

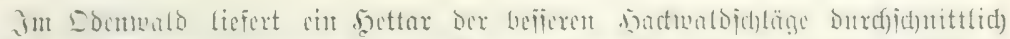

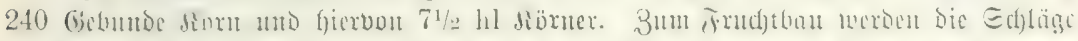

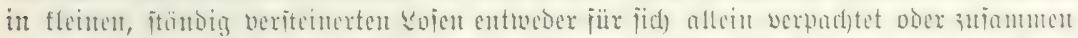

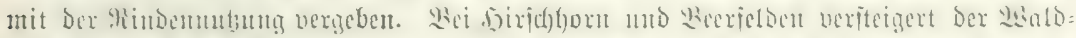

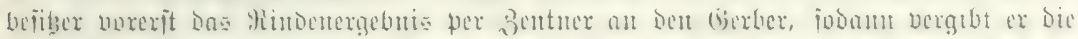

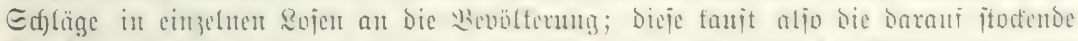

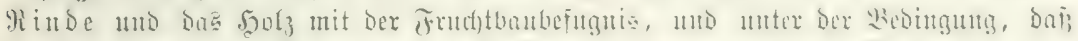

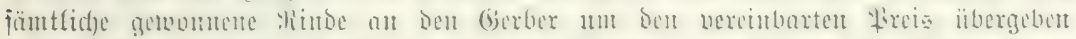

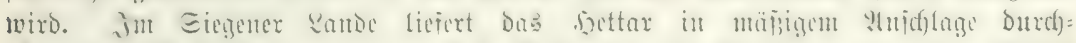

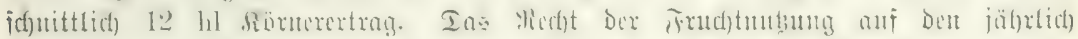

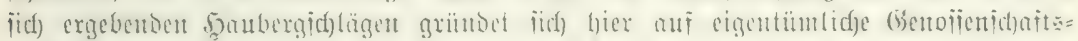
verfoultnitie.

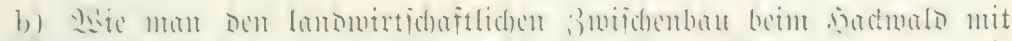

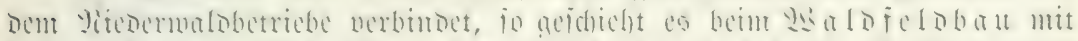

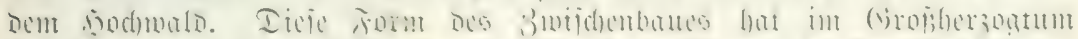

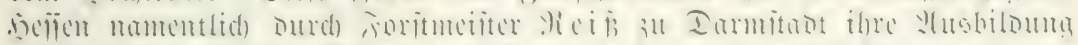

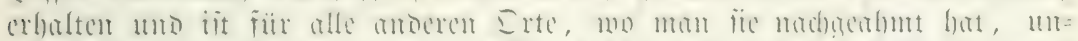

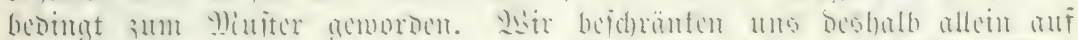

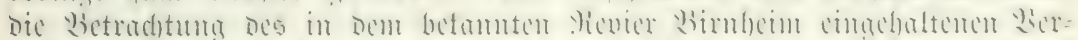

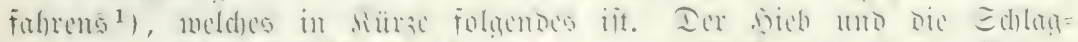

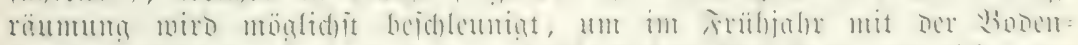

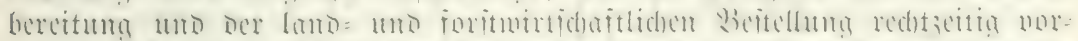

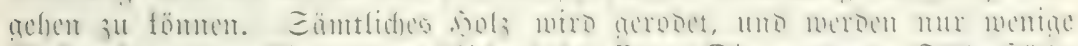

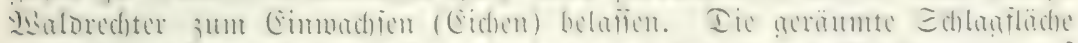

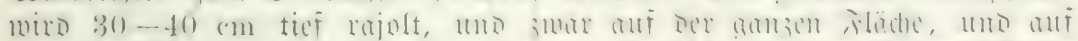

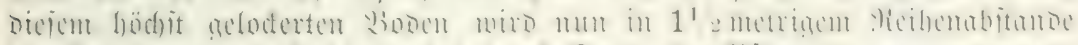
Dic (s)

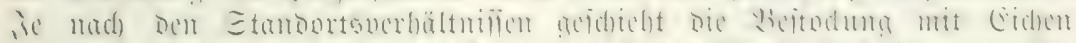

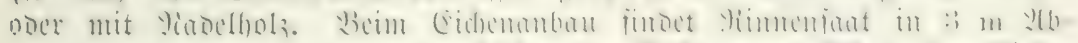

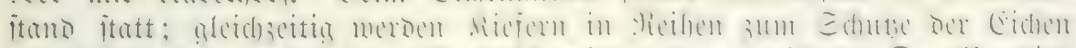

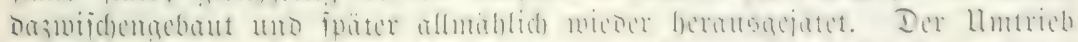

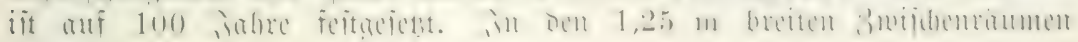

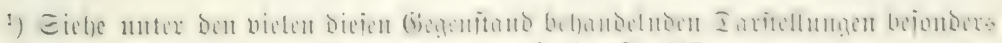
Forit: und Singozcitumg 1869, 2(prilcheft, banu cbendo Є. 4.47. 


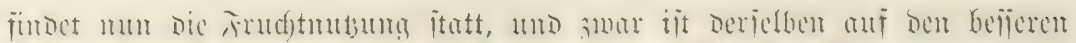

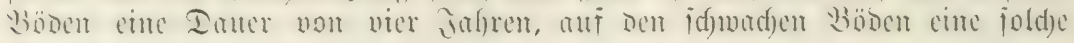
von żwei Эahren eingeräumt.

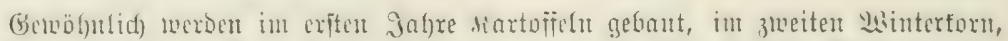

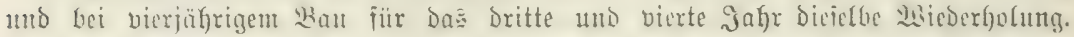

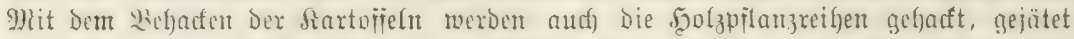
mo faft gerabe io befandelt wie im \$iflanggartu. Eollte es im eriften Jafre etma

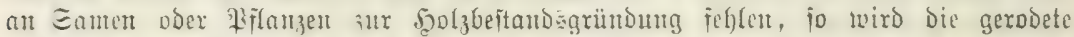

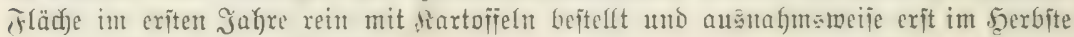
bie Şolzpĩlangung eingebradst.

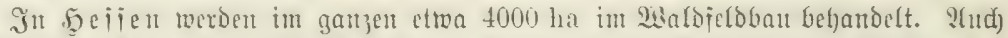

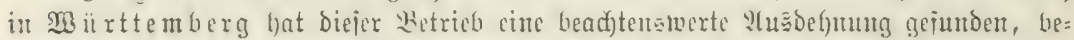

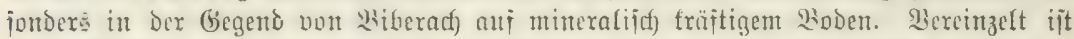

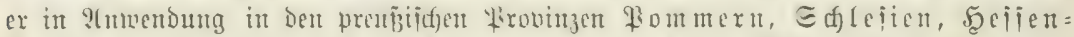

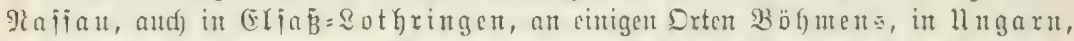
mo in Den walbjeldern aud) Mlaiz gebaut wird, u. f. m. Sndeifen ift bas Interefie

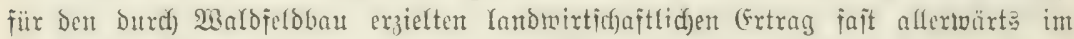
Sinfent begrifīen.

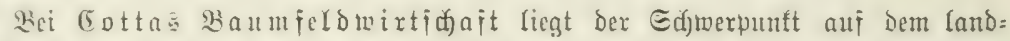

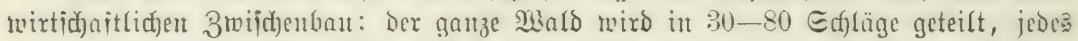
Jafre ein Edjlag gerooct und in jefre weitem Werbande $(4-17 \mathrm{~m})$ bepilauzt; zwifden

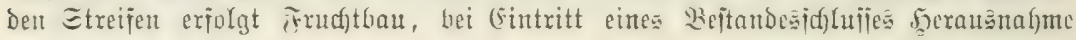
Der Şälite Der ßäume.

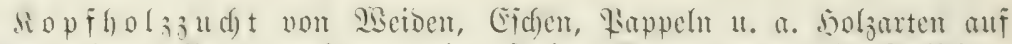

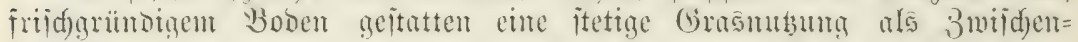
probuft.

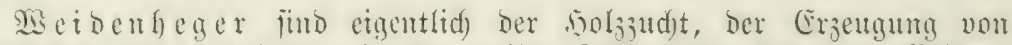

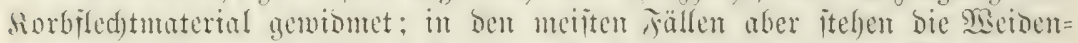

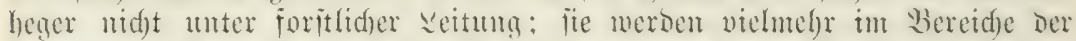

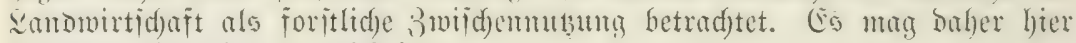
berielben Érmähnung gejd)ehen.

Bet entipred)ender

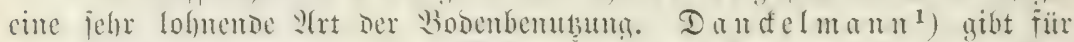

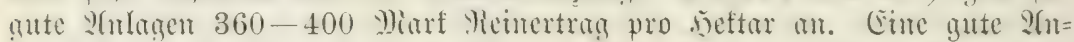

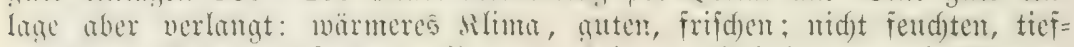

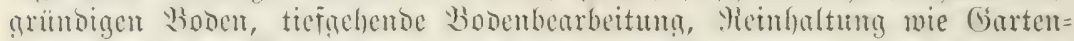
lund; bie beiten Leciocnurten fun Salix viminalis, purpurea, amygdalina,

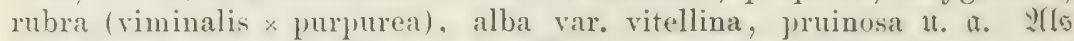

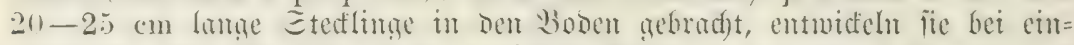

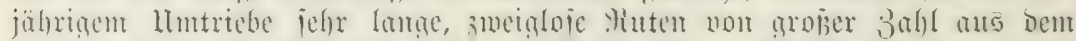

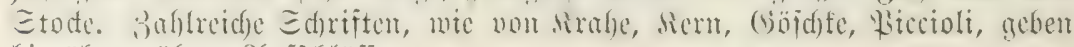

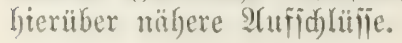

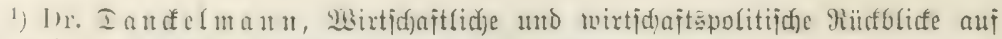

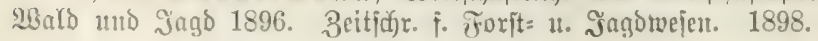




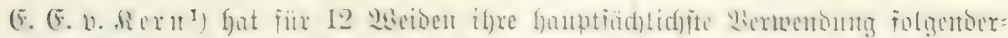

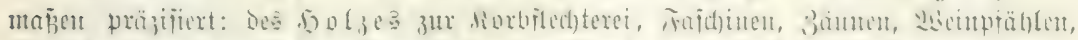

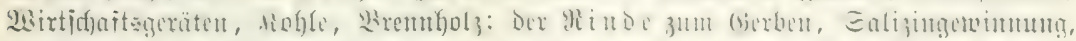

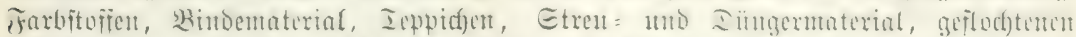

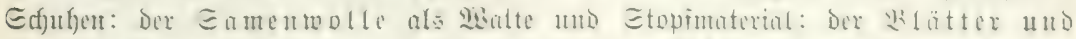

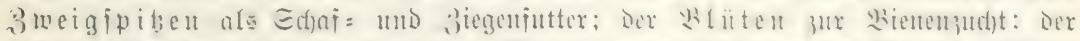

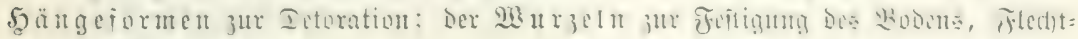

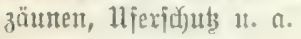

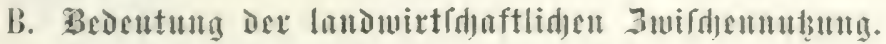

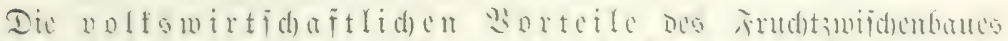

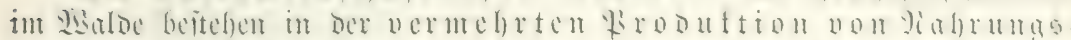

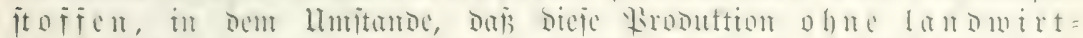

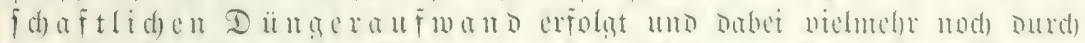

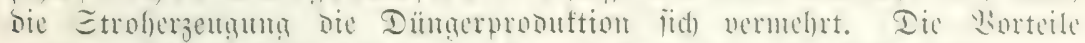

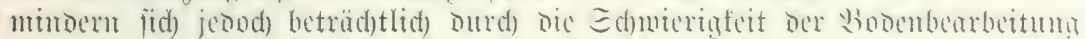

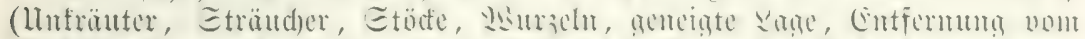

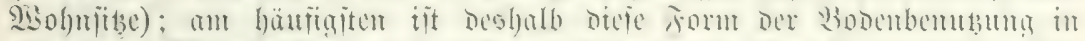

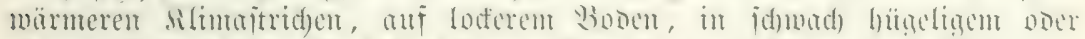

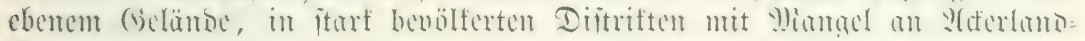
fläd)en.

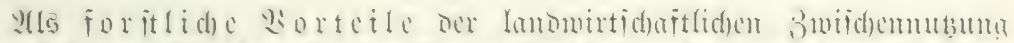

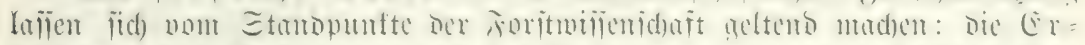
böl) ft amb 专

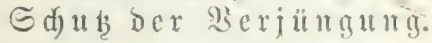

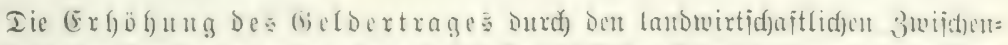

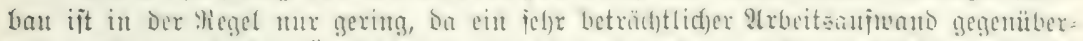

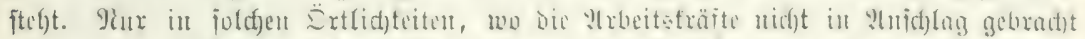

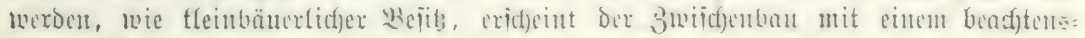

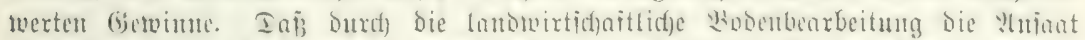

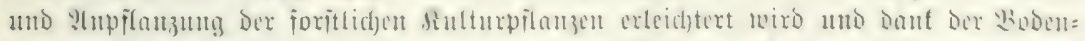

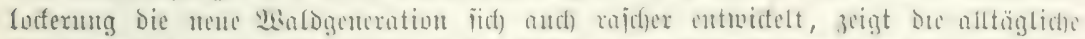

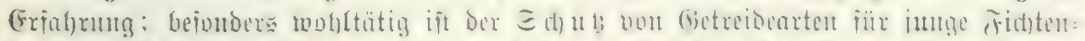

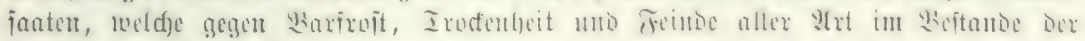

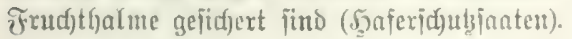

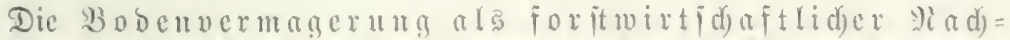

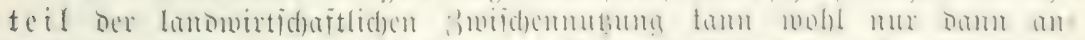

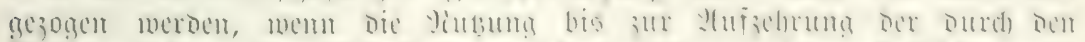

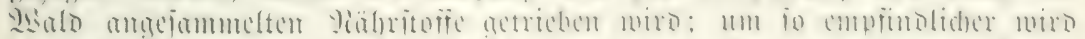

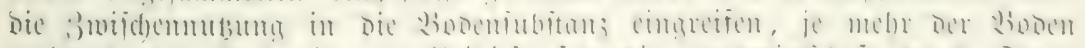

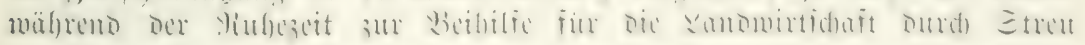

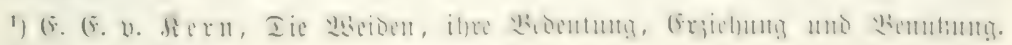
Tula 1896. (Miupitị).) 


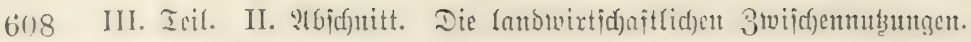

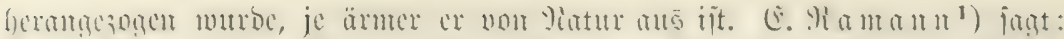

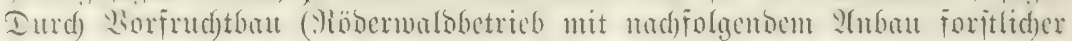

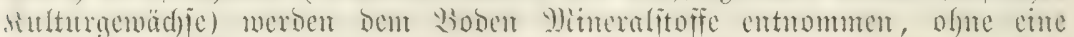

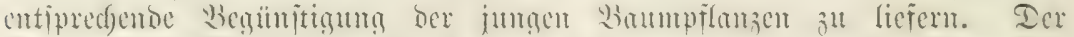

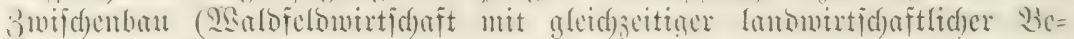

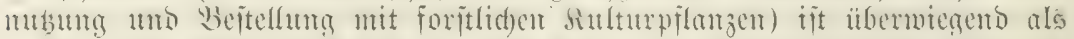

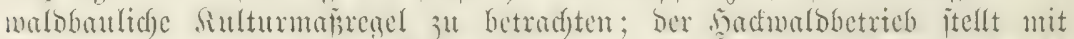

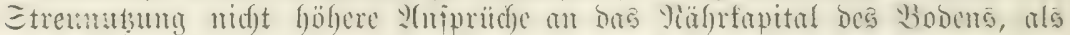

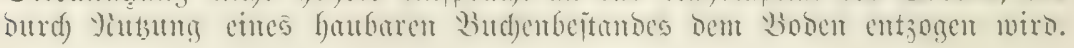

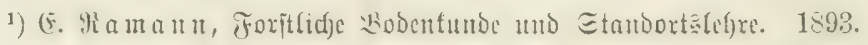




\section{Dritter 2lbichnitt.}

\section{Dix}

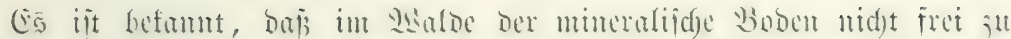

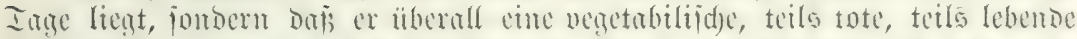

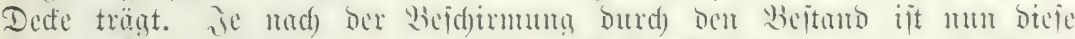

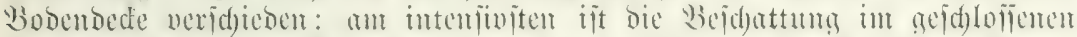

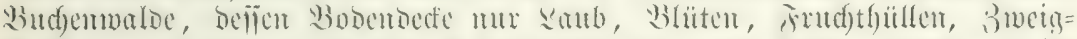

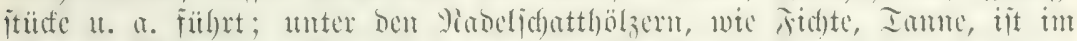

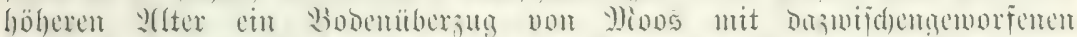

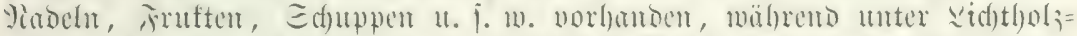

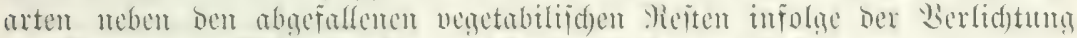

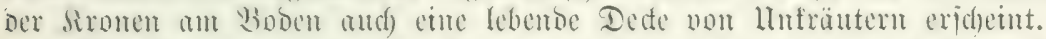

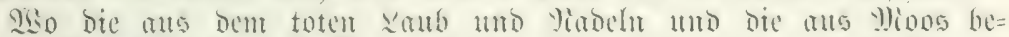

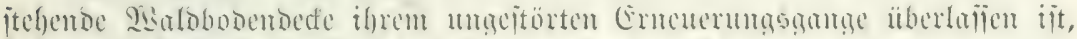

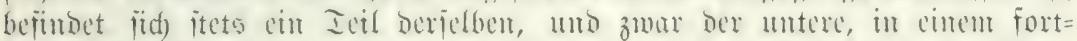

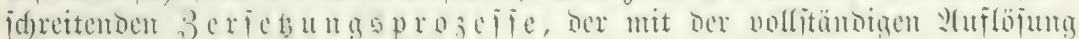

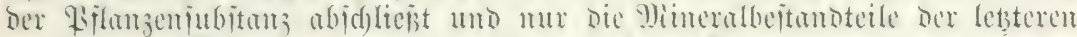

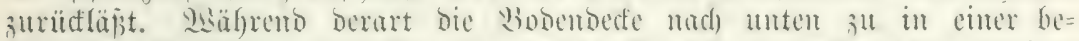

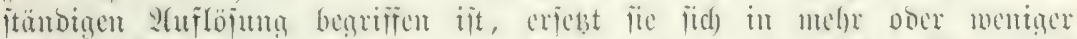

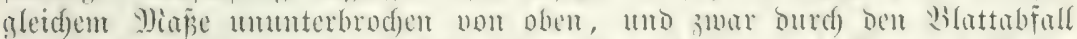

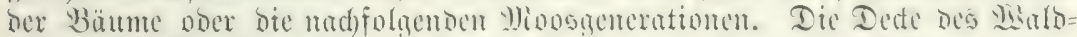

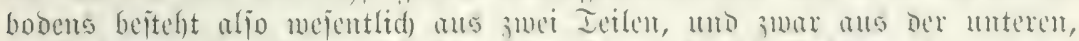

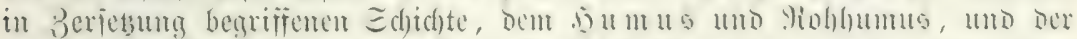

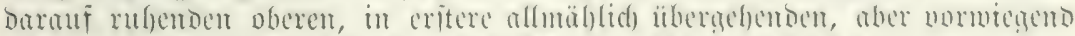

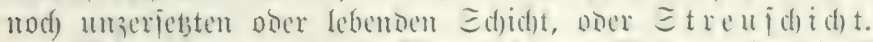

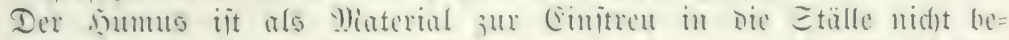

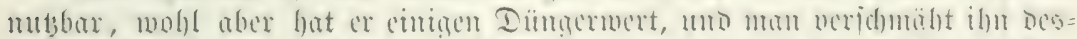

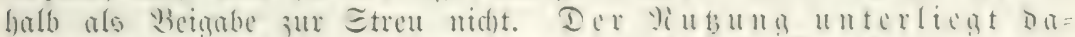
qe ge qe a

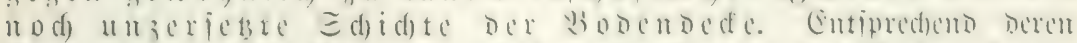
berfurit unterideciset

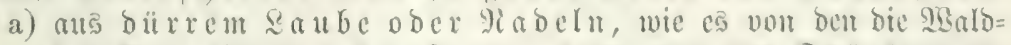

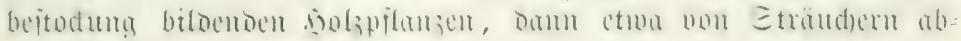
geworfen wird ;

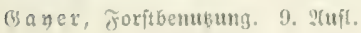




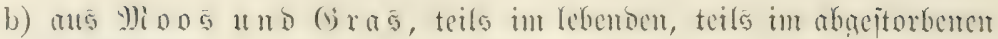
3uitande;

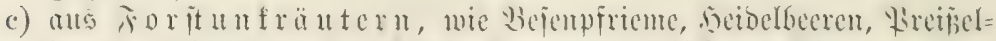

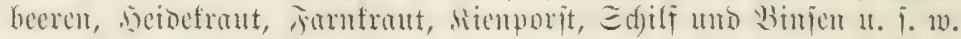

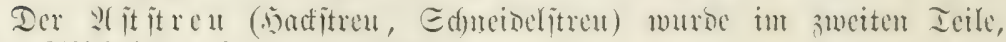
britter 2(bjoduritt Eeite 572 gebar)t.

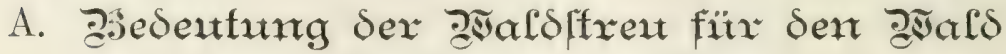 atud die Sol'zprodutition.}

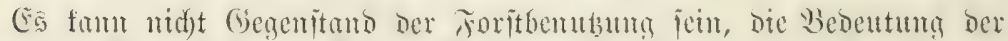

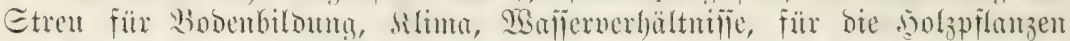

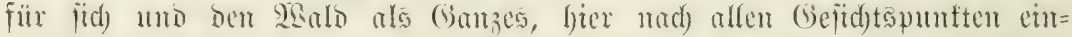

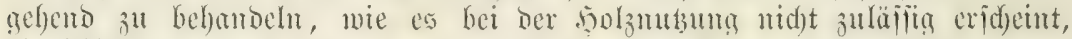

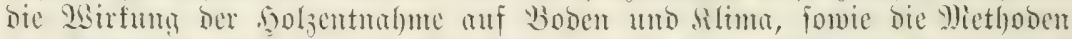

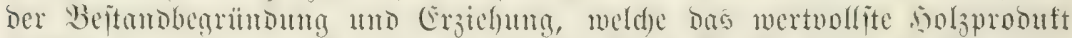

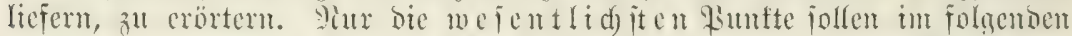

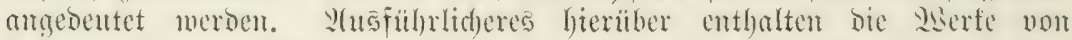

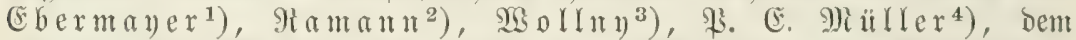

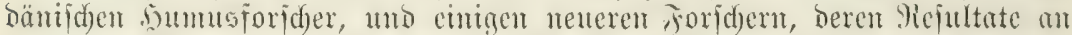
pajfenden Drten ermähnt merden follen; won früheren SAttoren jeicn ạc=

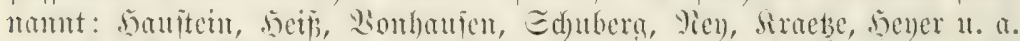

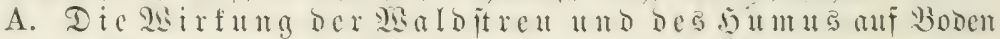

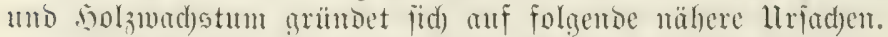

1. Der mif bem mincralifden Boben rutbente, meijt mux ju geringent

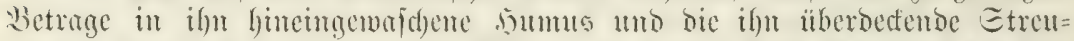

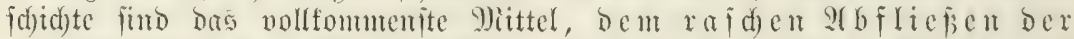

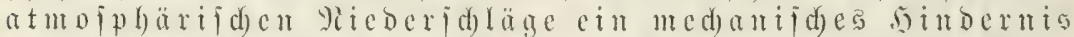
entgegensule ben und bic all befindiden $\mathfrak{B a f j e r}$ zu verbindern.

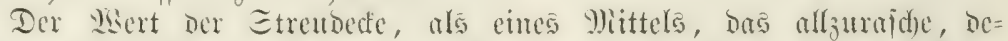

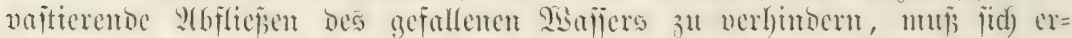

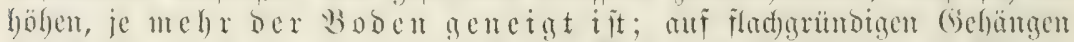

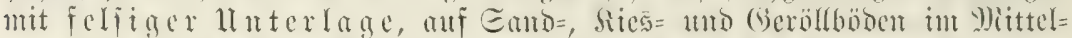

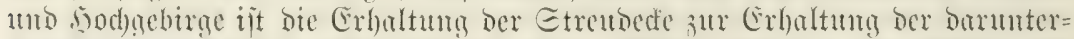

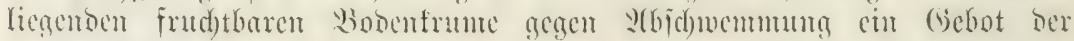
Siotwendigfeit.

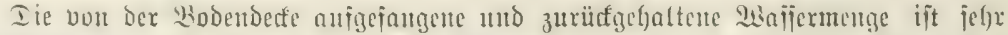

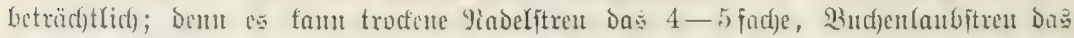

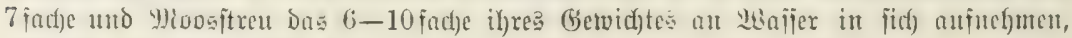

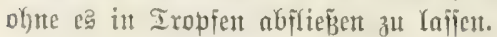

1) Sicke (Ebermaner, Die gejamte Refhre Dex Malditreu. SBerlin 1876.

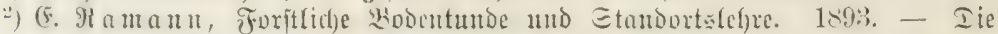

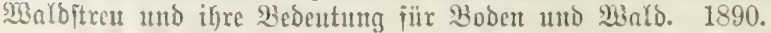

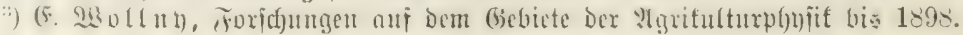

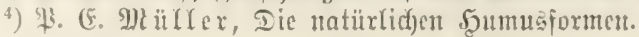




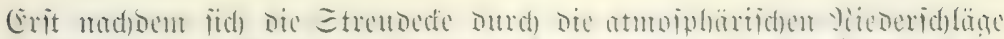

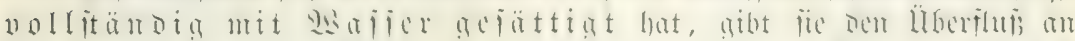

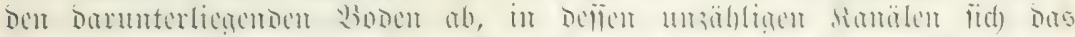

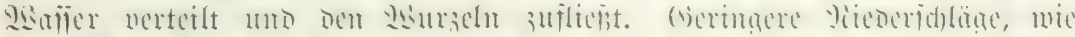

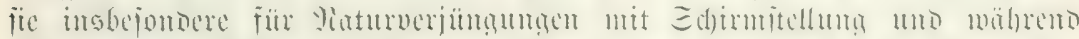

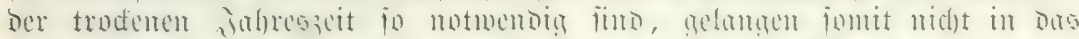

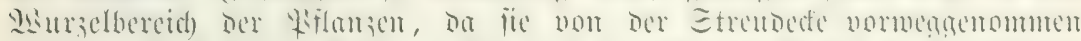

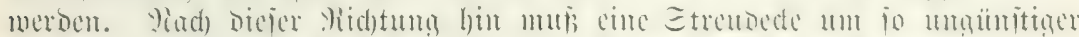

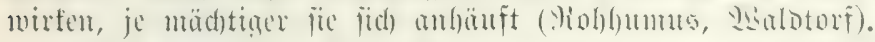

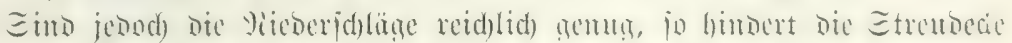

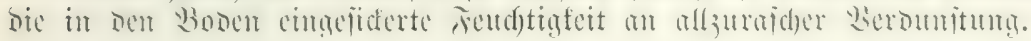

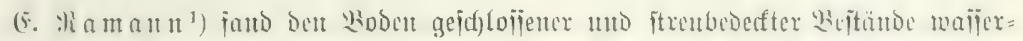

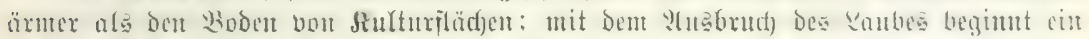

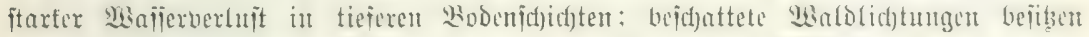

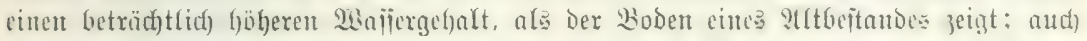

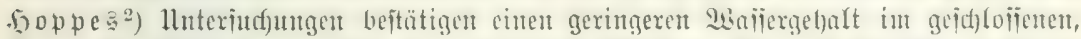

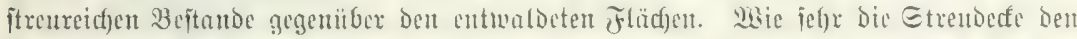

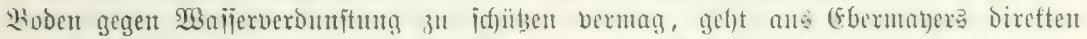

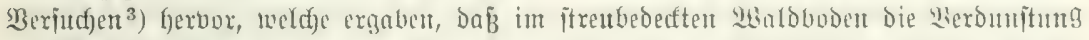

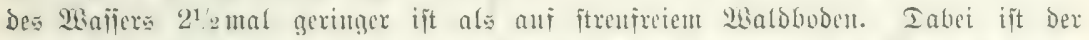

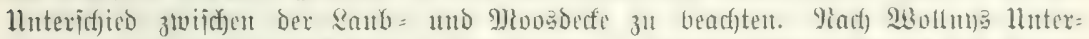

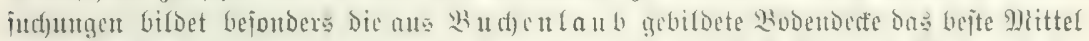

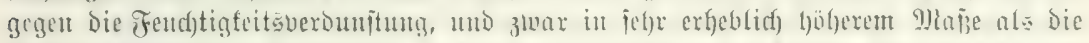

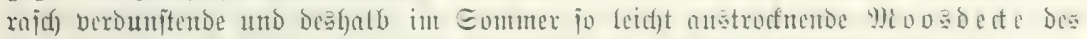

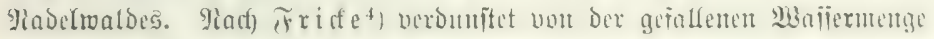

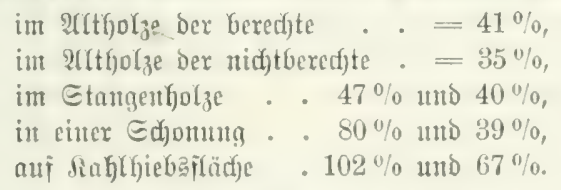

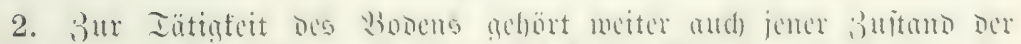
Sionfigtens, ber Den mötigen

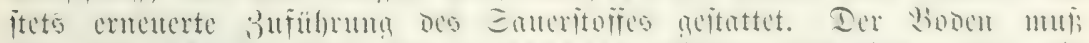

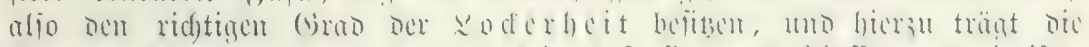

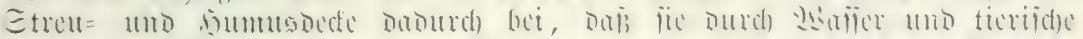

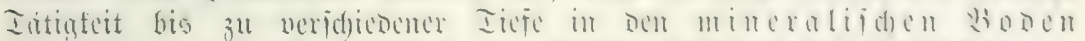

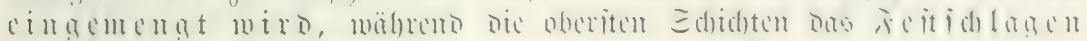
bes 3 व

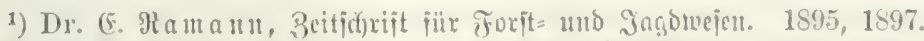

2) Dr. (E. SODppe, 3citjd)rift fïr bas gejante Forftwejent. 1895, 1900. แ110 Bodert.

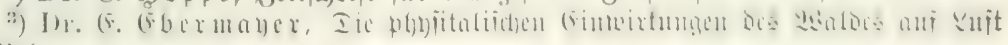

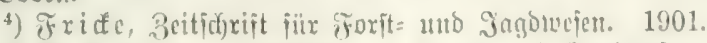

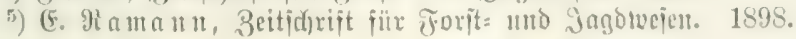




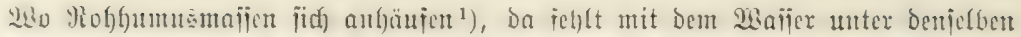
Die nötige Intd)mengung mit Snumbübeitanotcilen, Da ieflen aud) Die Iiere, wie

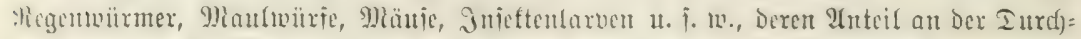

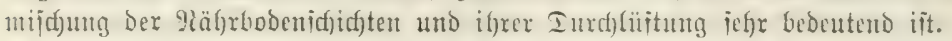

3. Die Etrendecte mildert bie Extreme in ben Iempera= turen bes Bেobent.

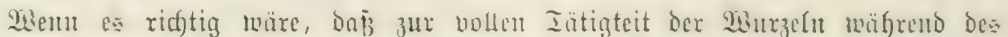
Wad)

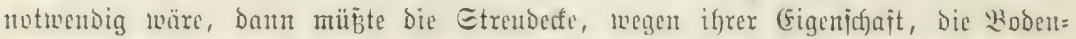

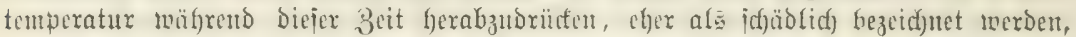

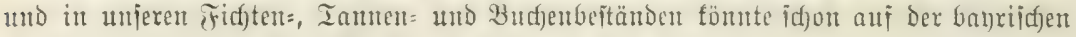

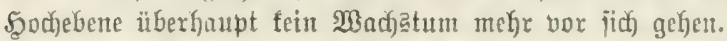

Ilniere llnteriud)ungen faben ergeben, Dnis mäbrend ber Monate Mai-2tuguit folgende Iemperaturen herrịdten:

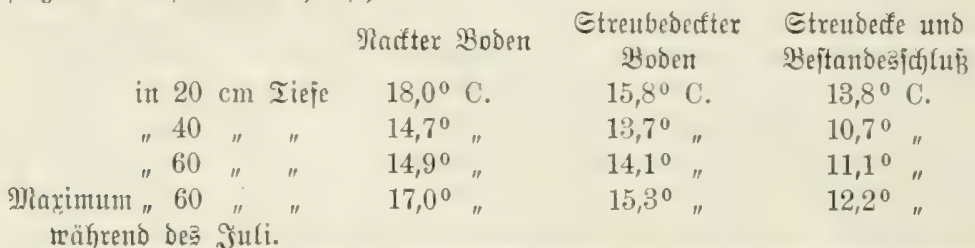

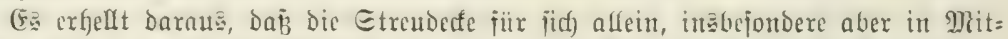

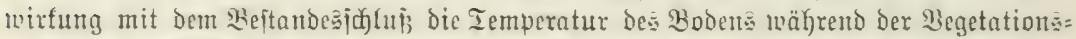

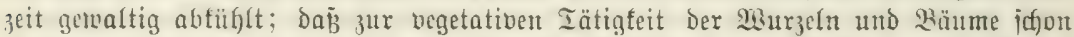
niedere Iemperaturen gentïgen, fo Dab̉ die stbtühfung bes Bodens wäfrend Des

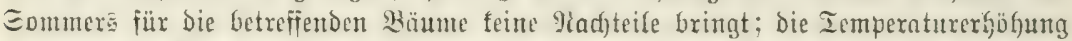

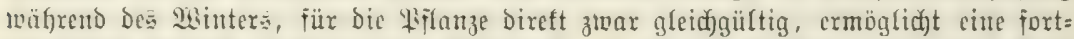

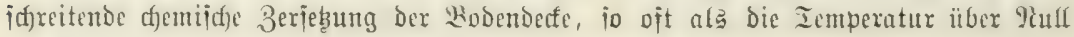
jidf erfebt.

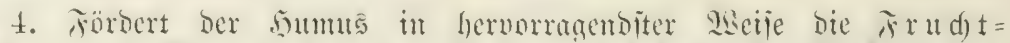

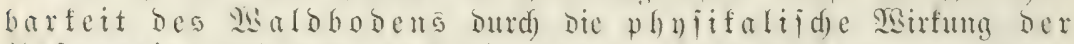

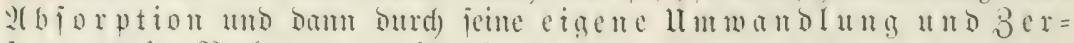

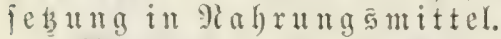

2)

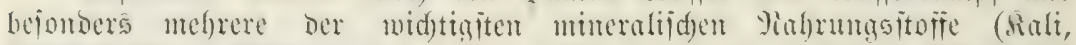

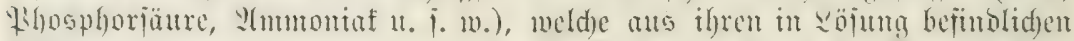

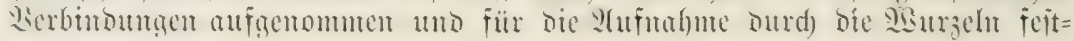
gehalten werben.

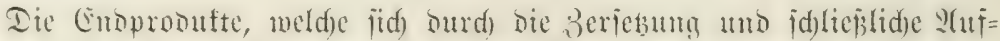

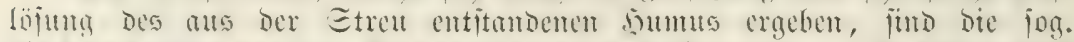

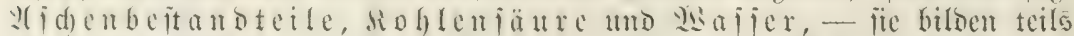

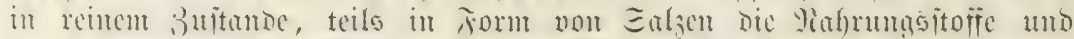

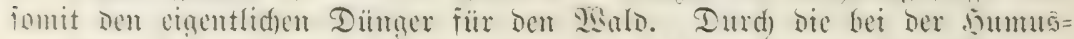

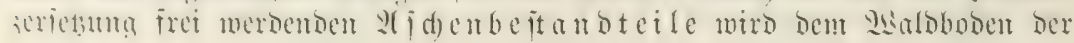

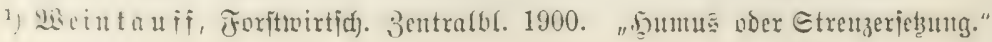




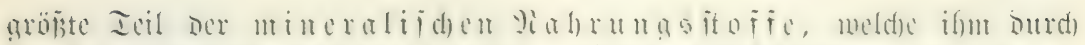

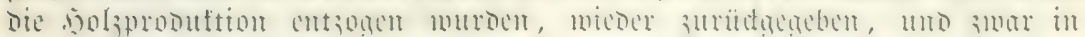
jener form, in welder fie am leidsteiten apjumilierbar finto.

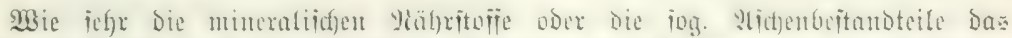

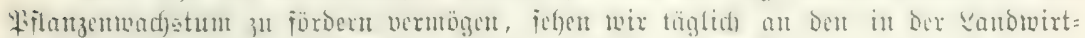

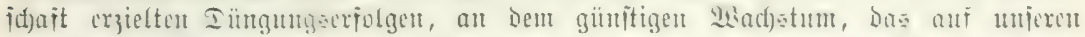

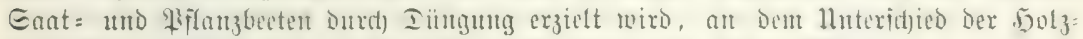

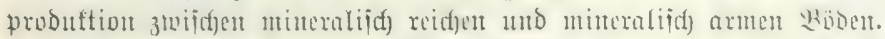

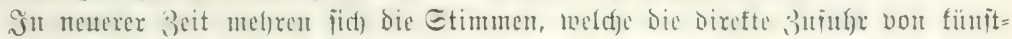

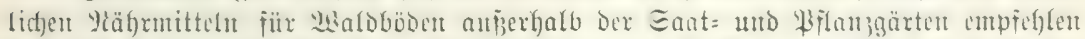
(Jembid), Ed)wappad), (isterberg, Miathes, Banmam, Friffe 11. a.); chento hat fidf Der

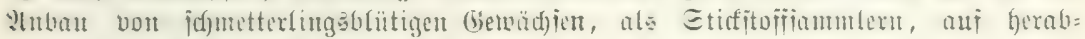
gefommenen Böben betwäbrt.

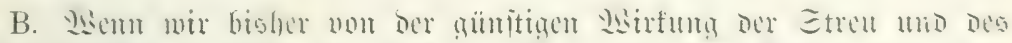

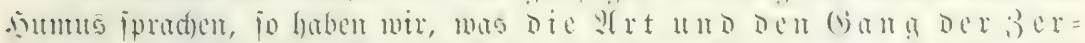
jeßsu

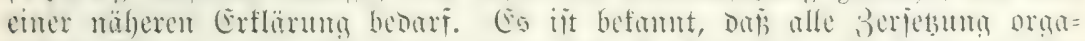

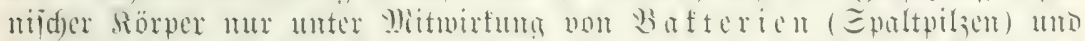

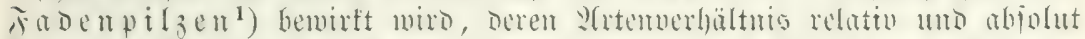

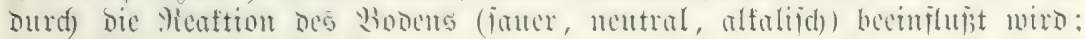

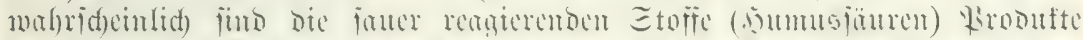

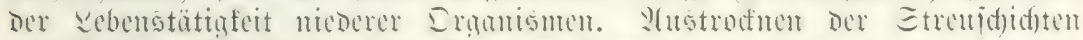

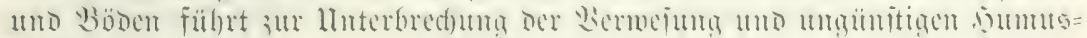
billoungen.

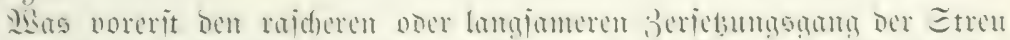

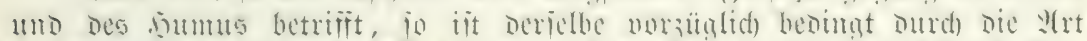

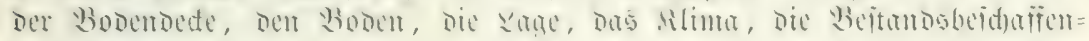
beit 11. f. tw.

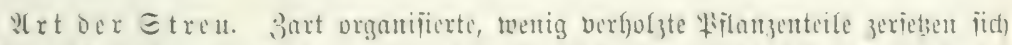

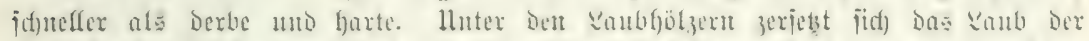

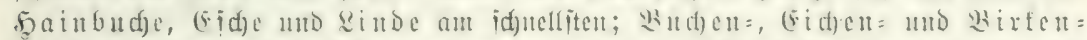

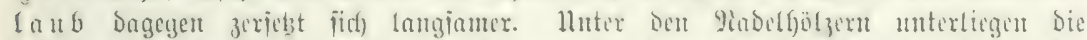

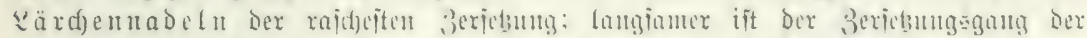

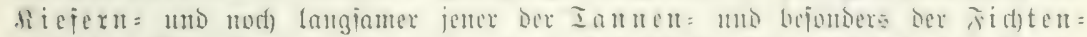

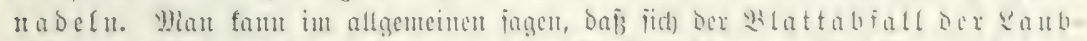

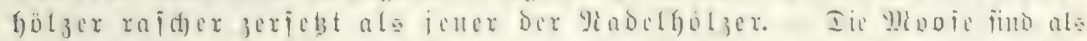

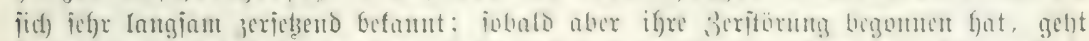

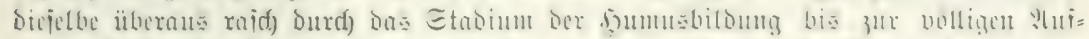

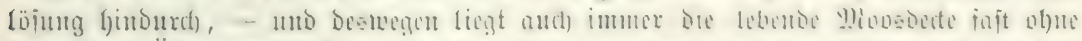

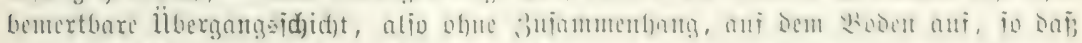
man ite (eid)t uvic cinen Icppid) abfeben famt.

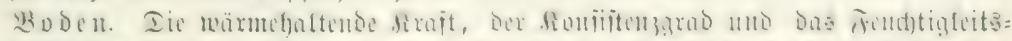

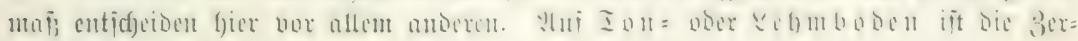

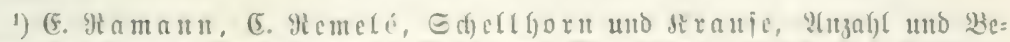

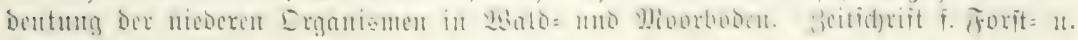
Singotweier. 1899. 


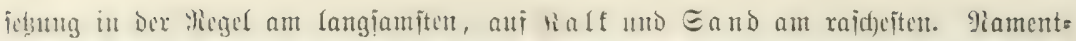

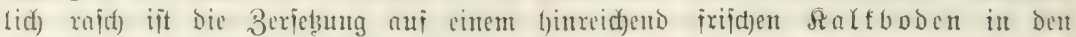

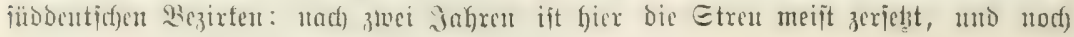

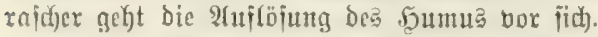

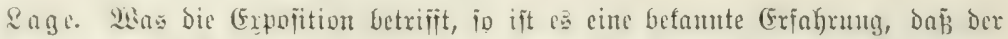

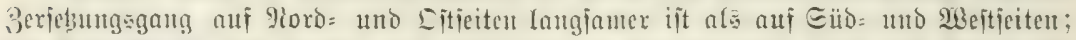

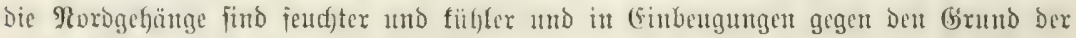

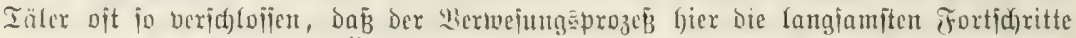
madjt; Stren fix) anthäuft.

MLima. Welche Rolle Die von Feuthtigteit unteritübte hobe wärme im 3ex=

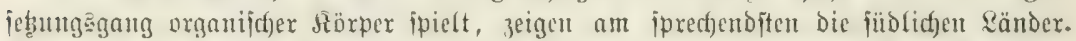
2lber aud) in unjeren Wireiten madft fidf högere suftmärme immer bemerthar; Der

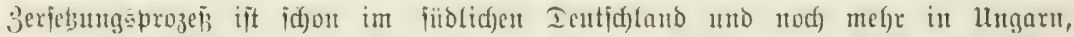

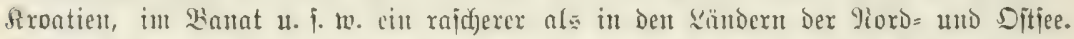

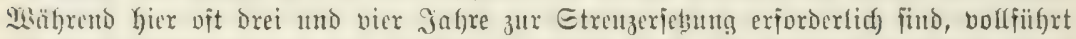

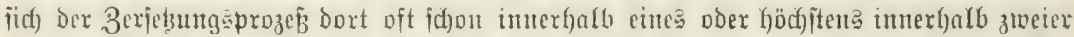

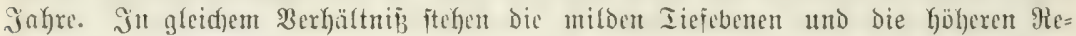
gionen ber Jjodfgebirge cinander gegeniibex; in Den Iebteren fint Die hohe Ruftjeudftig= teit unb geringere Märme cine ber Hrjadjen ber Dit auffalfend gropen 21tjammlung

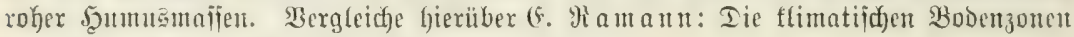
Furopa. Sodenfunde 1901. Feteraburg.

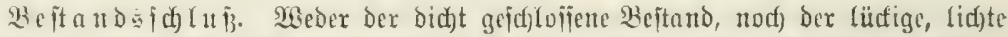

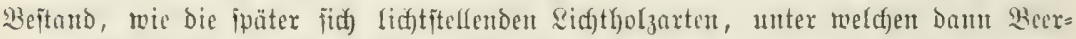

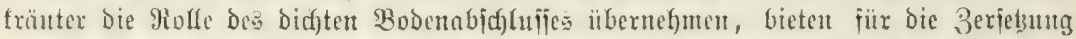

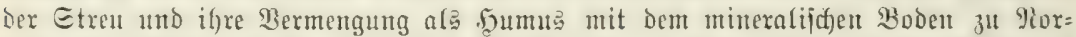

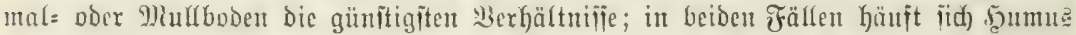

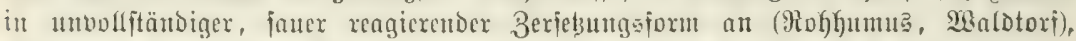

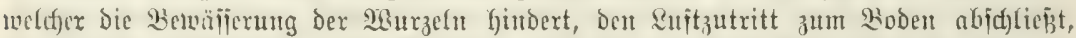

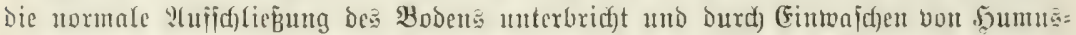

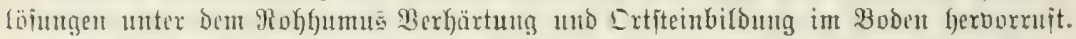

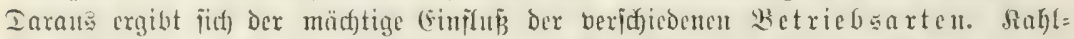

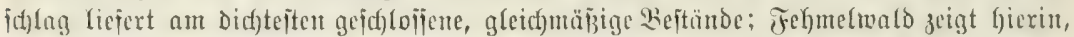

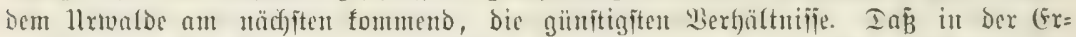

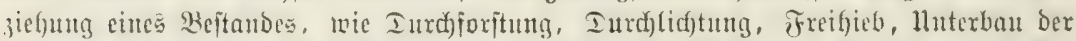

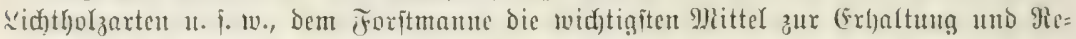
getumg Des normalen 3erjebungägange Der Etrendefte gegeben find, bebari feiner weiteren Bejpredung.

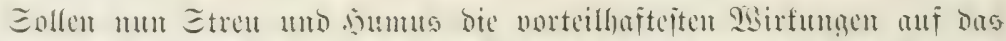

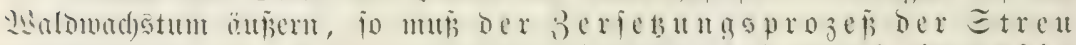

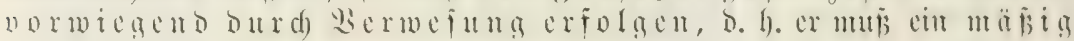
bejd) leunigter und unuterbrodjeuer jeit.

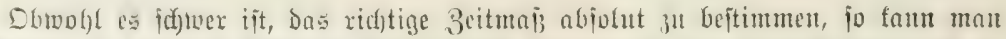

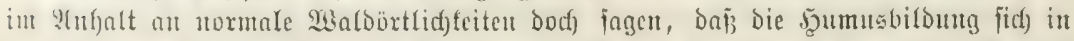

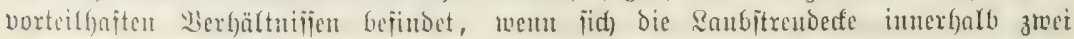

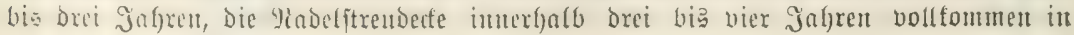




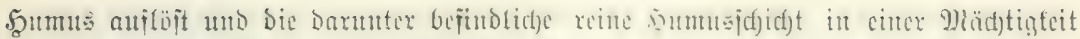
vou mux tocuigen Bentiutern borhanden ijt.

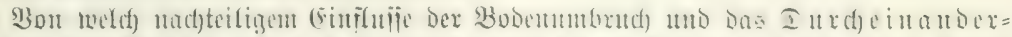

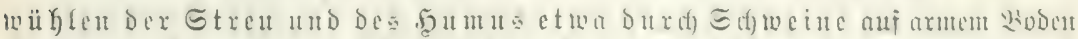

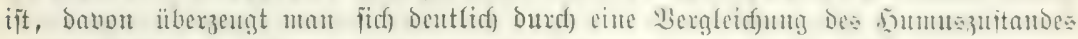

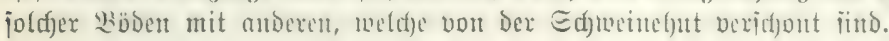

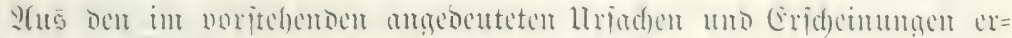

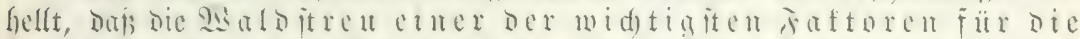
Frudetbateit De

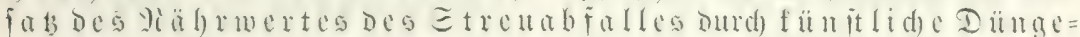

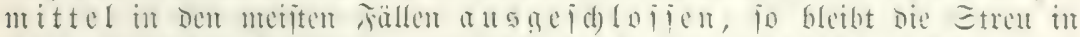

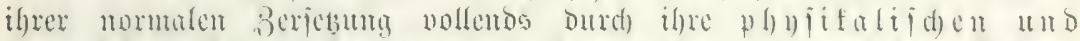
d) e mijd) u $\operatorname{erjeb(id).~}$

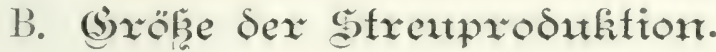

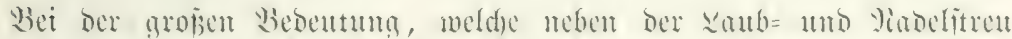

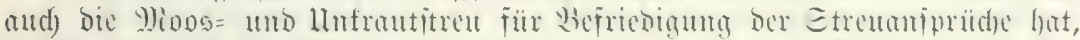

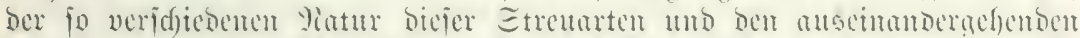

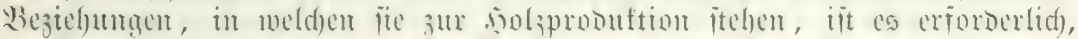

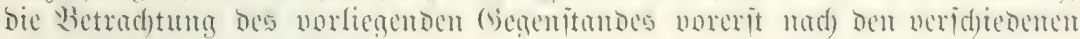
Streunten

\section{1. faub $=$ แก Alndelftect.}

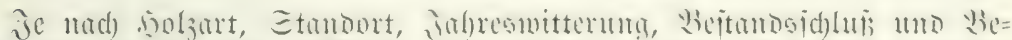

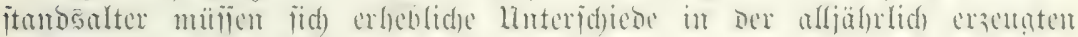
Blattmafje unjerer Maldungen ergeben.

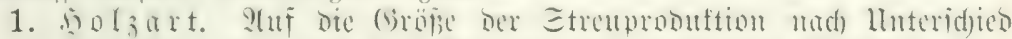

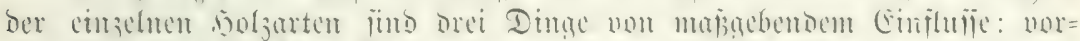

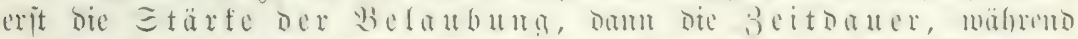

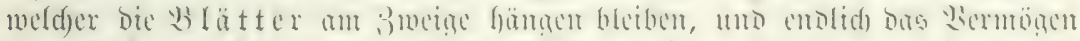

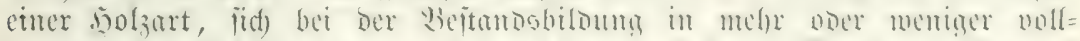

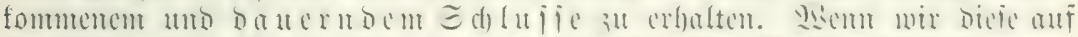

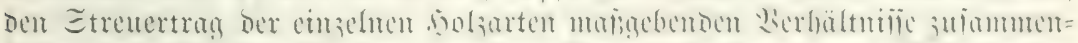

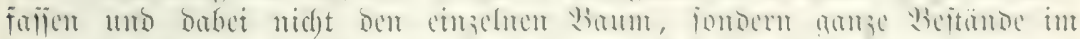

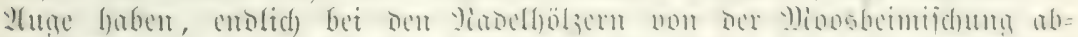

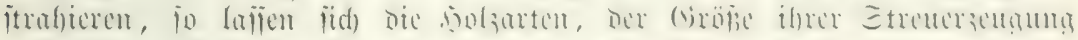
nad), in madjtebender Meihenfolge gruppicren:

$$
\text { एᄂ) } u \text { d) } c
$$

Yhorn, sinde, Édeltaitanic, naicl,

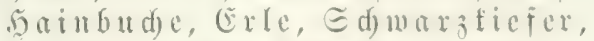

Il 4 me, (Eid)c, Ed) warjpapped,

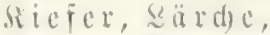

s) $\mathrm{i}$ (d) $\mathrm{te}$, I $\mathrm{a} \| \mathrm{nc}$,

(E) (d)

Wixte, Y Y 


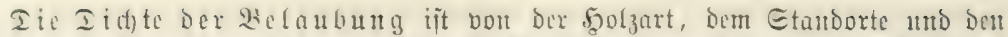

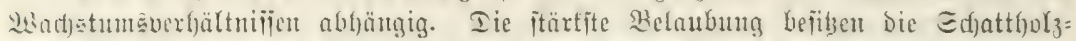

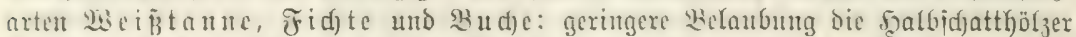

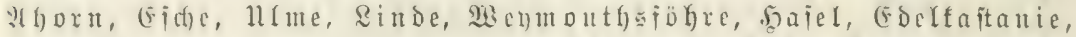

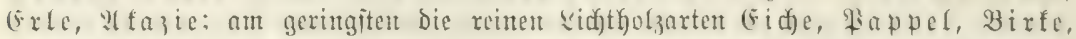

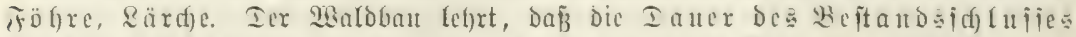

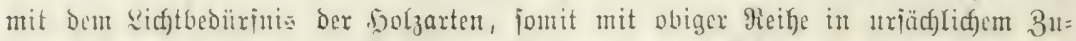

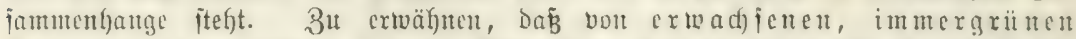

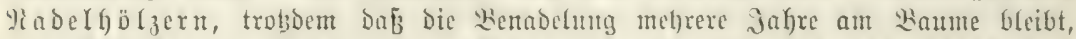

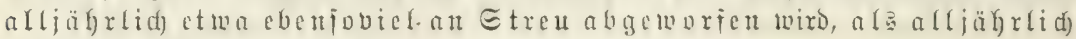
zit to ä df it, follte eigentlidi) nicht notwendig fein.

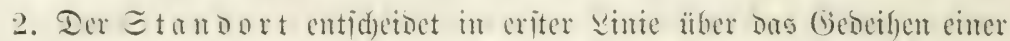
Solzart. Je mebr derielbe cinex gegebeneu solzartzajagt,

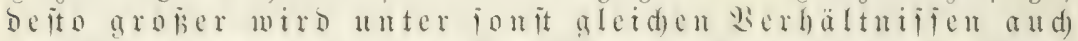
Di

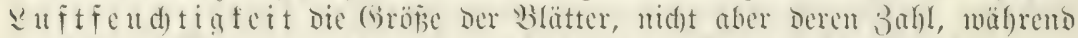

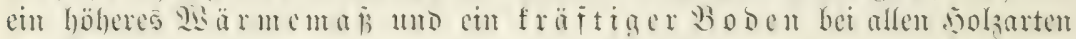
Die Gröp̈e der Blätter und aud) beren $3 a$ bl iteigert.

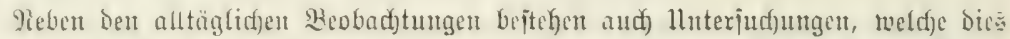

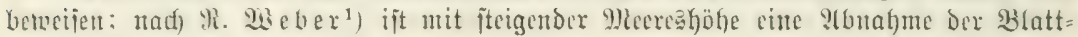
grö̈̆e verbunden.

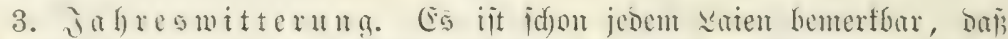

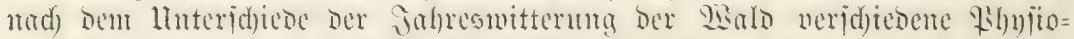

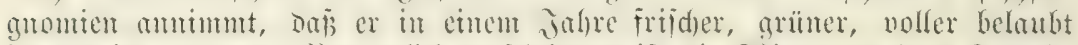

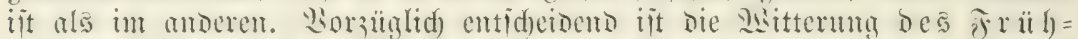

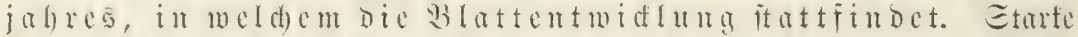

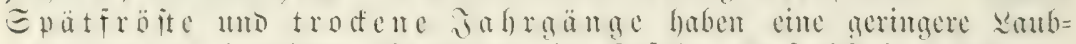

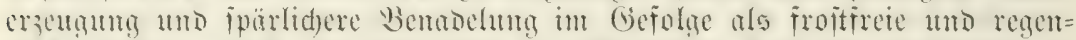

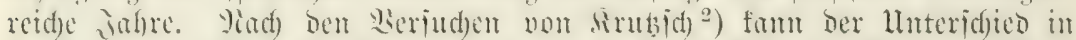

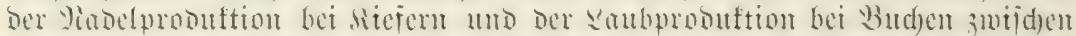

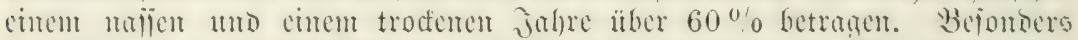

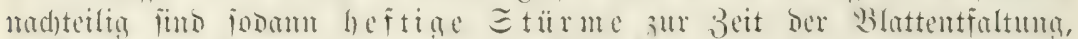

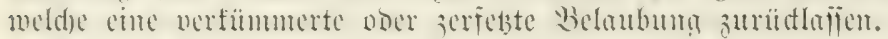

4. Bืeitan ber gebrängte ober fehr gejdylofene Stand der Beftände,

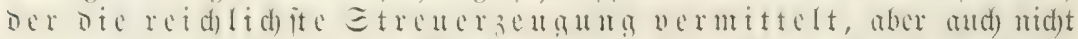

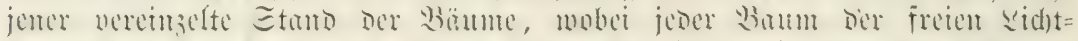

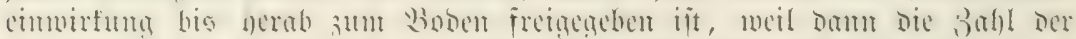

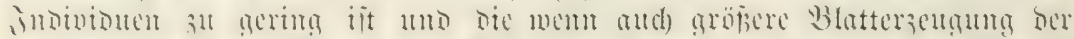

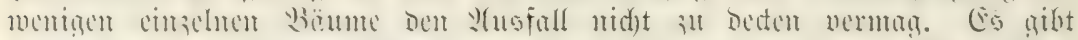

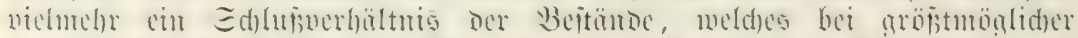

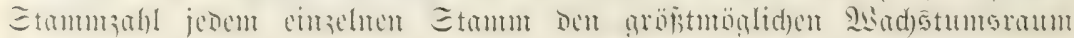

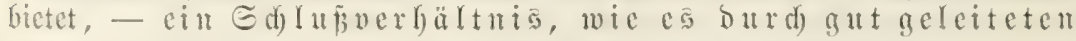

1) Eiefe (Ebermaner, Die Malditreu. E. 37.

2) Ifaranoter Jibroud), 19. SBo. Є. 193 ij. 


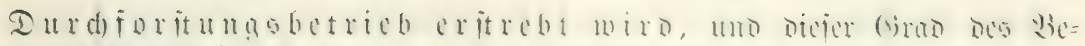

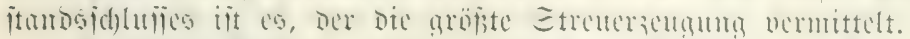

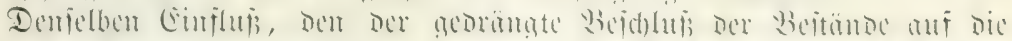

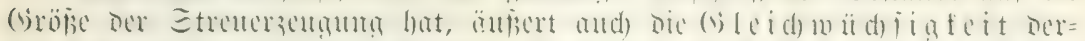

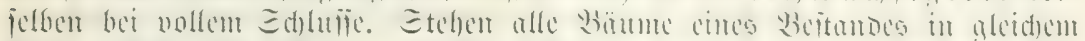

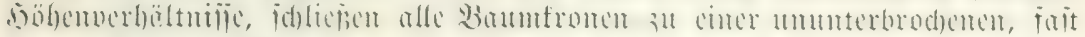

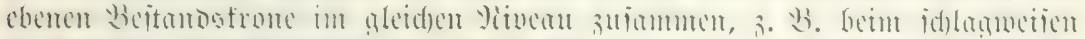

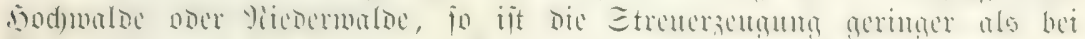

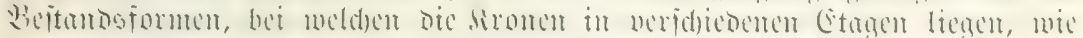
Felymelid)lag und Fehnelform.

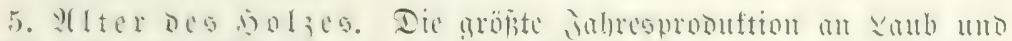

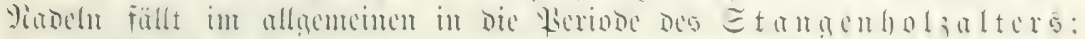

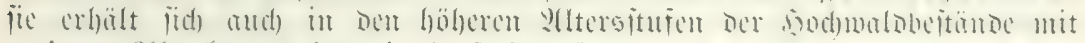
geringer צbuthme nabezu in berfelben Gröbe.

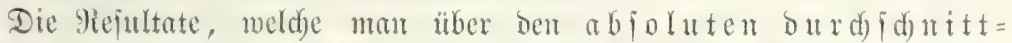

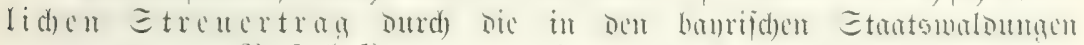
unternommenen Serfudje ${ }^{1}$ ) gemomen bat, fund folgende:

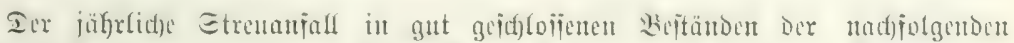

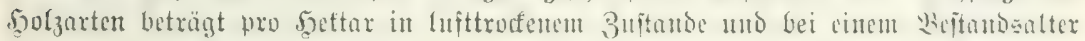

$$
\text { Budfe Fidute Ricjer }
$$

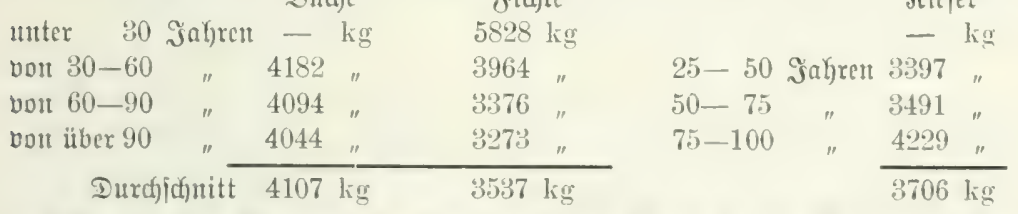

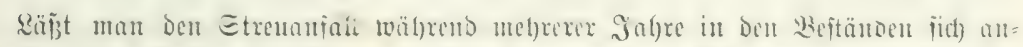

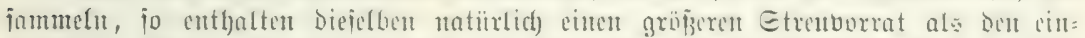

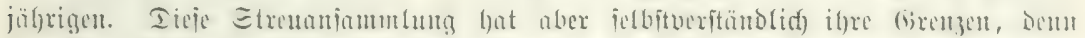

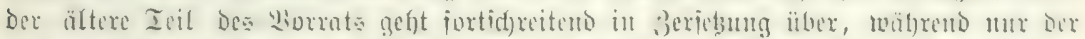

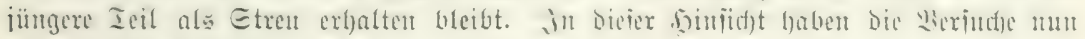
jolgende Durdyidjuttenxeiultate pro Seftar exgeben:

\begin{tabular}{|c|c|c|c|}
\hline & Bud & Fidute & Stisfer \\
\hline$\partial r$ & $8160 \mathrm{lig}$ & $7591 \mathrm{~kg}$ & $8887 \mathrm{~kg}$ \\
\hline jedjäjäbriger " & $8469 "$ & $9390 "$ & 13729 \\
\hline mehx als jedj引jähriger Streutertrag & 10417 " & 13857 & 18979 \\
\hline
\end{tabular}

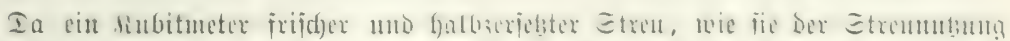

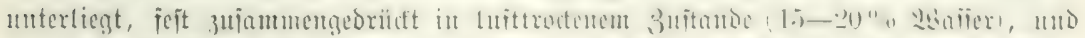

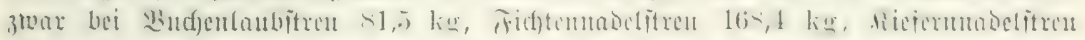

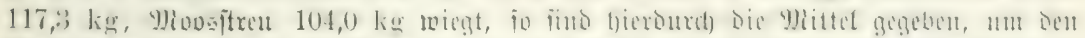

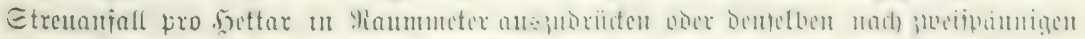
Fufferu (F)

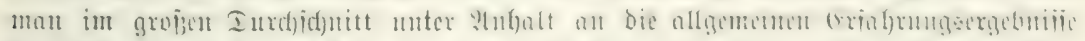

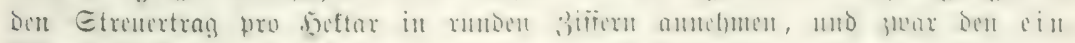
jäbrige शtupall:

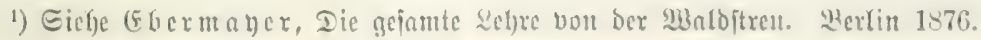




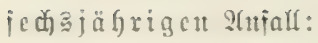

Bei Buctenbeitänoen mit $50 \mathrm{cbm}$,

" Ricjernbejtänden " 30 "

" Ficjtenbejtänden " 20 "

bei Budfenbeitänden mit $100 \mathrm{cbm}$, Riçernbeitütioen " 80 " Fichtenbeitänden " 55 "

\section{Alloogftert.}

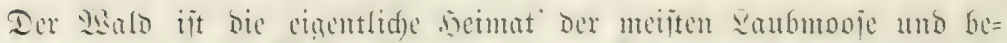

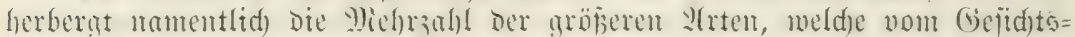
punte ber Etreumbuto in Betrod)t fommen. Die ceriten und bas Ge=

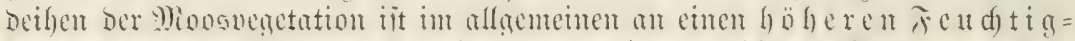

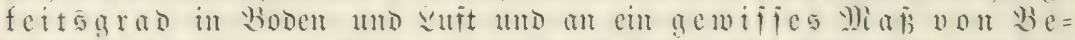

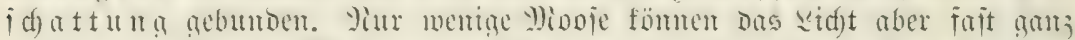

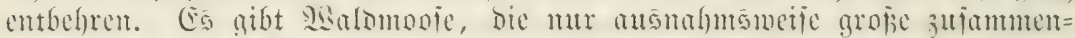
hängende Soliter bifoen, bagegen viele andere, welde immer in gröferes

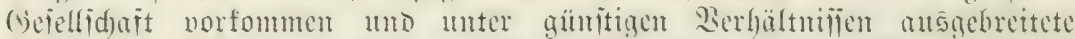

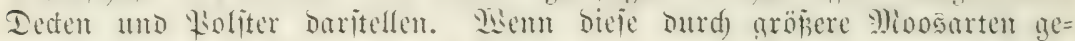

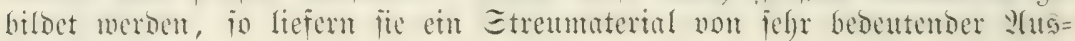
giebigfeit.

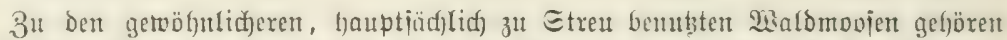
vorerit mefrere Utrten Der grojen battung Hypnum - namentfidf Iylocomium splendens, squarrosum, triquetrum uno loreum; Hypum Sichreberi, purum, cuspidatum, molluscum, cupressiforme: Brachsthecium rutalublum: ('ampothecium lutescens: Thuidium tamariscinum uto abietinum u. j. w. -; Dant Polytrichum formosum und urnigerum; Dicranum scoparium; Bartramia fontana; Climatium dendroides: an naijen, jumpiigen Srten bildon meben mefrexen Der vorgenamenten 2trten bie Sphagnum-2trten bie borferridjende Beftorfung.

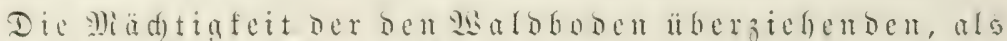

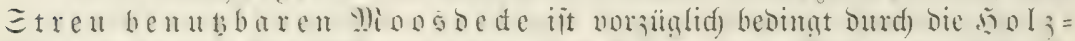

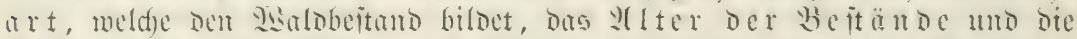

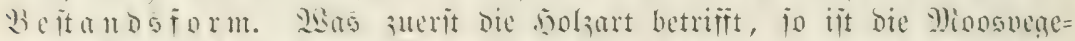

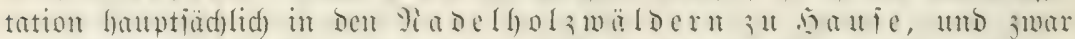

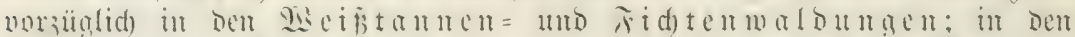

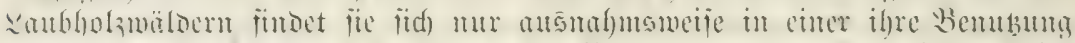

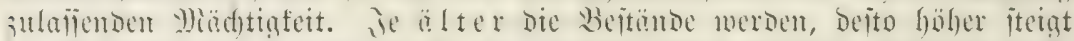

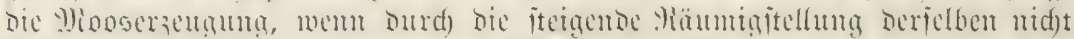

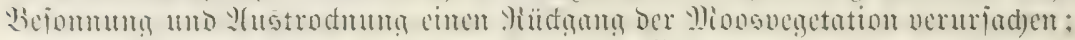
aud) bie Be it a m

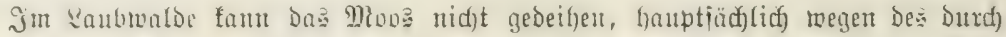

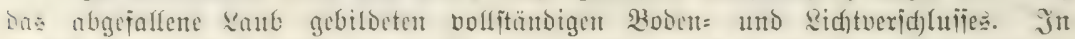

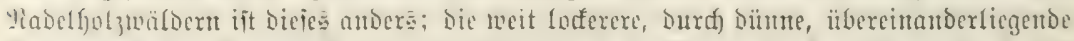

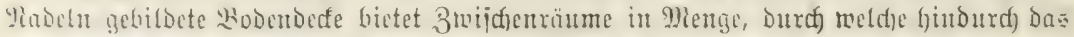

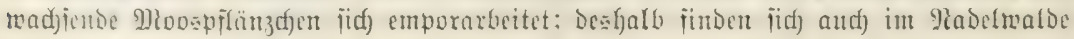




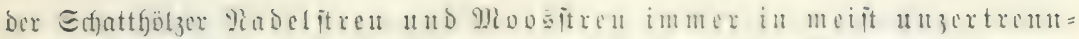

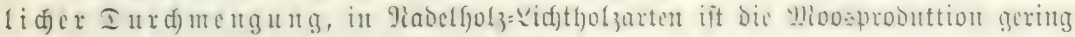

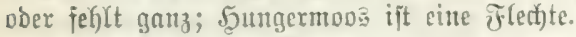

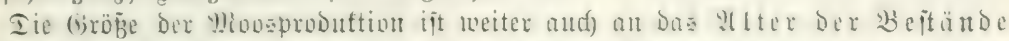

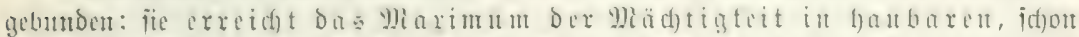

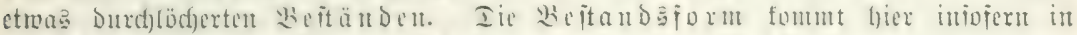

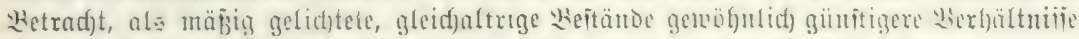

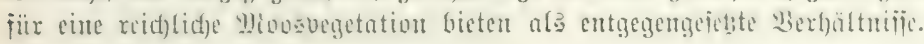

\section{3. İnkräแtcrftecu.}

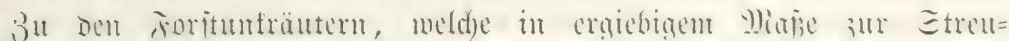

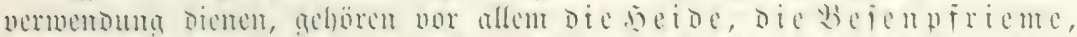

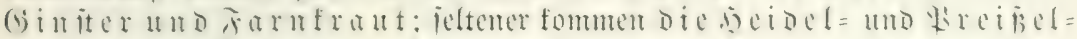

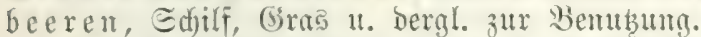

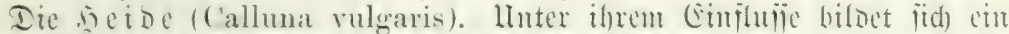

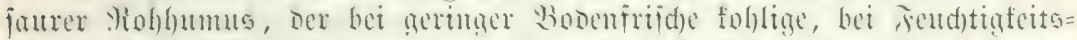

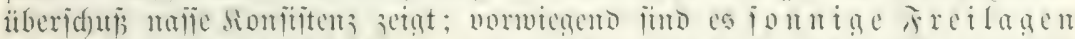

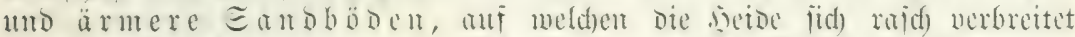

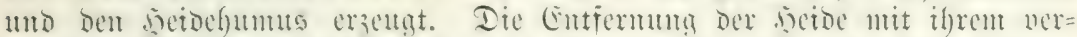

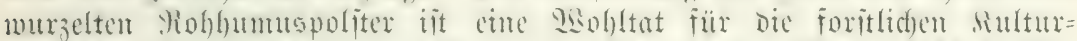
gemüd) idjattung) Diefes llnfrautes Serr zu werben vermögen.

Die

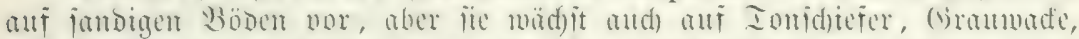

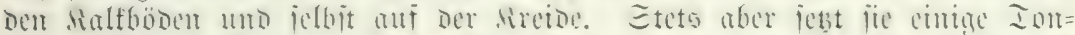

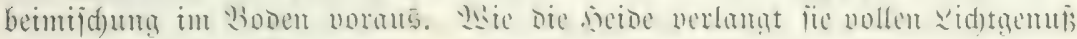
und einet hoben Särmegrab.

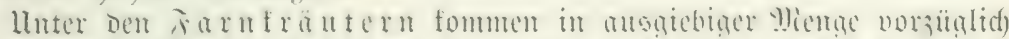

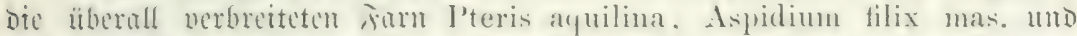

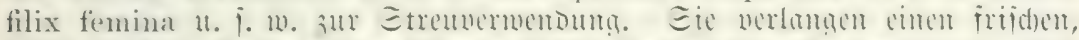

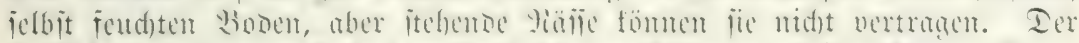

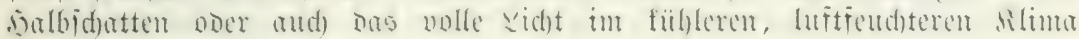
jino ifye bejten Etanoorte.

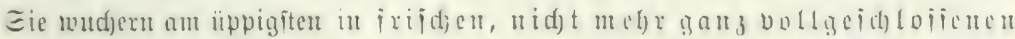

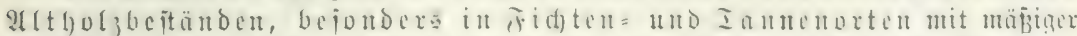

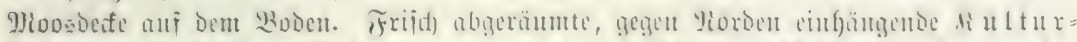

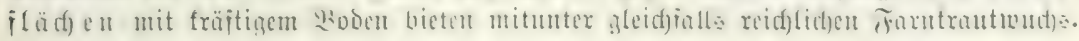

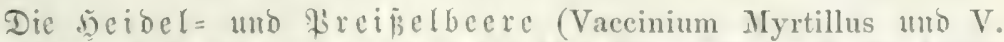

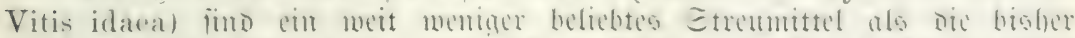

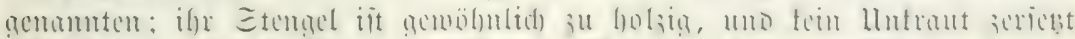

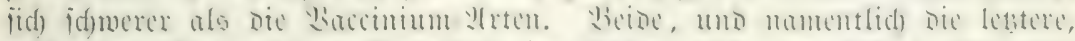

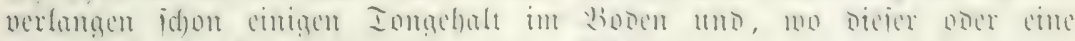

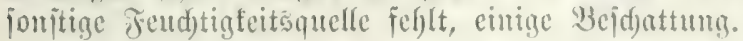

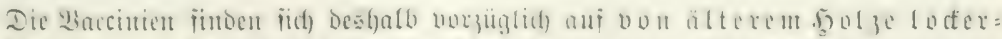

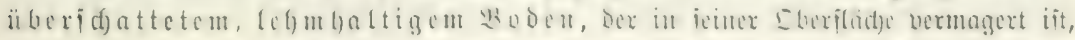




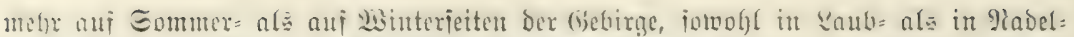

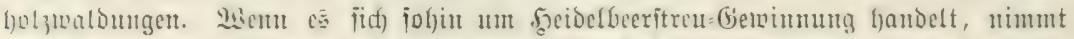

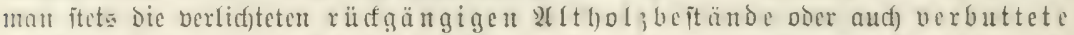

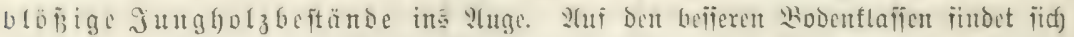
oft audf cin üppiger frecibelbeermud) in nod) nidft zun volfen Ed)Luif gefangten

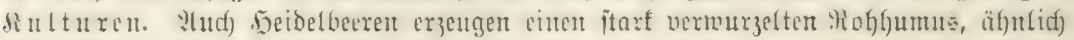
idjüblid) twie bie 5eibe.

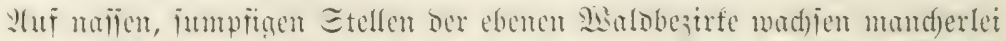

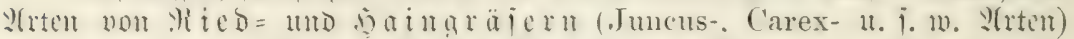

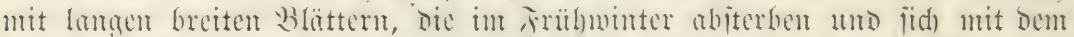

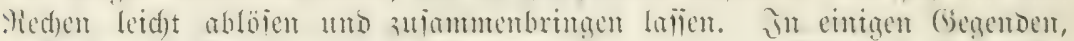

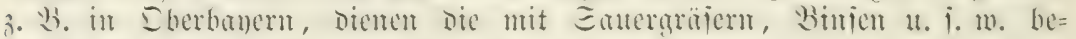
wad)jenten Bibiejenflüdyen geradezu als "Etreutwiejen".

\section{C. (Seninmung Ser Dafolfient.}

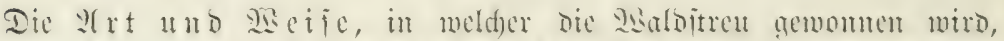
hängt von Der Etrenart, Drt 4 แ Reibe von Berbältnijien ab.

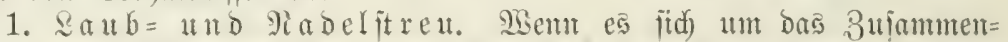

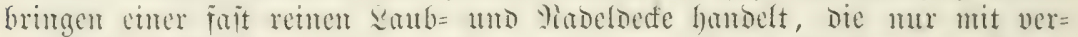

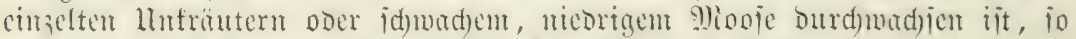
acidieht biejes immer nit Dem einfad)en hölzernen Yed)en.

(Eijerne Medjen find ïberall mit Recft verpönt, weif Damit nidft nur ben ojt

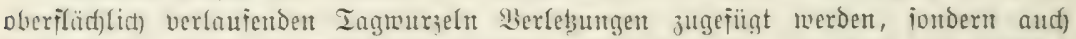
leid)t bis in bie foumusidjidft eingegrifien un dieje ielbit zum Ieil mit entrïgrt

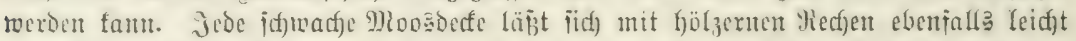

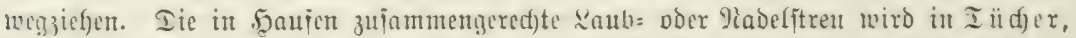

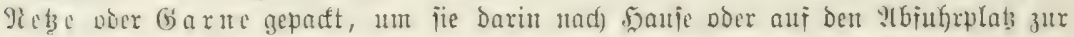

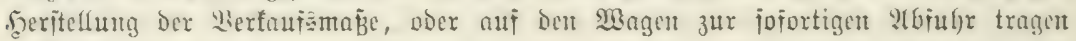
3น fömnen.

Mäfreno anf ebentem flarm Boben Der Hechen ungehindert arbeiten uno Die

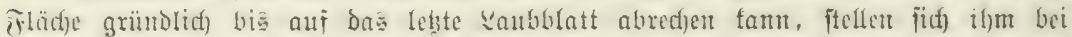

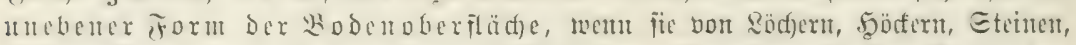

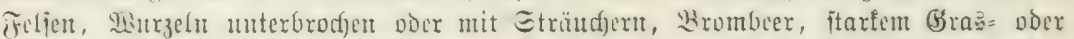

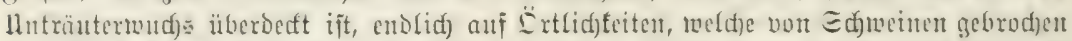

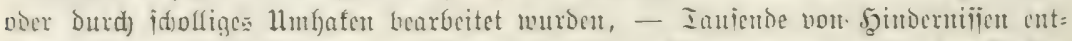

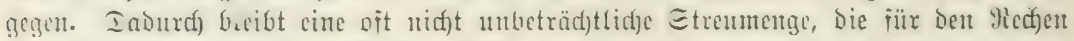

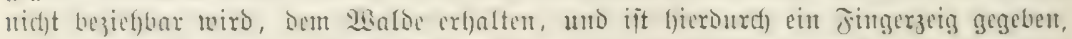

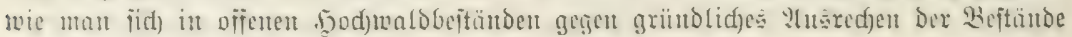

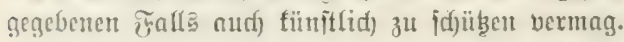

2. Wi ons it re

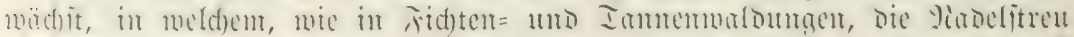

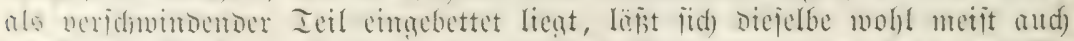

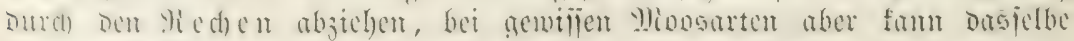
mu ourd) 2fusrupfen mit ben Sänden gewomen werben. 


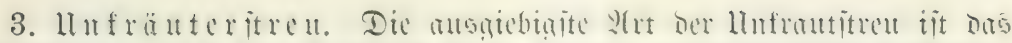

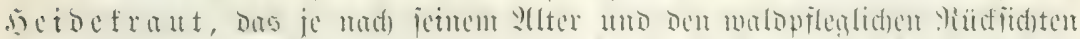

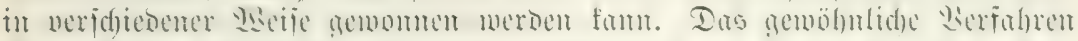

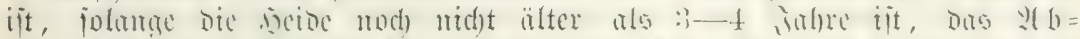

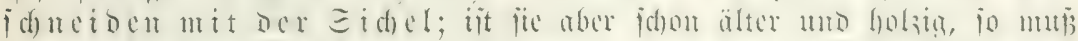

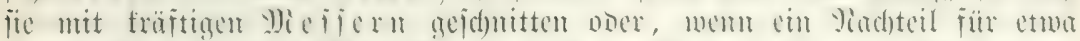

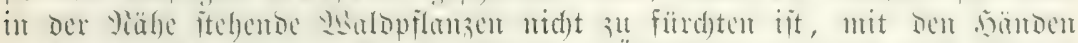

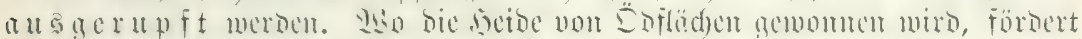

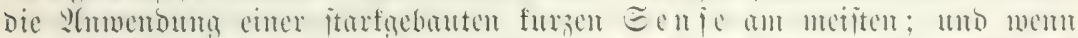

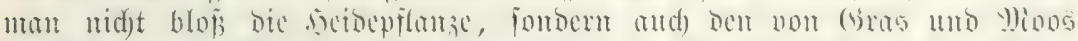

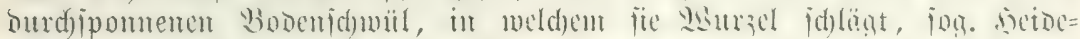

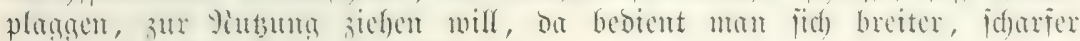

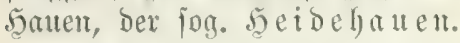

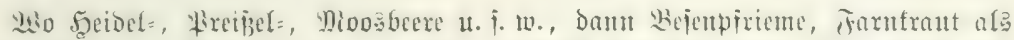

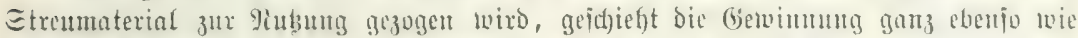

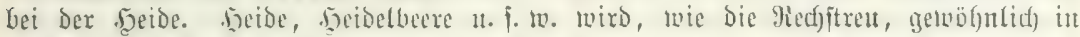
Tïd)ern mad) Den Sammefpläbent gebrad)t; Bejenpfrieme und Farufrant bindet man

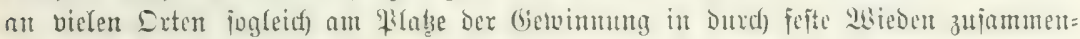
get)altene Bebunde.

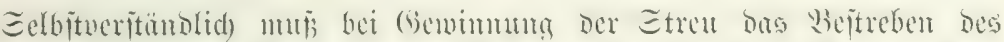

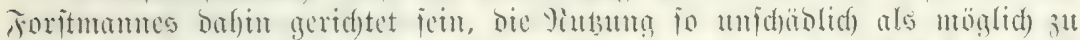

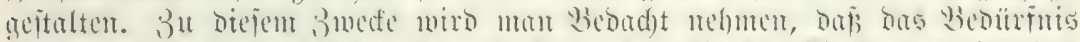

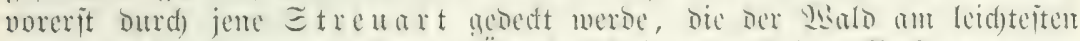

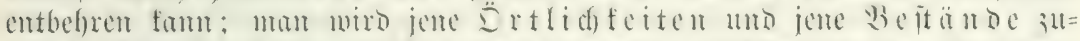

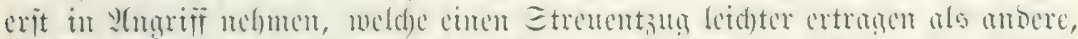

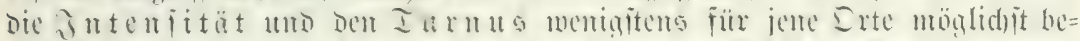

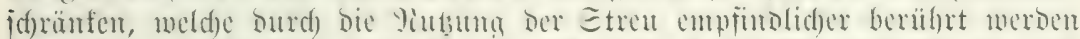

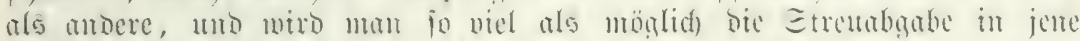
sabreszeit verlegen, in weld)er fie ant elciten zuläilig ift.

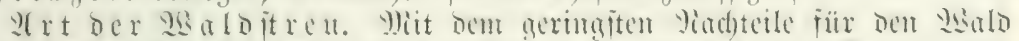

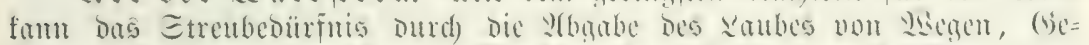

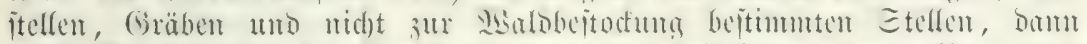

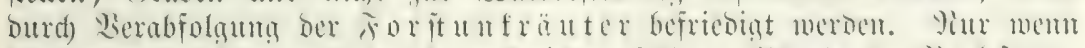

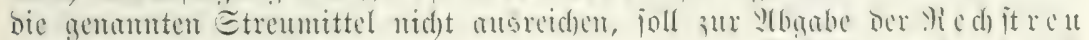
in

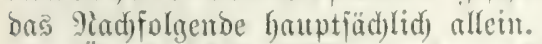

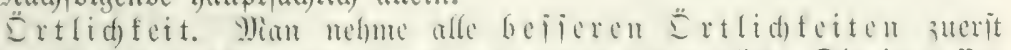

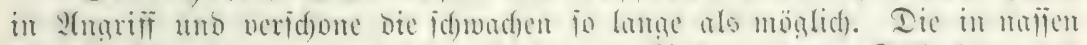

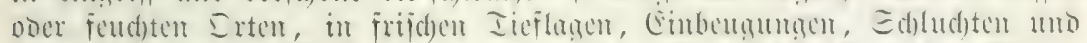

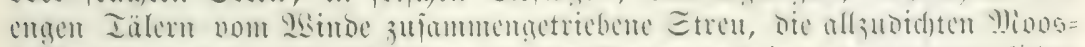

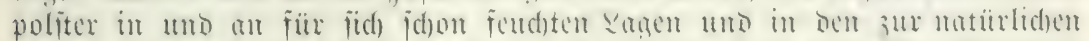

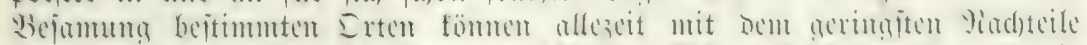

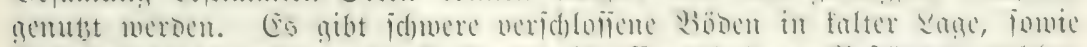

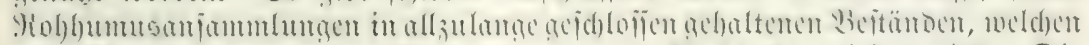

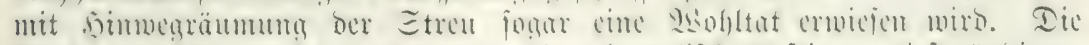

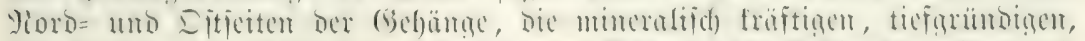

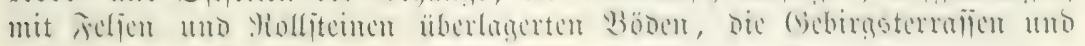




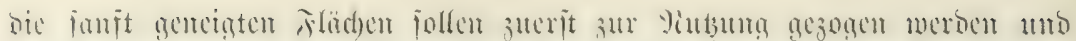

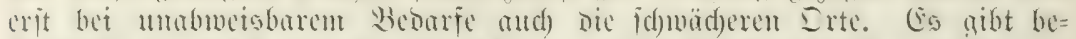

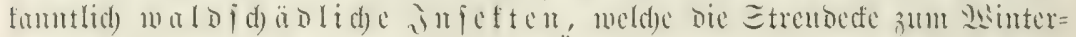

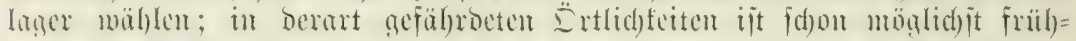

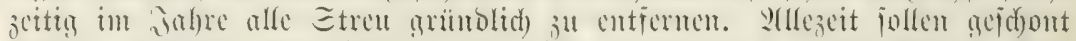

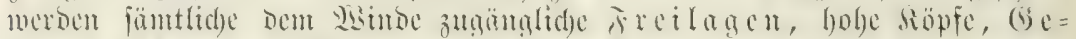

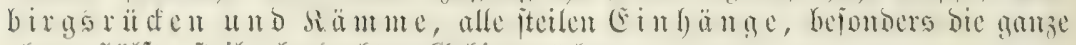
obere sälfte fteil abgebadter Sebirgstüden.

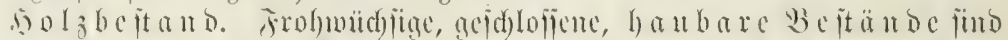

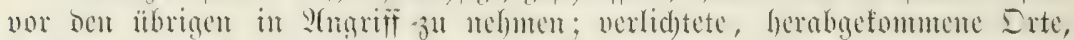

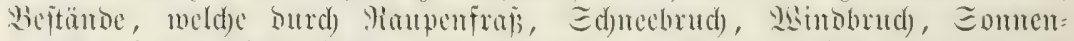

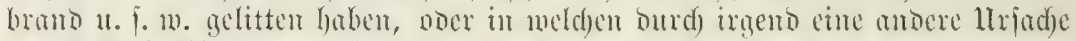

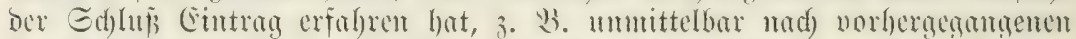

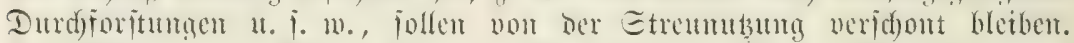

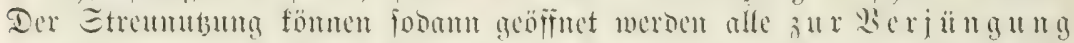
mocrfebenen, gle

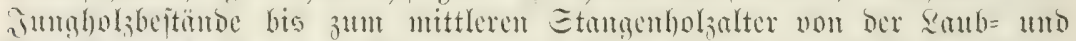

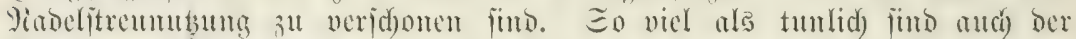

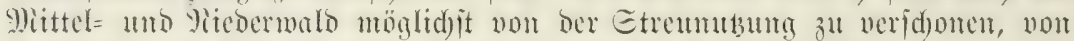

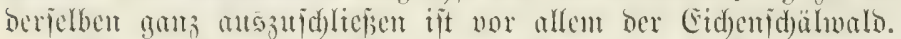

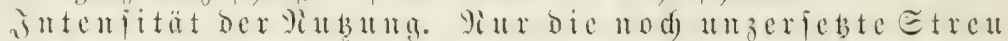
foll zur Yimbung gezogen, bie in jeriebung begriffent aber verjonnt werden. Das ijt freilich mu felten in vollem y)iaje ourd)jufithren, - man tuc,

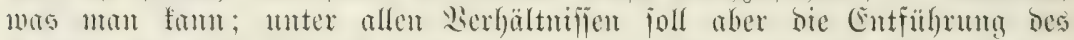

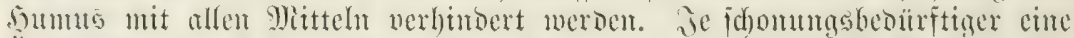
Ërtlid)feit ijt, Dejto melr muj; anf ein mu oberfläd)lides v(bred)en ber oberiten Etreubede hingearbeitet merben; acid)icht bic liu

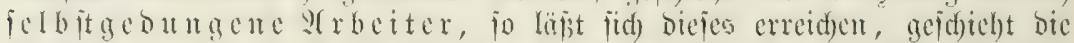

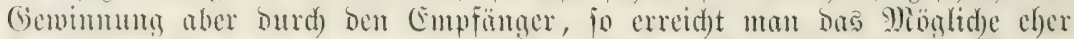

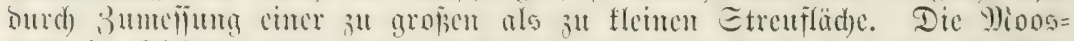

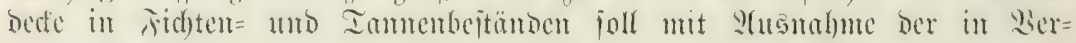

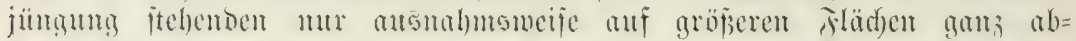
gezogen meroen, man geitatte, wem möglide, ma cin Durdurupen ober

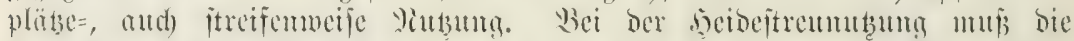

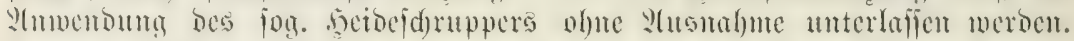

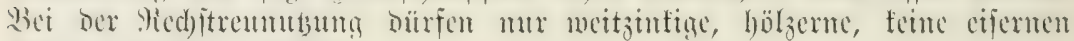
Sedjen zugelafien werden.

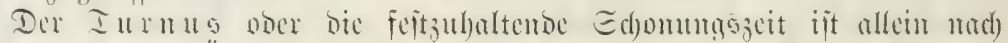

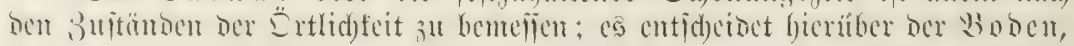

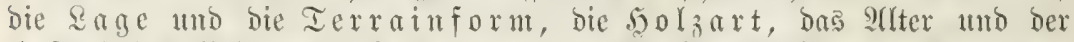

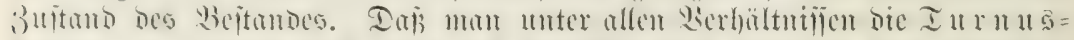
ba

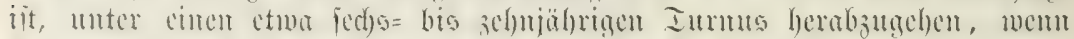

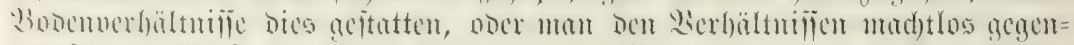

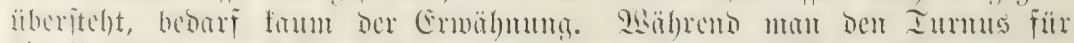

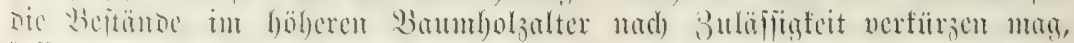

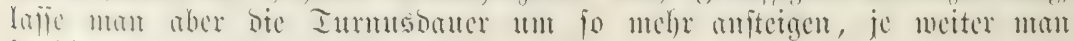
in bie jüngeren Bejtänbe vorgreift. 


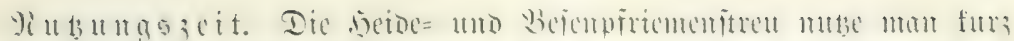

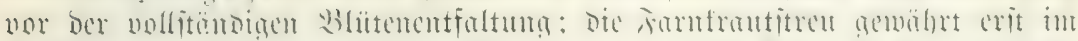

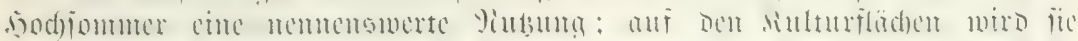

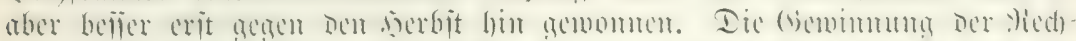

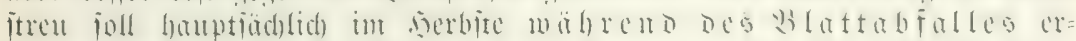

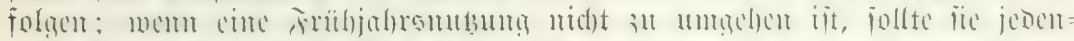

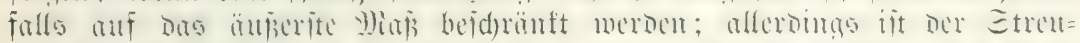

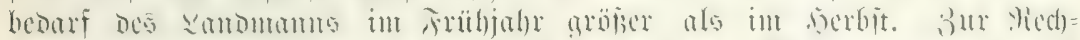

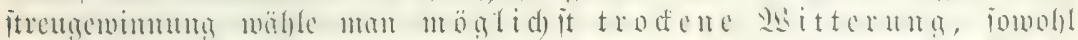

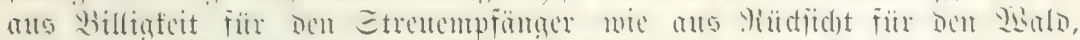

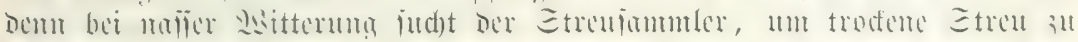

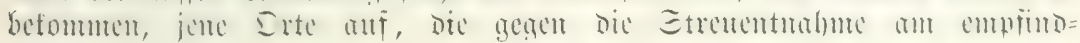
lidjiten jurto.

Streunu

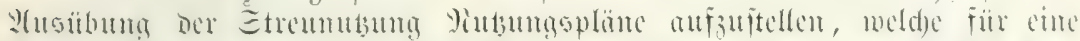

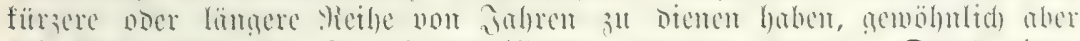

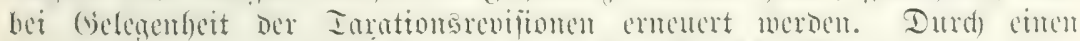

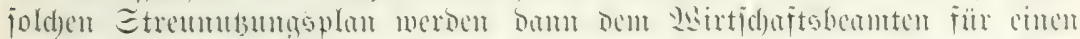

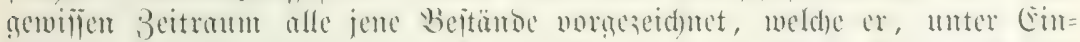

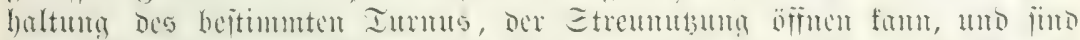

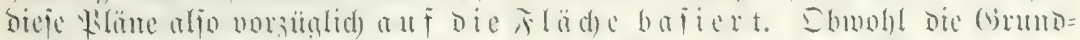

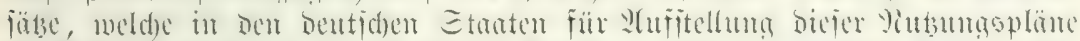

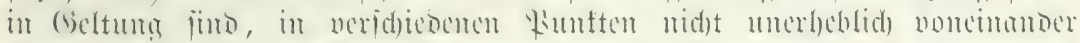

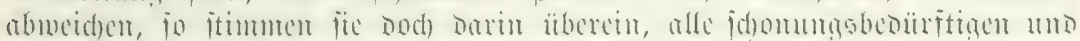

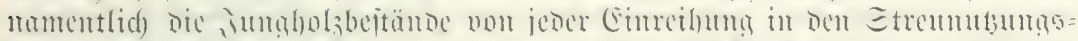

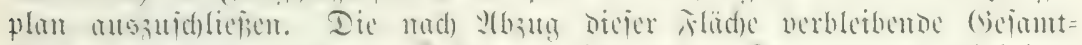

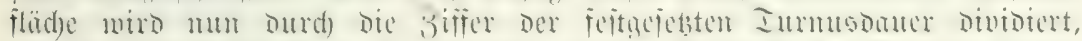

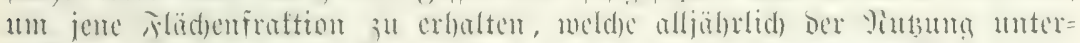

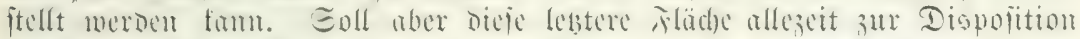

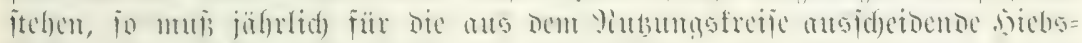

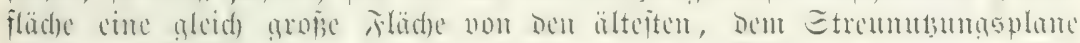

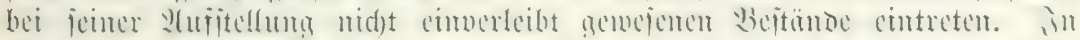

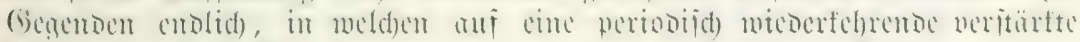

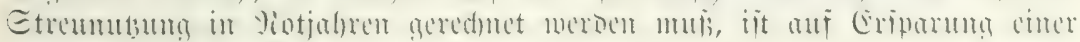
Etreurejerve Bebacht zu melmen.

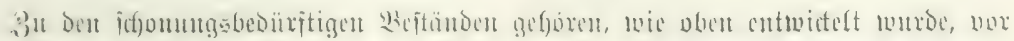

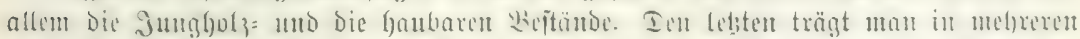

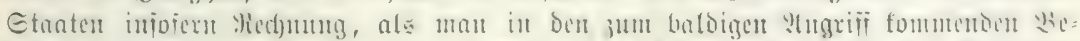

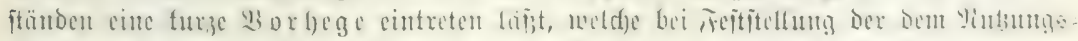

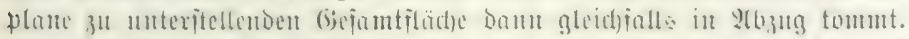

ju

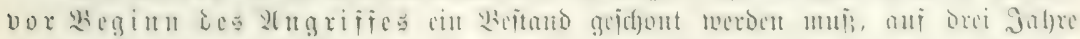

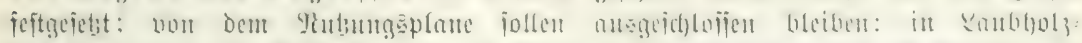

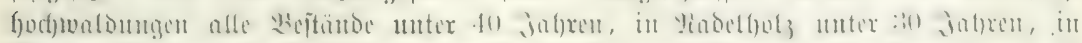

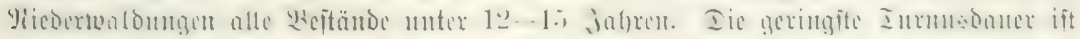

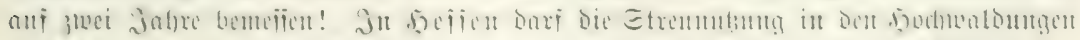

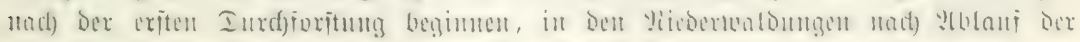




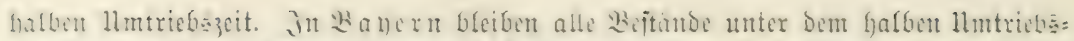

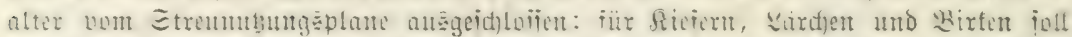

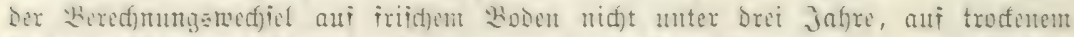

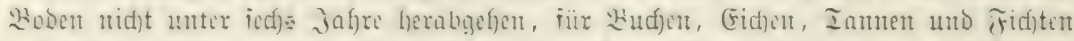

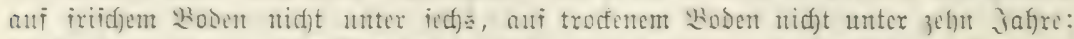

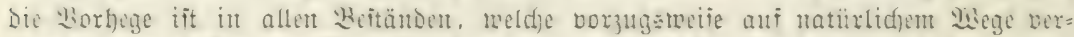

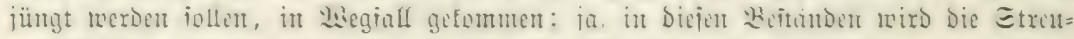
und thofhumusdece al hue entferm. In

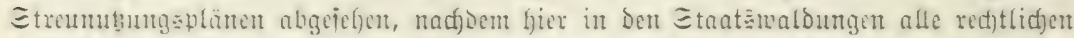

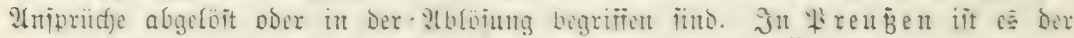

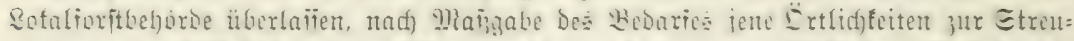

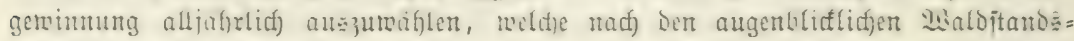
verhältnifien bie Etreumub̧ung nod) am Yeidfteịten ertragen ${ }^{3}$ ).

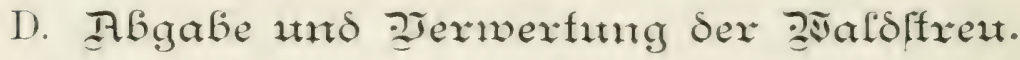

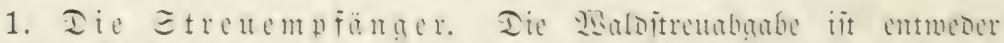

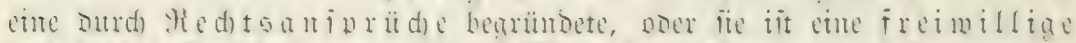

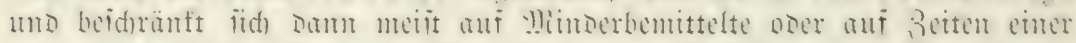

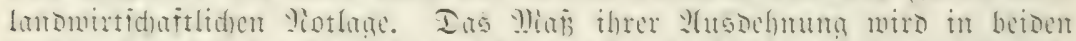

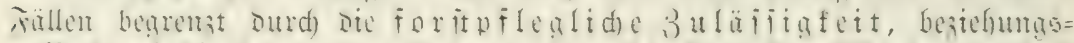

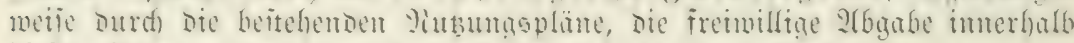
Diejer (Srenze, überdies nod) burd) Den mirflid)en Bebar

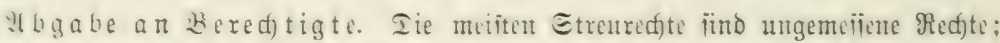

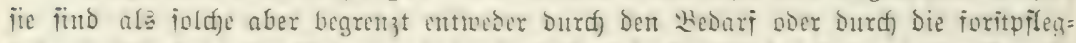

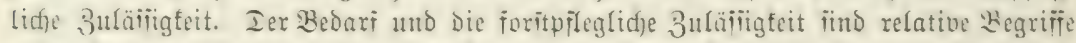

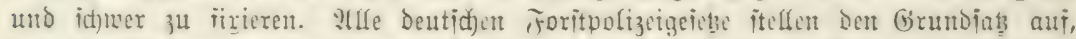

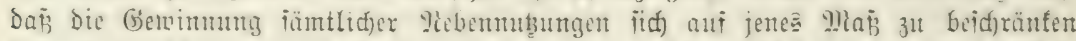

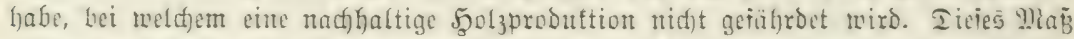

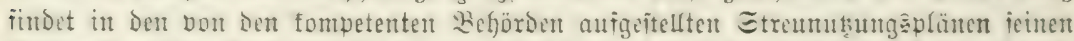

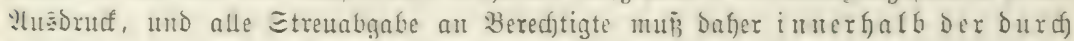

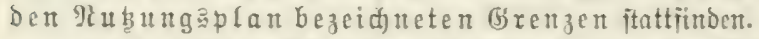

Treimillige 2lbgabe. Sie hat unr an ben Bebuiritigen 3 eriolgert.

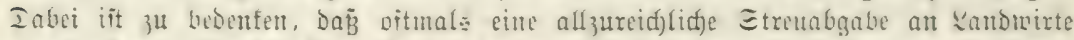

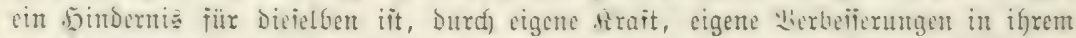

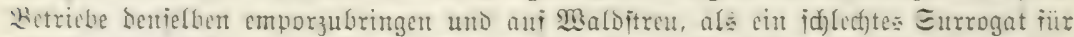

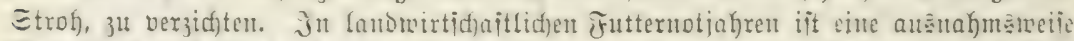

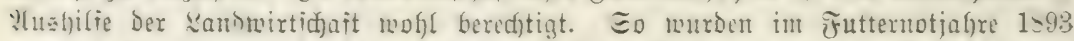

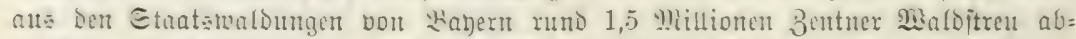

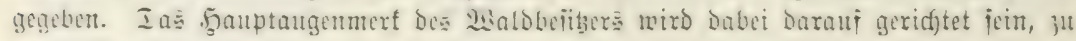
jorgen, baí bie Slotabgabe nidjt zur Morm wirb.

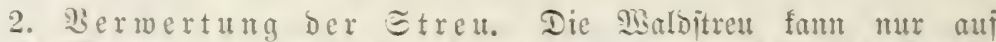

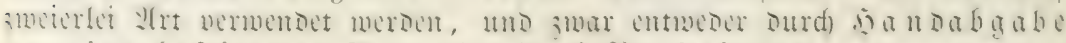
un eine beftimte Iare ober Durd) Beriteigerung.

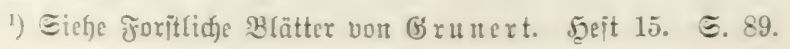




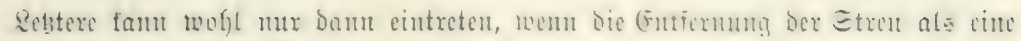

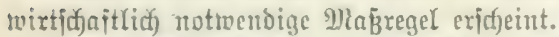

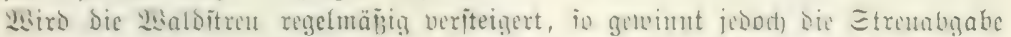

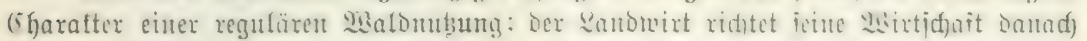

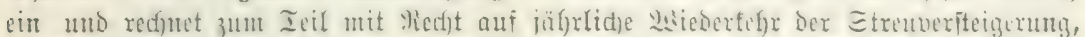

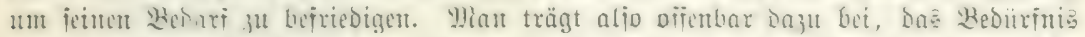

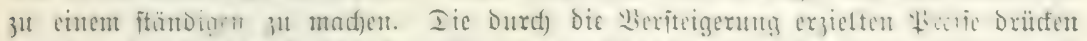

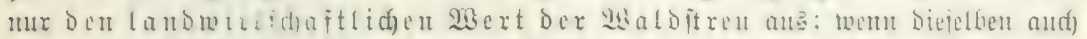

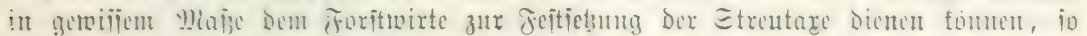

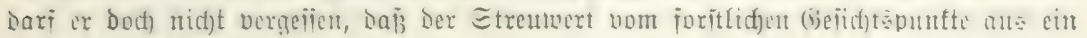
ganz anderer iit.

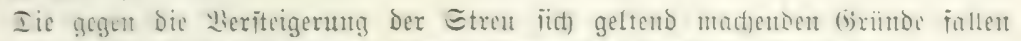

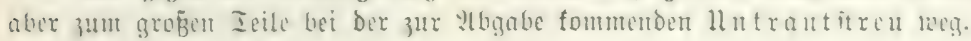

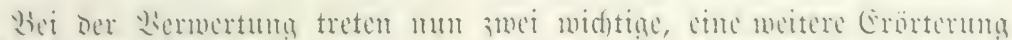

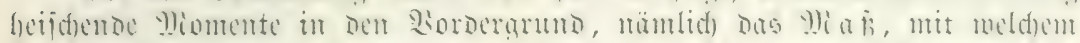

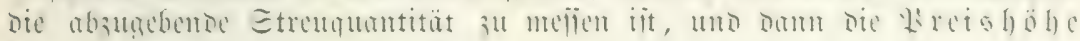
Der Iaxe.

a) छtxсы

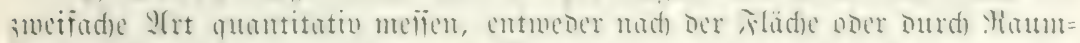

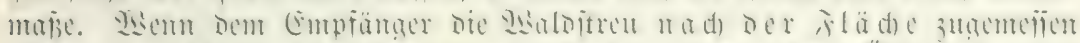

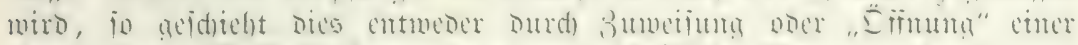

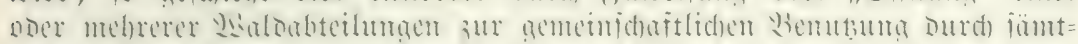

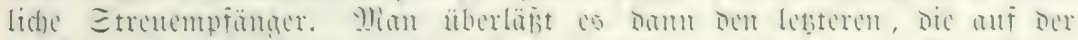

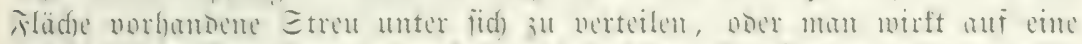

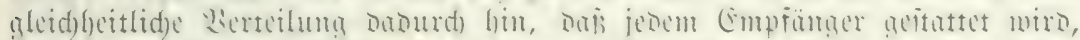

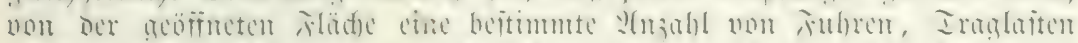

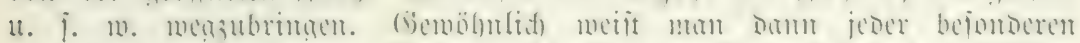

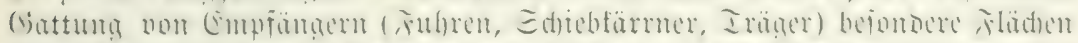

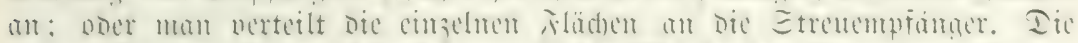

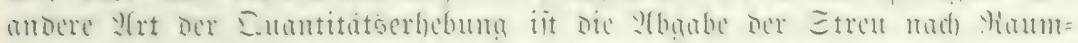

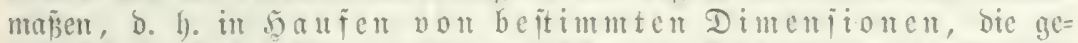

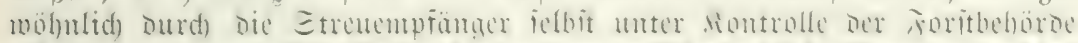

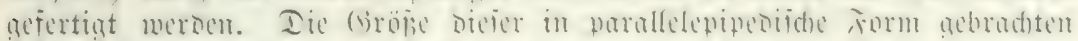

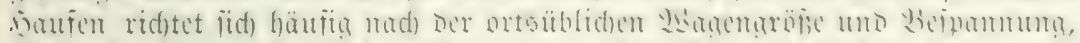

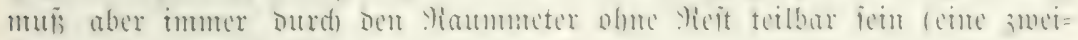

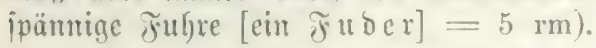

I

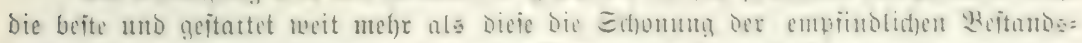

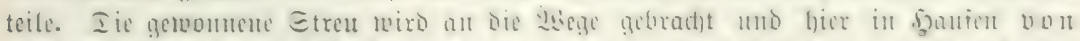

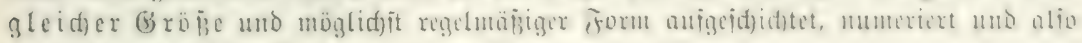

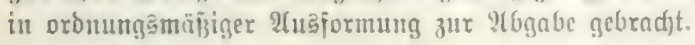

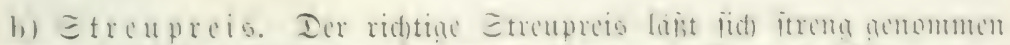

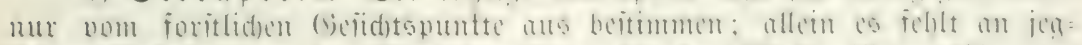

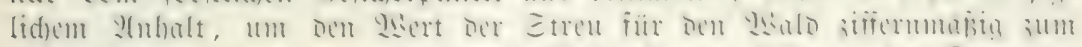

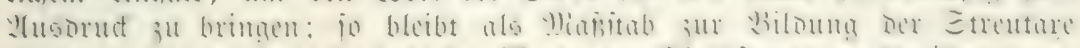

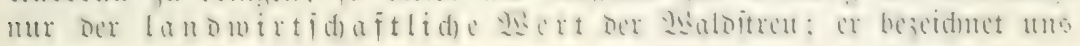

(5aทer, voritbenuถ̧ung. 9. 2tail. 


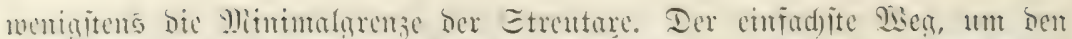
Lomowirtidafifliden

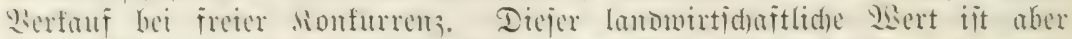

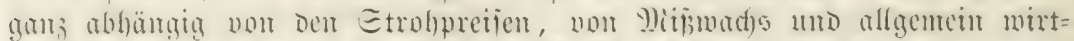

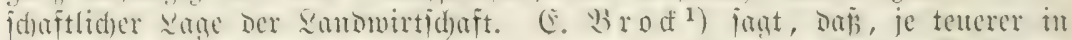

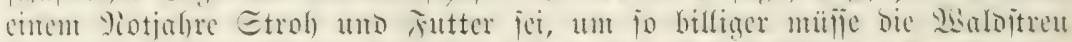

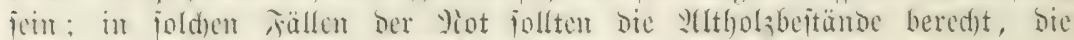

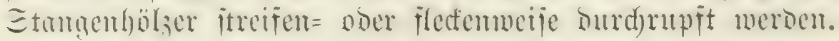

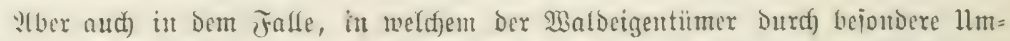

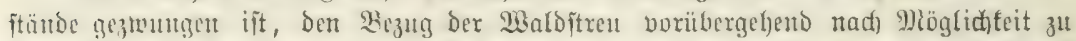

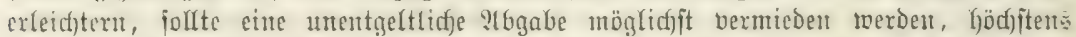
müren nad) llmítünen reduzierte Etreupreife ftatthait. Iicjen Etandpuntt

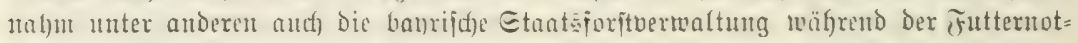
periobe $1893 / 94$ eitr.

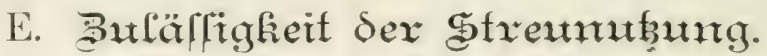

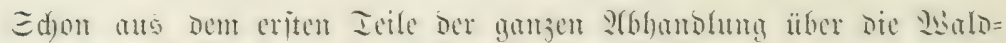

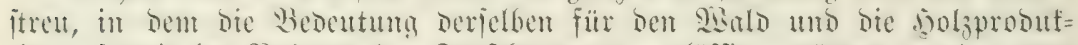
tion, fomeit im Rabmen ber joritbenubung äläfïin, erörtert murbe, mag

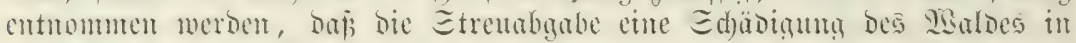

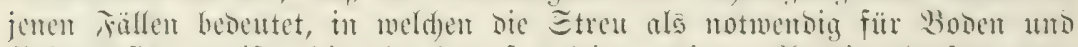

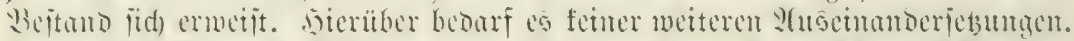

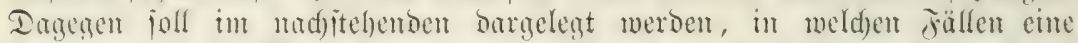

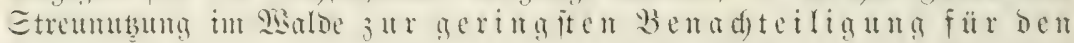

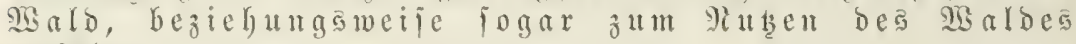
(mişd)lägt.

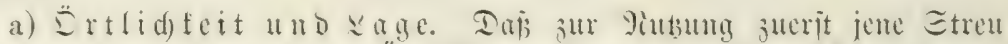
herangerogen wird, weldye in Ertlid)feiten lagert, wo fie gleidgülltig oder

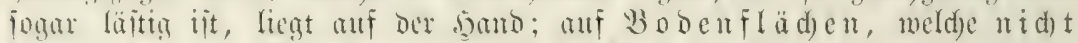

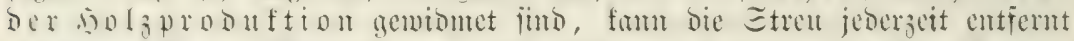

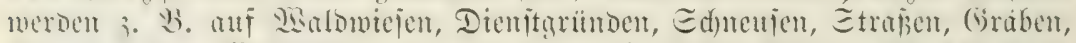

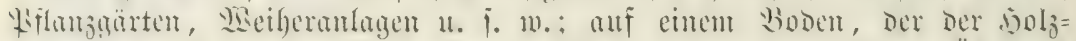

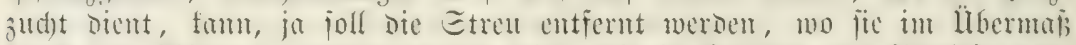

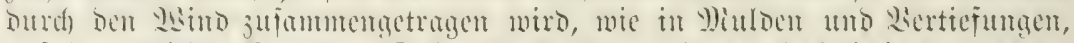

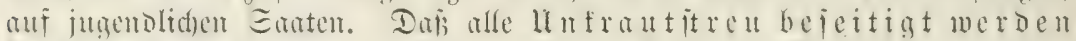

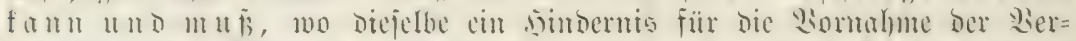

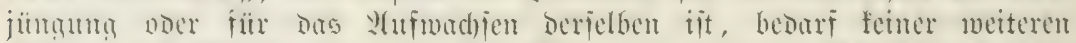

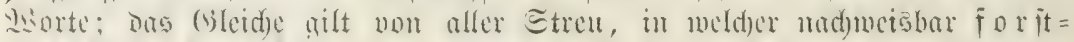

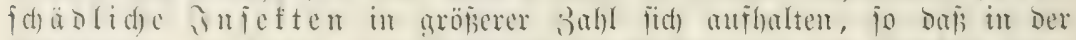

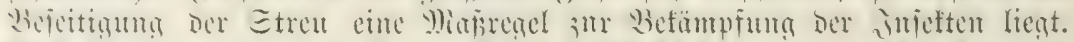

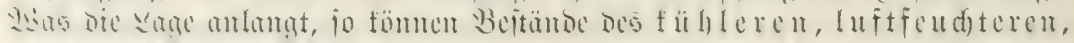

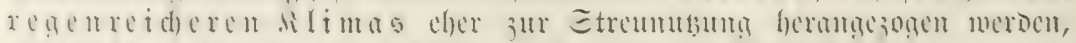

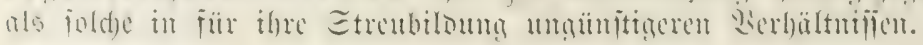

1) (E. Brodf, Der landwirtidjajtlidge Preiz 1894. 


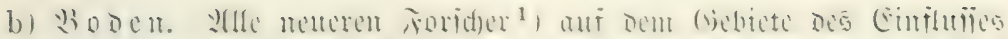

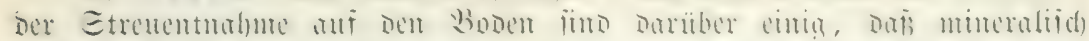

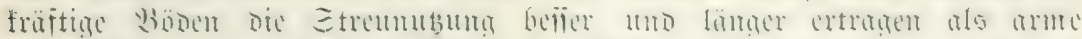

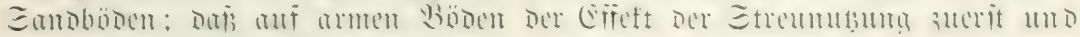
am ftärfiten fidf) fïl)lbar madje.

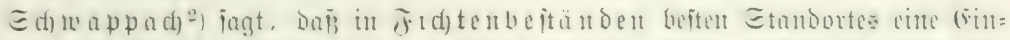

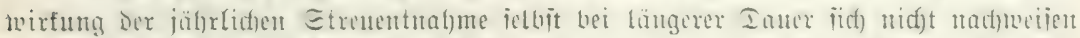

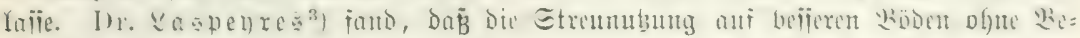

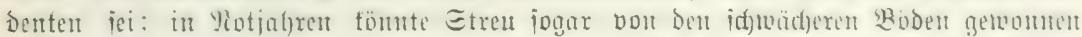

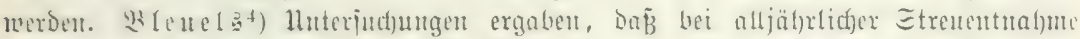

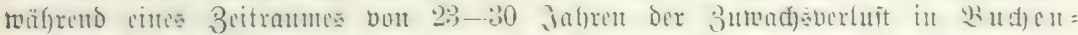

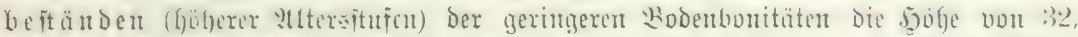

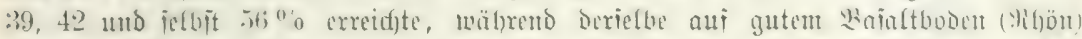

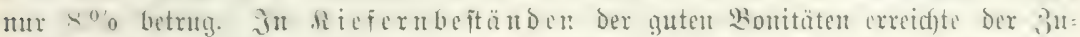

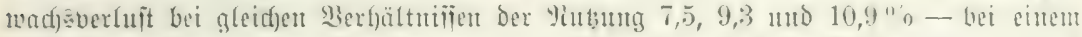

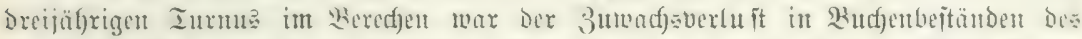

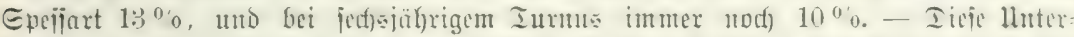

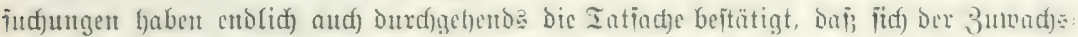

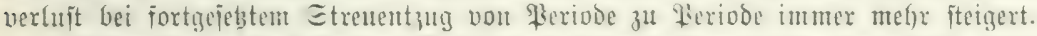

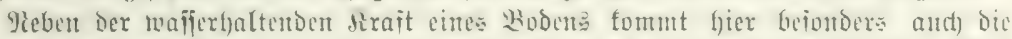

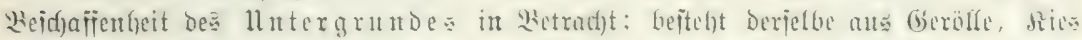

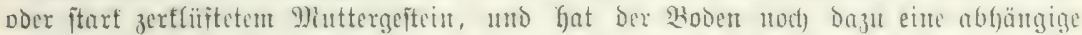

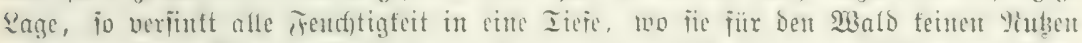

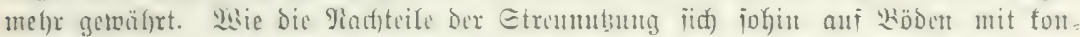

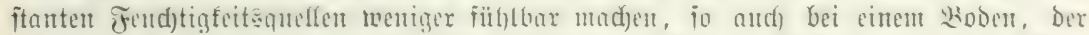

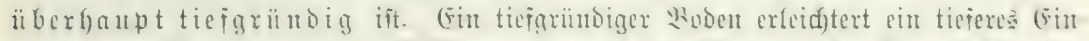

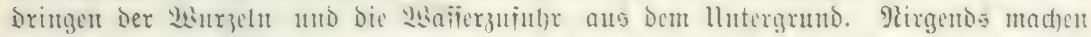

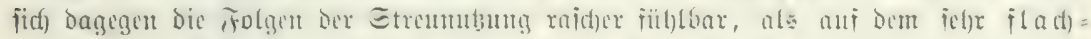

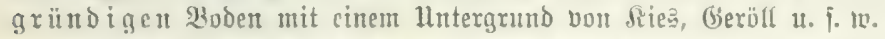

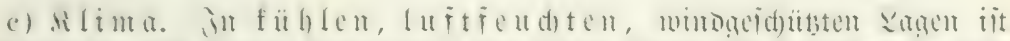

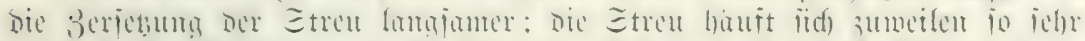

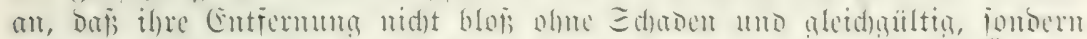

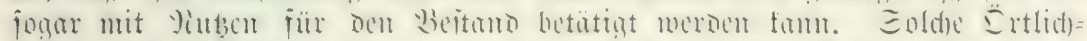

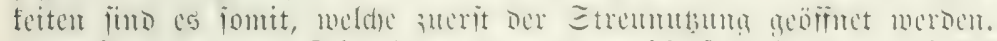

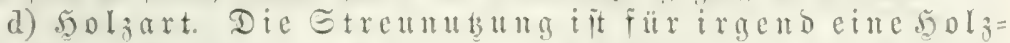
art um jo meniger uadeteig, je lod wertiger ber Gtand =

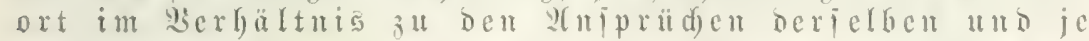

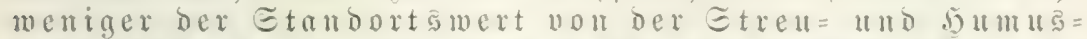

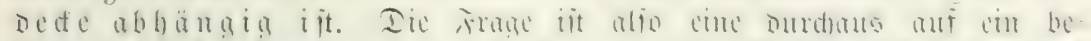

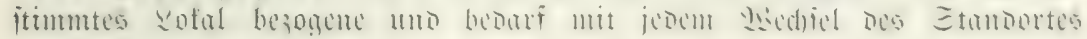
ciner wicberlyolten sojumg.

1) IR a ma $\|$ 1. c.

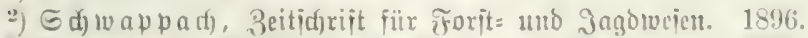

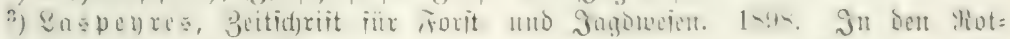
Gudjenbeittïnden แ. ๆ. เง. 1890.

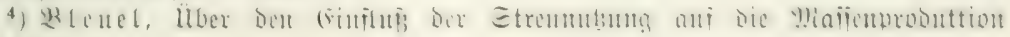

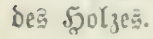




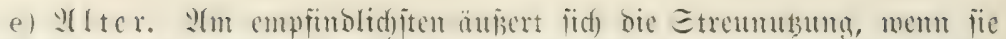

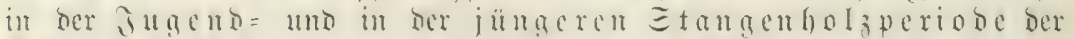

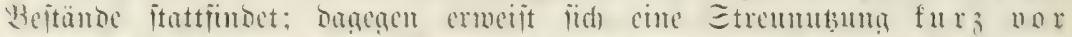

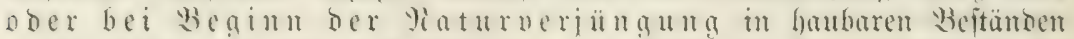

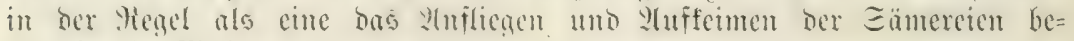
günitigende Mañregel.

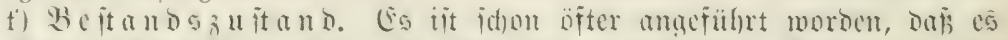

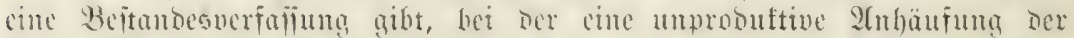

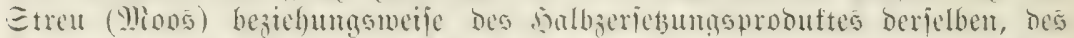

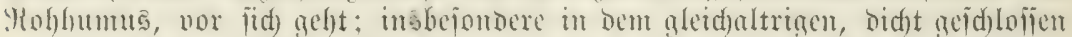

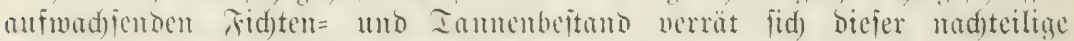

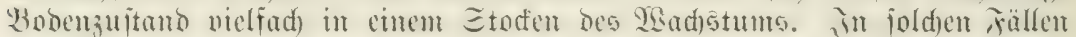

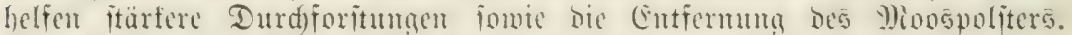

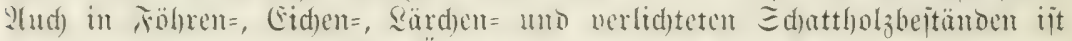

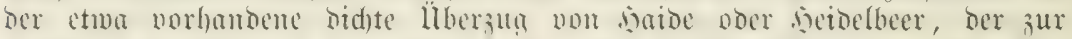

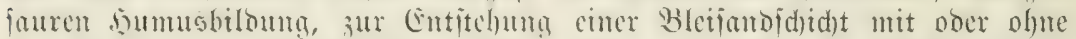

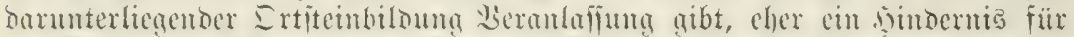

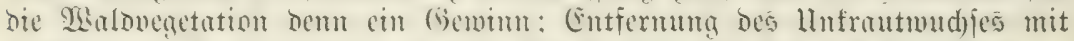

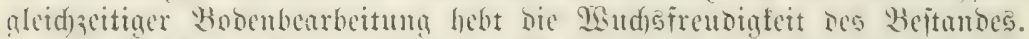

gr) Viu

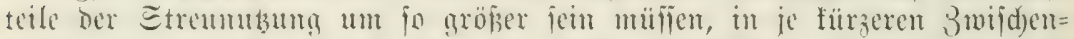

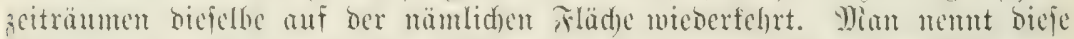

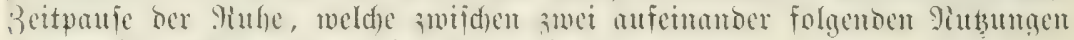

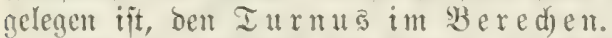

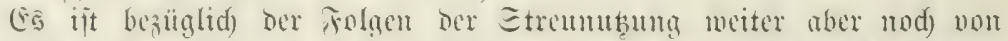

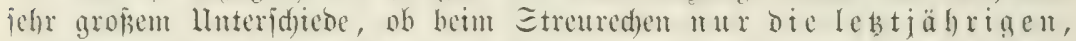
mod) unzerfezten Etreufdideten weggezogen werben, oder ob der

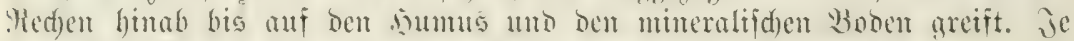

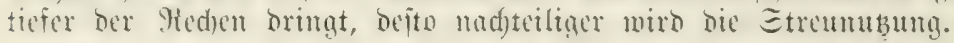

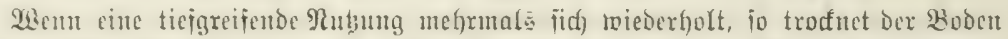

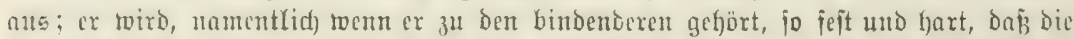

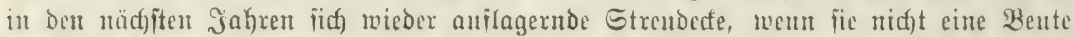

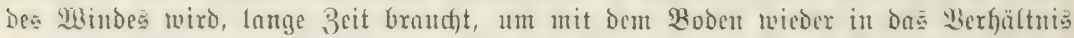

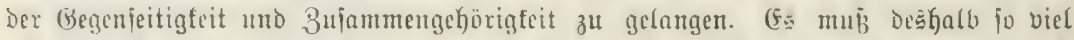
als möglich bafiut getrachtet werben, baj bei ber saubdedfe mur bie obere, tod)

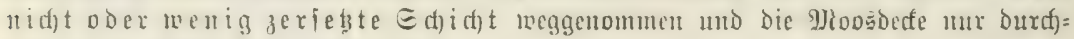
rupft oder plabweife abgezogen werde.

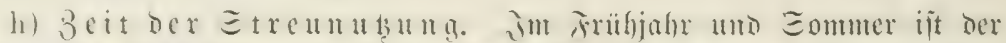

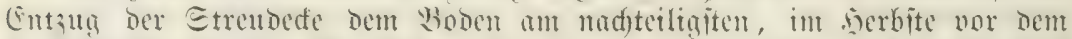

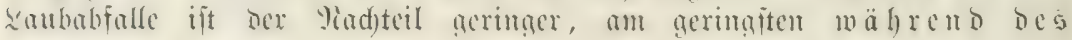
\&aแbabialle .

2airo turz vor bem Raubabfafle gerect)t, fo tif bie bercitz cin Jahr über alf bem

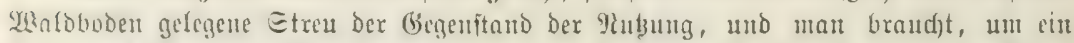
foitumtra Sunutum Etren zl gewiunen, von fold)er fdon jäbrigen alten Etrut immer mefor a

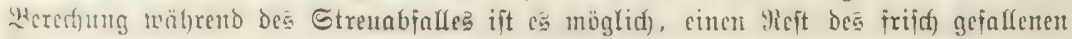
Bhattabivurfę dem Boden zu exhalten. 


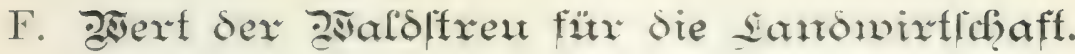

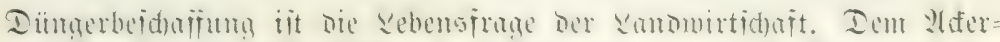

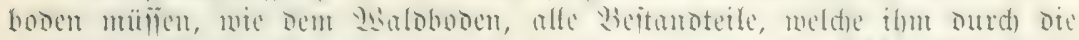

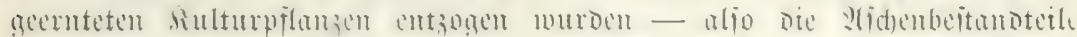

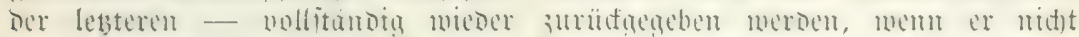

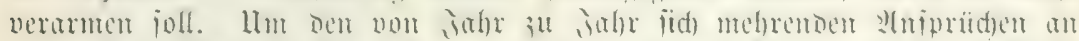

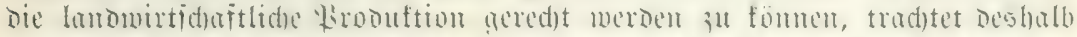

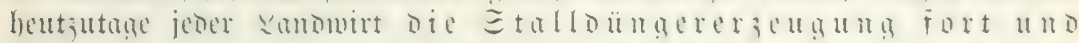
fort zu jteigern uno das nod) Feblende burd) fünjlide

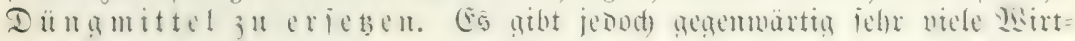

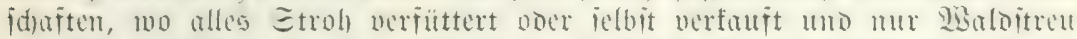

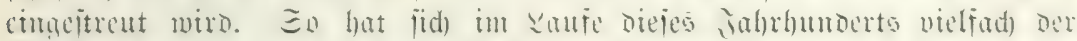

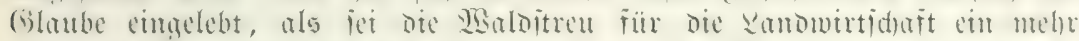

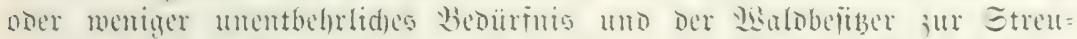

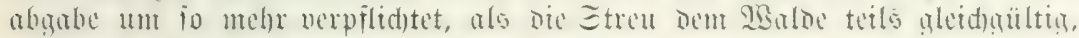
teils (als Injeftenbrutitätte!) pogar idjädlid) jei.

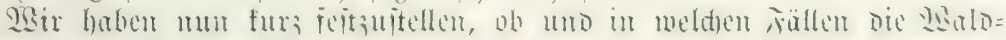
jtreu ein wirflide

1. Der Iandwirtida aftlid)

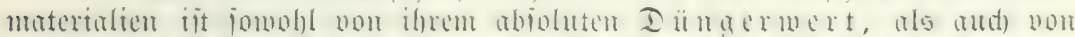

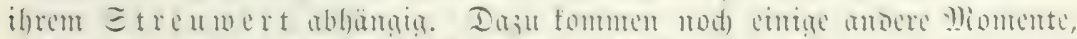

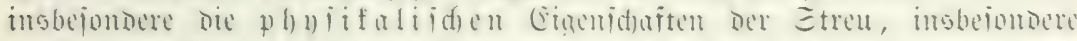
Die fräftige 2 ufloderung be Wobens.

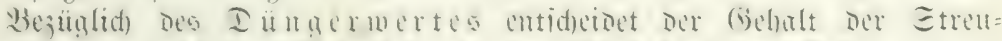

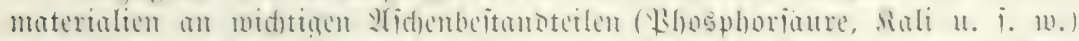

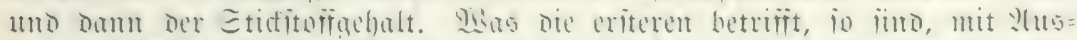

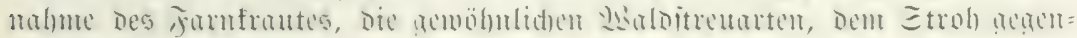
iiber, fefre arm.

Yadf) Den Hhteriud)urgen non

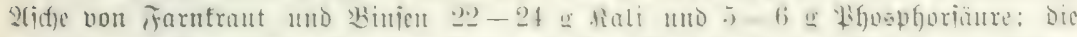

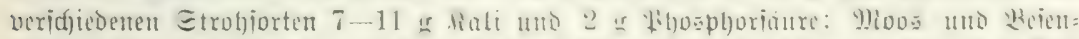

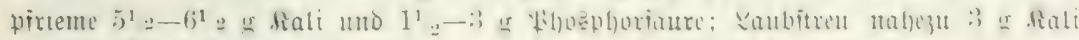

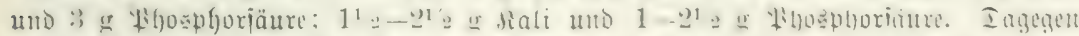

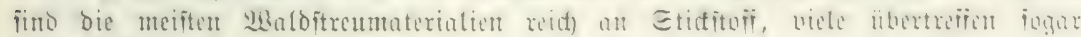
da⿱彐⿰冫⿰亅⿱丿丶丶 Etrof.

Der weit widjtigere sibertfaftor iit aber ber Etreumert, D. i. bie

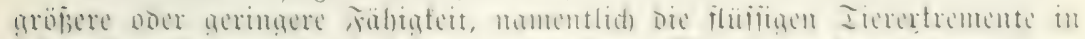

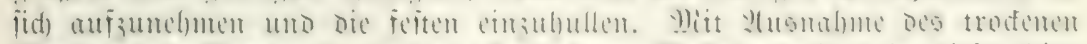

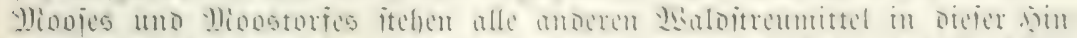

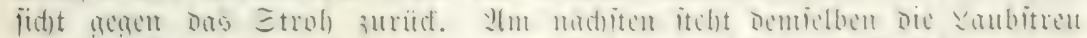

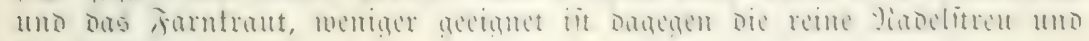
bie seide.

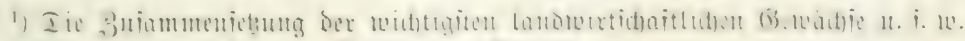

2) Tie gejamte Rebre der Walditreu. G. 109. 


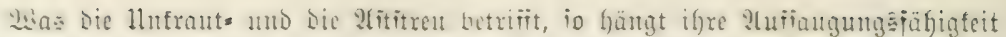

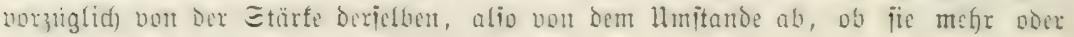
meniger gröbere oder jeinere Solzteile entfält.

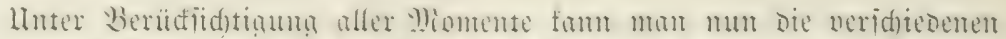

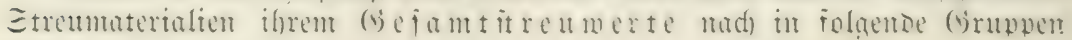
bringen:

e rite Girupe gloositreu, rein ober mit Mladeln gemijd,

zweite (G) rupe Getreidejtroh,

Dritte (3) r p pe Farmfrant,

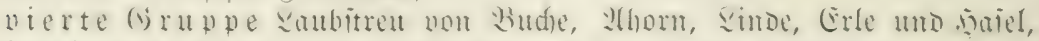
fï ied) it e (5) $x$ p pe unfraut= and atitreu.

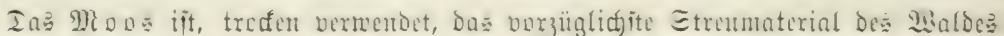

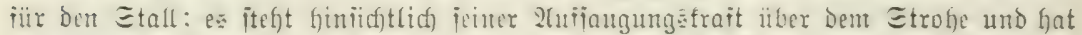

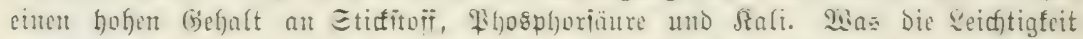

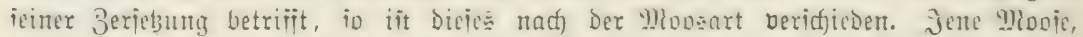

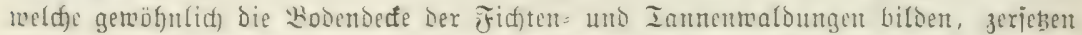

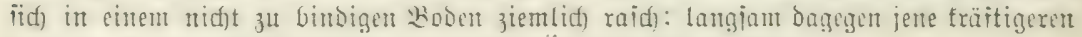

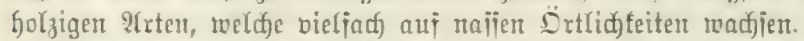

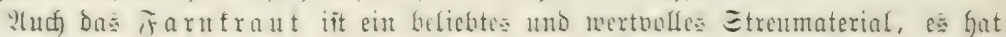

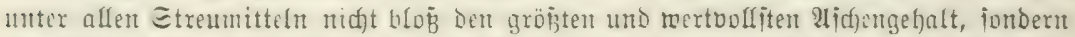
s: eriullt aud) Dic Frorderungen ber jautfeabiorption hinreidento gut, einen voll=

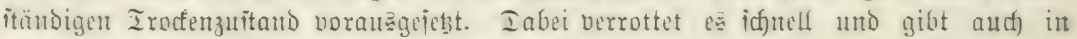
wentg bindendem Boben einen vorteilfaiten Sorferungsิ

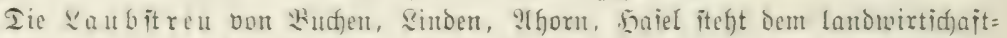
lidfen Wirte nach ber Etrohitren ziemlidf rahe; bei iffer Wormendung zur Iünger=

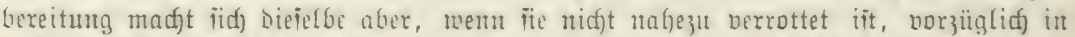

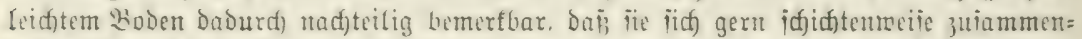

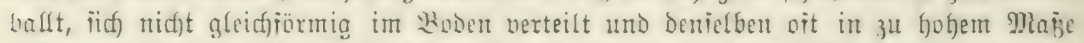

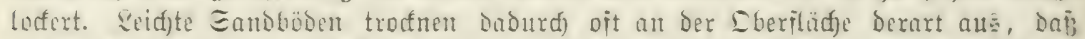
Das :aub mit bem Daranflebenden Iünger niót ielten ein Epiel ber Minde wiro.

Iic reine liabelitreu hat mu cinen geringen wert, ifr Iünger uno :luj=

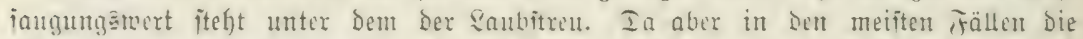

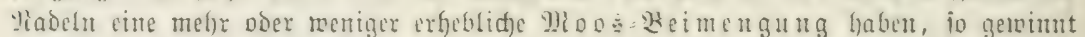
Daburd) Der wert Der Viabelitren in Der Jorm, wie fie gewifguliff bei Der Etreu= แutsung fait

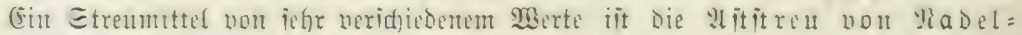

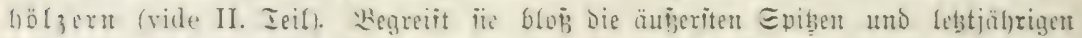

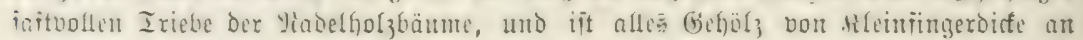

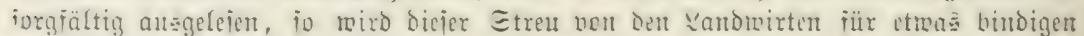
Whom in viclen Gegenben ein hoher Wiert beigelegt. Jim loferen Eanoboben, und wenn ïe jehr grobholzig î̃t, mag man fie nidjt.

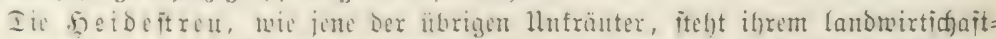
Lidjen Werte nad) anter Den vorhenanten Etruarten. Iod) medjelt berjelbe je nad)

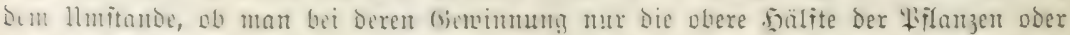

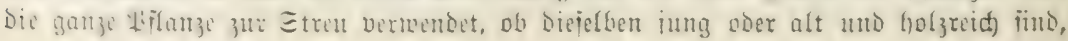




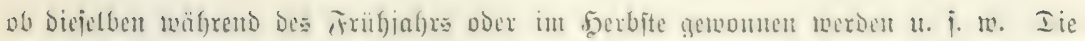

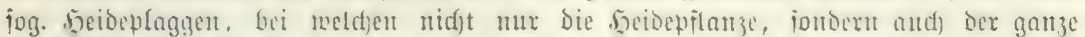

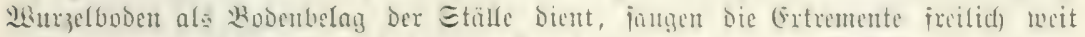

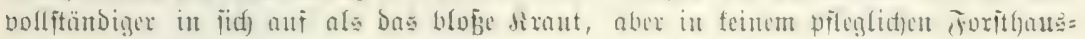
falte famt das \$laggenfanten geitattet werden.

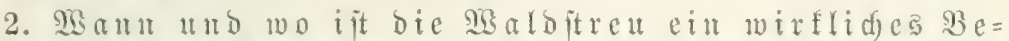

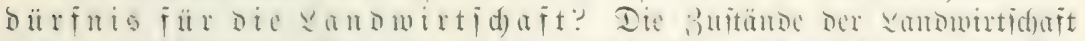

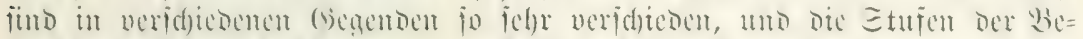

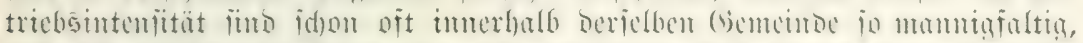

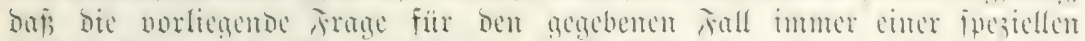

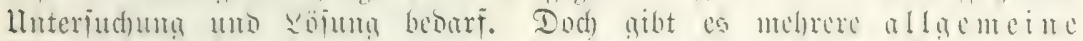

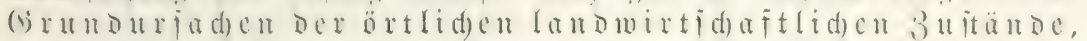

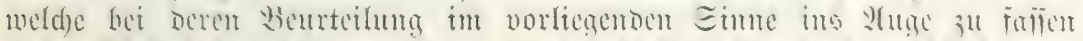

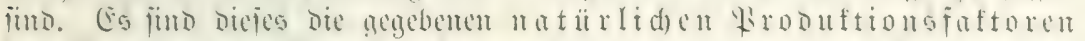

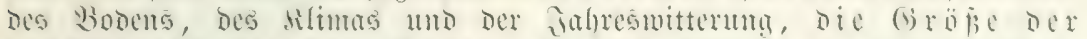

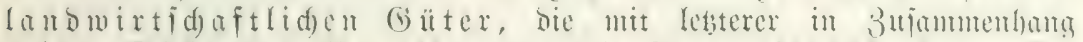

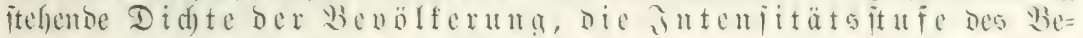

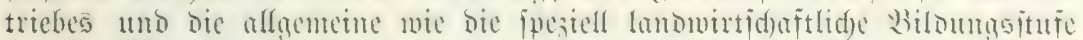

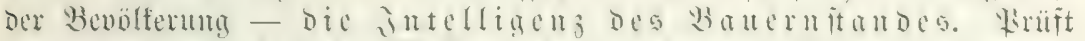

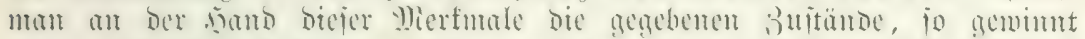

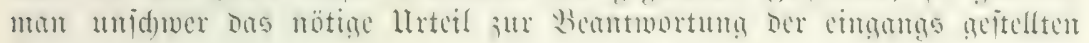
Frage.

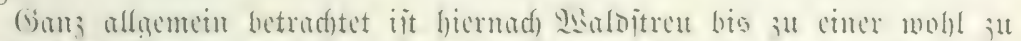

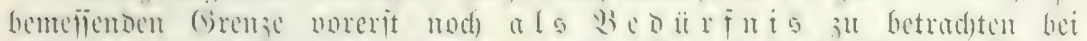

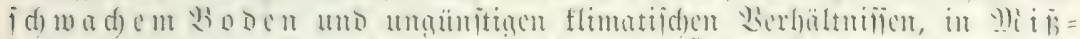

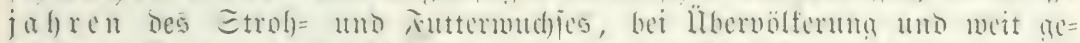

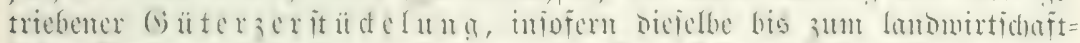

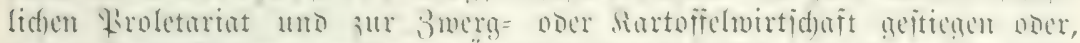

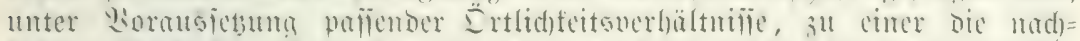

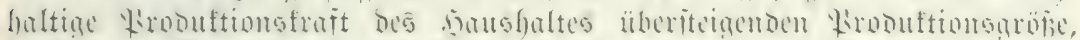

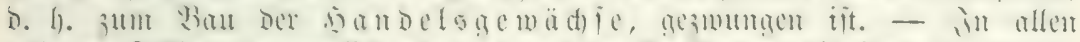

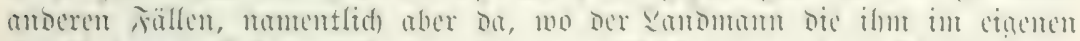

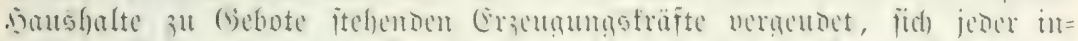

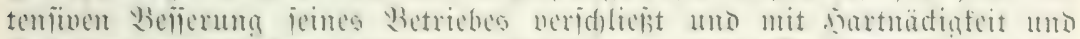

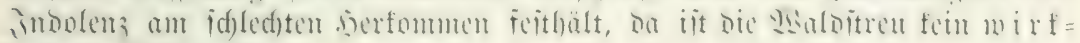

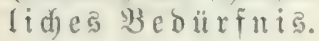




\section{Dierter 2lbijdnitt.}

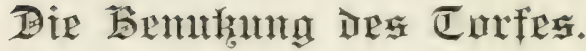

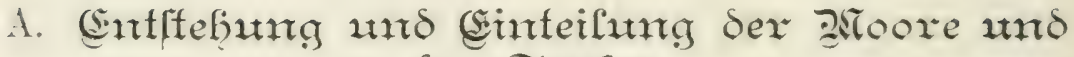 Ses Toxfes.}

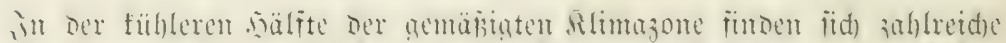

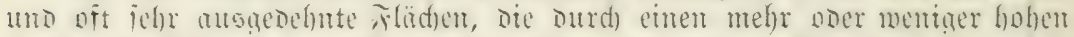

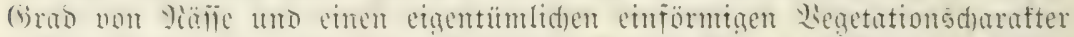

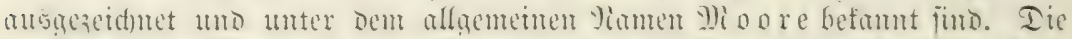

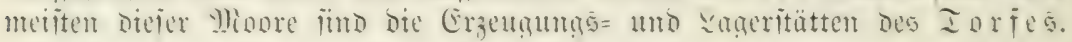

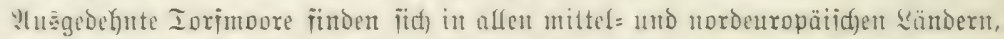

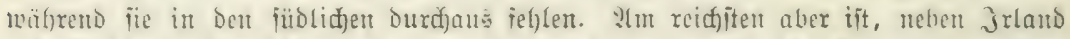

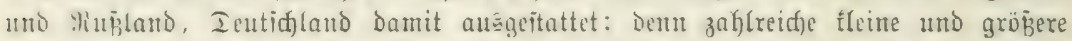

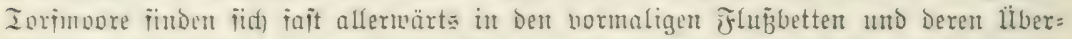

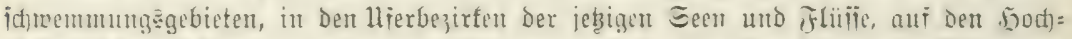

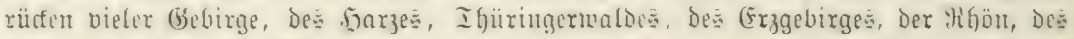

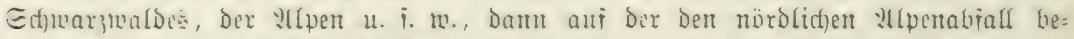

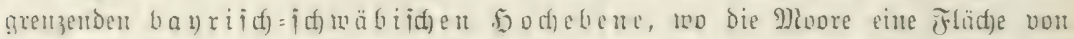

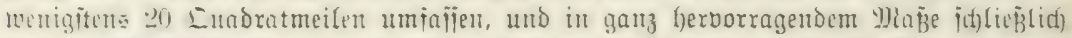

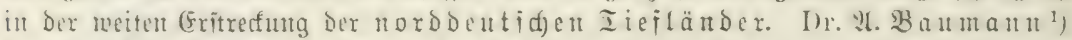

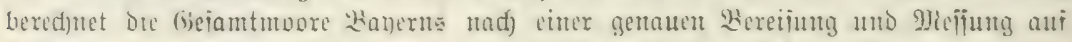

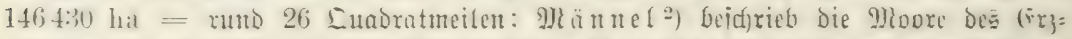

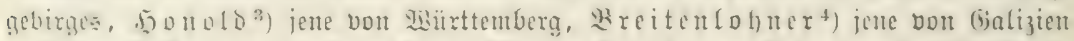

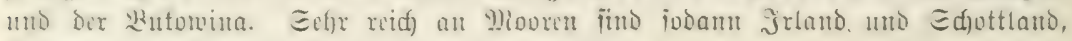
Dünemarf, Єđj)

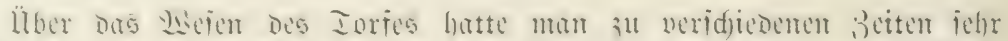

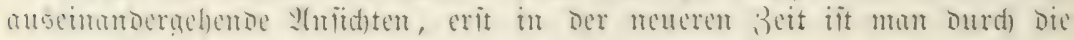

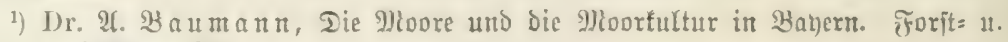
natitru. Beitid)r. 1897.

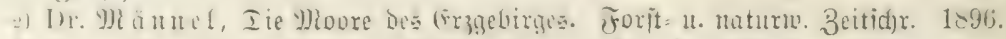

3) Sonold, Iie Torflager in Wüttemberg. 2tut bem Malde. 1900.

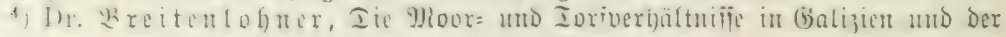
Butowina. Bentralbl. F. D. gẹ. Forịtwefert. 1875. 


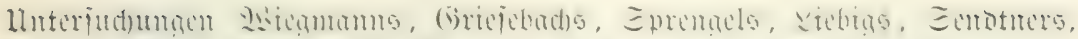

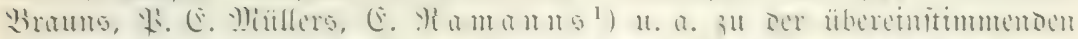

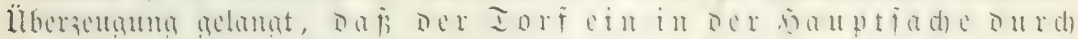

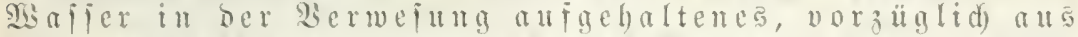

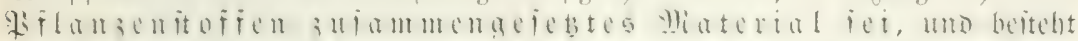

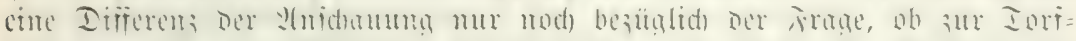

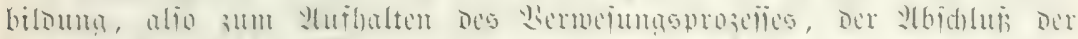

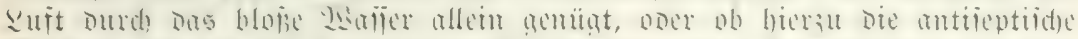

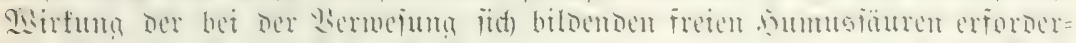

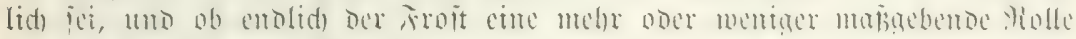
bei ber Iorfbildung ipielt ${ }^{2}$ ).

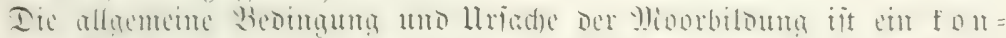

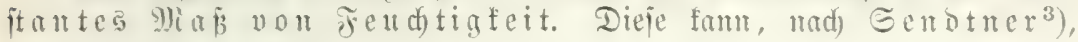
hervorgerufen werben:

a) burd) Smpermeabilität bes Bobens, mem die Gohle des

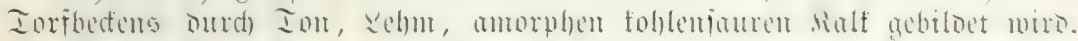

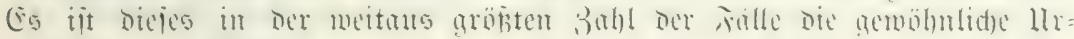
fade ber Torfbiloung;

b) Durd) Bermeabilität bes Bobens. Beiteht ber Boben aus

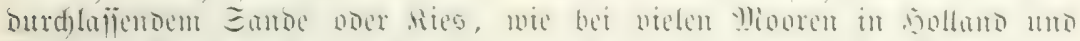

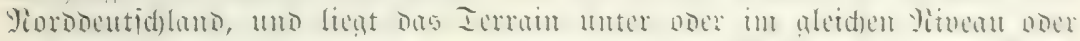

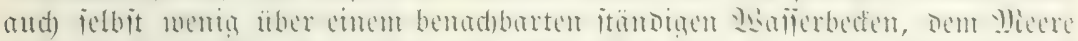

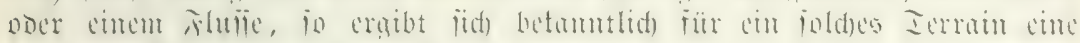
fonjtante Befeud)tuna burd) (Sirmomaifer;

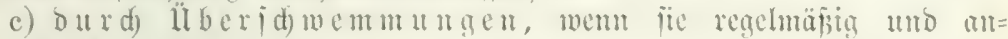
banerno jid) wiederholen;

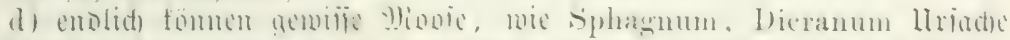

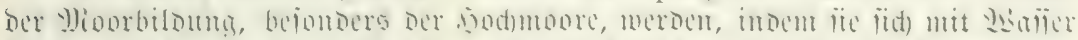

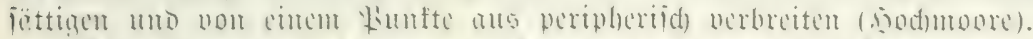

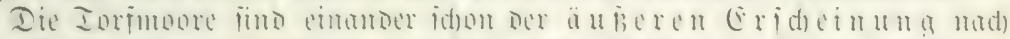

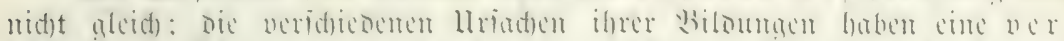

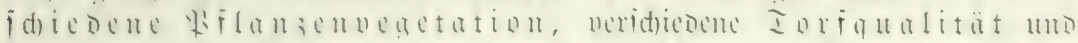

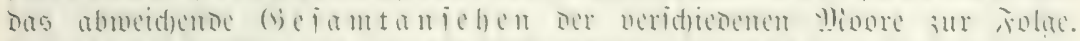

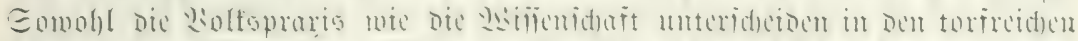

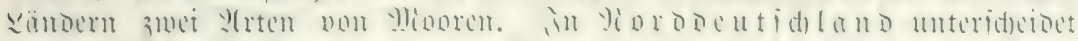

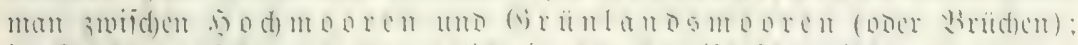
in E

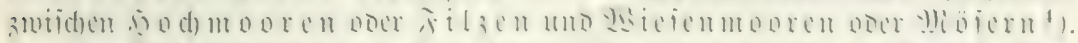

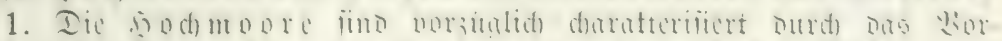

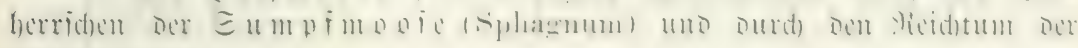

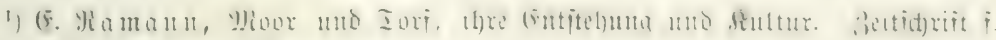
Torit $=$ u. Jagoweien. 1888.

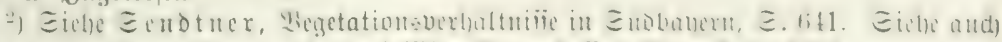

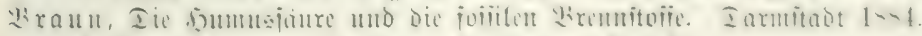

3) Megctationuerhältnifie in Eübbanern, G. 660.

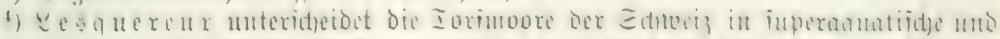

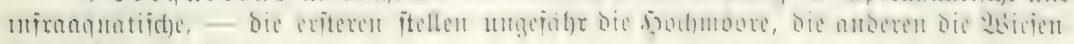
moore Dar (Eendturer). 


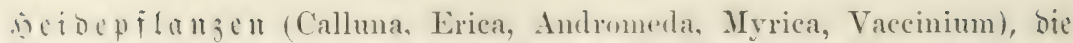

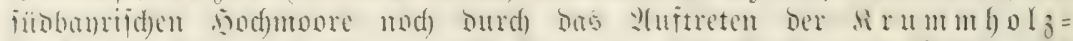

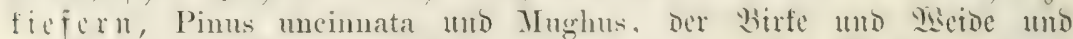

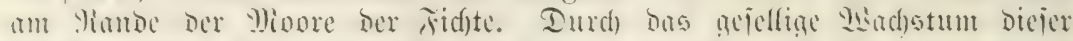

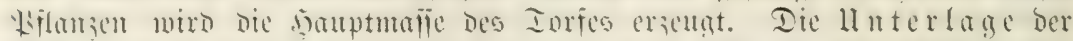

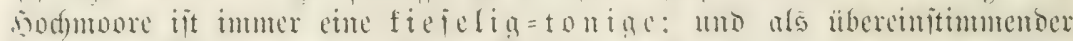

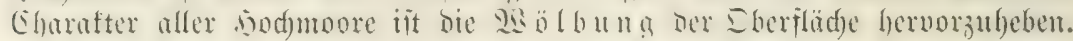

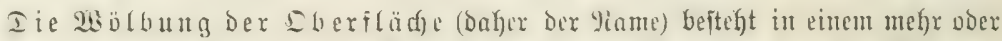

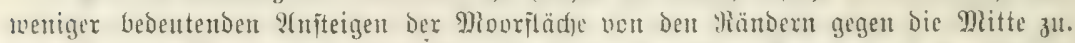
Sit ift bicie Woblonng unbebentend, vit iteigt fie aber auch) auf $6-7 \mathrm{~m}$ (wie im

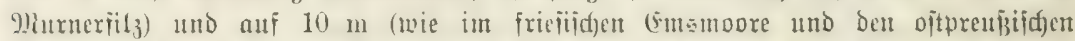

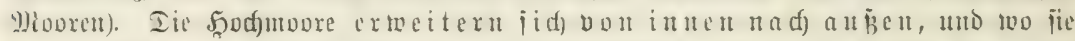

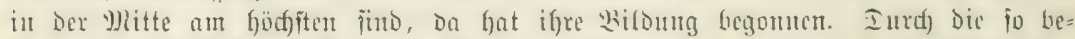

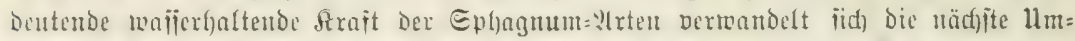

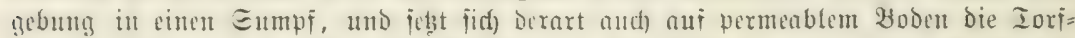

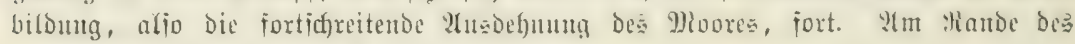
Şod)moores ifit bie grö̈̈te Feud)tigteitamenge.

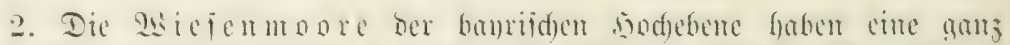

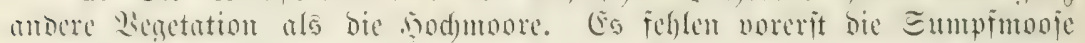

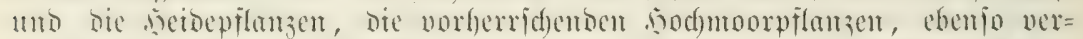

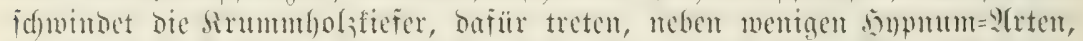

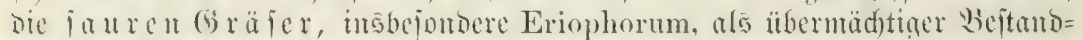

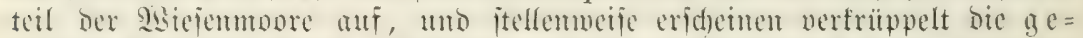

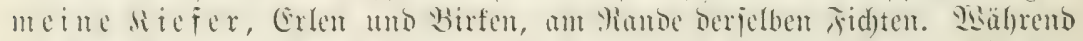

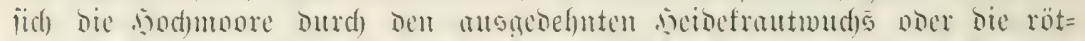

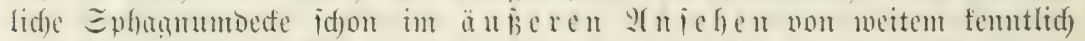

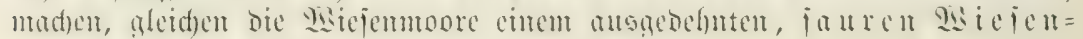

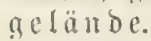

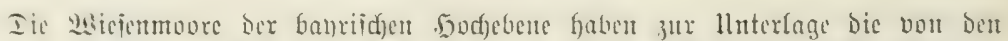

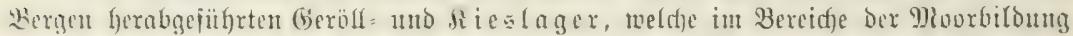
mit einer mrift mux jomad)en Rage von amorphem, fohleniaurem fialtiinter,

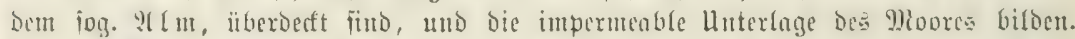

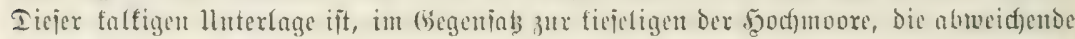

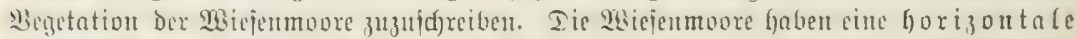

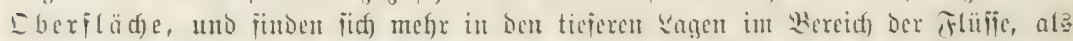

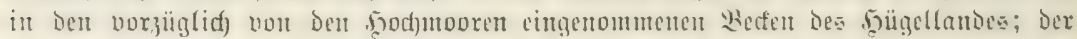

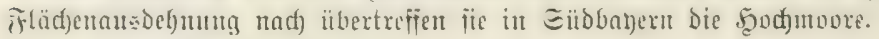

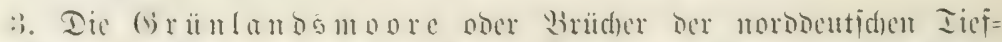

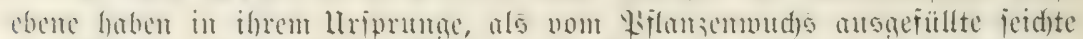

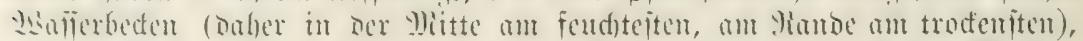

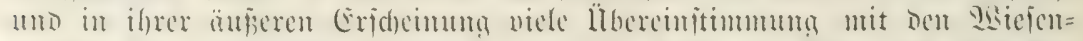

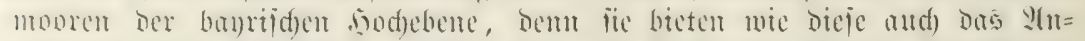

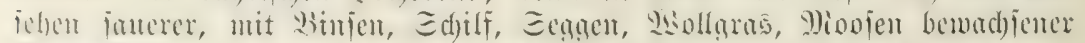

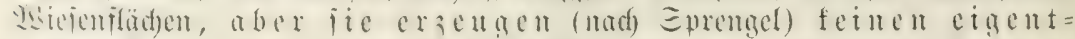

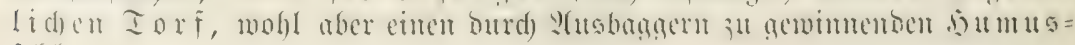
id) $l a m m$. 


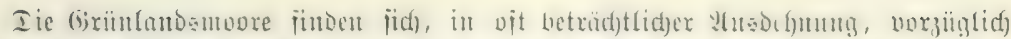

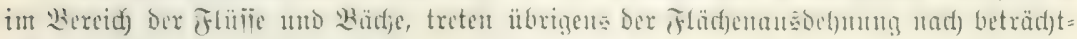

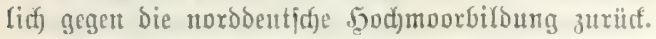

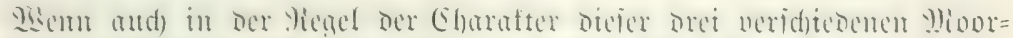

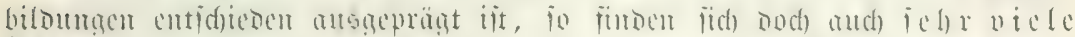
II ber

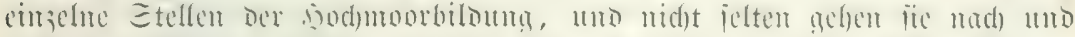

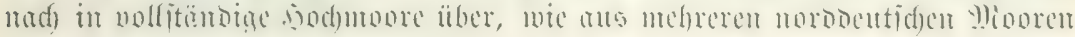
bervorgeht.

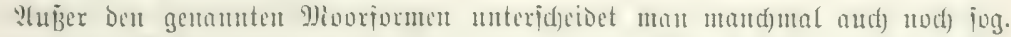

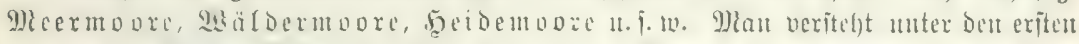

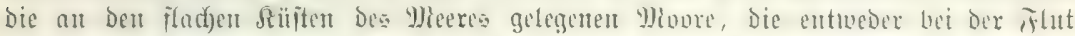

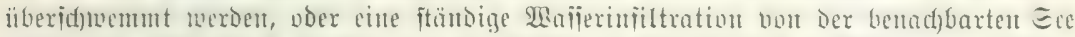

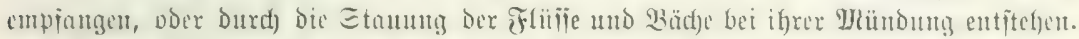

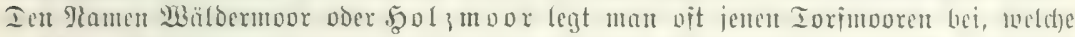

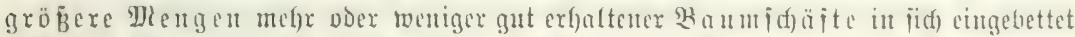

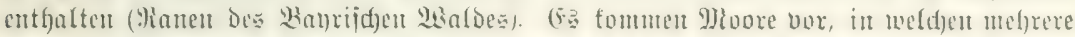
(bienerationen vun teils autred ftebendon $\Xi$ tö a

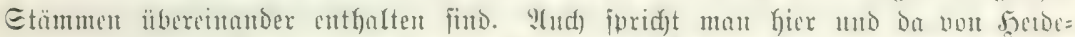

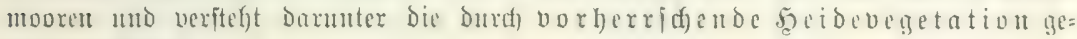
Gilocten 9) Thore.

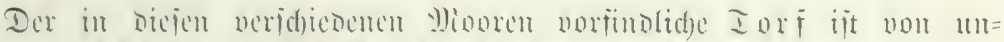

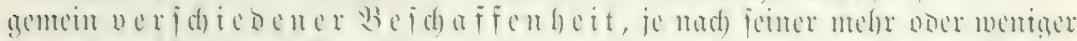

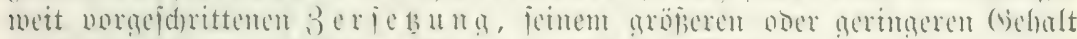
an .

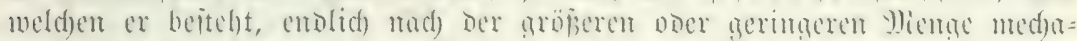

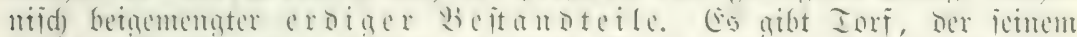

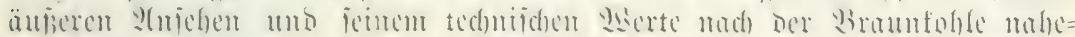

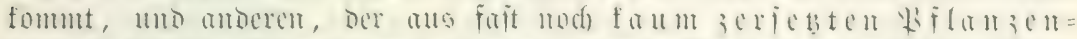

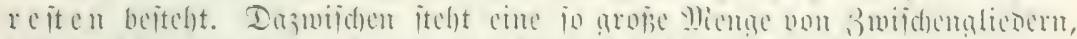

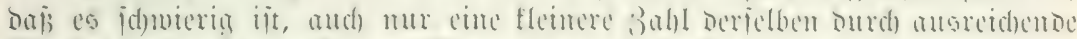

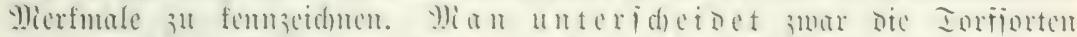

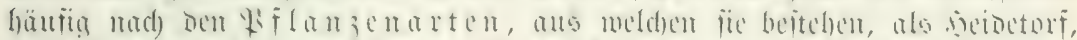

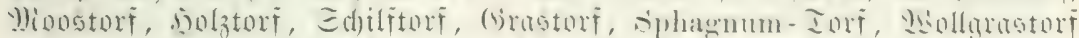

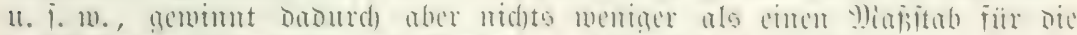

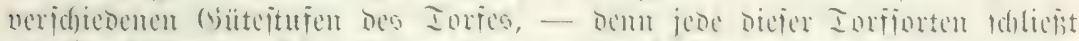

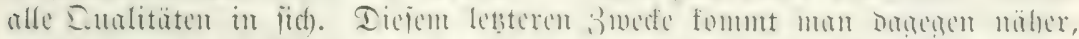
ment man Das עia

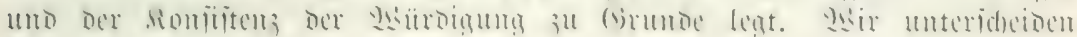
loiermad):

1. I ¿

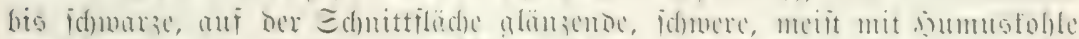

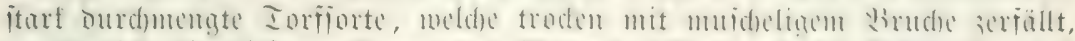

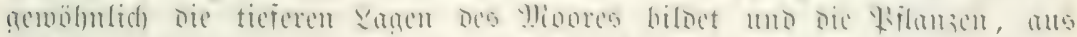
weldjen ex entitand, faum nod) erfemen läjt.

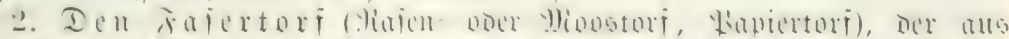

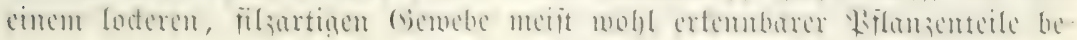


(tel)t uro Dound) Mionstorf (Hypnetum, Sphagnetum), seidetorf (Ericetum), Litejutorf (Eriophoretum), 三efilftori (Arundinetum), bortgrastorf (Cari-

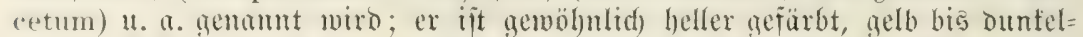

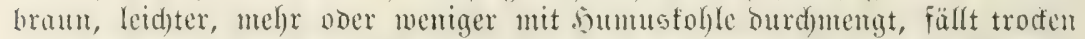

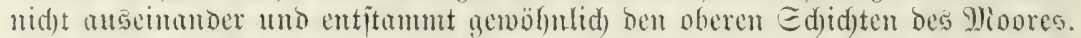

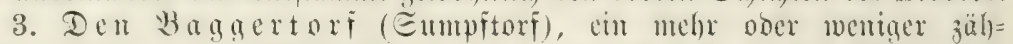

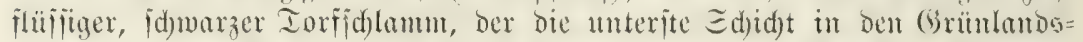

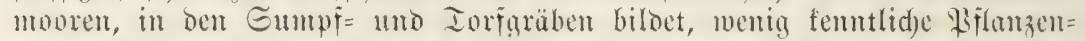
teile entl)ält, trocten fid) Durd) bejonderen (Blanz uno Sd)were autszeidjuet

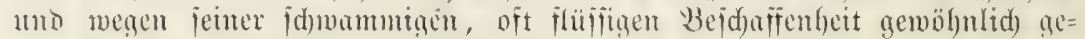
fdöpft uno anf veridjebene Meife geformt wiro.

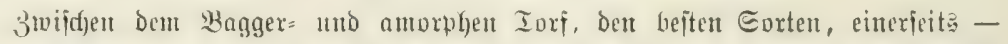

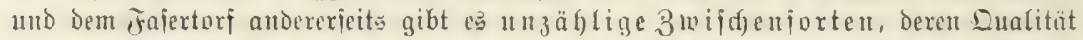

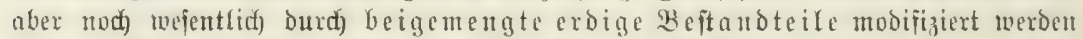

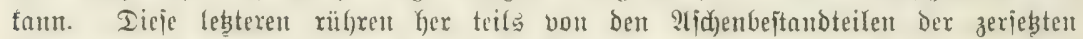

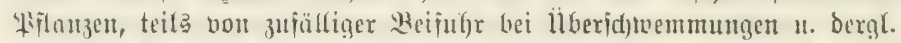

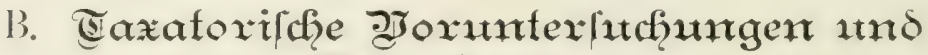 Betriebsplart.}

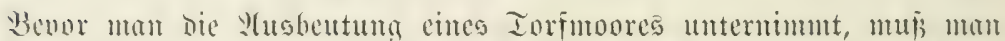

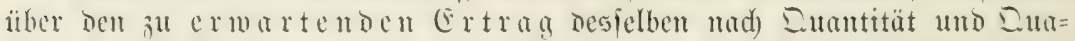
litüt mit binteid)ender Eidferbeit unterrid)tet fein, Damit man benefien fann, ob nad)

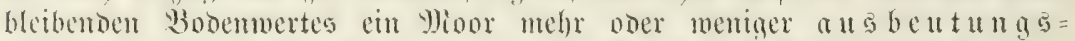

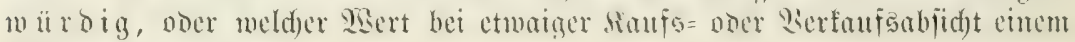
Moore beizuleger jei.

\section{1. (Q) antitüt.}

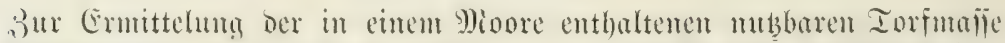

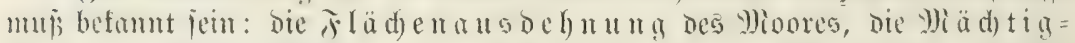

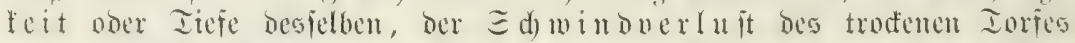

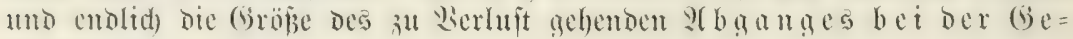
wi in $\pi$ un $\pi$.

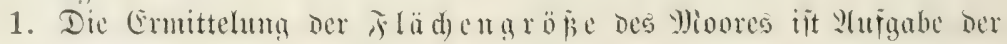
\$lanimetrie.

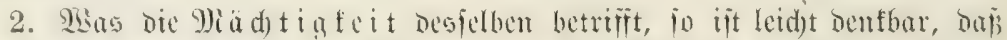

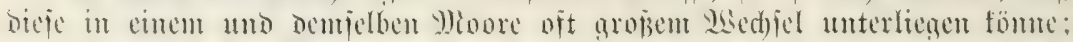

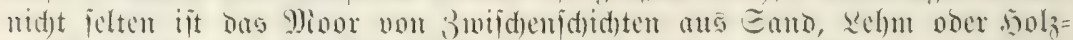

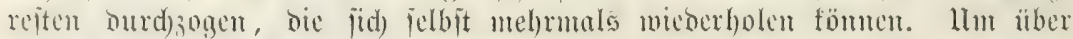

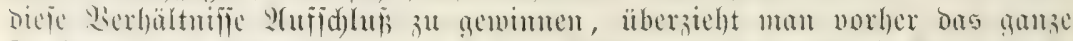

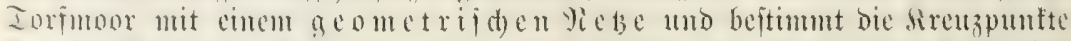

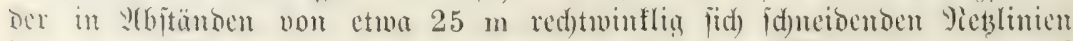

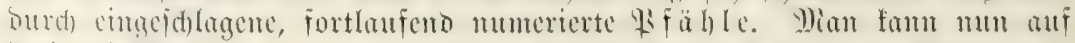

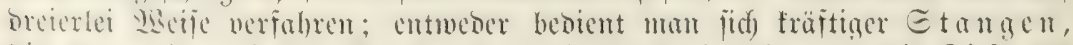

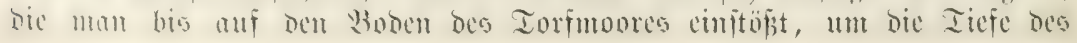




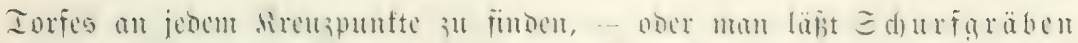

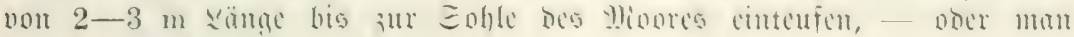
benust ben Iorfoolyer.

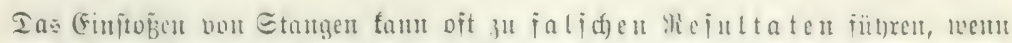

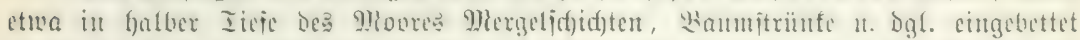

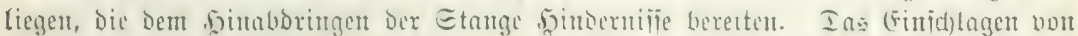

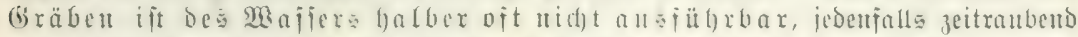

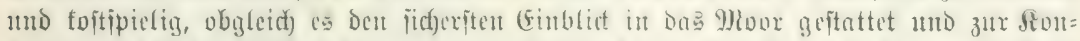

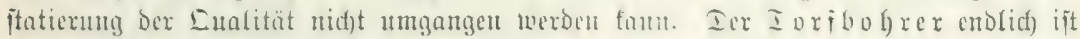

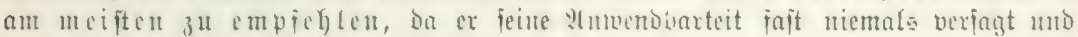

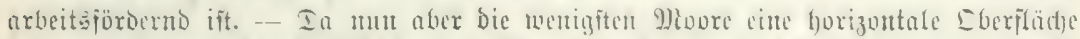

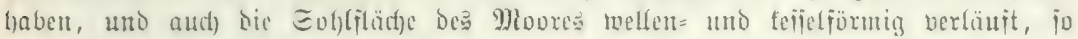

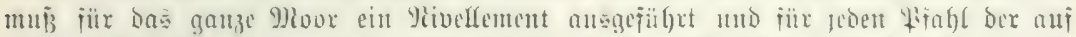

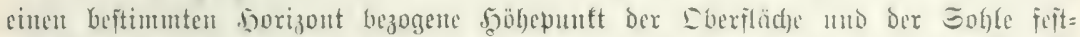

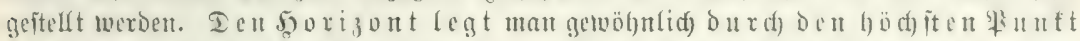

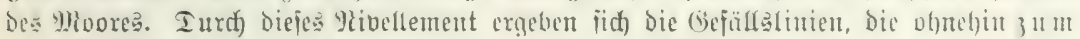
3 toefe ber entrö̈fierung exmittelt werocn milifen.

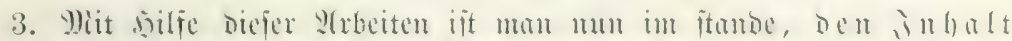

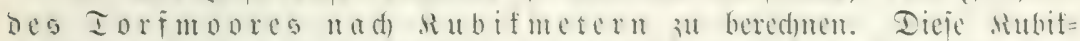

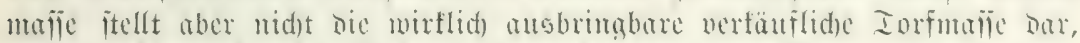

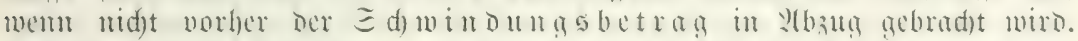

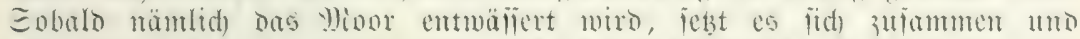

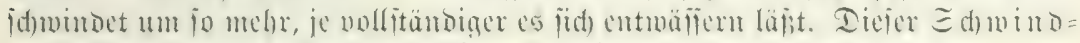
verluit muß burd) \$roben bepimmt merben.

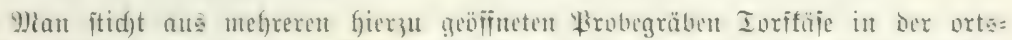

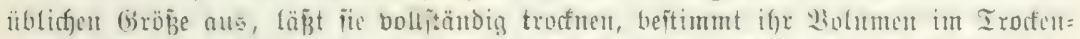

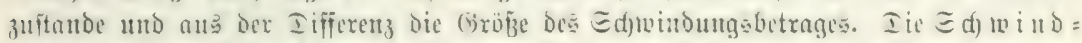

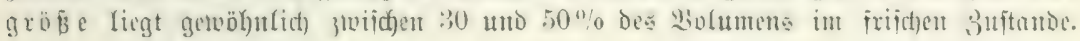

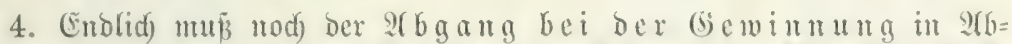

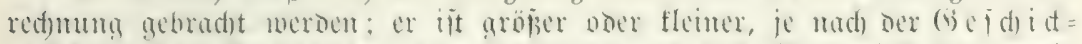

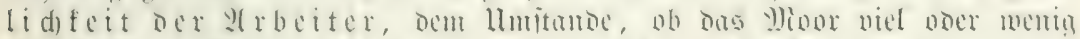

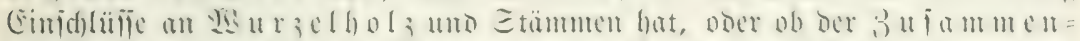

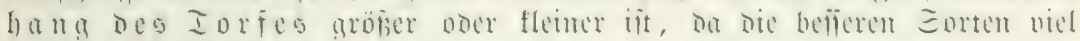
leid)ter zerbrödelu alढ bex geringere frajertorf.

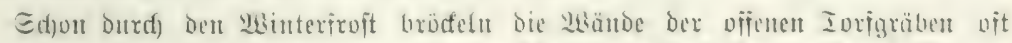

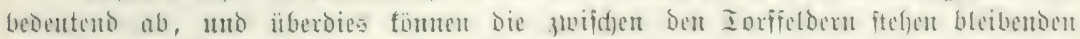

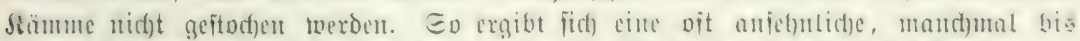

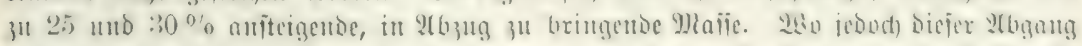

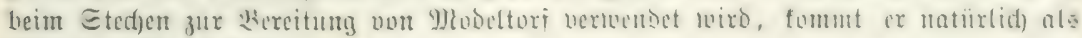
Berlujt nidjt in Med)nung.

\section{2. (Nualitït.}

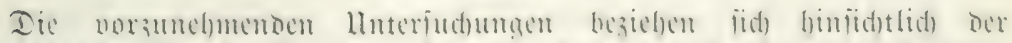

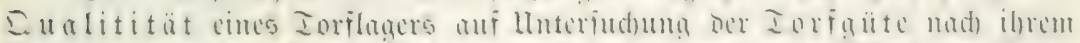

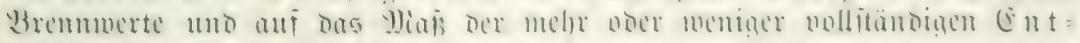

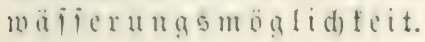




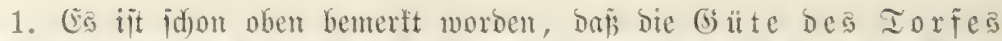

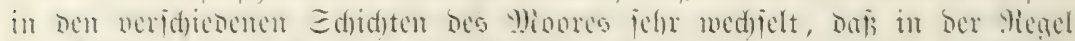

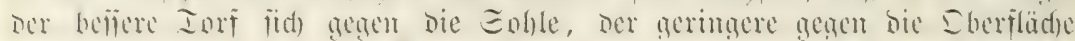

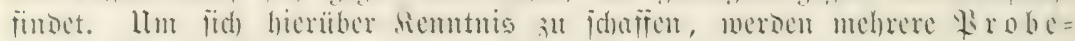

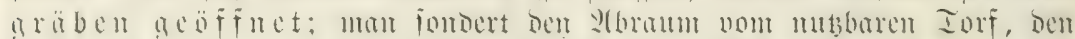

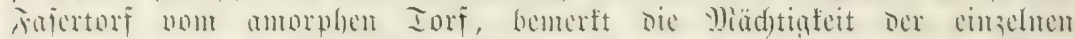

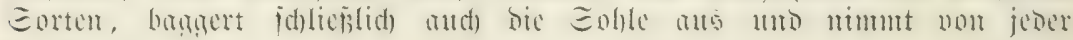
Eorte cine Brobe.

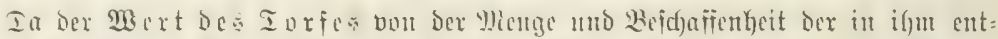
baltenen bremburen Etofie abhängt und un io gröjer ift, je geringer jein Majier=

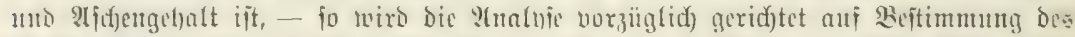

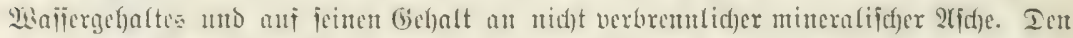

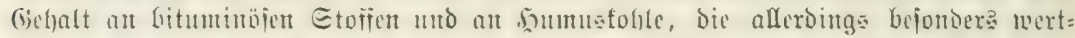

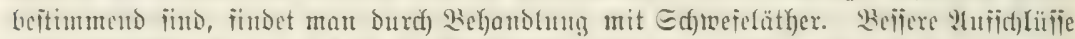

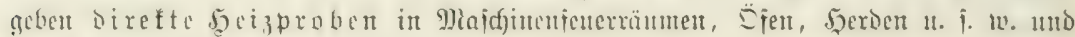
Bergleidye mit befannten Iorijorten.

2. Dex Lisert eime Iorflagers ijt aber meiter nod) Durd bie (Ent= wäjielu

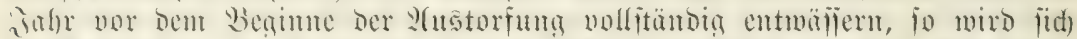

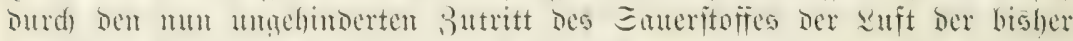

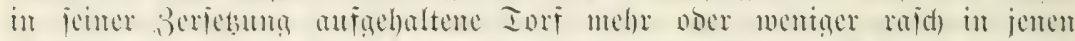

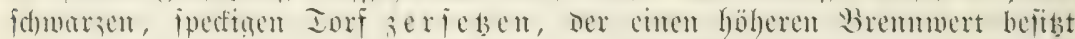
als Der habierjebte. Damit veremigt fid) Der meitere Gemim, Daj; Der an

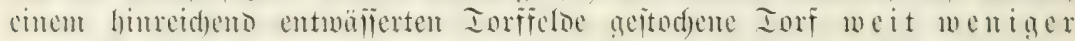
brö atelt alo in entgegengejersten falle.

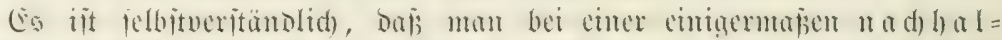

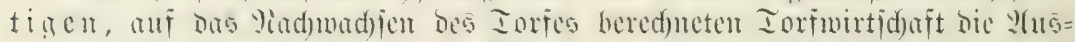

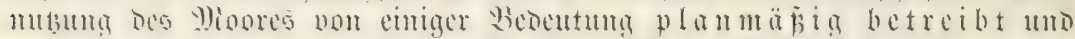

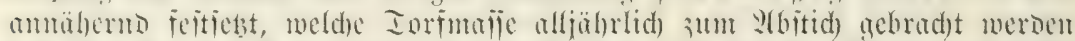

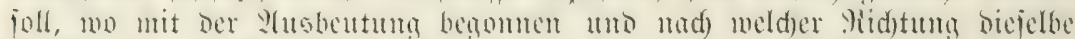

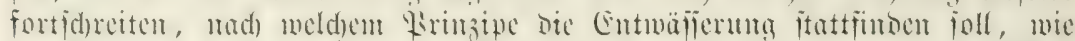
Dic

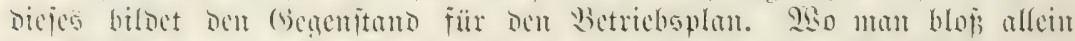

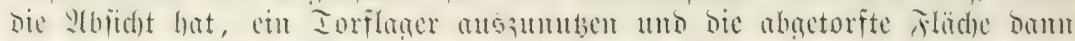

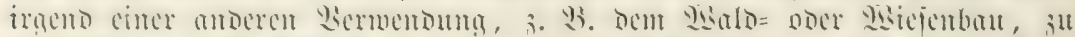

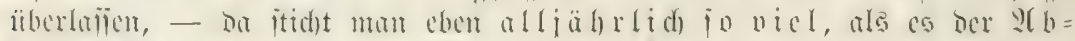

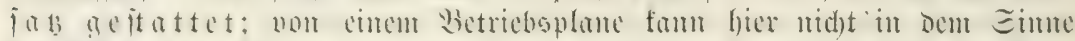

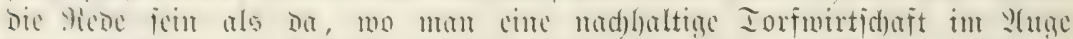

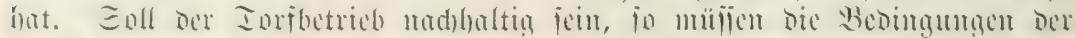

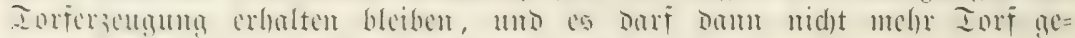

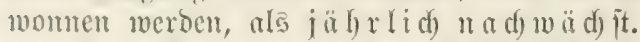

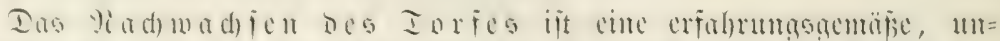

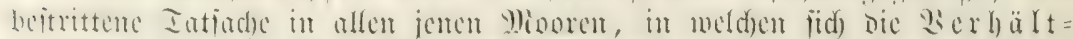

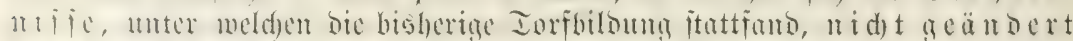

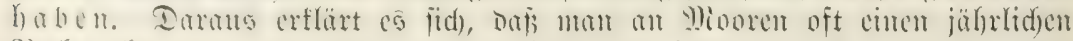

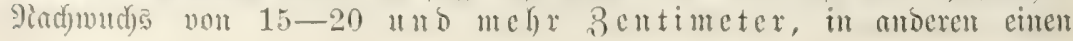




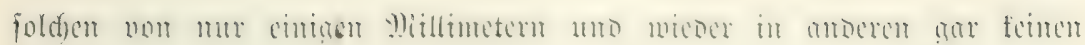
findet ${ }^{1}$ ).

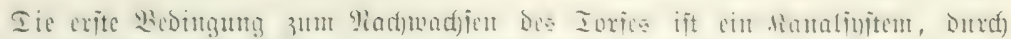

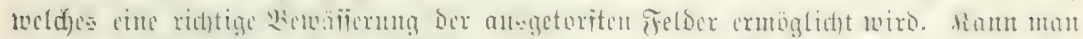

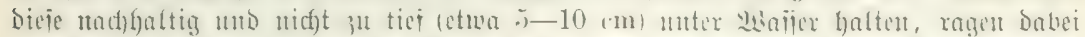

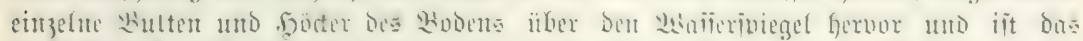

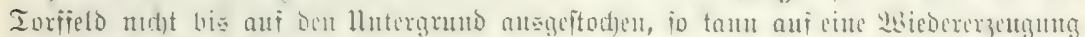

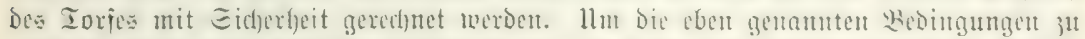

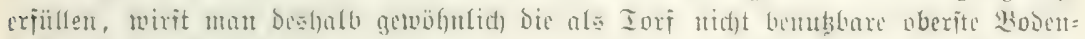

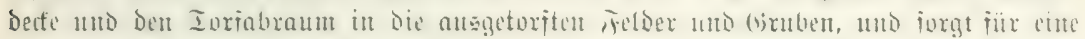
aušreidjende Majieriiberjtaung.

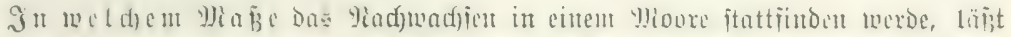

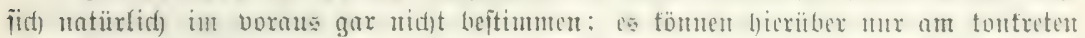

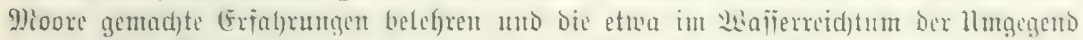

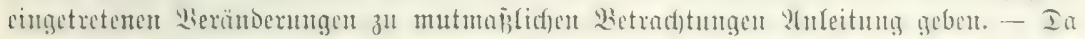

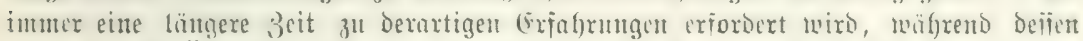

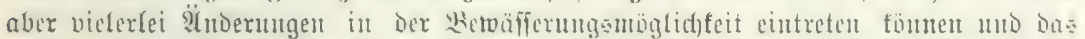

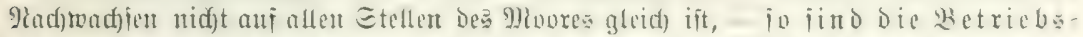

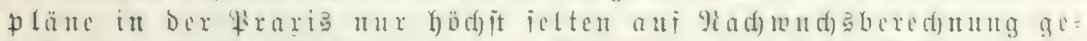

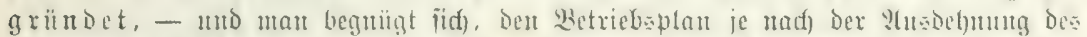

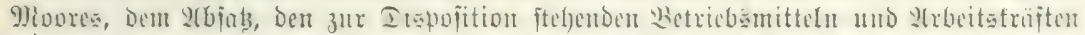

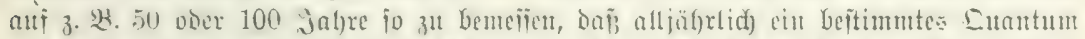

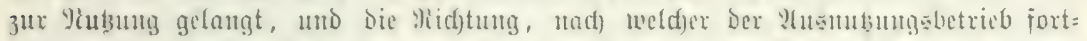

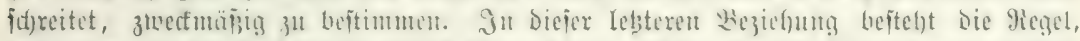

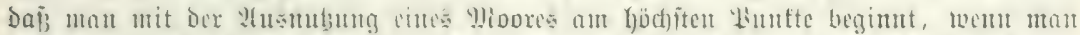

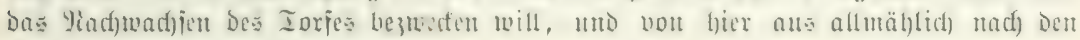
tiefer gelegenten Srten voridareitet.

\section{Eirtmölleratrag Ser Torfmoore.}

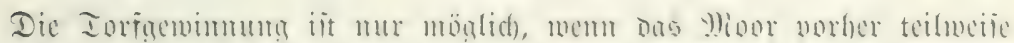

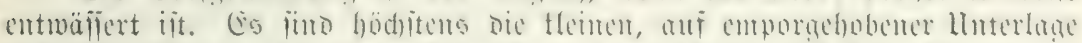

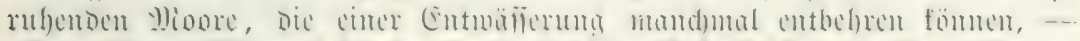

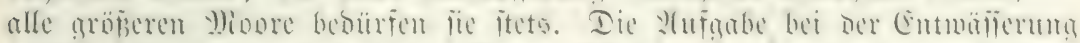

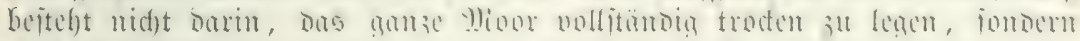
es bambelt fidf mu barum, jencu Icil bes 9)iopres, ber gerabe $\{u x$ :

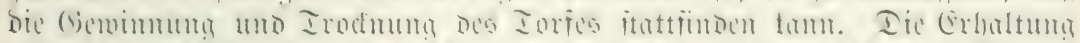

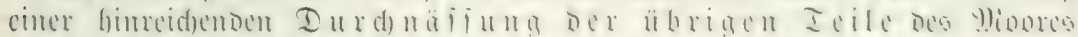

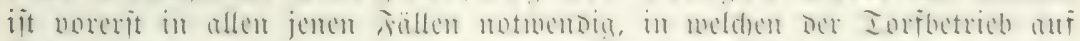

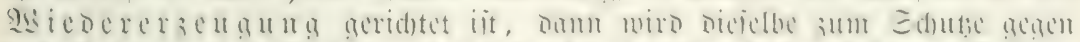

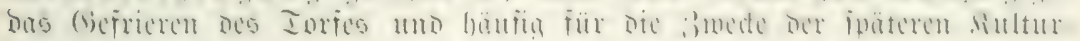
berubung bet abgetorften släd) criorberlid).

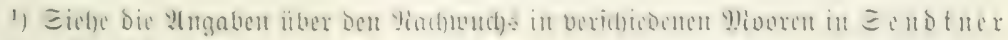
a. a. D. E. 616 . 


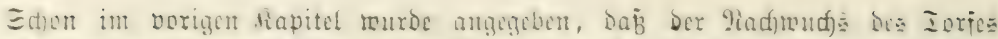

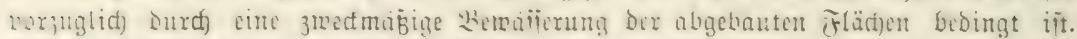

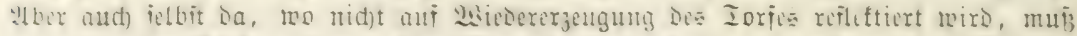
man bic tm llbbau liegenden meorteile nub Iorigraben über winter

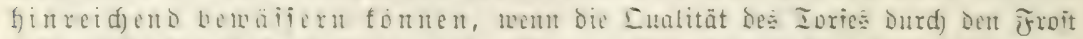

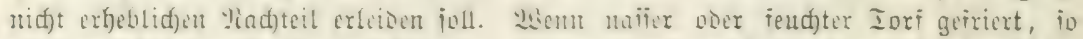

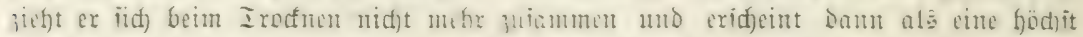

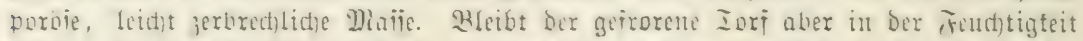

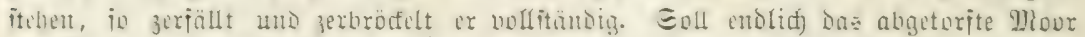

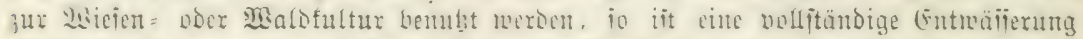

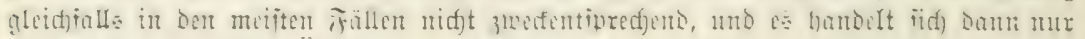
Darum, den wirflicfen ü̈berflü zu entiernen.

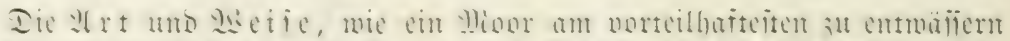

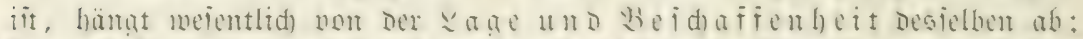

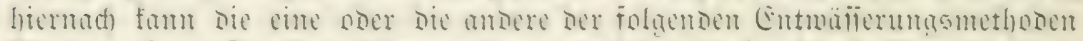

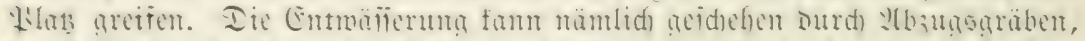

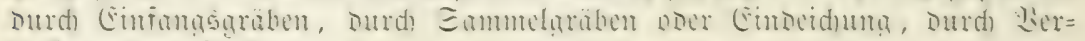
jenfung des gisajers.

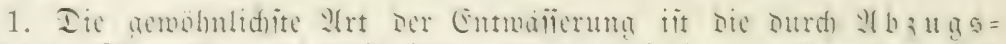

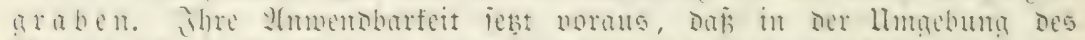

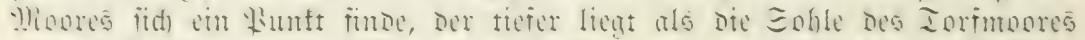

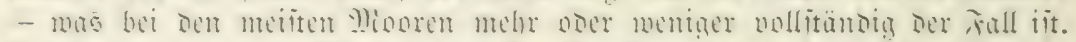

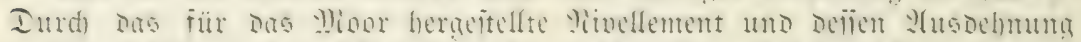

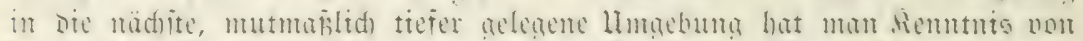

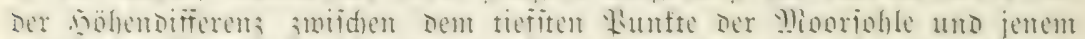

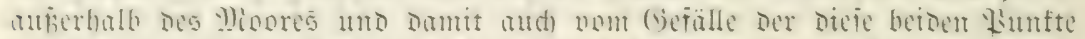

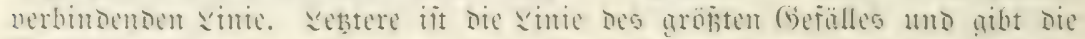

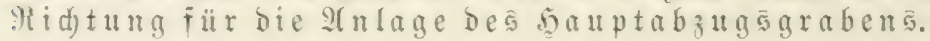

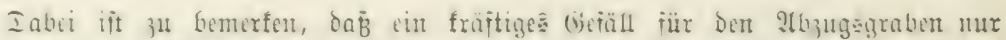

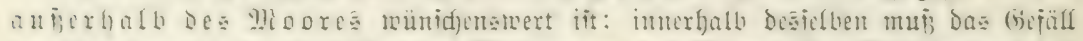

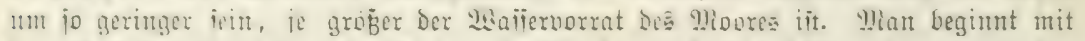

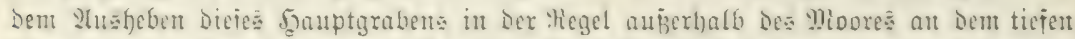

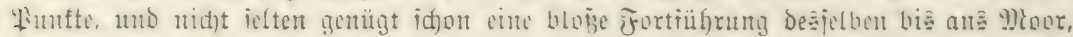

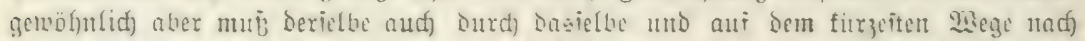

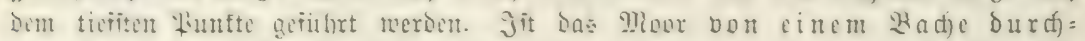

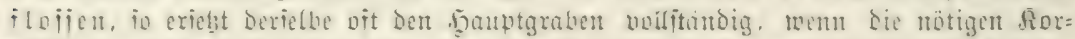

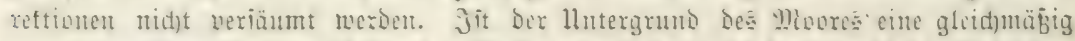

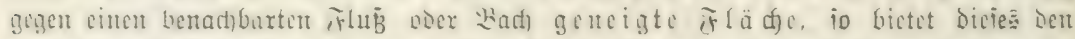

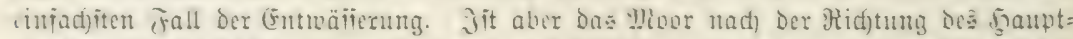

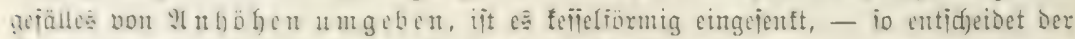

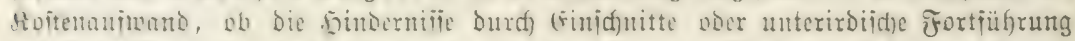

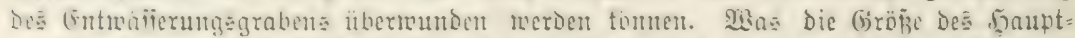

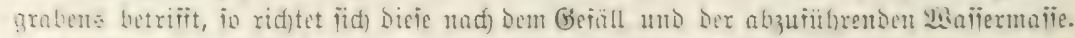

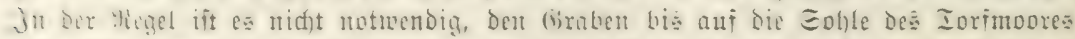

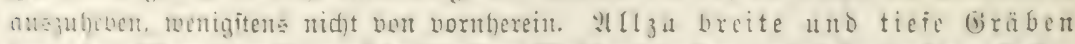

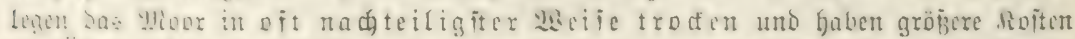

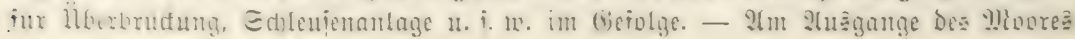


mui; Der Dauptgraben mit ciner cintaden $\Xi$ (d)

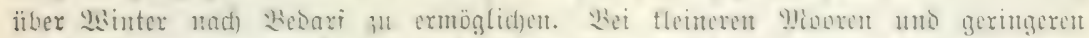

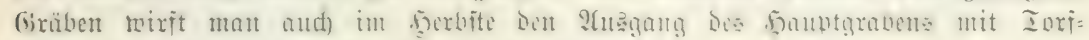
abraum 1t. j. to. 3u und exjetst baburch bic Erfleuje.

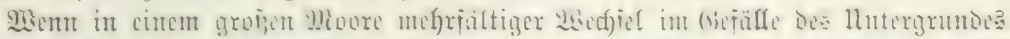

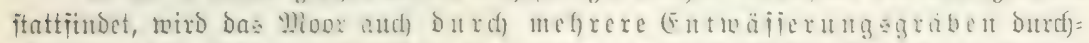

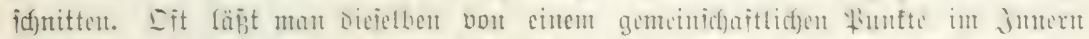

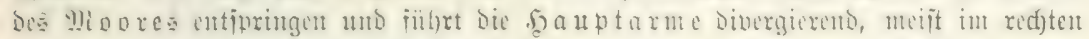
Minfel fidi) burdiftrenzento, mad) außzen.

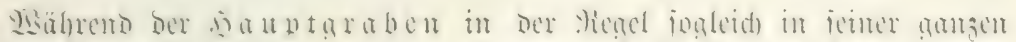

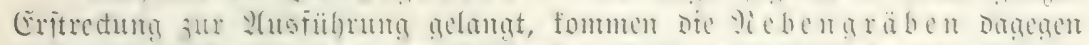

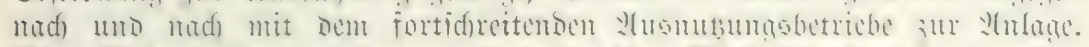

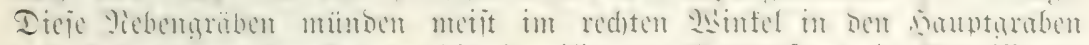

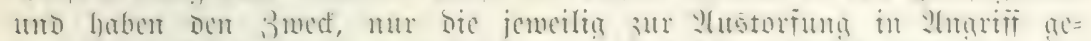

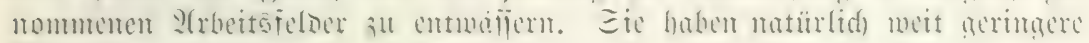
Dimenjionent.

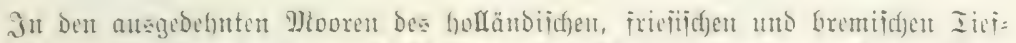

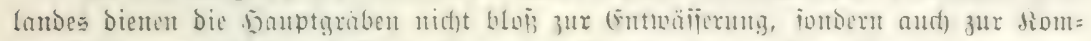

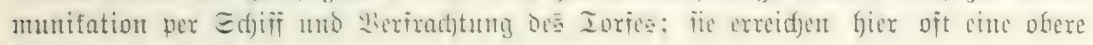
Rreite ton $8-10 \mathrm{~m}$.

2. Die Einfangagräben gaben Den Bued, Das bem yionere zu= flichente

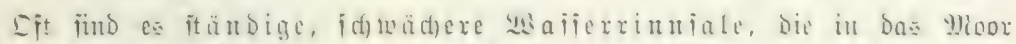

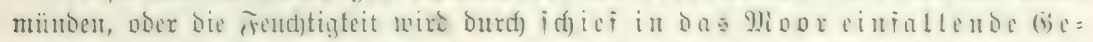

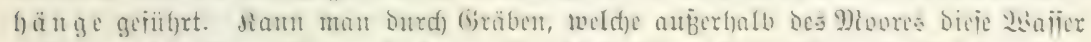

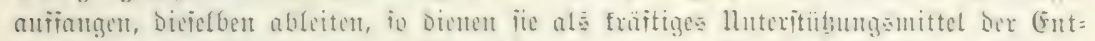

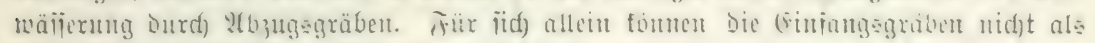
jelbftänoige (Entwäjierungàmetgode in Betrad)t tommen.

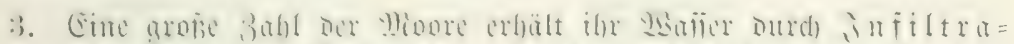

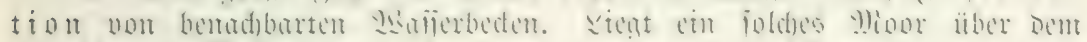

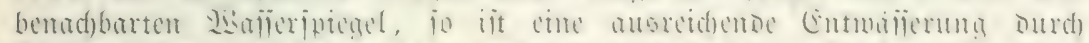

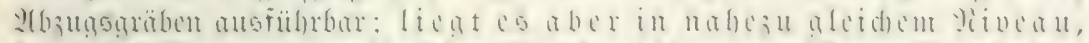

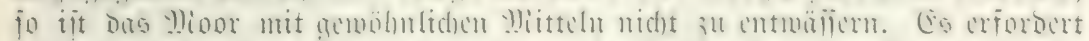

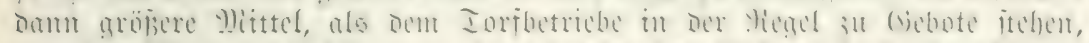

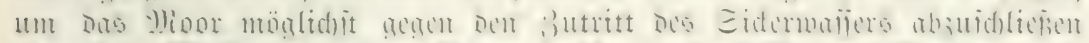

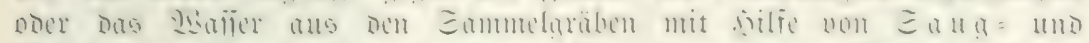
E d)

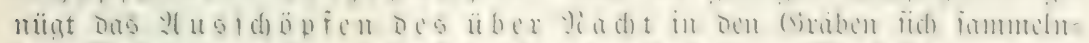

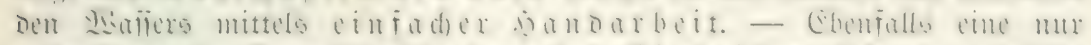

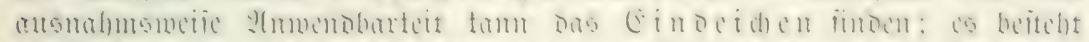

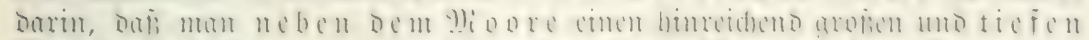

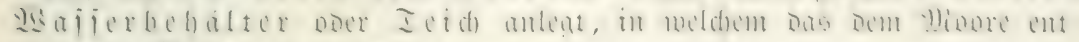

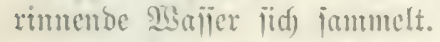

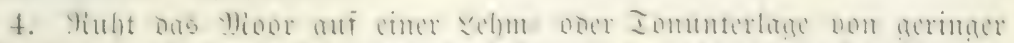

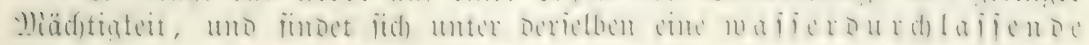

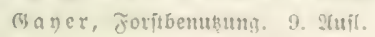




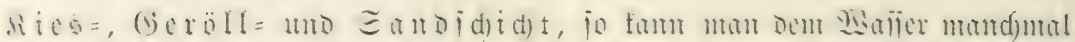

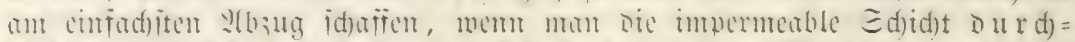

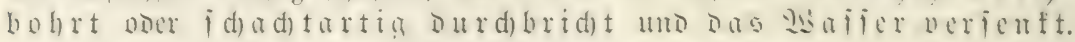

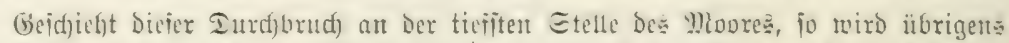

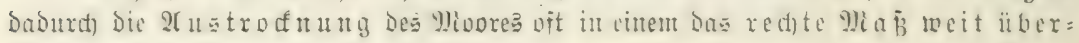
id)reitenden Grabe herbeigefïirt.

\section{Soxfgeninmurg.}

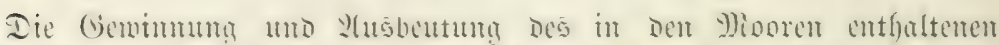

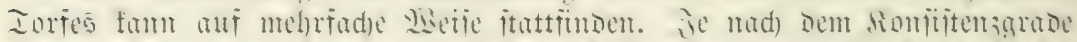

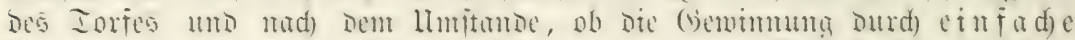

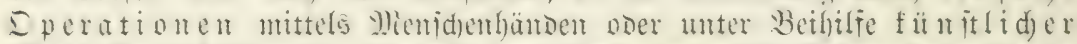

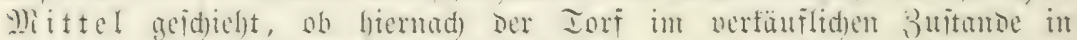

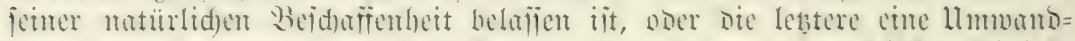

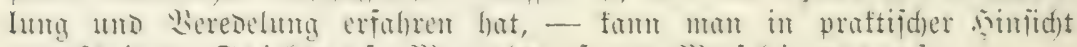

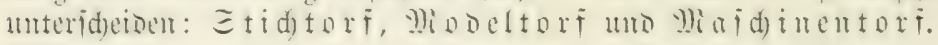

\section{Stidjtorf.}

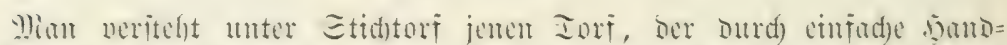

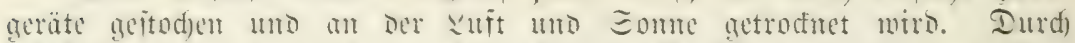

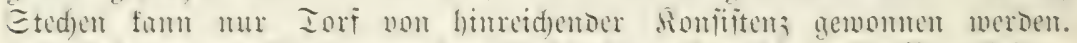

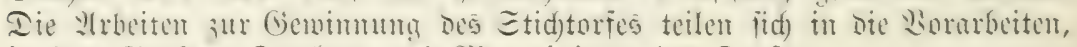
in bas Stedjen, Irodnen und Jiagazinieren bes̄ Iorfes.

\section{a. 2otatbeiten.}

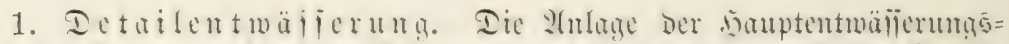

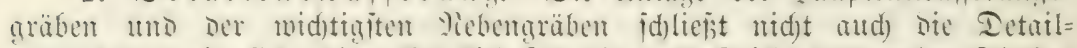

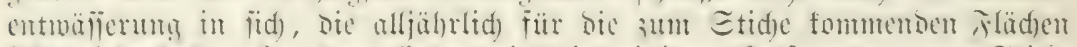

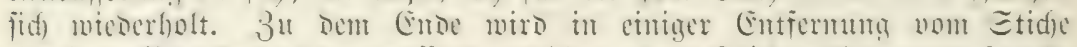

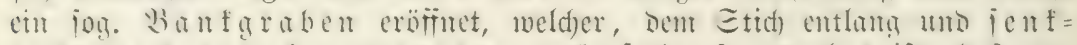

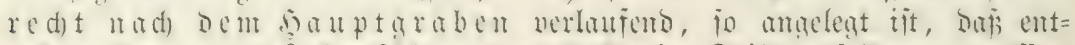

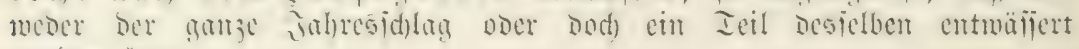
merben fam.

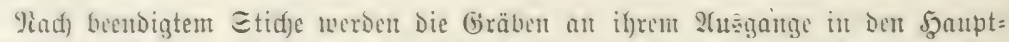

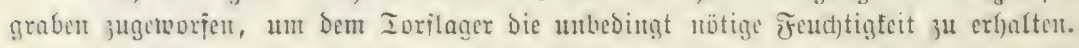

2. Viejeid)

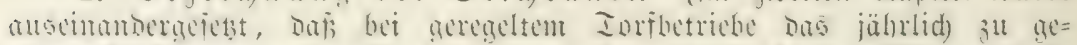

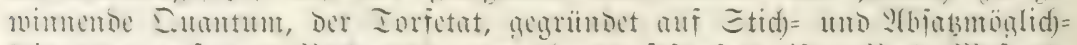

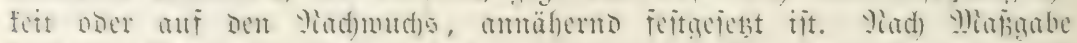

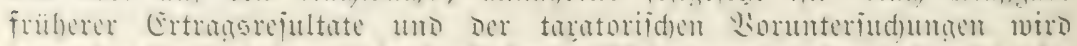

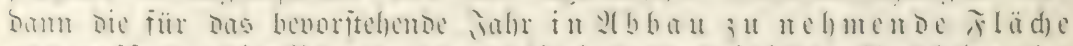

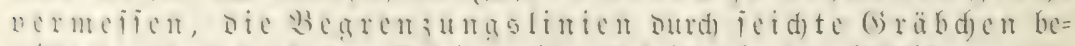

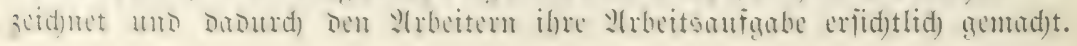




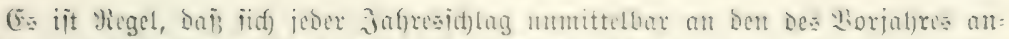

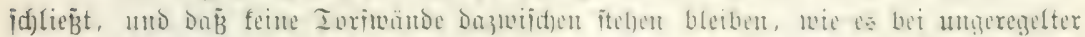

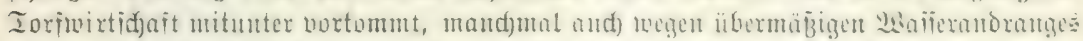

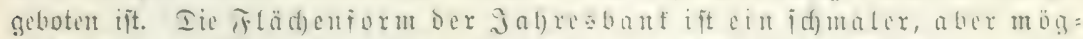

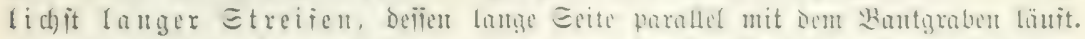

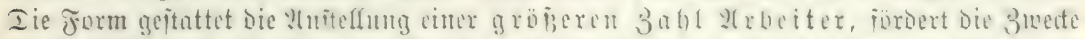

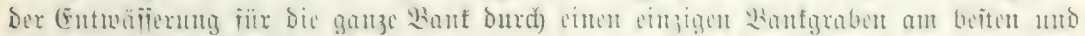

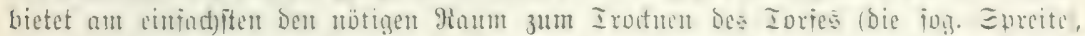

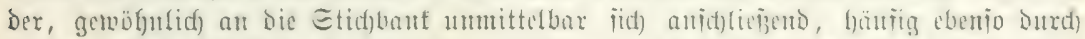

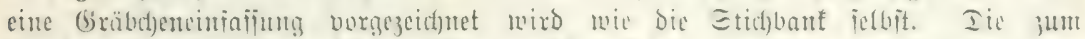

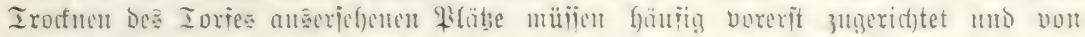

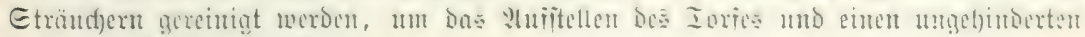
Su†tzug möglid, zu madjen.

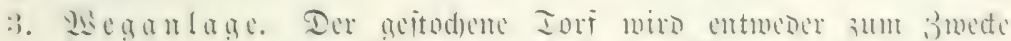

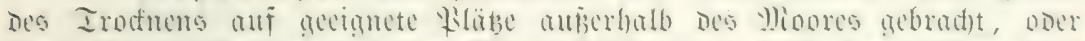

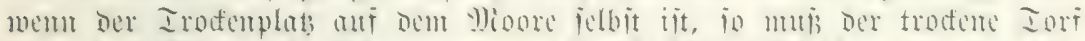

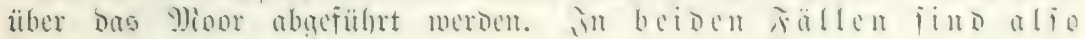
פgege notwendig.

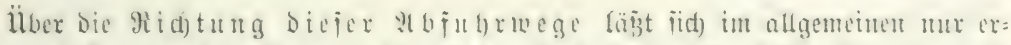

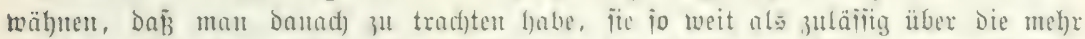

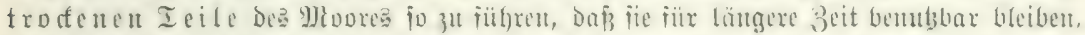

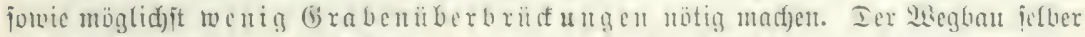

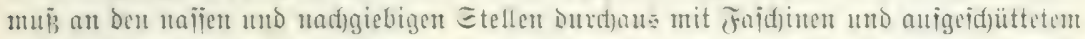

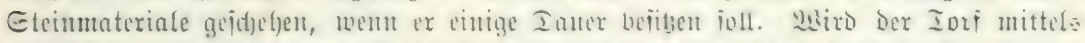

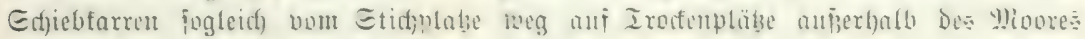
gebracft, fo genügert cinfad)e $\mathfrak{B}$ retterbafy un.

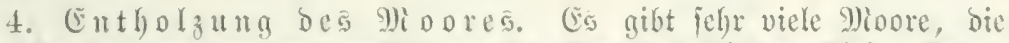

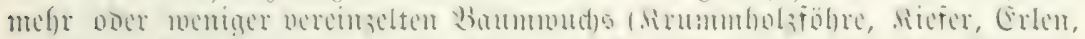

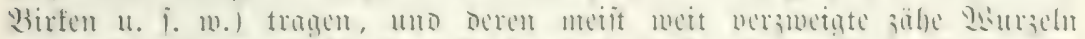

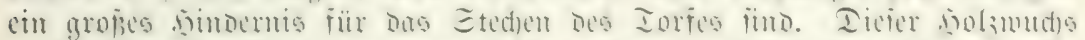

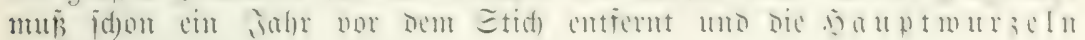
müīen ausgebrad)t werben.

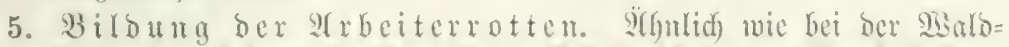

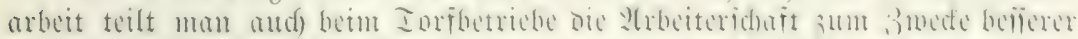

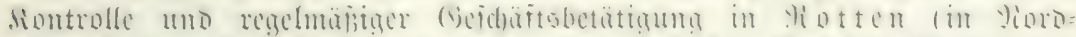

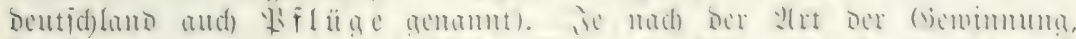

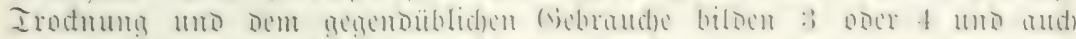

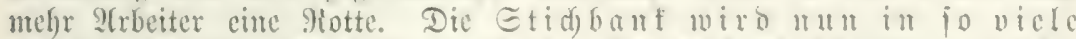

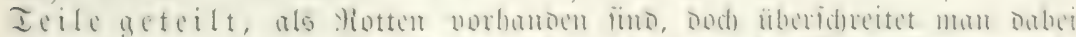

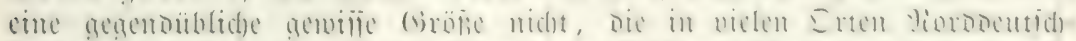
lambs mu ma :-

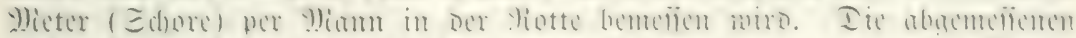

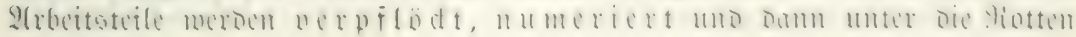
$v \in \mathfrak{l}$ it. 


\section{b. Eteden Des Iorie⿳亠丷厂}

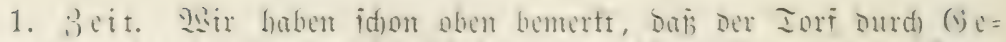

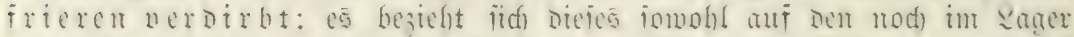

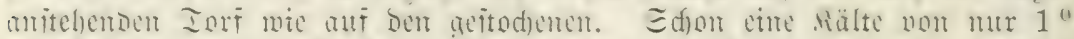

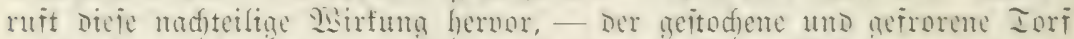

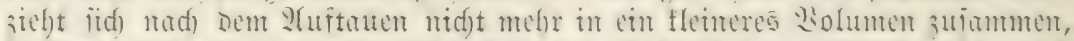

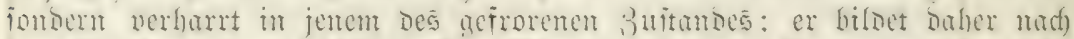

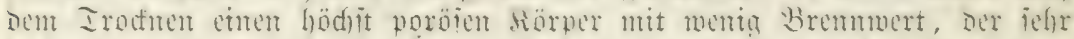
licd)t ierbrid)t und ierbrödelt. Ieshalf Bari man mit Dem $\Xi$ teden

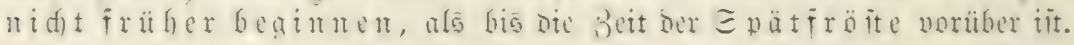

Eo norteifhajt aud) ein möglidjit irüf)zcitiger, nodf in Die Periode Der trucfenm

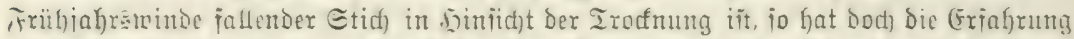

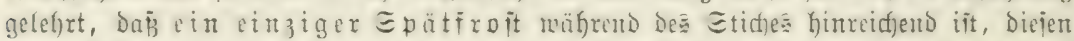

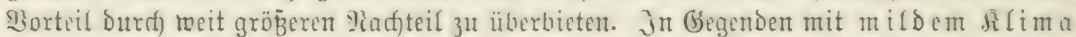

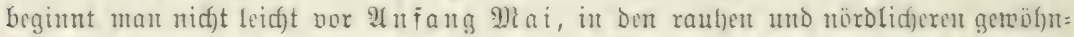

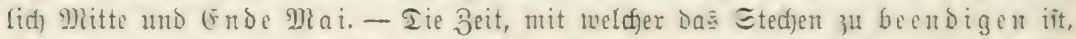

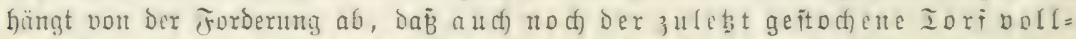

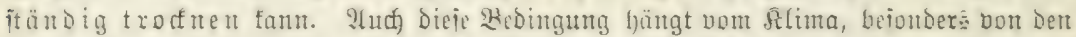

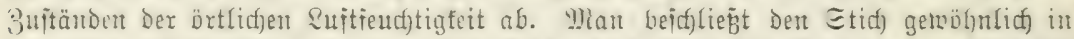

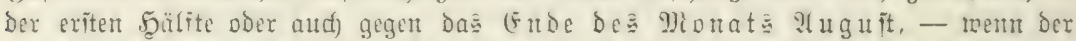

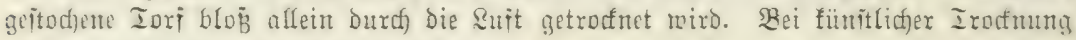

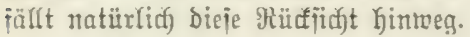

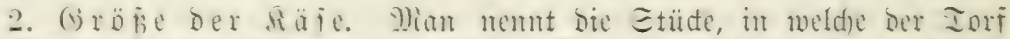

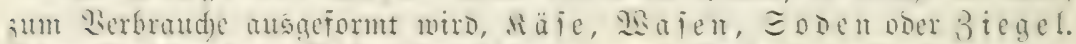

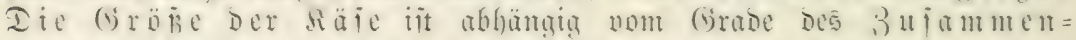

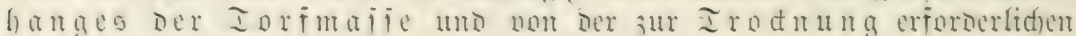
läneren noer fürzeren i) eit. ie leidfer mo Inderer Der Iorf it, Deito

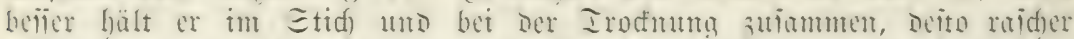

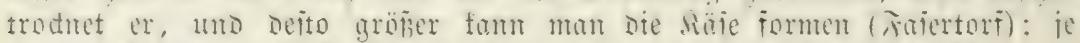

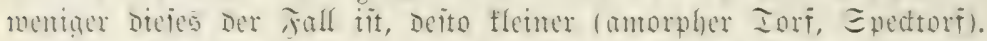

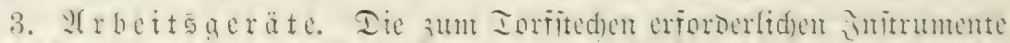

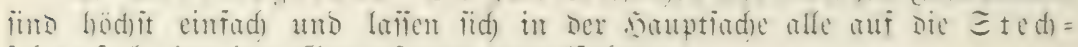

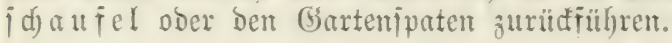

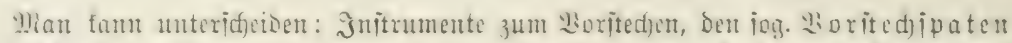

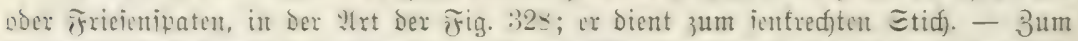

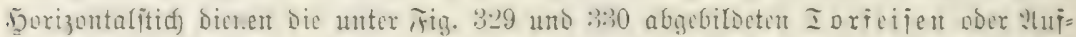

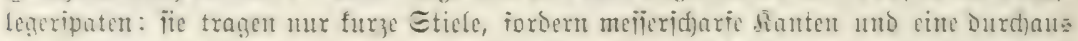

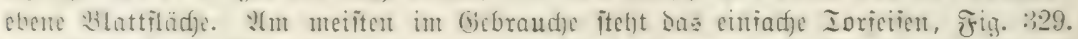

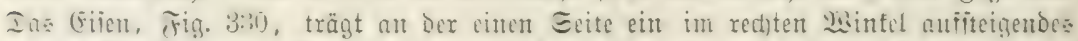

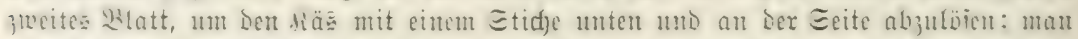

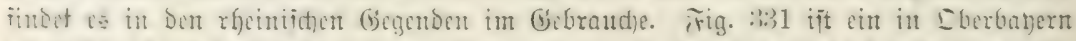

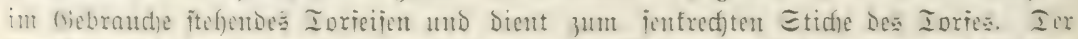

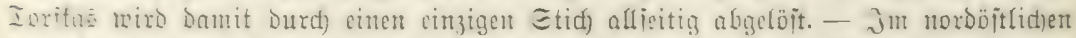

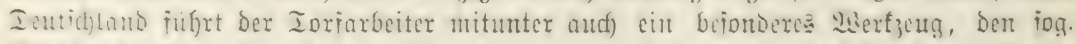

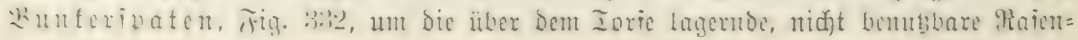




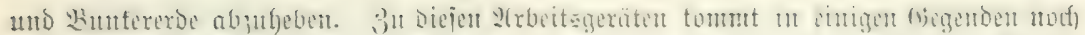

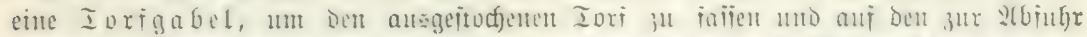

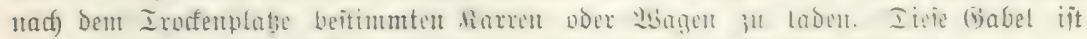

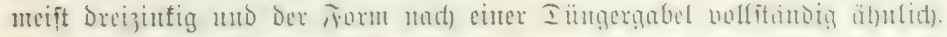

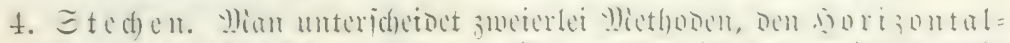

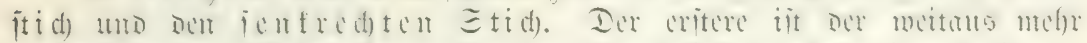

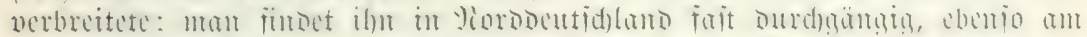

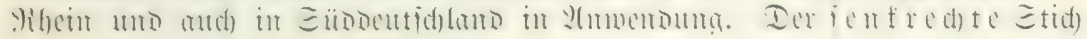

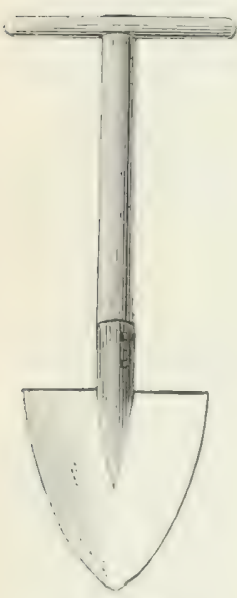

न̃ig. 328. Lotitedjpaten.

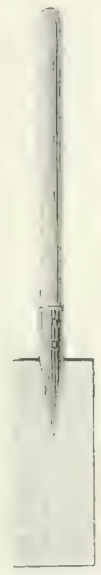

Fig. $3 *$

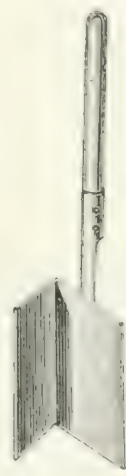

ঠig. 330.

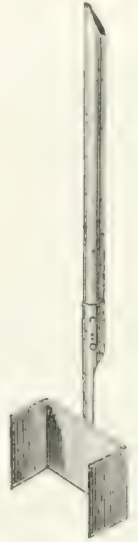

సีig. 331 Dberbayr. Iorjetjest.

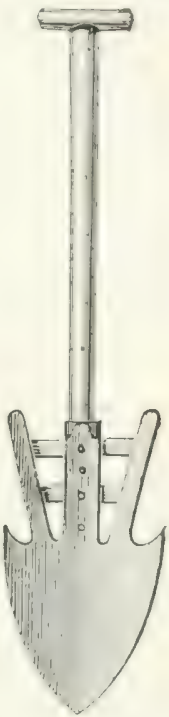

T̈ig. $35 ; 3$. gunteripaten.

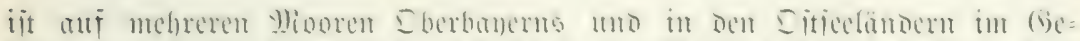

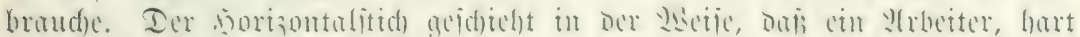

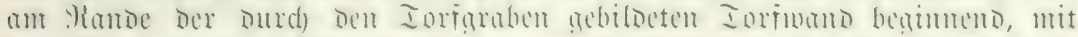

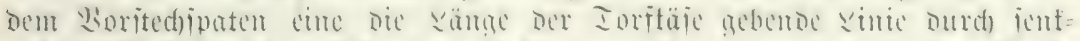

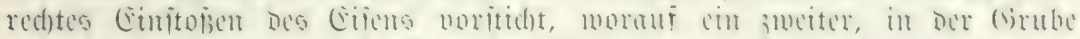

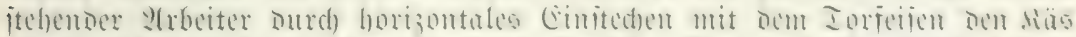

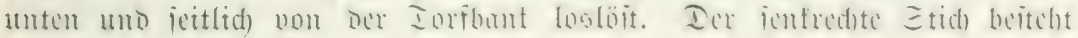
in einen cinfadjen \&uggraben bes Iorfers.

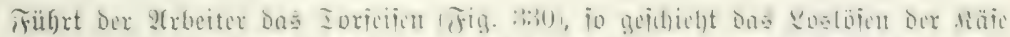

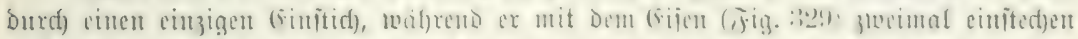

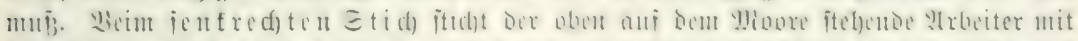

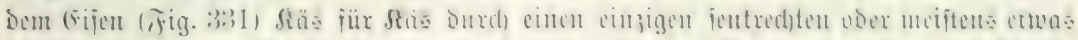

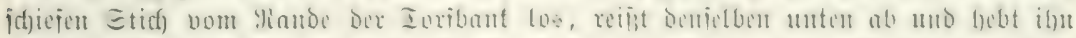

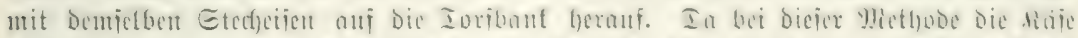

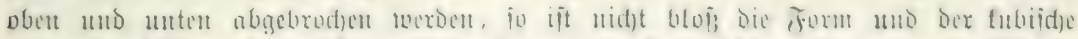

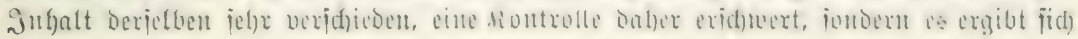




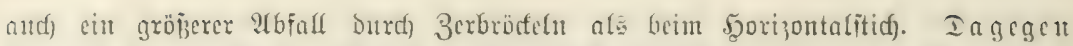

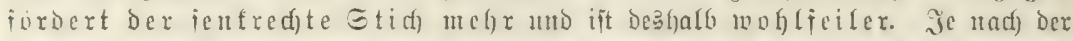

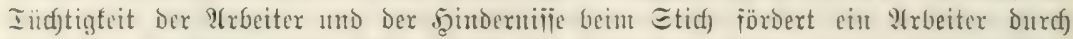
Den Sourizontalitid) 3000-5000, Durd) Den ienfredten Etid) unter gïnitigen S3er=

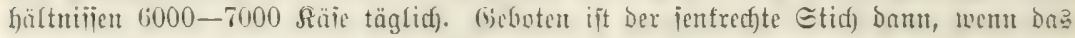
Mloor nidgt hintreidjend enträjijert ifł.

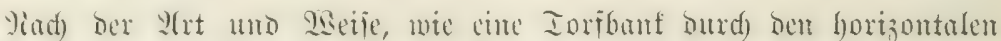

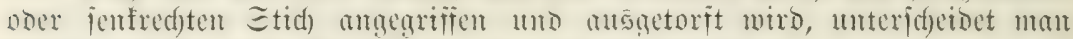
weiter zmijden bem Reibenjtid) แn bem Rulifjenjtid).

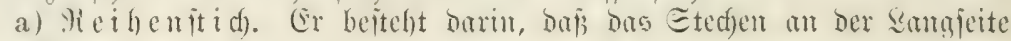
Der ansutorfemben Jahresfläde begomen un Etreifen an Etreifen un= mittelbar memandergeretht wird, bis man an ber entgegengejebten Eeite

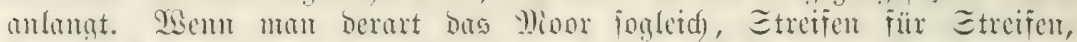

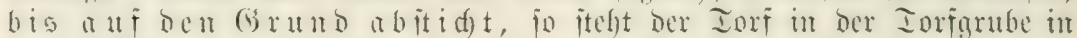

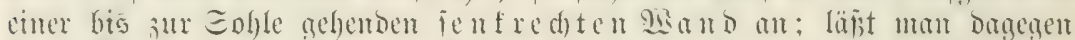

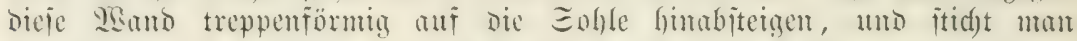
Derart fort, baj; juerit Der Etid) auf Der oberiten Etuic, Daun auf ber

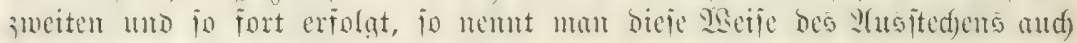
Den Ireppen= ober $\Subset t a f f e l i t i d)$.

Weuor mit bem Stechen üborfaupt begomen merben fam, wiro bie ban Iori

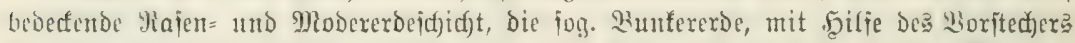

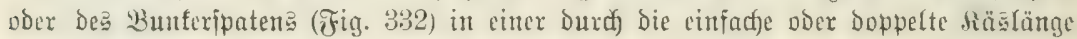
jidi) beftimmenden Breite abgeitodien und reggebradyt.

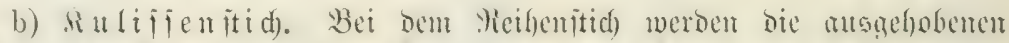

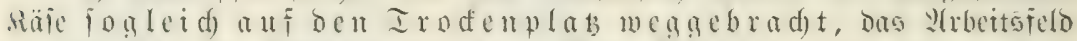

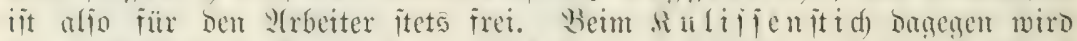

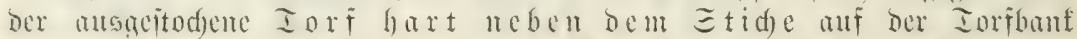

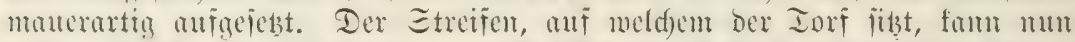

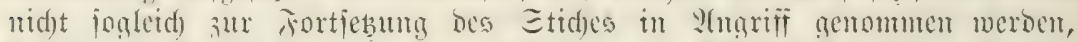

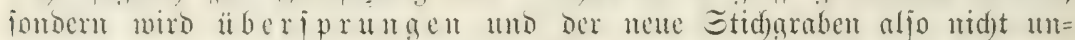
mittelbar an ben eriten angercibt. vit bes anfgeitelle Iorf troden mo

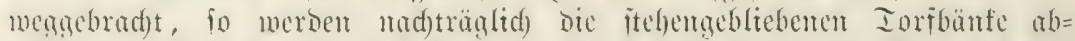

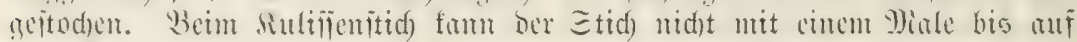

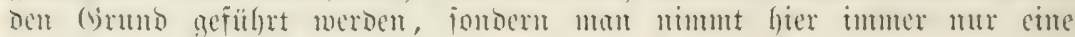
Edjidft $a b$.

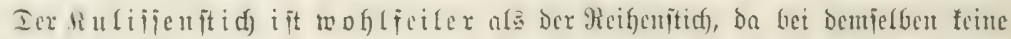

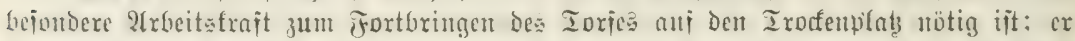

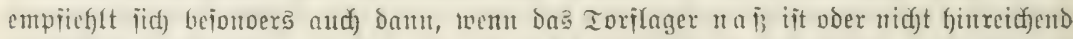

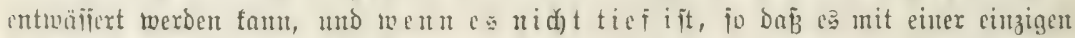

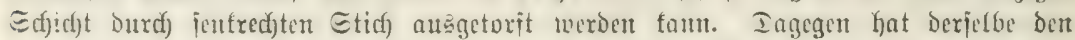

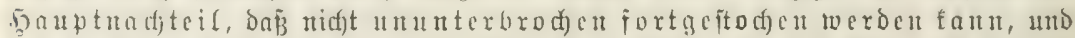

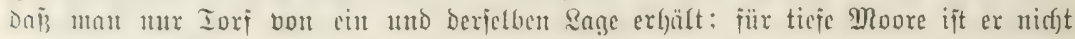
empiehlentwert.

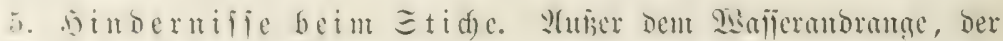

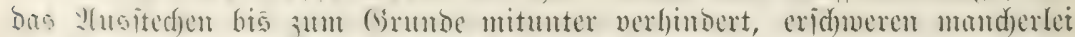

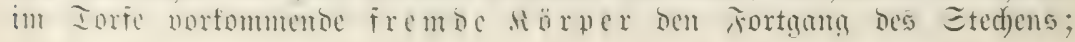




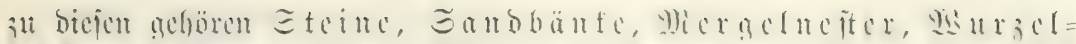

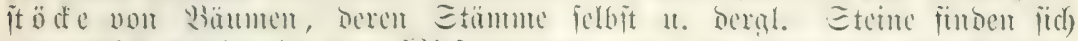

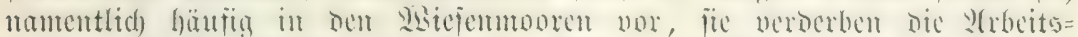

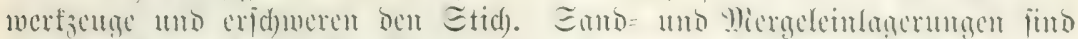

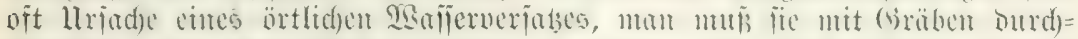

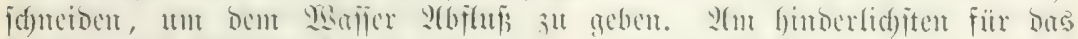

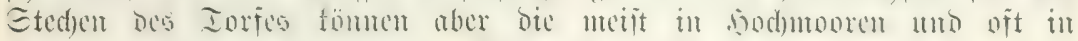

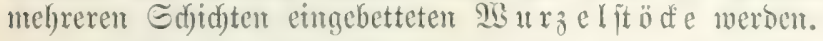

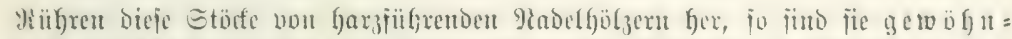

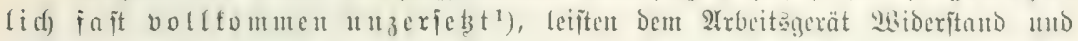

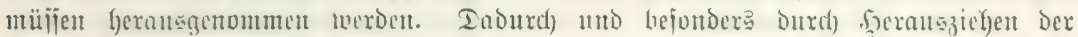

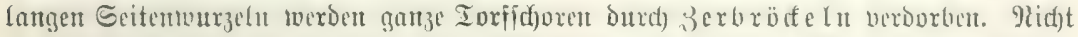

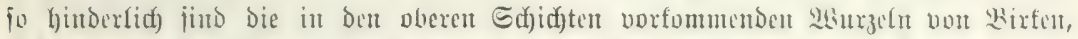

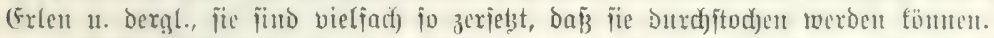

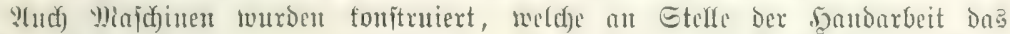

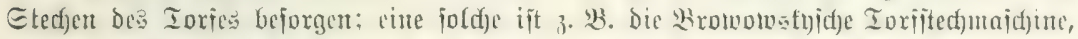
Die im norbdeutiden Iicflanoe Serbreitung gefunden gat und diäje vou :3-6 m \&änge

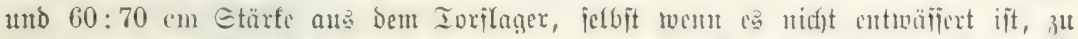

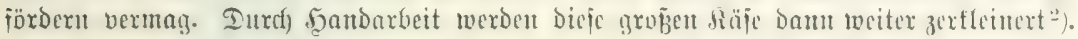

\section{c. Iroduen des Iorfeפ.}

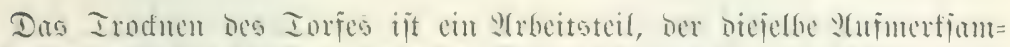

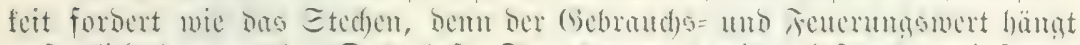

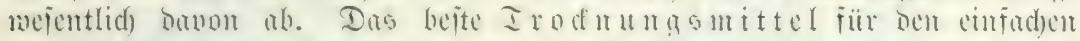

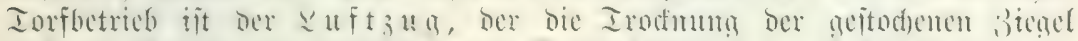

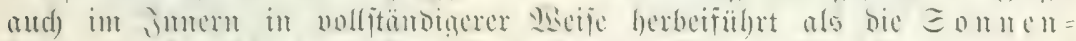

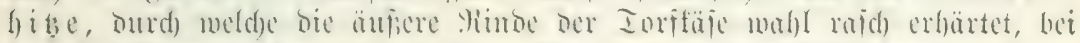

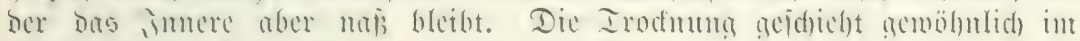
Freien, fam aber aud unter Dad) exfolgen.

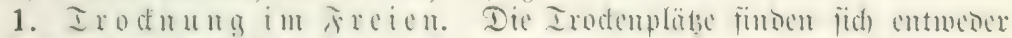

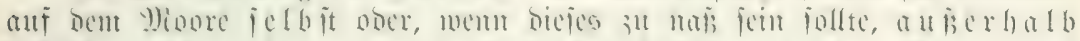

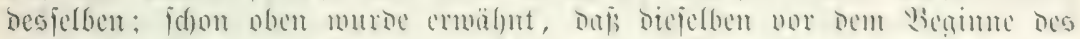

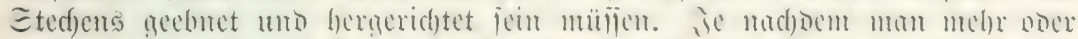

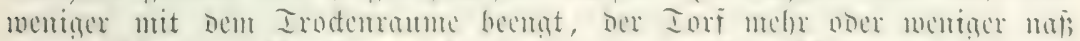

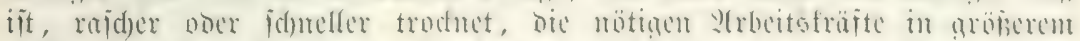

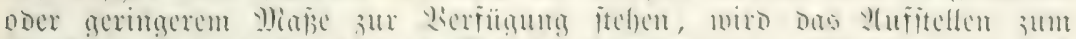

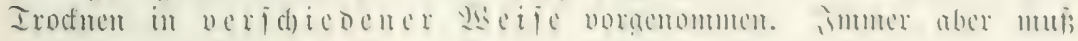

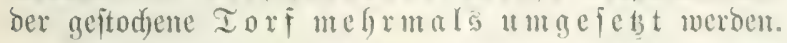

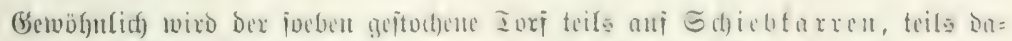

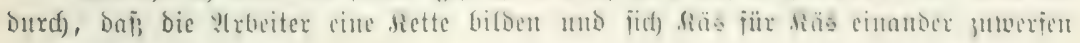

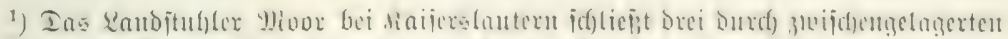

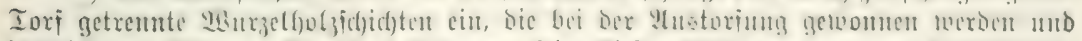

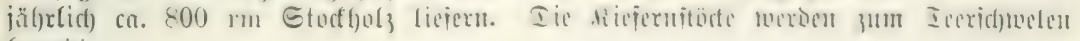
bernitist.

2) Fुaแ 


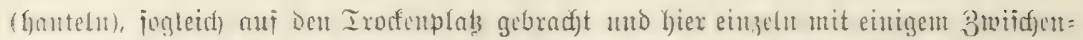
raume auf bit ho ge siante geftellt, wie

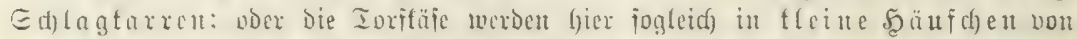

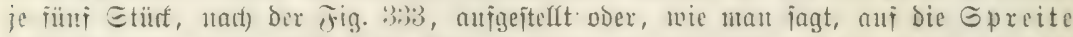

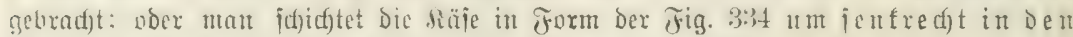

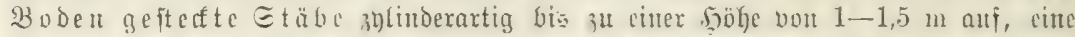

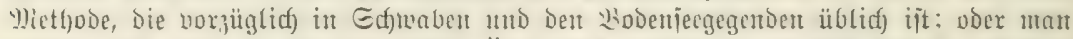

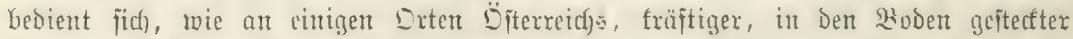

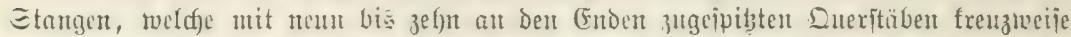

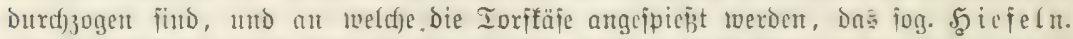

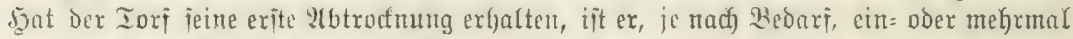

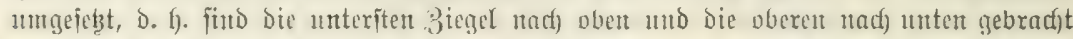

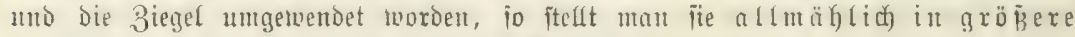

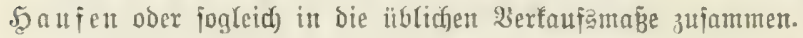

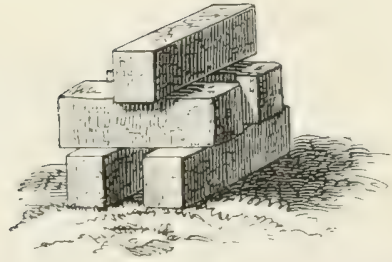

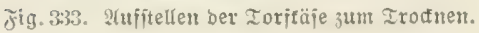

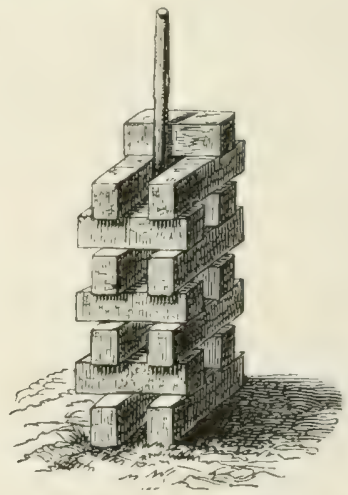

Fig. 334. 2(ufididiten ber Zorftäje an Etäben.

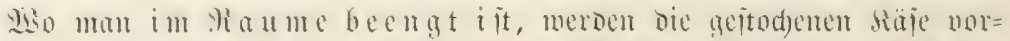

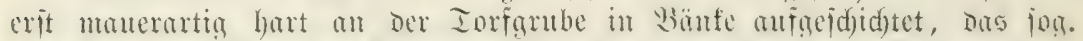
Deid)

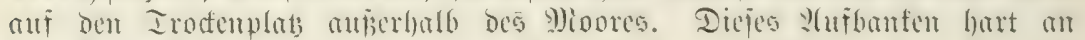

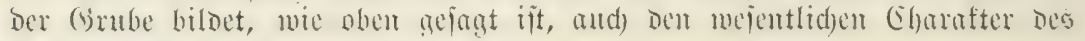
fiulifientitides.

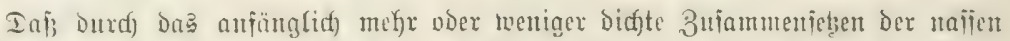

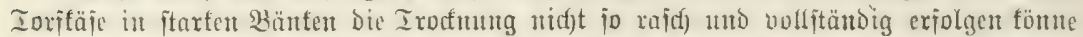

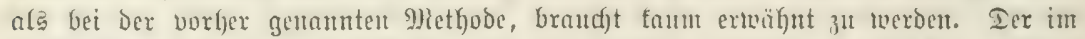

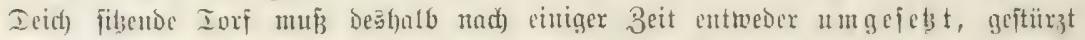

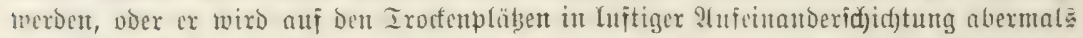

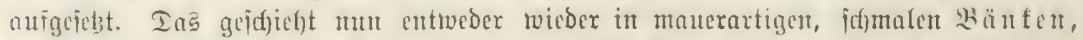

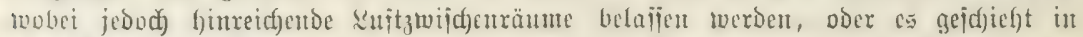

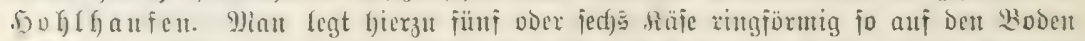

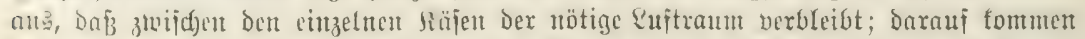

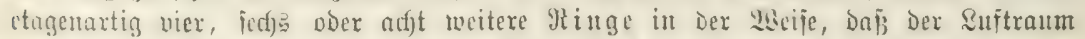

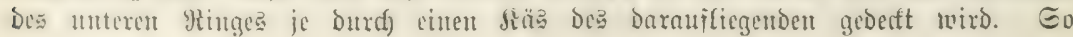




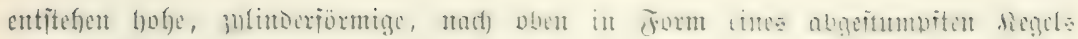
entende Ђุaนfen.

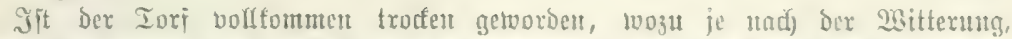

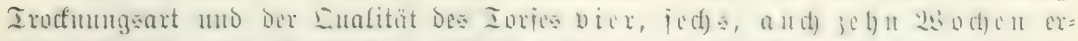

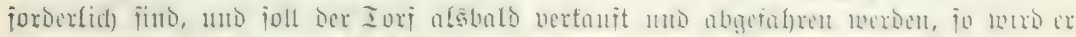

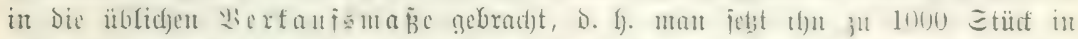

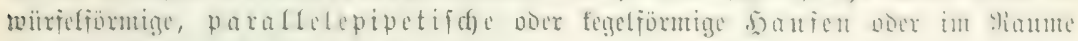

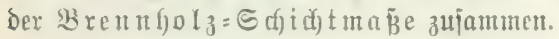

2. Irodnung $n$ ter. Dad). Mian bebient fid) an chugen Drten

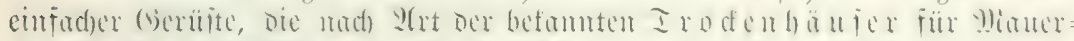

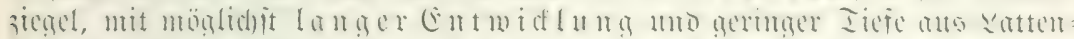

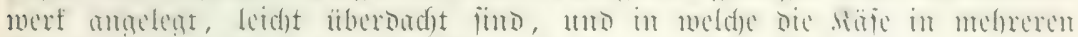

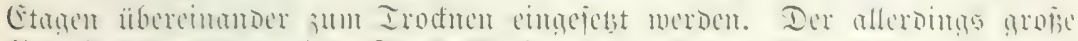

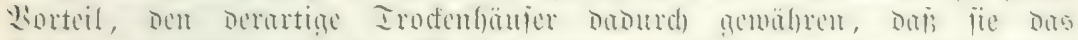
Iroctmugchẹd)

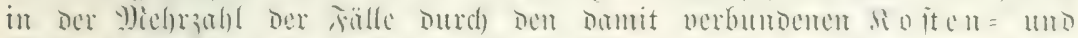

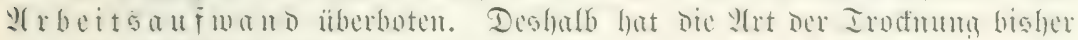

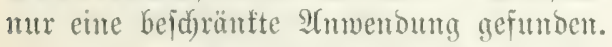

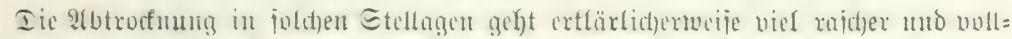

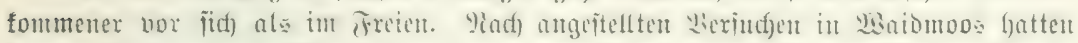

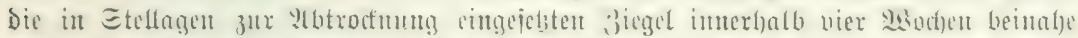

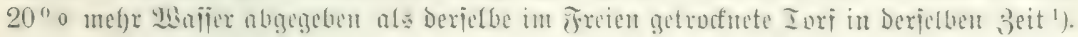

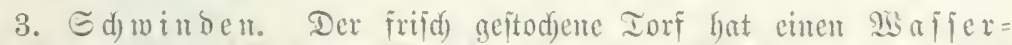

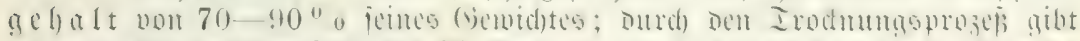

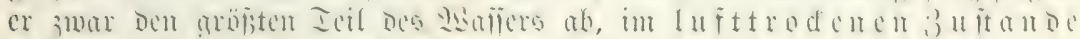
find aber tmmer mod) 26-30"

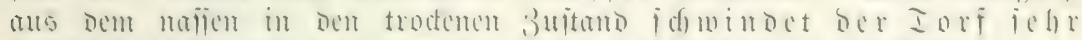

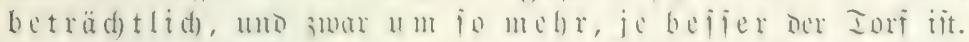

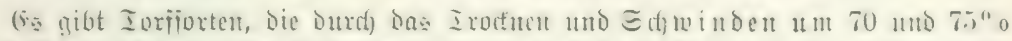

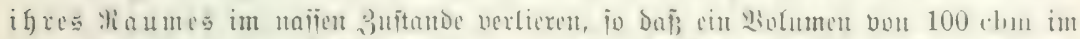

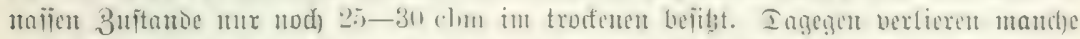

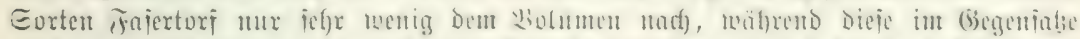

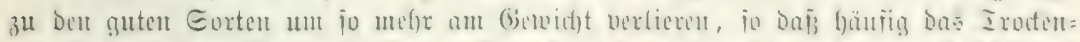

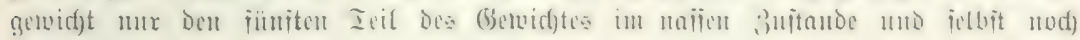
wentiger beträģt.

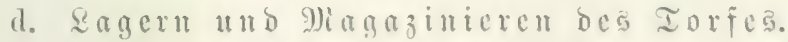

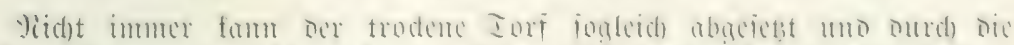

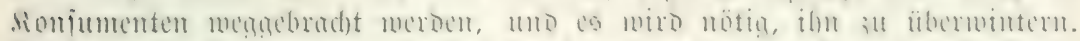

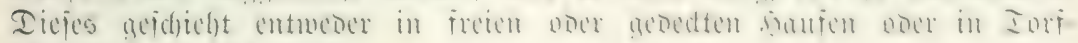
jouppen uro Ed)eumen.

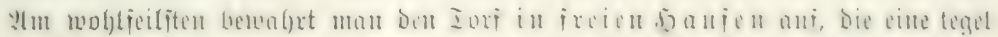

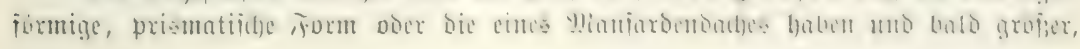

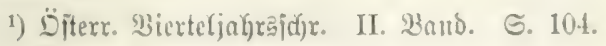


bals tleincr gemad)t werden. (i) ro ise şa

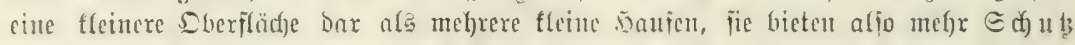
gegen die $\mathfrak{W}$ itterug. Iaygenen fann aber nod) nidft bolltommen trodfener Iorf in

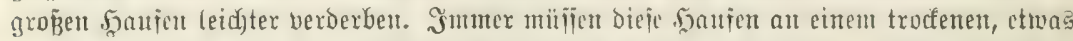

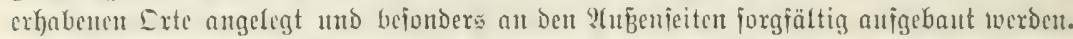

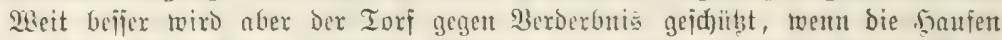

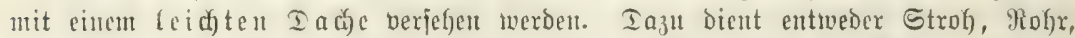

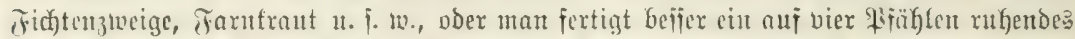

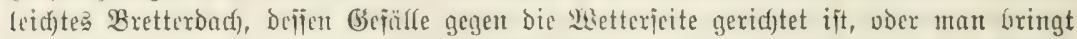

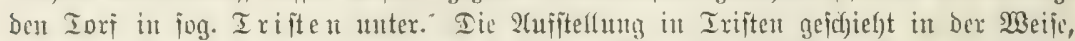

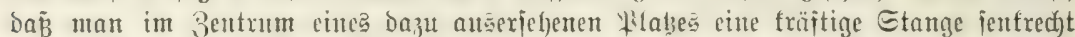

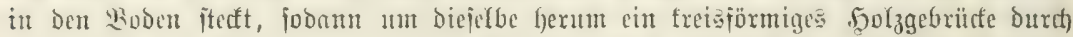
rabial non Dex Etange auzlnufonde Edfeiter fertigt (äfnlidf) wie bet ben Detern)

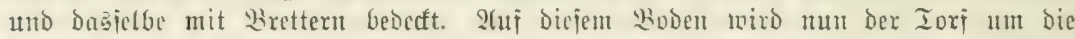

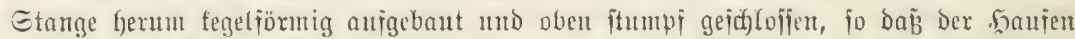

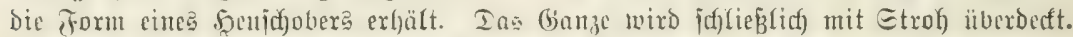
Ïberwintert man ben Iorf unter Derartiger Bebecfung, jo fann ber Scanfen ohne

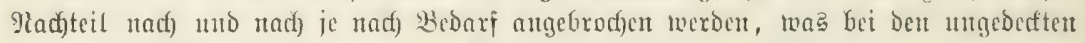
Saufen exflärlichermeife immer auf diofiten bex Iorfgüte gejojieht.

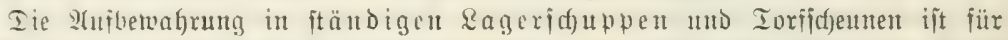
Die Ronierbation des Iories swar immex bie befte, aber nicht immer geitattet der Iorí= preis die bazu erforberfid)en Inlagefapitalien. Eoldje Ragerjánuppen ficllt man mit

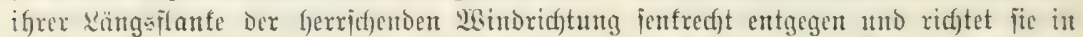

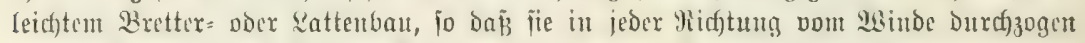

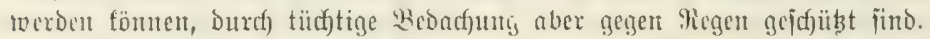

\section{Itodel= oDer Strcidjtorf.}

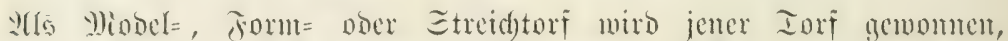

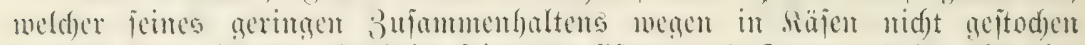

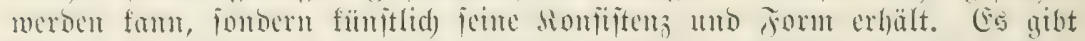

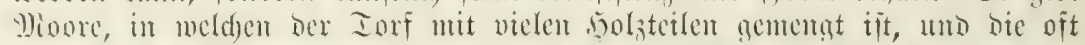

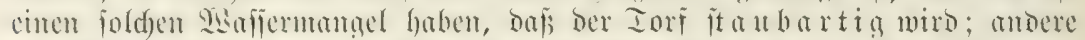

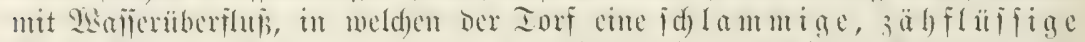

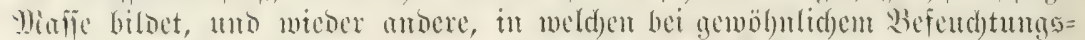

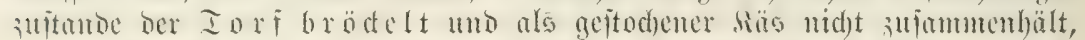

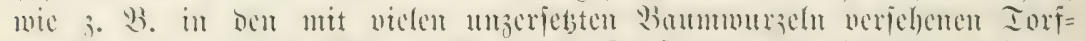

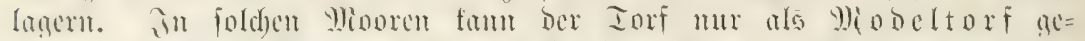

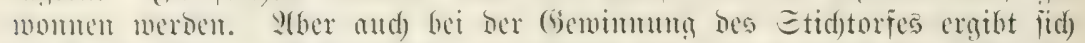

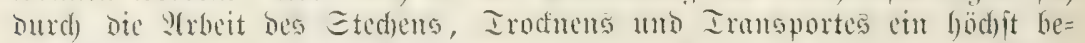
bentender, oft bis jum fünften ober nierten Ieil bes gemonnenen Etid)=

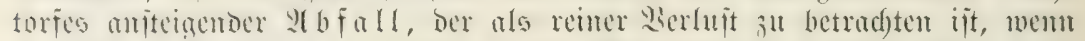

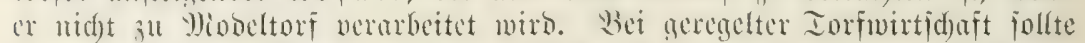
Daber anf jebem Mioore, bas ben Etid) sulajis, nidst mimber als in ber

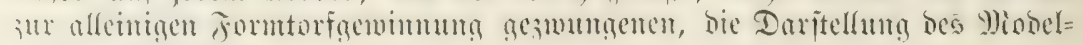
torfes itattintuen.

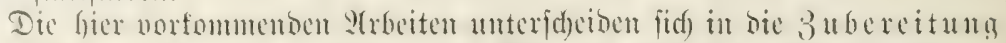

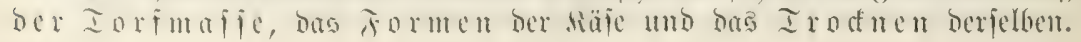




\section{a. Bubereitum ber Iorimajie.}

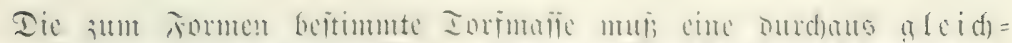

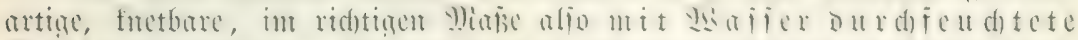
Diajic Dar it

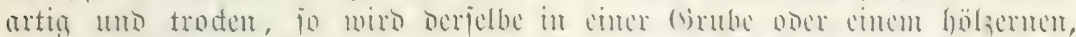

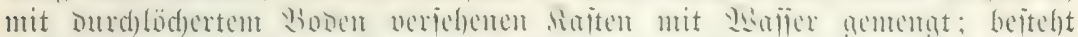

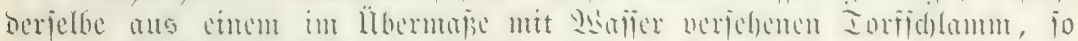

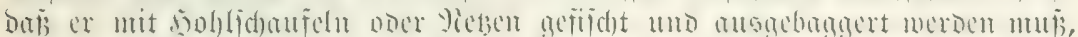

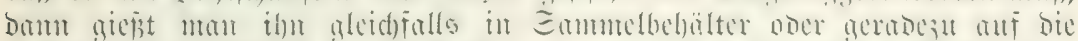

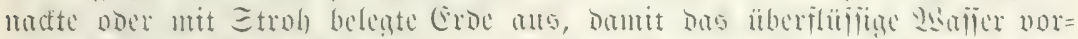

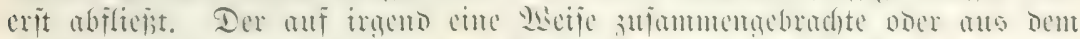

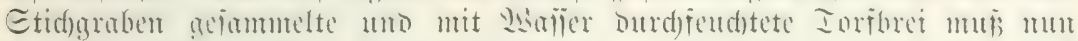

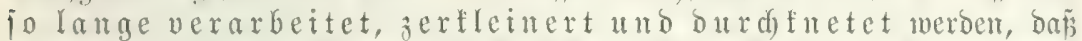

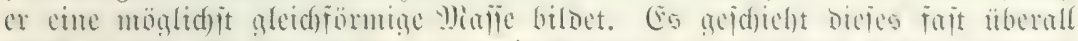

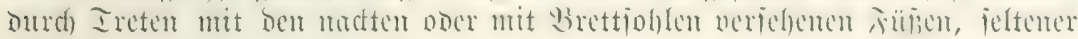
mit Silfe vou Same und Epaten.

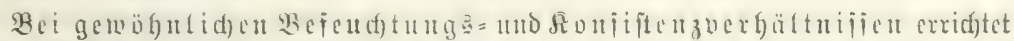

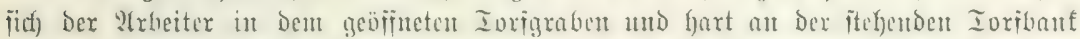

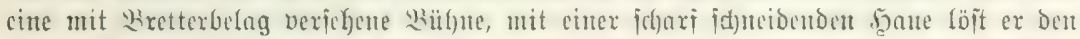

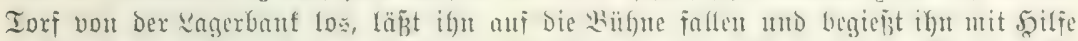

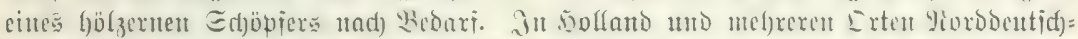

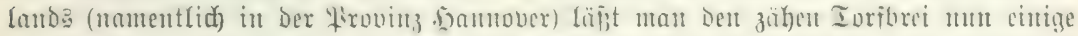

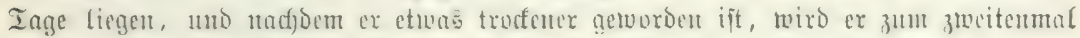

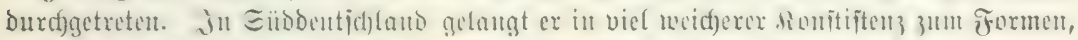

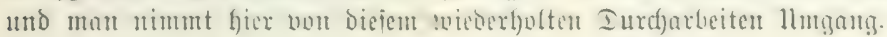

\section{b. Tormen bes Iorforetes.}

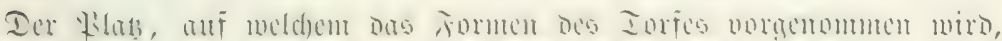

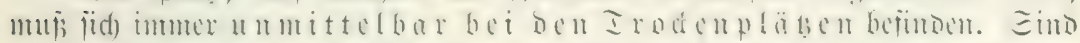

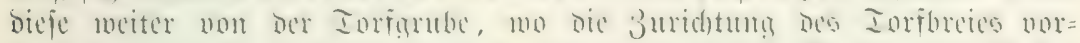

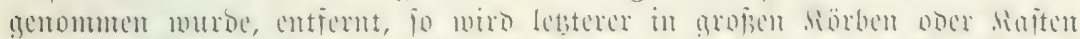

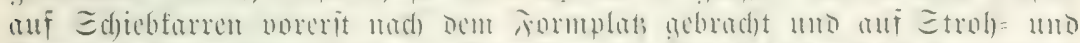

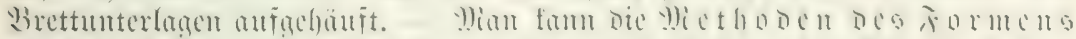

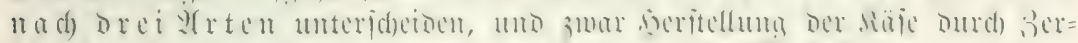

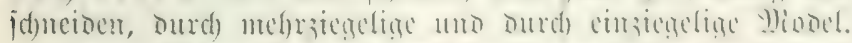

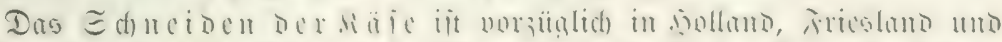

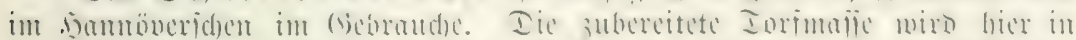

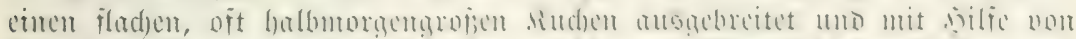

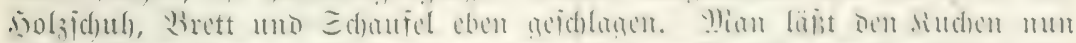

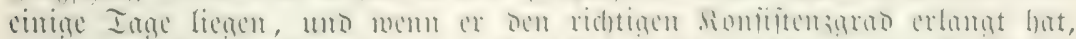

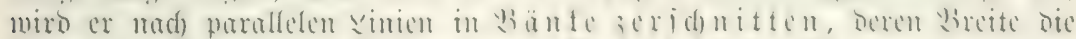

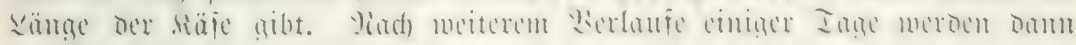
bie Bänfe in Säje serjd)nitten.

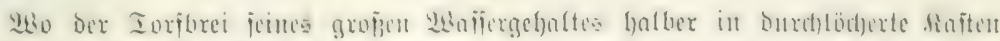

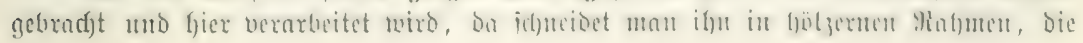




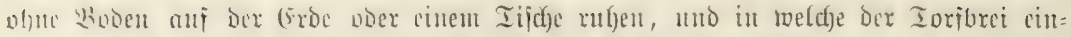

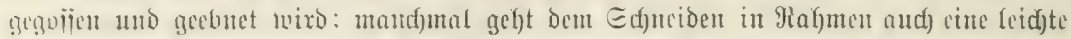
Liveinug Durd) en aupelegtes

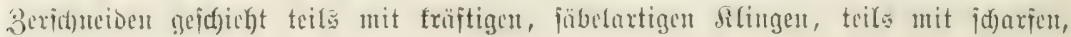
breiten Epaten.

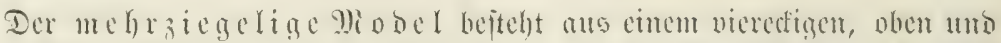

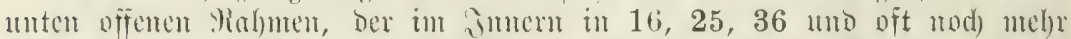

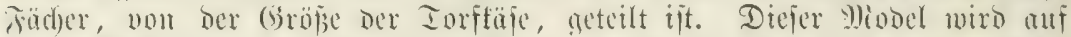

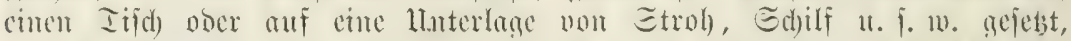

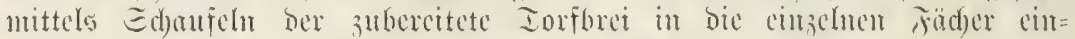

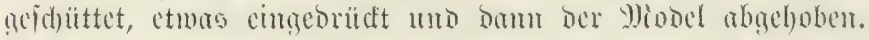

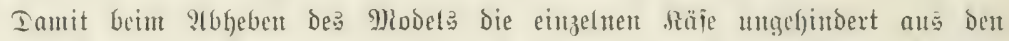

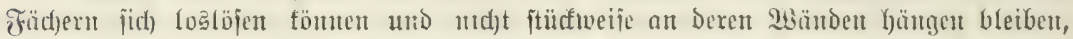

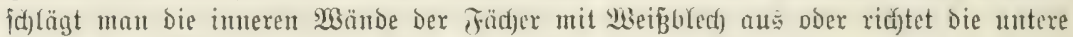
S̈ffmung Der Fädjer ctroas weiter ale bie obere.

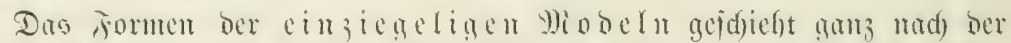
P(rt der Etembicalfabrifation. Der Urbeiter fteht nor emen Iijd), Deffen

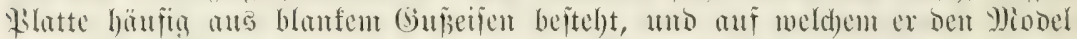

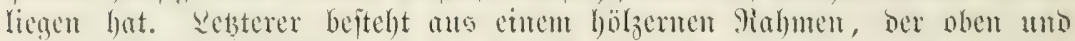

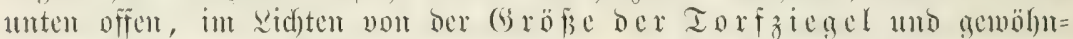

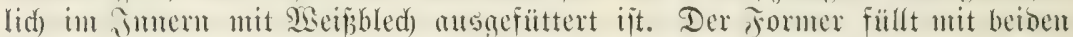

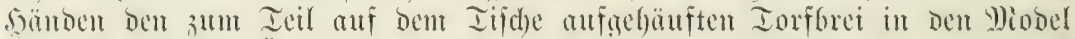

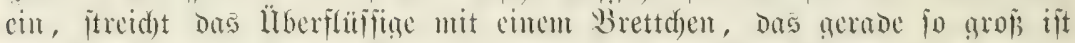

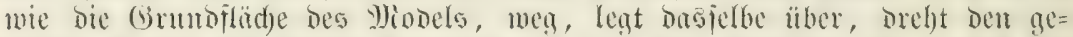

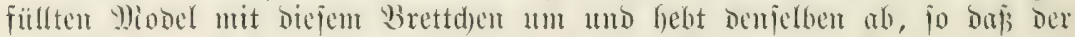

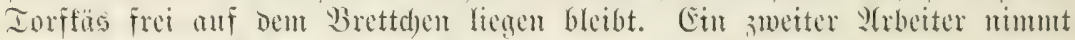

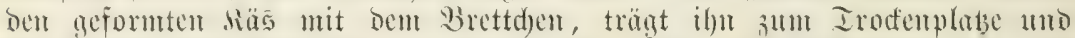

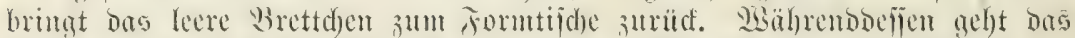

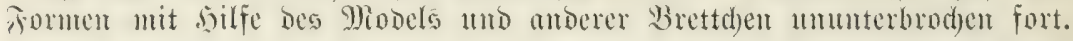

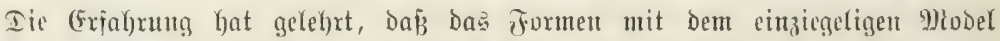
wenig̣tens ebufo arbeitsiönerno ift wie Das Formen mit Dem megrzicgeligen; cin Irbeiter ftreidyt mit einem fintoben, Der bie geformten diäfe abtrügt, 1000-1500 Riäfe

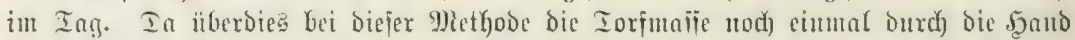

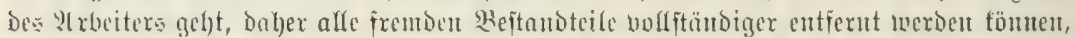

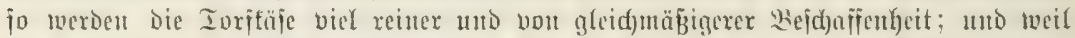

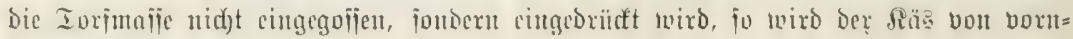
Gereiu fonpiftenter.

\section{c. Iroduentes 9iobeltor}

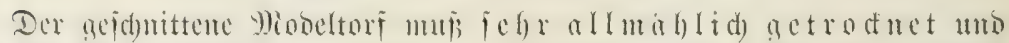

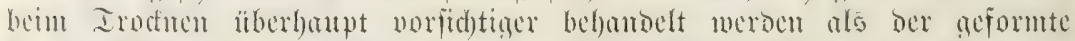

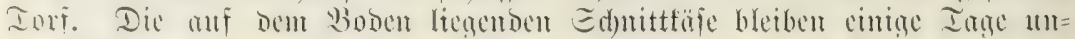

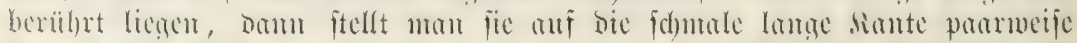

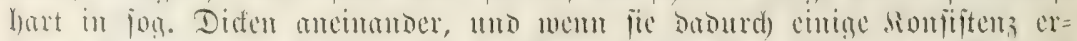

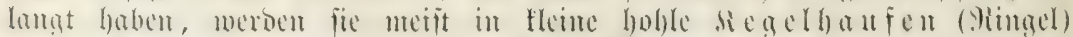

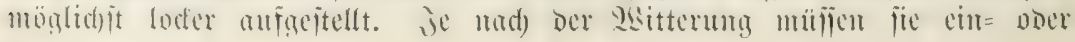




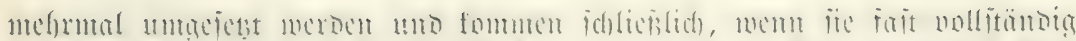

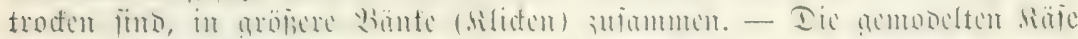

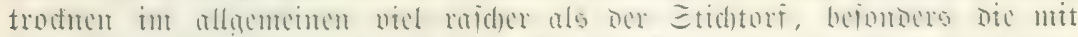

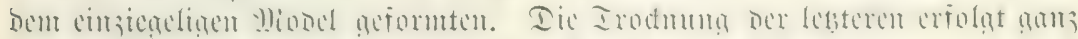

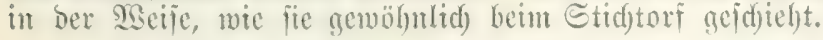

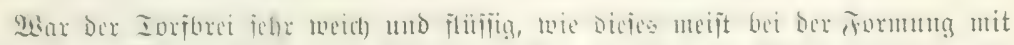

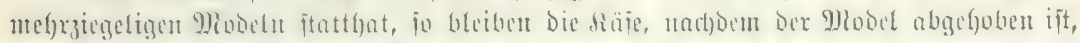

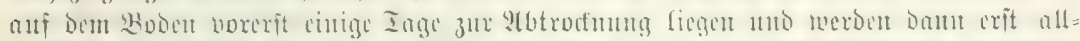

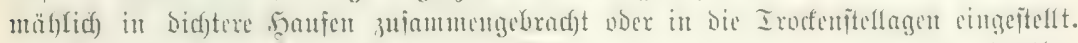

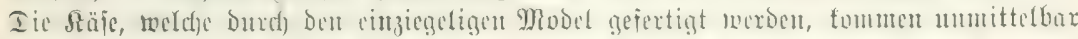

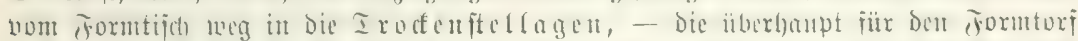

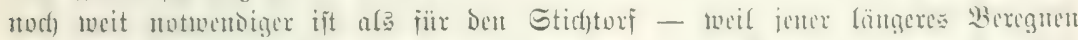

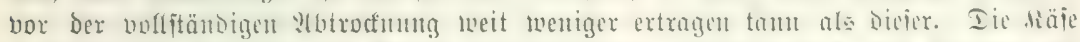

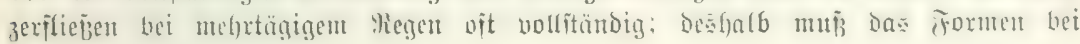
Regentvetter iiberfoupt unterbleibent.

\section{d. Dualität.}

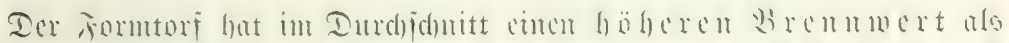

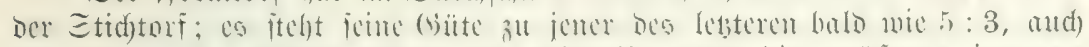

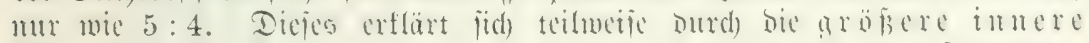
(i)!cid) förmiatcit, Dic (i)

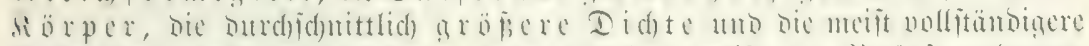

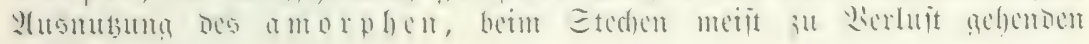
Iorfes.

\section{Ilaidjuctutorf ${ }^{1}$ ).}

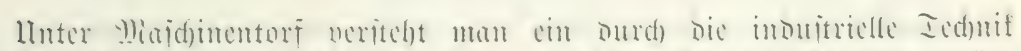

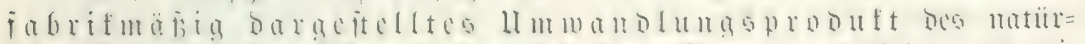

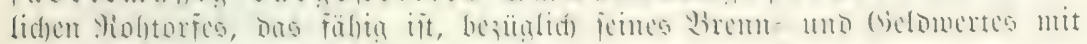
ben iibrigen Brenmmaterialien a fonfurrieren.

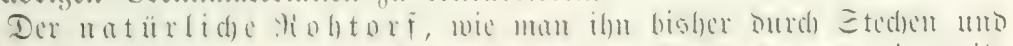

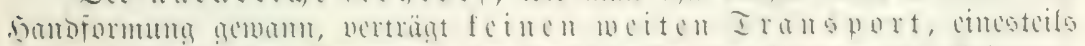

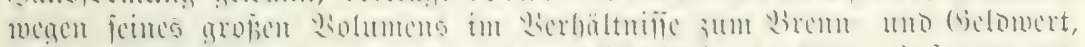

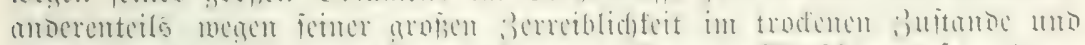

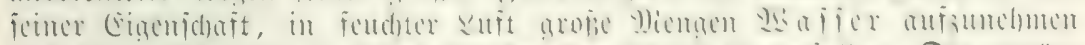

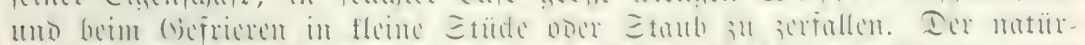

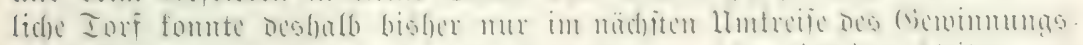

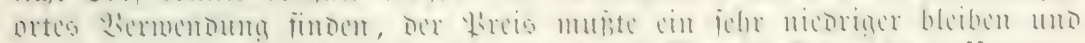

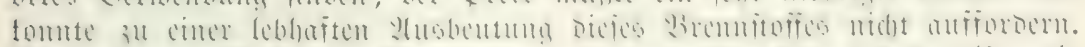

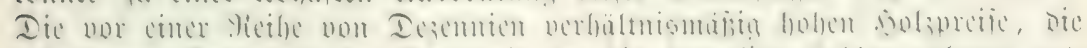

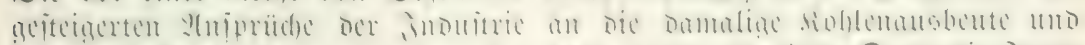

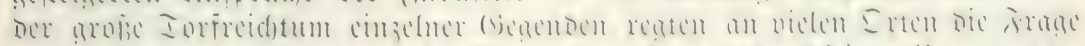

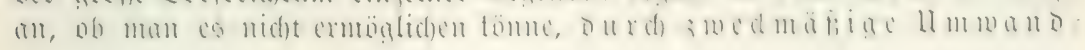

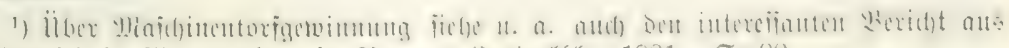

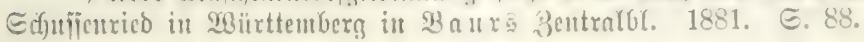




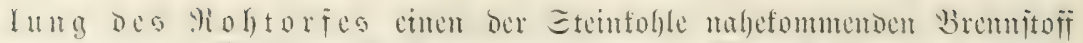

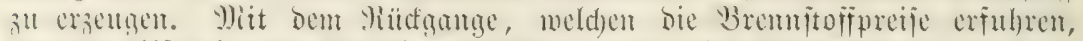

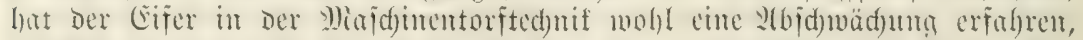

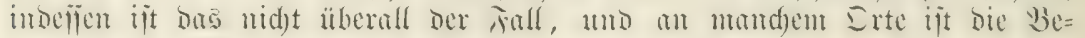
reiturg vou פiafdinentorf aud beute nod) im (somge.

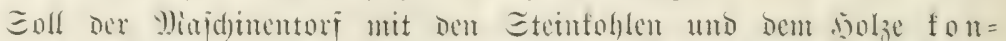

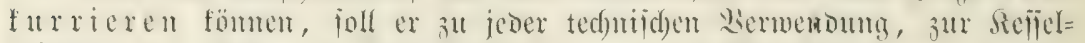

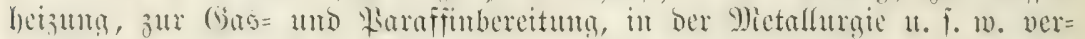
menobar merben, io mülien an eime tiedtige Iorfberetung folacnde Forberungeu geftellt unb biefe erfüllt werben:

a) (5) röbere Ronzentration Des Brenntoffes. Die Ser=

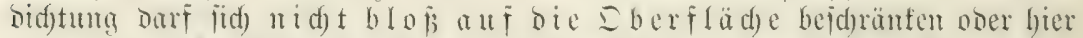

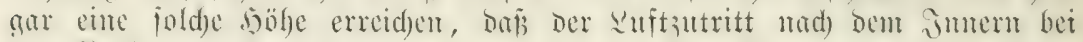

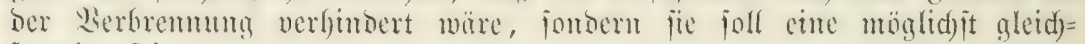
förmige jein.

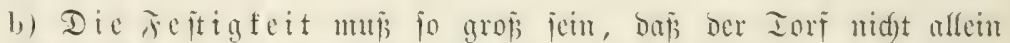

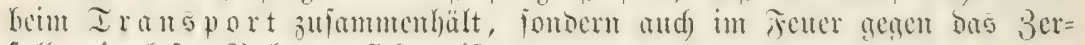
fallen in lojes \$tulver gefidjert ift.

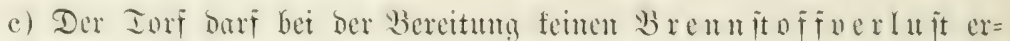

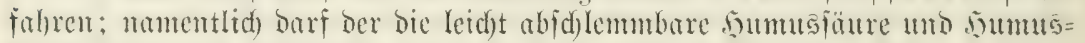

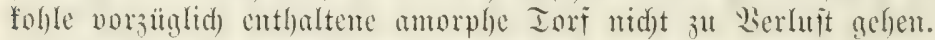

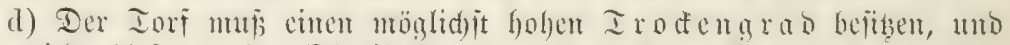
jwar nid)t bloj an ber Eberfläd)e, jondern and) im ferme ber cinzelnen Iorfitücte; er muis mo möglid) jente grobe matürlide bugrojtopität nerloren

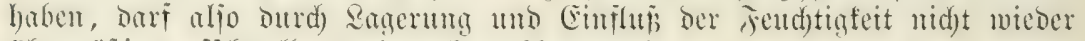
übermäpítg auffidyellen und unbraudjbar werben.

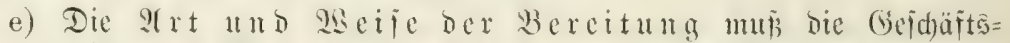

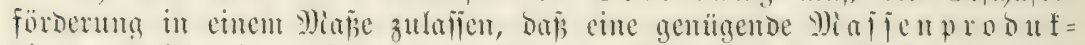

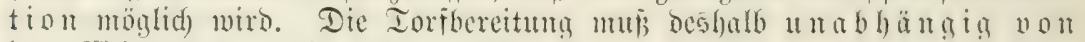
ber 93 itterung jein, mo enolid)

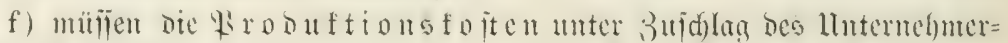

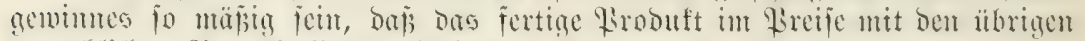
ortsiibliden Sremrtoffen unbebingt foufurieren fam.

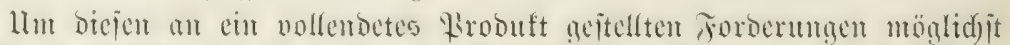

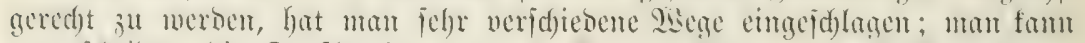

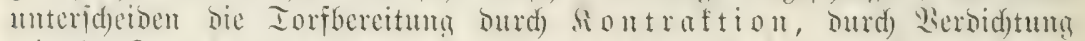

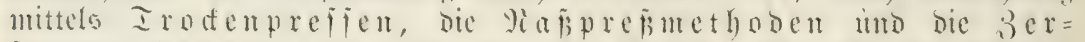
ft

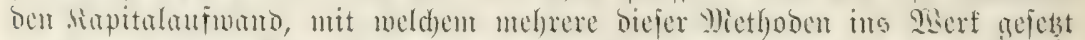

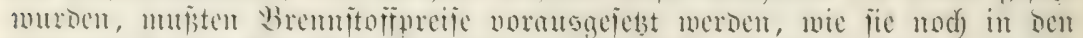

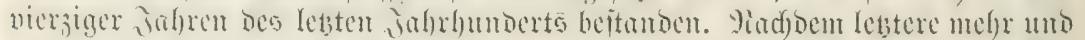

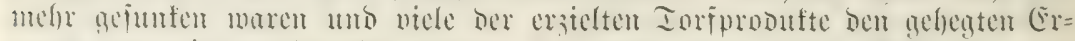

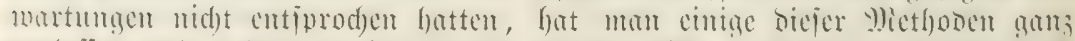

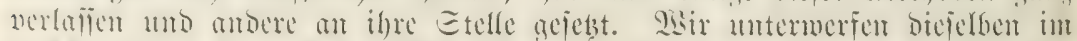

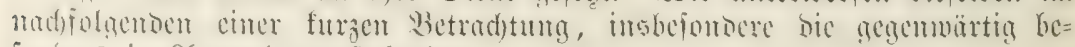

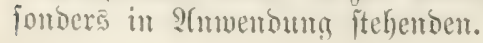




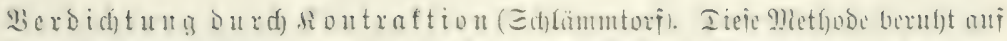

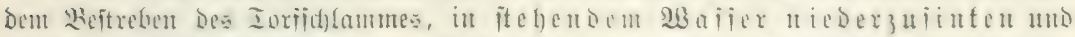

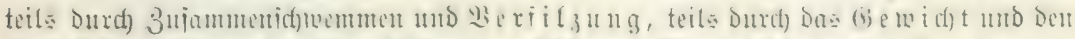

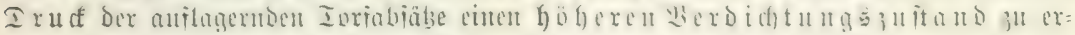
reichen, als ifn Dex gavöhnlidye Fafertori befitzt.

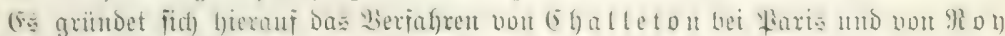

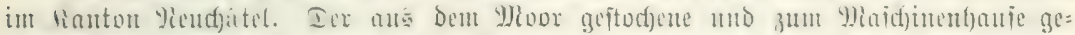

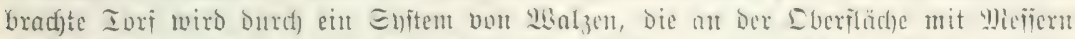

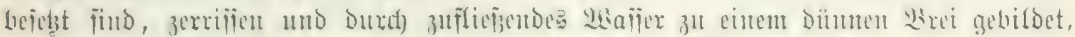

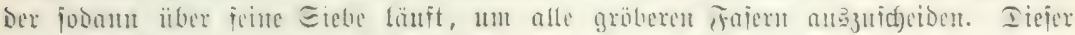

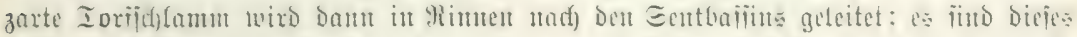

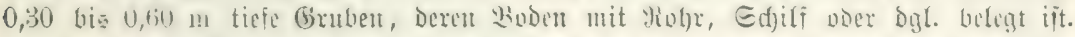

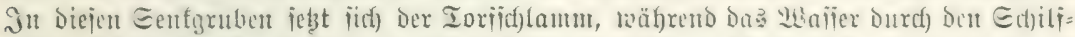
boden firtert, in furzer seit jo feft zujammen, Dab er j(t)on nach metheren Iaģen

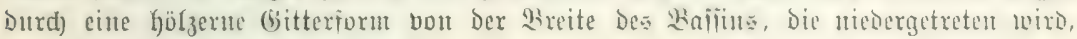
in Siäje gejuntitten weroen fann.

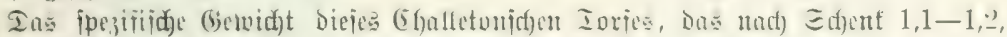
nad) Iulfo jelbit 1,8 beträgt, exreidyt alio jenes ber Eteintofle. Ilber bieiex Iori

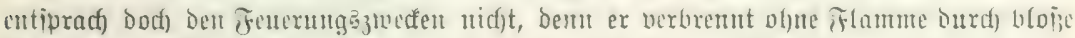
Sohlenglut, fällt im F̌ener auseinander und berjtopit Den Joft.

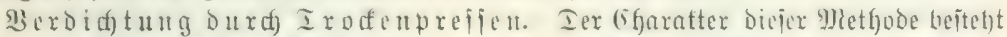

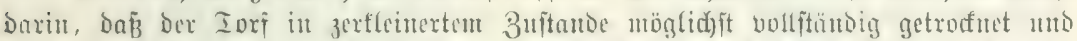

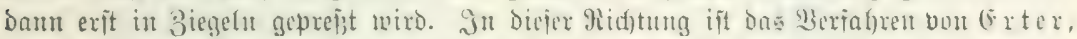

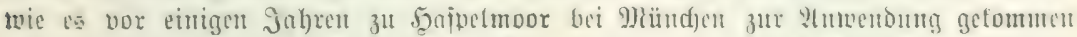

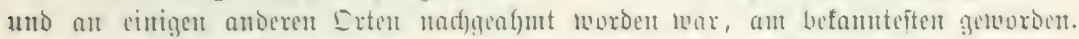

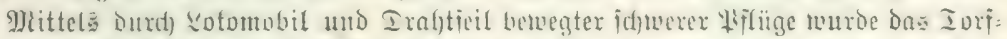

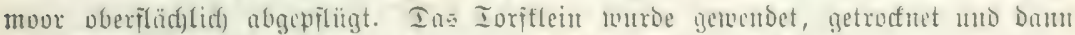

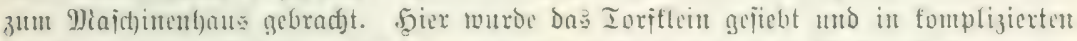

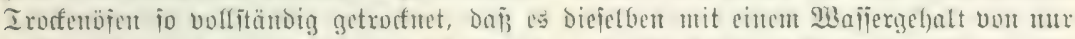

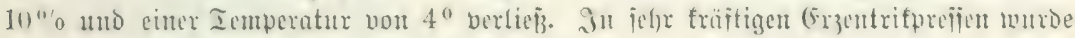
mun bicjes Iorfmet) zu fejten Biegelu gebracht.

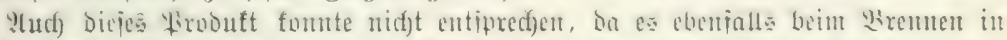

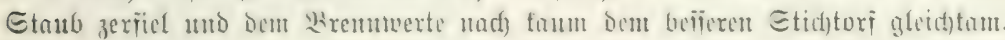

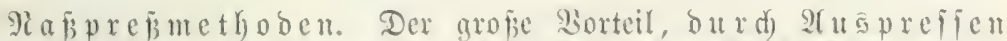

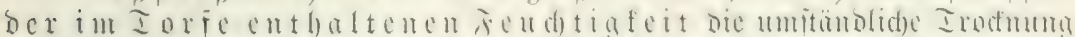

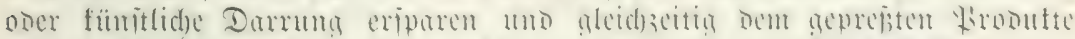

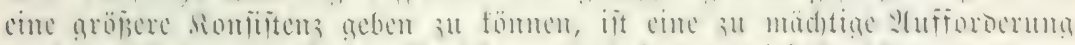

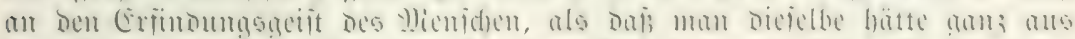

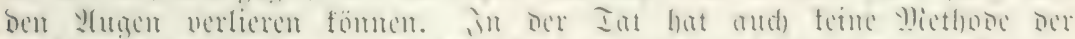

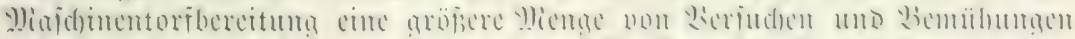

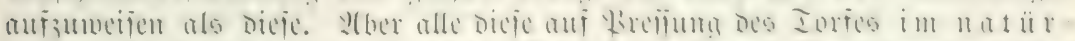

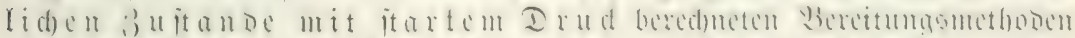

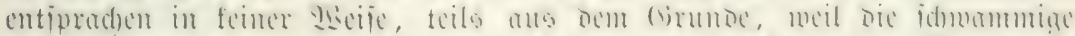

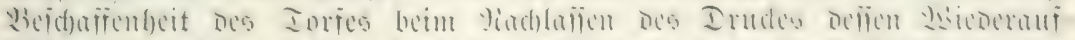

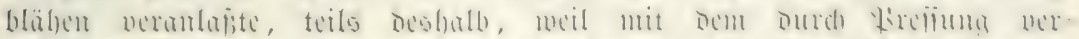
anlabiten

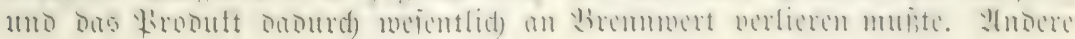




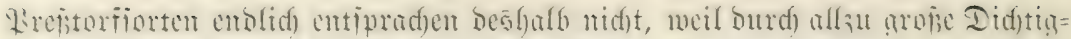

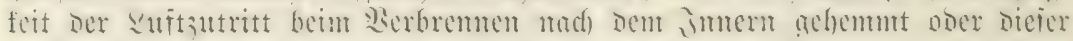

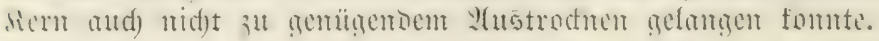

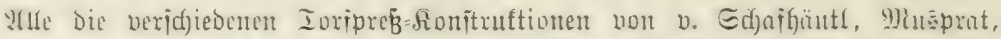

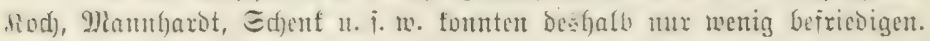

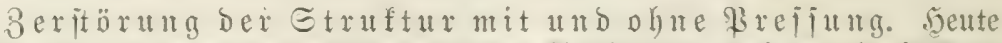

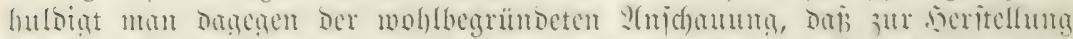

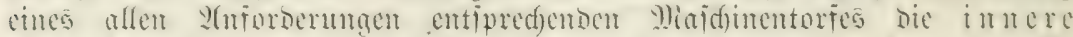
Etruftur Des matürliden Iorfes zeritout merben mitije, henor Derielbe

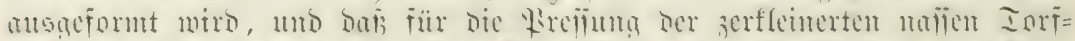

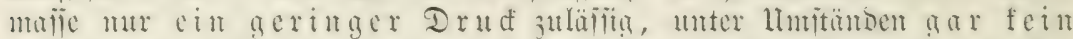

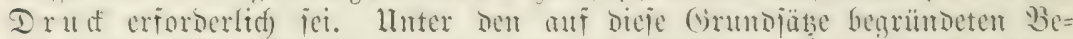

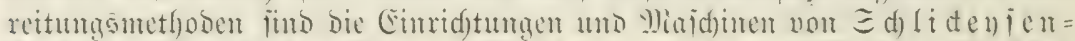

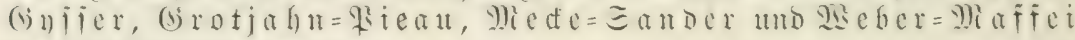
an befamteiten gemoroen.

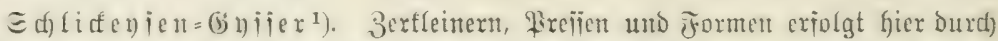

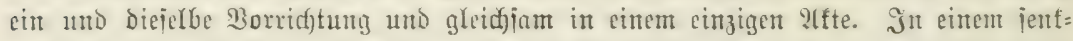
red)t itchenden, hohlen, gufjecifernen, oben trid)terförmig crmeiterten, unten won cincm

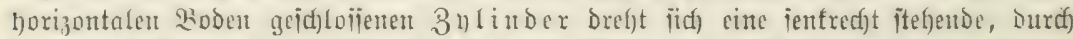

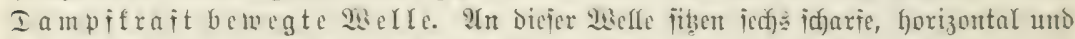
idjranbenförmig un diejetbe gefteffte Meejier, uno forrcipondierens Damit itehent weitere

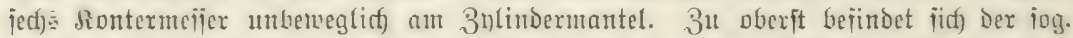

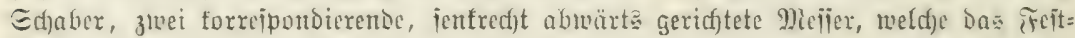
itisen und 2(nhüngen Des Torjes an bie 3nlindermandung verfüten. Şart über Dem

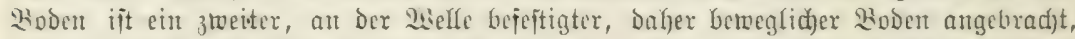

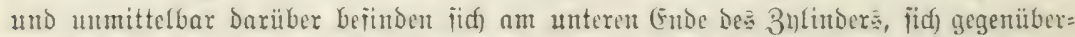

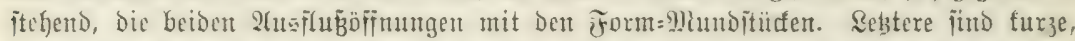

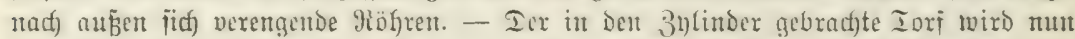

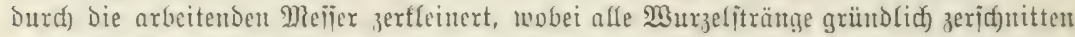
werom, alımüh(id) nad) untut gebrüngt, mobei burd) Die idfranbenförmige Eteflung

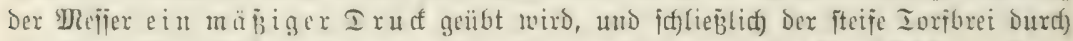

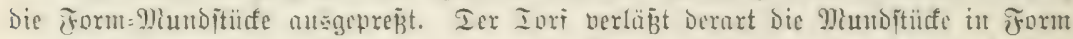

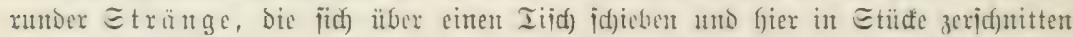
unto getrodinet twerden.

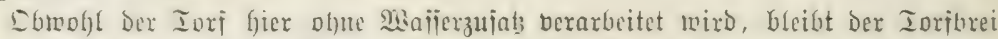

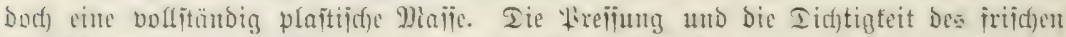

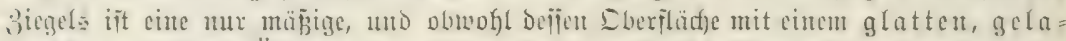

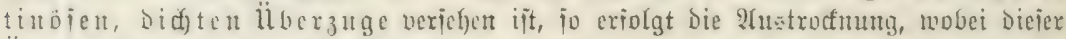

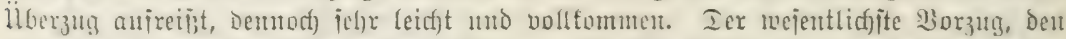

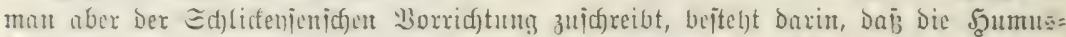

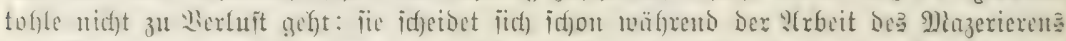

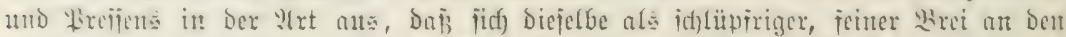

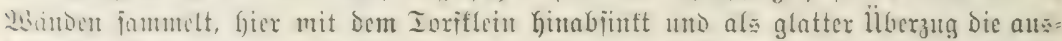

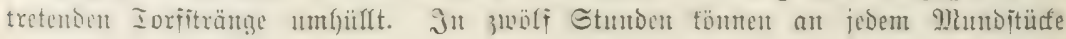

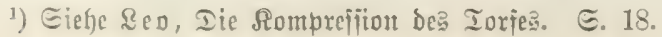




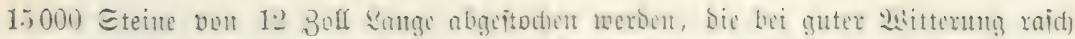

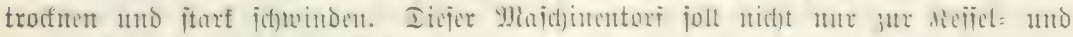

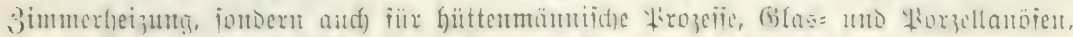

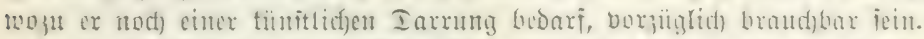

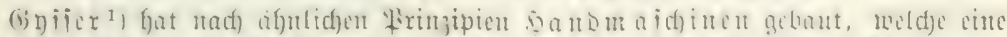

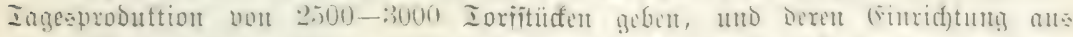

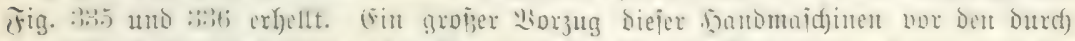

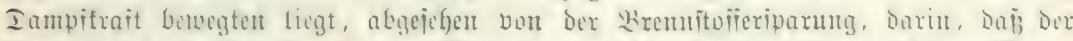

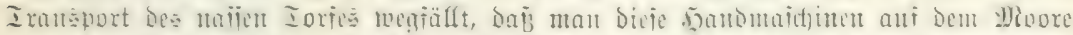

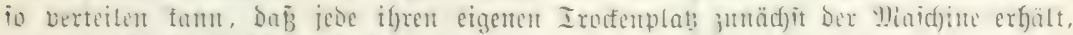

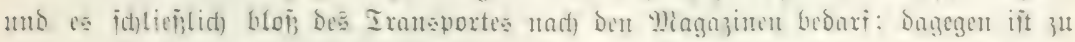

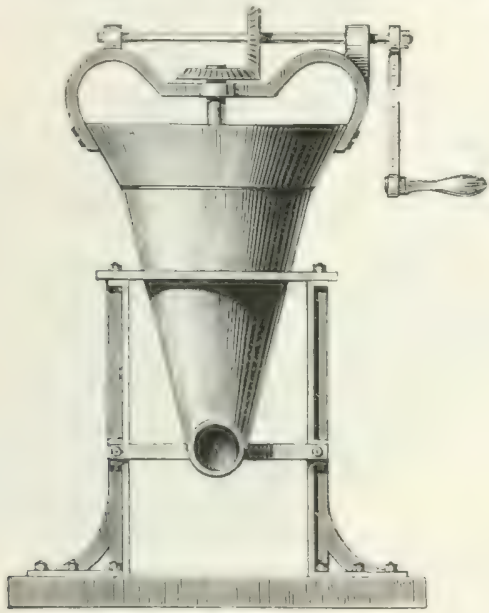

Jig.: 335. Jianbmajdrine oon Grilet jut Torjecrarbeitung.

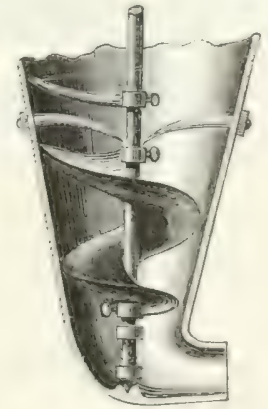

Jig. 336. Iurofictuitt burd) (5n)iers ynajoine.

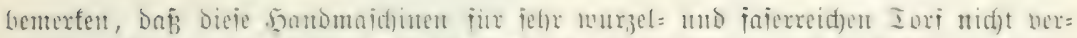

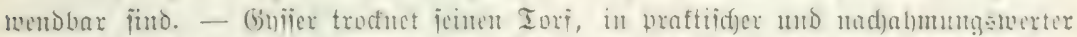

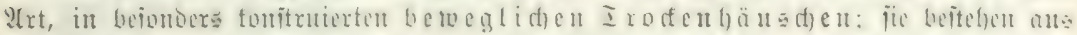

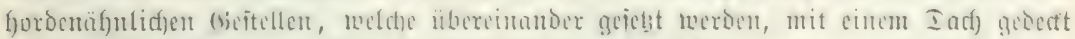
fint und ïberalffint nad) Bebari tranaportiert werder füntuct.

(i) rotiabut:

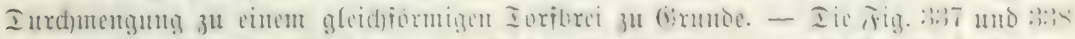

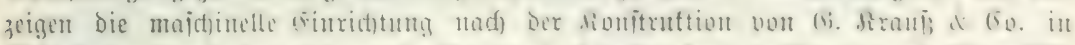

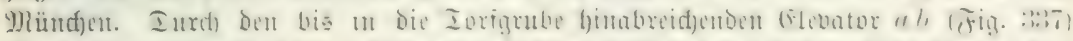

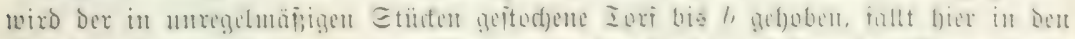

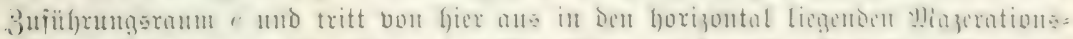

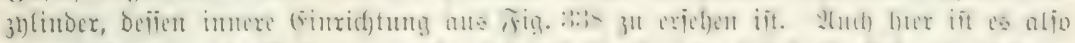

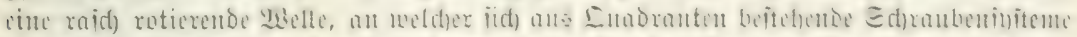

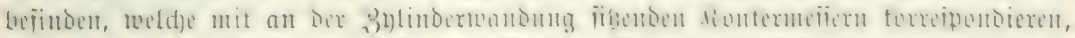

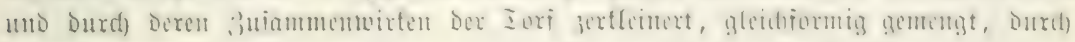

1) (B́lier, Ier Iori. whimar 1864. S. 64.

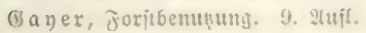




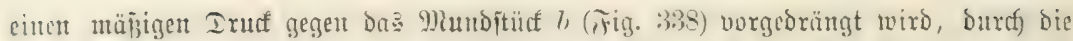

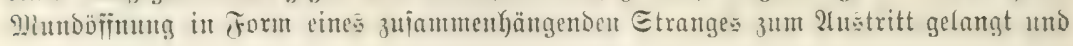

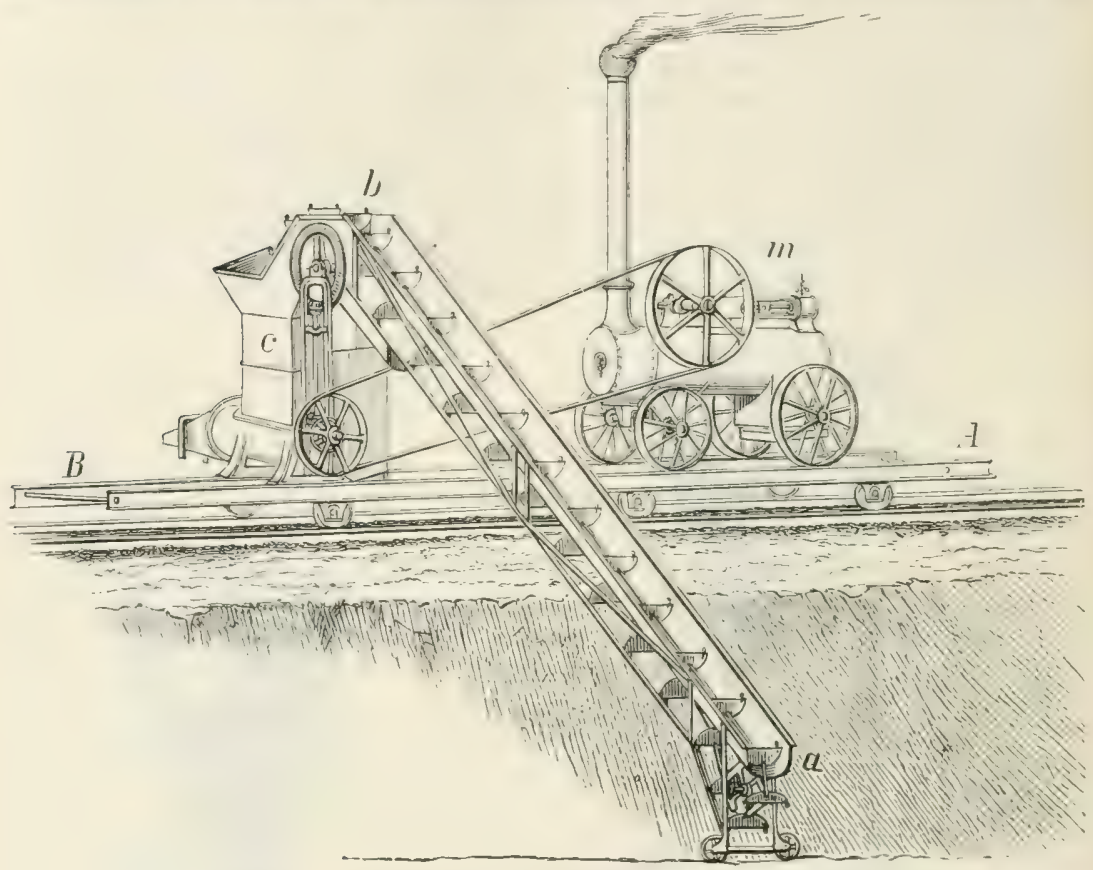

Jig. 337. \$rep̧torfmaijgine von Brotjahn mit \&aternoftermert.

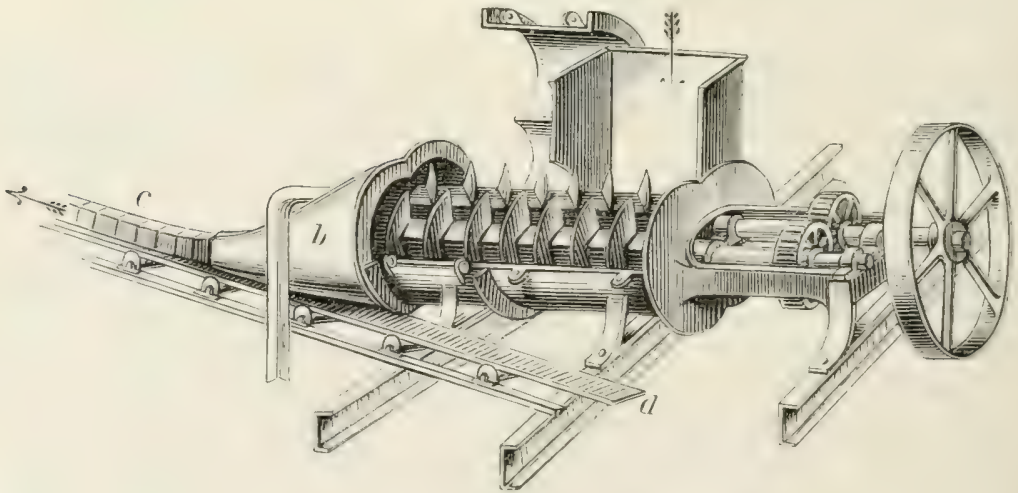

Fig. 338. Betfaferungä3ylinber obiger wajdine.

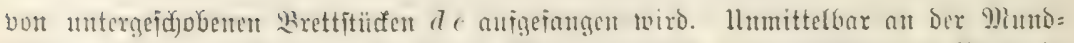

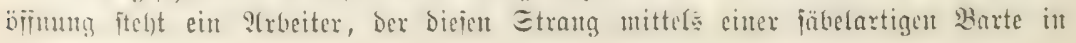




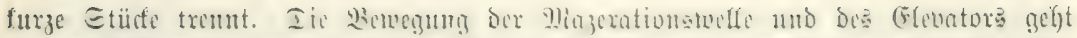

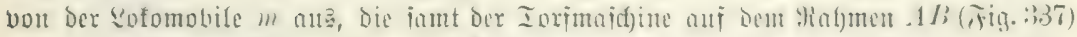

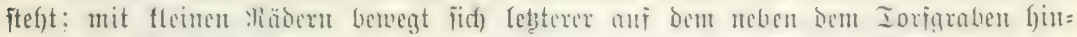

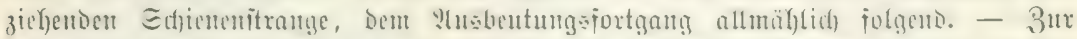

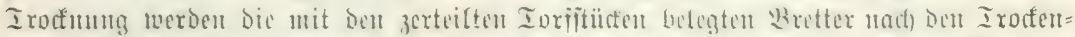

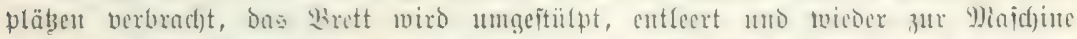

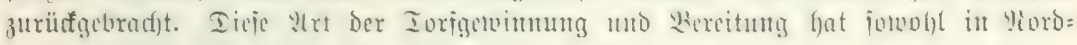
wic in Gübdcuticlanto cine bemerfentwerte Berbreitung getundent.

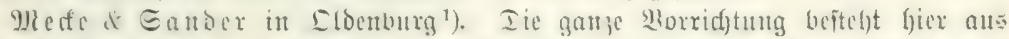

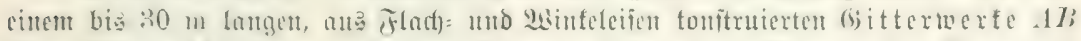

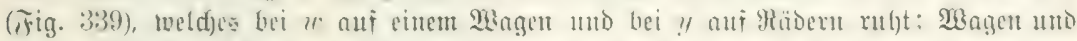

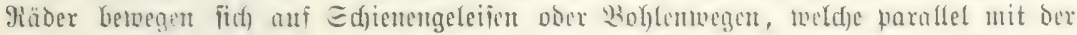

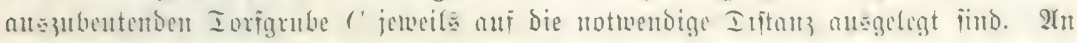

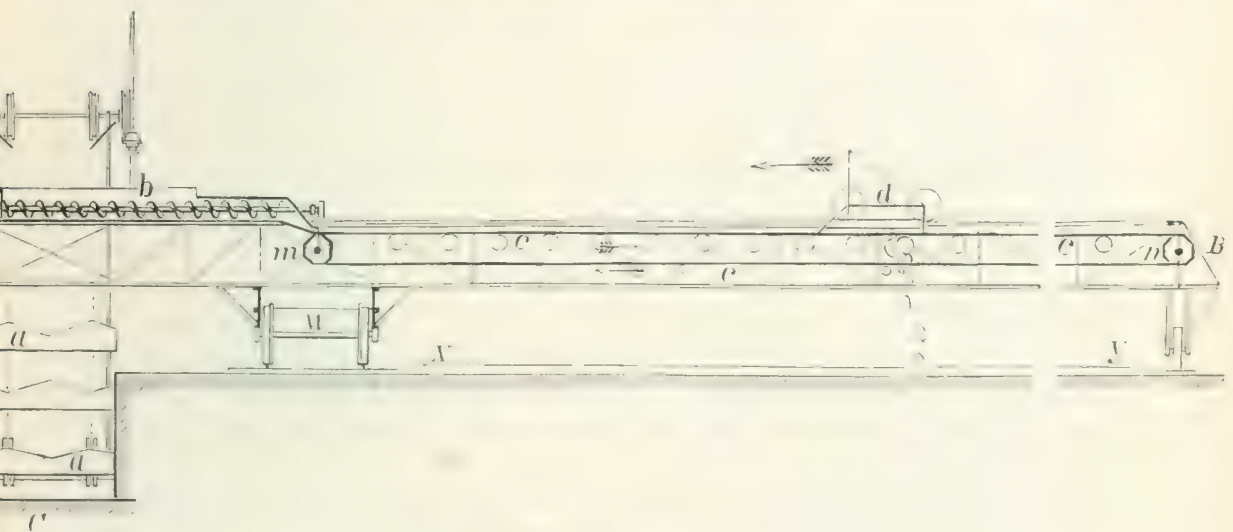

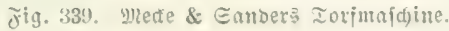

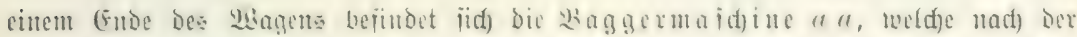

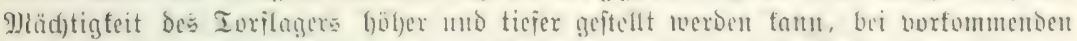

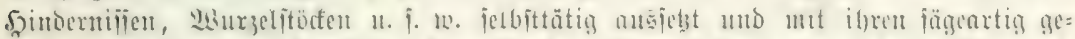

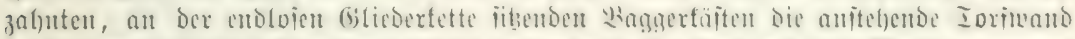

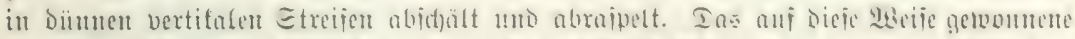

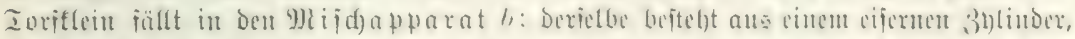

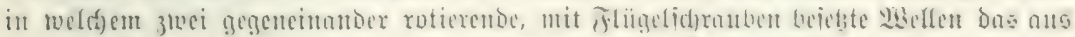

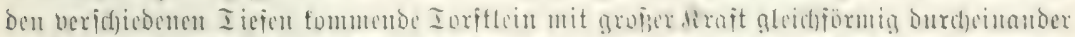

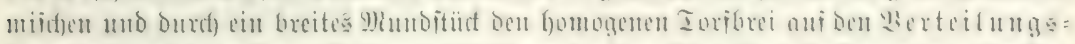

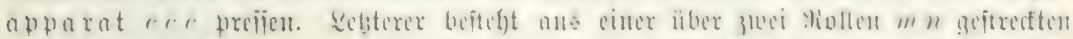

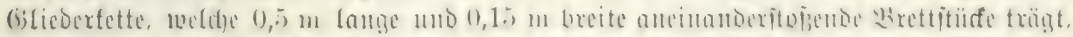

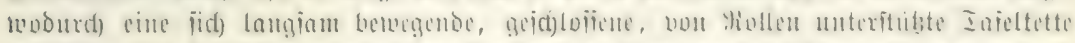

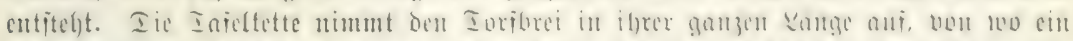

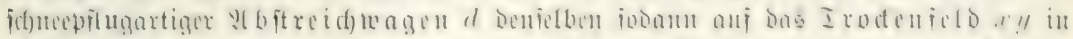

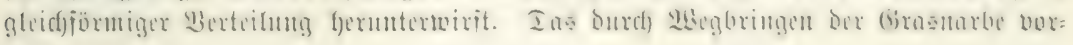

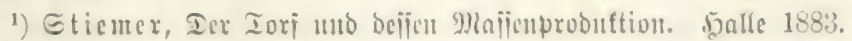




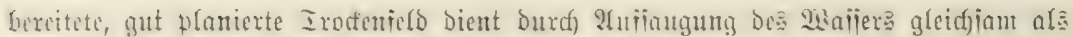

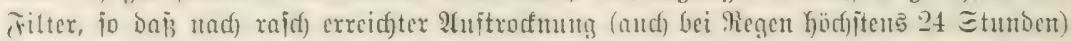
Der an

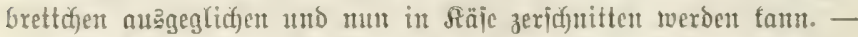

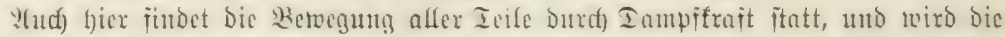

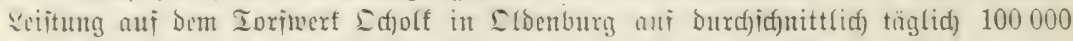
3iegel angegeben. Iex \&etricb jolf nom Regennetter fajt mabfängig fein.

Meber= Diajiei zu Etaltad) in Eibbrnern. Iieje idjun fänger bewälnte

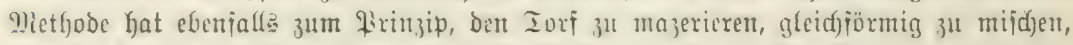

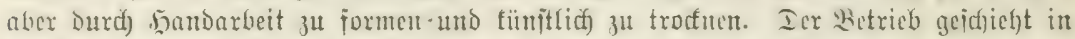

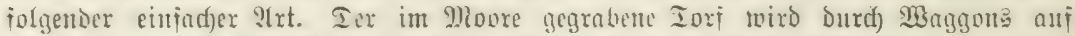

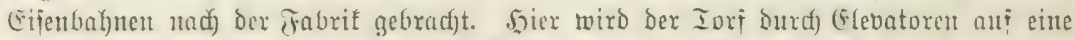

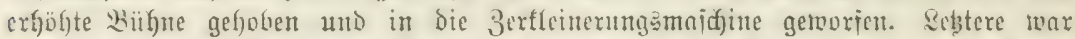

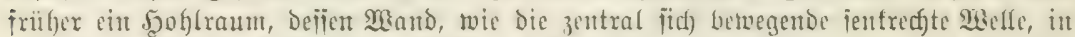

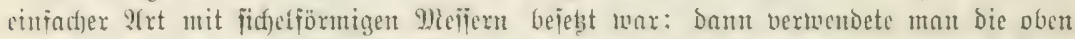

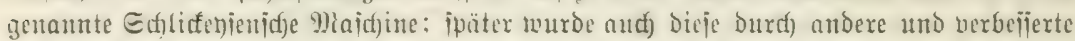

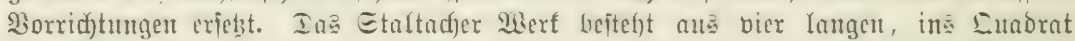

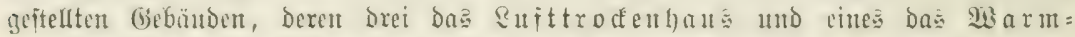

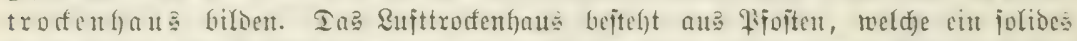
Ind) tragen utb in ?(bitänben won 4i) zu 4.5) ('m ïber cinander mit forizontal vor=

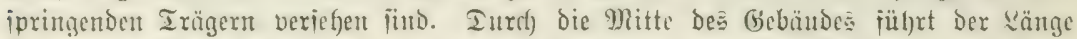
nad) tin Edjententrang, auj meld)em Die Maggon Das Iorfflein beibringen. Ier Vrbeiter legt mu auf Die unteriten Iräger cin Brett, bas nL Model = mo Iroden= Lanf bient, bringt barauf bon anz jieben Belfen beitehenden Formrafmen, fnetet ba

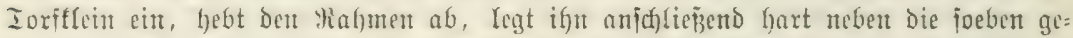
iertigten diäje, fnetet wieoer tiu und iäfrt jo jort, bie bas erite Brett bemodelt ift.

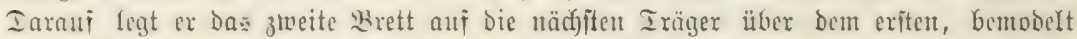

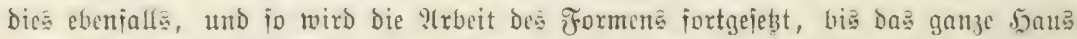

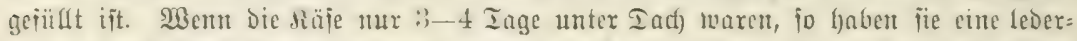
axtige Eberịläde befommen, bie aber immer nod) porö gemug iit, Die innere fouthtig=

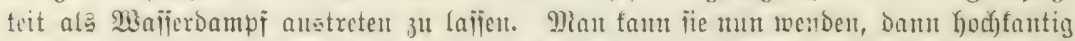
aufitellen, und berart allmäflid) zu einem Irofengrabe von 25 "' 2 afiergehalt fïfren, wohei ber Iori zu ieder Deizung braudfbar ijt. Eoll ber Iori berfoklt werben, io

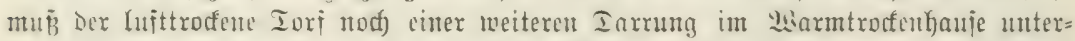
worfen werden, tooburdf ex nod etwa $15 \%$ Wajfer bertiert.

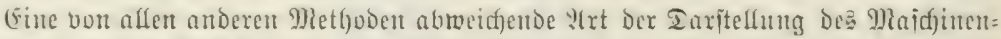

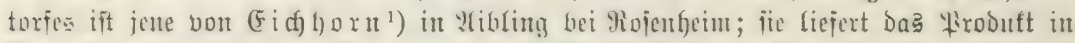

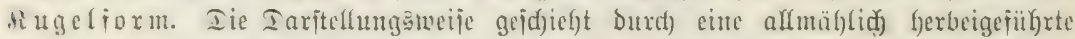
Nuntung Dex berfleineten Iorimajie in einem mit einer ?(rd)imedijonen Ed)raube veriefyenen, horizontal liegenden 3nlinber. I ie gerunbeten Iorfïtücf gelangent Danu

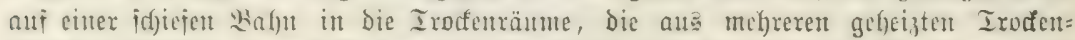

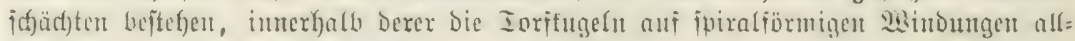

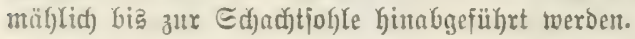

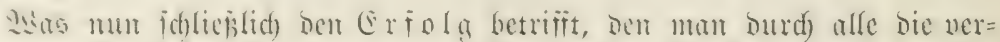

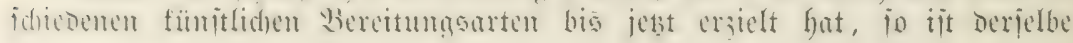

1) Ier Singelturi, Dargeitellt von Wien\}, sindurx und Fidfforn. Freiping 1867. 


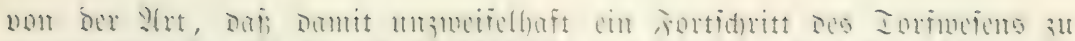

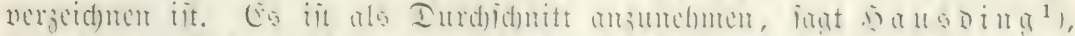

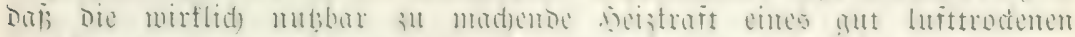

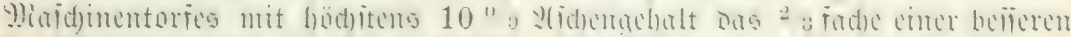

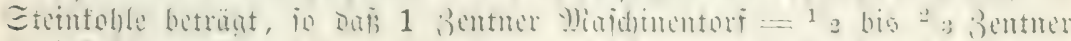

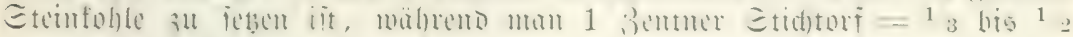
Bentuer Etemfohle gleidad)ten fam.

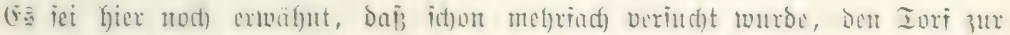

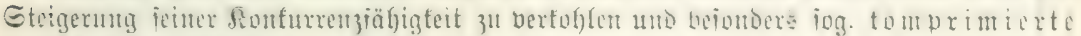
Iorftohle (ähnlid Der Solzfolde) herzuitellert.

Iorfitren ${ }^{2}$ ).

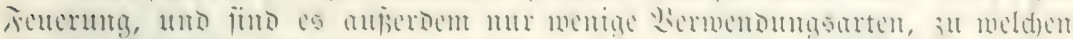

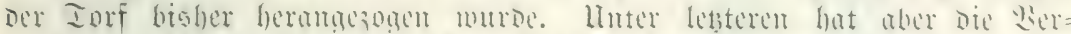

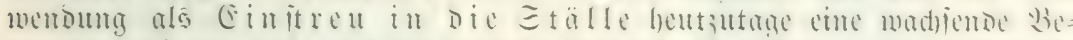

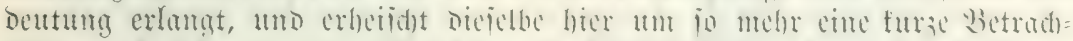

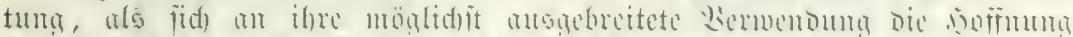

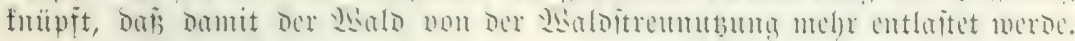

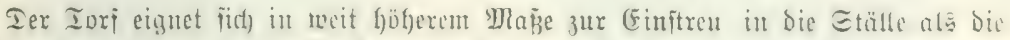

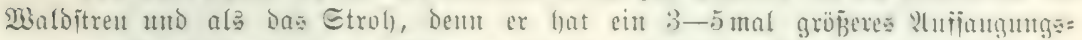

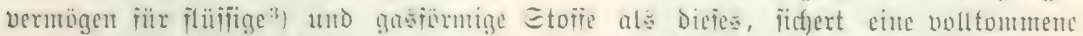

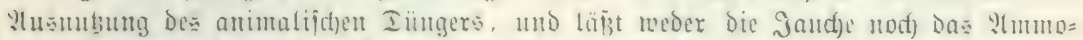

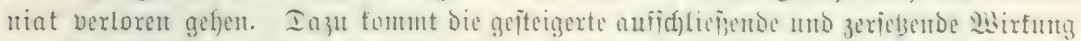

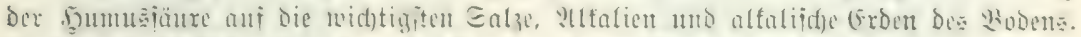

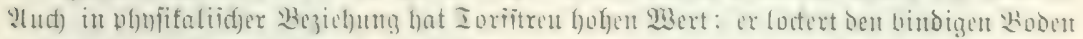

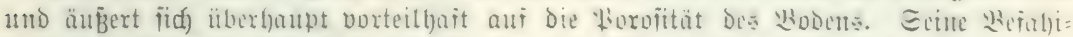

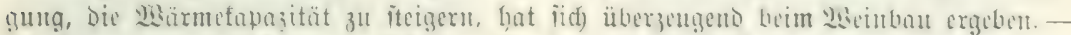

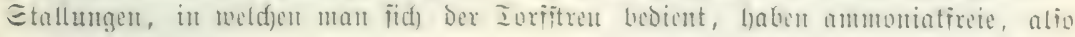

1) ๔. 212 jeinte eingang exmähnten Mertes.

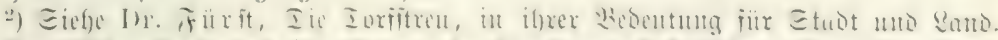

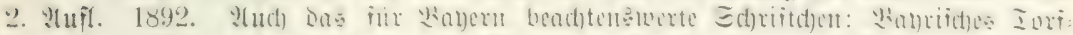

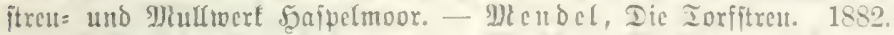

3) Yiact) ben lluterint)ungen unu Dic $\mathfrak{B a j i e r t a p a z i t a ̈ t : ~}$

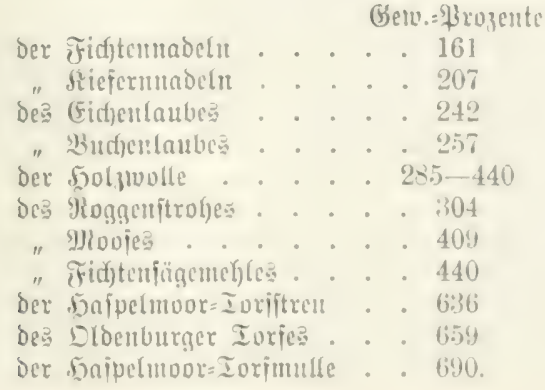




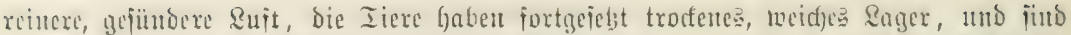

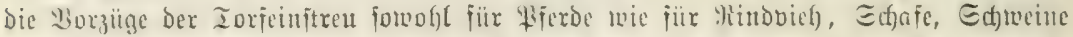

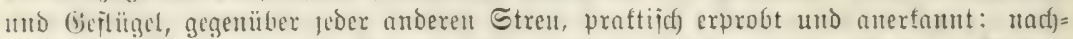

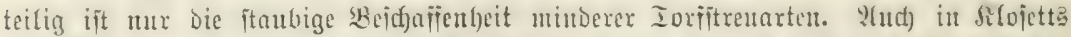

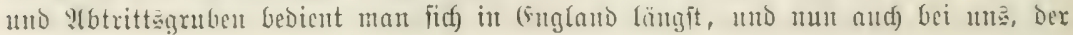
Torjitreu.

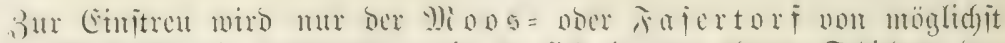

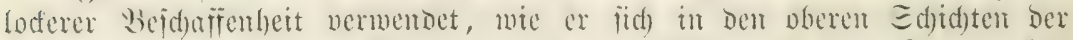

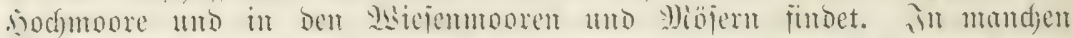

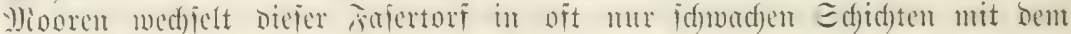

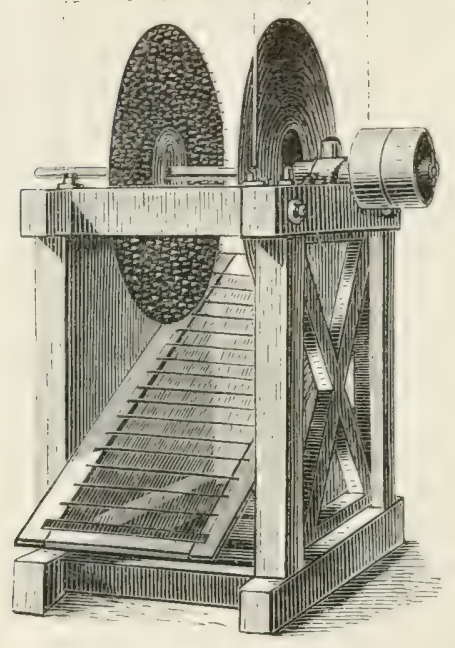

Fig. 340. Meip̄wolf, zur Berfajerung ber Iorfitreu.

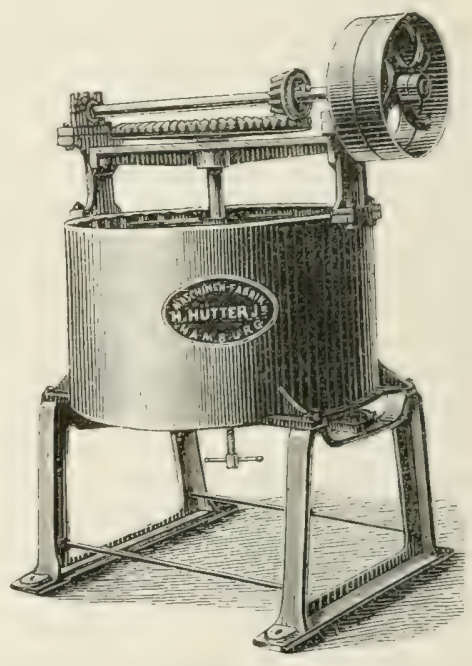

Jig. 341. Iorfmüble 3ur 2,u6ereitung von Torititreu.

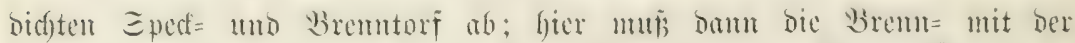

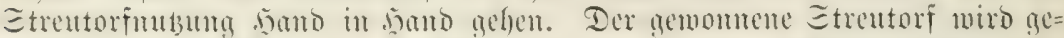

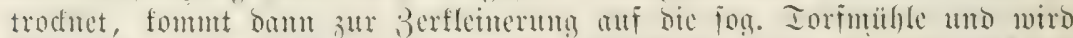

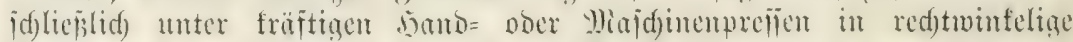

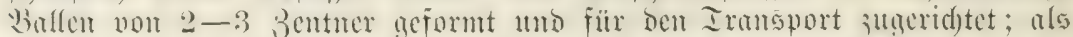

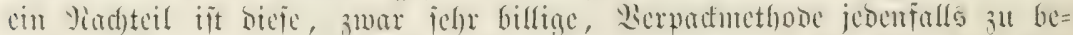

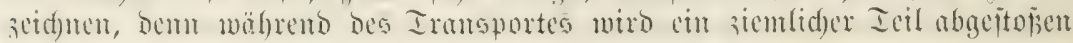
uno verunreinigt Ragerbäujer, Wege u. Dergl.

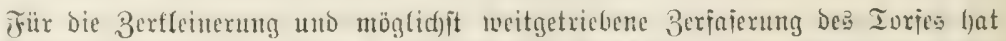

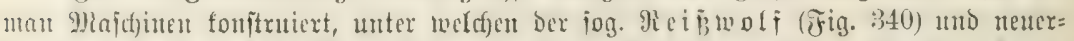

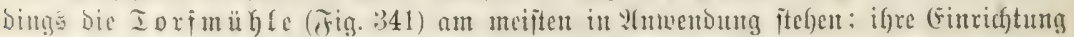

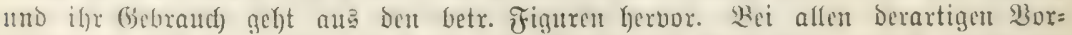

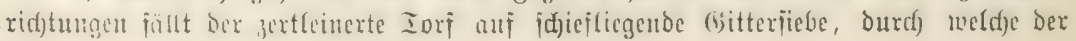




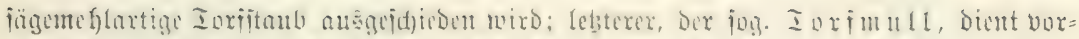

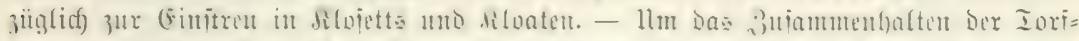

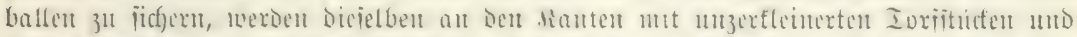

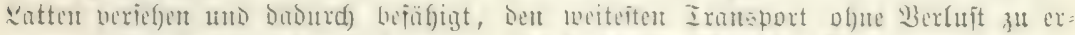

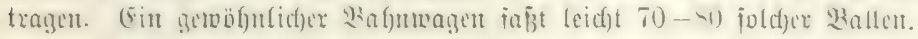

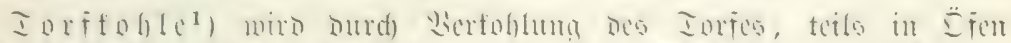

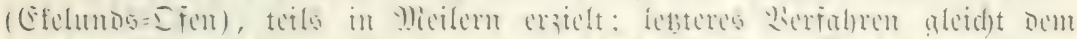

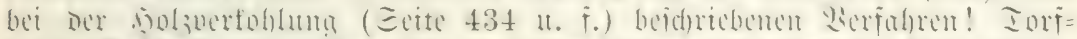

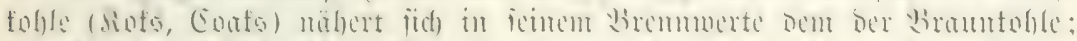

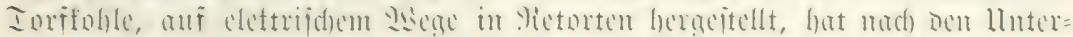
juduturgen in Efriftiania ${ }^{2}$ ) $76,9 \%$ Siolylemitoff.

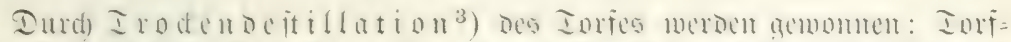

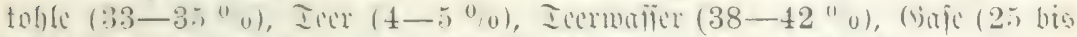

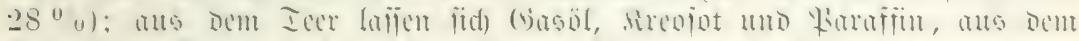

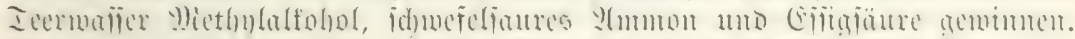

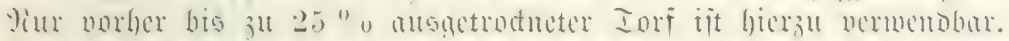

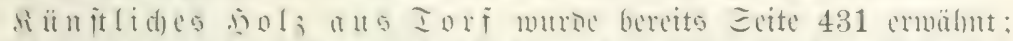

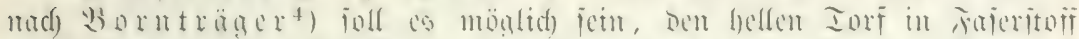
iu Wirifets

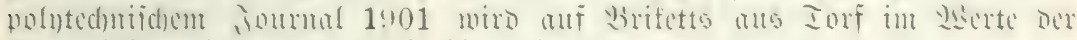
Braunfolle mit mur $1-3 \%$ alja) bingemiejer.

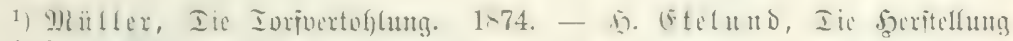
fomprimicrter ภohle aแ Bre Brutorf. 1892.

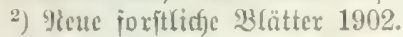

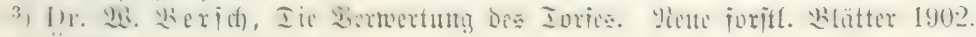

4) Difterr. Foritzcitung 1901. 


\section{fümfter 2lbichnitt.}

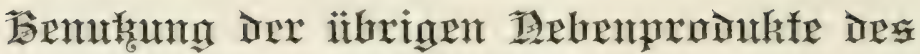 1t)althonens.}

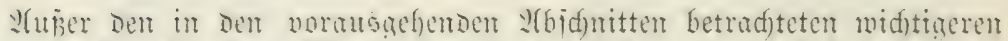

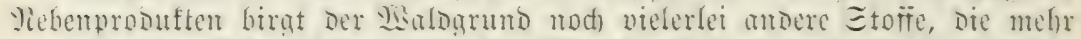

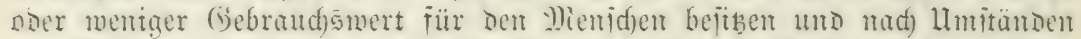

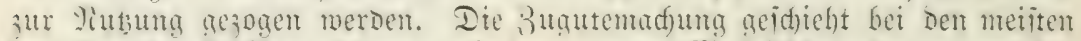

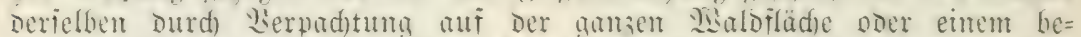

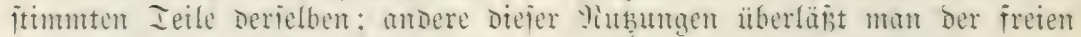

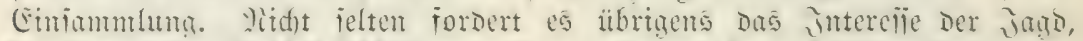
Dic Trane Der llnidüolidbeit vorerit zu crörtern, Dem für Den im gamien

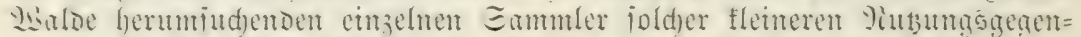

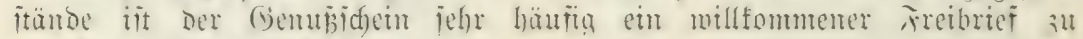
mandjerlei IIngejeblidjfeiten.

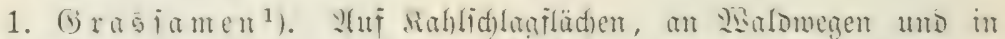

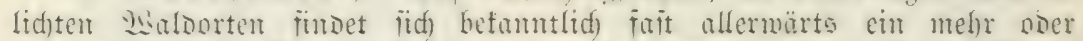

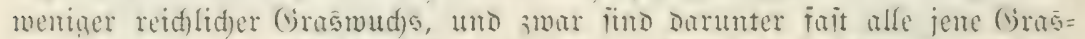

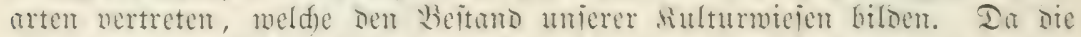

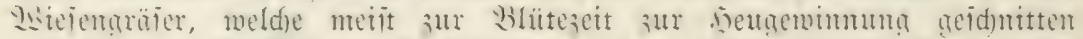

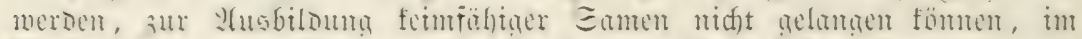

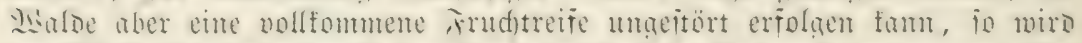

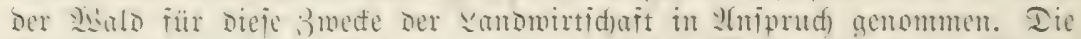

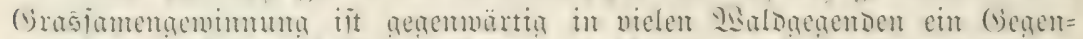

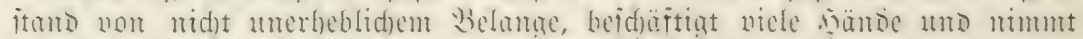

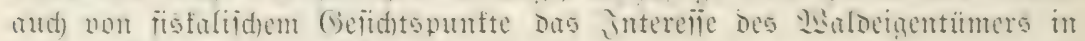
nidjt unbebeutendem Miape in 2 (npprud).

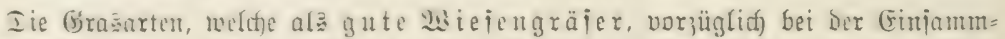

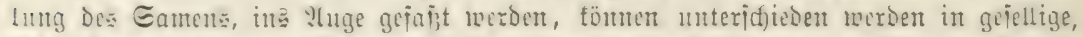

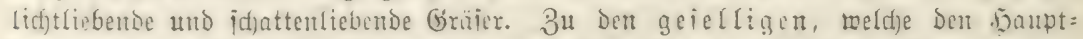

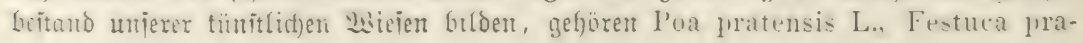

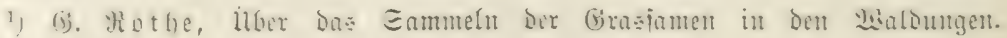
Etuttgart 1875 . 
tensis Iluds., Alopecurus pratensis L., Agrostis stolonifera L., Festuca rubra

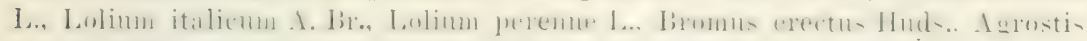
rulgaris $W$., Agrostis canina L., Festuca arundinacea L., Holeus lanatus,

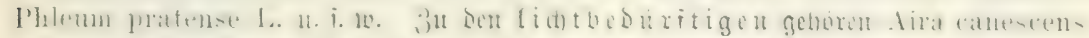
L., Arena pratensis L., Arena pubescens L., Arena flavescens L., Bromus

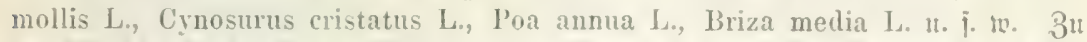

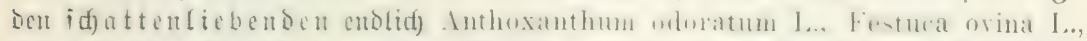

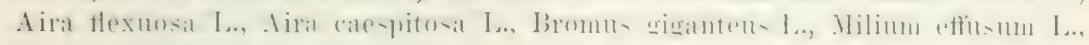
Holcus mollis L., Poa nemoralis L., Festuca sylvatica Vill. 11. i. 5. Dex Eame von Milium effusum ijt Bogeffutter.

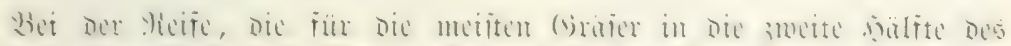

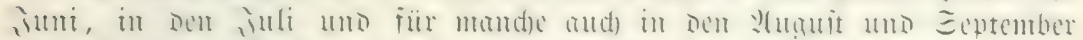

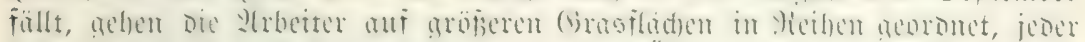

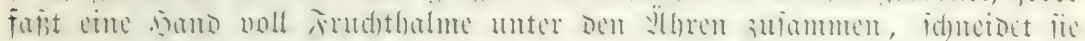

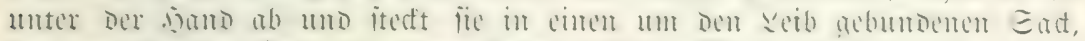

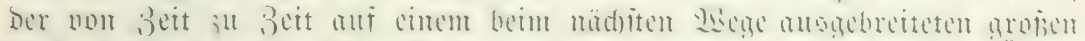

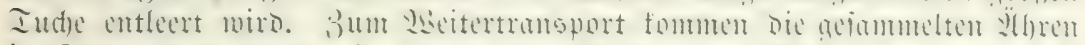

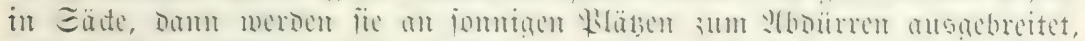

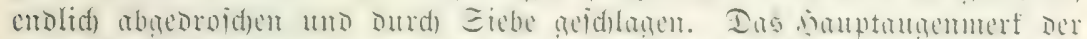

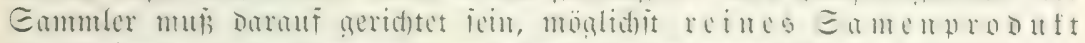

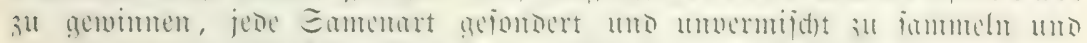

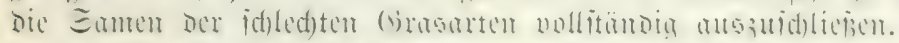

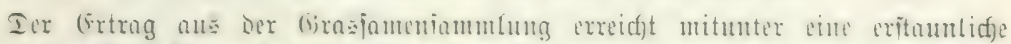

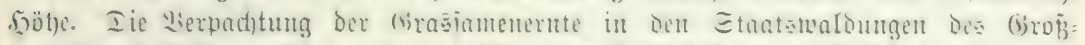

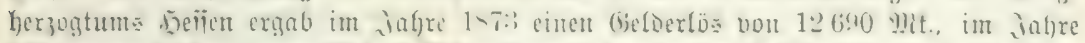

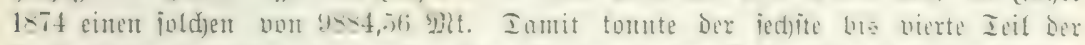

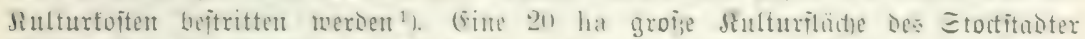

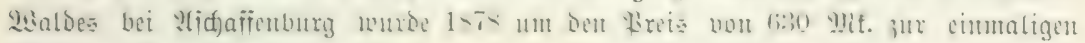
Girajamenutsung verpadstet, u. i. w.

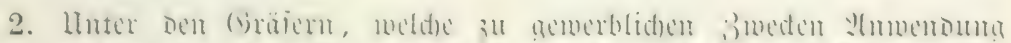

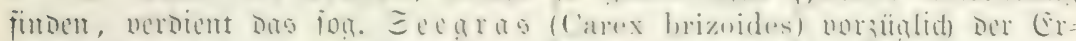

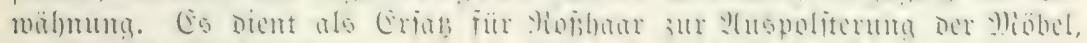

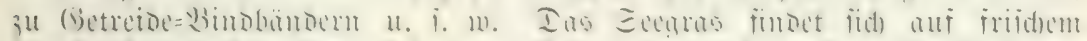

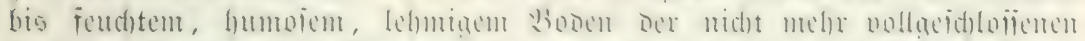

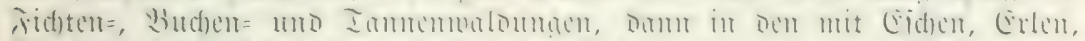

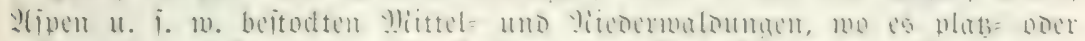

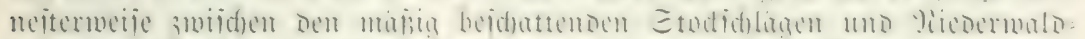

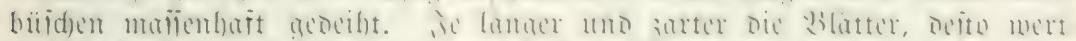

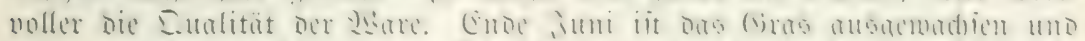

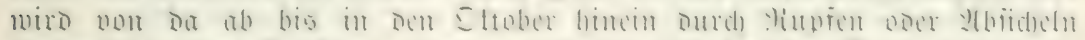

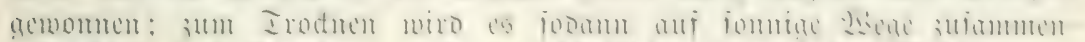

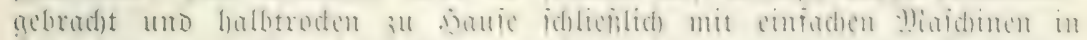

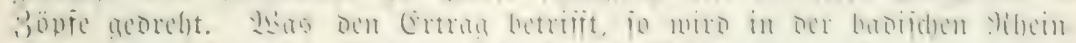

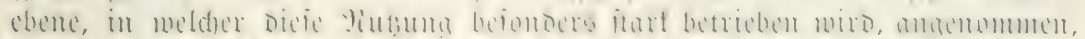

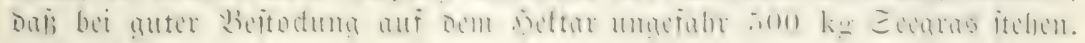

1) Motbc a. a. D. E. 7 . 


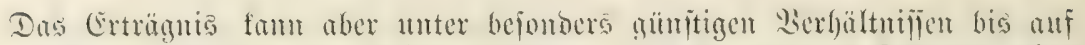

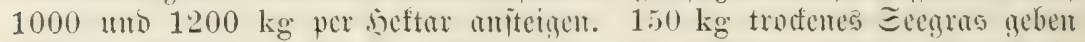
$125 \mathrm{~kg}$ aepontenc DSare, und $100 \mathrm{~kg}$ ber lesteres habes gegenuärtig cinen Ṗreis von $4-6$ glf.

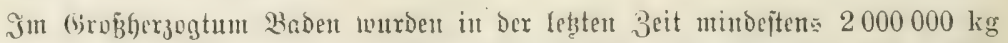

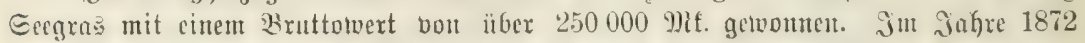

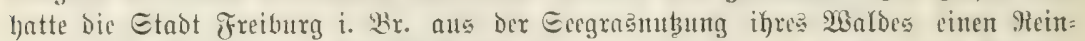

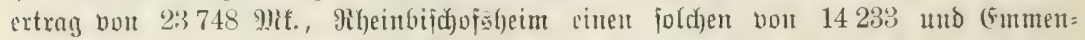

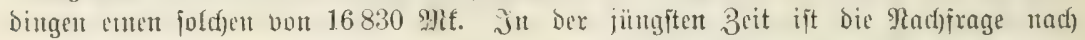
Eecgraz wieder etmą zurüdgegangen, - veranlapipt Durch) importierte Gurrogate ver=

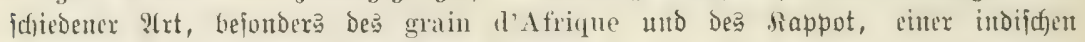
Jiflatzertwolle (Bombax? ${ }^{\mathbf{1}}$ ).

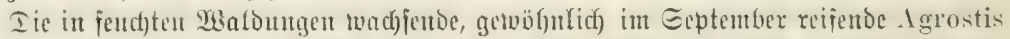

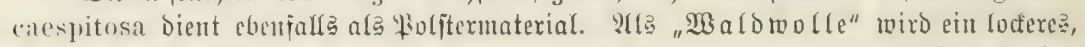

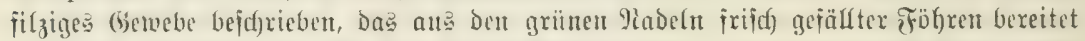

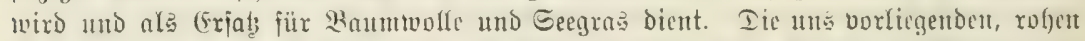

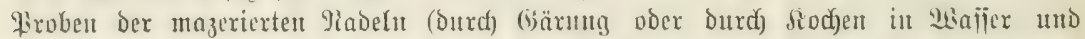

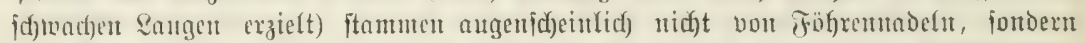

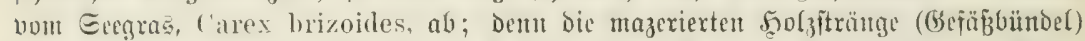

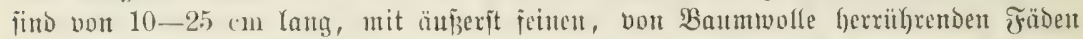

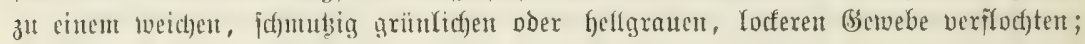

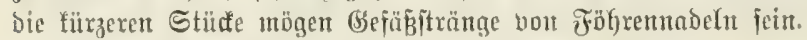

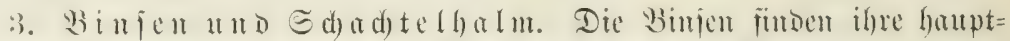

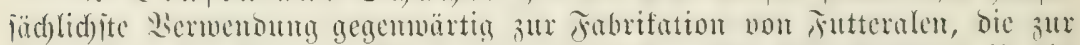

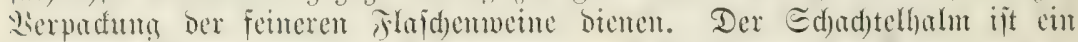

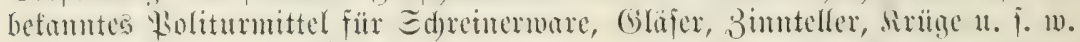

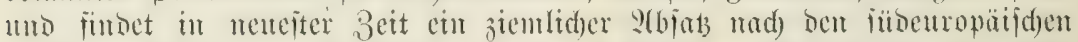

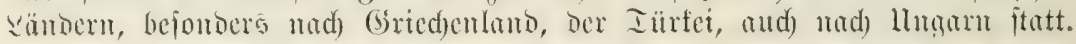

4. Miopje. Politrichum commune, jences oft futpholec, in naffen

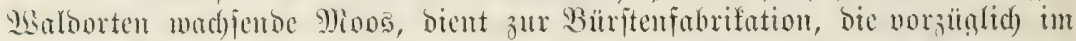

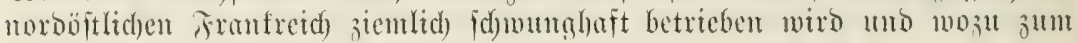
grofien Teile Deutidjland Das Miaterial liefert.

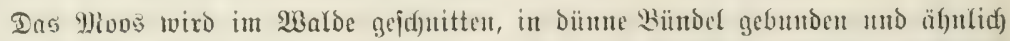

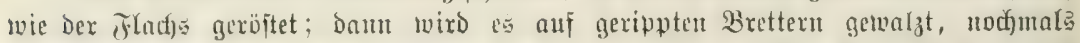

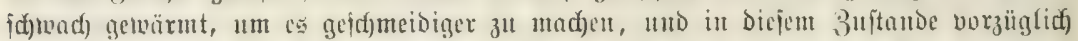

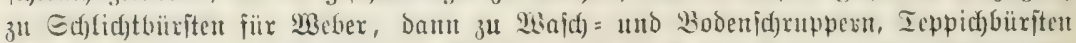
II. ¡. w. verarbitet. In derielben Weife werden and) bie Murzeln von Empetrum

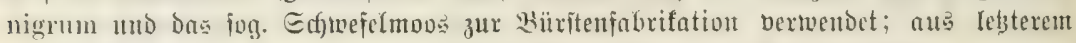

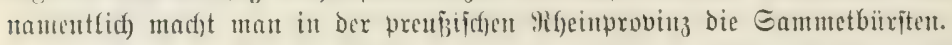

Dro Iamarisfenmog (Hyp. tamariscinum) wiro in grofier

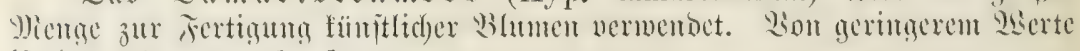
ift bag Hypum splendens.

1) Jit Schlichs Manual of Forestry Forest-utilisation by W. R. Fisher wird audf) Alva (Zostera marina) als Eurrogat erräfnt. 


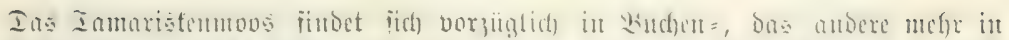

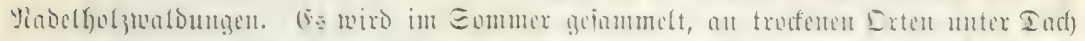

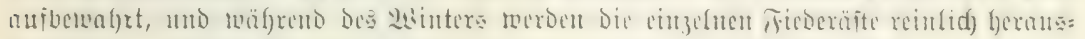

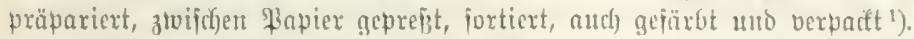

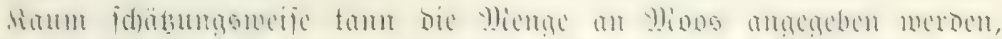

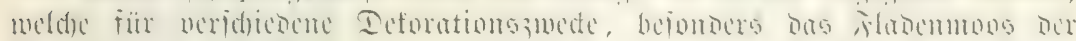

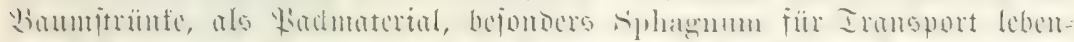

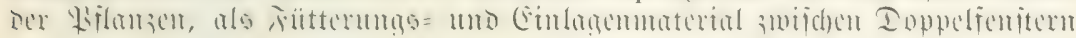

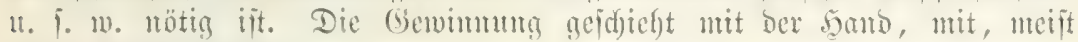
olne Ërloubrisidgein.

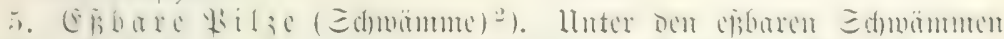

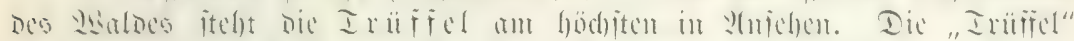

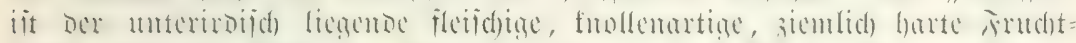

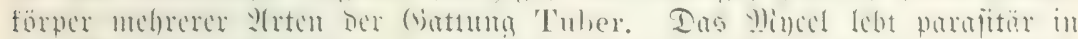
Den

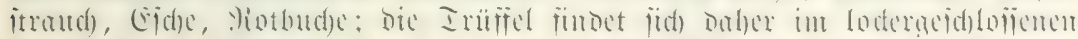

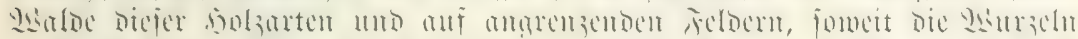

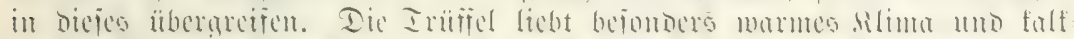

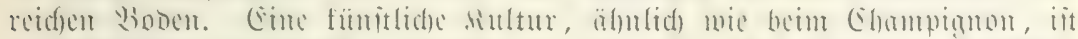

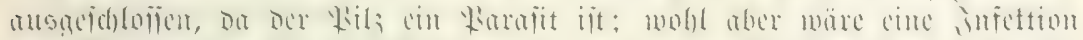

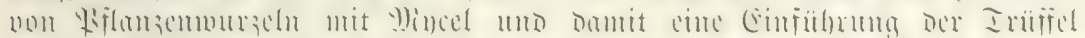

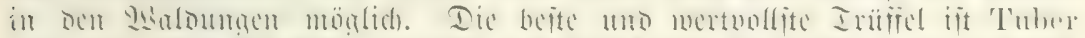

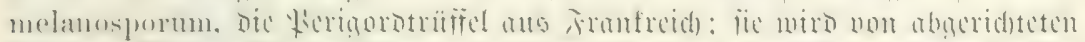

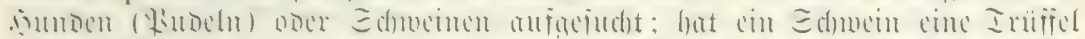

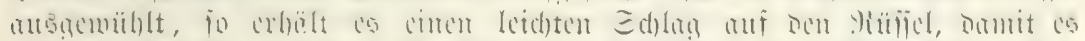

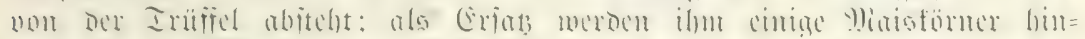

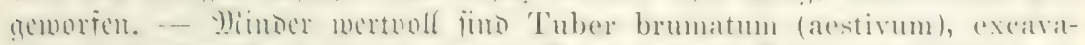

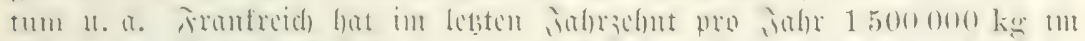

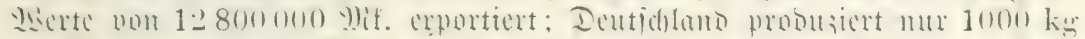

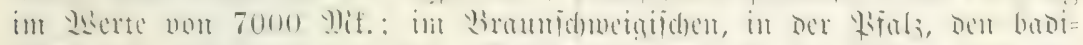

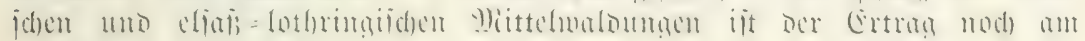
reidjiten.

Der E G a m

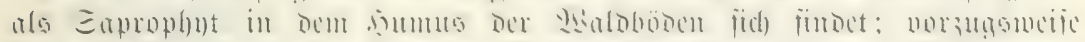

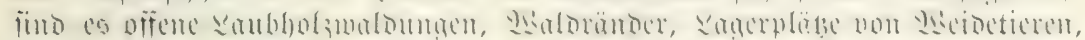

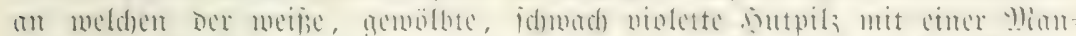

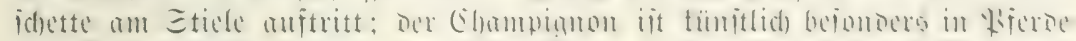

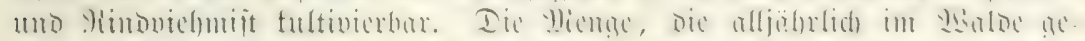

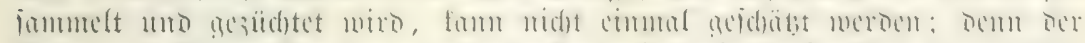

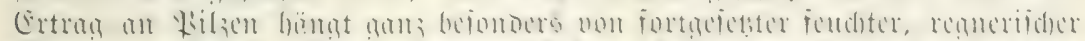

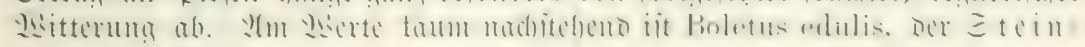

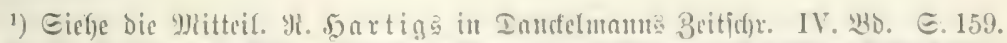

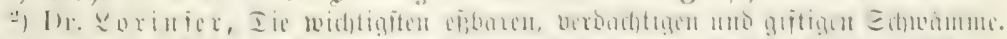

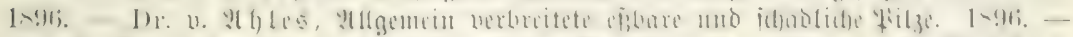
10. E. 黑

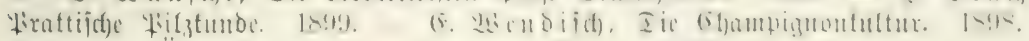

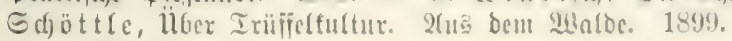




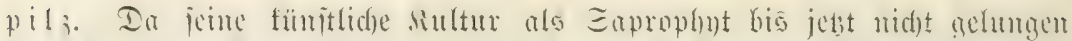

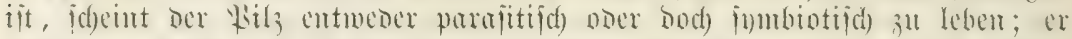

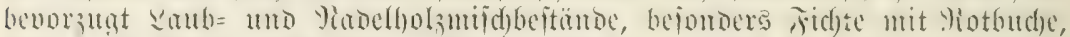

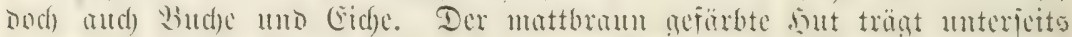

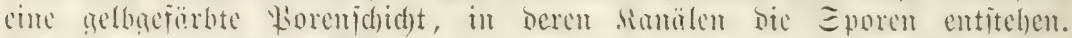

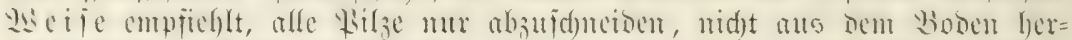
ansutrifien. Wiele mbere, wic Cantharellus, Clavaria Hrdnum, Men-

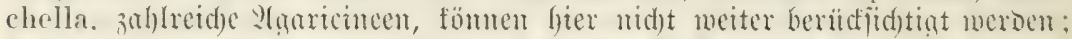

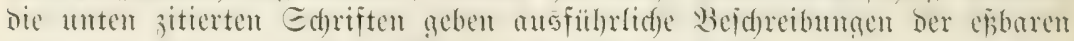
แno, waפ jebr nötig ijt, audj ber nidjt eह̂baren \$illze.

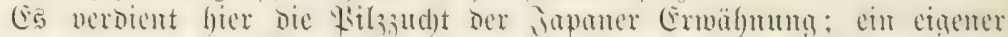
Jicoermalnbetrieb non (Eid)en, Pausania (Shi), and) Wudnen, liefert frijde

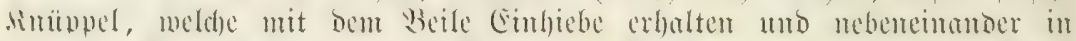

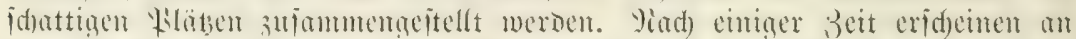

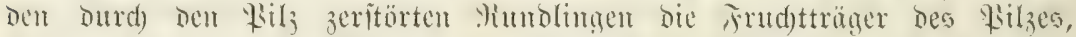
Shitake, Agaricus Shitake, melde mebreve jabre furburd) abgelejer

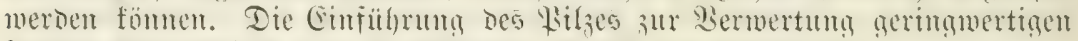

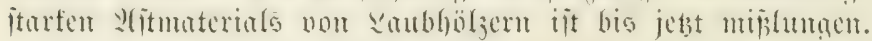

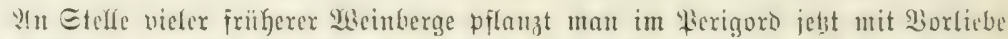

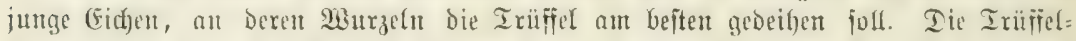
fultur lohnt urei = bis fïnfmal beifer als Der Dortige Meinbau. Eic ift heute vom

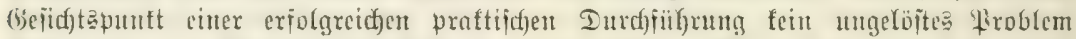

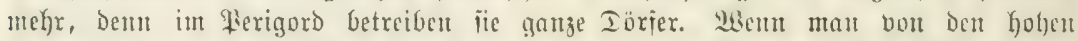

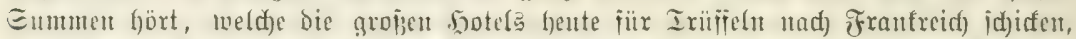

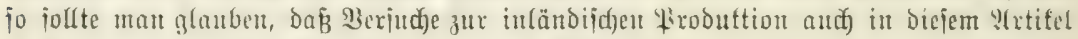
iit ben bazu gecignteten (Segenton wohl am \$labe twären.

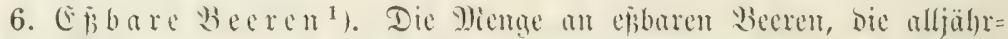

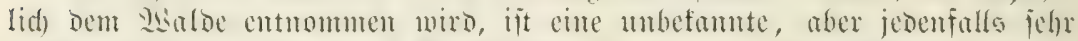

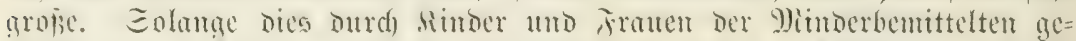

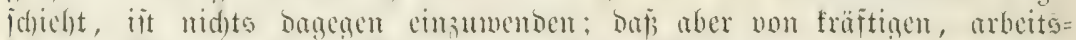

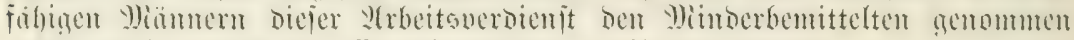
werbe, follte burd) den Marbeigentimer verfindert werben.

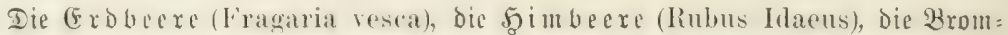

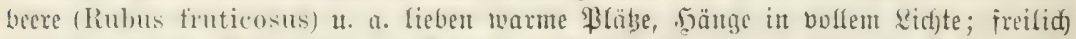

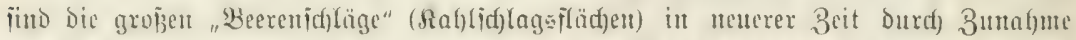

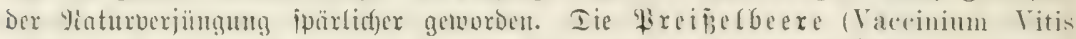

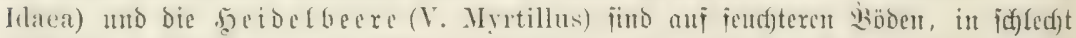

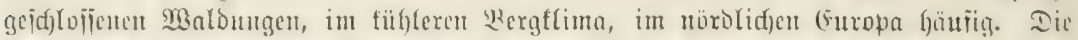

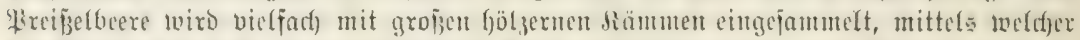
bie

1) (5. \&ariz, Sandelsblatt fïr Malderzeuguifie. 1894. — v. Grenerz, Iie

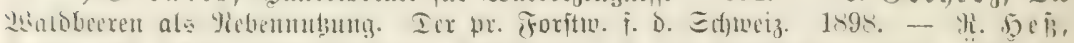

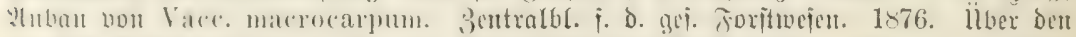

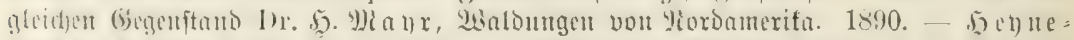

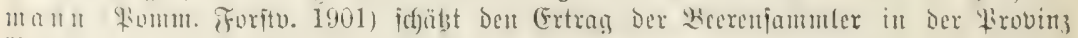
Honnum anf fïn ghiffionen Mlart. 


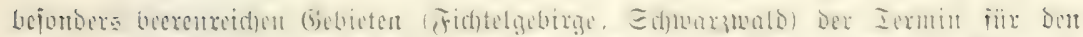

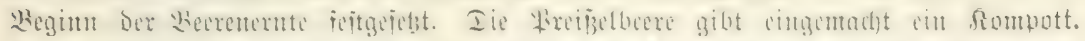

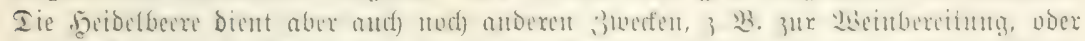

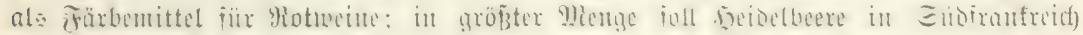

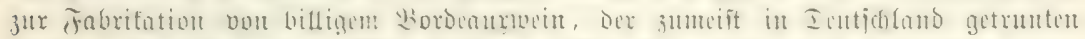

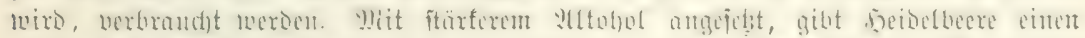

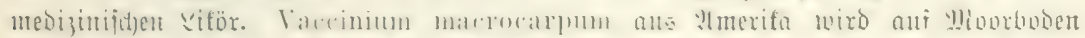

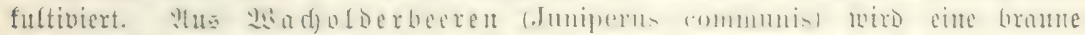

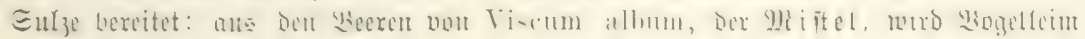
getodìt.

7. 2(โ

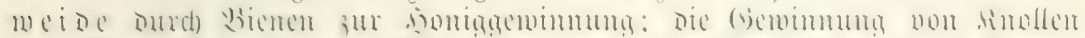

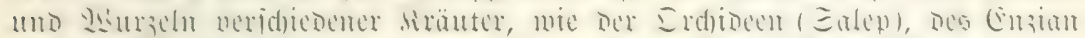

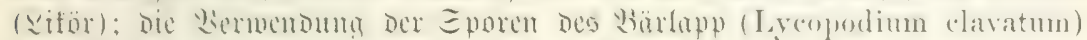

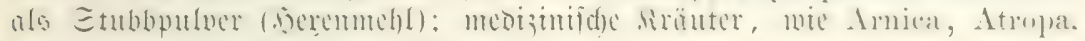
Colehicum; Brennejiel zu Gejpinjtajer «. ๙. m. 



\section{Dierter Teil.}

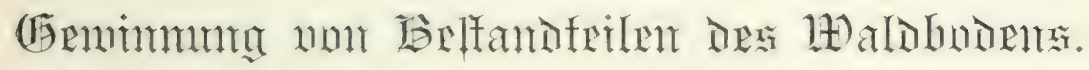





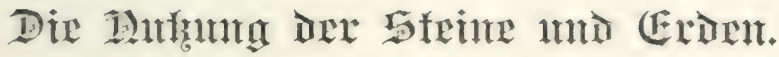

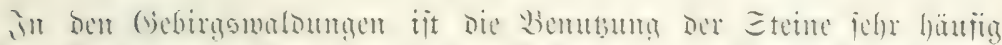

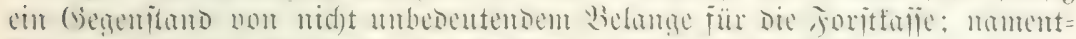

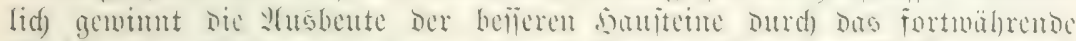

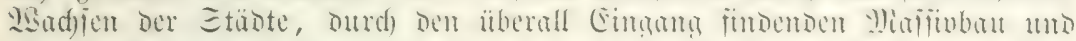

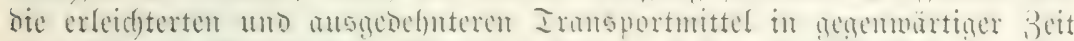

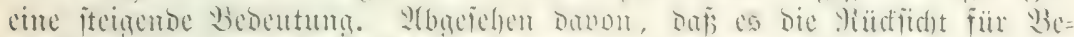

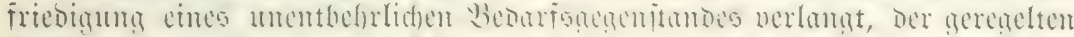

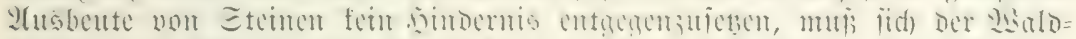

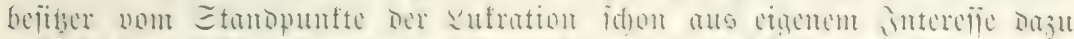

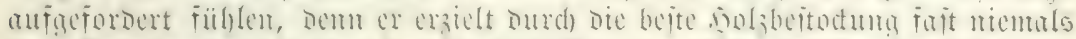

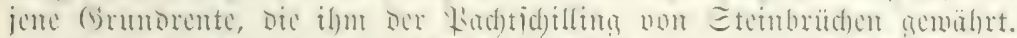

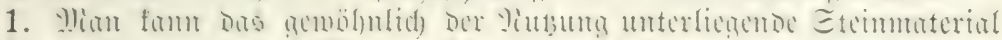

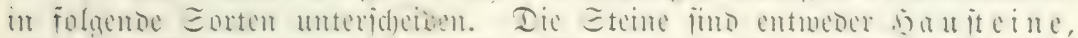

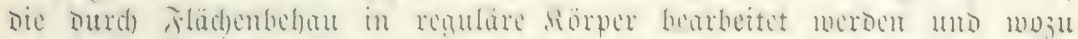

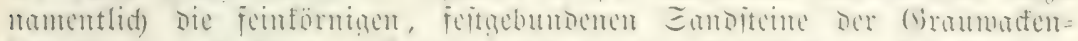

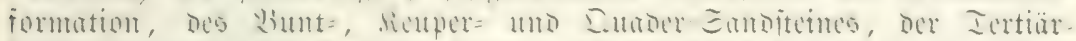

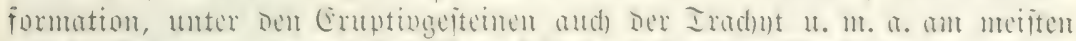

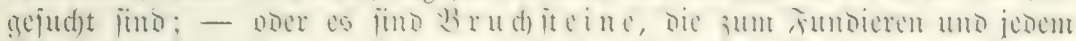

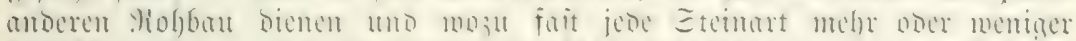

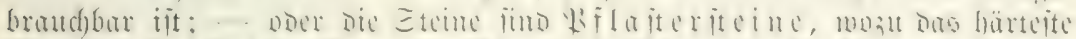

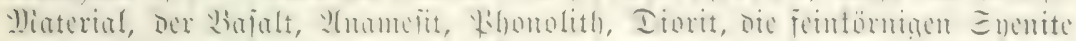

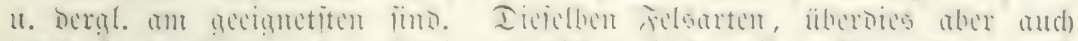

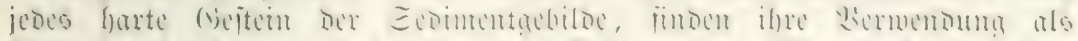

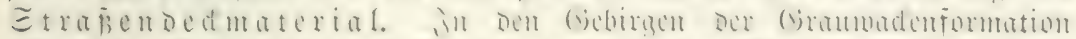

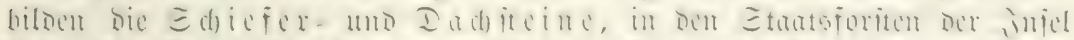

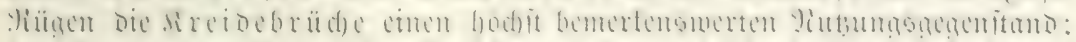

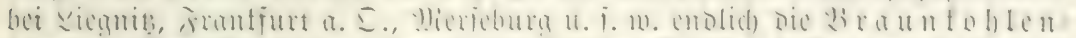

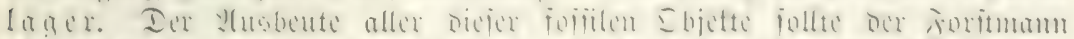

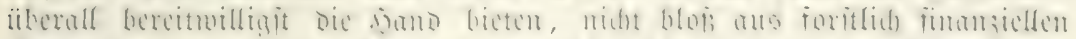

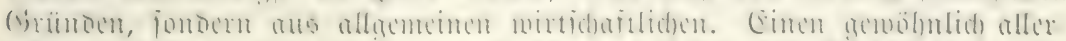

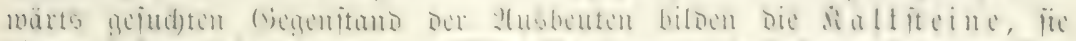

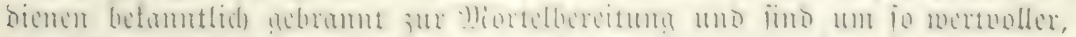

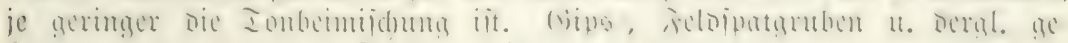

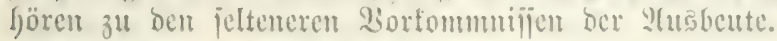

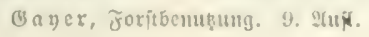




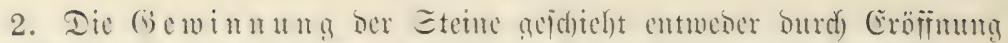

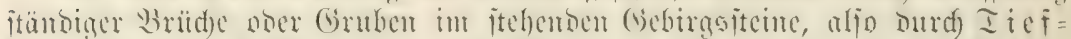

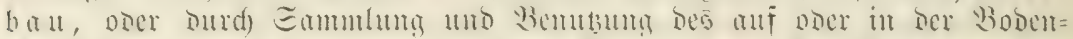

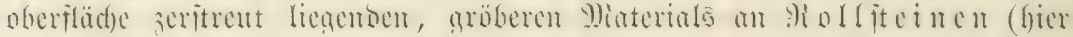
unb da aud) Finslinge genamt).

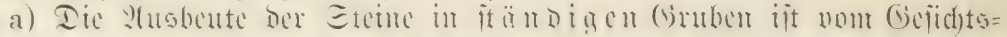

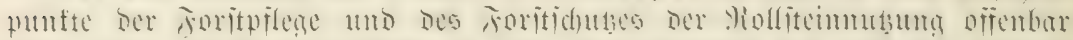

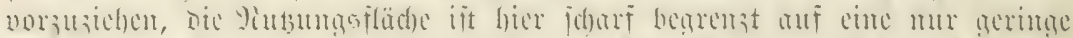

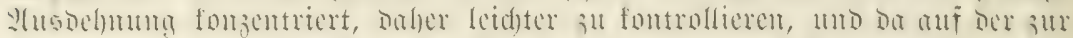

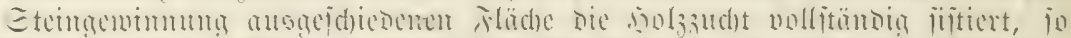

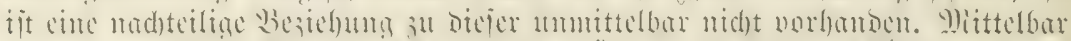

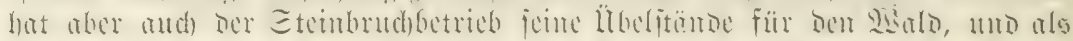

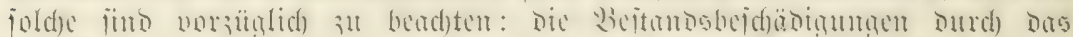

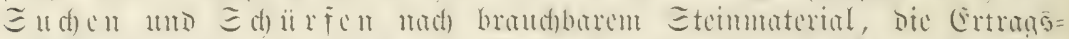

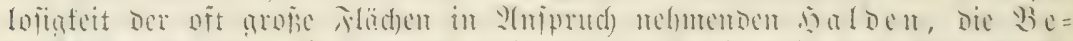

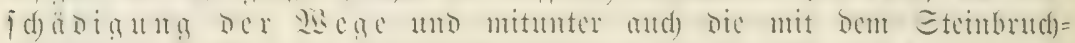

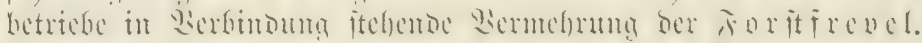

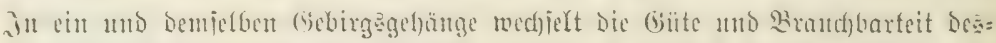

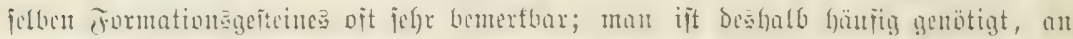

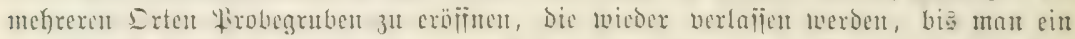

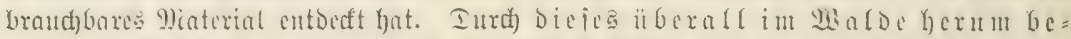
triebenc $\Xi$ di

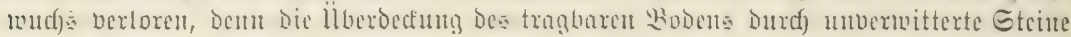

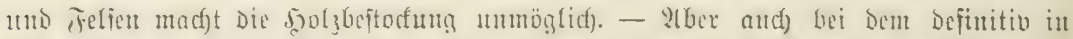

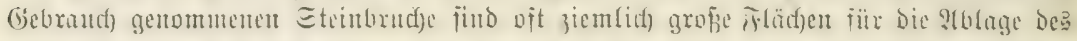

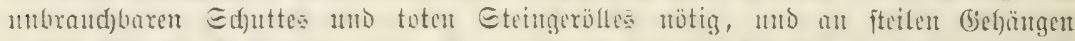

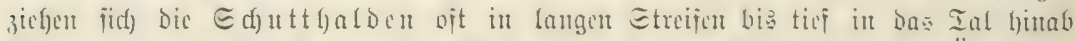

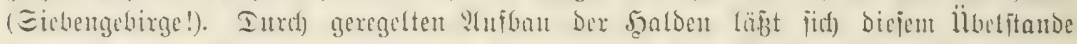

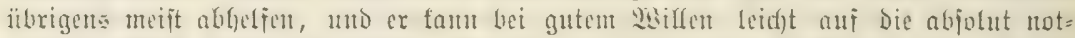

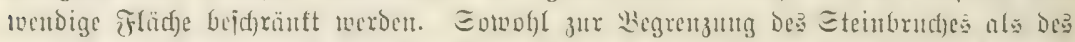

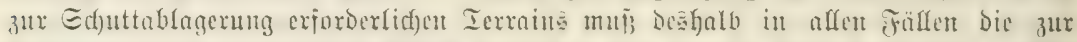

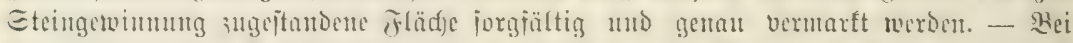

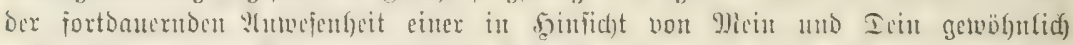

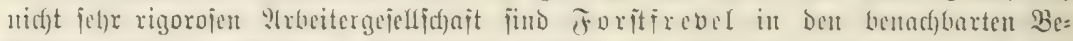

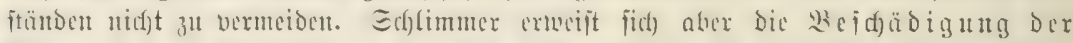

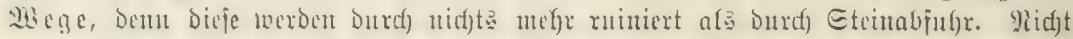

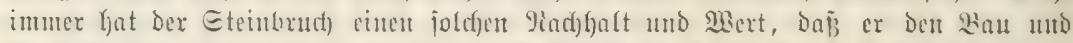

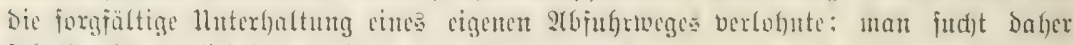

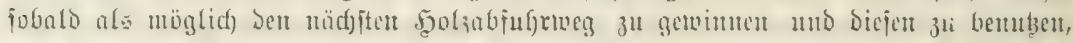

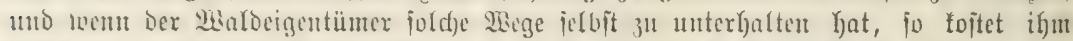

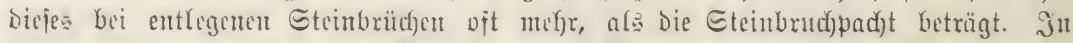

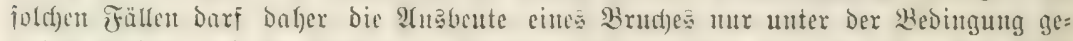

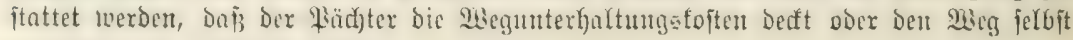
in jałrbarem 3 ujtanto erfärt.

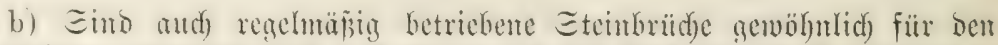

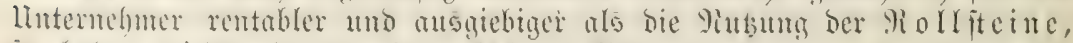

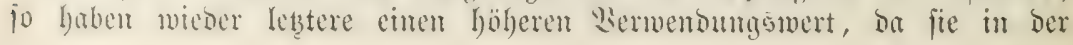




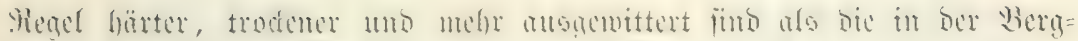

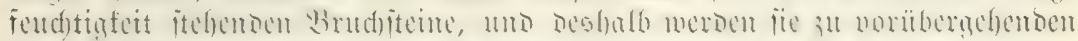

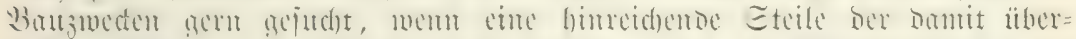

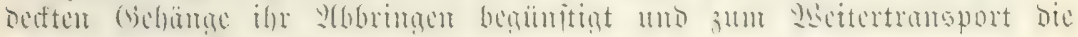
erforberlidjen givege bemtįbar find.

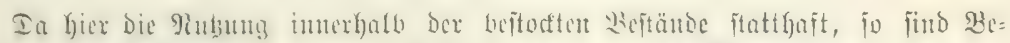

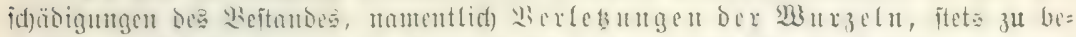

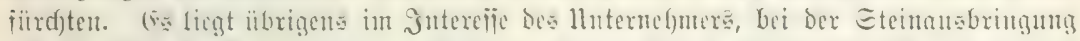

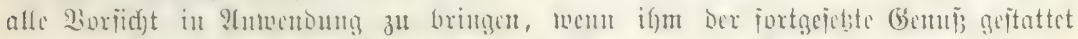

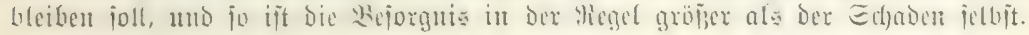

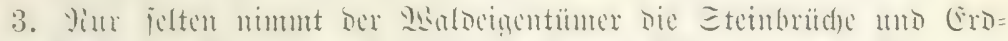

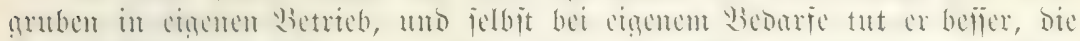

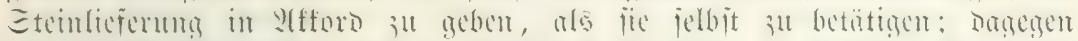

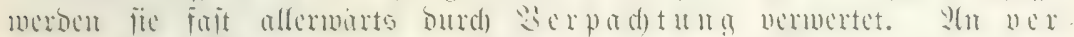
witterten 20 benbeitandeifen wären nod) fur zu crwäbnen: 三 a

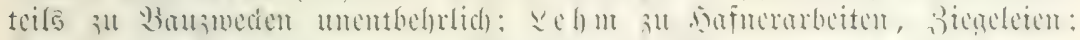
di a D

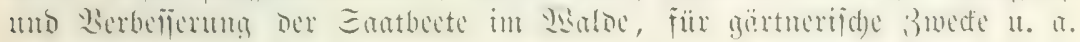




\section{Alphrabetitrtye}

2.

26gabe do Syol3es 365 . 2lbiablage 374 .

Abies, 5olzitruttur 34. Whnorme Getwebe 52. H6reiared)en 320 , 331.

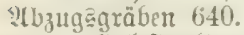
Acer, 5rol 3 itruftur 24. Aesculus, 5olzitruftur 27. Agaricus Shitake 668. 2(hornarten, 5 Jor $_{3}$ itruftur 24 .

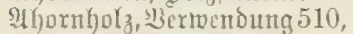
Iftazie, 5olzi Iffazientyol3, Sertertoung 511 .

Rlaungerberei 521.

2llpentöhlerei 439.

Alnus, 50 olzitruttur 25.

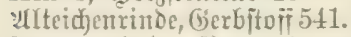
Stmarantfyolz, Mermenturg 512.

Wrtatomidge Eigenidjaiten 7. 2ututomijicje Jofflex 99.

?lpielfol 3,5013 itruttur 26. Vrabifider Ğummi 588.

Mrtrbeitäfträite 120.

UrbeitäLof) 124.

2(itreinfeit 98, 106.

2(ititrell 572, 630.

2tufbanten 648 .

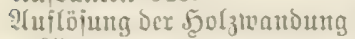
65.

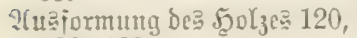
182,190 .

งโเลีนเก 213.

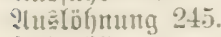

2rt 135.

\section{3.}

Baliam 577.

Baggertori 636 .

: bam6uล, 5ol 3 frtruftur 15,37 . Bambuastol 3. Sertendutg 513.

: Bandjägen 407.
| Bajtteil 11.

Baumfelobirtianat 606 .

B̈aumroden 174.

Bearbeitumgarähigfeit des

$520\left\{\begin{array}{l}23 \\ 900\end{array}\right.$

Bergbaufyolz 465.

Beil 140.

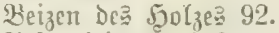

Bejempiricmen 619.

Betula, Solzitruftur 26.

Betulint 70,89

Biegiamfeit be bolze 80 . Biloungaloje 391.

Hinien 666 .

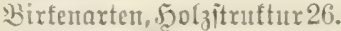
Birtenhol, , Sertwettoung 510 . Birtentmein 588.

Birnfol3, Etruttur 26.

B̉ättergetvinnunt 570.

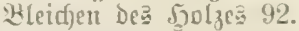

Blcifitititabrifation 496.

Blitibidä̃den 111.

상dholz 207.

Rloctba1s 457.

씸ofverfauf 371.

Rocfrecten 328.

Böttcherfol3 485.

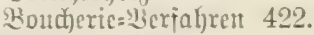

Breitbeil 140.

Bremten De星 Solze 92.

Bremtyol $387,186,210,506$.

Brennumide 520.

Bremunert ber Şölzer 87.

Brettrieje 264.

Bringung De $50 \mathrm{l}_{3} \mathrm{e}$ - 255.

- aui Riciet 274.

- aui Mialdbahnen 285.

Brudfiteine 673.

Brǘfenbaufjol 466.

B̉ruhèrekgolz̧verwentog. 513.

Bucten, Syolzitruftux 19.

Budientrof 3 , Sierwertog. 510.

Budjabaumfol3, Etrutt. 29.

- Mertwendung 512.

Buxus, א̧or
(5.

Cambium 11.

Carpinus, \$olzitruftur 24.

Carya, 5olgitruftur 27.

Castanea, Solzitruftur 21.

Cedrela, Ђolßitruftur 28.

Cedrus, Soljitruttur 34.

Eelluloie 66,545 .

Cembra, Solsitruftux 34.

(5)ampignton 667.

Ehemiide Eigenjuaften Des 5)olzę 66, 70.

- Febler 118.

(c)inin 589.

Crrptomeria, Soljitruftur 34.

Cupressineen, 50 ojotruttur 35.

(5)prejientyolz (audj3npreijen) Etruttur 35.

\section{จ.}

Iachjicjintoln 491.

Iampidaren 560.

Iampifägen 402.

Iaubhol3 486.

Inuer De 50 lge 81.

Ieptillation De: 5olzes 432.

Ietailverfauj 370 .

Iienjtestompetenz 394.

Iouglastante, folol 32.

- \$olzuermentoung 513.

Drahticilriejen 289.

Ireherfölzer 500.

Irehwüd)igteit 102.

Druffieftigfeit des 5olzes 75.

\section{(5.}

(5benfoly, פerwendung 512.

Edelfaitanic, 5olzitruft. 21.

(5olfaftanientiolz, Berwent= Dung 510.

(Eibenlyol3, Etruftur 35.

- Bermentung 512.

(Fiç)enrimbe, G'erbîtoî 523. 
(Fid)enarten, Solzitruftur 17. (Gerabjajajtigfeit 97. Solzbertventoung 509.

Eifengerberei 521.

(5[abeerfiolz, Mertwentog. 511. Erobeerc

(Eroricie 271.

(Erotwege 250.

Erlcuarten, $50 \gamma_{3}$ fruftur 25.

(5rlenfidoly, Sertwendung 510.

(Fidfenarten, 5ol3itruttux 20.

(5id)entholz, Siertwendung 510.

\section{ซ.}

Fagus, 5olaitruftur 19.

Föllart 137.

洋亗ungąbetrieb 120 .

Trälfungêregelt 176.

Franggebüude 322

Fangrecten 324.

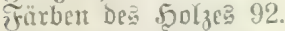

Frarbe Der 50 blzer 37.

- Fefler 112.

Farbitofi 588.

Farntraut 619,630 .

Trajertorf 655 .

Fajerverlauf, Feblex 102.

irnjerzelle 10.

Fehler Des Şolzes 99.

Treinfaierigteit Des Jolzew 70.

Fremelidylagbctrieb 71.

ifeitigfeit Des S1olze? 75 .

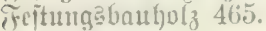

Frette 589.

Tefuerdarren 555.

Fidjtentjol3, Etruftur 32.

- Mcrinendutg 511.

Fidjtenrinde, jerbitoif 542.

istaderja)uitt 16.

orlecf)twaren 501.

I্t(intenjd)äite 499.

芷löberet 341.

F̈ofrenthol, Etruftur 32.

- Wertwendunta 511.

Formberbältnitie Der $50 l 3=$ arten 94.

- Trefler 115.

Fournierfobel 410.

Frourticriägen 408.

Fraxinus, 5olzitruttur 20.

Fräjemajdjuten 410.

irreinrbeiter $1 \% 0$.

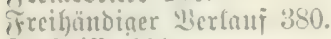

Froitriijc 111.

Frrüd)te Dex s及äume 548.

\section{(6).}

Gianterb)

(Satteriägen 397 .

Gefäßüünded 10.

(Befiūize 9. (3erbftoffe 520 .

(Gerud) Dex Sölzer 40.

- Fehler 115.

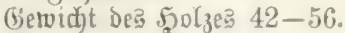

(5) Lauz dex Şölzer 40.

(6)aลgetviumung 601.

(iras̃rupfen fol.

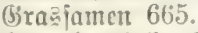

(Sreenlyartfolz, 刃ertwendung 512.

(5rubembantyol 461.

Girubenberfohlung 443.

Grünlandmoore 634.

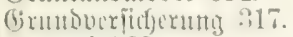

Gงแนmi 588.

\section{\$ู.}

Jaafe 135.

5aatfliöbc 484.

5adfivalobetrieb 604.

5̧ärte Der 5ölzer 41.

- Fefiler 115.

5ainbud)enarten, 5olaftrutturr 24.

Sonitbuct)entrolz, Şertoen= Dung 510.

Sandmertzenge 413,644 .

5arzauzbeute 585.

5ुarz, d)eutijac u. phly. Sic jdyafienheit 577.

5arzgallen 100.

5ุaräütge 575.

5arzgeljalt 52, 61, 79.

50arzgctuintmunty $575,579$.

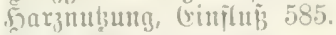

50×3, serteilung 578.

- 2ermentum 586.

S)aiclmuizliol; 511.

5)abtunifieren 422.

Sonbarteitäerträge 99.

5)anerlofusatturo 128.

5oanteinte 673 .

5eidulbere 649, 668.

5 cidocutoore 665.5.

jocidocitren 630

Socizfrait Dex Joülzer 87.

Sopue 141.

5irforibol3, Etruttur 27.

- \$3crumbutug 512 .

Ђicbäergebnitie 24:3.

5irnidunitt 1:).

5obed 414.

jobetmajodinen 410 .

5) o(f) banthols 456 .

5od)moore 633 .

हैं)

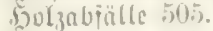

solznbitilir 228. 5olzbiegemaidinten 411.

5ol

5้olzgärten 354.

520l3hauerei $120,167$.

Ђูolzhauerwertzeuge 135.

5oljtofile 445.

5ुolzporen 9.

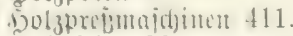

50 olzriejen 261.

5olzrölyren 9.

5olsidhleipmnid)inten $41:$.

jolzititrzest $2 \cdot 25$.

Solzteil 11.

5olztraniport 247.

- zu Wajiex 294.

5olztwege 252.

รัolzwolntajd)inet 411.

5)แmuลjidlamm 634.

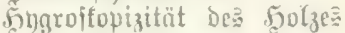
$57,63,419$.

ง.

Jalyecuring 13

Safarandaljolz, Serwentong 512.

Impräguierung 93, 421.

Gnjetten, furitlid) jaciolid)e 86.

Sntenĩtät D. Etreunnbung $622,628$.

Juglans, 5olsftruttux 23.

Juniperus, 5olzitruftur 35.

si.

Sialilid)lagbetrieb 71.

fralfitcinte 675 .

diampler voer diampjer 70 , 587.

Sinolitl 675 .

Sicilformen 153.

Sicimtrajt 567 .

Siernfarbe Der Jjölzer St.

Sermritie 109.

dicruid) äle 110.

siejer, fiche Fölrete.

Jiturupbercitung 586.

stinderipiduaren 49!9.

diixid)enarten, joul 3 fruft. 24.

dilnijififation De .5ol ze 2:37.

filaufert 298.

Jileumen Des 5olze 63 .

Rilöbcifen 115 ).

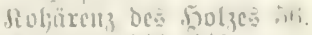

fioblifjol3 4.3. 441 .

Solditiatte 43:).

Siontifunin 587.

Atort 5.) 46 .

strcişägen 406. 
frummfyoloficiex 634 .

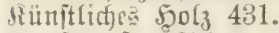
ภunititrä́ 251.

Stunitijd)lerci 477.

\section{צ.}

Särd)e, Syotzitruftur 32.

Rärdjentyol, Siertuenda. 511.

\&ärd)enrinde, Gerbitofi 544.

Ragerplats 354.

Rngern Do Iorje 649 .

Zangholz 206.

Larix, Sol3itruttur 32.

2atiden fol 3 , Perwentog. 513.

Raubjtreu 615,620 , 830 .

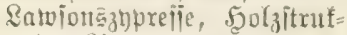
tur 3.5.

- 5olzberwendung 513.

Refim 675 .

Reitungägähigteiten des $50 \mathrm{l}=$ उe? 65,66 .

Ribriform 10.

Rignit 66.

Silientyolz 104.

Rindenarten, 5olaltruftur 26.

Rindenbait 546.

Rindentfolz. Bertwendog. 510.

Rohgerberet 521.

Rokneingeit 125.

Rofnituicm 126.

Rofrittoe 523 .

Ruitrifie 110 .

\&ufttroffengemid)t 60 .

\section{Mi.}

I) - Berwenoung 512.

Ilart 9.

d) Zarfítrahleu 11.

) Jarkitrahlencambium 11.

Miajdinenbnufyolz 468.

Majdinentori 642, 653.

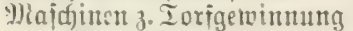
11. Bearbeitung 642,657 .

Mlattemutung 569.

Medizinifiche fröuter 669.

Micermoore 635.

3ieilerbertohlung 433 .

9 Hembrillabol3, Sertwentong 513.

Mliftel 669.

Mlodel 652.

Mobeltori $642,650$.

H)odellyctreinereifyol 478 .

\löbelidureinerei 476.

Moore 632.

Mlooje 666.

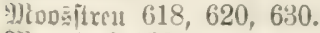

Itopồtori 632.
92.

Iadjuadjent Des Iorjes 630. Tiadelftreu $615,620,630$.

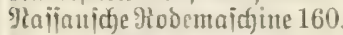
Jiatroutcelluloie 449.

Shutung Der Etrine.

Tiumerierapparate 238.

Tammerierj̧)lägel 239.

Jiubljol 186.

Siubreifig 209.

Öle $69,589$.

Stonomieholzbedari.

Olea, 5olzitruftur 29.

Dlivenbol3, Struttur 29.

- Berioenoung 513.

Dptimum 46.

Erganifation ber Selzhauer= ifiait 129.

Dralfäıre 451.

\section{3.}

Pabantfolz, Serwenog. 512. Tialmfol $15,36$.

- Berwendung 513.

Tiapierfabrifation 447.

Sappelfol $\}_{3}$ Etruftur 27.

- Merwendung 510.

Parendibmzellen 9.

Partriogefolz, Sermenoung 512.

Pausania 608.

Predfitederei 586.

Pecftori 635 .

Siferdefleijhtholz, Berwenog. 512.

Bilaiteriteine 678.

Pillaumenarten, 5ुolzitruft. 24.

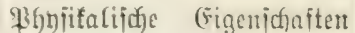
Deق 5jolzee 37.

Biandiorteholz 479.

अhloëm 11.

Picea, Solzitruftur.

Bilze, ç̋bare 667.

- pritidüblidte 86.

Pinus, 5ol3itrutt. 32, 33, 34.

Pirus, நolzitruttur 26.

Hineumatifae jmprägnic: rung 426.

Pitch-Pine, 5ुolzitruftux 32,33 .

- Mertwendung 513.

Podffol3, Nerwendung 512.

Polieren De? Solze 92, 418.

Fopulus, 5olzitruttur 27.

ISottajude 446.

Preişbredtung 243.
Ұreinelbeere 668 .

strüigelfyol3 189.

Prunus, 5olzitruttur 24.

Pseudotsuga, 5ூol

\section{2.}

Qualität De 2ories 653 .

Dllandef 436.

Duebradjohola, Serwendung 513.

Quellen de् .5olze 57-63. Quercus, Etrutt.D. 5ुol3ç 17.

\section{ir.}

Raummañe 231, 240.

Reiferfol3 190.

Heī̄er 415.

Kinde, Getwinnung 519.

- Eigenidajter 517.

Rindencelluloje 545.

Robinia, 5olzitruftur 22.

Robinie, Sुolgitruftur 22.

Robefiue 156.

Röbermaldabetrieb 602.

Hollitrine 674 .

Hojenthol3, Serwendung 512.

Hop̈taf́tanie, ફ口ol

- Solzuerivending 511.

Roteidje, Jolzitruftur 18.

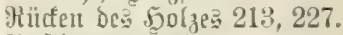

औuक்brennen 446.

Hütelfolzwirtjojait 603.

\section{ङ.}

Cäge, Merfalten D. 5olzç 91.

- Trormen 141, 145.

- Jiajujinen 397.

- Ealicin 589.

Salix, Ђol3itruttur 27.

Calzs, organ., anorganijaje 52.

巨amen, 2rojall 552.

- 24ujbetwahrung 55.

- Iarre 554.

- Ernte 552.

- Ertrügnis 550.

- Biite 567.

- Rlenganitalten 554.

- Meife 552.

Sämijadgerberei 521.

Eatintyol3 513.

Sand und Rites 675.

Echaitiorm 94.

- Fehler 115.

Ex̉äfiflerhol 485.

Edtälen ber (Fida) 528.

Eđältwerfzelıge.

Edärien ber 巨äge 152.

Edjeithol, 189.

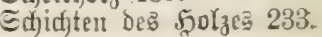


Edidjtmuthola 188, 209. Edjicben de马 5olzc弓 224. Edifitbauthol3 469 Edjlagaujuafme 237, 215. Ed)Ingrüumung 211. Edhlïmmtori 65.5 .

Ed)leipon. D. Solze 214, 260. Edititeln De Jolze 217. Ed)littentonftruttionen 218. Edumoren od. Edfmoden 604 . Ed)mcitelptreu 572.

Ed)nitthol3 454 .

Edmimarentiolz 417. Ed)ränter Der Eäge 153. Edjuttfalion 674. Echtwarztisiemfjolz 512. Edutuemmtridje 310. Edumere Der 5jözer 42-56. - Fehler 115.

Ed)mindon D. $5043657-6: 3$. - Des Iorto 649.

Effuindmañ 234.

Eergras 665.

Sequoia 34.

Eebert De3 Jolze 233.

Etlerembnm 10.

Eflerembumiajer 10.

Eommerfïlfung 55.

Sorbus 26.

Enmendarren 554.

Eortimente 186, 203.

Spaltaxt 154.

Epaltbarteit 73

Epantütign 5013116.

Epecturi 636.

Epcijefantüle 297.

Evertat3e 222.

Epicgelidjuitt 16.

Eprengidfraulien 197.

Etammfjol3 206.

Stammriejen 261.

Etangentiol $188,208$.

Stärfemehl 69.

Eteingruben 674.

Etcinforbredjer 330.

Etcimpilz 608 .

Etellmadjerfol3 481.

Etidjtori 612.

Stodiäule 112.

Stodfol3 190, 197.

Etodrodung 173.

Etorbe ber Etämme 225.

Etrapenpflafter 462.

Etraine! 248.

Strcidjuerlal3 321.

Etrenempiänger 624 .

Etreuentmafme, ifor 9luben 626.

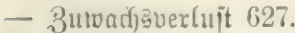

Etreugetwinumg
Strcumaห̃ 625.

Etremułung

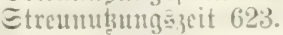

Etrcupreta 625.

Etreuvrodittion 615.

Etreuveriocrtung $62 \mathrm{t}$.

Etreuvicjen 620.

Strobus, 5olzitruttur 34.

Etruftur Des 5olzes 17.

Etuictmanc 2:30, 240.

Eubmififion 380.

Enlfitcelluloie 449.

Eumpindope 633 .

Elmmpitori 6:35.

Eumpizaprificulfo!3 513 .

Swietenia, Solsitruftur 28.

\section{I.}

Inmoriätenmoos 666 .

Iangentialidunitit 17.

Taune, Solzitruttux 34.

Tantenthula, Nertuentog. 511.

Tare 373.

Icaf, 5ol3itruttux 29. Wermenduna 512.

Iet(f)tijd)e (Figenjd)aften De? 5nolze $70-99$.

- Frbler 115.

Tectona, .5ol3itruttur 29.

Teeridimelerei 586.

Ierpentin 577 .

Tilia, $50 \mathfrak{l}_{3}$ itruttur 26.

Iijwlereigülzer 475.

Ioriarbinll 650 .

Turinrter 638 .

Ioribildung 633.

Toribofiner $6: 37$.

Ioritoble 66:

Torimoore, if)re Entmäjie= rutg $639,6+1$.

Ioriitreu 661.

Ioriitedyen 65t, 646 .

Iorizical 644,652 .

Iotfjar\}ung 581.

Iradjecul 9.

Iradjcibelt 10

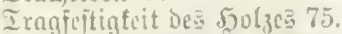

Irausportmitfoocu ('wert) 349 .

Irijt $294,335$.

Trommelonren 558.

Irüfïd 667 .

'Tsuga, 5olzitruttur 34.

Iuxmu im Etreured)en 628.

\section{1.}

lïbertandbrement ob. Gemgen 604.

iibermą3 234 .

ll ferveriid)erungen 315. llmenarten, 5ol3 3 truftur 21.

lltmentfol3, Siferioculog. 510.

Ulmus, 5o 0 3itruttur 21.

llnfräuteritreu $619,621$.

Ilnterute(buermannidfaiten $1: 30$.

\section{3.}

Vaccinium macrocarpum 668.

Weild)entyol3, Wertocnog. 513.

Seründerm De 50136396 .

Neräitellumg 106.

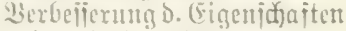
Des $5013 e=416$.

3ericinerung dę 5ूol ze 396 .

2ierfaui 370.

- madi Iaxe 373.

- ireifündia 380.

Berfanfabedingungen 392.

Bertauţmalie 230 .

Berfaujazcit 389.

sertablang 93, 433.

歨eriteigerung 376.

- IJublifation 393.

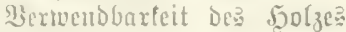
182,185

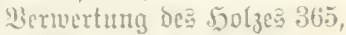
369

Weruertungämetfoben 389.

Bogelantgenmaicr 105.

SJogelbcerarten, 50l3itruftur 26.

Bogelberfol3, Sืermenoung 511

Mollnols 453 .

壮ollfernigfeit ber 5ölzer 97.

Mulfanipieren 423.

\section{8.}

Madjolocrbecren 668.

Milnchulder, 5oolsitrutt. 36.

- Mertwendurq 513.

2ilad) 589 .

Wianuterl)ol3 481.

Milocilembahucu 277.

9yaldiclobna 60.5.

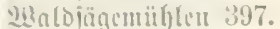

Waldoteite! 159.

Minalotori 611.

Linlumizarten, nol jitruft. 23.

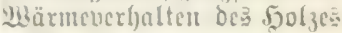
(6i) -6.5 .

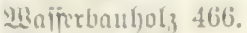

wequicie 272.

Wiblite 311.

Weidenarten, 5ol3itruft. 27.

Weidenbene 606.

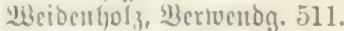

wheibcrmbutig 596. 
囚eibebief 595.

Meidezeit 599.

Wei Bbud)enarten, 520lz= itruftur 24.

weib̄gerberei 521.

Mellertgebäude 236.

Weffenhol 3190.

Mendehafen 160.

Menmouthstiejer, $\mathfrak{S p l}_{\mathbf{z}}=$ itruftur 34.

Miefenmoore 634.

23ildöatê 602.

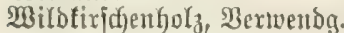
511.

Bildobjtifol $\mathfrak{Z}_{3}$, Berivendung 511.
Mimmerige $\mathfrak{H}_{0}$ ol 103.

Mindrifie 110 .

\$interfällung 85 .

W̉ofmannidje Ttodmaidjute 160.

Munoparendym 99, 576.

Murzelgetwinnuitg 573.

\section{3.}

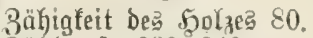

3ählmaß̄e 230, 240.

3argenfola 493.

3 ederthol 28.

- Merwendung 512, 513.

Beit ber 5ol łâfflung 163. 3eit be כorfitidjes 644 . 3erreī̄ung Des 5otzes 109. 3eriezungaprozefie D. Streu 609.

3iefrwege 253.

3igarrenfittenhol $\mathfrak{z}_{3}$, Struftur 28.

- Mertwendung 479.

Birbe, $\mathfrak{S O l}_{3}$ itruftur 34.

3irbelfieferlyolz, Berwentog. 512.

3 ưder 587.

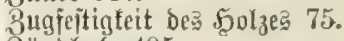

3ünolyolz 495.

3 miejelbilbung 108.

3middentbau, lanbwirt= idjaftlidjer 609. 


\title{
Der Waldbau.
}

\author{
Von Dr. Karl Gayer,
}

higl. Bayer. Geheimrat und o. it. Professor der Forstwissenschaft an der Universitait in Jüuchen.

\section{Vierte, verbesserte Auflage.}

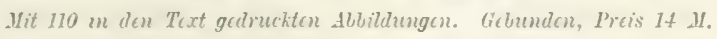

Die Forstwirtschaft verdankt in dem vorliegenden Buche dem Verfasser eine Arbeit iiber den Waldbau, in welcher derselbe seine aus langjähriger Erfahrung und Beobachtung hervorgegrangenen und aus einem selbständigen Studium der mamnigfachsten Wahlungen geschüpften Anschaumgen niedergelegt hat. Der Lmstand, dafs bereits die vierte Auflage erschienen ist, beweist die hohe Anerkennung, welche das Werk bei den Berufsgenossen des Verfassers gefunden hat. Es besteht aus drei Hauptteilen, in welchen die Bestandslehre, die Be-tamlsgrindung und die Bestands. erziehung gelehrt werden.

\section{Die Holzmelskunde.}

\section{Anleitung}

zur

Aufnalme der Bäume und Bestände nach Masse, Alter und Zuwachs.

\author{
Von Dr. Franz Baur,
}

o. o. Professor der Forstwiesenschaft an der Universitut in Munchen.

Vierte, umgearbeitete und vermehrte Auflage.

yit sis in den Test gedrurkten Abbitdungen. Gicbunden. Preis $12.1 \%$.

\section{Lehrbuch der niederen Geodäsie.}

Vorzüglich für die praktischen Bedürfnisse der

Forstmänner. Landwirte. Kameralisten und Geometer, sowie zum Gebrauch an

militärischen und technischen Bildungsanstalten,

bearbeitet von Dr. Franz Baur,

o. ï. I'rofeasor der Forstwirsenschaft an der Universitat in München.

Fünfte, vermehrte und verbesserte Auflage.

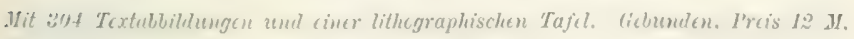

\section{Handbuch der Waldwertberechnung.}

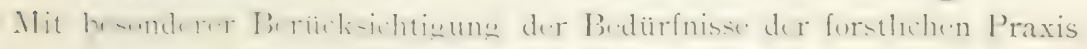
bearbeitet von Dr. Franz Baur, o. ¿. l'rufessur der Forstwiasentehaft an der Univerwitit in Minchen. 
Eigenschaften und forstliches Verhalten der wichtigeren

in Deutschland einheimischen und eingeführten Holzarten.

Leitfaden für Studierende. Praktiker und Waldbesitzer von $\mathrm{Dr}$. Richard Hefs,

Geh. Hofrat, o. vo. Prof, der Forstwissenschaft zu Giefsen.

Zweite, neubearbeitete und vermehrte Auflage.

richemen. Preis $z$. $y$.

\section{Die Forstbenutzung.}

Ein Grundrils zu Vorlesungen mit zahlreichen Literaturnachweisen.

Von Dr. Richard Hels,

Geh. Hofrat, o. u. Prof. der Forstwissenschaft zu Giefsen.

Zweite, neubearbeitete und erweiterte Auflage.

Preis 8 Y. Vielunden :" y.

Hilfstafeln zur Inhaltsbestimmung

\section{Bäumen und Beständen der Hauptholzarten.}

Arbeiten des Vereins deutscher forstlicher Versuchsanstalten.

lekemente Preis : $y$.

Handbuch

\section{forstlichen Wege- und Eisenbahnbaues.}

\section{Nach dem Nachlasse des Kigl. Bayer. Forstmeisters fin. Lizius}

bearbeitet von K. Dotzel,

Kgl. Bayer. Forstmeister uod Dozent an dex Kgl. Forstlehranstalt Aachatlenburg.

3lit if.5 Textablitdungen. Febunden. Preis $f$ M. in Pf.

\section{Der forstliche Hochbau.}

Von Maximilian Lizius,

Kgl, Bayer. Forstmeister und Docent an der Kgl. Forstlehranstalt Aschaffenburg.

Hit iffi Testmbilihungen. I'reis of $\mathrm{M}$.

\section{Handbuch \\ der \\ Staatsforstverwaltung in Preufsen.}

Geordnete Darstellung

der bezüglichen Gesetze. Kabinetts-Ordres, Verordnungen,

Entscheidungen höchster Gerichtshofe, Regulative, Staats-Ministerial-Beschlüsse und Ministerial-Verfügungen mit Quellenangabe.

Von E. Schlieckmann,

König1. preufsischer Oberforstmeister in Arnsberg.

Dritte, neubearbeitete Auflage.

Viebunten. Irris: :? $M$.

$\mathrm{Zu}$ beziehen durch jede Buchhandlung. 
Verlag von Paul Parey in Berlin SWV. Hedemannstr. 10.

\title{
Forstliche Zoologie.
}

Von Dr. Karl Eckstein,

\author{
Professor an der Königliclien Forstakademie in Fberawalde.
}

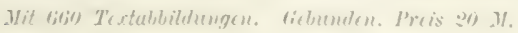

\section{Forstliche Botanik.}

Von Dr. Frank Schwarz,

I'rofessor an der Kïaiglichen Forstakademie in Eberswalde.

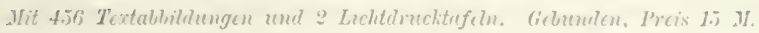

\section{Lehrbuch der mitteleuropäischen Forstinsektenkunde.}

\author{
Von Dr. J. F. Judeich, \\ weil, Kgl. sächs. Geh. Oberforstrat und Direktor der Forstakademie zu Tharand, \\ und Dr. H. Nitsche, \\ Professor der Zoologie an der Forstakademie zu Tharand
}

Als achte Auflage

Ratzeburgs Waldverderber und ihre Feinde

in vollständiger Umarbeitung herausgegeben.

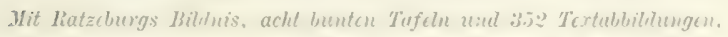

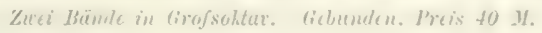

\section{Kauschingers Lehre vom Waldschutz.}

\author{
Sechste Auflage,
}

herausgegeben von $\mathrm{Dr}$. H. von Fürst,

Kgl. bayer. Oberforstrat, Dircktor Jer forstlichen Hochschuie in Aschattenbure.

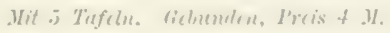

\section{Studien über die Schüttekrankheit der Kiefer.}

\section{Von Dr. Carl Freiherr von Tubeuf,}

\author{
kaiserl. Jiegierungsrat.
}

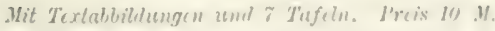

(Arbeiten aus der Biologischen Abteilung fur Land- und Forstwirtschaft am Kaiserlichen Gesundheitsante. 11. Band, I. Heft.) 


\title{
Forstwissenschaftliches Centralblatt.
}

\author{
Zugleich Publikationsorgan \\ tür die
}

forstliche Abteilung der Königl. Bayer. forstlichen Versuchsanstalt. Unter Mlitwirkung zablreicher Fachleute aus Wissenschaft und Praxis herausgegeben von

Dr. Hermann von Fürst,

k. b. Oberforstrat und Direktor der foratlichen Hochscbule Aschaffenburg.

\author{
Fünfundzwanzigster Jahrgang. \\ (Der ganzen Reihe XLVII. Jahrgang.) \\ Preis des Jahrganges ion 12 Heften 14 Mark.
}

Das Forstwissenschaftliche Centralblatt ist kein Parteiblatt, sondern ein Organ für alle gebildeten Forstwirte. Es bringt in Monatsheften von zusammen 40 Druckbogen Originalartikel, Mitteilungen, Literaturberichte und Notizen aus der Feder der bewährtesten Männer der Praxis und Wissenschaft. Die Originalartikel bezwecken bei einfacher, aber wissenschaftlicher Haltung die Weiterentwicklung aller Zweige der Forstwissenschaft; die Mitteil ungen orientieren den Leser bezüglich der Änderungen in der Gesetzgebung, Organisation u. s. w. der staats- und Gemeindeverwaltungen und bringen die Verhandlungen der wichtigeren Forstversammlungen; die Literaturberichte liefern objektive Referate uber die neuen Werke der Forst- und Jagdwissenschaft, sowie der verwandten Naturwissenschaften, während die Notizen kurze Mitteilungen uiber Erfindungen, Beobachtungen, Versuche, Naturereignisse, Erscheinungen im Pflanzen- und Tierleben, Personalveränderungen u. s. w. enthalten.

\section{Illustriertes Forst- und Jagd-Lexikon.}

\section{Zweite, verbesserte Auflage. \\ Unter Mitwirkung von}

Prof. Dr. Bühler-Tübingen, Prof. Ir. Conrad-Aschaffenburg, Forstrat Efslinger-Speyer, Forstmeister Freiherr von Nordenflycht-Lödderitz, Oberforstmeister Runnebaum-Stade, Prof. Dr. Spangenberg-Aschaffenburg, Prof. Dr. Weler-München, Prof. Dr. Wilhelm-WVien,

\section{Dr. Hermann von Fürst, \\ k. b. Oberforstrat und Direktor der forstlichen Hochschule Aschaffenburg. \\ Wit 600 Textablildungen.

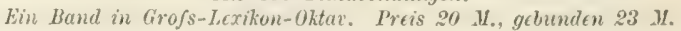

Die $z$ weite A ufla ge ${ }^{i_{\text {st }}}$ einer vcllständigen Umarbeitung unterworfen worden, und es steht danach zu hoffen, dafs sie sich in noch höherem Mafse die Zufriedenheit der Subskribenten erwerben wird.

Unter der altbewährten Führung des Oberforstrats Dr. von Fürst hat sich von neuem ein Stab von Mitarbeitern zusammengefunden, deren Namen allein wohl schon Bürgen sind, dafs das Forst- und Jagdlexikon von neuem das Ziel erreichen wird, das es sich gesteckt hat: unter strenger Begrenzung des Stoffes, seinen Lesern ein Werk zu sein, das in handlicher Form und bei mäfsigem Preis die erwünschte Müglichkeit rascher Orientierung auf dem ganzen Gebiet der Furstwissenschaft und Jagdkunde bietet.

In dieser Weise enthält das Fürst'sche Lexikon Tausende einzelner Artikel und gibt - aufgeschlagen an der betreffenden Stelle des Alphabets - eine augenblickliche, klare und bündige Antwort auf alle Fragen, wie sie sich dem Forstmanne läglich am Arbeitstische und im Walde aufwerfen.

Zu bezichen durch jede Buchhandlung. 



\section{LIBRARY \\ UNNVERSITY OE TORONTO}

SD

431

G38

1903

Gayer, Johann Karl

Die Forestbenutzung

9. verm. Aufl. bearb.

\section{Biolled}

\section{PLEASE DO NOT REMOVE}

CARDS OR SLIPS FROM THIS POCKET

\section{UNIVERSITY OF TORONTO LIBRARY}


